\title{
UNIFIED APPROACH FOR BRIDGE DECK DESIGN
}

\author{
by \\ Karim Meleka, \\ B.Eng., Ryerson University, 2013
}

\author{
A Major Research Paper \\ presented to Ryerson University \\ in partial fulfillment of the \\ requirements for the degree of \\ Master of Engineering \\ in the Program of \\ Civil Engineering \\ Toronto, Ontario, Canada, 2016 \\ (C) (Karim Meleka) 2016
}


I hereby declare that I am the sole author of this MRP. This is a true copy of the MRP, including any required final revisions, as accepted by my examiners.

I authorize Ryerson University to lend this MRP to other institutions or individuals for the purpose of scholarly research

I further authorize Ryerson University to reproduce this MRP by photocopying or by other means, in total or in part, at the request of other institutions or individuals for the purpose of scholarly research.

I understand that my MRP may be made electronically available to the public. 


\begin{abstract}
Karim Meleka

Master of Engineering, 2016

Civil Engineering, Ryerson University

Current Canadian Highway Bridge Design Code includes design provisions to establish live load demands in (i) reinforced concrete decks over longitudinal girders, (ii) orthotropic deck over longitudinal girders, and (iii) orthotropic deck over transverse beams. However, it only provides an equation for factored applied moment on concrete deck under single point load. Similar equations for orthotropic decks are as yet unavailable. As such, parametric study was conducted to lead to new empirical expressions for moment in bridge decks subjected to truck wheel loading considering each of the three cases of orthotropy: (i) relatively torsionally stiff, flexurally soft decks; (ii) relatively uniformly thick decks; and (iii) relatively torsionally soft, flexurally stiff decks. Using the proposed formulations, bridge deck design can be treated in a unified way across different deck types, accounting for longitudinal-transverse flexural rigidity of decks. Application of these methods can significantly simplify the analysis of decks and allow bridge engineers to make comparisons across different deck design alternatives.
\end{abstract}




\section{Table of Contents}

AUTHOR'S DECLARATION

Abstract iii

List of Tables $v$ v

List of Figures $\quad$ vi

List of Appendices viii

List of Symbols and Abbreviations $\quad x$

1. Background and introduction 1

1.1. Orthotropic Plate Theory 1

1.2. AASHTO Provisions $\quad 6$

1.3. Canadian Code Provisions 6

2. Finite Element Analysis $\quad 8$

$\begin{array}{llr}\text { 2.1. } & \text { Sensitivity Analysis } & 8\end{array}$

$\begin{array}{lll}\text { 2.2. } & \text { Finite Element Modeling } & 10\end{array}$

2.2.1. Main Bars transverse to Traffic 10

2.2.2. Main Bars Parallel to Traffic 18

3. Deflection 24

4. Development of Empirical Equations $\quad 25$

5. Conclusion $\quad 30$

Appendices

$\begin{array}{ll}\text { References } & 690\end{array}$ 


\section{List of Tables}

TABLE 1 Material Properties For CASE2

TABLE 2 COMPARISON BETWEEN ORTHOTROPIC FORMULATION AND FEA FOR CASE 2 


\section{List of Figures}

FIGURE 1 DECK TYPES DISCUSSED IN THE REPORT FROM THE LEFT FULLY/PARTIALLY FILLED DECKS, OPEN GRID DECKS AND TYPICALLY REINFORCED DECKS "THICK PLATE" (SOURCE: BGFMA, 2016)

FIGURE 2 SINGLE PATCH LOAD

FIGURE 3 COMPARISON OF MAXIMUM BENDING MOMENT AT DIFFERENT ELEMENT SIZES

FIGURE 4 MAXIMUM MOMENT OF DECK SLABS SUBJECTED TO CHBDC AXLE 4 FOR DIFFERENT D VALUES OF CASE 2

FIGURE 5 MAXIMUM MOMENT OF DECK SLABS SUBJECTED TO CHBDC AXLES 2 \& 3 FOR DIFFERENT D VALUES OF CASE 211

FIGURE 6 MAXIMUM MOMENT OF DECK SLABS SUBJECTED TO CHBDC TRUCK FOR DIFFERENT D VALUES OF CASE 2

FiguRE 7 COMPARISON BETWEEN FEA AND ORTHOTROPIC Plate THEORY FOR D $=0.25$ OF CASE 2

Figure 8 Comparison betWEen FEA AND ORTHOTROPiC Plate TheORy For D = 1 of CASE 2

FigURE 9 COMPARISON BETWEEN FEA AND ORTHOTROPIC PLATE THEORY FOR D $=8$ OF CASE 2

FIGURE 10 MAXIMUM MOMENT OF DECK SLABS SUBJECTED TO CHBDC AXLE 4 FOR DIFFERENT SPAN VALUES OF CASE 214

FIGURE 11 MAXIMUM MOMENT OF DECK SLABS SUBJECTED TO CHBDC AXLE $2 \& 3$ FOR DIFFERENT SPAN VALUES OF CASE 214

FIGURE 12 MAXIMUM MOMENT OF DECK SLABS SUBJECTED TO CHBDC TRUCK FOR DIFFERENT SPAN VALUES OF CASE 2

FIGURE 13 COMPARISON BETWEEN FEA AND ORTHOTROPIC PLATE THEORY FOR 1 M SPAN OF CASE 2

FiguRE 14 COMPARISON BETWEEN FEA AND ORTHOTROPIC PLATE THEORY FOR 2.5 M SPAN OF CASE 2

FiguRE 15 Comparison BETWEEN FEA AND ORTHOTROPIC Plate THEORY FOR 3.5 M SPAN OF CASE 2

FIGURE 16 MAXIMUM MOMENT OF 2-M SPAN SLAB SUBJECTED TO CHBDC AXLE 4 FOR DIFFERENT D VALUES OF CASE 2

FIGURE 17 MAXIMUM MOMENT OF 2-M SPAN SLAB SUBJECTED TO CHBDC AXLE 2 \& 3 FOR DIFFERENT D VALUES OF CASE 217

FIGURE 18 MAXIMUM MOMENT OF 2-M SPAN SLAB SUBJECTED TO CHBDC TRUCK FOR DIFFERENT D VALUES OF CASE 218

FIGURE 19 MAXIMUM MOMENT OF DECK SLABS SUBJECTED TO CHBDC AXLE 4 FOR DIFFERENT D VALUES OF CASE 2 MAIN BARS PARALLEL TO TRAFFIC $\quad 19$

FIGURE 20 MAXIMUM MOMENT OF DECK SLABS SUBJECTED TO CHBDC AXLE 2 \& 3 FOR DIFFERENT D VALUES OF CASE 2 MAIN

BARS PARALLEL TO TRAFFIC 19

FIGURE 21 MAXIMUM MOMENT OF DECK SLABS SUBJECTED TO CHBDC AXLE 4 FOR DIFFERENT SPAN VALUES OF CASE 2 MAIN BARS PARALLEL TO TRAFFIC 20

FIGURE 22 MAXIMUM MOMENT OF DECK SLABS SUBJECTED TO CHBDC AXLE 2 \& 3 FOR DIFFERENT SPAN VALUES OF CASE 2 MAIN BARS PARALLEL TO TRAFFIC 20

FIGURE 23 MAXIMUM MOMENT OF 2-M SPAN SLAB SUBJECTED TO CHBDC AXLE 4 FOR DIFFERENT D VALUES OF CASE 2 MAIN BARS PARALLEL TO TRAFFIC

FIGURE 24 MAXIMUM MOMENT OF 2-M SPAN SLAB SUBJECTED TO CHBDC AXLE 2 \& 3 FOR DIFFERENT D VALUES OF CASE 2 MAIN BARS PARALLEL TO TRAFFIC

FiguRE 25 COMPARISON BETWEEN FEA AND ORTHOTROPIC Plate THEORY FOR D $=0.25$ OF CASE 2 MAIN BARS PARALLEL TO TRAFFIC

FigurE 26 COMPARISON BETWEEN FEA AND ORTHOTROPIC PLATE THEORY FOR D = 1 OF CASE 2 MAIN BARS PARALLEL TO TRAFFIC

FiguRE 27 COMPARISON BETWEEN FEA AND ORTHOTROPIC PLATE THEORY FOR D $=8$ OF CASE 2 MAIN BARS PARALLEL TO TRAFFIC

FIGURE 28 MAXIMUM MOMENT COMPARISON BETWEEN FEA AND EMPIRICAL EQUATION FOR SPANS LESS THAN / EQUAL TO 3 M FOR MAIN BARS TRANSVERSE TO TRAFFIC DIRECTION

FIGURE 29 MAXIMUM DEFLECTION COMPARISON BETWEEN FEA AND EMPIRICAL EQUATION FOR SPANS LESS THAN / EQUAL TO 3 M FOR MAIN BARS TRANSVERSE TO TRAFFIC DIRECTION 
FIGURE 30 MAXIMUM MOMENT COMPARISON BETWEEN FEA AND EMPIRICAL EQUATION FOR SPANS GREATER THAN 3 M FOR MAIN BARS TRANSVERSE TO TRAFFIC DIRECTION

FIGURE 31 MAXIMUM DEFLECTION COMPARISON BETWEEN FEA AND EMPIRICAL EQUATION FOR SPANS GREATER THAN 3 M FOR MAIN BARS TRANSVERSE TO TRAFFIC DIRECTION

FIGURE 32 MAXIMUM MOMENT COMPARISON BETWEEN FEA AND EMPIRICAL EQUATION FOR SPANS LESS THAN / EQUAL TO 3 M FOR MAIN BARS PARALLEL TO TRAFFIC DIRECTION

FIGURE 33 MAXIMUM DEFLECTION COMPARISON BETWEEN FEA AND EMPIRICAL EQUATION FOR SPANS LESS THAN / EQUAL TO 3 M TRANSVERSE FOR MAIN BARS PARALLEL TO TRAFFIC DIRECTION

FIGURE 34 MAXIMUM MOMENT COMPARISON BETWEEN FEA AND EMPIRICAL EQUATION FOR SPANS GREATER THAN 3 M TRANSVERSE FOR MAIN BARS PARALLEL TO TRAFFIC DIRECTION

FIGURE 35 MAXIMUM DEFLECTION COMPARISON BETWEEN FEA AND EMPIRICAL EQUATION FOR SPANS GREATER THAN 3 M TRANSVERSE FOR MAIN BARS PARALLEL TO TRAFFIC DIRECTION 


\section{List of Appendices}

A.1 Loading Cases.

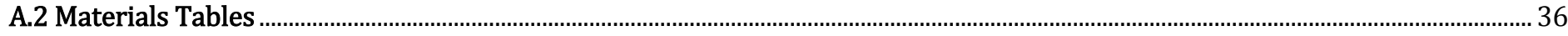

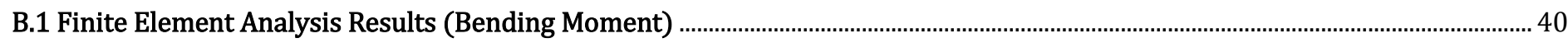

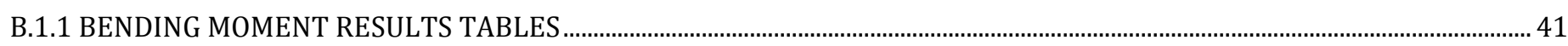

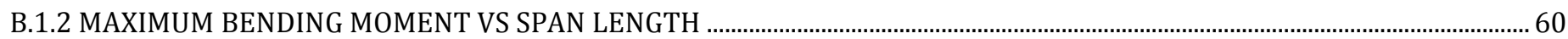

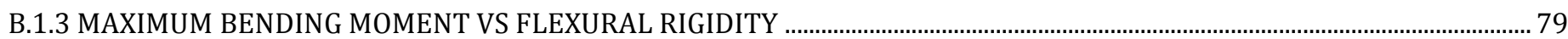

B.1.4 MAXIMUM BENDING MOMENT VS TORSIONAL RIGIDITY …….............................................................................................. 98

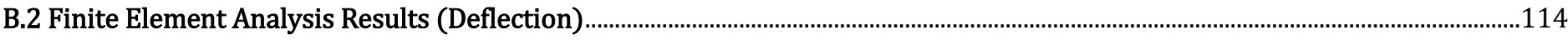

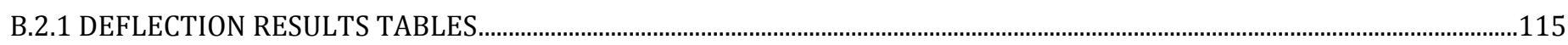

B.2.2 MAXIMUM Deflection VS SPAN LENGTH

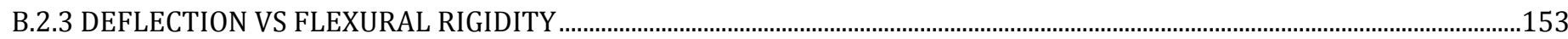

B.2.4 MAXIMUM DEFLECTION VS TORSIONAL RIGIDITY

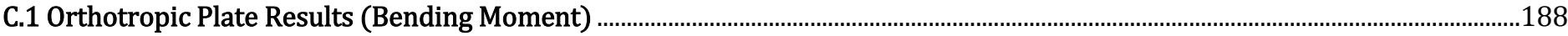

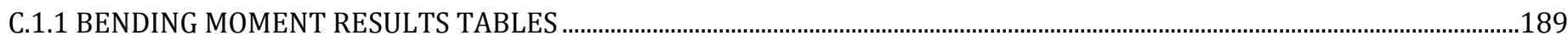

C.1.2 MAXIMUM BENDING MOMENT VS SPAN LENGTH.........................................................................................................................208

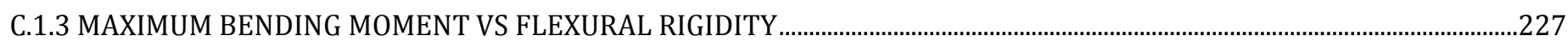

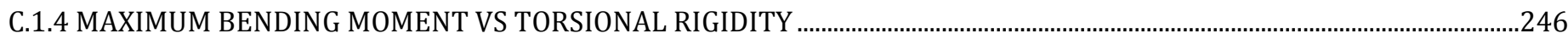

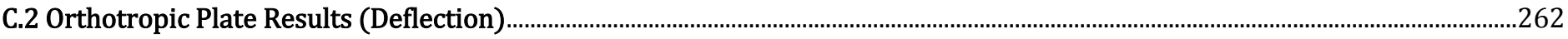

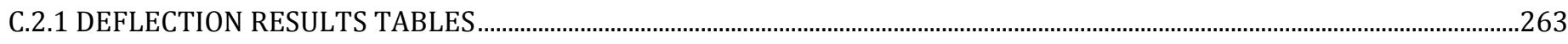

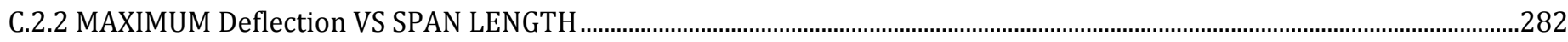

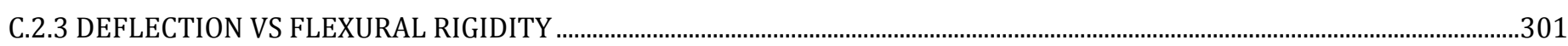

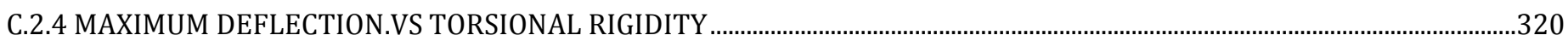

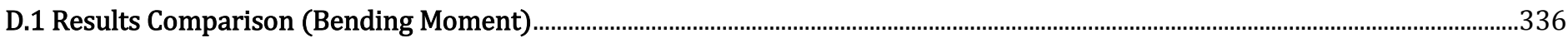

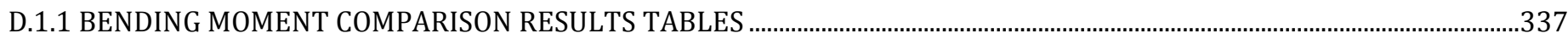

D.1.2 MAXIMUM BENDING MOMENT VS SPAN LENGTH …………............................................................................................................356

D.1.2 MAXIMUM BENDING MOMENT VS FLEXURAL RIGIDITY ……..............................................................................................429

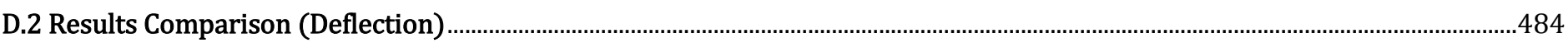

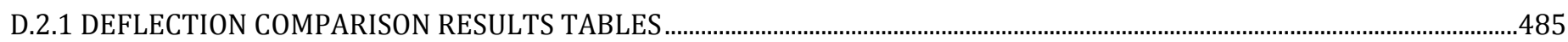

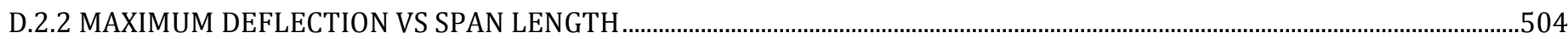

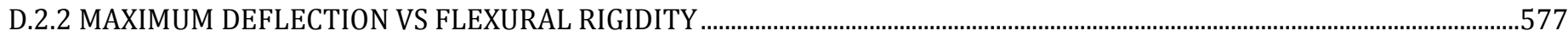

E.1 Factored Bending Moment

E.1.1 BENDING MOMENT RESULTS TABLES ………....................................................................................................................633

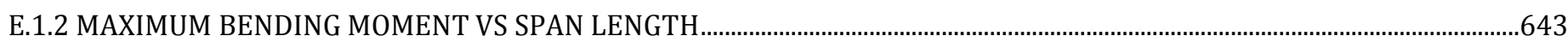

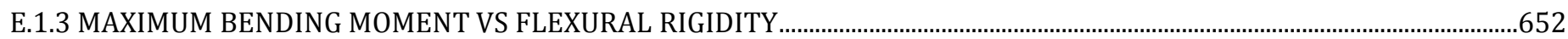

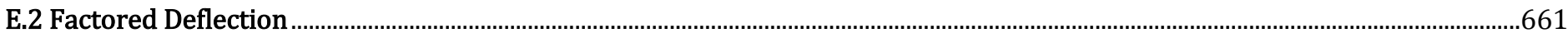

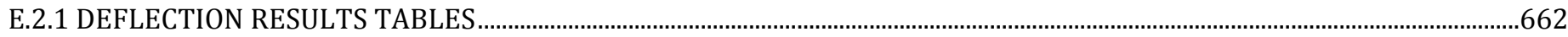




\section{List of Symbols and Abbreviations}

$\mathrm{D}_{\mathrm{x}}=$ flexural rigidity in the strong direction (short direction)

$\mathrm{D}_{\mathrm{y}}=$ flexural rigidity in the weak direction (long direction)

$\mathrm{D}_{1}=$ torsional rigidity contribution resultant from both strong and weak direction

$\mathrm{D}_{\mathrm{xy}}=$ torsional rigidity

$\mathrm{H}=$ the sum of torsional rigidity from strong and weak direction $\left(\mathrm{D}_{1}\right)$ and torsional rigidity $\left(\mathrm{D}_{\mathrm{xy}}\right)$

$\mathrm{w}(\mathrm{x}, \mathrm{y})=$ vertical deflection in the Cartesian coordinate system

$\mathrm{q}(\mathrm{x}, \mathrm{y})=$ vertical applied load in Cartesian coordinates

$\mathrm{M}_{\mathrm{x}}=$ moment in $\mathrm{x}$-direction

$\mathrm{M}_{\mathrm{y}}=$ moment in y-direction.

$\mathrm{E}_{\mathrm{X}}=$ modulus of elasticity in $\mathrm{x}$-direction

$\mathrm{E}_{\mathrm{y}}=$ modulus of elasticity in $\mathrm{y}$-direction

$\mathrm{L}=$ span length in $\mathrm{x}$-direction

$\zeta=$ tire distance from support

$\mathrm{u} / \mathrm{v}=$ tire dimensions.

$\mathrm{v}_{\mathrm{x}}=$ poison's in the $\mathrm{x}$-direction

$\mathrm{v}_{\mathrm{y}}=$ poison's in the $\mathrm{y}$-direction

$\mathrm{G}=$ Shear modulus

$\mathrm{t}=$ plate thickness

$\alpha=$ Torsional rigidity factor

$\mathrm{D}=\mathrm{D}_{\mathrm{x}} / \mathrm{D}_{\mathrm{y}}$

$\mathrm{P}=87.5(\mathrm{kN})$

$\mathrm{S}_{\mathrm{e}}=$ the effective span between girders web to web (m)

$\mathrm{E}=$ the moment distribution width

$\mathrm{S}=$ the effective $\operatorname{span}(\mathrm{m})$ 


\section{Background and introduction}

Many different types of bridge decks are being deployed and constructed. These types of decks include conventional slab on girder and combination of grid work of steel elements filled with concrete. The diversity of types of bridge decks provides both designers and contractors with a variety of tools to optimize design and construction. While the diversity of bridge decks has many benefits yet the lack of simple unified methodology of analysis is major drawback. Therefore, the urge for a unified methodology of analysis that combines all bridge decks under a single formula is vital. Since the main common property between all types of bridge decks is. their orthotropic properties. This can be the bases of a unified approach.
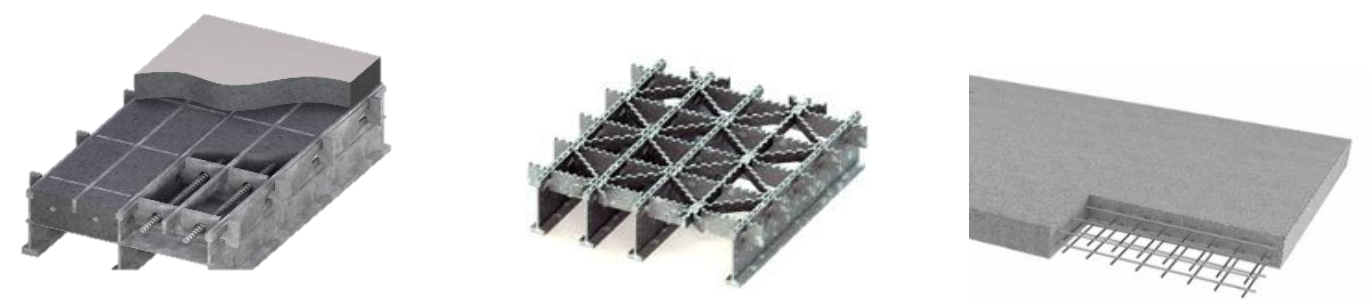

Figure 1 Deck types discussed in the report from the left fully/partially filled decks, open grid decks and typically reinforced decks "thick plate" (source: BGFMA, 2016)

\subsection{Orthotropic Plate Theory}

Earlier work done by (Timoshenko \& Woinowski-Krieger, 1959) proposed the following differential equations to predict the bending moments and twisting moment of thin plate:

$$
\begin{aligned}
& D_{x} \frac{\partial^{4} w}{\partial x^{4}}+2 H \frac{\partial^{4} w}{\partial x^{2} \partial y^{4}}+D_{y} \frac{\partial^{4} w}{\partial y^{4}}=q(x, y) \quad \text { where } H=D_{1}+2 D_{x y} \\
& M_{x}=-\left(D_{x} \frac{\partial^{2} w}{\partial x^{2}}+D_{1} \frac{\partial^{2} w}{\partial y^{2}}\right) \\
& M_{y}=-\left(D_{y} \frac{\partial^{2} w}{\partial y^{2}}+D_{1} \frac{\partial^{2} w}{\partial x^{2}}\right) \\
& M_{x}=2 D_{x y} \frac{\partial^{2} w}{\partial x \partial y}
\end{aligned}
$$

Where $D_{x}=$ flexural rigidity in the strong direction (short direction); $D_{y}=$ flexural rigidity in the weak direction (long direction); $\mathrm{D}_{1}=$ torsional rigidity contribution resultant from both strong and 
weak direction; $\mathrm{D}_{\mathrm{xy}}=$ torsional rigidity; $\mathrm{H}=$ the sum of torsional rigidity from strong and weak direction $\left(D_{1}\right)$ and torsional rigidity $\left(D_{x y}\right) ; w(x, y)=$ vertical deflection in the Cartesian coordinate system; $\mathrm{q}(\mathrm{x}, \mathrm{y})=$ vertical applied load in Cartesian coordinates; $\mathrm{M}_{\mathrm{x}}=$ moment in $\mathrm{x}$-direction; $\mathrm{M}_{\mathrm{y}}=$ moment in y-direction.

Depending on the torsional rigidity (Timoshenko \& Woinowski-Krieger, 1959) proposed three possible scenarios:

Case $1: H>\sqrt{D_{x} D_{y}}$; this case corresponds to relatively stiff torsional rigidity, flexurally soft decks which is consistent with partially and fully filled grid decks.

Case2: $\mathrm{H}=\sqrt{\mathrm{D}_{\mathrm{x}} \mathrm{D}_{\mathrm{y}}}$; this case corresponds to uniformly thick plate or typical reinforced concrete slab. Slab on girders or floor beam are perfect examples for this case.

Case $3: H<\sqrt{\mathrm{D}_{\mathrm{x}} \mathrm{D}_{\mathrm{y}}}$; this case corresponds to relatively soft torsional rigidity, flexurally stiff decks which is consistent with open grid decks.

As per (Higgins C. , 2003) and (Turan, 2009) simplified equations based on (Timoshenko \& Woinowski-Krieger, 1959)original work for isotropic plates, a conservative estimation for bending moment and deflection of an infinitely long plate can be obtained using the following equations:

Case1:

$$
\begin{aligned}
& \mathrm{M}_{\mathrm{x}}\left(\mathrm{y} \geq \frac{\mathrm{v}}{2}\right)= \frac{2 \mathrm{~L}^{2} \mathrm{q}}{\pi^{3}} \sum_{\mathrm{m}=1}^{\infty} \frac{1}{\mathrm{~m}^{3}} \sin \left(\frac{\mathrm{m} \pi \zeta}{\mathrm{L}}\right) \sin \left(\frac{\mathrm{m} \pi \mathrm{u}}{2 \mathrm{~L}}\right) \sin \left(\frac{\mathrm{m} \pi \mathrm{x}}{\mathrm{L}}\right) \\
& \times\left[\frac { \mathrm { t } _ { 1 } ^ { 2 } } { \mathrm { t } _ { 1 } ^ { 2 } - \mathrm { t } _ { 2 } ^ { 2 } } \left(\mathrm{e}^{\frac{\left[-\mathrm{m} \pi \mathrm{t}_{2}(2 \mathrm{y}-\mathrm{v})\right]}{2 \mathrm{~L}}}-\mathrm{e}^{\left.\frac{\left[-\mathrm{m} \pi \mathrm{t}_{2}(2 \mathrm{y}+\mathrm{v})\right]}{2 \mathrm{~L}}\right)}\right.\right. \\
&-\frac{\mathrm{t}_{1}^{2}}{\mathrm{t}_{1}^{2}-\mathrm{t}_{2}^{2}}\left(\mathrm{e}^{\frac{[-\mathrm{m \pi t}(2 \mathrm{y}-\mathrm{v})]}{2 \mathrm{~L}}}-\mathrm{e}^{\left.\left.\frac{\left[-\mathrm{m \pi t} \mathrm{t}_{1}(2 \mathrm{y}+\mathrm{v})\right]}{2 \mathrm{~L}}\right)\right]}\right. \\
& \mathrm{M}_{\mathrm{x}}(\mathrm{y}=0)=\frac{4 \mathrm{~L}^{2} \mathrm{q}}{\pi^{3}} \sum_{\mathrm{m}=1}^{\infty} \frac{1}{\mathrm{~m}^{3}} \sin \left(\frac{\mathrm{m \pi \zeta}}{\mathrm{L}}\right) \sin \left(\frac{\mathrm{m} \pi \mathrm{u}}{2 \mathrm{~L}}\right) \sin \left(\frac{\mathrm{m} \pi \mathrm{x}}{\mathrm{L}}\right) \\
& \times\left[1+\frac{\mathrm{t}_{1}^{2}}{\mathrm{t}_{1}^{2}-\mathrm{t}_{2}^{2}}\left(\mathrm{e}^{\frac{\left[-\mathrm{m} \pi \mathrm{t}_{1} \mathrm{v}\right]}{2 \mathrm{~L}}}\right)-\frac{\mathrm{t}_{1}^{2}}{\mathrm{t}_{1}^{2}-\mathrm{t}_{2}^{2}}\left(\mathrm{e}^{\frac{\left[-\mathrm{m} \pi \mathrm{t}_{2} \mathrm{v}\right]}{2 \mathrm{~L}}}\right)\right]
\end{aligned}
$$




$$
\begin{aligned}
& \mathrm{w}_{\mathrm{x}}\left(\mathrm{y} \geq \frac{\mathrm{v}}{2}\right)=\frac{2 \mathrm{~L}^{2} \mathrm{q}}{\pi^{5} \mathrm{D}_{\mathrm{x}}} \sum_{\mathrm{m}=1}^{\infty} \frac{1}{\mathrm{~m}^{5}} \sin \left(\frac{\mathrm{m} \pi \zeta}{\mathrm{L}}\right) \sin \left(\frac{\mathrm{m} \pi \mathrm{u}}{2 \mathrm{~L}}\right) \sin \left(\frac{\mathrm{m} \pi \mathrm{x}}{\mathrm{L}}\right) \\
& \times\left[\frac{\mathrm{t}_{1}^{2}}{\mathrm{t}_{1}^{2}-\mathrm{t}_{2}^{2}}\left(\mathrm{e}^{\frac{\left[-\mathrm{m} \pi \mathrm{t}_{2}(2 \mathrm{y}-\mathrm{v})\right]}{2 \mathrm{~L}}}-\mathrm{e}^{\frac{\left[-\mathrm{m}^{2} \mathrm{t}_{2}(2 \mathrm{y}+\mathrm{v})\right]}{2 \mathrm{~L}}}\right)\right. \\
& \left.-\frac{\mathrm{t}_{1}^{2}}{\mathrm{t}_{1}^{2}-\mathrm{t}_{2}^{2}}\left(\mathrm{e}^{\frac{\left[-\mathrm{m} \pi \mathrm{t}_{1}(2 \mathrm{y}-\mathrm{v})\right]}{2 \mathrm{~L}}}-\mathrm{e}^{\frac{\left[-\mathrm{m} \pi \mathrm{t}_{1}(2 \mathrm{y}+\mathrm{v})\right]}{2 \mathrm{~L}}}\right)\right] \\
& \mathrm{w}(\mathrm{y}=0)=\frac{4 \mathrm{~L}^{2} \mathrm{q}}{\pi^{5} \mathrm{D}_{\mathrm{x}}} \sum_{\mathrm{m}=1}^{\infty} \frac{1}{\mathrm{~m}^{3}} \sin \left(\frac{\mathrm{m} \pi \zeta}{\mathrm{L}}\right) \sin \left(\frac{\mathrm{m} \pi \mathrm{u}}{2 \mathrm{~L}}\right) \sin \left(\frac{\mathrm{m} \pi \mathrm{x}}{\mathrm{L}}\right) \\
& \times\left[1+\frac{\mathrm{t}_{1}^{2}}{\mathrm{t}_{1}^{2}-\mathrm{t}_{2}^{2}}\left(\mathrm{e}^{\frac{\left[-m \pi \mathrm{t}_{1} \mathrm{v}\right]}{2 \mathrm{~L}}}\right)-\frac{\mathrm{t}_{1}^{2}}{\mathrm{t}_{1}^{2}-\mathrm{t}_{2}^{2}}\left(\mathrm{e}^{\frac{\left[-\mathrm{m} \pi \mathrm{t}_{2} \mathrm{v}\right]}{2 \mathrm{~L}}}\right)\right]
\end{aligned}
$$

Where

$t_{1}=\sqrt{\frac{H}{D_{y}}+\frac{\sqrt{H^{2}-D_{x} D_{y}}}{D_{y}}}$ and $t_{2}=\sqrt{\frac{H}{D_{y}}-\frac{\sqrt{H^{2}-D_{x} D_{y}}}{D_{y}}}$

Case2:

$$
\begin{aligned}
\mathrm{M}_{\mathrm{x}}\left(\mathrm{y} \geq \frac{\mathrm{v}}{2}\right)= & \frac{\mathrm{Lq}}{\lambda \pi^{2}} \sum_{\mathrm{m}=1}^{\infty} \frac{1}{\mathrm{~m}^{2}} \sin \left(\frac{\mathrm{m} \pi \zeta}{\mathrm{L}}\right) \sin \left(\frac{\mathrm{m} \pi \mathrm{u}}{2 \mathrm{~L}}\right) \sin \left(\frac{\mathrm{m} \pi \mathrm{x}}{\mathrm{L}}\right) \\
& \times\left[\left(\frac{2 \mathrm{~L} \lambda}{\mathrm{m} \pi}+\mathrm{y}-\frac{\mathrm{v}}{2}\right) \mathrm{e}^{\frac{[-\mathrm{m} \pi(2 \mathrm{y}-\mathrm{v})]}{2 \mathrm{~L} \lambda}}-\left(\frac{2 \mathrm{~L} \lambda}{\mathrm{m} \pi}+\mathrm{y}+\frac{\mathrm{v}}{2}\right) \mathrm{e}^{\left.\frac{[-\mathrm{m} \pi(2 \mathrm{y}+\mathrm{v})]}{2 \mathrm{~L} \lambda}\right]}\right. \\
\mathrm{M}_{\mathrm{x}}(\mathrm{y}=0)= & \frac{4 \mathrm{~L}^{2} \mathrm{q}}{\pi^{3}} \sum_{\mathrm{m}=1}^{\infty} \frac{1}{\mathrm{~m}^{3}} \sin \left(\frac{\mathrm{m} \pi \zeta}{\mathrm{L}}\right) \sin \left(\frac{\mathrm{m} \pi \mathrm{u}}{2 \mathrm{~L}}\right) \sin \left(\frac{\mathrm{m} \pi \mathrm{x}}{\mathrm{L}}\right) \times\left[1-\left(1+\frac{\mathrm{m} \pi \mathrm{v}}{4 \mathrm{~L} \lambda}\right) \mathrm{e}^{\left.\frac{-\mathrm{m} \pi \mathrm{v}}{2 \mathrm{~L} \lambda}\right]}\right. \\
\mathrm{w}_{\mathrm{x}}\left(\mathrm{y} \geq \frac{\mathrm{v}}{2}\right)= & \frac{\mathrm{L}^{3} \mathrm{q}}{\lambda \pi^{4} \mathrm{D}_{\mathrm{x}}} \sum_{\mathrm{m}=1}^{\infty} \frac{1}{\mathrm{~m}^{4}} \sin \left(\frac{\mathrm{m} \pi \zeta}{\mathrm{L}}\right) \sin \left(\frac{\mathrm{m} \pi \mathrm{u}}{2 \mathrm{~L}}\right) \sin \left(\frac{\mathrm{m} \pi \mathrm{x}}{\mathrm{L}}\right) \\
& \times\left[\left(\frac{2 \mathrm{~L} \lambda}{\mathrm{m} \pi}+\mathrm{y}-\frac{\mathrm{v}}{2}\right) \mathrm{e}^{\frac{[-\mathrm{m} \pi(2 \mathrm{y}-\mathrm{v})]}{2 \mathrm{~L} \lambda}}-\left(\frac{2 \mathrm{~L} \lambda}{\mathrm{m} \pi}+\mathrm{y}+\frac{\mathrm{v}}{2}\right) \mathrm{e}^{\left.\frac{[-\mathrm{m} \pi(2 \mathrm{y}+\mathrm{v})]}{2 \mathrm{~L} \lambda}\right]}\right. \\
\mathrm{w}(\mathrm{y}=0)= & \frac{4 \mathrm{~L}^{4} \mathrm{q}}{\pi^{5} \mathrm{D}_{\mathrm{x}}} \sum_{\mathrm{m}=1}^{\infty} \frac{1}{\mathrm{~m}^{5}} \sin \left(\frac{\mathrm{m} \pi \zeta}{\mathrm{L}}\right) \sin \left(\frac{\mathrm{m} \pi \mathrm{u}}{2 \mathrm{~L}}\right) \sin \left(\frac{\mathrm{m} \pi \mathrm{x}}{\mathrm{L}}\right) \times\left[1-\left(1+\frac{\mathrm{m} \pi \mathrm{v}}{4 \mathrm{~L} \lambda}\right) \mathrm{e}^{\left.\frac{-\mathrm{m} \pi \mathrm{v}}{2 \mathrm{~L} \lambda}\right]}\right.
\end{aligned}
$$

\section{Case3:}




$$
\begin{aligned}
& M_{x}\left(y \geq \frac{v}{2}\right)=\frac{2 L^{2} q}{\pi^{3}} \sum_{m=1}^{\infty} \frac{1}{m^{3}} \sin \left(\frac{m \pi \zeta}{L}\right) \sin \left(\frac{m \pi u}{2 L}\right) \sin \left(\frac{m \pi x}{L}\right) \\
& \times\left[\mathrm{e}^{\frac{\left[-\mathrm{m} \pi \mathrm{t}_{1}(2 \mathrm{y}-\mathrm{v})\right]}{2 \mathrm{~L}}}\left(\cos \left(\frac{\mathrm{m} \pi \mathrm{t}_{2}\left(\mathrm{y}-\frac{\mathrm{v}}{2}\right)}{\mathrm{L}}\right)+\frac{\mathrm{t}_{1}^{2}-\mathrm{t}_{2}^{2}}{2 \mathrm{t}_{1} \mathrm{t}_{2}} \sin \left(\frac{\mathrm{m} \pi \mathrm{t}_{2}\left(\mathrm{y}-\frac{\mathrm{v}}{2}\right)}{\mathrm{L}}\right)\right)\right. \\
& \left.-\mathrm{e}^{\frac{\left[-m \pi \mathrm{t}_{1}(2 \mathrm{y}+\mathrm{v})\right]}{2 \mathrm{~L}}}\left(\cos \left(\frac{\mathrm{m} \pi \mathrm{t}_{2}\left(\mathrm{y}+\frac{\mathrm{v}}{2}\right)}{\mathrm{L}}\right)+\frac{\mathrm{t}_{1}^{2}-\mathrm{t}_{2}^{2}}{2 \mathrm{t}_{1} \mathrm{t}_{2}} \sin \left(\frac{\mathrm{m} \pi \mathrm{t}_{2}\left(\mathrm{y}+\frac{\mathrm{v}}{2}\right)}{\mathrm{L}}\right)\right)\right] \\
& \mathrm{M}_{\mathrm{x}}(\mathrm{y}=0)=\frac{4 \mathrm{~L}^{2} \mathrm{q}}{\pi^{3}} \sum_{\mathrm{m}=1}^{\infty} \frac{1}{\mathrm{~m}^{3}} \sin \left(\frac{\mathrm{m} \pi \zeta}{\mathrm{L}}\right) \sin \left(\frac{\mathrm{m} \pi \mathrm{u}}{2 \mathrm{~L}}\right) \sin \left(\frac{\mathrm{m} \pi \mathrm{x}}{\mathrm{L}}\right) \\
& \times\left[\mathrm{e}^{\frac{\left[-\mathrm{m} \pi \mathrm{t}_{1} \mathrm{v}\right]}{2 \mathrm{~L}}}\left(1-\left(\cos \left(\frac{\mathrm{m}^{\mathrm{t}} \mathrm{t}_{2} \mathrm{v}}{\mathrm{L}}\right)+\frac{\mathrm{t}_{1}^{2}-\mathrm{t}_{2}^{2}}{2 \mathrm{t}_{1} \mathrm{t}_{2}} \sin \left(\frac{\mathrm{m} \pi \mathrm{t}_{2} \mathrm{v}}{2 \mathrm{~L}}\right)\right)\right)\right] \\
& \mathrm{w}_{\mathrm{x}}\left(\mathrm{y} \geq \frac{\mathrm{v}}{2}\right)=\frac{2 \mathrm{~L}^{4} \mathrm{q}}{\pi^{5} \mathrm{D}_{\mathrm{x}}} \sum_{\mathrm{m}=1}^{\infty} \frac{1}{\mathrm{~m}^{5}} \sin \left(\frac{\mathrm{m} \pi \zeta}{\mathrm{L}}\right) \sin \left(\frac{\mathrm{m} \pi \mathrm{u}}{2 \mathrm{~L}}\right) \sin \left(\frac{\mathrm{m} \pi \mathrm{x}}{\mathrm{L}}\right) \\
& \times\left[\mathrm{e}^{\frac{\left[-\mathrm{m} \pi \mathrm{t}_{1}(2 \mathrm{y}-\mathrm{v})\right]}{2 \mathrm{~L}}}\left(\cos \left(\frac{\mathrm{m \pi t} \mathrm{t}_{2}\left(\mathrm{y}-\frac{\mathrm{v}}{2}\right)}{\mathrm{L}}\right)+\frac{\mathrm{t}_{1}^{2}-\mathrm{t}_{2}^{2}}{2 \mathrm{t}_{1} \mathrm{t}_{2}} \sin \left(\frac{\mathrm{m \pi t} \mathrm{t}_{2}\left(\mathrm{y}-\frac{\mathrm{v}}{2}\right)}{\mathrm{L}}\right)\right)\right. \\
& \left.-\mathrm{e}^{\frac{\left[-m \pi \mathrm{t}_{1}(2 \mathrm{y}+\mathrm{v})\right]}{2 \mathrm{~L}}}\left(\cos \left(\frac{\mathrm{m} \pi \mathrm{t}_{2}\left(\mathrm{y}+\frac{\mathrm{v}}{2}\right)}{\mathrm{L}}\right)+\frac{\mathrm{t}_{1}^{2}-\mathrm{t}_{2}^{2}}{2 \mathrm{t}_{1} \mathrm{t}_{2}} \sin \left(\frac{\mathrm{m} \pi \mathrm{t}_{2}\left(\mathrm{y}+\frac{\mathrm{v}}{2}\right)}{\mathrm{L}}\right)\right)\right] \\
& \mathrm{w}_{\mathrm{x}}(\mathrm{y}=0)=\frac{4 \mathrm{~L}^{2} \mathrm{q}}{\pi^{5} \mathrm{D}_{\mathrm{x}}} \sum_{\mathrm{m}=1}^{\infty} \frac{1}{\mathrm{~m}^{5}} \sin \left(\frac{\mathrm{m} \pi \zeta}{\mathrm{L}}\right) \sin \left(\frac{\mathrm{m} \pi \mathrm{u}}{2 \mathrm{~L}}\right) \sin \left(\frac{\mathrm{m} \pi \mathrm{x}}{\mathrm{L}}\right) \\
& \times\left[\mathrm{e}^{\frac{\left[-\mathrm{m} \pi \mathrm{t}_{1} \mathrm{v}\right]}{2 \mathrm{~L}}}\left(1-\left(\cos \left(\frac{\mathrm{m} \pi \mathrm{t}_{2} \mathrm{v}}{\mathrm{L}}\right)+\frac{\mathrm{t}_{1}^{2}-\mathrm{t}_{2}^{2}}{2 \mathrm{t}_{1} \mathrm{t}_{2}} \sin \left(\frac{\mathrm{m} \pi \mathrm{t}_{2} \mathrm{v}}{2 \mathrm{~L}}\right)\right)\right)\right]
\end{aligned}
$$

Where

$t_{1}=\sqrt{\frac{H}{D_{y}}+\frac{\sqrt{H^{2}-D_{x} D_{y}}}{D_{y}}}$ and $t_{2}=\sqrt{\frac{H}{D_{y}}-\frac{\sqrt{H^{2}-D_{x} D_{y}}}{D_{y}}}$

Where $\mathrm{E}_{\mathrm{x}}=$ modulus of elasticity in $\mathrm{x}$-direction; $\mathrm{E}_{\mathrm{y}}=$ modulus of elasticity in $\mathrm{y}$-direction; $\mathrm{D}_{\mathrm{x}}=$ flexural rigidity in the strong direction (short direction); $\mathrm{D}_{\mathrm{y}}=$ flexural rigidity in the weak direction (long direction); $\mathrm{D}_{1}=$ torsional rigidity contribution resultant from both strong and weak direction; $\mathrm{D}_{\mathrm{xy}}=$ torsional rigidity; $\mathrm{H}=$ the sum of torsional rigidity from strong and weak direction $\left(D_{1}\right)$ and torsional rigidity $\left(D_{x y}\right) ; w_{x}=$ vertical deflection in $x$-direction; $M_{x}=$ moment in $x-$ 
direction; $\mathrm{q}=$ vertical applied pressure; $\mathrm{L}=$ span length in $\mathrm{x}$-direction; $\zeta=$ tire distance from support; $\mathrm{u}$ and $\mathrm{v}=$ tire dimensions.

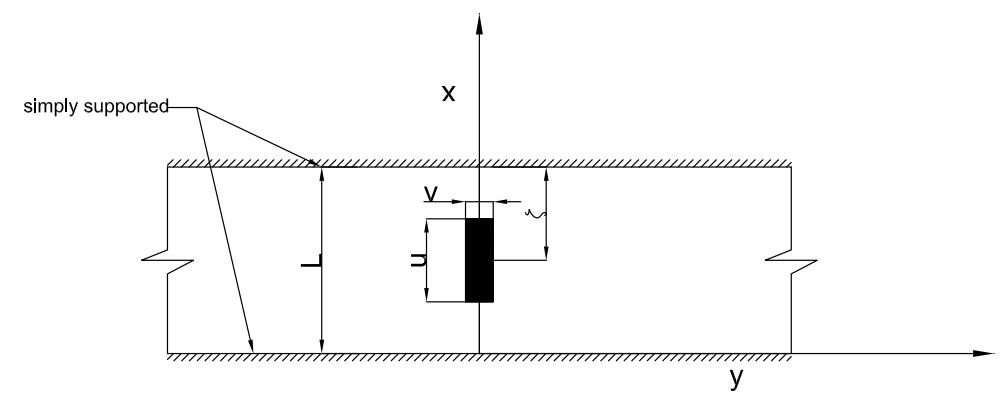

Figure 2 Single Patch load

$$
\begin{aligned}
& D_{x}=\frac{E_{x} t^{3}}{12\left(1-v_{x} v_{y}\right)} \\
& D_{y}=\frac{E_{y} t^{3}}{12\left(1-v_{x} v_{y}\right)} \\
& D_{x y}=\frac{G t^{3}}{12} \\
& D_{1}=D_{x} v_{y}
\end{aligned}
$$

Where $D_{\mathrm{x}}=$ flexural rigidity in the strong direction (short direction); $\mathrm{D}_{\mathrm{y}}=$ flexural rigidity in the weak direction (long direction); $\mathrm{D}_{\mathrm{xy}}=$ torsional rigidity; $\mathrm{D}_{1}=$ torsional rigidity contribution resultant from both strong and weak direction; $\mathrm{v}_{\mathrm{x}}=$ poison's in the $\mathrm{x}$-direction; $\mathrm{v}_{\mathrm{y}}=$ poison's in the $\mathrm{y}$-direction; $\mathrm{G}=$ Shear modulus; $\mathrm{t}=$ plate thickness.

\section{Assumptions}

In all cases discussed poison's ratio was assumed to be zero as per (Higgins, Turan, Connor, \& Liu, 2011), which sets equation 20 to zero. As reported in (Mangelsdorf, Baker, \& Swanson, 2002) while concrete in grid cells are experiencing poison's ration in biaxial behavior, they might be restricted to exhibit that behaviour due to the confinement of the grid, restricting the expansion of concrete laterally, leading to a practical assumption of poisons ration equal to zero. While (Baker, 1991) mentioned that comparing $D_{x}$ and $D_{y}$, the effect of $D_{1}$ is very small Based on these assumptions $D_{x}$ and $D_{y}$ would be reduced $E_{x} I_{x}$ and $E_{y} I_{y}$ respectively. To demonstrate the effect of $H$ on the deck performance for cases1, 2 and 3; $H$ can be presented as $H=\alpha \sqrt{D_{x} D_{y}}$. 


\subsection{AASHTO Provisions}

The current American Association of State Highway and Transportation Officials (AASHTO) specification covers a design procedure and formulation based on the orthotropic plate theory proposed by (Timoshenko \& Woinowski-Krieger, 1959), and further developed by (Higgins C. , 2003). Section 4.6.2.1.8 presents two different sets of equations where main reinforcement are transverse and parallel to traffic direction. These procedures can be summarized as follows: For bending:

$\mathrm{L} \leq 120$ in $(3050 \mathrm{~mm})$

$$
\begin{aligned}
& \left.M_{\text {transverse }}=1.28 \mathrm{D}^{0.197} \mathrm{~L}^{0.459} \mathrm{C} \text { (kip. in } / \text { in }\right) \\
& \mathrm{M}_{\text {parallel }}=0.73 \mathrm{D}^{0.123} \mathrm{~L}^{0.64} \mathrm{C}(\mathrm{kip} . \mathrm{in} / \mathrm{in}) \\
\mathrm{L}> & 120 \text { in }(3050 \mathrm{~mm}) \\
& \mathrm{M}_{\text {transverse }}=\frac{\mathrm{D}^{0.183}\left(3.7 \mathrm{~L}^{1.35}-956.3\right)}{\mathrm{L}} \mathrm{C}(\mathrm{kip} . \mathrm{in} / \mathrm{in}) \\
& \mathrm{M}_{\text {parallel }}=\frac{\mathrm{D}^{0.138}\left(3.1 \mathrm{~L}^{1.429}-1088.5\right)}{\mathrm{L}} \mathrm{C}(\mathrm{kip} . \mathrm{in} / \mathrm{in})
\end{aligned}
$$

For deflection

$$
\begin{aligned}
& \Delta_{\text {transverse }}=\frac{0.0052 \mathrm{D}^{0.19} \mathrm{~L}^{3}}{\mathrm{D}_{\mathrm{x}}} \text { (in) } \\
& \Delta_{\text {parallel }}=\frac{0.0072 \mathrm{D}^{0.11} \mathrm{~L}^{3}}{\mathrm{D}_{\mathrm{x}}} \text { (in) }
\end{aligned}
$$

where, $\mathrm{L}$ is the span length from center-center of supports, $\mathrm{C}$ is continuity factor (1) for simply supported (0.8) for continuous spans, $D$ is $D_{x} / D_{y}, D_{x}$ is the flexural rigidity of deck in main bar direction and $\mathrm{D}_{\mathrm{y}}$ is flexural rigidity of deck perpendicular to main bar directions. (AASHTO LRFD Bridge Design Specifications, 2014)

\subsection{Canadian Code Provisions}

The current provisions in the Canadian Highway Bridge Design Code "CHBDC"(2014), does not include a comprehensive method of analysis for bridge decks under live load except for section 5.7.1.7 which discusses the simplified elastic method for concrete deck slabs supported on longitudinal girders and still grid decks. These provisions can be summarized as follows:

For concrete slab decks on girders: 


$$
\text { Moment }(\mathrm{kNm} / \mathrm{m})=\frac{\left(\mathrm{S}_{\mathrm{e}+}+0.6\right) \mathrm{P}}{10}
$$

Where $\mathrm{P}=87.5 \mathrm{kN}$ and $\mathrm{S}_{\mathrm{e}}$ is the effective span between girders web to web; for continuous span the value for bending moment should be reduced by $80 \%$.

For steel grid decks:

$$
\begin{array}{ll}
\mathrm{E}=1.22+0.06 \mathrm{~S} \leq 2.1 \mathrm{~m} & \\
\text { Moment }(\mathrm{kNm})=0.1 \mathrm{PS} & \text { for simple spans } \\
\text { Moment }(\mathrm{kNm})=0.08 \mathrm{PS} & \text { for continuous spans }
\end{array}
$$

Where $\mathrm{E}$ is the moment distribution width, $\mathrm{P}=87.5 \mathrm{kN}$ and $\mathrm{S}$ is the effective span.

As demonstrated, the current CHBDC provisions does not provided a detailed comprehensive design approach for bridge decks with different flexural rigidities or torsional rigidities.

For other bridge deck analysis that does not fall under the limitations set in the CHBDC, the code refers to refined methods of analysis that includes "Orthotropic Plate theory".

The lack of a comprehensive method of analysis in the Canadian code could be challenging for designer especially without clear guidelines on the assumptions of the refined methods being used. 


\section{Finite Element Analysis}

For the purposes of this report the following analyses will be examining cases 1, 2 and 3 of orthotropic plate analyses and will be investigated using Canadian truck (CL-625). The following sections will discuss in detail the steps, procedures and analyses performed to validate the orthotropic plate theory procedure and compare it with Finite Element Analysis "FEA" using SAP2000.

\subsection{Sensitivity Analysis}

In order to ensure the accuracy of the FEA and the precision of the results a preliminary analysis was conducted to optimize the element size and shape. Therefore, different models were developed with different element sizes to check the precision of the results of each model compared to the orthotropic plate analysis. After different trials of different elements sizes, it was determined that the optimal element size would be $50 \mathrm{mmx} 50 \mathrm{~mm}$.

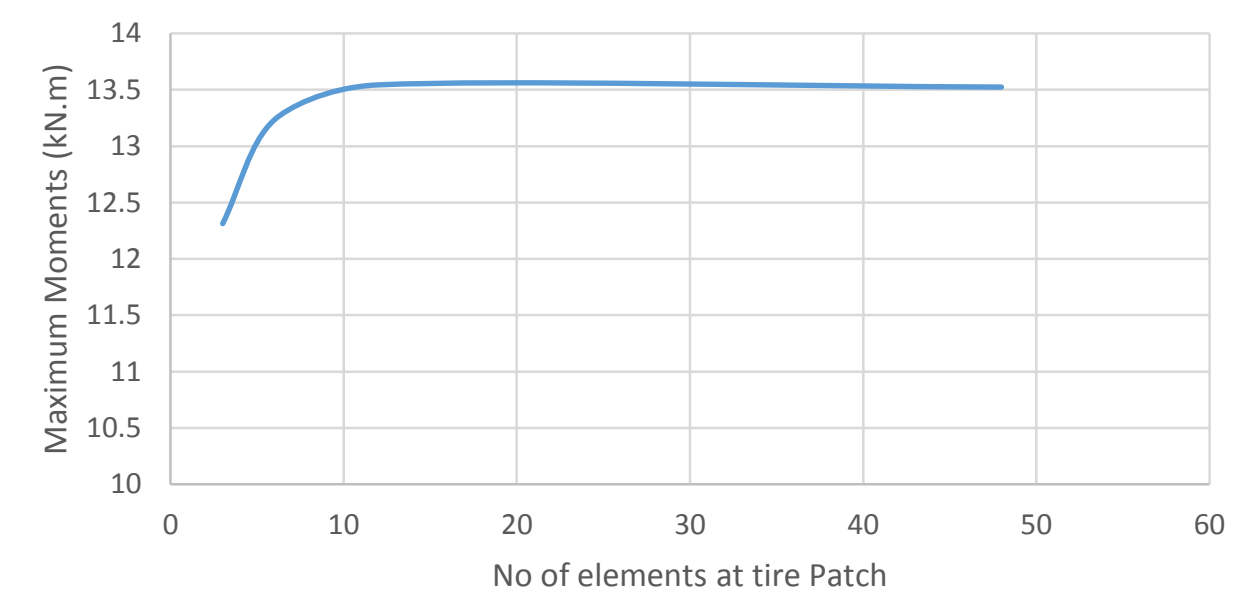

Figure 3 Comparison of maximum bending moment at different element sizes

Also another sensitivity analysis was conducted to check the response of the FEA with respect to the assumptions of the orthotropic plate theory in terms of material properties and rigidity values. The following tables summaries the material properties that will be used through the FEA along with a comparison of the corresponding results from orthotropic plate theory. 
Table 1 Material properties for case 2

\begin{tabular}{cccccccc}
\hline $\boldsymbol{D}$ & $\boldsymbol{E}_{\boldsymbol{x}}$ & $\boldsymbol{E}_{\boldsymbol{y}}$ & $\boldsymbol{v}$ & $\boldsymbol{D}_{\boldsymbol{x}}$ & $\boldsymbol{D}_{\boldsymbol{y}}$ & $\boldsymbol{D}_{\boldsymbol{x} \boldsymbol{y}}$ & $\boldsymbol{G}$ \\
\hline 0.25 & 24648000 & 98592000 & 0 & 16432 & 65728 & 16432 & 24648000 \\
\hline 0.5 & 24648000 & 49296000 & 0 & 16432 & 32864 & 11619 & 17428768 \\
\hline 0.75 & 24648000 & 32864000 & 0 & 16432 & 21909 & 9487 & 14230529 \\
\hline 1 & 24648000 & 24648000 & 0 & 16432 & 16432 & 8216 & 12324000 \\
\hline 2 & 24648000 & 12324000 & 0 & 16432 & 8216 & 5810 & 8714384 \\
\hline 4 & 24648000 & 6162000 & 0 & 16432 & 4108 & 4108 & 6162000 \\
\hline 6 & 24648000 & 4108000 & 0 & 16432 & 2739 & 3354 & 5031252 \\
\hline 8 & 24648000 & 3081000 & 0 & 16432 & 2054 & 2905 & 4357192 \\
\hline 10 & 24648000 & 2464800 & 0 & 16432 & 1643 & 2598 & 3897191 \\
\hline
\end{tabular}

Table 2 Comparison between Orthotropic formulation and FEA for case 2

\section{Orthotropic Formulation $\quad$ FEA $\quad$ \%error}

\begin{tabular}{cccccc}
\hline Moment & Deflection & Moment & Deflection & Moment & Deflection \\
\hline 8.423 & $5.17 \mathrm{E}-05$ & 8.453 & $5.18 \mathrm{E}-05$ & $0.35 \%$ & $0.24 \%$ \\
\hline 9.978 & $6.12 \mathrm{E}-05$ & 10.026 & $6.14 \mathrm{E}-05$ & $0.48 \%$ & $0.36 \%$ \\
\hline 11.010 & $6.75 \mathrm{E}-05$ & 11.073 & $6.78 \mathrm{E}-05$ & $0.57 \%$ & $0.46 \%$ \\
\hline 11.802 & $7.24 \mathrm{E}-05$ & 11.879 & $7.28 \mathrm{E}-05$ & $0.65 \%$ & $0.55 \%$ \\
\hline 13.931 & $8.54 \mathrm{E}-05$ & 14.055 & $8.60 \mathrm{E}-05$ & $0.89 \%$ & $0.78 \%$ \\
\hline 16.398 & $1.00 \mathrm{E}-04$ & 16.598 & $1.02 \mathrm{E}-04$ & $1.21 \%$ & $1.06 \%$ \\
\hline 18.010 & $1.10 \mathrm{E}-04$ & 18.273 & $1.12 \mathrm{E}-04$ & $1.44 \%$ & $1.38 \%$ \\
\hline 19.232 & $1.18 \mathrm{E}-04$ & 19.551 & $1.20 \mathrm{E}-04$ & $1.63 \%$ & $1.49 \%$ \\
\hline 20.225 & $1.24 \mathrm{E}-04$ & 20.479 & $1.25 \mathrm{E}-04$ & $1.24 \%$ & $1.13 \%$ \\
\hline
\end{tabular}

Since most of the results agree with orthotropic plate analysis with a variation in percent error varying between $0.24 \%-1.13 \%$, these material properties will be used through the analysis. Similarly, material properties were obtained for cases 1 and 3. 


\subsection{Finite Element Modeling}

To study the effect of torsional rigidity and bending rigidity on bridge decks and to validate the proposed orthotropic plate theory, three main variables were studied thoroughly; D which is the ratio between $D_{x}$ (rigidity in short direction) and $D_{y}$ (rigidity in the long direction), $L$ which is the span length center-center from supports and $\alpha$ which represents the torsional rigidity of the deck. These three variables will be studied for two main bridges configuration, where main bars are transverse to traffic (i.e. slab on girders/stingers) and main reinforcement are parallel to traffic (i.e. slab on floor beams).

The Canadian truck specified in CHBDC (CL-625) specified in section 3.8.3.2 will be used in these analysis, where loading cases will be divided as shown in Appendix A.1.

\subsubsection{Main Bars transverse to Traffic}

\section{Effect of Span Length "L"}

As discussed earlier, the relationship between the change in span length and the corresponding moment has to be studied and analyzed for better understanding of the effect of span length on the maximum moments produced due to different types of axle loadings. The following graphical illustrations demonstrate the effect of span length on the maximum moment for each loading case considered in this study. The following Figure 4 through Figure 6 determine the corresponding maximum moment for case 2 . It can be observed that as the span length increases from $1 \mathrm{~m}$ to $4 \mathrm{~m}$ the corresponding maximum bending moment increases, regardless of the rigidity ratio value" D". Furthermore, appendix B.1.2 covers cases 1, 2 and 3 which also exhibits the same behaviour where bending moment increase as the span length increases regardless of the $\alpha$ and $D$ values. 


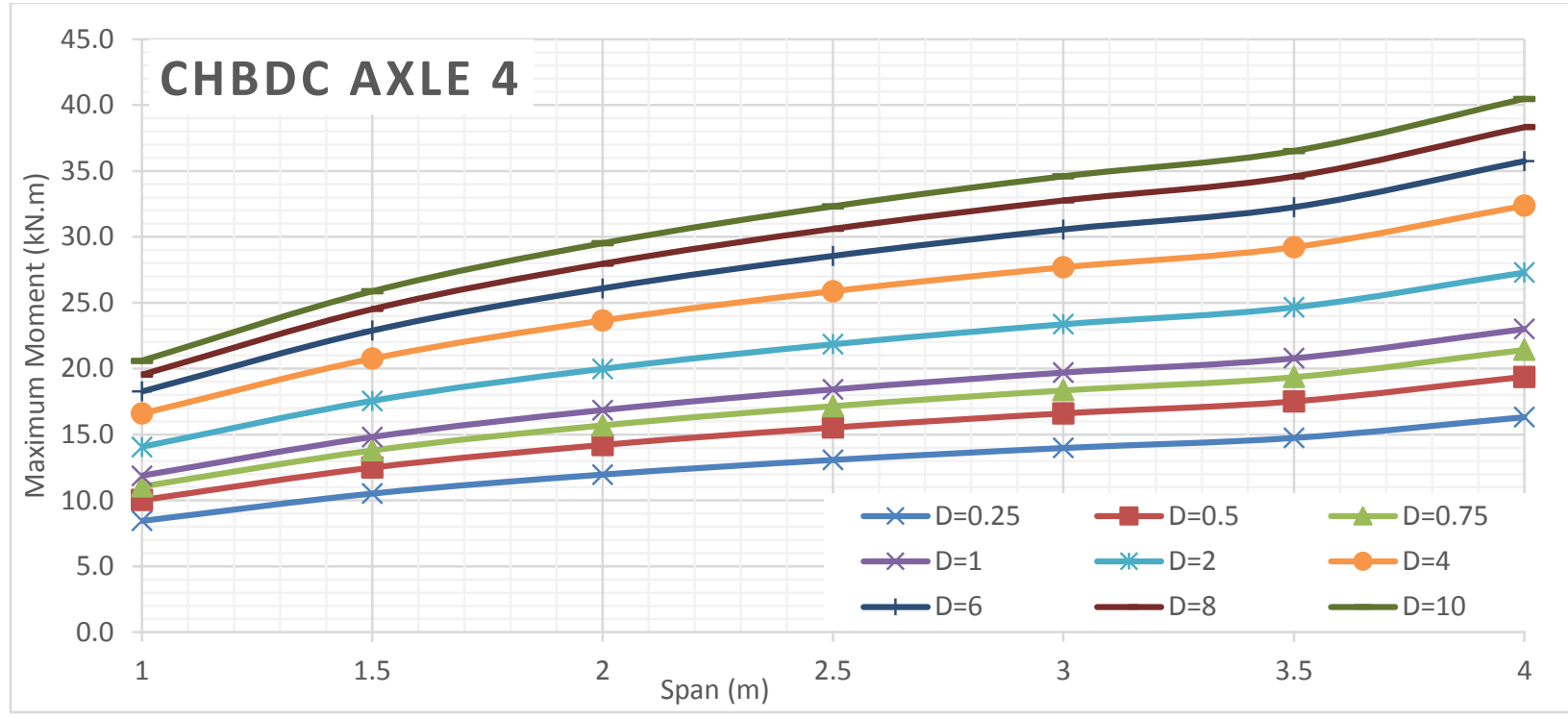

Figure 4 Maximum moment of deck slabs subjected to CHBDC axle 4 for different D values of case 2

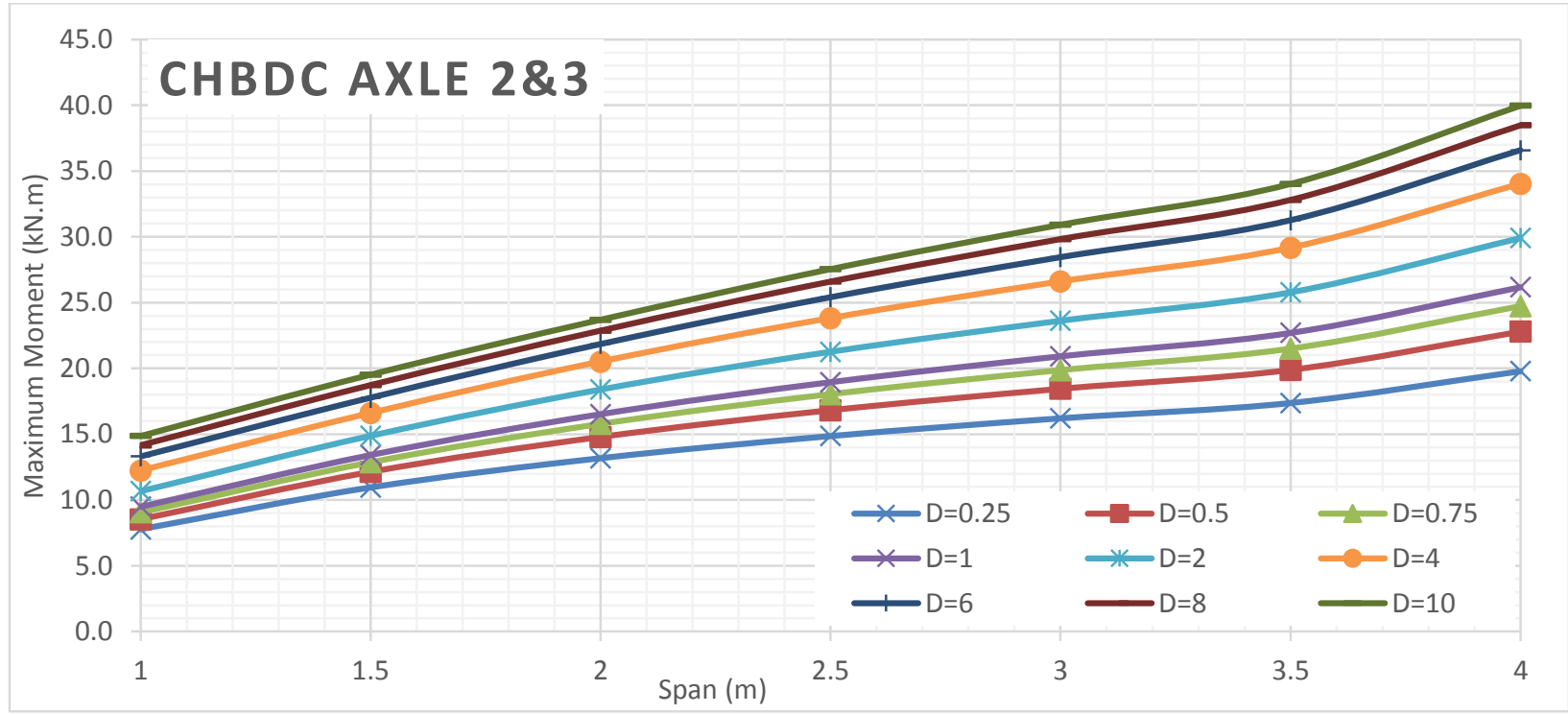

Figure 5 Maximum moment of deck slabs subjected to CHBDC axles $2 \& 3$ for different D values of case 2 


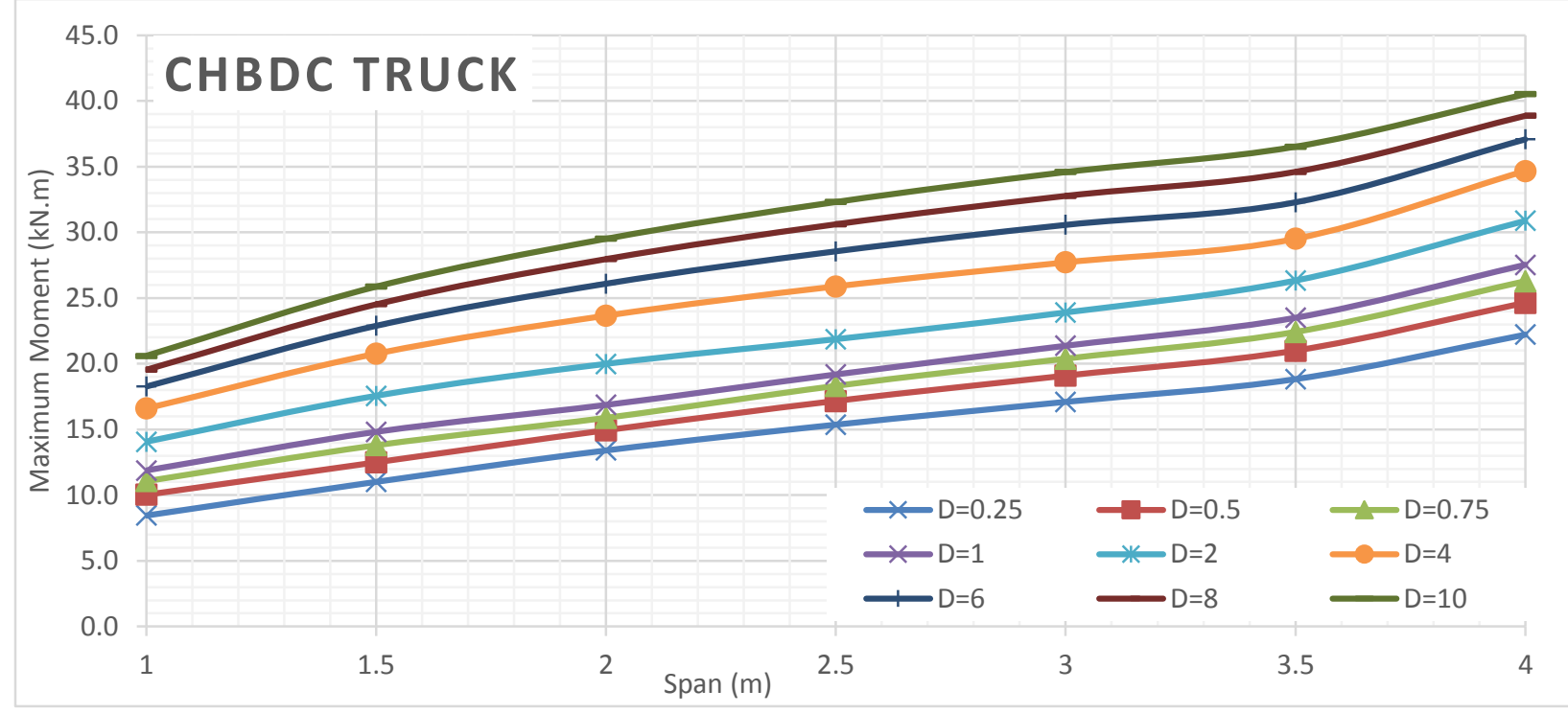

Figure 6 Maximum moment of deck slabs subjected to CHBDC truck for different D values of case 2

While previous figures, generally show a consistent relation between different rigidities, it is necessary to compare the results obtained from FEA with orthotropic plate formulations to ensure the validity of the results. Therefore, a comparison was established between the results of both analyses. Figure 7,Figure 8 and Figure 9 show that all results from both analyses, FEA and orthotropic plate theory, matches within a certain acceptable error percentage less than five percent. It is expected that there is an arithmetic error in the orthotropic plate analysis as the number of axles increase since the orthotropic plate formulation evaluates the bending moment due to a single tire patch. More comparisons for cases 1, 2 and 3 are included in appendix D.1.2.

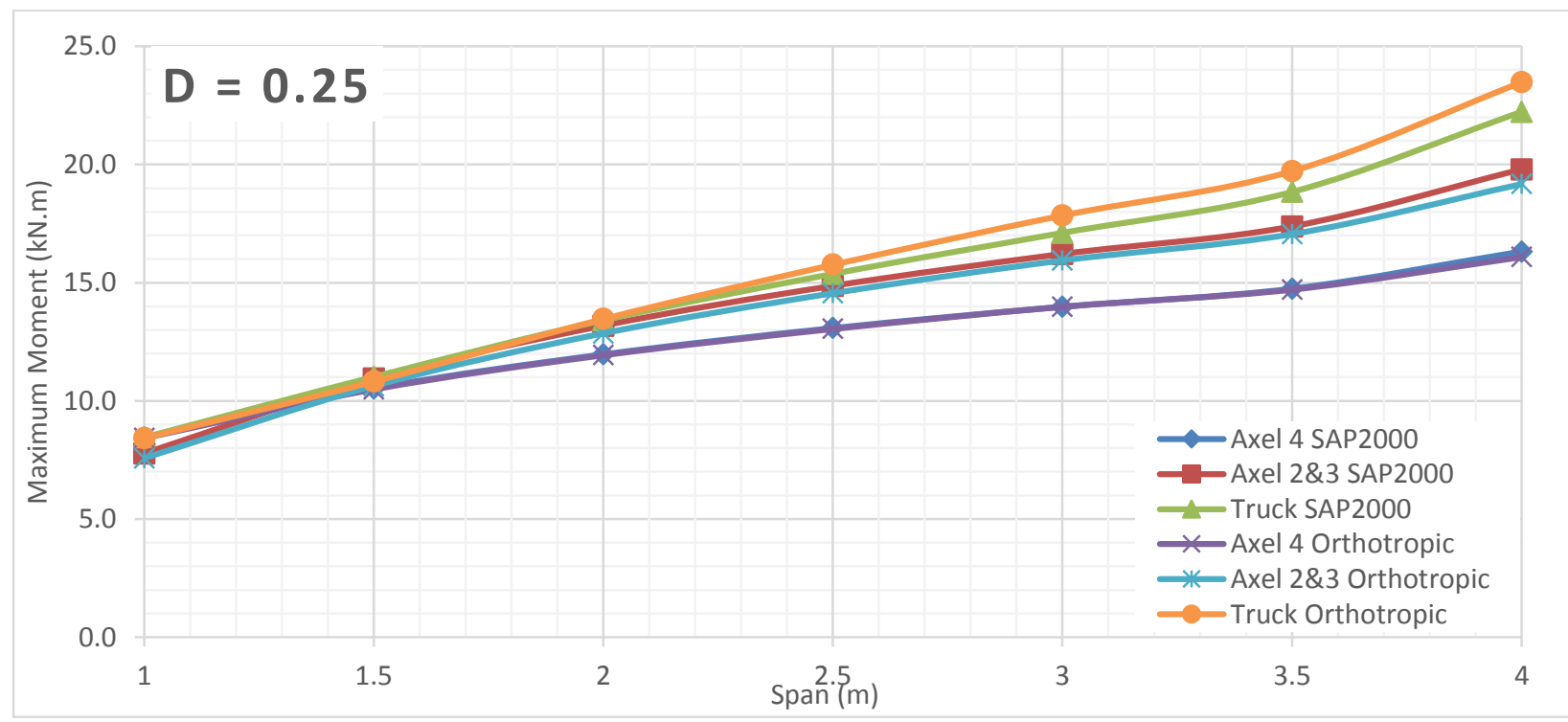

Figure 7 Comparison between FEA and Orthotropic Plate Theory for $\mathrm{D}=0.25$ of case 2 


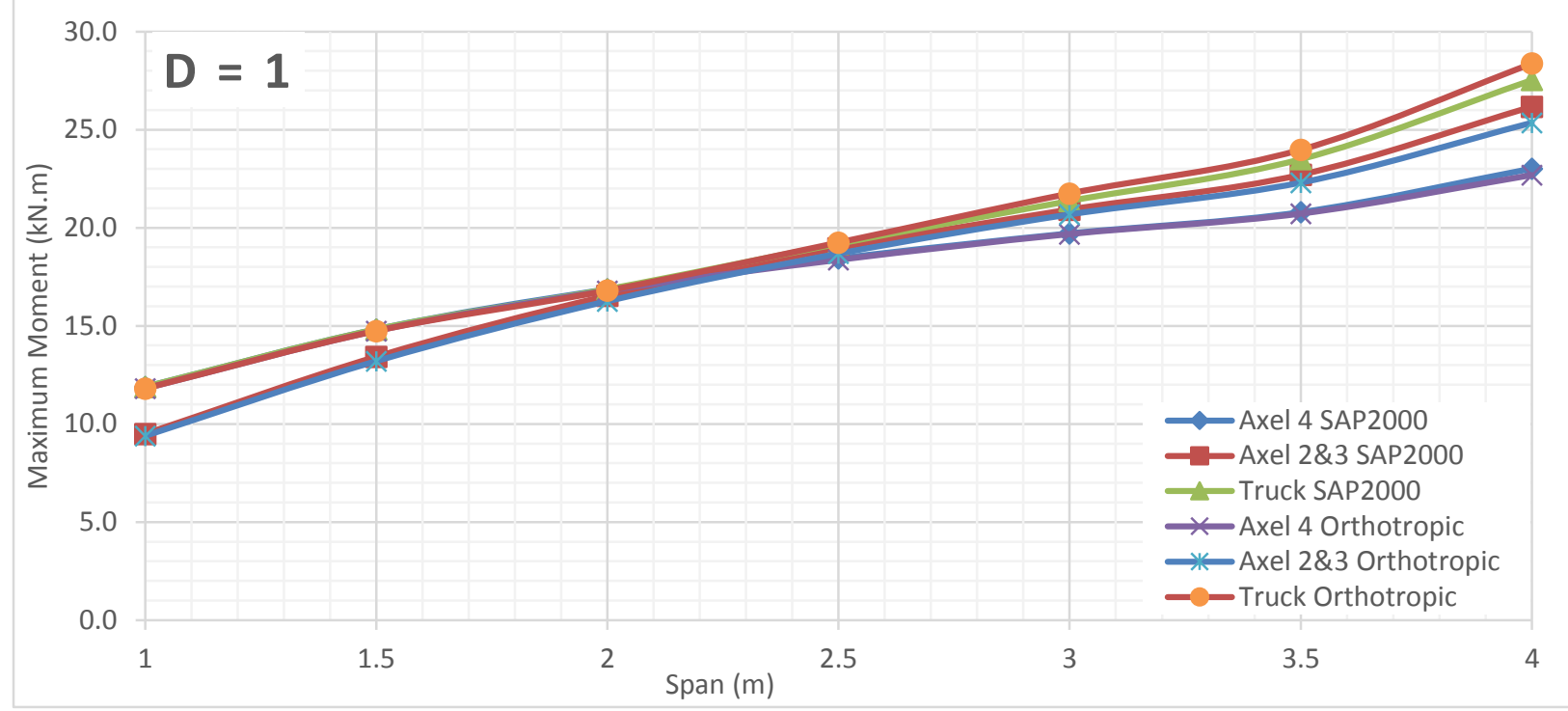

Figure 8 Comparison between FEA and Orthotropic Plate Theory for D $=1$ of case 2

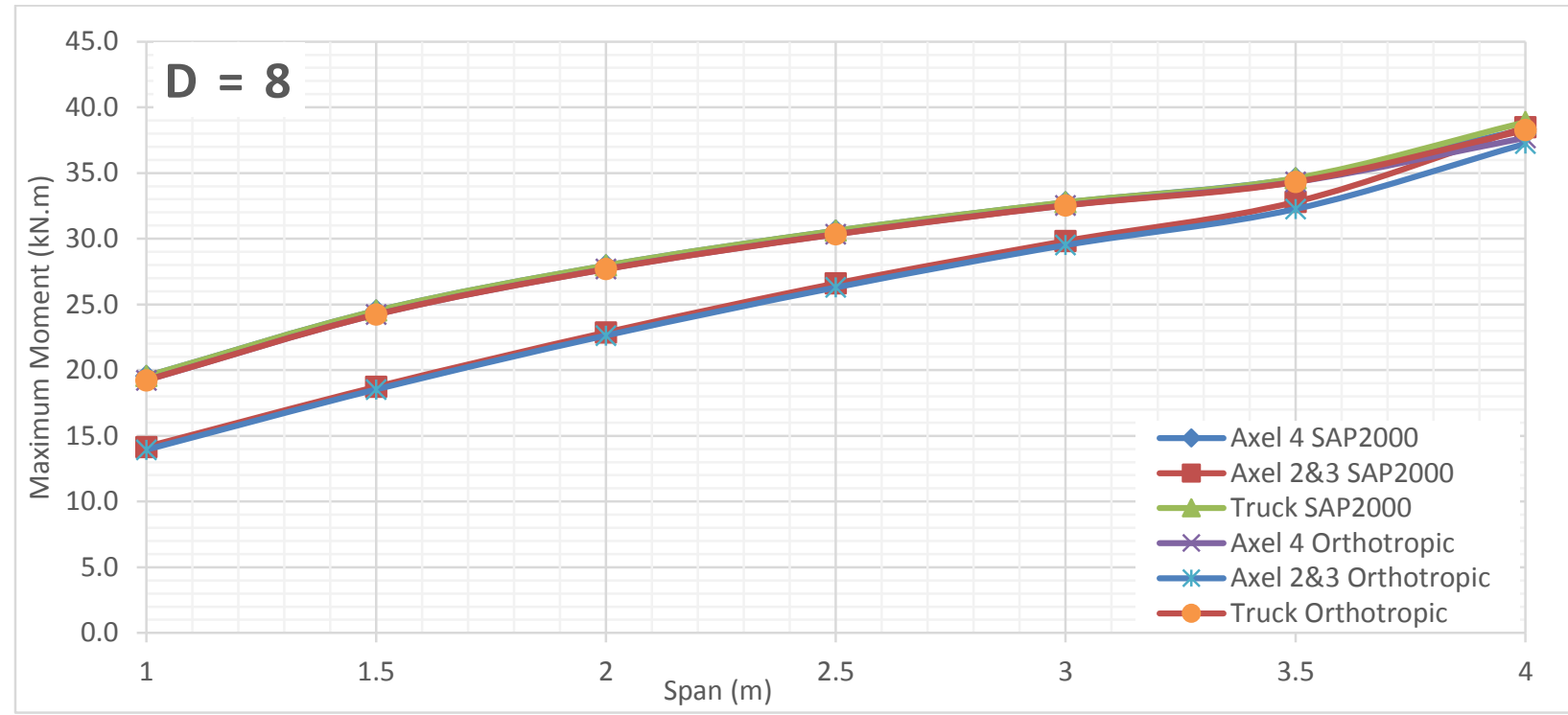

Figure 9 Comparison between FEA and Orthotropic Plate Theory for D $=8$ of case 2

\section{Effect of Flexural Bending Rigidity “D”}

Similarly, the response of the bending moments for decks were evaluated with respect to the change in flexural rigidity ratio " $\mathrm{D}$ ". Since flexural rigidity " $\mathrm{D}$ " is a ratio between the rigidity in the short direction " $\mathrm{D}_{\mathrm{x}}$ " and the long direction " $\mathrm{D}_{\mathrm{y}}$ ", for all " $\mathrm{D}$ " ratios " $\mathrm{D}_{\mathrm{x}}$ " was kept constant while " $\mathrm{D}_{\mathrm{y}}$ " varied to produce different rigidity ratios varying from 0.25 to 10 . As demonstrated in Figure 10 through Figure 12 as the D value increases, the short direction stiffens, the bending moment 
significantly increases for all span length. Further representations are included in appendix B.1.3 which covers cases 1,2 and 3.

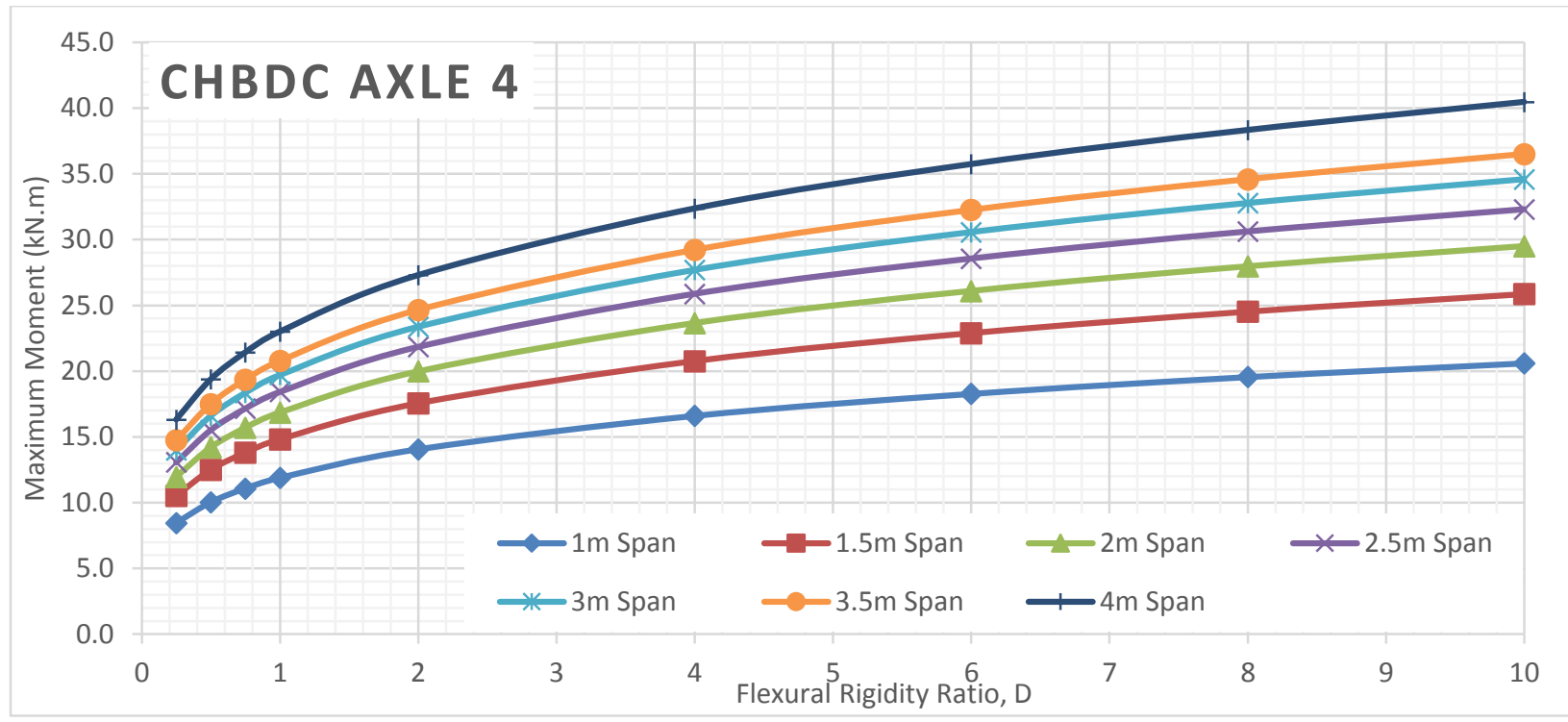

Figure 10 Maximum moment of deck slabs subjected to CHBDC axle 4 for different span values of case 2

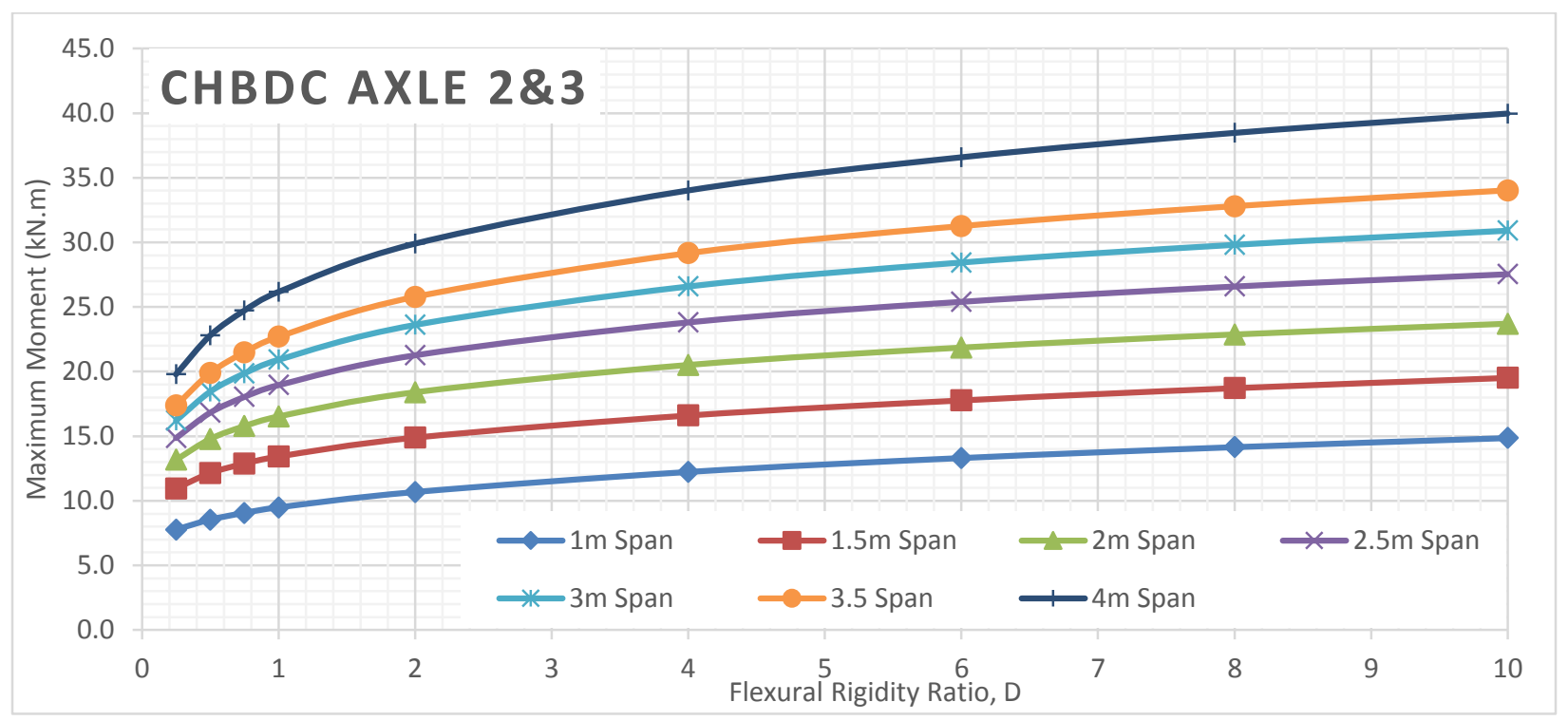

Figure 11 Maximum moment of deck slabs subjected to CHBDC axle 2 \& 3 for different span values of case 2 


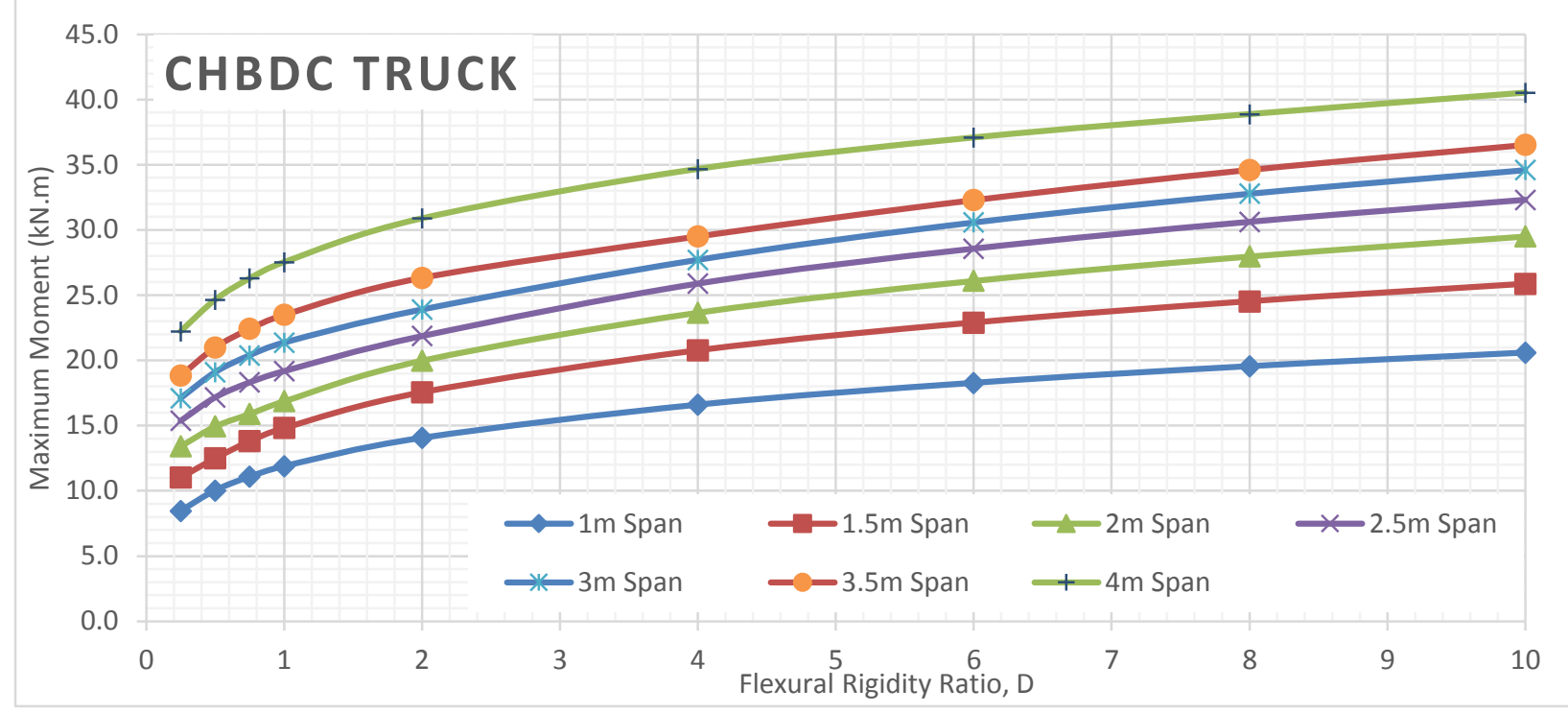

Figure 12 Maximum moment of deck slabs subjected to CHBDC truck for different span values of case 2

To validate the results obtained from the finite element analysis a comparison was established to compare the finite element analysis with the orthotropic plate formulation. The following Figure 25 through Figure 27 illustrates the close proximity between both analysis, which entails the validity of the analysis performed. Small marginal error can be see in these illustration as expected due to the arithmetic error in the orthotropic formulation as discussed earlier. Further comparisons are included in appendix D.1.3

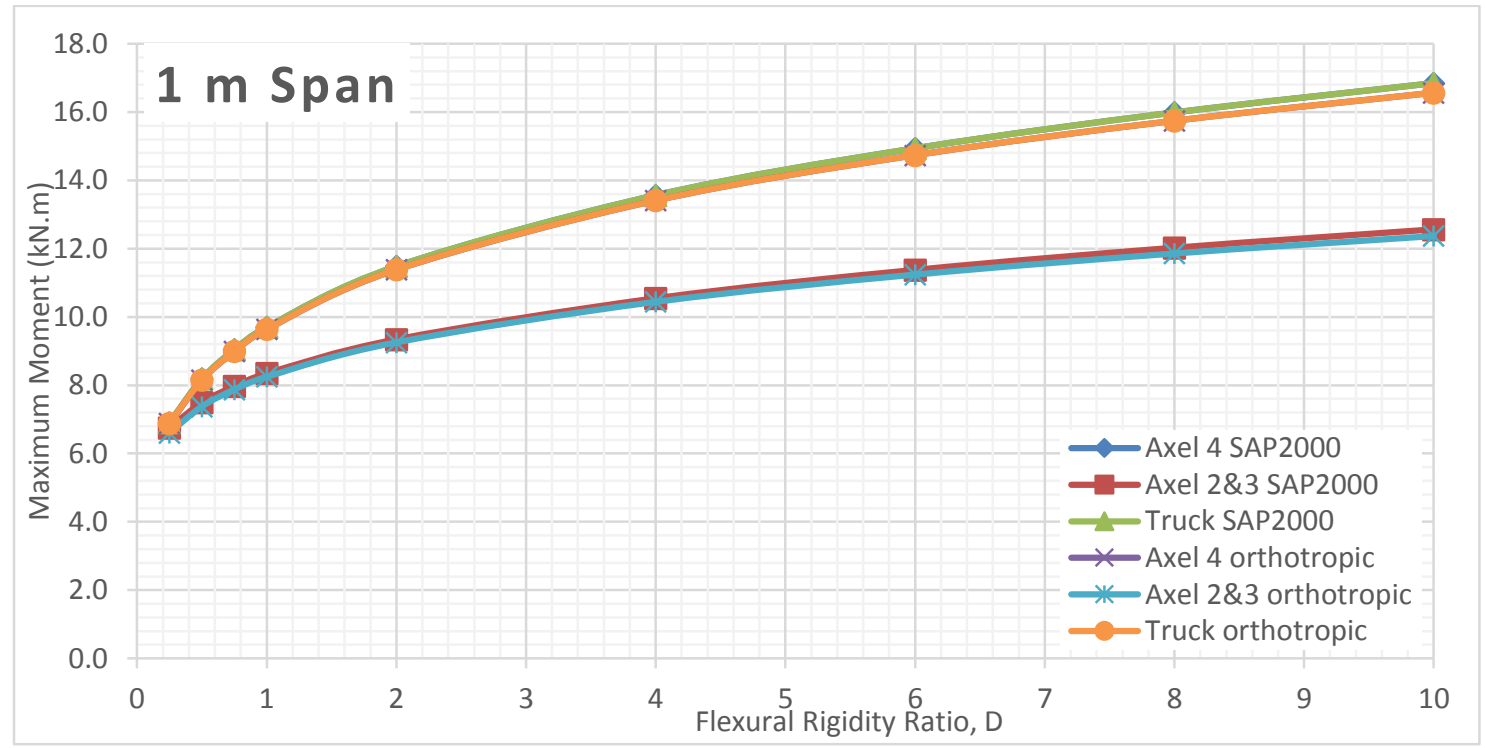

Figure 13 Comparison between FEA and Orthotropic Plate Theory for $1 \mathrm{~m}$ span of case 2 


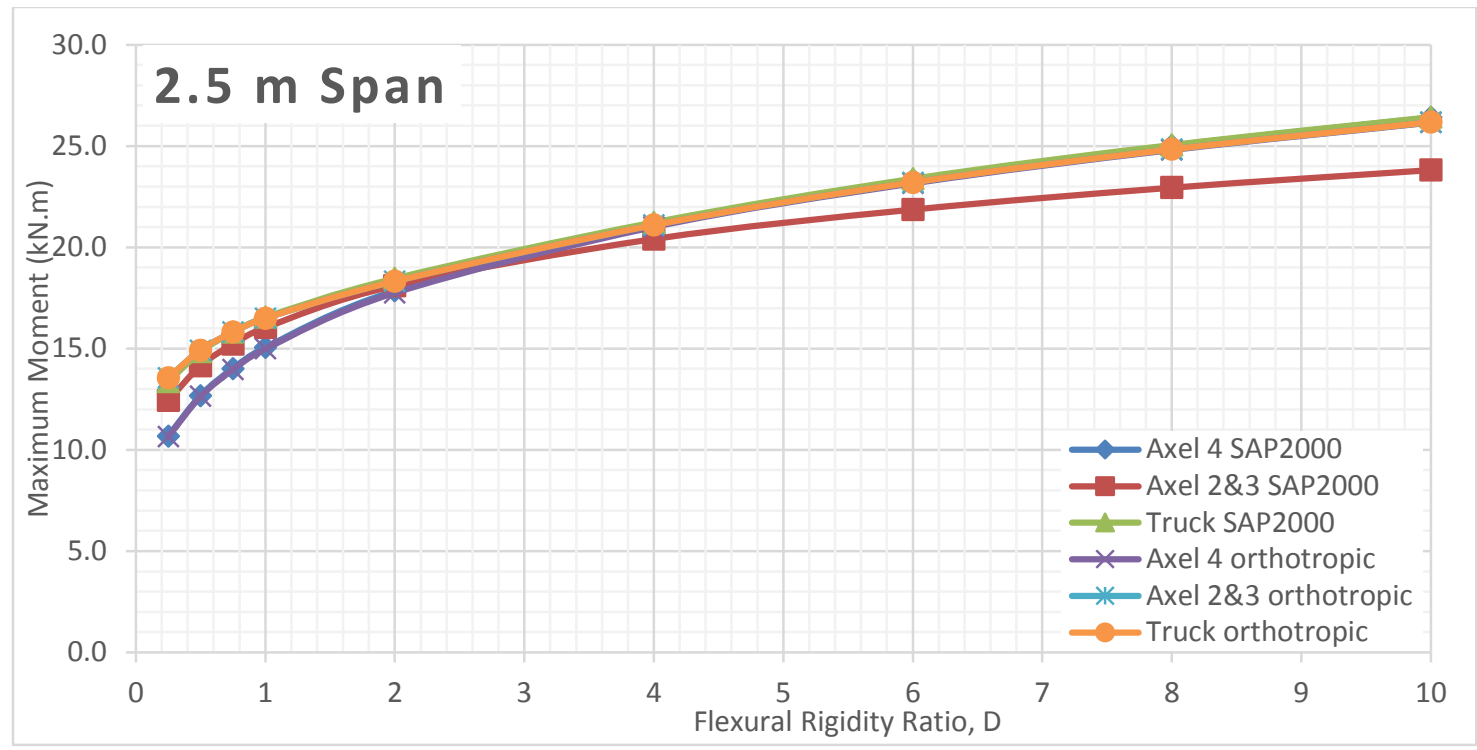

Figure 14 Comparison between FEA and Orthotropic Plate Theory for $2.5 \mathrm{~m}$ span of case 2

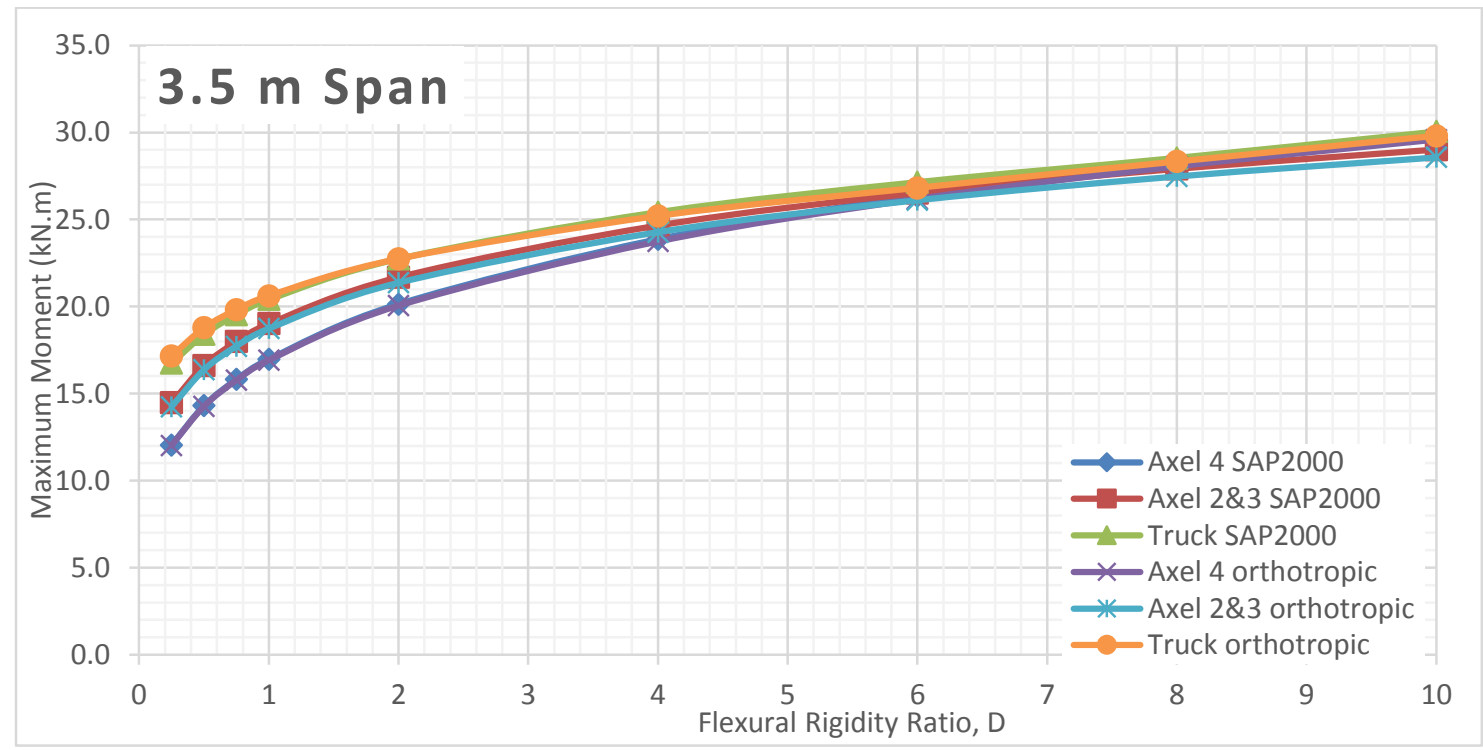

Figure 15 Comparison between FEA and Orthotropic Plate Theory for $3.5 \mathrm{~m}$ span of case 2

\section{Effect of Torsional Rigidity “ $\alpha$ ”}

While previous sections discussed the relationship between different maximum moment with respect to change in span length " $\mathrm{L}$ " and flexural rigidity " $\mathrm{D}$ ", it is important to examine the behaviour of maximum moment with respect to the change in $\alpha$. This will provide further insight at the bending moment behaviour for different deck types and covering cases 1, 2 and 3.Figure 16 through Figure 18 illustrates the change in bending moment as the $\alpha$ value increases from 0.25 to 10 , where $\alpha$ less than 1 presents case 3 "torsionally soft", $\alpha$ equal to 1 represents case 2 "uniformly 
reinforced" and $\alpha$ greater than 1 represents case 1 "torsionally stiff". It can be seen that as the torsional stiffness of decks increases the bending moment in the short direction of the deck slab decreases due to the increase in the carrying capacity of the deck torsionally. More detailed illustration and representations are included in appendix B.1.4

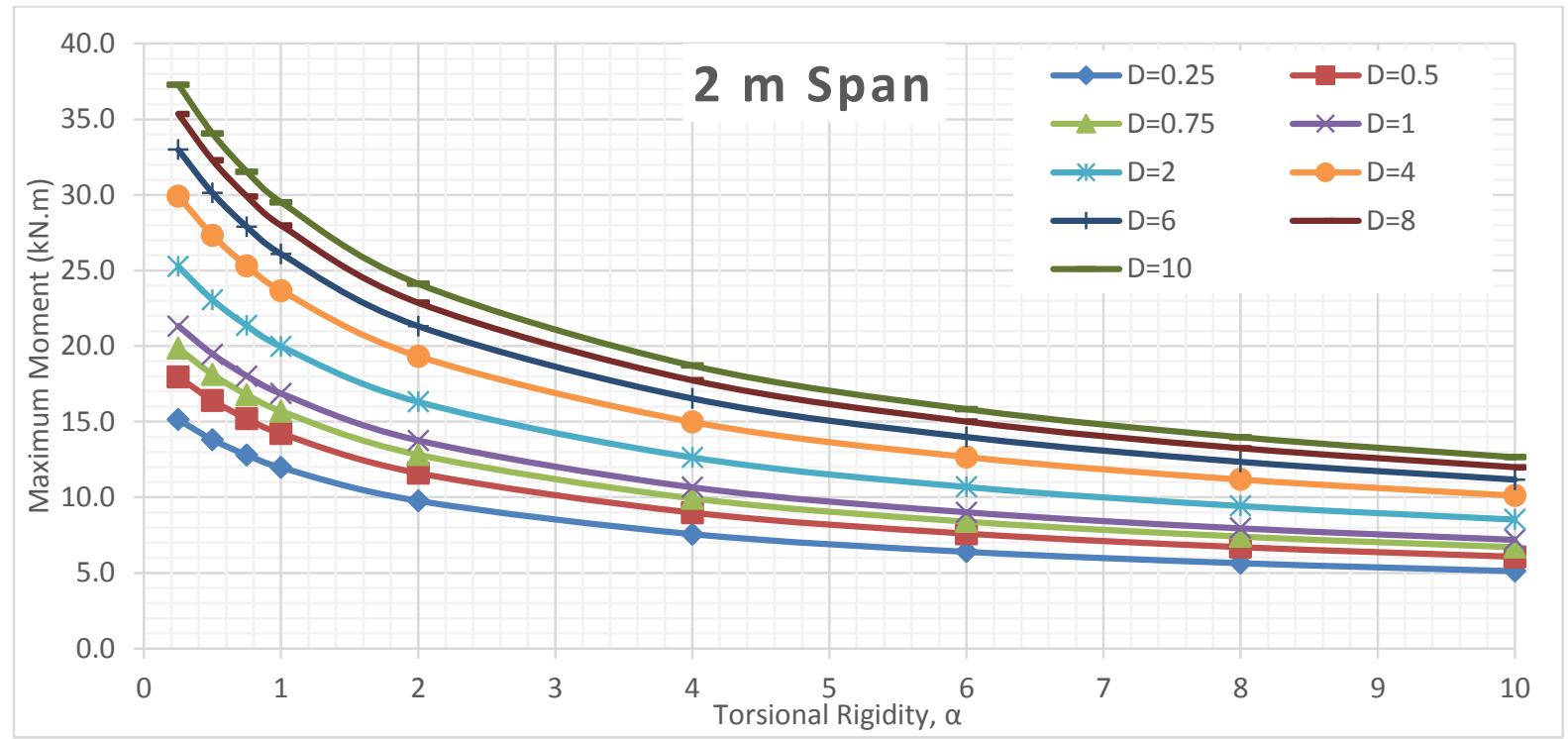

Figure 16 Maximum moment of 2-m span slab subjected to CHBDC axle 4 for different D values of case 2

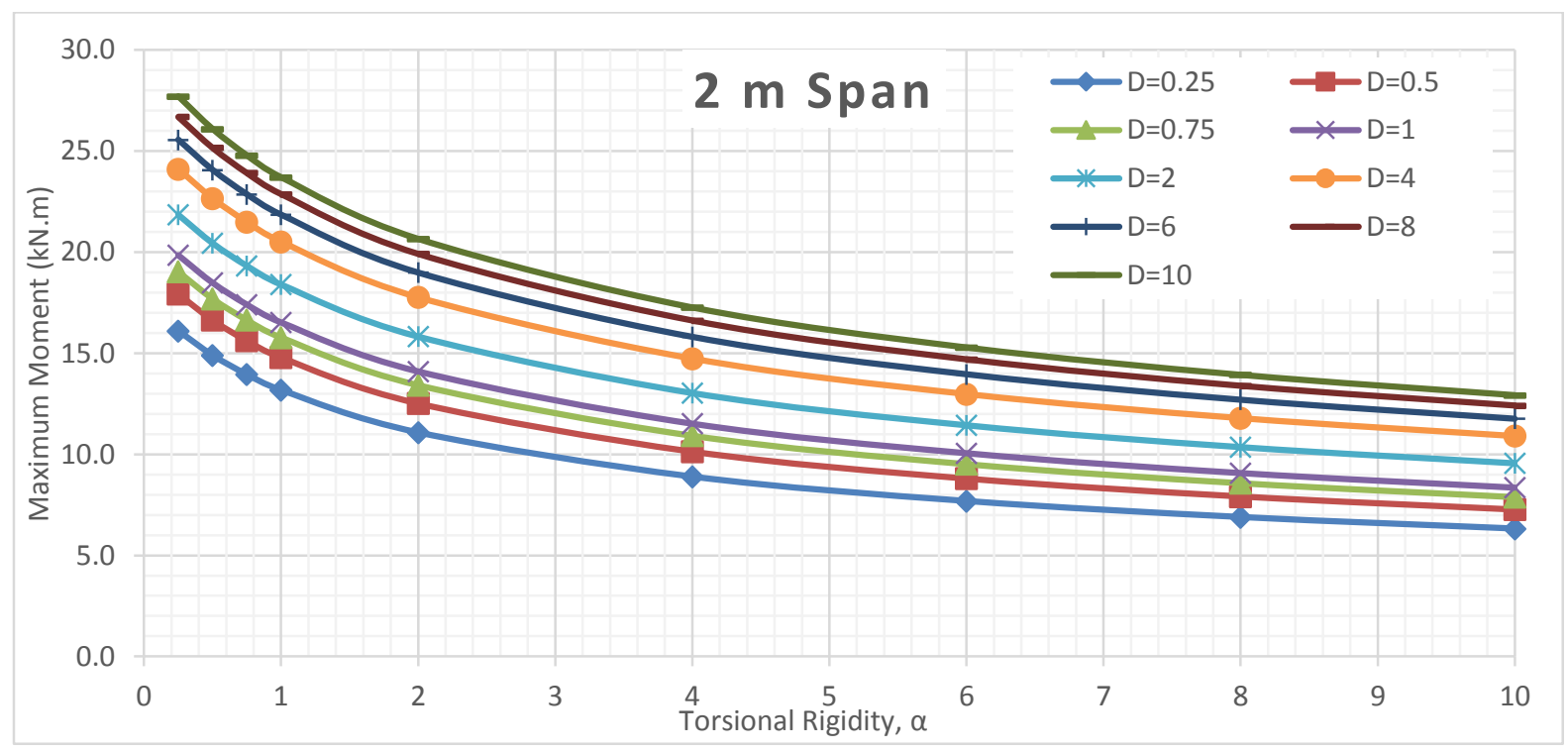

Figure 17 Maximum moment of 2-m span slab subjected to CHBDC axle $2 \& 3$ for different D values of case 2 


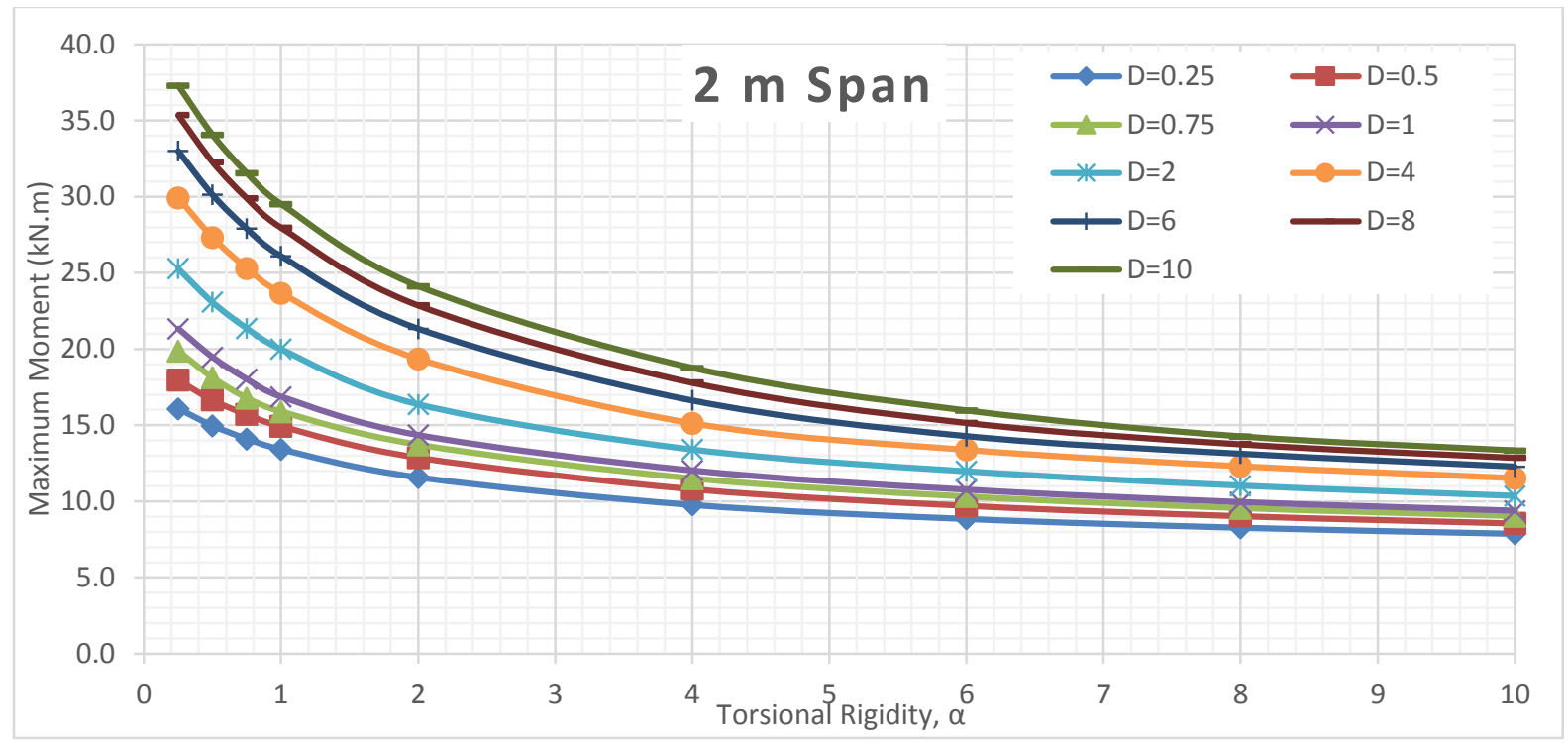

Figure 18 Maximum moment of 2-m span slab subjected to CHBDC truck for different D values of case 2

\subsubsection{Main Bars Parallel to Traffic}

Similar to section 2.2.1, same analysis was performed on cases where the main reinforcement in decks is parallel to traffic. Figure 19 and Figure 20 illustrates the results obtained for the loading cases analyzed. The relation remains consistent between maximum bending moment and span length where the bending moment increases as the span length increases. On the other hand, Figure 21 and Figure 22 demonstrate that as the rigidity increases in the short direction bending moment increases respectively. Furthermore, Figure 23 and Figure 24 illustrates the change in bending moment with respect to the change in $\alpha$ value. It can be seen that as the torsional stiffness increases; the bending moment in the short direction decreases due to the increase in the carrying capacity of the deck torsionally. Further illustrations are included in appendix B.1.1 to B.1.4 


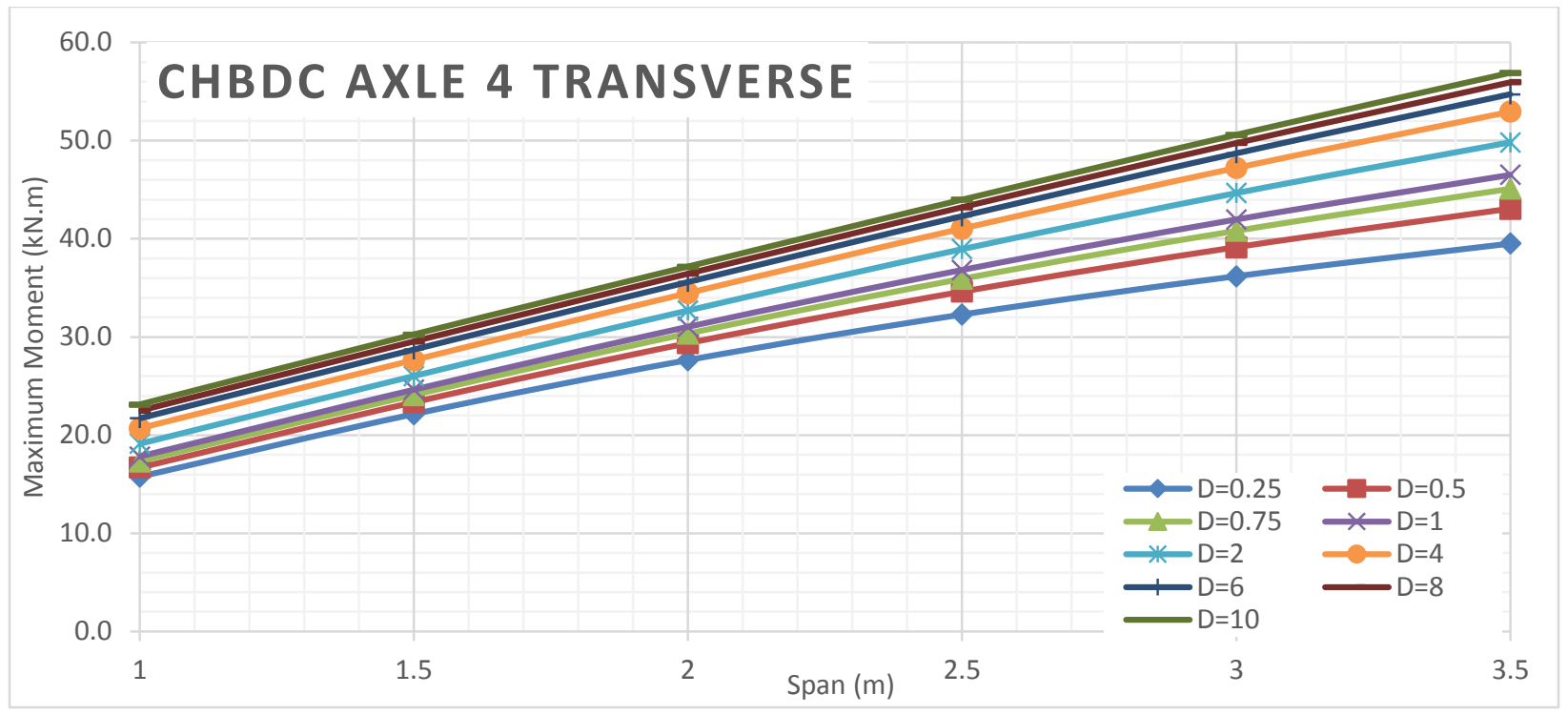

Figure 19 Maximum moment of deck slabs subjected to CHBDC axle 4 for different D values of case 2 main bars parallel to traffic

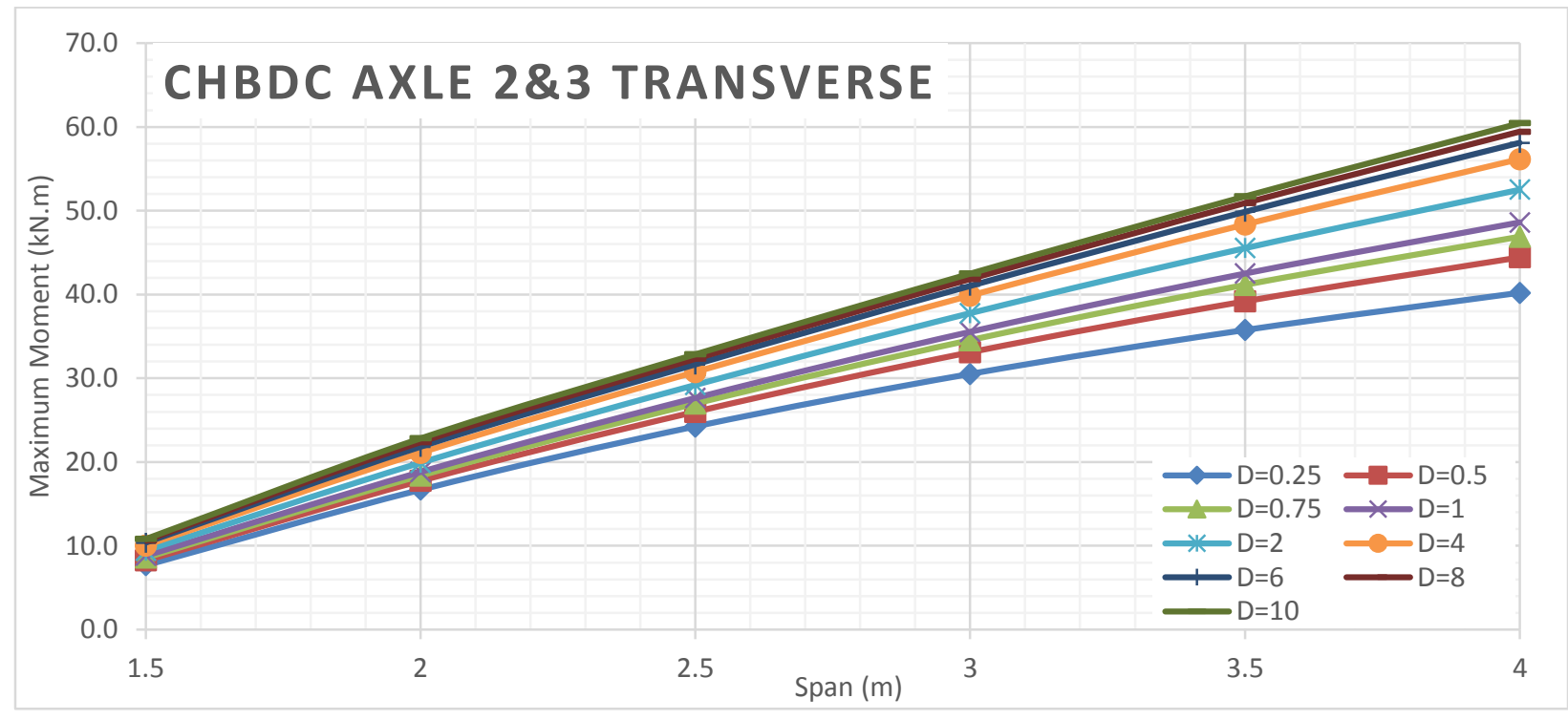

Figure 20 Maximum moment of deck slabs subjected to CHBDC axle $2 \& 3$ for different D values of case 2 main bars parallel to traffic 


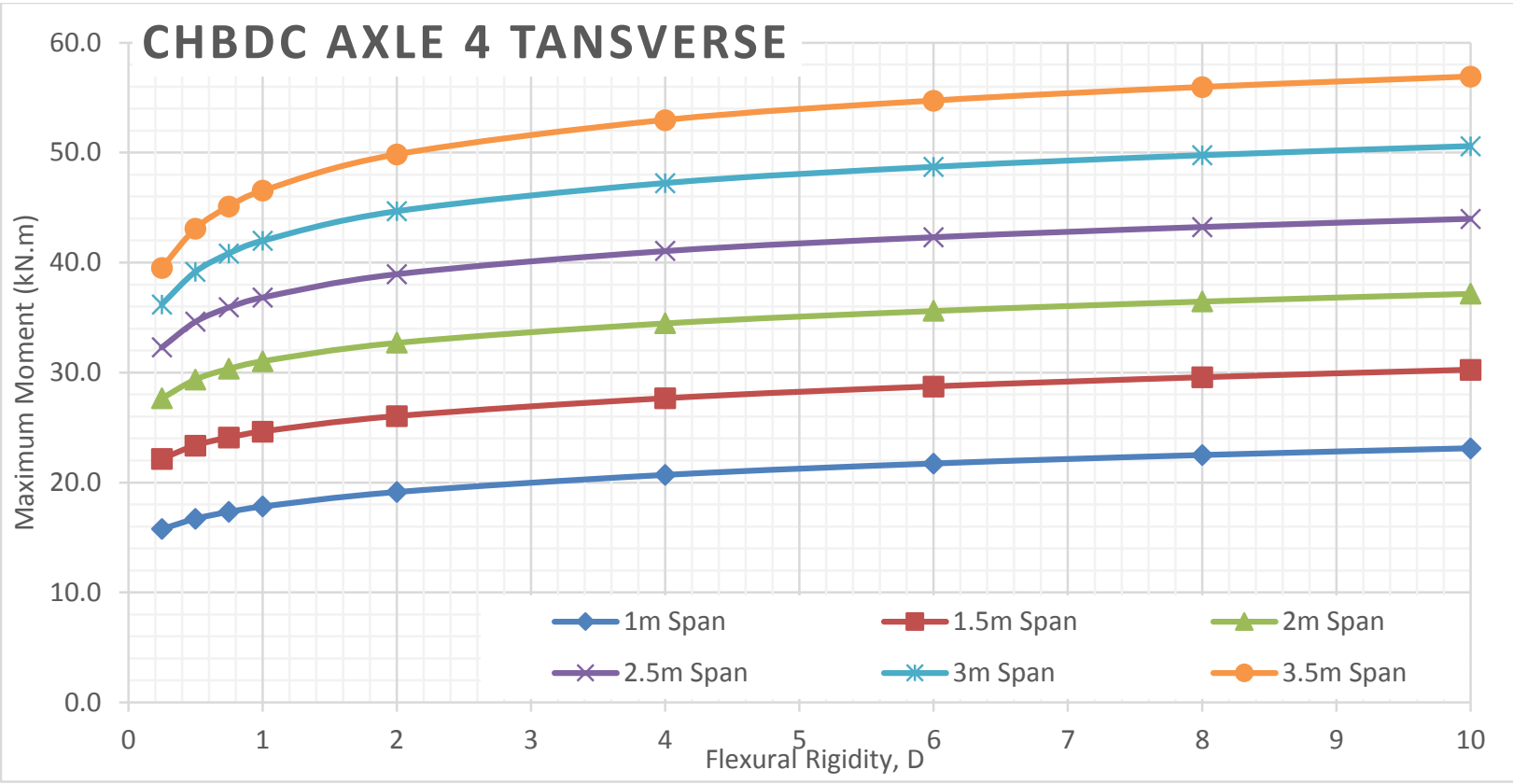

Figure 21 Maximum moment of deck slabs subjected to CHBDC axle 4 for different span values of case 2 main bars parallel to traffic

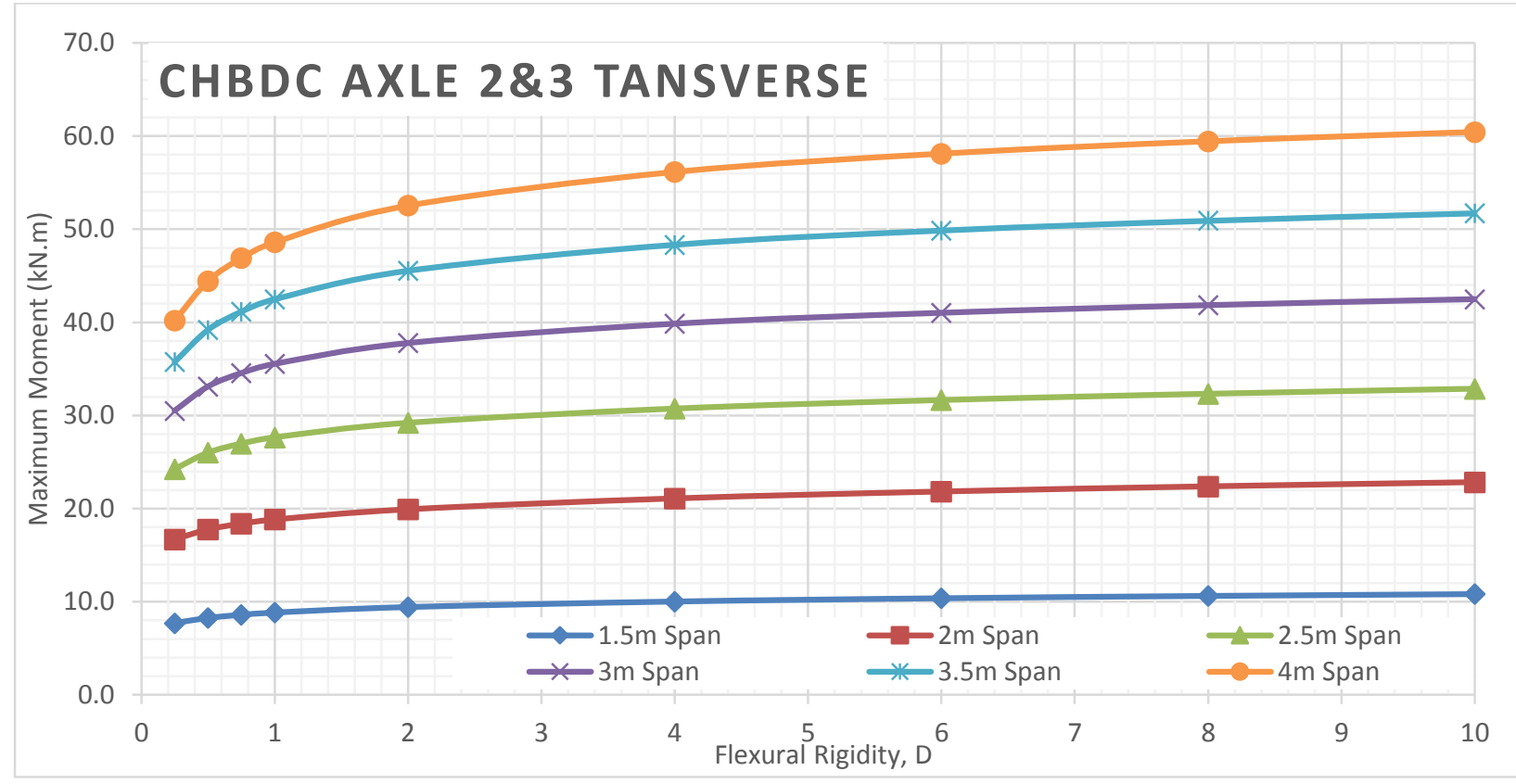

Figure 22 Maximum moment of deck slabs subjected to CHBDC axle 2 \& 3 for different span values of case 2 main bars parallel to traffic 


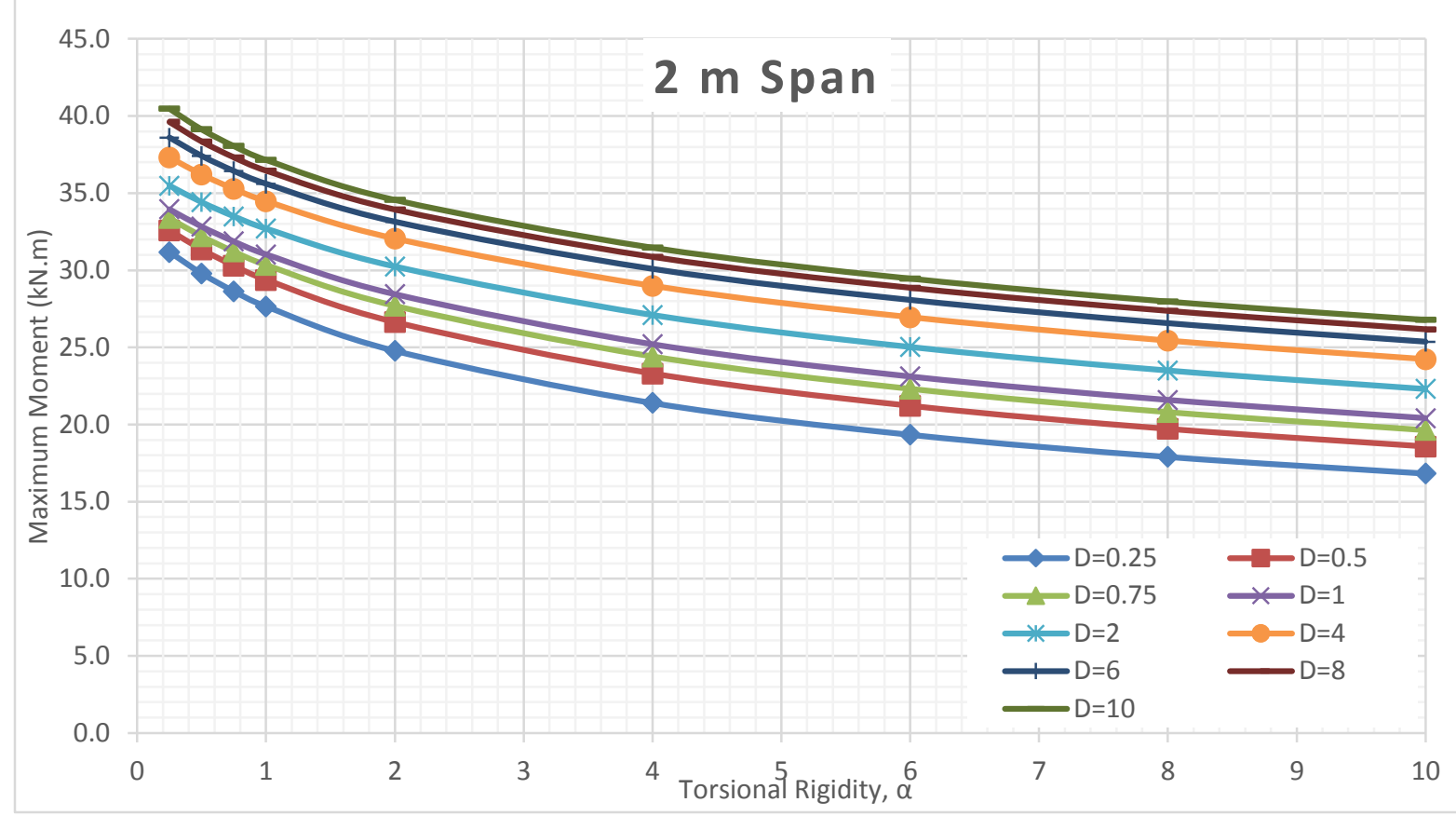

Figure 23 Maximum moment of 2-m span slab subjected to CHBDC axle 4 for different D values of case 2 main bars parallel to traffic

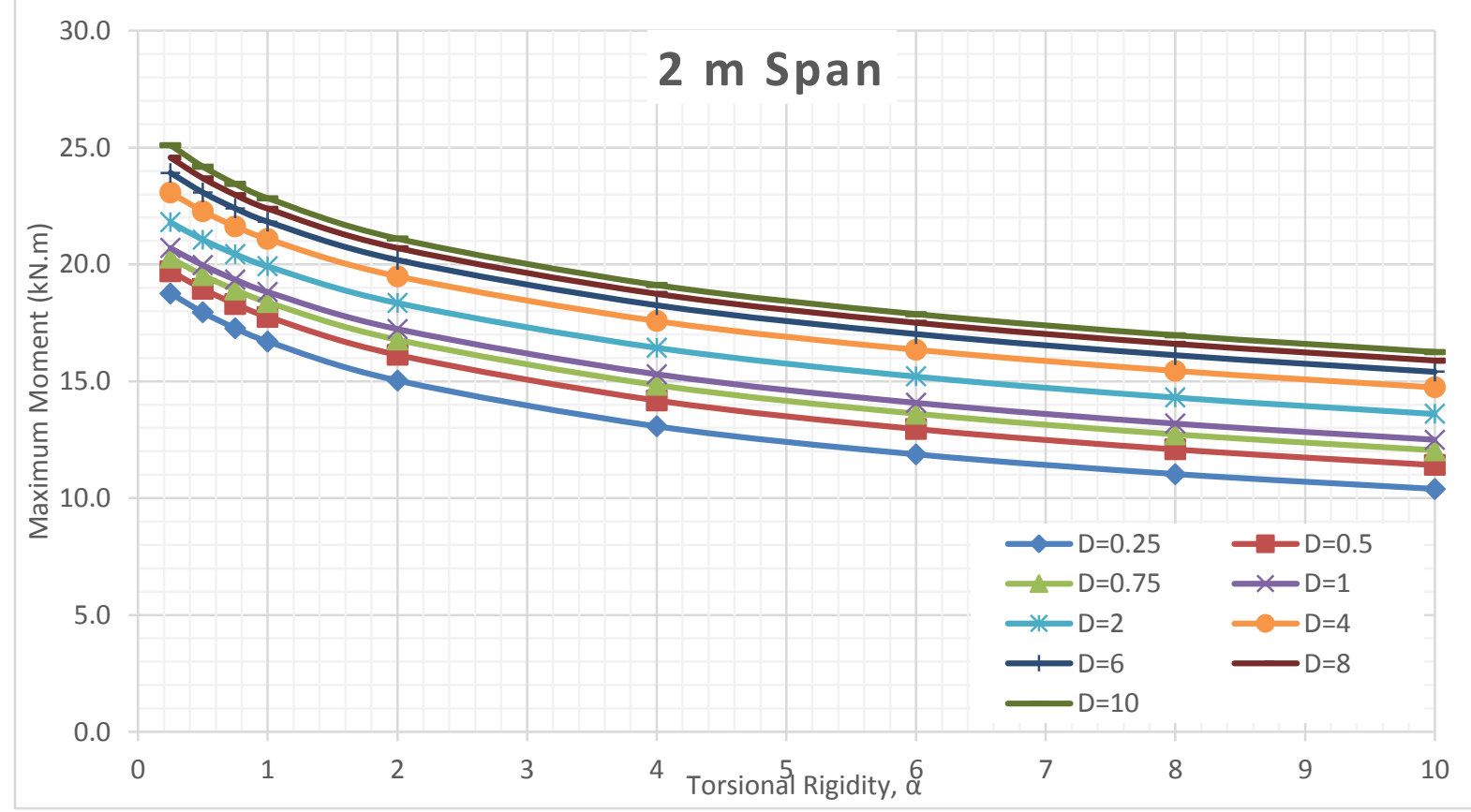

Figure 24 Maximum moment of 2-m span slab subjected to CHBDC axle $2 \& 3$ for different D values of case 2 main bars parallel to traffic

Additionally, FEA results were compared with orthotic plate theory analysis, both analyses showed very similar results with minor percentage of error, which is a result of the cumulative errors from 
the additions used in the orthotropic plate analysis. Further outputs, results and illustrations are included in appendices D.1

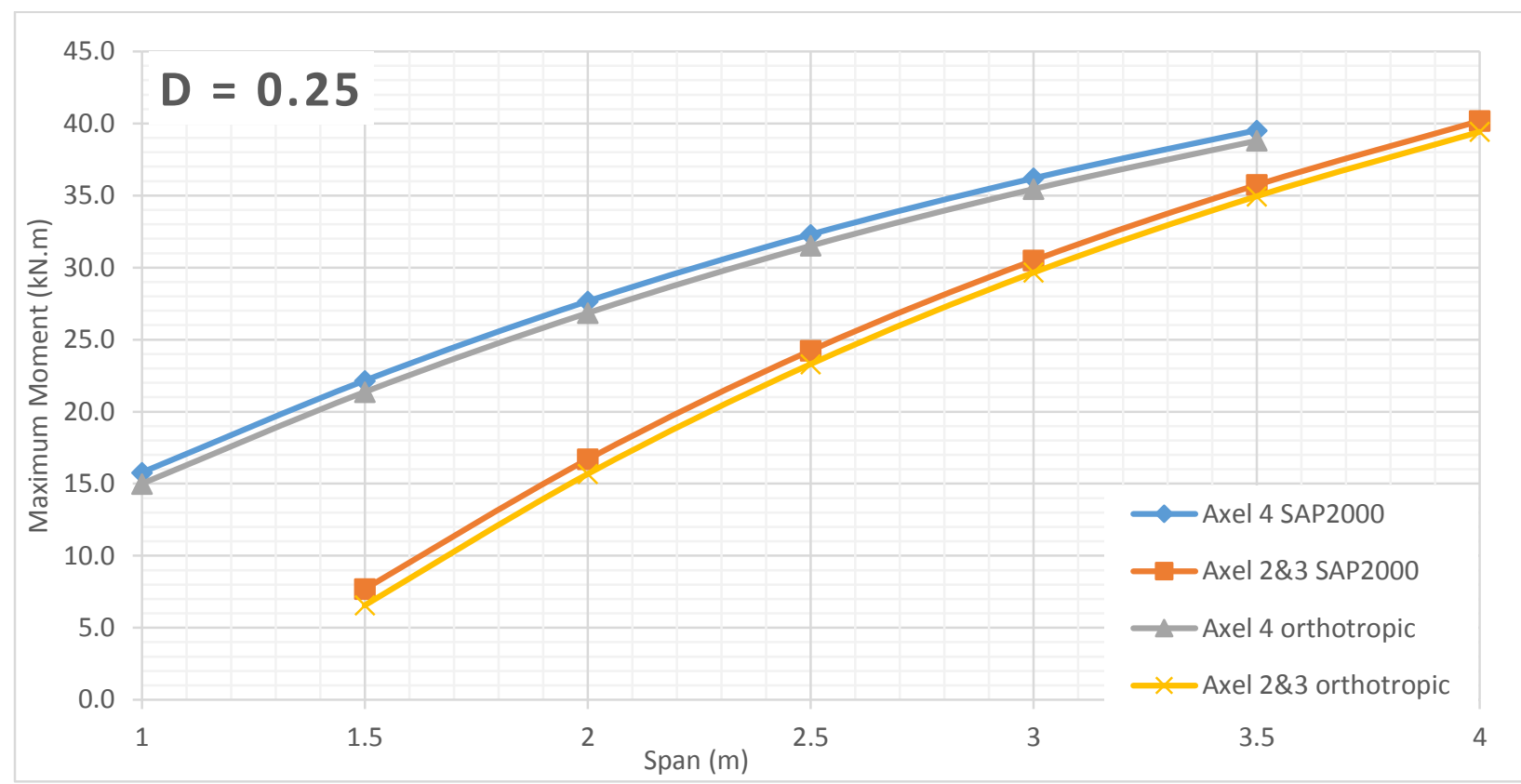

Figure 25 Comparison between FEA and Orthotropic Plate Theory for $\mathrm{D}=0.25$ of case 2 main bars parallel to traffic

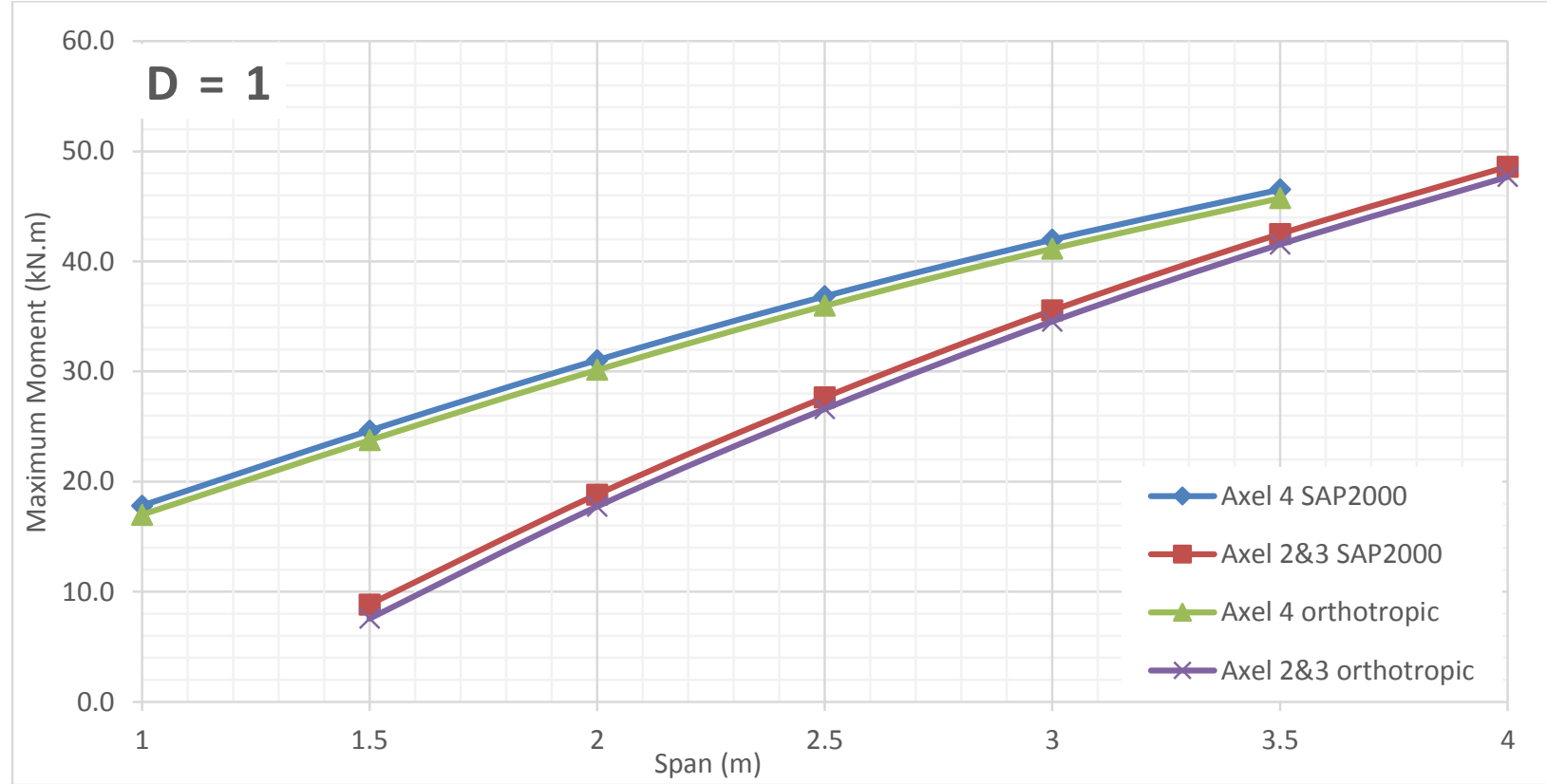

Figure 26 Comparison between FEA and Orthotropic Plate Theory for D $=1$ of case 2 main bars parallel to traffic 


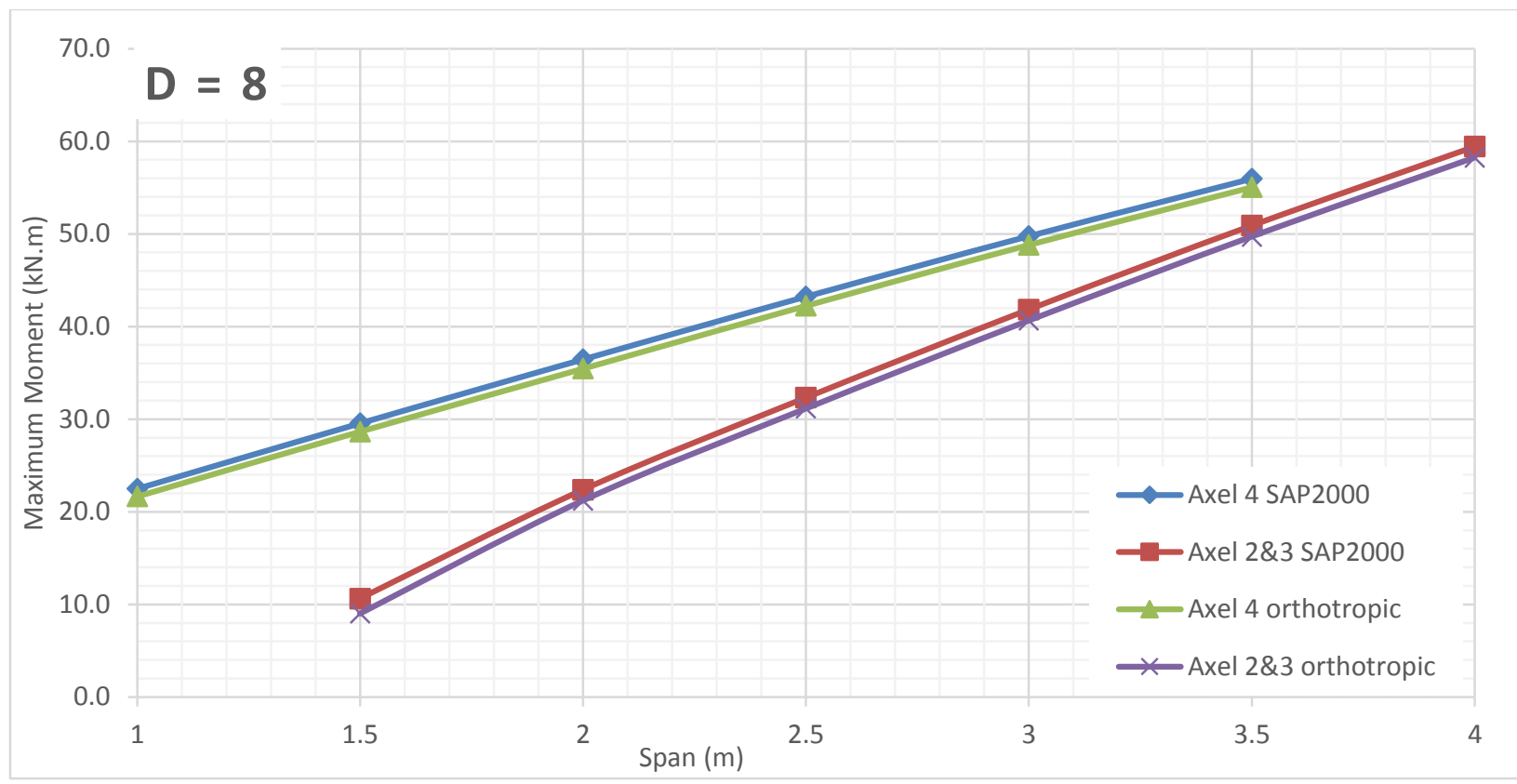

Figure 27 Comparison between FEA and Orthotropic Plate Theory for $\mathrm{D}=8$ of case 2 main bars parallel to traffic 


\section{Deflection}

For each of the previous cases investigated for bending moment, the corresponding deflections were obtained for both analyses; FEA and orthotropic plate theory. Similar to bending moment, all results are in agreement from both analyses and similar comparisons and illustration are included in appendices B.2, C.2 and D.2. 


\section{Development of Empirical Equations}

Since the current CHBDC provisions does not provide a detailed guideline for open, partially filled and fully filled grid deck systems for bending moment and deflections; it is extremely important to formulate a system of formulations to address these cases. In the previous sections, the relationships of bending moment and deflection were analyzed and studied with respect to span length "L", flexural rigidity " $D$ " and torsional rigidity " $\alpha$ ". These relationships can be further developed to formulate the intended equations. To develop these equations, the results obtained from axle 4 and axles 2 and 3 loading cases were multiplied by the corresponding dynamic load allowance values and lane load modification factors according to CHBDC requirement. Afterwards, the maximum values for bending moments and deflection were obtained and used to develop the following equations.

\section{For main bars transverse to traffic direction:}

For $L \leq 3 m$

$$
\begin{aligned}
& \text { Moment }(k N . m)=\left(-0.0351 L^{0.457}\right)(-0.245 \ln (\alpha)+1.073)\left(-335.906 D^{0.231}\right) \\
& \text { Deflection }(m)=\left(-0.0430 L^{2.274}\right)(-0.186 \ln (\alpha)+0.780)\left(-0.0019 D^{0.202}\right)
\end{aligned}
$$

For $L>3 m$

$$
\begin{aligned}
& \text { Moment }(k N . m)=\left(-0.0377 L^{0.140}\right)(-0.280 \ln (\alpha)+1.268)\left(-386.748 \mathrm{D}^{0.221}\right) \\
& \text { Deflection }(\mathrm{m})=\left(-0.0327 \mathrm{~L}^{3.012}\right)(-0.150 \ln (\alpha)+0.653)\left(-0.0015 \mathrm{D}^{0.194}\right)
\end{aligned}
$$

\section{For main bars parallel to traffic direction:}

For $\mathrm{L} \leq 3 \mathrm{~m}$

$$
\begin{aligned}
& \text { Moment }(\mathrm{kN} . \mathrm{m})=\left(-0.0364 \mathrm{~L}^{0.723}\right)(-0.0385 \ln (\alpha)+0.296)\left(-1585.769 \mathrm{D}^{0.0883}\right) \\
& \text { Deflection }=\left(-0.00145 \mathrm{~L}^{2.664}\right)(-0.167 \ln (\alpha)-1.205)\left(-0.0048 \mathrm{D}^{-0.0523}\right)
\end{aligned}
$$

For $\mathrm{L}>3 \mathrm{~m}$

$$
\begin{aligned}
& \text { Moment }(\mathrm{kN} . \mathrm{m})=\left(-0.0331 \mathrm{~L}^{0.832}\right)(-0.0440 \ln (\alpha)+0.270)\left(-1454.668 \mathrm{D}^{0.0891}\right) \\
& \text { Deflection }(\mathrm{m})=\left(-0.00556 \mathrm{~L}^{2.854}\right)(-0.119 \ln (\alpha)-0.712)\left(-0.0019 \mathrm{D}^{-0.0161}\right)
\end{aligned}
$$

The following illustrations demonstrate the results of the proposed empirical equations with respect to the results obtained from the finite element analyses. Figure 28 show the results for the bending moment equation for $L$ less than or equal to $3 \mathrm{~m}$. It can be seen that all bending moment generated by the empirical equation are slightly greater than the moment obtained from FEA. While 
the best fit line for the data and the $\mathrm{R}^{2}$ are showing good convergence of the data. Similarly, the same analyses were conducted for all proposed equations and similar results were attained as demonstrated in Figure 28 through Figure 35.

\section{For main bars transverse to traffic direction:}

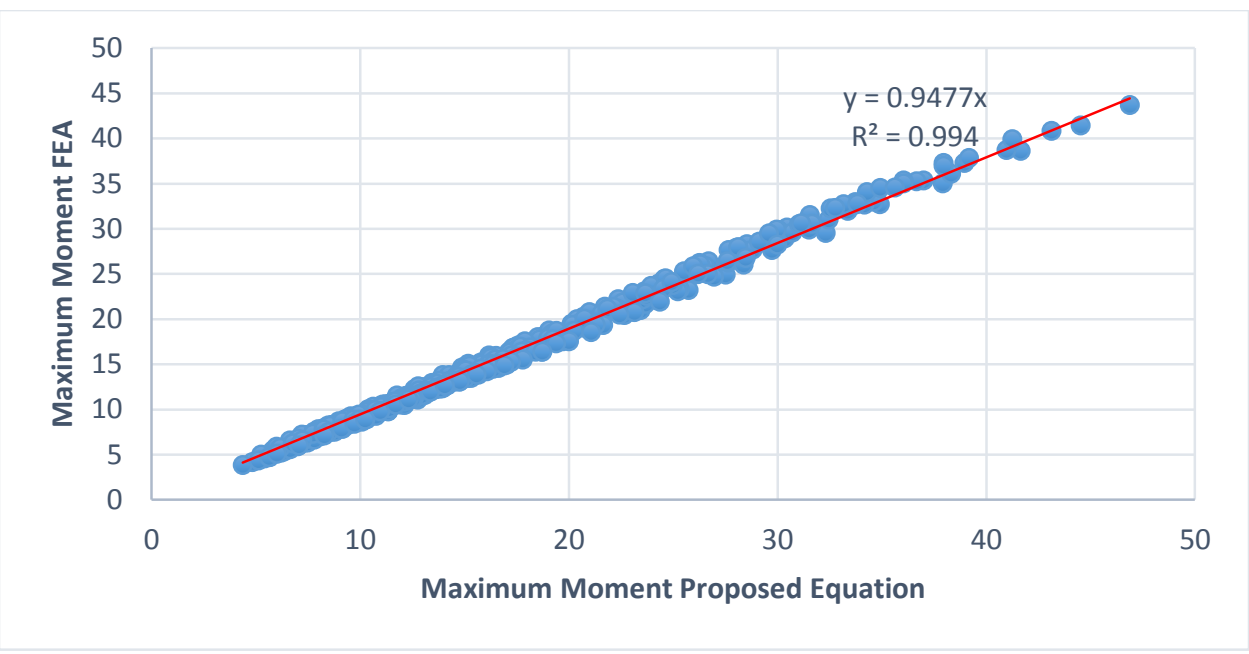

Figure 28 Maximum moment comparison between FEA and empirical equation for spans less than / equal to $3 \mathrm{~m}$ for main bars transverse to traffic direction

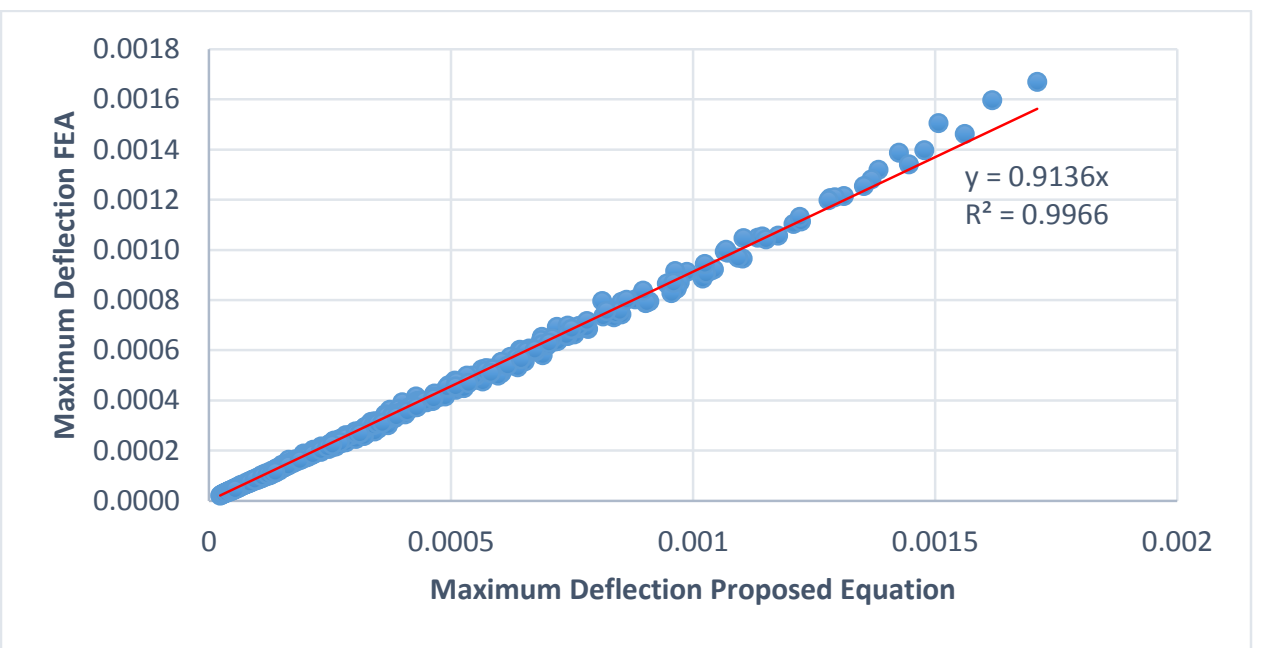

Figure 29 Maximum deflection comparison between FEA and empirical equation for spans less than / equal to $3 \mathrm{~m}$ for main bars transverse to traffic direction 


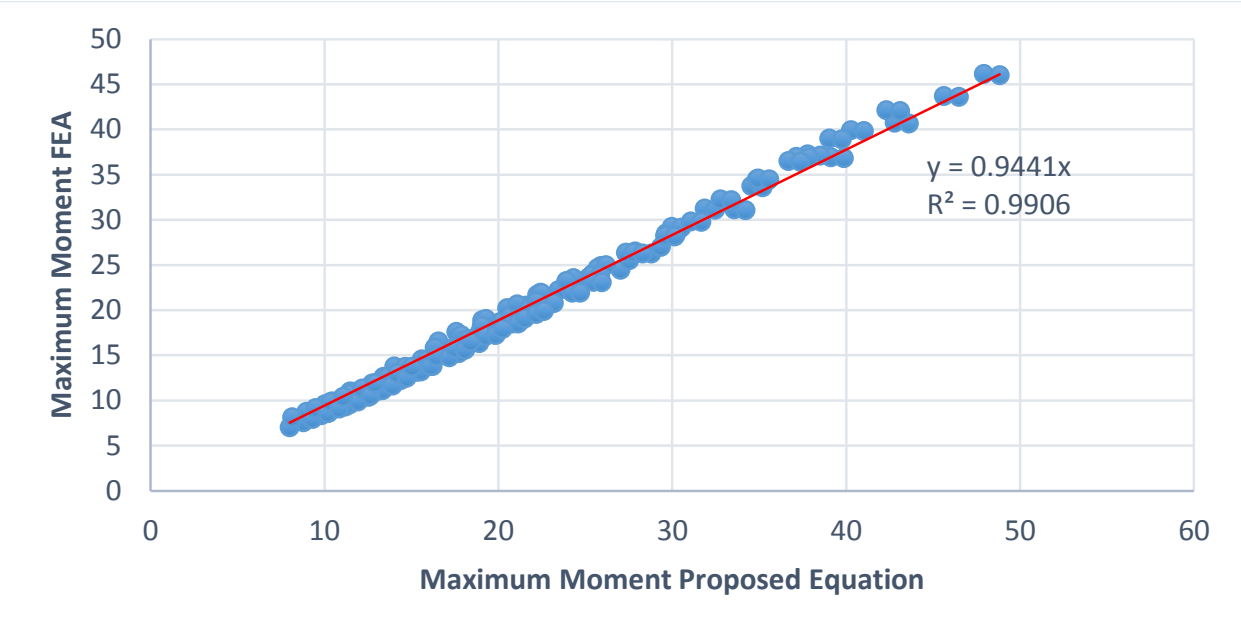

Figure 30 Maximum moment comparison between FEA and empirical equation for spans greater than $3 \mathrm{~m}$ for main bars transverse to traffic direction

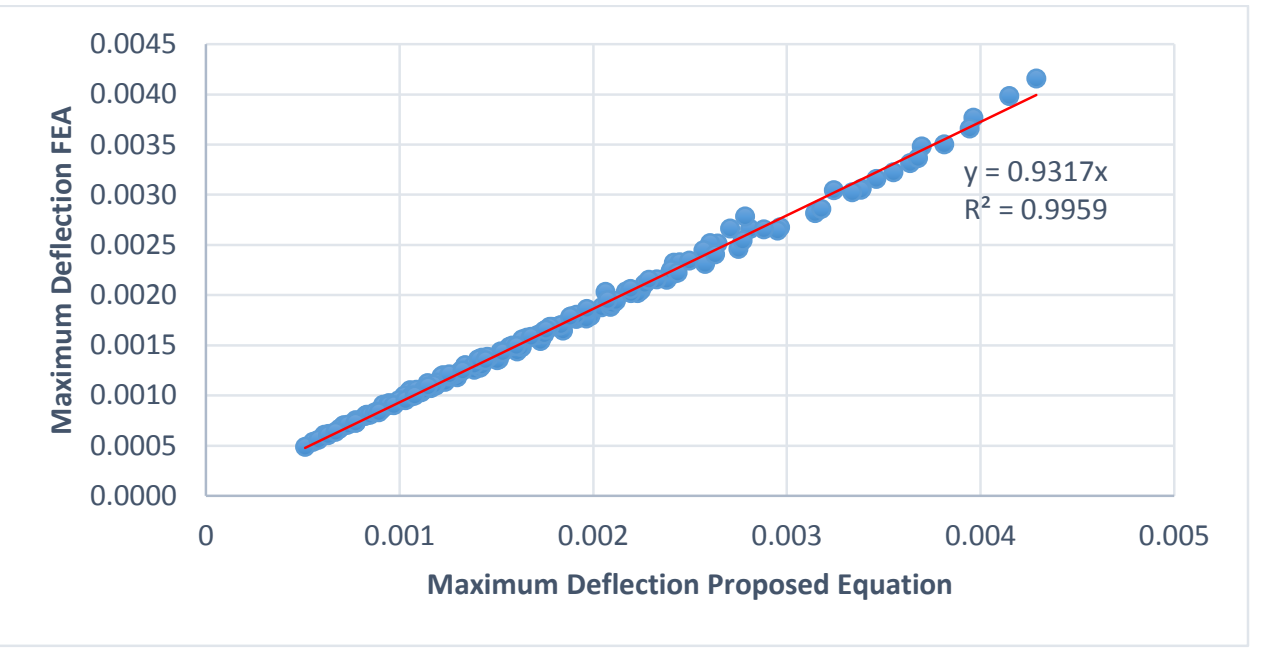

Figure 31 Maximum deflection comparison between FEA and empirical equation for spans greater than $3 \mathrm{~m}$ for main bars transverse to traffic direction 


\section{For main bars parallel to traffic direction:}

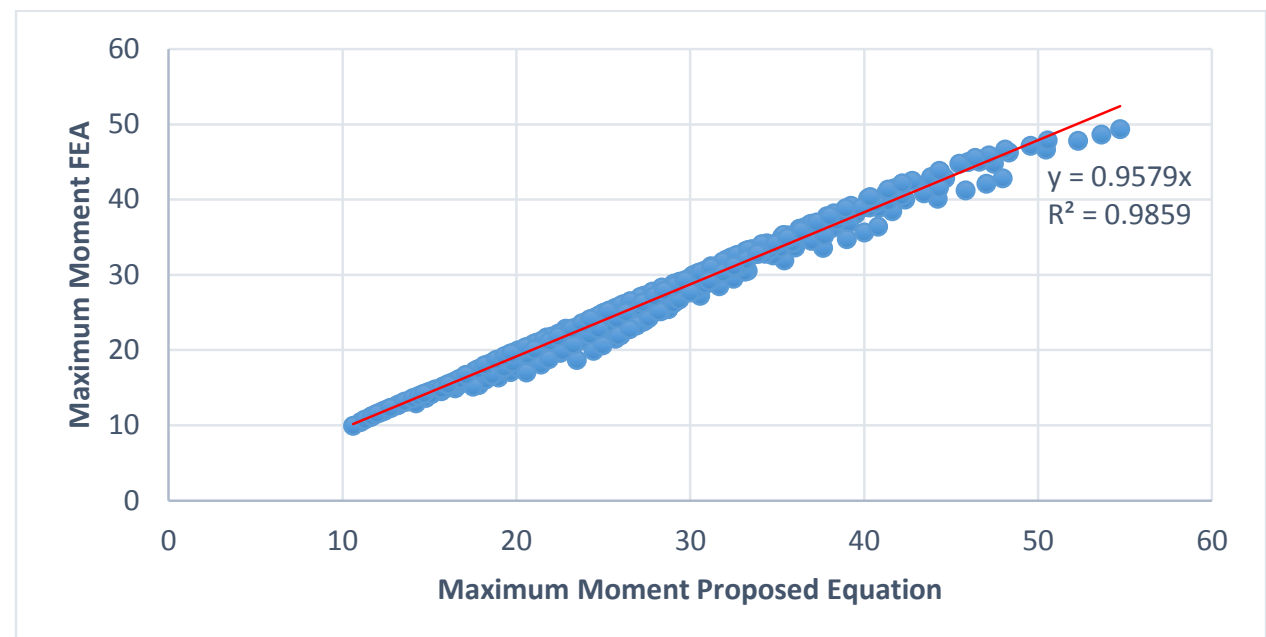

Figure 32 Maximum moment comparison between FEA and empirical equation for spans less than / equal to 3 m for main bars parallel to traffic direction

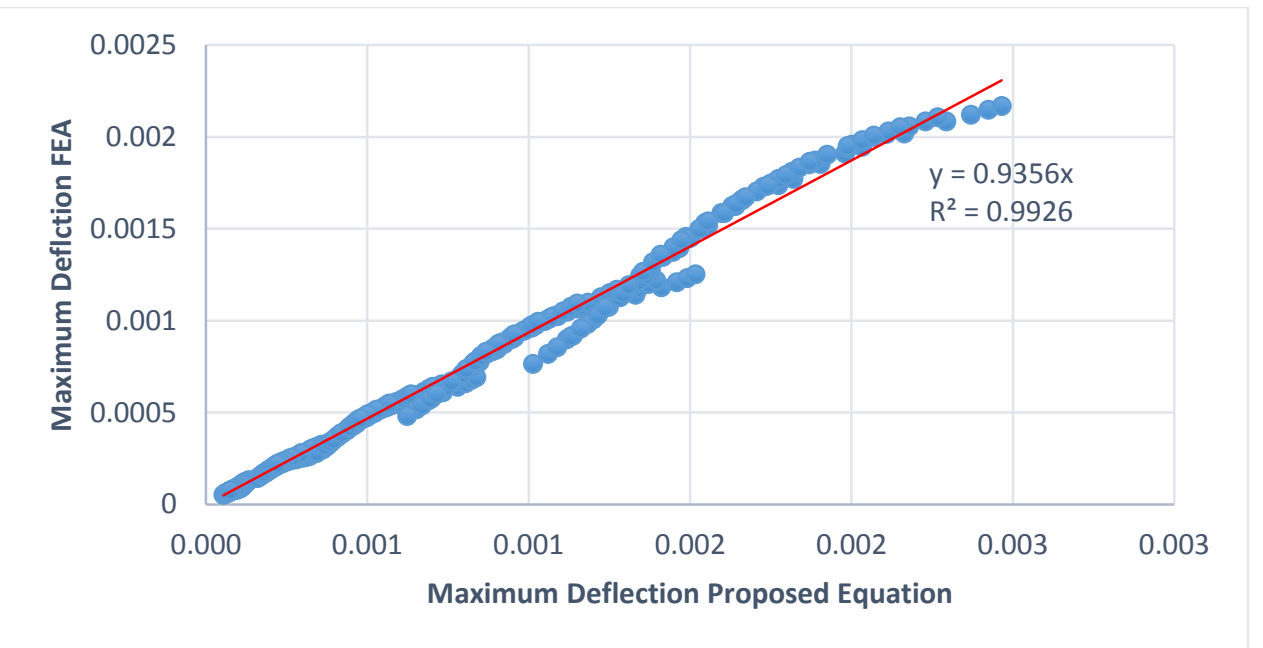

Figure 33 Maximum deflection comparison between FEA and empirical equation for spans less than / equal to $3 \mathrm{~m}$ transverse for main bars parallel to traffic direction 


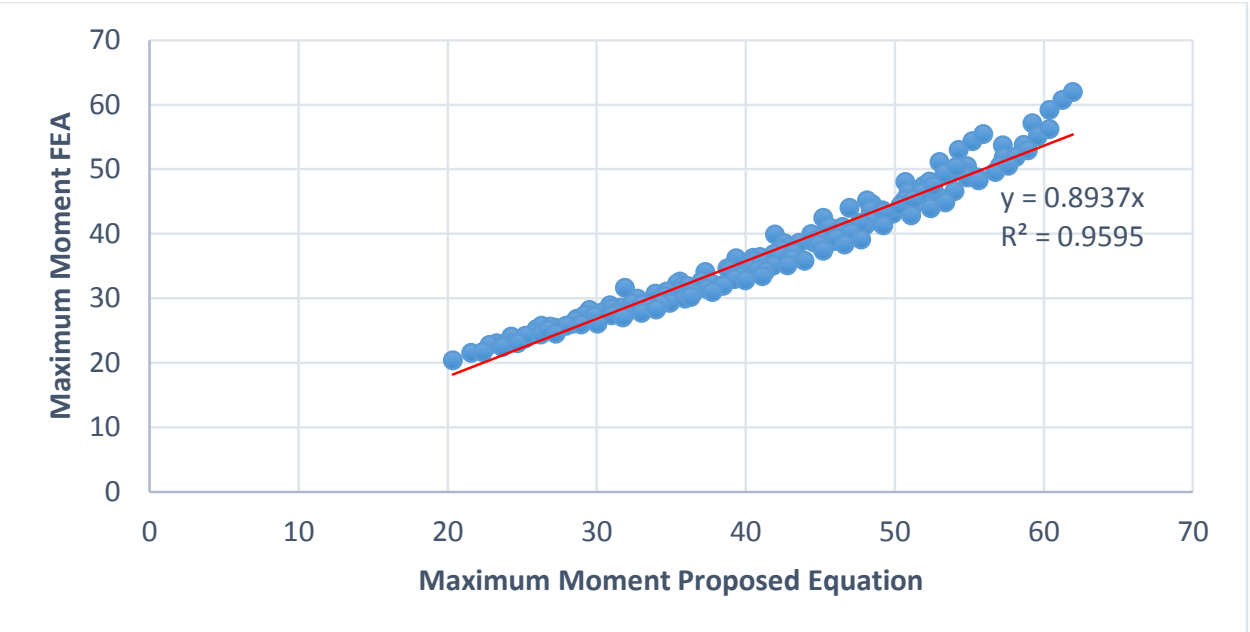

Figure 34 Maximum moment comparison between FEA and empirical equation for spans greater than $3 \mathrm{~m}$ transverse for main bars parallel to traffic direction

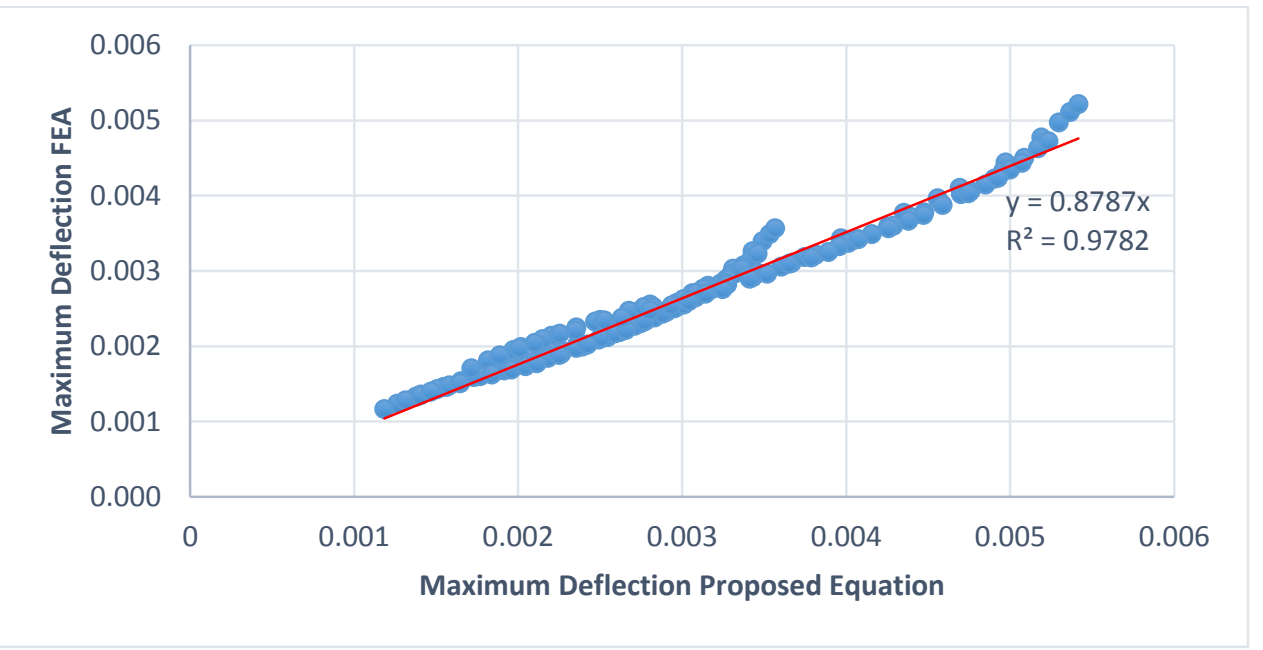

Figure 35 Maximum deflection comparison between FEA and empirical equation for spans greater than $3 \mathrm{~m}$ transverse for main bars parallel to traffic direction 


\section{Conclusion}

A detailed analysis for different bridge deck types was performed using finite element modeling and mathematical formulations for orthotropic plate theory. By comparing the results for both approaches, it can be seen that both approaches resulted in a very similar values for bending moment and deflection with minimum percent difference varying up to $10 \%$. Furthermore, studying the relationships between bending moment and deflection with the three main parameters; span length " $L$ ", flexural rigidity " $D$ ” and torsional rigidity “ $\alpha$ " improved the understanding of the behaviour of bending moment and deflection in different deck types covering cases 1, 2 and 3 as outlined in the orthotropic plate theory. Finally, based on these relationships general formulations were developed to cover all bridge deck types where main bars are perpendicular and transverse to the direction of traffic. Last of all, the proposed equations will fill a significant gap in the current $\mathrm{CHBC}$ provisions and will provide the designers with the tools to proceed with designing unlimited bridge deck configurations. 


\section{Appendices}




\section{A.1 Loading Cases}



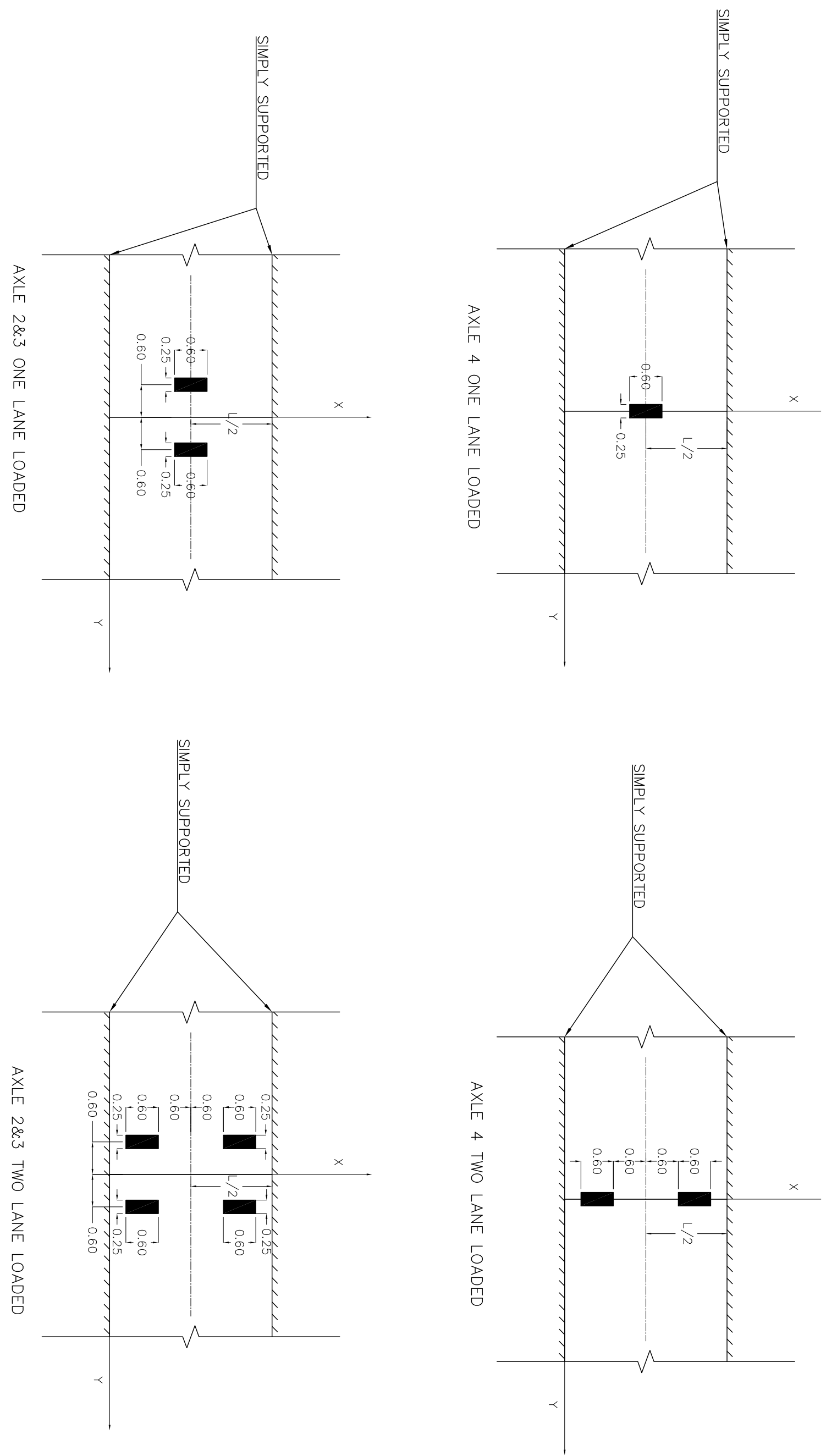

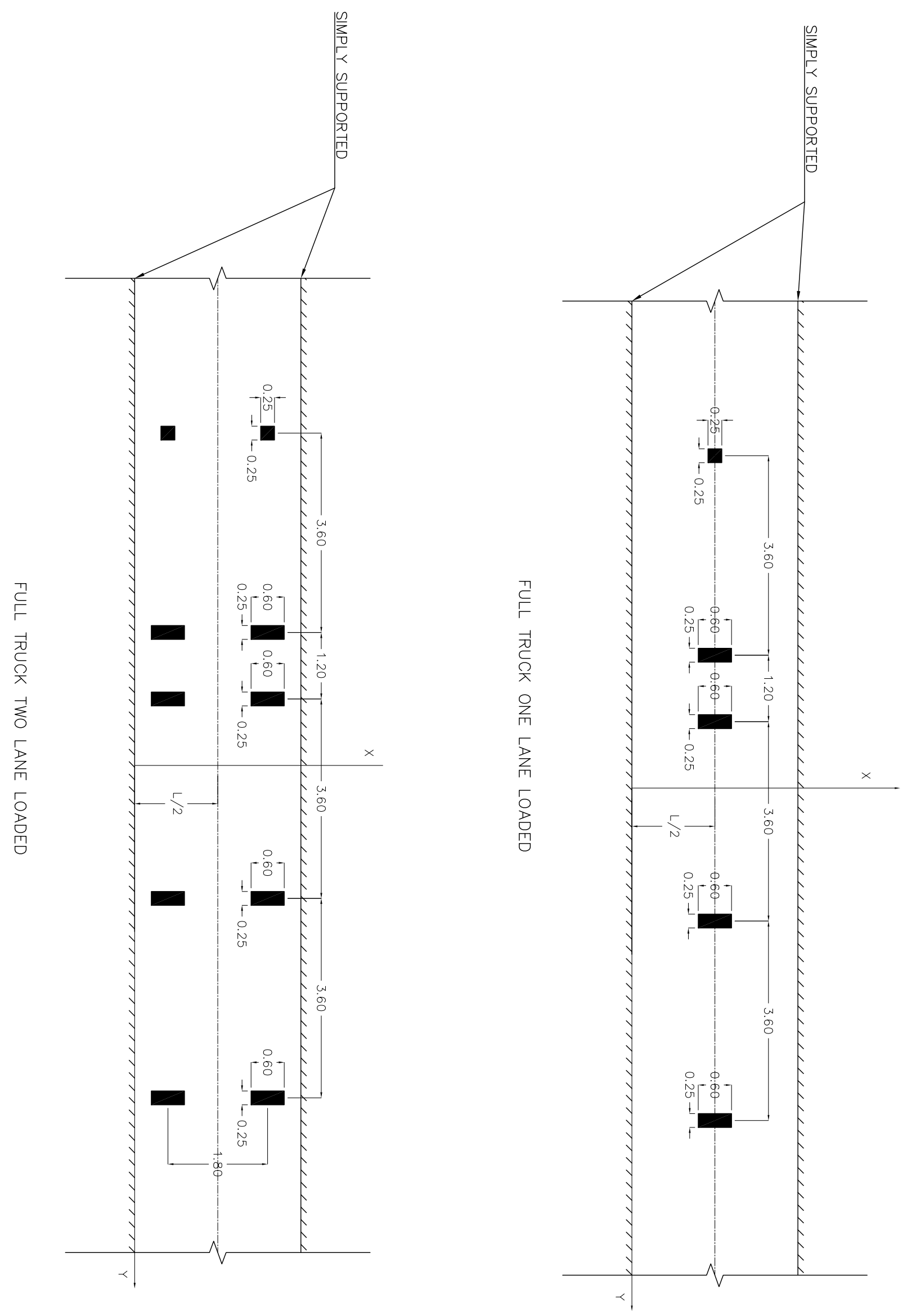

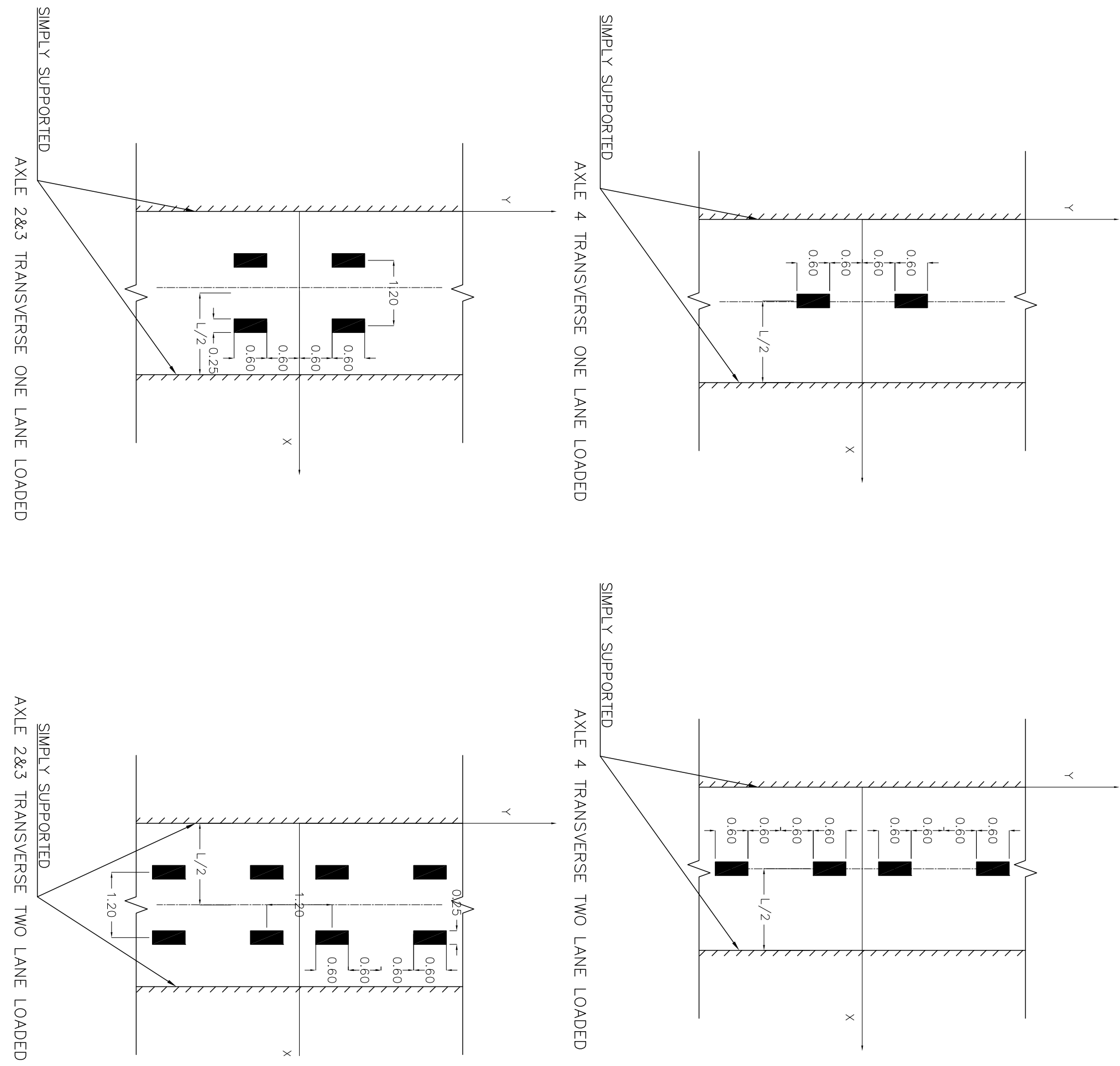
A.2 Materials Tables 
Table 1 Material properties for Alpha 0.25

Alpha 0.25

\begin{tabular}{|c|c|c|c|c|c|c|c|}
\hline D & Ex & Ey & v (Poisson's ratio) & Dx & Dy & Dxy & G \\
\hline 0.25 & 24648000 & 98592000 & 0 & 16432 & 65728 & 4108 & 6162000 \\
\hline 0.5 & 24648000 & 49296000 & 0 & 16432 & 32864 & 2905 & 4357192 \\
\hline 0.75 & 24648000 & 32864000 & 0 & 16432 & 21909 & 2372 & 3557632 \\
\hline 1 & 24648000 & 24648000 & 0 & 16432 & 16432 & 2054 & 3081000 \\
\hline 2 & 24648000 & 12324000 & 0 & 16432 & 8216 & 1452 & 2178596 \\
\hline 4 & 24648000 & 6162000 & 0 & 16432 & 4108 & 1027 & 1540500 \\
\hline 6 & 24648000 & 4108000 & 0 & 16432 & 2739 & 839 & 1257813 \\
\hline 8 & 24648000 & 3081000 & 0 & 16432 & 2054 & 726 & 1089298 \\
\hline 10 & 24648000 & 2464800 & 0 & 16432 & 1643 & 650 & 974298 \\
\hline
\end{tabular}

Table 2 Material properties for Alpha 0.5

Alpha 0.5

\begin{tabular}{|c|c|c|c|c|c|c|c|}
\hline$D$ & Ex & Ey & v (Poisson's ratio) & Dx & Dy & Dxy & G \\
\hline 0.25 & 24648000 & 98592000 & 0 & 16432 & 65728 & 8216 & 12324000 \\
\hline 0.5 & 24648000 & 49296000 & 0 & 16432 & 32864 & 5810 & 8714384 \\
\hline 0.75 & 24648000 & 32864000 & 0 & 16432 & 21909 & 4744 & 7115265 \\
\hline 1 & 24648000 & 24648000 & 0 & 16432 & 16432 & 4108 & 6162000 \\
\hline 2 & 24648000 & 12324000 & 0 & 16432 & 8216 & 2905 & 4357192 \\
\hline 4 & 24648000 & 6162000 & 0 & 16432 & 4108 & 2054 & 3081000 \\
\hline 6 & 24648000 & 4108000 & 0 & 16432 & 2739 & 1677 & 2515626 \\
\hline 8 & 24648000 & 3081000 & 0 & 16432 & 2054 & 1452 & 2178596 \\
\hline 10 & 24648000 & 2464800 & 0 & 16432 & 1643 & 1299 & 1948595 \\
\hline
\end{tabular}

Table 3 Material properties for Alpha 0.75

Alpha 0.75

\begin{tabular}{|c|c|c|c|c|c|c|c|}
\hline $\mathrm{D}$ & Ex & Ey & v (Poisson's ratio) & Dx & Dy & Dxy & G \\
\hline 0.25 & 24648000 & 98592000 & 0 & 16432 & 65728 & 12324 & 18486000 \\
\hline 0.5 & 24648000 & 49296000 & 0 & 16432 & 32864 & 8714 & 13071576 \\
\hline 0.75 & 24648000 & 32864000 & 0 & 16432 & 21909 & 7115 & 10672897 \\
\hline 1 & 24648000 & 24648000 & 0 & 16432 & 16432 & 6162 & 9243000 \\
\hline 2 & 24648000 & 12324000 & 0 & 16432 & 8216 & 4357 & 6535788 \\
\hline 4 & 24648000 & 6162000 & 0 & 16432 & 4108 & 3081 & 4621500 \\
\hline 6 & 24648000 & 4108000 & 0 & 16432 & 2739 & 2516 & 3773439 \\
\hline 8 & 24648000 & 3081000 & 0 & 16432 & 2054 & 2179 & 3267894 \\
\hline 10 & 24648000 & 2464800 & 0 & 16432 & 1643 & 1949 & 2922893 \\
\hline
\end{tabular}


Table 4 Material properties for Alpha 1

Alpha 1

\begin{tabular}{|c|c|c|c|c|c|c|c|}
\hline$D$ & Ex & Ey & v (Poisson's ratio) & Dx & Dy & Dxy & G \\
\hline 0.25 & 24648000 & 98592000 & 0 & 16432 & 65728 & 16432 & 24648000 \\
\hline 0.5 & 24648000 & 49296000 & 0 & 16432 & 32864 & 11619 & 17428768 \\
\hline 0.75 & 24648000 & 32864000 & 0 & 16432 & 21909 & 9487 & 14230529 \\
\hline 1 & 24648000 & 24648000 & 0 & 16432 & 16432 & 8216 & 12324000 \\
\hline 2 & 24648000 & 12324000 & 0 & 16432 & 8216 & 5810 & 8714384 \\
\hline 4 & 24648000 & 6162000 & 0 & 16432 & 4108 & 4108 & 6162000 \\
\hline 6 & 24648000 & 4108000 & 0 & 16432 & 2739 & 3354 & 5031252 \\
\hline 8 & 24648000 & 3081000 & 0 & 16432 & 2054 & 2905 & 4357192 \\
\hline 10 & 24648000 & 2464800 & 0 & 16432 & 1643 & 2598 & 3897191 \\
\hline
\end{tabular}

Table 5 Material properties for Alpha 2

Alpha 2

\begin{tabular}{|c|c|c|c|c|c|c|c|}
\hline $\mathrm{D}$ & Ex & Ey & v (Poisson's ratio) & Dx & Dy & Dxy & G \\
\hline 0.25 & 24648000 & 98592000 & 0 & 16432 & 65728 & 32864 & 49296000 \\
\hline 0.5 & 24648000 & 49296000 & 0 & 16432 & 32864 & 23238 & 34857536 \\
\hline 0.75 & 24648000 & 32864000 & 0 & 16432 & 21909 & 18974 & 28461059 \\
\hline 1 & 24648000 & 24648000 & 0 & 16432 & 16432 & 16432 & 24648000 \\
\hline 2 & 24648000 & 12324000 & 0 & 16432 & 8216 & 11619 & 17428768 \\
\hline 4 & 24648000 & 6162000 & 0 & 16432 & 4108 & 8216 & 12324000 \\
\hline 6 & 24648000 & 4108000 & 0 & 16432 & 2739 & 6708 & 10062504 \\
\hline 8 & 24648000 & 3081000 & 0 & 16432 & 2054 & 5810 & 8714384 \\
\hline 10 & 24648000 & 2464800 & 0 & 16432 & 1643 & 5196 & 7794382 \\
\hline
\end{tabular}

Table 6 Material properties for Alpha 4

Alpha 4

\begin{tabular}{|c|c|c|c|c|c|c|c|}
\hline$D$ & Ex & Ey & v (Poisson's ratio) & Dx & Dy & Dxy & G \\
\hline 0.25 & 24648000 & 98592000 & 0 & 16432 & 65728 & 65728 & 98592000 \\
\hline 0.5 & 24648000 & 49296000 & 0 & 16432 & 32864 & 46477 & 69715072 \\
\hline 0.75 & 24648000 & 32864000 & 0 & 16432 & 21909 & 37948 & 56922118 \\
\hline 1 & 24648000 & 24648000 & 0 & 16432 & 16432 & 32864 & 49296000 \\
\hline 2 & 24648000 & 12324000 & 0 & 16432 & 8216 & 23238 & 34857536 \\
\hline 4 & 24648000 & 6162000 & 0 & 16432 & 4108 & 16432 & 24648000 \\
\hline 6 & 24648000 & 4108000 & 0 & 16432 & 2739 & 13417 & 20125008 \\
\hline 8 & 24648000 & 3081000 & 0 & 16432 & 2054 & 11619 & 17428768 \\
\hline 10 & 24648000 & 2464800 & 0 & 16432 & 1643 & 10393 & 15588764 \\
\hline
\end{tabular}


Table 7 Material properties for Alpha 6

Alpha 6

\begin{tabular}{|c|c|c|c|c|c|c|c|}
\hline $\mathrm{D}$ & Ex & Ey & $\mathrm{v}$ (Poisson's ratio) & Dx & Dy & Dxy & G \\
\hline 0.25 & 24648000 & 98592000 & 0 & 16432 & 65728 & 98592 & 147888000 \\
\hline 0.5 & 24648000 & 49296000 & 0 & 16432 & 32864 & 69715 & 104572608 \\
\hline 0.75 & 24648000 & 32864000 & 0 & 16432 & 21909 & 56922 & 85383177 \\
\hline 1 & 24648000 & 24648000 & 0 & 16432 & 16432 & 49296 & 73944000 \\
\hline 2 & 24648000 & 12324000 & 0 & 16432 & 8216 & 34858 & 52286304 \\
\hline 4 & 24648000 & 6162000 & 0 & 16432 & 4108 & 24648 & 36972000 \\
\hline 6 & 24648000 & 4108000 & 0 & 16432 & 2739 & 20125 & 30187512 \\
\hline 8 & 24648000 & 3081000 & 0 & 16432 & 2054 & 17429 & 26143152 \\
\hline 10 & 24648000 & 2464800 & 0 & 16432 & 1643 & 15589 & 23383146 \\
\hline
\end{tabular}

Table 8 Material properties for Alpha 8

Alpha 8

\begin{tabular}{|c|c|c|c|c|c|c|c|}
\hline D & Ex & Ey & v (Poisson's ratio) & Dx & Dy & Dxy & G \\
\hline 0.25 & 24648000 & 98592000 & 0 & 16432 & 65728 & 131456 & 197184000 \\
\hline 0.5 & 24648000 & 49296000 & 0 & 16432 & 32864 & 92953 & 139430144 \\
\hline 0.75 & 24648000 & 32864000 & 0 & 16432 & 21909 & 75896 & 113844235 \\
\hline 1 & 24648000 & 24648000 & 0 & 16432 & 16432 & 65728 & 98592000 \\
\hline 2 & 24648000 & 12324000 & 0 & 16432 & 8216 & 46477 & 69715072 \\
\hline 4 & 24648000 & 6162000 & 0 & 16432 & 4108 & 32864 & 49296000 \\
\hline 6 & 24648000 & 4108000 & 0 & 16432 & 2739 & 26833 & 40250015 \\
\hline 8 & 24648000 & 3081000 & 0 & 16432 & 2054 & 23238 & 34857536 \\
\hline 10 & 24648000 & 2464800 & 0 & 16432 & 1643 & 20785 & 31177528 \\
\hline
\end{tabular}

Table 9 Material properties for Alpha 10

Alpha 10

\begin{tabular}{|c|c|c|c|c|c|c|c|}
\hline D & Ex & Ey & v (Poisson's ratio) & Dx & Dy & Dxy & G \\
\hline 0.25 & 24648000 & 98592000 & 0 & 16432 & 65728 & 164320 & 246480000 \\
\hline 0.5 & 24648000 & 49296000 & 0 & 16432 & 32864 & 116192 & 174287679 \\
\hline 0.75 & 24648000 & 32864000 & 0 & 16432 & 21909 & 94870 & 142305294 \\
\hline 1 & 24648000 & 24648000 & 0 & 16432 & 16432 & 82160 & 123240000 \\
\hline 2 & 24648000 & 12324000 & 0 & 16432 & 8216 & 58096 & 87143840 \\
\hline 4 & 24648000 & 6162000 & 0 & 16432 & 4108 & 41080 & 61620000 \\
\hline 6 & 24648000 & 4108000 & 0 & 16432 & 2739 & 33542 & 50312519 \\
\hline 8 & 24648000 & 3081000 & 0 & 16432 & 2054 & 29048 & 43571920 \\
\hline 10 & 24648000 & 2464800 & 0 & 16432 & 1643 & 25981 & 38971910 \\
\hline
\end{tabular}




\section{B.1 Finite Element}

Analysis Results (Bending Moment) 


\section{B.1.1 BENDING MOMENT RESULTS TABLES}




\section{Alpha 0.25 Bending Moment Results}

Table 10 Maximum moment results for alpha 0.25 for slabs subjected to CHBDC axle 4 loading (main bars perpendicular to traffic)

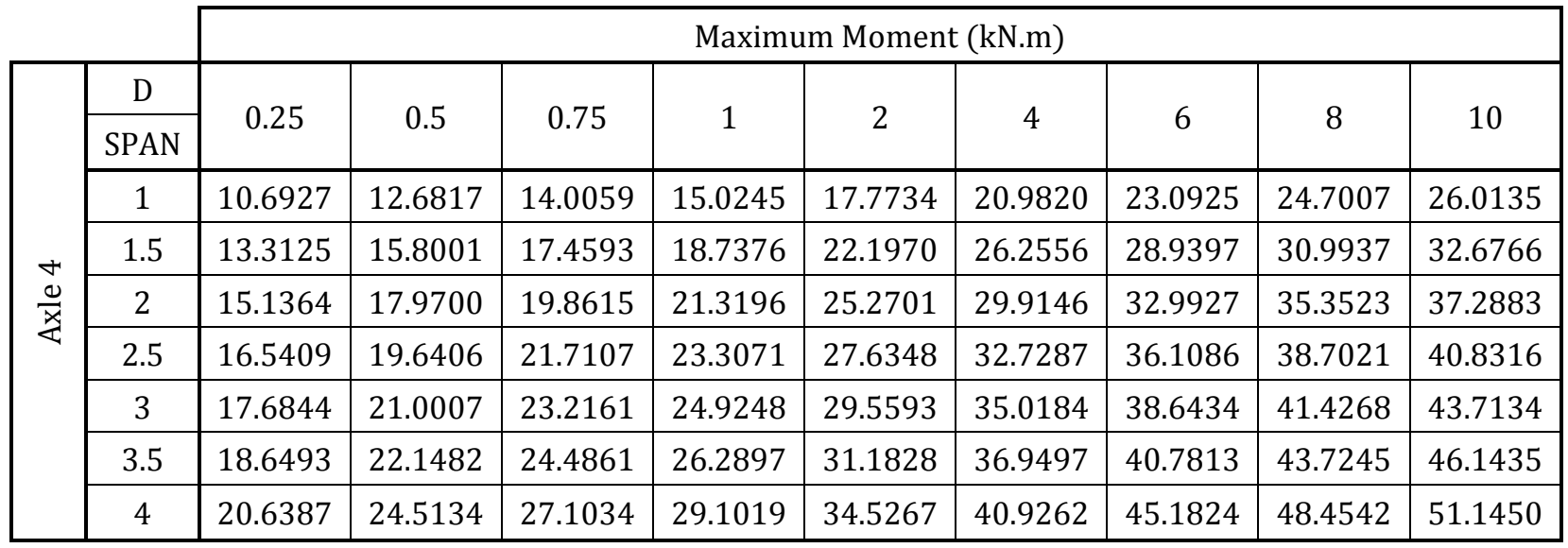

Table 11 Maximum moment results for alpha 0.25 for slabs subjected to CHBDC axle $2 \& 3$ loading (main bars perpendicular to traffic)

\begin{tabular}{|c|c|c|c|c|c|c|c|c|c|c|}
\hline & \multicolumn{9}{|c|}{ Maximum Moment (kN.m) } \\
\hline \multirow{9}{*}{ 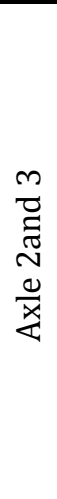 } & $\mathrm{D}$ & \multirow{2}{*}{0.25} & \multirow{2}{*}{0.5} & \multirow{2}{*}{0.75} & \multirow{2}{*}{1} & \multirow[b]{2}{*}{2} & \multirow[b]{2}{*}{4} & \multirow[b]{2}{*}{0} & \multirow[b]{2}{*}{0} & \multirow{2}{*}{10} \\
\hline & SPAN & & & & & & & & & \\
\hline & 1 & 9.0561 & 9.8074 & 10.4124 & 10.9201 & 12.5461 & 14.7303 & 16.2590 & 17.4466 & 18.4215 \\
\hline & 1.5 & 13.2348 & 14.4648 & 15.2088 & 15.7740 & 17.3116 & 19.2677 & 20.7894 & 22.0345 & 23.1038 \\
\hline & 2 & 16.1042 & 17.9346 & 19.0376 & 19.8527 & 21.8542 & 24.1066 & 25.5595 & 26.6847 & 27.7005 \\
\hline & 2.5 & 18.2557 & 20.5519 & 21.9666 & 23.0220 & 25.6295 & 28.4350 & 30.1620 & 31.4375 & 32.4656 \\
\hline & 3 & 19.9734 & 22.6356 & 24.3071 & 25.5566 & 28.6934 & 32.0913 & 34.1667 & 35.6778 & 36.8751 \\
\hline & 3.5 & 21.4830 & 24.5344 & 26.4776 & 27.9136 & 31.5617 & 35.4724 & 38.3171 & 40.4720 & 42.0559 \\
\hline & 4 & 24.5619 & 28.2231 & 30.5816 & 32.3412 & 36.8702 & 41.7423 & 44.8218 & 47.5464 & 49.6086 \\
\hline
\end{tabular}

Table 12 Maximum moment results for alpha 0.25 for slabs subjected to CHBDC truck loading (main bars perpendicular to traffic)

\begin{tabular}{|c|c|c|c|c|c|c|c|c|c|c|}
\hline & \multicolumn{9}{|c|}{ Maximum Moment (kN.m) } \\
\hline \multirow{9}{*}{ 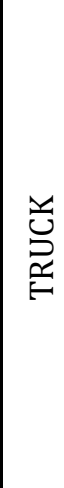 } & $\mathrm{D}$ & \multirow{2}{*}{0.25} & \multirow{2}{*}{0.5} & \multirow{2}{*}{0.75} & & \multirow{2}{*}{2} & & \multirow{2}{*}{6} & & \multirow{2}{*}{10} \\
\hline & SPAN & & & & & & & & & \\
\hline & 1 & 10.6926 & 12.6817 & 14.0059 & 15.0245 & 17.7734 & 20.9820 & 23.0925 & 24.7007 & 26.0135 \\
\hline & 1.5 & 13.3186 & 15.8038 & 17.4605 & 18.7378 & 22.1969 & 26.2556 & 28.9397 & 30.9937 & 32.6766 \\
\hline & 2 & 16.0717 & 17.9625 & 19.8692 & 21.3288 & 25.2729 & 29.9145 & 32.9925 & 35.3522 & 37.2882 \\
\hline & 2.5 & 18.3242 & 20.5439 & 21.9228 & 23.2777 & 27.6459 & 32.7347 & 36.1103 & 38.7023 & 40.8314 \\
\hline & 3 & 20.2259 & 22.7478 & 24.3675 & 25.5682 & 29.5184 & 35.0312 & 38.6558 & 41.4346 & 43.7179 \\
\hline & 3.5 & 22.0975 & 24.8889 & 26.7060 & 28.0665 & 31.5805 & 36.9147 & 40.7886 & 43.7407 & 46.1593 \\
\hline & 4 & 25.7944 & 28.9768 & 31.1178 & 32.7625 & 37.0622 & 41.7225 & 45.1033 & 48.4358 & 51.1531 \\
\hline
\end{tabular}


Table 13 Maximum moment results for alpha 0.25 for slabs subjected to CHBDC axle 4 loading (main bars parallel to traffic)

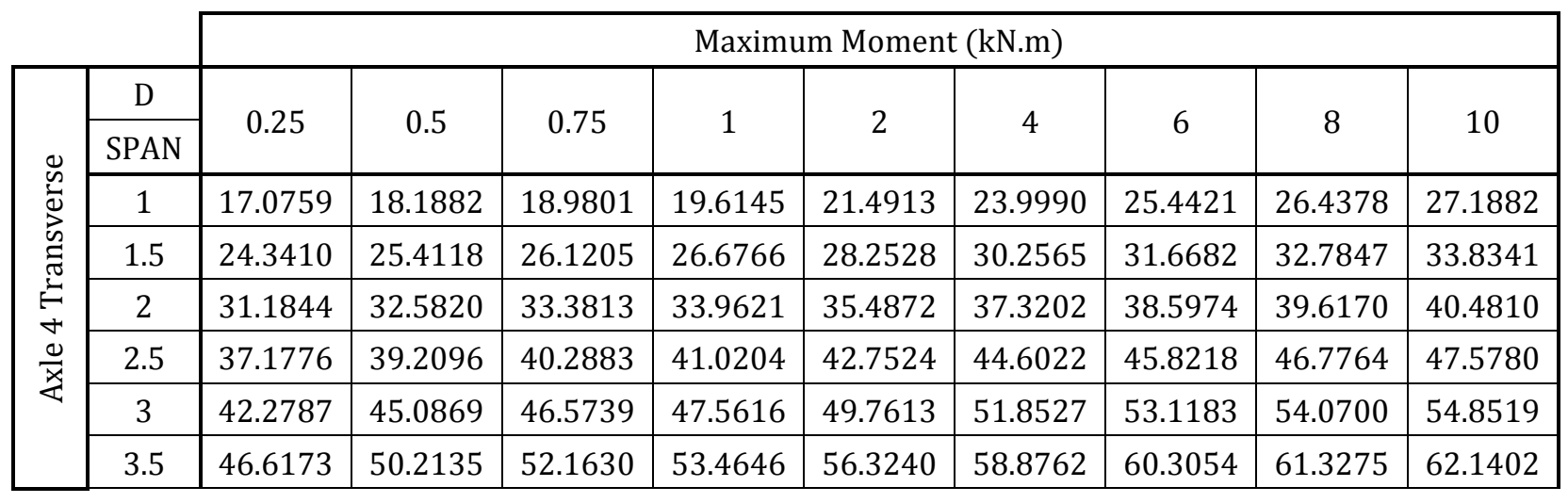

Table 14 Maximum moment results for alpha 0.25 for slabs subjected to CHBDC axle $2 \& 3$ loading (main bars parallel to traffic)

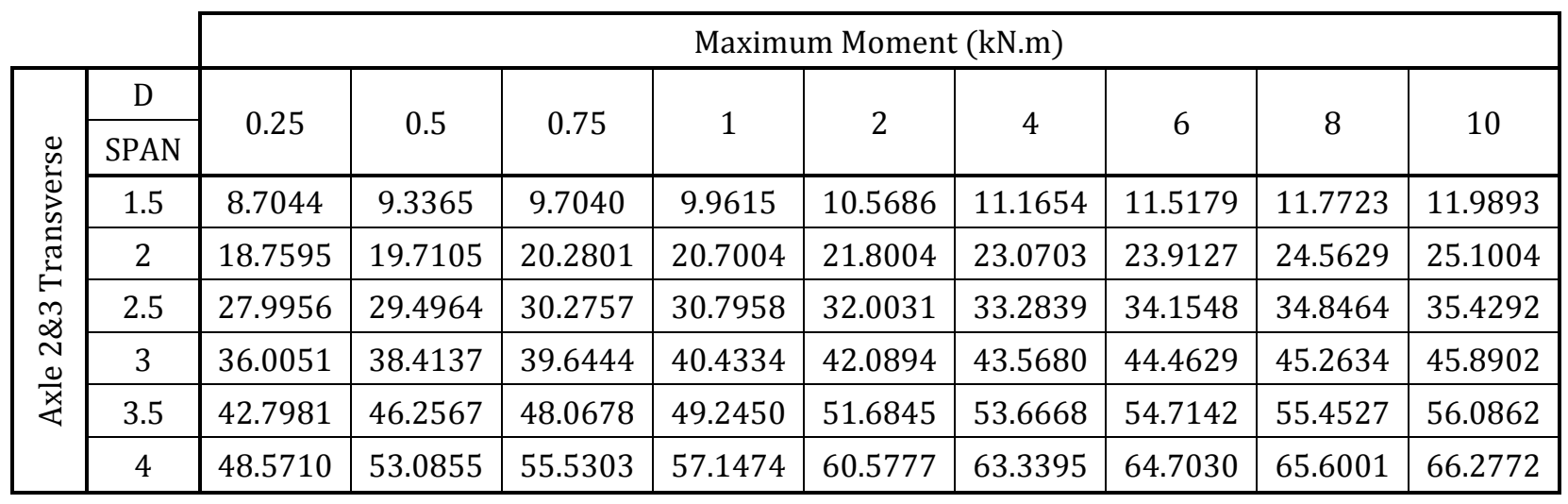




\section{Alpha 0.5 Bending Moment Results}

Table 15 Maximum moment results for alpha 0.5 for slabs subjected to CHBDC axle 4 loading (main bars perpendicular to traffic)

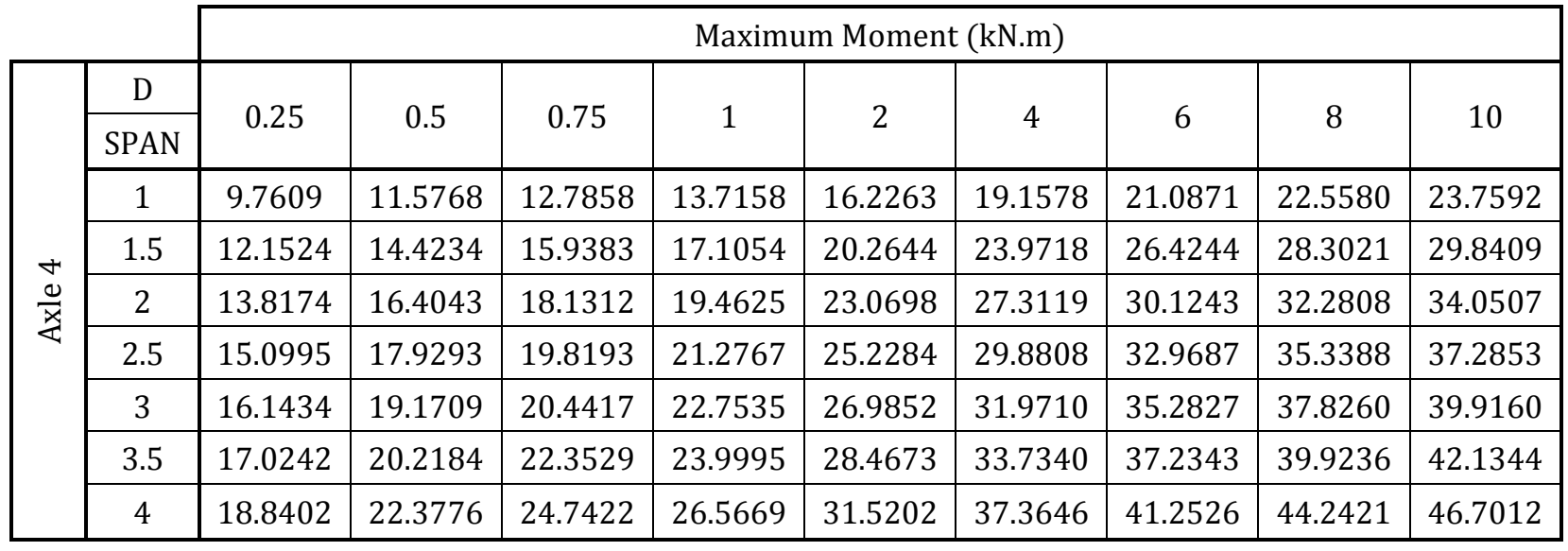

Table 16 Maximum moment results for alpha 0.5 for slabs subjected to CHBDC axle $2 \& 3$ loading (main bars perpendicular to traffic)

\begin{tabular}{|c|c|c|c|c|c|c|c|c|c|c|}
\hline & \multicolumn{9}{|c|}{ Maximum Moment (kN.m) } \\
\hline \multirow{9}{*}{ 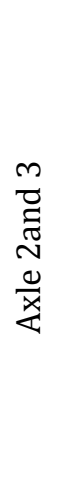 } & $\mathrm{D}$ & \multirow{2}{*}{0.25} & \multirow{2}{*}{5} & \multirow{2}{*}{0.75} & & \multirow{2}{*}{2} & & \multirow{2}{*}{6} & & \multirow{2}{*}{10} \\
\hline & SPAN & & & & & & & & & \\
\hline & 1 & 8.5416 & 9.3046 & 9.8773 & 10.3482 & 11.7755 & 13.6756 & 15.0039 & 16.0421 & 16.9002 \\
\hline & 1.5 & 12.2963 & 13.5131 & 14.2604 & 14.8246 & 16.3432 & 18.1978 & 19.5667 & 20.6803 & 21.6268 \\
\hline & 2 & 14.8973 & 16.6399 & 17.6996 & 18.4890 & 20.4486 & 22.6555 & 24.0708 & 25.1546 & 26.0899 \\
\hline & 2.5 & 16.8535 & 19.0121 & 20.3481 & 21.3475 & 23.8374 & 26.5475 & 28.2289 & 29.4742 & 30.4774 \\
\hline & 3 & 18.4186 & 20.9071 & 21.7849 & 23.6444 & 26.6031 & 29.8319 & 31.8232 & 33.2822 & 34.4432 \\
\hline & 3.5 & 19.7845 & 22.6074 & 24.4178 & 25.7583 & 29.1737 & 32.8715 & 35.1328 & 36.7778 & 38.0912 \\
\hline & 4 & 22.5863 & 25.9729 & 28.1556 & 29.7847 & 33.9732 & 38.5424 & 41.3520 & 43.3943 & 45.0033 \\
\hline
\end{tabular}

Table 17 Maximum moment results for alpha 0.5 for slabs subjected to CHBDC truck loading (main bars perpendicular to traffic)

\begin{tabular}{|c|c|c|c|c|c|c|c|c|c|c|}
\hline & \multicolumn{9}{|c|}{ Maximum Moment (kN.m) } \\
\hline \multirow{9}{*}{ 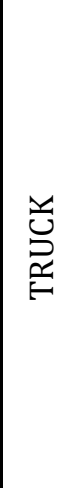 } & $\mathrm{D}$ & \multirow{2}{*}{0.25} & \multirow{2}{*}{0.5} & \multirow{2}{*}{0.75} & & \multirow{2}{*}{2} & & \multirow{2}{*}{6} & & \multirow{2}{*}{10} \\
\hline & SPAN & & & & & & & & & \\
\hline & 1 & 9.7610 & 11.5768 & 12.7858 & 13.7158 & 16.2263 & 19.1578 & 21.0871 & 22.5580 & 23.7592 \\
\hline & 1.5 & 12.2854 & 14.4236 & 15.9387 & 17.1057 & 20.2644 & 23.9717 & 26.4244 & 28.3021 & 29.8409 \\
\hline & 2 & 14.9631 & 16.6522 & 18.1225 & 19.4593 & 23.0704 & 27.3121 & 30.1243 & 32.2808 & 34.0507 \\
\hline & 2.5 & 17.0887 & 19.1367 & 20.4252 & 21.3892 & 25.2200 & 29.8813 & 32.9695 & 35.3392 & 37.2856 \\
\hline & 3 & 18.9173 & 21.2182 & 22.0899 & 23.8171 & 26.9328 & 31.9596 & 35.2807 & 37.8265 & 39.9169 \\
\hline & 3.5 & 20.7185 & 23.2541 & 24.9083 & 26.1519 & 29.3934 & 33.6797 & 37.2106 & 39.9132 & 42.1301 \\
\hline & 4 & 24.2597 & 27.1444 & 29.0771 & 30.5563 & 34.4684 & 38.7786 & 41.4719 & 44.1864 & 46.6668 \\
\hline
\end{tabular}


Table 18 Maximum moment results for alpha 0.5 for slabs subjected to CHBDC axle 4 loading (main bars parallel to traffic)

\begin{tabular}{|c|c|c|c|c|c|c|c|c|c|c|}
\hline & & \multicolumn{9}{|c|}{ Maximum Moment (kN.m) } \\
\hline \multirow{8}{*}{ 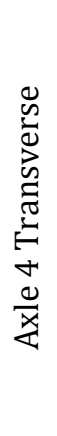 } & $\mathrm{D}$ & 025 & 05 & 075 & 1 & 2 & 4 & 6 & 8 & 10 \\
\hline & SPAN & $0.2 \mathrm{~J}$ & & & & & & & & \\
\hline & 1 & 16.5613 & 17.5927 & 18.3087 & 18.8749 & 20.4514 & 22.4019 & 23.6762 & 24.6371 & 25.3708 \\
\hline & 1.5 & 23.4968 & 24.6229 & 25.3346 & 25.8778 & 27.3675 & 29.1953 & 30.4561 & 31.4437 & 32.2632 \\
\hline & 2 & 29.7927 & 31.3376 & 32.2132 & 32.8373 & 34.4132 & 36.2037 & 37.4075 & 38.3510 & 39.1408 \\
\hline & 2.5 & 35.2115 & 37.3918 & 38.5781 & 39.3887 & 41.2892 & 43.2344 & 44.4602 & 45.3938 & 46.1639 \\
\hline & 3 & 39.8073 & 42.6991 & 43.3934 & 45.3502 & 47.7747 & 50.0735 & 51.4247 & 52.4134 & 53.2084 \\
\hline & 3.5 & 43.7170 & 47.3138 & 49.3175 & 50.6812 & 53.7576 & 56.5759 & 58.1523 & 59.2635 & 60.1328 \\
\hline
\end{tabular}

Table 19 Maximum moment results for alpha 0.5 for slabs subjected to CHBDC axle $2 \& 3$ loading (main bars parallel to traffic)

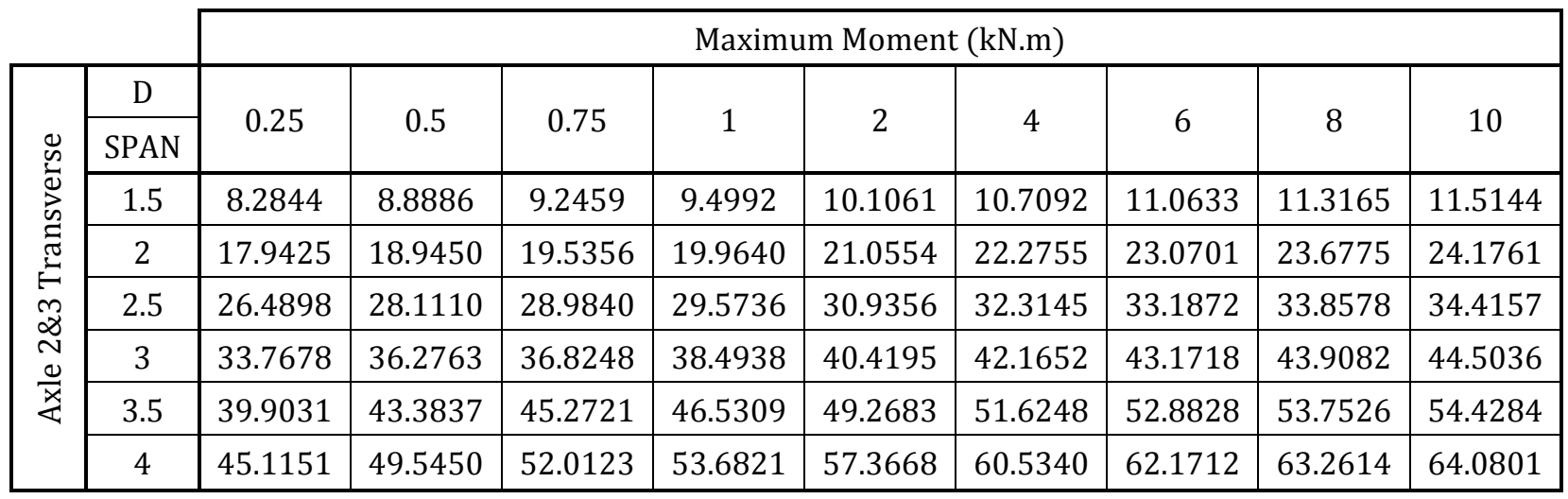




\section{Alpha 0.75 Bending Moment Results}

Table 20 Maximum moment results for alpha 0.75 for slabs subjected to CHBDC axle 4 loading (main bars perpendicular to traffic)

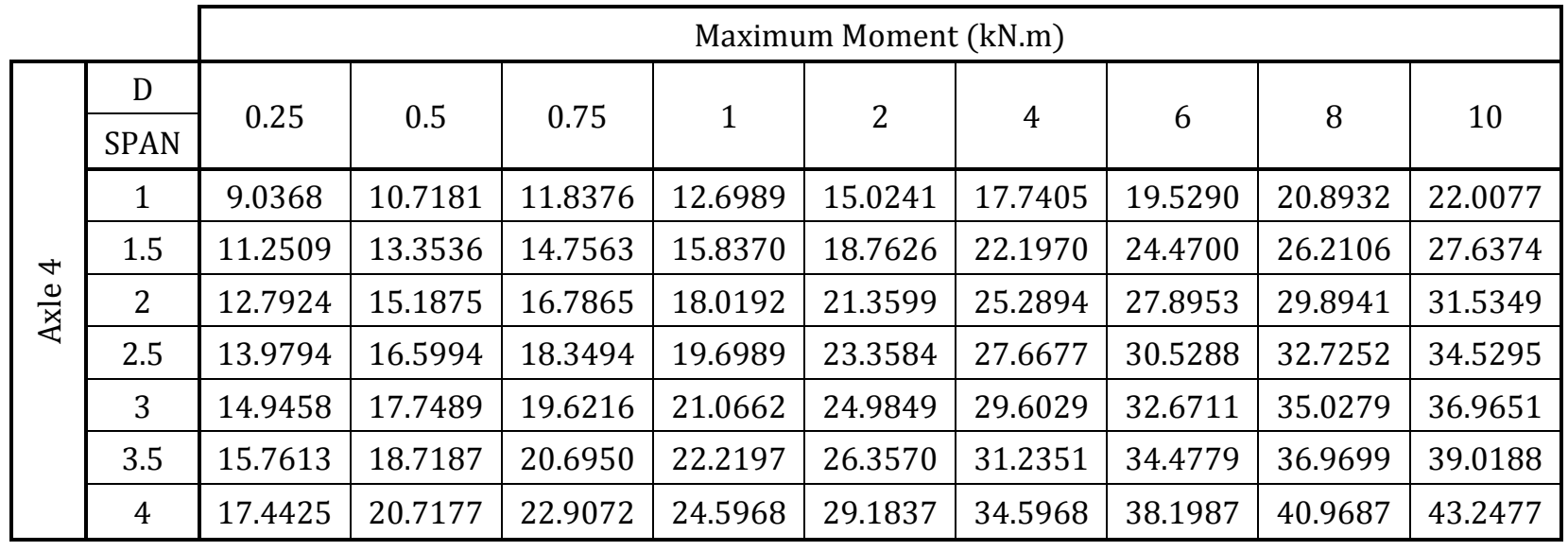

Table 21 Maximum moment results for alpha 0.75 for slabs subjected to CHBDC axle $2 \& 3$ loading (main bars perpendicular to traffic)

\begin{tabular}{|c|c|c|c|c|c|c|c|c|c|c|}
\hline & \multicolumn{9}{|c|}{ Maximum Moment (kN.m) } \\
\hline \multirow{9}{*}{ 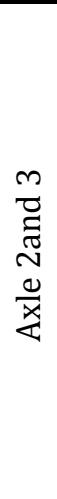 } & $\mathrm{D}$ & \multirow{2}{*}{0.25} & \multirow{2}{*}{0.5} & \multirow{2}{*}{0.75} & \multirow[b]{2}{*}{1} & \multirow[b]{2}{*}{2} & \multirow[b]{2}{*}{4} & \multirow{2}{*}{6} & \multirow[b]{2}{*}{0} & \multirow{2}{*}{10} \\
\hline & SPAN & & & & & & & & & \\
\hline & 1 & 8.1212 & 8.8869 & 9.4350 & 9.8793 & 11.1698 & 12.8716 & 14.0568 & 14.9857 & 15.7565 \\
\hline & 1.5 & 11.5549 & 12.7554 & 13.4991 & 14.0583 & 15.5510 & 17.3311 & 18.5857 & 19.6066 & 20.4671 \\
\hline & 2 & 13.9483 & 15.6201 & 16.6438 & 17.4102 & 19.3262 & 21.4838 & 22.8616 & 23.9091 & 24.7832 \\
\hline & 2.5 & 15.7532 & 17.8029 & 19.0762 & 20.0307 & 22.4238 & 25.0481 & 26.6848 & 27.8989 & 28.8765 \\
\hline & 3 & 17.1998 & 19.5514 & 21.0321 & 22.1438 & 24.9606 & 28.0511 & 29.9704 & 31.3826 & 32.5095 \\
\hline & 3.5 & 18.4542 & 21.0998 & 22.8047 & 24.0701 & 27.3026 & 30.8282 & 33.0007 & 34.5897 & 35.8547 \\
\hline & 4 & 21.0411 & 24.2159 & 26.2595 & 27.7879 & 31.7216 & 36.0446 & 38.7221 & 40.6802 & 42.2304 \\
\hline
\end{tabular}

Table 22 Maximum moment results for alpha 0.75 for slabs subjected to CHBDC truck loading (main bars perpendicular to traffic)

\begin{tabular}{|c|c|c|c|c|c|c|c|c|c|c|}
\hline & \multicolumn{9}{|c|}{ Maximum Moment (kN.m) } \\
\hline \multirow{9}{*}{ 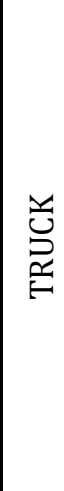 } & D & \multirow{2}{*}{0.25} & \multirow{2}{*}{0.5} & \multirow{2}{*}{0.75} & \multirow{2}{*}{1} & \multirow[b]{2}{*}{2} & \multirow{2}{*}{4} & \multirow{2}{*}{6} & \multirow{2}{*}{8} & \multirow{2}{*}{10} \\
\hline & SPAN & & & & & & & & & \\
\hline & 1 & 9.0367 & 10.7181 & 11.8376 & 12.6989 & 15.0241 & 17.7405 & 19.5290 & 20.8932 & 22.0077 \\
\hline & 1.5 & 11.5831 & 13.3526 & 14.7559 & 15.8369 & 18.7626 & 22.1970 & 24.4700 & 26.2106 & 27.6374 \\
\hline & 2 & 14.1020 & 15.7023 & 16.7817 & 18.0159 & 21.3591 & 25.2894 & 27.8953 & 29.8941 & 31.5349 \\
\hline & 2.5 & 16.1347 & 18.0451 & 19.2582 & 20.1686 & 23.3528 & 27.6661 & 30.5282 & 32.7250 & 34.5295 \\
\hline & 3 & 17.9106 & 20.0372 & 21.4196 & 22.4588 & 25.1359 & 29.5959 & 32.6672 & 35.0258 & 36.9638 \\
\hline & 3.5 & 19.6686 & 21.9968 & 23.5236 & 24.6757 & 27.6977 & 31.2259 & 34.4681 & 36.9625 & 39.0134 \\
\hline & 4 & 23.1088 & 25.7456 & 27.5160 & 28.8691 & 32.4747 & 36.4999 & 39.0404 & 40.9545 & 43.2340 \\
\hline
\end{tabular}

Table 23 Maximum moment results for alpha 0.75 for slabs subjected to CHBDC axle 4 loading (main bars parallel to traffic) 


\begin{tabular}{|c|c|c|c|c|c|c|c|c|c|c|}
\hline \multirow{7}{*}{ 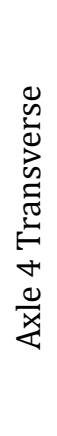 } & $\frac{\mathrm{D}}{\text { SPAN }}$ & 0.25 & 0.5 & 0.75 & 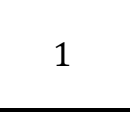 & 2 & 4 & 6 & 8 & 10 \\
\hline & 1 & 16.1334 & 17.1112 & 17.7742 & 18.2925 & 19.7189 & 21.4421 & 22.5719 & 23.4064 & 24.0655 \\
\hline & 1.5 & 22.7753 & 23.9487 & 24.6688 & 25.2072 & 26.6433 & 28.3495 & 29.5044 & 30.4014 & 31.1424 \\
\hline & 2 & 28.6369 & 30.2838 & 31.2160 & 31.8744 & 33.4993 & 35.2736 & 36.4311 & 37.3232 & 38.0619 \\
\hline & 2.5 & 33.6193 & 35.8906 & 37.1488 & 38.0139 & 40.0386 & 42.0659 & 43.3070 & 44.2332 & 44.9862 \\
\hline & 3 & 37.8296 & 40.7636 & 42.4027 & 43.5254 & 46.1024 & 48.5534 & 49.9742 & 50.9974 & 51.8087 \\
\hline & 3.5 & 41.4120 & 44.9899 & 47.0207 & 48.4205 & 51.6349 & 54.6351 & 56.3187 & 57.4983 & 58.4133 \\
\hline
\end{tabular}

Table 24 Maximum moment results for alpha 0.75 for slabs subjected to CHBDC axle $2 \& 3$ loading (main bars parallel to traffic)

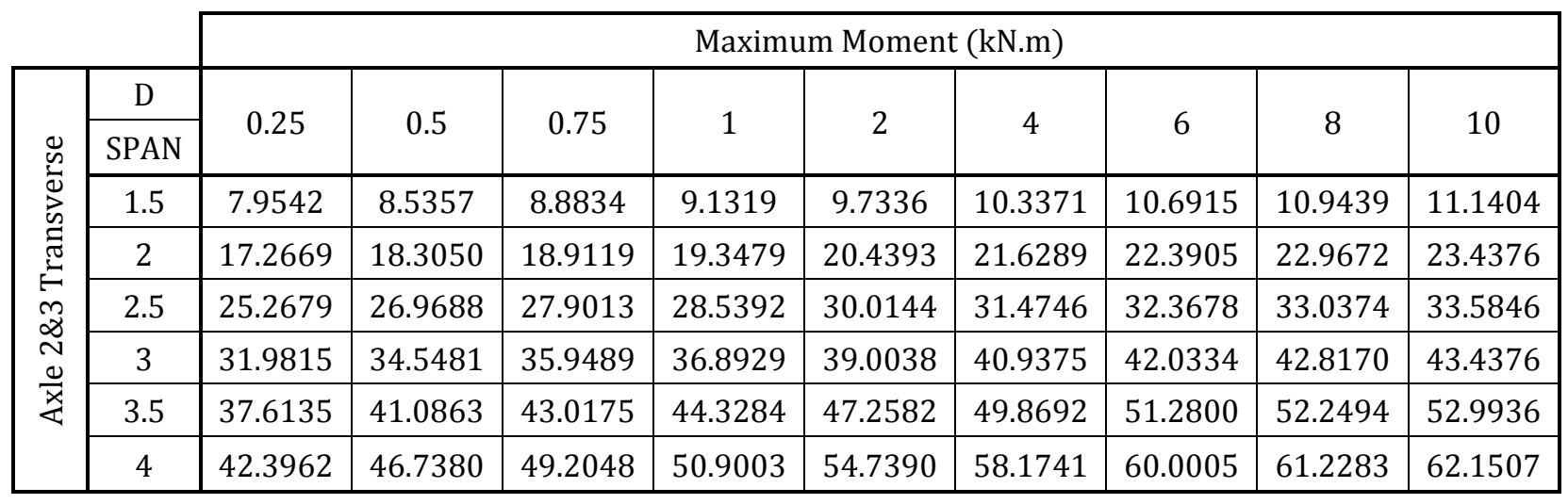




\section{Alpha 1 Bending Moment Results}

Table 25 Maximum moment results for alpha 1 for slabs subjected to CHBDC axle 4 loading (main bars perpendicular to traffic)

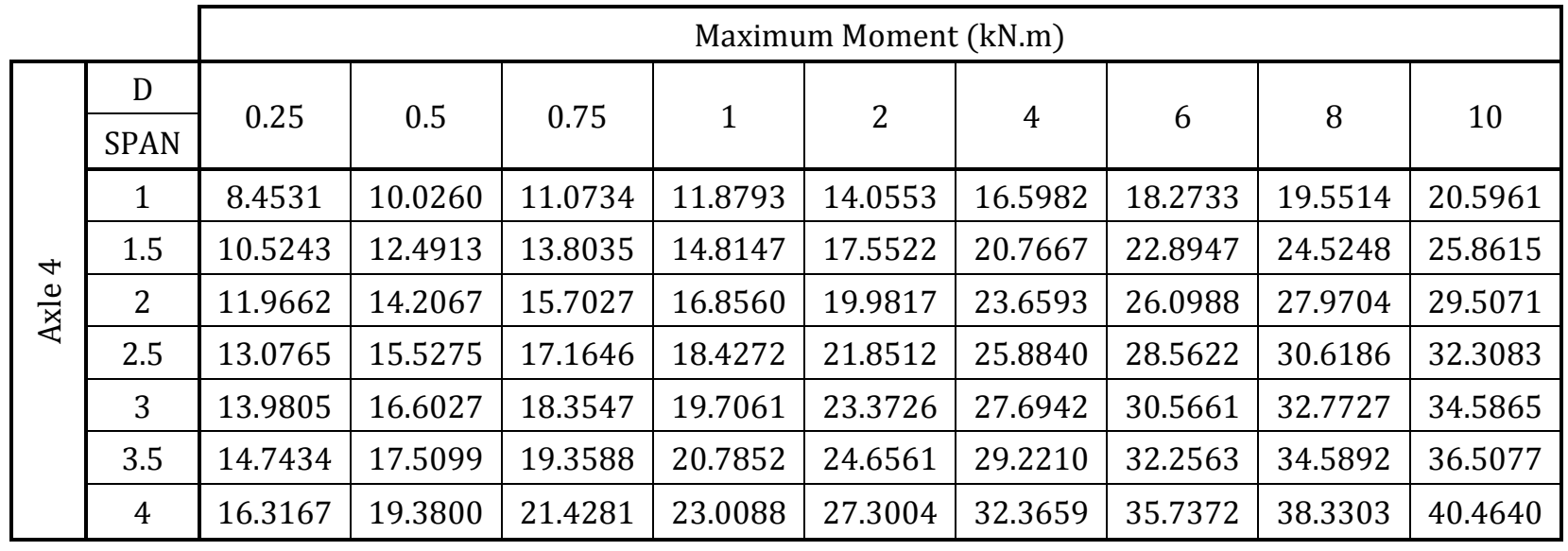

Table 26 Maximum moment results for alpha 1 for slabs subjected to CHBDC axle 2 \& 3 loading (main bars perpendicular to traffic)

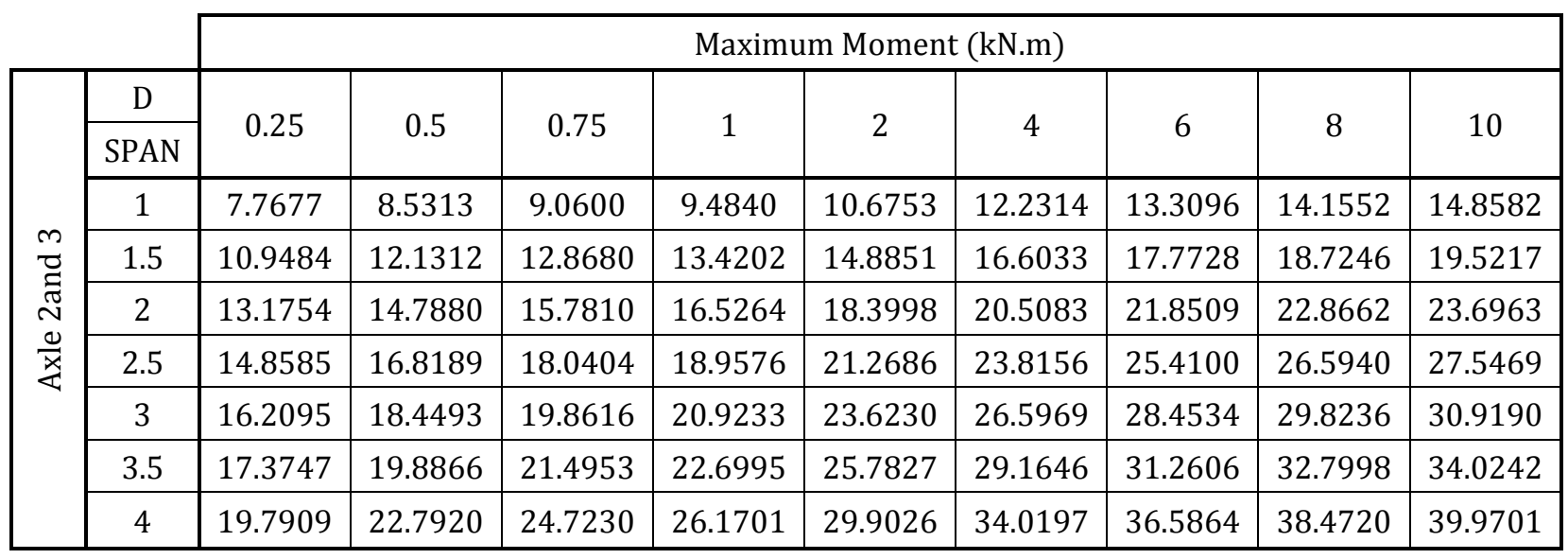

Table 27 Maximum moment results for alpha 1 for slabs subjected to CHBDC truck loading (main bars perpendicular to traffic)

\begin{tabular}{|c|c|c|c|c|c|c|c|c|c|c|}
\hline & \multicolumn{9}{|c|}{ Maximum Moment (kN.m) } \\
\hline \multirow{9}{*}{ 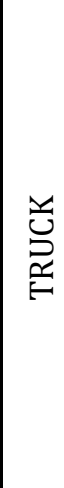 } & $\mathrm{D}$ & \multirow{2}{*}{0.25} & \multirow{2}{*}{0.5} & \multirow{2}{*}{0.75} & & \multirow{2}{*}{2} & & \multirow{2}{*}{6} & & \multirow{2}{*}{10} \\
\hline & SPAN & & & & & & & & & \\
\hline & 1 & 8.4532 & 10.0260 & 11.0734 & 11.8793 & 14.0553 & 16.5982 & 18.2733 & 19.5514 & 20.5961 \\
\hline & 1.5 & 11.0157 & 12.4933 & 13.8043 & 14.8150 & 17.5522 & 20.7667 & 22.8947 & 24.5248 & 25.8615 \\
\hline & 2 & 13.4090 & 14.9334 & 15.8890 & 16.8641 & 19.9833 & 23.6595 & 26.0989 & 27.9704 & 29.5071 \\
\hline & 2.5 & 15.3704 & 17.1673 & 18.3165 & 19.1816 & 21.8668 & 25.8873 & 28.5633 & 30.6191 & 32.3086 \\
\hline & 3 & 17.1063 & 19.0911 & 20.3873 & 21.3664 & 23.9035 & 27.7145 & 30.5747 & 32.7770 & 34.5890 \\
\hline & 3.5 & 18.8366 & 20.9945 & 22.4175 & 23.4947 & 26.3349 & 29.5101 & 32.2922 & 34.6096 & 36.5204 \\
\hline & 4 & 22.2232 & 24.6378 & 26.2752 & 27.5296 & 30.8837 & 34.6711 & 37.0807 & 38.8700 & 40.5154 \\
\hline
\end{tabular}

Table 28 Maximum moment results for alpha 1 for slabs subjected to CHBDC axle 4 loading (main bars parallel to traffic) 


\begin{tabular}{|c|c|c|c|c|c|c|c|c|c|c|}
\hline \multirow{7}{*}{ 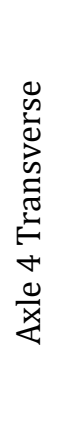 } & $\frac{\mathrm{D}}{\text { SPAN }}$ & 0.25 & 0.5 & 0.75 & 1 & 2 & 4 & 6 & 8 & 10 \\
\hline & 1 & 15.7661 & 16.7075 & 17.3325 & 17.8158 & 19.1316 & 20.6887 & 21.7224 & 22.4919 & 23.1043 \\
\hline & 1.5 & 22.1461 & 23.3594 & 24.0896 & 24.6275 & 26.0299 & 27.6498 & 28.7276 & 29.5580 & 30.2412 \\
\hline & 2 & 27.6522 & 29.3721 & 30.3472 & 31.0330 & 32.7020 & 34.4739 & 35.6018 & 36.4586 & 37.1611 \\
\hline & 2.5 & 32.2900 & 34.6174 & 35.9254 & 36.8295 & 38.9478 & 41.0446 & 42.3039 & 43.2298 & 43.9738 \\
\hline & 3 & 36.1936 & 39.1459 & 40.8210 & 41.9787 & 44.6625 & 47.2280 & 48.7054 & 49.7592 & 50.5872 \\
\hline & 3.5 & 39.5170 & 43.0666 & 45.1074 & 46.5280 & 49.8322 & 52.9612 & 54.7247 & 55.9577 & 56.9098 \\
\hline
\end{tabular}

Table 29 Maximum moment results for alpha 1 for slabs subjected to CHBDC axle 2 \& 3 loading (main bars parallel to traffic)

\begin{tabular}{|c|c|c|c|c|c|c|c|c|c|c|}
\hline & & \multicolumn{9}{|c|}{ Maximum Moment (kN.m) } \\
\hline \multirow{7}{*}{ 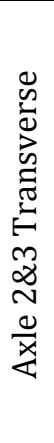 } & $\begin{array}{c}\mathrm{D} \\
\text { SPAN }\end{array}$ & 0.25 & 0.5 & 0.75 & 1 & 2 & 4 & 6 & 8 & 10 \\
\hline & 1.5 & 7.6906 & 8.2474 & 8.5863 & 8.8299 & 9.4243 & 10.0252 & 10.3787 & 10.6303 & 10.8258 \\
\hline & 2 & 16.6966 & 17.7565 & 18.3761 & 18.8186 & 19.9136 & 21.0841 & 21.8224 & 22.3765 & 22.8259 \\
\hline & 2.5 & 24.2457 & 26.0014 & 26.9758 & 27.6451 & 29.2054 & 30.7329 & 31.6472 & 32.3205 & 32.8631 \\
\hline & 3 & 30.5073 & 33.1036 & 34.5487 & 35.5350 & 37.7746 & 39.8488 & 41.0169 & 41.8416 & 42.4864 \\
\hline & 3.5 & 35.7400 & 39.1882 & 41.1406 & 42.4833 & 45.5416 & 48.3343 & 49.8595 & 50.9064 & 51.7057 \\
\hline & 4 & 40.1844 & 44.4358 & 46.8889 & 48.5944 & 52.5269 & 56.1449 & 58.1067 & 59.4360 & 60.4369 \\
\hline
\end{tabular}




\section{Alpha 2 Bending Moment Results}

Table 30 Maximum moment results for alpha 2 for slabs subjected to CHBDC axle 4 loading (main bars perpendicular to traffic)

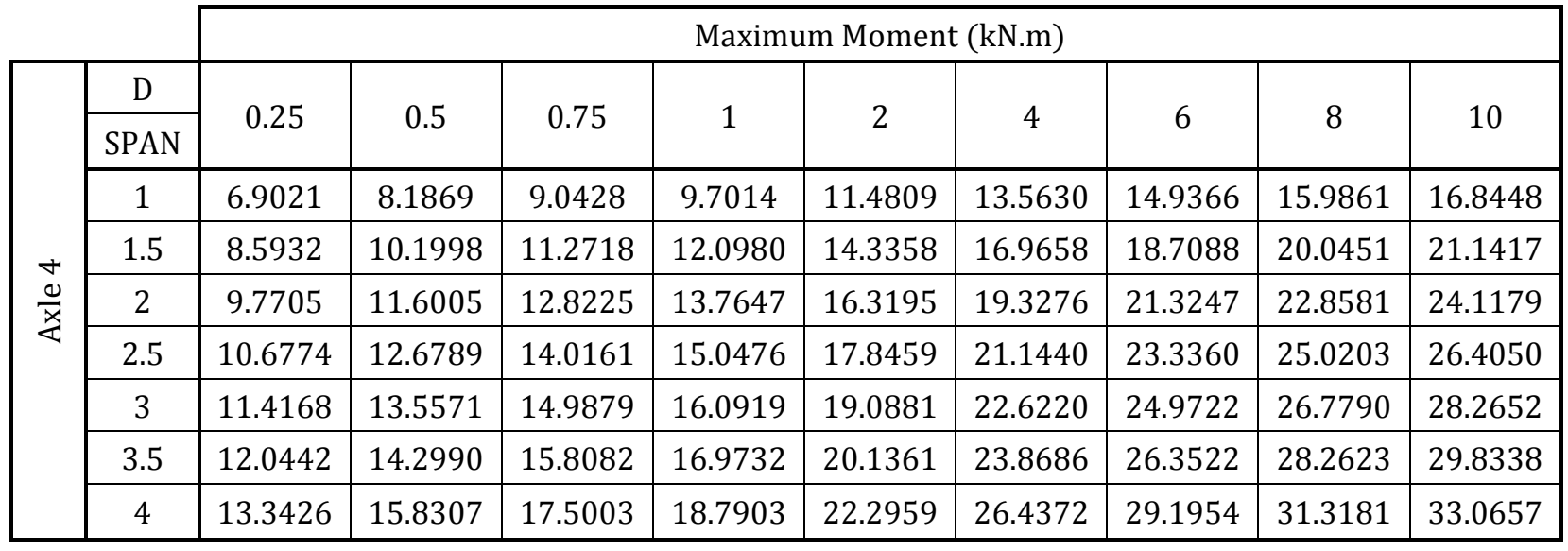

Table 31 Maximum moment results for alpha 2 for slabs subjected to CHBDC axle 2 \& 3 loading (main bars perpendicular to traffic)

\begin{tabular}{|c|c|c|c|c|c|c|c|c|c|c|}
\hline & \multicolumn{9}{|c|}{ Maximum Moment (kN.m) } \\
\hline \multirow{9}{*}{ 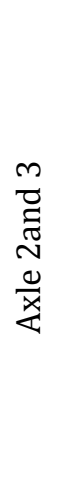 } & $\mathrm{D}$ & \multirow{2}{*}{0.25} & \multirow[t]{2}{*}{5} & \multirow{2}{*}{0.75} & & \multirow{2}{*}{2} & & \multirow{2}{*}{6} & & \multirow{2}{*}{10} \\
\hline & SPAN & & & & & & & & & \\
\hline & 1 & 6.7548 & 7.4940 & 7.9718 & 8.3461 & 9.3436 & 10.5461 & 11.3775 & 12.0256 & 12.5641 \\
\hline & 1.5 & 9.2908 & 10.4011 & 11.1002 & 11.6211 & 12.9816 & 14.5263 & 15.5237 & 16.2880 & 16.9389 \\
\hline & 2 & 11.0783 & 12.5211 & 13.4226 & 14.1004 & 15.8248 & 17.7620 & 18.9882 & 19.9063 & 20.6490 \\
\hline & 2.5 & 12.4399 & 14.1530 & 15.2304 & 16.0414 & 18.1116 & 20.4144 & 21.8677 & 22.9491 & 23.8189 \\
\hline & 3 & 13.5391 & 15.4714 & 16.6961 & 17.6203 & 19.9926 & 22.6293 & 24.2951 & 25.5328 & 26.5262 \\
\hline & 3.5 & 14.4760 & 16.6174 & 17.9888 & 19.0194 & 21.6783 & 24.6509 & 26.5194 & 27.9046 & 29.0137 \\
\hline & 4 & 16.4576 & 18.9734 & 20.5999 & 21.8272 & 25.0161 & 28.5692 & 30.8191 & 32.4895 & 33.8278 \\
\hline
\end{tabular}

Table 32 Maximum moment results for alpha 2 for slabs subjected to CHBDC truck loading (main bars perpendicular to traffic)

\begin{tabular}{|c|c|c|c|c|c|c|c|c|c|c|}
\hline & \multicolumn{9}{|c|}{ Maximum Moment (kN.m) } \\
\hline \multirow{9}{*}{ 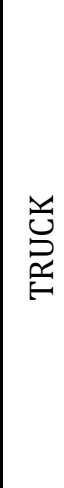 } & $\mathrm{D}$ & \multirow{2}{*}{0.25} & \multirow{2}{*}{0.5} & \multirow{2}{*}{0.75} & & \multirow{2}{*}{2} & & \multirow{2}{*}{6} & & \multirow{2}{*}{10} \\
\hline & SPAN & & & & & & & & & \\
\hline & 1 & 6.9104 & 8.1892 & 9.0437 & 9.7019 & 11.4810 & 13.5631 & 14.9366 & 15.9861 & 16.8448 \\
\hline & 1.5 & 9.4916 & 10.5342 & 11.3028 & 12.1181 & 14.3418 & 16.9672 & 18.7093 & 20.0453 & 21.1418 \\
\hline & 2 & 11.5765 & 12.8790 & 13.7160 & 14.3485 & 16.3736 & 19.3463 & 21.3338 & 22.8633 & 24.1212 \\
\hline & 2.5 & 13.3680 & 14.8491 & 15.8149 & 16.5497 & 18.4646 & 21.2338 & 23.3872 & 25.0532 & 26.4279 \\
\hline & 3 & 15.0136 & 16.6125 & 17.6710 & 18.4819 & 20.6169 & 23.0711 & 25.1348 & 26.8928 & 28.3496 \\
\hline & 3.5 & 16.7473 & 18.3980 & 19.5368 & 20.4087 & 22.7408 & 25.4218 & 27.1451 & 28.5390 & 30.0495 \\
\hline & 4 & 20.0388 & 21.8650 & 23.1013 & 24.0684 & 26.7430 & 29.8608 & 31.8874 & 33.4158 & 34.6524 \\
\hline
\end{tabular}

Table 33 Maximum moment results for alpha 2 for slabs subjected to CHBDC axle 4 loading (main bars parallel to traffic) 


\begin{tabular}{|c|c|c|c|c|c|c|c|c|c|c|}
\hline \multirow{7}{*}{ 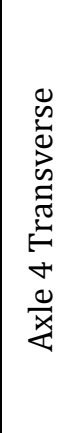 } & $\frac{\mathrm{D}}{\text { SPAN }}$ & 0.25 & 0.5 & 0.75 & & 2 & & & & 10 \\
\hline & 1 & 14.6566 & 15.5358 & 16.0842 & 16.4939 & 17.5678 & 18.7864 & 19.5723 & 20.1709 & 20.6609 \\
\hline & 1.5 & 20.2331 & 21.5429 & 22.3113 & 22.8604 & 24.2185 & 25.6700 & 26.5851 & 27.2713 & 27.8271 \\
\hline & 2 & 24.7786 & 26.6318 & 27.7003 & 28.4521 & 30.2477 & 32.0555 & 33.1420 & 33.9358 & 34.5685 \\
\hline & 2.5 & 28.5087 & 30.9181 & 32.3099 & 33.2912 & 35.6161 & 37.8962 & 39.2238 & 40.1712 & 40.9131 \\
\hline & 3 & 31.6303 & 34.5586 & 36.2711 & 37.4813 & 40.3657 & 43.1825 & 44.8013 & 45.9414 & 46.8238 \\
\hline & 3.5 & 34.3037 & 37.6955 & 39.7071 & 41.1368 & 44.5740 & 47.9505 & 49.8876 & 51.2452 & 52.2900 \\
\hline
\end{tabular}

Table 34 Maximum moment results for alpha 2 for slabs subjected to CHBDC axle 2 \& 3 loading (main bars parallel to traffic)

\begin{tabular}{|c|c|c|c|c|c|c|c|c|c|c|}
\hline & & \multicolumn{9}{|c|}{ Maximum Moment (kN.m) } \\
\hline \multirow{8}{*}{ 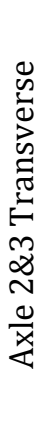 } & $\mathrm{D}$ & 025 & 0 & 075 & 1 & 2 & 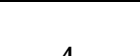 & 6 & 0 & 10 \\
\hline & SPAN & $0.2 \mathrm{~J}$ & 0.5 & 0.15 & 1 & 2 & 4 & 0 & 0 & 10 \\
\hline & 1.5 & 6.9645 & 7.4679 & 7.7746 & 7.9972 & 8.5573 & 9.1373 & 9.4825 & 9.7293 & 9.9215 \\
\hline & 2 & 15.0279 & 16.1288 & 16.7765 & 17.2362 & 18.3510 & 19.4939 & 20.1869 & 20.6939 & 21.0978 \\
\hline & 2.5 & 21.3394 & 23.1770 & 24.2341 & 24.9732 & 26.7130 & 28.4107 & 29.3956 & 30.0967 & 30.6451 \\
\hline & 3 & 26.4187 & 29.0049 & 30.5106 & 31.5679 & 34.0570 & 36.4441 & 37.7929 & 38.7324 & 39.4537 \\
\hline & 3.5 & 30.6364 & 33.9136 & 35.8540 & 37.2287 & 40.4961 & 43.6506 & 45.4285 & 46.6587 & 47.5961 \\
\hline & 4 & 34.2503 & 38.1342 & 40.4742 & 42.1482 & 46.1755 & 50.1158 & 52.3500 & 53.8971 & 55.0744 \\
\hline
\end{tabular}




\section{Alpha 4 Bending Moment Results}

Table 35 Maximum moment results for alpha 4 for slabs subjected to CHBDC axle 4 loading (main bars perpendicular to traffic)

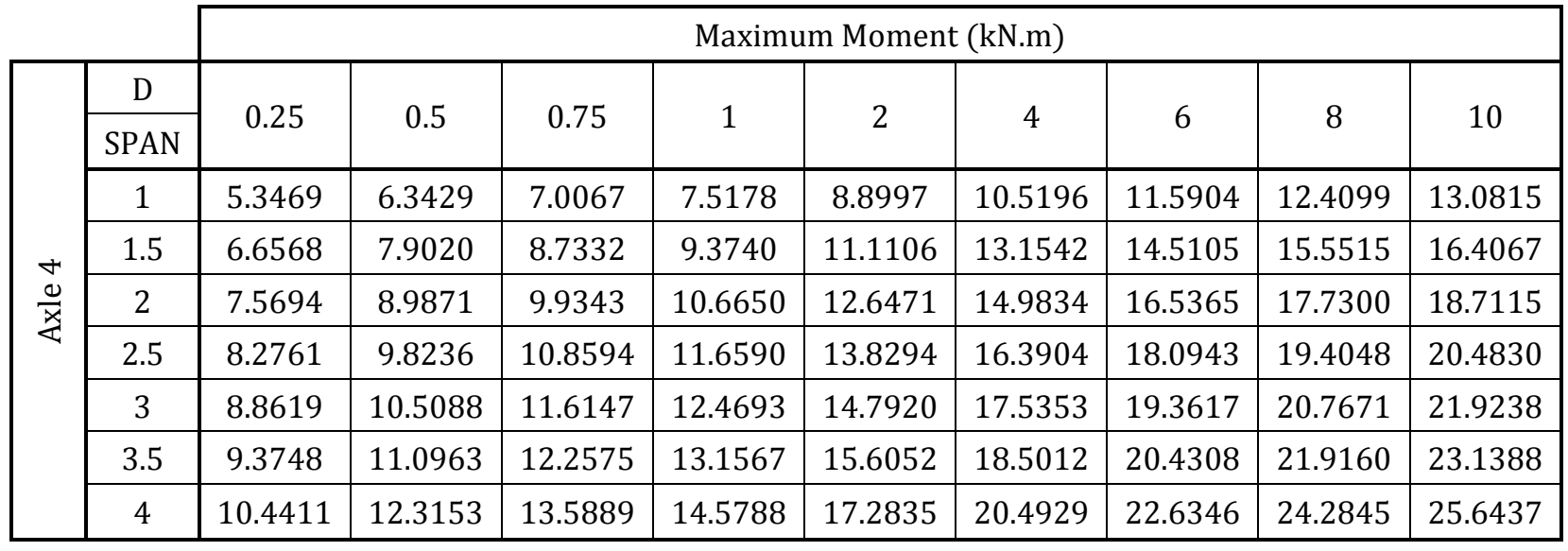

Table 36 Maximum moment results for alpha 4 for slabs subjected to CHBDC axle 2 \& 3 loading (main bars perpendicular to traffic)

\begin{tabular}{|c|c|c|c|c|c|c|c|c|c|c|}
\hline & \multicolumn{9}{|c|}{ Maximum Moment (kN.m) } \\
\hline \multirow{9}{*}{ 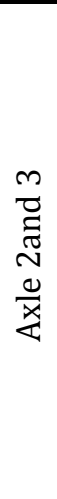 } & $\mathrm{D}$ & \multirow{2}{*}{0.25} & \multirow{2}{*}{0.5} & \multirow{2}{*}{0.75} & \multirow[b]{2}{*}{1} & \multirow[b]{2}{*}{2} & \multirow[b]{2}{*}{4} & \multirow{2}{*}{6} & \multirow[b]{2}{*}{0} & \multirow{2}{*}{10} \\
\hline & SPAN & & & & & & & & & \\
\hline & 1 & 5.6093 & 6.2930 & 6.7201 & 7.0458 & 7.8936 & 8.8420 & 9.4666 & 9.9557 & 10.3581 \\
\hline & 1.5 & 7.5346 & 8.5296 & 9.1601 & 9.6289 & 10.8397 & 12.1913 & 13.0470 & 13.6868 & 14.2035 \\
\hline & 2 & 8.8938 & 10.1368 & 10.9232 & 11.5150 & 13.0326 & 14.7345 & 15.8099 & 16.6114 & 17.2563 \\
\hline & 2.5 & 9.9423 & 11.3801 & 12.2956 & 12.9866 & 14.7709 & 16.7642 & 18.0311 & 18.9756 & 19.7354 \\
\hline & 3 & 10.8059 & 12.3956 & 13.4170 & 14.1895 & 16.1974 & 18.4441 & 19.8776 & 20.9479 & 21.8096 \\
\hline & 3.5 & 11.5576 & 13.2734 & 14.3923 & 15.2412 & 17.4581 & 19.9514 & 21.5437 & 22.7338 & 23.6924 \\
\hline & 4 & 13.1647 & 15.1254 & 16.4175 & 17.4051 & 20.0091 & 22.9520 & 24.8428 & 26.2590 & 27.4011 \\
\hline
\end{tabular}

Table 37 Maximum moment results for alpha 4 for slabs subjected to CHBDC axle truck loading (main bars perpendicular to traffic)

\begin{tabular}{|c|c|c|c|c|c|c|c|c|c|c|}
\hline & \multicolumn{9}{|c|}{ Maximum Moment (kN.m) } \\
\hline \multirow{9}{*}{ 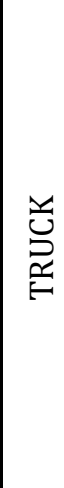 } & $\mathrm{D}$ & \multirow{2}{*}{0.25} & \multirow{2}{*}{0.5} & \multirow{2}{*}{0.75} & & \multirow{2}{*}{2} & & \multirow{2}{*}{6} & & \multirow{2}{*}{10} \\
\hline & SPAN & & & & & & & & & \\
\hline & 1 & 5.7271 & 6.3714 & 7.0214 & 7.5271 & 8.9024 & 10.5202 & 11.5906 & 12.4100 & 13.0815 \\
\hline & 1.5 & 7.9430 & 8.8302 & 9.4084 & 9.8415 & 11.1690 & 13.1765 & 14.5220 & 15.5584 & 16.4112 \\
\hline & 2 & 9.7696 & 10.8120 & 11.4990 & 12.0228 & 13.4042 & 15.1208 & 16.6221 & 17.7891 & 18.7549 \\
\hline & 2.5 & 11.4508 & 12.5681 & 13.3265 & 13.9121 & 15.4677 & 17.2793 & 18.4517 & 19.6200 & 20.6525 \\
\hline & 3 & 13.0589 & 14.2425 & 15.0344 & 15.6472 & 17.3273 & 19.3055 & 20.5986 & 21.5783 & 22.3749 \\
\hline & 3.5 & 14.7939 & 16.0136 & 16.8409 & 17.4813 & 19.2195 & 21.3279 & 22.7188 & 23.7771 & 24.6397 \\
\hline & 4 & 17.9858 & 19.3010 & 20.2040 & 20.9090 & 22.8438 & 25.1585 & 26.7444 & 27.9600 & 28.9573 \\
\hline
\end{tabular}

Table 38 Maximum moment results for alpha 4 for slabs subjected to CHBDC axle 4 loading (main bars parallel to traffic) 


\begin{tabular}{|c|c|c|c|c|c|c|c|c|c|c|}
\hline \multirow{7}{*}{ 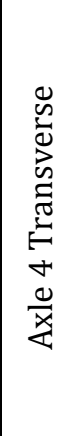 } & $\frac{\mathrm{D}}{\text { SPAN }}$ & 0.25 & 0.5 & 0.75 & 1 & 2 & 4 & 6 & 8 & 10 \\
\hline & 1 & 13.2545 & 14.1190 & 14.6328 & 15.0028 & 15.9254 & 16.9158 & 17.5384 & 18.0032 & 18.3781 \\
\hline & 1.5 & 17.8446 & 19.2297 & 20.0338 & 20.6063 & 21.9813 & 23.3658 & 24.1920 & 24.7908 & 25.2647 \\
\hline & 2 & 21.3971 & 23.2996 & 24.4150 & 25.2042 & 27.1049 & 28.9898 & 30.0873 & 30.8668 & 31.4737 \\
\hline & 2.5 & 24.2672 & 26.6232 & 28.0277 & 29.0302 & 31.4531 & 33.8724 & 35.2762 & 36.2667 & 37.0326 \\
\hline & 3 & 26.6927 & 29.4234 & 31.0803 & 32.2744 & 35.1889 & 38.1329 & 39.8501 & 41.0627 & 41.9993 \\
\hline & 3.5 & 28.8328 & 31.8587 & 33.7271 & 35.0871 & 38.4479 & 41.8844 & 43.9070 & 45.3405 & 46.4497 \\
\hline
\end{tabular}

Table 39 Maximum moment results for alpha 4 for slabs subjected to CHBDC axle $2 \& 3$ loading (main bars parallel to traffic)

\begin{tabular}{|c|c|c|c|c|c|c|c|c|c|c|}
\hline & & \multicolumn{9}{|c|}{ Maximum Moment (kN.m) } \\
\hline \multirow{8}{*}{ 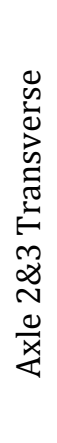 } & $\mathrm{D}$ & \multirow{2}{*}{0.25} & \multirow{2}{*}{0.5} & \multirow{2}{*}{0.75} & \multirow{2}{*}{1} & \multirow{2}{*}{2} & \multirow{2}{*}{4} & \multirow{2}{*}{6} & \multirow{2}{*}{8} & \multirow{2}{*}{10} \\
\hline & SPAN & & & & & & & & & \\
\hline & 1.5 & 6.1742 & 6.6287 & 6.9060 & 7.1080 & 7.6129 & 8.1421 & 8.4673 & 8.7019 & 8.8859 \\
\hline & 2 & 13.0664 & 14.1803 & 14.8359 & 15.3016 & 16.4361 & 17.5775 & 18.2509 & 18.7331 & 19.1106 \\
\hline & 2.5 & 18.0873 & 19.8870 & 20.9597 & 21.7248 & 23.5674 & 25.3893 & 26.4484 & 27.1938 & 27.7689 \\
\hline & 3 & 22.0525 & 24.4458 & 25.9029 & 26.9538 & 29.5164 & 32.0795 & 33.5615 & 34.6008 & 35.3989 \\
\hline & 3.5 & 25.3945 & 28.2645 & 30.0502 & 31.3540 & 34.5812 & 37.8657 & 39.7845 & 41.1362 & 42.1764 \\
\hline & 4 & 28.3616 & 31.5971 & 33.6515 & 35.1694 & 38.9848 & 42.9408 & 45.2804 & 46.9392 & 48.2211 \\
\hline
\end{tabular}




\section{Alpha 6 Bending Moment Results}

Table 40 Maximum moment results for alpha 6 for slabs subjected to CHBDC axle 4 loading (main bars perpendicular to traffic)

\begin{tabular}{|c|c|c|c|c|c|c|c|c|c|c|}
\hline & \multicolumn{9}{|c|}{ Maximum Moment (kN.m) } \\
\hline \multirow{9}{*}{$\frac{\vec{d}}{\vec{x}}$} & $\mathrm{D}$ & \multirow{2}{*}{0.25} & \multirow{2}{*}{0.5} & \multirow{2}{*}{0.75} & \multirow{2}{*}{1} & \multirow{2}{*}{2} & \multirow{2}{*}{4} & \multirow{2}{*}{6} & \multirow{2}{*}{8} & \multirow{2}{*}{10} \\
\hline & SPAN & & & & & & & & & \\
\hline & 1 & 4.5194 & 5.3618 & 5.9234 & 6.3560 & 7.5263 & 8.8999 & 9.8091 & 10.5058 & 11.0772 \\
\hline & 1.5 & 5.6267 & 6.6794 & 7.3825 & 7.9246 & 9.3945 & 11.1257 & 12.2757 & 13.1592 & 13.8853 \\
\hline & 2 & 6.4007 & 7.5973 & 8.3979 & 9.0158 & 10.6930 & 12.6715 & 13.9878 & 15.0000 & 15.8329 \\
\hline & 2.5 & 7.0087 & 8.3087 & 9.1821 & 9.8572 & 11.6926 & 13.8606 & 15.3043 & 16.4153 & 17.3299 \\
\hline & 3 & 7.5272 & 8.8999 & 9.8279 & 10.5472 & 12.5077 & 14.8286 & 16.3756 & 17.5667 & 18.5476 \\
\hline & 3.5 & 7.9974 & 9.4193 & 10.3872 & 11.1401 & 13.1999 & 15.6465 & 17.2798 & 18.5381 & 19.5747 \\
\hline & 4 & 8.9708 & 10.4985 & 11.5488 & 12.3704 & 14.6322 & 17.3355 & 19.1456 & 20.5419 & 21.6932 \\
\hline
\end{tabular}

Table 41 Maximum moment results for alpha 6 for slabs subjected to CHBDC axle 2 \& 3 loading (main bars perpendicular to traffic)

\begin{tabular}{|c|c|c|c|c|c|c|c|c|c|c|}
\hline & \multicolumn{9}{|c|}{ Maximum Moment (kN.m) } \\
\hline \multirow{9}{*}{ 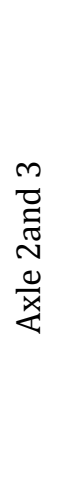 } & $\mathrm{D}$ & \multirow{2}{*}{0.25} & \multirow{2}{*}{.5} & \multirow{2}{*}{0.75} & & \multirow{2}{*}{2} & & \multirow{2}{*}{6} & & \multirow{2}{*}{10} \\
\hline & SPAN & & & & & & & & & \\
\hline & 1 & 4.9346 & 5.5731 & 5.9717 & 6.2688 & 7.0434 & 7.8954 & 8.4367 & 8.8448 & 9.1883 \\
\hline & 1.5 & 6.5480 & 7.4596 & 8.0393 & 8.4706 & 9.5815 & 10.8179 & 11.5970 & 12.1770 & 12.6433 \\
\hline & 2 & 7.6893 & 8.8055 & 9.5173 & 10.0534 & 11.4363 & 12.9823 & 13.9621 & 14.6920 & 15.2788 \\
\hline & 2.5 & 8.5842 & 9.8526 & 10.6686 & 11.2865 & 12.8929 & 14.6907 & 15.8381 & 16.6949 & 17.3846 \\
\hline & 3 & 9.3440 & 10.7219 & 11.6191 & 12.3007 & 14.0884 & 16.0986 & 17.3881 & 18.3532 & 19.1314 \\
\hline & 3.5 & 10.0297 & 11.4834 & 12.4483 & 13.1866 & 15.1366 & 17.3490 & 18.7725 & 19.8402 & 20.7023 \\
\hline & 4 & 11.4834 & 13.1103 & 14.2006 & 15.0431 & 17.2953 & 19.8755 & 21.5499 & 22.8104 & 23.8304 \\
\hline
\end{tabular}

Table 42 Maximum moment results for alpha 6 for slabs subjected to CHBDC truck loading (main bars perpendicular to traffic)

\begin{tabular}{|c|c|c|c|c|c|c|c|c|c|c|}
\hline & \multicolumn{9}{|c|}{ Maximum Moment (kN.m) } \\
\hline \multirow{9}{*}{ 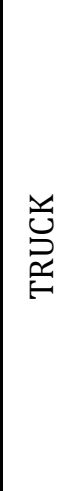 } & D & \multirow{2}{*}{0.25} & \multirow{2}{*}{0.5} & \multirow{2}{*}{0.75} & \multirow{2}{*}{1} & \multirow{2}{*}{2} & \multirow{2}{*}{4} & \multirow[b]{2}{*}{6} & \multirow{2}{*}{8} & \multirow{2}{*}{10} \\
\hline & SPAN & & & & & & & & & \\
\hline & 1 & 5.1177 & 5.7031 & 6.0741 & 6.3871 & 7.5379 & 8.9033 & 9.8106 & 10.5066 & 11.0777 \\
\hline & 1.5 & 7.1179 & 7.8956 & 8.4069 & 8.7927 & 9.8142 & 11.1941 & 12.3164 & 13.1862 & 13.9046 \\
\hline & 2 & 8.8494 & 9.7195 & 10.3106 & 10.7647 & 11.9738 & 13.3767 & 14.2834 & 15.1575 & 15.9563 \\
\hline & 2.5 & 10.4824 & 11.4171 & 12.0442 & 12.5291 & 13.8586 & 15.4303 & 16.4591 & 17.2393 & 17.8738 \\
\hline & 3 & 12.0654 & 13.0405 & 13.7021 & 14.2157 & 15.6072 & 17.2846 & 18.4034 & 19.2568 & 19.9537 \\
\hline & 3.5 & 13.8186 & 14.8038 & 15.4797 & 16.0071 & 17.4567 & 19.1910 & 20.3615 & 21.2721 & 22.0188 \\
\hline & 4 & 16.9764 & 18.0201 & 18.7451 & 19.3156 & 20.9015 & 22.8233 & 24.1153 & 25.1126 & 25.9458 \\
\hline
\end{tabular}

Table 43 Maximum moment results for alpha 6 for slabs subjected to CHBDC axle 4 loading (main bars parallel to traffic) 


\begin{tabular}{|c|c|c|c|c|c|c|c|c|c|c|}
\hline \multirow{7}{*}{ 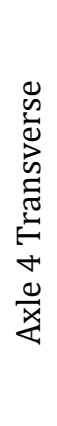 } & $\frac{\mathrm{D}}{\text { SPAN }}$ & 0.25 & 0.5 & 0.75 & 1 & 2 & 4 & 6 & 8 & 10 \\
\hline & 1 & 12.3257 & 13.1960 & 13.7081 & 14.0721 & 14.9577 & 15.8741 & 16.4353 & 16.8489 & 17.1801 \\
\hline & 1.5 & 16.3131 & 17.7154 & 18.5345 & 19.1133 & 20.5102 & 21.8983 & 22.7102 & 23.2893 & 23.7417 \\
\hline & 2 & 19.3388 & 21.2060 & 22.3191 & 23.1136 & 25.0338 & 26.9567 & 28.0735 & 28.8621 & 29.4721 \\
\hline & 2.5 & 21.7966 & 24.0337 & 25.3962 & 26.3803 & 28.7901 & 31.2325 & 32.6634 & 33.6752 & 34.4573 \\
\hline & 3 & 23.9246 & 26.4364 & 27.9985 & 29.1406 & 31.9796 & 34.9006 & 36.6324 & 37.8633 & 38.8175 \\
\hline & 3.5 & 25.8656 & 28.5708 & 30.2849 & 31.5526 & 34.7517 & 38.1004 & 40.1099 & 41.5474 & 42.6663 \\
\hline
\end{tabular}

Table 44 Maximum moment results for alpha 6 for slabs subjected to CHBDC axle 2 \& 3 loading (main bars parallel to traffic)

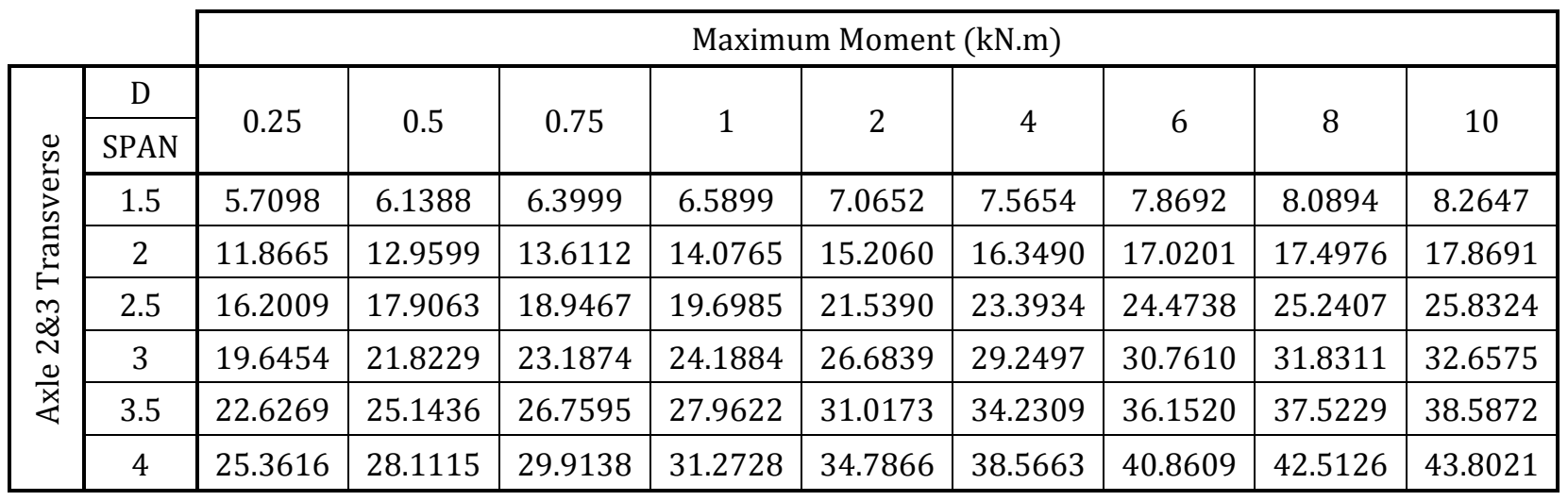




\section{Alpha 8 Bending Moment Results}

Table 45 Maximum moment results for alpha 8 for slabs subjected to CHBDC axle 4 loading (main bars perpendicular to traffic)

\begin{tabular}{|c|c|c|c|c|c|c|c|c|c|c|}
\hline & \multicolumn{9}{|c|}{ Maximum Moment (kN.m) } \\
\hline \multirow{9}{*}{$\frac{\vec{u}}{\frac{\vec{x}}{\alpha}}$} & $\mathrm{D}$ & \multirow{2}{*}{0.25} & \multirow{2}{*}{0.5} & \multirow{2}{*}{0.75} & \multirow{2}{*}{1} & \multirow{2}{*}{2} & \multirow{2}{*}{4} & \multirow{2}{*}{6} & \multirow{2}{*}{8} & \multirow{2}{*}{10} \\
\hline & SPAN & & & & & & & & & \\
\hline & 1 & 3.9862 & 4.7296 & 5.2253 & 5.6072 & 6.6411 & 7.8556 & 8.6605 & 9.2776 & 9.7842 \\
\hline & 1.5 & 4.9633 & 5.8917 & 6.5120 & 6.9905 & 8.2883 & 9.8180 & 10.8348 & 11.6164 & 12.2591 \\
\hline & 2 & 5.6513 & 6.7030 & 7.4085 & 7.9534 & 9.4336 & 11.1812 & 12.3445 & 13.2396 & 13.9763 \\
\hline & 2.5 & 6.2028 & 7.3381 & 8.1047 & 8.6985 & 10.3161 & 12.2300 & 13.5056 & 14.4877 & 15.2965 \\
\hline & 3 & 6.6871 & 7.8765 & 8.6860 & 9.3158 & 11.0386 & 13.0849 & 14.4509 & 15.5034 & 16.3705 \\
\hline & 3.5 & 7.1388 & 8.3613 & 9.1999 & 9.8552 & 11.6575 & 13.8097 & 15.2501 & 16.3612 & 17.2770 \\
\hline & 4 & 8.0712 & 9.3657 & 10.2669 & 10.9758 & 12.9414 & 15.3093 & 16.9016 & 18.1324 & 19.1483 \\
\hline
\end{tabular}

Table 46 Maximum moment results for alpha 8 for slabs subjected to CHBDC axle $2 \& 3$ loading (main bars perpendicular to traffic)

\begin{tabular}{|c|c|c|c|c|c|c|c|c|c|c|}
\hline & \multicolumn{9}{|c|}{ Maximum Moment (kN.m) } \\
\hline \multirow{9}{*}{ 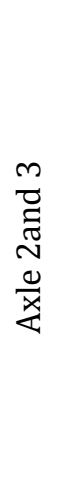 } & $\mathrm{D}$ & \multirow{2}{*}{0.25} & \multirow{2}{*}{.5} & \multirow{2}{*}{0.75} & & \multirow{2}{*}{2} & & \multirow{2}{*}{6} & & \multirow{2}{*}{10} \\
\hline & SPAN & & & & & & & & & \\
\hline & 1 & 4.4714 & 5.0738 & 5.4505 & 5.7288 & 6.4553 & 7.2492 & 7.7494 & 8.1226 & 8.4237 \\
\hline & 1.5 & 5.8885 & 6.7362 & 7.2770 & 7.6800 & 8.7176 & 9.8727 & 10.6000 & 11.1406 & 11.5747 \\
\hline & 2 & 6.8967 & 7.9194 & 8.5760 & 9.0714 & 10.3552 & 11.7892 & 12.7007 & 13.3799 & 13.9261 \\
\hline & 2.5 & 7.7040 & 8.8485 & 9.5920 & 10.1571 & 11.6350 & 13.2933 & 14.3552 & 15.1491 & 15.7888 \\
\hline & 3 & 8.4104 & 9.6356 & 10.4426 & 11.0589 & 12.6885 & 14.5309 & 15.7181 & 16.6084 & 17.3272 \\
\hline & 3.5 & 9.0667 & 10.3426 & 11.1940 & 11.8529 & 13.6105 & 15.6228 & 16.9262 & 17.9068 & 18.7000 \\
\hline & 4 & 10.4460 & 11.8450 & 12.7951 & 13.5343 & 15.5352 & 17.8570 & 19.3770 & 20.5264 & 21.4592 \\
\hline
\end{tabular}

Table 47 Maximum moment results for alpha 8 for slabs subjected to CHBDC truck loading (main bars perpendicular to traffic)

\begin{tabular}{|c|c|c|c|c|c|c|c|c|c|c|}
\hline & \multicolumn{9}{|c|}{ Maximum Moment (kN.m) } \\
\hline \multirow{9}{*}{ 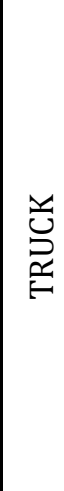 } & D & \multirow[b]{2}{*}{0.25} & \multirow[b]{2}{*}{0.5} & \multirow[b]{2}{*}{0.75} & \multirow{2}{*}{1} & \multirow[b]{2}{*}{2} & \multirow[b]{2}{*}{4} & \multirow[b]{2}{*}{6} & \multirow[b]{2}{*}{8} & \multirow[b]{2}{*}{10} \\
\hline & SPAN & & & & & & & & & \\
\hline & 1 & 4.7123 & 5.2501 & 5.5934 & 5.8542 & 6.6679 & 7.8653 & 8.6653 & 9.2804 & 9.7860 \\
\hline & 1.5 & 6.5898 & 7.2853 & 7.7465 & 8.0967 & 9.0277 & 10.0912 & 10.9187 & 11.6758 & 12.3037 \\
\hline & 2 & 8.2753 & 9.0376 & 9.5493 & 9.9511 & 11.0344 & 12.3031 & 13.1283 & 13.7521 & 14.2585 \\
\hline & 2.5 & 9.8806 & 10.6911 & 11.2416 & 11.6682 & 12.8232 & 14.2223 & 15.1478 & 15.8526 & 16.4276 \\
\hline & 3 & 11.4525 & 12.2892 & 12.8635 & 13.3108 & 14.5324 & 15.9893 & 16.9791 & 17.7423 & 18.3679 \\
\hline & 3.5 & 13.2241 & 14.0577 & 14.6347 & 15.0877 & 16.3447 & 17.8634 & 18.8820 & 19.6671 & 20.3232 \\
\hline & 4 & 16.3662 & 17.2389 & 17.8501 & 18.3339 & 19.6916 & 21.3550 & 22.4828 & 23.3577 & 24.0810 \\
\hline
\end{tabular}

Table 48 Maximum moment results for alpha 8 for slabs subjected to CHBDC axle 4 loading (main bars parallel to traffic) 


\begin{tabular}{|c|c|c|c|c|c|c|c|c|c|c|}
\hline \multirow{7}{*}{ 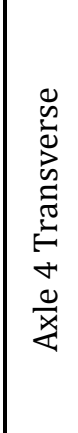 } & $\frac{\mathrm{D}}{\text { SPAN }}$ & 0.25 & 0.5 & 0.75 & & 2 & & & & 10 \\
\hline & 1 & 11.6298 & 12.5124 & 13.0229 & 13.3871 & 14.2649 & 15.1539 & 15.6878 & 16.0767 & 16.3856 \\
\hline & 1.5 & 15.2050 & 16.6006 & 17.4233 & 18.0070 & 19.4111 & 20.8107 & 21.6239 & 22.1999 & 22.6470 \\
\hline & 2 & 17.9024 & 19.7119 & 20.8056 & 21.5922 & 23.5081 & 25.4396 & 26.5681 & 27.3651 & 27.9809 \\
\hline & 2.5 & 20.1274 & 22.2388 & 23.5467 & 24.5008 & 26.8657 & 29.2897 & 30.7253 & 31.7446 & 32.5343 \\
\hline & 3 & 22.1052 & 24.4204 & 25.8866 & 26.9705 & 29.7051 & 32.5663 & 34.2811 & 35.5096 & 36.4657 \\
\hline & 3.5 & 23.9572 & 26.4025 & 27.9793 & 29.1590 & 32.1845 & 35.4181 & 37.3798 & 38.7982 & 39.9080 \\
\hline
\end{tabular}

Table 49 Maximum moment results for alpha 8 for slabs subjected to CHBDC axle 2 \& 3 loading (main bars parallel to traffic)

\begin{tabular}{|c|c|c|c|c|c|c|c|c|c|c|}
\hline & & \multicolumn{9}{|c|}{ Maximum Moment (kN.m) } \\
\hline \multirow{8}{*}{ 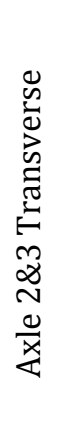 } & $\mathrm{D}$ & \multirow{2}{*}{0.25} & \multirow{2}{*}{0.5} & \multirow{2}{*}{0.75} & \multirow{2}{*}{1} & \multirow{2}{*}{2} & \multirow{2}{*}{4} & \multirow{2}{*}{6} & \multirow{2}{*}{8} & \multirow{2}{*}{10} \\
\hline & SPAN & & & & & & & & & \\
\hline & 1.5 & 5.3862 & 5.7981 & 6.0487 & 6.2309 & 6.6860 & 7.1652 & 7.4569 & 7.6689 & 7.8361 \\
\hline & 2 & 11.0236 & 12.0871 & 12.7275 & 13.1877 & 14.3094 & 15.4468 & 16.1168 & 16.5931 & 16.9631 \\
\hline & 2.5 & 14.9318 & 16.5368 & 17.5339 & 18.2620 & 20.0685 & 21.9181 & 23.0063 & 23.7771 & 24.3767 \\
\hline & 3 & 18.0875 & 20.0715 & 21.3418 & 22.2859 & 24.6807 & 27.1971 & 28.7016 & 29.7758 & 30.6100 \\
\hline & 3.5 & 20.8893 & 23.1217 & 24.5872 & 25.6934 & 28.5590 & 31.6508 & 33.5328 & 34.8897 & 35.9505 \\
\hline & 4 & 23.5203 & 25.9090 & 27.5079 & 28.7305 & 31.9571 & 35.5255 & 37.7362 & 39.3463 & 40.6137 \\
\hline
\end{tabular}




\section{Alpha 10 Bending Moment Results}

Table 50 Maximum moment results for alpha 10 for slabs subjected to CHBDC axle 4 loading (main bars perpendicular to traffic)

\begin{tabular}{|c|c|c|c|c|c|c|c|c|c|c|}
\hline & \multicolumn{9}{|c|}{ Maximum Moment (kN.m) } \\
\hline & $\mathrm{D}$ & \multirow{2}{*}{0.25} & \multirow{2}{*}{0.5} & \multirow{2}{*}{0.75} & \multirow{2}{*}{1} & \multirow{2}{*}{2} & \multirow[t]{2}{*}{4} & \multirow{2}{*}{6} & \multirow{2}{*}{8} & \multirow{2}{*}{10} \\
\hline & SPAN & & & & & & & & & \\
\hline \multirow{7}{*}{$\frac{\vec{d}}{\vec{x}}$} & 1 & 3.6060 & 4.2788 & 4.7275 & 5.0733 & 6.0099 & 7.1109 & 7.8410 & 8.4013 & 8.8615 \\
\hline & 1.5 & 4.4911 & 5.3302 & 5.8914 & 6.3245 & 7.4996 & 8.8853 & 9.8070 & 10.5158 & 11.0988 \\
\hline & 2 & 5.1209 & 6.0674 & 6.7041 & 7.1965 & 8.5357 & 10.1183 & 11.1724 & 11.9838 & 12.6518 \\
\hline & 2.5 & 5.6374 & 6.6521 & 7.3407 & 7.8754 & 9.3358 & 11.0675 & 12.2229 & 13.1128 & 13.8459 \\
\hline & 3 & 6.1028 & 7.1582 & 7.8809 & 8.4451 & 9.9949 & 11.8429 & 13.0790 & 14.0321 & 14.8178 \\
\hline & 3.5 & 6.5457 & 7.6239 & 8.3681 & 8.9519 & 10.5658 & 12.5039 & 13.8051 & 14.8100 & 15.6392 \\
\hline & 4 & 7.4571 & 8.5862 & 9.3769 & 10.0035 & 11.7518 & 13.8740 & 15.3077 & 16.4184 & 17.3364 \\
\hline
\end{tabular}

Table 51 Maximum moment results for alpha 10 for slabs subjected to CHBDC axle 2 \& 3 loading (main bars perpendicular to traffic)

\begin{tabular}{|c|c|c|c|c|c|c|c|c|c|c|}
\hline & \multicolumn{9}{|c|}{ Maximum Moment (kN.m) } \\
\hline \multirow{9}{*}{ 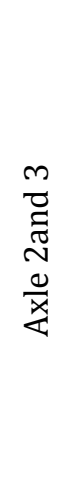 } & $\mathrm{D}$ & \multirow{2}{*}{0.25} & \multirow{2}{*}{0.5} & \multirow{2}{*}{0.75} & \multirow{2}{*}{1} & \multirow{2}{*}{2} & \multirow{2}{*}{4} & \multirow{2}{*}{6} & \multirow[b]{2}{*}{0} & \multirow{2}{*}{10} \\
\hline & SPAN & & & & & & & & & \\
\hline & 1 & 4.1263 & 4.6987 & 5.0578 & 5.3228 & 6.0125 & 6.7653 & 7.2377 & 7.5888 & 7.8712 \\
\hline & 1.5 & 5.4061 & 6.2023 & 6.7118 & 7.0923 & 8.0726 & 9.1653 & 9.8536 & 10.3651 & 10.7756 \\
\hline & 2 & 6.3252 & 7.2733 & 7.8862 & 8.3496 & 9.5555 & 10.9034 & 11.7622 & 12.4028 & 12.9181 \\
\hline & 2.5 & 7.0783 & 8.1252 & 8.8115 & 9.3351 & 10.7124 & 12.2631 & 13.2593 & 14.0050 & 14.6064 \\
\hline & 3 & 7.7548 & 8.8621 & 9.5987 & 10.1640 & 11.6697 & 13.3826 & 14.4911 & 15.3240 & 15.9972 \\
\hline & 3.5 & 8.3964 & 9.5389 & 10.3076 & 10.9028 & 12.5104 & 14.3673 & 15.5776 & 16.4909 & 17.2311 \\
\hline & 4 & 9.7355 & 10.9681 & 11.8131 & 12.4743 & 14.2819 & 16.4032 & 17.8034 & 18.8666 & 19.7318 \\
\hline
\end{tabular}

Table 52 Maximum moment results for alpha 10 for slabs subjected to CHBDC truck loading (main bars perpendicular to traffic)

\begin{tabular}{|c|c|c|c|c|c|c|c|c|c|c|}
\hline & \multicolumn{9}{|c|}{ Maximum Moment (kN.m) } \\
\hline \multirow{9}{*}{ 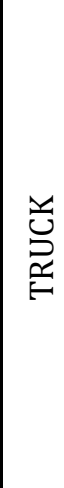 } & $\mathrm{D}$ & \multirow{2}{*}{0.25} & \multirow{2}{*}{0.5} & \multirow{2}{*}{0.75} & & \multirow{2}{*}{2} & & \multirow{2}{*}{6} & & \multirow{2}{*}{10} \\
\hline & SPAN & & & & & & & & & \\
\hline & 1 & 4.4177 & 4.9167 & 5.2377 & 5.4812 & 6.1212 & 7.1299 & 7.8513 & 8.4077 & 8.8657 \\
\hline & 1.5 & 6.2241 & 6.8486 & 7.2704 & 7.5924 & 8.4521 & 9.4405 & 10.0770 & 10.6161 & 11.1768 \\
\hline & 2 & 7.8761 & 8.5599 & 9.0229 & 9.3800 & 10.3599 & 11.5234 & 12.2852 & 12.8630 & 13.3328 \\
\hline & 2.5 & 9.4654 & 10.1850 & 10.6780 & 11.0613 & 12.1056 & 13.3565 & 14.2024 & 14.8491 & 15.3782 \\
\hline & 3 & 11.0317 & 11.7693 & 12.2792 & 12.6778 & 13.7740 & 15.0902 & 15.9714 & 16.6577 & 17.2286 \\
\hline & 3.5 & 12.8199 & 13.5463 & 14.0525 & 14.4519 & 15.5681 & 16.9279 & 17.8458 & 18.5558 & 19.1416 \\
\hline & 4 & 15.9538 & 16.7078 & 17.2391 & 17.6615 & 18.8552 & 20.3307 & 21.3381 & 22.1229 & 22.7735 \\
\hline
\end{tabular}

Table 53 Maximum moment results for alpha 10 for slabs subjected to CHBDC axle 4 loading (main bars parallel to traffic) 


\begin{tabular}{|c|c|c|c|c|c|c|c|c|c|c|}
\hline \multirow{7}{*}{ 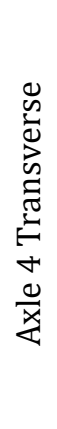 } & $\frac{\mathrm{D}}{\text { SPAN }}$ & 0.25 & 0.5 & 0.75 & 1 & 2 & 4 & 6 & 8 & 10 \\
\hline & 1 & 11.0754 & 11.9654 & 12.4811 & 12.8443 & 13.7213 & 14.6007 & 15.1218 & 15.4978 & 15.7944 \\
\hline & 1.5 & 14.3484 & 15.7266 & 16.5460 & 17.1301 & 18.5372 & 19.9441 & 20.7619 & 21.3395 & 21.7865 \\
\hline & 2 & 16.8241 & 18.5697 & 19.6375 & 20.4107 & 22.3096 & 24.2352 & 25.3687 & 26.1709 & 26.7912 \\
\hline & 2.5 & 18.9061 & 20.8987 & 22.1503 & 23.0709 & 25.3775 & 27.7703 & 29.1960 & 30.2150 & 31.0066 \\
\hline & 3 & 20.8005 & 22.9463 & 24.3240 & 25.3516 & 27.9760 & 30.7652 & 32.4497 & 33.6655 & 34.6159 \\
\hline & 3.5 & 22.6080 & 24.8436 & 26.3031 & 27.4043 & 30.2646 & 33.3744 & 35.2836 & 36.6699 & 37.7626 \\
\hline
\end{tabular}

Table 54 Maximum moment results for alpha 10 for slabs subjected to CHBDC axle $2 \& 3$ loading (main bars parallel to traffic)

\begin{tabular}{|c|c|c|c|c|c|c|c|c|c|c|}
\hline & & \multicolumn{9}{|c|}{ Maximum Moment (kN.m) } \\
\hline \multirow{7}{*}{ 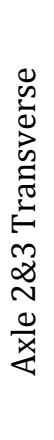 } & $\frac{D}{\text { SPAN }}$ & 0.25 & 0.5 & 0.75 & 1 & 2 & 4 & 6 & 8 & 10 \\
\hline & 1.5 & 5.1402 & 5.5388 & 5.7821 & 5.9587 & 6.3991 & 6.8624 & 7.1447 & 7.3500 & 7.5121 \\
\hline & 2 & 10.3864 & 11.4173 & 12.0442 & 12.4972 & 13.6081 & 14.7363 & 15.4048 & 15.8802 & 16.2495 \\
\hline & 2.5 & 14.0077 & 15.5171 & 16.4692 & 17.1707 & 18.9313 & 20.7595 & 21.8453 & 22.6182 & 23.2176 \\
\hline & 3 & 16.9858 & 18.8038 & 19.9875 & 20.8764 & 23.1634 & 25.6112 & 27.0935 & 28.1596 & 28.9916 \\
\hline & 3.5 & 19.6866 & 21.6918 & 23.0296 & 24.0501 & 26.7348 & 29.6923 & 31.5200 & 32.8494 & 33.8950 \\
\hline & 4 & 22.2648 & 24.3790 & 25.8149 & 26.9239 & 29.8963 & 33.2560 & 35.3724 & 36.9291 & 38.1629 \\
\hline
\end{tabular}




\section{B.1.2 MAXIMUM BENDING MOMENT VS SPAN LENGTH}




\section{Alpha 0.25 Bending Moment VS Span Length for Different D Values}

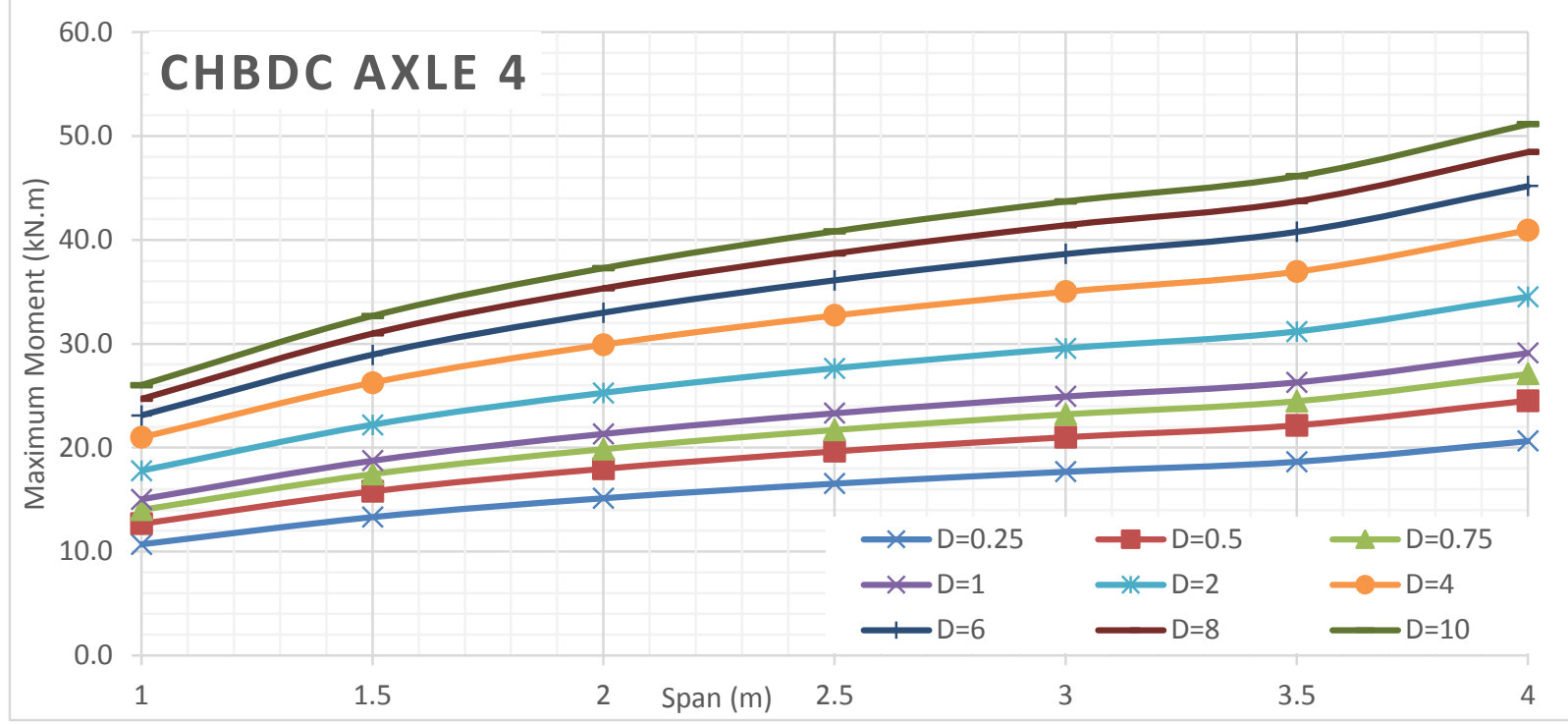

Figure 1 Maximum moment of deck slabs subjected to CHBDC axle 4 for different D values of alpha 0.25 FEA analyses

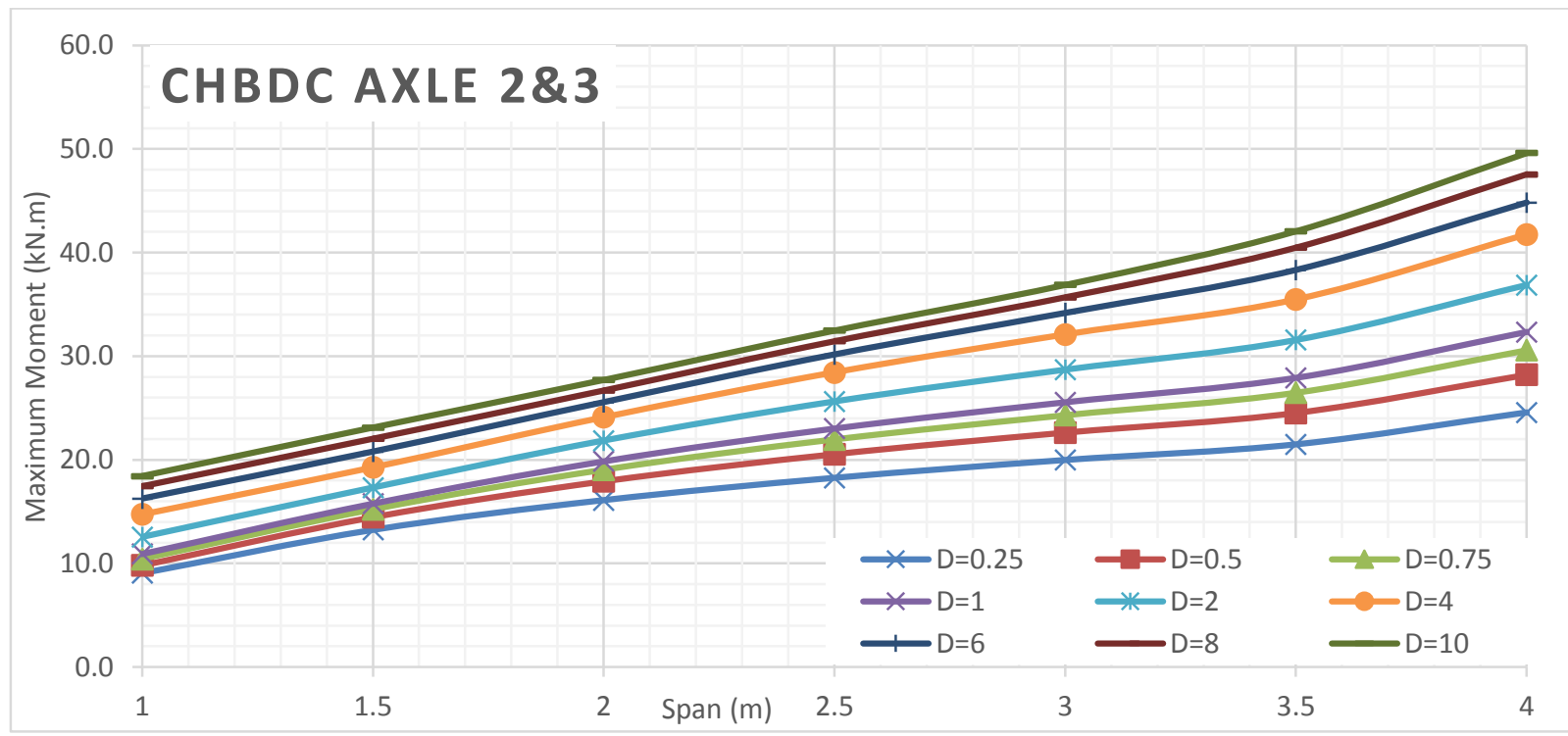

Figure 2 Maximum moment of deck slabs subjected to CHBDC axle $2 \& 3$ for different D values of alpha 0.25 FEA analyses 


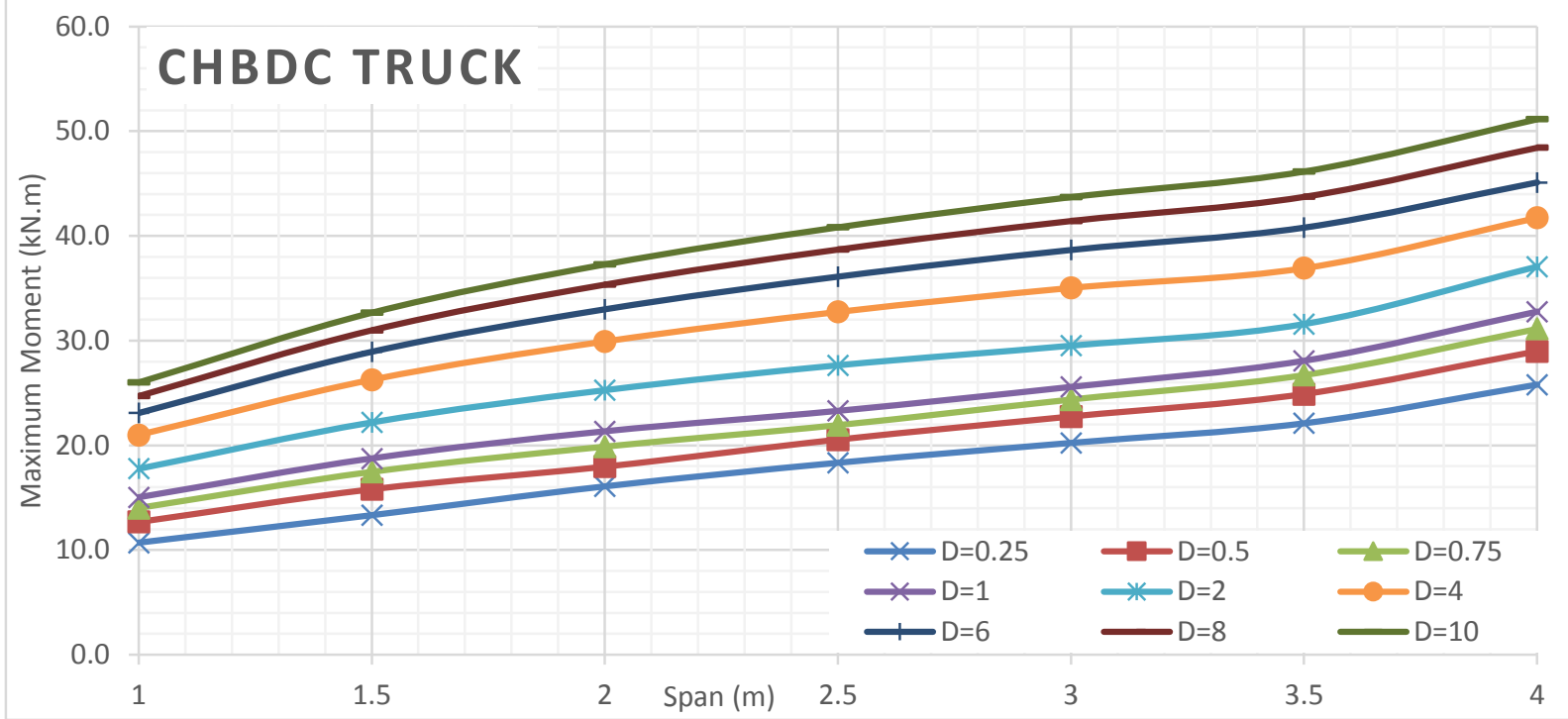

Figure 3 Maximum moment of deck slabs subjected to CHBDC truck for different D values of alpha 0.25 FEA analyses

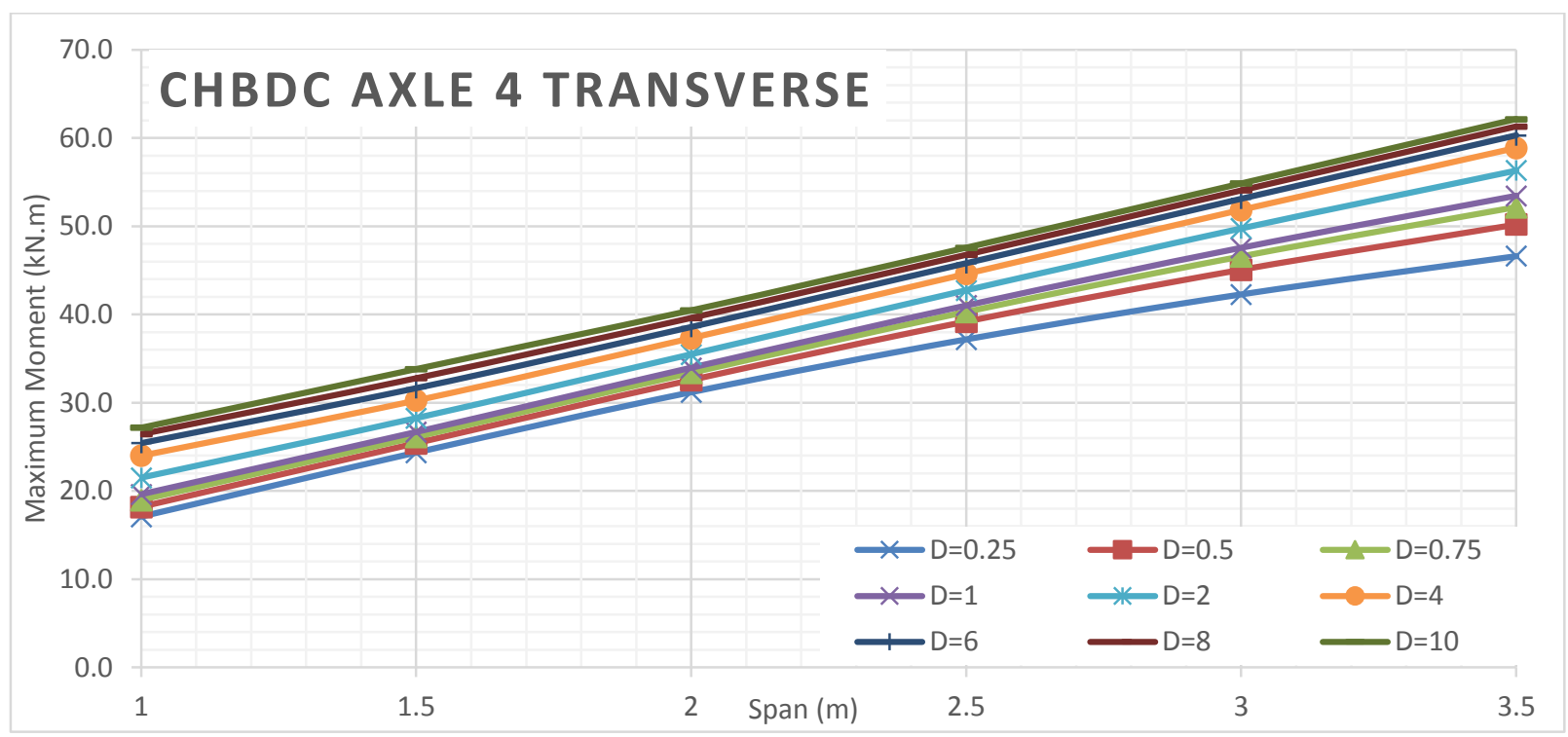

Figure 4 Maximum moment of deck slabs subjected to CHBDC axle 4 for different D values of alpha 0.25 FEA analyses

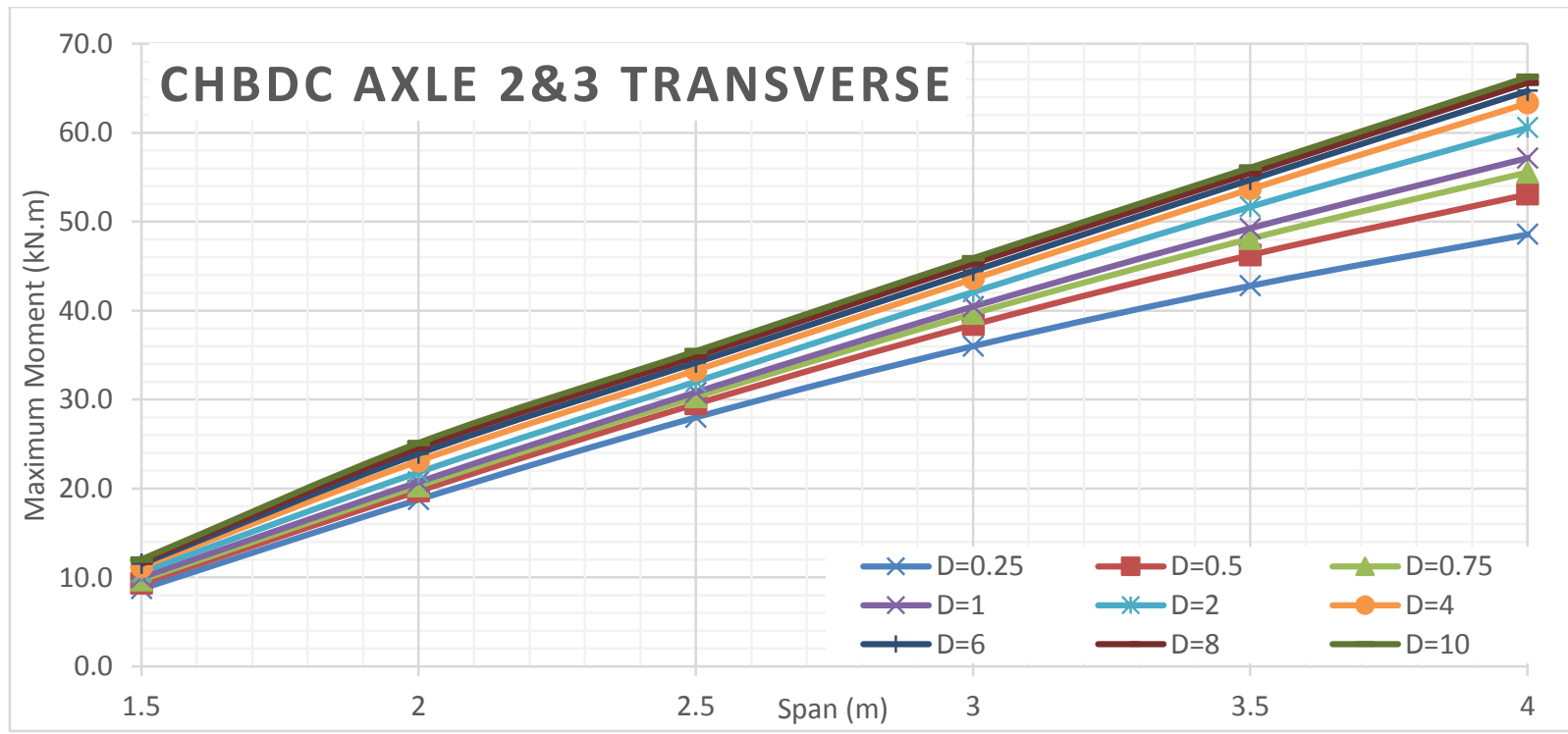

Figure 5 Maximum moment of deck slabs subjected to CHBDC axle $2 \& 3$ for different D values of alpha 0.25 FEA analyses 


\section{Alpha 0.5 Bending Moment VS Span Length for Different D Values}

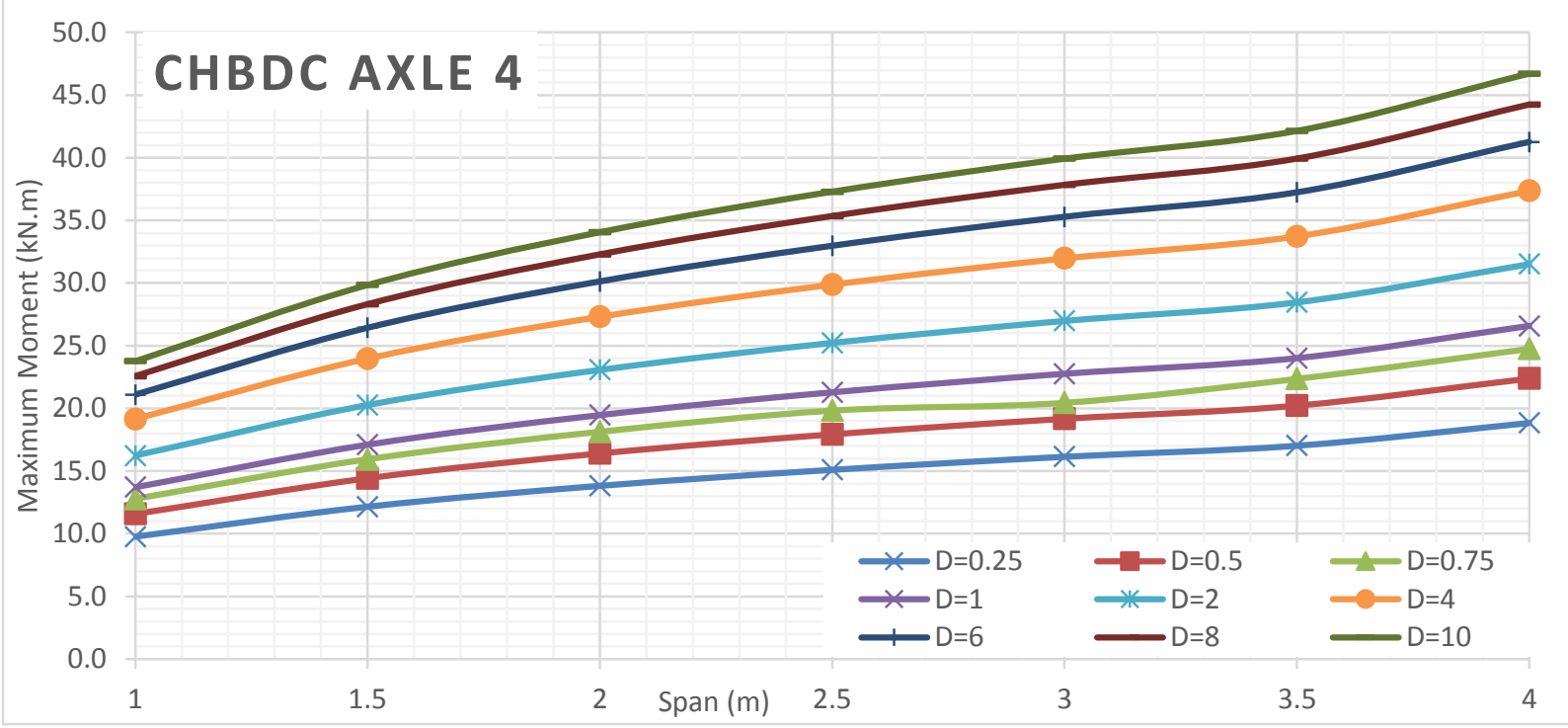

Figure 6 Maximum moment of deck slabs subjected to CHBDC axle 4 for different D values of alpha 0.5 FEA analyses

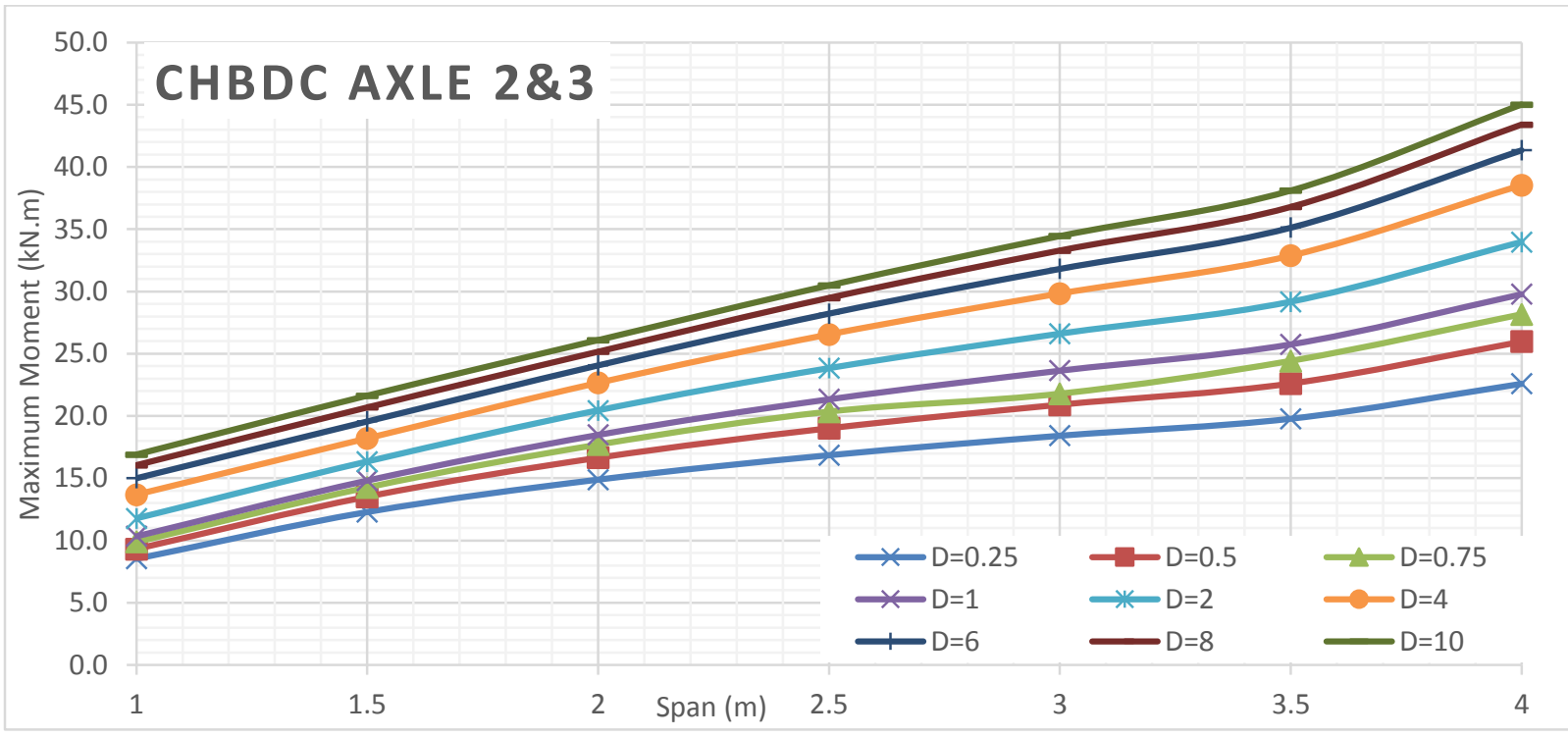

Figure 7 Maximum moment of deck slabs subjected to CHBDC axle $2 \& 3$ for different D values of alpha 0.5 FEA analyses 


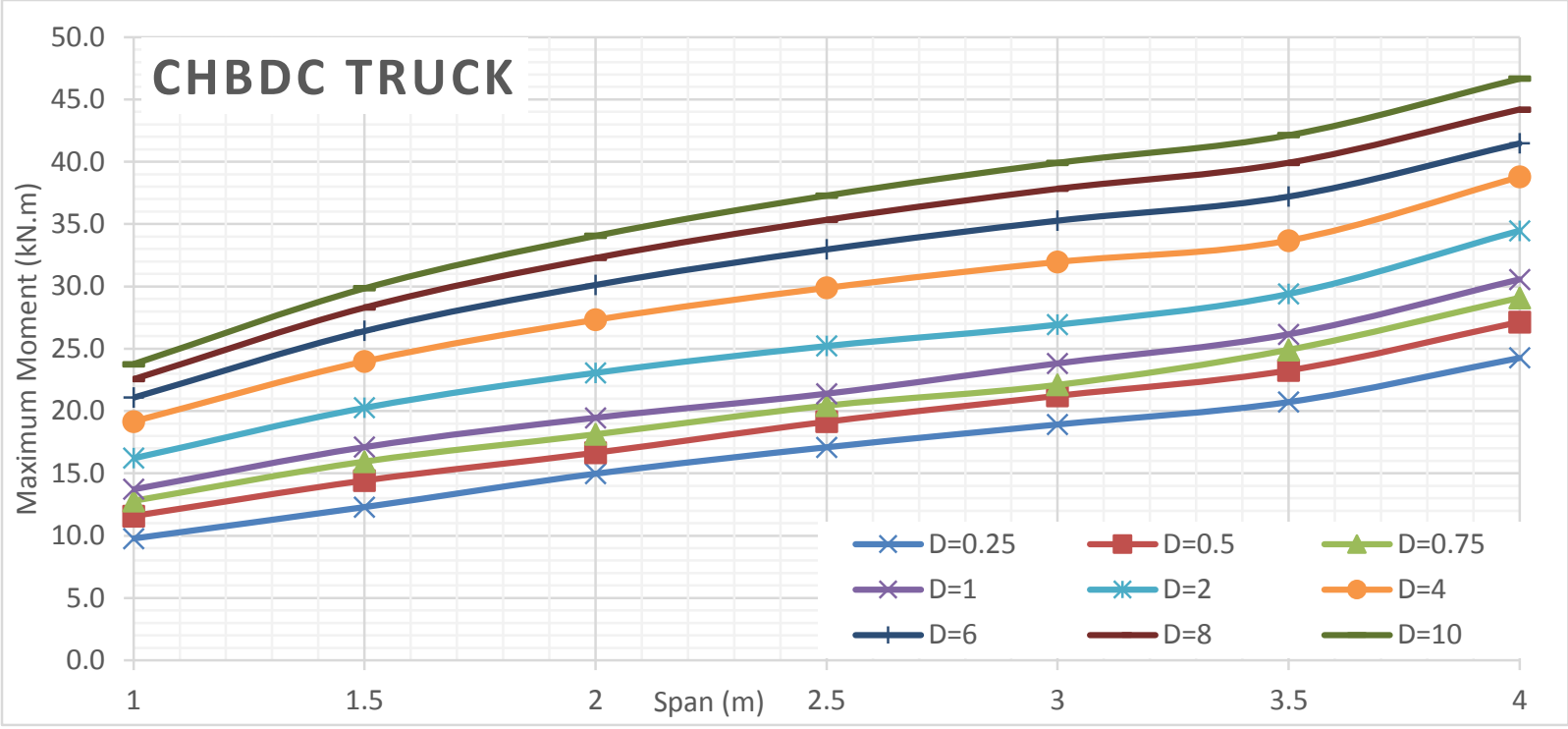

Figure 8 Maximum moment of deck slabs subjected to CHBDC truck for different D values of alpha 0.5 FEA analyses

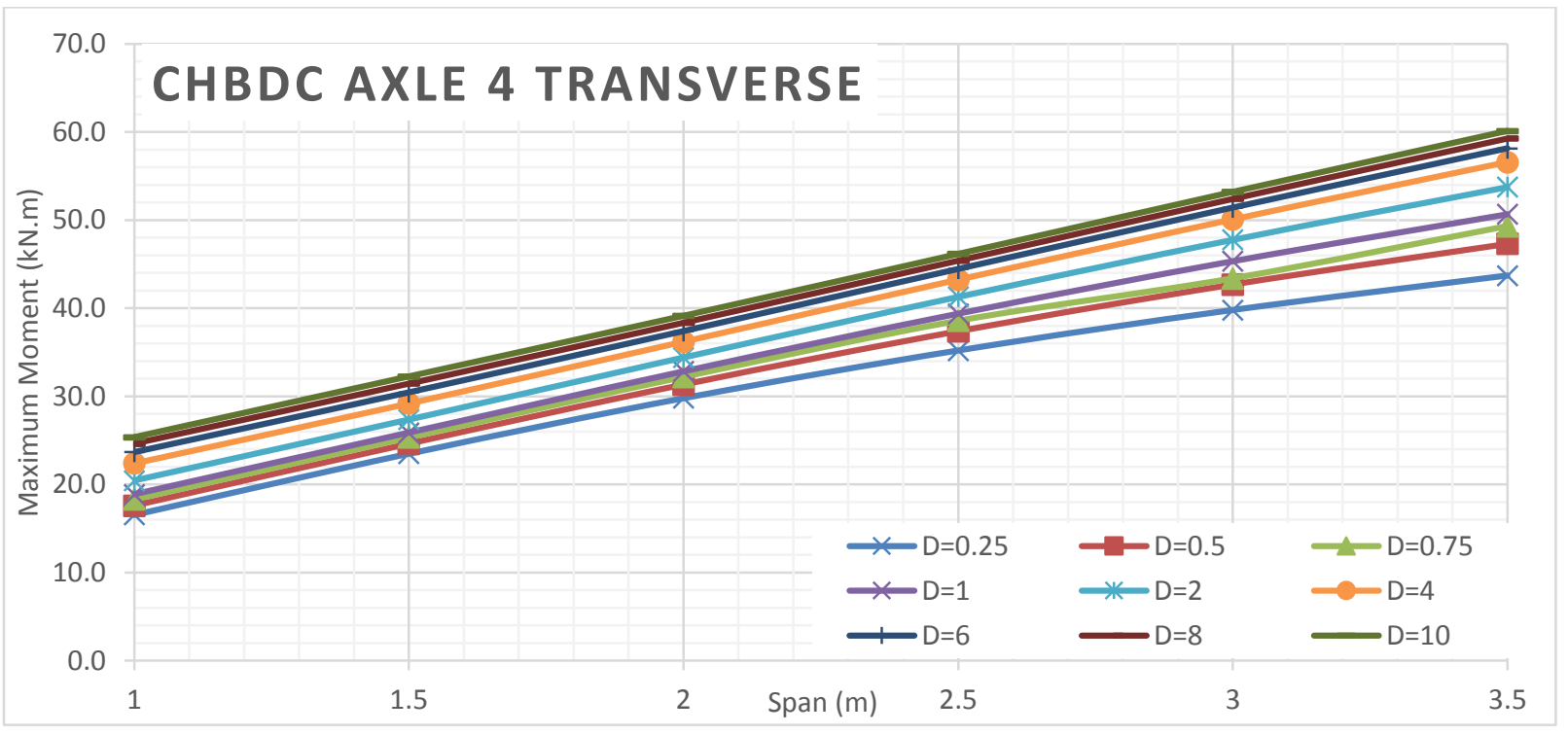

Figure 9 Maximum moment of deck slabs subjected to CHBDC axle 4 for different D values of alpha 0.5 FEA analyses

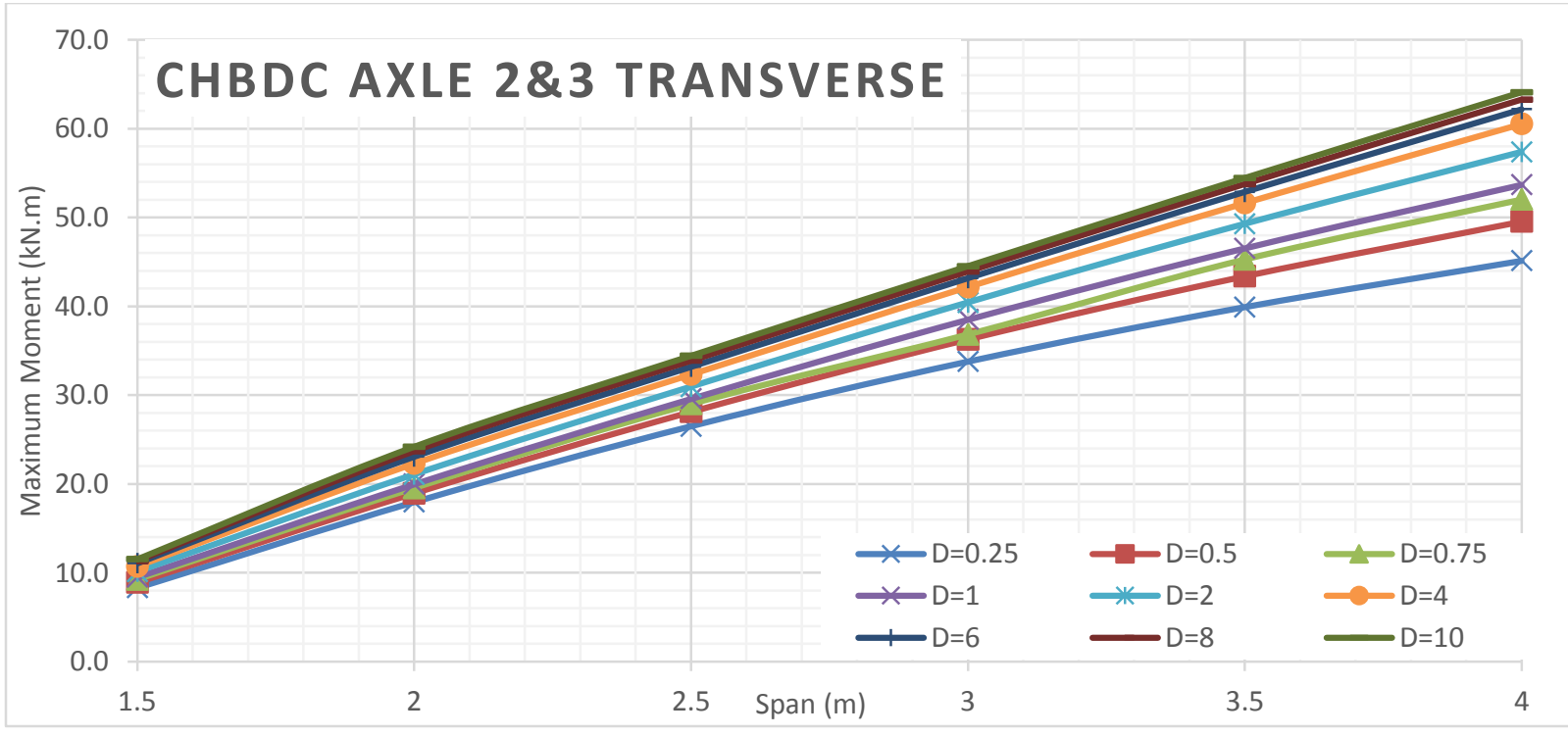

Figure 10 Maximum moment of deck slabs subjected to CHBDC axle $2 \& 3$ for different D values of alpha 0.5 FEA analyses 


\section{Alpha 0.75 Bending Moment VS Span Length for Different D Values}

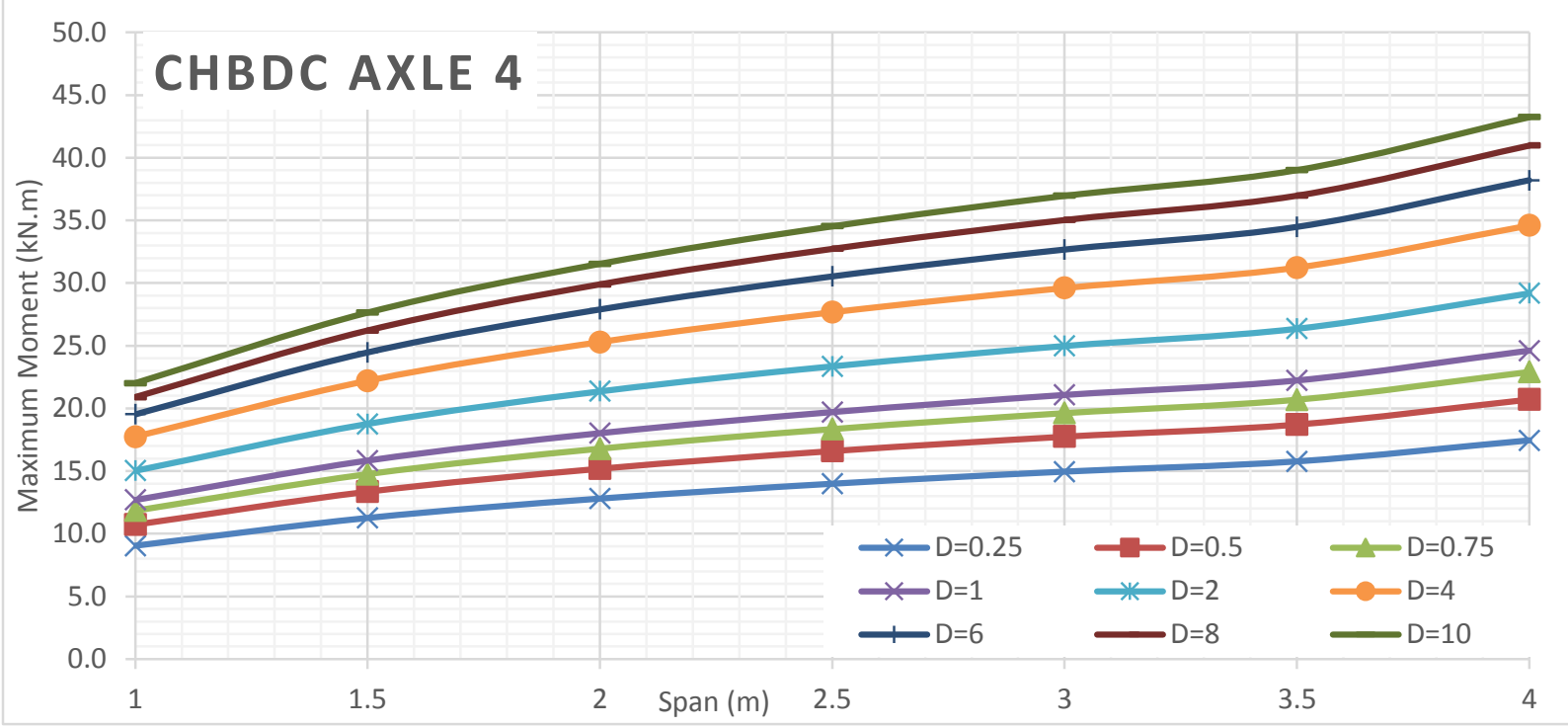

Figure 11 Maximum moment of deck slabs subjected to CHBDC axle 4 for different $D$ values of alpha 0.75 FEA analyses

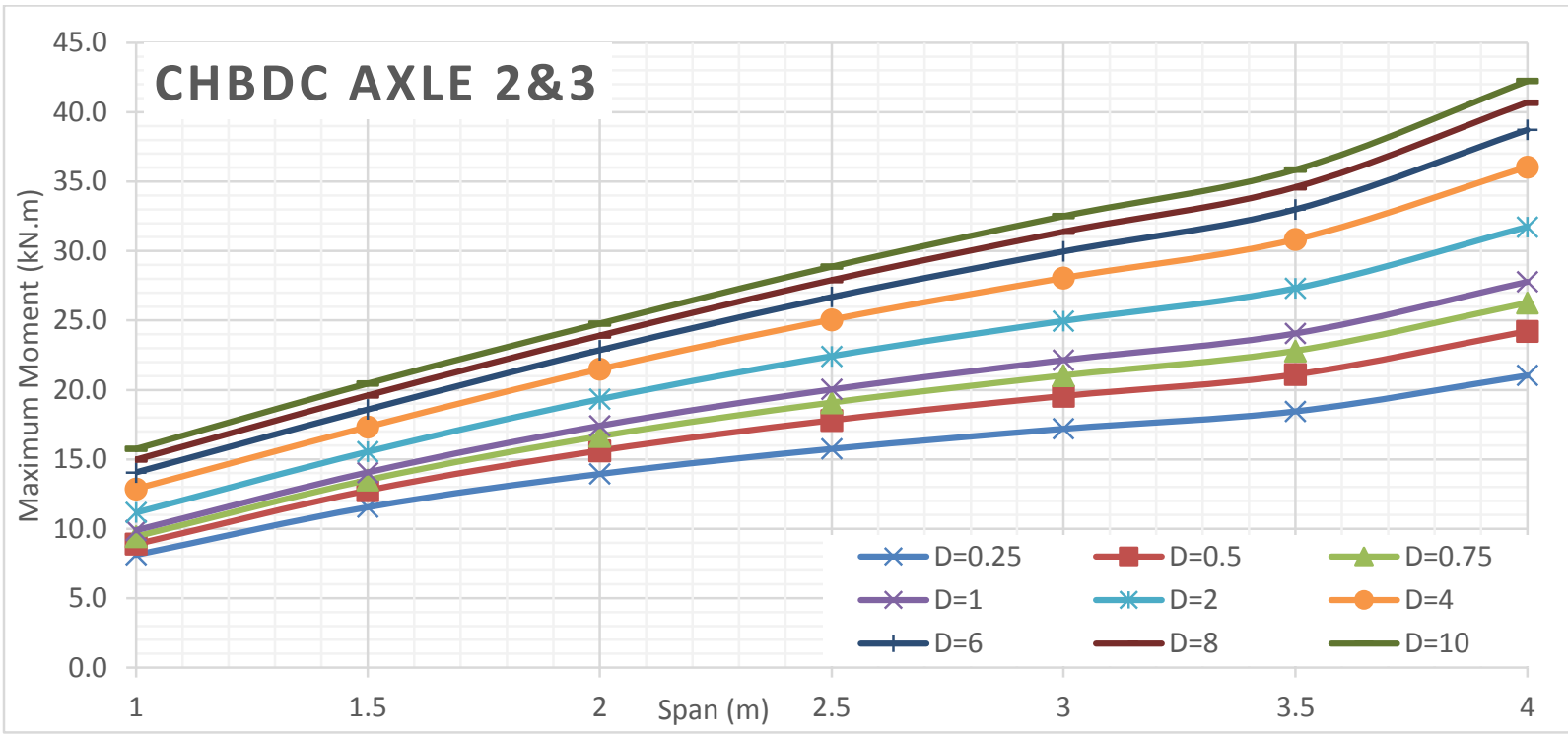

Figure 12 Maximum moment of deck slabs subjected to CHBDC axle $2 \& 3$ for different $D$ values of alpha 0.75 FEA analyses 


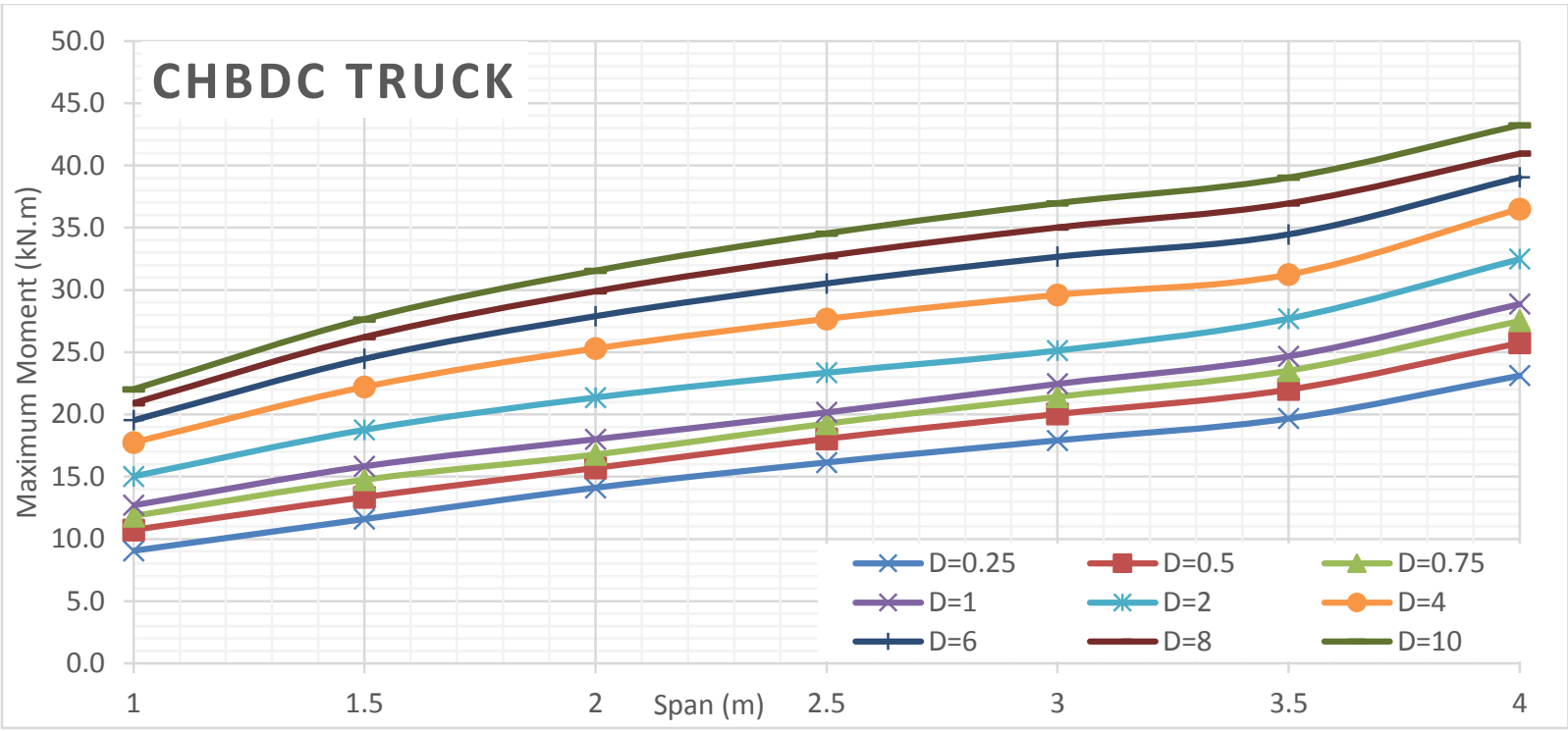

Figure 13 Maximum moment of deck slabs subjected to CHBDC truck for different D values of alpha 0.75 FEA analyses

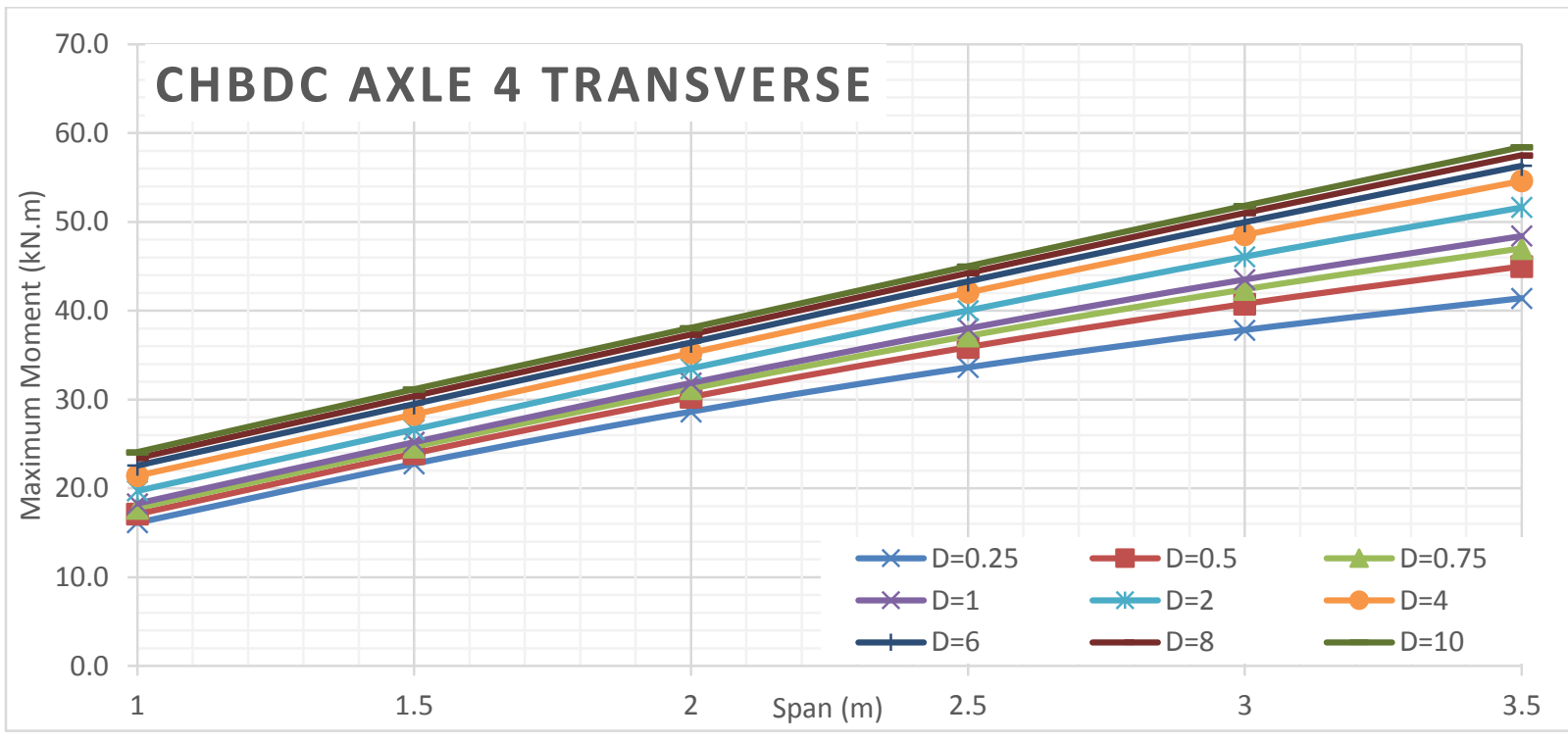

Figure 14 Maximum moment of deck slabs subjected to CHBDC axle 4 for different D values of alpha 0.75 FEA analyses

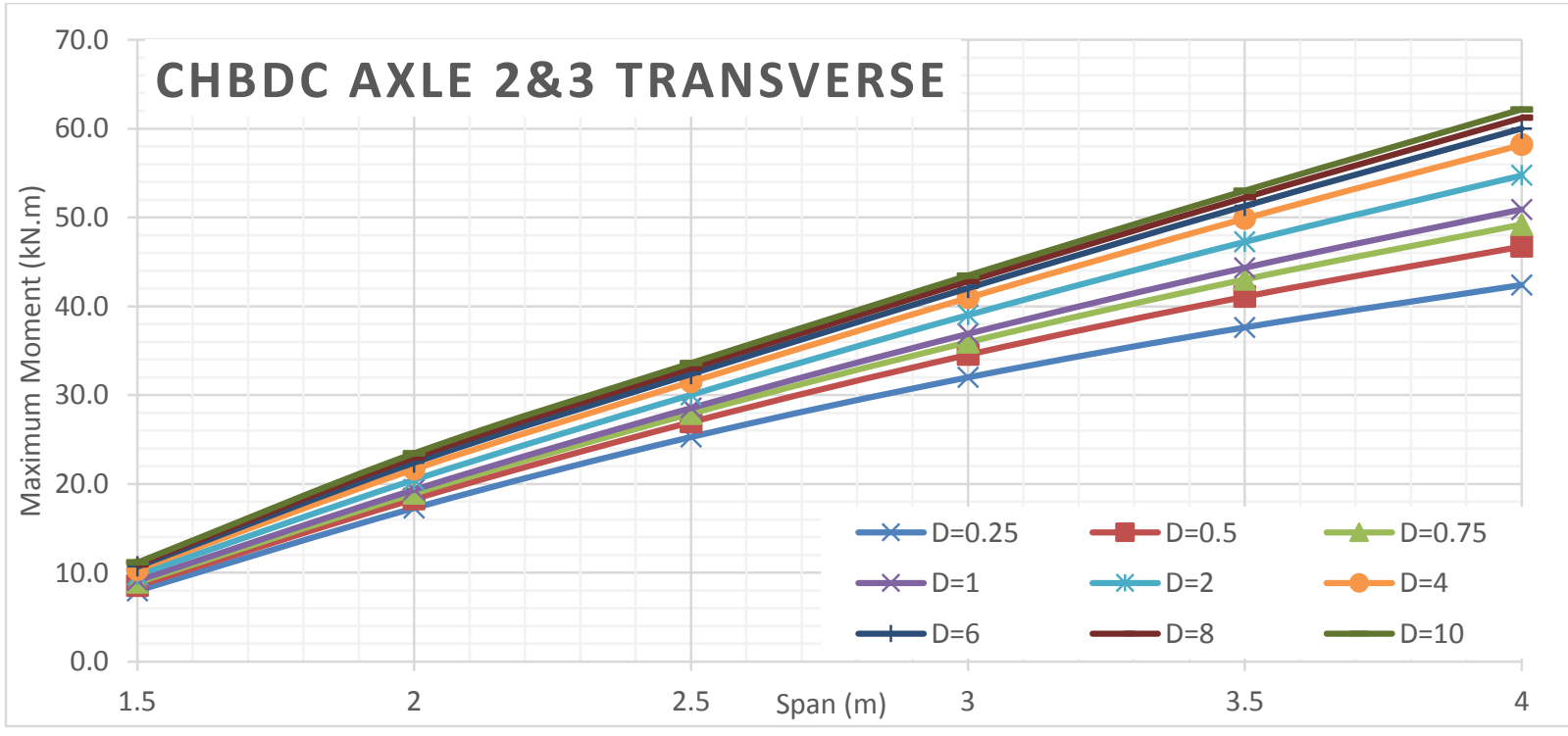

Figure 15 Maximum moment of deck slabs subjected to CHBDC axle $2 \& 3$ for different D values of alpha 0.75 FEA analyses 


\section{Alpha 1 Bending Moment VS Span Length for Different D Values}

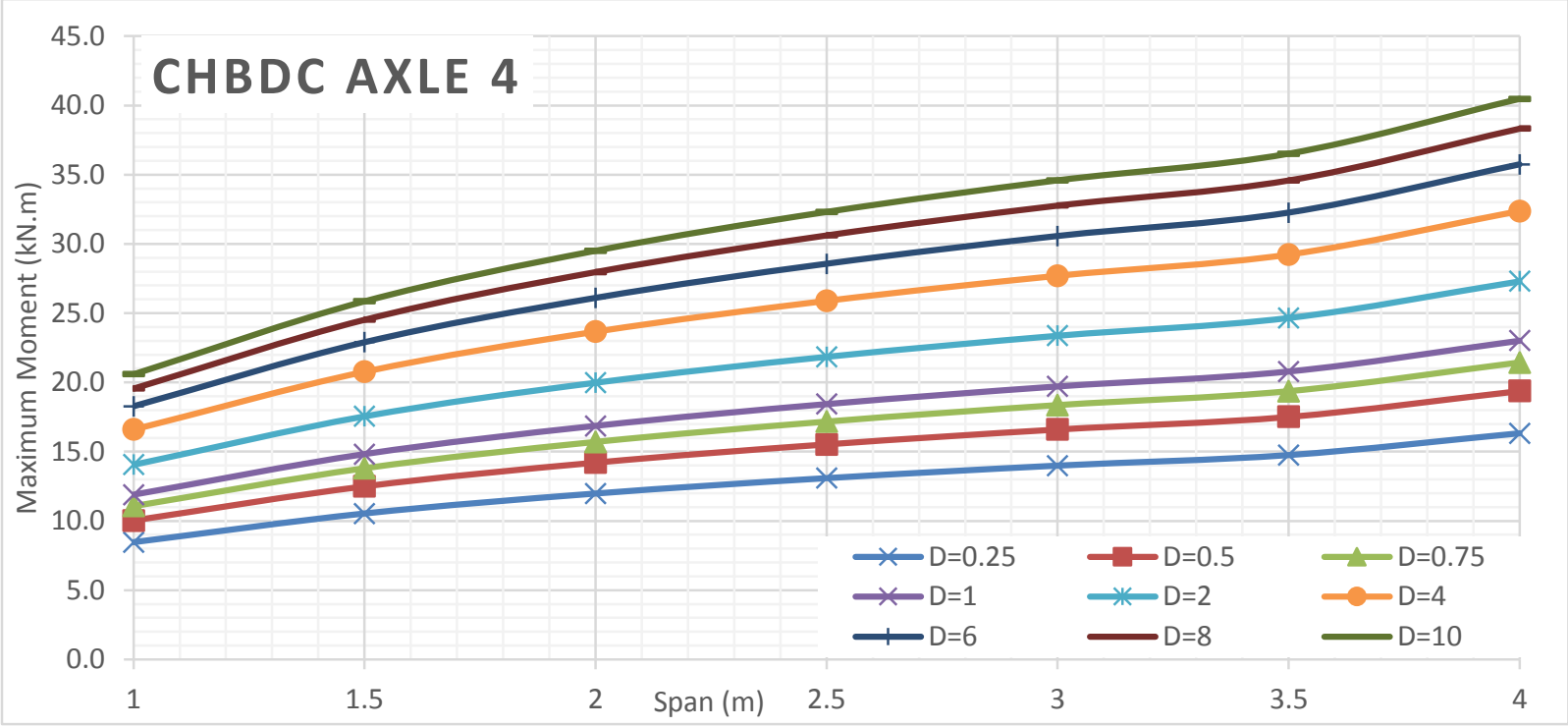

Figure 16 Maximum moment of deck slabs subjected to CHBDC axle 4 for different D values of alpha 1 FEA analyses

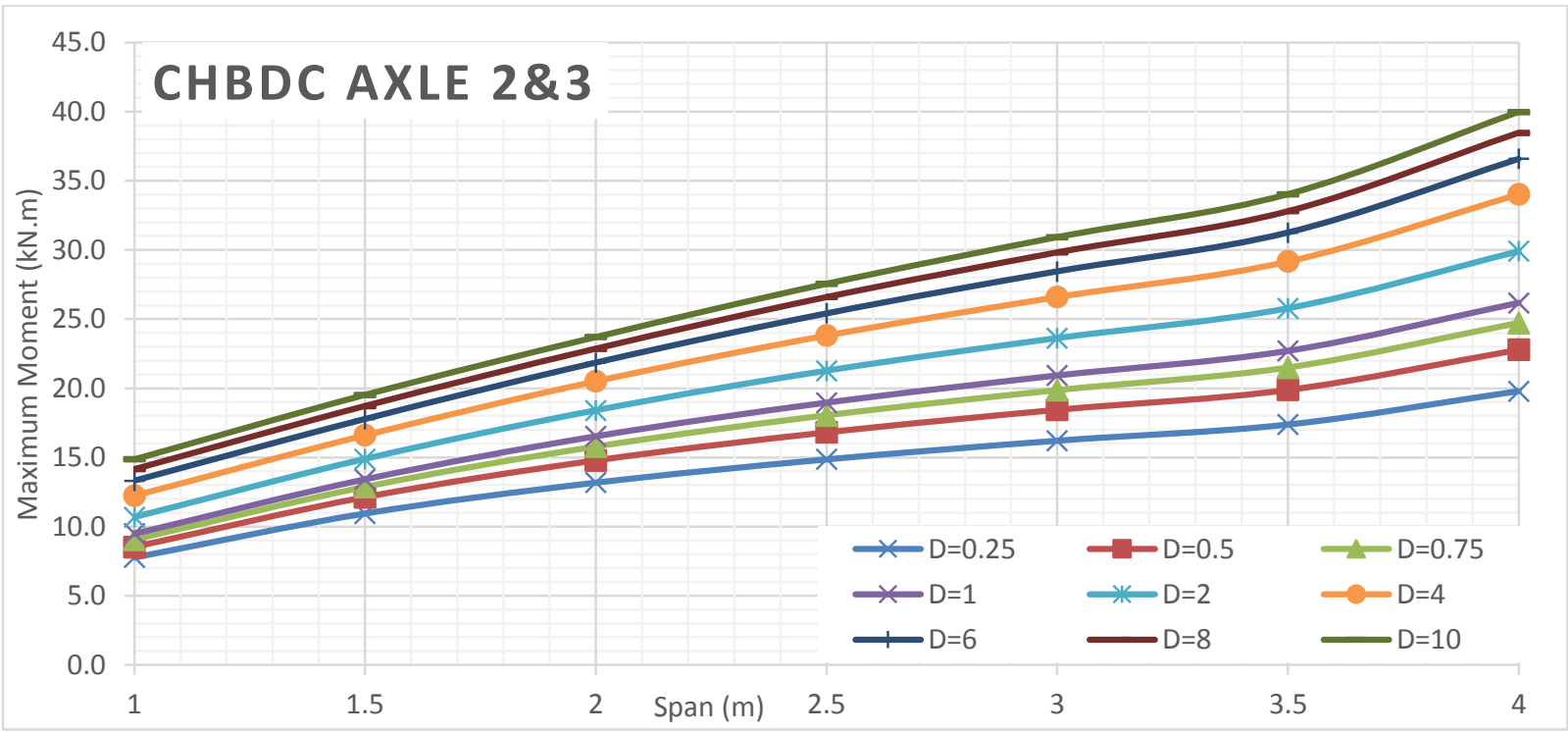

Figure 17 Maximum moment of deck slabs subjected to CHBDC axle $2 \& 3$ for different D values of alpha 1 FEA analyses 


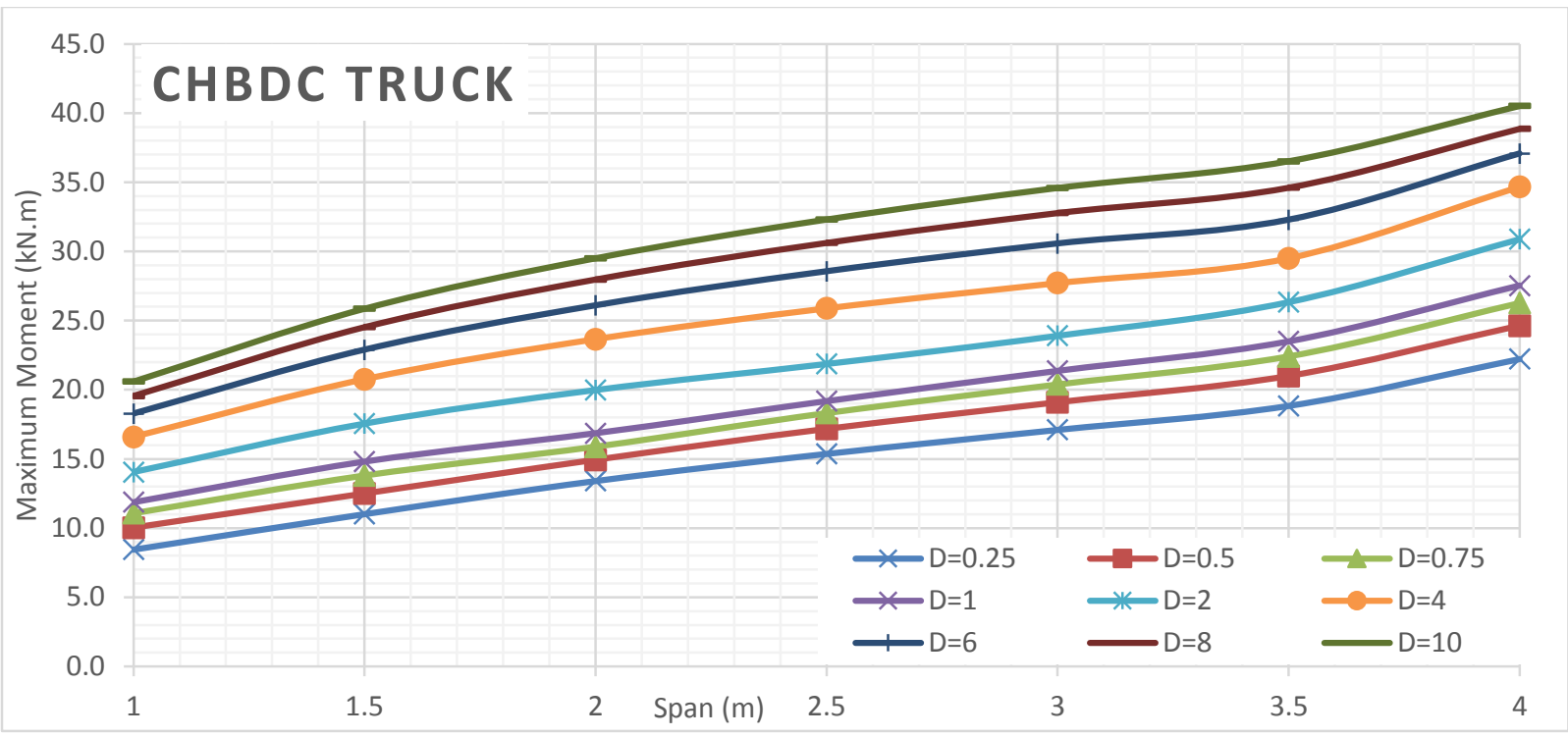

Figure 18 Maximum moment of deck slabs subjected to CHBDC truck for different D values of alpha 1 FEA analyses

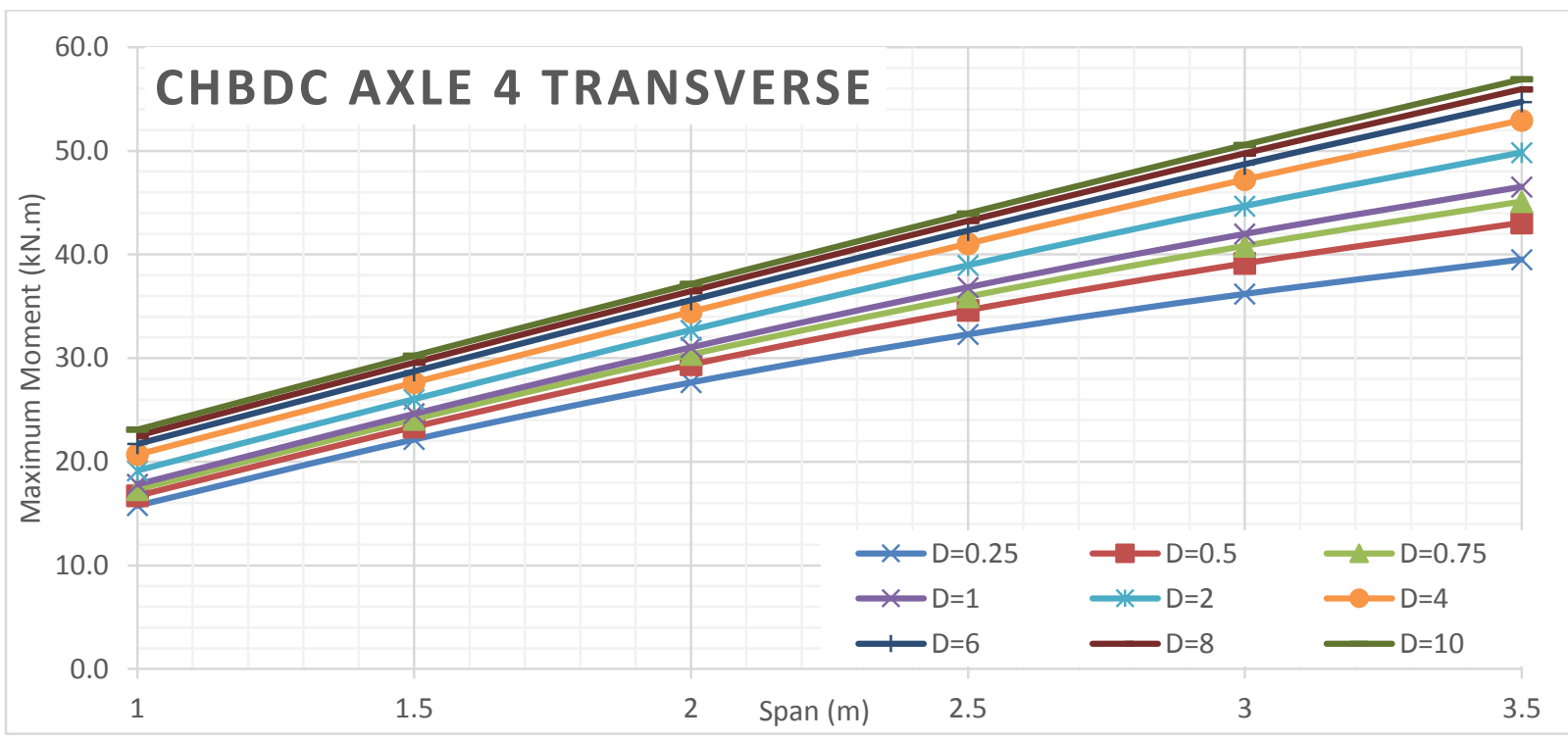

Figure 19 Maximum moment of deck slabs subjected to CHBDC axle 4 for different D values of alpha 1 FEA analyses

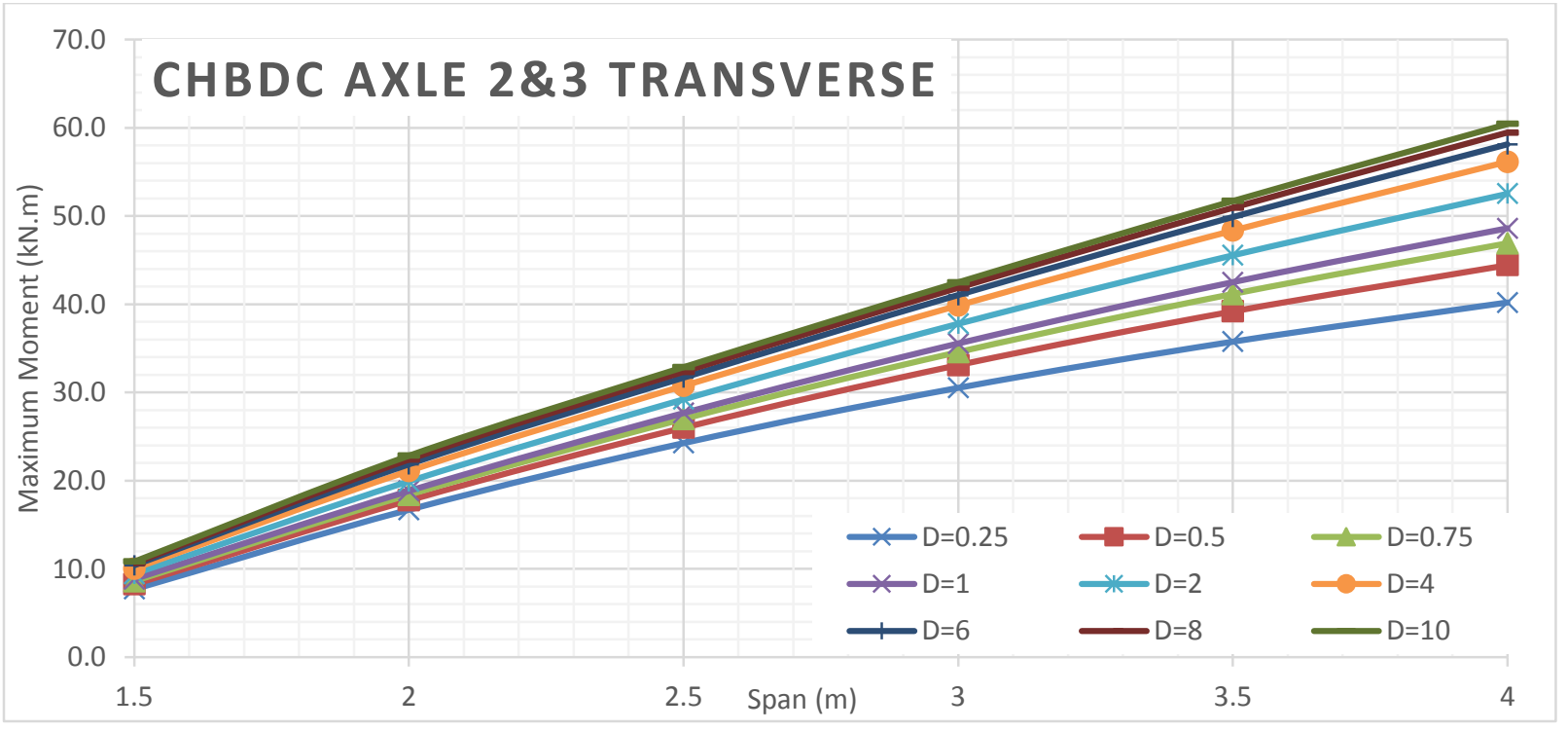

Figure 20 Maximum moment of deck slabs subjected to CHBDC axle $2 \& 3$ for different D values of alpha 1 FEA analyses 


\section{Alpha 2 Bending Moment VS Span Length for Different D Values}

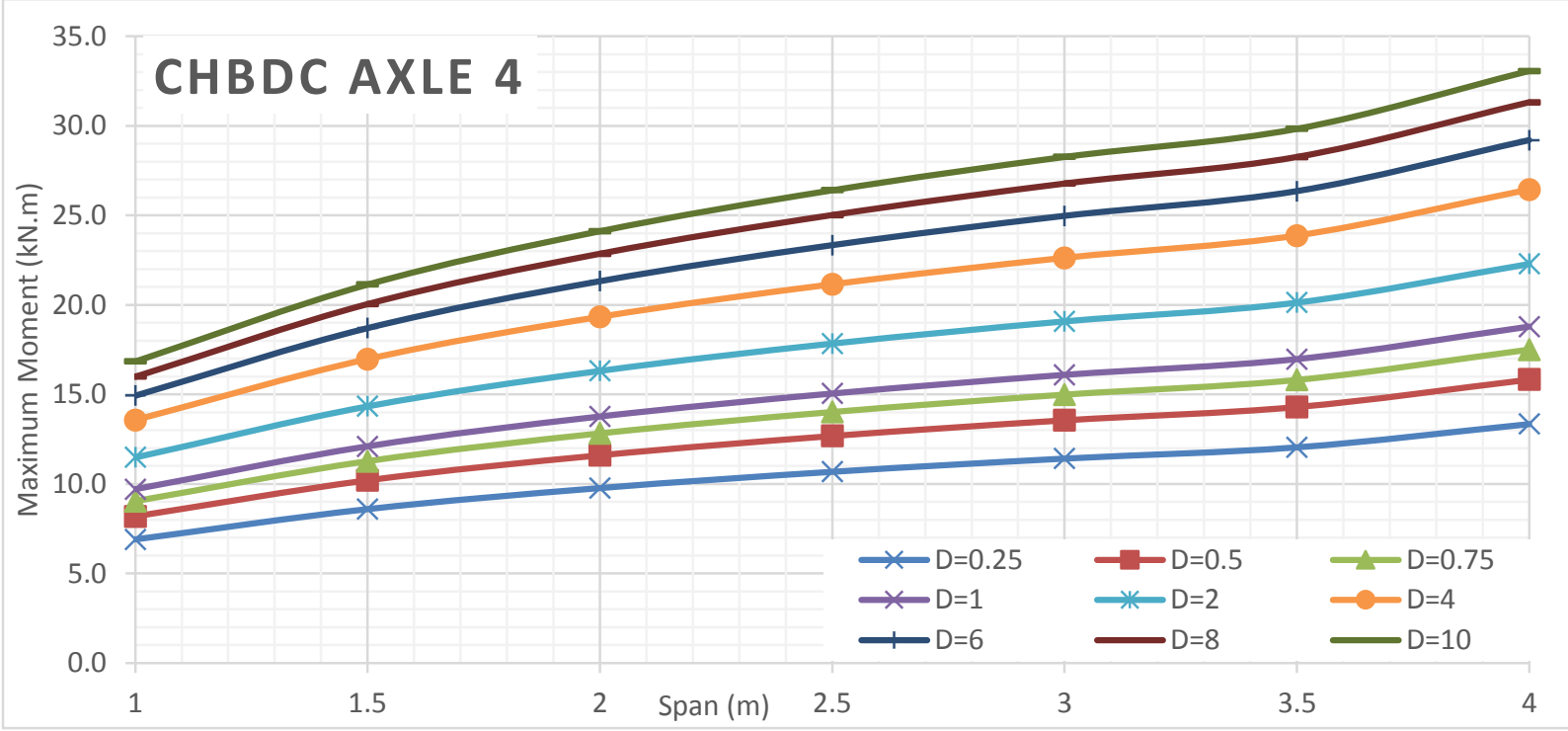

Figure 21 Maximum moment of deck slabs subjected to CHBDC axle 4 for different D values of alpha 2 FEA analyses

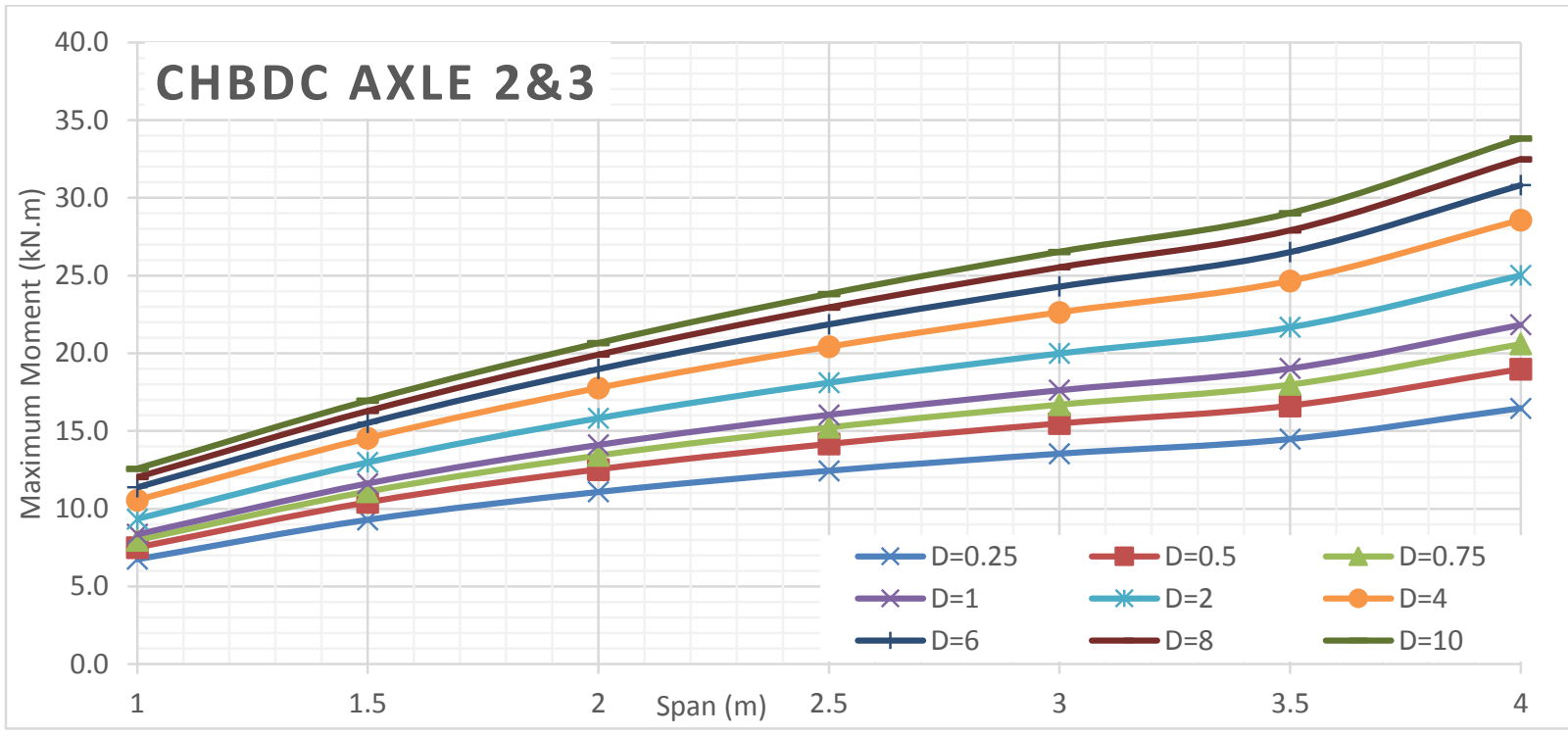

Figure 22 Maximum moment of deck slabs subjected to CHBDC axle $2 \& 3$ for different D values of alpha 2 FEA analyses 


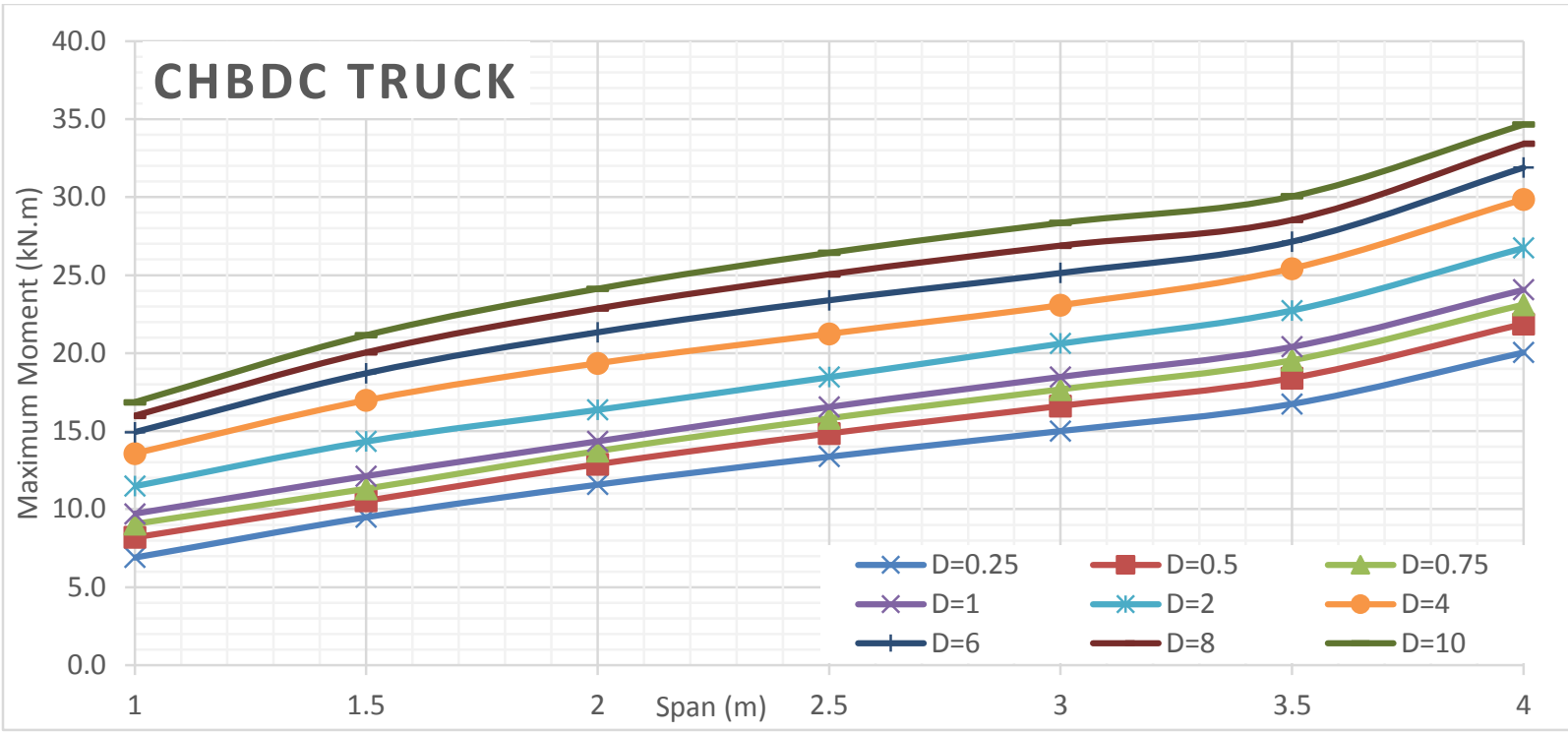

Figure 23 Maximum moment of deck slabs subjected to CHBDC truck for different D values of alpha 2 FEA analyses

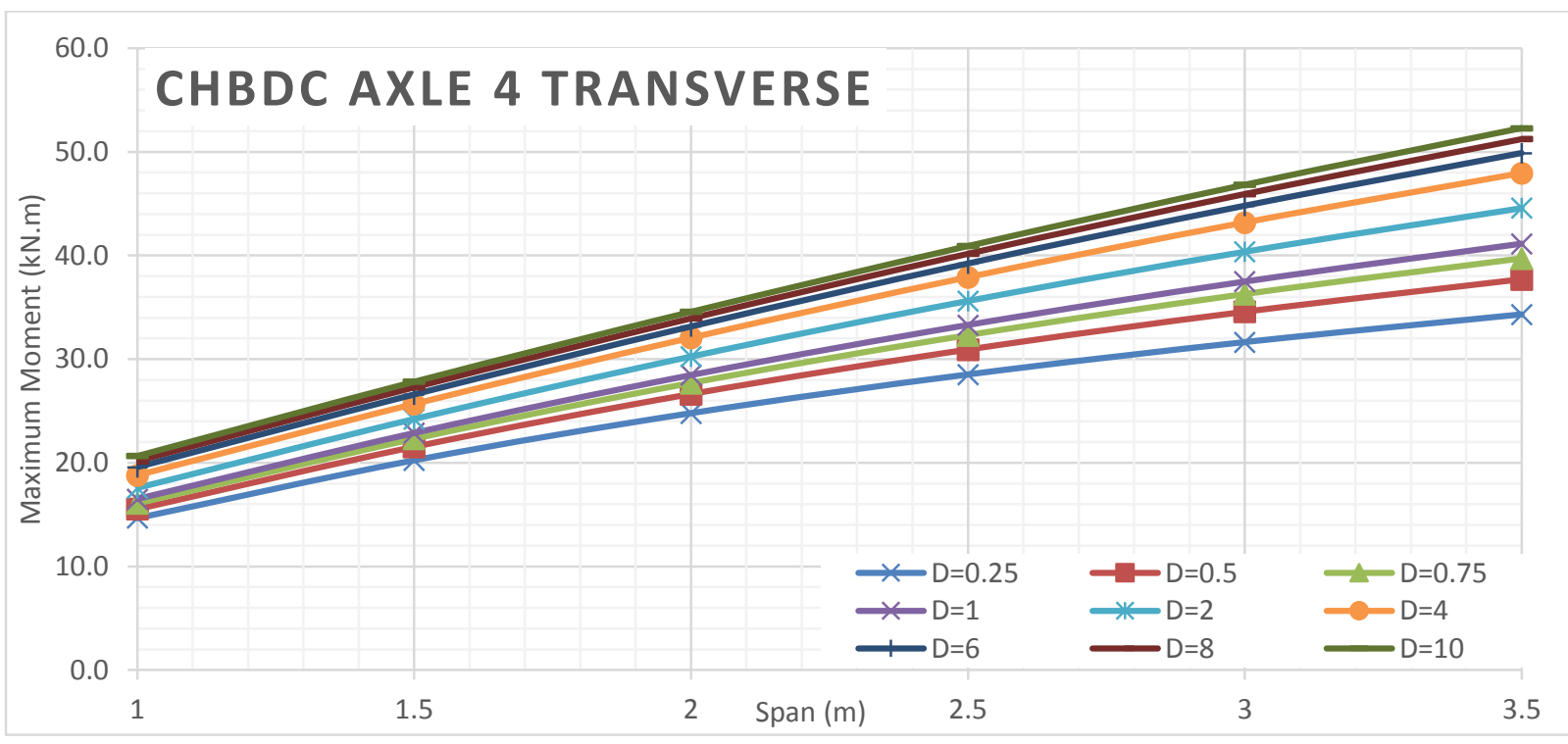

Figure 24 Maximum moment of deck slabs subjected to CHBDC axle 4 for different D values of alpha 2 FEA analyses

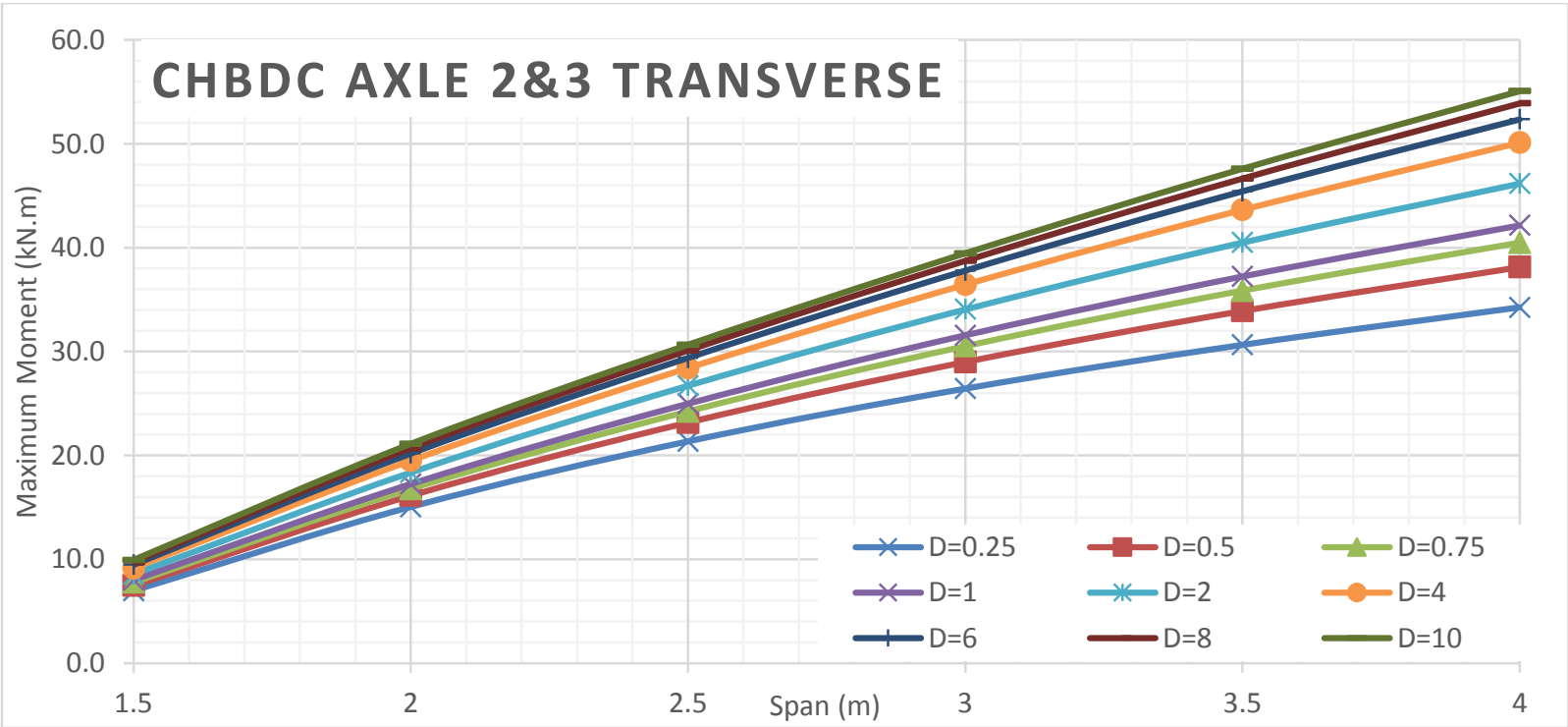

Figure 25 Maximum moment of deck slabs subjected to CHBDC axle $2 \& 3$ for different D values of alpha 2 FEA analyses 


\section{Alpha 4 Bending Moment VS Span Length for Different D Values}

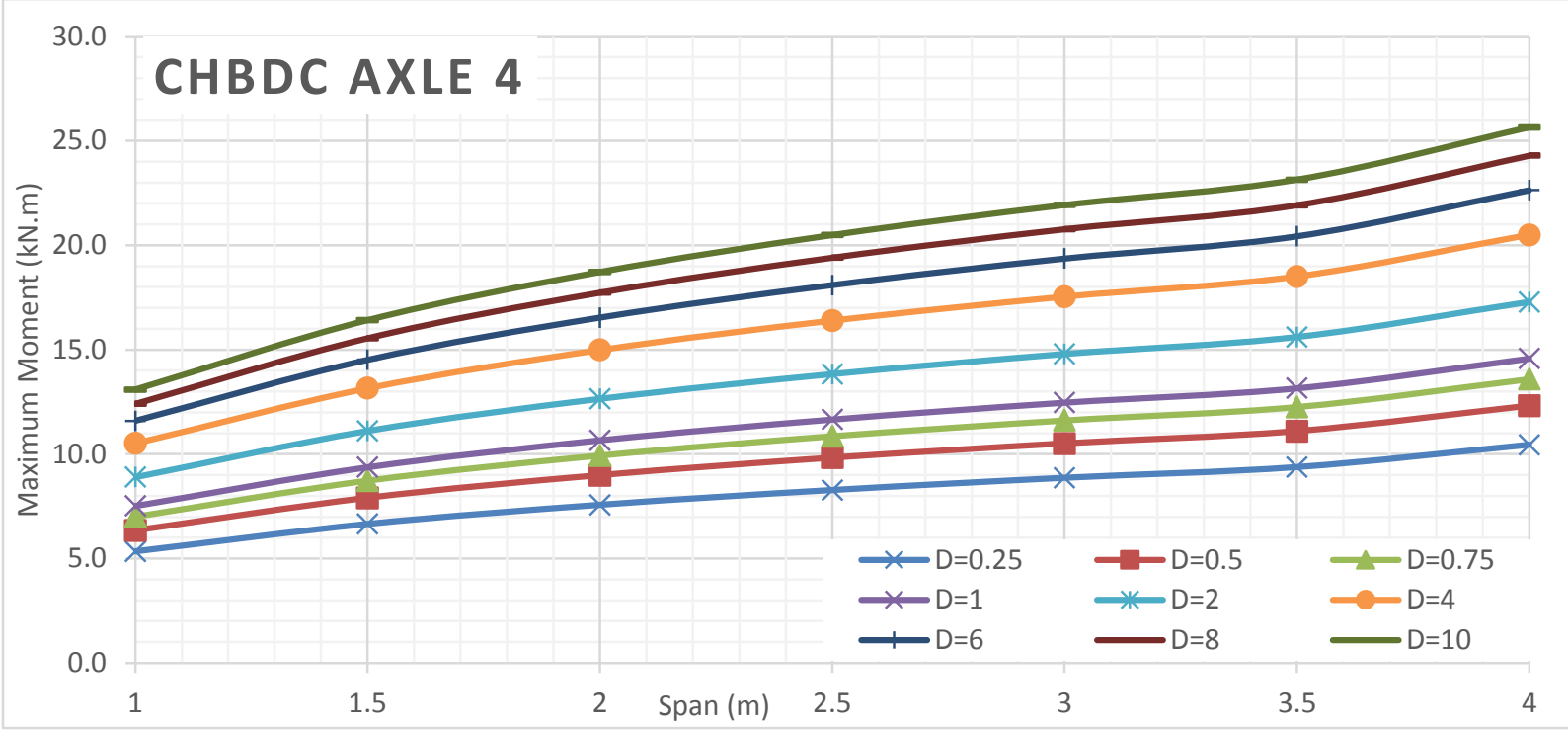

Figure 26 Maximum moment of deck slabs subjected to CHBDC axle 4 for different D values of alpha 4 FEA analyses

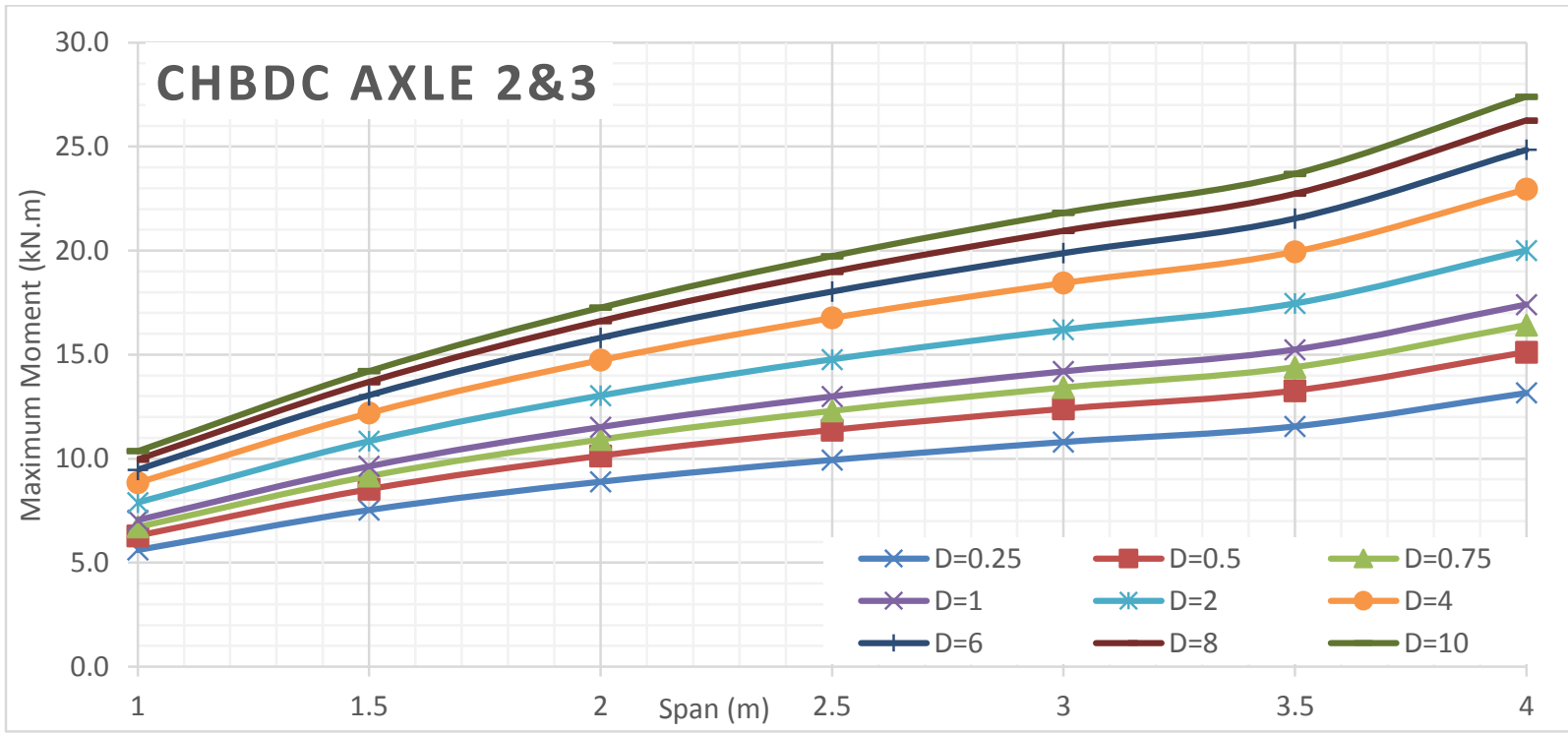

Figure 27 Maximum moment of deck slabs subjected to CHBDC axle $2 \& 3$ for different D values of alpha 4 FEA analyses 


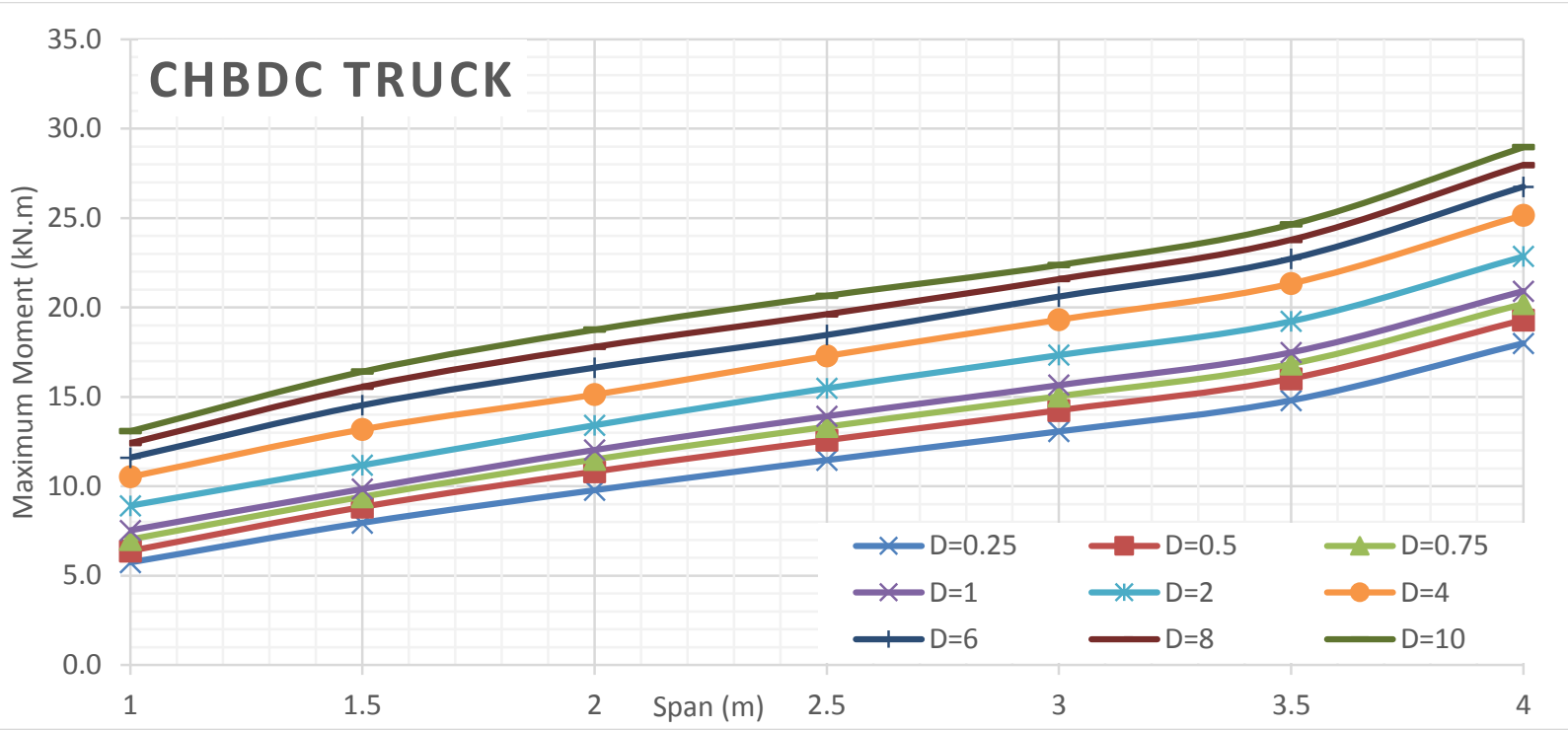

Figure 28 Maximum moment of deck slabs subjected to CHBDC truck for different D values of alpha 4 FEA analyses

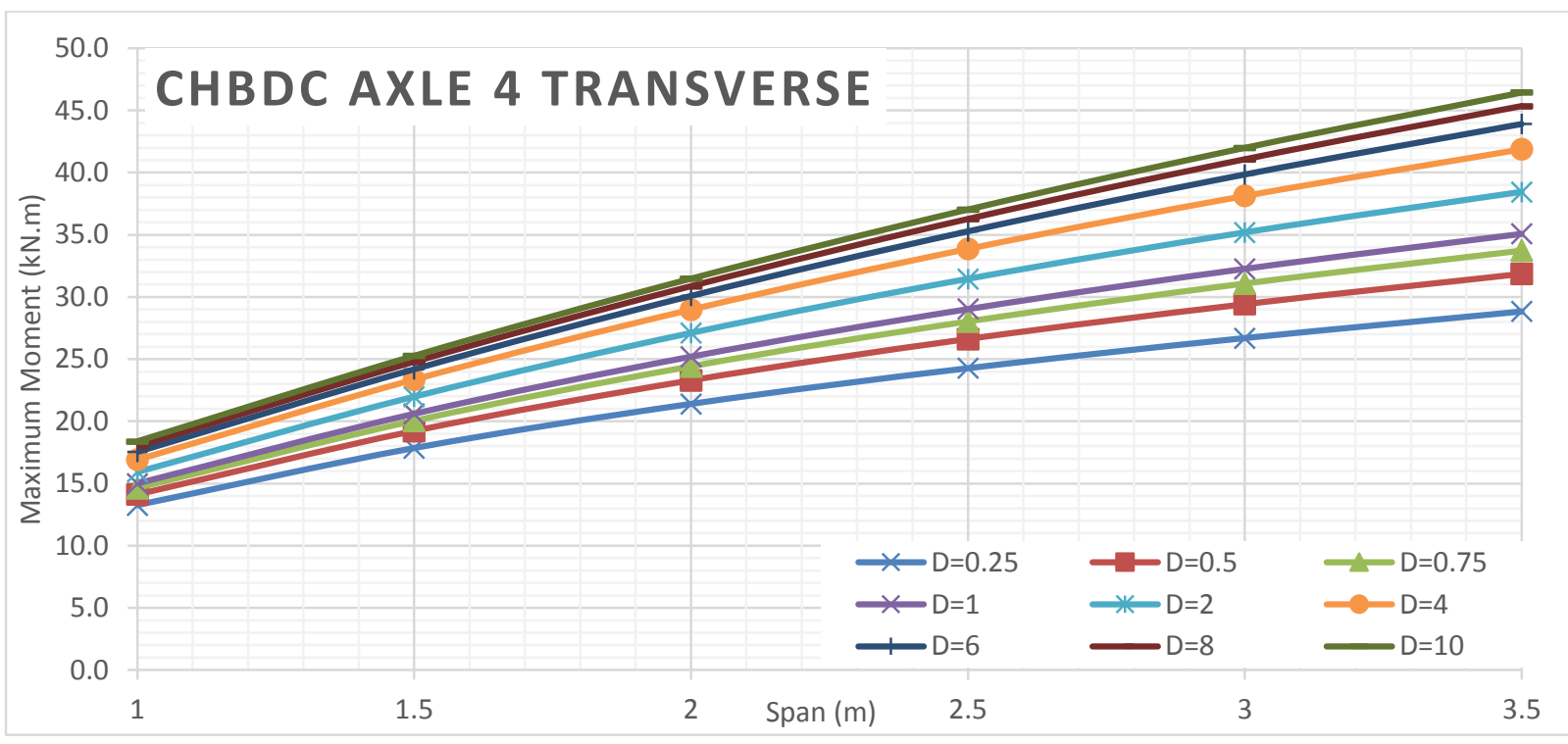

Figure 29 Maximum moment of deck slabs subjected to CHBDC axle 4 for different D values of alpha 4 FEA analyses

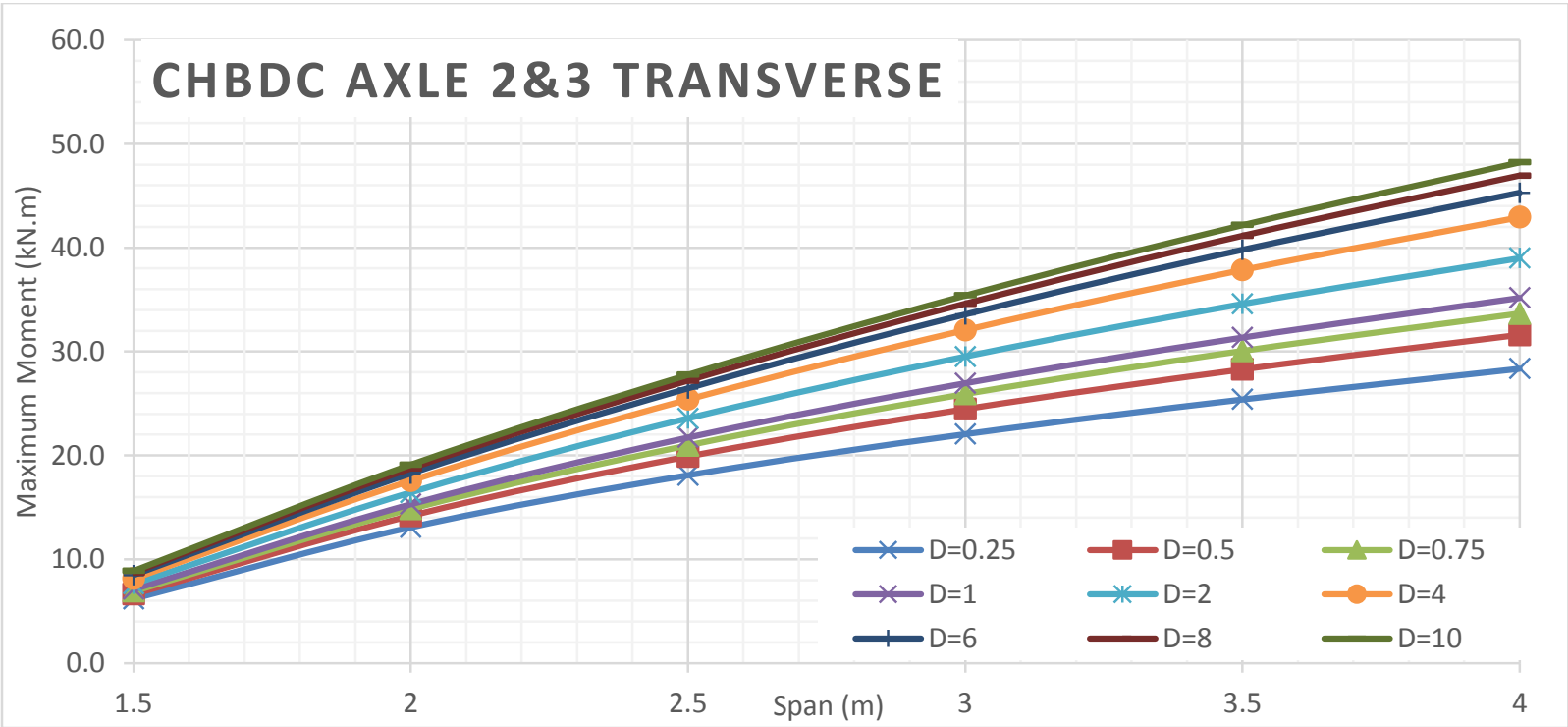

Figure 30 Maximum moment of deck slabs subjected to CHBDC axle $2 \& 3$ for different D values of alpha 4 FEA analyses 


\section{Alpha 6 Bending Moment VS Span Length for Different D Values}

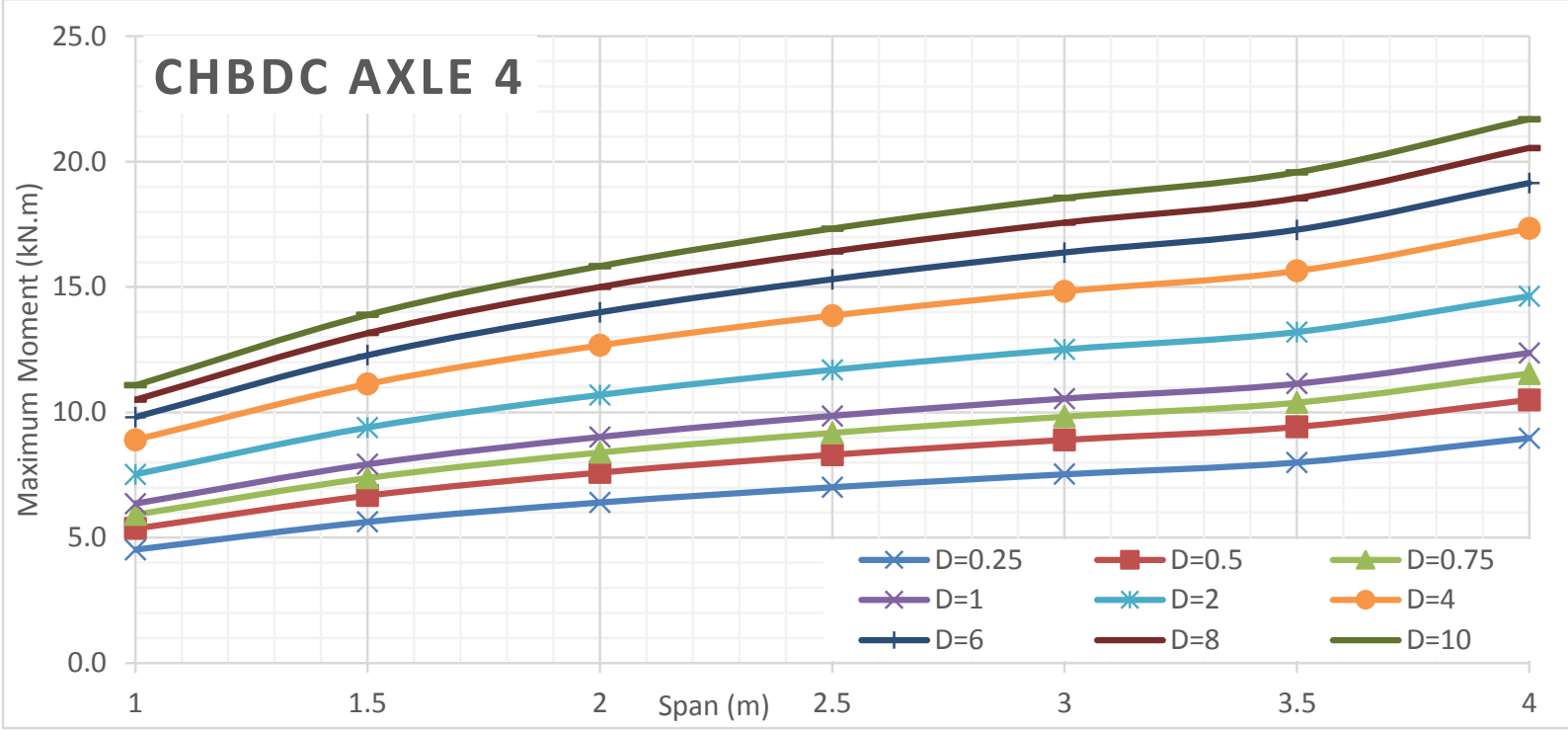

Figure 31 Maximum moment of deck slabs subjected to CHBDC axle 4 for different D values of alpha 6 FEA analyses

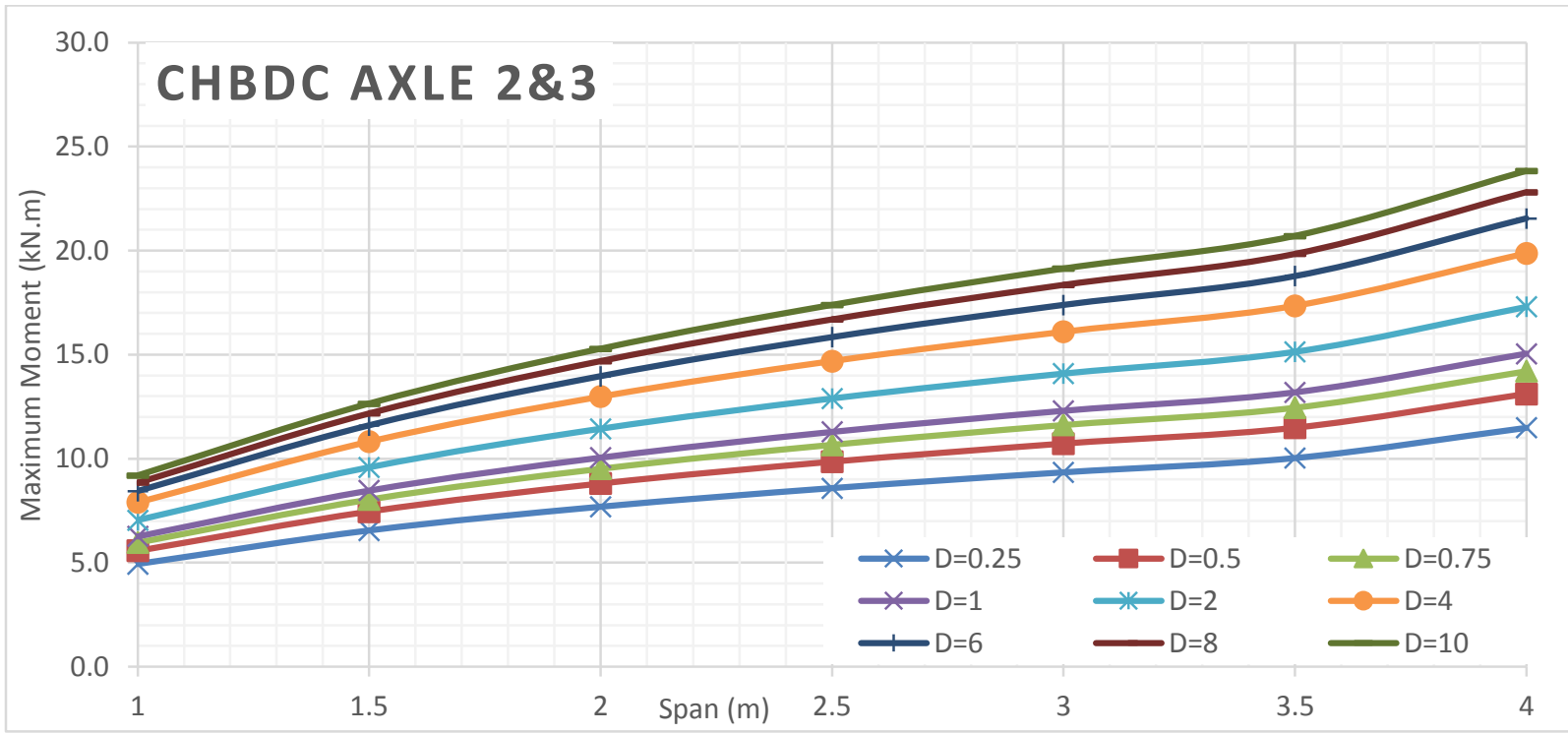

Figure 32 Maximum moment of deck slabs subjected to CHBDC axle $2 \& 3$ for different D values of alpha 6 FEA analyses 


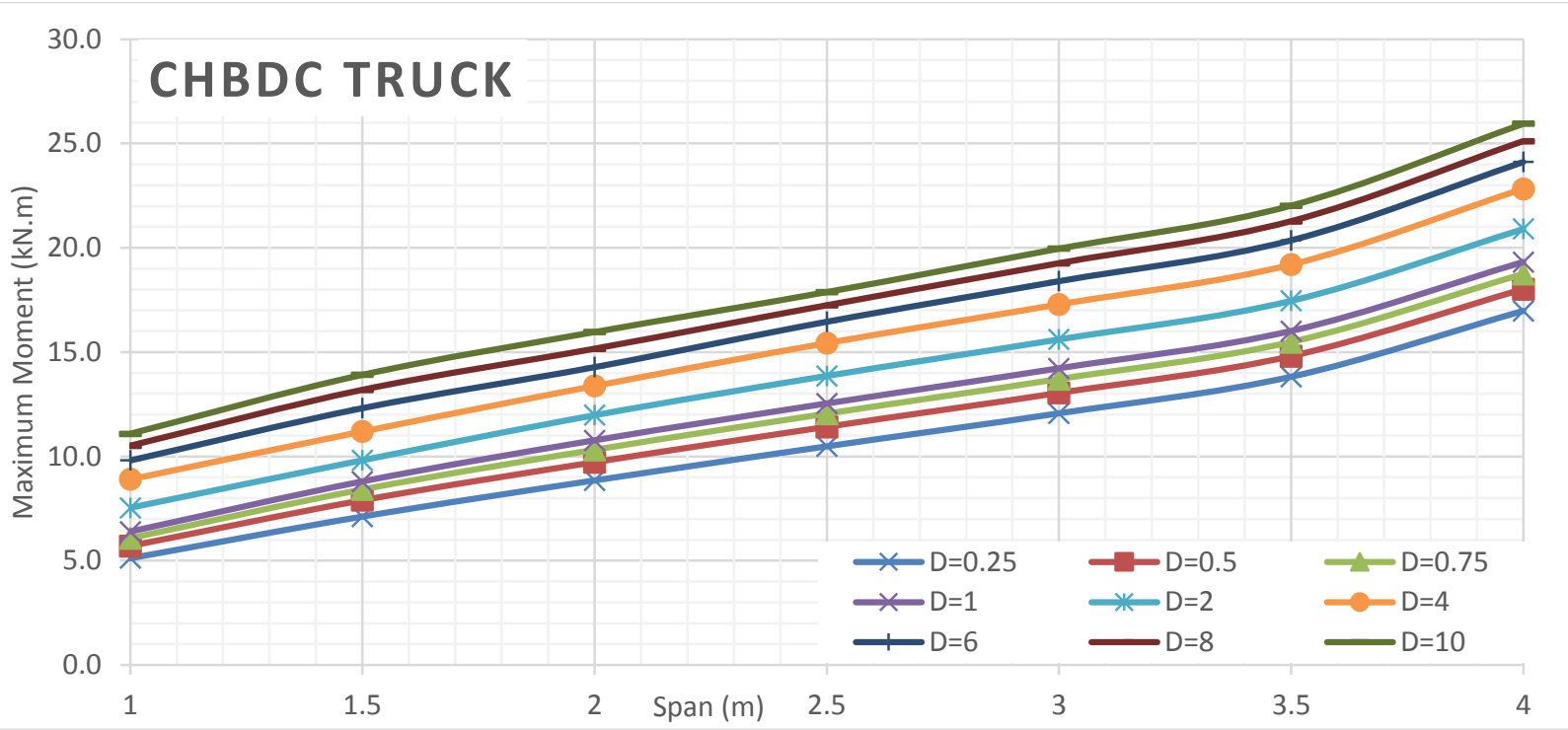

Figure 33 Maximum moment of deck slabs subjected to CHBDC truck for different D values of alpha 6 FEA analyses

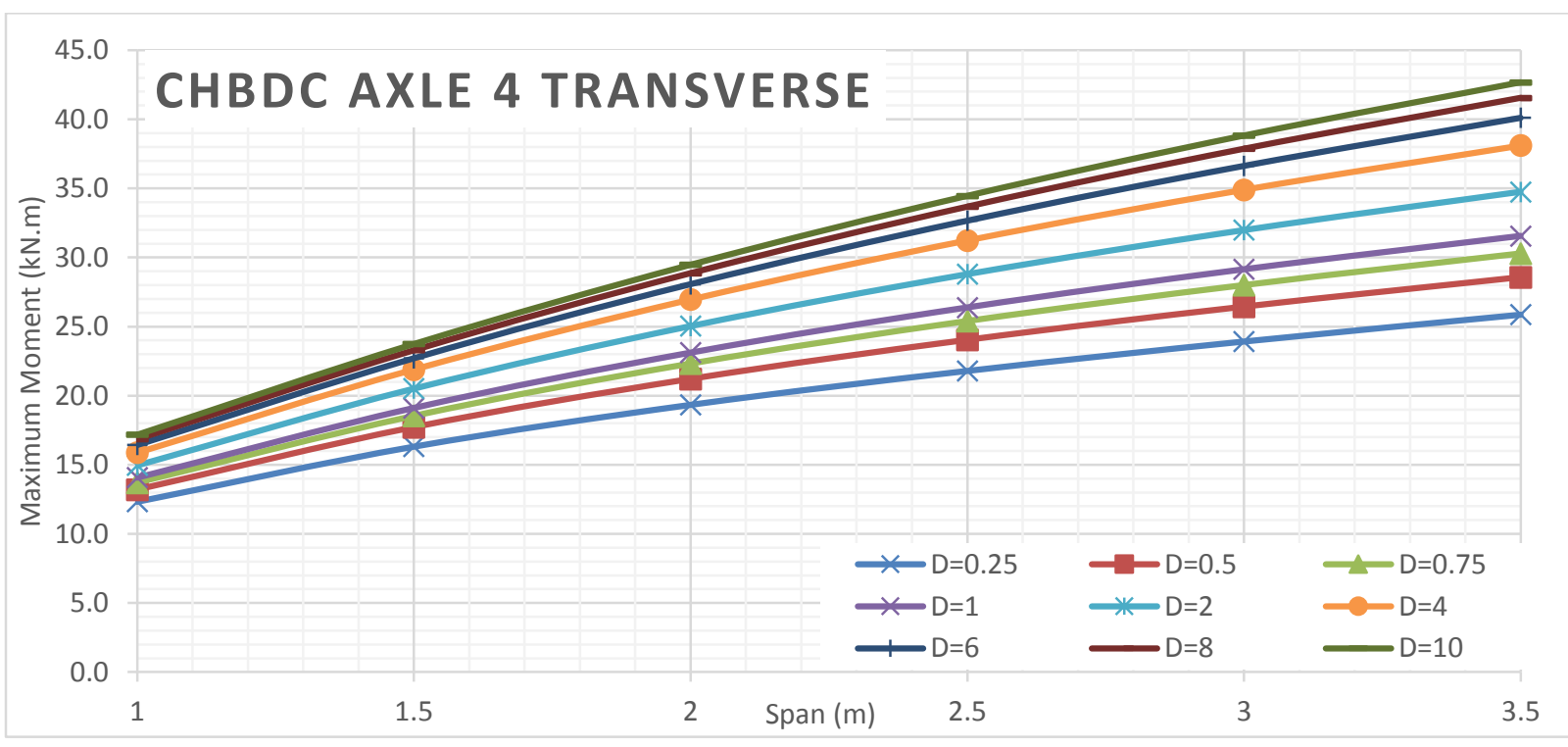

Figure 34 Maximum moment of deck slabs subjected to CHBDC axle 4 for different D values of alpha 6 FEA analyses

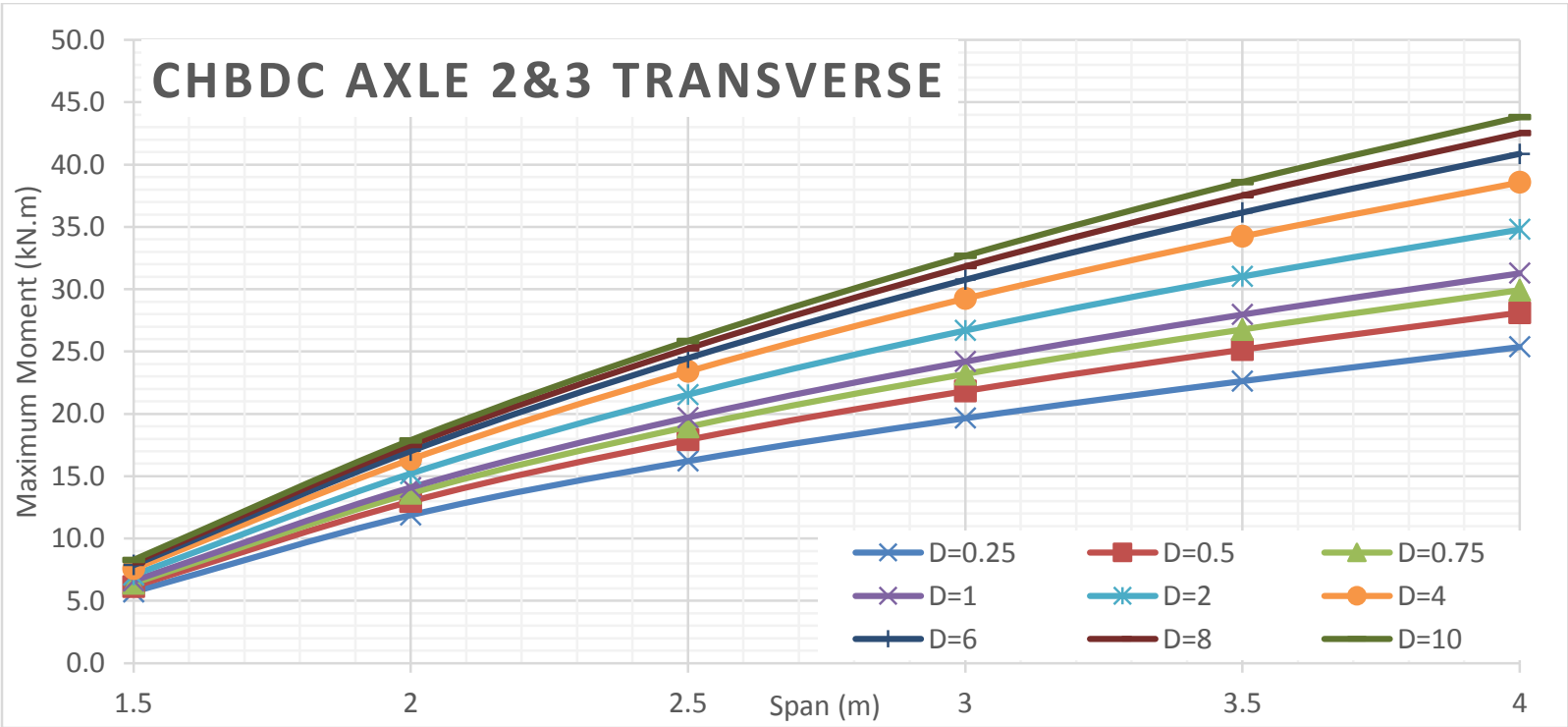

Figure 35 Maximum moment of deck slabs subjected to CHBDC axle $2 \& 3$ for different D values of alpha 6 FEA analyses 


\section{Alpha 8 Bending Moment VS Span Length for Different D Values}

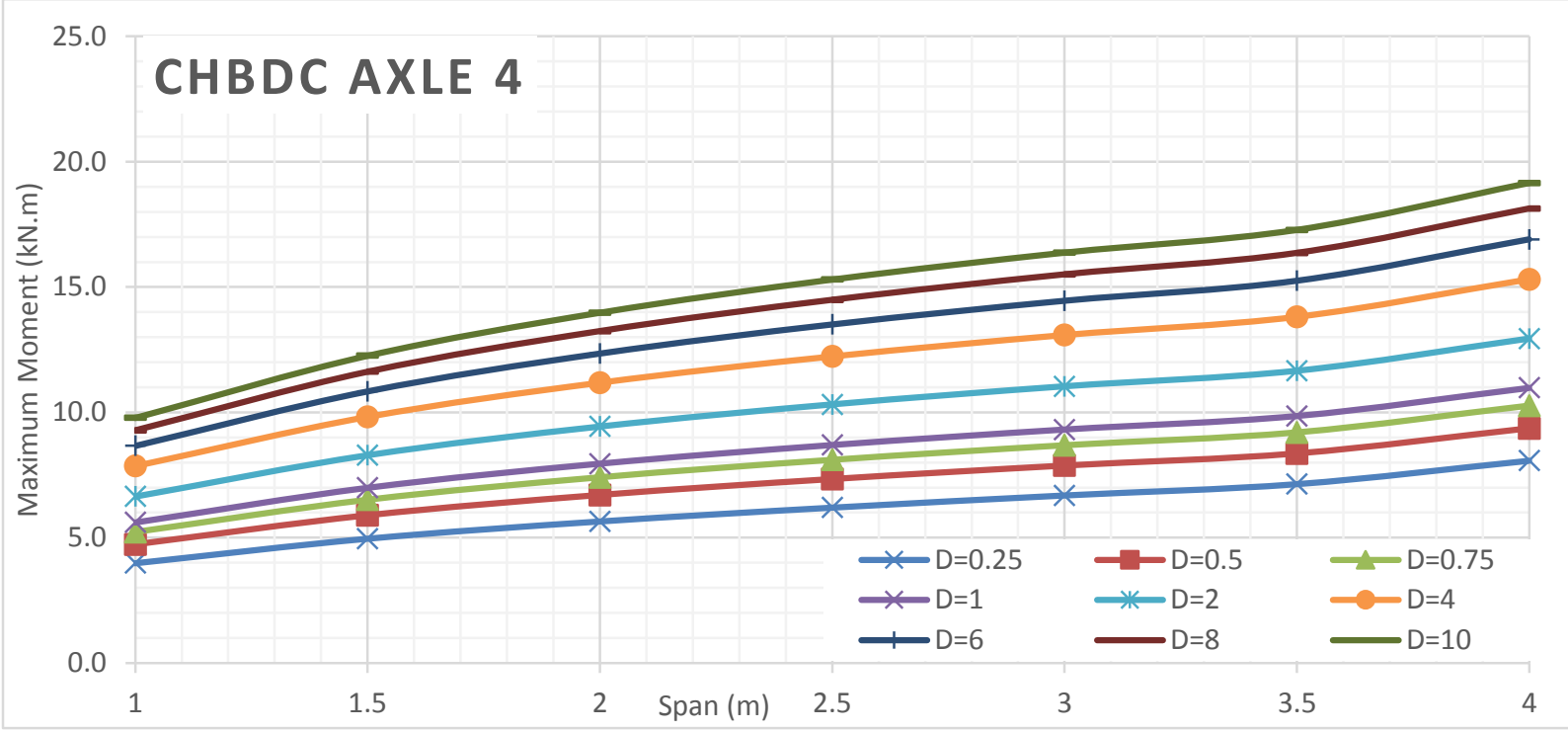

Figure 36 Maximum moment of deck slabs subjected to CHBDC axle 4 for different D values of alpha 8 FEA analyses

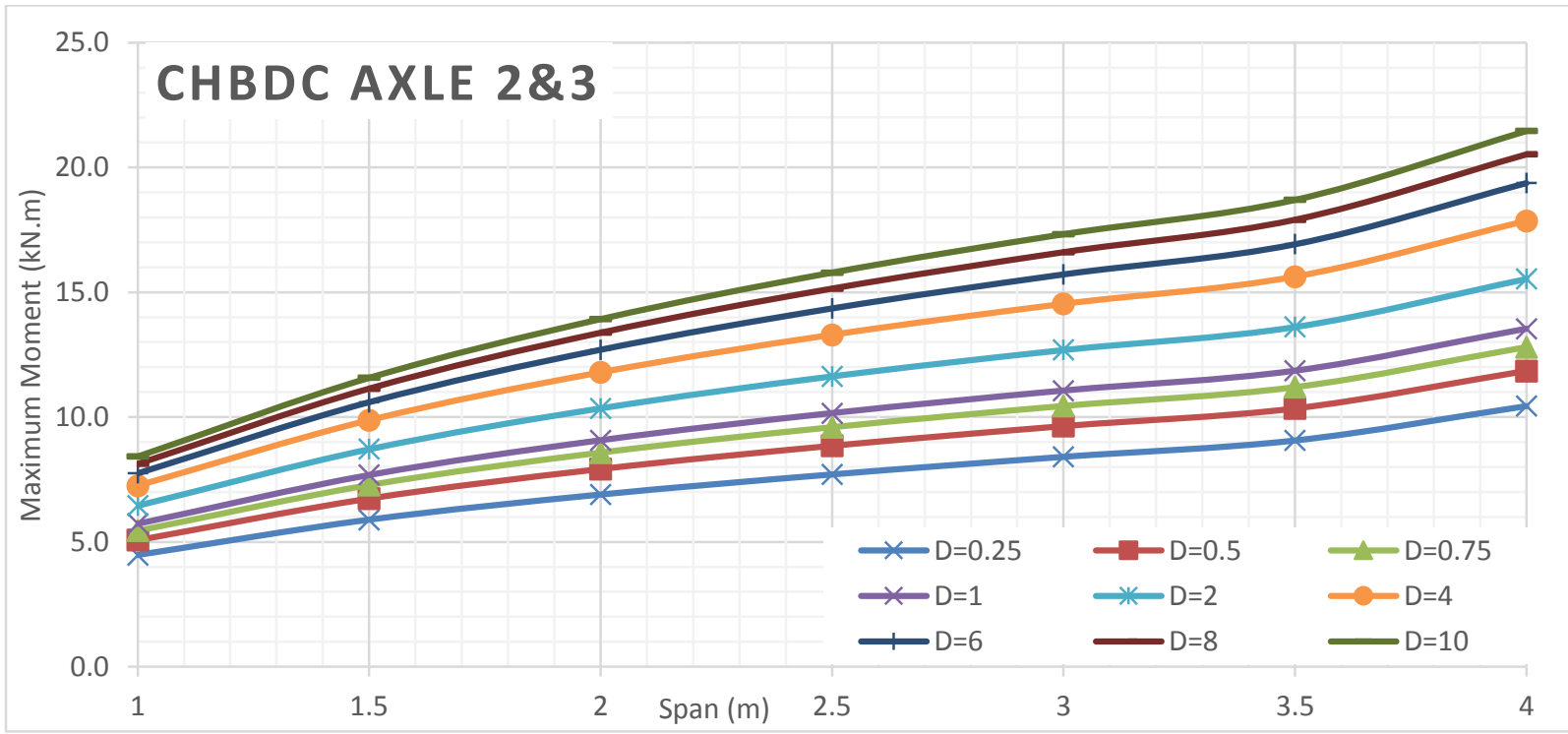

Figure 37 Maximum moment of deck slabs subjected to CHBDC axle $2 \& 3$ for different D values of alpha 8 FEA analyses 


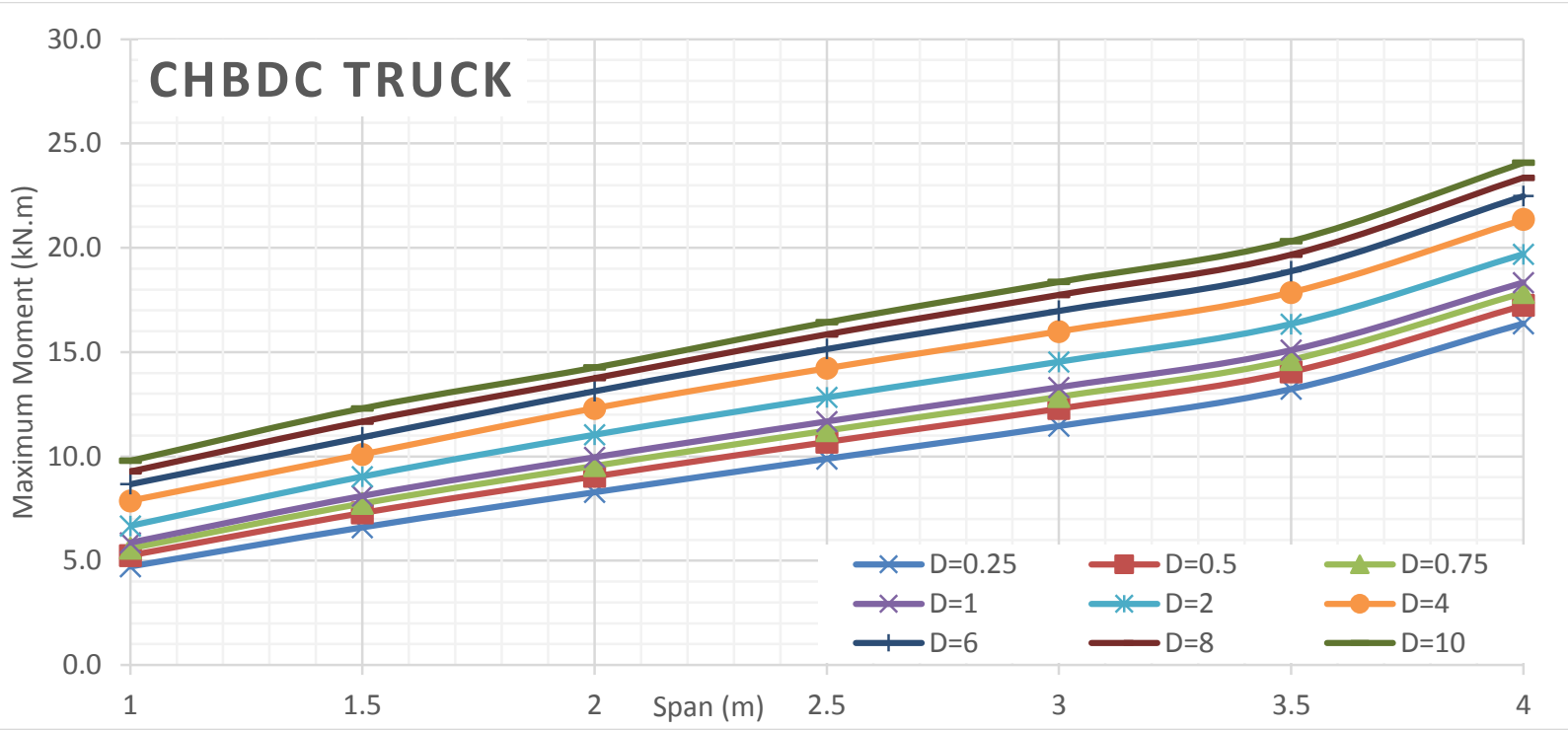

Figure 38 Maximum moment of deck slabs subjected to CHBDC truck for different D values of alpha 8 FEA analyses

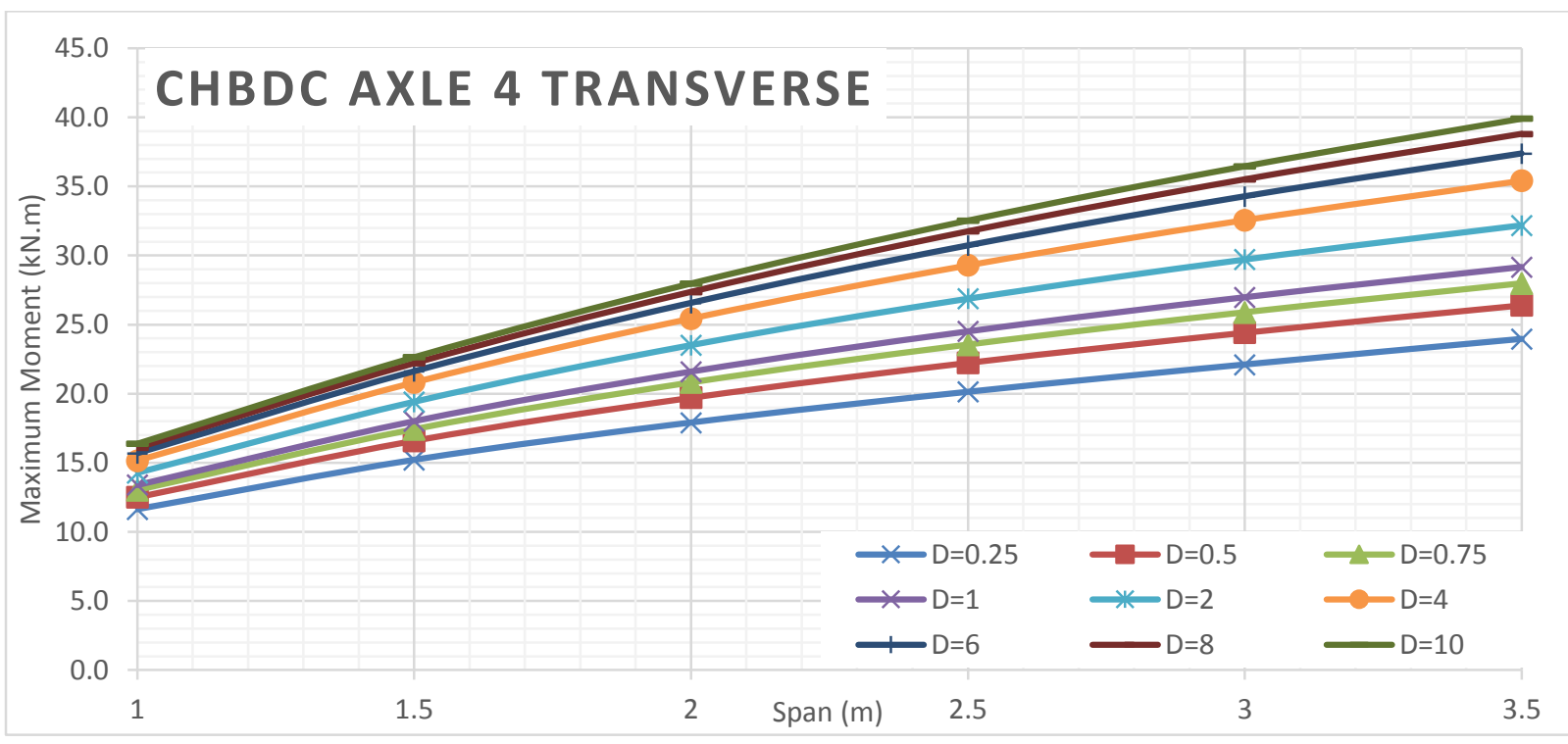

Figure 39 Maximum moment of deck slabs subjected to CHBDC axle 4 for different D values of alpha 8 FEA analyses

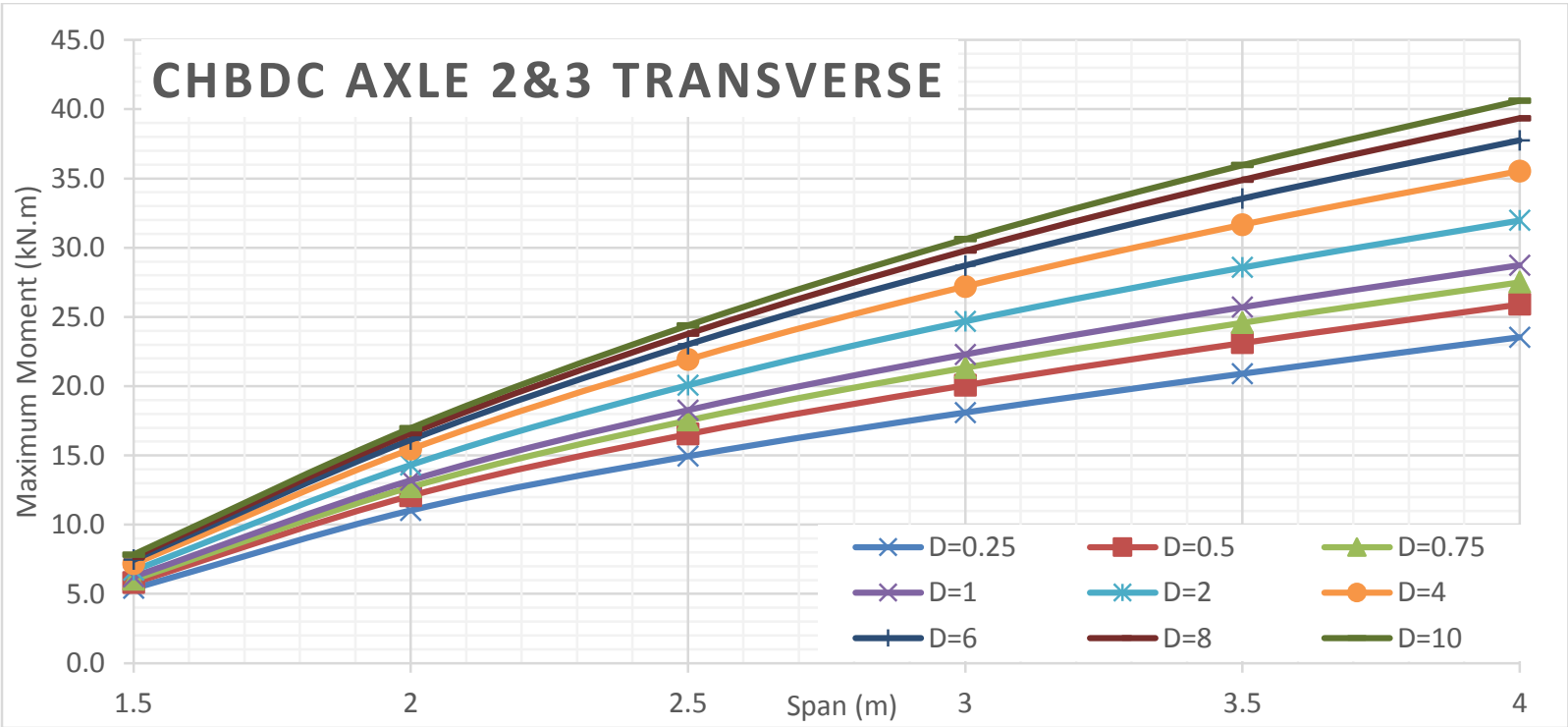

Figure 40 Maximum moment of deck slabs subjected to CHBDC axle $2 \& 3$ for different D values of alpha 8 FEA analyses 


\section{Alpha 10 Bending Moment VS Span Length for Different D Values}

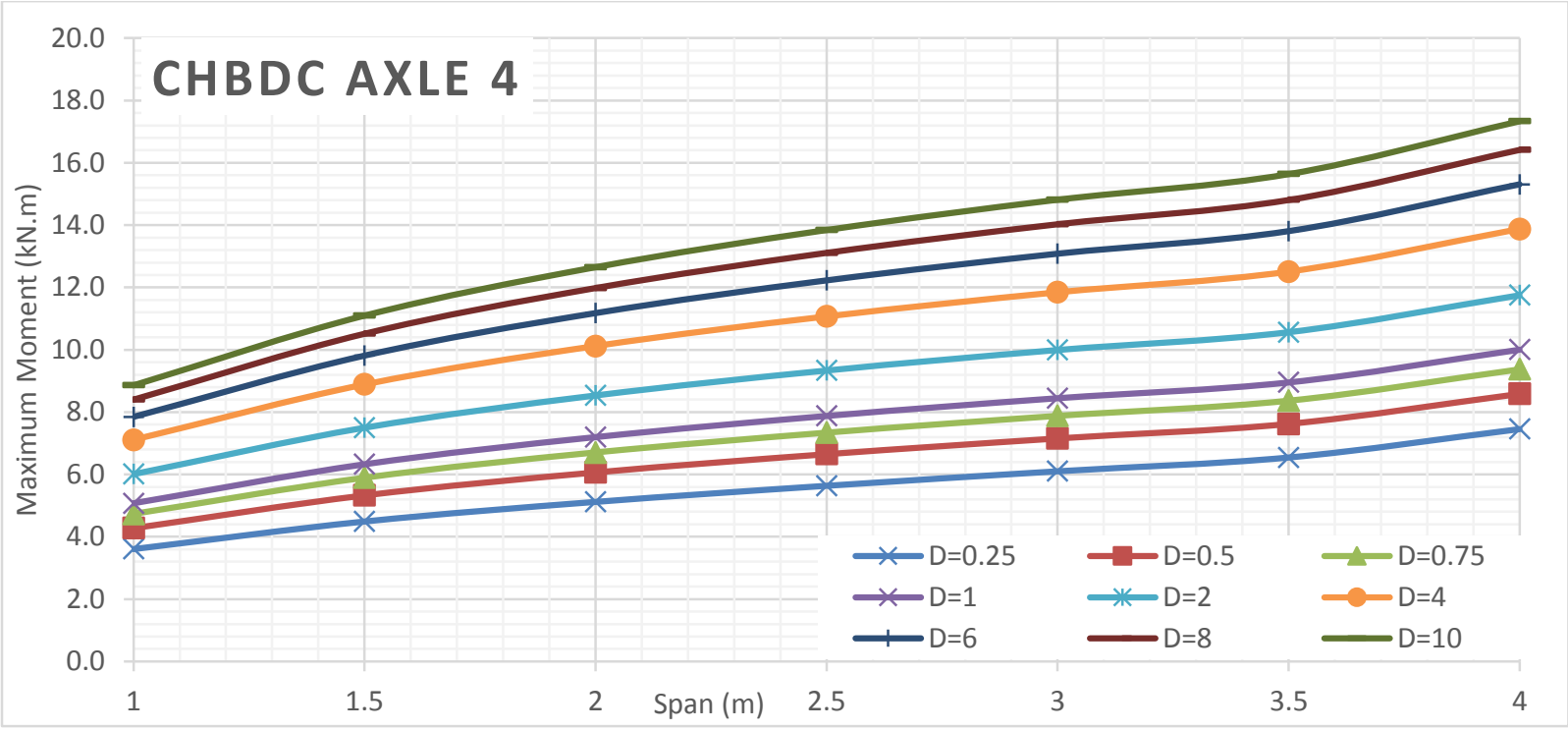

Figure 41 Maximum moment of deck slabs subjected to CHBDC axle 4 for different D values of alpha 10 FEA analyses

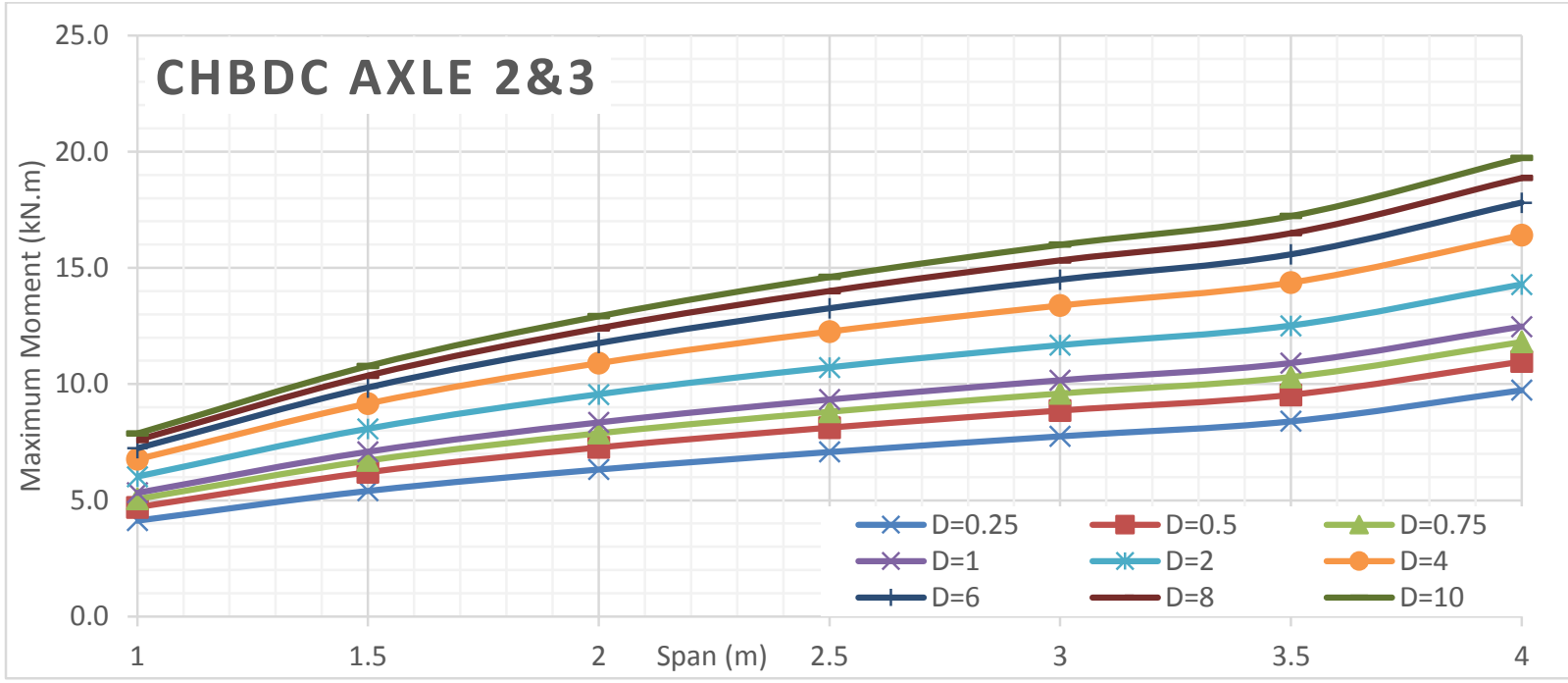

Figure 42 Maximum moment of deck slabs subjected to CHBDC axle $2 \& 3$ for different D values of alpha 10 FEA analyses 


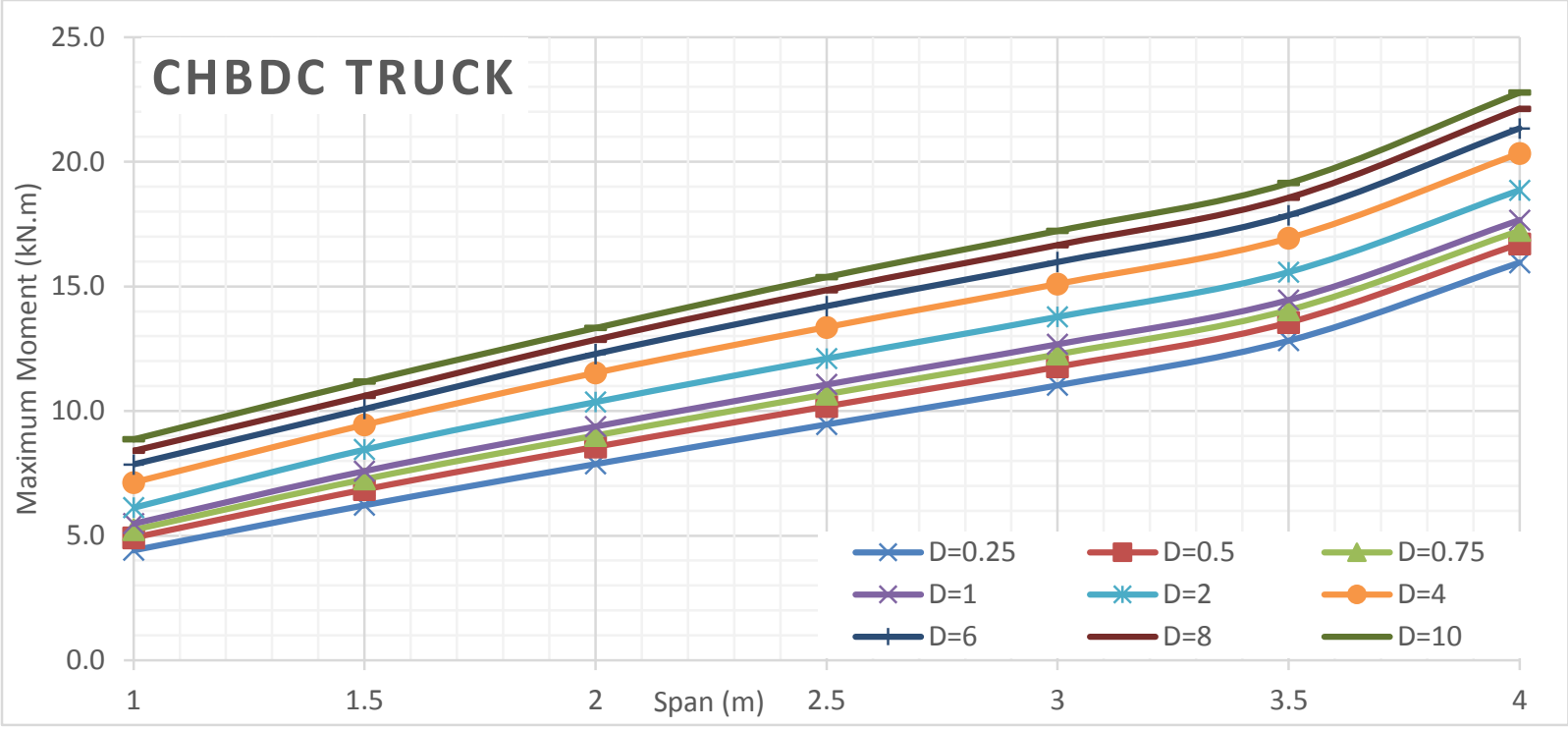

Figure 43 Maximum moment of deck slabs subjected to CHBDC truck for different D values of alpha 10 FEA analyses

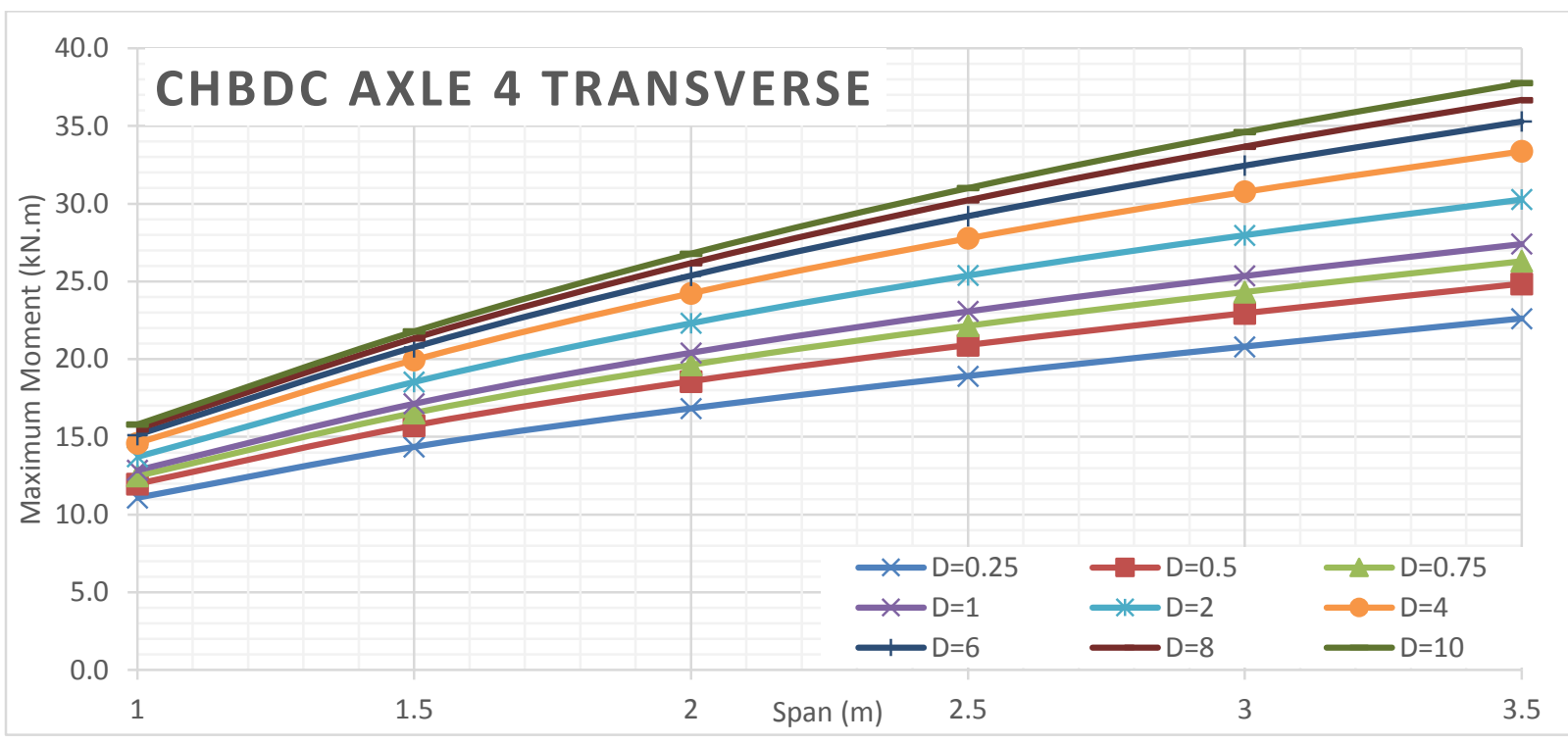

Figure 44 Maximum moment of deck slabs subjected to CHBDC axle 4 for different D values of alpha 10 FEA analyses

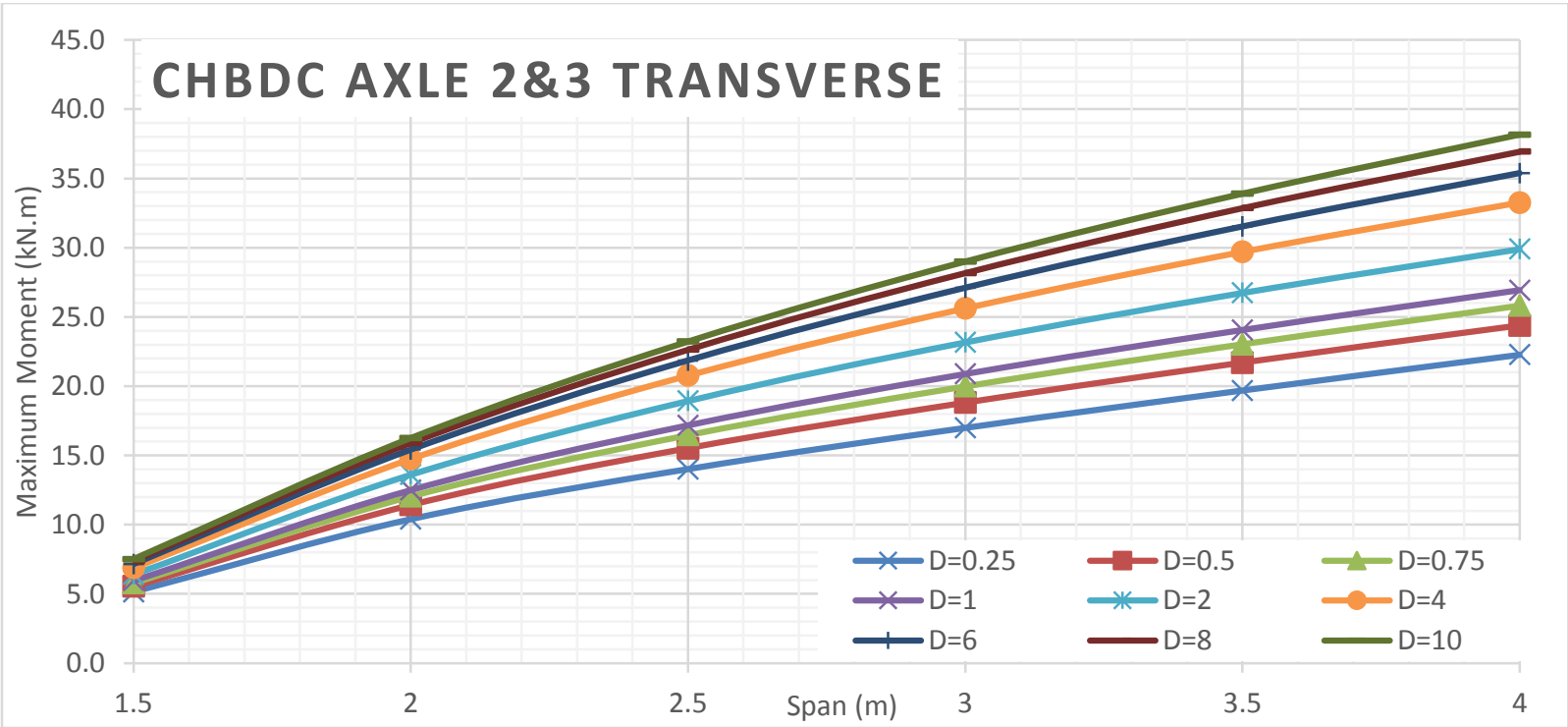

Figure 45 Maximum moment of deck slabs subjected to CHBDC axle $2 \& 3$ for different D values of alpha 10 FEA analyses 
B.1.3 MAXIMUM BENDING MOMENT VS FLEXURAL RIGIDITY 


\section{Alpha 0.25 Bending Moment VS Flexural Rigidity for Different Span Length}

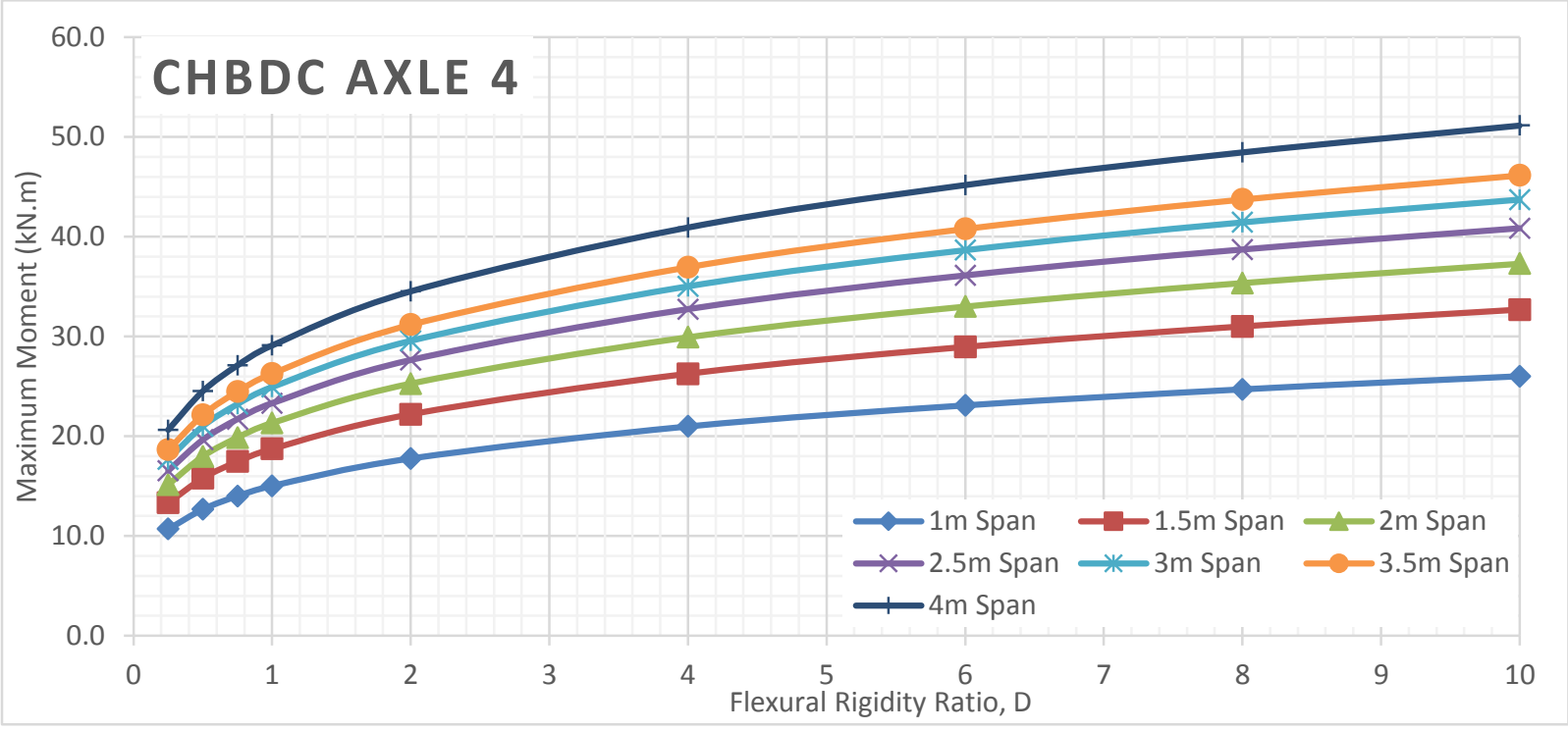

Figure 46 Maximum moment of deck slabs subjected to CHBDC axle 4 for different span values of alpha 0.25 FEA analyses

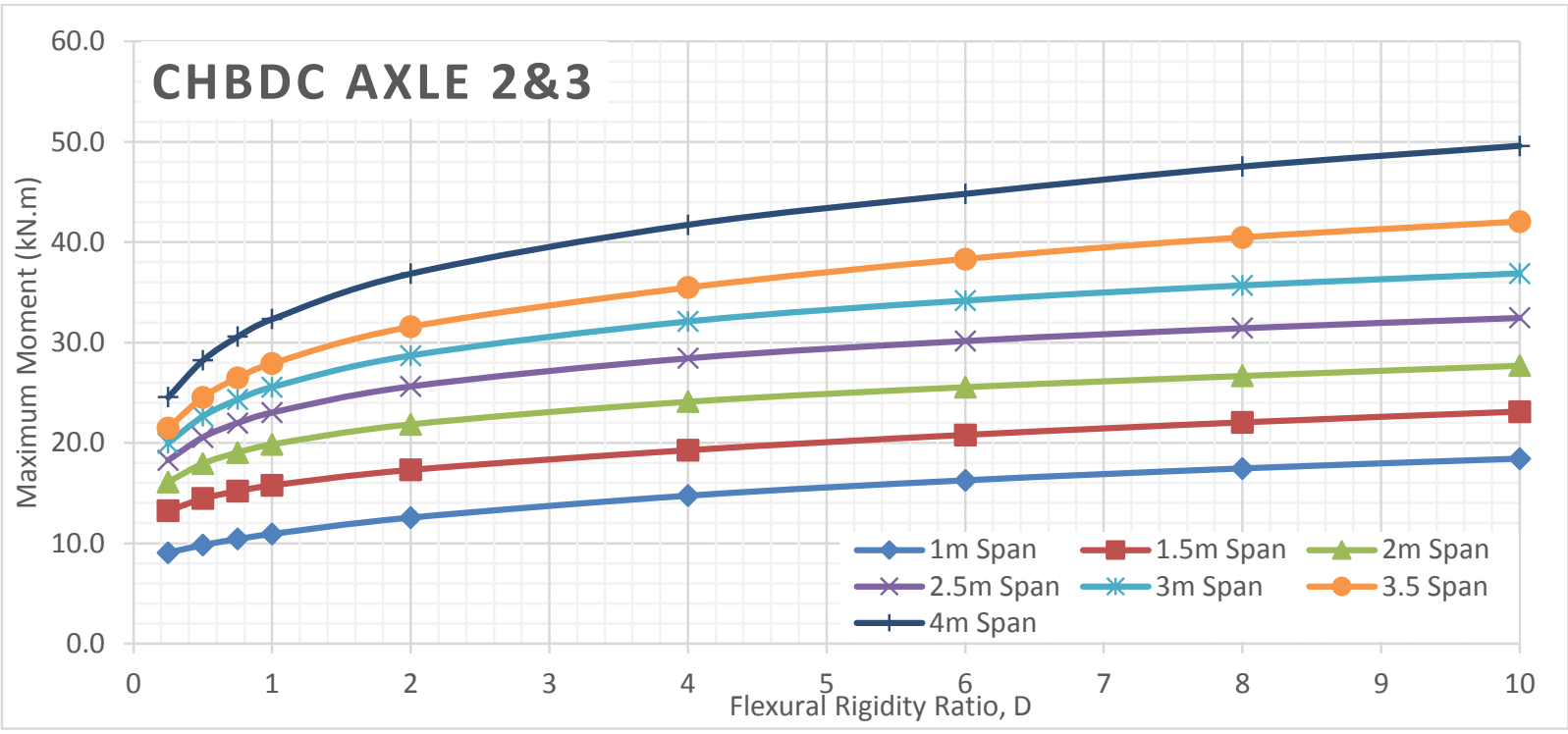

Figure 47 Maximum moment of deck slabs subjected to CHBDC axle $2 \& 3$ for different span values of alpha 0.25 FEA analyses 


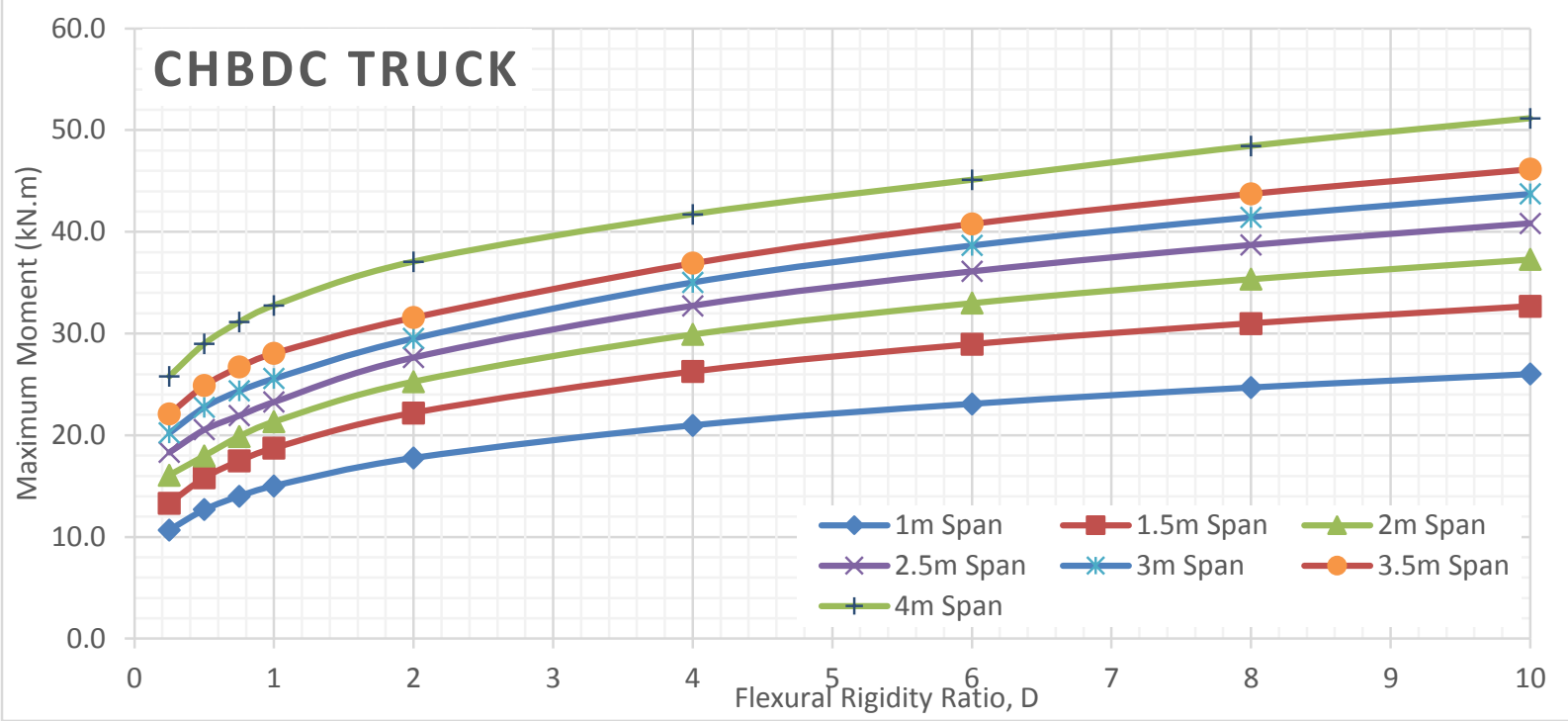

Figure 48 Maximum moment of deck slabs subjected to CHBDC truck for different span values of alpha 0.25 FEA analyses

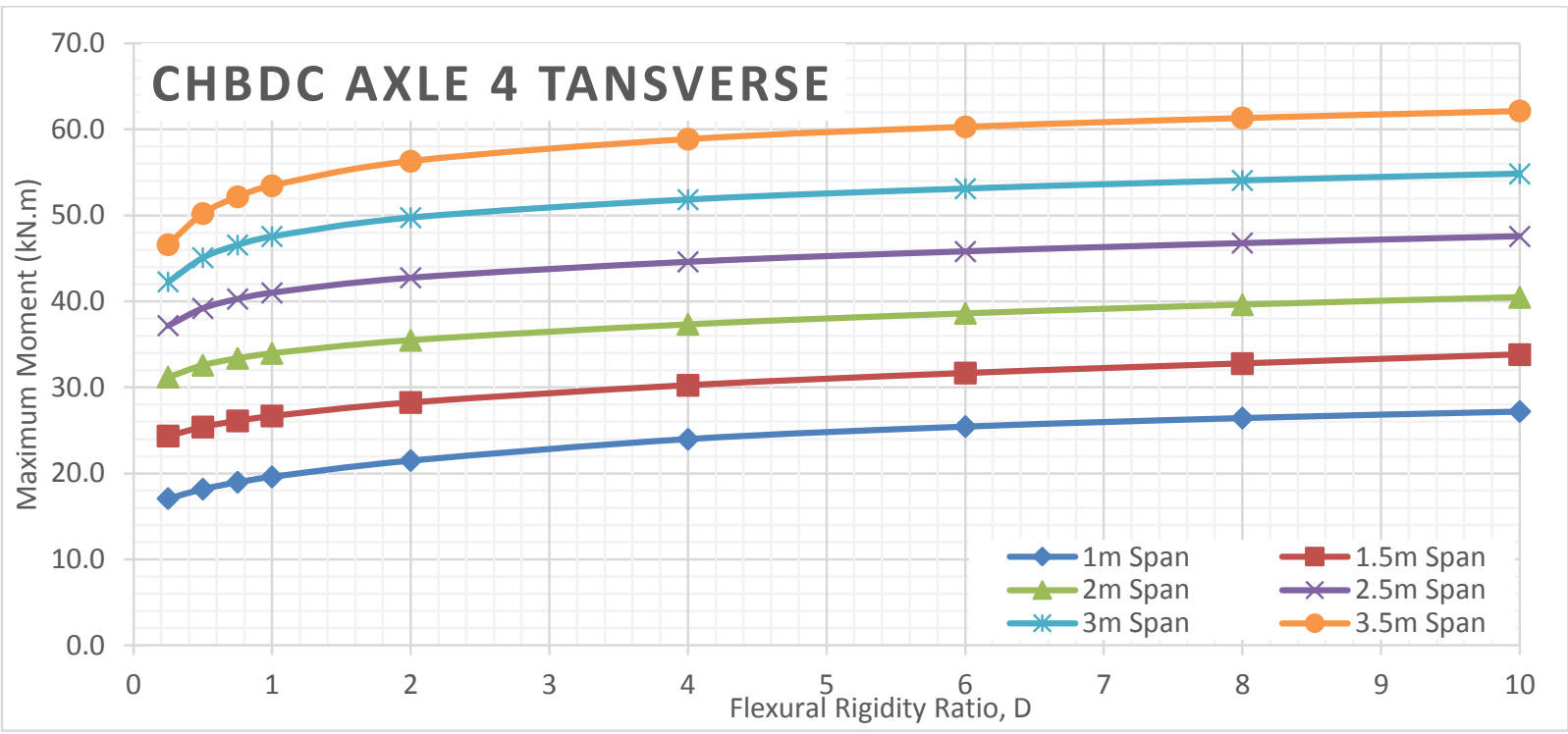

Figure 49 Maximum moment of deck slabs subjected to CHBDC axle 4 for different span values of alpha 0.25 FEA analyses

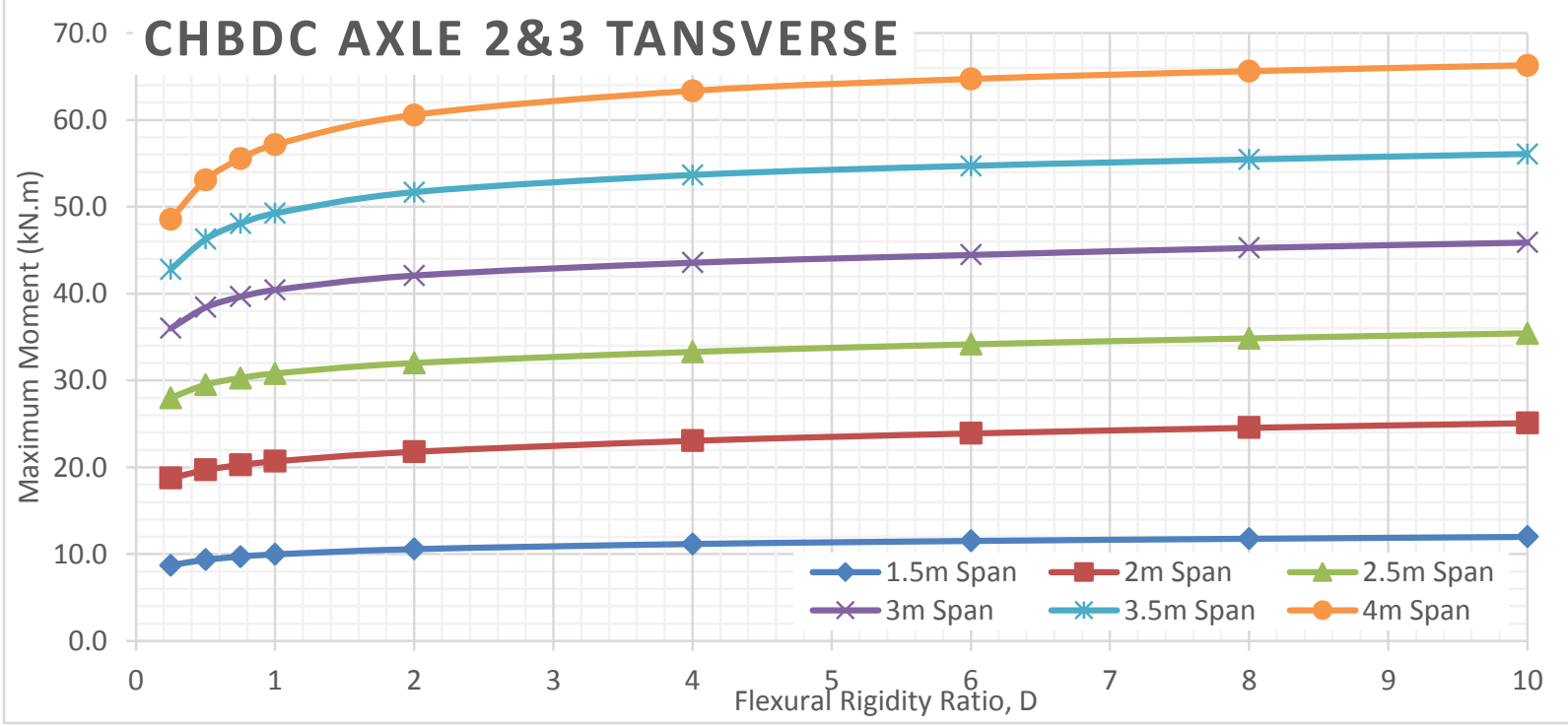

Figure 50 Maximum moment of deck slabs subjected to CHBDC axle $2 \& 3$ for different span values of alpha 0.25 FEA analyses 


\section{Alpha 0.5 Bending Moment VS Flexural Rigidity for Different Span Length}

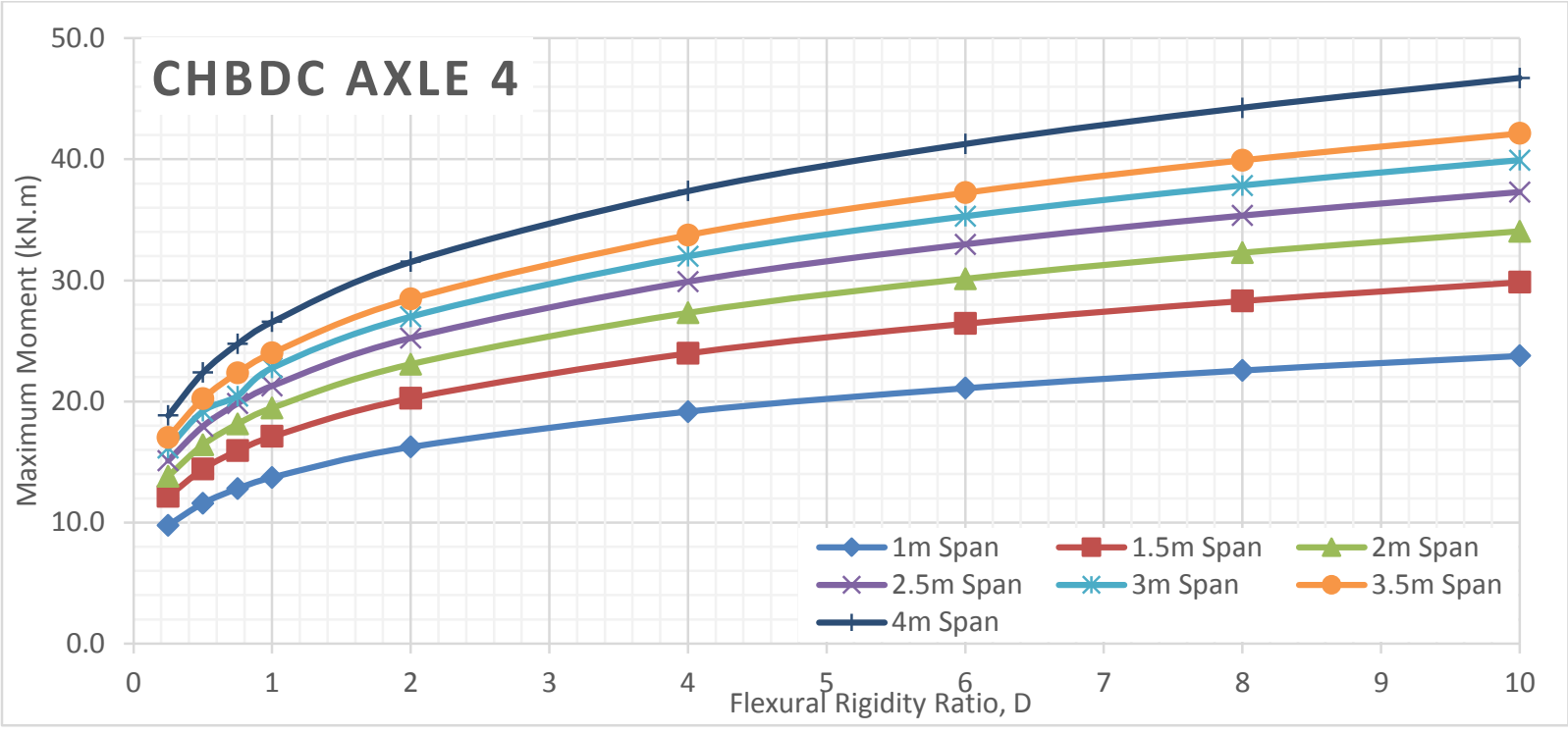

Figure 51 Maximum moment of deck slabs subjected to CHBDC axle 4 for different span values of alpha 0.5 FEA analyses

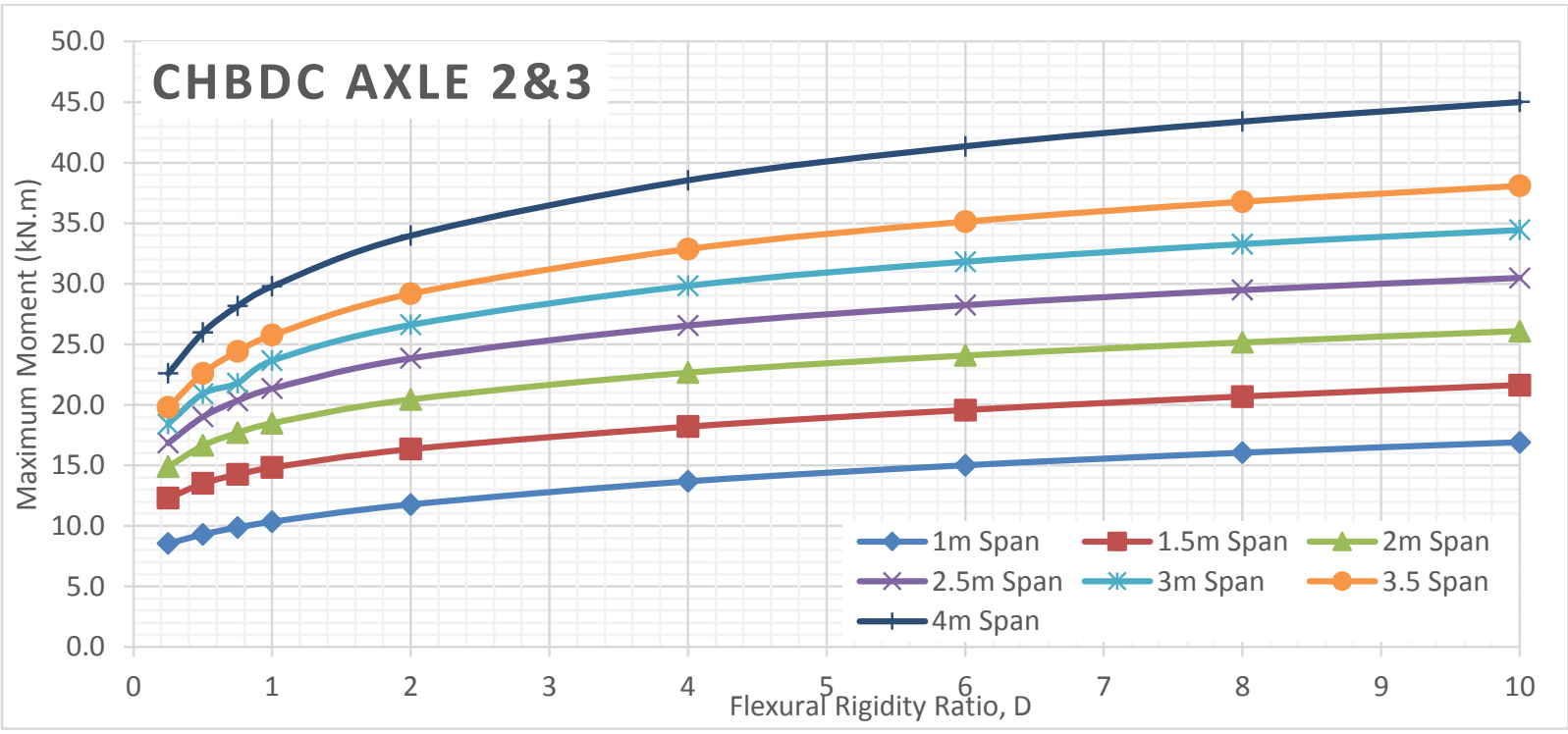

Figure 52 Maximum moment of deck slabs subjected to CHBDC axle $2 \& 3$ for different span values of alpha 0.5 FEA analyses 


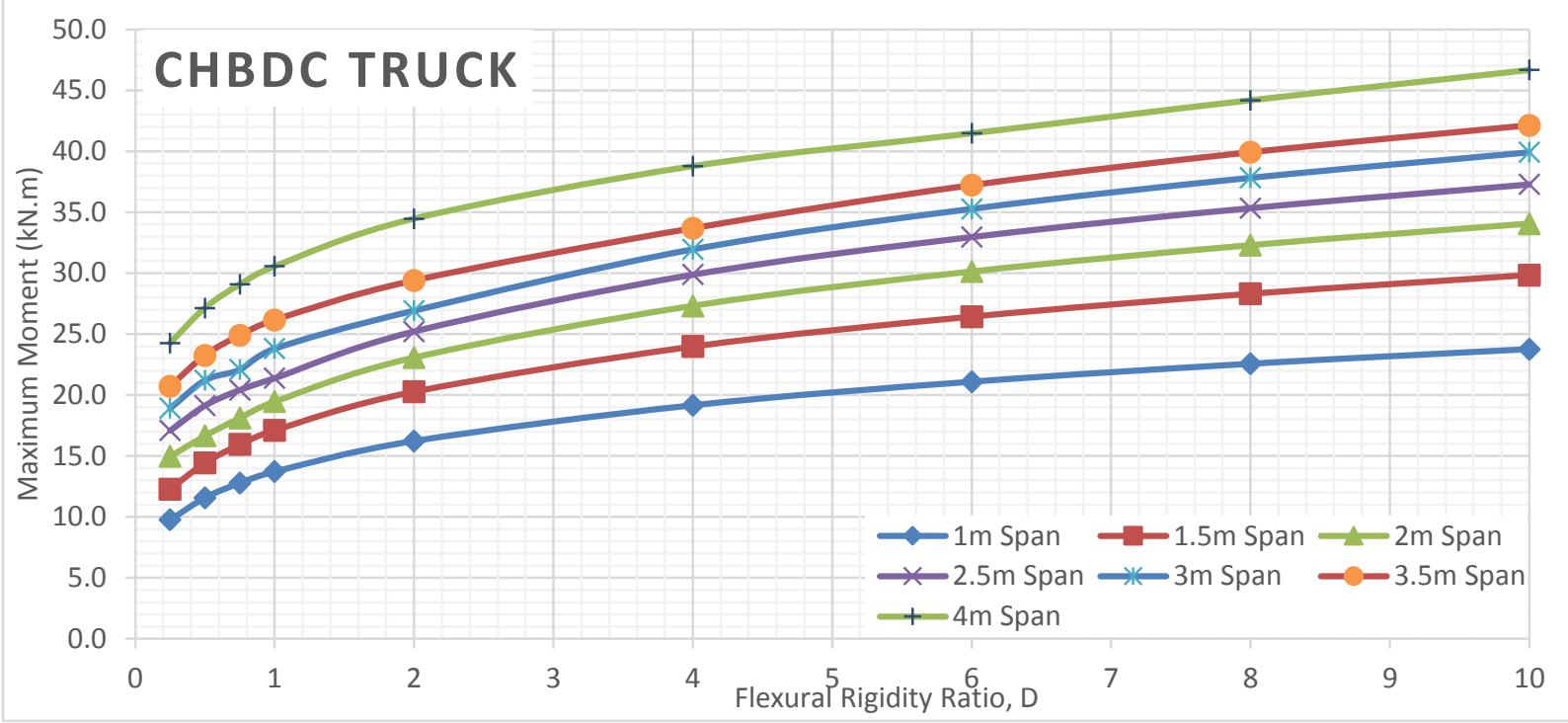

Figure 53 Maximum moment of deck slabs subjected to CHBDC truck for different span values of alpha 0.5 FEA analyses

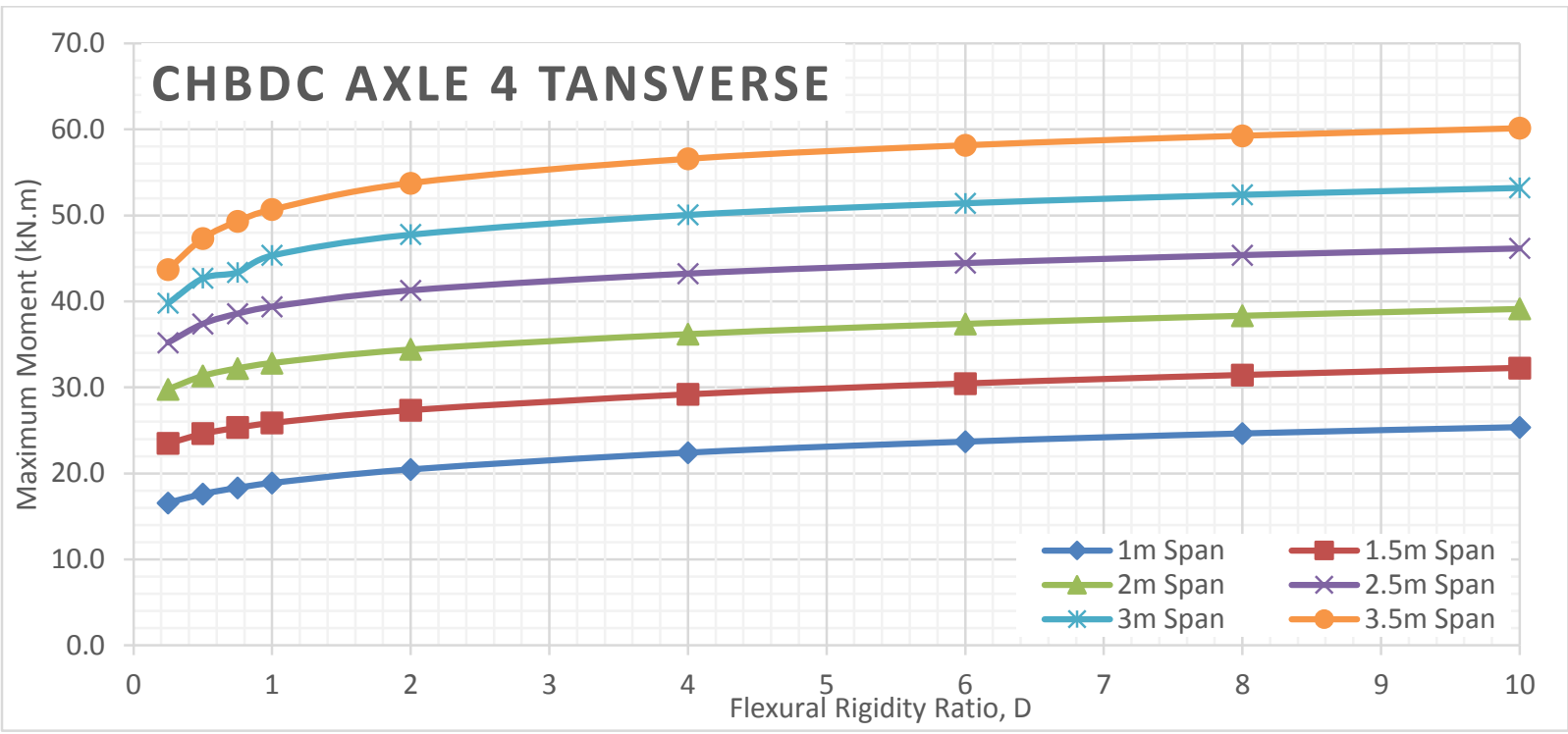

Figure 54 Maximum moment of deck slabs subjected to CHBDC axle 4 for different span values of alpha 0.5 FEA analyses

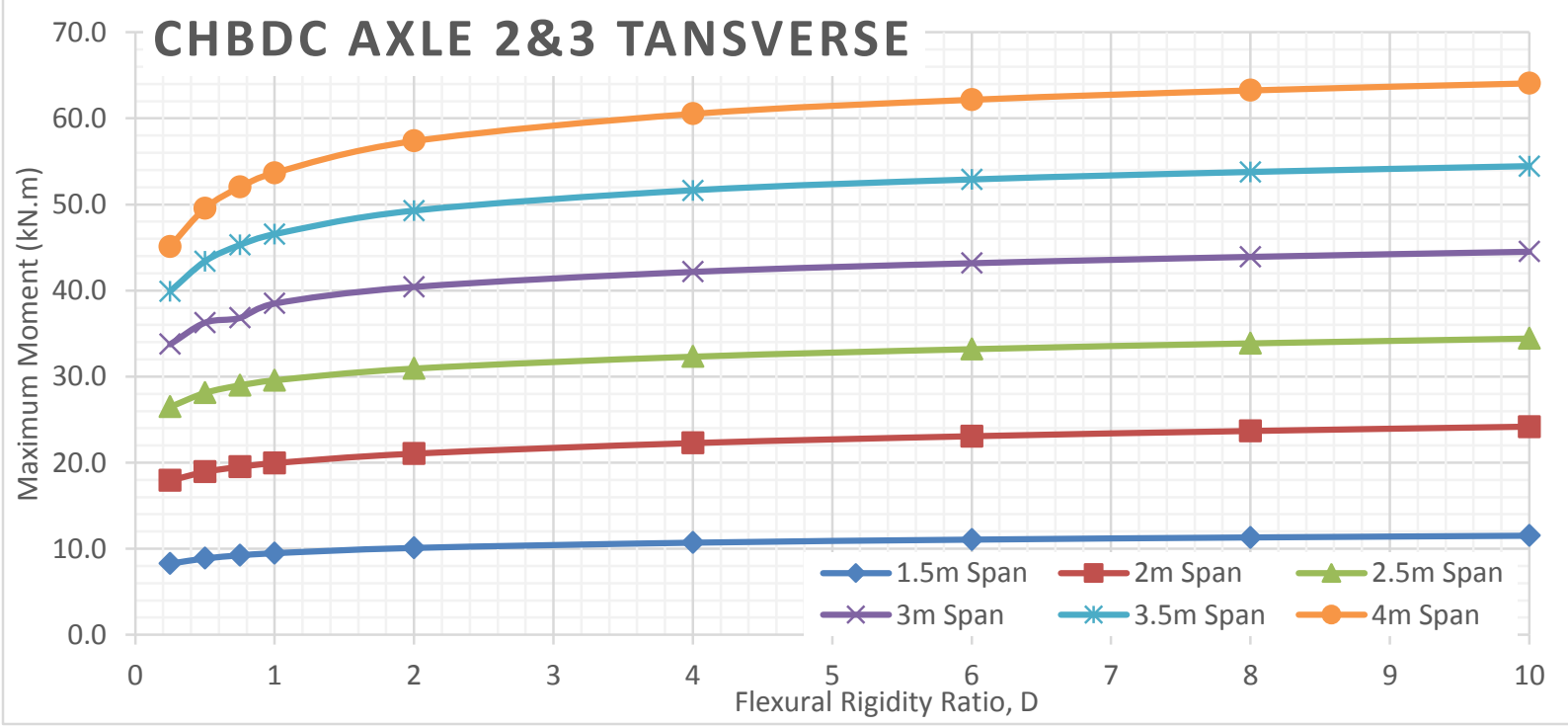

Figure 55 Maximum moment of deck slabs subjected to CHBDC axle $2 \& 3$ for different span values of alpha 0.5 FEA analyses 


\section{Alpha 0.75 Bending Moment VS Flexural Rigidity for Different Span Length}

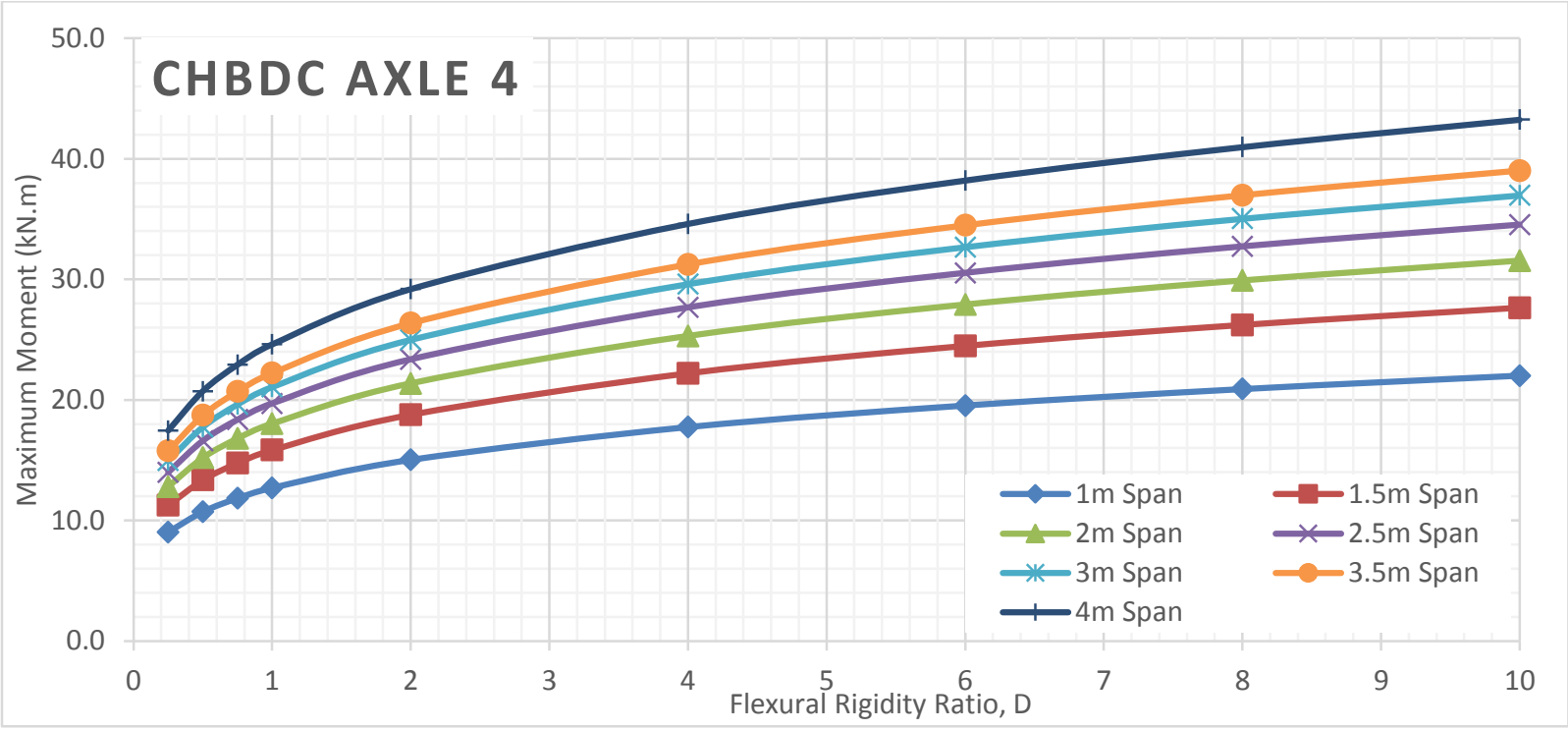

Figure 56 Maximum moment of deck slabs subjected to CHBDC axle 4 for different span values of alpha 0.75 FEA analyses

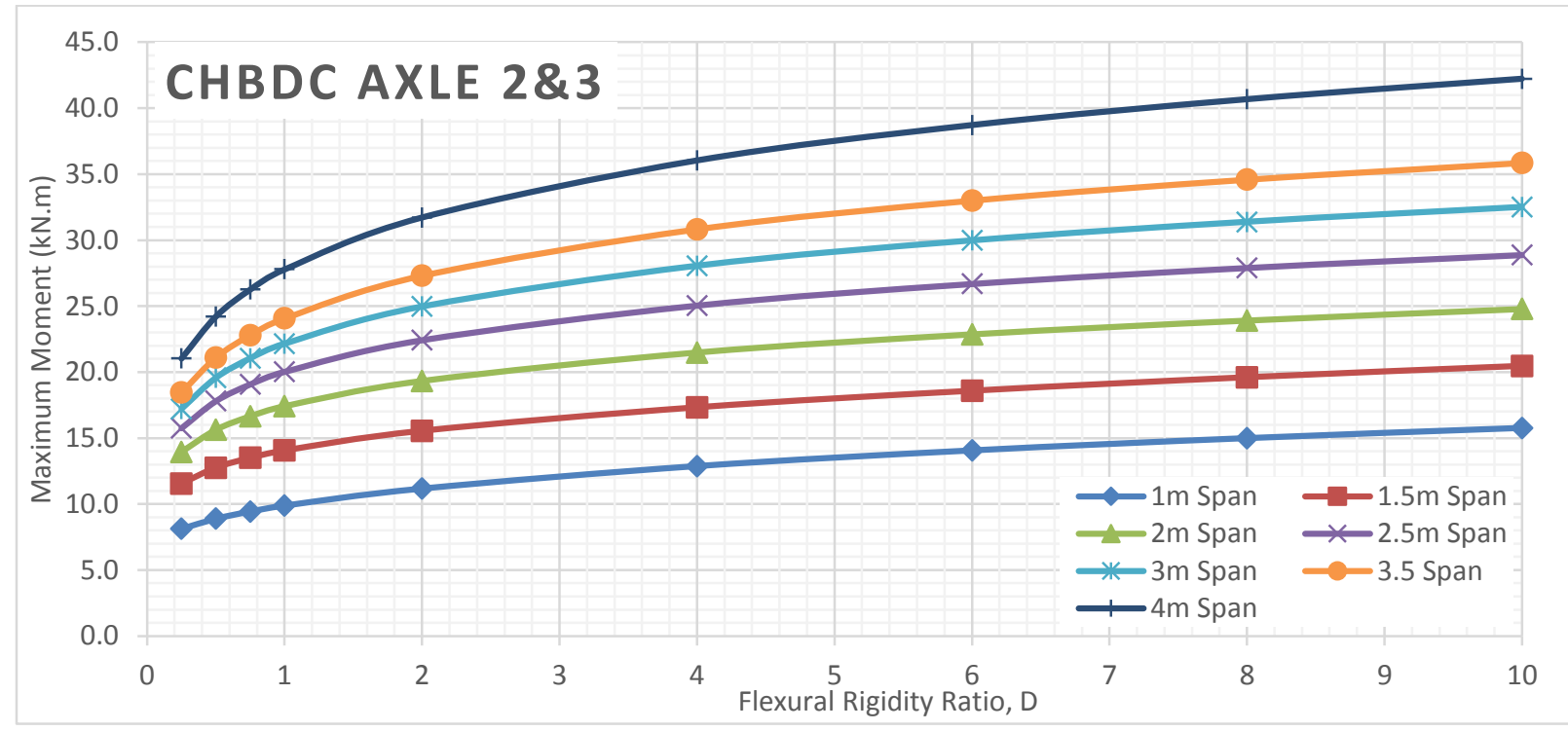

Figure 57 Maximum moment of deck slabs subjected to CHBDC axle $2 \& 3$ for different span values of alpha 0.75 FEA analyses 


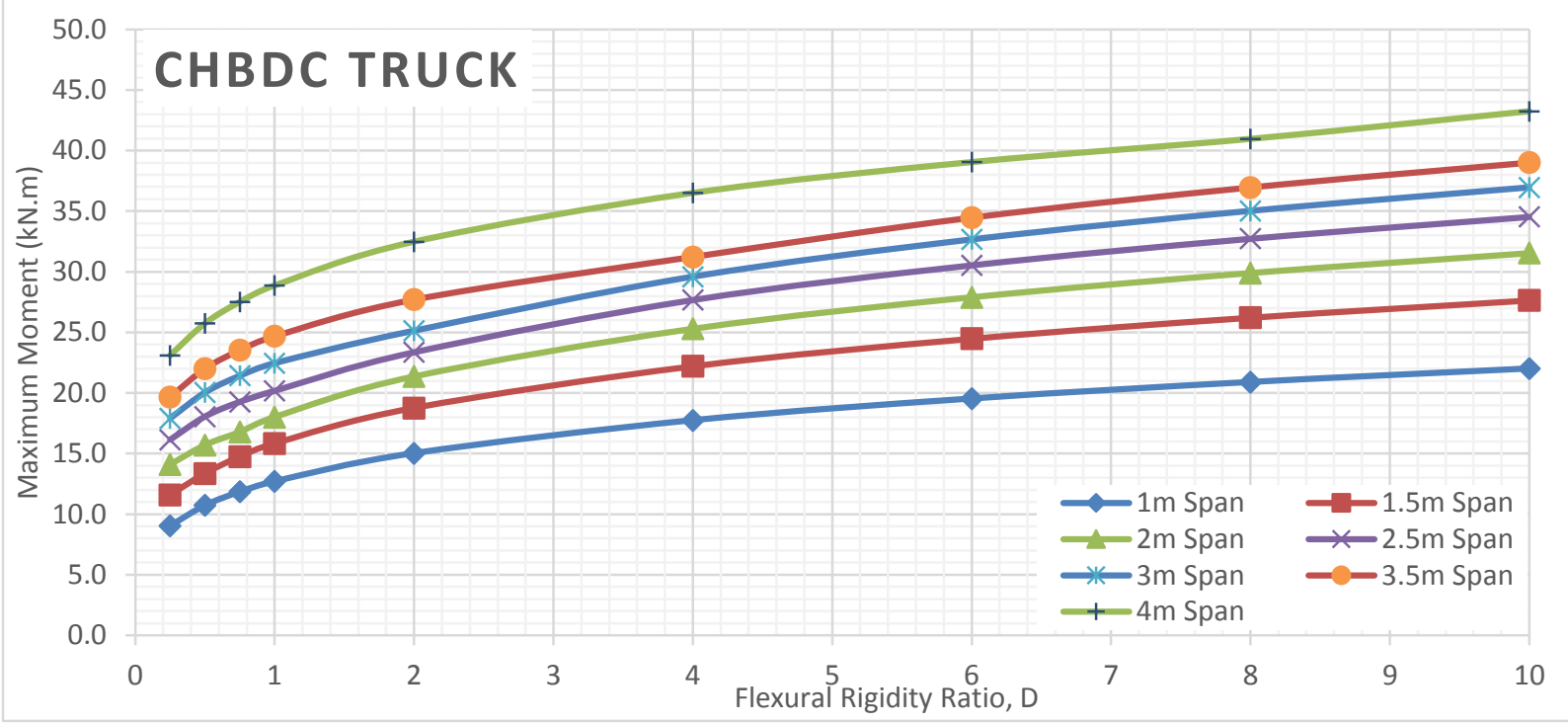

Figure 58 Maximum moment of deck slabs subjected to CHBDC truck for different span values of alpha 0.75 FEA analyses

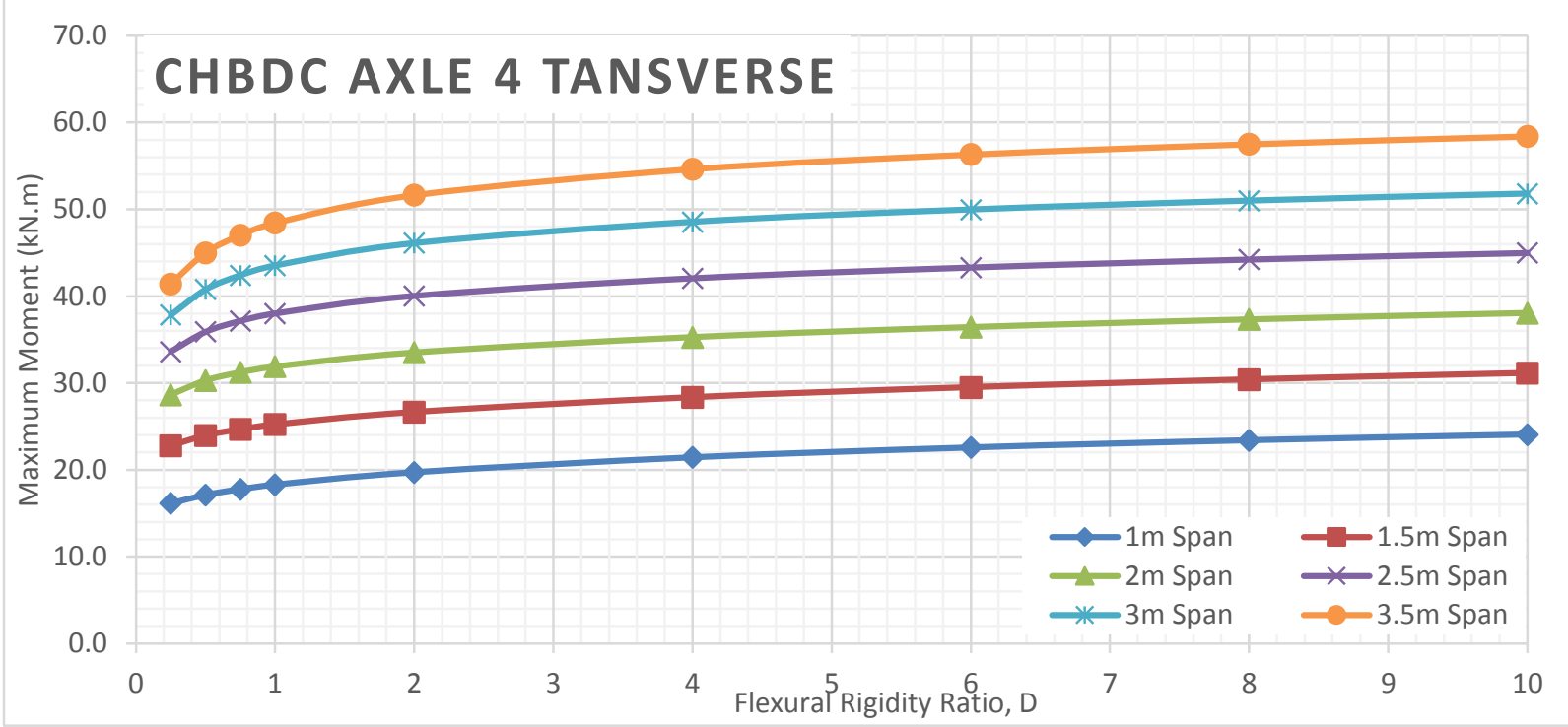

Figure 59 Maximum moment of deck slabs subjected to CHBDC axle 4 for different span values of alpha 0.75 FEA analyses

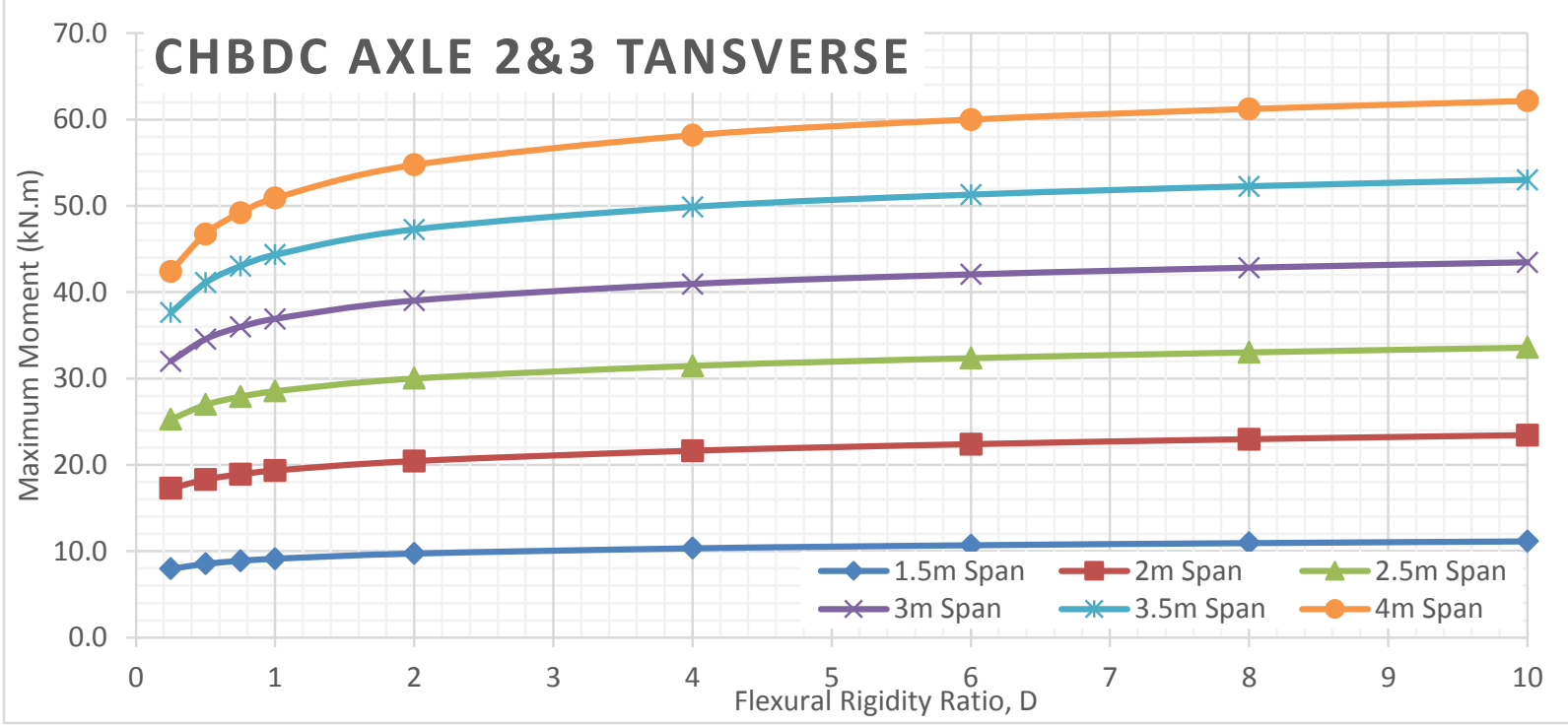

Figure 60 Maximum moment of deck slabs subjected to CHBDC axle $2 \& 3$ for different span values of alpha 0.75 FEA analyses 


\section{Alpha 1 Bending Moment VS Flexural Rigidity for Different Span Length}

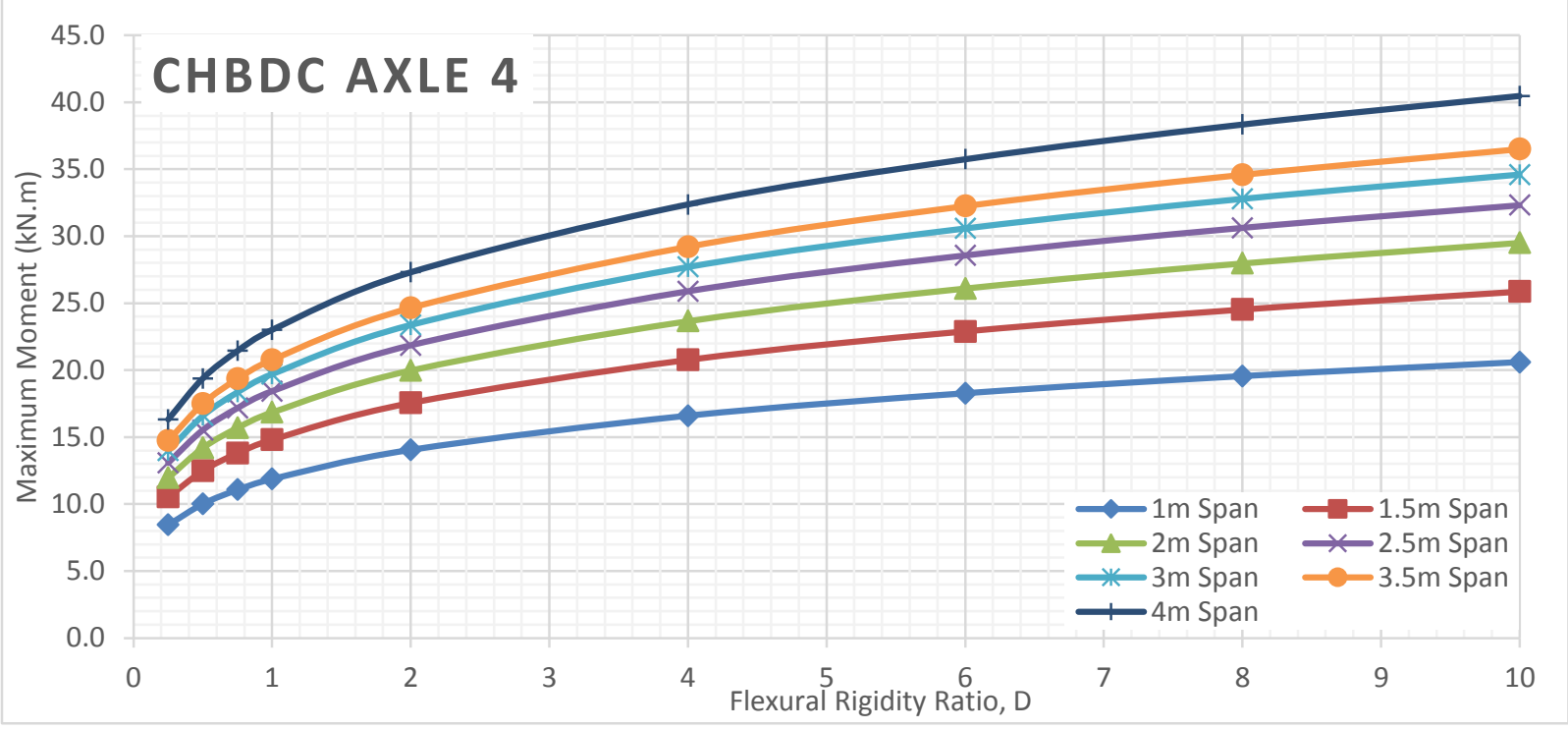

Figure 61 Maximum moment of deck slabs subjected to CHBDC axle 4 for different span values of alpha 1 FEA analyses

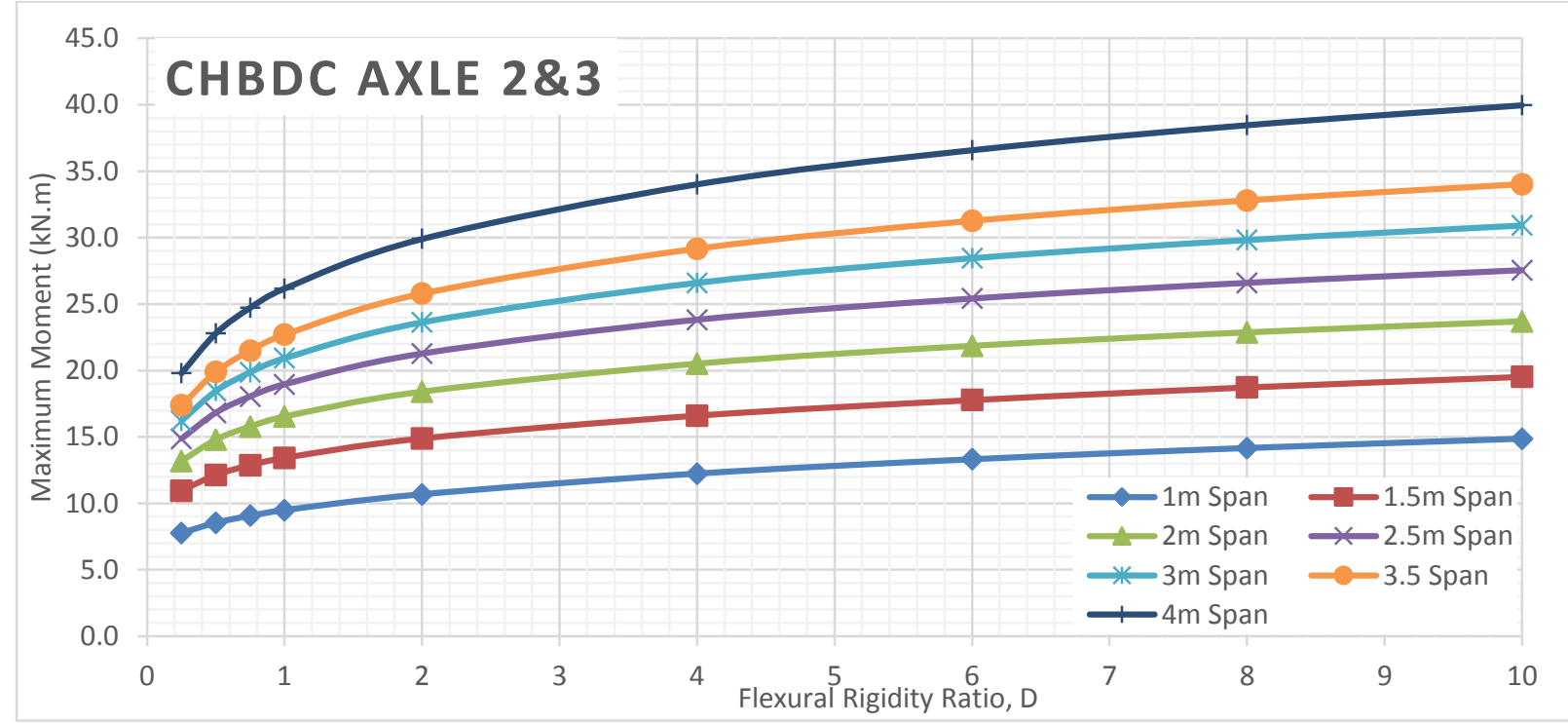

Figure 62 Maximum moment of deck slabs subjected to CHBDC axle $2 \& 3$ for different span values of alpha 1 FEA analyses 


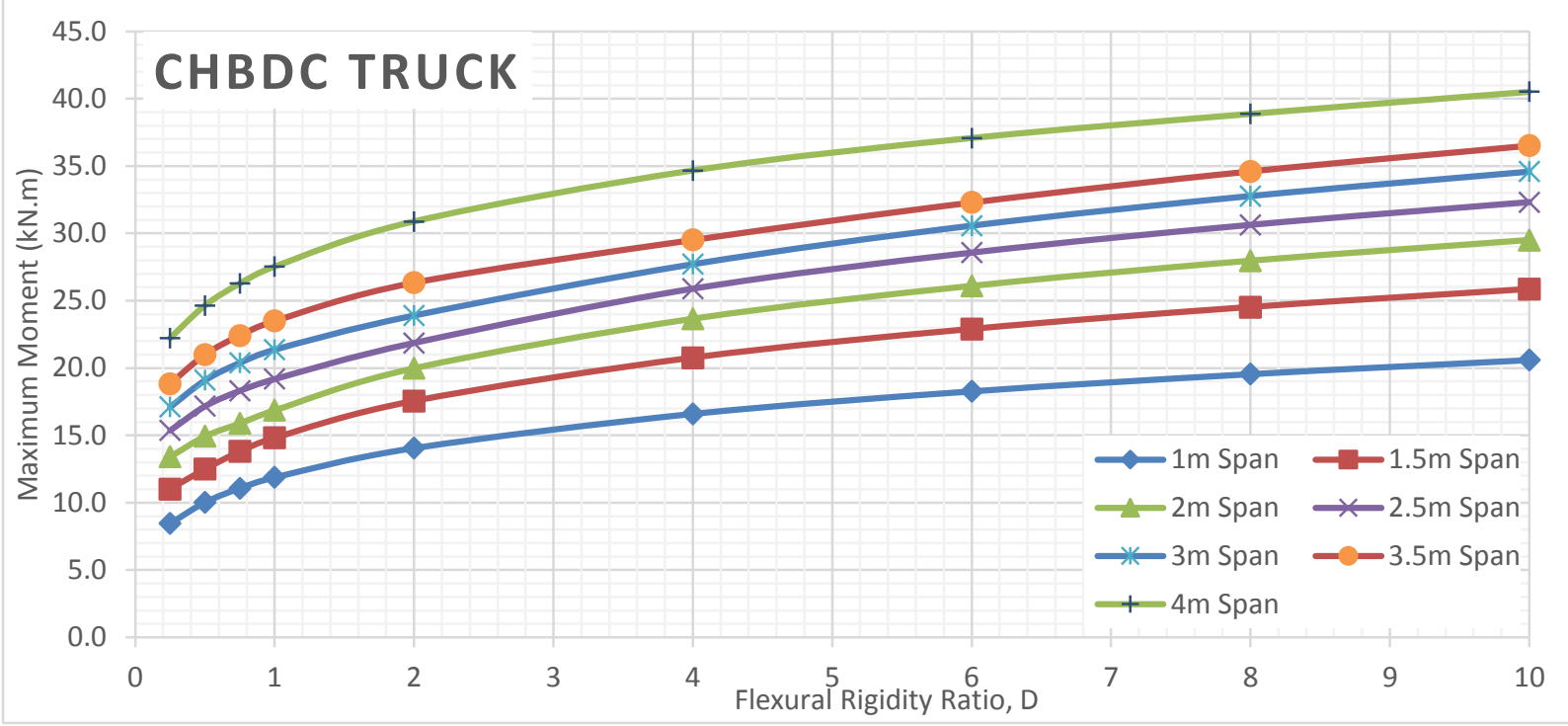

Figure 63 Maximum moment of deck slabs subjected to CHBDC truck for different span values of alpha 1 FEA analyses

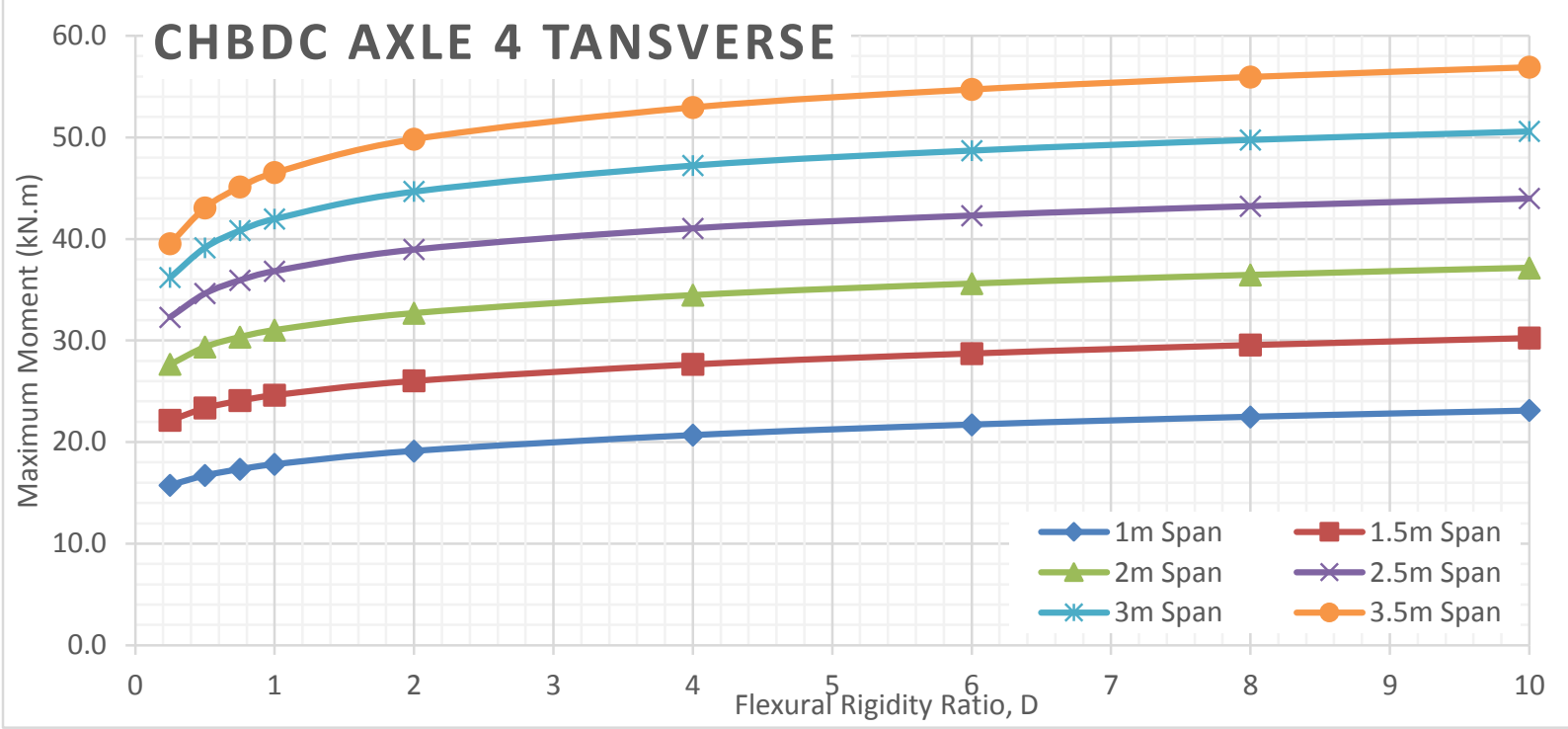

Figure 64 Maximum moment of deck slabs subjected to CHBDC axle 4 for different span values of alpha 1 FEA analyses

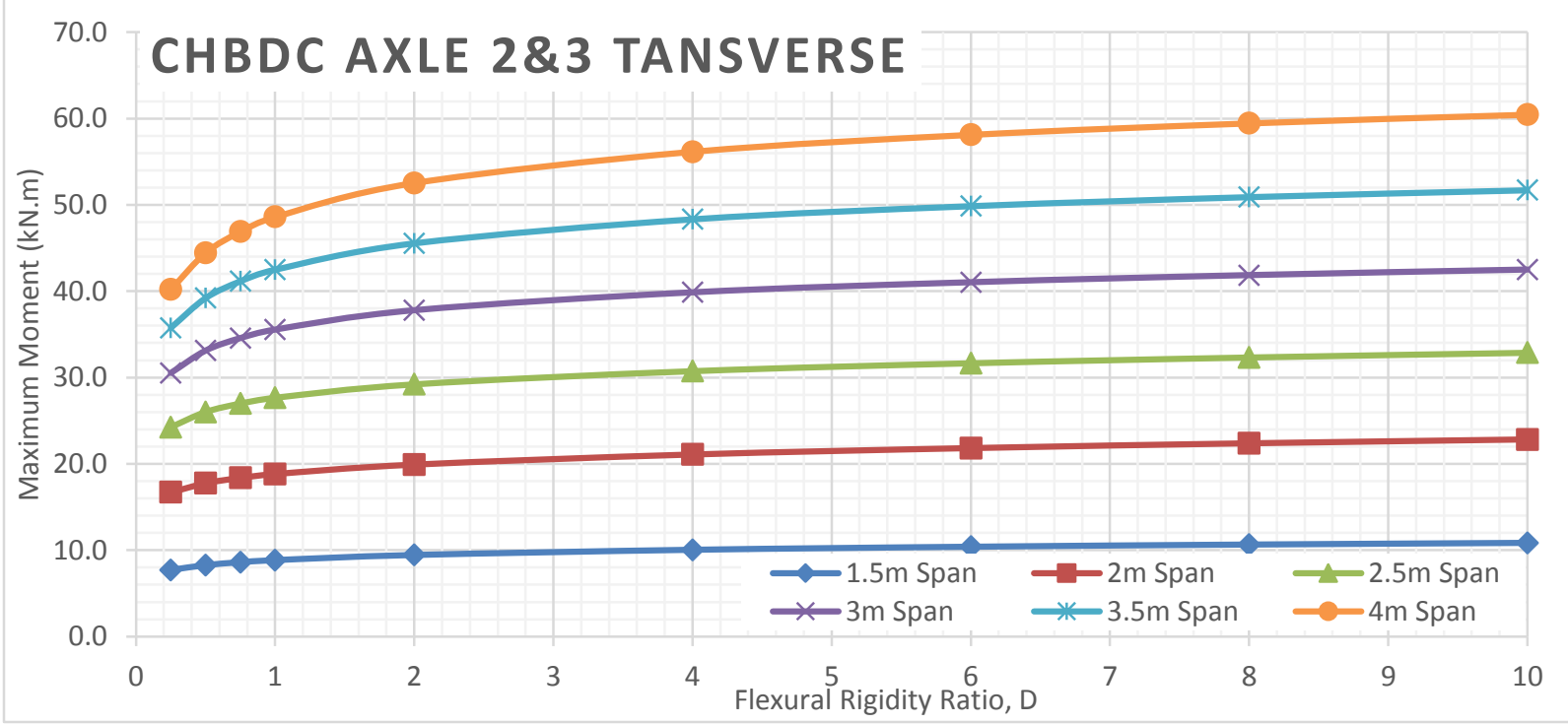

Figure 65 Maximum moment of deck slabs subjected to CHBDC axle $2 \& 3$ for different span values of alpha 1 FEA analyses 


\section{Alpha 2 Bending Moment VS Flexural Rigidity for Different Span Length}

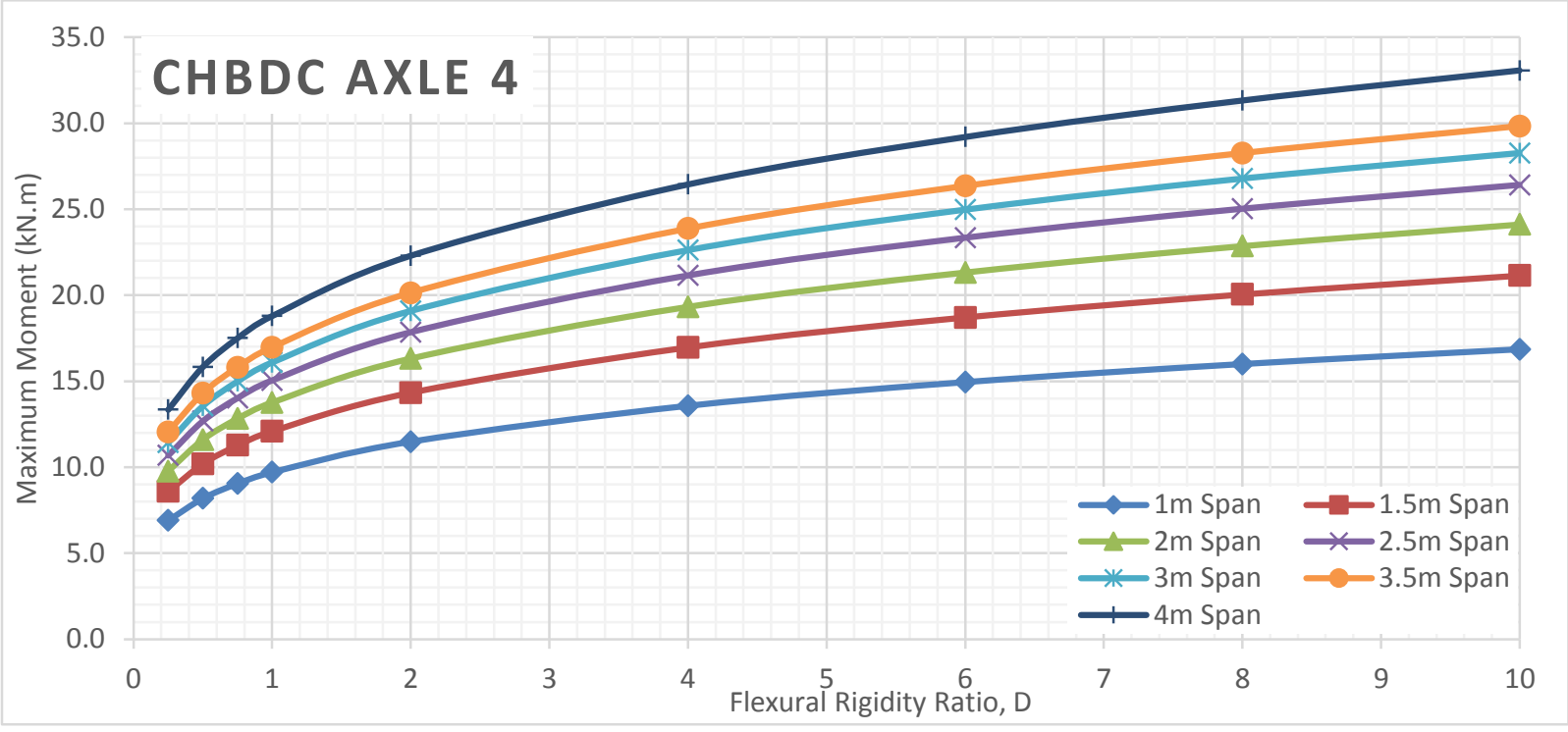

Figure 66 Maximum moment of deck slabs subjected to CHBDC axle 4 for different span values of alpha 2 FEA analyses

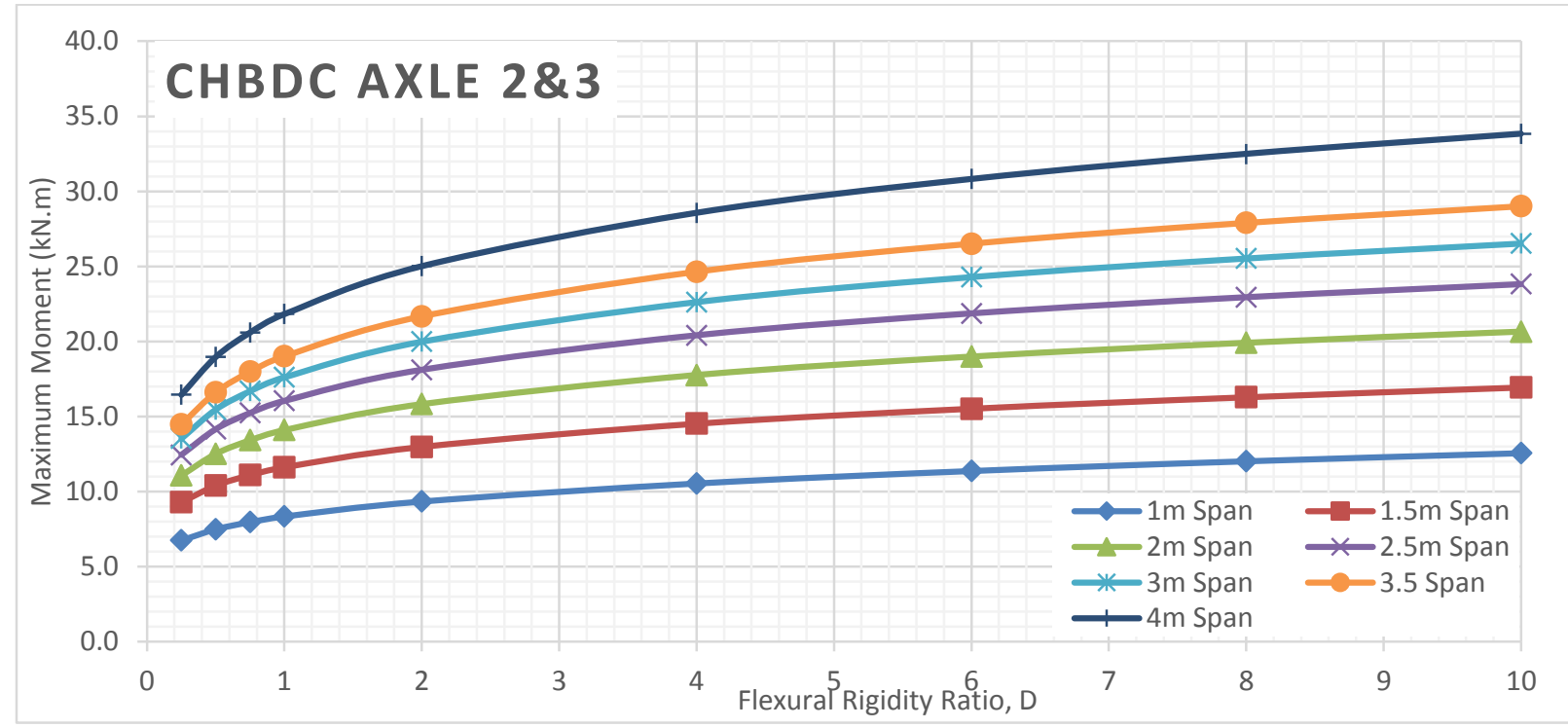

Figure 67 Maximum moment of deck slabs subjected to CHBDC axle $2 \& 3$ for different span values of alpha 2 FEA analyses 


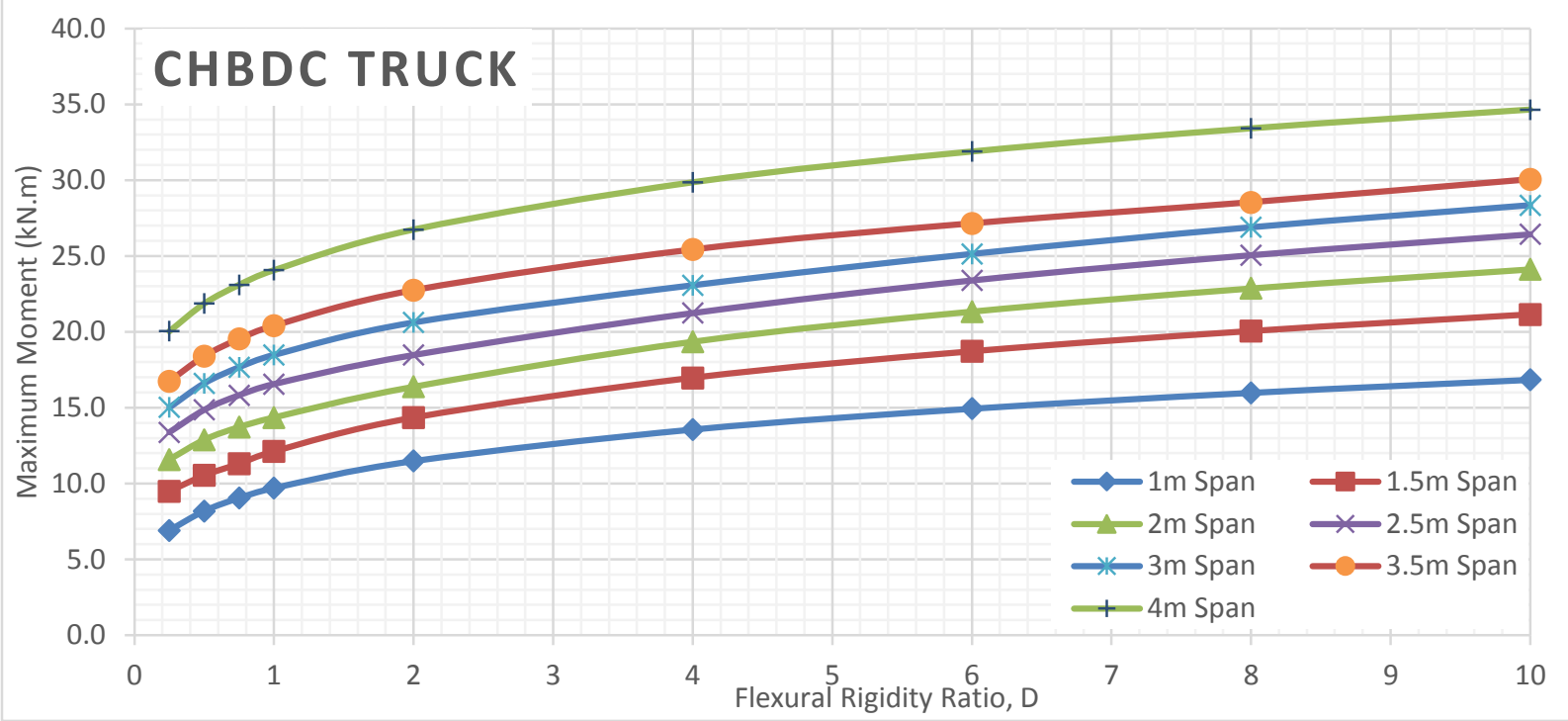

Figure 68 Maximum moment of deck slabs subjected to CHBDC truck for different span values of alpha 2 FEA analyses

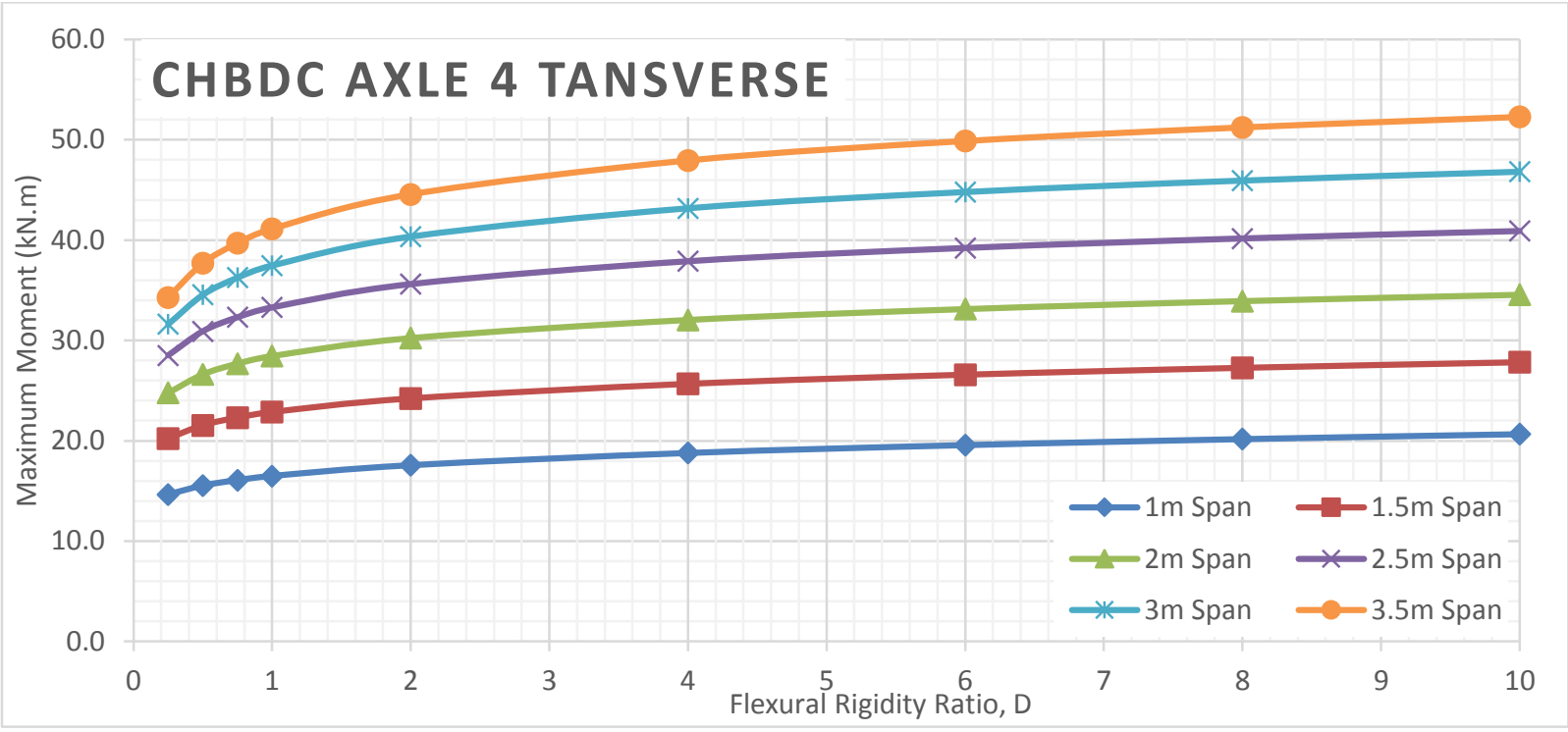

Figure 69 Maximum moment of deck slabs subjected to CHBDC axle 4 for different span values of alpha 2 FEA analyses

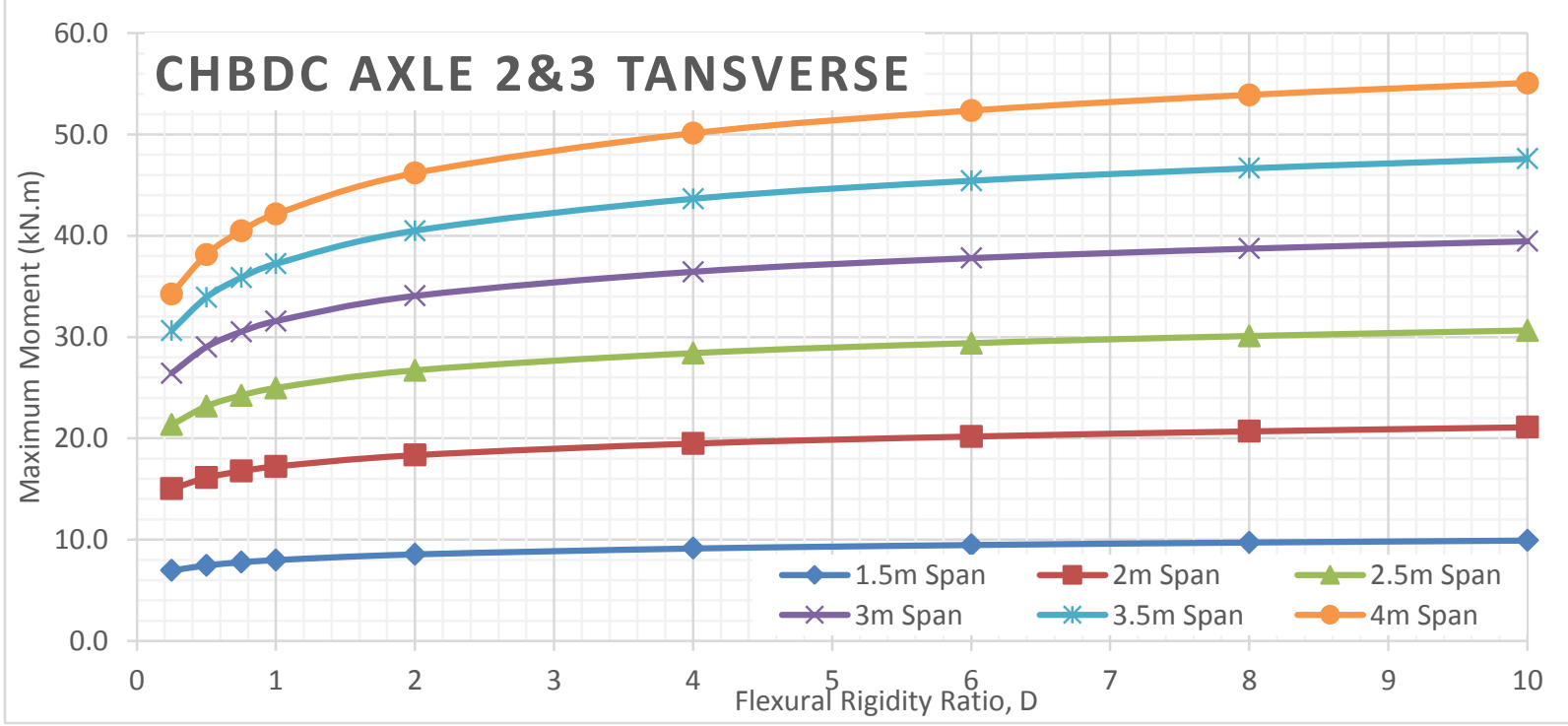

Figure 70 Maximum moment of deck slabs subjected to CHBDC axle $2 \& 3$ for different span values of alpha 2 FEA analyses 


\section{Alpha 4 Bending Moment VS Flexural Rigidity for Different Span Length}

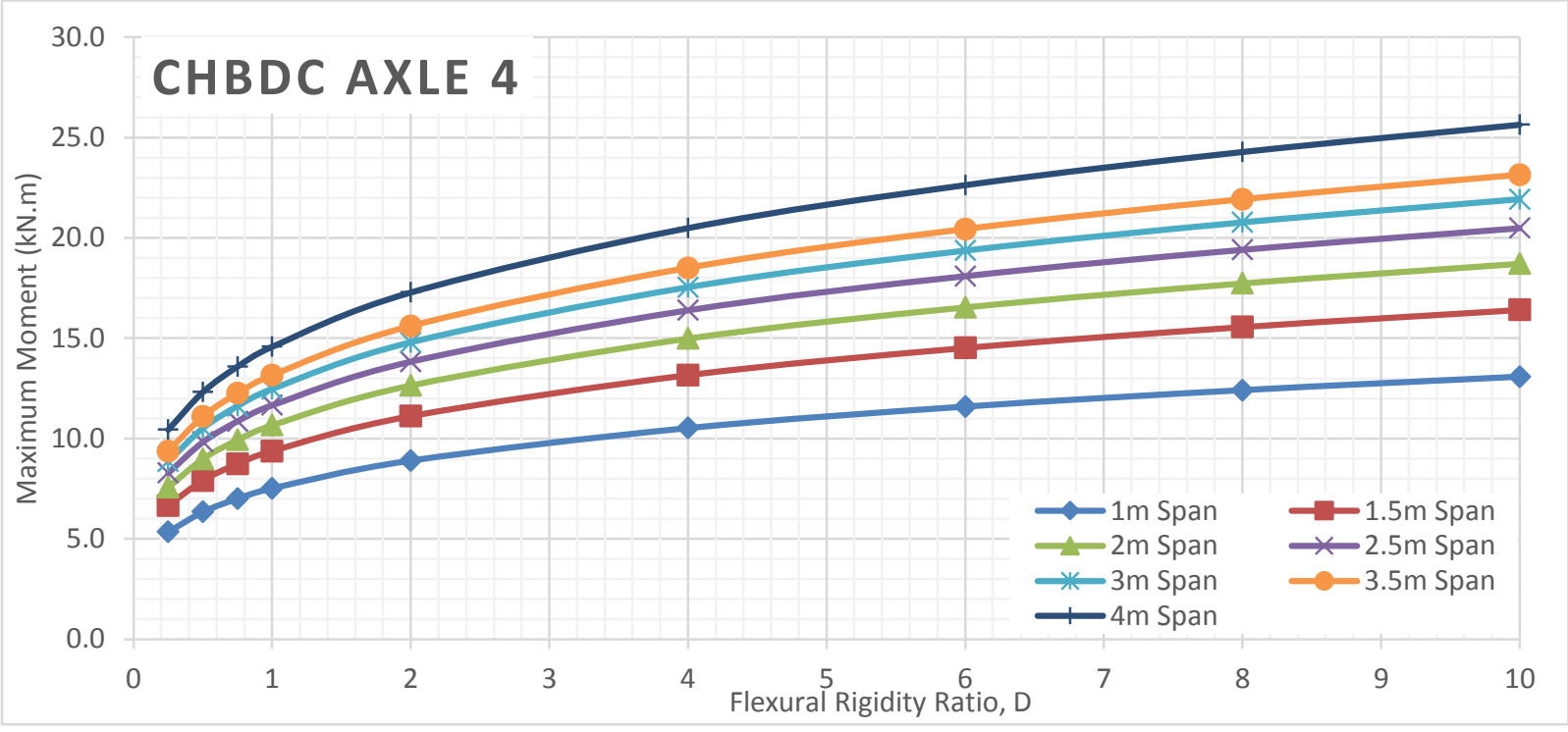

Figure 71 Maximum moment of deck slabs subjected to CHBDC axle 4 for different span values of alpha 4 FEA analyses

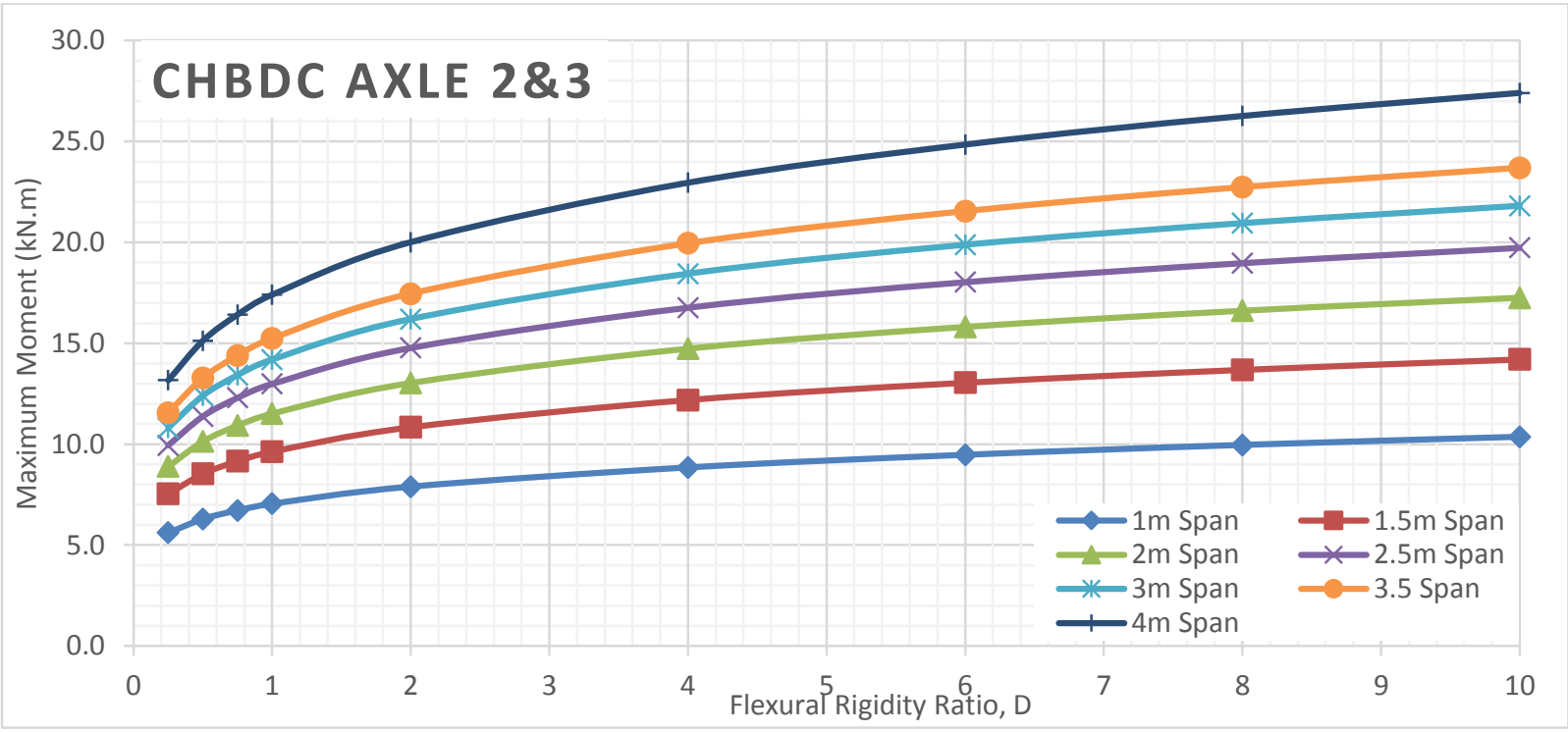

Figure 72 Maximum moment of deck slabs subjected to CHBDC axle $2 \& 3$ for different span values of alpha 4 FEA analyses 


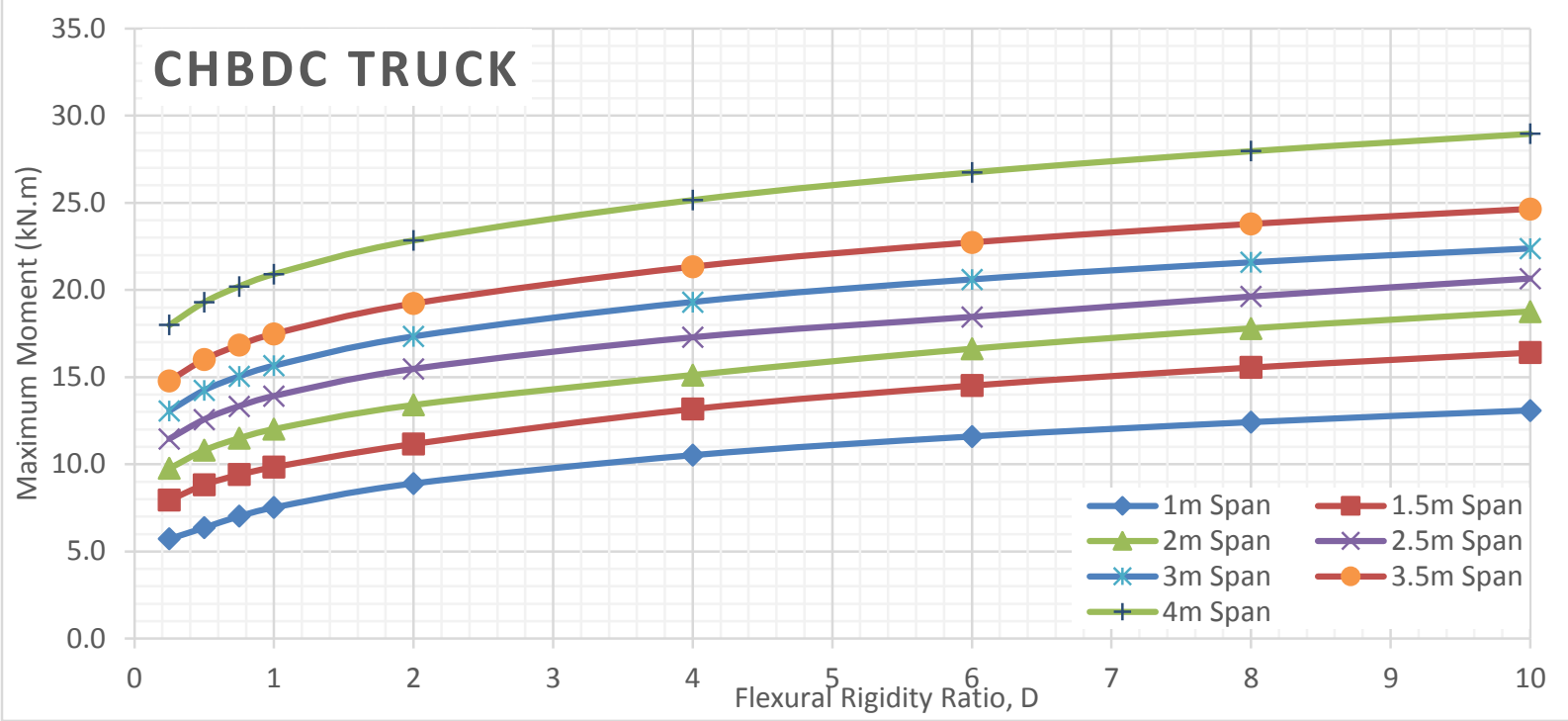

Figure 73 Maximum moment of deck slabs subjected to CHBDC truck for different span values of alpha 4 FEA analyses

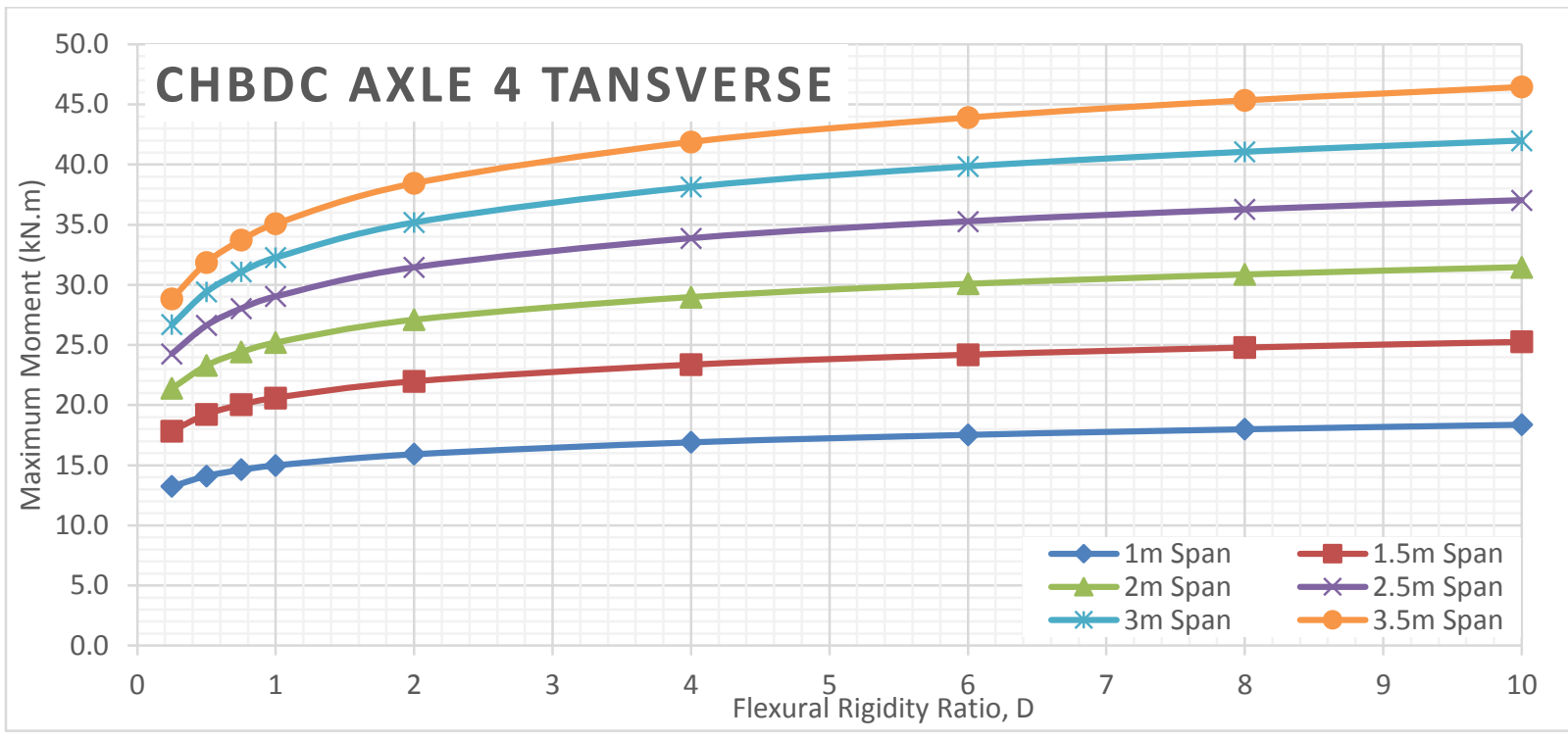

Figure 74 Maximum moment of deck slabs subjected to CHBDC axle 4 for different span values of alpha 4 FEA analyses

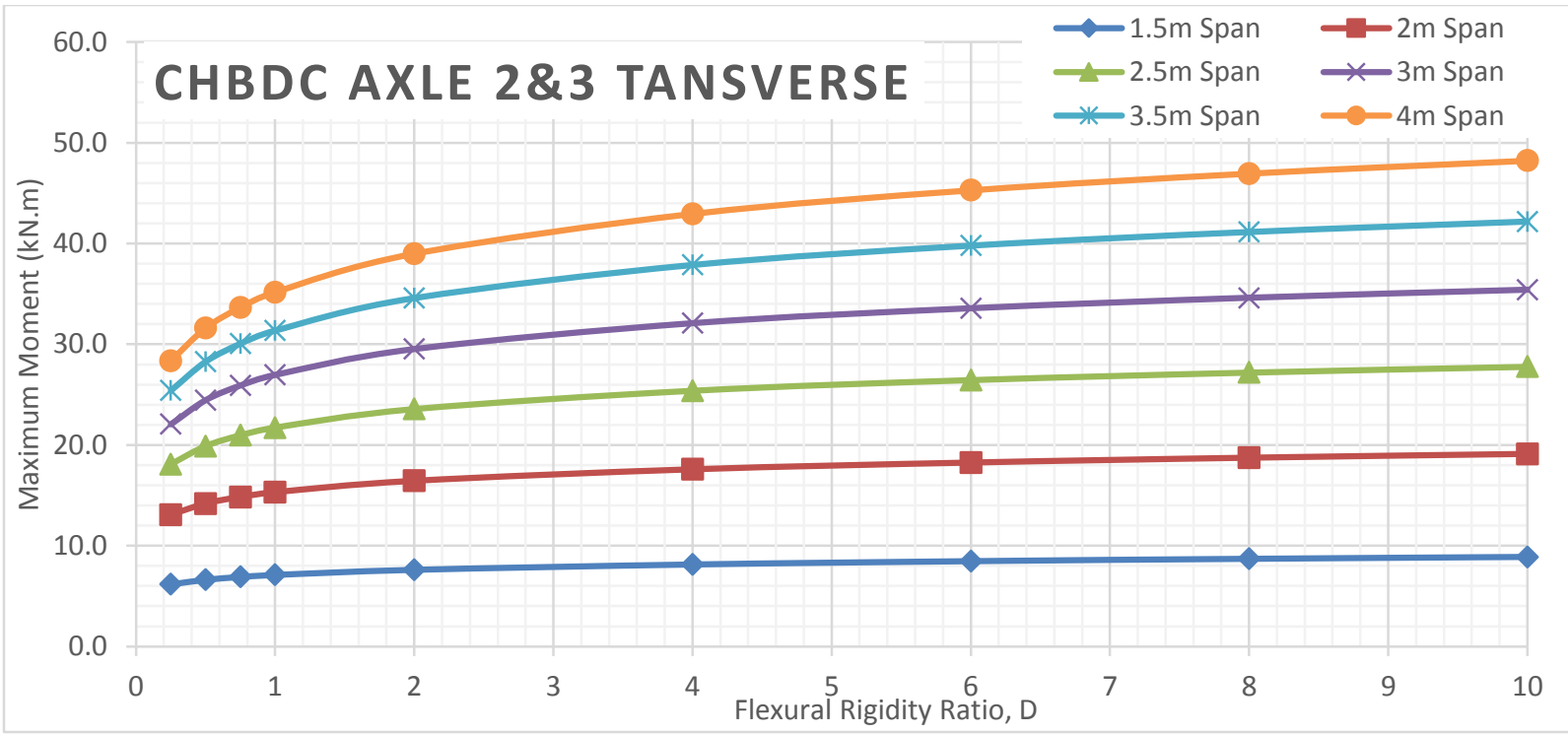

Figure 75 Maximum moment of deck slabs subjected to CHBDC axle $2 \& 3$ for different span values of alpha 4 FEA analyses 


\section{Alpha 6 Bending Moment VS Flexural Rigidity for Different Span Length}

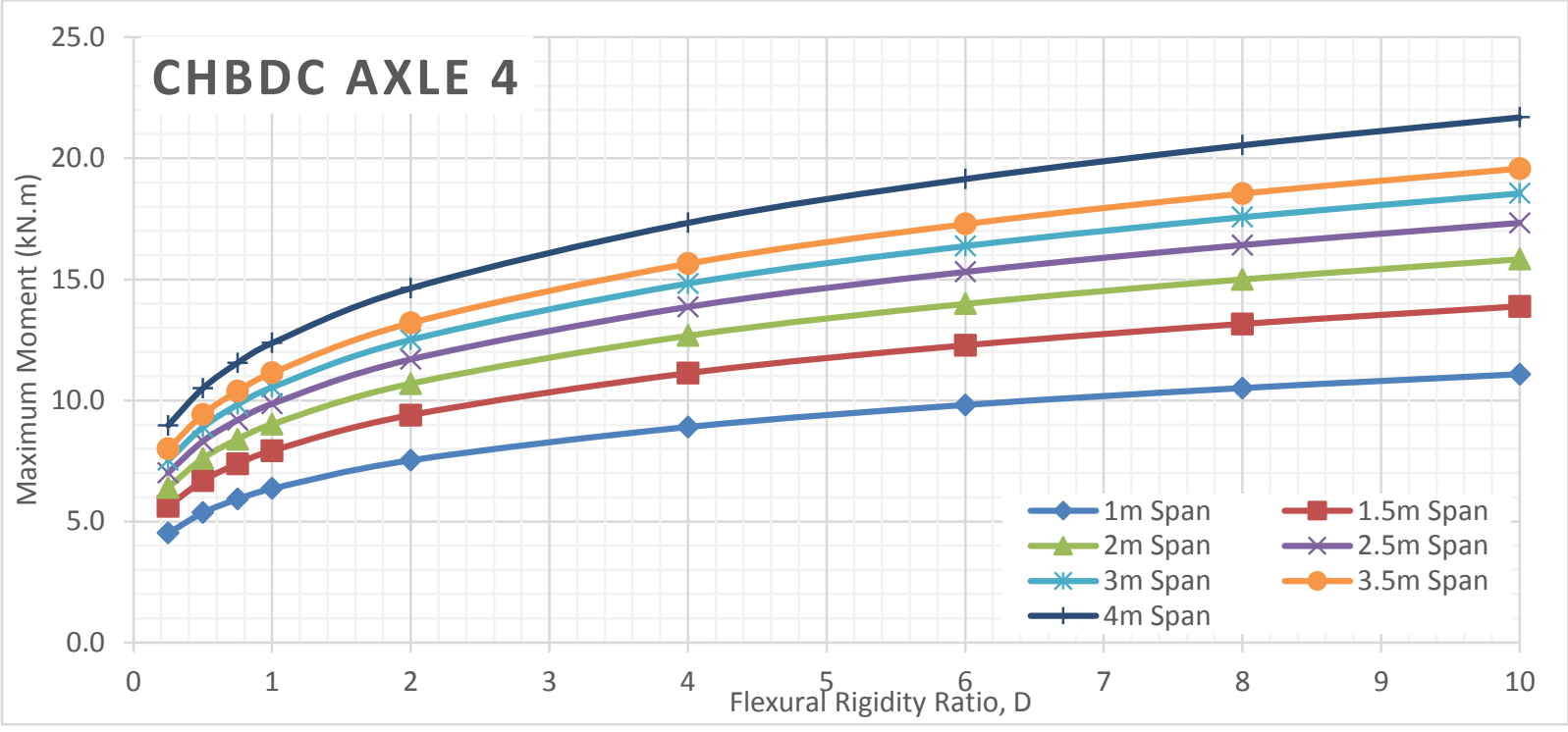

Figure 76 Maximum moment of deck slabs subjected to CHBDC axle 4 for different span values of alpha 6 FEA analyses

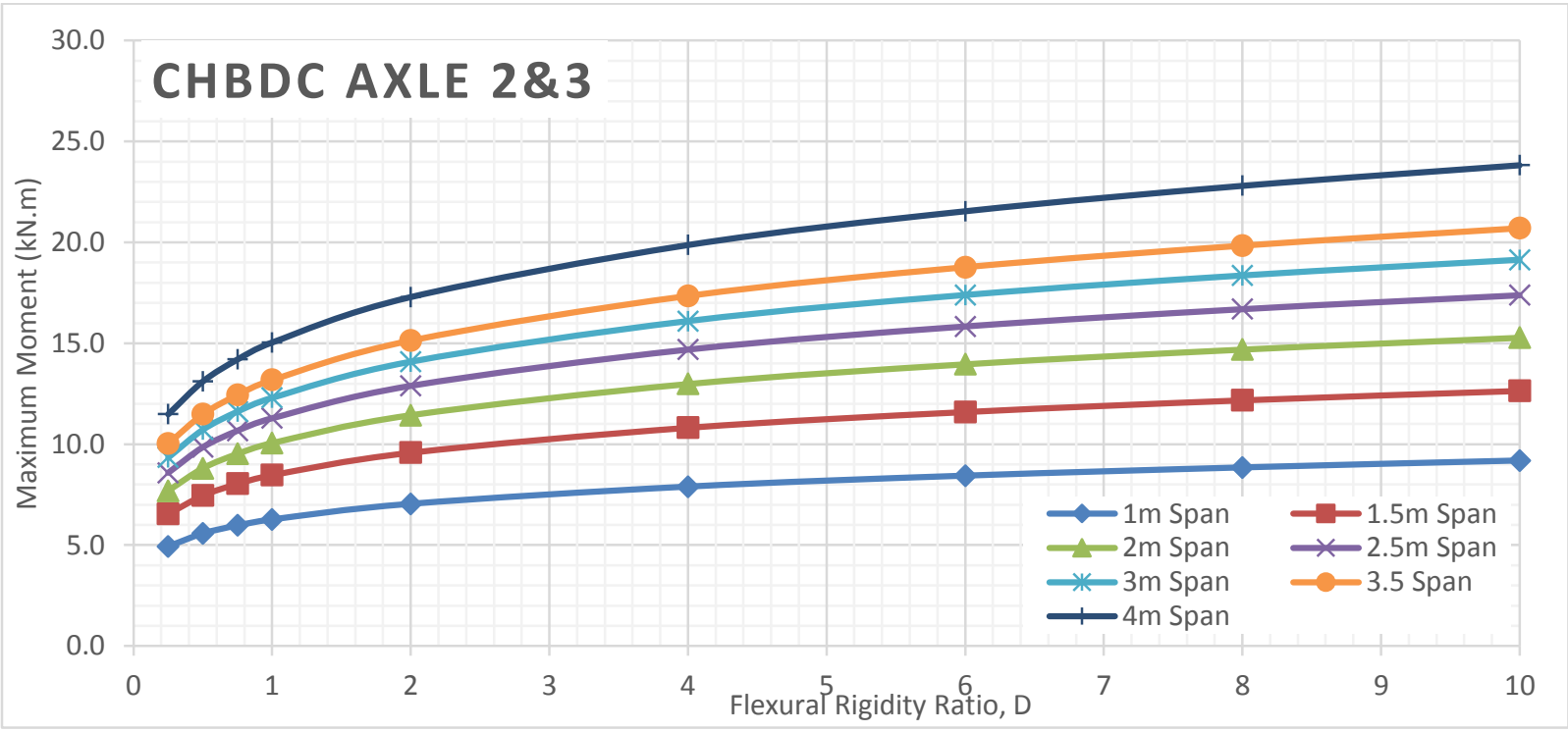

Figure 77 Maximum moment of deck slabs subjected to CHBDC axle $2 \& 3$ for different span values of alpha 6 FEA analyses 


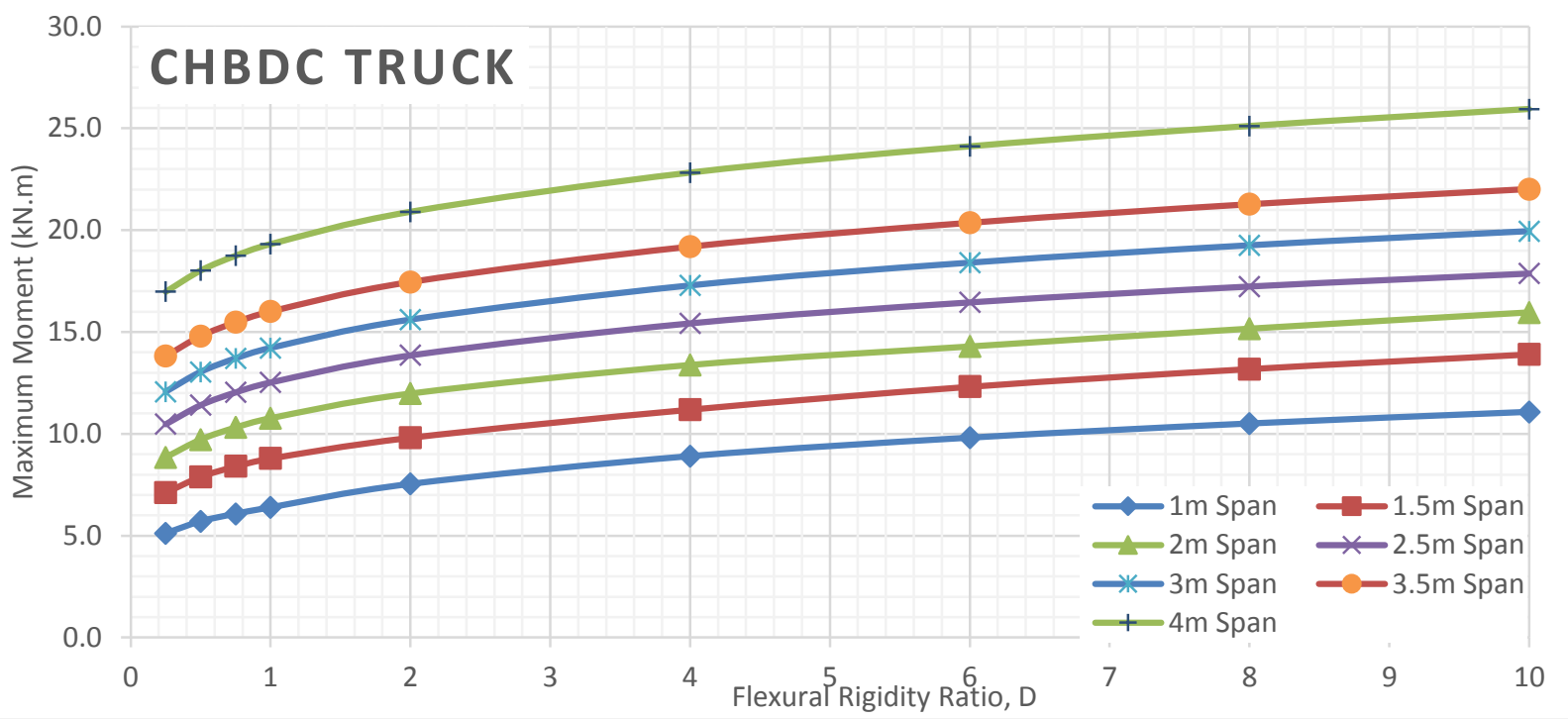

Figure 78 Maximum moment of deck slabs subjected to CHBDC truck for different span values of alpha 6 FEA analyses

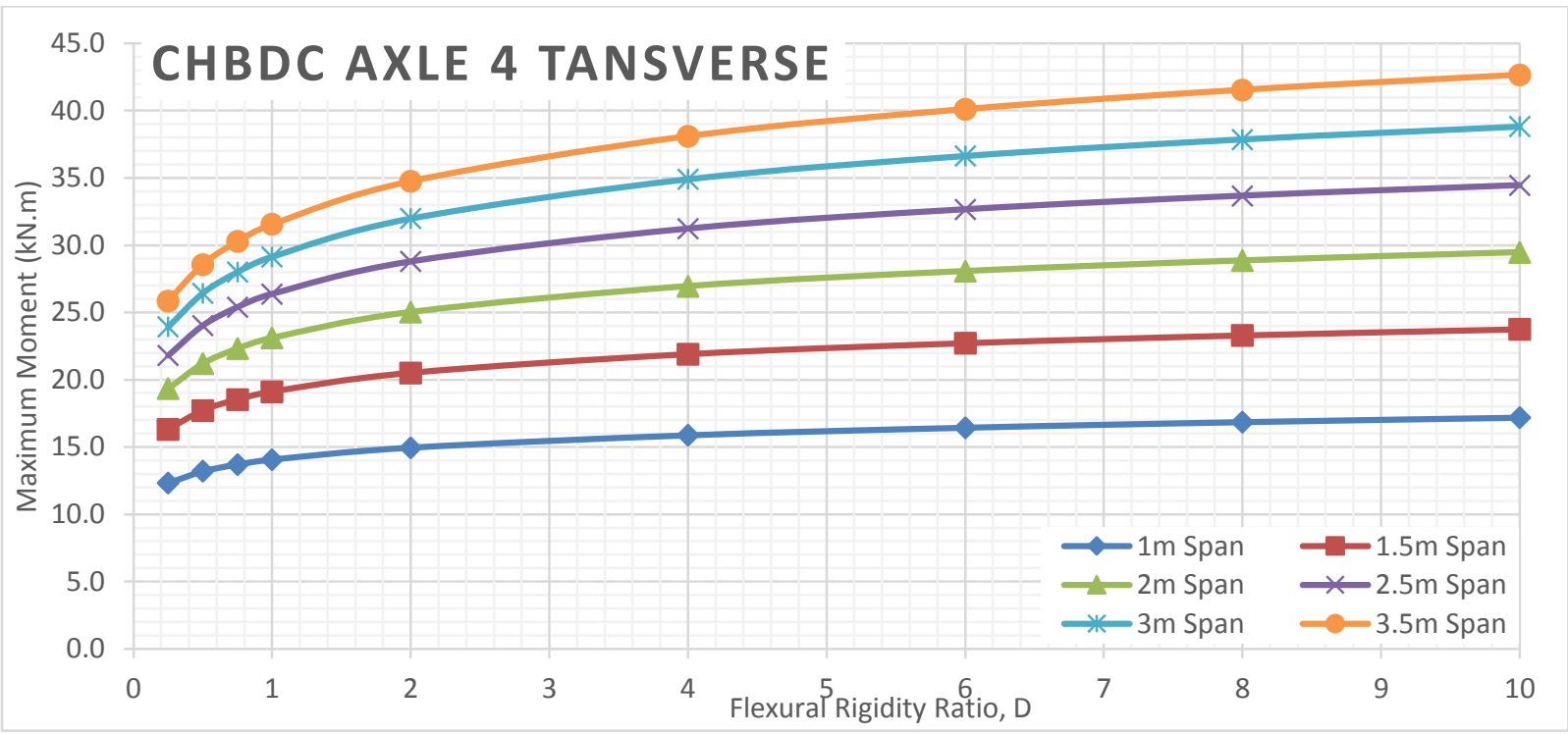

Figure 79 Maximum moment of deck slabs subjected to CHBDC axle 4 for different span values of alpha 6 FEA analyses

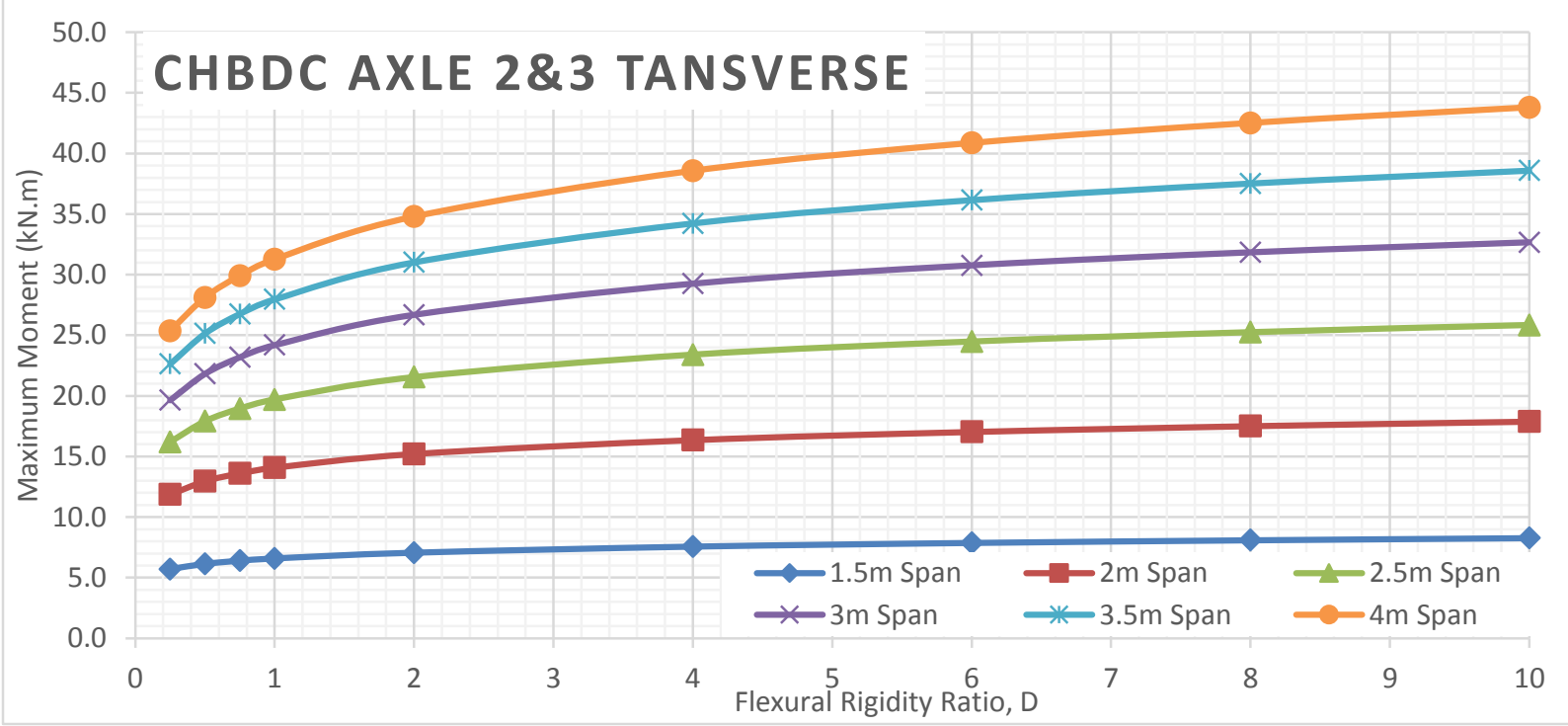

Figure 80 Maximum moment of deck slabs subjected to CHBDC axle $2 \& 3$ for different span values of alpha 6 FEA analyses 


\section{Alpha 8 Bending Moment VS Flexural Rigidity for Different Span Length}

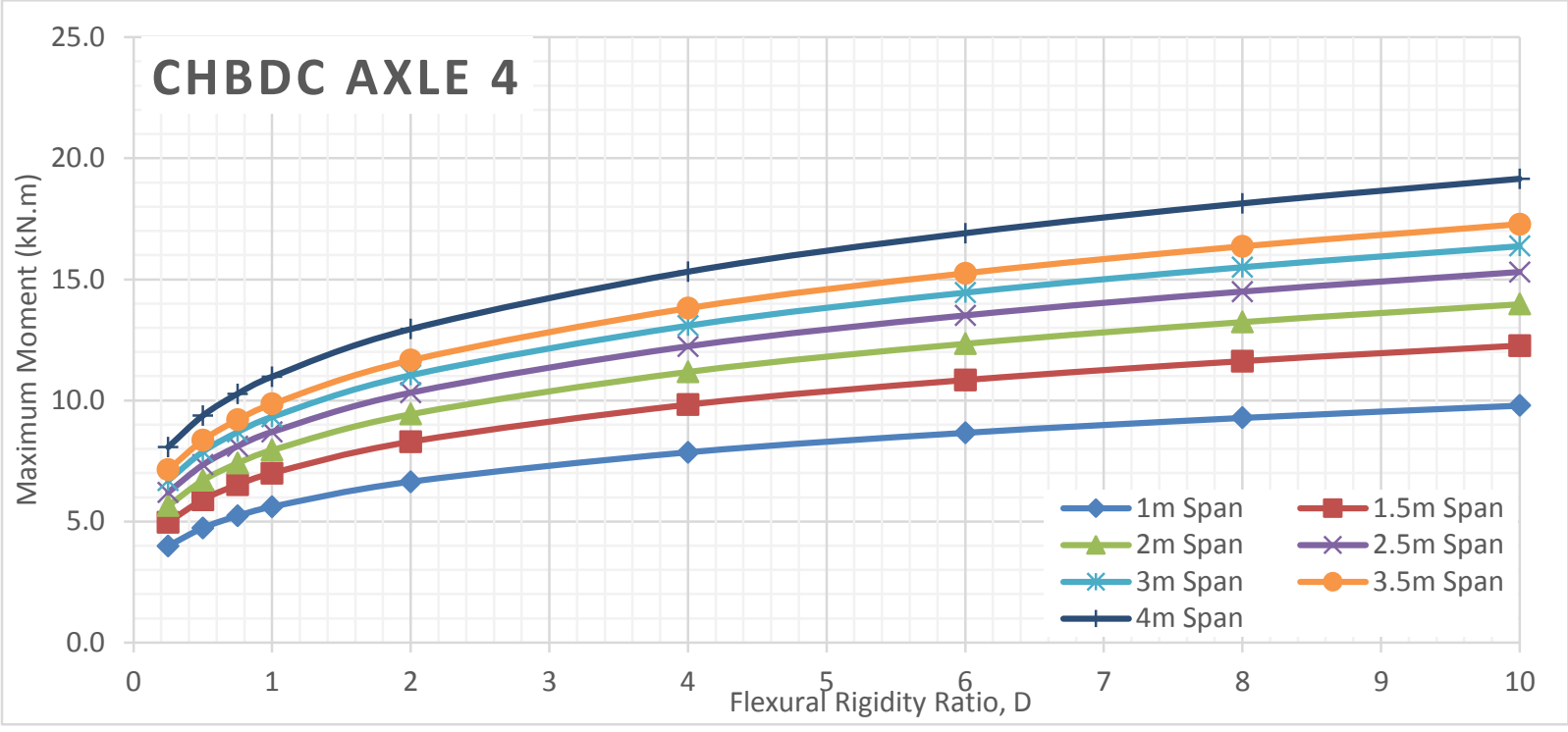

Figure 81 Maximum moment of deck slabs subjected to CHBDC axle 4 for different span values of alpha 8 FEA analyses

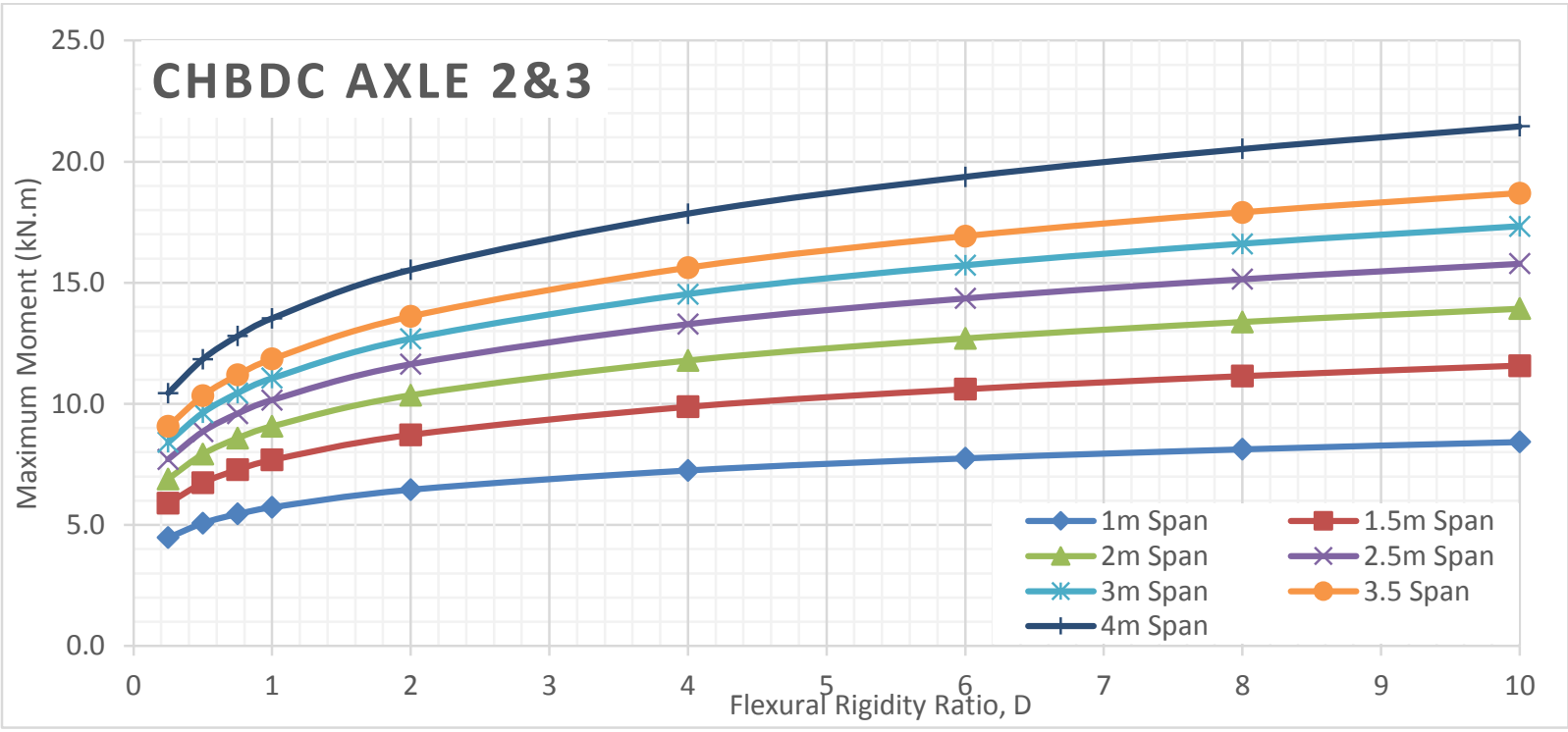

Figure 82 Maximum moment of deck slabs subjected to CHBDC axle $2 \& 3$ for different span values of alpha 8 FEA analyses 


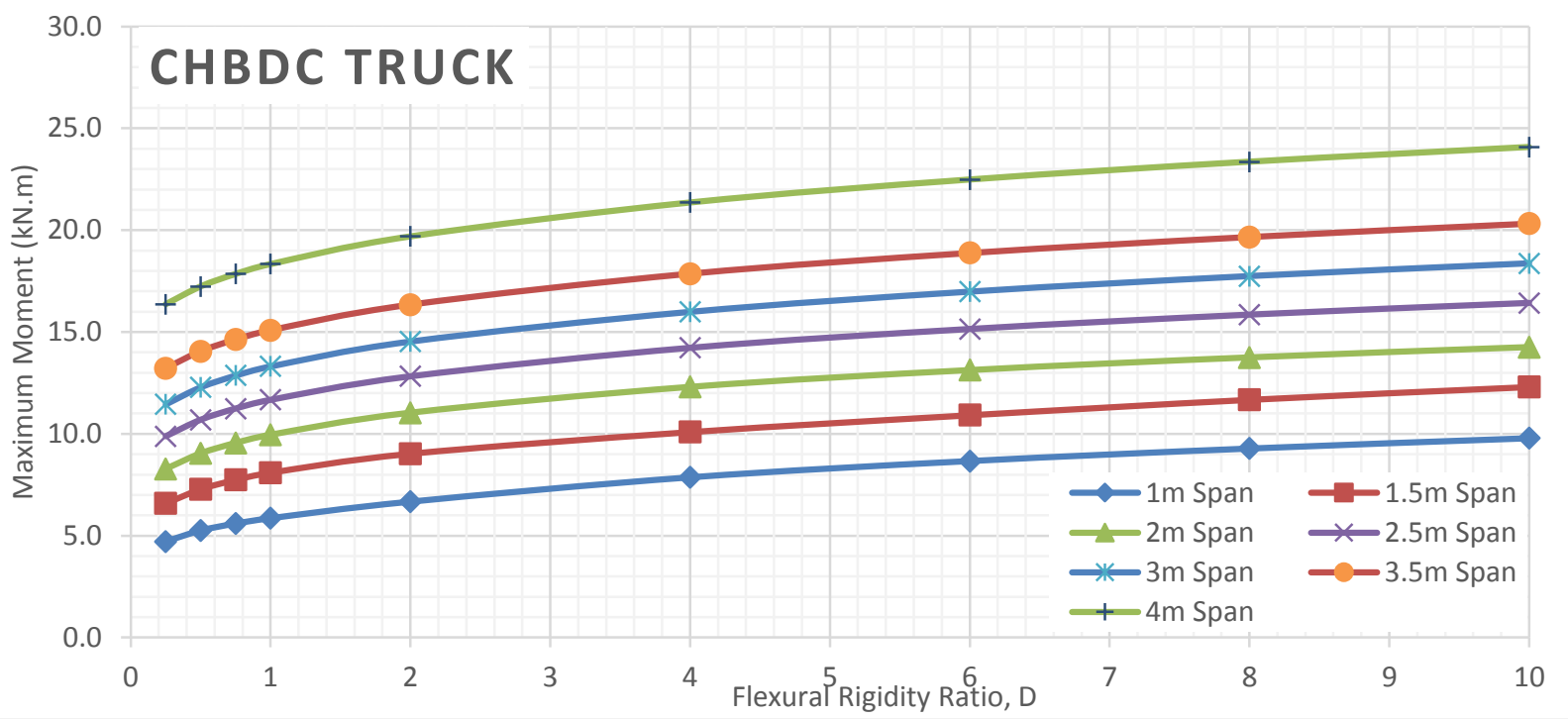

Figure 83 Maximum moment of deck slabs subjected to CHBDC truck for different span values of alpha 8 FEA analyses

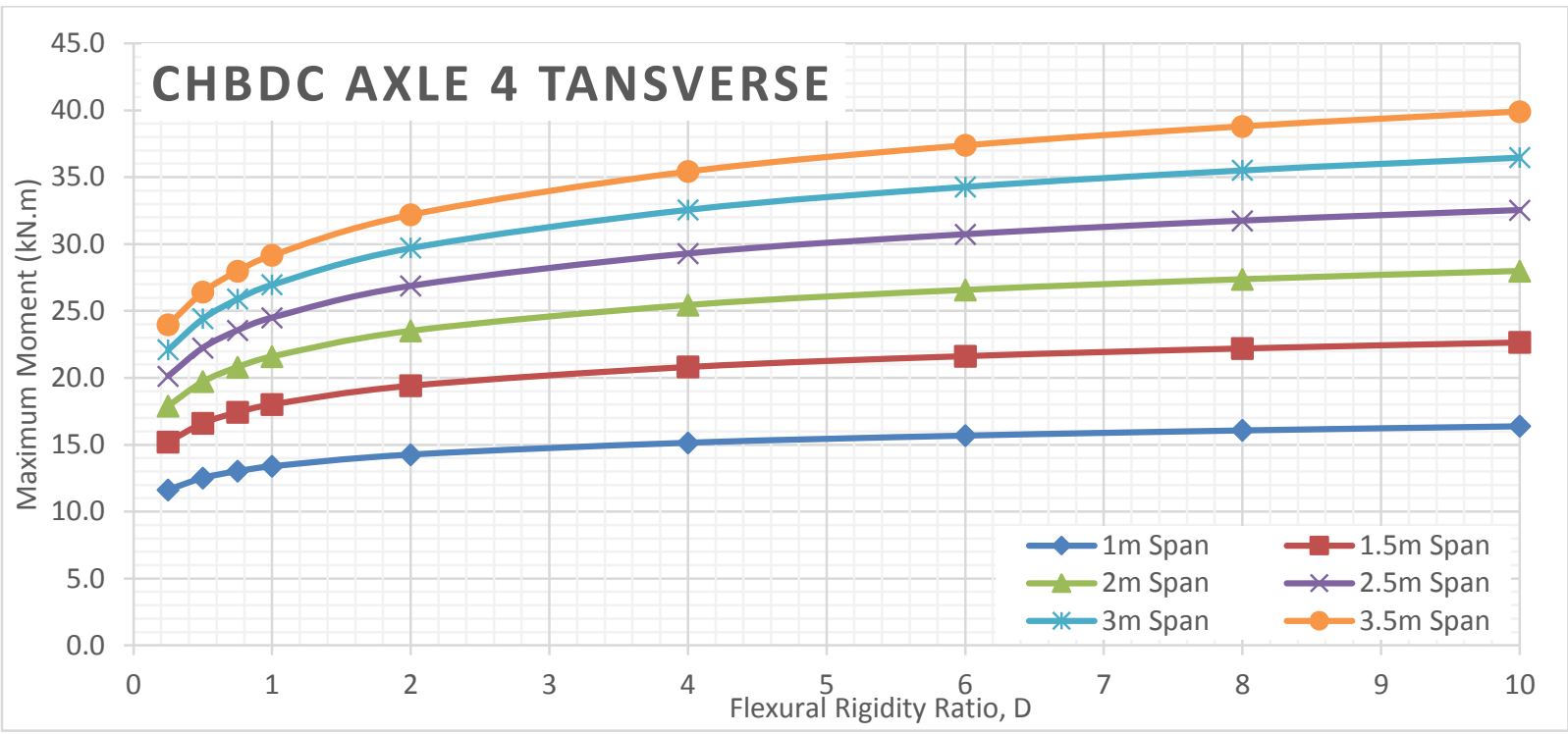

Figure 84 Maximum moment of deck slabs subjected to CHBDC axle 4 for different span values of alpha 8 FEA analyses

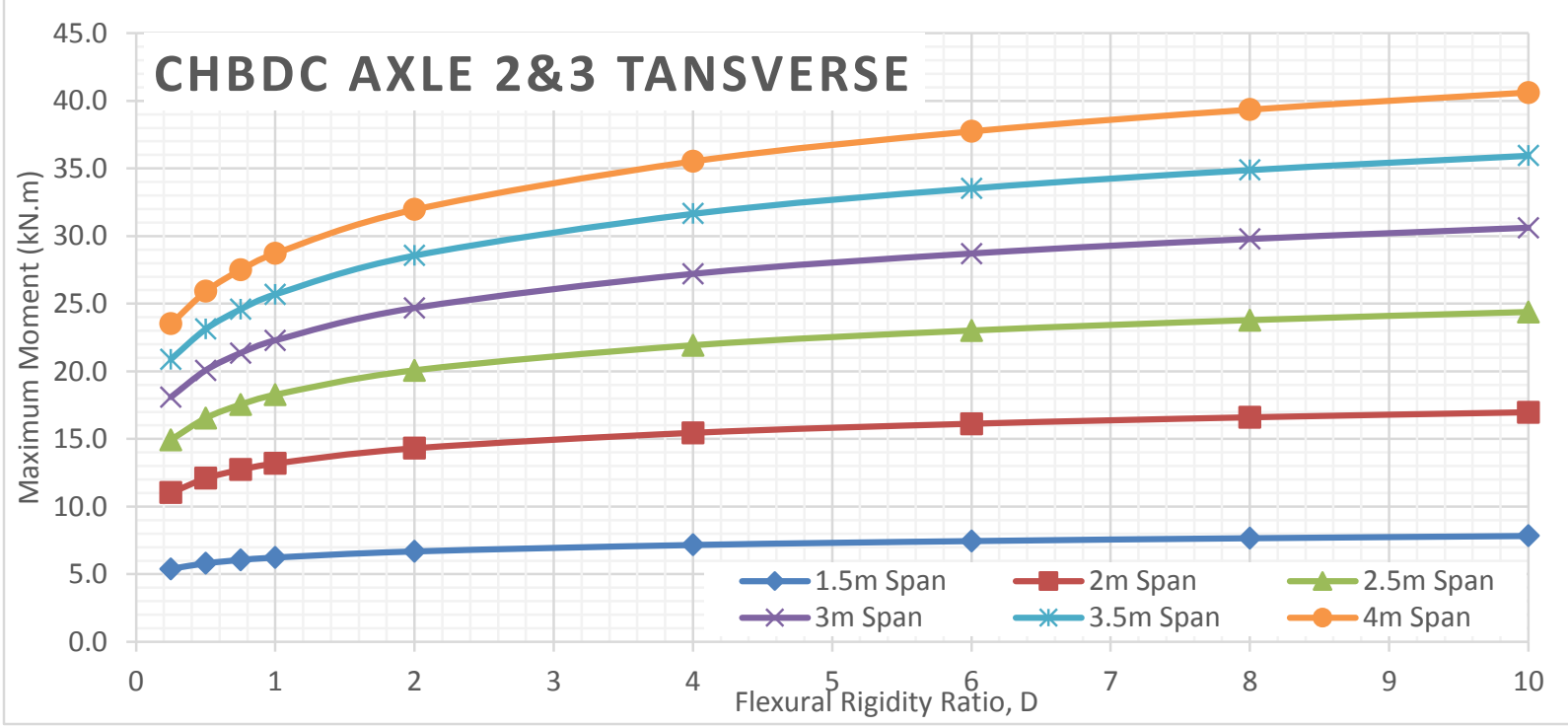

Figure 85 Maximum moment of deck slabs subjected to CHBDC axle $2 \& 3$ for different span values of alpha 8 FEA analyses 


\section{Alpha 10 Bending Moment VS Flexural Rigidity for Different Span Length}

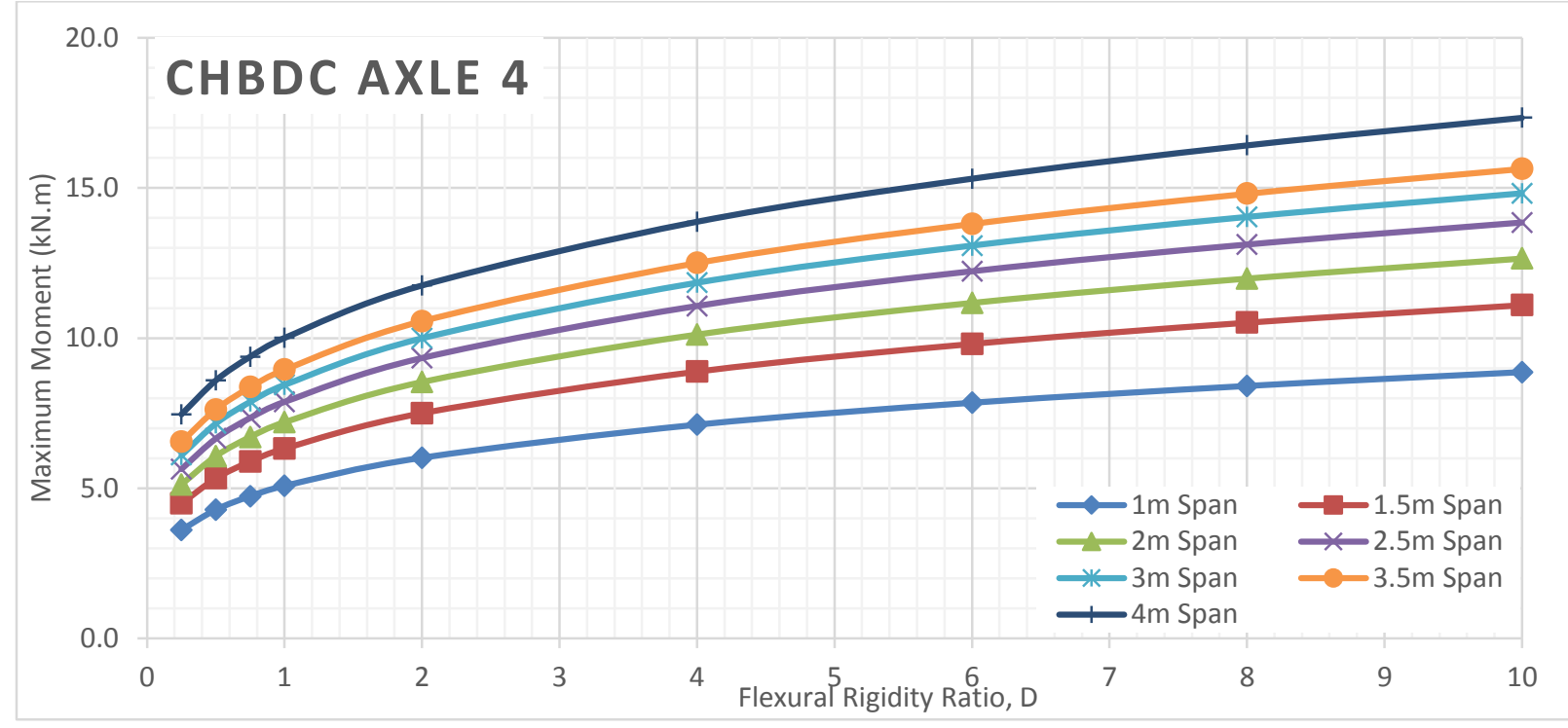

Figure 86 Maximum moment of deck slabs subjected to CHBDC axle 4 for different span values of alpha 10 FEA analyses

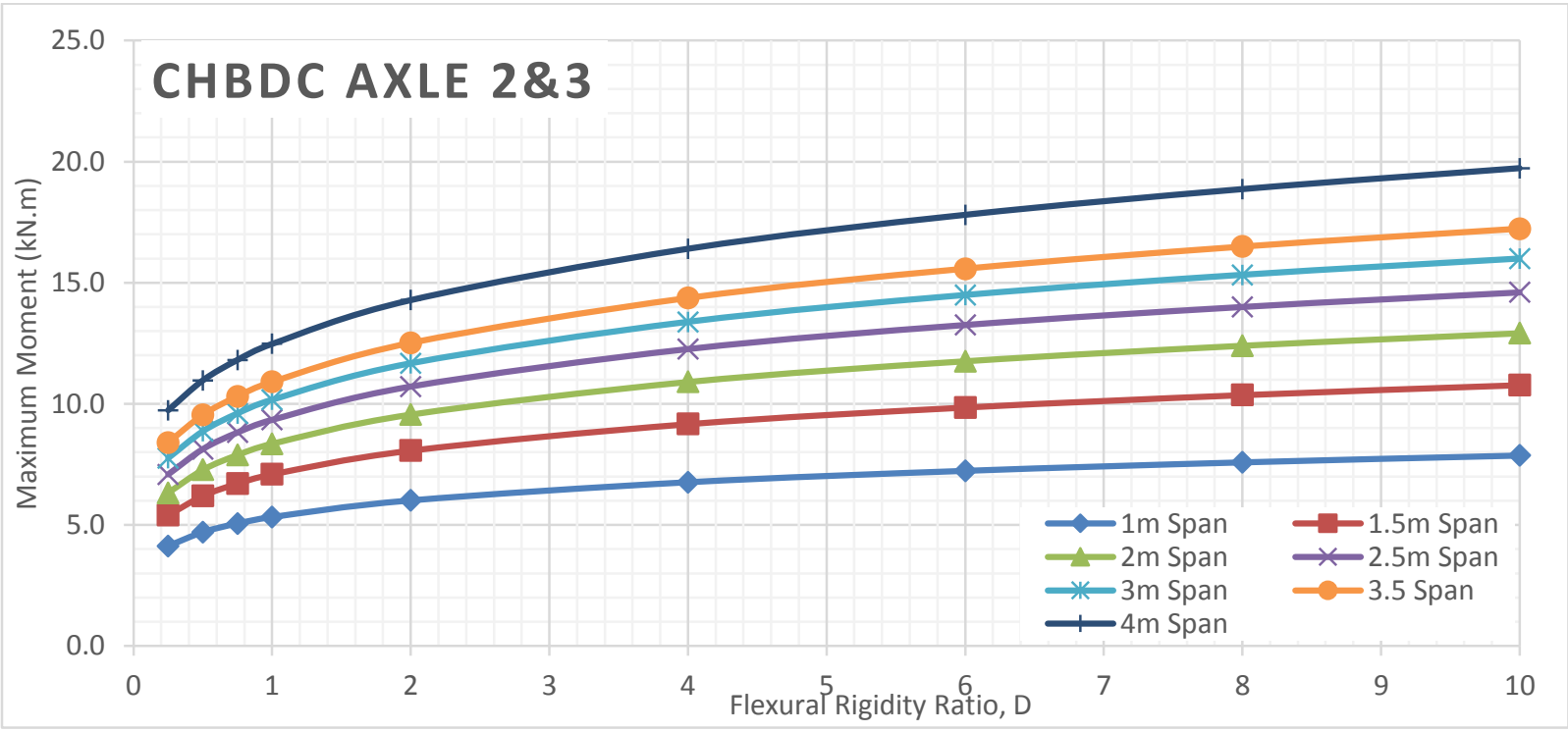

Figure 87 Maximum moment of deck slabs subjected to CHBDC axle 2 \&3 for different span values of alpha 10 FEA analyses 


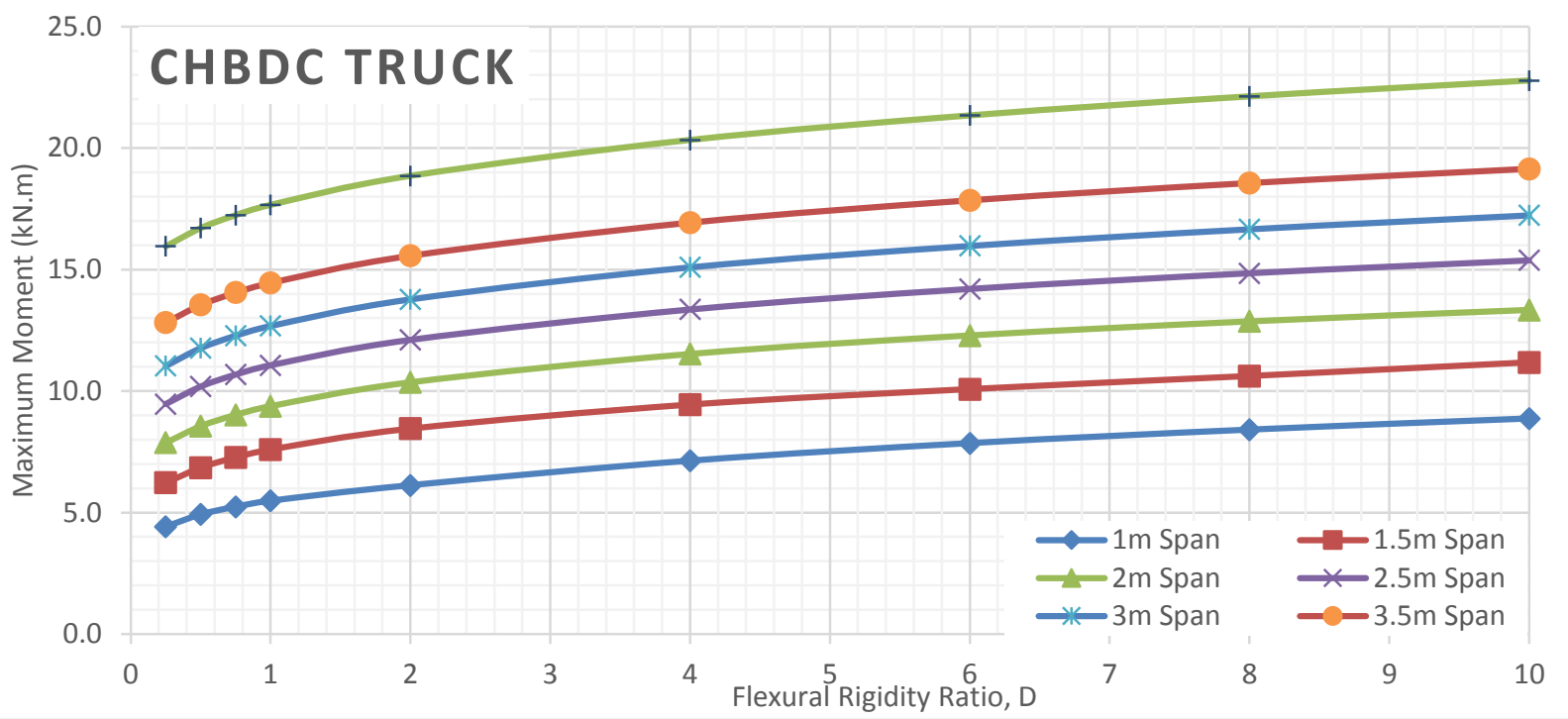

Figure 88 Maximum moment of deck slabs subjected to CHBDC truck for different span values of alpha 10 FEA analyses

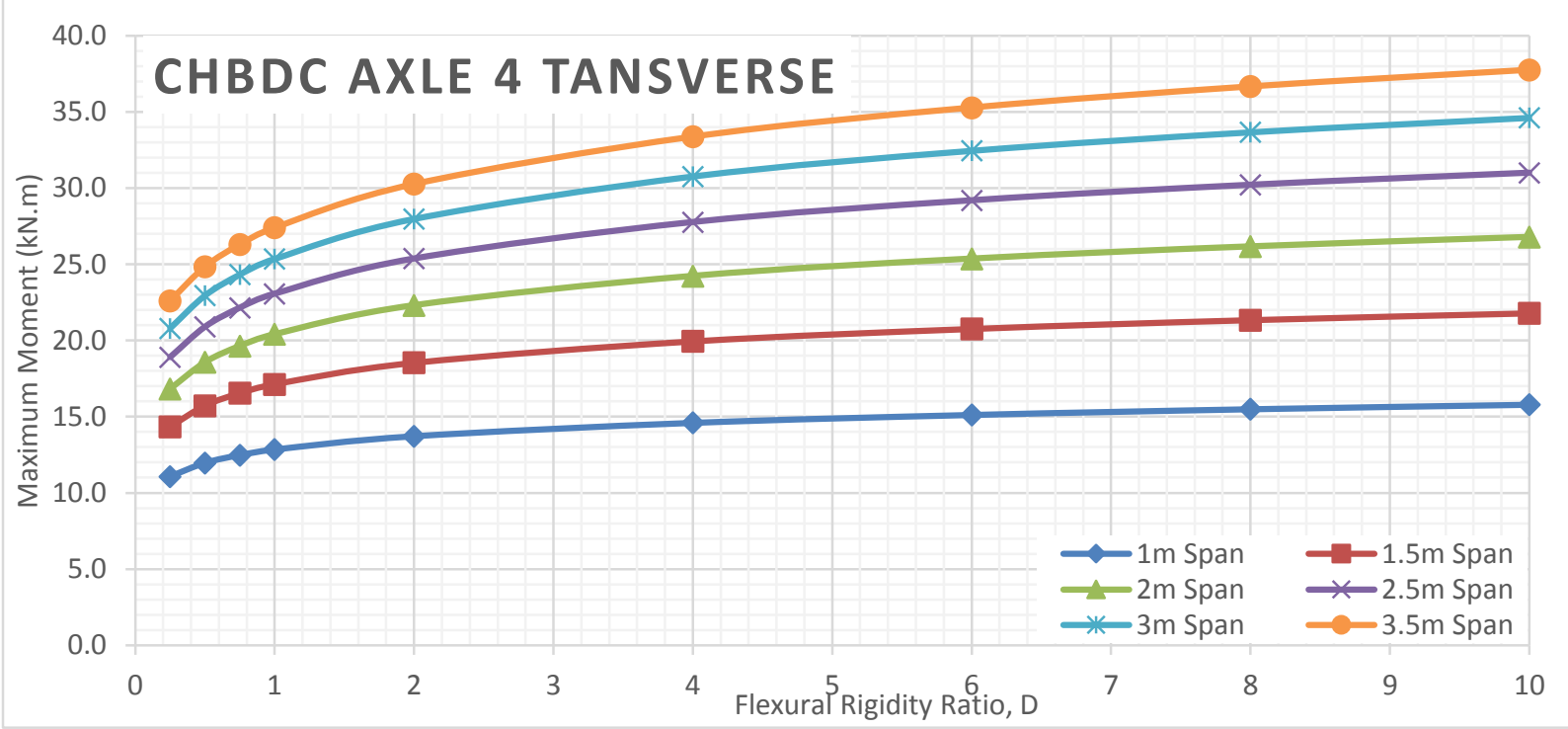

Figure 89 Maximum moment of deck slabs subjected to CHBDC axle 4 for different span values of alpha 10 FEA analyses

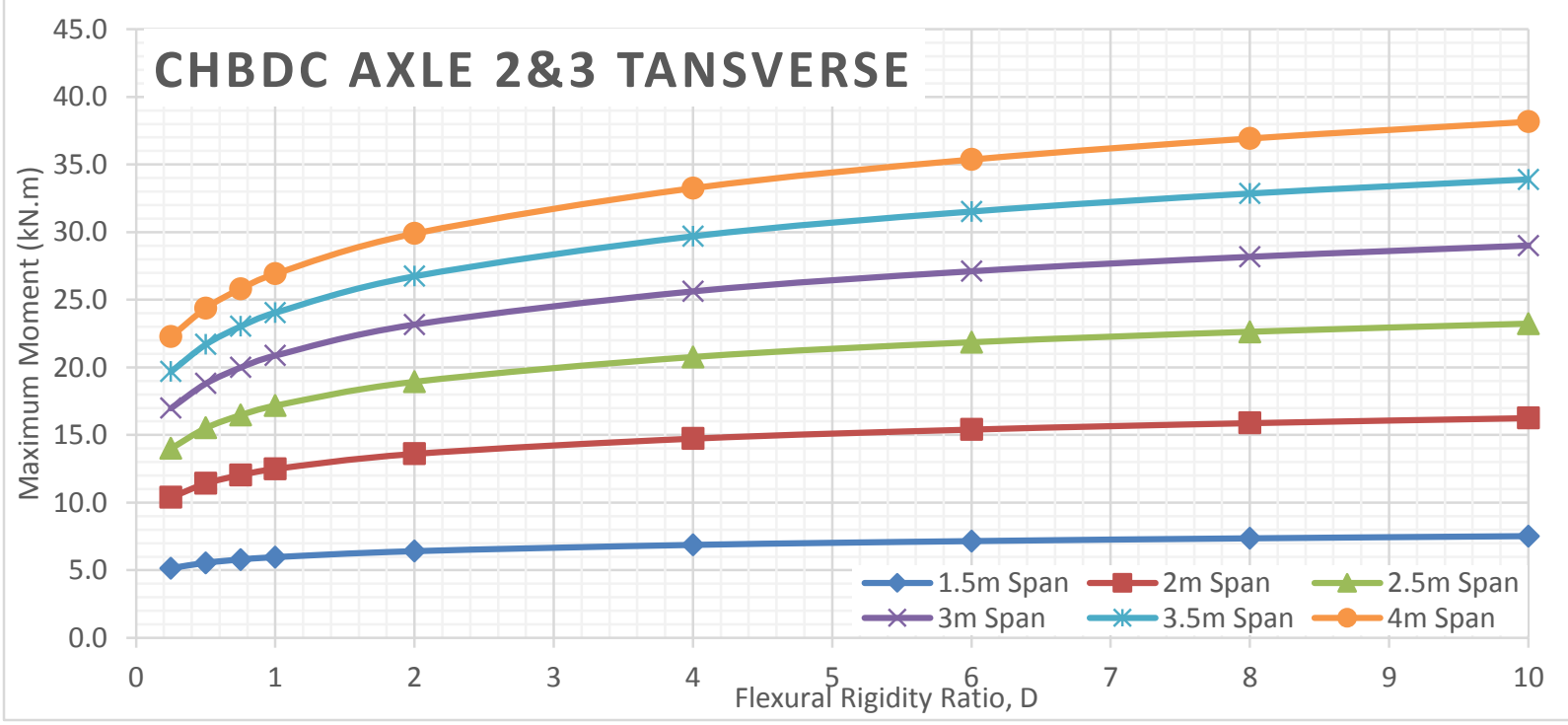

Figure 90 Maximum moment of deck slabs subjected to CHBDC axle $2 \& 3$ for different span values of alpha 10 FEA analyses 


\section{B.1.4 MAXIMUM BENDING MOMENT VS TORSIONAL RIGIDITY}




\section{Axle 4 Bending Moment VS Torsional Rigidity for Different D Values at Different span length}

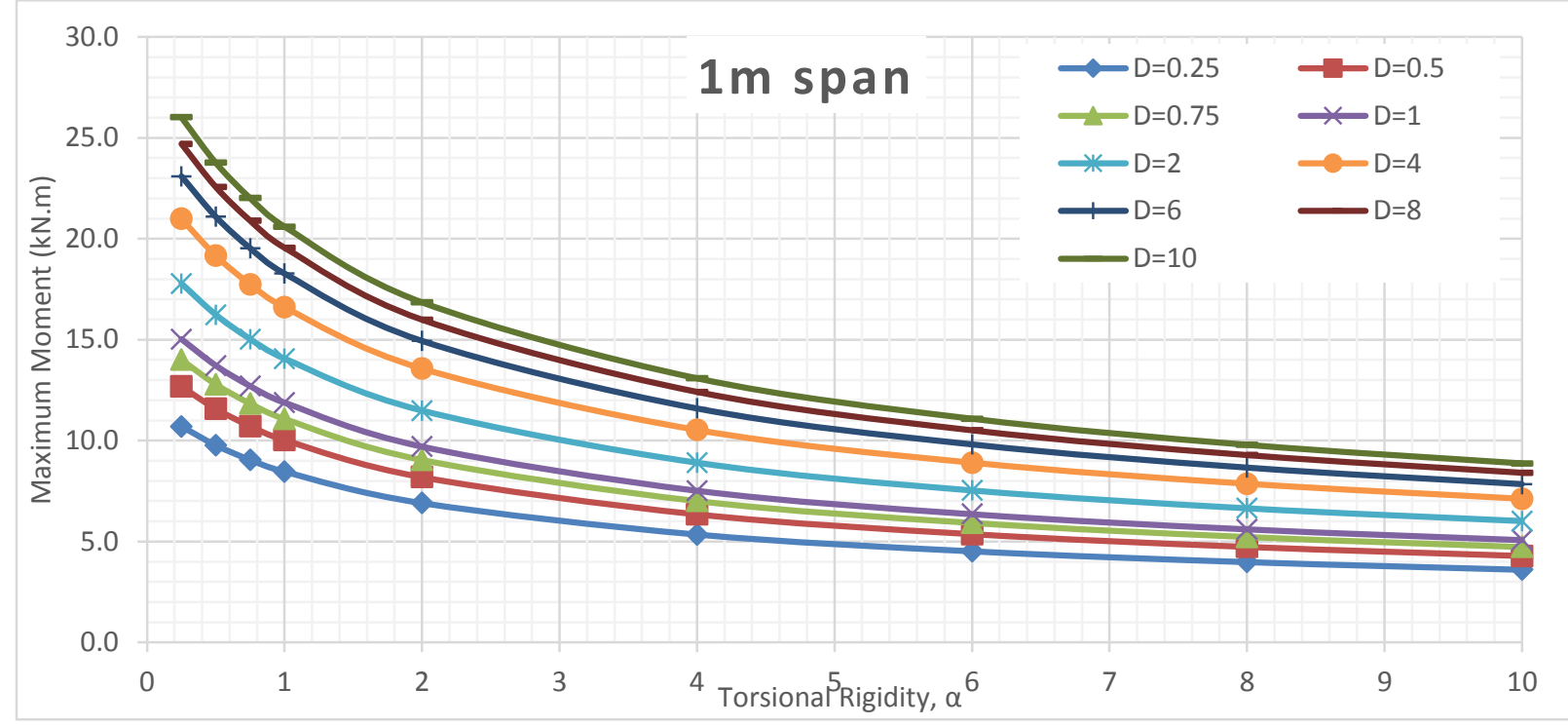

Figure 91 Maximum moment of $1 \mathrm{~m}$ span slab subjected to CHBDC axle 4 for different D values FEA analyses

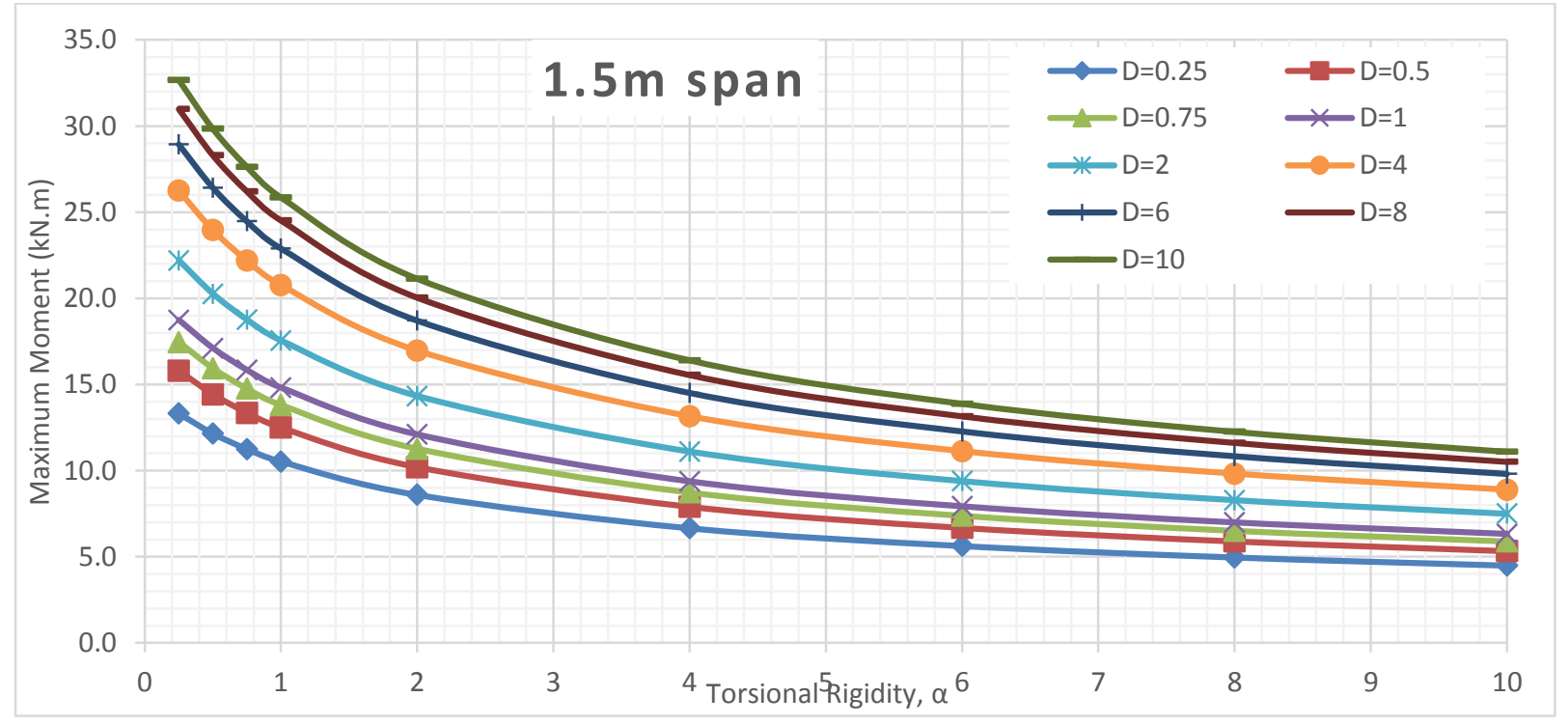

Figure 92 Maximum moment of $1.5 \mathrm{~m}$ span slab subjected to CHBDC axle 4 for different $\mathrm{D}$ values FEA analyses 


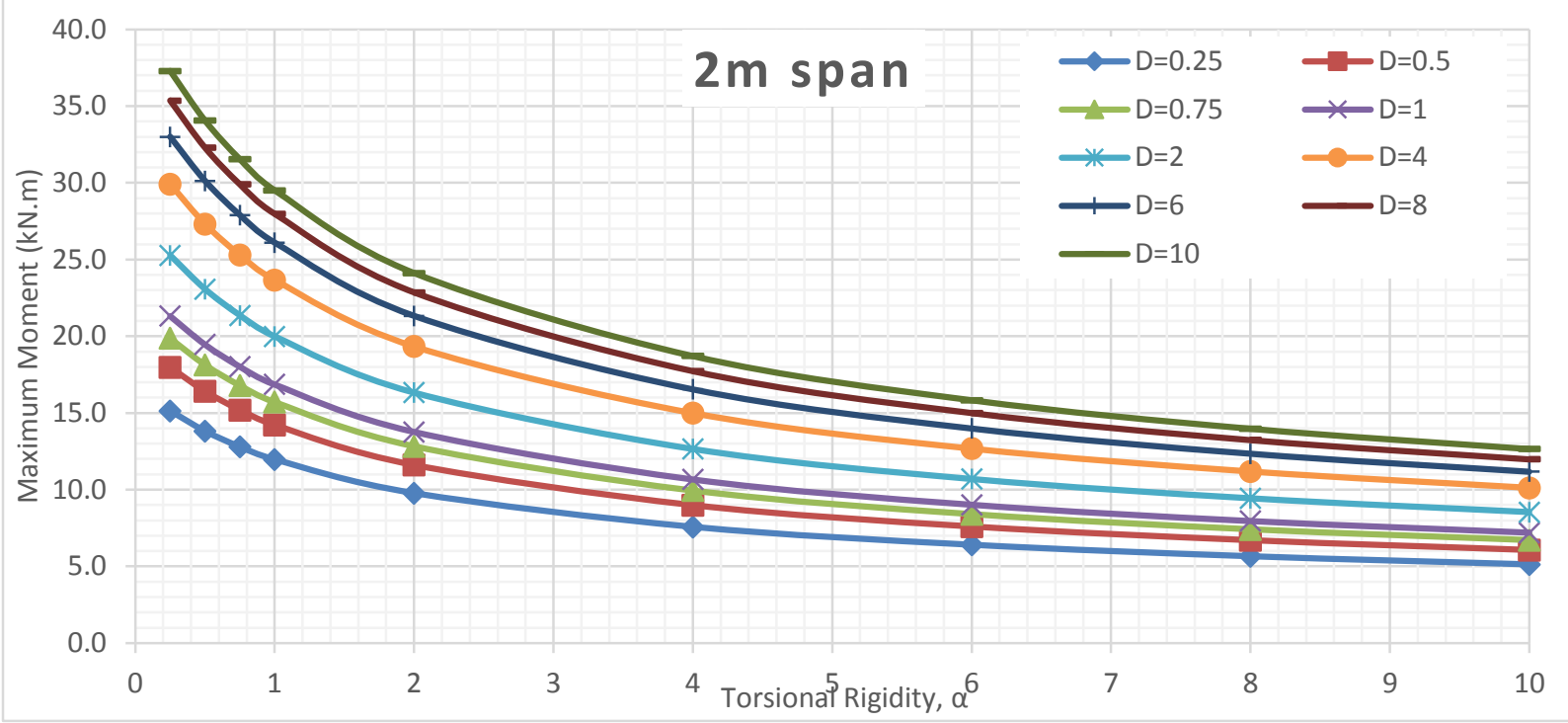

Figure 93 Maximum moment of $2 \mathrm{~m}$ span slab subjected to CHBDC axle 4 for different D values FEA analyses

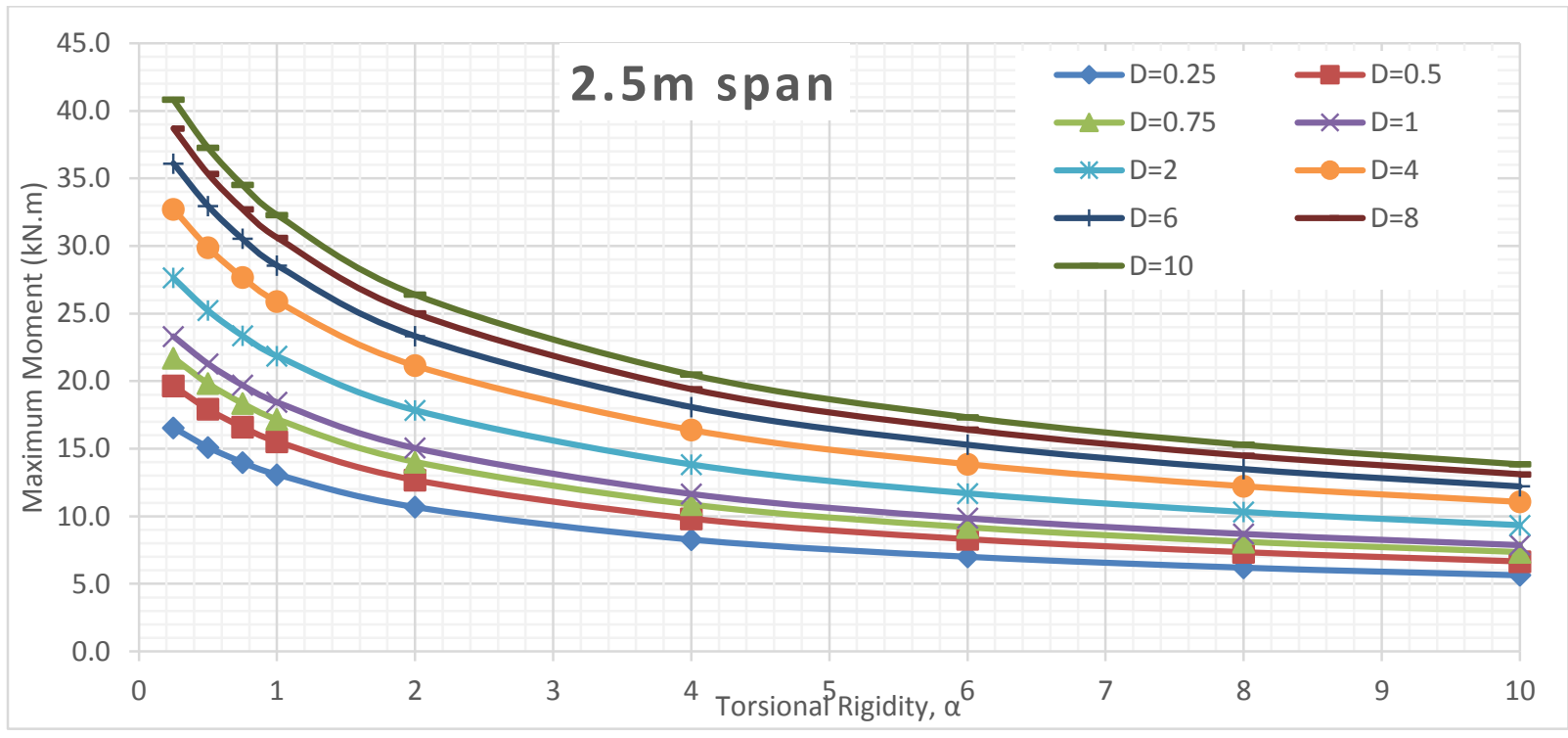

Figure 94 Maximum moment of $2.5 \mathrm{~m}$ span slab subjected to CHBDC axle 4 for different D values FEA analyses

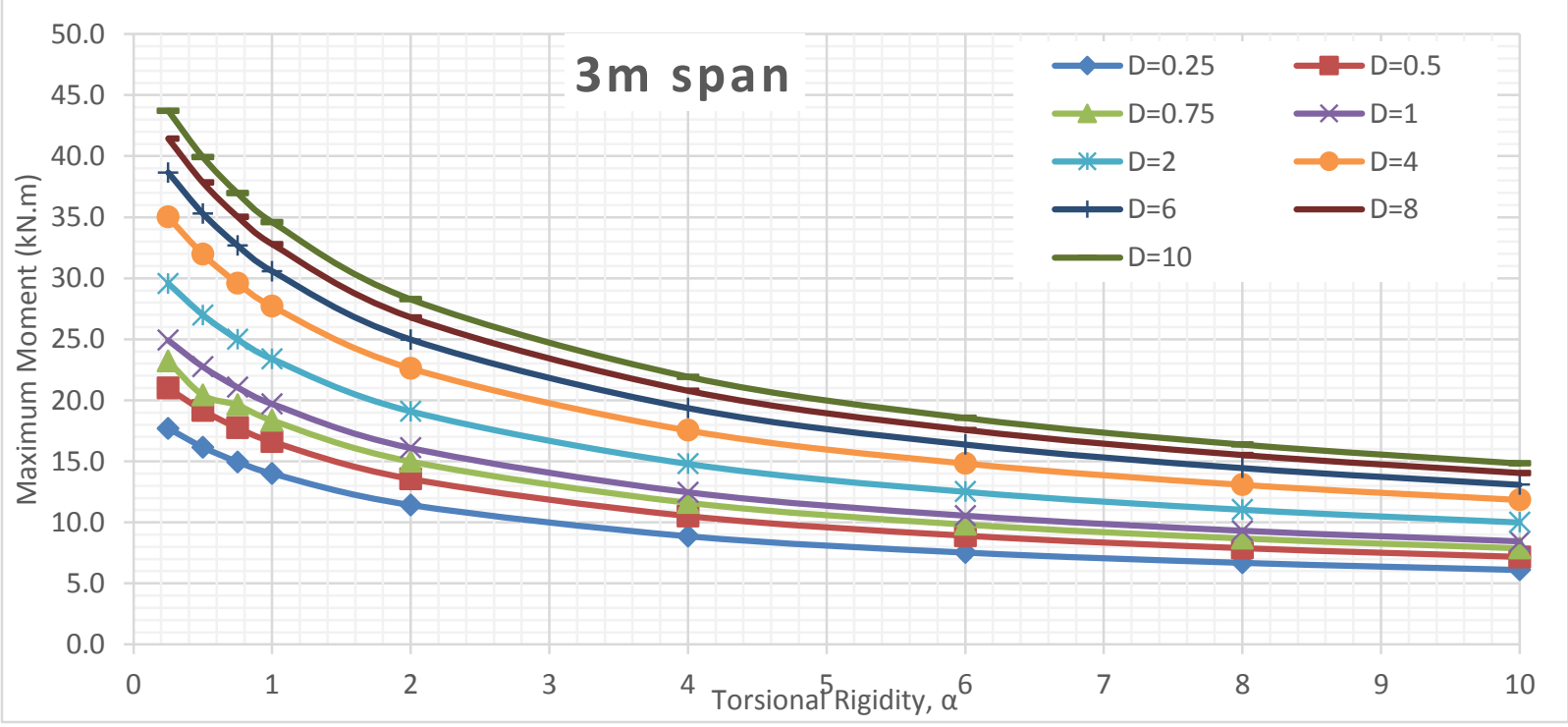

Figure 95 Maximum moment of $3 \mathrm{~m}$ span slab subjected to CHBDC axle 4 for different D values FEA analyses 


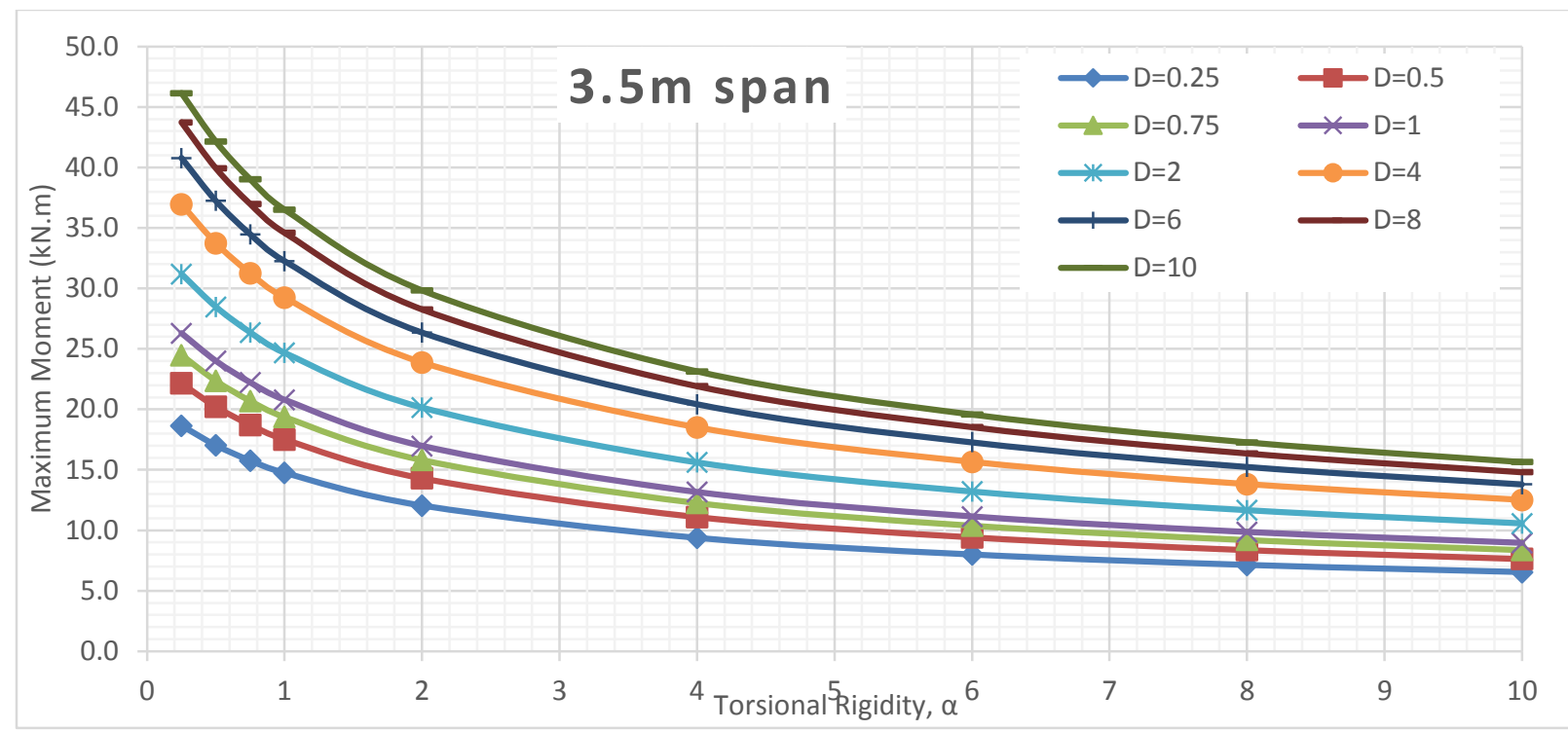

Figure 96 Maximum moment of $3.5 \mathrm{~m}$ span slab subjected to CHBDC axle 4 for different D values FEA analyses

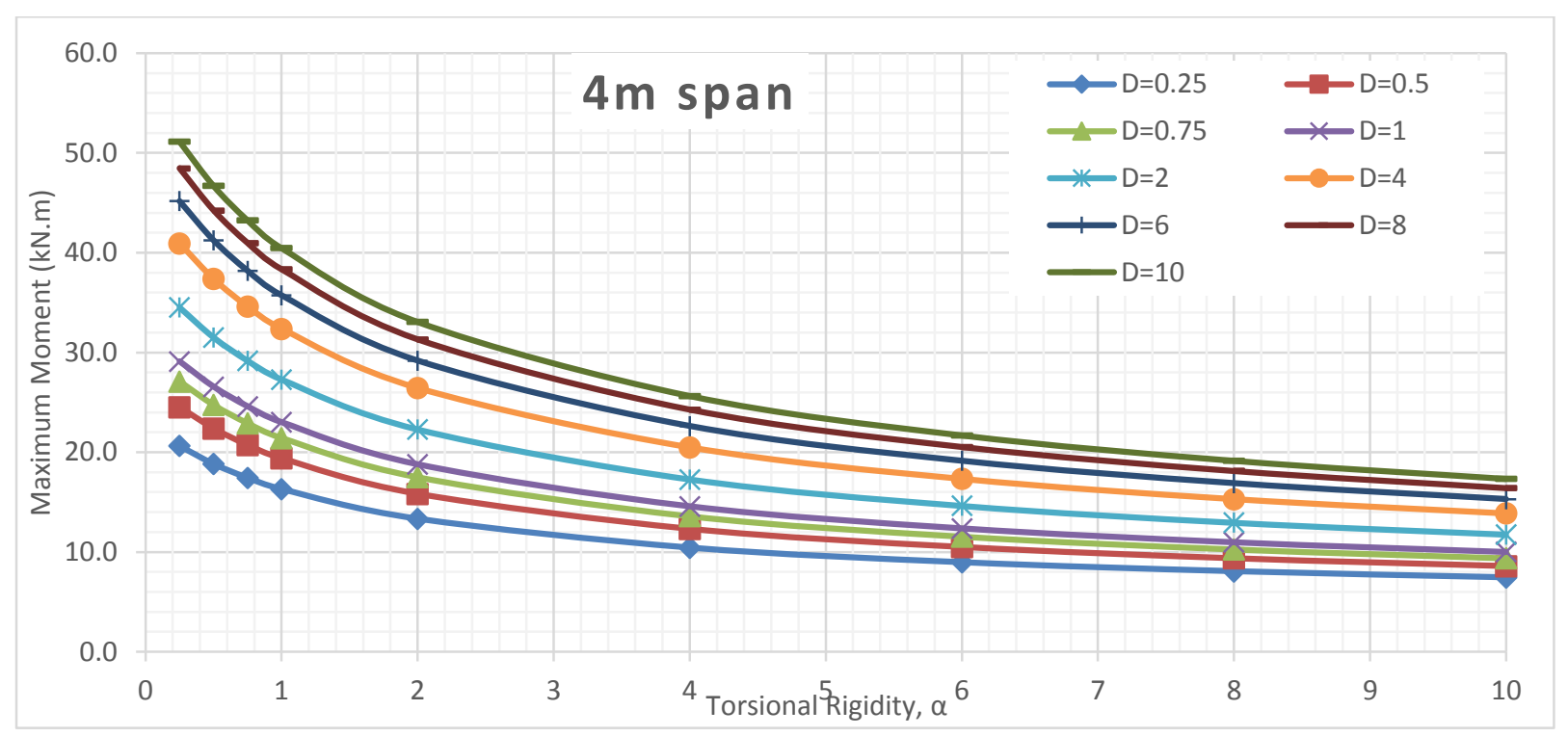

Figure 97 Maximum moment of $4 \mathrm{~m}$ span slab subjected to CHBDC axle 4 for different D values FEA analyses 


\section{Axle 2 \&3 Bending Moment VS Torsional Rigidity for Different D Values at Different span length}

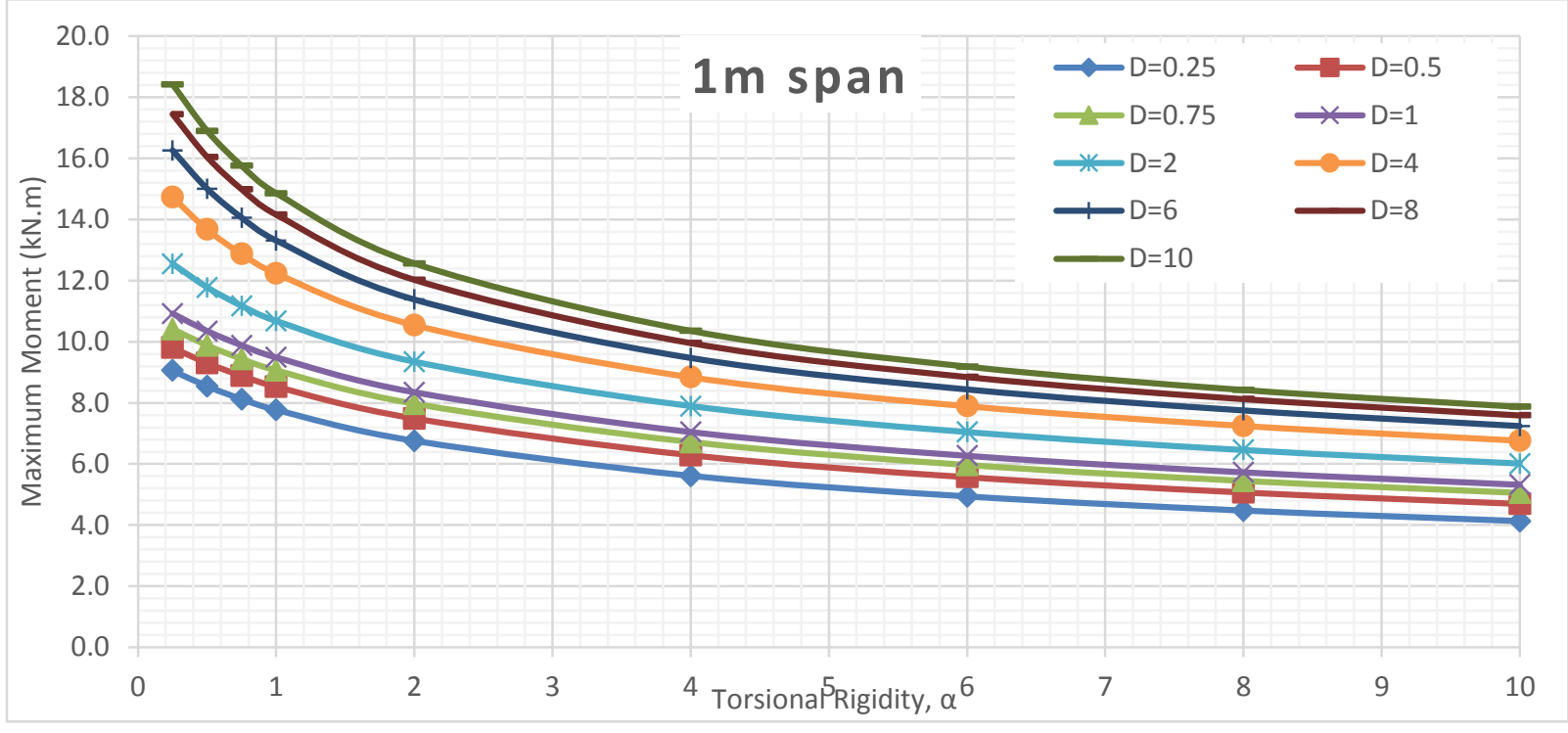

Figure 98 Maximum moment of $1 \mathrm{~m}$ span slab subjected to CHBDC axle 2 \& 3 for different D values FEA analyses

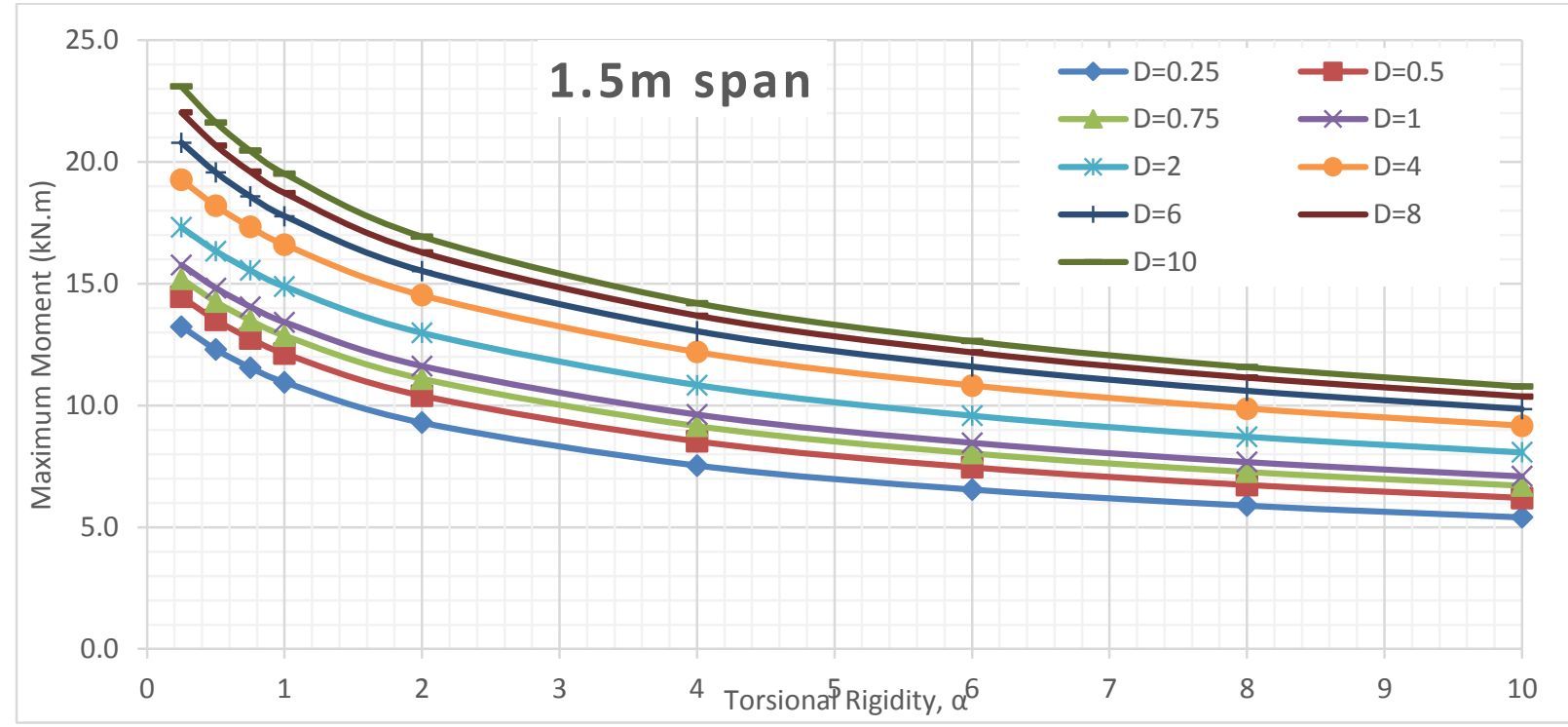

Figure 99 Maximum moment of $1.5 \mathrm{~m}$ span slab subjected to CHBDC axle 2 \& 3 for different D values FEA analyses 


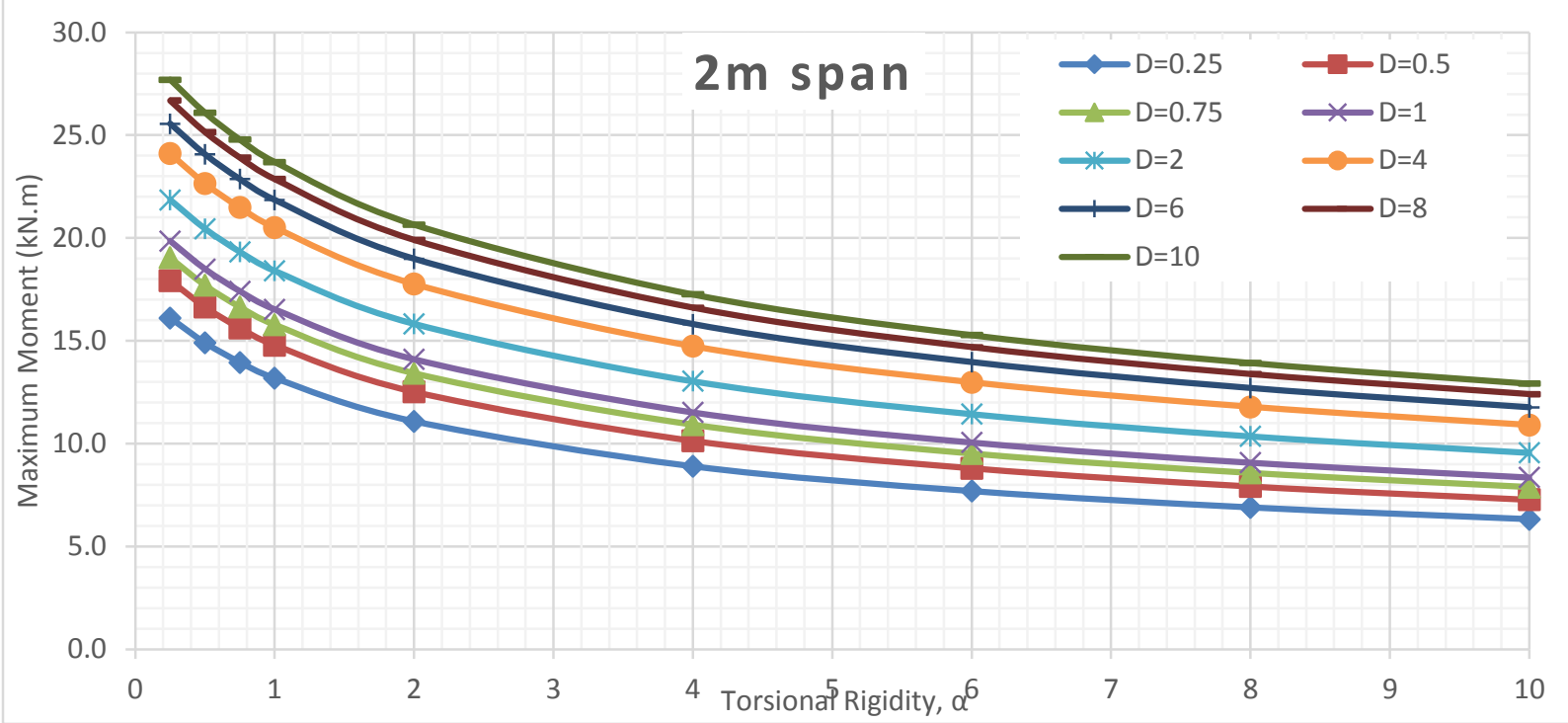

Figure 100 Maximum moment of $2 \mathrm{~m}$ span slab subjected to CHBDC axle 2 \& 3 for different $D$ values FEA analyses

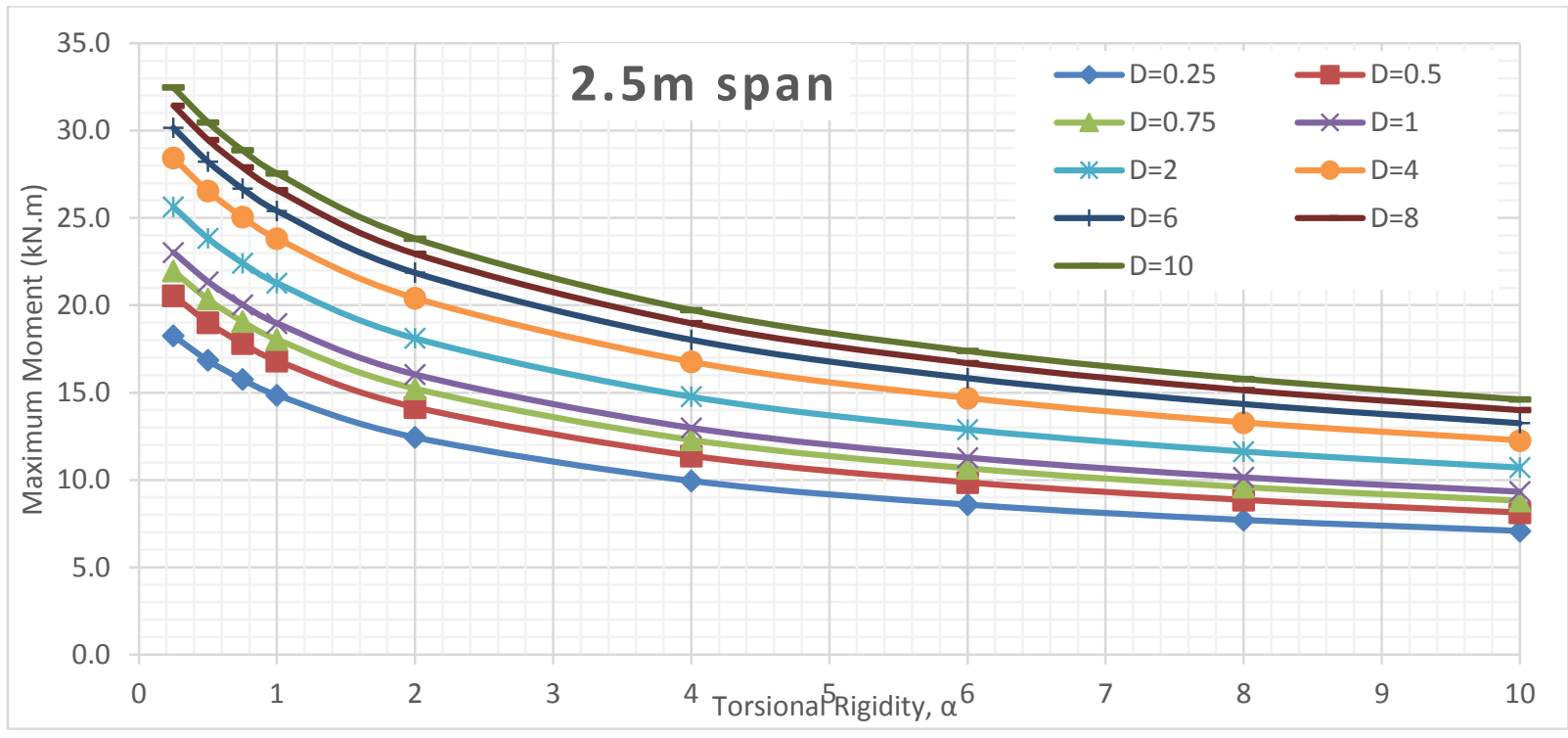

Figure 101 Maximum moment of $2.5 \mathrm{~m}$ span slab subjected to CHBDC axle 2 \& 3 for different D values FEA analyses

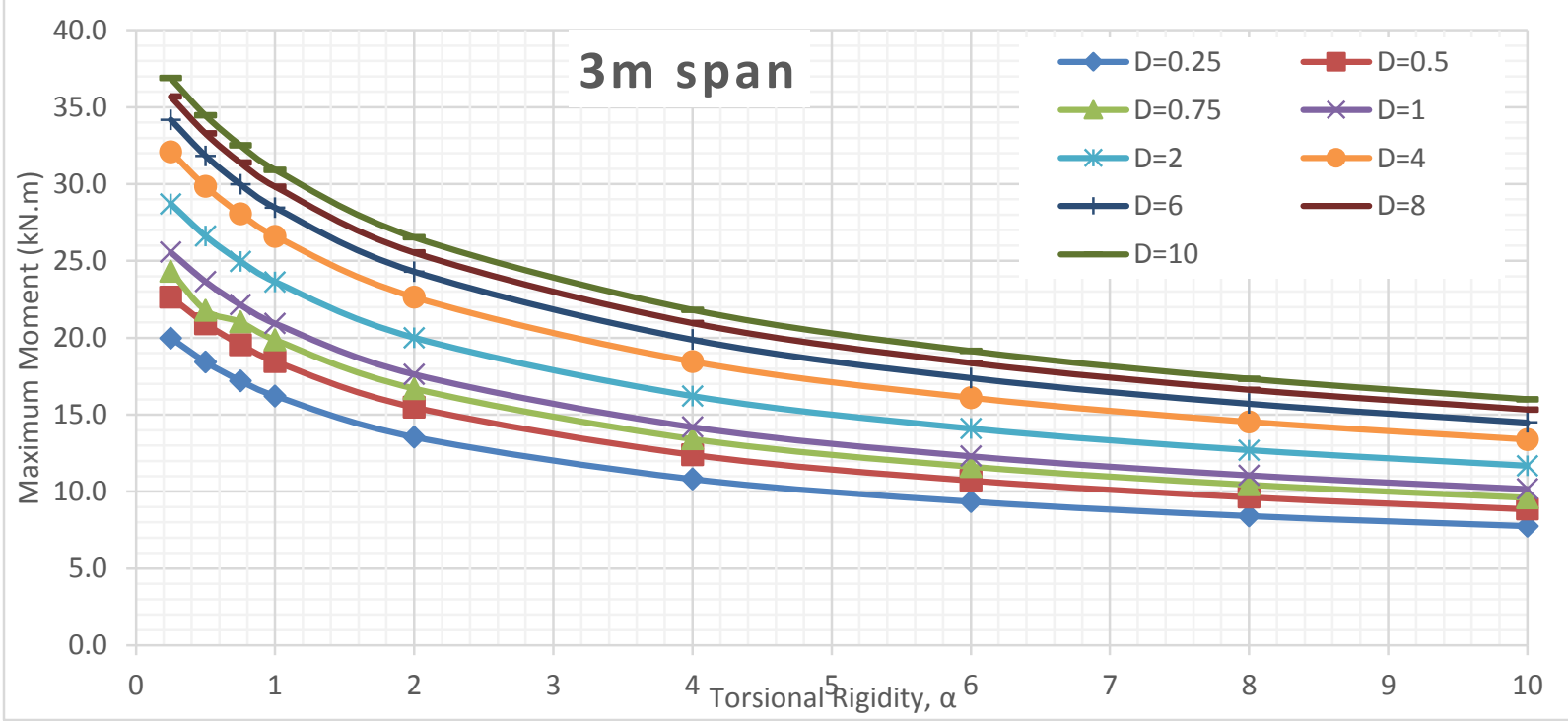

Figure 102 Maximum moment of $3 \mathrm{~m}$ span slab subjected to CHBDC axle 2 \& 3 for different D values FEA analyses 


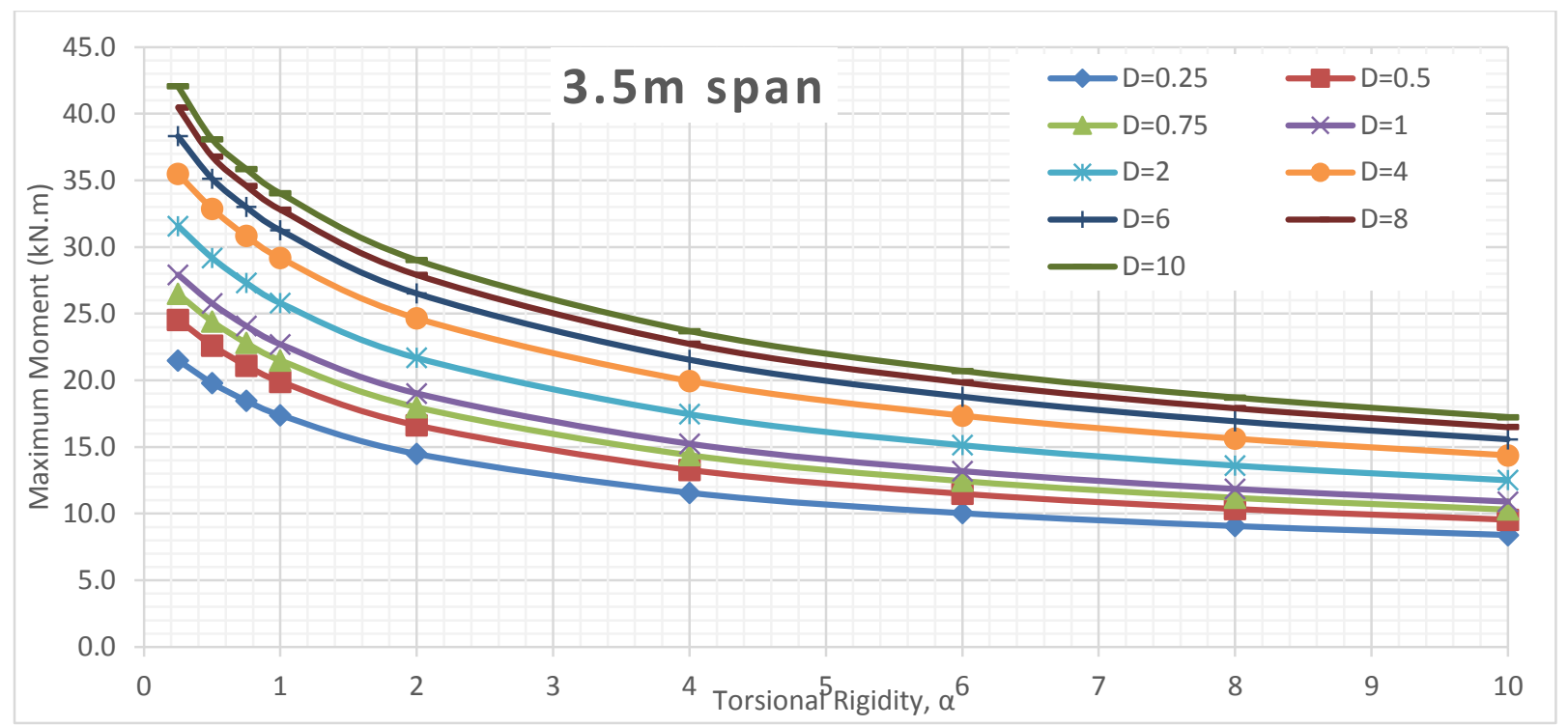

Figure 103 Maximum moment of $3.5 \mathrm{~m}$ span slab subjected to CHBDC axle 2 \& 3 for different D values FEA analyses

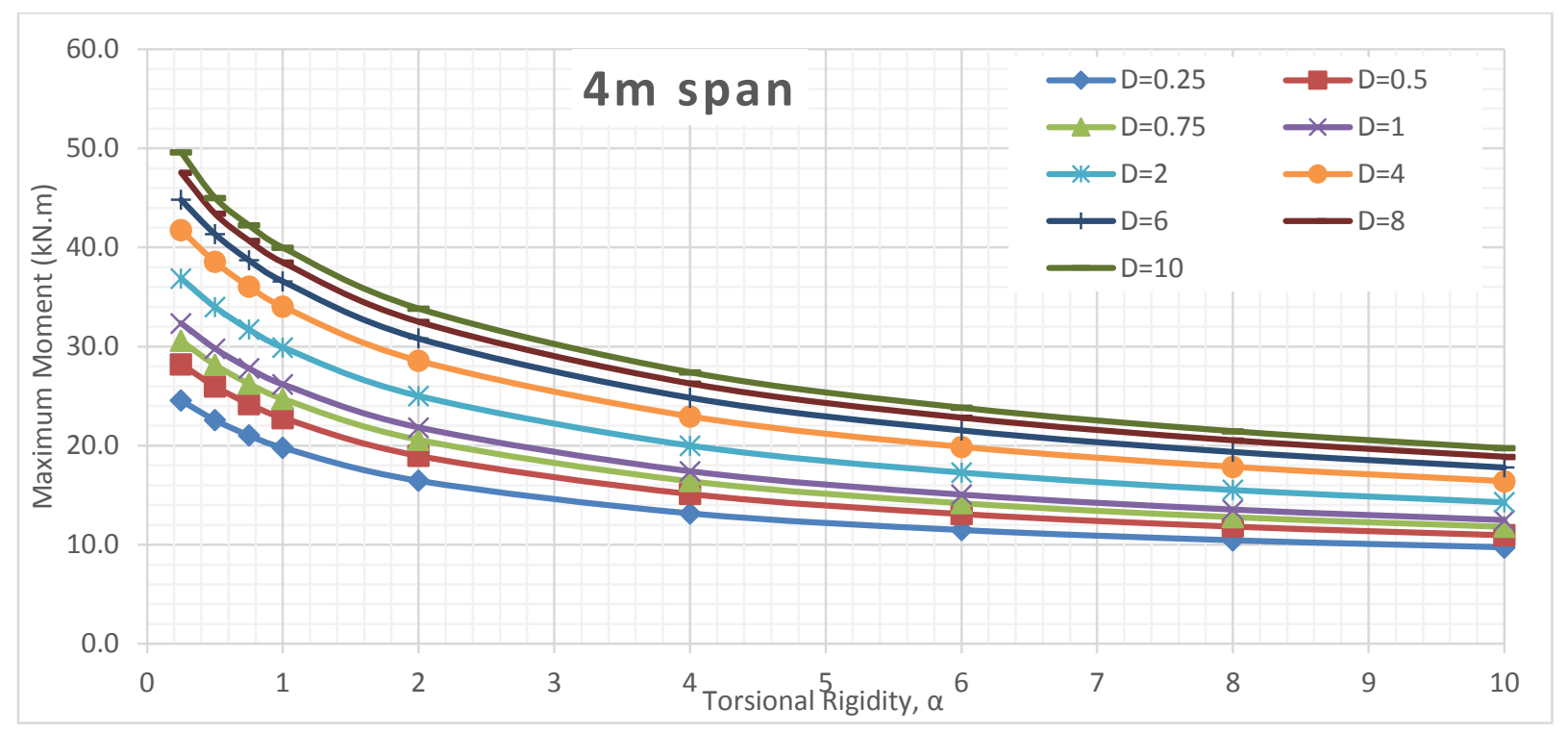

Figure 104 Maximum moment of $4 \mathrm{~m}$ span slab subjected to CHBDC axle $2 \& 3$ for different D values FEA analyses 


\section{Truck Bending Moment VS Torsional Rigidity for Different D Values at Different span length}

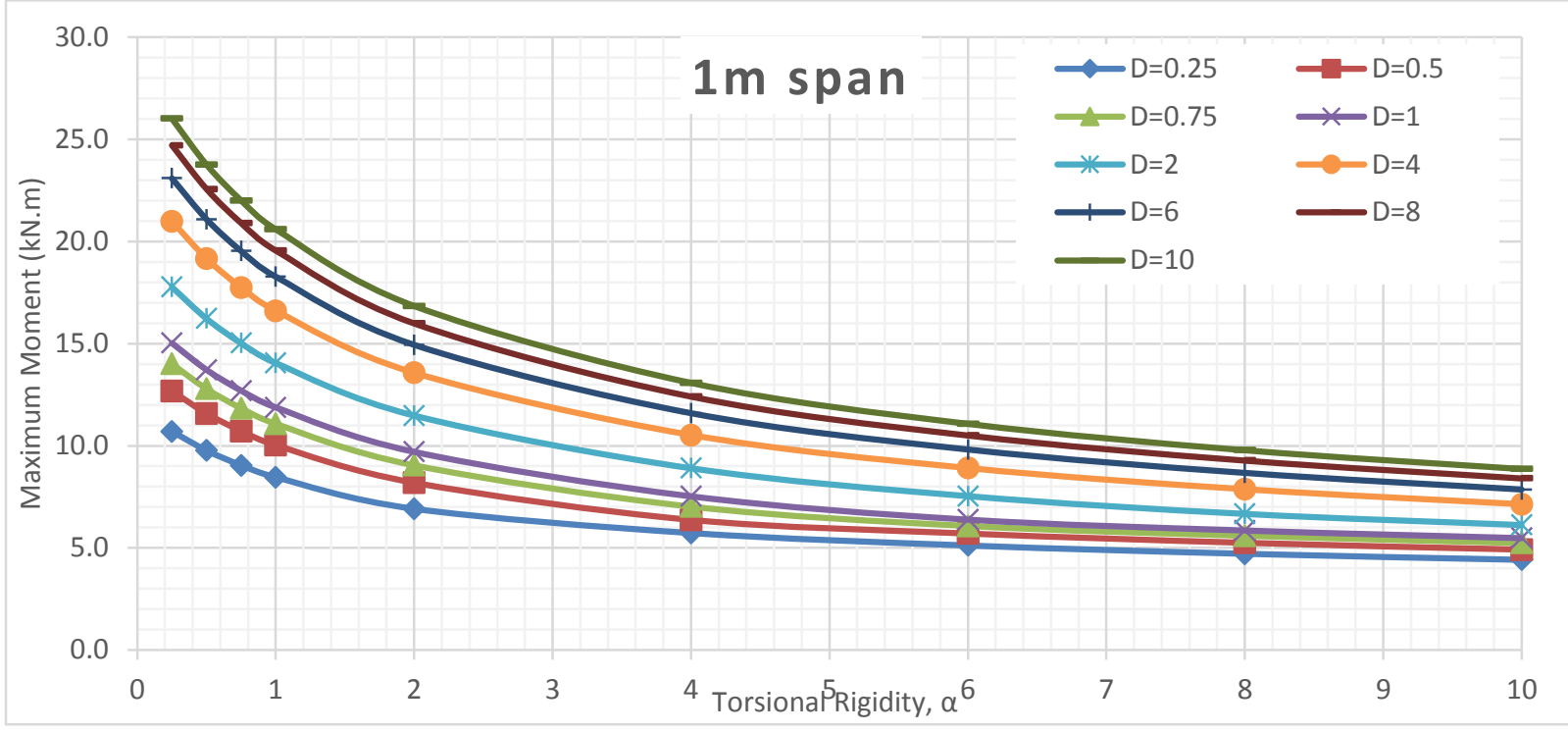

Figure 105 Maximum moment of $1 \mathrm{~m}$ span slab subjected to CHBDC truck for different D values FEA analyses

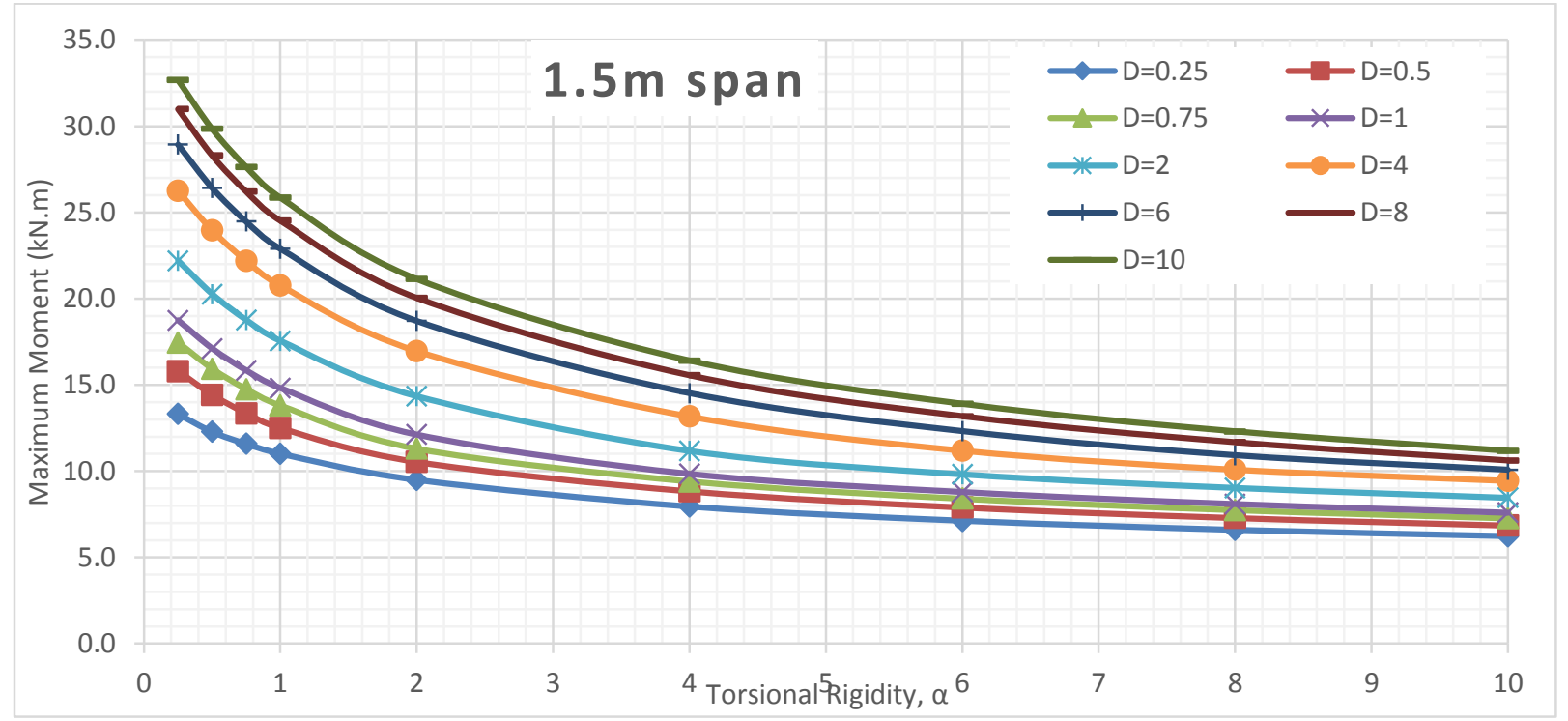

Figure 106 Maximum moment of $1.5 \mathrm{~m}$ span slab subjected to CHBDC truck for different D values FEA analyses 


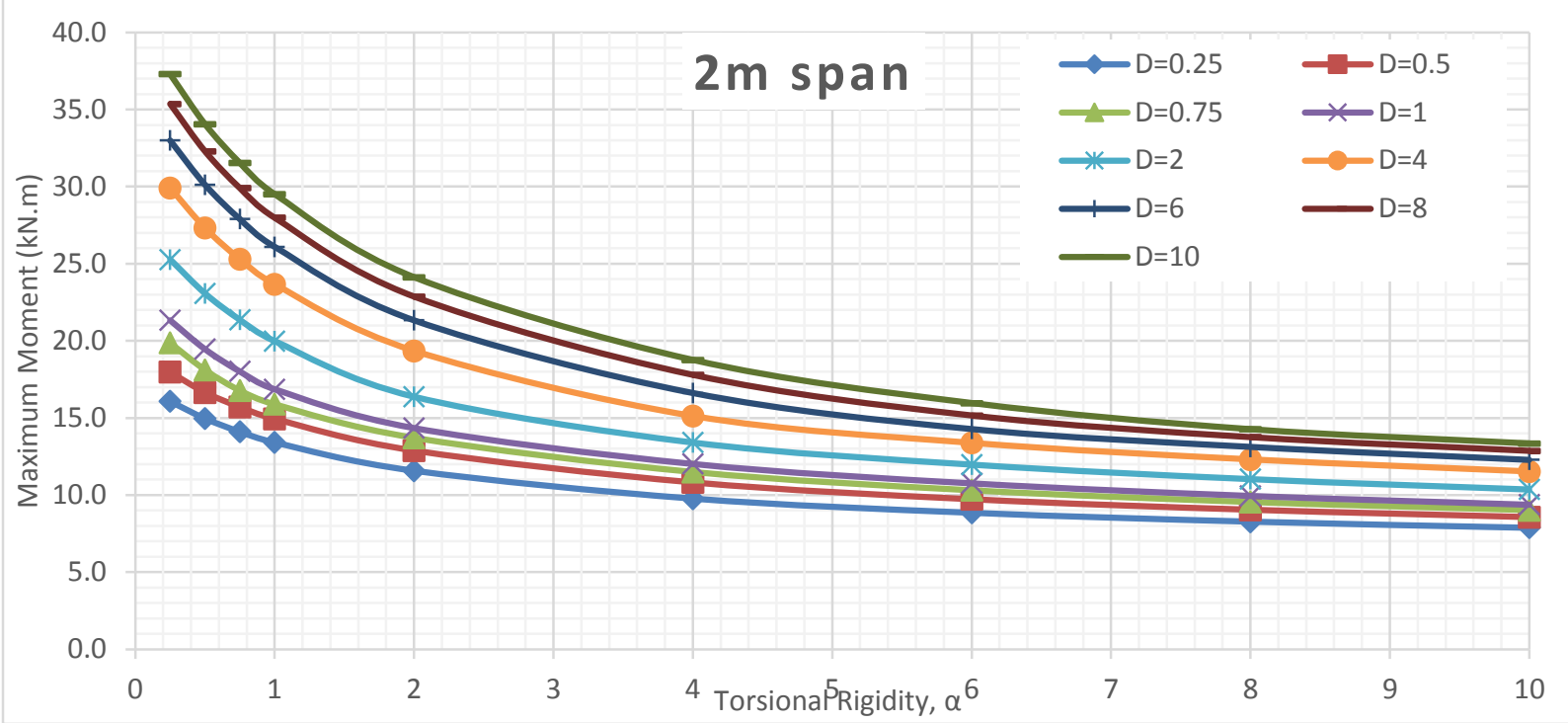

Figure 107 Maximum moment of $2 \mathrm{~m}$ span slab subjected to CHBDC truck for different D values FEA analyses

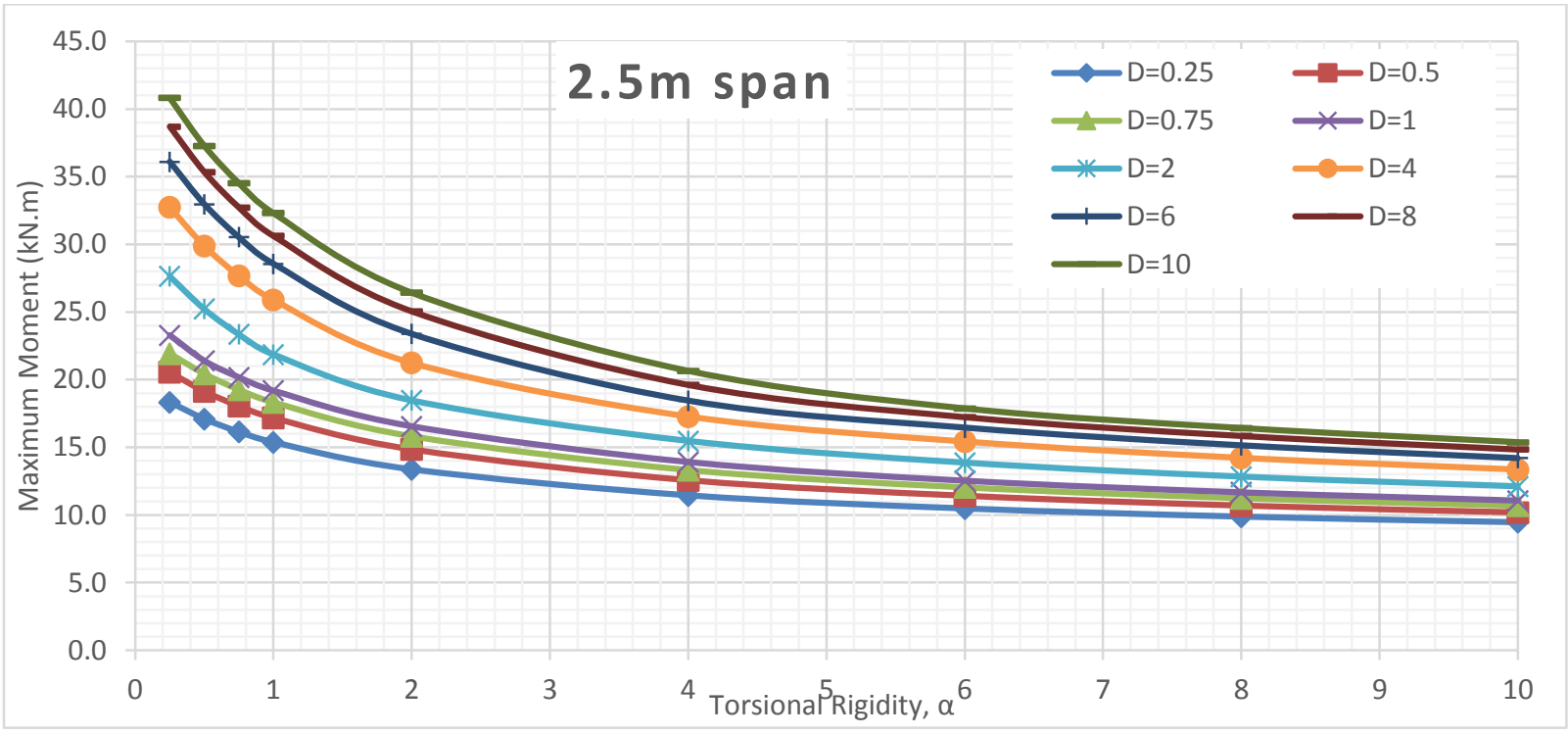

Figure 108 Maximum moment of $2.5 \mathrm{~m}$ span slab subjected to CHBDC truck for different D values FEA analyses

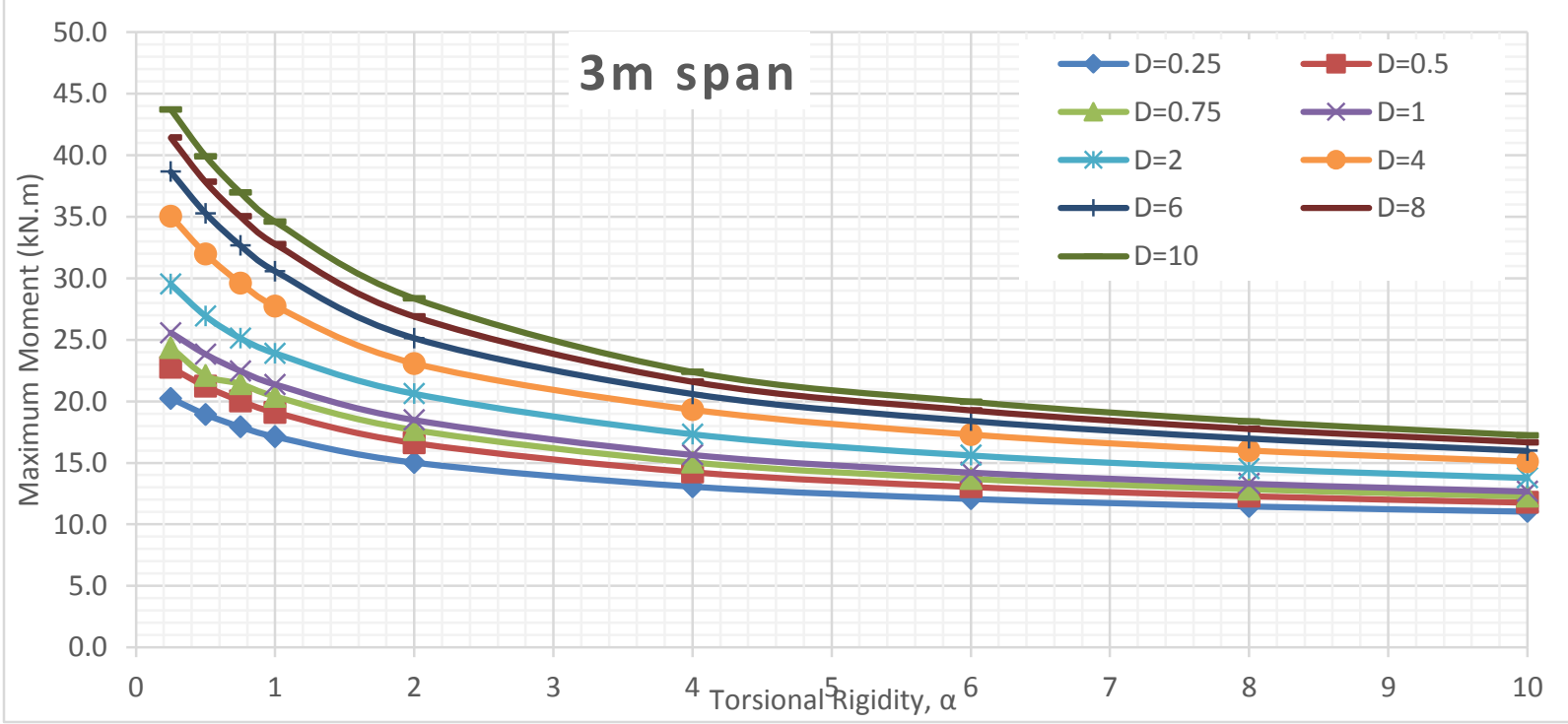

Figure 109 Maximum moment of $3 \mathrm{~m}$ span slab subjected to CHBDC truck for different D values FEA analyses 


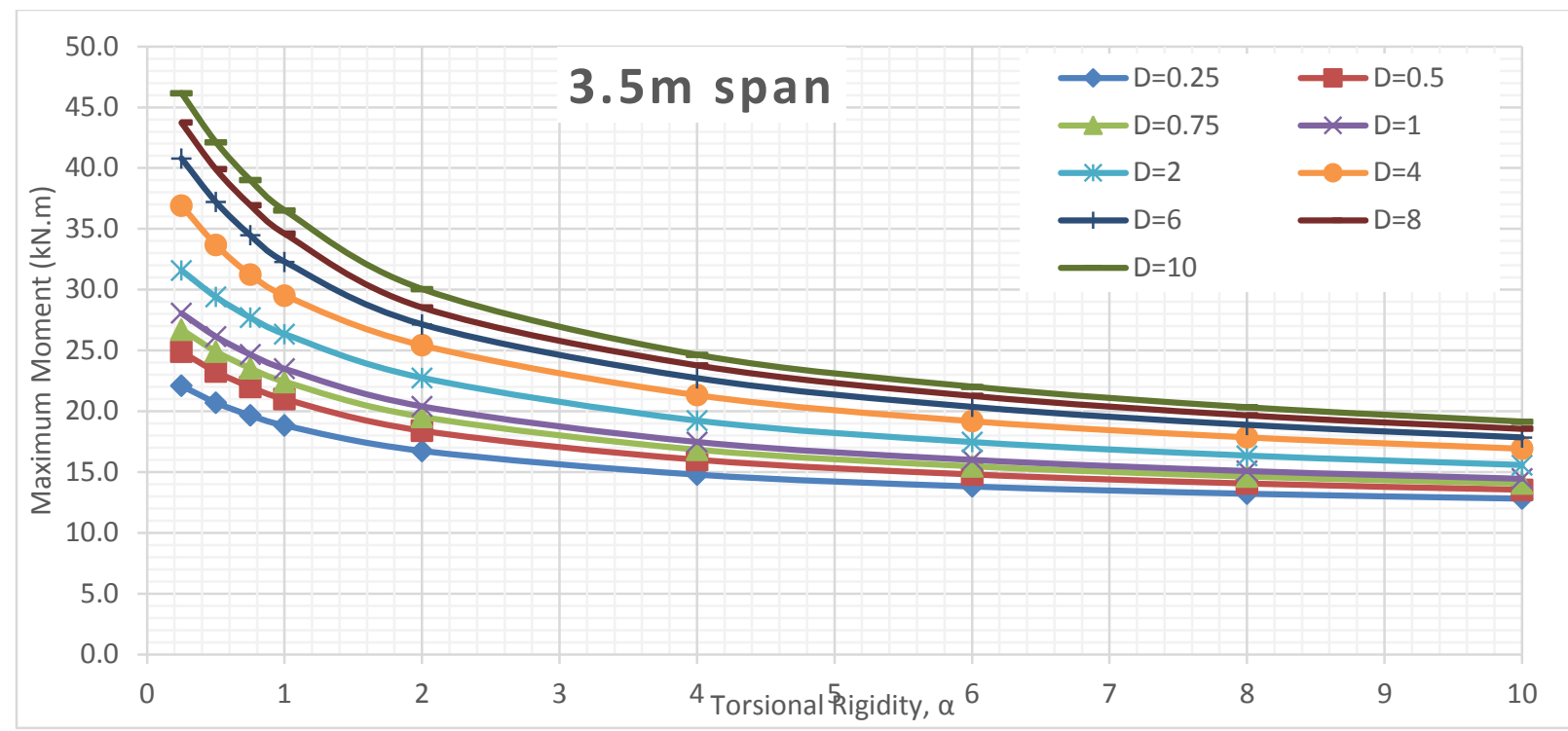

Figure 110 Maximum moment of $3.5 \mathrm{~m}$ span slab subjected to CHBDC truck for different D values FEA analyses

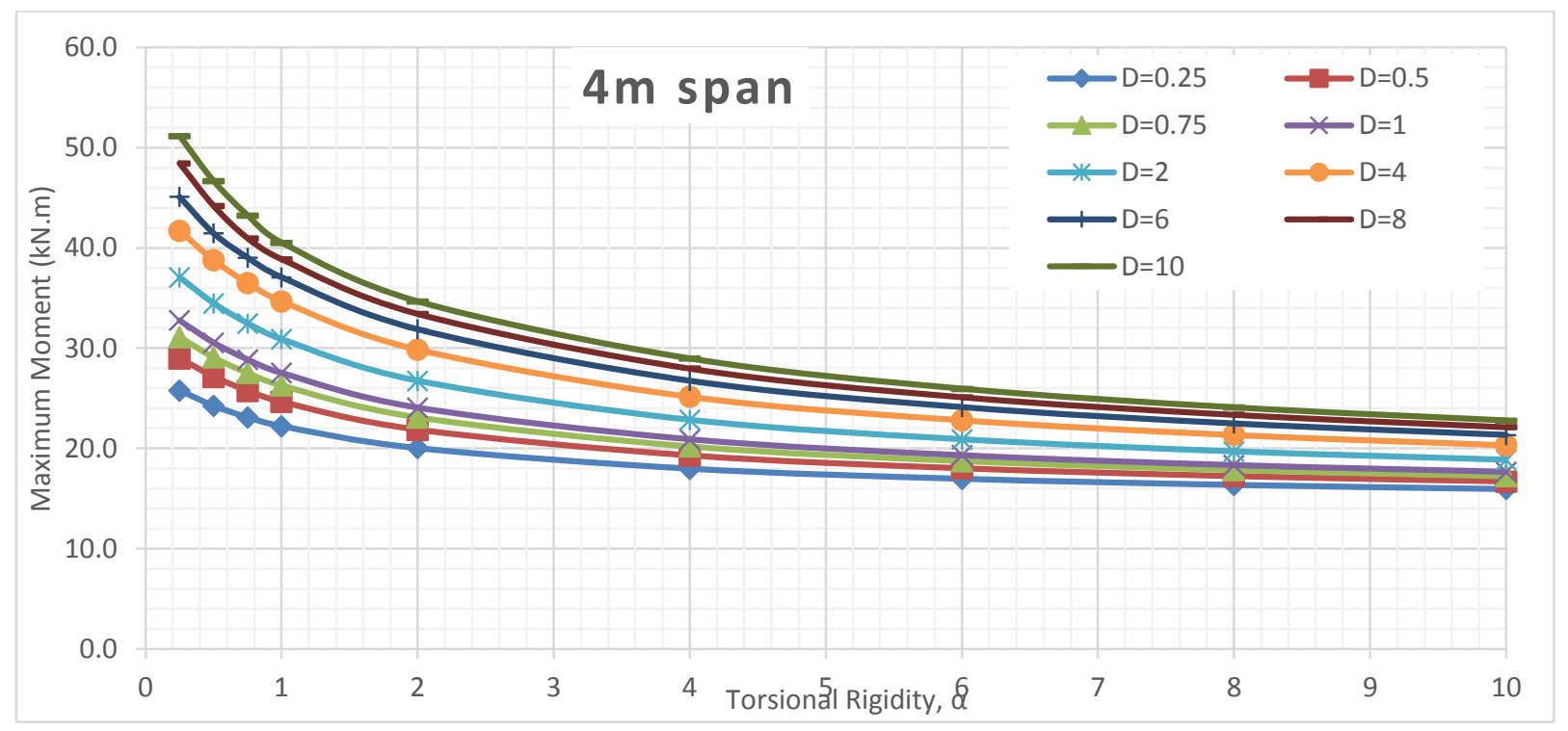

Figure 111 Maximum moment of $4 \mathrm{~m}$ span slab subjected to CHBDC truck for different D values FEA analyses 


\section{Axle 4 Transverse Bending Moment VS Torsional Rigidity for Different D Values at Different span length}

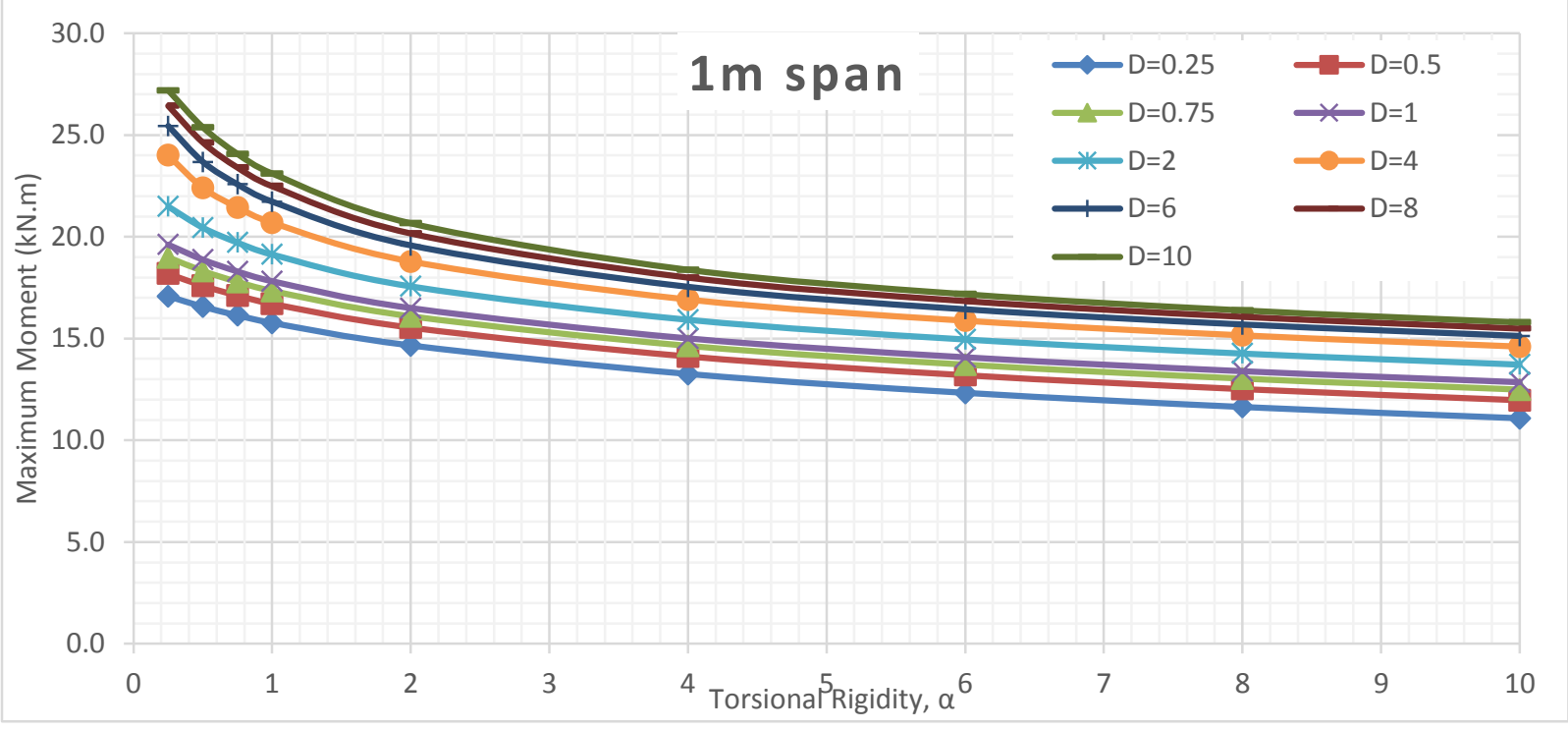

Figure 112 Maximum moment of $1 \mathrm{~m}$ span slab subjected to CHBDC axle 4 for different D values FEA analyses

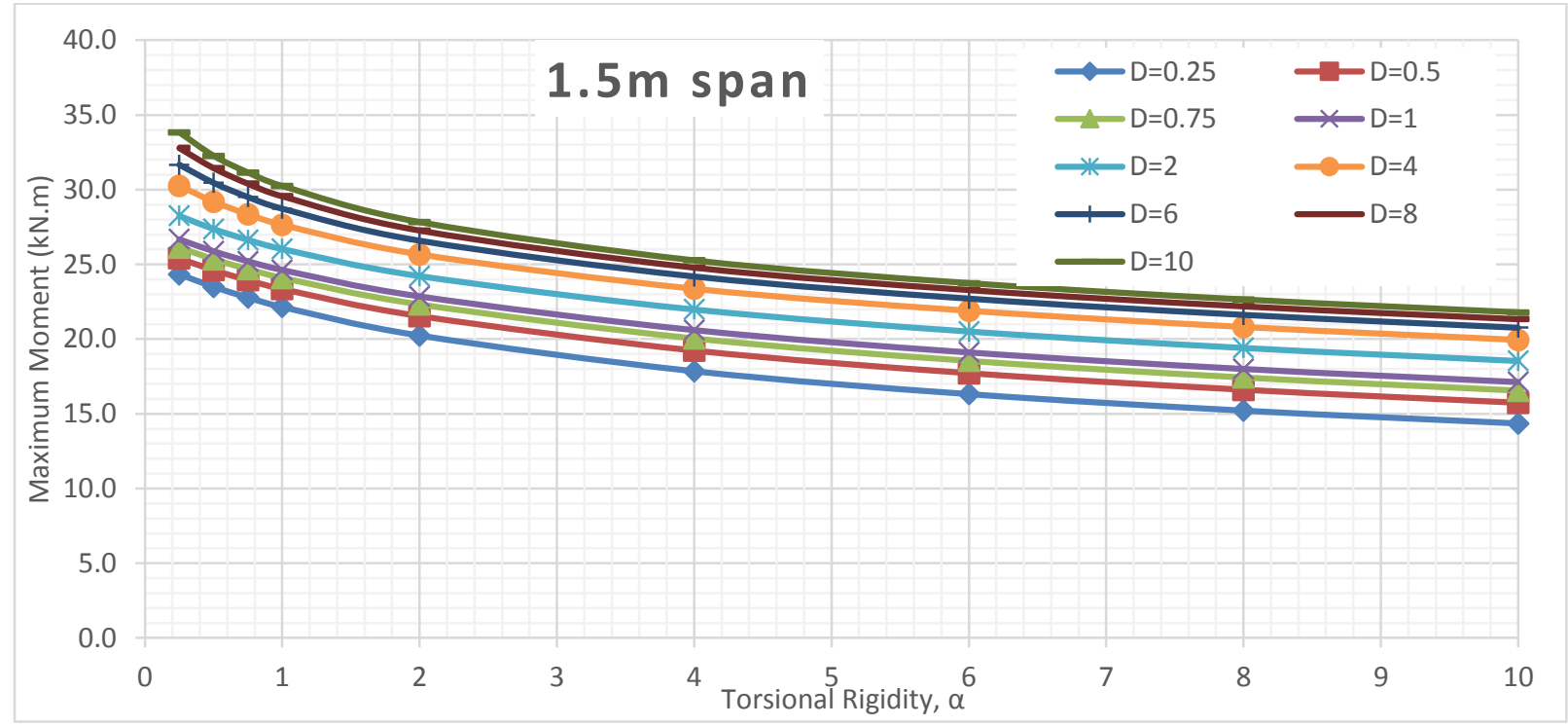

Figure 113 Maximum moment of $1.5 \mathrm{~m}$ span slab subjected to CHBDC axle 4 for different $D$ values FEA analyses 


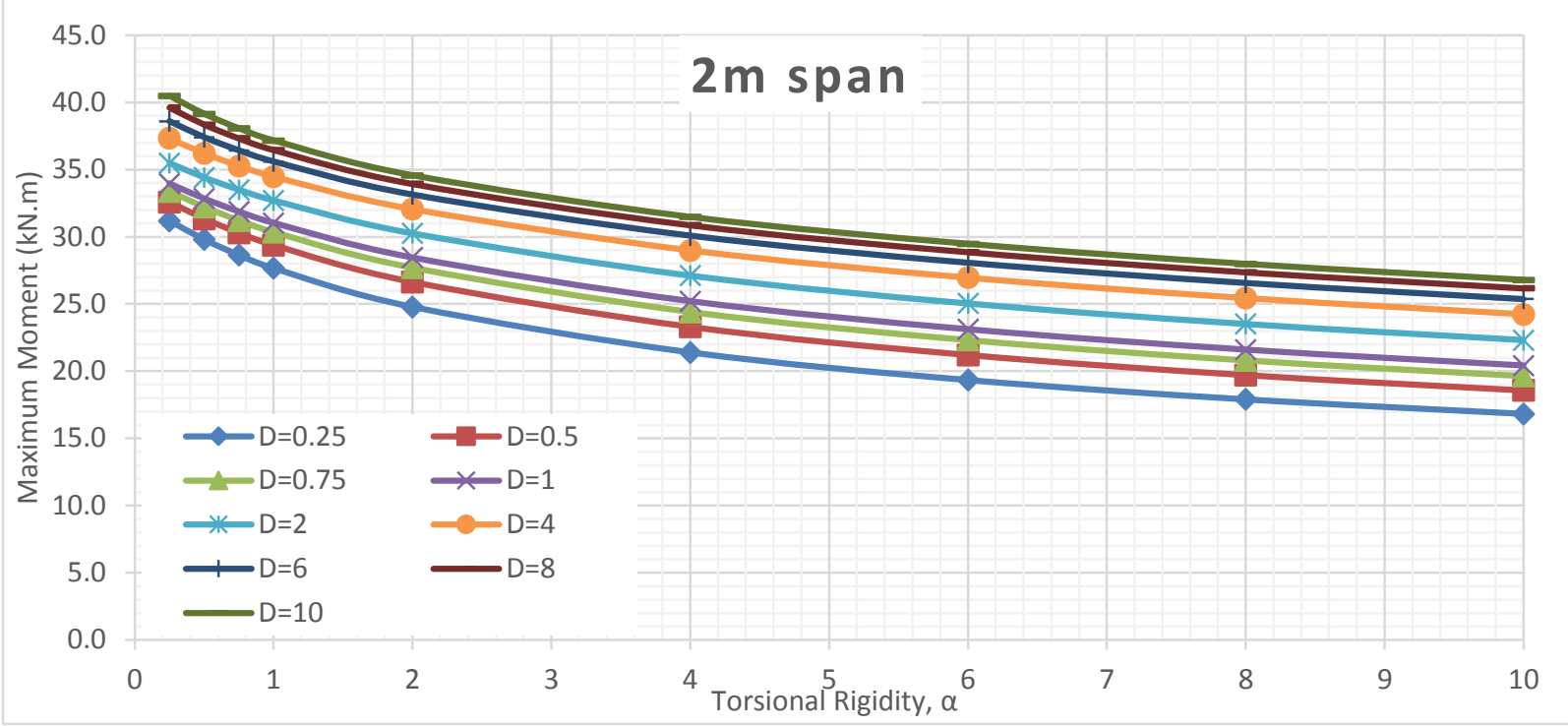

Figure 114 Maximum moment of $2 \mathrm{~m}$ span slab subjected to CHBDC axle 4 for different D values FEA analyses

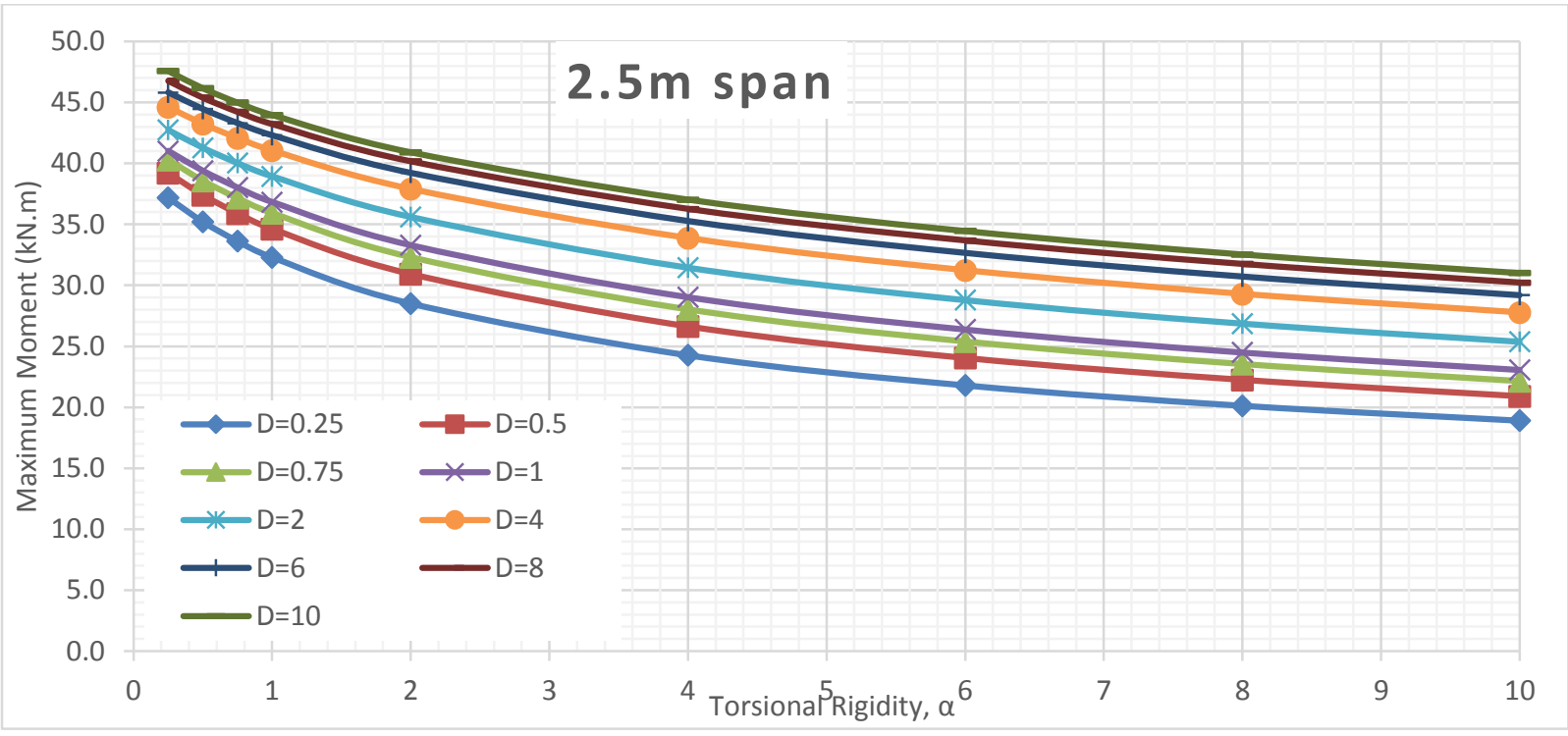

Figure 115 Maximum moment of $2.5 \mathrm{~m}$ span slab subjected to CHBDC axle 4 for different D values FEA analyses

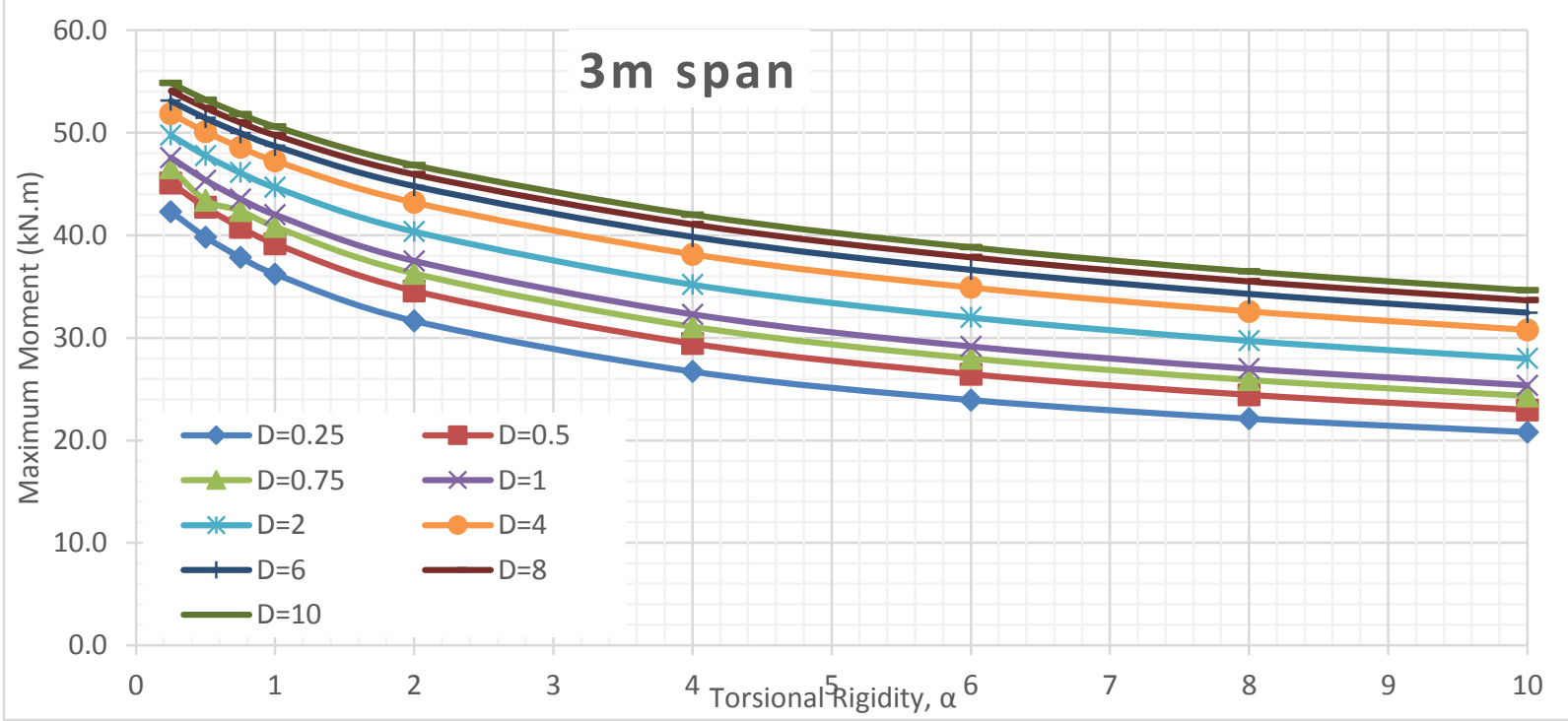

Figure 116 Maximum moment of $3 \mathrm{~m}$ span slab subjected to CHBDC axle 4 for different D values FEA analyses 


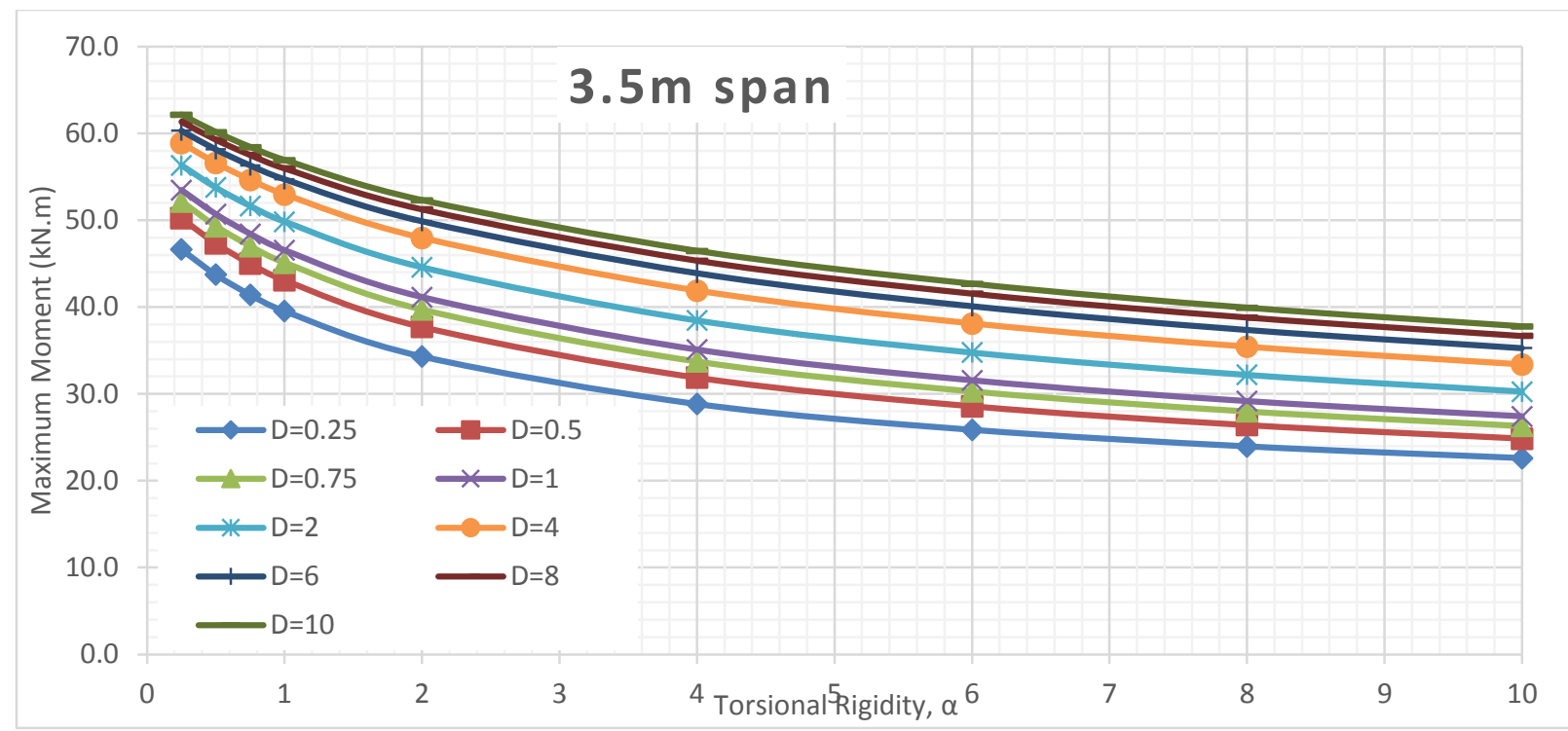

Figure 117 Maximum moment of $3.5 \mathrm{~m}$ span slab subjected to $\mathrm{CHBDC}$ axle 4 for different $\mathrm{D}$ values FEA analyses 


\section{Axle 2 \& 3 Transverse Bending Moment VS Torsional Rigidity for Different D Values at Different span length}

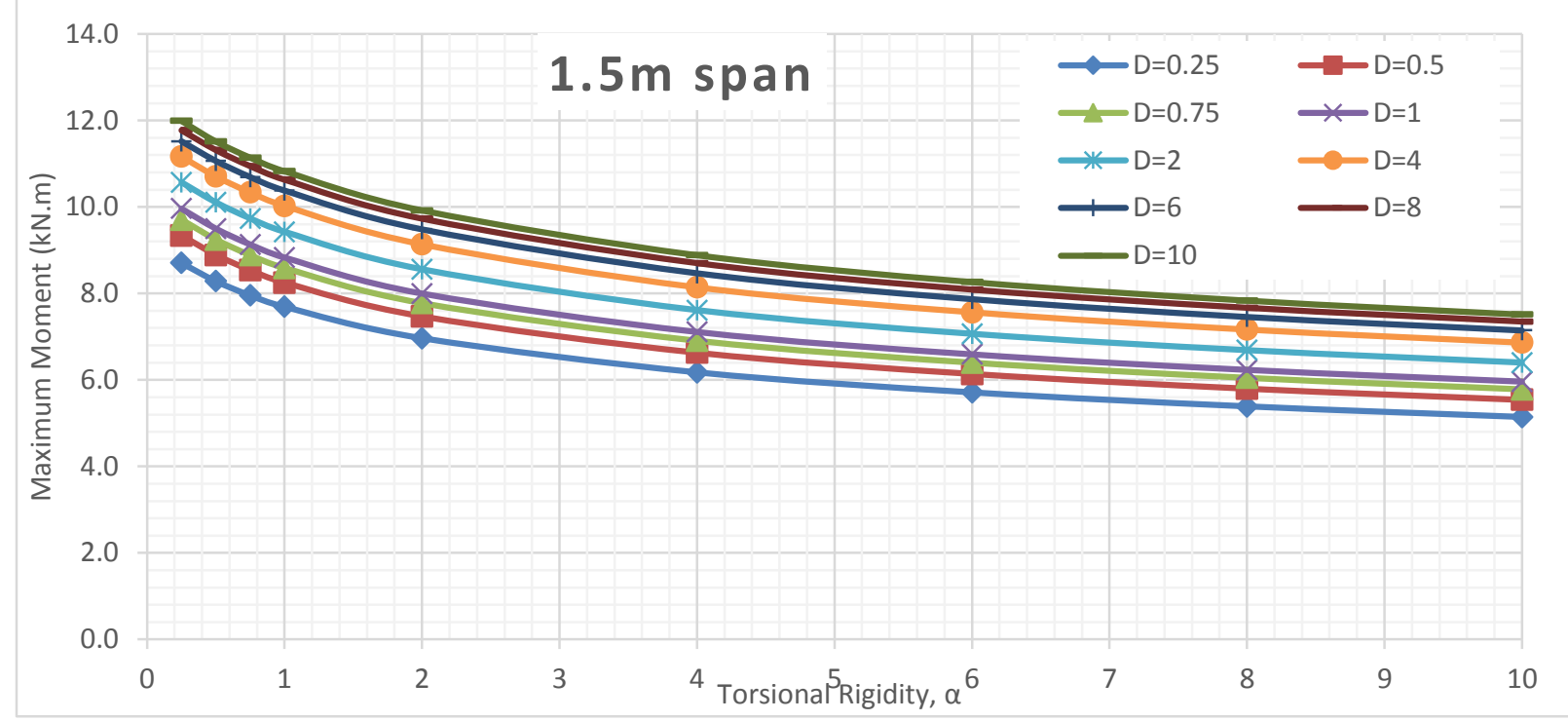

Figure 118 Maximum moment of $1.5 \mathrm{~m}$ span slab subjected to CHBDC axle 2 \& 3 for different D values FEA analyses

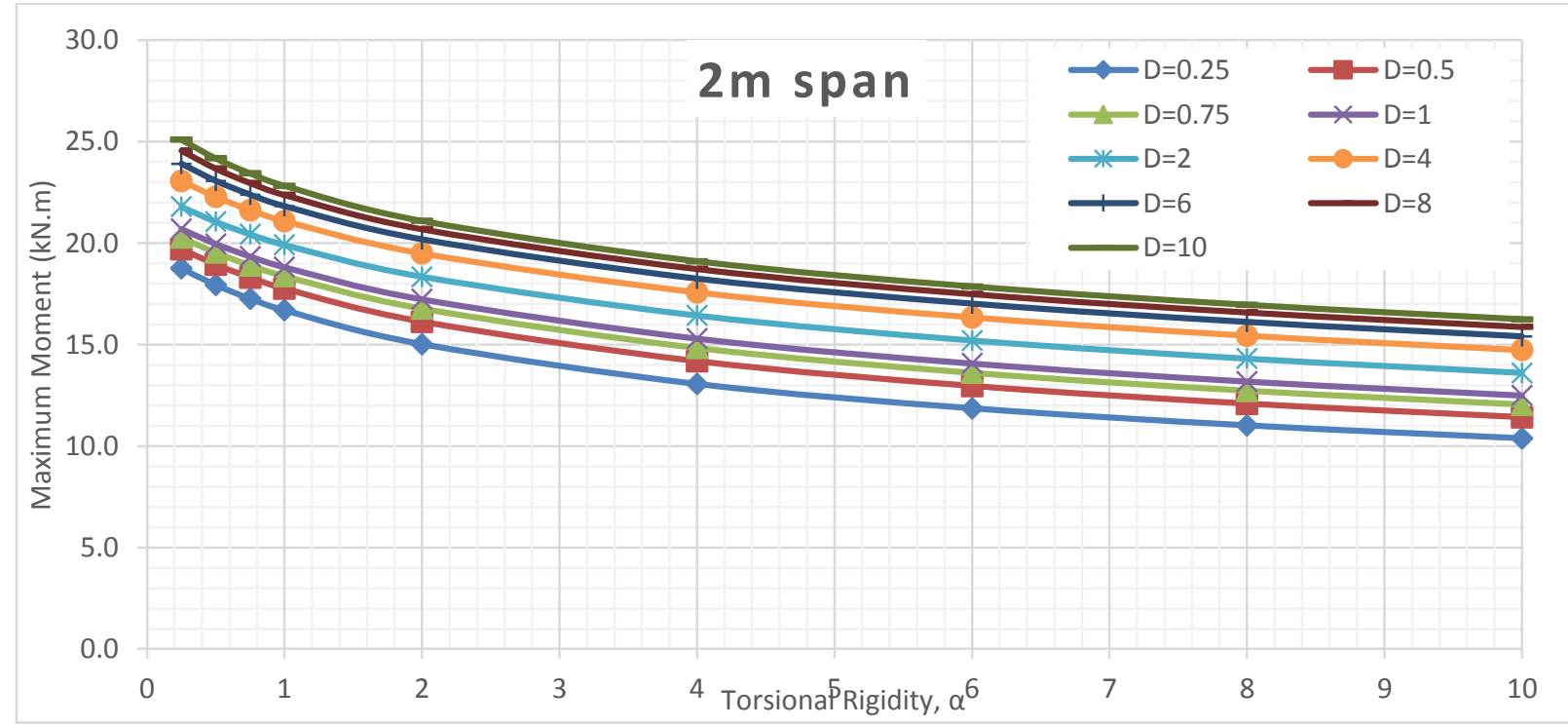

Figure 119 Maximum moment of $2 \mathrm{~m}$ span slab subjected to CHBDC axle 2 \& 3 for different $D$ values FEA analyses 


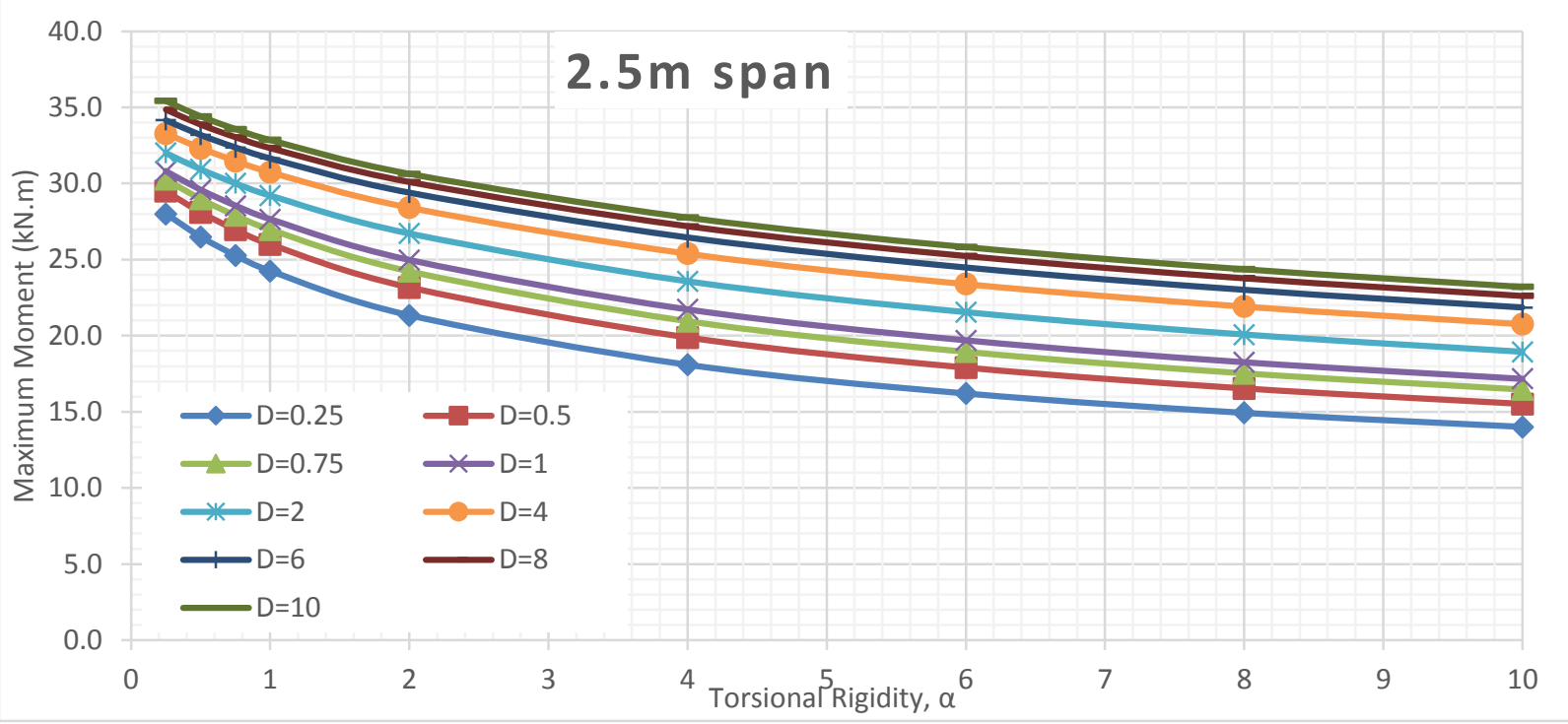

Figure 120 Maximum moment of $2.5 \mathrm{~m}$ span slab subjected to CHBDC axle 2 \& 3 for different D values FEA analyses

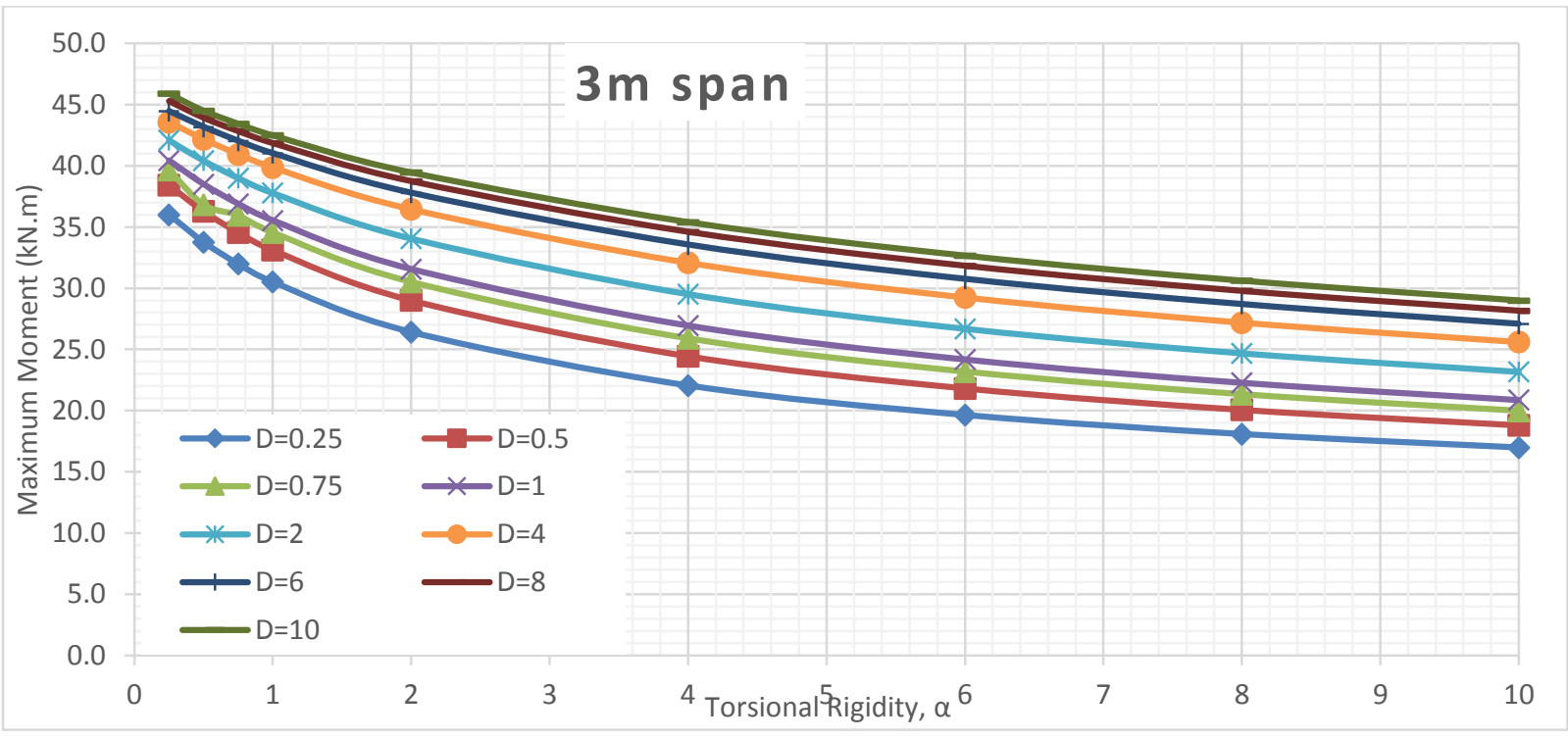

Figure 121 Maximum moment of $3 \mathrm{~m}$ span slab subjected to CHBDC axle 2 \& 3 for different $\mathrm{D}$ values FEA analyses

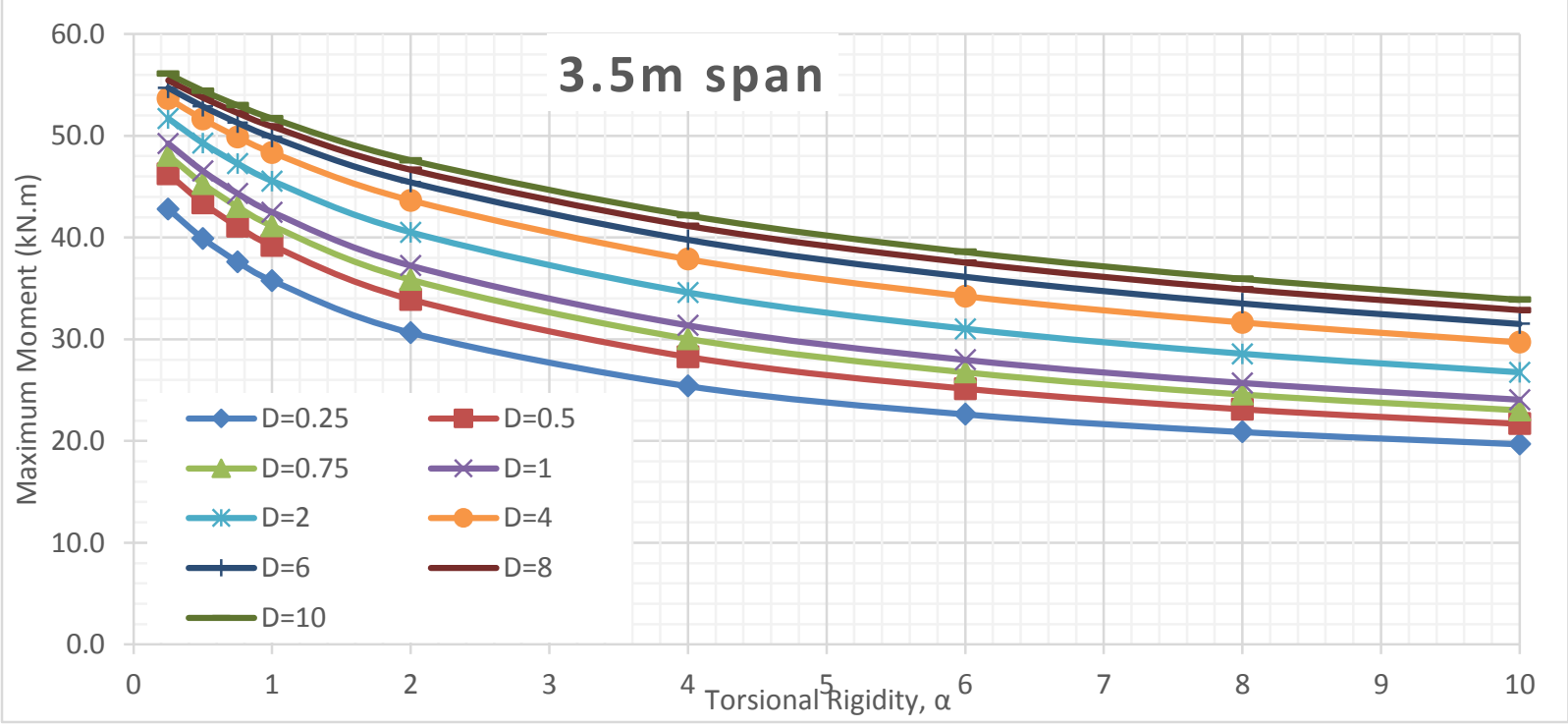

Figure 122 Maximum moment of $3.5 \mathrm{~m}$ span slab subjected to CHBDC axle 2 \& 3 for different D values FEA analyses 


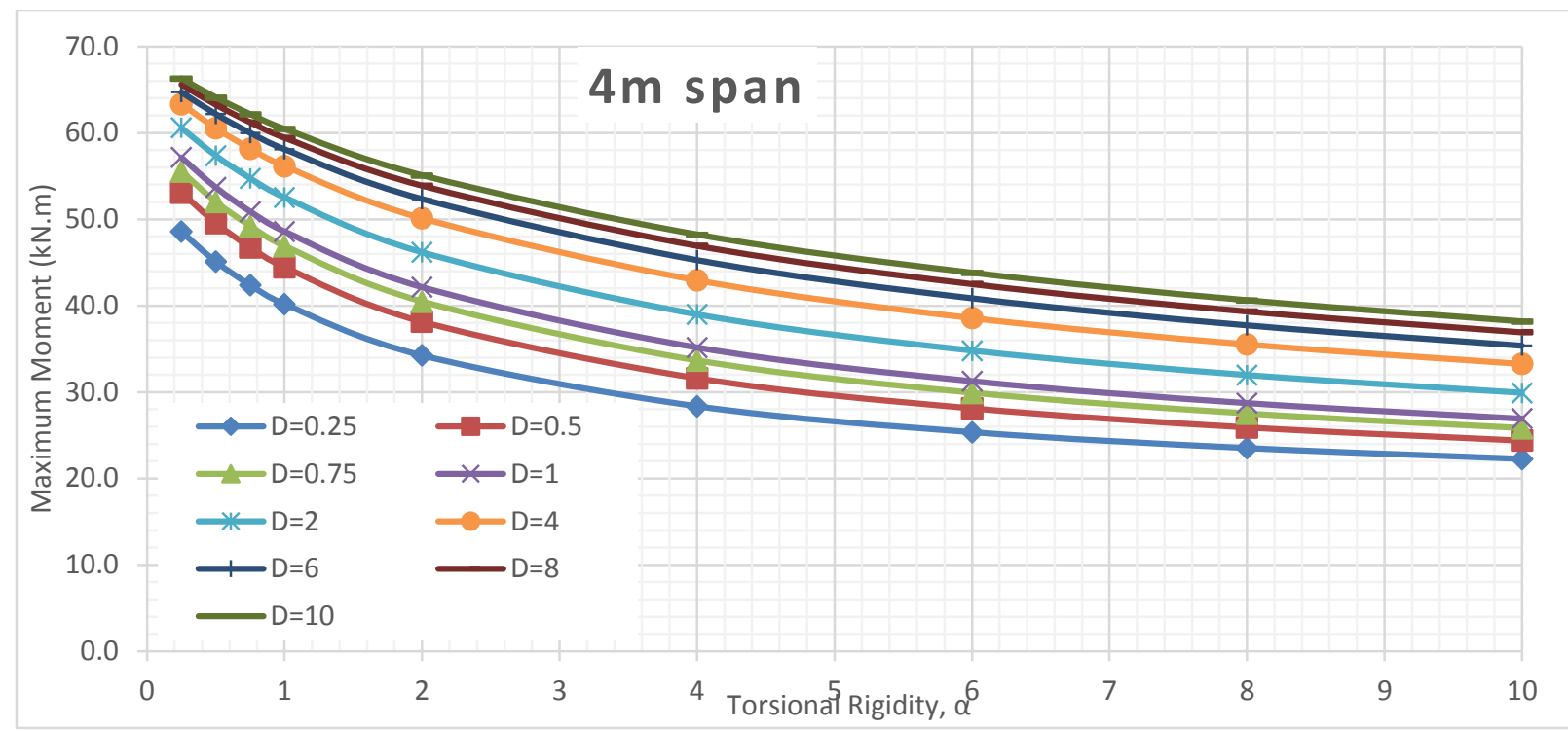

Figure 123 Maximum moment of $4 \mathrm{~m}$ span slab subjected to CHBDC axle 2 \& 3 for different D values FEA analyses 
B.2 Finite Element Analysis Results (Deflection) 


\section{B.2.1 DEFLECTION RESULTS TABLES}




\section{Alpha 0.25 Deflection Results}

Table 55 Maximum deflection results for alpha 0.25 for slabs subjected to CHBDC axle 4 loading (main bars perpendicular to traffic)

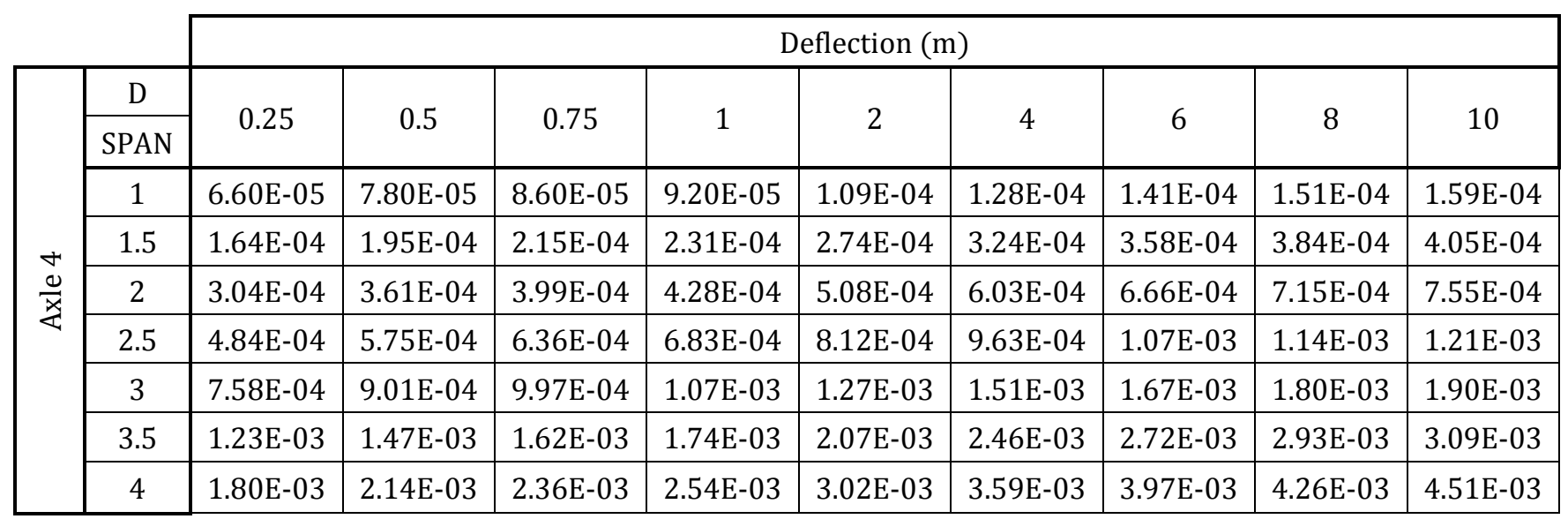

Table 56 Maximum deflection results for alpha 0.25 for slabs subjected to CHBDC axle $2 \& 3$ loading (main bars perpendicular to traffic)

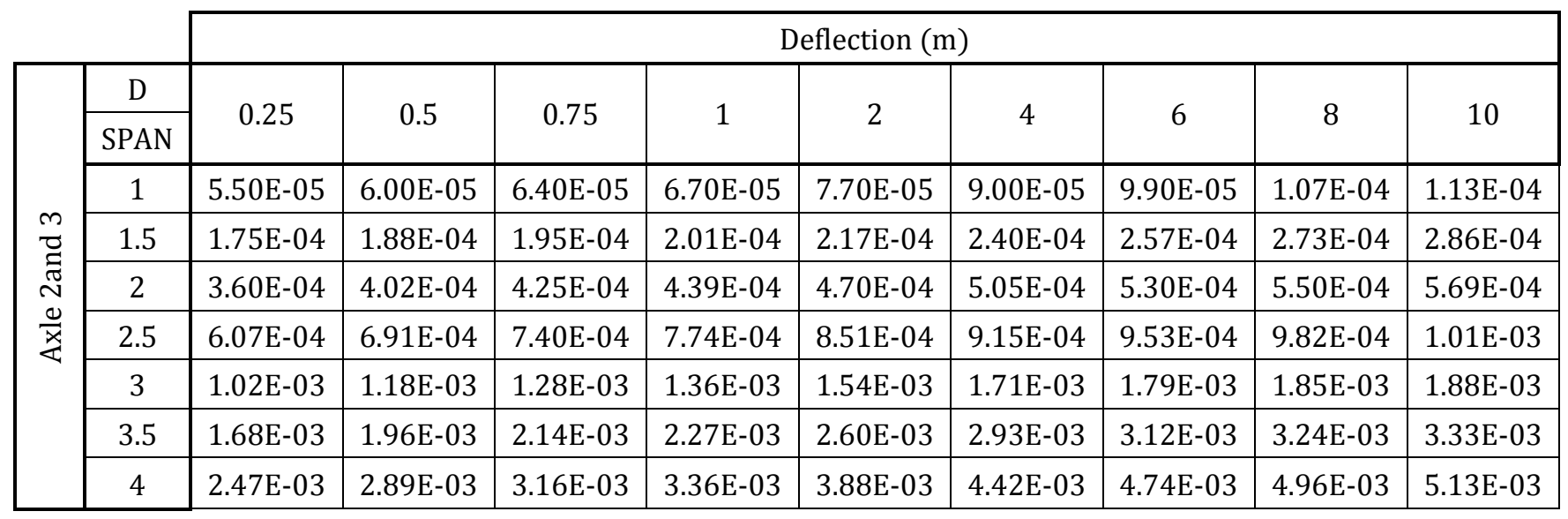

Table 57 Maximum deflection results for alpha 0.25 for slabs subjected to CHBDC truck loading (main bars perpendicular to traffic)

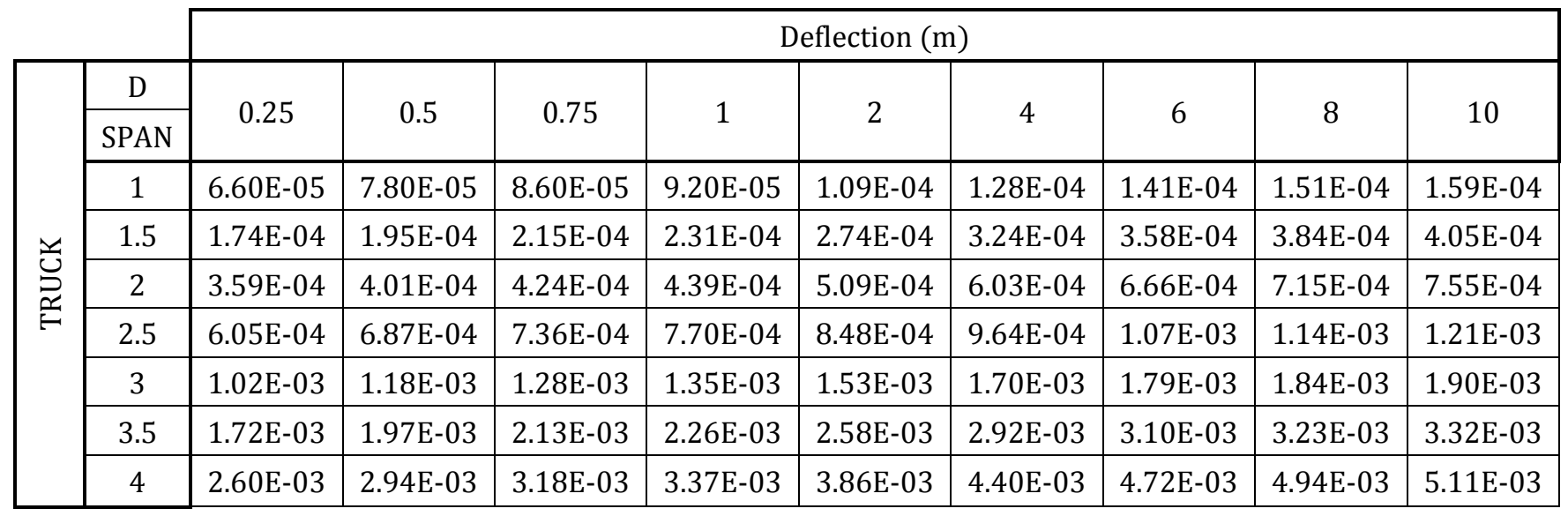


Table 58 Maximum deflection results for alpha 0.25 for slabs subjected to CHBDC axle 4 loading (main bars parallel to traffic)

\begin{tabular}{|c|c|c|c|c|c|c|c|c|c|c|}
\hline & & \multicolumn{9}{|c|}{ Deflection (m) } \\
\hline \multirow{7}{*}{ 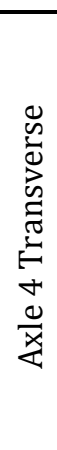 } & $\frac{\mathrm{D}}{\mathrm{SPAN}}$ & 0.25 & 0.5 & 0.75 & 1 & & 4 & 6 & 0 & 10 \\
\hline & 1 & $8.70 \mathrm{E}-05$ & $9.20 \mathrm{E}-05$ & $9.60 \mathrm{E}-05$ & $1.00 \mathrm{E}-04$ & $1.11 \mathrm{E}-04$ & $1.26 \mathrm{E}-04$ & $1.35 \mathrm{E}-04$ & $1.41 \mathrm{E}-04$ & $1.46 \mathrm{E}-04$ \\
\hline & 1.5 & $2.72 \mathrm{E}-04$ & $2.81 \mathrm{E}-04$ & $2.88 \mathrm{E}-04$ & $2.93 \mathrm{E}-04$ & $3.09 \mathrm{E}-04$ & $3.32 \mathrm{E}-04$ & $3.50 \mathrm{E}-04$ & $3.64 \mathrm{E}-04$ & $3.78 \mathrm{E}-04$ \\
\hline & 2 & $6.15 \mathrm{E}-04$ & $6.34 \mathrm{E}-04$ & $6.46 \mathrm{E}-04$ & $6.54 \mathrm{E}-04$ & $6.78 \mathrm{E}-04$ & 7.09E-04 & 7.33E-04 & $7.52 \mathrm{E}-04$ & 7.69E-04 \\
\hline & 2.5 & $1.14 \mathrm{E}-03$ & $1.19 \mathrm{E}-03$ & $1.22 \mathrm{E}-03$ & $1.23 \mathrm{E}-03$ & $1.27 \mathrm{E}-03$ & $1.31 \mathrm{E}-03$ & $1.34 \mathrm{E}-03$ & $1.37 \mathrm{E}-03$ & $1.39 \mathrm{E}-03$ \\
\hline & 3 & $1.85 \mathrm{E}-03$ & $1.96 \mathrm{E}-03$ & $2.02 \mathrm{E}-03$ & $2.06 \mathrm{E}-03$ & $2.13 \mathrm{E}-03$ & $2.19 \mathrm{E}-03$ & $2.23 \mathrm{E}-03$ & $2.27 \mathrm{E}-03$ & $2.29 \mathrm{E}-03$ \\
\hline & 3.5 & $2.73 \mathrm{E}-03$ & $2.95 \mathrm{E}-03$ & $3.07 \mathrm{E}-03$ & $3.14 \mathrm{E}-03$ & $3.28 \mathrm{E}-03$ & $3.39 \mathrm{E}-03$ & $3.45 \mathrm{E}-03$ & $3.49 \mathrm{E}-03$ & $3.53 \mathrm{E}-03$ \\
\hline
\end{tabular}

Table 59 Maximum deflection results for alpha 0.25 for slabs subjected to CHBDC axle $2 \& 3$ loading (main bars parallel to traffic)

\begin{tabular}{|c|c|c|c|c|c|c|c|c|c|c|}
\hline & & \multicolumn{9}{|c|}{ Deflection (m) } \\
\hline \multirow{8}{*}{ 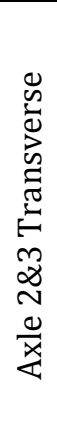 } & $\mathrm{D}$ & \multirow{2}{*}{0.25} & \multirow{2}{*}{0.5} & \multirow{2}{*}{0.75} & \multirow{2}{*}{1} & \multirow[b]{2}{*}{2} & \multirow{2}{*}{4} & \multirow{2}{*}{6} & \multirow[b]{2}{*}{0} & \multirow{2}{*}{10} \\
\hline & SPAN & & & & & & & & & \\
\hline & 1.5 & $1.16 \mathrm{E}-04$ & $1.20 \mathrm{E}-04$ & $1.23 \mathrm{E}-04$ & $1.24 \mathrm{E}-04$ & $1.28 \mathrm{E}-04$ & $1.36 \mathrm{E}-04$ & $1.44 \mathrm{E}-04$ & $1.50 \mathrm{E}-04$ & $1.56 \mathrm{E}-04$ \\
\hline & 2 & $4.99 \mathrm{E}-04$ & $5.18 \mathrm{E}-04$ & $5.28 \mathrm{E}-04$ & $5.35 \mathrm{E}-04$ & $5.54 \mathrm{E}-04$ & $5.70 \mathrm{E}-04$ & $5.84 \mathrm{E}-04$ & $5.98 \mathrm{E}-04$ & $6.10 \mathrm{E}-04$ \\
\hline & 2.5 & $1.15 \mathrm{E}-03$ & $1.21 \mathrm{E}-03$ & $1.24 \mathrm{E}-03$ & $1.25 \mathrm{E}-03$ & $1.30 \mathrm{E}-03$ & $1.34 \mathrm{E}-03$ & $1.36 \mathrm{E}-03$ & $1.38 \mathrm{E}-03$ & $1.40 \mathrm{E}-03$ \\
\hline & 3 & $2.08 \mathrm{E}-03$ & $2.22 \mathrm{E}-03$ & $2.29 \mathrm{E}-03$ & $2.33 \mathrm{E}-03$ & $2.42 \mathrm{E}-03$ & $2.49 \mathrm{E}-03$ & $2.54 \mathrm{E}-03$ & $2.57 \mathrm{E}-03$ & $2.59 \mathrm{E}-03$ \\
\hline & 3.5 & $3.28 \mathrm{E}-03$ & $3.55 \mathrm{E}-03$ & $3.69 \mathrm{E}-03$ & $3.78 \mathrm{E}-03$ & $3.96 \mathrm{E}-03$ & $4.10 \mathrm{E}-03$ & $4.18 \mathrm{E}-03$ & $4.23 \mathrm{E}-03$ & $4.27 \mathrm{E}-03$ \\
\hline & 4 & $4.75 \mathrm{E}-03$ & $5.21 \mathrm{E}-03$ & $5.45 \mathrm{E}-03$ & $5.61 \mathrm{E}-03$ & $5.95 \mathrm{E}-03$ & $6.21 \mathrm{E}-03$ & $6.34 \mathrm{E}-03$ & $6.42 \mathrm{E}-03$ & $6.48 \mathrm{E}-03$ \\
\hline
\end{tabular}




\section{Alpha 0.5 Deflection Results}

Table 60 Maximum deflection results for alpha 0.5 for slabs subjected to CHBDC axle 4 loading (main bars perpendicular to traffic)

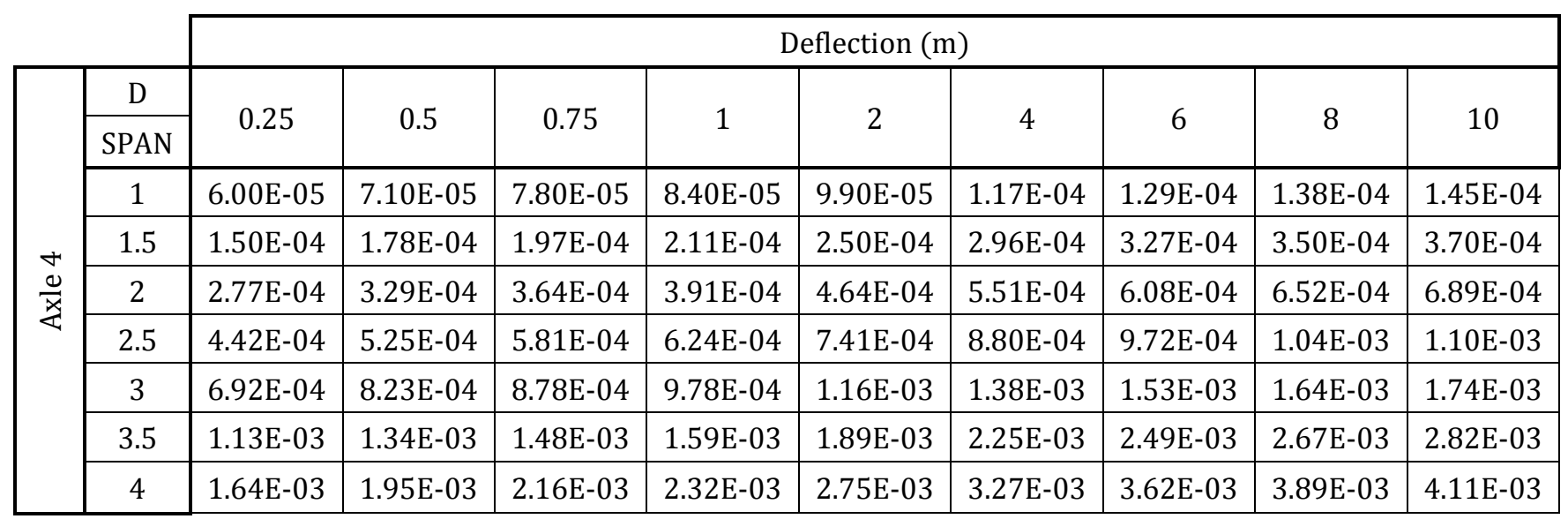

Table 61 Maximum deflection results for alpha 0.5 for slabs subjected to CHBDC axle $2 \& 3$ loading (main bars perpendicular to traffic)

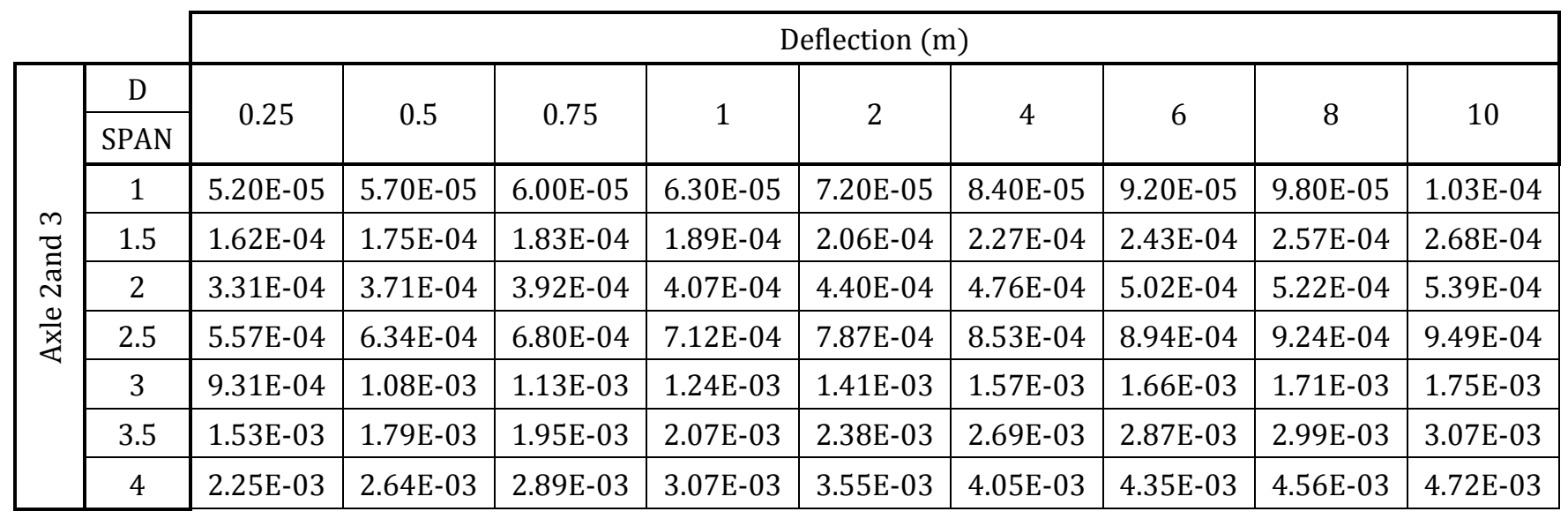

Table 62 Maximum deflection results for alpha 0.5 for slabs subjected to CHBDC truck loading (main bars perpendicular to traffic)

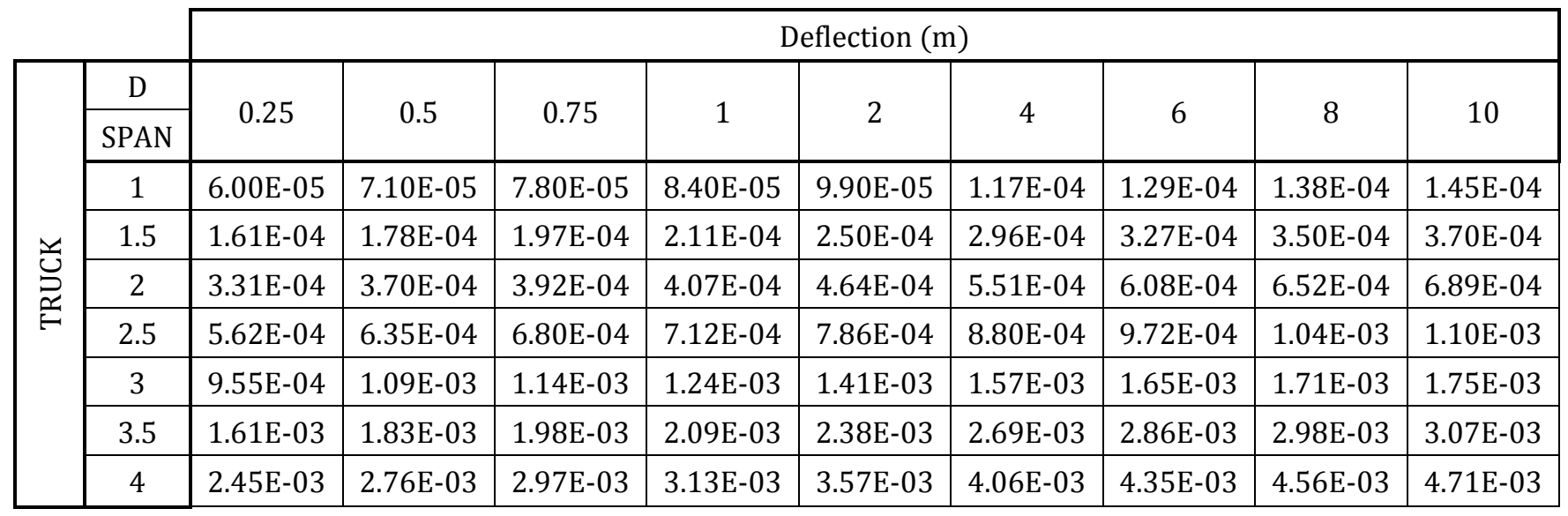


Table 63 Maximum deflection results for alpha 0.5 for slabs subjected to CHBDC axle 4 loading (main bars parallel to traffic)

\begin{tabular}{|c|c|c|c|c|c|c|c|c|c|c|}
\hline & & \multicolumn{9}{|c|}{ Deflection (m) } \\
\hline \multirow{7}{*}{ 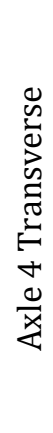 } & $\begin{array}{c}\mathrm{D} \\
\text { SPAN }\end{array}$ & 0.25 & 0.5 & 0.75 & 1 & 2 & 4 & 6 & 8 & 10 \\
\hline & 1 & $8.50 \mathrm{E}-05$ & $9.00 \mathrm{E}-05$ & $9.30 \mathrm{E}-05$ & $9.60 \mathrm{E}-05$ & $1.05 \mathrm{E}-04$ & $1.17 \mathrm{E}-04$ & $1.25 \mathrm{E}-04$ & $1.31 \mathrm{E}-04$ & $1.35 \mathrm{E}-04$ \\
\hline & 1.5 & $2.64 \mathrm{E}-04$ & $2.74 \mathrm{E}-04$ & $2.80 \mathrm{E}-04$ & $2.85 \mathrm{E}-04$ & $3.00 \mathrm{E}-04$ & $3.20 \mathrm{E}-04$ & $3.36 \mathrm{E}-04$ & $3.49 \mathrm{E}-04$ & $3.59 \mathrm{E}-04$ \\
\hline & 2 & $5.88 \mathrm{E}-04$ & $6.12 \mathrm{E}-04$ & $6.26 \mathrm{E}-04$ & $6.35 \mathrm{E}-04$ & $6.60 \mathrm{E}-04$ & $6.90 \mathrm{E}-04$ & 7.12E-04 & $7.30 \mathrm{E}-04$ & $7.45 \mathrm{E}-04$ \\
\hline & 2.5 & $1.07 \mathrm{E}-03$ & $1.14 \mathrm{E}-03$ & 1.17E-03 & 1.19E-03 & $1.23 \mathrm{E}-03$ & $1.28 \mathrm{E}-03$ & $1.31 \mathrm{E}-03$ & $1.33 \mathrm{E}-03$ & $1.35 \mathrm{E}-03$ \\
\hline & 3 & $1.73 \mathrm{E}-03$ & $1.85 \mathrm{E}-03$ & $1.88 \mathrm{E}-03$ & $1.96 \mathrm{E}-03$ & $2.05 \mathrm{E}-03$ & $2.12 \mathrm{E}-03$ & 2.17E-03 & $2.21 \mathrm{E}-03$ & $2.23 \mathrm{E}-03$ \\
\hline & 3.5 & $2.54 \mathrm{E}-03$ & $2.77 \mathrm{E}-03$ & $2.88 \mathrm{E}-03$ & $2.96 \mathrm{E}-03$ & $3.13 \mathrm{E}-03$ & $3.26 \mathrm{E}-03$ & $3.34 \mathrm{E}-03$ & 3.39E-03 & $3.43 \mathrm{E}-03$ \\
\hline
\end{tabular}

Table 64 Maximum deflection results for alpha 0.5 for slabs subjected to CHBDC axle 2 \& 3 loading (main bars parallel to traffic)

\begin{tabular}{|c|c|c|c|c|c|c|c|c|c|c|}
\hline & & \multicolumn{9}{|c|}{ Deflection (m) } \\
\hline \multirow{7}{*}{ 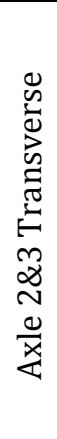 } & $\begin{array}{c}\mathrm{D} \\
\text { SPAN }\end{array}$ & 0.25 & 0.5 & 0.75 & 1 & 2 & 4 & 6 & 8 & 10 \\
\hline & 1.5 & $1.12 \mathrm{E}-04$ & $1.16 \mathrm{E}-04$ & 1.19E-04 & 1.20E-04 & $1.25 \mathrm{E}-04$ & 1.32E-04 & $1.38 \mathrm{E}-04$ & $1.44 \mathrm{E}-04$ & $1.48 \mathrm{E}-04$ \\
\hline & 2 & $4.77 \mathrm{E}-04$ & $4.99 \mathrm{E}-04$ & $5.10 \mathrm{E}-04$ & $5.18 \mathrm{E}-04$ & $5.36 \mathrm{E}-04$ & $5.54 \mathrm{E}-04$ & $5.68 \mathrm{E}-04$ & $5.80 \mathrm{E}-04$ & $5.91 \mathrm{E}-04$ \\
\hline & 2.5 & $1.08 \mathrm{E}-03$ & $1.15 \mathrm{E}-03$ & $1.18 \mathrm{E}-03$ & $1.20 \mathrm{E}-03$ & $1.25 \mathrm{E}-03$ & $1.30 \mathrm{E}-03$ & $1.32 \mathrm{E}-03$ & $1.34 \mathrm{E}-03$ & $1.36 \mathrm{E}-03$ \\
\hline & 3 & $1.94 \mathrm{E}-03$ & $2.09 \mathrm{E}-03$ & $2.12 \mathrm{E}-03$ & $2.21 \mathrm{E}-03$ & $2.32 \mathrm{E}-03$ & $2.41 \mathrm{E}-03$ & $2.46 \mathrm{E}-03$ & $2.49 \mathrm{E}-03$ & $2.52 \mathrm{E}-03$ \\
\hline & 3.5 & $3.05 \mathrm{E}-03$ & $3.32 \mathrm{E}-03$ & $3.47 \mathrm{E}-03$ & $3.56 \mathrm{E}-03$ & $3.77 \mathrm{E}-03$ & $3.95 \mathrm{E}-03$ & 4.04E-03 & $4.10 \mathrm{E}-03$ & $4.14 \mathrm{E}-03$ \\
\hline & 4 & 4.39E-03 & $4.84 \mathrm{E}-03$ & $5.09 \mathrm{E}-03$ & $5.26 \mathrm{E}-03$ & $5.62 \mathrm{E}-03$ & $5.93 \mathrm{E}-03$ & $6.09 \mathrm{E}-03$ & $6.19 \mathrm{E}-03$ & $6.26 \mathrm{E}-03$ \\
\hline
\end{tabular}




\section{Alpha 0.75 Deflection Results}

Table 65 Maximum deflection results for alpha 0.75 for slabs subjected to CHBDC axle 4 loading (main bars perpendicular to traffic)

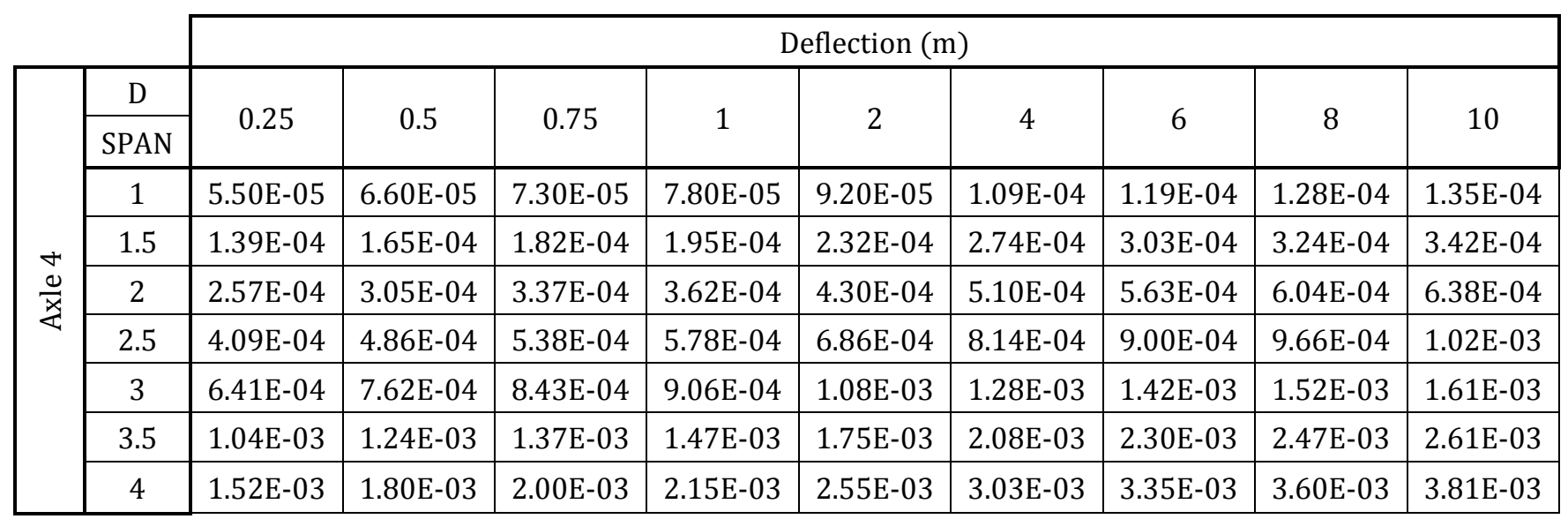

Table 66 Maximum deflection results for alpha 0.75 for slabs subjected to CHBDC axle $2 \& 3$ loading (main bars perpendicular to traffic)

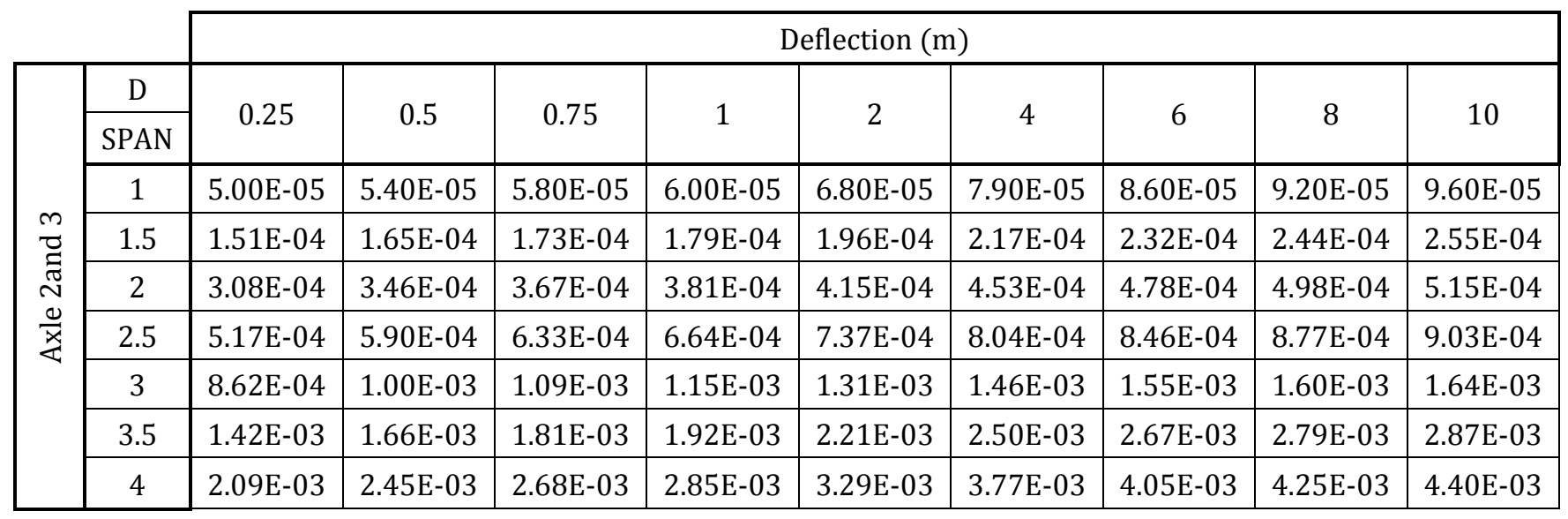

Table 67 Maximum deflection results for alpha 0.75 for slabs subjected to CHBDC truck loading (main bars perpendicular to traffic)

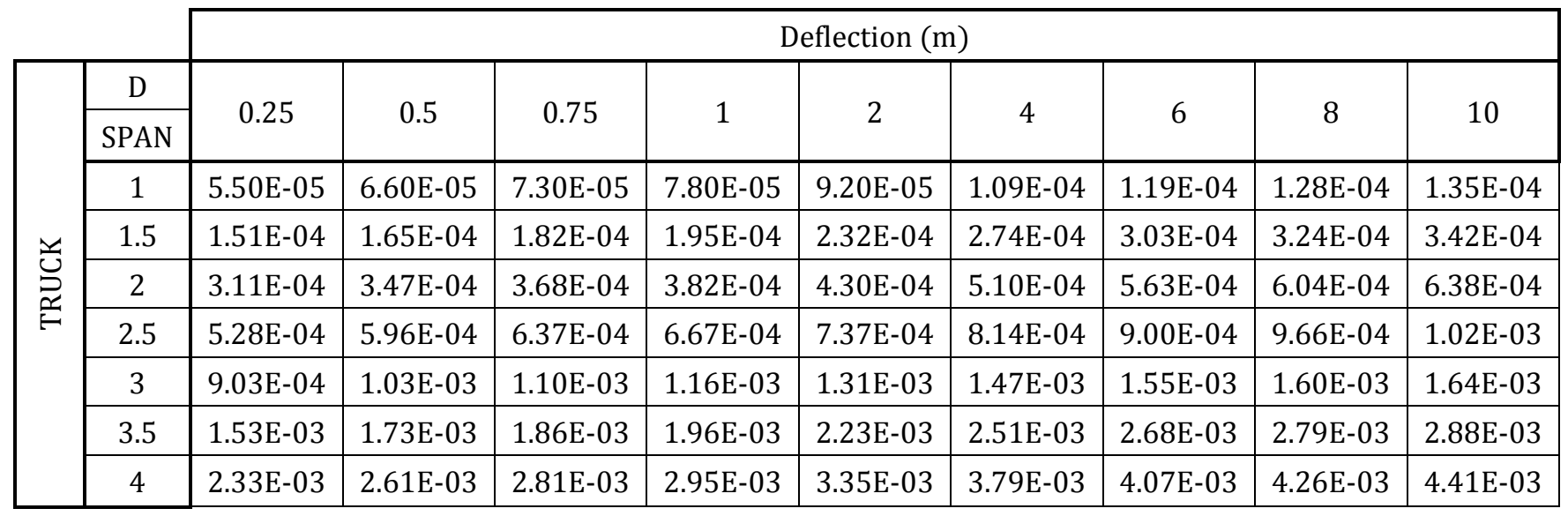


Table 68 Maximum deflection results for alpha 0.75 for slabs subjected to CHBDC axle 4 loading (main bars parallel to traffic)

\begin{tabular}{|c|c|c|c|c|c|c|c|c|c|c|}
\hline & & \multicolumn{9}{|c|}{ Deflection (m) } \\
\hline \multirow{8}{*}{ 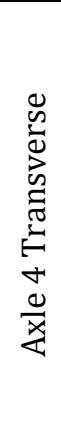 } & D & 025 & 05 & 075 & 1 & 2 & 4 & 6 & 8 & 10 \\
\hline & SPAN & 0.25 & 0.5 & 0.15 & & & & & & \\
\hline & 1 & $8.30 \mathrm{E}-05$ & $8.70 \mathrm{E}-05$ & $9.10 \mathrm{E}-05$ & $9.30 \mathrm{E}-05$ & $1.01 \mathrm{E}-04$ & $1.11 \mathrm{E}-04$ & $1.18 \mathrm{E}-04$ & $1.23 \mathrm{E}-04$ & $1.27 \mathrm{E}-04$ \\
\hline & 1.5 & $2.56 \mathrm{E}-04$ & $2.67 \mathrm{E}-04$ & $2.74 \mathrm{E}-04$ & $2.79 \mathrm{E}-04$ & $2.93 \mathrm{E}-04$ & $3.12 \mathrm{E}-04$ & $3.25 \mathrm{E}-04$ & $3.37 \mathrm{E}-04$ & $3.46 \mathrm{E}-04$ \\
\hline & 2 & $5.65 \mathrm{E}-04$ & 5.93E-04 & $6.08 \mathrm{E}-04$ & $6.18 \mathrm{E}-04$ & $6.45 \mathrm{E}-04$ & $6.75 \mathrm{E}-04$ & $6.95 \mathrm{E}-04$ & $7.12 \mathrm{E}-04$ & $7.26 \mathrm{E}-04$ \\
\hline & 2.5 & $1.02 \mathrm{E}-03$ & $1.09 \mathrm{E}-03$ & $1.12 \mathrm{E}-03$ & $1.15 \mathrm{E}-03$ & $1.20 \mathrm{E}-03$ & $1.25 \mathrm{E}-03$ & $1.28 \mathrm{E}-03$ & $1.30 \mathrm{E}-03$ & $1.32 \mathrm{E}-03$ \\
\hline & 3 & $1.63 \mathrm{E}-03$ & $1.76 \mathrm{E}-03$ & $1.83 \mathrm{E}-03$ & $1.88 \mathrm{E}-03$ & $1.98 \mathrm{E}-03$ & $2.06 \mathrm{E}-03$ & $2.12 \mathrm{E}-03$ & $2.15 E-03$ & $2.18 \mathrm{E}-03$ \\
\hline & 3.5 & $2.39 \mathrm{E}-03$ & $2.61 \mathrm{E}-03$ & $2.74 \mathrm{E}-03$ & $2.82 \mathrm{E}-03$ & $3.00 \mathrm{E}-03$ & $3.15 \mathrm{E}-03$ & $3.24 \mathrm{E}-03$ & $3.30 \mathrm{E}-03$ & $3.34 \mathrm{E}-03$ \\
\hline
\end{tabular}

Table 69 Maximum deflection results for alpha 0.75 for slabs subjected to CHBDC axle $2 \& 3$ loading (main bars parallel to traffic)

\begin{tabular}{|c|c|c|c|c|c|c|c|c|c|c|}
\hline & & \multicolumn{9}{|c|}{ Deflection (m) } \\
\hline \multirow{8}{*}{ 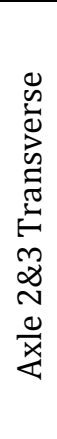 } & $\mathrm{D}$ & \multirow{2}{*}{0.25} & \multirow{2}{*}{0.5} & \multirow{2}{*}{0.75} & \multirow{2}{*}{1} & \multirow[b]{2}{*}{2} & \multirow{2}{*}{4} & \multirow{2}{*}{6} & \multirow[b]{2}{*}{0} & \multirow{2}{*}{10} \\
\hline & SPAN & & & & & & & & & \\
\hline & 1.5 & $1.09 \mathrm{E}-04$ & $1.13 \mathrm{E}-04$ & $1.16 \mathrm{E}-04$ & 1.17E-04 & $1.22 \mathrm{E}-04$ & $1.29 \mathrm{E}-04$ & $1.34 \mathrm{E}-04$ & $1.39 \mathrm{E}-04$ & $1.43 \mathrm{E}-04$ \\
\hline & 2 & $4.57 \mathrm{E}-04$ & $4.82 \mathrm{E}-04$ & $4.95 \mathrm{E}-04$ & 5.03E-04 & $5.22 \mathrm{E}-04$ & $5.41 \mathrm{E}-04$ & $5.55 \mathrm{E}-04$ & $5.67 \mathrm{E}-04$ & $5.77 \mathrm{E}-04$ \\
\hline & 2.5 & $1.03 \mathrm{E}-03$ & $1.10 \mathrm{E}-03$ & $1.14 \mathrm{E}-03$ & $1.16 \mathrm{E}-03$ & $1.22 \mathrm{E}-03$ & $1.26 \mathrm{E}-03$ & $1.29 \mathrm{E}-03$ & $1.31 \mathrm{E}-03$ & $1.33 \mathrm{E}-03$ \\
\hline & 3 & $1.83 \mathrm{E}-03$ & $1.98 \mathrm{E}-03$ & $2.07 \mathrm{E}-03$ & $2.12 \mathrm{E}-03$ & $2.24 \mathrm{E}-03$ & $2.34 \mathrm{E}-03$ & $2.39 \mathrm{E}-03$ & $2.43 \mathrm{E}-03$ & $2.46 \mathrm{E}-03$ \\
\hline & 3.5 & $2.86 \mathrm{E}-03$ & $3.14 \mathrm{E}-03$ & $3.29 \mathrm{E}-03$ & $3.39 \mathrm{E}-03$ & $3.61 \mathrm{E}-03$ & $3.81 \mathrm{E}-03$ & $3.91 \mathrm{E}-03$ & $3.98 \mathrm{E}-03$ & $4.03 \mathrm{E}-03$ \\
\hline & 4 & $4.11 \mathrm{E}-03$ & $4.55 \mathrm{E}-03$ & $4.80 \mathrm{E}-03$ & 4.97E-03 & $5.36 \mathrm{E}-03$ & $5.69 \mathrm{E}-03$ & $5.87 \mathrm{E}-03$ & $5.98 \mathrm{E}-03$ & $6.07 \mathrm{E}-03$ \\
\hline
\end{tabular}




\section{Alpha 1 Deflection Results}

Table 70 Maximum deflection results for alpha 1 for slabs subjected to CHBDC axle 4 loading (main bars perpendicular to traffic)

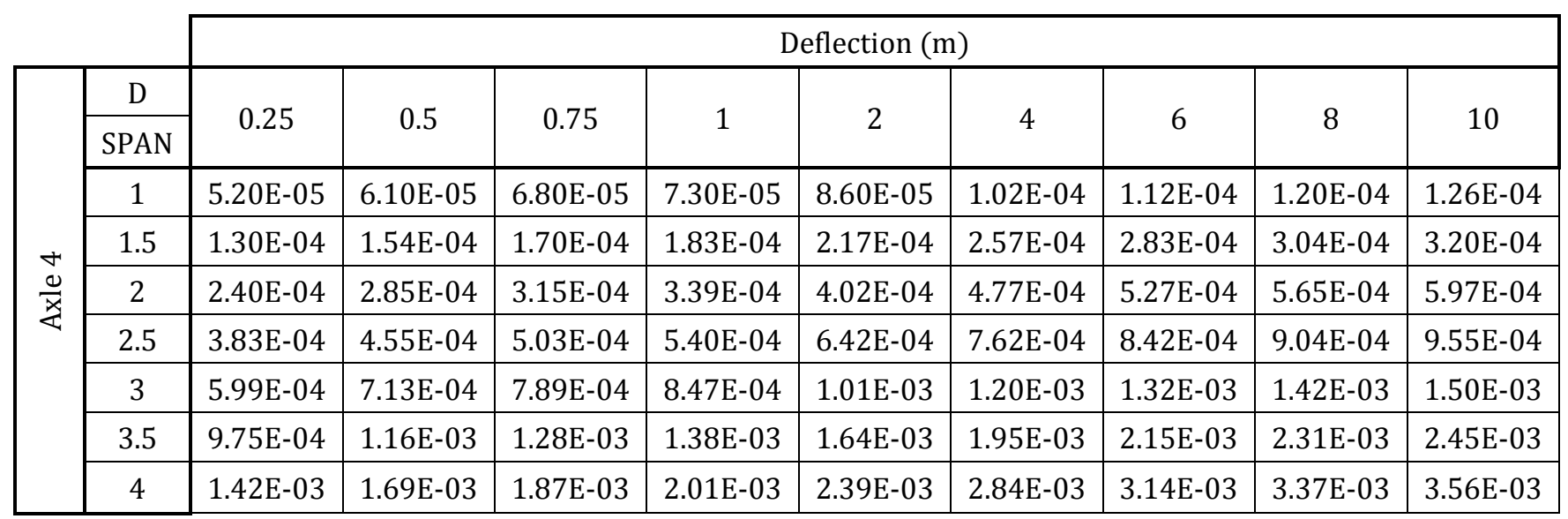

Table 71 Maximum deflection results for alpha 1 for slabs subjected to CHBDC axle 2 \& 3 loading (main bars perpendicular to traffic)

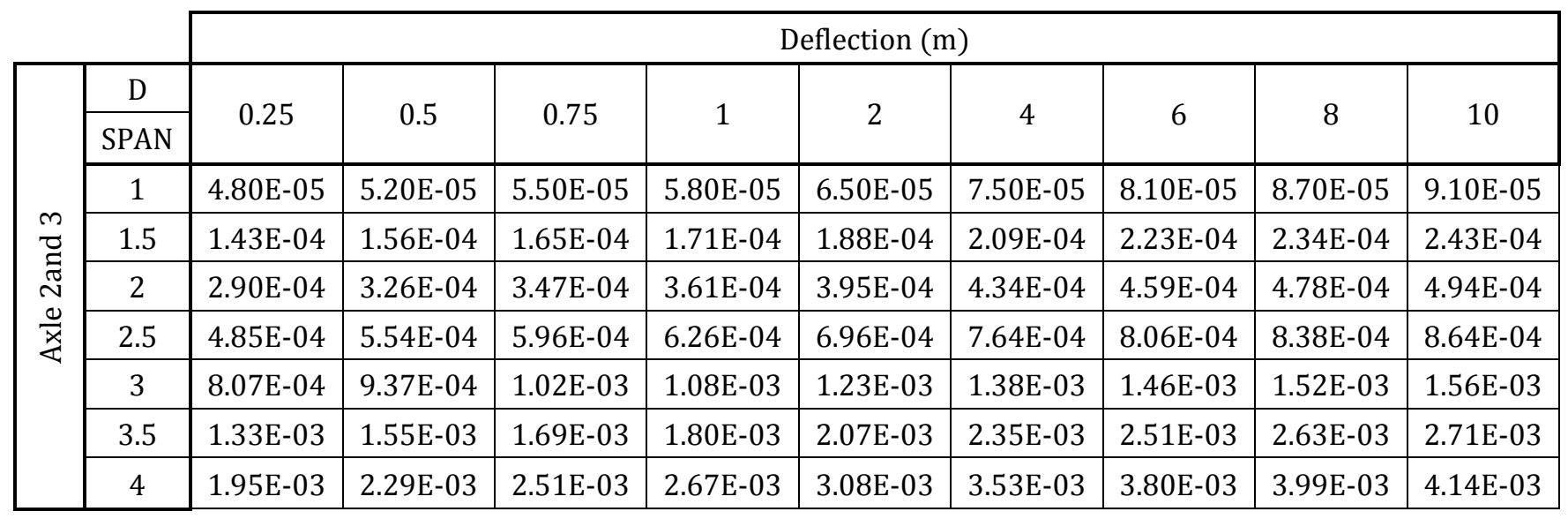

Table 72 Maximum deflection results for alpha 1 for slabs subjected to CHBDC truck loading (main bars perpendicular to traffic)

\begin{tabular}{|c|c|c|c|c|c|c|c|c|c|c|}
\hline & \multicolumn{9}{|c|}{ Deflection (m) } \\
\hline \multirow{9}{*}{$\begin{array}{l}\text { y } \\
\text { X } \\
\text { E }\end{array}$} & D & \multirow{2}{*}{0.25} & \multirow{2}{*}{0.5} & \multirow{2}{*}{0.75} & \multirow{2}{*}{1} & \multirow[b]{2}{*}{2} & \multirow[b]{2}{*}{4} & \multirow{2}{*}{6} & \multirow{2}{*}{8} & \multirow{2}{*}{10} \\
\hline & SPAN & & & & & & & & & \\
\hline & 1 & $5.20 \mathrm{E}-05$ & $6.10 \mathrm{E}-05$ & $6.80 \mathrm{E}-05$ & $7.30 \mathrm{E}-05$ & $8.60 \mathrm{E}-05$ & $1.02 \mathrm{E}-04$ & $1.12 \mathrm{E}-04$ & $1.20 \mathrm{E}-04$ & $1.26 \mathrm{E}-04$ \\
\hline & 1.5 & $1.43 \mathrm{E}-04$ & $1.57 \mathrm{E}-04$ & $1.70 \mathrm{E}-04$ & $1.83 \mathrm{E}-04$ & 2.17E-04 & $2.57 \mathrm{E}-04$ & 2.83E-04 & $3.04 \mathrm{E}-04$ & $3.20 \mathrm{E}-04$ \\
\hline & 2 & $2.94 \mathrm{E}-04$ & $3.28 \mathrm{E}-04$ & $3.48 \mathrm{E}-04$ & $3.62 \mathrm{E}-04$ & $4.02 \mathrm{E}-04$ & 4.77E-04 & $5.27 \mathrm{E}-04$ & $5.65 \mathrm{E}-04$ & $5.97 \mathrm{E}-04$ \\
\hline & 2.5 & $5.02 \mathrm{E}-04$ & $5.64 \mathrm{E}-04$ & $6.03 \mathrm{E}-04$ & $6.31 \mathrm{E}-04$ & $6.99 \mathrm{E}-04$ & $7.66 \mathrm{E}-04$ & $8.42 \mathrm{E}-04$ & $9.04 \mathrm{E}-04$ & $9.55 \mathrm{E}-04$ \\
\hline & 3 & $8.61 \mathrm{E}-04$ & $9.73 \mathrm{E}-04$ & $1.05 \mathrm{E}-03$ & $1.10 \mathrm{E}-03$ & $1.24 \mathrm{E}-03$ & $1.38 \mathrm{E}-03$ & $1.46 \mathrm{E}-03$ & $1.52 \mathrm{E}-03$ & $1.56 \mathrm{E}-03$ \\
\hline & 3.5 & $1.47 \mathrm{E}-03$ & $1.65 \mathrm{E}-03$ & $1.77 \mathrm{E}-03$ & $1.86 \mathrm{E}-03$ & $2.11 \mathrm{E}-03$ & $2.37 \mathrm{E}-03$ & $2.53 \mathrm{E}-03$ & $2.64 \mathrm{E}-03$ & $2.72 \mathrm{E}-03$ \\
\hline & 4 & $2.24 \mathrm{E}-03$ & $2.50 \mathrm{E}-03$ & $2.68 \mathrm{E}-03$ & $2.81 \mathrm{E}-03$ & $3.18 \mathrm{E}-03$ & $3.59 \mathrm{E}-03$ & $3.84 \mathrm{E}-03$ & $4.02 \mathrm{E}-03$ & $4.16 \mathrm{E}-03$ \\
\hline
\end{tabular}


Table 73 Maximum deflection results for alpha 1 for slabs subjected to CHBDC axle 4 loading (main bars parallel to traffic)

\begin{tabular}{|c|c|c|c|c|c|c|c|c|c|c|}
\hline & & \multicolumn{9}{|c|}{ Deflection (m) } \\
\hline \multirow{7}{*}{ 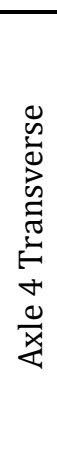 } & $\frac{\mathrm{D}}{\mathrm{SPAN}}$ & 0.25 & 0.5 & 0.75 & 1 & & 4 & 6 & 8 & 10 \\
\hline & 1 & $8.10 \mathrm{E}-05$ & $8.60 \mathrm{E}-05$ & $8.90 \mathrm{E}-05$ & $9.10 \mathrm{E}-05$ & $9.80 \mathrm{E}-05$ & $1.07 \mathrm{E}-04$ & $1.13 \mathrm{E}-04$ & $1.18 \mathrm{E}-04$ & $1.22 \mathrm{E}-04$ \\
\hline & 1.5 & $2.49 \mathrm{E}-04$ & $2.61 \mathrm{E}-04$ & $2.68 \mathrm{E}-04$ & $2.73 \mathrm{E}-04$ & $2.87 \mathrm{E}-04$ & $3.05 \mathrm{E}-04$ & $3.17 \mathrm{E}-04$ & $3.27 \mathrm{E}-04$ & $3.36 \mathrm{E}-04$ \\
\hline & 2 & $5.45 \mathrm{E}-04$ & $5.75 \mathrm{E}-04$ & 5.92E-04 & $6.03 \mathrm{E}-04$ & $6.31 \mathrm{E}-04$ & $6.61 \mathrm{E}-04$ & $6.81 \mathrm{E}-04$ & $6.97 \mathrm{E}-04$ & $7.10 \mathrm{E}-04$ \\
\hline & 2.5 & $9.78 \mathrm{E}-04$ & $1.05 \mathrm{E}-03$ & $1.08 \mathrm{E}-03$ & $1.11 \mathrm{E}-03$ & $1.17 \mathrm{E}-03$ & $1.22 \mathrm{E}-03$ & $1.25 \mathrm{E}-03$ & $1.28 \mathrm{E}-03$ & $1.30 \mathrm{E}-03$ \\
\hline & 3 & $1.55 \mathrm{E}-03$ & $1.68 \mathrm{E}-03$ & $1.76 \mathrm{E}-03$ & $1.81 \mathrm{E}-03$ & $1.91 \mathrm{E}-03$ & $2.01 \mathrm{E}-03$ & $2.07 \mathrm{E}-03$ & $2.10 \mathrm{E}-03$ & $2.14 \mathrm{E}-03$ \\
\hline & 3.5 & $2.26 \mathrm{E}-03$ & $2.49 \mathrm{E}-03$ & $2.61 \mathrm{E}-03$ & $2.70 \mathrm{E}-03$ & $2.89 \mathrm{E}-03$ & $3.06 \mathrm{E}-03$ & $3.15 \mathrm{E}-03$ & $3.21 \mathrm{E}-03$ & $3.26 \mathrm{E}-03$ \\
\hline
\end{tabular}

Table 74 Maximum deflection results for alpha 1 for slabs subjected to CHBDC axle 2 \& 3 loading (main bars parallel to traffic)

\begin{tabular}{|c|c|c|c|c|c|c|c|c|c|c|}
\hline & & \multicolumn{9}{|c|}{ Deflection (m) } \\
\hline \multirow{8}{*}{ 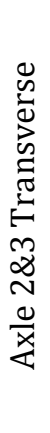 } & $\mathrm{D}$ & \multirow{2}{*}{0.25} & \multirow{2}{*}{0.5} & \multirow{2}{*}{0.75} & \multirow[b]{2}{*}{1} & & \multirow{2}{*}{4} & \multirow{2}{*}{5} & \multirow{2}{*}{8} & \multirow{2}{*}{10} \\
\hline & SPAN & & & & & & & & & \\
\hline & 1.5 & $1.06 \mathrm{E}-04$ & $1.10 \mathrm{E}-04$ & $1.13 \mathrm{E}-04$ & $1.14 \mathrm{E}-04$ & $1.19 \mathrm{E}-04$ & $1.26 \mathrm{E}-04$ & $1.31 \mathrm{E}-04$ & $1.35 \mathrm{E}-04$ & $1.39 \mathrm{E}-04$ \\
\hline & 2 & $4.41 \mathrm{E}-04$ & $4.67 \mathrm{E}-04$ & $4.81 \mathrm{E}-04$ & $4.90 \mathrm{E}-04$ & $5.10 \mathrm{E}-04$ & $5.29 \mathrm{E}-04$ & $5.43 \mathrm{E}-04$ & $5.55 \mathrm{E}-04$ & $5.65 \mathrm{E}-04$ \\
\hline & 2.5 & $9.85 \mathrm{E}-04$ & $1.06 \mathrm{E}-03$ & $1.10 \mathrm{E}-03$ & $1.12 \mathrm{E}-03$ & $1.18 \mathrm{E}-03$ & $1.23 \mathrm{E}-03$ & $1.26 \mathrm{E}-03$ & $1.28 \mathrm{E}-03$ & $1.30 \mathrm{E}-03$ \\
\hline & 3 & $1.74 \mathrm{E}-03$ & $1.90 \mathrm{E}-03$ & $1.98 \mathrm{E}-03$ & $2.04 \mathrm{E}-03$ & 2.17E-03 & $2.28 \mathrm{E}-03$ & 2.33E-03 & $2.37 \mathrm{E}-03$ & $2.40 \mathrm{E}-03$ \\
\hline & 3.5 & $2.71 \mathrm{E}-03$ & $2.98 \mathrm{E}-03$ & $3.14 \mathrm{E}-03$ & $3.24 \mathrm{E}-03$ & $3.48 \mathrm{E}-03$ & $3.69 \mathrm{E}-03$ & $3.80 \mathrm{E}-03$ & 3.87E-03 & $3.92 \mathrm{E}-03$ \\
\hline & 4 & $3.88 \mathrm{E}-03$ & $4.31 \mathrm{E}-03$ & $4.56 \mathrm{E}-03$ & $4.74 \mathrm{E}-03$ & 5.13E-03 & $5.49 \mathrm{E}-03$ & $5.68 \mathrm{E}-03$ & $5.80 \mathrm{E}-03$ & $5.90 \mathrm{E}-03$ \\
\hline
\end{tabular}




\section{Alpha 2 Deflection Results}

Table 75 Maximum deflection results for alpha 2 for slabs subjected to CHBDC axle 4 loading (main bars perpendicular to traffic)

\begin{tabular}{|c|c|c|c|c|c|c|c|c|c|c|}
\hline & \multicolumn{9}{|c|}{ Deflection (m) } \\
\hline \multirow{9}{*}{$\frac{\vec{a}}{\frac{0}{x}}$} & $\mathrm{D}$ & \multirow{2}{*}{0.25} & \multirow{2}{*}{0.5} & \multirow{2}{*}{0.75} & \multirow{2}{*}{1} & & \multirow{2}{*}{4} & & & \multirow{2}{*}{10} \\
\hline & SPAN & & & & & & & & & \\
\hline & 1 & $4.20 \mathrm{E}-05$ & $5.00 \mathrm{E}-05$ & $5.50 \mathrm{E}-05$ & $5.90 \mathrm{E}-05$ & $7.00 \mathrm{E}-05$ & $8.30 \mathrm{E}-05$ & $9.10 \mathrm{E}-05$ & $9.80 \mathrm{E}-05$ & $1.03 \mathrm{E}-04$ \\
\hline & 1.5 & $1.06 \mathrm{E}-04$ & $1.26 \mathrm{E}-04$ & $1.39 \mathrm{E}-04$ & $1.49 \mathrm{E}-04$ & $1.77 \mathrm{E}-04$ & $2.10 \mathrm{E}-04$ & $2.31 \mathrm{E}-04$ & $2.48 \mathrm{E}-04$ & $2.62 \mathrm{E}-04$ \\
\hline & 2 & $1.96 \mathrm{E}-04$ & 2.33E-04 & $2.58 \mathrm{E}-04$ & $2.77 \mathrm{E}-04$ & $3.28 \mathrm{E}-04$ & $3.89 \mathrm{E}-04$ & $4.30 \mathrm{E}-04$ & 4.62E-04 & $4.88 \mathrm{E}-04$ \\
\hline & 2.5 & $3.12 \mathrm{E}-04$ & $3.71 \mathrm{E}-04$ & $4.11 \mathrm{E}-04$ & $4.41 \mathrm{E}-04$ & $5.24 \mathrm{E}-04$ & $6.22 \mathrm{E}-04$ & $6.88 \mathrm{E}-04$ & 7.38E-04 & $7.80 \mathrm{E}-04$ \\
\hline & 3 & $4.90 \mathrm{E}-04$ & $5.82 \mathrm{E}-04$ & $6.44 \mathrm{E}-04$ & $6.92 \mathrm{E}-04$ & 8.22E-04 & $9.77 \mathrm{E}-04$ & $1.08 \mathrm{E}-03$ & $1.16 \mathrm{E}-03$ & $1.23 \mathrm{E}-03$ \\
\hline & 3.5 & $7.96 \mathrm{E}-04$ & $9.46 \mathrm{E}-04$ & $1.05 \mathrm{E}-03$ & $1.13 \mathrm{E}-03$ & $1.34 \mathrm{E}-03$ & $1.59 \mathrm{E}-03$ & $1.76 \mathrm{E}-03$ & $1.89 \mathrm{E}-03$ & $2.00 \mathrm{E}-03$ \\
\hline & 4 & $1.16 \mathrm{E}-03$ & $1.38 \mathrm{E}-03$ & $1.53 \mathrm{E}-03$ & $1.64 \mathrm{E}-03$ & $1.95 \mathrm{E}-03$ & $2.32 \mathrm{E}-03$ & $2.56 \mathrm{E}-03$ & $2.75 \mathrm{E}-03$ & $2.91 \mathrm{E}-03$ \\
\hline
\end{tabular}

Table 76 Maximum deflection results for alpha 2 for slabs subjected to CHBDC axle 2 \& 3 loading (main bars perpendicular to traffic)

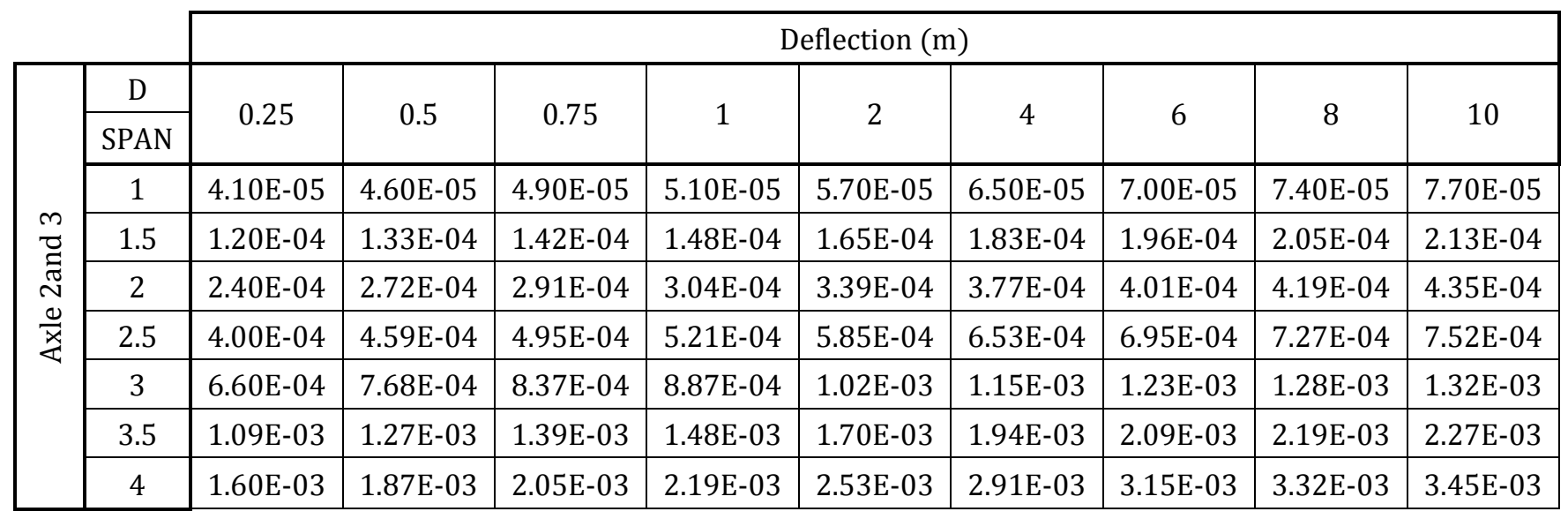

Table 77 Maximum deflection results for alpha 2 for slabs subjected to CHBDC truck loading (main bars perpendicular to traffic)

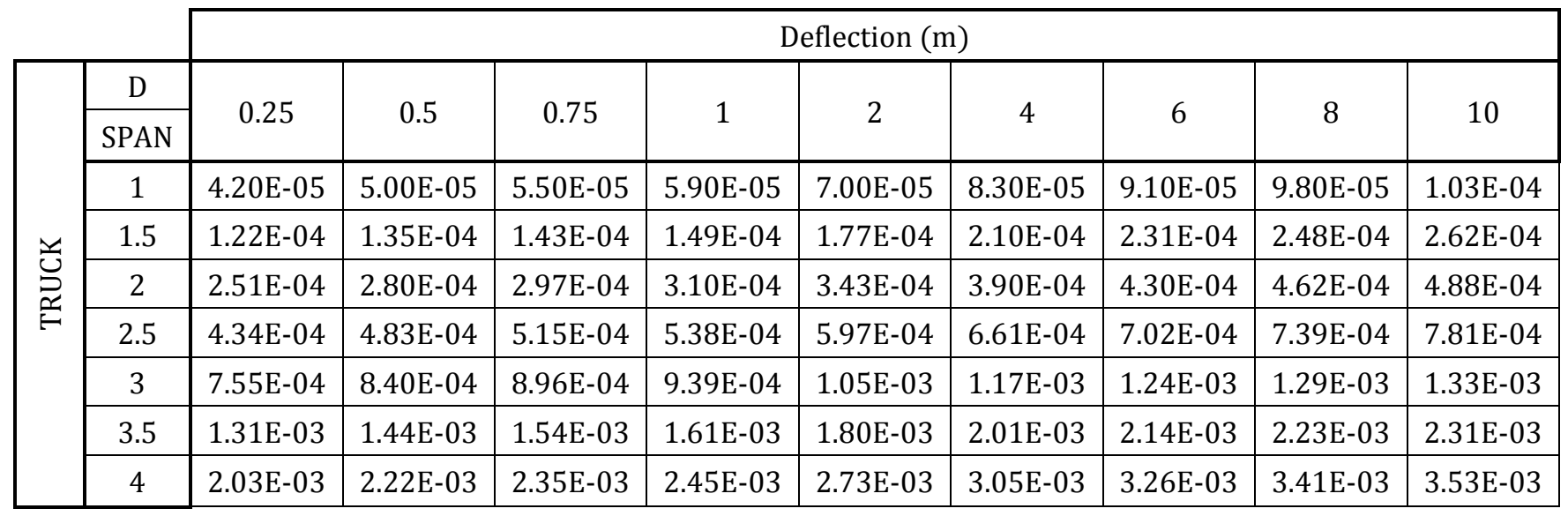


Table 78 Maximum deflection results for alpha 2 for slabs subjected to CHBDC axle 4 loading (main bars parallel to traffic)

\begin{tabular}{|c|c|c|c|c|c|c|c|c|c|c|}
\hline & & \multicolumn{9}{|c|}{ Deflection (m) } \\
\hline \multirow{7}{*}{ 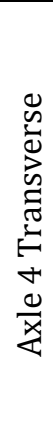 } & $\begin{array}{c}\mathrm{D} \\
\text { SPAN }\end{array}$ & 0.25 & 0.5 & 0.75 & 1 & 2 & 4 & 6 & 8 & 10 \\
\hline & 1 & $7.60 \mathrm{E}-05$ & $8.00 \mathrm{E}-05$ & $8.30 \mathrm{E}-05$ & $8.50 \mathrm{E}-05$ & $9.00 \mathrm{E}-05$ & $9.70 \mathrm{E}-05$ & $1.01 \mathrm{E}-04$ & $1.05 \mathrm{E}-04$ & $1.07 \mathrm{E}-04$ \\
\hline & 1.5 & $2.28 \mathrm{E}-04$ & $2.42 \mathrm{E}-04$ & $2.50 \mathrm{E}-04$ & $2.55 \mathrm{E}-04$ & $2.69 \mathrm{E}-04$ & $2.84 \mathrm{E}-04$ & $2.94 \mathrm{E}-04$ & $3.02 \mathrm{E}-04$ & $3.09 \mathrm{E}-04$ \\
\hline & 2 & $4.85 \mathrm{E}-04$ & $5.21 \mathrm{E}-04$ & $5.41 \mathrm{E}-04$ & $5.55 \mathrm{E}-04$ & $5.87 \mathrm{E}-04$ & $6.19 \mathrm{E}-04$ & $6.38 \mathrm{E}-04$ & $6.53 \mathrm{E}-04$ & $6.65 \mathrm{E}-04$ \\
\hline & 2.5 & $8.52 \mathrm{E}-04$ & $9.28 \mathrm{E}-04$ & $9.70 \mathrm{E}-04$ & $9.99 \mathrm{E}-04$ & $1.07 \mathrm{E}-03$ & $1.13 \mathrm{E}-03$ & $1.17 \mathrm{E}-03$ & $1.19 \mathrm{E}-03$ & $1.21 \mathrm{E}-03$ \\
\hline & 3 & $1.33 \mathrm{E}-03$ & $1.47 \mathrm{E}-03$ & $1.54 \mathrm{E}-03$ & $1.60 \mathrm{E}-03$ & $1.72 \mathrm{E}-03$ & $1.84 \mathrm{E}-03$ & $1.91 \mathrm{E}-03$ & $1.95 \mathrm{E}-03$ & $1.99 \mathrm{E}-03$ \\
\hline & 3.5 & $1.92 \mathrm{E}-03$ & $2.14 \mathrm{E}-03$ & $2.27 \mathrm{E}-03$ & $2.35 \mathrm{E}-03$ & $2.56 \mathrm{E}-03$ & $2.76 \mathrm{E}-03$ & 2.87E-03 & $2.94 \mathrm{E}-03$ & $3.00 \mathrm{E}-03$ \\
\hline
\end{tabular}

Table 79 Maximum deflection results for alpha 2 for slabs subjected to CHBDC axle 2 \& 3 loading (main bars parallel to traffic)

\begin{tabular}{|c|c|c|c|c|c|c|c|c|c|c|}
\hline & & \multicolumn{9}{|c|}{ Deflection (m) } \\
\hline \multirow{7}{*}{ 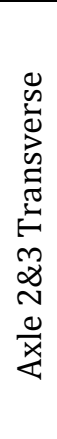 } & $\begin{array}{c}\mathrm{D} \\
\text { SPAN }\end{array}$ & 0.25 & 0.5 & 0.75 & 1 & 2 & 4 & 6 & 8 & 10 \\
\hline & 1.5 & $9.60 \mathrm{E}-05$ & $1.02 \mathrm{E}-04$ & $1.05 \mathrm{E}-04$ & 1.07E-04 & 1.12E-04 & $1.18 \mathrm{E}-04$ & $1.22 \mathrm{E}-04$ & $1.25 \mathrm{E}-04$ & $1.28 \mathrm{E}-04$ \\
\hline & 2 & $3.91 \mathrm{E}-04$ & $4.21 \mathrm{E}-04$ & $4.37 \mathrm{E}-04$ & $4.48 \mathrm{E}-04$ & $4.72 \mathrm{E}-04$ & $4.96 \mathrm{E}-04$ & $5.10 \mathrm{E}-04$ & $5.21 \mathrm{E}-04$ & $5.30 \mathrm{E}-04$ \\
\hline & 2.5 & $8.55 \mathrm{E}-04$ & $9.34 \mathrm{E}-04$ & $9.79 \mathrm{E}-04$ & $1.01 \mathrm{E}-03$ & $1.08 \mathrm{E}-03$ & $1.14 \mathrm{E}-03$ & $1.17 \mathrm{E}-03$ & $1.20 \mathrm{E}-03$ & $1.22 \mathrm{E}-03$ \\
\hline & 3 & $1.49 \mathrm{E}-03$ & $1.65 \mathrm{E}-03$ & $1.74 \mathrm{E}-03$ & $1.80 \mathrm{E}-03$ & $1.94 \mathrm{E}-03$ & $2.07 \mathrm{E}-03$ & $2.14 \mathrm{E}-03$ & $2.19 \mathrm{E}-03$ & $2.23 \mathrm{E}-03$ \\
\hline & 3.5 & $2.29 \mathrm{E}-03$ & $2.56 \mathrm{E}-03$ & $2.71 \mathrm{E}-03$ & $2.82 \mathrm{E}-03$ & $3.08 \mathrm{E}-03$ & $3.32 \mathrm{E}-03$ & $3.45 \mathrm{E}-03$ & $3.54 \mathrm{E}-03$ & $3.60 \mathrm{E}-03$ \\
\hline & 4 & $3.27 \mathrm{E}-03$ & $3.66 \mathrm{E}-03$ & $3.90 \mathrm{E}-03$ & $4.07 \mathrm{E}-03$ & $4.48 \mathrm{E}-03$ & $4.88 \mathrm{E}-03$ & $5.09 \mathrm{E}-03$ & $5.24 \mathrm{E}-03$ & 5.35E-03 \\
\hline
\end{tabular}




\section{Alpha 4 Deflection Results}

Table 80 Maximum deflection results for alpha 4 for slabs subjected to CHBDC axle 4 loading (main bars perpendicular to traffic)

\begin{tabular}{|c|c|c|c|c|c|c|c|c|c|c|}
\hline & \multicolumn{9}{|c|}{ Deflection (m) } \\
\hline \multirow{9}{*}{$\frac{\vec{a}}{\frac{0}{x}}$} & $\mathrm{D}$ & \multirow{2}{*}{0.25} & \multirow{2}{*}{0.5} & \multirow{2}{*}{0.75} & \multirow{2}{*}{1} & & \multirow{2}{*}{4} & & & \multirow{2}{*}{10} \\
\hline & SPAN & & & & & & & & & \\
\hline & 1 & $3.30 \mathrm{E}-05$ & $3.90 \mathrm{E}-05$ & $4.30 \mathrm{E}-05$ & $4.60 \mathrm{E}-05$ & $5.50 \mathrm{E}-05$ & $6.40 \mathrm{E}-05$ & 7.10E-05 & $7.60 \mathrm{E}-05$ & $8.00 \mathrm{E}-05$ \\
\hline & 1.5 & $8.20 \mathrm{E}-05$ & $9.70 \mathrm{E}-05$ & $1.08 \mathrm{E}-04$ & $1.16 \mathrm{E}-04$ & 1.37E-04 & $1.62 \mathrm{E}-04$ & $1.79 \mathrm{E}-04$ & $1.92 \mathrm{E}-04$ & $2.03 \mathrm{E}-04$ \\
\hline & 2 & $1.52 \mathrm{E}-04$ & $1.80 \mathrm{E}-04$ & $2.00 \mathrm{E}-04$ & $2.14 \mathrm{E}-04$ & $2.54 \mathrm{E}-04$ & $3.02 \mathrm{E}-04$ & 3.33E-04 & $3.58 \mathrm{E}-04$ & $3.78 \mathrm{E}-04$ \\
\hline & 2.5 & $2.42 \mathrm{E}-04$ & $2.88 \mathrm{E}-04$ & $3.18 \mathrm{E}-04$ & $3.42 \mathrm{E}-04$ & $4.06 \mathrm{E}-04$ & 4.82E-04 & 5.33E-04 & $5.72 \mathrm{E}-04$ & $6.04 \mathrm{E}-04$ \\
\hline & 3 & $3.80 \mathrm{E}-04$ & $4.51 \mathrm{E}-04$ & $4.99 \mathrm{E}-04$ & $5.36 \mathrm{E}-04$ & $6.37 \mathrm{E}-04$ & 7.57E-04 & 8.37E-04 & 8.99E-04 & $9.50 \mathrm{E}-04$ \\
\hline & 3.5 & $6.22 \mathrm{E}-04$ & 7.35E-04 & 8.12E-04 & 8.72E-04 & $1.04 \mathrm{E}-03$ & $1.23 \mathrm{E}-03$ & $1.36 \mathrm{E}-03$ & $1.46 \mathrm{E}-03$ & $1.55 \mathrm{E}-03$ \\
\hline & 4 & $9.13 \mathrm{E}-04$ & $1.07 \mathrm{E}-03$ & 1.19E-03 & $1.27 \mathrm{E}-03$ & $1.51 \mathrm{E}-03$ & $1.79 \mathrm{E}-03$ & $1.98 \mathrm{E}-03$ & $2.13 \mathrm{E}-03$ & $2.25 \mathrm{E}-03$ \\
\hline
\end{tabular}

Table 81 Maximum deflection results for alpha 4 for slabs subjected to CHBDC axle $2 \& 3$ loading (main bars perpendicular to traffic)

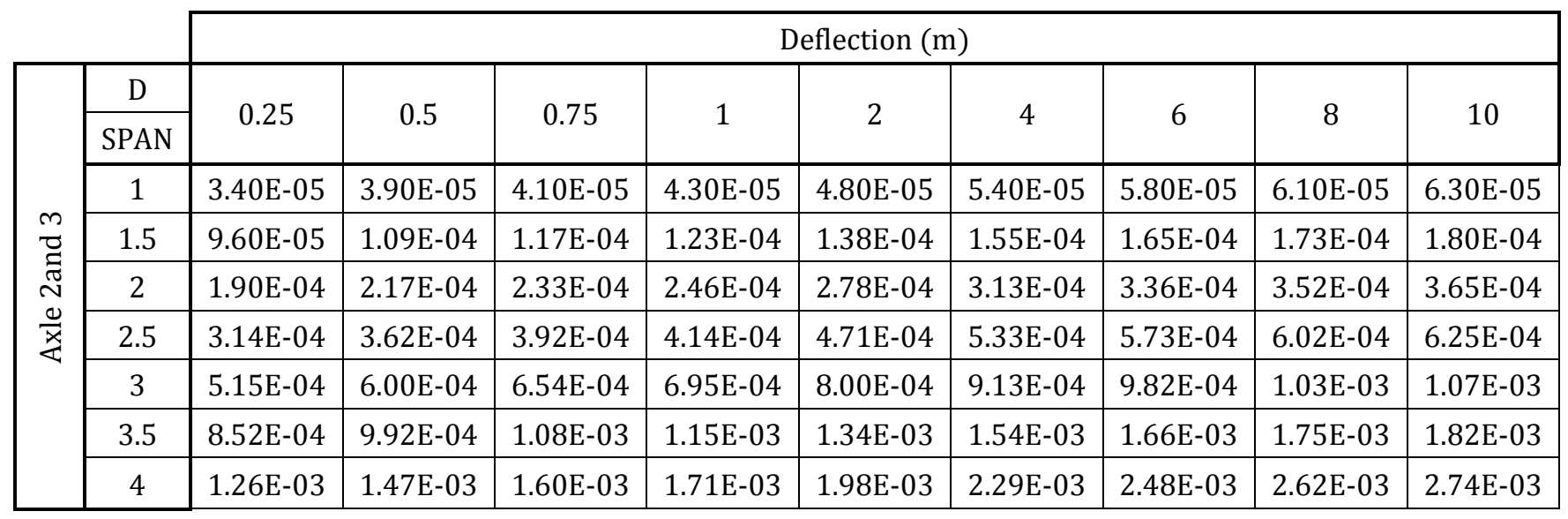

Table 82 Maximum deflection results for alpha 4 for slabs subjected to CHBDC truck loading (main bars perpendicular to traffic)

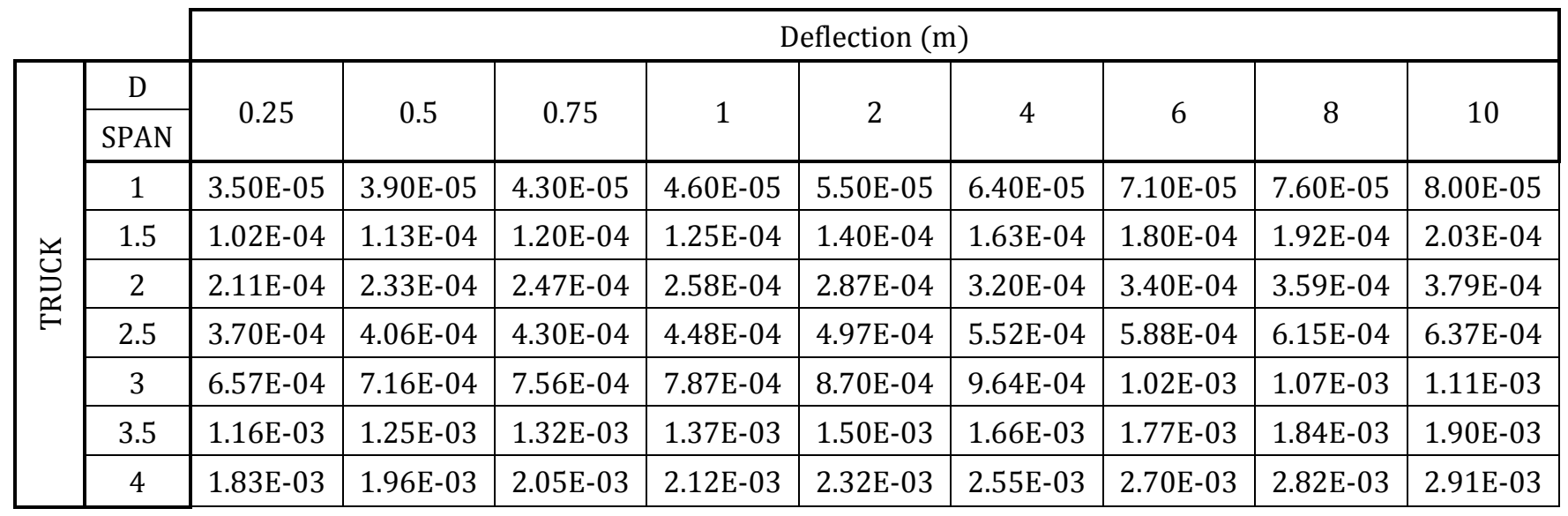


Table 83 Maximum deflection results for alpha 4 for slabs subjected to CHBDC axle 4 loading (main bars parallel to traffic)

\begin{tabular}{|c|c|c|c|c|c|c|c|c|c|c|}
\hline & & \multicolumn{9}{|c|}{ Deflection (m) } \\
\hline \multirow{7}{*}{ 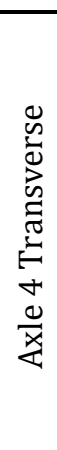 } & $\frac{\mathrm{D}}{\mathrm{SPAN}}$ & 0.25 & 0.5 & 0.75 & 1 & & 4 & 6 & 8 & 10 \\
\hline & 1 & $6.90 \mathrm{E}-05$ & $7.30 \mathrm{E}-05$ & $7.60 \mathrm{E}-05$ & $7.80 \mathrm{E}-05$ & $8.20 \mathrm{E}-05$ & $8.70 \mathrm{E}-05$ & $9.10 \mathrm{E}-05$ & $9.30 \mathrm{E}-05$ & $9.50 \mathrm{E}-05$ \\
\hline & 1.5 & $2.00 \mathrm{E}-04$ & $2.16 \mathrm{E}-04$ & $2.25 \mathrm{E}-04$ & $2.31 \mathrm{E}-04$ & $2.46 \mathrm{E}-04$ & $2.61 \mathrm{E}-04$ & $2.70 \mathrm{E}-04$ & $2.76 \mathrm{E}-04$ & $2.81 \mathrm{E}-04$ \\
\hline & 2 & $4.13 \mathrm{E}-04$ & $4.52 \mathrm{E}-04$ & $4.74 \mathrm{E}-04$ & $4.90 \mathrm{E}-04$ & $5.27 \mathrm{E}-04$ & $5.63 \mathrm{E}-04$ & $5.83 \mathrm{E}-04$ & $5.98 \mathrm{E}-04$ & $6.09 \mathrm{E}-04$ \\
\hline & 2.5 & $7.10 \mathrm{E}-04$ & $7.86 \mathrm{E}-04$ & $8.31 \mathrm{E}-04$ & $8.62 \mathrm{E}-04$ & $9.38 \mathrm{E}-04$ & $1.01 \mathrm{E}-03$ & $1.05 \mathrm{E}-03$ & $1.08 \mathrm{E}-03$ & $1.10 \mathrm{E}-03$ \\
\hline & 3 & $1.10 \mathrm{E}-03$ & $1.22 \mathrm{E}-03$ & $1.30 \mathrm{E}-03$ & $1.35 \mathrm{E}-03$ & $1.49 \mathrm{E}-03$ & $1.62 \mathrm{E}-03$ & $1.69 \mathrm{E}-03$ & $1.74 \mathrm{E}-03$ & $1.78 \mathrm{E}-03$ \\
\hline & 3.5 & $1.57 \mathrm{E}-03$ & $1.76 \mathrm{E}-03$ & $1.88 \mathrm{E}-03$ & $1.96 \mathrm{E}-03$ & $2.17 \mathrm{E}-03$ & $2.38 \mathrm{E}-03$ & $2.51 \mathrm{E}-03$ & $2.59 \mathrm{E}-03$ & $2.66 \mathrm{E}-03$ \\
\hline
\end{tabular}

Table 84 Maximum deflection results for alpha 4 for slabs subjected to CHBDC axle 2 \& 3 loading (main bars parallel to traffic)

\begin{tabular}{|c|c|c|c|c|c|c|c|c|c|c|}
\hline & & \multicolumn{9}{|c|}{ Deflection (m) } \\
\hline \multirow{8}{*}{ 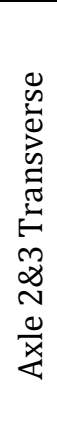 } & D & \multirow{2}{*}{0.25} & \multirow{2}{*}{0.5} & \multirow{2}{*}{0.75} & \multirow{2}{*}{1} & \multirow[b]{2}{*}{2} & \multirow{2}{*}{4} & \multirow{2}{*}{6} & \multirow[b]{2}{*}{8} & \multirow{2}{*}{10} \\
\hline & $\begin{array}{l}\text { SPAN } \\
\end{array}$ & & & & & & & & & \\
\hline & 1.5 & $8.40 \mathrm{E}-05$ & $9.00 \mathrm{E}-05$ & $9.40 \mathrm{E}-05$ & $9.70 \mathrm{E}-05$ & $1.03 \mathrm{E}-04$ & $1.09 \mathrm{E}-04$ & $1.12 \mathrm{E}-04$ & $1.15 \mathrm{E}-04$ & $1.17 \mathrm{E}-04$ \\
\hline & 2 & 3.31E-04 & 3.63E-04 & $3.81 \mathrm{E}-04$ & 3.93E-04 & 4.23E-04 & $4.51 \mathrm{E}-04$ & 4.67E-04 & 4.78E-04 & 4.87E-04 \\
\hline & 2.5 & $7.10 \mathrm{E}-04$ & 7.88E-04 & 8.34E-04 & $8.66 \mathrm{E}-04$ & $9.42 \mathrm{E}-04$ & $1.02 \mathrm{E}-03$ & $1.06 \mathrm{E}-03$ & $1.09 \mathrm{E}-03$ & $1.11 \mathrm{E}-03$ \\
\hline & 3 & $1.22 \mathrm{E}-03$ & 1.37E-03 & $1.45 \mathrm{E}-03$ & $1.52 \mathrm{E}-03$ & $1.67 \mathrm{E}-03$ & $1.81 \mathrm{E}-03$ & $1.90 \mathrm{E}-03$ & $1.96 \mathrm{E}-03$ & $2.00 \mathrm{E}-03$ \\
\hline & 3.5 & 1.87E-03 & $2.10 \mathrm{E}-03$ & $2.24 \mathrm{E}-03$ & $2.35 \mathrm{E}-03$ & $2.60 \mathrm{E}-03$ & $2.86 \mathrm{E}-03$ & $3.00 \mathrm{E}-03$ & 3.10E-03 & $3.18 \mathrm{E}-03$ \\
\hline & 4 & $2.66 \mathrm{E}-03$ & $2.99 E-03$ & $3.20 \mathrm{E}-03$ & $3.36 \mathrm{E}-03$ & $3.74 \mathrm{E}-03$ & $4.14 \mathrm{E}-03$ & 4.37E-03 & $4.53 E-03$ & $4.66 \mathrm{E}-03$ \\
\hline
\end{tabular}




\section{Alpha 6 Deflection Results}

Table 85 Maximum deflection results for alpha 6 for slabs subjected to CHBDC axle 4 loading (main bars perpendicular to traffic)

\begin{tabular}{|c|c|c|c|c|c|c|c|c|c|c|}
\hline & \multicolumn{9}{|c|}{ Deflection (m) } \\
\hline \multirow{9}{*}{$\frac{\vec{a}}{\frac{0}{x}}$} & $\mathrm{D}$ & \multirow{2}{*}{0.25} & \multirow{2}{*}{0.5} & \multirow{2}{*}{0.75} & \multirow{2}{*}{1} & & \multirow{2}{*}{4} & & & \multirow{2}{*}{10} \\
\hline & SPAN & & & & & & & & & \\
\hline & 1 & $2.80 \mathrm{E}-05$ & $3.30 \mathrm{E}-05$ & $3.60 \mathrm{E}-05$ & $3.90 \mathrm{E}-05$ & $4.60 \mathrm{E}-05$ & $5.50 \mathrm{E}-05$ & $6.00 \mathrm{E}-05$ & $6.40 \mathrm{E}-05$ & $6.80 \mathrm{E}-05$ \\
\hline & 1.5 & $6.90 \mathrm{E}-05$ & $8.20 \mathrm{E}-05$ & $9.10 \mathrm{E}-05$ & $9.80 \mathrm{E}-05$ & $1.16 \mathrm{E}-04$ & $1.37 \mathrm{E}-04$ & $1.52 \mathrm{E}-04$ & $1.63 \mathrm{E}-04$ & $1.72 \mathrm{E}-04$ \\
\hline & 2 & $1.28 \mathrm{E}-04$ & $1.52 \mathrm{E}-04$ & $1.69 \mathrm{E}-04$ & $1.81 \mathrm{E}-04$ & $2.15 \mathrm{E}-04$ & $2.55 \mathrm{E}-04$ & $2.82 \mathrm{E}-04$ & 3.03E-04 & $3.20 \mathrm{E}-04$ \\
\hline & 2.5 & $2.05 \mathrm{E}-04$ & $2.43 \mathrm{E}-04$ & $2.69 \mathrm{E}-04$ & $2.89 \mathrm{E}-04$ & 3.43E-04 & 4.07E-04 & $4.50 \mathrm{E}-04$ & $4.84 \mathrm{E}-04$ & $5.11 \mathrm{E}-04$ \\
\hline & 3 & $3.24 \mathrm{E}-04$ & 3.82E-04 & $4.22 \mathrm{E}-04$ & $4.53 \mathrm{E}-04$ & $5.38 \mathrm{E}-04$ & $6.40 \mathrm{E}-04$ & $7.08 \mathrm{E}-04$ & 7.60E-04 & 8.03E-04 \\
\hline & 3.5 & 5.33E-04 & $6.25 \mathrm{E}-04$ & $6.89 \mathrm{E}-04$ & 7.39E-04 & 8.76E-04 & $1.04 \mathrm{E}-03$ & $1.15 \mathrm{E}-03$ & $1.24 \mathrm{E}-03$ & $1.31 \mathrm{E}-03$ \\
\hline & 4 & $7.90 \mathrm{E}-04$ & 9.19E-04 & $1.01 \mathrm{E}-03$ & $1.08 \mathrm{E}-03$ & $1.28 \mathrm{E}-03$ & $1.52 \mathrm{E}-03$ & $1.68 \mathrm{E}-03$ & $1.80 \mathrm{E}-03$ & $1.90 \mathrm{E}-03$ \\
\hline
\end{tabular}

Table 86 Maximum deflection results for alpha 6 for slabs subjected to CHBDC axle $2 \& 3$ loading (main bars perpendicular to traffic)

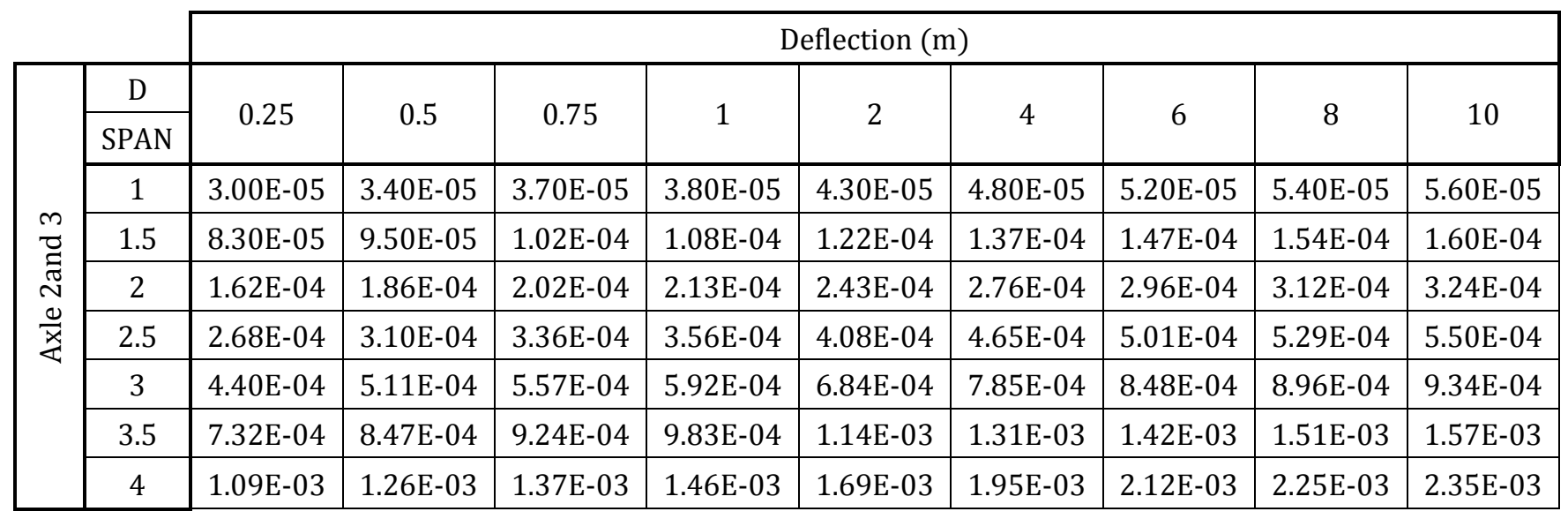

Table 87 Maximum deflection results for alpha 6 for slabs subjected to CHBDC truck loading (main bars perpendicular to traffic)

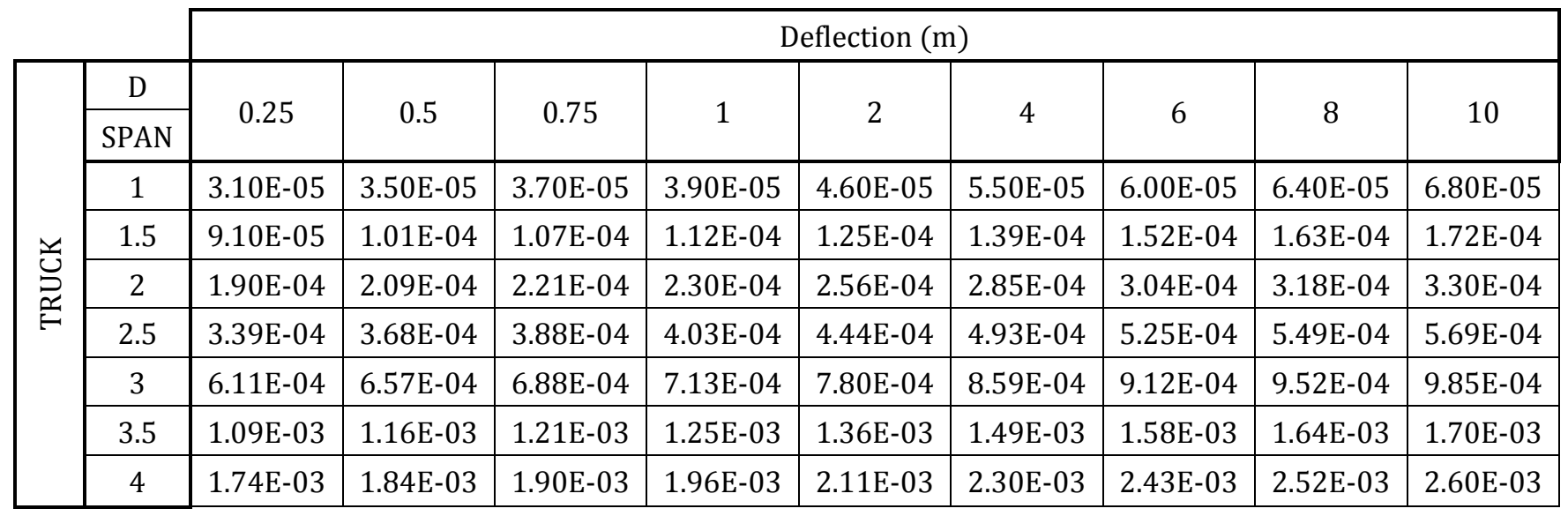


Table 88 Maximum deflection results for alpha 6 for slabs subjected to CHBDC axle 4 loading (main bars parallel to traffic)

\begin{tabular}{|c|c|c|c|c|c|c|c|c|c|c|}
\hline & & \multicolumn{9}{|c|}{ Deflection (m) } \\
\hline \multirow{8}{*}{ 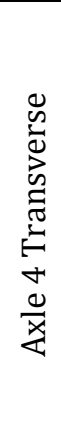 } & D & 025 & 05 & 075 & 1 & 2 & 4 & 6 & 8 & 10 \\
\hline & SPAN & 0.25 & 0.5 & 0.15 & & & & & & \\
\hline & 1 & $6.40 \mathrm{E}-05$ & $6.90 \mathrm{E}-05$ & $7.10 \mathrm{E}-05$ & $7.30 \mathrm{E}-05$ & $7.80 \mathrm{E}-05$ & $8.20 \mathrm{E}-05$ & 8.50E-05 & $8.70 \mathrm{E}-05$ & $8.90 \mathrm{E}-05$ \\
\hline & 1.5 & $1.82 \mathrm{E}-04$ & $1.99 \mathrm{E}-04$ & $2.08 \mathrm{E}-04$ & $2.15 \mathrm{E}-04$ & $2.30 \mathrm{E}-04$ & $2.45 \mathrm{E}-04$ & $2.54 \mathrm{E}-04$ & $2.60 \mathrm{E}-04$ & $2.65 \mathrm{E}-04$ \\
\hline & 2 & $3.69 \mathrm{E}-04$ & $4.08 \mathrm{E}-04$ & $4.31 \mathrm{E}-04$ & $4.47 \mathrm{E}-04$ & $4.86 \mathrm{E}-04$ & $5.24 \mathrm{E}-04$ & $5.45 \mathrm{E}-04$ & $5.60 \mathrm{E}-04$ & $5.72 \mathrm{E}-04$ \\
\hline & 2.5 & $6.28 \mathrm{E}-04$ & $7.01 \mathrm{E}-04$ & $7.44 \mathrm{E}-04$ & $7.76 \mathrm{E}-04$ & 8.53E-04 & $9.29 \mathrm{E}-04$ & $9.73 \mathrm{E}-04$ & $1.00 \mathrm{E}-03$ & $1.03 \mathrm{E}-03$ \\
\hline & 3 & $9.66 \mathrm{E}-04$ & $1.08 \mathrm{E}-03$ & $1.15 \mathrm{E}-03$ & $1.21 \mathrm{E}-03$ & $1.34 \mathrm{E}-03$ & $1.47 \mathrm{E}-03$ & $1.55 \mathrm{E}-03$ & $1.60 \mathrm{E}-03$ & $1.64 \mathrm{E}-03$ \\
\hline & 3.5 & $1.39 \mathrm{E}-03$ & $1.55 \mathrm{E}-03$ & $1.66 \mathrm{E}-03$ & $1.74 \mathrm{E}-03$ & $1.94 \mathrm{E}-03$ & $2.15 \mathrm{E}-03$ & $2.27 \mathrm{E}-03$ & $2.36 \mathrm{E}-03$ & $2.43 \mathrm{E}-03$ \\
\hline
\end{tabular}

Table 89 Maximum deflection results for alpha 6 for slabs subjected to CHBDC axle $2 \& 3$ loading (main bars parallel to traffic)

\begin{tabular}{|c|c|c|c|c|c|c|c|c|c|c|}
\hline & & \multicolumn{9}{|c|}{ Deflection (m) } \\
\hline \multirow{8}{*}{ 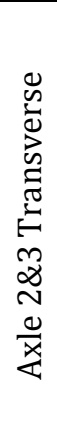 } & $\mathrm{D}$ & \multirow{2}{*}{0.25} & \multirow{2}{*}{0.5} & \multirow{2}{*}{0.75} & \multirow{2}{*}{1} & & \multirow{2}{*}{4} & \multirow{2}{*}{6} & \multirow[b]{2}{*}{0} & \multirow{2}{*}{10} \\
\hline & SPAN & & & & & & & & & \\
\hline & 1.5 & $7.60 \mathrm{E}-05$ & $8.30 \mathrm{E}-05$ & $8.70 \mathrm{E}-05$ & $8.90 \mathrm{E}-05$ & $9.60 \mathrm{E}-05$ & $1.02 \mathrm{E}-04$ & $1.06 \mathrm{E}-04$ & $1.08 \mathrm{E}-04$ & $1.10 \mathrm{E}-04$ \\
\hline & 2 & $2.94 \mathrm{E}-04$ & $3.26 \mathrm{E}-04$ & $3.45 \mathrm{E}-04$ & $3.58 \mathrm{E}-04$ & $3.89 \mathrm{E}-04$ & $4.20 \mathrm{E}-04$ & 4.37E-04 & $4.49 \mathrm{E}-04$ & $4.58 \mathrm{E}-04$ \\
\hline & 2.5 & $6.26 \mathrm{E}-04$ & $7.00 \mathrm{E}-04$ & $7.45 \mathrm{E}-04$ & $7.77 \mathrm{E}-04$ & $8.54 \mathrm{E}-04$ & $9.32 \mathrm{E}-04$ & $9.76 \mathrm{E}-04$ & $1.01 \mathrm{E}-03$ & $1.03 \mathrm{E}-03$ \\
\hline & 3 & $1.07 \mathrm{E}-03$ & $1.21 \mathrm{E}-03$ & $1.29 \mathrm{E}-03$ & $1.35 \mathrm{E}-03$ & $1.50 \mathrm{E}-03$ & $1.65 \mathrm{E}-03$ & $1.73 \mathrm{E}-03$ & $1.79 \mathrm{E}-03$ & $1.84 \mathrm{E}-03$ \\
\hline & 3.5 & $1.65 \mathrm{E}-03$ & $1.85 \mathrm{E}-03$ & $1.98 \mathrm{E}-03$ & $2.07 \mathrm{E}-03$ & $2.31 \mathrm{E}-03$ & $2.56 \mathrm{E}-03$ & $2.71 \mathrm{E}-03$ & $2.82 \mathrm{E}-03$ & $2.90 \mathrm{E}-03$ \\
\hline & 4 & $2.36 \mathrm{E}-03$ & $2.64 \mathrm{E}-03$ & $2.82 \mathrm{E}-03$ & $2.96 \mathrm{E}-03$ & $3.31 \mathrm{E}-03$ & $3.69 \mathrm{E}-03$ & $3.92 \mathrm{E}-03$ & $4.08 E-03$ & $4.21 \mathrm{E}-03$ \\
\hline
\end{tabular}




\section{Alpha 8 Deflection Results}

Table 90 Maximum deflection results for alpha 8 for slabs subjected to CHBDC axle 4 loading (main bars perpendicular to traffic)

\begin{tabular}{|c|c|c|c|c|c|c|c|c|c|c|}
\hline & \multicolumn{9}{|c|}{ Deflection (m) } \\
\hline \multirow{9}{*}{$\frac{\vec{d}}{x}$} & $\mathrm{D}$ & \multirow{2}{*}{0.25} & \multirow{2}{*}{0.5} & \multirow{2}{*}{0.75} & \multirow{2}{*}{1} & & \multirow{2}{*}{4} & & & \multirow{2}{*}{10} \\
\hline & SPAN & & & & & & & & & \\
\hline & 1 & $2.40 \mathrm{E}-05$ & $2.90 \mathrm{E}-05$ & $3.20 \mathrm{E}-05$ & $3.40 \mathrm{E}-05$ & $4.10 \mathrm{E}-05$ & $4.80 \mathrm{E}-05$ & $5.30 \mathrm{E}-05$ & $5.70 \mathrm{E}-05$ & $6.00 \mathrm{E}-05$ \\
\hline & 1.5 & $6.10 \mathrm{E}-05$ & 7.30E-05 & $8.00 \mathrm{E}-05$ & $8.60 \mathrm{E}-05$ & $1.02 \mathrm{E}-04$ & $1.21 \mathrm{E}-04$ & $1.34 \mathrm{E}-04$ & $1.44 \mathrm{E}-04$ & $1.52 \mathrm{E}-04$ \\
\hline & 2 & 1.13E-04 & $1.35 \mathrm{E}-04$ & $1.49 \mathrm{E}-04$ & $1.60 \mathrm{E}-04$ & $1.90 \mathrm{E}-04$ & $2.25 \mathrm{E}-04$ & $2.49 \mathrm{E}-04$ & $2.67 \mathrm{E}-04$ & 2.82E-04 \\
\hline & 2.5 & $1.82 \mathrm{E}-04$ & $2.15 \mathrm{E}-04$ & $2.38 \mathrm{E}-04$ & $2.55 \mathrm{E}-04$ & 3.03E-04 & $3.59 \mathrm{E}-04$ & 3.97E-04 & $4.27 \mathrm{E}-04$ & $4.51 \mathrm{E}-04$ \\
\hline & 3 & $2.89 \mathrm{E}-04$ & 3.39E-04 & $3.74 \mathrm{E}-04$ & $4.01 \mathrm{E}-04$ & $4.75 \mathrm{E}-04$ & $5.64 \mathrm{E}-04$ & $6.24 \mathrm{E}-04$ & $6.70 \mathrm{E}-04$ & 7.08E-04 \\
\hline & 3.5 & $4.79 \mathrm{E}-04$ & $5.57 \mathrm{E}-04$ & $6.12 \mathrm{E}-04$ & $6.55 \mathrm{E}-04$ & 7.74E-04 & $9.18 \mathrm{E}-04$ & $1.02 \mathrm{E}-03$ & $1.09 \mathrm{E}-03$ & $1.15 \mathrm{E}-03$ \\
\hline & 4 & 7.16E-04 & 8.24E-04 & $9.00 \mathrm{E}-04$ & $9.61 \mathrm{E}-04$ & $1.13 \mathrm{E}-03$ & $1.34 \mathrm{E}-03$ & $1.48 \mathrm{E}-03$ & $1.59 \mathrm{E}-03$ & $1.68 \mathrm{E}-03$ \\
\hline
\end{tabular}

Table 91 Maximum deflection results for alpha 8 for slabs subjected to CHBDC axle $2 \& 3$ loading (main bars perpendicular to traffic)

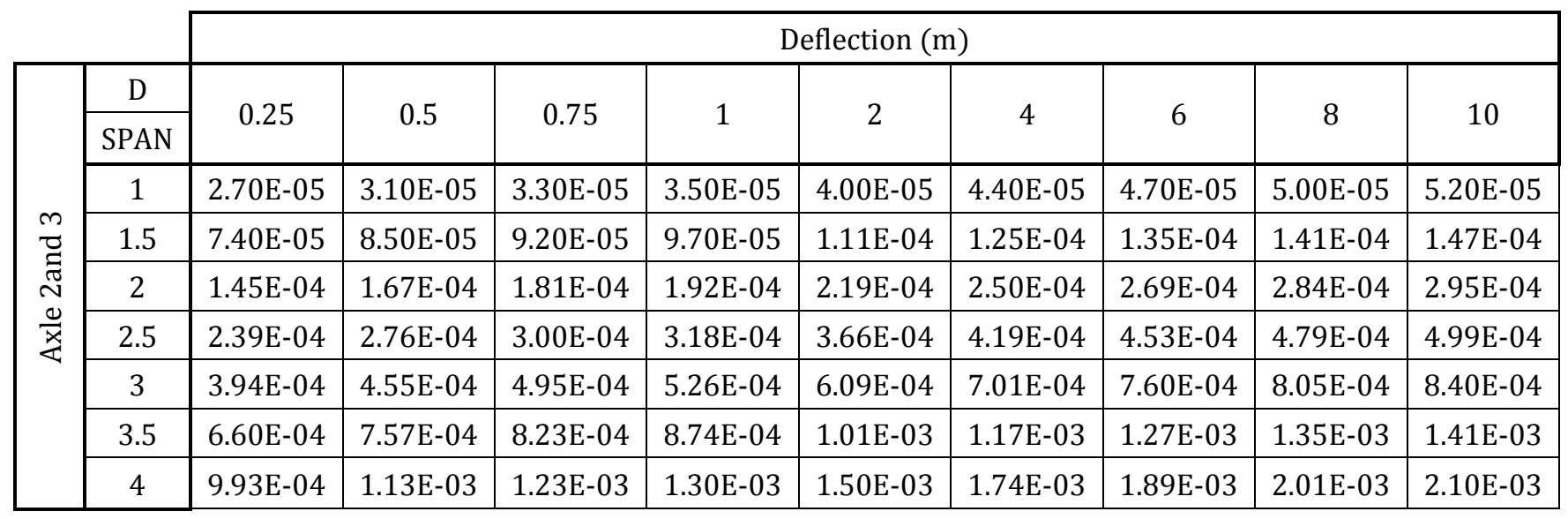

Table 92 Maximum deflection results for alpha 8 for slabs subjected to CHBDC truck loading (main bars perpendicular to traffic)

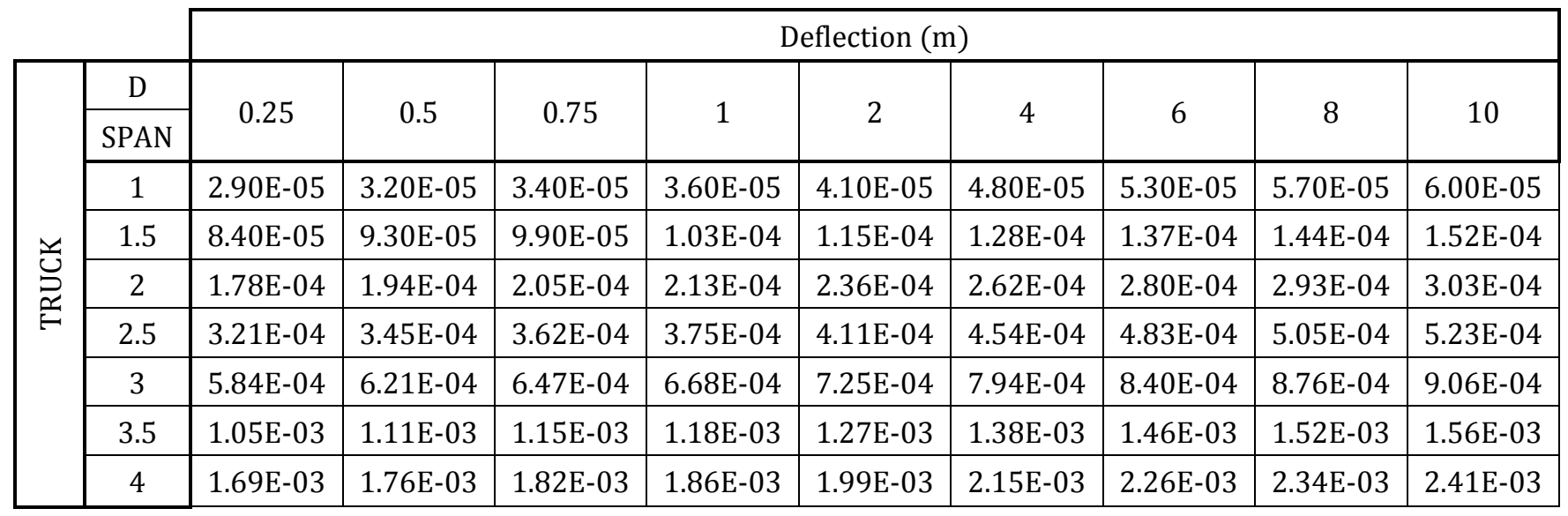


Table 93 Maximum deflection results for alpha 8 for slabs subjected to CHBDC axle 4 loading (main bars parallel to traffic)

\begin{tabular}{|c|c|c|c|c|c|c|c|c|c|c|}
\hline & & \multicolumn{9}{|c|}{ Deflection (m) } \\
\hline \multirow{7}{*}{ 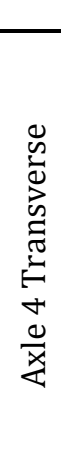 } & $\begin{array}{c}\mathrm{D} \\
\text { SPAN }\end{array}$ & 0.25 & 0.5 & 0.75 & 1 & 2 & 4 & 6 & 8 & 10 \\
\hline & 1 & $6.10 \mathrm{E}-05$ & $6.50 \mathrm{E}-05$ & $6.80 \mathrm{E}-05$ & $7.00 \mathrm{E}-05$ & $7.40 \mathrm{E}-05$ & $7.90 \mathrm{E}-05$ & 8.10E-05 & $8.30 \mathrm{E}-05$ & $8.50 \mathrm{E}-05$ \\
\hline & 1.5 & $1.69 \mathrm{E}-04$ & $1.85 \mathrm{E}-04$ & $1.95 \mathrm{E}-04$ & $2.02 \mathrm{E}-04$ & $2.18 \mathrm{E}-04$ & 2.33E-04 & $2.42 \mathrm{E}-04$ & $2.49 \mathrm{E}-04$ & $2.53 \mathrm{E}-04$ \\
\hline & 2 & $3.38 \mathrm{E}-04$ & $3.76 \mathrm{E}-04$ & $3.99 \mathrm{E}-04$ & $4.15 \mathrm{E}-04$ & $4.55 \mathrm{E}-04$ & $4.94 \mathrm{E}-04$ & $5.16 \mathrm{E}-04$ & $5.32 \mathrm{E}-04$ & $5.43 \mathrm{E}-04$ \\
\hline & 2.5 & $5.74 \mathrm{E}-04$ & $6.42 \mathrm{E}-04$ & $6.84 \mathrm{E}-04$ & 7.14E-04 & $7.91 \mathrm{E}-04$ & $8.68 \mathrm{E}-04$ & $9.13 \mathrm{E}-04$ & $9.44 \mathrm{E}-04$ & $9.69 \mathrm{E}-04$ \\
\hline & 3 & 8.82E-04 & $9.87 \mathrm{E}-04$ & $1.05 \mathrm{E}-03$ & $1.10 \mathrm{E}-03$ & $1.23 \mathrm{E}-03$ & $1.36 \mathrm{E}-03$ & $1.44 \mathrm{E}-03$ & $1.49 \mathrm{E}-03$ & $1.54 \mathrm{E}-03$ \\
\hline & 3.5 & $1.27 \mathrm{E}-03$ & $1.42 \mathrm{E}-03$ & $1.52 \mathrm{E}-03$ & $1.59 \mathrm{E}-03$ & $1.78 \mathrm{E}-03$ & $1.98 \mathrm{E}-03$ & $2.10 \mathrm{E}-03$ & $2.19 \mathrm{E}-03$ & $2.25 \mathrm{E}-03$ \\
\hline
\end{tabular}

Table 94 Maximum deflection results for alpha 8 for slabs subjected to CHBDC axle 2 \& 3 loading (main bars parallel to traffic)

\begin{tabular}{|c|c|c|c|c|c|c|c|c|c|c|}
\hline & & \multicolumn{9}{|c|}{ Deflection (m) } \\
\hline \multirow{8}{*}{ 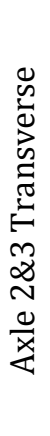 } & $\mathrm{D}$ & \multirow{2}{*}{0.25} & \multirow{2}{*}{0.5} & \multirow{2}{*}{0.75} & \multirow{2}{*}{1} & & \multirow{2}{*}{4} & \multirow{2}{*}{5} & \multirow[b]{2}{*}{0} & \multirow{2}{*}{10} \\
\hline & SPAN & & & & & & & & & \\
\hline & 1.5 & $7.00 \mathrm{E}-05$ & $7.70 \mathrm{E}-05$ & $8.10 \mathrm{E}-05$ & $8.40 \mathrm{E}-05$ & $9.10 \mathrm{E}-05$ & $9.70 \mathrm{E}-05$ & $1.01 \mathrm{E}-04$ & $1.04 \mathrm{E}-04$ & $1.06 \mathrm{E}-04$ \\
\hline & 2 & $2.69 \mathrm{E}-04$ & $3.00 \mathrm{E}-04$ & $3.18 \mathrm{E}-04$ & $3.32 \mathrm{E}-04$ & $3.64 \mathrm{E}-04$ & $3.95 \mathrm{E}-04$ & $4.13 \mathrm{E}-04$ & $4.26 \mathrm{E}-04$ & $4.35 \mathrm{E}-04$ \\
\hline & 2.5 & $5.70 \mathrm{E}-04$ & $6.39 \mathrm{E}-04$ & $6.82 \mathrm{E}-04$ & 7.13E-04 & 7.91E-04 & $8.69 \mathrm{E}-04$ & $9.14 \mathrm{E}-04$ & $9.46 \mathrm{E}-04$ & $9.71 \mathrm{E}-04$ \\
\hline & 3 & $9.80 \mathrm{E}-04$ & $1.10 \mathrm{E}-03$ & $1.17 \mathrm{E}-03$ & $1.23 \mathrm{E}-03$ & $1.37 \mathrm{E}-03$ & $1.52 \mathrm{E}-03$ & $1.61 \mathrm{E}-03$ & $1.67 \mathrm{E}-03$ & $1.72 \mathrm{E}-03$ \\
\hline & 3.5 & $1.51 \mathrm{E}-03$ & $1.69 \mathrm{E}-03$ & $1.80 \mathrm{E}-03$ & 1.89E-03 & 2.12E-03 & $2.36 \mathrm{E}-03$ & $2.50 \mathrm{E}-03$ & $2.61 \mathrm{E}-03$ & $2.69 \mathrm{E}-03$ \\
\hline & 4 & $2.17 \mathrm{E}-03$ & $2.41 \mathrm{E}-03$ & $2.57 \mathrm{E}-03$ & $2.70 \mathrm{E}-03$ & $3.02 \mathrm{E}-03$ & $3.38 \mathrm{E}-03$ & $3.60 \mathrm{E}-03$ & $3.76 \mathrm{E}-03$ & $3.89 \mathrm{E}-03$ \\
\hline
\end{tabular}




\section{Alpha 10 Deflection Results}

Table 95 Maximum deflection results for alpha 10 for slabs subjected to CHBDC axle 4 loading (main bars perpendicular to traffic)

\begin{tabular}{|c|c|c|c|c|c|c|c|c|c|c|}
\hline & \multicolumn{9}{|c|}{ Deflection (m) } \\
\hline \multirow{9}{*}{$\frac{\vec{d}}{x}$} & $\mathrm{D}$ & \multirow{2}{*}{0.25} & \multirow{2}{*}{0.5} & \multirow{2}{*}{0.75} & \multirow{2}{*}{1} & & \multirow{2}{*}{4} & & & \multirow{2}{*}{10} \\
\hline & SPAN & & & & & & & & & \\
\hline & 1 & $2.20 \mathrm{E}-05$ & $2.60 \mathrm{E}-05$ & $2.90 \mathrm{E}-05$ & $3.10 \mathrm{E}-05$ & $3.70 \mathrm{E}-05$ & $4.40 \mathrm{E}-05$ & $4.80 \mathrm{E}-05$ & $5.10 \mathrm{E}-05$ & $5.40 \mathrm{E}-05$ \\
\hline & 1.5 & $5.50 \mathrm{E}-05$ & $6.60 \mathrm{E}-05$ & $7.30 \mathrm{E}-05$ & $7.80 \mathrm{E}-05$ & $9.30 \mathrm{E}-05$ & $1.10 \mathrm{E}-04$ & $1.21 \mathrm{E}-04$ & $1.30 \mathrm{E}-04$ & $1.37 \mathrm{E}-04$ \\
\hline & 2 & $1.03 \mathrm{E}-04$ & $1.22 \mathrm{E}-04$ & $1.35 \mathrm{E}-04$ & $1.45 \mathrm{E}-04$ & $1.72 \mathrm{E}-04$ & $2.04 \mathrm{E}-04$ & $2.25 \mathrm{E}-04$ & $2.42 \mathrm{E}-04$ & $2.55 \mathrm{E}-04$ \\
\hline & 2.5 & $1.66 \mathrm{E}-04$ & $1.95 \mathrm{E}-04$ & $2.15 \mathrm{E}-04$ & $2.31 \mathrm{E}-04$ & $2.74 \mathrm{E}-04$ & $3.25 \mathrm{E}-04$ & $3.59 \mathrm{E}-04$ & $3.86 \mathrm{E}-04$ & $4.08 \mathrm{E}-04$ \\
\hline & 3 & $2.65 \mathrm{E}-04$ & 3.09E-04 & $3.39 \mathrm{E}-04$ & 3.64E-04 & $4.30 \mathrm{E}-04$ & $5.11 \mathrm{E}-04$ & $5.65 \mathrm{E}-04$ & $6.06 \mathrm{E}-04$ & $6.41 \mathrm{E}-04$ \\
\hline & 3.5 & 4.42E-04 & $5.10 \mathrm{E}-04$ & $5.58 \mathrm{E}-04$ & $5.96 \mathrm{E}-04$ & 7.02E-04 & 8.32E-04 & 9.19E-04 & $9.87 \mathrm{E}-04$ & $1.04 \mathrm{E}-03$ \\
\hline & 4 & $6.67 \mathrm{E}-04$ & 7.59E-04 & $8.26 \mathrm{E}-04$ & 8.79E-04 & $1.03 \mathrm{E}-03$ & $1.21 \mathrm{E}-03$ & $1.34 \mathrm{E}-03$ & $1.44 \mathrm{E}-03$ & $1.52 \mathrm{E}-03$ \\
\hline
\end{tabular}

Table 96 Maximum deflection results for alpha 10 for slabs subjected to CHBDC axle 2 \& 3 loading (main bars perpendicular to traffic)

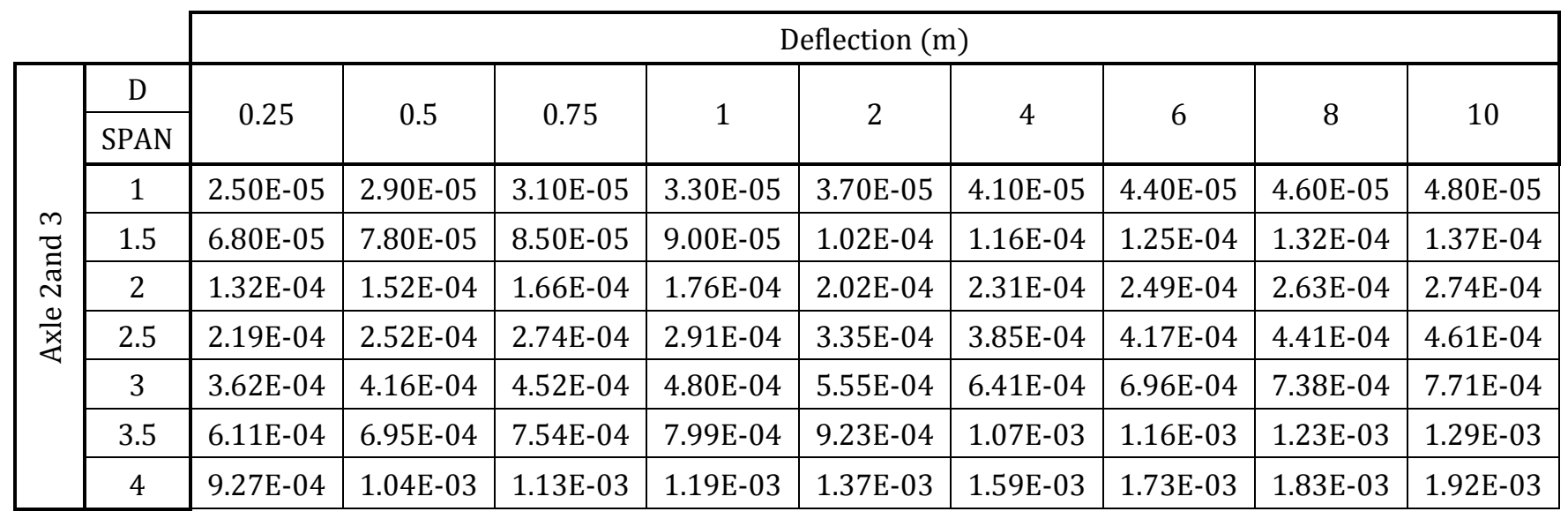

Table 97 Maximum deflection results for alpha 10 for slabs subjected to CHBDC truck loading (main bars perpendicular to traffic)

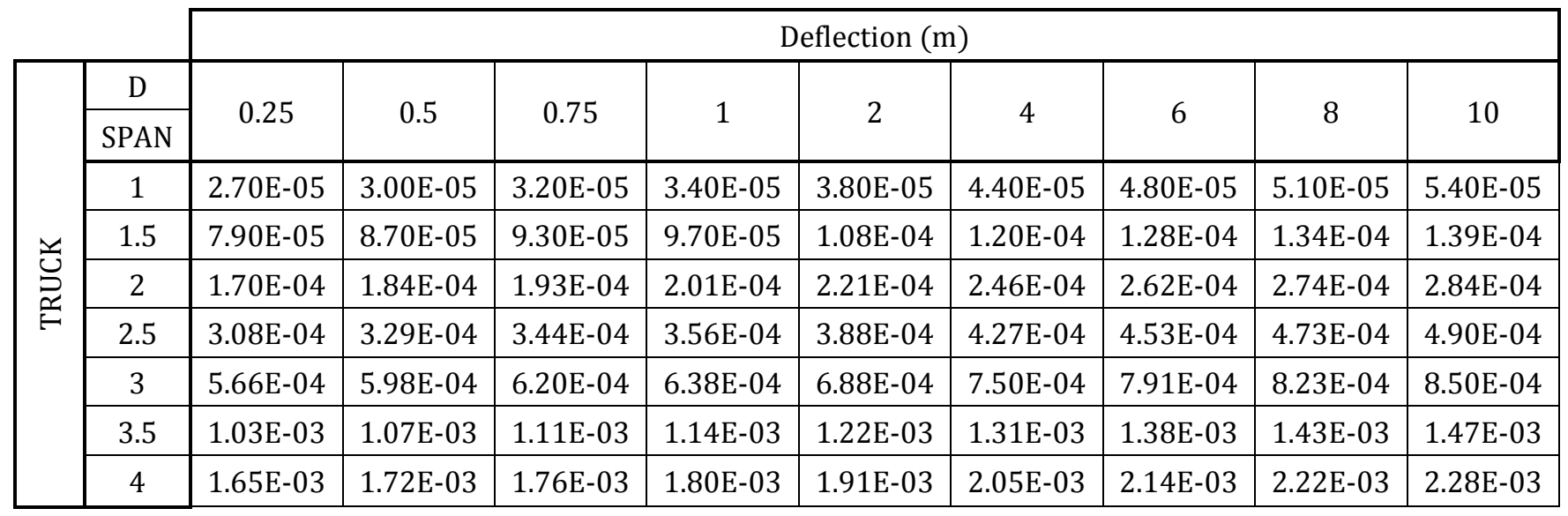


Table 98 Maximum deflection results for alpha 10 for slabs subjected to CHBDC axle 4 loading (main bars parallel to traffic)

\begin{tabular}{|c|c|c|c|c|c|c|c|c|c|c|}
\hline & & \multicolumn{9}{|c|}{ Deflection (m) } \\
\hline \multirow{8}{*}{ 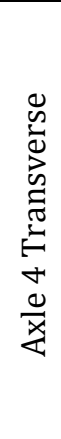 } & D & 025 & 05 & 075 & 1 & 2 & 4 & 6 & 8 & 10 \\
\hline & SPAN & 0.25 & 0.5 & 0.15 & & & & & & \\
\hline & 1 & $5.80 \mathrm{E}-05$ & $6.20 \mathrm{E}-05$ & $6.50 \mathrm{E}-05$ & $6.70 \mathrm{E}-05$ & $7.20 \mathrm{E}-05$ & $7.60 \mathrm{E}-05$ & $7.80 \mathrm{E}-05$ & $8.00 \mathrm{E}-05$ & $8.20 \mathrm{E}-05$ \\
\hline & 1.5 & $1.58 \mathrm{E}-04$ & $1.75 \mathrm{E}-04$ & $1.85 \mathrm{E}-04$ & $1.92 \mathrm{E}-04$ & $2.08 \mathrm{E}-04$ & $2.24 \mathrm{E}-04$ & $2.33 \mathrm{E}-04$ & $2.39 \mathrm{E}-04$ & $2.44 \mathrm{E}-04$ \\
\hline & 2 & $3.15 \mathrm{E}-04$ & $3.52 \mathrm{E}-04$ & $3.74 \mathrm{E}-04$ & $3.90 \mathrm{E}-04$ & $4.30 \mathrm{E}-04$ & $4.69 \mathrm{E}-04$ & $4.92 \mathrm{E}-04$ & $5.08 \mathrm{E}-04$ & $5.20 \mathrm{E}-04$ \\
\hline & 2.5 & $5.35 \mathrm{E}-04$ & $5.98 \mathrm{E}-04$ & $6.38 \mathrm{E}-04$ & $6.68 \mathrm{E}-04$ & 7.42E-04 & 8.19E-04 & 8.64E-04 & 8.96E-04 & $9.21 \mathrm{E}-04$ \\
\hline & 3 & $8.24 \mathrm{E}-04$ & $9.19 \mathrm{E}-04$ & $9.82 \mathrm{E}-04$ & $1.03 \mathrm{E}-03$ & $1.15 \mathrm{E}-03$ & $1.28 \mathrm{E}-03$ & $1.36 \mathrm{E}-03$ & $1.41 \mathrm{E}-03$ & $1.45 \mathrm{E}-03$ \\
\hline & 3.5 & $1.20 \mathrm{E}-03$ & $1.33 \mathrm{E}-03$ & $1.41 \mathrm{E}-03$ & $1.48 \mathrm{E}-03$ & $1.65 \mathrm{E}-03$ & $1.85 \mathrm{E}-03$ & $1.97 \mathrm{E}-03$ & $2.05 \mathrm{E}-03$ & $2.12 \mathrm{E}-03$ \\
\hline
\end{tabular}

Table 99 Maximum deflection results for alpha 10 for slabs subjected to CHBDC axle 2 \& 3 loading (main bars parallel to traffic)

\begin{tabular}{|c|c|c|c|c|c|c|c|c|c|c|}
\hline & & \multicolumn{9}{|c|}{ Deflection (m) } \\
\hline \multirow{8}{*}{ 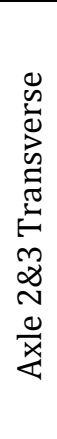 } & $\mathrm{D}$ & \multirow{2}{*}{0.25} & \multirow{2}{*}{0.5} & \multirow{2}{*}{0.75} & \multirow{2}{*}{1} & & \multirow{2}{*}{4} & \multirow{2}{*}{6} & \multirow[b]{2}{*}{0} & \multirow{2}{*}{10} \\
\hline & SPAN & & & & & & & & & \\
\hline & 1.5 & $6.60 \mathrm{E}-05$ & $7.30 \mathrm{E}-05$ & $7.70 \mathrm{E}-05$ & $8.00 \mathrm{E}-05$ & $8.70 \mathrm{E}-05$ & $9.30 \mathrm{E}-05$ & $9.70 \mathrm{E}-05$ & $1.00 \mathrm{E}-04$ & $1.02 \mathrm{E}-04$ \\
\hline & 2 & $2.50 \mathrm{E}-04$ & $2.80 \mathrm{E}-04$ & $2.98 \mathrm{E}-04$ & $3.11 \mathrm{E}-04$ & $3.43 \mathrm{E}-04$ & $3.75 \mathrm{E}-04$ & $3.94 \mathrm{E}-04$ & 4.07E-04 & 4.17E-04 \\
\hline & 2.5 & $5.30 \mathrm{E}-04$ & $5.95 \mathrm{E}-04$ & $6.35 \mathrm{E}-04$ & $6.65 \mathrm{E}-04$ & $7.41 \mathrm{E}-04$ & $8.19 \mathrm{E}-04$ & $8.65 \mathrm{E}-04$ & $8.98 \mathrm{E}-04$ & $9.23 \mathrm{E}-04$ \\
\hline & 3 & $9.14 \mathrm{E}-04$ & $1.02 \mathrm{E}-03$ & $1.09 \mathrm{E}-03$ & $1.15 \mathrm{E}-03$ & $1.28 \mathrm{E}-03$ & $1.43 \mathrm{E}-03$ & $1.51 \mathrm{E}-03$ & $1.58 \mathrm{E}-03$ & $1.63 \mathrm{E}-03$ \\
\hline & 3.5 & $1.42 \mathrm{E}-03$ & $1.57 \mathrm{E}-03$ & $1.68 \mathrm{E}-03$ & $1.76 \mathrm{E}-03$ & $1.97 \mathrm{E}-03$ & $2.20 \mathrm{E}-03$ & $2.34 \mathrm{E}-03$ & $2.45 \mathrm{E}-03$ & $2.53 \mathrm{E}-03$ \\
\hline & 4 & $2.05 \mathrm{E}-03$ & $2.26 \mathrm{E}-03$ & $2.40 \mathrm{E}-03$ & $2.51 \mathrm{E}-03$ & $2.81 \mathrm{E}-03$ & $3.15 \mathrm{E}-03$ & $3.36 \mathrm{E}-03$ & $3.52 \mathrm{E}-03$ & $3.64 \mathrm{E}-03$ \\
\hline
\end{tabular}




\section{B.2.2 MAXIMUM Deflection VS SPAN LENGTH}




\section{Alpha 0.25 Deflection VS Span Length for Different D Values}

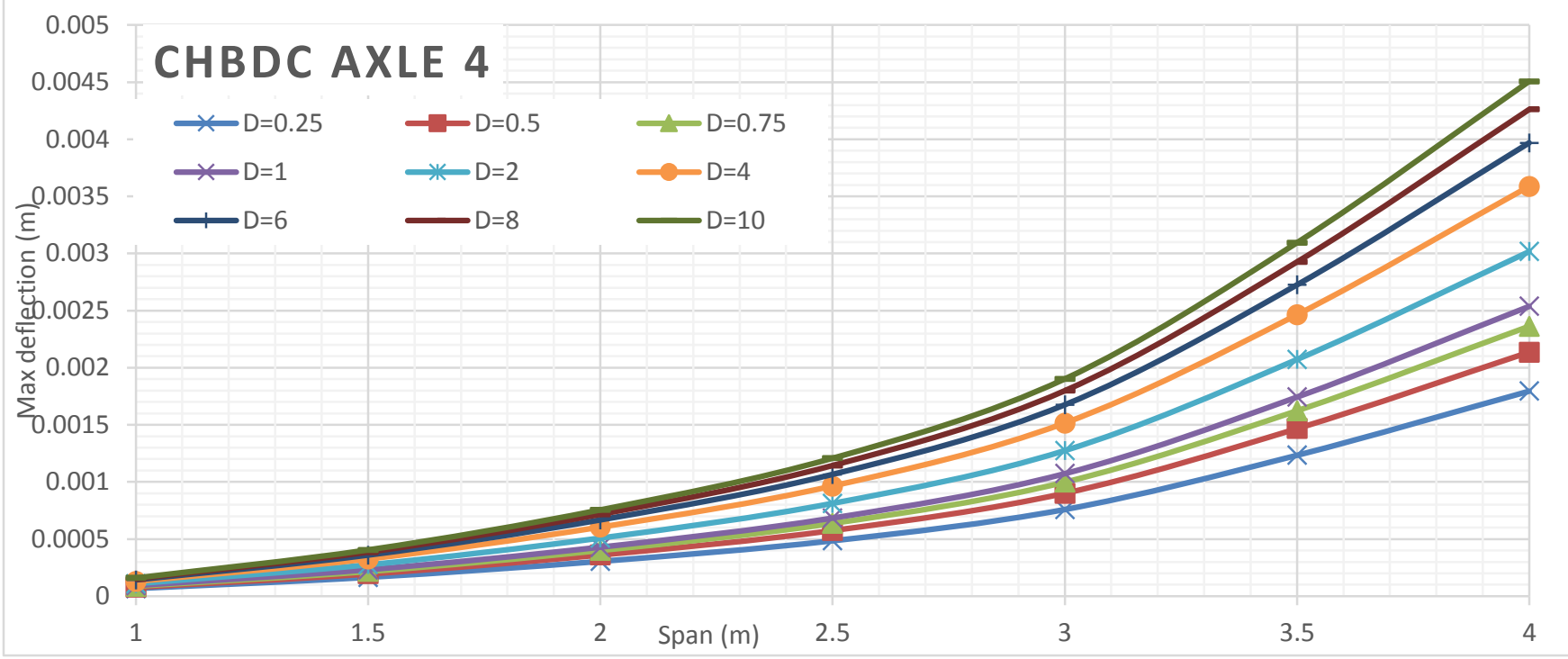

Figure 124 Maximum deflection of deck slabs subjected to CHBDC axle 4 for different D values of alpha 0.25 FEA analyses

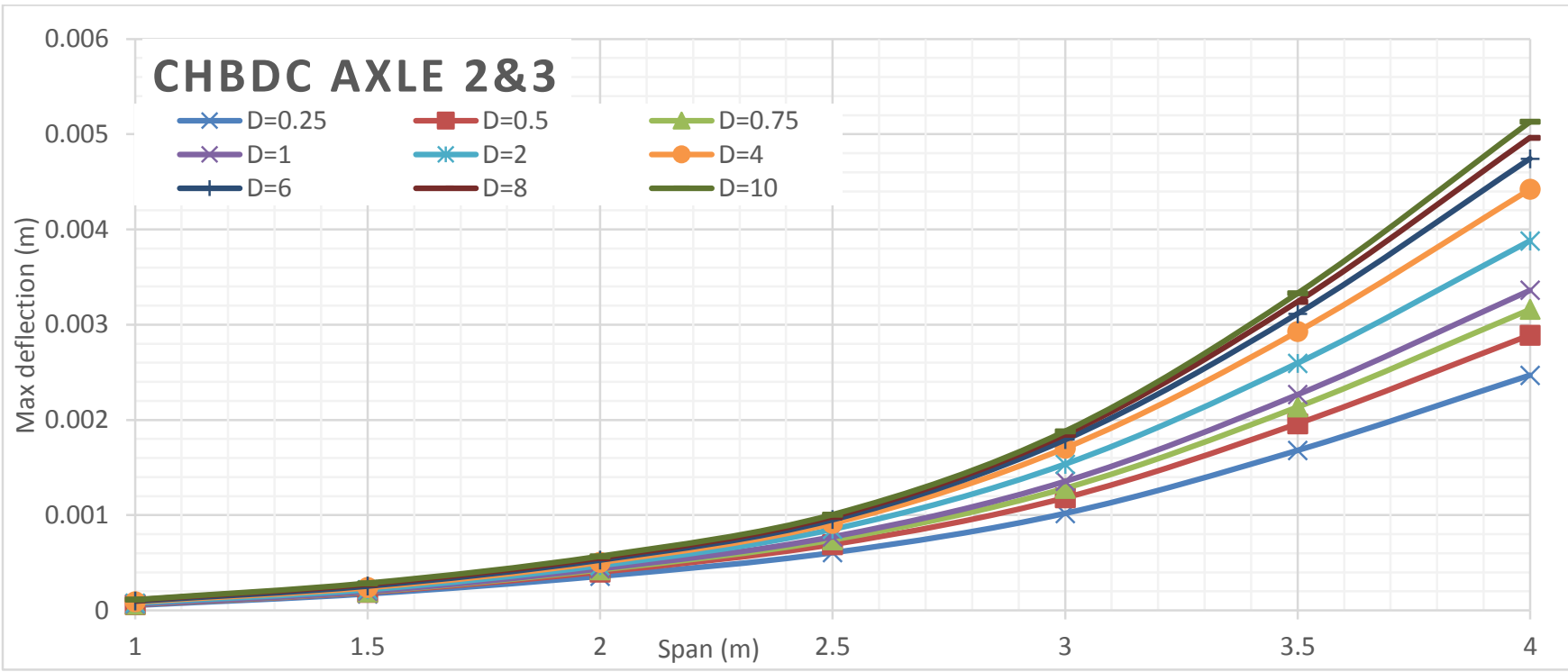

Figure 125 Maximum deflection of deck slabs subjected to CHBDC axle $2 \& 3$ for different D values of alpha 0.25 FEA analyses 


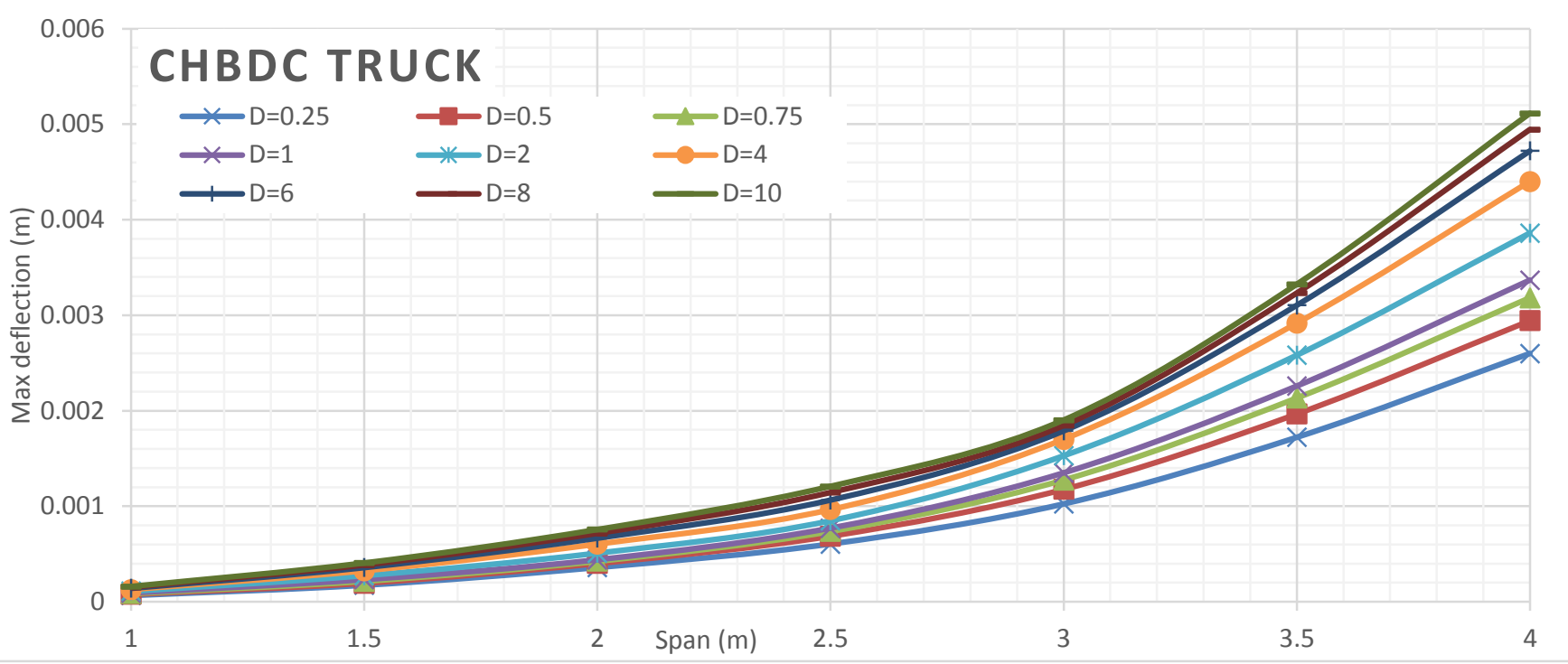

Figure 126 Maximum deflection of deck slabs subjected to CHBDC truck for different D values of alpha 0.25 FEA analyses

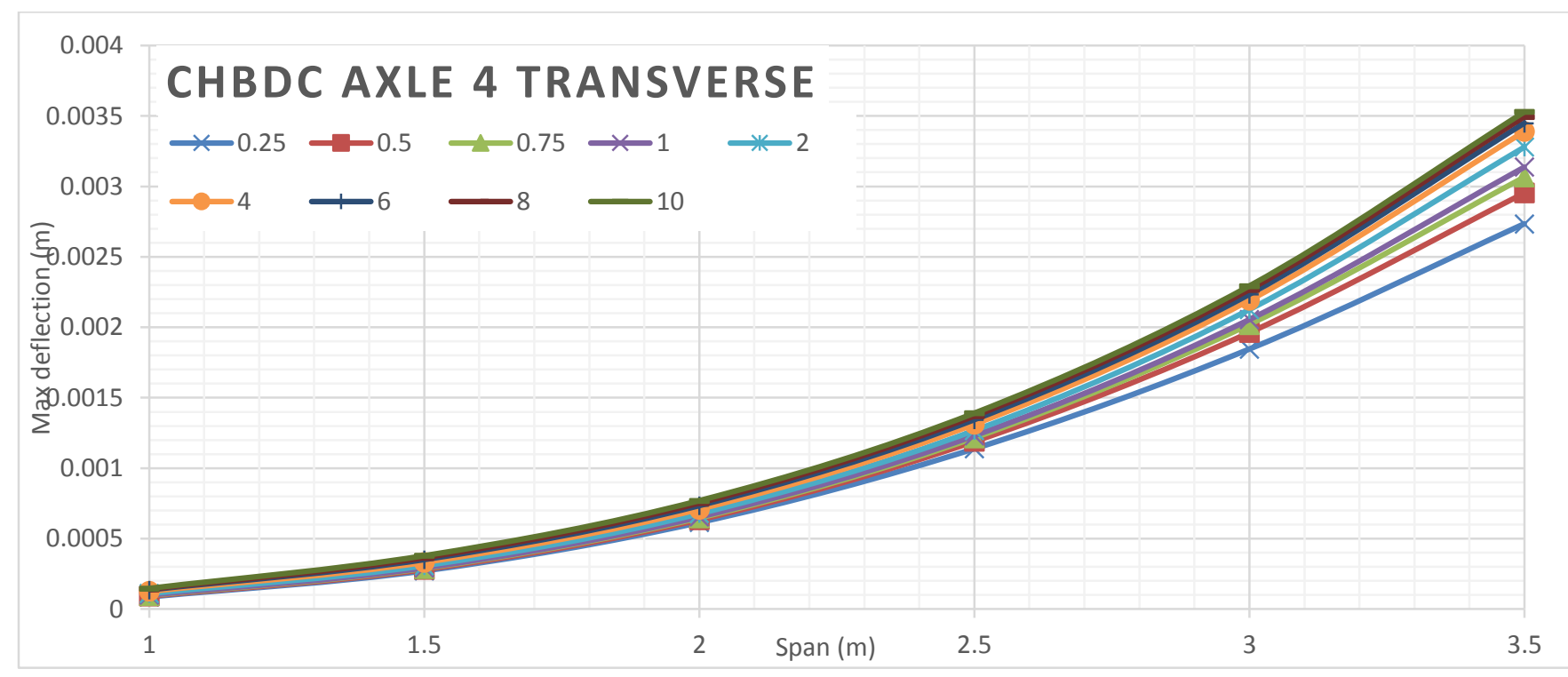

Figure 127 Maximum deflection of deck slabs subjected to CHBDC axle 4 for different $D$ values of alpha 0.25 FEA analyses

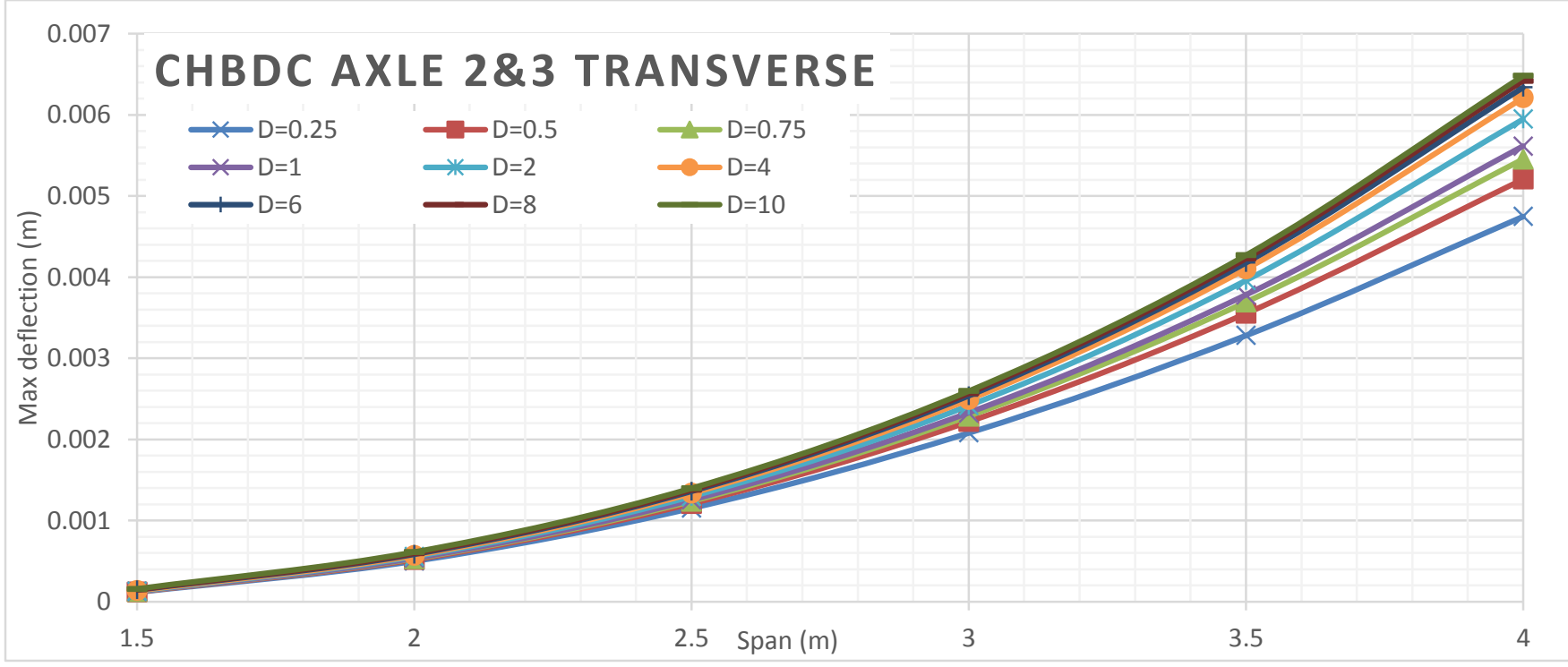

Figure 128 Maximum deflection of deck slabs subjected to CHBDC axle $2 \& 3$ for different $D$ values of alpha 0.25 FEA analyses 


\section{Alpha 0.5 Deflection VS Span Length for Different D Values}

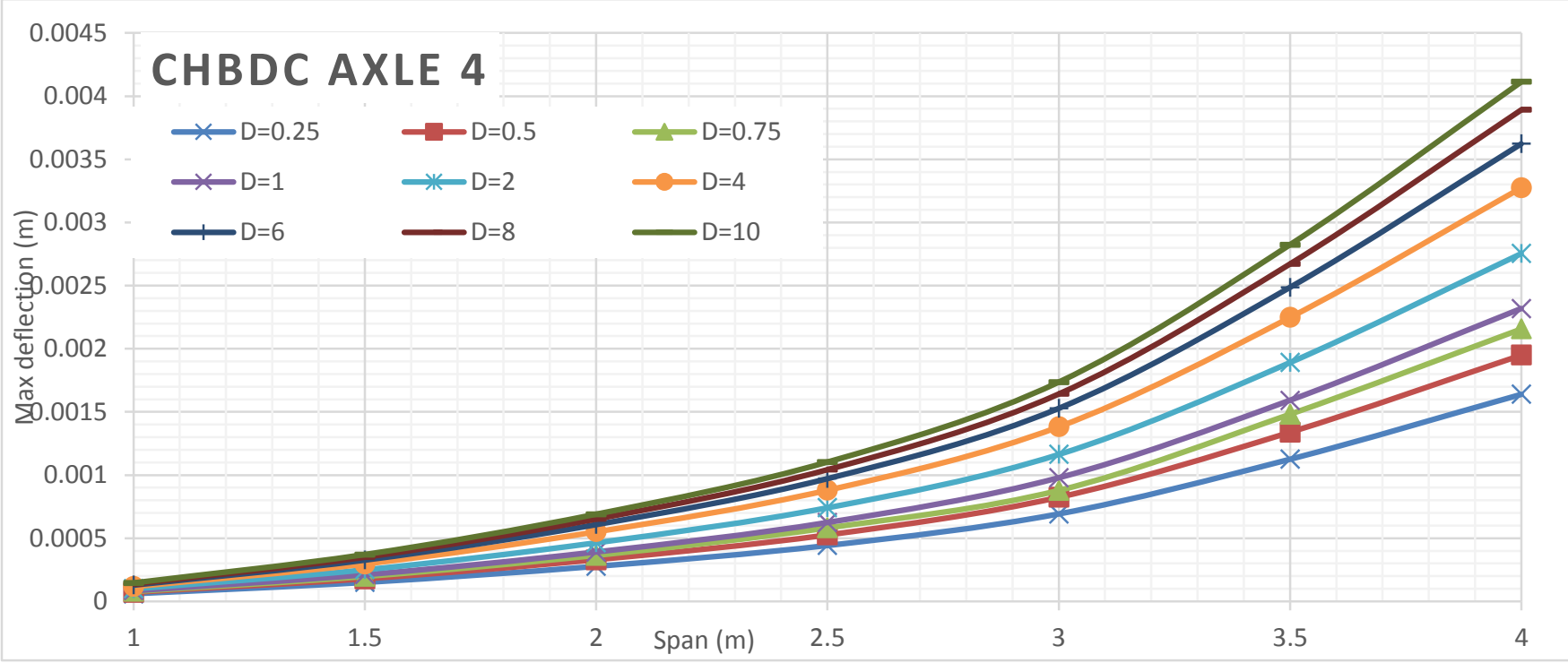

Figure 129 Maximum deflection of deck slabs subjected to CHBDC axle 4 for different D values of alpha 0.5 FEA analyses

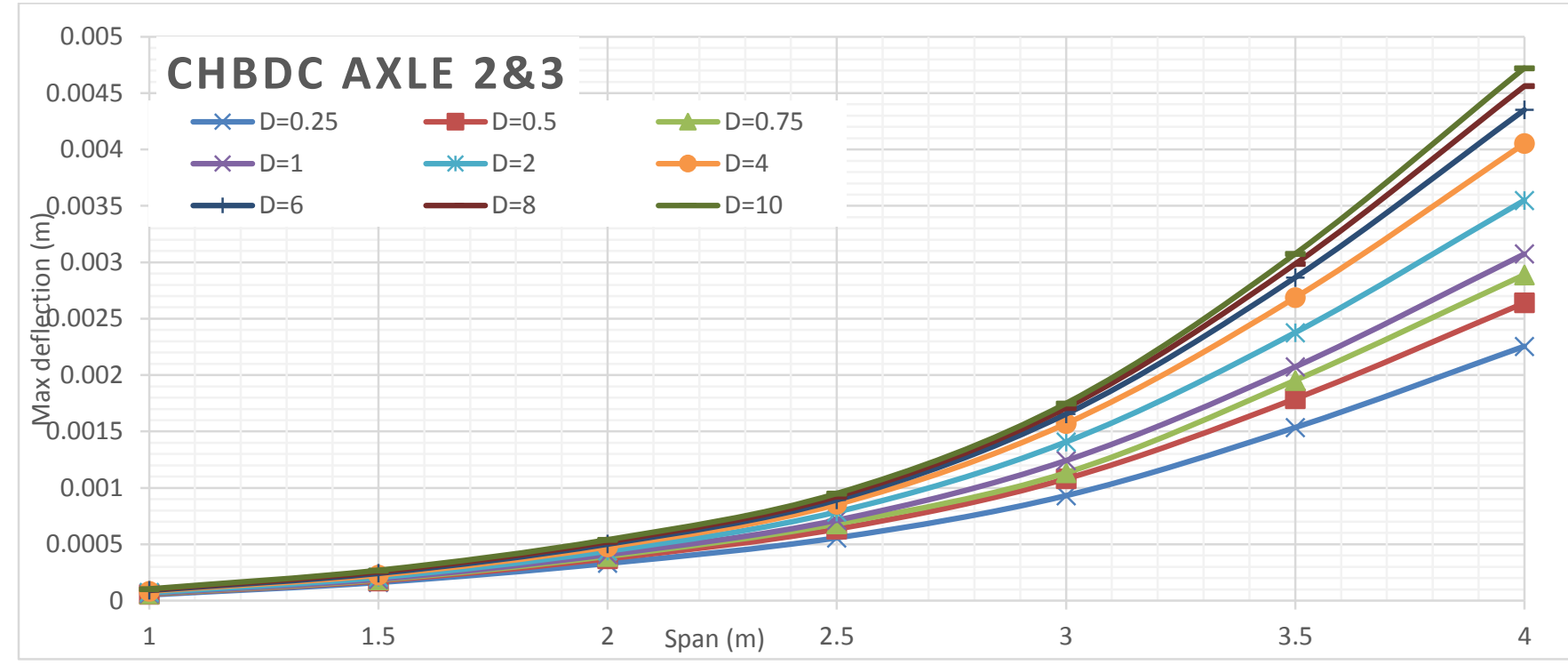

Figure 130 Maximum deflection of deck slabs subjected to CHBDC axle $2 \& 3$ for different D values of alpha 0.5 FEA analyses 


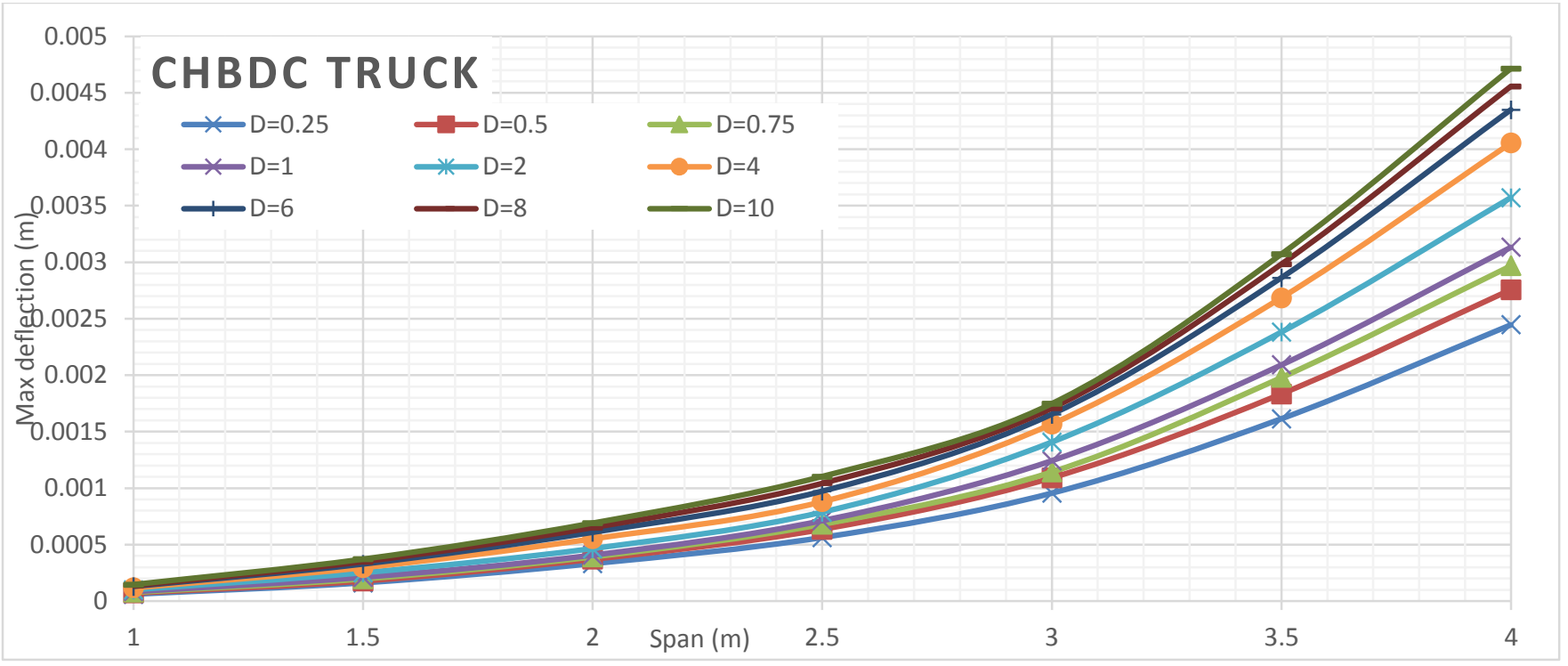

Figure 131 Maximum deflection of deck slabs subjected to CHBDC truck for different D values of alpha 0.5 FEA analyses

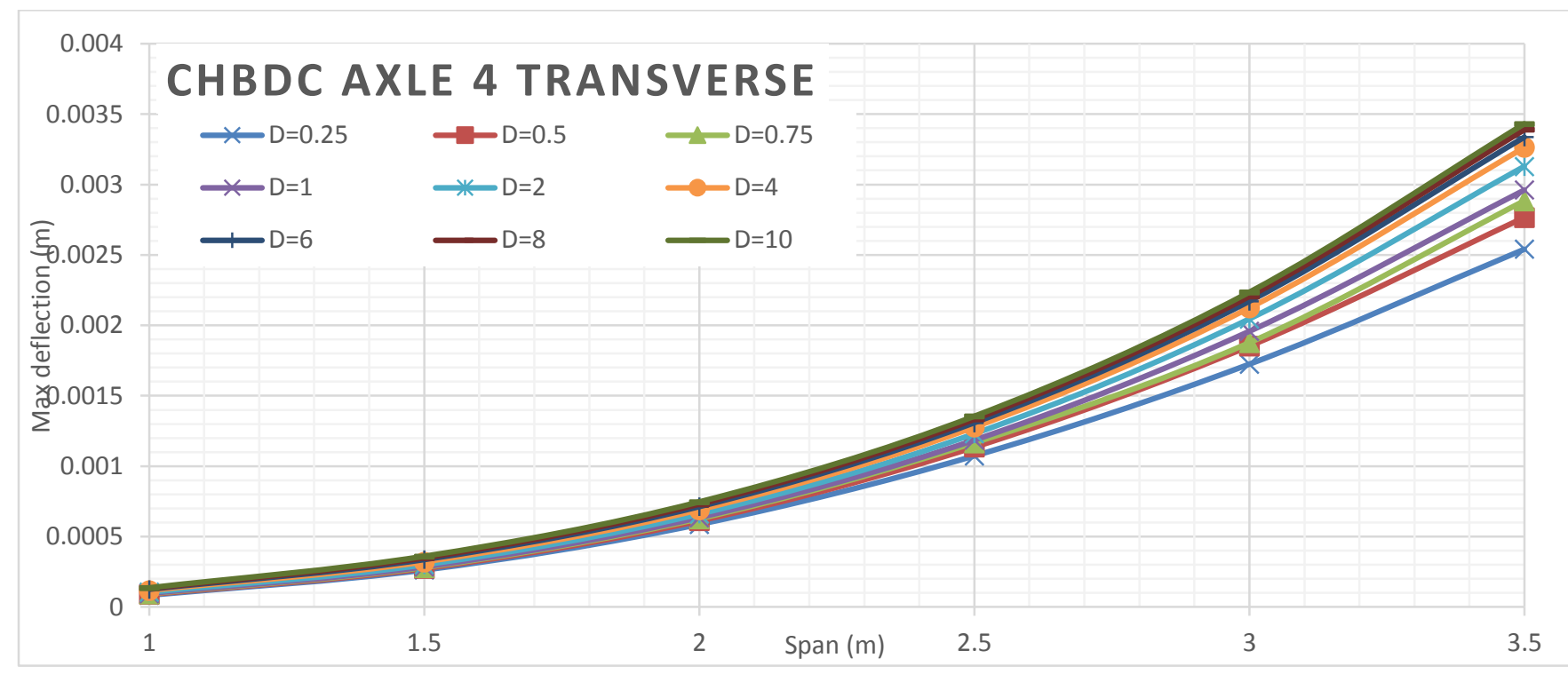

Figure 132 Maximum deflection of deck slabs subjected to CHBDC axle 4 for different D values of alpha 0.5 FEA analyses

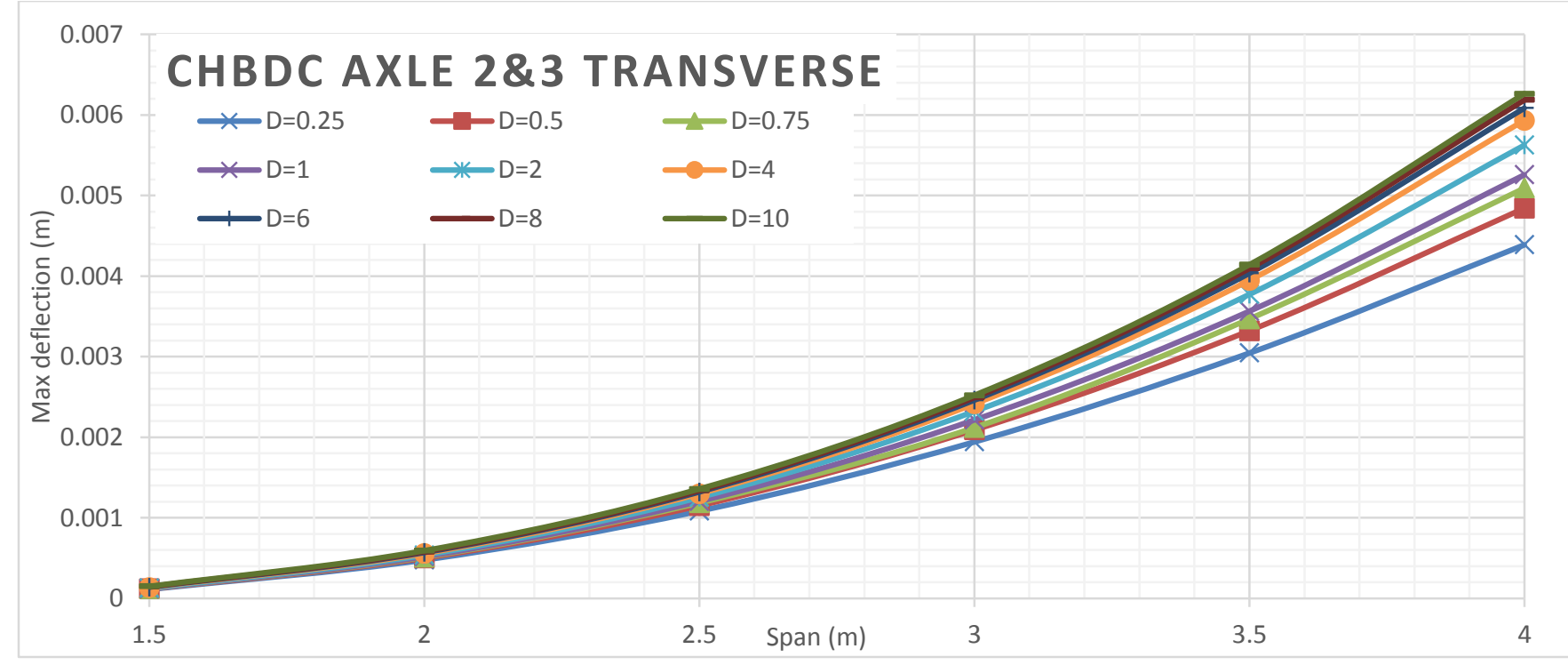

Figure 133 Maximum deflection of deck slabs subjected to CHBDC axle $2 \& 3$ for different $D$ values of alpha 0.5 FEA analyses 


\section{Alpha 0.75 Deflection VS Span Length for Different D Values}

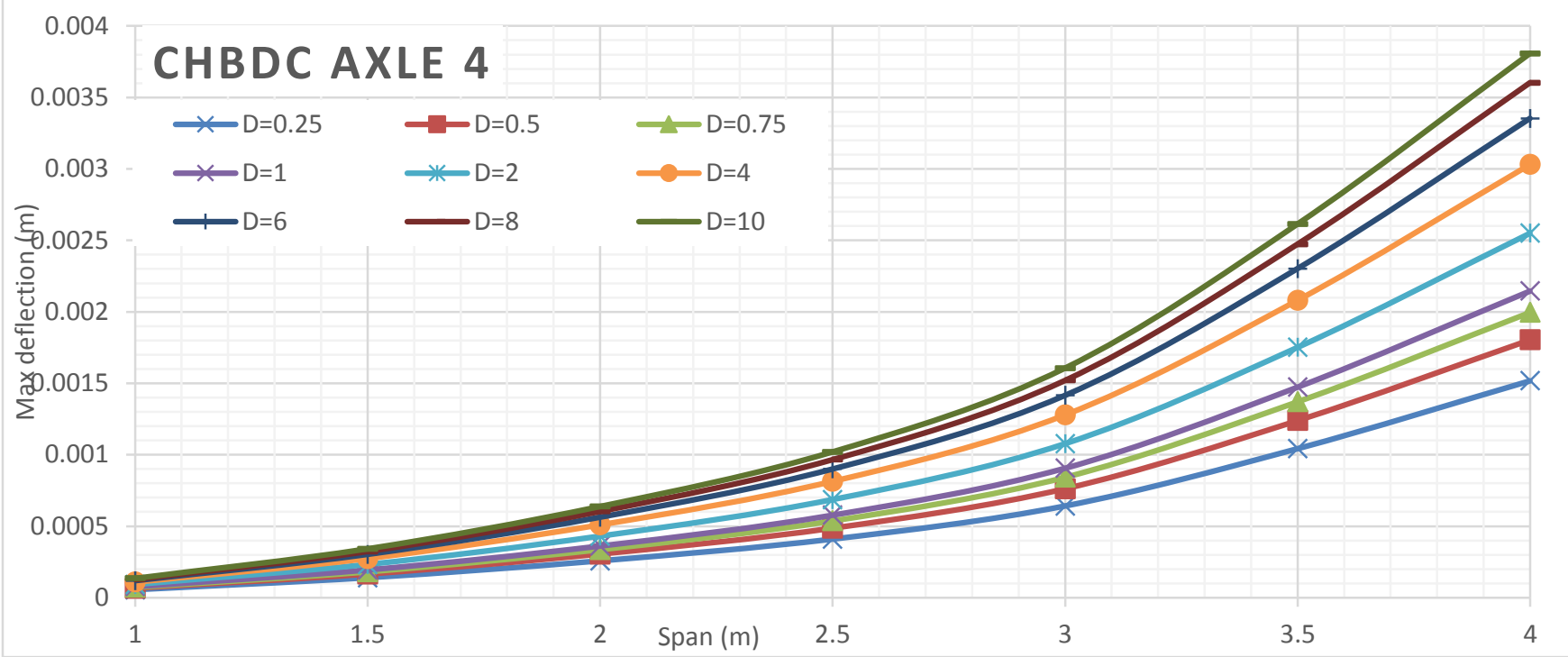

Figure 134 Maximum deflection of deck slabs subjected to CHBDC axle 4 for different D values of alpha 0.75 FEA analyses

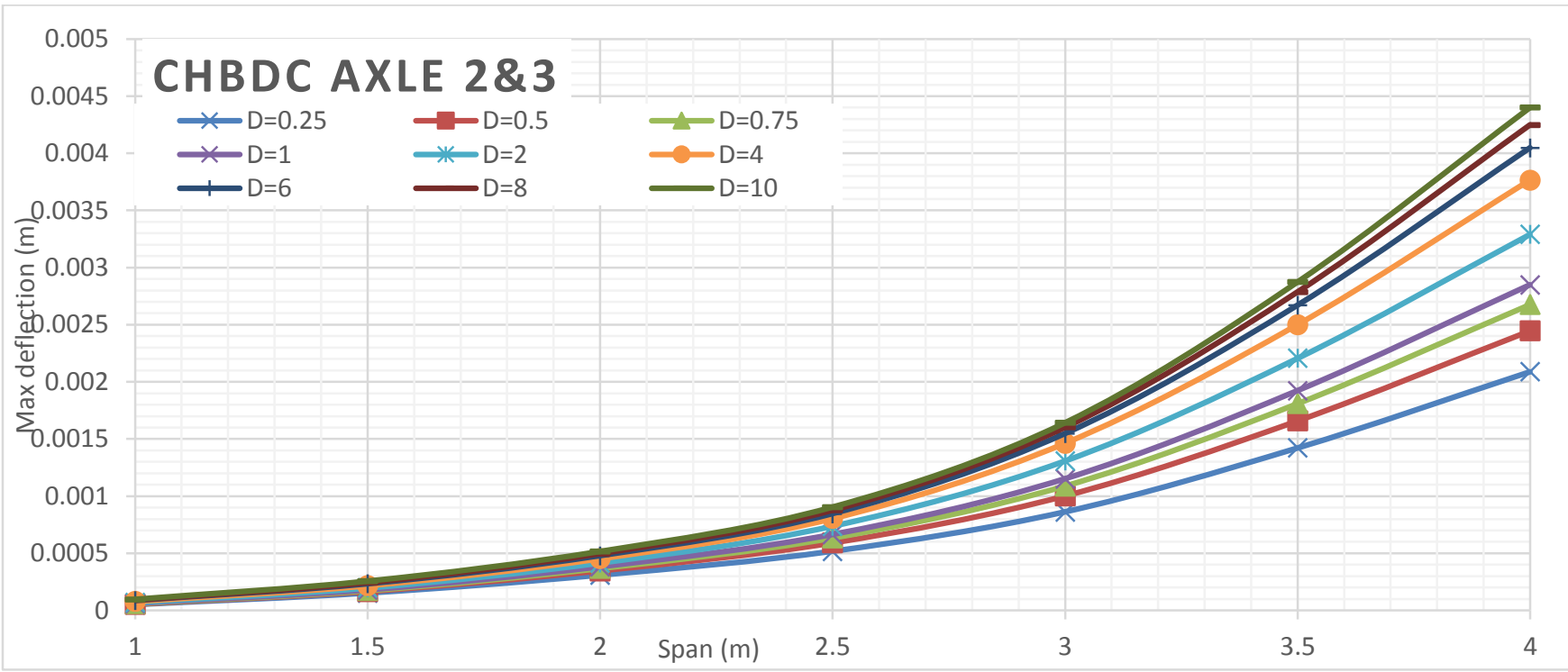

Figure 135 Maximum deflection of deck slabs subjected to CHBDC axle $2 \& 3$ for different D values of alpha 0.75 FEA analyses 


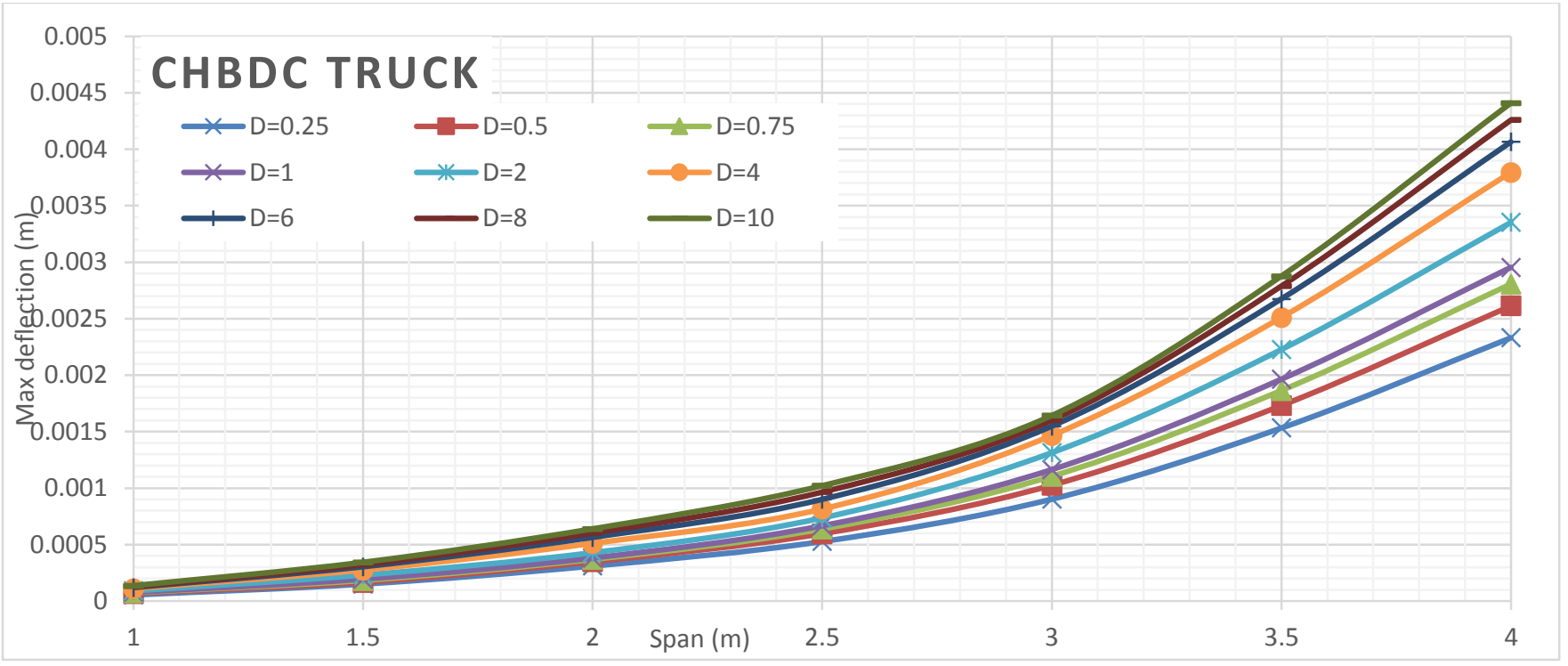

Figure 136 Maximum deflection of deck slabs subjected to CHBDC truck for different D values of alpha 0.75 FEA analyses

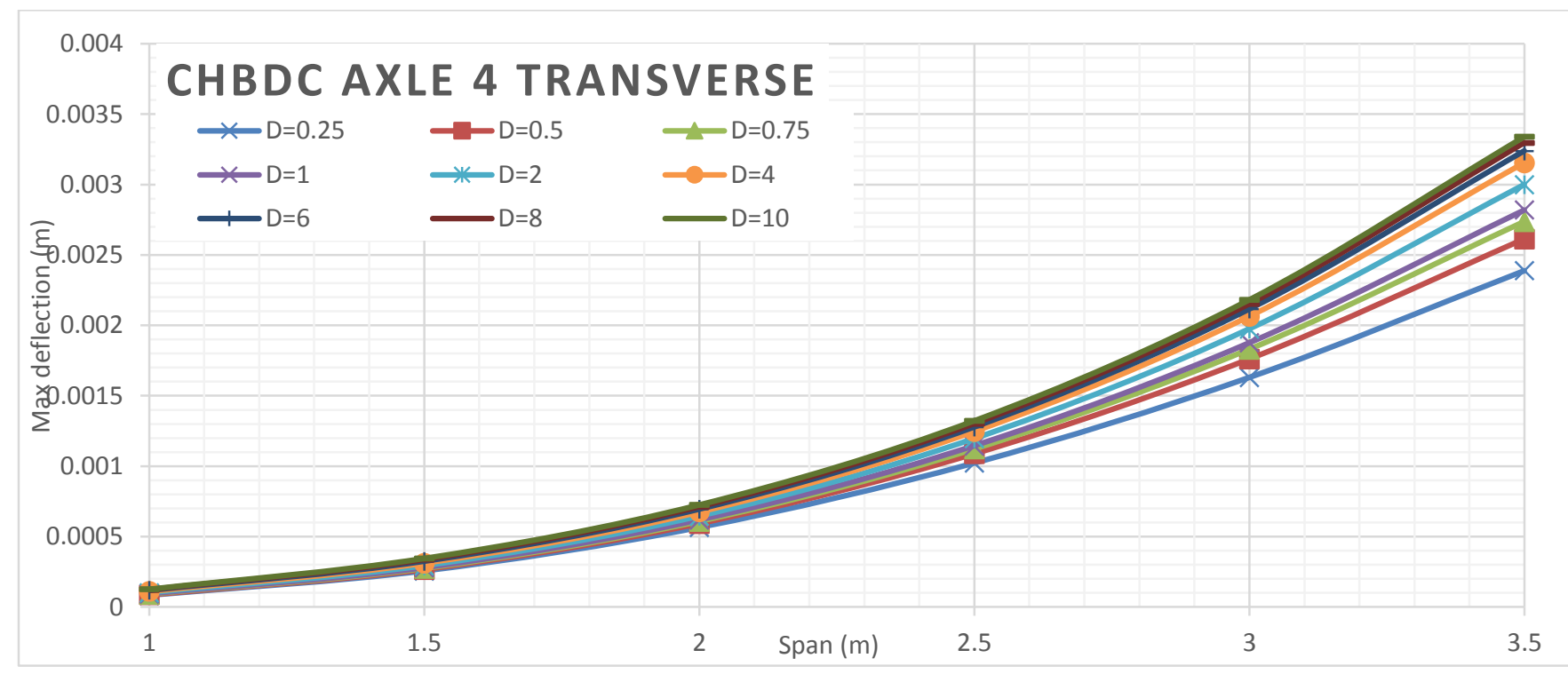

Figure 137 Maximum deflection of deck slabs subjected to CHBDC axle 4 for different $D$ values of alpha 0.75 FEA analyses

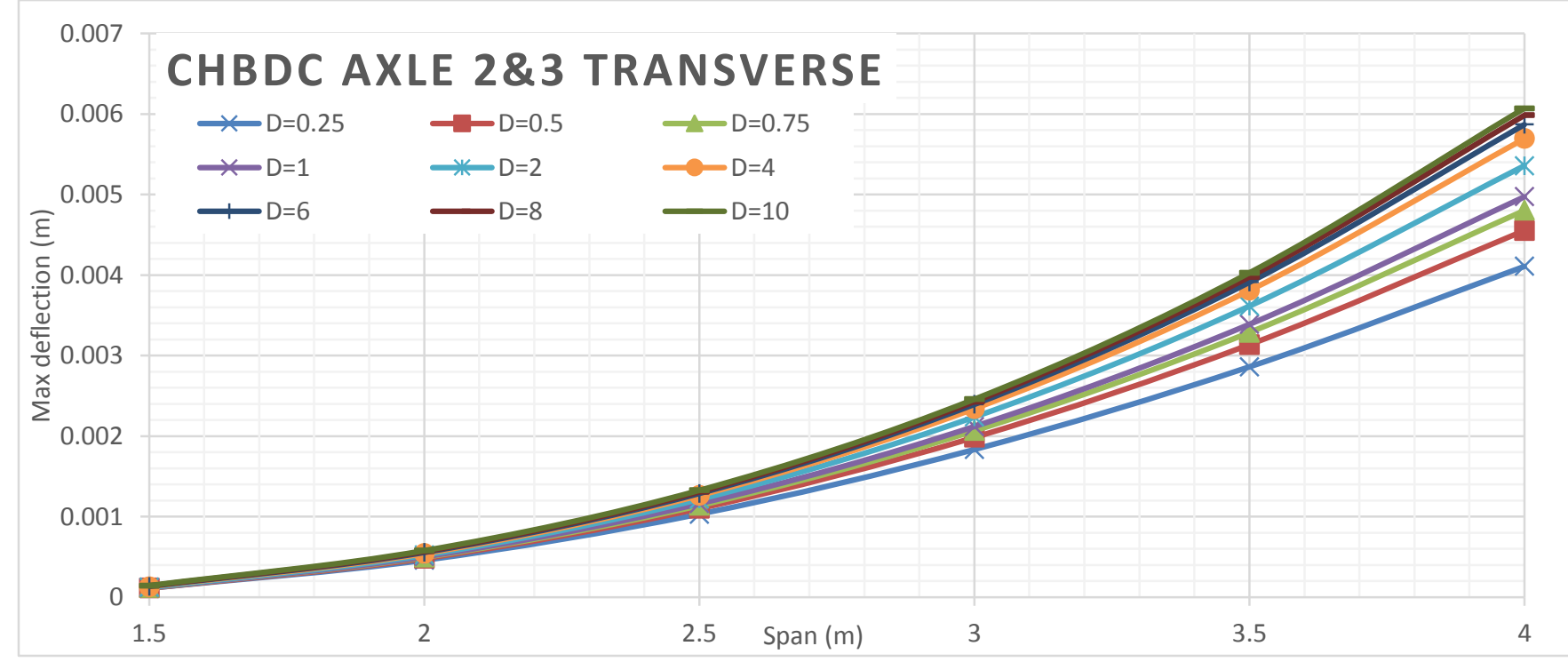

Figure 138 Maximum deflection of deck slabs subjected to CHBDC axle $2 \& 3$ for different $D$ values of alpha 0.75 FEA analyses 


\section{Alpha 1 Deflection VS Span Length for Different D Values}

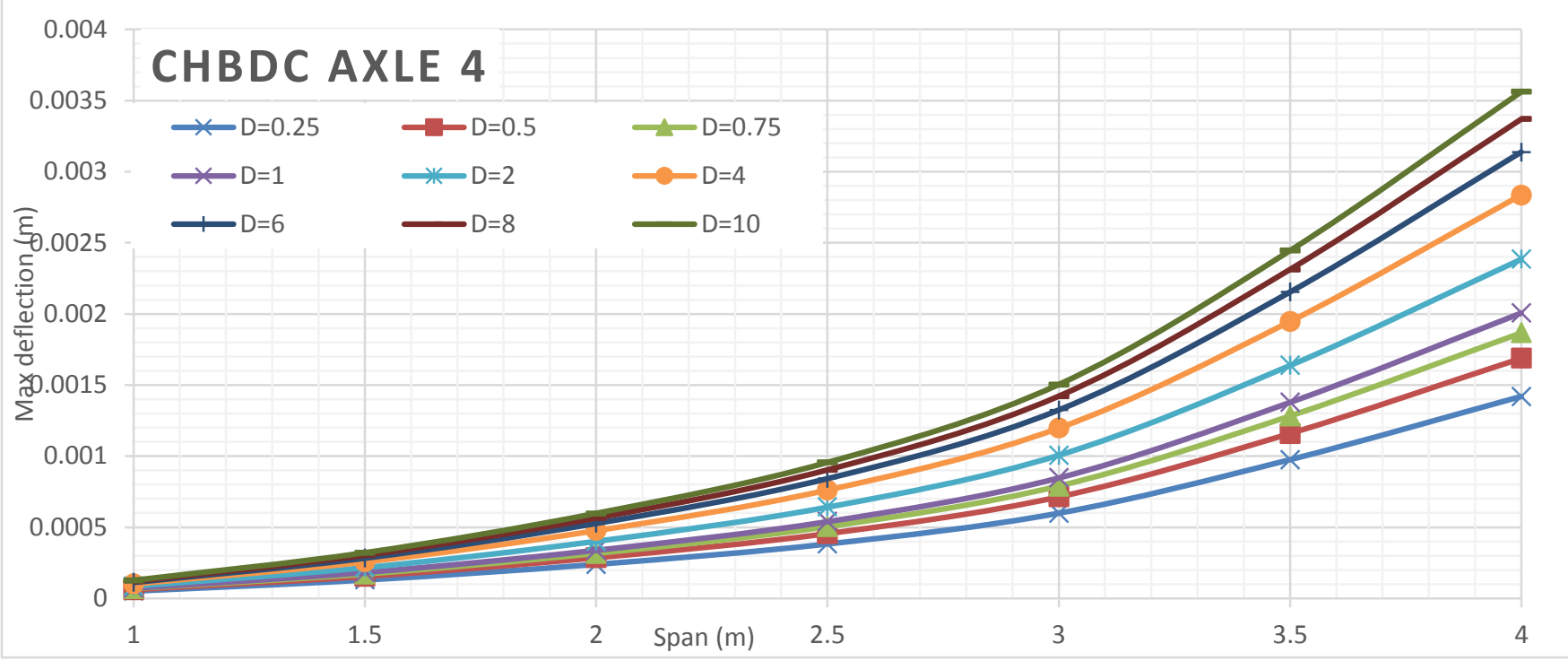

Figure 139 Maximum deflection of deck slabs subjected to CHBDC axle 4 for different D values of alpha 1 FEA analyses

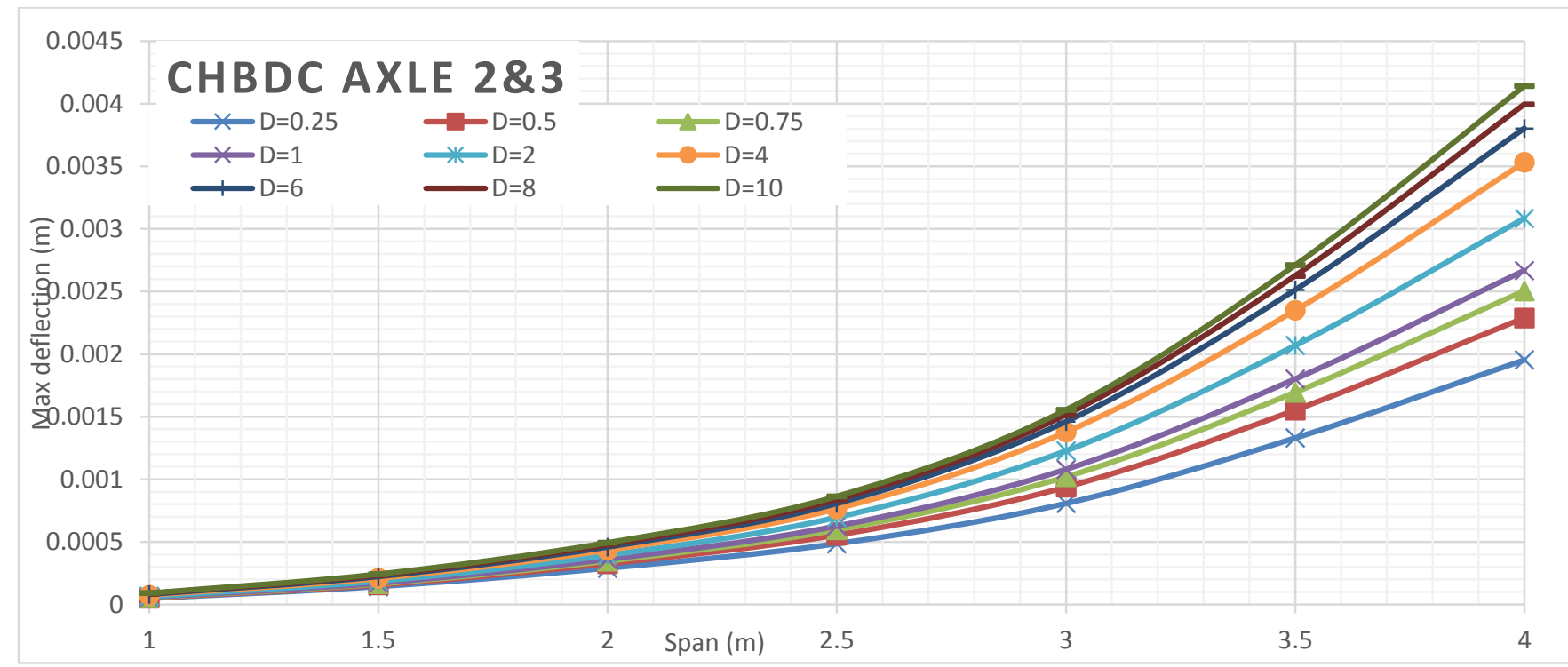

Figure 140 Maximum deflection of deck slabs subjected to CHBDC axle $2 \& 3$ for different $D$ values of alpha 1 FEA analyses 


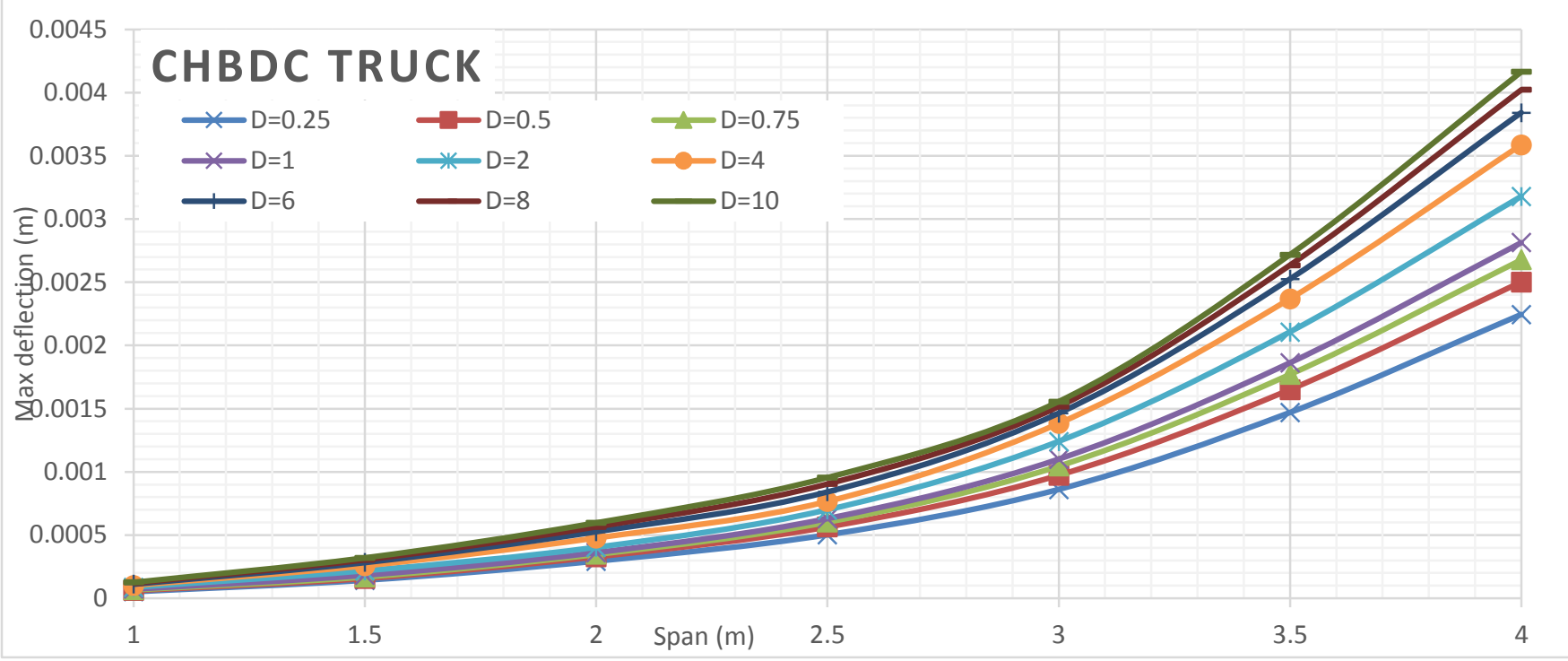

Figure 141 Maximum deflection of deck slabs subjected to CHBDC truck for different D values of alpha 1 FEA analyses

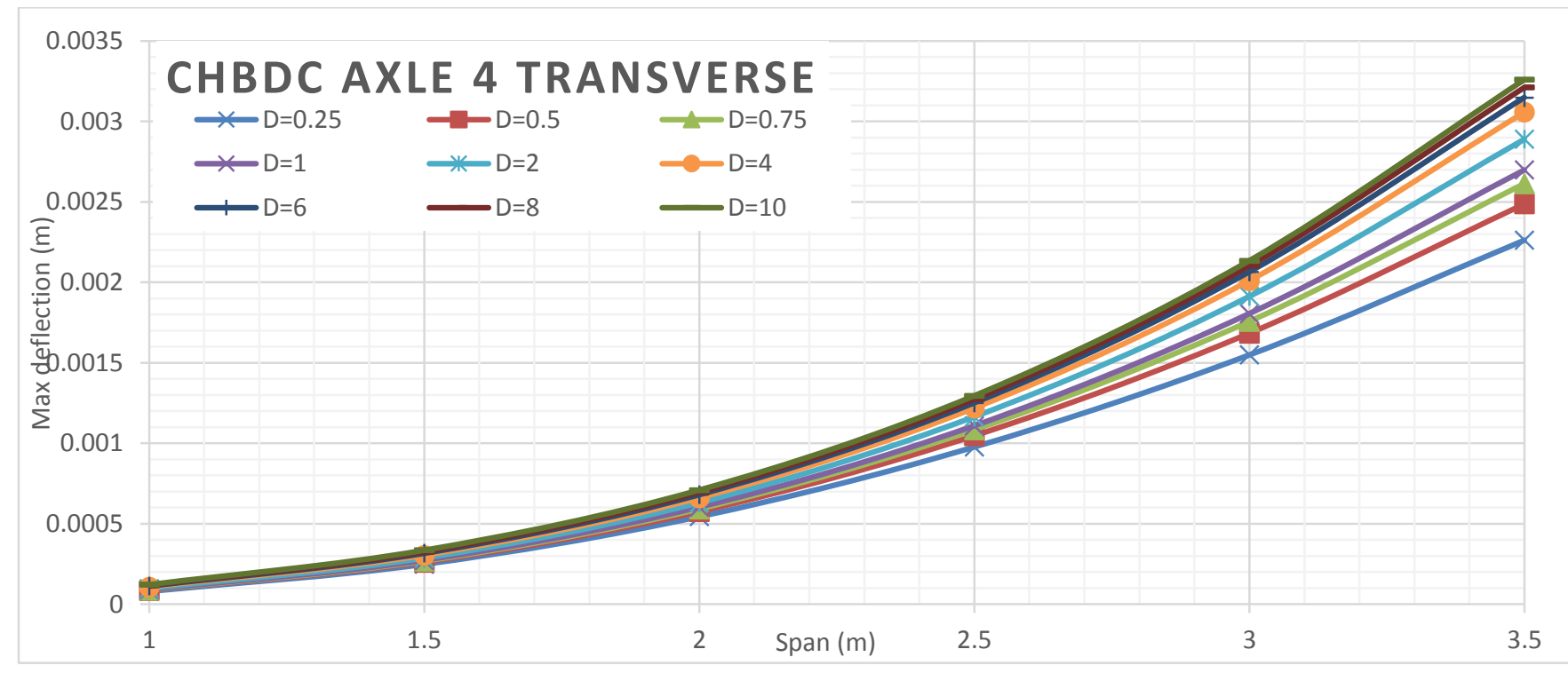

Figure 142 Maximum deflection of deck slabs subjected to CHBDC axle 4 for different D values of alpha 1 FEA analyses

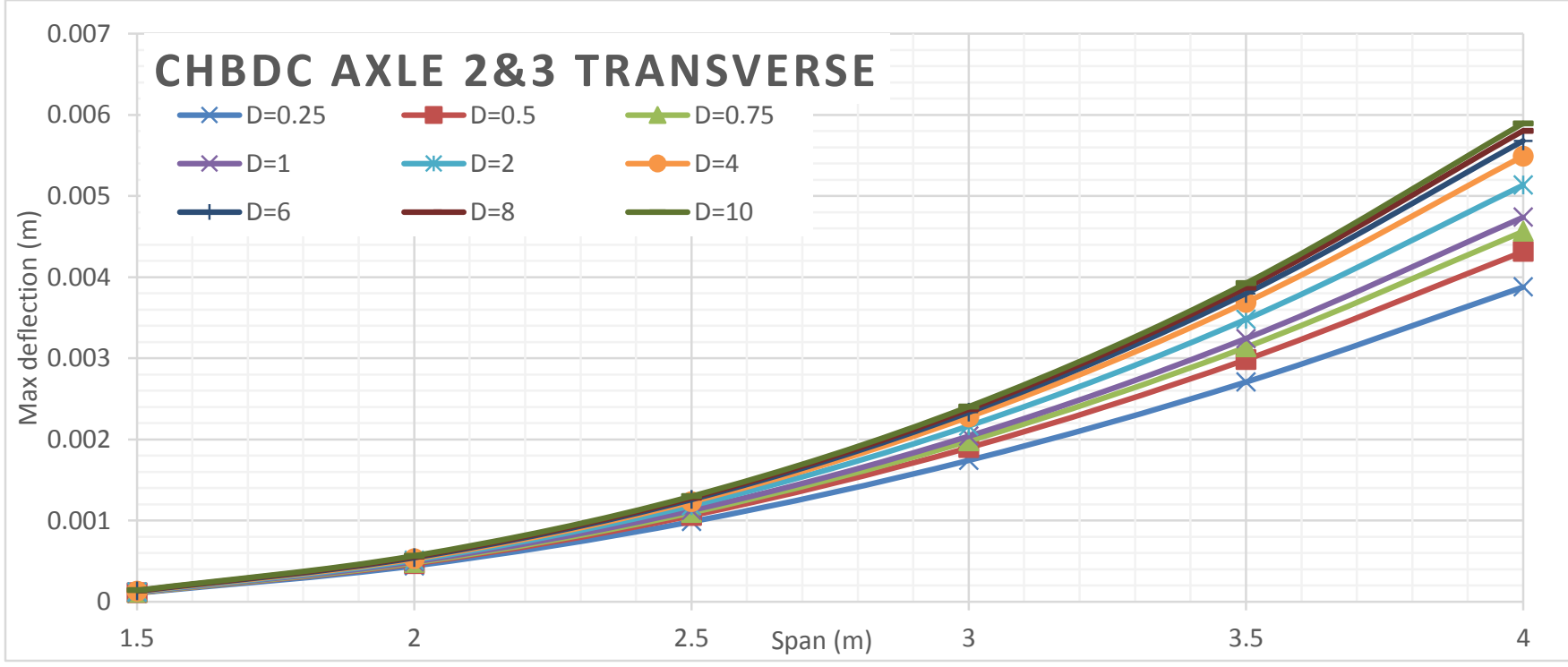

Figure 143 Maximum deflection of deck slabs subjected to CHBDC axle $2 \& 3$ for different D values of alpha 1 FEA analyses 


\section{Alpha 2 Deflection VS Span Length for Different D Values}

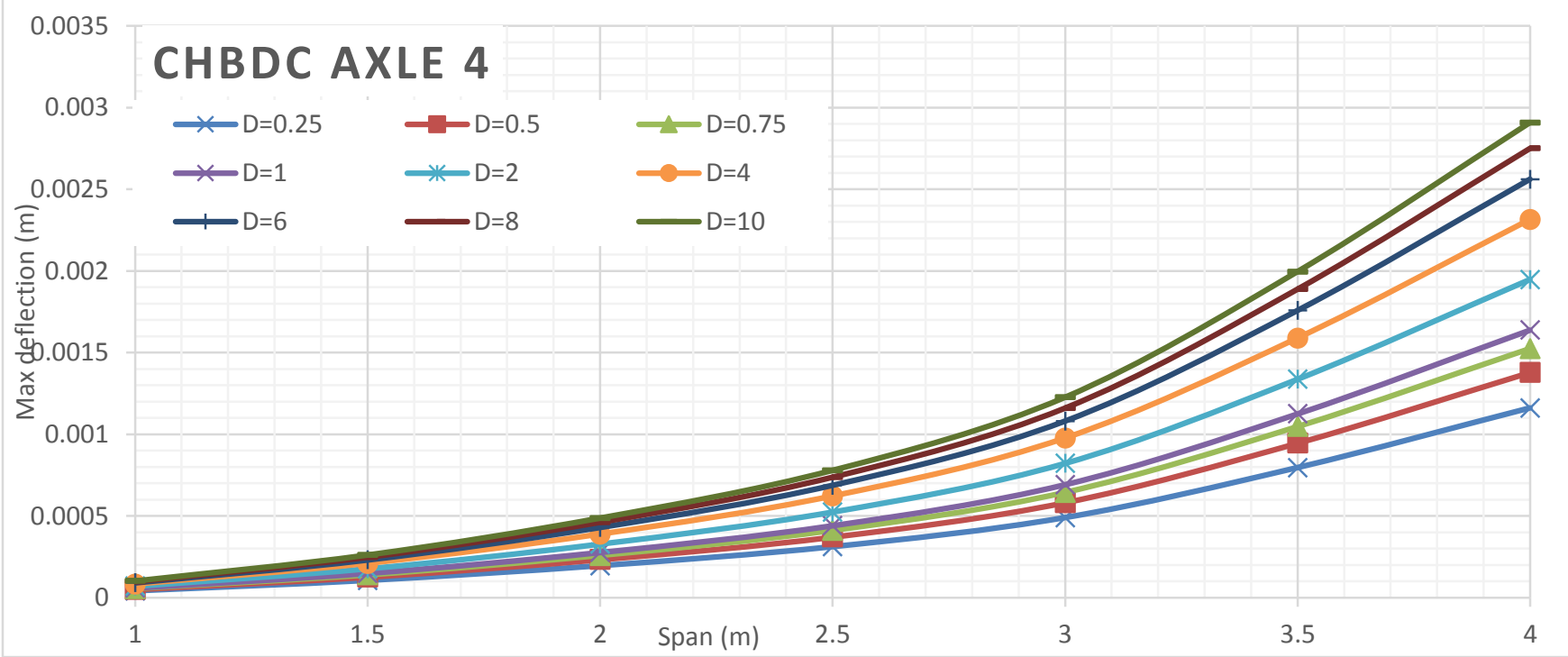

Figure 144 Maximum deflection of deck slabs subjected to CHBDC axle 4 for different D values of alpha 2 FEA analyses

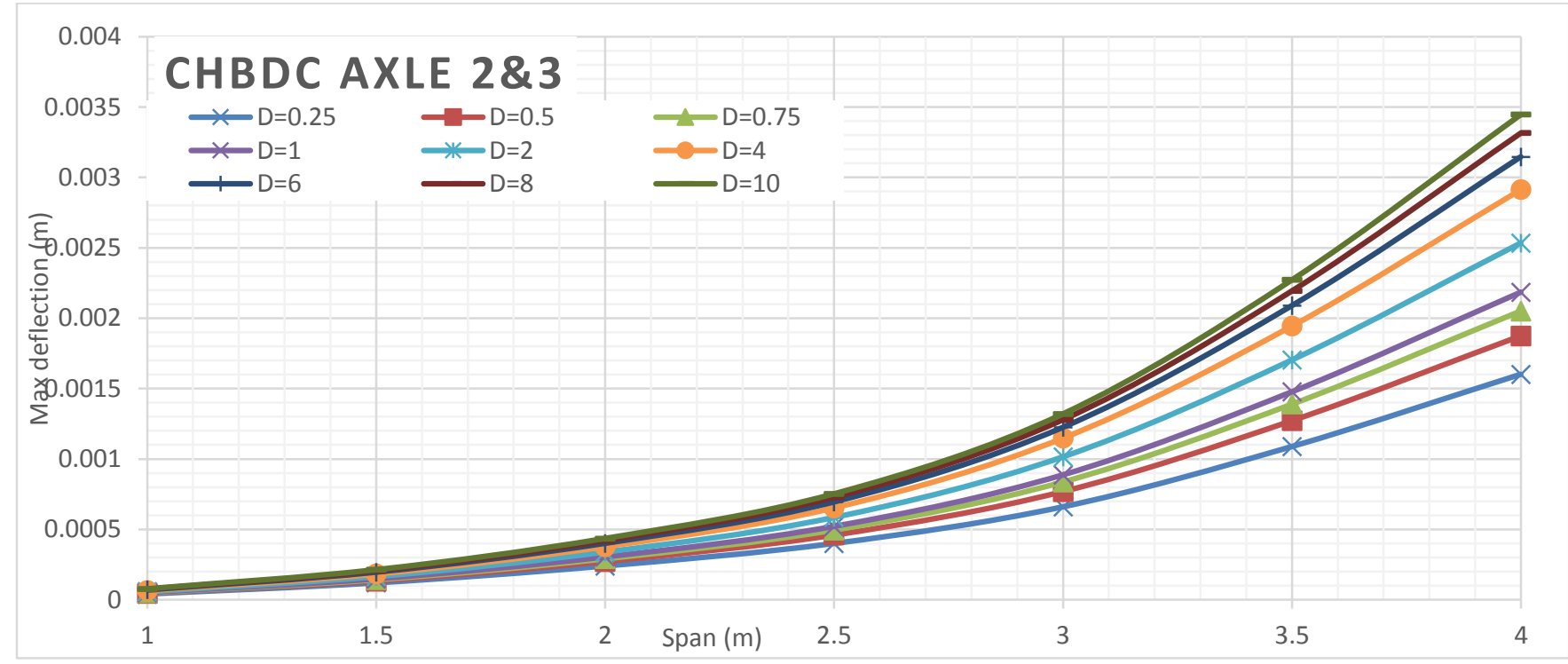

Figure 145 Maximum deflection of deck slabs subjected to CHBDC axle $2 \& 3$ for different D values of alpha 2 FEA analyses 


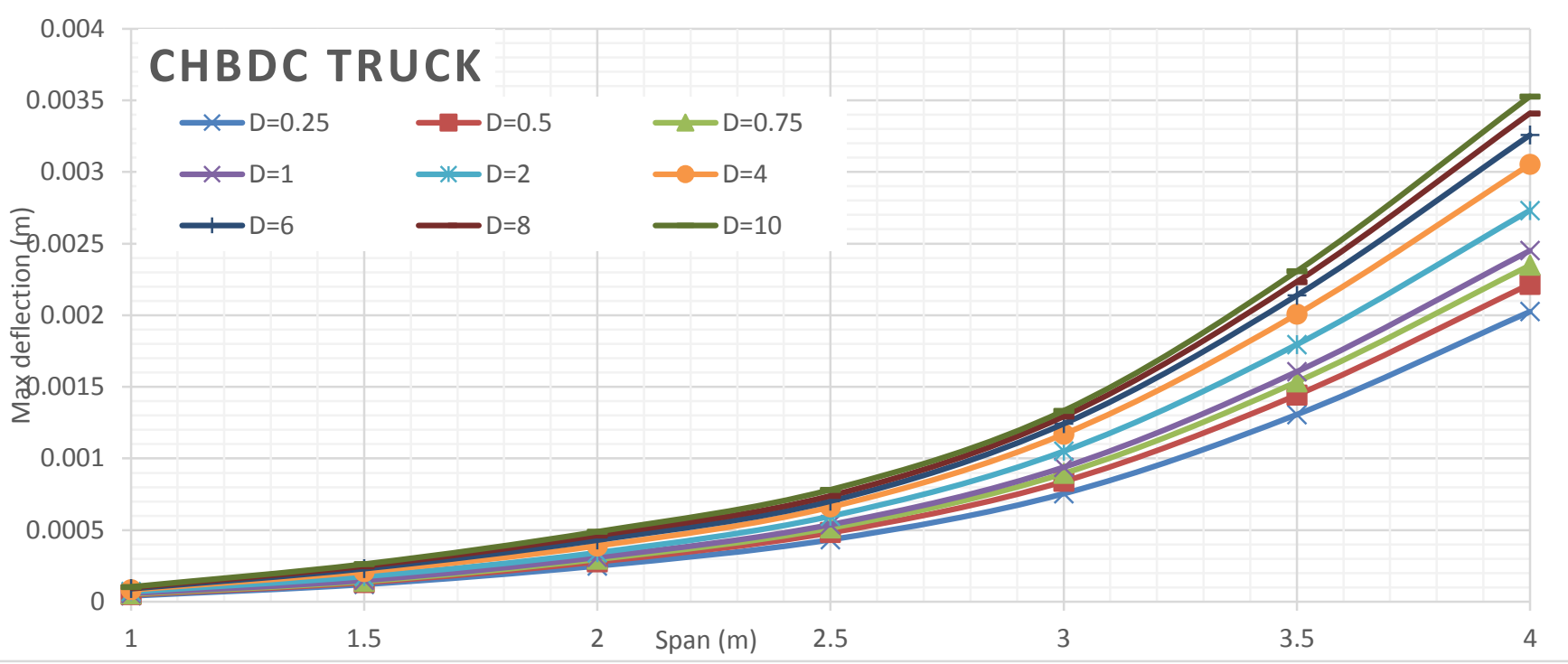

Figure 146 Maximum deflection of deck slabs subjected to CHBDC truck for different D values of alpha 2 FEA analyses

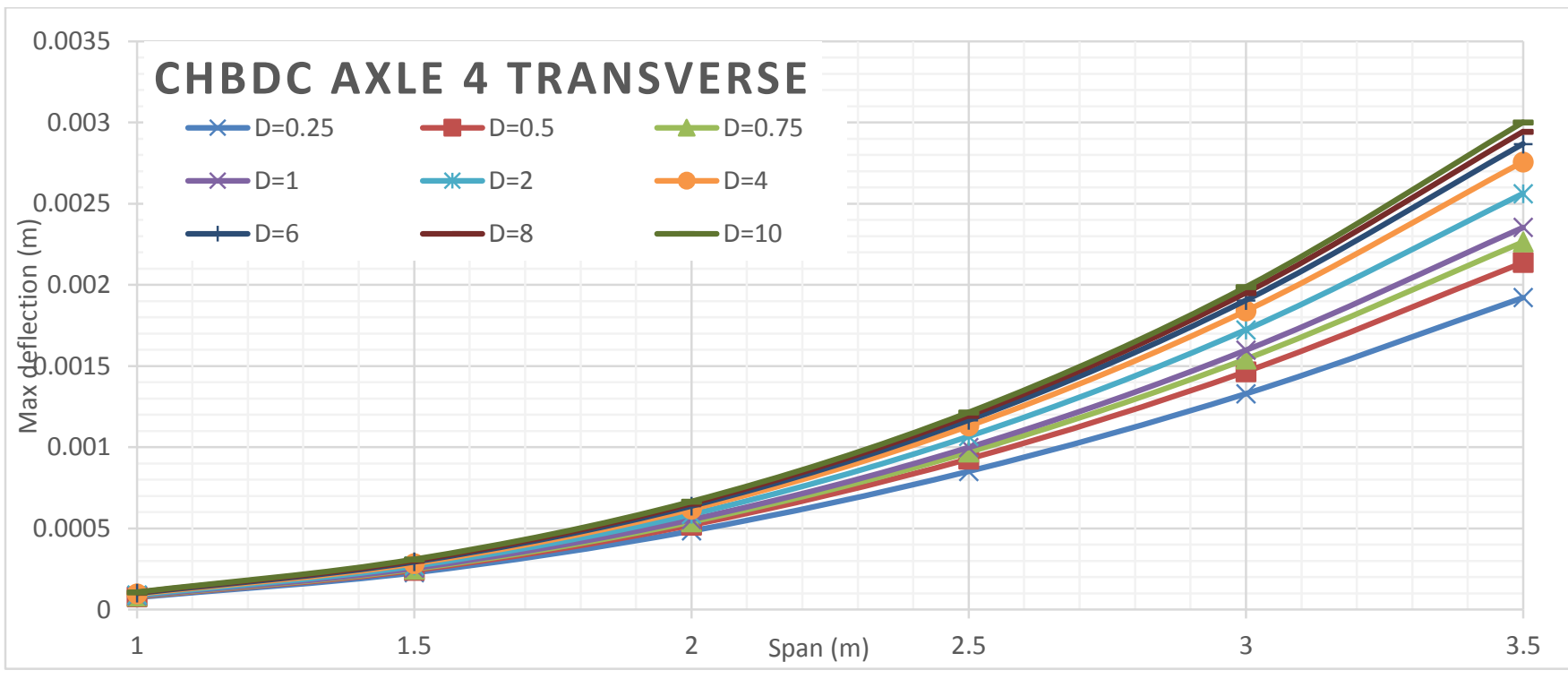

Figure 147 Maximum deflection of deck slabs subjected to CHBDC axle 4 for different D values of alpha 2 FEA analyses

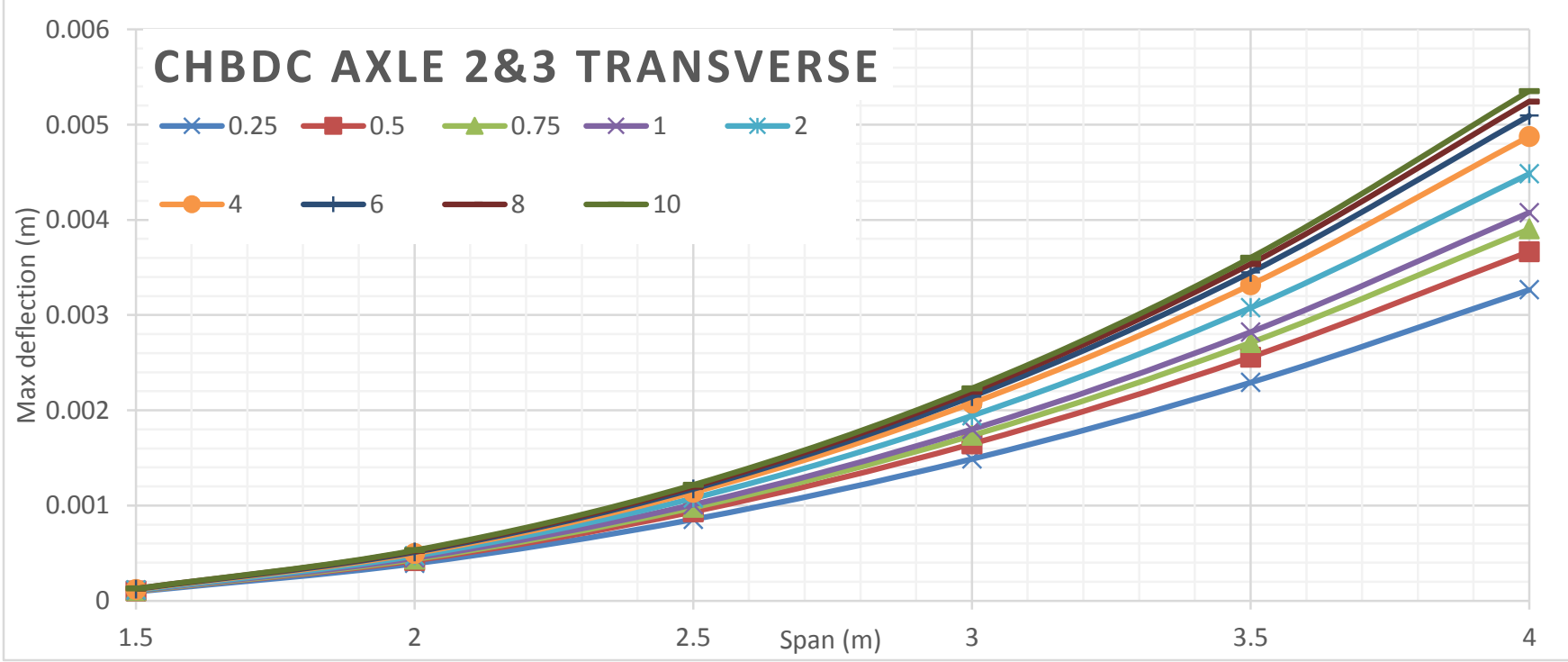

Figure 148 Maximum deflection of deck slabs subjected to CHBDC axle 2 \& 3 for different D values of alpha 2 FEA analyses 


\section{Alpha 4 Deflection VS Span Length for Different D Values}

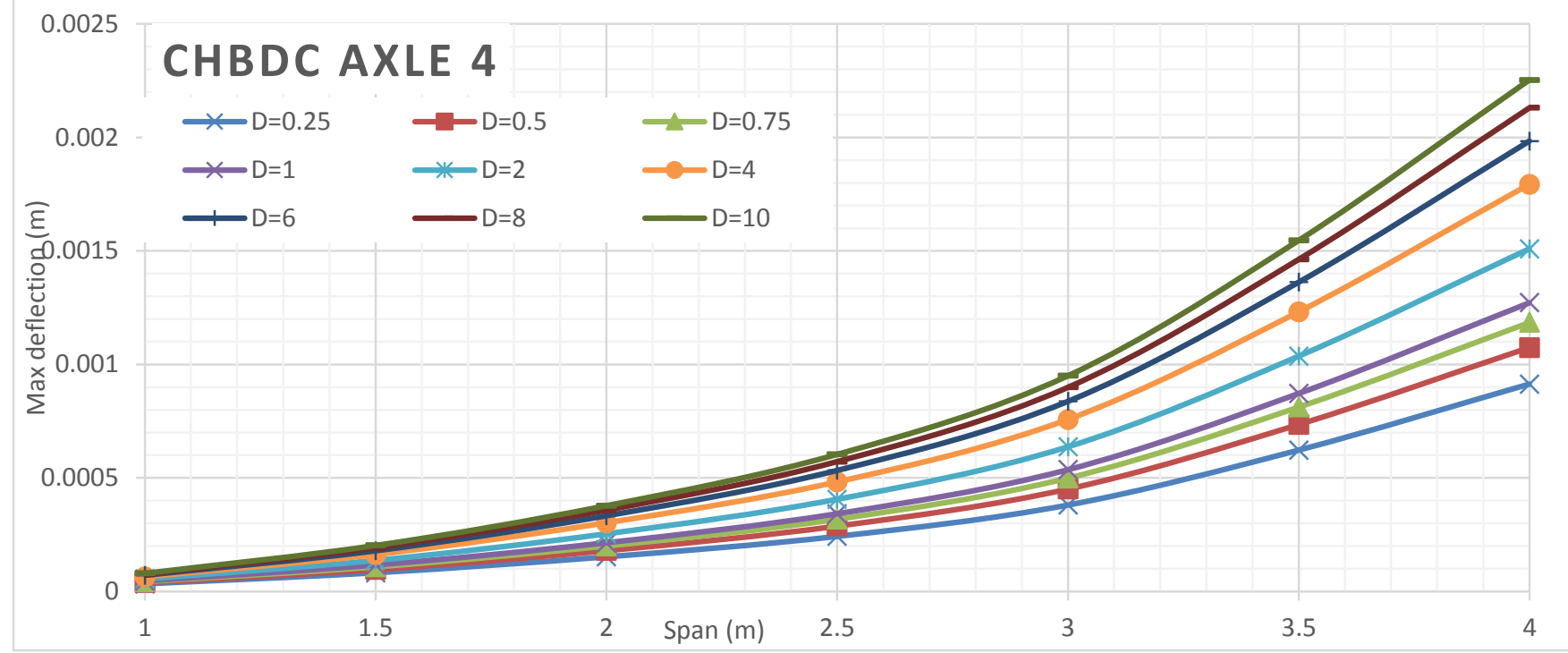

Figure 149 Maximum deflection of deck slabs subjected to CHBDC axle 4 for different D values of alpha 4 FEA analyses

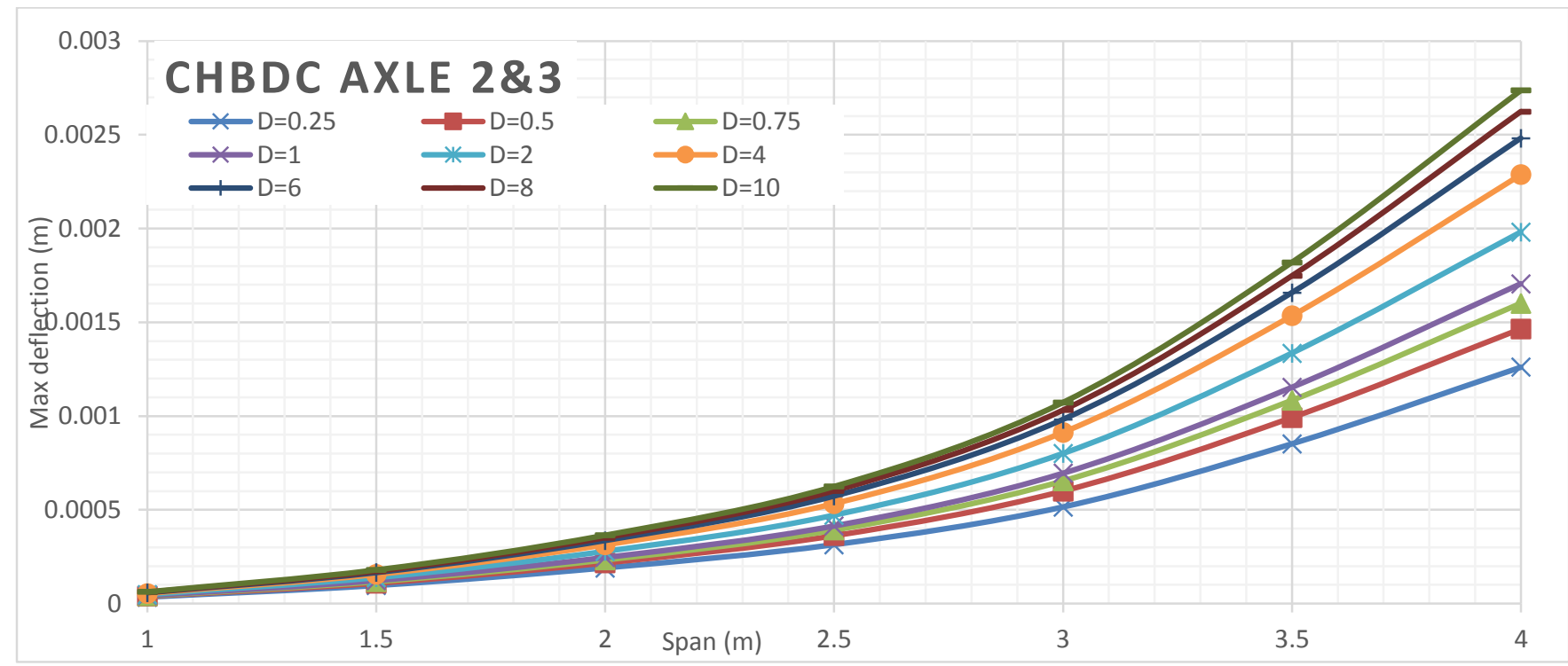

Figure 150 Maximum deflection of deck slabs subjected to CHBDC axle $2 \& 3$ for different $D$ values of alpha 4 FEA analyses 


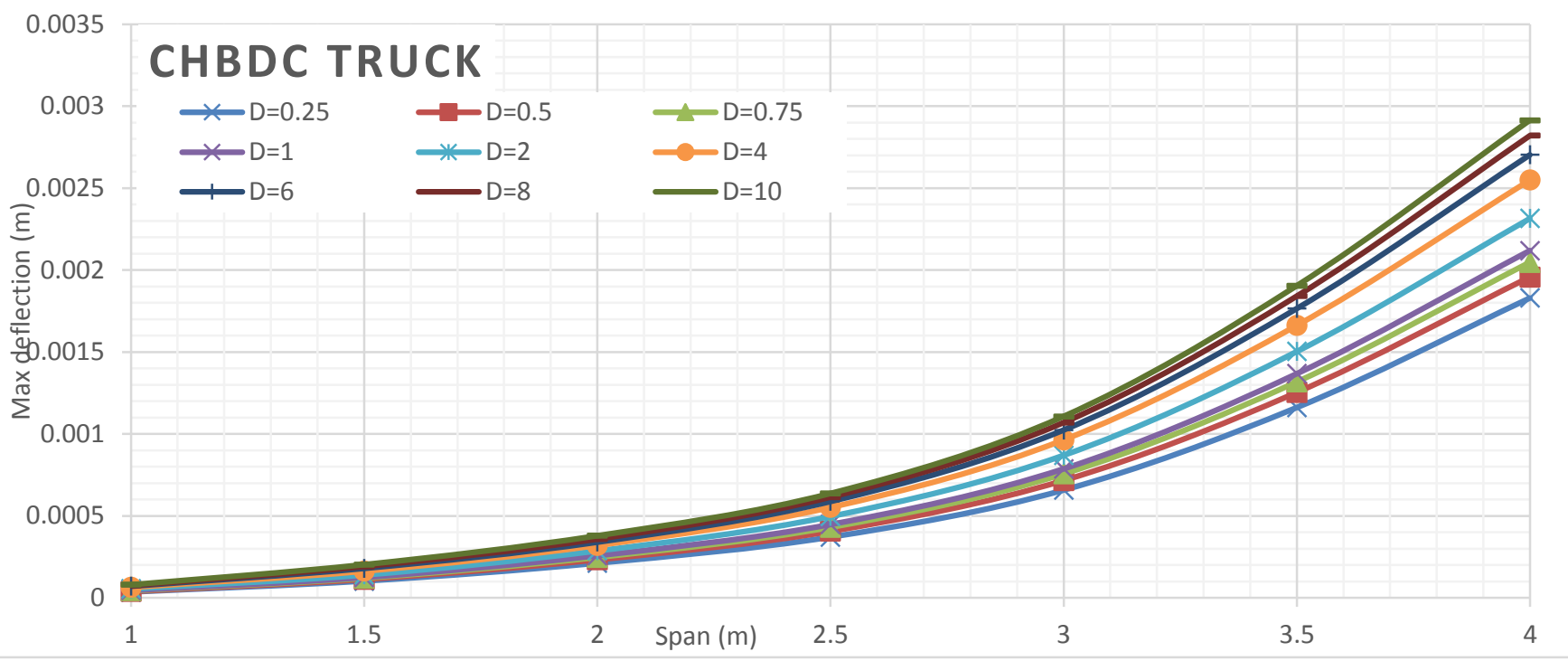

Figure 151 Maximum deflection of deck slabs subjected to CHBDC truck for different D values of alpha 4 FEA analyses

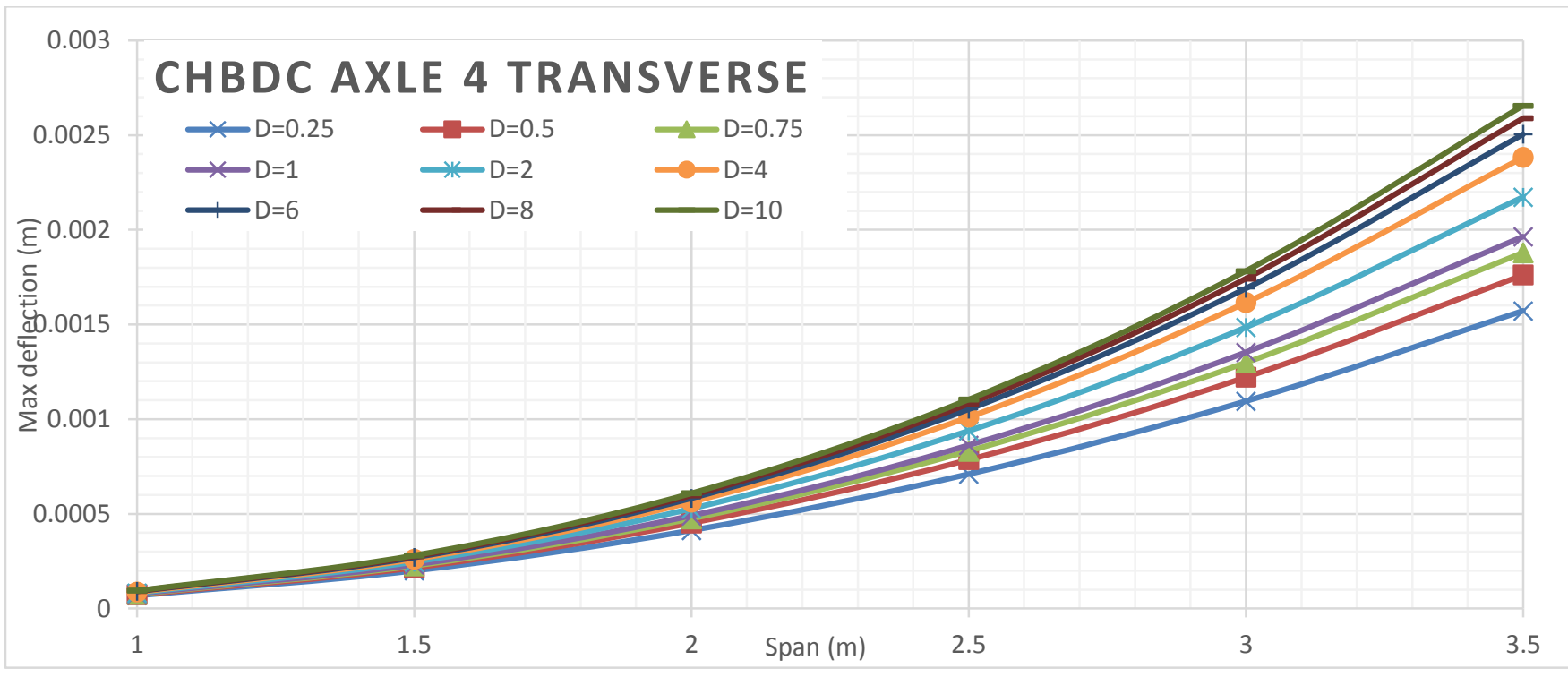

Figure 152 Maximum deflection of deck slabs subjected to CHBDC axle 4 for different D values of alpha 4 FEA analyses

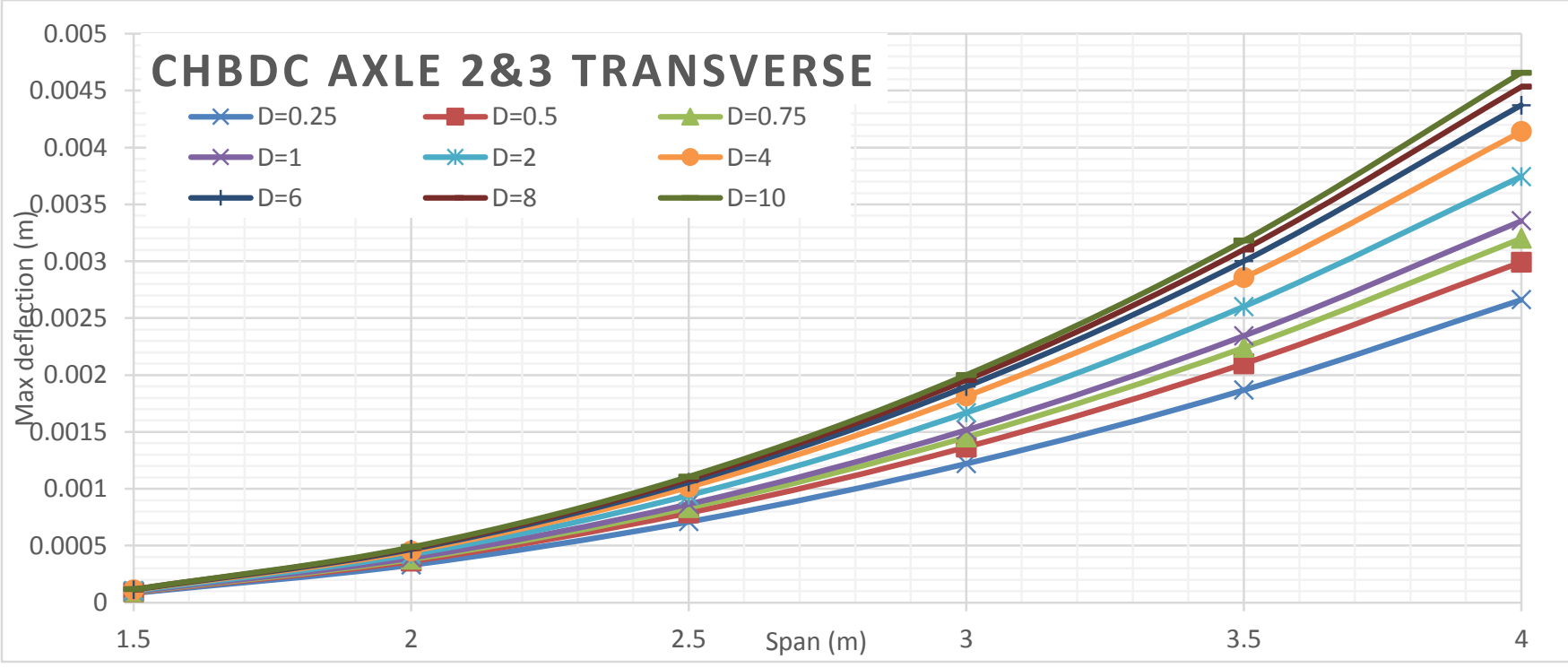

Figure 153 Maximum deflection of deck slabs subjected to CHBDC axle $2 \& 3$ for different D values of alpha 4 FEA analyses 


\section{Alpha 6 Deflection VS Span Length for Different D Values}

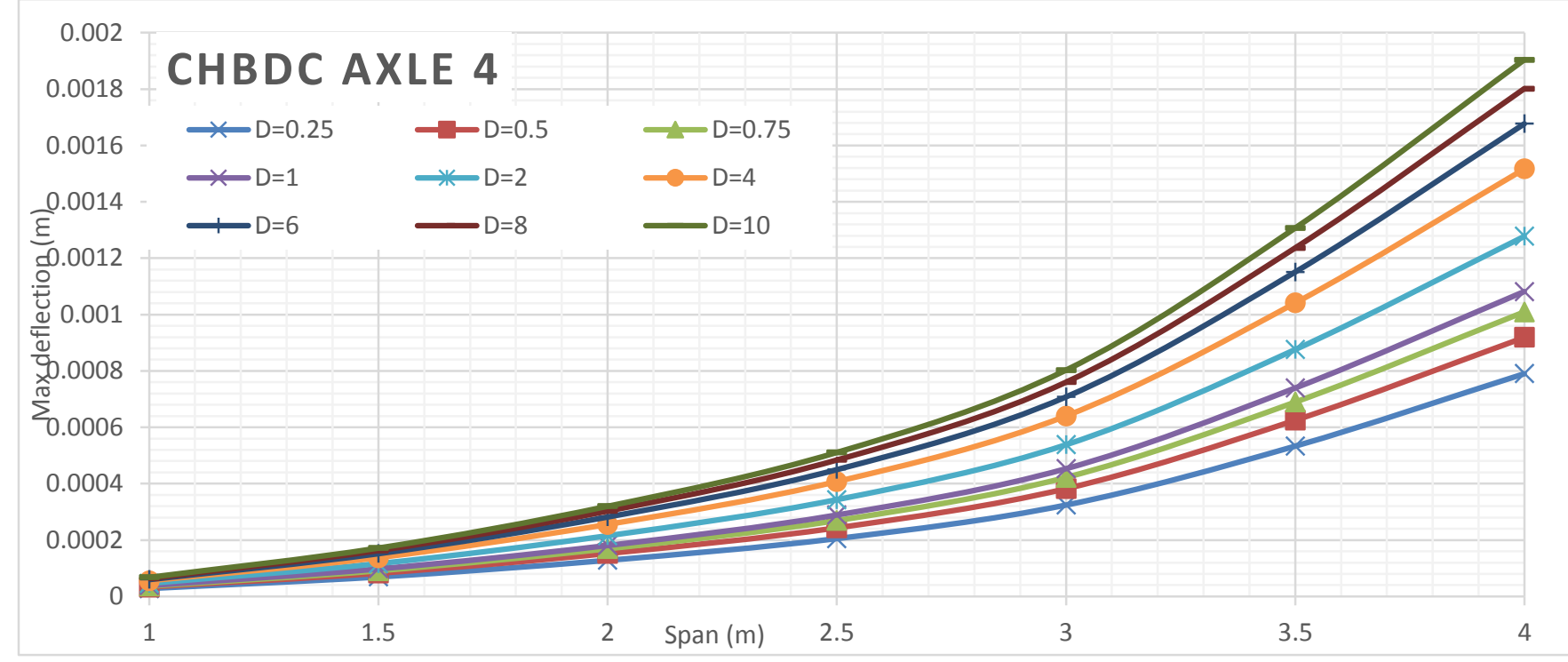

Figure 154 Maximum deflection of deck slabs subjected to CHBDC axle 4 for different D values of alpha 6 FEA analyses

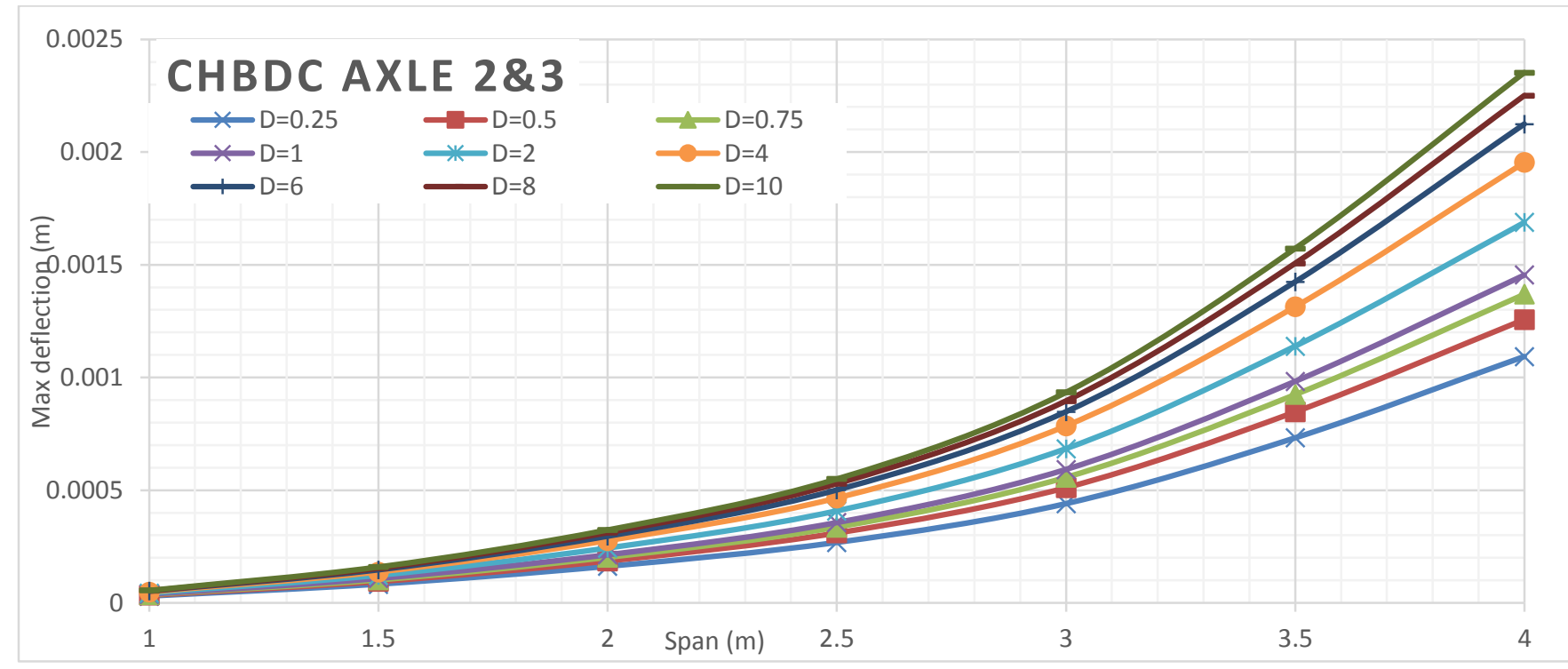

Figure 155 Maximum deflection of deck slabs subjected to CHBDC axle $2 \& 3$ for different D values of alpha 6 FEA analyses 


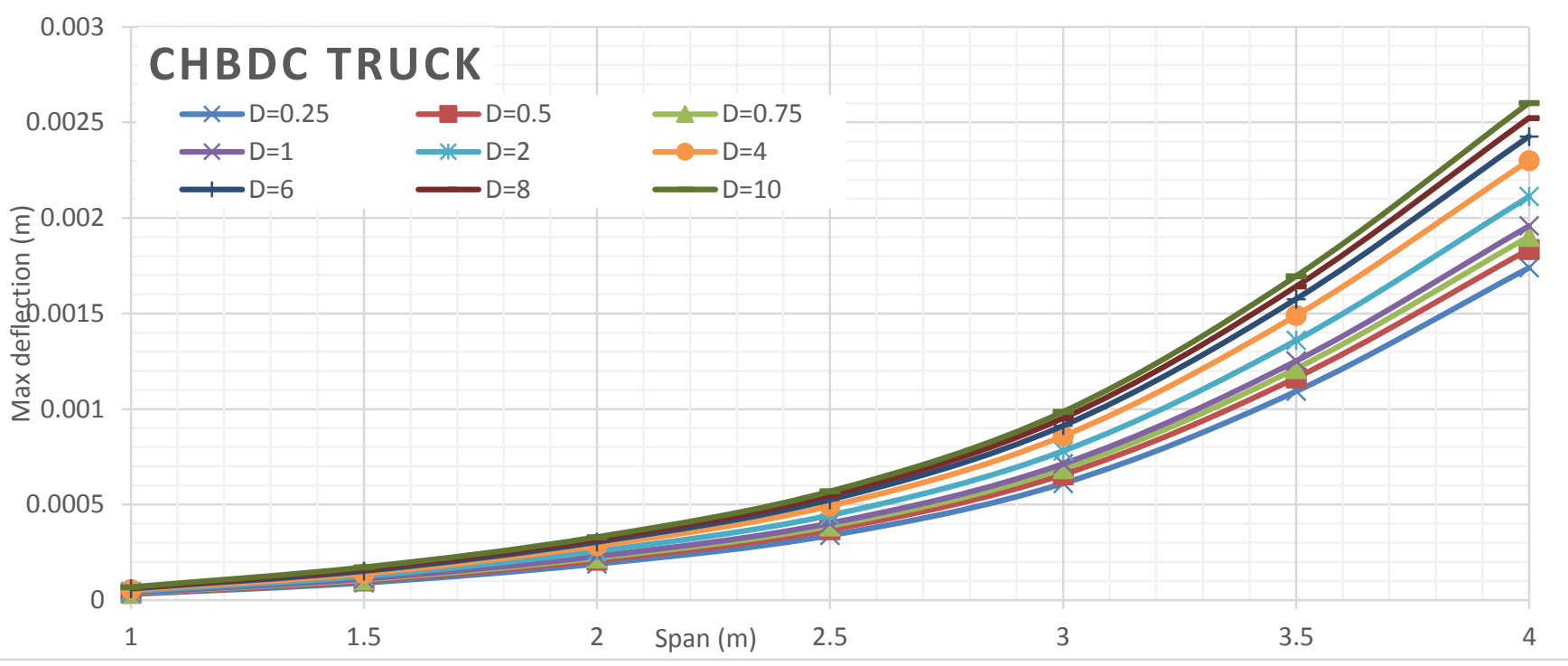

Figure 156 Maximum deflection of deck slabs subjected to CHBDC truck for different D values of alpha 6 FEA analyses

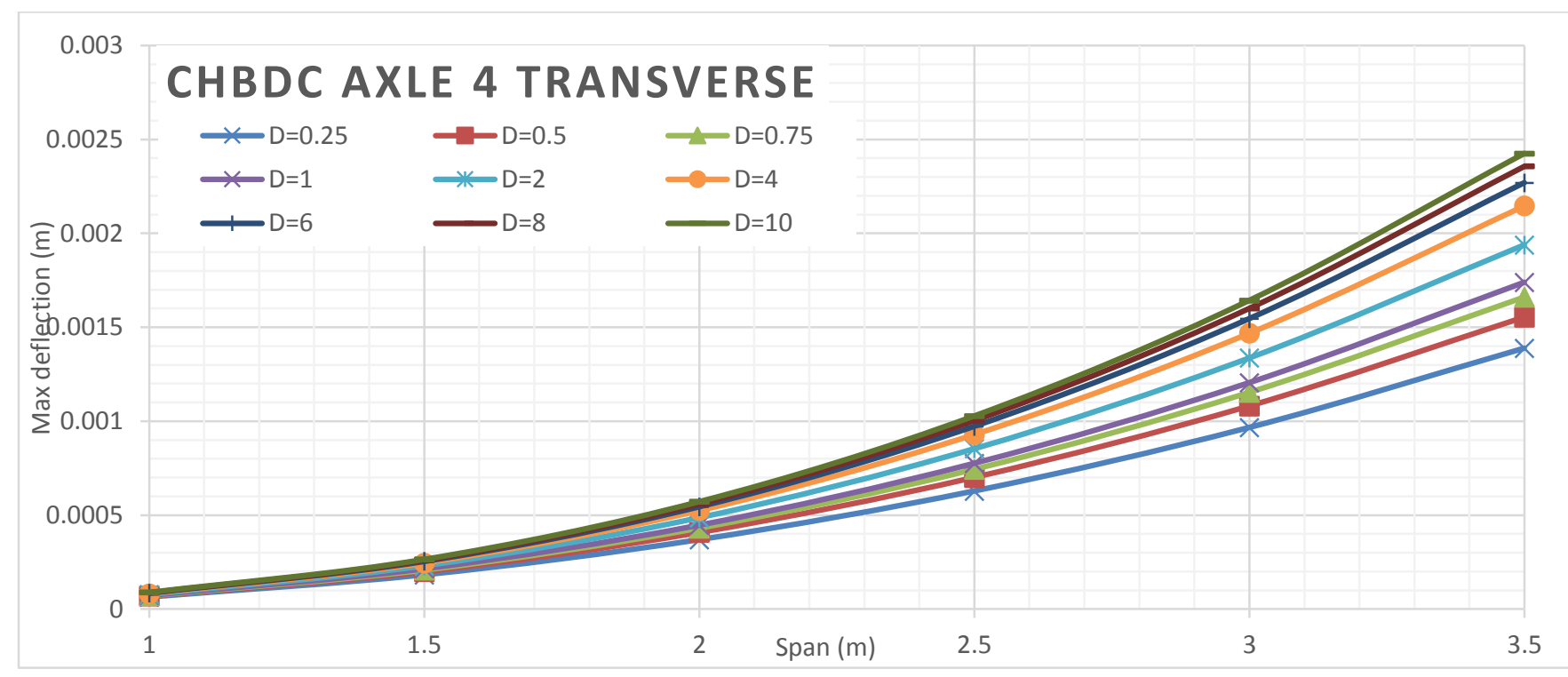

Figure 157 Maximum deflection of deck slabs subjected to CHBDC axle 4 for different D values of alpha 6 FEA analyses

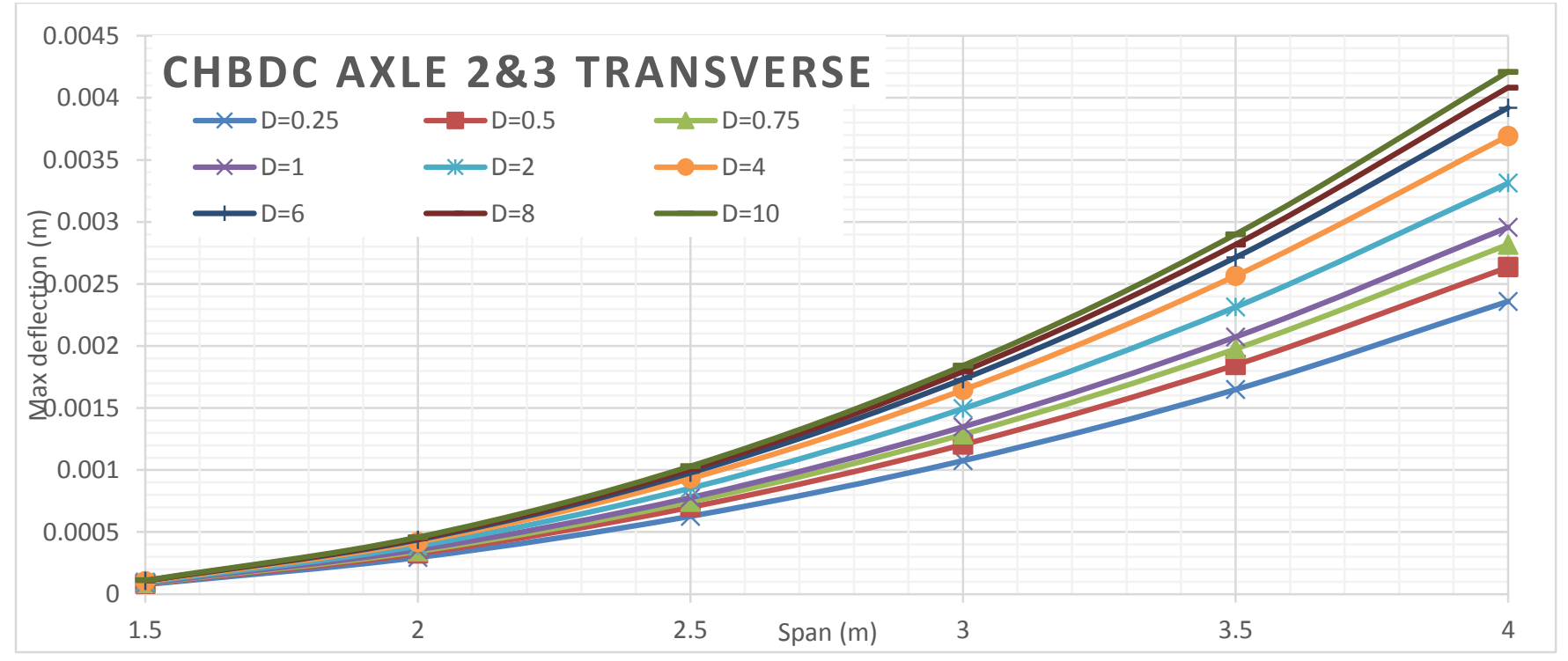

Figure 158 Maximum deflection of deck slabs subjected to CHBDC axle $2 \& 3$ for different D values of alpha 6 FEA analyses 


\section{Alpha 8 Deflection VS Span Length for Different D Values}

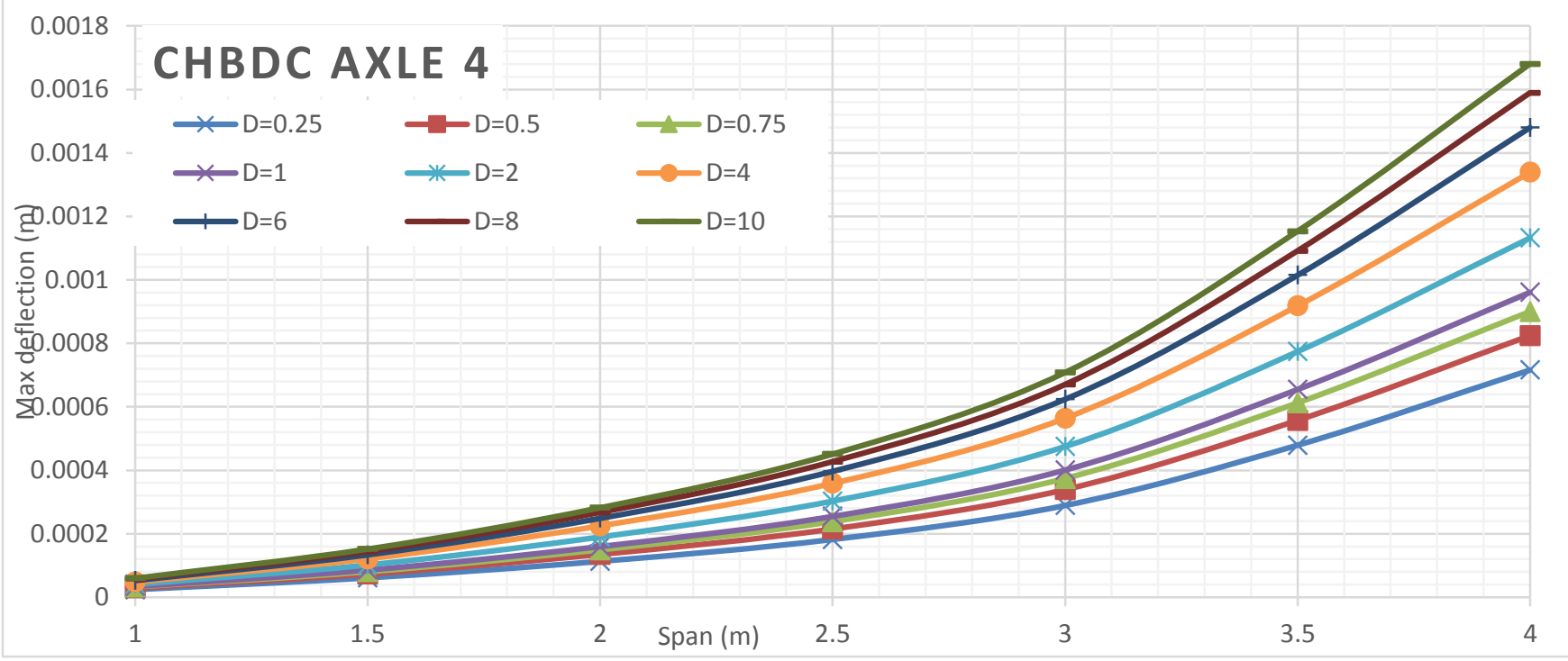

Figure 159 Maximum deflection of deck slabs subjected to CHBDC axle 4 for different D values of alpha 8 FEA analyses

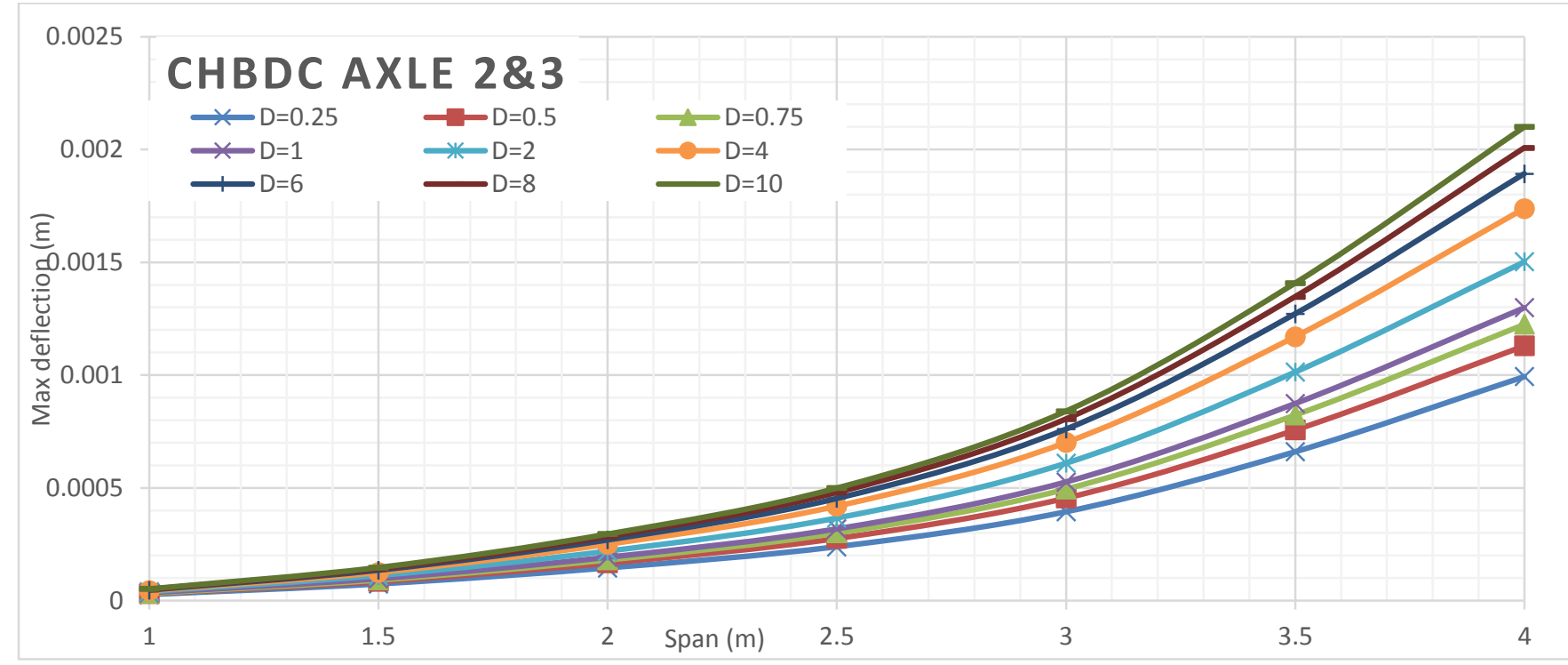

Figure 160 Maximum deflection of deck slabs subjected to CHBDC axle $2 \& 3$ for different D values of alpha 8 FEA analyses 


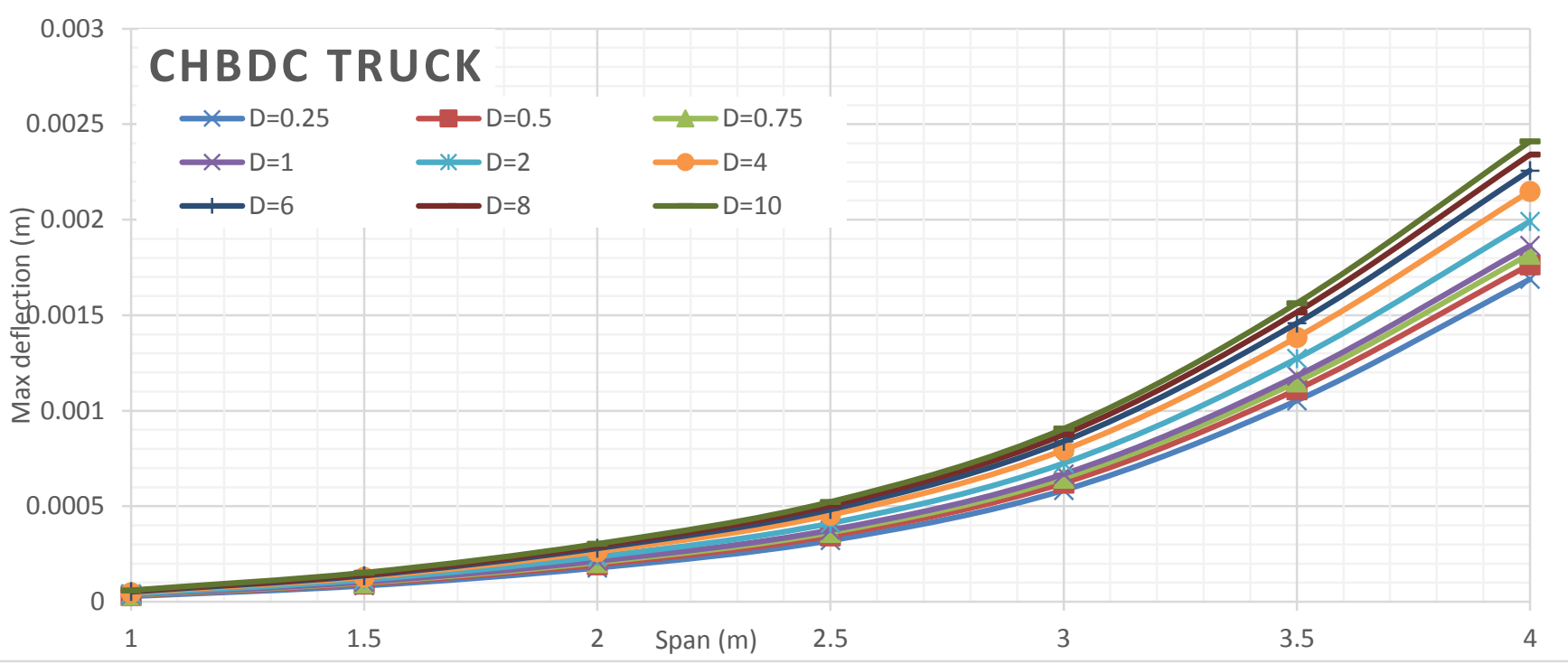

Figure 161 Maximum deflection of deck slabs subjected to CHBDC truck for different D values of alpha 8 FEA analyses

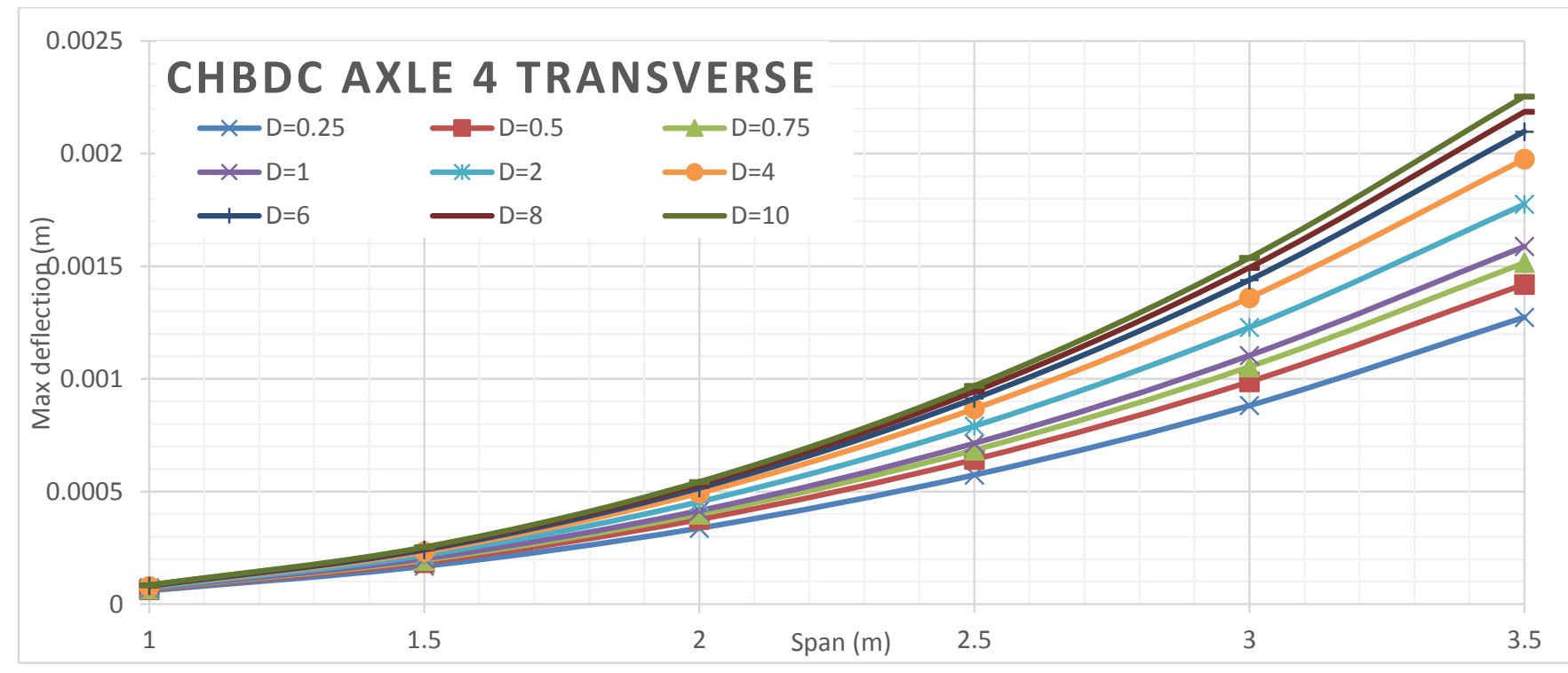

Figure 162 Maximum deflection of deck slabs subjected to CHBDC axle 4 for different D values of alpha 8 FEA analyses

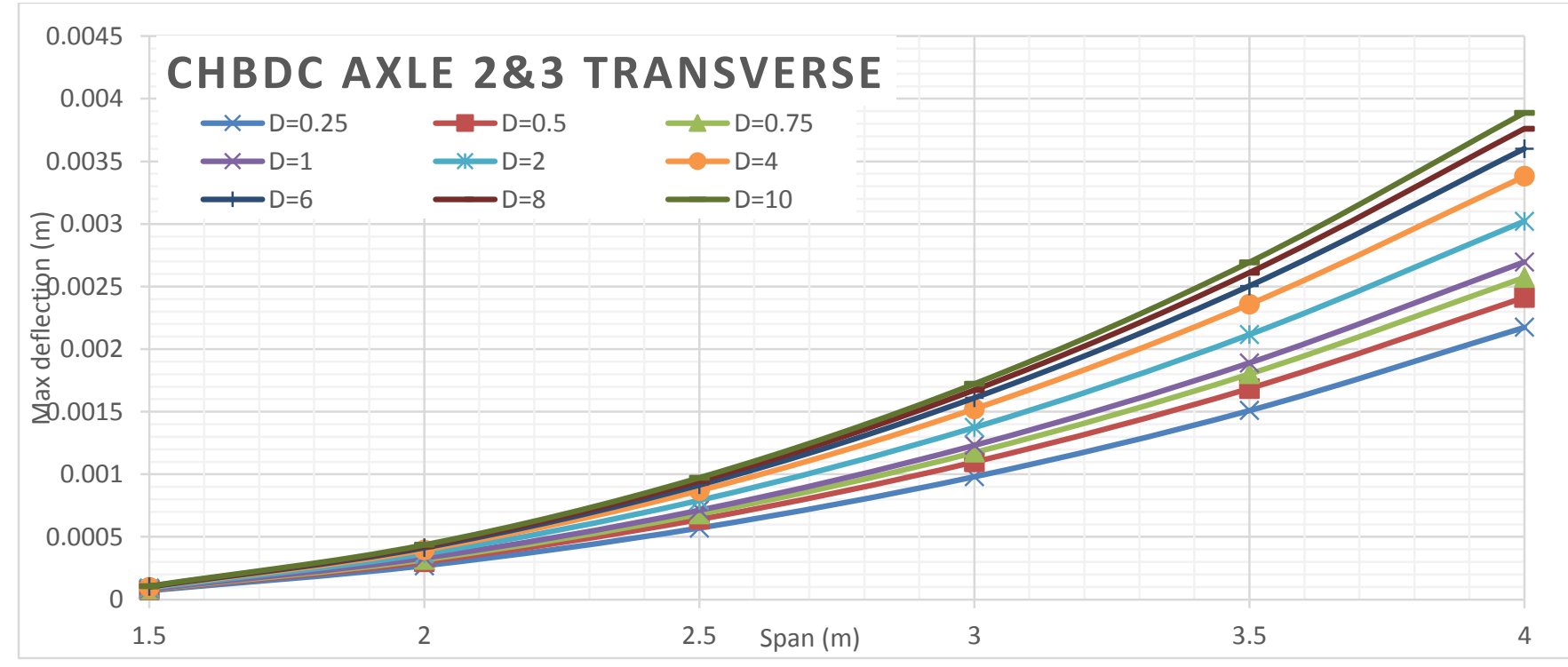

Figure 163 Maximum deflection of deck slabs subjected to CHBDC axle $2 \& 3$ for different D values of alpha 8 FEA analyses 


\section{Alpha 10 Deflection VS Span Length for Different D Values}

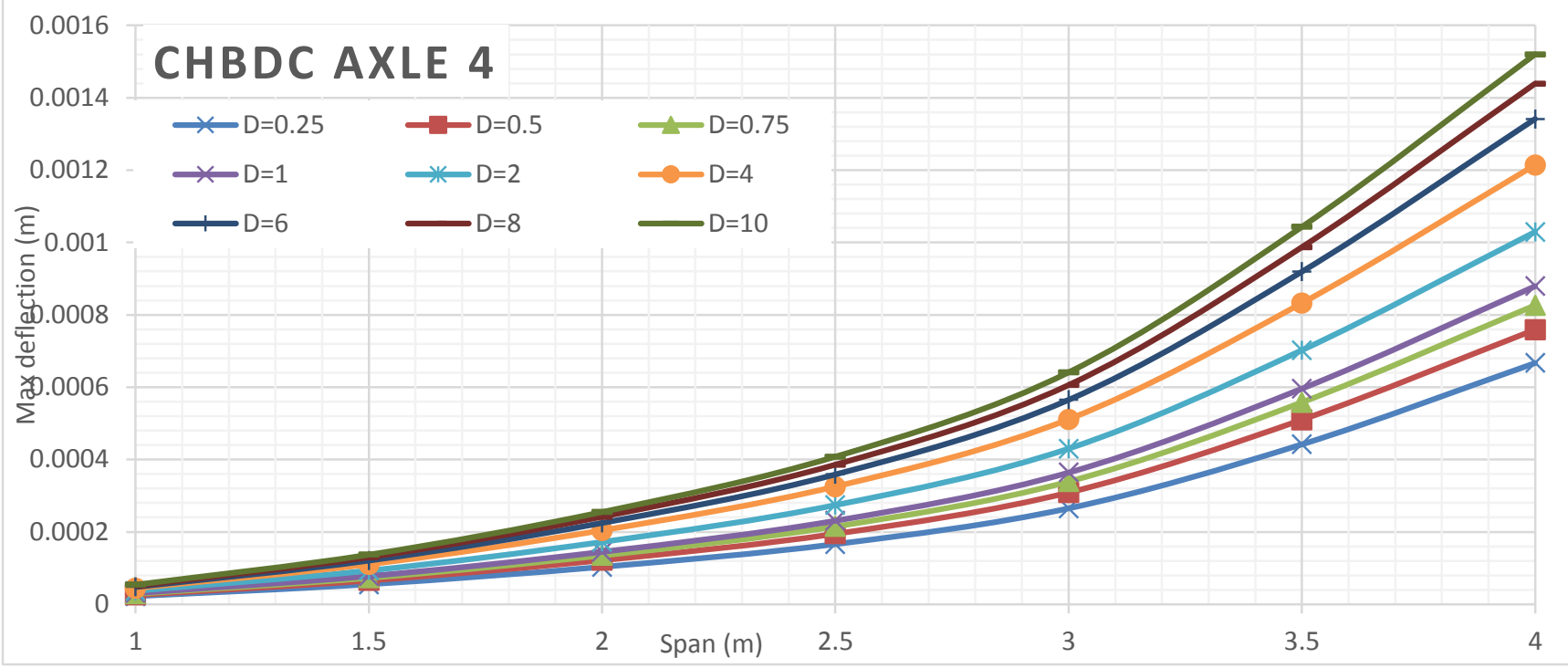

Figure 164 Maximum deflection of deck slabs subjected to CHBDC axle 4 for different D values of alpha 10 FEA analyses

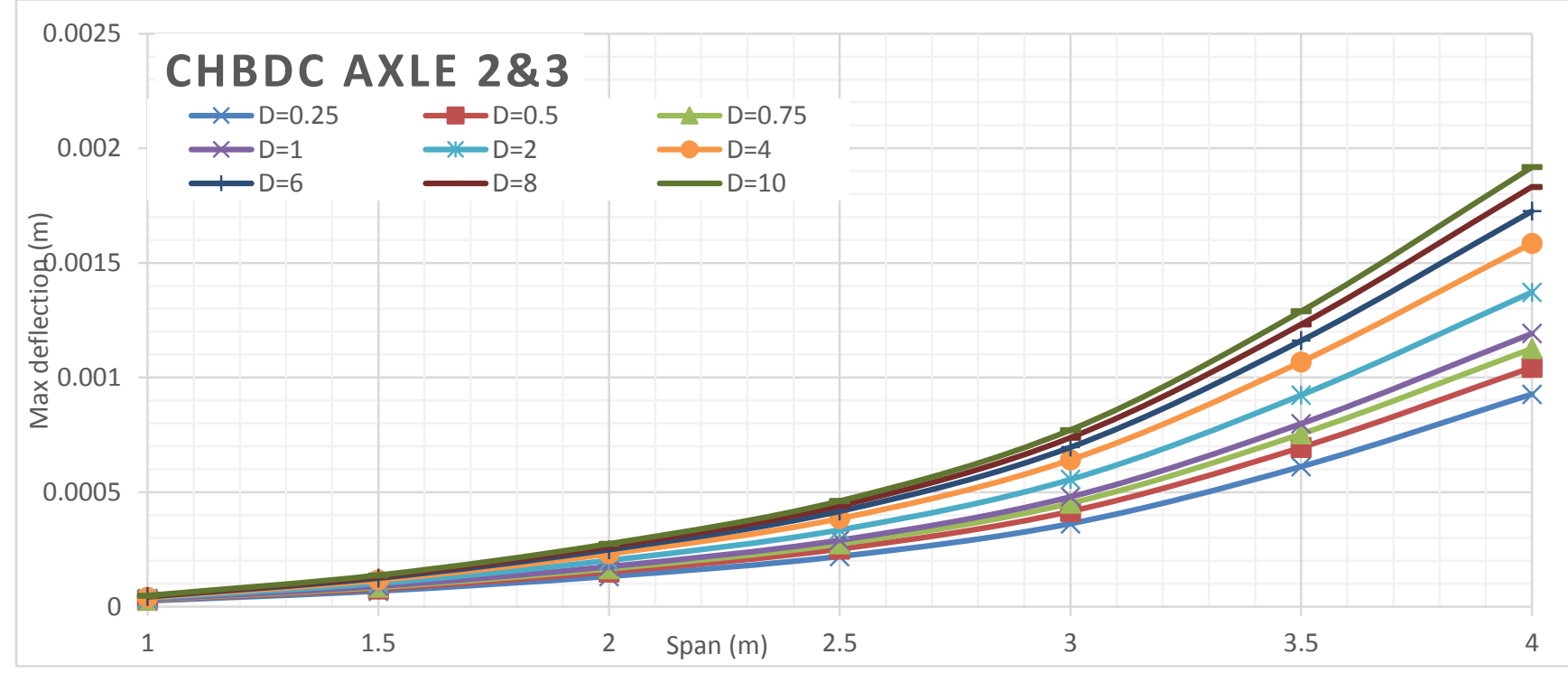

Figure 165 Maximum deflection of deck slabs subjected to CHBDC axle 2 \& 3 for different D values of alpha 10 FEA analyses 


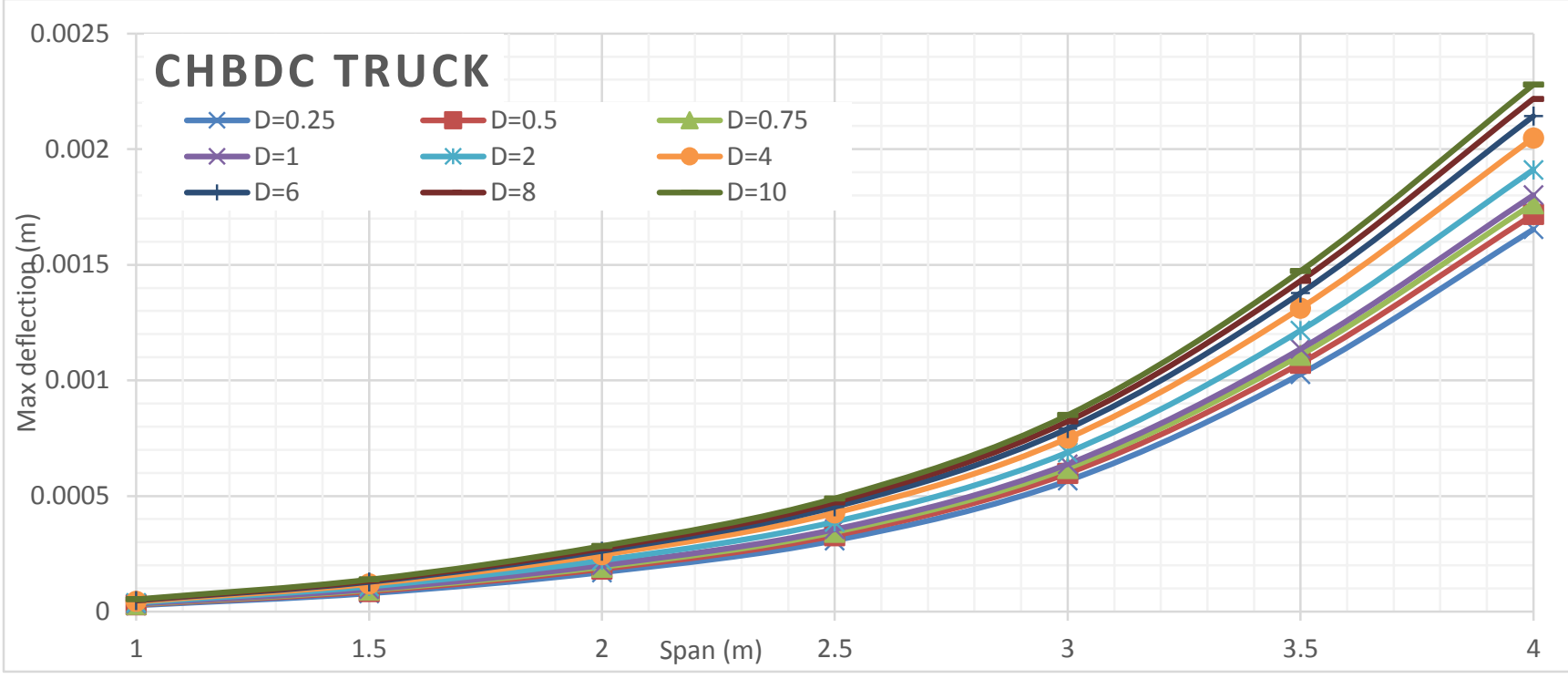

Figure 166 Maximum deflection of deck slabs subjected to CHBDC truck for different D values of alpha 10 FEA analyses

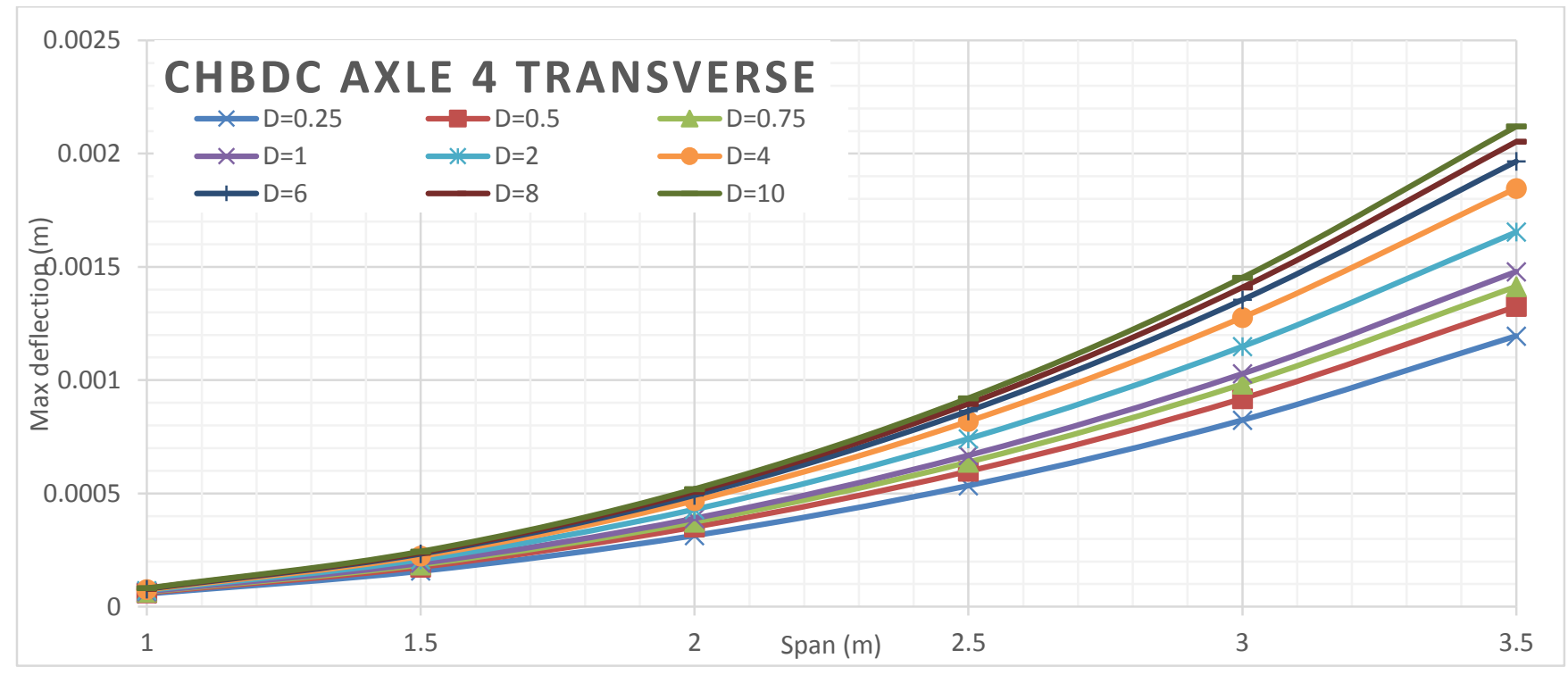

Figure 167 Maximum deflection of deck slabs subjected to CHBDC axle 4 for different D values of alpha 10 FEA analyses

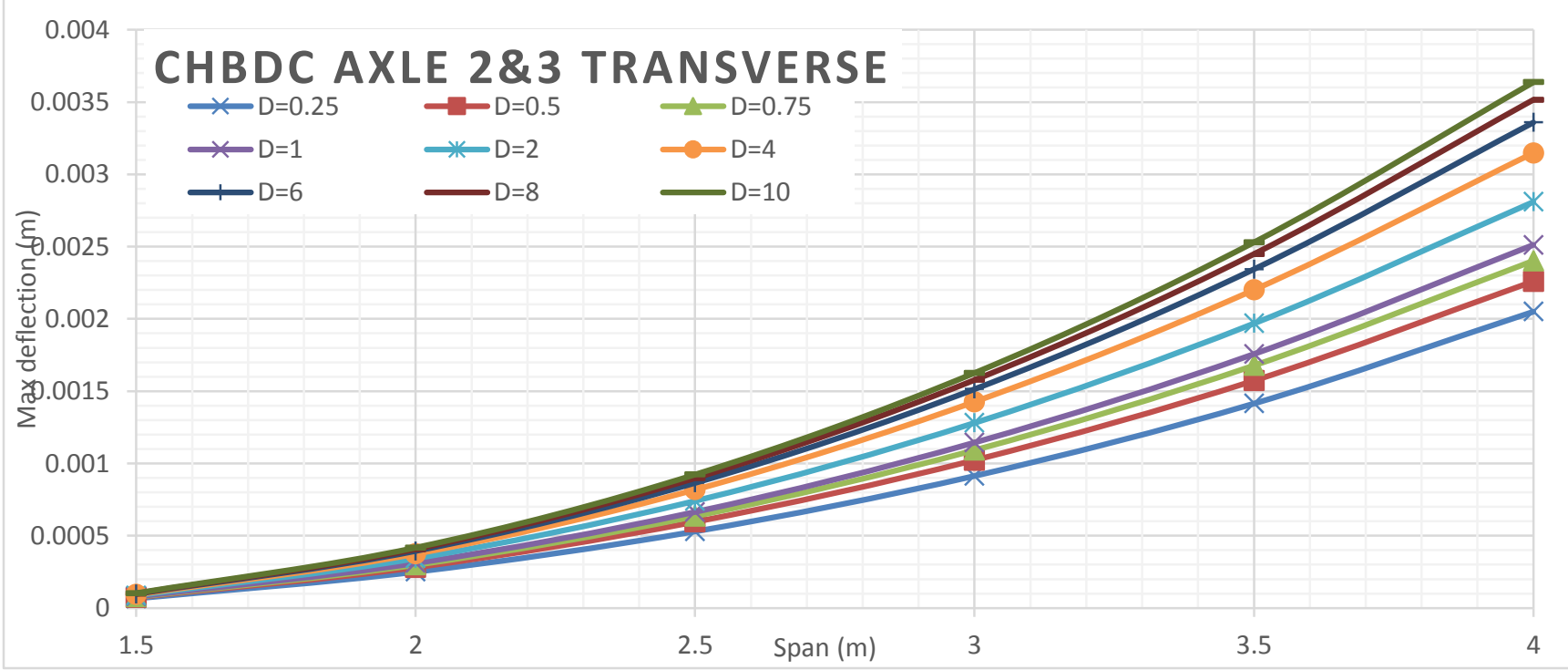

Figure 168 Maximum deflection of deck slabs subjected to CHBDC axle $2 \& 3$ for different D values of alpha 10 FEA analyses 


\section{B.2.3 DEFLECTION VS FLEXURAL RIGIDITY}




\section{Alpha 0.25 Deflection VS Flexural Rigidity for Different Span Length}

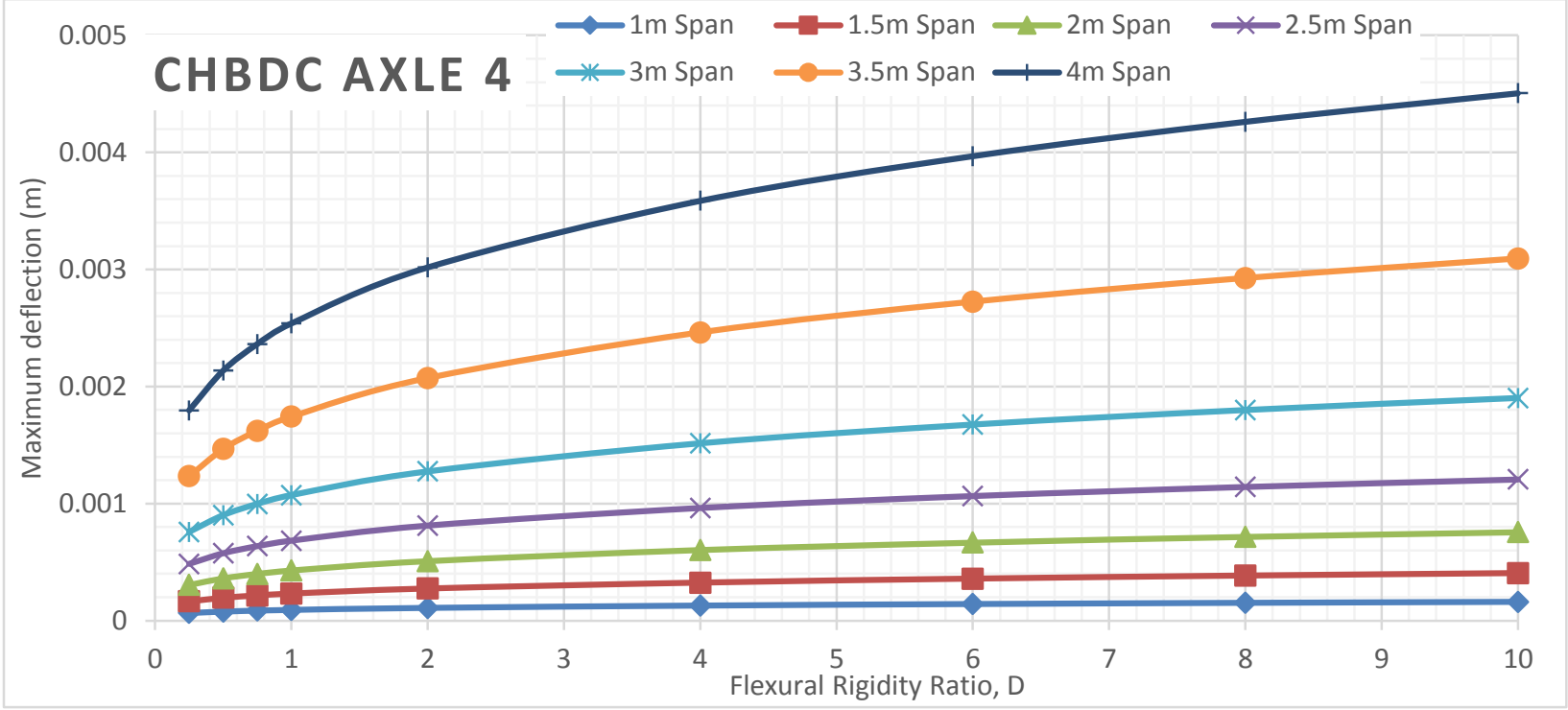

Figure 169 Maximum deflection of deck slabs subjected to CHBDC axle 4 for different span values of alpha 0.25 FEA analyses

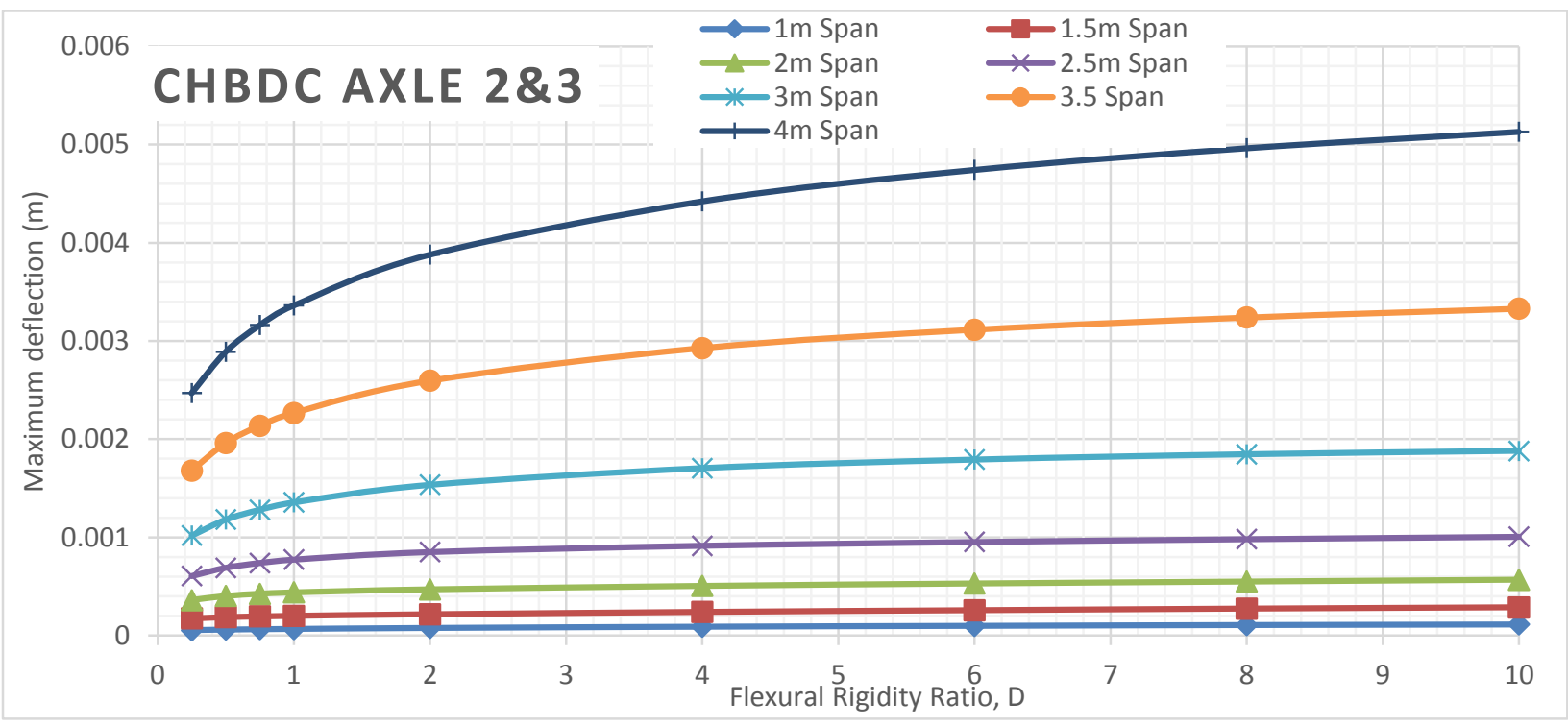

Figure 170 Maximum deflection of deck slabs subjected to CHBDC axle $2 \& 3$ for different span values of alpha 0.25 FEA analyses 


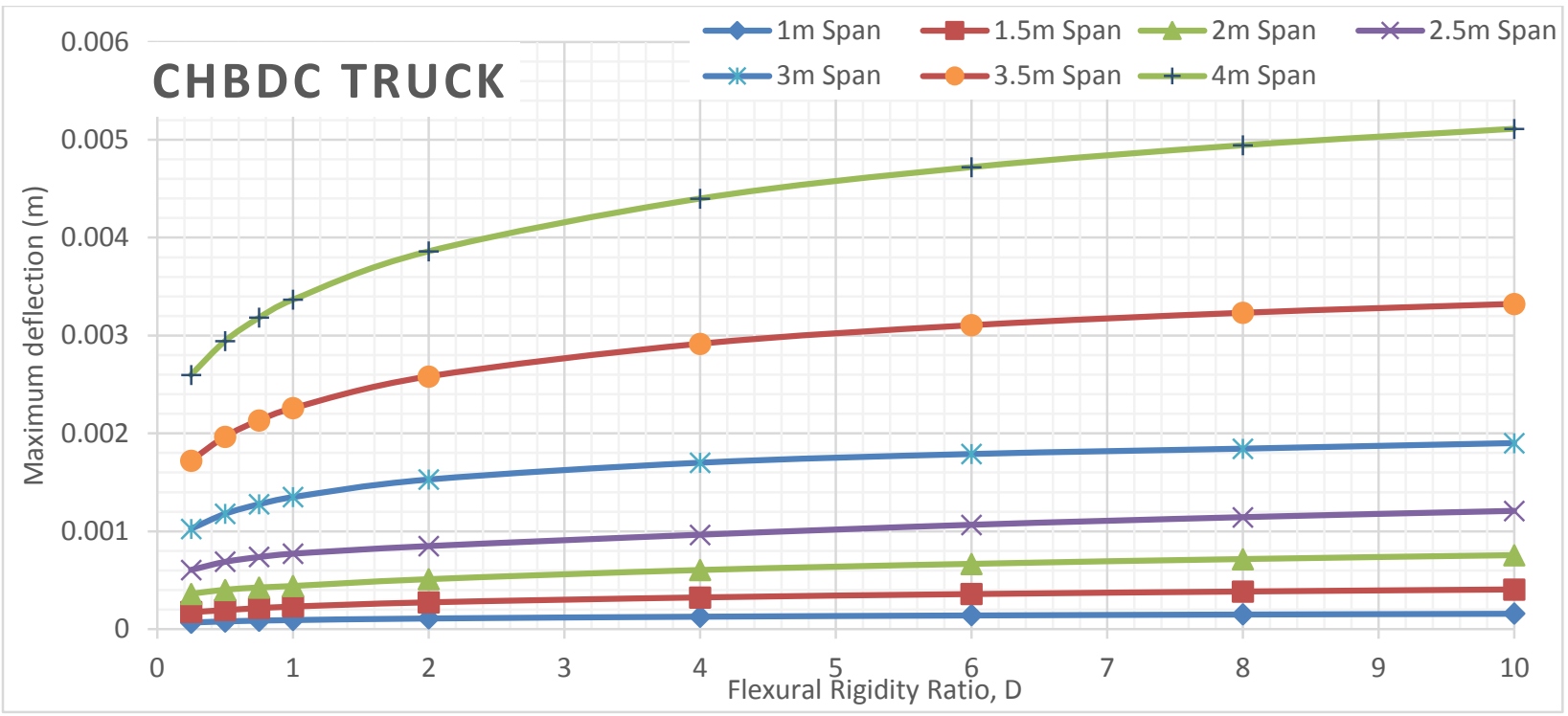

Figure 171 Maximum deflection of deck slabs subjected to CHBDC truck for different span values of alpha 0.25 FEA analyses

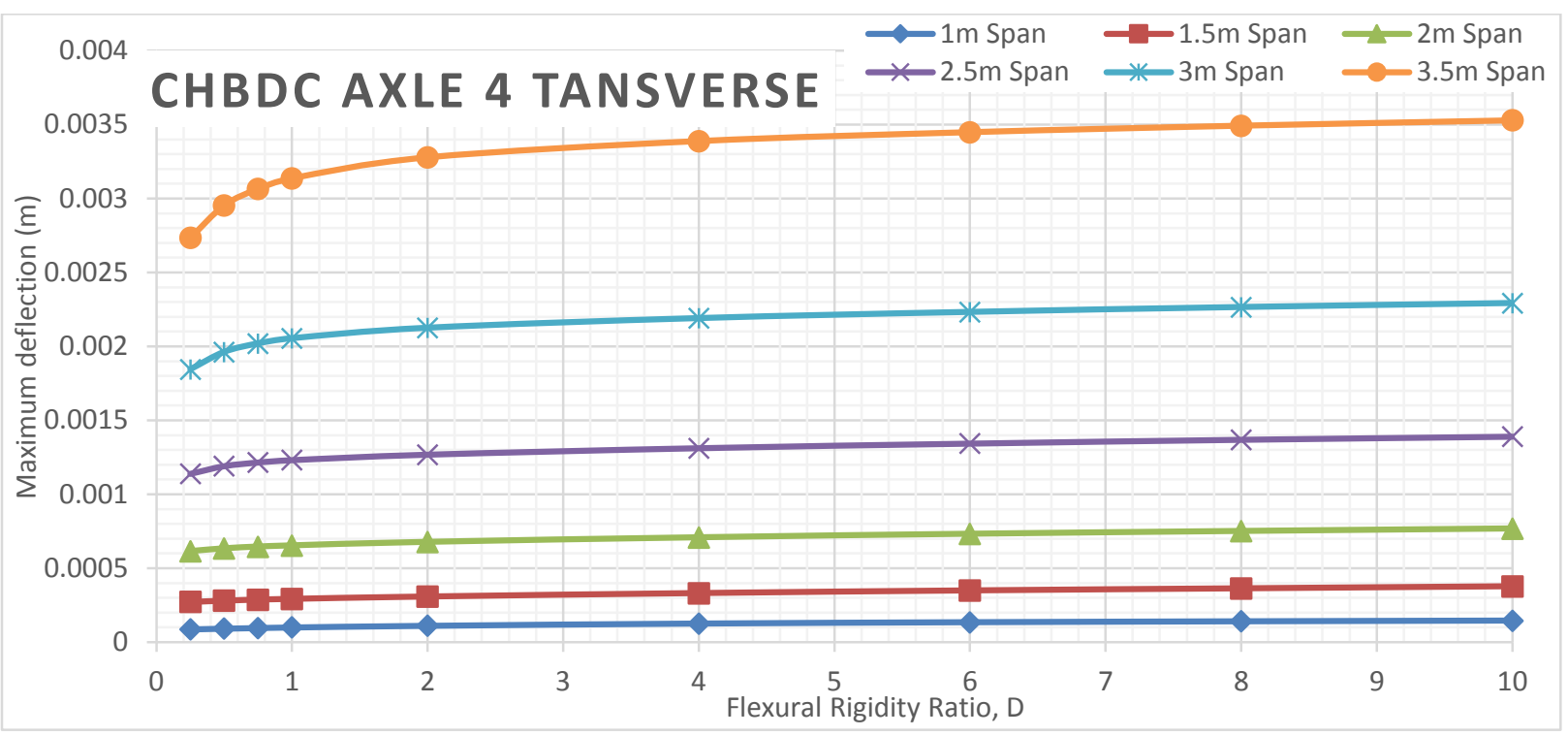

Figure 172 Maximum deflection of deck slabs subjected to CHBDC axle 4 for different span values of alpha 0.25 FEA analyses

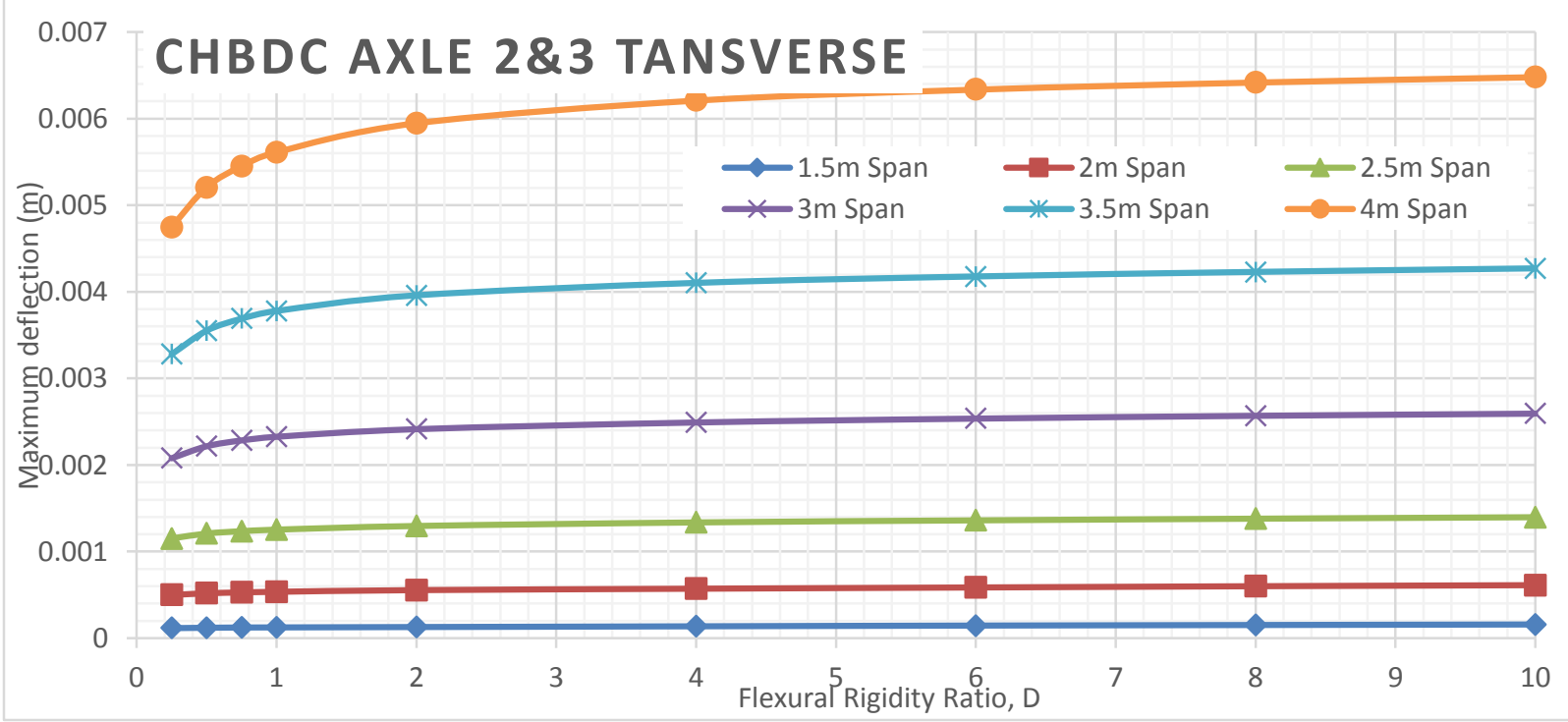

Figure 173 Maximum deflection of deck slabs subjected to CHBDC axle 2 \& 3 for different span values of alpha 0.25 FEA analyses 


\section{Alpha 0.5 Deflection VS Flexural Rigidity for Different Span Length}

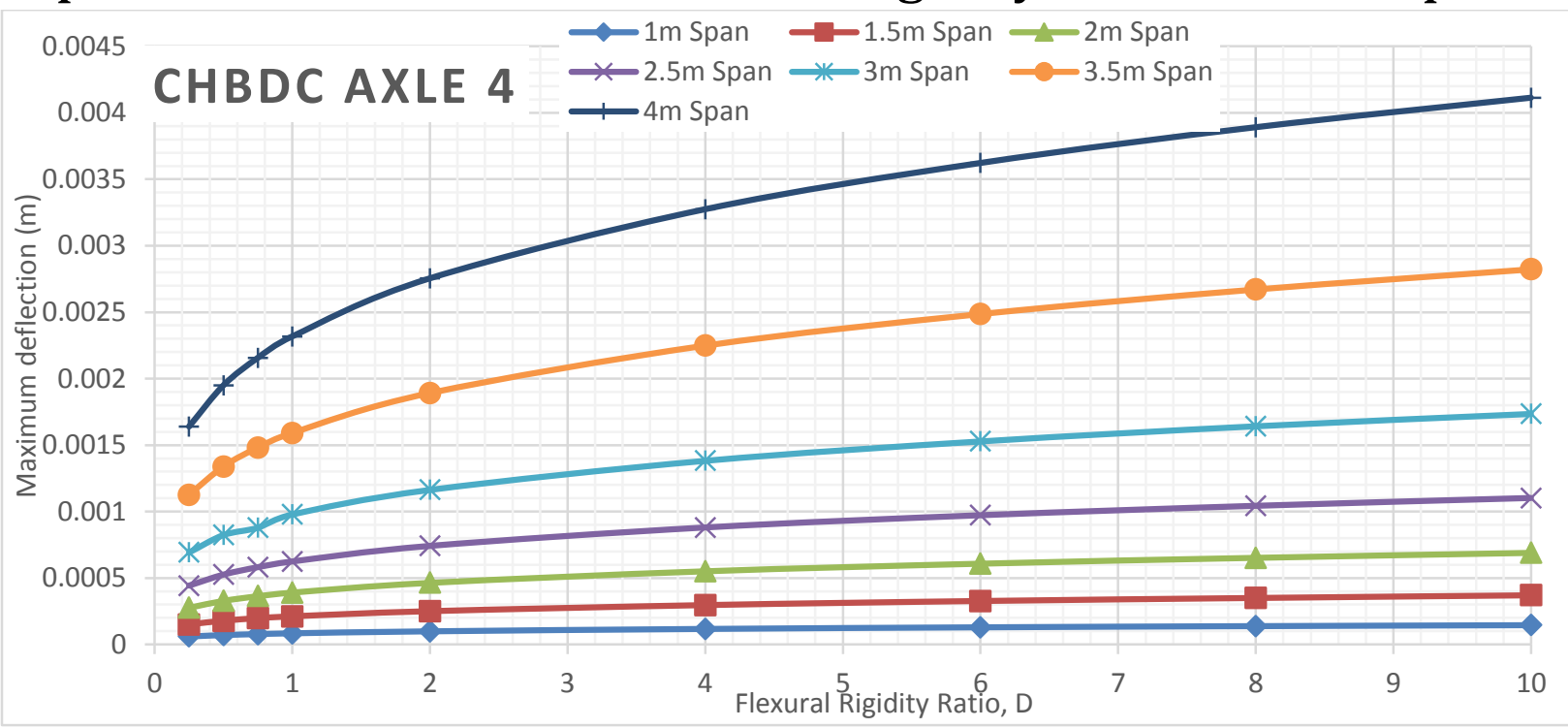

Figure 174 Maximum deflection of deck slabs subjected to CHBDC axle 4 for different span values of alpha 0.5 FEA analyses

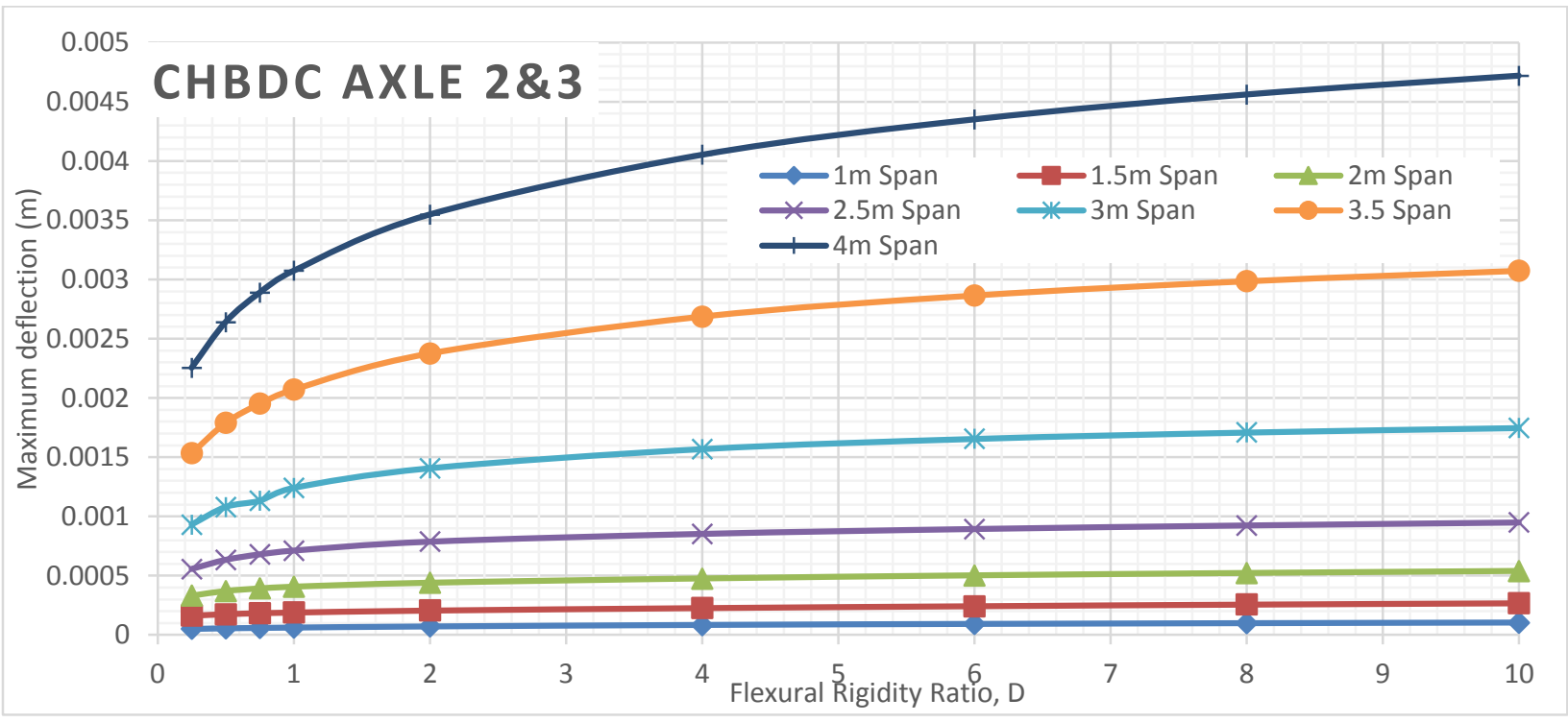

Figure 175 Maximum deflection of deck slabs subjected to CHBDC axle $2 \& 3$ for different span values of alpha 0.5 FEA analyses 


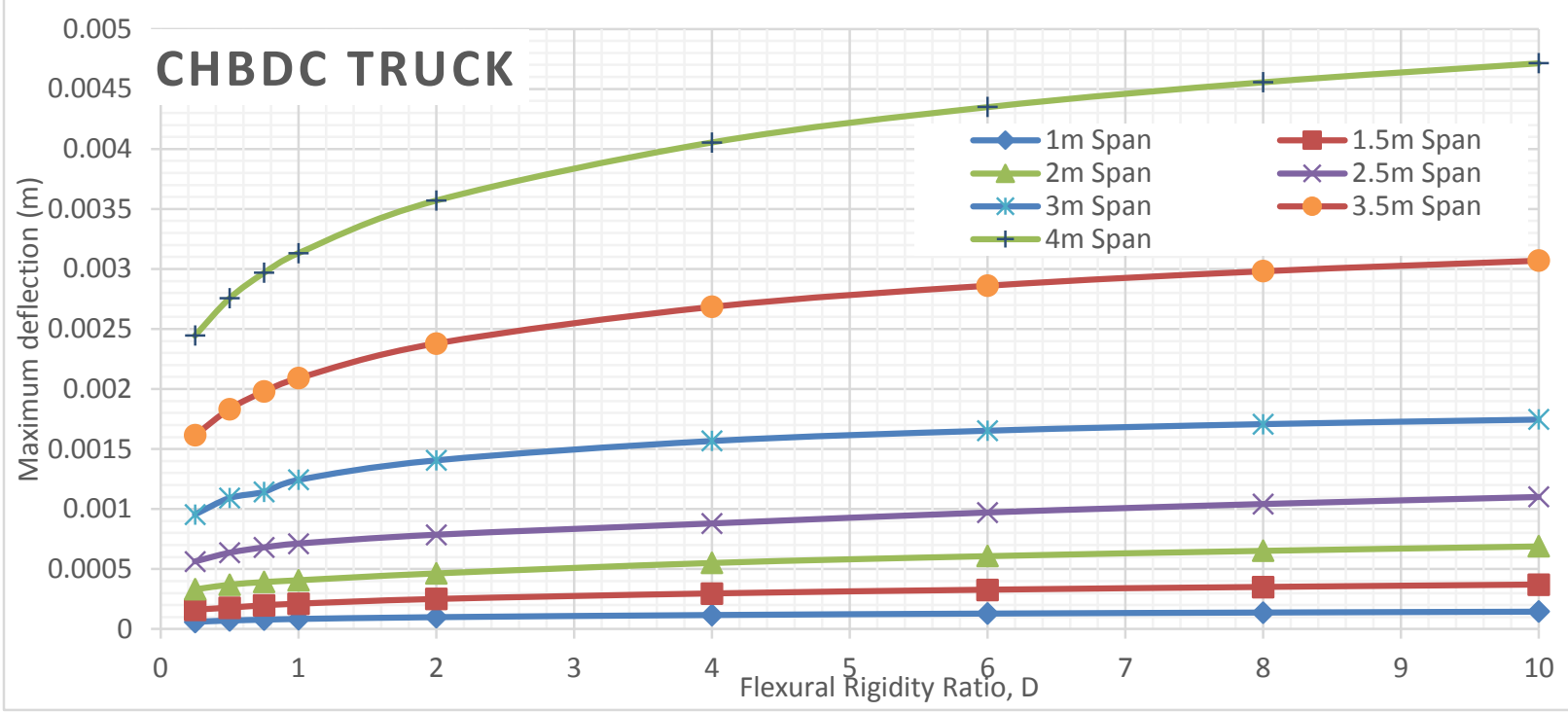

Figure 176 Maximum deflection of deck slabs subjected to CHBDC truck for different span values of alpha 0.5 FEA analyses

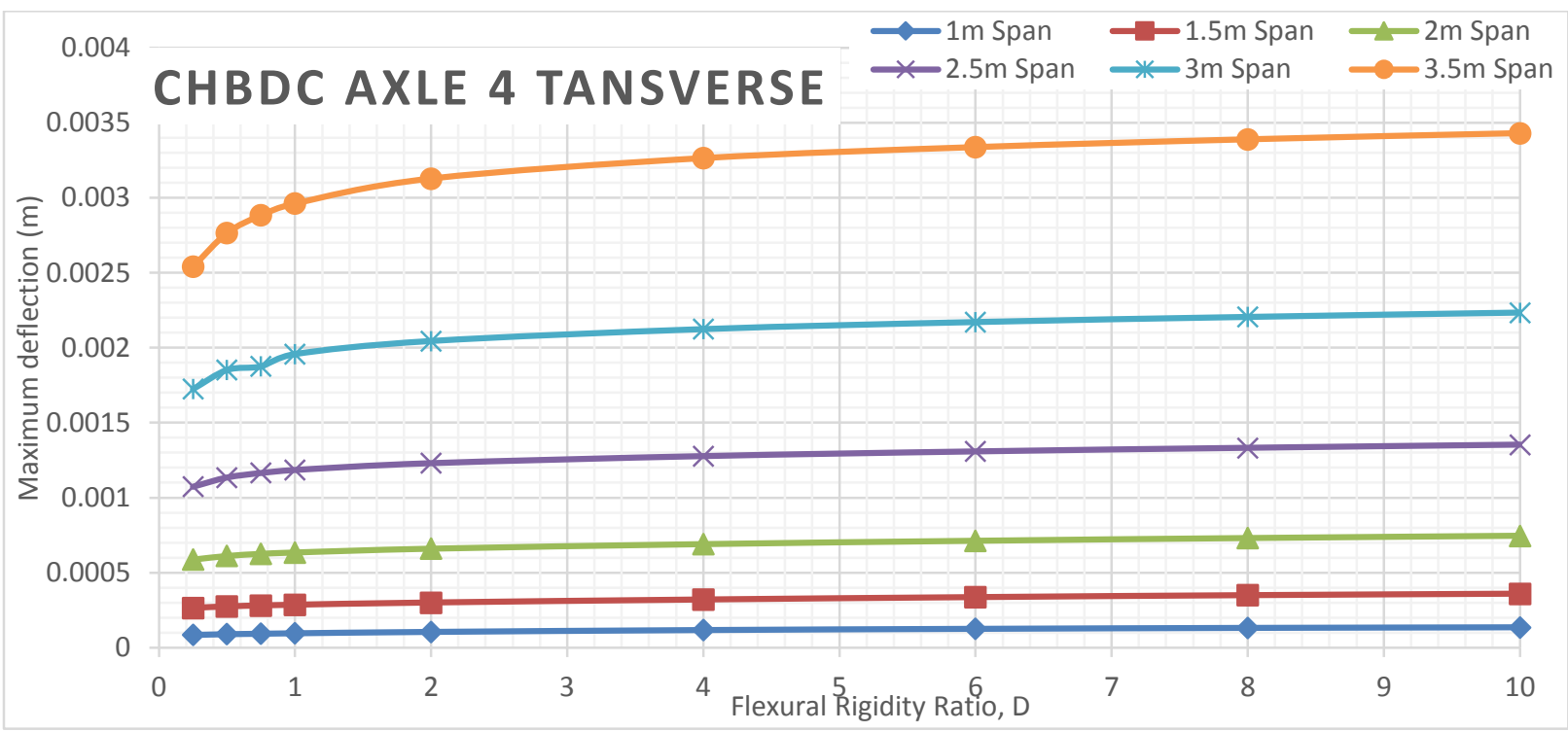

Figure 177 Maximum deflection of deck slabs subjected to CHBDC axle 4 for different span values of alpha 0.5 FEA analyses

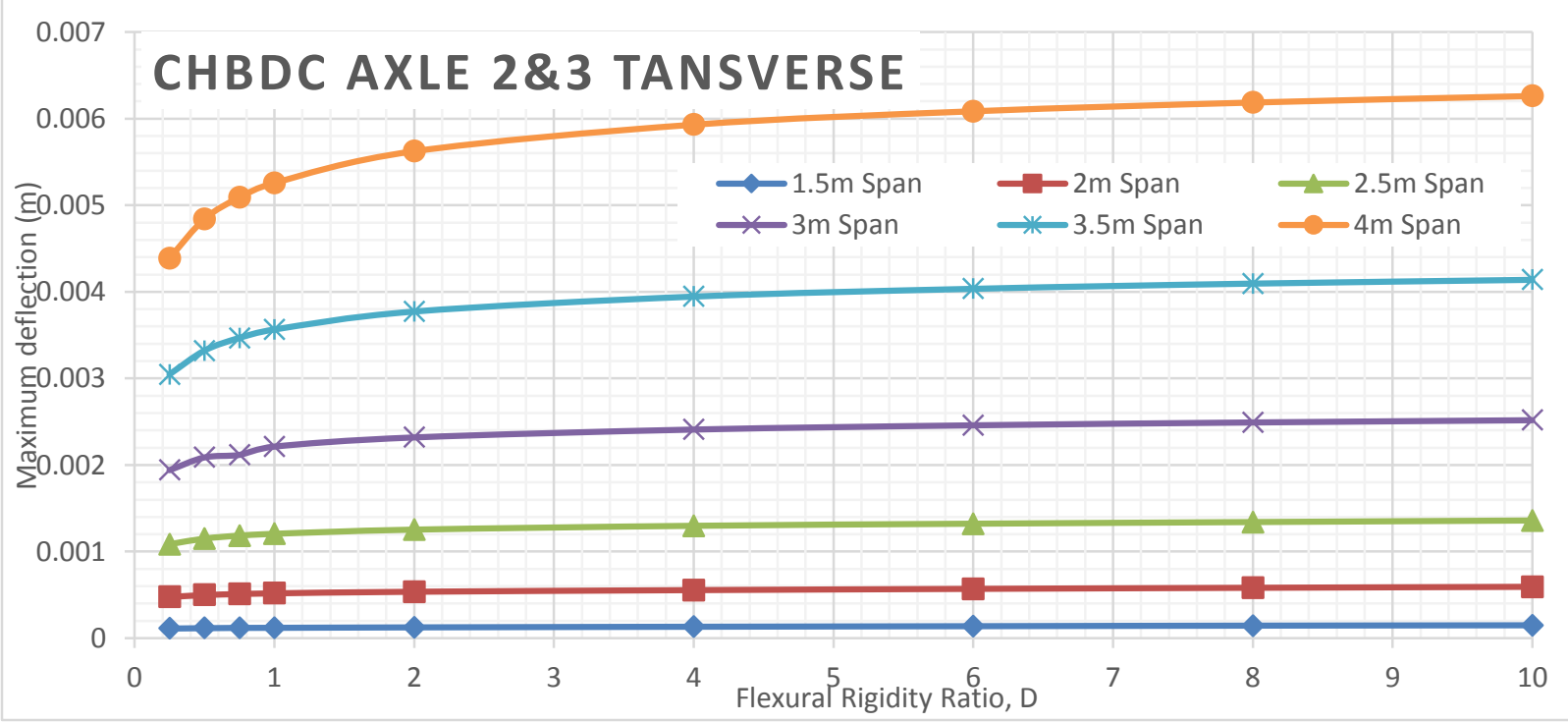

Figure 178 Maximum deflection of deck slabs subjected to CHBDC axle $2 \& 3$ for different span values of alpha 0.5 FEA analyses 


\section{Alpha 0.75 Deflection VS Flexural Rigidity for Different Span Length}

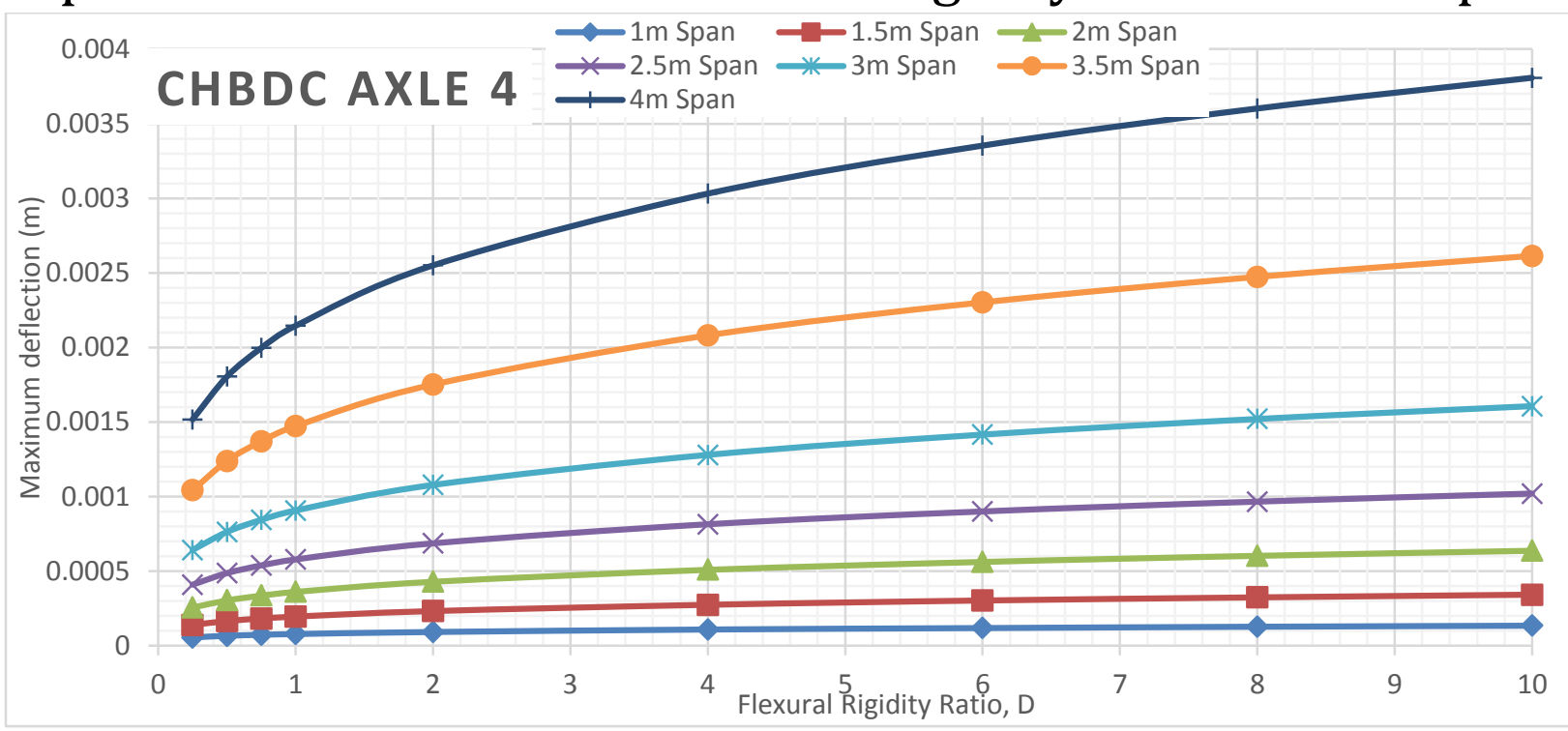

Figure 179 Maximum deflection of deck slabs subjected to CHBDC axle 4 for different span values of alpha 0.75 FEA analyses

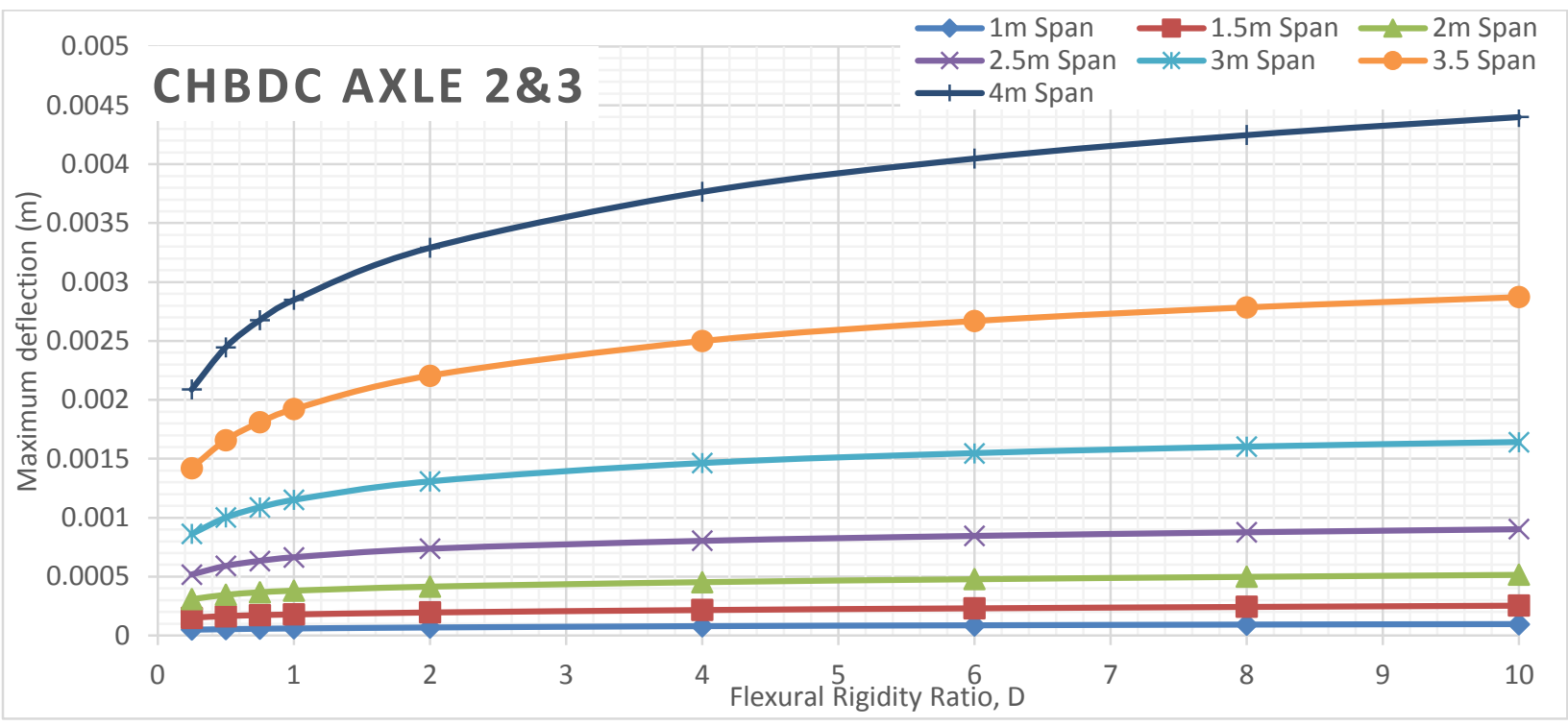

Figure 180 Maximum deflection of deck slabs subjected to CHBDC axle $2 \& 3$ for different span values of alpha 0.75 FEA analyses 


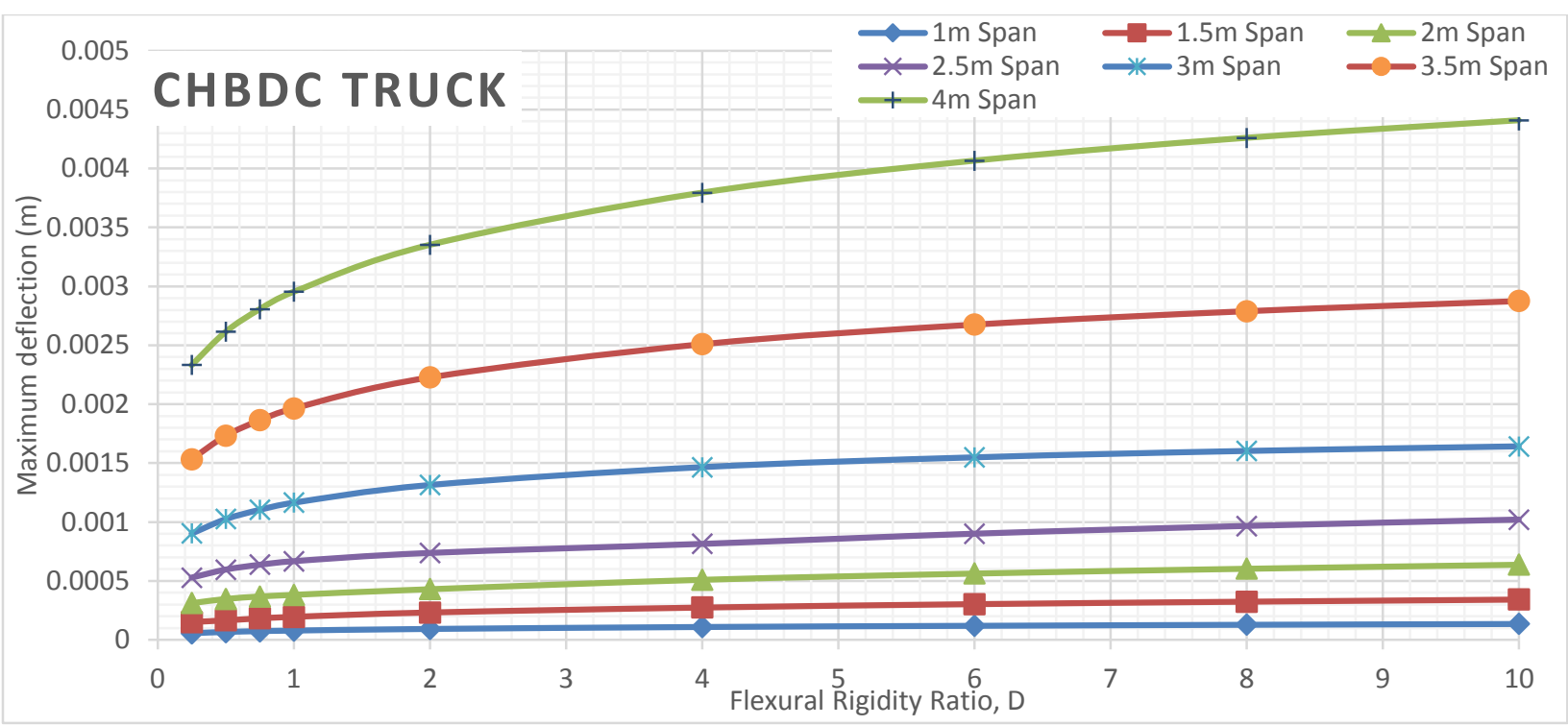

Figure 181 Maximum deflection of deck slabs subjected to CHBDC truck for different span values of alpha 0.75 FEA analyses

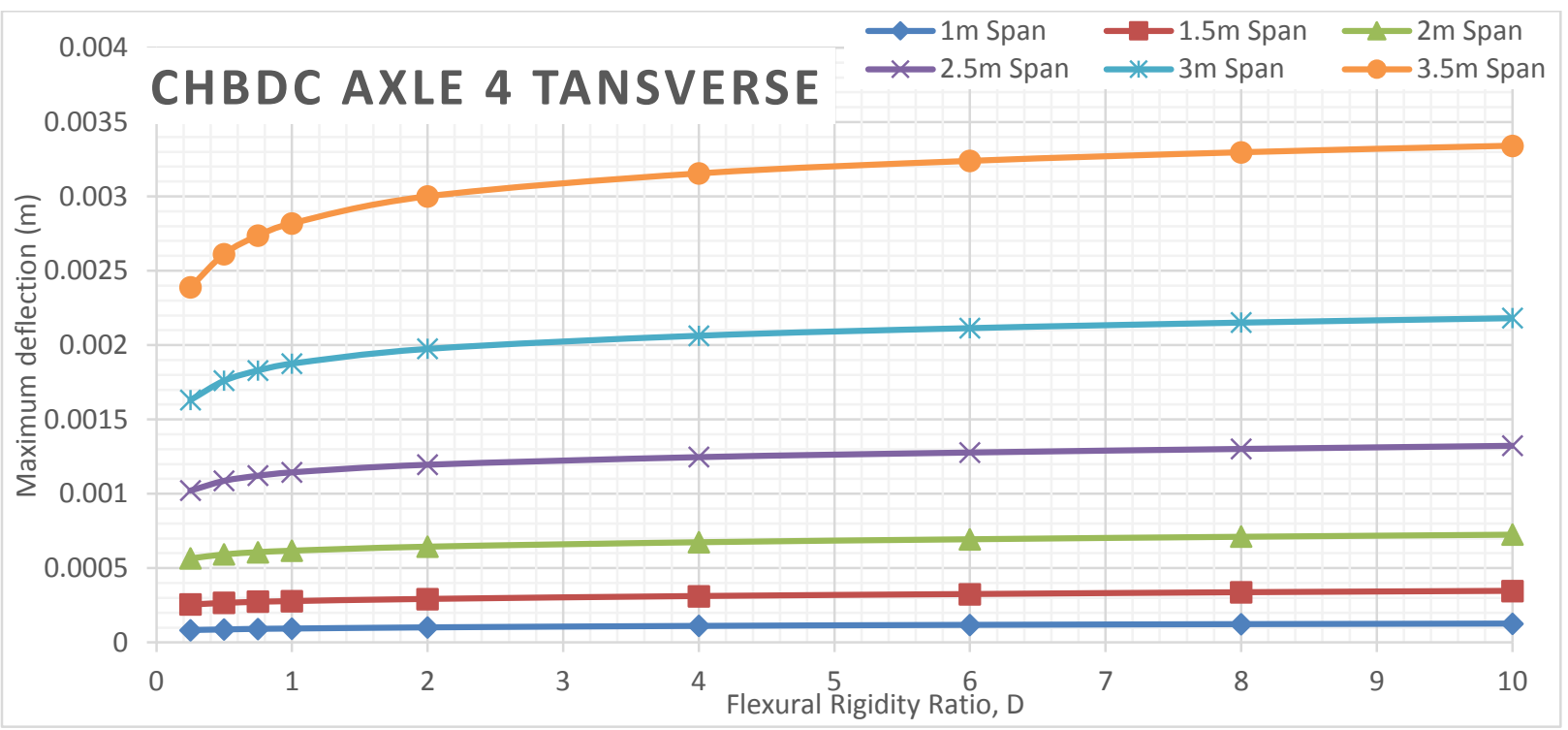

Figure 182 Maximum deflection of deck slabs subjected to CHBDC axle 4 for different span values of alpha 0.75 FEA analyses

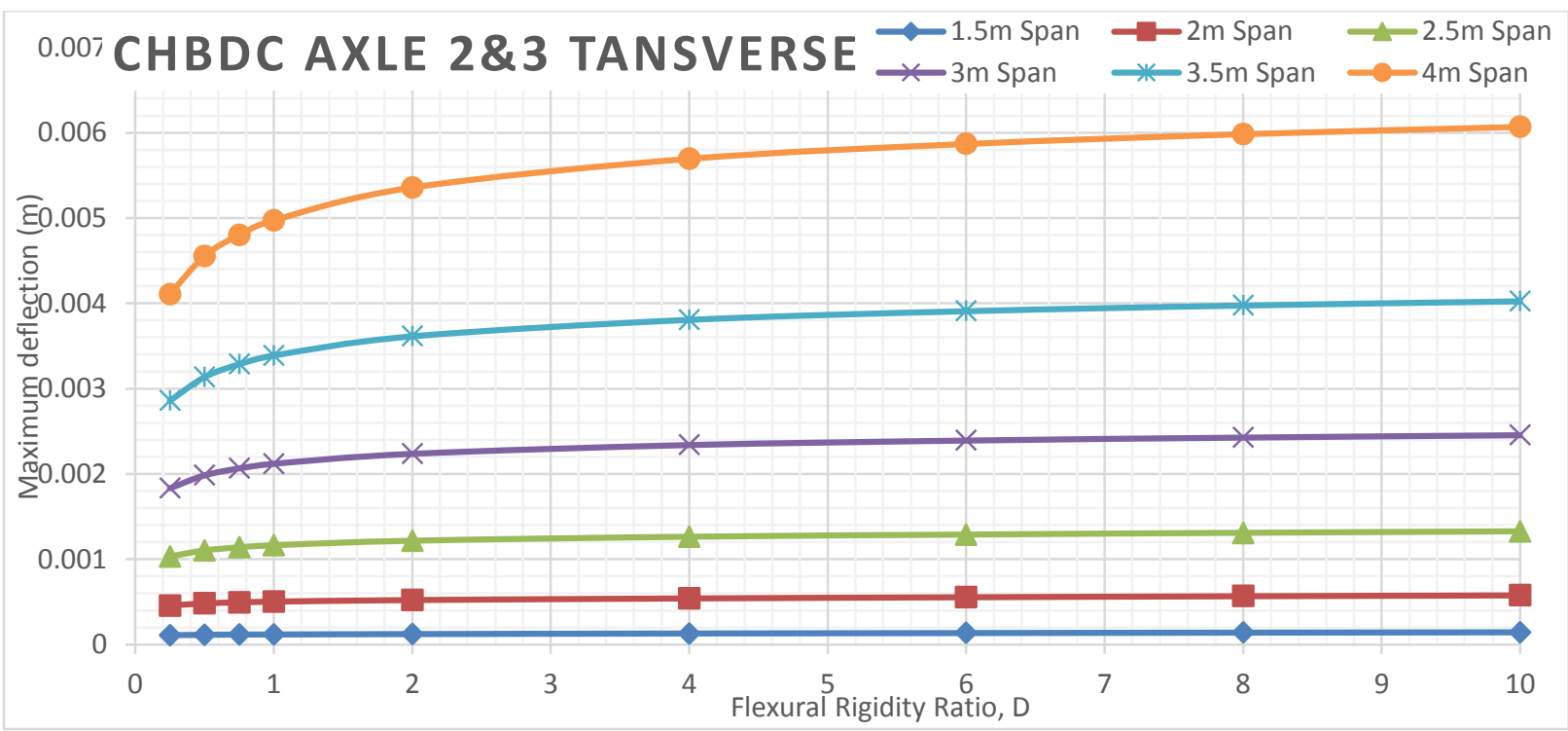

Figure 183 Maximum deflection of deck slabs subjected to CHBDC axle $2 \& 3$ for different span values of alpha 0.75 FEA analyses 


\section{Alpha 1 Deflection VS Flexural Rigidity for Different Span Length}

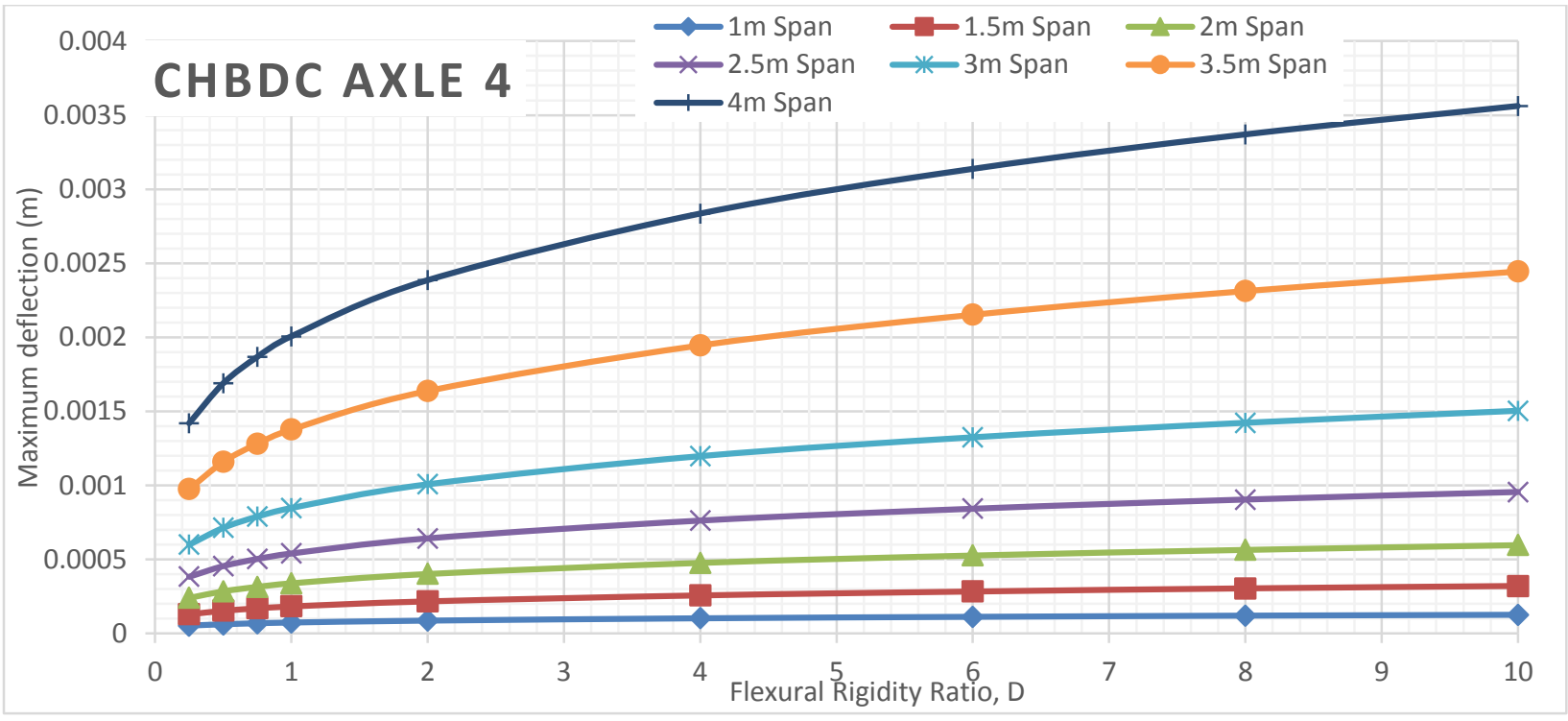

Figure 184 Maximum deflection of deck slabs subjected to CHBDC axle 4 for different span values of alpha 1 FEA analyses

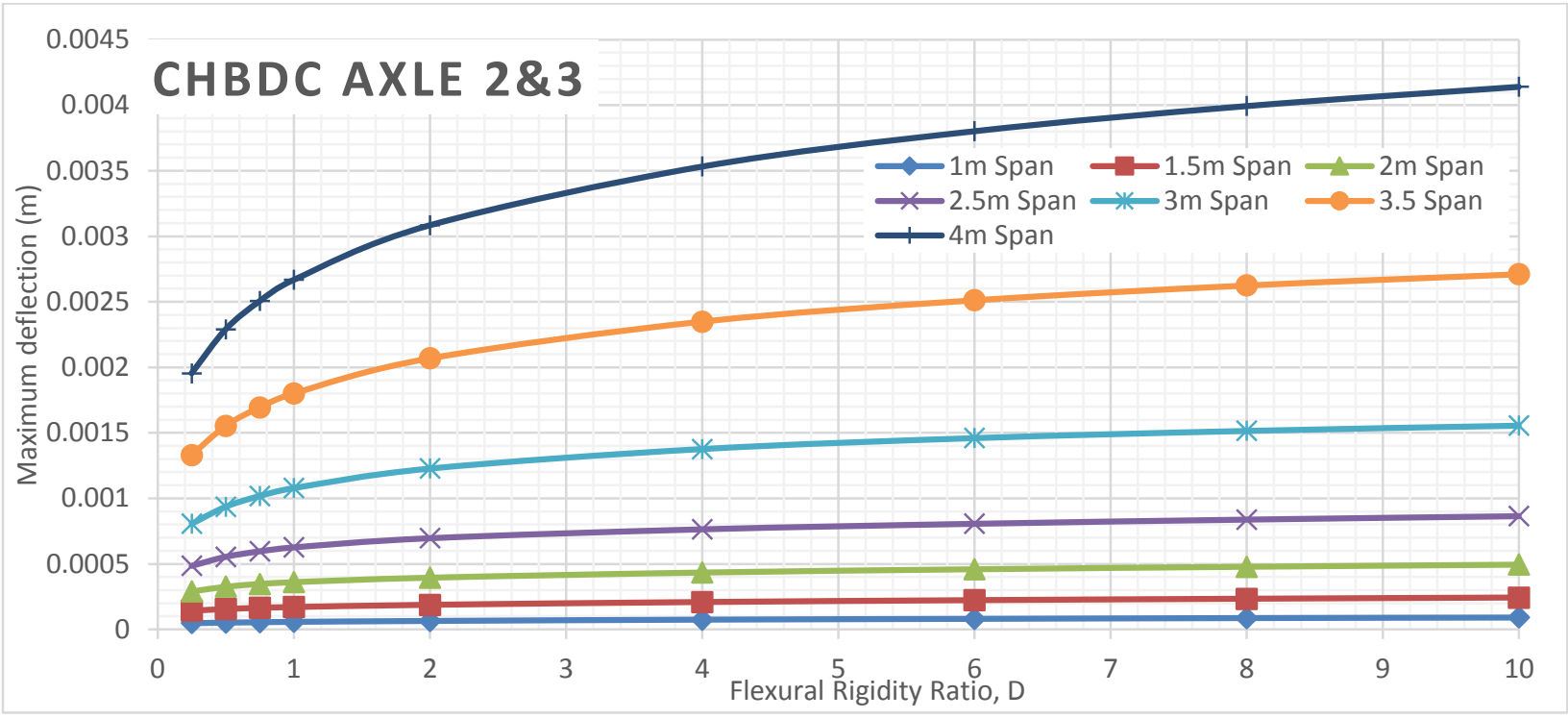

Figure 185 Maximum deflection of deck slabs subjected to CHBDC axle 2 \& 3 for different span values of alpha 1 FEA analyses 


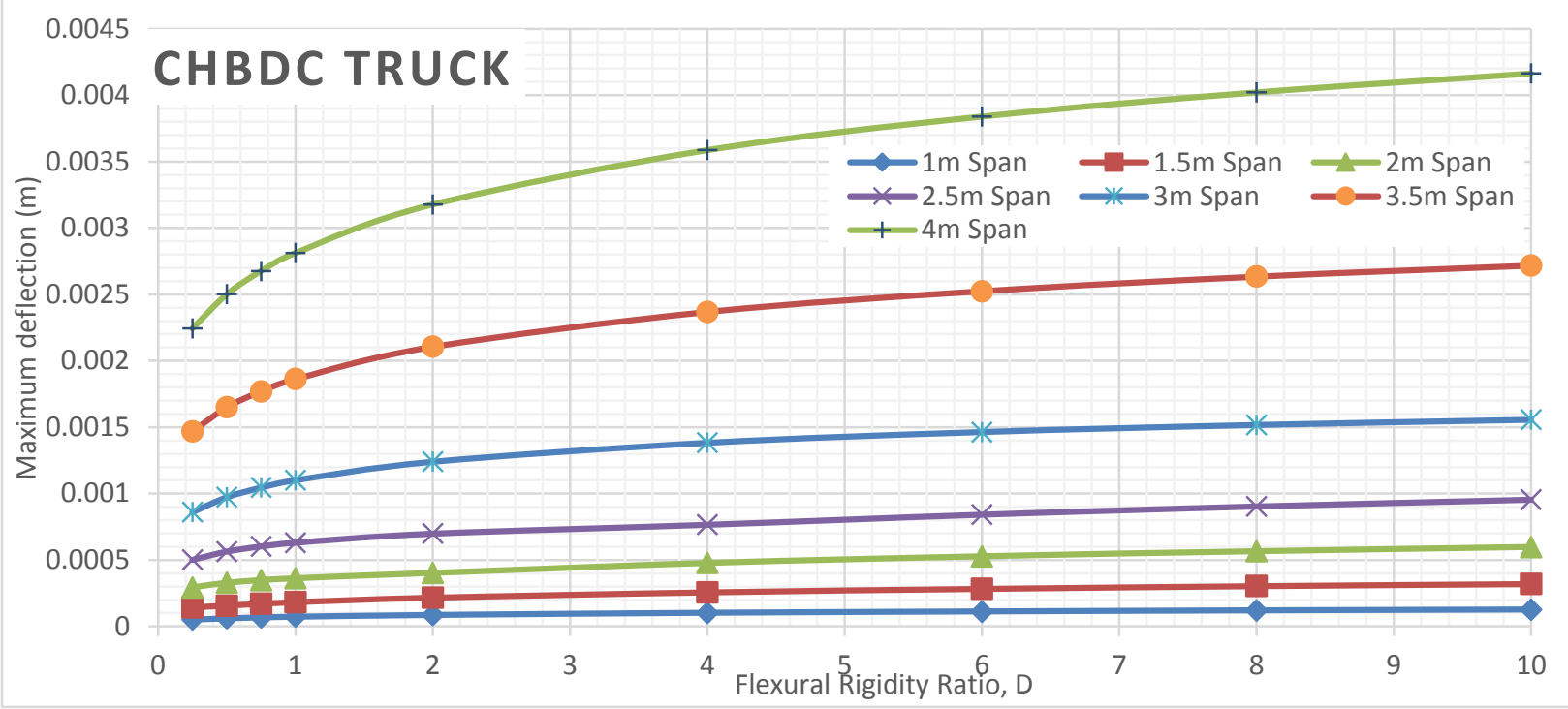

Figure 186 Maximum deflection of deck slabs subjected to CHBDC truck for different span values of alpha 1 FEA analyses

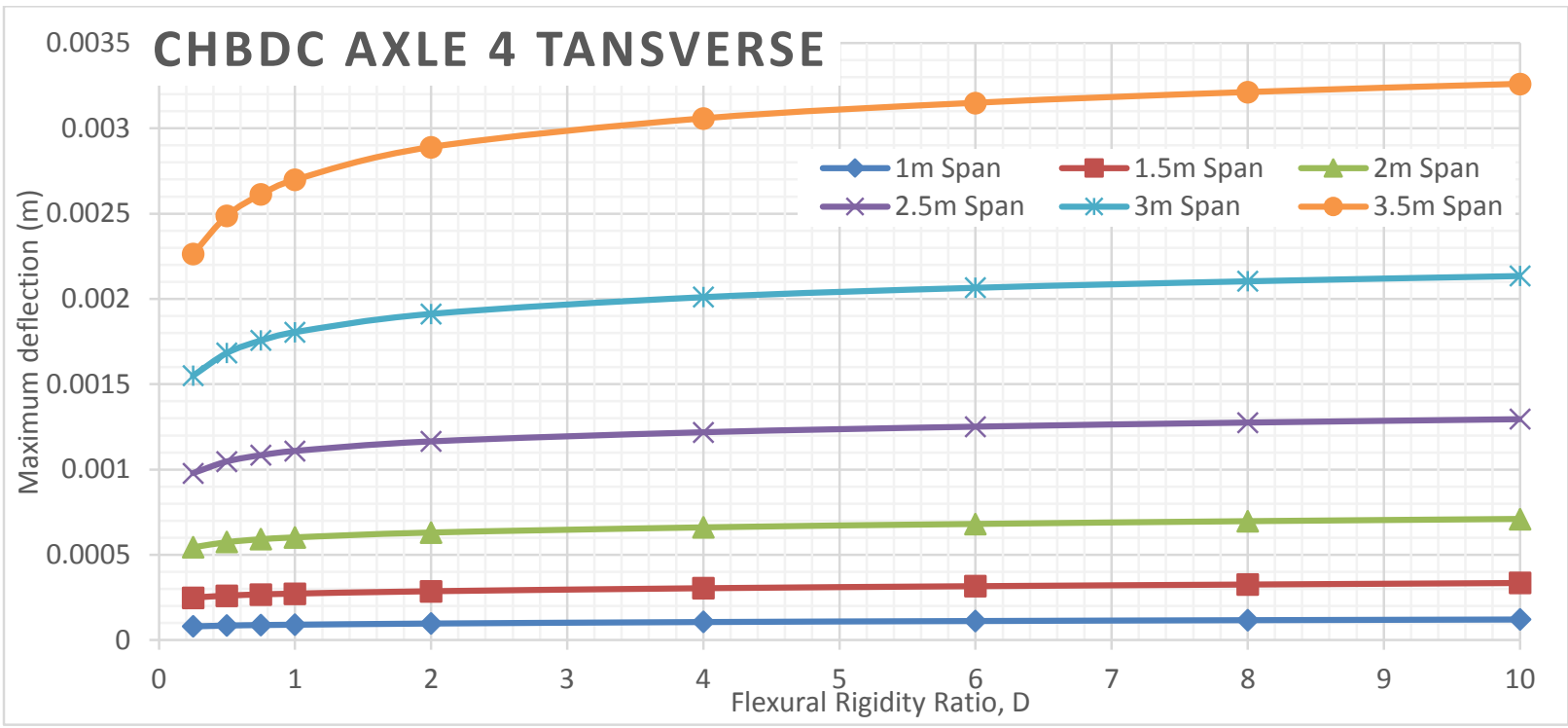

Figure 187 Maximum deflection of deck slabs subjected to CHBDC axle 4 for different span values of alpha 1 FEA analyses

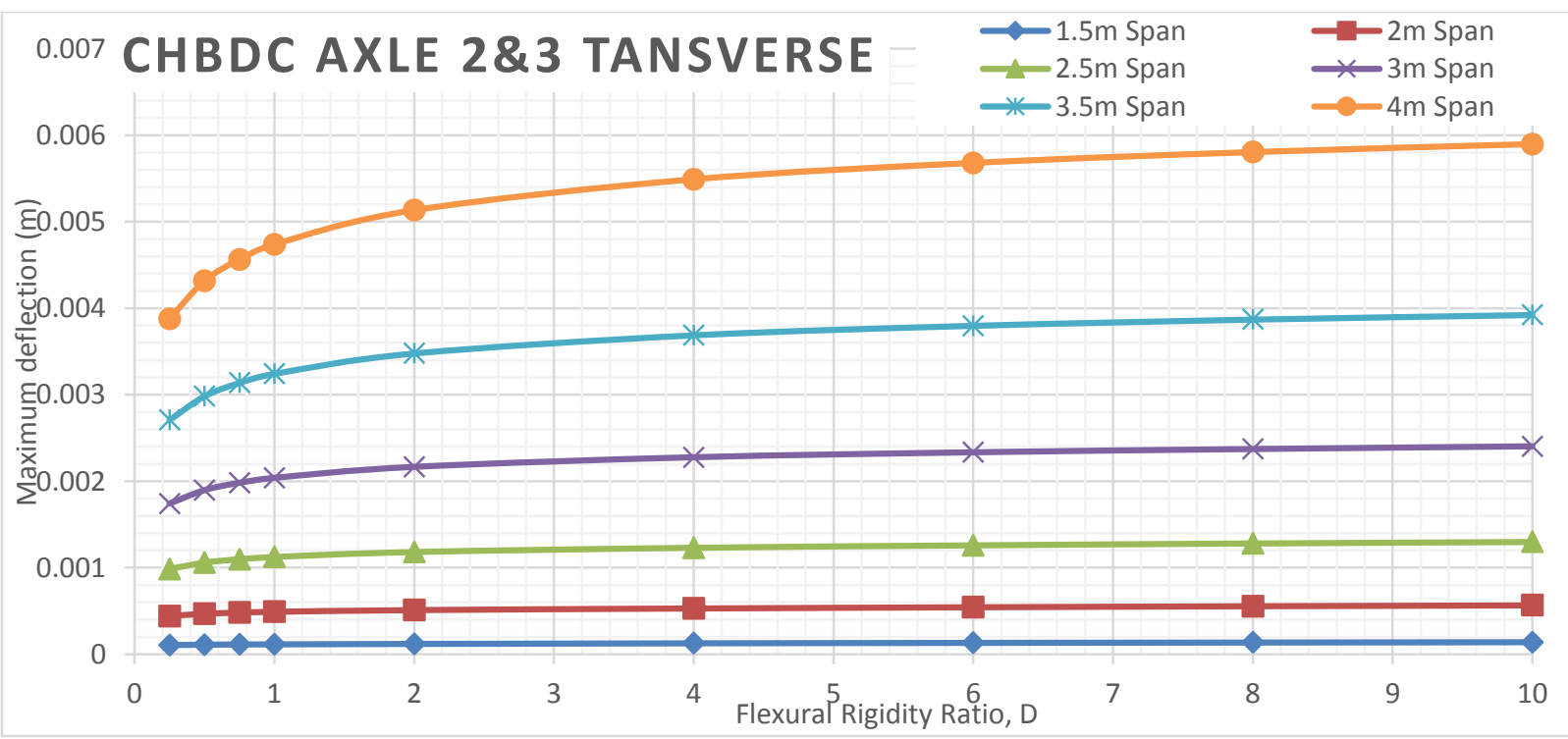

Figure 188 Maximum deflection of deck slabs subjected to CHBDC axle 2 \& 3 for different span values of alpha 1 FEA analyses 


\section{Alpha 2 Deflection VS Flexural Rigidity for Different Span Length}

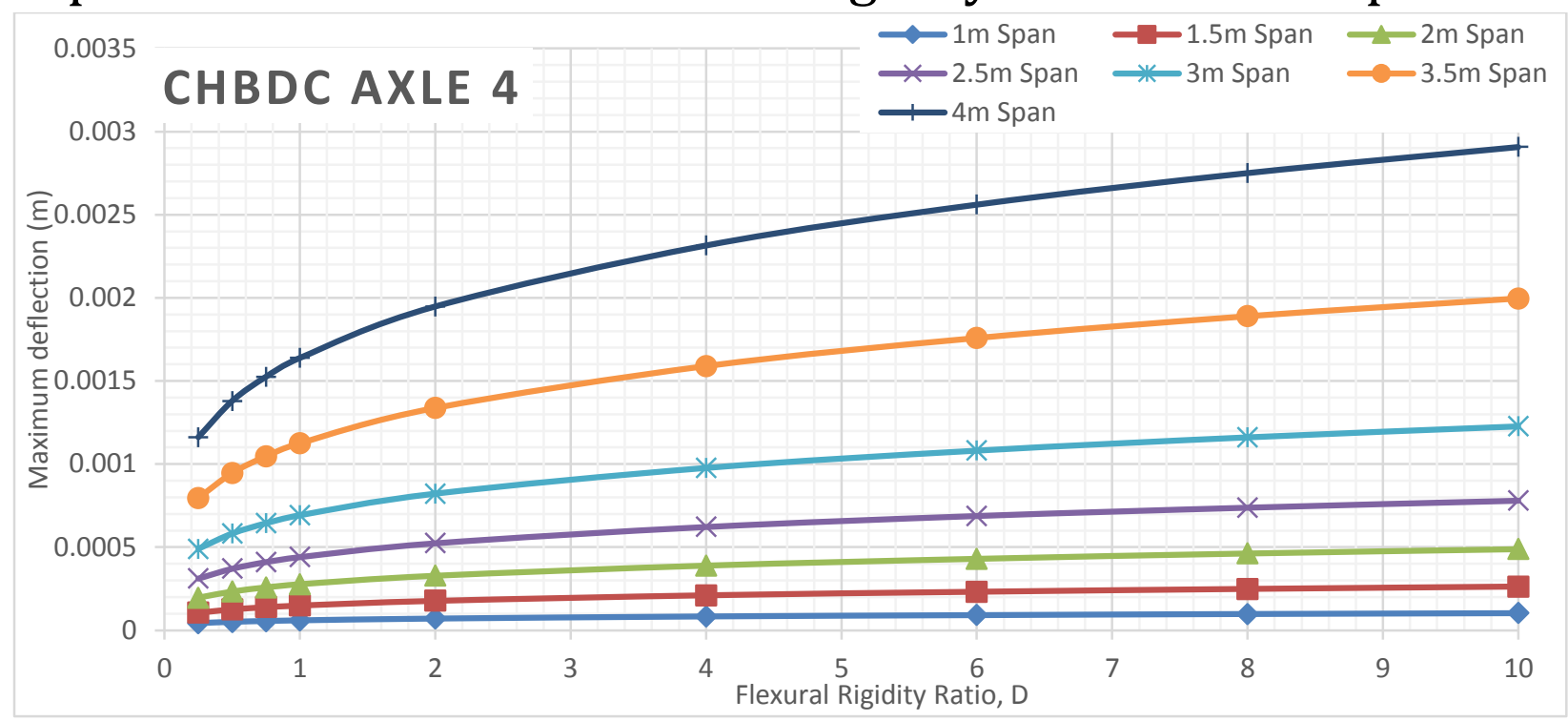

Figure 189 Maximum deflection of deck slabs subjected to CHBDC axle 4 for different span values of alpha 2 FEA analyses

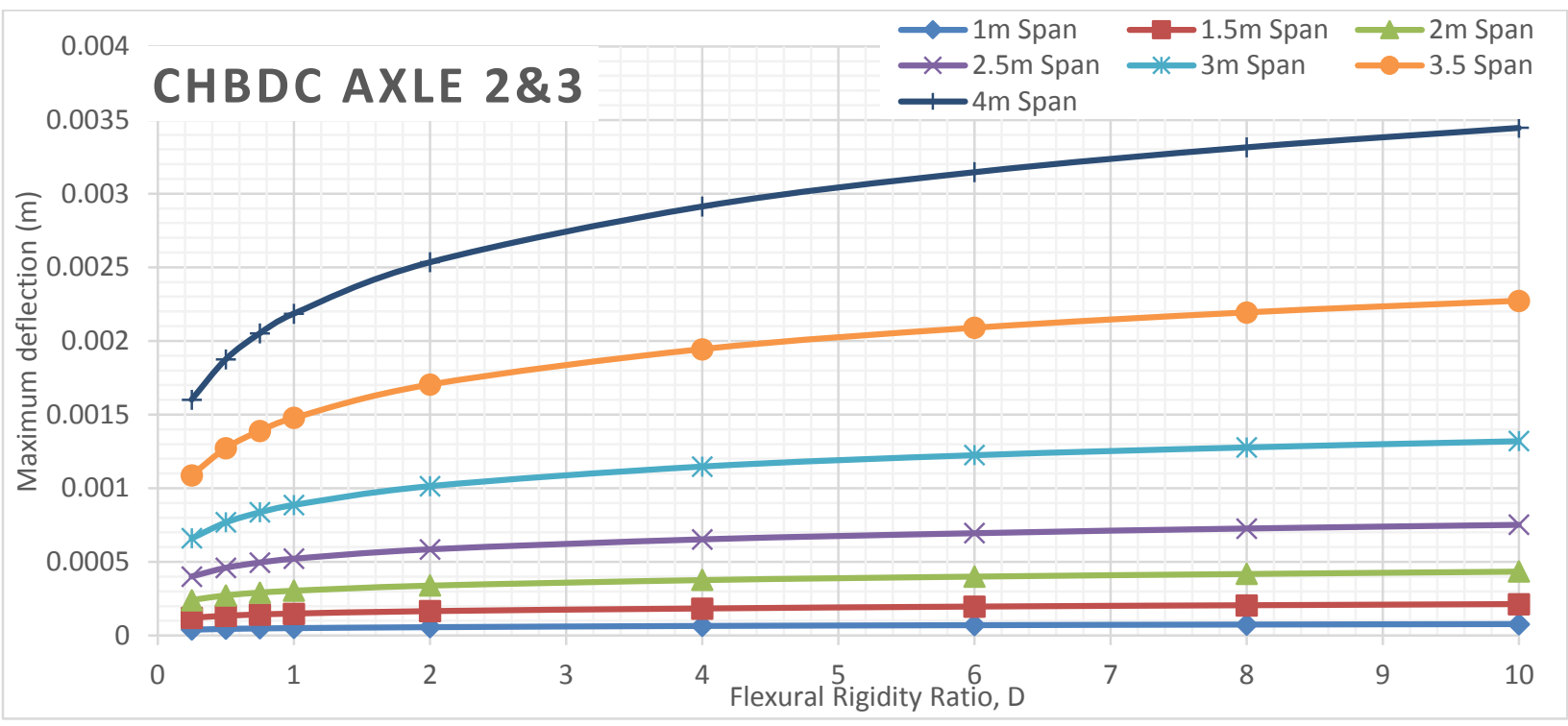

Figure 190 Maximum deflection of deck slabs subjected to CHBDC axle 2 \& 3 for different span values of alpha 2 FEA analyses 


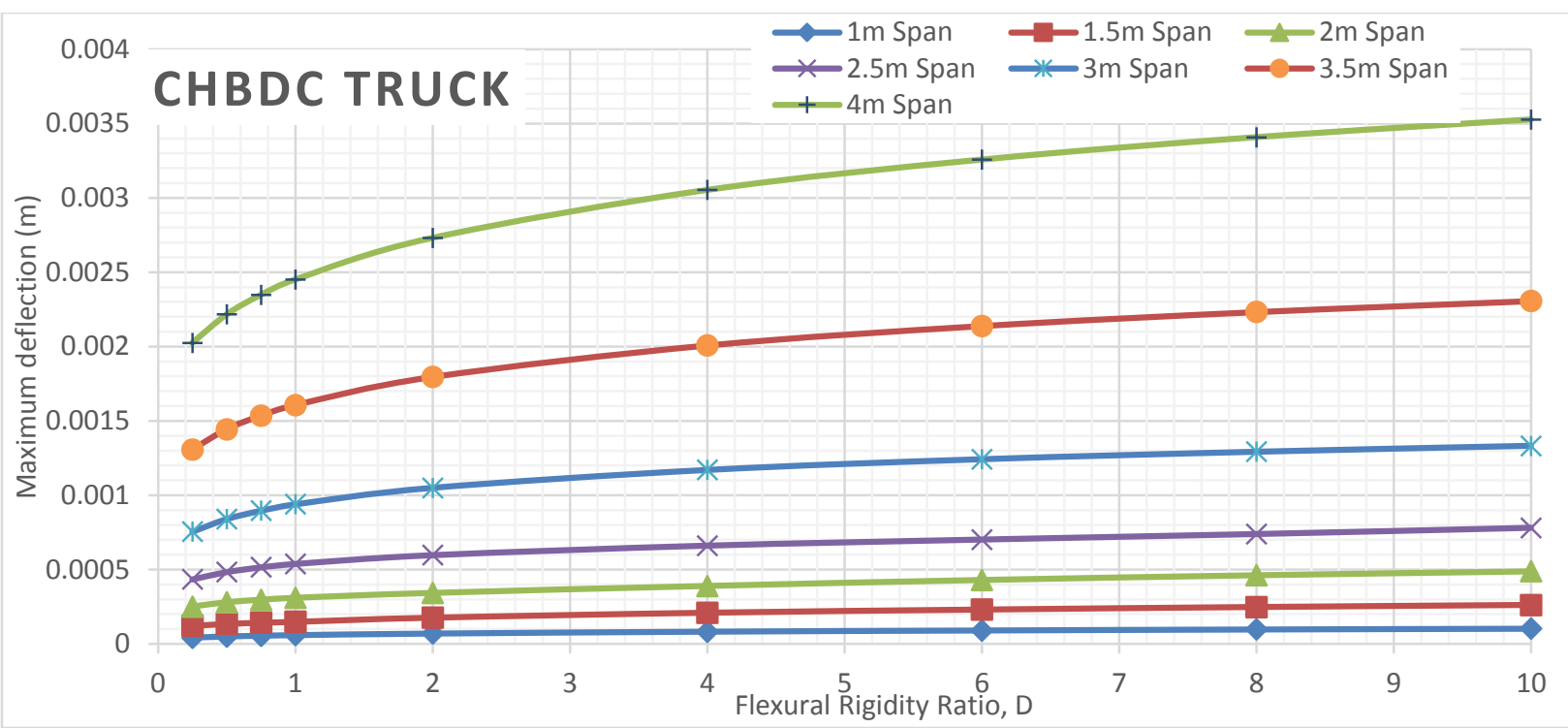

Figure 191 Maximum deflection of deck slabs subjected to CHBDC truck for different span values of alpha 2 FEA analyses

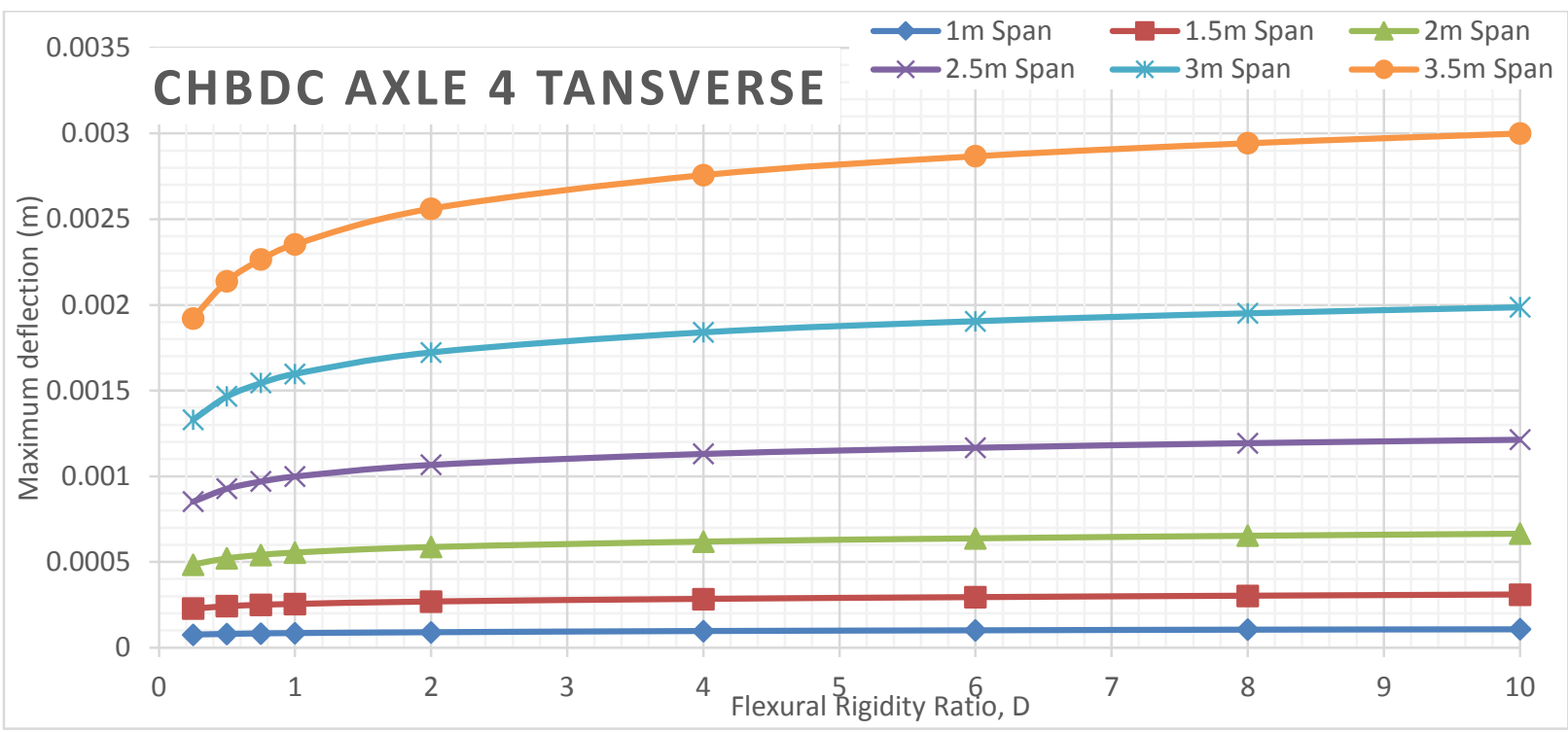

Figure 192 Maximum deflection of deck slabs subjected to CHBDC axle 4 for different span values of alpha 2 FEA analyses

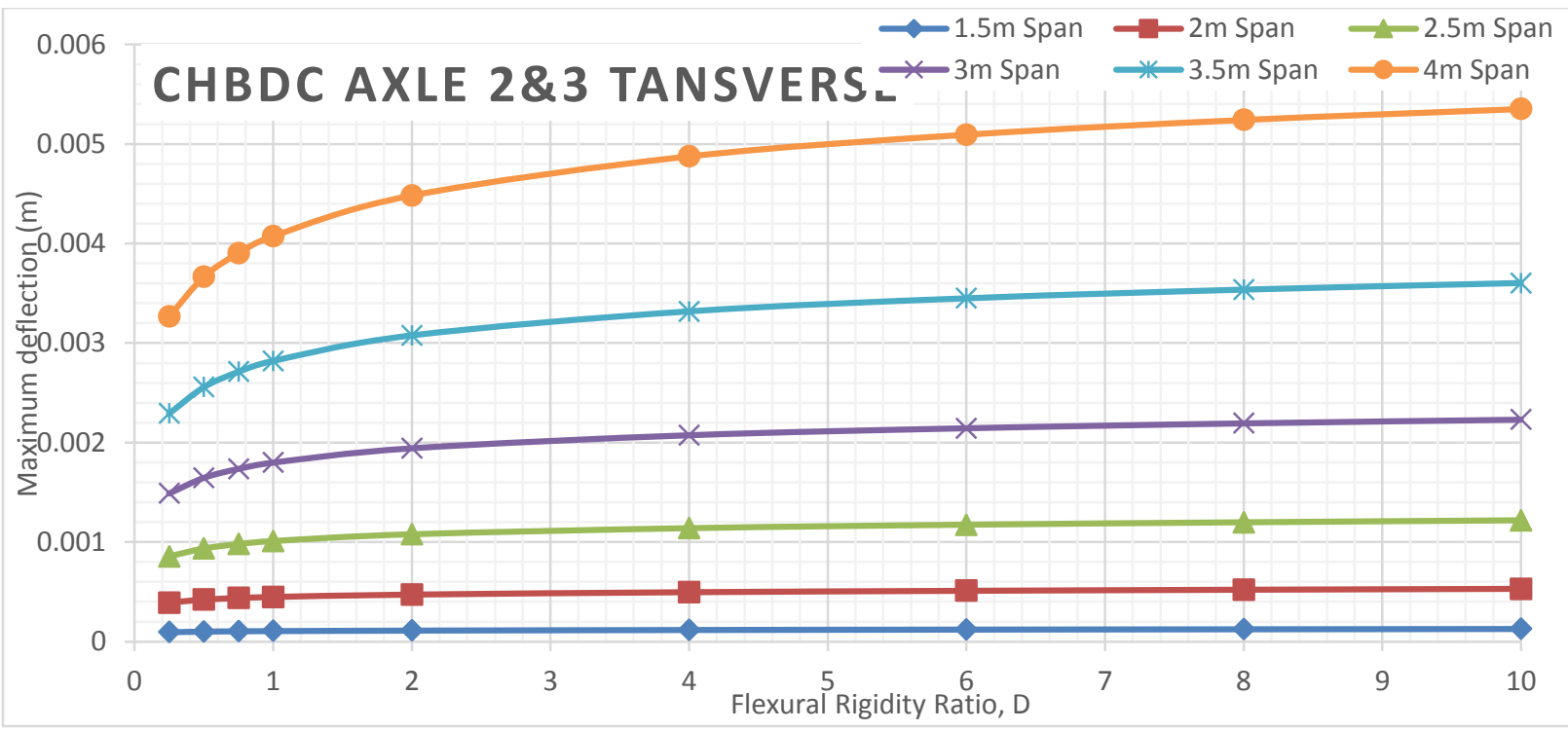

Figure 193 Maximum deflection of deck slabs subjected to CHBDC axle 2 \& 3 for different span values of alpha 2 FEA analyses 


\section{Alpha 4 Deflection VS Flexural Rigidity for Different Span Length}

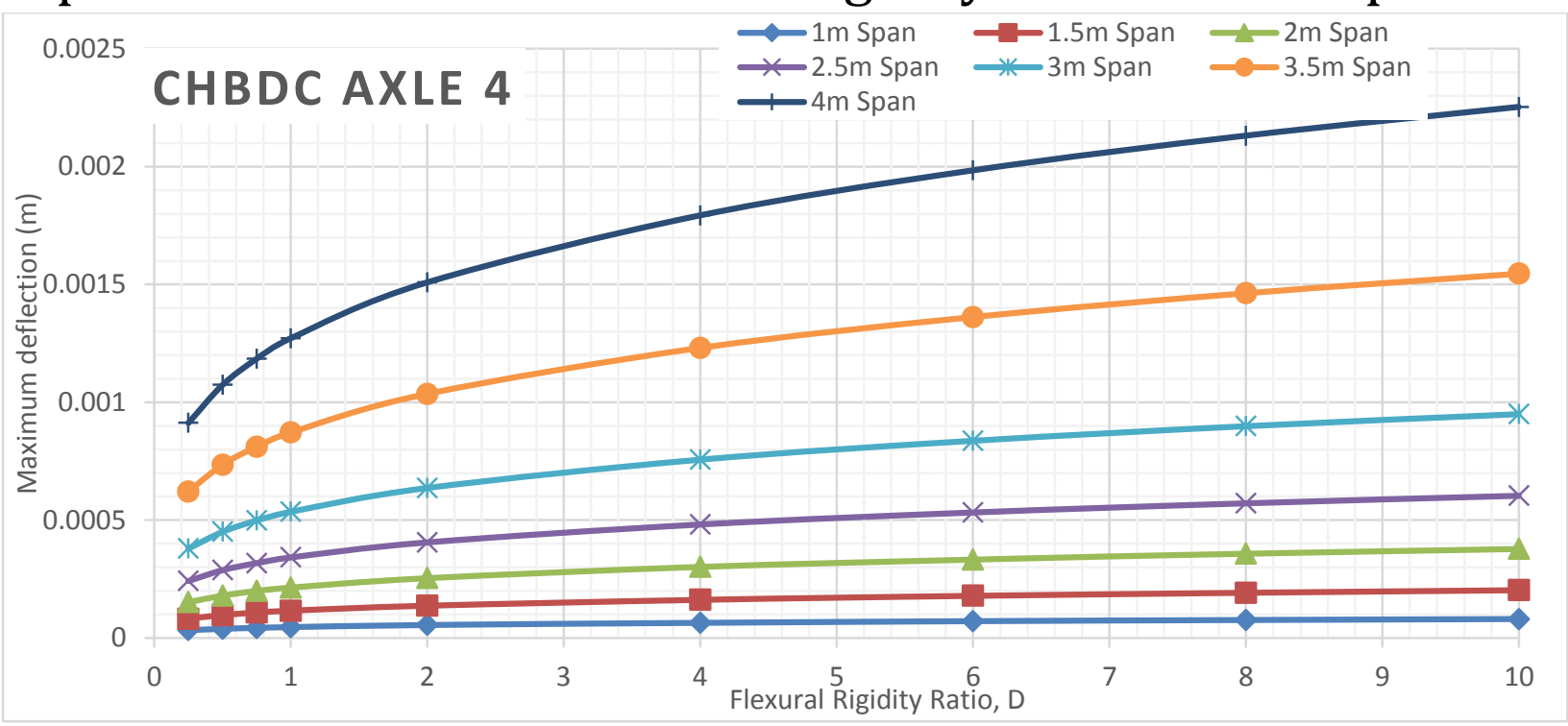

Figure 194 Maximum deflection of deck slabs subjected to CHBDC axle 4 for different span values of alpha 4 FEA analyses

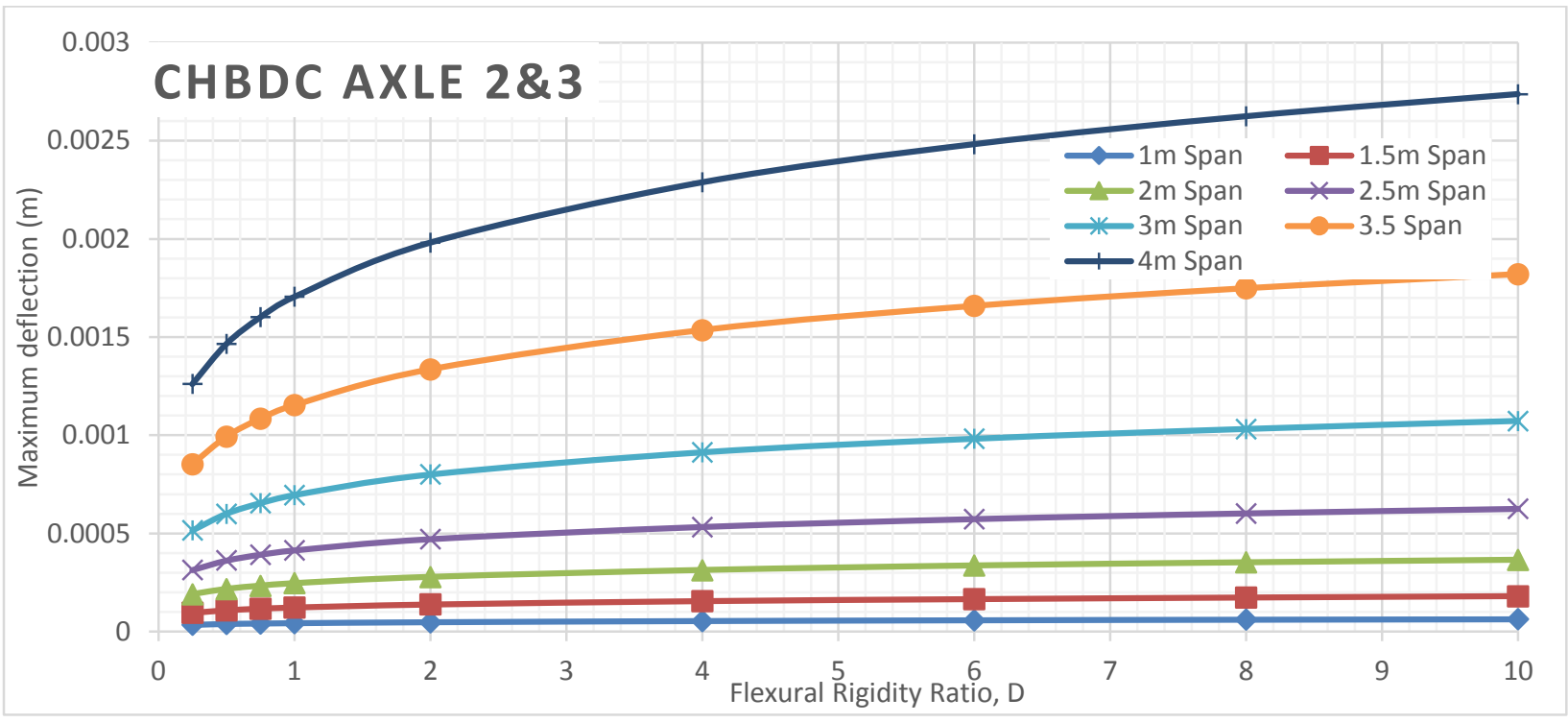

Figure 195 Maximum deflection of deck slabs subjected to CHBDC axle 2 \& 3 for different span values of alpha 4 FEA analyses 


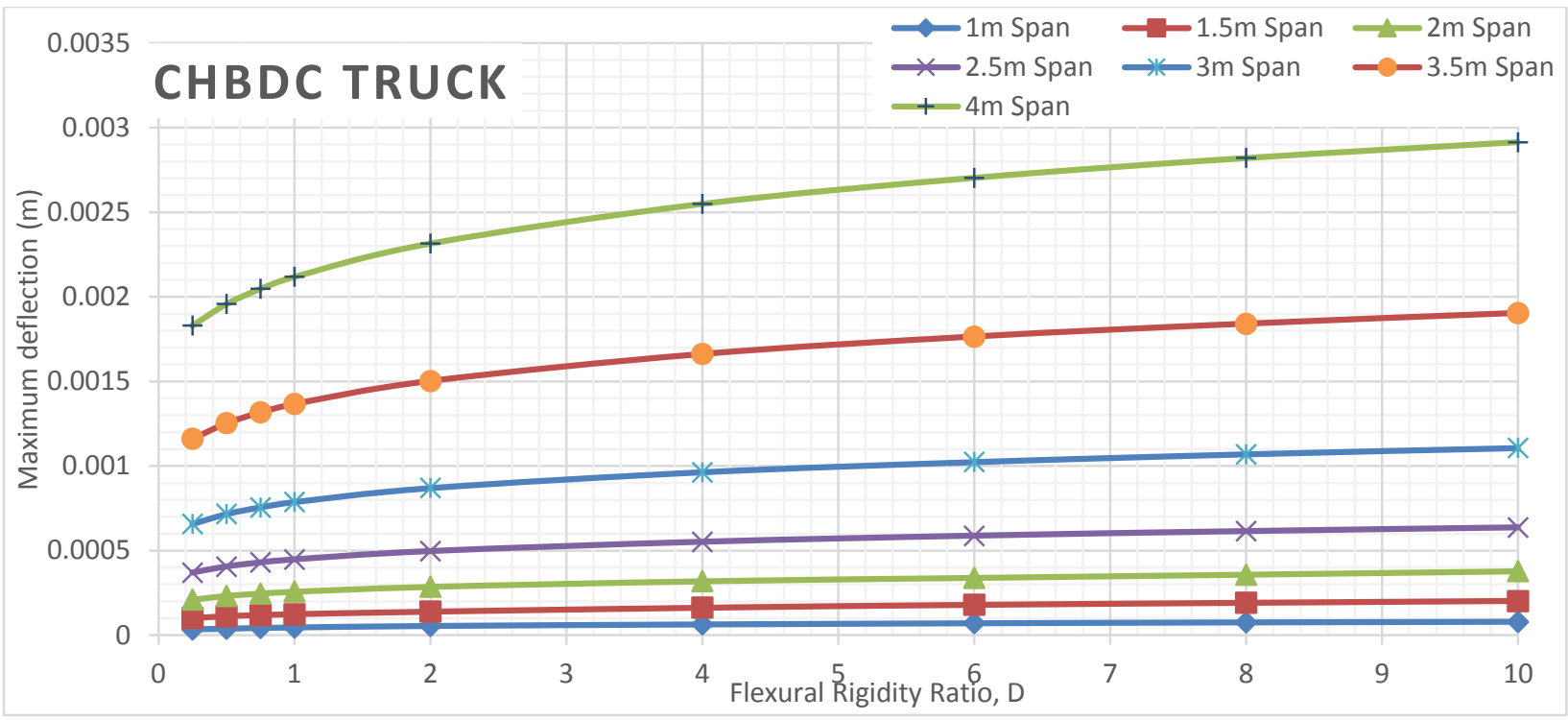

Figure 196 Maximum deflection of deck slabs subjected to CHBDC truck for different span values of alpha 4 FEA analyses

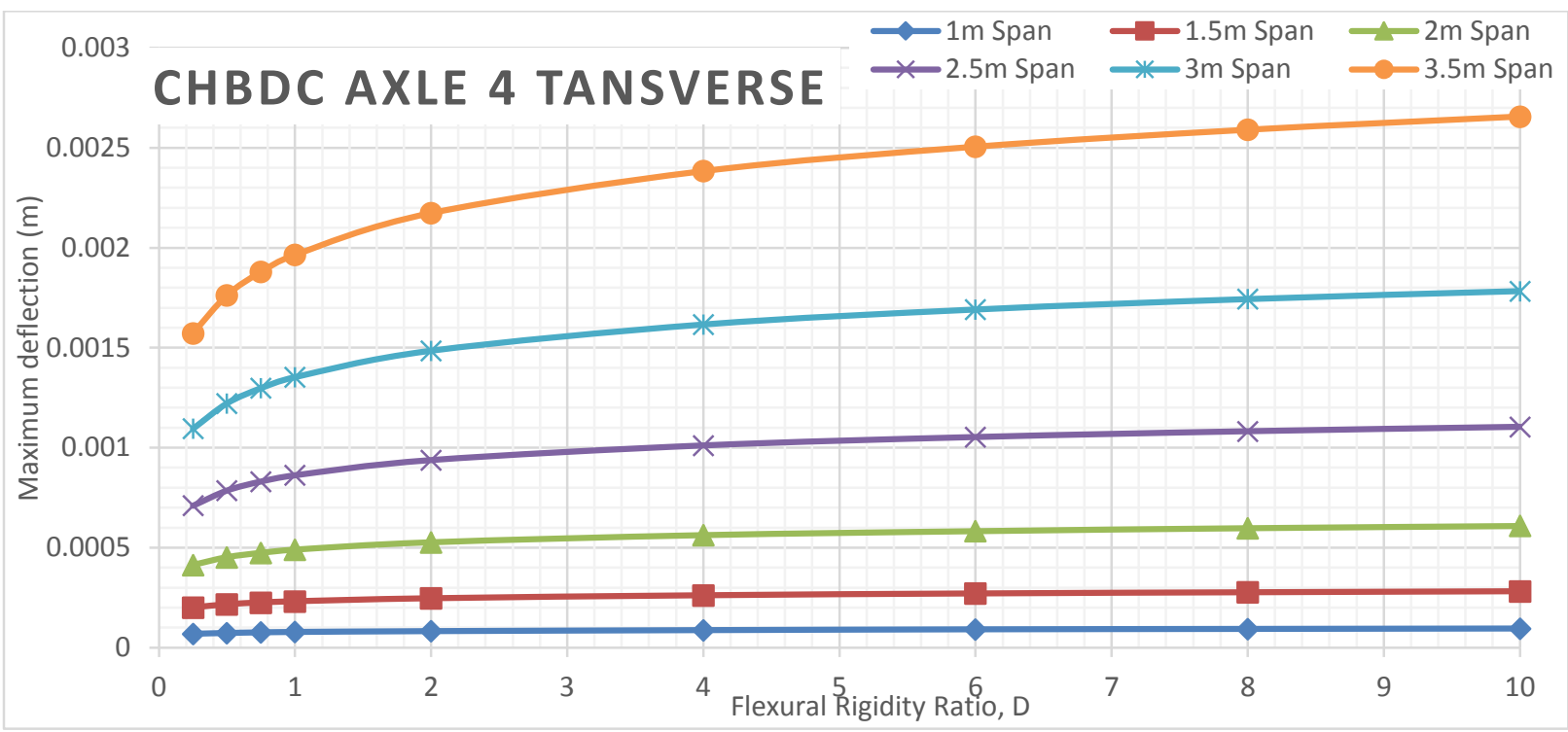

Figure 197 Maximum deflection of deck slabs subjected to CHBDC axle 4 for different span values of alpha 4 FEA analyses

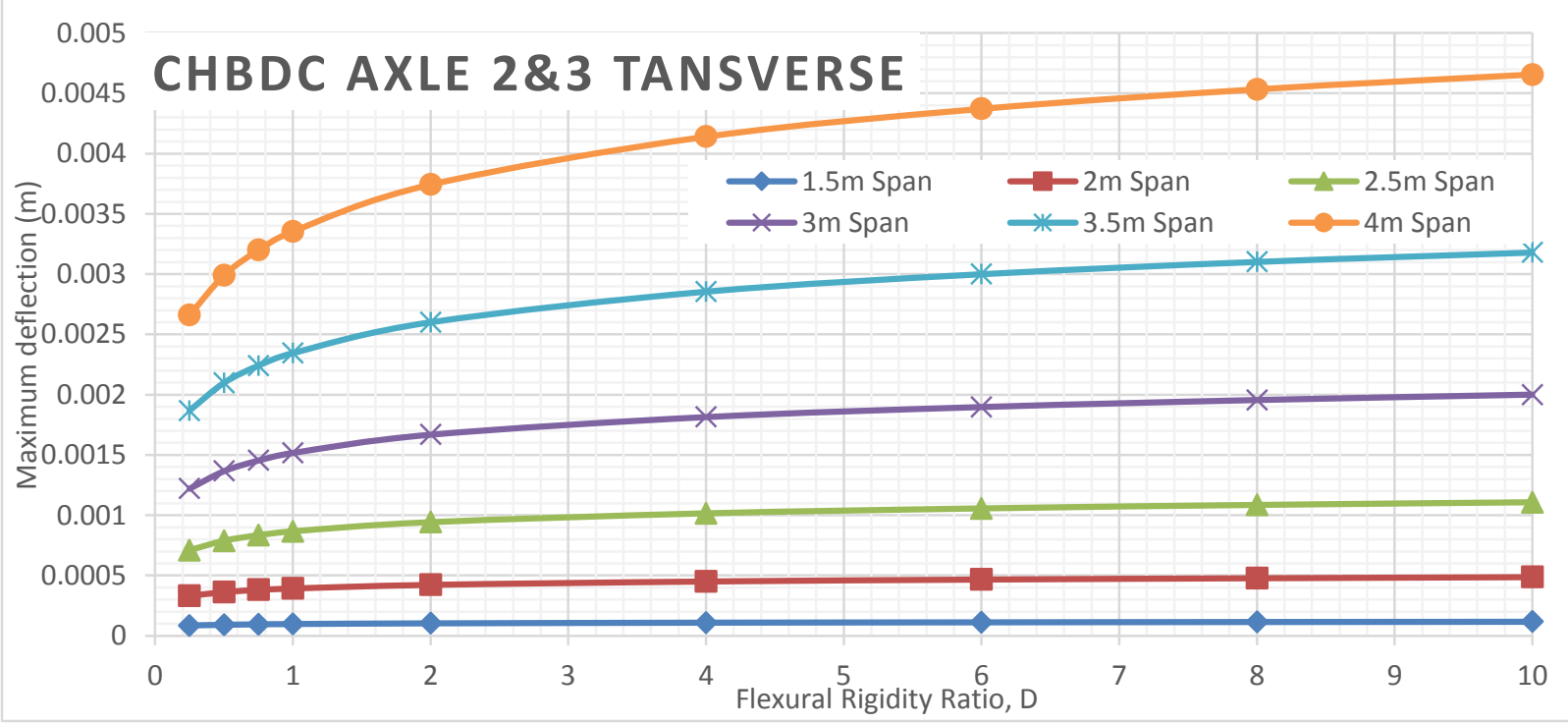

Figure 198 Maximum deflection of deck slabs subjected to CHBDC axle 2 \& 3 for different span values of alpha 4 FEA analyses 


\section{Alpha 6 Deflection VS Flexural Rigidity for Different Span Length}

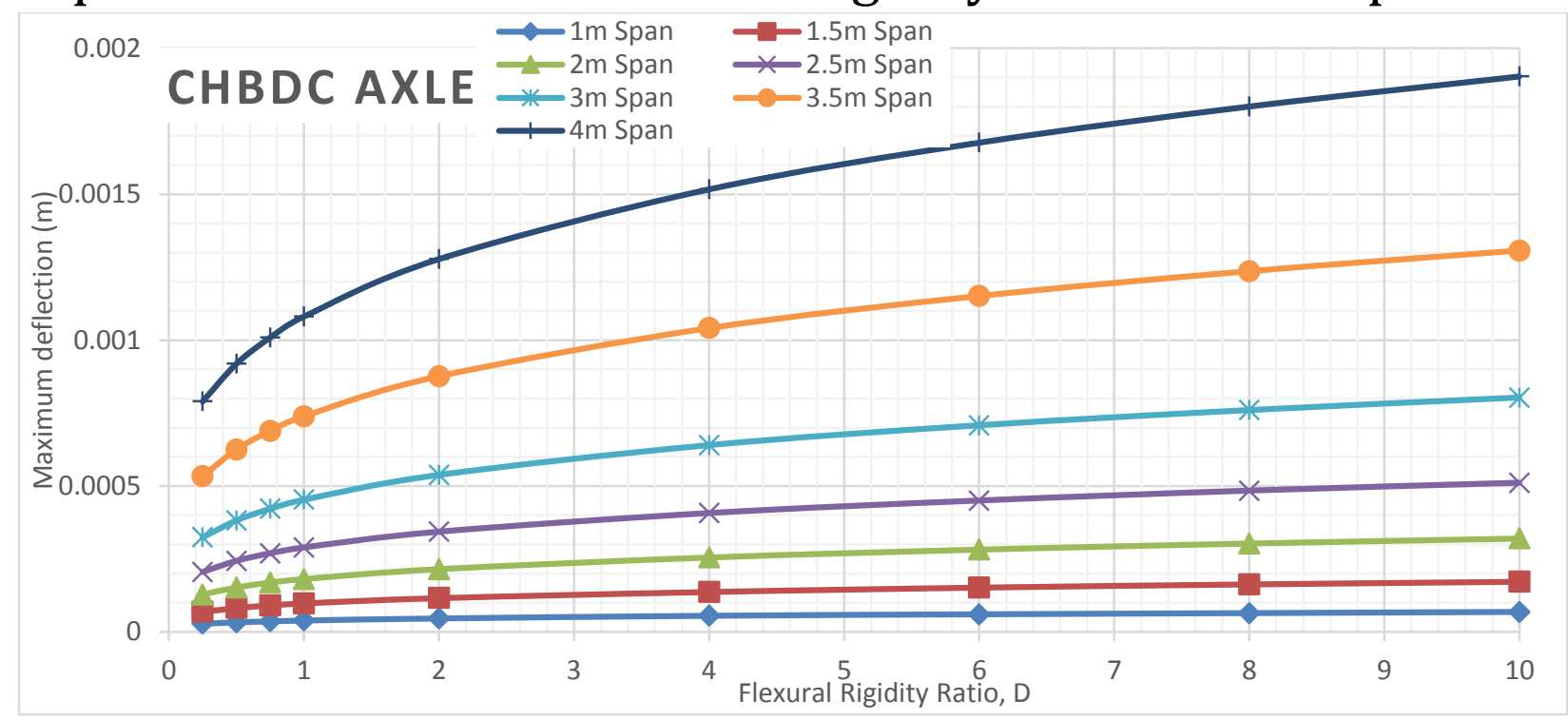

Figure 199 Maximum deflection of deck slabs subjected to CHBDC axle 4 for different span values of alpha 6 FEA analyses

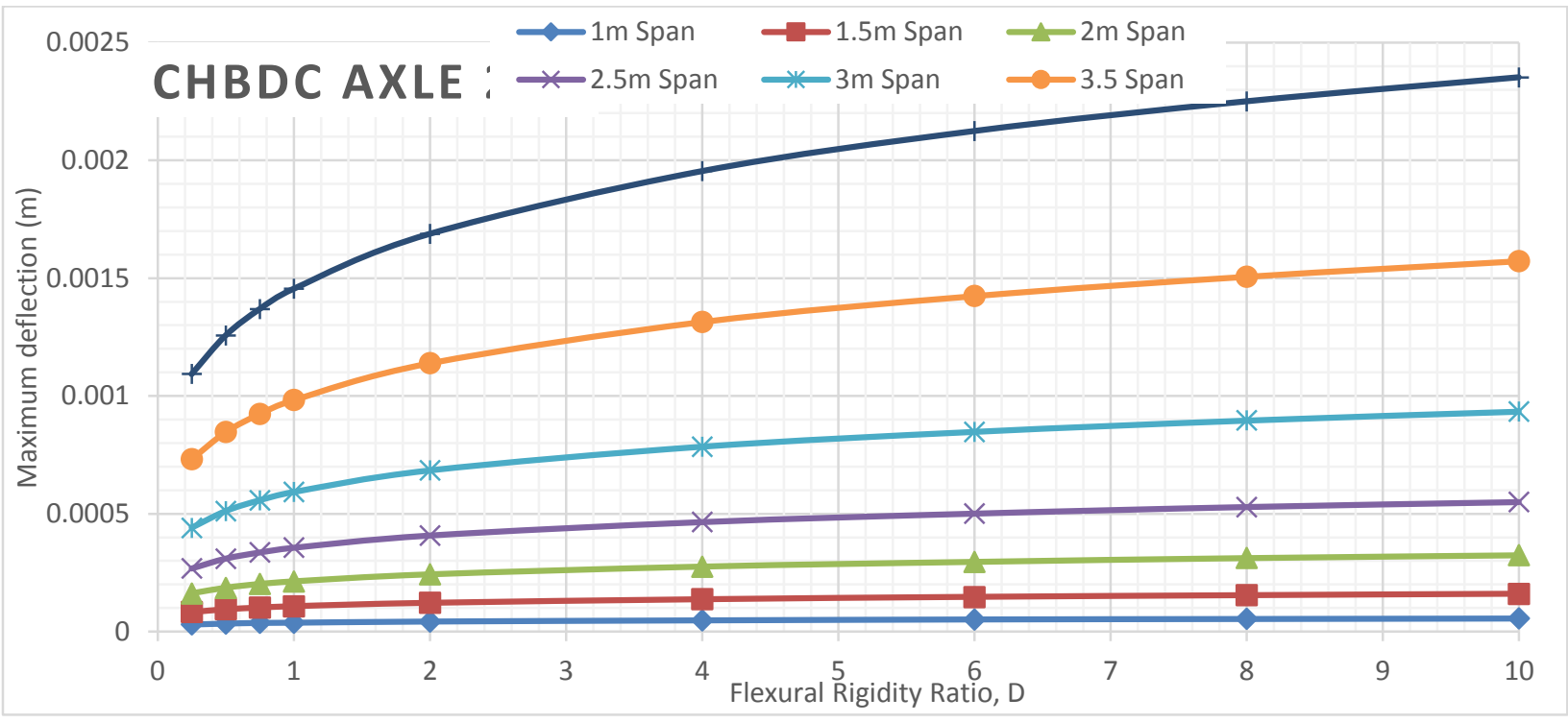

Figure 200 Maximum deflection of deck slabs subjected to CHBDC axle $2 \& 3$ for different span values of alpha 6 FEA analyses 


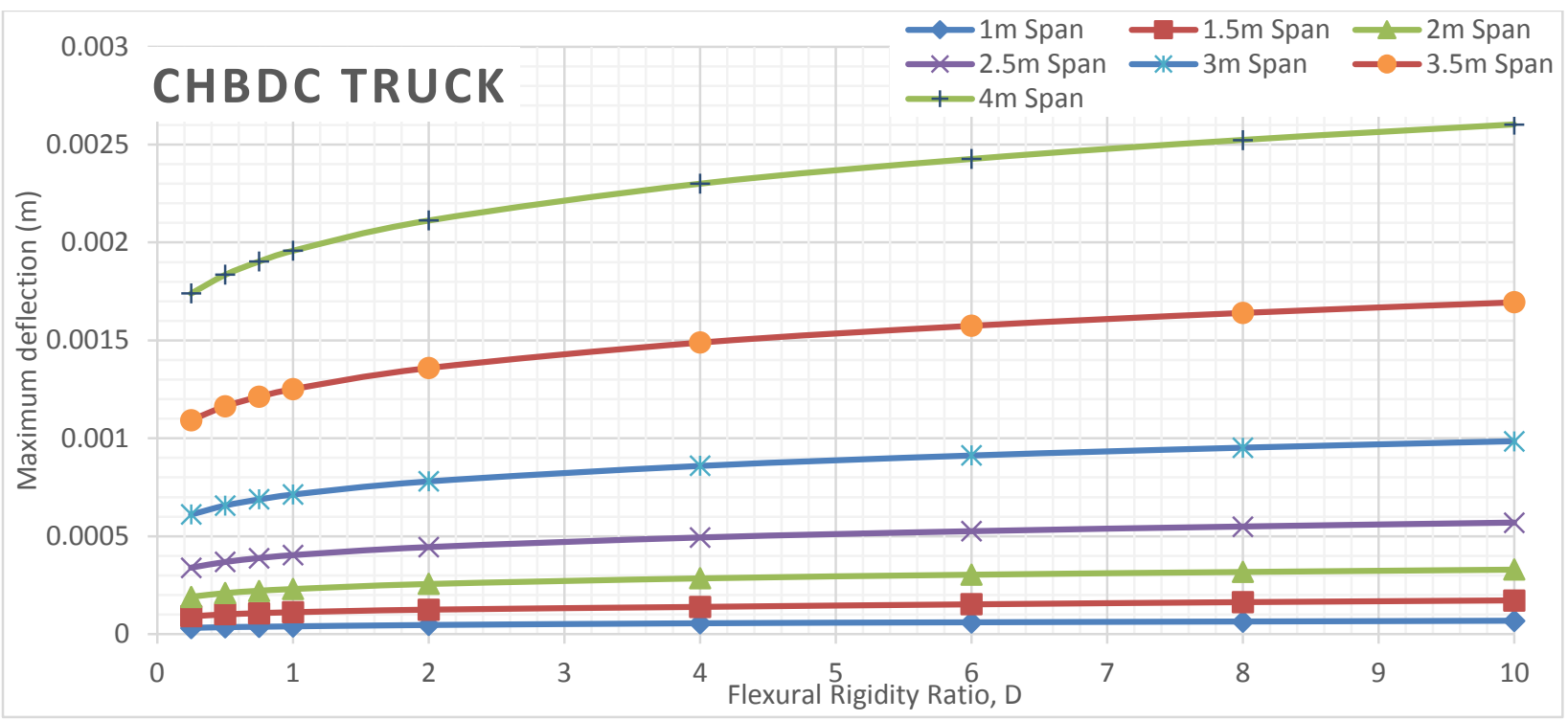

Figure 201 Maximum deflection of deck slabs subjected to CHBDC truck for different span values of alpha 6 FEA analyses

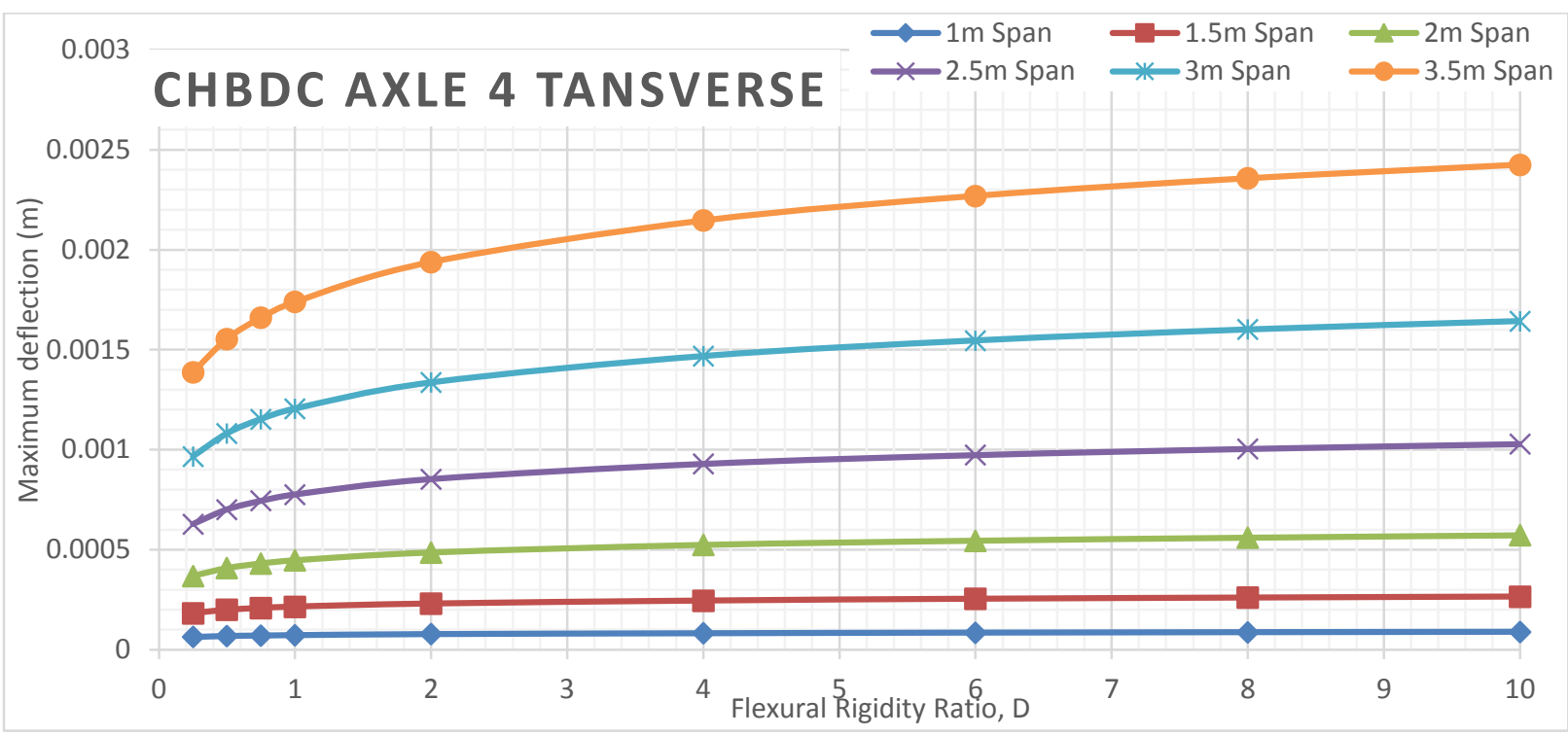

Figure 202 Maximum deflection of deck slabs subjected to CHBDC axle 4 for different span values of alpha 6 FEA analyses

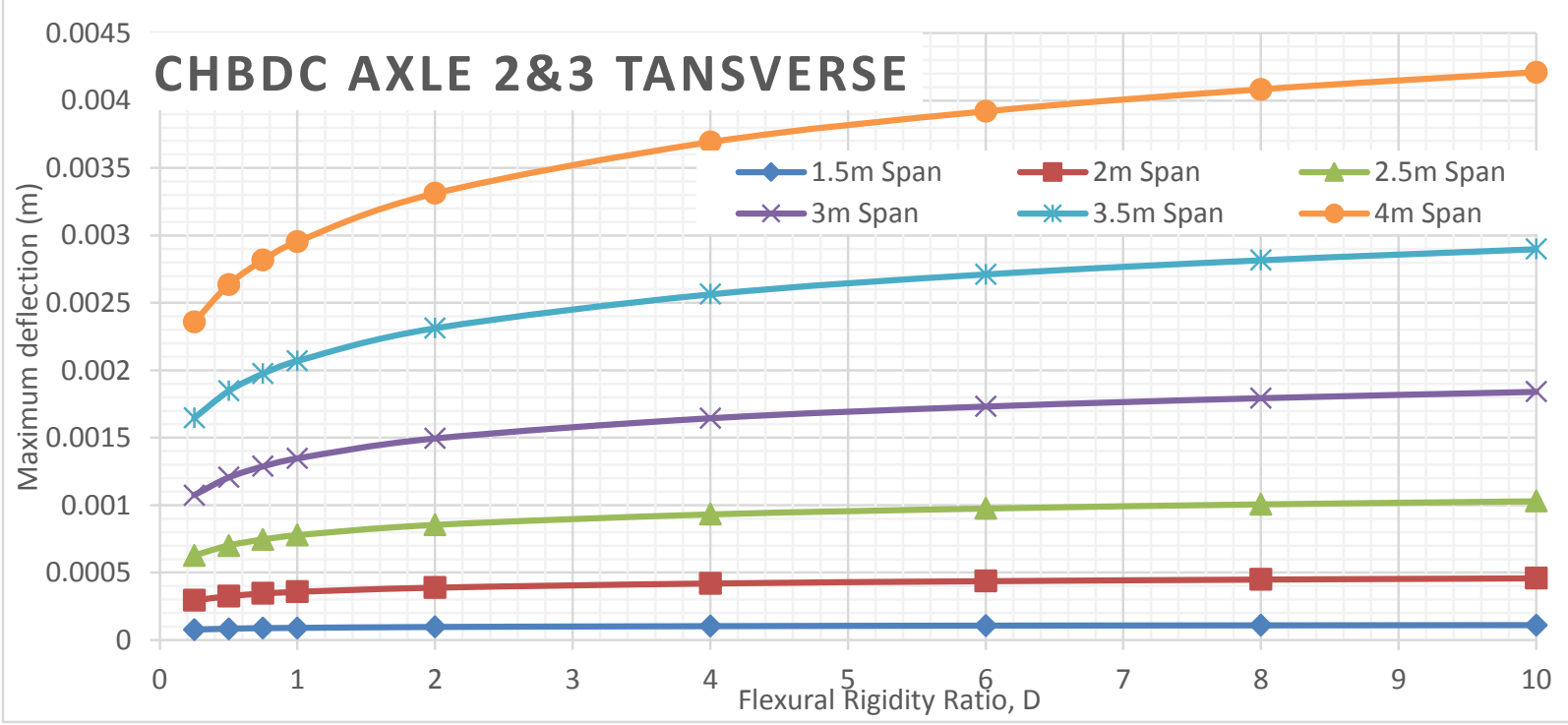

Figure 203 Maximum deflection of deck slabs subjected to CHBDC axle 2 \& 3 for different span values of alpha 6 FEA analyses 


\section{Alpha 8 Deflection VS Flexural Rigidity for Different Span Length}

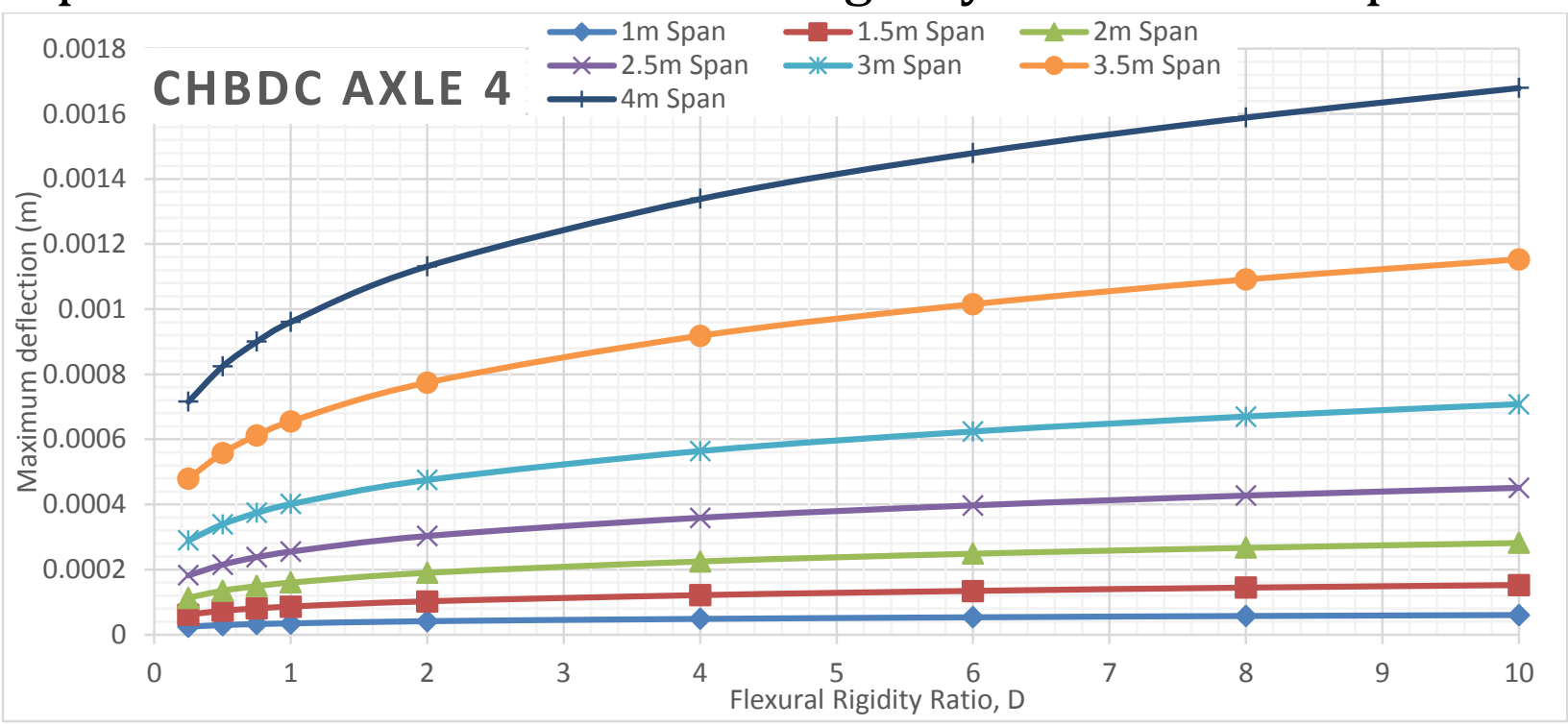

Figure 204 Maximum deflection of deck slabs subjected to CHBDC axle 4 for different span values of alpha 8 FEA analyses

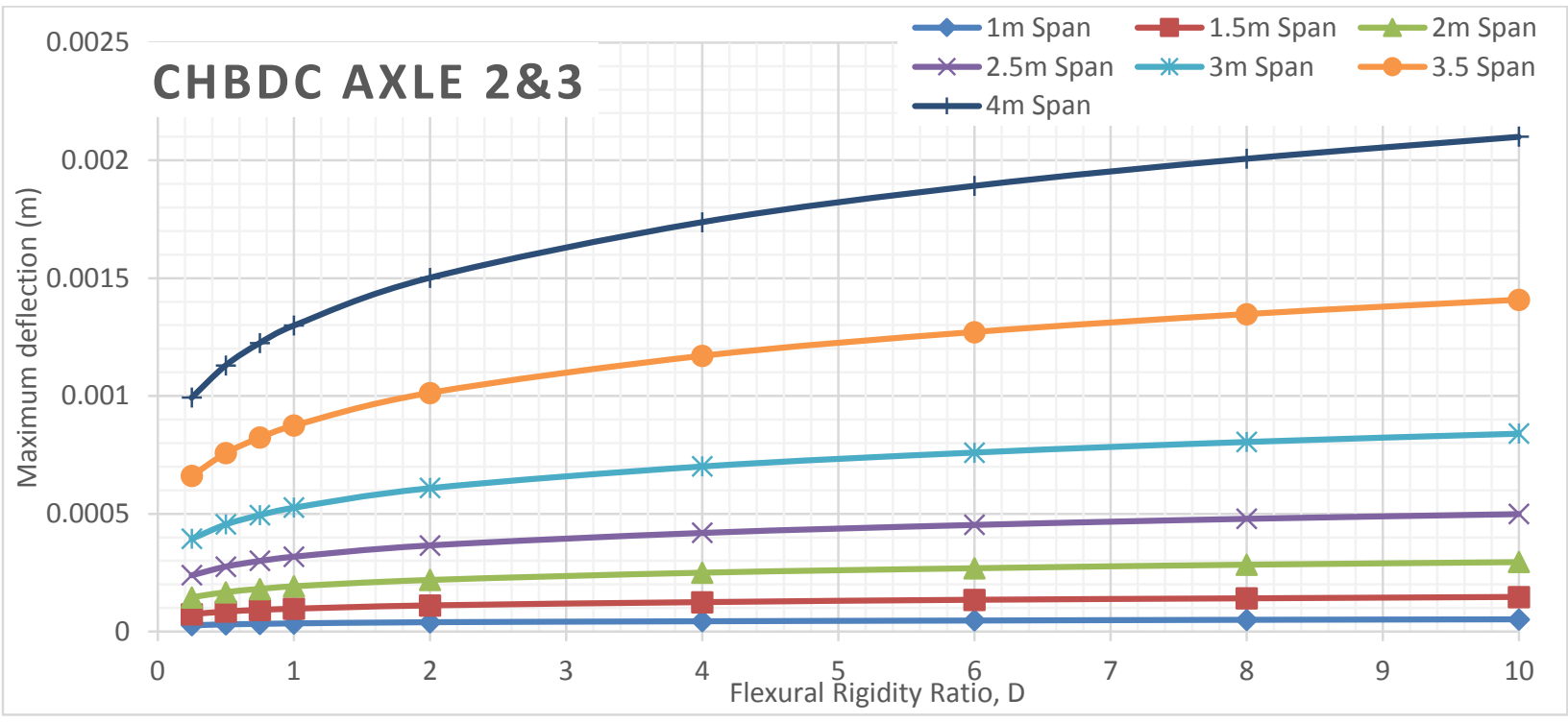

Figure 205 Maximum deflection of deck slabs subjected to CHBDC axle $2 \& 3$ for different span values of alpha 8 FEA analyses 


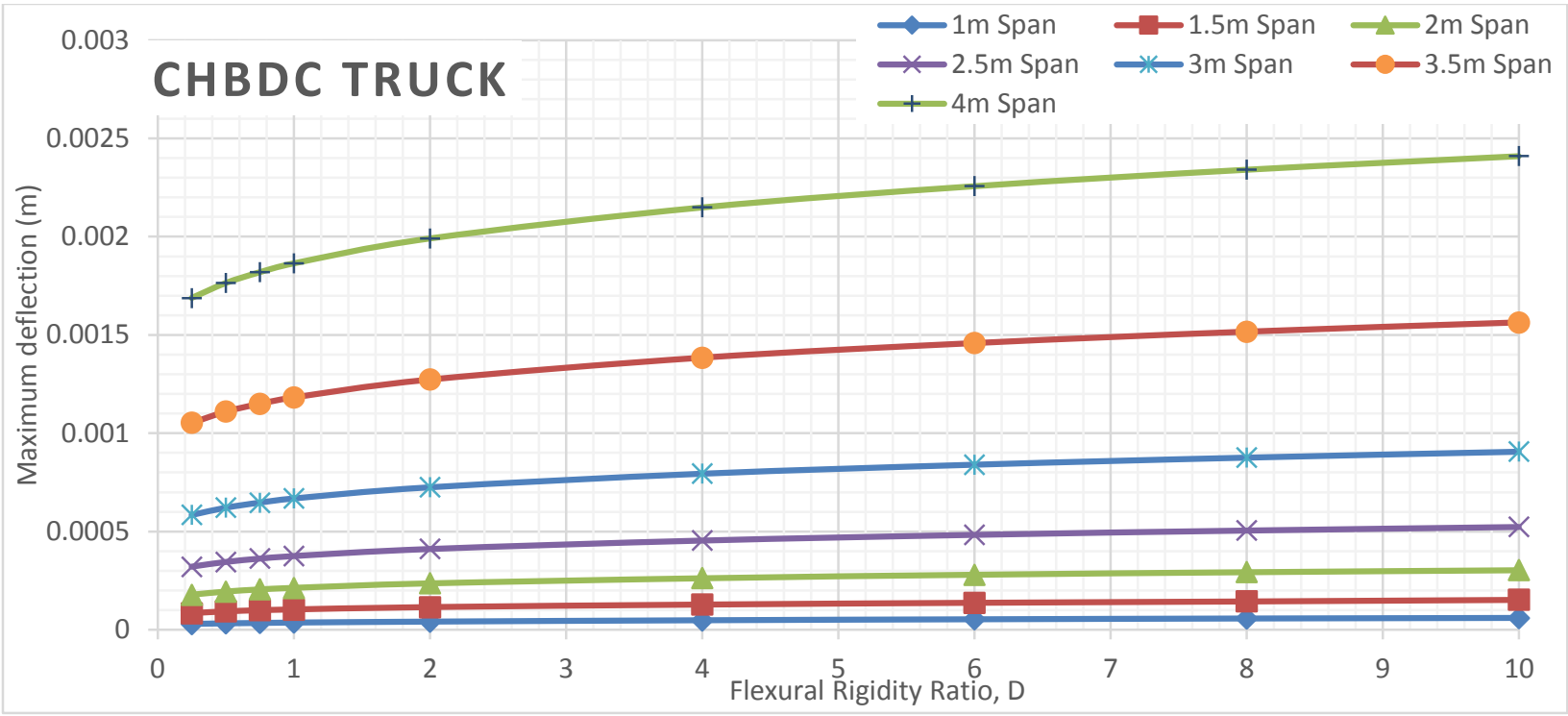

Figure 206 Maximum deflection of deck slabs subjected to CHBDC truck for different span values of alpha 8 FEA analyses

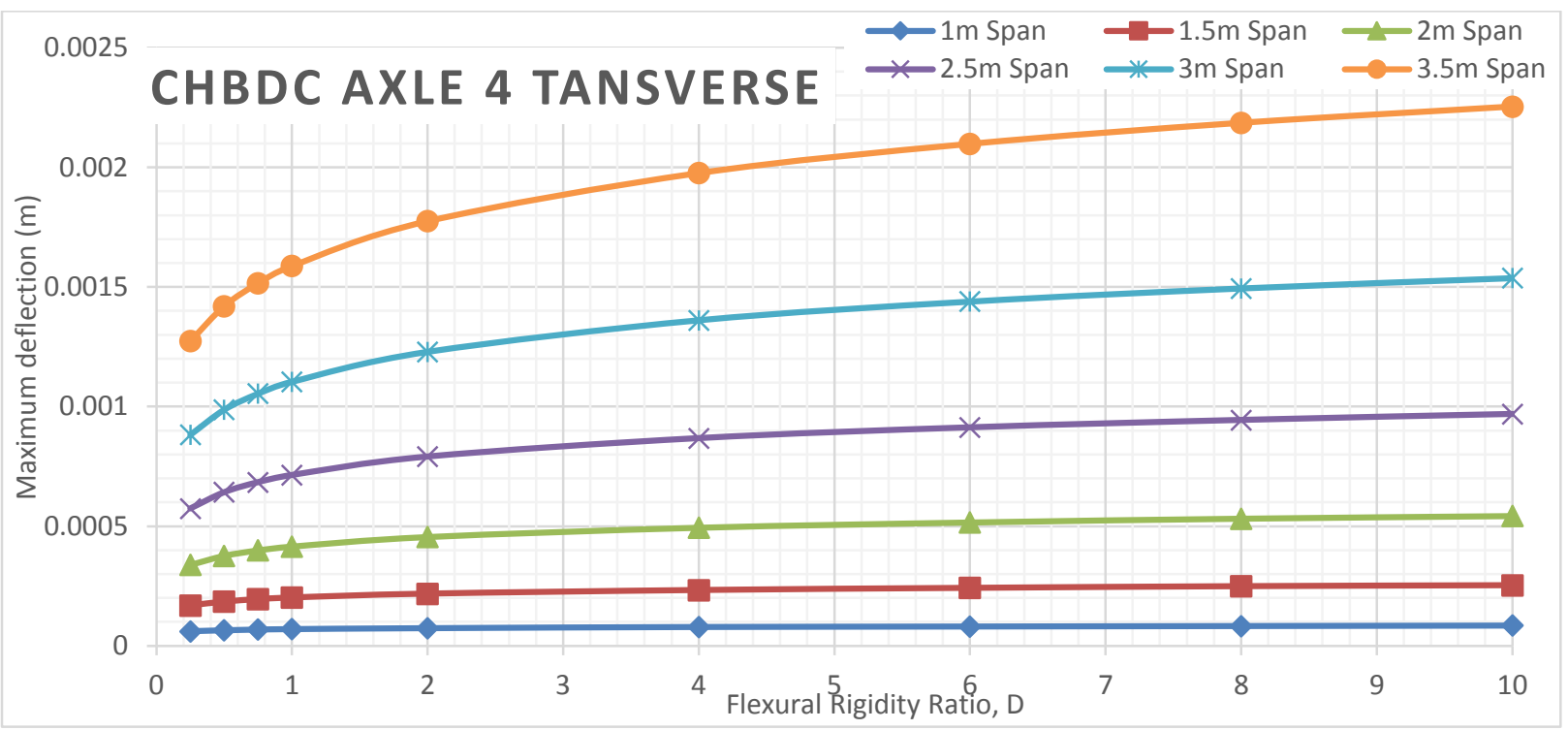

Figure 207 Maximum deflection of deck slabs subjected to CHBDC axle 4 for different span values of alpha 8 FEA analyses

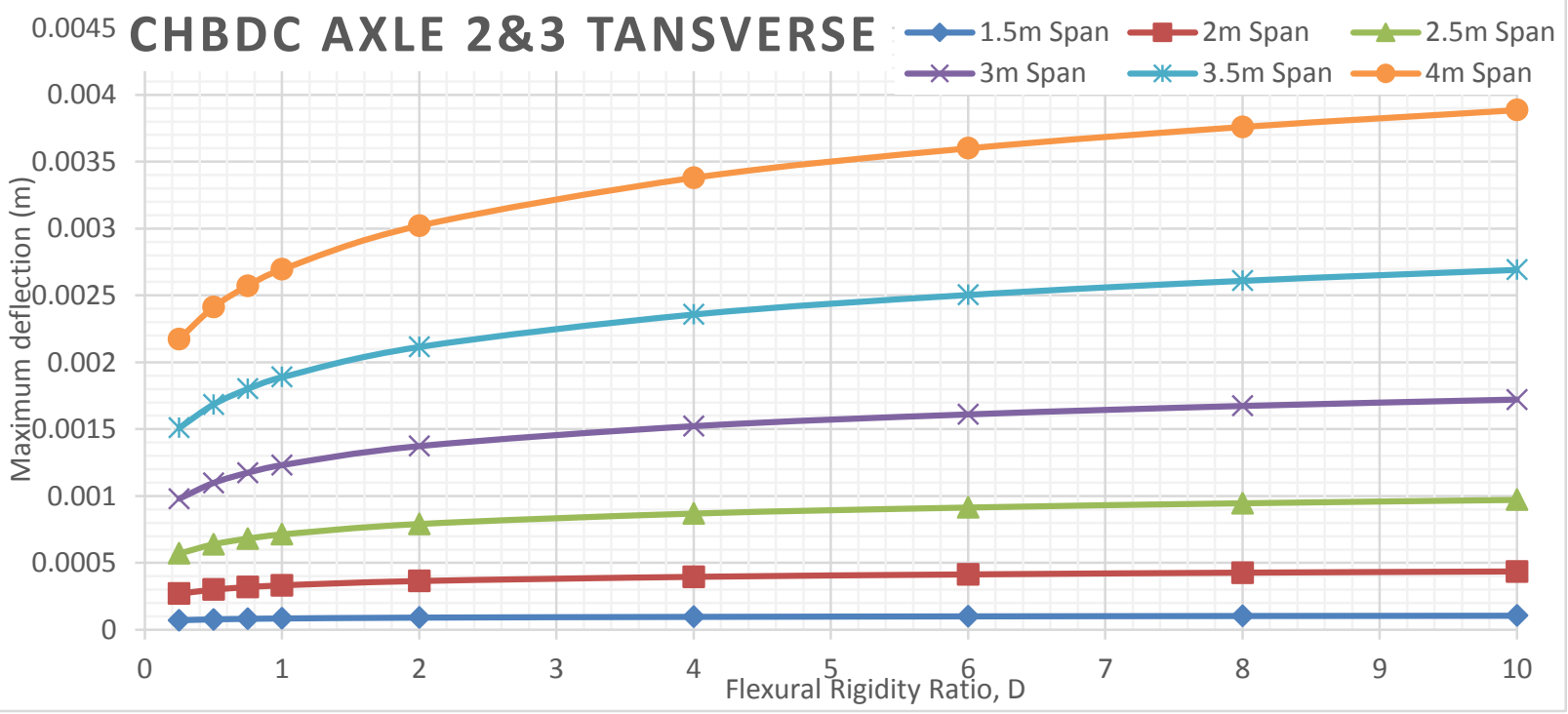

Figure 208 Maximum deflection of deck slabs subjected to CHBDC axle 2 \& 3 for different span values of alpha 8 FEA analyses 


\section{Alpha 10 Deflection VS Flexural Rigidity for Different Span Length}

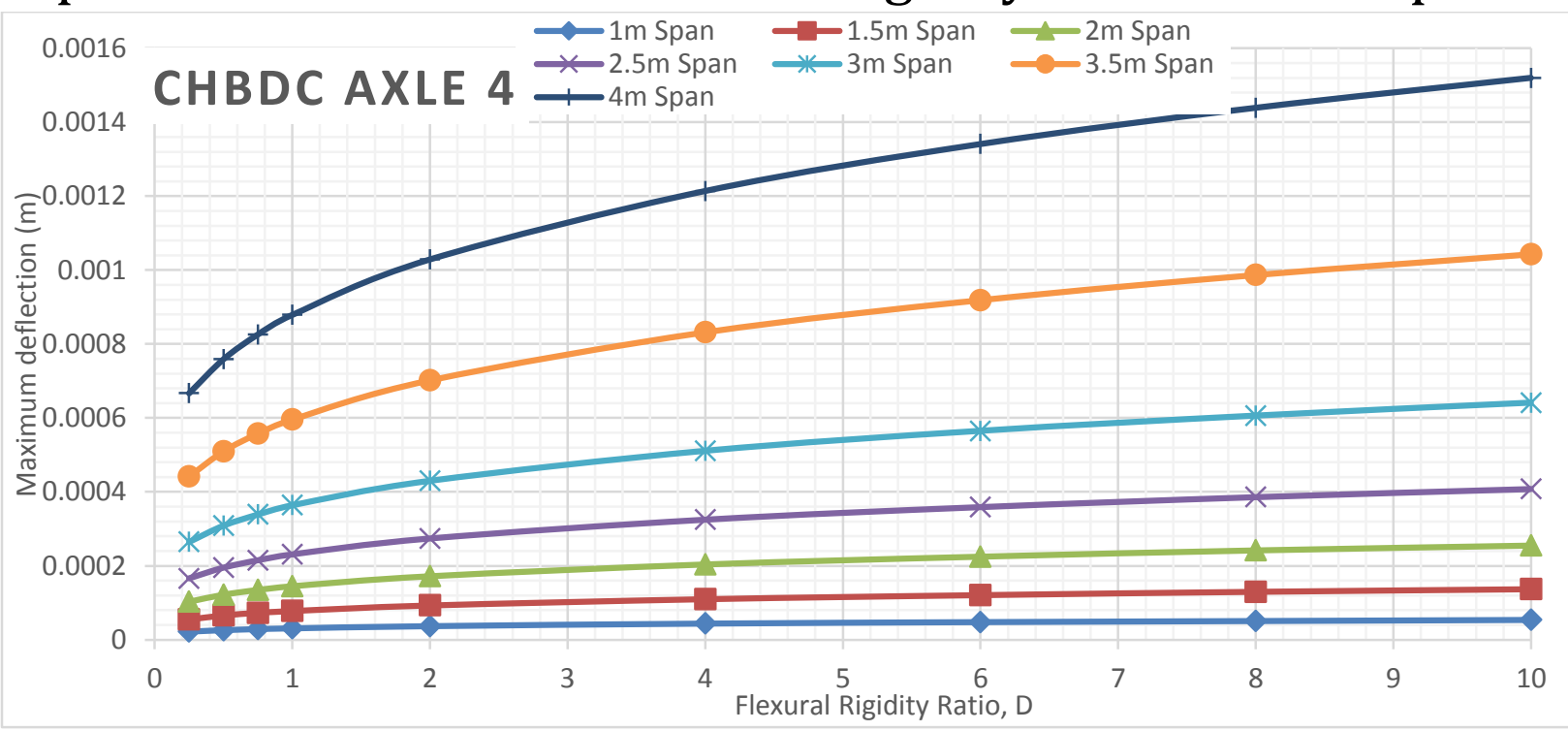

Figure 209 Maximum deflection of deck slabs subjected to CHBDC axle 4 for different span values of alpha 10 FEA analyses

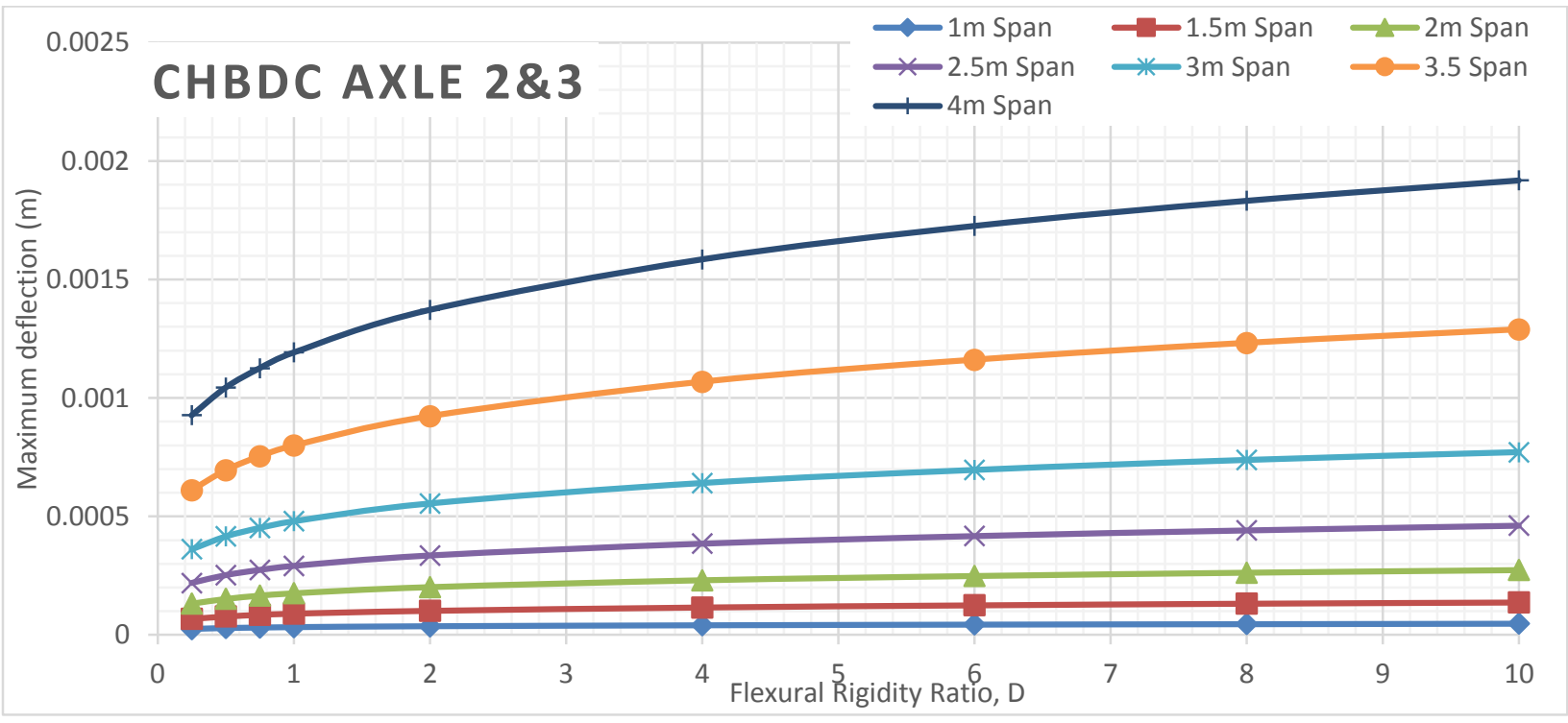

Figure 210 Maximum deflection of deck slabs subjected to CHBDC axle 2 \& 3 for different span values of alpha 10 FEA analyses 


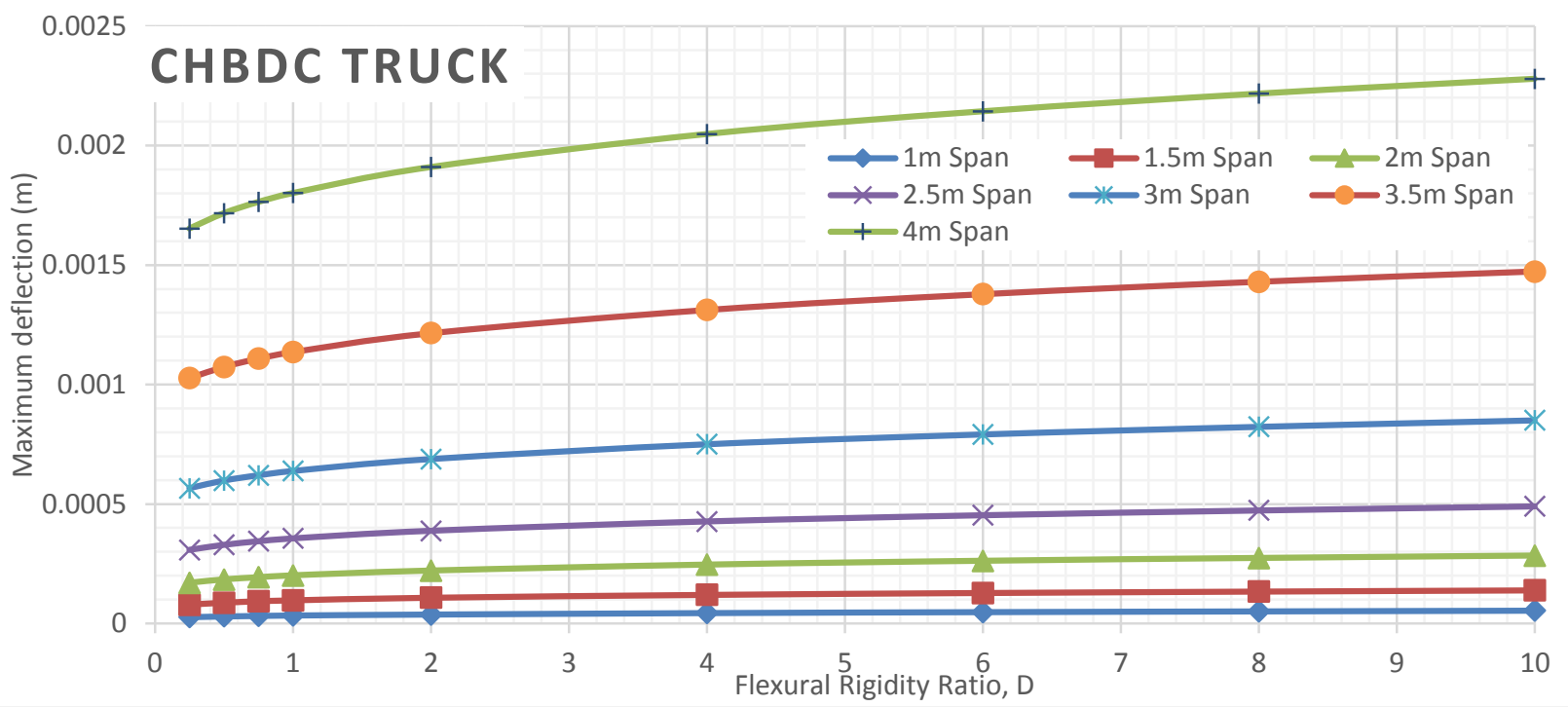

Figure 211 Maximum deflection of deck slabs subjected to CHBDC truck for different span values of alpha 10 FEA analyses

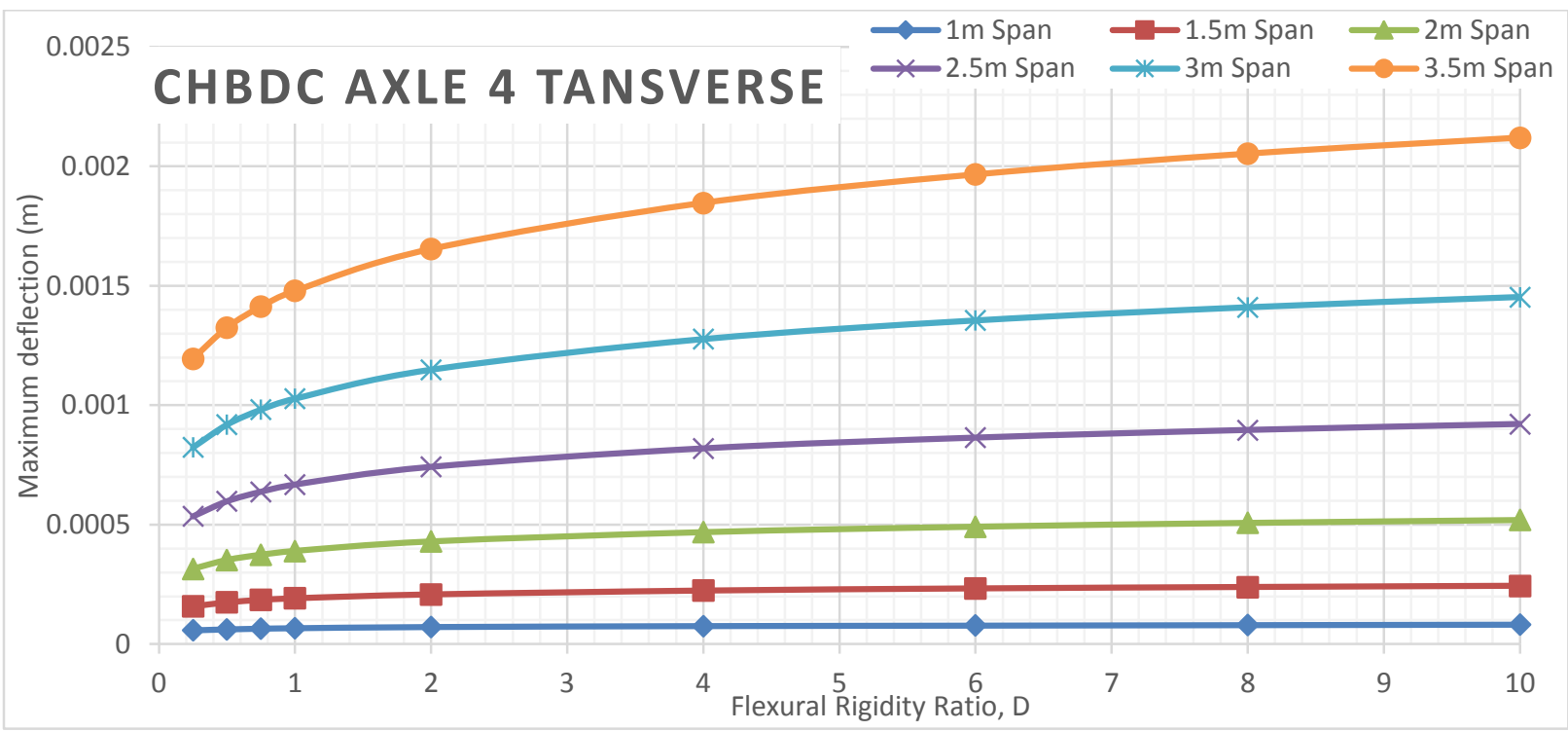

Figure 212 Maximum deflection of deck slabs subjected to CHBDC axle 4 for different span values of alpha 10 FEA analyses

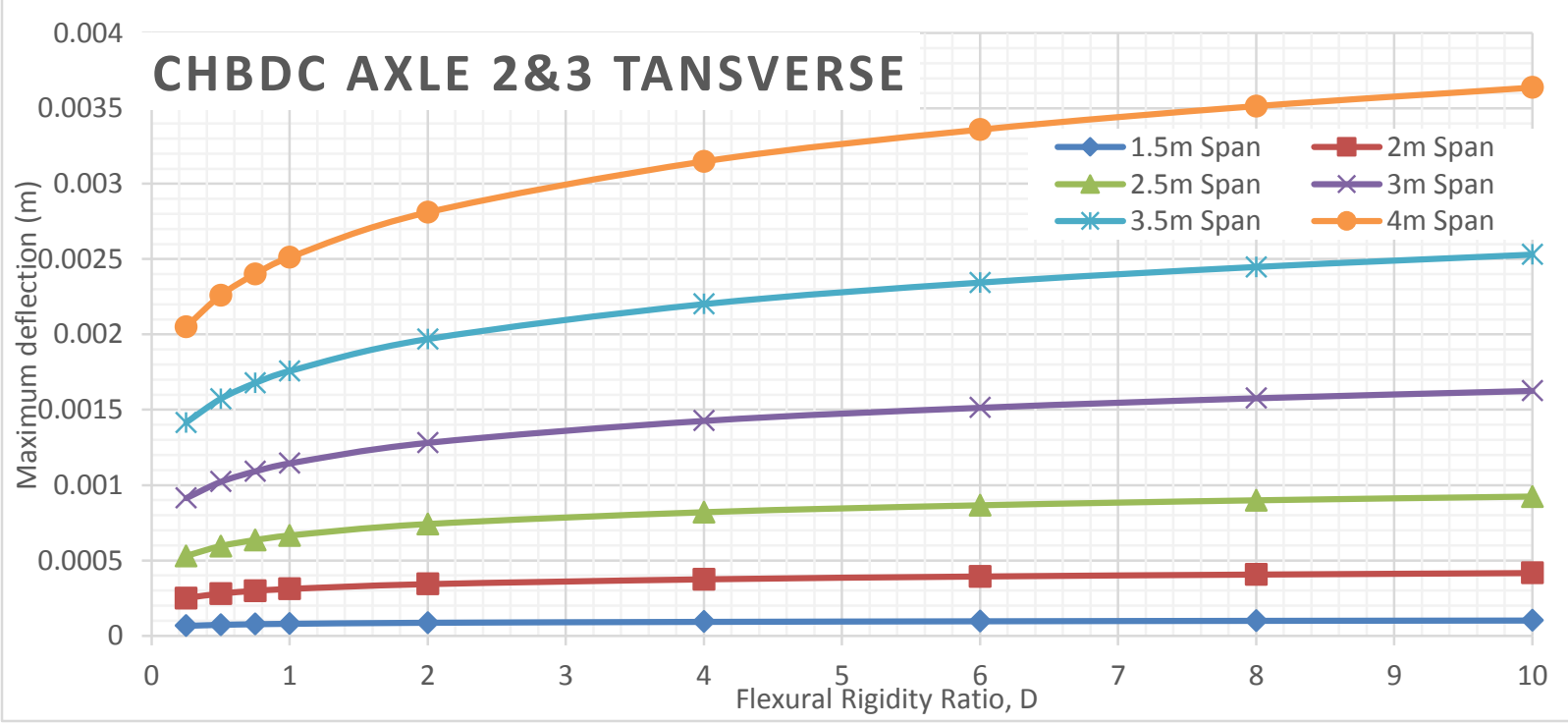

Figure 213 Maximum deflection of deck slabs subjected to CHBDC axle $2 \& 3$ for different span values of alpha 10 FEA analyses 


\section{B.2.4 MAXIMUM DEFLECTION VS TORSIONAL RIGIDITY}




\section{Axle 4 Deflection VS Torsional Rigidity for Different D Values at Different span length}

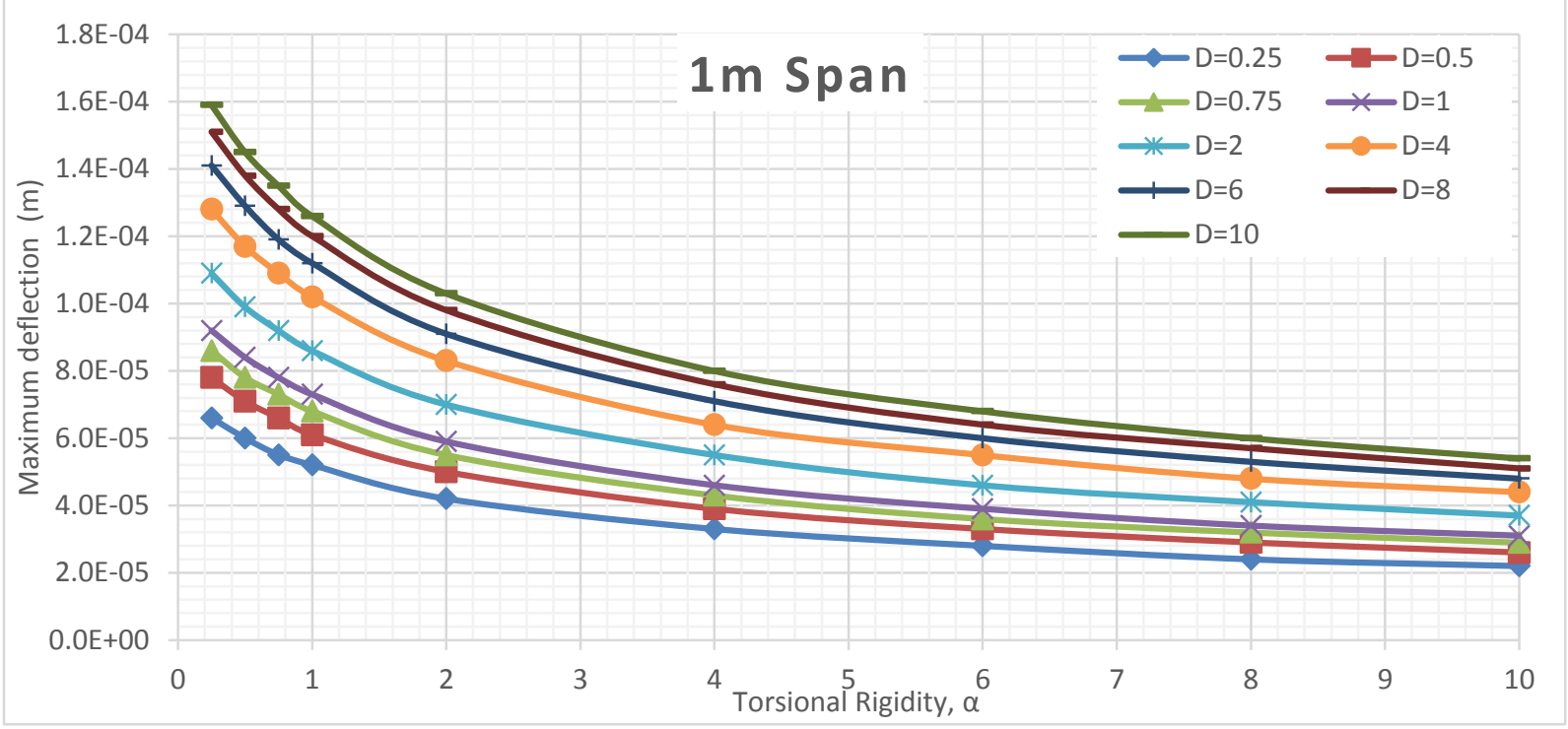

Figure 214 Maximum deflection of $1 \mathrm{~m}$ span slab subjected to CHBDC axle 4 for different $\mathrm{D}$ values FEA analyses

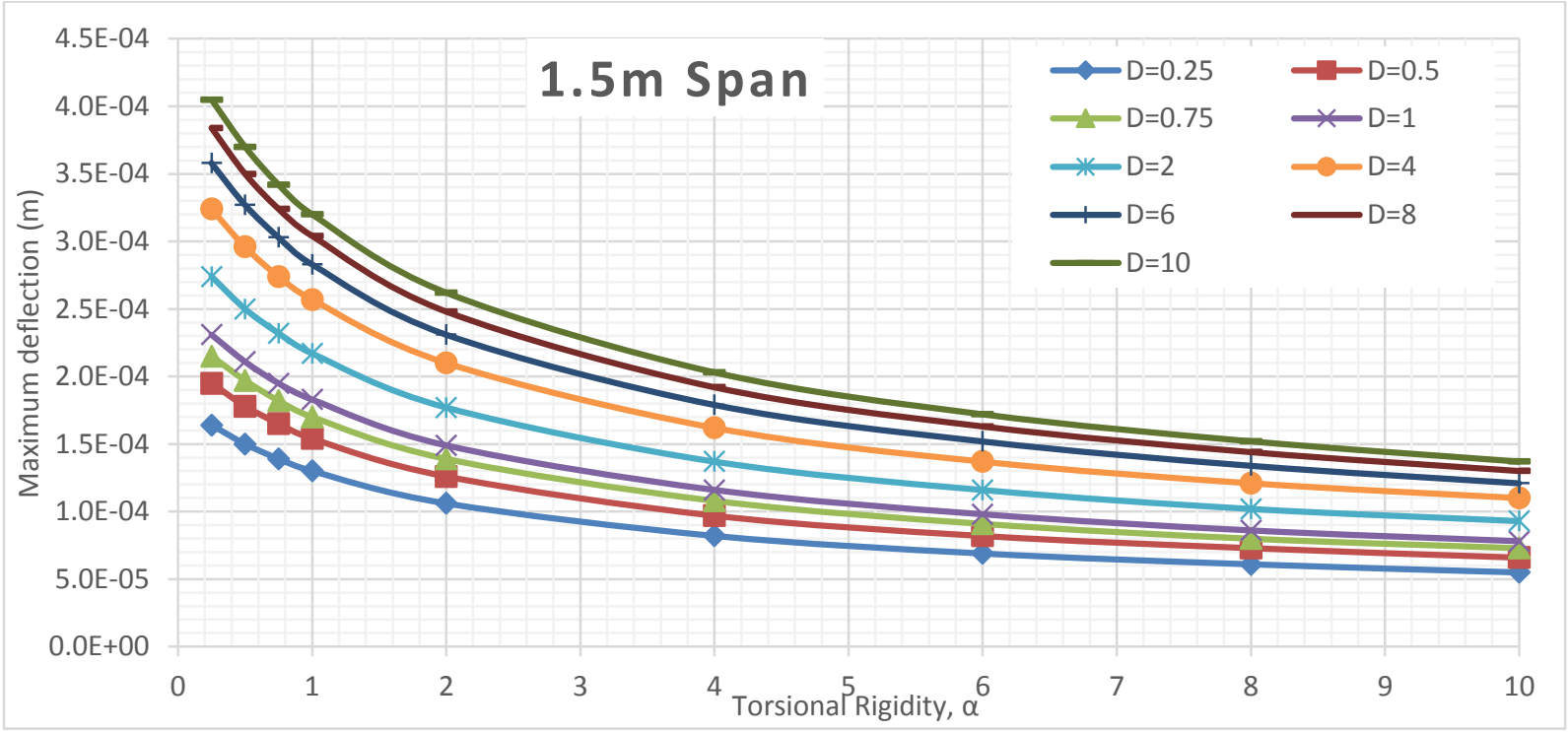

Figure 215 Maximum deflection of $1.5 \mathrm{~m}$ span slab subjected to CHBDC axle 4 for different D values FEA analyses 


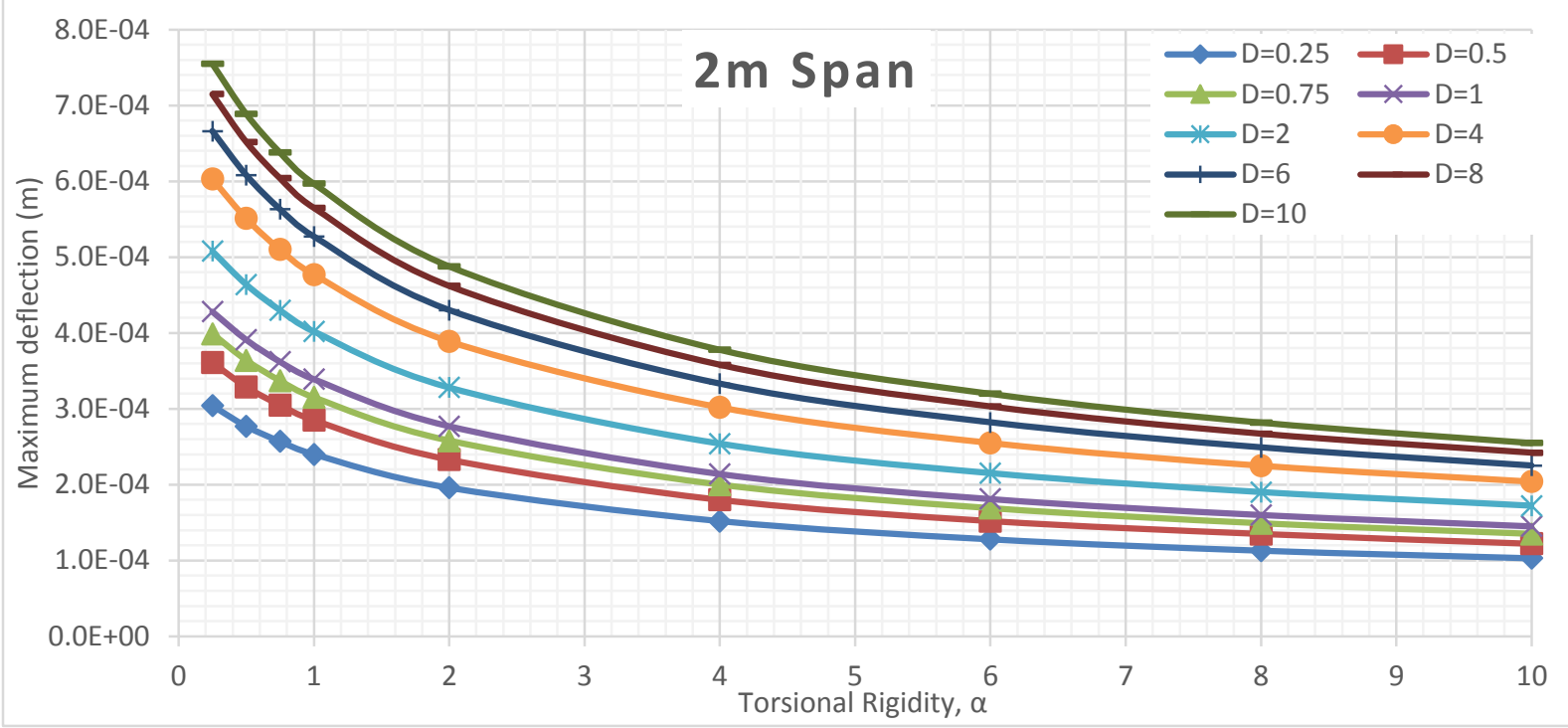

Figure 216 Maximum deflection of $2 \mathrm{~m}$ span slab subjected to CHBDC axle 4 for different $\mathrm{D}$ values FEA analyses

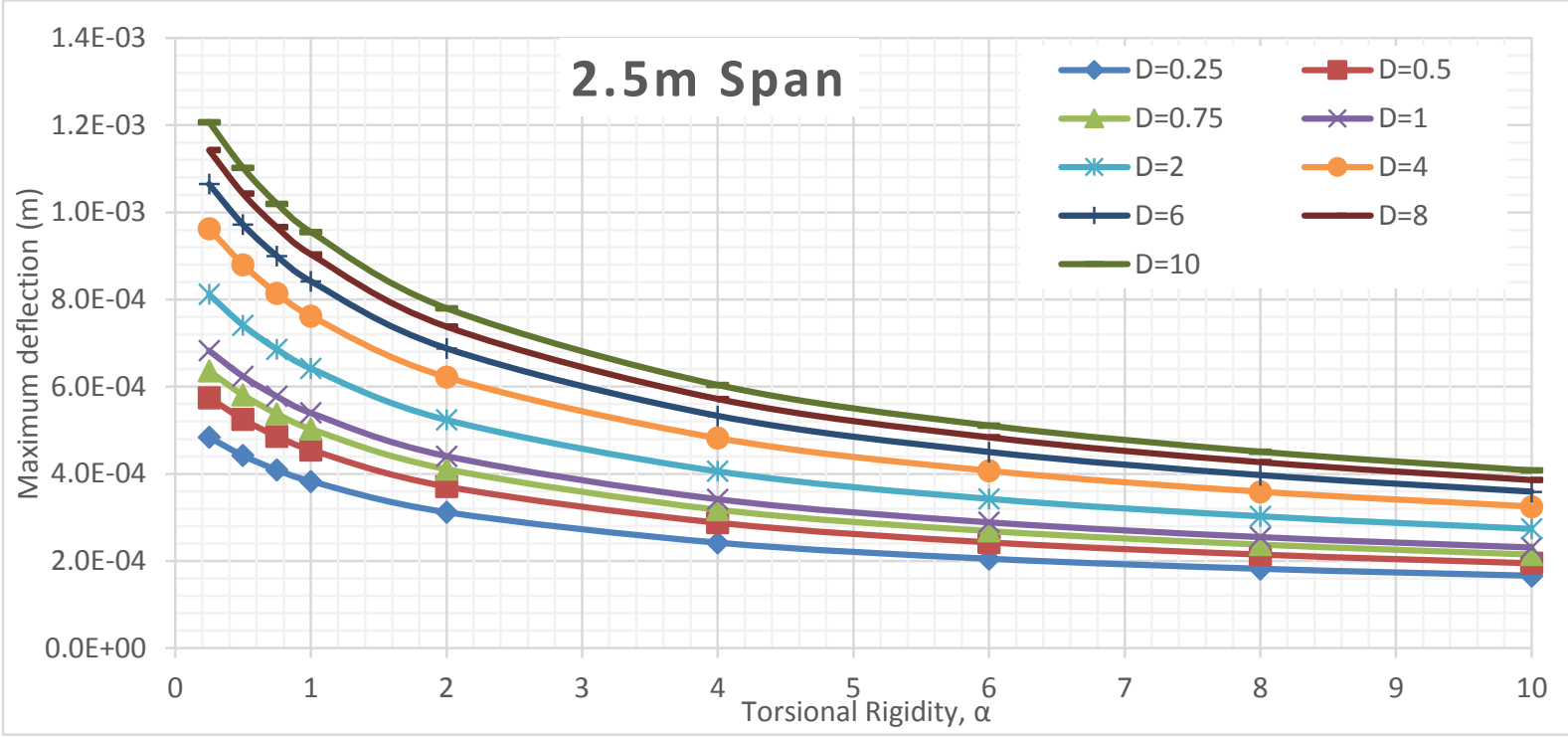

Figure 217 Maximum deflection of $2.5 \mathrm{~m}$ span slab subjected to CHBDC axle 4 for different D values FEA analyses

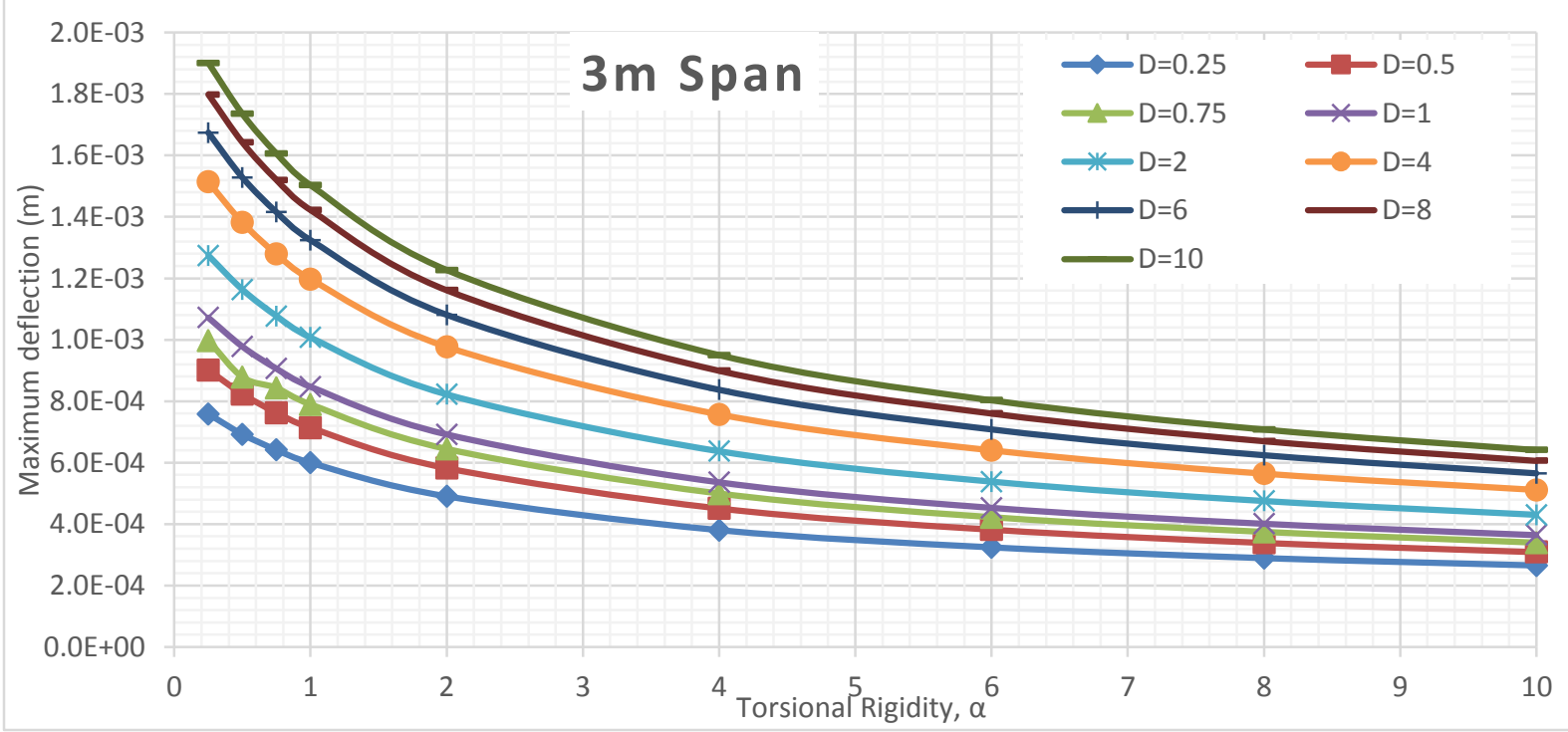

Figure 218 Maximum deflection of $3 \mathrm{~m}$ span slab subjected to CHBDC axle 4 for different $\mathrm{D}$ values FEA analyses 


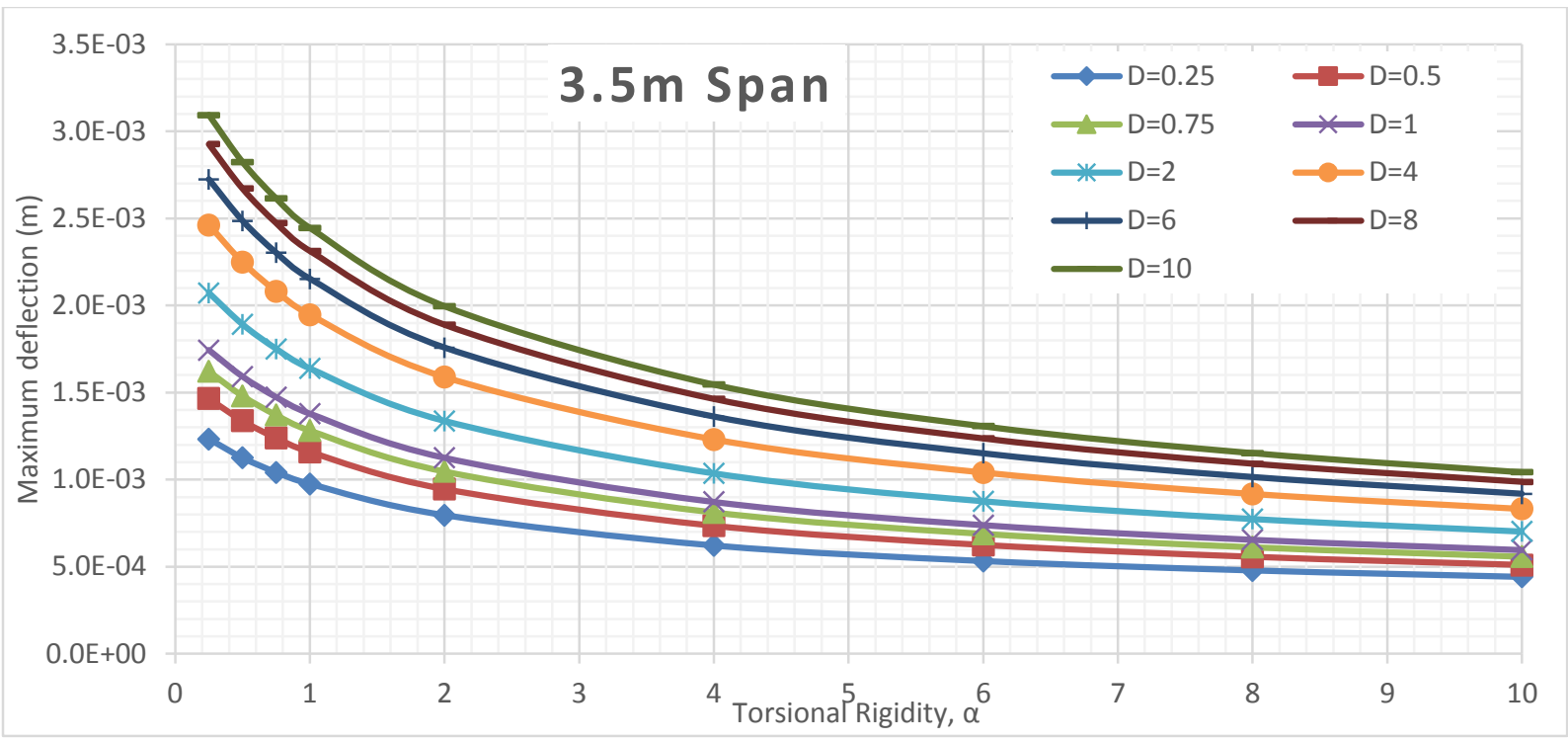

Figure 219 Maximum deflection of $3.5 \mathrm{~m}$ span slab subjected to CHBDC axle 4 for different D values FEA analyses

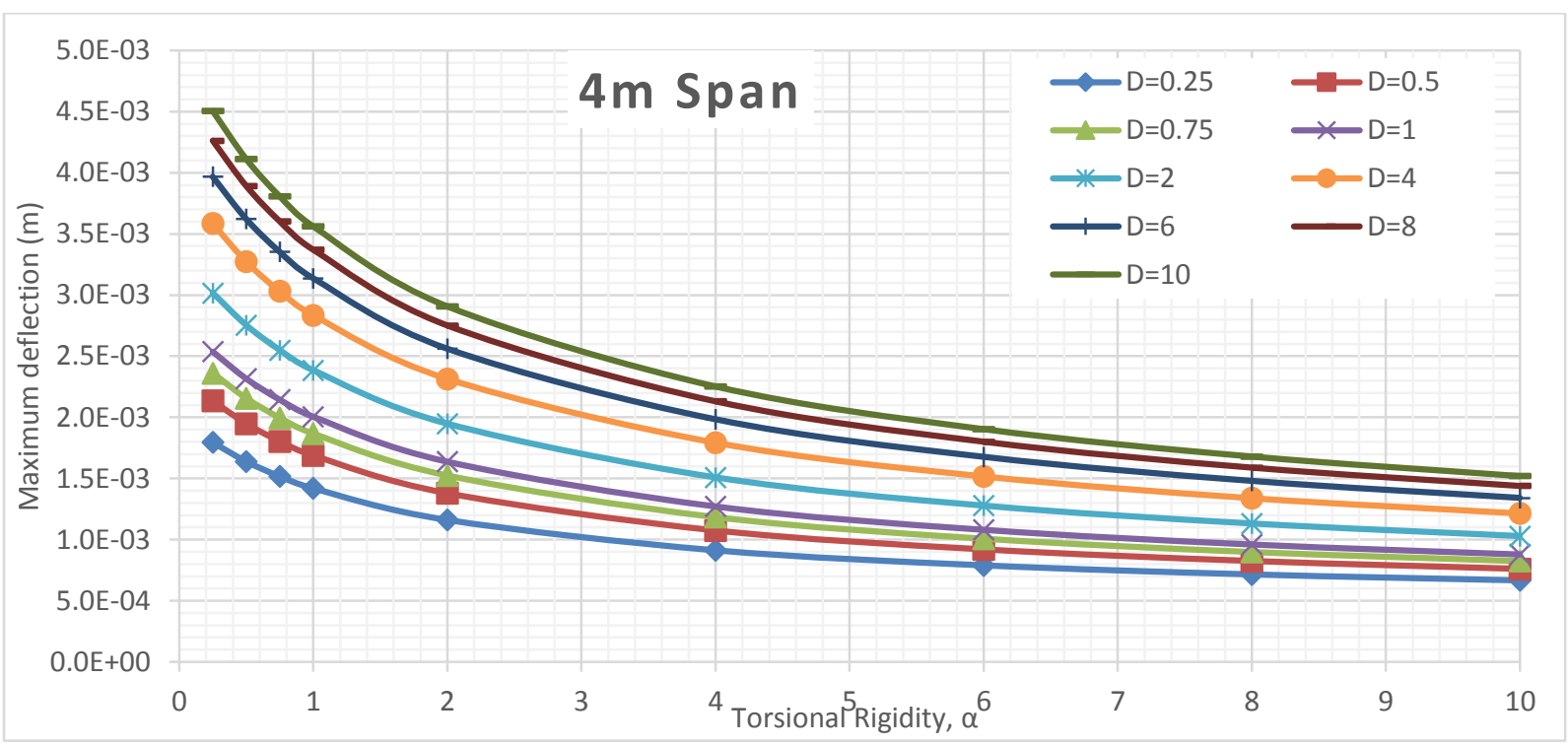

Figure 220 Maximum deflection of $4 \mathrm{~m}$ span slab subjected to CHBDC axle 4 for different D values FEA analyses 


\section{Axle 2 \& 3 Deflection VS Torsional Rigidity for Different D Values at Different span length}

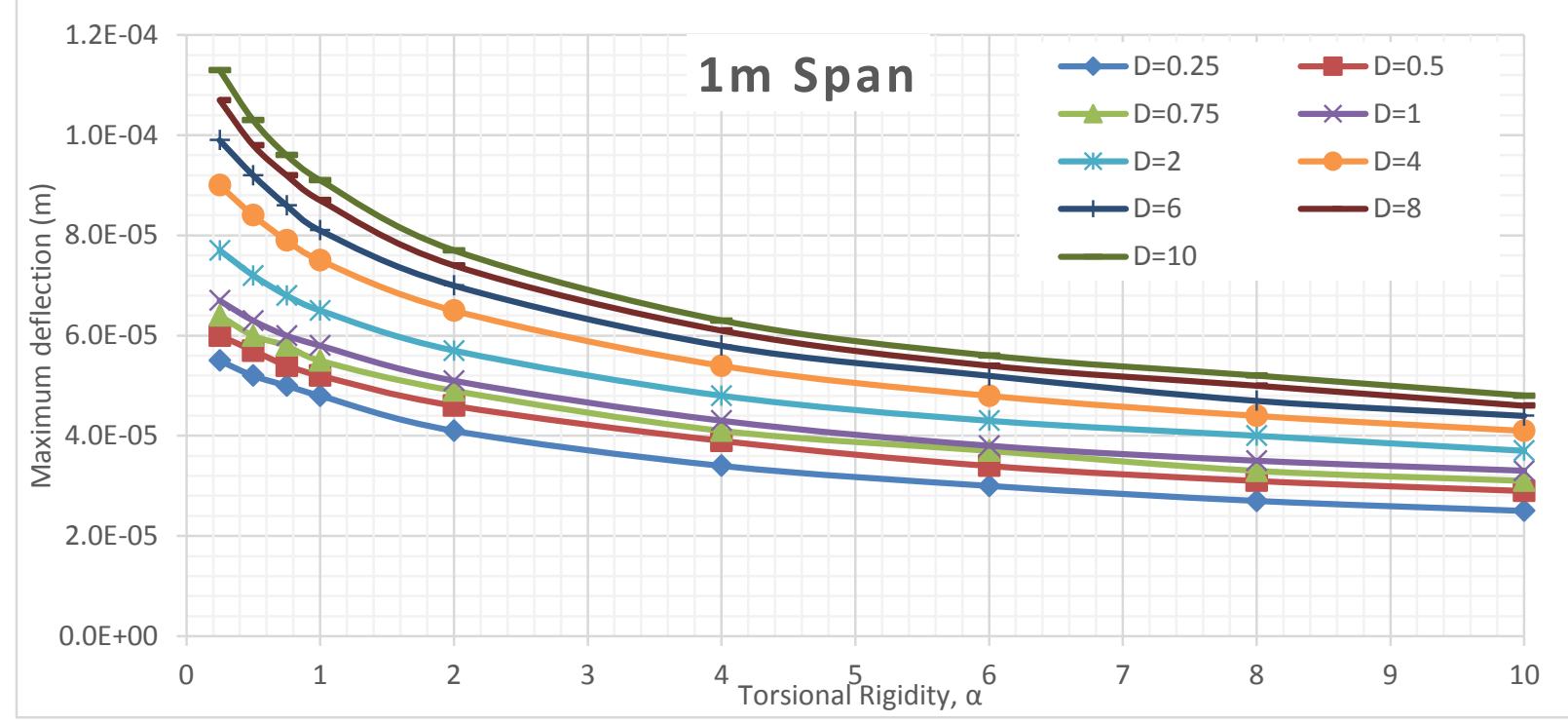

Figure 221 Maximum deflection of $1 \mathrm{~m}$ span slab subjected to CHBDC axle 2 \& 3 for different D values FEA analyses

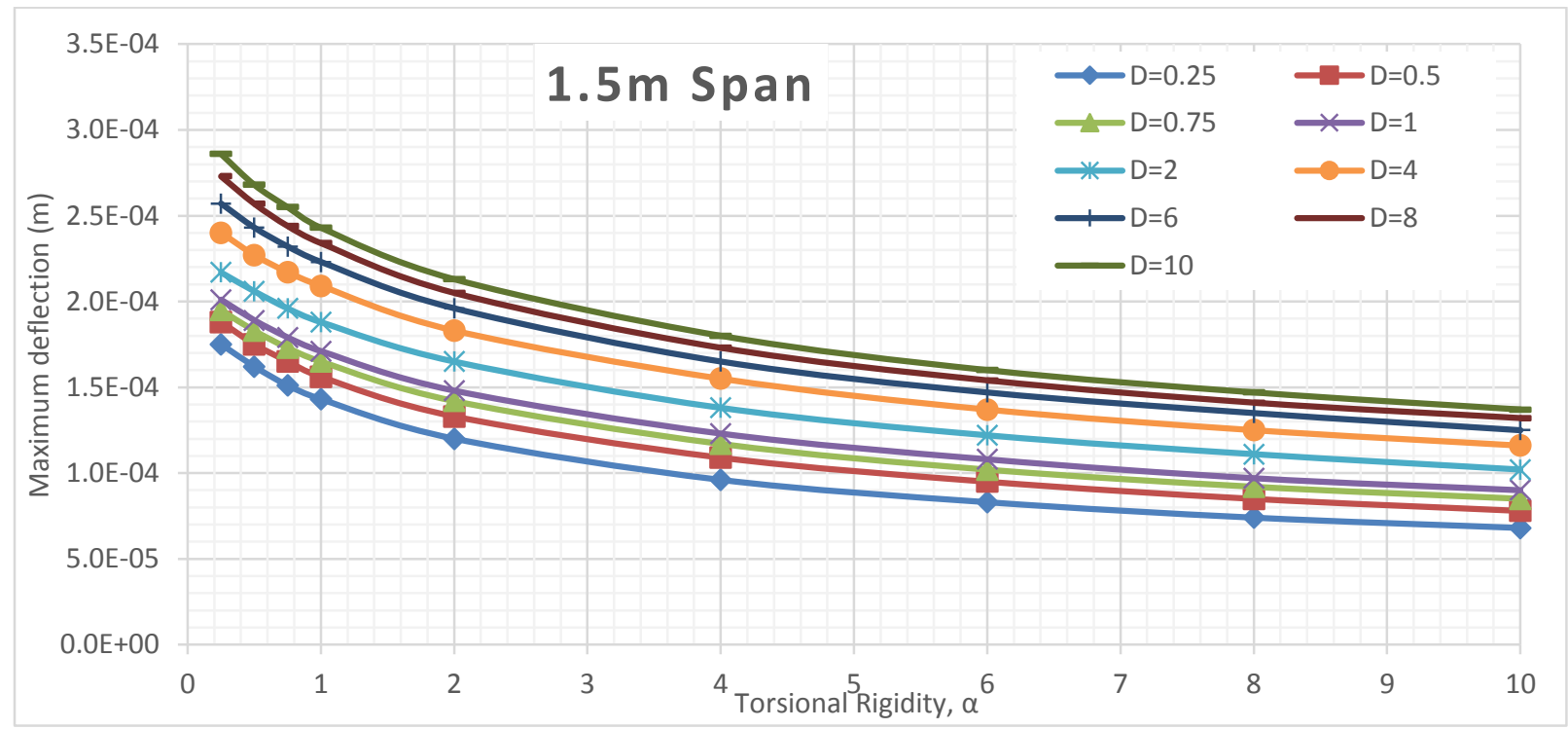

Figure 222 Maximum deflection of $1.5 \mathrm{~m}$ span slab subjected to CHBDC axle $2 \& 3$ for different D values FEA analyses 


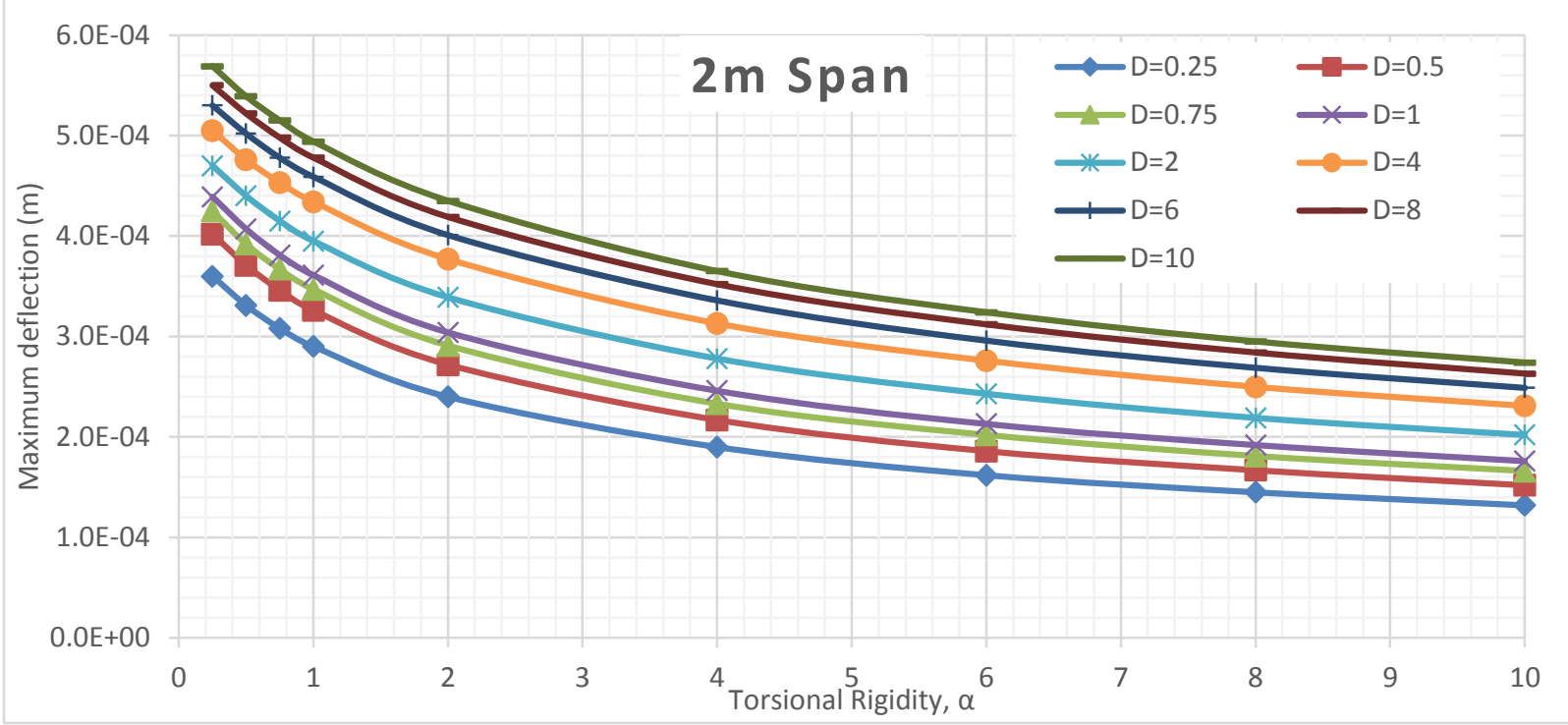

Figure 223 Maximum deflection of $2 \mathrm{~m}$ span slab subjected to CHBDC axle 2 \& 3 for different D values FEA analyses

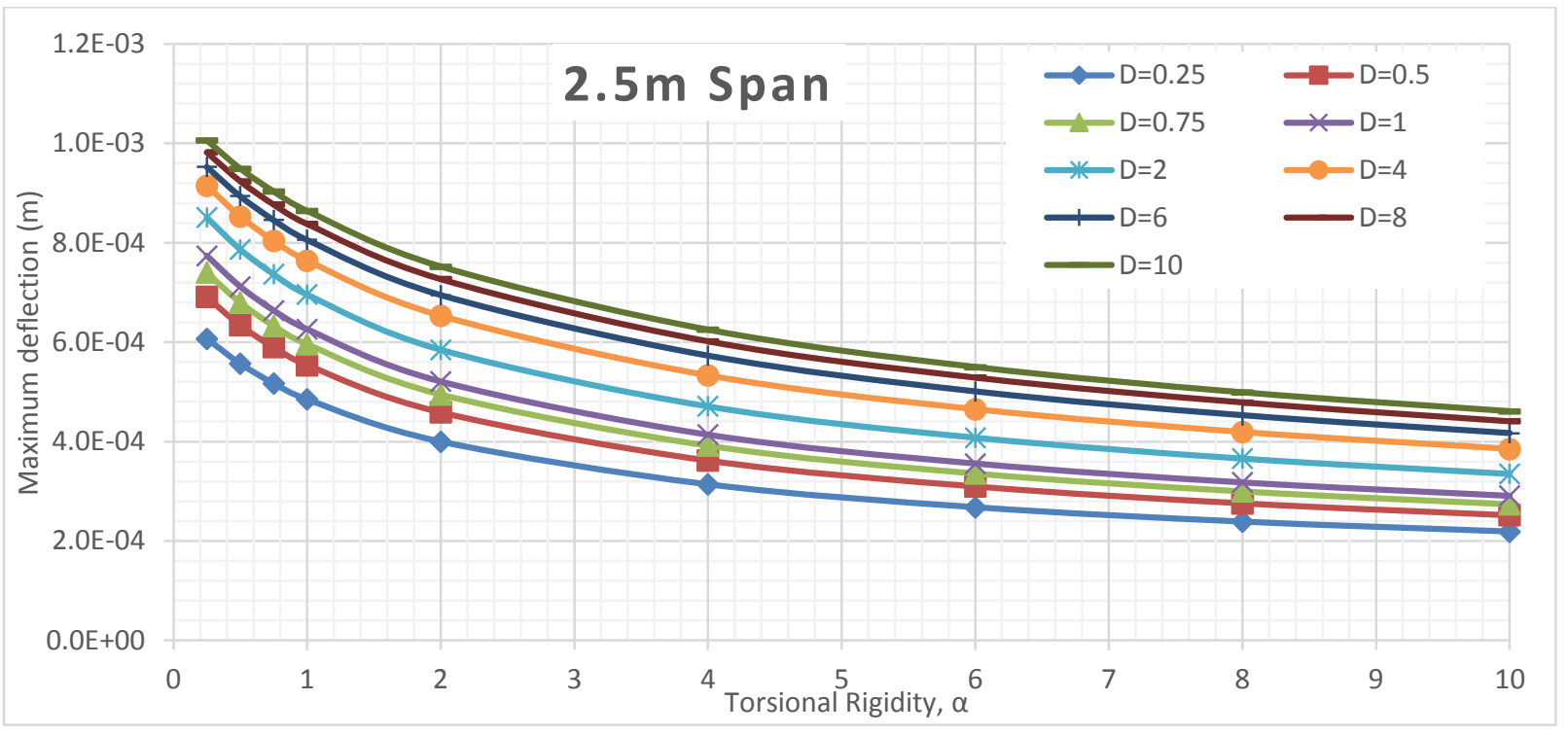

Figure 224 Maximum deflection of $2.5 \mathrm{~m}$ span slab subjected to CHBDC axle 2 \& 3 for different D values FEA analyses

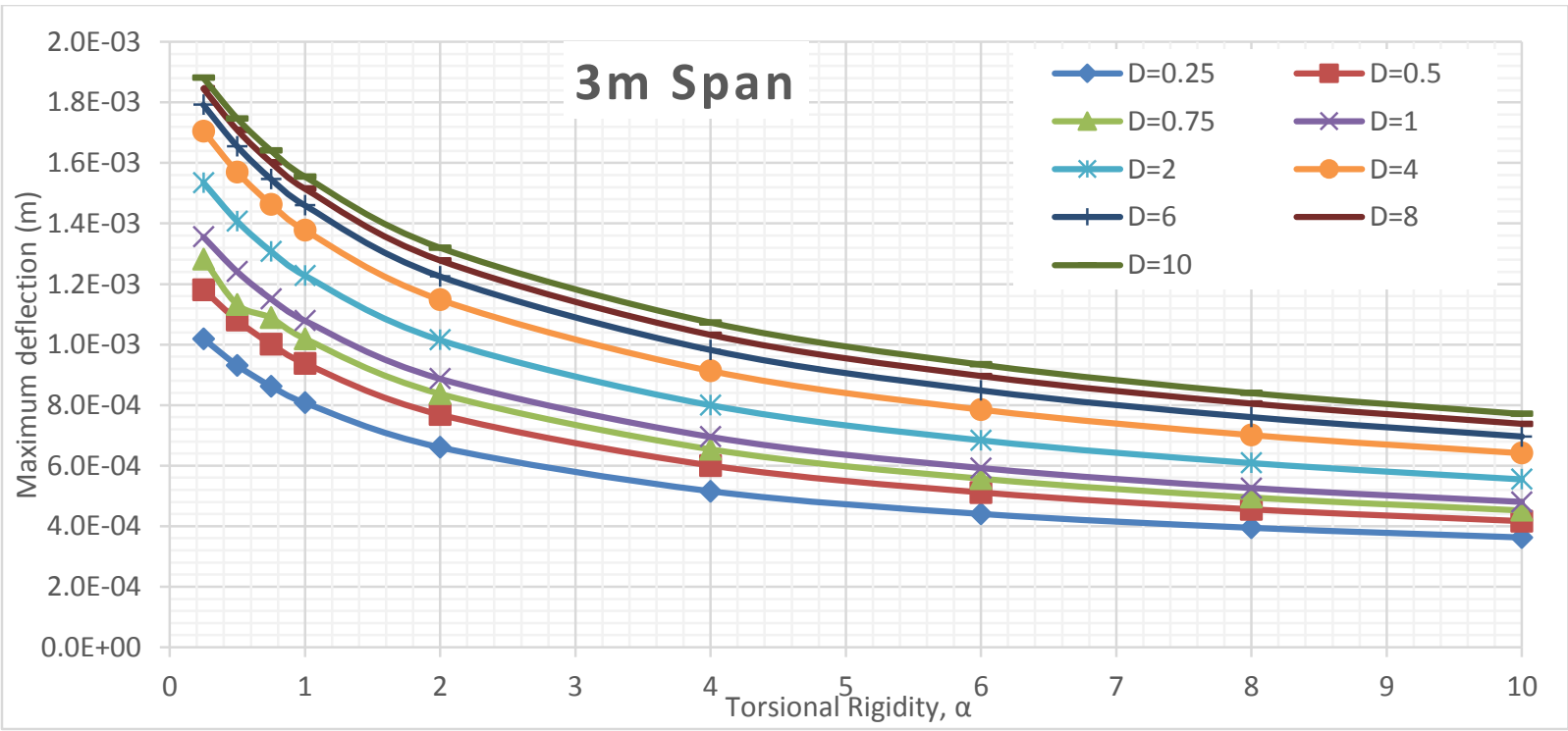

Figure 225 Maximum deflection of $3 \mathrm{~m}$ span slab subjected to CHBDC axle $2 \& 3$ for different D values FEA analyses 


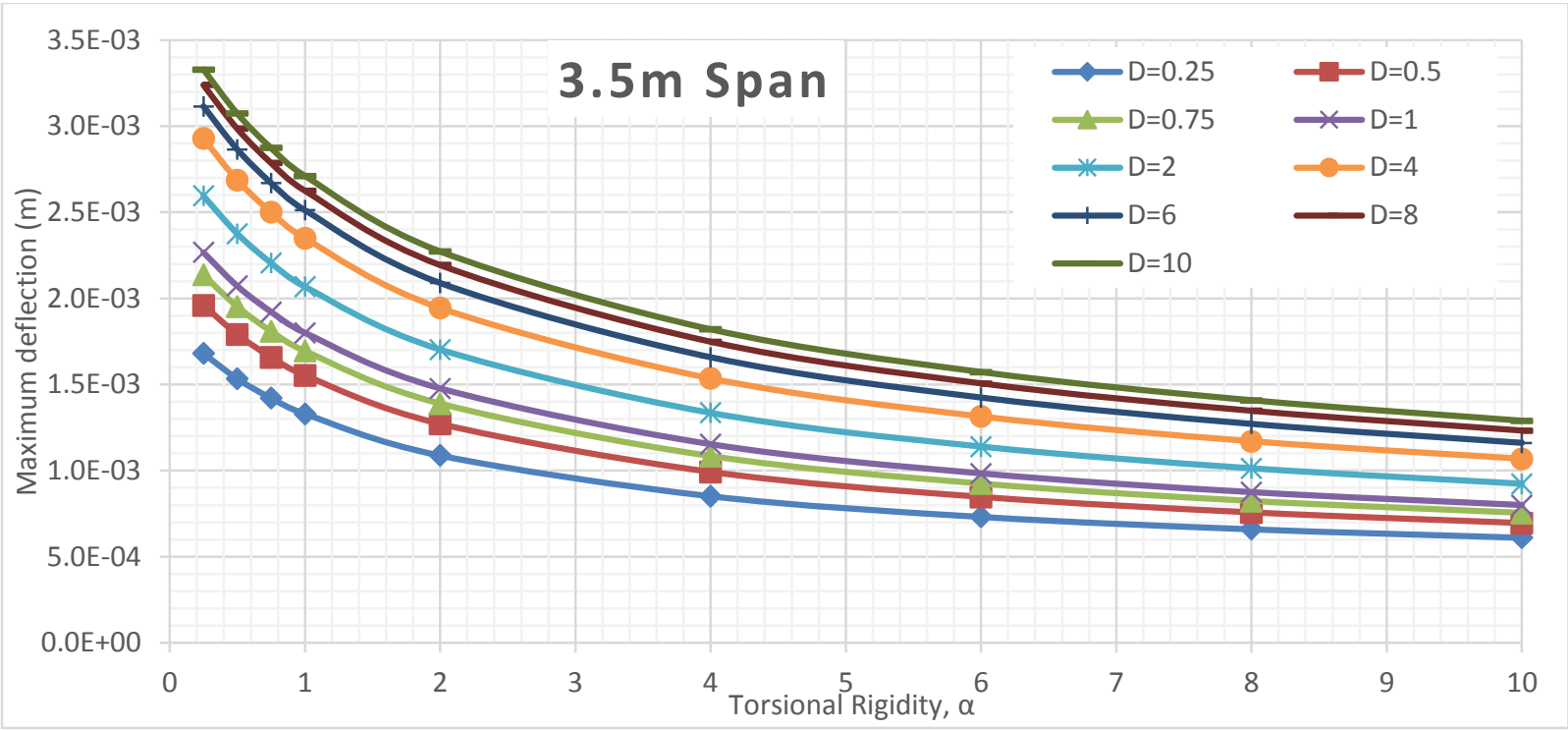

Figure 226 Maximum deflection of $3.5 \mathrm{~m}$ span slab subjected to CHBDC axle 2 \& 3 for different D values FEA analyses

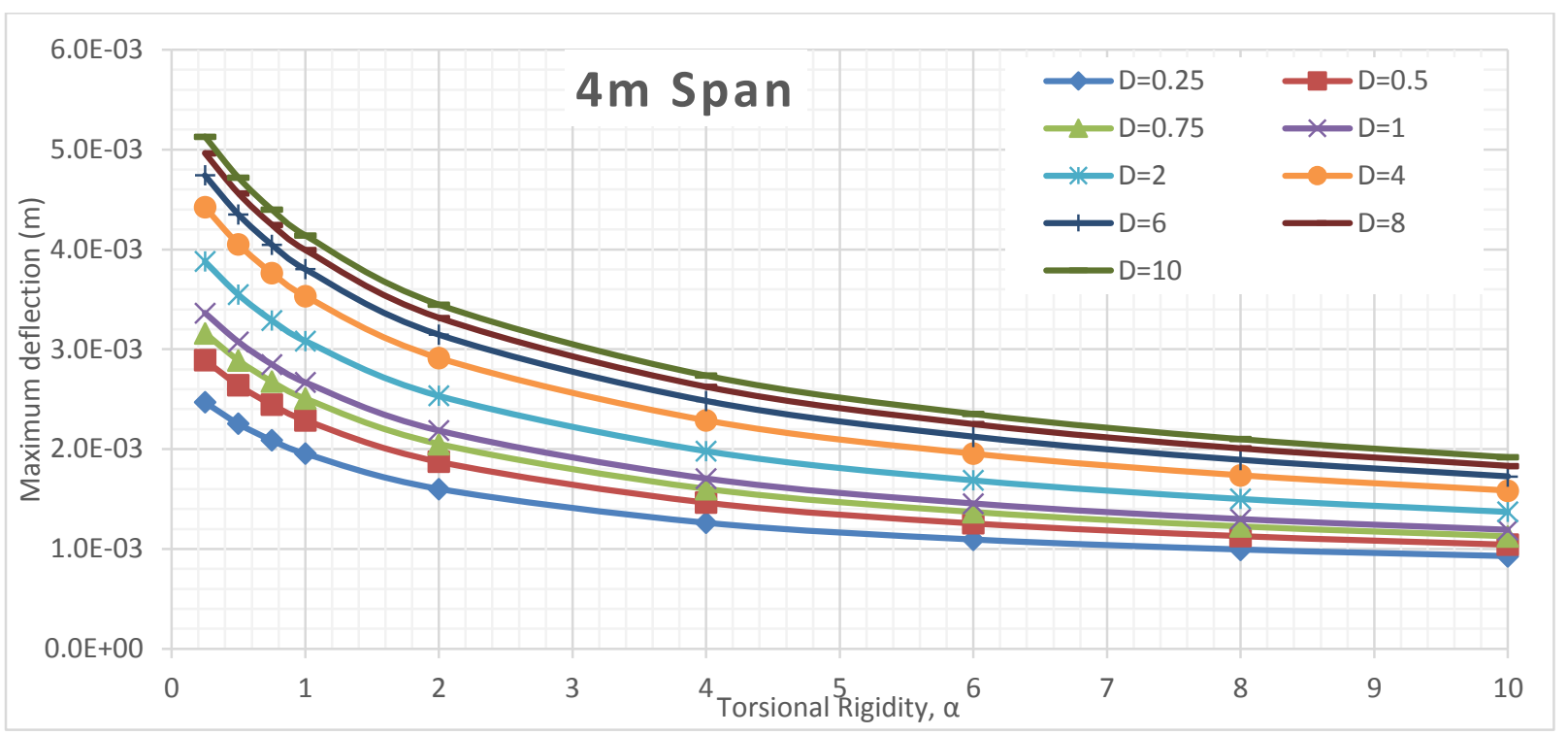

Figure 227 Maximum deflection of $4 \mathrm{~m}$ span slab subjected to CHBDC axle $2 \& 3$ for different D values FEA analyses 


\section{Truck Deflection VS Torsional Rigidity for Different D Values at Different span length}

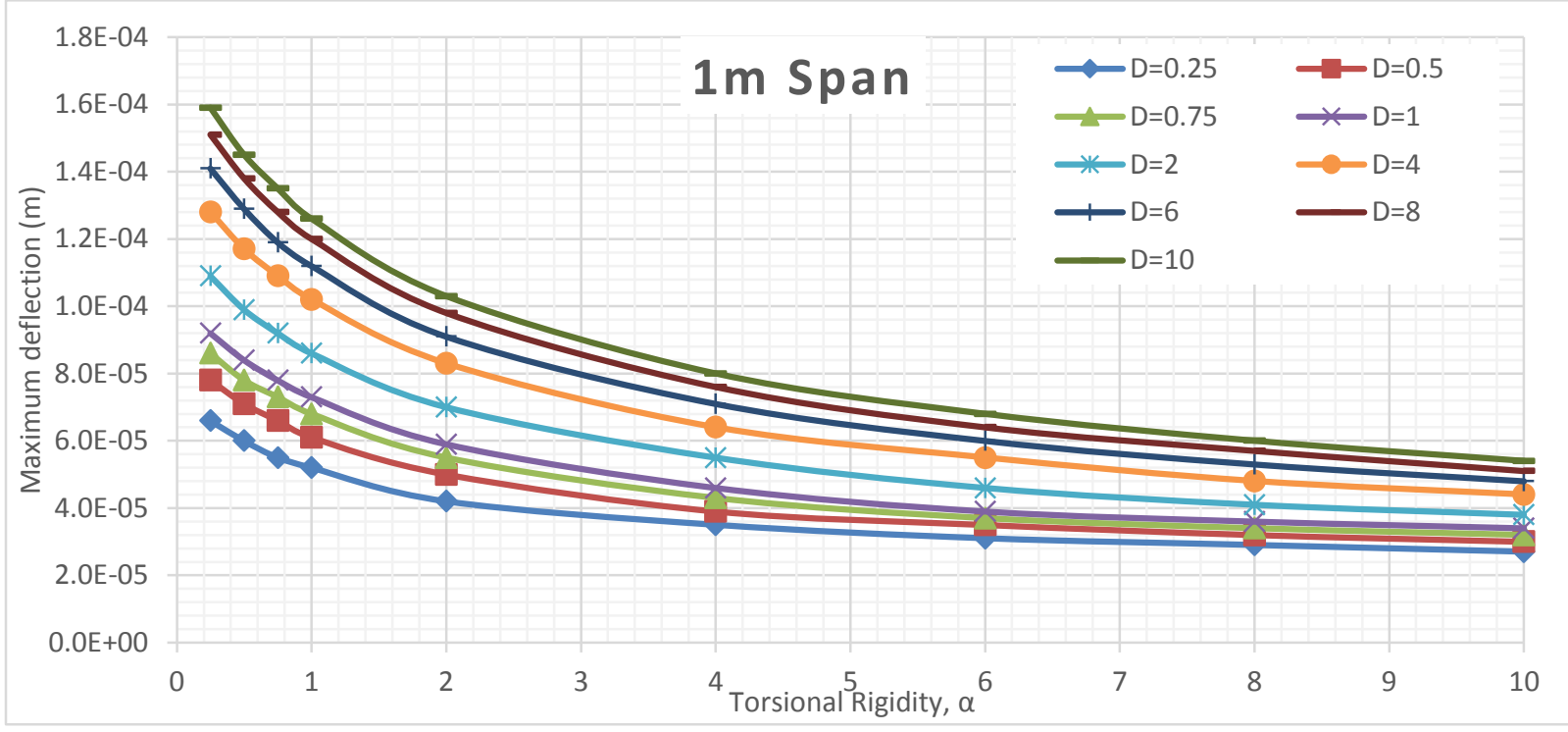

Figure 228 Maximum deflection of $1 \mathrm{~m}$ span slab subjected to CHBDC truck for different D values FEA analyses

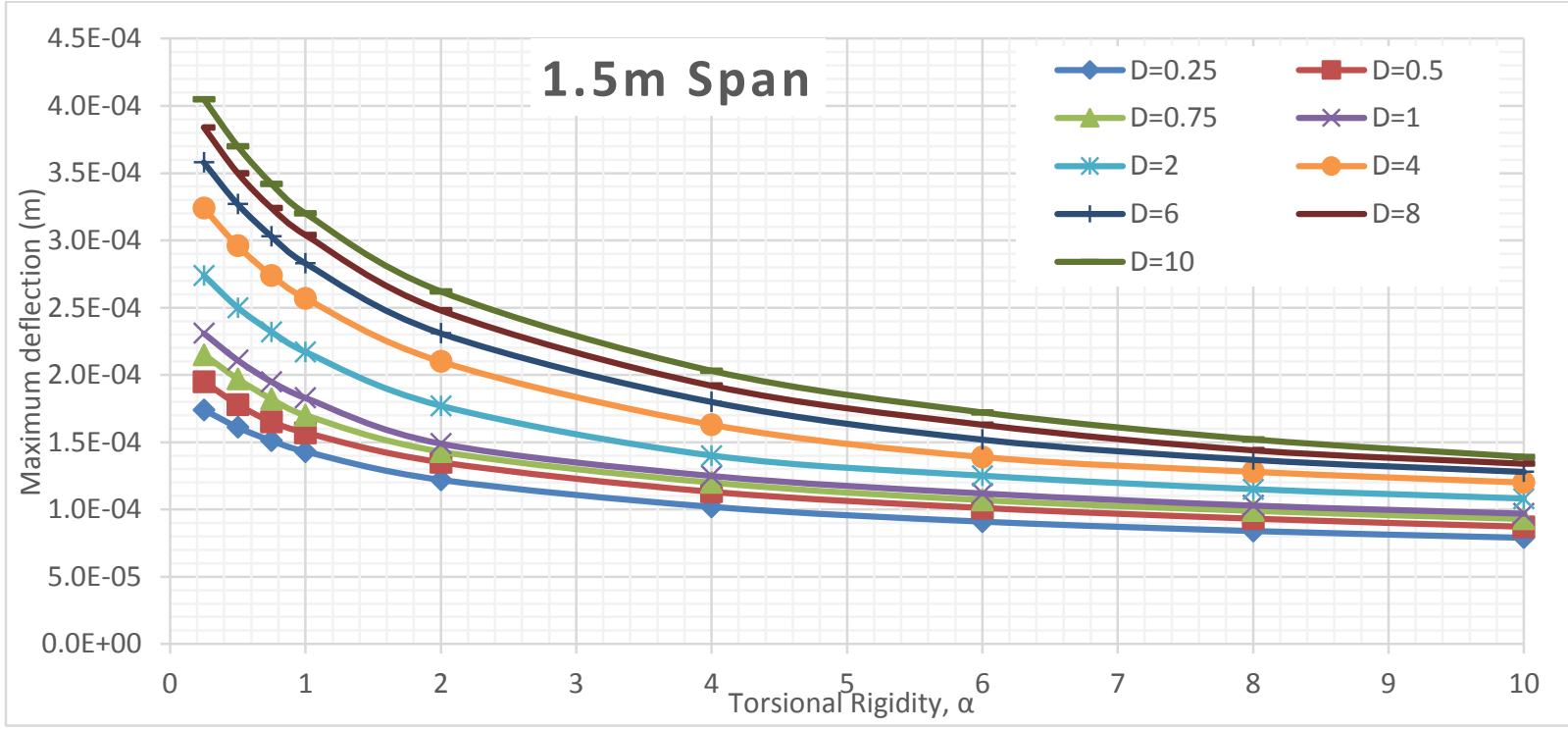

Figure 229 Maximum deflection of $1.5 \mathrm{~m}$ span slab subjected to CHBDC truck for different $\mathrm{D}$ values FEA analyses 


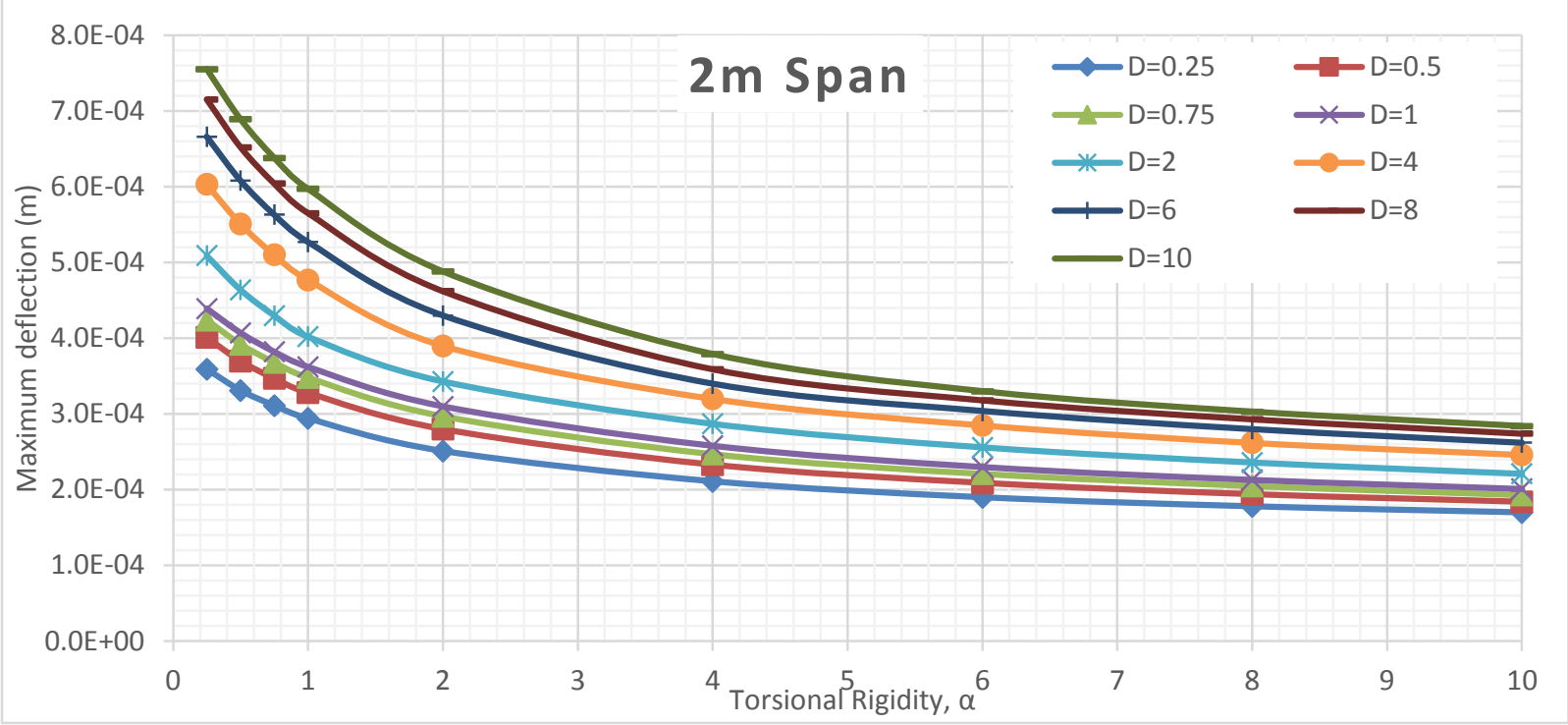

Figure 230 Maximum deflection of $2 \mathrm{~m}$ span slab subjected to CHBDC truck for different D values FEA analyses

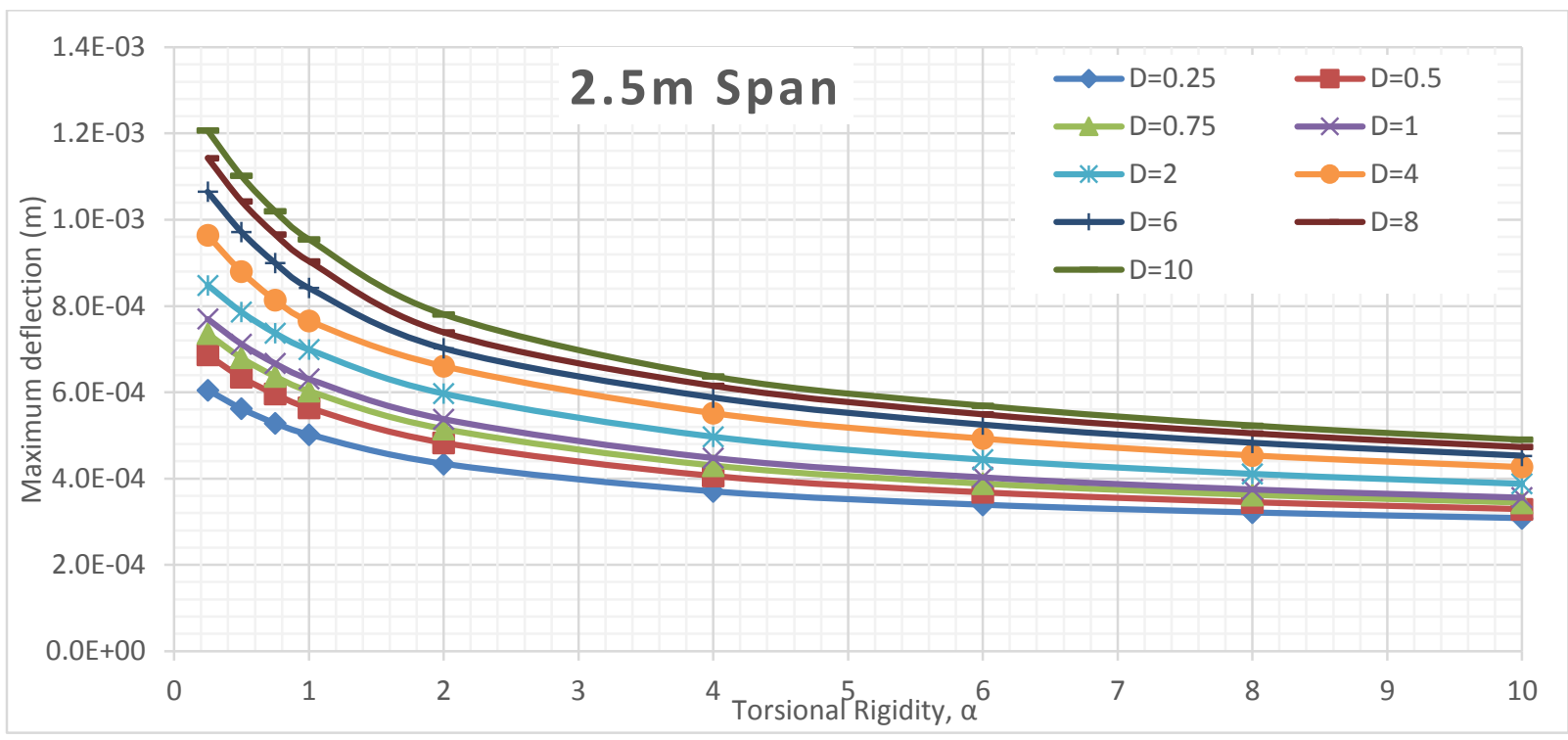

Figure 231 Maximum deflection of $2.5 \mathrm{~m}$ span slab subjected to CHBDC truck for different D values FEA analyses

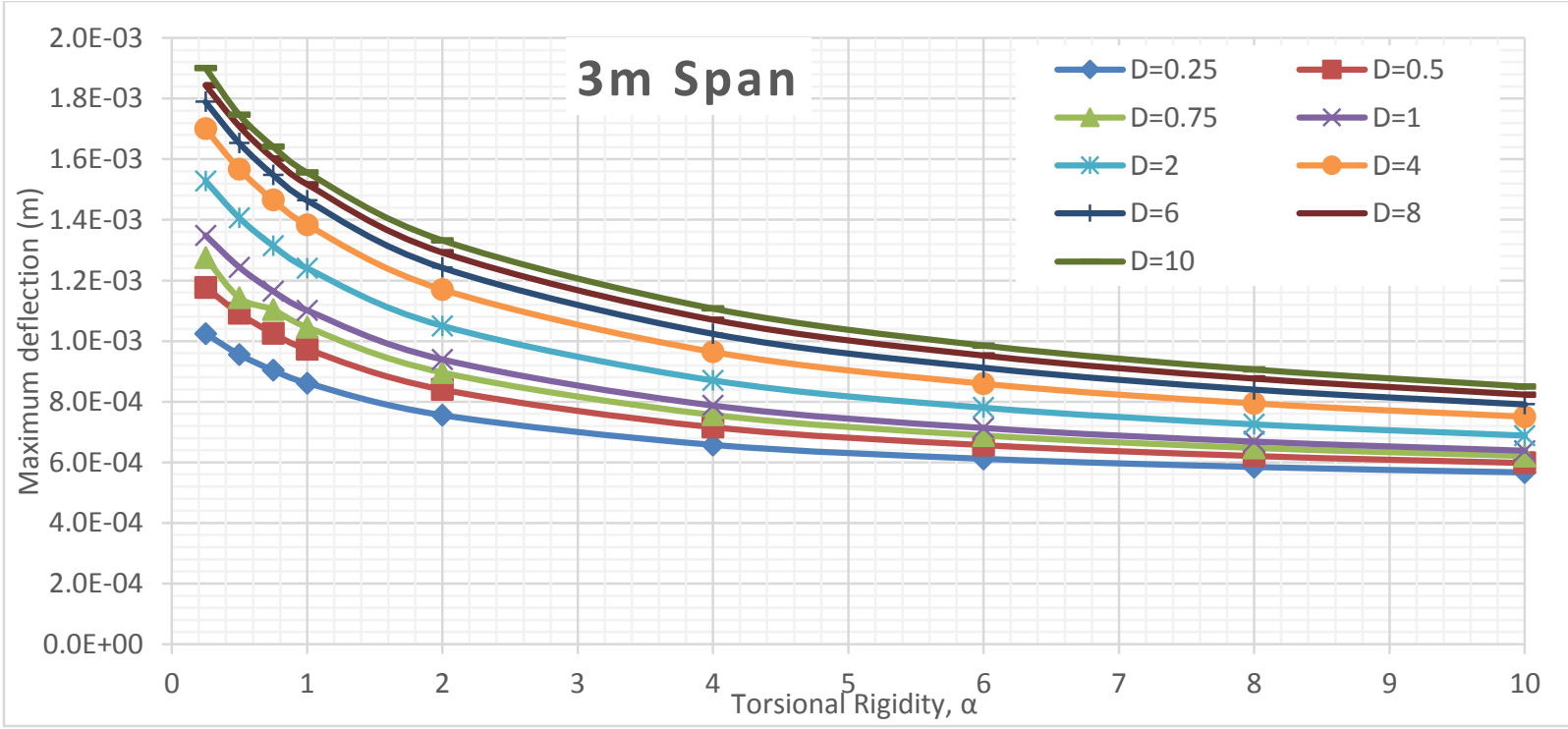

Figure 232 Maximum deflection of $3 \mathrm{~m}$ span slab subjected to CHBDC truck for different $\mathrm{D}$ values FEA analyses 


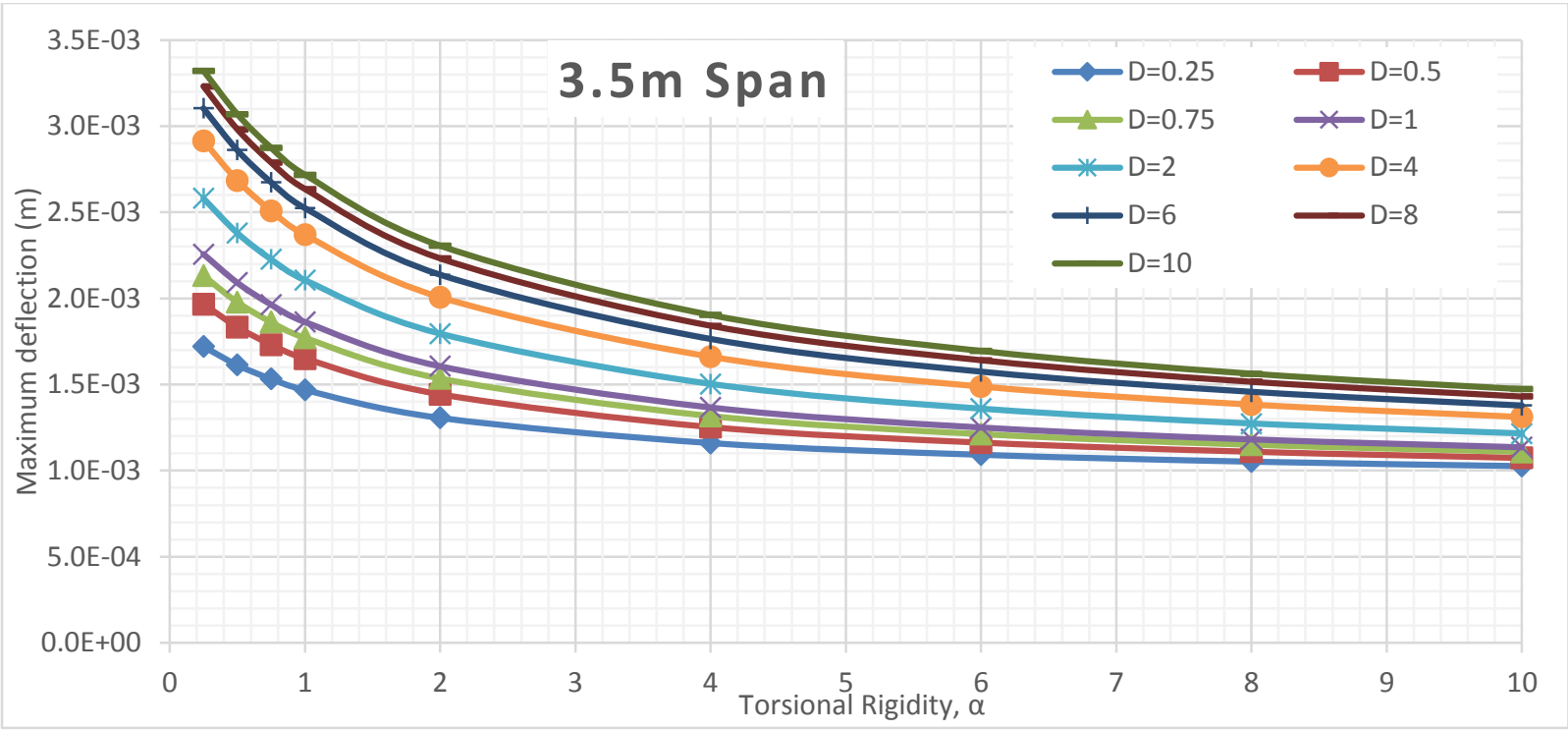

Figure 233 Maximum deflection of $3.5 \mathrm{~m}$ span slab subjected to CHBDC truck for different D values FEA analyses

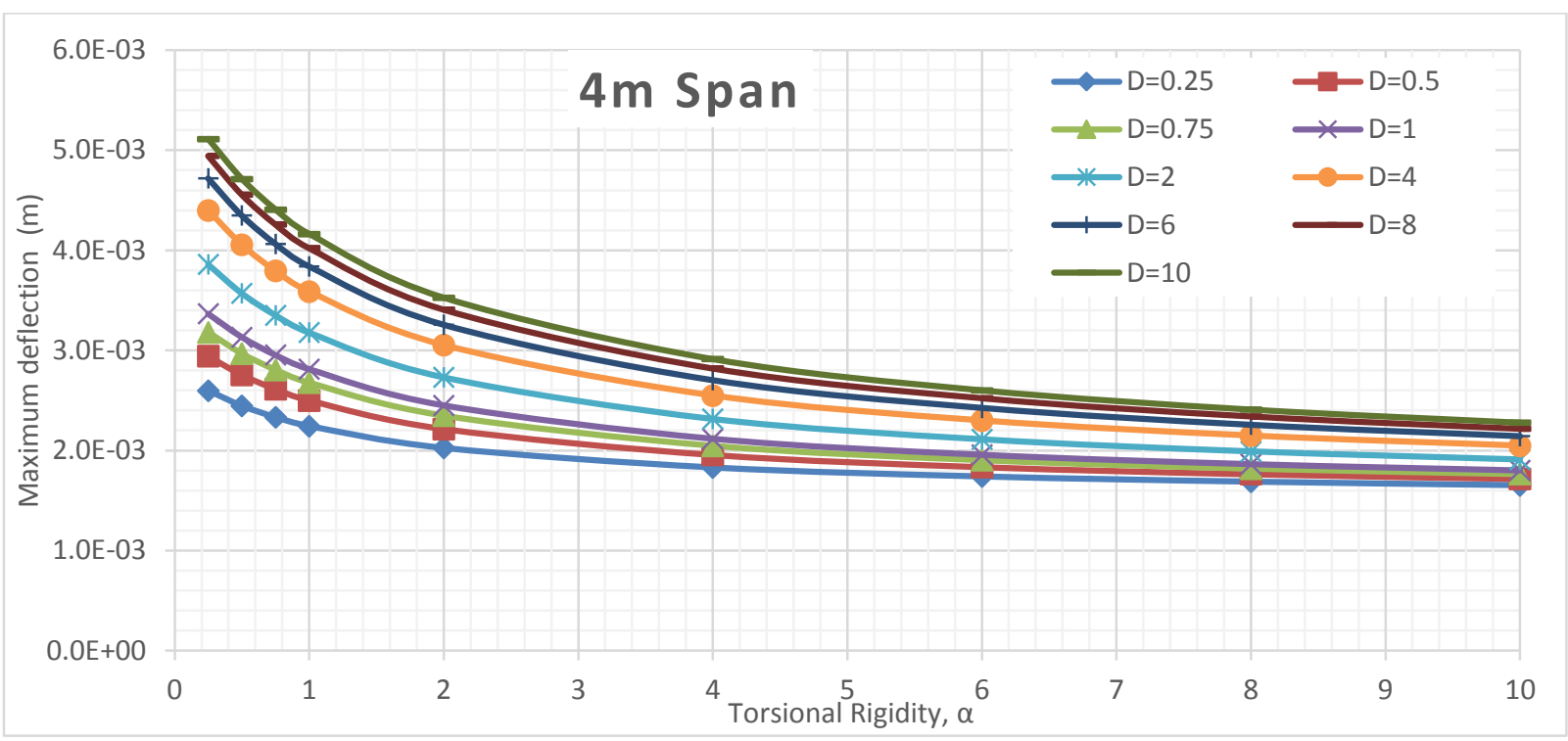

Figure 234 Maximum deflection of $4 \mathrm{~m}$ span slab subjected to CHBDC truck for different D values FEA analyses 


\section{Axle 4 Transverse Deflection VS Torsional Rigidity for Different D Values at Different span length}

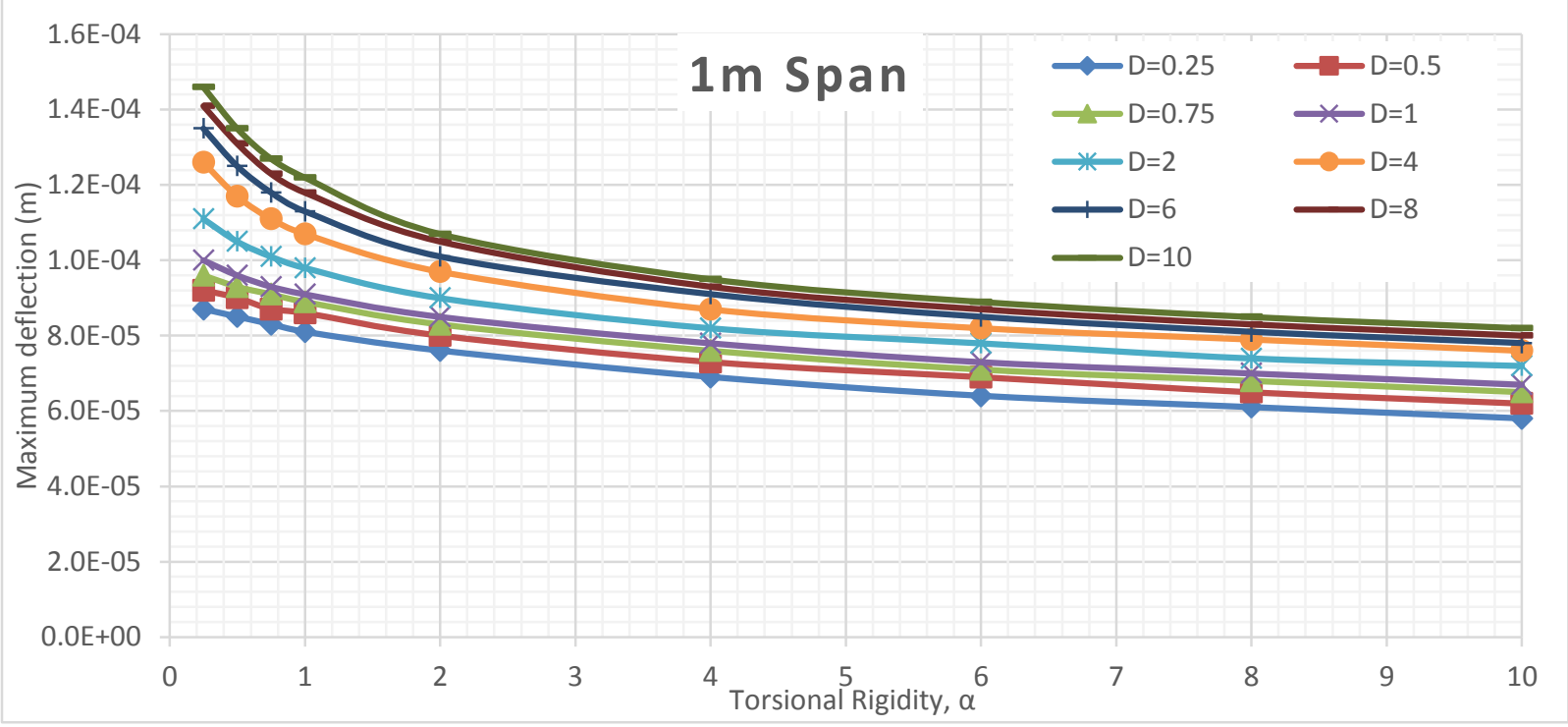

Figure 235 Maximum deflection of $1 \mathrm{~m}$ span slab subjected to CHBDC axle 4 for different $\mathrm{D}$ values FEA analyses

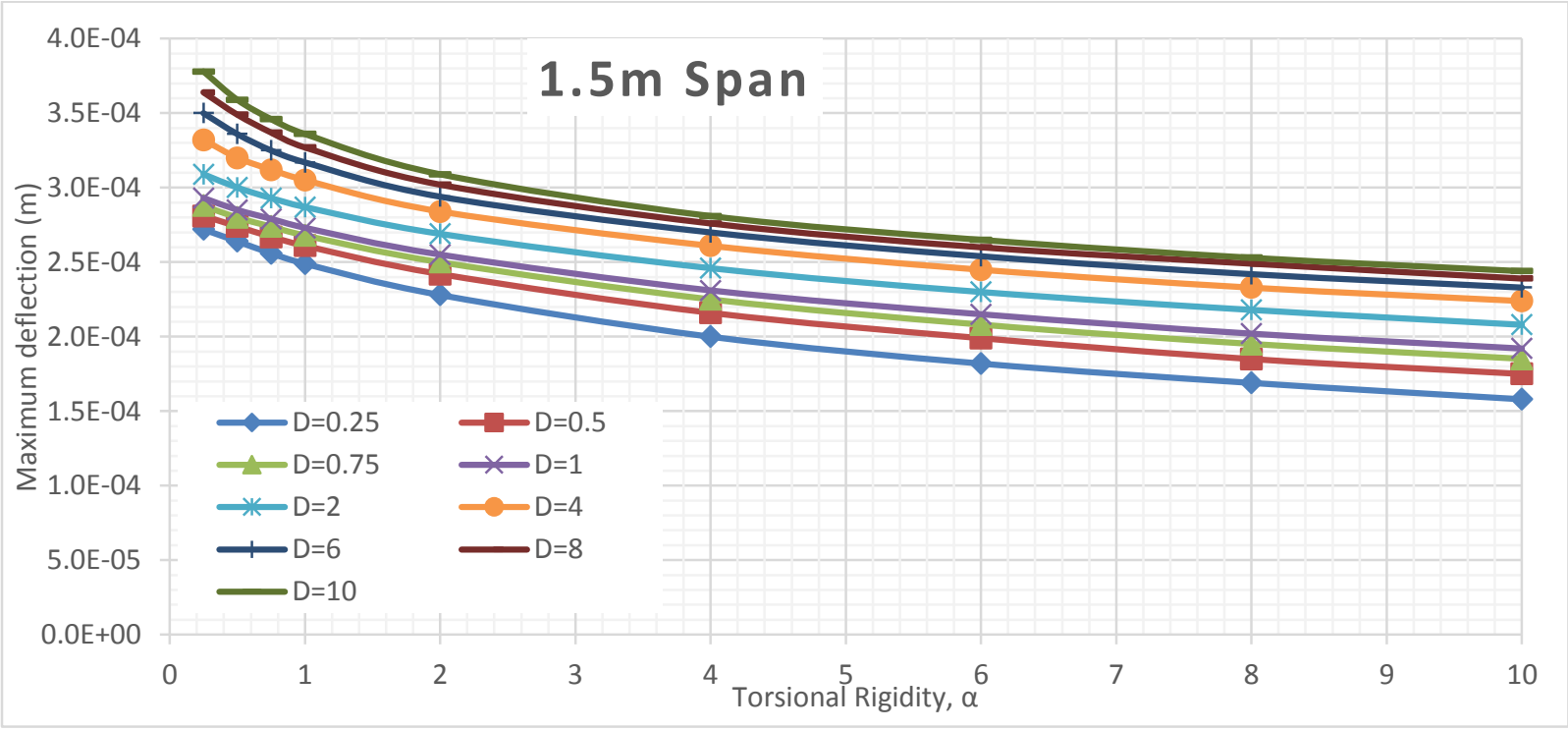

Figure 236 Maximum deflection of $1.5 \mathrm{~m}$ span slab subjected to CHBDC axle 4 for different D values FEA analyses 


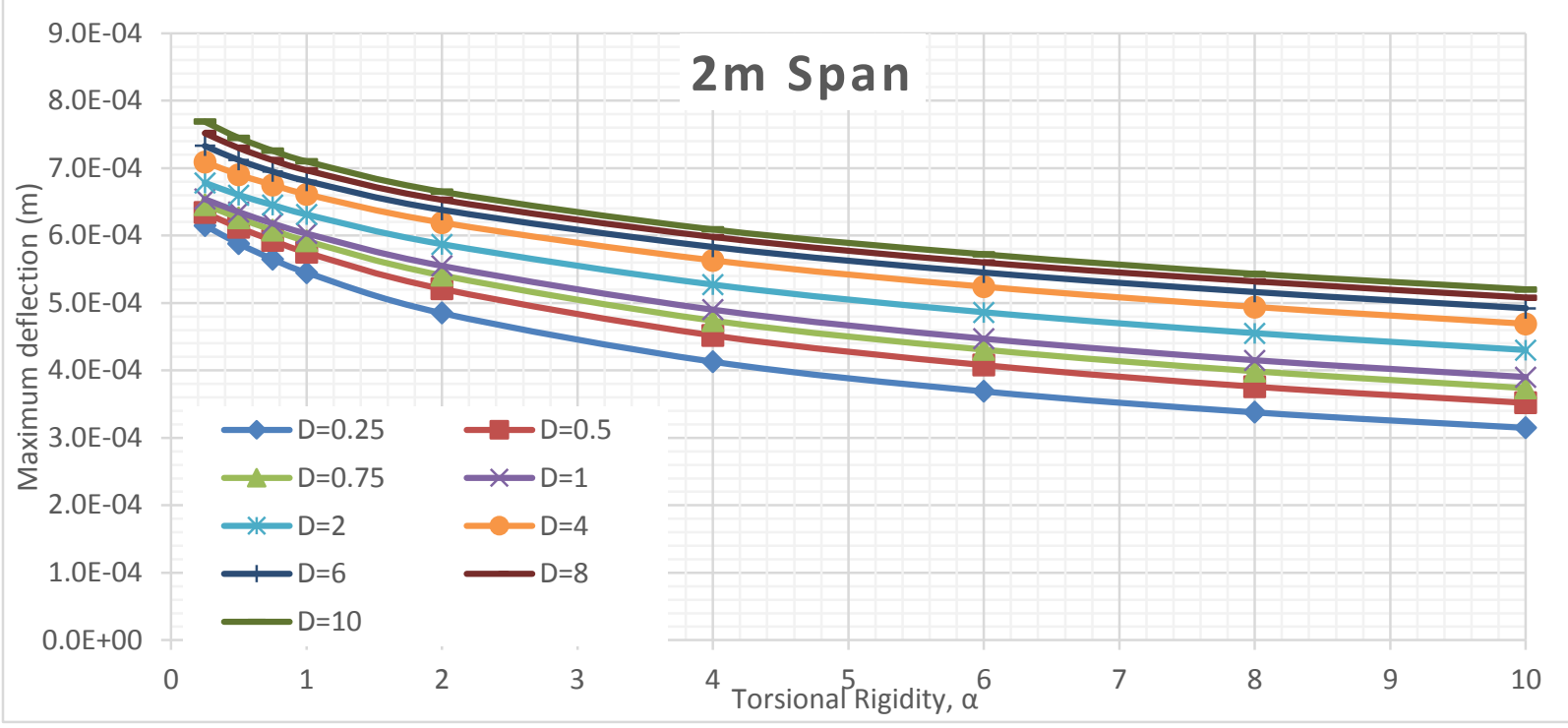

Figure 237 Maximum deflection of $2 \mathrm{~m}$ span slab subjected to CHBDC axle 4 for different D values FEA analyses

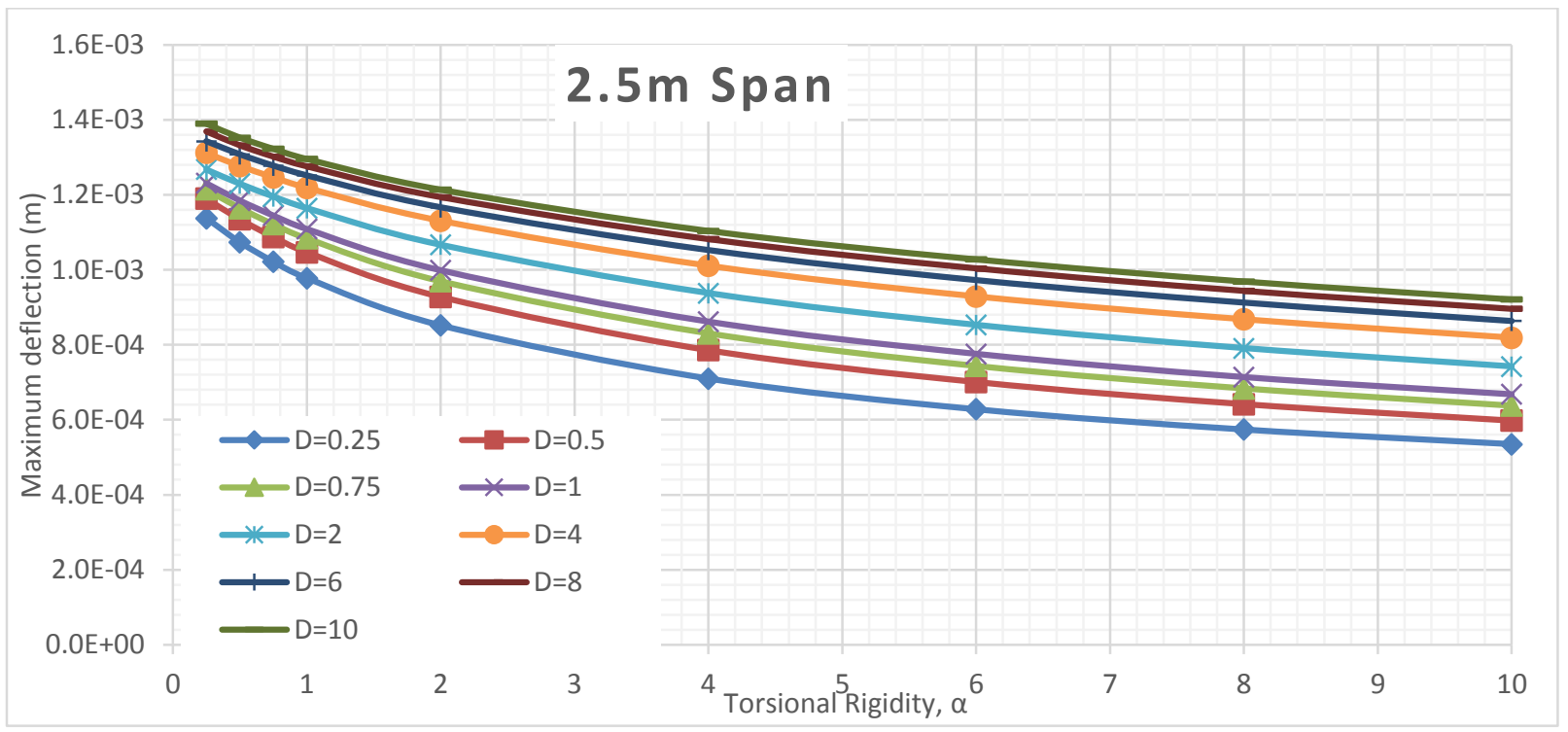

Figure 238 Maximum deflection of $2.5 \mathrm{~m}$ span slab subjected to CHBDC axle 4 for different D values FEA analyses

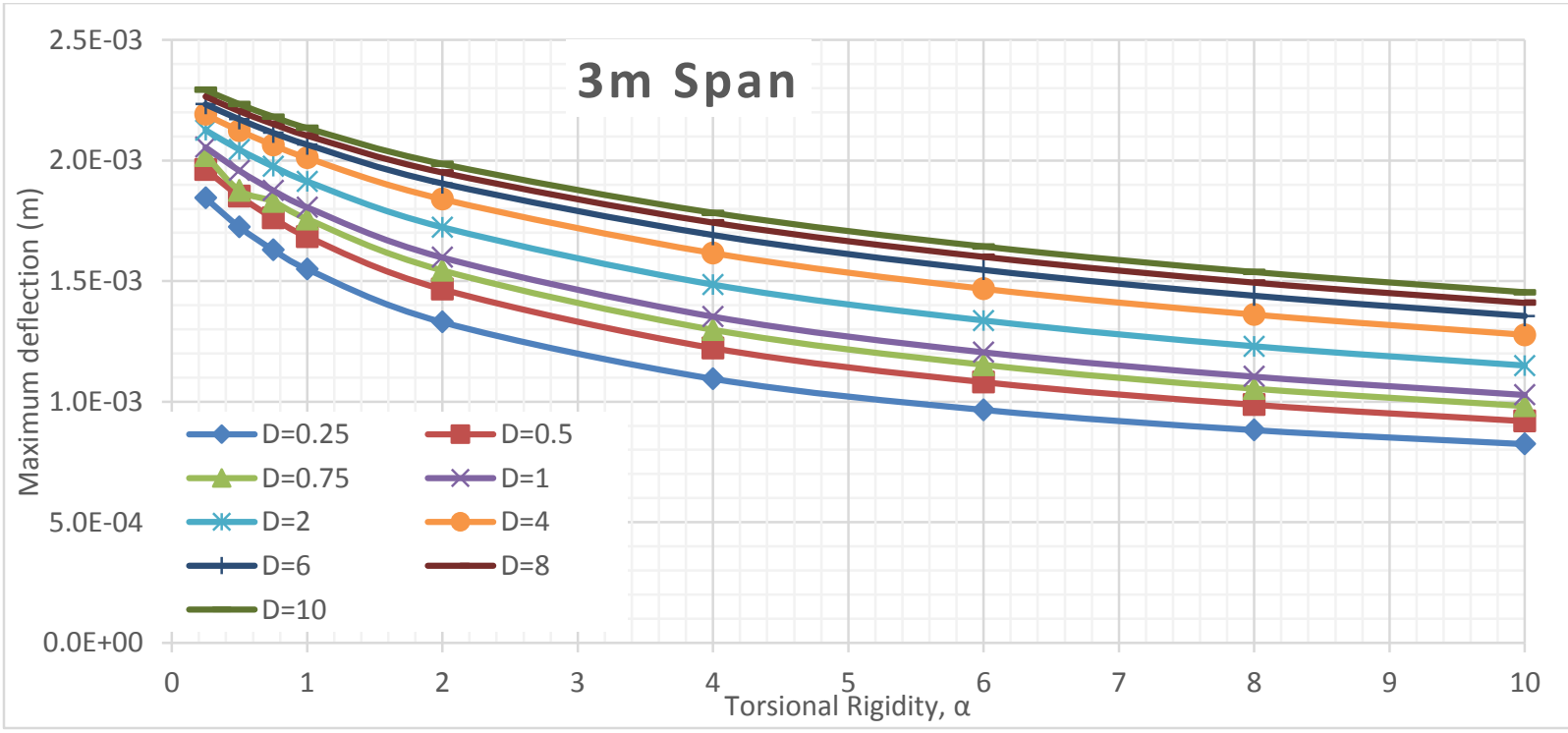

Figure 239 Maximum deflection of $3 \mathrm{~m}$ span slab subjected to CHBDC axle 4 for different $\mathrm{D}$ values FEA analyses 


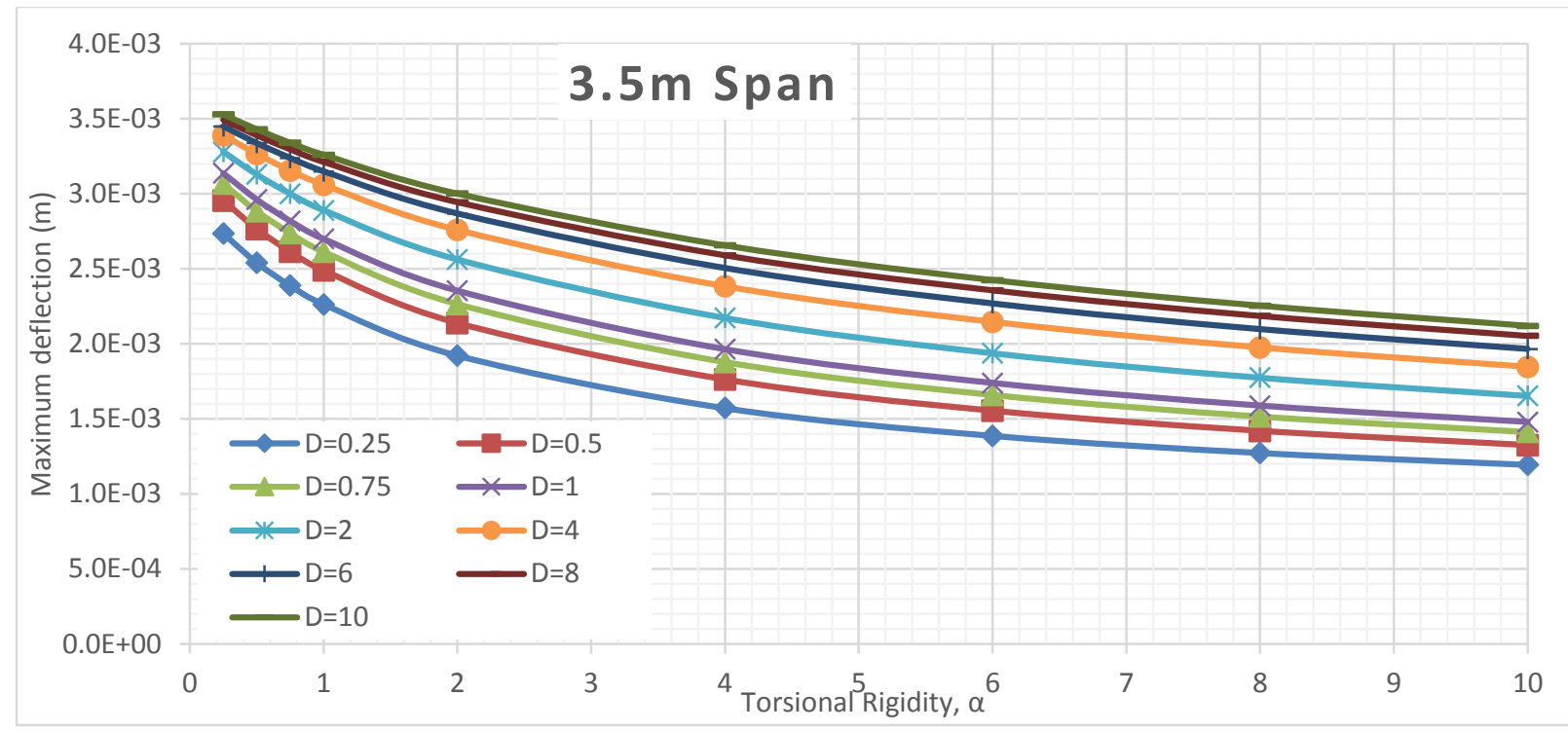

Figure 240 Maximum deflection of $3.5 \mathrm{~m}$ span slab subjected to CHBDC axle 4 for different D values FEA analyses 


\section{Axle 2 \& 3 Transverse Deflection VS Torsional Rigidity for Different D Values at Different span length}

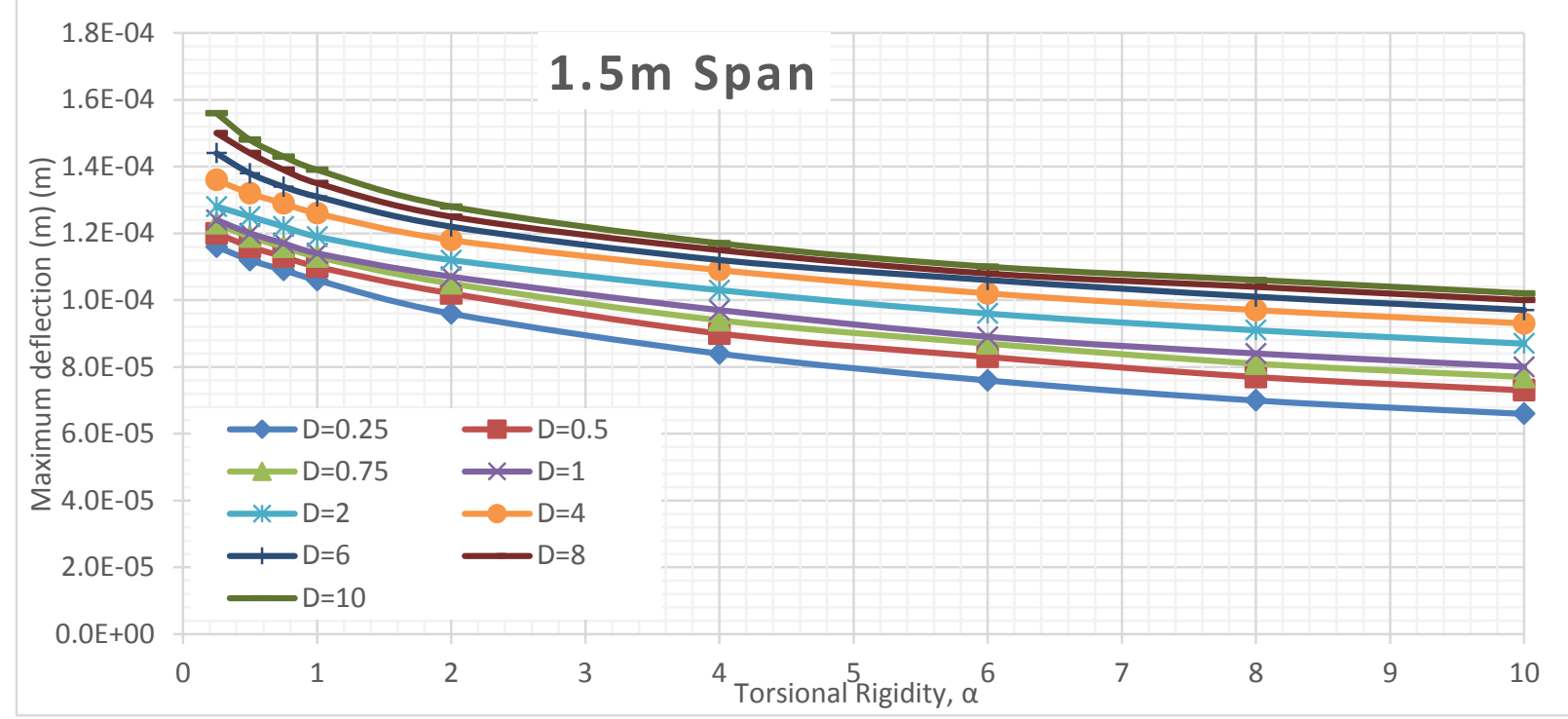

Figure 241 Maximum deflection of $1.5 \mathrm{~m}$ span slab subjected to CHBDC axle 2 \& 3 for different D values FEA analyses

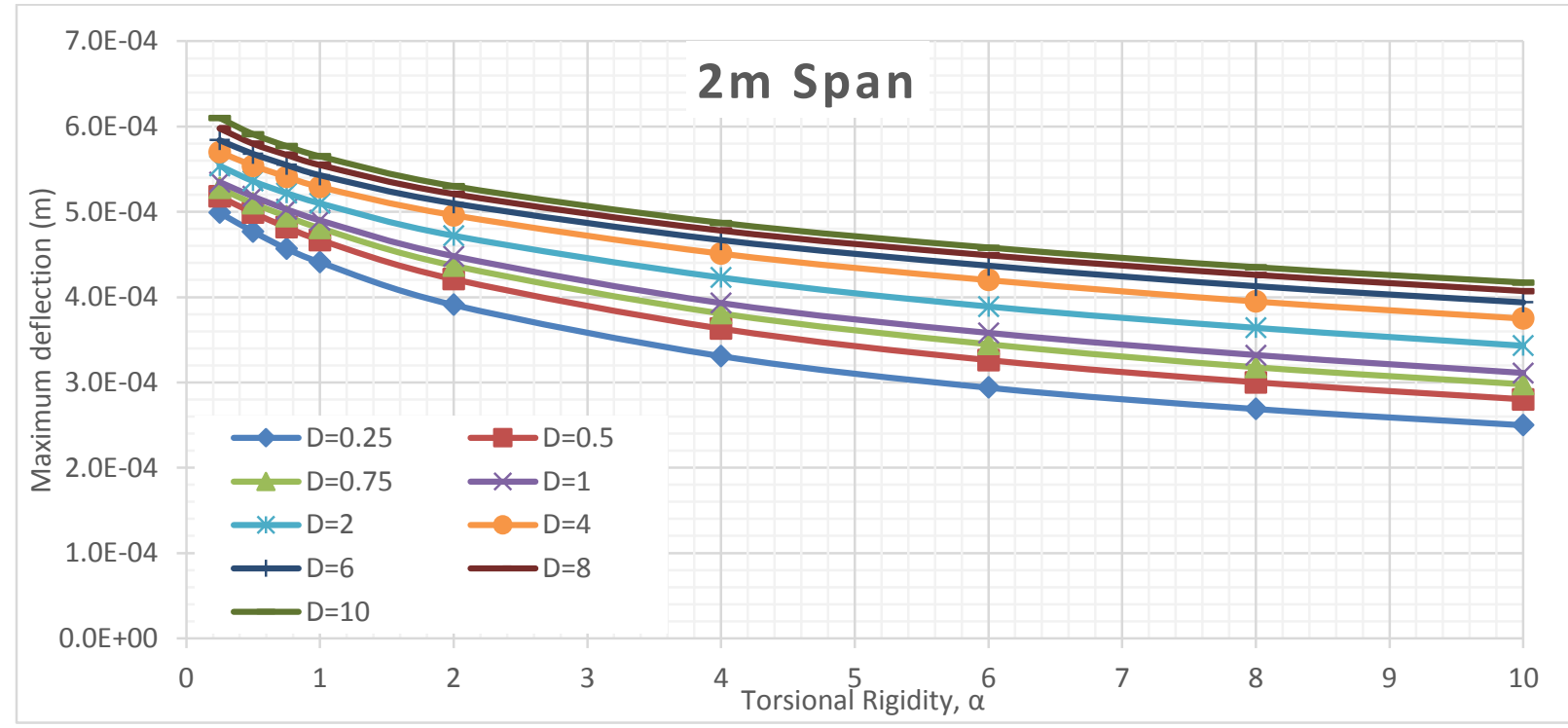

Figure 242 Maximum deflection of $2 \mathrm{~m}$ span slab subjected to CHBDC axle $2 \& 3$ for different D values FEA analyses 


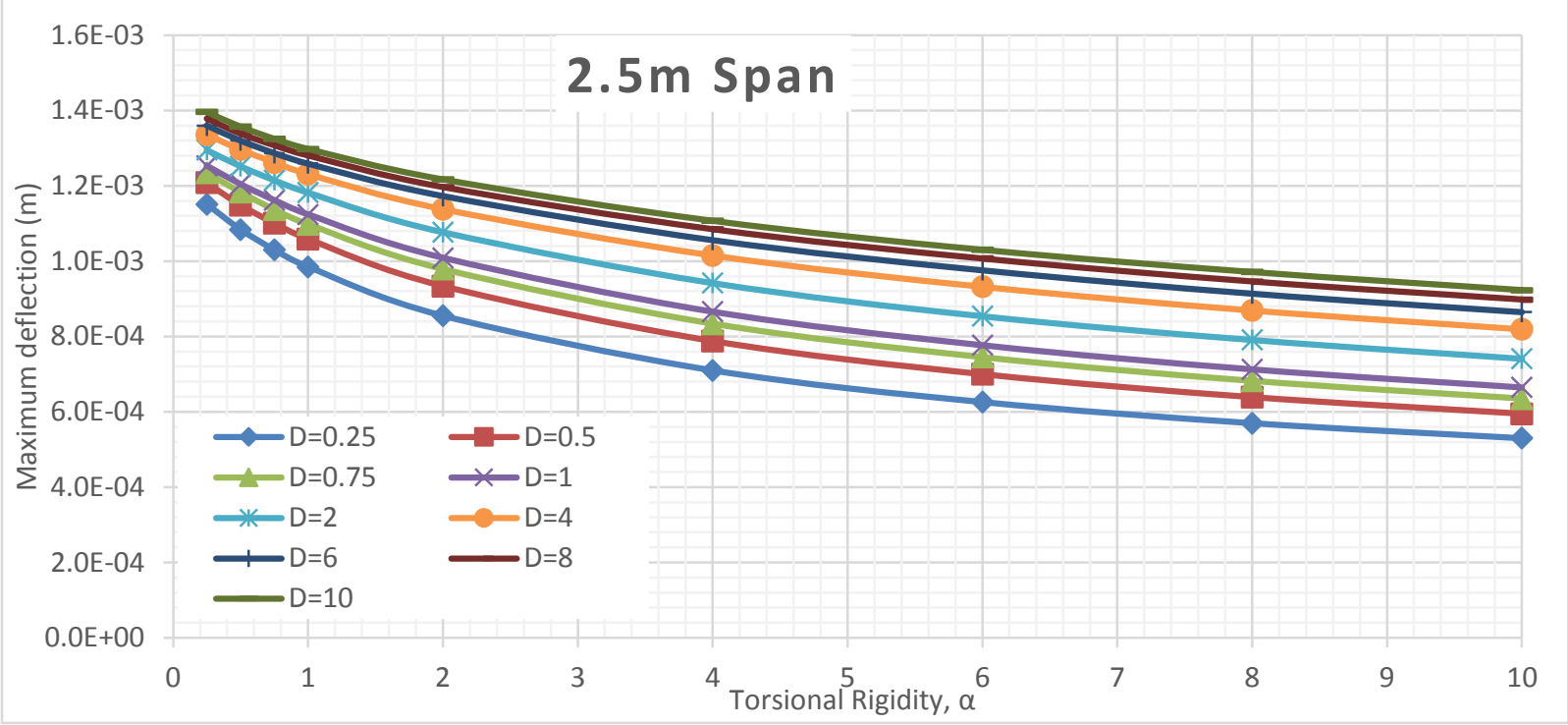

Figure 243 Maximum deflection of $2.5 \mathrm{~m}$ span slab subjected to CHBDC axle 2 \& 3 for different D values FEA analyses

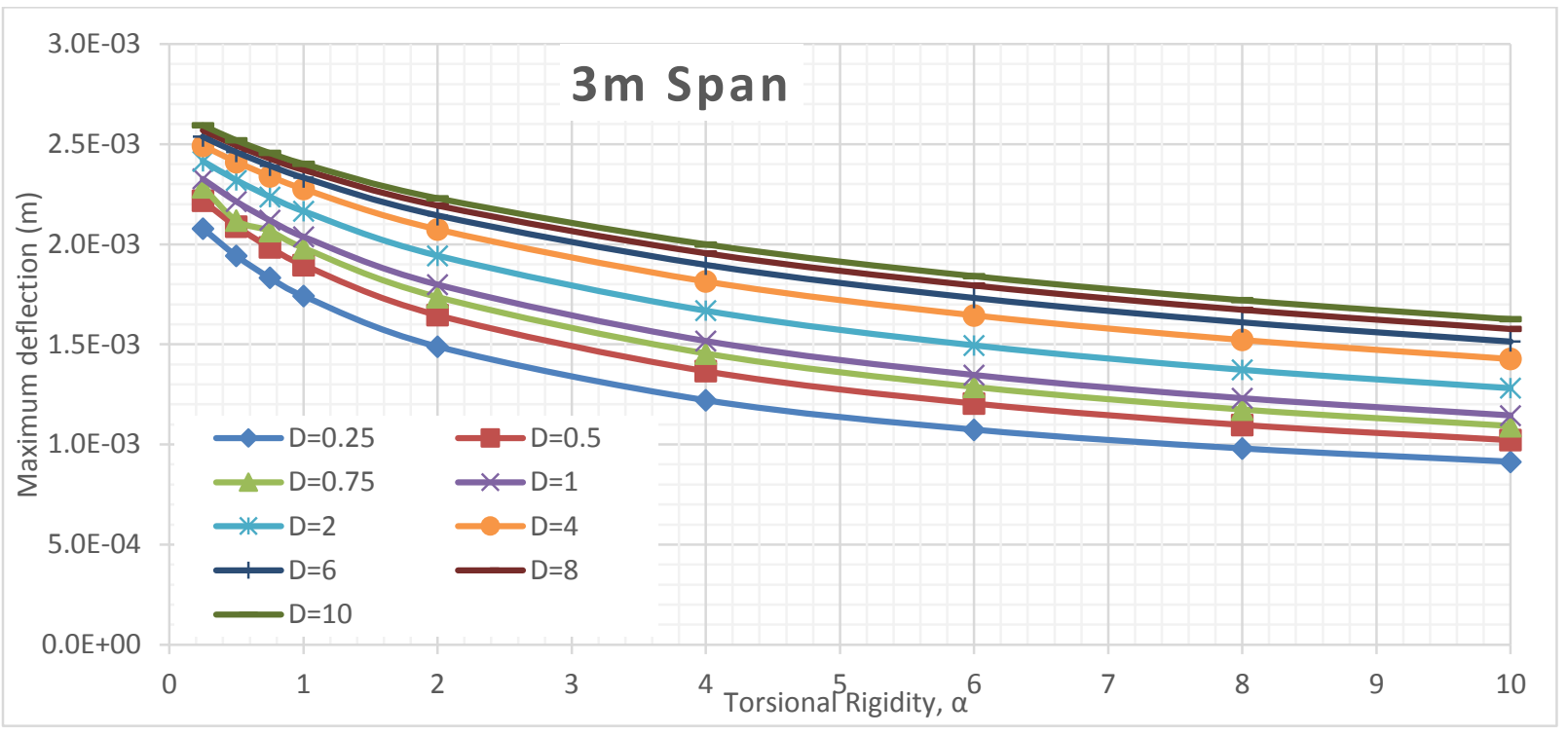

Figure 244 Maximum deflection of $3 \mathrm{~m}$ span slab subjected to CHBDC axle 2 \& 3 for different D values FEA analyses

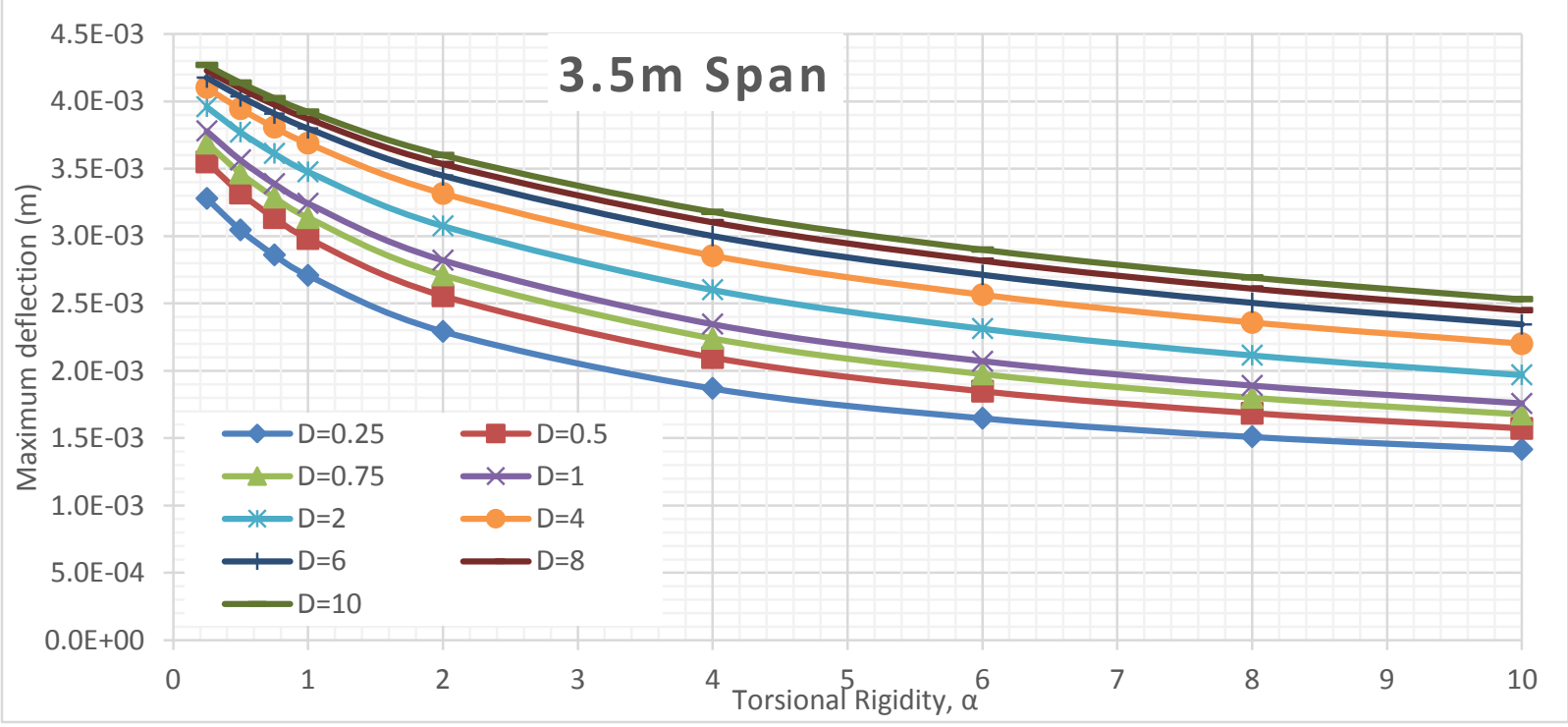

Figure 245 Maximum deflection of $3.5 \mathrm{~m}$ span slab subjected to CHBDC axle $2 \& 3$ for different D values FEA analyses 


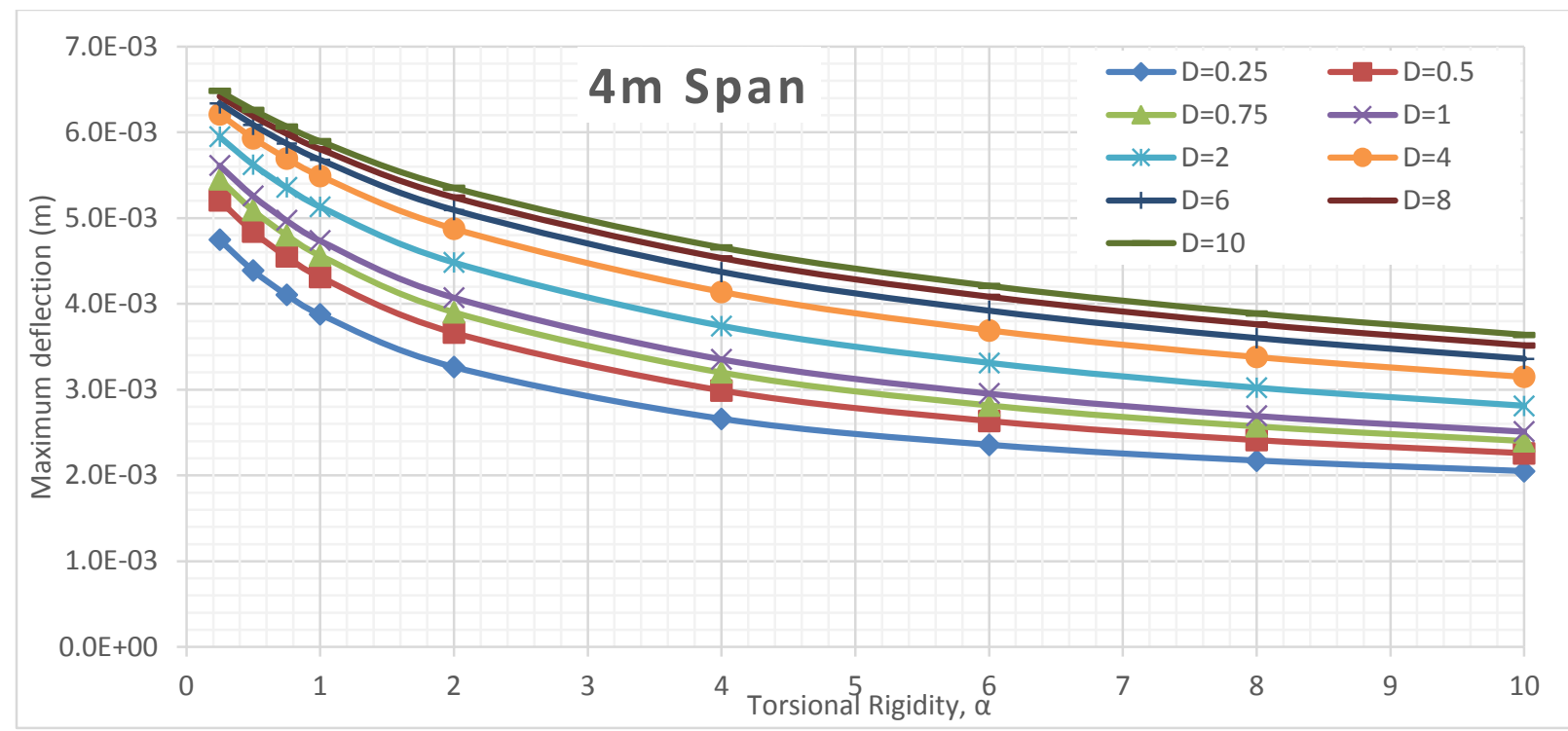

Figure 246 Maximum deflection of $4 \mathrm{~m}$ span slab subjected to CHBDC axle 2 \& 3 for different D values FEA analyses 
C.1 Orthotropic Plate Results (Bending Moment) 


\section{C.1.1 BENDING MOMENT RESULTS TABLES}




\section{Alpha 0.25 Bending Moment Results}

Table 100 Maximum moment results for alpha 0.25 for slabs subjected to CHBDC axle 4 loading (main bars perpendicular to traffic)

\begin{tabular}{|c|c|c|c|c|c|c|c|c|c|c|}
\hline & \multicolumn{9}{|c|}{ Maximum Moment (kN.m) } \\
\hline \multirow{9}{*}{$\begin{array}{l}+ \\
\frac{0}{x} \\
\frac{0}{x}\end{array}$} & $\mathrm{D}$ & \multirow{2}{*}{25} & \multirow{2}{*}{0.5} & \multirow{2}{*}{0.75} & \multirow[t]{2}{*}{1} & & & & \multirow{2}{*}{8} & \multirow{2}{*}{10} \\
\hline & SPAN & & & & & & & & & \\
\hline & 1 & 10.6531 & 12.6182 & 13.9219 & 14.9219 & 17.6071 & 20.7121 & 22.7347 & 24.2641 & 25.5045 \\
\hline & 1.5 & 13.2693 & 15.7350 & 17.3755 & 18.6367 & 22.0377 & 26.0017 & 28.6054 & 30.5875 & 32.2043 \\
\hline & 2 & 15.0973 & 17.9095 & 19.7829 & 21.2245 & 25.1184 & 29.6711 & 32.6714 & 34.9613 & 36.8334 \\
\hline & 2.5 & 16.5026 & 19.5815 & 21.6336 & 23.2137 & 27.4856 & 32.4890 & 35.7922 & 38.3171 & 40.3837 \\
\hline & 3 & 17.6847 & 20.9810 & 23.1787 & 24.8712 & 29.4500 & 34.8189 & 38.3678 & 41.0830 & 43.3071 \\
\hline & 3.5 & 18.6093 & 22.0867 & 24.4064 & 26.1936 & 31.0311 & 36.7085 & 40.4645 & 43.3401 & 45.6970 \\
\hline & 4 & 20.3552 & 24.1740 & 26.7240 & 28.6899 & 34.0167 & 40.2787 & 44.4278 & 47.6081 & 50.2171 \\
\hline
\end{tabular}

Table 101 Maximum moment results for alpha 0.25 for slabs subjected to CHBDC axle 2 \& 3 loading (main bars perpendicular to traffic)

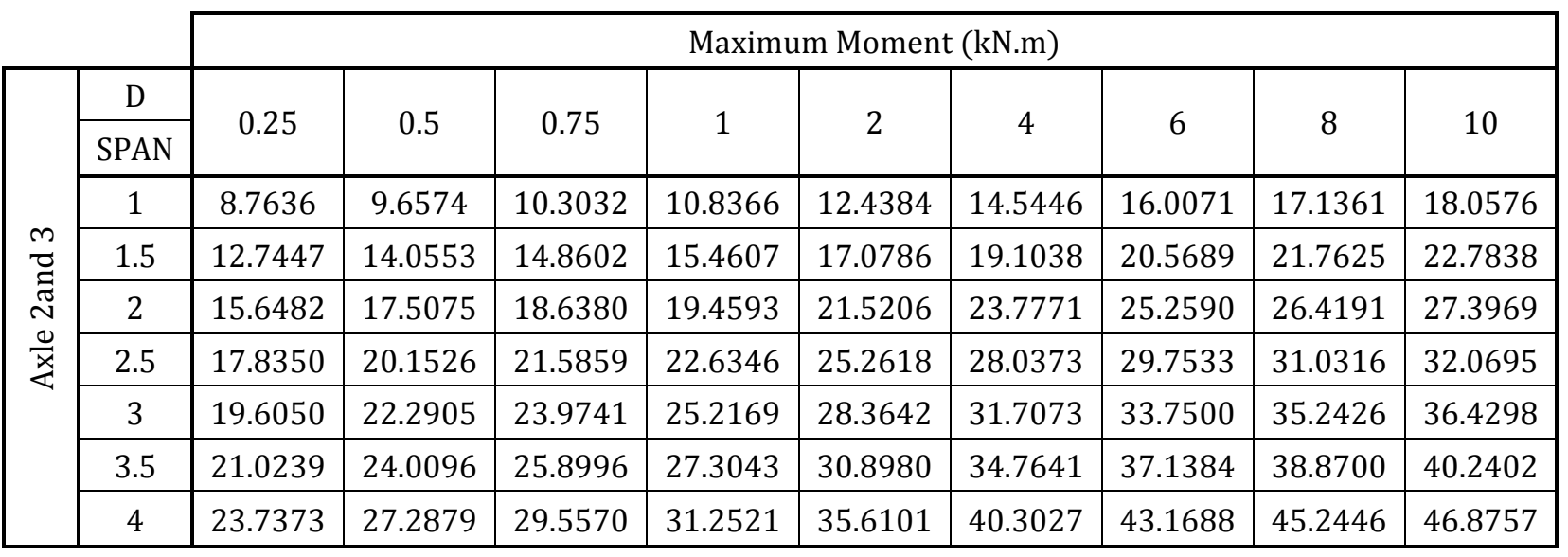

Table 102 Maximum moment results for alpha 0.25 for slabs subjected to CHBDC axle 4 loading (main bars perpendicular to traffic)

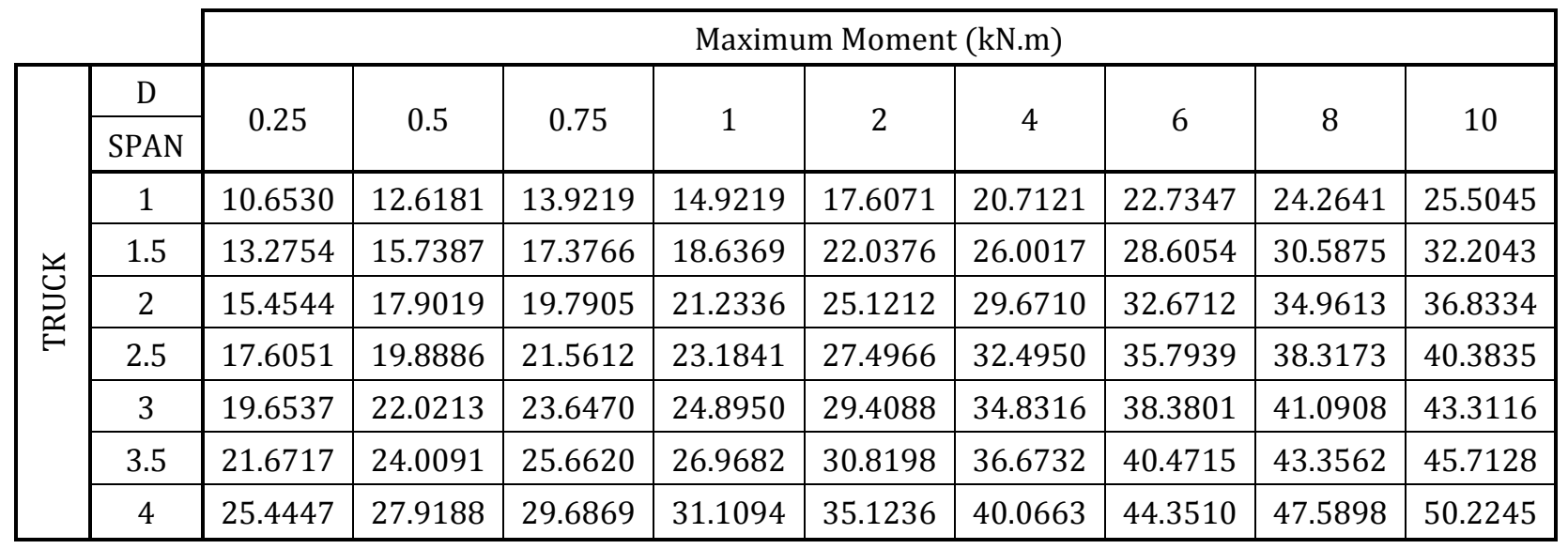


Table 103 Maximum moment results for alpha 0.25 for slabs subjected to CHBDC axle 4 loading (main bars Parallel to traffic)

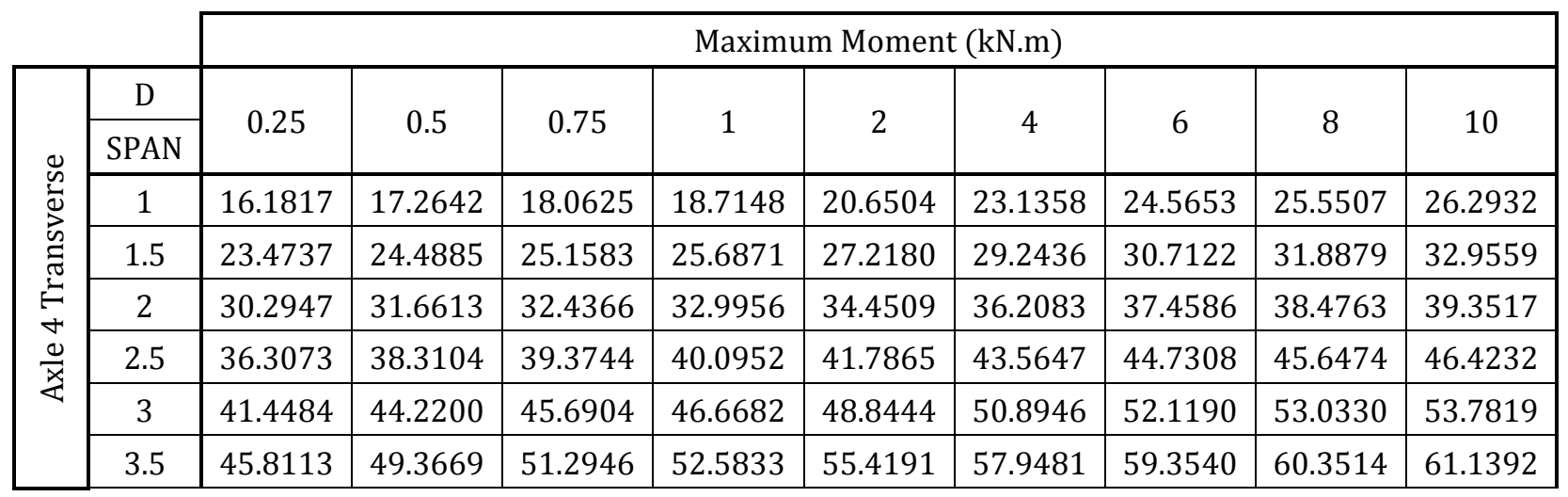

Table 104 Maximum moment results for alpha 0.25 for slabs subjected to CHBDC axle $2 \& 3$ loading (main bars Parallel to traffic)

\begin{tabular}{|c|c|c|c|c|c|c|c|c|c|c|}
\hline & & \multicolumn{9}{|c|}{ Maximum Moment (kN.m) } \\
\hline \multirow{8}{*}{ 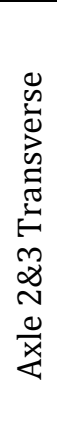 } & $\mathrm{D}$ & \multirow{2}{*}{0.25} & \multirow{2}{*}{0.5} & \multirow{2}{*}{0.75} & \multirow{2}{*}{1} & & \multirow[b]{2}{*}{4} & \multirow[b]{2}{*}{0} & \multirow{2}{*}{8} & \multirow{2}{*}{10} \\
\hline & SPAN & & & & & & & & & \\
\hline & 1.5 & 7.4724 & 8.0104 & 8.3157 & 8.5263 & 9.0125 & 9.4780 & 9.7487 & 9.9428 & 10.1056 \\
\hline & 2 & 17.6176 & 18.5841 & 19.1669 & 19.5942 & 20.6912 & 21.9237 & 22.7326 & 23.3566 & 23.8736 \\
\hline & 2.5 & 26.8916 & 28.3609 & 29.1298 & 29.6453 & 30.8403 & 32.0897 & 32.9149 & 33.5694 & 34.1272 \\
\hline & 3 & 34.9848 & 37.3503 & 38.5559 & 39.3294 & 40.9478 & 42.3485 & 43.1599 & 43.7717 & 44.2833 \\
\hline & 3.5 & 41.8302 & 45.2359 & 47.0211 & 48.1772 & 50.5678 & 52.4638 & 53.4246 & 54.0833 & 54.6005 \\
\hline & 4 & 47.6380 & 52.0864 & 54.4965 & 56.0899 & 59.4590 & 62.1346 & 63.4222 & 64.2481 & 64.8579 \\
\hline
\end{tabular}




\section{Alpha 0.5 Bending Moment Results}

Table 105 Maximum moment results for alpha 0.5 for slabs subjected to CHBDC axle 4 loading (main bars perpendicular to traffic)

\begin{tabular}{|c|c|c|c|c|c|c|c|c|c|c|}
\hline & \multicolumn{9}{|c|}{ Maximum Moment (kN.m) } \\
\hline \multirow{9}{*}{$\frac{\vec{d}}{x}$} & $\mathrm{D}$ & \multirow{2}{*}{.25} & \multirow{2}{*}{0.5} & \multirow{2}{*}{0.75} & \multirow{2}{*}{1} & & \multirow[t]{2}{*}{4} & & \multirow{2}{*}{8} & \multirow{2}{*}{10} \\
\hline & SPAN & & & & & & & & & \\
\hline & 1 & 9.7254 & 11.5197 & 12.7104 & 13.6238 & 16.0774 & 18.9172 & 20.7690 & 22.1707 & 23.3085 \\
\hline & 1.5 & 12.1131 & 14.3643 & 15.8624 & 17.0143 & 20.1212 & 23.7447 & 26.1266 & 27.9412 & 29.4223 \\
\hline & 2 & 13.7821 & 16.3498 & 18.0603 & 19.3768 & 22.9337 & 27.0946 & 29.8385 & 31.9340 & 33.6480 \\
\hline & 2.5 & 15.0649 & 17.8759 & 19.7498 & 21.1927 & 25.0947 & 29.6670 & 32.6874 & 34.9974 & 36.8890 \\
\hline & 3 & 16.1455 & 19.1555 & 21.1625 & 22.7083 & 26.8909 & 31.7971 & 35.0419 & 37.5256 & 39.5611 \\
\hline & 3.5 & 16.9885 & 20.1633 & 22.2813 & 23.9133 & 28.3314 & 33.5188 & 36.9525 & 39.5826 & 41.7391 \\
\hline & 4 & 18.5805 & 22.0662 & 24.3939 & 26.1885 & 31.0521 & 36.7719 & 40.5639 & 43.4716 & 45.8581 \\
\hline
\end{tabular}

Table 106 Maximum moment results for alpha 0.5 for slabs subjected to CHBDC axle $2 \& 3$ loading (main bars perpendicular to traffic)

\begin{tabular}{|c|c|c|c|c|c|c|c|c|c|c|}
\hline & \multicolumn{9}{|c|}{ Maximum Moment (kN.m) } \\
\hline \multirow{9}{*}{ 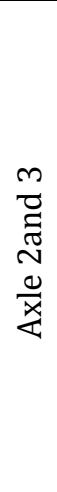 } & $\mathrm{D}$ & \multirow{2}{*}{.25} & \multirow{2}{*}{0.5} & \multirow{2}{*}{0.75} & \multirow{2}{*}{1} & & \multirow{2}{*}{4} & & \multirow{2}{*}{8} & \multirow{2}{*}{10} \\
\hline & SPAN & & & & & & & & & \\
\hline & 1 & 8.2888 & 9.1597 & 9.7658 & 10.2543 & 11.6789 & 13.5113 & 14.7821 & 15.7694 & 16.5811 \\
\hline & 1.5 & 11.8786 & 13.1635 & 13.9583 & 14.5508 & 16.1273 & 18.0334 & 19.3689 & 20.4376 & 21.3426 \\
\hline & 2 & 14.4974 & 16.2673 & 17.3531 & 18.1469 & 20.1552 & 22.3597 & 23.7922 & 24.8985 & 25.8193 \\
\hline & 2.5 & 16.4809 & 18.6578 & 20.0107 & 21.0049 & 23.5145 & 26.1970 & 27.8669 & 29.1115 & 30.1195 \\
\hline & 3 & 18.0924 & 20.5998 & 22.1761 & 23.3426 & 26.3113 & 29.4948 & 31.4579 & 32.9005 & 34.0519 \\
\hline & 3.5 & 19.3845 & 22.1626 & 23.9243 & 25.2356 & 28.6008 & 32.2452 & 34.5000 & 36.1538 & 37.4683 \\
\hline & 4 & 21.8504 & 25.1352 & 27.2360 & 28.8070 & 32.8577 & 37.2527 & 39.9621 & 41.9391 & 43.5018 \\
\hline
\end{tabular}

Table 107 Maximum moment results for alpha 0.5 for slabs subjected to CHBDC axle 4 loading (main bars perpendicular to traffic)

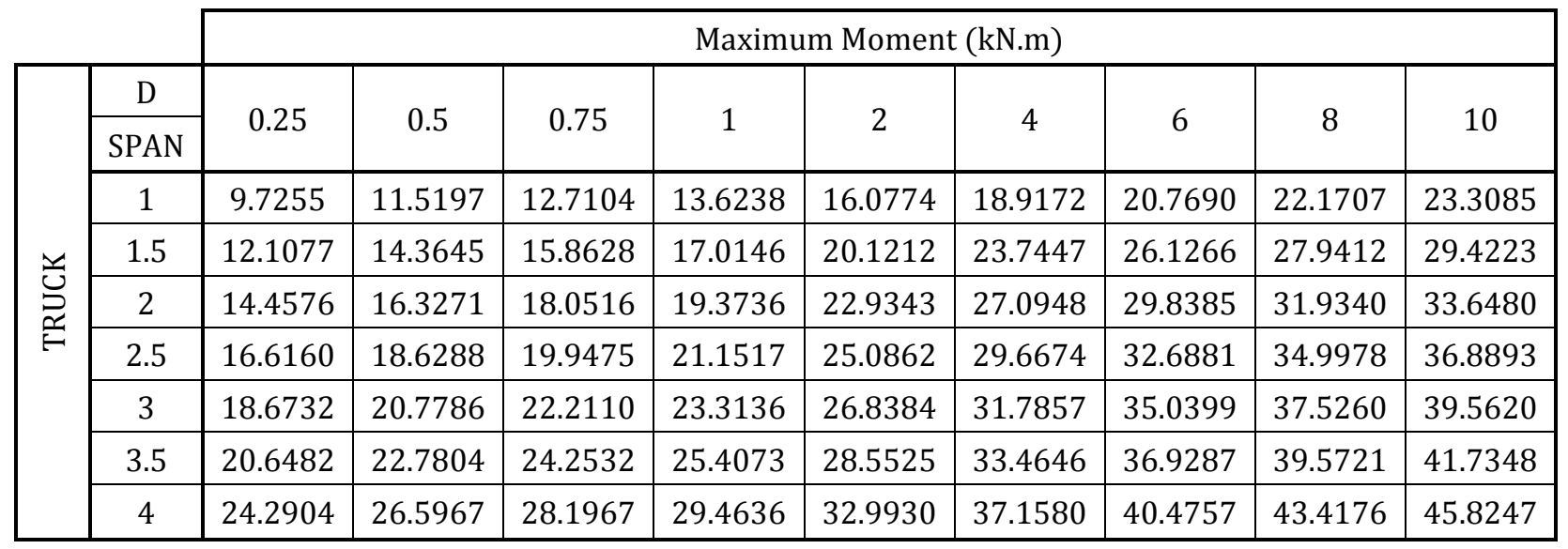


Table 108 Maximum moment results for alpha 0.5 for slabs subjected to CHBDC axle 4 loading (main bars Parallel to traffic)

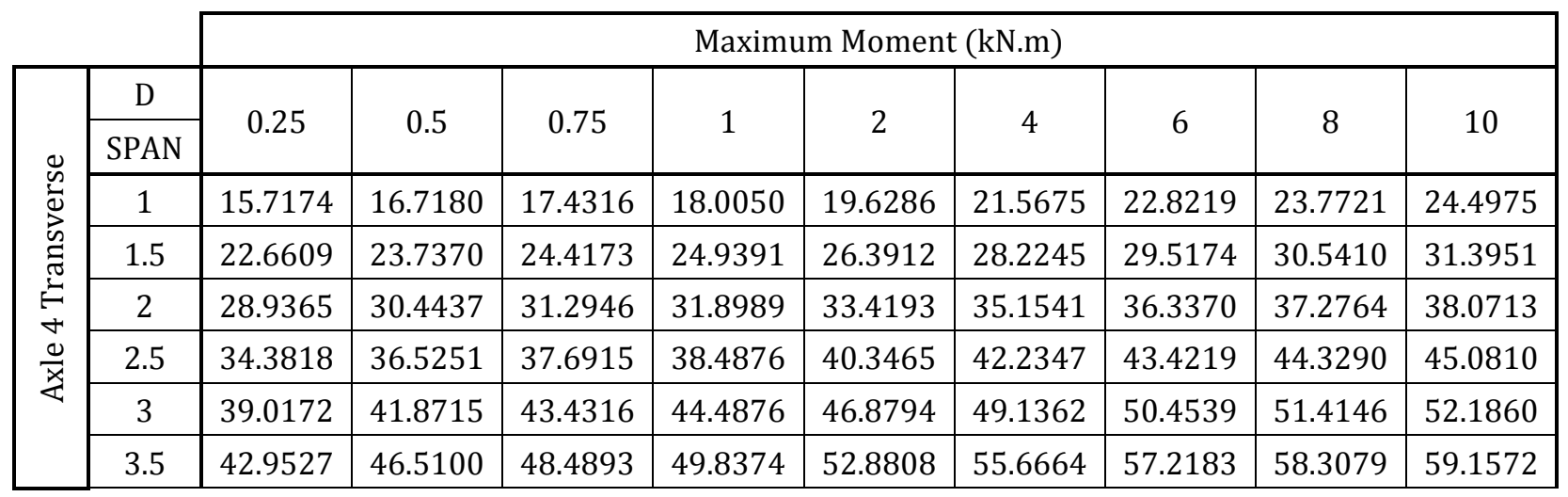

Table 109 Maximum moment results for alpha 0.5 for slabs subjected to CHBDC axle 2 \& 3 loading (main bars Parallel to traffic)

\begin{tabular}{|c|c|c|c|c|c|c|c|c|c|c|}
\hline & & \multicolumn{9}{|c|}{ Maximum Moment (kN.m) } \\
\hline \multirow{8}{*}{ 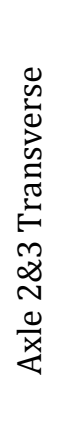 } & $\mathrm{D}$ & \multirow{2}{*}{0.25} & \multirow{2}{*}{0.5} & \multirow{2}{*}{0.75} & \multirow{2}{*}{1} & & \multirow{2}{*}{4} & & \multirow{2}{*}{8} & \multirow{2}{*}{10} \\
\hline & SPAN & & & & & & & & & \\
\hline & 1.5 & 7.0958 & 7.6159 & 7.9173 & 8.1283 & 8.6242 & 9.1049 & 9.3824 & 9.5792 & 9.7320 \\
\hline & 2 & 16.8469 & 17.8396 & 18.4303 & 18.8589 & 19.9432 & 21.1373 & 21.9079 & 22.4951 & 22.9769 \\
\hline & 2.5 & 25.4483 & 27.0294 & 27.8812 & 28.4585 & 29.7938 & 31.1399 & 31.9875 & 32.6380 & 33.1798 \\
\hline & 3 & 32.8157 & 35.2704 & 36.5756 & 37.4385 & 39.3149 & 40.9820 & 41.9245 & 42.6084 & 43.1607 \\
\hline & 3.5 & 39.0068 & 42.4219 & 44.2769 & 45.5128 & 48.1887 & 50.4571 & 51.6421 & 52.4483 & 53.0683 \\
\hline & 4 & 44.2532 & 48.6093 & 51.0362 & 52.6779 & 56.2918 & 59.3693 & 60.9360 & 61.9643 & 62.7271 \\
\hline
\end{tabular}




\section{Alpha 0.75 Bending Moment Results}

Table 110 Maximum moment results for alpha 0.75 for slabs subjected to CHBDC axle 4 loading (main bars perpendicular to traffic)

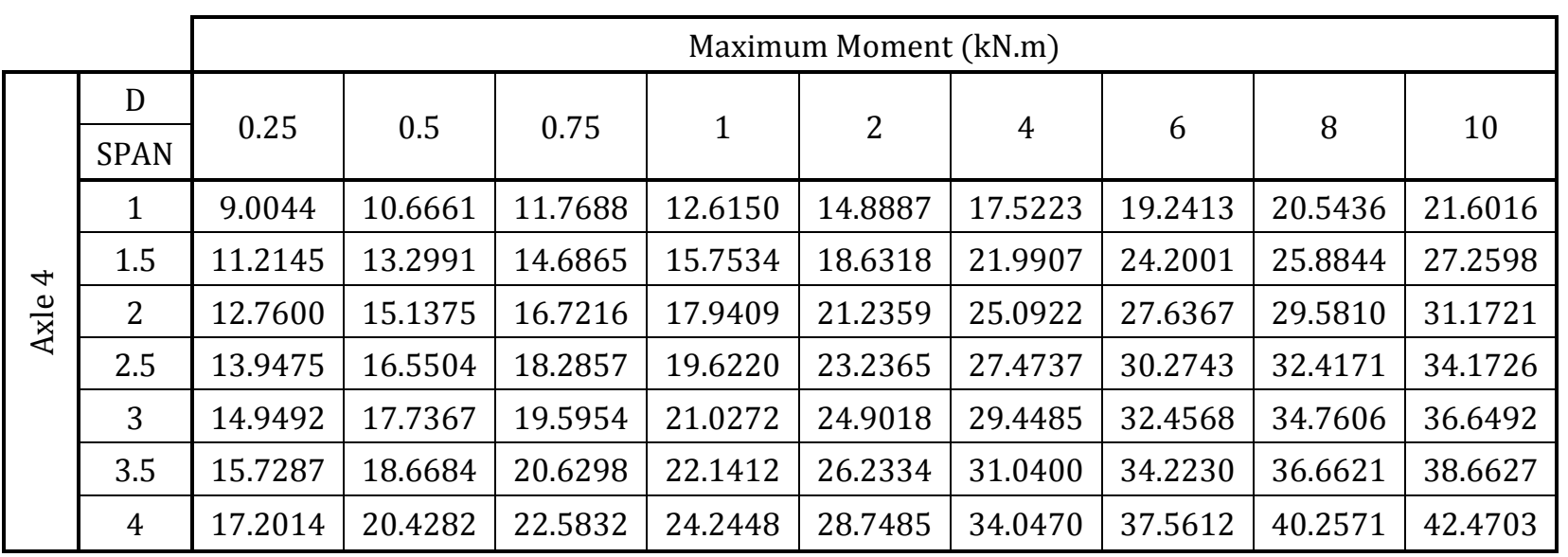

Table 111 Maximum moment results for alpha 0.75 for slabs subjected to CHBDC axle $2 \& 3$ loading (main bars perpendicular to traffic)

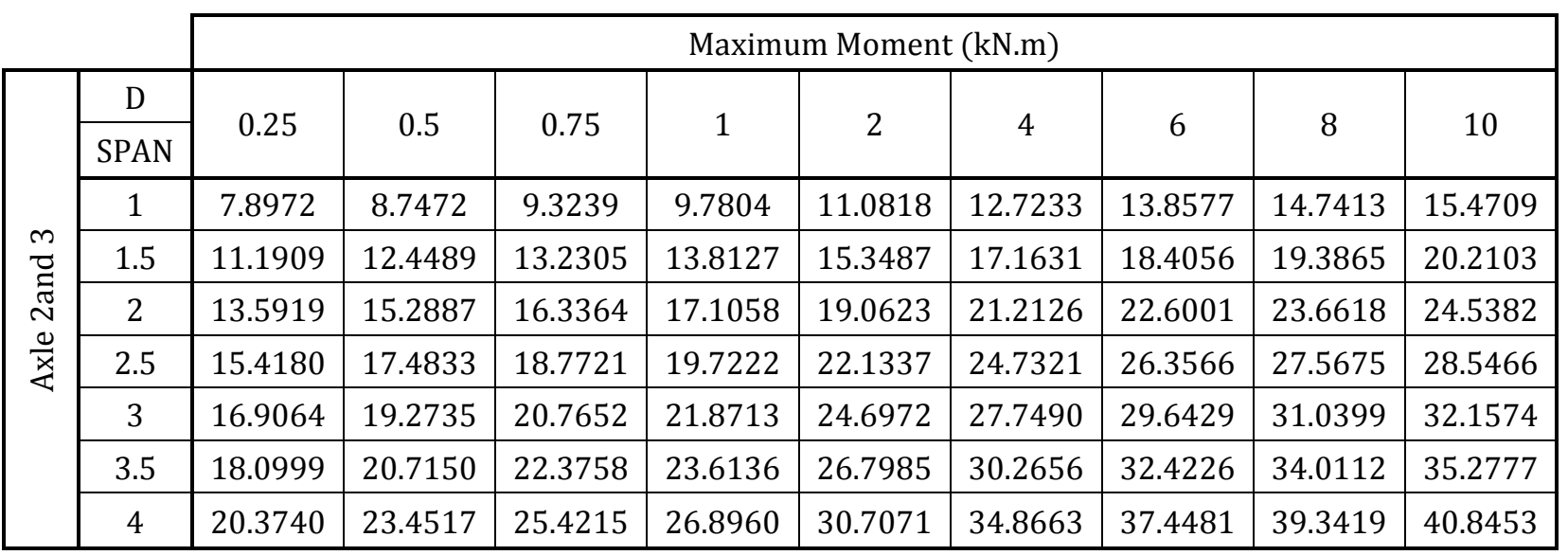

Table 112 Maximum moment results for alpha 0.75 for slabs subjected to CHBDC axle 4 loading (main bars perpendicular to traffic)

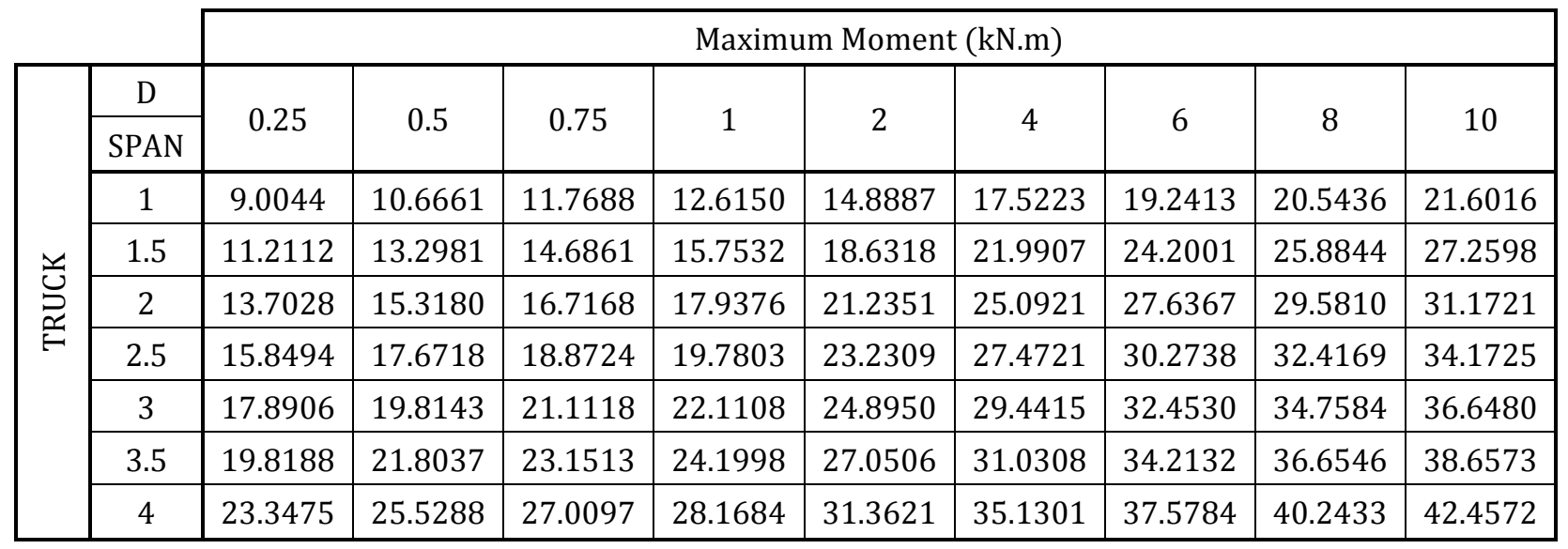


Table 113 Maximum moment results for alpha 0.75 for slabs subjected to CHBDC axle 4 loading (main bars Parallel to traffic)

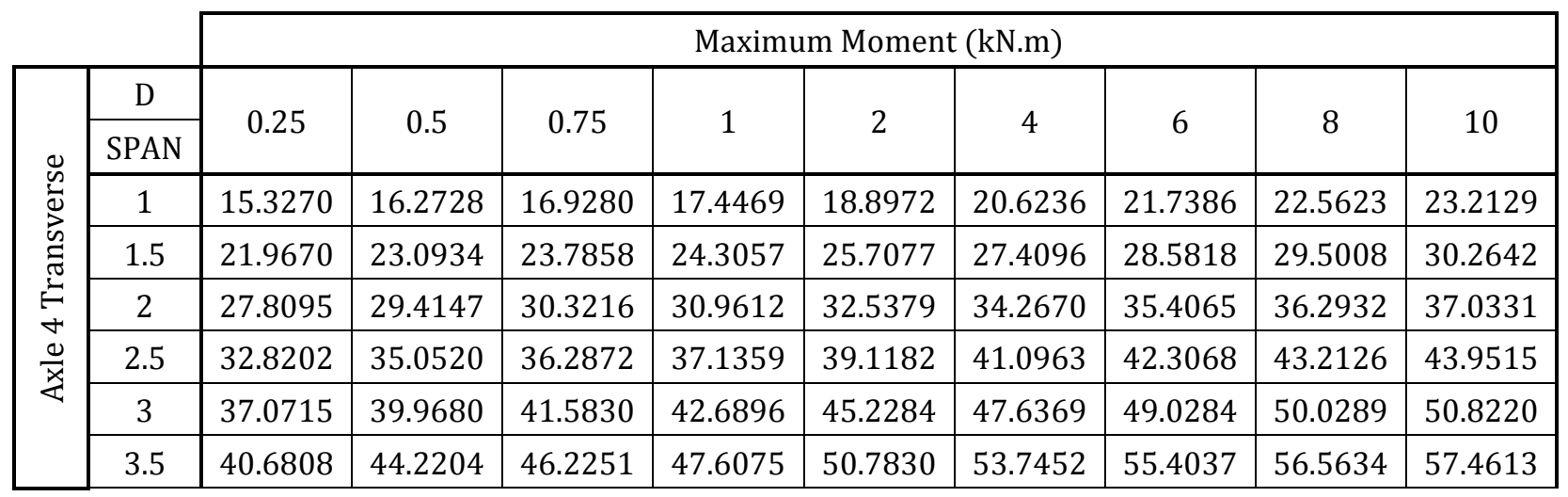

Table 114 Maximum moment results for alpha 0.75 for slabs subjected to CHBDC axle $2 \& 3$ loading (main bars Parallel to traffic)

\begin{tabular}{|c|c|c|c|c|c|c|c|c|c|c|}
\hline & & \multicolumn{9}{|c|}{ Maximum Moment (kN.m) } \\
\hline \multirow{8}{*}{ 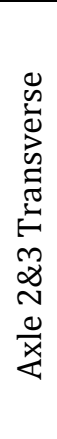 } & $\mathrm{D}$ & \multirow{2}{*}{0.25} & \multirow{2}{*}{0.5} & \multirow{2}{*}{0.75} & \multirow{2}{*}{1} & \multirow[b]{2}{*}{2} & \multirow[b]{2}{*}{4} & \multirow[b]{2}{*}{0} & \multirow{2}{*}{8} & \multirow{2}{*}{10} \\
\hline & SPAN & & & & & & & & & \\
\hline & 1.5 & 6.8001 & 7.3042 & 7.6006 & 7.8101 & 8.3090 & 8.7977 & 9.0798 & 9.2789 & 9.4329 \\
\hline & 2 & 16.2121 & 17.2237 & 17.8214 & 18.2522 & 19.3301 & 20.4974 & 21.2398 & 21.8001 & 22.2562 \\
\hline & 2.5 & 24.2783 & 25.9301 & 26.8377 & 27.4581 & 28.8962 & 30.3203 & 31.1904 & 31.8428 & 32.3765 \\
\hline & 3 & 31.0849 & 33.5872 & 34.9546 & 35.8757 & 37.9278 & 39.7879 & 40.8311 & 41.5738 & 42.1617 \\
\hline & 3.5 & 36.7743 & 40.1742 & 42.0662 & 43.3500 & 46.2108 & 48.7357 & 50.0823 & 50.9988 & 51.6979 \\
\hline & 4 & 41.5906 & 45.8543 & 48.2770 & 49.9416 & 53.7033 & 57.0473 & 58.8073 & 59.9800 & 60.8544 \\
\hline
\end{tabular}




\section{Alpha 1 Bending Moment Results}

Table 115 Maximum moment results for alpha 1 for slabs subjected to CHBDC axle 4 loading (main bars perpendicular to traffic)

\begin{tabular}{|c|c|c|c|c|c|c|c|c|c|c|}
\hline & \multicolumn{9}{|c|}{ Maximum Moment (kN.m) } \\
\hline \multirow{9}{*}{$\frac{\vec{d}}{x}$} & $\mathrm{D}$ & \multirow{2}{*}{25} & \multirow{2}{*}{0.5} & \multirow{2}{*}{0.75} & \multirow[t]{2}{*}{1} & & \multirow{2}{*}{4} & & \multirow{2}{*}{8} & \multirow{2}{*}{10} \\
\hline & SPAN & & & & & & & & & \\
\hline & 1 & 8.4232 & 9.9780 & 11.0099 & 11.8019 & 13.9306 & 16.3979 & 18.0098 & 19.2319 & 20.2254 \\
\hline & 1.5 & 10.4902 & 12.4405 & 13.7387 & 14.7370 & 17.4313 & 20.5768 & 22.6472 & 24.2262 & 25.5163 \\
\hline & 2 & 11.9361 & 14.1604 & 15.6426 & 16.7835 & 19.8673 & 23.4781 & 25.8619 & 27.6841 & 29.1759 \\
\hline & 2.5 & 13.0468 & 15.4819 & 17.1055 & 18.3560 & 21.7387 & 25.7058 & 28.3291 & 30.3371 & 31.9826 \\
\hline & 3 & 13.9848 & 16.5929 & 18.3322 & 19.6721 & 23.2984 & 27.5552 & 30.3729 & 32.5314 & 34.3016 \\
\hline & 3.5 & 14.7133 & 17.4635 & 19.2986 & 20.7127 & 24.5423 & 29.0418 & 32.0228 & 34.3078 & 36.1827 \\
\hline & 4 & 16.0897 & 19.1080 & 21.1238 & 22.6782 & 26.8919 & 31.8509 & 35.1411 & 37.6660 & 39.7396 \\
\hline
\end{tabular}

Table 116 Maximum moment results for alpha 1 for slabs subjected to CHBDC axle 2 \& 3 loading (main bars perpendicular to traffic)

\begin{tabular}{|c|c|c|c|c|c|c|c|c|c|c|}
\hline & \multicolumn{9}{|c|}{ Maximum Moment (kN.m) } \\
\hline \multirow{9}{*}{ 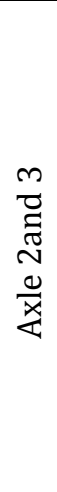 } & $\mathrm{D}$ & \multirow{2}{*}{.25} & \multirow{2}{*}{0.5} & \multirow{2}{*}{0.75} & \multirow{2}{*}{1} & & \multirow{2}{*}{4} & & \multirow{2}{*}{8} & \multirow{2}{*}{10} \\
\hline & SPAN & & & & & & & & & \\
\hline & 1 & 7.5657 & 8.3968 & 8.9505 & 9.3830 & 10.5940 & 12.0957 & 13.1281 & 13.9330 & 14.5989 \\
\hline & 1.5 & 10.6258 & 11.8574 & 12.6247 & 13.1959 & 14.6940 & 16.4347 & 17.6068 & 18.5227 & 19.2866 \\
\hline & 2 & 12.8537 & 14.4889 & 15.5035 & 16.2510 & 18.1584 & 20.2563 & 21.6031 & 22.6273 & 23.4676 \\
\hline & 2.5 & 14.5534 & 16.5271 & 17.7628 & 18.6760 & 21.0037 & 23.5261 & 25.1077 & 26.2867 & 27.2387 \\
\hline & 3 & 15.9426 & 18.1952 & 19.6177 & 20.6743 & 23.3820 & 26.3220 & 28.1550 & 29.5108 & 30.5968 \\
\hline & 3.5 & 17.0566 & 19.5391 & 21.1177 & 22.2956 & 25.3330 & 28.6533 & 30.7278 & 32.2603 & 33.4849 \\
\hline & 4 & 19.1767 & 22.0869 & 23.9509 & 25.3473 & 28.9643 & 32.9300 & 35.4047 & 37.2273 & 38.6787 \\
\hline
\end{tabular}

Table 117 Maximum moment results for alpha 1 for slabs subjected to CHBDC axle 4 loading (main bars perpendicular to traffic)

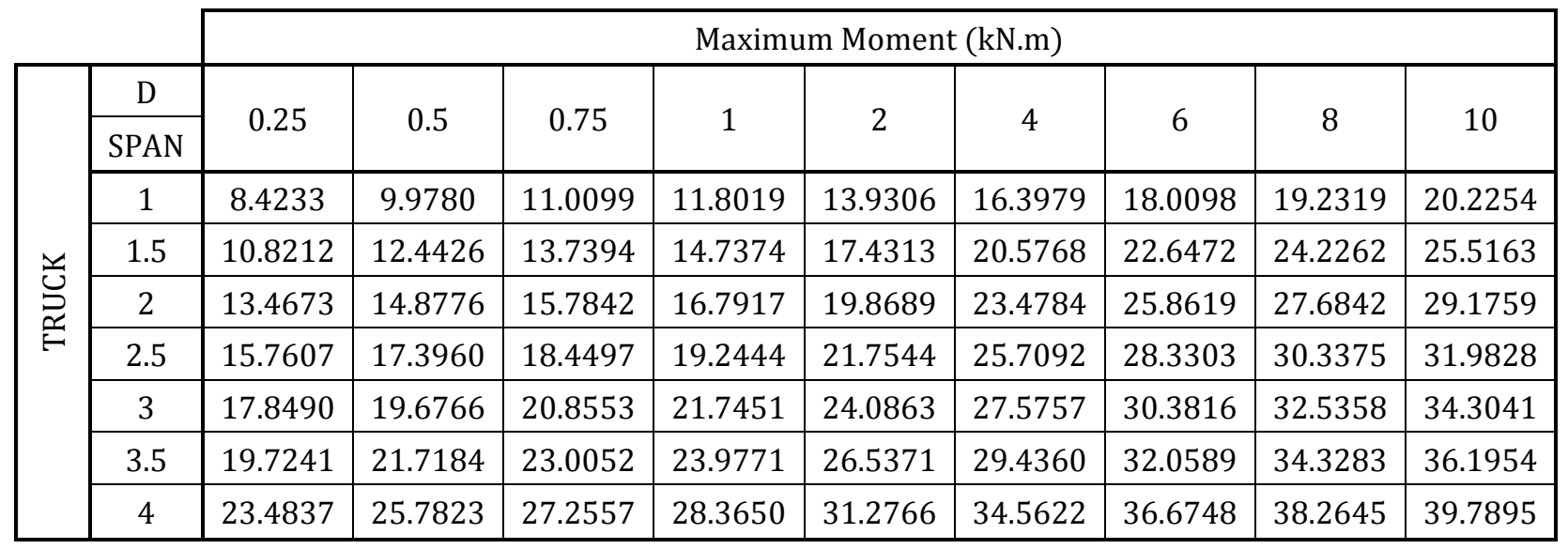


Table 118 Maximum moment results for alpha 1 for slabs subjected to CHBDC axle 4 loading (main bars Parallel to traffic)

\begin{tabular}{|c|c|c|c|c|c|c|c|c|c|c|}
\hline & & \multicolumn{9}{|c|}{ Maximum Moment (kN.m) } \\
\hline \multirow{8}{*}{ 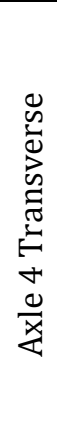 } & $\mathrm{D}$ & \multirow{2}{*}{0.25} & \multirow{2}{*}{0.5} & \multirow{2}{*}{.75} & \multirow{2}{*}{1} & & & & \multirow{2}{*}{8} & \multirow{2}{*}{10} \\
\hline & SPAN & & & & & & & & & \\
\hline & 1 & 14.9893 & 15.8975 & 16.5110 & 16.9907 & 18.3153 & 19.8839 & 20.9027 & 21.6614 & 22.2654 \\
\hline & 1.5 & 21.3623 & 22.5298 & 23.2343 & 23.7550 & 25.1249 & 26.7337 & 27.8195 & 28.6630 & 29.3605 \\
\hline & 2 & 26.8500 & 28.5257 & 29.4750 & 30.1424 & 31.7670 & 33.4992 & 34.6105 & 35.4608 & 36.1620 \\
\hline & 2.5 & 31.5146 & 33.8033 & 35.0863 & 35.9728 & 38.0481 & 40.0999 & 41.3331 & 42.2418 & 42.9741 \\
\hline & 3 & 35.4618 & 38.3772 & 40.0265 & 41.1665 & 43.8087 & 46.3312 & 47.7817 & 48.8159 & 49.6285 \\
\hline & 3.5 & 38.8123 & 42.3240 & 44.3389 & 45.7410 & 49.0027 & 52.0903 & 53.8285 & 55.0424 & 55.9791 \\
\hline
\end{tabular}

Table 119 Maximum moment results for alpha 1 for slabs subjected to CHBDC axle 2 \& 3 loading (main bars Parallel to traffic)

\begin{tabular}{|c|c|c|c|c|c|c|c|c|c|c|}
\hline & & \multicolumn{9}{|c|}{ Maximum Moment (kN.m) } \\
\hline \multirow{7}{*}{ 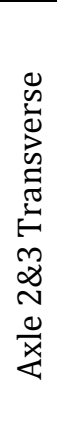 } & $\begin{array}{c}\mathrm{D} \\
\text { SPAN }\end{array}$ & 0.25 & 0.5 & 0.75 & 1 & 2 & 4 & 6 & 8 & 10 \\
\hline & 1.5 & 6.5593 & 7.0491 & 7.3402 & 7.5474 & 8.0455 & 8.5381 & 8.8231 & 9.0240 & 9.1791 \\
\hline & 2 & 15.6747 & 16.6997 & 17.3031 & 17.7363 & 18.8112 & 19.9592 & 20.6805 & 21.2204 & 21.6573 \\
\hline & 2.5 & 23.3006 & 24.9981 & 25.9445 & 26.5957 & 28.1111 & 29.5984 & 30.4898 & 31.1469 & 31.6771 \\
\hline & 3 & 29.6571 & 32.1824 & 33.5895 & 34.5497 & 36.7258 & 38.7298 & 39.8520 & 40.6429 & 41.2615 \\
\hline & 3.5 & 34.9466 & 38.3185 & 40.2281 & 41.5409 & 44.5251 & 47.2331 & 48.6999 & 49.7010 & 50.4623 \\
\hline & 4 & 39.4206 & 43.5951 & 46.0024 & 47.6753 & 51.5267 & 55.0531 & 56.9520 & 58.2310 & 59.1894 \\
\hline
\end{tabular}




\section{Alpha 2 Bending Moment Results}

Table 120 Maximum moment results for alpha 2 for slabs subjected to CHBDC axle 4 loading (main bars perpendicular to traffic)

\begin{tabular}{|c|c|c|c|c|c|c|c|c|c|c|}
\hline & \multicolumn{9}{|c|}{ Maximum Moment (kN.m) } \\
\hline \multirow{9}{*}{$\frac{\vec{d}}{x}$} & $\mathrm{D}$ & \multirow{2}{*}{25} & \multirow{2}{*}{0.5} & \multirow{2}{*}{0.75} & \multirow[t]{2}{*}{1} & & \multirow{2}{*}{4} & & \multirow{2}{*}{8} & \multirow{2}{*}{10} \\
\hline & SPAN & & & & & & & & & \\
\hline & 1 & 6.8788 & 8.1494 & 8.9932 & 9.6411 & 11.3844 & 13.4096 & 14.7363 & 15.7445 & 16.5658 \\
\hline & 1.5 & 8.5654 & 10.1588 & 11.2198 & 12.0362 & 14.2408 & 16.8190 & 18.5191 & 19.8178 & 20.8804 \\
\hline & 2 & 9.7465 & 11.5637 & 12.7749 & 13.7077 & 16.2304 & 19.1883 & 21.1441 & 22.6412 & 23.8683 \\
\hline & 2.5 & 10.6532 & 12.6425 & 13.9692 & 14.9914 & 17.7582 & 21.0070 & 23.1585 & 24.8072 & 26.1598 \\
\hline & 3 & 11.4214 & 13.5527 & 14.9744 & 16.0700 & 19.0365 & 22.5226 & 24.8332 & 26.6050 & 28.0595 \\
\hline & 3.5 & 12.0145 & 14.2611 & 15.7606 & 16.9164 & 20.0479 & 23.7313 & 26.1746 & 28.0494 & 29.5891 \\
\hline & 4 & 13.1357 & 15.6000 & 17.2461 & 18.5157 & 21.9590 & 26.0154 & 28.7101 & 30.7799 & 32.4812 \\
\hline
\end{tabular}

Table 121 Maximum moment results for alpha 2 for slabs subjected to CHBDC axle 2 \& 3 loading (main bars perpendicular to traffic)

\begin{tabular}{|c|c|c|c|c|c|c|c|c|c|c|}
\hline & \multicolumn{9}{|c|}{ Maximum Moment (kN.m) } \\
\hline \multirow{9}{*}{ 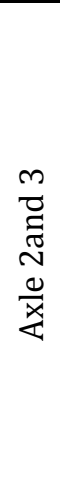 } & $\mathrm{D}$ & \multirow{2}{*}{0.25} & \multirow{2}{*}{0.5} & \multirow{2}{*}{0.75} & \multirow[b]{2}{*}{1} & & \multirow[b]{2}{*}{4} & & \multirow{2}{*}{8} & \multirow{2}{*}{10} \\
\hline & SPAN & & & & & & & & & \\
\hline & 1 & 6.6070 & 7.3779 & 7.8727 & 8.2481 & 9.2547 & 10.4428 & 11.2408 & 11.8594 & 12.3712 \\
\hline & 1.5 & 9.0670 & 10.2046 & 10.9177 & 11.4478 & 12.8220 & 14.3660 & 15.3688 & 16.1334 & 16.7604 \\
\hline & 2 & 10.8466 & 12.3031 & 13.2174 & 13.8956 & 15.6390 & 17.5587 & 18.7788 & 19.6950 & 20.4378 \\
\hline & 2.5 & 12.2138 & 13.9340 & 15.0204 & 15.8285 & 17.9081 & 20.1900 & 21.6291 & 22.7019 & 23.5660 \\
\hline & 3 & 13.3397 & 15.2799 & 16.5125 & 17.4323 & 19.8084 & 22.4220 & 24.0686 & 25.2932 & 26.2771 \\
\hline & 3.5 & 14.2429 & 16.3653 & 17.7206 & 18.7353 & 21.3675 & 24.2763 & 26.1126 & 27.4785 & 28.5754 \\
\hline & 4 & 15.9563 & 18.4170 & 19.9977 & 21.1850 & 24.2783 & 27.7103 & 29.8792 & 31.4917 & 32.7851 \\
\hline
\end{tabular}

Table 122 Maximum moment results for alpha 2 for slabs subjected to CHBDC axle 4 loading (main bars perpendicular to traffic)

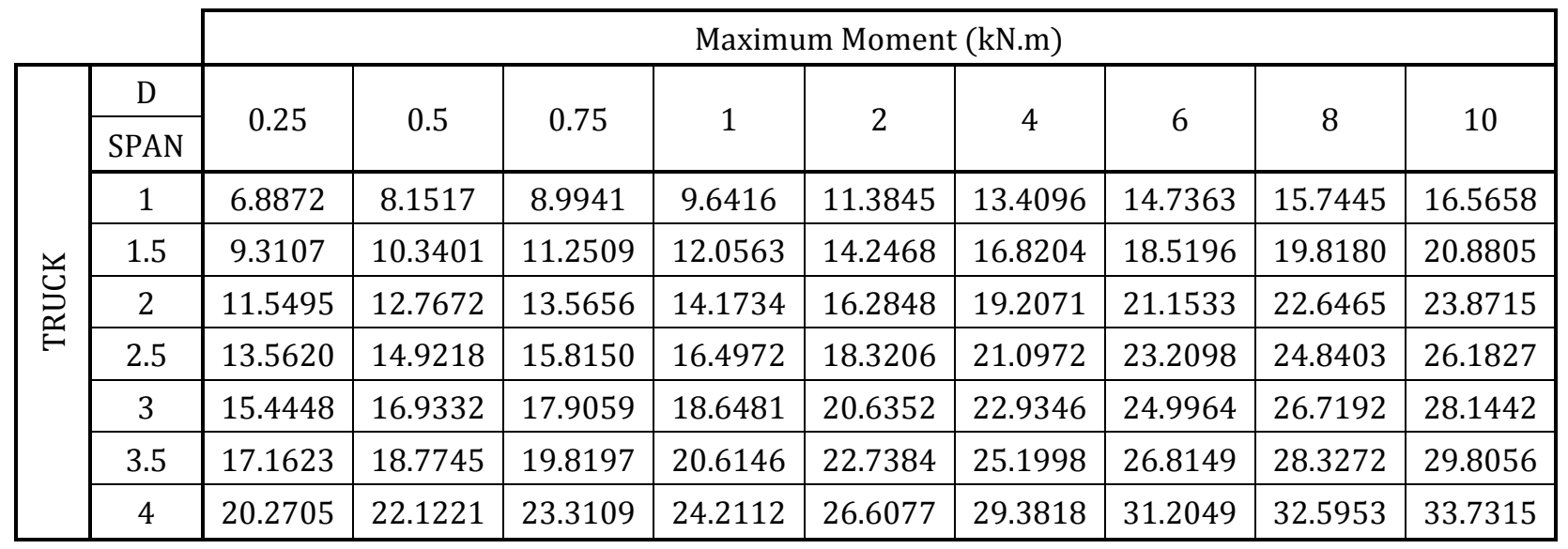


Table 123 Maximum moment results for alpha 2 for slabs subjected to CHBDC axle 4 loading (main bars Parallel to traffic)

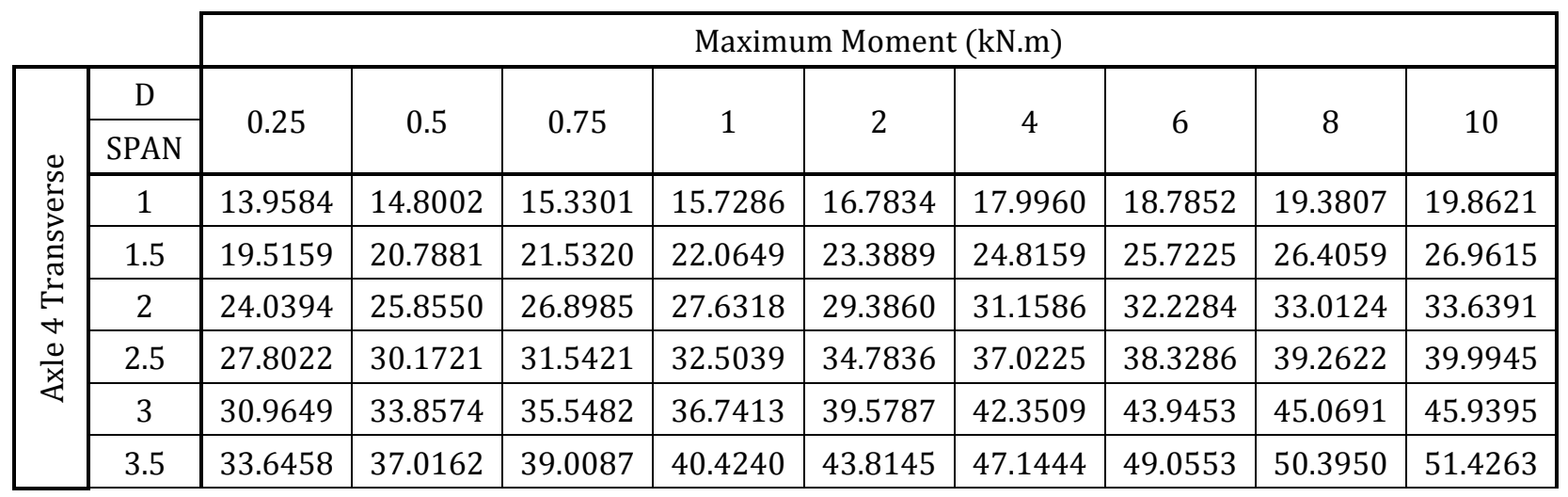

Table 124 Maximum moment results for alpha 2 for slabs subjected to CHBDC axle 2 \& 3 loading (main bars Parallel to traffic)

\begin{tabular}{|c|c|c|c|c|c|c|c|c|c|c|}
\hline & & \multicolumn{9}{|c|}{ Maximum Moment (kN.m) } \\
\hline \multirow{7}{*}{ 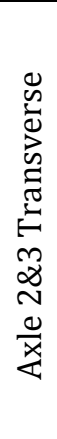 } & $\begin{array}{c}\mathrm{D} \\
\text { SPAN }\end{array}$ & 0.25 & 0.5 & 0.75 & 1 & 2 & 4 & 6 & 8 & 10 \\
\hline & 1.5 & 5.9041 & 6.3502 & 6.6213 & 6.8173 & 7.2993 & 7.7892 & 8.0768 & 8.2804 & 8.4379 \\
\hline & 2 & 14.1119 & 15.1607 & 15.7770 & 16.2166 & 17.2900 & 18.3992 & 19.0742 & 19.5685 & 19.9621 \\
\hline & 2.5 & 20.5228 & 22.2870 & 23.3045 & 24.0175 & 25.7022 & 27.3487 & 28.3055 & 28.9883 & 29.5232 \\
\hline & 3 & 25.6918 & 28.2036 & 29.6644 & 30.6901 & 33.1058 & 35.4246 & 36.7365 & 37.6516 & 38.3553 \\
\hline & 3.5 & 29.9408 & 33.1596 & 35.0569 & 36.3990 & 39.5855 & 42.6576 & 44.3871 & 45.5832 & 46.4945 \\
\hline & 4 & 33.5248 & 37.3891 & 39.6959 & 41.3409 & 45.2875 & 49.1384 & 51.3177 & 52.8247 & 53.9704 \\
\hline
\end{tabular}




\section{Alpha 4 Bending Moment Results}

Table 125 Maximum moment results for alpha 4 for slabs subjected to CHBDC axle 4 loading (main bars perpendicular to traffic)

\begin{tabular}{|c|c|c|c|c|c|c|c|c|c|c|}
\hline & \multicolumn{9}{|c|}{ Maximum Moment (kN.m) } \\
\hline \multirow{9}{*}{$\frac{\vec{d}}{x}$} & $\mathrm{D}$ & \multirow{2}{*}{.25} & \multirow{2}{*}{0.5} & \multirow{2}{*}{0.75} & \multirow{2}{*}{1} & & \multirow[t]{2}{*}{4} & & \multirow{2}{*}{8} & \multirow{2}{*}{10} \\
\hline & SPAN & & & & & & & & & \\
\hline & 1 & 5.3299 & 6.3156 & 6.9708 & 7.4742 & 8.8308 & 10.4117 & 11.4509 & 12.2429 & 12.8897 \\
\hline & 1.5 & 6.6352 & 7.8708 & 8.6940 & 9.3277 & 11.0411 & 13.0491 & 14.3764 & 15.3922 & 16.2248 \\
\hline & 2 & 7.5507 & 8.9596 & 9.8992 & 10.6231 & 12.5828 & 14.8847 & 16.4099 & 17.5792 & 18.5390 \\
\hline & 2.5 & 8.2528 & 9.7950 & 10.8241 & 11.6172 & 13.7660 & 16.2933 & 17.9699 & 19.2567 & 20.3136 \\
\hline & 3 & 8.8500 & 10.5029 & 11.6061 & 12.4565 & 14.7608 & 17.4729 & 19.2732 & 20.6557 & 21.7917 \\
\hline & 3.5 & 9.3078 & 11.0495 & 12.2124 & 13.1090 & 15.5403 & 18.4041 & 20.3067 & 21.7684 & 22.9702 \\
\hline & 4 & 10.1739 & 12.0830 & 13.3586 & 14.3429 & 17.0138 & 20.1645 & 22.2605 & 23.8724 & 25.1985 \\
\hline
\end{tabular}

Table 126 Maximum moment results for alpha 4 for slabs subjected to CHBDC axle 2 \& 3 loading (main bars perpendicular to traffic)

\begin{tabular}{|c|c|c|c|c|c|c|c|c|c|c|}
\hline & \multicolumn{9}{|c|}{ Maximum Moment (kN.m) } \\
\hline \multirow{9}{*}{ 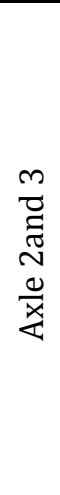 } & $\mathrm{D}$ & \multirow{2}{*}{0.25} & \multirow{2}{*}{0.5} & \multirow{2}{*}{0.75} & \multirow[b]{2}{*}{1} & & \multirow{2}{*}{4} & & \multirow{2}{*}{8} & \multirow{2}{*}{10} \\
\hline & SPAN & & & & & & & & & \\
\hline & 1 & 5.5101 & 6.2023 & 6.6378 & 6.9624 & 7.8057 & 8.7551 & 9.3717 & 9.8415 & 10.2265 \\
\hline & 1.5 & 7.3942 & 8.3982 & 9.0310 & 9.5016 & 10.7150 & 12.0540 & 12.9042 & 13.5415 & 14.0570 \\
\hline & 2 & 8.7441 & 9.9916 & 10.7824 & 11.3722 & 12.8967 & 14.5791 & 15.6434 & 16.4375 & 17.0771 \\
\hline & 2.5 & 9.7852 & 11.2289 & 12.1488 & 12.8368 & 14.6219 & 16.5989 & 17.8513 & 18.7857 & 19.5378 \\
\hline & 3 & 10.6487 & 12.2570 & 13.2859 & 14.0574 & 16.0654 & 18.2980 & 19.7157 & 20.7744 & 21.6269 \\
\hline & 3.5 & 11.3416 & 13.0861 & 14.2061 & 15.0479 & 17.2455 & 19.6987 & 21.2607 & 22.4288 & 23.3703 \\
\hline & 4 & 12.6527 & 14.6511 & 15.9403 & 16.9120 & 19.4590 & 22.3159 & 24.1404 & 25.5069 & 26.6091 \\
\hline
\end{tabular}

Table 127 Maximum moment results for alpha 4 for slabs subjected to CHBDC axle 4 loading (main bars perpendicular to traffic)

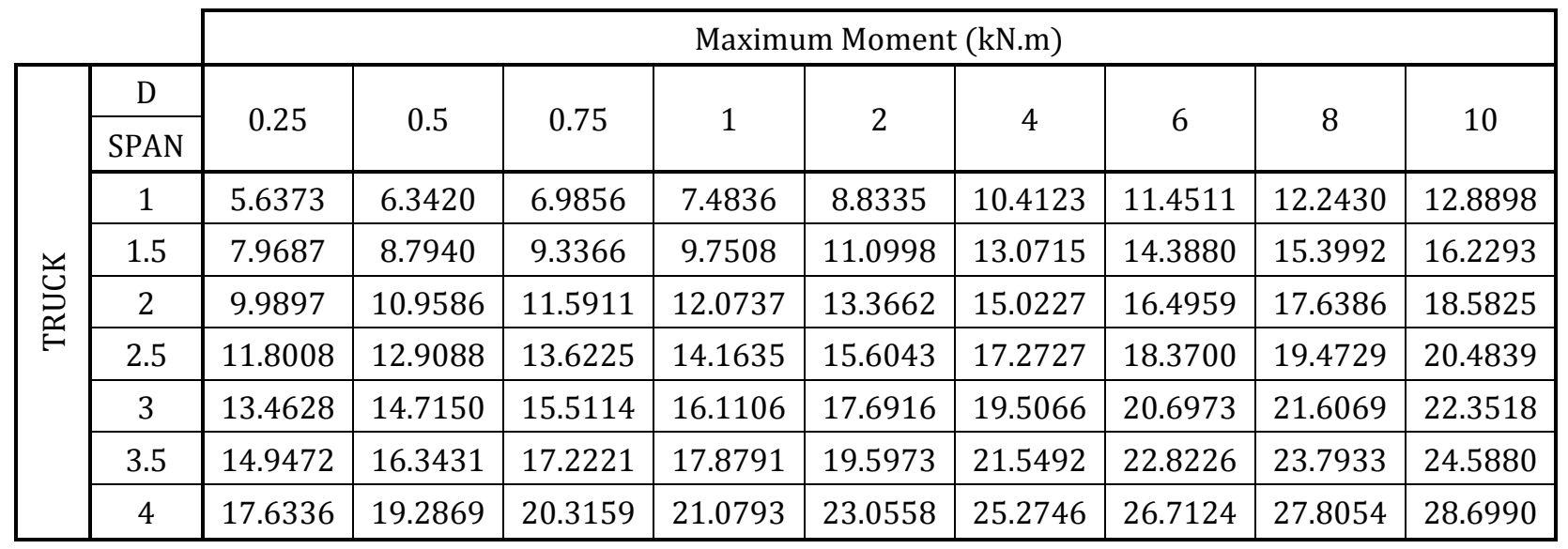


Table 128 Maximum moment results for alpha 4 for slabs subjected to CHBDC axle 4 loading (main bars Parallel to traffic)

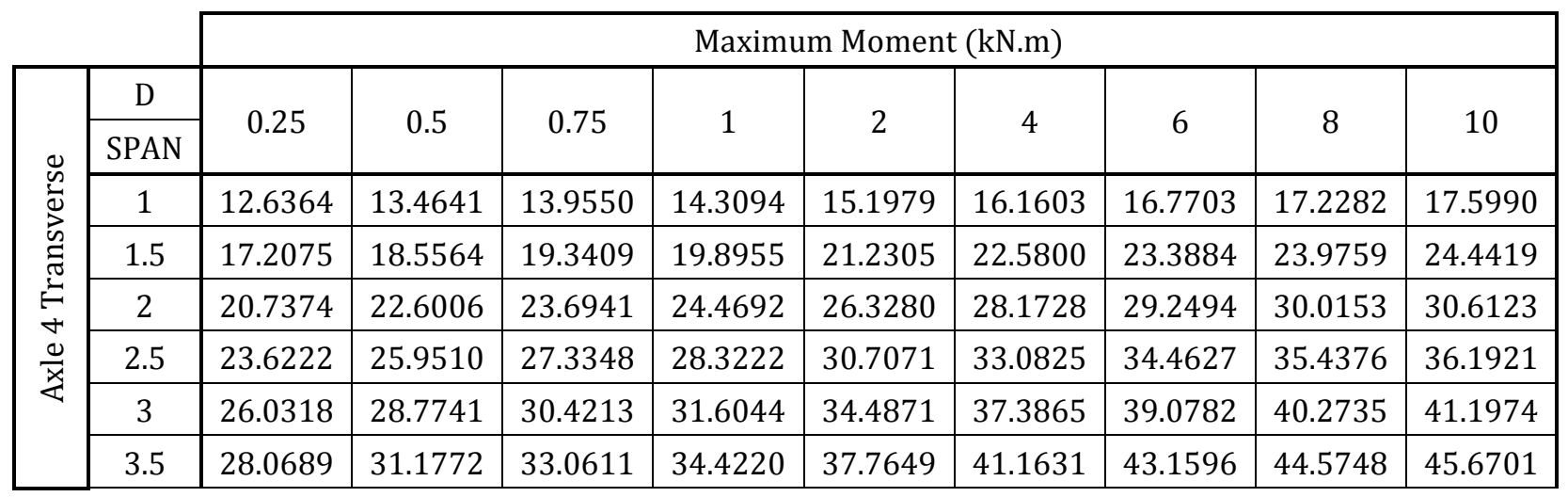

Table 129 Maximum moment results for alpha 4 for slabs subjected to CHBDC axle 2 \& 3 loading (main bars Parallel to traffic)

\begin{tabular}{|c|c|c|c|c|c|c|c|c|c|c|}
\hline & & \multicolumn{9}{|c|}{ Maximum Moment (kN.m) } \\
\hline \multirow{7}{*}{ 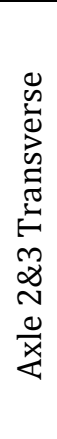 } & $\begin{array}{c}\mathrm{D} \\
\text { SPAN }\end{array}$ & 0.25 & 0.5 & 0.75 & 1 & 2 & 4 & 6 & 8 & 10 \\
\hline & 1.5 & 5.2097 & 5.6048 & 5.8477 & 6.0253 & 6.4697 & 6.9339 & 7.2124 & 7.4121 & 7.5679 \\
\hline & 2 & 12.2858 & 13.3307 & 13.9490 & 14.3903 & 15.4626 & 16.5500 & 17.1959 & 17.6604 & 18.0248 \\
\hline & 2.5 & 17.4011 & 19.1360 & 20.1668 & 20.9019 & 22.6757 & 24.4384 & 25.4601 & 26.1805 & 26.7372 \\
\hline & 3 & 21.3919 & 23.7611 & 25.1866 & 26.2106 & 28.7013 & 31.1927 & 32.6360 & 33.6499 & 34.4297 \\
\hline & 3.5 & 24.6315 & 27.5615 & 29.3447 & 30.6349 & 33.8047 & 37.0156 & 38.8902 & 40.2112 & 41.2285 \\
\hline & 4 & 27.3547 & 30.7793 & 32.8832 & 34.4147 & 38.2111 & 42.1051 & 44.3999 & 46.0256 & 47.2816 \\
\hline
\end{tabular}




\section{Alpha 6 Bending Moment Results}

Table 130 Maximum moment results for alpha 6 for slabs subjected to CHBDC axle 4 loading (main bars perpendicular to traffic)

\begin{tabular}{|c|c|c|c|c|c|c|c|c|c|c|}
\hline & \multicolumn{9}{|c|}{ Maximum Moment (kN.m) } \\
\hline \multirow{9}{*}{$\begin{array}{l}\vec{d} \\
\frac{0}{x}\end{array}$} & $\mathrm{D}$ & \multirow{2}{*}{0.25} & \multirow{2}{*}{0.5} & \multirow{2}{*}{0.75} & \multirow{2}{*}{1} & \multirow{2}{*}{2} & & \multirow{2}{*}{6} & \multirow{2}{*}{8} & \multirow{2}{*}{10} \\
\hline & SPAN & & & & & & & & & \\
\hline & 1 & 4.5057 & 5.3399 & 5.8946 & 6.3211 & 7.4717 & 8.8153 & 9.7004 & 10.3763 & 10.9292 \\
\hline & 1.5 & 5.6083 & 6.6534 & 7.3501 & 7.8866 & 9.3382 & 11.0419 & 12.1697 & 13.0340 & 13.7430 \\
\hline & 2 & 6.3823 & 7.5740 & 8.3691 & 8.9818 & 10.6415 & 12.5935 & 13.8885 & 14.8823 & 15.6986 \\
\hline & 2.5 & 6.9756 & 8.2799 & 9.1506 & 9.8218 & 11.6414 & 13.7838 & 15.2067 & 16.2997 & 17.1982 \\
\hline & 3 & 7.4814 & 8.8797 & 9.8133 & 10.5331 & 12.4847 & 14.7838 & 16.3116 & 17.4858 & 18.4513 \\
\hline & 3.5 & 7.8676 & 9.3405 & 10.3243 & 11.0830 & 13.1414 & 15.5681 & 17.1820 & 18.4229 & 19.4437 \\
\hline & 4 & 8.5982 & 10.2121 & 11.2908 & 12.1232 & 14.3831 & 17.0513 & 18.8278 & 20.1949 & 21.3204 \\
\hline
\end{tabular}

Table 131 Maximum moment results for alpha 6 for slabs subjected to CHBDC axle 2 \& 3 loading (main bars perpendicular to traffic)

\begin{tabular}{|c|c|c|c|c|c|c|c|c|c|c|}
\hline & \multicolumn{9}{|c|}{ Maximum Moment (kN.m) } \\
\hline \multirow{9}{*}{ 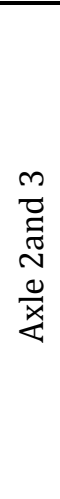 } & $\mathrm{D}$ & \multirow{2}{*}{0.25} & \multirow{2}{*}{0.5} & \multirow{2}{*}{0.75} & \multirow{2}{*}{1} & & \multirow{2}{*}{4} & & \multirow{2}{*}{8} & \multirow{2}{*}{10} \\
\hline & SPAN & & & & & & & & & \\
\hline & 1 & 4.8589 & 5.4984 & 5.8997 & 6.1973 & 6.9634 & 7.8097 & 8.3497 & 8.7564 & 9.0869 \\
\hline & 1.5 & 6.4448 & 7.3584 & 7.9364 & 8.3669 & 9.4772 & 10.6984 & 11.4692 & 12.0438 & 12.5065 \\
\hline & 2 & 7.5745 & 8.6938 & 9.4069 & 9.9402 & 11.3231 & 12.8529 & 13.8209 & 14.5423 & 15.1227 \\
\hline & 2.5 & 8.4461 & 9.7288 & 10.5500 & 11.1660 & 12.7703 & 14.5553 & 15.6890 & 16.5357 & 17.2175 \\
\hline & 3 & 9.1716 & 10.5910 & 11.5030 & 12.1886 & 13.9801 & 15.9822 & 17.2580 & 18.2127 & 18.9825 \\
\hline & 3.5 & 9.7533 & 11.2857 & 12.2730 & 13.0169 & 14.9656 & 17.1520 & 18.5494 & 19.5971 & 20.4429 \\
\hline & 4 & 10.8534 & 12.5971 & 13.7253 & 14.5776 & 16.8189 & 19.3464 & 20.9681 & 22.1865 & 23.1716 \\
\hline
\end{tabular}

Table 132 Maximum moment results for alpha 6 for slabs subjected to CHBDC axle 4 loading (main bars perpendicular to traffic)

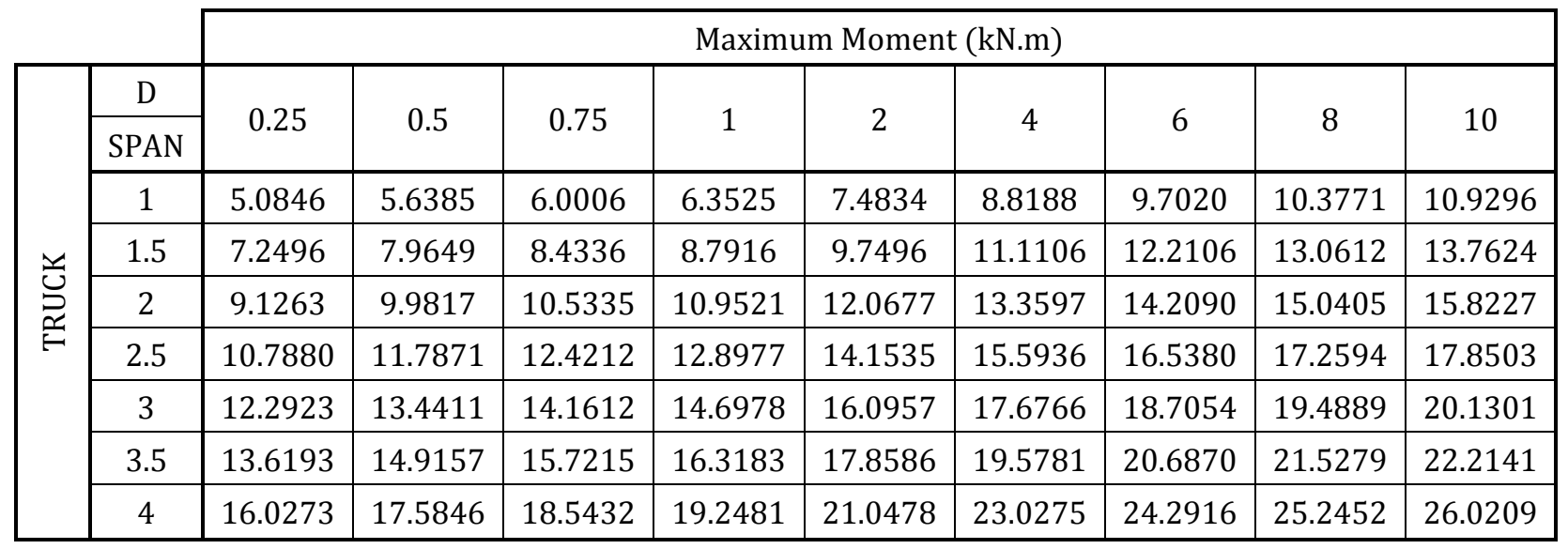


Table 133 Maximum moment results for alpha 6 for slabs subjected to CHBDC axle 4 loading (main bars Parallel to traffic)

\begin{tabular}{|c|c|c|c|c|c|c|c|c|c|c|}
\hline & & \multicolumn{9}{|c|}{ Maximum Moment (kN.m) } \\
\hline \multirow{8}{*}{ 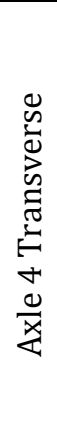 } & $\mathrm{D}$ & \multirow{2}{*}{0.25} & \multirow{2}{*}{.5} & \multirow{2}{*}{0.75} & \multirow{2}{*}{1} & & & & \multirow{2}{*}{8} & \multirow{2}{*}{10} \\
\hline & SPAN & & & & & & & & & \\
\hline & 1 & 11.7517 & 12.5899 & 13.0781 & 13.4252 & 14.2720 & 15.1533 & 15.6965 & 16.0986 & 16.4218 \\
\hline & 1.5 & 15.7256 & 17.0900 & 17.8885 & 18.4537 & 19.8088 & 21.1569 & 21.9473 & 22.5122 & 22.9542 \\
\hline & 2 & 18.7184 & 20.5549 & 21.6468 & 22.4263 & 24.3105 & 26.1898 & 27.2828 & 28.0554 & 28.6536 \\
\hline & 2.5 & 21.1461 & 23.3907 & 24.7428 & 25.7159 & 28.0940 & 30.4959 & 31.9013 & 32.8958 & 33.6650 \\
\hline & 3 & 23.1679 & 25.7661 & 27.3469 & 28.4920 & 31.3171 & 34.2073 & 35.9137 & 37.1266 & 38.0671 \\
\hline & 3.5 & 24.8737 & 27.7805 & 29.5628 & 30.8607 & 34.0875 & 37.4257 & 39.4138 & 40.8343 & 41.9396 \\
\hline
\end{tabular}

Table 134 Maximum moment results for alpha 6 for slabs subjected to CHBDC axle 2 \& 3 loading (main bars Parallel to traffic)

\begin{tabular}{|c|c|c|c|c|c|c|c|c|c|c|}
\hline & & \multicolumn{9}{|c|}{ Maximum Moment (kN.m) } \\
\hline \multirow{7}{*}{ 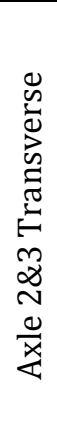 } & $\begin{array}{c}\mathrm{D} \\
\text { SPAN }\end{array}$ & 0.25 & 0.5 & 0.75 & 1 & 2 & 4 & 6 & 8 & 10 \\
\hline & 1.5 & 4.8121 & 5.1787 & 5.4042 & 5.5694 & 5.9852 & 6.4249 & 6.6917 & 6.8847 & 7.0361 \\
\hline & 2 & 11.1665 & 12.1917 & 12.8023 & 13.2395 & 14.3041 & 15.3821 & 16.0189 & 16.4740 & 16.8293 \\
\hline & 2.5 & 15.5562 & 17.2269 & 18.2339 & 18.9589 & 20.7301 & 22.5173 & 23.5616 & 24.2996 & 24.8698 \\
\hline & 3 & 18.9249 & 21.1553 & 22.5179 & 23.5069 & 25.9504 & 28.4491 & 29.9201 & 30.9625 & 31.7683 \\
\hline & 3.5 & 21.6418 & 24.3520 & 26.0252 & 27.2481 & 30.2996 & 33.4639 & 35.3467 & 36.6889 & 37.7306 \\
\hline & 4 & 23.9207 & 27.0476 & 28.9935 & 30.4233 & 34.0198 & 37.7941 & 40.0617 & 41.6882 & 42.9562 \\
\hline
\end{tabular}




\section{Alpha 8 Bending Moment Results}

Table 135 Maximum moment results for alpha 8 for slabs subjected to CHBDC axle 4 loading (main bars perpendicular to traffic)

\begin{tabular}{|c|c|c|c|c|c|c|c|c|c|c|}
\hline & \multicolumn{9}{|c|}{ Maximum Moment (kN.m) } \\
\hline \multirow{9}{*}{$\frac{\vec{d}}{x}$} & $\mathrm{D}$ & \multirow{2}{*}{0.25} & \multirow{2}{*}{.5} & \multirow{2}{*}{0.75} & \multirow{2}{*}{1} & & \multirow{2}{*}{4} & & \multirow{2}{*}{8} & \multirow{2}{*}{10} \\
\hline & SPAN & & & & & & & & & \\
\hline & 1 & 3.9745 & 4.7110 & 5.2010 & 5.5779 & 6.5955 & 7.7856 & 8.5709 & 9.1713 & 9.6630 \\
\hline & 1.5 & 4.9465 & 5.8689 & 6.4839 & 6.9577 & 8.2404 & 9.7474 & 10.7462 & 11.5122 & 12.1411 \\
\hline & 2 & 5.6293 & 6.6810 & 7.3828 & 7.9239 & 9.3901 & 11.1160 & 12.2620 & 13.1422 & 13.8656 \\
\hline & 2.5 & 6.1525 & 7.3035 & 8.0720 & 8.6646 & 10.2717 & 12.1656 & 13.4244 & 14.3920 & 15.1877 \\
\hline & 3 & 6.5993 & 7.8334 & 8.6575 & 9.2931 & 11.0171 & 13.0495 & 14.4011 & 15.4404 & 16.2954 \\
\hline & 3.5 & 6.9393 & 8.2390 & 9.1073 & 9.7772 & 11.5949 & 13.7395 & 15.1667 & 16.2647 & 17.1683 \\
\hline & 4 & 7.5828 & 9.0065 & 9.9583 & 10.6928 & 12.6878 & 15.0446 & 16.6147 & 17.8236 & 18.8192 \\
\hline
\end{tabular}

Table 136 Maximum moment results for alpha 8 for slabs subjected to CHBDC axle 2 \& 3 loading (main bars perpendicular to traffic)

\begin{tabular}{|c|c|c|c|c|c|c|c|c|c|c|}
\hline & \multicolumn{9}{|c|}{ Maximum Moment (kN.m) } \\
\hline \multirow{9}{*}{ 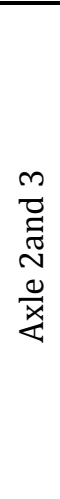 } & $\mathrm{D}$ & \multirow{2}{*}{0.25} & \multirow{2}{*}{0.5} & \multirow{2}{*}{0.75} & & \multirow{2}{*}{2} & \multirow[b]{2}{*}{4} & \multirow{2}{*}{6} & \multirow{2}{*}{8} & \multirow{2}{*}{10} \\
\hline & SPAN & & & & & & & & & \\
\hline & 1 & 4.4100 & 5.0101 & 5.3869 & 5.6663 & 6.3829 & 7.1682 & 7.6646 & 8.0358 & 8.3359 \\
\hline & 1.5 & 5.8059 & 6.6528 & 7.1904 & 7.5914 & 8.6271 & 9.7665 & 10.4846 & 11.0189 & 11.4482 \\
\hline & 2 & 6.7967 & 7.8253 & 8.4830 & 8.9757 & 10.2566 & 11.6770 & 12.5768 & 13.2476 & 13.7871 \\
\hline & 2.5 & 7.5609 & 8.7326 & 9.4852 & 10.0509 & 11.5280 & 13.1766 & 14.2259 & 15.0102 & 15.6422 \\
\hline & 3 & 8.1981 & 9.4895 & 10.3216 & 10.9484 & 12.5902 & 14.4312 & 15.6072 & 16.4883 & 17.1995 \\
\hline & 3.5 & 8.7087 & 10.0984 & 10.9963 & 11.6738 & 13.4531 & 15.4558 & 16.7391 & 17.7025 & 18.4812 \\
\hline & 4 & 9.6741 & 11.2485 & 12.2696 & 13.0421 & 15.0782 & 17.3821 & 18.8643 & 19.9799 & 20.8833 \\
\hline
\end{tabular}

Table 137 Maximum moment results for alpha 8 for slabs subjected to CHBDC axle 4 loading (main bars perpendicular to traffic)

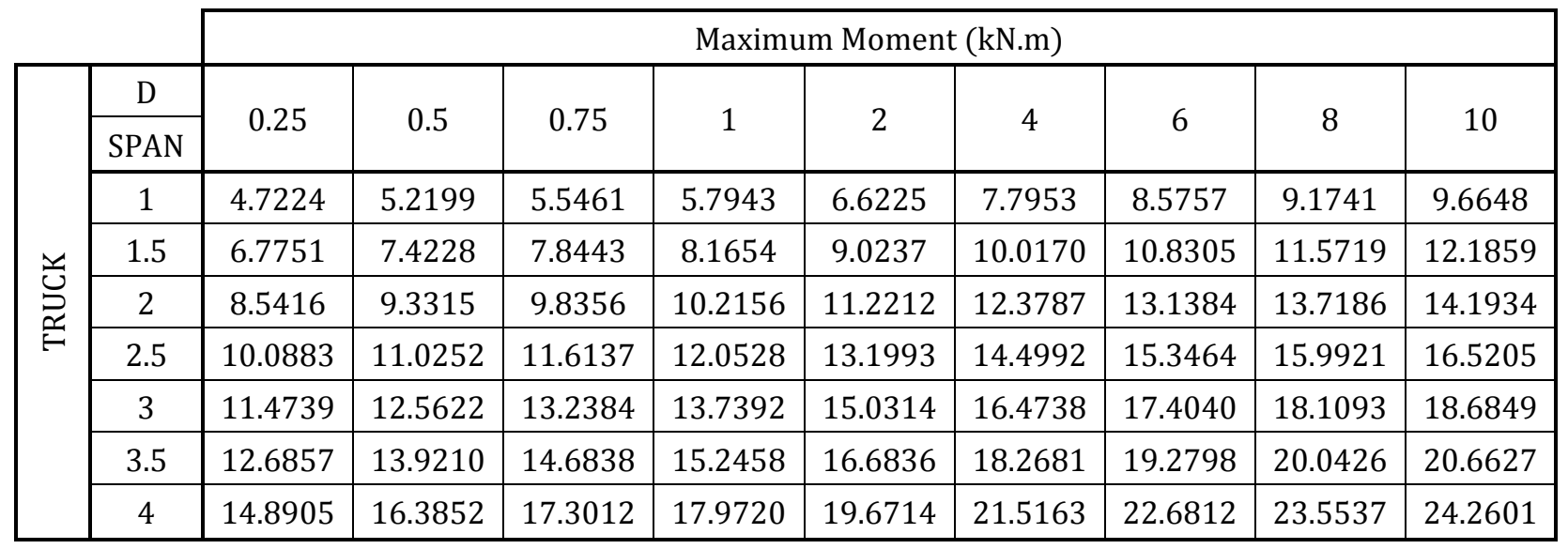


Table 138 Maximum moment results for alpha 8 for slabs subjected to CHBDC axle 4 loading (main bars Parallel to traffic)

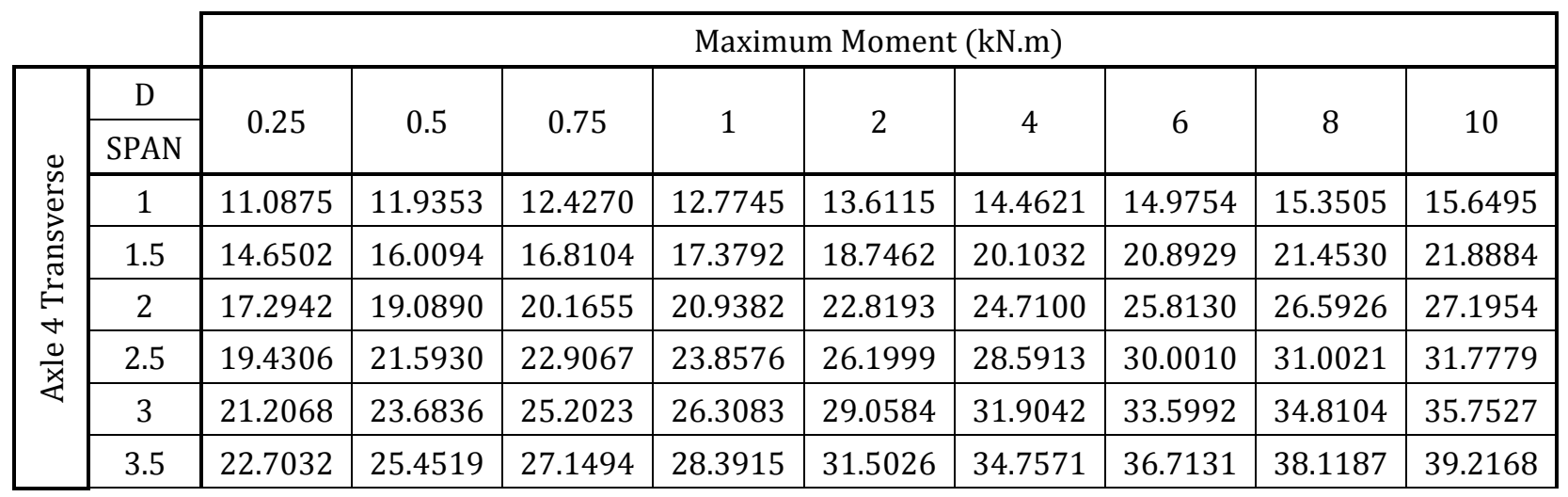

Table 139 Maximum moment results for alpha 8 for slabs subjected to CHBDC axle 2 \& 3 loading (main bars Parallel to traffic)

\begin{tabular}{|c|c|c|c|c|c|c|c|c|c|c|}
\hline & & \multicolumn{9}{|c|}{ Maximum Moment (kN.m) } \\
\hline \multirow{7}{*}{ 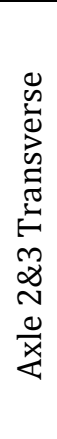 } & $\begin{array}{c}\mathrm{D} \\
\text { SPAN }\end{array}$ & 0.25 & 0.5 & 0.75 & 1 & 2 & 4 & 6 & 8 & 10 \\
\hline & 1.5 & 4.5383 & 4.8870 & 5.1009 & 5.2576 & 5.6523 & 6.0719 & 6.3282 & 6.5145 & 6.6613 \\
\hline & 2 & 10.3724 & 11.3760 & 11.9767 & 12.4081 & 13.4619 & 14.5315 & 15.1631 & 15.6138 & 15.9649 \\
\hline & 2.5 & 14.2804 & 15.8881 & 16.8659 & 17.5740 & 19.3188 & 21.0999 & 22.1491 & 22.8936 & 23.4700 \\
\hline & 3 & 17.2498 & 19.3637 & 20.6669 & 21.6187 & 23.9927 & 26.4549 & 27.9211 & 28.9673 & 29.7799 \\
\hline & 3.5 & 19.6350 & 22.1755 & 23.7570 & 24.9196 & 27.8478 & 30.9279 & 32.7828 & 34.1155 & 35.1557 \\
\hline & 4 & 21.6327 & 24.5402 & 26.3632 & 27.7100 & 31.1270 & 34.7620 & 36.9719 & 38.5696 & 39.8225 \\
\hline
\end{tabular}




\section{Alpha 10 Bending Moment Results}

Table 140 Maximum moment results for alpha 10 for slabs subjected to CHBDC axle 4 loading (main bars perpendicular to traffic)

\begin{tabular}{|c|c|c|c|c|c|c|c|c|c|c|}
\hline & \multicolumn{9}{|c|}{ Maximum Moment (kN.m) } \\
\hline \multirow{9}{*}{$\begin{array}{l}\vec{\sigma} \\
\frac{\sigma}{x}\end{array}$} & D & \multirow{2}{*}{0.25} & \multirow{2}{*}{0.5} & \multirow{2}{*}{0.75} & \multirow[t]{2}{*}{1} & \multirow[t]{2}{*}{2} & & \multirow[t]{2}{*}{6} & \multirow[t]{2}{*}{8} & \multirow{2}{*}{10} \\
\hline & SPAN & & & & & & & & & \\
\hline & 1 & 3.5958 & 4.2626 & 4.7065 & 5.0480 & 5.9706 & 7.0508 & 7.7646 & 8.3108 & 8.7585 \\
\hline & 1.5 & 4.4747 & 5.3095 & 5.8664 & 6.2954 & 7.4576 & 8.8240 & 9.7304 & 10.4260 & 10.9973 \\
\hline & 2 & 5.0925 & 6.0443 & 6.6796 & 7.1695 & 8.4976 & 10.0620 & 11.1015 & 11.9002 & 12.5570 \\
\hline & 2.5 & 5.5656 & 6.6073 & 7.3029 & 7.8395 & 9.2950 & 11.0113 & 12.1528 & 13.0305 & 13.7528 \\
\hline & 3 & 5.9702 & 7.0872 & 7.8333 & 8.4088 & 9.9703 & 11.8122 & 13.0378 & 13.9806 & 14.7565 \\
\hline & 3.5 & 6.2774 & 7.4537 & 8.2396 & 8.8460 & 10.4921 & 12.4352 & 13.7290 & 14.7247 & 15.5444 \\
\hline & 4 & 6.8590 & 8.1471 & 9.0083 & 9.6731 & 11.4791 & 13.6135 & 15.0363 & 16.1320 & 17.0348 \\
\hline
\end{tabular}

Table 141 Maximum moment results for alpha 10 for slabs subjected to CHBDC axle $2 \& 3$ loading (main bars perpendicular to traffic)

\begin{tabular}{|c|c|c|c|c|c|c|c|c|c|c|}
\hline & \multicolumn{9}{|c|}{ Maximum Moment (kN.m) } \\
\hline \multirow{9}{*}{ 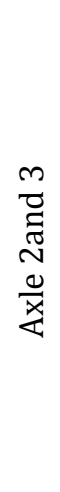 } & $\mathrm{D}$ & \multirow{2}{*}{0.25} & \multirow{2}{*}{0.5} & \multirow{2}{*}{0.75} & \multirow{2}{*}{1} & \multirow{2}{*}{2} & \multirow[b]{2}{*}{4} & \multirow[b]{2}{*}{6} & \multirow{2}{*}{8} & \multirow{2}{*}{10} \\
\hline & SPAN & & & & & & & & & \\
\hline & 1 & 4.0745 & 4.6432 & 5.0009 & 5.2662 & 5.9465 & 6.6895 & 7.1567 & 7.5047 & 7.7849 \\
\hline & 1.5 & 5.3356 & 6.1304 & 6.6364 & 7.0143 & 7.9922 & 9.0694 & 9.7483 & 10.2531 & 10.6584 \\
\hline & 2 & 6.2287 & 7.1882 & 7.8033 & 8.2649 & 9.4672 & 10.8036 & 11.6512 & 12.2835 & 12.7922 \\
\hline & 2.5 & 6.9172 & 8.0057 & 8.7066 & 9.2342 & 10.6146 & 12.1591 & 13.1439 & 13.8807 & 14.4748 \\
\hline & 3 & 7.4920 & 8.6881 & 9.4607 & 10.0435 & 11.5729 & 13.2922 & 14.3924 & 15.2176 & 15.8842 \\
\hline & 3.5 & 7.9521 & 9.2366 & 10.0682 & 10.6965 & 12.3496 & 14.2148 & 15.4121 & 16.3120 & 17.0399 \\
\hline & 4 & 8.8223 & 10.2728 & 11.2153 & 11.9291 & 13.8140 & 15.9517 & 17.3298 & 18.3683 & 19.2100 \\
\hline
\end{tabular}

Table 142 Maximum moment results for alpha 10 for slabs subjected to CHBDC axle 4 loading (main bars perpendicular to traffic)

\begin{tabular}{|c|c|c|c|c|c|c|c|c|c|c|}
\hline & \multicolumn{9}{|c|}{ Maximum Moment (kN.m) } \\
\hline \multirow{9}{*}{ 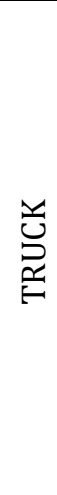 } & $\mathrm{D}$ & \multirow{2}{*}{0.25} & \multirow{2}{*}{0.5} & \multirow{2}{*}{0.75} & \multirow{2}{*}{1} & \multirow[b]{2}{*}{2} & \multirow[b]{2}{*}{4} & \multirow[b]{2}{*}{0} & \multirow{2}{*}{8} & \multirow{2}{*}{10} \\
\hline & SPAN & & & & & & & & & \\
\hline & 1 & 4.4609 & 4.9170 & 5.2162 & 5.4444 & 6.0513 & 7.0700 & 7.7750 & 8.3173 & 8.7628 \\
\hline & 1.5 & 6.4267 & 7.0288 & 7.4178 & 7.7131 & 8.5001 & 9.4100 & 10.0066 & 10.5268 & 11.0757 \\
\hline & 2 & 8.1040 & 8.8508 & 9.3233 & 9.6776 & 10.6085 & 11.6719 & 12.3676 & 12.8985 & 13.3330 \\
\hline & 2.5 & 9.5583 & 10.4540 & 11.0125 & 11.4270 & 12.5009 & 13.7062 & 14.4865 & 15.0793 & 15.5636 \\
\hline & 3 & 10.8503 & 11.8973 & 12.5442 & 13.0213 & 14.2437 & 15.5941 & 16.4581 & 17.1102 & 17.6408 \\
\hline & 3.5 & 11.9726 & 13.1646 & 13.8979 & 14.4364 & 15.8063 & 17.3015 & 18.2486 & 18.9590 & 19.5345 \\
\hline & 4 & 14.0202 & 15.4676 & 16.3533 & 17.0006 & 18.6331 & 20.3902 & 21.4903 & 22.3097 & 22.9704 \\
\hline
\end{tabular}


Table 143 Maximum moment results for alpha 10 for slabs subjected to CHBDC axle 4 loading (main bars Parallel to traffic)

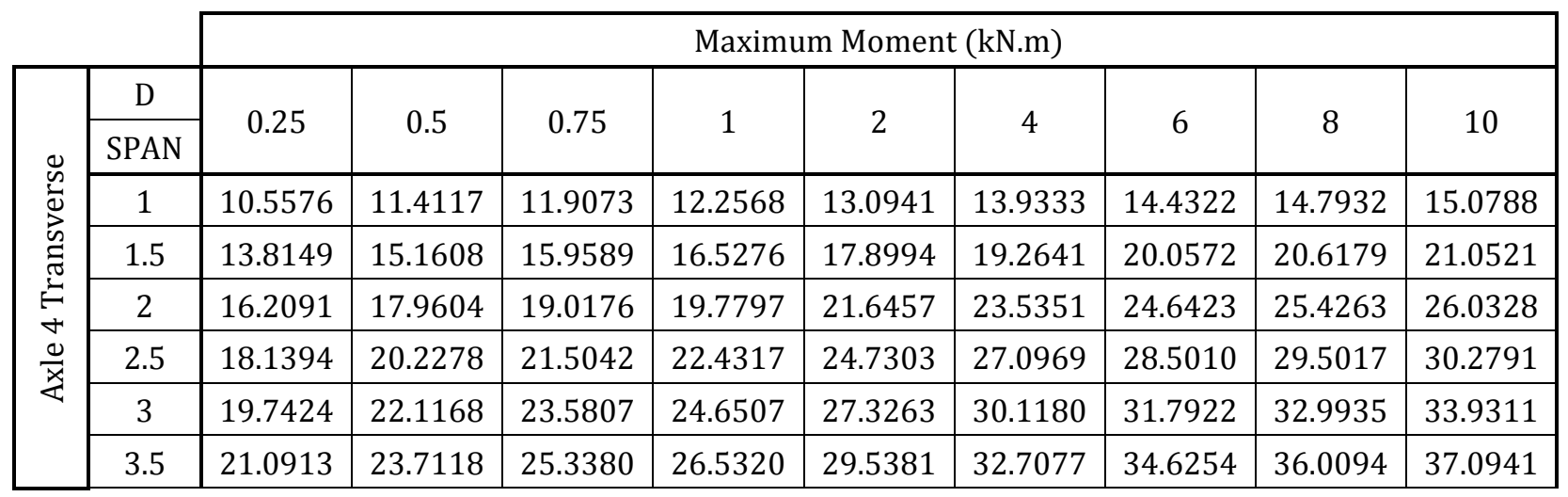

Table 144 Maximum moment results for alpha 10 for slabs subjected to CHBDC axle 2 \& 3 loading (main bars Parallel to traffic)

\begin{tabular}{|c|c|c|c|c|c|c|c|c|c|c|}
\hline & & \multicolumn{9}{|c|}{ Maximum Moment (kN.m) } \\
\hline \multirow{8}{*}{ 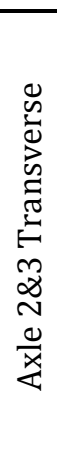 } & $\mathrm{D}$ & \multirow{2}{*}{0.25} & \multirow{2}{*}{0.5} & \multirow{2}{*}{0.75} & \multirow[b]{2}{*}{1} & & \multirow{2}{*}{4} & \multirow[b]{2}{*}{6} & \multirow{2}{*}{8} & \multirow{2}{*}{10} \\
\hline & SPAN & & & & & & & & & \\
\hline & 1.5 & 4.3309 & 4.6676 & 4.8733 & 5.0237 & 5.4025 & 5.8059 & 6.0532 & 6.2336 & 6.3761 \\
\hline & 2 & 9.7638 & 10.7464 & 11.3371 & 11.7623 & 12.8041 & 13.8651 & 14.4924 & 14.9400 & 15.2886 \\
\hline & 2.5 & 13.3214 & 14.8725 & 15.8218 & 16.5121 & 18.2238 & 19.9869 & 21.0326 & 21.7776 & 22.3560 \\
\hline & 3 & 16.0068 & 18.0235 & 19.2743 & 20.1917 & 22.4949 & 24.9080 & 26.3571 & 27.3967 & 28.2074 \\
\hline & 3.5 & 18.1579 & 20.5626 & 22.0678 & 23.1787 & 25.9940 & 28.9846 & 30.8010 & 32.1135 & 33.1425 \\
\hline & 4 & 19.9575 & 22.6941 & 24.4185 & 25.6969 & 28.9593 & 32.4619 & 34.6088 & 36.1696 & 37.3989 \\
\hline
\end{tabular}




\section{C.1.2 MAXIMUM BENDING MOMENT VS SPAN LENGTH}




\section{Alpha 0.25 Bending Moment VS Span Length for Different D Values}

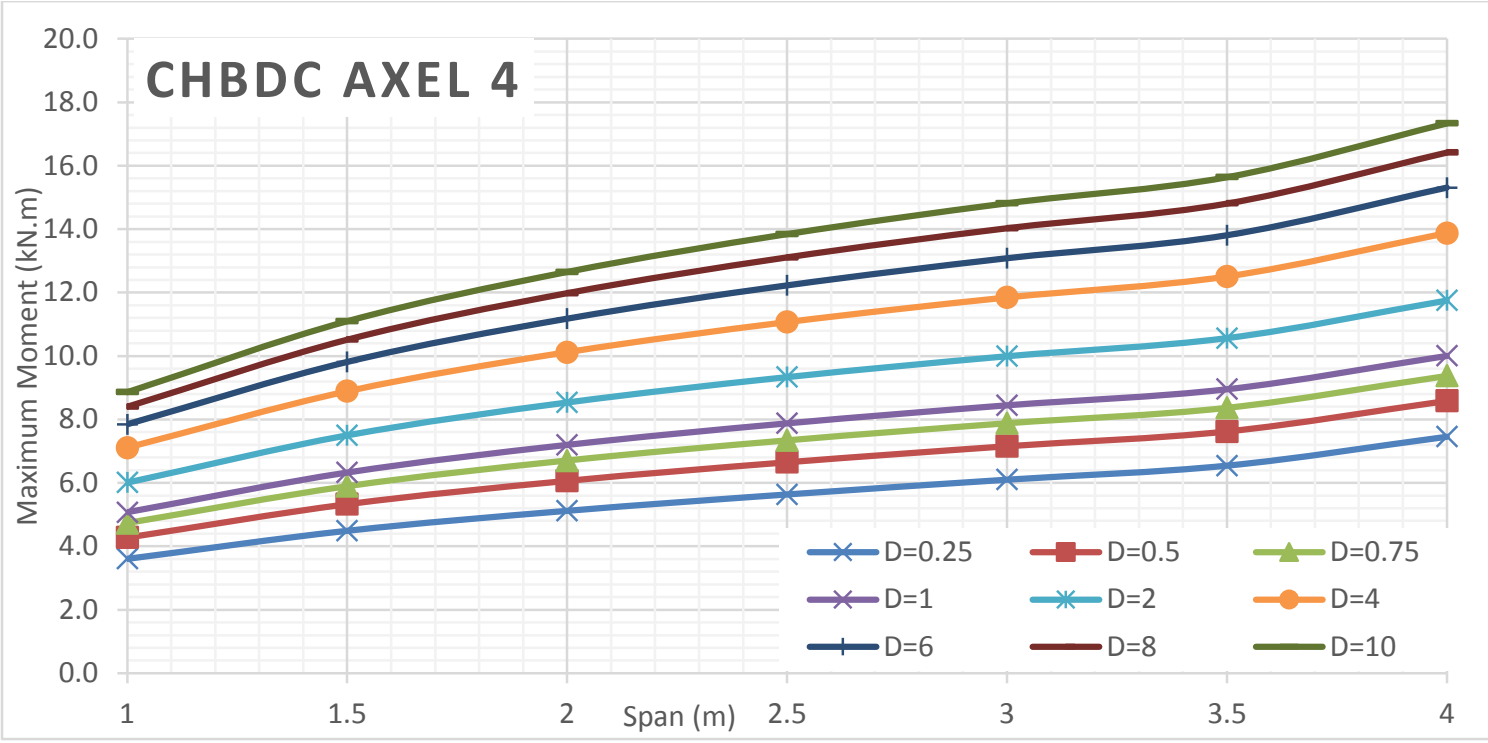

Figure 247 Maximum moment of deck slabs subjected to CHBDC axle 4 for different D values of alpha 0.25 Orthotropic analyses

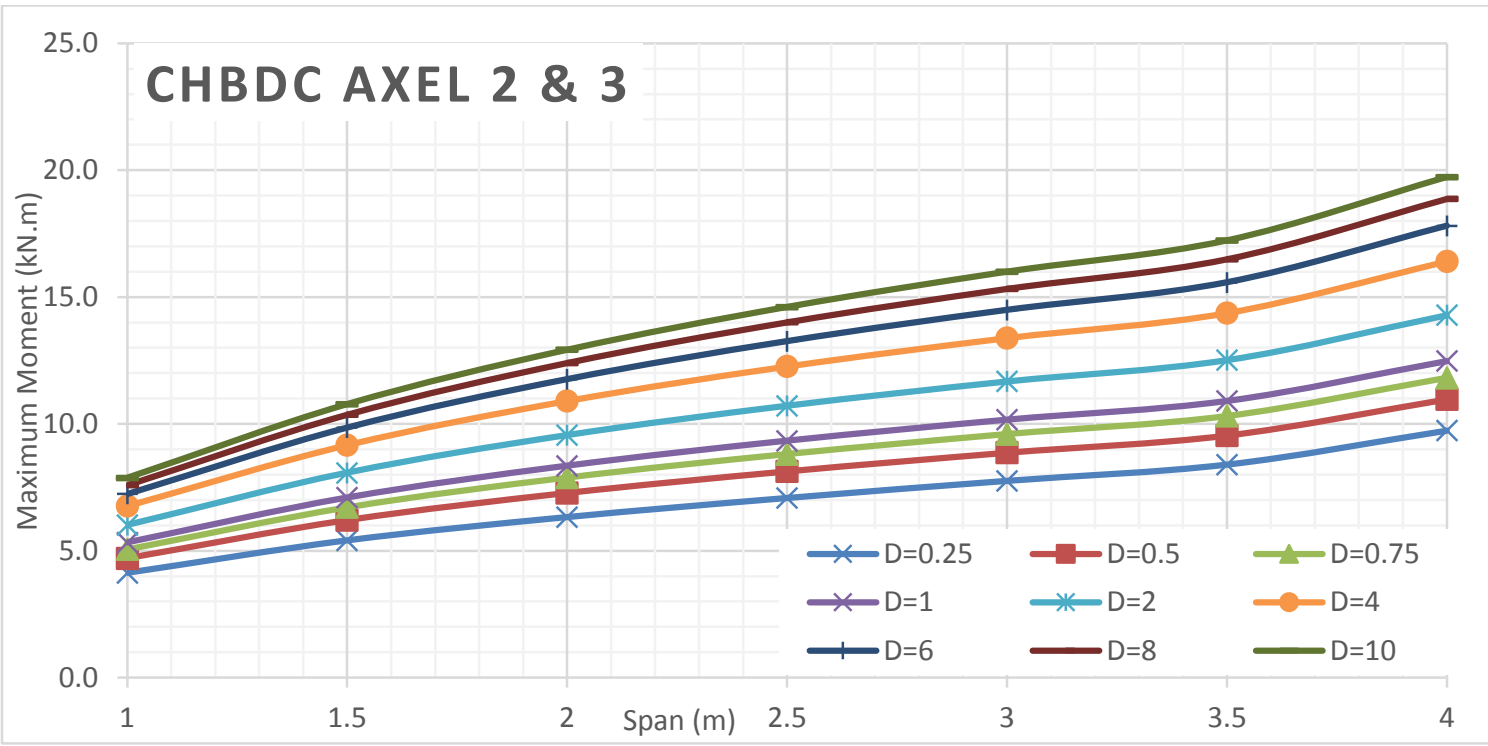

Figure 248 Maximum moment of deck slabs subjected to CHBDC axle $2 \& 3$ for different D values of alpha 0.25 Orthotropic analyses 


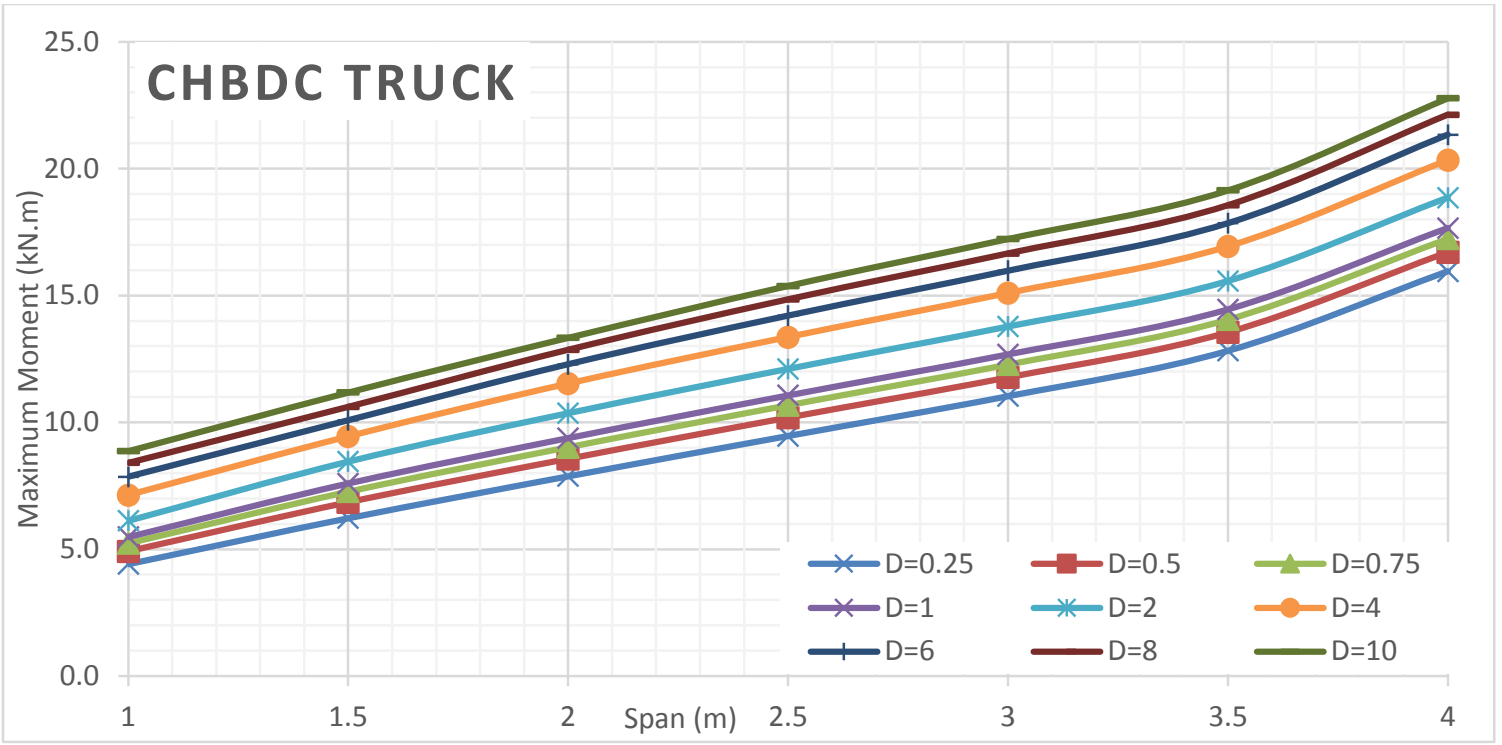

Figure 249 Maximum moment of deck slabs subjected to CHBDC truck for different D values of alpha 0.25 Orthotropic analyses

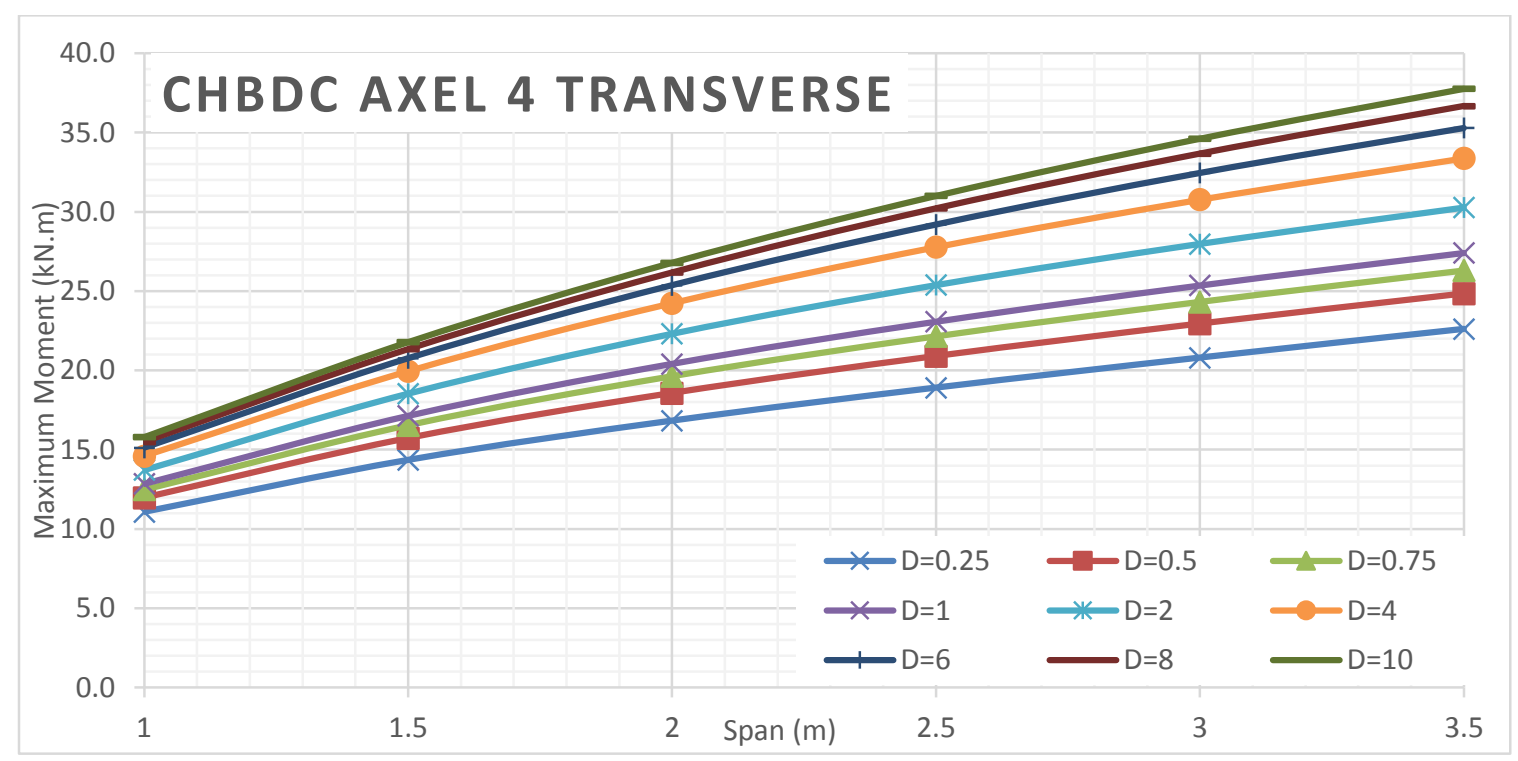

Figure 250 Maximum moment of deck slabs subjected to CHBDC axle 4 for different D values of alpha 0.25 Orthotropic analyses

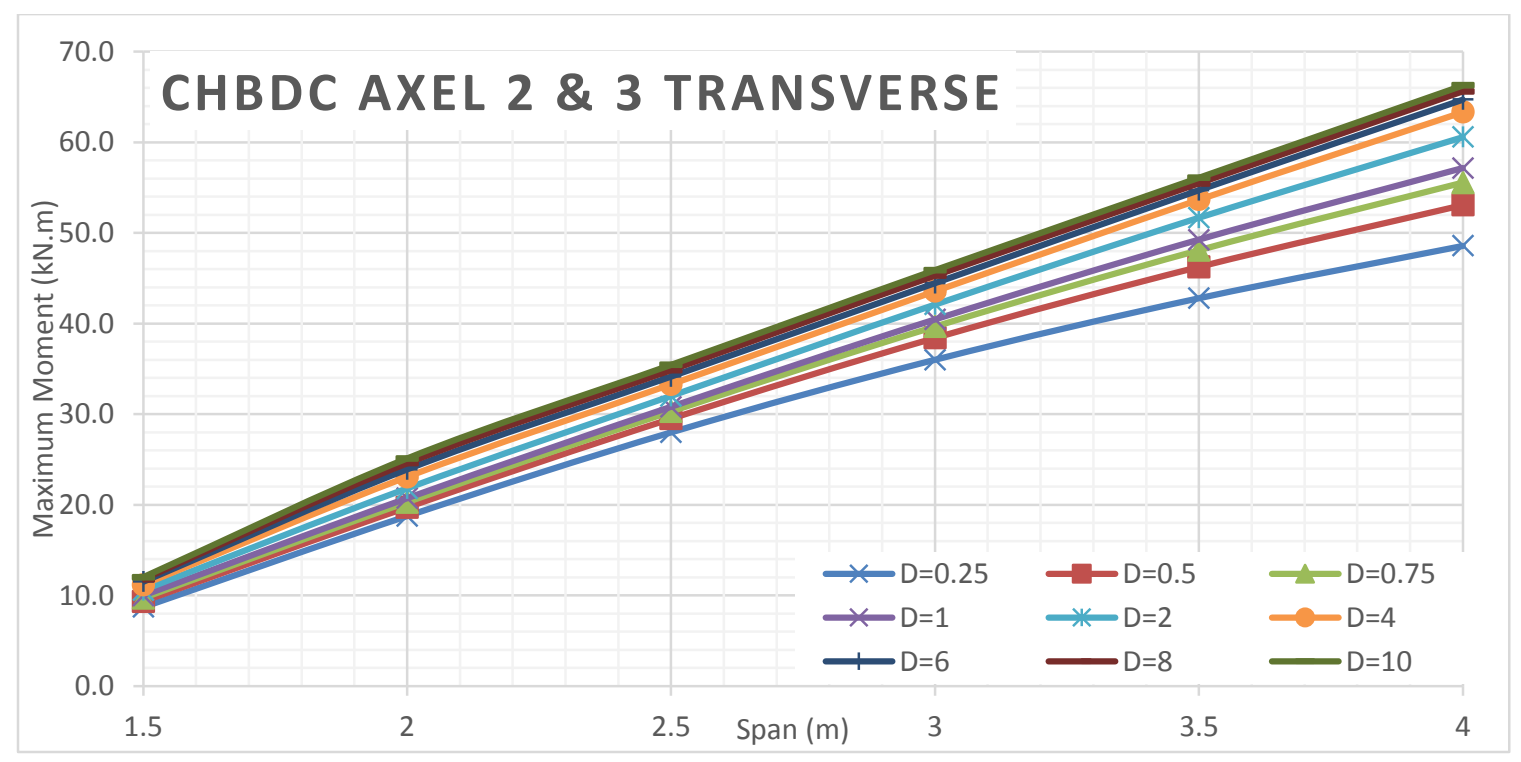

Figure 251 Maximum moment of deck slabs subjected to CHBDC axle $2 \& 3$ for different D values of alpha 0.25 Orthotropic analyses 


\section{Alpha 0.5 Bending Moment VS Span Length for Different D Values}

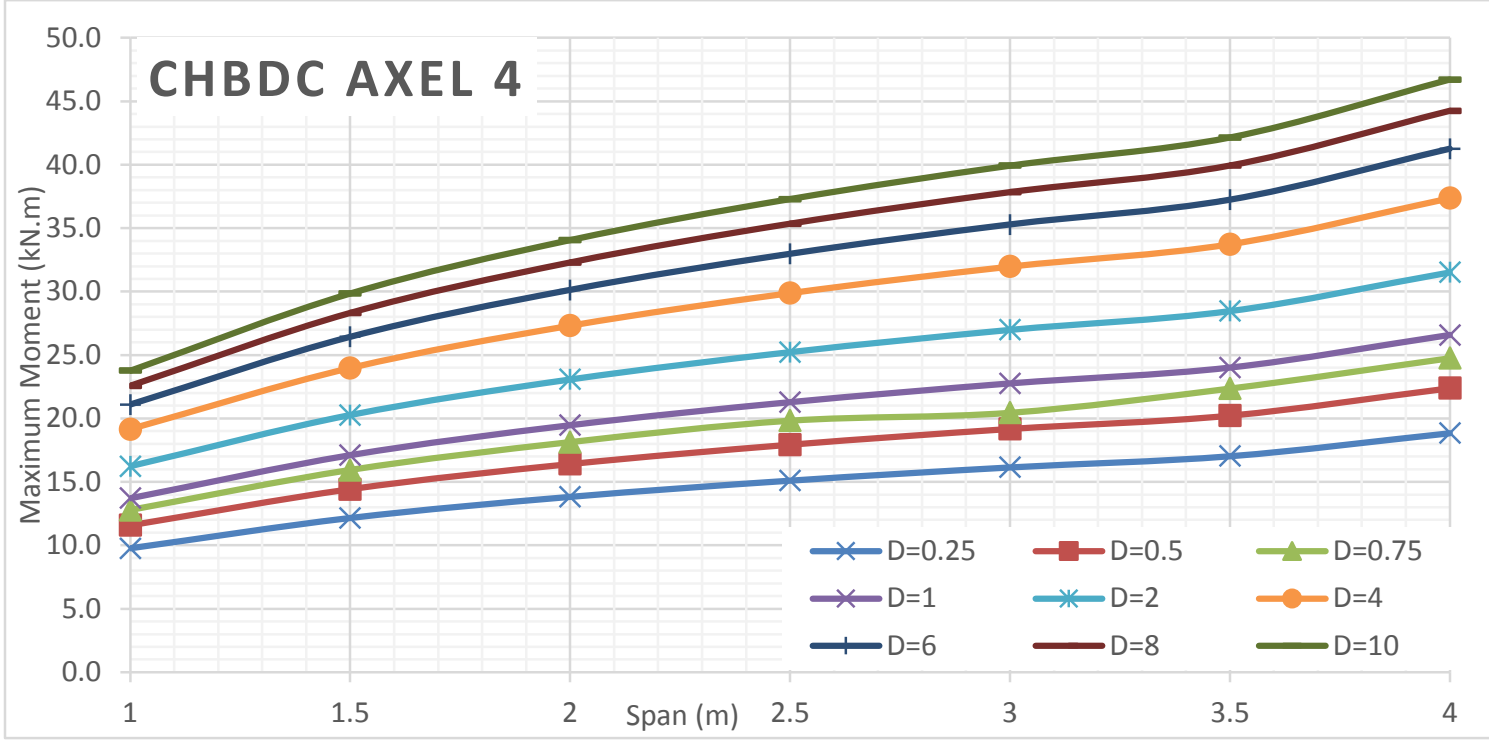

Figure 252 Maximum moment of deck slabs subjected to CHBDC axle 4 for different D values of alpha 0.5 Orthotropic analyses

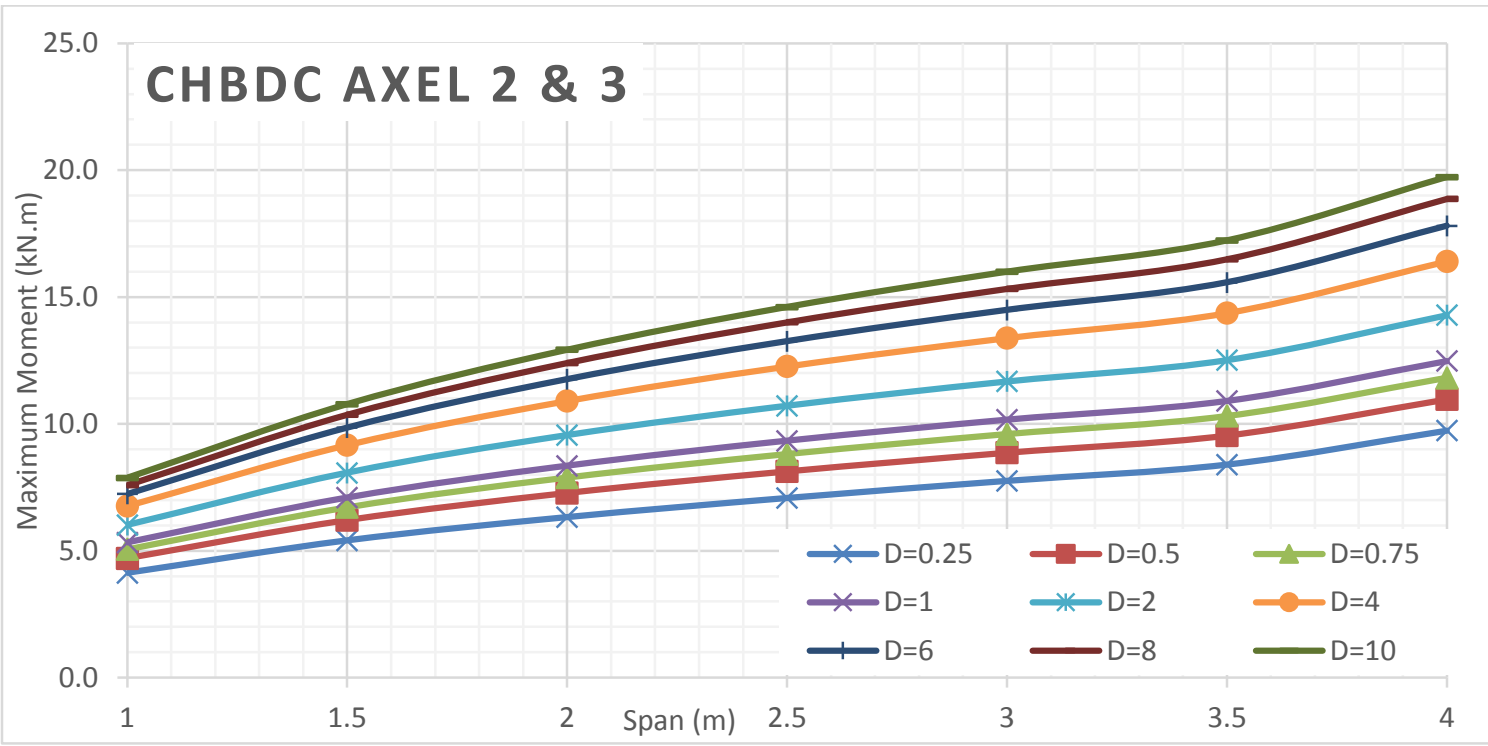

Figure 253 Maximum moment of deck slabs subjected to CHBDC axle $2 \& 3$ for different D values of alpha 0.5 Orthotropic analyses 


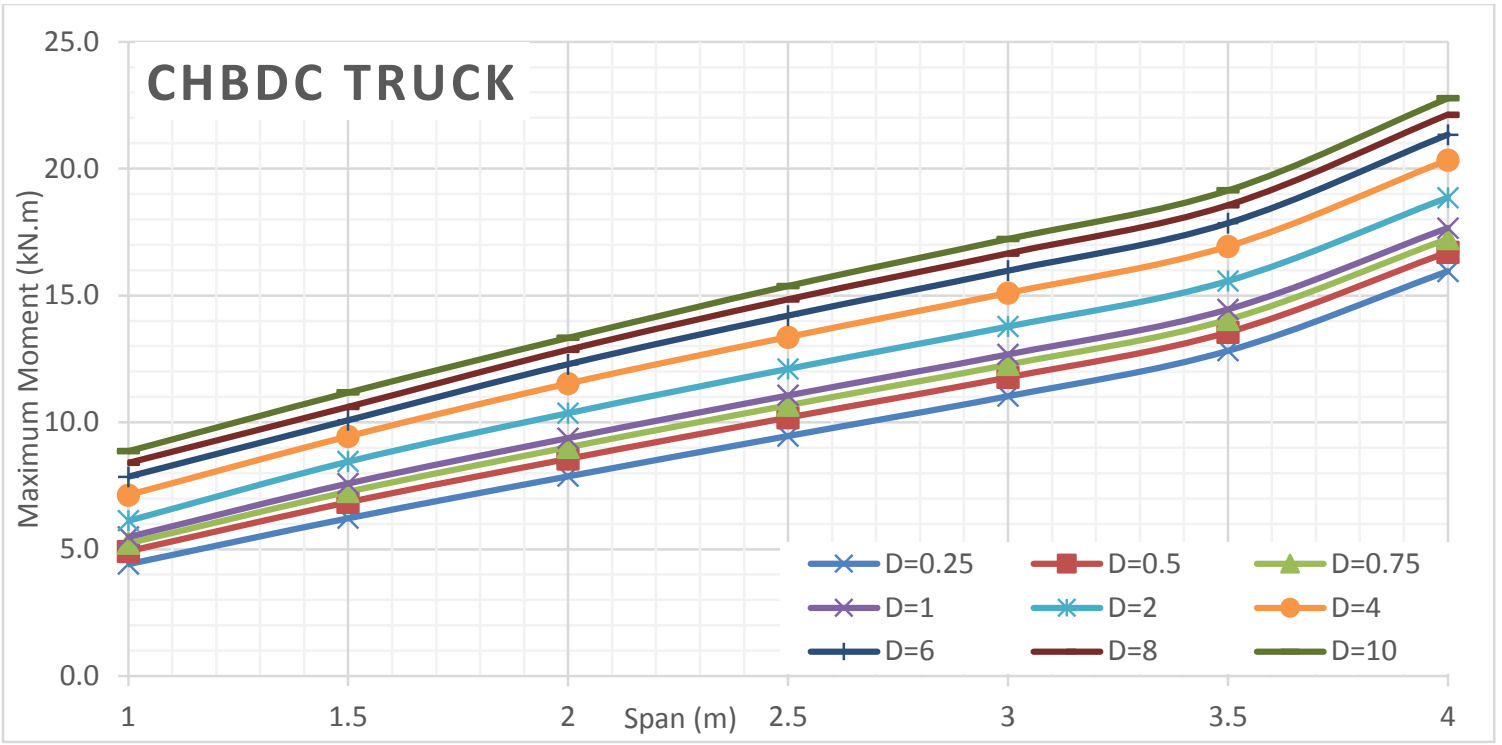

Figure 254 Maximum moment of deck slabs subjected to CHBDC truck for different D values of alpha 0.5 Orthotropic analyses

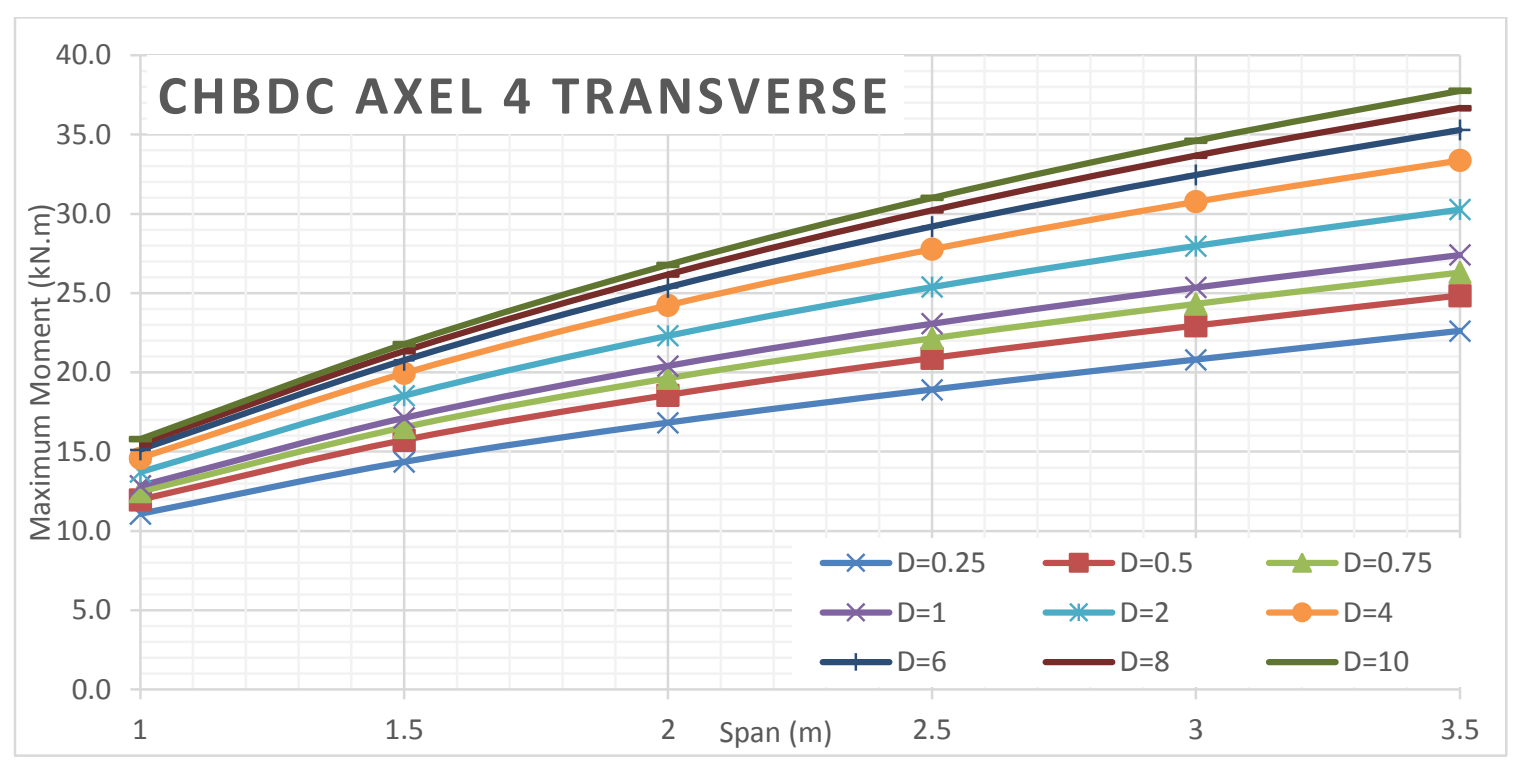

Figure 255 Maximum moment of deck slabs subjected to CHBDC axle 4 for different D values of alpha 0.5 Orthotropic analyses

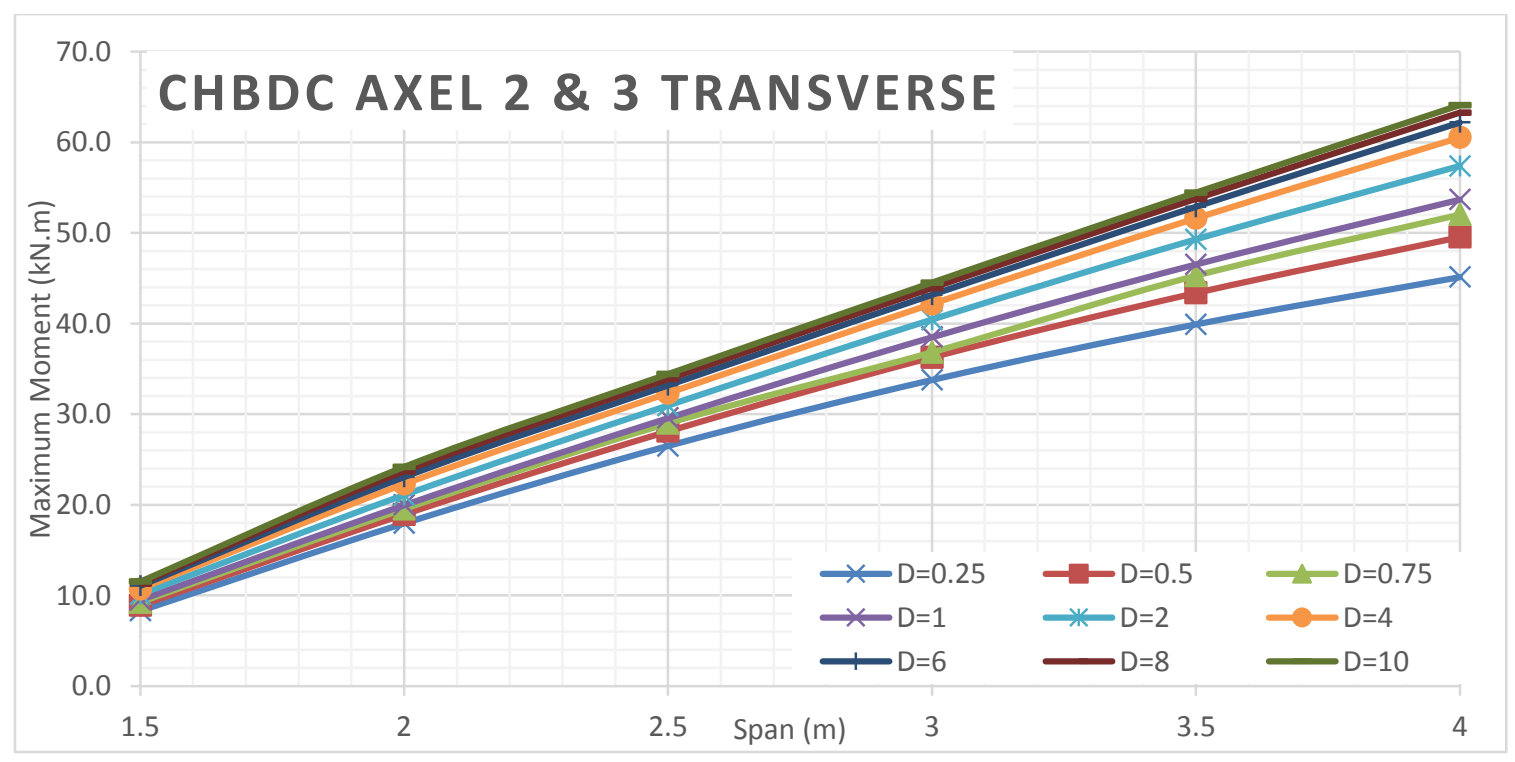

Figure 256 Maximum moment of deck slabs subjected to CHBDC axle $2 \& 3$ for different D values of alpha 0.5 Orthotropic analyses 


\section{Alpha 0.75 Bending Moment VS Span Length for Different D Values}

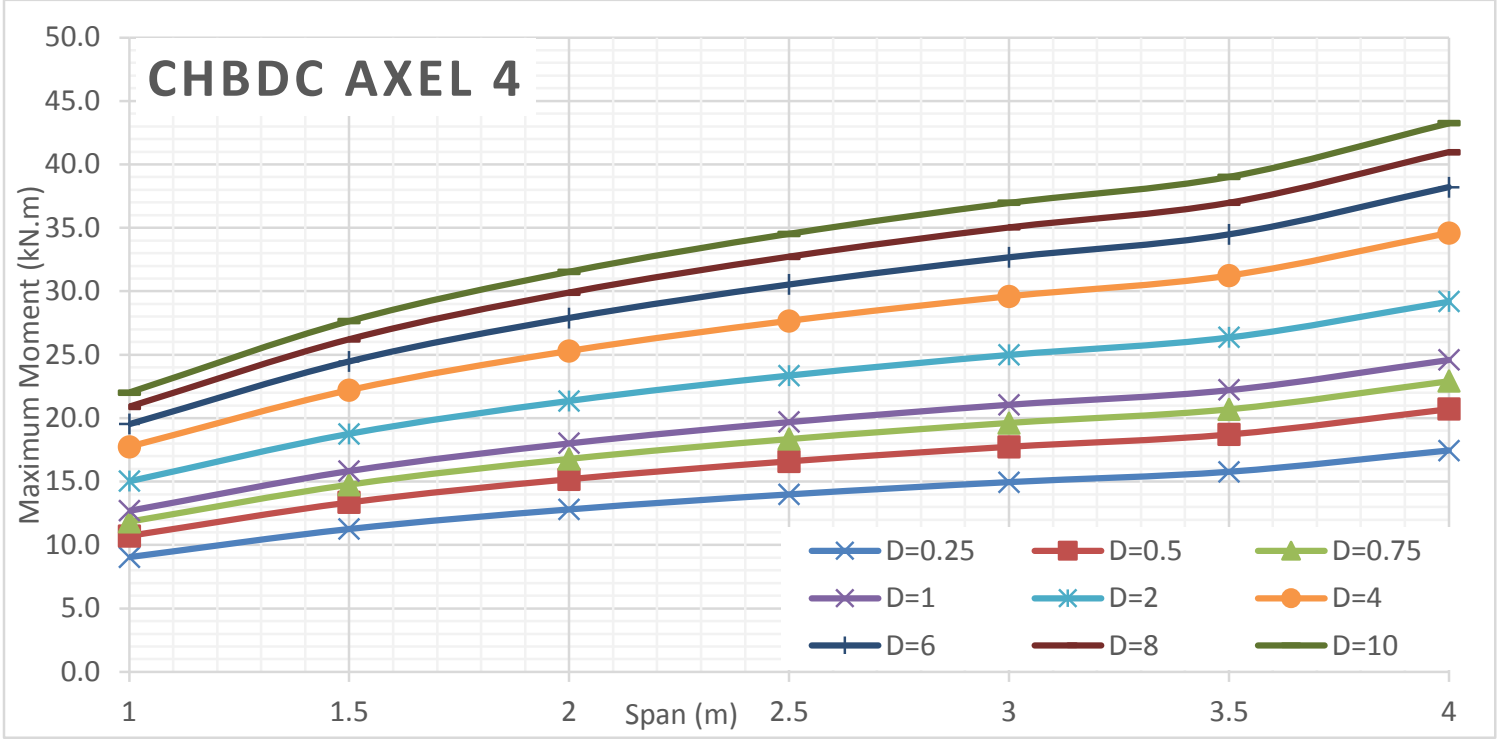

Figure 257 Maximum moment of deck slabs subjected to CHBDC axle 4 for different D values of alpha 0.75 Orthotropic analyses

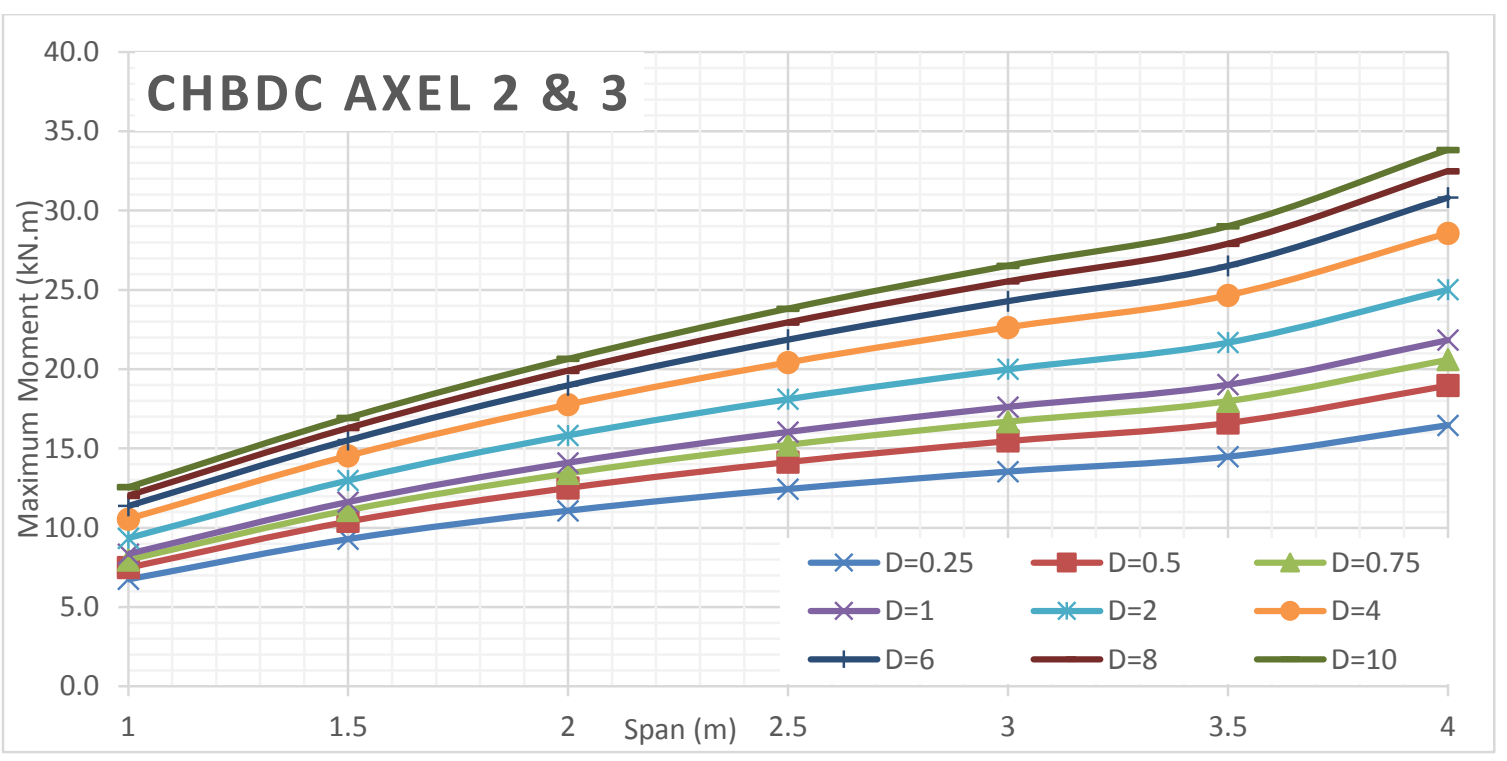

Figure 258 Maximum moment of deck slabs subjected to CHBDC axle $2 \& 3$ for different D values of alpha 0.75 Orthotropic analyses 


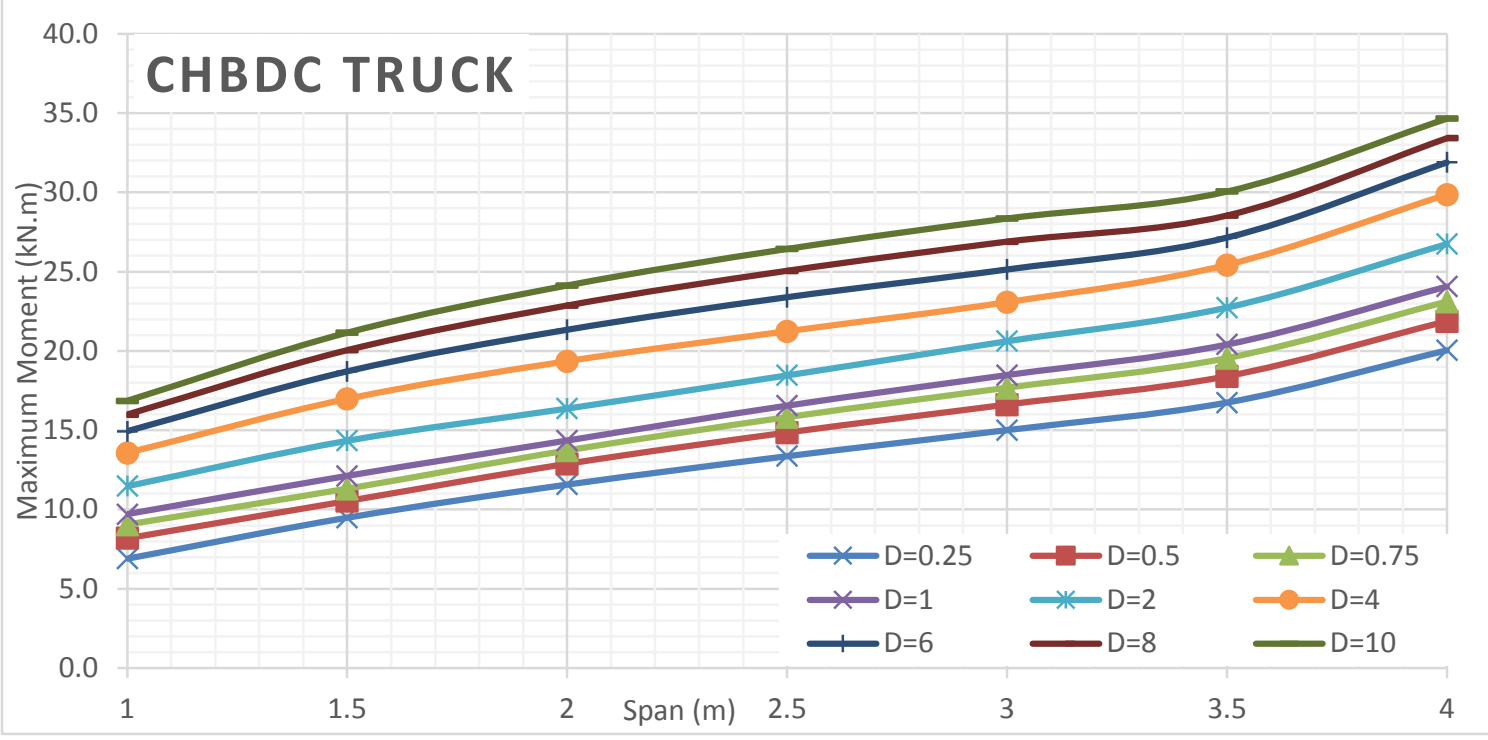

Figure 259 Maximum moment of deck slabs subjected to CHBDC truck for different D values of alpha 0.75 Orthotropic analyses

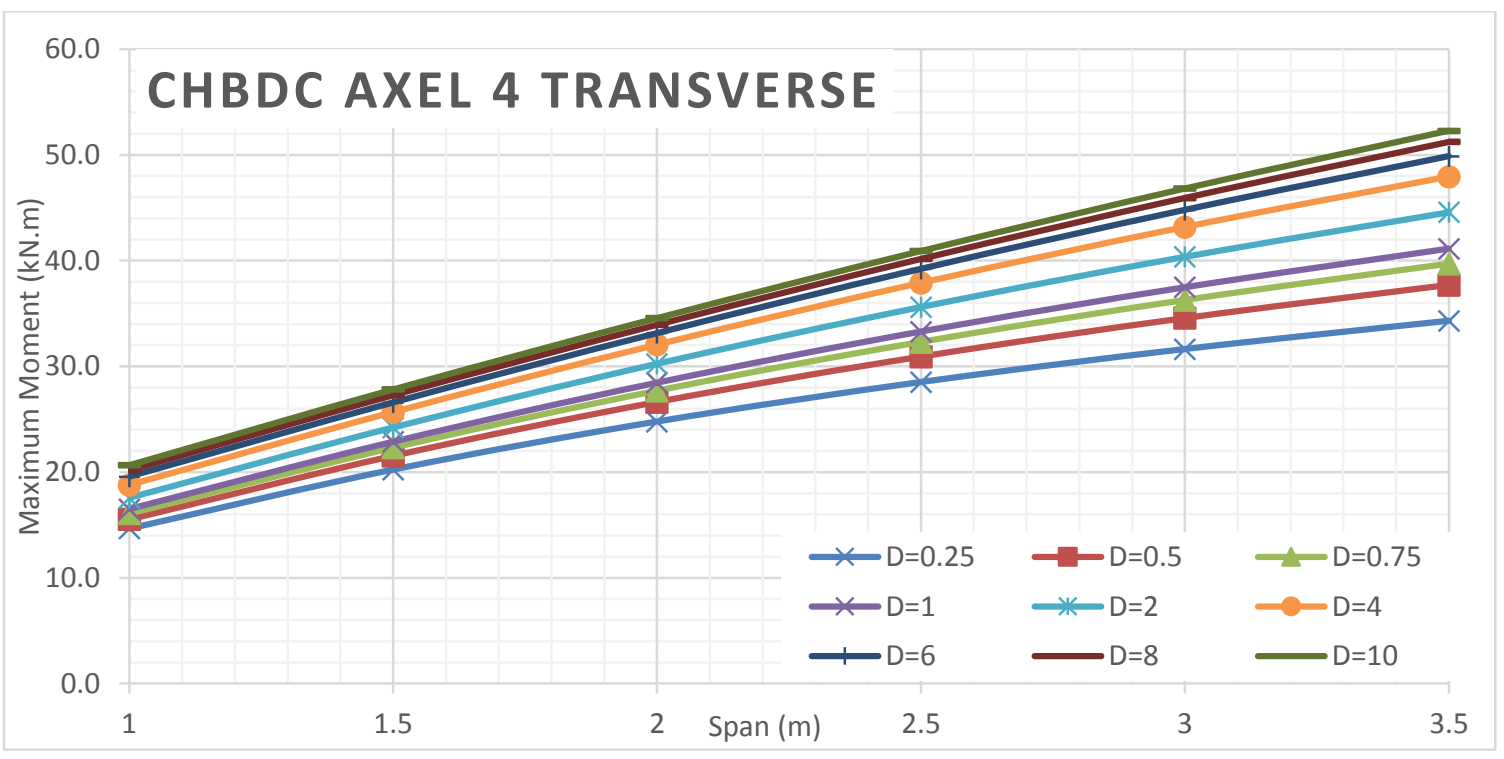

Figure 260 Maximum moment of deck slabs subjected to CHBDC axle 4 for different D values of alpha 0.75 Orthotropic analyses

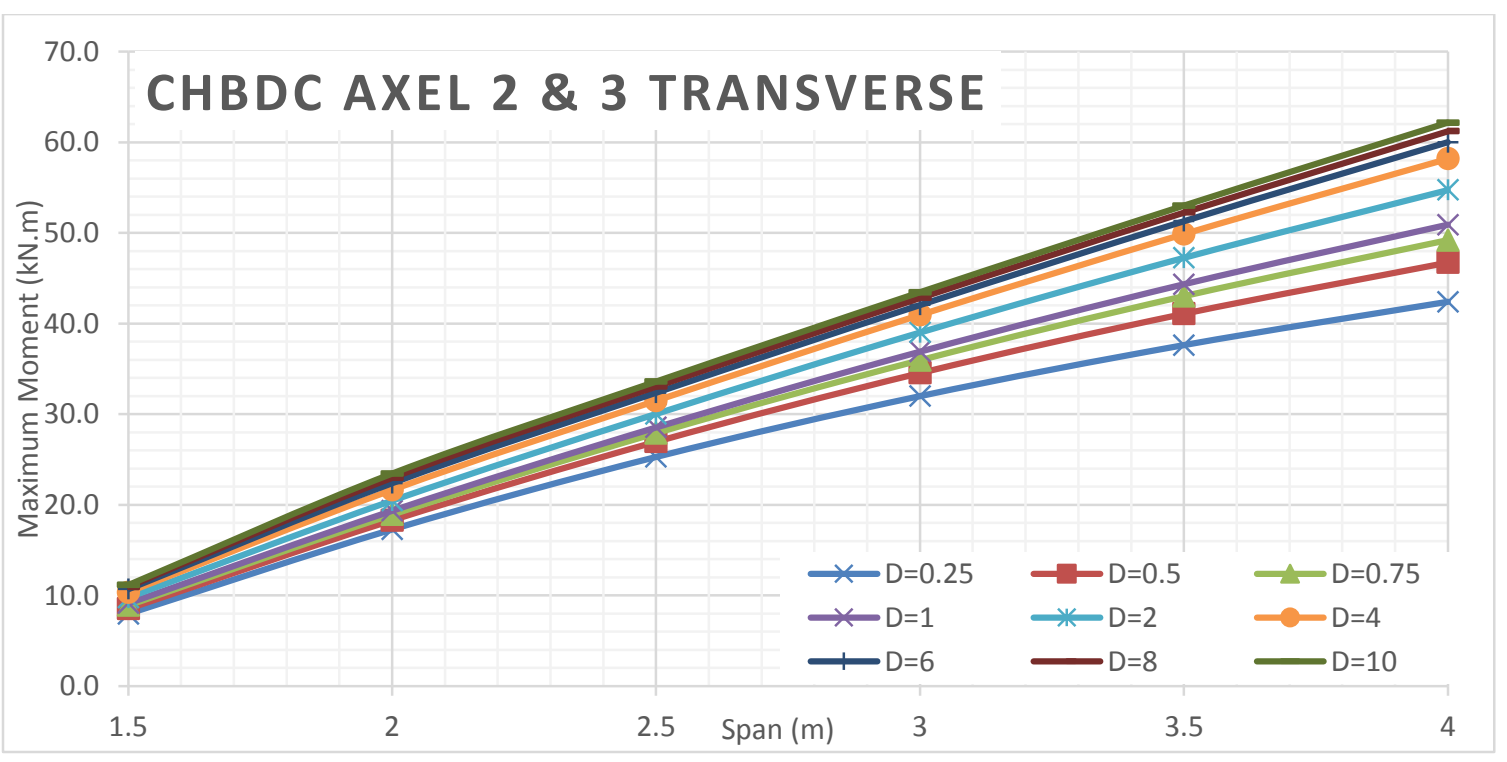

Figure 261 Maximum moment of deck slabs subjected to CHBDC axle $2 \& 3$ for different D values of alpha 0.75 Orthotropic analyses 


\section{Alpha 1 Bending Moment VS Span Length for Different D Values}

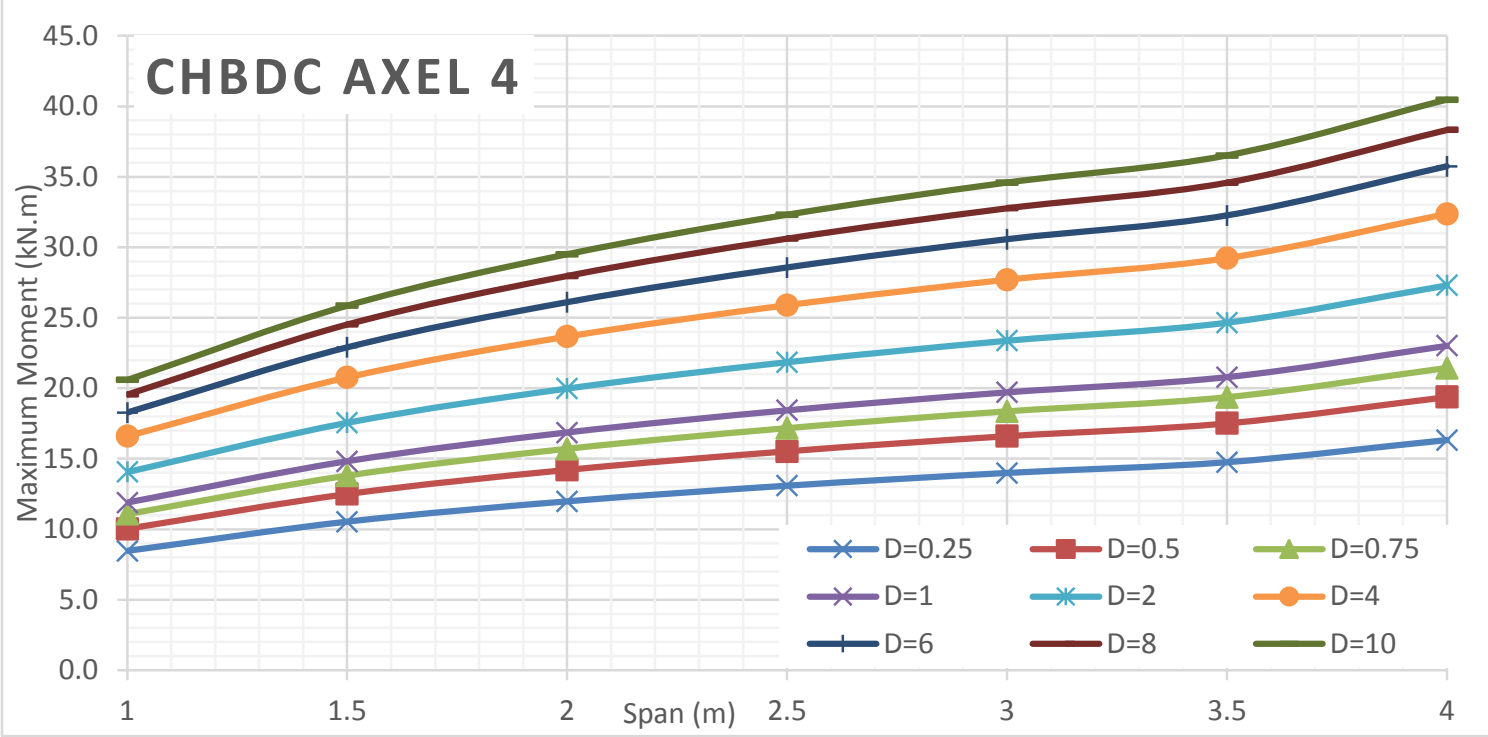

Figure 262 Maximum moment of deck slabs subjected to CHBDC axle 4 for different D values of alpha 1 Orthotropic analyses

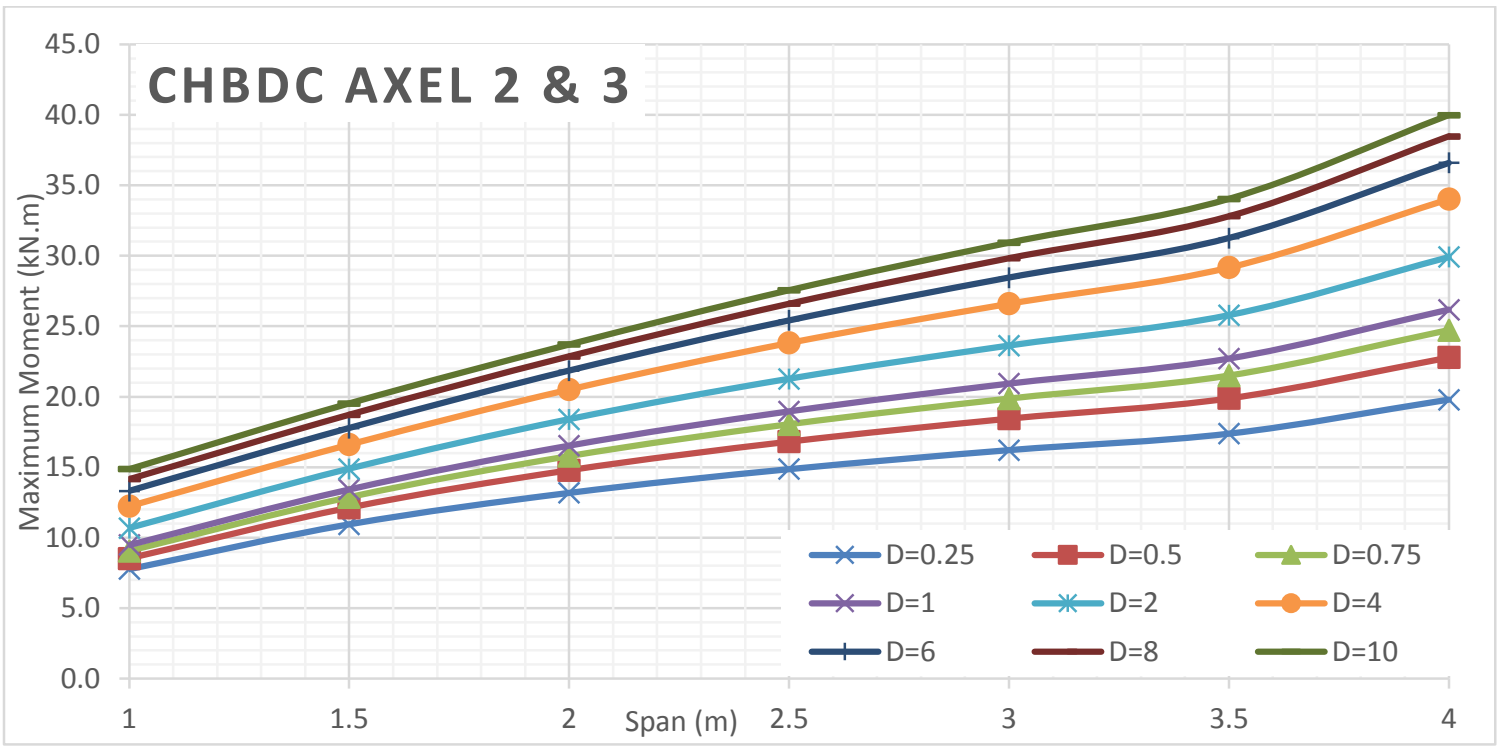

Figure 263 Maximum moment of deck slabs subjected to CHBDC axle 2 \& 3 for different D values of alpha 1 Orthotropic analyses 


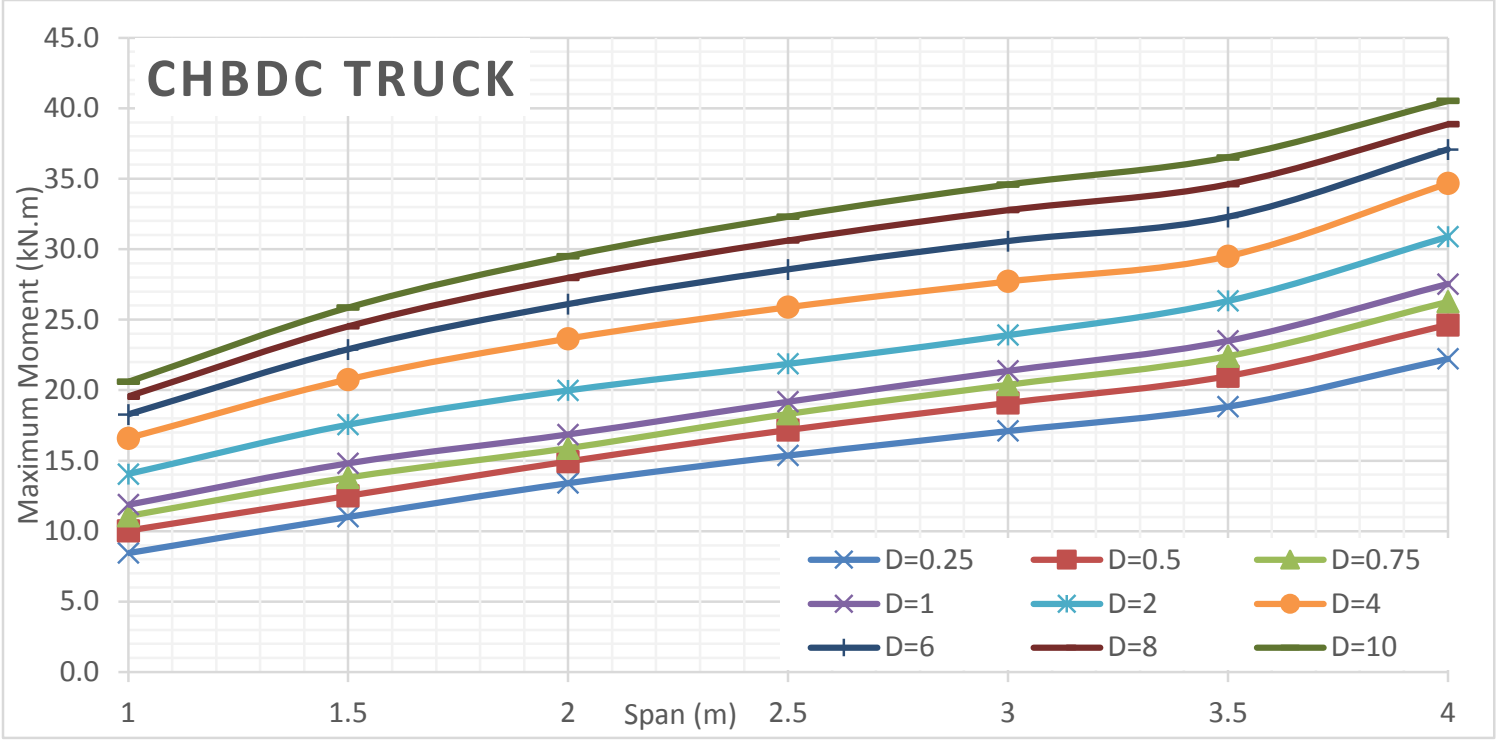

Figure 264 Maximum moment of deck slabs subjected to CHBDC truck for different D values of alpha 1 Orthotropic analyses

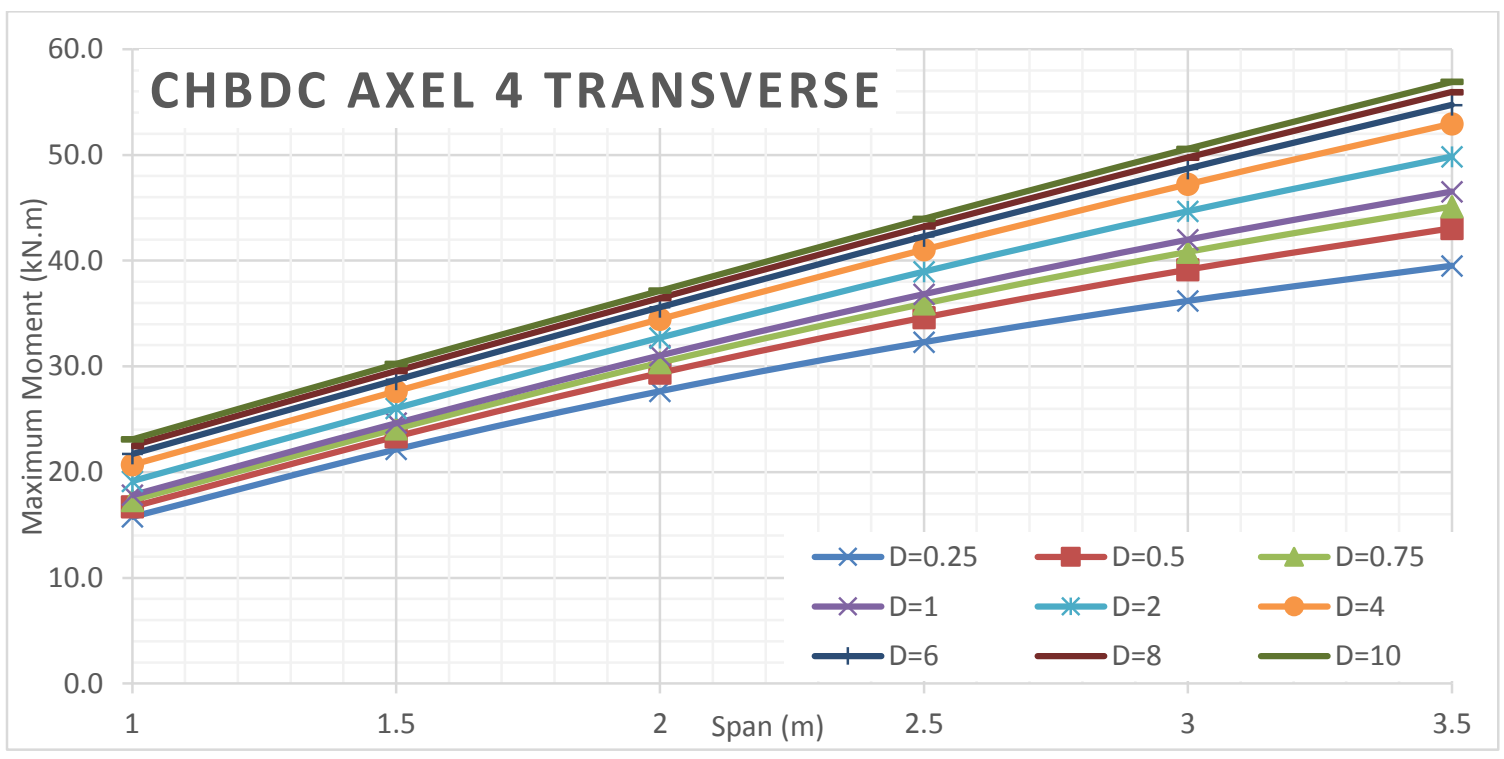

Figure 265 Maximum moment of deck slabs subjected to CHBDC axle 4 for different D values of alpha 1 Orthotropic analyses

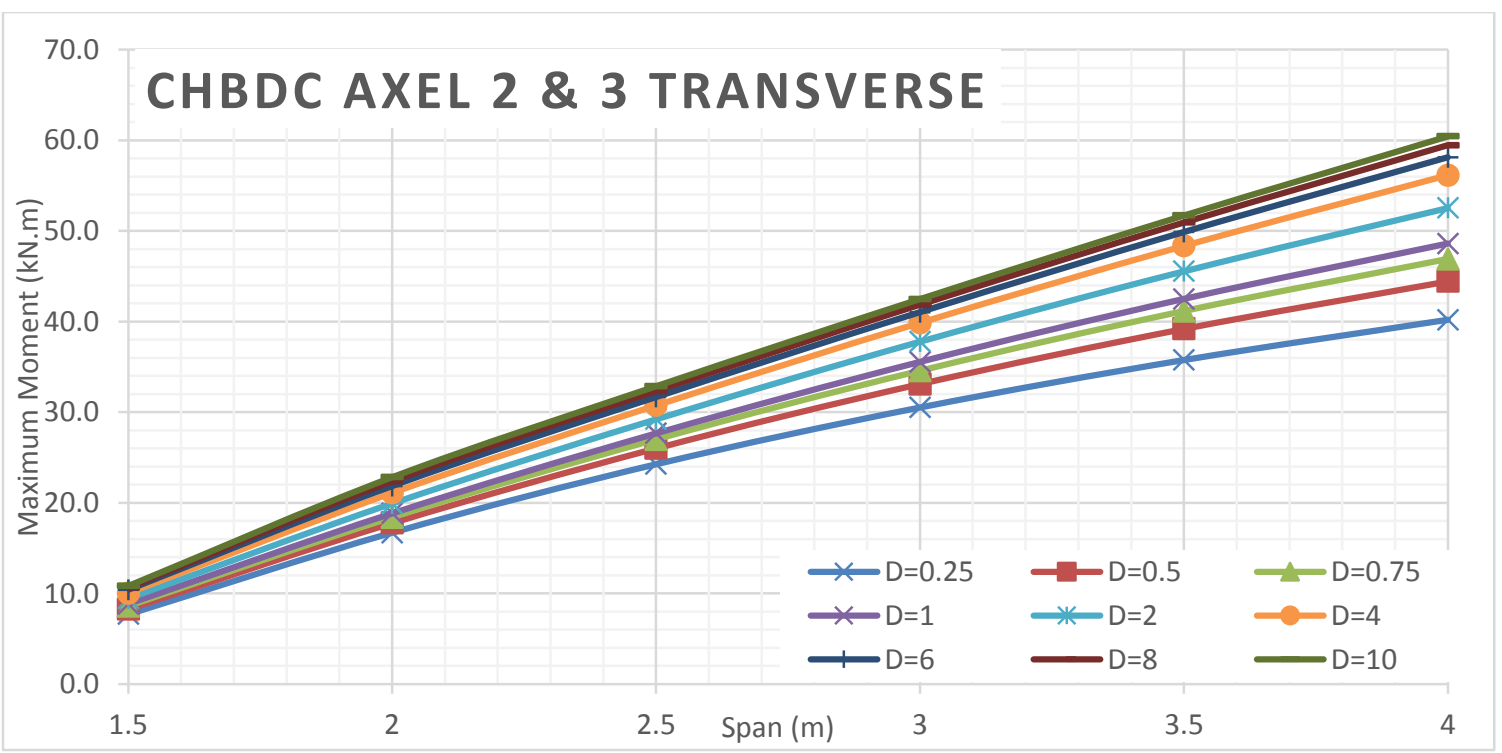

Figure 266 Maximum moment of deck slabs subjected to CHBDC axle $2 \& 3$ for different D values of alpha 1 Orthotropic analyses 


\section{Alpha 2 Bending Moment VS Span Length for Different D Values}

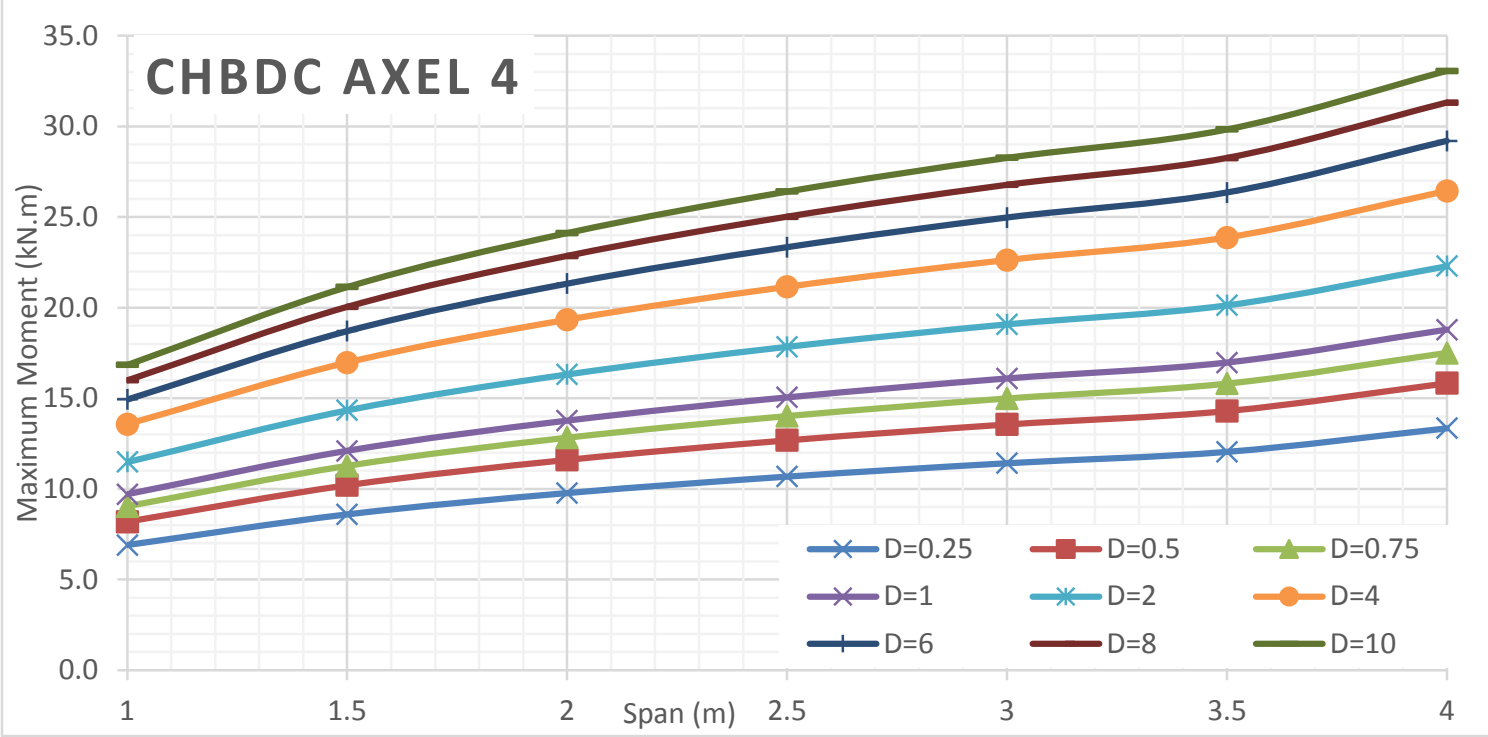

Figure 267 Maximum moment of deck slabs subjected to CHBDC axle 4 for different D values of alpha 2 Orthotropic analyses

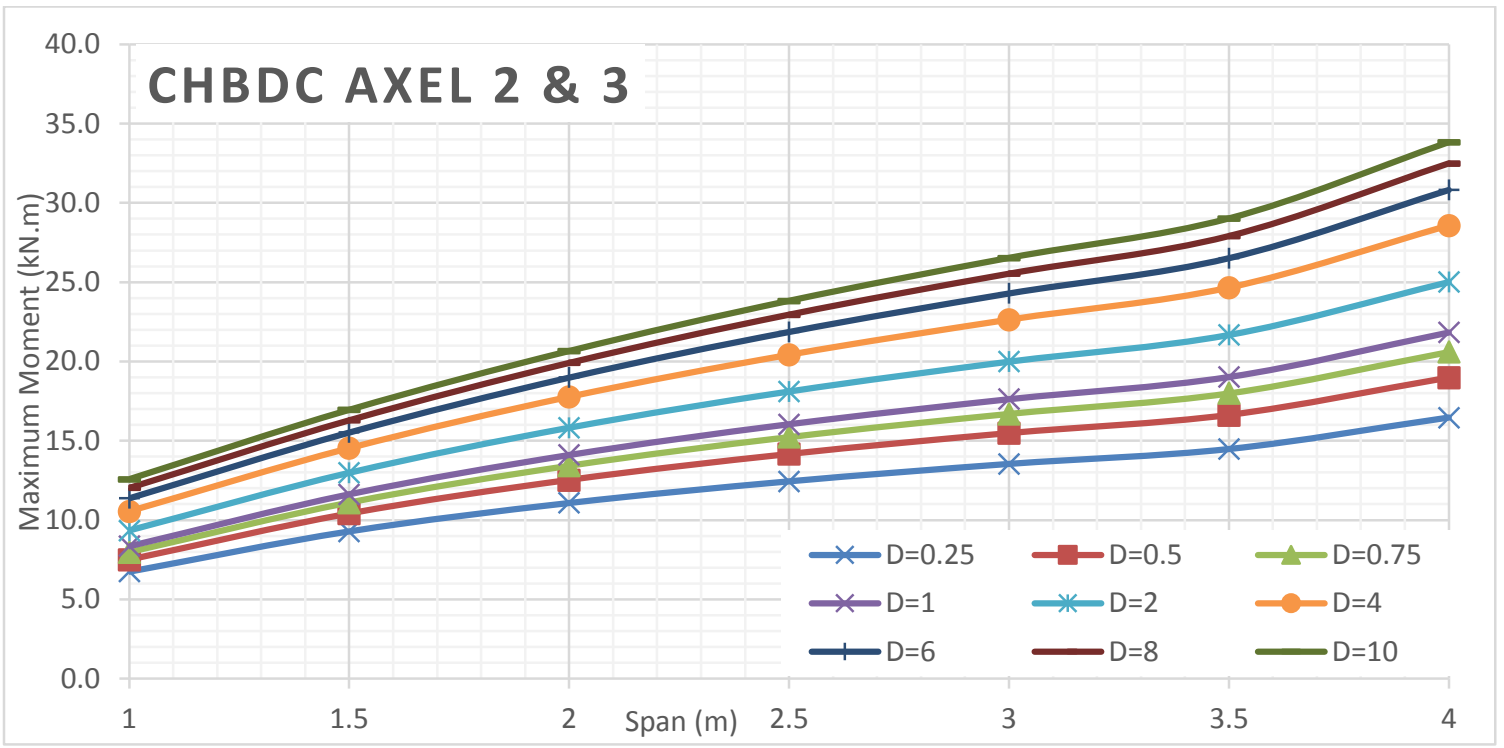

Figure 268 Maximum moment of deck slabs subjected to CHBDC axle $2 \& 3$ for different D values of alpha 2 Orthotropic analyses 


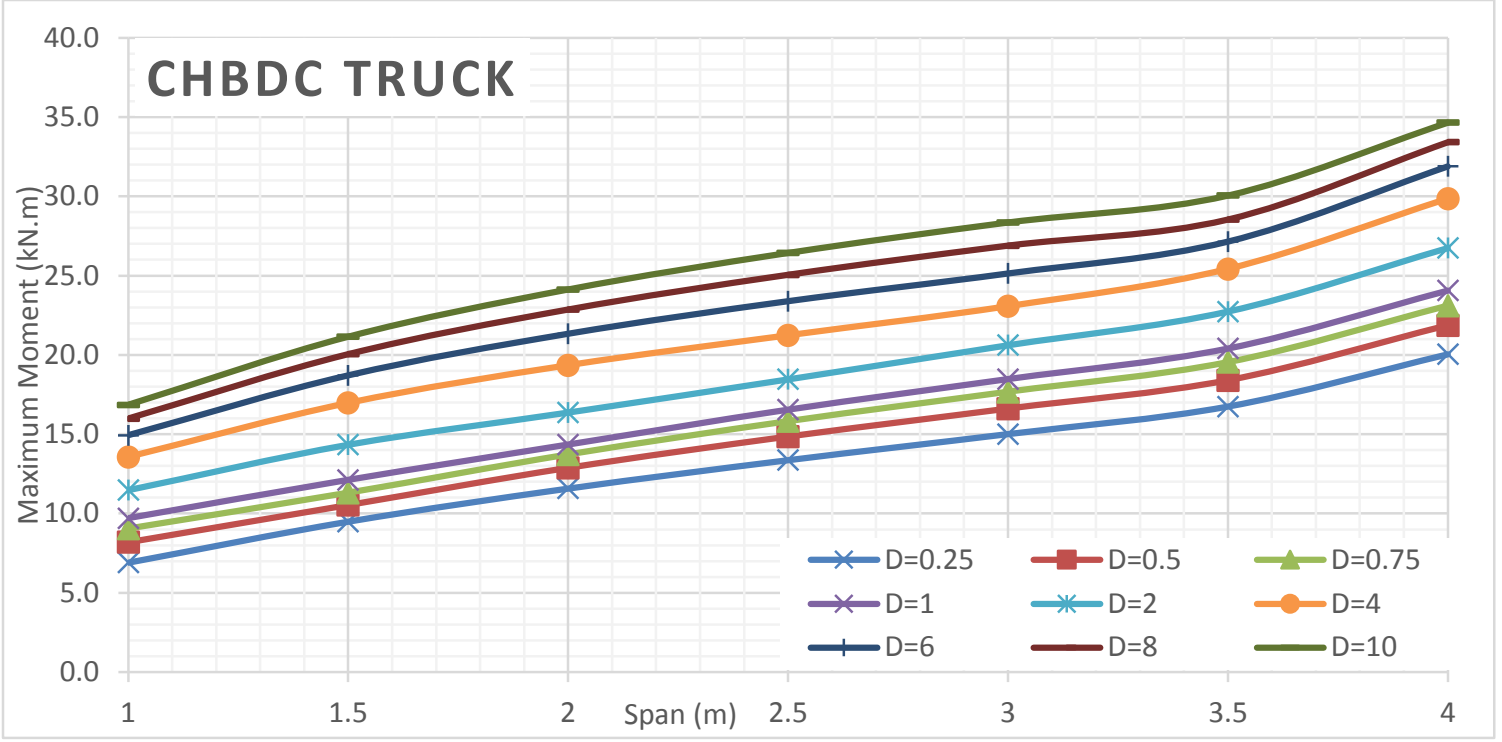

Figure 269 Maximum moment of deck slabs subjected to CHBDC truck for different D values of alpha 2 Orthotropic analyses

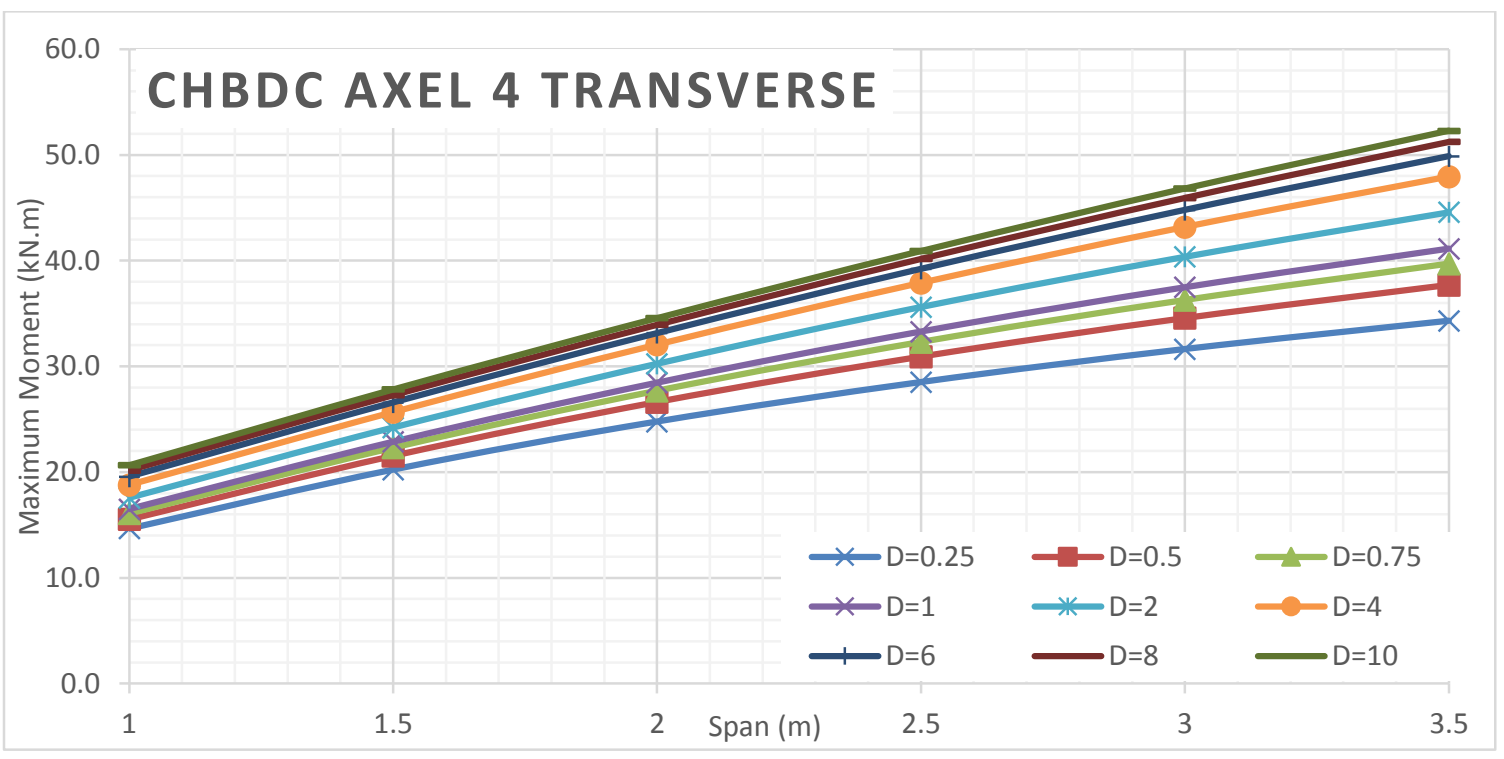

Figure 270 Maximum moment of deck slabs subjected to CHBDC axle 4 for different D values of alpha 2 Orthotropic analyses

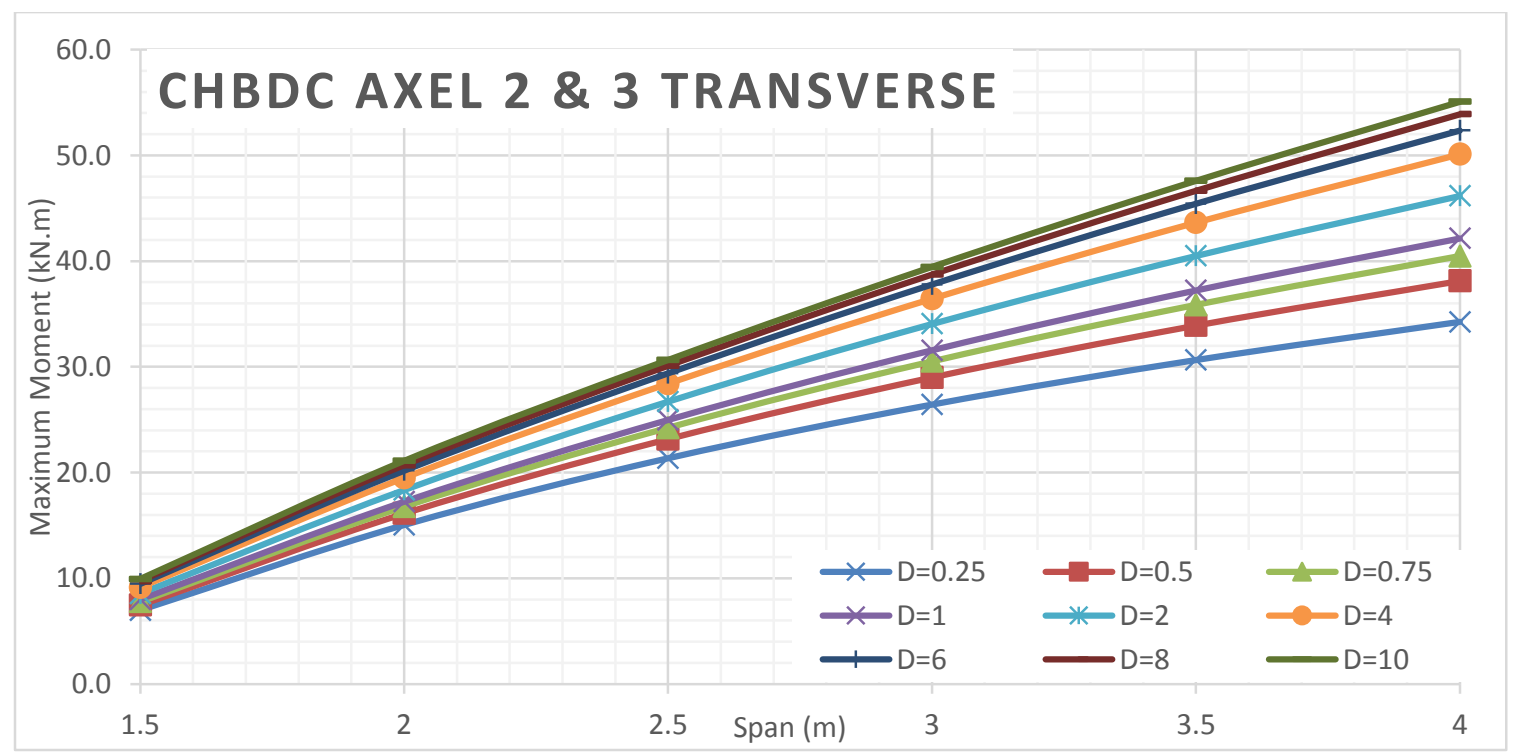

Figure 271 Maximum moment of deck slabs subjected to CHBDC axle 2 \& 3 for different D values of alpha 2 Orthotropic analyses 


\section{Alpha 4 Bending Moment VS Span Length for Different D Values}

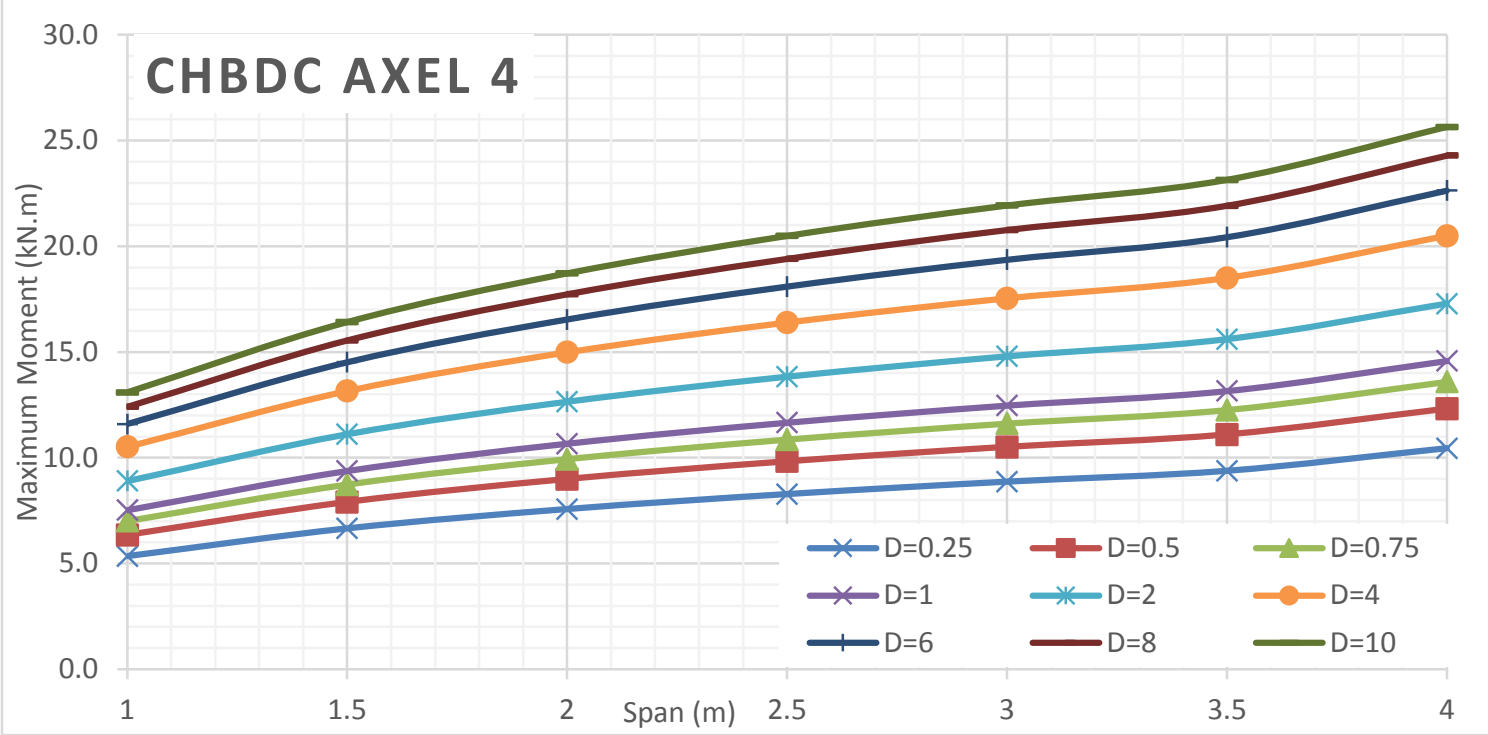

Figure 272 Maximum moment of deck slabs subjected to CHBDC axle 4 for different D values of alpha 4 Orthotropic analyses

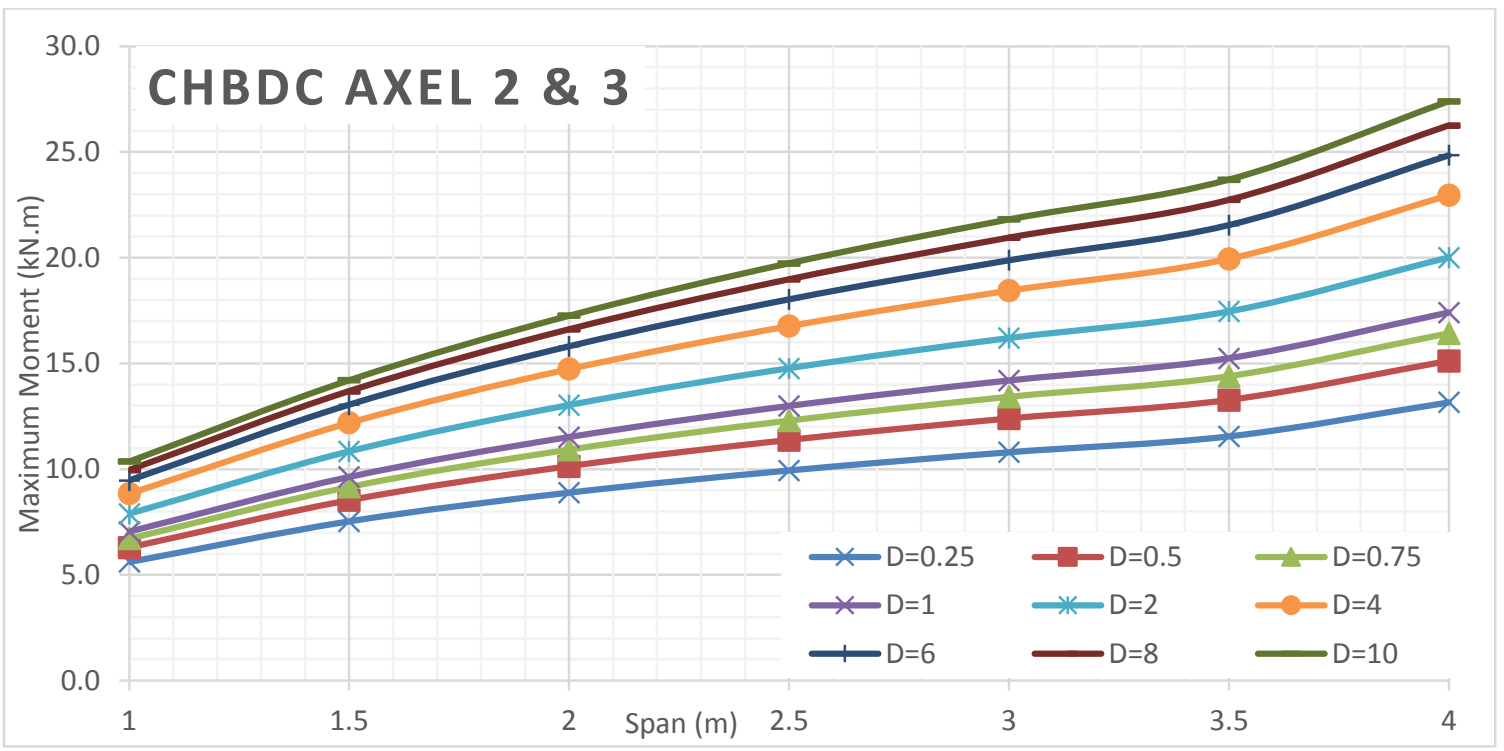

Figure 273 Maximum moment of deck slabs subjected to CHBDC axle $2 \& 3$ for different D values of alpha 4 Orthotropic analyses 


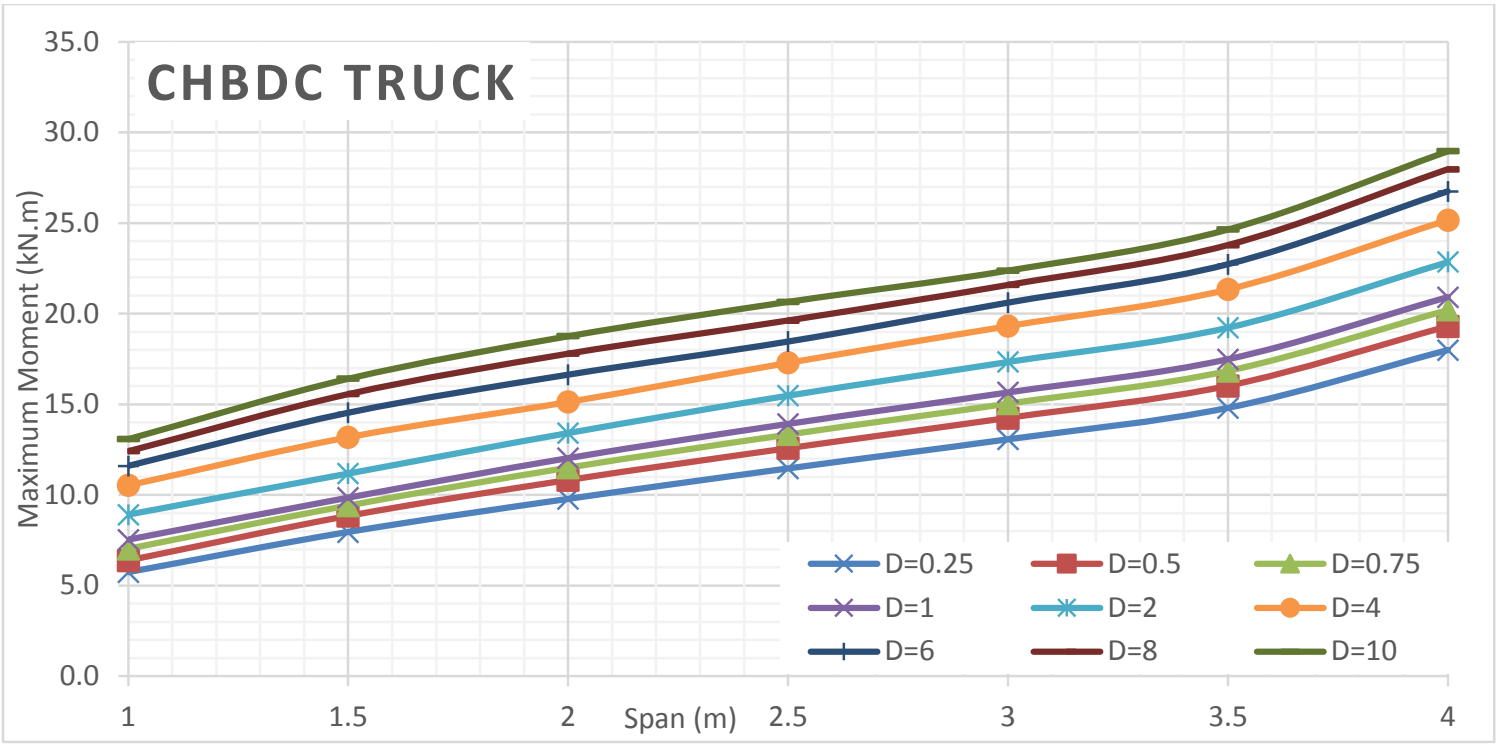

Figure 274 Maximum moment of deck slabs subjected to CHBDC truck for different D values of alpha 4 Orthotropic analyses

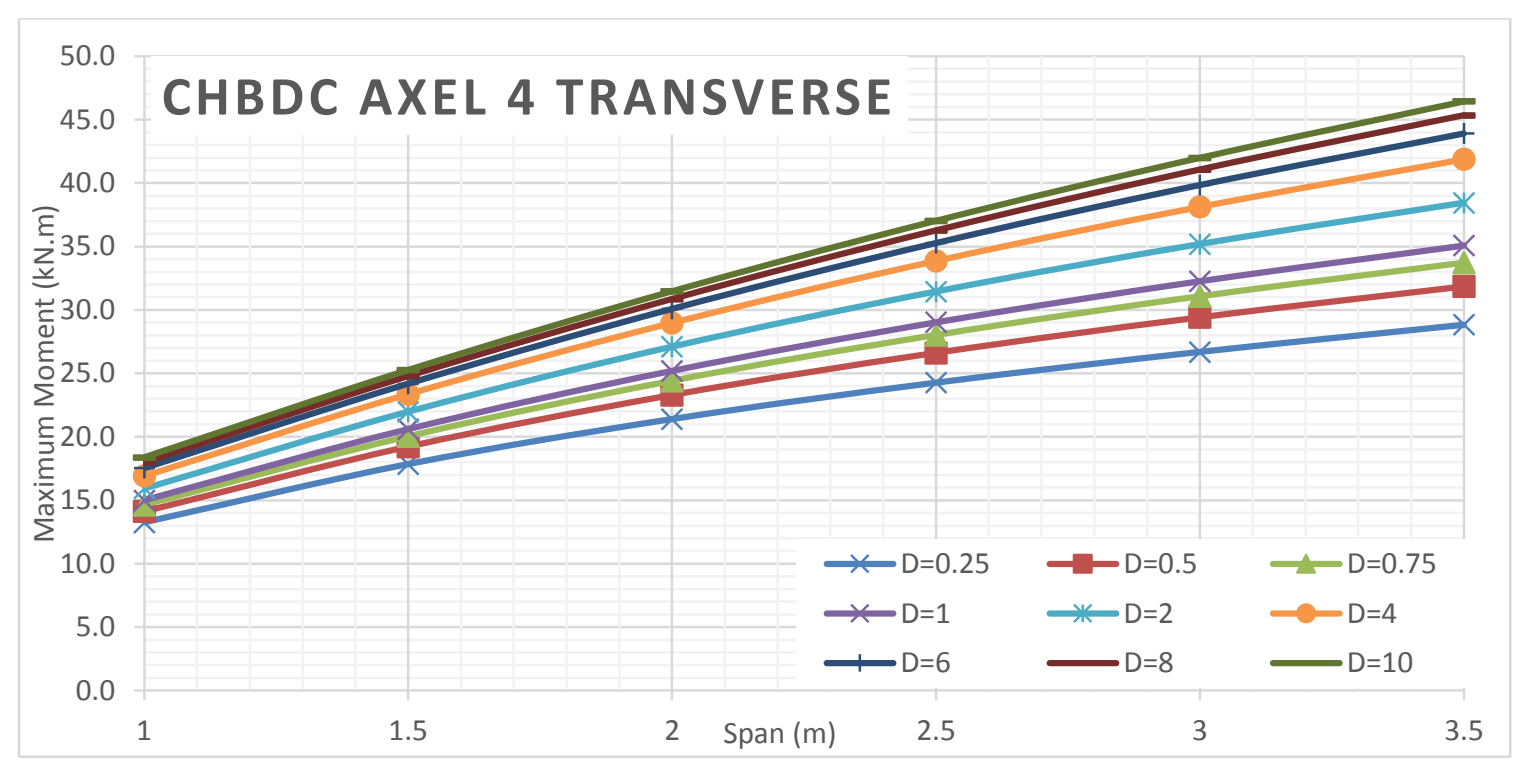

Figure 275 Maximum moment of deck slabs subjected to CHBDC axle 4 for different D values of alpha 4 Orthotropic analyses

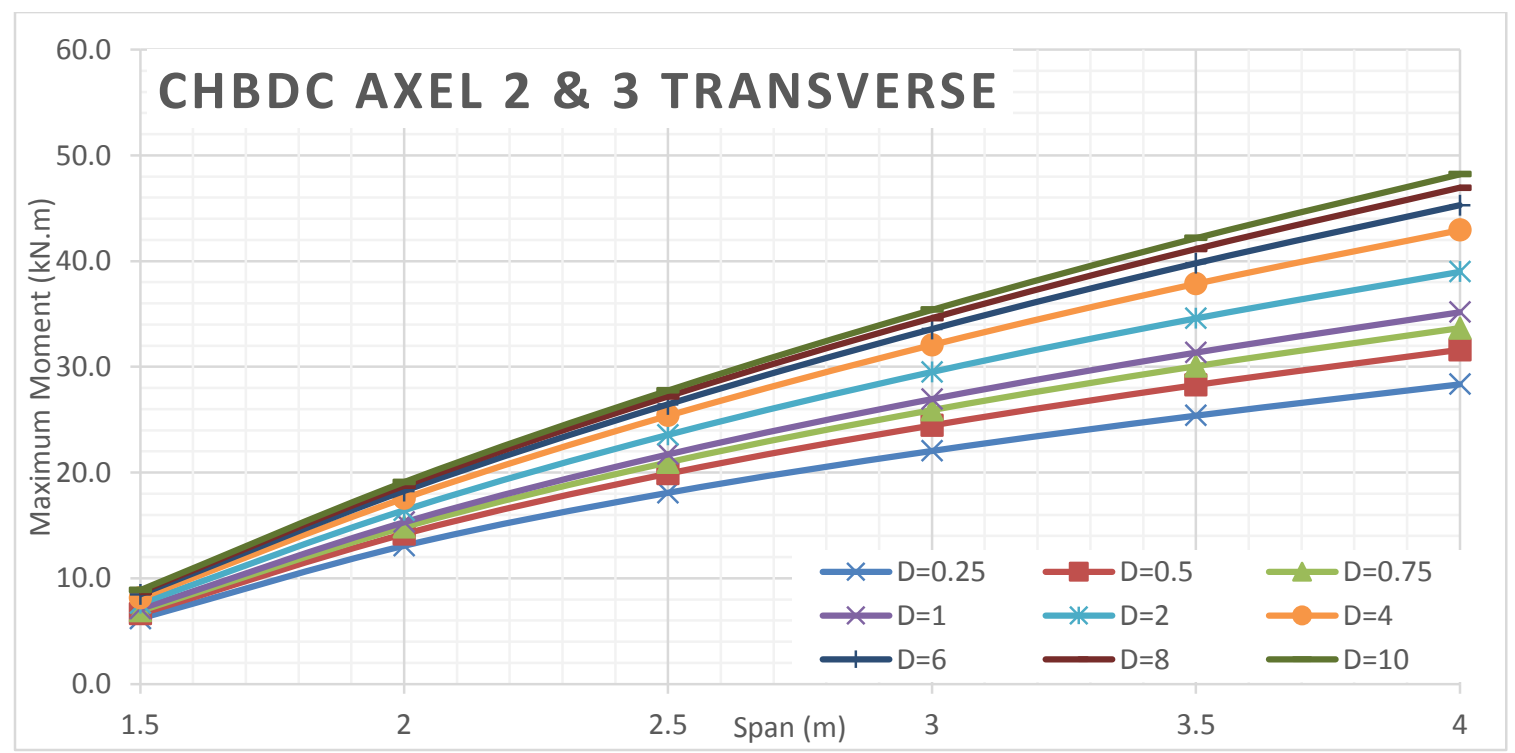

Figure 276 Maximum moment of deck slabs subjected to CHBDC axle $2 \& 3$ for different D values of alpha 4 Orthotropic analyses 


\section{Alpha 6 Bending Moment VS Span Length for Different D Values}

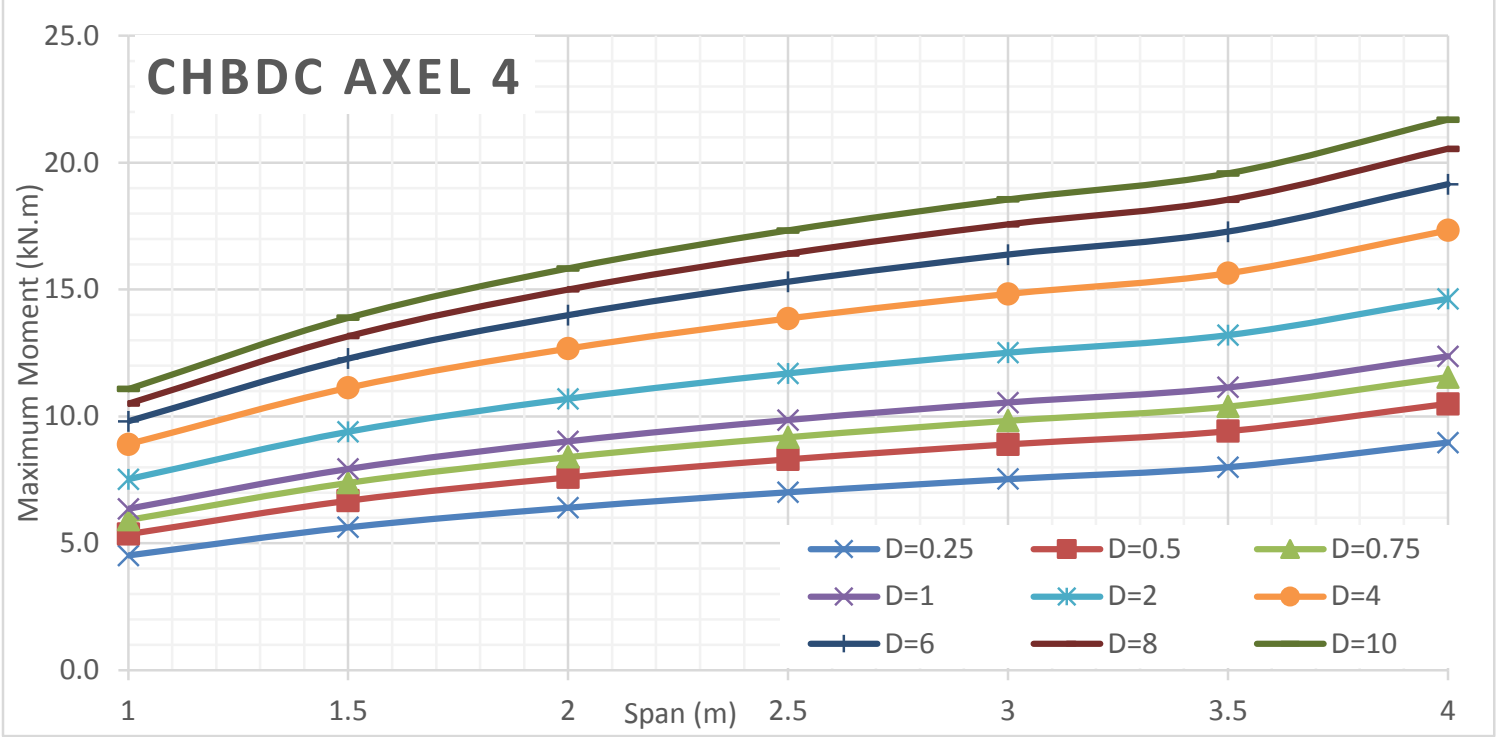

Figure 277 Maximum moment of deck slabs subjected to CHBDC axle 4 for different D values of alpha 6 Orthotropic analyses

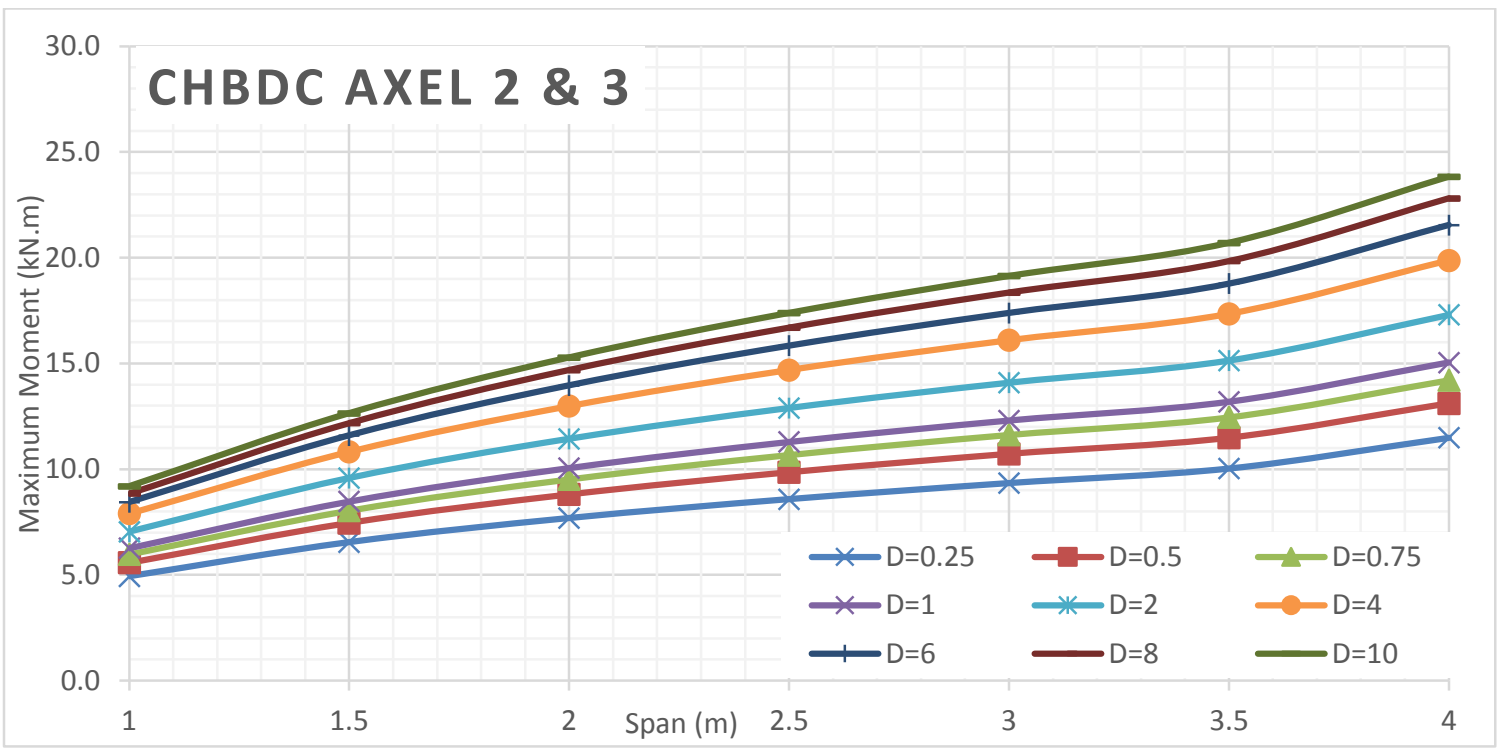

Figure 278 Maximum moment of deck slabs subjected to CHBDC axle $2 \& 3$ for different D values of alpha 6 Orthotropic analyses 


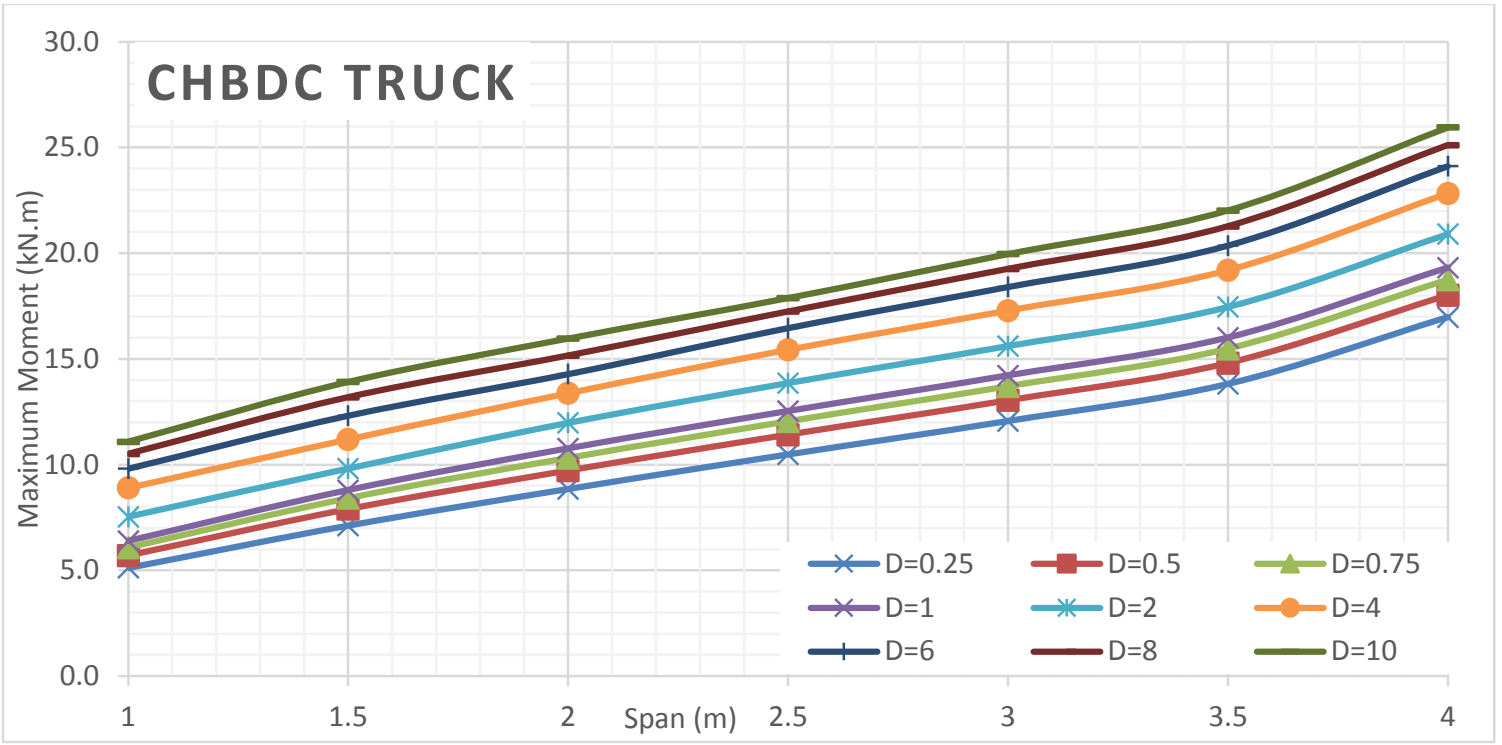

Figure 279 Maximum moment of deck slabs subjected to CHBDC truck for different D values of alpha 6 Orthotropic analyses

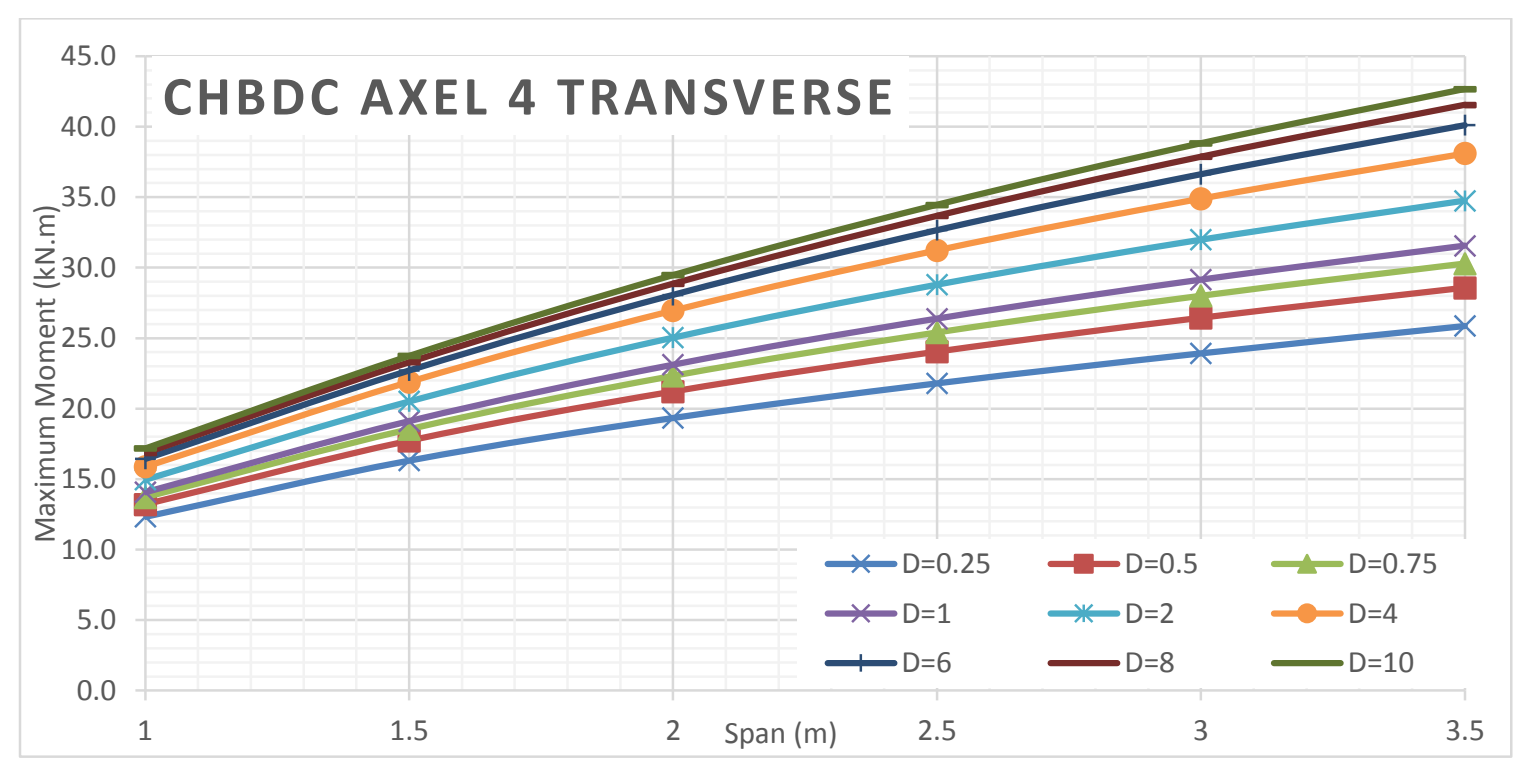

Figure 280 Maximum moment of deck slabs subjected to CHBDC axle 4 for different D values of alpha 6 Orthotropic analyses

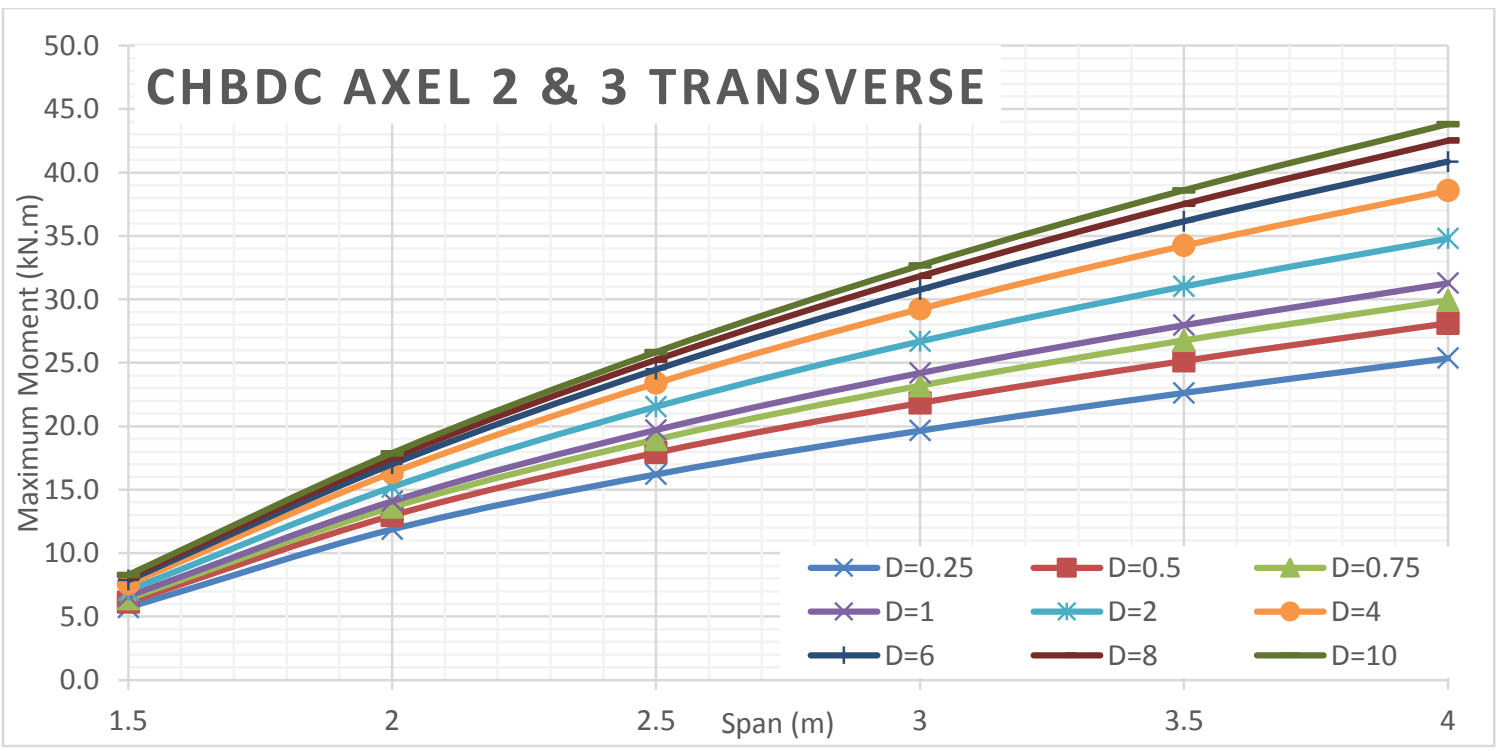

Figure 281 Maximum moment of deck slabs subjected to CHBDC axle 2 \& 3 for different D values of alpha 6 Orthotropic analyses 


\section{Alpha 8 Bending Moment VS Span Length for Different D Values}

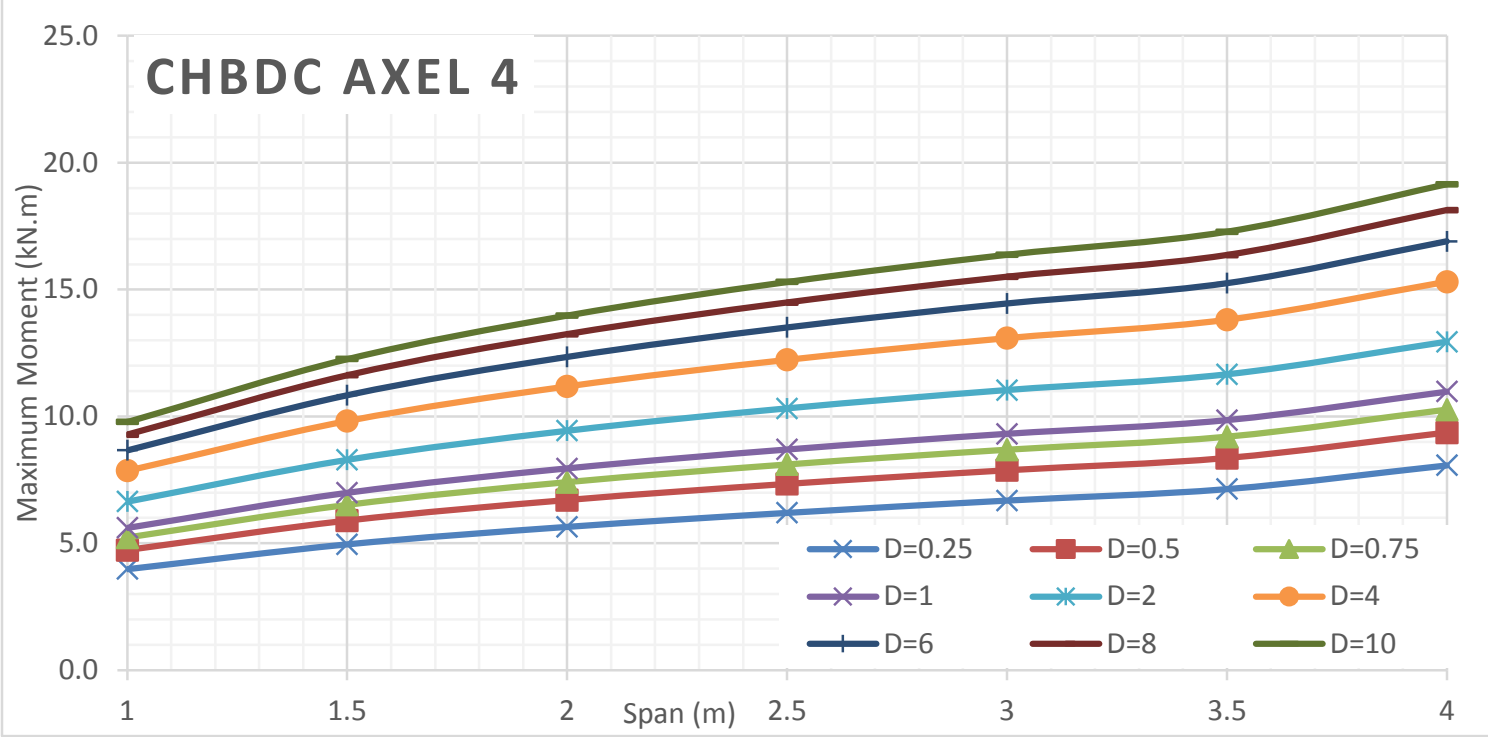

Figure 282 Maximum moment of deck slabs subjected to CHBDC axle 4 for different D values of alpha 8 Orthotropic analyses

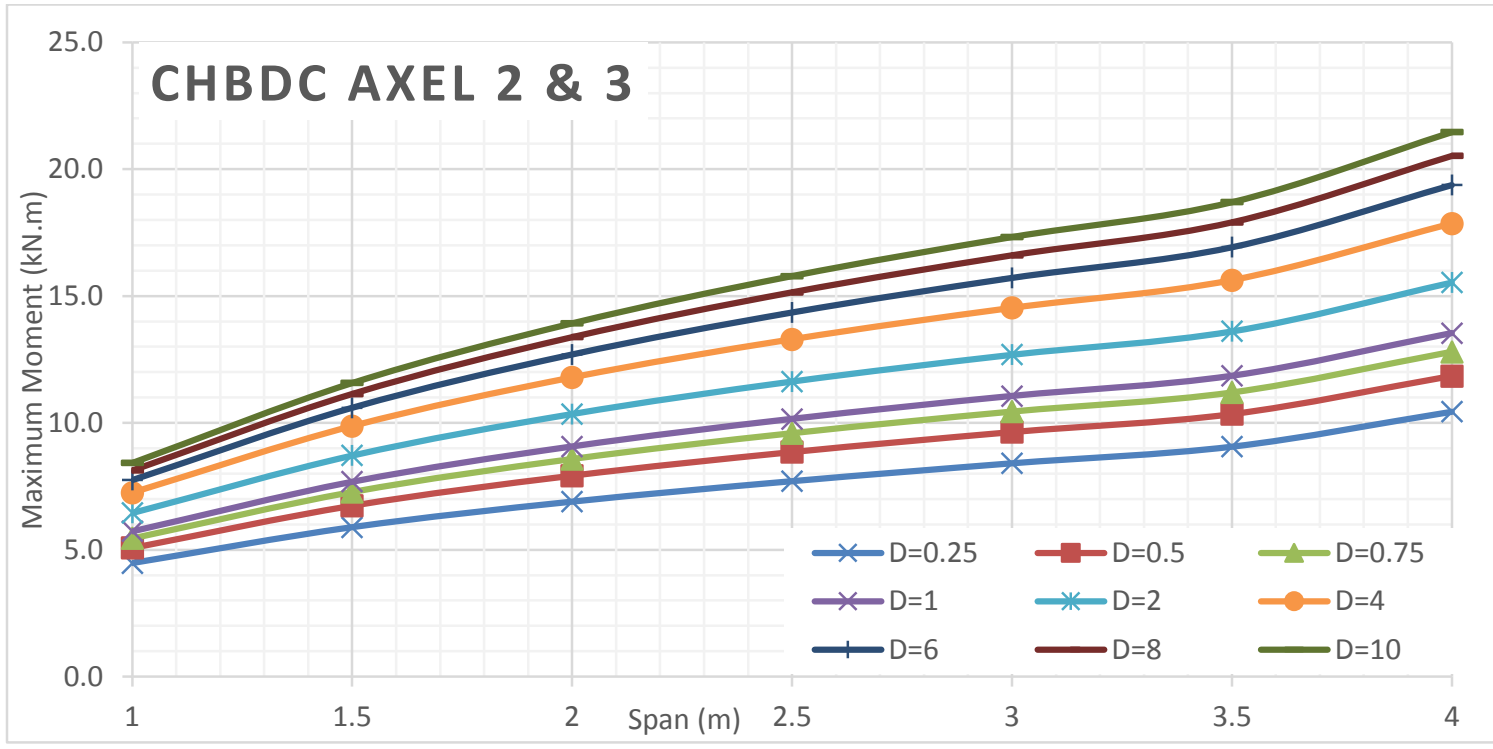

Figure 283 Maximum moment of deck slabs subjected to CHBDC axle $2 \& 3$ for different D values of alpha 8 Orthotropic analyses 


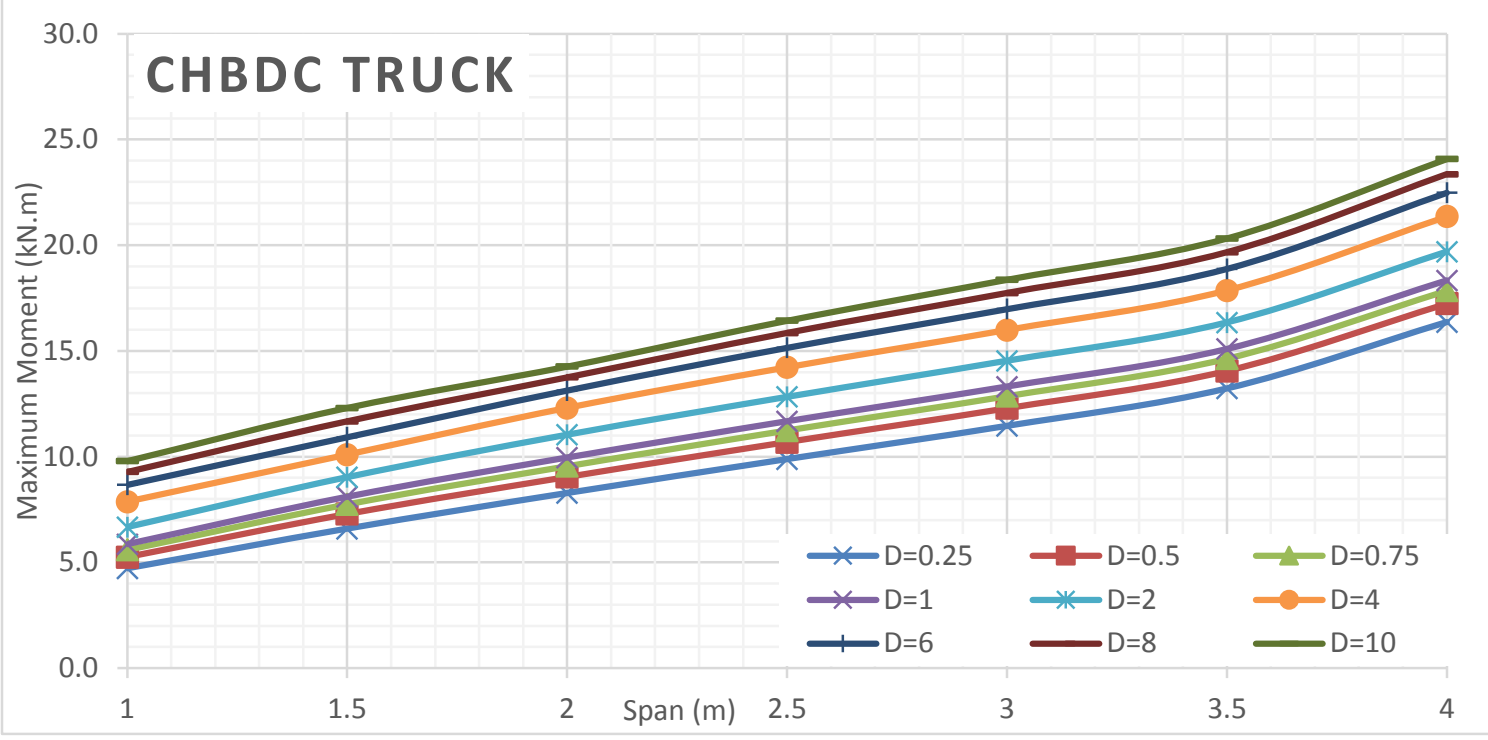

Figure 284 Maximum moment of deck slabs subjected to CHBDC truck for different D values of alpha 8 Orthotropic analyses

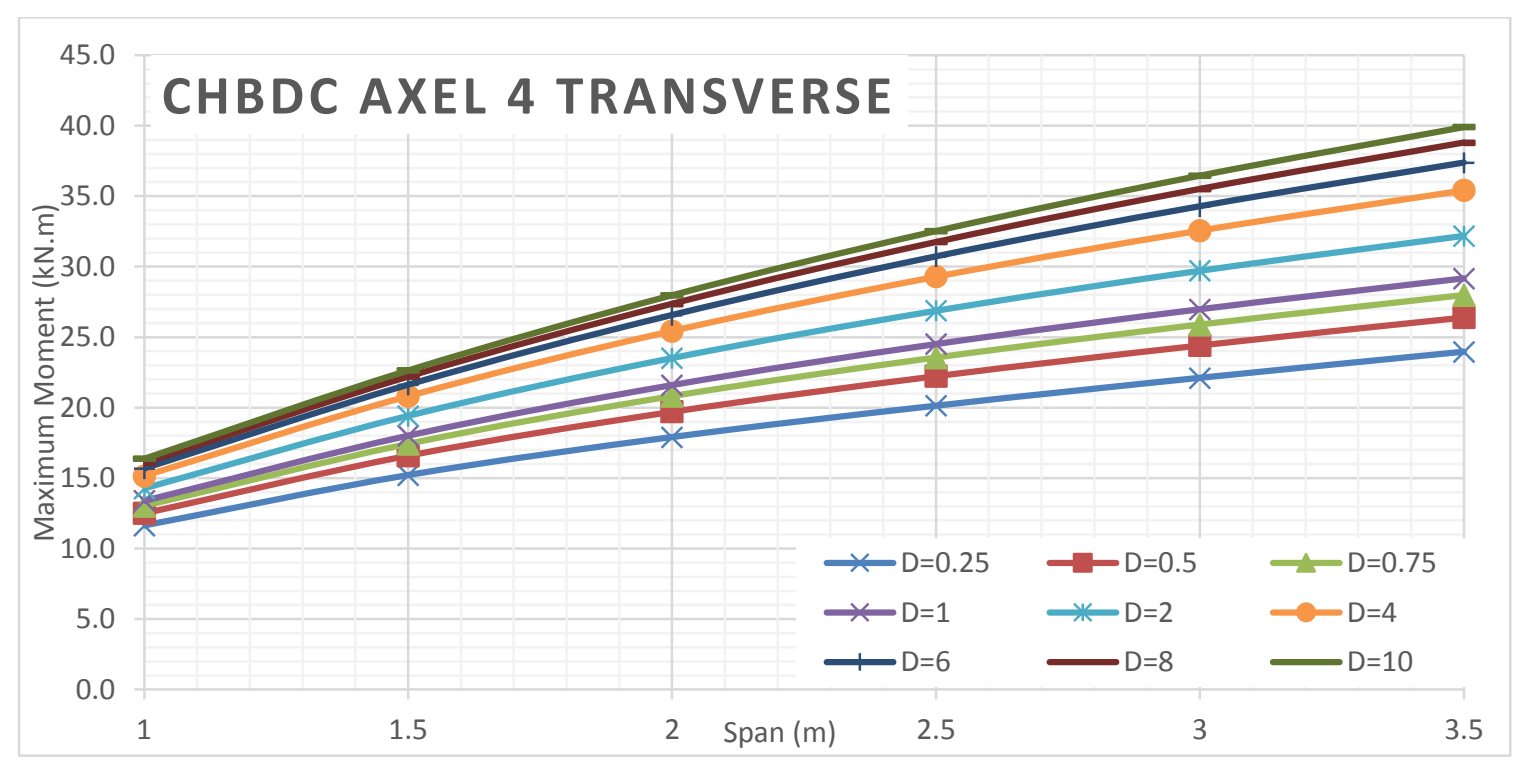

Figure 285 Maximum moment of deck slabs subjected to CHBDC axle 4 for different D values of alpha 8 Orthotropic analyses

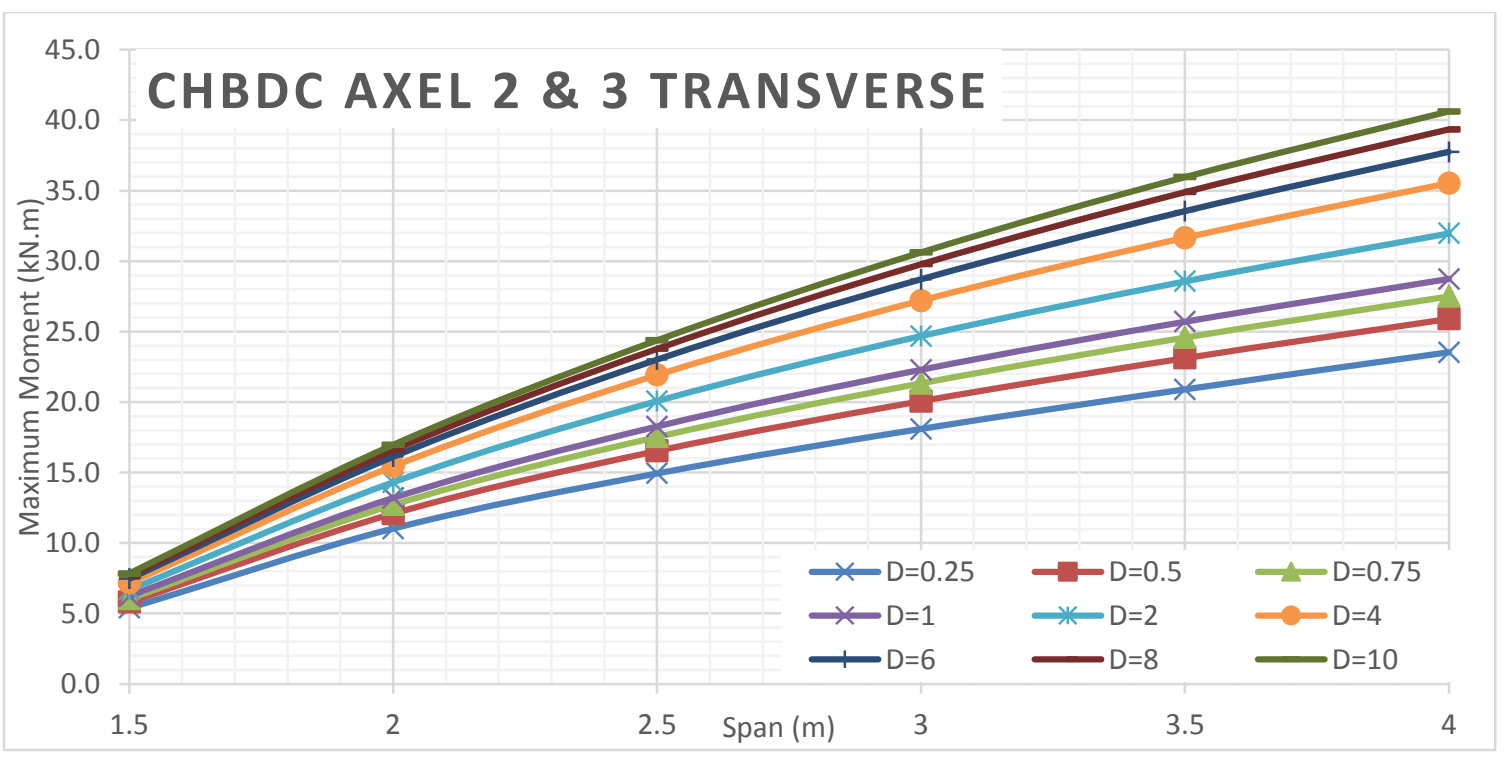

Figure 286 Maximum moment of deck slabs subjected to CHBDC axle 2 \& 3 for different D values of alpha 8 Orthotropic analyses 


\section{Alpha 10 Bending Moment VS Span Length for Different D Values}

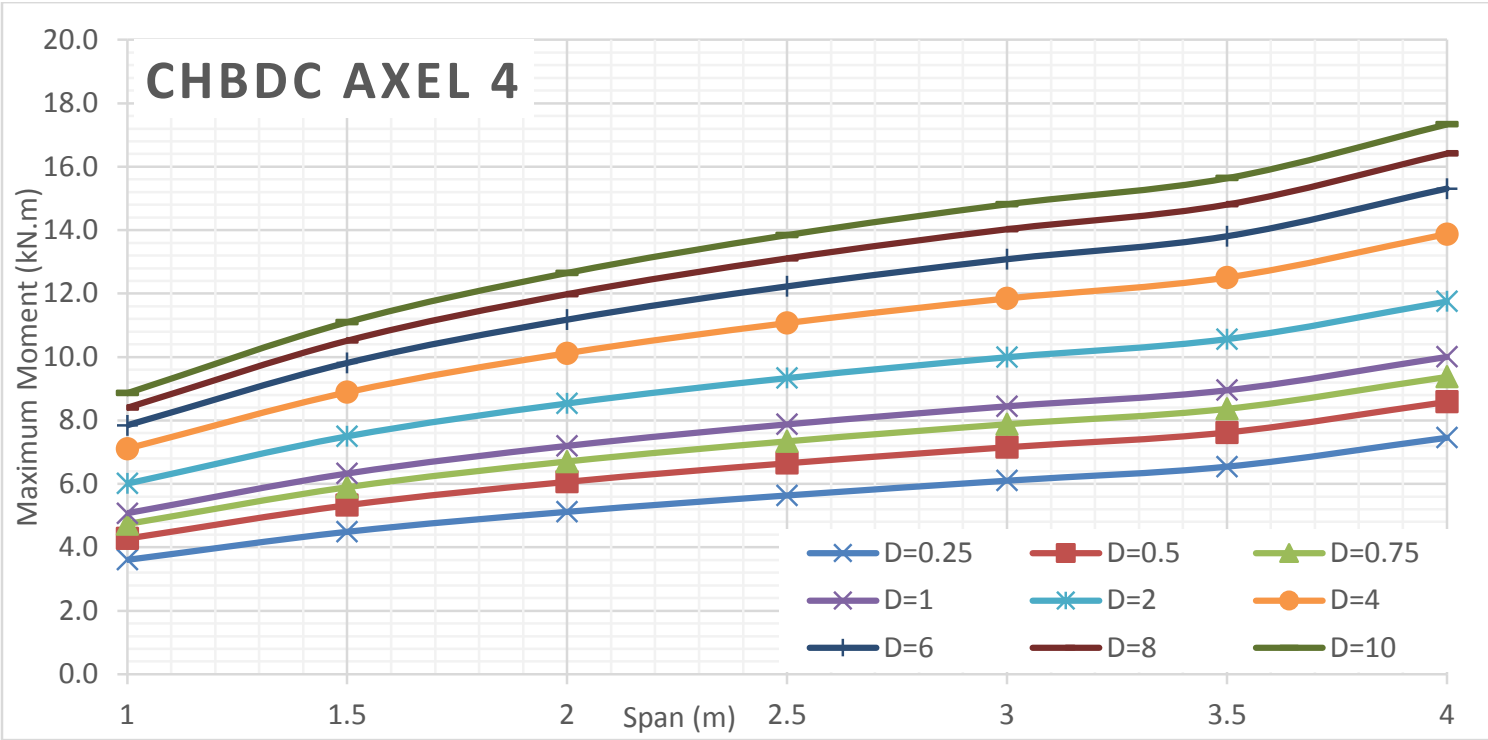

Figure 287 Maximum moment of deck slabs subjected to CHBDC axle 4 for different D values of alpha 10 Orthotropic analyses

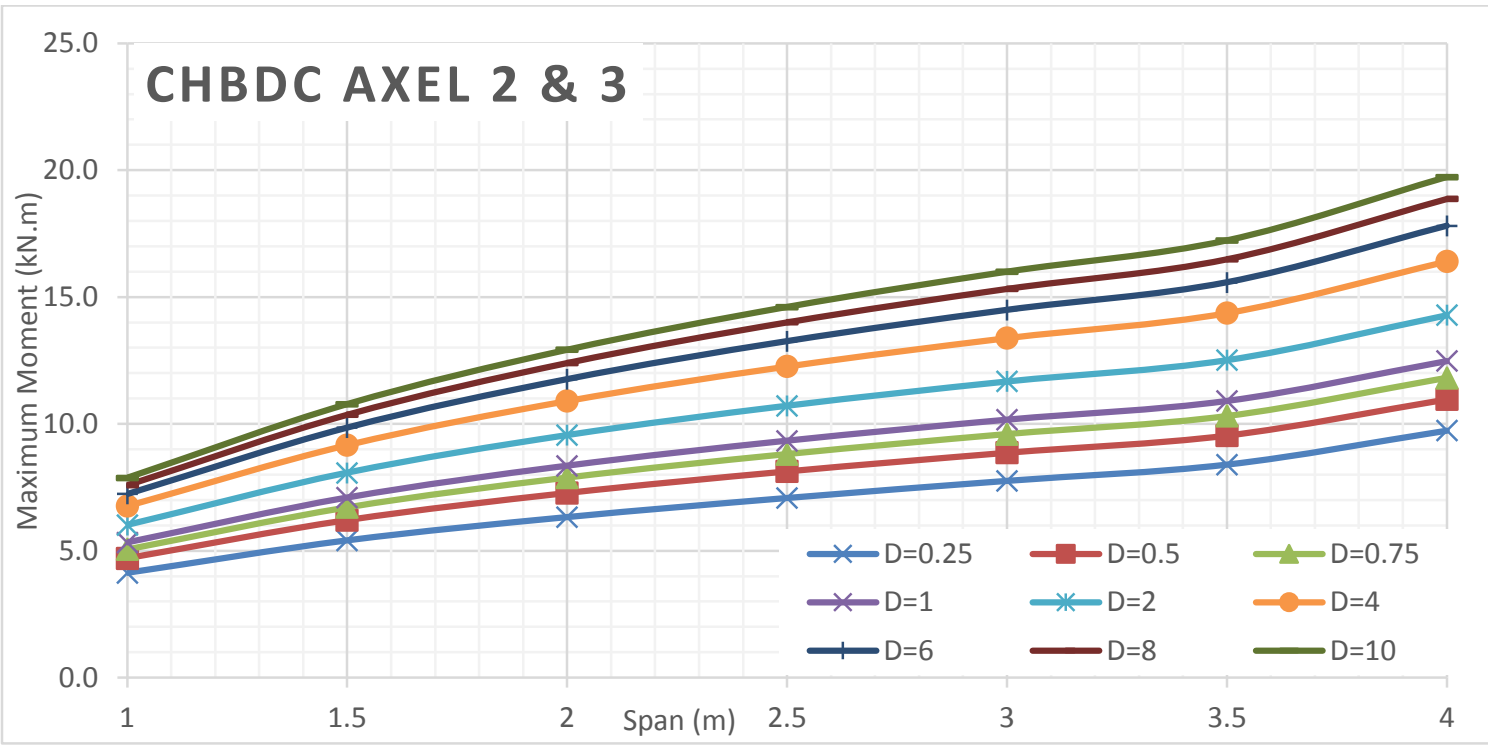

Figure 288 Maximum moment of deck slabs subjected to CHBDC axle $2 \& 3$ for different D values of alpha 10 Orthotropic analyses 


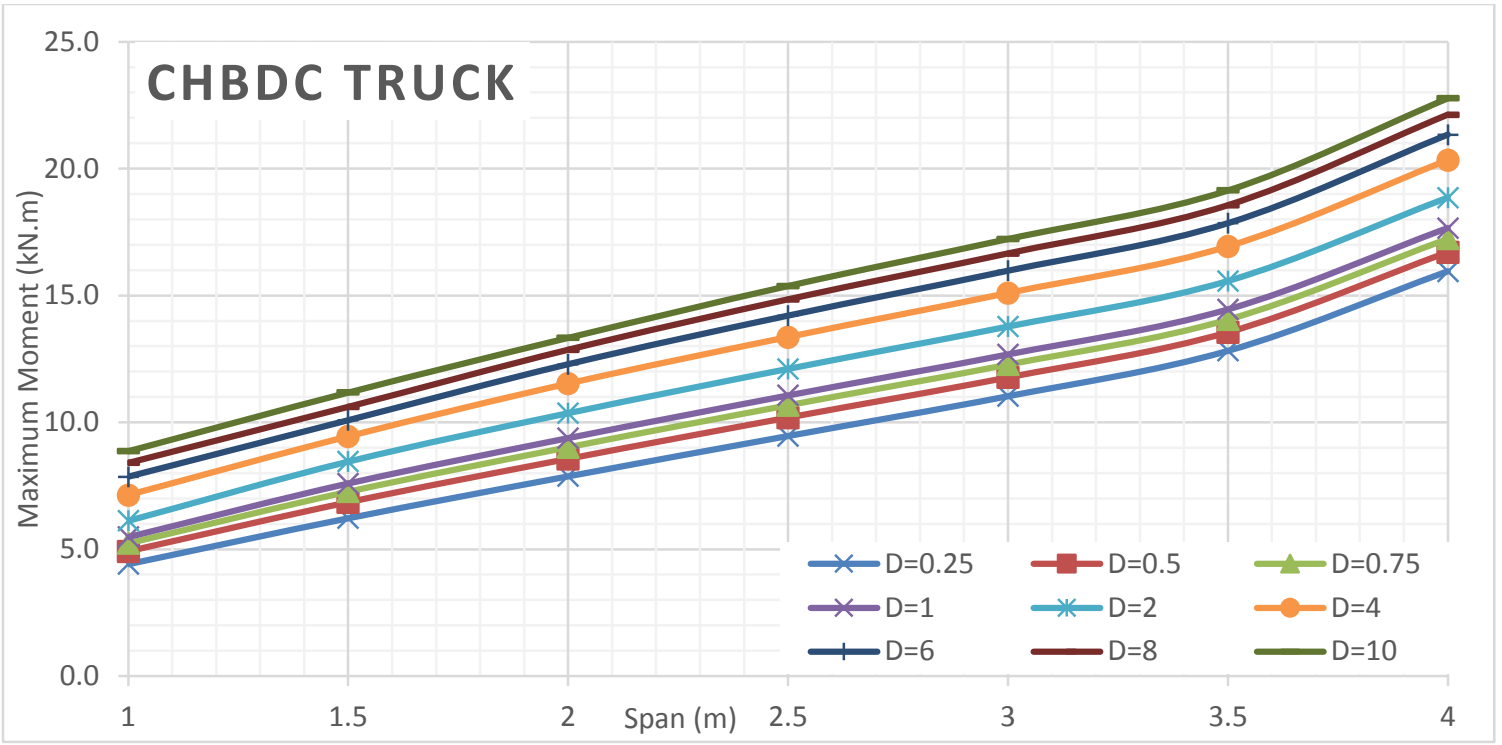

Figure 289 Maximum moment of deck slabs subjected to CHBDC truck for different D values of alpha 10 Orthotropic analyses

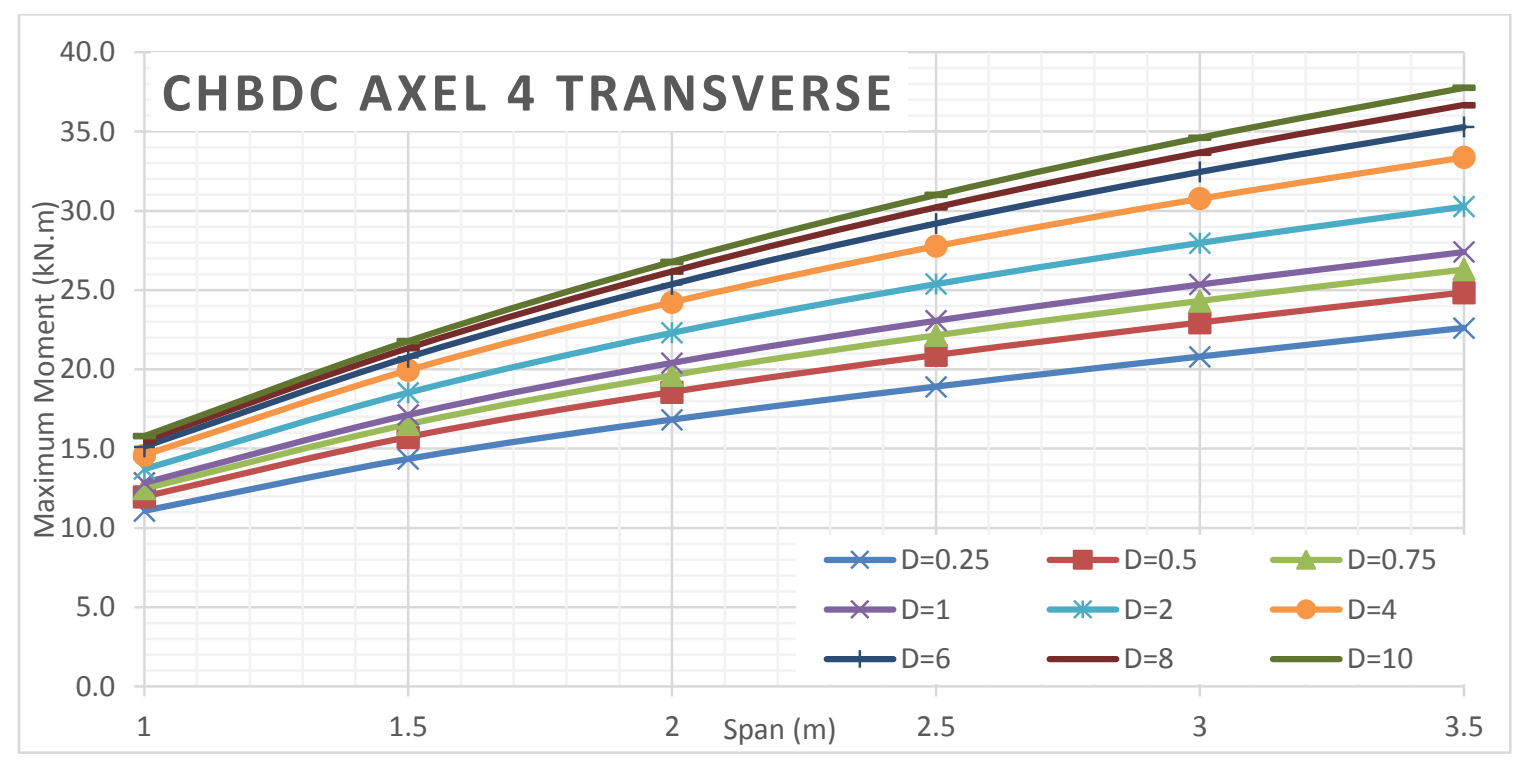

Figure 290 Maximum moment of deck slabs subjected to CHBDC axle 4 for different D values of alpha 10 Orthotropic analyses

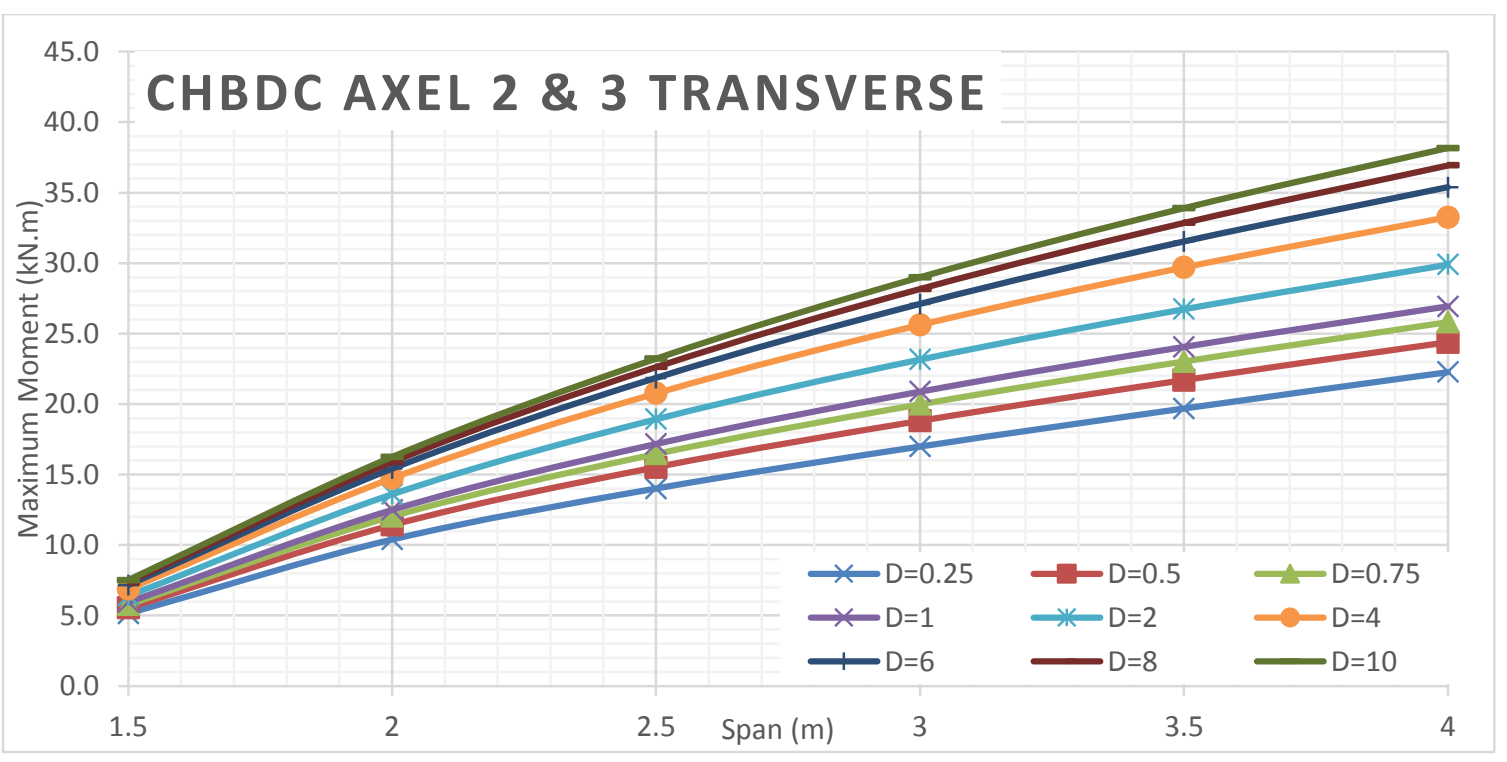

Figure 291 Maximum moment of deck slabs subjected to CHBDC axle 2 \& 3 for different D values of alpha 10 Orthotropic analyses 


\section{C.1.3 MAXIMUM BENDING}

MOMENT VS FLEXURAL RIGIDITY 


\section{Alpha 0.25 Bending Moment VS Flexural Rigidity for Different Span Length}

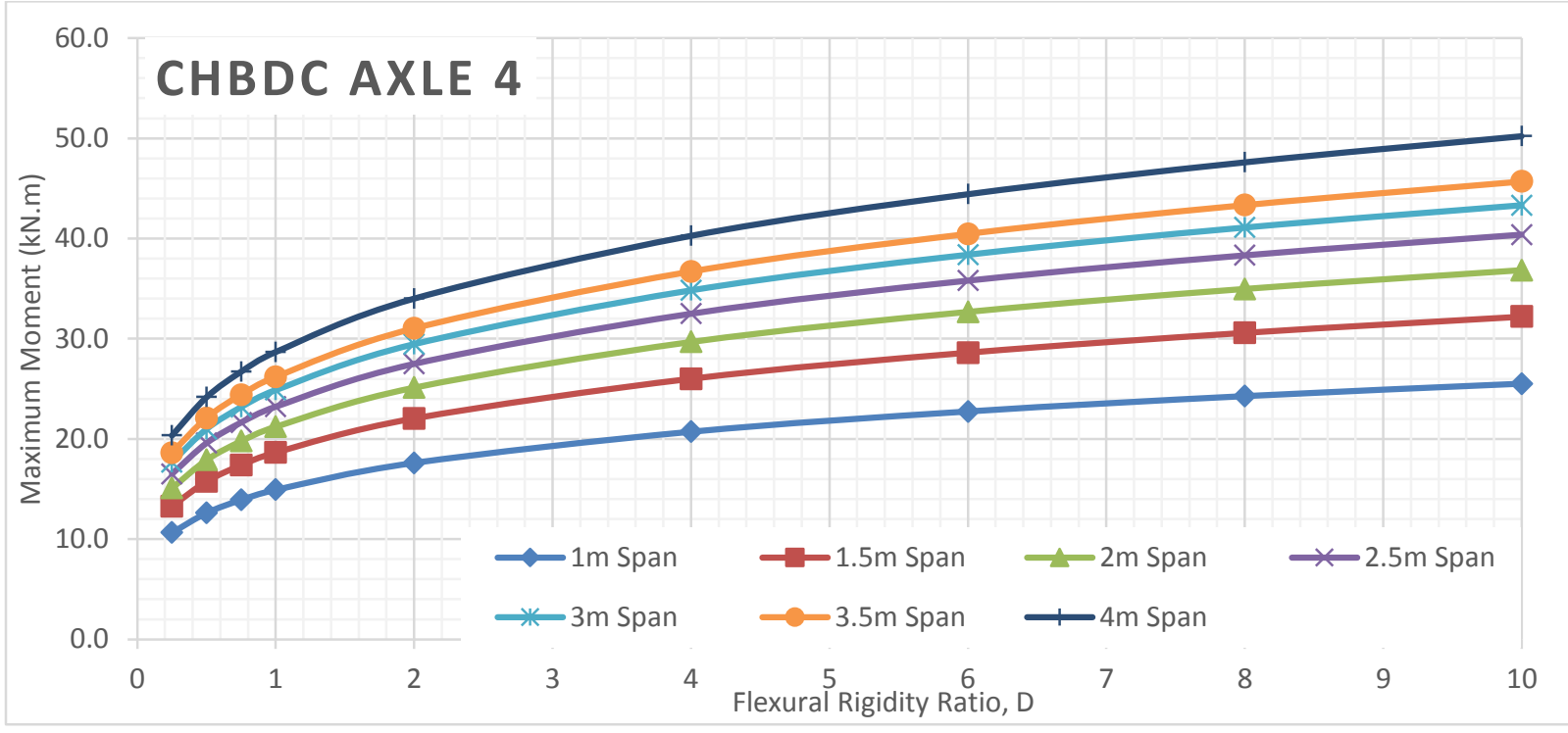

Figure 292 Maximum moment of deck slabs subjected to CHBDC axle 4 for different span values of alpha 0.25 Orthotropic analyses

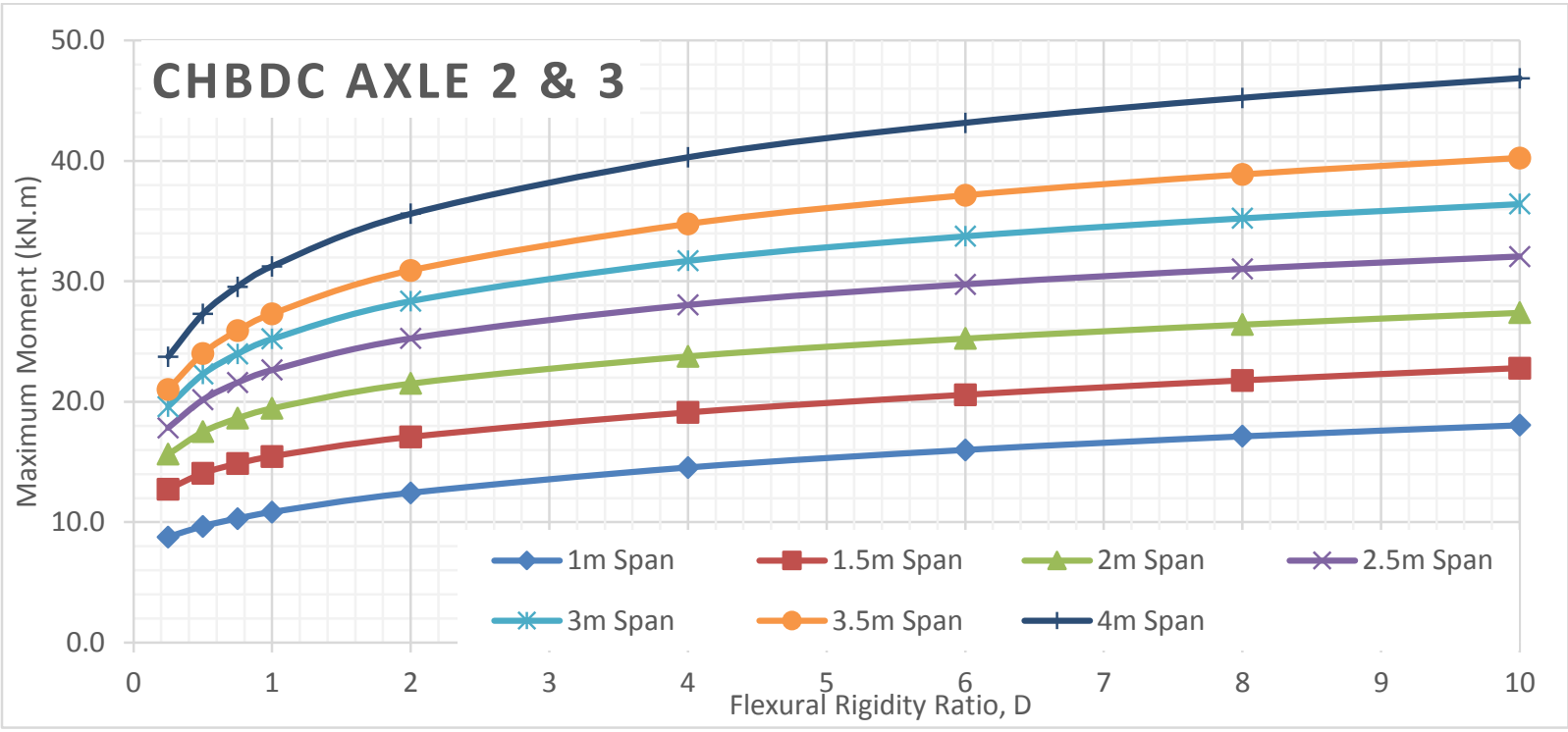

Figure 293 Maximum moment of deck slabs subjected to CHBDC axle $2 \& 3$ for different span values of alpha 0.25 Orthotropic analyses 


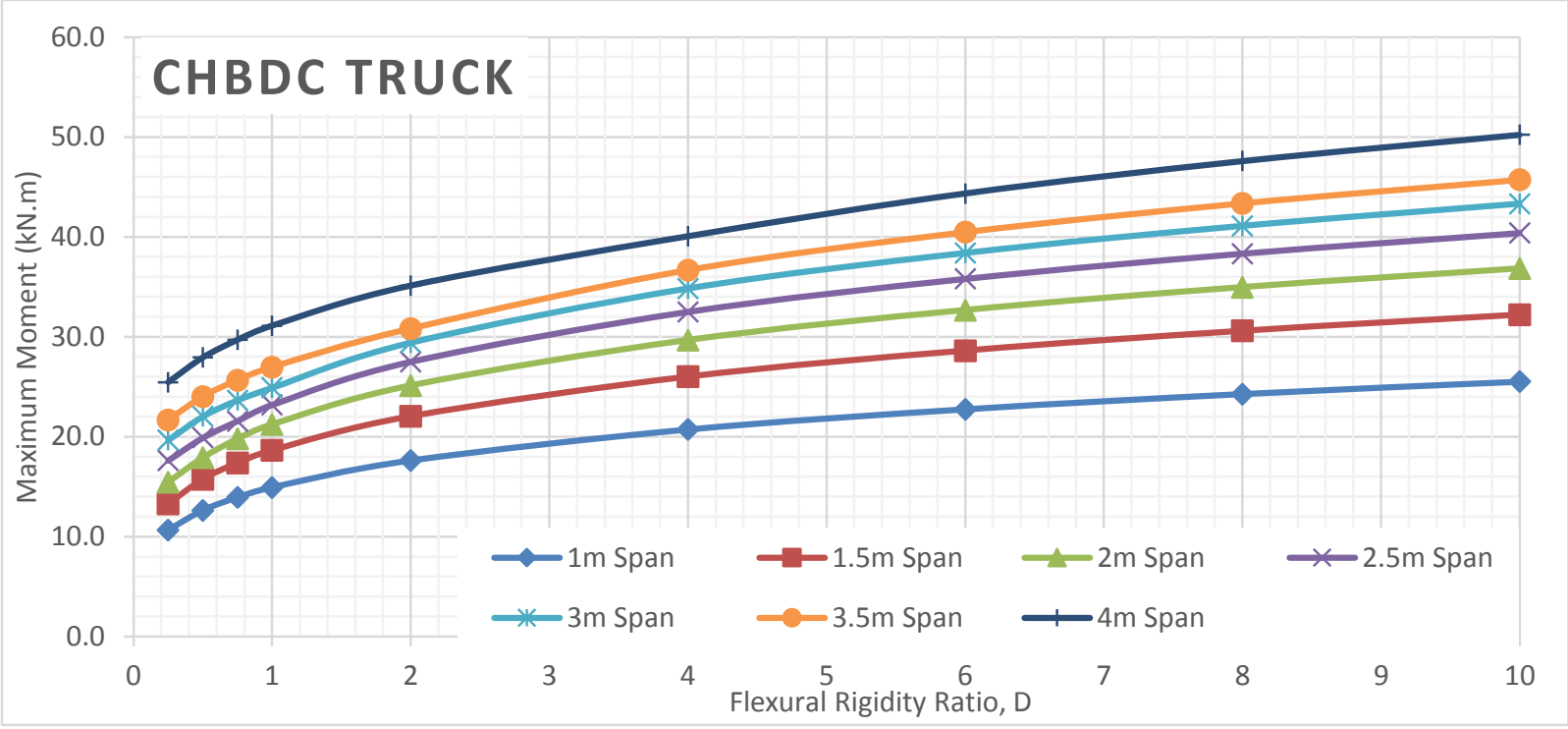

Figure 294 Maximum moment of deck slabs subjected to CHBDC truck for different span values of alpha 0.25 Orthotropic analyses

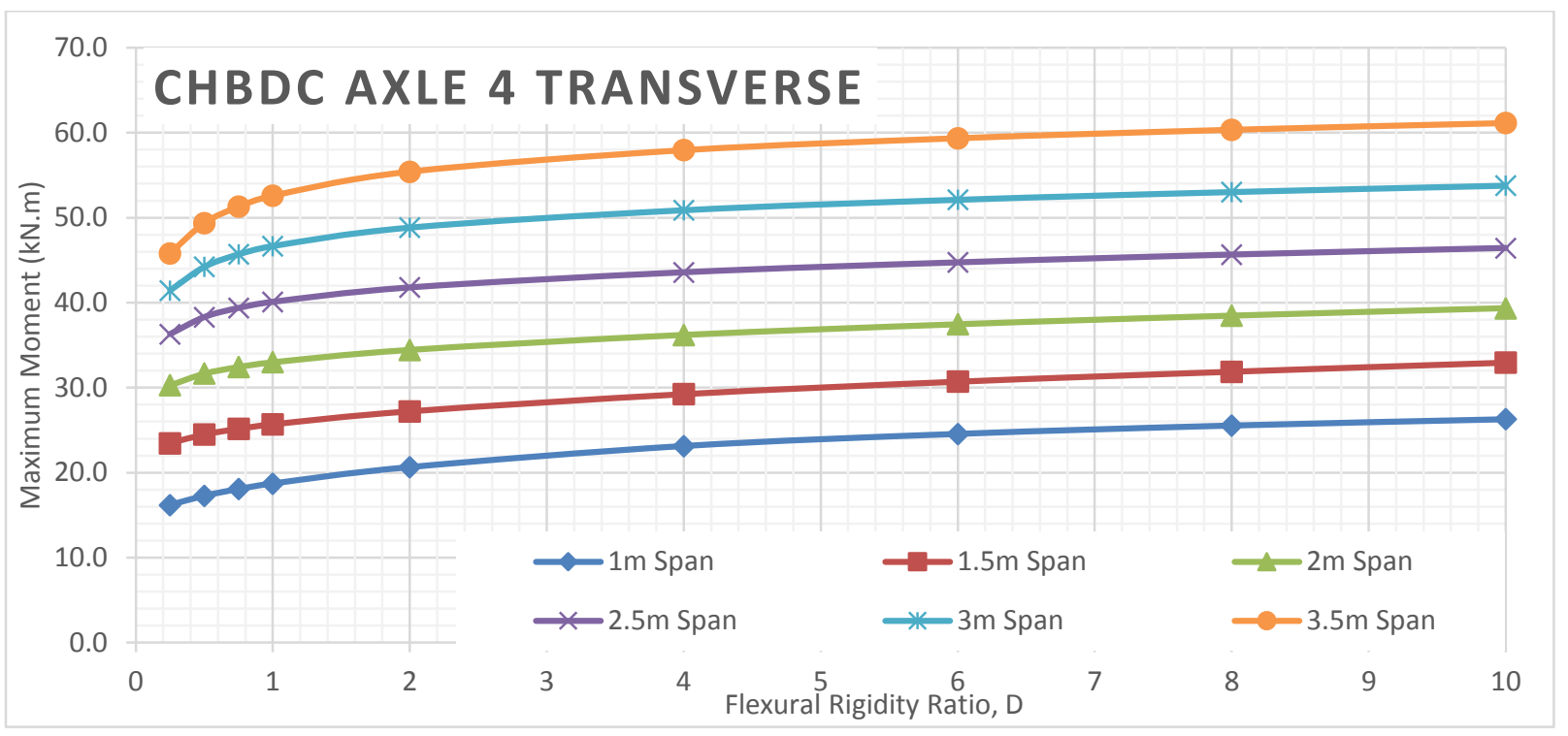

Figure 295 Maximum moment of deck slabs subjected to CHBDC axle 4 for different span values of alpha 0.25 Orthotropic analyses

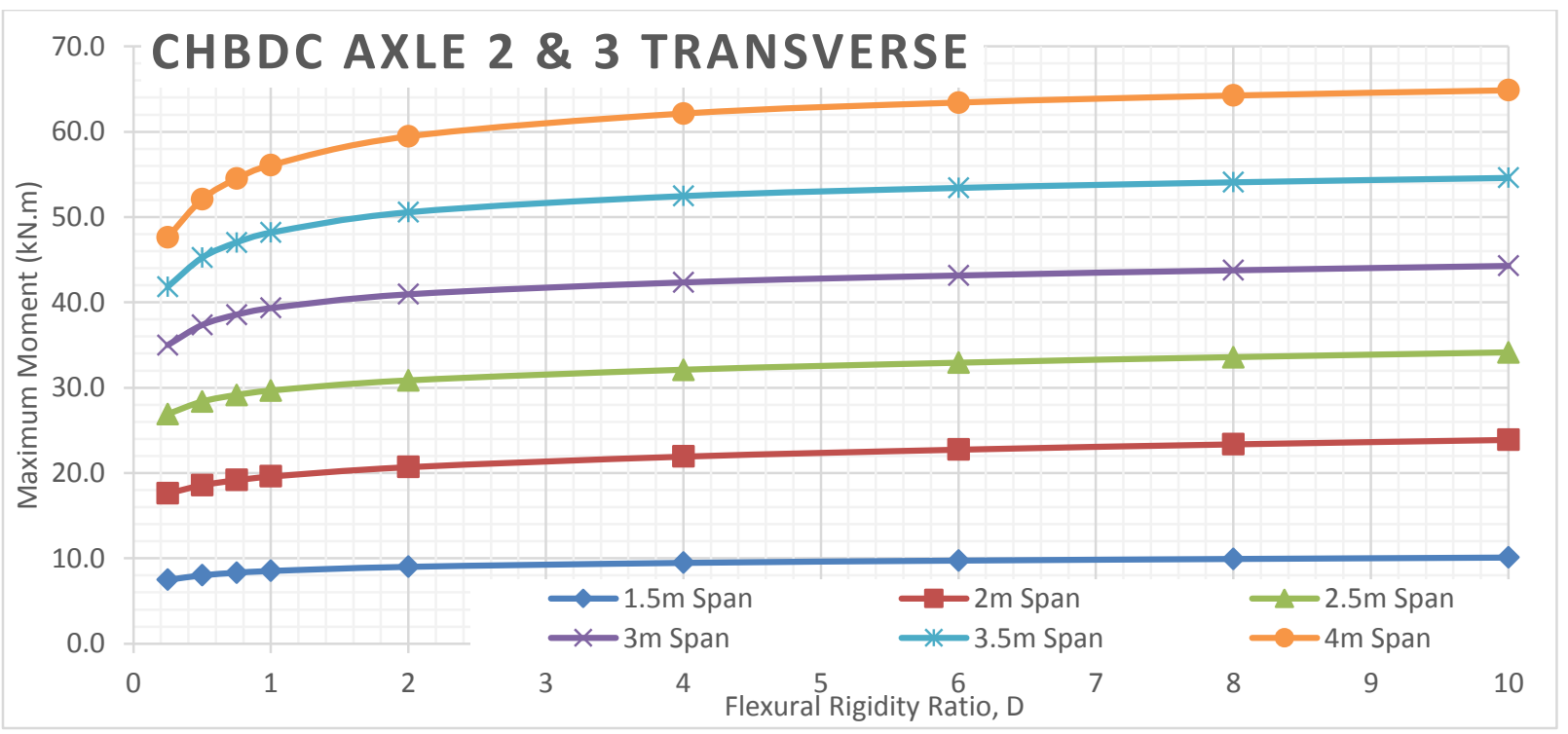

Figure 296 Maximum moment of deck slabs subjected to CHBDC axle $2 \& 3$ for different span values of alpha 0.25 Orthotropic analyses 


\section{Alpha 0.5 Bending Moment VS Flexural Rigidity for Different Span Length}

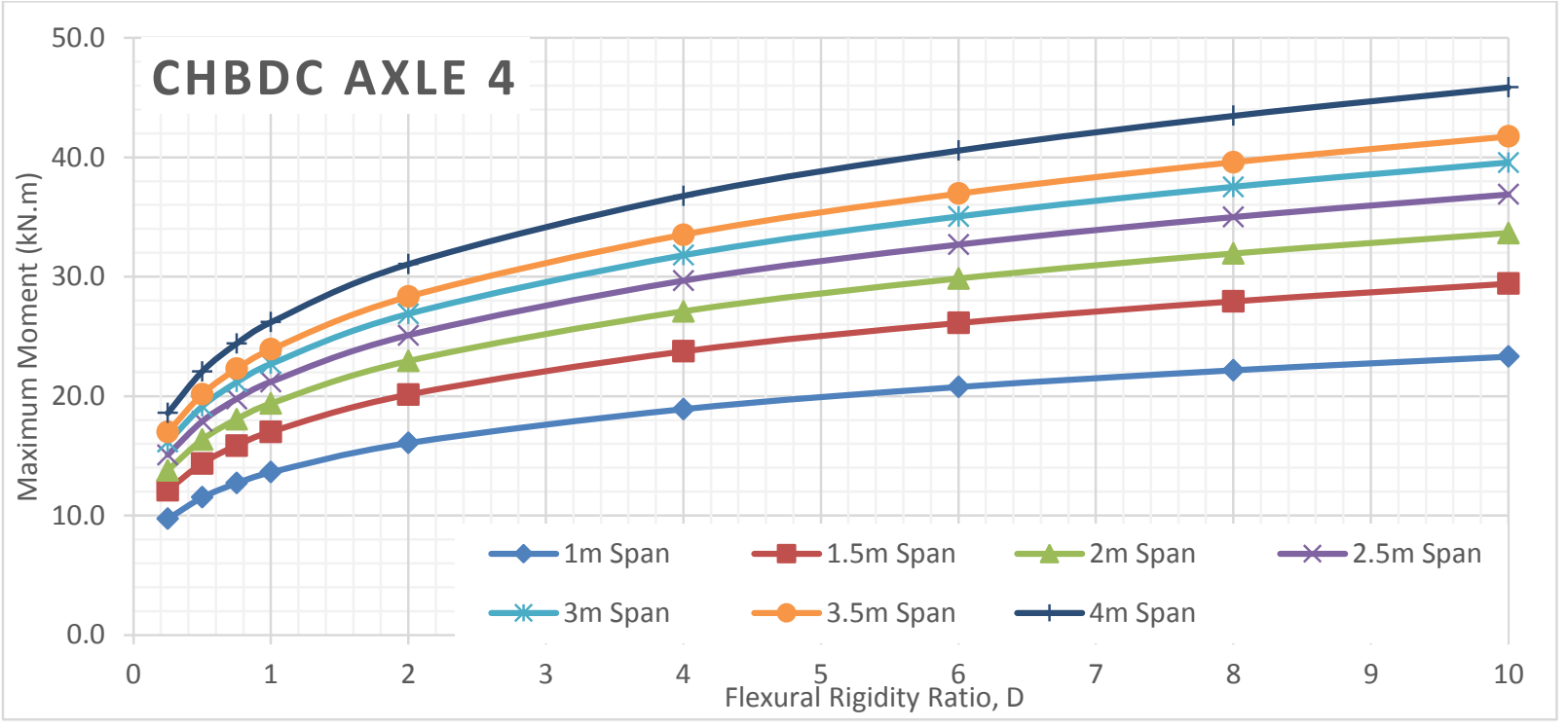

Figure 297 Maximum moment of deck slabs subjected to CHBDC axle 4 for different span values of alpha 0.5 Orthotropic analyses

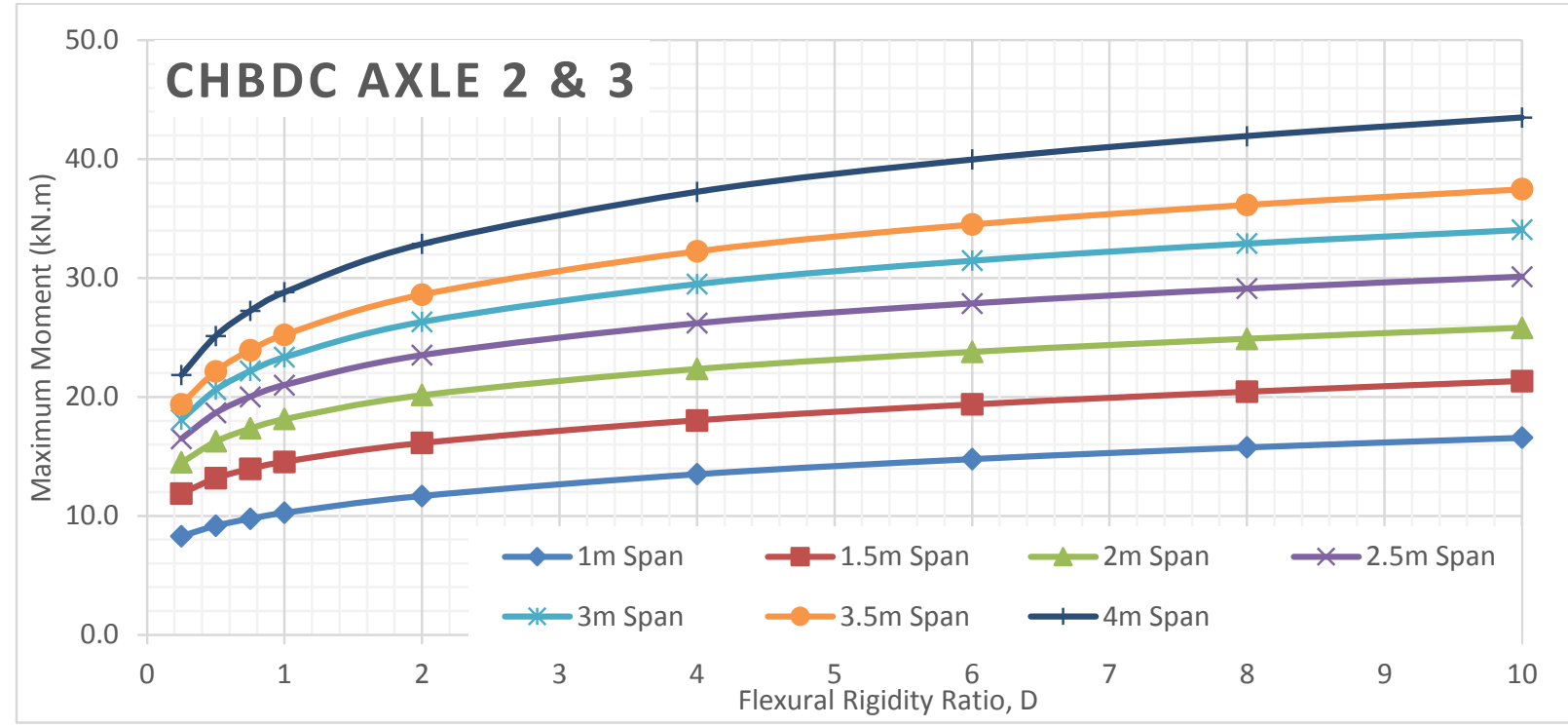

Figure 298 Maximum moment of deck slabs subjected to CHBDC axle $2 \& 3$ for different span values of alpha 0.5 Orthotropic analyses 


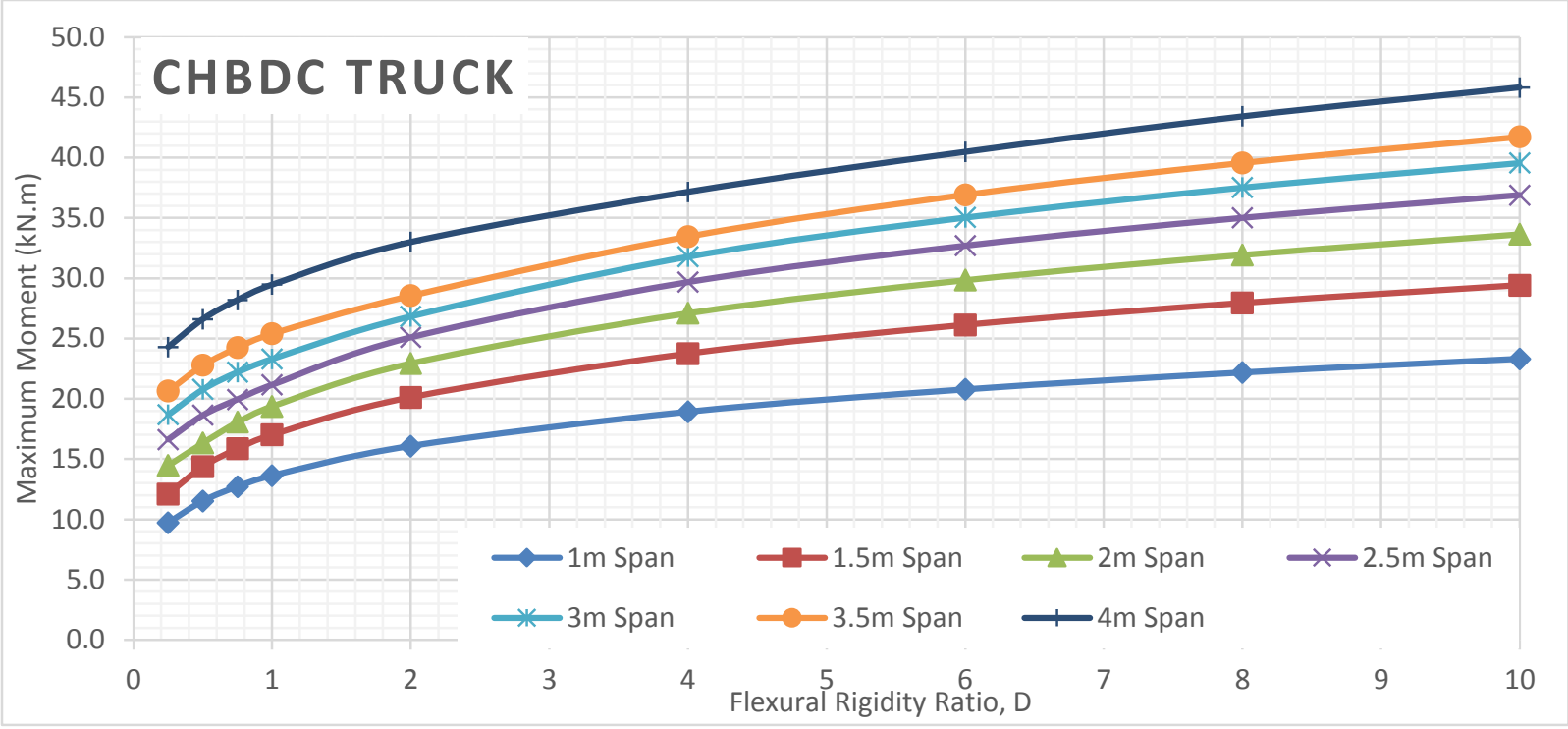

Figure 299 Maximum moment of deck slabs subjected to CHBDC truck for different span values of alpha 0.5 Orthotropic analyses

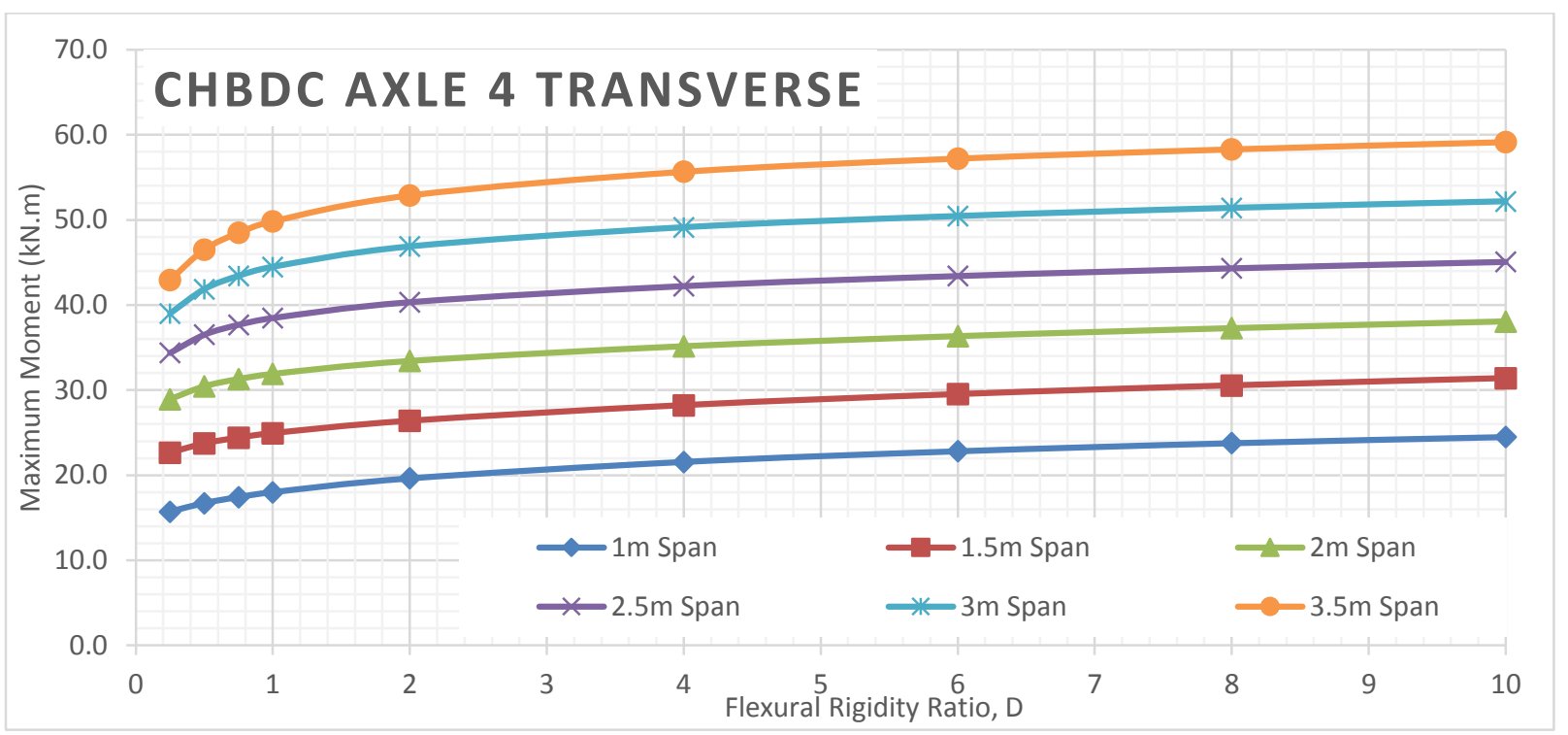

Figure 300 Maximum moment of deck slabs subjected to CHBDC axle 4 for different span values of alpha 0.5 Orthotropic analyses

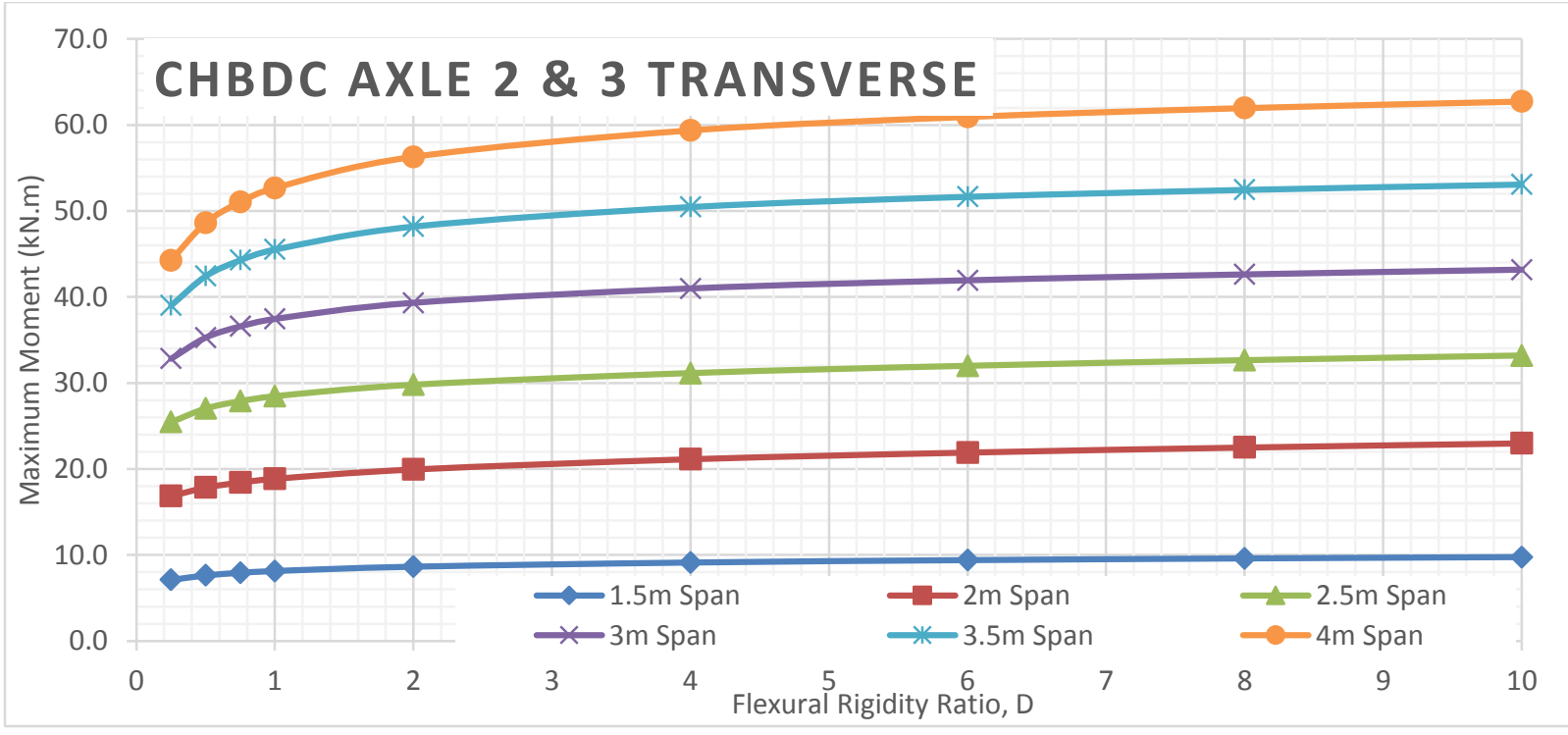

Figure 301 Maximum moment of deck slabs subjected to CHBDC axle 2 \& 3 for different span values of alpha 0.5 Orthotropic analyses 


\section{Alpha 0.75 Bending Moment VS Flexural Rigidity for Different Span Length}

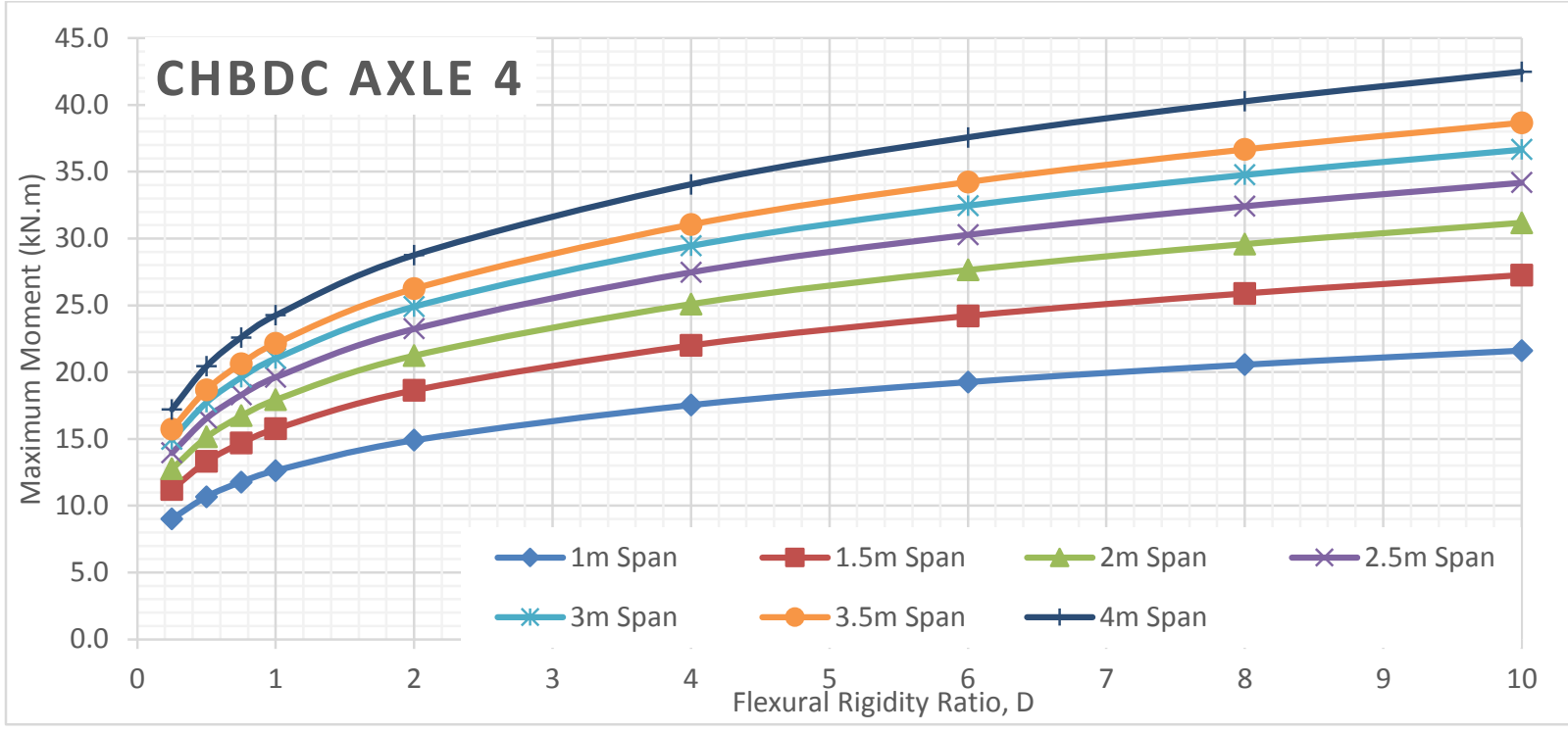

Figure 302 Maximum moment of deck slabs subjected to CHBDC axle 4 for different span values of alpha 0.75 Orthotropic analyses

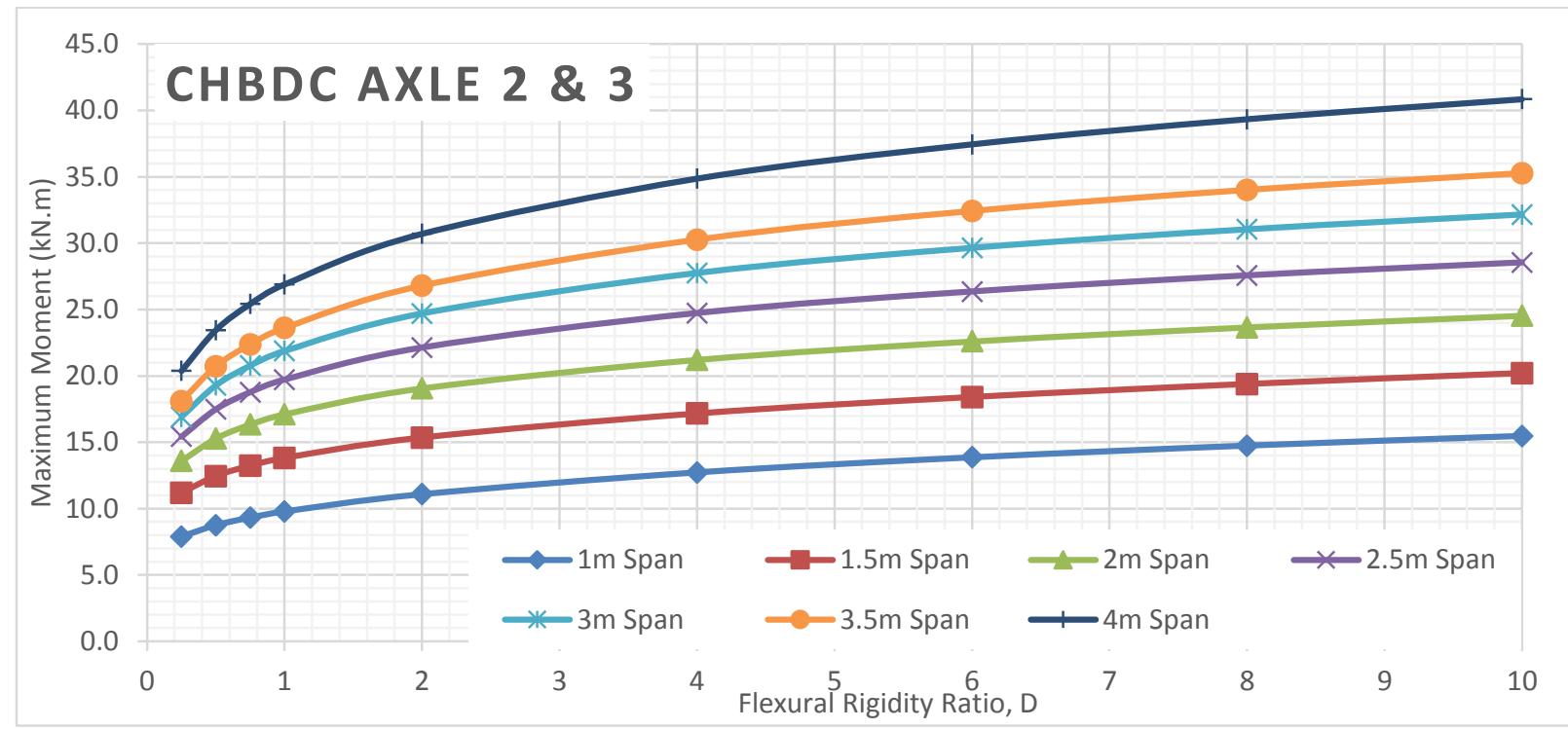

Figure 303 Maximum moment of deck slabs subjected to CHBDC axle $2 \& 3$ for different span values of alpha 0.75 Orthotropic analyses 


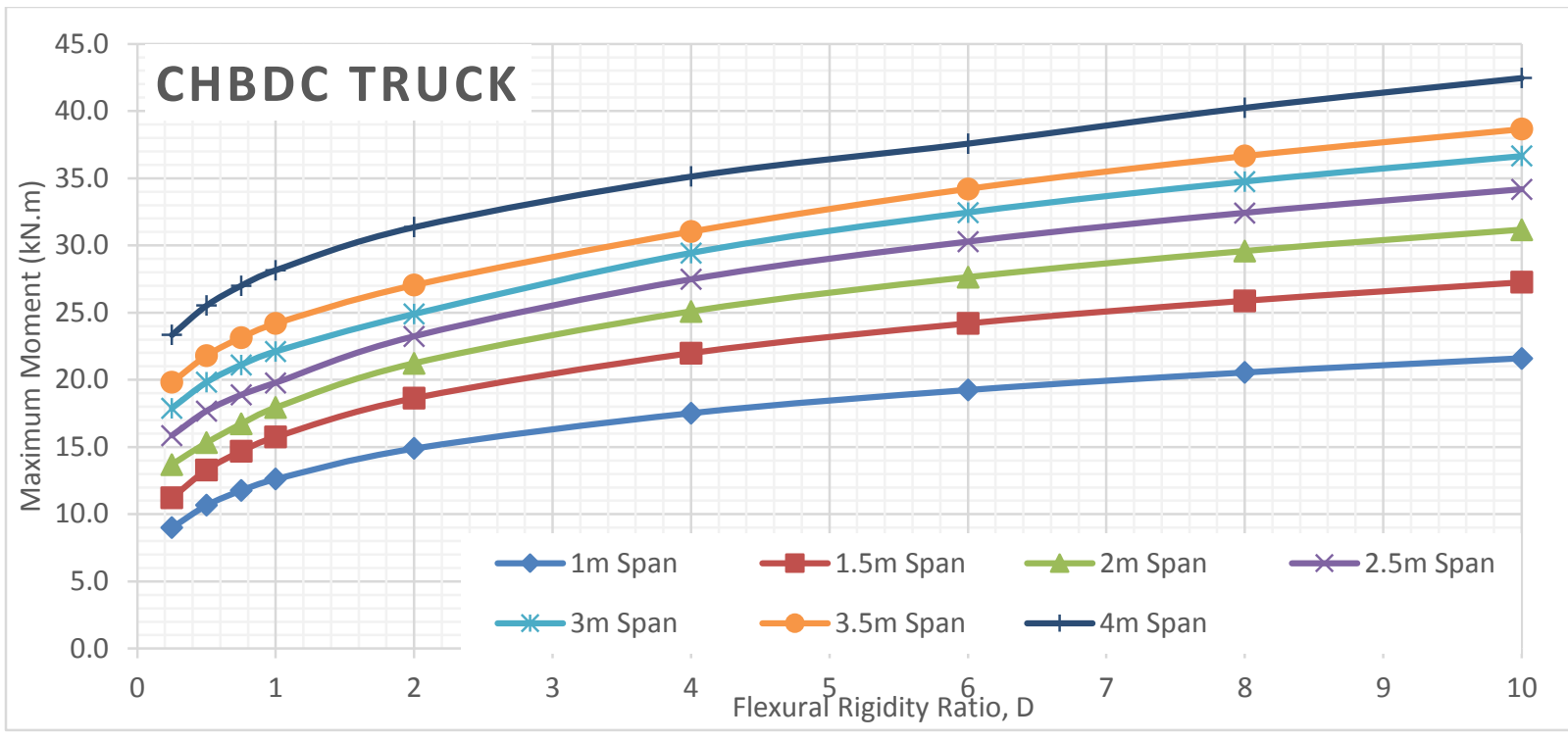

Figure 304 Maximum moment of deck slabs subjected to CHBDC truck for different span values of alpha 0.75 Orthotropic analyses

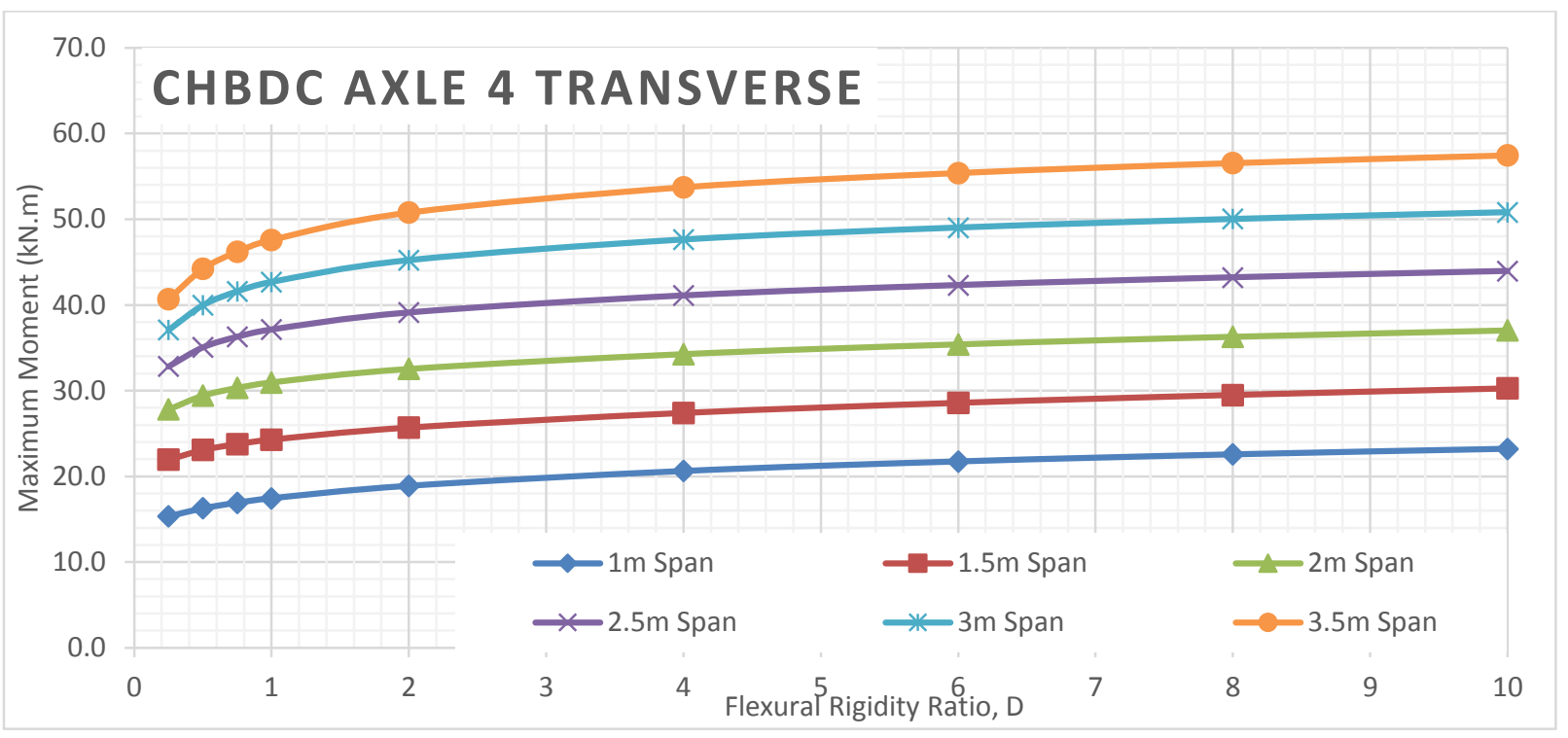

Figure 305 Maximum moment of deck slabs subjected to CHBDC axle 4 for different span values of alpha 0.75 Orthotropic analyses

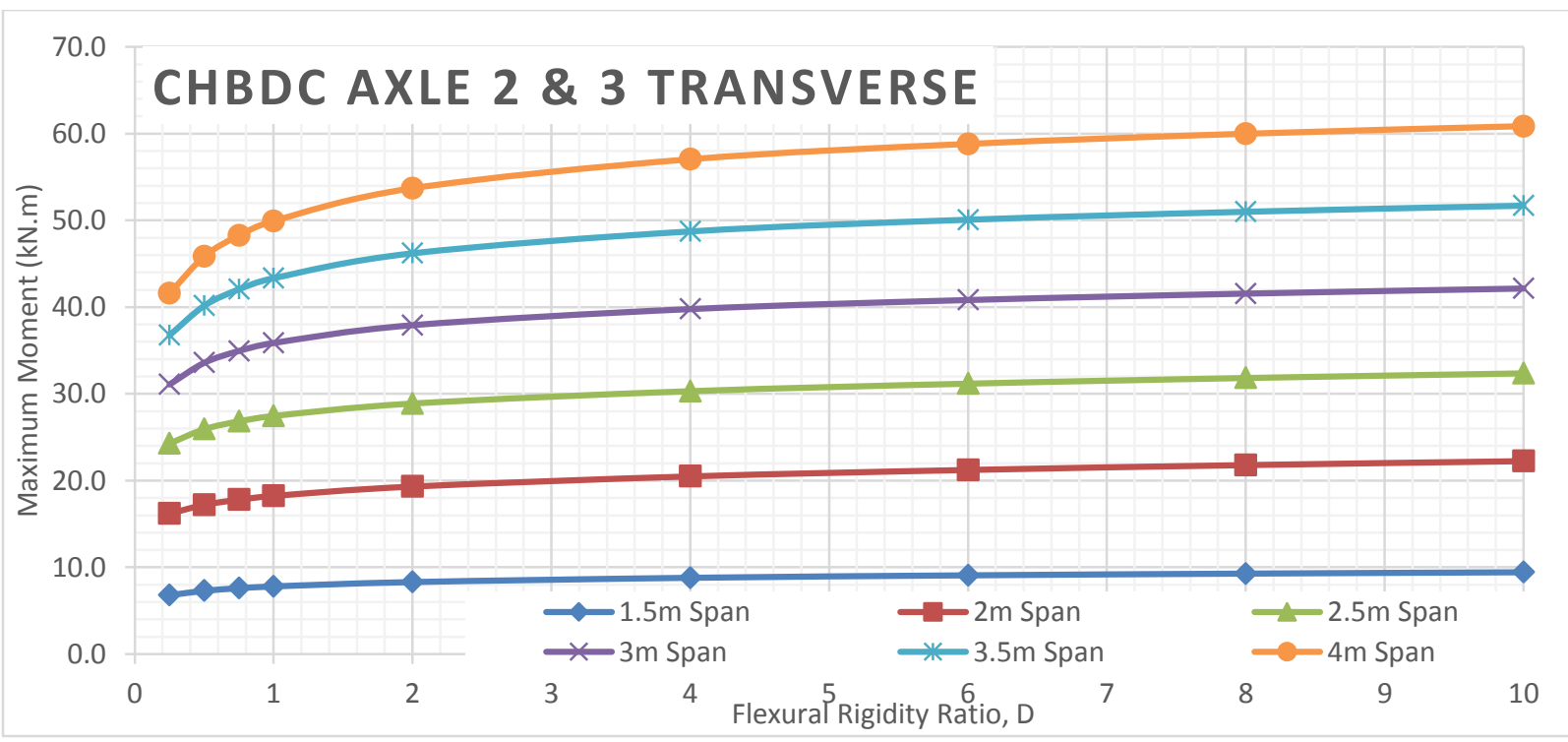

Figure 306 Maximum moment of deck slabs subjected to CHBDC axle $2 \& 3$ for different span values of alpha 0.75 Orthotropic analyses 


\section{Alpha 1 Bending Moment VS Flexural Rigidity for Different Span Length}

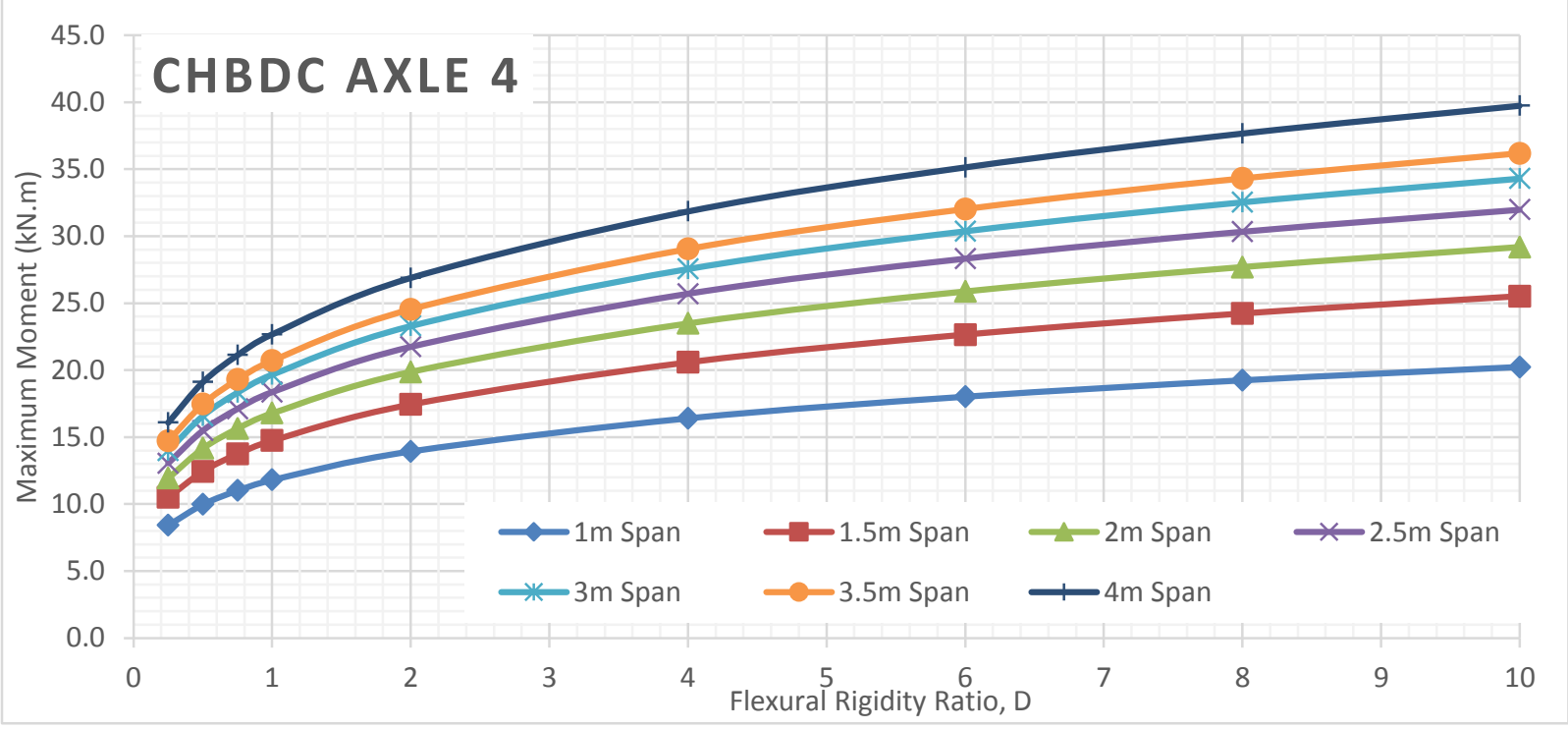

Figure 307 Maximum moment of deck slabs subjected to CHBDC axle 4 for different span values of alpha 1 Orthotropic analyses

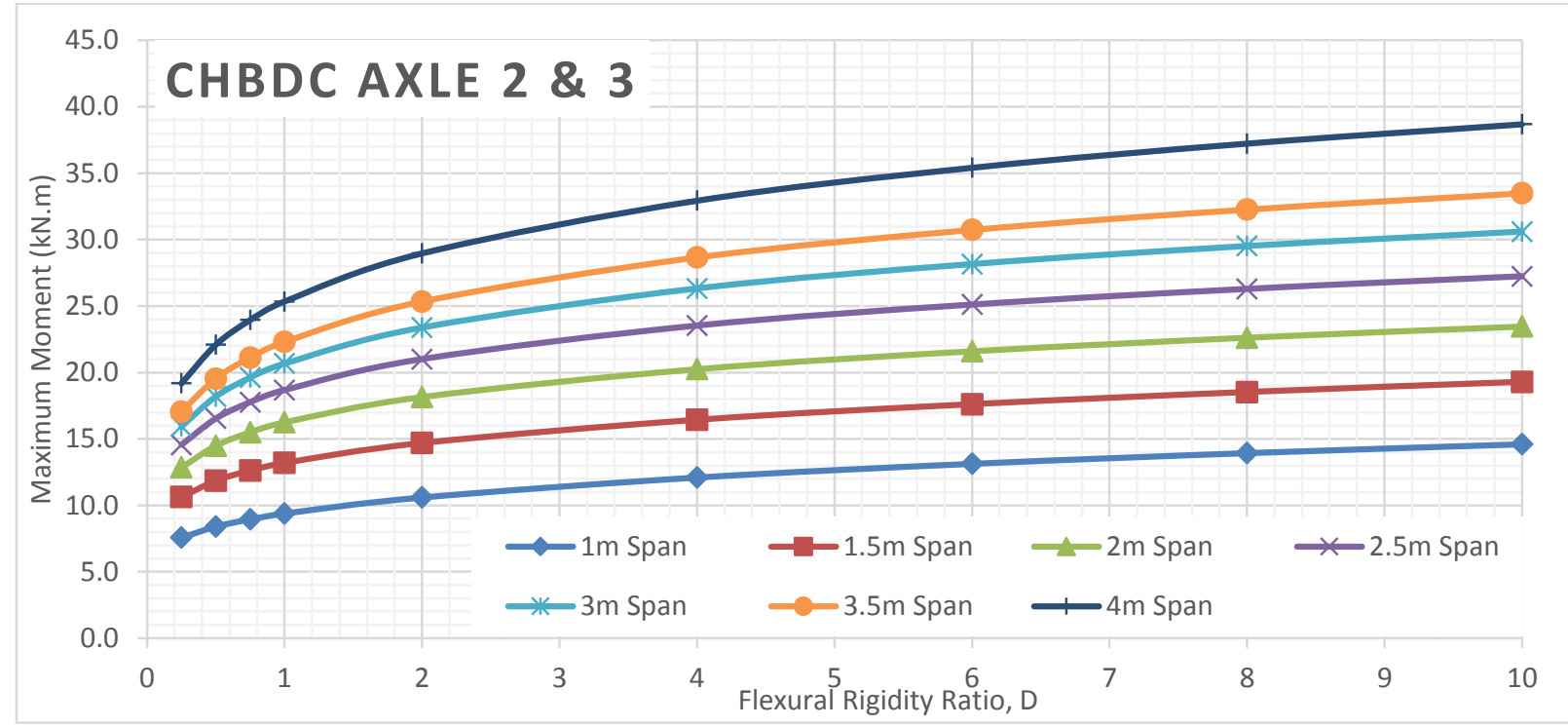

Figure 308 Maximum moment of deck slabs subjected to CHBDC axle 2 \& 3 for different span values of alpha 1 Orthotropic analyses 


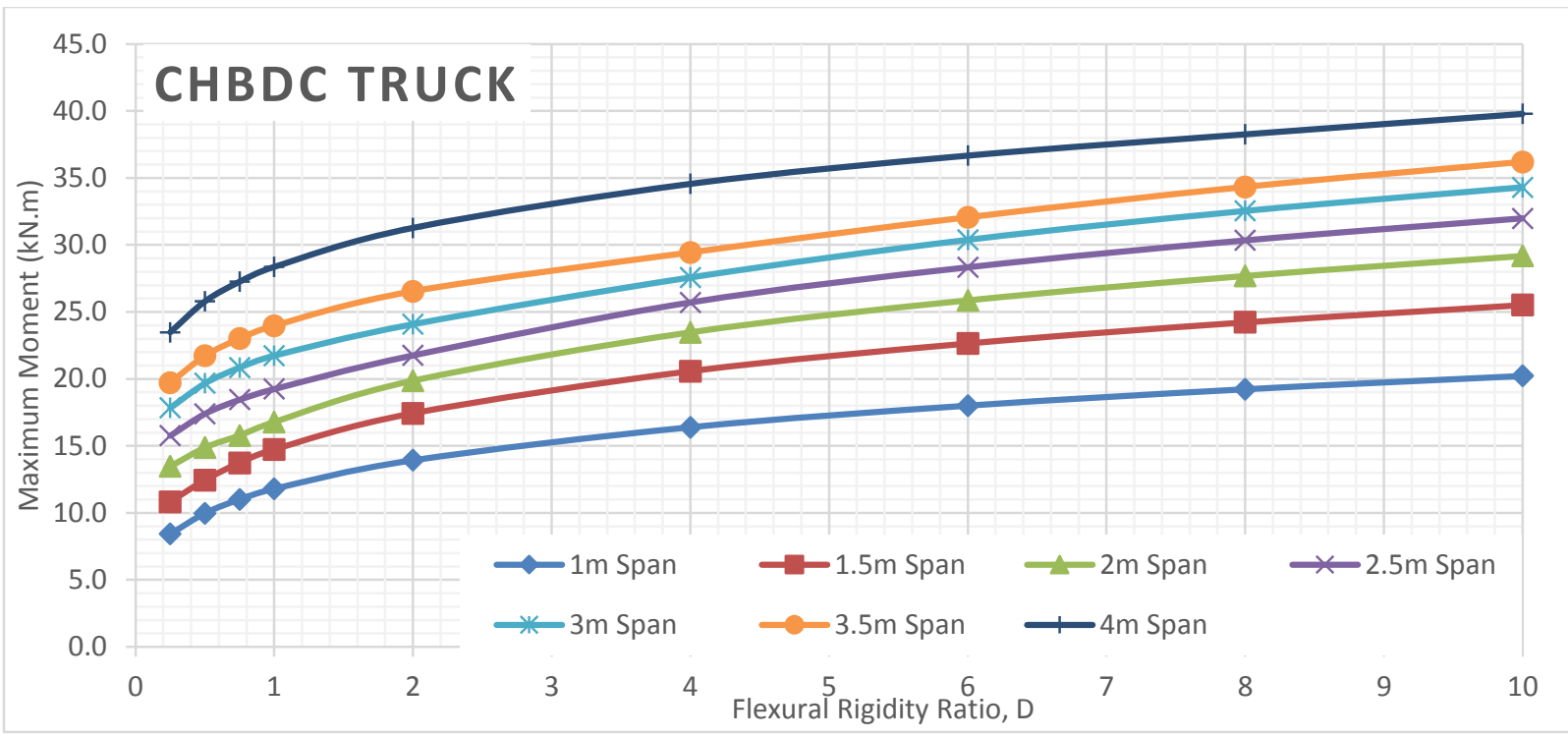

Figure 309 Maximum moment of deck slabs subjected to CHBDC truck for different span values of alpha 1 Orthotropic analyses

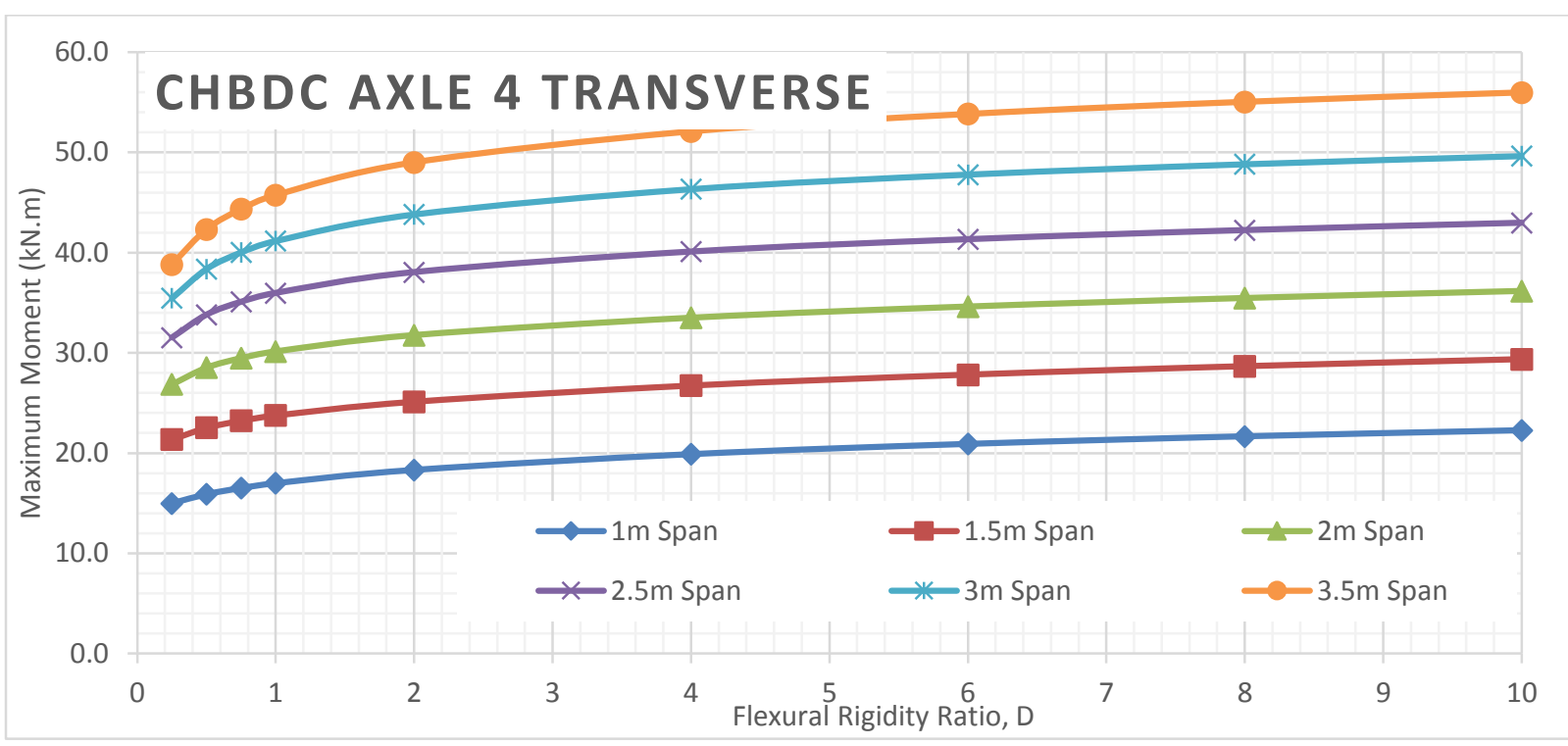

Figure 310 Maximum moment of deck slabs subjected to CHBDC axle 4 for different span values of alpha 1 Orthotropic analyses

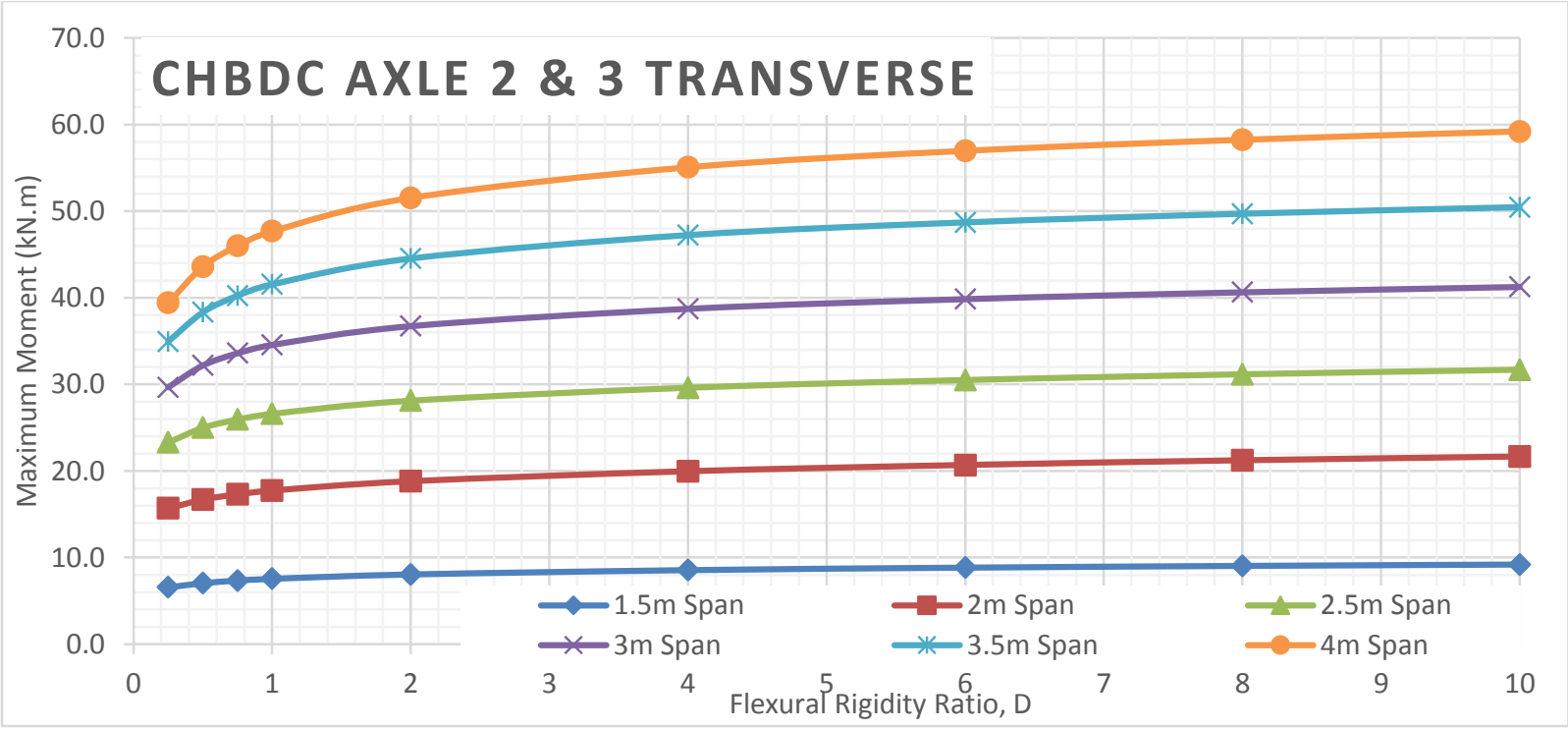

Figure 311 Maximum moment of deck slabs subjected to CHBDC axle 2 \& 3 for different span values of alpha 1 Orthotropic analyses 


\section{Alpha 2 Bending Moment VS Flexural Rigidity for Different Span Length}

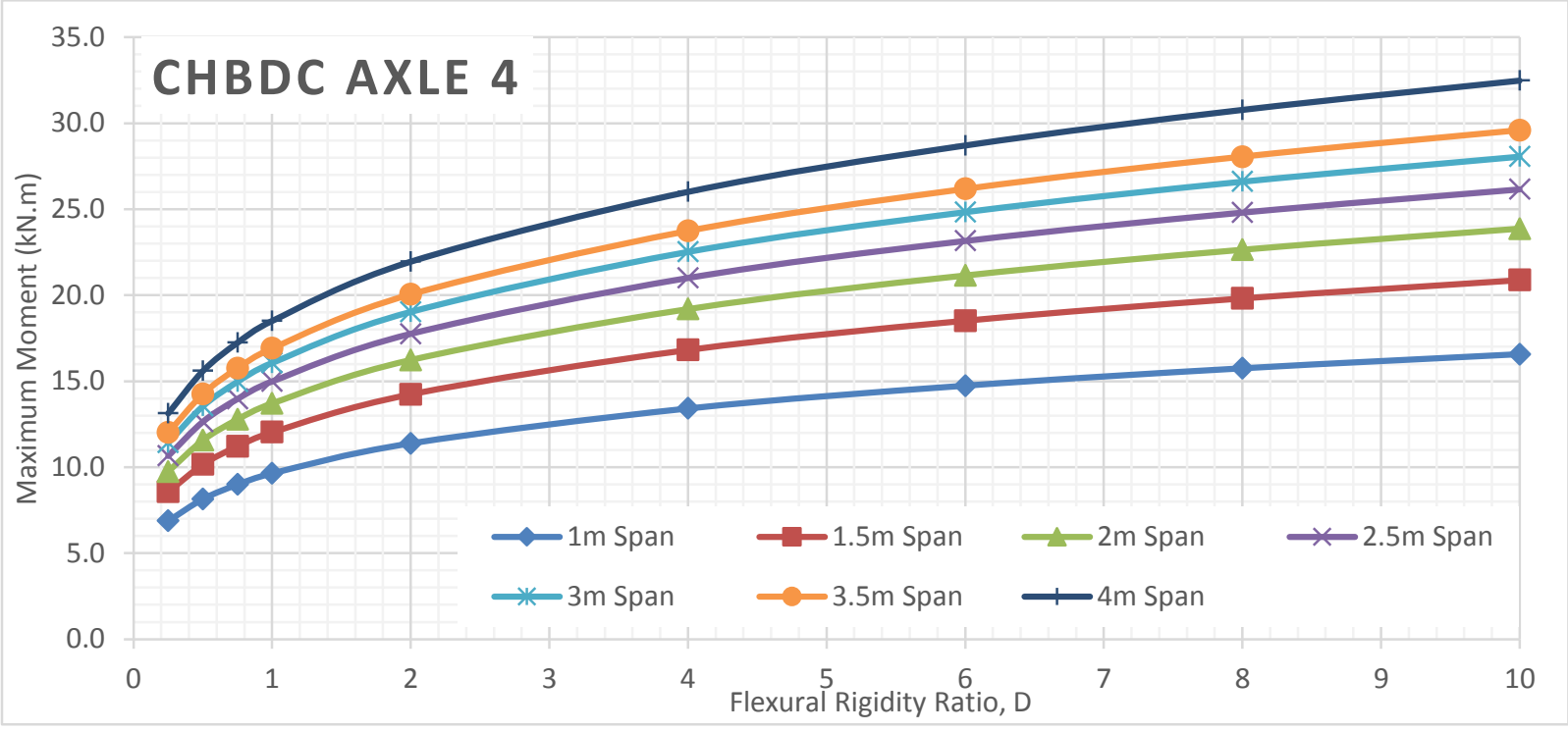

Figure 312 Maximum moment of deck slabs subjected to CHBDC axle 4 for different span values of alpha 2 Orthotropic analyses

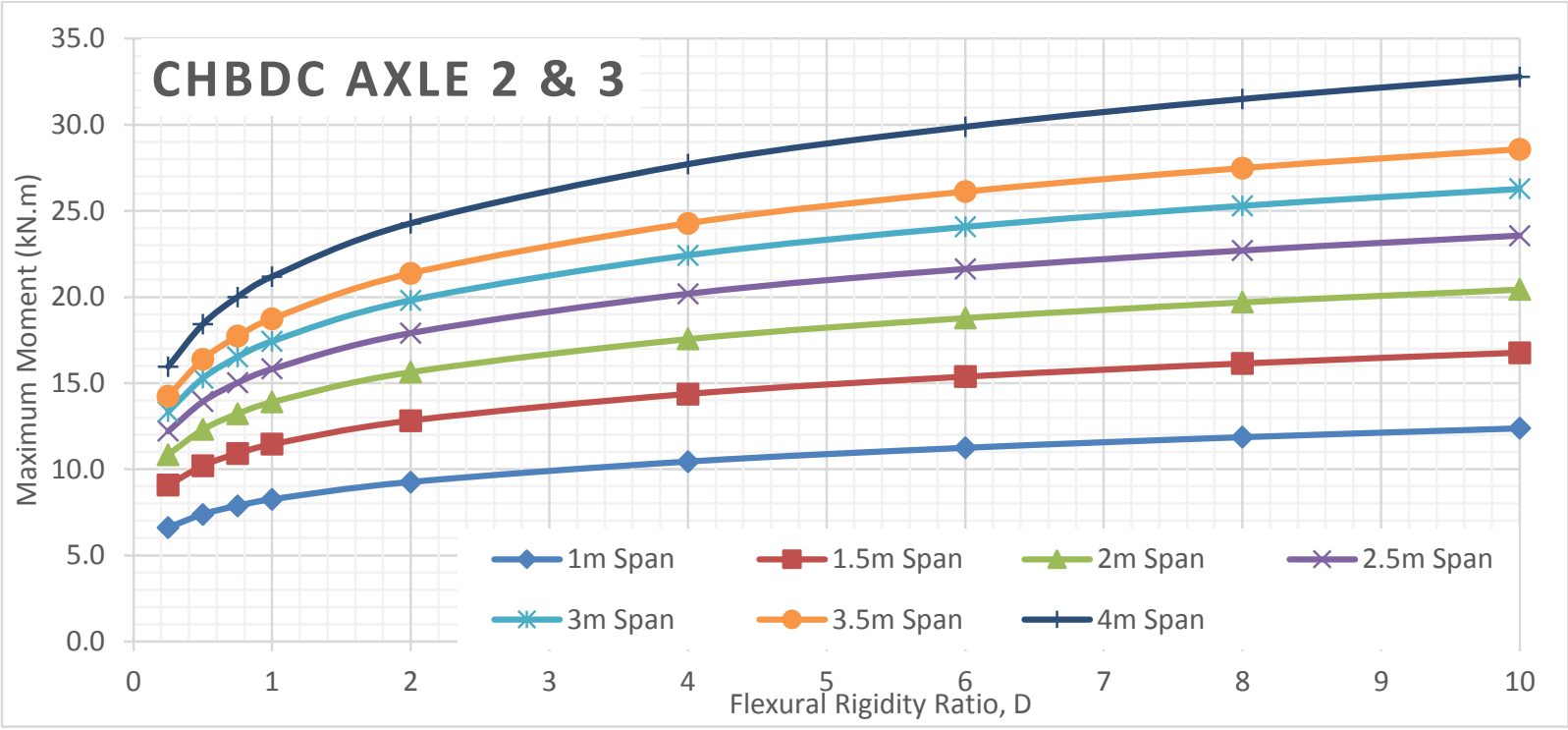

Figure 313 Maximum moment of deck slabs subjected to CHBDC axle $2 \& 3$ for different span values of alpha 2 Orthotropic analyses 


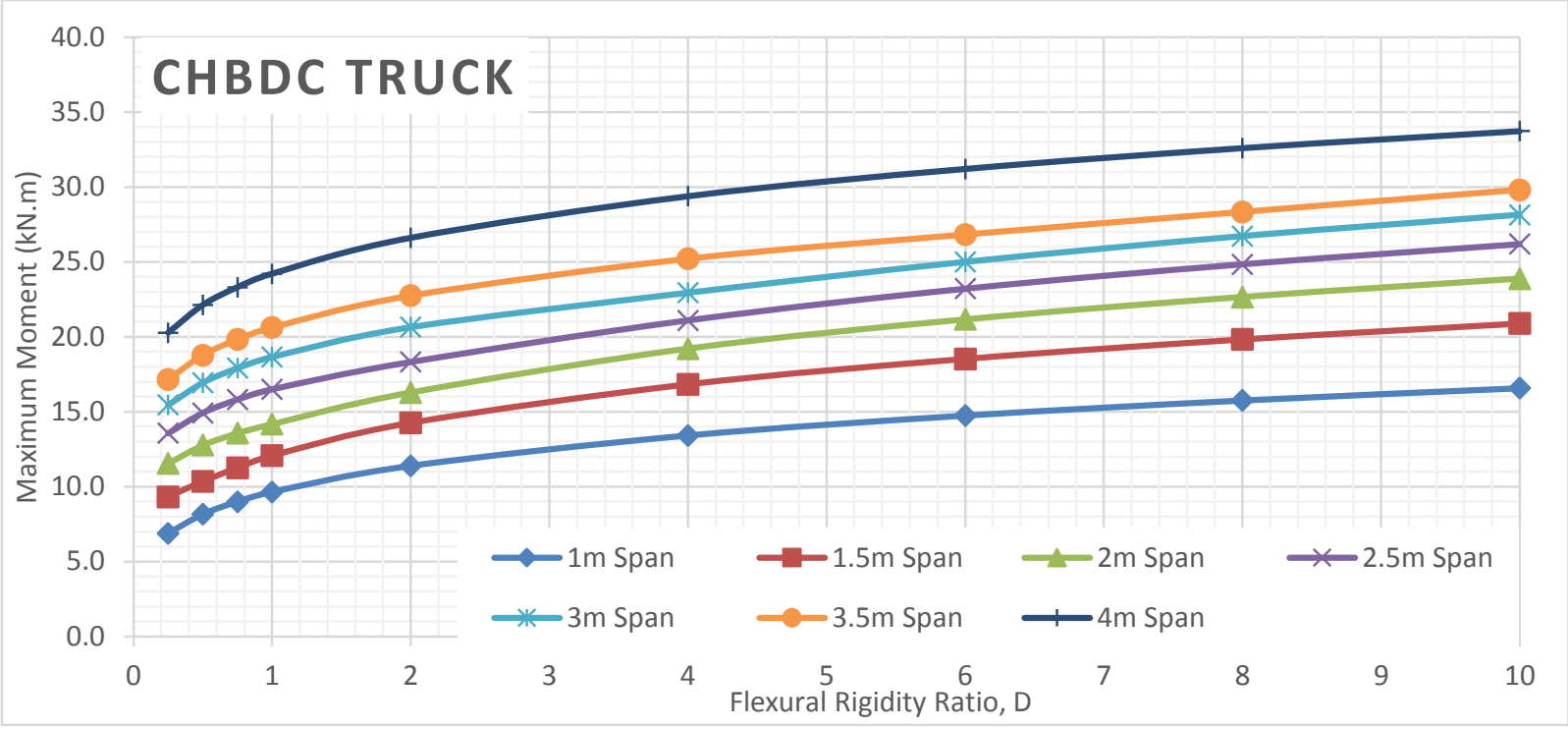

Figure 314 Maximum moment of deck slabs subjected to CHBDC truck for different span values of alpha 2 Orthotropic analyses

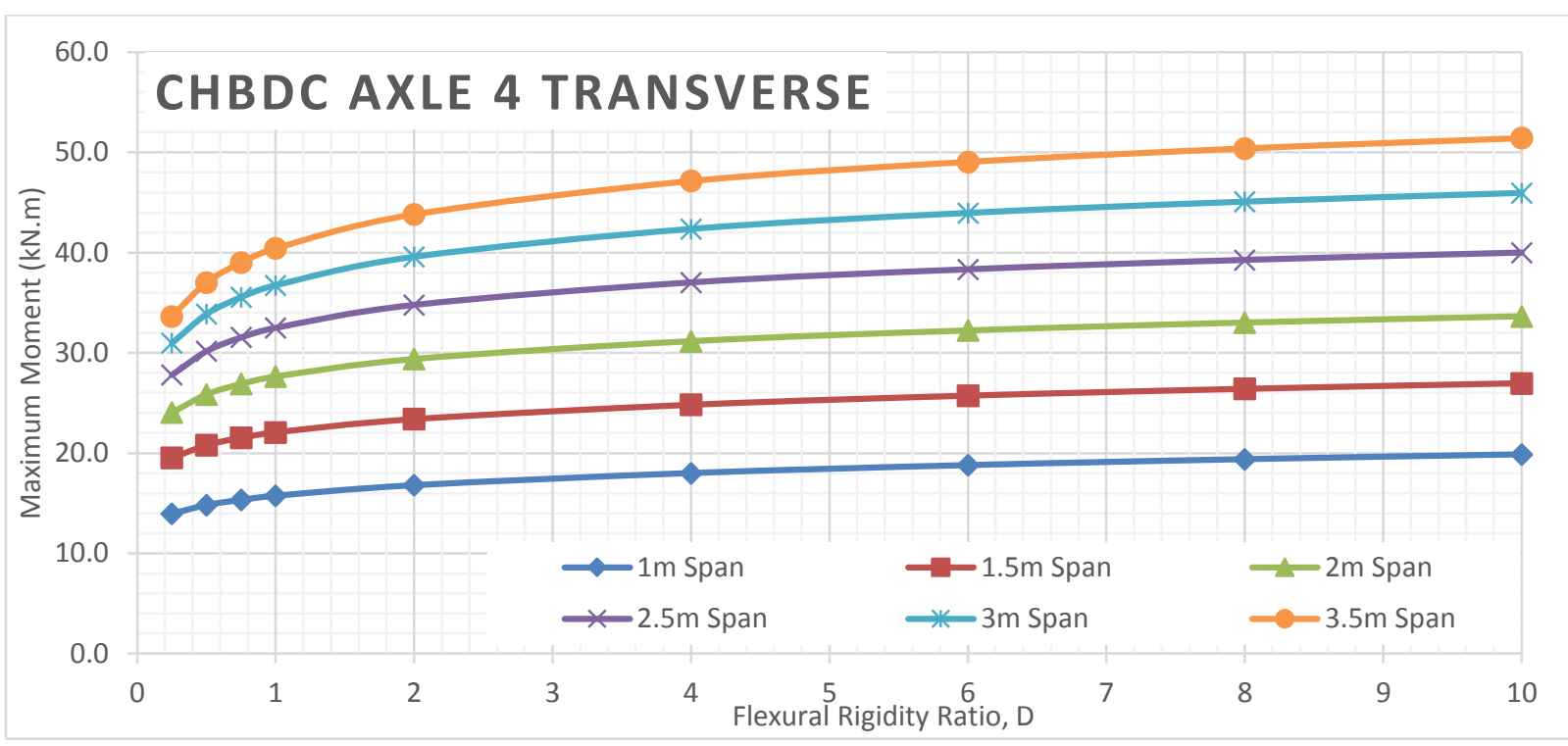

Figure 315 Maximum moment of deck slabs subjected to CHBDC axle 4 for different span values of alpha 2 Orthotropic analyses

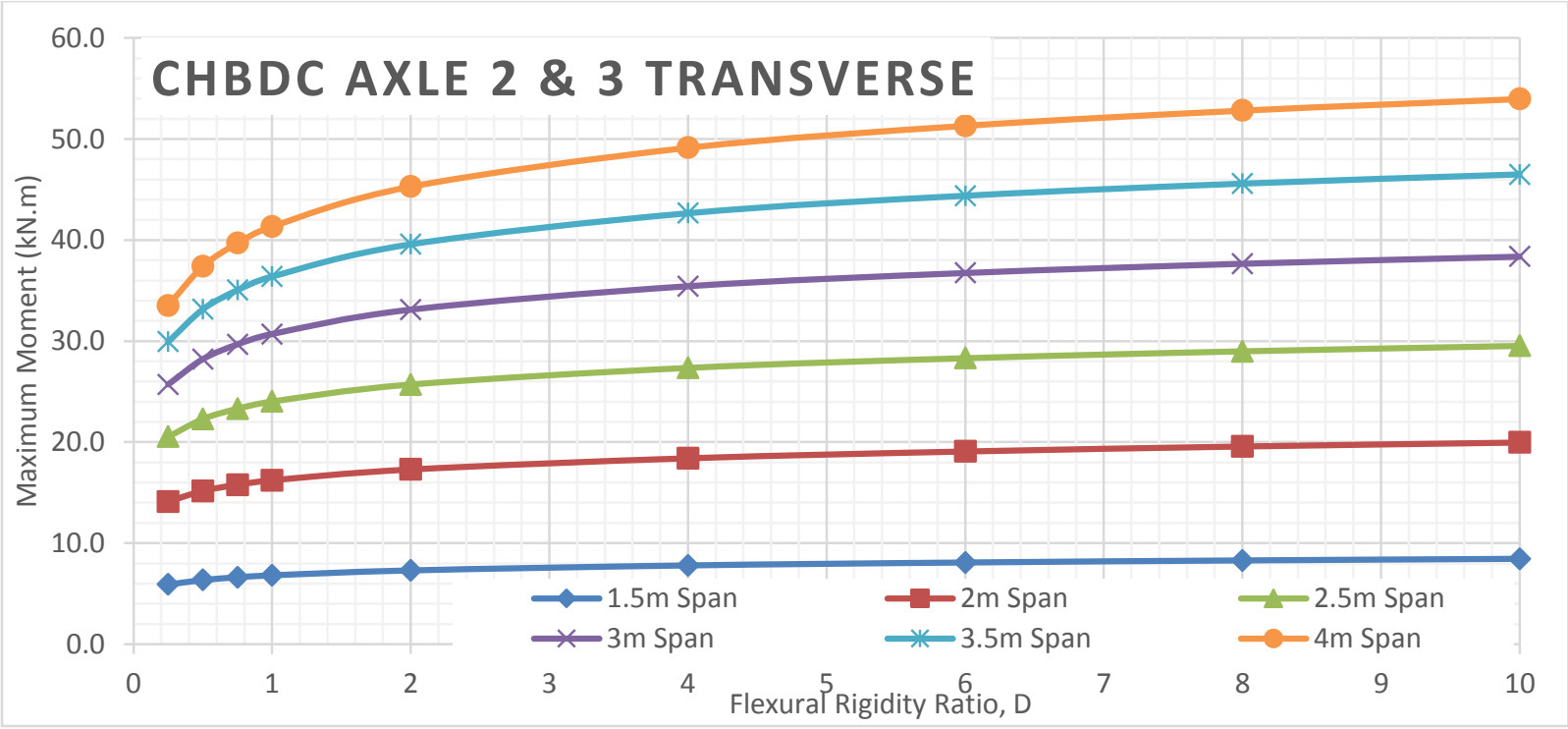

Figure 316 Maximum moment of deck slabs subjected to CHBDC axle 2 \& 3 for different span values of alpha 2 Orthotropic analyses 


\section{Alpha 4 Bending Moment VS Flexural Rigidity for Different Span Length}

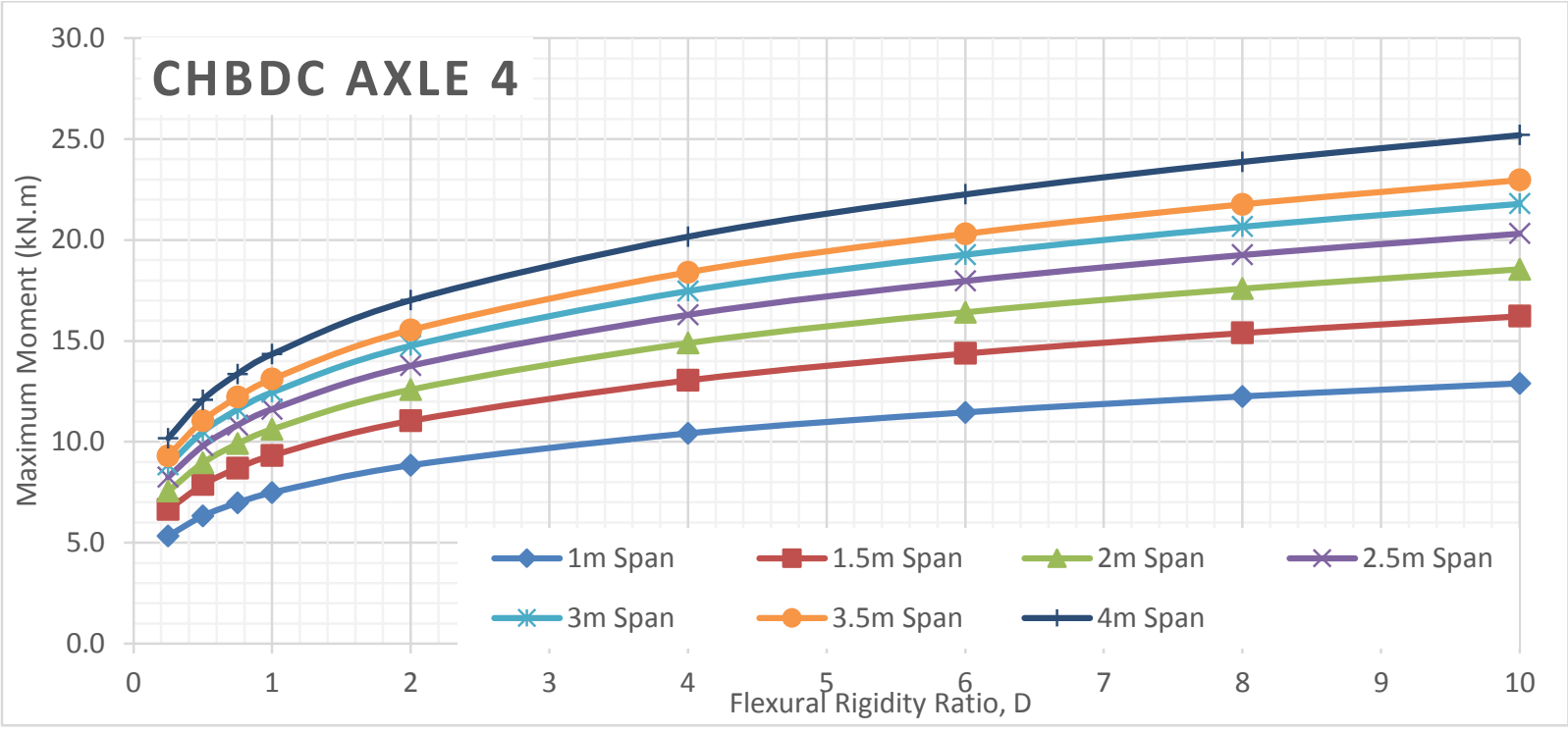

Figure 317 Maximum moment of deck slabs subjected to CHBDC axle 4 for different span values of alpha 4 Orthotropic analyses

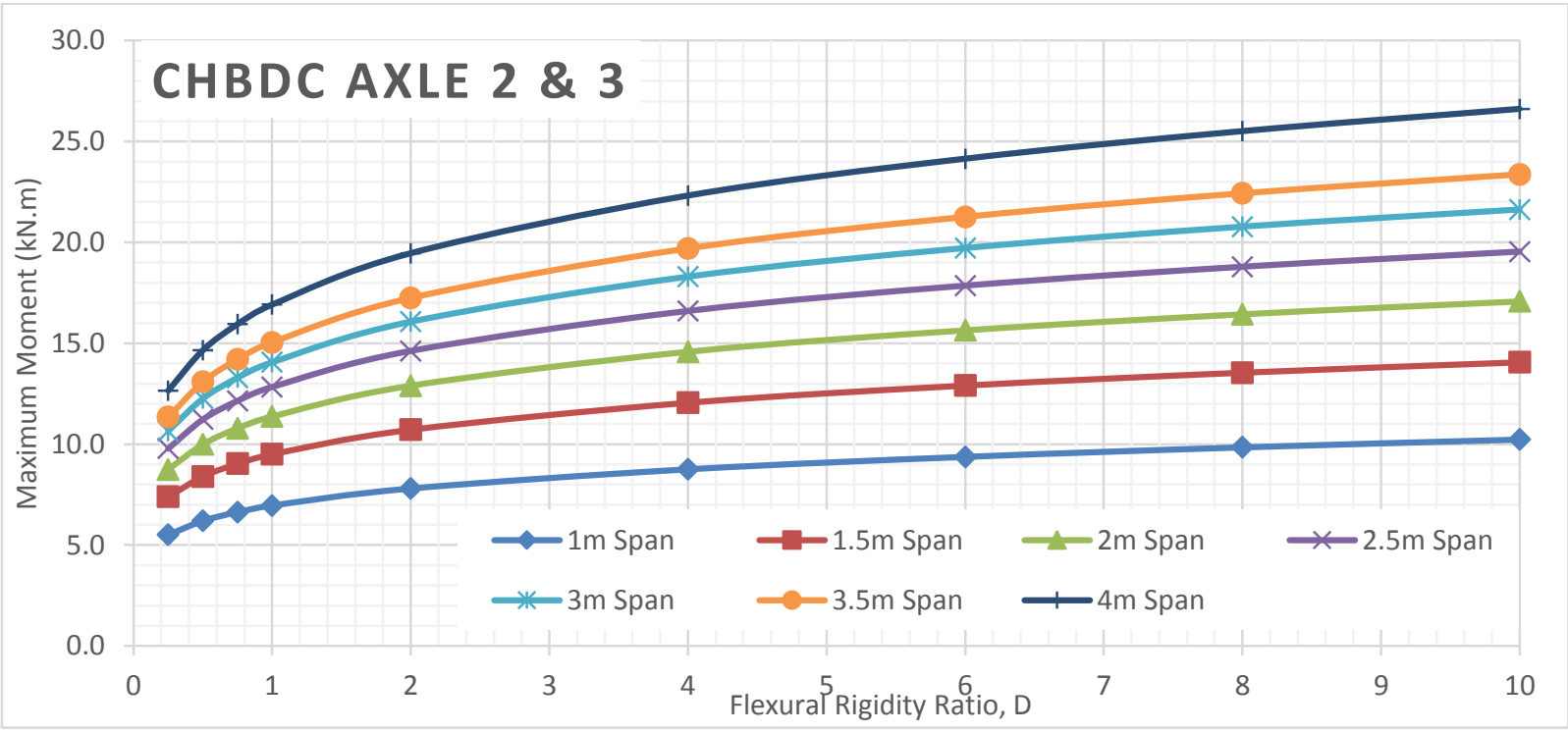

Figure 318 Maximum moment of deck slabs subjected to CHBDC axle 2 \& 3 for different span values of alpha 4 Orthotropic analyses 


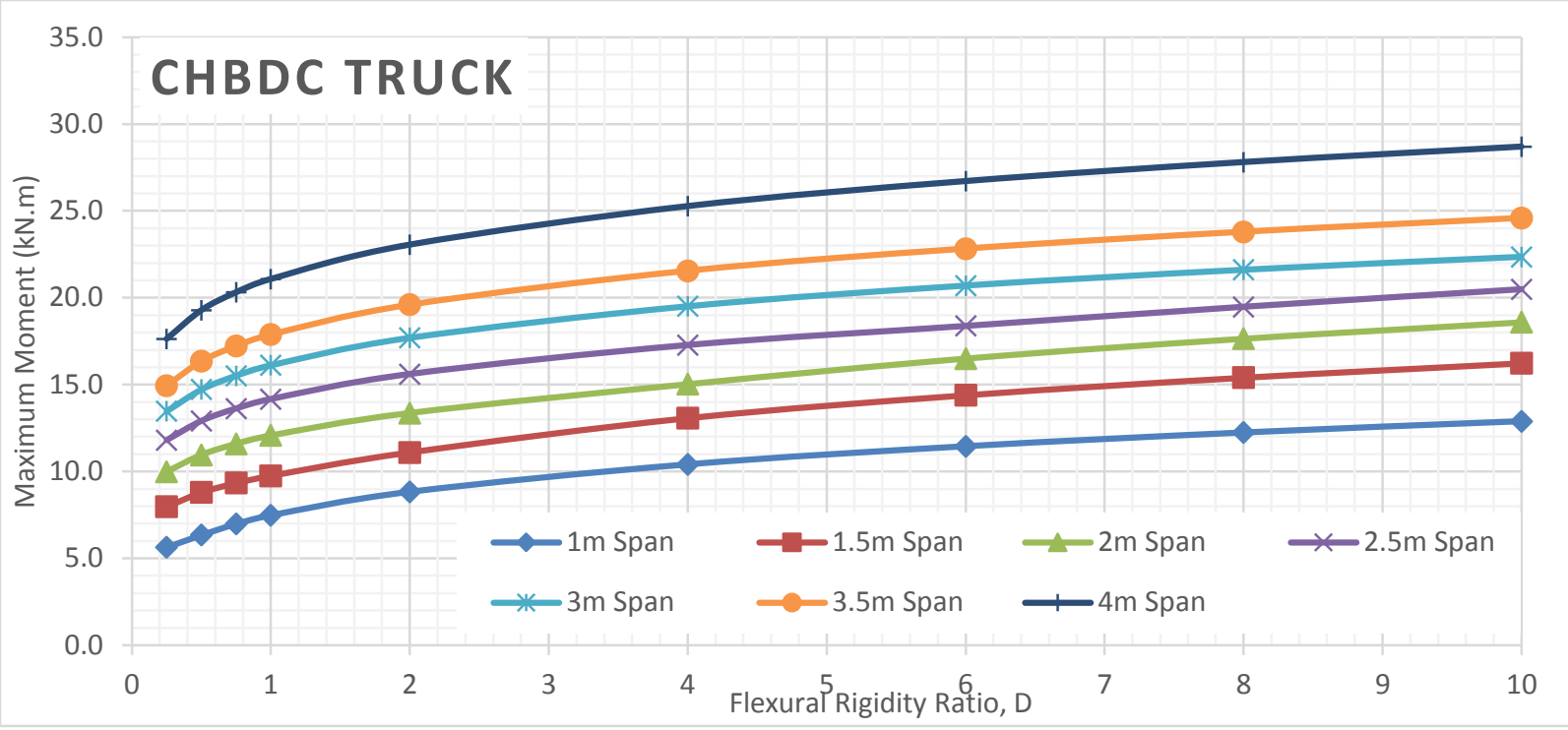

Figure 319 Maximum moment of deck slabs subjected to CHBDC truck for different span values of alpha 4 Orthotropic analyses

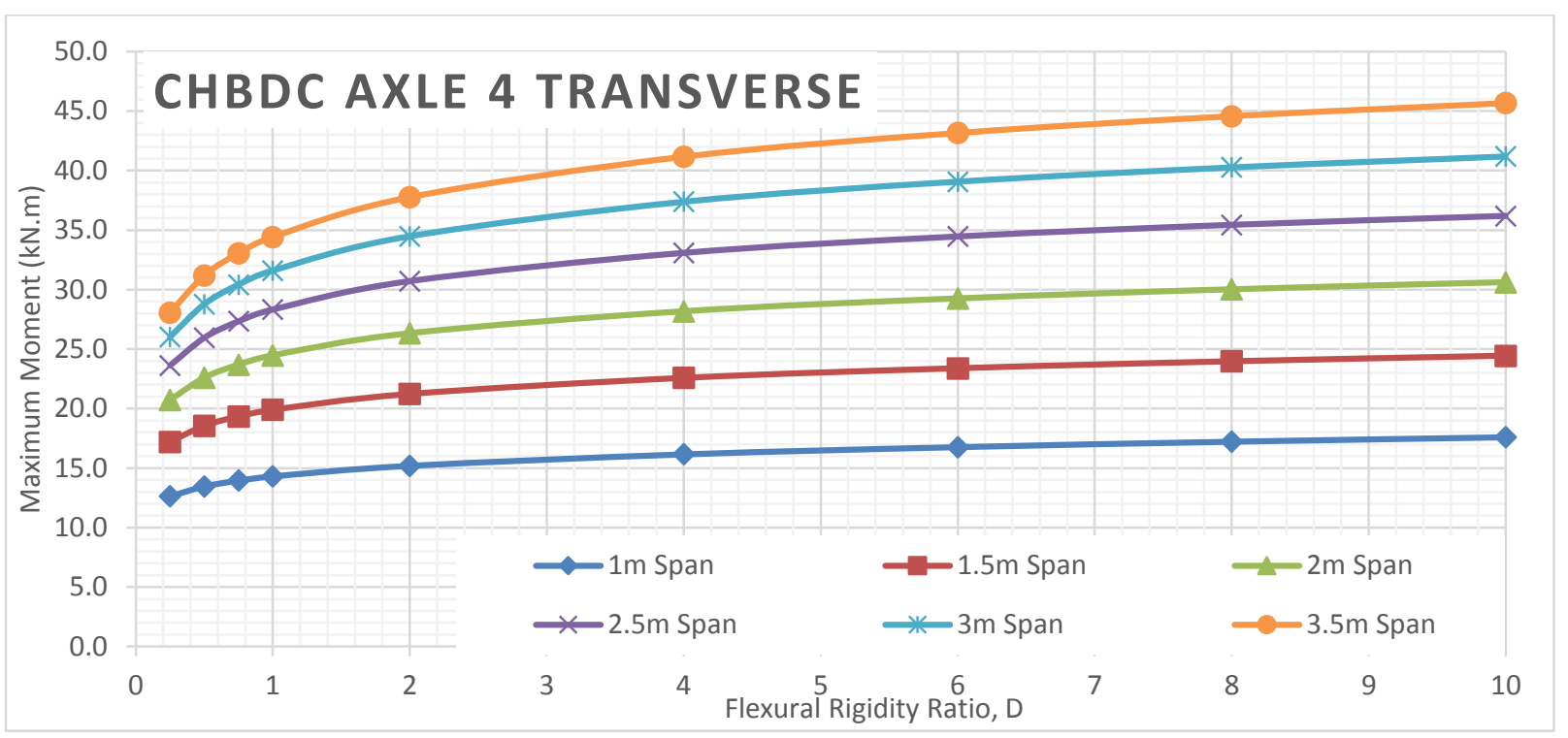

Figure 320 Maximum moment of deck slabs subjected to CHBDC axle 4 for different span values of alpha 4 Orthotropic analyses

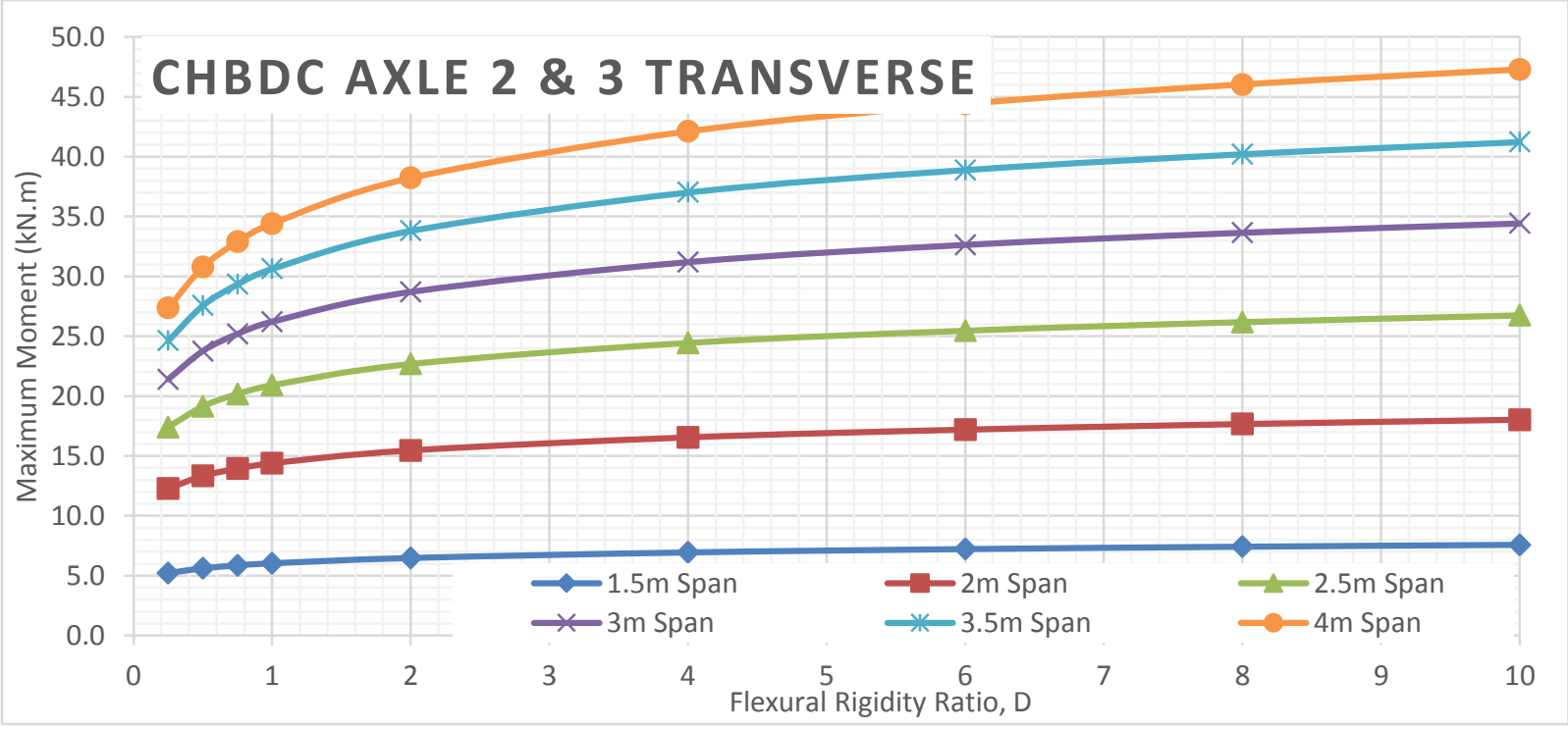

Figure 321 Maximum moment of deck slabs subjected to CHBDC axle 2 \& 3 for different span values of alpha 4 Orthotropic analyses 


\section{Alpha 6 Bending Moment VS Flexural Rigidity for Different Span Length}

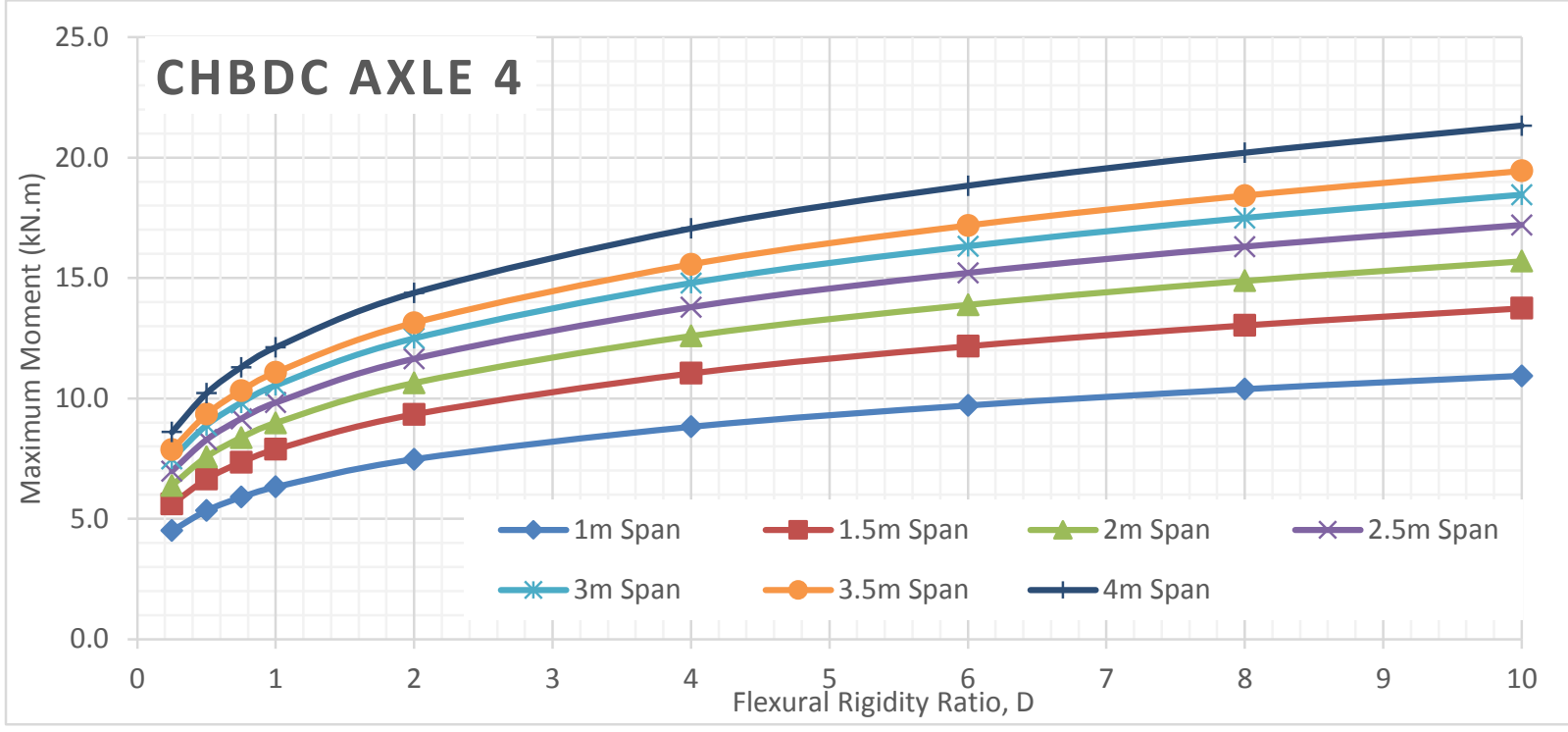

Figure 322 Maximum moment of deck slabs subjected to CHBDC axle 4 for different span values of alpha 6 Orthotropic analyses

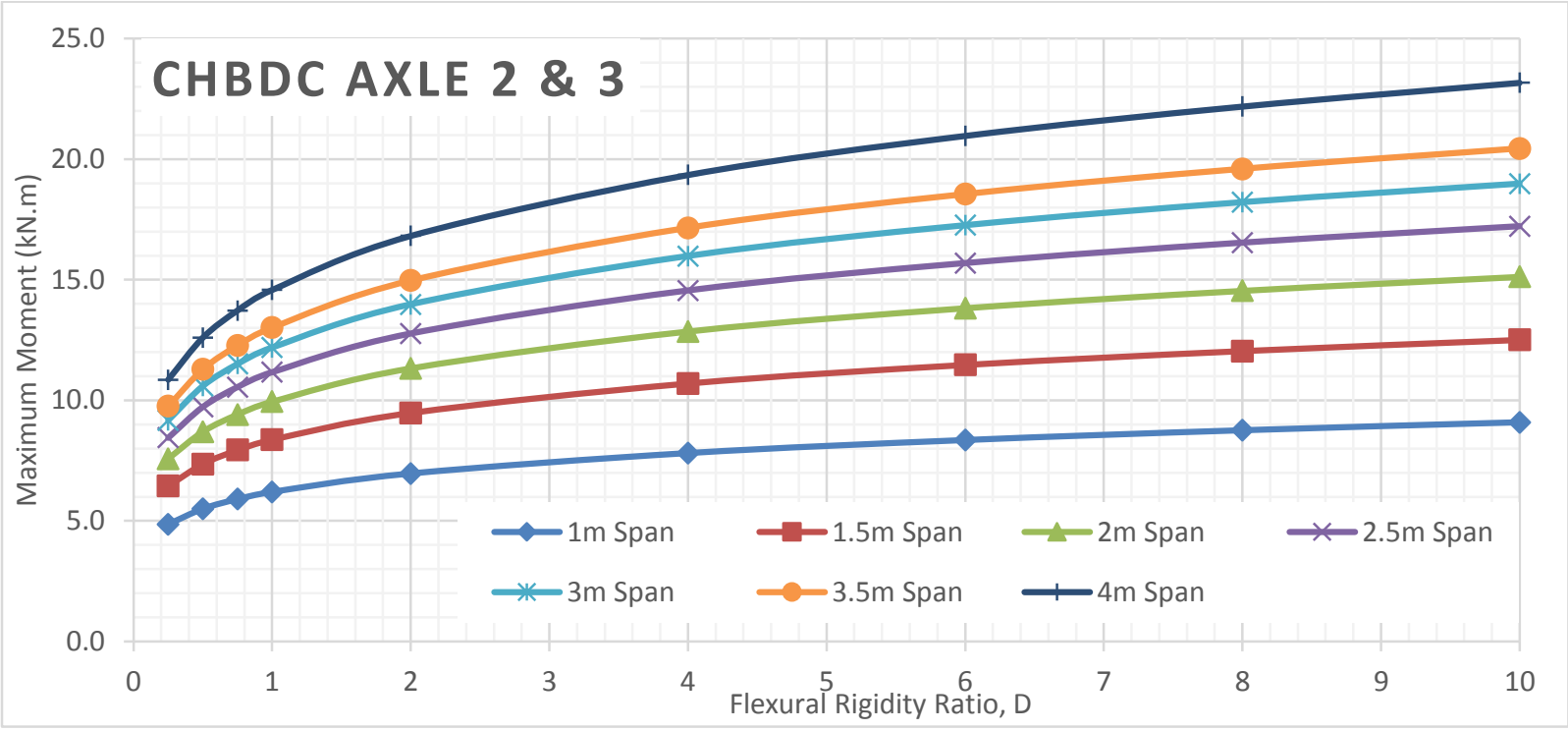

Figure 323 Maximum moment of deck slabs subjected to CHBDC axle $2 \& 3$ for different span values of alpha 6 Orthotropic analyses 


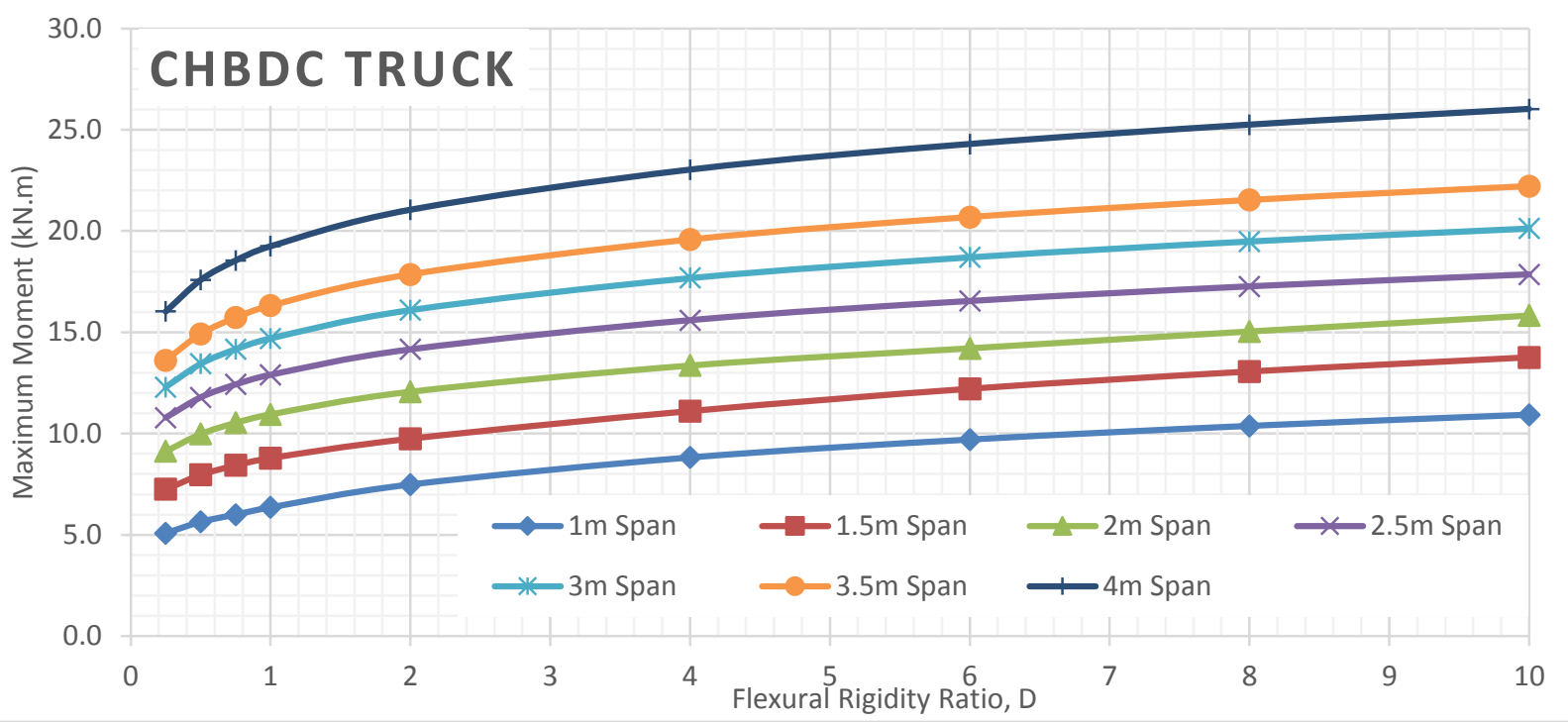

Figure 324 Maximum moment of deck slabs subjected to CHBDC truck for different span values of alpha 6 Orthotropic analyses

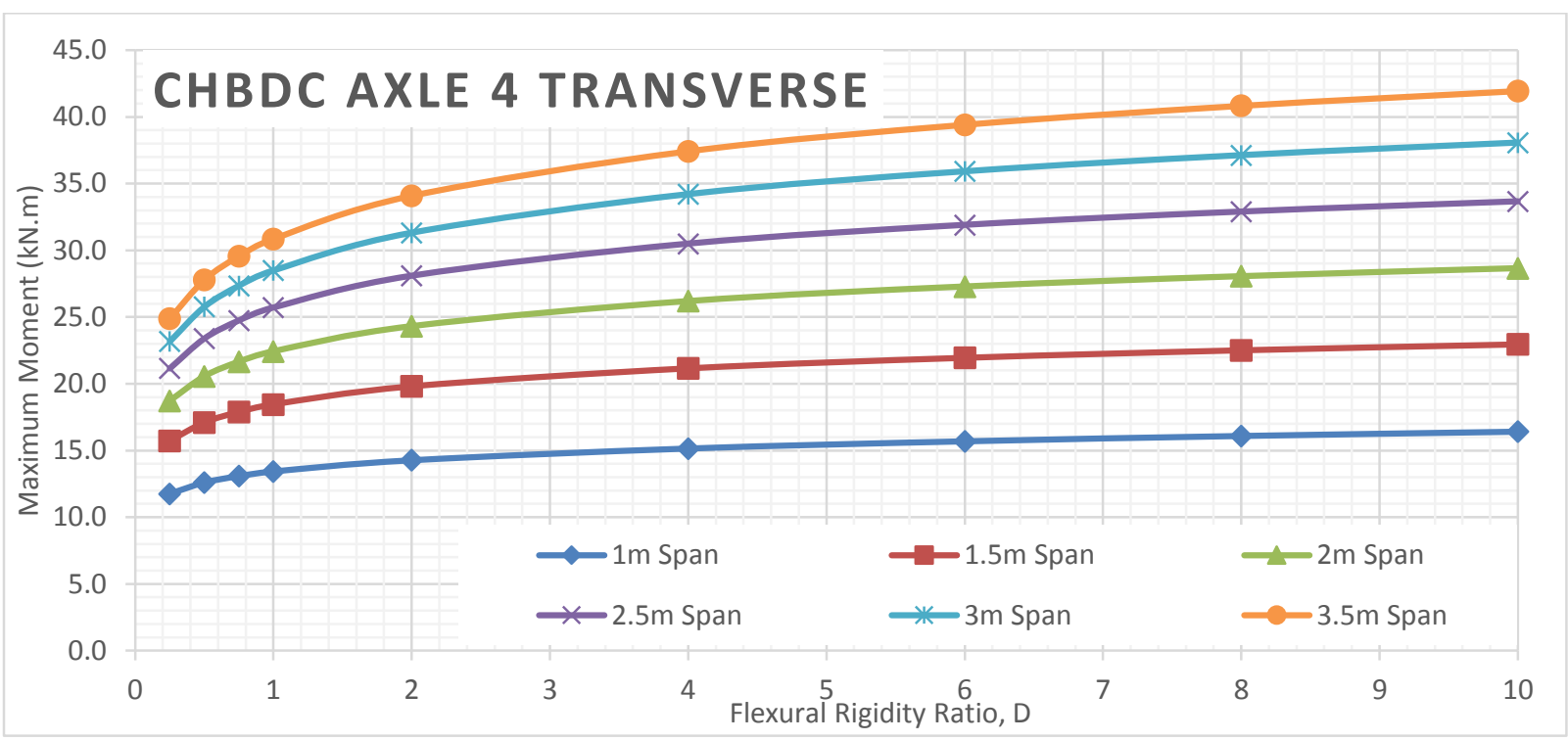

Figure 325 Maximum moment of deck slabs subjected to CHBDC axle 4 for different span values of alpha 6 Orthotropic analyses

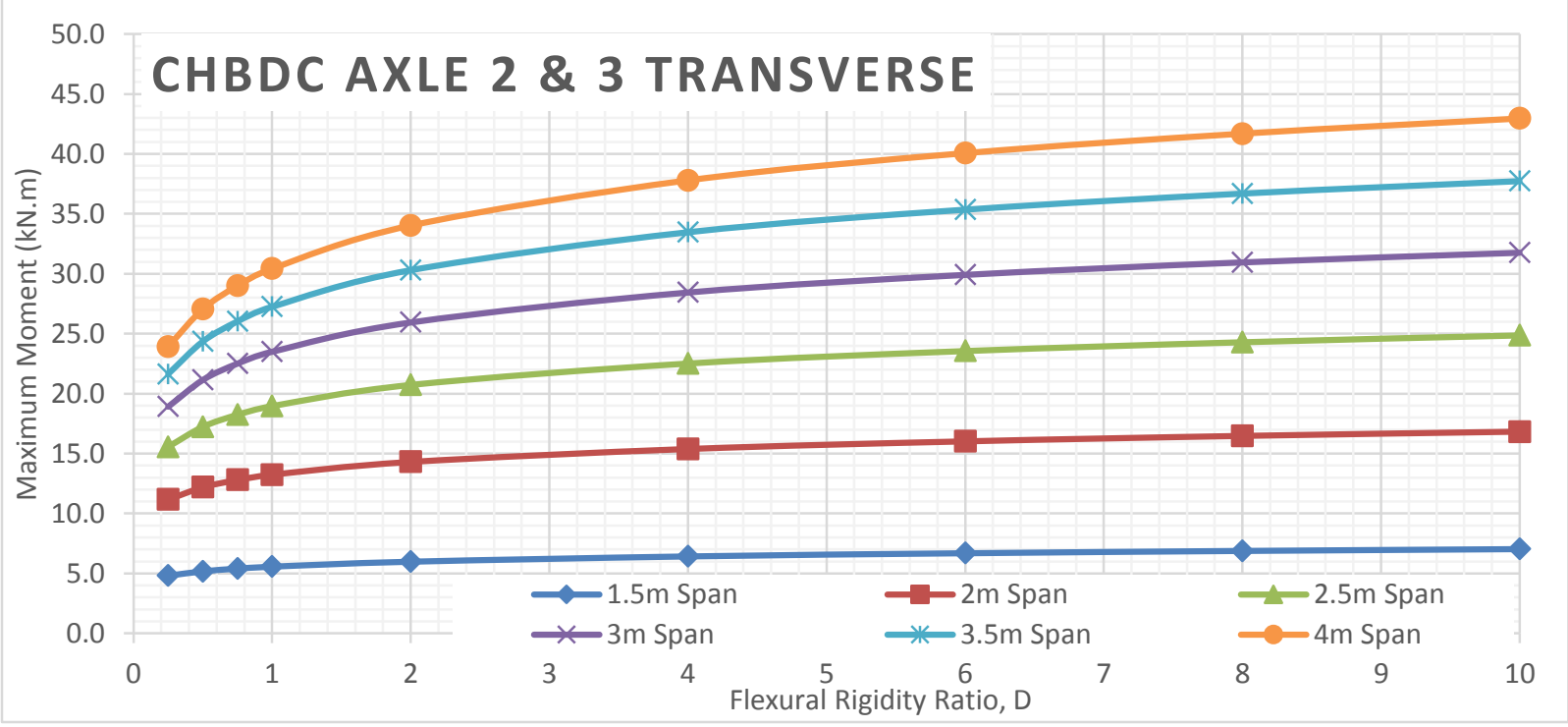

Figure 326 Maximum moment of deck slabs subjected to CHBDC axle 2 \& 3 for different span values of alpha 6 Orthotropic analyses 


\section{Alpha 8 Bending Moment VS Flexural Rigidity for Different Span Length}

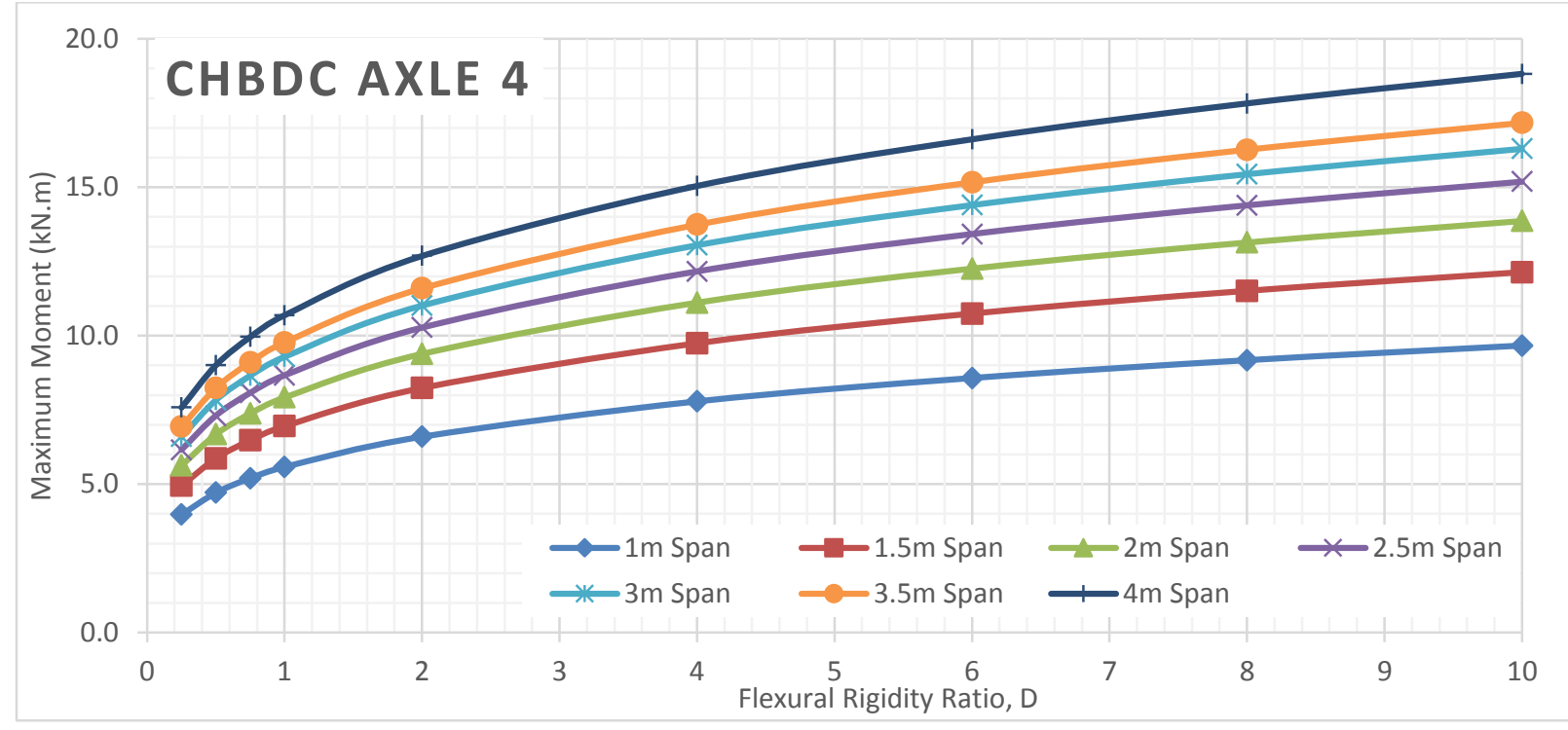

Figure 327 Maximum moment of deck slabs subjected to CHBDC axle 4 for different span values of alpha 8 Orthotropic analyses

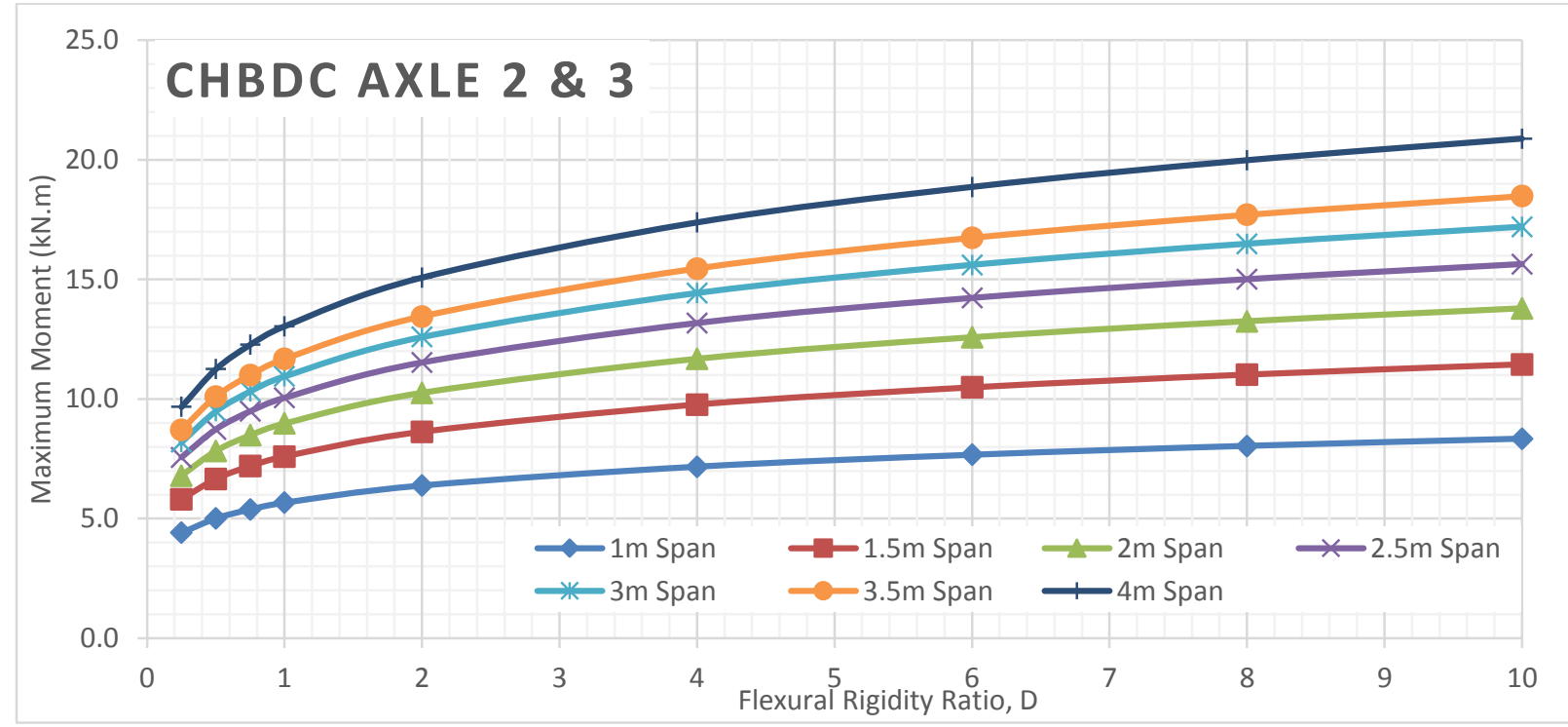

Figure 328 Maximum moment of deck slabs subjected to CHBDC axle 2 \& 3 for different span values of alpha 8 Orthotropic analyses 


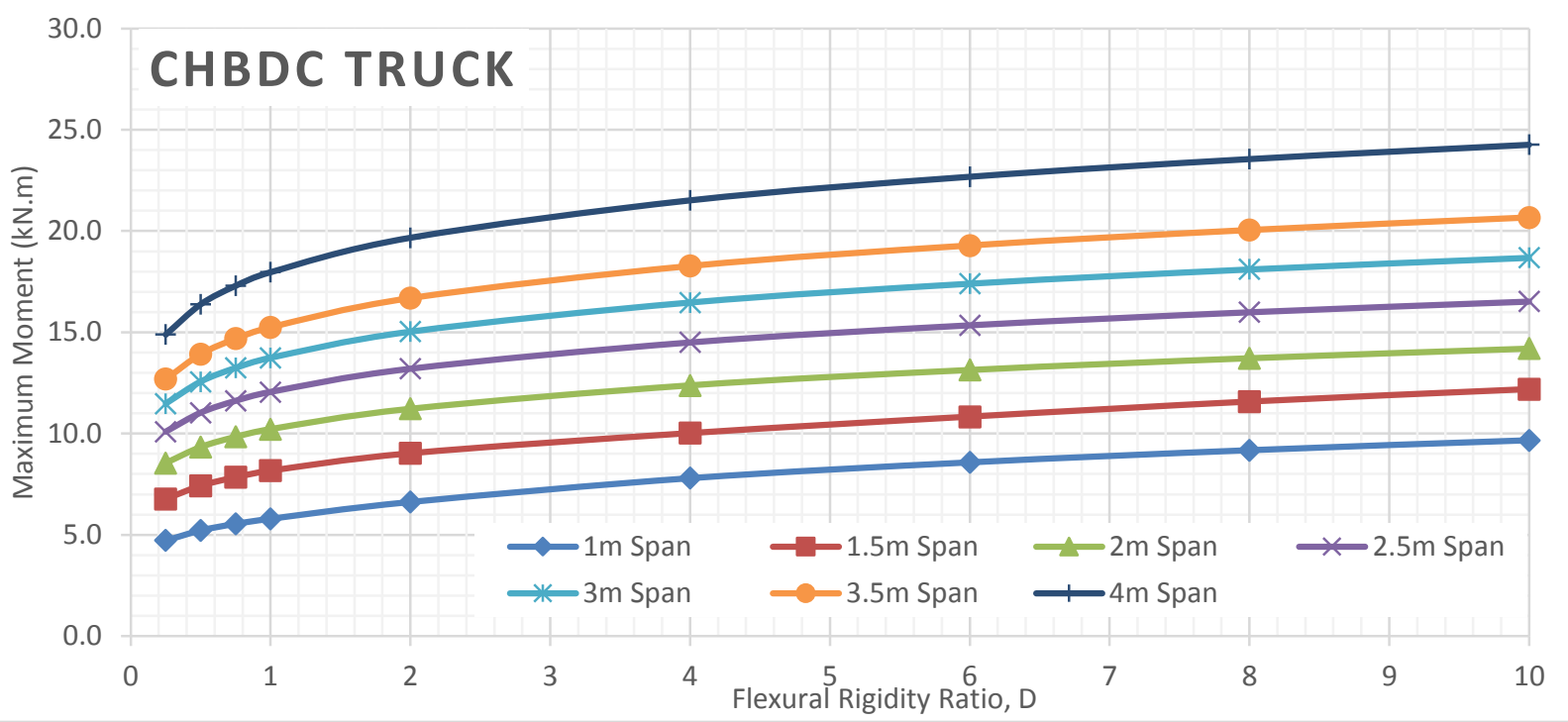

Figure 329 Maximum moment of deck slabs subjected to CHBDC truck for different span values of alpha 8 Orthotropic analyses

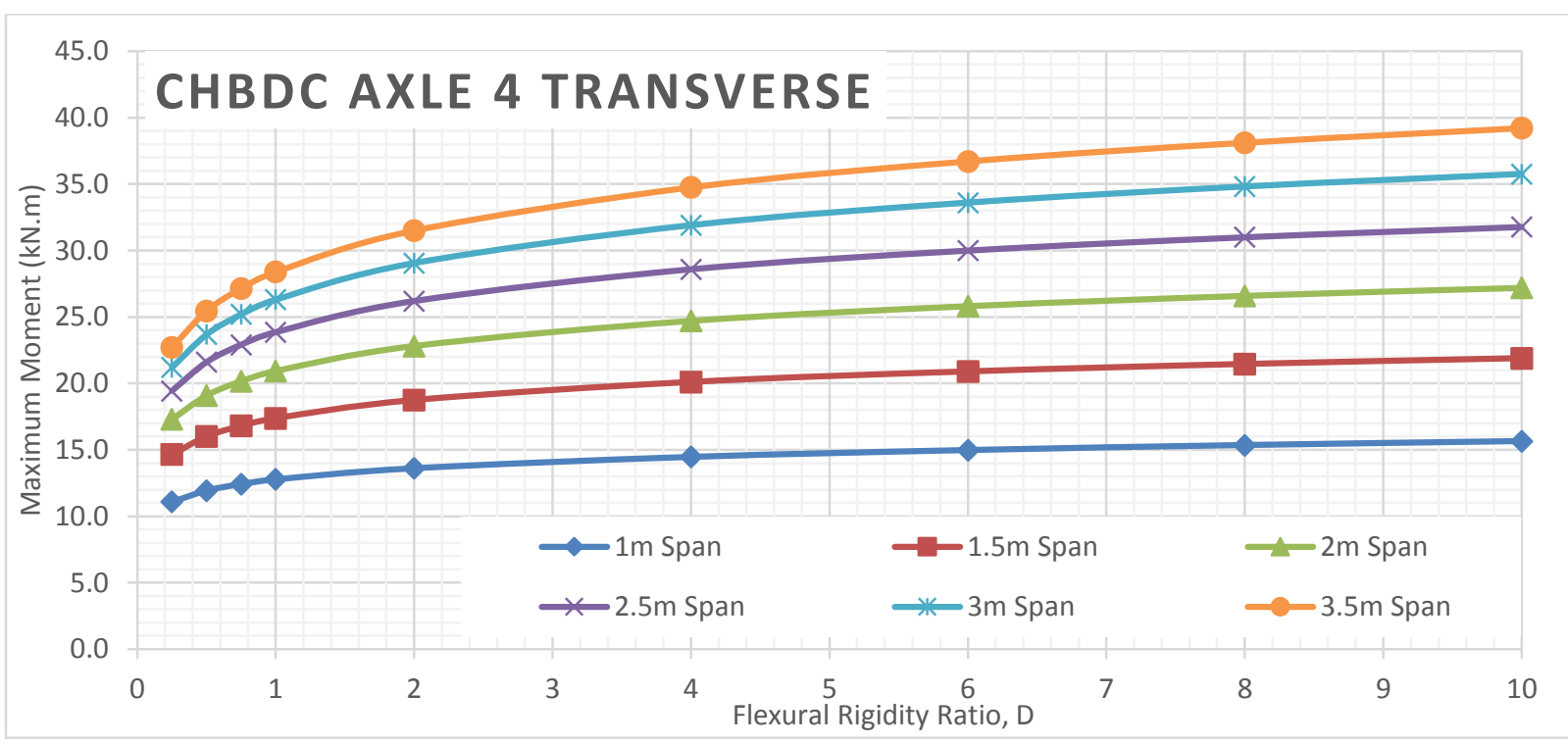

Figure 330 Maximum moment of deck slabs subjected to CHBDC axle 4 for different span values of alpha 8 Orthotropic analyses

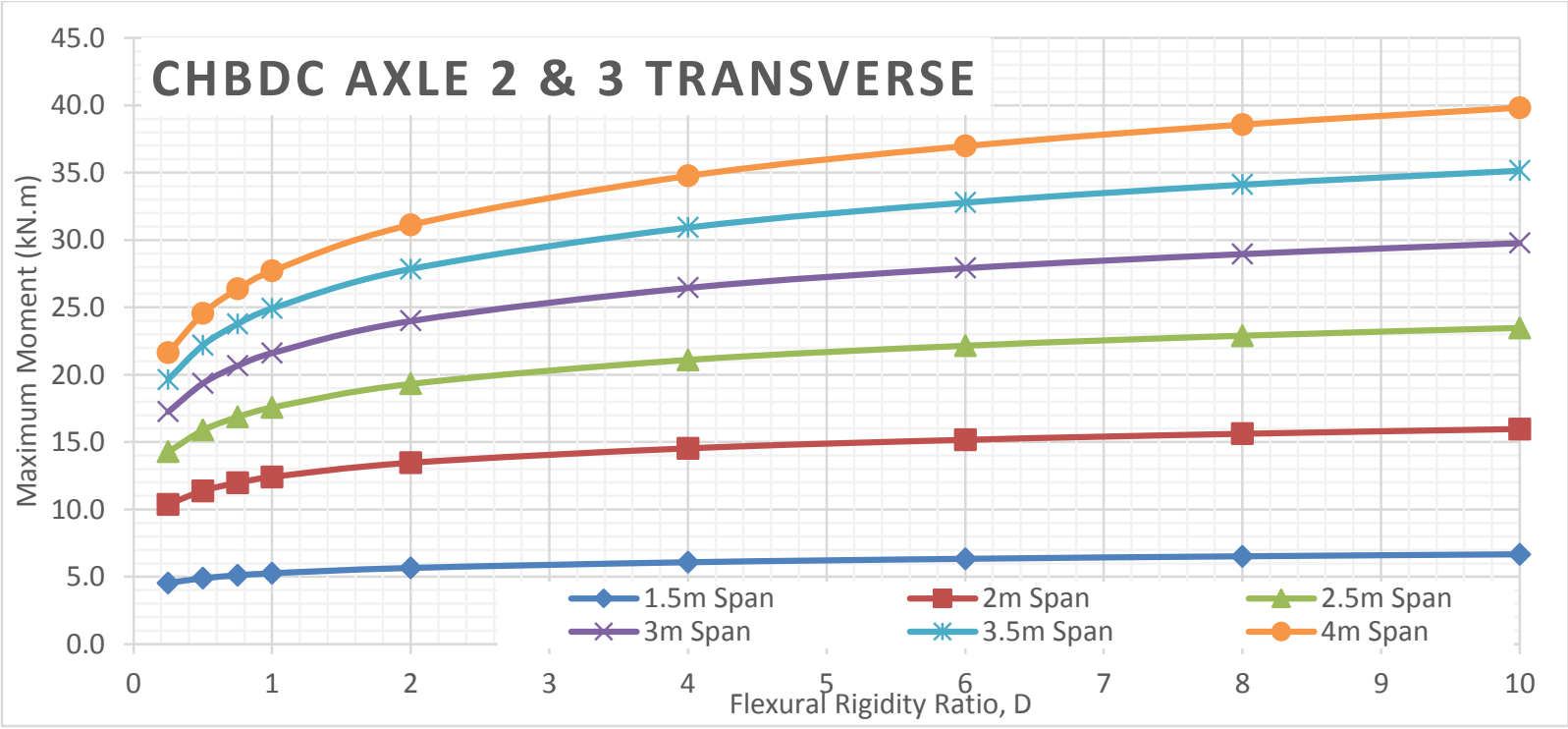

Figure 331 Maximum moment of deck slabs subjected to CHBDC axle $2 \& 3$ for different span values of alpha 8 Orthotropic analyses 


\section{Alpha 10 Bending Moment VS Flexural Rigidity for Different Span Length}

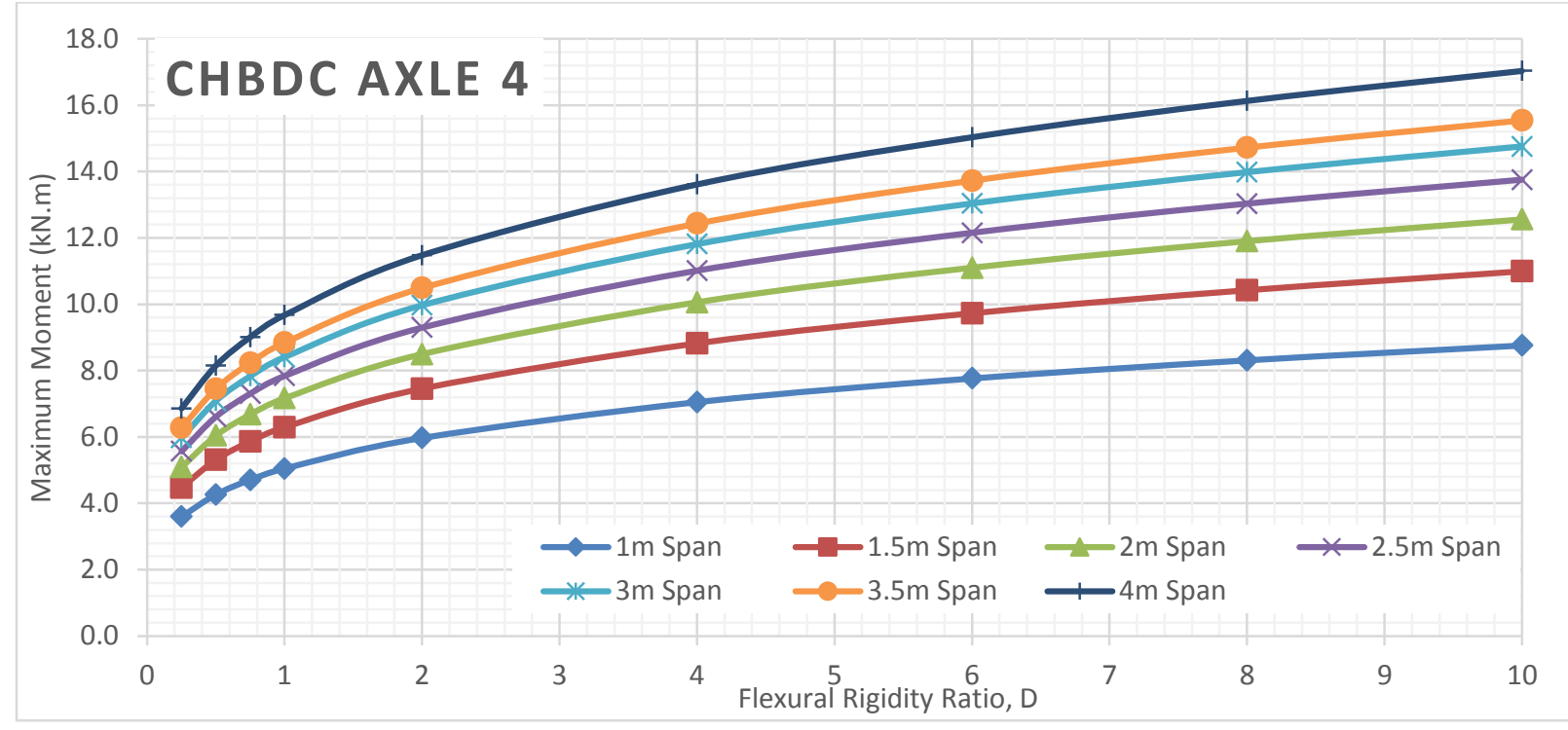

Figure 332 Maximum moment of deck slabs subjected to CHBDC axle 4 for different span values of alpha 10 Orthotropic analyses

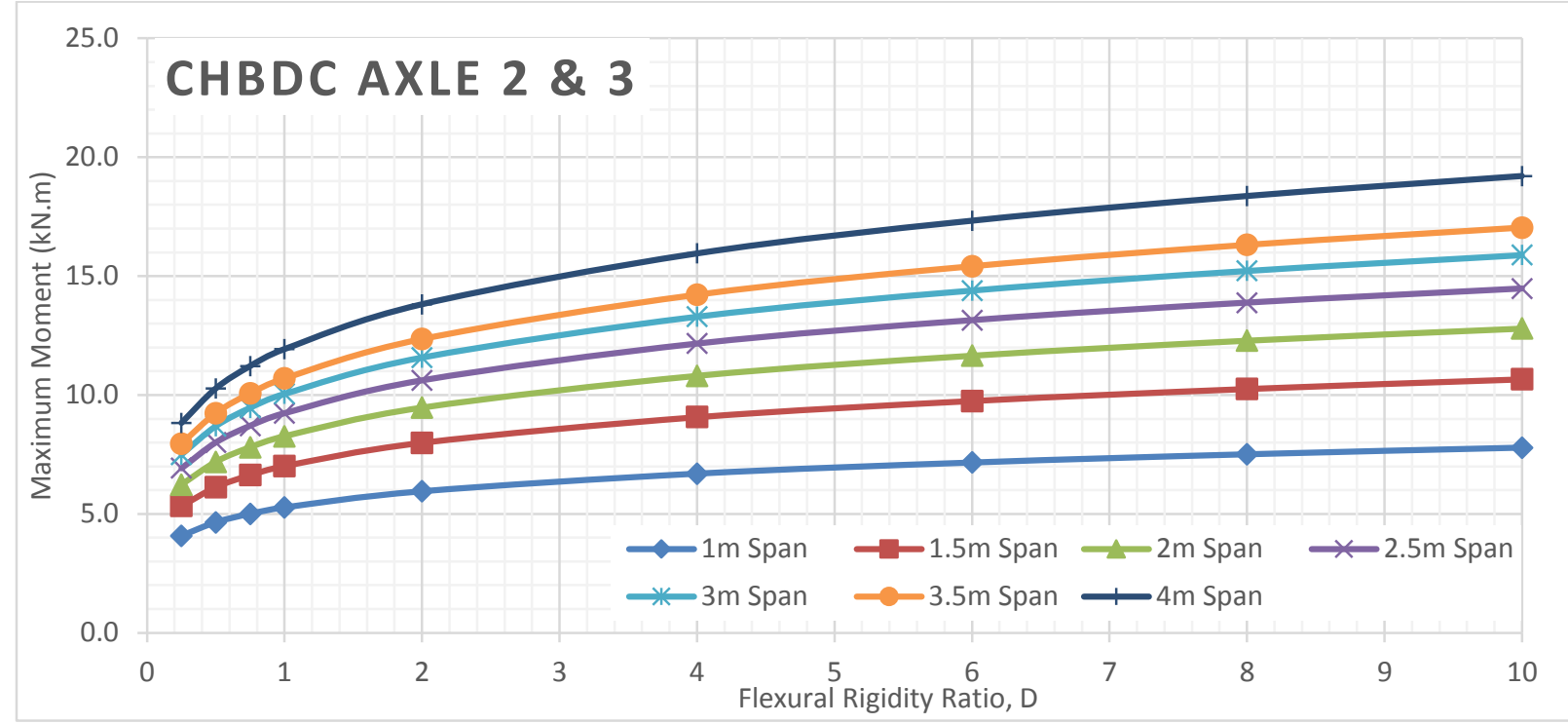

Figure 333 Maximum moment of deck slabs subjected to CHBDC axle 2 \& 3 for different span values of alpha 10 Orthotropic analyses 


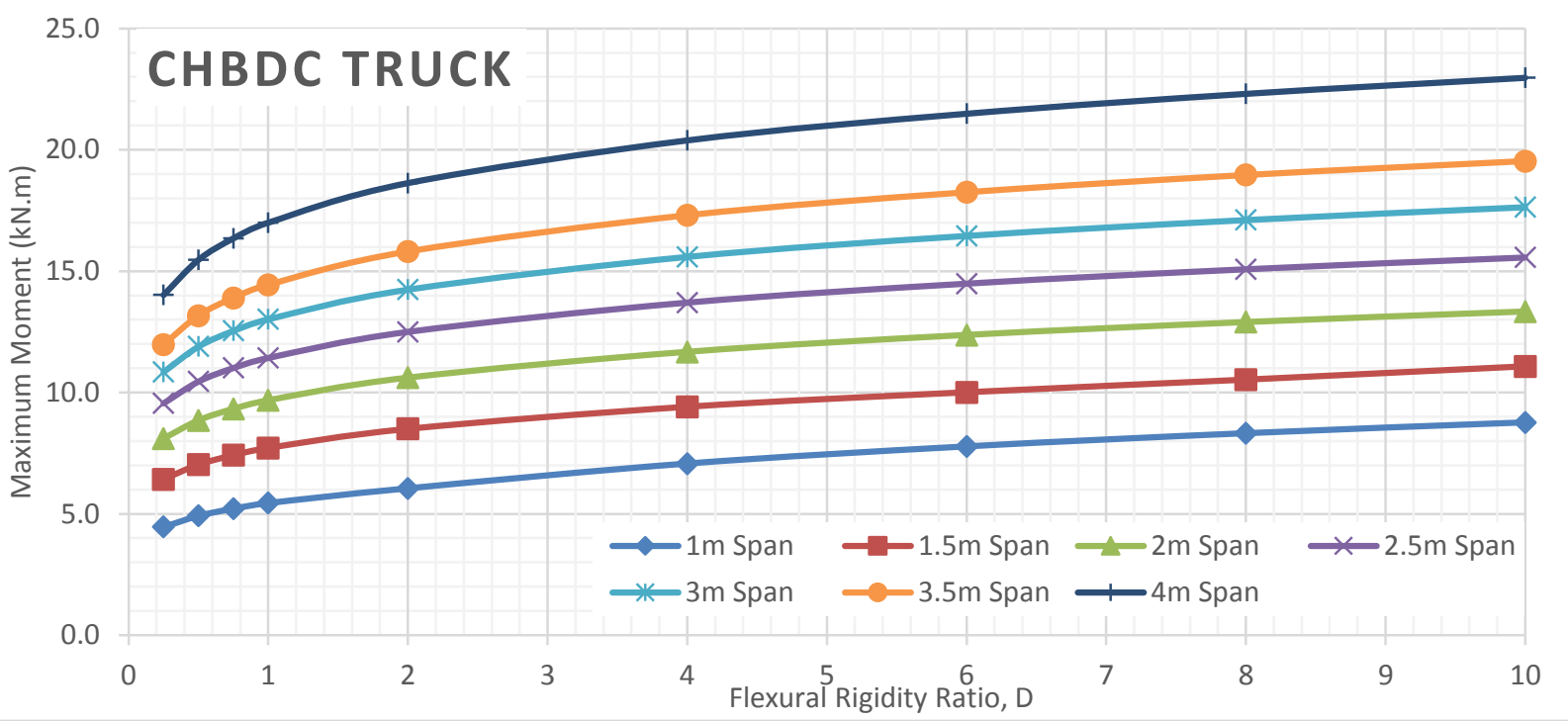

Figure 334 Maximum moment of deck slabs subjected to CHBDC truck for different span values of alpha 10 Orthotropic analyses

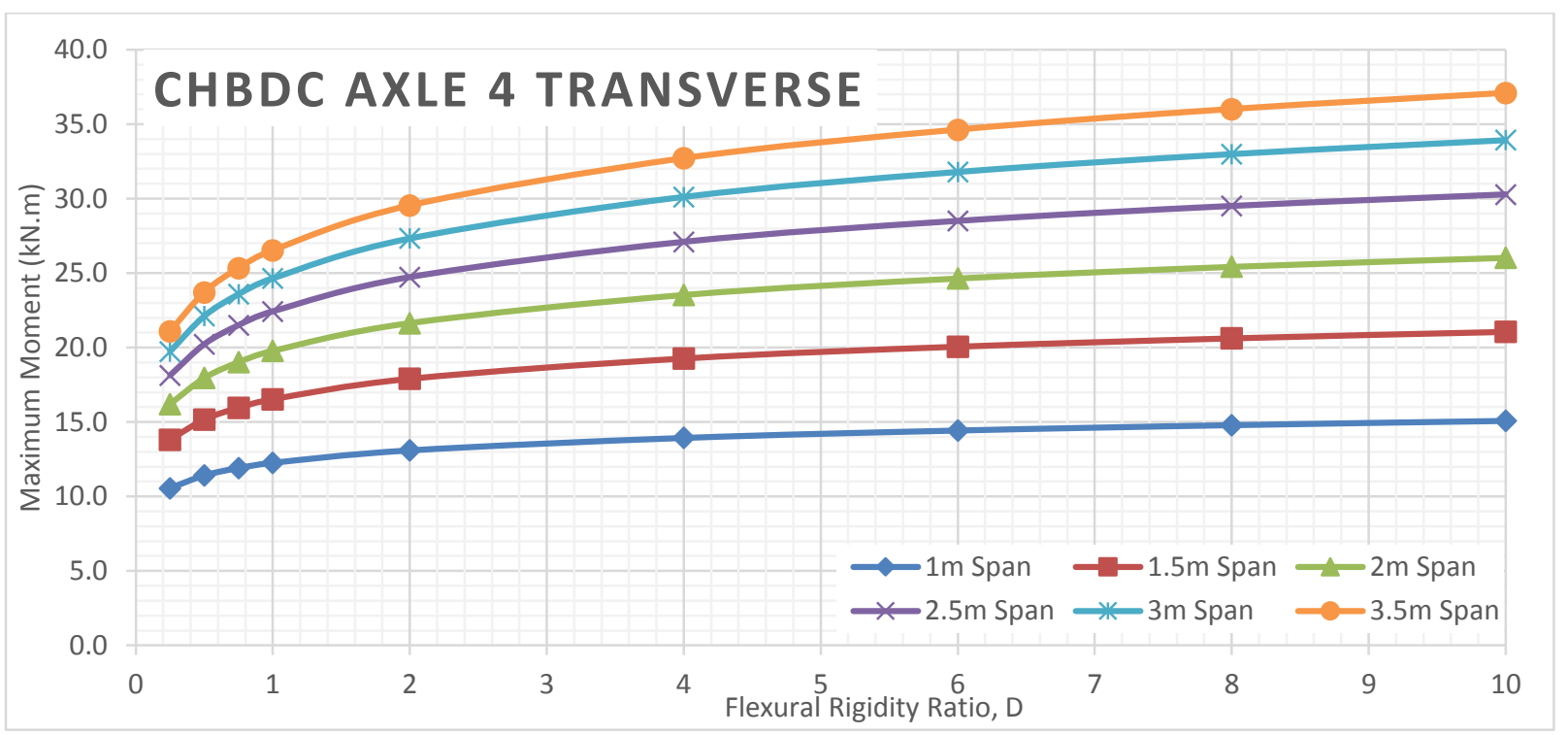

Figure 335 Maximum moment of deck slabs subjected to CHBDC axle 4 for different span values of alpha 10 Orthotropic analyses

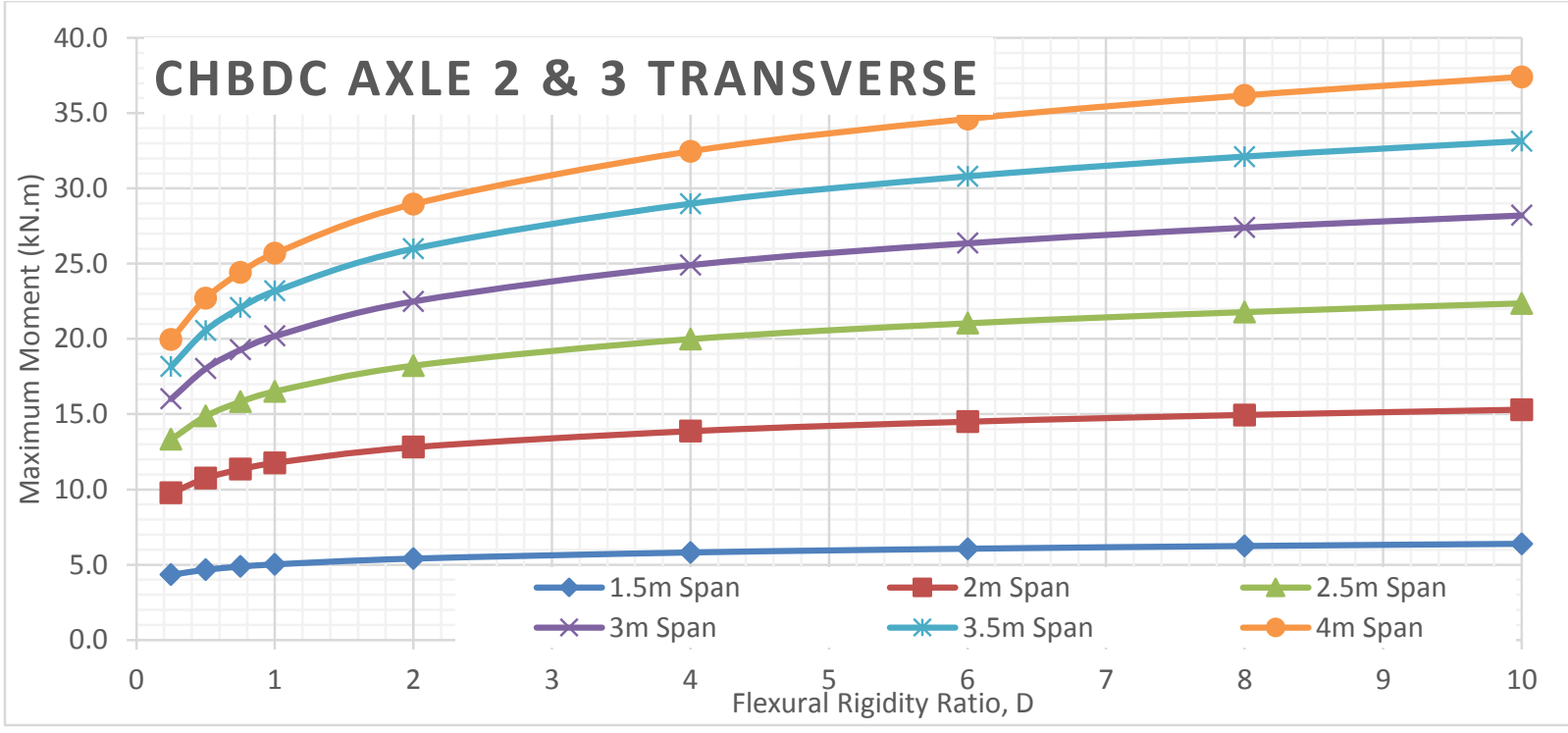

Figure 336 Maximum moment of deck slabs subjected to CHBDC axle 2 \& 3 for different span values of alpha 10 Orthotropic analyses 


\section{C.1.4 MAXIMUM BENDING MOMENT VS TORSIONAL RIGIDITY}




\section{Axle 4 Bending Moment VS Torsional Rigidity for Different D Values at Different span length}

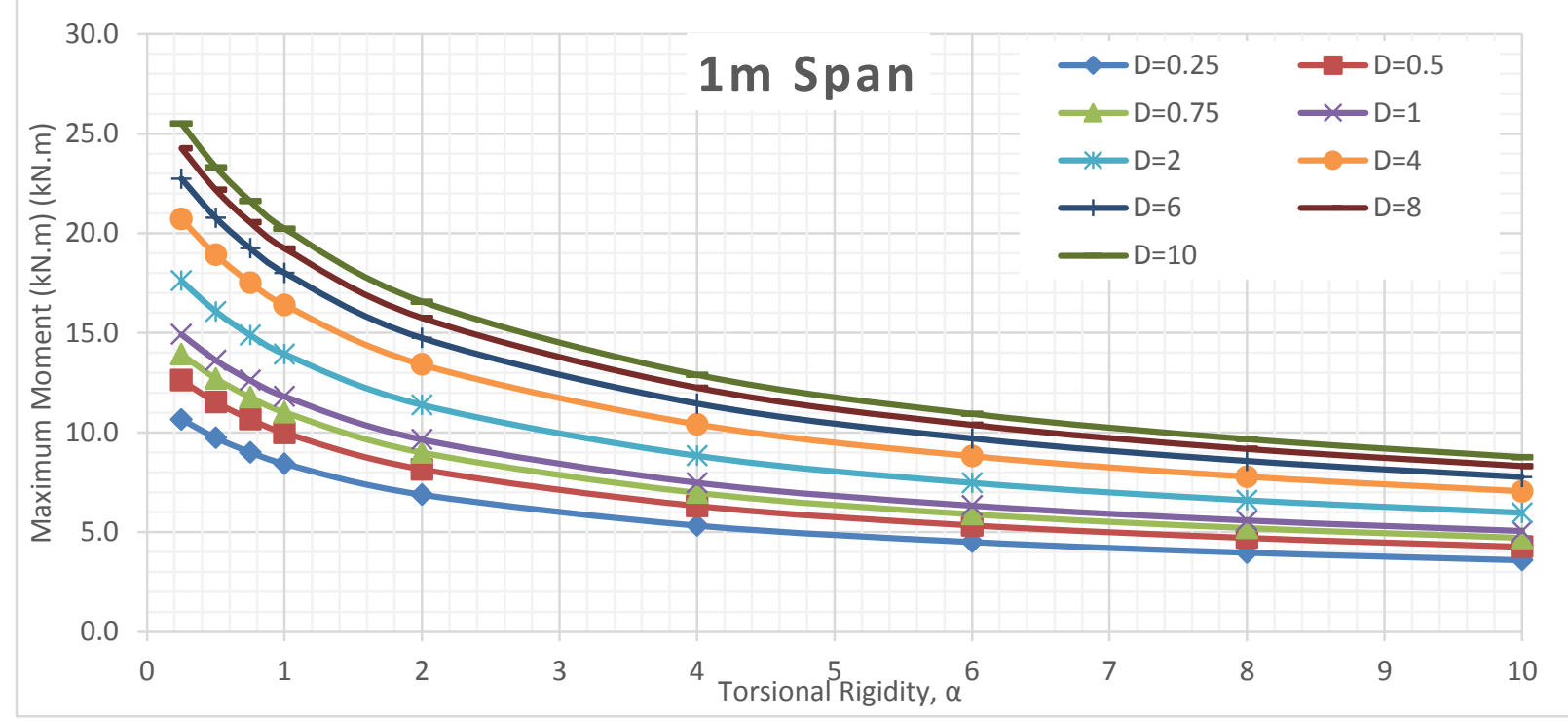

Figure 337 Maximum moment of $1 \mathrm{~m}$ span slab subjected to CHBDC axle 4 for different D values Orthotropic analyses

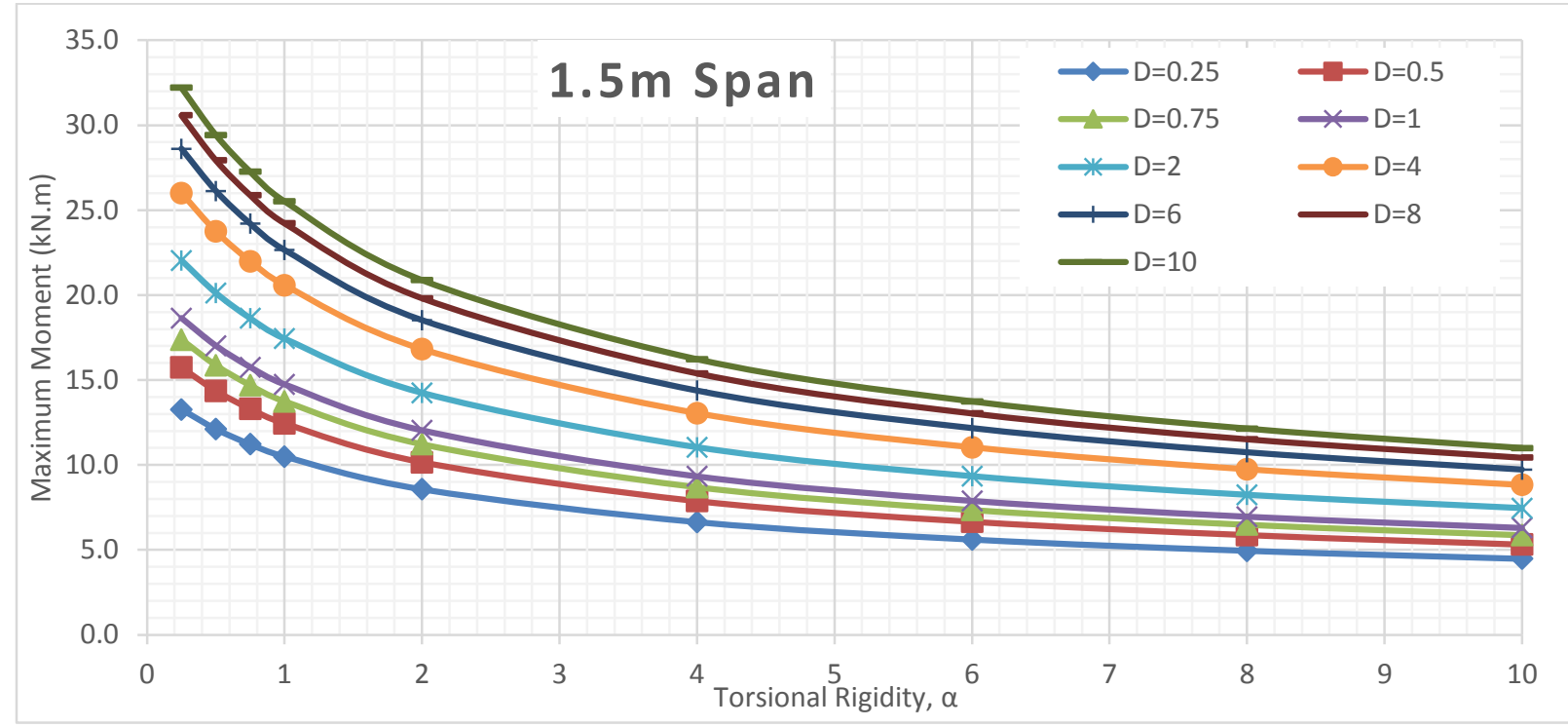

Figure 338 Maximum moment of $1.5 \mathrm{~m}$ span slab subjected to CHBDC axle 4 for different D values Orthotropic analyses 


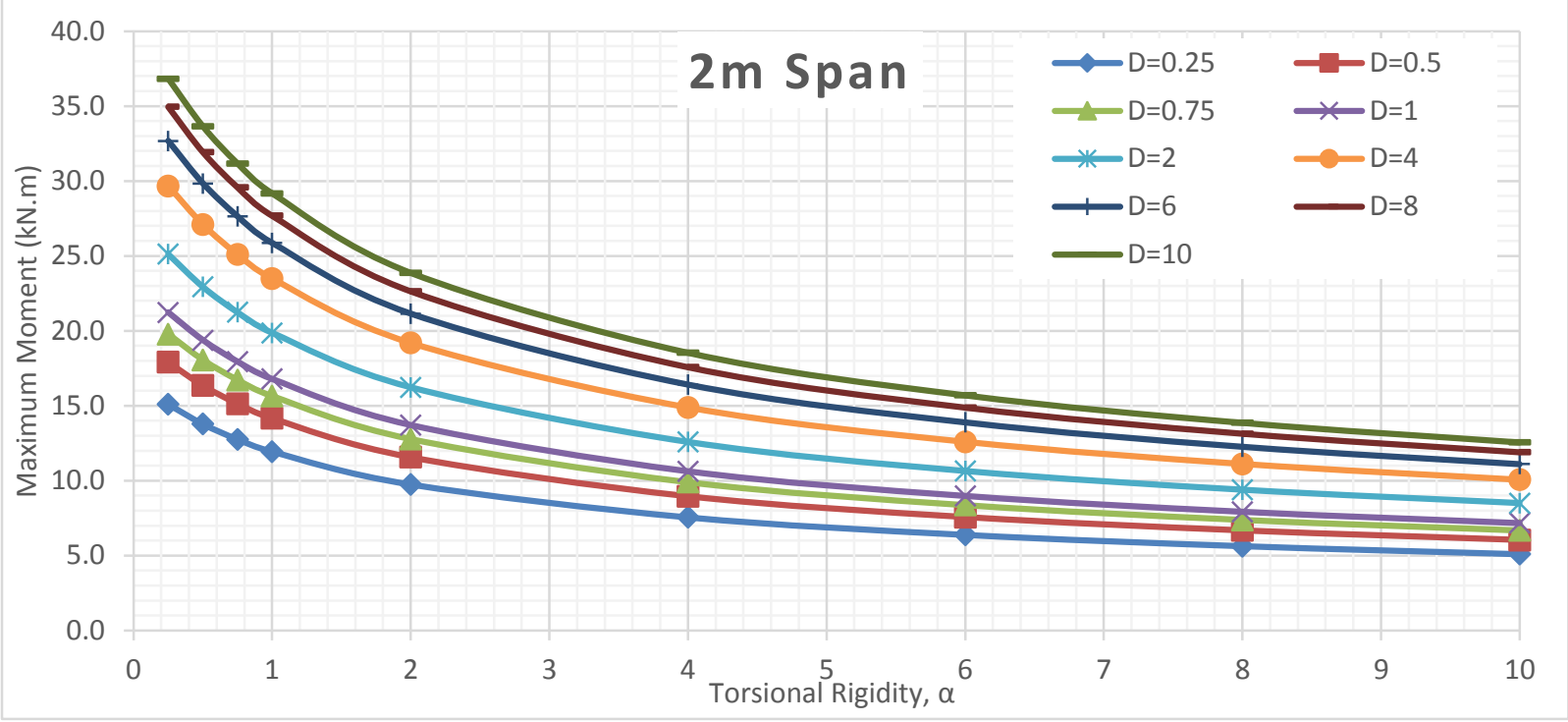

Figure 339 Maximum moment of $2 \mathrm{~m}$ span slab subjected to CHBDC axle 4 for different D values Orthotropic analyses

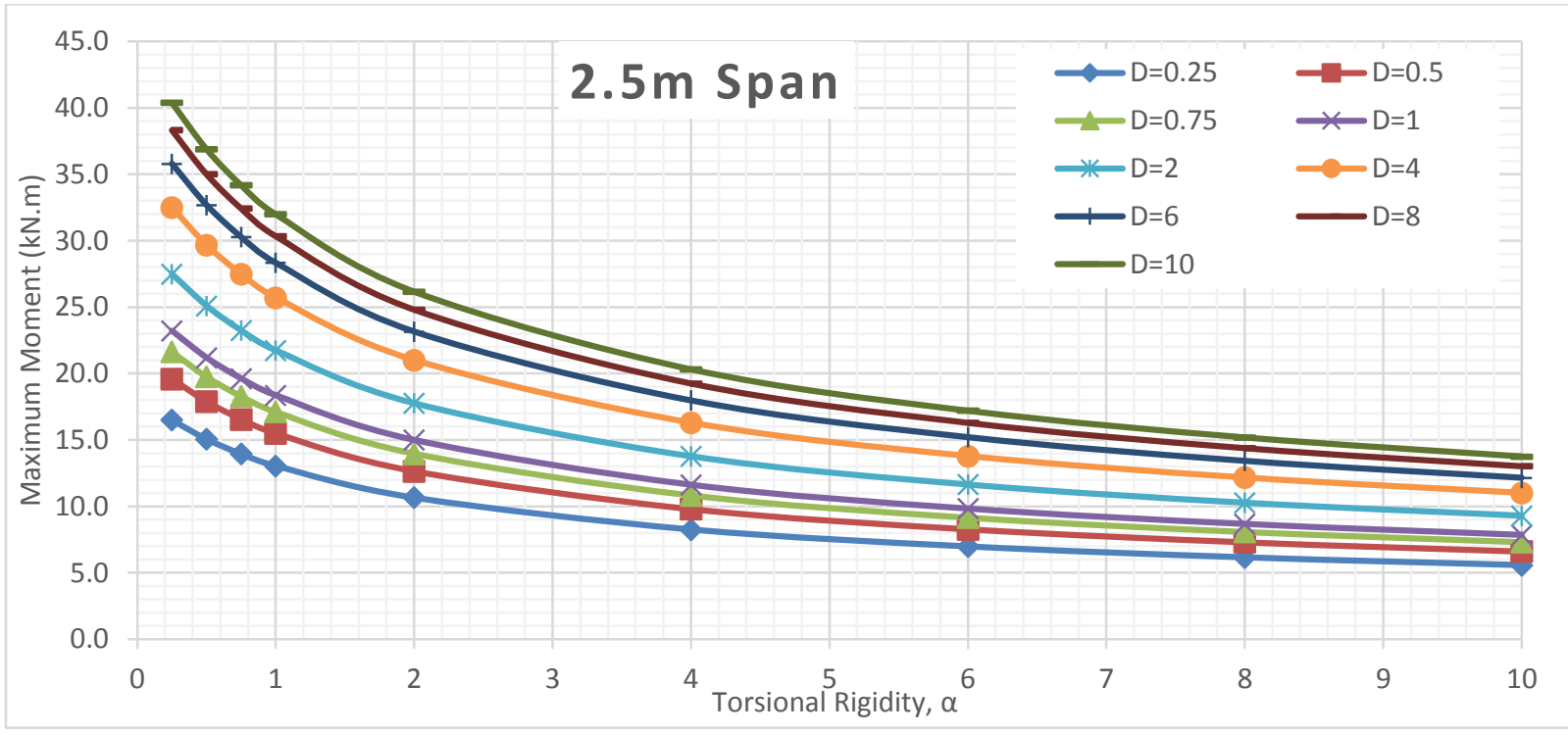

Figure 340 Maximum moment of $2.5 \mathrm{~m}$ span slab subjected to CHBDC axle 4 for different D values Orthotropic analyses

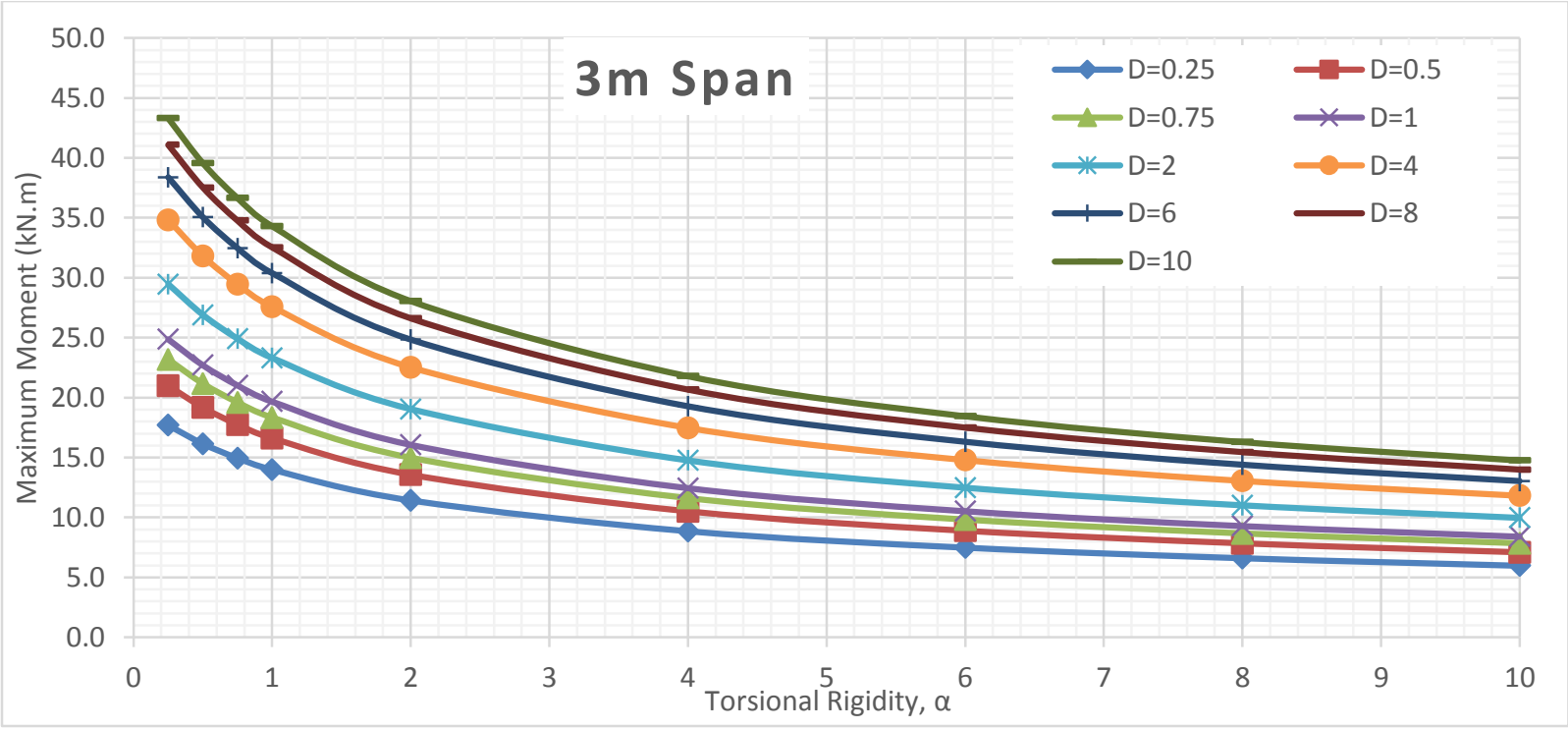

Figure 341 Maximum moment of $3 \mathrm{~m}$ span slab subjected to CHBDC axle 4 for different D values Orthotropic analyses 


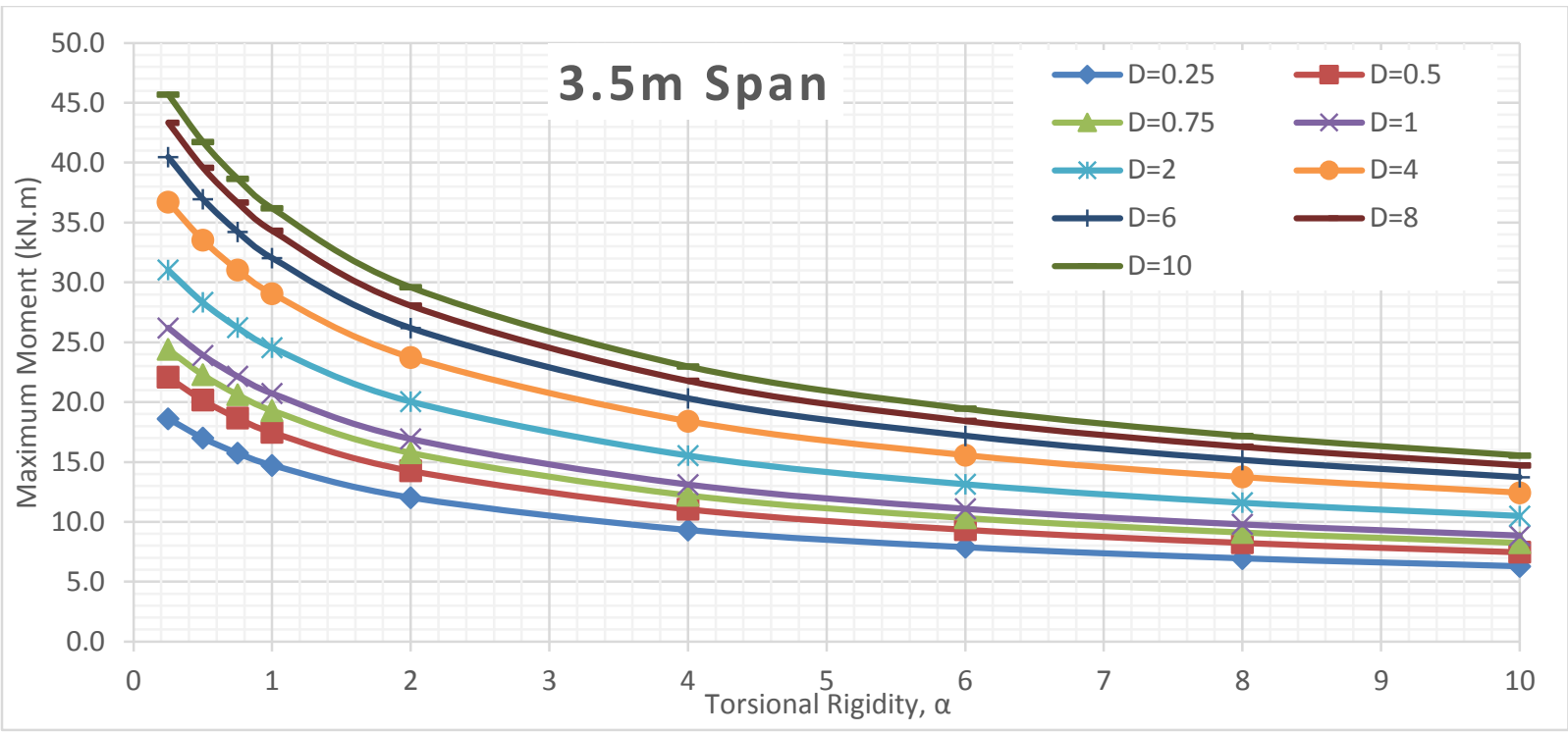

Figure 342 Maximum moment of $3.5 \mathrm{~m}$ span slab subjected to CHBDC axle 4 for different D values Orthotropic analyses

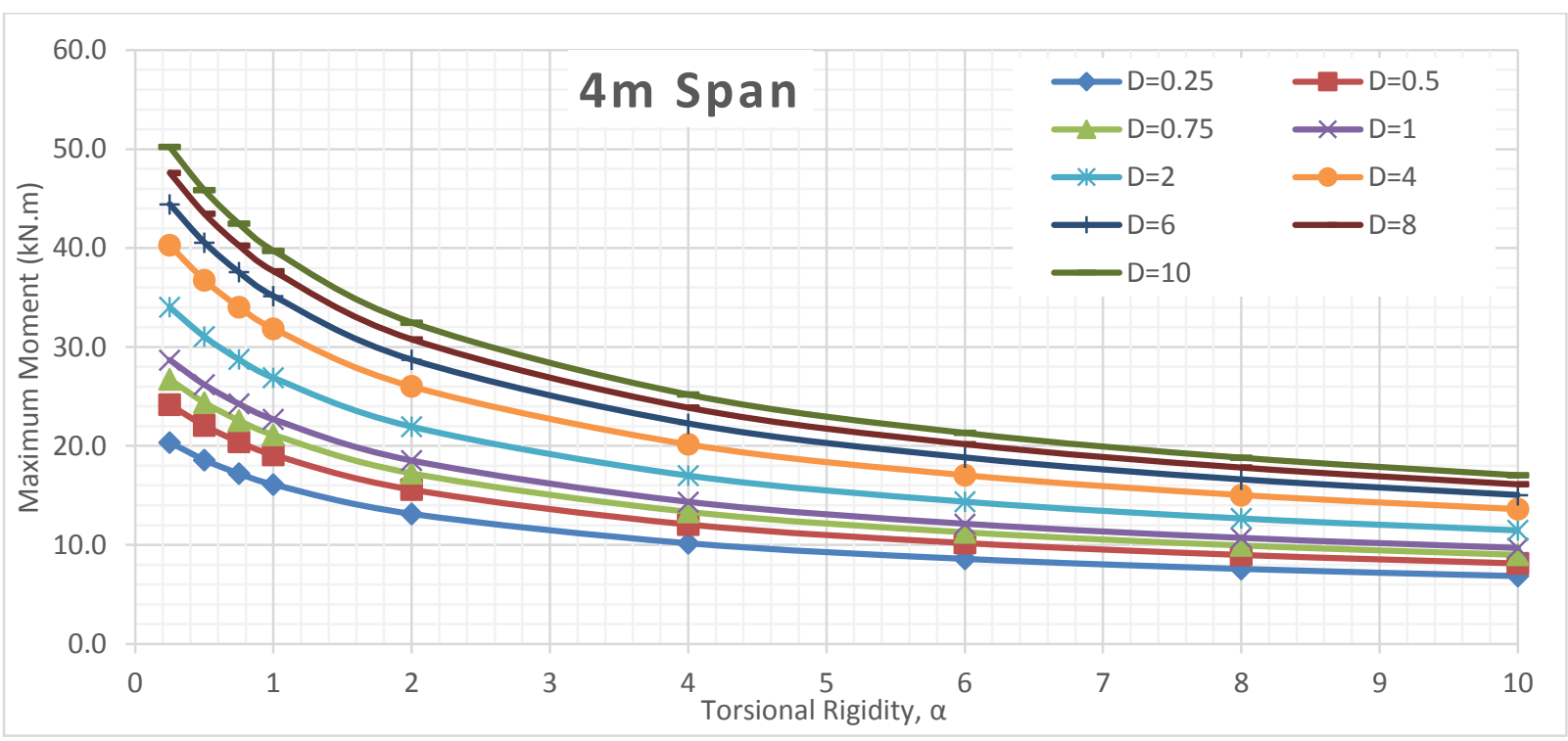

Figure 343 Maximum moment of $4 \mathrm{~m}$ span slab subjected to CHBDC axle 4 for different D values Orthotropic analyses 


\section{Axle 2 and 3 Bending Moment VS Torsional Rigidity for Different D Values at Different span length}

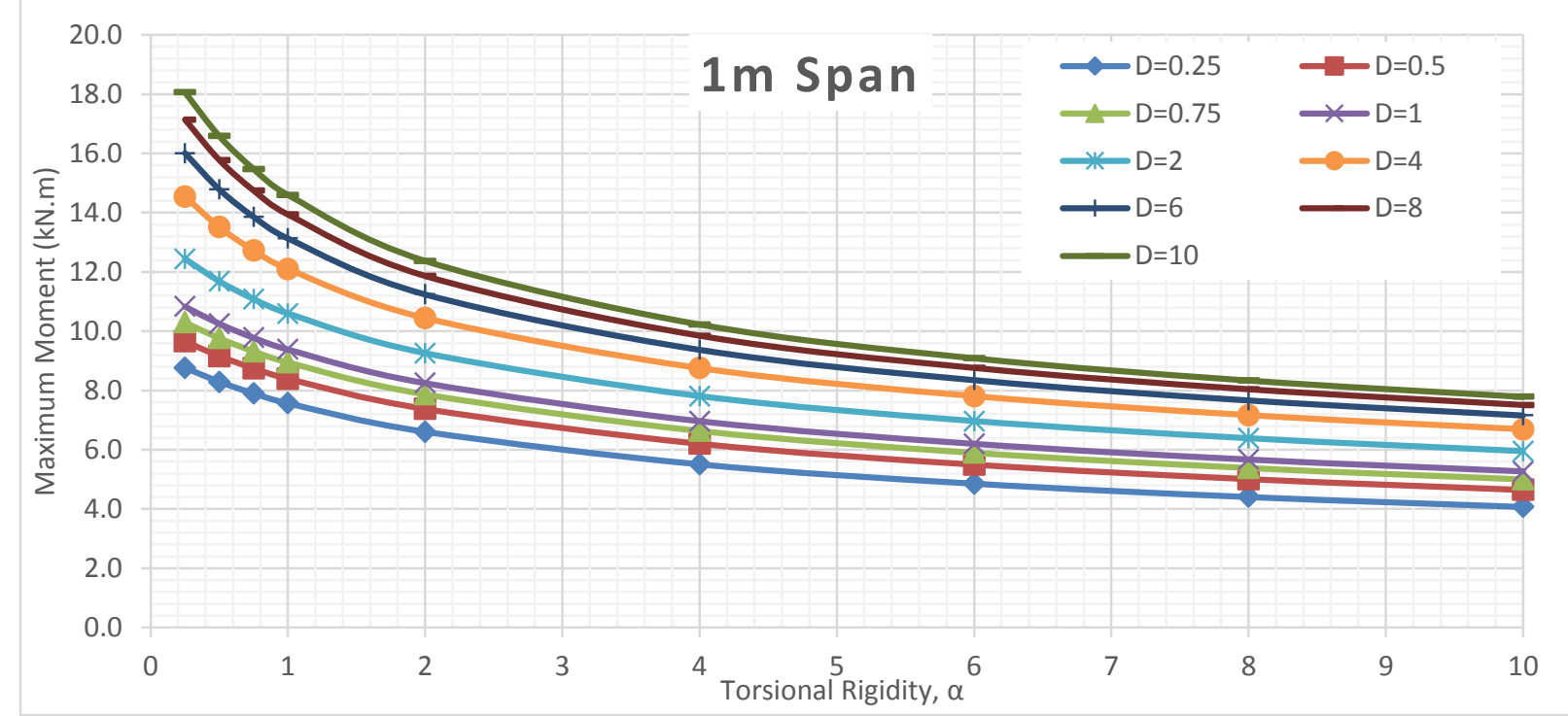

Figure 344 Maximum moment of $1 \mathrm{~m}$ span slab subjected to CHBDC axle 2 \& 3 for different D values Orthotropic analyses

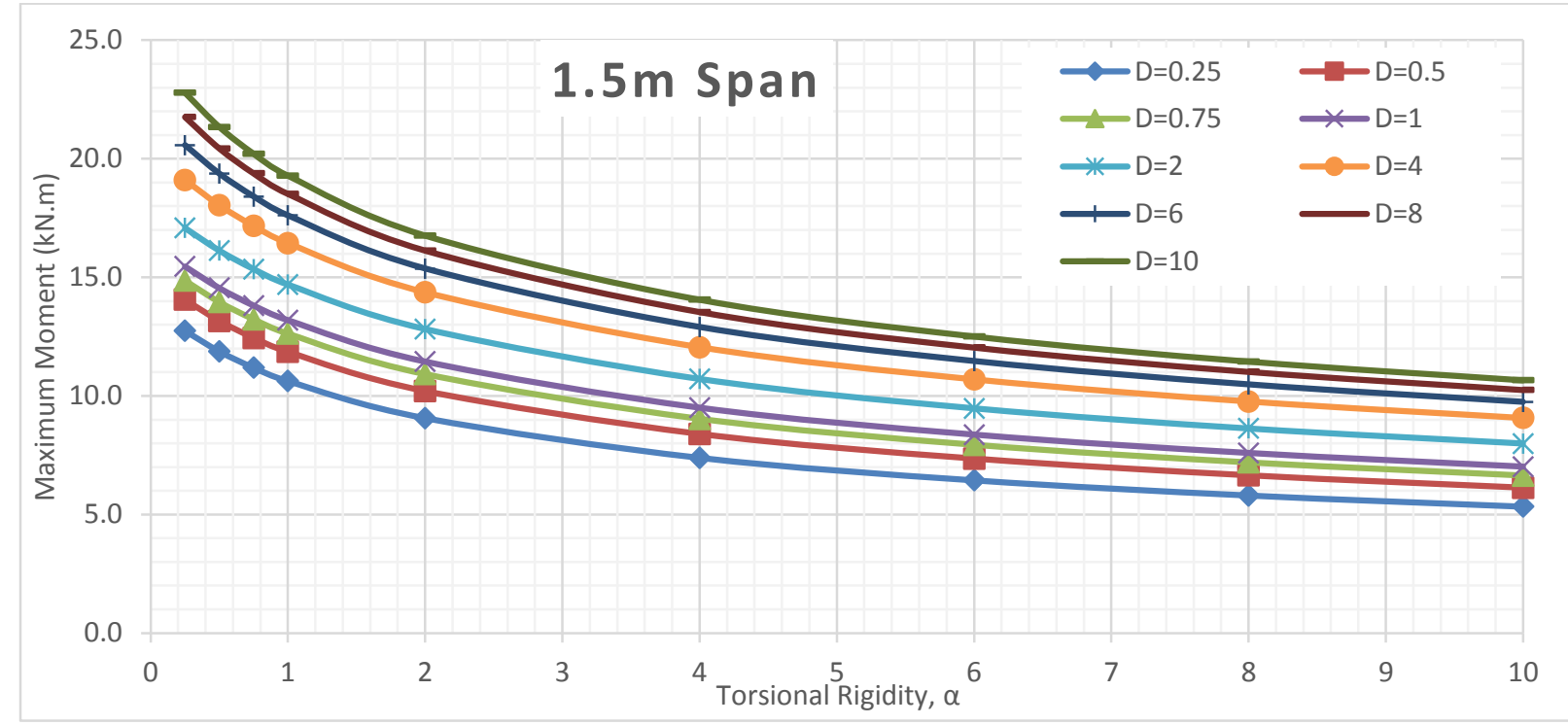

Figure 345 Maximum moment of $1.5 \mathrm{~m}$ span slab subjected to CHBDC axle 2 \& 3 for different D values Orthotropic analyses 


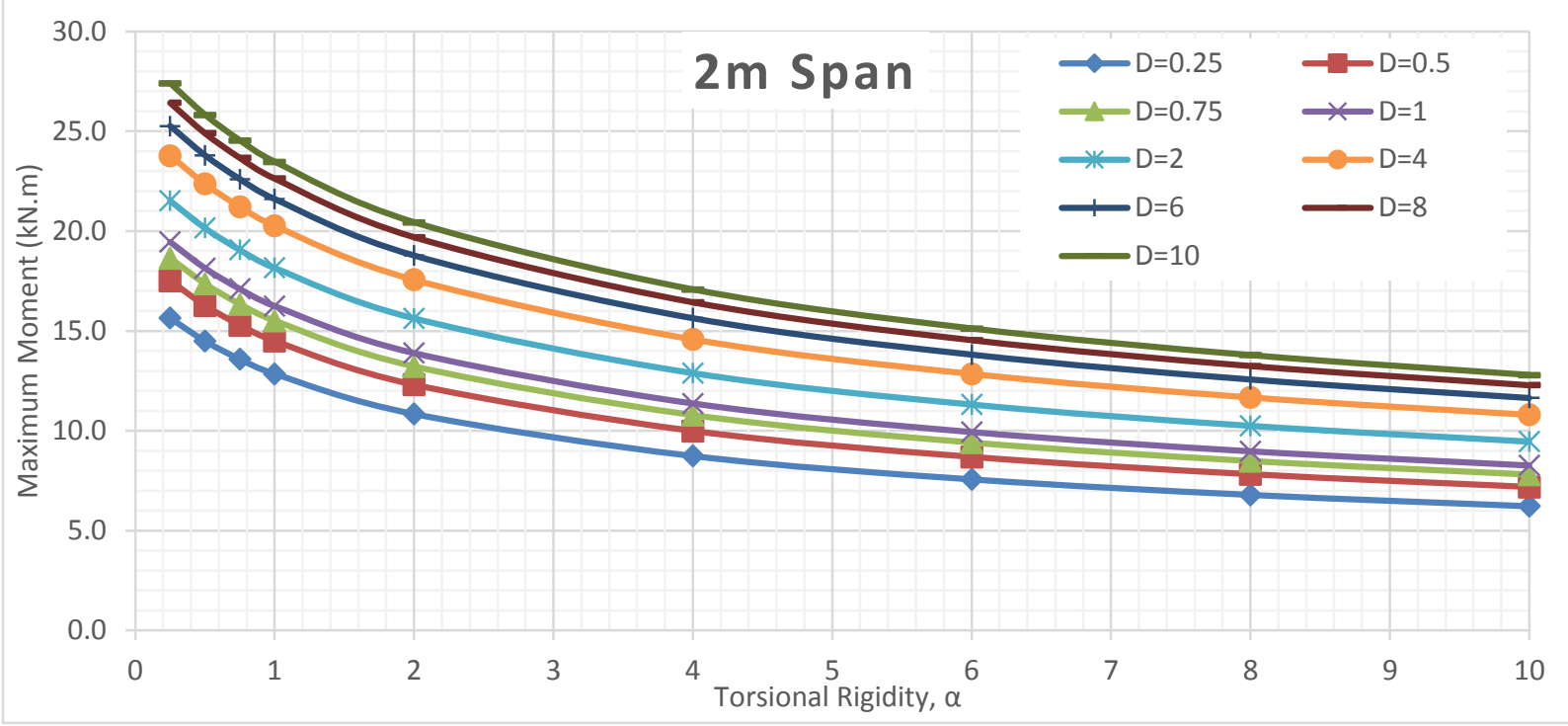

Figure 346 Maximum moment of $2 \mathrm{~m}$ span slab subjected to CHBDC axle 2 \& 3 for different D values Orthotropic analyses

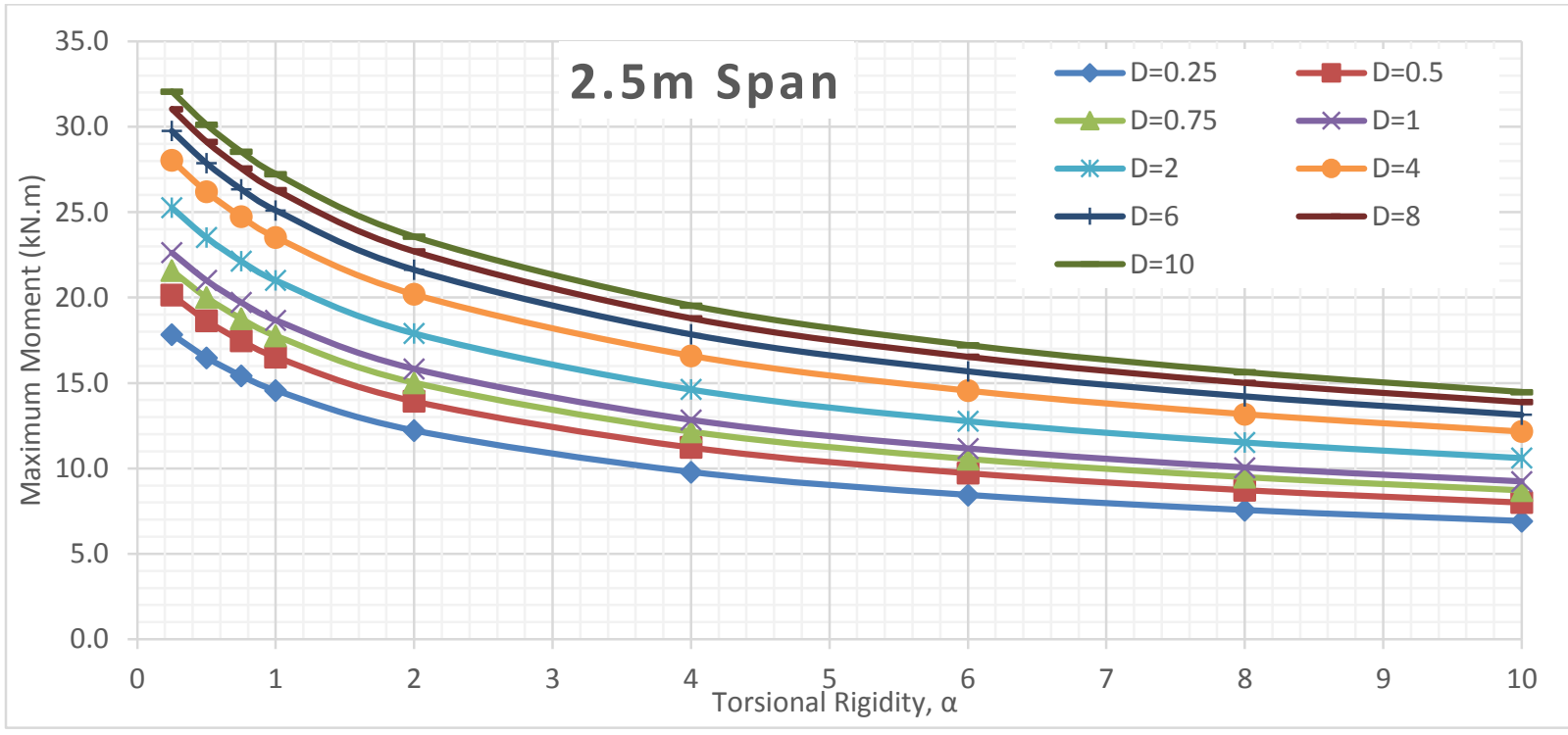

Figure 347 Maximum moment of $2.5 \mathrm{~m}$ span slab subjected to CHBDC axle $2 \& 3$ for different D values Orthotropic analyses

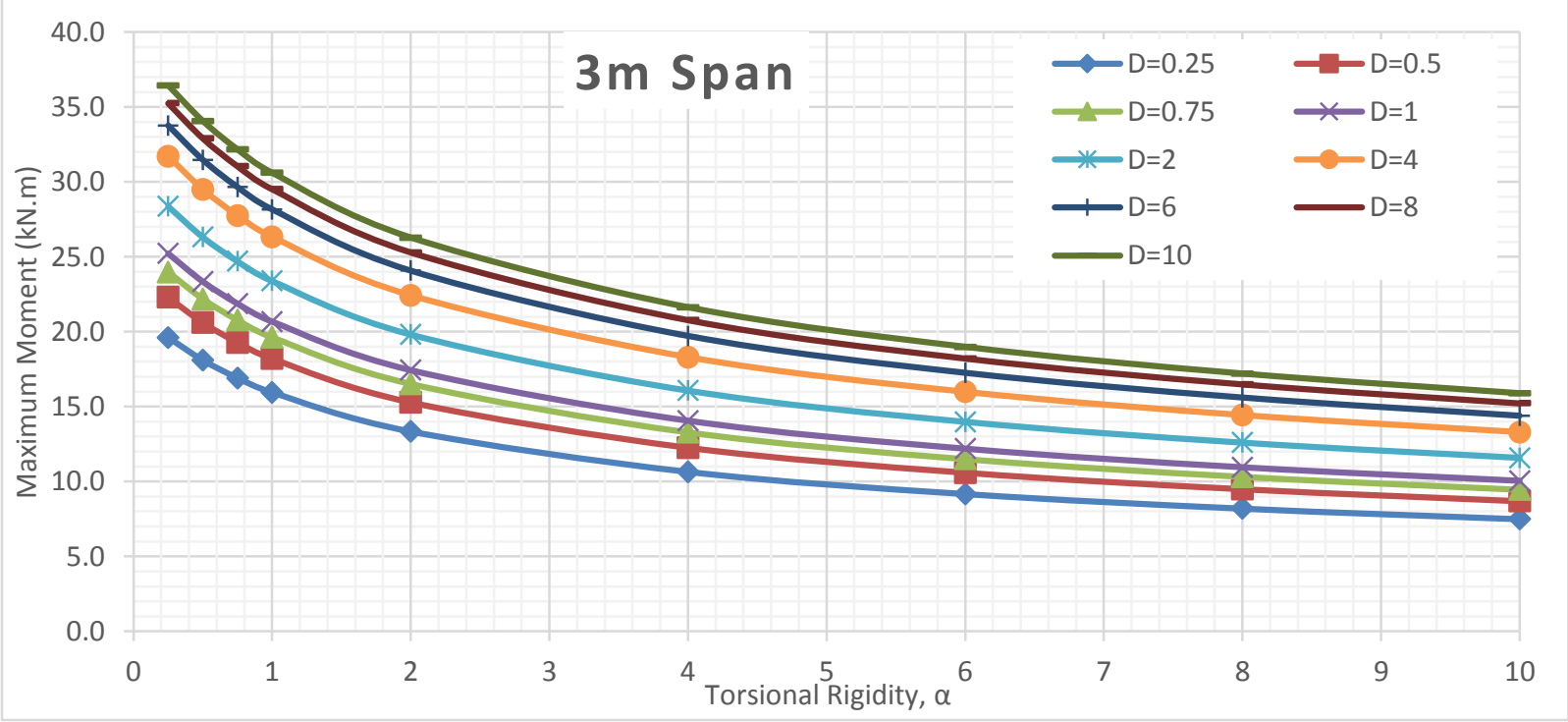

Figure 348 Maximum moment of $3 \mathrm{~m}$ span slab subjected to CHBDC axle 2 \& 3 for different $D$ values Orthotropic analyses 


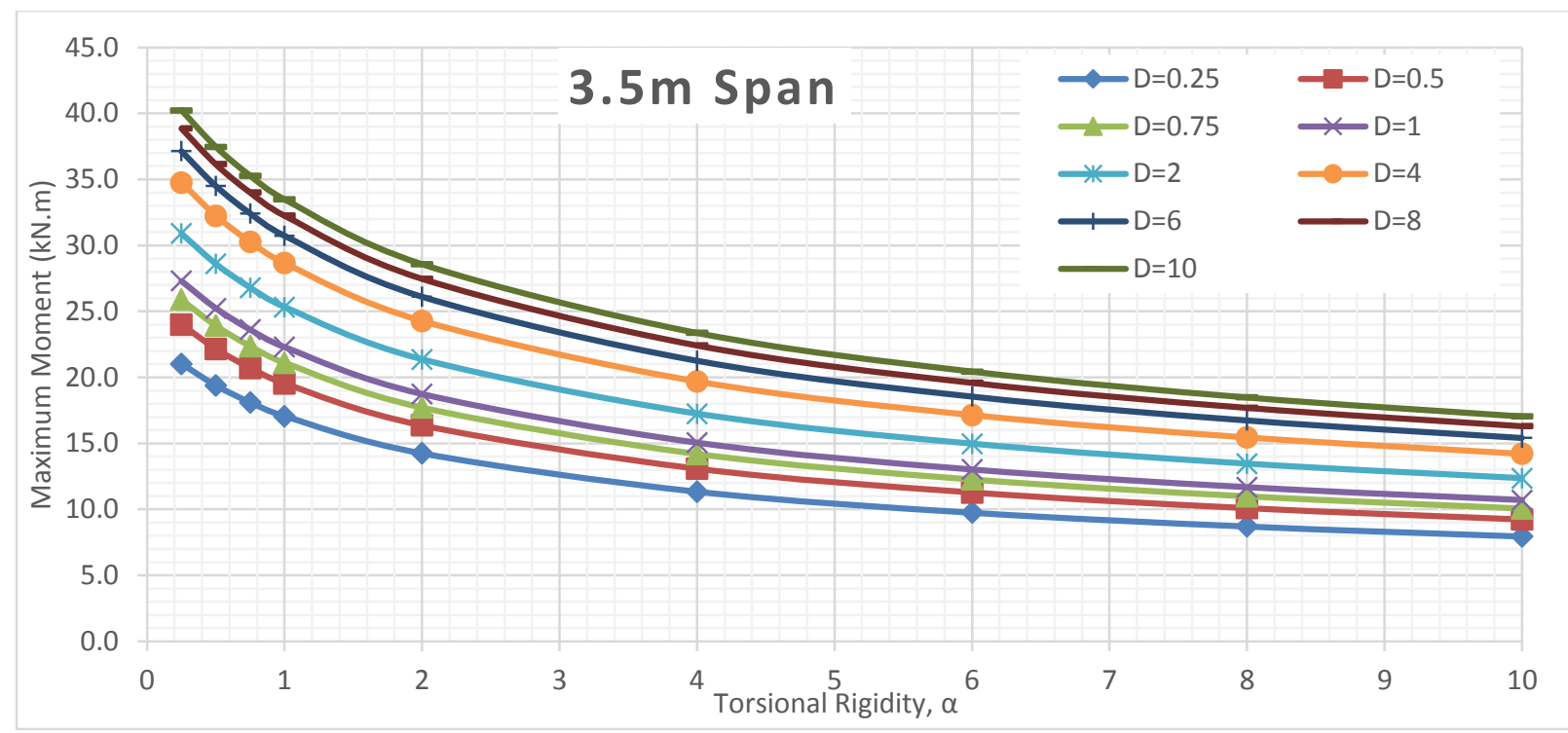

Figure 349 Maximum moment of 3.5 m span slab subjected to CHBDC axle 2 \& 3 for different D values Orthotropic analyses

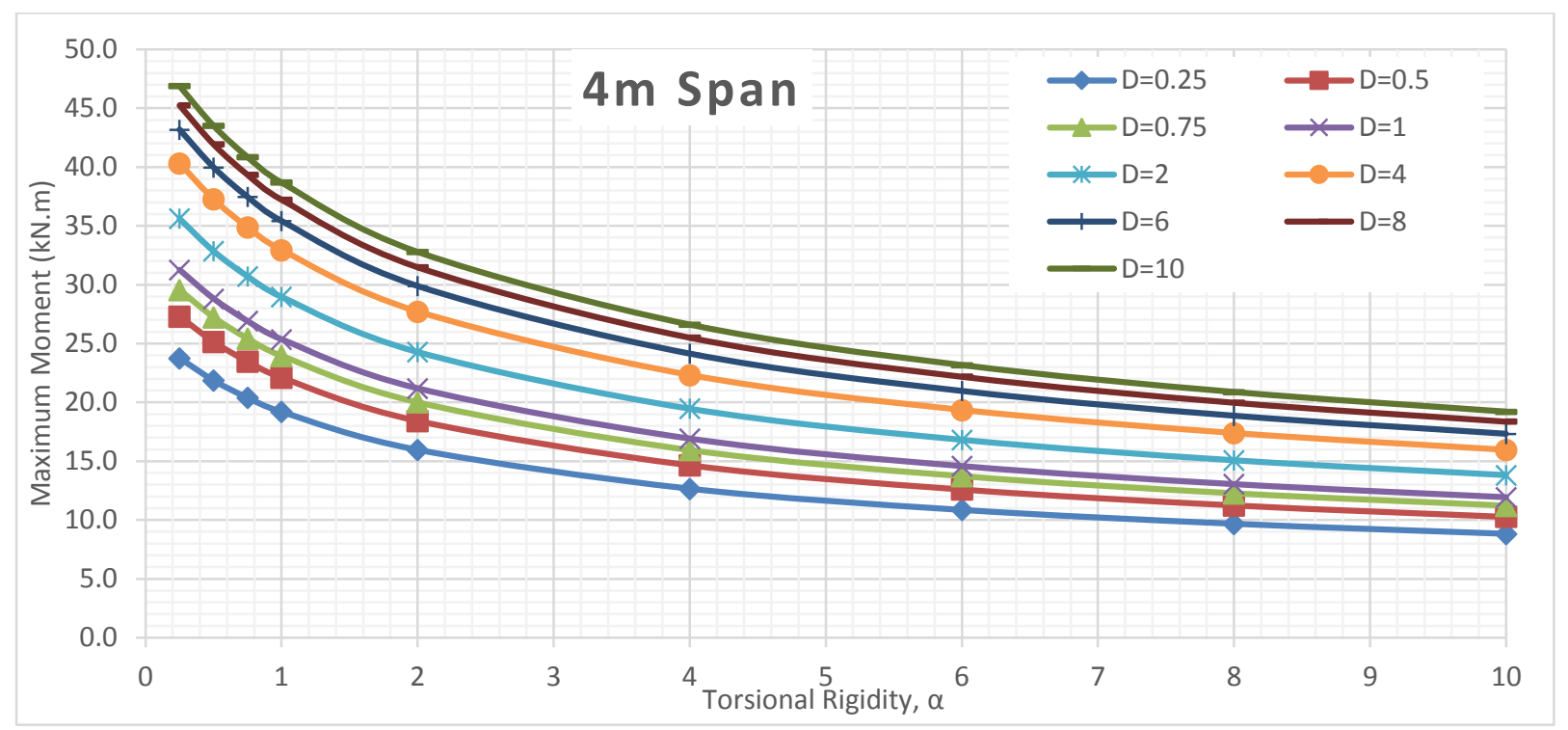

Figure 350 Maximum moment of $4 \mathrm{~m}$ span slab subjected to CHBDC axle $2 \& 3$ for different D values Orthotropic analyses 


\section{Truck Bending Moment VS Torsional Rigidity for Different D Values at Different span length}

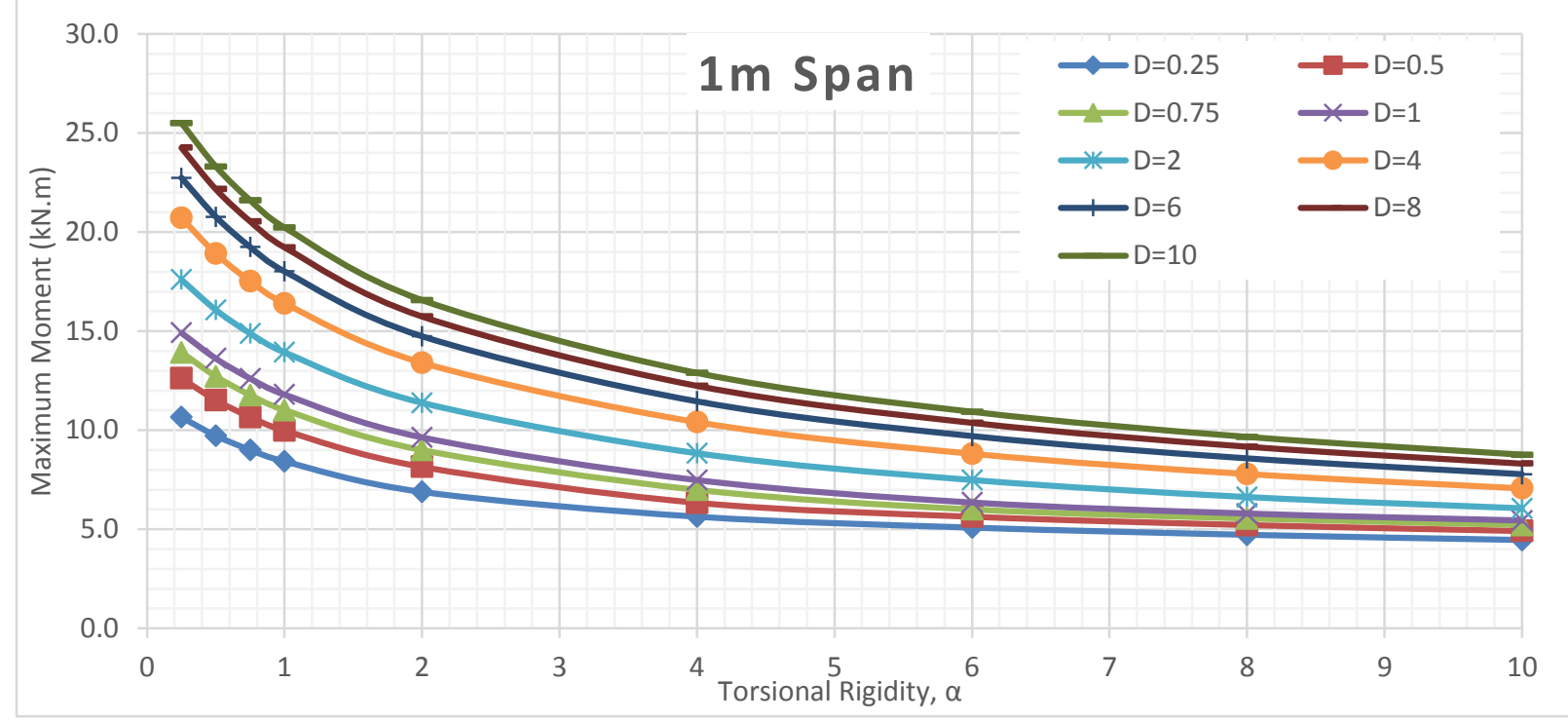

Figure 351 Maximum moment of $1 \mathrm{~m}$ span slab subjected to CHBDC truck for different D values Orthotropic analyses

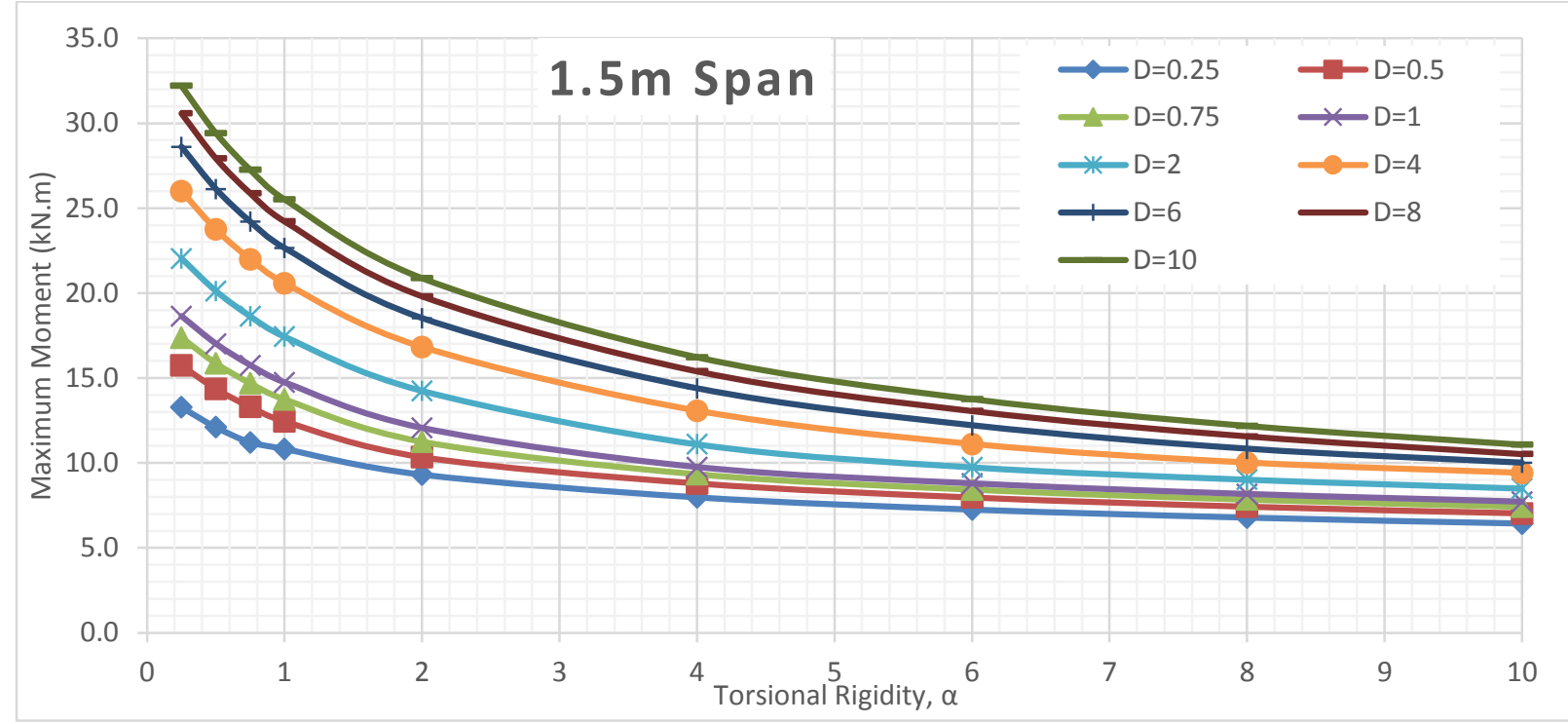

Figure 352 Maximum moment of $1.5 \mathrm{~m}$ span slab subjected to CHBDC truck for different D values Orthotropic analyses 


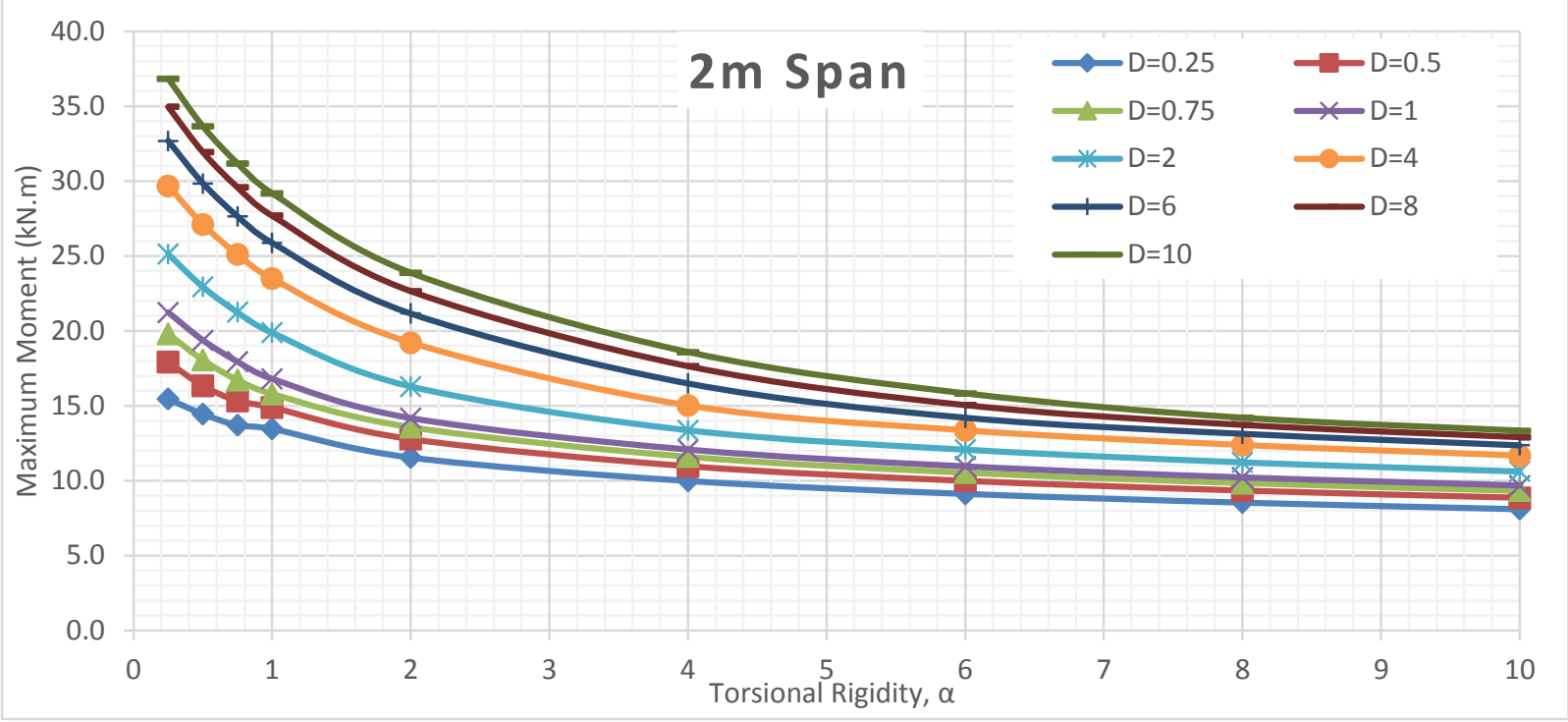

Figure 353 Maximum moment of $2 \mathrm{~m}$ span slab subjected to CHBDC truck for different D values Orthotropic analyses

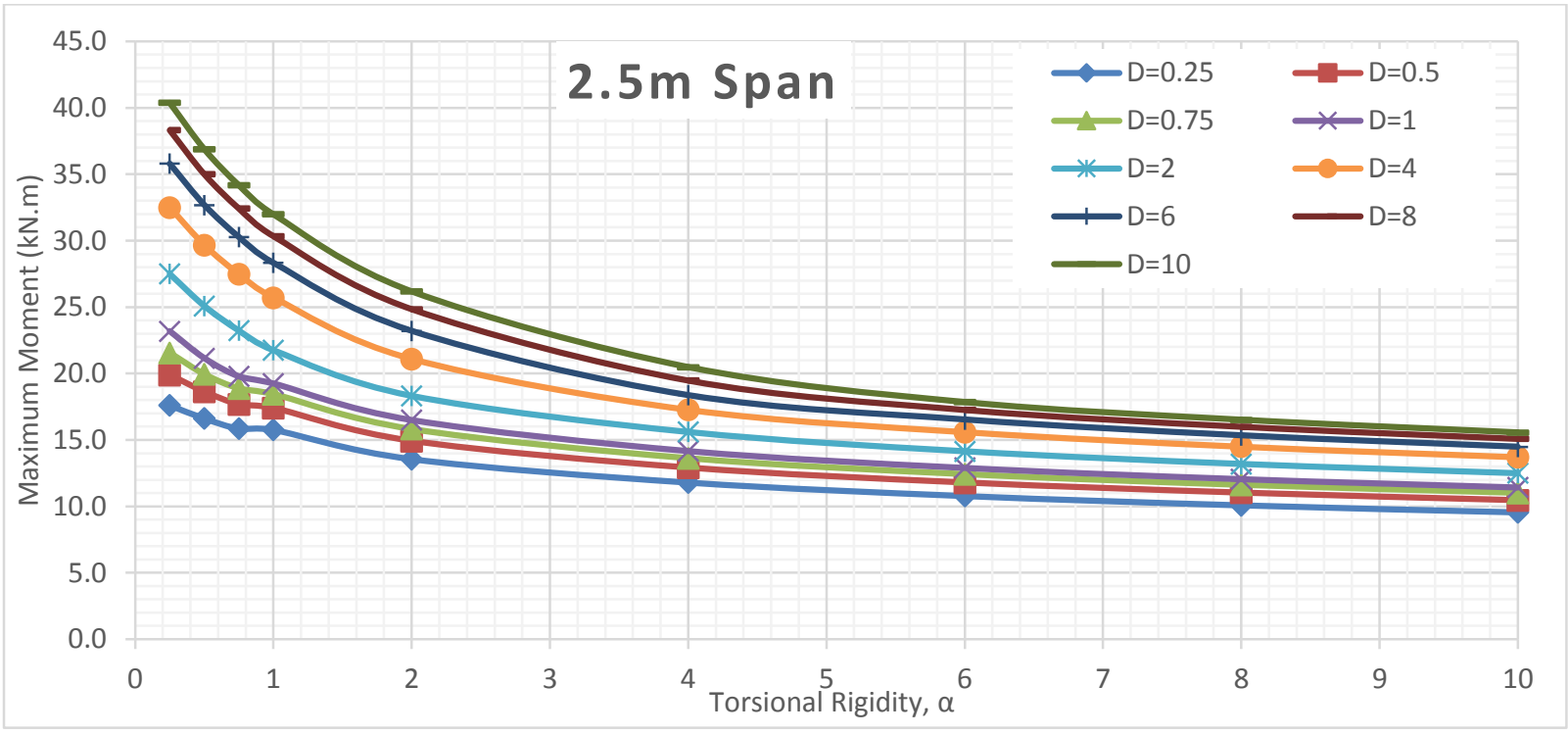

Figure 354 Maximum moment of $2.5 \mathrm{~m}$ span slab subjected to CHBDC truck for different D values Orthotropic analyses

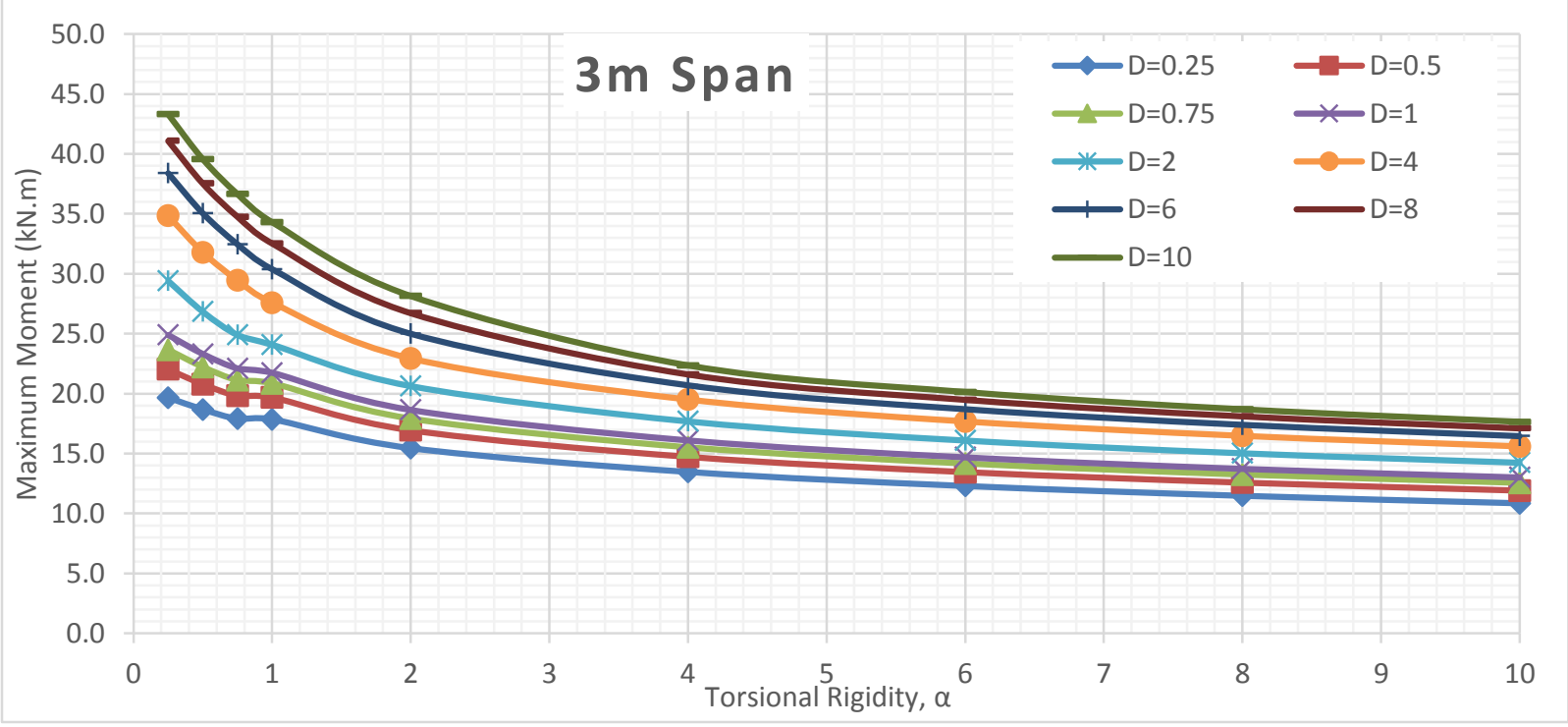

Figure 355 Maximum moment of $3 \mathrm{~m}$ span slab subjected to CHBDC truck for different D values Orthotropic analyses 


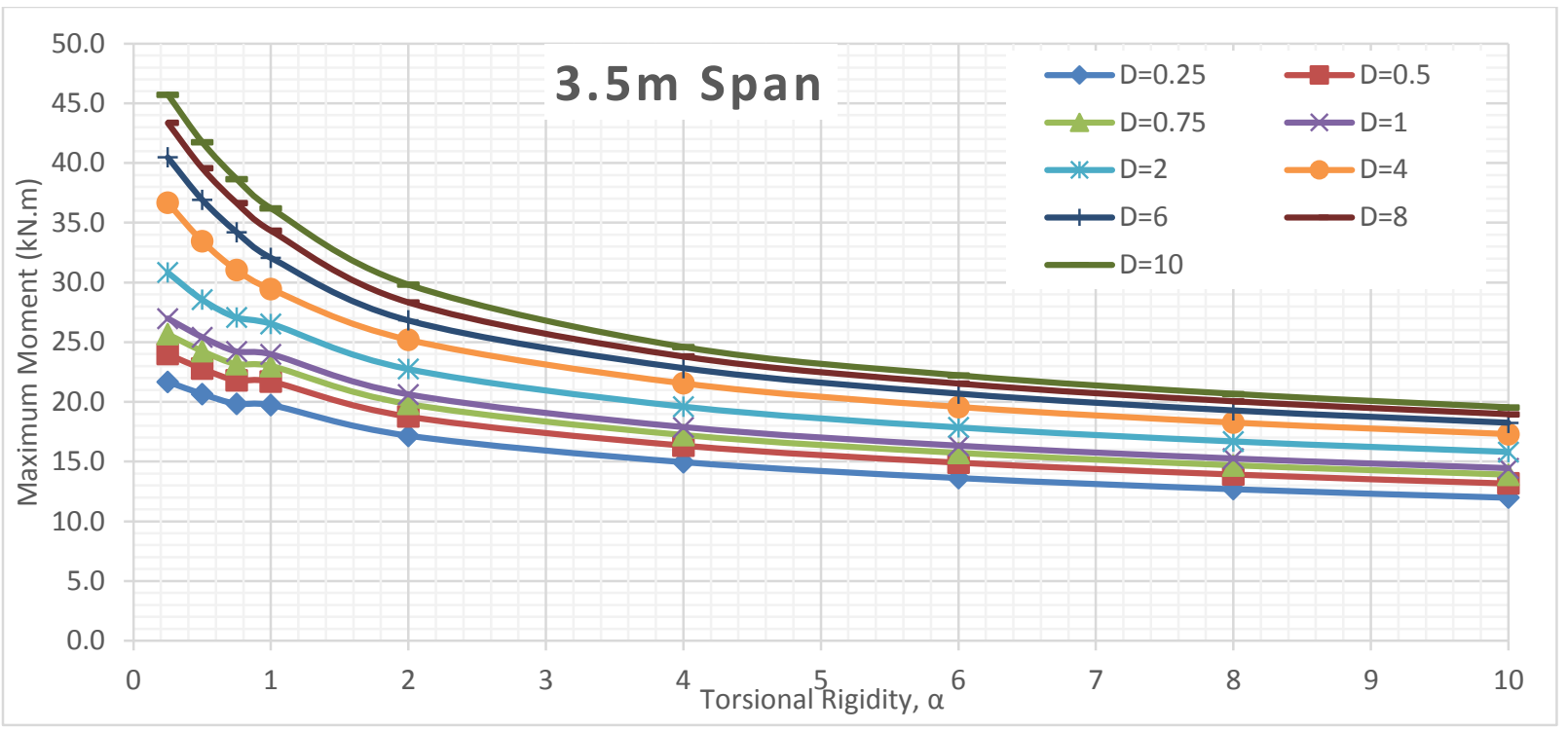

Figure 356 Maximum moment of $3.5 \mathrm{~m}$ span slab subjected to CHBDC truck for different D values Orthotropic analyses

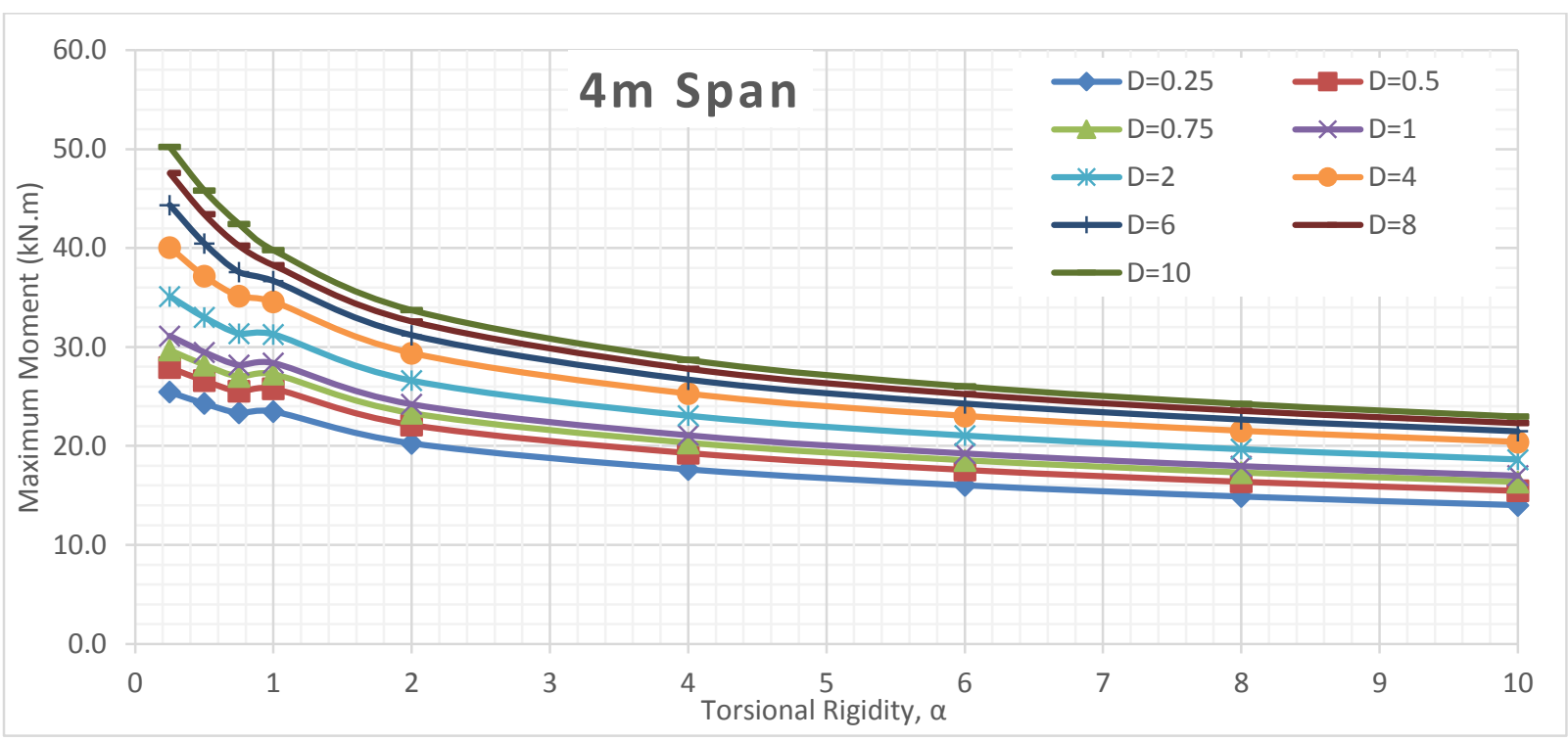

Figure 357 Maximum moment of $4 \mathrm{~m}$ span slab subjected to CHBDC truck for different D values Orthotropic analyses 


\section{Axle 4 Transverse Bending Moment VS Torsional Rigidity for Different D Values at Different span length}

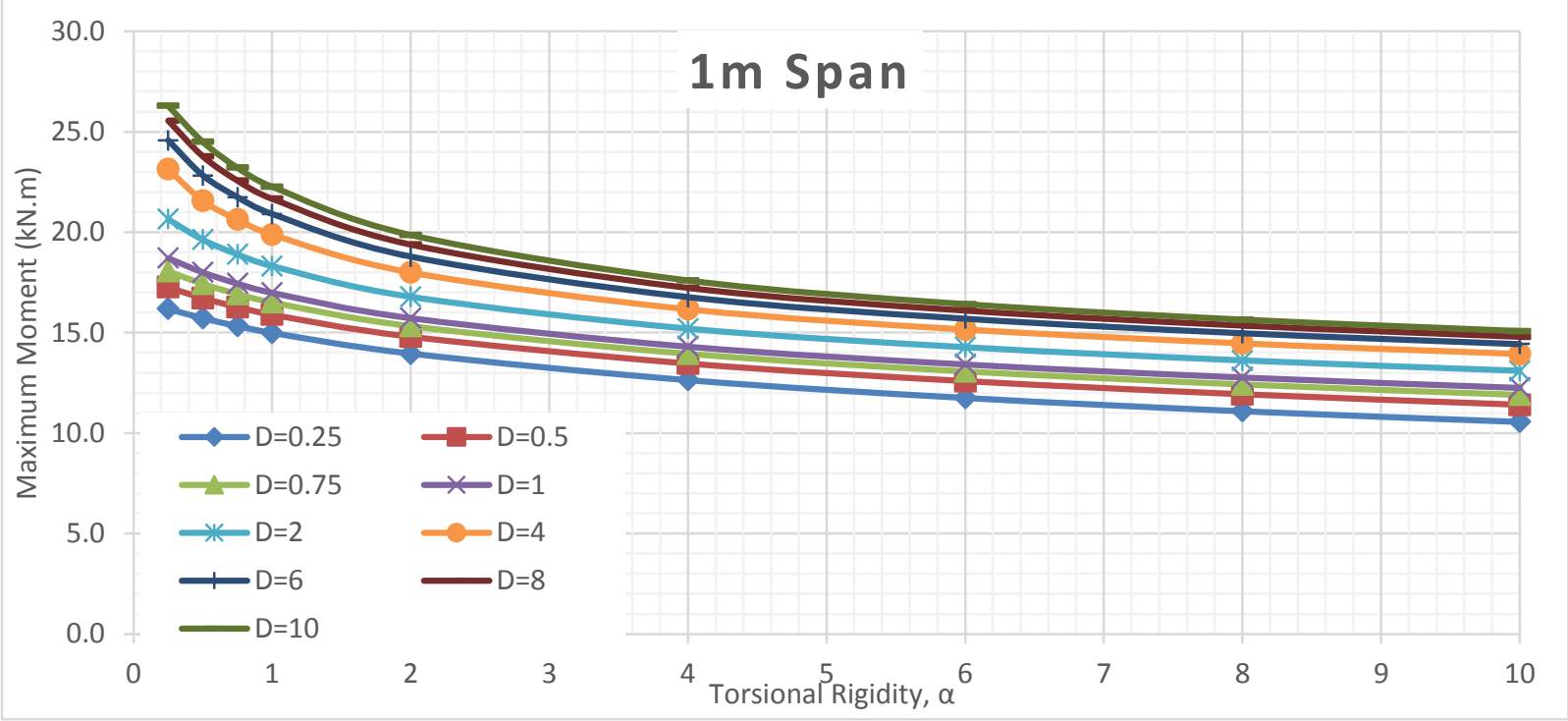

Figure 358 Maximum moment of $1 \mathrm{~m}$ span slab subjected to CHBDC axle 4 for different D values Orthotropic analyses

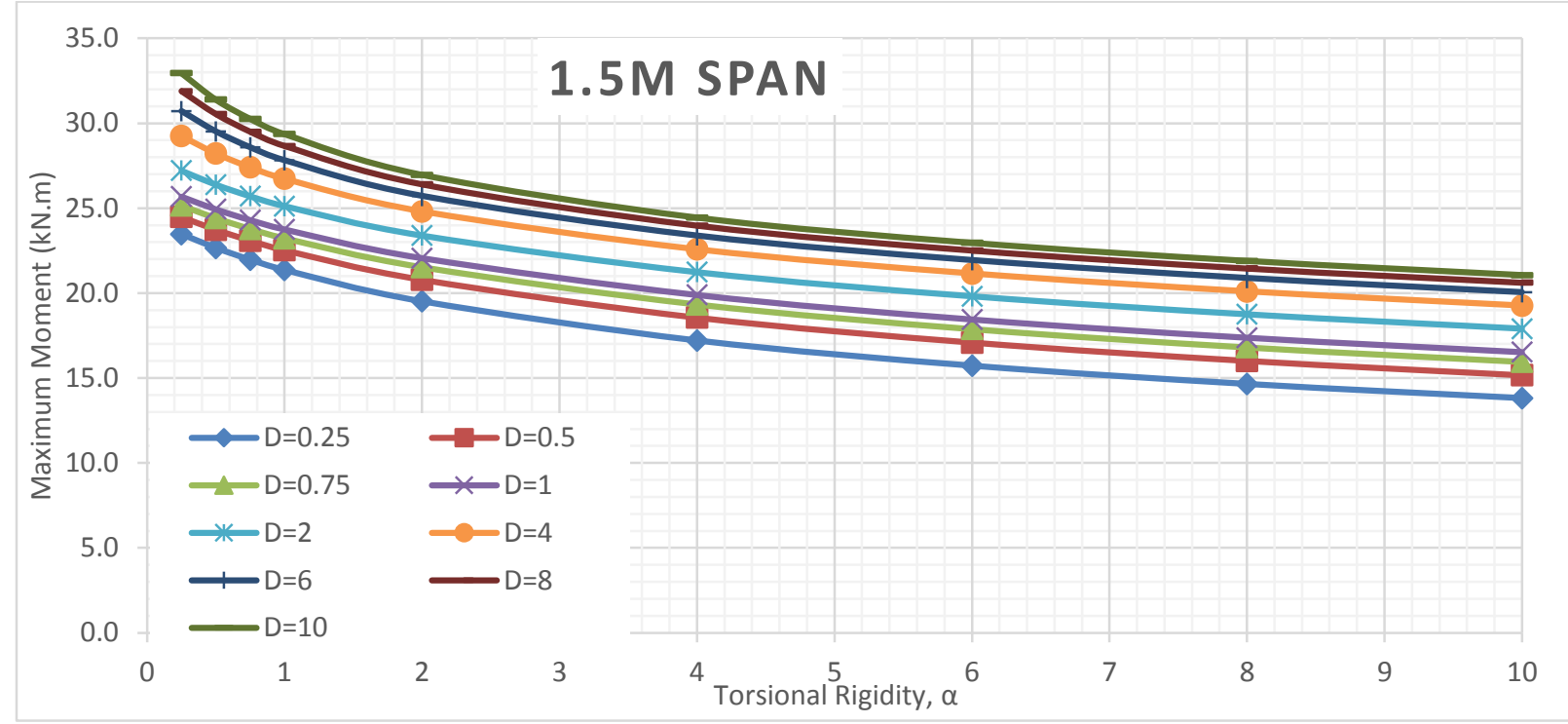

Figure 359 Maximum moment of $1.5 \mathrm{~m}$ span slab subjected to CHBDC axle 4 for different D values Orthotropic analyses 


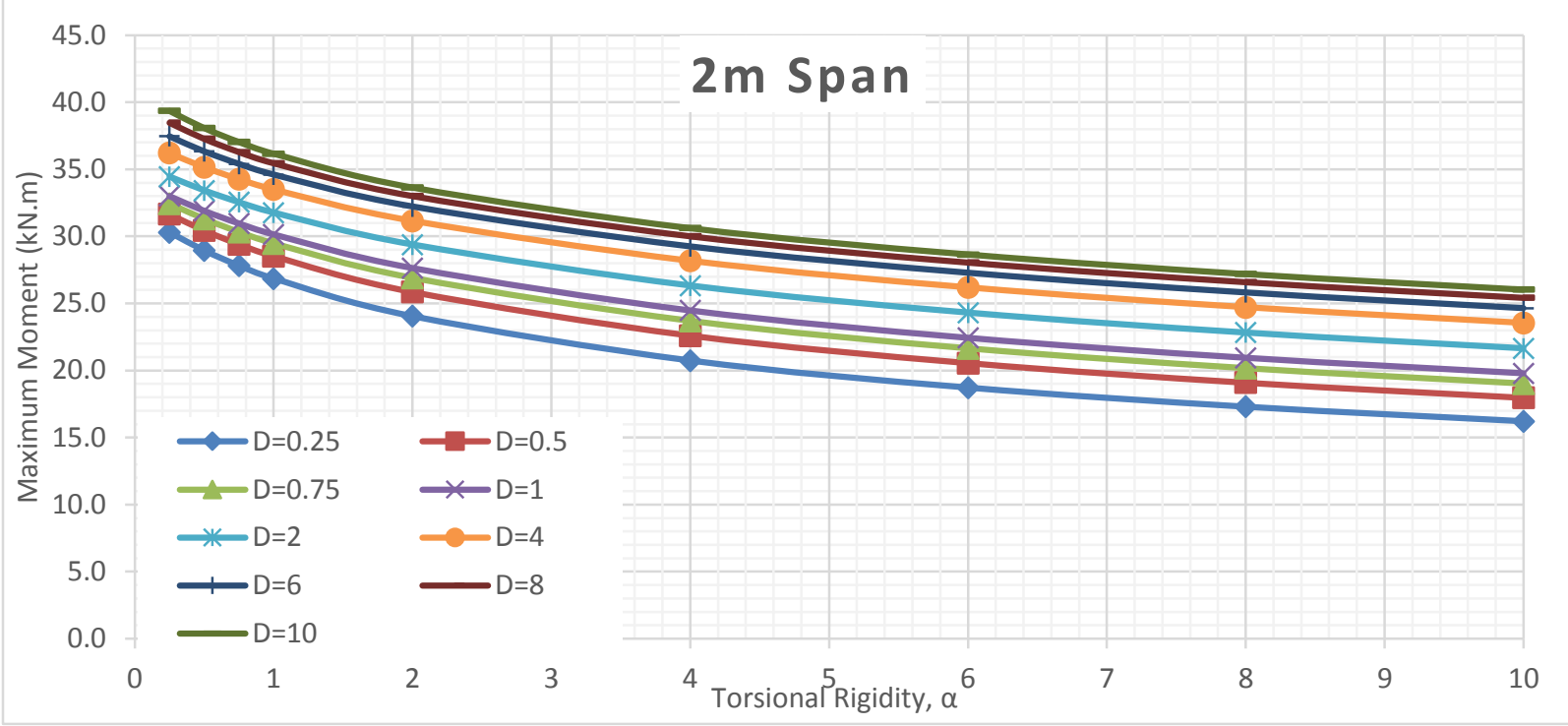

Figure 360 Maximum moment of $2 \mathrm{~m}$ span slab subjected to CHBDC axle 4 for different D values Orthotropic analyses

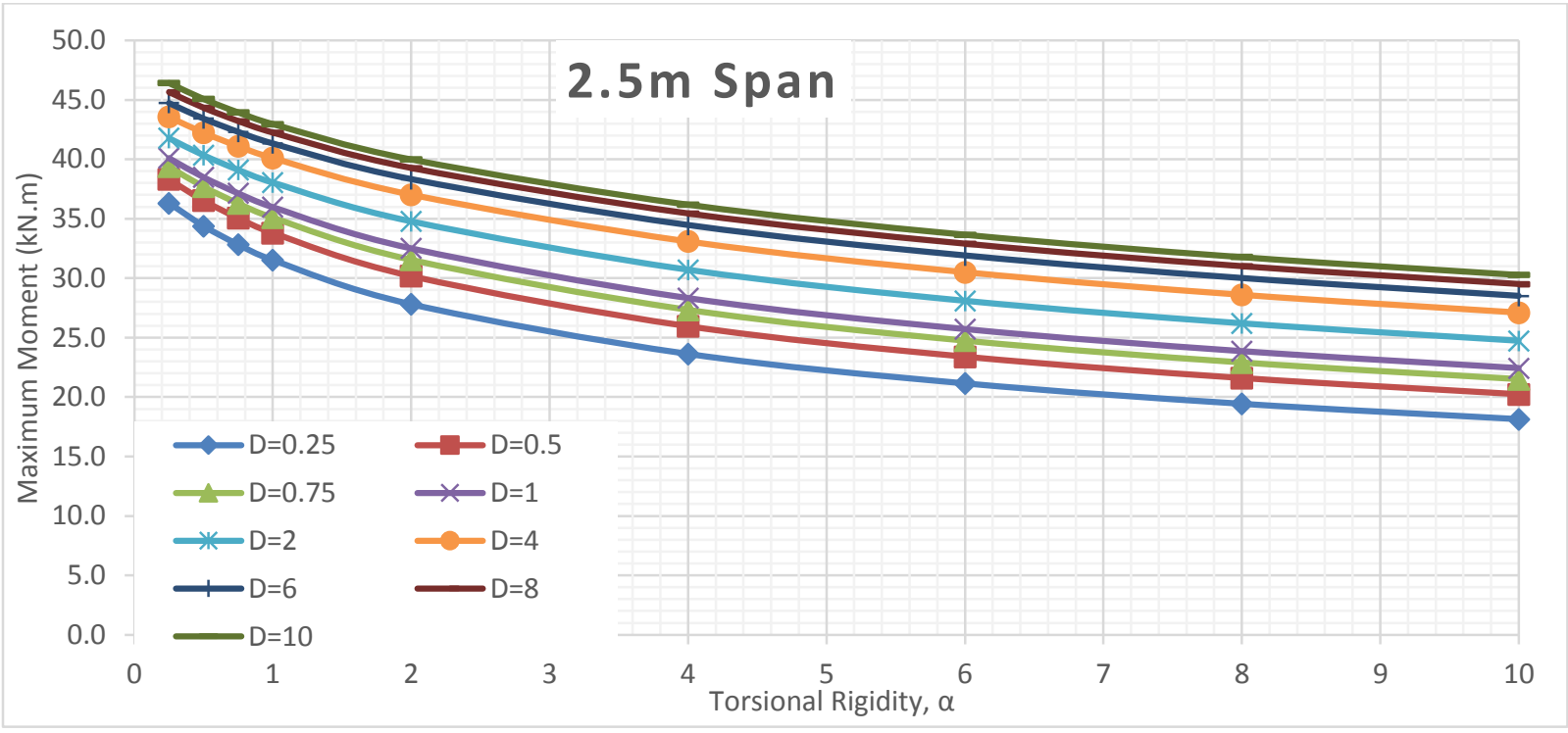

Figure 361 Maximum moment of $2.5 \mathrm{~m}$ span slab subjected to CHBDC axle 4 for different D values Orthotropic analyses

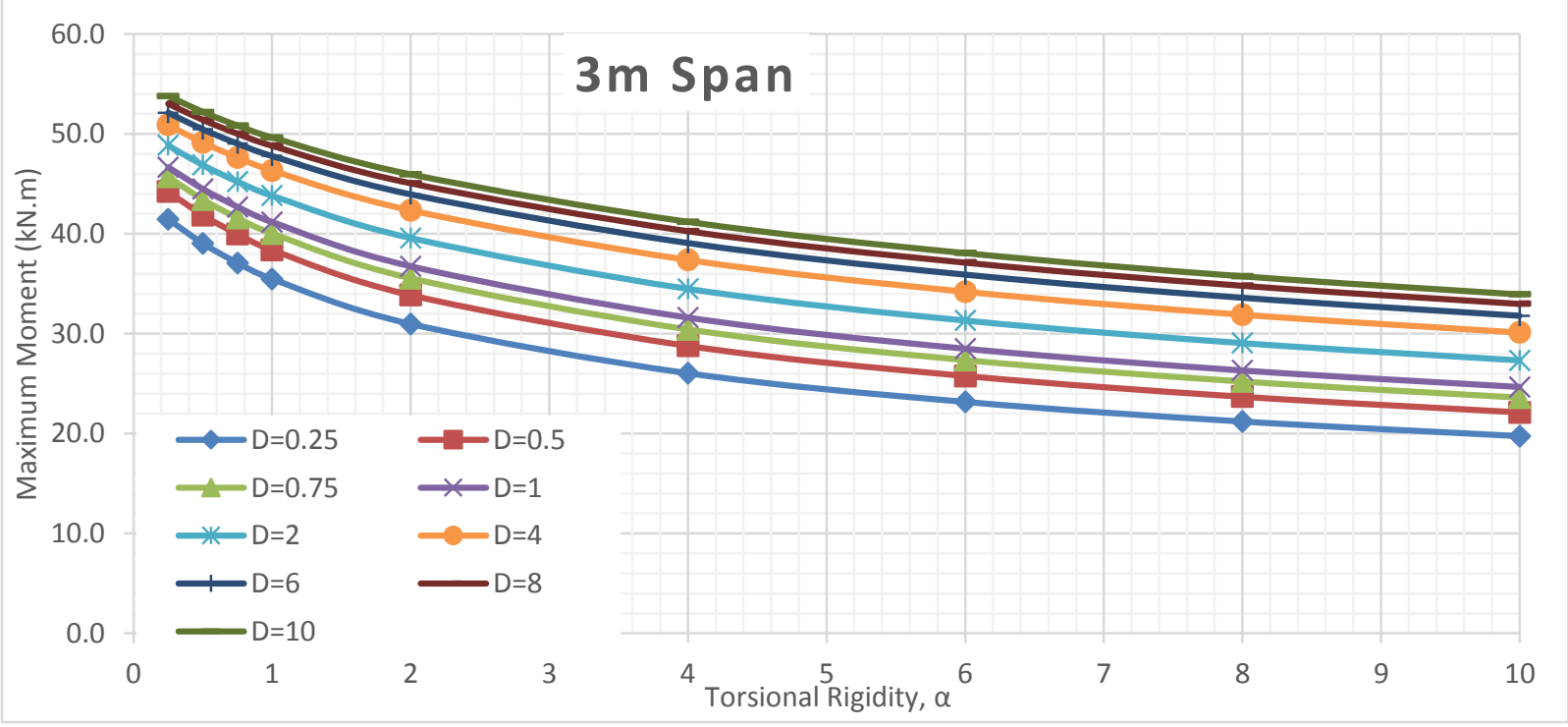

Figure 362 Maximum moment of $3 \mathrm{~m}$ span slab subjected to CHBDC axle 4 for different D values Orthotropic analyses 


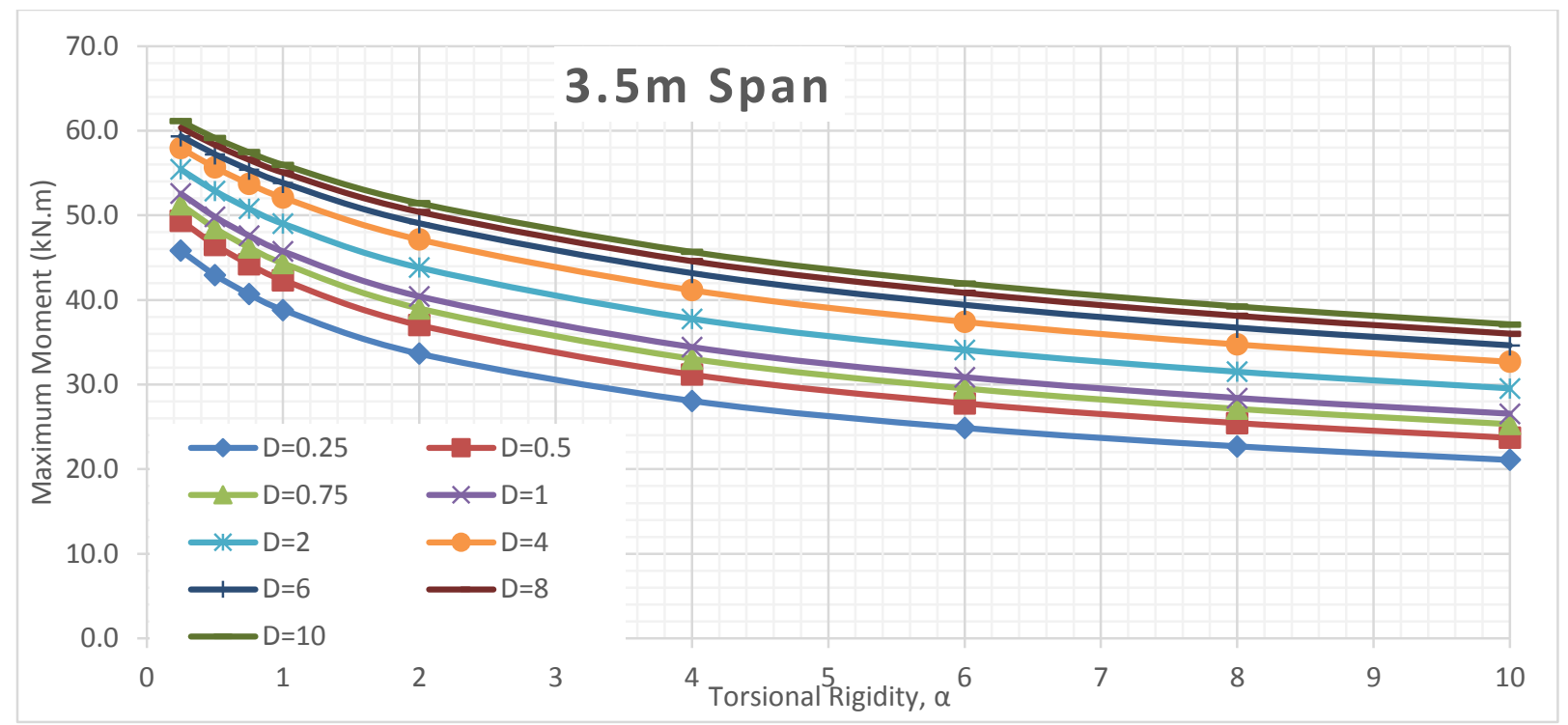

Figure 363 Maximum moment of $3.5 \mathrm{~m}$ span slab subjected to CHBDC axle 4 for different D values Orthotropic analyses 


\section{Axle 2 and 3 Transverse Bending Moment VS Torsional Rigidity for Different D Values at Different span length}

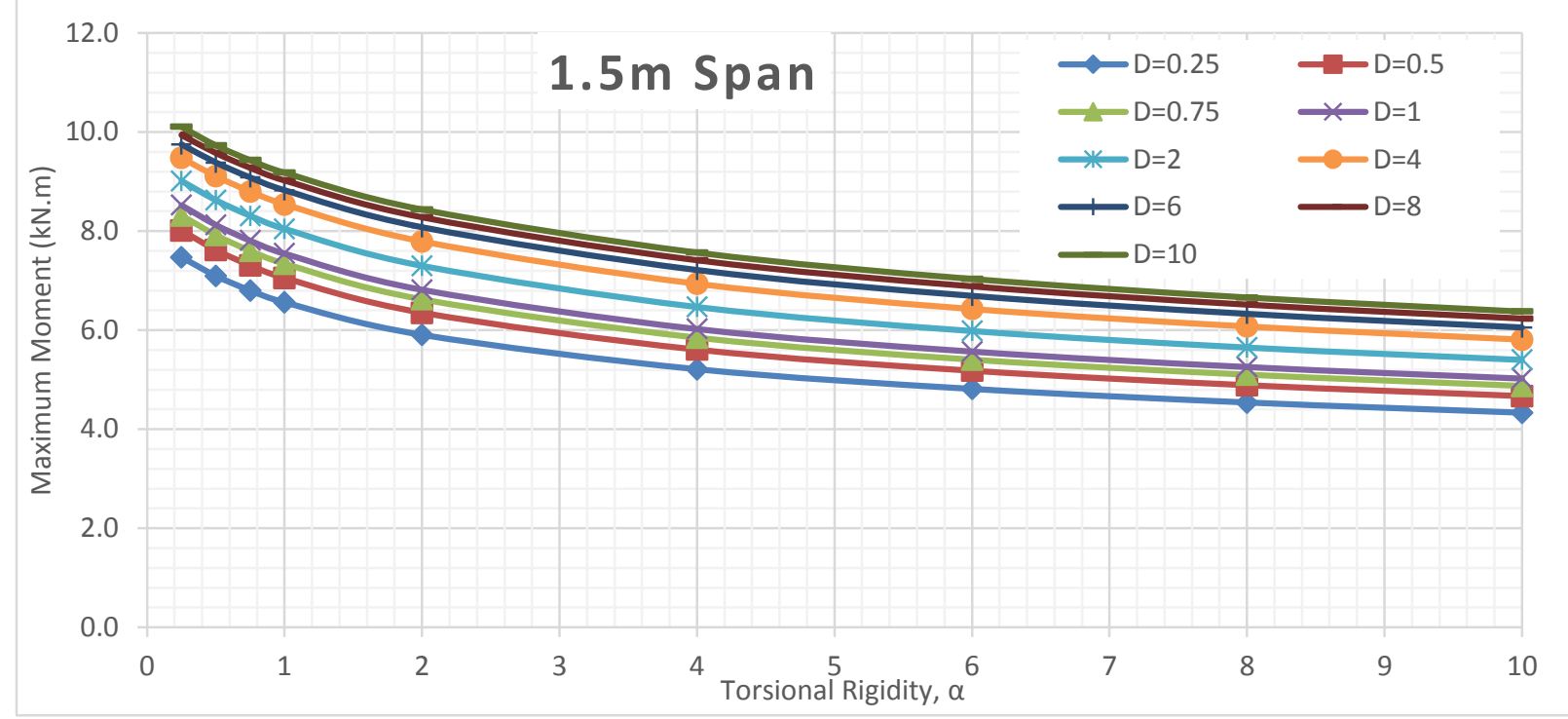

Figure 364 Maximum moment of $1.5 \mathrm{~m}$ span slab subjected to CHBDC axle 2 \& 3 for different D values Orthotropic analyses

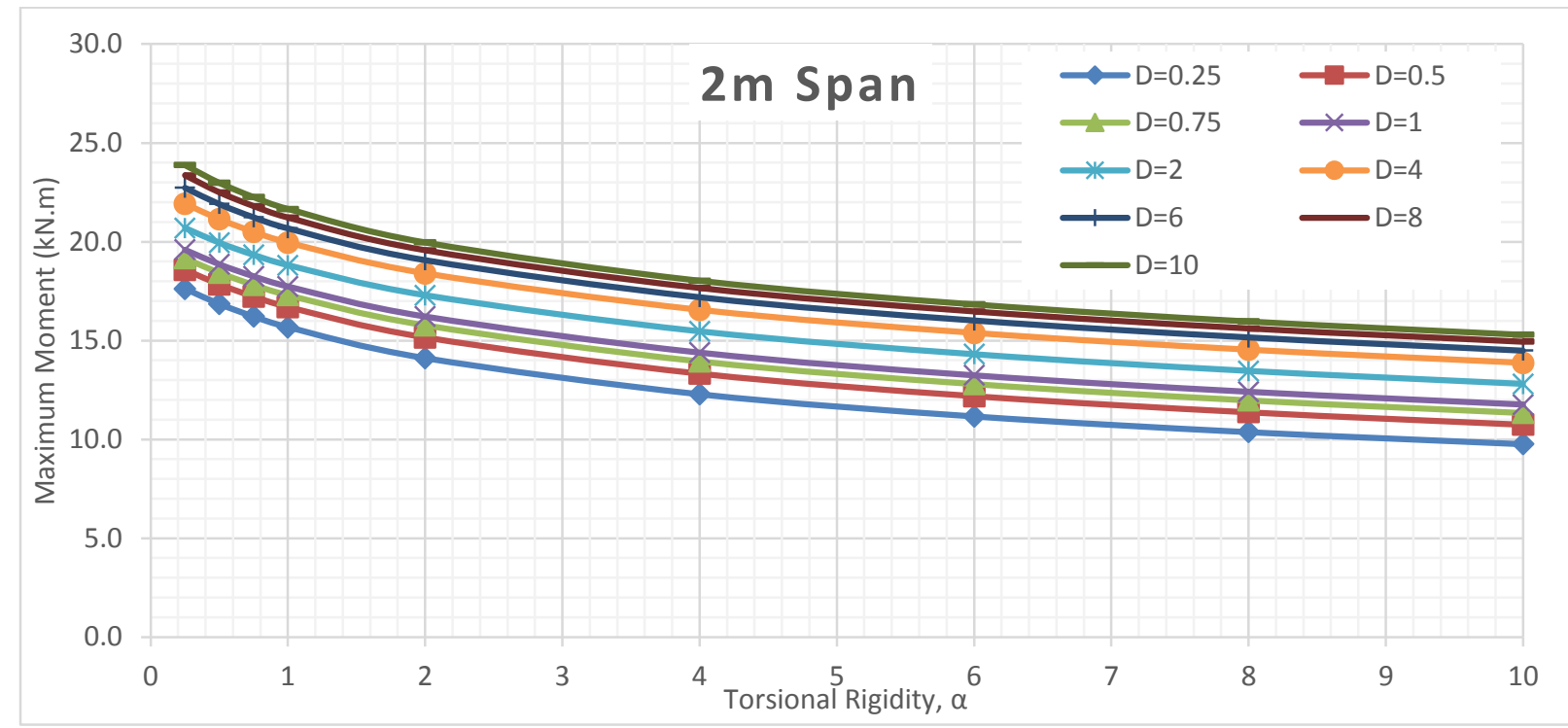

Figure 365 Maximum moment of $2 \mathrm{~m}$ span slab subjected to CHBDC axle 2 \& 3 for different D values Orthotropic analyses 


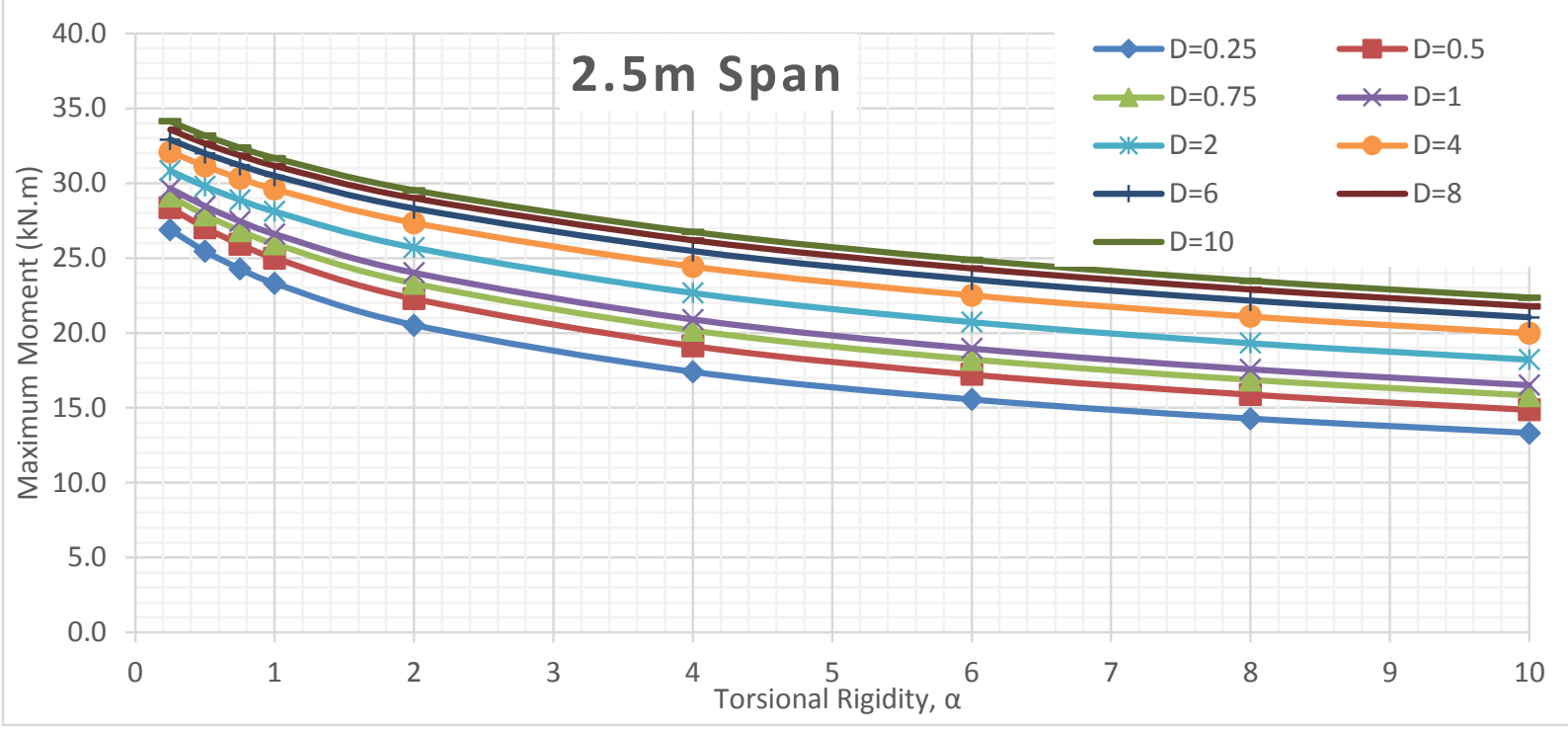

Figure 366 Maximum moment of $2.5 \mathrm{~m}$ span slab subjected to CHBDC axle 2 \& 3 for different D values Orthotropic analyses

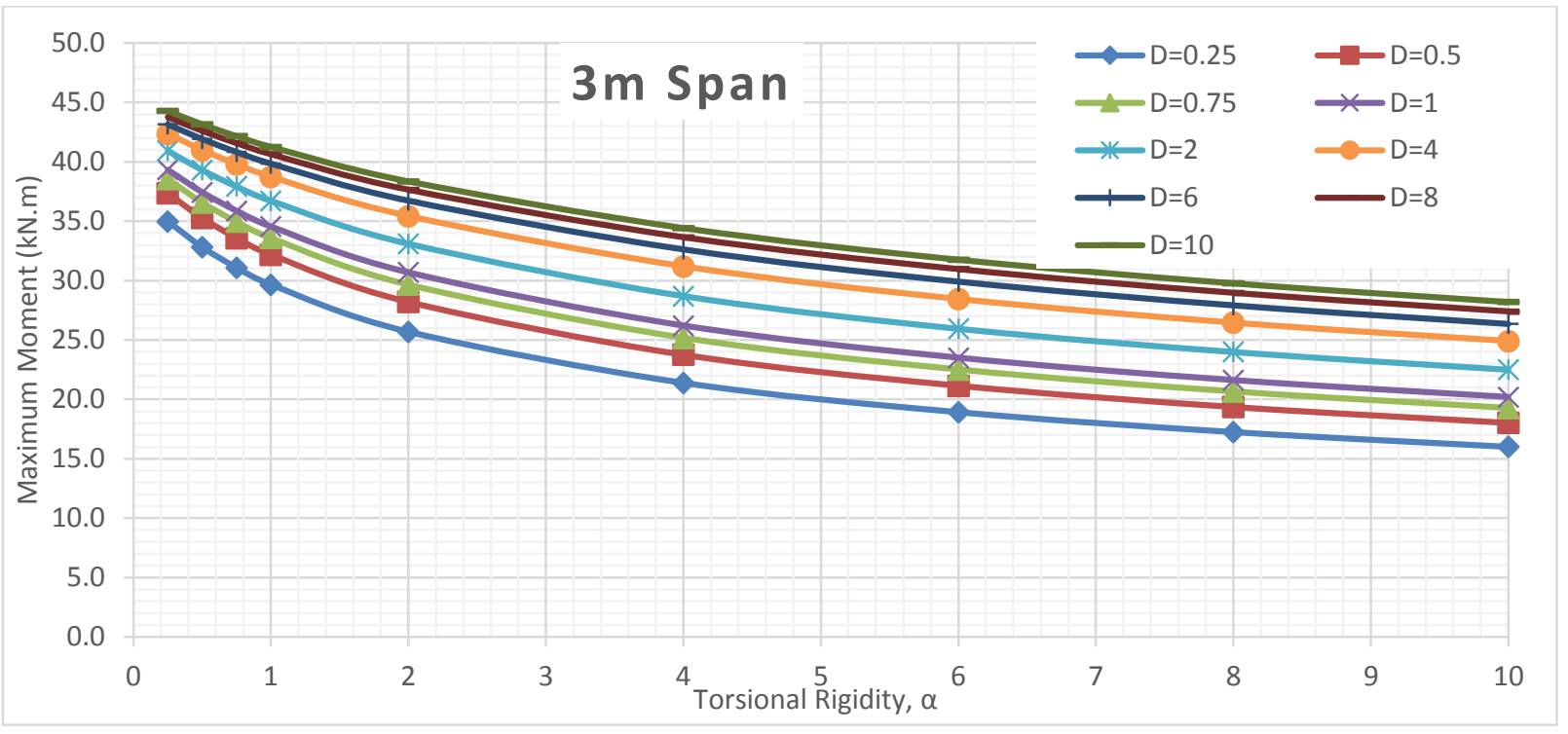

Figure 367 Maximum moment of $3 \mathrm{~m}$ span slab subjected to CHBDC axle 2 \& 3 for different D values Orthotropic analyses

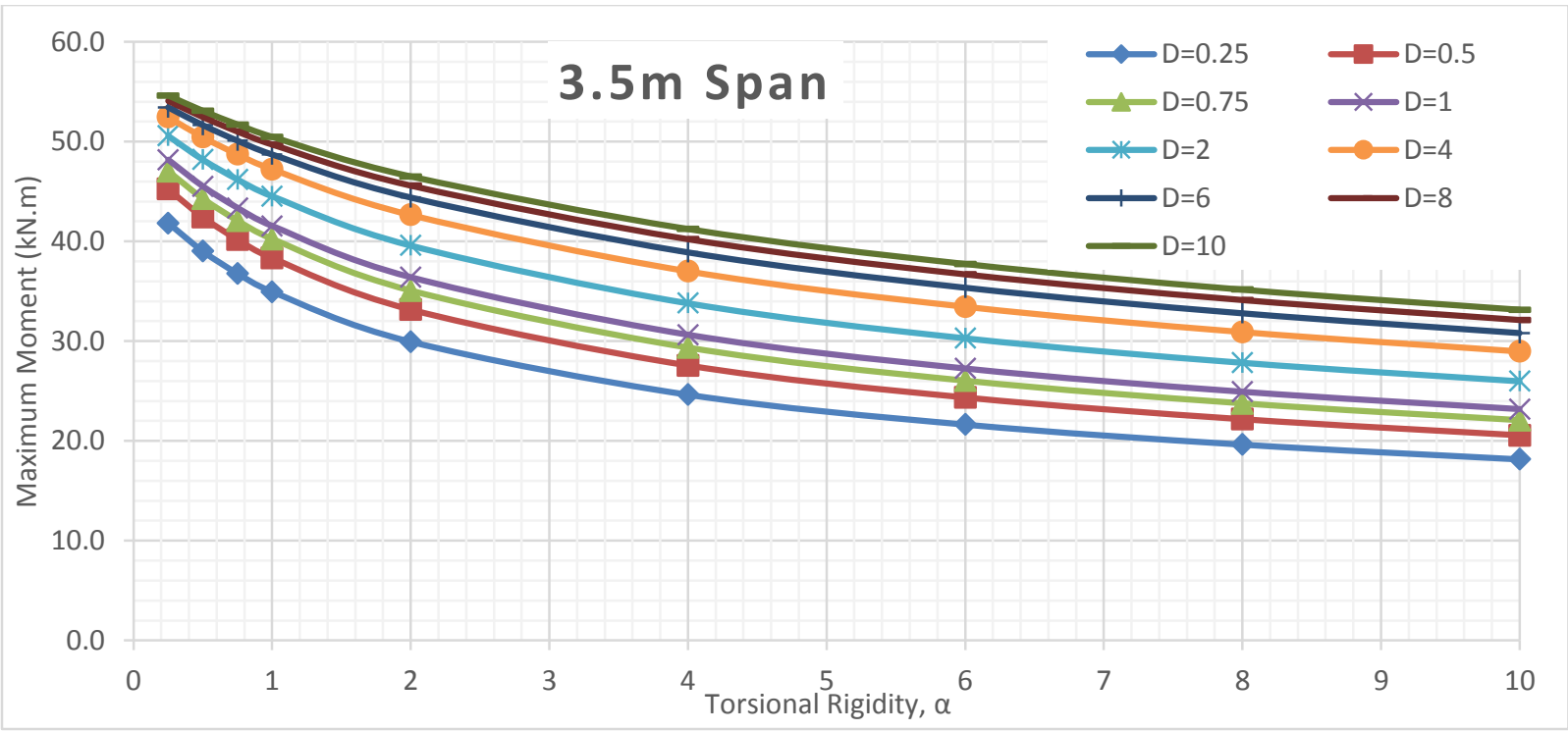

Figure 368 Maximum moment of $3.5 \mathrm{~m}$ span slab subjected to CHBDC axle $2 \& 3$ for different D values Orthotropic analyses 


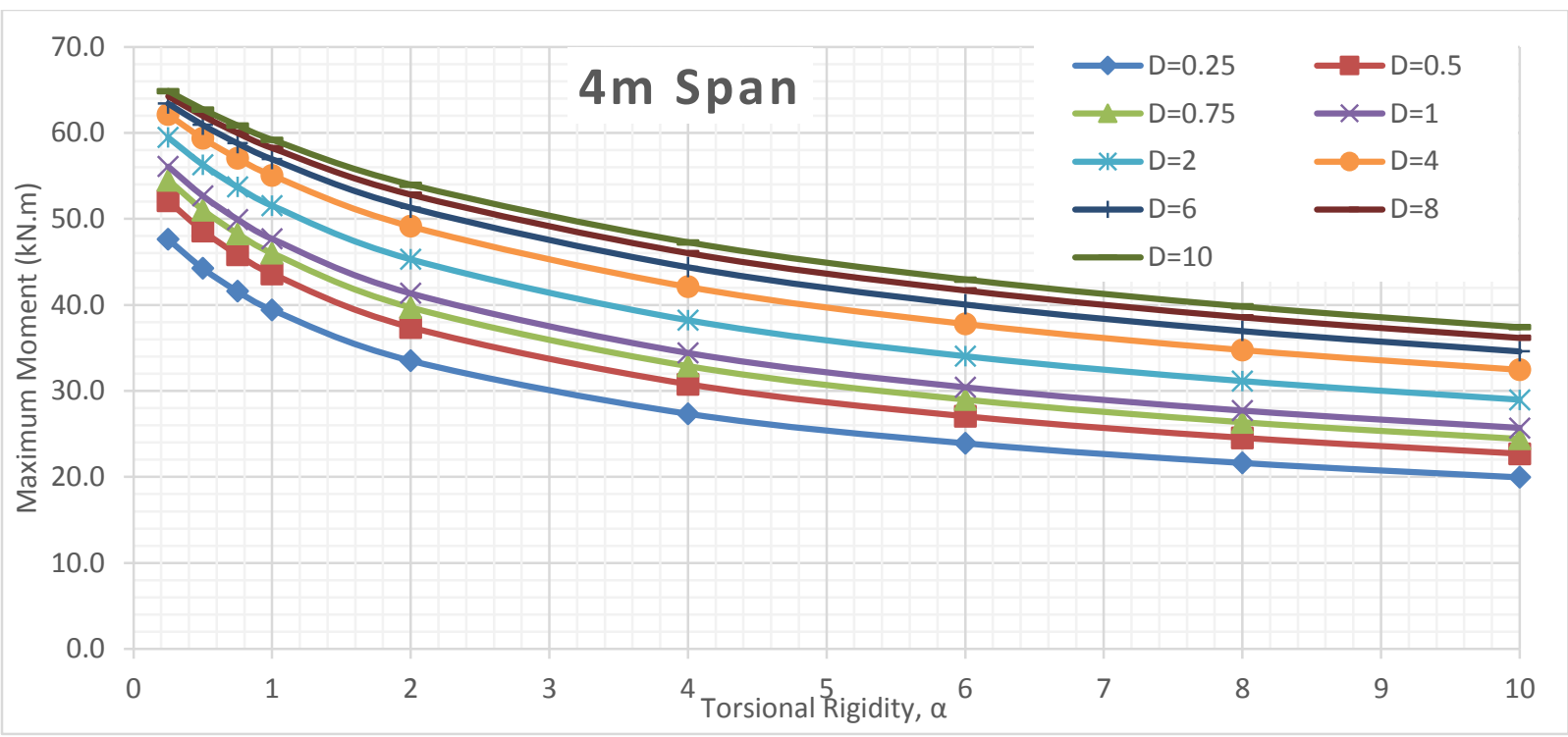

Figure 369 Maximum moment of $4 \mathrm{~m}$ span slab subjected to CHBDC axle 2 \& 3 for different D values Orthotropic analyses 
C.2 Orthotropic Plate Results (Deflection) 


\section{C.2.1 DEFLECTION RESULTS TABLES}




\section{Alpha 0.25 Deflection Results}

Table 145 Maximum deflection results for alpha 0.25 for slabs subjected to CHBDC axle 4 loading (main bars perpendicular to traffic)

\begin{tabular}{|c|c|c|c|c|c|c|c|c|c|c|}
\hline & \multicolumn{9}{|c|}{ Maximum Moment (kN.m) } \\
\hline \multirow{9}{*}{$\frac{0}{x}$} & D & \multirow{2}{*}{0.25} & \multirow{2}{*}{0.5} & \multirow{2}{*}{0.75} & \multirow{2}{*}{1} & \multirow[b]{2}{*}{2} & \multirow{2}{*}{4} & \multirow[b]{2}{*}{6} & \multirow{2}{*}{8} & \multirow{2}{*}{10} \\
\hline & SPAN & & & & & & & & & \\
\hline & 1 & $6.54 \mathrm{E}-05$ & $7.74 \mathrm{E}-05$ & $8.53 E-05$ & $9.14 \mathrm{E}-05$ & $1.08 \mathrm{E}-04$ & $1.27 \mathrm{E}-04$ & $1.39 \mathrm{E}-04$ & $1.48 \mathrm{E}-04$ & $1.56 \mathrm{E}-04$ \\
\hline & 1.5 & $1.64 \mathrm{E}-04$ & $1.94 \mathrm{E}-04$ & $2.15 \mathrm{E}-04$ & $2.30 \mathrm{E}-04$ & $2.73 \mathrm{E}-04$ & $3.22 \mathrm{E}-04$ & $3.55 \mathrm{E}-04$ & $3.80 \mathrm{E}-04$ & $4.01 \mathrm{E}-04$ \\
\hline & 2 & $3.03 \mathrm{E}-04$ & $3.60 \mathrm{E}-04$ & $3.98 \mathrm{E}-04$ & $4.28 \mathrm{E}-04$ & 5.07E-04 & $6.01 \mathrm{E}-04$ & $6.63 \mathrm{E}-04$ & $7.11 \mathrm{E}-04$ & $7.50 \mathrm{E}-04$ \\
\hline & 2.5 & $4.84 \mathrm{E}-04$ & $5.75 \mathrm{E}-04$ & $6.36 \mathrm{E}-04$ & $6.82 \mathrm{E}-04$ & $8.10 \mathrm{E}-04$ & $9.61 \mathrm{E}-04$ & $1.06 \mathrm{E}-03$ & $1.14 \mathrm{E}-03$ & $1.20 \mathrm{E}-03$ \\
\hline & 3 & $7.58 \mathrm{E}-04$ & $9.01 \mathrm{E}-04$ & $9.97 \mathrm{E}-04$ & $1.07 \mathrm{E}-03$ & $1.27 \mathrm{E}-03$ & $1.51 \mathrm{E}-03$ & $1.67 \mathrm{E}-03$ & $1.80 \mathrm{E}-03$ & $1.90 \mathrm{E}-03$ \\
\hline & 3.5 & $1.23 \mathrm{E}-03$ & $1.47 \mathrm{E}-03$ & $1.62 \mathrm{E}-03$ & $1.74 \mathrm{E}-03$ & $2.07 \mathrm{E}-03$ & $2.46 \mathrm{E}-03$ & $2.72 \mathrm{E}-03$ & $2.92 \mathrm{E}-03$ & $3.09 \mathrm{E}-03$ \\
\hline & 4 & $1.79 \mathrm{E}-03$ & $2.13 \mathrm{E}-03$ & $2.36 \mathrm{E}-03$ & $2.54 \mathrm{E}-03$ & $3.02 \mathrm{E}-03$ & $3.58 \mathrm{E}-03$ & $3.96 \mathrm{E}-03$ & $4.26 \mathrm{E}-03$ & $4.50 \mathrm{E}-03$ \\
\hline
\end{tabular}

Table 146 Maximum deflection results for alpha 0.25 for slabs subjected to CHBDC axle 2 \& 3 loading (main bars perpendicular to traffic)

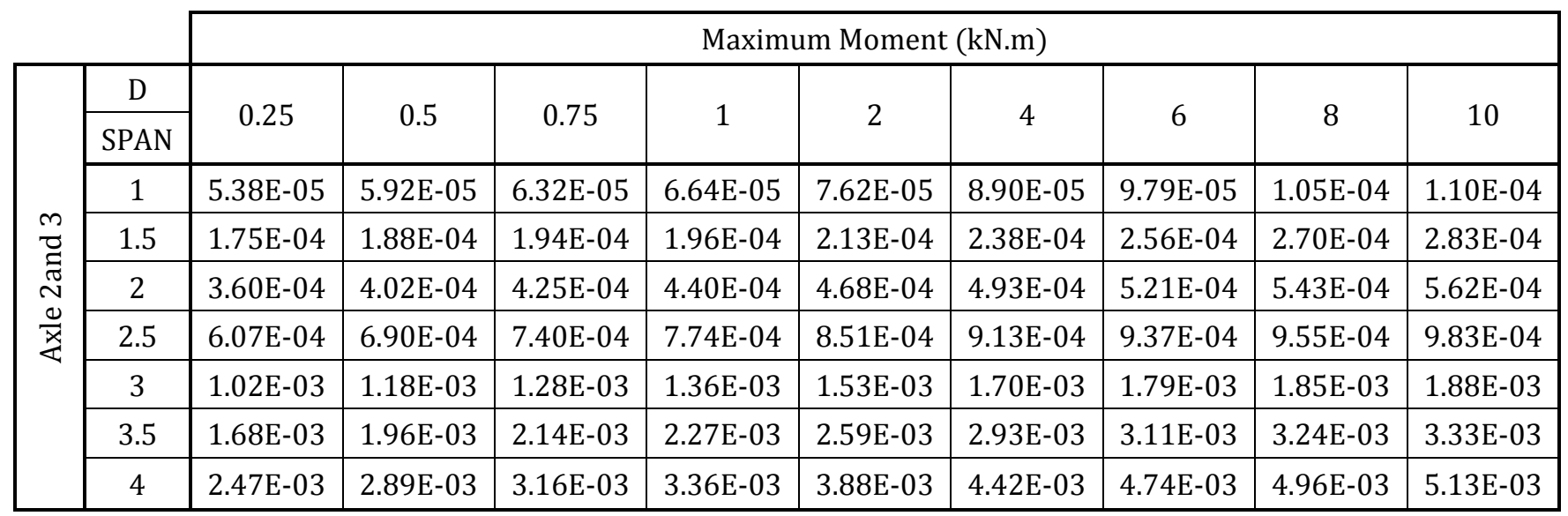

Table 147 Maximum deflection results for alpha 0.25 for slabs subjected to CHBDC truck loading (main bars perpendicular to traffic)

\begin{tabular}{|c|c|c|c|c|c|c|c|c|c|c|}
\hline & \multicolumn{9}{|c|}{ Maximum Moment (kN.m) } \\
\hline \multirow{9}{*}{ 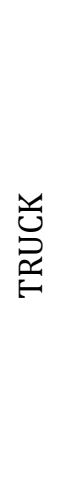 } & $\mathrm{D}$ & & & & & & & & & \\
\hline & SPAN & 0.25 & 0.5 & 0.75 & 1 & 2 & 4 & 6 & 8 & 10 \\
\hline & 1 & $6.54 \mathrm{E}-05$ & 7.74E-05 & $8.53 \mathrm{E}-05$ & $9.14 \mathrm{E}-05$ & $1.08 \mathrm{E}-04$ & $1.27 \mathrm{E}-04$ & $1.39 \mathrm{E}-04$ & $1.48 \mathrm{E}-04$ & $1.56 \mathrm{E}-04$ \\
\hline & 1.5 & $1.74 \mathrm{E}-04$ & $1.94 \mathrm{E}-04$ & $2.15 \mathrm{E}-04$ & $2.30 \mathrm{E}-04$ & $2.73 \mathrm{E}-04$ & $3.22 \mathrm{E}-04$ & $3.55 \mathrm{E}-04$ & $3.80 \mathrm{E}-04$ & $4.01 \mathrm{E}-04$ \\
\hline & 2 & $3.57 \mathrm{E}-04$ & $3.98 \mathrm{E}-04$ & $4.22 \mathrm{E}-04$ & $4.37 \mathrm{E}-04$ & $5.07 \mathrm{E}-04$ & $6.01 \mathrm{E}-04$ & $6.63 \mathrm{E}-04$ & $7.11 \mathrm{E}-04$ & $7.50 \mathrm{E}-04$ \\
\hline & 2.5 & $6.08 \mathrm{E}-04$ & $6.84 \mathrm{E}-04$ & 7.32E-04 & $7.66 \mathrm{E}-04$ & 8.45E-04 & $9.61 \mathrm{E}-04$ & $1.06 \mathrm{E}-03$ & $1.14 \mathrm{E}-03$ & $1.20 \mathrm{E}-03$ \\
\hline & 3 & $1.05 \mathrm{E}-03$ & $1.18 \mathrm{E}-03$ & $1.27 \mathrm{E}-03$ & $1.34 \mathrm{E}-03$ & $1.52 \mathrm{E}-03$ & $1.69 \mathrm{E}-03$ & $1.78 \mathrm{E}-03$ & $1.84 \mathrm{E}-03$ & $1.90 \mathrm{E}-03$ \\
\hline & 3.5 & $1.79 \mathrm{E}-03$ & $2.01 \mathrm{E}-03$ & $2.15 \mathrm{E}-03$ & $2.27 \mathrm{E}-03$ & $2.57 \mathrm{E}-03$ & $2.90 \mathrm{E}-03$ & $3.09 \mathrm{E}-03$ & $3.22 \mathrm{E}-03$ & $3.31 \mathrm{E}-03$ \\
\hline & 4 & $2.75 \mathrm{E}-03$ & 3.05E-03 & $3.26 \mathrm{E}-03$ & $3.42 \mathrm{E}-03$ & 3.87E-03 & $4.38 \mathrm{E}-03$ & 4.69E-03 & $4.91 \mathrm{E}-03$ & $5.08 \mathrm{E}-03$ \\
\hline
\end{tabular}


Table 148 Maximum deflection results for alpha 0.25 for slabs subjected to CHBDC axle 4 loading (main bars parallel to traffic)

\begin{tabular}{|c|c|c|c|c|c|c|c|c|c|c|}
\hline & & \multicolumn{9}{|c|}{ Maximum Moment (kN.m) } \\
\hline \multirow{8}{*}{ 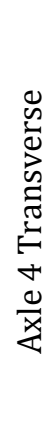 } & $\mathrm{D}$ & \multirow{2}{*}{0.25} & \multirow{2}{*}{0.5} & \multirow{2}{*}{0.75} & \multirow[t]{2}{*}{1} & \multirow[t]{2}{*}{2} & \multirow{2}{*}{4} & \multirow{2}{*}{6} & \multirow[t]{2}{*}{8} & \multirow{2}{*}{10} \\
\hline & SPAN & & & & & & & & & \\
\hline & 1 & $8.43 \mathrm{E}-05$ & $9.00 \mathrm{E}-05$ & $9.45 \mathrm{E}-05$ & $9.82 \mathrm{E}-05$ & $1.10 \mathrm{E}-04$ & $1.25 \mathrm{E}-04$ & $1.34 \mathrm{E}-04$ & $1.40 \mathrm{E}-04$ & $1.45 \mathrm{E}-04$ \\
\hline & 1.5 & $2.65 \mathrm{E}-04$ & 2.73E-04 & $2.79 \mathrm{E}-04$ & $2.85 \mathrm{E}-04$ & $3.02 \mathrm{E}-04$ & $3.27 \mathrm{E}-04$ & $3.46 \mathrm{E}-04$ & $3.62 \mathrm{E}-04$ & $3.76 \mathrm{E}-04$ \\
\hline & 2 & $6.00 \mathrm{E}-04$ & $6.19 \mathrm{E}-04$ & $6.30 \mathrm{E}-04$ & $6.38 \mathrm{E}-04$ & $6.60 \mathrm{E}-04$ & $6.91 \mathrm{E}-04$ & $7.16 \mathrm{E}-04$ & $7.38 \mathrm{E}-04$ & 7.57E-04 \\
\hline & 2.5 & $1.11 \mathrm{E}-03$ & $1.16 \mathrm{E}-03$ & $1.19 \mathrm{E}-03$ & $1.20 \mathrm{E}-03$ & $1.24 \mathrm{E}-03$ & $1.28 \mathrm{E}-03$ & $1.31 \mathrm{E}-03$ & $1.33 \mathrm{E}-03$ & $1.36 \mathrm{E}-03$ \\
\hline & 3 & $1.81 \mathrm{E}-03$ & $1.92 \mathrm{E}-03$ & $1.97 \mathrm{E}-03$ & $2.01 \mathrm{E}-03$ & $2.08 \mathrm{E}-03$ & $2.14 \mathrm{E}-03$ & $2.18 \mathrm{E}-03$ & $2.21 \mathrm{E}-03$ & $2.24 \mathrm{E}-03$ \\
\hline & 3.5 & $2.68 \mathrm{E}-03$ & 2.89E-03 & $3.00 \mathrm{E}-03$ & 3.07E-03 & $3.21 \mathrm{E}-03$ & 3.32E-03 & 3.37E-03 & $3.41 \mathrm{E}-03$ & $3.45 \mathrm{E}-03$ \\
\hline
\end{tabular}

Table 149 Maximum deflection results for alpha 0.25 for slabs subjected to CHBDC axle 2 \& 3 loading (main bars parallel to traffic)

\begin{tabular}{|c|c|c|c|c|c|c|c|c|c|c|}
\hline & & \multicolumn{9}{|c|}{ Maximum Moment (kN.m) } \\
\hline \multirow{8}{*}{ 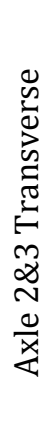 } & $\mathrm{D}$ & \multirow{2}{*}{0.25} & \multirow{2}{*}{0.5} & \multirow{2}{*}{0.75} & \multirow{2}{*}{1} & & \multirow{2}{*}{4} & \multirow{2}{*}{6} & \multirow[b]{2}{*}{0} & \multirow{2}{*}{10} \\
\hline & SPAN & & & & & & & & & \\
\hline & 1.5 & $1.16 \mathrm{E}-04$ & $1.20 \mathrm{E}-04$ & $1.22 \mathrm{E}-04$ & $1.24 \mathrm{E}-04$ & $1.26 \mathrm{E}-04$ & $1.34 \mathrm{E}-04$ & $1.42 \mathrm{E}-04$ & $1.49 \mathrm{E}-04$ & $1.55 \mathrm{E}-04$ \\
\hline & 2 & $4.99 \mathrm{E}-04$ & $5.17 \mathrm{E}-04$ & $5.27 \mathrm{E}-04$ & $5.35 \mathrm{E}-04$ & $5.52 \mathrm{E}-04$ & $5.67 \mathrm{E}-04$ & $5.71 \mathrm{E}-04$ & $5.83 \mathrm{E}-04$ & $5.98 \mathrm{E}-04$ \\
\hline & 2.5 & $1.15 \mathrm{E}-03$ & $1.21 \mathrm{E}-03$ & $1.23 \mathrm{E}-03$ & $1.25 \mathrm{E}-03$ & $1.29 \mathrm{E}-03$ & $1.33 \mathrm{E}-03$ & $1.36 \mathrm{E}-03$ & $1.37 \mathrm{E}-03$ & $1.38 \mathrm{E}-03$ \\
\hline & 3 & $2.08 \mathrm{E}-03$ & $2.22 \mathrm{E}-03$ & $2.28 \mathrm{E}-03$ & 2.33E-03 & $2.41 \mathrm{E}-03$ & $2.49 \mathrm{E}-03$ & $2.53 \mathrm{E}-03$ & $2.57 \mathrm{E}-03$ & $2.59 \mathrm{E}-03$ \\
\hline & 3.5 & $3.28 \mathrm{E}-03$ & $3.55 \mathrm{E}-03$ & $3.69 \mathrm{E}-03$ & $3.78 \mathrm{E}-03$ & $3.96 \mathrm{E}-03$ & $4.10 \mathrm{E}-03$ & $4.17 \mathrm{E}-03$ & $4.23 \mathrm{E}-03$ & $4.27 \mathrm{E}-03$ \\
\hline & 4 & $4.74 \mathrm{E}-03$ & $5.20 \mathrm{E}-03$ & $5.45 \mathrm{E}-03$ & $5.61 \mathrm{E}-03$ & $5.95 \mathrm{E}-03$ & $6.21 \mathrm{E}-03$ & $6.33 \mathrm{E}-03$ & $6.42 \mathrm{E}-03$ & $6.48 \mathrm{E}-03$ \\
\hline
\end{tabular}




\section{Alpha 0.5 Deflection Results}

Table 150 Maximum deflection results for alpha 0.5 for slabs subjected to CHBDC axle 4 loading (main bars perpendicular to traffic)

\begin{tabular}{|c|c|c|c|c|c|c|c|c|c|c|}
\hline & \multicolumn{9}{|c|}{ Maximum Moment (kN.m) } \\
\hline \multirow{9}{*}{$\begin{array}{l}\stackrel{+}{a} \\
\frac{a}{x}\end{array}$} & $\mathrm{D}$ & \multirow{2}{*}{0.25} & \multirow{2}{*}{0.5} & \multirow{2}{*}{0.75} & \multirow[b]{2}{*}{1} & \multirow[b]{2}{*}{2} & \multirow[b]{2}{*}{4} & \multirow[b]{2}{*}{6} & \multirow{2}{*}{8} & \multirow[b]{2}{*}{10} \\
\hline & SPAN & & & & & & & & & \\
\hline & 1 & $5.97 \mathrm{E}-05$ & $7.06 \mathrm{E}-05$ & $7.79 \mathrm{E}-05$ & $8.35 \mathrm{E}-05$ & $9.85 \mathrm{E}-05$ & $1.16 \mathrm{E}-04$ & $1.27 \mathrm{E}-04$ & $1.36 \mathrm{E}-04$ & $1.43 \mathrm{E}-04$ \\
\hline & 1.5 & $1.50 \mathrm{E}-04$ & $1.77 \mathrm{E}-04$ & $1.96 \mathrm{E}-04$ & $2.10 \mathrm{E}-04$ & $2.49 \mathrm{E}-04$ & $2.94 \mathrm{E}-04$ & $3.24 \mathrm{E}-04$ & $3.47 \mathrm{E}-04$ & $3.66 \mathrm{E}-04$ \\
\hline & 2 & $2.77 \mathrm{E}-04$ & $3.29 \mathrm{E}-04$ & $3.64 \mathrm{E}-04$ & $3.90 \mathrm{E}-04$ & $4.63 \mathrm{E}-04$ & $5.48 \mathrm{E}-04$ & $6.05 \mathrm{E}-04$ & $6.49 \mathrm{E}-04$ & $6.85 \mathrm{E}-04$ \\
\hline & 2.5 & $4.42 \mathrm{E}-04$ & $5.25 \mathrm{E}-04$ & $5.80 \mathrm{E}-04$ & $6.23 \mathrm{E}-04$ & $7.40 \mathrm{E}-04$ & 8.77E-04 & $9.69 \mathrm{E}-04$ & $1.04 \mathrm{E}-03$ & $1.10 \mathrm{E}-03$ \\
\hline & 3 & $6.92 \mathrm{E}-04$ & $8.23 \mathrm{E}-04$ & $9.10 \mathrm{E}-04$ & $9.78 \mathrm{E}-04$ & $1.16 \mathrm{E}-03$ & $1.38 \mathrm{E}-03$ & $1.53 \mathrm{E}-03$ & $1.64 \mathrm{E}-03$ & $1.73 \mathrm{E}-03$ \\
\hline & 3.5 & $1.13 \mathrm{E}-03$ & $1.34 \mathrm{E}-03$ & $1.48 \mathrm{E}-03$ & $1.59 \mathrm{E}-03$ & $1.89 \mathrm{E}-03$ & $2.25 \mathrm{E}-03$ & $2.48 \mathrm{E}-03$ & $2.67 \mathrm{E}-03$ & $2.82 \mathrm{E}-03$ \\
\hline & 4 & $1.64 \mathrm{E}-03$ & $1.95 \mathrm{E}-03$ & $2.16 \mathrm{E}-03$ & $2.32 \mathrm{E}-03$ & $2.75 \mathrm{E}-03$ & $3.27 \mathrm{E}-03$ & $3.62 \mathrm{E}-03$ & $3.89 \mathrm{E}-03$ & $4.11 \mathrm{E}-03$ \\
\hline
\end{tabular}

Table 151 Maximum deflection results for alpha 0.5 for slabs subjected to CHBDC axle 2 \& 3 loading (main bars perpendicular to traffic)

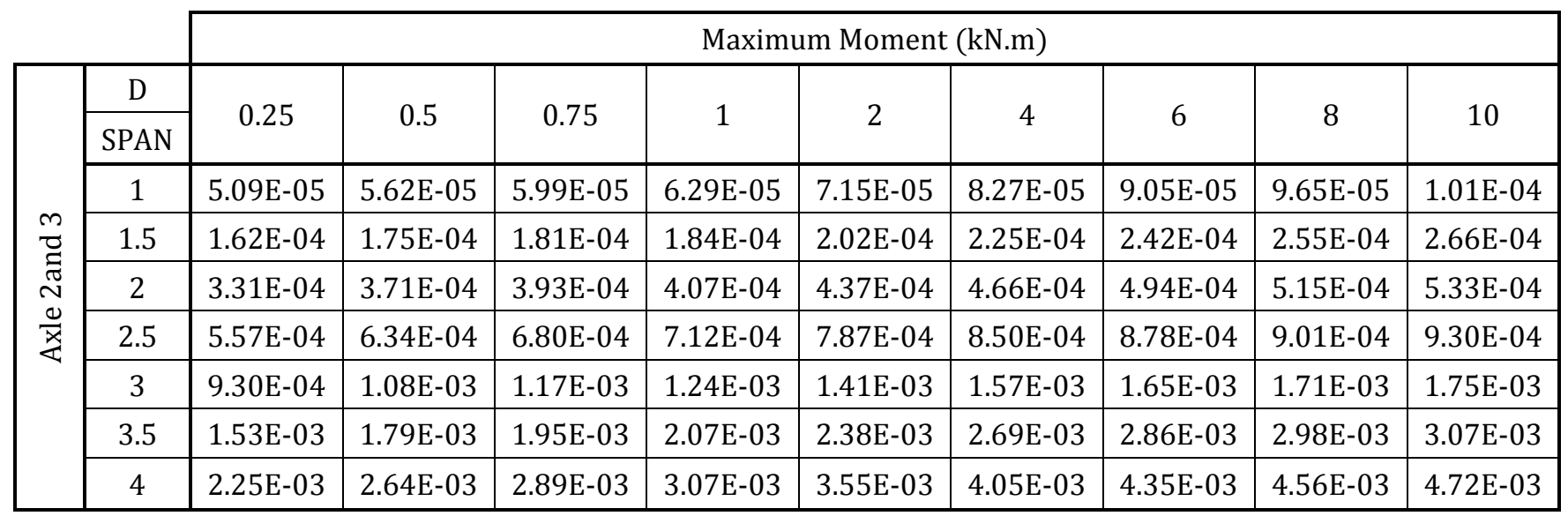

Table 152 Maximum deflection results for alpha 0.5 for slabs subjected to CHBDC truck loading (main bars perpendicular to traffic)

\begin{tabular}{|c|c|c|c|c|c|c|c|c|c|c|}
\hline & \multicolumn{9}{|c|}{ Maximum Moment (kN.m) } \\
\hline \multirow{9}{*}{ 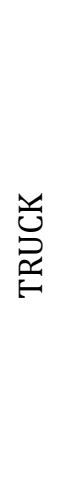 } & $\mathrm{D}$ & & & & & & & & & \\
\hline & SPAN & 0.25 & 0.5 & 0.75 & 1 & 2 & 4 & 6 & 8 & 10 \\
\hline & 1 & $5.97 \mathrm{E}-05$ & 7.06E-05 & $7.79 \mathrm{E}-05$ & 8.35E-05 & $9.85 \mathrm{E}-05$ & $1.16 \mathrm{E}-04$ & $1.27 \mathrm{E}-04$ & $1.36 \mathrm{E}-04$ & $1.43 \mathrm{E}-04$ \\
\hline & 1.5 & $1.61 \mathrm{E}-04$ & $1.77 \mathrm{E}-04$ & $1.96 \mathrm{E}-04$ & $2.10 \mathrm{E}-04$ & $2.49 \mathrm{E}-04$ & $2.94 \mathrm{E}-04$ & $3.24 \mathrm{E}-04$ & $3.47 \mathrm{E}-04$ & $3.66 \mathrm{E}-04$ \\
\hline & 2 & $3.32 \mathrm{E}-04$ & $3.70 \mathrm{E}-04$ & $3.91 \mathrm{E}-04$ & $4.06 \mathrm{E}-04$ & 4.63E-04 & $5.48 \mathrm{E}-04$ & $6.05 \mathrm{E}-04$ & $6.49 \mathrm{E}-04$ & $6.85 \mathrm{E}-04$ \\
\hline & 2.5 & $5.71 \mathrm{E}-04$ & $6.38 \mathrm{E}-04$ & $6.81 \mathrm{E}-04$ & 7.12E-04 & 7.85E-04 & $8.77 \mathrm{E}-04$ & $9.69 \mathrm{E}-04$ & $1.04 \mathrm{E}-03$ & $1.10 \mathrm{E}-03$ \\
\hline & 3 & $9.89 \mathrm{E}-04$ & $1.11 \mathrm{E}-03$ & $1.19 \mathrm{E}-03$ & $1.25 \mathrm{E}-03$ & $1.41 \mathrm{E}-03$ & $1.56 \mathrm{E}-03$ & $1.65 \mathrm{E}-03$ & $1.71 \mathrm{E}-03$ & $1.74 \mathrm{E}-03$ \\
\hline & 3.5 & $1.70 \mathrm{E}-03$ & $1.89 \mathrm{E}-03$ & $2.02 \mathrm{E}-03$ & $2.12 \mathrm{E}-03$ & $2.39 \mathrm{E}-03$ & $2.68 \mathrm{E}-03$ & $2.86 \mathrm{E}-03$ & $2.98 \mathrm{E}-03$ & $3.06 \mathrm{E}-03$ \\
\hline & 4 & $2.62 \mathrm{E}-03$ & $2.89 \mathrm{E}-03$ & $3.08 \mathrm{E}-03$ & $3.22 \mathrm{E}-03$ & $3.62 \mathrm{E}-03$ & 4.07E-03 & 4.35E-03 & $4.55 \mathrm{E}-03$ & $4.71 \mathrm{E}-03$ \\
\hline
\end{tabular}


Table 153 Maximum deflection results for alpha 0.5 for slabs subjected to CHBDC axle 4 loading (main bars parallel to traffic)

\begin{tabular}{|c|c|c|c|c|c|c|c|c|c|c|}
\hline & & \multicolumn{9}{|c|}{ Maximum Moment (kN.m) } \\
\hline \multirow{8}{*}{ 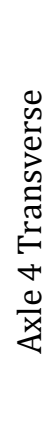 } & $\mathrm{D}$ & \multirow{2}{*}{0.25} & \multirow{2}{*}{0.5} & \multirow{2}{*}{0.75} & \multirow[t]{2}{*}{1} & \multirow[t]{2}{*}{2} & \multirow{2}{*}{4} & \multirow{2}{*}{6} & \multirow[t]{2}{*}{8} & \multirow{2}{*}{10} \\
\hline & SPAN & & & & & & & & & \\
\hline & 1 & $8.24 \mathrm{E}-05$ & $8.75 \mathrm{E}-05$ & $9.14 \mathrm{E}-05$ & $9.47 \mathrm{E}-05$ & $1.04 \mathrm{E}-04$ & $1.16 \mathrm{E}-04$ & $1.23 \mathrm{E}-04$ & $1.29 \mathrm{E}-04$ & $1.34 \mathrm{E}-04$ \\
\hline & 1.5 & $2.57 \mathrm{E}-04$ & 2.67E-04 & $2.73 \mathrm{E}-04$ & $2.78 \mathrm{E}-04$ & $2.94 \mathrm{E}-04$ & $3.16 \mathrm{E}-04$ & 3.33E-04 & $3.46 \mathrm{E}-04$ & $3.57 \mathrm{E}-04$ \\
\hline & 2 & $5.74 \mathrm{E}-04$ & $5.98 \mathrm{E}-04$ & $6.11 \mathrm{E}-04$ & $6.21 \mathrm{E}-04$ & $6.45 \mathrm{E}-04$ & $6.76 \mathrm{E}-04$ & $6.98 \mathrm{E}-04$ & $7.18 \mathrm{E}-04$ & 7.35E-04 \\
\hline & 2.5 & $1.05 \mathrm{E}-03$ & $1.11 \mathrm{E}-03$ & $1.14 \mathrm{E}-03$ & $1.16 \mathrm{E}-03$ & $1.20 \mathrm{E}-03$ & $1.25 \mathrm{E}-03$ & $1.28 \mathrm{E}-03$ & $1.30 \mathrm{E}-03$ & $1.33 \mathrm{E}-03$ \\
\hline & 3 & $1.69 \mathrm{E}-03$ & $1.81 \mathrm{E}-03$ & $1.87 \mathrm{E}-03$ & $1.92 \mathrm{E}-03$ & $2.00 \mathrm{E}-03$ & $2.08 \mathrm{E}-03$ & $2.12 \mathrm{E}-03$ & $2.16 \mathrm{E}-03$ & $2.19 \mathrm{E}-03$ \\
\hline & 3.5 & $2.49 \mathrm{E}-03$ & $2.71 \mathrm{E}-03$ & $2.82 \mathrm{E}-03$ & $2.90 \mathrm{E}-03$ & $3.06 \mathrm{E}-03$ & $3.20 \mathrm{E}-03$ & $3.27 \mathrm{E}-03$ & 3.32E-03 & $3.36 \mathrm{E}-03$ \\
\hline
\end{tabular}

Table 154 Maximum deflection results for alpha 0.5 for slabs subjected to CHBDC axle $2 \& 3$ loading (main bars parallel to traffic)

\begin{tabular}{|c|c|c|c|c|c|c|c|c|c|c|}
\hline & & \multicolumn{9}{|c|}{ Maximum Moment (kN.m) } \\
\hline \multirow{8}{*}{ 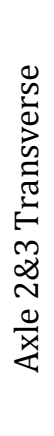 } & $\mathrm{D}$ & \multirow{2}{*}{0.25} & \multirow{2}{*}{0.5} & \multirow{2}{*}{0.75} & \multirow{2}{*}{1} & & \multirow{2}{*}{4} & \multirow{2}{*}{5} & \multirow[b]{2}{*}{0} & \multirow{2}{*}{10} \\
\hline & SPAN & & & & & & & & & \\
\hline & 1.5 & $1.12 \mathrm{E}-04$ & $1.16 \mathrm{E}-04$ & $1.18 \mathrm{E}-04$ & $1.20 \mathrm{E}-04$ & $1.22 \mathrm{E}-04$ & $1.30 \mathrm{E}-04$ & $1.37 \mathrm{E}-04$ & $1.43 \mathrm{E}-04$ & $1.48 \mathrm{E}-04$ \\
\hline & 2 & $4.76 \mathrm{E}-04$ & $4.98 \mathrm{E}-04$ & $5.09 \mathrm{E}-04$ & 5.17E-04 & $5.35 \mathrm{E}-04$ & $5.49 \mathrm{E}-04$ & $5.53 \mathrm{E}-04$ & $5.68 \mathrm{E}-04$ & $5.81 \mathrm{E}-04$ \\
\hline & 2.5 & $1.08 \mathrm{E}-03$ & $1.15 \mathrm{E}-03$ & $1.18 \mathrm{E}-03$ & $1.20 \mathrm{E}-03$ & $1.25 \mathrm{E}-03$ & $1.29 \mathrm{E}-03$ & $1.32 \mathrm{E}-03$ & $1.33 \mathrm{E}-03$ & $1.34 \mathrm{E}-03$ \\
\hline & 3 & $1.94 \mathrm{E}-03$ & $2.09 \mathrm{E}-03$ & $2.16 \mathrm{E}-03$ & $2.21 \mathrm{E}-03$ & $2.32 \mathrm{E}-03$ & $2.41 \mathrm{E}-03$ & $2.46 \mathrm{E}-03$ & $2.49 \mathrm{E}-03$ & $2.52 \mathrm{E}-03$ \\
\hline & 3.5 & $3.04 \mathrm{E}-03$ & $3.32 \mathrm{E}-03$ & $3.47 \mathrm{E}-03$ & $3.56 \mathrm{E}-03$ & $3.77 \mathrm{E}-03$ & $3.94 \mathrm{E}-03$ & 4.03E-03 & $4.09 \mathrm{E}-03$ & 4.14E-03 \\
\hline & 4 & $4.39 \mathrm{E}-03$ & $4.84 \mathrm{E}-03$ & $5.09 \mathrm{E}-03$ & $5.26 \mathrm{E}-03$ & $5.62 \mathrm{E}-03$ & $5.93 \mathrm{E}-03$ & $6.08 \mathrm{E}-03$ & $6.18 \mathrm{E}-03$ & $6.26 \mathrm{E}-03$ \\
\hline
\end{tabular}




\section{Alpha 0.75 Deflection Results}

Table 155 Maximum deflection results for alpha 0.75 for slabs subjected to CHBDC axle 4 loading (main bars perpendicular to traffic)

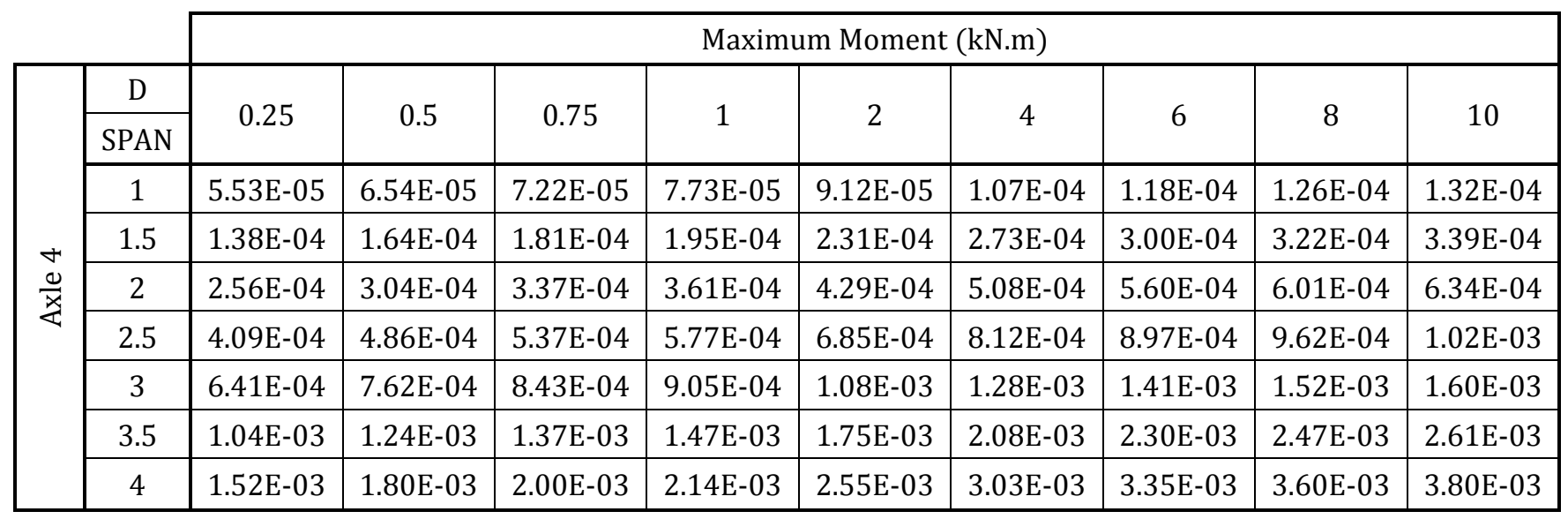

Table 156 Maximum deflection results for alpha 0.75 for slabs subjected to CHBDC axle 2 \& 3 loading (main bars perpendicular to traffic)

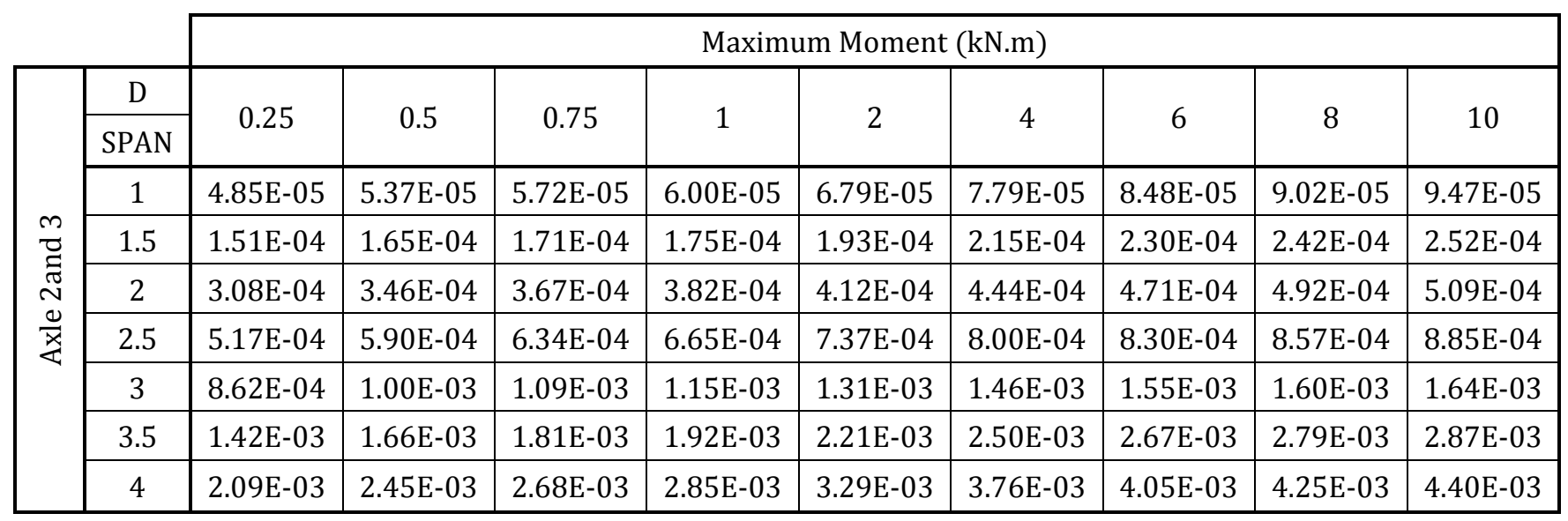

Table 157 Maximum deflection results for alpha 0.75 for slabs subjected to CHBDC truck loading (main bars perpendicular to traffic)

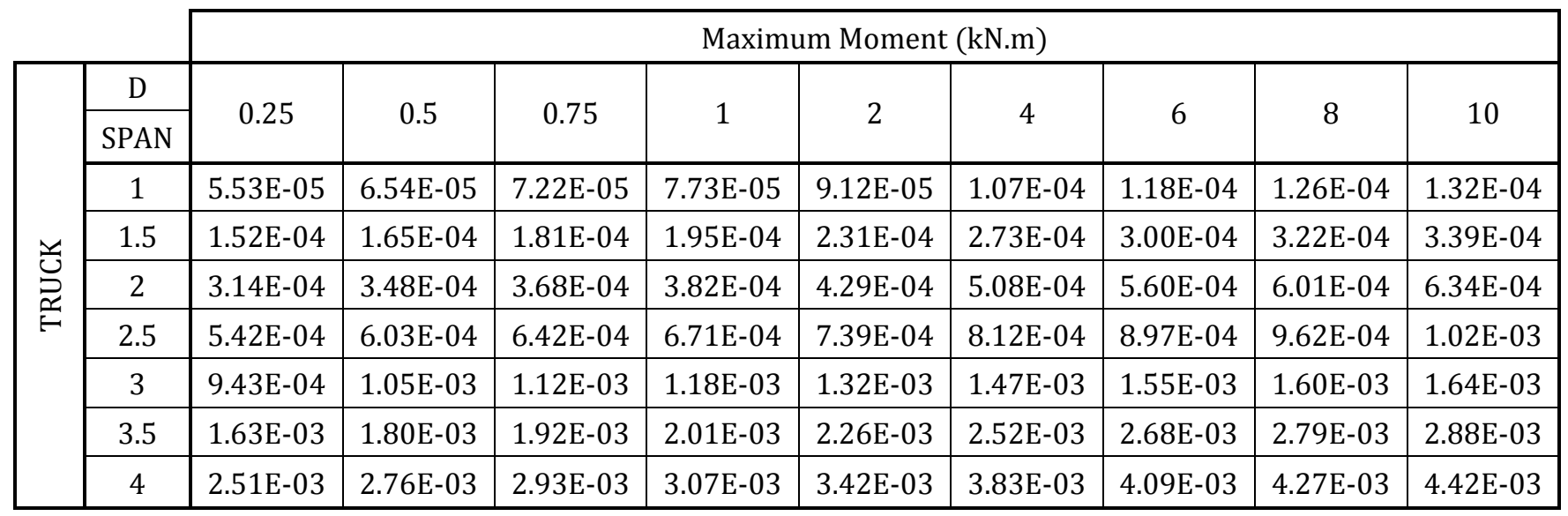


Table 158 Maximum deflection results for alpha 0.75 for slabs subjected to CHBDC axle 4 loading (main bars parallel to traffic)

\begin{tabular}{|c|c|c|c|c|c|c|c|c|c|c|}
\hline & & \multicolumn{9}{|c|}{ Maximum Moment (kN.m) } \\
\hline \multirow{8}{*}{ 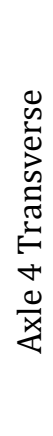 } & $\mathrm{D}$ & \multirow{2}{*}{0.25} & \multirow{2}{*}{0.5} & \multirow{2}{*}{0.75} & \multirow{2}{*}{1} & \multirow[t]{2}{*}{2} & \multirow[t]{2}{*}{4} & \multirow{2}{*}{6} & \multirow[t]{2}{*}{8} & \multirow{2}{*}{10} \\
\hline & SPAN & & & & & & & & & \\
\hline & 1 & $8.08 \mathrm{E}-05$ & $8.55 \mathrm{E}-05$ & $8.90 \mathrm{E}-05$ & $9.19 \mathrm{E}-05$ & $1.00 \mathrm{E}-04$ & $1.10 \mathrm{E}-04$ & $1.17 \mathrm{E}-04$ & $1.22 \mathrm{E}-04$ & $1.26 \mathrm{E}-04$ \\
\hline & 1.5 & $2.50 \mathrm{E}-04$ & $2.61 \mathrm{E}-04$ & $2.68 \mathrm{E}-04$ & $2.73 \mathrm{E}-04$ & $2.88 \mathrm{E}-04$ & $3.08 \mathrm{E}-04$ & $3.22 \mathrm{E}-04$ & $3.34 \mathrm{E}-04$ & $3.44 \mathrm{E}-04$ \\
\hline & 2 & $5.52 \mathrm{E}-04$ & $5.80 \mathrm{E}-04$ & $5.95 \mathrm{E}-04$ & $6.05 \mathrm{E}-04$ & $6.32 \mathrm{E}-04$ & $6.62 \mathrm{E}-04$ & $6.84 \mathrm{E}-04$ & $7.01 \mathrm{E}-04$ & 7.16E-04 \\
\hline & 2.5 & $1.00 \mathrm{E}-03$ & $1.06 \mathrm{E}-03$ & $1.10 \mathrm{E}-03$ & $1.12 \mathrm{E}-03$ & $1.17 \mathrm{E}-03$ & $1.22 \mathrm{E}-03$ & $1.25 \mathrm{E}-03$ & $1.28 \mathrm{E}-03$ & $1.30 \mathrm{E}-03$ \\
\hline & 3 & $1.60 \mathrm{E}-03$ & $1.73 \mathrm{E}-03$ & $1.79 \mathrm{E}-03$ & $1.84 \mathrm{E}-03$ & $1.94 \mathrm{E}-03$ & $2.02 \mathrm{E}-03$ & 2.07E-03 & $2.11 \mathrm{E}-03$ & $2.14 \mathrm{E}-03$ \\
\hline & 3.5 & $2.35 \mathrm{E}-03$ & $2.56 \mathrm{E}-03$ & $2.68 \mathrm{E}-03$ & $2.76 \mathrm{E}-03$ & $2.94 \mathrm{E}-03$ & 3.09E-03 & 3.18E-03 & $3.23 \mathrm{E}-03$ & $3.28 \mathrm{E}-03$ \\
\hline
\end{tabular}

Table 159 Maximum deflection results for alpha 0.75 for slabs subjected to CHBDC axle 2 \& 3 loading (main bars parallel to traffic)

\begin{tabular}{|c|c|c|c|c|c|c|c|c|c|c|}
\hline & & \multicolumn{9}{|c|}{ Maximum Moment (kN.m) } \\
\hline \multirow{7}{*}{ 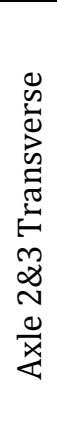 } & $\begin{array}{c}\mathrm{D} \\
\text { SPAN }\end{array}$ & 0.25 & 0.5 & 0.75 & 1 & 2 & 4 & 6 & 8 & 10 \\
\hline & 1.5 & $1.08 \mathrm{E}-04$ & $1.13 \mathrm{E}-04$ & $1.15 \mathrm{E}-04$ & 1.17E-04 & 1.19E-04 & 1.27E-04 & 1.33E-04 & $1.38 \mathrm{E}-04$ & $1.42 \mathrm{E}-04$ \\
\hline & 2 & $4.57 \mathrm{E}-04$ & $4.81 \mathrm{E}-04$ & $4.94 \mathrm{E}-04$ & $5.02 \mathrm{E}-04$ & $5.21 \mathrm{E}-04$ & $5.35 \mathrm{E}-04$ & $5.42 \mathrm{E}-04$ & $5.56 \mathrm{E}-04$ & $5.68 \mathrm{E}-04$ \\
\hline & 2.5 & $1.03 \mathrm{E}-03$ & $1.10 \mathrm{E}-03$ & $1.14 \mathrm{E}-03$ & $1.16 \mathrm{E}-03$ & $1.21 \mathrm{E}-03$ & $1.26 \mathrm{E}-03$ & $1.28 \mathrm{E}-03$ & $1.30 \mathrm{E}-03$ & $1.31 \mathrm{E}-03$ \\
\hline & 3 & $1.83 \mathrm{E}-03$ & $1.98 \mathrm{E}-03$ & $2.06 \mathrm{E}-03$ & $2.12 \mathrm{E}-03$ & $2.24 \mathrm{E}-03$ & $2.34 \mathrm{E}-03$ & $2.39 \mathrm{E}-03$ & $2.43 \mathrm{E}-03$ & $2.45 \mathrm{E}-03$ \\
\hline & 3.5 & $2.86 \mathrm{E}-03$ & $3.13 \mathrm{E}-03$ & $3.29 \mathrm{E}-03$ & $3.39 \mathrm{E}-03$ & $3.61 \mathrm{E}-03$ & $3.81 \mathrm{E}-03$ & $3.91 \mathrm{E}-03$ & $3.97 \mathrm{E}-03$ & $4.02 \mathrm{E}-03$ \\
\hline & 4 & $4.11 \mathrm{E}-03$ & $4.55 \mathrm{E}-03$ & $4.80 \mathrm{E}-03$ & $4.97 \mathrm{E}-03$ & $5.35 \mathrm{E}-03$ & $5.69 \mathrm{E}-03$ & $5.87 \mathrm{E}-03$ & $5.98 \mathrm{E}-03$ & $6.06 \mathrm{E}-03$ \\
\hline
\end{tabular}




\section{Alpha 1 Deflection Results}

Table 160 Maximum deflection results for alpha 1 for slabs subjected to CHBDC axle 4 loading (main bars perpendicular to traffic)

\begin{tabular}{|c|c|c|c|c|c|c|c|c|c|c|}
\hline & \multicolumn{9}{|c|}{ Maximum Moment (kN.m) } \\
\hline \multirow{9}{*}{$\frac{+}{\frac{d}{x}}$} & D & \multirow{2}{*}{0.25} & \multirow{2}{*}{0.5} & \multirow{2}{*}{0.75} & \multirow{2}{*}{1} & & \multirow{2}{*}{4} & \multirow{2}{*}{6} & \multirow{2}{*}{8} & \multirow{2}{*}{10} \\
\hline & SPAN & & & & & & & & & \\
\hline & 1 & $5.17 \mathrm{E}-05$ & $6.12 \mathrm{E}-05$ & $6.75 \mathrm{E}-05$ & $7.24 \mathrm{E}-05$ & $8.54 \mathrm{E}-05$ & $1.00 \mathrm{E}-04$ & $1.10 \mathrm{E}-04$ & $1.18 \mathrm{E}-04$ & $1.24 \mathrm{E}-04$ \\
\hline & 1.5 & $1.30 \mathrm{E}-04$ & $1.54 \mathrm{E}-04$ & $1.70 \mathrm{E}-04$ & $1.82 \mathrm{E}-04$ & $2.16 \mathrm{E}-04$ & $2.55 \mathrm{E}-04$ & $2.81 \mathrm{E}-04$ & $3.01 \mathrm{E}-04$ & $3.17 \mathrm{E}-04$ \\
\hline & 2 & $2.40 \mathrm{E}-04$ & $2.85 \mathrm{E}-04$ & $3.15 \mathrm{E}-04$ & $3.38 \mathrm{E}-04$ & $4.01 \mathrm{E}-04$ & $4.75 \mathrm{E}-04$ & $5.24 \mathrm{E}-04$ & $5.62 \mathrm{E}-04$ & $5.93 \mathrm{E}-04$ \\
\hline & 2.5 & $3.82 \mathrm{E}-04$ & $4.54 \mathrm{E}-04$ & $5.02 \mathrm{E}-04$ & $5.40 \mathrm{E}-04$ & $6.41 \mathrm{E}-04$ & $7.60 \mathrm{E}-04$ & 8.39E-04 & $9.00 \mathrm{E}-04$ & $9.51 \mathrm{E}-04$ \\
\hline & 3 & $5.99 \mathrm{E}-04$ & $7.12 \mathrm{E}-04$ & $7.88 \mathrm{E}-04$ & $8.47 \mathrm{E}-04$ & $1.01 \mathrm{E}-03$ & $1.20 \mathrm{E}-03$ & $1.32 \mathrm{E}-03$ & $1.42 \mathrm{E}-03$ & $1.50 \mathrm{E}-03$ \\
\hline & 3.5 & $9.74 \mathrm{E}-04$ & $1.16 \mathrm{E}-03$ & $1.28 \mathrm{E}-03$ & $1.38 \mathrm{E}-03$ & $1.64 \mathrm{E}-03$ & $1.94 \mathrm{E}-03$ & $2.15 \mathrm{E}-03$ & $2.31 \mathrm{E}-03$ & $2.44 \mathrm{E}-03$ \\
\hline & 4 & $1.42 \mathrm{E}-03$ & $1.69 \mathrm{E}-03$ & $1.87 \mathrm{E}-03$ & $2.01 \mathrm{E}-03$ & $2.38 \mathrm{E}-03$ & $2.83 \mathrm{E}-03$ & $3.13 E-03$ & $3.37 \mathrm{E}-03$ & $3.56 \mathrm{E}-03$ \\
\hline
\end{tabular}

Table 161 Maximum deflection results for alpha 1 for slabs subjected to CHBDC axle 2 \& 3 loading (main bars perpendicular to traffic)

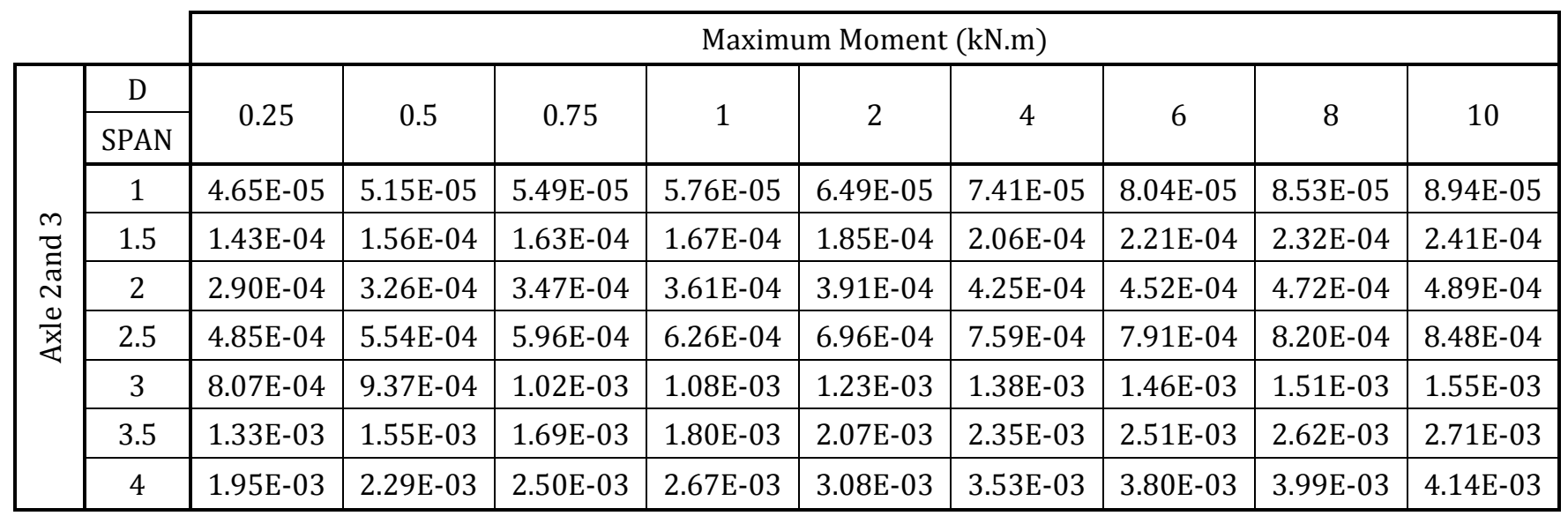

Table 162 Maximum deflection results for alpha 1 for slabs subjected to CHBDC truck loading (main bars perpendicular to traffic)

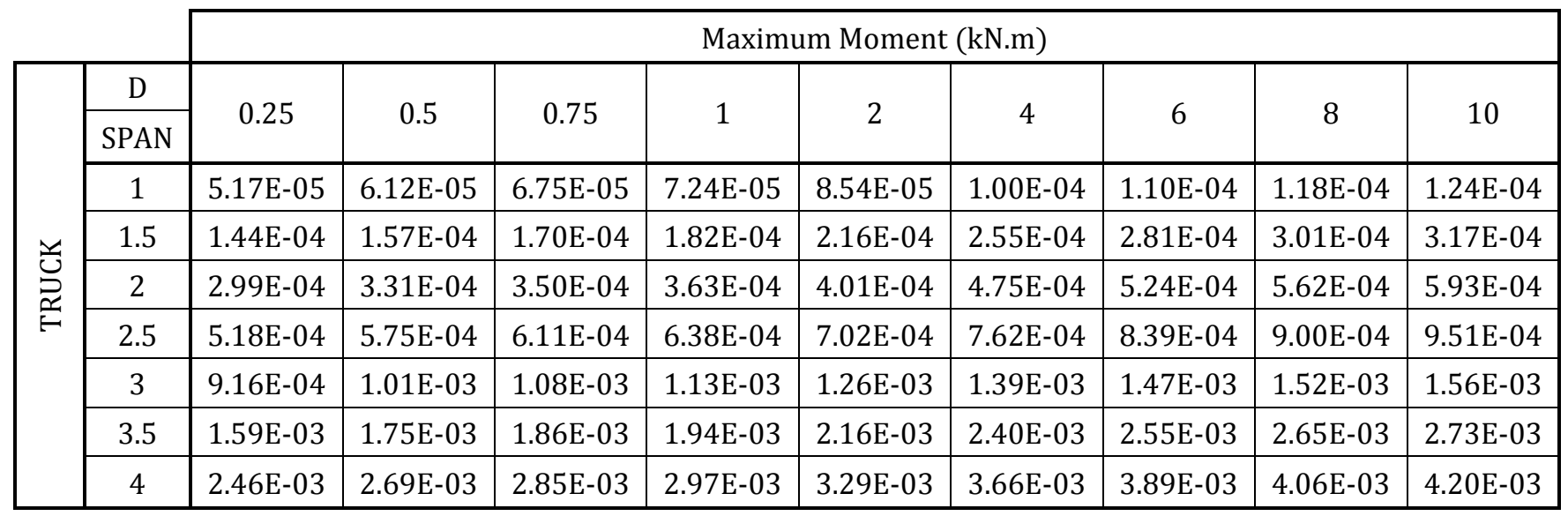


Table 163 Maximum deflection results for alpha 1 for slabs subjected to CHBDC axle 4 loading (main bars parallel to traffic)

\begin{tabular}{|c|c|c|c|c|c|c|c|c|c|c|}
\hline & & \multicolumn{9}{|c|}{ Maximum Moment (kN.m) } \\
\hline \multirow{8}{*}{ 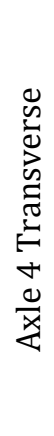 } & $\mathrm{D}$ & \multirow{2}{*}{0.25} & \multirow{2}{*}{0.5} & \multirow{2}{*}{0.75} & \multirow[t]{2}{*}{1} & \multirow[t]{2}{*}{2} & \multirow{2}{*}{4} & \multirow{2}{*}{6} & \multirow[t]{2}{*}{8} & \multirow{2}{*}{10} \\
\hline & SPAN & & & & & & & & & \\
\hline & 1 & $7.93 \mathrm{E}-05$ & $8.38 \mathrm{E}-05$ & $8.71 \mathrm{E}-05$ & 8.97E-05 & $9.71 \mathrm{E}-05$ & $1.06 \mathrm{E}-04$ & $1.12 \mathrm{E}-04$ & $1.17 \mathrm{E}-04$ & $1.20 \mathrm{E}-04$ \\
\hline & 1.5 & $2.44 \mathrm{E}-04$ & $2.56 \mathrm{E}-04$ & $2.63 \mathrm{E}-04$ & $2.68 \mathrm{E}-04$ & $2.82 \mathrm{E}-04$ & $3.01 \mathrm{E}-04$ & $3.14 \mathrm{E}-04$ & $3.24 \mathrm{E}-04$ & 3.33E-04 \\
\hline & 2 & $5.33 \mathrm{E}-04$ & $5.63 \mathrm{E}-04$ & $5.80 \mathrm{E}-04$ & $5.91 \mathrm{E}-04$ & $6.19 \mathrm{E}-04$ & $6.50 \mathrm{E}-04$ & $6.71 \mathrm{E}-04$ & $6.87 \mathrm{E}-04$ & $7.01 \mathrm{E}-04$ \\
\hline & 2.5 & $9.58 \mathrm{E}-04$ & $1.03 \mathrm{E}-03$ & $1.06 \mathrm{E}-03$ & $1.09 \mathrm{E}-03$ & $1.14 \mathrm{E}-03$ & $1.20 \mathrm{E}-03$ & $1.23 \mathrm{E}-03$ & $1.25 \mathrm{E}-03$ & $1.28 \mathrm{E}-03$ \\
\hline & 3 & $1.52 \mathrm{E}-03$ & $1.65 \mathrm{E}-03$ & $1.72 \mathrm{E}-03$ & $1.77 \mathrm{E}-03$ & $1.88 \mathrm{E}-03$ & $1.97 \mathrm{E}-03$ & 2.03E-03 & $2.07 \mathrm{E}-03$ & $2.10 \mathrm{E}-03$ \\
\hline & 3.5 & $2.23 \mathrm{E}-03$ & $2.44 \mathrm{E}-03$ & $2.56 \mathrm{E}-03$ & $2.65 \mathrm{E}-03$ & $2.83 \mathrm{E}-03$ & $3.00 \mathrm{E}-03$ & 3.09E-03 & $3.15 \mathrm{E}-03$ & $3.20 \mathrm{E}-03$ \\
\hline
\end{tabular}

Table 164 Maximum deflection results for alpha 1 for slabs subjected to CHBDC axle 2 \& 3 loading (main bars parallel to traffic)

\begin{tabular}{|c|c|c|c|c|c|c|c|c|c|c|}
\hline & & \multicolumn{9}{|c|}{ Maximum Moment (kN.m) } \\
\hline \multirow{8}{*}{ 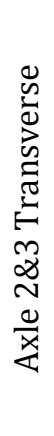 } & $\mathrm{D}$ & \multirow{2}{*}{0.25} & \multirow{2}{*}{0.5} & \multirow{2}{*}{0.75} & \multirow{2}{*}{1} & & \multirow{2}{*}{4} & \multirow{2}{*}{5} & \multirow[b]{2}{*}{0} & \multirow{2}{*}{10} \\
\hline & SPAN & & & & & & & & & \\
\hline & 1.5 & $1.05 \mathrm{E}-04$ & $1.10 \mathrm{E}-04$ & $1.12 \mathrm{E}-04$ & $1.14 \mathrm{E}-04$ & $1.17 \mathrm{E}-04$ & $1.24 \mathrm{E}-04$ & $1.29 \mathrm{E}-04$ & $1.34 \mathrm{E}-04$ & $1.38 \mathrm{E}-04$ \\
\hline & 2 & $4.40 \mathrm{E}-04$ & $4.66 \mathrm{E}-04$ & $4.80 \mathrm{E}-04$ & $4.89 \mathrm{E}-04$ & $5.09 \mathrm{E}-04$ & $5.23 \mathrm{E}-04$ & $5.33 \mathrm{E}-04$ & $5.46 \mathrm{E}-04$ & $5.57 \mathrm{E}-04$ \\
\hline & 2.5 & $9.84 \mathrm{E}-04$ & $1.06 \mathrm{E}-03$ & $1.10 \mathrm{E}-03$ & $1.12 \mathrm{E}-03$ & $1.18 \mathrm{E}-03$ & $1.23 \mathrm{E}-03$ & $1.25 \mathrm{E}-03$ & $1.27 \mathrm{E}-03$ & $1.28 \mathrm{E}-03$ \\
\hline & 3 & $1.74 \mathrm{E}-03$ & $1.89 \mathrm{E}-03$ & $1.98 \mathrm{E}-03$ & $2.04 \mathrm{E}-03$ & $2.16 \mathrm{E}-03$ & $2.27 \mathrm{E}-03$ & $2.33 \mathrm{E}-03$ & $2.37 \mathrm{E}-03$ & $2.39 \mathrm{E}-03$ \\
\hline & 3.5 & 2.71E-03 & $2.98 \mathrm{E}-03$ & 3.13E-03 & $3.24 \mathrm{E}-03$ & $3.48 \mathrm{E}-03$ & $3.69 \mathrm{E}-03$ & $3.80 \mathrm{E}-03$ & $3.87 E-03$ & $3.92 \mathrm{E}-03$ \\
\hline & 4 & $3.88 \mathrm{E}-03$ & $4.31 \mathrm{E}-03$ & $4.56 \mathrm{E}-03$ & $4.73 \mathrm{E}-03$ & $5.13 \mathrm{E}-03$ & $5.49 \mathrm{E}-03$ & $5.67 \mathrm{E}-03$ & $5.80 \mathrm{E}-03$ & $5.89 \mathrm{E}-03$ \\
\hline
\end{tabular}




\section{Alpha 2 Deflection Results}

Table 165 Maximum deflection results for alpha 2 for slabs subjected to CHBDC axle 4 loading (main bars perpendicular to traffic)

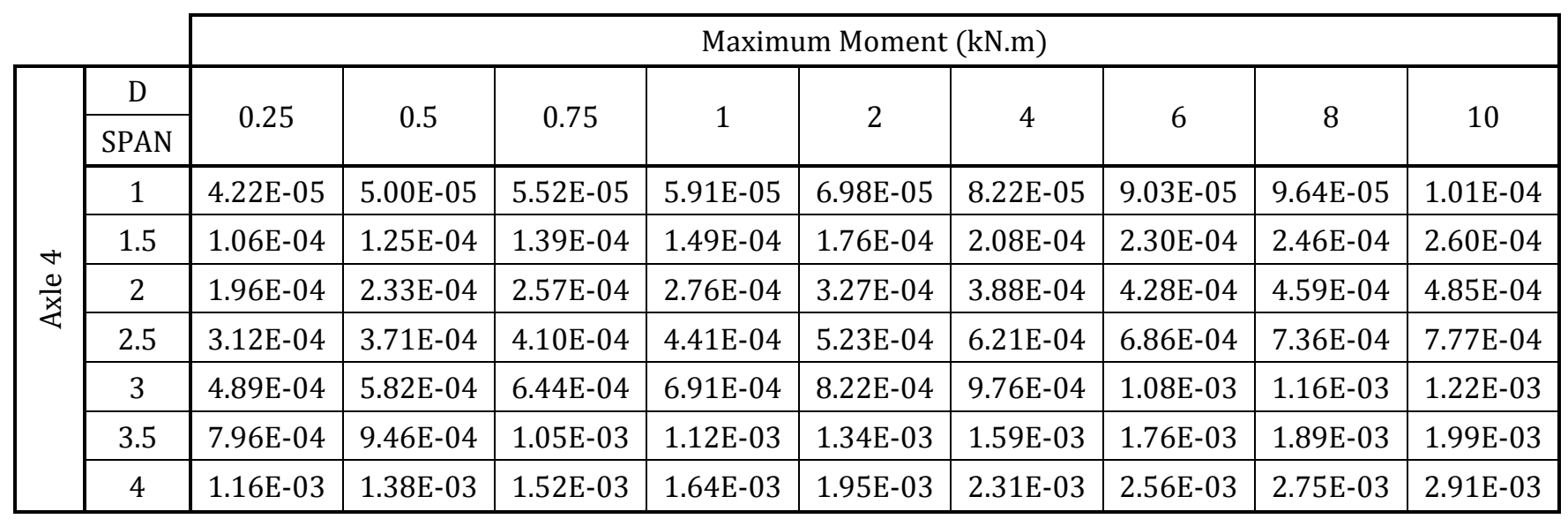

Table 166 Maximum deflection results for alpha 2 for slabs subjected to CHBDC axle 2 \& 3 loading (main bars perpendicular to traffic)

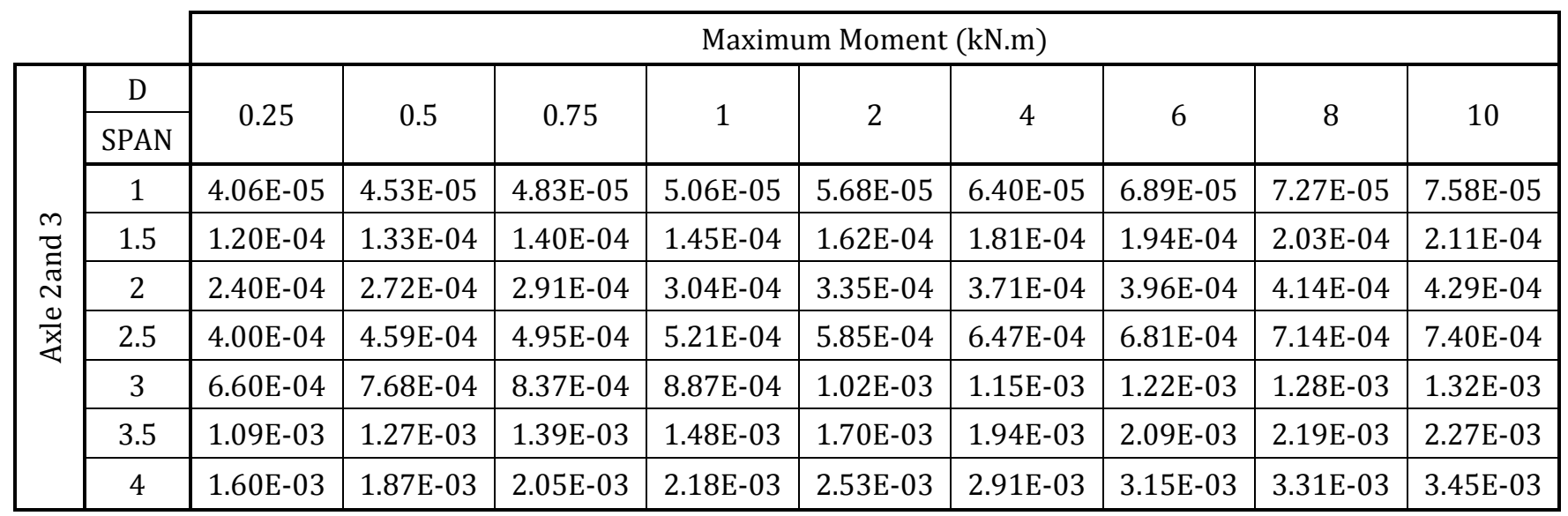

Table 167 Maximum deflection results for alpha 2 for slabs subjected to CHBDC truck loading (main bars perpendicular to traffic)

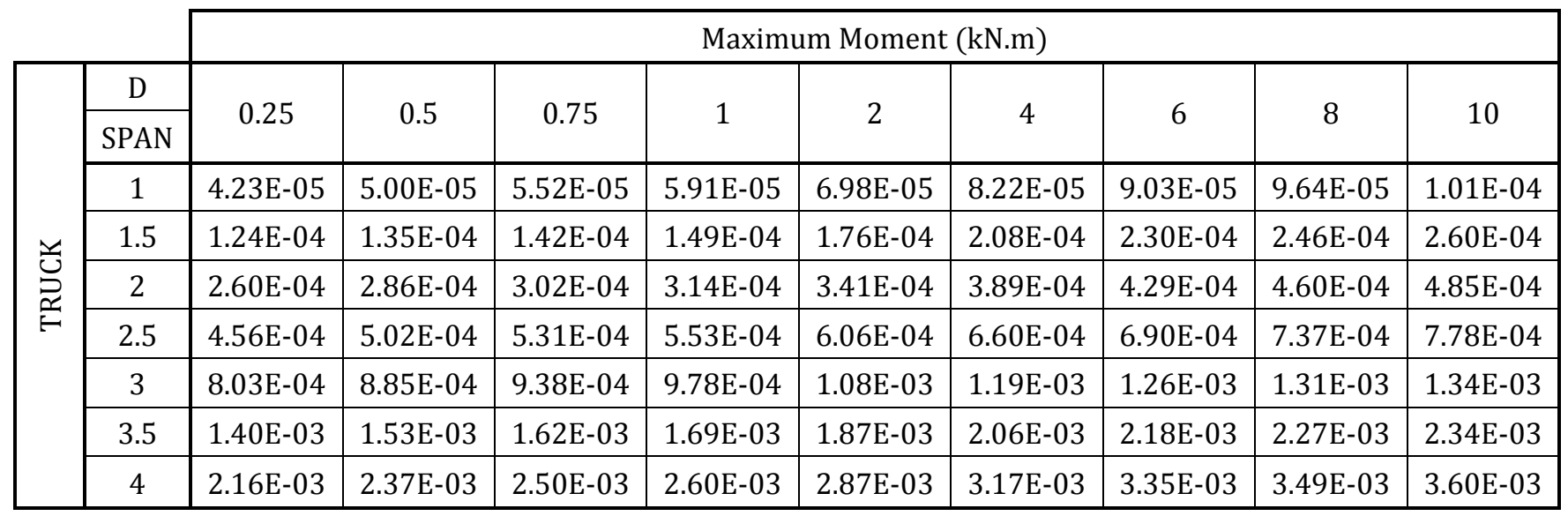


Table 168 Maximum deflection results for alpha 2 for slabs subjected to CHBDC axle 4 loading (main bars parallel to traffic)

\begin{tabular}{|c|c|c|c|c|c|c|c|c|c|c|}
\hline & & \multicolumn{9}{|c|}{ Maximum Moment (kN.m) } \\
\hline \multirow{8}{*}{ 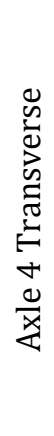 } & $\mathrm{D}$ & \multirow{2}{*}{0.25} & \multirow{2}{*}{0.5} & \multirow{2}{*}{0.75} & \multirow[t]{2}{*}{1} & \multirow[t]{2}{*}{2} & \multirow{2}{*}{4} & \multirow{2}{*}{6} & \multirow[t]{2}{*}{8} & \multirow{2}{*}{10} \\
\hline & SPAN & & & & & & & & & \\
\hline & 1 & $7.45 \mathrm{E}-05$ & $7.88 \mathrm{E}-05$ & $8.15 \mathrm{E}-05$ & $8.35 \mathrm{E}-05$ & $8.91 \mathrm{E}-05$ & $9.58 \mathrm{E}-05$ & $1.00 \mathrm{E}-04$ & $1.04 \mathrm{E}-04$ & $1.06 \mathrm{E}-04$ \\
\hline & 1.5 & $2.24 \mathrm{E}-04$ & $2.38 \mathrm{E}-04$ & $2.46 \mathrm{E}-04$ & $2.51 \mathrm{E}-04$ & $2.65 \mathrm{E}-04$ & $2.81 \mathrm{E}-04$ & $2.91 \mathrm{E}-04$ & $2.99 \mathrm{E}-04$ & $3.06 \mathrm{E}-04$ \\
\hline & 2 & $4.76 \mathrm{E}-04$ & $5.12 \mathrm{E}-04$ & $5.32 \mathrm{E}-04$ & $5.46 \mathrm{E}-04$ & $5.78 \mathrm{E}-04$ & $6.11 \mathrm{E}-04$ & $6.31 \mathrm{E}-04$ & $6.45 \mathrm{E}-04$ & $6.57 \mathrm{E}-04$ \\
\hline & 2.5 & 8.37E-04 & $9.12 \mathrm{E}-04$ & $9.54 \mathrm{E}-04$ & $9.83 \mathrm{E}-04$ & $1.05 \mathrm{E}-03$ & $1.11 \mathrm{E}-03$ & $1.15 \mathrm{E}-03$ & $1.18 \mathrm{E}-03$ & $1.20 \mathrm{E}-03$ \\
\hline & 3 & $1.31 \mathrm{E}-03$ & $1.44 \mathrm{E}-03$ & $1.52 \mathrm{E}-03$ & $1.57 \mathrm{E}-03$ & $1.69 \mathrm{E}-03$ & $1.81 \mathrm{E}-03$ & $1.88 \mathrm{E}-03$ & $1.92 \mathrm{E}-03$ & $1.96 \mathrm{E}-03$ \\
\hline & 3.5 & $1.89 \mathrm{E}-03$ & $2.10 \mathrm{E}-03$ & 2.23E-03 & $2.31 \mathrm{E}-03$ & $2.52 \mathrm{E}-03$ & $2.72 \mathrm{E}-03$ & $2.82 \mathrm{E}-03$ & $2.90 \mathrm{E}-03$ & $2.96 \mathrm{E}-03$ \\
\hline
\end{tabular}

Table 169 Maximum deflection results for alpha 2 for slabs subjected to CHBDC axle 2 \& 3 loading (main bars parallel to traffic)

\begin{tabular}{|c|c|c|c|c|c|c|c|c|c|c|}
\hline & & \multicolumn{9}{|c|}{ Maximum Moment (kN.m) } \\
\hline \multirow{8}{*}{ 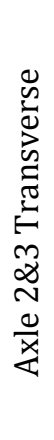 } & $\mathrm{D}$ & \multirow{2}{*}{0.25} & \multirow{2}{*}{0.5} & \multirow{2}{*}{0.75} & \multirow{2}{*}{1} & & \multirow{2}{*}{4} & \multirow{2}{*}{6} & \multirow[b]{2}{*}{0} & \multirow{2}{*}{10} \\
\hline & SPAN & & & & & & & & & \\
\hline & 1.5 & $9.58 \mathrm{E}-05$ & $1.01 \mathrm{E}-04$ & $1.04 \mathrm{E}-04$ & $1.06 \mathrm{E}-04$ & $1.10 \mathrm{E}-04$ & $1.16 \mathrm{E}-04$ & $1.21 \mathrm{E}-04$ & $1.24 \mathrm{E}-04$ & $1.27 \mathrm{E}-04$ \\
\hline & 2 & $3.90 \mathrm{E}-04$ & $4.20 \mathrm{E}-04$ & $4.36 \mathrm{E}-04$ & 4.47E-04 & $4.71 \mathrm{E}-04$ & $4.89 \mathrm{E}-04$ & $5.03 \mathrm{E}-04$ & $5.14 \mathrm{E}-04$ & $5.24 \mathrm{E}-04$ \\
\hline & 2.5 & $8.54 \mathrm{E}-04$ & $9.33 \mathrm{E}-04$ & $9.78 \mathrm{E}-04$ & $1.01 \mathrm{E}-03$ & $1.08 \mathrm{E}-03$ & $1.14 \mathrm{E}-03$ & $1.17 \mathrm{E}-03$ & $1.18 \mathrm{E}-03$ & $1.20 \mathrm{E}-03$ \\
\hline & 3 & $1.49 \mathrm{E}-03$ & $1.64 \mathrm{E}-03$ & $1.73 \mathrm{E}-03$ & $1.80 \mathrm{E}-03$ & $1.94 \mathrm{E}-03$ & 2.07E-03 & $2.14 \mathrm{E}-03$ & $2.19 \mathrm{E}-03$ & $2.22 \mathrm{E}-03$ \\
\hline & 3.5 & $2.29 \mathrm{E}-03$ & $2.55 \mathrm{E}-03$ & $2.71 \mathrm{E}-03$ & $2.82 \mathrm{E}-03$ & 3.07E-03 & $3.32 \mathrm{E}-03$ & $3.45 \mathrm{E}-03$ & 3.53E-03 & $3.60 \mathrm{E}-03$ \\
\hline & 4 & $3.25 \mathrm{E}-03$ & $3.66 \mathrm{E}-03$ & $3.90 \mathrm{E}-03$ & $4.07 \mathrm{E}-03$ & $4.48 \mathrm{E}-03$ & 4.87E-03 & $5.09 \mathrm{E}-03$ & $5.24 \mathrm{E}-03$ & $5.35 \mathrm{E}-03$ \\
\hline
\end{tabular}




\section{Alpha 4 Deflection Results}

Table 170 Maximum deflection results for alpha 4 for slabs subjected to CHBDC axle 4 loading (main bars perpendicular to traffic)

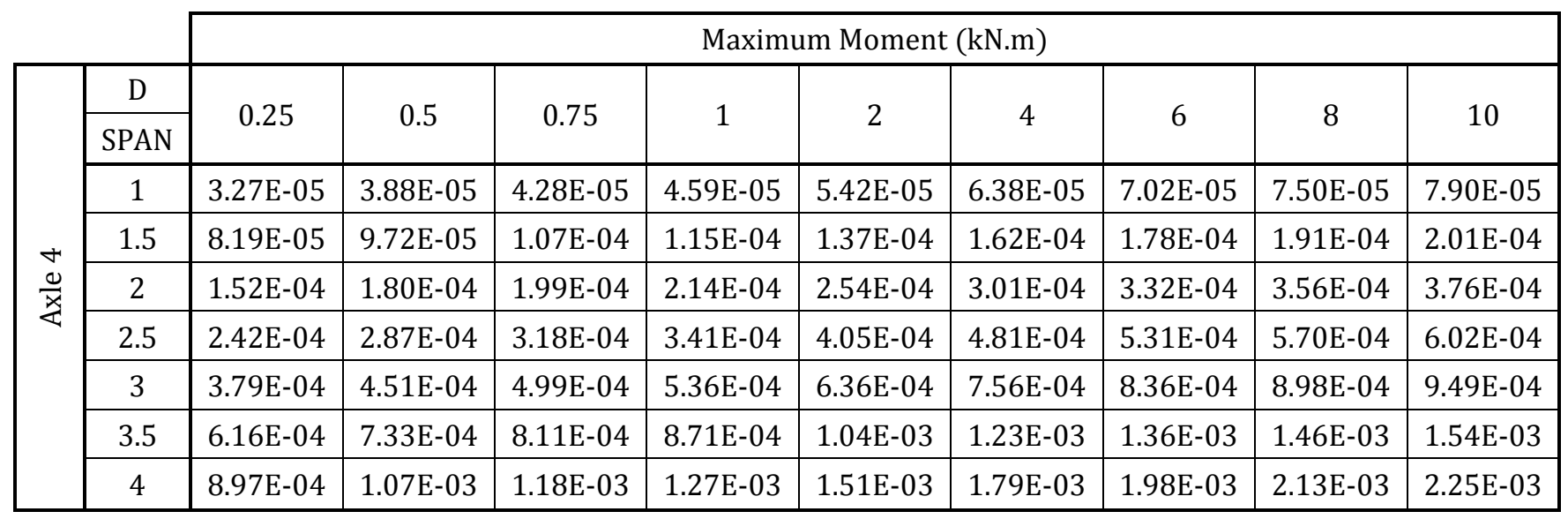

Table 171 Maximum deflection results for alpha 4 for slabs subjected to CHBDC axle 2 \& 3 loading (main bars perpendicular to traffic)

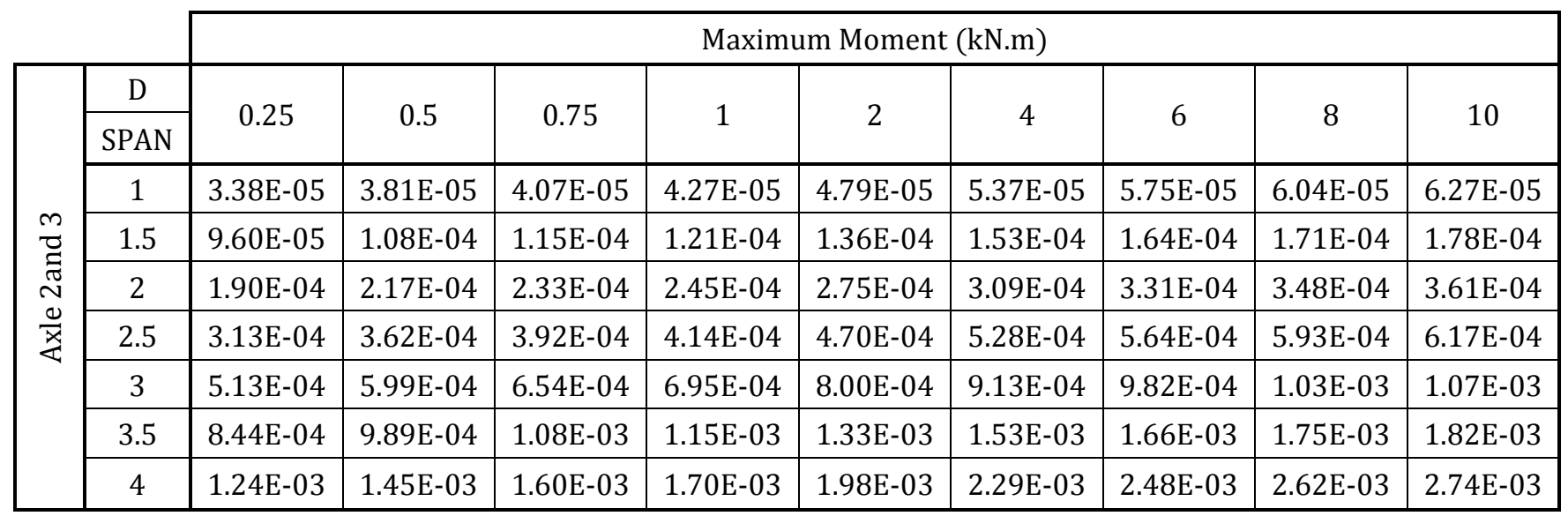

Table 172 Maximum deflection results for alpha 4 for slabs subjected to CHBDC truck loading (main bars perpendicular to traffic)

\begin{tabular}{|c|c|c|c|c|c|c|c|c|c|c|}
\hline & \multicolumn{9}{|c|}{ Maximum Moment (kN.m) } \\
\hline \multirow{9}{*}{ 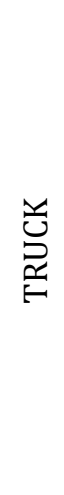 } & $\mathrm{D}$ & \multirow{2}{*}{0.25} & \multirow{2}{*}{0.5} & \multirow{2}{*}{0.75} & \multirow[b]{2}{*}{1} & \multirow{2}{*}{2} & \multirow{2}{*}{4} & \multirow{2}{*}{6} & \multirow{2}{*}{8} & \multirow{2}{*}{10} \\
\hline & SPAN & & & & & & & & & \\
\hline & 1 & $3.45 E-05$ & $3.89 \mathrm{E}-05$ & $4.29 \mathrm{E}-05$ & $4.59 \mathrm{E}-05$ & $5.42 \mathrm{E}-05$ & $6.38 \mathrm{E}-05$ & $7.02 \mathrm{E}-05$ & $7.50 \mathrm{E}-05$ & $7.90 \mathrm{E}-05$ \\
\hline & 1.5 & $1.05 \mathrm{E}-04$ & $1.15 \mathrm{E}-04$ & $1.20 \mathrm{E}-04$ & $1.24 \mathrm{E}-04$ & $1.37 \mathrm{E}-04$ & $1.62 \mathrm{E}-04$ & $1.78 \mathrm{E}-04$ & $1.91 \mathrm{E}-04$ & $2.02 \mathrm{E}-04$ \\
\hline & 2 & $2.22 \mathrm{E}-04$ & $2.43 \mathrm{E}-04$ & $2.56 \mathrm{E}-04$ & $2.65 \mathrm{E}-04$ & $2.89 \mathrm{E}-04$ & $3.13 \mathrm{E}-04$ & $3.34 \mathrm{E}-04$ & $3.58 \mathrm{E}-04$ & $3.77 \mathrm{E}-04$ \\
\hline & 2.5 & $3.93 \mathrm{E}-04$ & $4.29 \mathrm{E}-04$ & $4.53 \mathrm{E}-04$ & $4.70 \mathrm{E}-04$ & $5.13 \mathrm{E}-04$ & $5.59 \mathrm{E}-04$ & $5.87 \mathrm{E}-04$ & $6.07 \mathrm{E}-04$ & $6.22 \mathrm{E}-04$ \\
\hline & 3 & $6.93 \mathrm{E}-04$ & $7.60 \mathrm{E}-04$ & $8.02 \mathrm{E}-04$ & 8.33E-04 & $9.14 \mathrm{E}-04$ & $1.00 \mathrm{E}-03$ & $1.06 \mathrm{E}-03$ & $1.10 \mathrm{E}-03$ & 1.13E-03 \\
\hline & 3.5 & $1.21 \mathrm{E}-03$ & $1.32 \mathrm{E}-03$ & $1.40 \mathrm{E}-03$ & $1.45 \mathrm{E}-03$ & $1.59 \mathrm{E}-03$ & $1.74 \mathrm{E}-03$ & $1.84 \mathrm{E}-03$ & $1.91 \mathrm{E}-03$ & $1.97 \mathrm{E}-03$ \\
\hline & 4 & $1.86 \mathrm{E}-03$ & $2.04 \mathrm{E}-03$ & $2.16 \mathrm{E}-03$ & $2.24 \mathrm{E}-03$ & $2.46 \mathrm{E}-03$ & $2.69 \mathrm{E}-03$ & $2.84 \mathrm{E}-03$ & $2.95 \mathrm{E}-03$ & $3.04 \mathrm{E}-03$ \\
\hline
\end{tabular}


Table 173 Maximum deflection results for alpha 4 for slabs subjected to CHBDC axle 4 loading (main bars parallel to traffic)

\begin{tabular}{|c|c|c|c|c|c|c|c|c|c|c|}
\hline & & \multicolumn{9}{|c|}{ Maximum Moment (kN.m) } \\
\hline \multirow{8}{*}{ 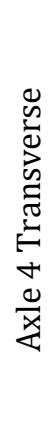 } & $\mathrm{D}$ & \multirow{2}{*}{0.25} & \multirow{2}{*}{0.5} & \multirow{2}{*}{0.75} & \multirow{2}{*}{1} & \multirow[t]{2}{*}{2} & \multirow{2}{*}{4} & \multirow{2}{*}{6} & \multirow[t]{2}{*}{8} & \multirow{2}{*}{10} \\
\hline & SPAN & & & & & & & & & \\
\hline & 1 & $6.79 \mathrm{E}-05$ & 7.22E-05 & $7.47 \mathrm{E}-05$ & $7.66 \mathrm{E}-05$ & $8.11 \mathrm{E}-05$ & $8.61 \mathrm{E}-05$ & $8.93 \mathrm{E}-05$ & $9.18 \mathrm{E}-05$ & $9.38 \mathrm{E}-05$ \\
\hline & 1.5 & $1.97 \mathrm{E}-04$ & 2.13E-04 & $2.22 \mathrm{E}-04$ & $2.28 \mathrm{E}-04$ & $2.43 \mathrm{E}-04$ & $2.58 \mathrm{E}-04$ & $2.67 \mathrm{E}-04$ & $2.73 \mathrm{E}-04$ & $2.78 \mathrm{E}-04$ \\
\hline & 2 & $4.07 \mathrm{E}-04$ & $4.46 \mathrm{E}-04$ & $4.68 \mathrm{E}-04$ & $4.84 \mathrm{E}-04$ & $5.21 \mathrm{E}-04$ & $5.57 \mathrm{E}-04$ & $5.77 \mathrm{E}-04$ & $5.92 \mathrm{E}-04$ & $6.03 \mathrm{E}-04$ \\
\hline & 2.5 & $6.99 \mathrm{E}-04$ & $7.75 \mathrm{E}-04$ & $8.20 \mathrm{E}-04$ & $8.51 \mathrm{E}-04$ & $9.26 \mathrm{E}-04$ & $1.00 \mathrm{E}-03$ & $1.04 \mathrm{E}-03$ & $1.07 \mathrm{E}-03$ & $1.09 \mathrm{E}-03$ \\
\hline & 3 & $1.08 \mathrm{E}-03$ & $1.20 \mathrm{E}-03$ & $1.28 \mathrm{E}-03$ & $1.33 \mathrm{E}-03$ & $1.47 \mathrm{E}-03$ & $1.60 \mathrm{E}-03$ & $1.67 \mathrm{E}-03$ & $1.72 \mathrm{E}-03$ & $1.76 \mathrm{E}-03$ \\
\hline & 3.5 & $1.54 \mathrm{E}-03$ & $1.73 \mathrm{E}-03$ & $1.85 \mathrm{E}-03$ & $1.94 \mathrm{E}-03$ & $2.14 \mathrm{E}-03$ & $2.35 \mathrm{E}-03$ & $2.48 \mathrm{E}-03$ & $2.56 \mathrm{E}-03$ & 2.63E-03 \\
\hline
\end{tabular}

Table 174 Maximum deflection results for alpha 4 for slabs subjected to CHBDC axle 2 \& 3 loading (main bars parallel to traffic)

\begin{tabular}{|c|c|c|c|c|c|c|c|c|c|c|}
\hline & & \multicolumn{9}{|c|}{ Maximum Moment (kN.m) } \\
\hline \multirow{8}{*}{ 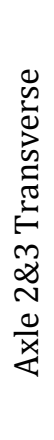 } & $\mathrm{D}$ & \multirow{2}{*}{0.25} & \multirow{2}{*}{0.5} & \multirow{2}{*}{0.75} & \multirow[b]{2}{*}{1} & & \multirow{2}{*}{4} & \multirow{2}{*}{6} & \multirow[b]{2}{*}{0} & \multirow{2}{*}{10} \\
\hline & SPAN & & & & & & & & & \\
\hline & 1.5 & $8.36 \mathrm{E}-05$ & $9.00 \mathrm{E}-05$ & $9.34 \mathrm{E}-05$ & $9.57 \mathrm{E}-05$ & $1.01 \mathrm{E}-04$ & $1.07 \mathrm{E}-04$ & $1.11 \mathrm{E}-04$ & $1.13 \mathrm{E}-04$ & $1.16 \mathrm{E}-04$ \\
\hline & 2 & $3.30 \mathrm{E}-04$ & $3.62 \mathrm{E}-04$ & $3.80 \mathrm{E}-04$ & $3.93 \mathrm{E}-04$ & $4.21 \mathrm{E}-04$ & $4.46 \mathrm{E}-04$ & $4.62 \mathrm{E}-04$ & $4.73 \mathrm{E}-04$ & $4.82 \mathrm{E}-04$ \\
\hline & 2.5 & $7.08 \mathrm{E}-04$ & 7.87E-04 & 8.33E-04 & $8.65 \mathrm{E}-04$ & $9.41 \mathrm{E}-04$ & $1.01 \mathrm{E}-03$ & $1.05 \mathrm{E}-03$ & $1.07 \mathrm{E}-03$ & $1.09 \mathrm{E}-03$ \\
\hline & 3 & $1.21 \mathrm{E}-03$ & $1.36 \mathrm{E}-03$ & $1.45 \mathrm{E}-03$ & $1.51 \mathrm{E}-03$ & $1.67 \mathrm{E}-03$ & $1.81 \mathrm{E}-03$ & $1.89 \mathrm{E}-03$ & $1.95 \mathrm{E}-03$ & $1.99 \mathrm{E}-03$ \\
\hline & 3.5 & $1.85 \mathrm{E}-03$ & $2.09 \mathrm{E}-03$ & $2.24 \mathrm{E}-03$ & $2.34 \mathrm{E}-03$ & $2.60 \mathrm{E}-03$ & $2.85 \mathrm{E}-03$ & $3.00 \mathrm{E}-03$ & $3.10 \mathrm{E}-03$ & $3.17 \mathrm{E}-03$ \\
\hline & 4 & $2.61 \mathrm{E}-03$ & $2.96 \mathrm{E}-03$ & $3.18 \mathrm{E}-03$ & $3.34 \mathrm{E}-03$ & $3.74 \mathrm{E}-03$ & 4.14E-03 & 4.37E-03 & $4.53 \mathrm{E}-03$ & $4.65 \mathrm{E}-03$ \\
\hline
\end{tabular}




\section{Alpha 6 Deflection Results}

Table 175 Maximum deflection results for alpha 6 for slabs subjected to CHBDC axle 4 loading (main bars perpendicular to traffic)

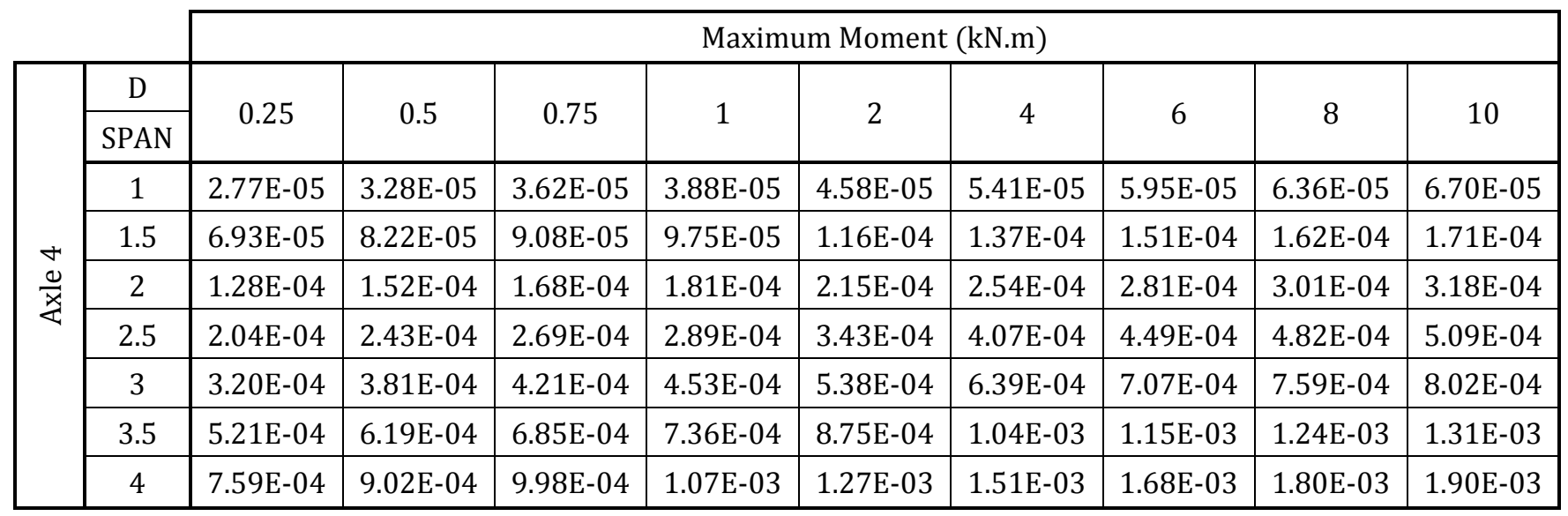

Table 176 Maximum deflection results for alpha 6 for slabs subjected to CHBDC axle 2 \& 3 loading (main bars perpendicular to traffic)

\begin{tabular}{|c|c|c|c|c|c|c|c|c|c|c|}
\hline & \multicolumn{9}{|c|}{ Maximum Moment (kN.m) } \\
\hline \multirow{9}{*}{ 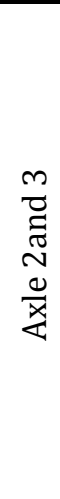 } & $\mathrm{D}$ & \multirow{2}{*}{0.25} & \multirow{2}{*}{0.5} & \multirow{2}{*}{0.75} & \multirow[b]{2}{*}{1} & & \multirow{2}{*}{4} & \multirow{2}{*}{6} & & \multirow{2}{*}{10} \\
\hline & SPAN & & & & & & & & & \\
\hline & 1 & $2.98 \mathrm{E}-05$ & $3.37 \mathrm{E}-05$ & $3.62 \mathrm{E}-05$ & $3.80 \mathrm{E}-05$ & $4.27 \mathrm{E}-05$ & $4.79 \mathrm{E}-05$ & $5.12 \mathrm{E}-05$ & $5.37 \mathrm{E}-05$ & $5.57 \mathrm{E}-05$ \\
\hline & 1.5 & 8.29E-05 & $9.40 \mathrm{E}-05$ & $1.01 \mathrm{E}-04$ & $1.06 \mathrm{E}-04$ & $1.20 \mathrm{E}-04$ & $1.36 \mathrm{E}-04$ & $1.46 \mathrm{E}-04$ & $1.53 \mathrm{E}-04$ & $1.59 \mathrm{E}-04$ \\
\hline & 2 & $1.62 \mathrm{E}-04$ & $1.86 \mathrm{E}-04$ & $2.01 \mathrm{E}-04$ & $2.13 \mathrm{E}-04$ & $2.40 \mathrm{E}-04$ & $2.72 \mathrm{E}-04$ & $2.93 \mathrm{E}-04$ & $3.08 \mathrm{E}-04$ & $3.21 \mathrm{E}-04$ \\
\hline & 2.5 & $2.67 \mathrm{E}-04$ & $3.09 \mathrm{E}-04$ & $3.36 \mathrm{E}-04$ & $3.56 \mathrm{E}-04$ & $4.07 \mathrm{E}-04$ & $4.61 \mathrm{E}-04$ & $4.95 \mathrm{E}-04$ & $5.22 \mathrm{E}-04$ & $5.44 \mathrm{E}-04$ \\
\hline & 3 & $4.35 \mathrm{E}-04$ & $5.09 \mathrm{E}-04$ & $5.56 \mathrm{E}-04$ & $5.91 \mathrm{E}-04$ & $6.84 \mathrm{E}-04$ & $7.85 \mathrm{E}-04$ & $8.48 \mathrm{E}-04$ & $8.94 \mathrm{E}-04$ & $9.30 \mathrm{E}-04$ \\
\hline & 3.5 & 7.15E-04 & 8.38E-04 & $9.18 \mathrm{E}-04$ & $9.79 \mathrm{E}-04$ & $1.14 \mathrm{E}-03$ & $1.31 \mathrm{E}-03$ & $1.42 \mathrm{E}-03$ & $1.51 \mathrm{E}-03$ & $1.57 \mathrm{E}-03$ \\
\hline & 4 & $1.05 \mathrm{E}-03$ & $1.23 \mathrm{E}-03$ & $1.35 \mathrm{E}-03$ & $1.44 \mathrm{E}-03$ & $1.68 \mathrm{E}-03$ & $1.95 \mathrm{E}-03$ & $2.12 \mathrm{E}-03$ & $2.25 \mathrm{E}-03$ & $2.35 \mathrm{E}-03$ \\
\hline
\end{tabular}

Table 177 Maximum deflection results for alpha 6 for slabs subjected to CHBDC truck loading (main bars perpendicular to traffic)

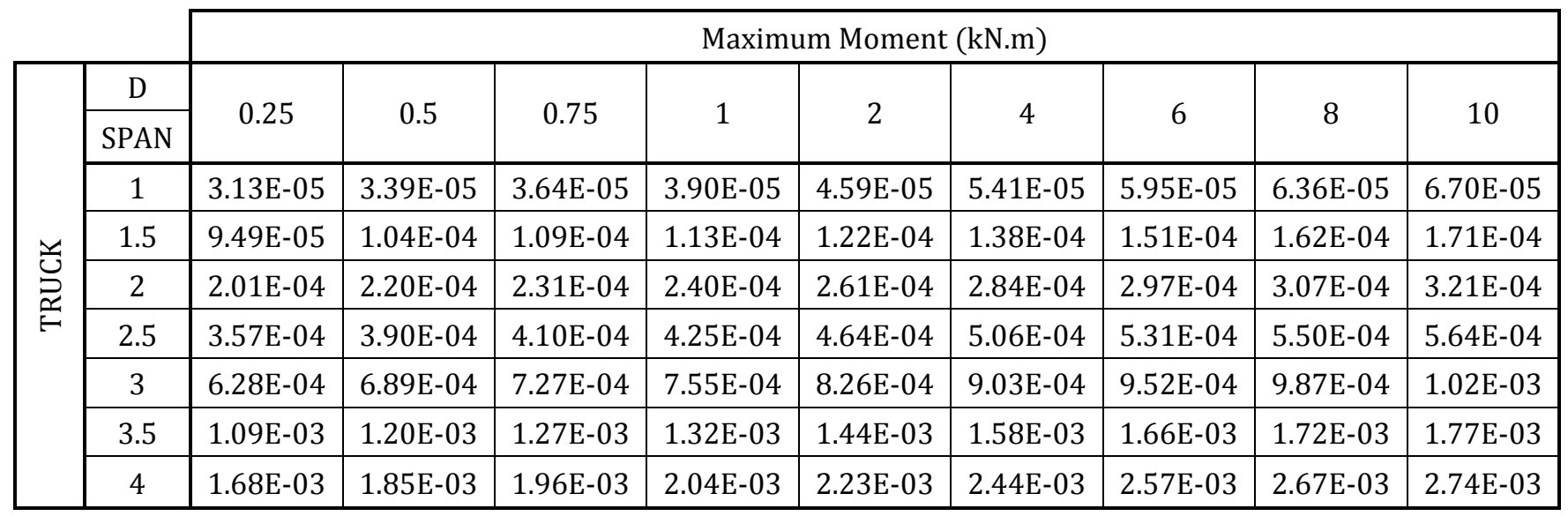


Table 178 Maximum deflection results for alpha 6 for slabs subjected to CHBDC axle 4 loading (main bars parallel to traffic)

\begin{tabular}{|c|c|c|c|c|c|c|c|c|c|c|}
\hline & & \multicolumn{9}{|c|}{ Maximum Moment (kN.m) } \\
\hline \multirow{8}{*}{ 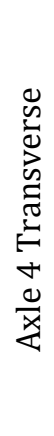 } & $\mathrm{D}$ & \multirow{2}{*}{0.25} & \multirow{2}{*}{0.5} & \multirow{2}{*}{0.75} & \multirow{2}{*}{1} & \multirow[t]{2}{*}{2} & \multirow{2}{*}{4} & \multirow{2}{*}{6} & \multirow[t]{2}{*}{8} & \multirow{2}{*}{10} \\
\hline & SPAN & & & & & & & & & \\
\hline & 1 & $6.33 \mathrm{E}-05$ & $6.77 \mathrm{E}-05$ & 7.03E-05 & $7.21 \mathrm{E}-05$ & $7.64 \mathrm{E}-05$ & $8.10 \mathrm{E}-05$ & $8.38 \mathrm{E}-05$ & $8.59 \mathrm{E}-05$ & $8.76 \mathrm{E}-05$ \\
\hline & 1.5 & $1.80 \mathrm{E}-04$ & $1.96 \mathrm{E}-04$ & $2.05 \mathrm{E}-04$ & $2.12 \mathrm{E}-04$ & $2.27 \mathrm{E}-04$ & $2.43 \mathrm{E}-04$ & $2.51 \mathrm{E}-04$ & $2.57 \mathrm{E}-04$ & $2.62 \mathrm{E}-04$ \\
\hline & 2 & $3.64 \mathrm{E}-04$ & $4.03 \mathrm{E}-04$ & $4.26 \mathrm{E}-04$ & $4.42 \mathrm{E}-04$ & $4.81 \mathrm{E}-04$ & $5.18 \mathrm{E}-04$ & $5.40 \mathrm{E}-04$ & $5.55 \mathrm{E}-04$ & $5.67 \mathrm{E}-04$ \\
\hline & 2.5 & $6.18 \mathrm{E}-04$ & $6.91 \mathrm{E}-04$ & $7.35 \mathrm{E}-04$ & 7.67E-04 & $8.44 \mathrm{E}-04$ & $9.20 \mathrm{E}-04$ & $9.64 \mathrm{E}-04$ & $9.94 \mathrm{E}-04$ & $1.02 \mathrm{E}-03$ \\
\hline & 3 & $9.42 \mathrm{E}-04$ & $1.06 \mathrm{E}-03$ & $1.14 \mathrm{E}-03$ & $1.19 \mathrm{E}-03$ & $1.32 \mathrm{E}-03$ & $1.45 \mathrm{E}-03$ & $1.53 \mathrm{E}-03$ & $1.59 \mathrm{E}-03$ & $1.63 \mathrm{E}-03$ \\
\hline & 3.5 & $1.34 \mathrm{E}-03$ & $1.52 \mathrm{E}-03$ & $1.63 \mathrm{E}-03$ & $1.71 \mathrm{E}-03$ & $1.91 \mathrm{E}-03$ & $2.12 \mathrm{E}-03$ & $2.25 \mathrm{E}-03$ & 2.33E-03 & $2.40 \mathrm{E}-03$ \\
\hline
\end{tabular}

Table 179 Maximum deflection results for alpha 6 for slabs subjected to CHBDC axle 2 \& 3 loading (main bars parallel to traffic)

\begin{tabular}{|c|c|c|c|c|c|c|c|c|c|c|}
\hline & & \multicolumn{9}{|c|}{ Maximum Moment (kN.m) } \\
\hline \multirow{8}{*}{ 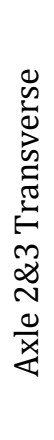 } & $\mathrm{D}$ & \multirow{2}{*}{0.25} & \multirow{2}{*}{0.5} & \multirow{2}{*}{0.75} & \multirow[b]{2}{*}{1} & & \multirow{2}{*}{4} & \multirow{2}{*}{6} & \multirow[b]{2}{*}{0} & \multirow{2}{*}{10} \\
\hline & SPAN & & & & & & & & & \\
\hline & 1.5 & $7.56 \mathrm{E}-05$ & $8.24 \mathrm{E}-05$ & $8.62 \mathrm{E}-05$ & 8.87E-05 & $9.48 \mathrm{E}-05$ & $1.01 \mathrm{E}-04$ & $1.05 \mathrm{E}-04$ & $1.07 \mathrm{E}-04$ & $1.09 \mathrm{E}-04$ \\
\hline & 2 & 2.93E-04 & $3.25 \mathrm{E}-04$ & $3.44 \mathrm{E}-04$ & 3.57E-04 & 3.87E-04 & $4.15 \mathrm{E}-04$ & $4.32 \mathrm{E}-04$ & $4.44 \mathrm{E}-04$ & $4.53 \mathrm{E}-04$ \\
\hline & 2.5 & $6.22 \mathrm{E}-04$ & $6.98 \mathrm{E}-04$ & 7.43E-04 & 7.76E-04 & 8.53E-04 & $9.28 \mathrm{E}-04$ & $9.69 \mathrm{E}-04$ & $9.97 \mathrm{E}-04$ & $1.02 \mathrm{E}-03$ \\
\hline & 3 & $1.06 \mathrm{E}-03$ & $1.20 \mathrm{E}-03$ & $1.28 \mathrm{E}-03$ & $1.34 \mathrm{E}-03$ & $1.49 \mathrm{E}-03$ & $1.64 \mathrm{E}-03$ & $1.73 \mathrm{E}-03$ & $1.79 \mathrm{E}-03$ & $1.83 \mathrm{E}-03$ \\
\hline & 3.5 & $1.60 \mathrm{E}-03$ & $1.82 \mathrm{E}-03$ & $1.96 \mathrm{E}-03$ & $2.06 \mathrm{E}-03$ & $2.31 \mathrm{E}-03$ & $2.56 \mathrm{E}-03$ & $2.71 \mathrm{E}-03$ & $2.81 \mathrm{E}-03$ & $2.89 \mathrm{E}-03$ \\
\hline & 4 & $2.25 \mathrm{E}-03$ & $2.57 \mathrm{E}-03$ & $2.77 \mathrm{E}-03$ & $2.92 \mathrm{E}-03$ & $3.30 \mathrm{E}-03$ & $3.69 \mathrm{E}-03$ & 3.92E-03 & $4.08 \mathrm{E}-03$ & $4.20 \mathrm{E}-03$ \\
\hline
\end{tabular}




\section{Alpha 8 Deflection Results}

Table 180 Maximum deflection results for alpha 8 for slabs subjected to CHBDC axle 4 loading (main bars perpendicular to traffic)

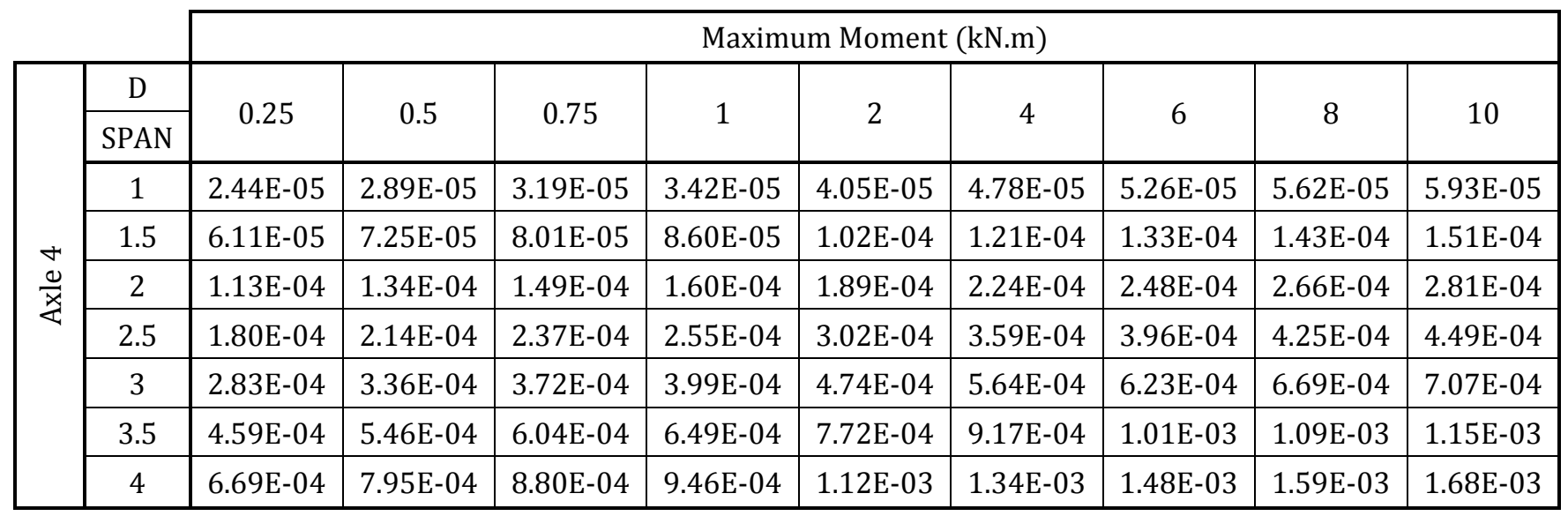

Table 181 Maximum deflection results for alpha 8 for slabs subjected to CHBDC axle 2 \& 3 loading (main bars perpendicular to traffic)

\begin{tabular}{|c|c|c|c|c|c|c|c|c|c|c|}
\hline & \multicolumn{9}{|c|}{ Maximum Moment (kN.m) } \\
\hline \multirow{9}{*}{ 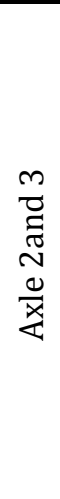 } & $\mathrm{D}$ & \multirow{2}{*}{0.25} & \multirow{2}{*}{0.5} & \multirow{2}{*}{0.75} & \multirow[b]{2}{*}{1} & & \multirow{2}{*}{4} & & & \multirow{2}{*}{10} \\
\hline & SPAN & & & & & & & & & \\
\hline & 1 & $2.71 \mathrm{E}-05$ & $3.07 \mathrm{E}-05$ & $3.31 \mathrm{E}-05$ & $3.48 \mathrm{E}-05$ & $3.92 \mathrm{E}-05$ & $4.40 \mathrm{E}-05$ & $4.70 \mathrm{E}-05$ & $4.93 \mathrm{E}-05$ & $5.12 \mathrm{E}-05$ \\
\hline & 1.5 & 7.43E-05 & $8.47 \mathrm{E}-05$ & $9.11 \mathrm{E}-05$ & $9.63 \mathrm{E}-05$ & $1.10 \mathrm{E}-04$ & $1.24 \mathrm{E}-04$ & $1.33 \mathrm{E}-04$ & $1.40 \mathrm{E}-04$ & $1.45 \mathrm{E}-04$ \\
\hline & 2 & $1.44 \mathrm{E}-04$ & $1.67 \mathrm{E}-04$ & $1.80 \mathrm{E}-04$ & $1.91 \mathrm{E}-04$ & $2.17 \mathrm{E}-04$ & $2.47 \mathrm{E}-04$ & $2.67 \mathrm{E}-04$ & $2.81 \mathrm{E}-04$ & $2.92 \mathrm{E}-04$ \\
\hline & 2.5 & $2.37 \mathrm{E}-04$ & $2.75 \mathrm{E}-04$ & $3.00 \mathrm{E}-04$ & $3.18 \mathrm{E}-04$ & $3.65 \mathrm{E}-04$ & $4.15 \mathrm{E}-04$ & $4.48 \mathrm{E}-04$ & $4.73 \mathrm{E}-04$ & $4.93 \mathrm{E}-04$ \\
\hline & 3 & $3.85 \mathrm{E}-04$ & $4.50 \mathrm{E}-04$ & 4.93E-04 & $5.25 \mathrm{E}-04$ & $6.08 \mathrm{E}-04$ & $7.01 \mathrm{E}-04$ & $7.60 \mathrm{E}-04$ & $8.03 \mathrm{E}-04$ & 8.37E-04 \\
\hline & 3.5 & $6.32 \mathrm{E}-04$ & 7.41E-04 & 8.13E-04 & 8.67E-04 & $1.01 \mathrm{E}-03$ & $1.17 \mathrm{E}-03$ & $1.27 \mathrm{E}-03$ & $1.35 \mathrm{E}-03$ & $1.41 \mathrm{E}-03$ \\
\hline & 4 & $9.26 \mathrm{E}-04$ & $1.09 \mathrm{E}-03$ & $1.20 \mathrm{E}-03$ & $1.28 \mathrm{E}-03$ & $1.49 \mathrm{E}-03$ & $1.73 \mathrm{E}-03$ & $1.89 \mathrm{E}-03$ & $2.01 \mathrm{E}-03$ & $2.10 \mathrm{E}-03$ \\
\hline
\end{tabular}

Table 182 Maximum deflection results for alpha 8 for slabs subjected to CHBDC truck loading (main bars perpendicular to traffic)

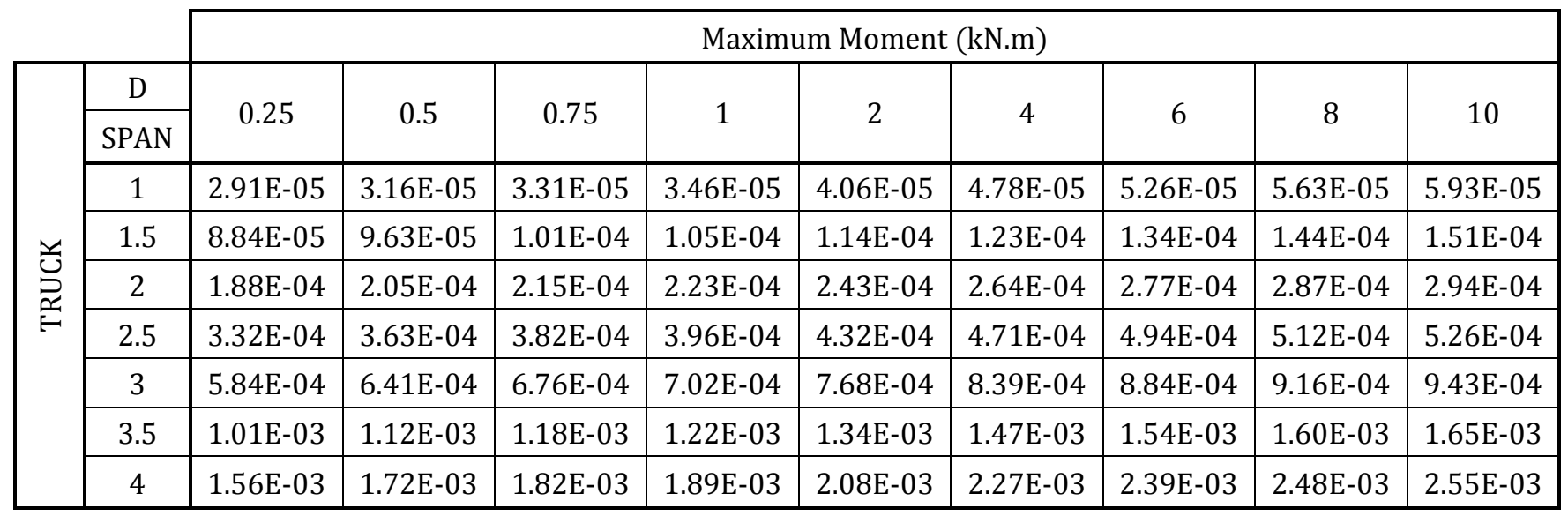


Table 183 Maximum deflection results for alpha 8 for slabs subjected to CHBDC axle 4 loading (main bars parallel to traffic)

\begin{tabular}{|c|c|c|c|c|c|c|c|c|c|c|}
\hline & & \multicolumn{9}{|c|}{ Maximum Moment (kN.m) } \\
\hline \multirow{8}{*}{ 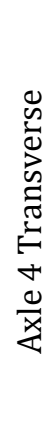 } & $\mathrm{D}$ & \multirow{2}{*}{0.25} & \multirow{2}{*}{0.5} & \multirow{2}{*}{0.75} & \multirow[t]{2}{*}{1} & \multirow[t]{2}{*}{2} & \multirow[t]{2}{*}{4} & \multirow{2}{*}{6} & \multirow[t]{2}{*}{8} & \multirow{2}{*}{10} \\
\hline & SPAN & & & & & & & & & \\
\hline & 1 & $5.97 \mathrm{E}-05$ & $6.43 \mathrm{E}-05$ & $6.69 \mathrm{E}-05$ & $6.87 \mathrm{E}-05$ & $7.31 \mathrm{E}-05$ & 7.75E-05 & $8.01 \mathrm{E}-05$ & $8.20 \mathrm{E}-05$ & $8.36 \mathrm{E}-05$ \\
\hline & 1.5 & $1.67 \mathrm{E}-04$ & $1.83 \mathrm{E}-04$ & $1.93 \mathrm{E}-04$ & $1.99 \mathrm{E}-04$ & $2.15 \mathrm{E}-04$ & $2.31 \mathrm{E}-04$ & $2.40 \mathrm{E}-04$ & $2.46 \mathrm{E}-04$ & $2.51 \mathrm{E}-04$ \\
\hline & 2 & $3.33 \mathrm{E}-04$ & $3.72 \mathrm{E}-04$ & $3.94 \mathrm{E}-04$ & $4.11 \mathrm{E}-04$ & $4.50 \mathrm{E}-04$ & $4.89 \mathrm{E}-04$ & $5.11 \mathrm{E}-04$ & $5.27 \mathrm{E}-04$ & $5.38 \mathrm{E}-04$ \\
\hline & 2.5 & $5.62 \mathrm{E}-04$ & $6.32 \mathrm{E}-04$ & $6.75 \mathrm{E}-04$ & $7.06 \mathrm{E}-04$ & $7.83 \mathrm{E}-04$ & $8.60 \mathrm{E}-04$ & $9.04 \mathrm{E}-04$ & $9.36 \mathrm{E}-04$ & $9.60 \mathrm{E}-04$ \\
\hline & 3 & 8.51E-04 & $9.66 \mathrm{E}-04$ & $1.04 \mathrm{E}-03$ & $1.09 \mathrm{E}-03$ & $1.22 \mathrm{E}-03$ & $1.35 \mathrm{E}-03$ & $1.43 \mathrm{E}-03$ & $1.48 \mathrm{E}-03$ & $1.52 \mathrm{E}-03$ \\
\hline & 3.5 & $1.20 \mathrm{E}-03$ & $1.37 \mathrm{E}-03$ & $1.48 \mathrm{E}-03$ & $1.56 \mathrm{E}-03$ & $1.75 \mathrm{E}-03$ & $1.96 \mathrm{E}-03$ & $2.08 \mathrm{E}-03$ & 2.17E-03 & 2.23E-03 \\
\hline
\end{tabular}

Table 184 Maximum deflection results for alpha 8 for slabs subjected to CHBDC axle 2 \& 3 loading (main bars parallel to traffic)

\begin{tabular}{|c|c|c|c|c|c|c|c|c|c|c|}
\hline & & \multicolumn{9}{|c|}{ Maximum Moment (kN.m) } \\
\hline \multirow{8}{*}{ 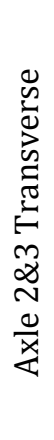 } & $\mathrm{D}$ & \multirow{2}{*}{0.25} & \multirow{2}{*}{0.5} & \multirow{2}{*}{0.75} & \multirow{2}{*}{1} & & \multirow{2}{*}{4} & \multirow{2}{*}{6} & \multirow[b]{2}{*}{0} & \multirow{2}{*}{10} \\
\hline & SPAN & & & & & & & & & \\
\hline & 1.5 & $6.98 \mathrm{E}-05$ & 7.67E-05 & 8.07E-05 & $8.34 \mathrm{E}-05$ & $8.98 \mathrm{E}-05$ & $9.63 \mathrm{E}-05$ & $9.99 \mathrm{E}-05$ & $1.02 \mathrm{E}-04$ & $1.04 \mathrm{E}-04$ \\
\hline & 2 & $2.68 \mathrm{E}-04$ & $2.99 \mathrm{E}-04$ & $3.18 \mathrm{E}-04$ & $3.31 \mathrm{E}-04$ & $3.62 \mathrm{E}-04$ & $3.92 \mathrm{E}-04$ & $4.09 \mathrm{E}-04$ & $4.21 \mathrm{E}-04$ & $4.31 \mathrm{E}-04$ \\
\hline & 2.5 & $5.63 \mathrm{E}-04$ & $6.36 \mathrm{E}-04$ & $6.80 \mathrm{E}-04$ & 7.12E-04 & 7.89E-04 & 8.66E-04 & $9.09 \mathrm{E}-04$ & $9.39 \mathrm{E}-04$ & $9.61 \mathrm{E}-04$ \\
\hline & 3 & $9.53 \mathrm{E}-04$ & $1.08 \mathrm{E}-03$ & $1.17 \mathrm{E}-03$ & $1.22 \mathrm{E}-03$ & 1.37E-03 & $1.52 \mathrm{E}-03$ & $1.61 \mathrm{E}-03$ & $1.67 \mathrm{E}-03$ & $1.71 \mathrm{E}-03$ \\
\hline & 3.5 & $1.44 \mathrm{E}-03$ & $1.64 \mathrm{E}-03$ & $1.77 \mathrm{E}-03$ & $1.87 \mathrm{E}-03$ & $2.11 \mathrm{E}-03$ & $2.35 \mathrm{E}-03$ & $2.50 \mathrm{E}-03$ & $2.60 \mathrm{E}-03$ & $2.69 \mathrm{E}-03$ \\
\hline & 4 & $2.01 \mathrm{E}-03$ & $2.31 \mathrm{E}-03$ & $2.50 \mathrm{E}-03$ & $2.64 \mathrm{E}-03$ & $2.99 \mathrm{E}-03$ & 3.37E-03 & 3.59E-03 & $3.75 \mathrm{E}-03$ & $3.88 \mathrm{E}-03$ \\
\hline
\end{tabular}




\section{Alpha 10 Deflection Results}

Table 185 Maximum deflection results for alpha 10 for slabs subjected to CHBDC axle 4 loading (main bars perpendicular to traffic)

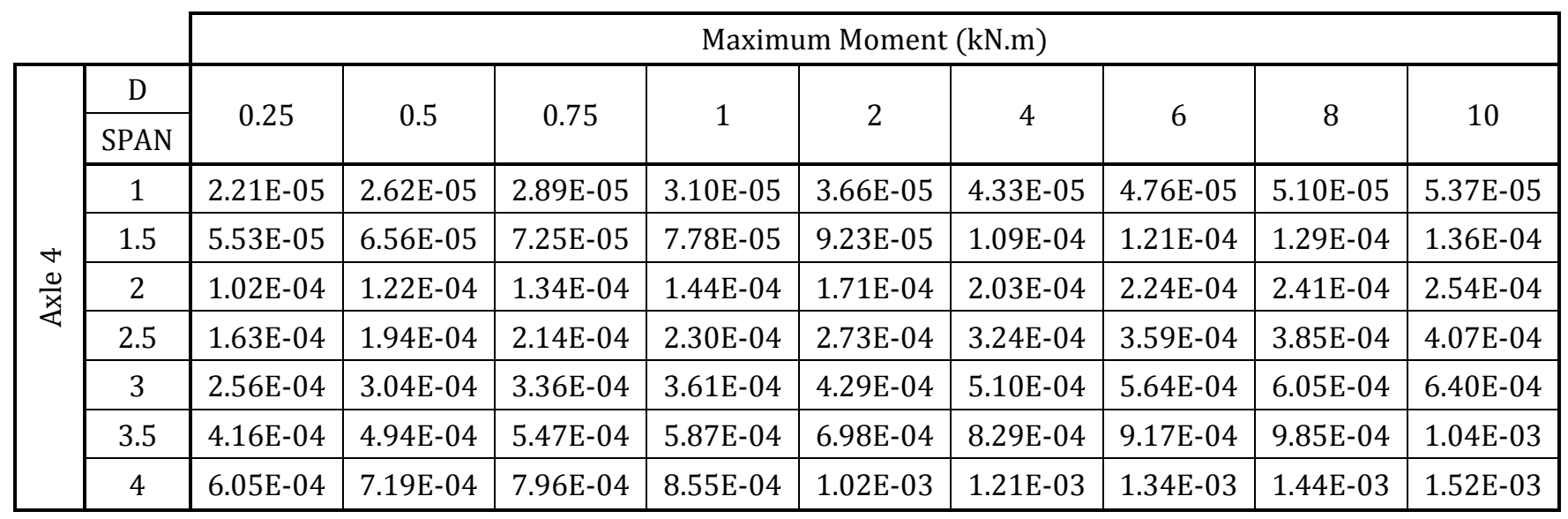

Table 186 Maximum deflection results for alpha 10 for slabs subjected to CHBDC axle 2 \& 3 loading (main bars perpendicular to traffic)

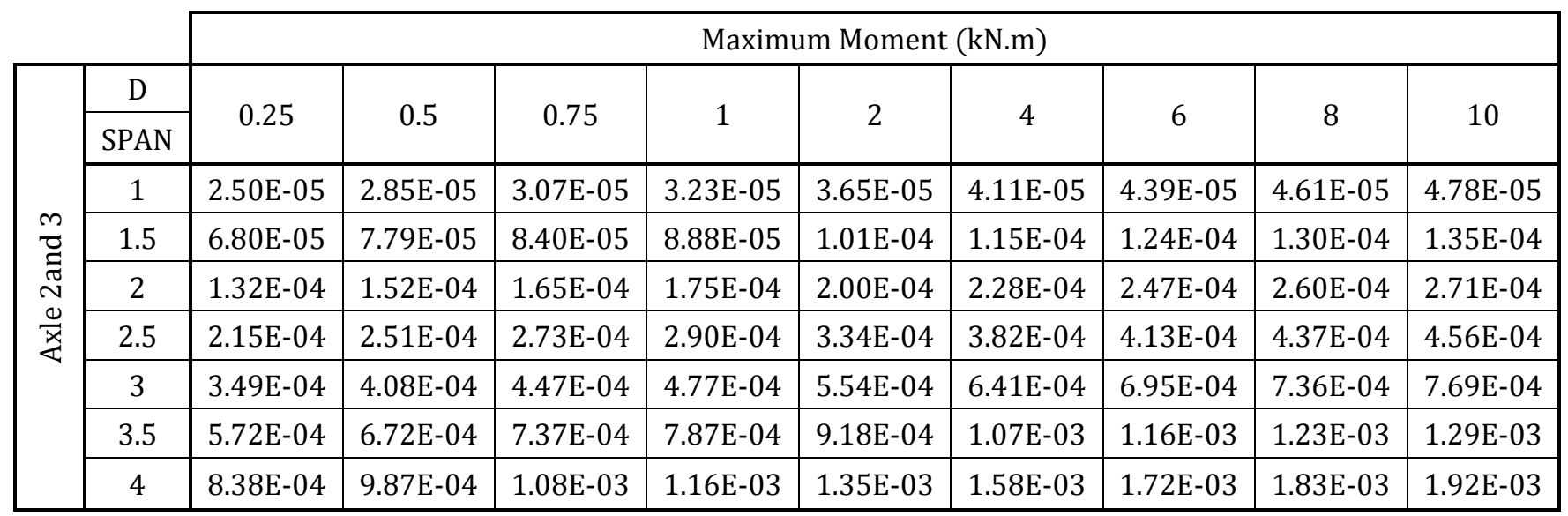

Table 187 Maximum deflection results for alpha 10 for slabs subjected to CHBDC truck loading (main bars perpendicular to traffic)

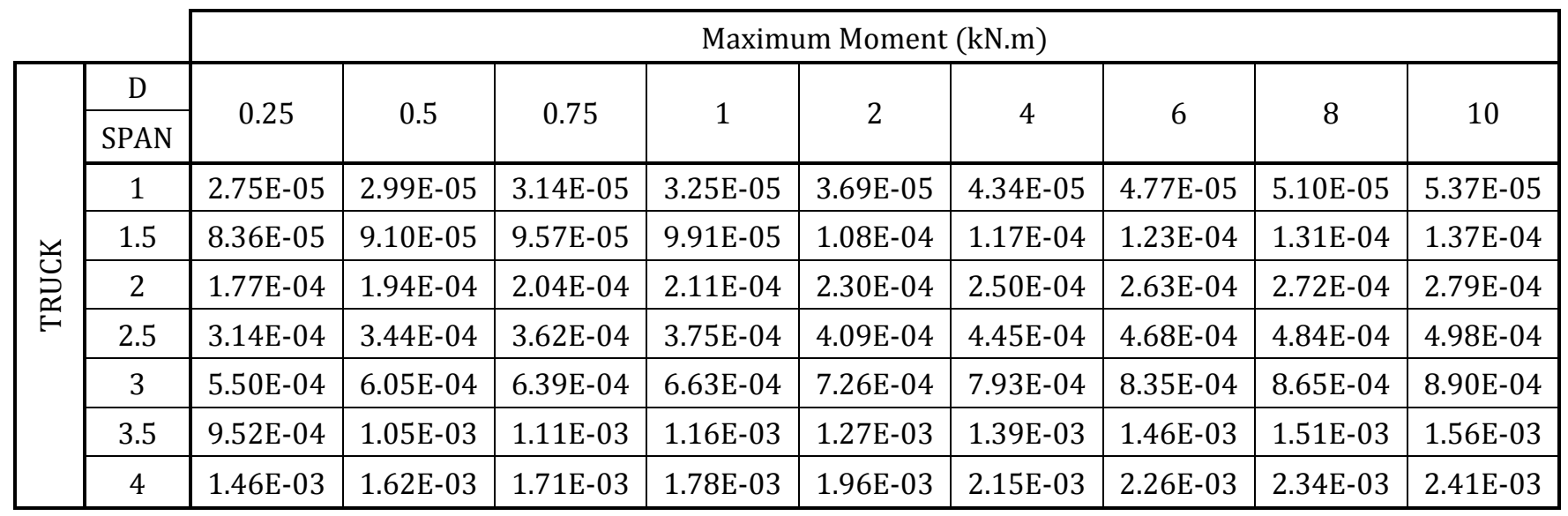


Table 188 Maximum deflection results for alpha 10 for slabs subjected to CHBDC axle 4 loading (main bars parallel to traffic)

\begin{tabular}{|c|c|c|c|c|c|c|c|c|c|c|}
\hline & & \multicolumn{9}{|c|}{ Maximum Moment (kN.m) } \\
\hline \multirow{8}{*}{ 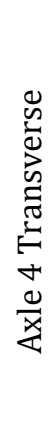 } & $\mathrm{D}$ & \multirow{2}{*}{0.25} & \multirow{2}{*}{0.5} & \multirow{2}{*}{0.75} & \multirow{2}{*}{1} & \multirow[t]{2}{*}{2} & \multirow{2}{*}{4} & \multirow{2}{*}{6} & \multirow[t]{2}{*}{8} & \multirow{2}{*}{10} \\
\hline & SPAN & & & & & & & & & \\
\hline & 1 & $5.67 \mathrm{E}-05$ & $6.14 \mathrm{E}-05$ & $6.41 \mathrm{E}-05$ & $6.60 \mathrm{E}-05$ & $7.04 \mathrm{E}-05$ & $7.48 \mathrm{E}-05$ & $7.73 \mathrm{E}-05$ & 7.92E-05 & $8.06 \mathrm{E}-05$ \\
\hline & 1.5 & $1.56 \mathrm{E}-04$ & $1.73 \mathrm{E}-04$ & $1.82 \mathrm{E}-04$ & $1.89 \mathrm{E}-04$ & $2.06 \mathrm{E}-04$ & $2.21 \mathrm{E}-04$ & $2.30 \mathrm{E}-04$ & $2.37 \mathrm{E}-04$ & $2.42 \mathrm{E}-04$ \\
\hline & 2 & $3.10 \mathrm{E}-04$ & $3.48 \mathrm{E}-04$ & $3.70 \mathrm{E}-04$ & $3.86 \mathrm{E}-04$ & $4.26 \mathrm{E}-04$ & $4.65 \mathrm{E}-04$ & $4.88 \mathrm{E}-04$ & $5.03 \mathrm{E}-04$ & $5.16 \mathrm{E}-04$ \\
\hline & 2.5 & $5.19 \mathrm{E}-04$ & $5.87 \mathrm{E}-04$ & $6.29 \mathrm{E}-04$ & $6.60 \mathrm{E}-04$ & $7.35 \mathrm{E}-04$ & 8.12E-04 & 8.57E-04 & $8.89 \mathrm{E}-04$ & 9.13E-04 \\
\hline & 3 & $7.84 \mathrm{E}-04$ & 8.93E-04 & $9.61 \mathrm{E}-04$ & $1.01 \mathrm{E}-03$ & $1.14 \mathrm{E}-03$ & $1.26 \mathrm{E}-03$ & $1.34 \mathrm{E}-03$ & $1.40 \mathrm{E}-03$ & $1.44 \mathrm{E}-03$ \\
\hline & 3.5 & $1.10 \mathrm{E}-03$ & $1.27 \mathrm{E}-03$ & $1.37 \mathrm{E}-03$ & $1.44 \mathrm{E}-03$ & $1.63 \mathrm{E}-03$ & $1.83 \mathrm{E}-03$ & $1.95 \mathrm{E}-03$ & 2.03E-03 & 2.10E-03 \\
\hline
\end{tabular}

Table 189 Maximum deflection results for alpha 10 for slabs subjected to CHBDC axle 2 \& 3 loading (main bars parallel to traffic)

\begin{tabular}{|c|c|c|c|c|c|c|c|c|c|c|}
\hline & & \multicolumn{9}{|c|}{ Maximum Moment (kN.m) } \\
\hline \multirow{7}{*}{ 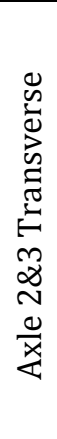 } & $\begin{array}{c}\mathrm{D} \\
\text { SPAN }\end{array}$ & 0.25 & 0.5 & 0.75 & 1 & 2 & 4 & 6 & 8 & 10 \\
\hline & 1.5 & $6.53 \mathrm{E}-05$ & $7.23 \mathrm{E}-05$ & $7.63 \mathrm{E}-05$ & $7.91 \mathrm{E}-05$ & $8.57 \mathrm{E}-05$ & $9.23 \mathrm{E}-05$ & $9.61 \mathrm{E}-05$ & $9.87 \mathrm{E}-05$ & $1.01 \mathrm{E}-04$ \\
\hline & 2 & $2.48 \mathrm{E}-04$ & $2.79 \mathrm{E}-04$ & $2.97 \mathrm{E}-04$ & $3.10 \mathrm{E}-04$ & $3.42 \mathrm{E}-04$ & $3.72 \mathrm{E}-04$ & $3.90 \mathrm{E}-04$ & $4.03 E-04$ & $4.13 \mathrm{E}-04$ \\
\hline & 2.5 & $5.19 E-04$ & $5.89 \mathrm{E}-04$ & $6.32 \mathrm{E}-04$ & $6.63 \mathrm{E}-04$ & $7.39 \mathrm{E}-04$ & $8.16 \mathrm{E}-04$ & $8.60 \mathrm{E}-04$ & 8.91E-04 & $9.15 \mathrm{E}-04$ \\
\hline & 3 & $8.75 \mathrm{E}-04$ & $1.00 \mathrm{E}-03$ & $1.08 \mathrm{E}-03$ & $1.13 \mathrm{E}-03$ & $1.28 \mathrm{E}-03$ & $1.42 \mathrm{E}-03$ & $1.51 \mathrm{E}-03$ & $1.57 \mathrm{E}-03$ & $1.62 \mathrm{E}-03$ \\
\hline & 3.5 & $1.32 \mathrm{E}-03$ & $1.51 \mathrm{E}-03$ & $1.63 \mathrm{E}-03$ & $1.72 \mathrm{E}-03$ & $1.95 \mathrm{E}-03$ & $2.19 \mathrm{E}-03$ & $2.34 \mathrm{E}-03$ & $2.44 \mathrm{E}-03$ & $2.52 \mathrm{E}-03$ \\
\hline & 4 & $1.84 \mathrm{E}-03$ & $2.12 \mathrm{E}-03$ & $2.30 \mathrm{E}-03$ & $2.43 \mathrm{E}-03$ & $2.77 \mathrm{E}-03$ & $3.13 \mathrm{E}-03$ & $3.35 \mathrm{E}-03$ & $3.50 \mathrm{E}-03$ & $3.63 \mathrm{E}-03$ \\
\hline
\end{tabular}




\section{C.2.2 MAXIMUM Deflection VS SPAN LENGTH}




\section{Alpha 0.25 Deflection VS Span Length for Different D Values}

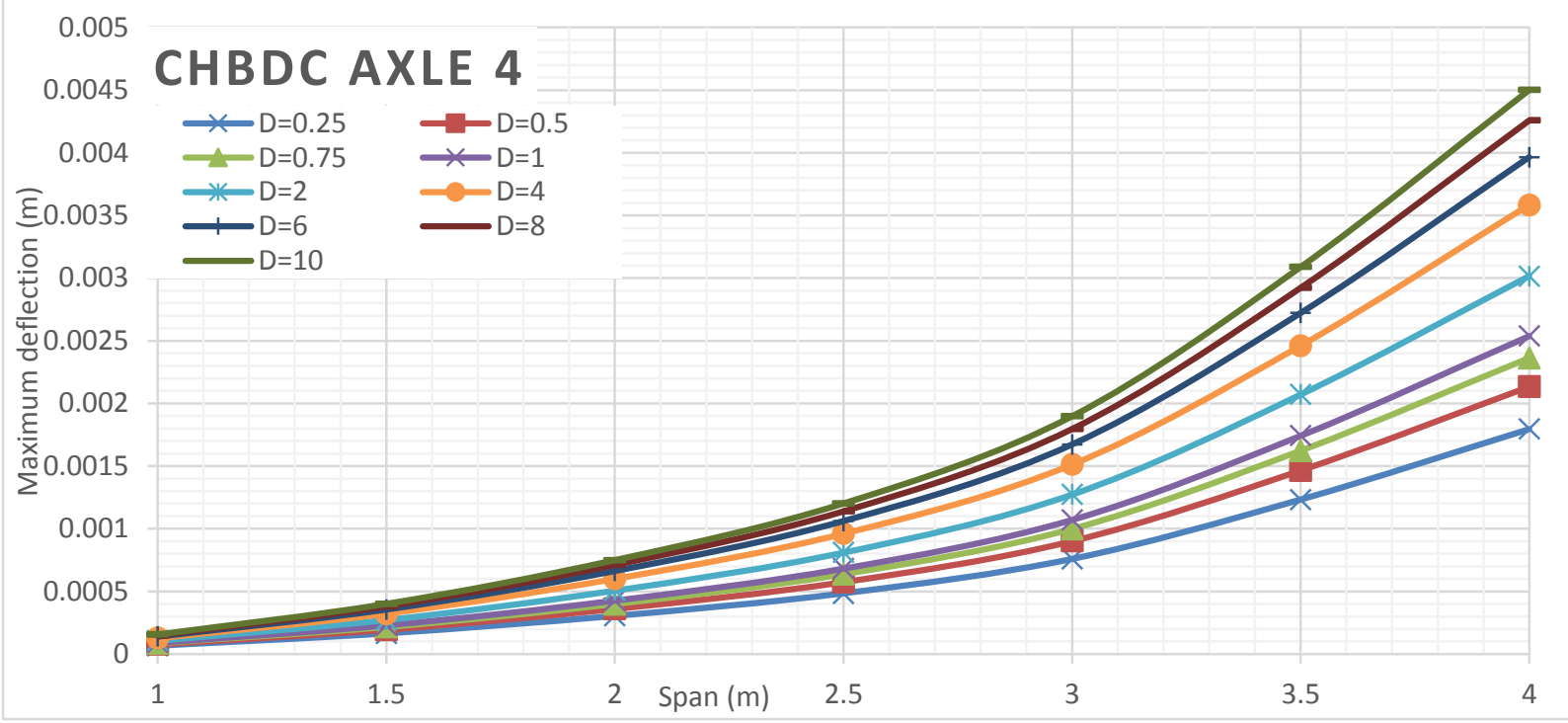

Figure 370 Maximum deflection of deck slabs subjected to CHBDC axle 4 for different D values of alpha 0.25 Orthotropic analyses

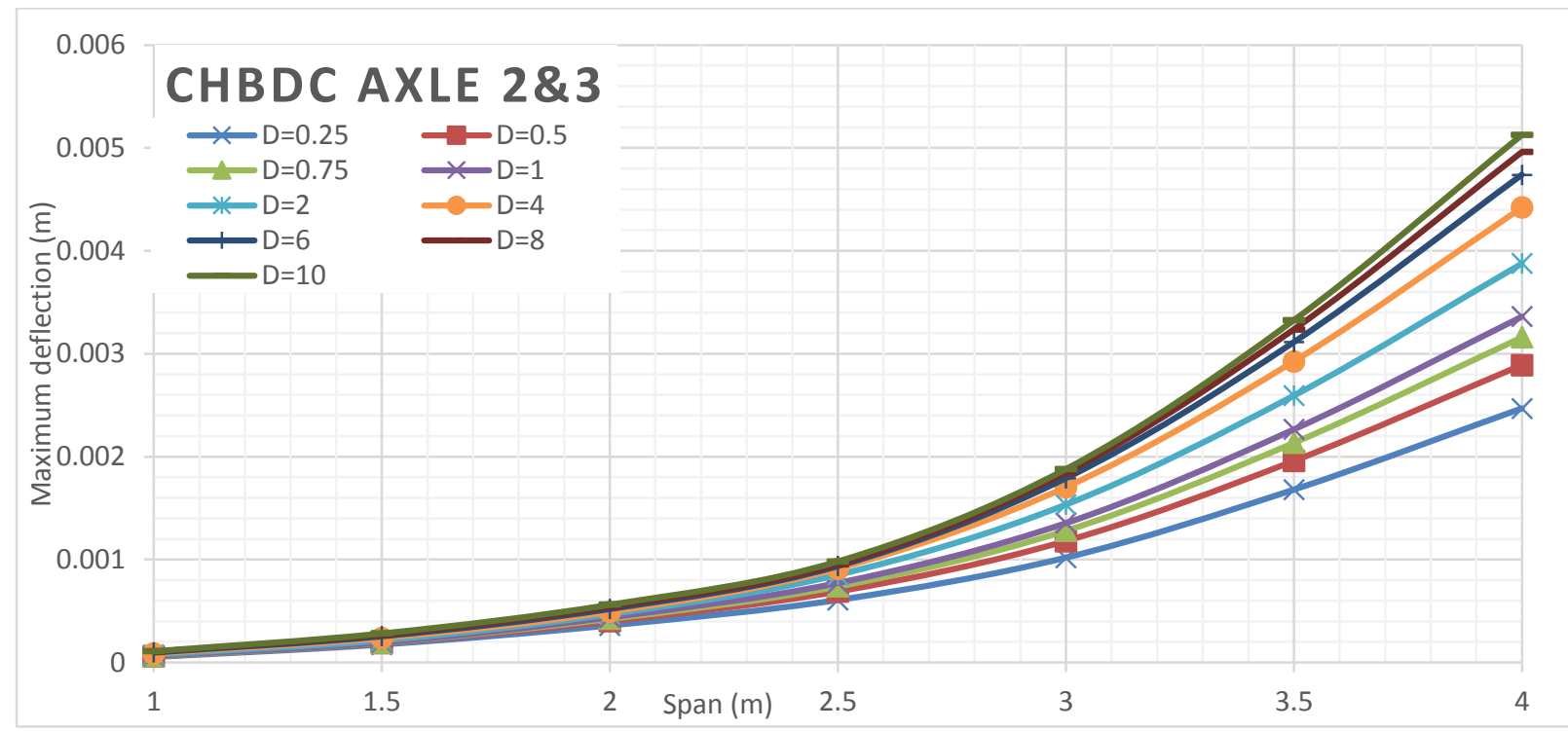

Figure 371 Maximum deflection of deck slabs subjected to CHBDC axle 2 \& 3 for different D values of alpha 0.25 Orthotropic analyses 


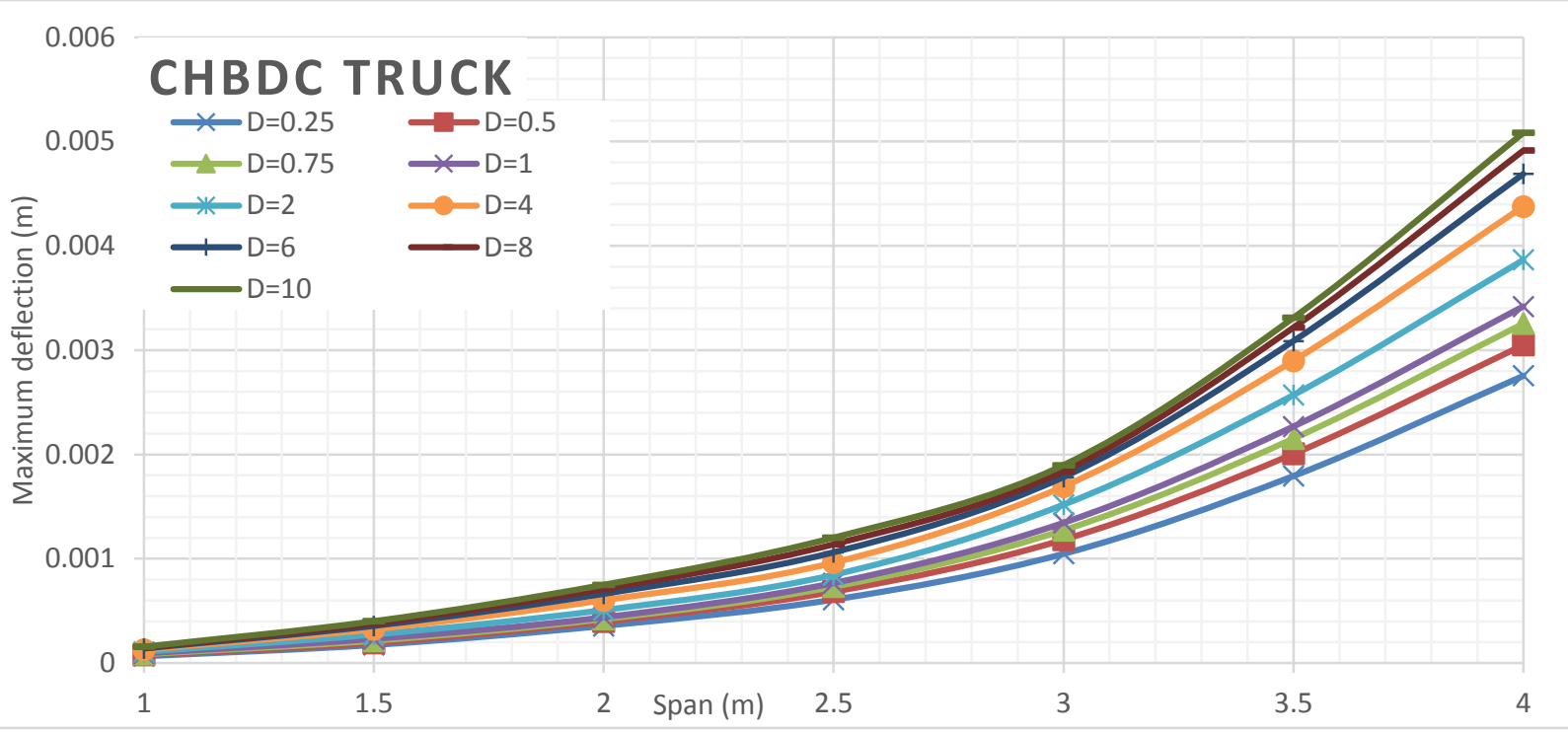

Figure 372 Maximum deflection of deck slabs subjected to CHBDC truck for different D values of alpha 0.25 Orthotropic analyses

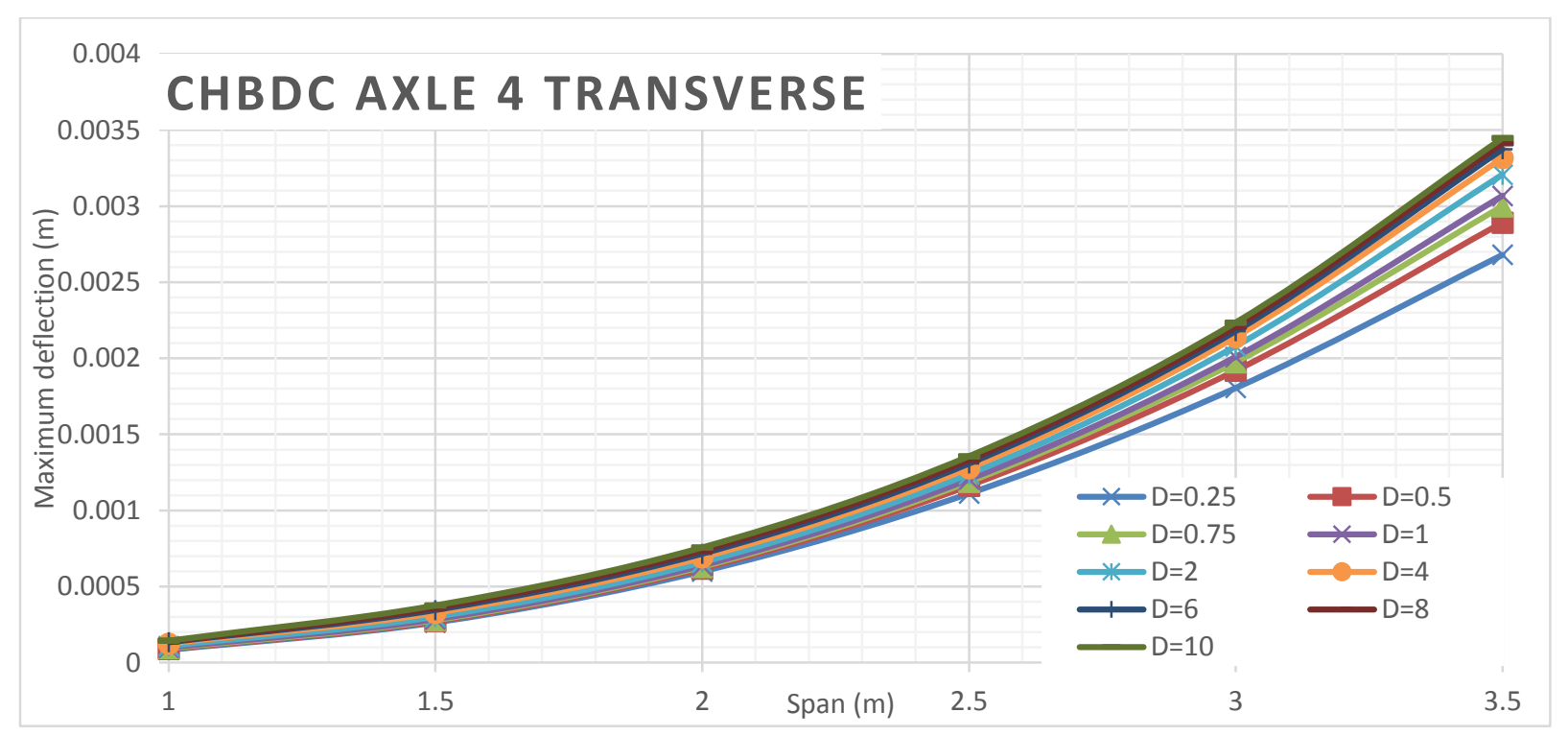

Figure 373 Maximum deflection of deck slabs subjected to CHBDC axle 4 for different D values of alpha 0.25 Orthotropic analyses

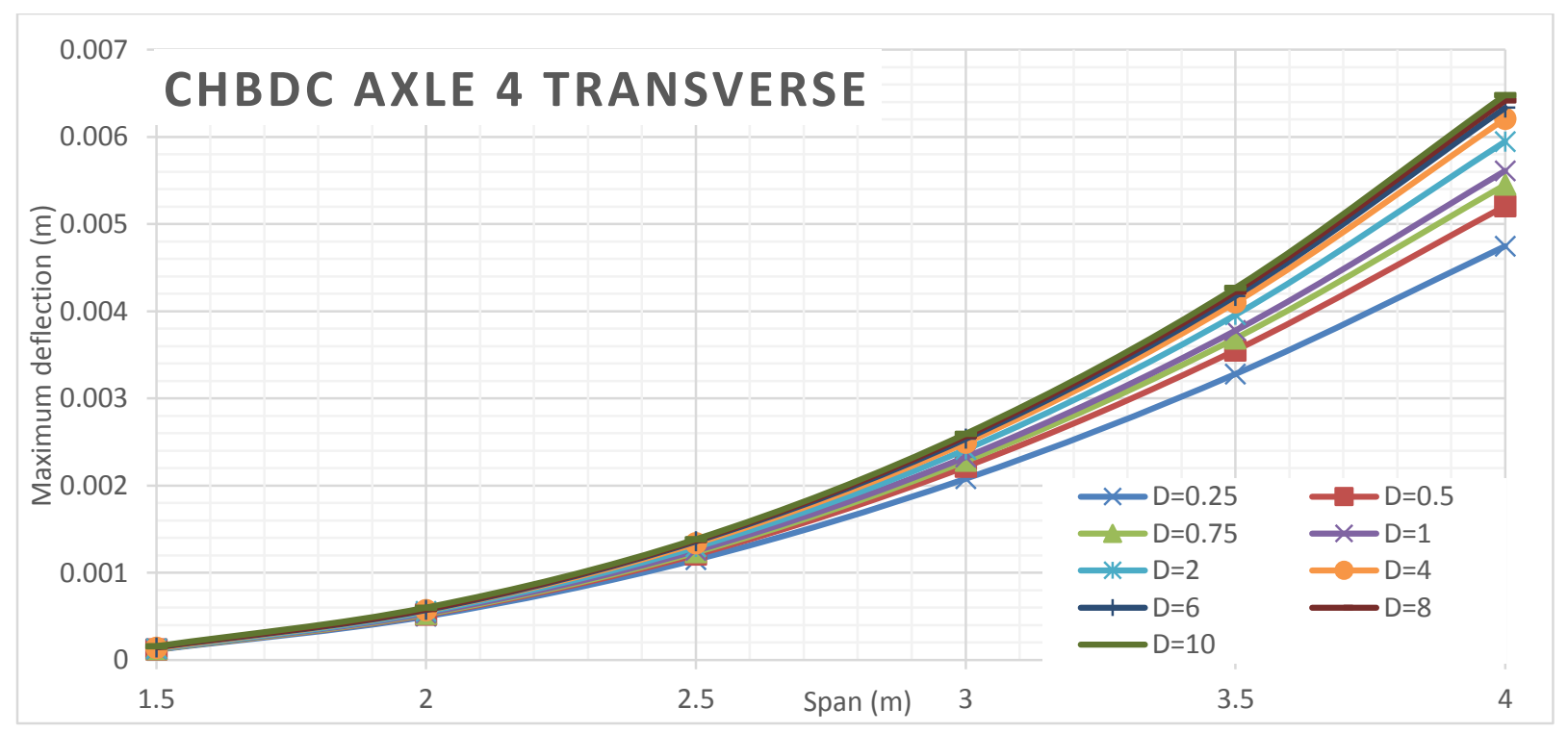

Figure 374 Maximum deflection of deck slabs subjected to CHBDC axle $2 \& 3$ for different D values of alpha 0.25 Orthotropic analyses 


\section{Alpha 0.5 Deflection VS Span Length for Different D Values}

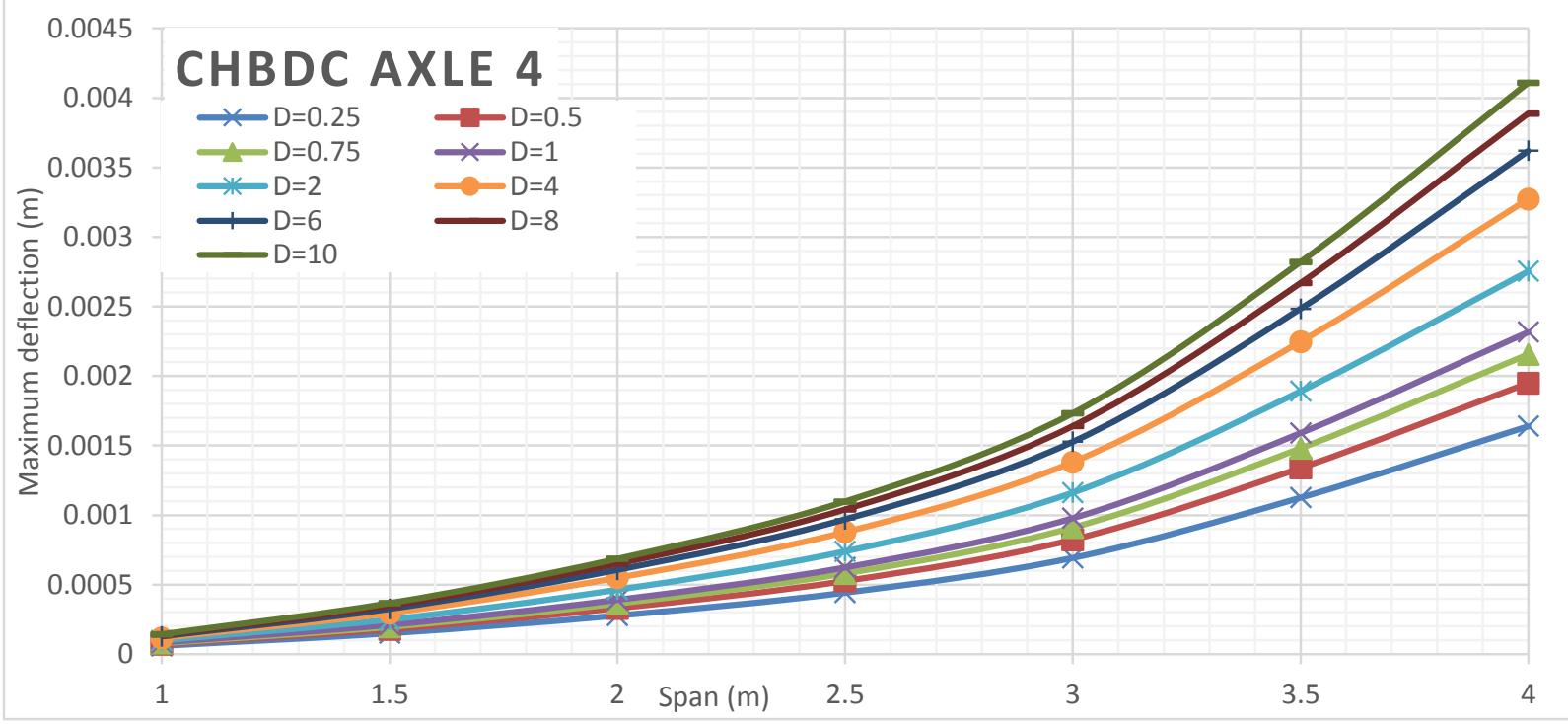

Figure 375 Maximum deflection of deck slabs subjected to CHBDC axle 4 for different D values of alpha 0.5 Orthotropic analyses

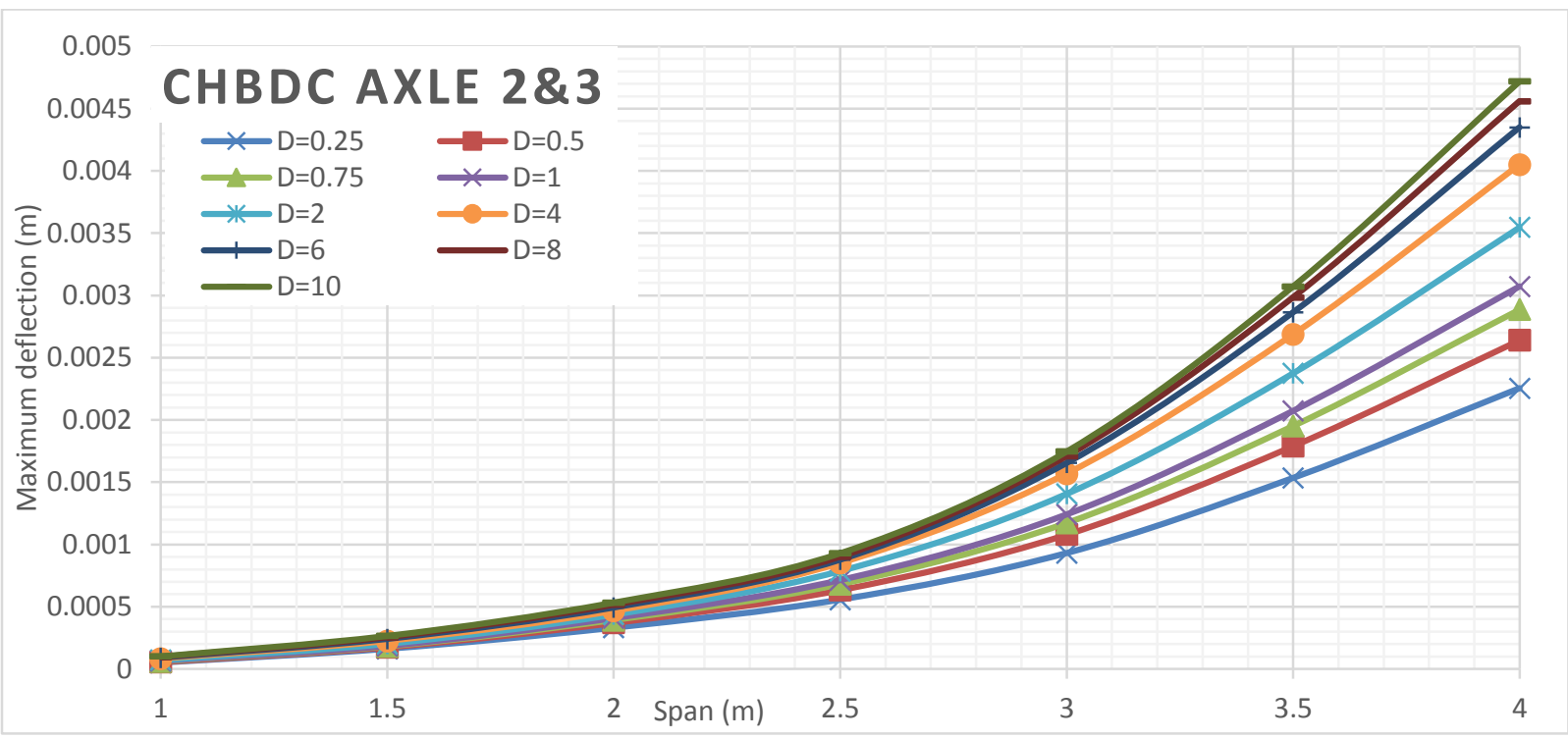

Figure 376 Maximum deflection of deck slabs subjected to CHBDC axle $2 \& 3$ for different D values of alpha 0.5 Orthotropic analyses 


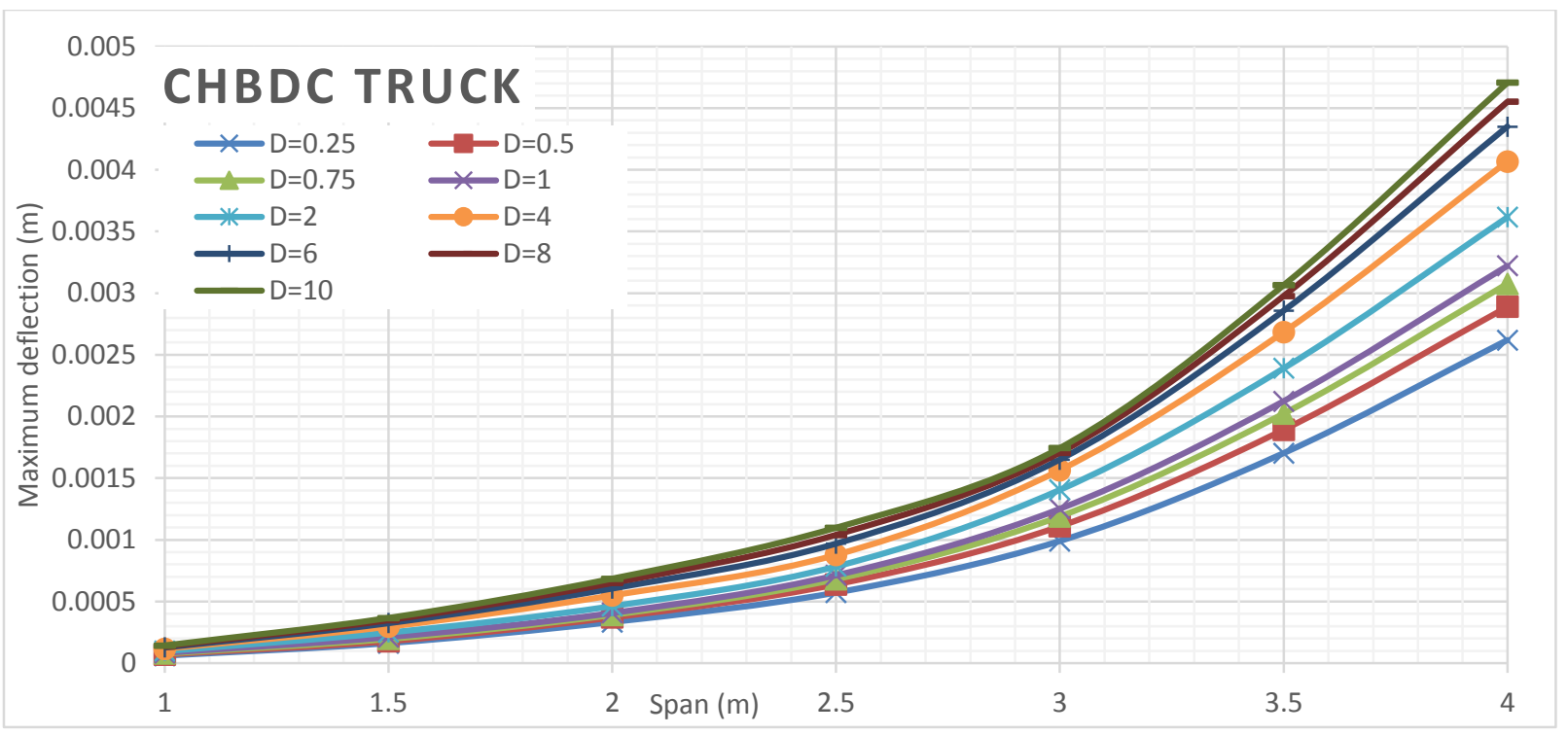

Figure 377 Maximum deflection of deck slabs subjected to CHBDC truck for different D values of alpha 0.5 Orthotropic analyses

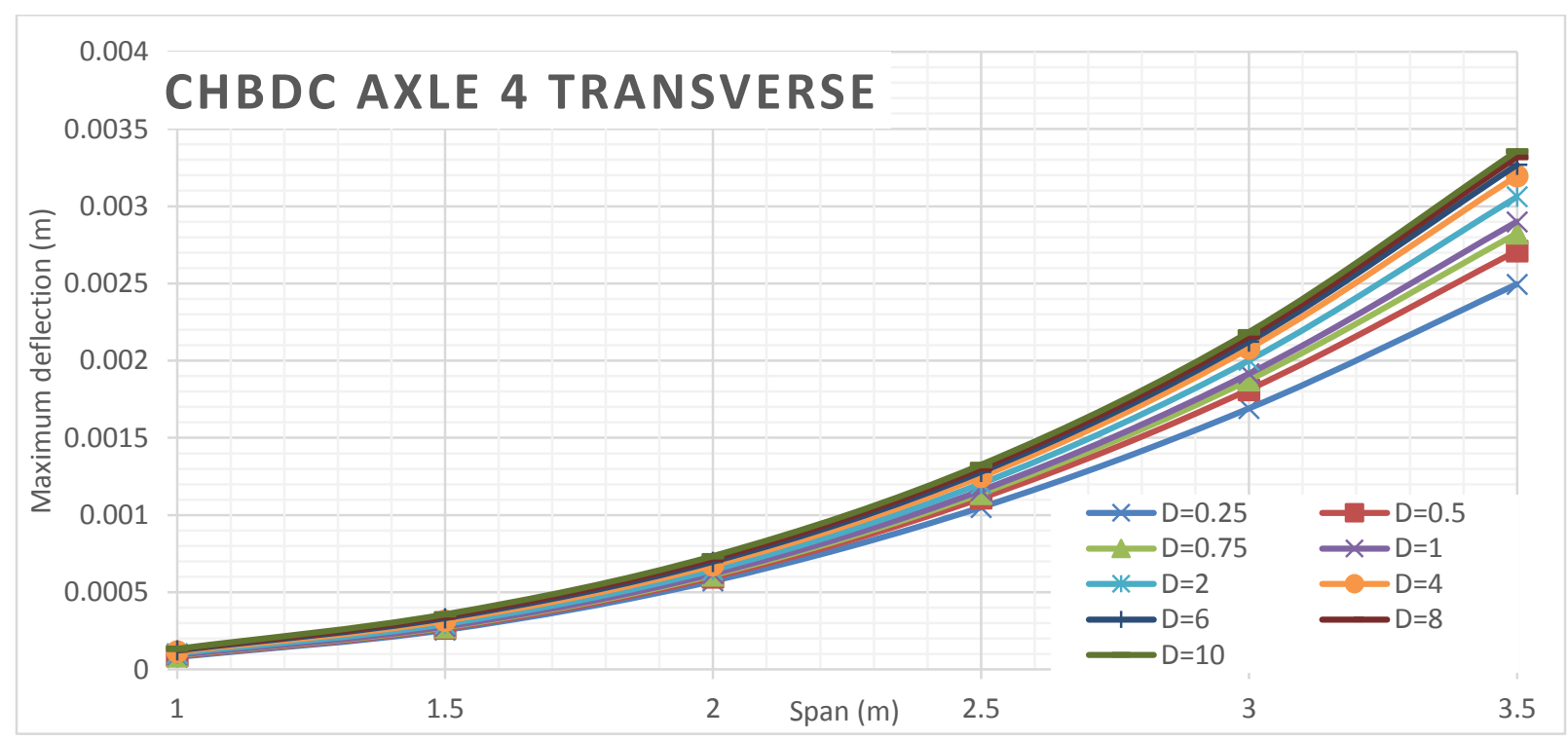

Figure 378 Maximum deflection of deck slabs subjected to CHBDC axle 4 for different D values of alpha 0.5 Orthotropic analyses

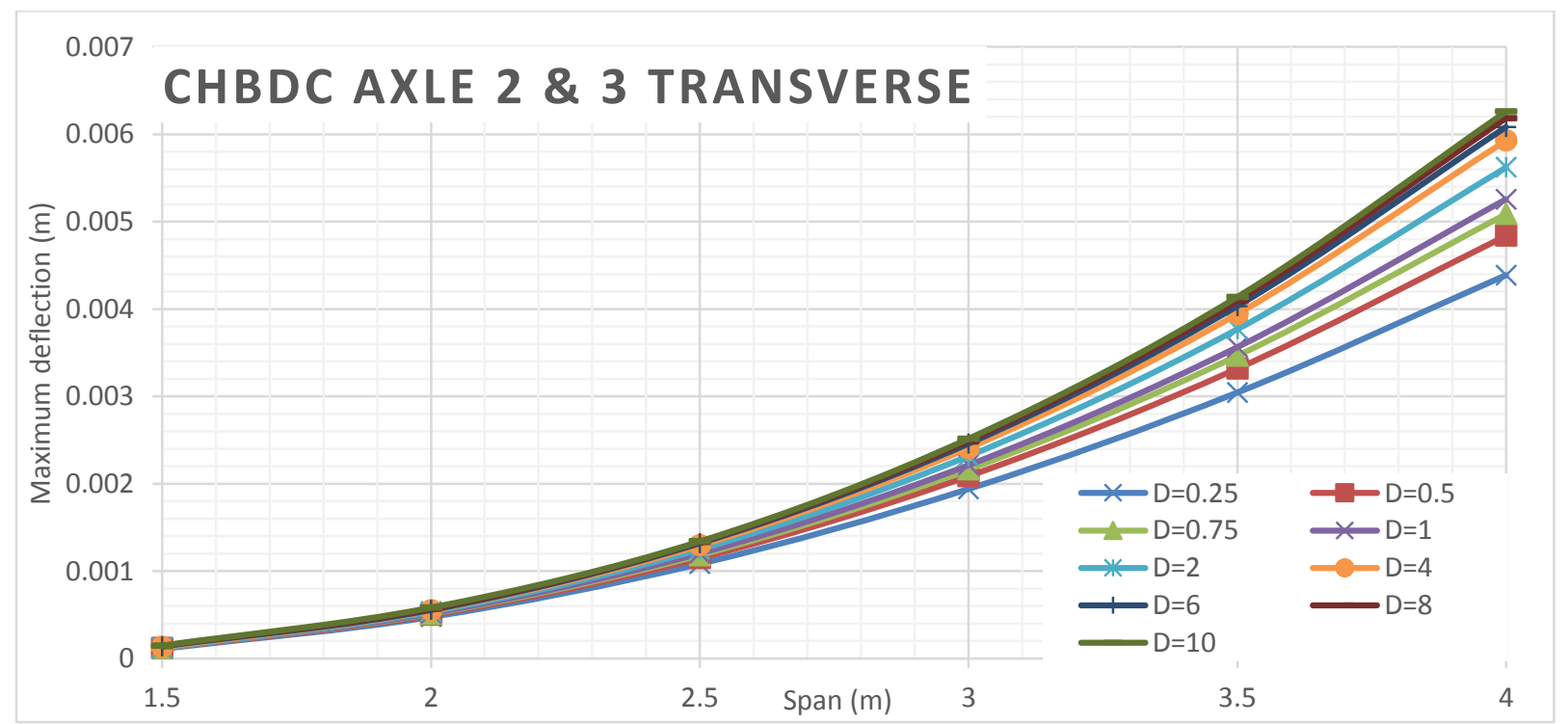

Figure 379 Maximum deflection of deck slabs subjected to CHBDC axle $2 \& 3$ for different D values of alpha 0.5 Orthotropic analyses 


\section{Alpha 0.75 Deflection VS Span Length for Different D Values}

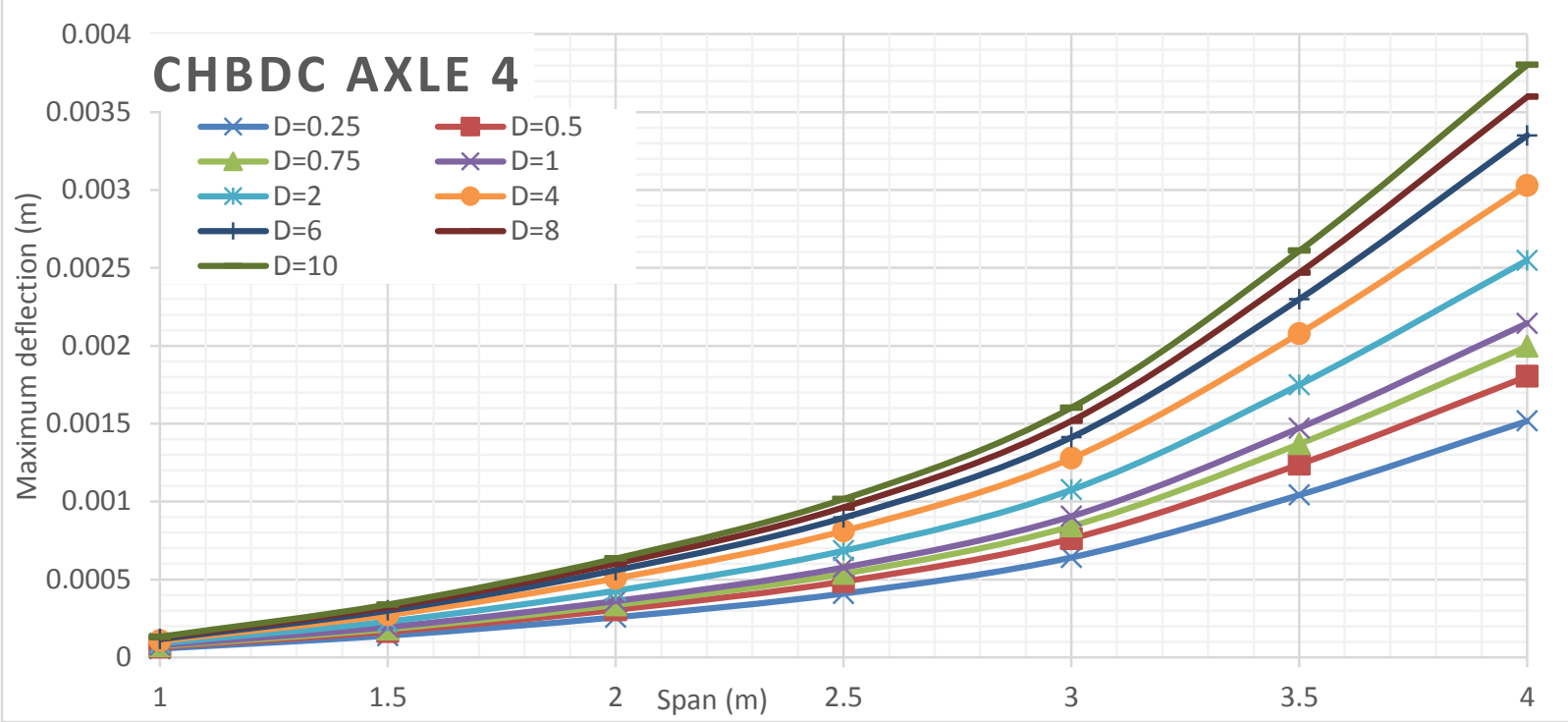

Figure 380 Maximum deflection of deck slabs subjected to CHBDC axle 4 for different D values of alpha 0.75 Orthotropic analyses

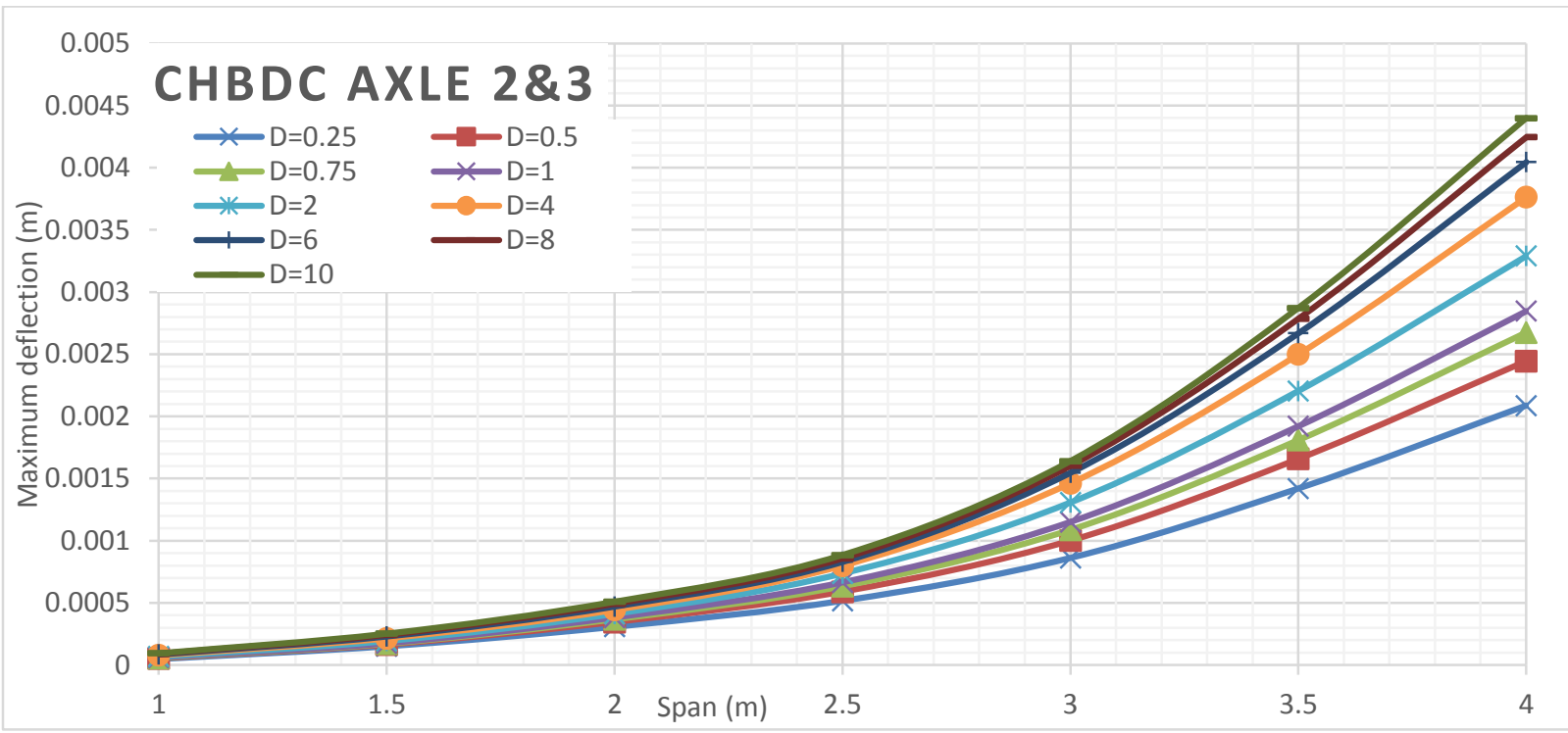

Figure 381 Maximum deflection of deck slabs subjected to CHBDC axle $2 \& 3$ for different D values of alpha 0.75 Orthotropic analyses 


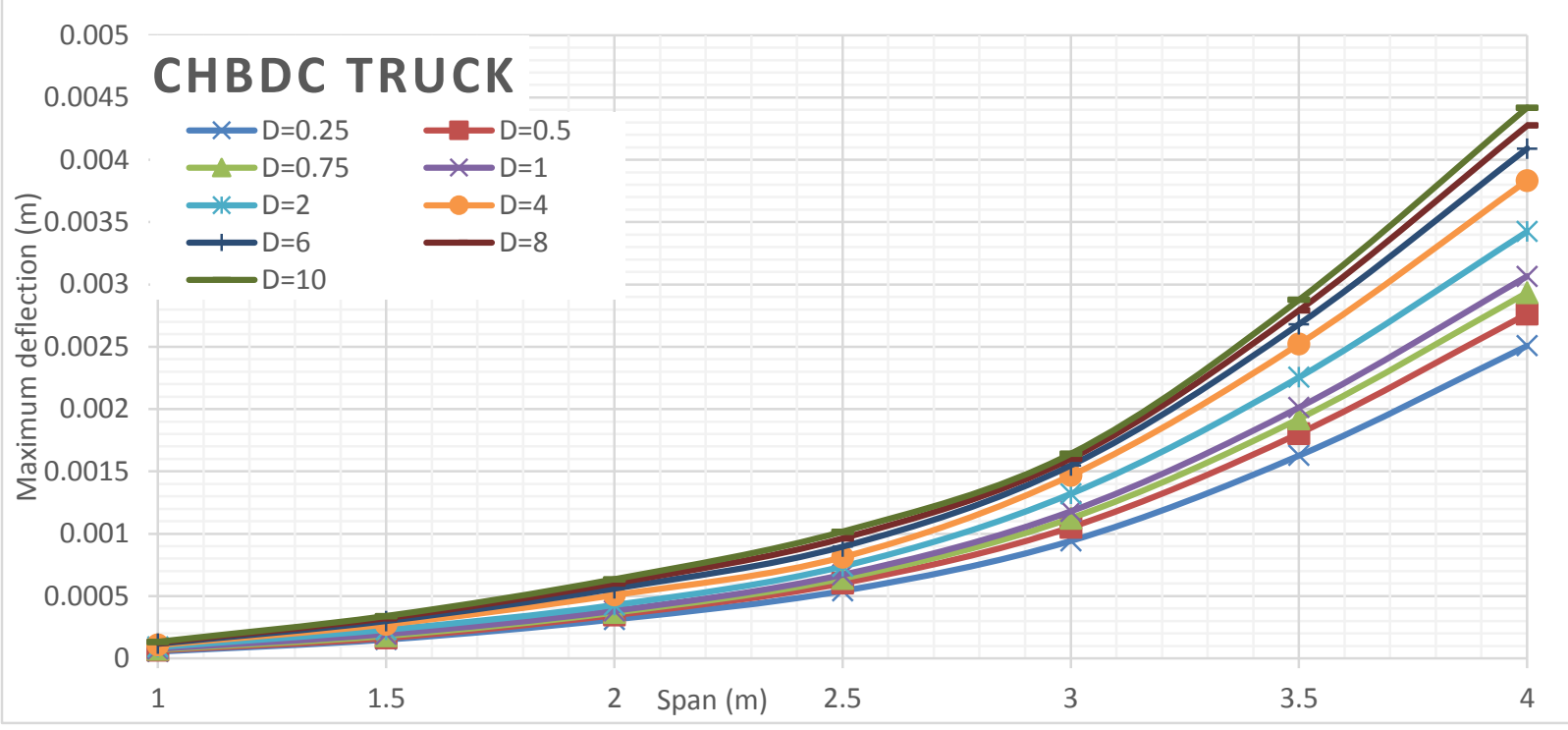

Figure 382 Maximum deflection of deck slabs subjected to CHBDC truck for different D values of alpha 0.75 Orthotropic analyses

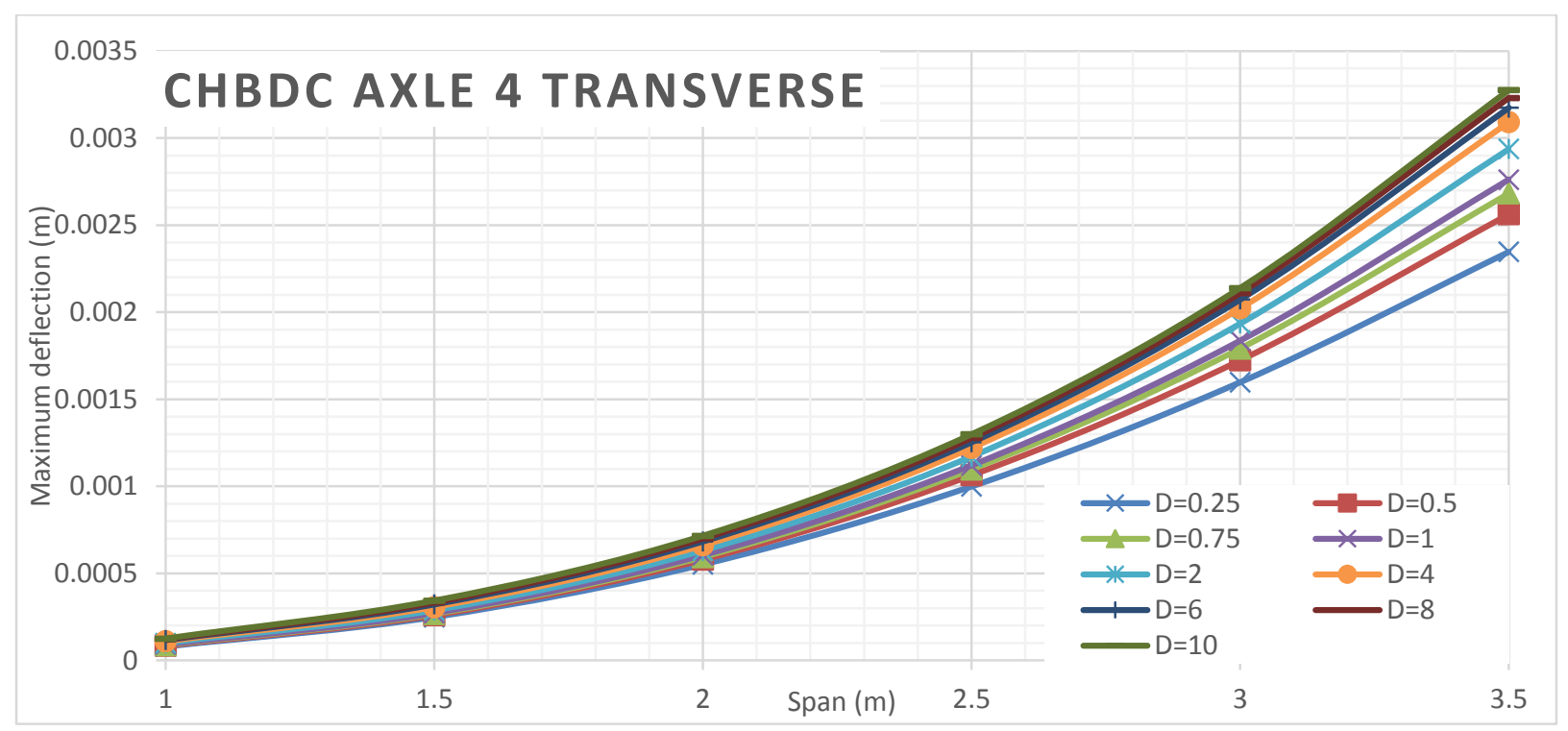

Figure 383 Maximum deflection of deck slabs subjected to CHBDC axle 4 for different D values of alpha 0.75 Orthotropic analyses

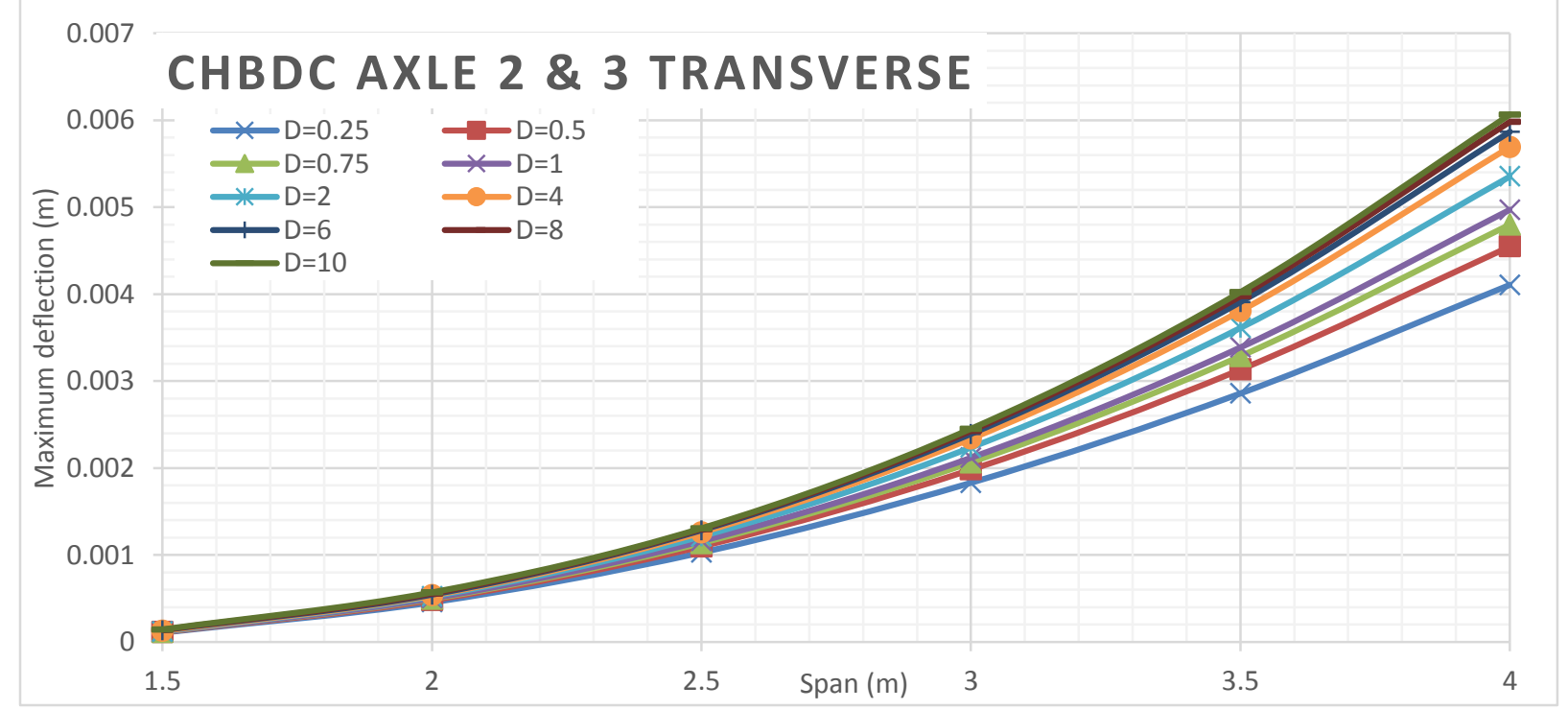

Figure 384 Maximum deflection of deck slabs subjected to CHBDC axle $2 \& 3$ for different D values of alpha 0.75 Orthotropic analyses 


\section{Alpha 1 Deflection VS Span Length for Different D Values}

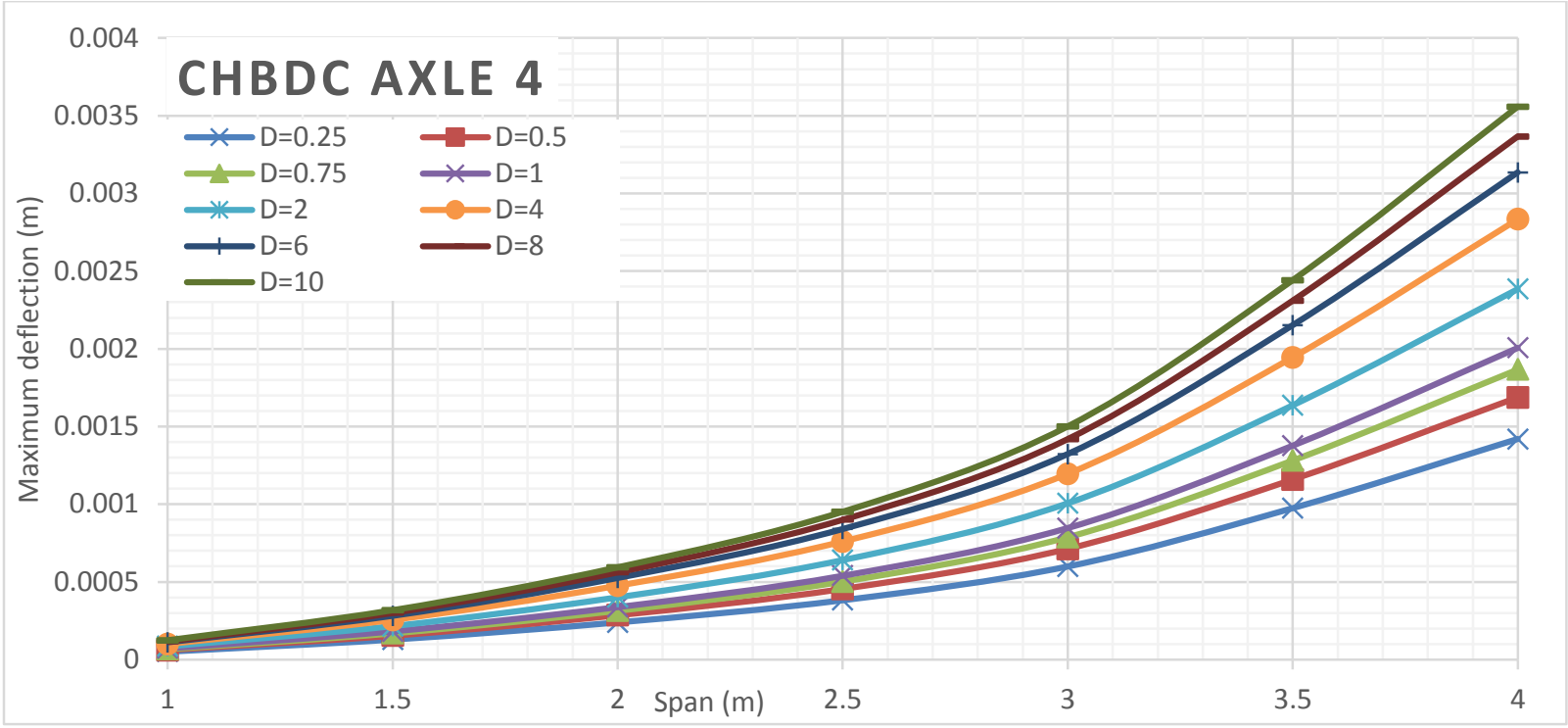

Figure 385 Maximum deflection of deck slabs subjected to CHBDC axle 4 for different D values of alpha 1 Orthotropic analyses

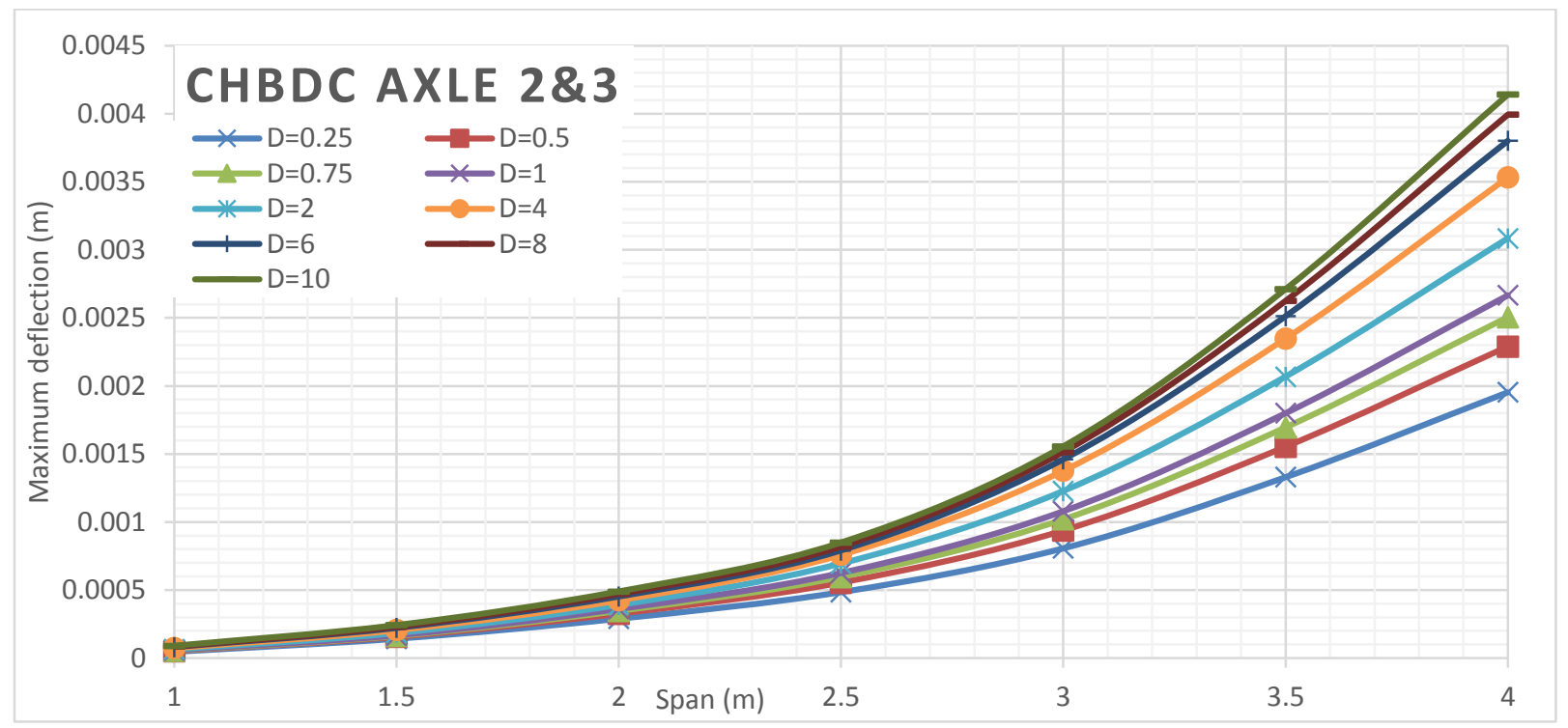

Figure 386 Maximum deflection of deck slabs subjected to CHBDC axle 2 \& 3 for different D values of alpha 1 Orthotropic analyses 


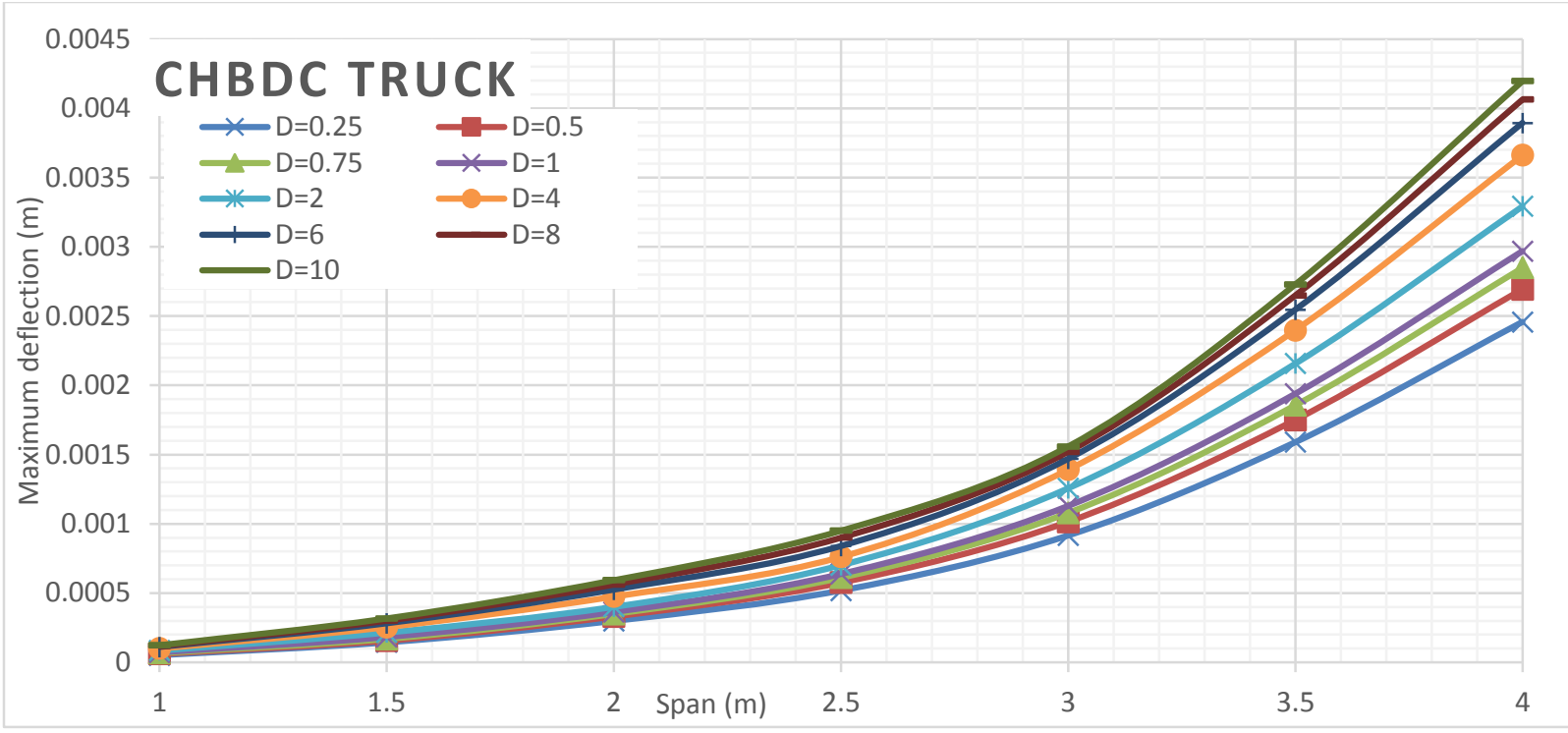

Figure 387 Maximum deflection of deck slabs subjected to CHBDC truck for different D values of alpha 1 Orthotropic analyses

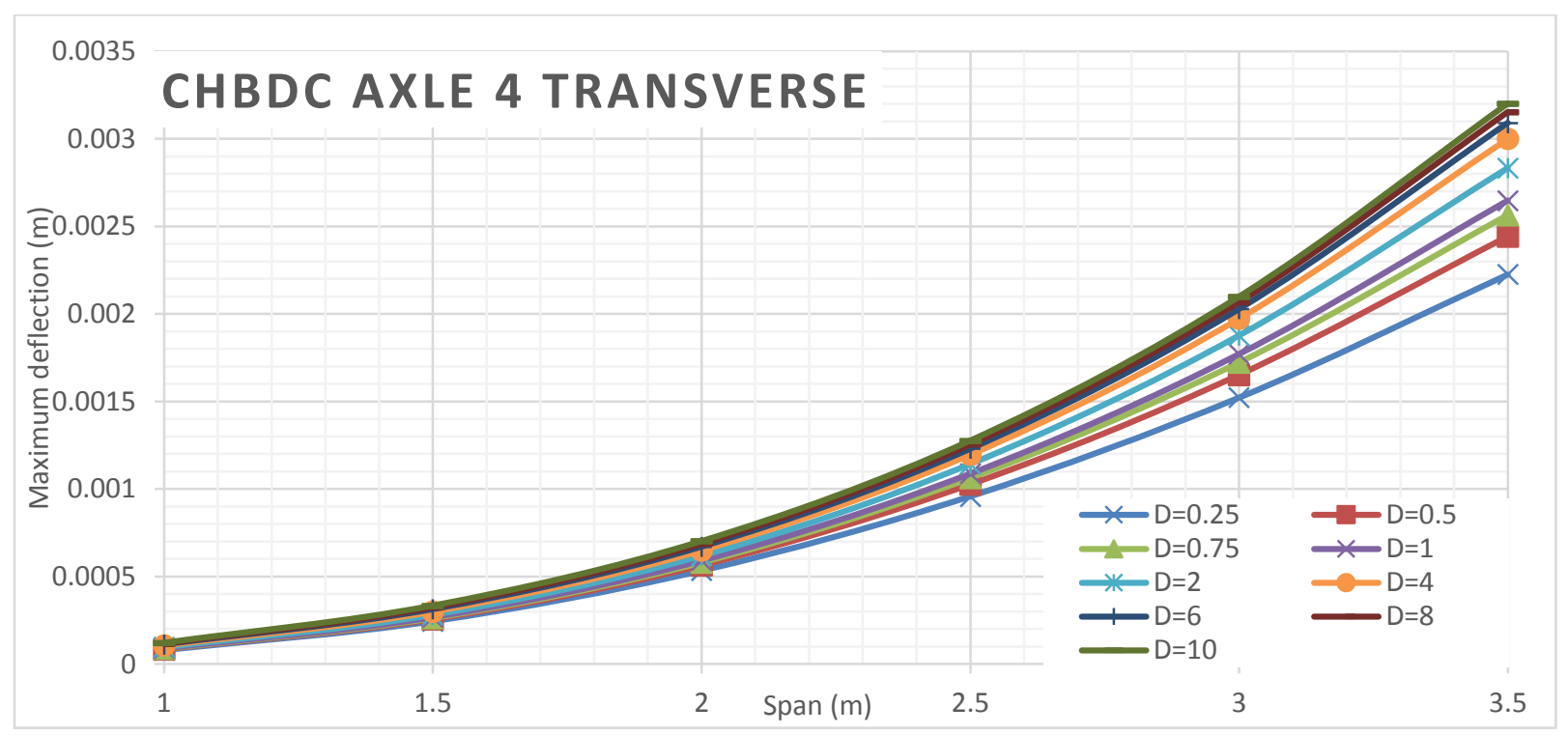

Figure 388 Maximum deflection of deck slabs subjected to CHBDC axle 4 for different D values of alpha 1 Orthotropic analyses

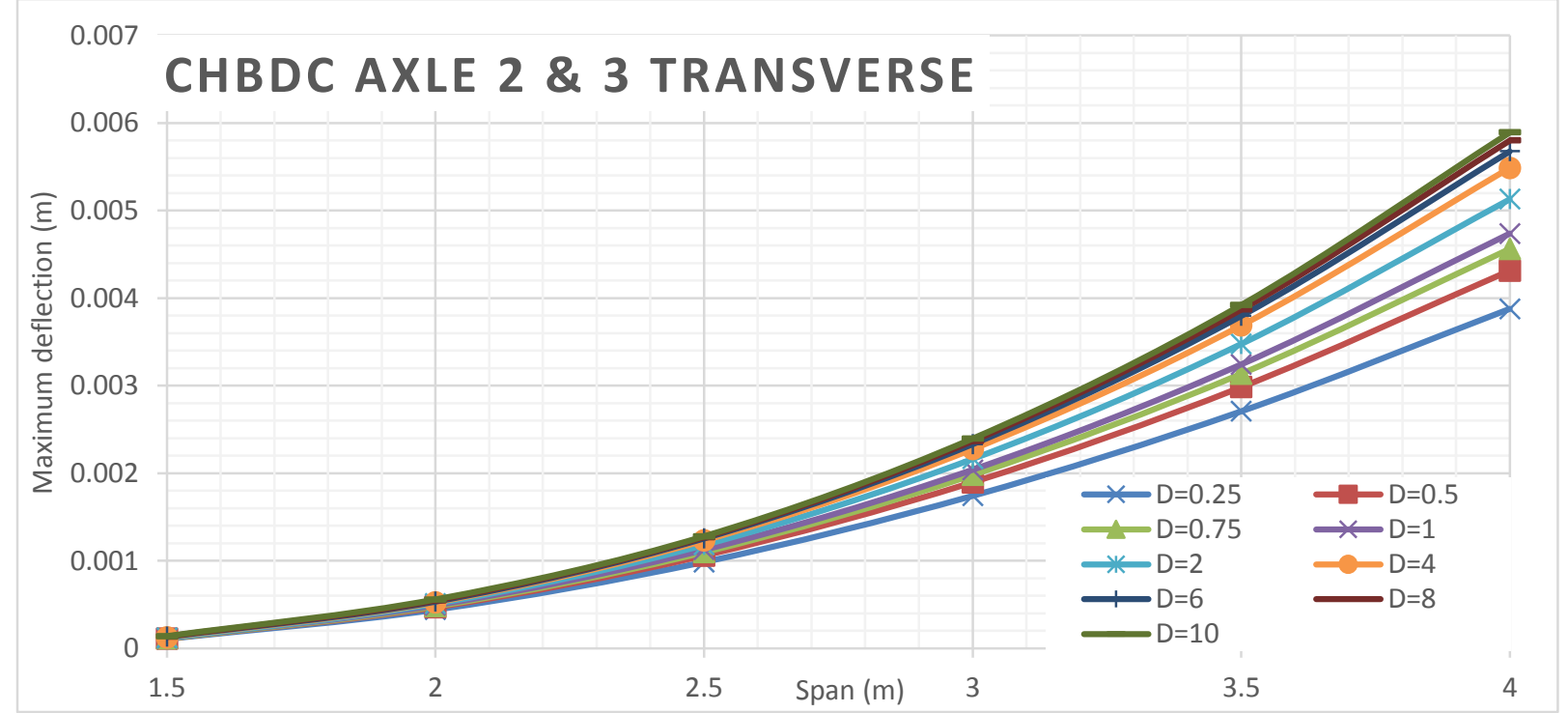

Figure 389 Maximum deflection of deck slabs subjected to CHBDC axle 2 \& 3 for different D values of alpha 1 Orthotropic analyses 


\section{Alpha 2 Deflection VS Span Length for Different D Values}

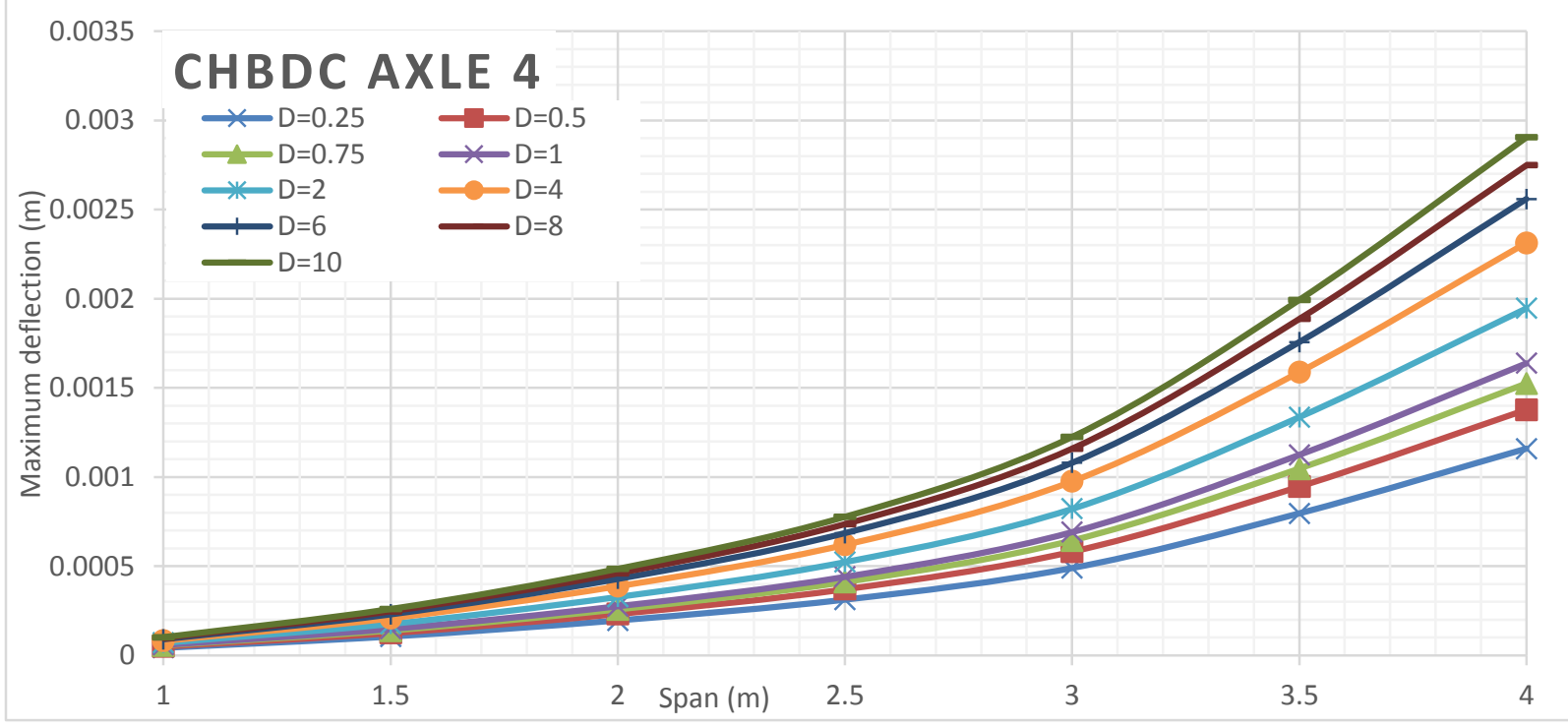

Figure 390 Maximum deflection of deck slabs subjected to CHBDC axle 4 for different D values of alpha 2 Orthotropic analyses

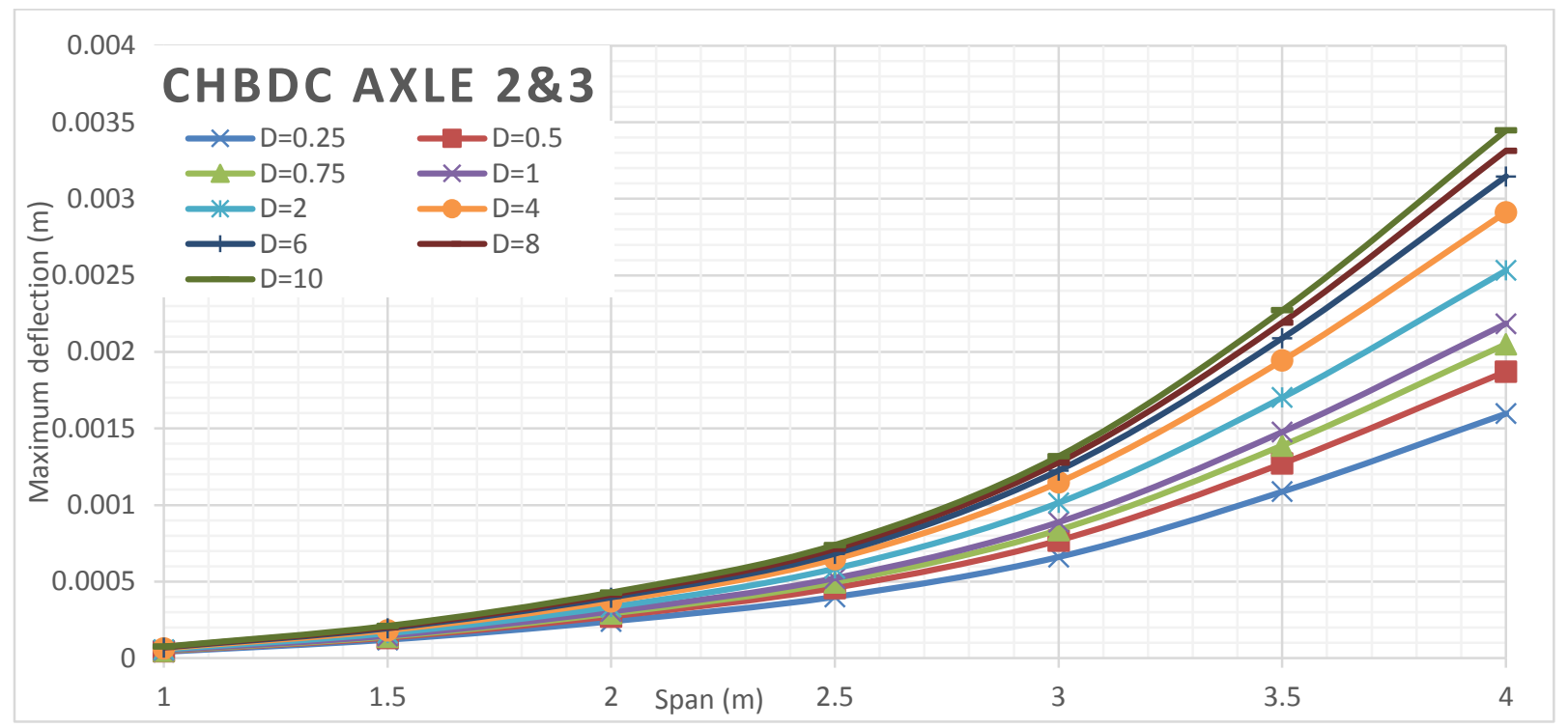

Figure 391 Maximum deflection of deck slabs subjected to CHBDC axle 2 \& 3 for different D values of alpha 2 Orthotropic analyses 


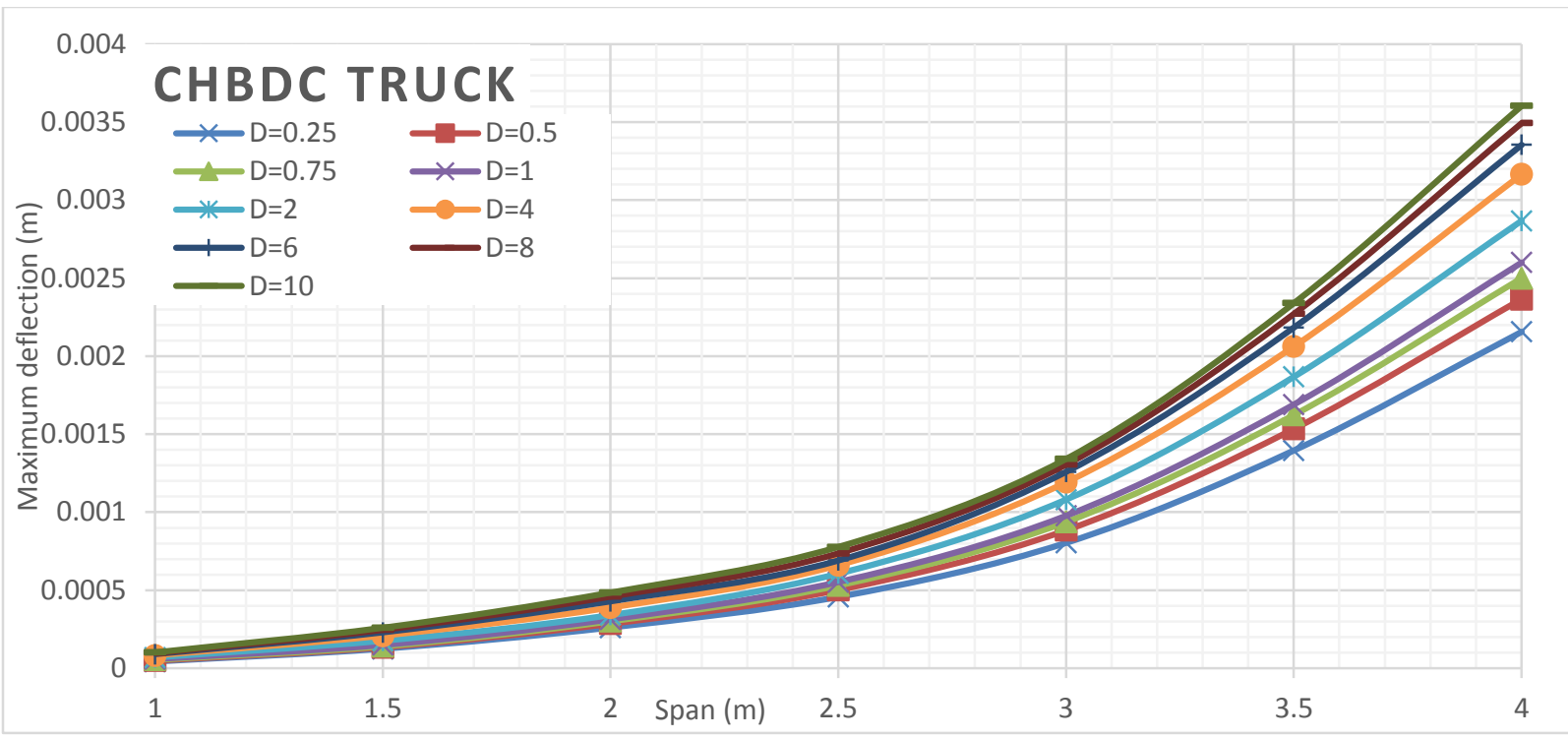

Figure 392 Maximum deflection of deck slabs subjected to CHBDC truck for different D values of alpha 2 Orthotropic analyses

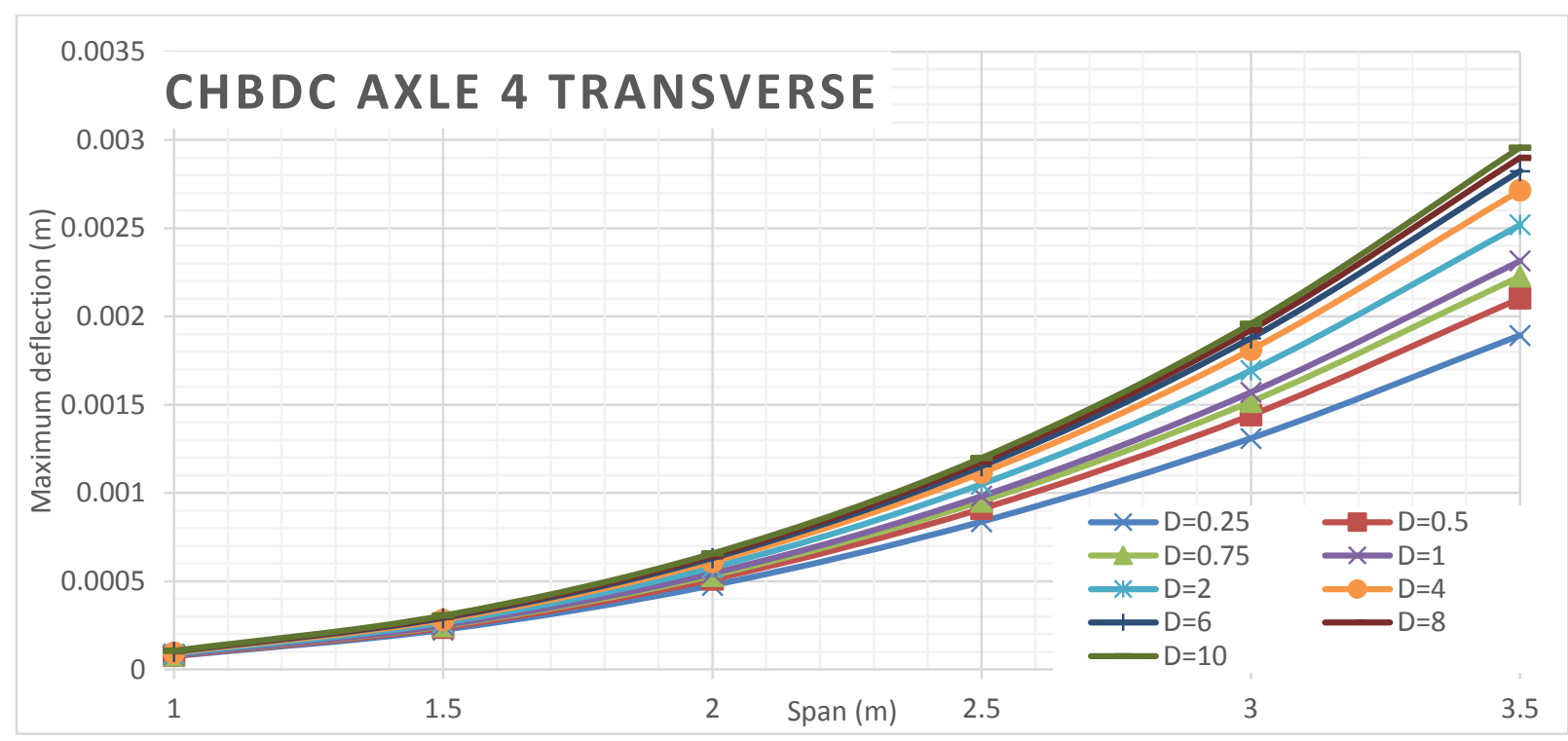

Figure 393 Maximum deflection of deck slabs subjected to CHBDC axle 4 for different D values of alpha 2 Orthotropic analyses

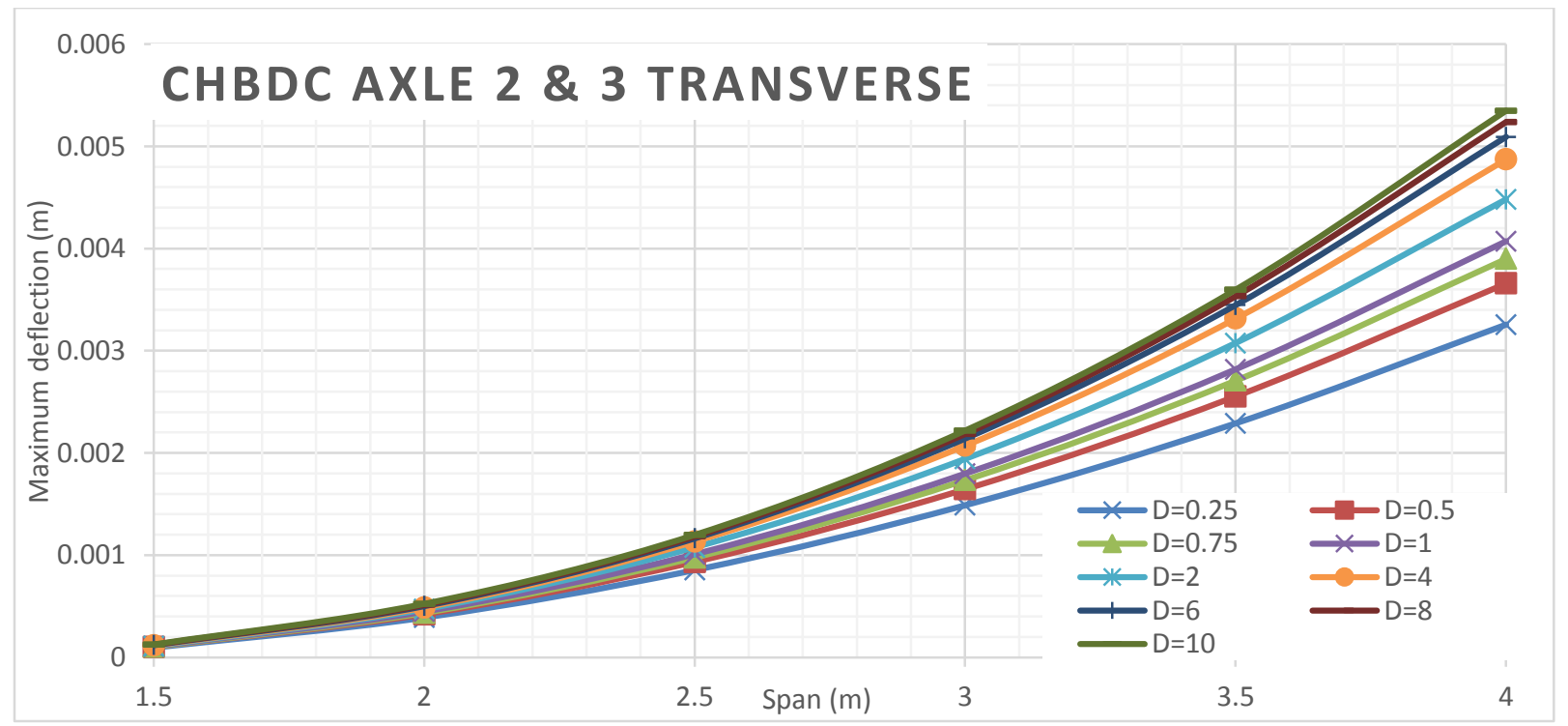

Figure 394 Maximum deflection of deck slabs subjected to CHBDC axle 2 \& 3 for different D values of alpha 2 Orthotropic analyses 


\section{Alpha 4 Deflection VS Span Length for Different D Values}

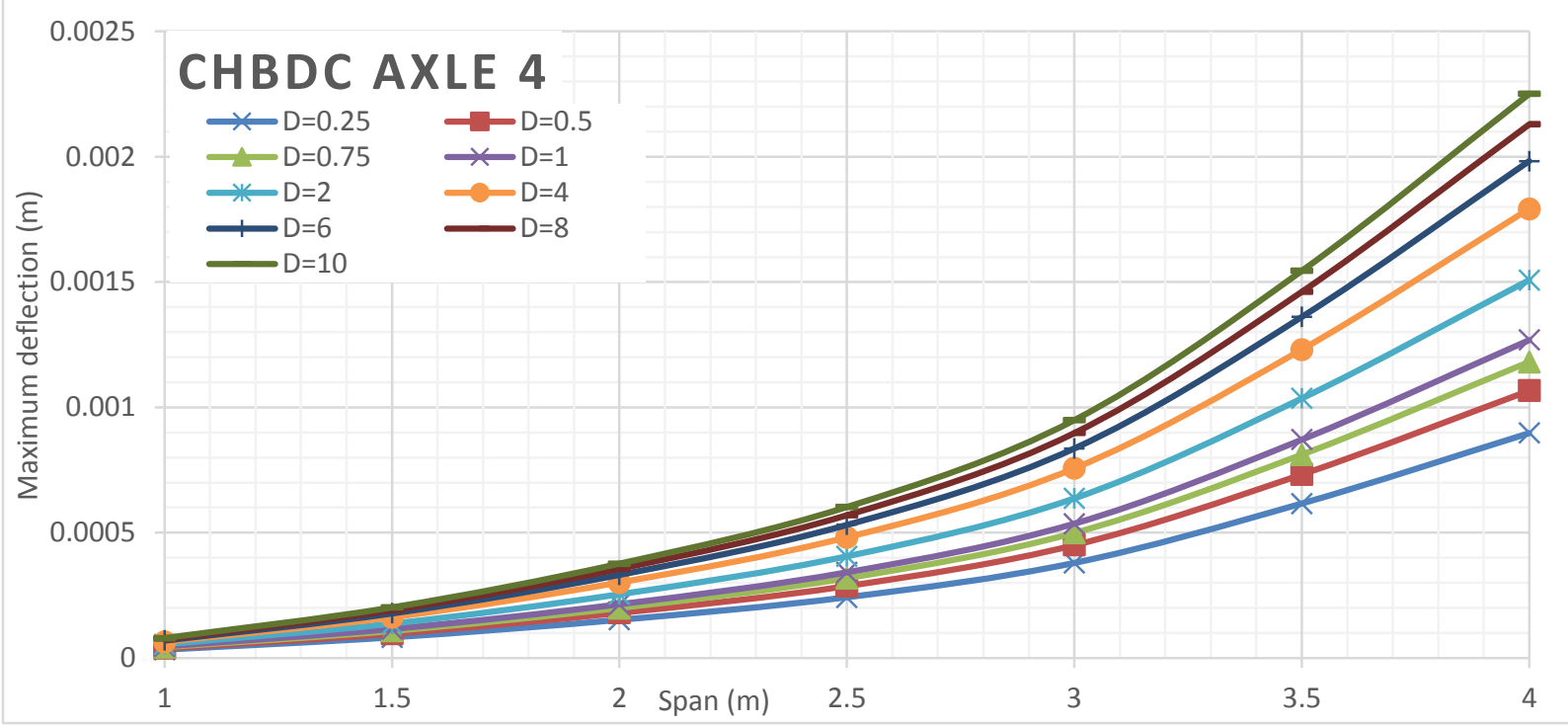

Figure 395 Maximum deflection of deck slabs subjected to CHBDC axle 4 for different D values of alpha 4 Orthotropic analyses

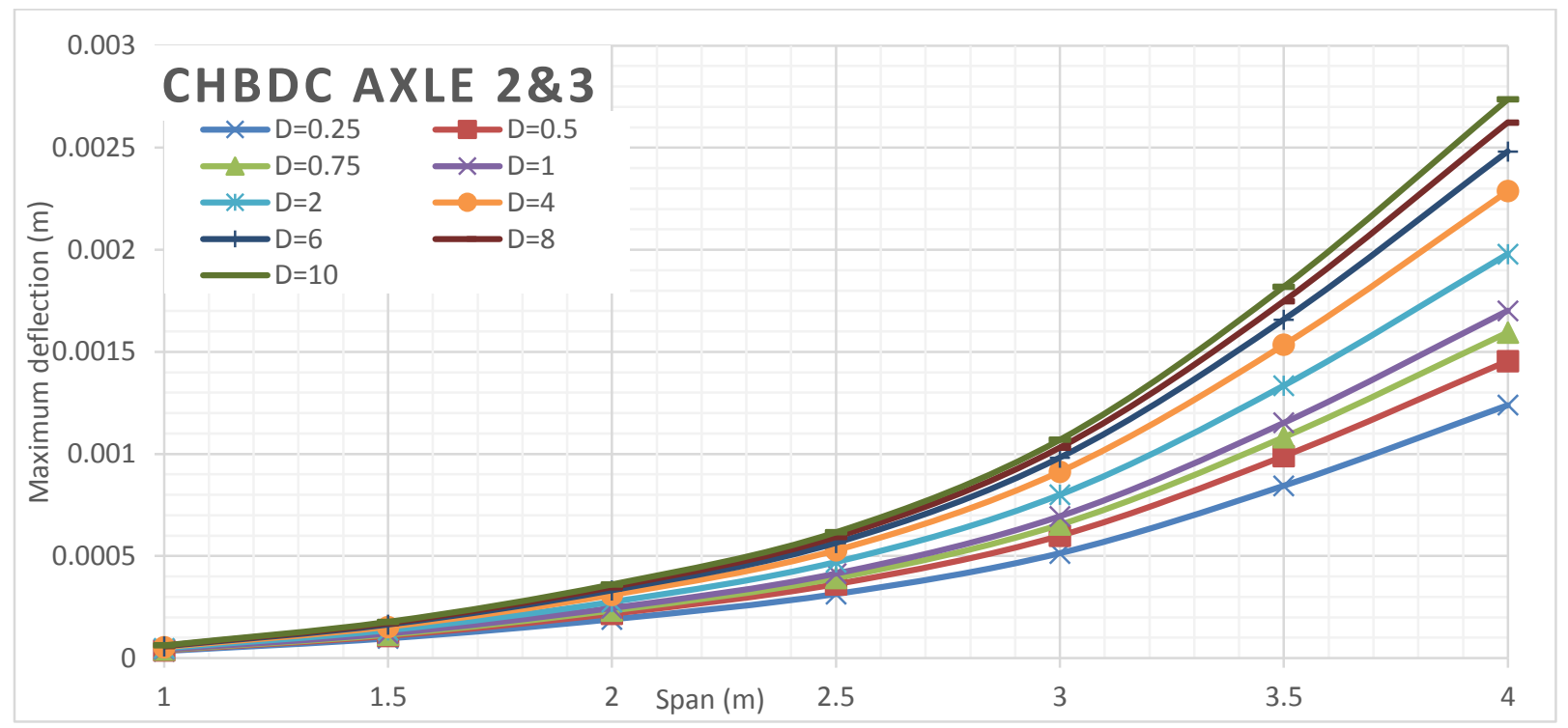

Figure 396 Maximum deflection of deck slabs subjected to CHBDC axle 2 \& 3 for different D values of alpha 4 Orthotropic analyses 


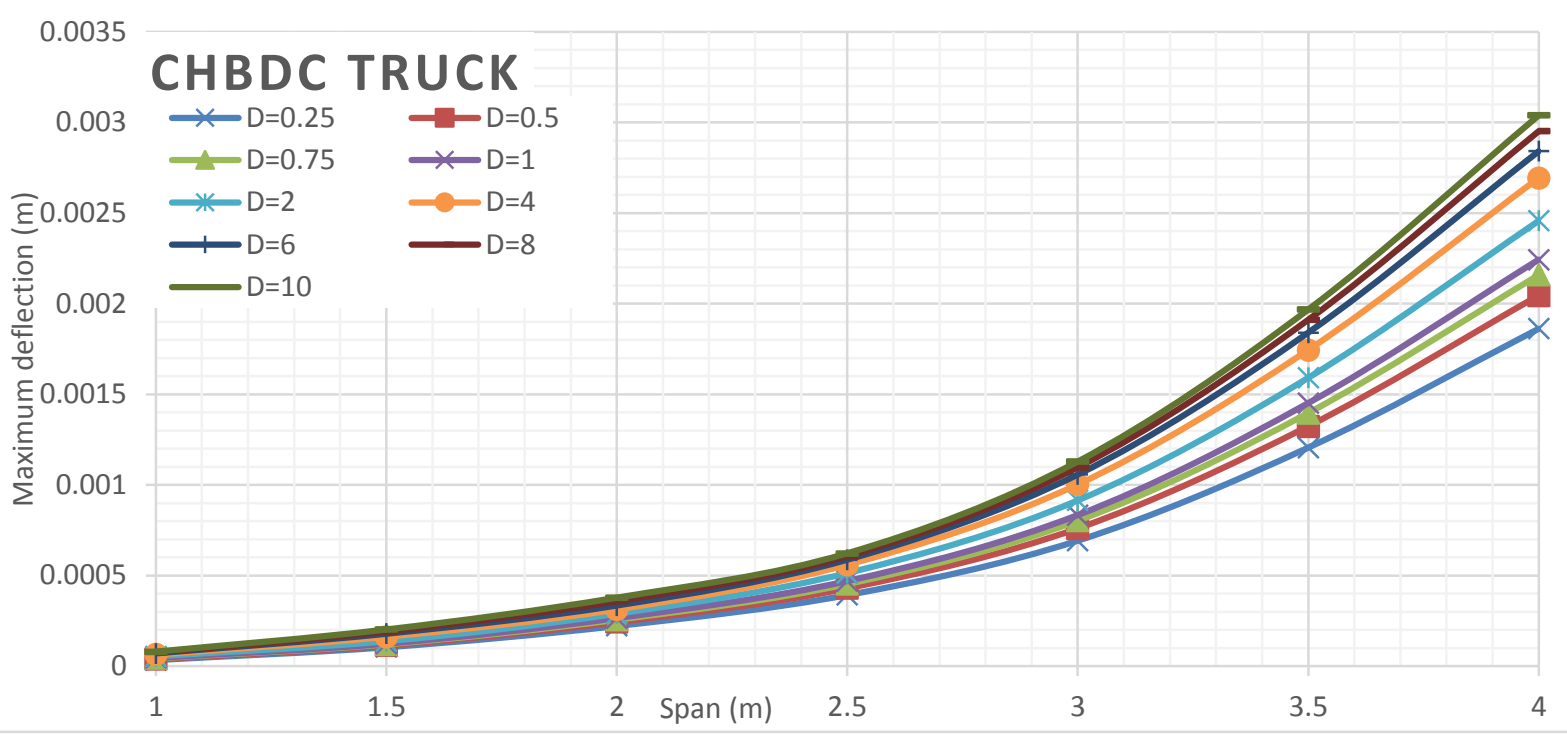

Figure 397 Maximum deflection of deck slabs subjected to CHBDC truck for different D values of alpha 4 Orthotropic analyses

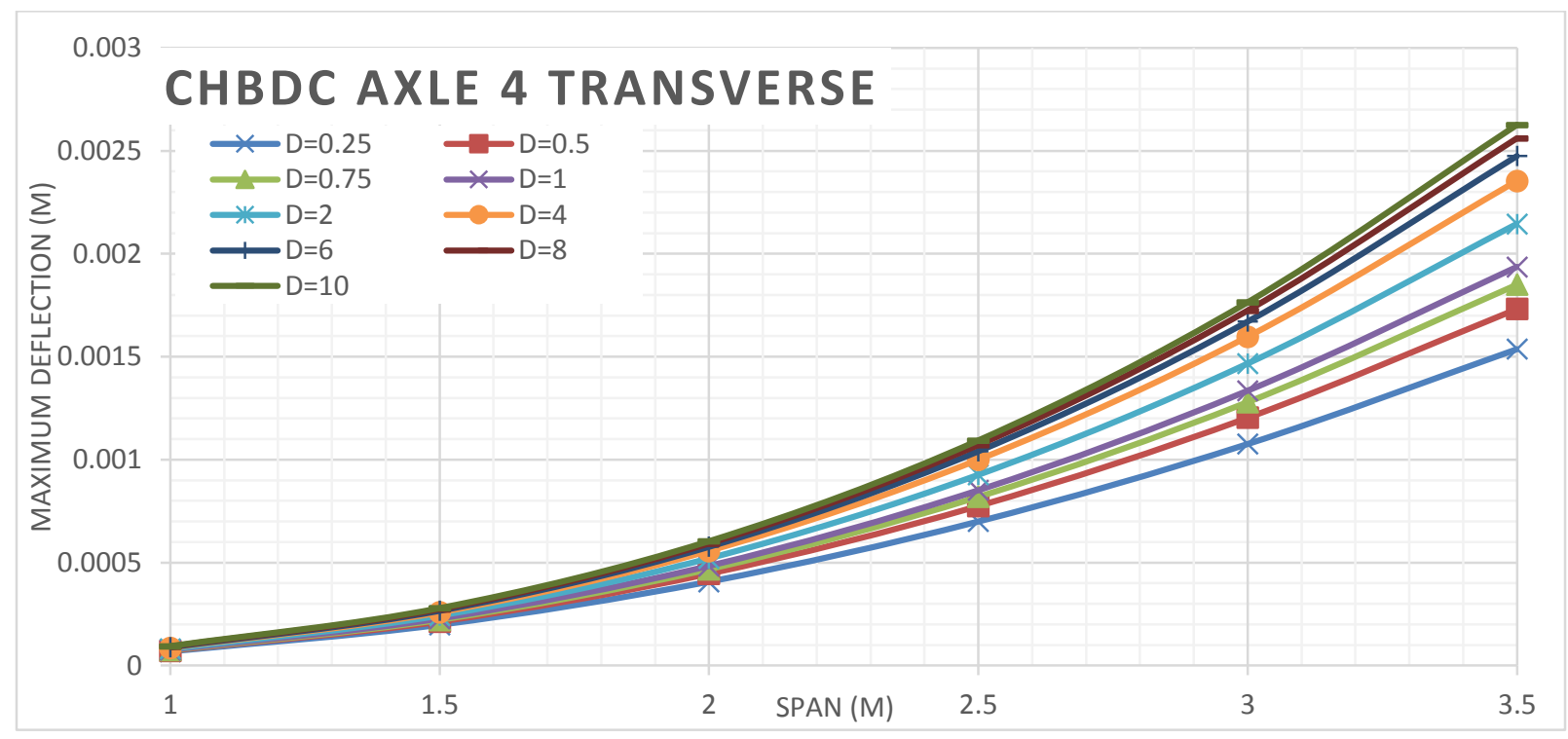

Figure 398 Maximum deflection of deck slabs subjected to CHBDC axle 4 for different D values of alpha 4 Orthotropic analyses

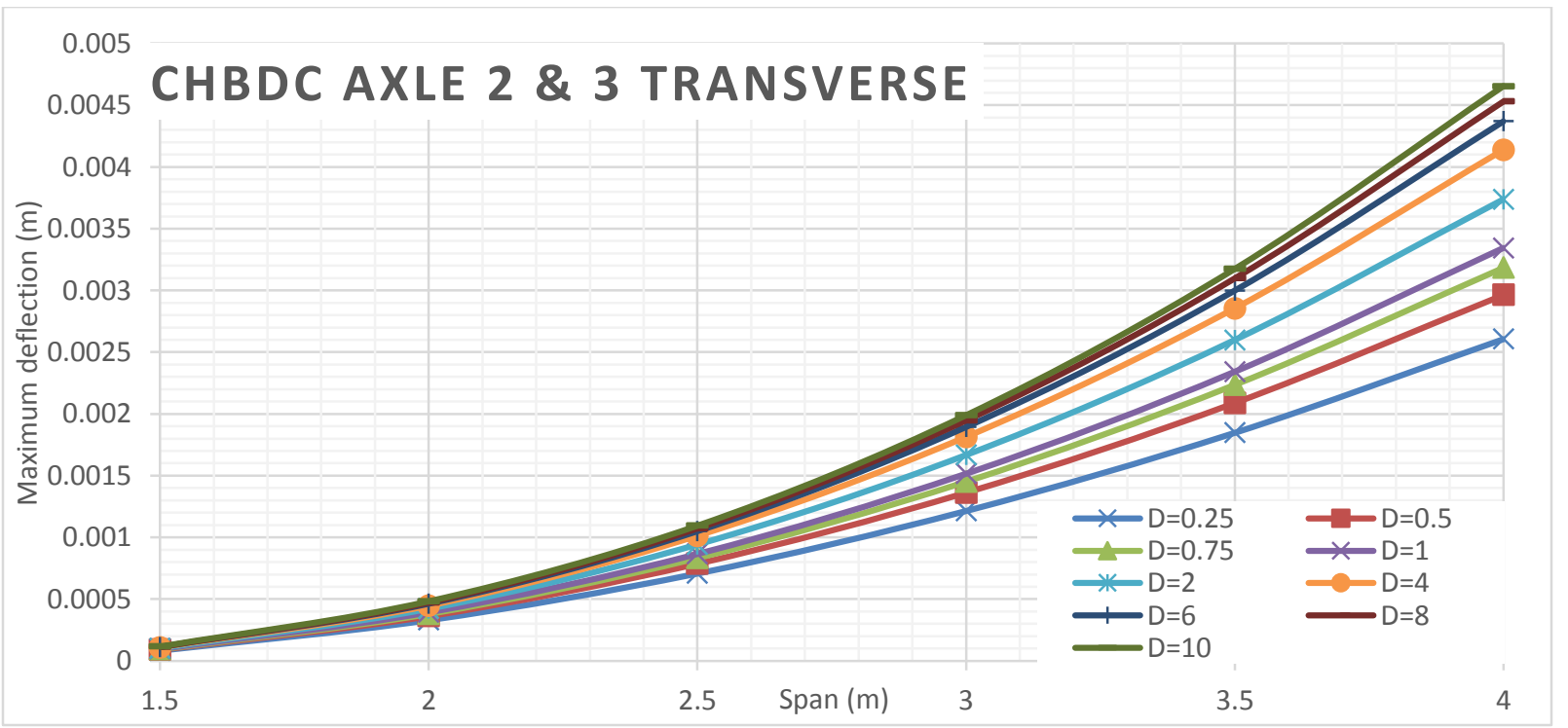

Figure 399 Maximum deflection of deck slabs subjected to CHBDC axle 2 \& 3 for different D values of alpha 4 Orthotropic analyses 


\section{Alpha 6 Deflection VS Span Length for Different D Values}

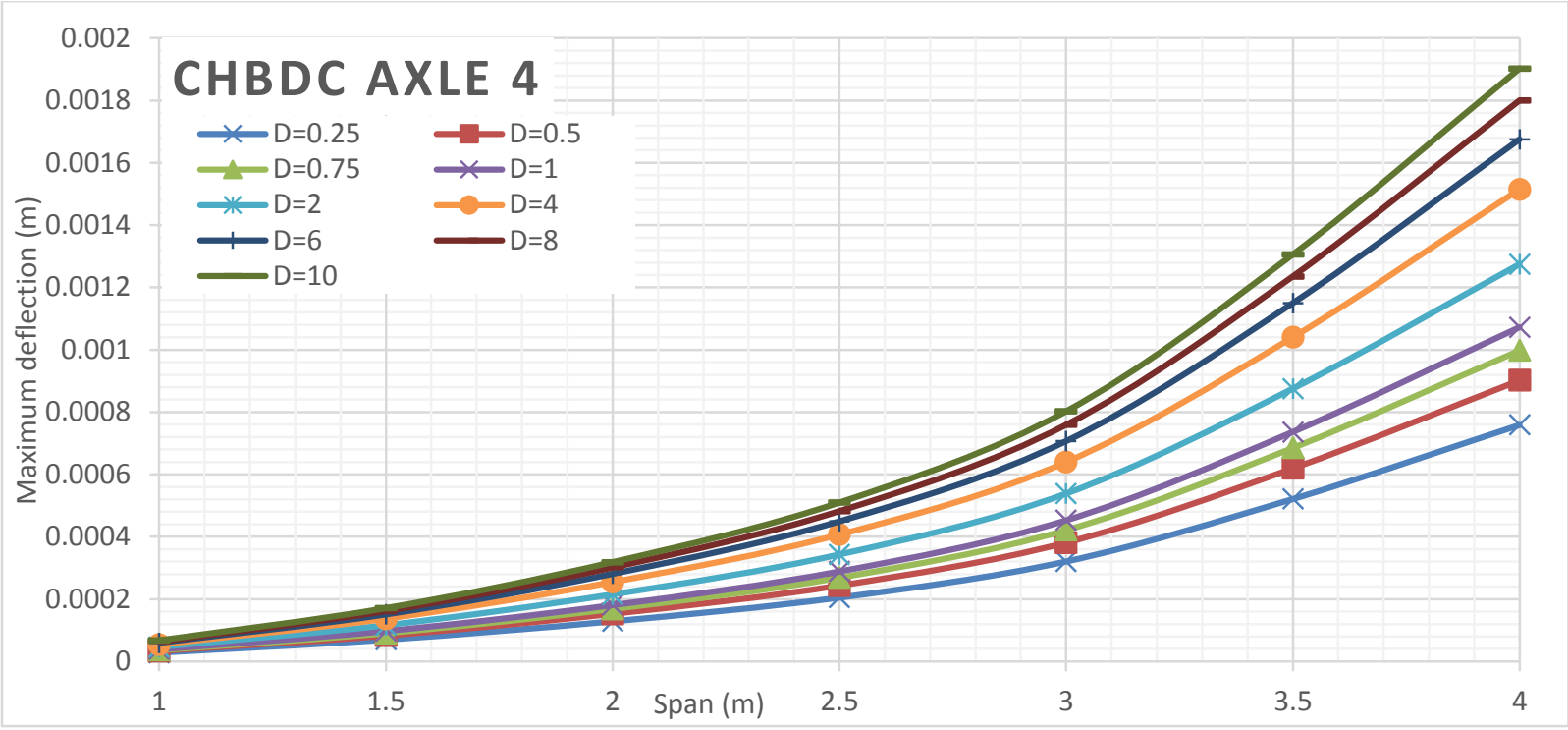

Figure 400 Maximum deflection of deck slabs subjected to CHBDC axle 4 for different D values of alpha 6 Orthotropic analyses

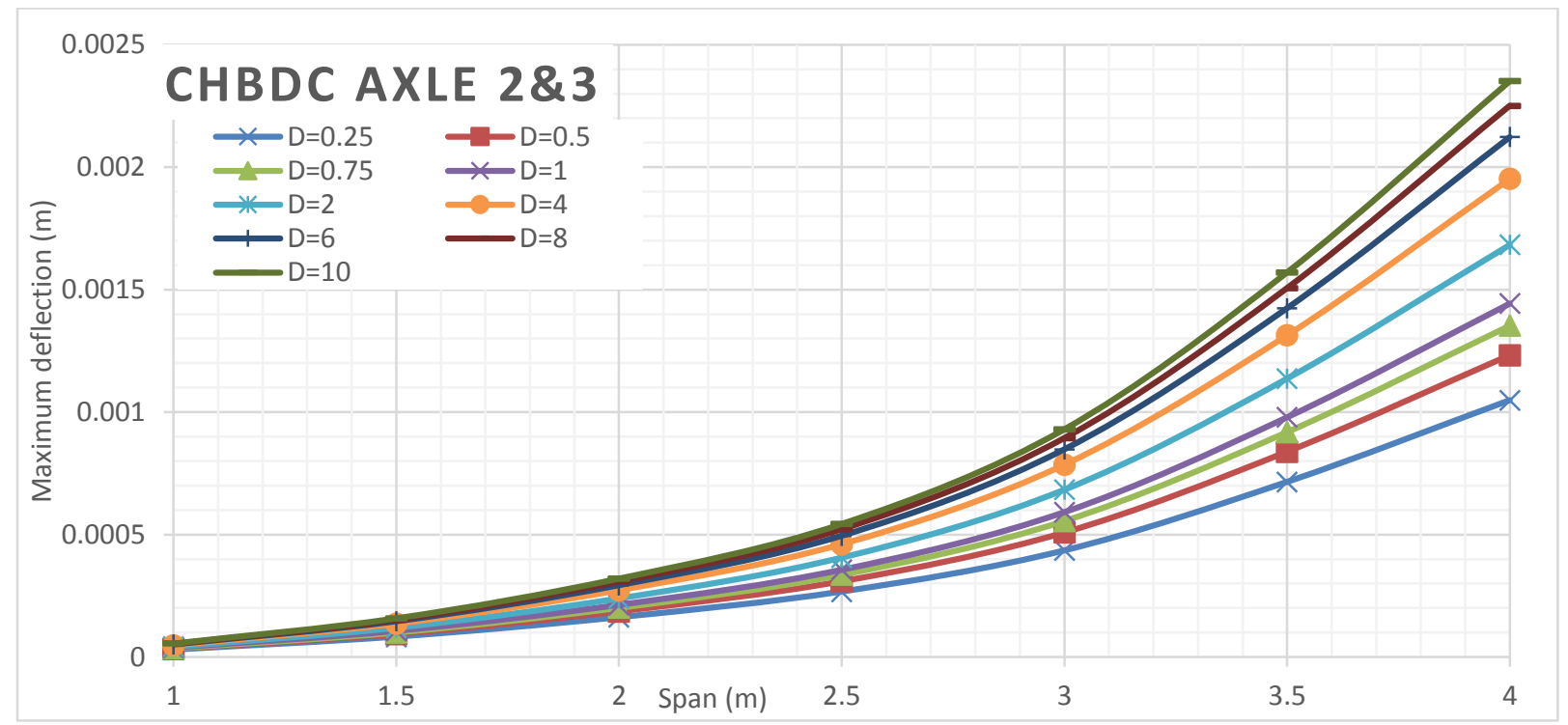

Figure 401 Maximum deflection of deck slabs subjected to CHBDC axle 2 \& 3 for different D values of alpha 6 Orthotropic analyses 


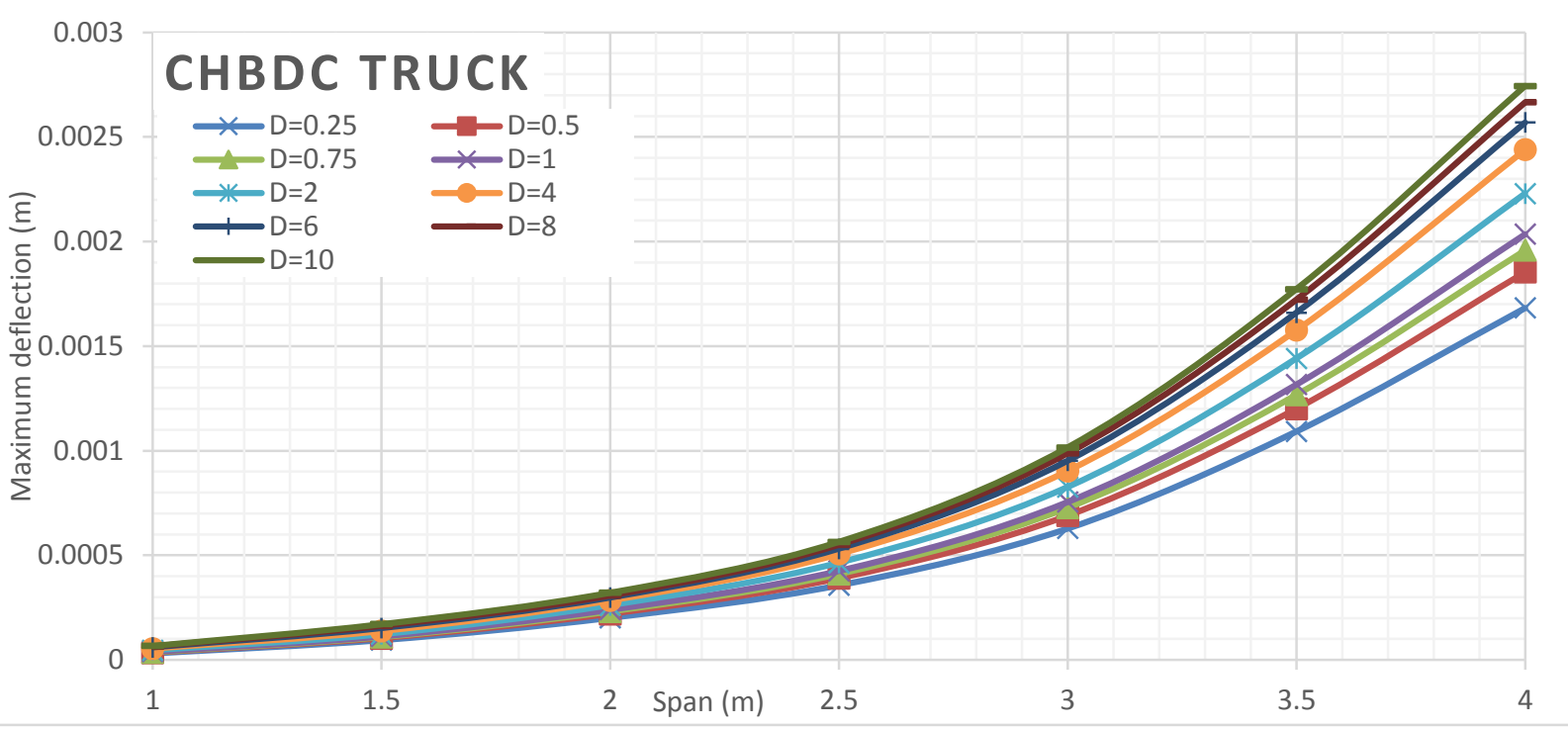

Figure 402 Maximum deflection of deck slabs subjected to CHBDC truck for different D values of alpha 6 Orthotropic analyses

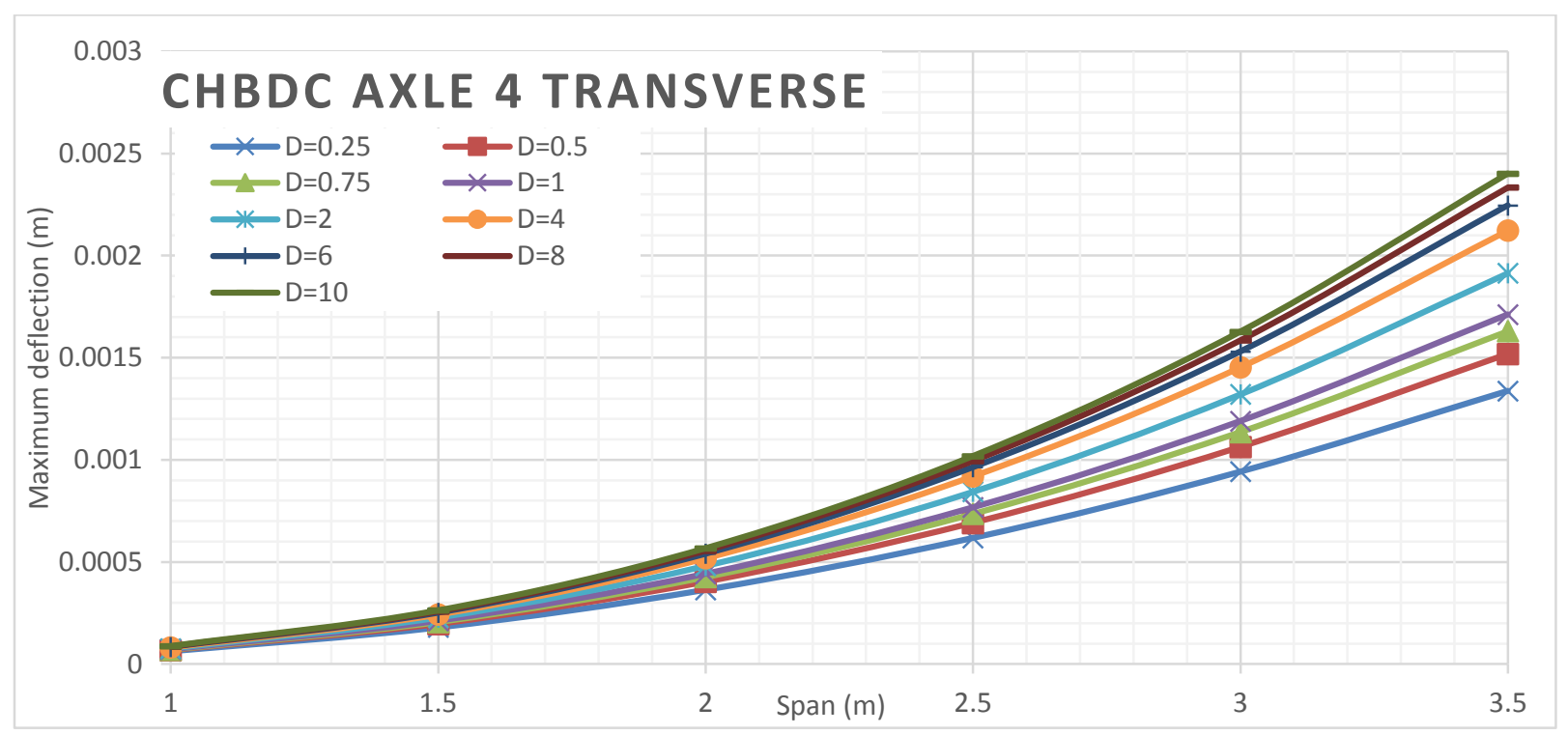

Figure 403 Maximum deflection of deck slabs subjected to CHBDC axle 4 for different D values of alpha 6 Orthotropic analyses

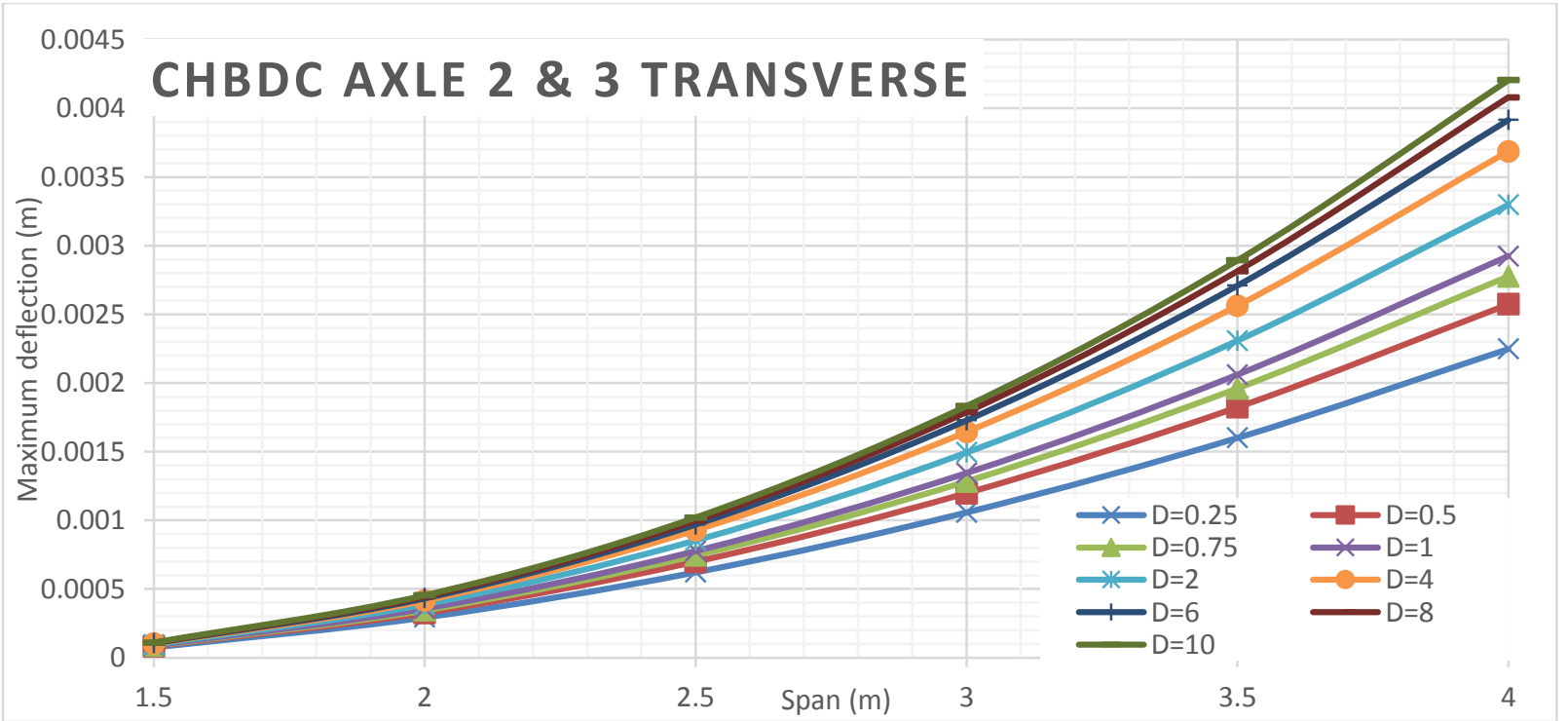

Figure 404 Maximum deflection of deck slabs subjected to CHBDC axle $2 \& 3$ for different D values of alpha 6 Orthotropic analyses 


\section{Alpha 8 Deflection VS Span Length for Different D Values}

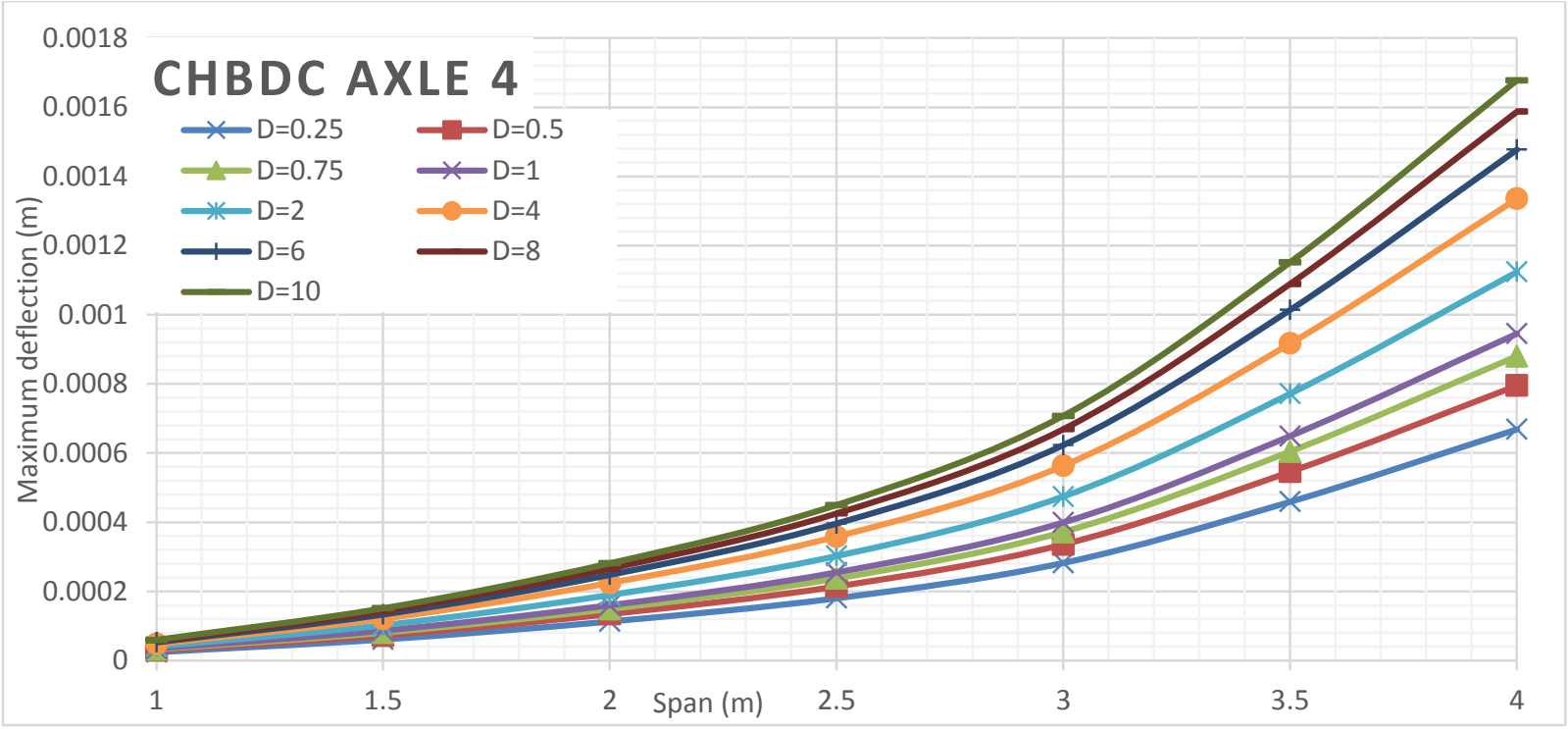

Figure 405 Maximum deflection of deck slabs subjected to CHBDC axle 4 for different D values of alpha 8 Orthotropic analyses

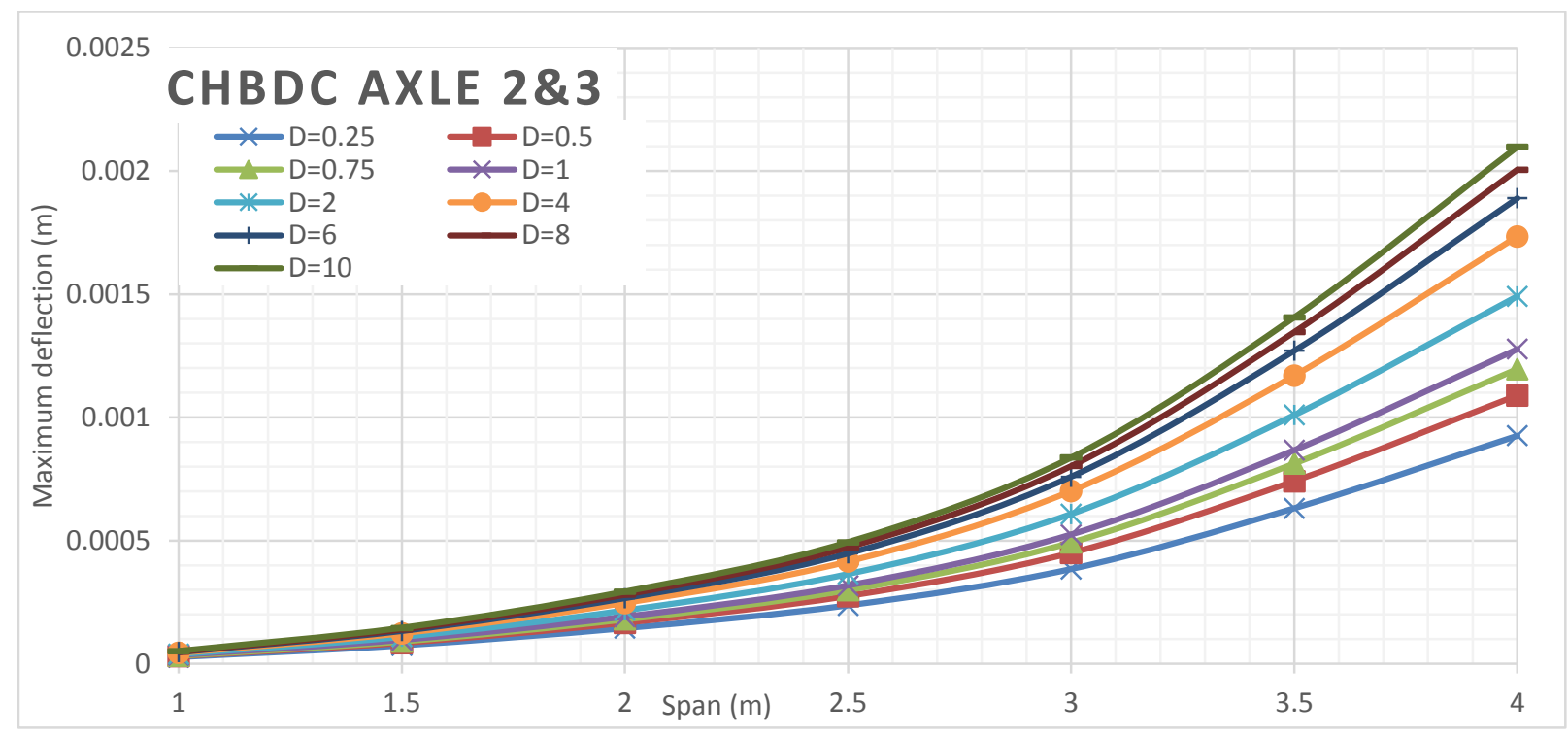

Figure 406 Maximum deflection of deck slabs subjected to CHBDC axle 2 \& 3 for different D values of alpha 8 Orthotropic analyses 


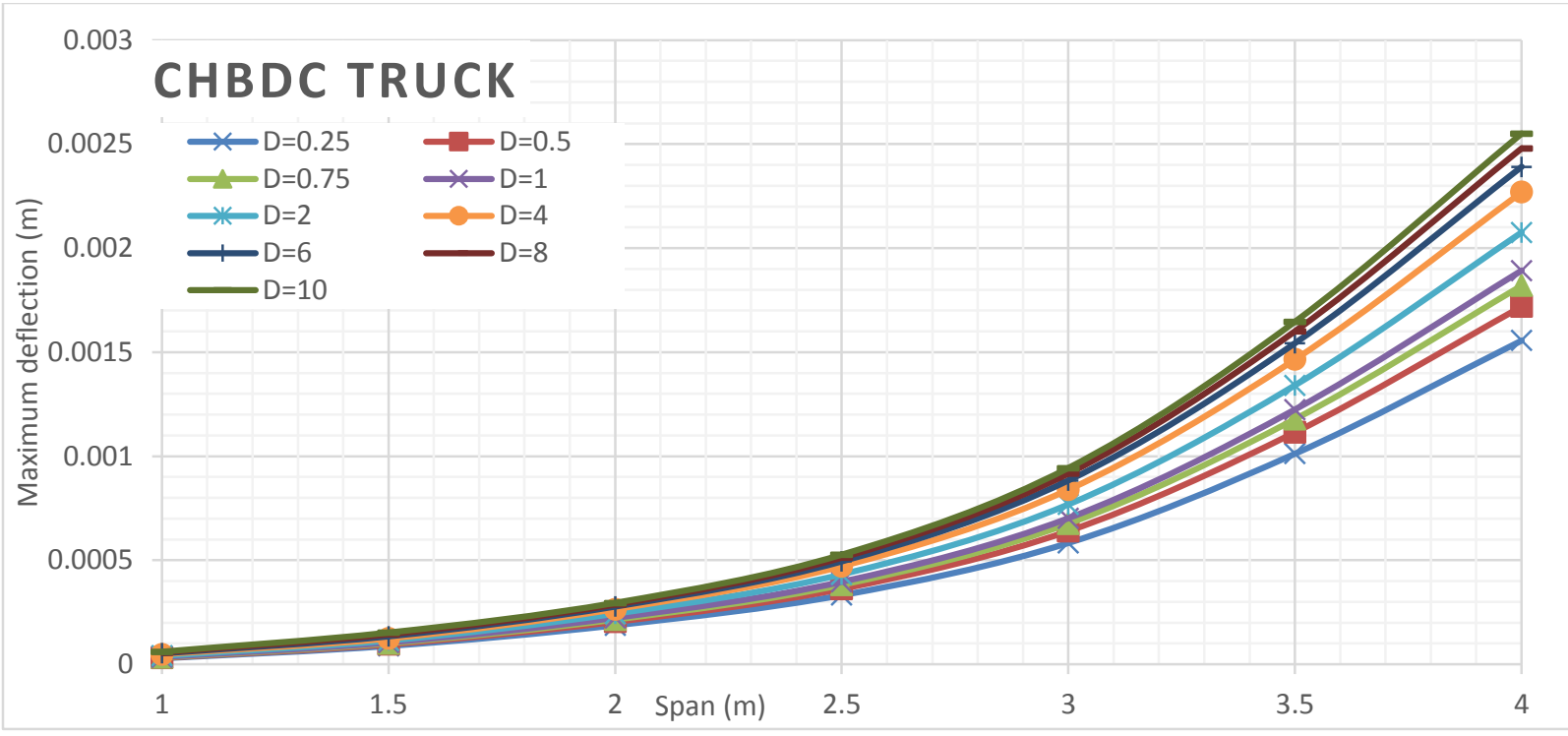

Figure 407 Maximum deflection of deck slabs subjected to CHBDC truck for different D values of alpha 8 Orthotropic analyses

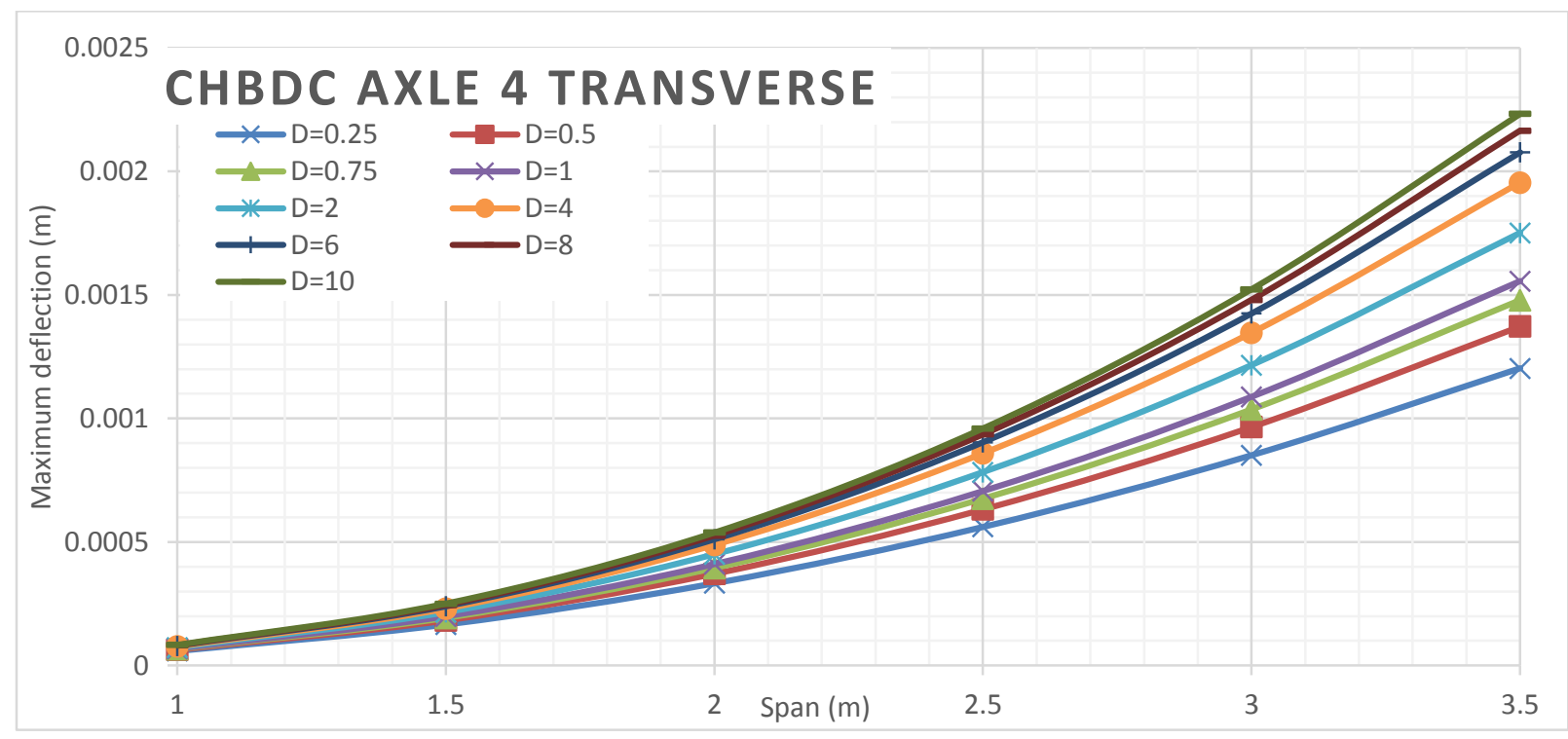

Figure 408 Maximum deflection of deck slabs subjected to CHBDC axle 4 for different D values of alpha 8 Orthotropic analyses

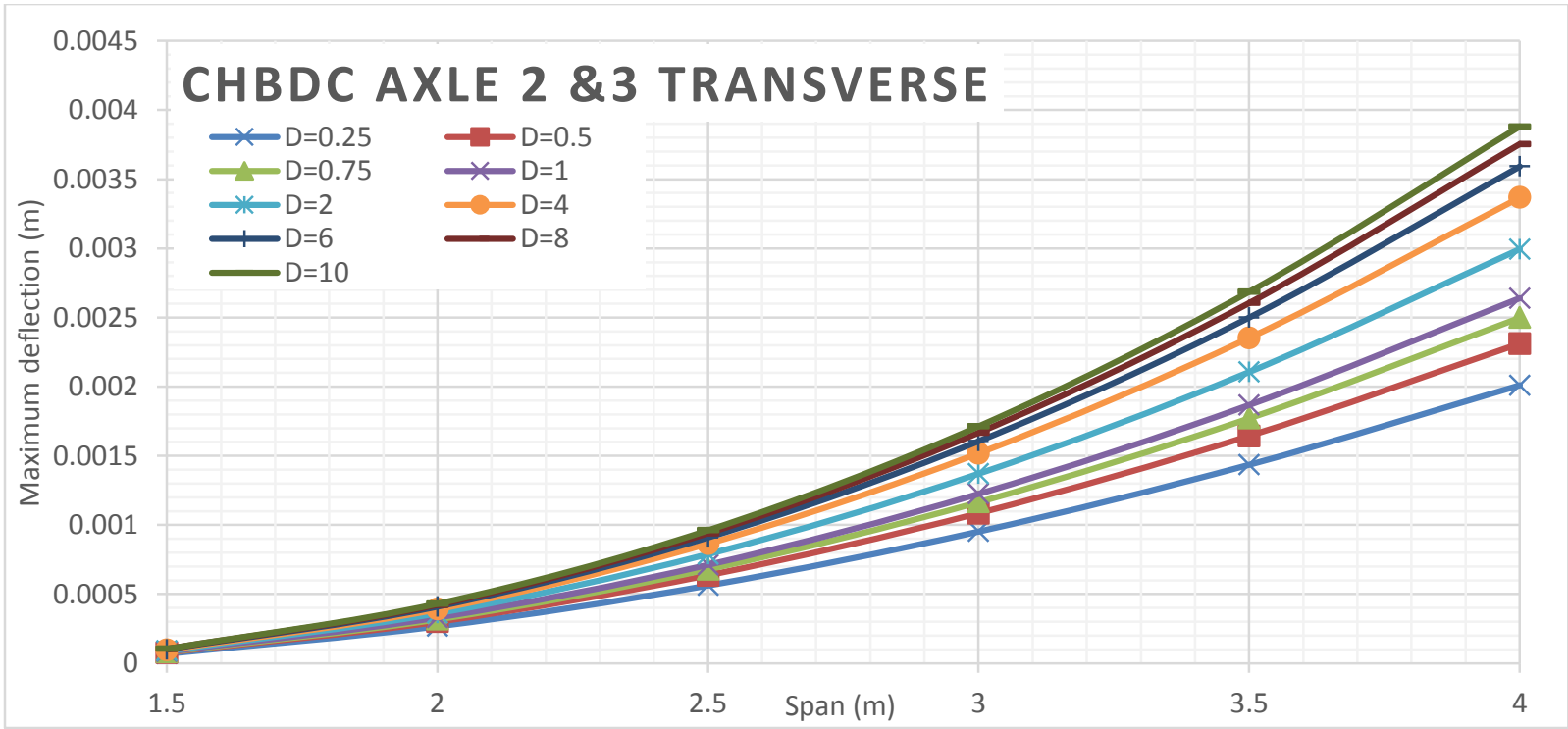

Figure 409 Maximum deflection of deck slabs subjected to CHBDC axle $2 \& 3$ for different D values of alpha 8 Orthotropic analyses 


\section{Alpha 10 Deflection VS Span Length for Different D Values}

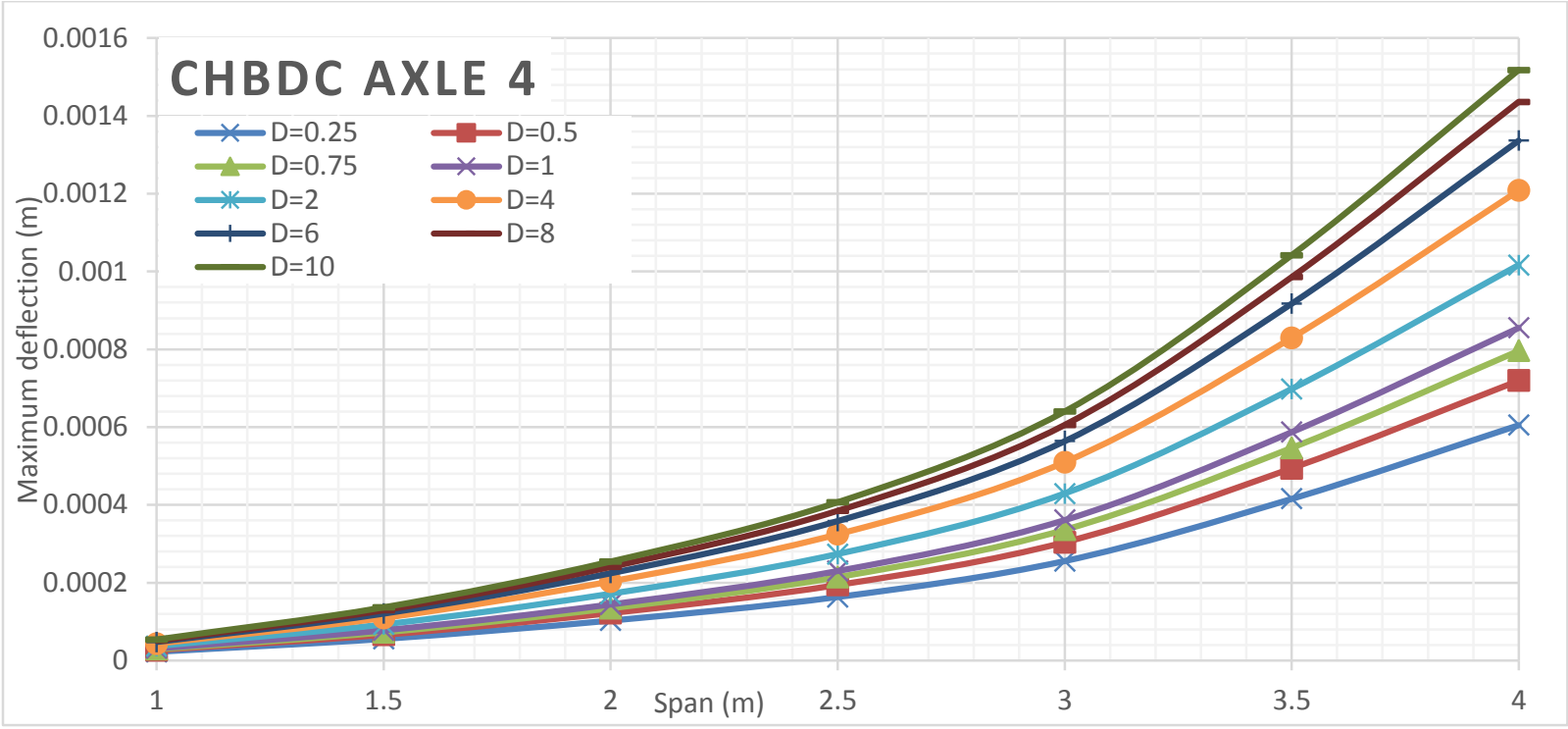

Figure 410 Maximum deflection of deck slabs subjected to CHBDC axle 4 for different D values of alpha 10 Orthotropic analyses

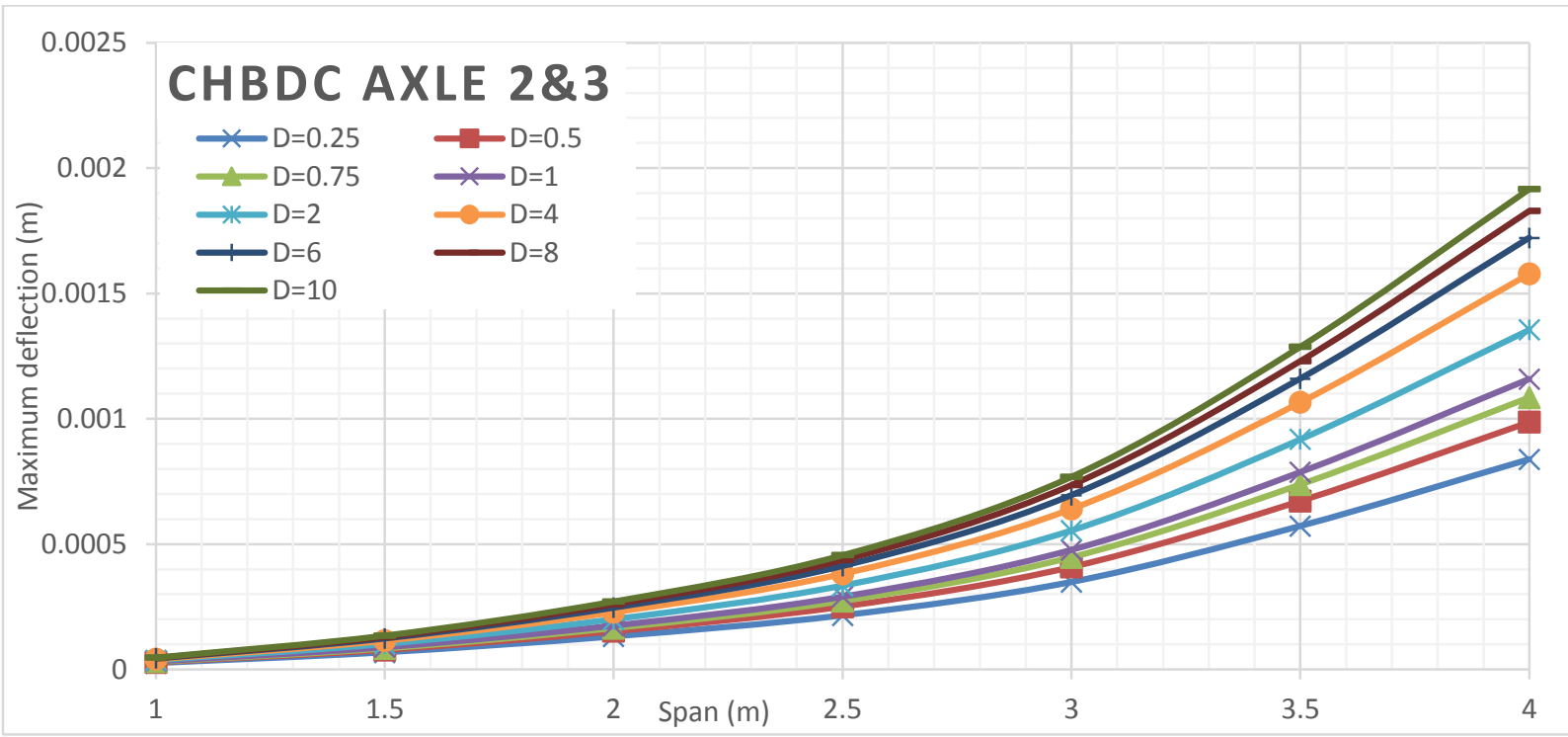

Figure 411 Maximum deflection of deck slabs subjected to CHBDC axle $2 \& 3$ for different D values of alpha 10 Orthotropic analyses 


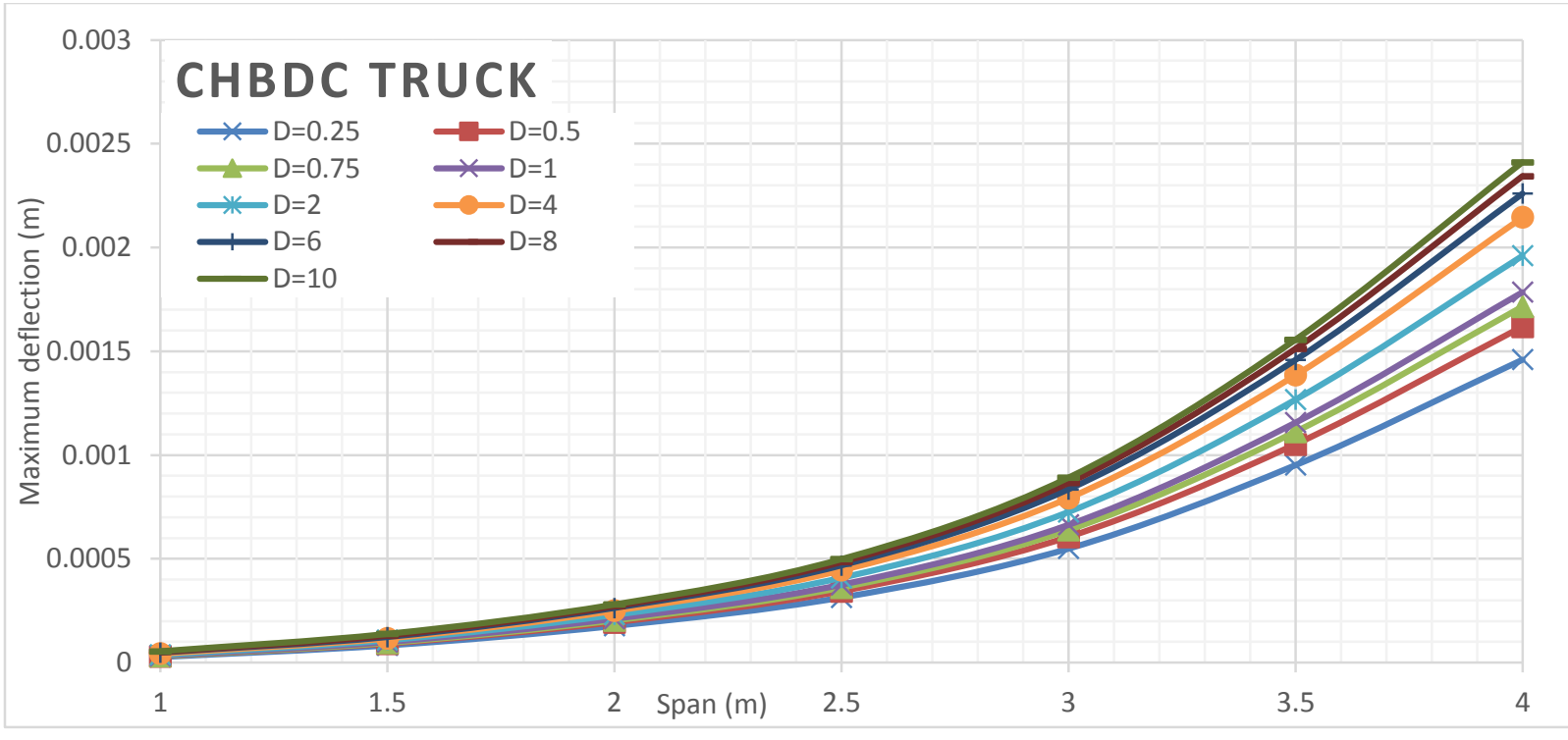

Figure 412 Maximum deflection of deck slabs subjected to CHBDC truck for different D values of alpha 10 Orthotropic analyses

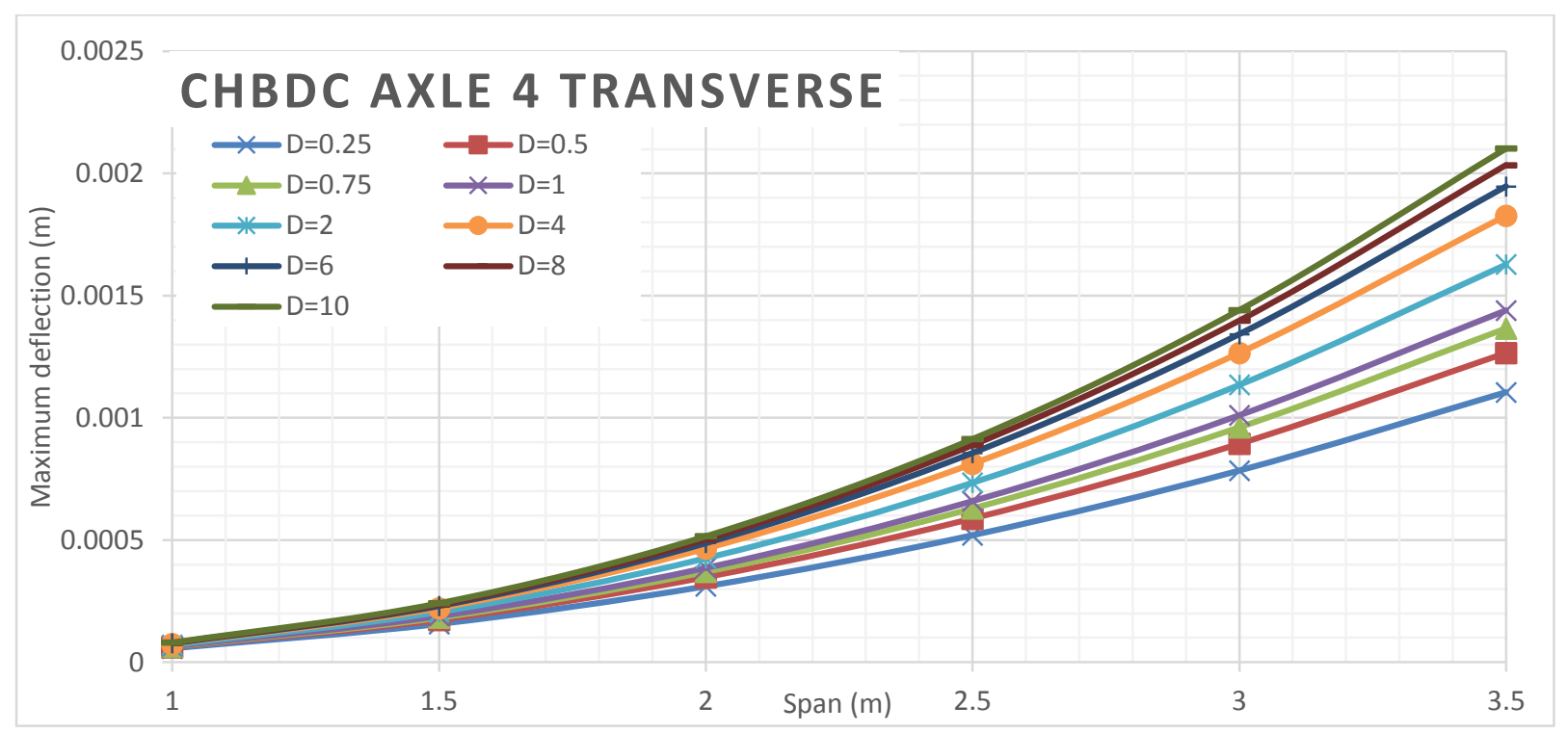

Figure 413 Maximum deflection of deck slabs subjected to CHBDC axle 4 for different D values of alpha 10 Orthotropic analyses

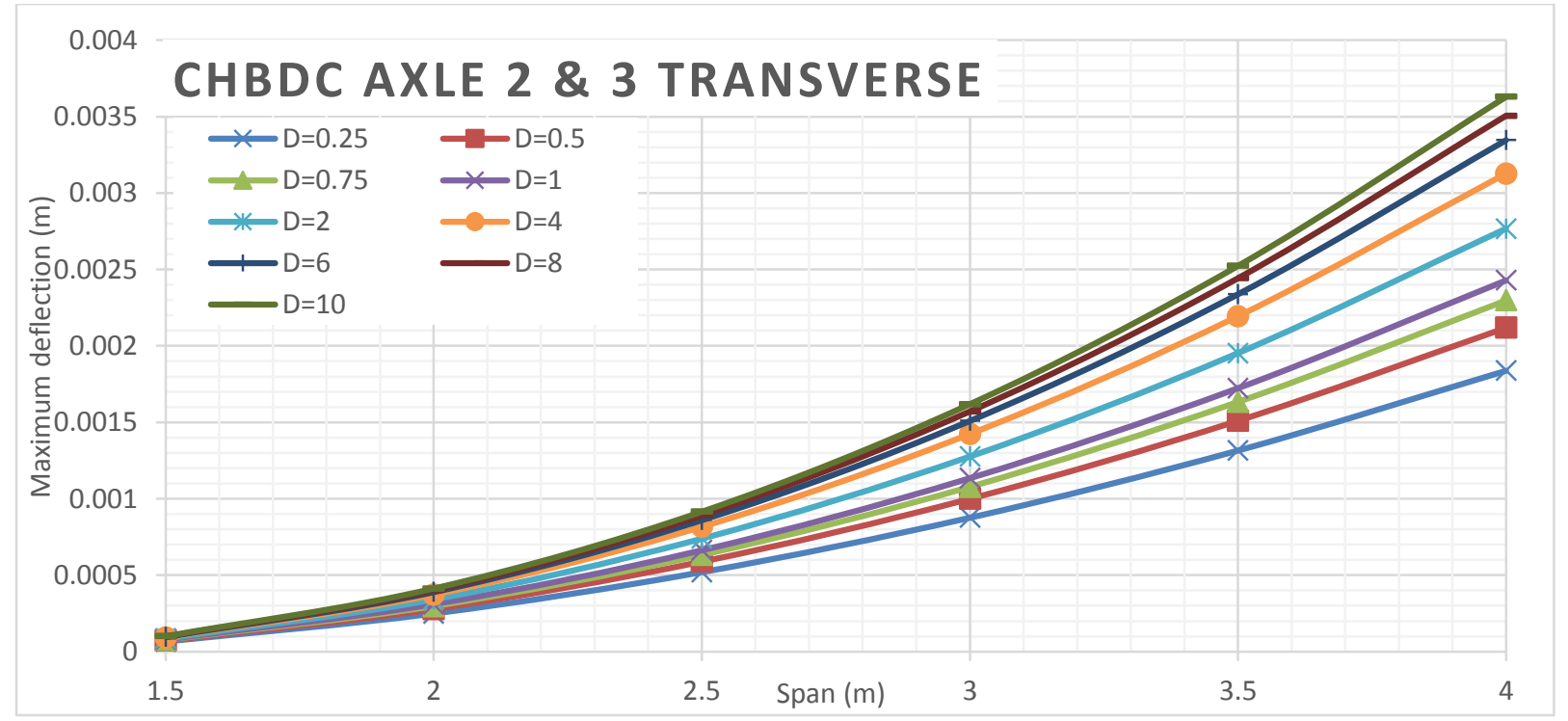

Figure 414 Maximum deflection of deck slabs subjected to CHBDC axle 2 \& 3 for different D values of alpha 10 Orthotropic analyses 


\section{C.2.3 DEFLECTION VS FLEXURAL RIGIDITY}




\section{Alpha 0.25 Deflection VS Flexural Rigidity for Different Span Length}

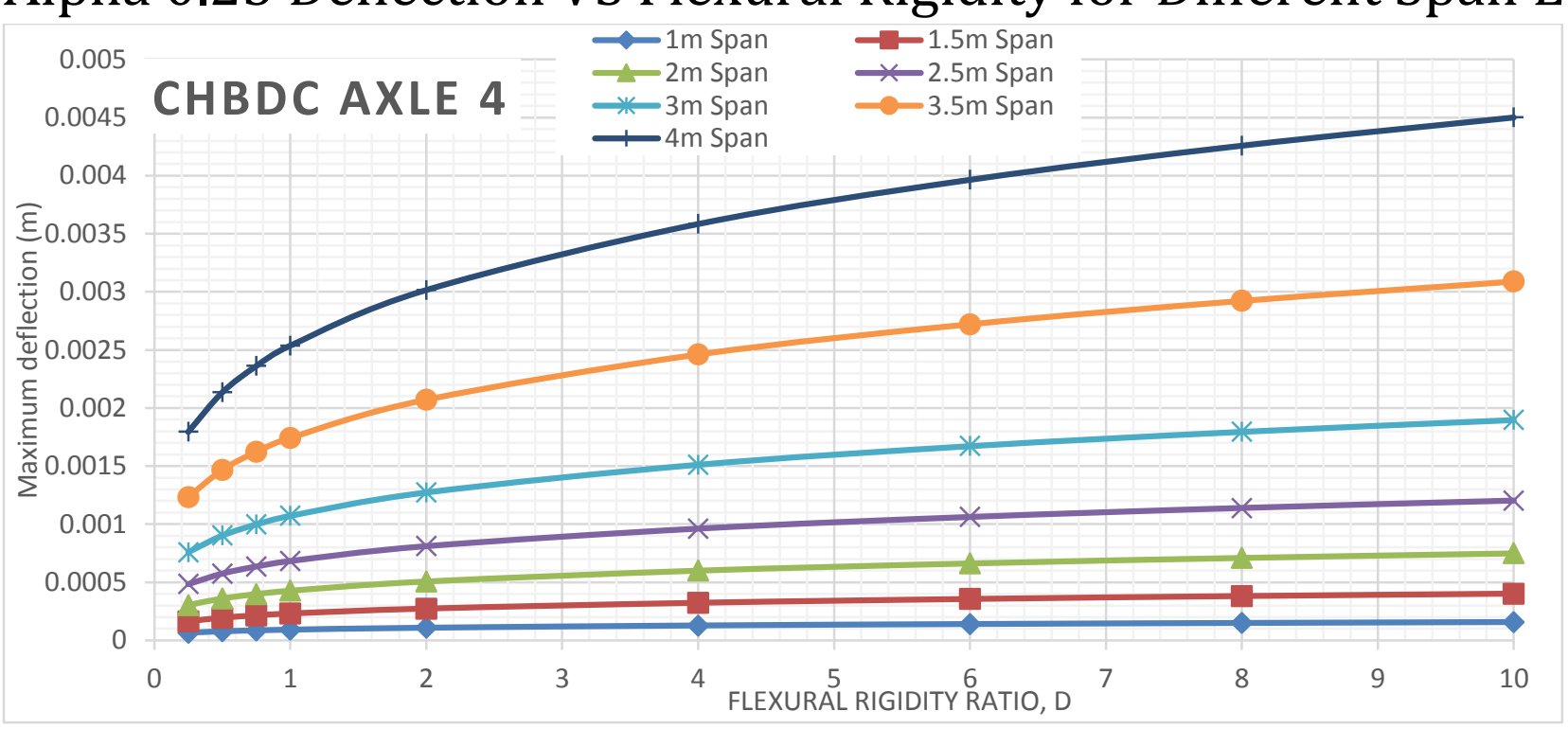

Figure 415 Maximum deflection of deck slabs subjected to CHBDC axle 4 for different span values of alpha 0.25 Orthotropic analyses

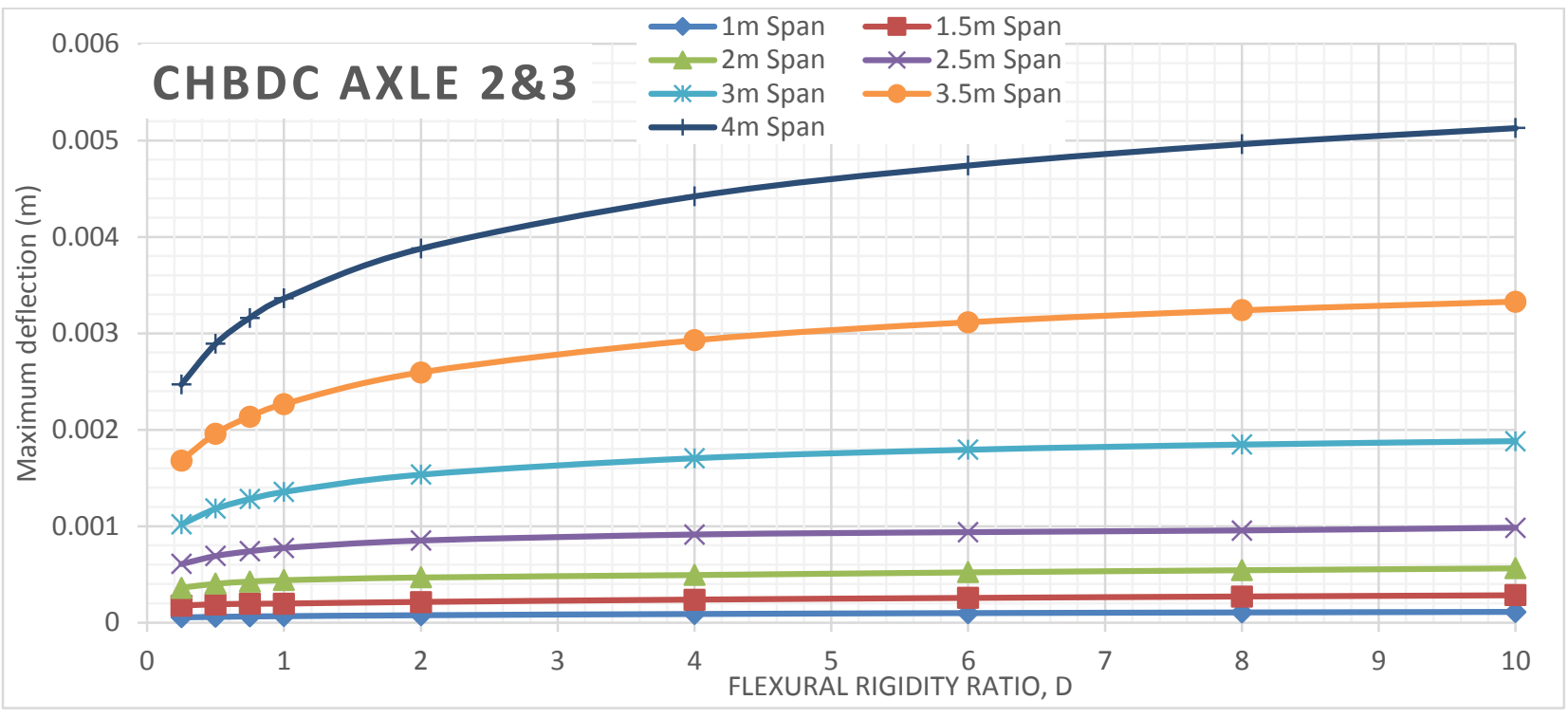

Figure 416 Maximum deflection of deck slabs subjected to CHBDC axle $2 \& 3$ for different span values of alpha 0.25 Orthotropic analyses 


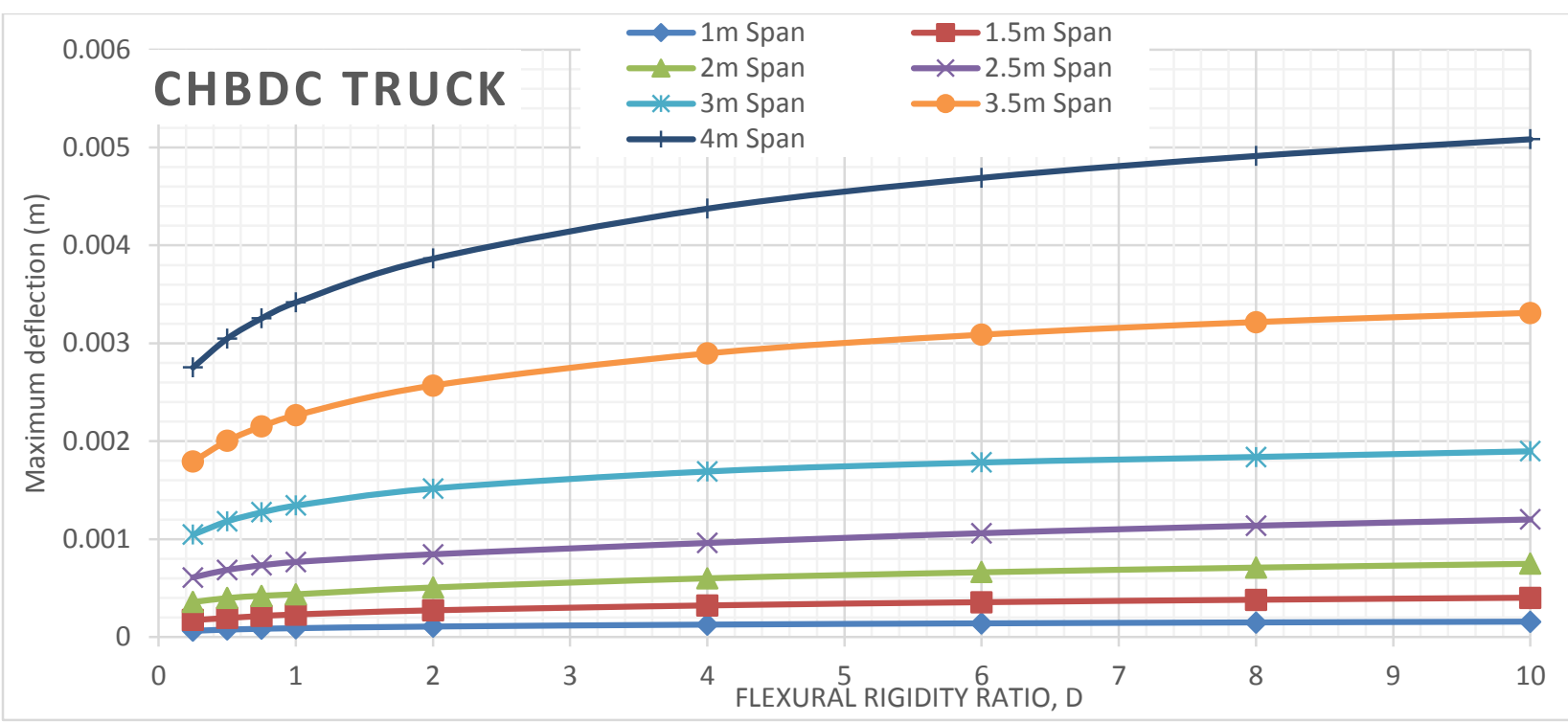

Figure 417 Maximum deflection of deck slabs subjected to CHBDC truck for different span values of alpha 0.25 Orthotropic analyses

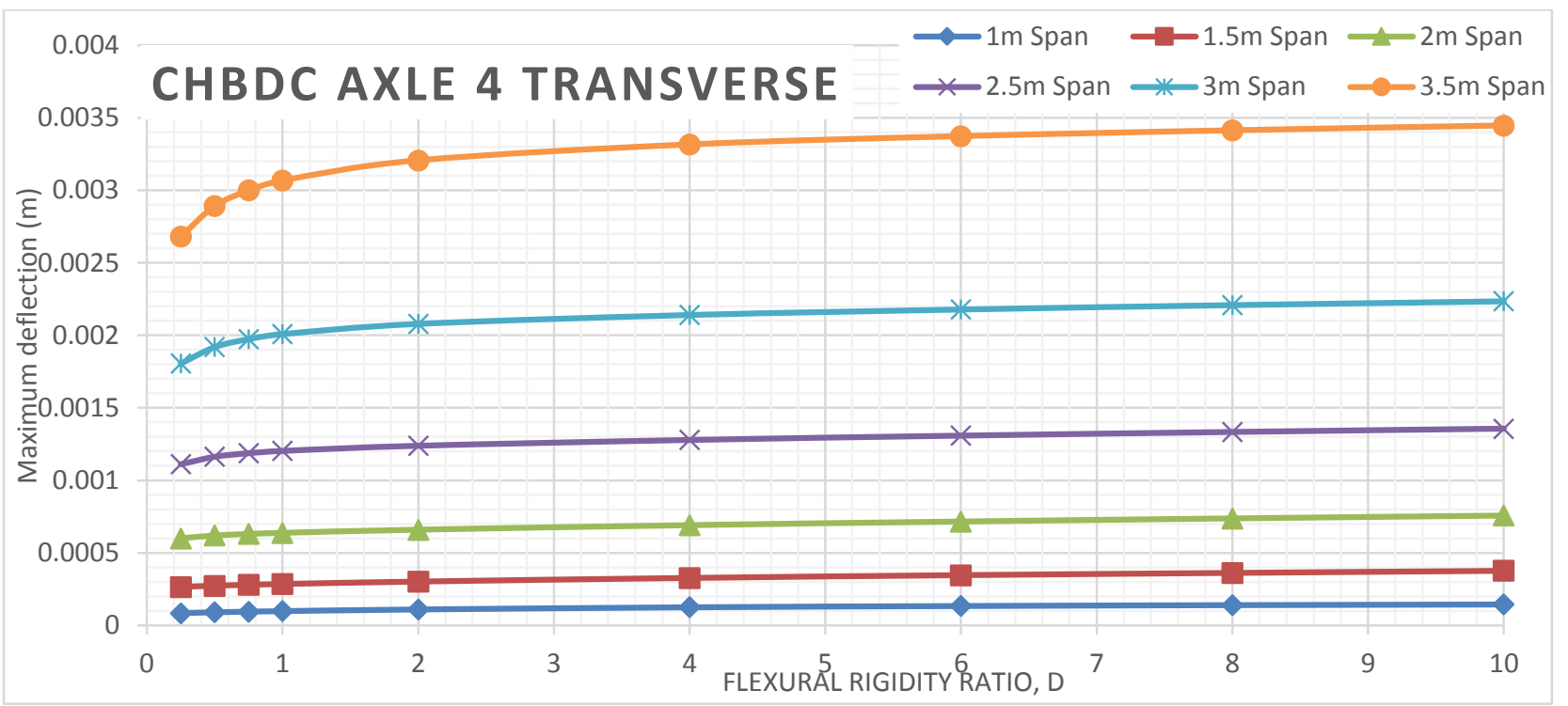

Figure 418 Maximum deflection of deck slabs subjected to CHBDC axle 4 for different span values of alpha 0.25 Orthotropic analyses

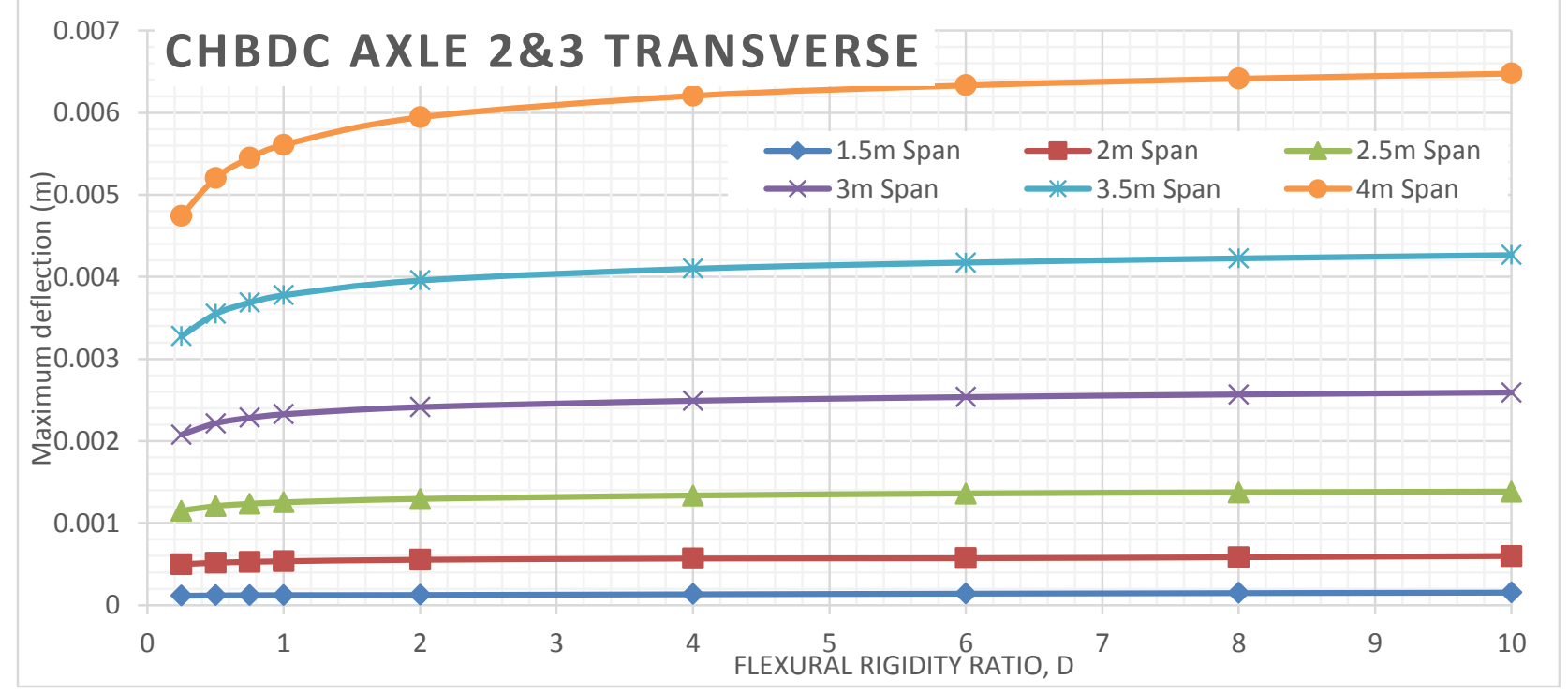

Figure 419 Maximum deflection of deck slabs subjected to CHBDC axle $2 \& 3$ for different span values of alpha 0.25 Orthotropic analyses 


\section{Alpha 0.5 Deflection VS Flexural Rigidity for Different Span Length}

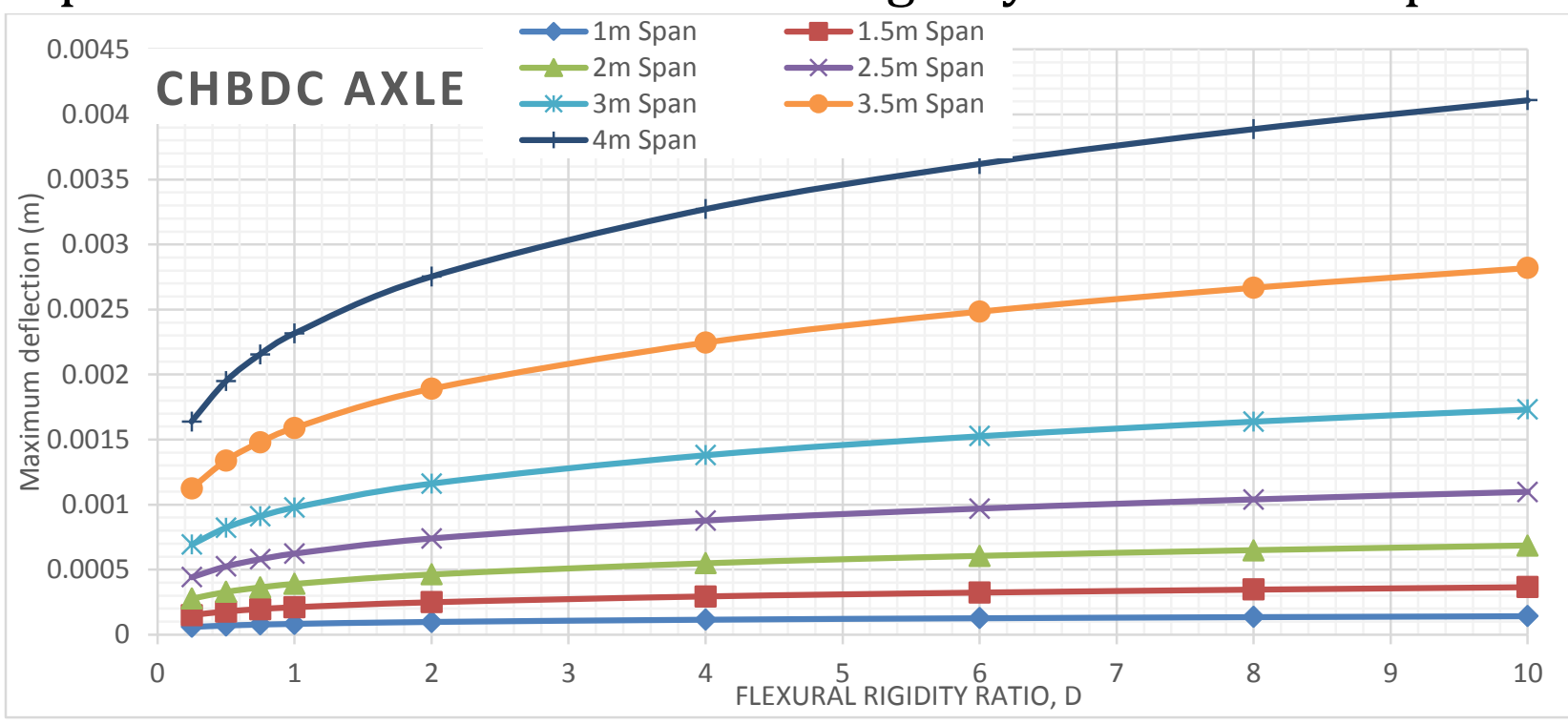

Figure 420 Maximum deflection of deck slabs subjected to CHBDC axle 4 for different span values of alpha 0.5 Orthotropic analyses

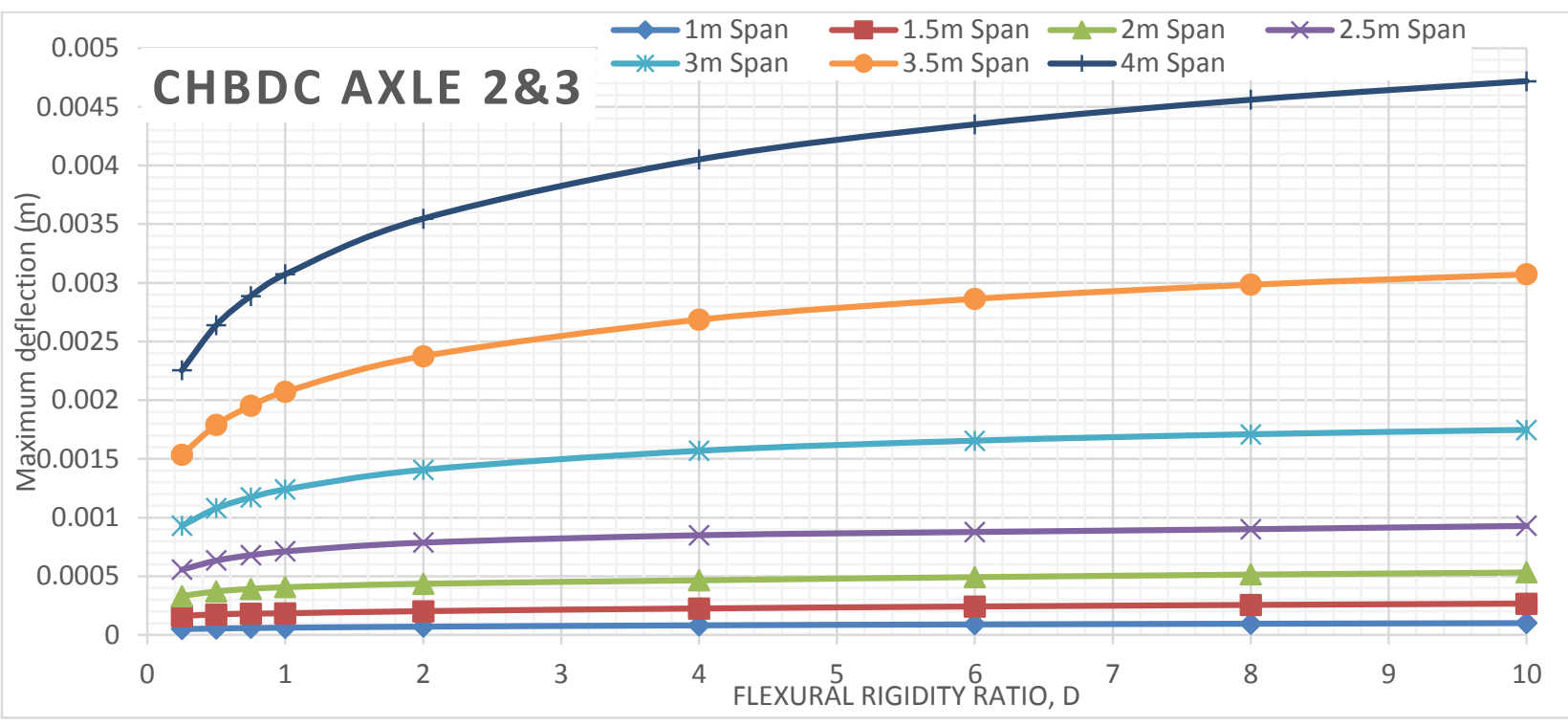

Figure 421 Maximum deflection of deck slabs subjected to CHBDC axle $2 \& 3$ for different span values of alpha 0.5 Orthotropic analyses 


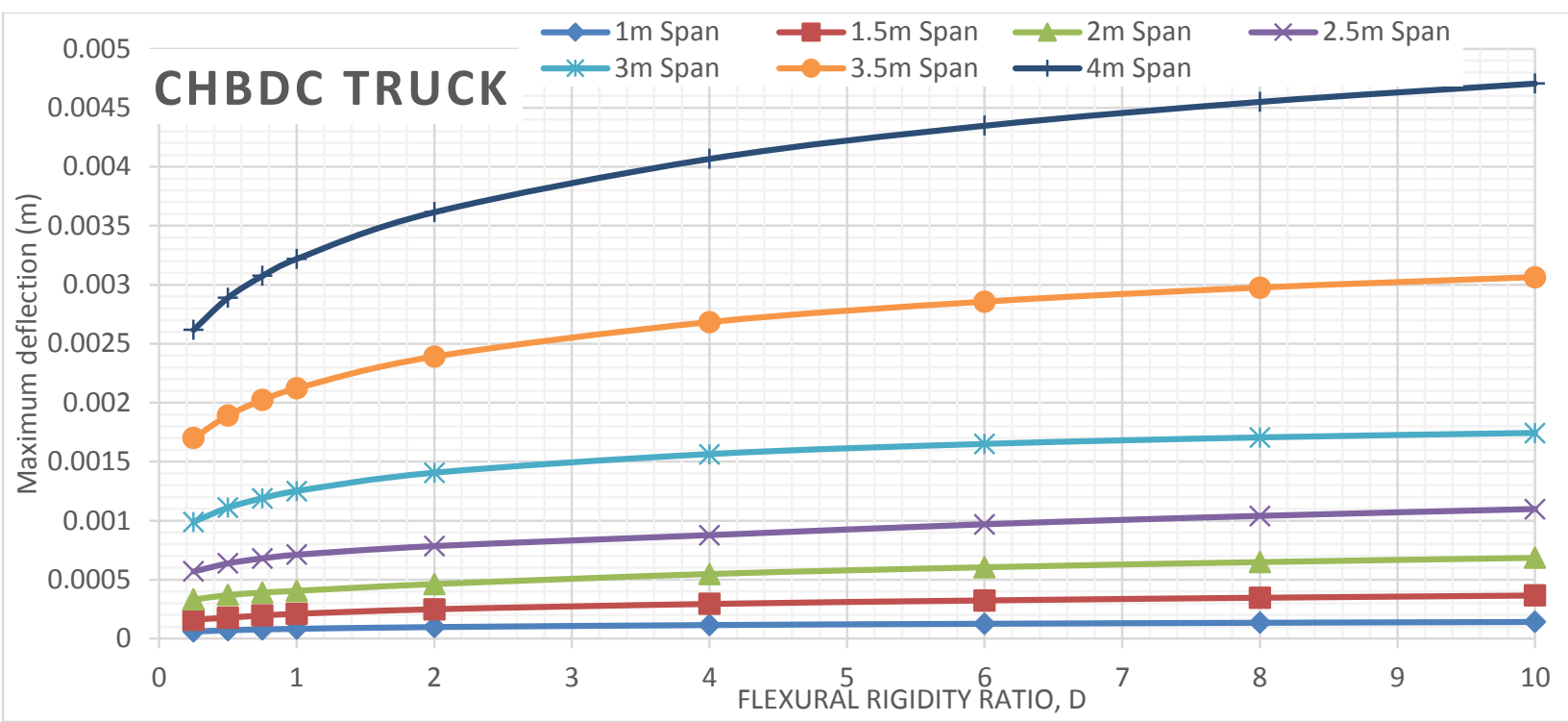

Figure 422 Maximum deflection of deck slabs subjected to CHBDC truck for different span values of alpha 0.5 Orthotropic analyses

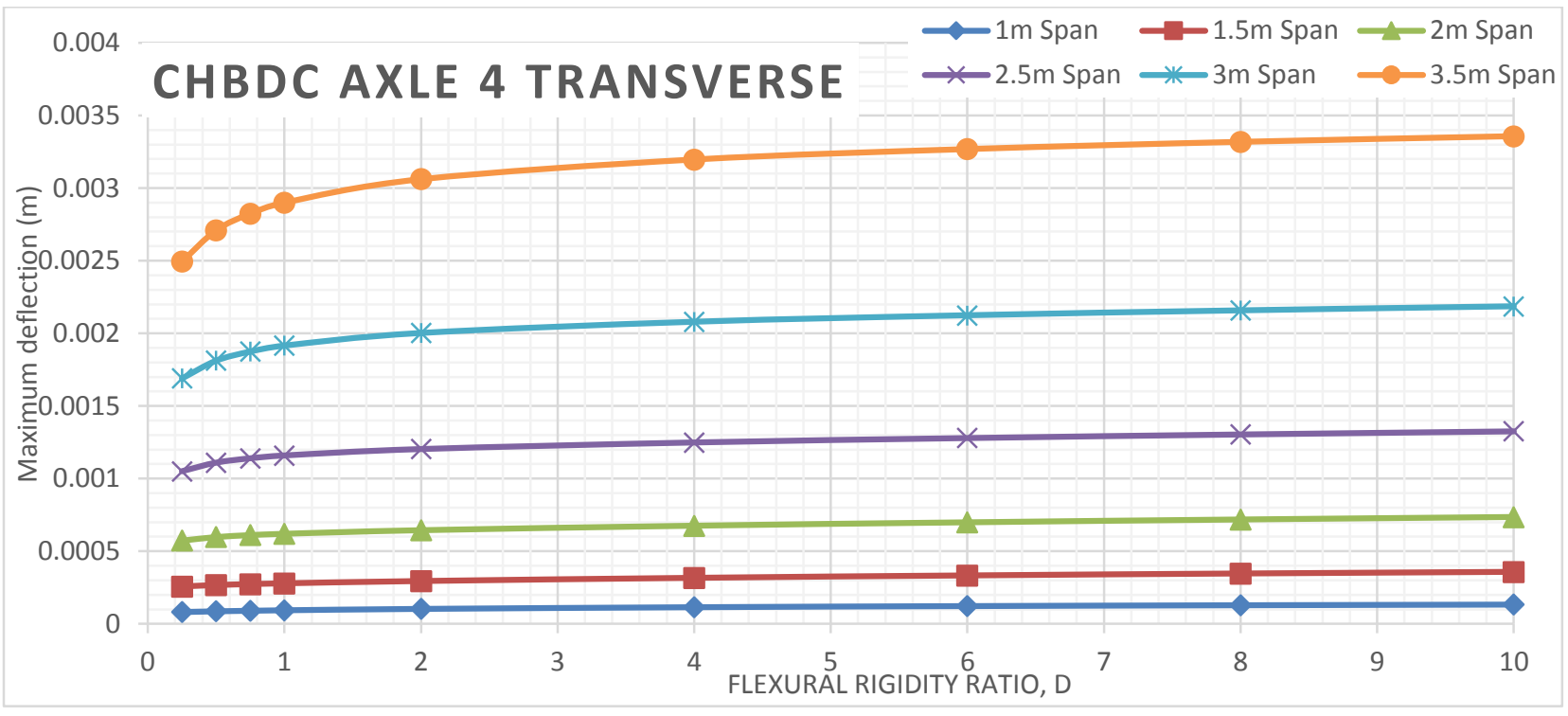

Figure 423 Maximum deflection of deck slabs subjected to CHBDC axle 4 for different span values of alpha 0.5 Orthotropic analyses

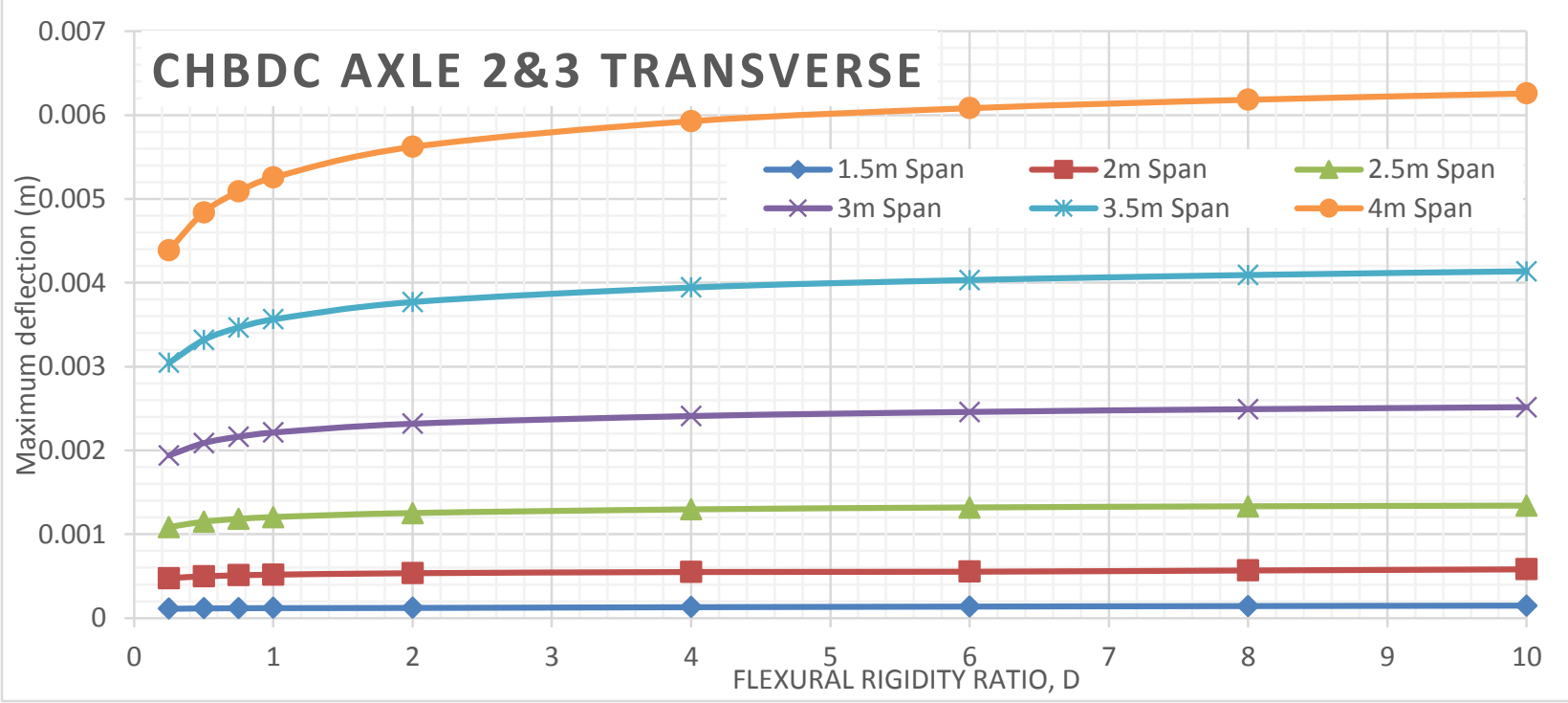

Figure 424 Maximum deflection of deck slabs subjected to CHBDC axle $2 \& 3$ for different span values of alpha 0.5 Orthotropic analyses 


\section{Alpha 0.75 Deflection VS Flexural Rigidity for Different Span Length}

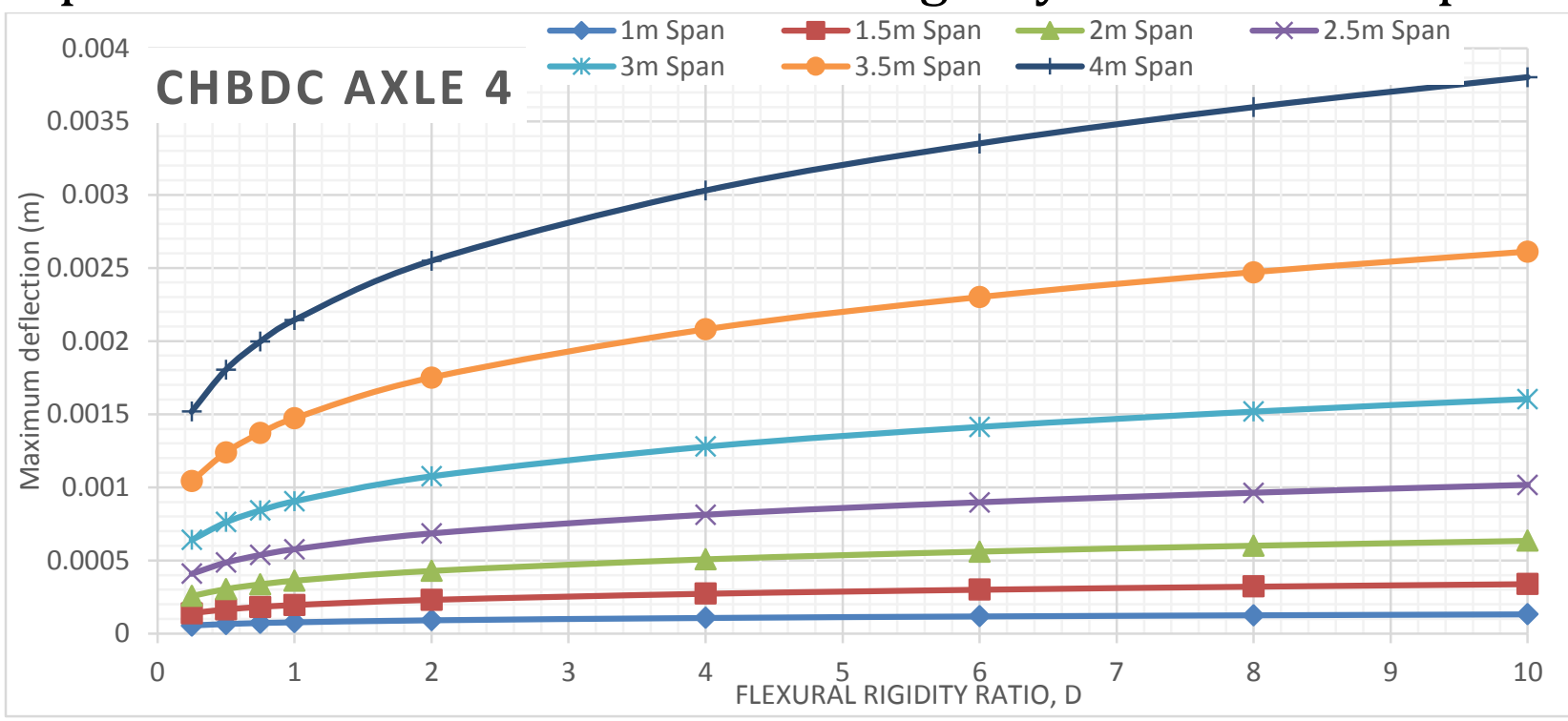

Figure 425 Maximum deflection of deck slabs subjected to CHBDC axle 4 for different span values of alpha 0.75 Orthotropic analyses

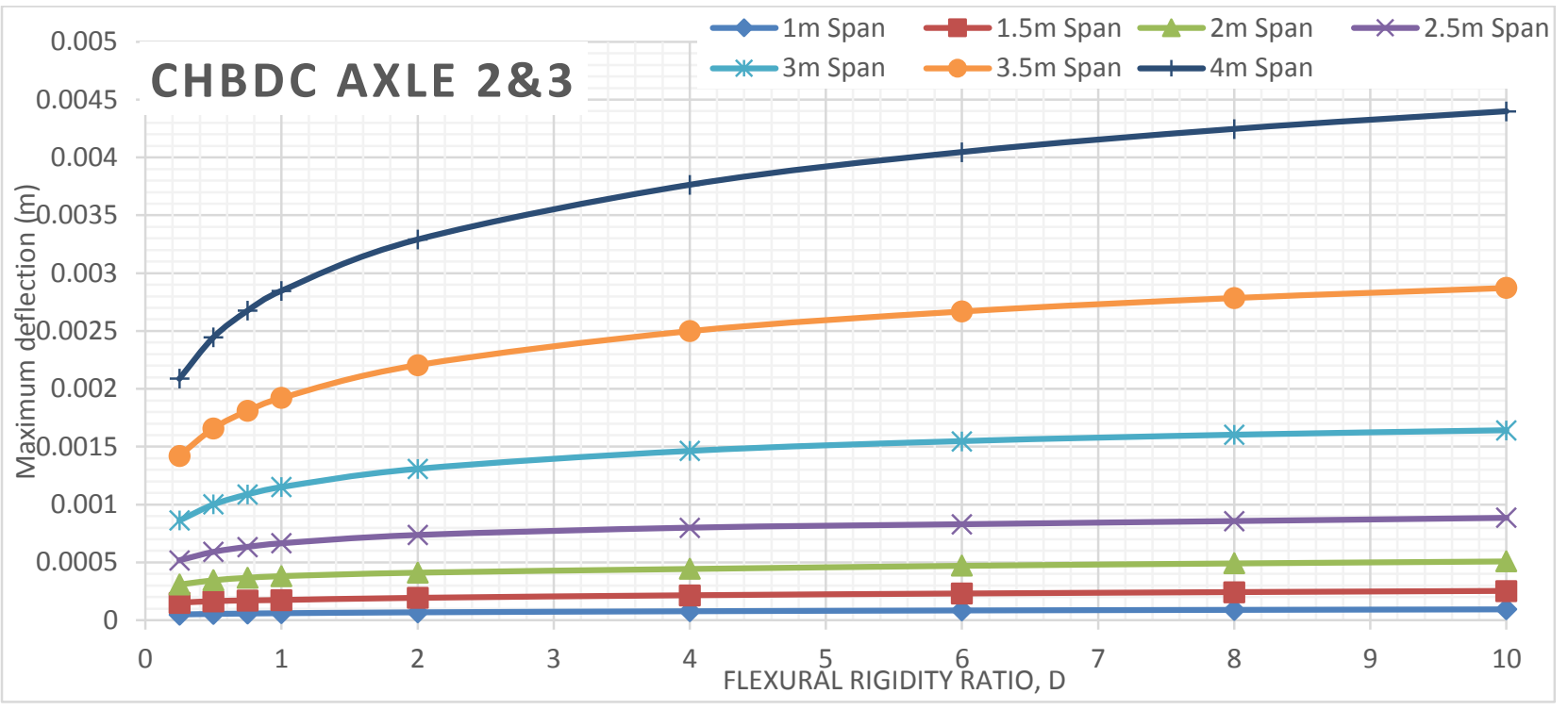

Figure 426 Maximum deflection of deck slabs subjected to CHBDC axle $2 \& 3$ for different span values of alpha 0.75 Orthotropic analyses 


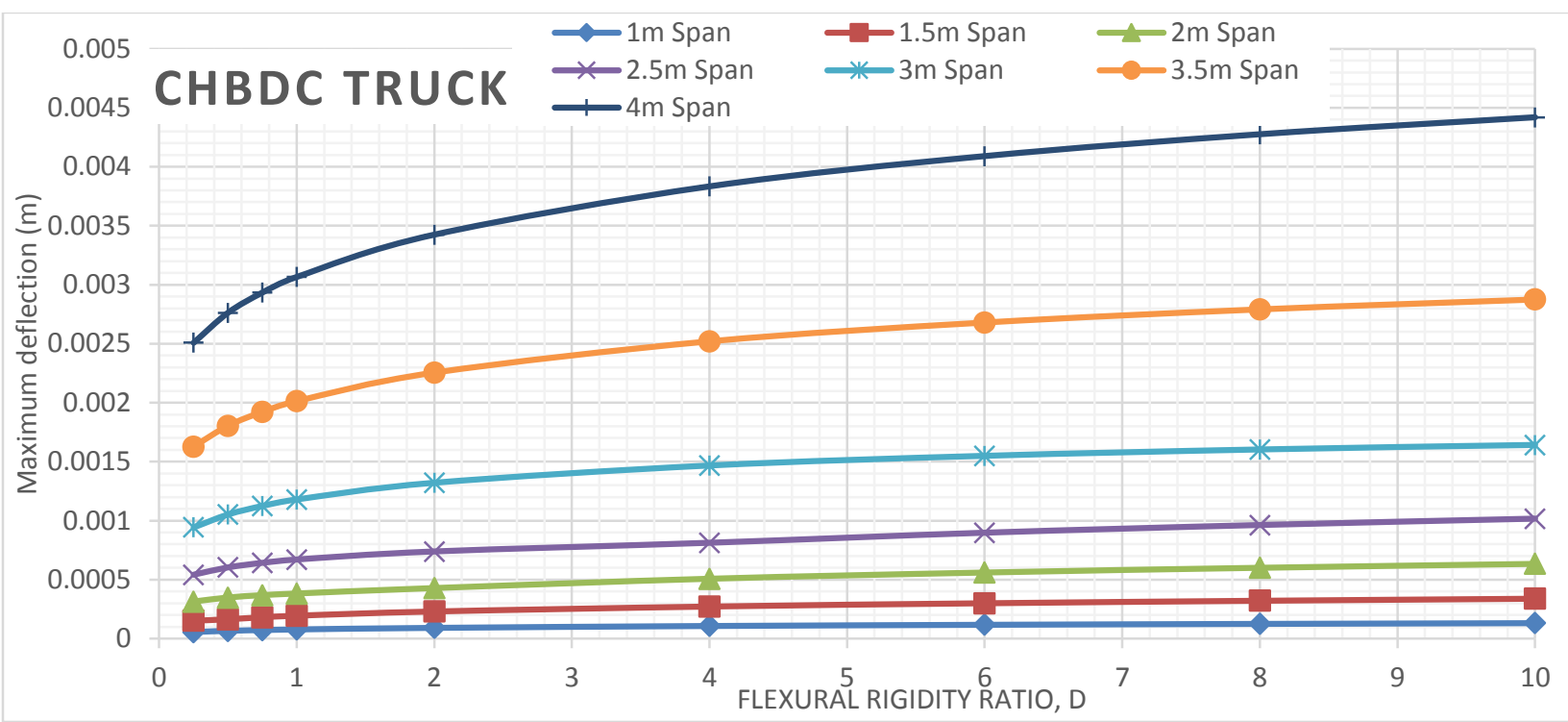

Figure 427 Maximum deflection of deck slabs subjected to CHBDC truck for different span values of alpha 0.75 Orthotropic analyses

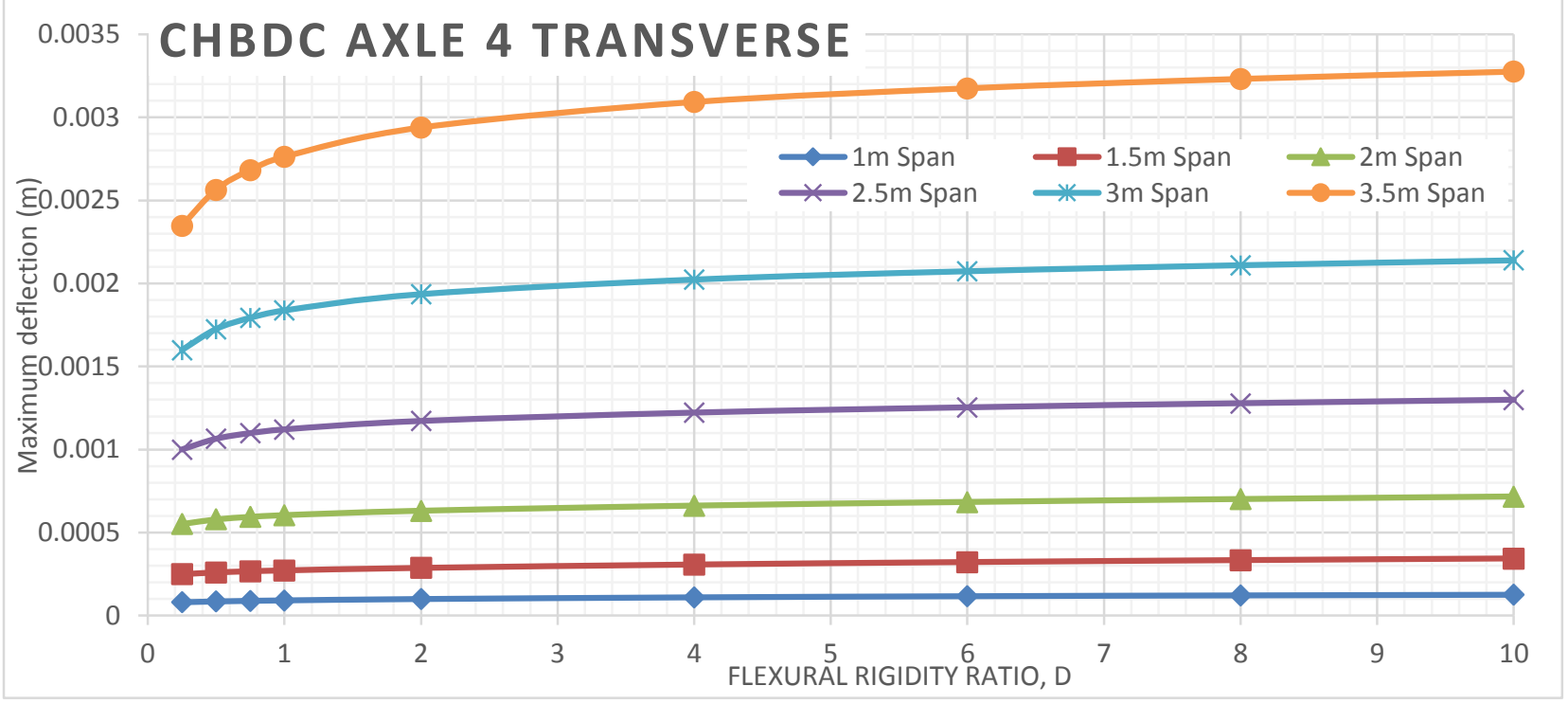

Figure 428 Maximum deflection of deck slabs subjected to CHBDC axle 4 for different span values of alpha 0.75 Orthotropic analyses

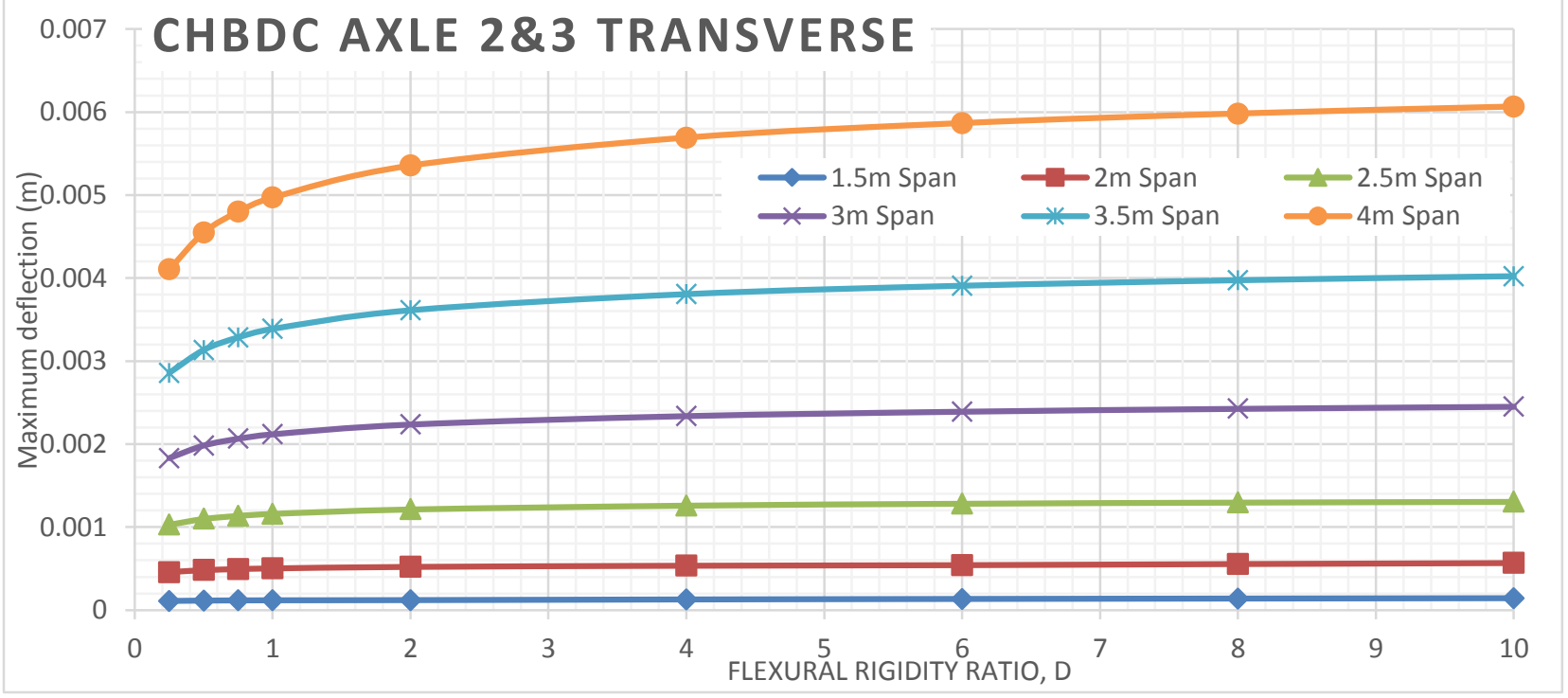

Figure 429 Maximum deflection of deck slabs subjected to CHBDC axle $2 \& 3$ for different span values of alpha 0.75 Orthotropic analyses 


\section{Alpha 1 Deflection VS Flexural Rigidity for Different Span Length}

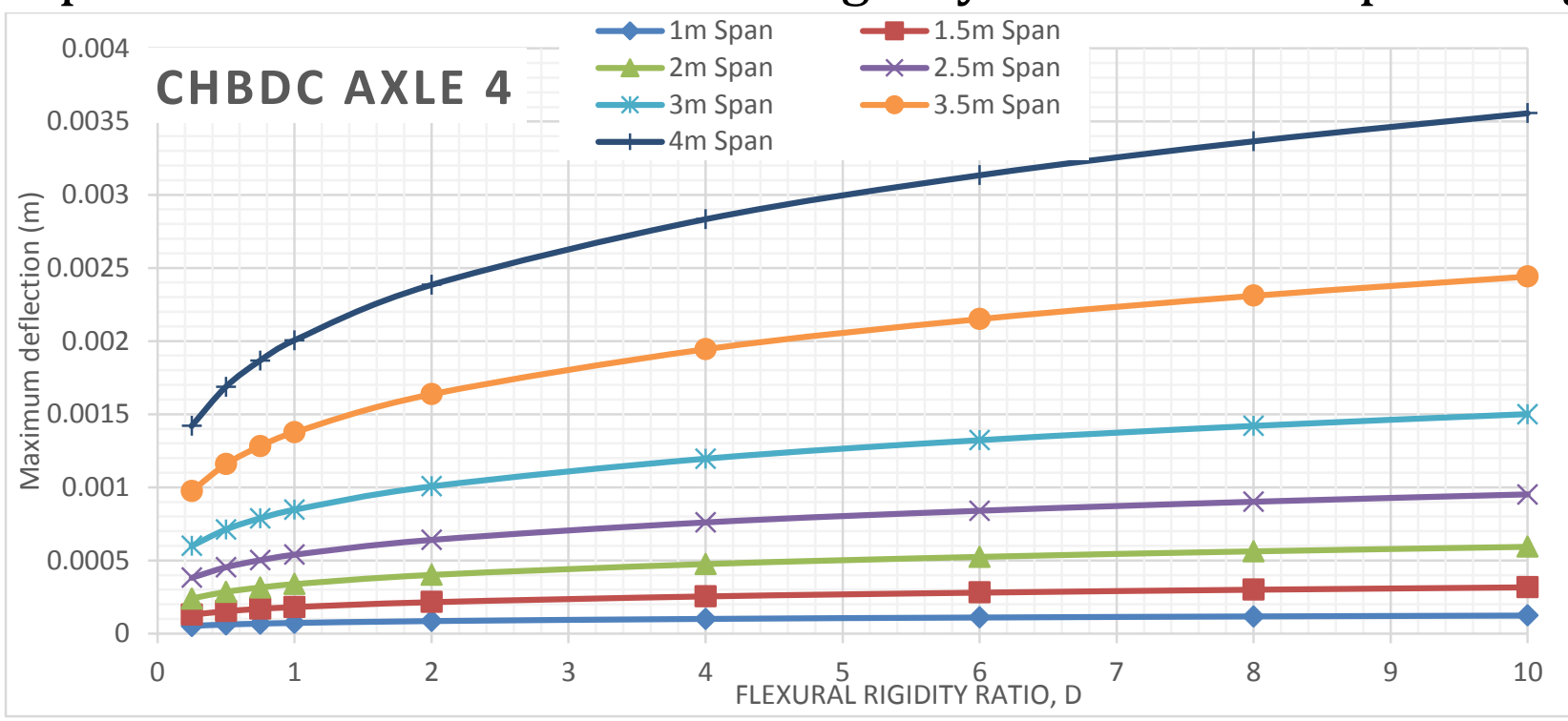

Figure 430 Maximum deflection of deck slabs subjected to CHBDC axle 4 for different span values of alpha 1 Orthotropic analyses

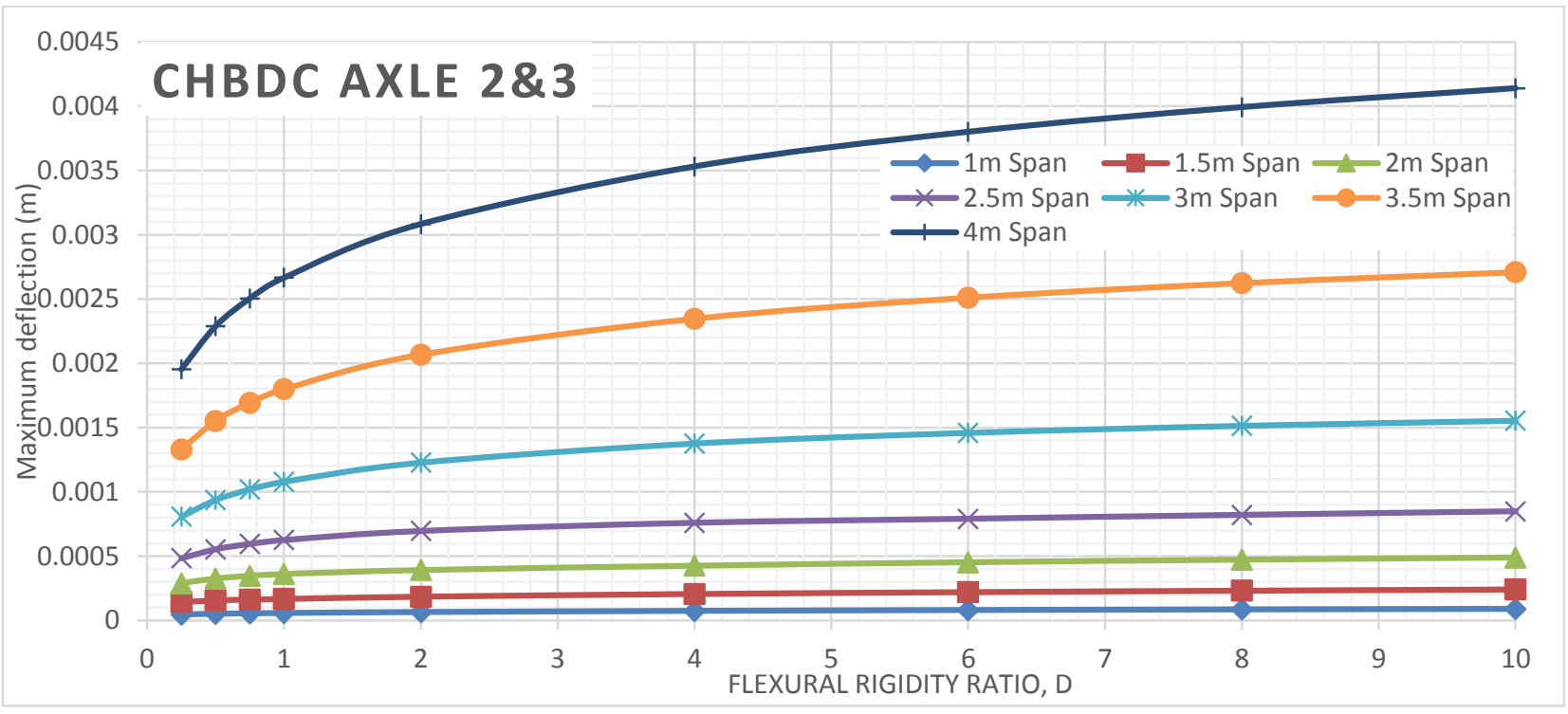

Figure 431 Maximum deflection of deck slabs subjected to CHBDC axle 2 \& 3 for different span values of alpha 1 Orthotropic analyses 


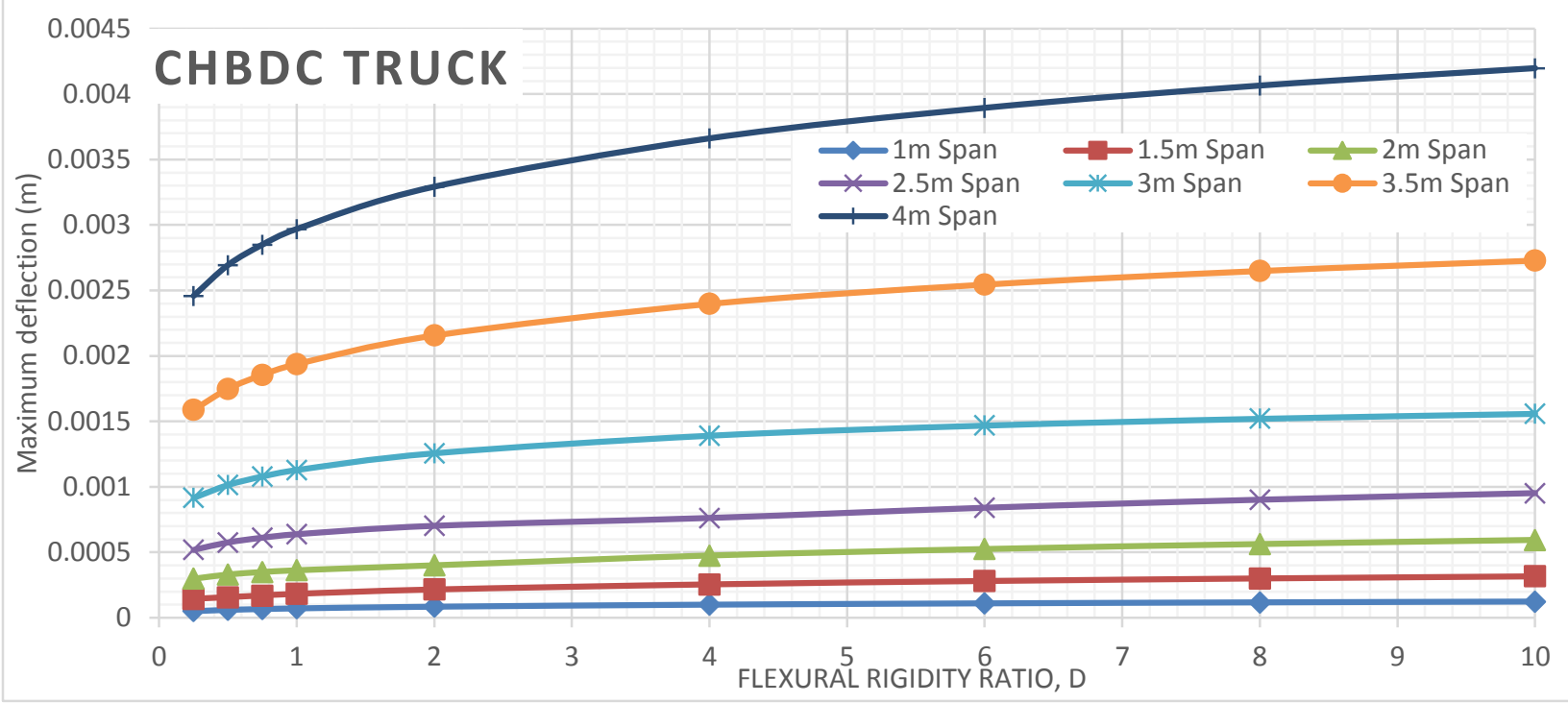

Figure 432 Maximum deflection of deck slabs subjected to CHBDC truck for different span values of alpha 1 Orthotropic analyses

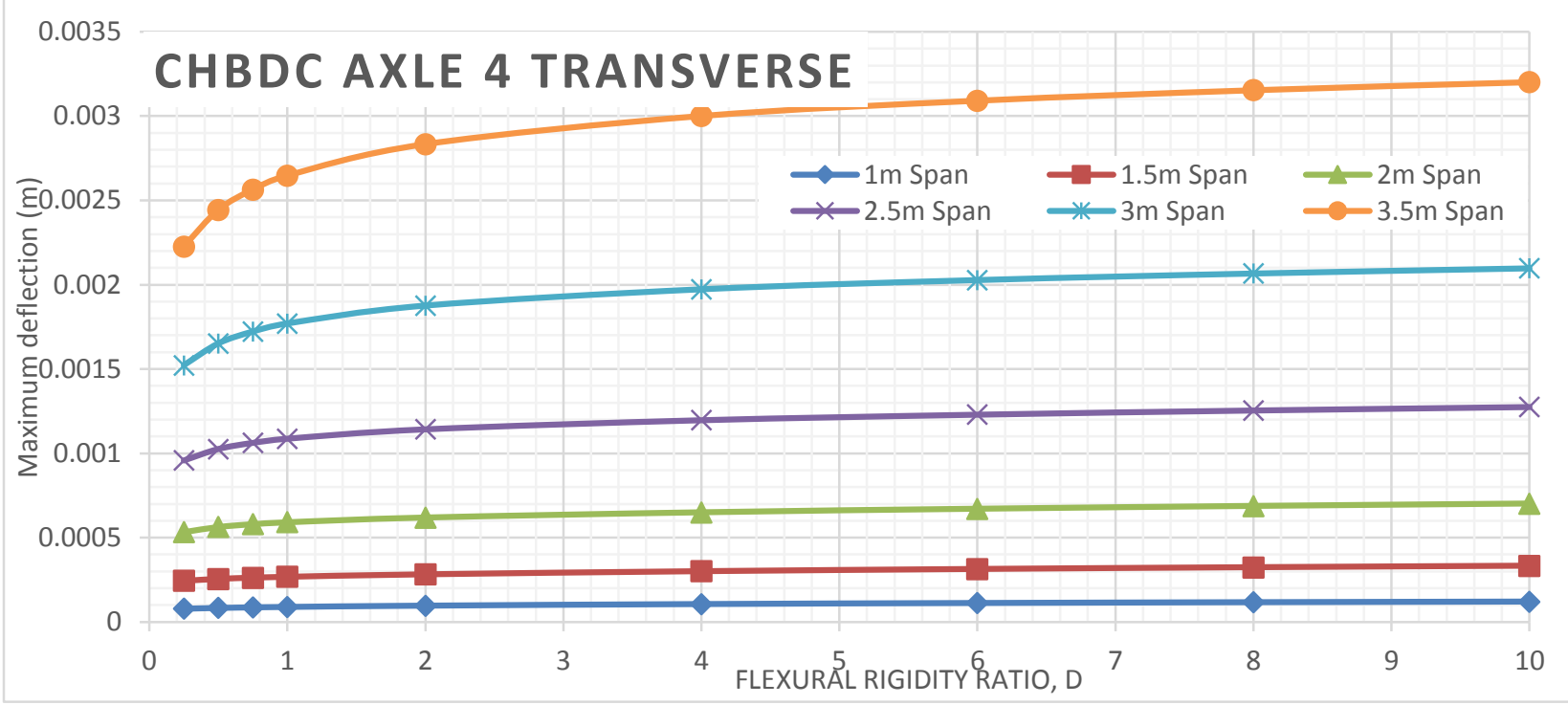

Figure 433 Maximum deflection of deck slabs subjected to CHBDC axle 4 for different span values of alpha 1 Orthotropic analyses

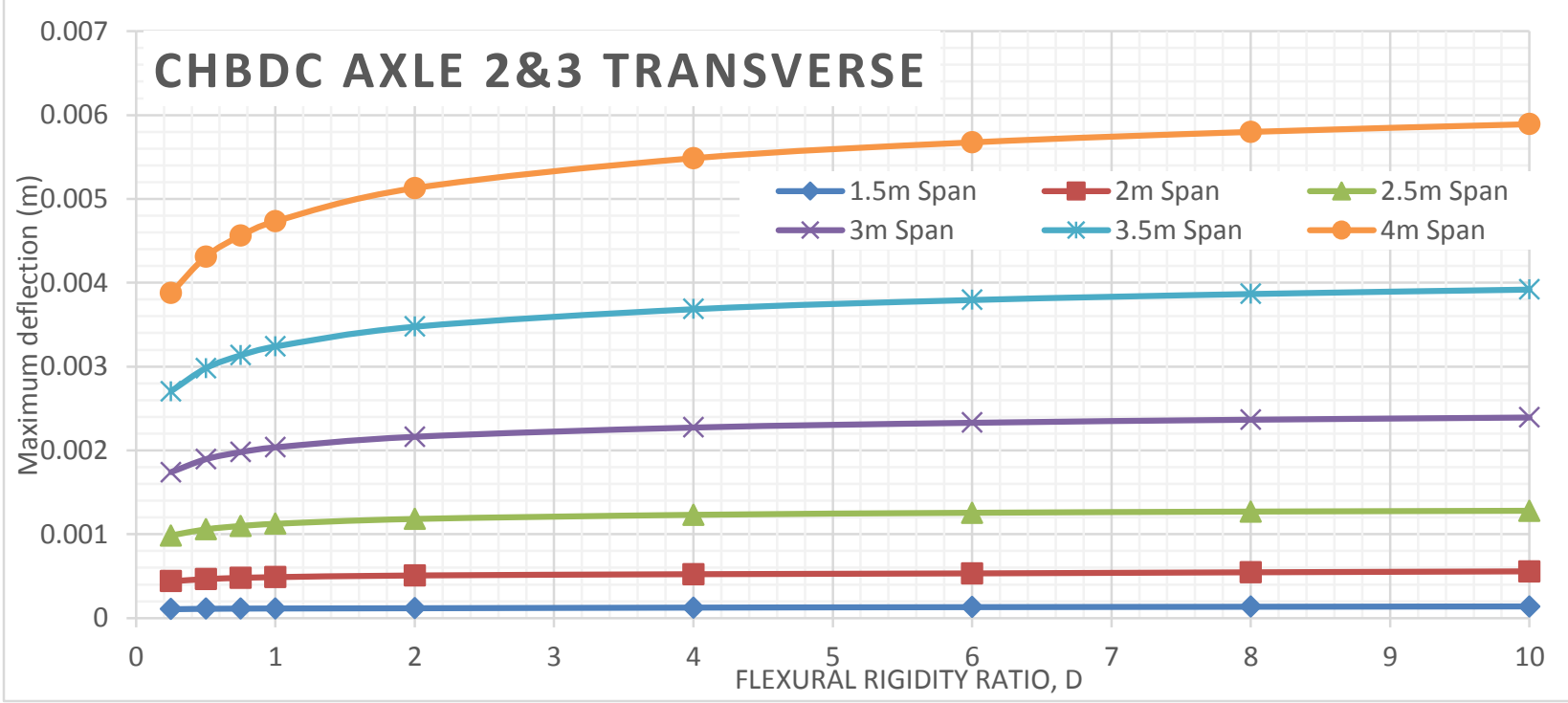

Figure 434 Maximum deflection of deck slabs subjected to CHBDC axle 2 \& 3 for different span values of alpha 1 Orthotropic analyses 


\section{Alpha 2 Deflection VS Flexural Rigidity for Different Span Length}

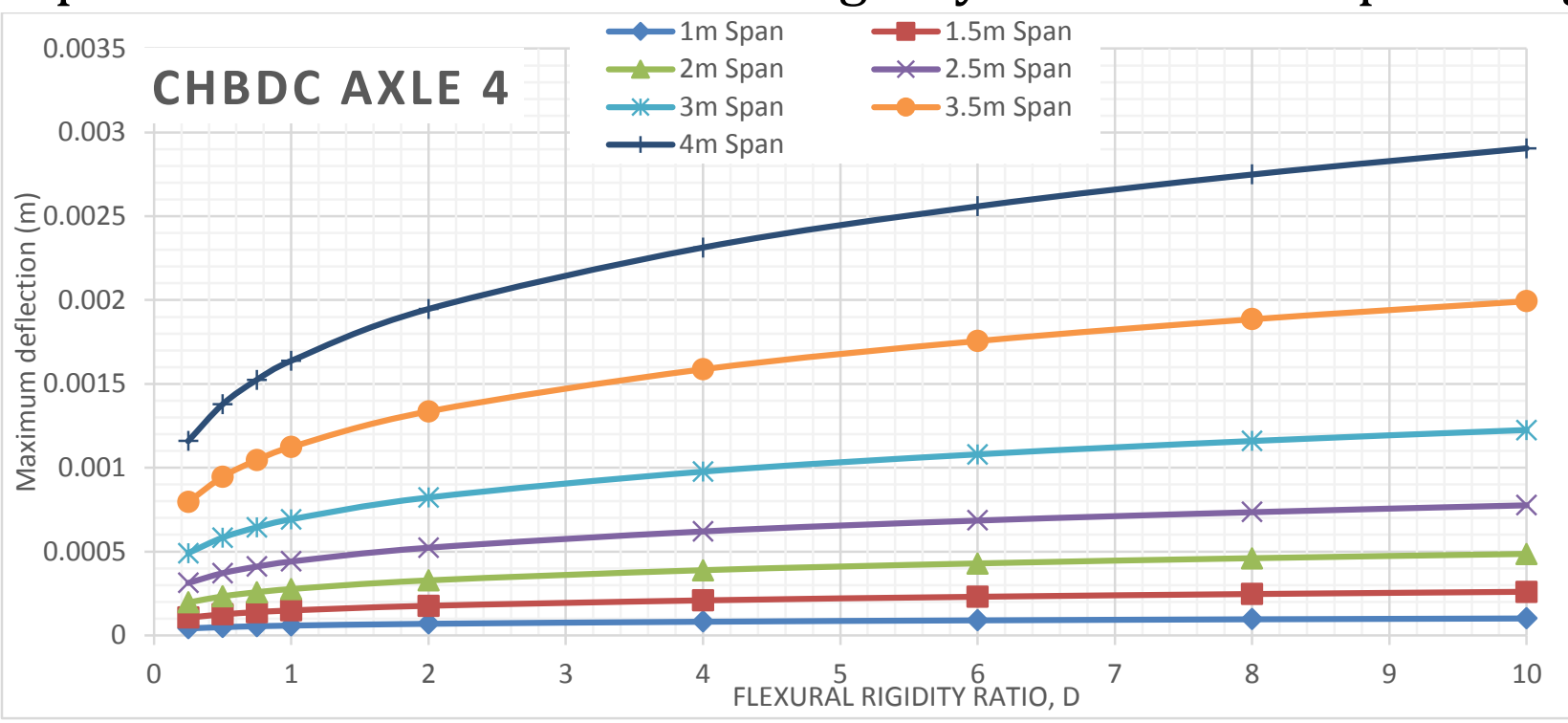

Figure 435 Maximum deflection of deck slabs subjected to CHBDC axle 4 for different span values of alpha 2 Orthotropic analyses

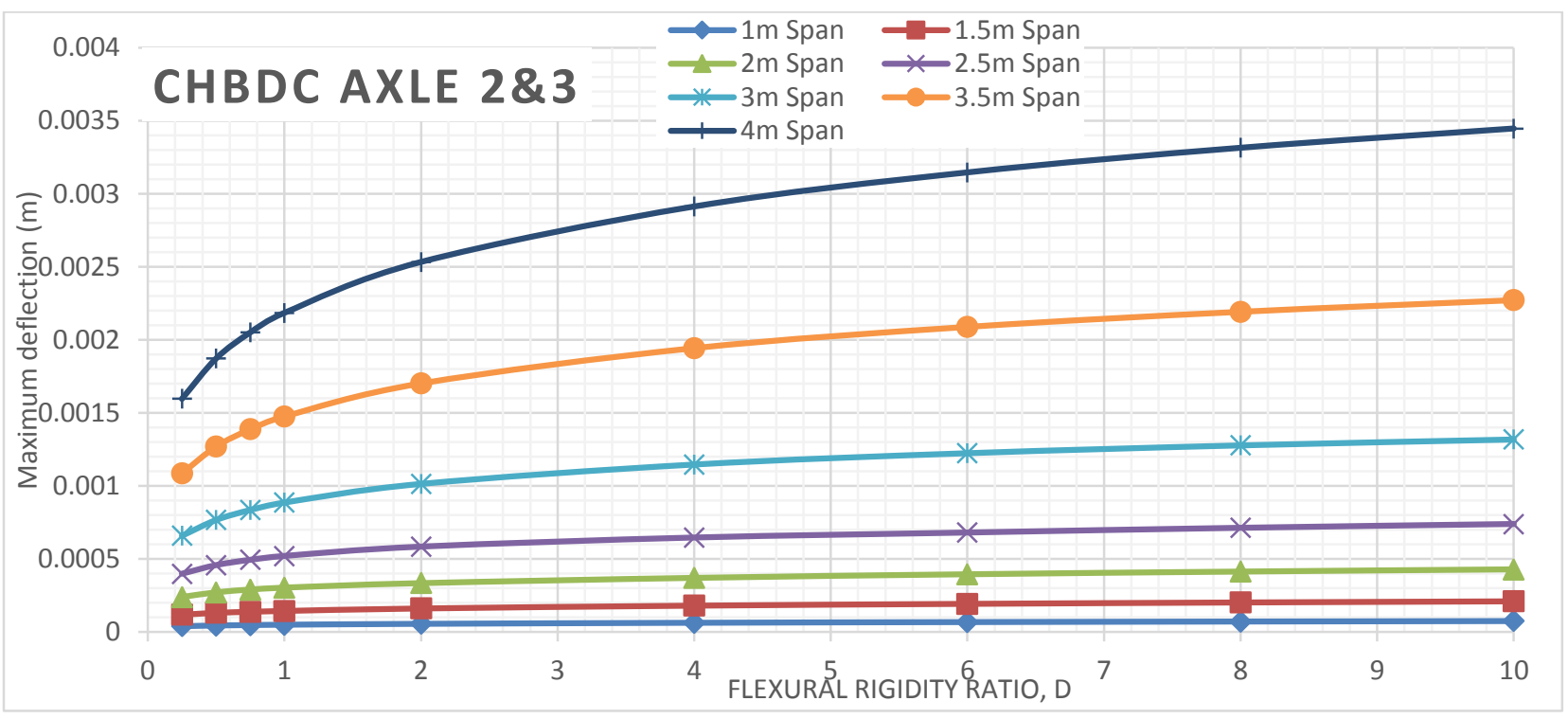

Figure 436 Maximum deflection of deck slabs subjected to CHBDC axle 2 \& 3 for different span values of alpha 2 Orthotropic analyses 


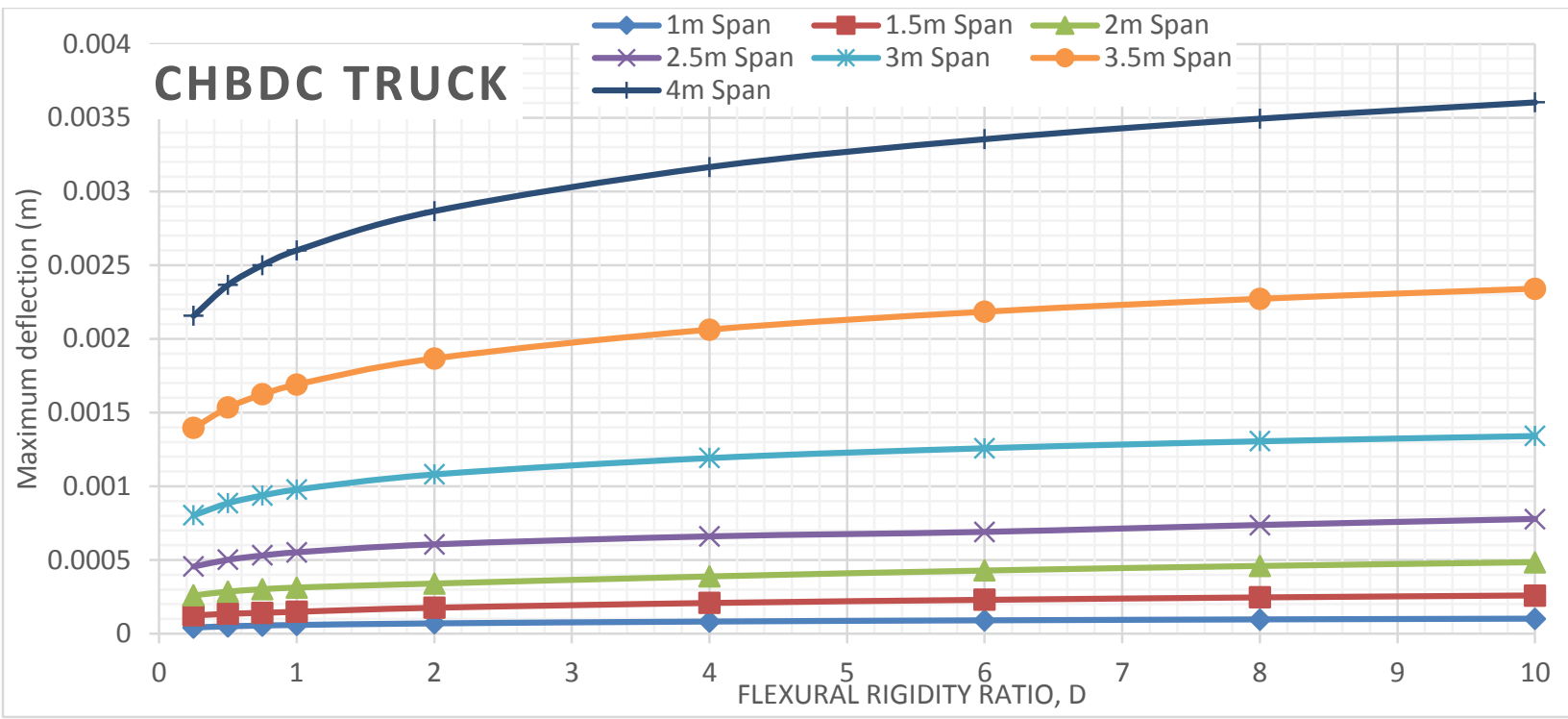

Figure 437 Maximum deflection of deck slabs subjected to CHBDC truck for different span values of alpha 2 Orthotropic analyses

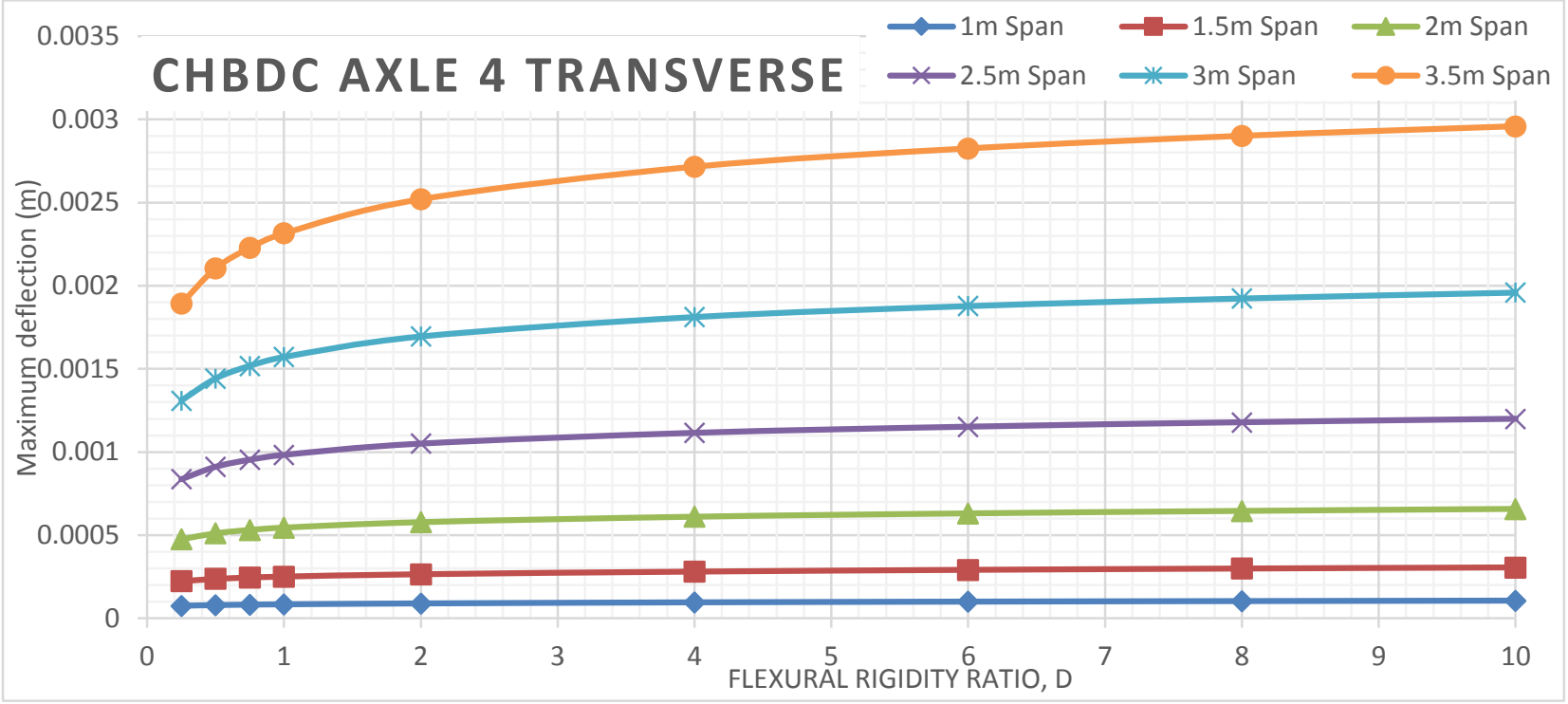

Figure 438 Maximum deflection of deck slabs subjected to CHBDC axle 4 for different span values of alpha 2 Orthotropic analyses

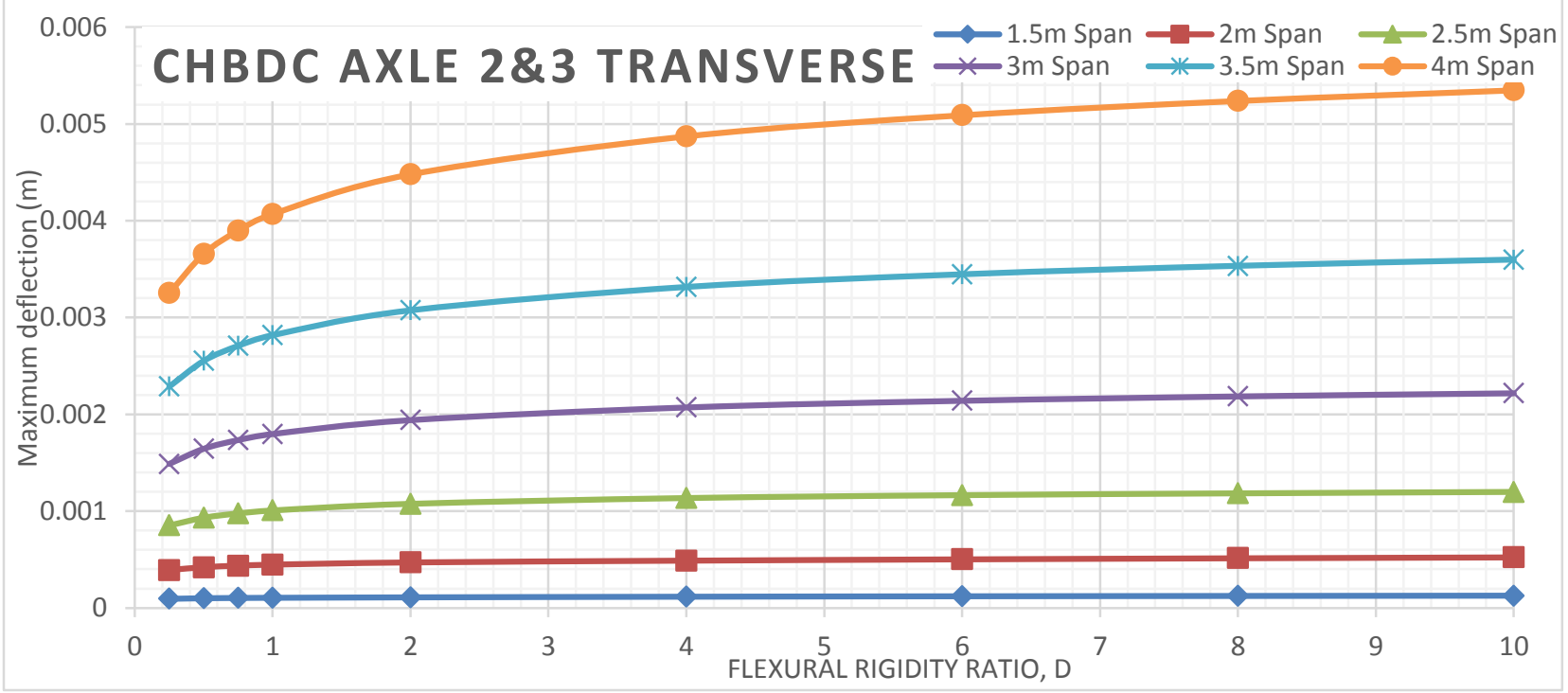

Figure 439 Maximum deflection of deck slabs subjected to CHBDC axle 2 \& 3 for different span values of alpha 2 Orthotropic analyses 


\section{Alpha 4 Deflection VS Flexural Rigidity for Different Span Length}

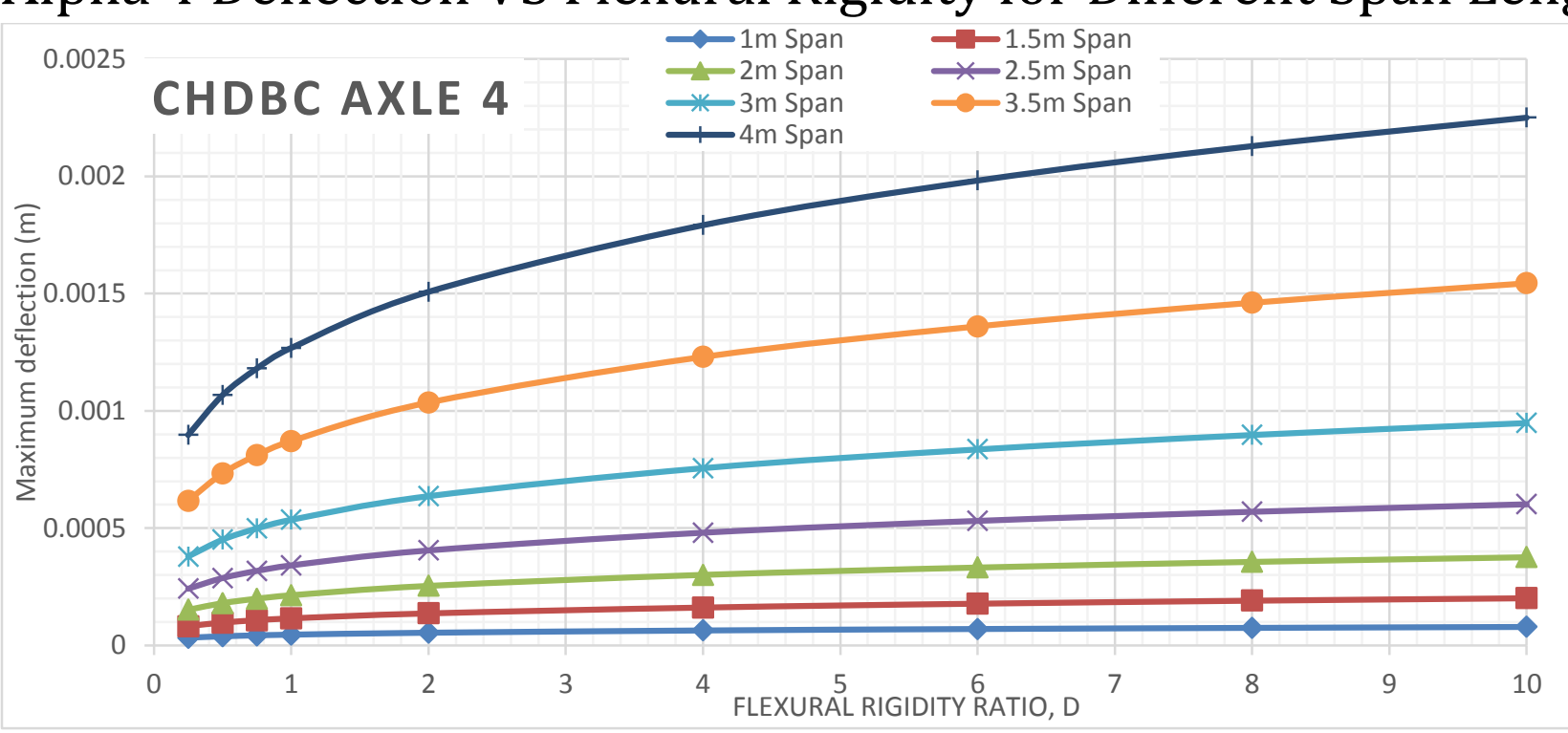

Figure 440 Maximum deflection of deck slabs subjected to CHBDC axle 4 for different span values of alpha 4 Orthotropic analyses

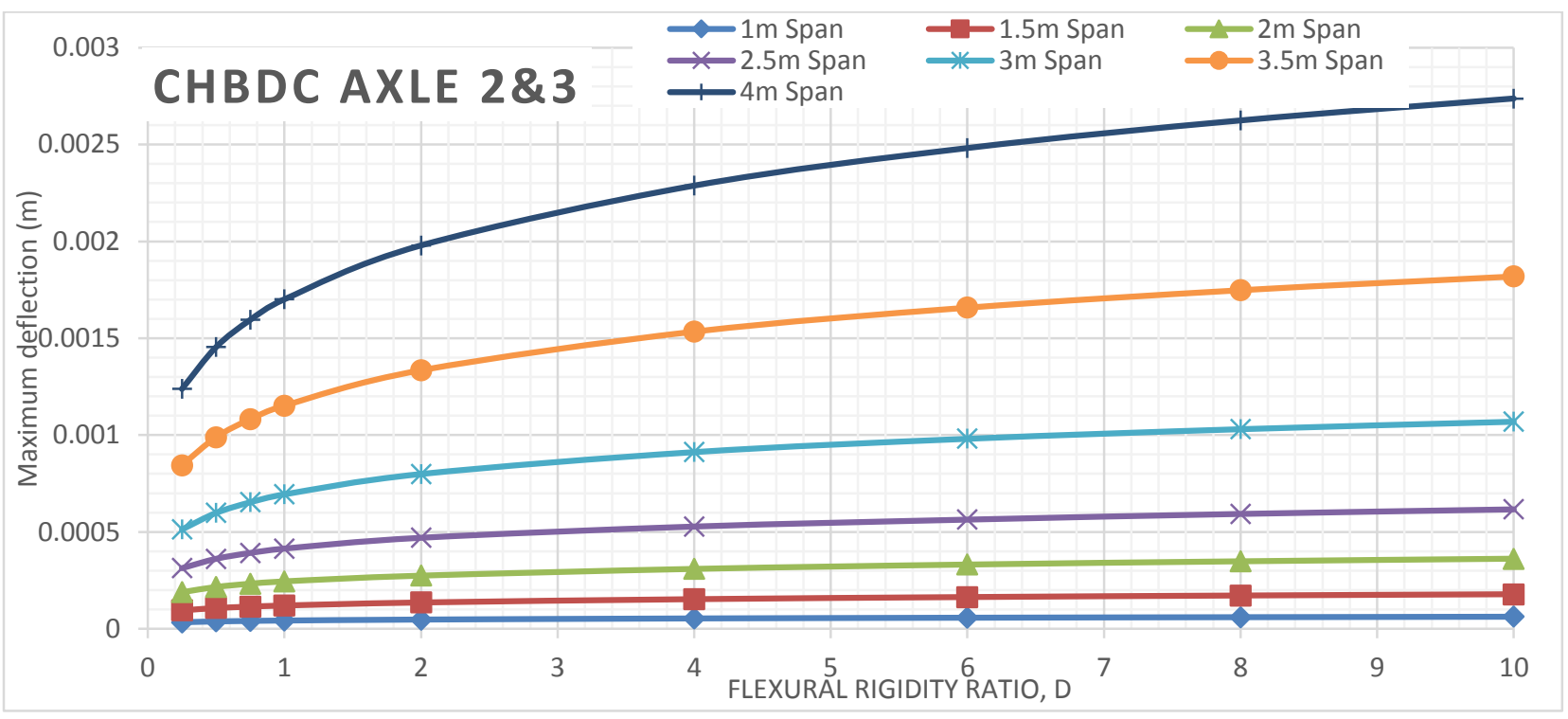

Figure 441 Maximum deflection of deck slabs subjected to CHBDC axle 2 \& 3 for different span values of alpha 4 Orthotropic analyses 


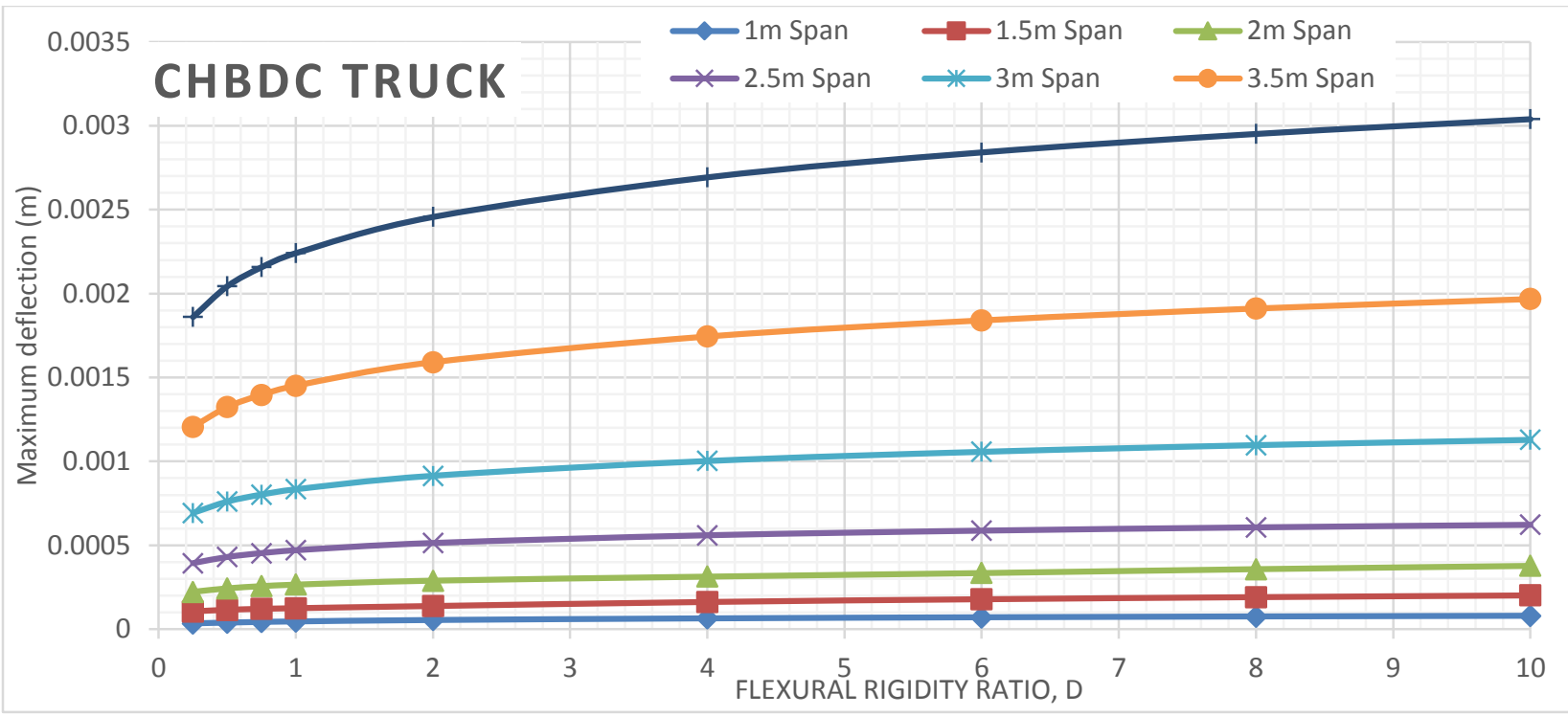

Figure 442 Maximum deflection of deck slabs subjected to CHBDC truck for different span values of alpha 4 Orthotropic analyses

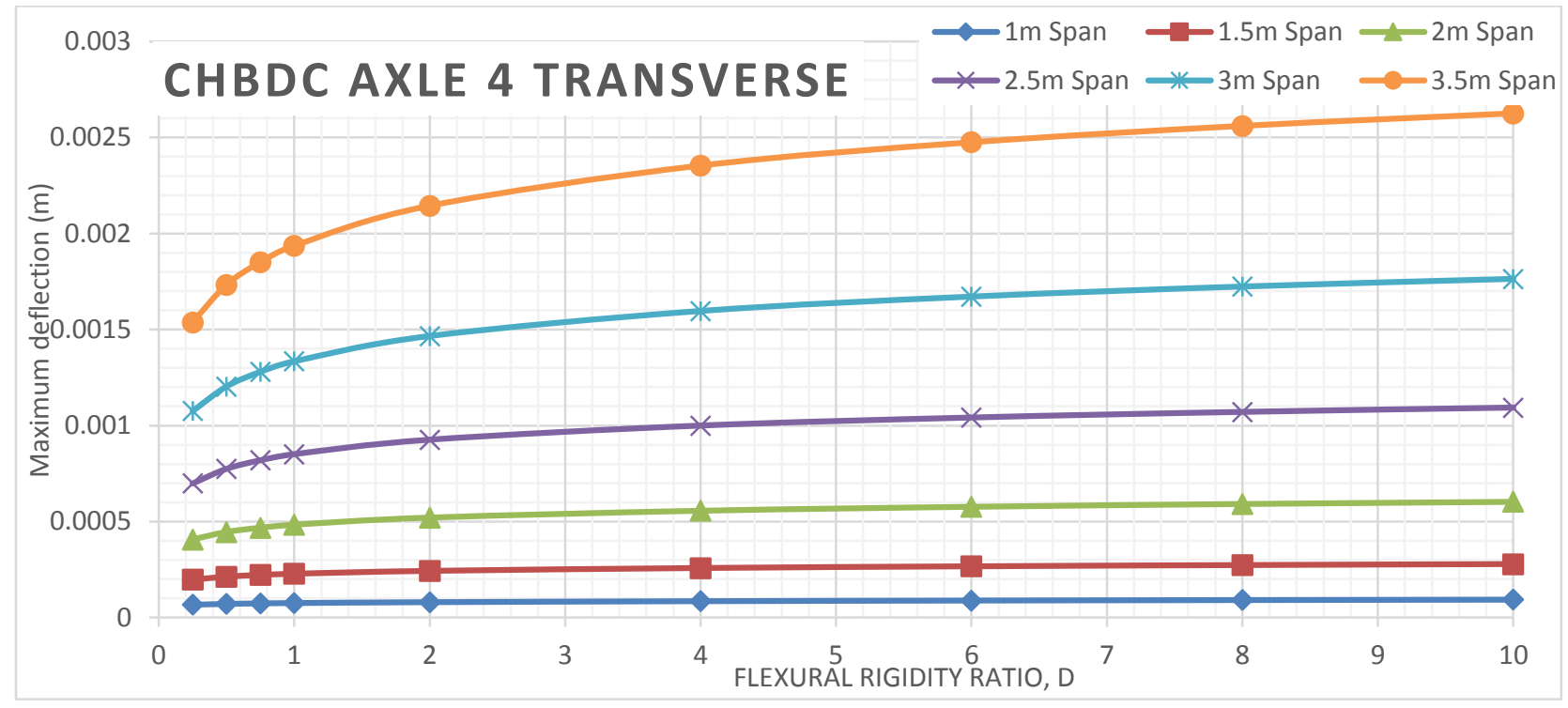

Figure 443 Maximum deflection of deck slabs subjected to CHBDC axle 4 for different span values of alpha 4 Orthotropic analyses

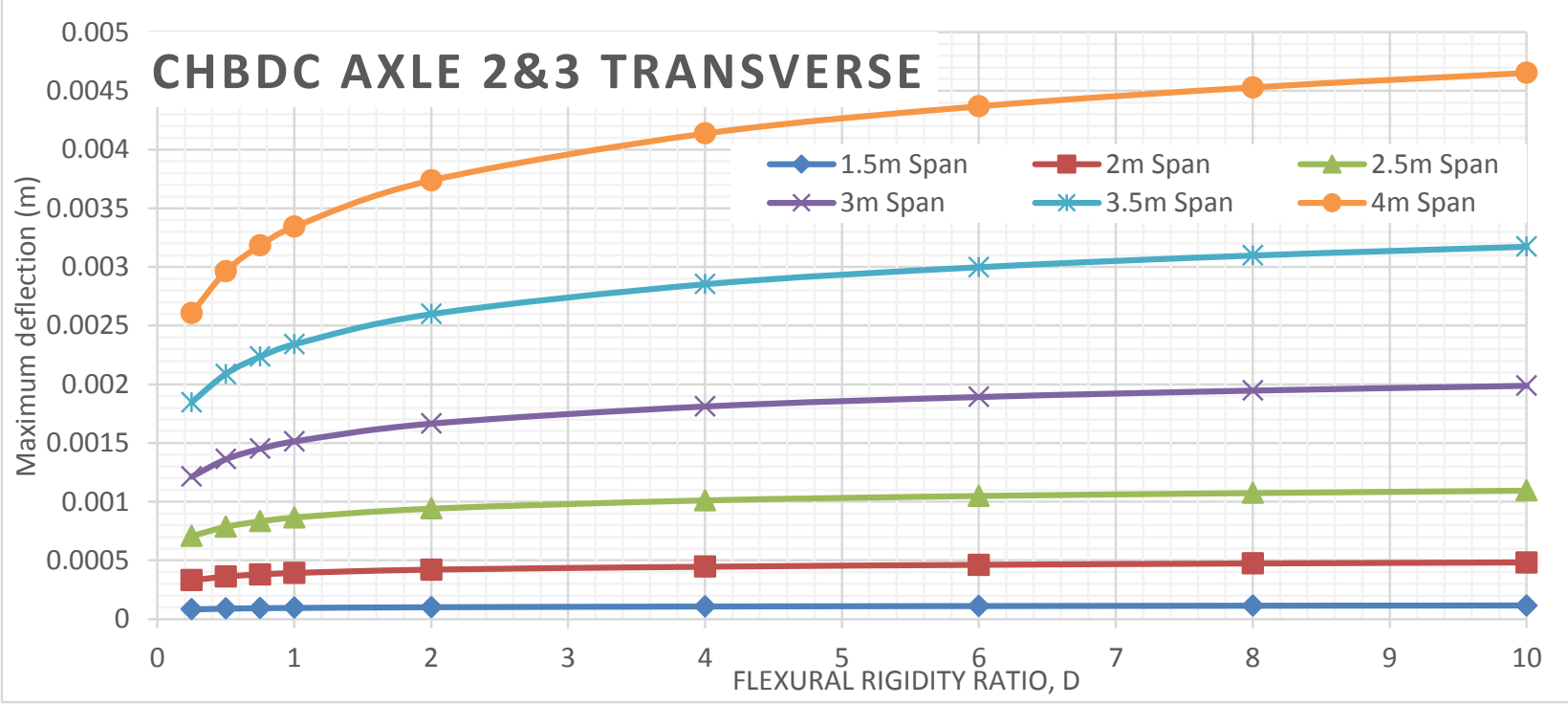

Figure 444 Maximum deflection of deck slabs subjected to CHBDC axle 2 \& 3 for different span values of alpha 4 Orthotropic analyses 


\section{Alpha 6 Deflection VS Flexural Rigidity for Different Span Length}

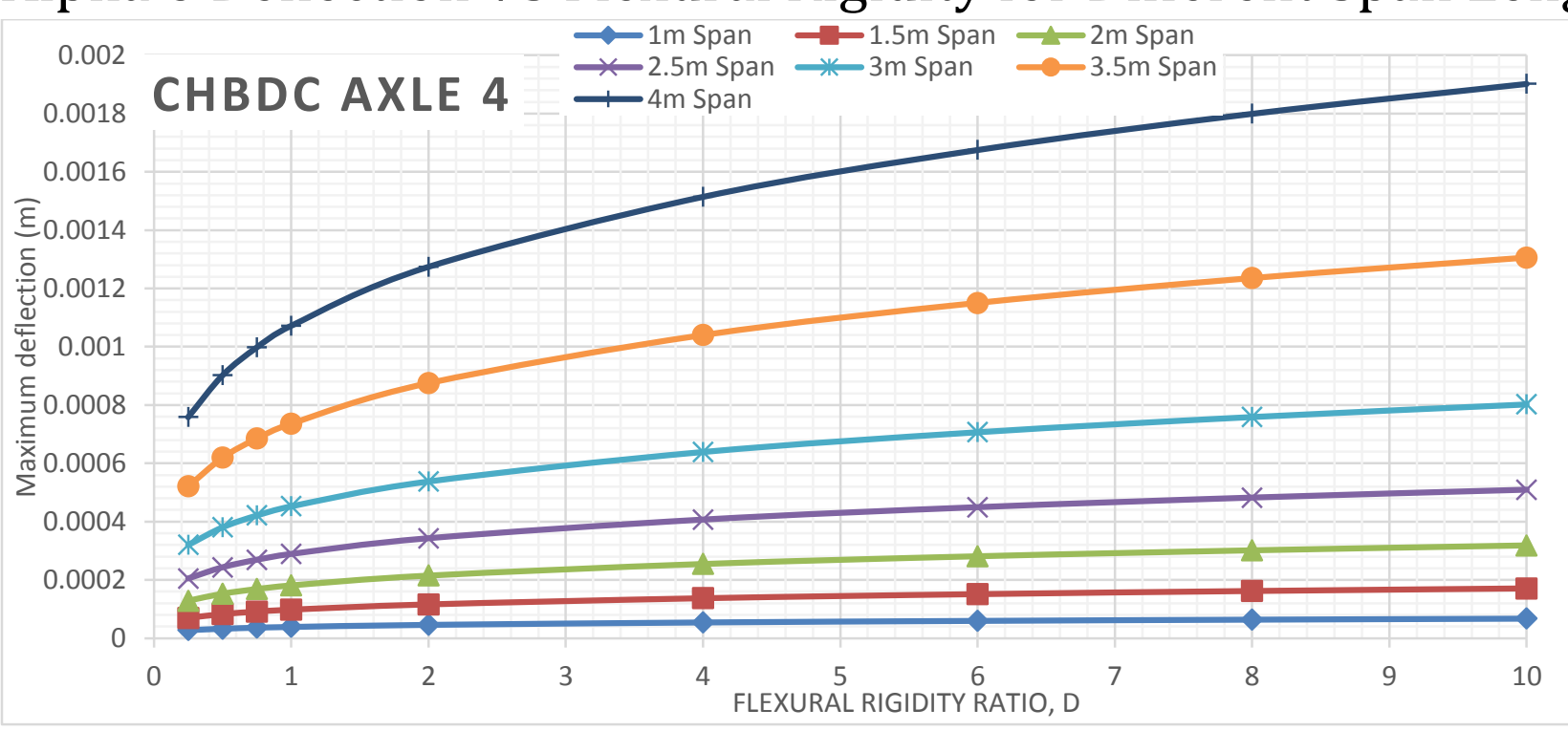

Figure 445 Maximum deflection of deck slabs subjected to CHBDC axle 4 for different span values of alpha 6 Orthotropic analyses

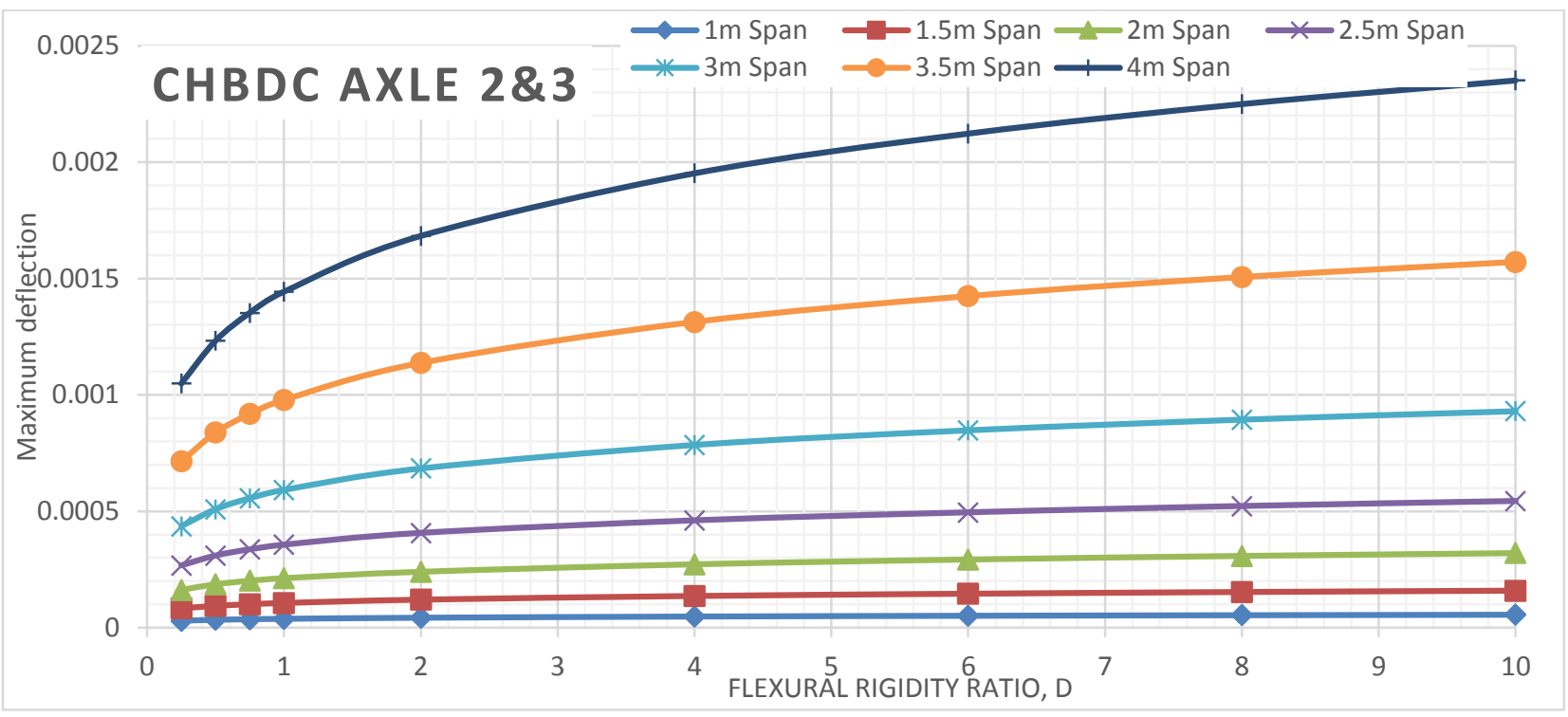

Figure 446 Maximum deflection of deck slabs subjected to CHBDC axle 2 \& 3 for different span values of alpha 6 Orthotropic analyses 


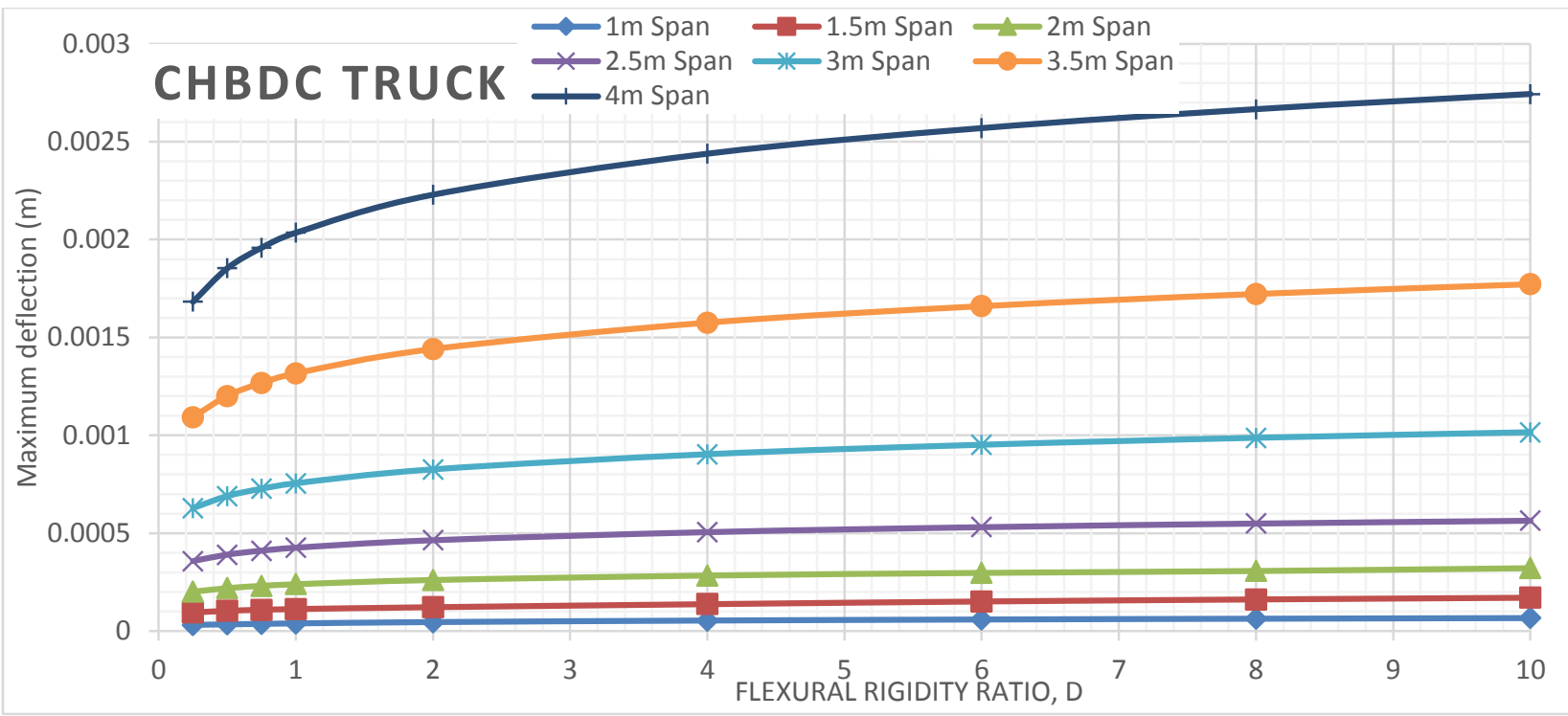

Figure 447 Maximum deflection of deck slabs subjected to CHBDC truck for different span values of alpha 6 Orthotropic analyses

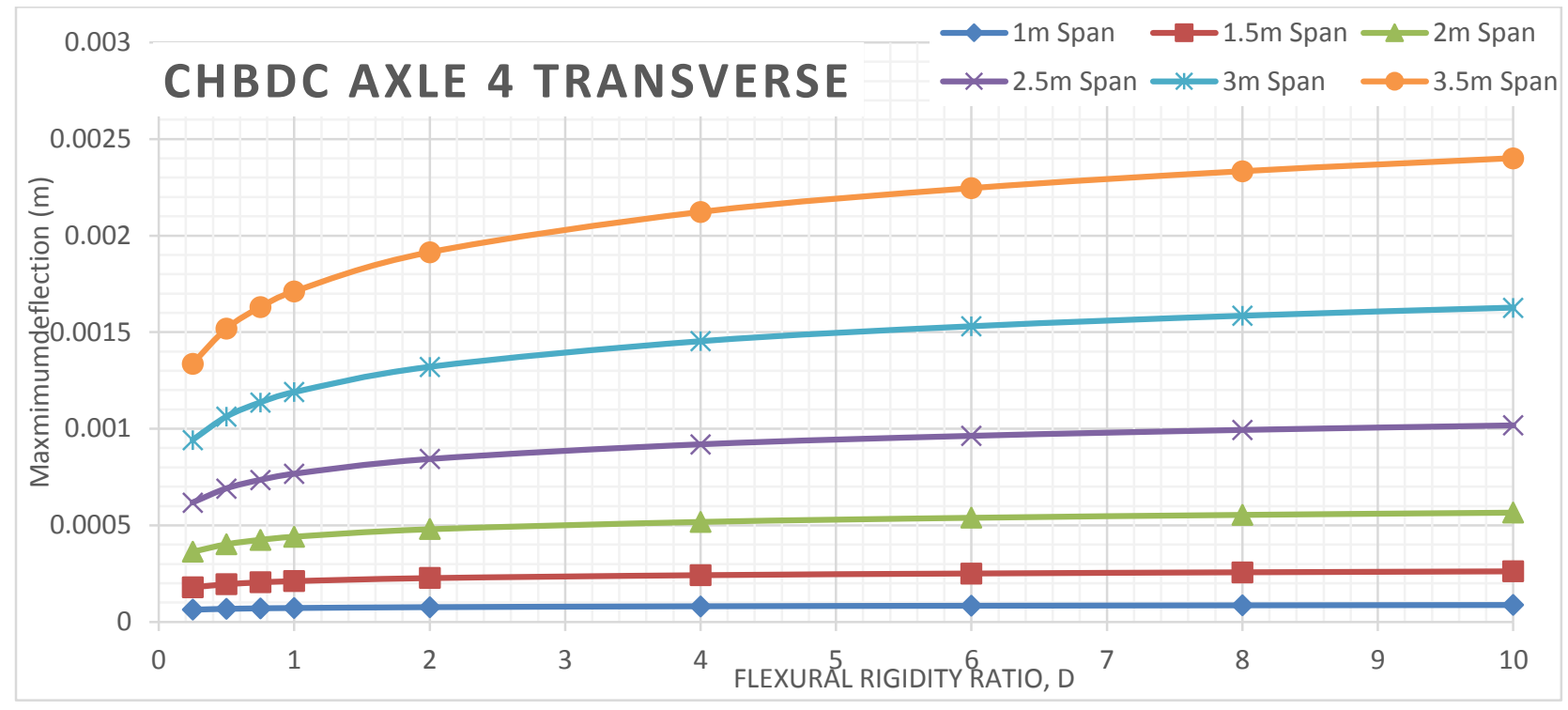

Figure 448 Maximum deflection of deck slabs subjected to CHBDC axle 4 for different span values of alpha 6 Orthotropic analyses

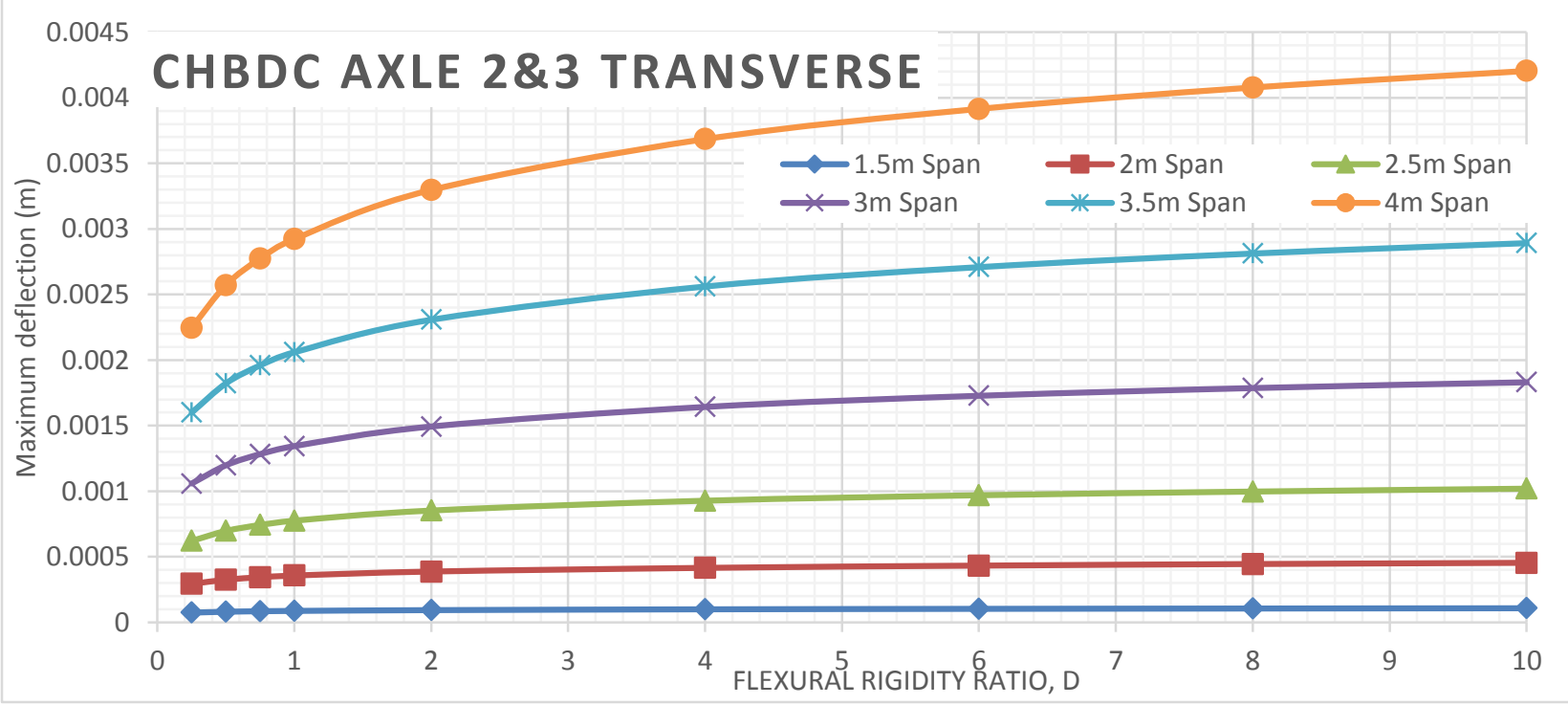

Figure 449 Maximum deflection of deck slabs subjected to CHBDC axle 2 \& 3 for different span values of alpha 6 Orthotropic analyses 


\section{Alpha 8 Deflection VS Flexural Rigidity for Different Span Length}

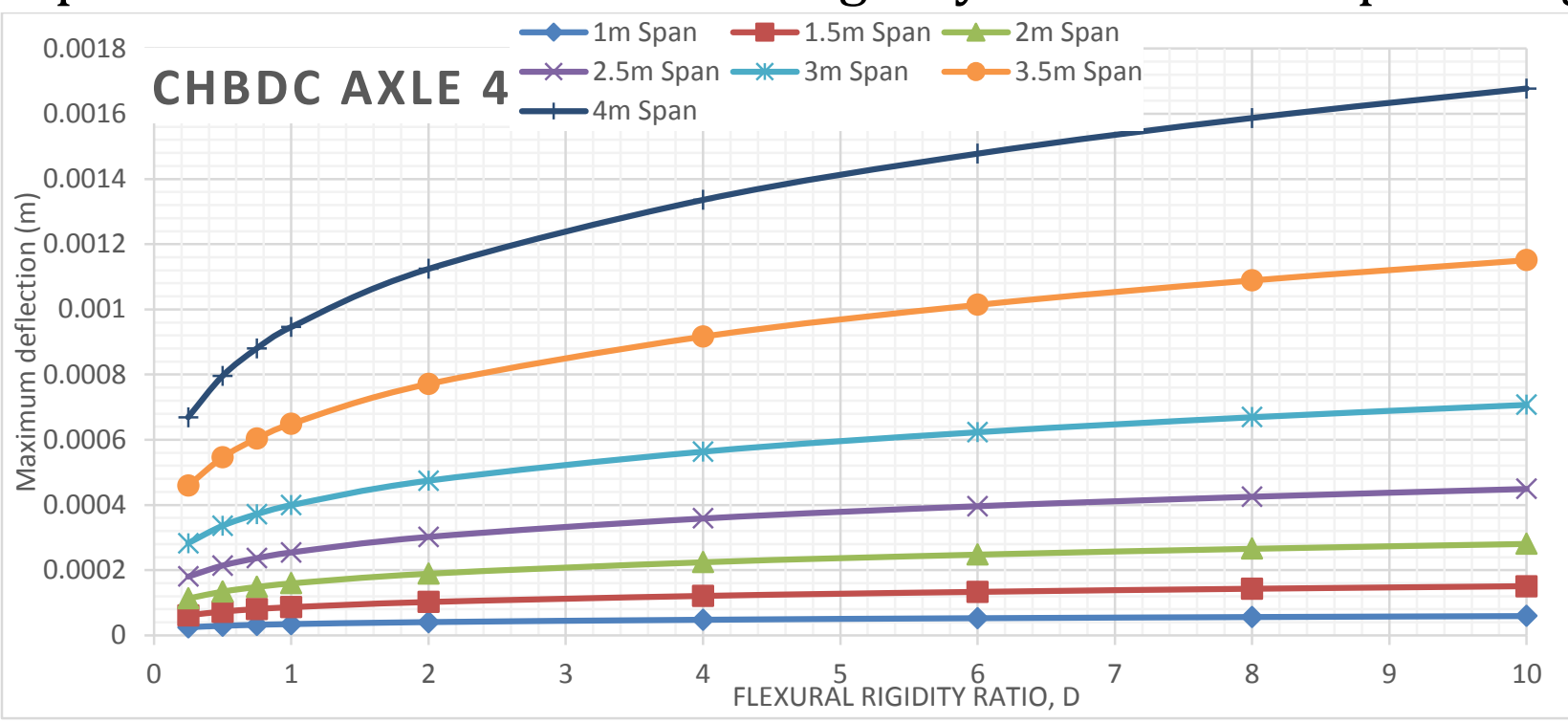

Figure 450 Maximum deflection of deck slabs subjected to CHBDC axle 4 for different span values of alpha 8 Orthotropic analyses

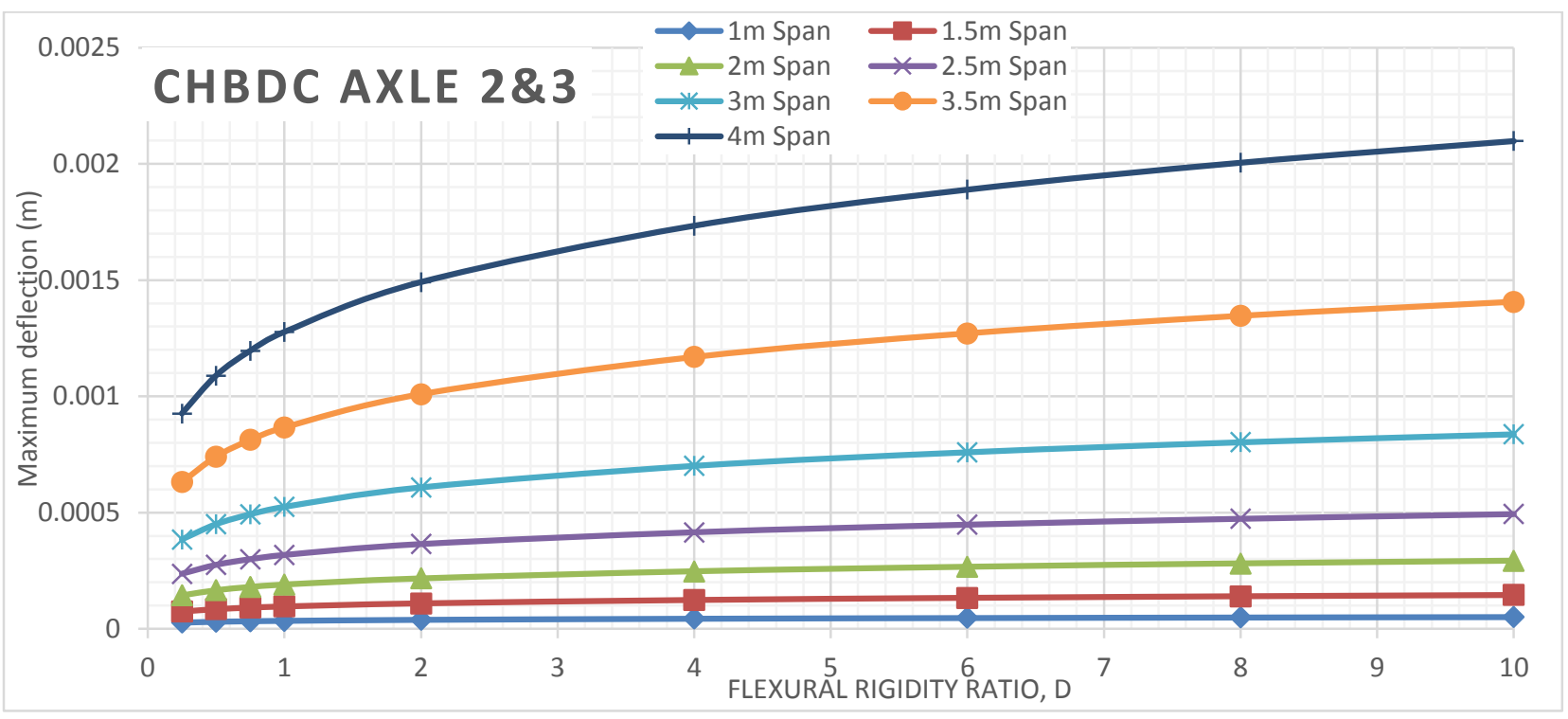

Figure 451 Maximum deflection of deck slabs subjected to CHBDC axle 2 \& 3 for different span values of alpha 8 Orthotropic analyses 


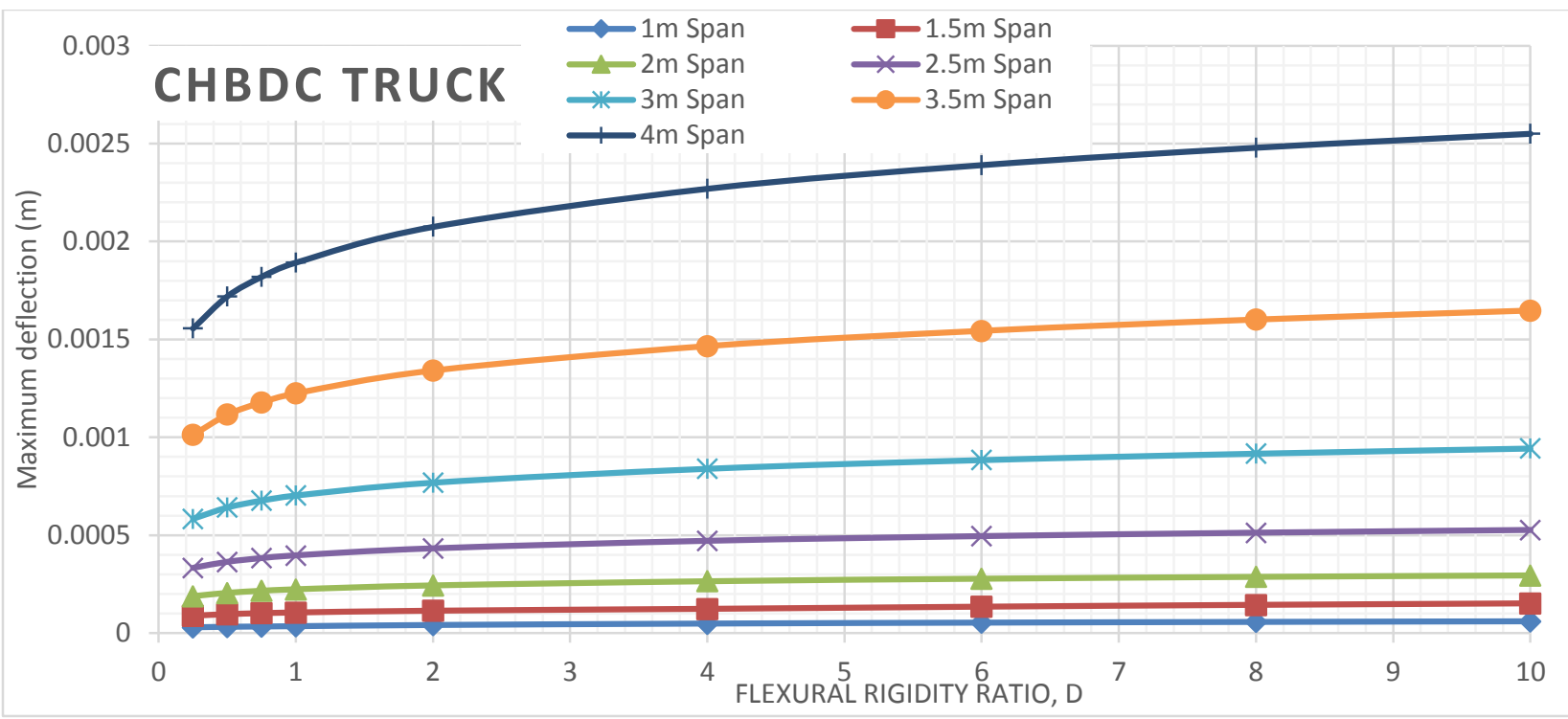

Figure 452 Maximum deflection of deck slabs subjected to CHBDC truck for different span values of alpha 8 Orthotropic analyses

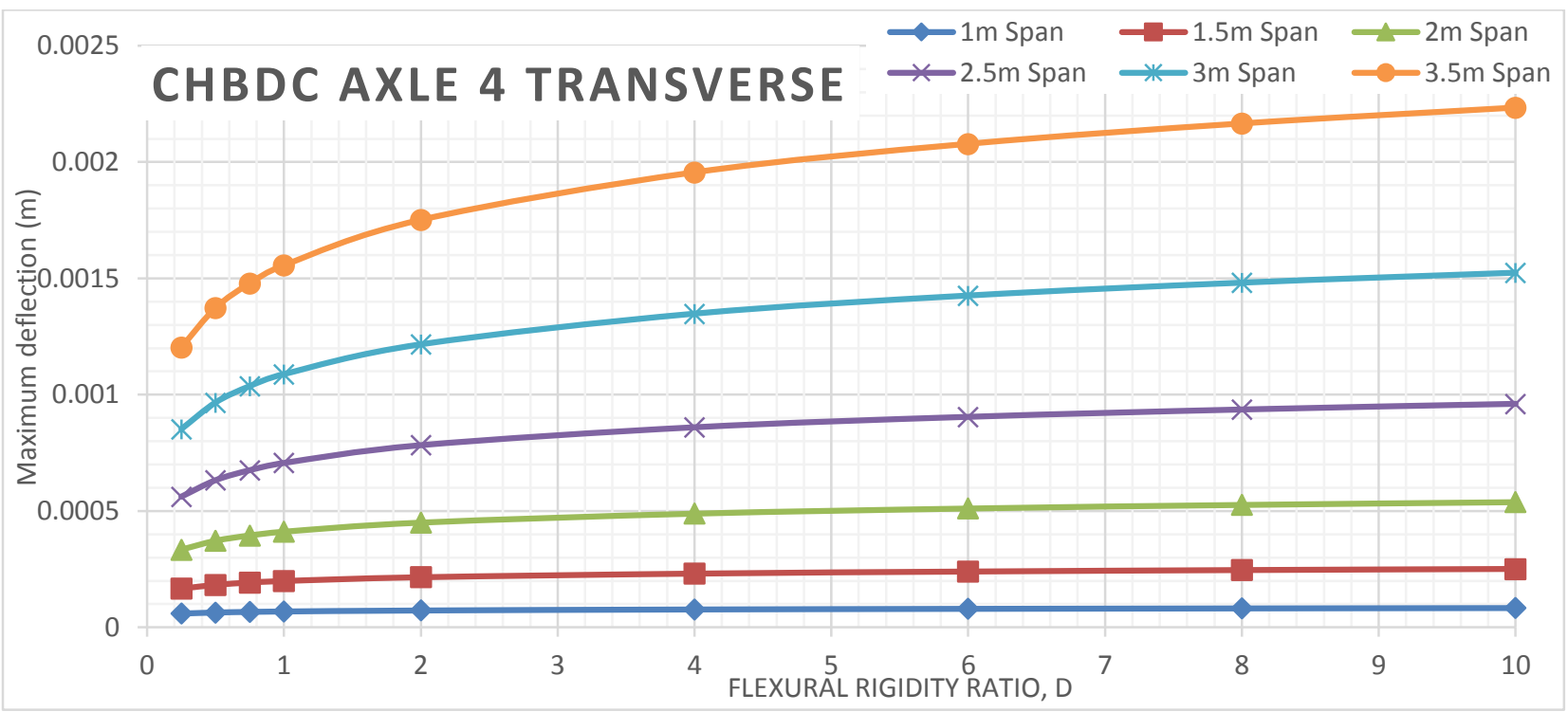

Figure 453 Maximum deflection of deck slabs subjected to CHBDC axle 4 for different span values of alpha 8 Orthotropic analyses

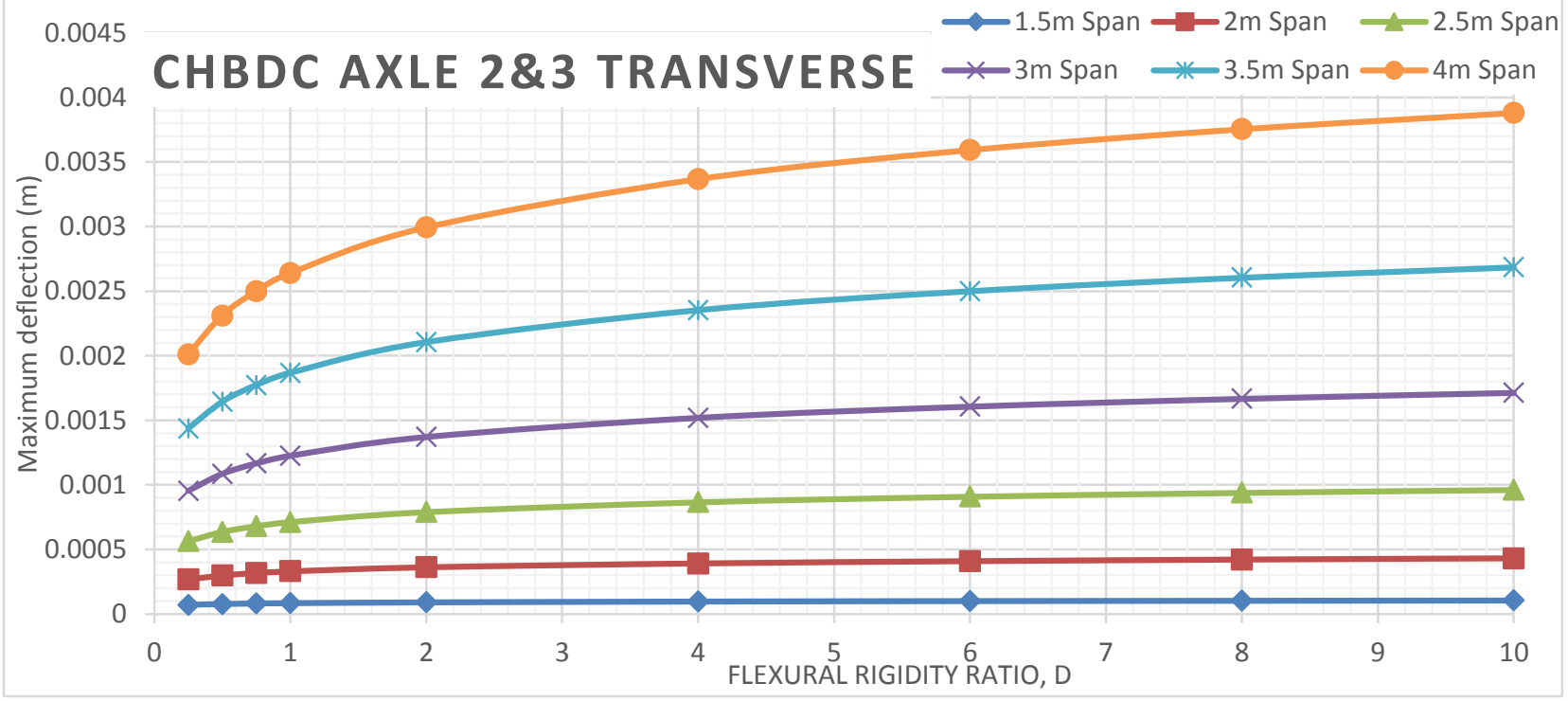

Figure 454 Maximum deflection of deck slabs subjected to CHBDC axle 2 \& 3 for different span values of alpha 8 Orthotropic analyses 


\section{Alpha 10 Deflection VS Flexural Rigidity for Different Span Length}

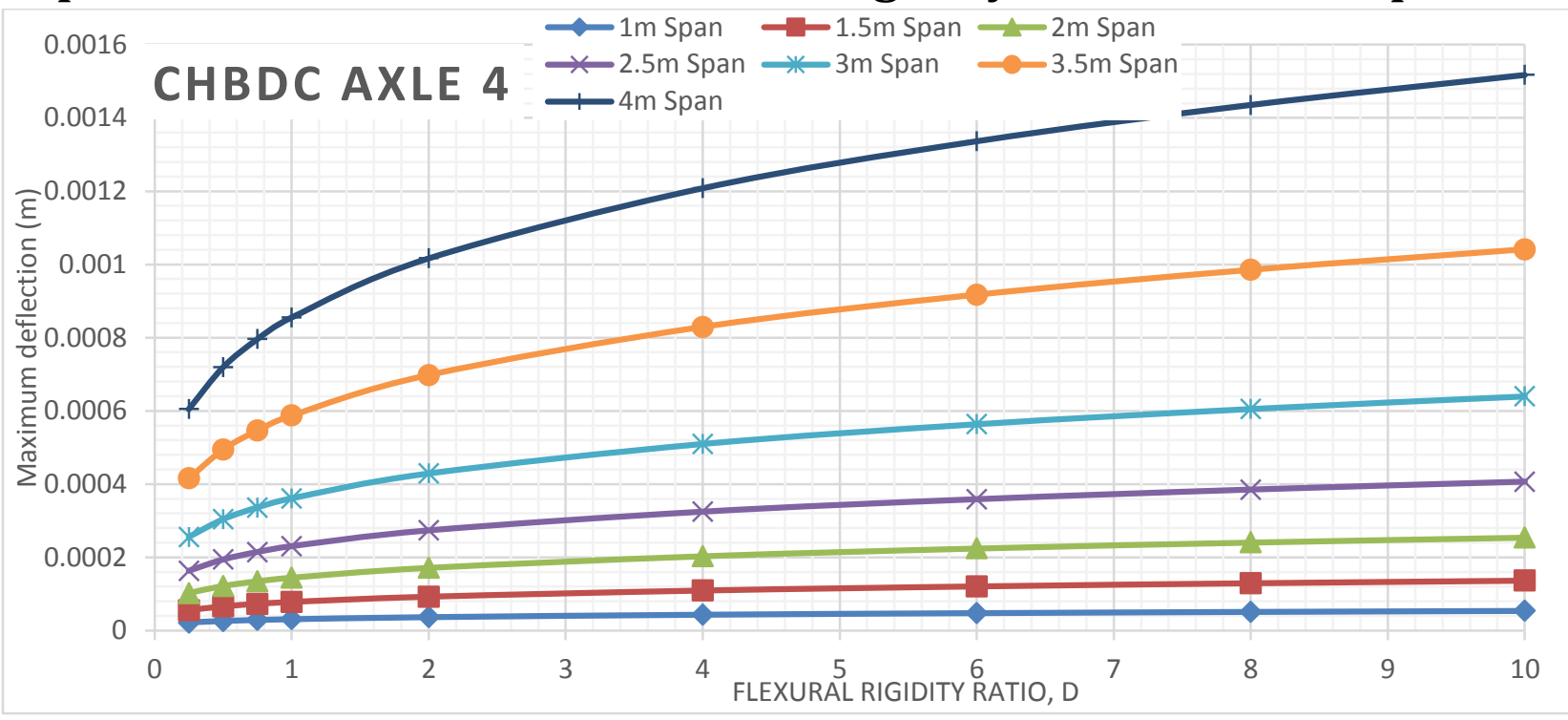

Figure 455 Maximum deflection of deck slabs subjected to CHBDC axle 4 for different span values of alpha 10 Orthotropic analyses

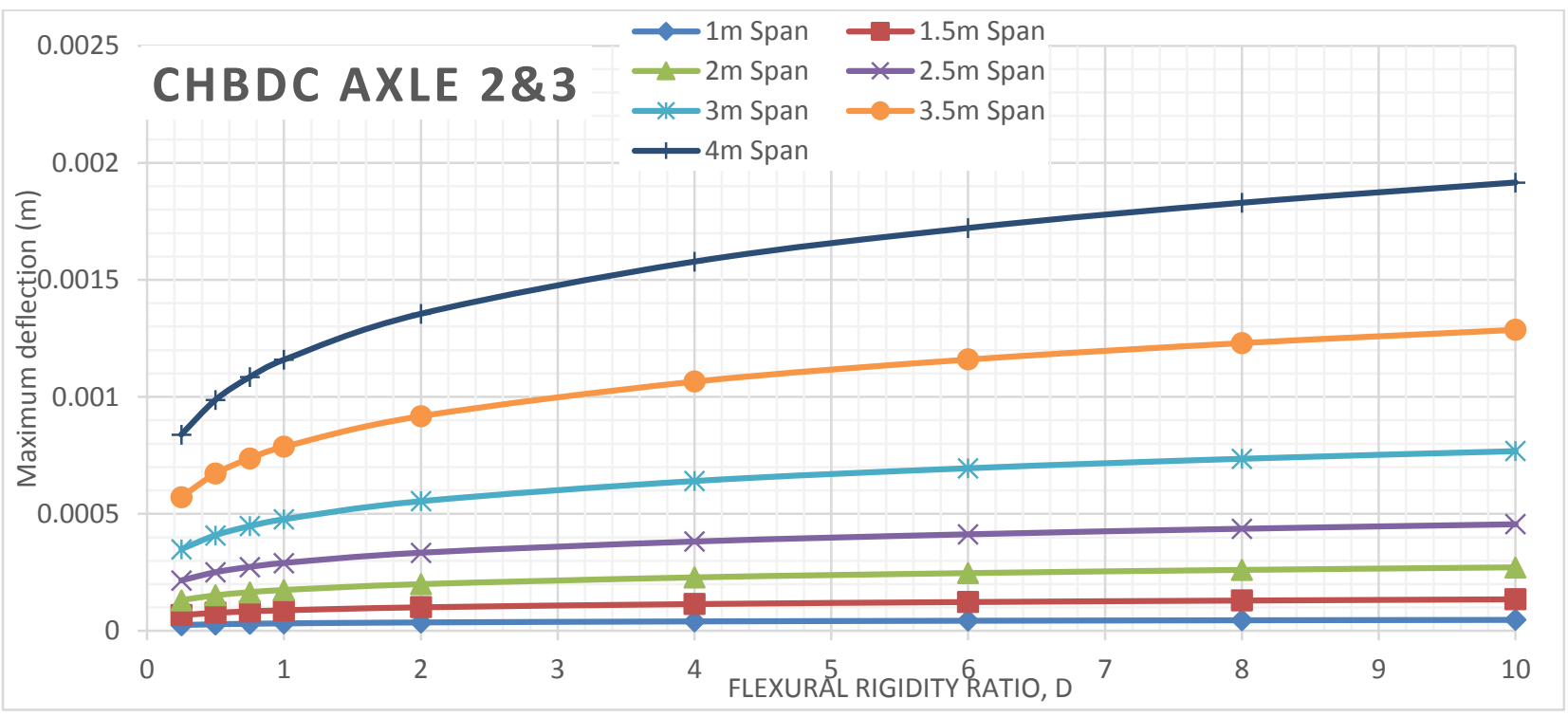

Figure 456 Maximum deflection of deck slabs subjected to CHBDC axle 2 \& 3 for different span values of alpha 10 Orthotropic analyses 


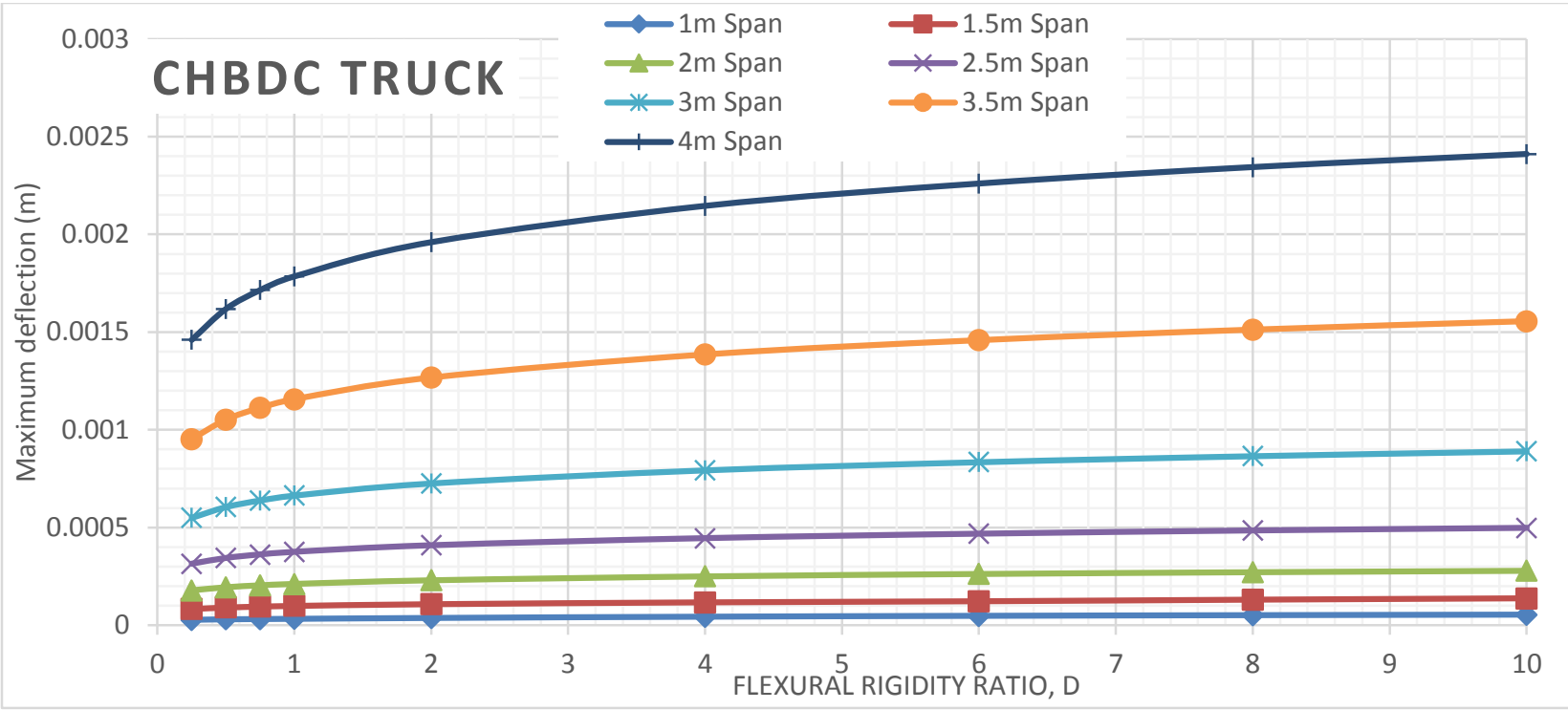

Figure 457 Maximum deflection of deck slabs subjected to CHBDC truck for different span values of alpha 10 Orthotropic analyses

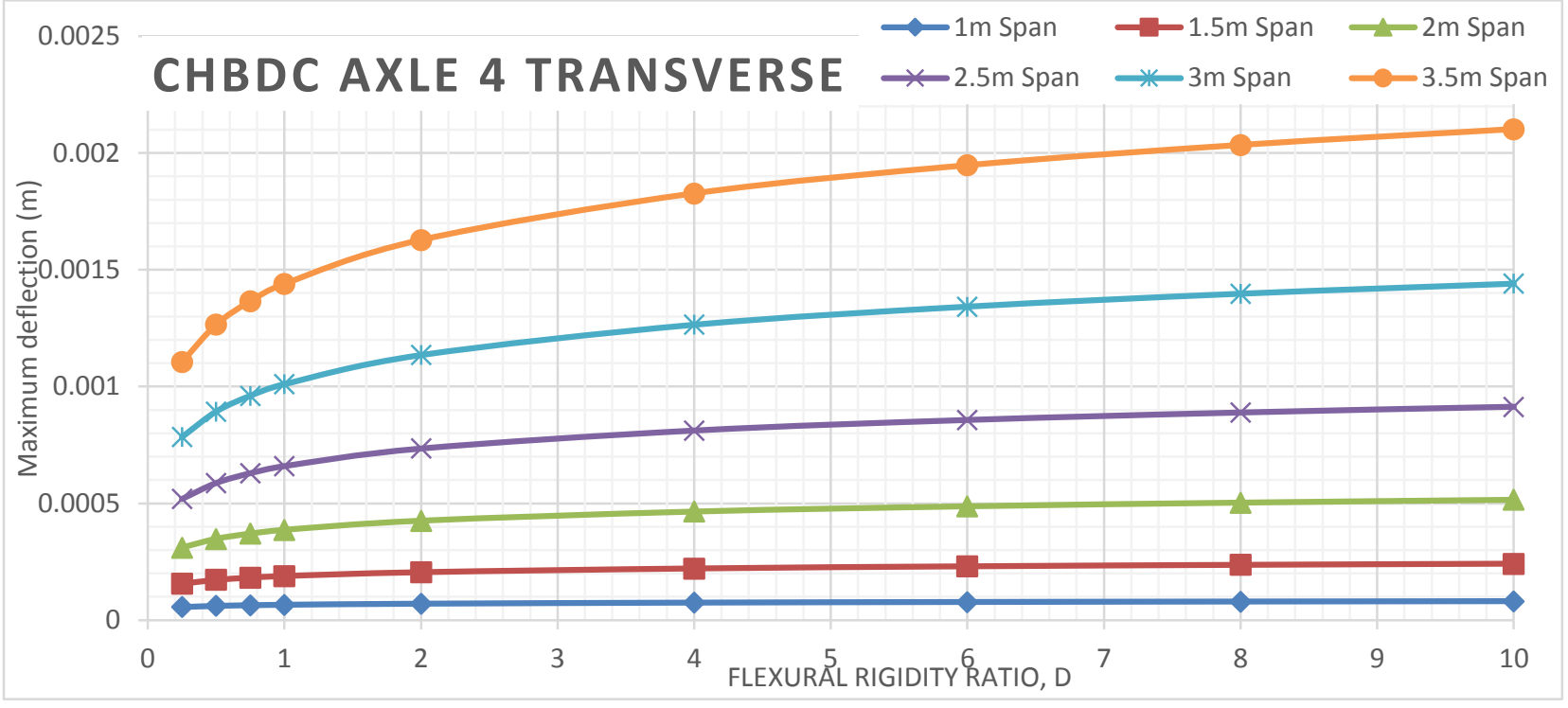

Figure 458 Maximum deflection of deck slabs subjected to CHBDC axle 4 for different span values of alpha 10 Orthotropic analyses

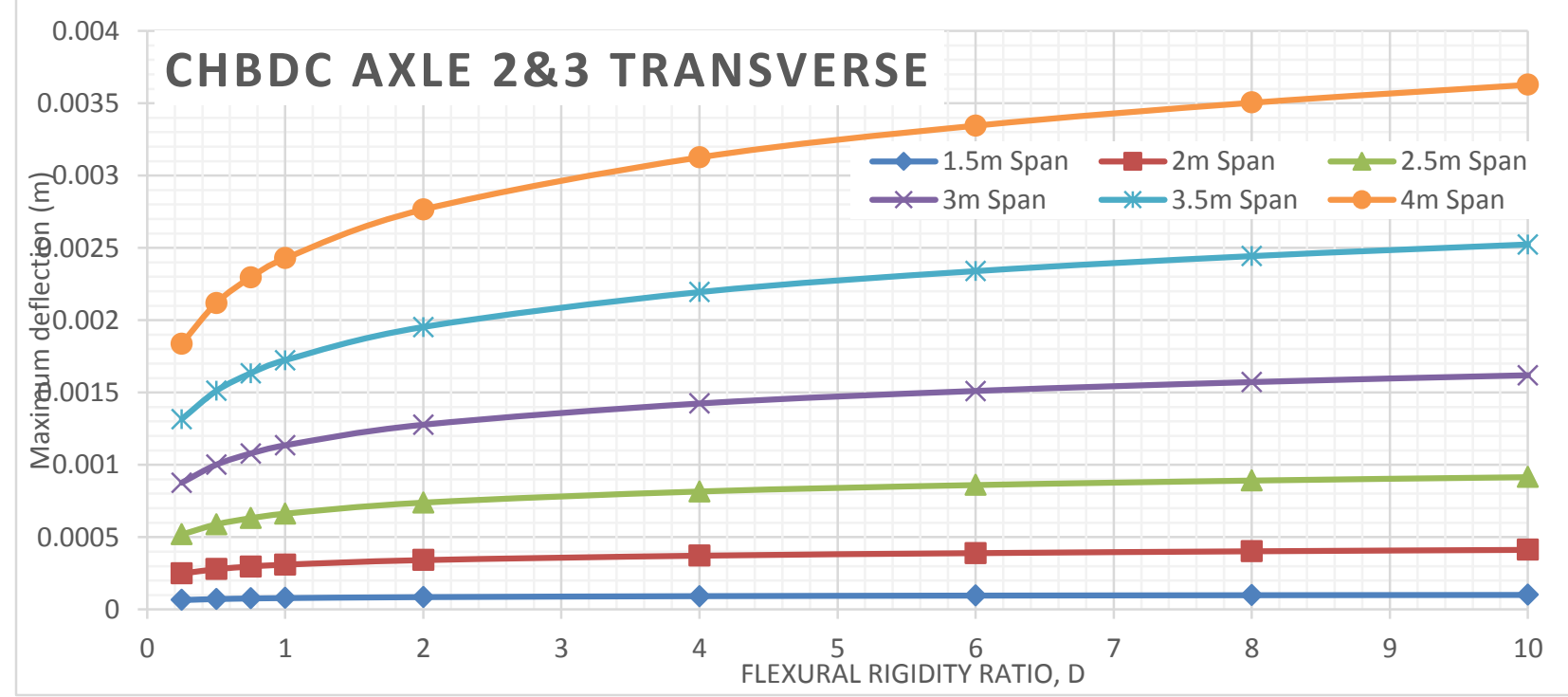

Figure 459 Maximum deflection of deck slabs subjected to CHBDC axle $2 \& 3$ for different span values of alpha 10 Orthotropic analyses 


\section{C.2.4 MAXIMUM DEFLECTION.VS TORSIONAL RIGIDITY}




\section{Axle 4 Deflection VS Torsional Rigidity for Different D Values at Different span length}

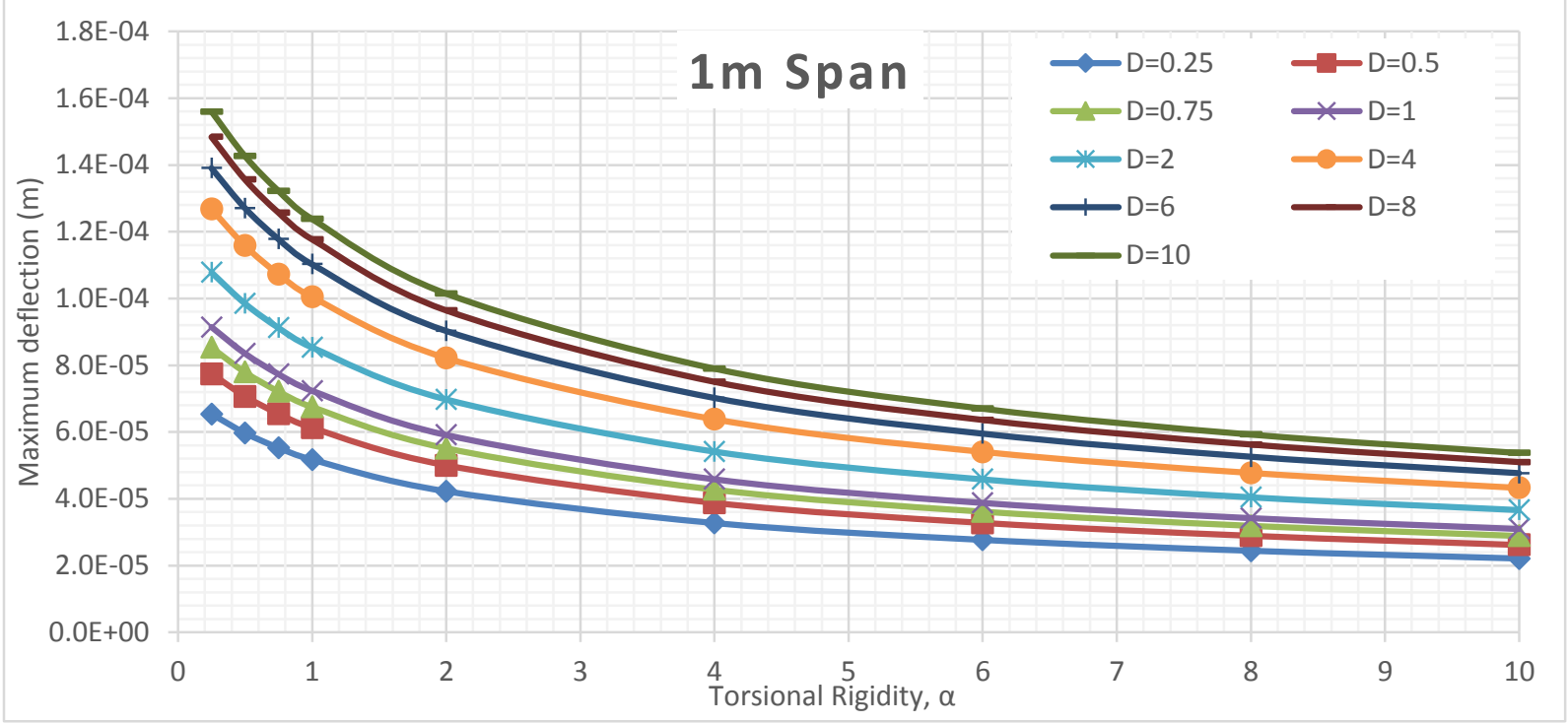

Figure 460 Maximum deflection of $1 \mathrm{~m}$ span slab subjected to CHBDC axle 4 for different D values Orthotropic analyses

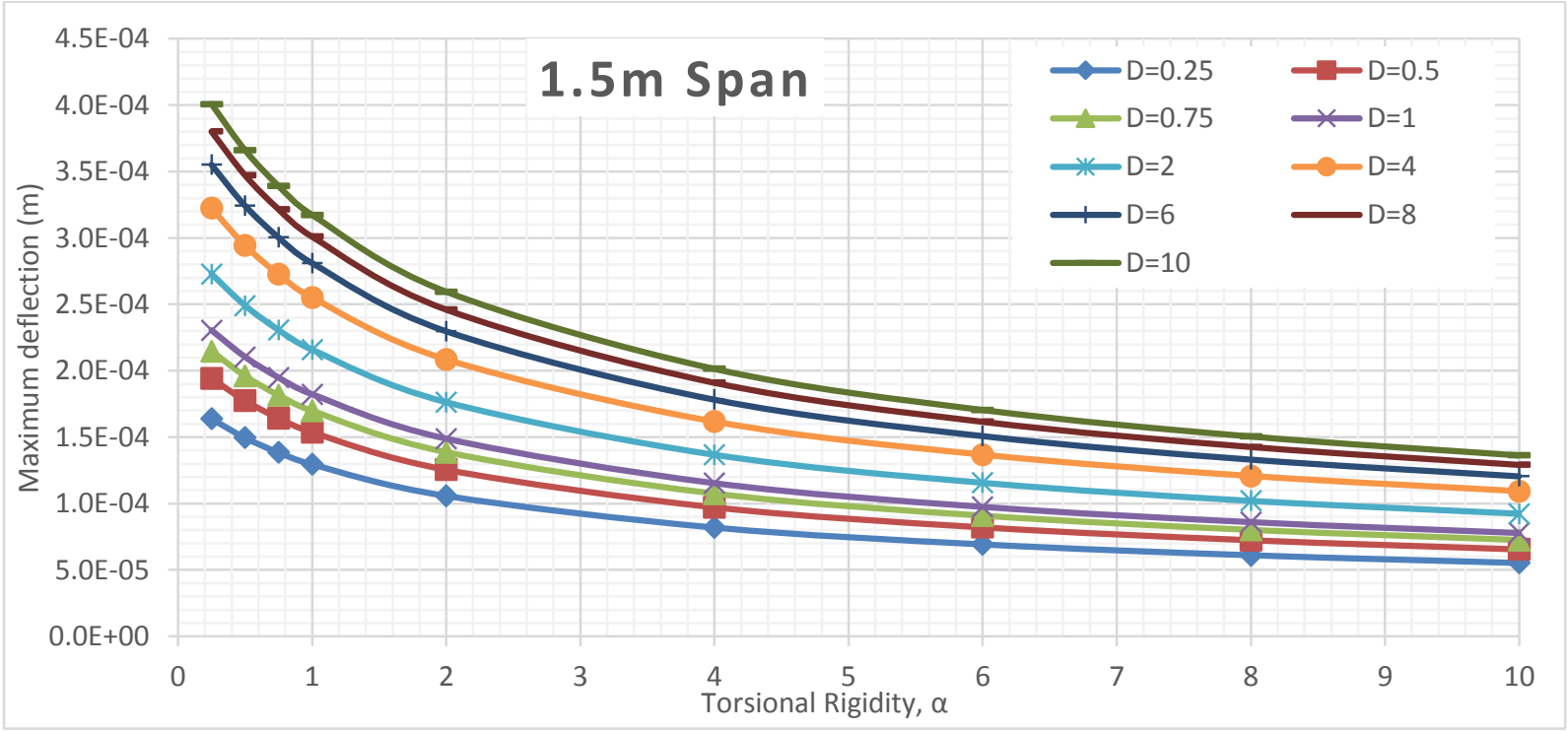

Figure 461 Maximum deflection of $1.5 \mathrm{~m}$ span slab subjected to CHBDC axle 4 for different D values Orthotropic analyses 


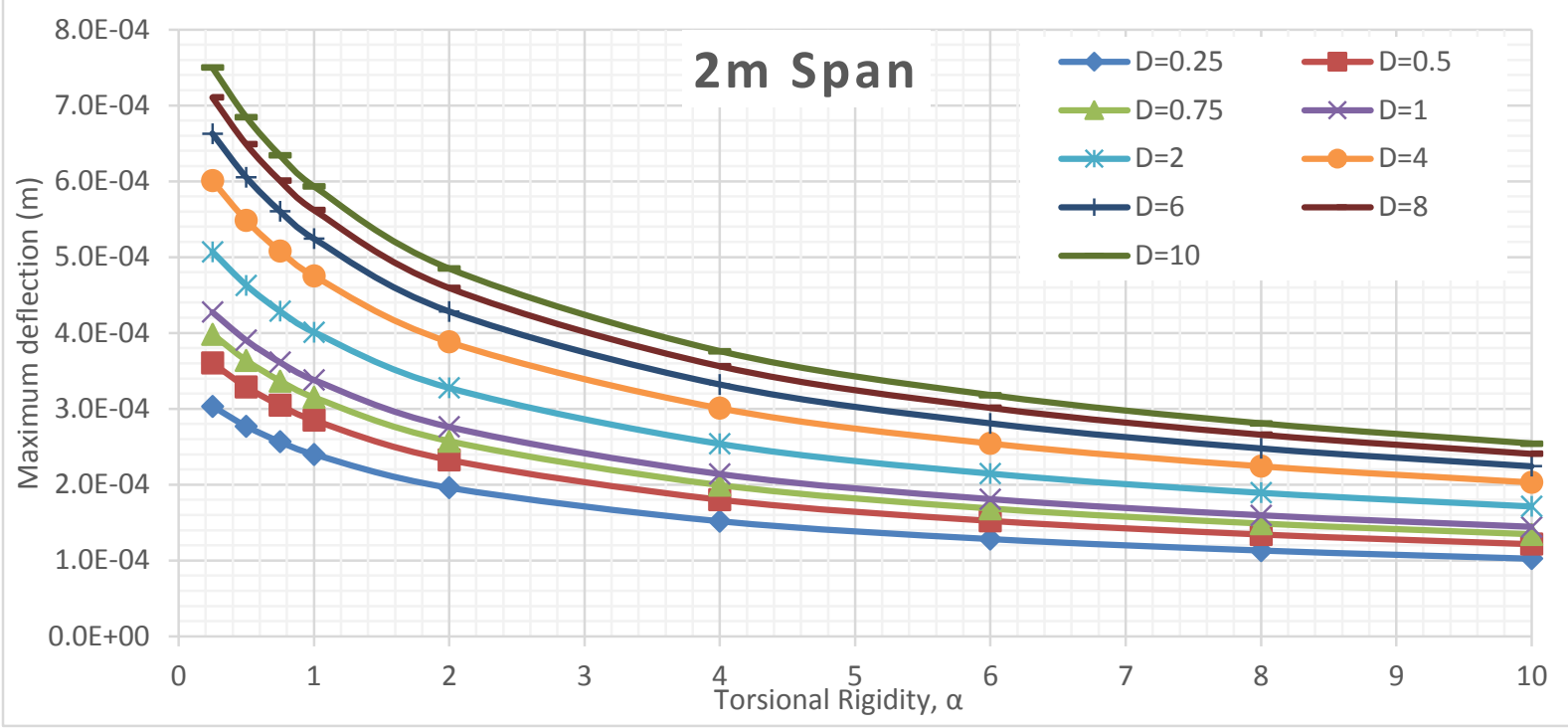

Figure 462 Maximum deflection of $2 \mathrm{~m}$ span slab subjected to CHBDC axle 4 for different D values Orthotropic analyses

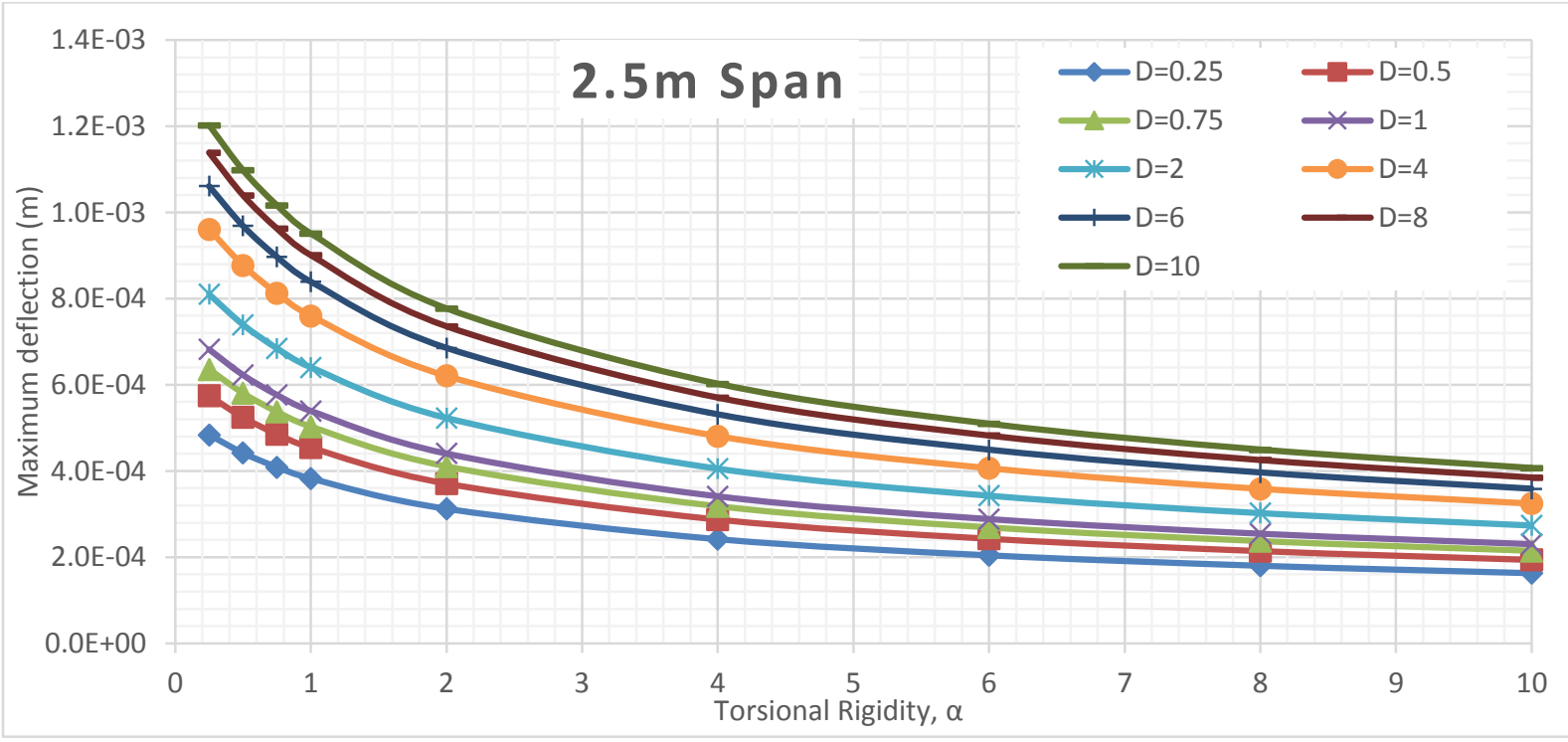

Figure 463 Maximum deflection of $2.5 \mathrm{~m}$ span slab subjected to CHBDC axle 4 for different D values Orthotropic analyses

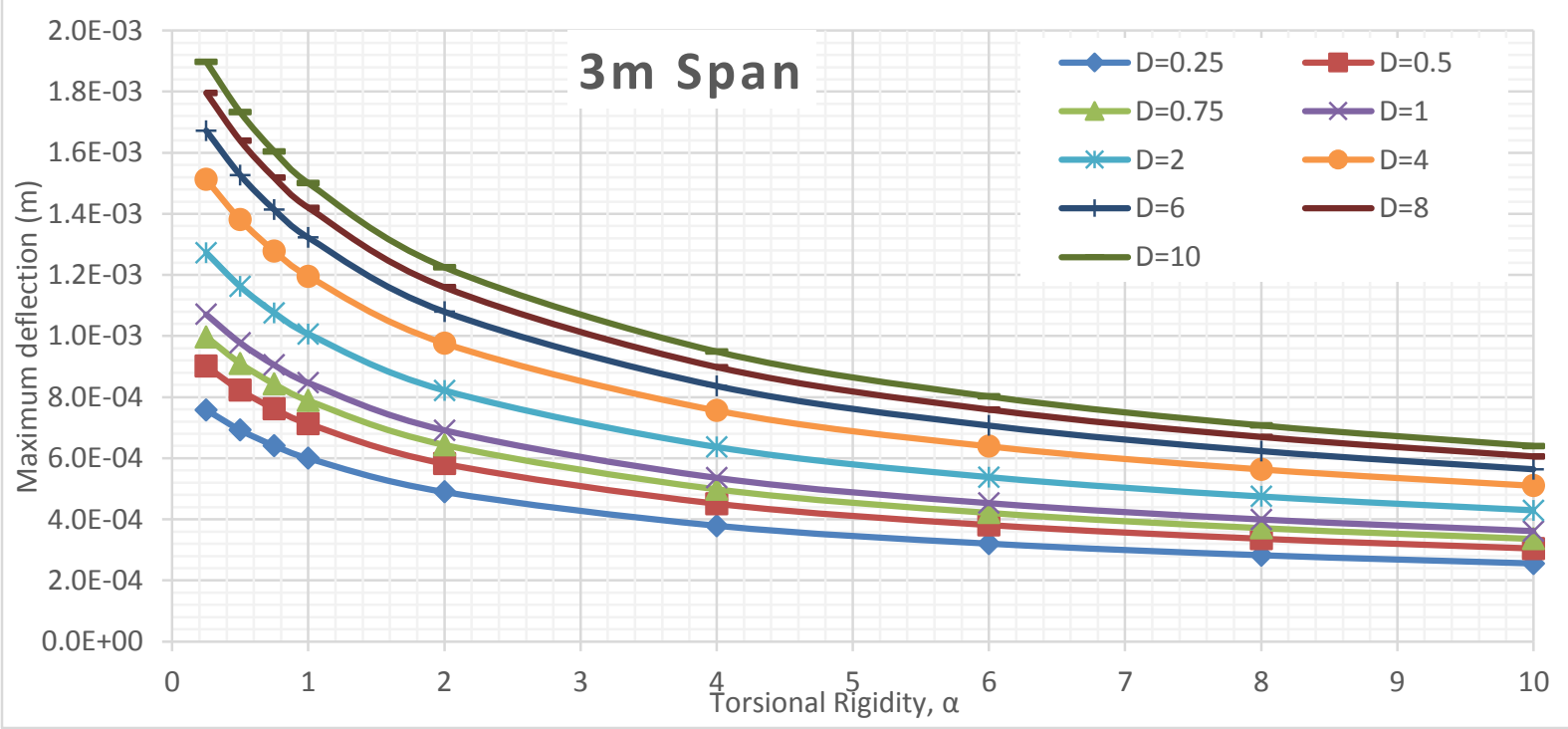

Figure 464 Maximum deflection of $3 \mathrm{~m}$ span slab subjected to CHBDC axle 4 for different D values Orthotropic analyses 


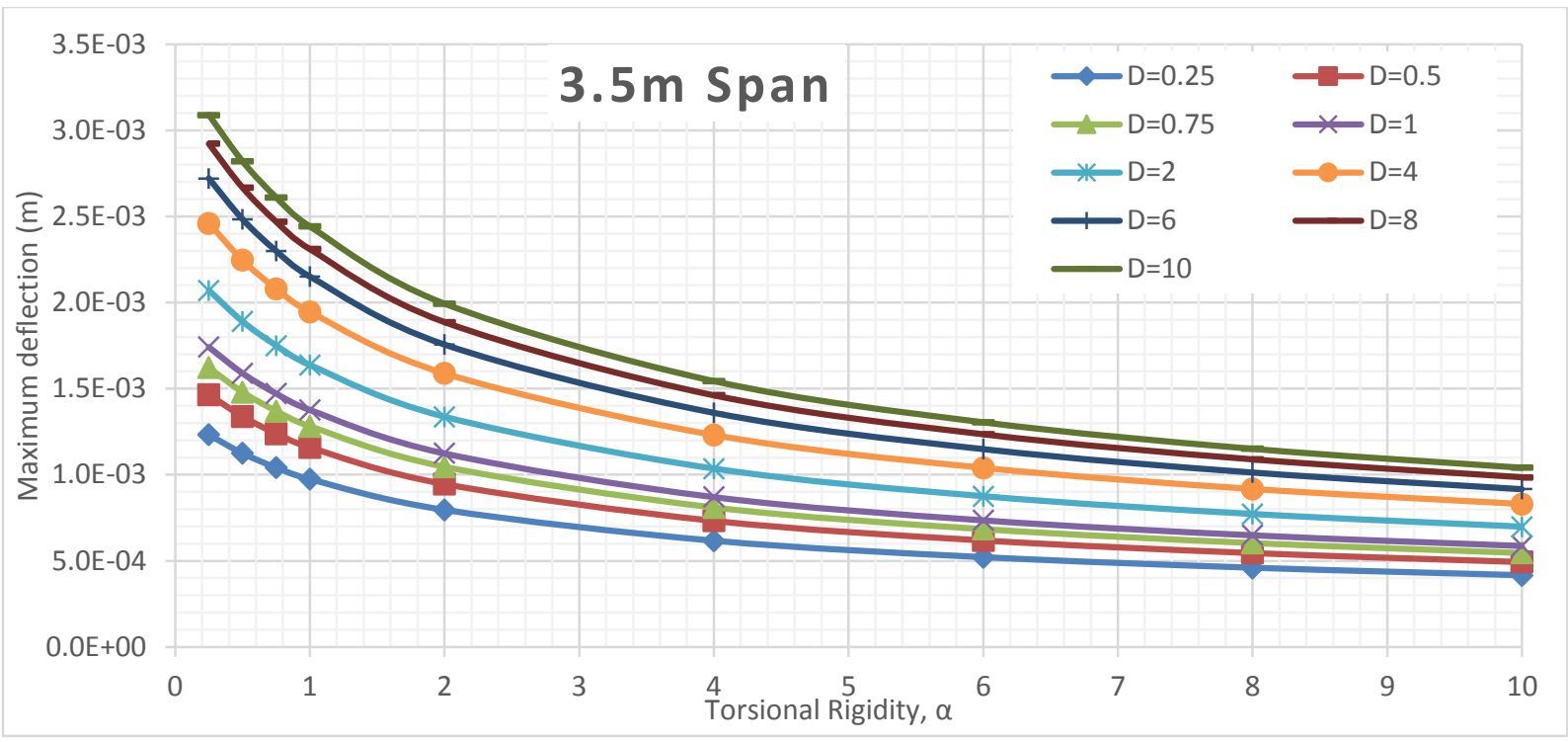

Figure 465 Maximum deflection of $3.5 \mathrm{~m}$ span slab subjected to CHBDC axle 4 for different D values Orthotropic analyses

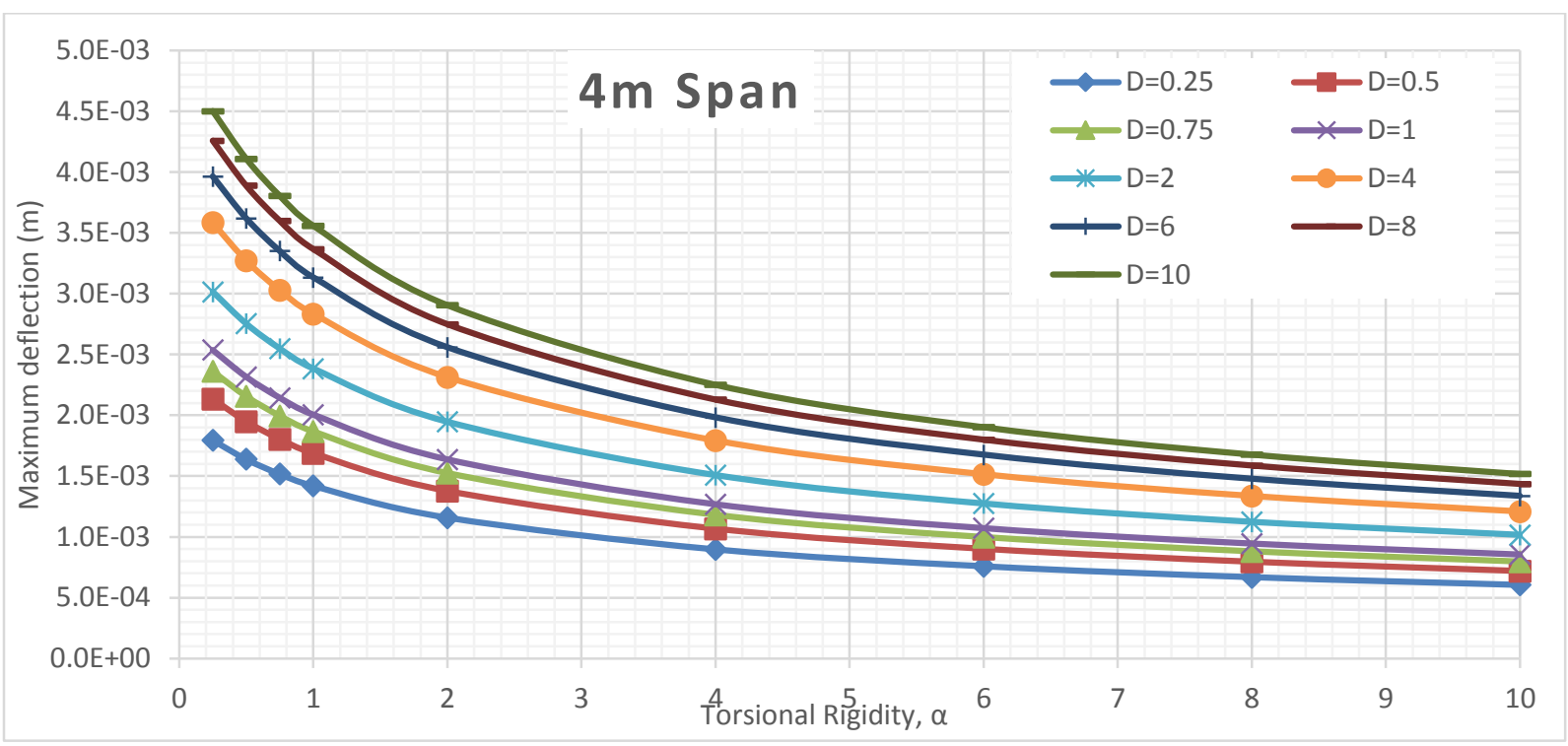

Figure 466 Maximum deflection of $4 \mathrm{~m}$ span slab subjected to CHBDC axle 4 for different D values Orthotropic analyses 


\section{Axle 2 \& 3 Deflection VS Torsional Rigidity for Different D Values at Different span length}

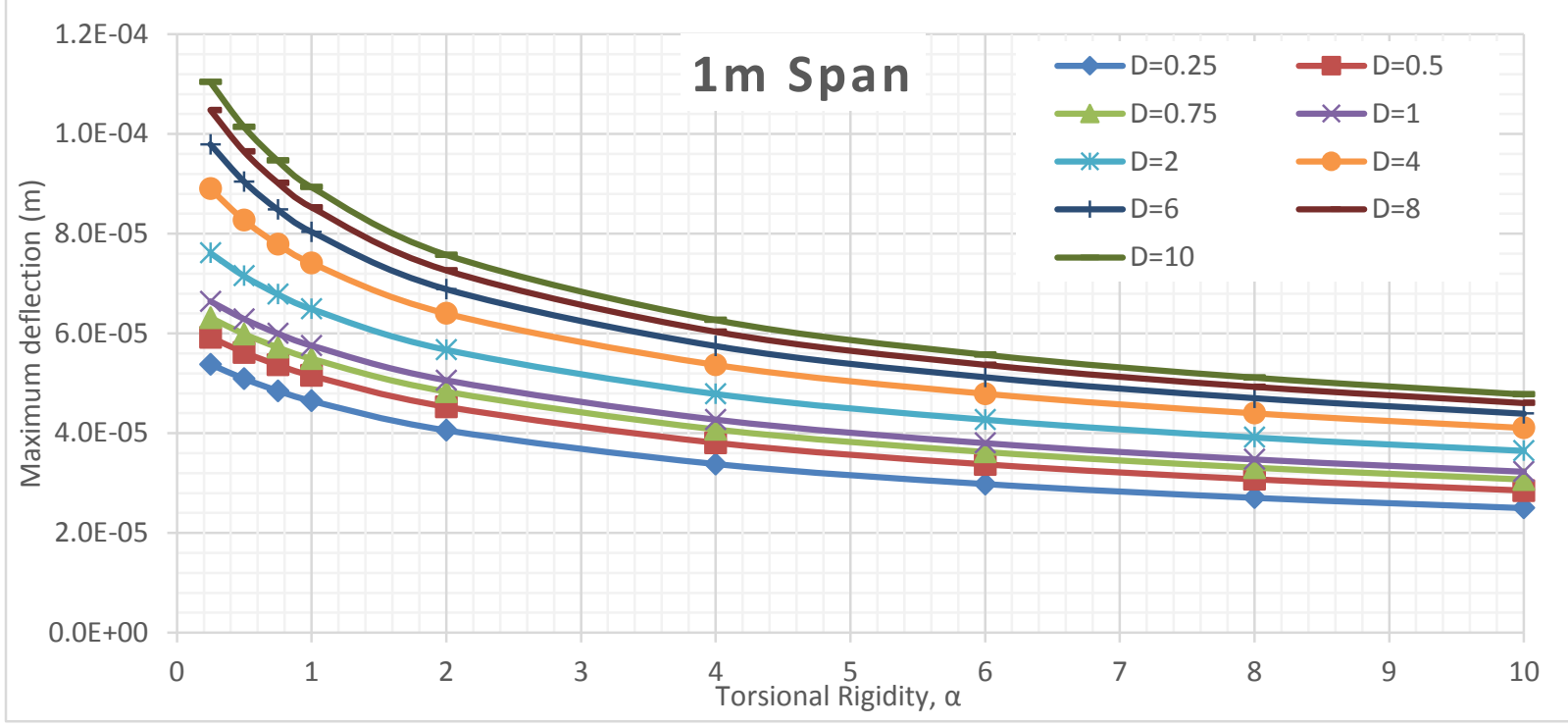

Figure 467 Maximum deflection of $1 \mathrm{~m}$ span slab subjected to CHBDC axle 2 \& 3 for different D values Orthotropic analyses

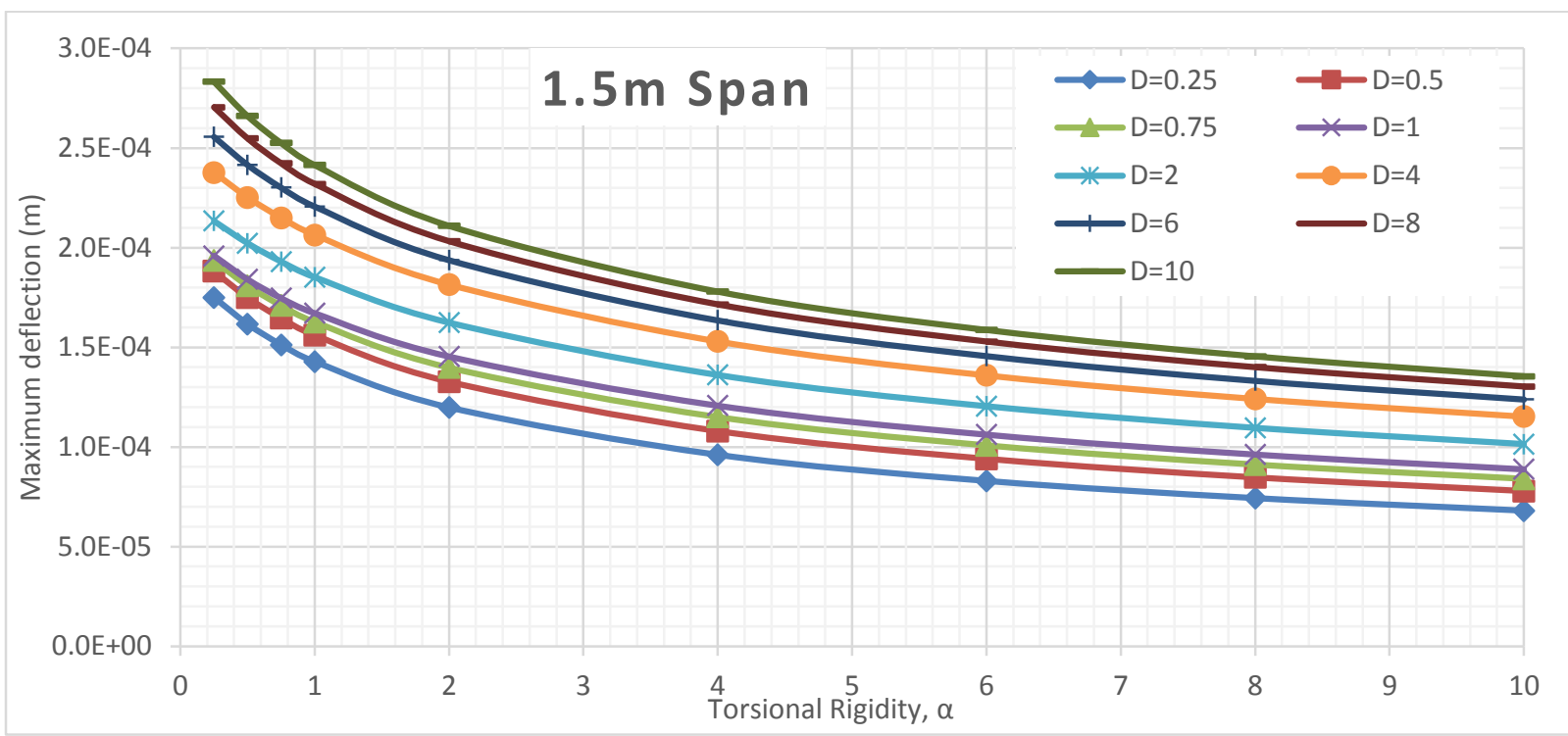

Figure 468 Maximum deflection of $1.5 \mathrm{~m}$ span slab subjected to CHBDC axle $2 \& 3$ for different D values Orthotropic analyses 


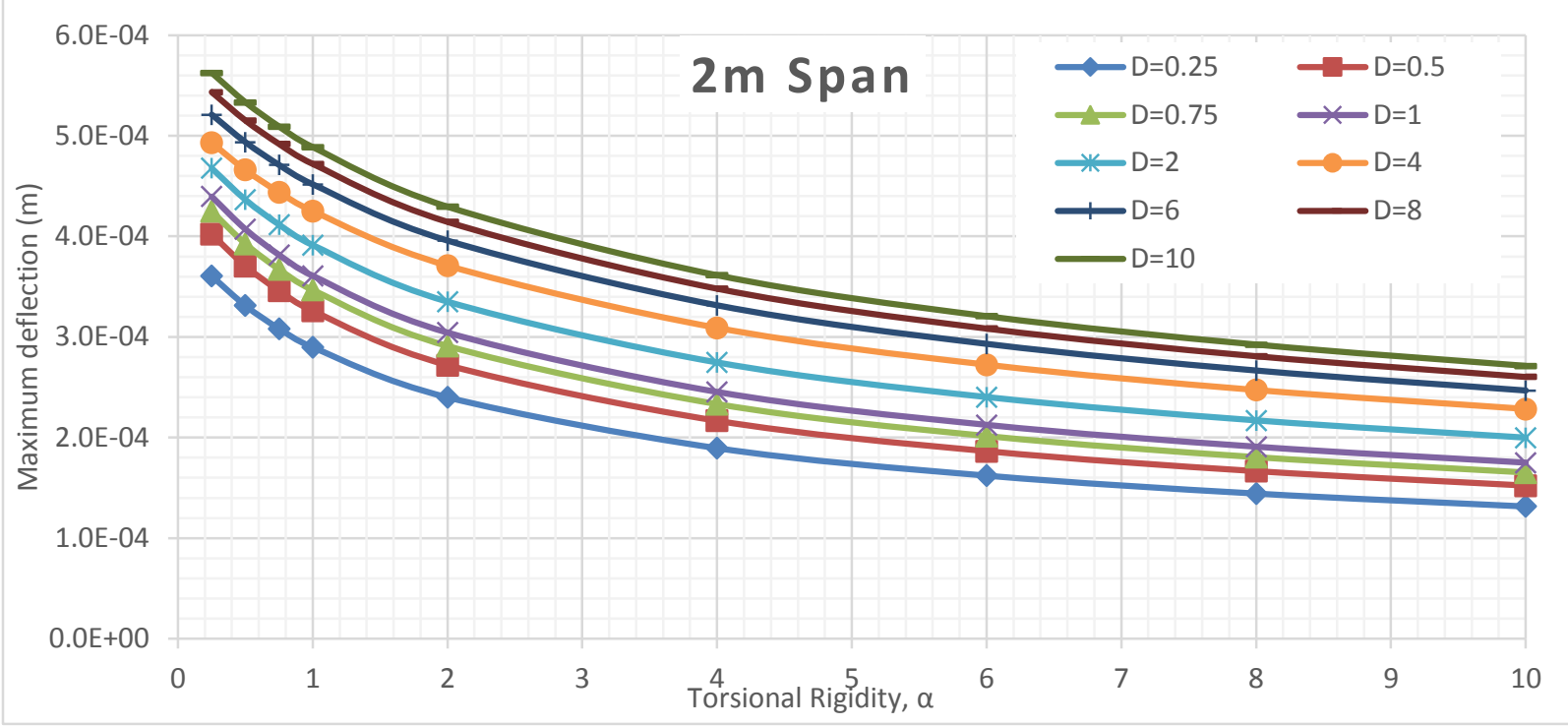

Figure 469 Maximum deflection of $2 \mathrm{~m}$ span slab subjected to CHBDC axle 2 \& 3 for different D values Orthotropic analyses

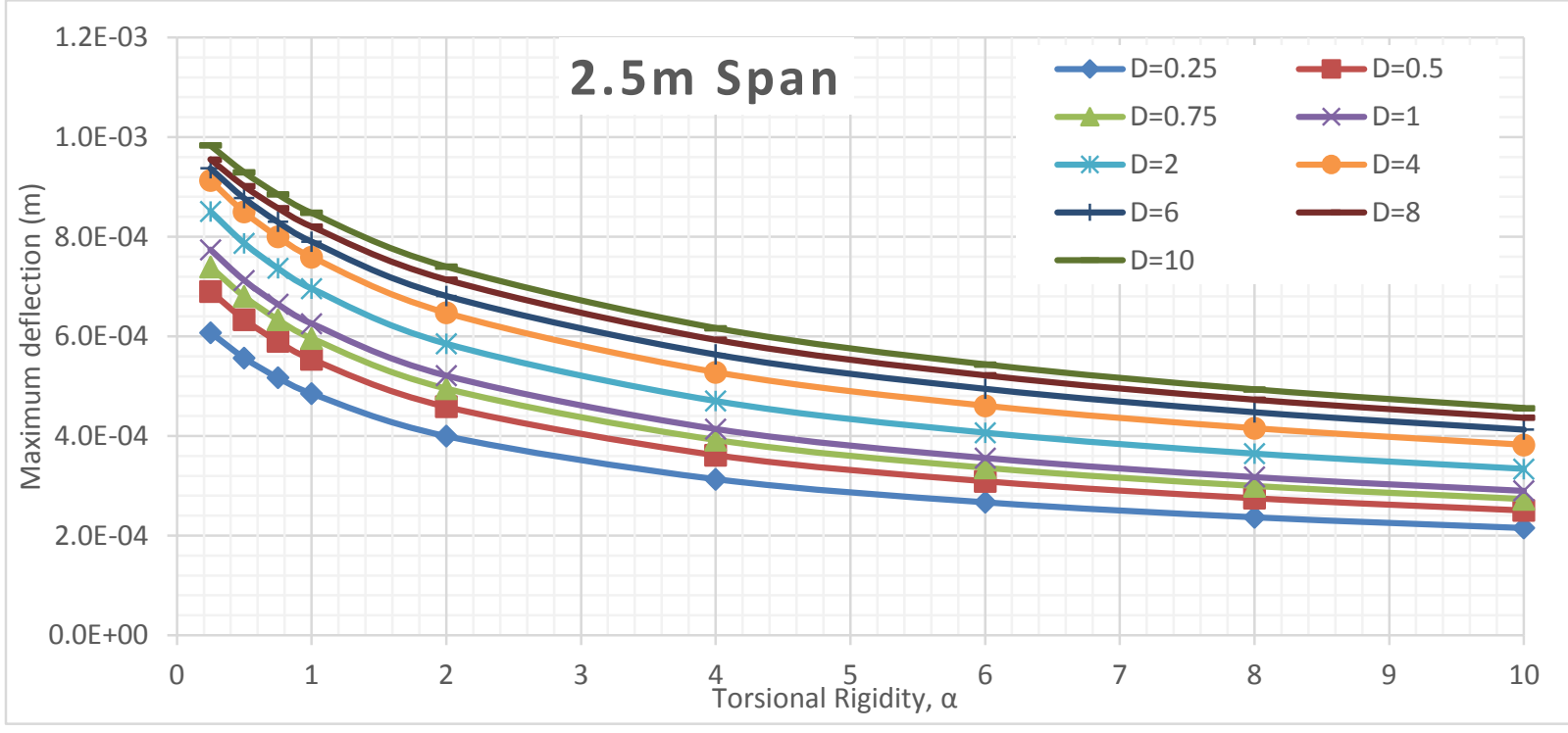

Figure 470 Maximum deflection of $2.5 \mathrm{~m}$ span slab subjected to CHBDC axle 2 \& 3 for different D values Orthotropic analyses

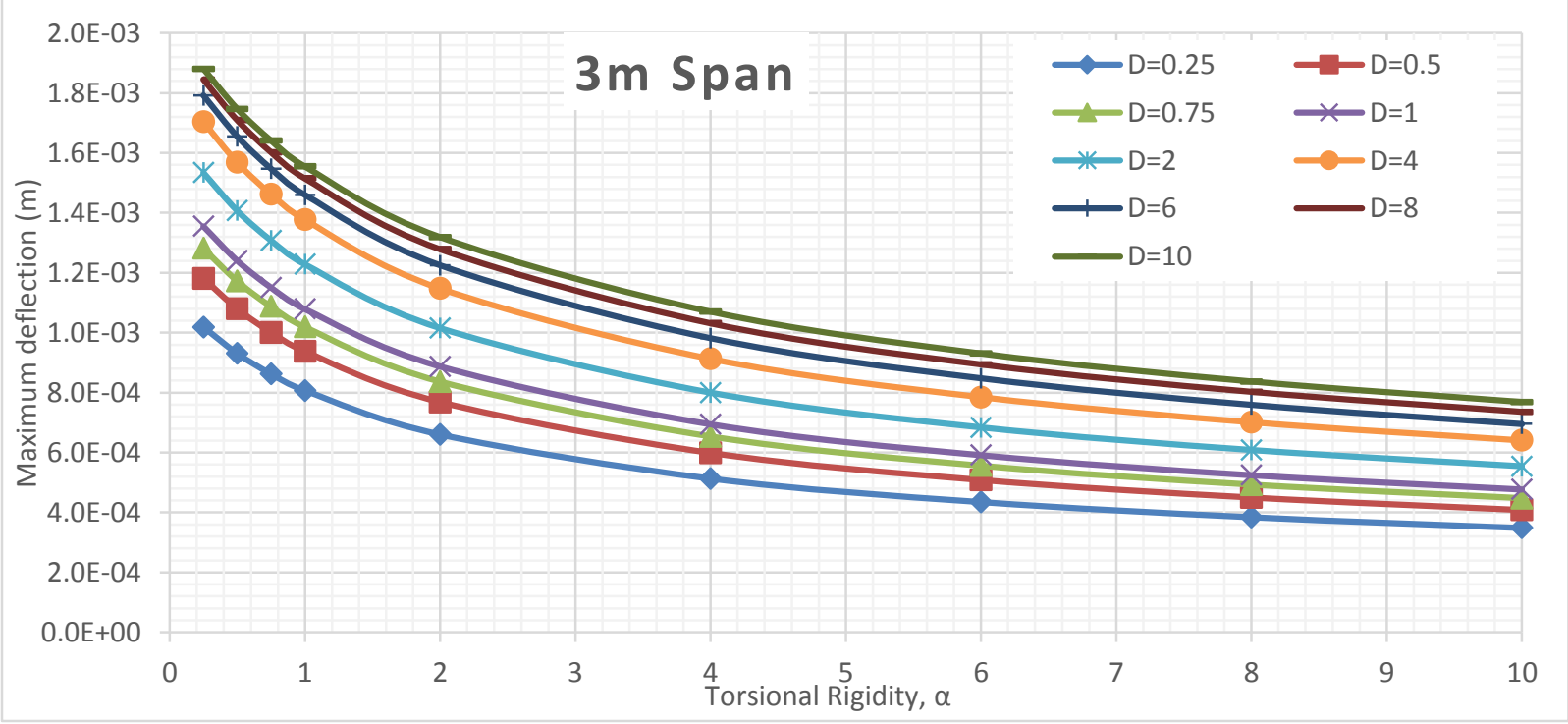

Figure 471 Maximum deflection of $3 \mathrm{~m}$ span slab subjected to CHBDC axle 2 \& 3 for different D values Orthotropic analyses 


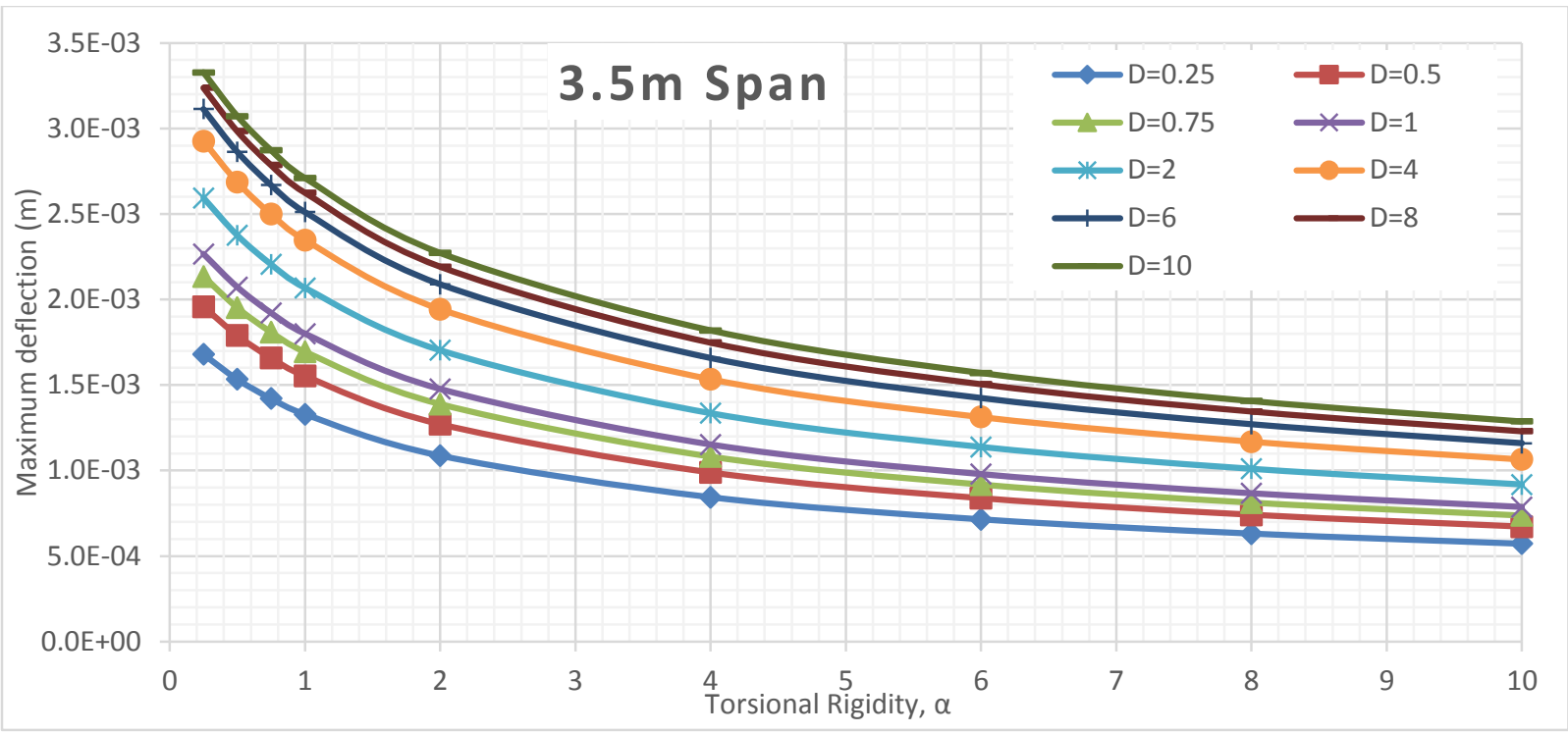

Figure 472 Maximum deflection of $3.5 \mathrm{~m}$ span slab subjected to CHBDC axle 2 \& 3 for different D values Orthotropic analyses

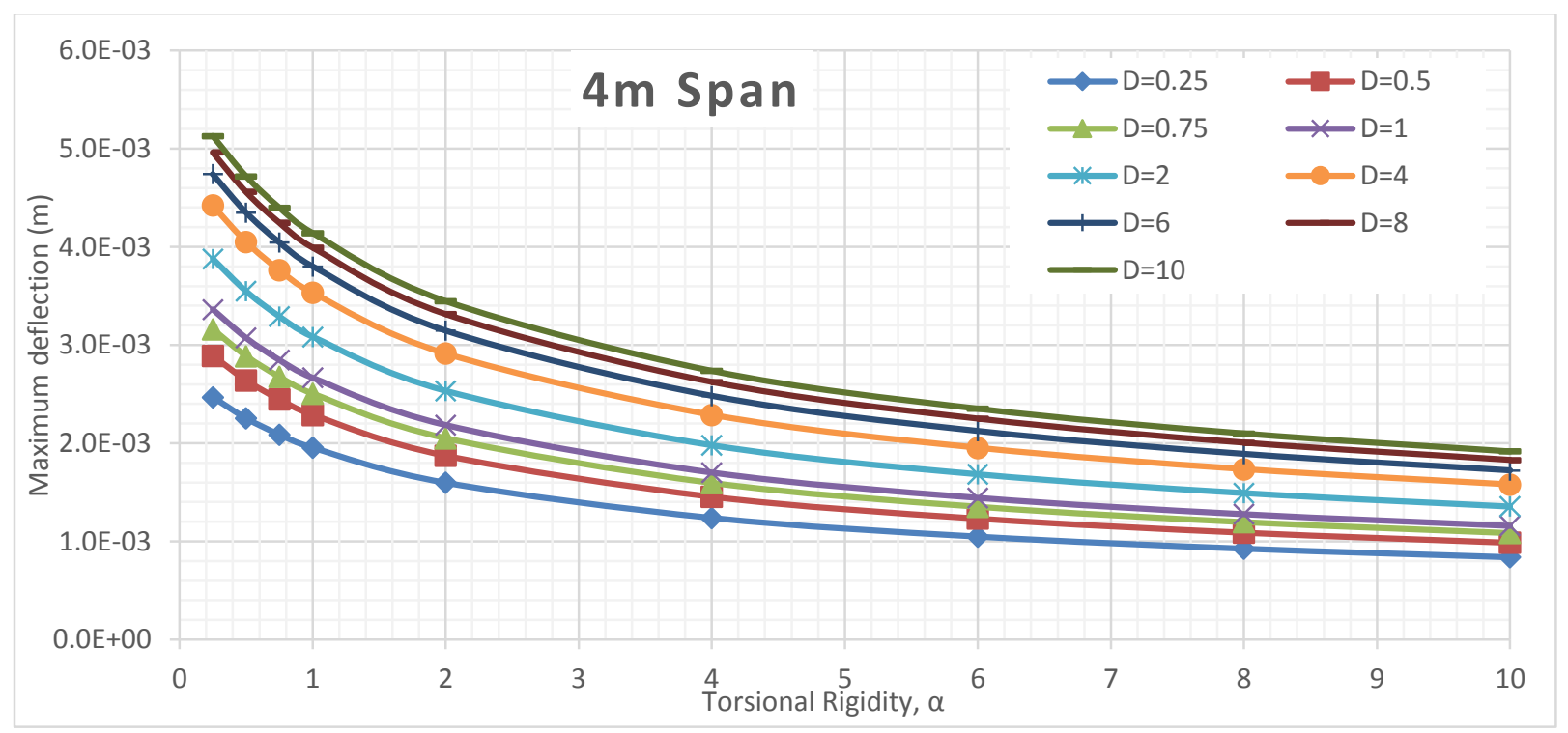

Figure 473 Maximum deflection of $4 \mathrm{~m}$ span slab subjected to CHBDC axle 2 \& 3 for different D values Orthotropic analyses 


\section{Truck Deflection VS Torsional Rigidity for Different D Values at Different span length}

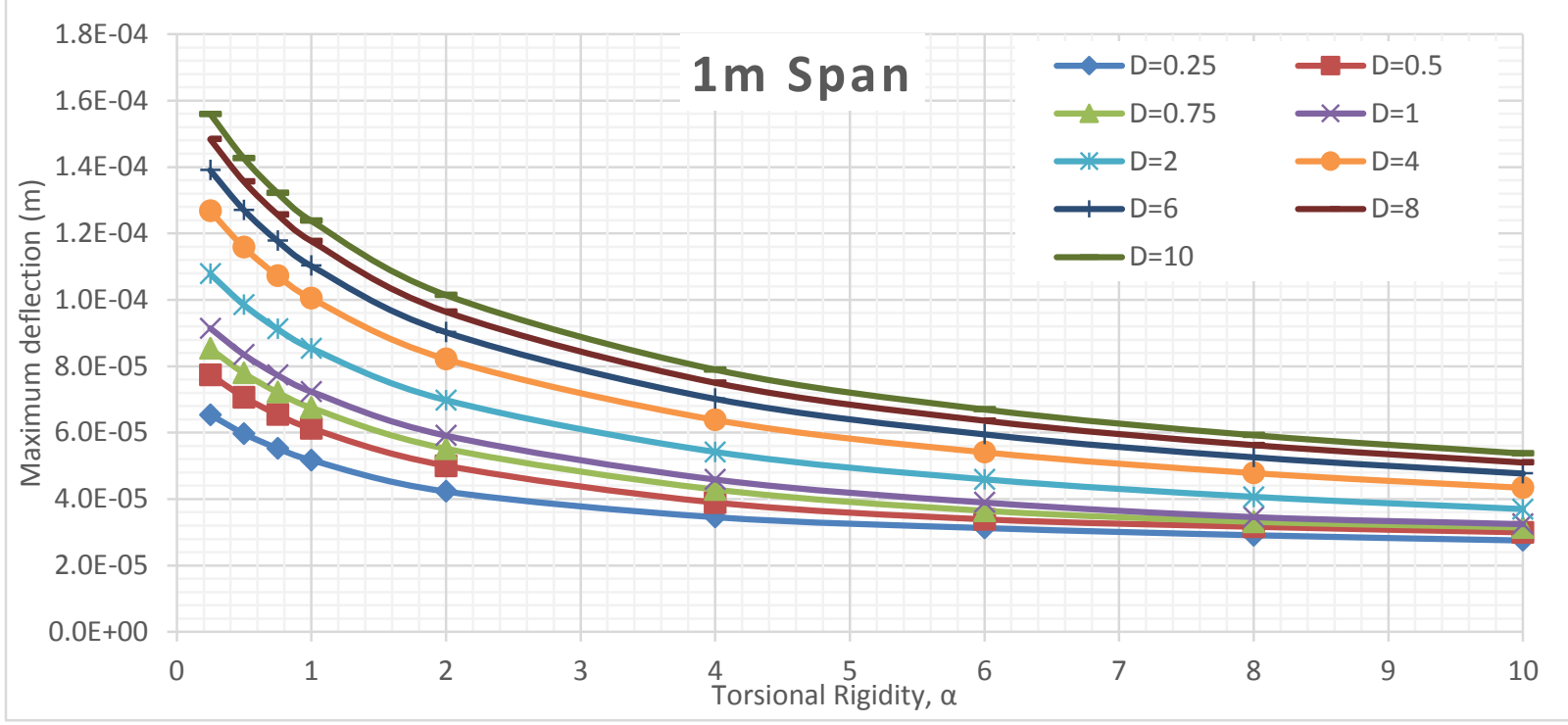

Figure 474 Maximum deflection of $1 \mathrm{~m}$ span slab subjected to CHBDC truck for different D values Orthotropic analyses

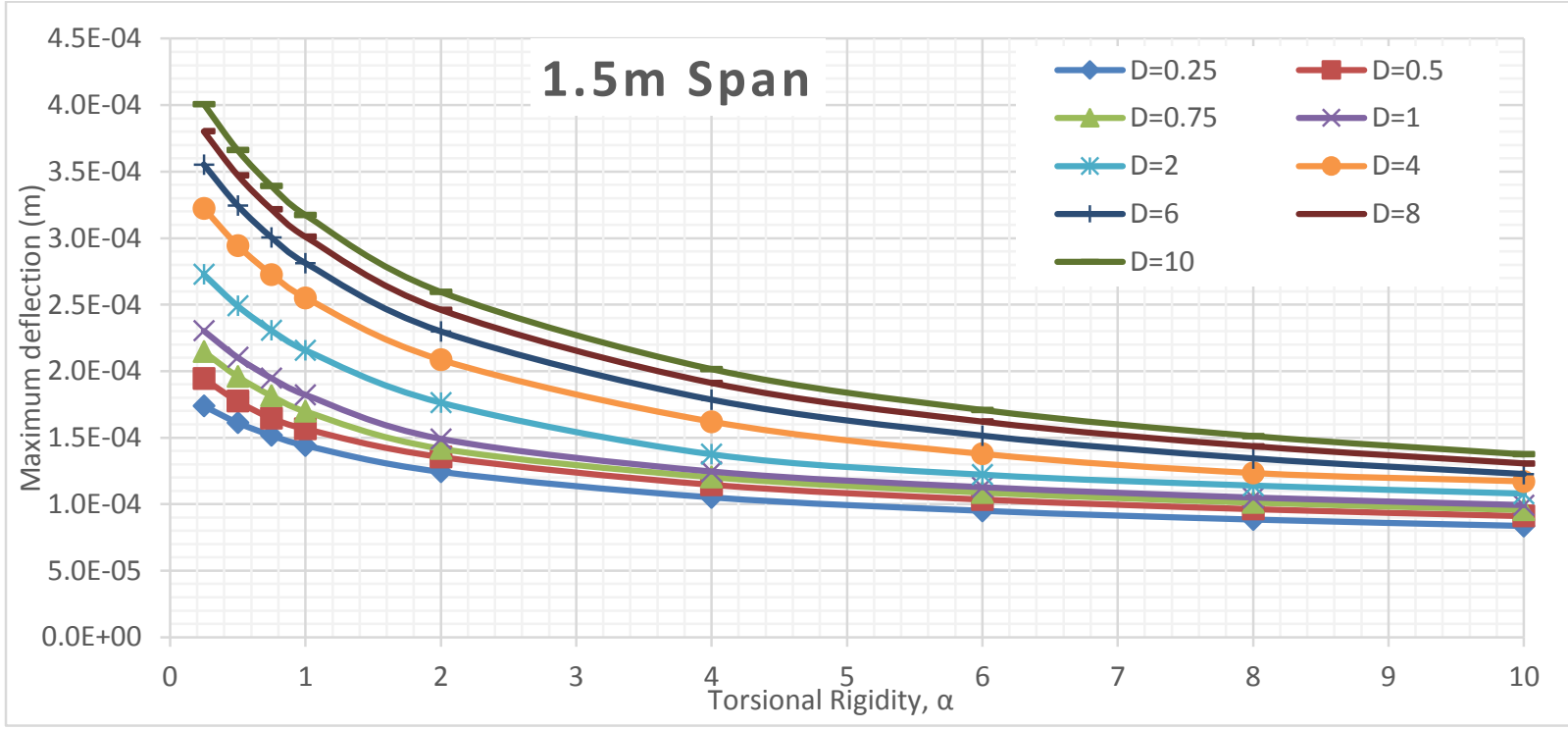

Figure 475 Maximum deflection of $1.5 \mathrm{~m}$ span slab subjected to CHBDC truck for different D values Orthotropic analyses 


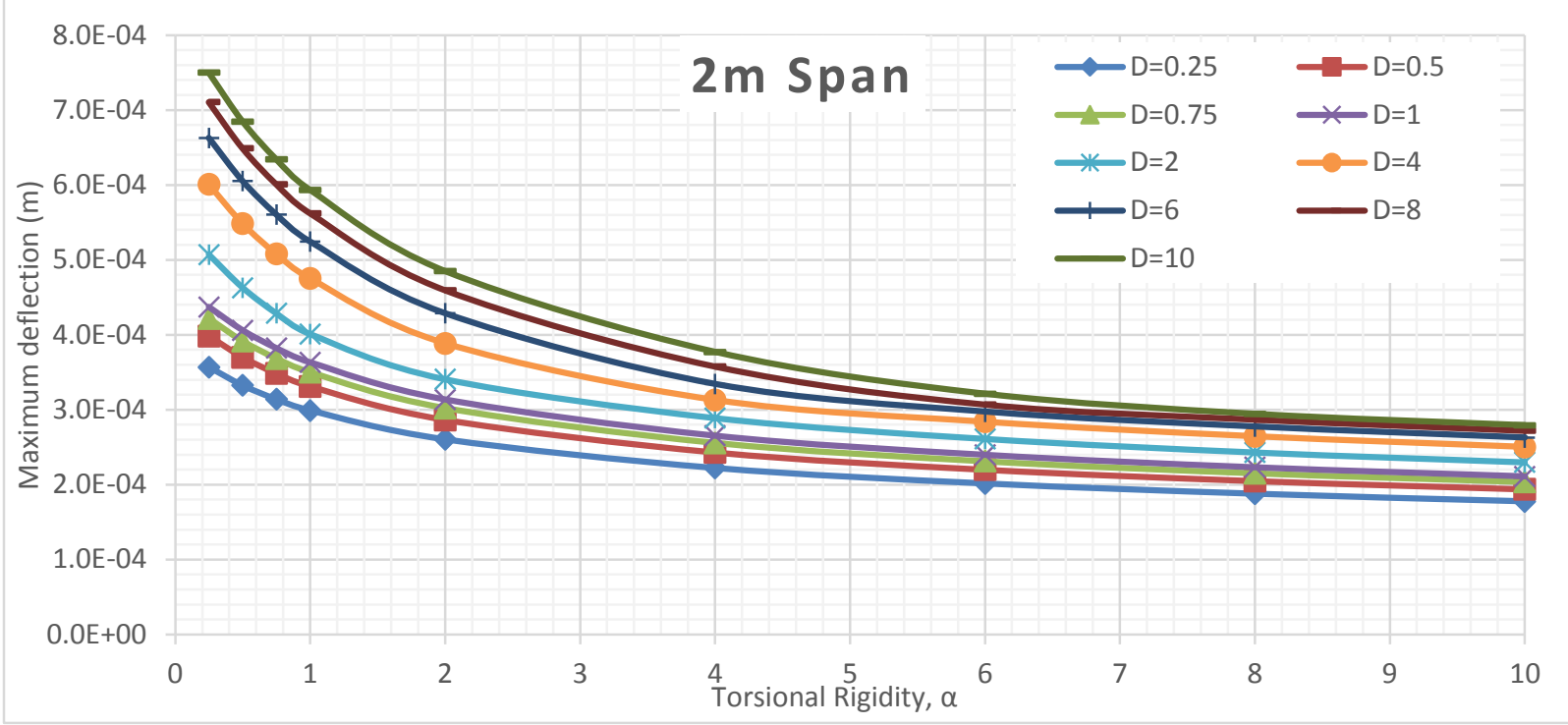

Figure 476 Maximum deflection of $2 \mathrm{~m}$ span slab subjected to CHBDC truck for different D values Orthotropic analyses

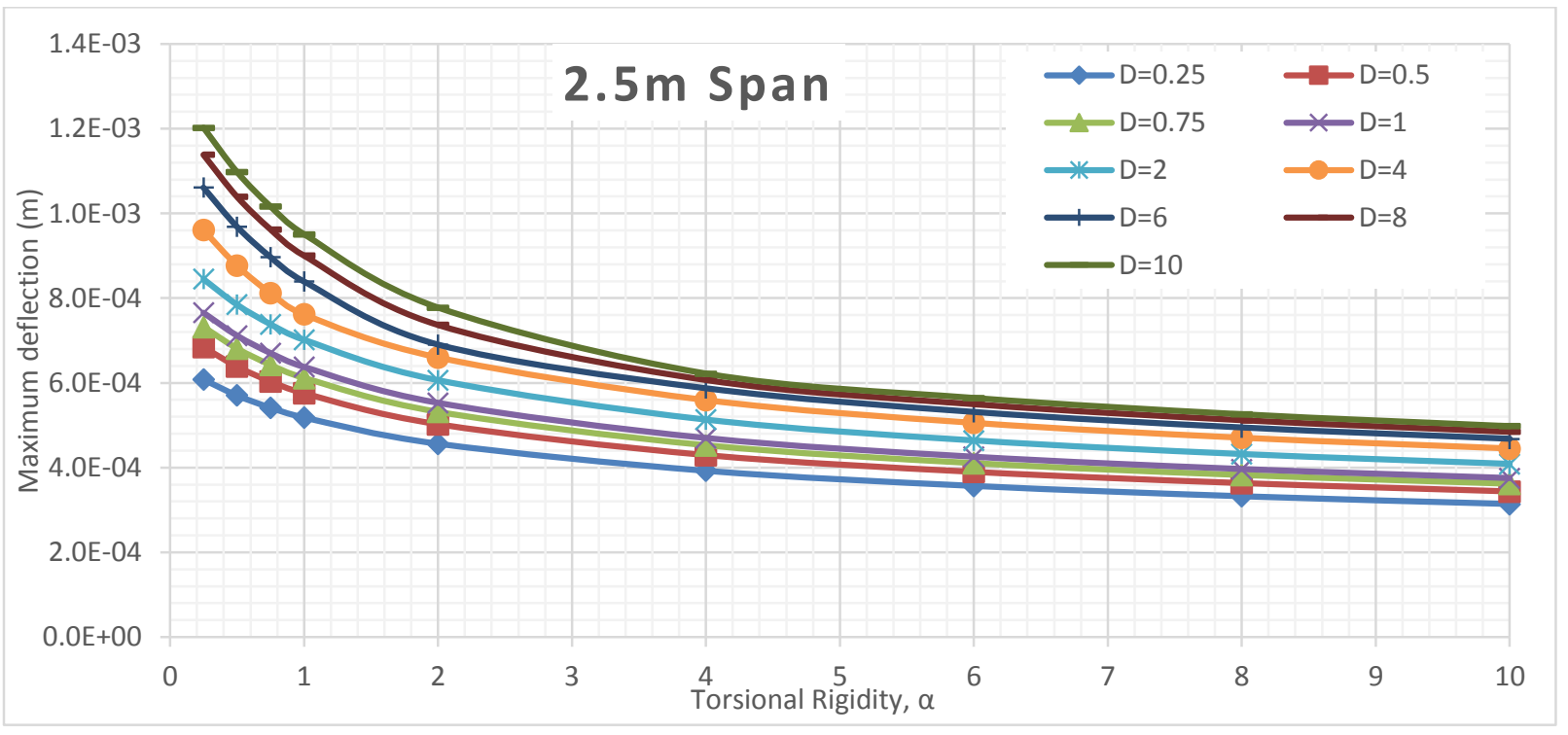

Figure 477 Maximum deflection of $2.5 \mathrm{~m}$ span slab subjected to CHBDC truck for different D values Orthotropic analyses

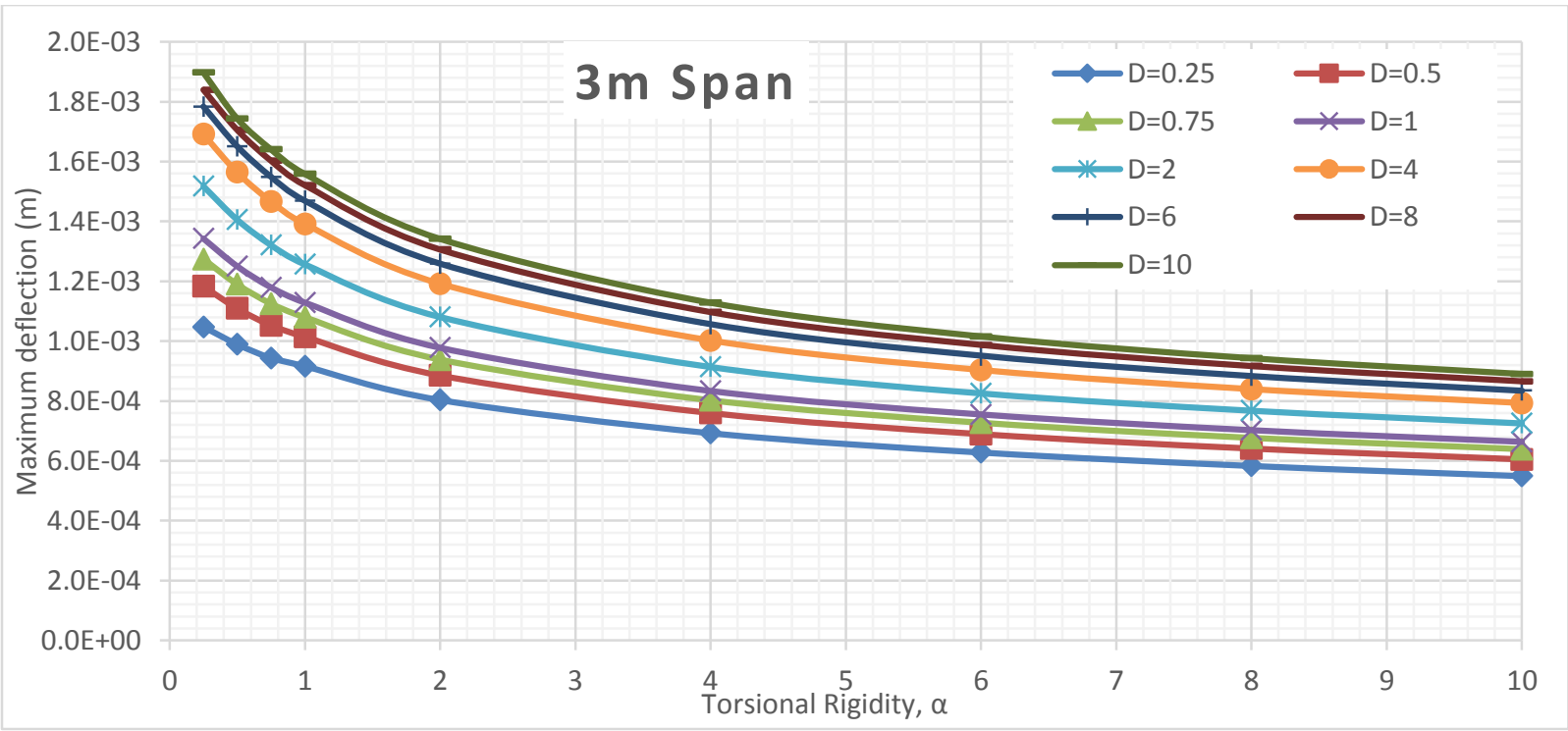

Figure 478 Maximum deflection of $3 \mathrm{~m}$ span slab subjected to CHBDC truck for different D values Orthotropic analyses 


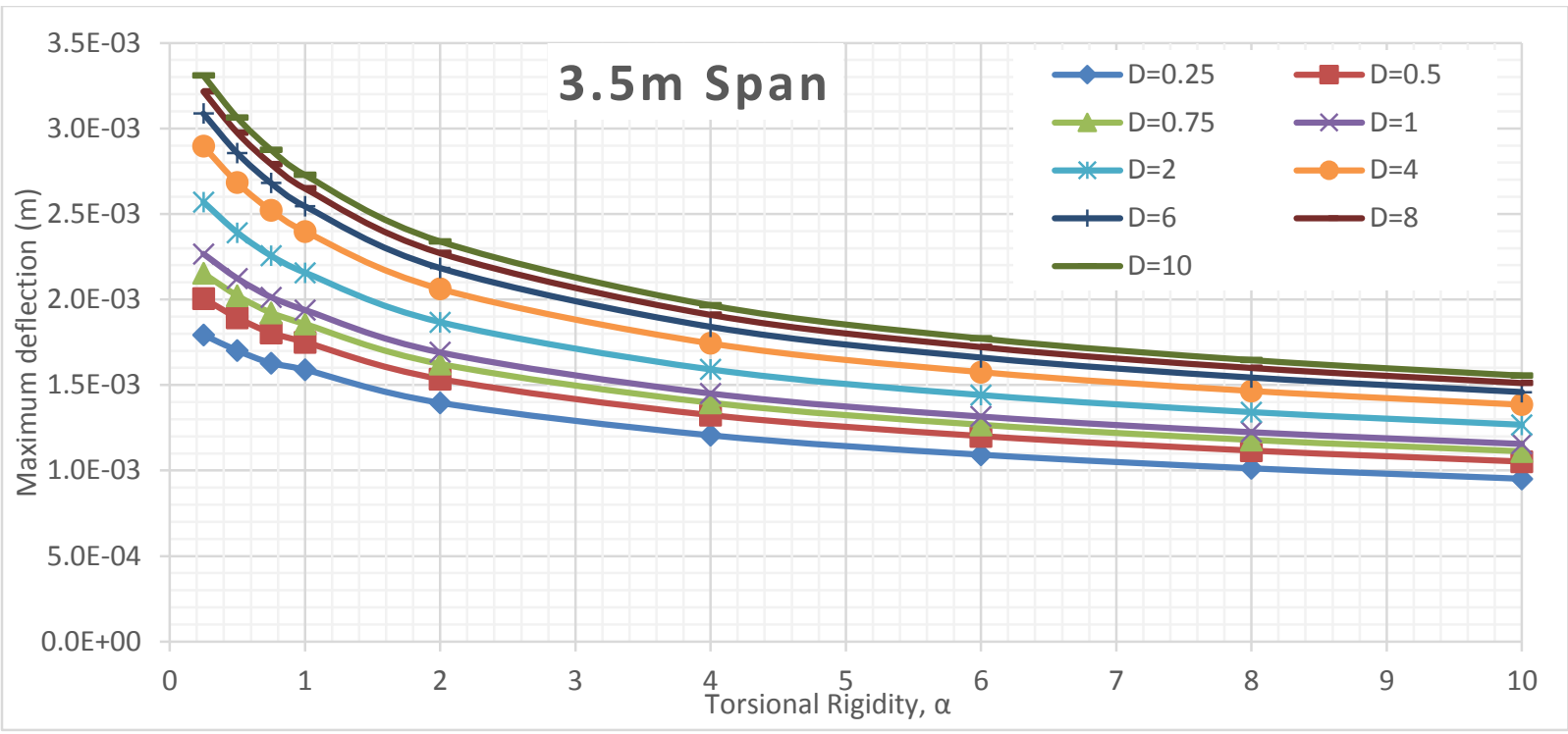

Figure 479 Maximum deflection of $3.5 \mathrm{~m}$ span slab subjected to CHBDC truck for different D values Orthotropic analyses

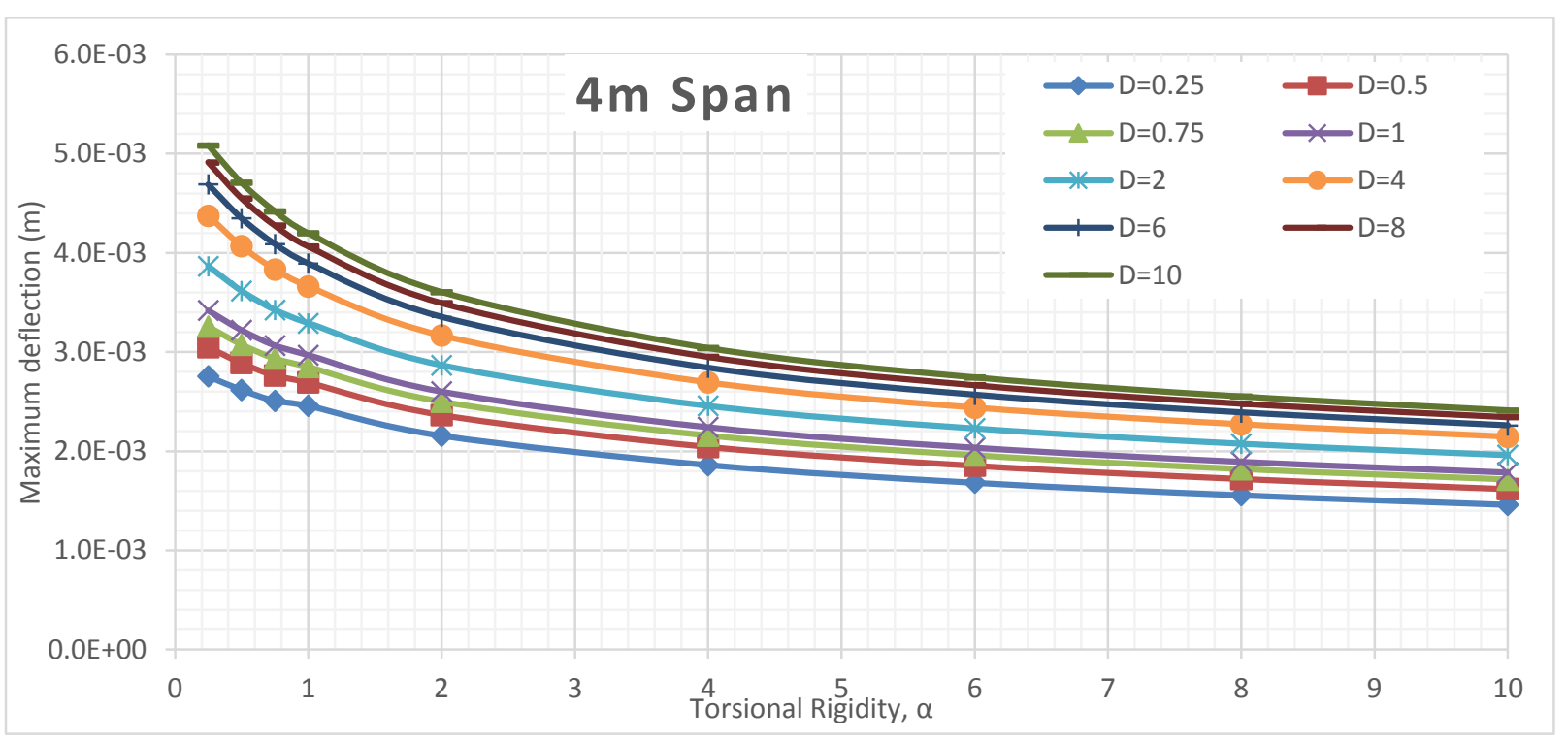

Figure 480 Maximum deflection of $4 \mathrm{~m}$ span slab subjected to CHBDC truck for different D values Orthotropic analyses 


\section{Axle 4 Transverse Deflection VS Torsional Rigidity for Different D Values at Different span length}

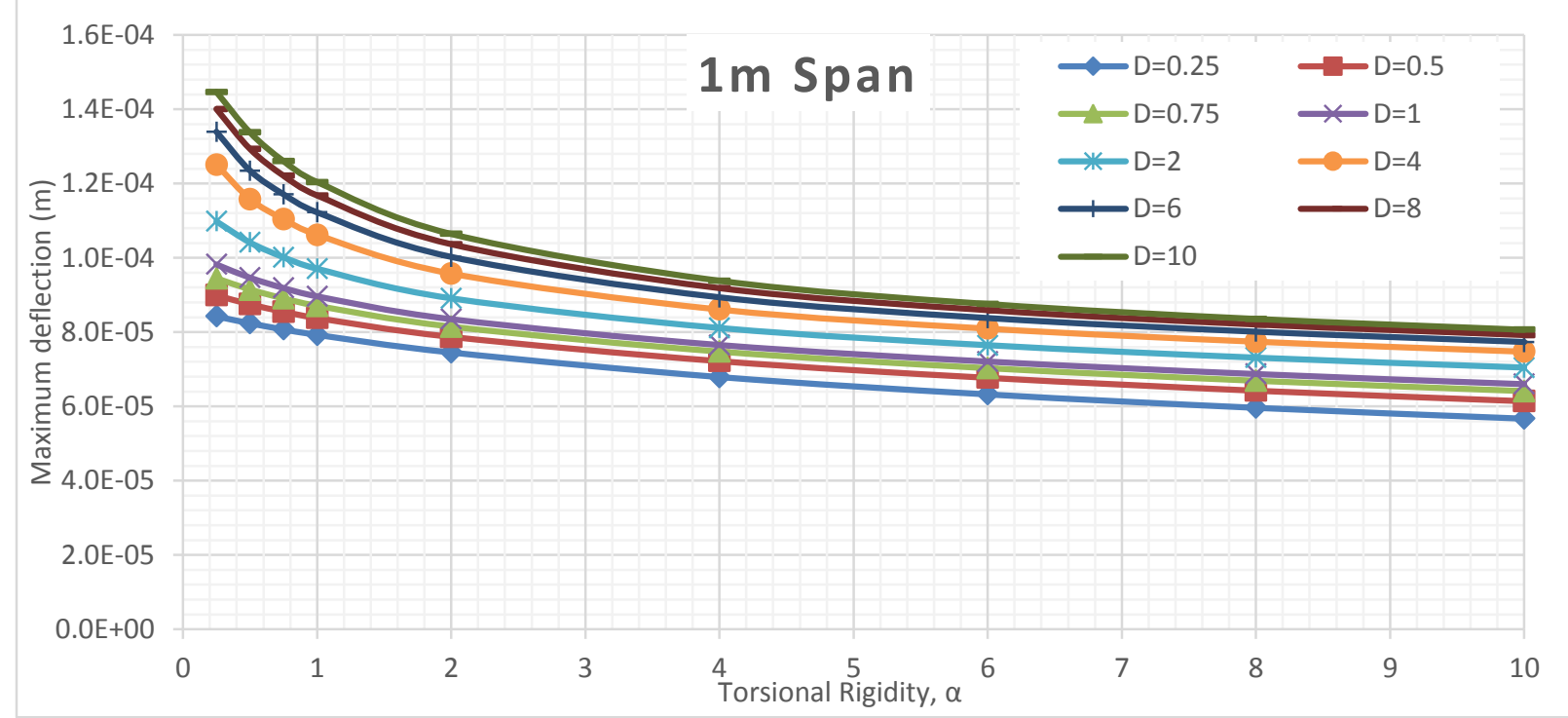

Figure 481 Maximum deflection of $1 \mathrm{~m}$ span slab subjected to CHBDC axle 4 for different D values Orthotropic analyses

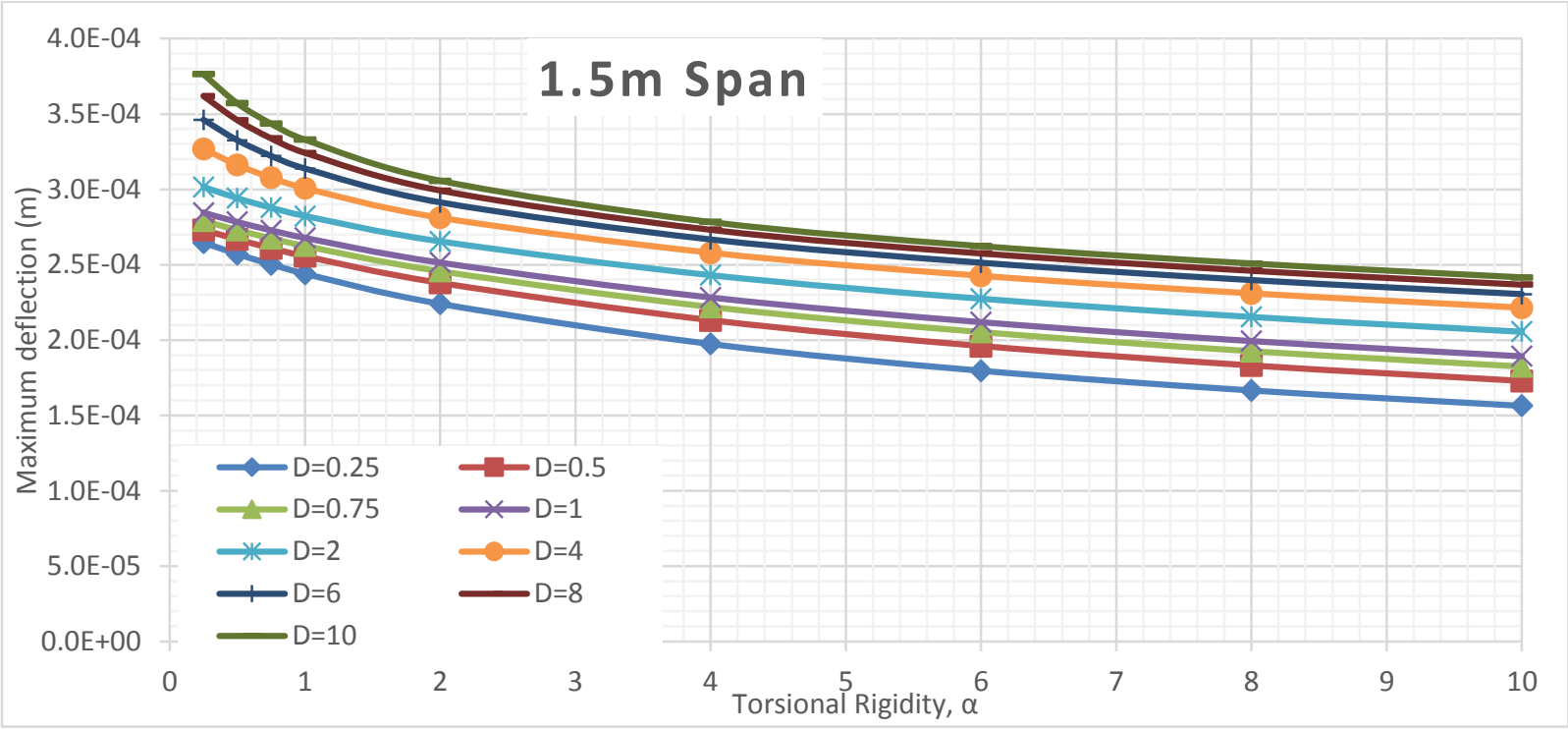

Figure 482 Maximum deflection of $1.5 \mathrm{~m}$ span slab subjected to CHBDC axle 4 for different D values Orthotropic analyses 


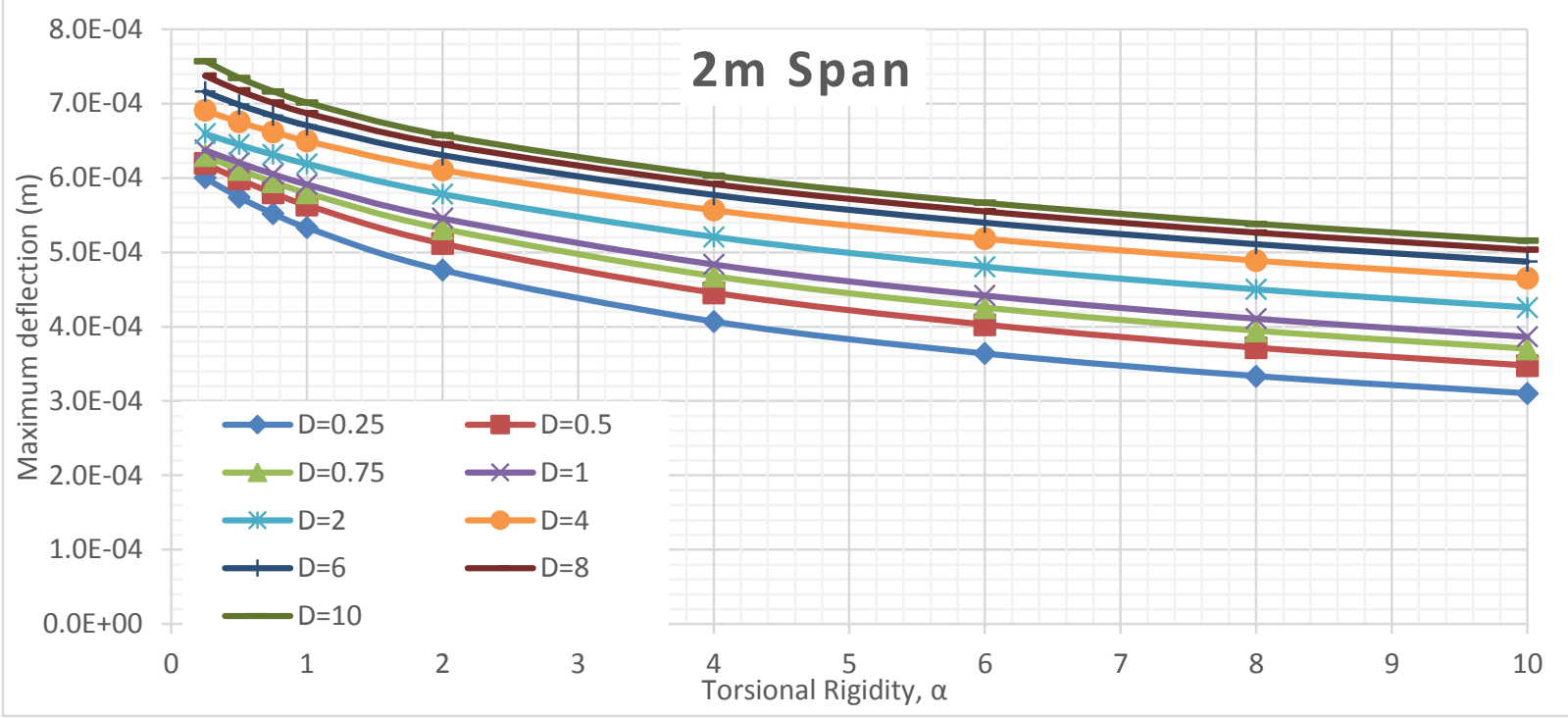

Figure 483 Maximum deflection of $2 \mathrm{~m}$ span slab subjected to CHBDC axle 4 for different D values Orthotropic analyses

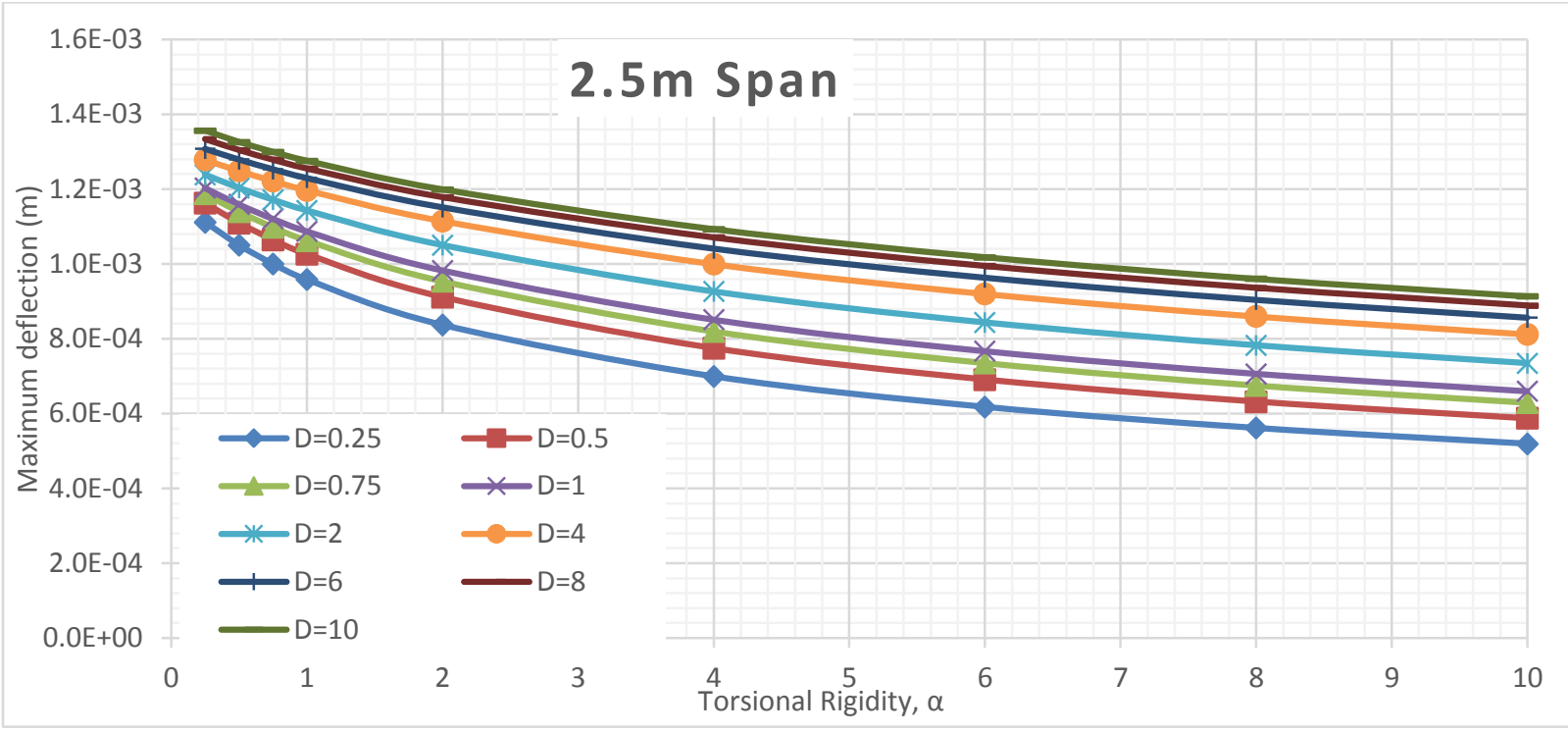

Figure 484 Maximum deflection of $2.5 \mathrm{~m}$ span slab subjected to CHBDC axle 4 for different D values Orthotropic analyses

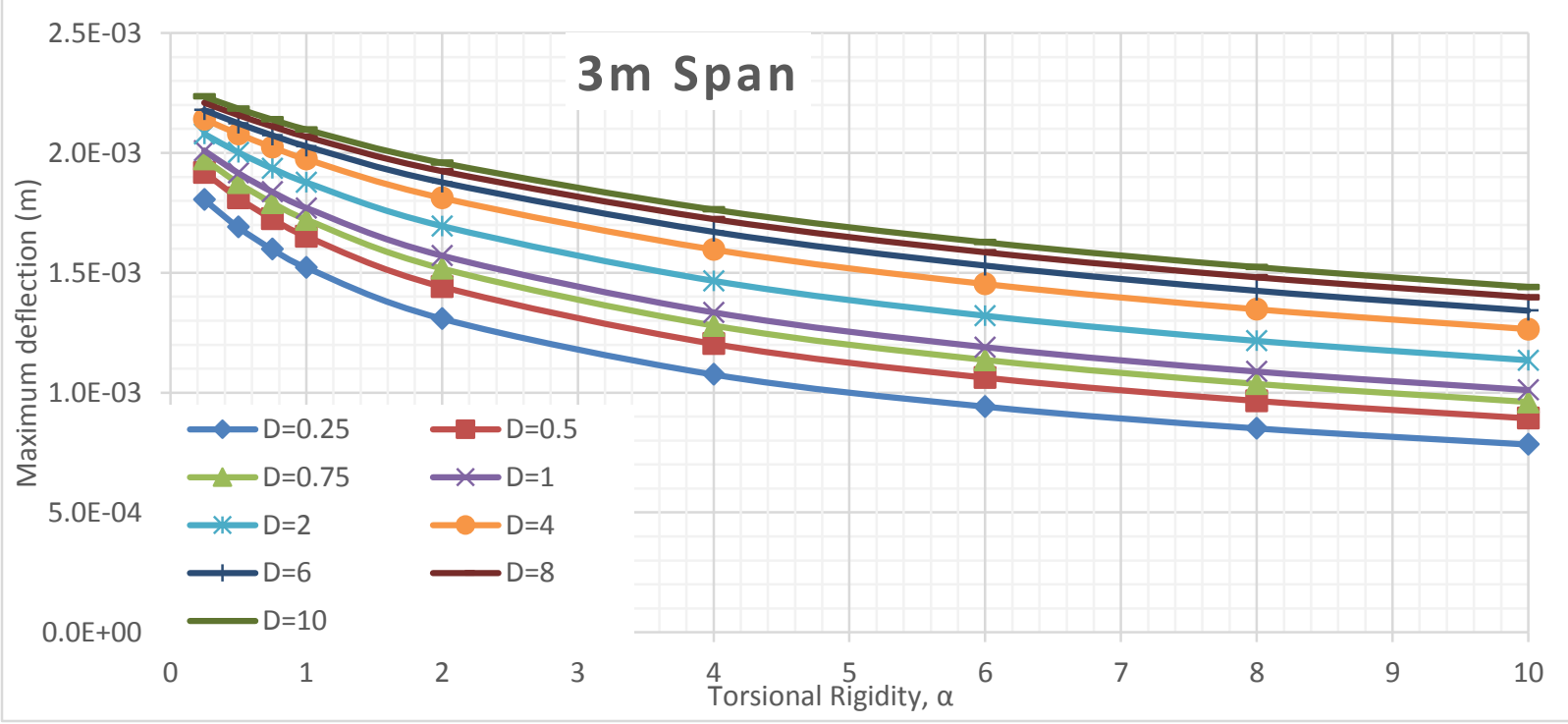

Figure 485 Maximum deflection of $3 \mathrm{~m}$ span slab subjected to CHBDC axle 4 for different D values Orthotropic analyses 


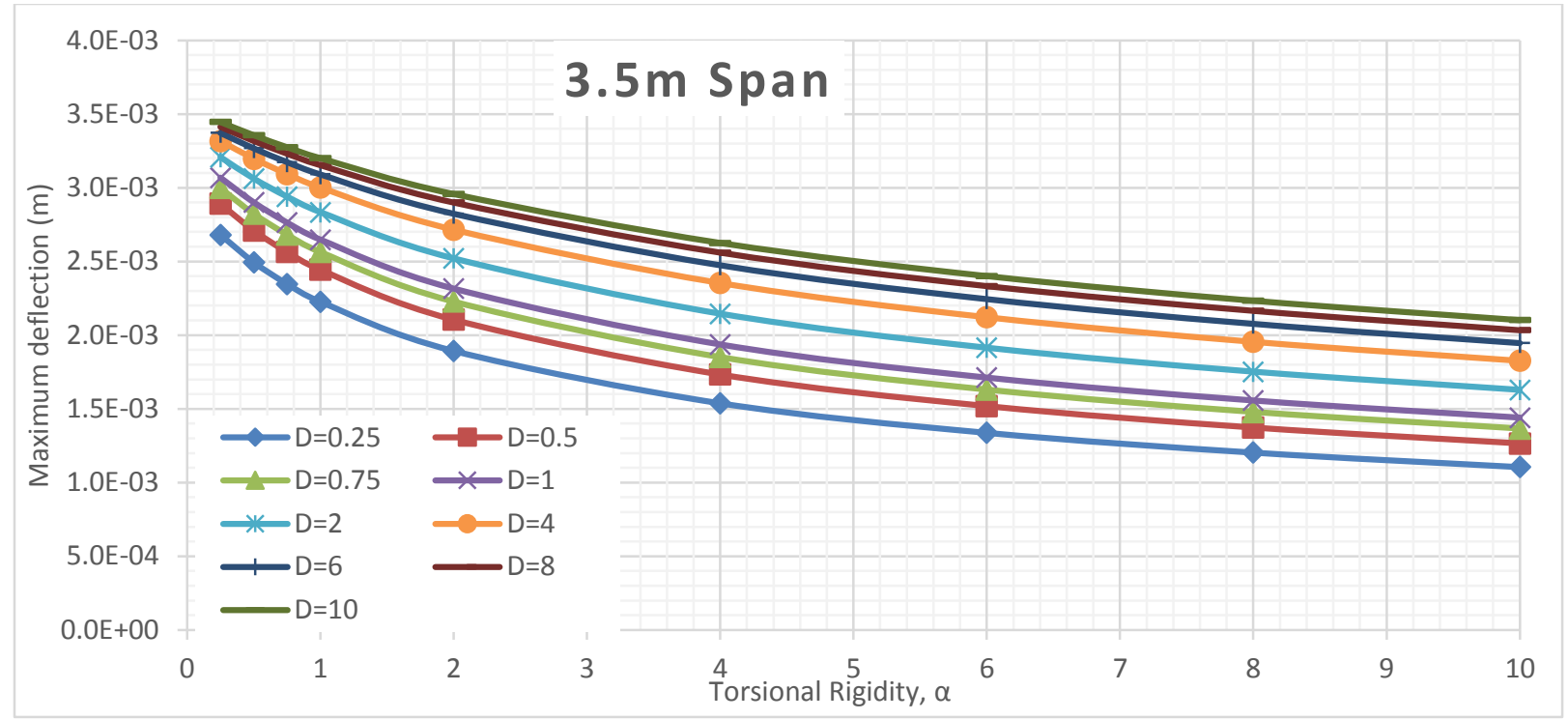

Figure 486 Maximum deflection of $3.5 \mathrm{~m}$ span slab subjected to CHBDC axle 4 for different D values Orthotropic analyses 


\section{Axle 2 \& 3 Transverse Deflection VS Torsional Rigidity for Different D Values at Different span length}

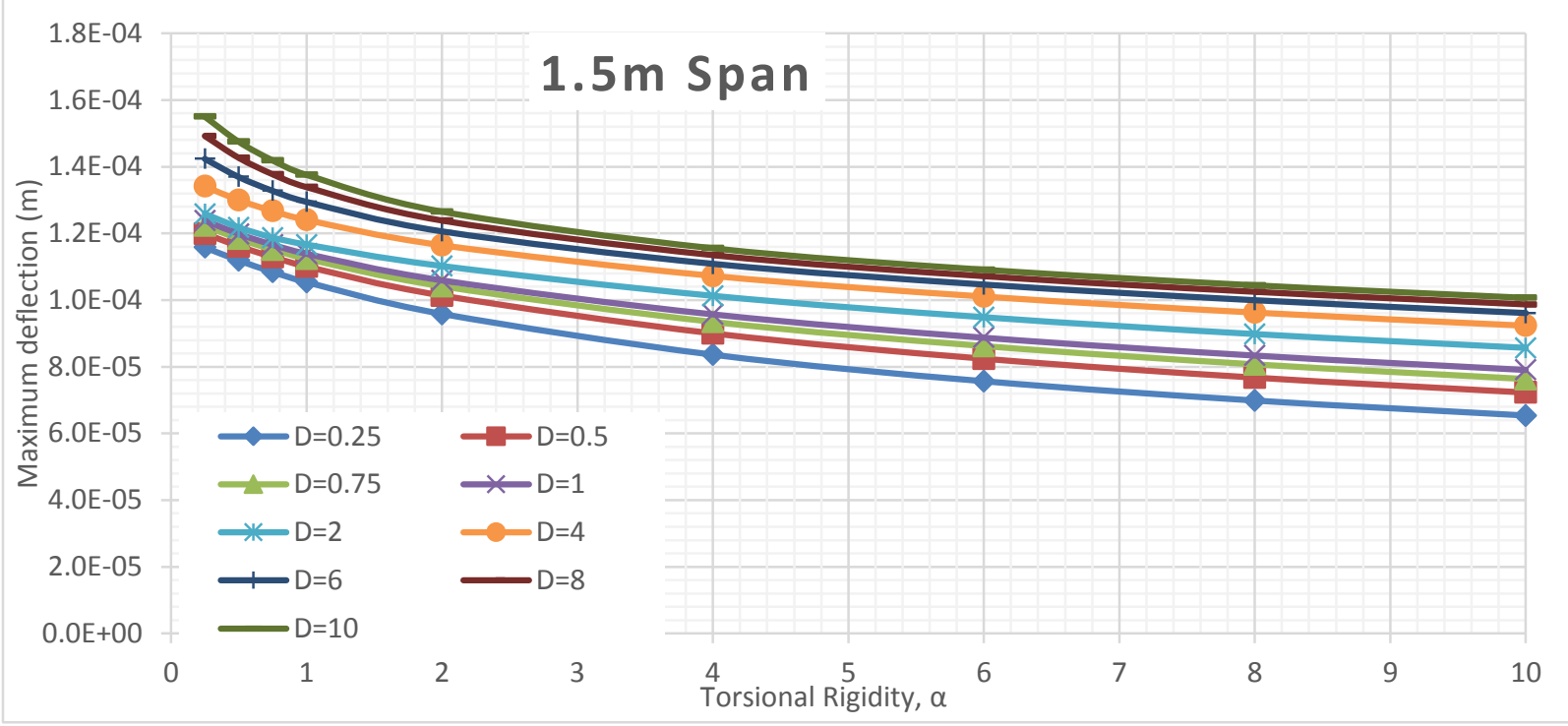

Figure 487 Maximum deflection of $1.5 \mathrm{~m}$ span slab subjected to CHBDC axle 2 \& 3 for different D values Orthotropic analyses

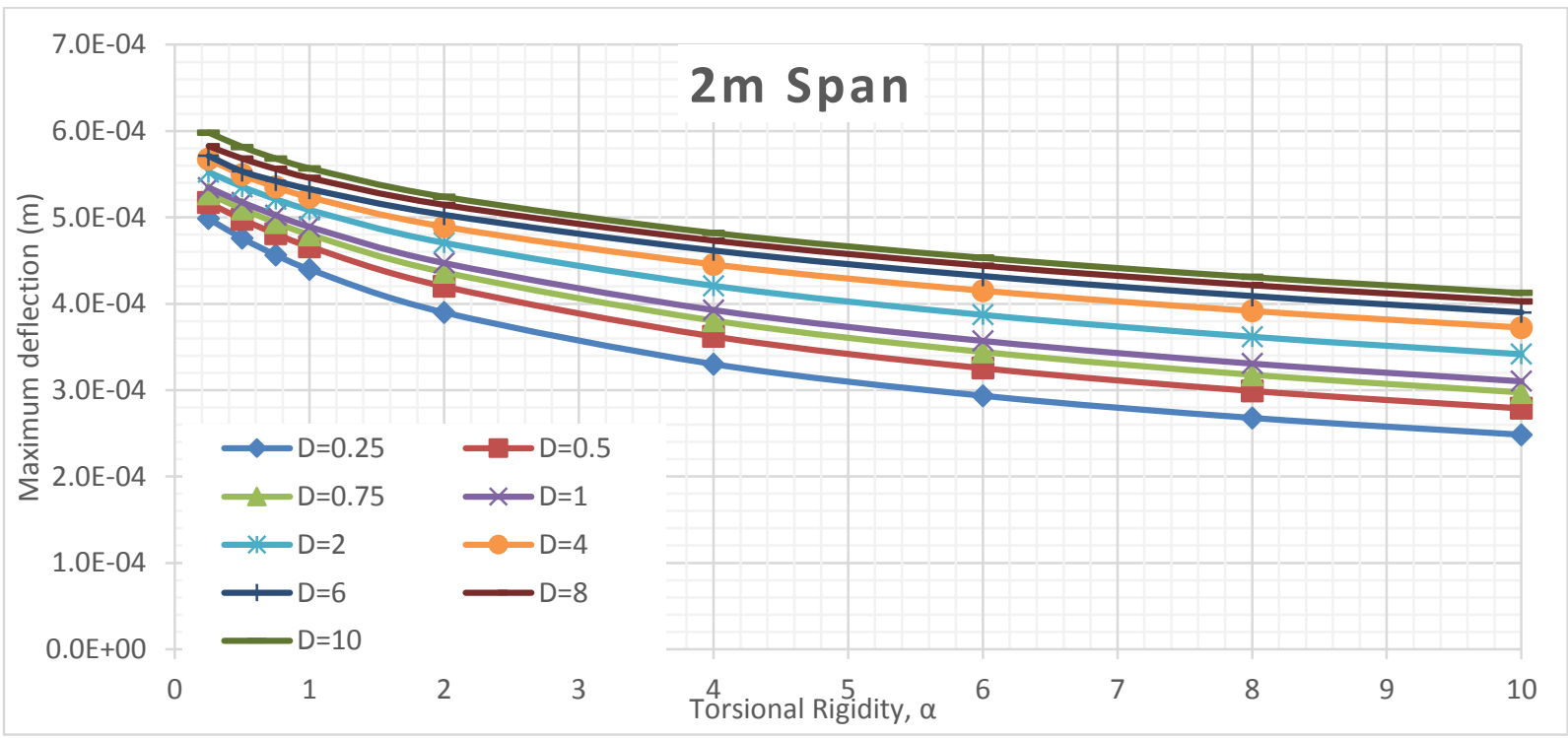

Figure 488 Maximum deflection of $2 \mathrm{~m}$ span slab subjected to CHBDC axle $2 \& 3$ for different D values Orthotropic analyses 


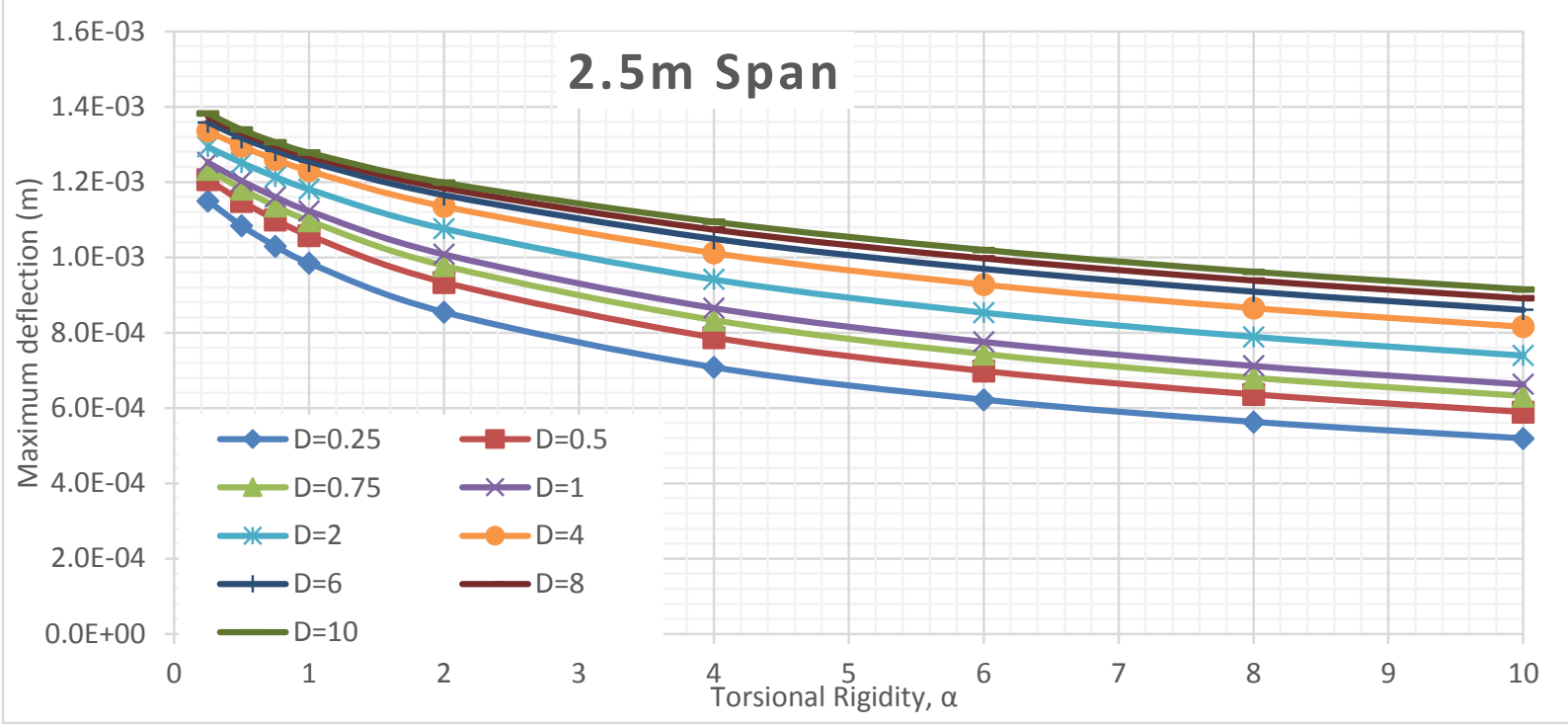

Figure 489 Maximum deflection of $2.5 \mathrm{~m}$ span slab subjected to CHBDC axle 2 \& 3 for different D values Orthotropic analyses

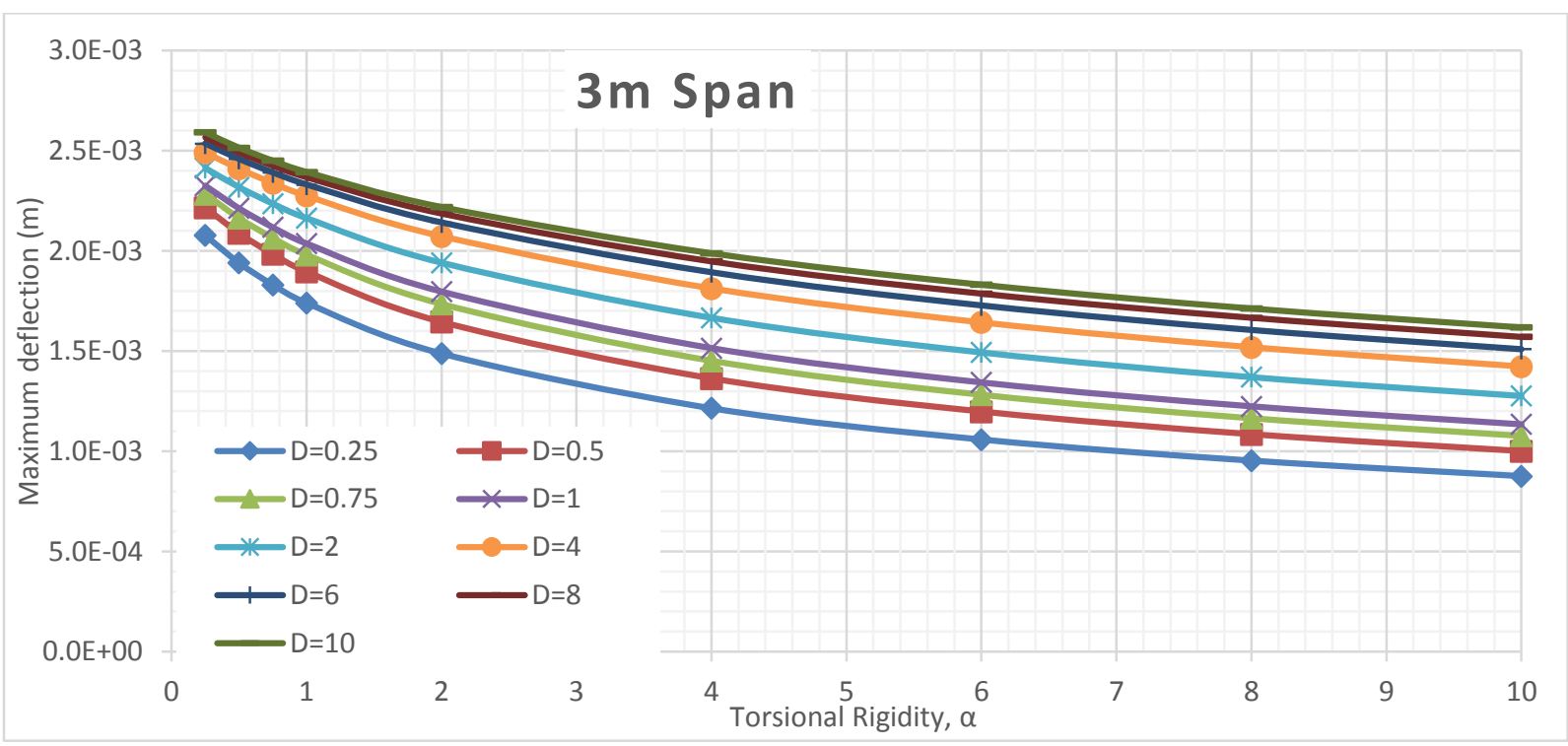

Figure 490 Maximum deflection of $3 \mathrm{~m}$ span slab subjected to CHBDC axle 2 \& 3 for different D values Orthotropic analyses

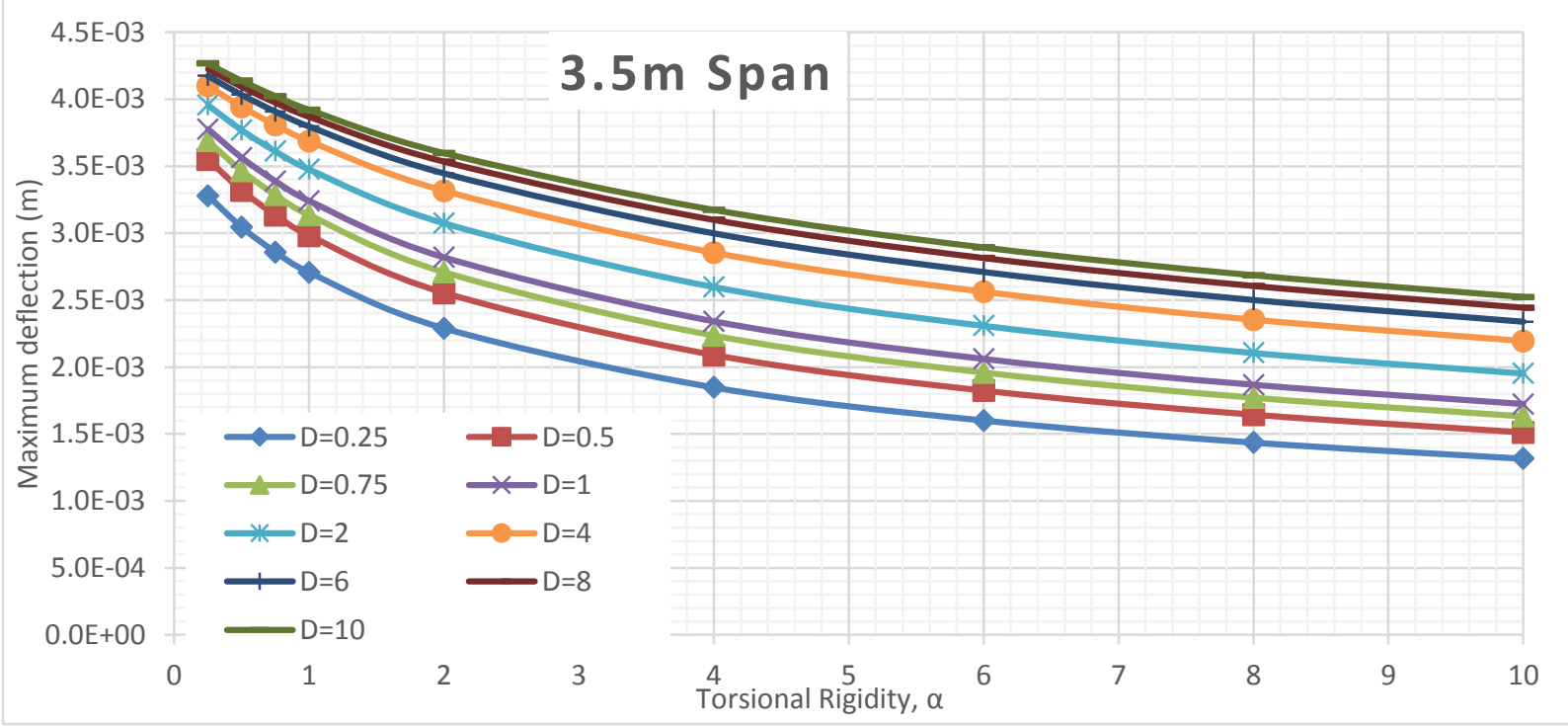

Figure 491 Maximum deflection of $3.5 \mathrm{~m}$ span slab subjected to CHBDC axle 2 \& 3 for different D values Orthotropic analyses 


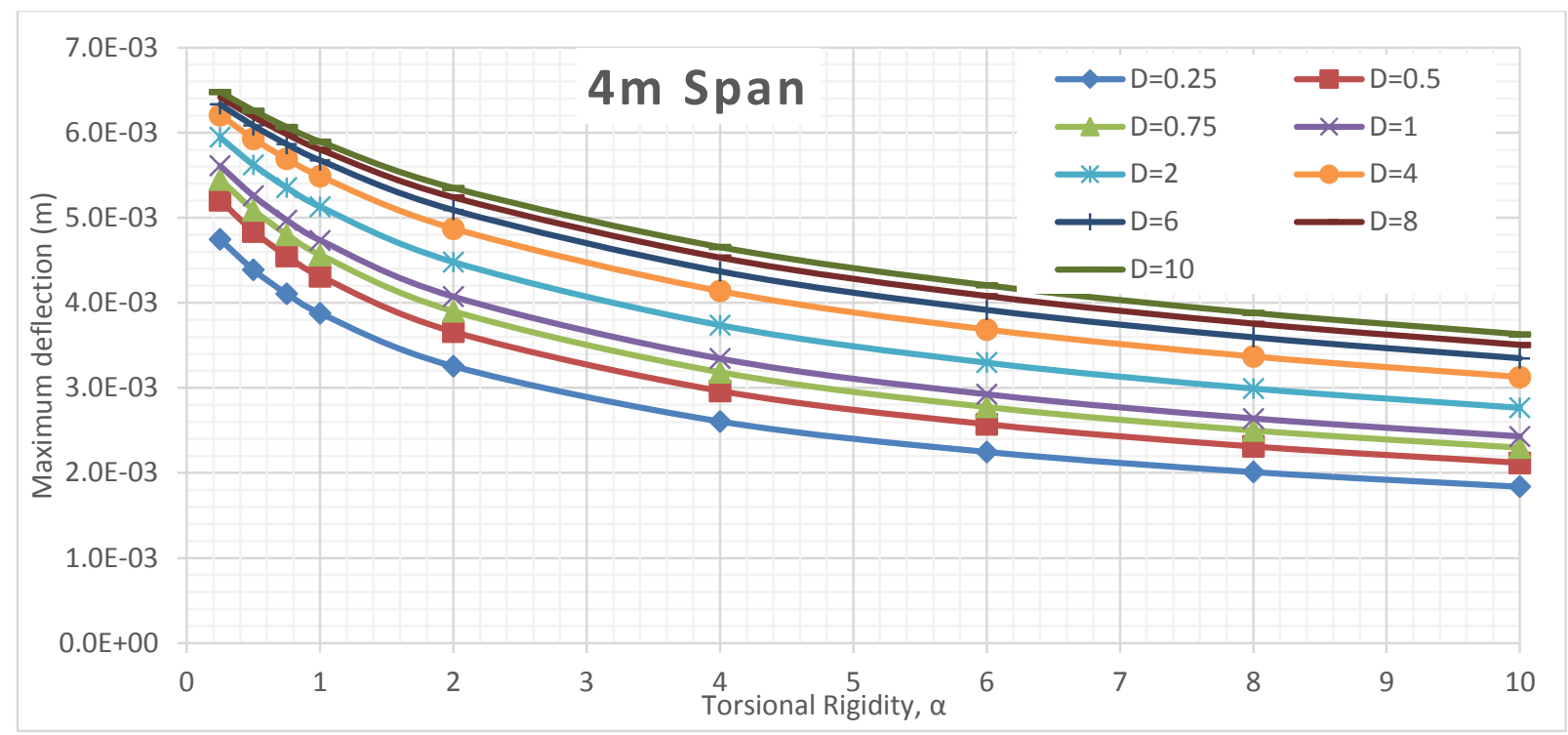

Figure 492 Maximum deflection of 4 m span slab subjected to CHBDC axle 2 \& 3 for different D values Orthotropic analyses 


\section{D.1 Results Comparison (Bending Moment)}




\section{D.1.1 BENDING MOMENT COMPARISON RESULTS TABLES}




\section{Alpha 0.25 Bending Moment Comparison}

Table 190 Maximum moment results comparison for alpha 0.25 for slabs subjected to CHBDC axle 4 loading (main bars perpendicular to traffic)

\begin{tabular}{|c|c|c|c|c|c|c|c|c|c|c|}
\hline & \multicolumn{9}{|c|}{ Maximum Moment (kN.m) } \\
\hline \multirow{9}{*}{$\begin{array}{l}+\vec{x} \\
\frac{0}{x}\end{array}$} & $\mathrm{D}$ & \multirow{2}{*}{0.25} & \multirow{2}{*}{0.5} & \multirow{2}{*}{0.75} & \multirow{2}{*}{1} & \multirow[b]{2}{*}{2} & \multirow{2}{*}{4} & \multirow{2}{*}{6} & \multirow{2}{*}{8} & \multirow{2}{*}{10} \\
\hline & SPAN & & & & & & & & & \\
\hline & 1 & $0.372 \%$ & $0.504 \%$ & $0.604 \%$ & $0.688 \%$ & $0.945 \%$ & $1.303 \%$ & $1.574 \%$ & $1.799 \%$ & $1.996 \%$ \\
\hline & 1.5 & $0.325 \%$ & $0.414 \%$ & $0.482 \%$ & $0.541 \%$ & $0.723 \%$ & $0.976 \%$ & $1.169 \%$ & $1.328 \%$ & $1.467 \%$ \\
\hline & 2 & $0.259 \%$ & $0.338 \%$ & $0.397 \%$ & $0.448 \%$ & $0.604 \%$ & $0.821 \%$ & $0.984 \%$ & $1.118 \%$ & $1.235 \%$ \\
\hline & 2.5 & $0.232 \%$ & $0.302 \%$ & $0.356 \%$ & $0.402 \%$ & $0.543 \%$ & $0.738 \%$ & $0.884 \%$ & $1.005 \%$ & $1.109 \%$ \\
\hline & 3 & $0.002 \%$ & $0.094 \%$ & $0.162 \%$ & $0.215 \%$ & $0.371 \%$ & $0.573 \%$ & $0.718 \%$ & $0.837 \%$ & $0.938 \%$ \\
\hline & 3.5 & $0.215 \%$ & $0.279 \%$ & $0.327 \%$ & $0.367 \%$ & $0.489 \%$ & $0.657 \%$ & $0.783 \%$ & $0.887 \%$ & $0.977 \%$ \\
\hline & 4 & $1.393 \%$ & $1.404 \%$ & $1.420 \%$ & $1.436 \%$ & $1.499 \%$ & $1.608 \%$ & $1.698 \%$ & $1.777 \%$ & $1.848 \%$ \\
\hline
\end{tabular}

Table 191 Maximum moment results comparison for alpha 0.25 for slabs subjected to CHBDC axle 2 \& 3 loading (main bars perpendicular to traffic)

\begin{tabular}{|c|c|c|c|c|c|c|c|c|c|c|}
\hline & \multicolumn{9}{|c|}{ Maximum Moment (kN.m) } \\
\hline \multirow{9}{*}{ 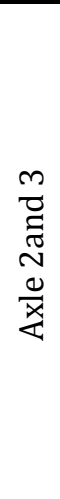 } & $\mathrm{D}$ & \multirow{2}{*}{0.25} & \multirow{2}{*}{0.5} & \multirow{2}{*}{0.75} & \multirow{2}{*}{1} & & \multirow{2}{*}{4} & \multirow{2}{*}{6} & \multirow[b]{2}{*}{0} & \multirow{2}{*}{10} \\
\hline & SPAN & & & & & & & & & \\
\hline & 1 & $3.337 \%$ & $1.553 \%$ & $1.060 \%$ & $0.771 \%$ & $0.866 \%$ & $1.277 \%$ & $1.574 \%$ & $1.812 \%$ & $2.015 \%$ \\
\hline & 1.5 & $3.846 \%$ & $2.914 \%$ & $2.346 \%$ & $2.026 \%$ & $1.364 \%$ & $0.858 \%$ & $1.072 \%$ & $1.250 \%$ & $1.405 \%$ \\
\hline & 2 & $2.914 \%$ & $2.439 \%$ & $2.144 \%$ & $2.021 \%$ & $1.550 \%$ & $1.386 \%$ & $1.190 \%$ & $1.005 \%$ & $1.108 \%$ \\
\hline & 2.5 & $2.359 \%$ & $1.981 \%$ & $1.764 \%$ & $1.712 \%$ & $1.456 \%$ & $1.418 \%$ & $1.374 \%$ & $1.308 \%$ & $1.235 \%$ \\
\hline & 3 & $1.879 \%$ & $1.548 \%$ & $1.389 \%$ & $1.347 \%$ & $1.161 \%$ & $1.211 \%$ & $1.235 \%$ & $1.235 \%$ & $1.222 \%$ \\
\hline & 3.5 & $2.184 \%$ & $2.186 \%$ & $2.232 \%$ & $2.231 \%$ & $2.148 \%$ & $2.037 \%$ & $3.174 \%$ & $4.121 \%$ & $4.512 \%$ \\
\hline & 4 & $3.474 \%$ & $3.427 \%$ & $3.467 \%$ & $3.485 \%$ & $3.539 \%$ & $3.572 \%$ & $3.829 \%$ & $5.088 \%$ & $5.830 \%$ \\
\hline
\end{tabular}

Table 192 Maximum moment results comparison for alpha 0.25 for slabs subjected to CHBDC truck loading (main bars perpendicular to traffic)

\begin{tabular}{|c|c|c|c|c|c|c|c|c|c|c|}
\hline & \multicolumn{9}{|c|}{ Maximum Moment (kN.m) } \\
\hline \multirow{9}{*}{ 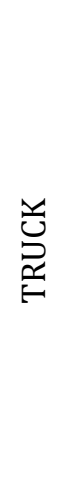 } & $\mathrm{D}$ & \multirow{2}{*}{0.25} & \multirow{2}{*}{0.5} & \multirow{2}{*}{0.75} & \multirow{2}{*}{1} & \multirow{2}{*}{2} & \multirow{2}{*}{4} & \multirow{2}{*}{6} & \multirow{2}{*}{8} & \multirow{2}{*}{10} \\
\hline & SPAN & & & & & & & & & \\
\hline & 1 & $0.372 \%$ & $0.504 \%$ & $0.604 \%$ & $0.688 \%$ & $0.945 \%$ & $1.303 \%$ & $1.574 \%$ & $1.799 \%$ & $1.996 \%$ \\
\hline & 1.5 & $0.326 \%$ & $0.413 \%$ & $0.483 \%$ & $0.541 \%$ & $0.723 \%$ & $0.976 \%$ & $1.169 \%$ & $1.328 \%$ & $1.467 \%$ \\
\hline & 2 & $3.995 \%$ & $0.339 \%$ & $0.398 \%$ & $0.448 \%$ & $0.604 \%$ & $0.821 \%$ & $0.983 \%$ & $1.118 \%$ & $1.235 \%$ \\
\hline & 2.5 & $4.085 \%$ & $3.295 \%$ & $1.677 \%$ & $0.404 \%$ & $0.543 \%$ & $0.738 \%$ & $0.884 \%$ & $1.005 \%$ & $1.109 \%$ \\
\hline & 3 & $2.912 \%$ & $3.299 \%$ & $3.047 \%$ & $2.704 \%$ & $0.373 \%$ & $0.573 \%$ & $0.718 \%$ & $0.837 \%$ & $0.938 \%$ \\
\hline & 3.5 & $1.965 \%$ & $3.665 \%$ & $4.068 \%$ & $4.072 \%$ & $2.468 \%$ & $0.659 \%$ & $0.783 \%$ & $0.887 \%$ & $0.977 \%$ \\
\hline & 4 & $1.374 \%$ & $3.790 \%$ & $4.820 \%$ & $5.314 \%$ & $5.519 \%$ & $4.134 \%$ & $1.696 \%$ & $1.778 \%$ & $1.849 \%$ \\
\hline
\end{tabular}

Table 193 Maximum moment results comparison for alpha 0.25 for slabs subjected to CHBDC axle 4 loading (main bars parallel to traffic) Maximum Moment (kN.m) 


\begin{tabular}{|c|c|c|c|c|c|c|c|c|c|c|}
\hline \multirow{7}{*}{ 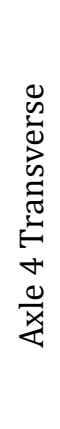 } & $\frac{\text { D }}{\text { SPAN }}$ & .25 & 0.5 & 0.75 & & & 4 & 6 & 8 & 10 \\
\hline & 1 & $5.526 \%$ & $5.352 \%$ & $5.080 \%$ & $4.807 \%$ & $4.072 \%$ & $3.731 \%$ & $3.569 \%$ & $3.472 \%$ & $3.404 \%$ \\
\hline & 1.5 & $3.695 \%$ & $3.770 \%$ & $3.825 \%$ & $3.852 \%$ & $3.802 \%$ & $3.463 \%$ & $3.113 \%$ & $2.812 \%$ & $2.665 \%$ \\
\hline & 2 & $2.937 \%$ & $2.908 \%$ & $2.913 \%$ & $2.929 \%$ & $3.008 \%$ & $3.071 \%$ & $3.040 \%$ & $2.965 \%$ & $2.870 \%$ \\
\hline & 2.5 & $2.397 \%$ & $2.347 \%$ & $2.321 \%$ & $2.308 \%$ & $2.312 \%$ & $2.381 \%$ & $2.439 \%$ & $2.473 \%$ & $2.488 \%$ \\
\hline & 3 & $2.003 \%$ & $1.960 \%$ & $1.934 \%$ & $1.914 \%$ & $1.877 \%$ & $1.883 \%$ & $1.917 \%$ & $1.955 \%$ & $1.990 \%$ \\
\hline & 3.5 & $1.759 \%$ & $1.715 \%$ & $1.693 \%$ & $1.676 \%$ & $1.633 \%$ & $1.602 \%$ & $1.603 \%$ & $1.617 \%$ & $1.637 \%$ \\
\hline
\end{tabular}

Table 194 Maximum moment results comparison for alpha 0.25 for slabs subjected to CHBDC axle 2 \& 3 loading (main bars parallel to traffic)

\begin{tabular}{|c|c|c|c|c|c|c|c|c|c|c|}
\hline & & \multicolumn{9}{|c|}{ Maximum Moment (kN.m) } \\
\hline \multirow{8}{*}{ 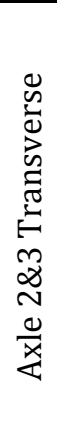 } & $\mathrm{D}$ & \multirow{2}{*}{0.25} & \multirow{2}{*}{0.5} & \multirow{2}{*}{0.75} & \multirow{2}{*}{1} & \multirow{2}{*}{2} & \multirow{2}{*}{4} & \multirow{2}{*}{6} & \multirow{2}{*}{8} & \multirow{2}{*}{10} \\
\hline & SPAN & & & & & & & & & \\
\hline & 1.5 & $16.487 \%$ & $16.554 \%$ & $16.695 \%$ & $16.833 \%$ & $17.266 \%$ & $17.804 \%$ & $18.148 \%$ & $18.401 \%$ & $18.640 \%$ \\
\hline & 2 & $6.481 \%$ & $6.061 \%$ & $5.808 \%$ & $5.646 \%$ & $5.361 \%$ & $5.230 \%$ & $5.191 \%$ & $5.165 \%$ & $5.139 \%$ \\
\hline & 2.5 & $4.105 \%$ & $4.004 \%$ & $3.934 \%$ & $3.881 \%$ & $3.771 \%$ & $3.721 \%$ & $3.767 \%$ & $3.804 \%$ & $3.815 \%$ \\
\hline & 3 & $2.916 \%$ & $2.847 \%$ & $2.823 \%$ & $2.807 \%$ & $2.788 \%$ & $2.880 \%$ & $3.019 \%$ & $3.408 \%$ & $3.629 \%$ \\
\hline & 3.5 & $2.314 \%$ & $2.257 \%$ & $2.226 \%$ & $2.216 \%$ & $2.208 \%$ & $2.293 \%$ & $2.414 \%$ & $2.532 \%$ & $2.721 \%$ \\
\hline & 4 & $1.959 \%$ & $1.918 \%$ & $1.897 \%$ & $1.885 \%$ & $1.881 \%$ & $1.939 \%$ & $2.020 \%$ & $2.104 \%$ & $2.188 \%$ \\
\hline
\end{tabular}




\section{Alpha 0.5 Bending Moment Comparison}

Table 195 Maximum moment results comparison for alpha 0.5 for slabs subjected to CHBDC axle 4 loading (main bars perpendicular to traffic)

\begin{tabular}{|c|c|c|c|c|c|c|c|c|c|c|}
\hline & \multicolumn{9}{|c|}{ Maximum Moment (kN.m) } \\
\hline \multirow{9}{*}{$\frac{\vec{d}}{x}$} & $\mathrm{D}$ & \multirow{2}{*}{0.25} & \multirow{2}{*}{0.5} & \multirow{2}{*}{0.75} & \multirow{2}{*}{1} & & \multirow{2}{*}{4} & \multirow{2}{*}{6} & \multirow[b]{2}{*}{8} & \multirow{2}{*}{10} \\
\hline & SPAN & & & & & & & & & \\
\hline & 1 & $0.365 \%$ & $0.495 \%$ & $0.594 \%$ & $0.675 \%$ & $0.926 \%$ & $1.272 \%$ & $1.532 \%$ & $1.747 \%$ & $1.933 \%$ \\
\hline & 1.5 & $0.324 \%$ & $0.411 \%$ & $0.479 \%$ & $0.536 \%$ & $0.712 \%$ & $0.956 \%$ & $1.140 \%$ & $1.292 \%$ & $1.423 \%$ \\
\hline & 2 & $0.256 \%$ & $0.334 \%$ & $0.392 \%$ & $0.442 \%$ & $0.593 \%$ & $0.802 \%$ & $0.958 \%$ & $1.086 \%$ & $1.197 \%$ \\
\hline & 2.5 & $0.230 \%$ & $0.299 \%$ & $0.352 \%$ & $0.396 \%$ & $0.533 \%$ & $0.721 \%$ & $0.861 \%$ & $0.976 \%$ & $1.074 \%$ \\
\hline & 3 & $0.013 \%$ & $0.080 \%$ & $3.406 \%$ & $0.199 \%$ & $0.351 \%$ & $0.547 \%$ & $0.687 \%$ & $0.801 \%$ & $0.897 \%$ \\
\hline & 3.5 & $0.210 \%$ & $0.273 \%$ & $0.321 \%$ & $0.360 \%$ & $0.480 \%$ & $0.642 \%$ & $0.763 \%$ & $0.862 \%$ & $0.947 \%$ \\
\hline & 4 & $1.398 \%$ & $1.411 \%$ & $1.428 \%$ & $1.445 \%$ & $1.507 \%$ & $1.612 \%$ & $1.698 \%$ & $1.772 \%$ & $1.839 \%$ \\
\hline
\end{tabular}

Table 196 Maximum moment results comparison for alpha 0.5 for slabs subjected to CHBDC axle 2 \& 3 loading (main bars perpendicular to traffic)

\begin{tabular}{|c|c|c|c|c|c|c|c|c|c|c|}
\hline & \multicolumn{9}{|c|}{ Maximum Moment (kN.m) } \\
\hline \multirow{9}{*}{ 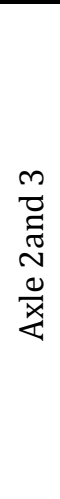 } & $\mathrm{D}$ & \multirow{2}{*}{0.25} & \multirow{2}{*}{0.5} & \multirow{2}{*}{0.75} & \multirow{2}{*}{1} & & \multirow{2}{*}{4} & \multirow{2}{*}{6} & \multirow[b]{2}{*}{0} & \multirow{2}{*}{10} \\
\hline & SPAN & & & & & & & & & \\
\hline & 1 & $3.050 \%$ & $1.582 \%$ & $1.141 \%$ & $0.915 \%$ & $0.827 \%$ & $1.216 \%$ & $1.500 \%$ & $1.729 \%$ & $1.924 \%$ \\
\hline & 1.5 & $3.517 \%$ & $2.656 \%$ & $2.164 \%$ & $1.881 \%$ & $1.339 \%$ & $0.911 \%$ & $1.021 \%$ & $1.187 \%$ & $1.331 \%$ \\
\hline & 2 & $2.758 \%$ & $2.291 \%$ & $1.997 \%$ & $1.885 \%$ & $1.456 \%$ & $1.323 \%$ & $1.171 \%$ & $1.029 \%$ & $1.048 \%$ \\
\hline & 2.5 & $2.261 \%$ & $1.899 \%$ & $1.686 \%$ & $1.631 \%$ & $1.373 \%$ & $1.338 \%$ & $1.299 \%$ & $1.246 \%$ & $1.188 \%$ \\
\hline & 3 & $1.803 \%$ & $1.492 \%$ & $1.764 \%$ & $1.293 \%$ & $1.109 \%$ & $1.143 \%$ & $1.161 \%$ & $1.160 \%$ & $1.149 \%$ \\
\hline & 3.5 & $2.064 \%$ & $2.007 \%$ & $2.063 \%$ & $2.071 \%$ & $2.003 \%$ & $1.942 \%$ & $1.834 \%$ & $1.726 \%$ & $1.662 \%$ \\
\hline & 4 & $3.368 \%$ & $3.333 \%$ & $3.376 \%$ & $3.394 \%$ & $3.395 \%$ & $3.462 \%$ & $3.478 \%$ & $3.470 \%$ & $3.452 \%$ \\
\hline
\end{tabular}

Table 197 Maximum moment results comparison for alpha 0.5 for slabs subjected to CHBDC truck loading (main bars perpendicular to traffic)

\begin{tabular}{|c|c|c|c|c|c|c|c|c|c|c|}
\hline & \multicolumn{9}{|c|}{ Maximum Moment (kN.m) } \\
\hline \multirow{9}{*}{ 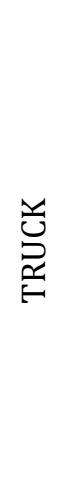 } & $\mathrm{D}$ & \multirow{2}{*}{0.25} & \multirow{2}{*}{0.5} & \multirow{2}{*}{0.75} & \multirow{2}{*}{1} & \multirow{2}{*}{2} & \multirow{2}{*}{4} & \multirow{2}{*}{6} & \multirow{2}{*}{8} & \multirow{2}{*}{10} \\
\hline & SPAN & & & & & & & & & \\
\hline & 1 & $0.365 \%$ & $0.495 \%$ & $0.594 \%$ & $0.675 \%$ & $0.926 \%$ & $1.272 \%$ & $1.532 \%$ & $1.747 \%$ & $1.933 \%$ \\
\hline & 1.5 & $1.468 \%$ & $0.411 \%$ & $0.478 \%$ & $0.536 \%$ & $0.711 \%$ & $0.956 \%$ & $1.140 \%$ & $1.292 \%$ & $1.423 \%$ \\
\hline & 2 & $3.496 \%$ & $1.991 \%$ & $0.393 \%$ & $0.442 \%$ & $0.593 \%$ & $0.802 \%$ & $0.958 \%$ & $1.086 \%$ & $1.197 \%$ \\
\hline & 2.5 & $2.845 \%$ & $2.726 \%$ & $2.395 \%$ & $1.123 \%$ & $0.533 \%$ & $0.721 \%$ & $0.861 \%$ & $0.975 \%$ & $1.074 \%$ \\
\hline & 3 & $1.307 \%$ & $2.115 \%$ & $0.545 \%$ & $2.159 \%$ & $0.352 \%$ & $0.547 \%$ & $0.687 \%$ & $0.801 \%$ & $0.897 \%$ \\
\hline & 3.5 & $0.341 \%$ & $2.080 \%$ & $2.701 \%$ & $2.931 \%$ & $2.945 \%$ & $0.643 \%$ & $0.763 \%$ & $0.862 \%$ & $0.947 \%$ \\
\hline & 4 & $0.126 \%$ & $2.059 \%$ & $3.122 \%$ & $3.709 \%$ & $4.472 \%$ & $4.361 \%$ & $2.461 \%$ & $1.771 \%$ & $1.838 \%$ \\
\hline
\end{tabular}

Table 198 Maximum moment results comparison for alpha 0.5 for slabs subjected to CHBDC axle 4 loading (main bars parallel to traffic) Maximum Moment (kN.m) 


\begin{tabular}{|c|c|c|c|c|c|c|c|c|c|c|}
\hline \multirow{7}{*}{ 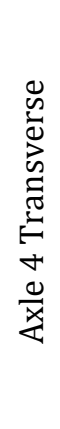 } & $\frac{\text { D }}{\text { SPAN }}$ & .25 & 0.5 & 0.75 & & & 4 & 6 & 8 & 10 \\
\hline & 1 & $5.369 \%$ & $5.232 \%$ & $5.031 \%$ & $4.832 \%$ & $4.192 \%$ & $3.869 \%$ & $3.743 \%$ & $3.639 \%$ & $3.565 \%$ \\
\hline & 1.5 & $3.689 \%$ & $3.732 \%$ & $3.757 \%$ & $3.764 \%$ & $3.699 \%$ & $3.439 \%$ & $3.180 \%$ & $2.956 \%$ & $2.765 \%$ \\
\hline & 2 & $2.959 \%$ & $2.936 \%$ & $2.935 \%$ & $2.942 \%$ & $2.974 \%$ & $2.986 \%$ & $2.946 \%$ & $2.883 \%$ & $2.809 \%$ \\
\hline & 2.5 & $2.413 \%$ & $2.373 \%$ & $2.352 \%$ & $2.341 \%$ & $2.336 \%$ & $2.367 \%$ & $2.391 \%$ & $2.402 \%$ & $2.402 \%$ \\
\hline & 3 & $2.025 \%$ & $1.977 \%$ & $0.088 \%$ & $1.939 \%$ & $1.910 \%$ & $1.908 \%$ & $1.924 \%$ & $1.943 \%$ & $1.959 \%$ \\
\hline & 3.5 & $1.779 \%$ & $1.728 \%$ & $1.708 \%$ & $1.693 \%$ & $1.658 \%$ & $1.634 \%$ & $1.632 \%$ & $1.639 \%$ & $1.649 \%$ \\
\hline
\end{tabular}

Table 199 Maximum moment results comparison for alpha 0.5 for slabs subjected to CHBDC axle 2 \& 3 loading (main bars parallel to traffic)

\begin{tabular}{|c|c|c|c|c|c|c|c|c|c|c|}
\hline & & \multicolumn{9}{|c|}{ Maximum Moment (kN.m) } \\
\hline \multirow{8}{*}{ 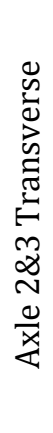 } & $\mathrm{D}$ & \multirow{2}{*}{0.25} & \multirow{2}{*}{0.5} & \multirow{2}{*}{0.75} & \multirow{2}{*}{1} & \multirow{2}{*}{2} & \multirow{2}{*}{4} & \multirow{2}{*}{6} & \multirow{2}{*}{8} & \multirow{2}{*}{10} \\
\hline & SPAN & & & & & & & & & \\
\hline & 1.5 & $16.750 \%$ & $16.711 \%$ & $16.781 \%$ & $16.866 \%$ & $17.182 \%$ & $17.620 \%$ & $17.915 \%$ & $18.137 \%$ & $18.315 \%$ \\
\hline & 2 & $6.503 \%$ & $6.196 \%$ & $5.997 \%$ & $5.860 \%$ & $5.577 \%$ & $5.385 \%$ & $5.305 \%$ & $5.256 \%$ & $5.219 \%$ \\
\hline & 2.5 & $4.093 \%$ & $4.002 \%$ & $3.955 \%$ & $3.918 \%$ & $3.832 \%$ & $3.772 \%$ & $3.751 \%$ & $3.737 \%$ & $3.725 \%$ \\
\hline & 3 & $2.901 \%$ & $2.852 \%$ & $0.681 \%$ & $2.819 \%$ & $2.810 \%$ & $2.887 \%$ & $2.975 \%$ & $3.051 \%$ & $3.111 \%$ \\
\hline & 3.5 & $2.298 \%$ & $2.267 \%$ & $2.248 \%$ & $2.237 \%$ & $2.240 \%$ & $2.314 \%$ & $2.403 \%$ & $2.487 \%$ & $2.563 \%$ \\
\hline & 4 & $1.948 \%$ & $1.925 \%$ & $1.913 \%$ & $1.906 \%$ & $1.910 \%$ & $1.962 \%$ & $2.027 \%$ & $2.093 \%$ & $2.157 \%$ \\
\hline
\end{tabular}




\section{Alpha 0.75 Bending Moment Comparison}

Table 200 Maximum moment results comparison for alpha 0.75 for slabs subjected to CHBDC axle 4 loading (main bars perpendicular to traffic)

\begin{tabular}{|c|c|c|c|c|c|c|c|c|c|c|}
\hline & \multicolumn{9}{|c|}{ Maximum Moment (kN.m) } \\
\hline \multirow{9}{*}{$\begin{array}{l}+\vec{x} \\
\frac{0}{x}\end{array}$} & $\mathrm{D}$ & \multirow{2}{*}{0.25} & \multirow{2}{*}{0.5} & \multirow{2}{*}{0.75} & \multirow{2}{*}{1} & \multirow{2}{*}{2} & \multirow{2}{*}{4} & \multirow{2}{*}{6} & \multirow{2}{*}{8} & \multirow{2}{*}{10} \\
\hline & SPAN & & & & & & & & & \\
\hline & 1 & $0.360 \%$ & $0.488 \%$ & $0.584 \%$ & $0.665 \%$ & $0.909 \%$ & $1.245 \%$ & $1.495 \%$ & $1.702 \%$ & $1.880 \%$ \\
\hline & 1.5 & $0.324 \%$ & $0.410 \%$ & $0.475 \%$ & $0.531 \%$ & $0.702 \%$ & $0.938 \%$ & $1.115 \%$ & $1.260 \%$ & $1.385 \%$ \\
\hline & 2 & $0.254 \%$ & $0.330 \%$ & $0.388 \%$ & $0.436 \%$ & $0.584 \%$ & $0.786 \%$ & $0.936 \%$ & $1.058 \%$ & $1.164 \%$ \\
\hline & 2.5 & $0.229 \%$ & $0.296 \%$ & $0.349 \%$ & $0.392 \%$ & $0.525 \%$ & $0.706 \%$ & $0.841 \%$ & $0.950 \%$ & $1.044 \%$ \\
\hline & 3 & $0.023 \%$ & $0.069 \%$ & $0.133 \%$ & $0.185 \%$ & $0.334 \%$ & $0.524 \%$ & $0.660 \%$ & $0.769 \%$ & $0.862 \%$ \\
\hline & 3.5 & $0.207 \%$ & $0.269 \%$ & $0.316 \%$ & $0.355 \%$ & $0.471 \%$ & $0.629 \%$ & $0.745 \%$ & $0.840 \%$ & $0.921 \%$ \\
\hline & 4 & $1.402 \%$ & $1.417 \%$ & $1.435 \%$ & $1.452 \%$ & $1.514 \%$ & $1.615 \%$ & $1.697 \%$ & $1.768 \%$ & $1.830 \%$ \\
\hline
\end{tabular}

Table 201 Maximum moment results comparison for alpha 0.75 for slabs subjected to CHBDC axle 2 \& 3 loading (main bars perpendicular to traffic)

\begin{tabular}{|c|c|c|c|c|c|c|c|c|c|c|}
\hline & \multicolumn{9}{|c|}{ Maximum Moment (kN.m) } \\
\hline \multirow{9}{*}{ 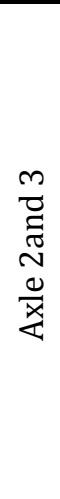 } & $\mathrm{D}$ & \multirow{2}{*}{0.25} & \multirow{2}{*}{0.5} & \multirow{2}{*}{0.75} & \multirow{2}{*}{1} & & \multirow{2}{*}{4} & \multirow{2}{*}{6} & \multirow[b]{2}{*}{0} & \multirow{2}{*}{10} \\
\hline & SPAN & & & & & & & & & \\
\hline & 1 & $2.837 \%$ & $1.597 \%$ & $1.192 \%$ & $1.011 \%$ & $0.795 \%$ & $1.165 \%$ & $1.437 \%$ & $1.658 \%$ & $1.846 \%$ \\
\hline & 1.5 & $3.253 \%$ & $2.462 \%$ & $2.030 \%$ & $1.778 \%$ & $1.318 \%$ & $0.979 \%$ & $0.979 \%$ & $1.135 \%$ & $1.271 \%$ \\
\hline & 2 & $2.622 \%$ & $2.167 \%$ & $1.881 \%$ & $1.779 \%$ & $1.385 \%$ & $1.279 \%$ & $1.157 \%$ & $1.045 \%$ & $0.999 \%$ \\
\hline & 2.5 & $2.174 \%$ & $1.828 \%$ & $1.620 \%$ & $1.564 \%$ & $1.311 \%$ & $1.278 \%$ & $1.245 \%$ & $1.202 \%$ & $1.156 \%$ \\
\hline & 3 & $1.736 \%$ & $1.442 \%$ & $1.285 \%$ & $1.246 \%$ & $1.066 \%$ & $1.089 \%$ & $1.105 \%$ & $1.104 \%$ & $1.095 \%$ \\
\hline & 3.5 & $1.958 \%$ & $1.858 \%$ & $1.917 \%$ & $1.933 \%$ & $1.881 \%$ & $1.859 \%$ & $1.783 \%$ & $1.701 \%$ & $1.636 \%$ \\
\hline & 4 & $3.274 \%$ & $3.258 \%$ & $3.296 \%$ & $3.316 \%$ & $3.304 \%$ & $3.379 \%$ & $3.402 \%$ & $3.402 \%$ & $3.391 \%$ \\
\hline
\end{tabular}

Table 202 Maximum moment results comparison for alpha 0.75 for slabs subjected to CHBDC truck loading (main bars perpendicular to traffic)

\begin{tabular}{|c|c|c|c|c|c|c|c|c|c|c|}
\hline & \multicolumn{9}{|c|}{ Maximum Moment (kN.m) } \\
\hline \multirow{9}{*}{ 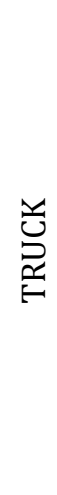 } & $\mathrm{D}$ & \multirow{2}{*}{0.25} & \multirow{2}{*}{0.5} & \multirow{2}{*}{0.75} & \multirow{2}{*}{1} & \multirow{2}{*}{2} & \multirow{2}{*}{4} & \multirow{2}{*}{6} & \multirow{2}{*}{8} & \multirow{2}{*}{10} \\
\hline & SPAN & & & & & & & & & \\
\hline & 1 & $0.359 \%$ & $0.488 \%$ & $0.584 \%$ & $0.665 \%$ & $0.909 \%$ & $1.245 \%$ & $1.495 \%$ & $1.702 \%$ & $1.880 \%$ \\
\hline & 1.5 & $3.317 \%$ & $0.410 \%$ & $0.475 \%$ & $0.531 \%$ & $0.702 \%$ & $0.938 \%$ & $1.115 \%$ & $1.260 \%$ & $1.385 \%$ \\
\hline & 2 & $2.913 \%$ & $2.509 \%$ & $0.388 \%$ & $0.437 \%$ & $0.584 \%$ & $0.786 \%$ & $0.936 \%$ & $1.058 \%$ & $1.164 \%$ \\
\hline & 2.5 & $1.800 \%$ & $2.113 \%$ & $2.044 \%$ & $1.963 \%$ & $0.525 \%$ & $0.706 \%$ & $0.840 \%$ & $0.950 \%$ & $1.045 \%$ \\
\hline & 3 & $0.112 \%$ & $1.125 \%$ & $1.458 \%$ & $1.574 \%$ & $0.968 \%$ & $0.524 \%$ & $0.660 \%$ & $0.769 \%$ & $0.862 \%$ \\
\hline & 3.5 & $0.758 \%$ & $0.885 \%$ & $1.608 \%$ & $1.967 \%$ & $2.392 \%$ & $0.629 \%$ & $0.745 \%$ & $0.840 \%$ & $0.921 \%$ \\
\hline & 4 & $1.023 \%$ & $0.849 \%$ & $1.874 \%$ & $2.488 \%$ & $3.548 \%$ & $3.899 \%$ & $3.891 \%$ & $1.767 \%$ & $1.830 \%$ \\
\hline
\end{tabular}

Table 203 Maximum moment results comparison for alpha 0.75 for slabs subjected to CHBDC axle 4 loading (main bars parallel to traffic) Maximum Moment (kN.m) 


\begin{tabular}{|c|c|c|c|c|c|c|c|c|c|c|}
\hline \multirow{7}{*}{ 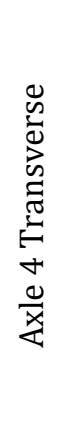 } & $\frac{\text { D }}{\text { SPAN }}$ & .25 & 0.5 & 0.75 & & & 4 & 6 & 8 & 10 \\
\hline & 1 & $5.261 \%$ & $5.152 \%$ & $4.999 \%$ & $4.847 \%$ & $4.348 \%$ & $3.969 \%$ & $3.833 \%$ & $3.741 \%$ & $3.673 \%$ \\
\hline & 1.5 & $3.679 \%$ & $3.704 \%$ & $3.712 \%$ & $3.709 \%$ & $3.639 \%$ & $3.429 \%$ & $3.228 \%$ & $3.053 \%$ & $2.902 \%$ \\
\hline & 2 & $2.975 \%$ & $2.955 \%$ & $2.950 \%$ & $2.949 \%$ & $2.955 \%$ & $2.938 \%$ & $2.894 \%$ & $2.838 \%$ & $2.778 \%$ \\
\hline & 2.5 & $2.435 \%$ & $2.392 \%$ & $2.374 \%$ & $2.364 \%$ & $2.353 \%$ & $2.359 \%$ & $2.364 \%$ & $2.362 \%$ & $2.354 \%$ \\
\hline & 3 & $2.045 \%$ & $1.991 \%$ & $1.971 \%$ & $1.958 \%$ & $1.932 \%$ & $1.924 \%$ & $1.929 \%$ & $1.936 \%$ & $1.941 \%$ \\
\hline & 3.5 & $1.797 \%$ & $1.740 \%$ & $1.721 \%$ & $1.708 \%$ & $1.677 \%$ & $1.656 \%$ & $1.651 \%$ & $1.653 \%$ & $1.657 \%$ \\
\hline
\end{tabular}

Table 204 Maximum moment results comparison for alpha 0.75 for slabs subjected to CHBDC axle 2 \& 3 loading (main bars parallel to traffic)

\begin{tabular}{|c|c|c|c|c|c|c|c|c|c|c|}
\hline & & \multicolumn{9}{|c|}{ Maximum Moment (kN.m) } \\
\hline \multirow{8}{*}{ 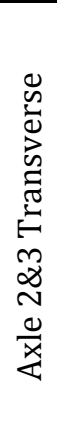 } & $\mathrm{D}$ & \multirow{2}{*}{0.25} & \multirow{2}{*}{0.5} & \multirow{2}{*}{0.75} & \multirow{2}{*}{1} & \multirow{2}{*}{2} & \multirow{2}{*}{4} & \multirow{2}{*}{6} & \multirow{2}{*}{8} & \multirow{2}{*}{10} \\
\hline & SPAN & & & & & & & & & \\
\hline & 1.5 & $16.971 \%$ & $16.860 \%$ & $16.877 \%$ & $16.924 \%$ & $17.145 \%$ & $17.497 \%$ & $17.750 \%$ & $17.944 \%$ & $18.102 \%$ \\
\hline & 2 & $6.506 \%$ & $6.278 \%$ & $6.119 \%$ & $6.003 \%$ & $5.738 \%$ & $5.520 \%$ & $5.417 \%$ & $5.354 \%$ & $5.308 \%$ \\
\hline & 2.5 & $4.076 \%$ & $4.006 \%$ & $3.963 \%$ & $3.937 \%$ & $3.870 \%$ & $3.807 \%$ & $3.775 \%$ & $3.751 \%$ & $3.731 \%$ \\
\hline & 3 & $2.884 \%$ & $2.861 \%$ & $2.844 \%$ & $2.835 \%$ & $2.837 \%$ & $2.889 \%$ & $2.945 \%$ & $2.990 \%$ & $3.026 \%$ \\
\hline & 3.5 & $2.282 \%$ & $2.270 \%$ & $2.262 \%$ & $2.257 \%$ & $2.267 \%$ & $2.326 \%$ & $2.392 \%$ & $2.452 \%$ & $2.506 \%$ \\
\hline & 4 & $1.937 \%$ & $1.927 \%$ & $1.922 \%$ & $1.920 \%$ & $1.928 \%$ & $1.975 \%$ & $2.029 \%$ & $2.081 \%$ & $2.130 \%$ \\
\hline
\end{tabular}




\section{Alpha 1 Bending Moment Comparison}

Table 205 Maximum moment results comparison for alpha 1 for slabs subjected to CHBDC axle 4 loading (main bars perpendicular to traffic)

\begin{tabular}{|c|c|c|c|c|c|c|c|c|c|c|}
\hline & \multicolumn{9}{|c|}{ Maximum Moment (kN.m) } \\
\hline \multirow{9}{*}{$\frac{+}{\frac{0}{x}}$} & $\mathrm{D}$ & \multirow{2}{*}{0.25} & \multirow{2}{*}{0.5} & \multirow{2}{*}{0.75} & \multirow{2}{*}{1} & \multirow[b]{2}{*}{2} & \multirow{2}{*}{4} & \multirow{2}{*}{6} & \multirow{2}{*}{8} & \multirow{2}{*}{10} \\
\hline & SPAN & & & & & & & & & \\
\hline & 1 & $0.354 \%$ & $0.481 \%$ & $0.576 \%$ & $0.656 \%$ & $0.895 \%$ & $1.221 \%$ & $1.463 \%$ & $1.661 \%$ & $1.833 \%$ \\
\hline & 1.5 & $0.325 \%$ & $0.408 \%$ & $0.472 \%$ & $0.527 \%$ & $0.694 \%$ & $0.923 \%$ & $1.093 \%$ & $1.232 \%$ & $1.353 \%$ \\
\hline & 2 & $0.252 \%$ & $0.327 \%$ & $0.384 \%$ & $0.432 \%$ & $0.576 \%$ & $0.772 \%$ & $0.916 \%$ & $1.034 \%$ & $1.135 \%$ \\
\hline & 2.5 & $0.227 \%$ & $0.294 \%$ & $0.345 \%$ & $0.388 \%$ & $0.518 \%$ & $0.693 \%$ & $0.823 \%$ & $0.928 \%$ & $1.018 \%$ \\
\hline & 3 & $0.030 \%$ & $0.059 \%$ & $0.123 \%$ & $0.173 \%$ & $0.319 \%$ & $0.504 \%$ & $0.636 \%$ & $0.742 \%$ & $0.831 \%$ \\
\hline & 3.5 & $0.205 \%$ & $0.266 \%$ & $0.312 \%$ & $0.350 \%$ & $0.464 \%$ & $0.617 \%$ & $0.729 \%$ & $0.820 \%$ & $0.898 \%$ \\
\hline & 4 & $1.411 \%$ & $1.423 \%$ & $1.441 \%$ & $1.458 \%$ & $1.519 \%$ & $1.617 \%$ & $1.696 \%$ & $1.764 \%$ & $1.823 \%$ \\
\hline
\end{tabular}

Table 206 Maximum moment results comparison for alpha 1 for slabs subjected to CHBDC axle 2 \& 3 loading (main bars perpendicular to traffic)

\begin{tabular}{|c|c|c|c|c|c|c|c|c|c|c|}
\hline & \multicolumn{9}{|c|}{ Maximum Moment (kN.m) } \\
\hline \multirow{9}{*}{$\begin{array}{l}m \\
\tilde{J} \\
\tilde{J} \\
\stackrel{u}{x} \\
\frac{\vec{x}}{4}\end{array}$} & $\mathrm{D}$ & \multirow{2}{*}{0.25} & \multirow{2}{*}{0.5} & \multirow{2}{*}{0.75} & \multirow{2}{*}{1} & & \multirow{2}{*}{4} & \multirow{2}{*}{6} & \multirow{2}{*}{8} & \multirow{2}{*}{10} \\
\hline & SPAN & & & & & & & & & \\
\hline & 1 & $2.670 \%$ & $1.602 \%$ & $1.223 \%$ & $1.077 \%$ & $0.767 \%$ & $1.122 \%$ & $1.382 \%$ & $1.595 \%$ & $1.776 \%$ \\
\hline & 1.5 & $3.036 \%$ & $2.309 \%$ & $1.927 \%$ & $1.700 \%$ & $1.300 \%$ & $1.026 \%$ & $0.943 \%$ & $1.090 \%$ & $1.219 \%$ \\
\hline & 2 & $2.503 \%$ & $2.064 \%$ & $1.790 \%$ & $1.695 \%$ & $1.330 \%$ & $1.244 \%$ & $1.147 \%$ & $1.056 \%$ & $0.975 \%$ \\
\hline & 2.5 & $2.096 \%$ & $1.765 \%$ & $1.563 \%$ & $1.508 \%$ & $1.261 \%$ & $1.230 \%$ & $1.204 \%$ & $1.169 \%$ & $1.132 \%$ \\
\hline & 3 & $1.674 \%$ & $1.397 \%$ & $1.243 \%$ & $1.204 \%$ & $1.031 \%$ & $1.044 \%$ & $1.060 \%$ & $1.060 \%$ & $1.053 \%$ \\
\hline & 3.5 & $1.865 \%$ & $1.779 \%$ & $1.788 \%$ & $1.811 \%$ & $1.775 \%$ & $1.784 \%$ & $1.734 \%$ & $1.672 \%$ & $1.611 \%$ \\
\hline & 4 & $3.203 \%$ & $3.192 \%$ & $3.224 \%$ & $3.246 \%$ & $3.239 \%$ & $3.309 \%$ & $3.338 \%$ & $3.344 \%$ & $3.339 \%$ \\
\hline
\end{tabular}

Table 207 Maximum moment results comparison for alpha 1 for slabs subjected to CHBDC truck loading (main bars perpendicular to traffic)

\begin{tabular}{|c|c|c|c|c|c|c|c|c|c|c|}
\hline & \multicolumn{9}{|c|}{ Maximum Moment (kN.m) } \\
\hline \multirow{9}{*}{ 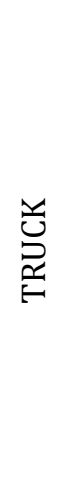 } & $\mathrm{D}$ & \multirow{2}{*}{0.25} & \multirow{2}{*}{0.5} & \multirow{2}{*}{0.75} & \multirow{2}{*}{1} & \multirow{2}{*}{2} & \multirow{2}{*}{4} & \multirow{2}{*}{6} & \multirow{2}{*}{8} & \multirow{2}{*}{10} \\
\hline & SPAN & & & & & & & & & \\
\hline & 1 & $0.354 \%$ & $0.481 \%$ & $0.576 \%$ & $0.656 \%$ & $0.895 \%$ & $1.221 \%$ & $1.463 \%$ & $1.661 \%$ & $1.833 \%$ \\
\hline & 1.5 & $1.798 \%$ & $0.407 \%$ & $0.473 \%$ & $0.527 \%$ & $0.694 \%$ & $0.923 \%$ & $1.093 \%$ & $1.232 \%$ & $1.353 \%$ \\
\hline & 2 & $0.433 \%$ & $0.375 \%$ & $0.664 \%$ & $0.431 \%$ & $0.576 \%$ & $0.772 \%$ & $0.916 \%$ & $1.034 \%$ & $1.135 \%$ \\
\hline & 2.5 & $2.476 \%$ & $1.315 \%$ & $0.722 \%$ & $0.326 \%$ & $0.517 \%$ & $0.693 \%$ & $0.823 \%$ & $0.928 \%$ & $1.019 \%$ \\
\hline & 3 & $4.161 \%$ & $2.976 \%$ & $2.244 \%$ & $1.741 \%$ & $0.759 \%$ & $0.504 \%$ & $0.636 \%$ & $0.741 \%$ & $0.831 \%$ \\
\hline & 3.5 & $4.500 \%$ & $3.333 \%$ & $2.555 \%$ & $2.012 \%$ & $0.762 \%$ & $0.252 \%$ & $0.728 \%$ & $0.819 \%$ & $0.898 \%$ \\
\hline & 4 & $5.368 \%$ & $4.439 \%$ & $3.597 \%$ & $2.945 \%$ & $1.256 \%$ & $0.315 \%$ & $1.107 \%$ & $1.582 \%$ & $1.824 \%$ \\
\hline
\end{tabular}

Table 208 Maximum moment results comparison for alpha 1 for slabs subjected to CHBDC axle 4 loading (main bars parallel to traffic) Maximum Moment (kN.m) 


\begin{tabular}{|c|c|c|c|c|c|c|c|c|c|c|}
\hline \multirow{7}{*}{ 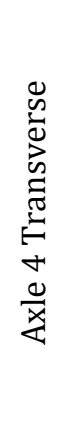 } & $\frac{\mathrm{D}}{\text { SPAN }}$ & & 0.5 & 0.75 & & 2 & 4 & 6 & 8 & 10 \\
\hline & 1 & $5.182 \%$ & $5.095 \%$ & $4.975 \%$ & $4.856 \%$ & $4.457 \%$ & $4.048 \%$ & $3.922 \%$ & $3.834 \%$ & $3.768 \%$ \\
\hline & 1.5 & $3.669 \%$ & $3.682 \%$ & $3.681 \%$ & $3.673 \%$ & $3.602 \%$ & $3.427 \%$ & $3.264 \%$ & $3.123 \%$ & $2.999 \%$ \\
\hline & 2 & $2.988 \%$ & $2.967 \%$ & $2.959 \%$ & $2.955 \%$ & $2.943 \%$ & $2.910 \%$ & $2.864 \%$ & $2.814 \%$ & $2.763 \%$ \\
\hline & 2.5 & $2.460 \%$ & $2.408 \%$ & $2.392 \%$ & $2.382 \%$ & $2.365 \%$ & $2.356 \%$ & $2.349 \%$ & $2.339 \%$ & $2.326 \%$ \\
\hline & 3 & $2.064 \%$ & $2.003 \%$ & $1.985 \%$ & $1.973 \%$ & $1.949 \%$ & $1.936 \%$ & $1.933 \%$ & $1.932 \%$ & $1.932 \%$ \\
\hline & 3.5 & $1.816 \%$ & $1.755 \%$ & $1.733 \%$ & $1.721 \%$ & $1.693 \%$ & $1.672 \%$ & $1.665 \%$ & $1.663 \%$ & $1.662 \%$ \\
\hline
\end{tabular}

Table 209 Maximum moment results comparison for alpha 1 for slabs subjected to CHBDC axle 2 \& 3 loading (main bars parallel to traffic)

\begin{tabular}{|c|c|c|c|c|c|c|c|c|c|c|}
\hline & & \multicolumn{9}{|c|}{ Maximum Moment (kN.m) } \\
\hline \multirow{8}{*}{ 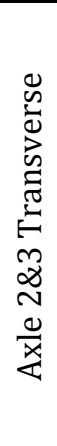 } & $\mathrm{D}$ & \multirow{2}{*}{0.25} & \multirow{2}{*}{0.5} & \multirow{2}{*}{0.75} & \multirow{2}{*}{1} & \multirow{2}{*}{2} & \multirow{2}{*}{4} & \multirow{2}{*}{6} & \multirow{2}{*}{8} & \multirow{2}{*}{10} \\
\hline & SPAN & & & & & & & & & \\
\hline & 1.5 & $17.247 \%$ & $16.999 \%$ & $16.976 \%$ & $16.992 \%$ & $17.137 \%$ & $17.417 \%$ & $17.630 \%$ & $17.800 \%$ & $17.940 \%$ \\
\hline & 2 & $6.520 \%$ & $6.328 \%$ & $6.201 \%$ & $6.102 \%$ & $5.861 \%$ & $5.636 \%$ & $5.521 \%$ & $5.448 \%$ & $5.396 \%$ \\
\hline & 2.5 & $4.056 \%$ & $4.013 \%$ & $3.975 \%$ & $3.946 \%$ & $3.893 \%$ & $3.833 \%$ & $3.796 \%$ & $3.768 \%$ & $3.744 \%$ \\
\hline & 3 & $2.867 \%$ & $2.862 \%$ & $2.856 \%$ & $2.852 \%$ & $2.856 \%$ & $2.889 \%$ & $2.923 \%$ & $2.949 \%$ & $2.969 \%$ \\
\hline & 3.5 & $2.270 \%$ & $2.270 \%$ & $2.268 \%$ & $2.269 \%$ & $2.283 \%$ & $2.331 \%$ & $2.381 \%$ & $2.425 \%$ & $2.464 \%$ \\
\hline & 4 & $1.937 \%$ & $1.928 \%$ & $1.927 \%$ & $1.928 \%$ & $1.941 \%$ & $1.983 \%$ & $2.028 \%$ & $2.069 \%$ & $2.108 \%$ \\
\hline
\end{tabular}




\section{Alpha 2 Bending Moment Comparison}

Table 210 Maximum moment results comparison for alpha 2 for slabs subjected to CHBDC axle 4 loading (main bars perpendicular to traffic)

\begin{tabular}{|c|c|c|c|c|c|c|c|c|c|c|}
\hline & \multicolumn{9}{|c|}{ Maximum Moment (kN.m) } \\
\hline \multirow{9}{*}{$\frac{\vec{d}}{x}$} & $\mathrm{D}$ & \multirow{2}{*}{0.25} & \multirow{2}{*}{0.5} & \multirow{2}{*}{0.75} & \multirow{2}{*}{1} & & \multirow{2}{*}{4} & \multirow{2}{*}{6} & \multirow[b]{2}{*}{8} & \multirow{2}{*}{10} \\
\hline & SPAN & & & & & & & & & \\
\hline & 1 & $0.339 \%$ & $0.461 \%$ & $0.552 \%$ & $0.626 \%$ & $0.848 \%$ & $1.144 \%$ & $1.359 \%$ & $1.535 \%$ & $1.684 \%$ \\
\hline & 1.5 & $0.325 \%$ & $0.404 \%$ & $0.463 \%$ & $0.514 \%$ & $0.667 \%$ & $0.873 \%$ & $1.024 \%$ & $1.147 \%$ & $1.252 \%$ \\
\hline & 2 & $0.246 \%$ & $0.318 \%$ & $0.372 \%$ & $0.416 \%$ & $0.549 \%$ & $0.726 \%$ & $0.854 \%$ & $0.958 \%$ & $1.046 \%$ \\
\hline & 2.5 & $0.227 \%$ & $0.288 \%$ & $0.335 \%$ & $0.375 \%$ & $0.494 \%$ & $0.652 \%$ & $0.767 \%$ & $0.859 \%$ & $0.937 \%$ \\
\hline & 3 & $0.040 \%$ & $0.033 \%$ & $0.090 \%$ & $0.137 \%$ & $0.271 \%$ & $0.441 \%$ & $0.560 \%$ & $0.654 \%$ & $0.733 \%$ \\
\hline & 3.5 & $0.247 \%$ & $0.266 \%$ & $0.302 \%$ & $0.336 \%$ & $0.440 \%$ & $0.579 \%$ & $0.679 \%$ & $0.759 \%$ & $0.827 \%$ \\
\hline & 4 & $1.575 \%$ & $1.479 \%$ & $1.474 \%$ & $1.483 \%$ & $1.534 \%$ & $1.621 \%$ & $1.690 \%$ & $1.748 \%$ & $1.799 \%$ \\
\hline
\end{tabular}

Table 211 Maximum moment results comparison for alpha 2 for slabs subjected to CHBDC axle 2 \& 3 loading (main bars perpendicular to traffic)

\begin{tabular}{|c|c|c|c|c|c|c|c|c|c|c|}
\hline & \multicolumn{9}{|c|}{ Maximum Moment (kN.m) } \\
\hline \multirow{9}{*}{$\begin{array}{l}m \\
\tilde{J} \\
\tilde{J} \\
\stackrel{u}{x} \\
\frac{\vec{x}}{4}\end{array}$} & $\mathrm{D}$ & \multirow{2}{*}{0.25} & \multirow{2}{*}{0.5} & \multirow{2}{*}{0.75} & \multirow{2}{*}{1} & & \multirow{2}{*}{4} & \multirow{2}{*}{6} & \multirow{2}{*}{8} & \multirow{2}{*}{10} \\
\hline & SPAN & & & & & & & & & \\
\hline & 1 & $2.237 \%$ & $1.573 \%$ & $1.259 \%$ & $1.188 \%$ & $0.961 \%$ & $0.990 \%$ & $1.216 \%$ & $1.402 \%$ & $1.560 \%$ \\
\hline & 1.5 & $2.469 \%$ & $1.925 \%$ & $1.672 \%$ & $1.514 \%$ & $1.245 \%$ & $1.116 \%$ & $1.008 \%$ & $0.958 \%$ & $1.065 \%$ \\
\hline & 2 & $2.136 \%$ & $1.772 \%$ & $1.552 \%$ & $1.474 \%$ & $1.188 \%$ & $1.158 \%$ & $1.115 \%$ & $1.073 \%$ & $1.033 \%$ \\
\hline & 2.5 & $1.851 \%$ & $1.572 \%$ & $1.398 \%$ & $1.345 \%$ & $1.136 \%$ & $1.111 \%$ & $1.103 \%$ & $1.089 \%$ & $1.073 \%$ \\
\hline & 3 & $1.495 \%$ & $1.253 \%$ & $1.112 \%$ & $1.079 \%$ & $0.930 \%$ & $0.924 \%$ & $0.941 \%$ & $0.947 \%$ & $0.948 \%$ \\
\hline & 3.5 & $1.636 \%$ & $1.540 \%$ & $1.513 \%$ & $1.517 \%$ & $1.455 \%$ & $1.543 \%$ & $1.558 \%$ & $1.551 \%$ & $1.534 \%$ \\
\hline & 4 & $3.141 \%$ & $3.021 \%$ & $3.012 \%$ & $3.031 \%$ & $3.039 \%$ & $3.100 \%$ & $3.146 \%$ & $3.168 \%$ & $3.180 \%$ \\
\hline
\end{tabular}

Table 212 Maximum moment results comparison for alpha 2 for slabs subjected to CHBDC truck loading (main bars perpendicular to traffic)

\begin{tabular}{|c|c|c|c|c|c|c|c|c|c|c|}
\hline & \multicolumn{9}{|c|}{ Maximum Moment (kN.m) } \\
\hline \multirow{9}{*}{ 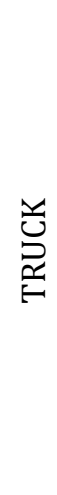 } & $\mathrm{D}$ & \multirow{2}{*}{0.25} & \multirow{2}{*}{0.5} & \multirow{2}{*}{0.75} & \multirow{2}{*}{1} & \multirow{2}{*}{2} & \multirow{2}{*}{4} & \multirow{2}{*}{6} & \multirow{2}{*}{8} & \multirow{2}{*}{10} \\
\hline & SPAN & & & & & & & & & \\
\hline & 1 & $0.337 \%$ & $0.460 \%$ & $0.551 \%$ & $0.626 \%$ & $0.848 \%$ & $1.144 \%$ & $1.359 \%$ & $1.535 \%$ & $1.684 \%$ \\
\hline & 1.5 & $1.943 \%$ & $1.877 \%$ & $0.461 \%$ & $0.513 \%$ & $0.666 \%$ & $0.873 \%$ & $1.024 \%$ & $1.147 \%$ & $1.251 \%$ \\
\hline & 2 & $0.234 \%$ & $0.876 \%$ & $1.109 \%$ & $1.236 \%$ & $0.546 \%$ & $0.725 \%$ & $0.854 \%$ & $0.958 \%$ & $1.046 \%$ \\
\hline & 2.5 & $1.430 \%$ & $0.487 \%$ & $0.001 \%$ & $0.318 \%$ & $0.786 \%$ & $0.648 \%$ & $0.764 \%$ & $0.857 \%$ & $0.937 \%$ \\
\hline & 3 & $2.792 \%$ & $1.894 \%$ & $1.312 \%$ & $0.891 \%$ & $0.089 \%$ & $0.595 \%$ & $0.554 \%$ & $0.650 \%$ & $0.730 \%$ \\
\hline & 3.5 & $2.418 \%$ & $2.006 \%$ & $1.427 \%$ & $0.999 \%$ & $0.010 \%$ & $0.881 \%$ & $1.231 \%$ & $0.748 \%$ & $0.818 \%$ \\
\hline & 4 & $1.143 \%$ & $1.162 \%$ & $0.899 \%$ & $0.590 \%$ & $0.509 \%$ & $1.630 \%$ & $2.187 \%$ & $2.517 \%$ & $2.730 \%$ \\
\hline
\end{tabular}

Table 213 Maximum moment results comparison for alpha 2 for slabs subjected to CHBDC axle 4 loading (main bars parallel to traffic) Maximum Moment (kN.m) 


\begin{tabular}{|c|c|c|c|c|c|c|c|c|c|c|}
\hline \multirow{7}{*}{ 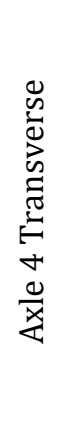 } & $\frac{\text { D }}{\text { SPAN }}$ & .25 & 0.5 & 0.75 & & & 4 & 6 & 8 & 10 \\
\hline & 1 & $5.002 \%$ & $4.970 \%$ & $4.919 \%$ & $4.866 \%$ & $4.674 \%$ & $4.392 \%$ & $4.190 \%$ & $4.077 \%$ & $4.022 \%$ \\
\hline & 1.5 & $3.675 \%$ & $3.631 \%$ & $3.619 \%$ & $3.605 \%$ & $3.547 \%$ & $3.442 \%$ & $3.353 \%$ & $3.277 \%$ & $3.211 \%$ \\
\hline & 2 & $3.075 \%$ & $3.004 \%$ & $2.981 \%$ & $2.969 \%$ & $2.932 \%$ & $2.879 \%$ & $2.835 \%$ & $2.797 \%$ & $2.763 \%$ \\
\hline & 2.5 & $2.541 \%$ & $2.472 \%$ & $2.434 \%$ & $2.422 \%$ & $2.393 \%$ & $2.360 \%$ & $2.336 \%$ & $2.315 \%$ & $2.297 \%$ \\
\hline & 3 & $2.149 \%$ & $2.071 \%$ & $2.034 \%$ & $2.014 \%$ & $1.988 \%$ & $1.964 \%$ & $1.948 \%$ & $1.935 \%$ & $1.925 \%$ \\
\hline & 3.5 & $1.955 \%$ & $1.835 \%$ & $1.790 \%$ & $1.763 \%$ & $1.734 \%$ & $1.710 \%$ & $1.697 \%$ & $1.687 \%$ & $1.680 \%$ \\
\hline
\end{tabular}

Table 214 Maximum moment results comparison for alpha 2 for slabs subjected to CHBDC axle 2 \& 3 loading (main bars parallel to traffic)

\begin{tabular}{|c|c|c|c|c|c|c|c|c|c|c|}
\hline & & \multicolumn{9}{|c|}{ Maximum Moment (kN.m) } \\
\hline \multirow{8}{*}{ 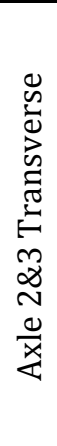 } & $\mathrm{D}$ & \multirow{2}{*}{0.25} & \multirow{2}{*}{0.5} & \multirow{2}{*}{0.75} & \multirow{2}{*}{1} & \multirow{2}{*}{2} & \multirow{2}{*}{4} & \multirow{2}{*}{6} & \multirow{2}{*}{8} & \multirow{2}{*}{10} \\
\hline & SPAN & & & & & & & & & \\
\hline & 1.5 & $17.961 \%$ & $17.600 \%$ & $17.418 \%$ & $17.307 \%$ & $17.235 \%$ & $17.307 \%$ & $17.404 \%$ & $17.497 \%$ & $17.583 \%$ \\
\hline & 2 & $6.491 \%$ & $6.386 \%$ & $6.335 \%$ & $6.288 \%$ & $6.136 \%$ & $5.949 \%$ & $5.833 \%$ & $5.751 \%$ & $5.689 \%$ \\
\hline & 2.5 & $3.979 \%$ & $3.994 \%$ & $3.989 \%$ & $3.979 \%$ & $3.933 \%$ & $3.883 \%$ & $3.851 \%$ & $3.824 \%$ & $3.800 \%$ \\
\hline & 3 & $2.829 \%$ & $2.841 \%$ & $2.852 \%$ & $2.860 \%$ & $2.873 \%$ & $2.878 \%$ & $2.876 \%$ & $2.870 \%$ & $2.864 \%$ \\
\hline & 3.5 & $2.323 \%$ & $2.274 \%$ & $2.274 \%$ & $2.279 \%$ & $2.300 \%$ & $2.328 \%$ & $2.346 \%$ & $2.359 \%$ & $2.369 \%$ \\
\hline & 4 & $2.164 \%$ & $1.993 \%$ & $1.961 \%$ & $1.953 \%$ & $1.961 \%$ & $1.989 \%$ & $2.012 \%$ & $2.030 \%$ & $2.046 \%$ \\
\hline
\end{tabular}




\section{Alpha 4 Bending Moment Comparison}

Table 215 Maximum moment results comparison for alpha 4 for slabs subjected to CHBDC axle 4 loading (main bars perpendicular to traffic)

\begin{tabular}{|c|c|c|c|c|c|c|c|c|c|c|}
\hline & \multicolumn{9}{|c|}{ Maximum Moment (kN.m) } \\
\hline \multirow{9}{*}{$\frac{\vec{d}}{x}$} & $\mathrm{D}$ & \multirow{2}{*}{0.25} & \multirow{2}{*}{0.5} & \multirow{2}{*}{0.75} & \multirow{2}{*}{1} & & & \multirow{2}{*}{6} & \multirow[b]{2}{*}{8} & \multirow{2}{*}{10} \\
\hline & SPAN & & & & & & & & & \\
\hline & 1 & $0.320 \%$ & $0.432 \%$ & $0.516 \%$ & $0.584 \%$ & $0.780 \%$ & $1.037 \%$ & $1.219 \%$ & $1.364 \%$ & $1.488 \%$ \\
\hline & 1.5 & $0.325 \%$ & $0.397 \%$ & $0.451 \%$ & $0.496 \%$ & $0.630 \%$ & $0.806 \%$ & $0.933 \%$ & $1.035 \%$ & $1.121 \%$ \\
\hline & 2 & $0.248 \%$ & $0.307 \%$ & $0.354 \%$ & $0.394 \%$ & $0.511 \%$ & $0.663 \%$ & $0.771 \%$ & $0.858 \%$ & $0.931 \%$ \\
\hline & 2.5 & $0.282 \%$ & $0.292 \%$ & $0.326 \%$ & $0.359 \%$ & $0.461 \%$ & $0.596 \%$ & $0.692 \%$ & $0.769 \%$ & $0.834 \%$ \\
\hline & 3 & $0.135 \%$ & $0.056 \%$ & $0.074 \%$ & $0.103 \%$ & $0.211 \%$ & $0.357 \%$ & $0.459 \%$ & $0.539 \%$ & $0.606 \%$ \\
\hline & 3.5 & $0.720 \%$ & $0.424 \%$ & $0.370 \%$ & $0.363 \%$ & $0.418 \%$ & $0.528 \%$ & $0.611 \%$ & $0.678 \%$ & $0.734 \%$ \\
\hline & 4 & $2.627 \%$ & $1.923 \%$ & $1.724 \%$ & $1.645 \%$ & $1.585 \%$ & $1.628 \%$ & $1.681 \%$ & $1.726 \%$ & $1.767 \%$ \\
\hline
\end{tabular}

Table 216 Maximum moment results comparison for alpha 4 for slabs subjected to CHBDC axle 2 \& 3 loading (main bars perpendicular to traffic)

\begin{tabular}{|c|c|c|c|c|c|c|c|c|c|c|}
\hline & \multicolumn{9}{|c|}{ Maximum Moment (kN.m) } \\
\hline \multirow{9}{*}{$\begin{array}{l}m \\
\tilde{D} \\
\tilde{J} \\
\sim \\
\frac{0}{x} \\
\frac{x}{x}\end{array}$} & $\mathrm{D}$ & \multirow{2}{*}{0.25} & \multirow{2}{*}{0.5} & \multirow{2}{*}{0.75} & \multirow{2}{*}{1} & & \multirow{2}{*}{4} & \multirow{2}{*}{6} & \multirow{2}{*}{8} & \multirow{2}{*}{10} \\
\hline & SPAN & & & & & & & & & \\
\hline & 1 & $1.801 \%$ & $1.463 \%$ & $1.240 \%$ & $1.198 \%$ & $1.126 \%$ & $0.993 \%$ & $1.013 \%$ & $1.160 \%$ & $1.287 \%$ \\
\hline & 1.5 & $1.898 \%$ & $1.564 \%$ & $1.429 \%$ & $1.339 \%$ & $1.163 \%$ & $1.139 \%$ & $1.106 \%$ & $1.073 \%$ & $1.042 \%$ \\
\hline & 2 & $1.712 \%$ & $1.453 \%$ & $1.306 \%$ & $1.256 \%$ & $1.054 \%$ & $1.066 \%$ & $1.065 \%$ & $1.058 \%$ & $1.049 \%$ \\
\hline & 2.5 & $1.606 \%$ & $1.346 \%$ & $1.209 \%$ & $1.167 \%$ & $1.019 \%$ & $0.996 \%$ & $1.007 \%$ & $1.011 \%$ & $1.012 \%$ \\
\hline & 3 & $1.476 \%$ & $1.131 \%$ & $0.987 \%$ & $0.940 \%$ & $0.822 \%$ & $0.798 \%$ & $0.821 \%$ & $0.835 \%$ & $0.845 \%$ \\
\hline & 3.5 & $1.905 \%$ & $1.432 \%$ & $1.311 \%$ & $1.285 \%$ & $1.233 \%$ & $1.283 \%$ & $1.331 \%$ & $1.360 \%$ & $1.378 \%$ \\
\hline & 4 & $4.047 \%$ & $3.237 \%$ & $2.994 \%$ & $2.915 \%$ & $2.827 \%$ & $2.850 \%$ & $2.910 \%$ & $2.949 \%$ & $2.976 \%$ \\
\hline
\end{tabular}

Table 217 Maximum moment results comparison for alpha 4 for slabs subjected to CHBDC truck loading (main bars perpendicular to traffic)

\begin{tabular}{|c|c|c|c|c|c|c|c|c|c|c|}
\hline & \multicolumn{9}{|c|}{ Maximum Moment (kN.m) } \\
\hline \multirow{9}{*}{ 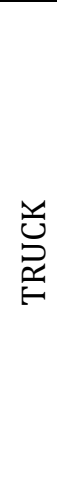 } & $\mathrm{D}$ & \multirow{2}{*}{0.25} & \multirow{2}{*}{0.5} & \multirow{2}{*}{0.75} & \multirow{2}{*}{1} & \multirow{2}{*}{2} & \multirow{2}{*}{4} & \multirow{2}{*}{6} & \multirow[b]{2}{*}{8} & \multirow{2}{*}{10} \\
\hline & SPAN & & & & & & & & & \\
\hline & 1 & $1.593 \%$ & $0.463 \%$ & $0.512 \%$ & $0.581 \%$ & $0.780 \%$ & $1.037 \%$ & $1.219 \%$ & $1.364 \%$ & $1.487 \%$ \\
\hline & 1.5 & $0.322 \%$ & $0.411 \%$ & $0.769 \%$ & $0.930 \%$ & $0.624 \%$ & $0.803 \%$ & $0.931 \%$ & $1.034 \%$ & $1.121 \%$ \\
\hline & 2 & $2.203 \%$ & $1.338 \%$ & $0.795 \%$ & $0.422 \%$ & $0.284 \%$ & $0.653 \%$ & $0.765 \%$ & $0.853 \%$ & $0.928 \%$ \\
\hline & 2.5 & $2.966 \%$ & $2.639 \%$ & $2.173 \%$ & $1.775 \%$ & $0.875 \%$ & $0.038 \%$ & $0.445 \%$ & $0.755 \%$ & $0.823 \%$ \\
\hline & 3 & $3.000 \%$ & $3.211 \%$ & $3.075 \%$ & $2.876 \%$ & $2.059 \%$ & $1.031 \%$ & $0.477 \%$ & $0.132 \%$ & $0.103 \%$ \\
\hline & 3.5 & $1.025 \%$ & $2.016 \%$ & $2.213 \%$ & $2.225 \%$ & $1.928 \%$ & $1.027 \%$ & $0.455 \%$ & $0.068 \%$ & $0.210 \%$ \\
\hline & 4 & $1.997 \%$ & $0.073 \%$ & $0.551 \%$ & $0.808 \%$ & $0.920 \%$ & $0.459 \%$ & $0.120 \%$ & $0.556 \%$ & $0.900 \%$ \\
\hline
\end{tabular}

Table 218 Maximum moment results comparison for alpha 4 for slabs subjected to CHBDC axle 4 loading (main bars parallel to traffic) Maximum Moment (kN.m) 


\begin{tabular}{|c|c|c|c|c|c|c|c|c|c|c|}
\hline \multirow{7}{*}{ 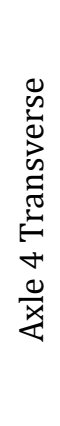 } & $\begin{array}{c}\text { D } \\
\text { SPAN }\end{array}$ & .25 & 0.5 & 0.75 & & 2 & 4 & 6 & 8 & 10 \\
\hline & 1 & $4.892 \%$ & $4.864 \%$ & $4.857 \%$ & $4.846 \%$ & $4.787 \%$ & $4.675 \%$ & $4.580 \%$ & $4.498 \%$ & $4.427 \%$ \\
\hline & 1.5 & $3.703 \%$ & $3.628 \%$ & $3.583 \%$ & $3.572 \%$ & $3.536 \%$ & $3.480 \%$ & $3.436 \%$ & $3.399 \%$ & $3.366 \%$ \\
\hline & 2 & $3.181 \%$ & $3.093 \%$ & $3.042 \%$ & $3.004 \%$ & $2.951 \%$ & $2.900 \%$ & $2.865 \%$ & $2.837 \%$ & $2.814 \%$ \\
\hline & 2.5 & $2.731 \%$ & $2.590 \%$ & $2.535 \%$ & $2.500 \%$ & $2.429 \%$ & $2.388 \%$ & $2.361 \%$ & $2.340 \%$ & $2.322 \%$ \\
\hline & 3 & $2.539 \%$ & $2.257 \%$ & $2.166 \%$ & $2.120 \%$ & $2.035 \%$ & $1.996 \%$ & $1.975 \%$ & $1.959 \%$ & $1.947 \%$ \\
\hline & 3.5 & $2.722 \%$ & $2.186 \%$ & $2.015 \%$ & $1.932 \%$ & $1.809 \%$ & $1.752 \%$ & $1.732 \%$ & $1.718 \%$ & $1.707 \%$ \\
\hline
\end{tabular}

Table 219 Maximum moment results comparison for alpha 4 for slabs subjected to CHBDC axle 2 \& 3 loading (main bars parallel to traffic)

\begin{tabular}{|c|c|c|c|c|c|c|c|c|c|c|}
\hline & & \multicolumn{9}{|c|}{ Maximum Moment (kN.m) } \\
\hline \multirow{8}{*}{ 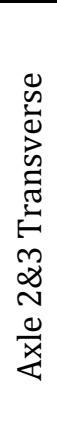 } & $\mathrm{D}$ & \multirow{2}{*}{0.25} & \multirow{2}{*}{0.5} & \multirow{2}{*}{0.75} & \multirow{2}{*}{1} & \multirow{2}{*}{2} & \multirow{2}{*}{4} & \multirow{2}{*}{6} & \multirow{2}{*}{8} & \multirow{2}{*}{10} \\
\hline & SPAN & & & & & & & & & \\
\hline & 1.5 & $18.514 \%$ & $18.269 \%$ & $18.097 \%$ & $17.969 \%$ & $17.670 \%$ & $17.424 \%$ & $17.399 \%$ & $17.401 \%$ & $17.416 \%$ \\
\hline & 2 & $6.353 \%$ & $6.373 \%$ & $6.358 \%$ & $6.333 \%$ & $6.296 \%$ & $6.209 \%$ & $6.135 \%$ & $6.074 \%$ & $6.024 \%$ \\
\hline & 2.5 & $3.943 \%$ & $3.924 \%$ & $3.932 \%$ & $3.937 \%$ & $3.932 \%$ & $3.891 \%$ & $3.882 \%$ & $3.870 \%$ & $3.859 \%$ \\
\hline & 3 & $3.088 \%$ & $2.881 \%$ & $2.844 \%$ & $2.836 \%$ & $2.840 \%$ & $2.843 \%$ & $2.836 \%$ & $2.826 \%$ & $2.815 \%$ \\
\hline & 3.5 & $3.098 \%$ & $2.551 \%$ & $2.404 \%$ & $2.347 \%$ & $2.297 \%$ & $2.297 \%$ & $2.300 \%$ & $2.300 \%$ & $2.299 \%$ \\
\hline & 4 & $3.681 \%$ & $2.657 \%$ & $2.337 \%$ & $2.193 \%$ & $2.025 \%$ & $1.985 \%$ & $1.983 \%$ & $1.985 \%$ & $1.987 \%$ \\
\hline
\end{tabular}




\section{Alpha 6 Bending Moment Comparison}

Table 220 Maximum moment results comparison for alpha 6 for slabs subjected to CHBDC axle 4 loading (main bars perpendicular to traffic)

\begin{tabular}{|c|c|c|c|c|c|c|c|c|c|c|}
\hline & \multicolumn{9}{|c|}{ Maximum Moment (kN.m) } \\
\hline \multirow{9}{*}{$\frac{+}{\frac{0}{x}}$} & $\mathrm{D}$ & \multirow{2}{*}{0.25} & \multirow{2}{*}{0.5} & \multirow{2}{*}{0.75} & \multirow{2}{*}{1} & \multirow[b]{2}{*}{ 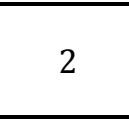 } & \multirow{2}{*}{4} & \multirow{2}{*}{6} & \multirow{2}{*}{8} & \multirow{2}{*}{10} \\
\hline & SPAN & & & & & & & & & \\
\hline & 1 & $0.304 \%$ & $0.411 \%$ & $0.488 \%$ & $0.551 \%$ & $0.730 \%$ & $0.960 \%$ & $1.120 \%$ & $1.248 \%$ & $1.355 \%$ \\
\hline & 1.5 & $0.328 \%$ & $0.391 \%$ & $0.441 \%$ & $0.482 \%$ & $0.603 \%$ & $0.759 \%$ & $0.871 \%$ & $0.961 \%$ & $1.035 \%$ \\
\hline & 2 & $0.288 \%$ & $0.308 \%$ & $0.345 \%$ & $0.379 \%$ & $0.484 \%$ & $0.619 \%$ & $0.715 \%$ & $0.791 \%$ & $0.855 \%$ \\
\hline & 2.5 & $0.474 \%$ & $0.348 \%$ & $0.344 \%$ & $0.360 \%$ & $0.440 \%$ & $0.557 \%$ & $0.642 \%$ & $0.709 \%$ & $0.766 \%$ \\
\hline & 3 & $0.612 \%$ & $0.227 \%$ & $0.149 \%$ & $0.134 \%$ & $0.184 \%$ & $0.303 \%$ & $0.392 \%$ & $0.463 \%$ & $0.522 \%$ \\
\hline & 3.5 & $1.650 \%$ & $0.844 \%$ & $0.610 \%$ & $0.515 \%$ & $0.446 \%$ & $0.503 \%$ & $0.569 \%$ & $0.625 \%$ & $0.674 \%$ \\
\hline & 4 & $4.334 \%$ & $2.805 \%$ & $2.285 \%$ & $2.039 \%$ & $1.732 \%$ & $1.667 \%$ & $1.688 \%$ & $1.718 \%$ & $1.748 \%$ \\
\hline
\end{tabular}

Table 221 Maximum moment results comparison for alpha 6 for slabs subjected to CHBDC axle 2 \& 3 loading (main bars perpendicular to traffic)

\begin{tabular}{|c|c|c|c|c|c|c|c|c|c|c|}
\hline & \multicolumn{9}{|c|}{ Maximum Moment (kN.m) } \\
\hline \multirow{9}{*}{$\begin{array}{l}m \\
\tilde{J} \\
\tilde{J} \\
\stackrel{u}{x} \\
\frac{\vec{x}}{4}\end{array}$} & $\mathrm{D}$ & \multirow{2}{*}{0.25} & \multirow{2}{*}{0.5} & \multirow{2}{*}{0.75} & \multirow{2}{*}{1} & & \multirow{2}{*}{4} & \multirow{2}{*}{6} & \multirow{2}{*}{8} & \multirow{2}{*}{10} \\
\hline & SPAN & & & & & & & & & \\
\hline & 1 & $1.558 \%$ & $1.358 \%$ & $1.221 \%$ & $1.153 \%$ & $1.149 \%$ & $1.097 \%$ & $1.042 \%$ & $1.009 \%$ & $1.116 \%$ \\
\hline & 1.5 & $1.601 \%$ & $1.376 \%$ & $1.296 \%$ & $1.239 \%$ & $1.100 \%$ & $1.117 \%$ & $1.114 \%$ & $1.106 \%$ & $1.094 \%$ \\
\hline & 2 & $1.515 \%$ & $1.285 \%$ & $1.174 \%$ & $1.139 \%$ & $1.000 \%$ & $1.007 \%$ & $1.022 \%$ & $1.029 \%$ & $1.032 \%$ \\
\hline & 2.5 & $1.635 \%$ & $1.273 \%$ & $1.125 \%$ & $1.079 \%$ & $0.960 \%$ & $0.930 \%$ & $0.950 \%$ & $0.963 \%$ & $0.970 \%$ \\
\hline & 3 & $1.880 \%$ & $1.236 \%$ & $1.010 \%$ & $0.919 \%$ & $0.775 \%$ & $0.729 \%$ & $0.754 \%$ & $0.772 \%$ & $0.785 \%$ \\
\hline & 3.5 & $2.834 \%$ & $1.752 \%$ & $1.428 \%$ & $1.304 \%$ & $1.143 \%$ & $1.149 \%$ & $1.203 \%$ & $1.241 \%$ & $1.269 \%$ \\
\hline & 4 & $5.805 \%$ & $4.074 \%$ & $3.463 \%$ & $3.193 \%$ & $2.833 \%$ & $2.735 \%$ & $2.775 \%$ & $2.812 \%$ & $2.843 \%$ \\
\hline
\end{tabular}

Table 222 Maximum moment results comparison for alpha 6 for slabs subjected to CHBDC truck loading (main bars perpendicular to traffic)

\begin{tabular}{|c|c|c|c|c|c|c|c|c|c|c|}
\hline & \multicolumn{9}{|c|}{ Maximum Moment (kN.m) } \\
\hline \multirow{9}{*}{ 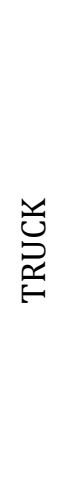 } & $\mathrm{D}$ & \multirow{2}{*}{0.25} & \multirow{2}{*}{0.5} & \multirow{2}{*}{0.75} & \multirow{2}{*}{1} & \multirow{2}{*}{2} & \multirow{2}{*}{4} & \multirow{2}{*}{6} & \multirow{2}{*}{8} & \multirow{2}{*}{10} \\
\hline & SPAN & & & & & & & & & \\
\hline & 1 & $0.651 \%$ & $1.145 \%$ & $1.226 \%$ & $0.545 \%$ & $0.729 \%$ & $0.959 \%$ & $1.120 \%$ & $1.248 \%$ & $1.355 \%$ \\
\hline & 1.5 & $1.816 \%$ & $0.870 \%$ & $0.317 \%$ & $0.012 \%$ & $0.662 \%$ & $0.752 \%$ & $0.866 \%$ & $0.957 \%$ & $1.033 \%$ \\
\hline & 2 & $3.034 \%$ & $2.627 \%$ & $2.116 \%$ & $1.711 \%$ & $0.778 \%$ & $0.127 \%$ & $0.524 \%$ & $0.778 \%$ & $0.844 \%$ \\
\hline & 2.5 & $2.832 \%$ & $3.139 \%$ & $3.036 \%$ & $2.858 \%$ & $2.084 \%$ & $1.047 \%$ & $0.477 \%$ & $0.116 \%$ & $0.132 \%$ \\
\hline & 3 & $1.846 \%$ & $2.980 \%$ & $3.242 \%$ & $3.280 \%$ & $3.035 \%$ & $2.218 \%$ & $1.614 \%$ & $1.191 \%$ & $0.876 \%$ \\
\hline & 3.5 & $1.463 \%$ & $0.750 \%$ & $1.538 \%$ & $1.907 \%$ & $2.250 \%$ & $1.977 \%$ & $1.574 \%$ & $1.188 \%$ & $0.879 \%$ \\
\hline & 4 & $5.922 \%$ & $2.477 \%$ & $1.089 \%$ & $0.351 \%$ & $0.695 \%$ & $0.887 \%$ & $0.726 \%$ & $0.525 \%$ & $0.289 \%$ \\
\hline
\end{tabular}

Table 223 Maximum moment results comparison for alpha 6 for slabs subjected to CHBDC axle 4 loading (main bars parallel to traffic) Maximum Moment (kN.m) 


\begin{tabular}{|c|c|c|c|c|c|c|c|c|c|c|}
\hline \multirow{7}{*}{ 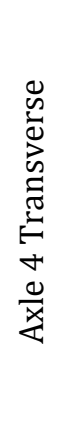 } & $\frac{\text { D }}{\text { SPAN }}$ & .25 & 0.5 & 0.75 & & & 4 & 6 & 8 & 10 \\
\hline & 1 & $4.884 \%$ & $4.815 \%$ & $4.817 \%$ & $4.819 \%$ & $4.805 \%$ & $4.757 \%$ & $4.707 \%$ & $4.661 \%$ & $4.618 \%$ \\
\hline & 1.5 & $3.736 \%$ & $3.660 \%$ & $3.611 \%$ & $3.574 \%$ & $3.541 \%$ & $3.504 \%$ & $3.476 \%$ & $3.452 \%$ & $3.431 \%$ \\
\hline & 2 & $3.314 \%$ & $3.168 \%$ & $3.106 \%$ & $3.065 \%$ & $2.975 \%$ & $2.928 \%$ & $2.898 \%$ & $2.875 \%$ & $2.857 \%$ \\
\hline & 2.5 & $3.076 \%$ & $2.749 \%$ & $2.641 \%$ & $2.584 \%$ & $2.478 \%$ & $2.415 \%$ & $2.389 \%$ & $2.369 \%$ & $2.354 \%$ \\
\hline & 3 & $3.266 \%$ & $2.602 \%$ & $2.383 \%$ & $2.276 \%$ & $2.115 \%$ & $2.027 \%$ & $2.001 \%$ & $1.984 \%$ & $1.971 \%$ \\
\hline & 3.5 & $3.988 \%$ & $2.845 \%$ & $2.443 \%$ & $2.242 \%$ & $1.949 \%$ & $1.803 \%$ & $1.766 \%$ & $1.746 \%$ & $1.733 \%$ \\
\hline
\end{tabular}

Table 224 Maximum moment results comparison for alpha 6 for slabs subjected to CHBDC axle 2 \& 3 loading (main bars parallel to traffic)

\begin{tabular}{|c|c|c|c|c|c|c|c|c|c|c|}
\hline & & \multicolumn{9}{|c|}{ Maximum Moment (kN.m) } \\
\hline \multirow{7}{*}{ 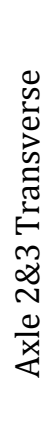 } & $\begin{array}{c}\text { D } \\
\text { SPAN }\end{array}$ & 0.25 & 0.5 & 0.75 & 1 & 2 & 4 & 6 & 8 & 10 \\
\hline & 1.5 & $18.655 \%$ & $18.540 \%$ & $18.424 \%$ & $18.323 \%$ & $18.044 \%$ & $17.751 \%$ & $17.596 \%$ & $17.499 \%$ & $17.461 \%$ \\
\hline & 2 & $6.269 \%$ & $6.301 \%$ & $6.318 \%$ & $6.322 \%$ & $6.305 \%$ & $6.286 \%$ & $6.250 \%$ & $6.213 \%$ & $6.179 \%$ \\
\hline & 2.5 & $4.144 \%$ & $3.944 \%$ & $3.909 \%$ & $3.901 \%$ & $3.902 \%$ & $3.891 \%$ & $3.871 \%$ & $3.873 \%$ & $3.871 \%$ \\
\hline & 3 & $3.807 \%$ & $3.156 \%$ & $2.973 \%$ & $2.899 \%$ & $2.826 \%$ & $2.814 \%$ & $2.811 \%$ & $2.805 \%$ & $2.799 \%$ \\
\hline & 3.5 & $4.552 \%$ & $3.251 \%$ & $2.821 \%$ & $2.621 \%$ & $2.369 \%$ & $2.292 \%$ & $2.278 \%$ & $2.273 \%$ & $2.270 \%$ \\
\hline & 4 & $6.024 \%$ & $3.933 \%$ & $3.174 \%$ & $2.792 \%$ & $2.254 \%$ & $2.043 \%$ & $1.995 \%$ & $1.977 \%$ & $1.969 \%$ \\
\hline
\end{tabular}




\section{Alpha 8 Bending Moment Comparison}

Table 225 Maximum moment results comparison for alpha 8 for slabs subjected to CHBDC axle 4 loading (main bars perpendicular to traffic)

\begin{tabular}{|c|c|c|c|c|c|c|c|c|c|c|}
\hline & \multicolumn{9}{|c|}{ Maximum Moment (kN.m) } \\
\hline \multirow{9}{*}{$\frac{+}{\frac{d}{x}}$} & $\mathrm{D}$ & \multirow{2}{*}{0.25} & \multirow{2}{*}{0.5} & \multirow{2}{*}{0.75} & \multirow{2}{*}{1} & \multirow[b]{2}{*}{ 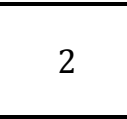 } & \multirow{2}{*}{4} & \multirow{2}{*}{6} & \multirow{2}{*}{8} & \multirow{2}{*}{10} \\
\hline & SPAN & & & & & & & & & \\
\hline & 1 & $0.294 \%$ & $0.395 \%$ & $0.467 \%$ & $0.524 \%$ & $0.691 \%$ & $0.899 \%$ & $1.046 \%$ & $1.159 \%$ & $1.255 \%$ \\
\hline & 1.5 & $0.340 \%$ & $0.389 \%$ & $0.433 \%$ & $0.471 \%$ & $0.581 \%$ & $0.724 \%$ & $0.824 \%$ & $0.905 \%$ & $0.972 \%$ \\
\hline & 2 & $0.390 \%$ & $0.329 \%$ & $0.347 \%$ & $0.373 \%$ & $0.463 \%$ & $0.586 \%$ & $0.672 \%$ & $0.741 \%$ & $0.799 \%$ \\
\hline & 2.5 & $0.818 \%$ & $0.474 \%$ & $0.405 \%$ & $0.391 \%$ & $0.432 \%$ & $0.529 \%$ & $0.605 \%$ & $0.665 \%$ & $0.716 \%$ \\
\hline & 3 & $1.331 \%$ & $0.550 \%$ & $0.329 \%$ & $0.244 \%$ & $0.195 \%$ & $0.271 \%$ & $0.346 \%$ & $0.408 \%$ & $0.461 \%$ \\
\hline & 3.5 & $2.875 \%$ & $1.484 \%$ & $1.017 \%$ & $0.798 \%$ & $0.540 \%$ & $0.511 \%$ & $0.550 \%$ & $0.593 \%$ & $0.633 \%$ \\
\hline & 4 & $6.440 \%$ & $3.988 \%$ & $3.099 \%$ & $2.646 \%$ & $1.998 \%$ & $1.760 \%$ & $1.727 \%$ & $1.732 \%$ & $1.748 \%$ \\
\hline
\end{tabular}

Table 226 Maximum moment results comparison for alpha 8 for slabs subjected to CHBDC axle 2 \& 3 loading (main bars perpendicular to traffic)

\begin{tabular}{|c|c|c|c|c|c|c|c|c|c|c|}
\hline & \multicolumn{9}{|c|}{ Maximum Moment (kN.m) } \\
\hline \multirow{9}{*}{$\begin{array}{l}m \\
\tilde{J} \\
\tilde{J} \\
\stackrel{u}{x} \\
\frac{\vec{x}}{4}\end{array}$} & $\mathrm{D}$ & \multirow{2}{*}{0.25} & \multirow{2}{*}{0.5} & \multirow{2}{*}{0.75} & \multirow{2}{*}{1} & & \multirow{2}{*}{4} & \multirow{2}{*}{6} & \multirow{2}{*}{8} & \multirow{2}{*}{10} \\
\hline & SPAN & & & & & & & & & \\
\hline & 1 & $1.392 \%$ & $1.271 \%$ & $1.180 \%$ & $1.104 \%$ & $1.134 \%$ & $1.130 \%$ & $1.107 \%$ & $1.080 \%$ & $1.054 \%$ \\
\hline & 1.5 & $1.423 \%$ & $1.254 \%$ & $1.205 \%$ & $1.167 \%$ & $1.049 \%$ & $1.087 \%$ & $1.100 \%$ & $1.104 \%$ & $1.105 \%$ \\
\hline & 2 & $1.471 \%$ & $1.202 \%$ & $1.097 \%$ & $1.066 \%$ & $0.962 \%$ & $0.961 \%$ & $0.985 \%$ & $0.999 \%$ & $1.008 \%$ \\
\hline & 2.5 & $1.893 \%$ & $1.327 \%$ & $1.126 \%$ & $1.056 \%$ & $0.928 \%$ & $0.886 \%$ & $0.909 \%$ & $0.925 \%$ & $0.937 \%$ \\
\hline & 3 & $2.590 \%$ & $1.540 \%$ & $1.173 \%$ & $1.009 \%$ & $0.781 \%$ & $0.691 \%$ & $0.711 \%$ & $0.728 \%$ & $0.743 \%$ \\
\hline & 3.5 & $4.111 \%$ & $2.418 \%$ & $1.798 \%$ & $1.534 \%$ & $1.170 \%$ & $1.080 \%$ & $1.118 \%$ & $1.154 \%$ & $1.184 \%$ \\
\hline & 4 & $7.979 \%$ & $5.303 \%$ & $4.283 \%$ & $3.774 \%$ & $3.031 \%$ & $2.732 \%$ & $2.718 \%$ & $2.735 \%$ & $2.758 \%$ \\
\hline
\end{tabular}

Table 227 Maximum moment results comparison for alpha 8 for slabs subjected to CHBDC truck loading (main bars perpendicular to traffic)

\begin{tabular}{|c|c|c|c|c|c|c|c|c|c|c|}
\hline & \multicolumn{9}{|c|}{ Maximum Moment (kN.m) } \\
\hline \multirow{9}{*}{ 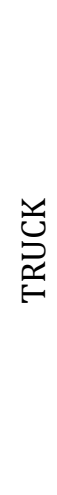 } & $\mathrm{D}$ & \multirow{2}{*}{0.25} & \multirow{2}{*}{0.5} & \multirow{2}{*}{0.75} & \multirow{2}{*}{1} & \multirow{2}{*}{2} & \multirow{2}{*}{4} & \multirow{2}{*}{6} & \multirow{2}{*}{8} & \multirow{2}{*}{10} \\
\hline & SPAN & & & & & & & & & \\
\hline & 1 & $0.214 \%$ & $0.579 \%$ & $0.853 \%$ & $1.033 \%$ & $0.686 \%$ & $0.898 \%$ & $1.045 \%$ & $1.159 \%$ & $1.255 \%$ \\
\hline & 1.5 & $2.734 \%$ & $1.852 \%$ & $1.247 \%$ & $0.841 \%$ & $0.044 \%$ & $0.740 \%$ & $0.815 \%$ & $0.897 \%$ & $0.967 \%$ \\
\hline & 2 & $3.118 \%$ & $3.150 \%$ & $2.911 \%$ & $2.590 \%$ & $1.665 \%$ & $0.611 \%$ & $0.077 \%$ & $0.245 \%$ & $0.459 \%$ \\
\hline & 2.5 & $2.059 \%$ & $3.031 \%$ & $3.204 \%$ & $3.191 \%$ & $2.849 \%$ & $1.910 \%$ & $1.294 \%$ & $0.872 \%$ & $0.562 \%$ \\
\hline & 3 & $0.187 \%$ & $2.173 \%$ & $2.832 \%$ & $3.118 \%$ & $3.319 \%$ & $2.941 \%$ & $2.442 \%$ & $2.027 \%$ & $1.697 \%$ \\
\hline & 3.5 & $4.245 \%$ & $0.982 \%$ & $0.334 \%$ & $1.037 \%$ & $2.032 \%$ & $2.215 \%$ & $2.063 \%$ & $1.873 \%$ & $1.643 \%$ \\
\hline & 4 & $9.910 \%$ & $5.210 \%$ & $3.173 \%$ & $2.014 \%$ & $0.103 \%$ & $0.750 \%$ & $0.875 \%$ & $0.832 \%$ & $0.738 \%$ \\
\hline
\end{tabular}

Table 228 Maximum moment results comparison for alpha 8 for slabs subjected to CHBDC axle 4 loading (main bars parallel to traffic) Maximum Moment (kN.m) 


\begin{tabular}{|c|c|c|c|c|c|c|c|c|c|c|}
\hline \multirow{7}{*}{ 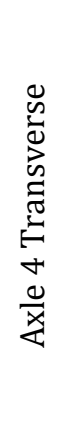 } & $\frac{\mathrm{D}}{\text { SPAN }}$ & & 0.5 & 0.75 & & & & 6 & 8 & 0 \\
\hline & 1 & $4.891 \%$ & $4.835 \%$ & $4.795 \%$ & $4.796 \%$ & $4.800 \%$ & $4.783 \%$ & $4.757 \%$ & $4.731 \%$ & $4.704 \%$ \\
\hline & 1.5 & $3.787 \%$ & $3.693 \%$ & $3.646 \%$ & $3.612 \%$ & $3.547 \%$ & $3.520 \%$ & $3.499 \%$ & $3.481 \%$ & $3.466 \%$ \\
\hline & 2 & $3.517 \%$ & $3.263 \%$ & $3.174 \%$ & $3.123 \%$ & $3.018 \%$ & $2.953 \%$ & $2.925 \%$ & $2.905 \%$ & $2.888 \%$ \\
\hline & 2.5 & $3.586 \%$ & $2.991 \%$ & $2.794 \%$ & $2.696 \%$ & $2.541 \%$ & $2.443 \%$ & $2.414 \%$ & $2.395 \%$ & $2.380 \%$ \\
\hline & 3 & $4.236 \%$ & $3.111 \%$ & $2.715 \%$ & $2.517 \%$ & $2.225 \%$ & $2.075 \%$ & $2.029 \%$ & $2.009 \%$ & $1.994 \%$ \\
\hline & 3.5 & $5.523 \%$ & $3.735 \%$ & $3.057 \%$ & $2.703 \%$ & $2.165 \%$ & $1.902 \%$ & $1.816 \%$ & $1.783 \%$ & $1.763 \%$ \\
\hline
\end{tabular}

Table 229 Maximum moment results comparison for alpha 8 for slabs subjected to CHBDC axle 2 \& 3 loading (main bars parallel to traffic)

\begin{tabular}{|c|c|c|c|c|c|c|c|c|c|c|}
\hline & & \multicolumn{9}{|c|}{ Maximum Moment (kN.m) } \\
\hline \multirow{8}{*}{ 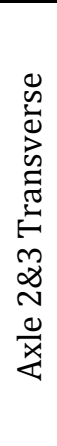 } & $\mathrm{D}$ & \multirow{2}{*}{0.25} & \multirow{2}{*}{0.5} & \multirow{2}{*}{0.75} & \multirow{2}{*}{1} & \multirow{2}{*}{2} & \multirow{2}{*}{4} & \multirow{2}{*}{6} & \multirow{2}{*}{8} & \multirow{2}{*}{10} \\
\hline & SPAN & & & & & & & & & \\
\hline & 1.5 & $18.684 \%$ & $18.643 \%$ & $18.580 \%$ & $18.513 \%$ & $18.288 \%$ & $18.006 \%$ & $17.836 \%$ & $17.720 \%$ & $17.635 \%$ \\
\hline & 2 & $6.278 \%$ & $6.251 \%$ & $6.269 \%$ & $6.283 \%$ & $6.296 \%$ & $6.299 \%$ & $6.290 \%$ & $6.272 \%$ & $6.253 \%$ \\
\hline & 2.5 & $4.562 \%$ & $4.083 \%$ & $3.961 \%$ & $3.915 \%$ & $3.881 \%$ & $3.878 \%$ & $3.870 \%$ & $3.859 \%$ & $3.863 \%$ \\
\hline & 3 & $4.856 \%$ & $3.655 \%$ & $3.266 \%$ & $3.086 \%$ & $2.868 \%$ & $2.805 \%$ & $2.795 \%$ & $2.791 \%$ & $2.788 \%$ \\
\hline & 3.5 & $6.388 \%$ & $4.267 \%$ & $3.495 \%$ & $3.105 \%$ & $2.554 \%$ & $2.337 \%$ & $2.288 \%$ & $2.269 \%$ & $2.261 \%$ \\
\hline & 4 & $8.726 \%$ & $5.578 \%$ & $4.342 \%$ & $3.683 \%$ & $2.667 \%$ & $2.196 \%$ & $2.067 \%$ & $2.014 \%$ & $1.987 \%$ \\
\hline
\end{tabular}




\section{Alpha 10 Bending Moment Comparison}

Table 230 Maximum moment results comparison for alpha 10 for slabs subjected to CHBDC axle 4 loading (main bars perpendicular to traffic)

\begin{tabular}{|c|c|c|c|c|c|c|c|c|c|c|}
\hline & \multicolumn{9}{|c|}{ Maximum Moment (kN.m) } \\
\hline \multirow{9}{*}{$\frac{+}{\frac{d}{x}}$} & $\mathrm{D}$ & \multirow{2}{*}{0.25} & \multirow{2}{*}{0.5} & \multirow{2}{*}{0.75} & \multirow{2}{*}{1} & \multirow[b]{2}{*}{2} & \multirow{2}{*}{4} & \multirow{2}{*}{6} & \multirow{2}{*}{8} & \multirow{2}{*}{10} \\
\hline & SPAN & & & & & & & & & \\
\hline & 1 & $0.284 \%$ & $0.380 \%$ & $0.447 \%$ & $0.502 \%$ & $0.659 \%$ & $0.852 \%$ & $0.984 \%$ & $1.089 \%$ & $1.176 \%$ \\
\hline & 1.5 & $0.367 \%$ & $0.390 \%$ & $0.427 \%$ & $0.462 \%$ & $0.564 \%$ & $0.695 \%$ & $0.787 \%$ & $0.862 \%$ & $0.923 \%$ \\
\hline & 2 & $0.558 \%$ & $0.383 \%$ & $0.366 \%$ & $0.376 \%$ & $0.448 \%$ & $0.559 \%$ & $0.639 \%$ & $0.702 \%$ & $0.755 \%$ \\
\hline & 2.5 & $1.290 \%$ & $0.679 \%$ & $0.517 \%$ & $0.458 \%$ & $0.439 \%$ & $0.511 \%$ & $0.577 \%$ & $0.631 \%$ & $0.677 \%$ \\
\hline & 3 & $2.221 \%$ & $1.001 \%$ & $0.607 \%$ & $0.431 \%$ & $0.247 \%$ & $0.260 \%$ & $0.316 \%$ & $0.368 \%$ & $0.415 \%$ \\
\hline & 3.5 & $4.273 \%$ & $2.284 \%$ & $1.560 \%$ & $1.197 \%$ & $0.703 \%$ & $0.553 \%$ & $0.555 \%$ & $0.580 \%$ & $0.610 \%$ \\
\hline & 4 & $8.720 \%$ & $5.390 \%$ & $4.091 \%$ & $3.415 \%$ & $2.376 \%$ & $1.913 \%$ & $1.805 \%$ & $1.775 \%$ & $1.771 \%$ \\
\hline
\end{tabular}

Table 231 Maximum moment results comparison for alpha 10 for slabs subjected to CHBDC axle 2 \& 3 loading (main bars perpendicular to traffic)

\begin{tabular}{|c|c|c|c|c|c|c|c|c|c|c|}
\hline & \multicolumn{9}{|c|}{ Maximum Moment (kN.m) } \\
\hline \multirow{9}{*}{ 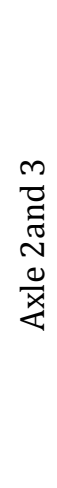 } & D & \multirow{2}{*}{0.25} & \multirow{2}{*}{0.5} & \multirow{2}{*}{0.75} & \multirow{2}{*}{1} & \multirow{2}{*}{2} & \multirow[t]{2}{*}{4} & \multirow{2}{*}{6} & \multirow{2}{*}{8} & \multirow{2}{*}{10} \\
\hline & SPAN & & & & & & & & & \\
\hline & 1 & $1.272 \%$ & $1.196 \%$ & $1.138 \%$ & $1.075 \%$ & $1.109 \%$ & $1.134 \%$ & $1.132 \%$ & $1.121 \%$ & $1.109 \%$ \\
\hline & 1.5 & $1.322 \%$ & $1.173 \%$ & $1.137 \%$ & $1.111 \%$ & $1.007 \%$ & $1.058 \%$ & $1.080 \%$ & $1.092 \%$ & $1.099 \%$ \\
\hline & 2 & $1.549 \%$ & $1.183 \%$ & $1.062 \%$ & $1.025 \%$ & $0.933 \%$ & $0.924 \%$ & $0.952 \%$ & $0.971 \%$ & $0.984 \%$ \\
\hline & 2.5 & $2.329 \%$ & $1.493 \%$ & $1.205 \%$ & $1.093 \%$ & $0.922 \%$ & $0.855 \%$ & $0.878 \%$ & $0.896 \%$ & $0.909 \%$ \\
\hline & 3 & $3.508 \%$ & $2.002 \%$ & $1.459 \%$ & $1.200 \%$ & $0.836 \%$ & $0.680 \%$ & $0.686 \%$ & $0.699 \%$ & $0.712 \%$ \\
\hline & 3.5 & $5.587 \%$ & $3.273 \%$ & $2.378 \%$ & $1.929 \%$ & $1.302 \%$ & $1.073 \%$ & $1.074 \%$ & $1.097 \%$ & $1.122 \%$ \\
\hline & 4 & $10.351 \%$ & $6.768 \%$ & $5.330 \%$ & $4.570 \%$ & $3.387 \%$ & $2.830 \%$ & $2.733 \%$ & $2.713 \%$ & $2.717 \%$ \\
\hline
\end{tabular}

Table 232 Maximum moment results comparison for alpha 10 for slabs subjected to CHBDC truck loading (main bars perpendicular to traffic)

\begin{tabular}{|c|c|c|c|c|c|c|c|c|c|c|}
\hline & \multicolumn{9}{|c|}{ Maximum Moment (kN.m) } \\
\hline \multirow{9}{*}{ 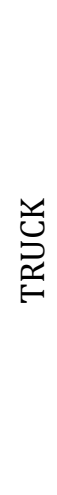 } & $\mathrm{D}$ & \multirow{2}{*}{0.25} & \multirow{2}{*}{0.5} & \multirow{2}{*}{0.75} & \multirow[b]{2}{*}{1} & \multirow{2}{*}{2} & \multirow{2}{*}{4} & \multirow{2}{*}{6} & \multirow{2}{*}{8} & \multirow{2}{*}{10} \\
\hline & SPAN & & & & & & & & & \\
\hline & 1 & $0.968 \%$ & $0.006 \%$ & $0.411 \%$ & $0.677 \%$ & $1.155 \%$ & $0.847 \%$ & $0.982 \%$ & $1.087 \%$ & $1.174 \%$ \\
\hline & 1.5 & $3.153 \%$ & $2.564 \%$ & $1.988 \%$ & $1.565 \%$ & $0.565 \%$ & $0.324 \%$ & $0.704 \%$ & $0.848 \%$ & $0.913 \%$ \\
\hline & 2 & $2.812 \%$ & $3.287 \%$ & $3.222 \%$ & $3.075 \%$ & $2.343 \%$ & $1.272 \%$ & $0.667 \%$ & $0.275 \%$ & $0.001 \%$ \\
\hline & 2.5 & $0.971 \%$ & $2.574 \%$ & $3.037 \%$ & $3.200 \%$ & $3.162 \%$ & $2.552 \%$ & $1.961 \%$ & $1.526 \%$ & $1.191 \%$ \\
\hline & 3 & $1.672 \%$ & $1.076 \%$ & $2.113 \%$ & $2.638 \%$ & $3.298 \%$ & $3.231 \%$ & $2.957 \%$ & $2.644 \%$ & $2.336 \%$ \\
\hline & 3.5 & $7.077 \%$ & $2.899 \%$ & $1.112 \%$ & $0.107 \%$ & $1.507 \%$ & $2.159 \%$ & $2.207 \%$ & $2.127 \%$ & $2.011 \%$ \\
\hline & 4 & $13.792 \%$ & $8.018 \%$ & $5.417 \%$ & $3.888 \%$ & $1.192 \%$ & $0.292 \%$ & $0.708 \%$ & $0.838 \%$ & $0.857 \%$ \\
\hline
\end{tabular}

Table 233 Maximum moment results comparison for alpha 10 for slabs subjected to CHBDC axle 4 loading (main bars parallel to traffic) Maximum Moment (kN.m) 


\begin{tabular}{|c|c|c|c|c|c|c|c|c|c|c|}
\hline \multirow{7}{*}{ 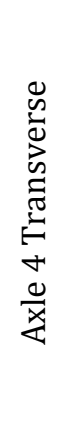 } & $\frac{\mathrm{D}}{\text { SPAN }}$ & & 0.5 & 0.75 & & 2 & 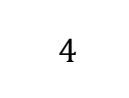 & 6 & 8 & 10 \\
\hline & 1 & $4.904 \%$ & $4.852 \%$ & $4.819 \%$ & $4.793 \%$ & $4.790 \%$ & $4.790 \%$ & $4.778 \%$ & $4.763 \%$ & $4.746 \%$ \\
\hline & 1.5 & $3.861 \%$ & $3.732 \%$ & $3.679 \%$ & $3.645 \%$ & $3.564 \%$ & $3.530 \%$ & $3.514 \%$ & $3.500 \%$ & $3.488 \%$ \\
\hline & 2 & $3.794 \%$ & $3.393 \%$ & $3.259 \%$ & $3.190 \%$ & $3.067 \%$ & $2.975 \%$ & $2.948 \%$ & $2.928 \%$ & $2.913 \%$ \\
\hline & 2.5 & $4.227 \%$ & $3.317 \%$ & $3.004 \%$ & $2.849 \%$ & $2.617 \%$ & $2.485 \%$ & $2.439 \%$ & $2.418 \%$ & $2.403 \%$ \\
\hline & 3 & $5.359 \%$ & $3.750 \%$ & $3.152 \%$ & $2.843 \%$ & $2.378 \%$ & $2.149 \%$ & $2.068 \%$ & $2.037 \%$ & $2.018 \%$ \\
\hline & 3.5 & 7.191\% & $4.773 \%$ & $3.809 \%$ & $3.288 \%$ & $2.459 \%$ & $2.038 \%$ & $1.901 \%$ & $1.834 \%$ & $1.802 \%$ \\
\hline
\end{tabular}

Table 234 Maximum moment results comparison for alpha 10 for slabs subjected to CHBDC axle 2 \& 3 loading (main bars parallel to traffic)

\begin{tabular}{|c|c|c|c|c|c|c|c|c|c|c|}
\hline & & \multicolumn{9}{|c|}{ Maximum Moment (kN.m) } \\
\hline \multirow{8}{*}{ 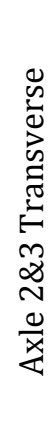 } & $\mathrm{D}$ & \multirow{2}{*}{0.25} & \multirow{2}{*}{0.5} & \multirow{2}{*}{0.75} & \multirow{2}{*}{1} & \multirow{2}{*}{2} & \multirow{2}{*}{4} & \multirow{2}{*}{6} & \multirow{2}{*}{8} & \multirow{2}{*}{10} \\
\hline & SPAN & & & & & & & & & \\
\hline & 1.5 & $18.687 \%$ & $18.665 \%$ & $18.648 \%$ & $18.611 \%$ & $18.446 \%$ & $18.197 \%$ & $18.031 \%$ & $17.909 \%$ & $17.816 \%$ \\
\hline & 2 & $6.377 \%$ & $6.243 \%$ & $6.237 \%$ & $6.248 \%$ & $6.279 \%$ & $6.284 \%$ & $6.296 \%$ & $6.293 \%$ & $6.285 \%$ \\
\hline & 2.5 & $5.152 \%$ & $4.334 \%$ & $4.092 \%$ & $3.989 \%$ & $3.883 \%$ & $3.866 \%$ & $3.864 \%$ & $3.860 \%$ & $3.854 \%$ \\
\hline & 3 & $6.116 \%$ & $4.329 \%$ & $3.701 \%$ & $3.391 \%$ & $2.972 \%$ & $2.823 \%$ & $2.794 \%$ & $2.785 \%$ & $2.780 \%$ \\
\hline & 3.5 & $8.419 \%$ & $5.492 \%$ & $4.359 \%$ & $3.760 \%$ & $2.850 \%$ & $2.442 \%$ & $2.334 \%$ & $2.291 \%$ & $2.270 \%$ \\
\hline & 4 & $11.561 \%$ & $7.424 \%$ & $5.719 \%$ & $4.775 \%$ & $3.236 \%$ & $2.446 \%$ & $2.206 \%$ & $2.100 \%$ & $2.043 \%$ \\
\hline
\end{tabular}




\section{D.1.2 MAXIMUM BENDING MOMENT VS SPAN LENGTH}




\section{Alpha 0.25 Bending Moment VS Span Length for Different D Values (Main bars perpendicular to traffic)}

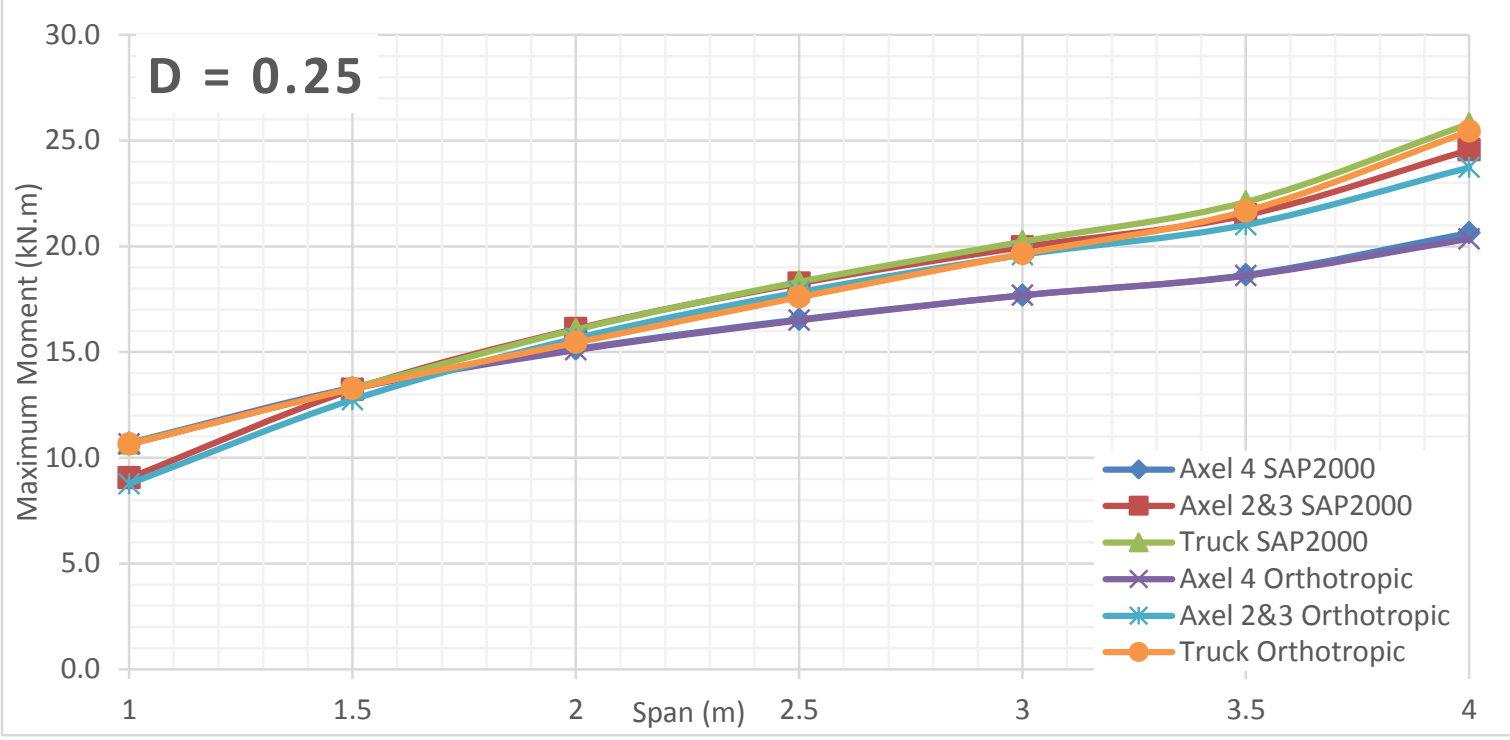

Figure 493 Moment comparison between FEA and Orthotropic Plate Theory for D = 0.25 of alpha 0.25 (main bars perpendicular traffic)

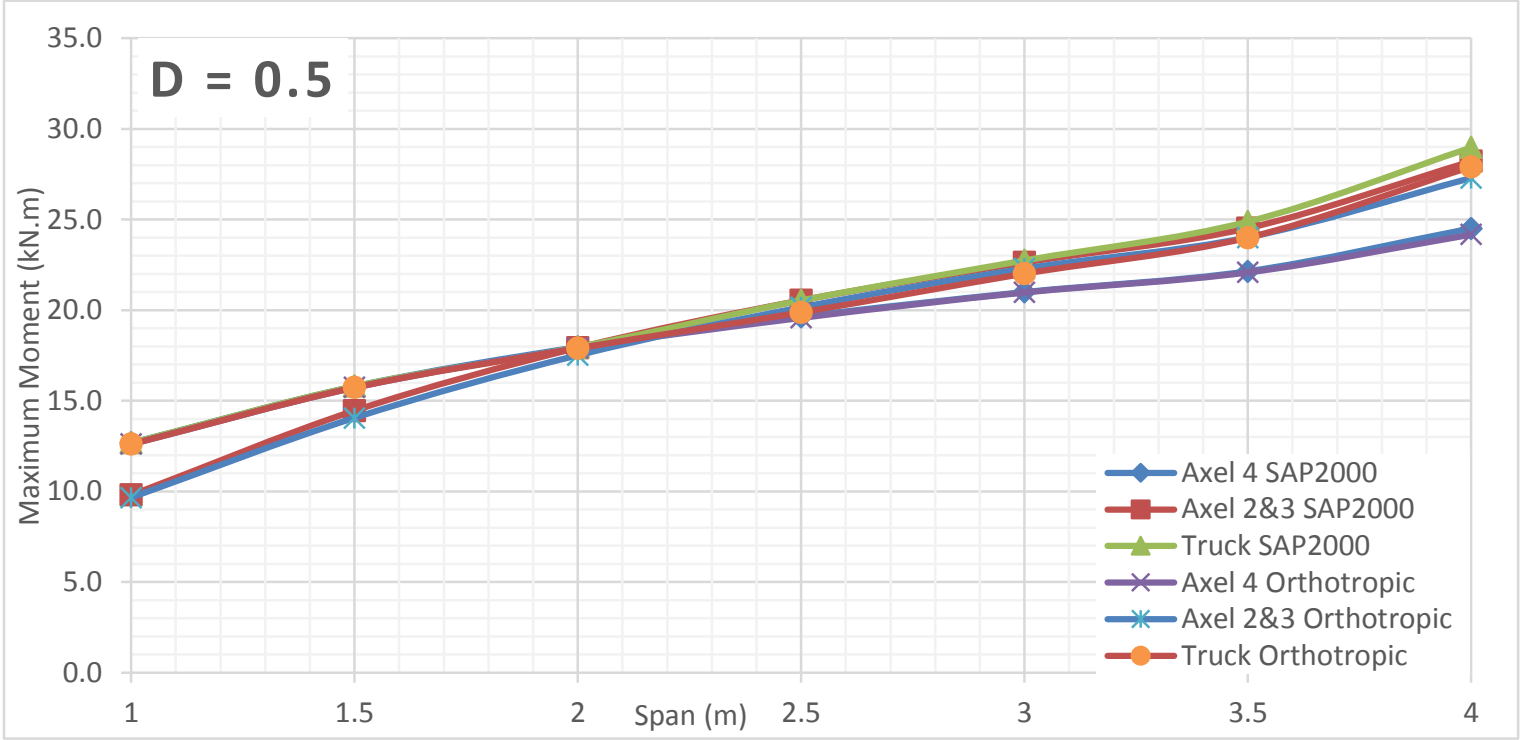

Figure 494 Moment comparison between FEA and Orthotropic Plate Theory for $D=0.5$ of alpha 0.25 (main bars perpendicular traffic) 


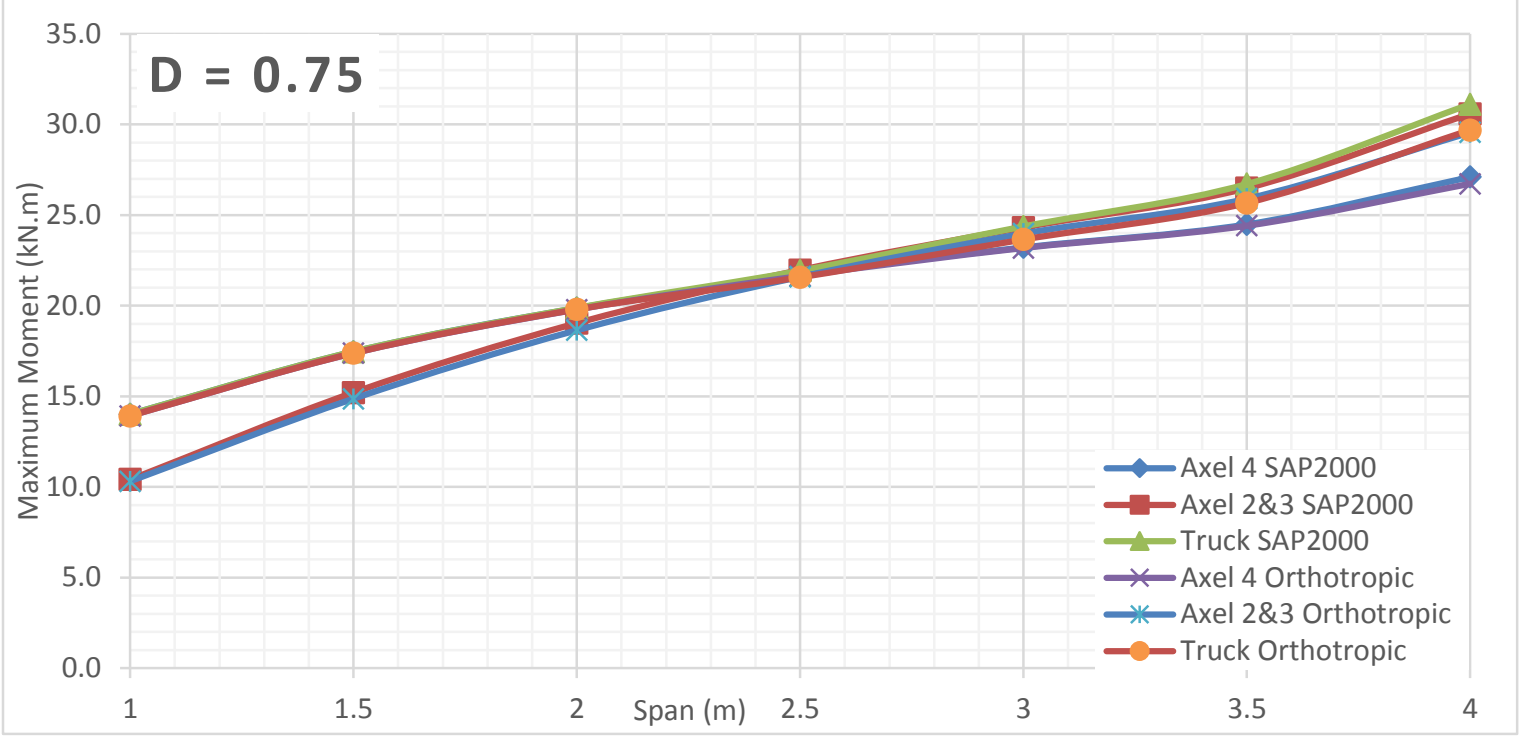

Figure 495 Moment comparison between FEA and Orthotropic Plate Theory for $D=0.75$ of alpha 0.25 (main bars perpendicular traffic)

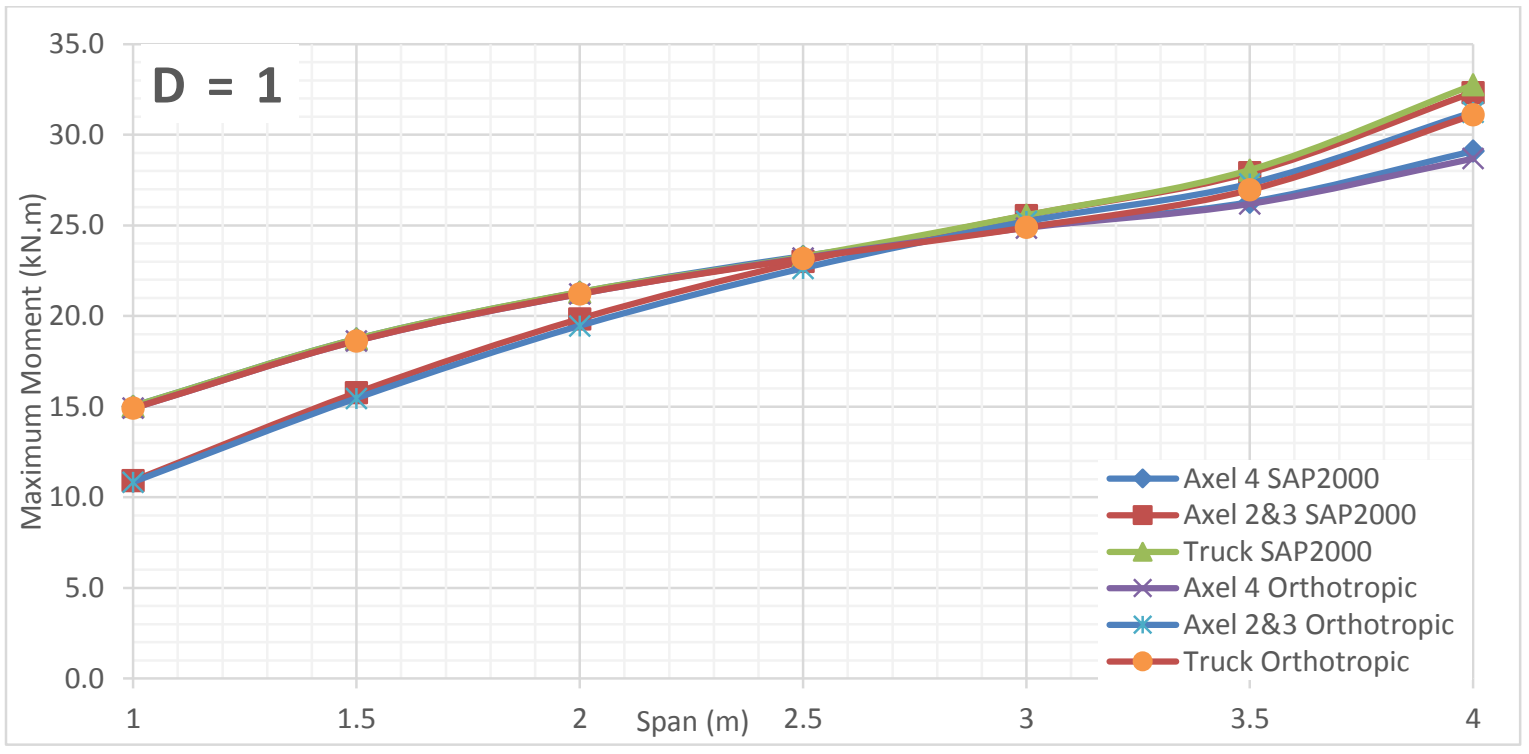

Figure 496 Moment comparison between FEA and Orthotropic Plate Theory for $D=1$ of alpha 0.25 (main bars perpendicular traffic)

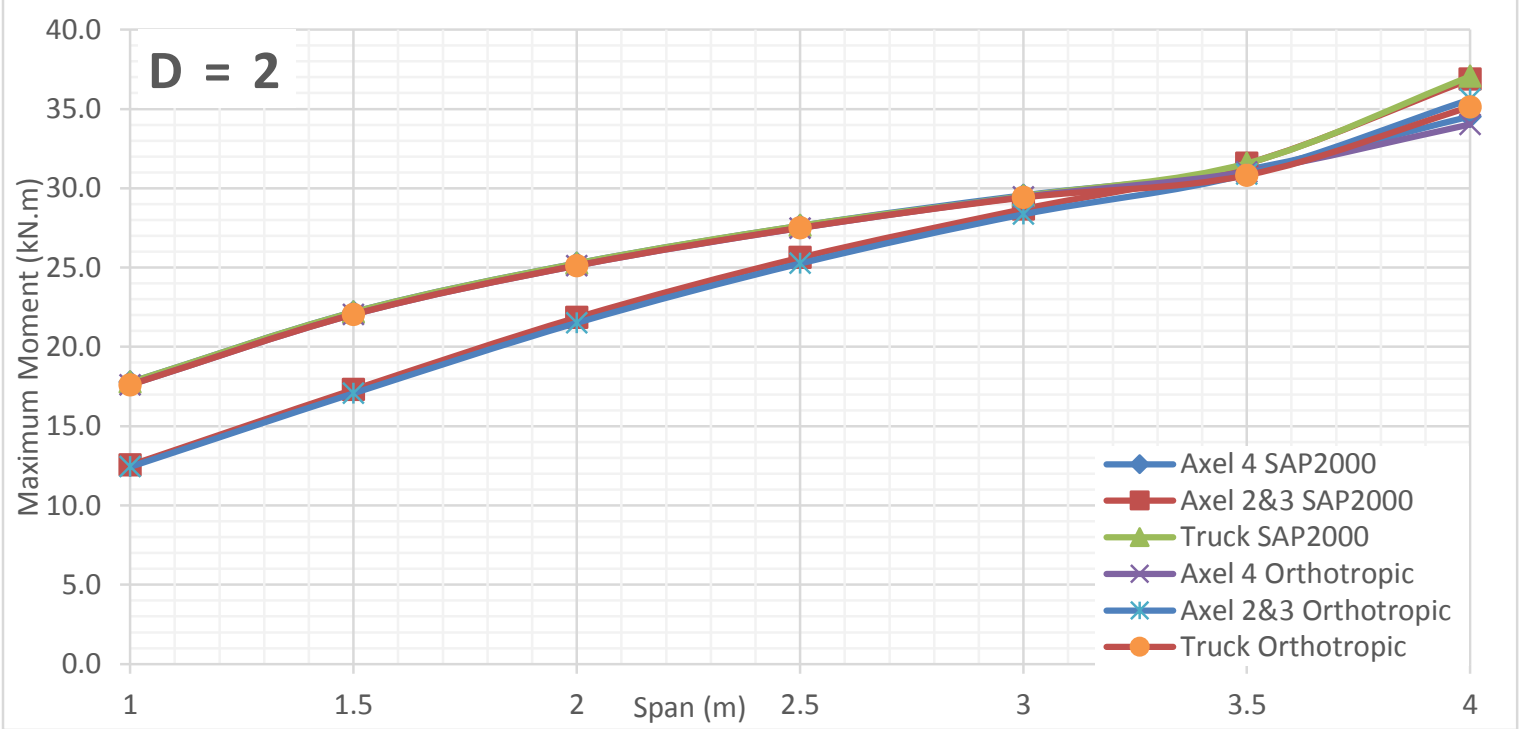

Figure 497 Moment comparison between FEA and Orthotropic Plate Theory for $D=2$ of alpha 0.25 (main bars perpendicular traffic) 


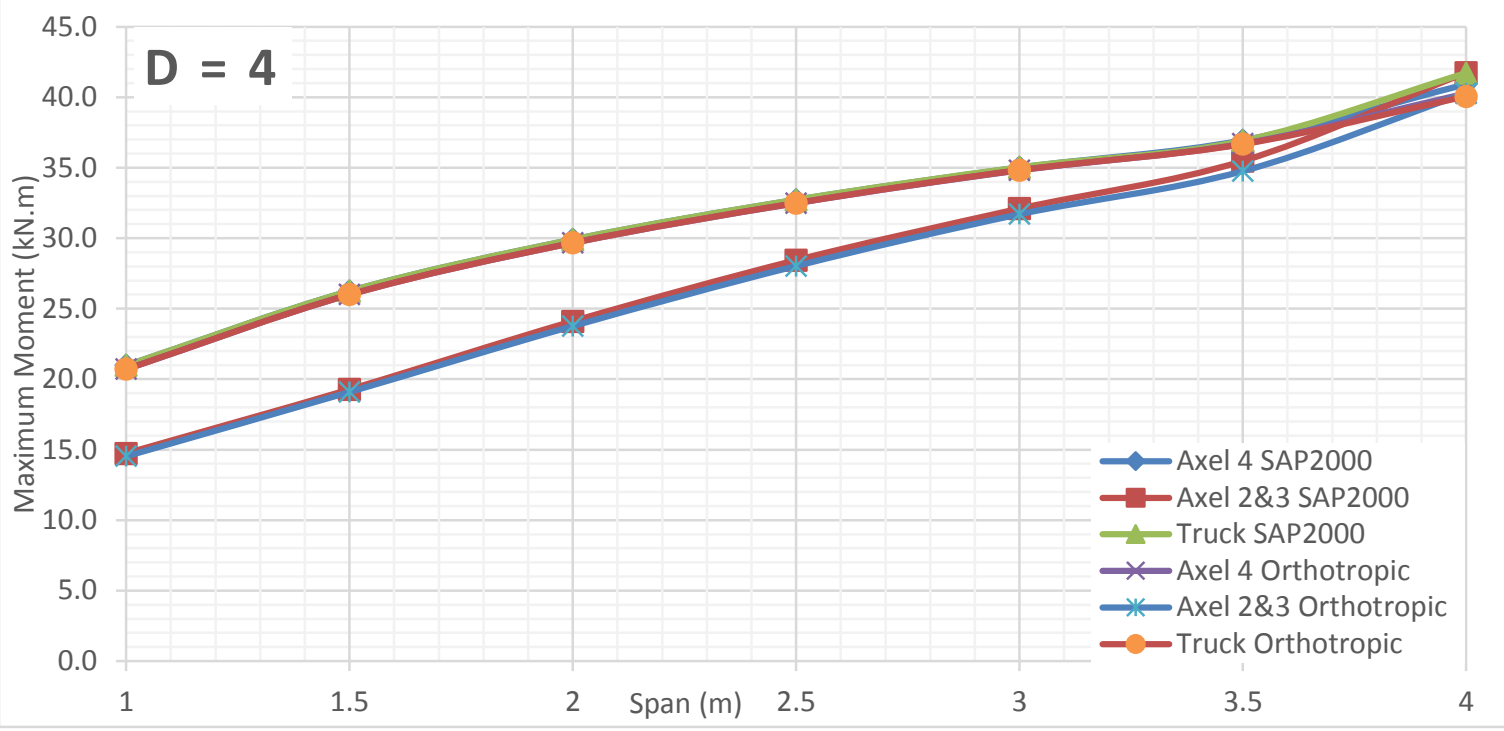

Figure 498 Moment comparison between FEA and Orthotropic Plate Theory for $D=4$ of alpha 0.25 (main bars perpendicular traffic)

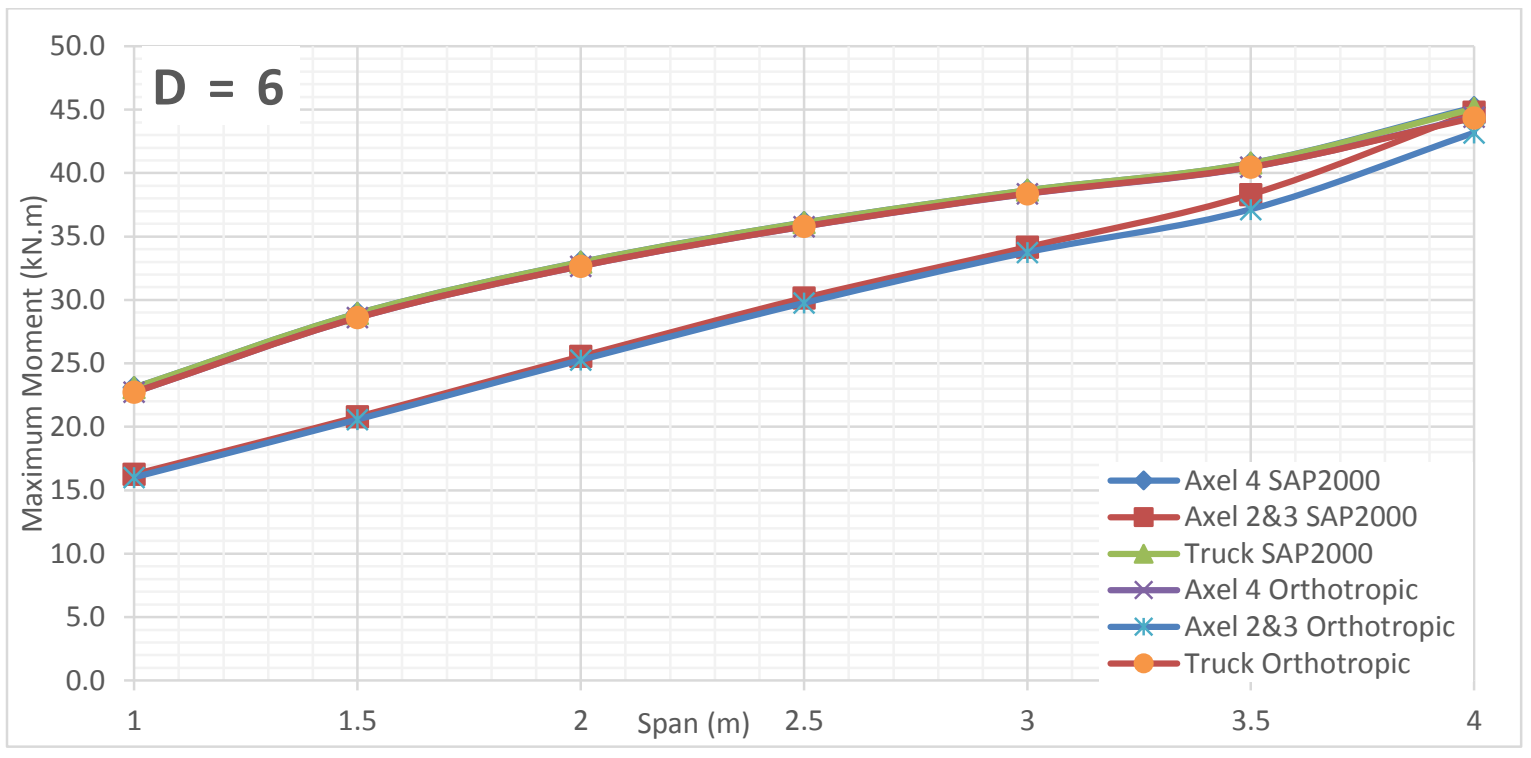

Figure 499 Moment comparison between FEA and Orthotropic Plate Theory for D $=6$ of alpha 0.25 (main bars perpendicular traffic)

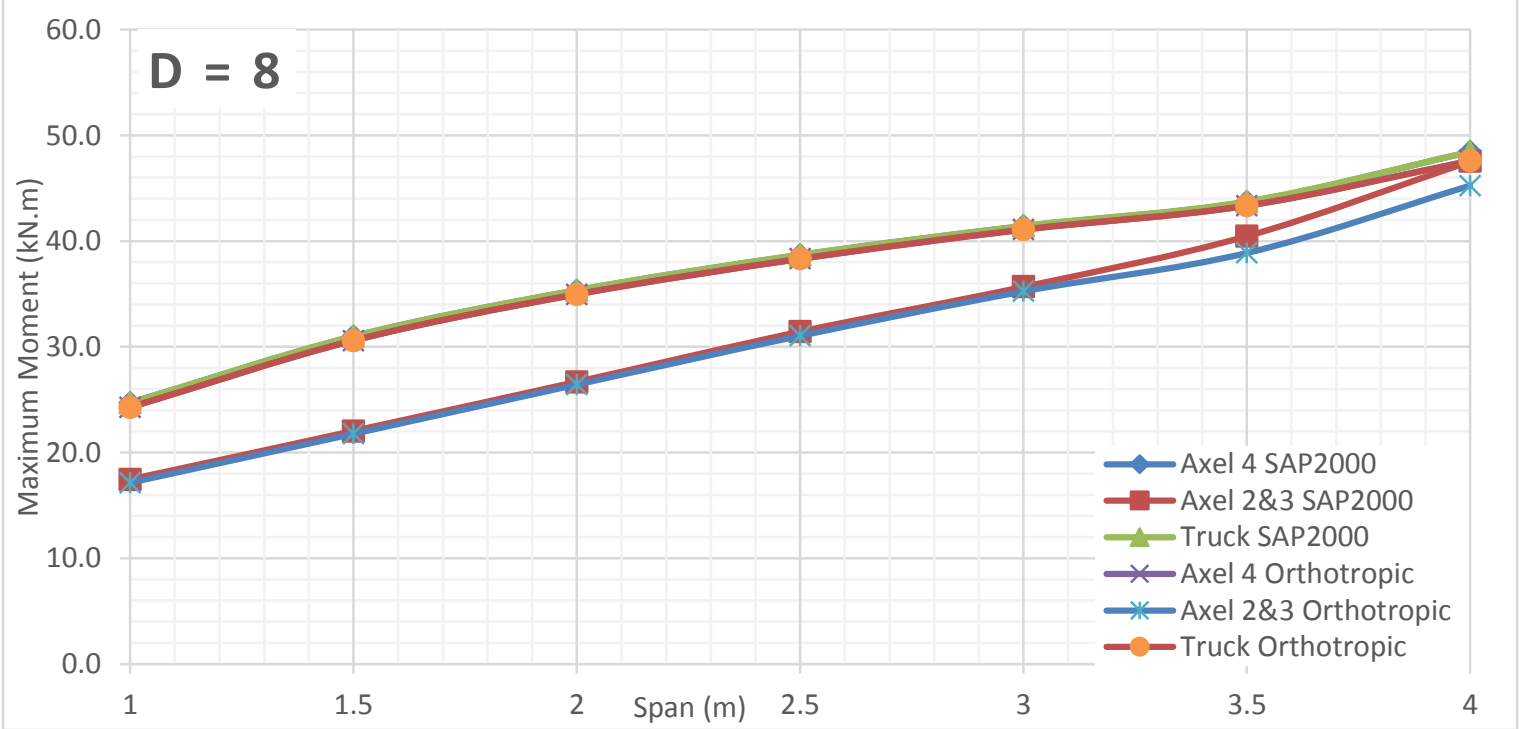

Figure 500 Moment comparison between FEA and Orthotropic Plate Theory for $D=8$ of alpha 0.25 (main bars perpendicular traffic) 


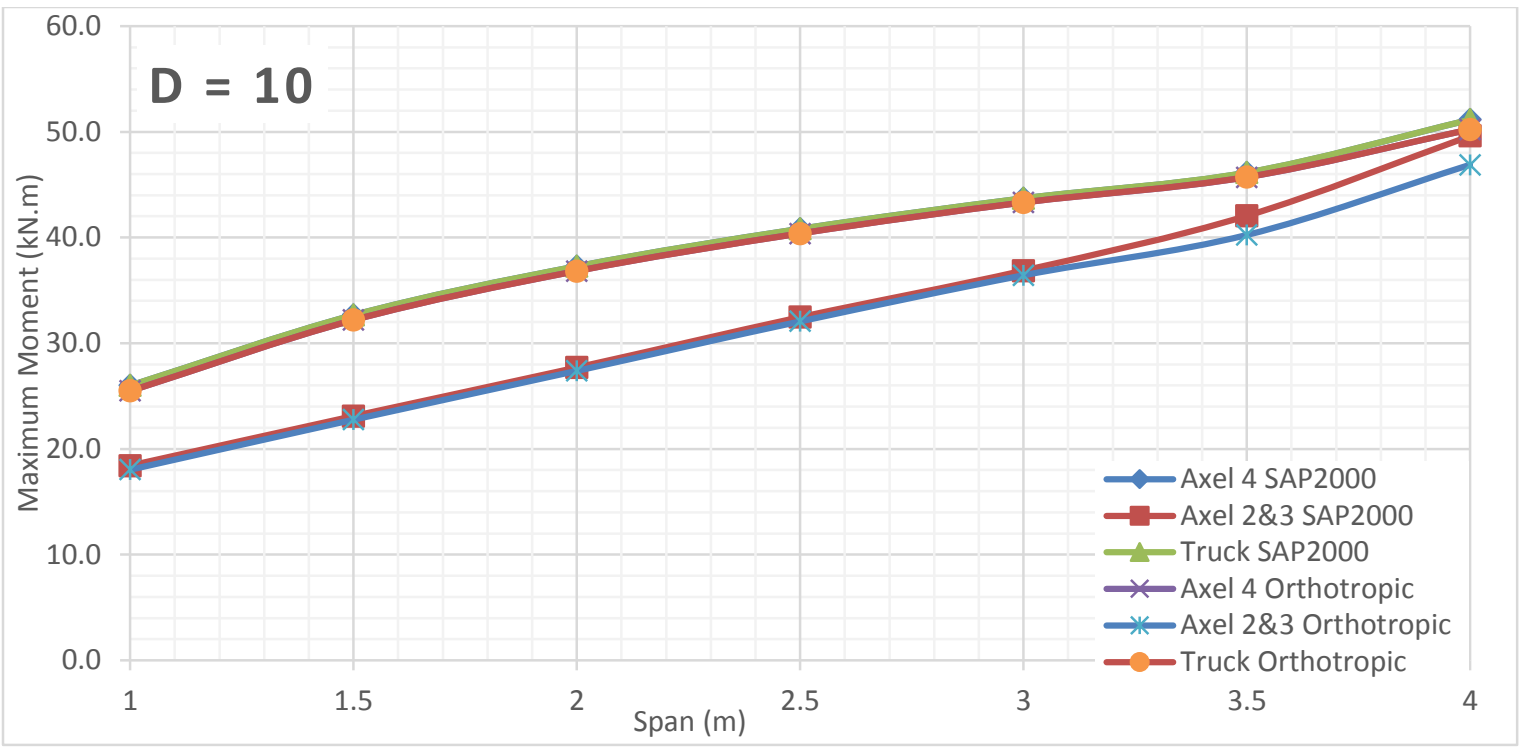

Figure 501 Moment comparison between FEA and Orthotropic Plate Theory for $D=10$ of alpha 0.25 (main bars perpendicular traffic) 


\section{Alpha 0.25 Bending Moment VS Span Length for Different D Values (Main bars parallel to traffic)}

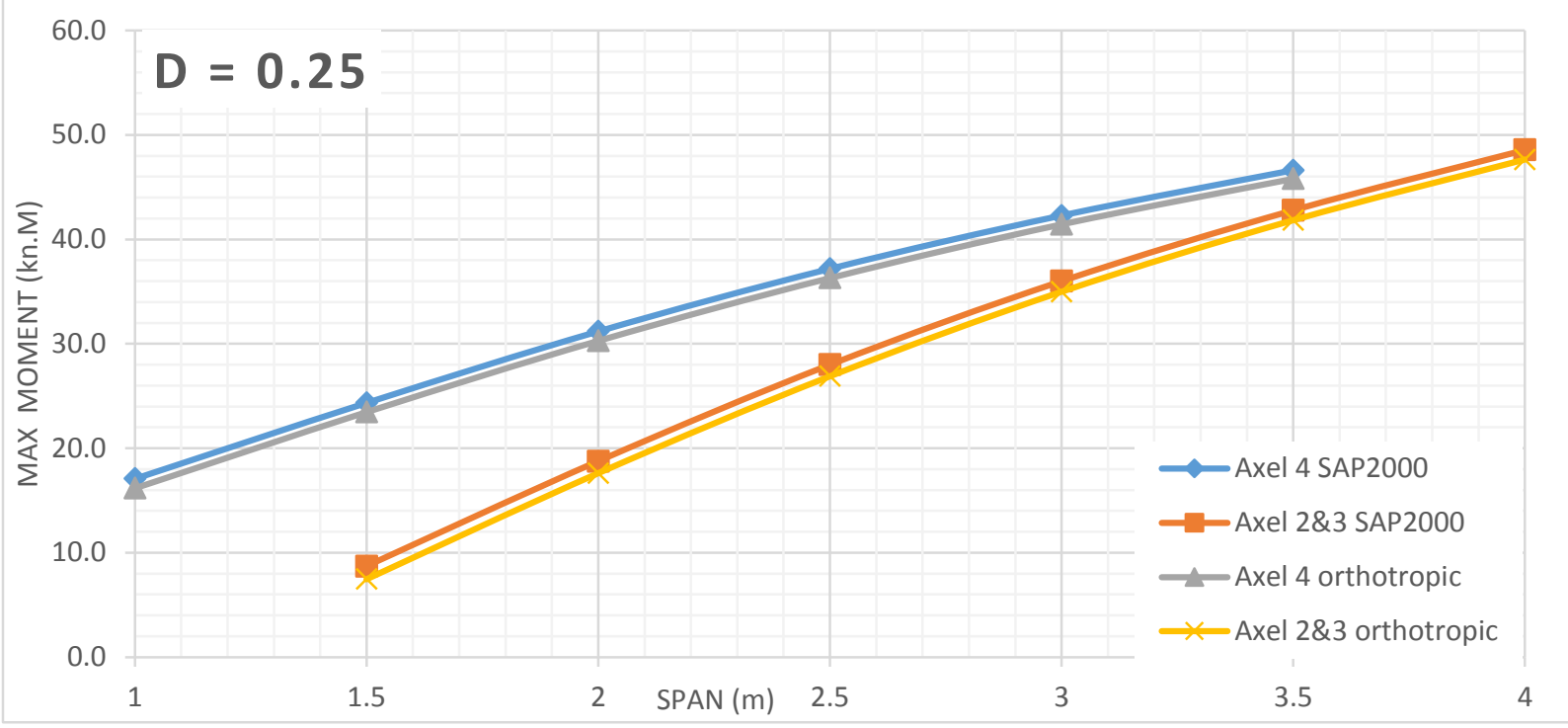

Figure 502 Moment comparison between FEA and Orthotropic Plate Theory for $D=0.25$ of alpha 0.25 (main bars parallel traffic)

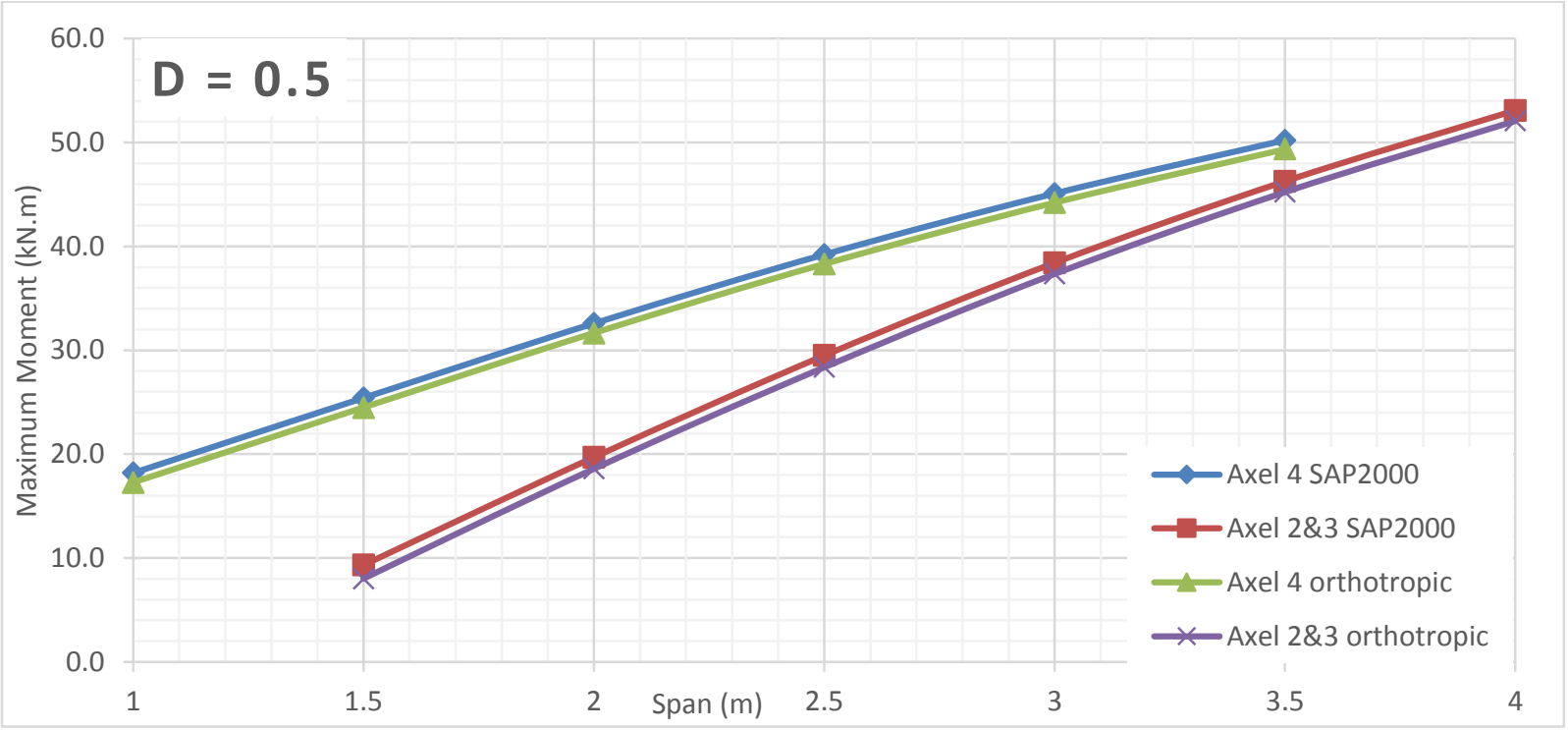

Figure 503 Moment comparison between FEA and Orthotropic Plate Theory for D $=0.5$ of alpha 0.25 (main bars parallel traffic) 


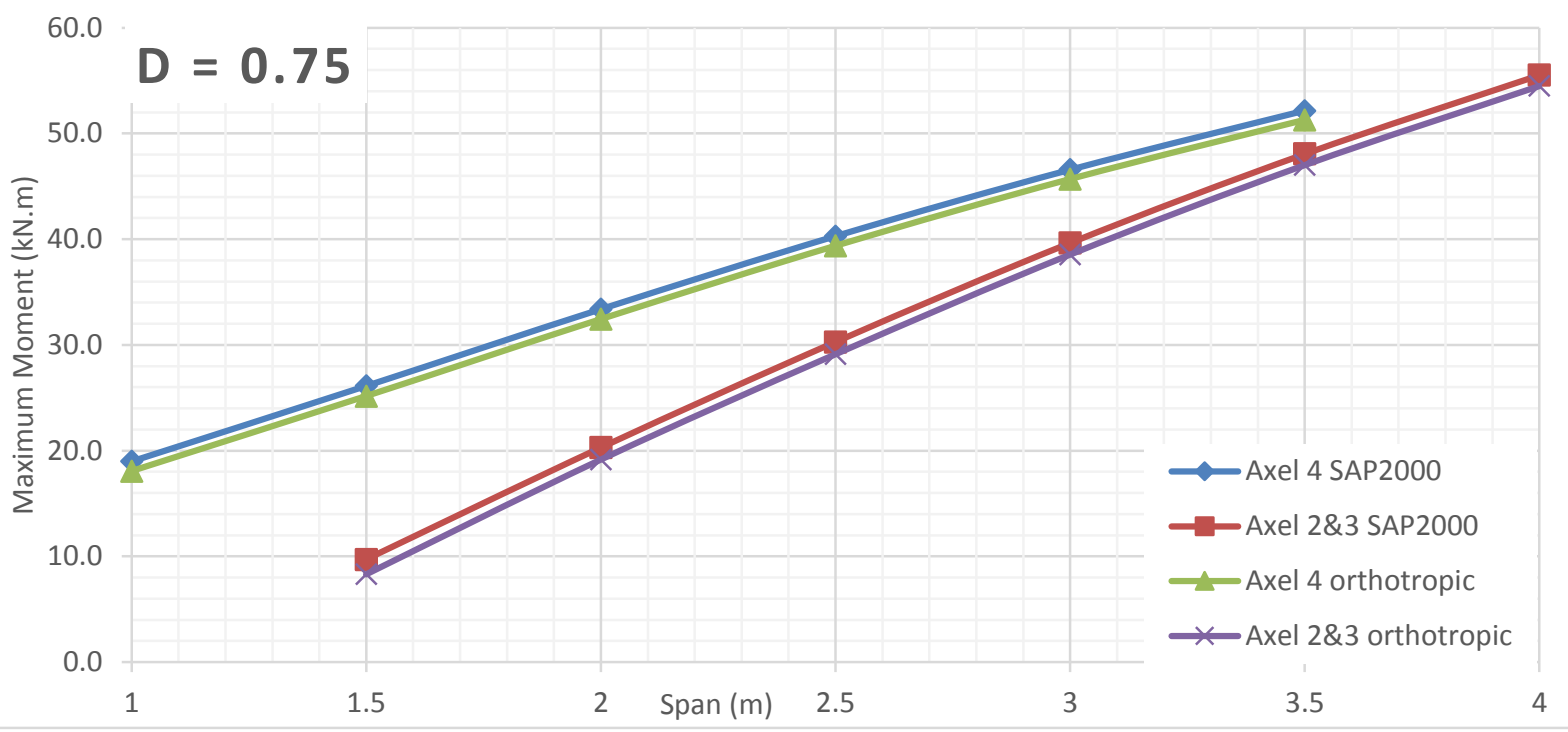

Figure 504 Moment comparison between FEA and Orthotropic Plate Theory for $\mathrm{D}=0.75$ of alpha 0.25 (main bars parallel traffic)

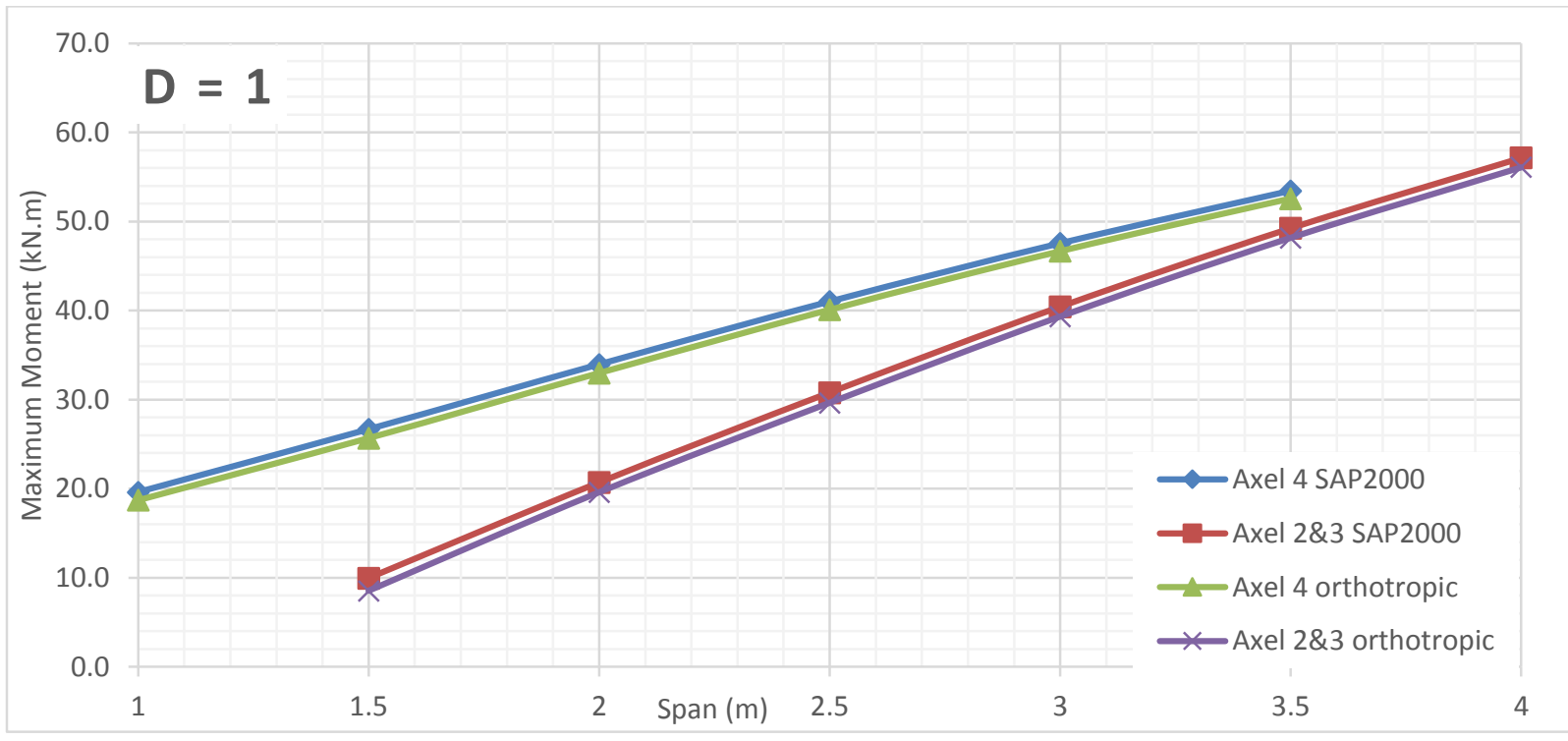

Figure 505 Moment comparison between FEA and Orthotropic Plate Theory for $D=1$ of alpha 0.25 (main bars parallel traffic)

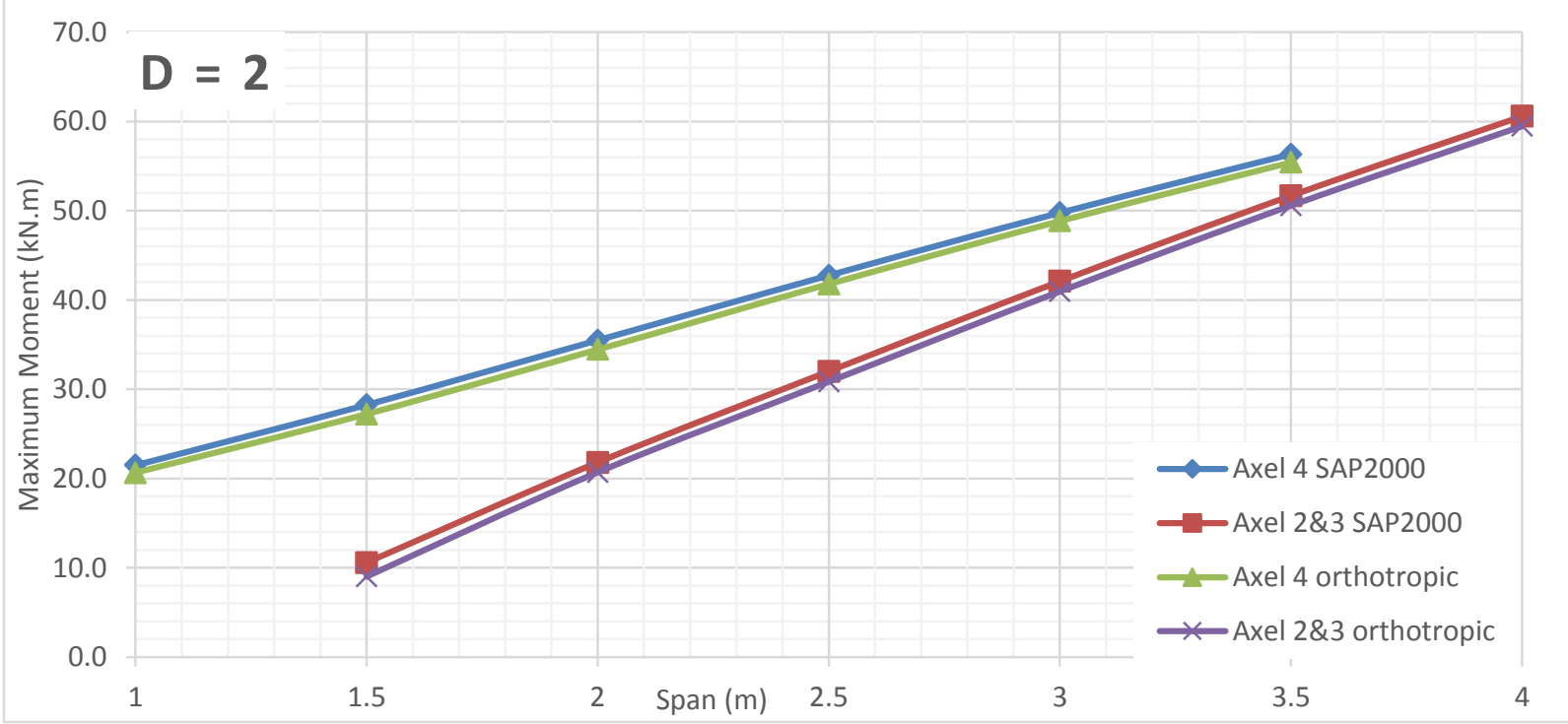

Figure 506 Moment comparison between FEA and Orthotropic Plate Theory for $\mathrm{D}=2$ of alpha 0.25 (main bars parallel traffic) 


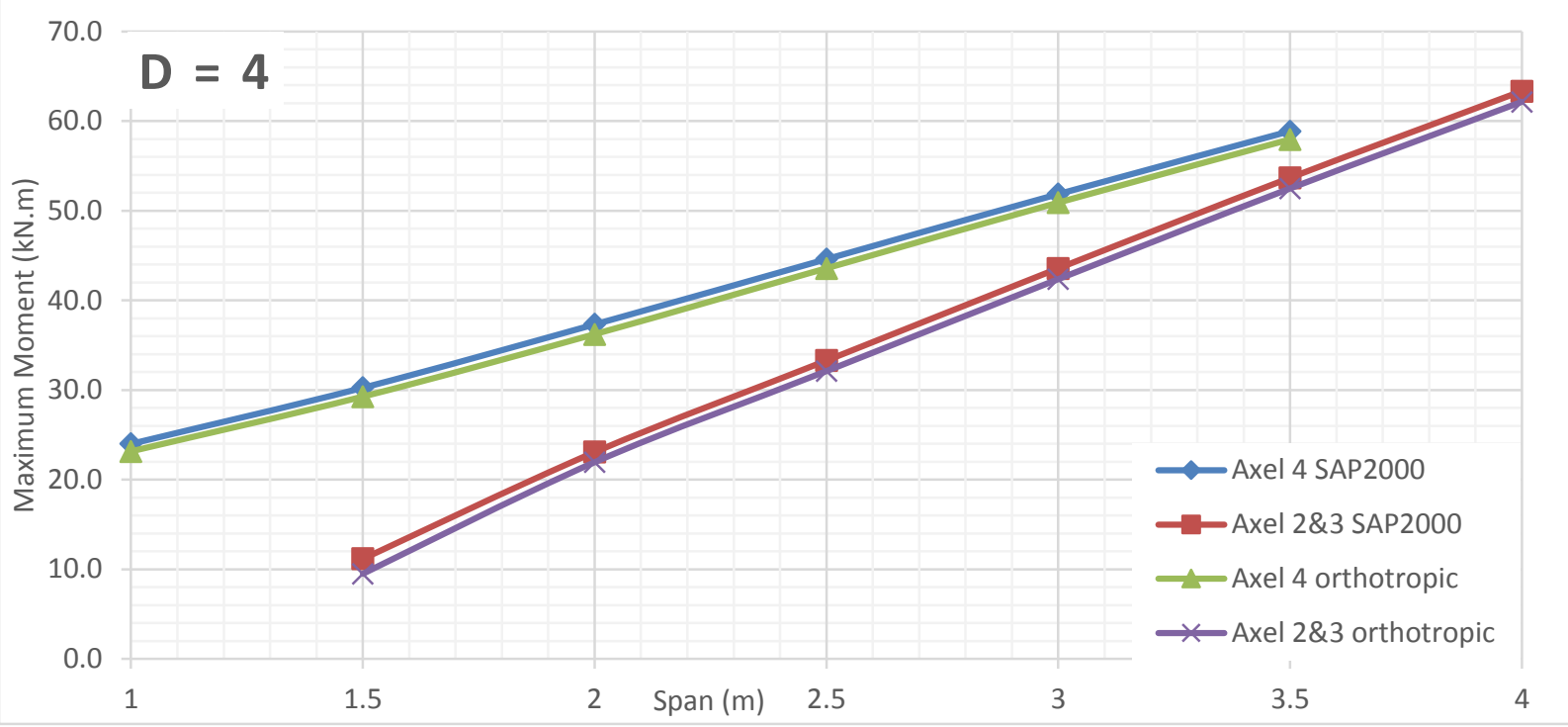

Figure 507 Moment comparison between FEA and Orthotropic Plate Theory for D $=4$ of alpha 0.25 (main bars parallel traffic)

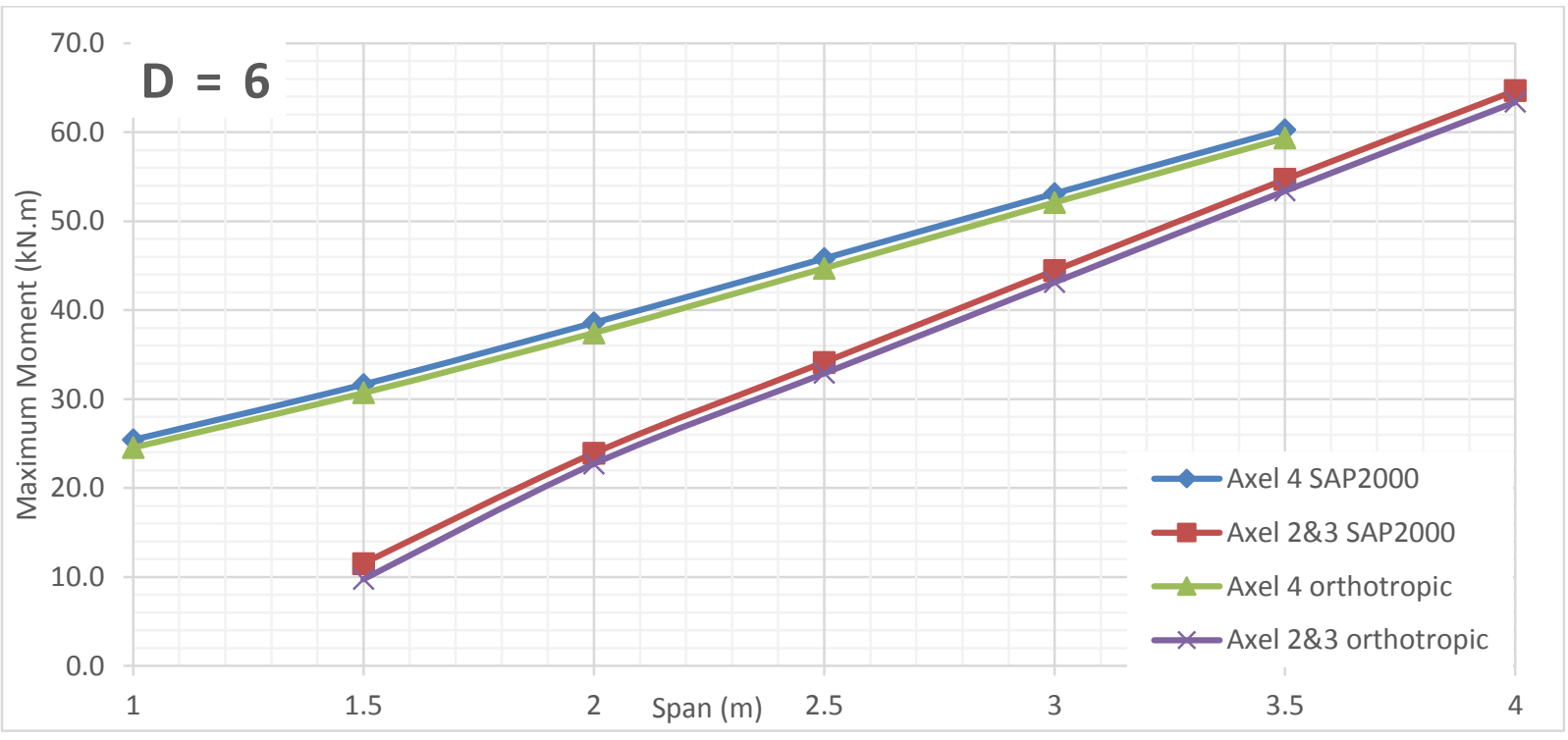

Figure 508 Moment comparison between FEA and Orthotropic Plate Theory for D $=6$ of alpha 0.25 (main bars parallel traffic)

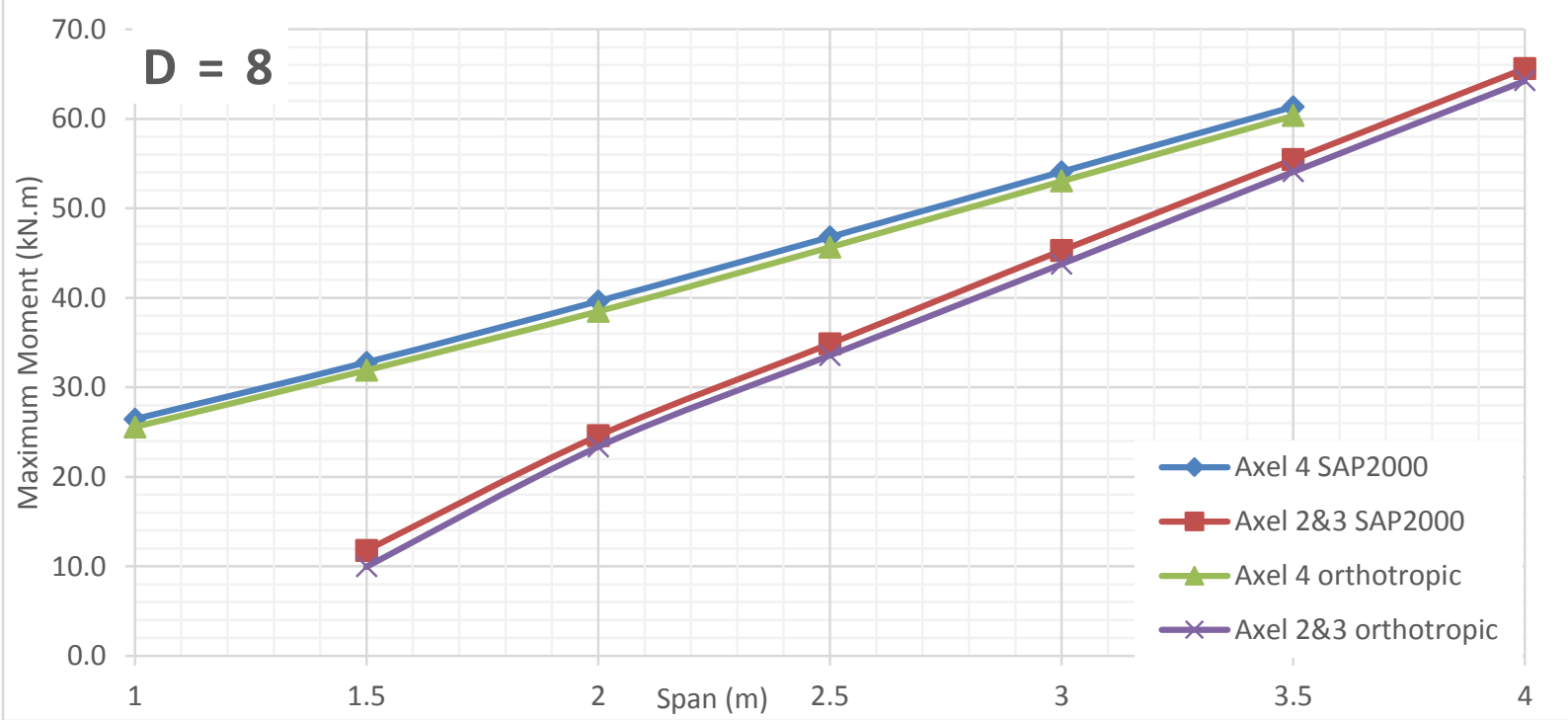

Figure 509 Moment comparison between FEA and Orthotropic Plate Theory for $\mathrm{D}=8$ of alpha 0.25 (main bars parallel traffic) 


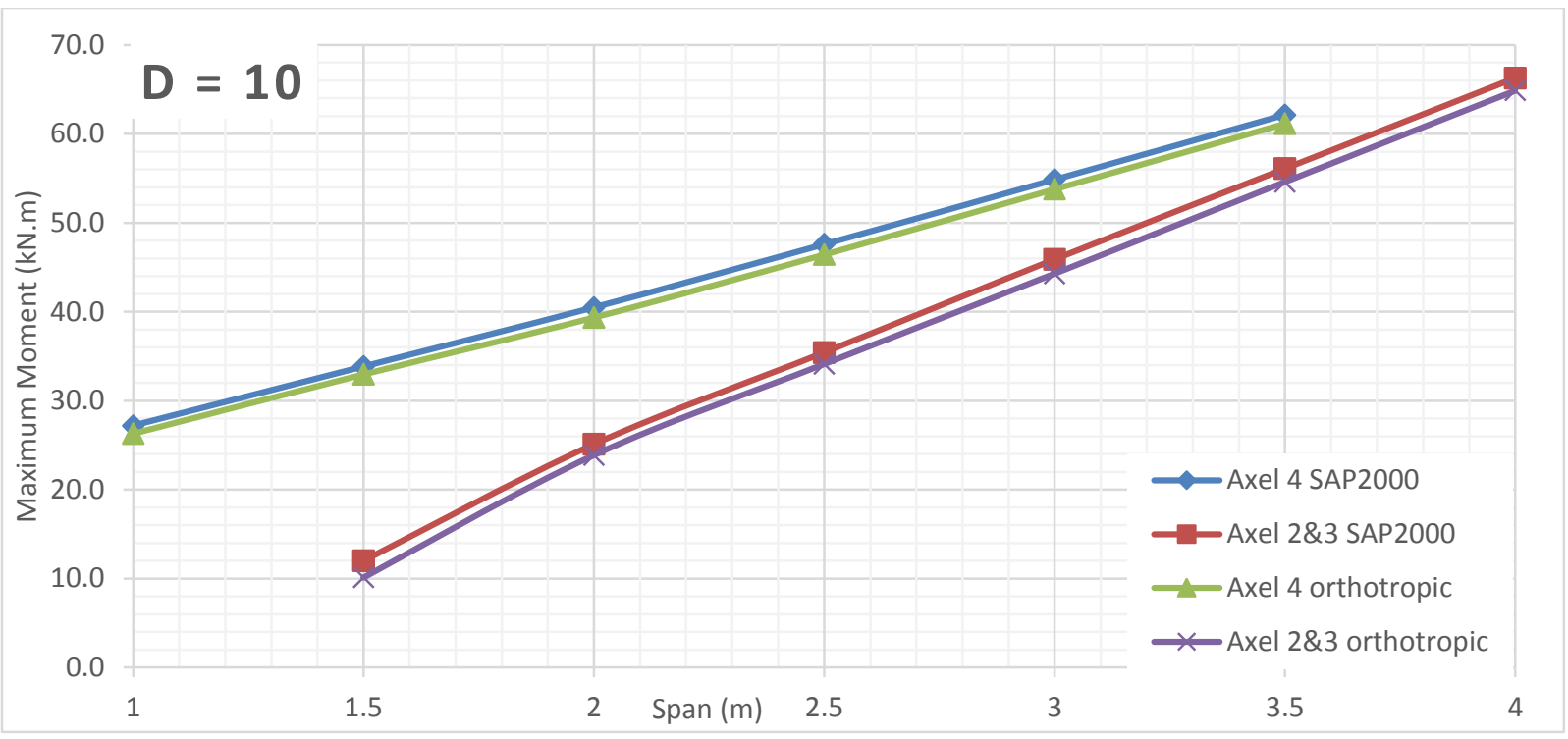

Figure 510 Moment comparison between FEA and Orthotropic Plate Theory for $\mathrm{D}=10$ of alpha 0.25 (main bars parallel traffic) 


\section{Alpha 0.5 Bending Moment VS Span Length for Different D Values (Main bars perpendicular to traffic)}

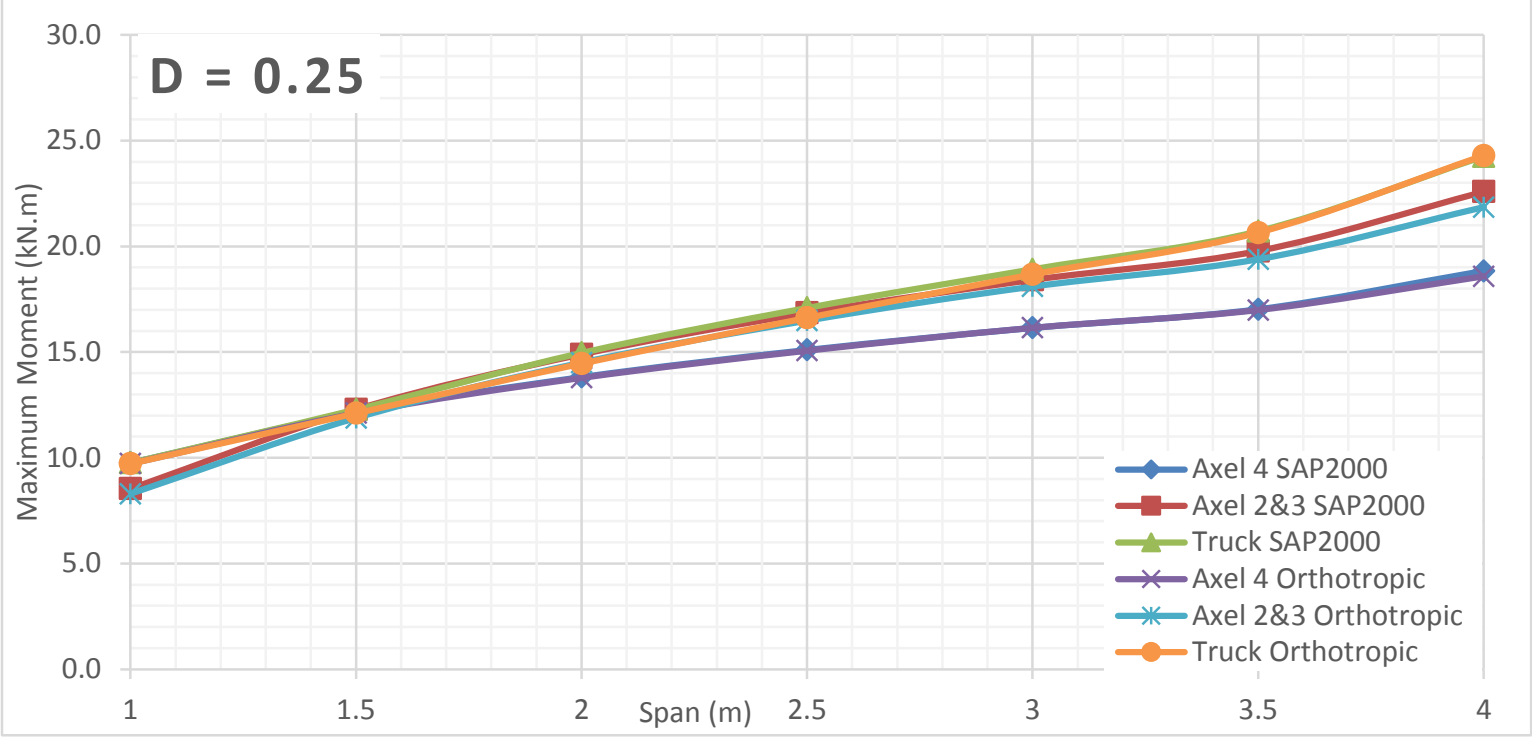

Figure 511 Moment comparison between FEA and Orthotropic Plate Theory for $\mathrm{D}=0.25$ of alpha 0.5 (main bars perpendicular traffic)

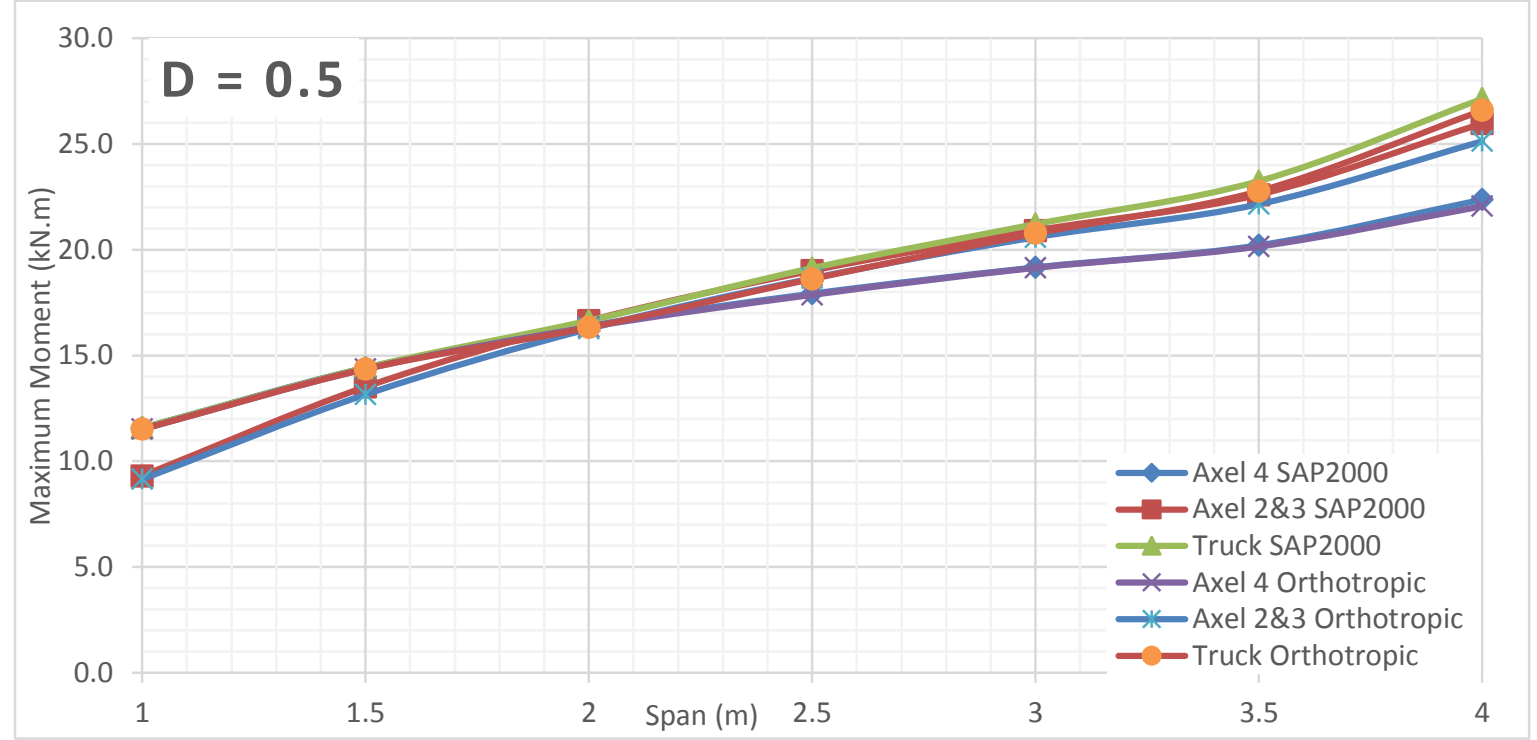

Figure 512 Moment comparison between FEA and Orthotropic Plate Theory for $D=0.5$ of alpha 0.5 (main bars perpendicular traffic) 


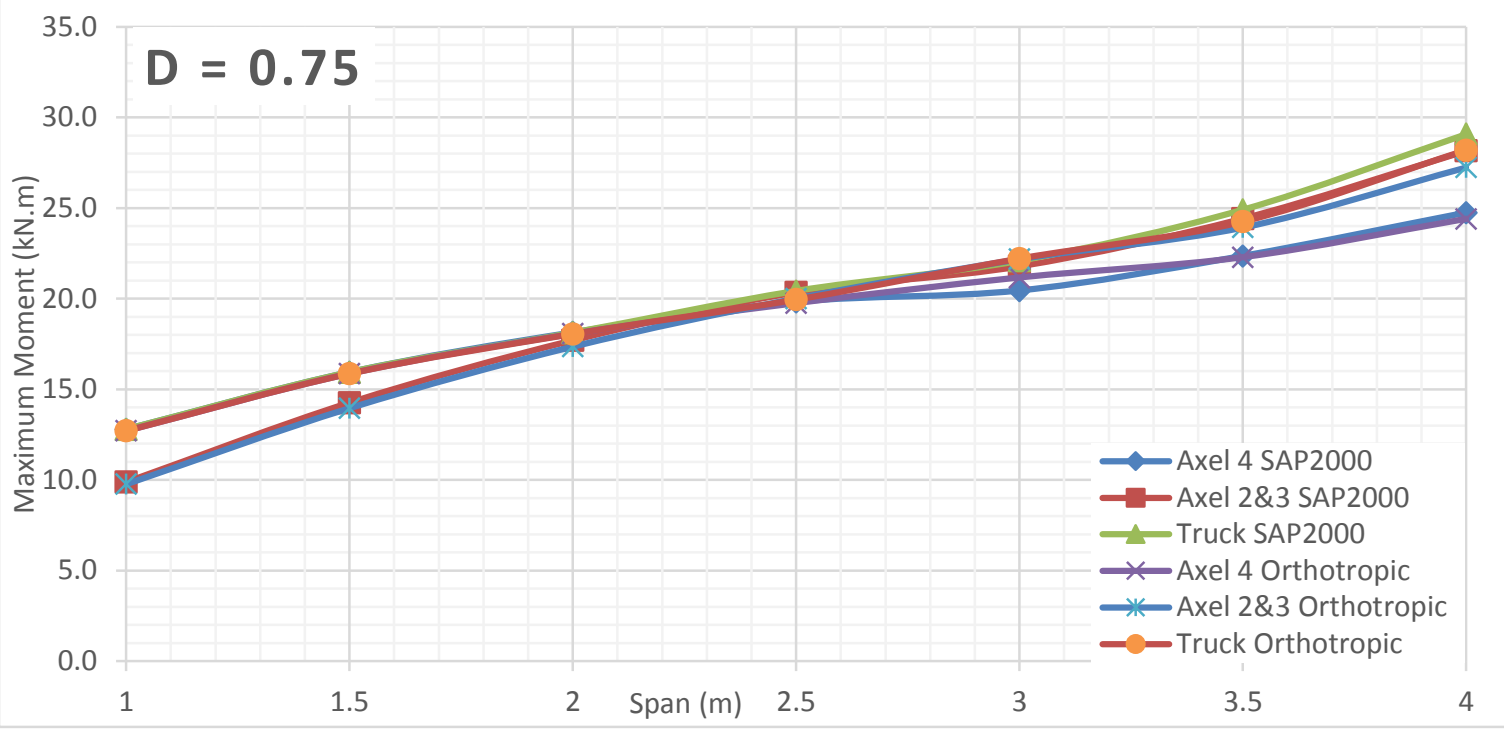

Figure 513 Moment comparison between FEA and Orthotropic Plate Theory for D $=0.75$ of alpha 0.5 (main bars perpendicular traffic)

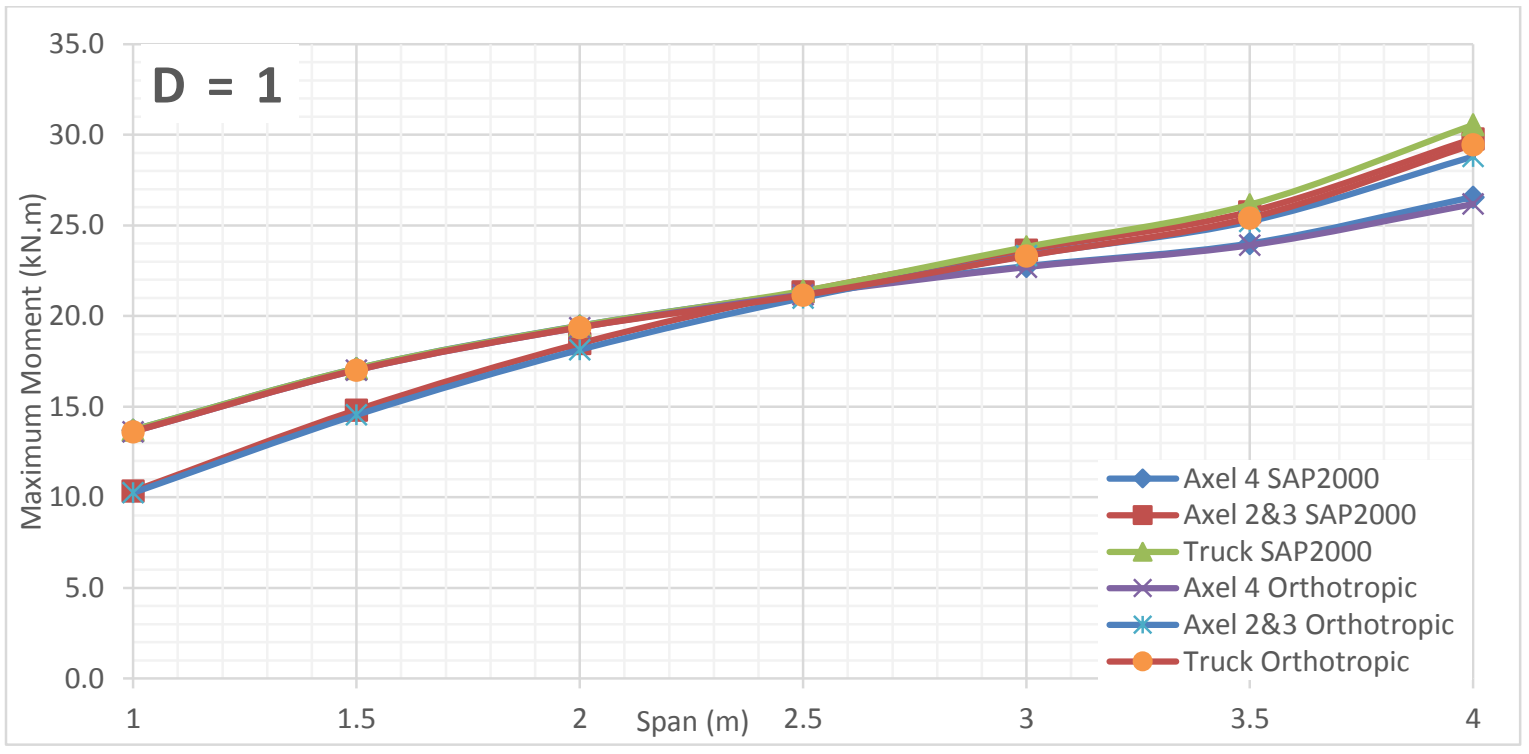

Figure 514 Moment comparison between FEA and Orthotropic Plate Theory for D = 1 of alpha 0.5 (main bars perpendicular traffic)

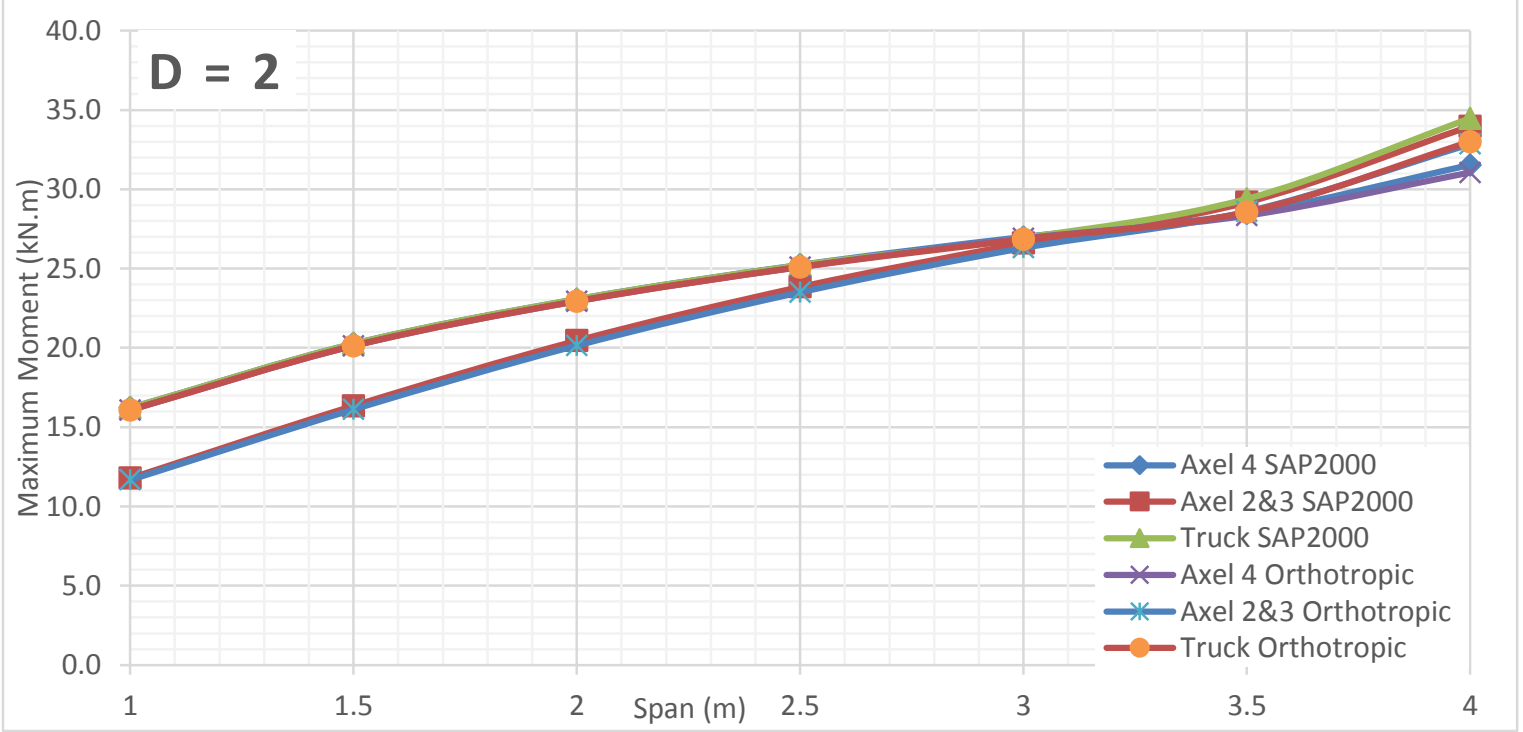

Figure 515 Moment comparison between FEA and Orthotropic Plate Theory for $D=2$ of alpha 0.5 (main bars perpendicular traffic) 


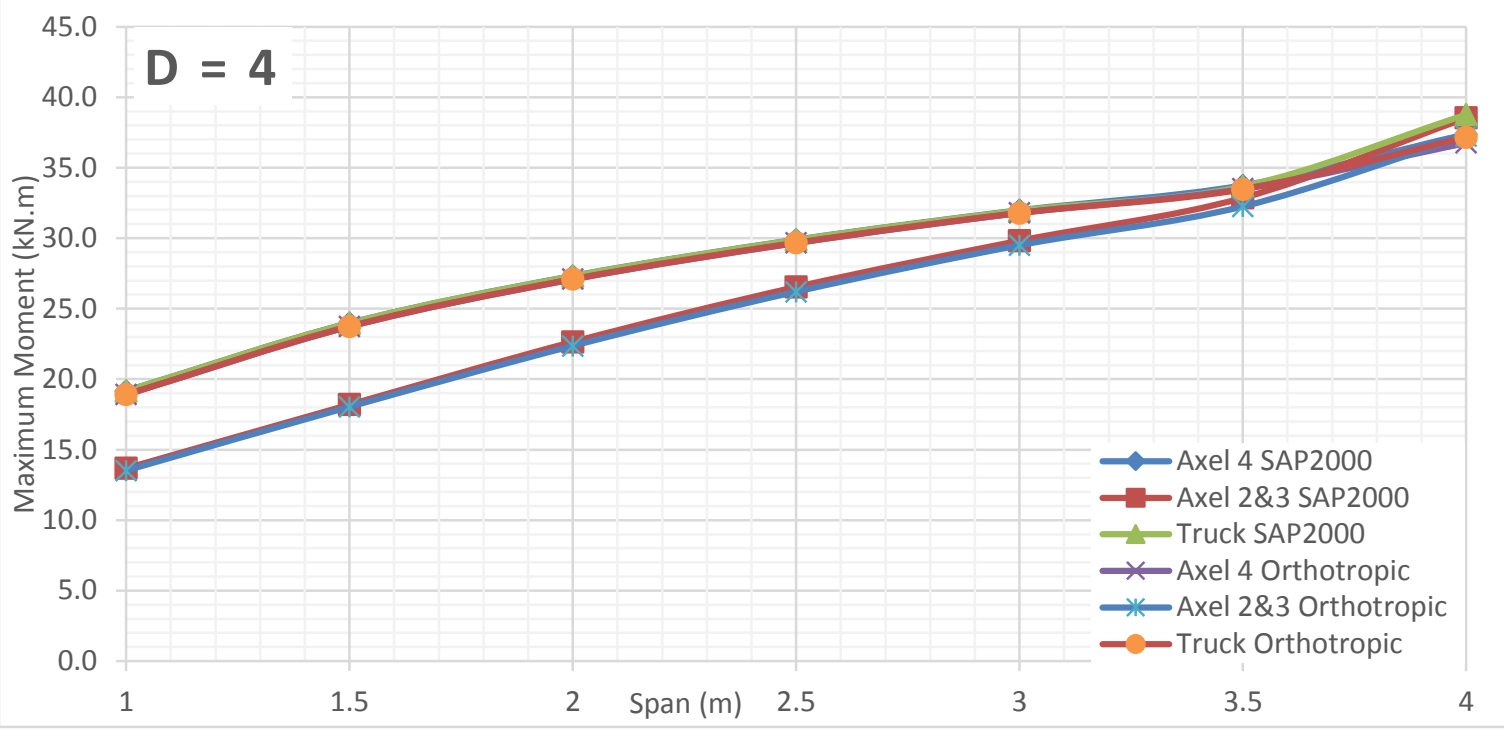

Figure 516 Moment comparison between FEA and Orthotropic Plate Theory for D = 4 of alpha 0.5 (main bars perpendicular traffic)

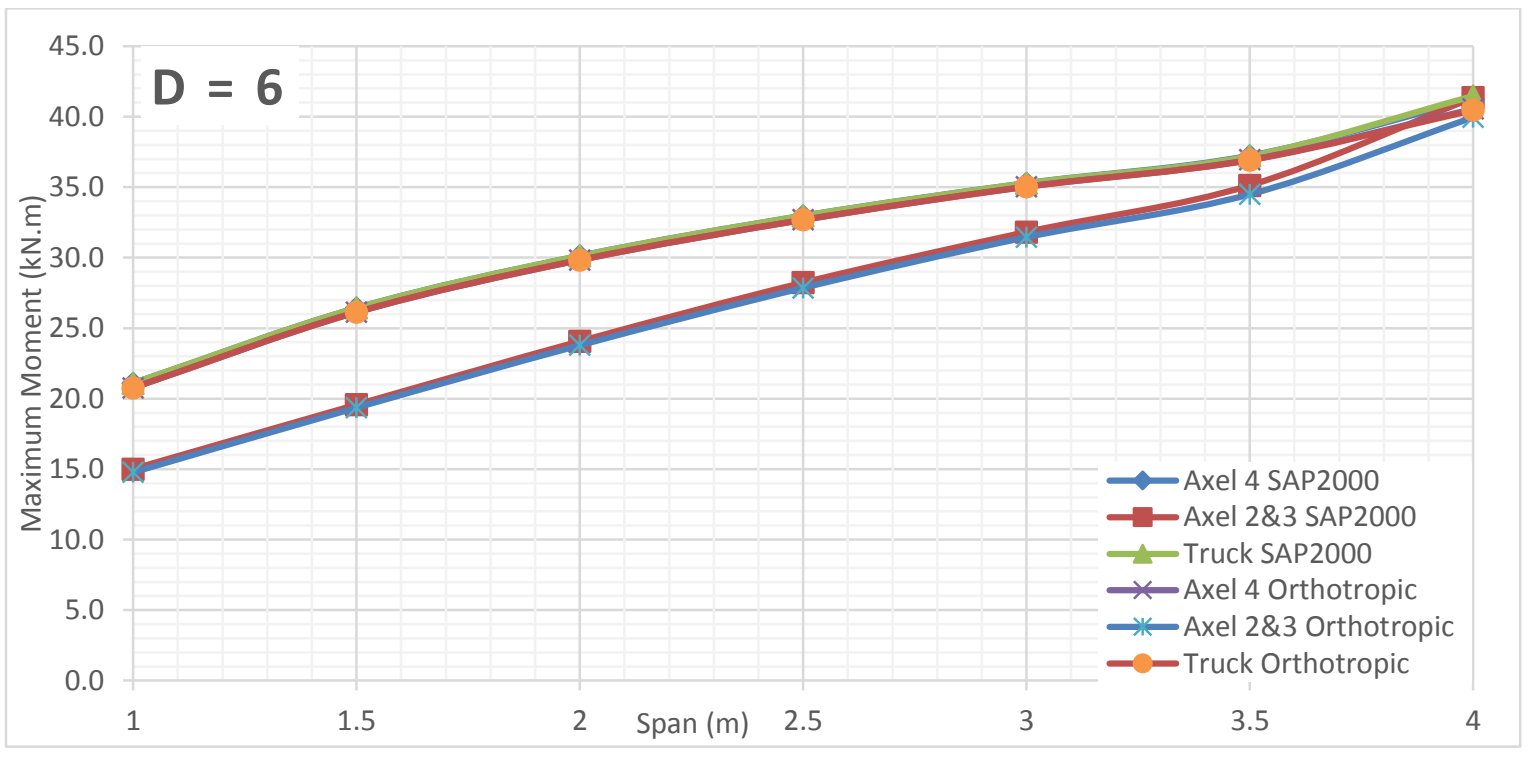

Figure 517 Moment comparison between FEA and Orthotropic Plate Theory for $D=6$ of alpha 0.5 (main bars perpendicular traffic)

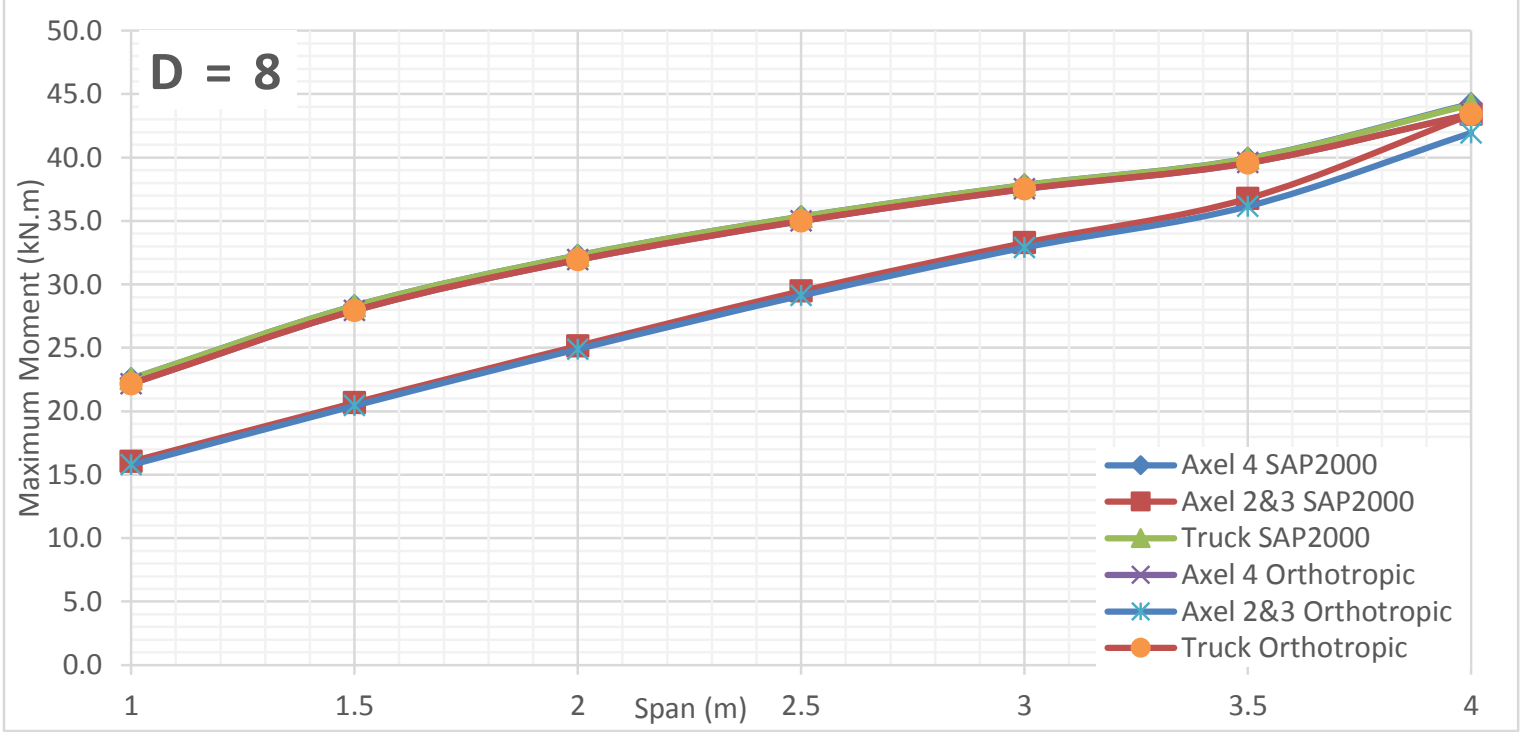

Figure 518 Moment comparison between FEA and Orthotropic Plate Theory for $D=8$ of alpha 0.5 (main bars perpendicular traffic) 


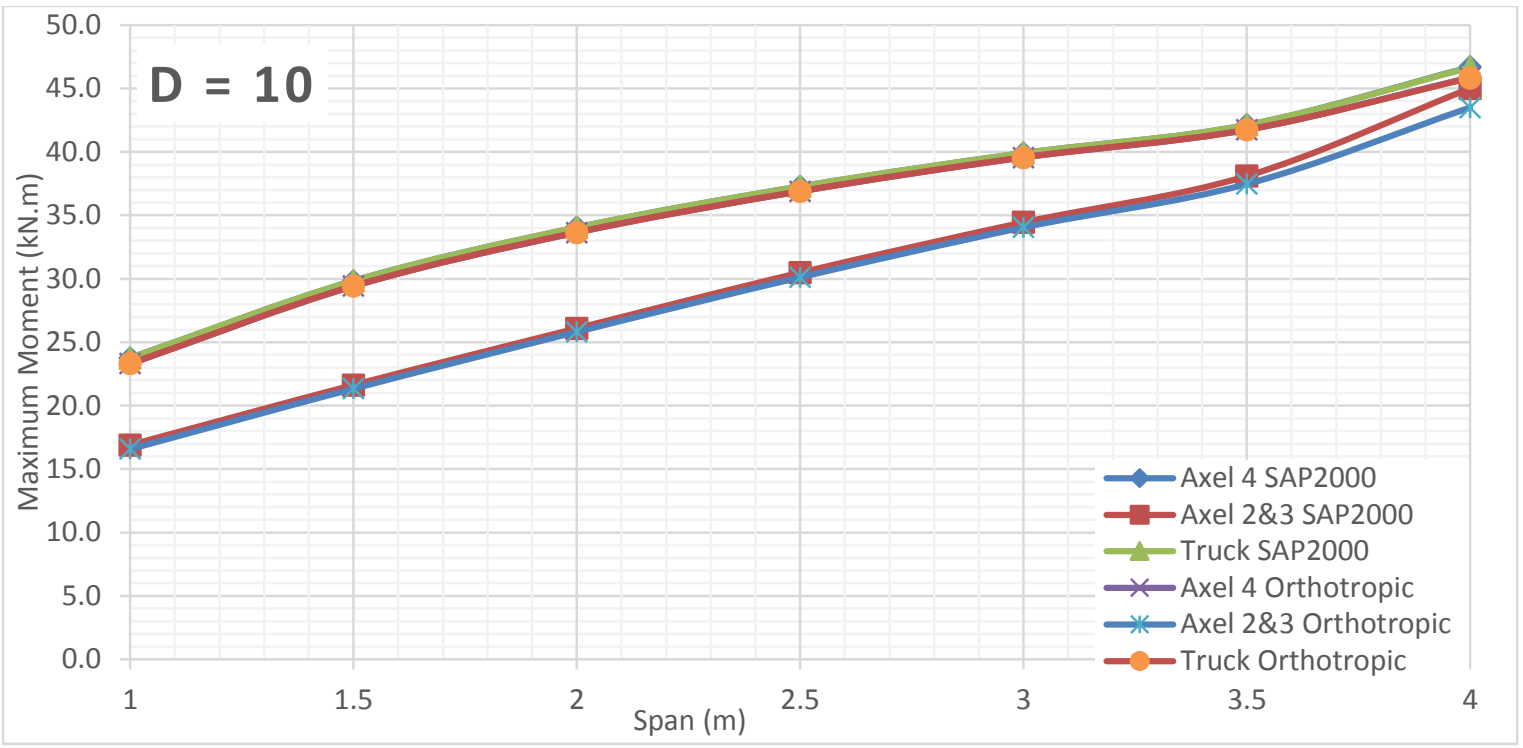

Figure 519 Moment comparison between FEA and Orthotropic Plate Theory for $\mathrm{D}=10$ of alpha 0.5 (main bars perpendicular traffic) 


\section{Alpha 0.5 Bending Moment VS Span Length for Different D Values (Main bars parallel to traffic)}

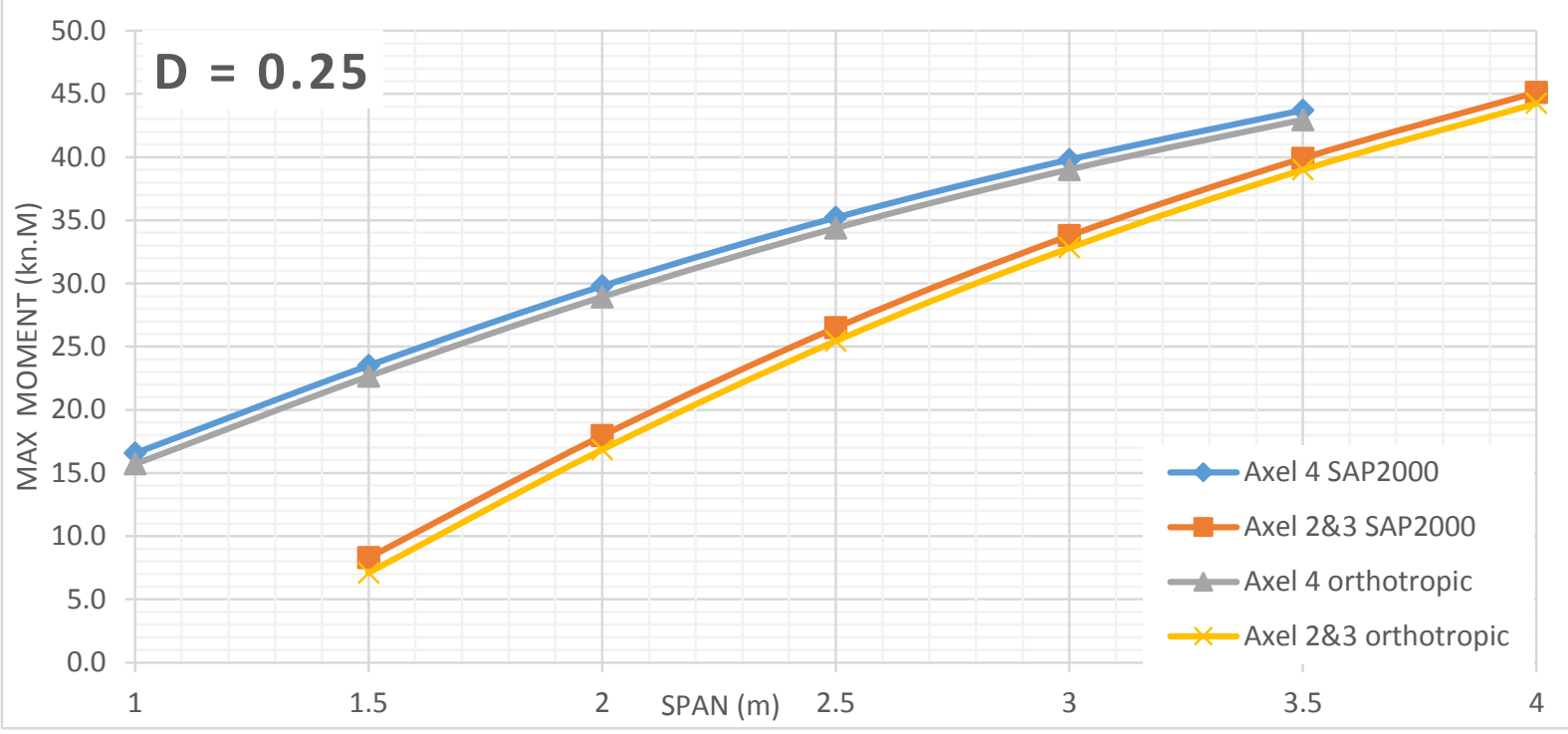

Figure 520 Moment comparison between FEA and Orthotropic Plate Theory for D $=0.25$ of alpha 0.5 (main bars parallel traffic)

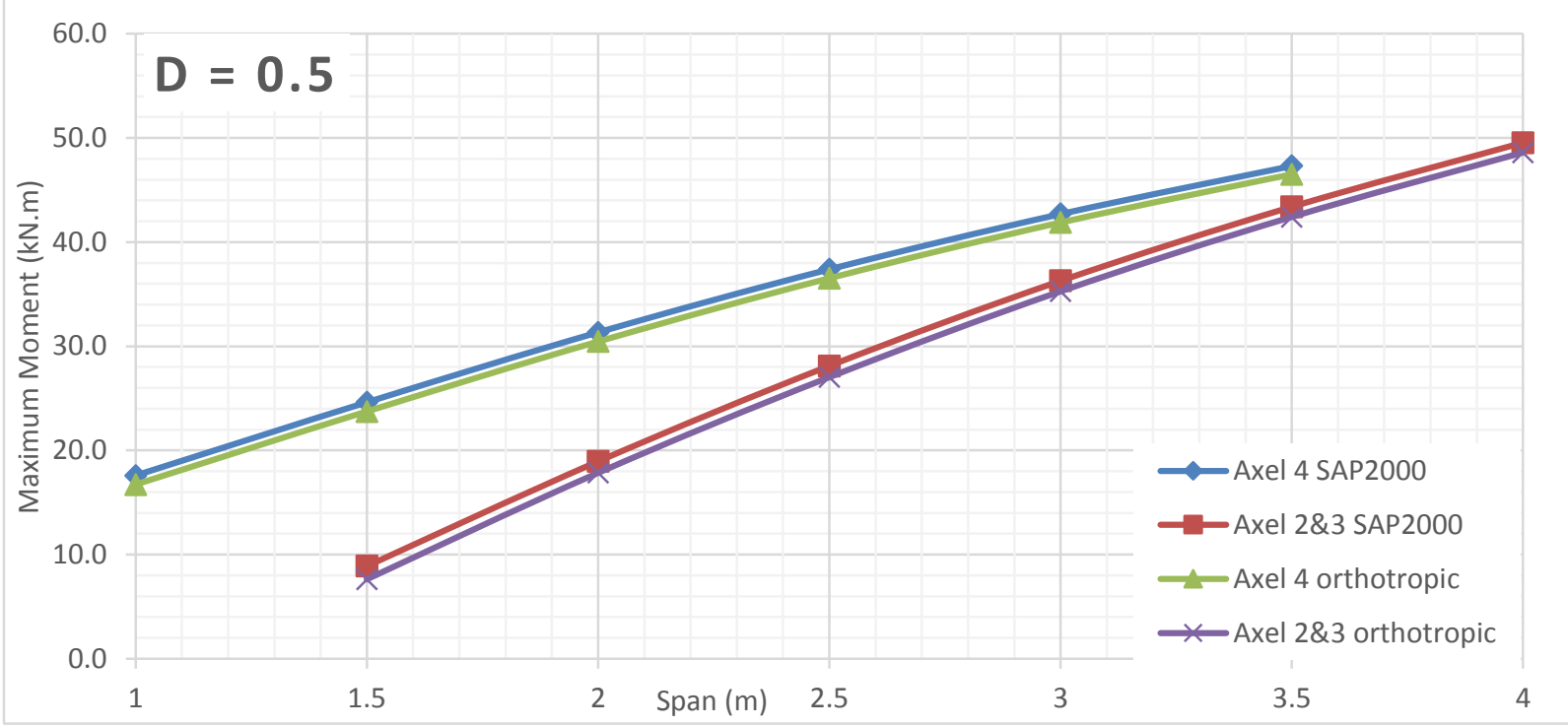

Figure 521 Moment comparison between FEA and Orthotropic Plate Theory for D $=0.5$ of alpha 0.5 (main bars parallel traffic) 


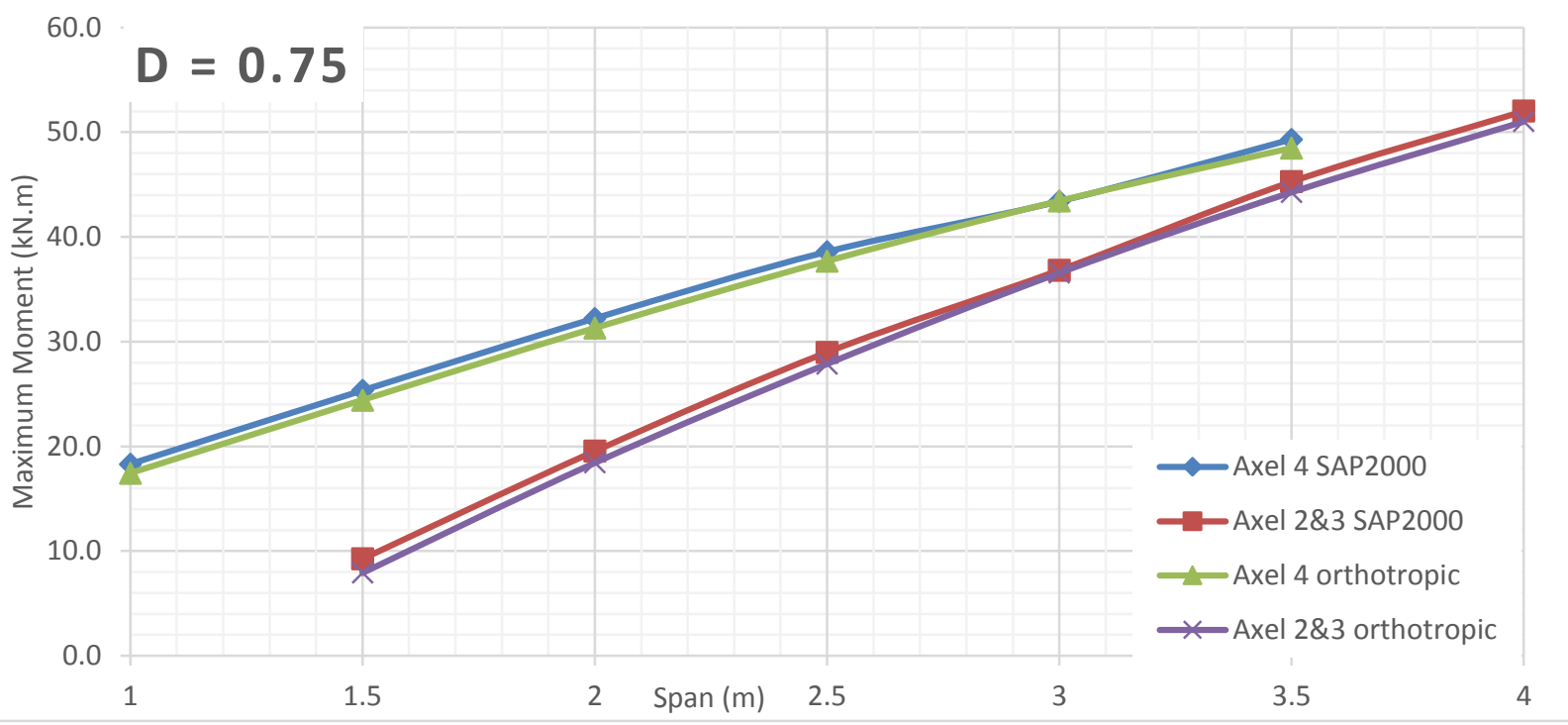

Figure 522 Moment comparison between FEA and Orthotropic Plate Theory for $D=0.75$ of alpha 0.5 (main bars parallel traffic)

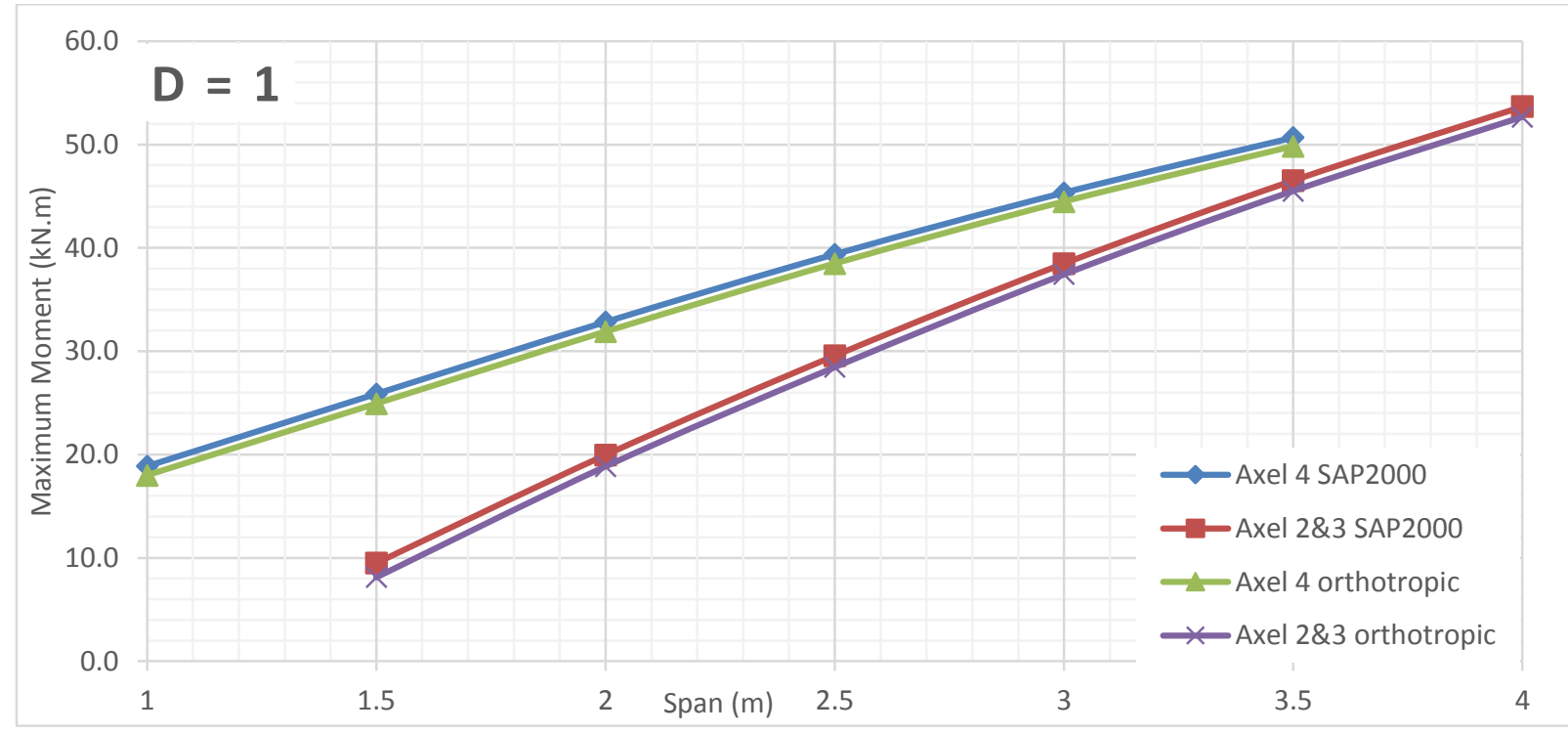

Figure 523 Moment comparison between FEA and Orthotropic Plate Theory for D = 1 of alpha 0.5 (main bars parallel traffic)

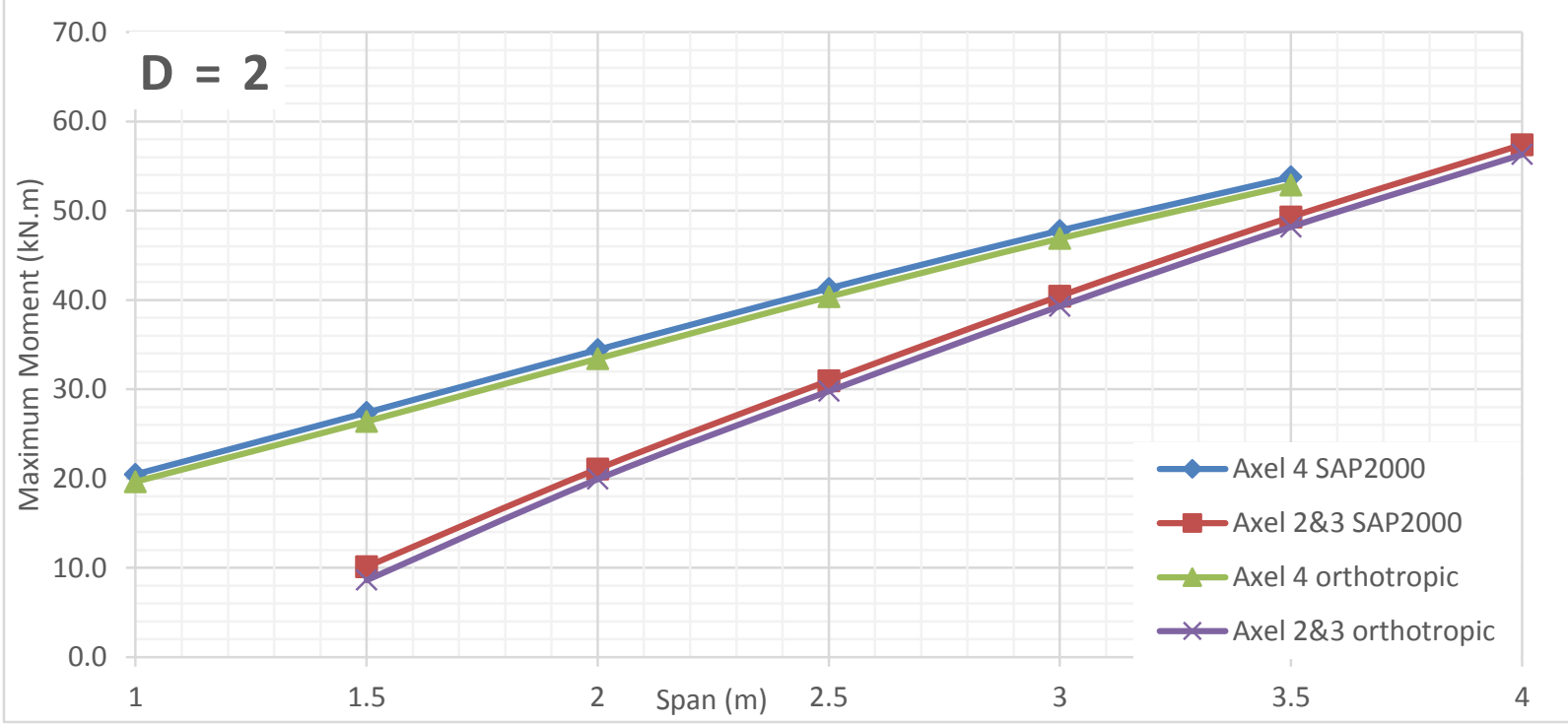

Figure 524 Moment comparison between FEA and Orthotropic Plate Theory for $\mathrm{D}=2$ of alpha 0.5 (main bars parallel traffic) 


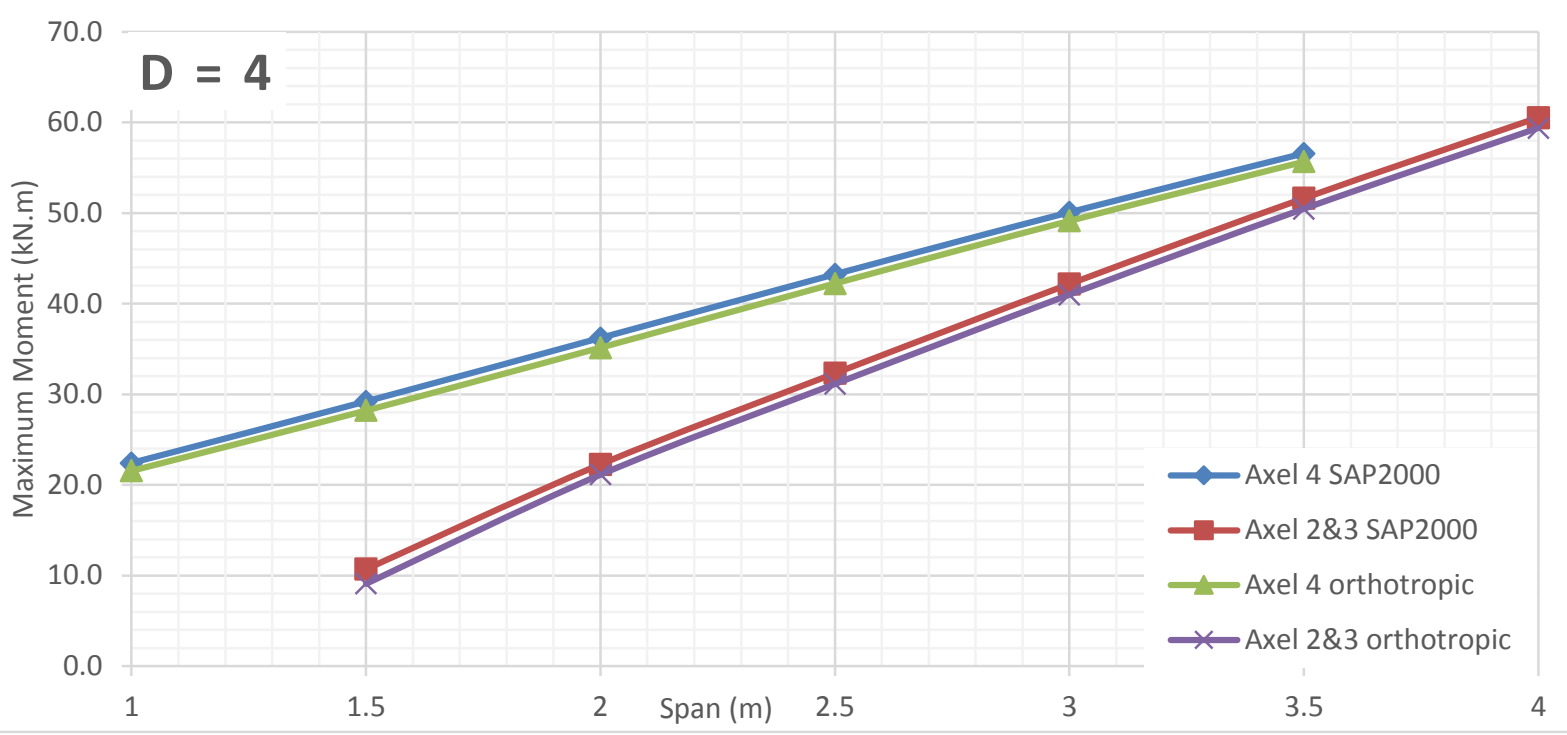

Figure 525 Moment comparison between FEA and Orthotropic Plate Theory for D $=4$ of alpha 0.5 (main bars parallel traffic)

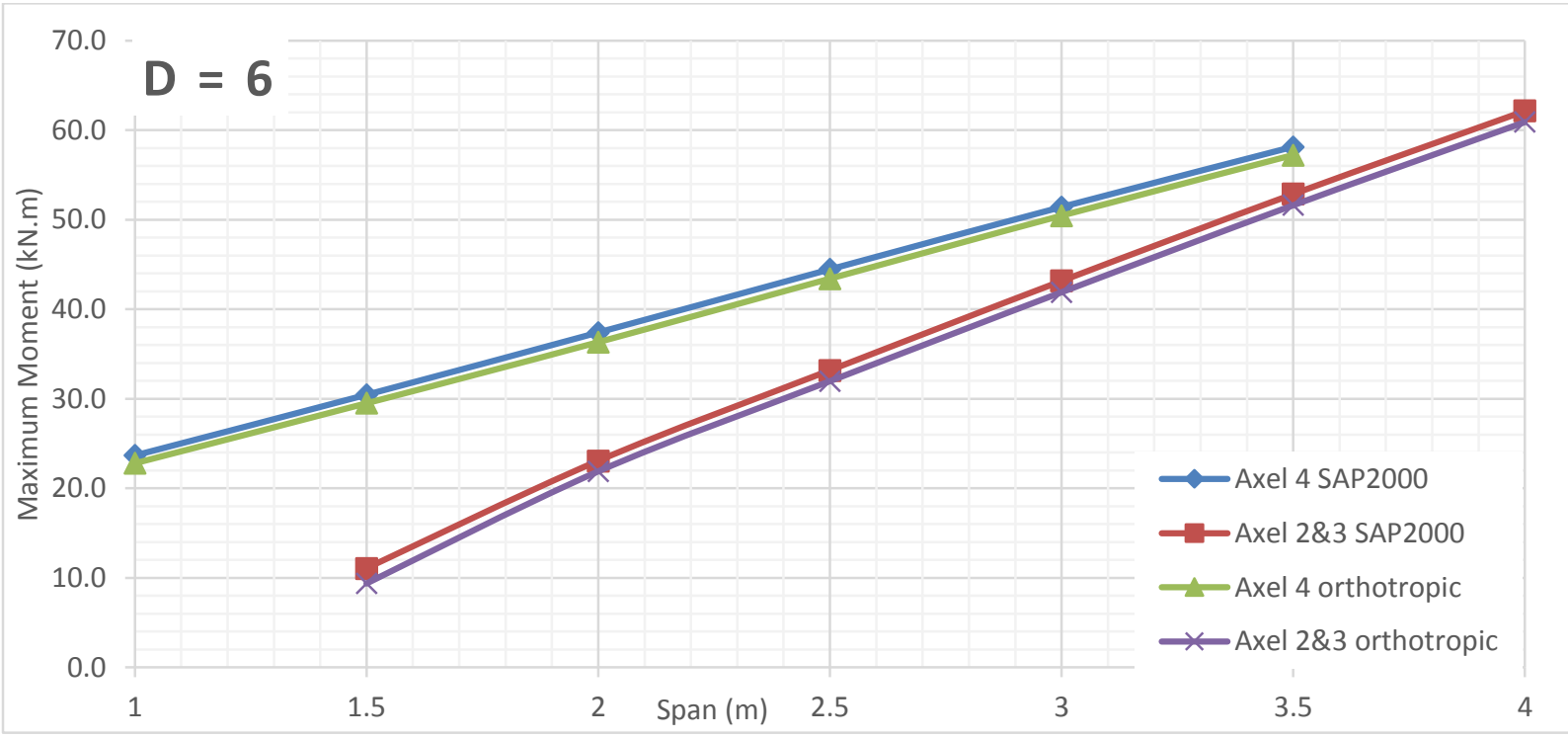

Figure 526 Moment comparison between FEA and Orthotropic Plate Theory for D = 6 of alpha 0.5 (main bars parallel traffic)

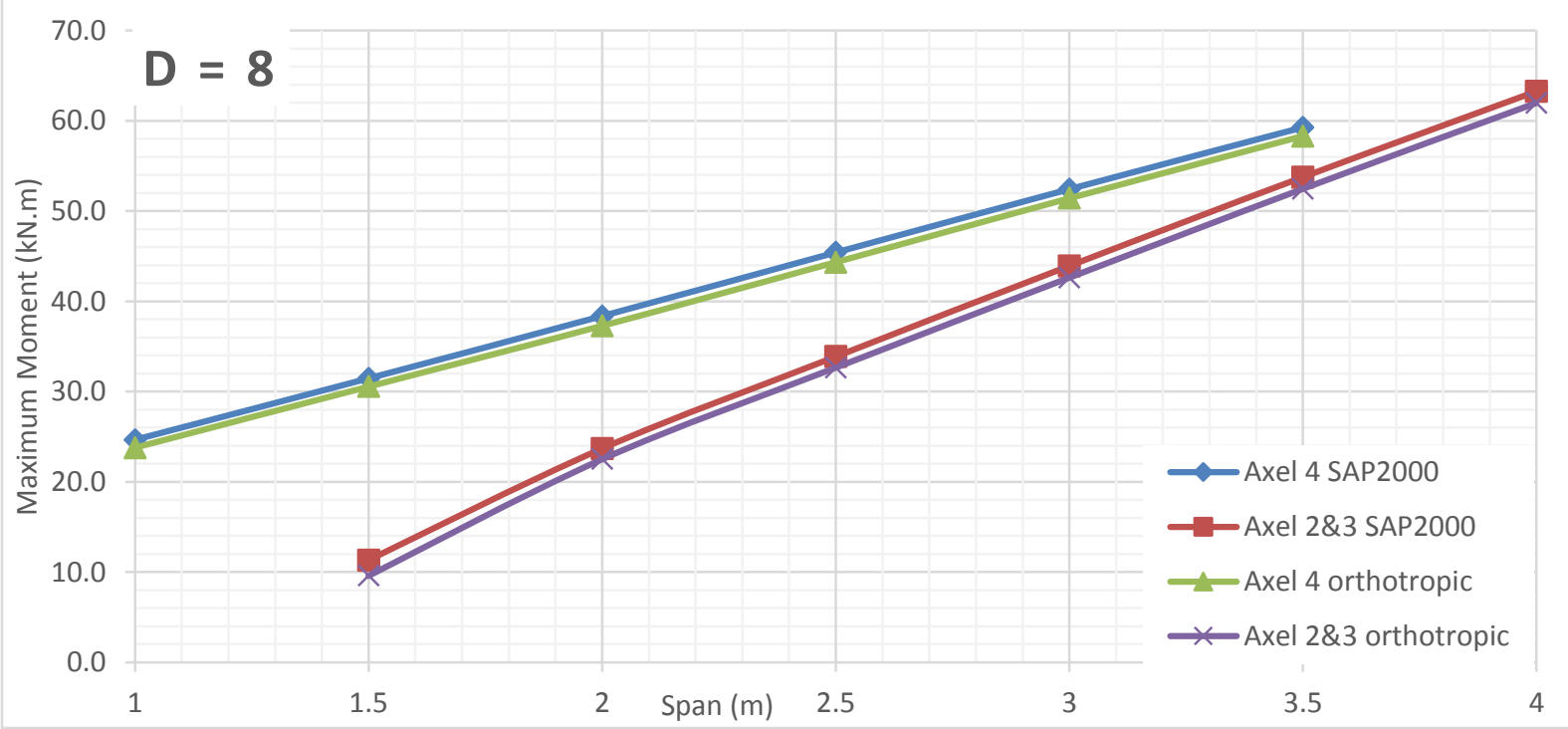

Figure 527 Moment comparison between FEA and Orthotropic Plate Theory for $\mathrm{D}=8$ of alpha 0.5 (main bars parallel traffic) 


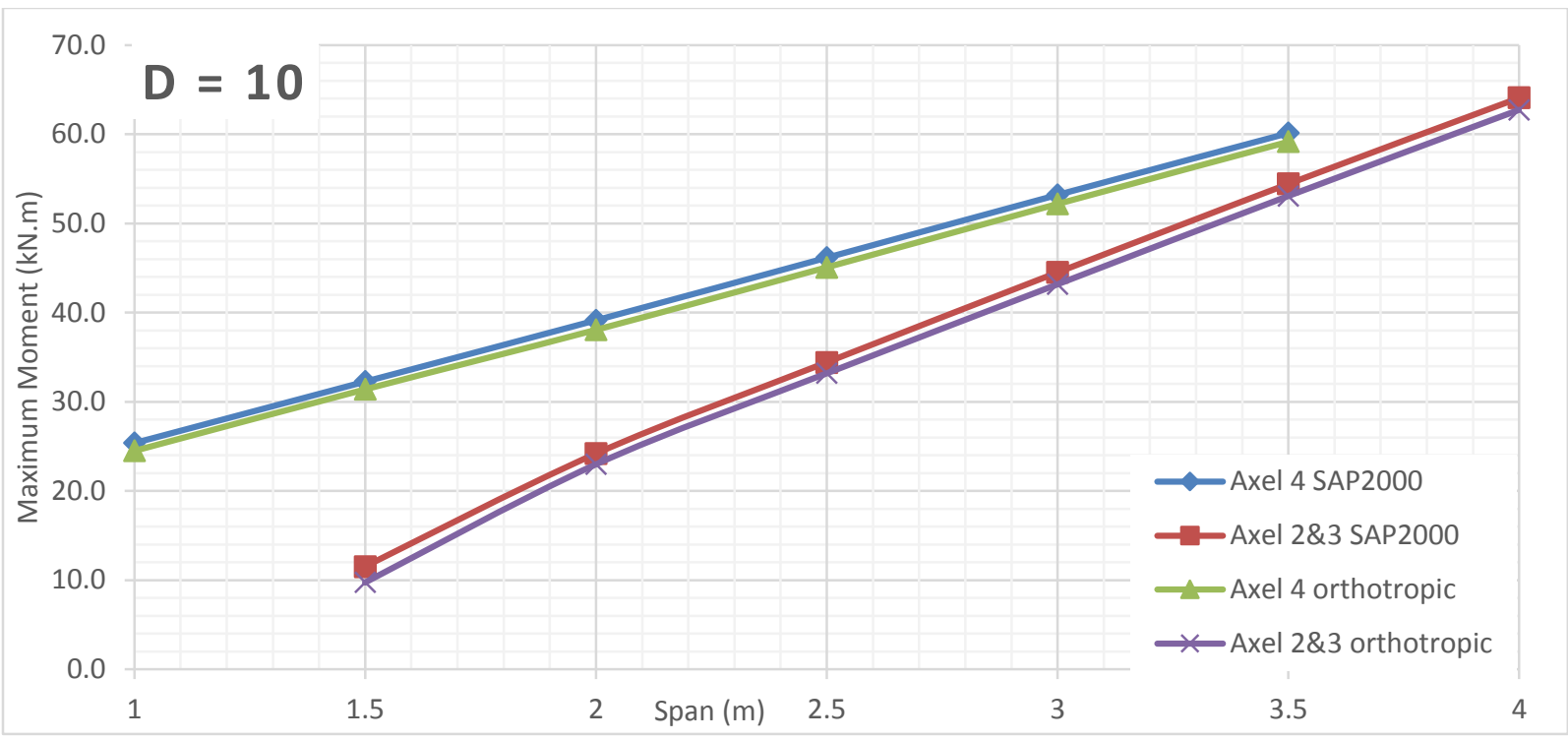

Figure 528 Moment comparison between FEA and Orthotropic Plate Theory for D $=10$ of alpha 0.5 (main bars parallel traffic) 


\section{Alpha 0.75 Bending Moment VS Span Length for Different D Values (Main bars perpendicular to traffic)}

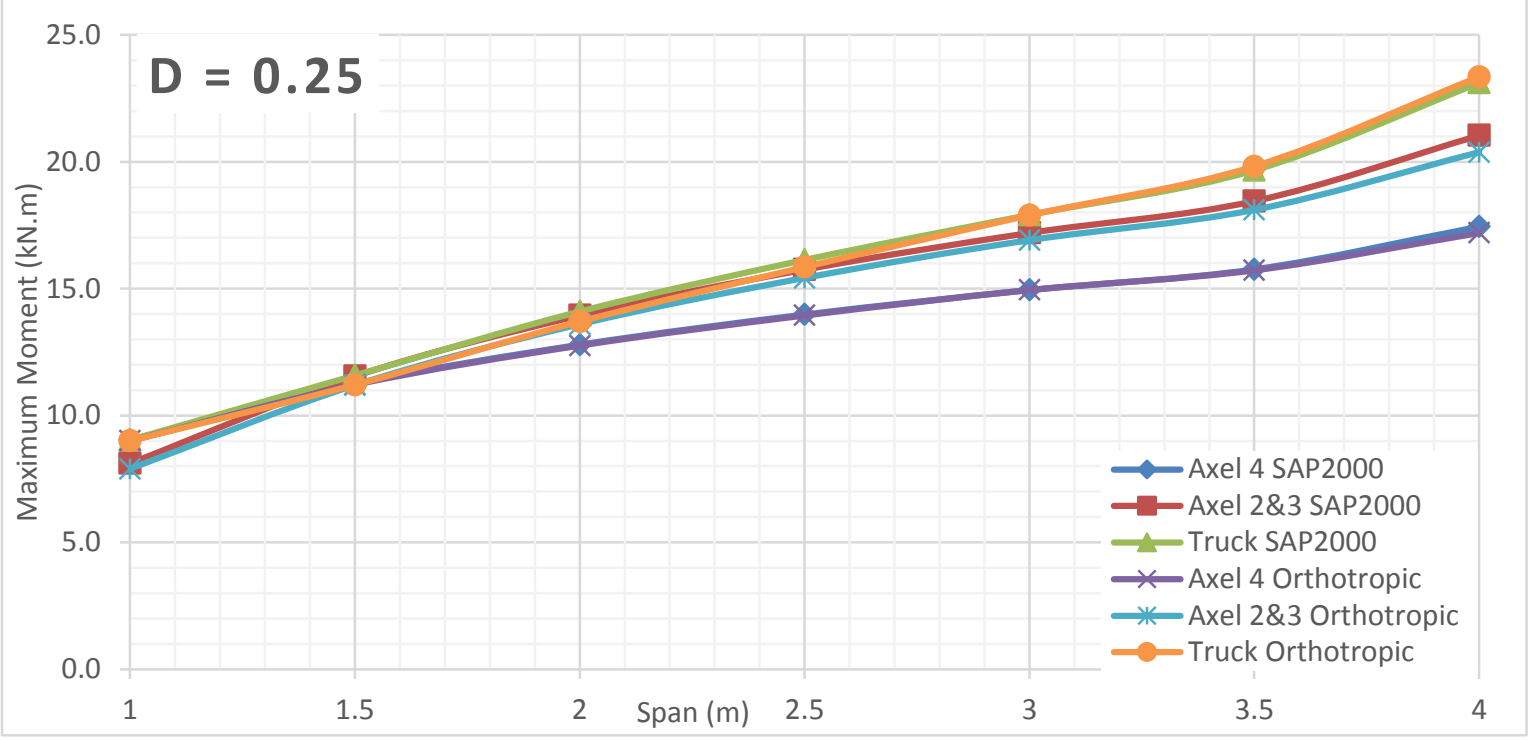

Figure 529 Moment comparison between FEA and Orthotropic Plate Theory for D $=0.25$ of alpha 0.75 (main bars perpendicular traffic)

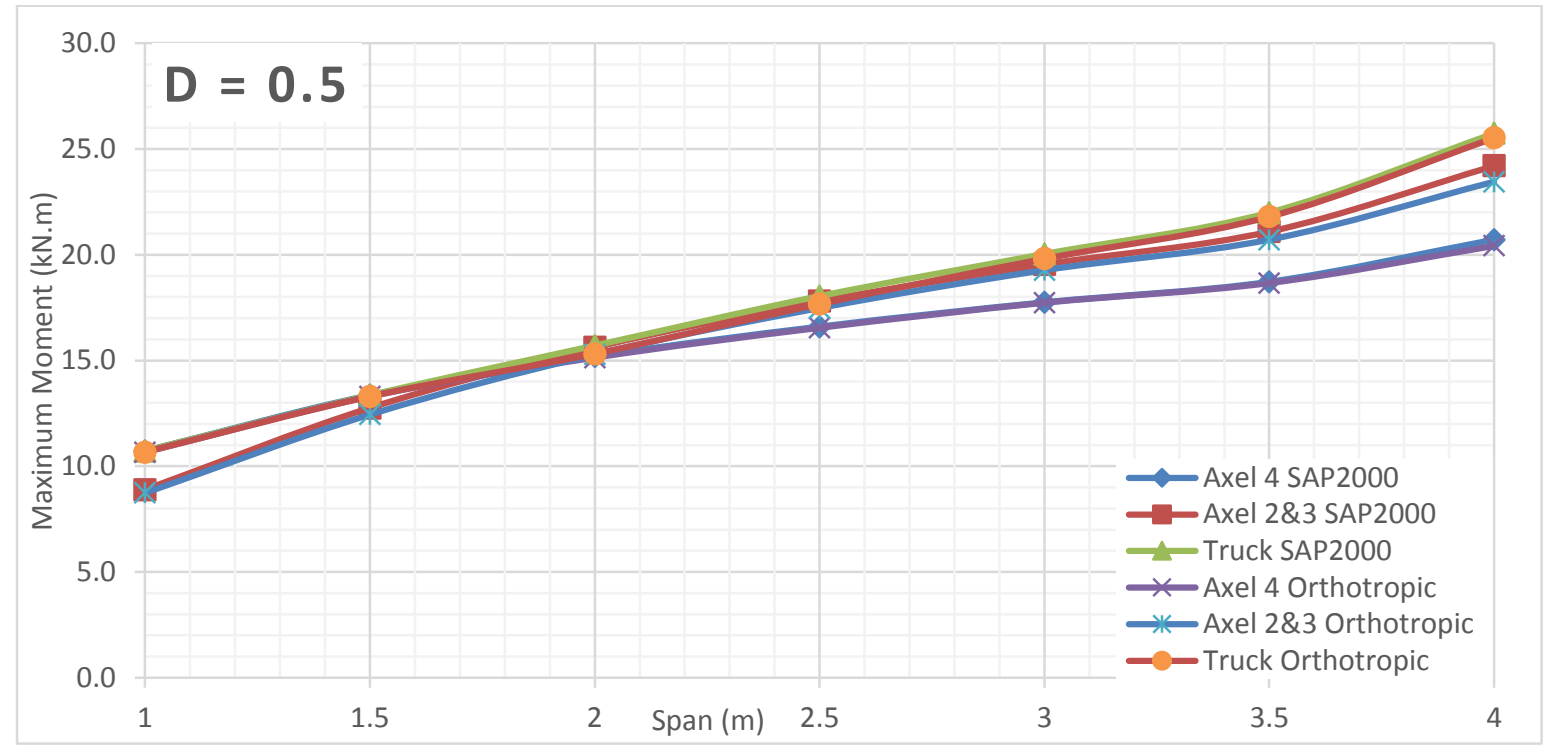

Figure 530 Moment comparison between FEA and Orthotropic Plate Theory for $D=0.5$ of alpha 0.75 (main bars perpendicular traffic) 


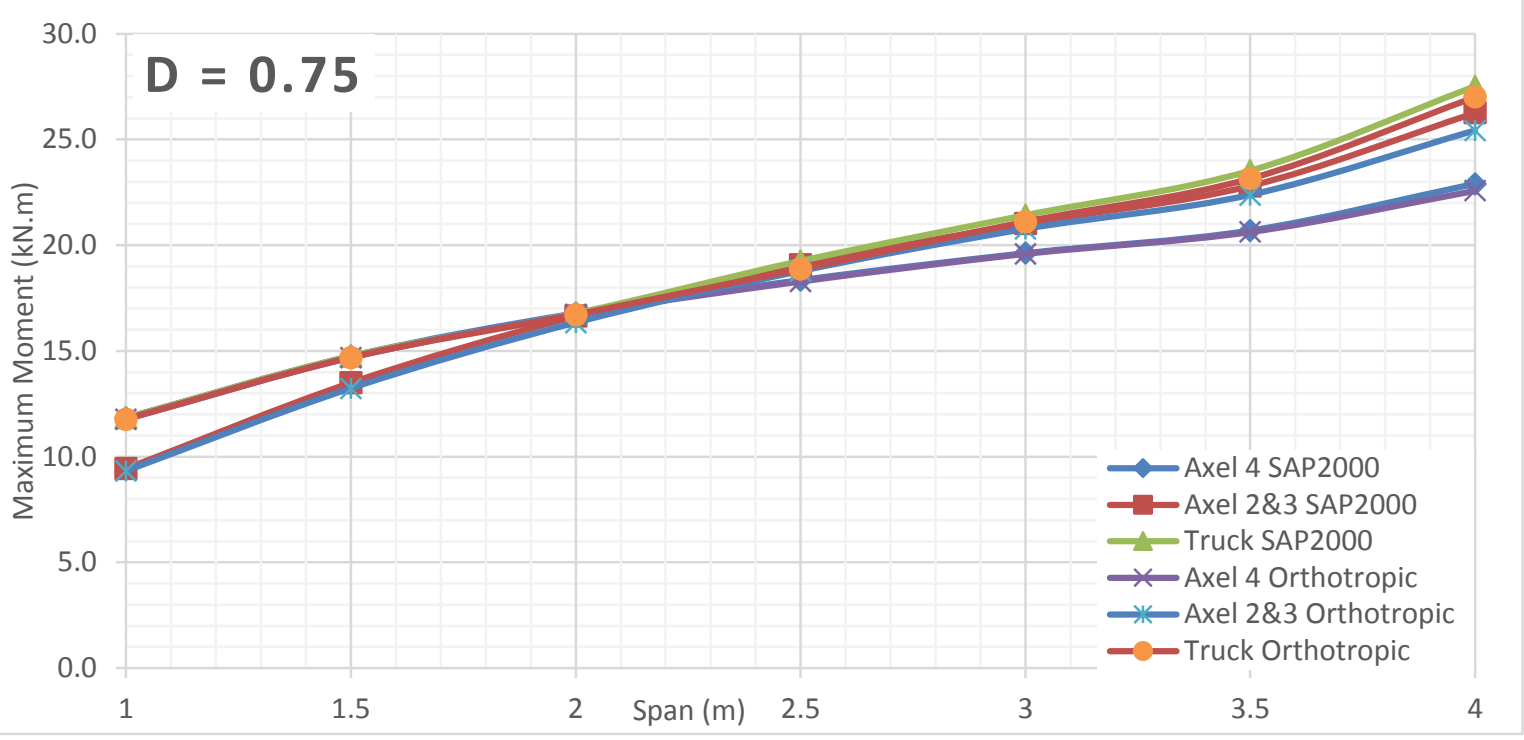

Figure 531 Moment comparison between FEA and Orthotropic Plate Theory for $D=0.75$ of alpha 0.75 (main bars perpendicular traffic)

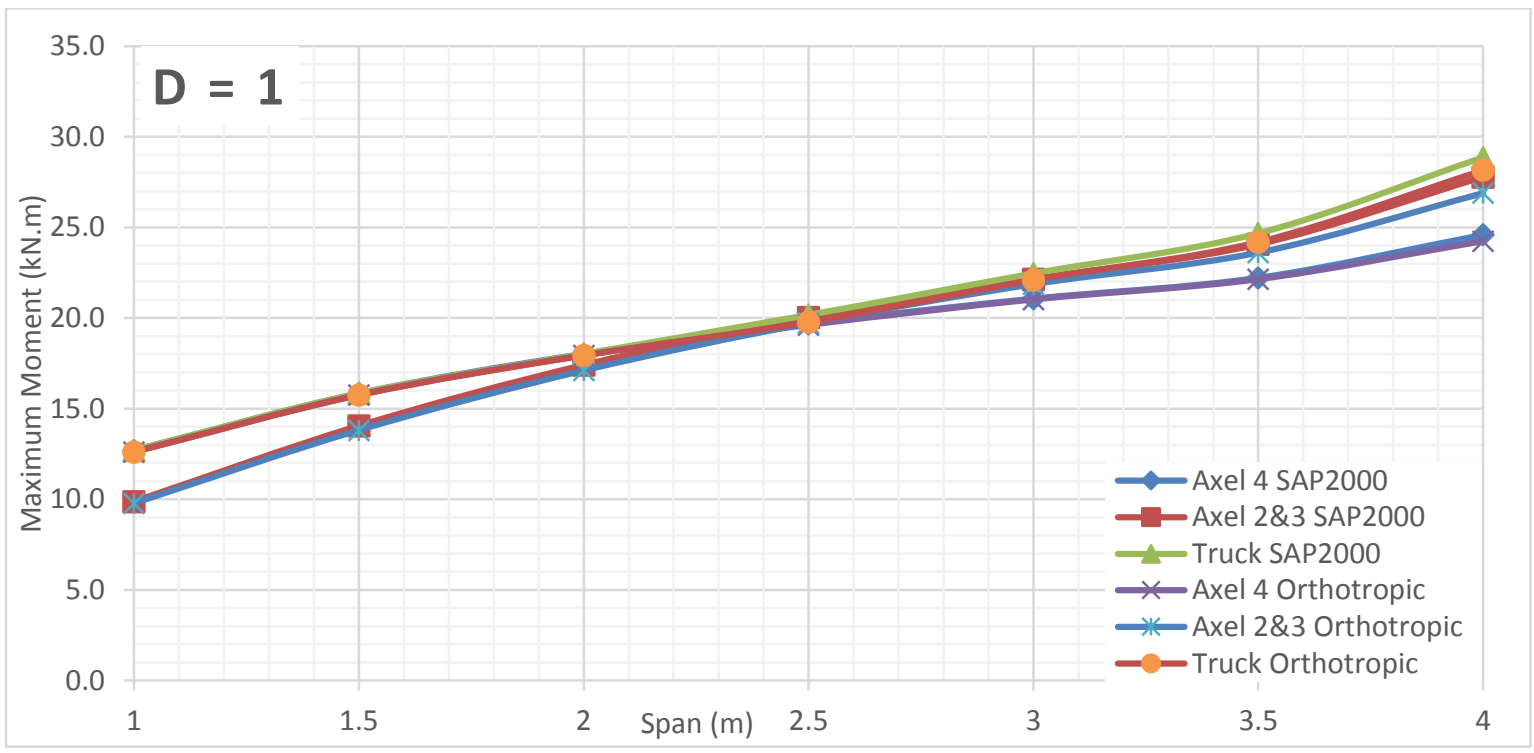

Figure 532 Moment comparison between FEA and Orthotropic Plate Theory for $\mathrm{D}=1$ of alpha 0.75 (main bars perpendicular traffic)

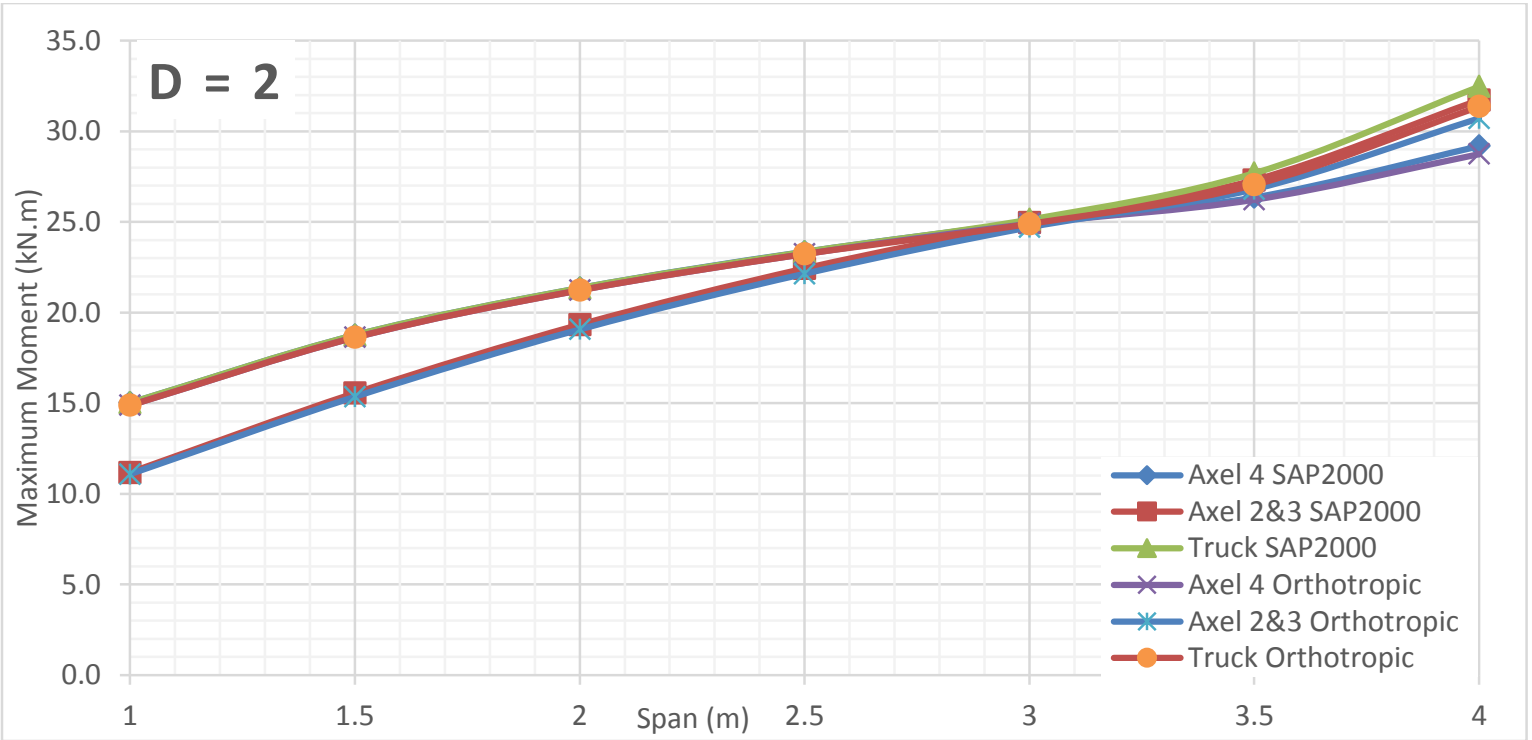

Figure 533 Moment comparison between FEA and Orthotropic Plate Theory for $\mathrm{D}=2$ of alpha 0.75 (main bars perpendicular traffic) 


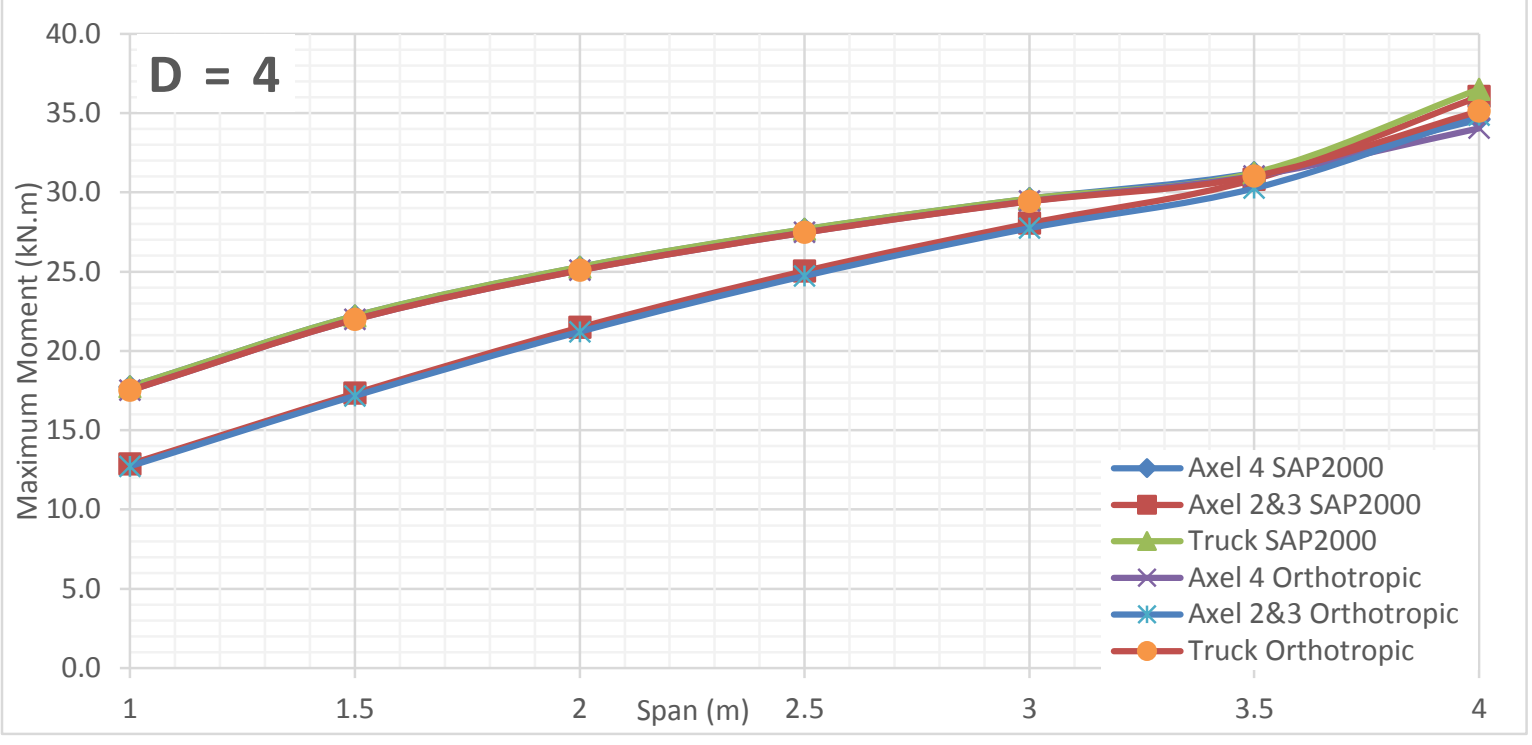

Figure 534 Moment comparison between FEA and Orthotropic Plate Theory for $D=4$ of alpha 0.75 (main bars perpendicular traffic)

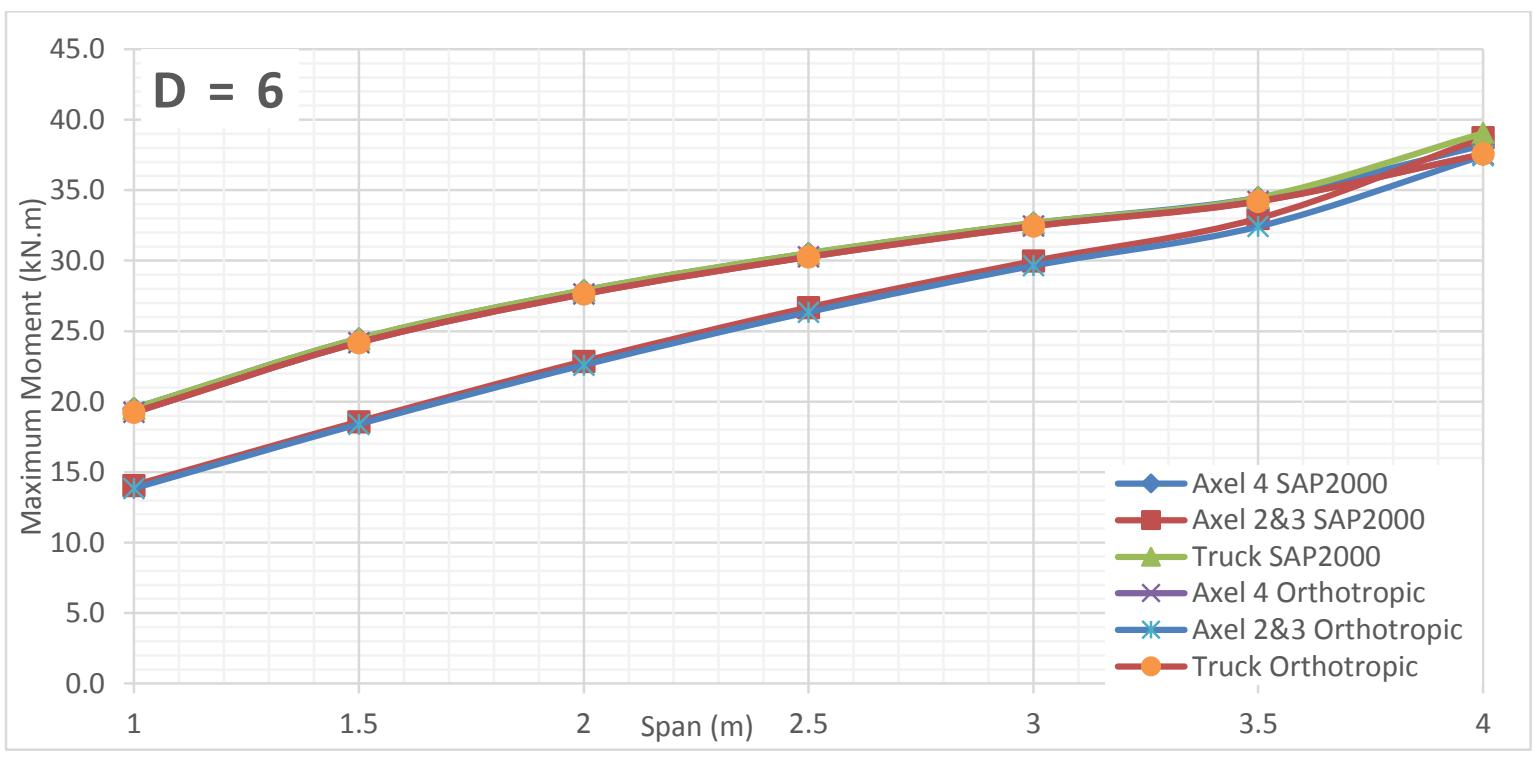

Figure 535 Moment comparison between FEA and Orthotropic Plate Theory for D $=6$ of alpha 0.75 (main bars perpendicular traffic)

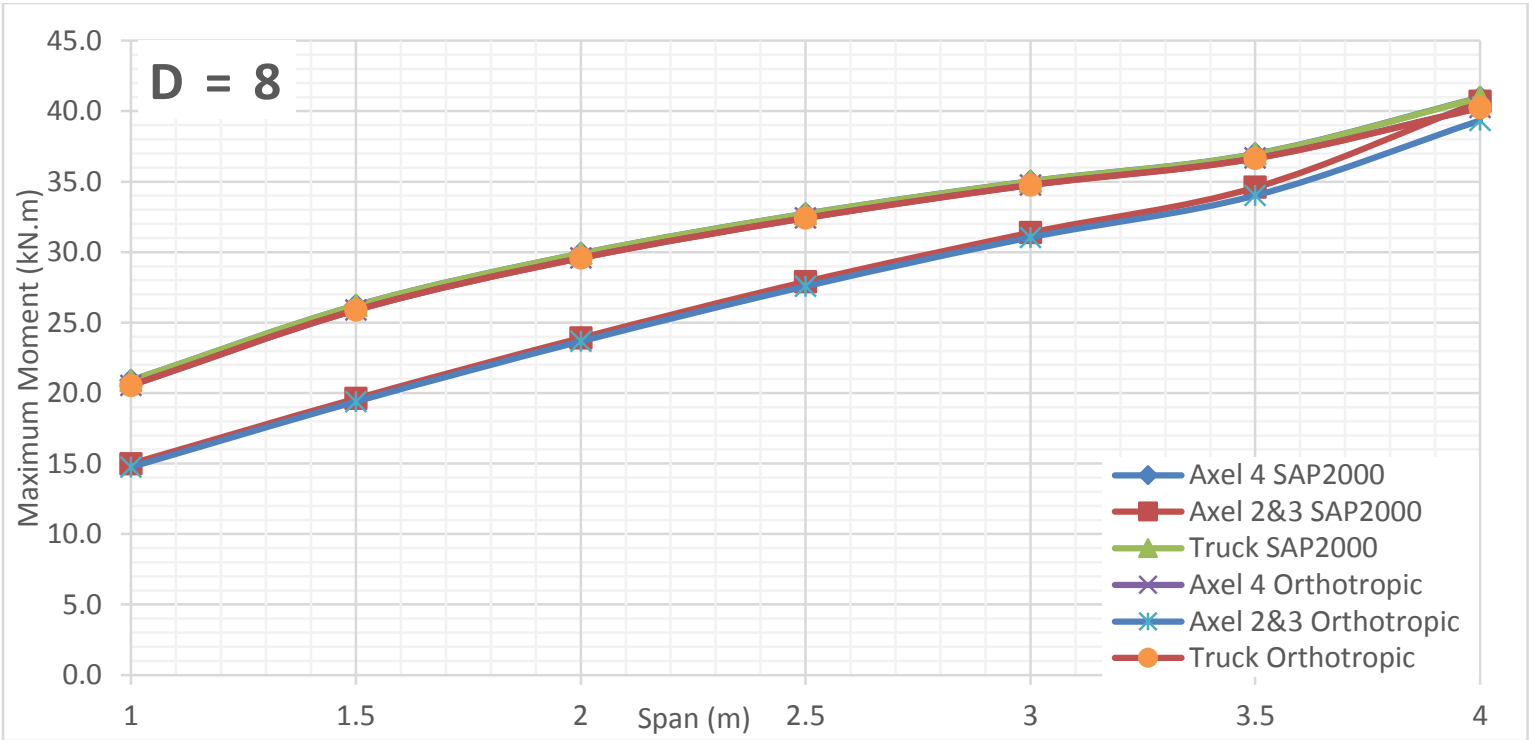

Figure 536 Moment comparison between FEA and Orthotropic Plate Theory for $\mathrm{D}=8$ of alpha 0.75 (main bars perpendicular traffic) 


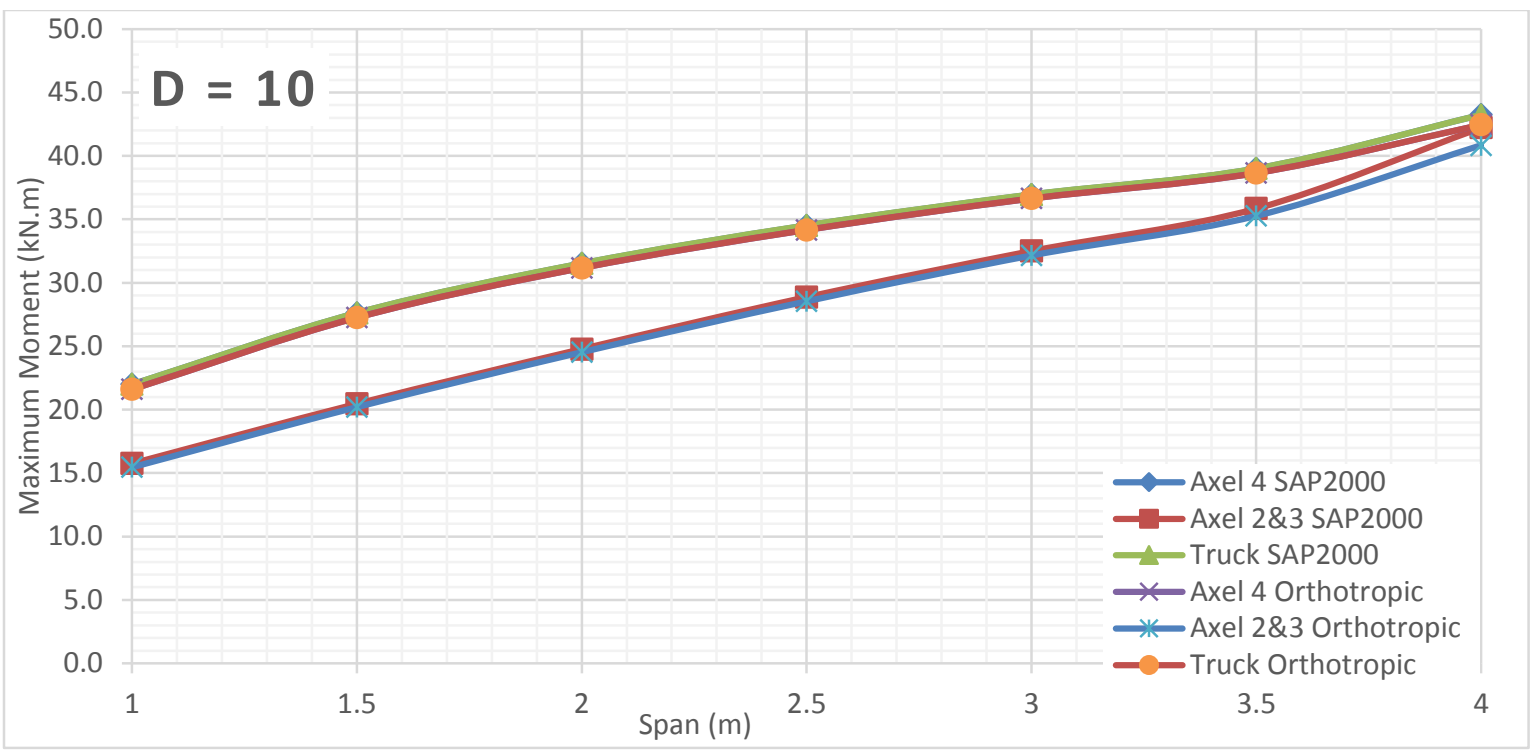

Figure 537 Moment comparison between FEA and Orthotropic Plate Theory for D = 10 of alpha 0.75 (main bars perpendicular traffic) 


\section{Alpha 0.75 Bending Moment VS Span Length for Different D Values (Main bars parallel to traffic)}

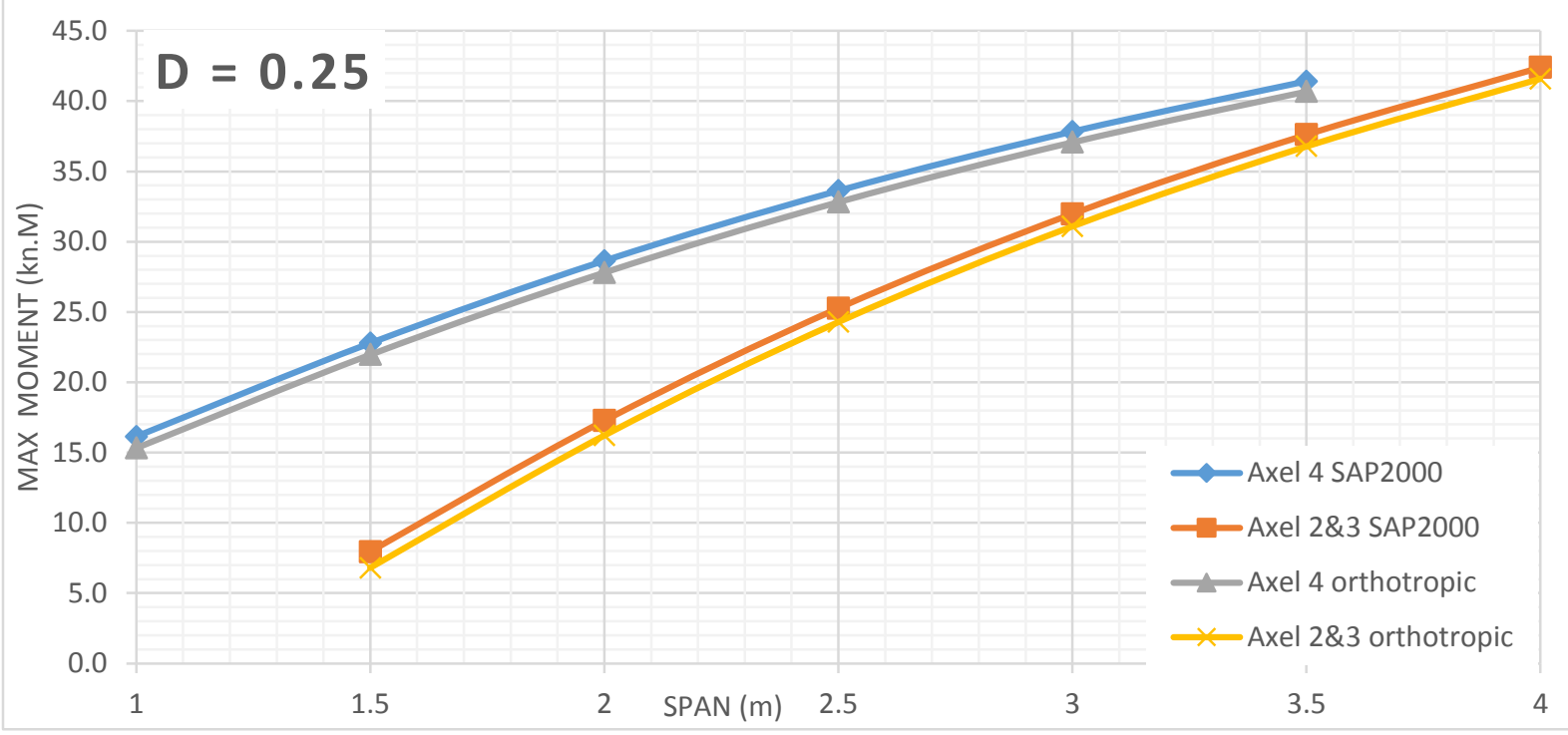

Figure 538 Moment comparison between FEA and Orthotropic Plate Theory for D $=0.25$ of alpha 0.75 (main bars parallel traffic)

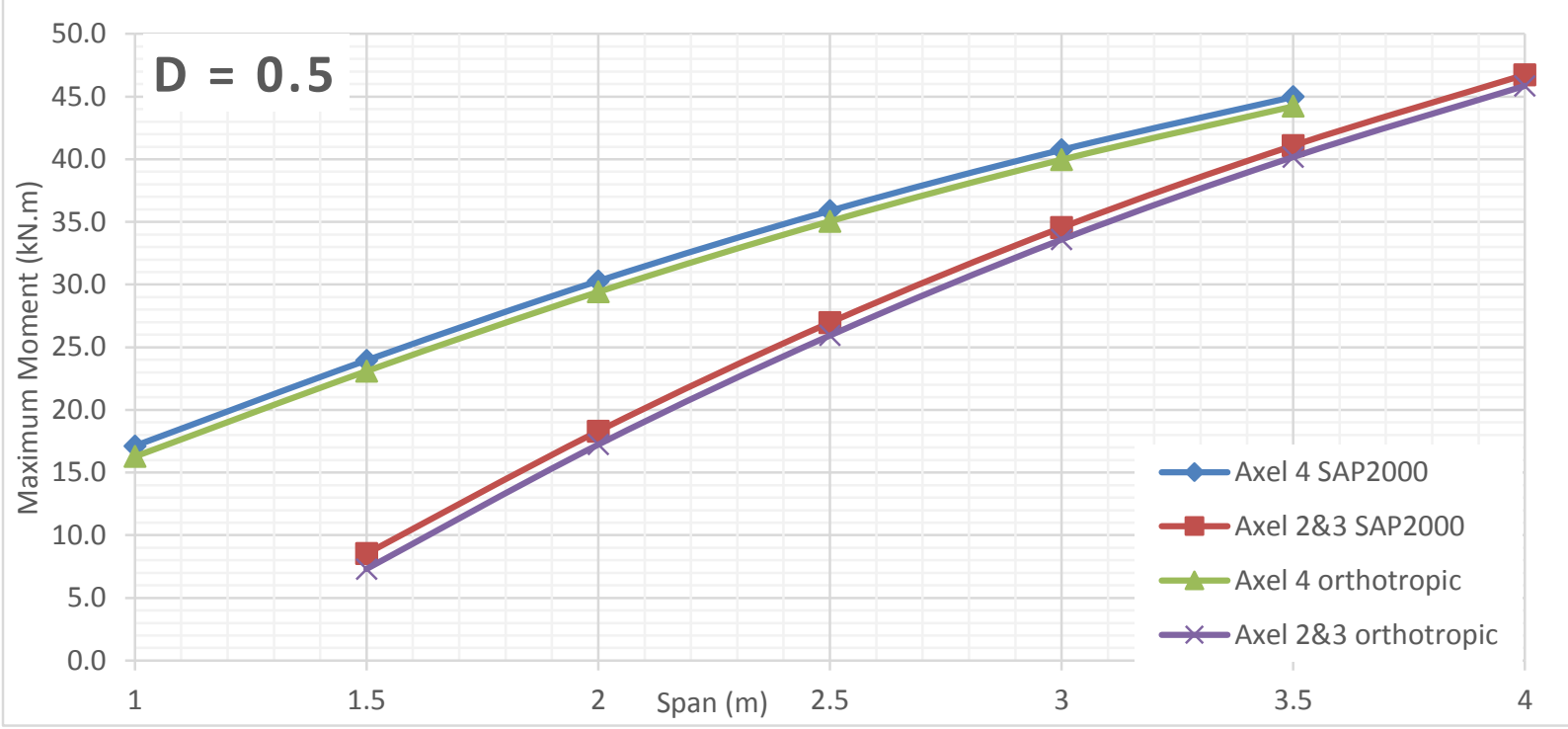

Figure 539 Moment comparison between FEA and Orthotropic Plate Theory for D $=0.5$ of alpha 0.75 (main bars parallel traffic) 


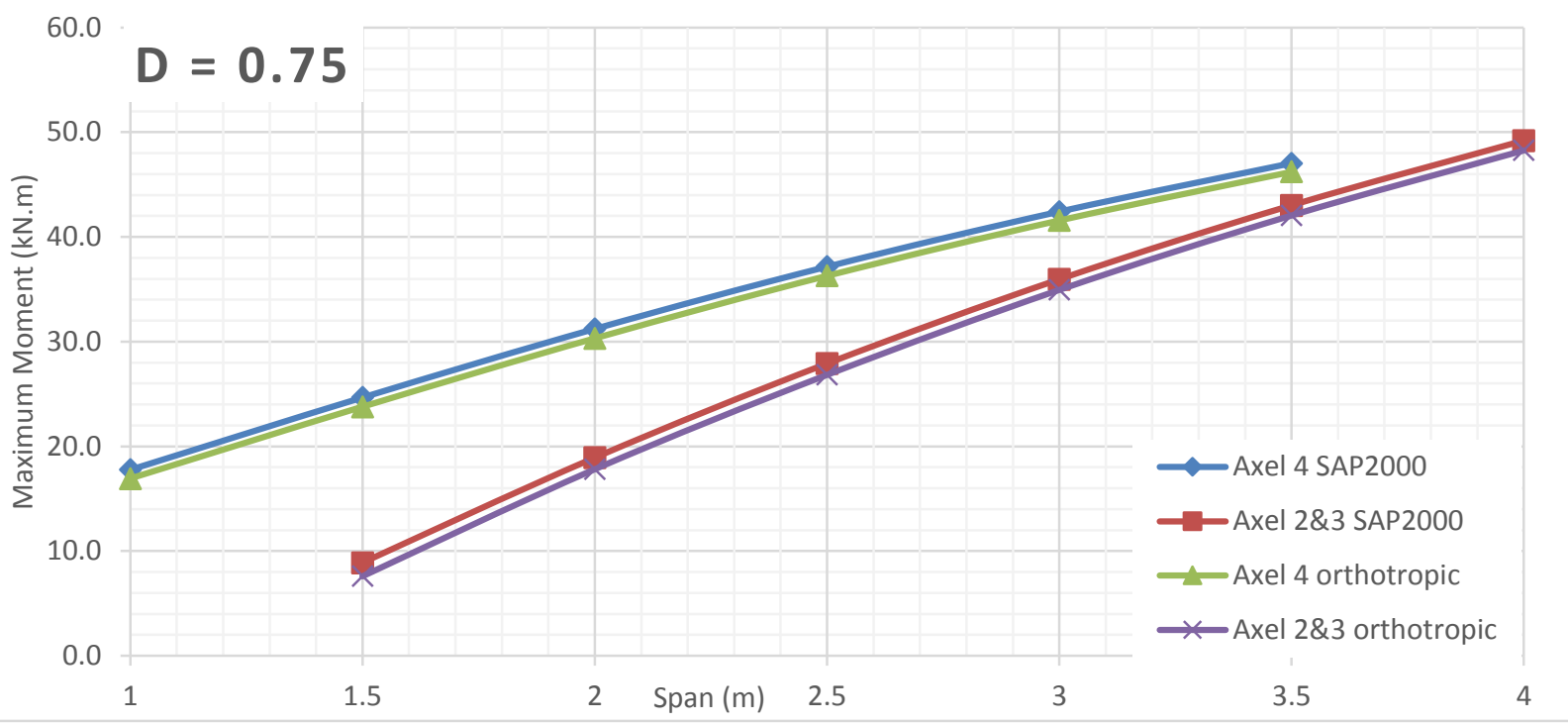

Figure 540 Moment comparison between FEA and Orthotropic Plate Theory for $\mathrm{D}=0.75$ of alpha 0.75 (main bars parallel traffic)

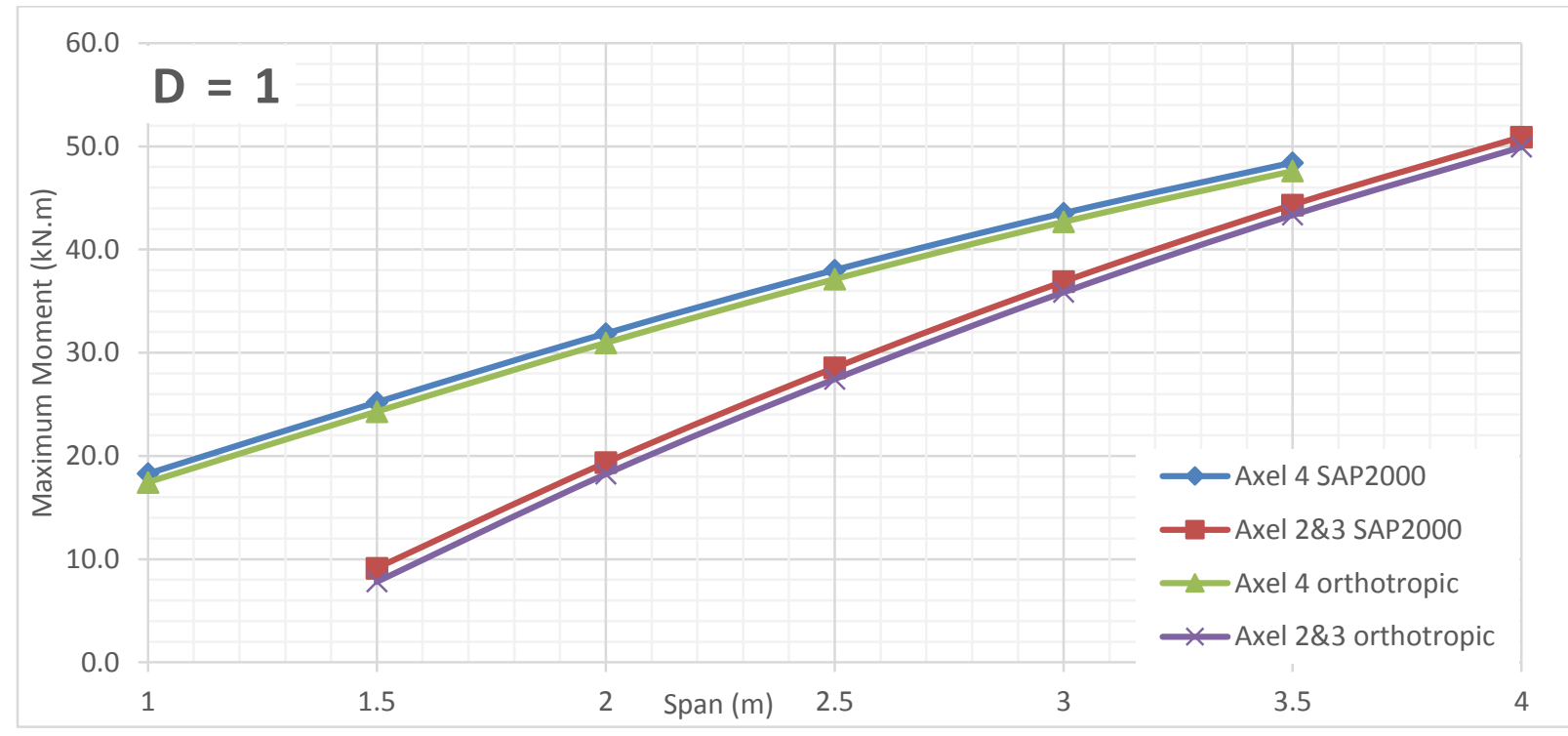

Figure 541 Moment comparison between FEA and Orthotropic Plate Theory for D = 1 of alpha 0.75 (main bars parallel traffic)

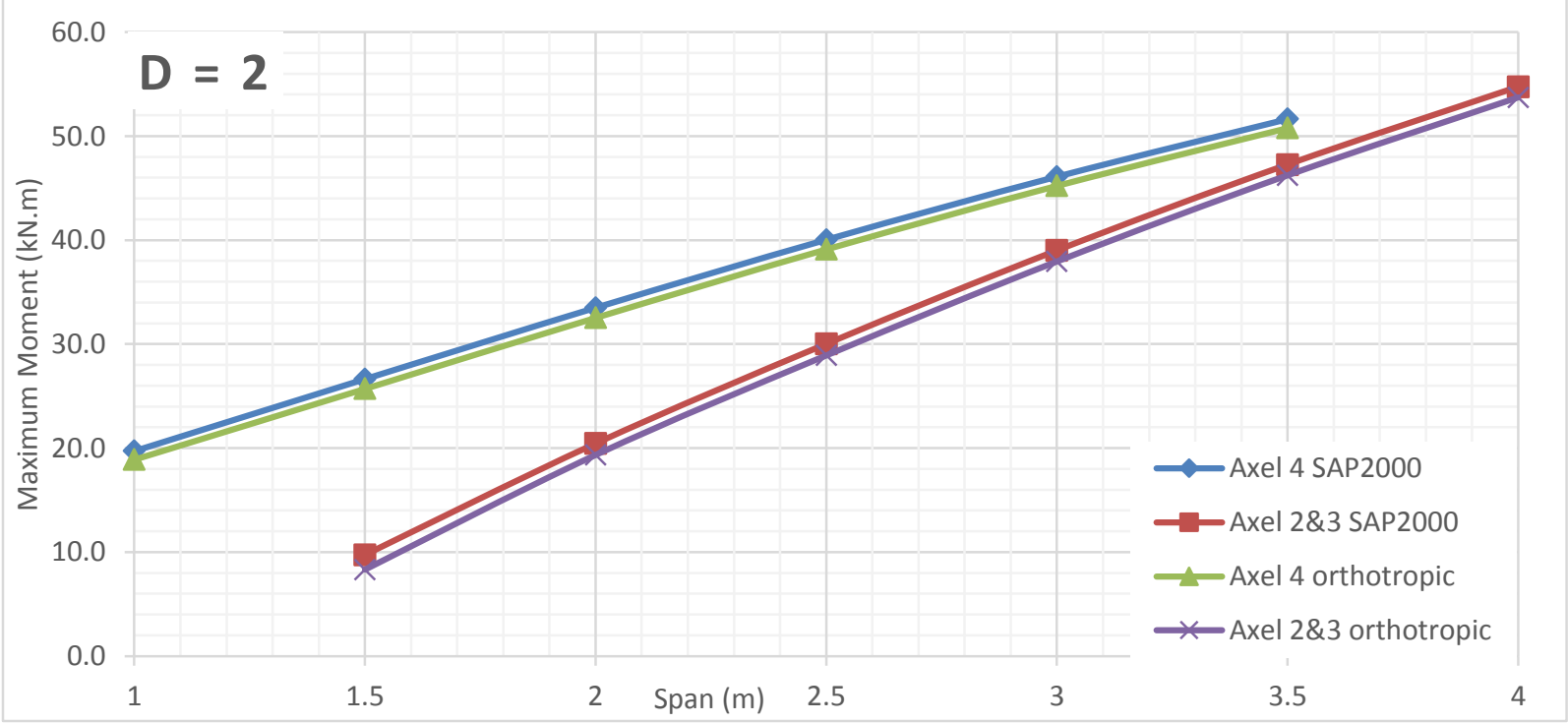

Figure 542 Moment comparison between FEA and Orthotropic Plate Theory for $D=2$ of alpha 0.75 (main bars parallel traffic) 


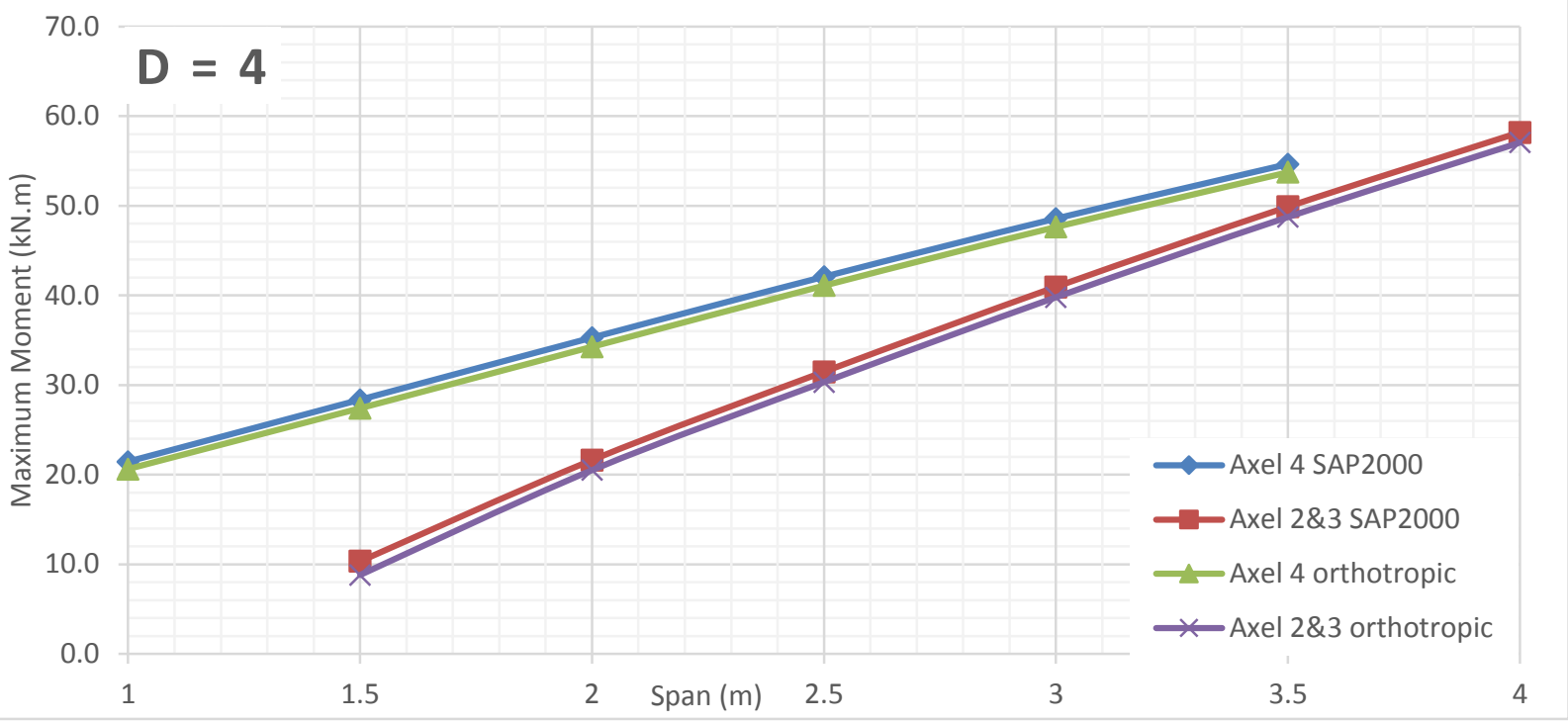

Figure 543 Moment comparison between FEA and Orthotropic Plate Theory for D $=4$ of alpha 0.75 (main bars parallel traffic)

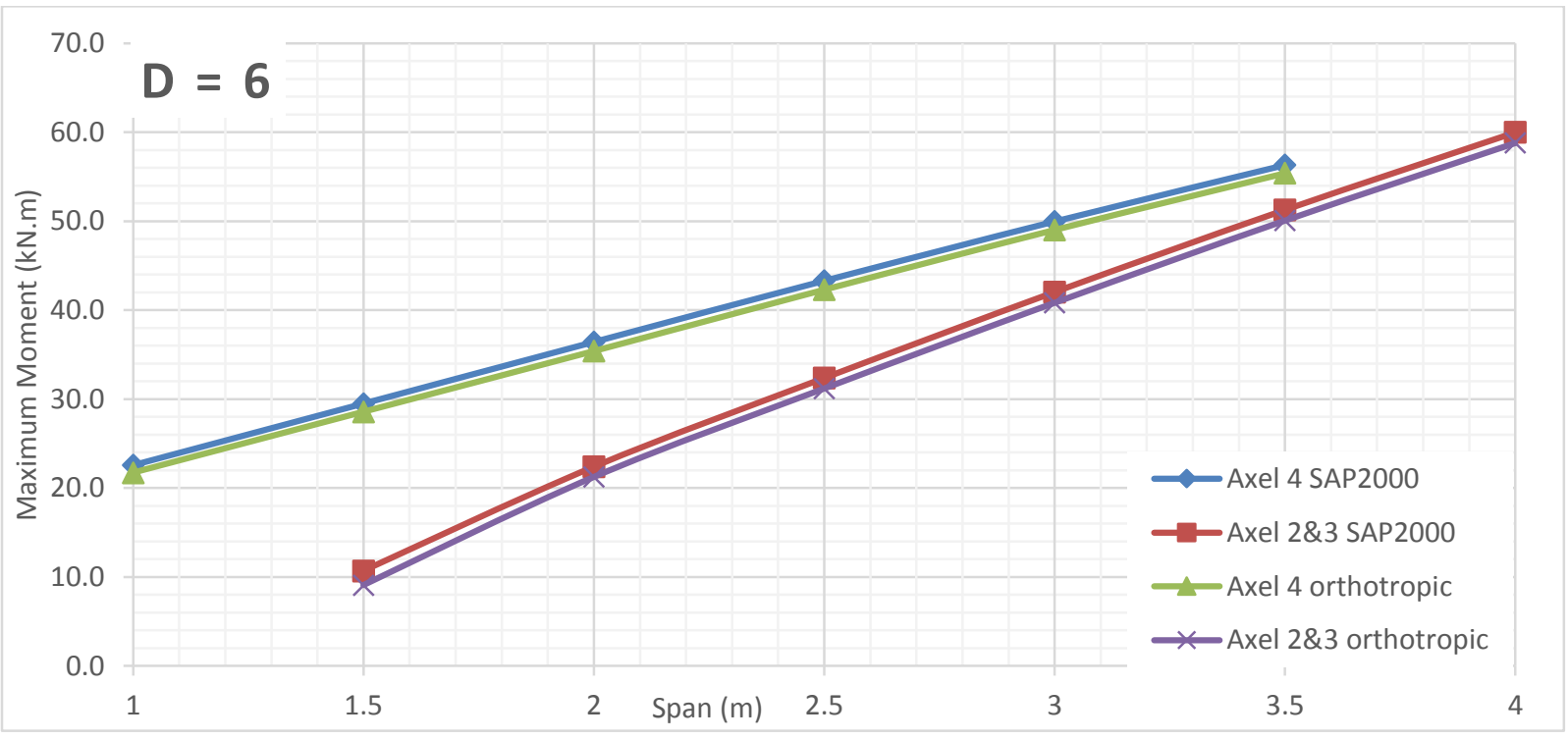

Figure 544 Moment comparison between FEA and Orthotropic Plate Theory for D $=6$ of alpha 0.75 (main bars parallel traffic)

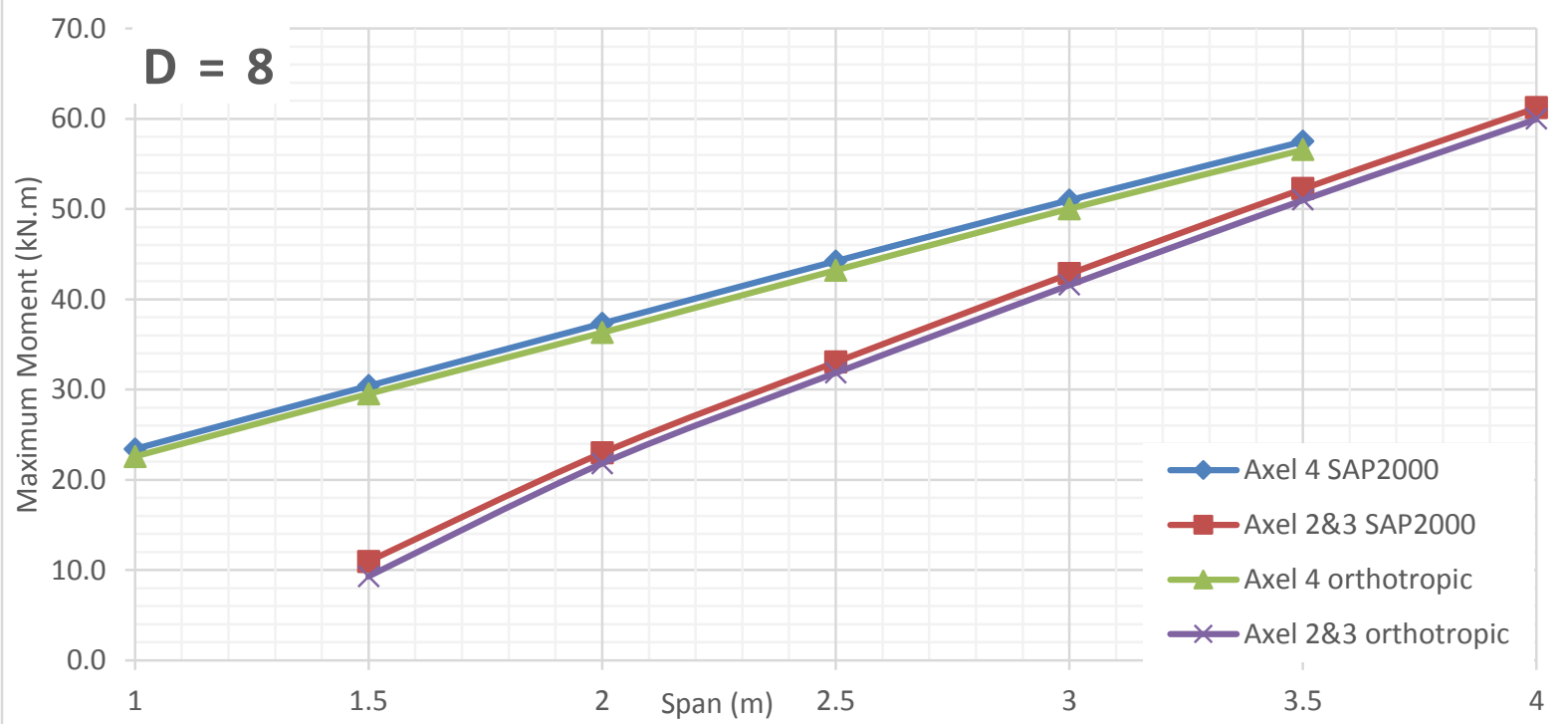

Figure 545 Moment comparison between FEA and Orthotropic Plate Theory for $\mathrm{D}=8$ of alpha 0.75 (main bars parallel traffic) 


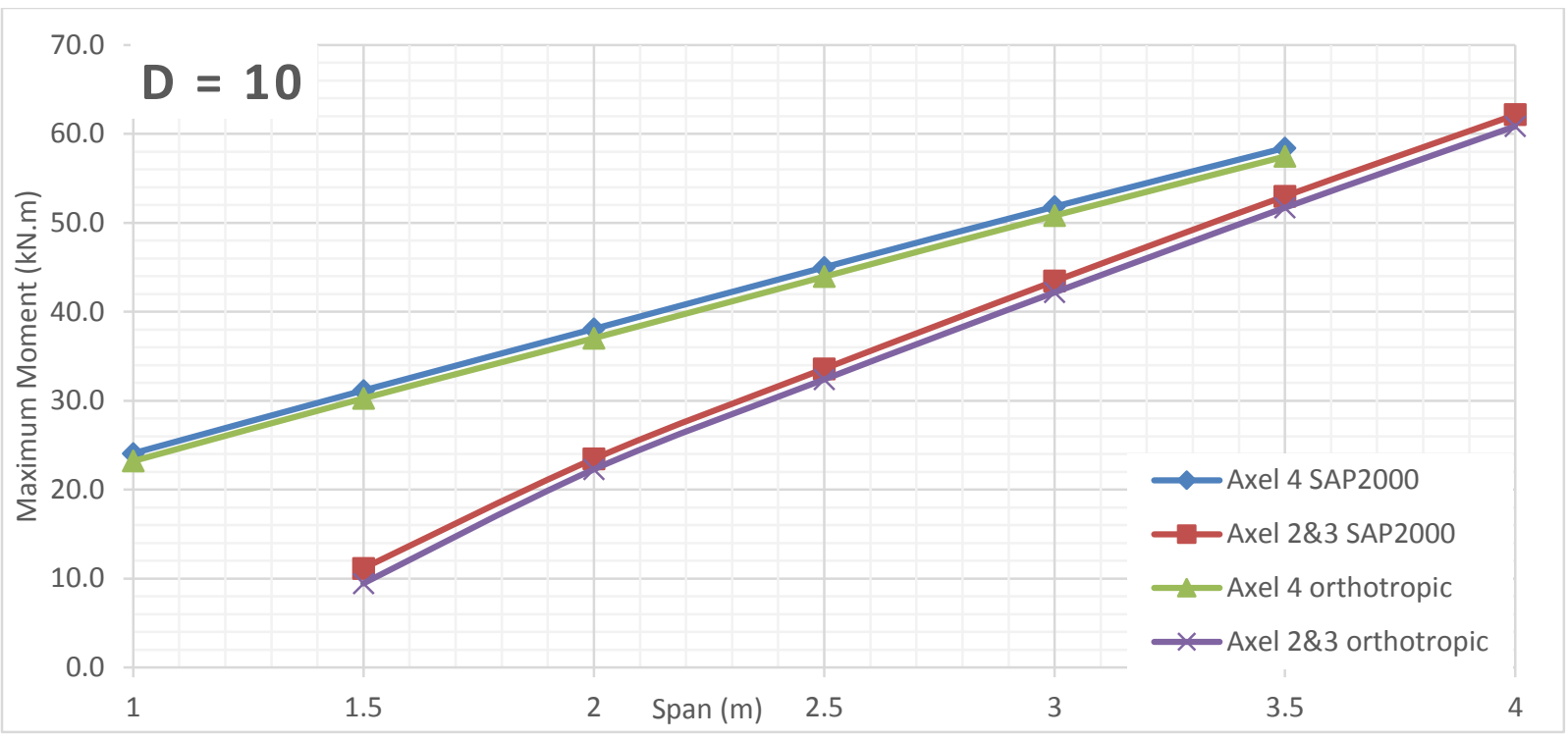

Figure 546 Moment comparison between FEA and Orthotropic Plate Theory for D = 10 of alpha 0.75 (main bars parallel traffic) 


\section{Alpha 1 Bending Moment VS Span Length for Different D Values (Main bars perpendicular to traffic)}

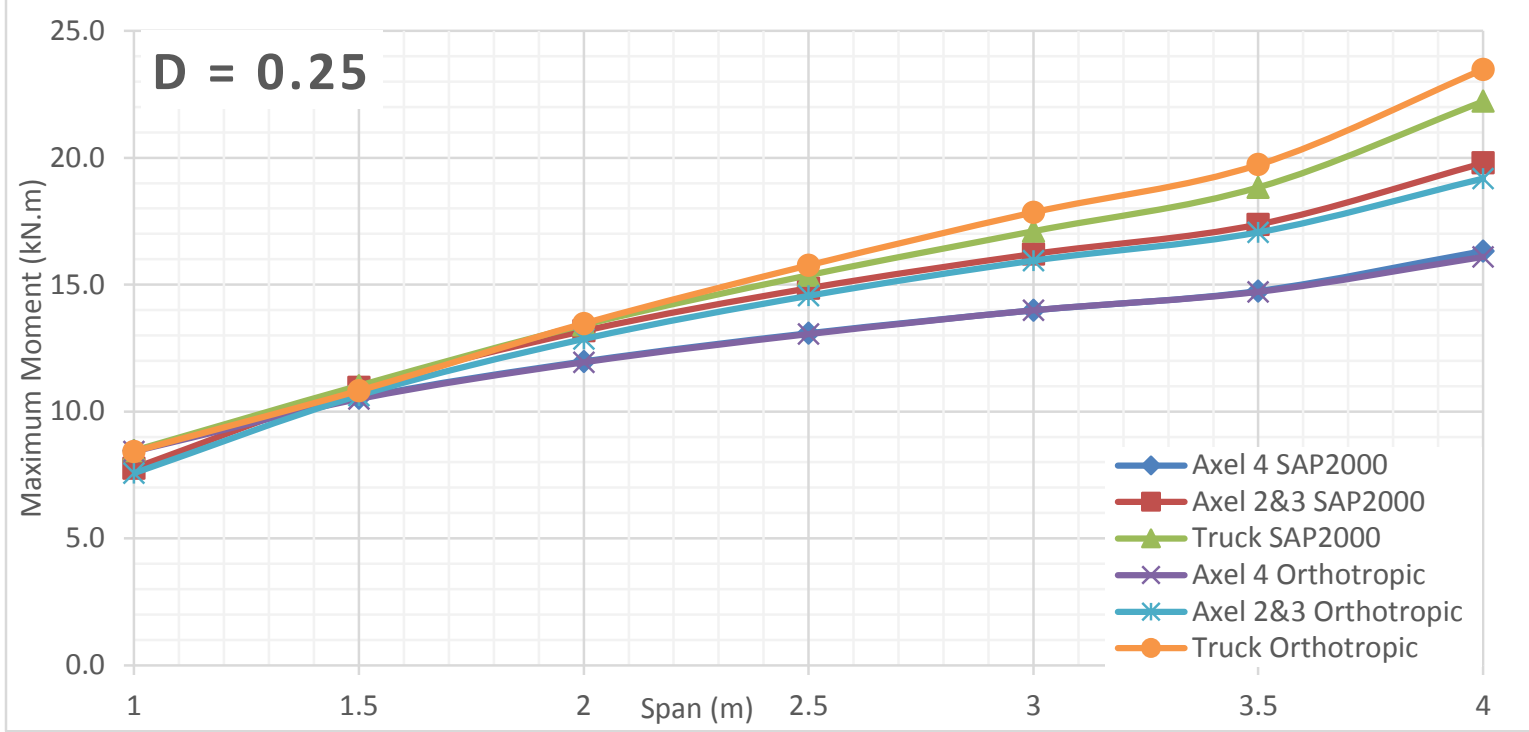

Figure 547 Moment comparison between FEA and Orthotropic Plate Theory for $D=0.25$ of alpha 1 (main bars perpendicular traffic)

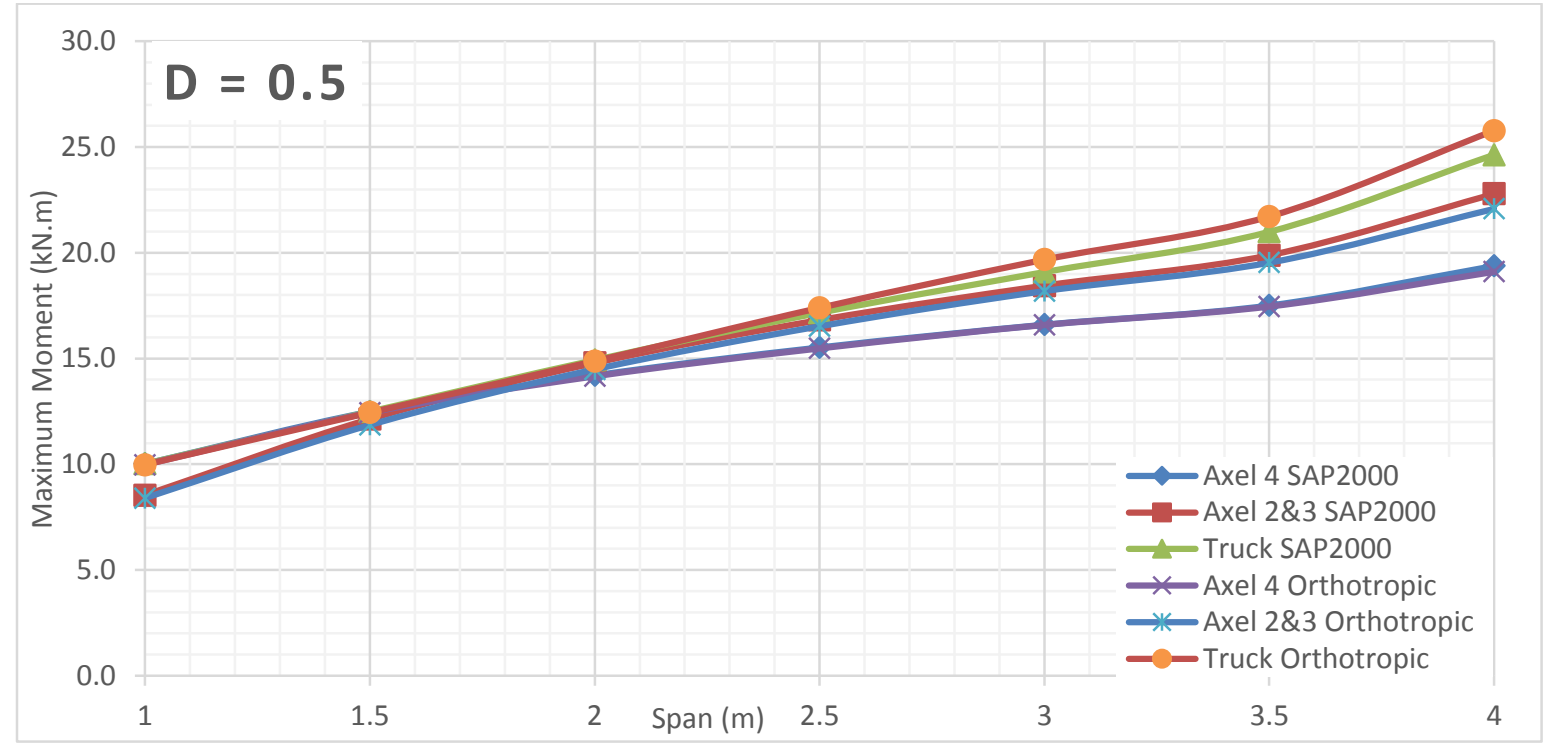

Figure 548 Moment comparison between FEA and Orthotropic Plate Theory for $D=0.5$ of alpha 1 (main bars perpendicular traffic) 


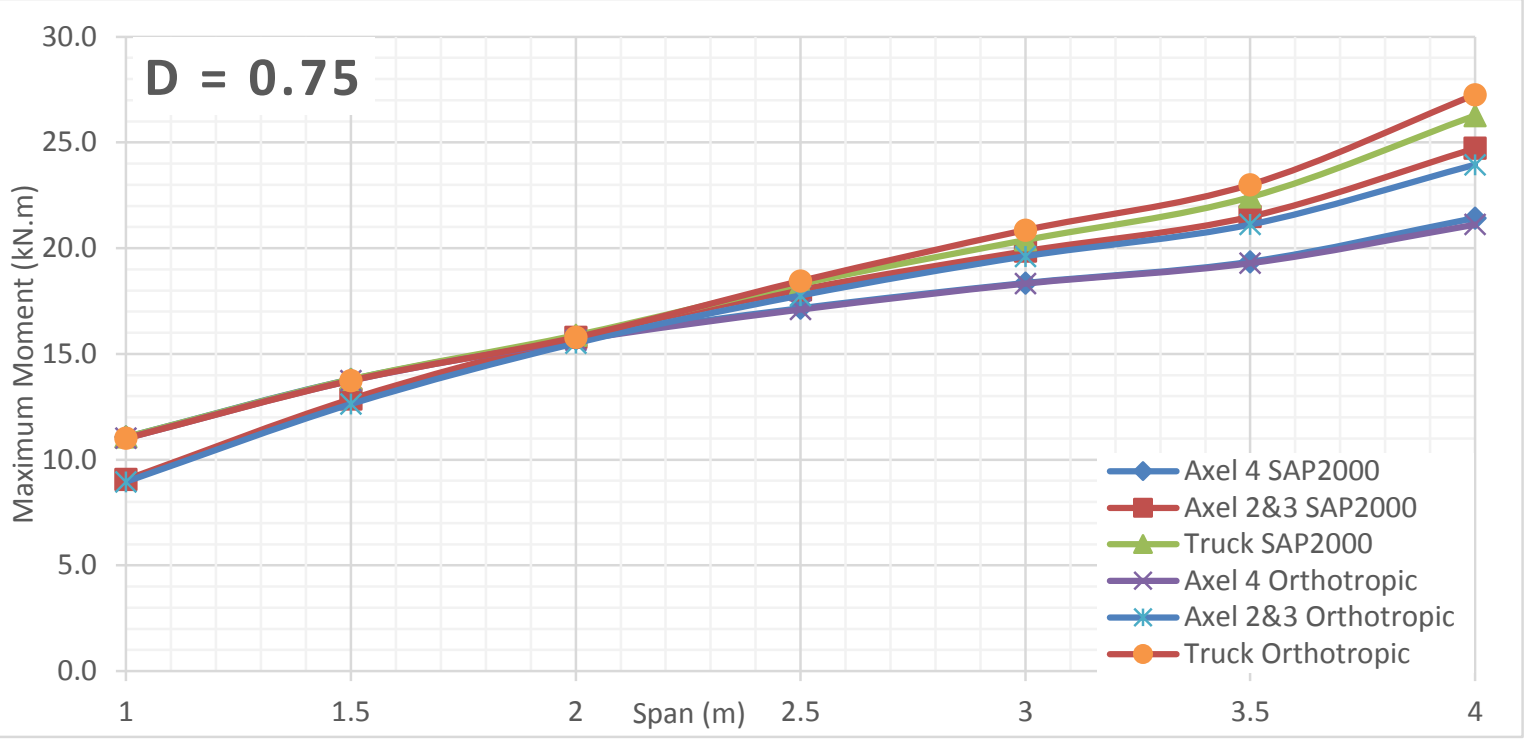

Figure 549 Moment comparison between FEA and Orthotropic Plate Theory for $D=0.75$ of alpha 1 (main bars perpendicular traffic)

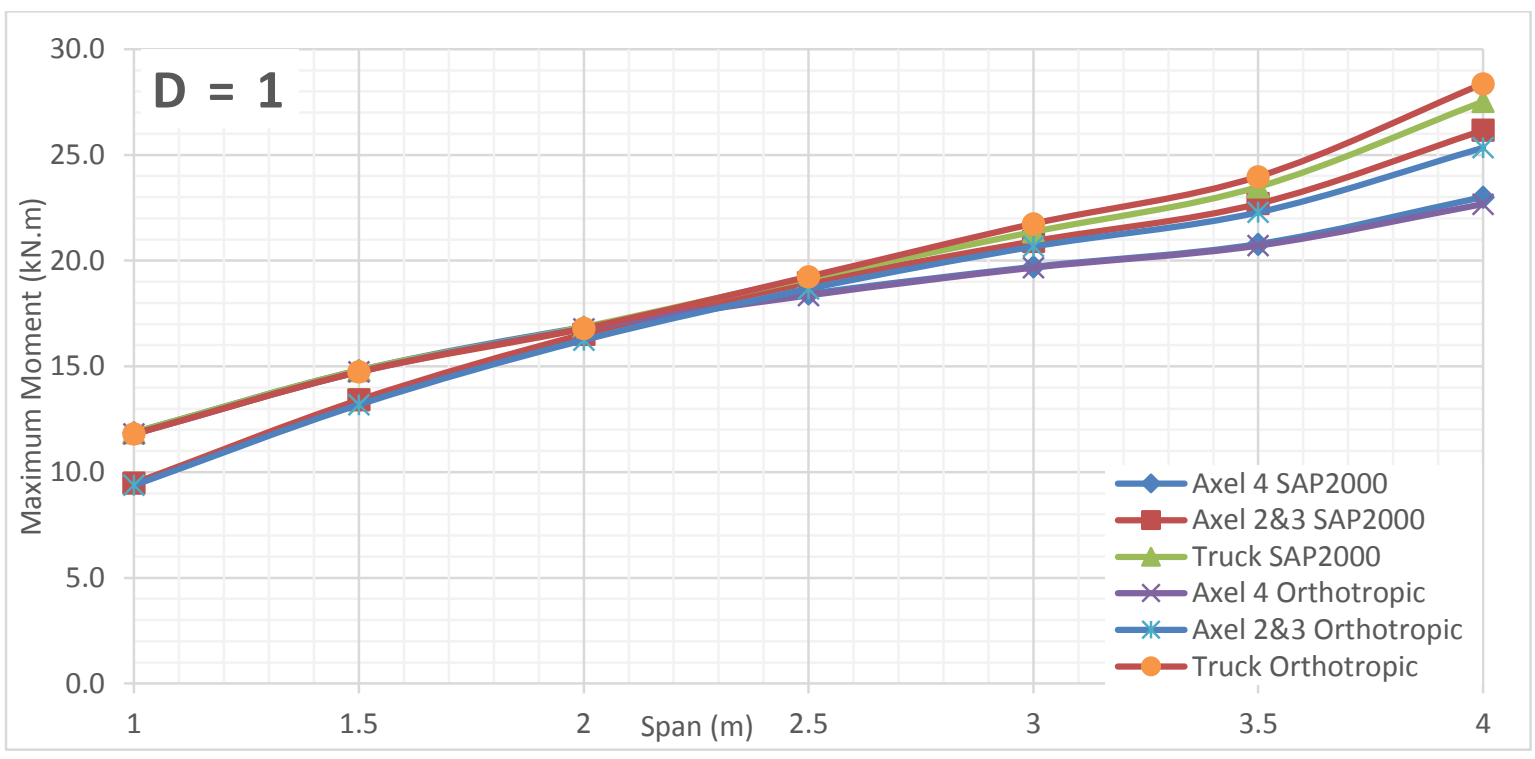

Figure 550 Moment comparison between FEA and Orthotropic Plate Theory for $\mathrm{D}=1$ of alpha 1 (main bars perpendicular traffic)

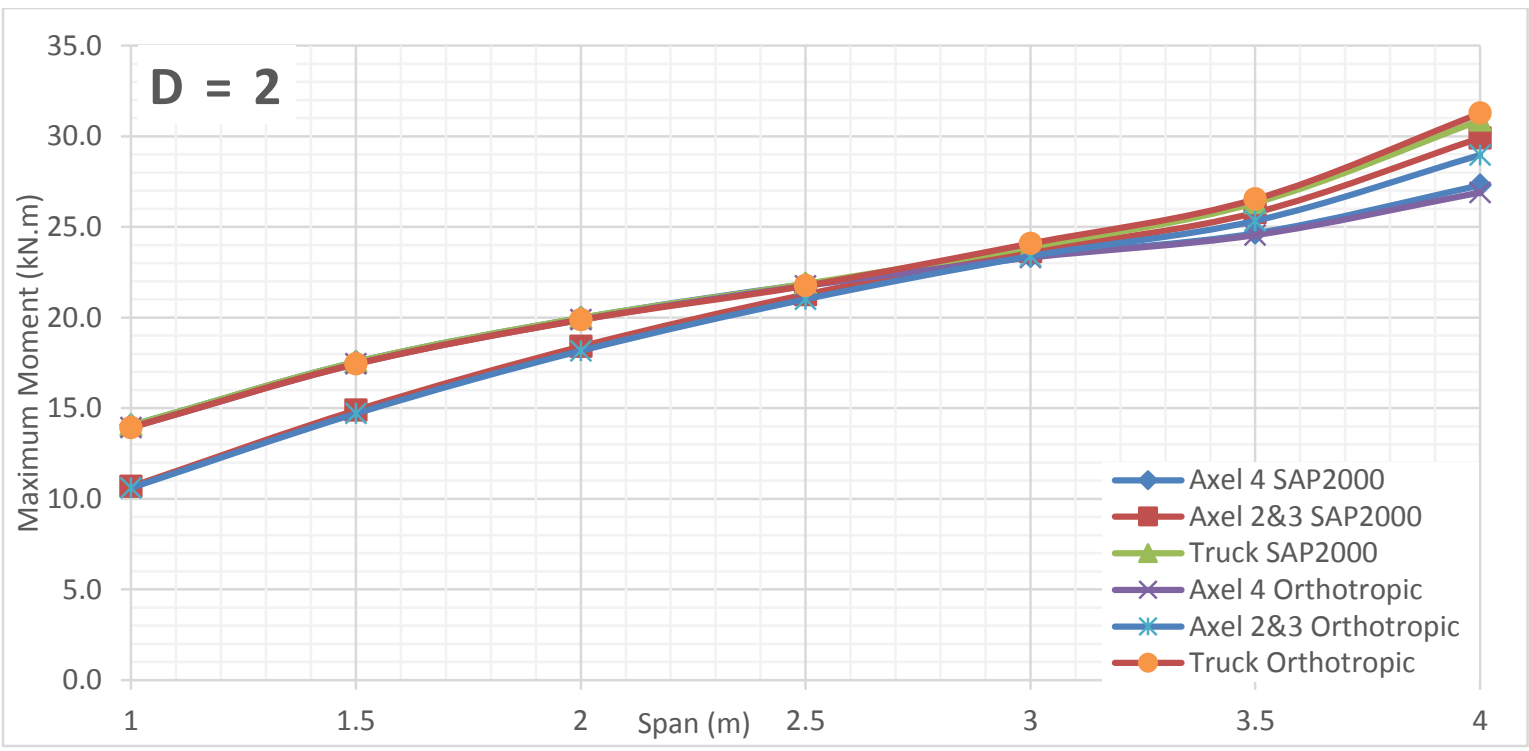

Figure 551 Moment comparison between FEA and Orthotropic Plate Theory for $\mathrm{D}=2$ of alpha 1 (main bars perpendicular traffic) 


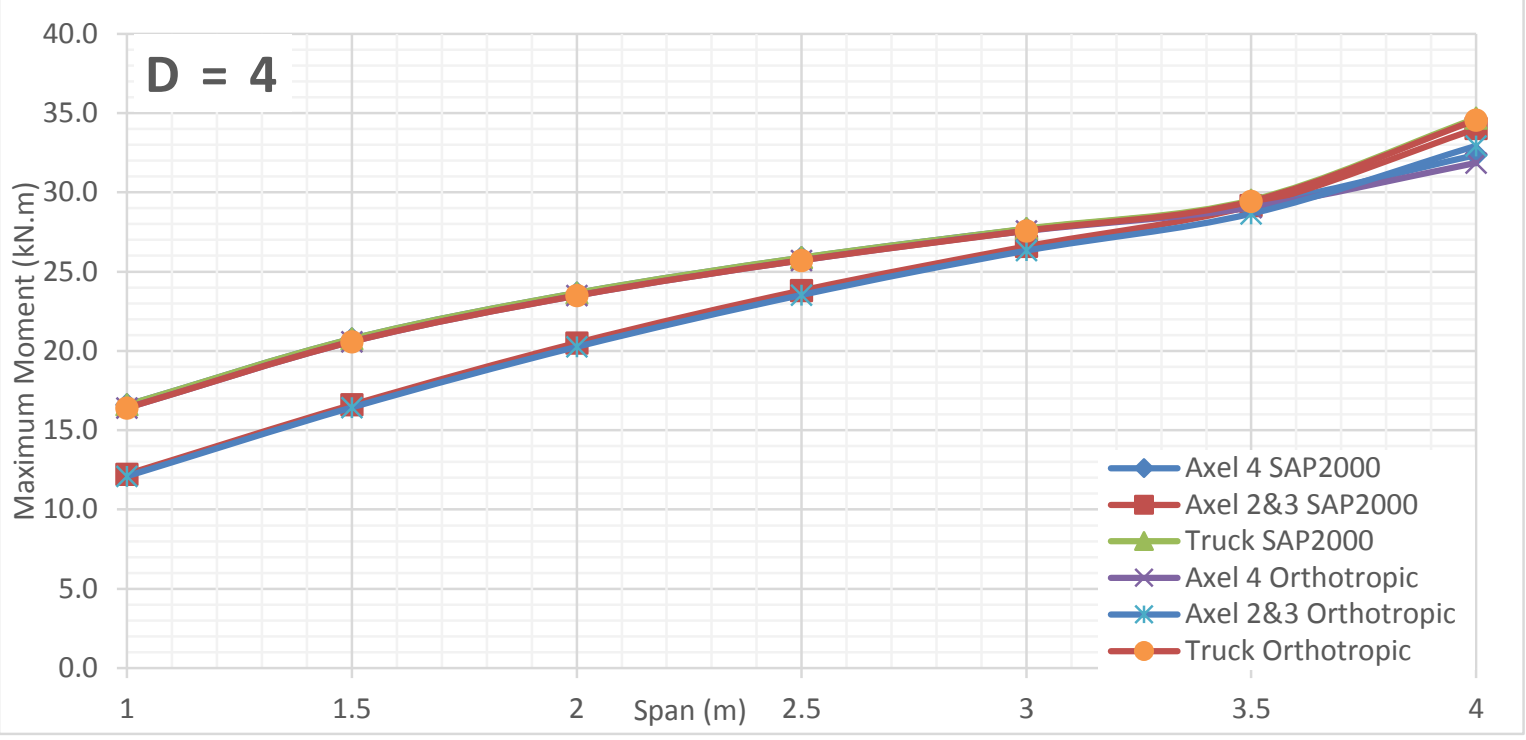

Figure 552 Moment comparison between FEA and Orthotropic Plate Theory for $D=4$ of alpha 1 (main bars perpendicular traffic)

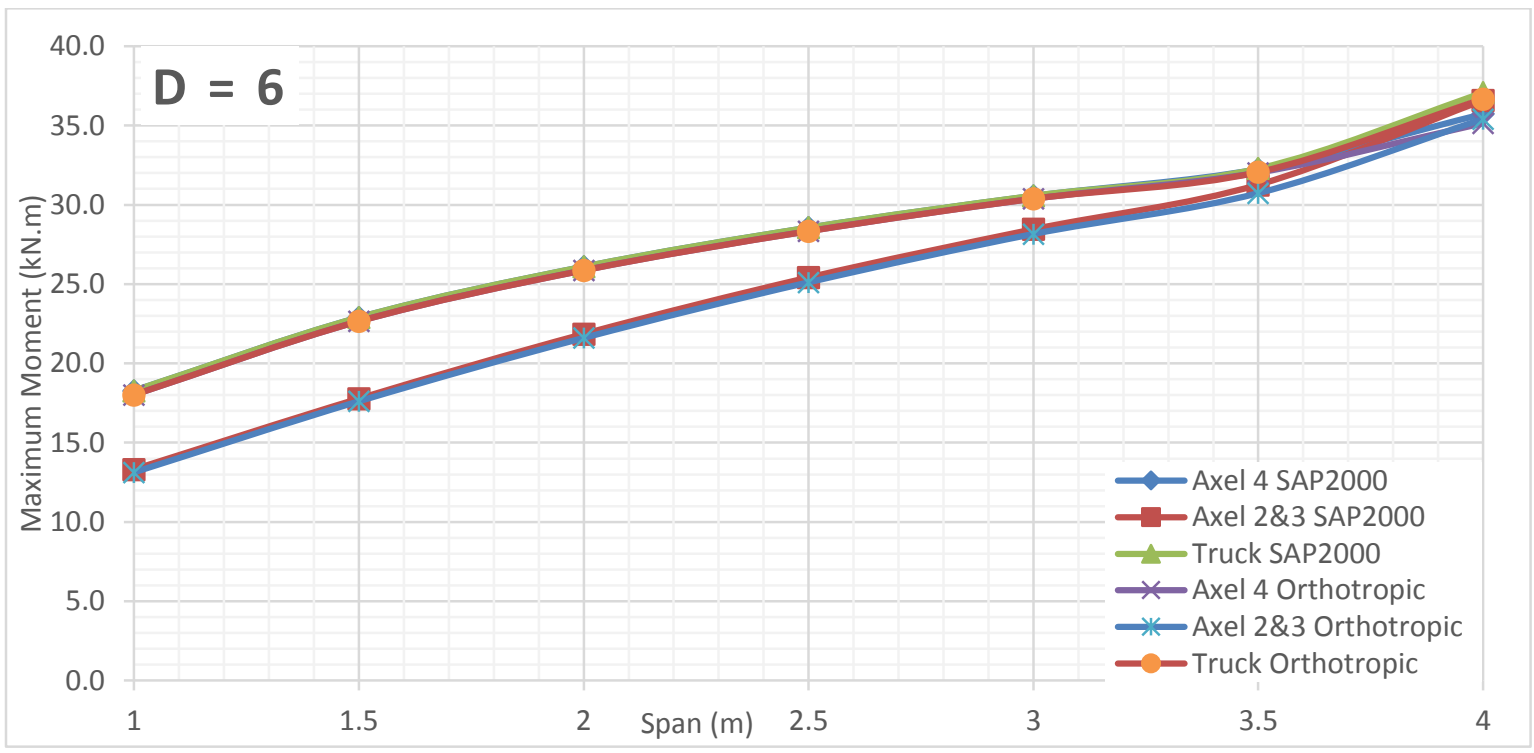

Figure 553 Moment comparison between FEA and Orthotropic Plate Theory for $D=6$ of alpha 1 (main bars perpendicular traffic)

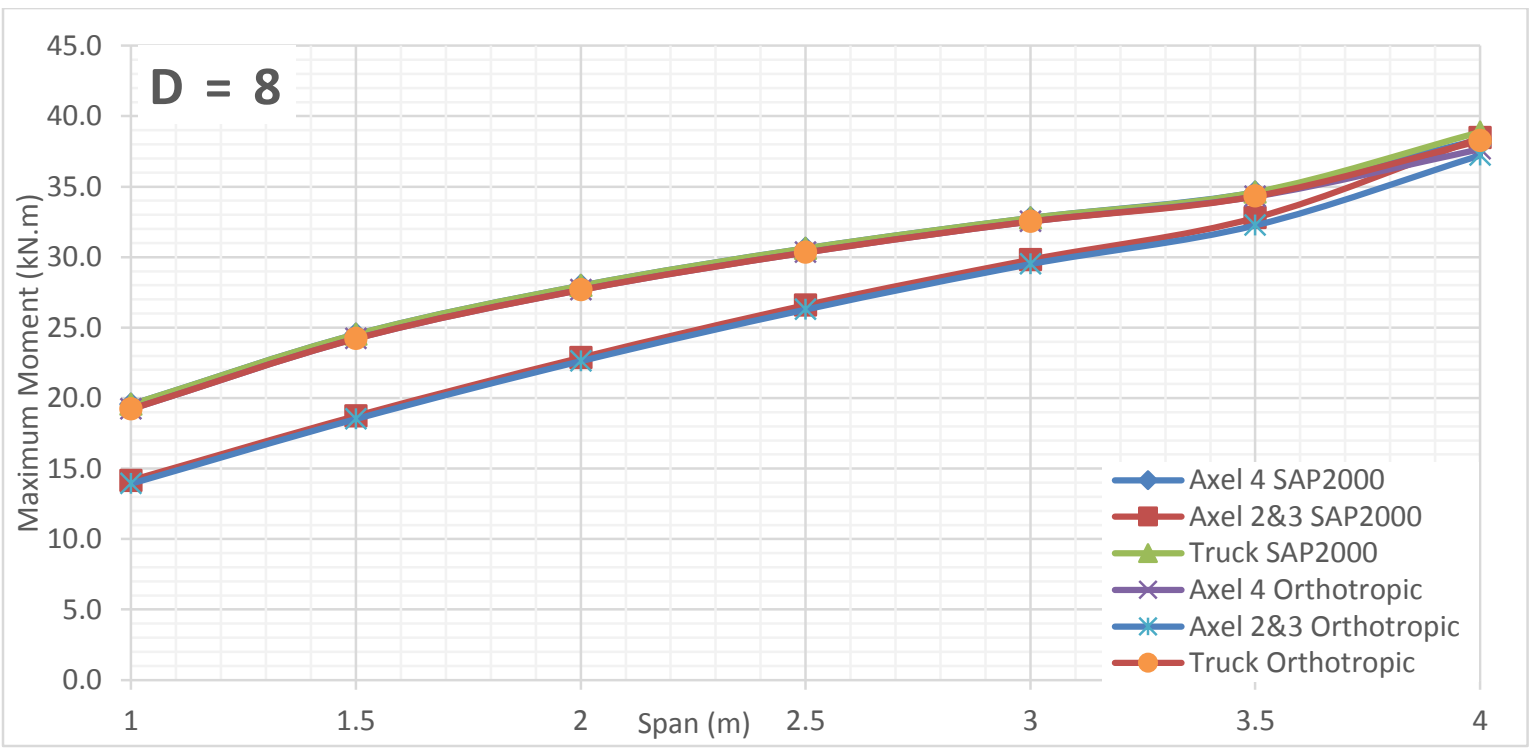

Figure 554 Moment comparison between FEA and Orthotropic Plate Theory for $D=8$ of alpha 1 (main bars perpendicular traffic) 


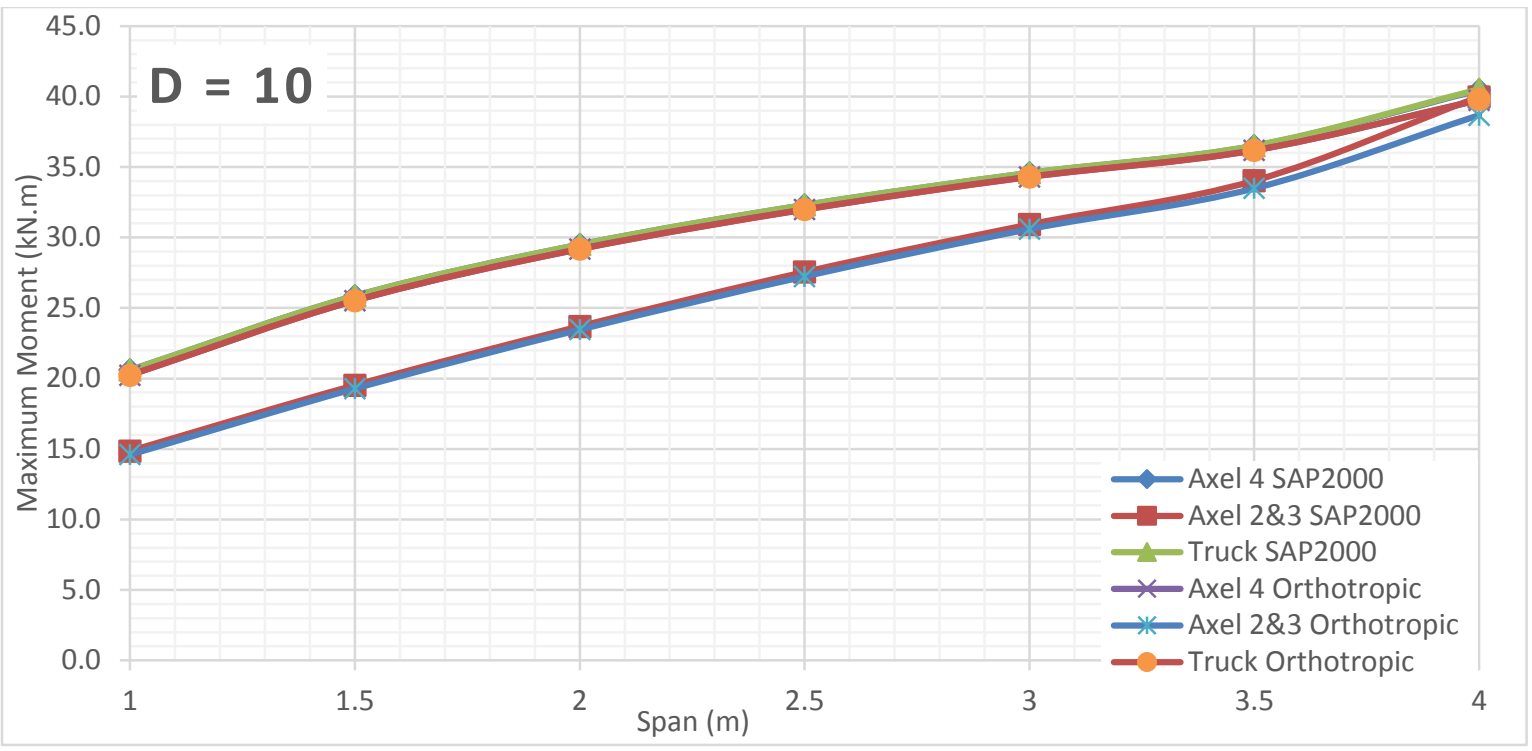

Figure 555 Moment comparison between FEA and Orthotropic Plate Theory for $D=10$ of alpha 1 (main bars perpendicular traffic) 


\section{Alpha 1 Bending Moment VS Span Length for Different D Values (Main bars parallel to traffic)}

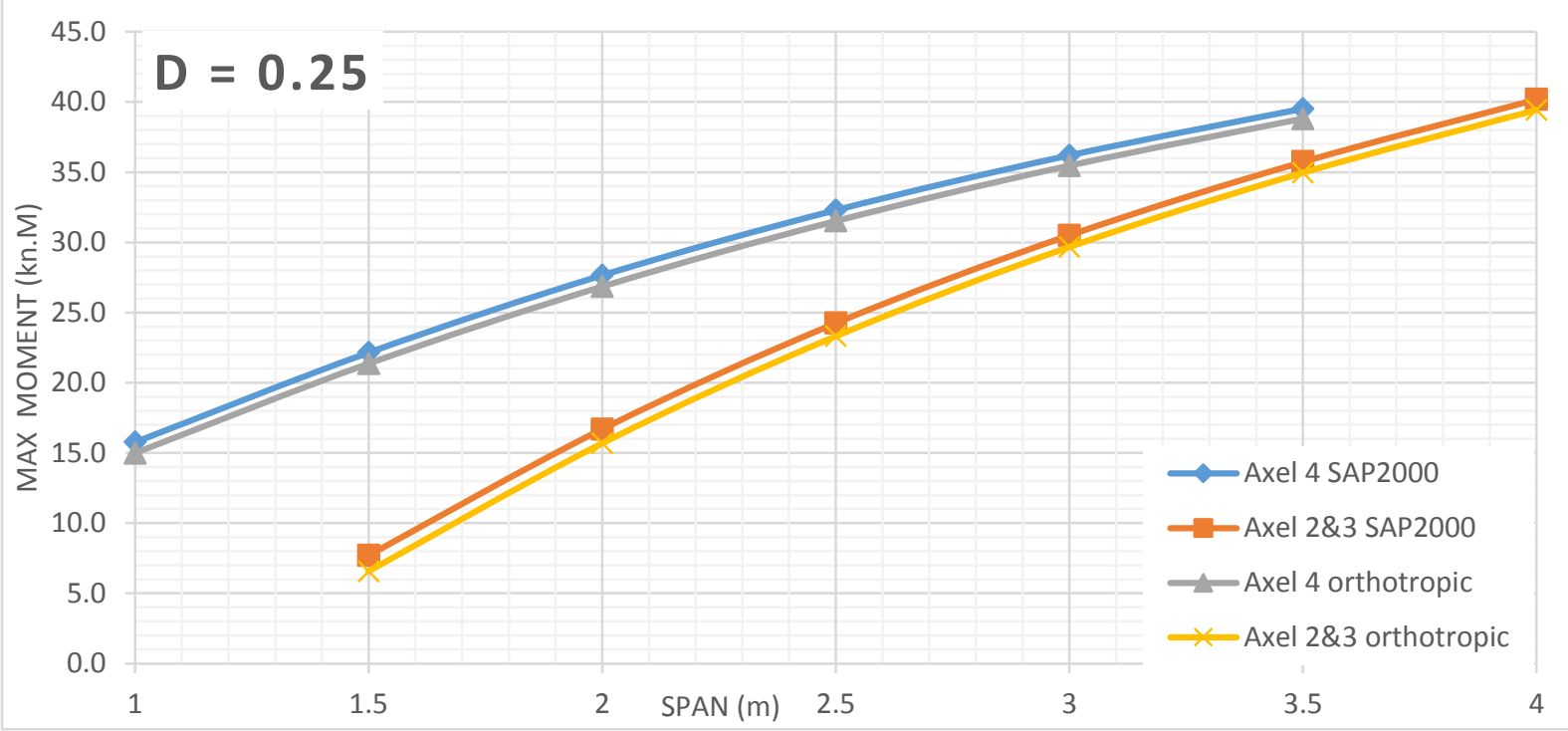

Figure 556 Moment comparison between FEA and Orthotropic Plate Theory for $D=0.25$ of alpha 1 (main bars parallel traffic)

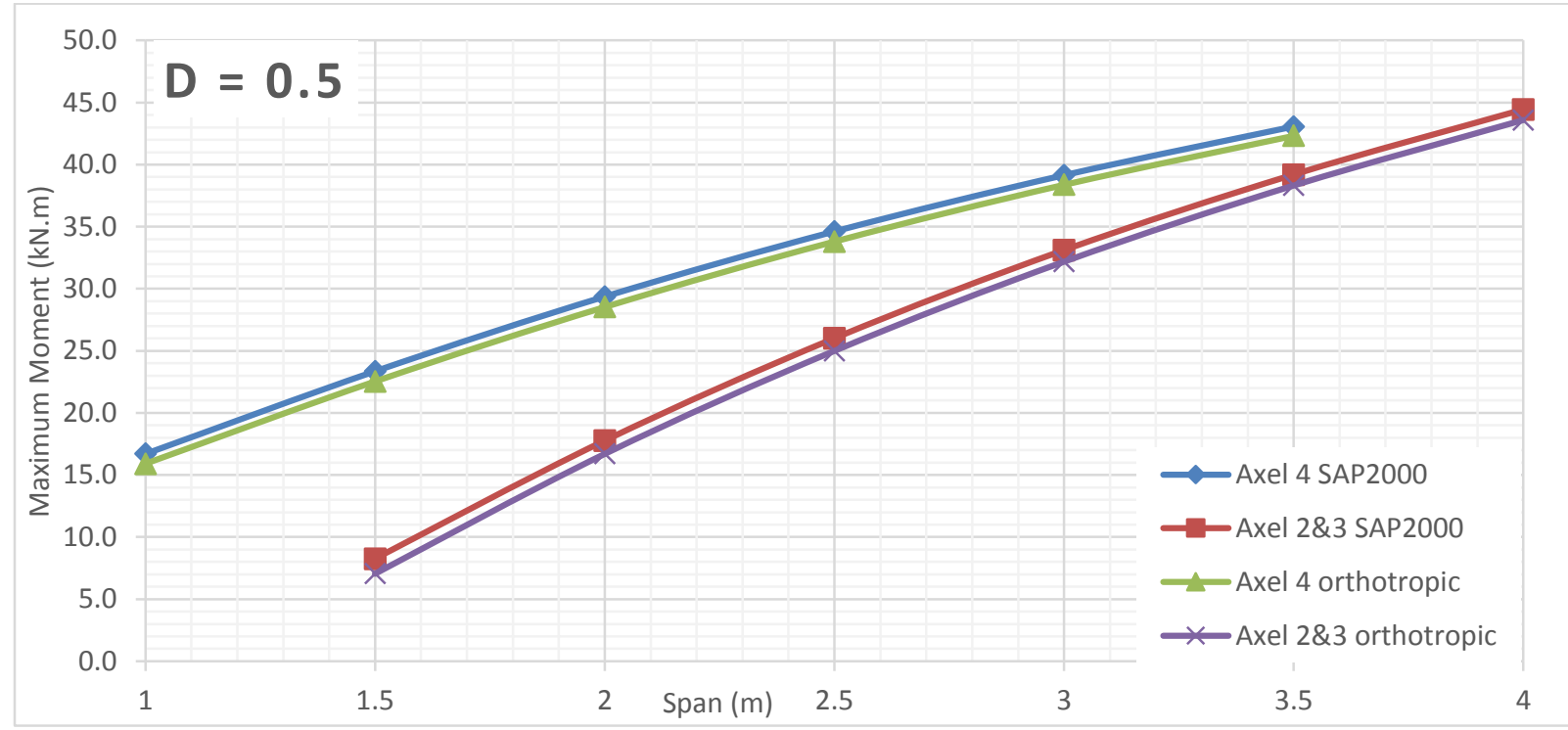

Figure 557 Moment comparison between FEA and Orthotropic Plate Theory for $D=0.5$ of alpha 1 (main bars parallel traffic) 


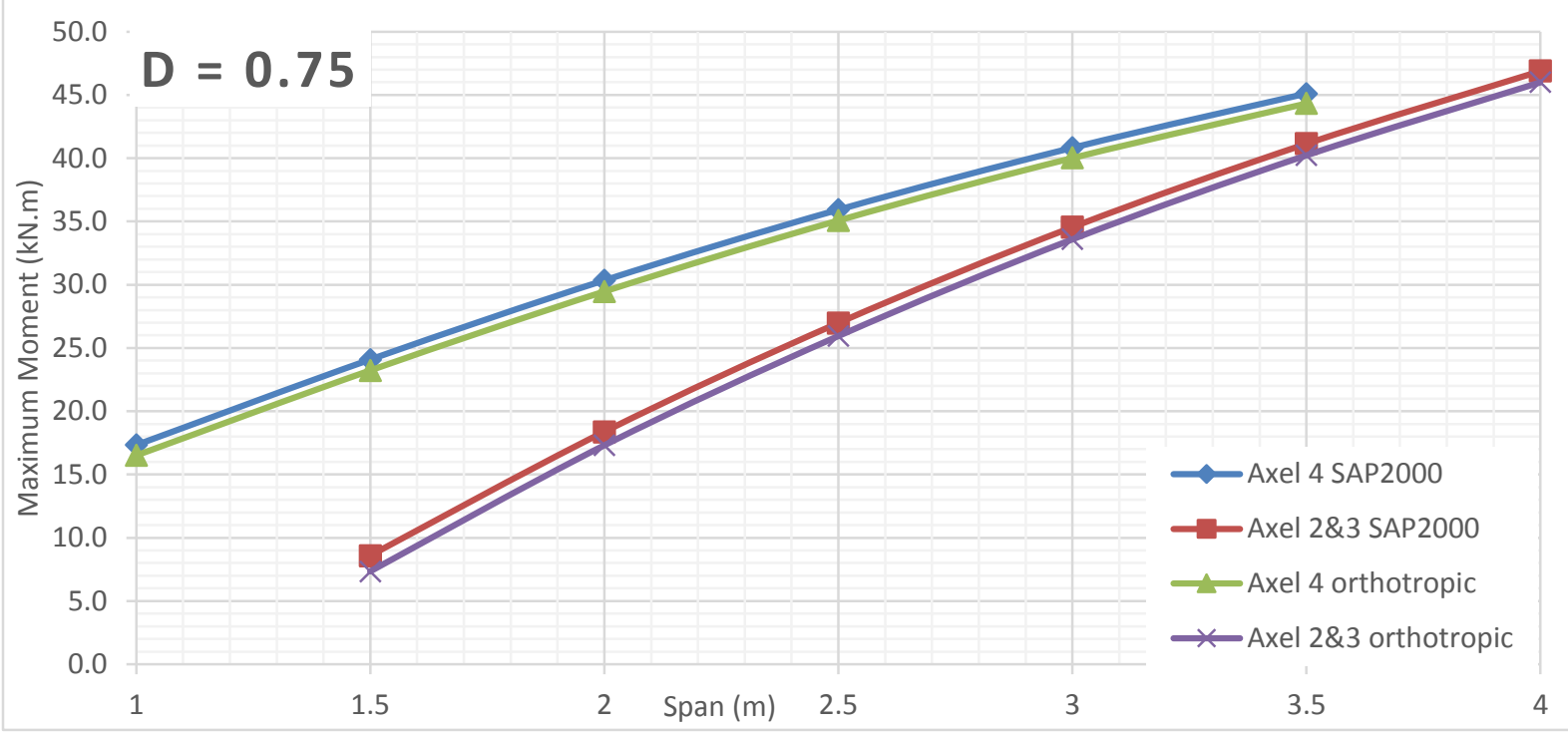

Figure 558 Moment comparison between FEA and Orthotropic Plate Theory for $D=0.75$ of alpha 1 (main bars parallel traffic)

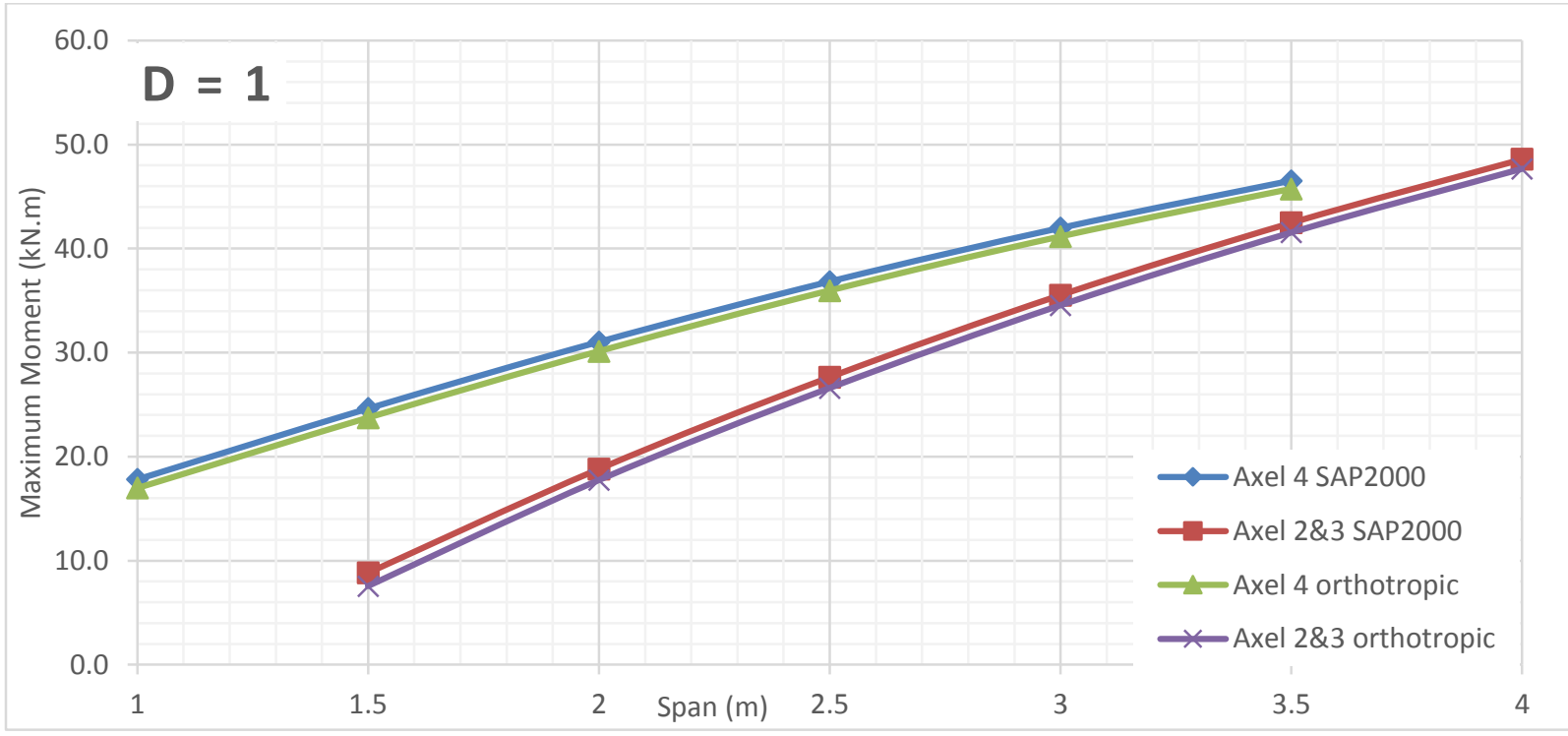

Figure 559 Moment comparison between FEA and Orthotropic Plate Theory for D = 1 of alpha 1 (main bars parallel traffic)

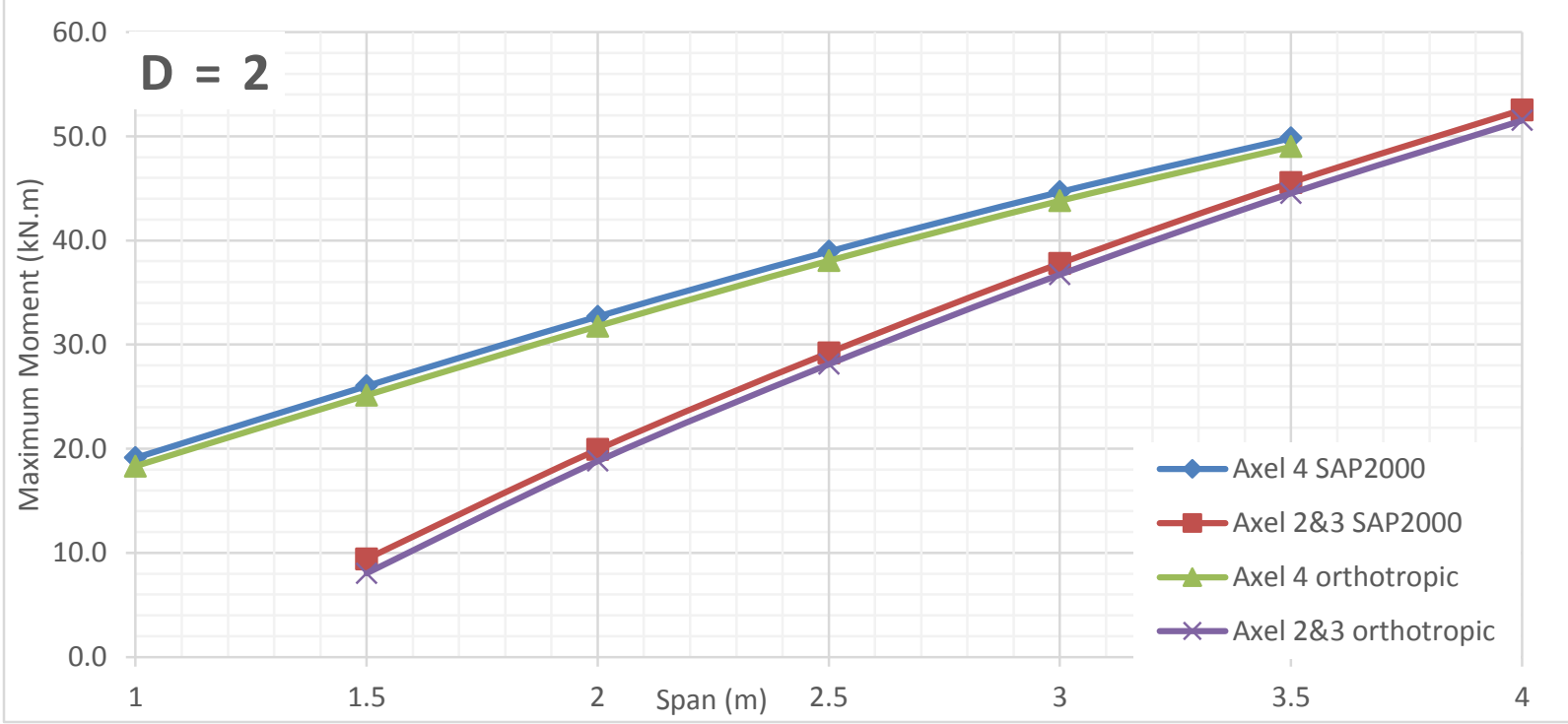

Figure 560 Moment comparison between FEA and Orthotropic Plate Theory for $D=2$ of alpha 1 (main bars parallel traffic) 


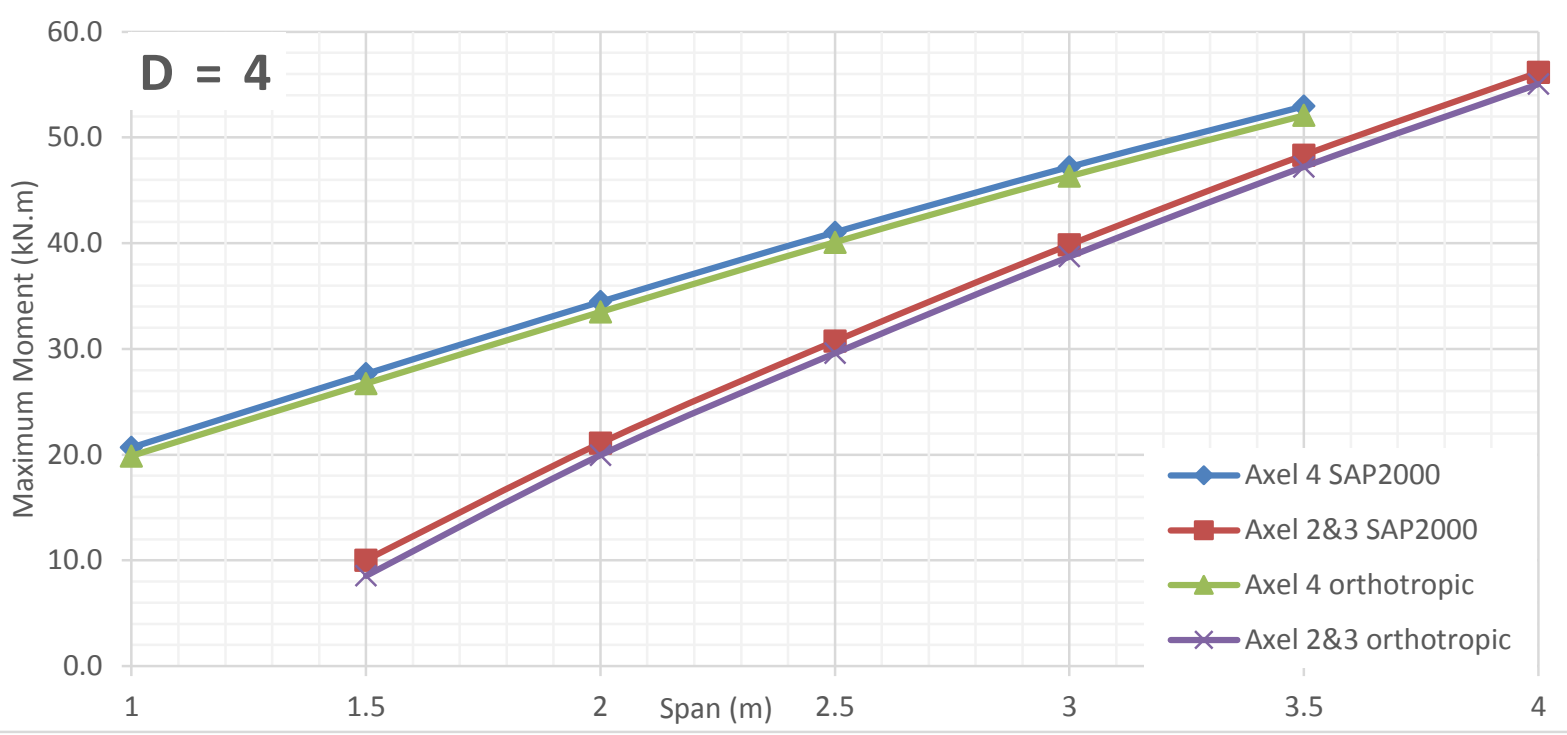

Figure 561 Moment comparison between FEA and Orthotropic Plate Theory for D = 4 of alpha 1 (main bars parallel traffic)

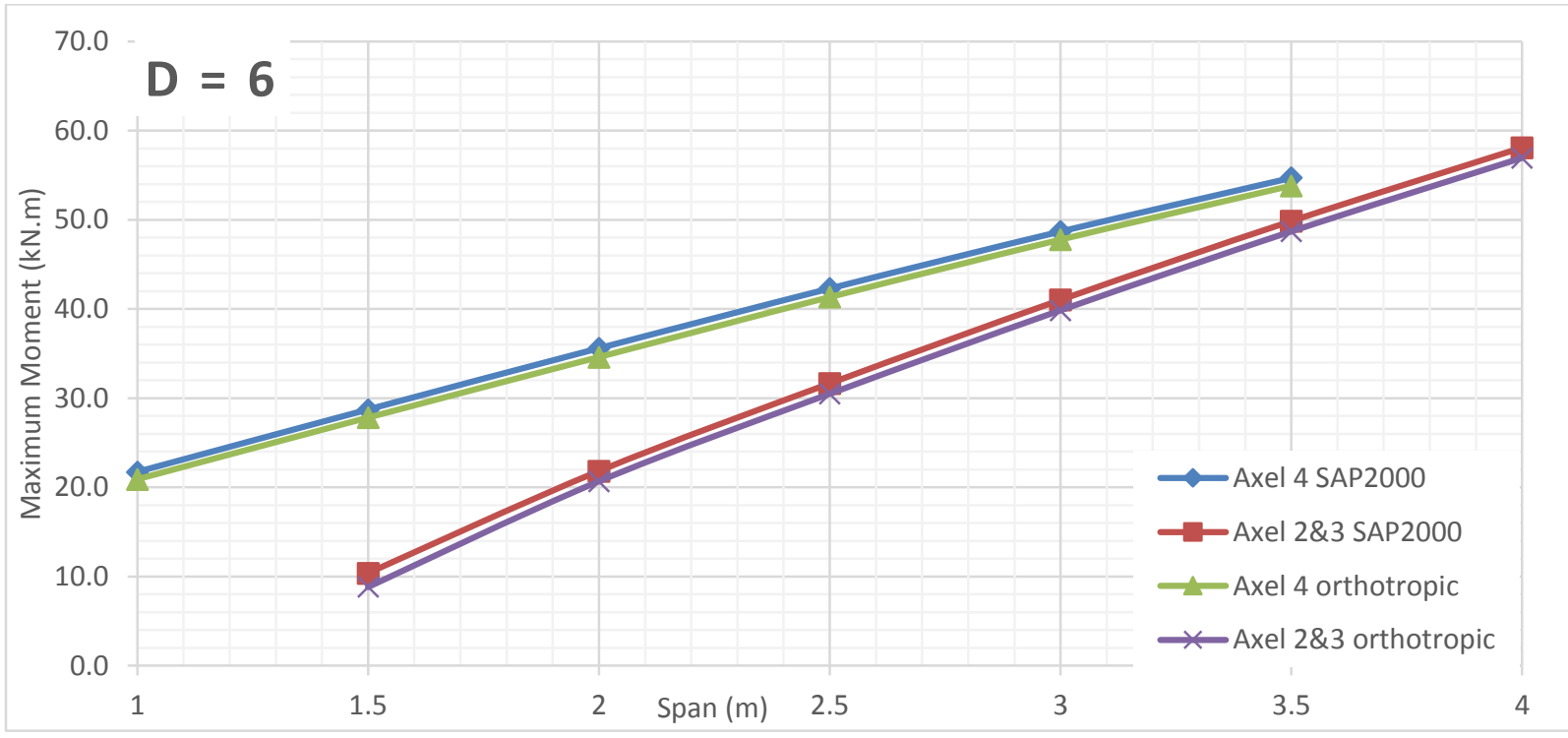

Figure 562 Moment comparison between FEA and Orthotropic Plate Theory for D = 6 of alpha 1 (main bars parallel traffic)

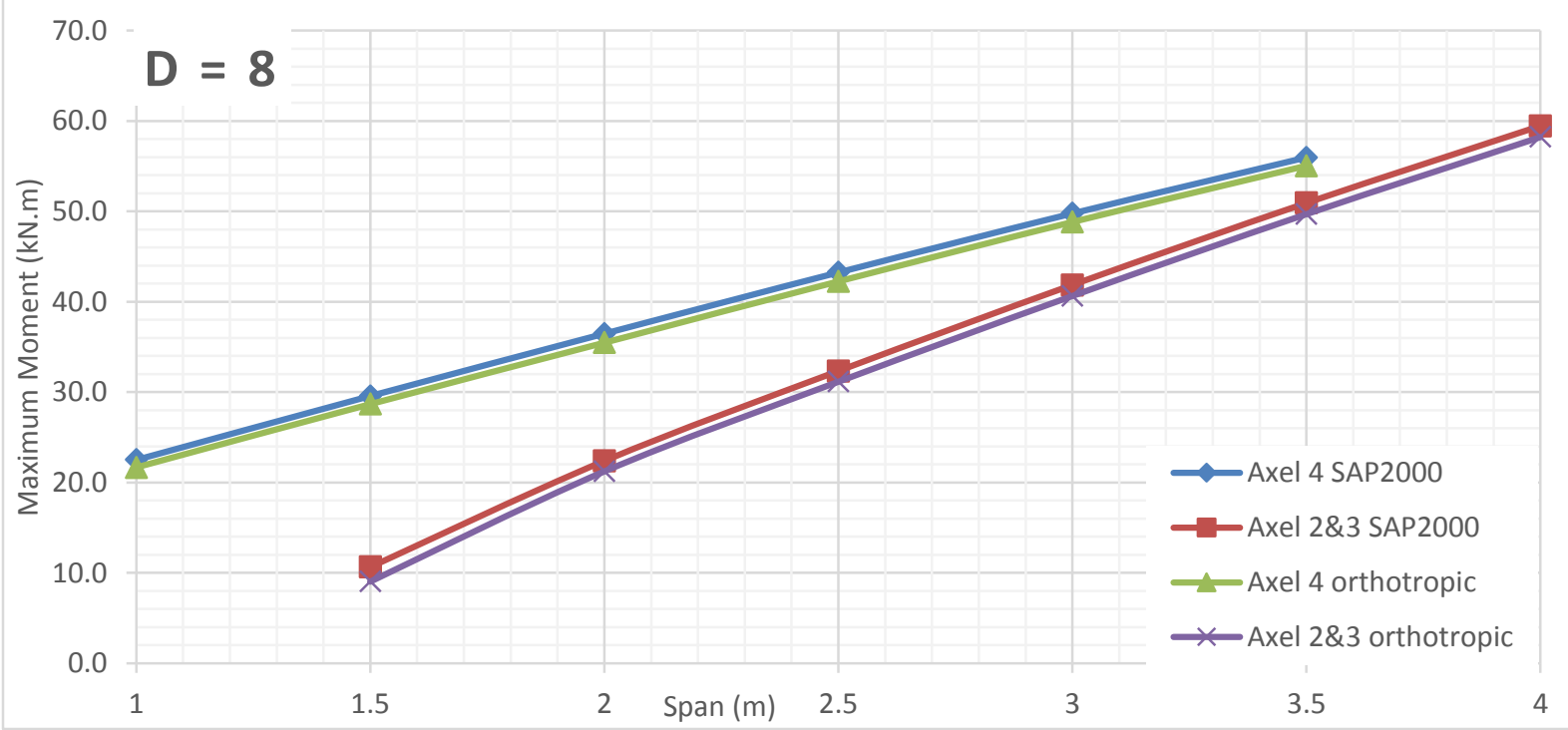

Figure 563 Moment comparison between FEA and Orthotropic Plate Theory for $D=8$ of alpha 1 (main bars parallel traffic) 


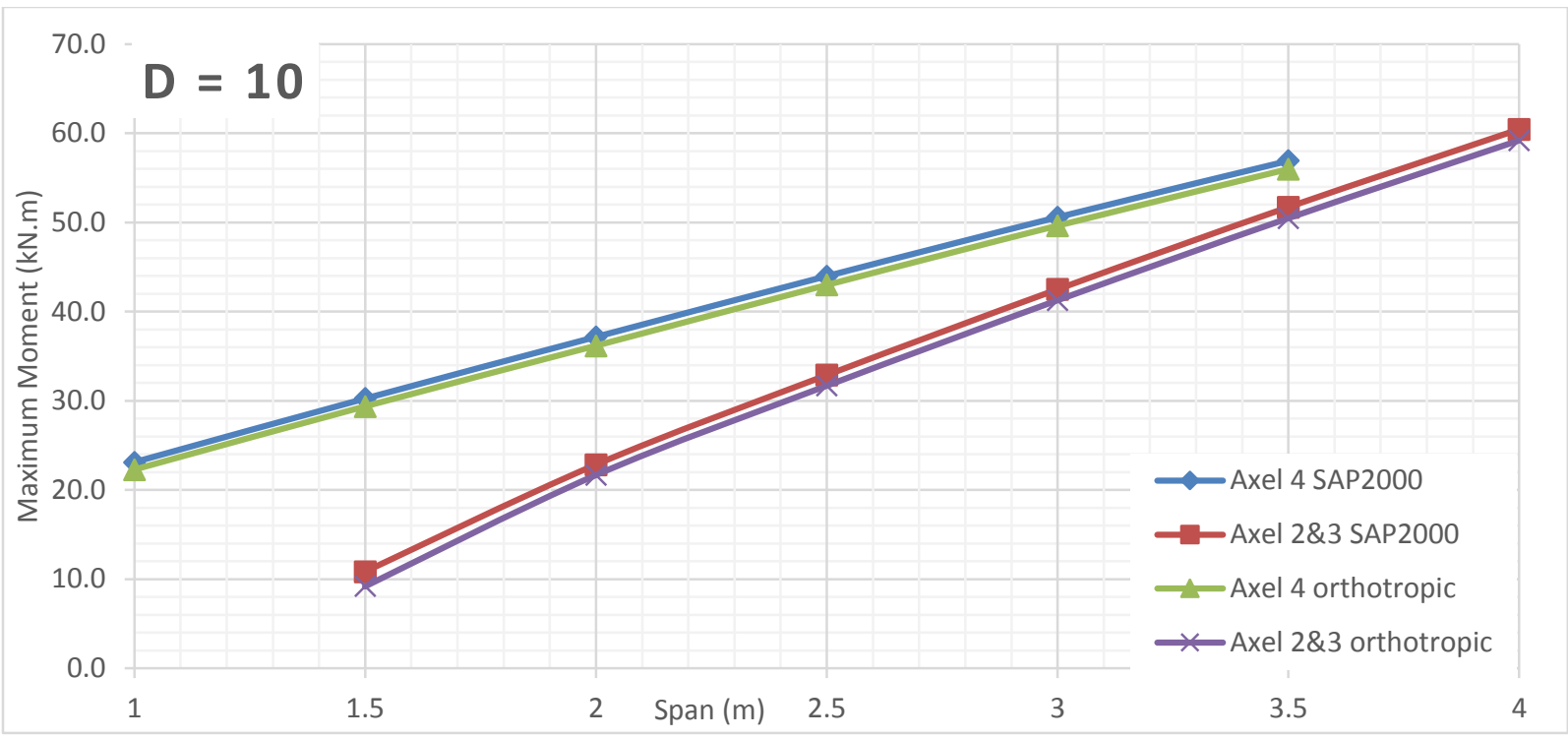

Figure 564 Moment comparison between FEA and Orthotropic Plate Theory for D = 10 of alpha 1 (main bars parallel traffic) 


\section{Alpha 2 Bending Moment VS Span Length for Different D Values (Main bars perpendicular to traffic)}

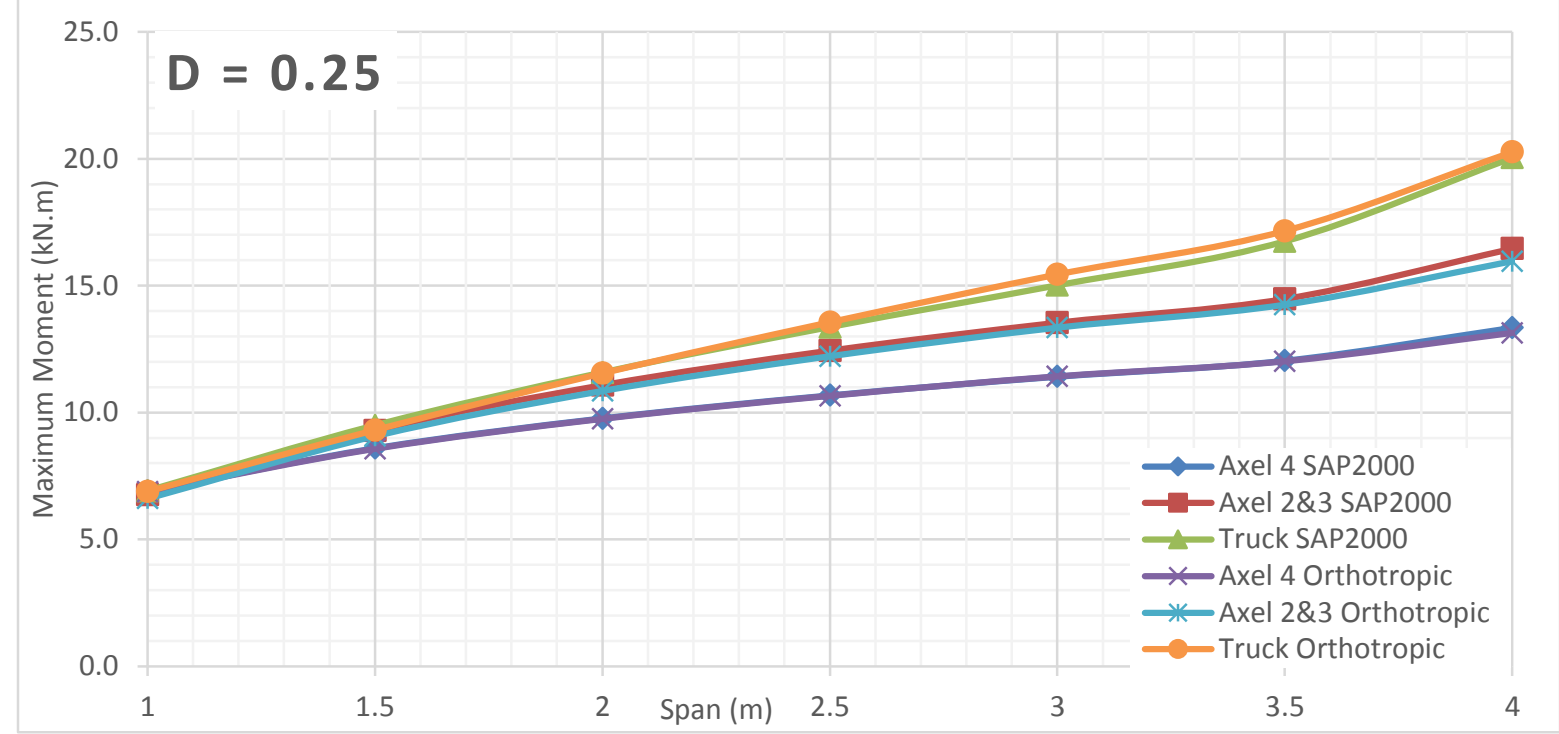

Figure 565 Moment comparison between FEA and Orthotropic Plate Theory for $D=0.25$ of alpha 2 (main bars perpendicular traffic)

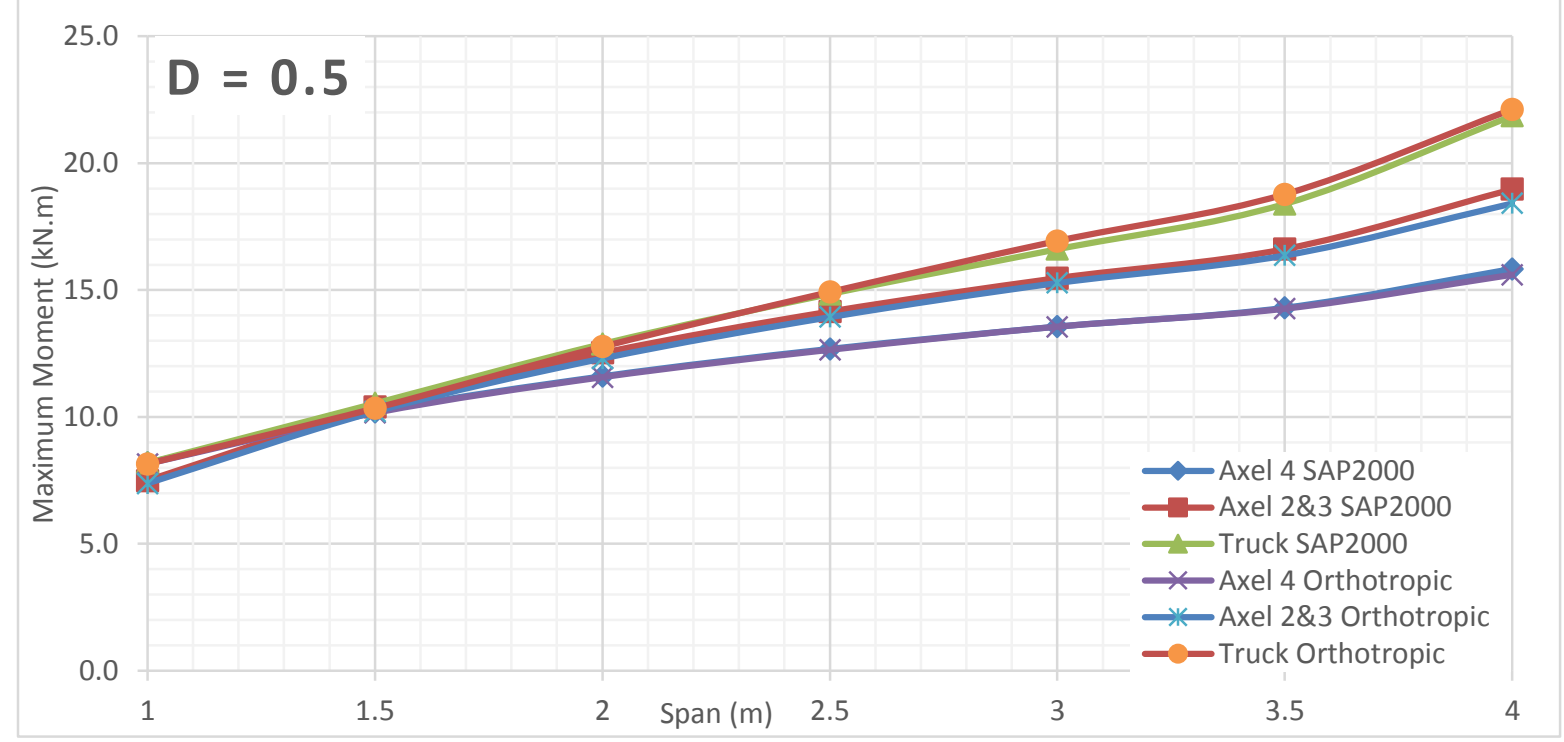

Figure 566 Moment comparison between FEA and Orthotropic Plate Theory for $D=0.5$ of alpha 2 (main bars perpendicular traffic) 


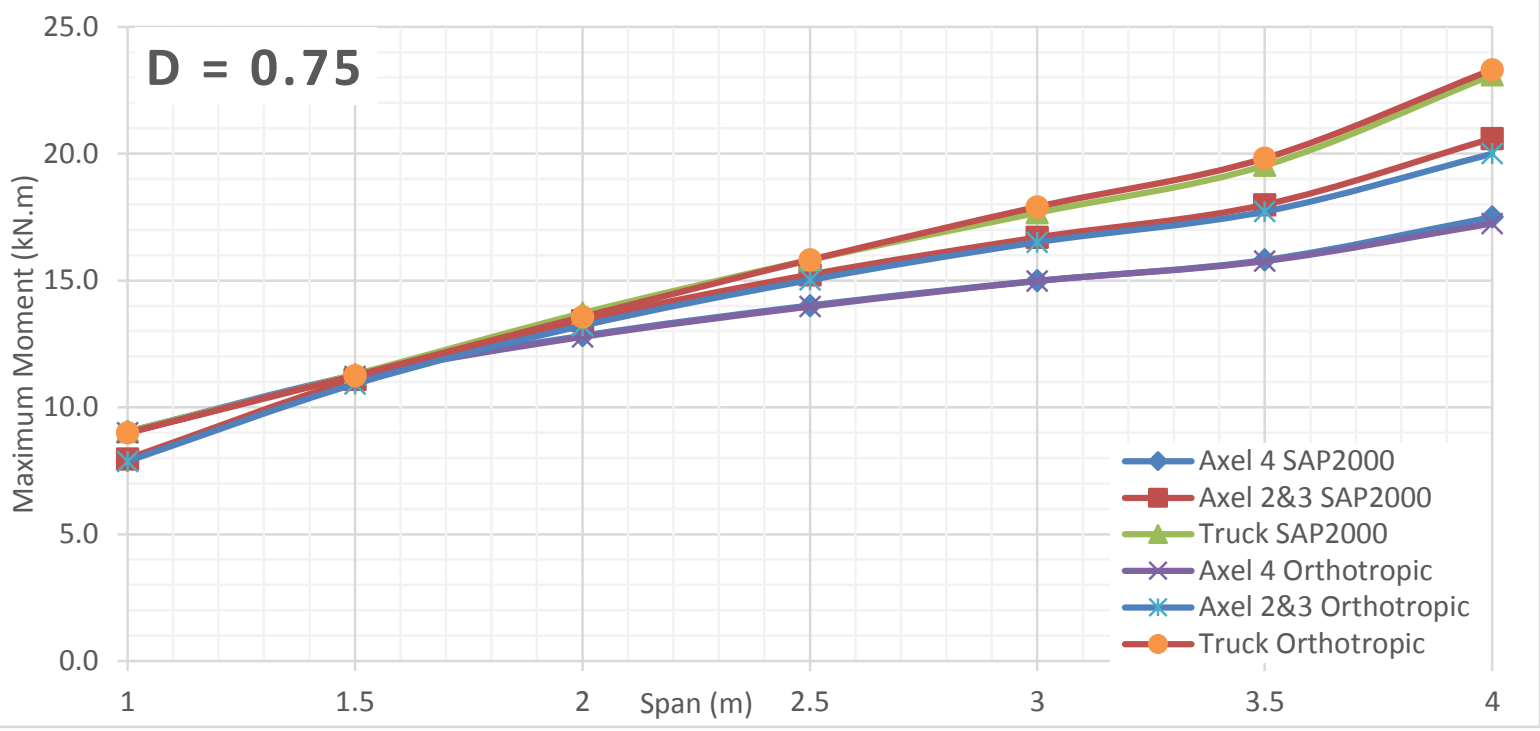

Figure 567 Moment comparison between FEA and Orthotropic Plate Theory for D $=0.75$ of alpha 2 (main bars perpendicular traffic)

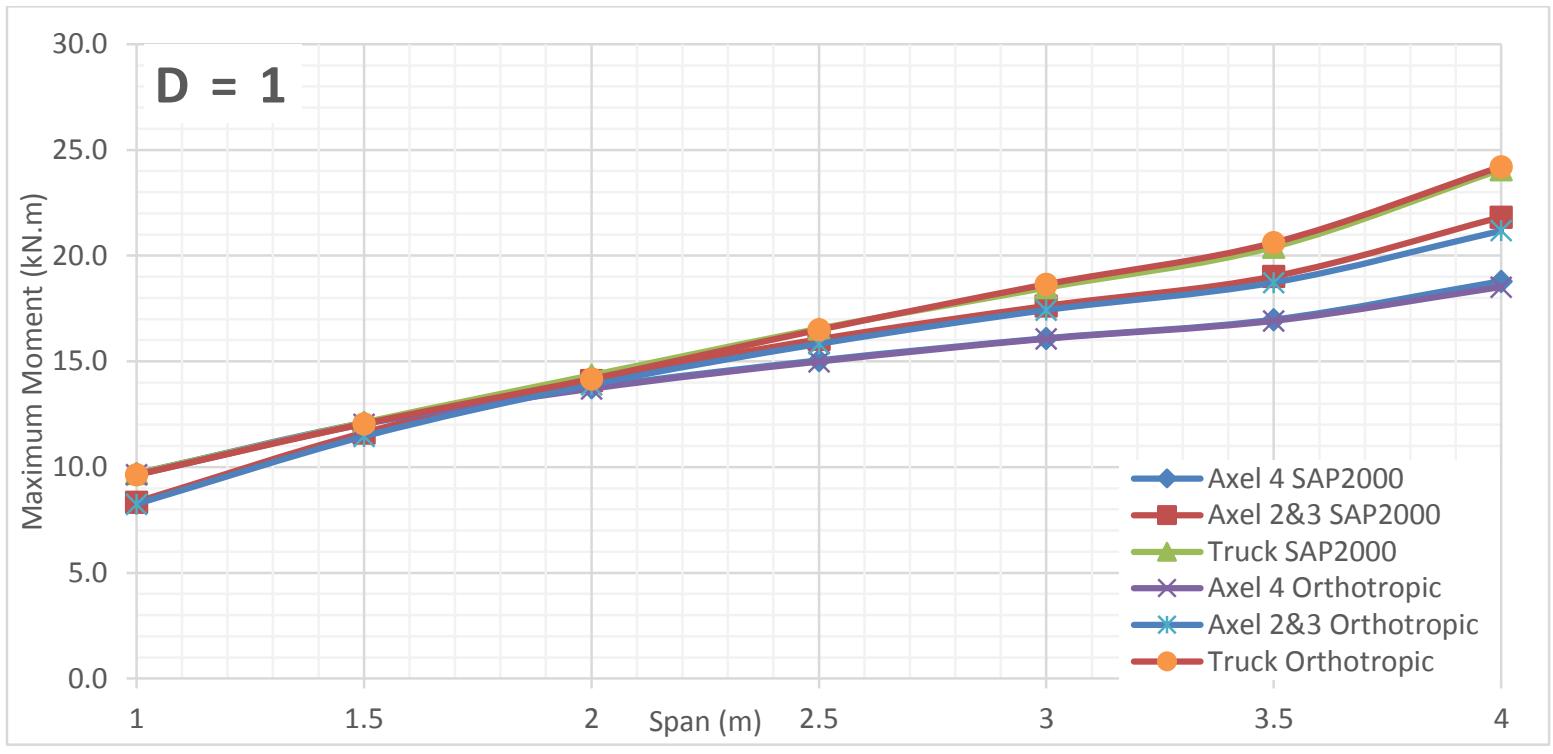

Figure 568 Moment comparison between FEA and Orthotropic Plate Theory for D = 1 of alpha 2 (main bars perpendicular traffic)

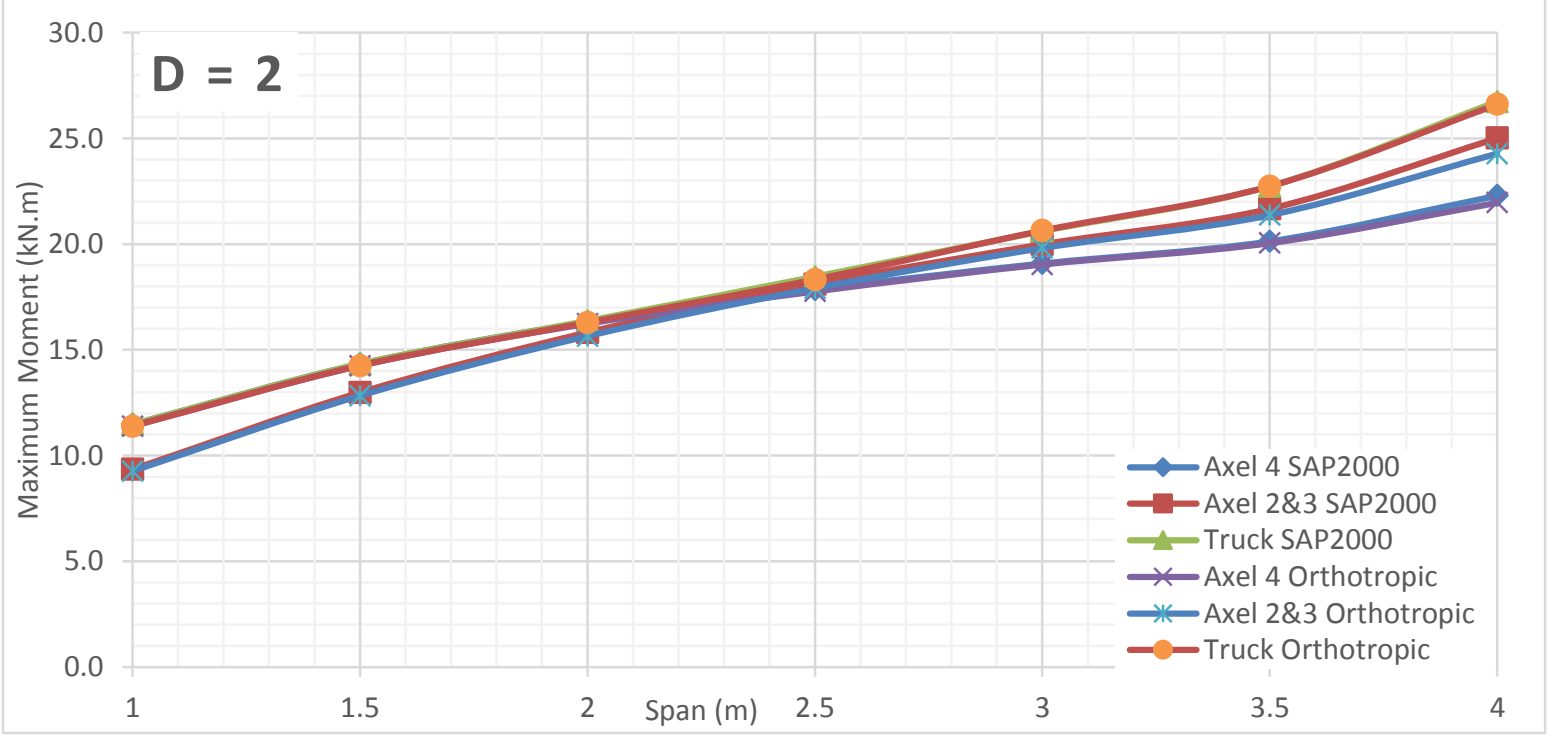

Figure 569 Moment comparison between FEA and Orthotropic Plate Theory for $D=2$ of alpha 2 (main bars perpendicular traffic) 


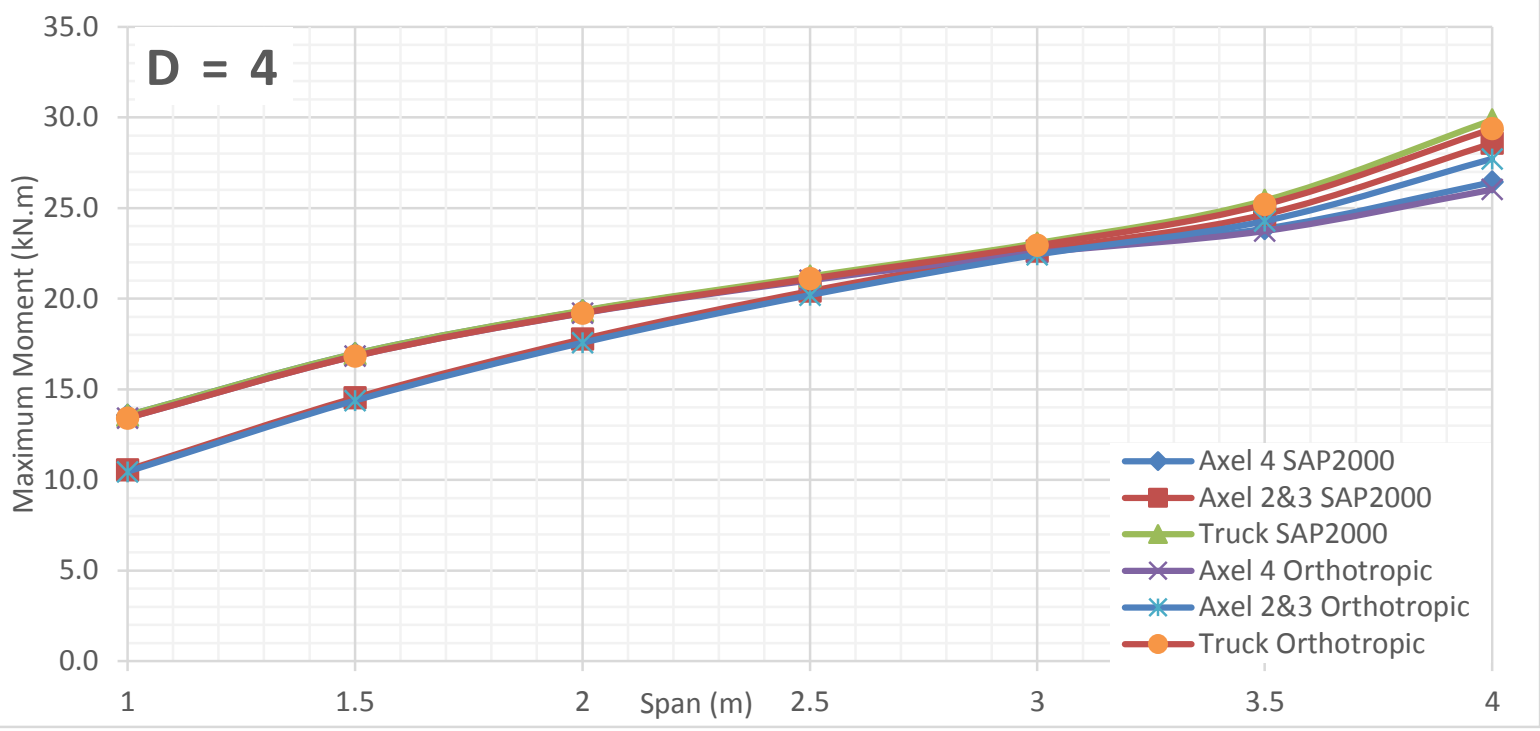

Figure 570 Moment comparison between FEA and Orthotropic Plate Theory for $D=4$ of alpha 2 (main bars perpendicular traffic)

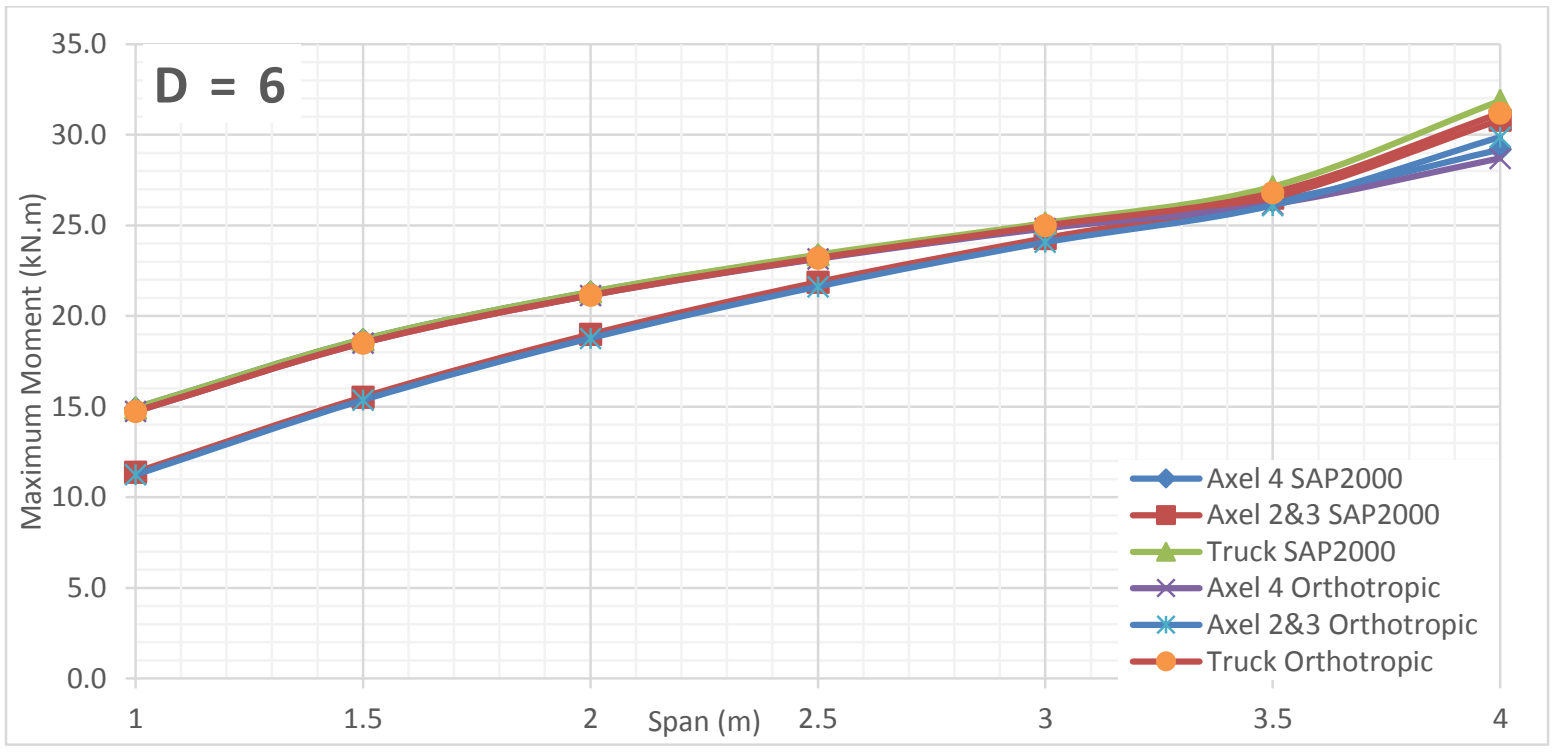

Figure 571 Moment comparison between FEA and Orthotropic Plate Theory for $D=6$ of alpha 2 (main bars perpendicular traffic)

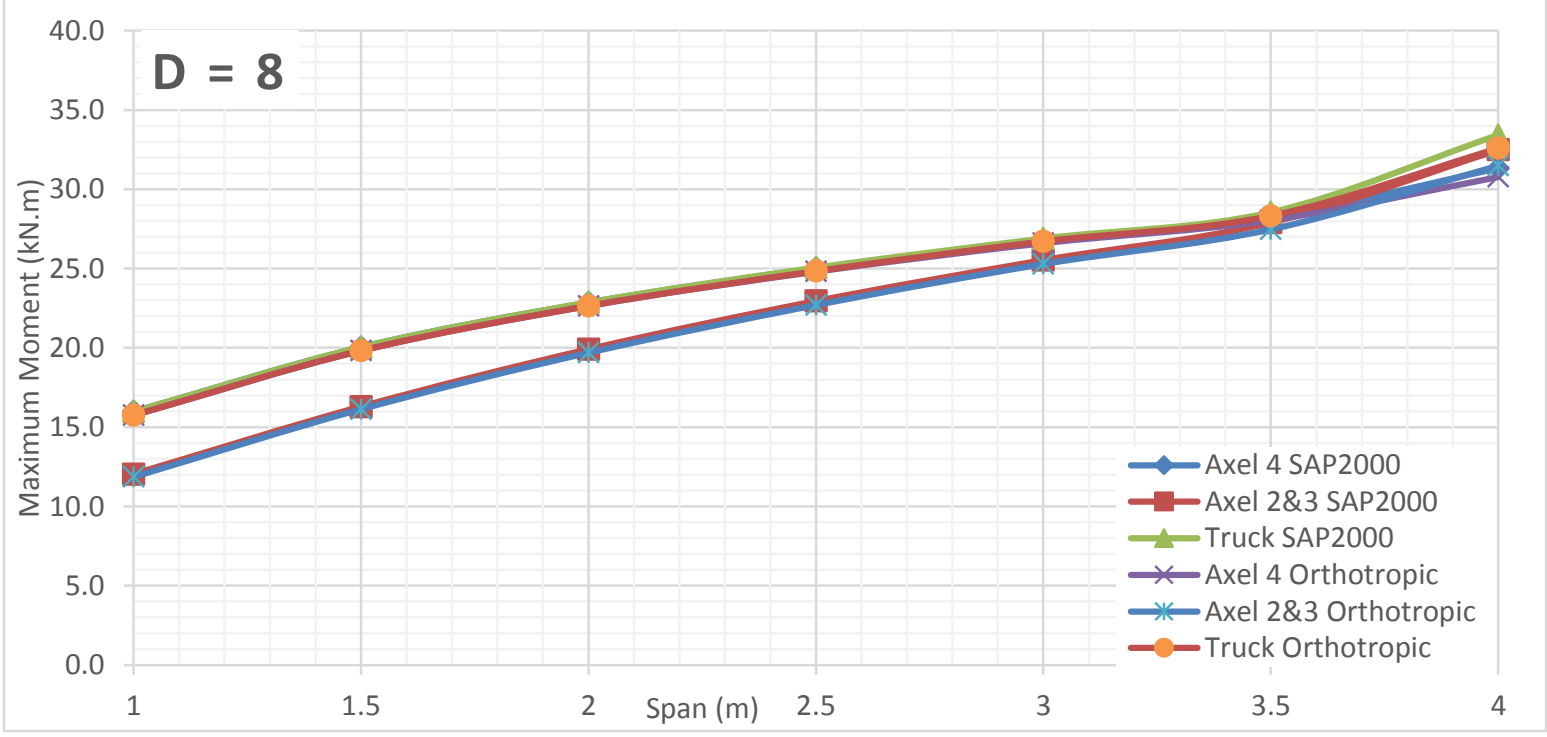

Figure 572 Moment comparison between FEA and Orthotropic Plate Theory for $D=8$ of alpha 2 (main bars perpendicular traffic) 


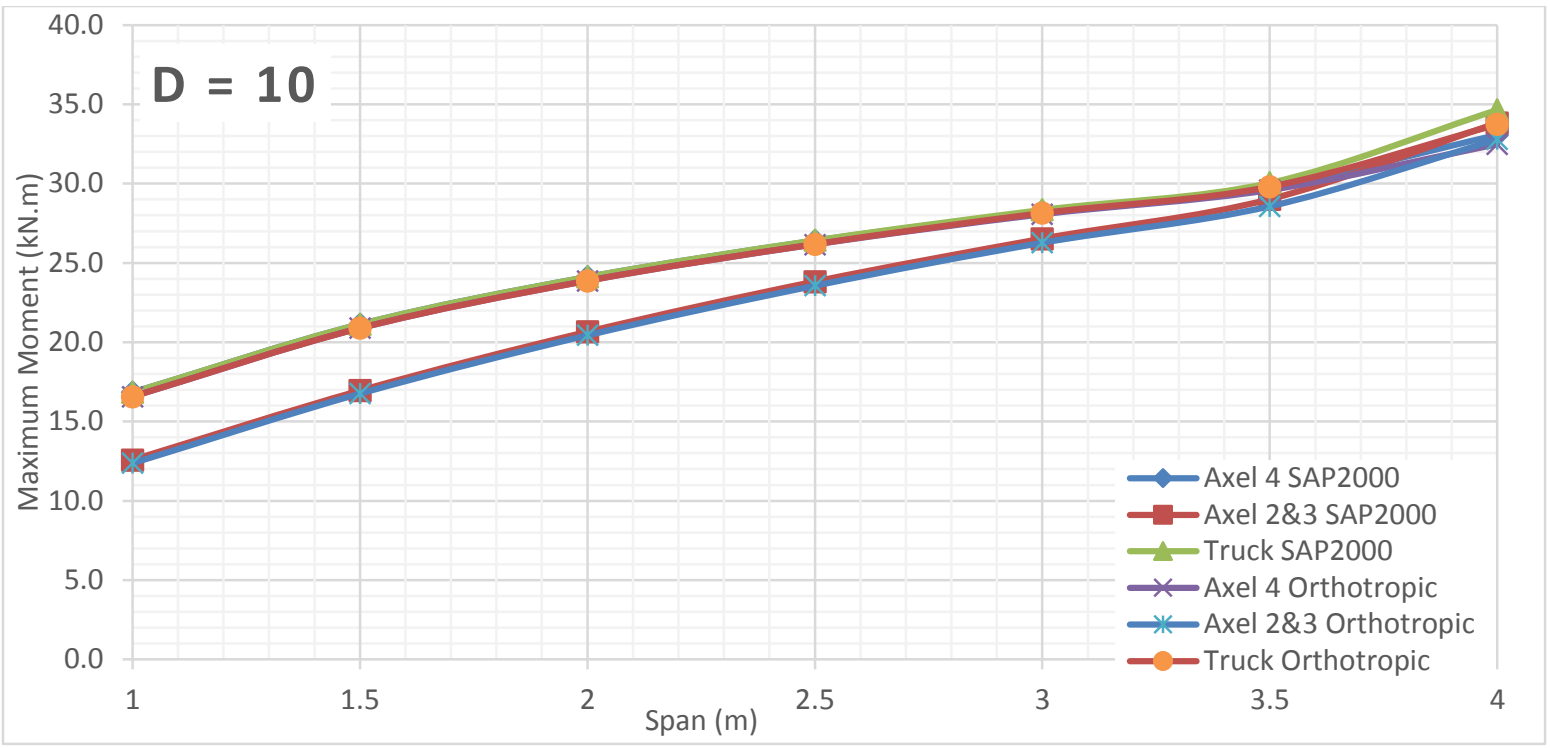

Figure 573 Moment comparison between FEA and Orthotropic Plate Theory for D = 10 of alpha 2 (main bars perpendicular traffic) 


\section{Alpha 2 Bending Moment VS Span Length for Different D Values (Main bars parallel to traffic)}

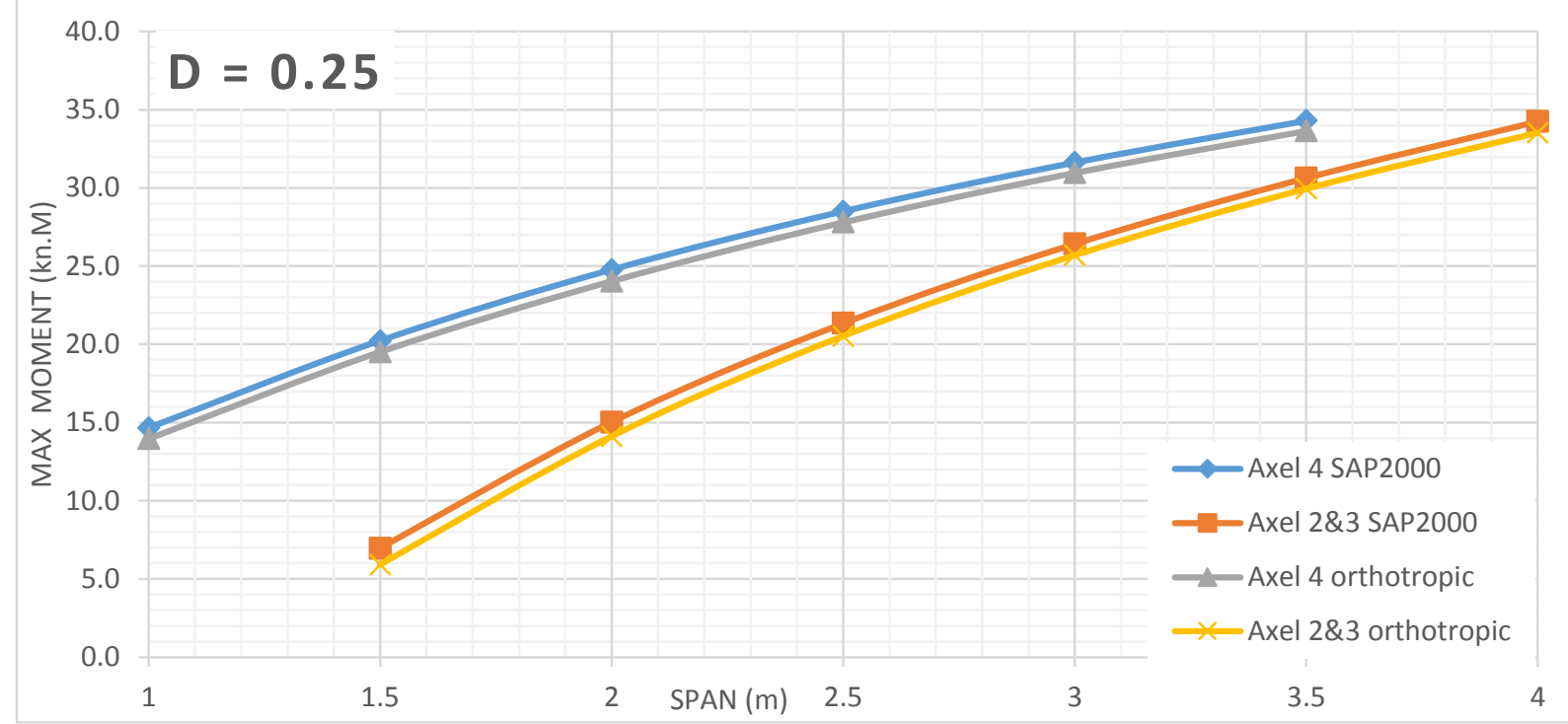

Figure 574 Moment comparison between FEA and Orthotropic Plate Theory for $D=0.25$ of alpha 2 (main bars parallel traffic)

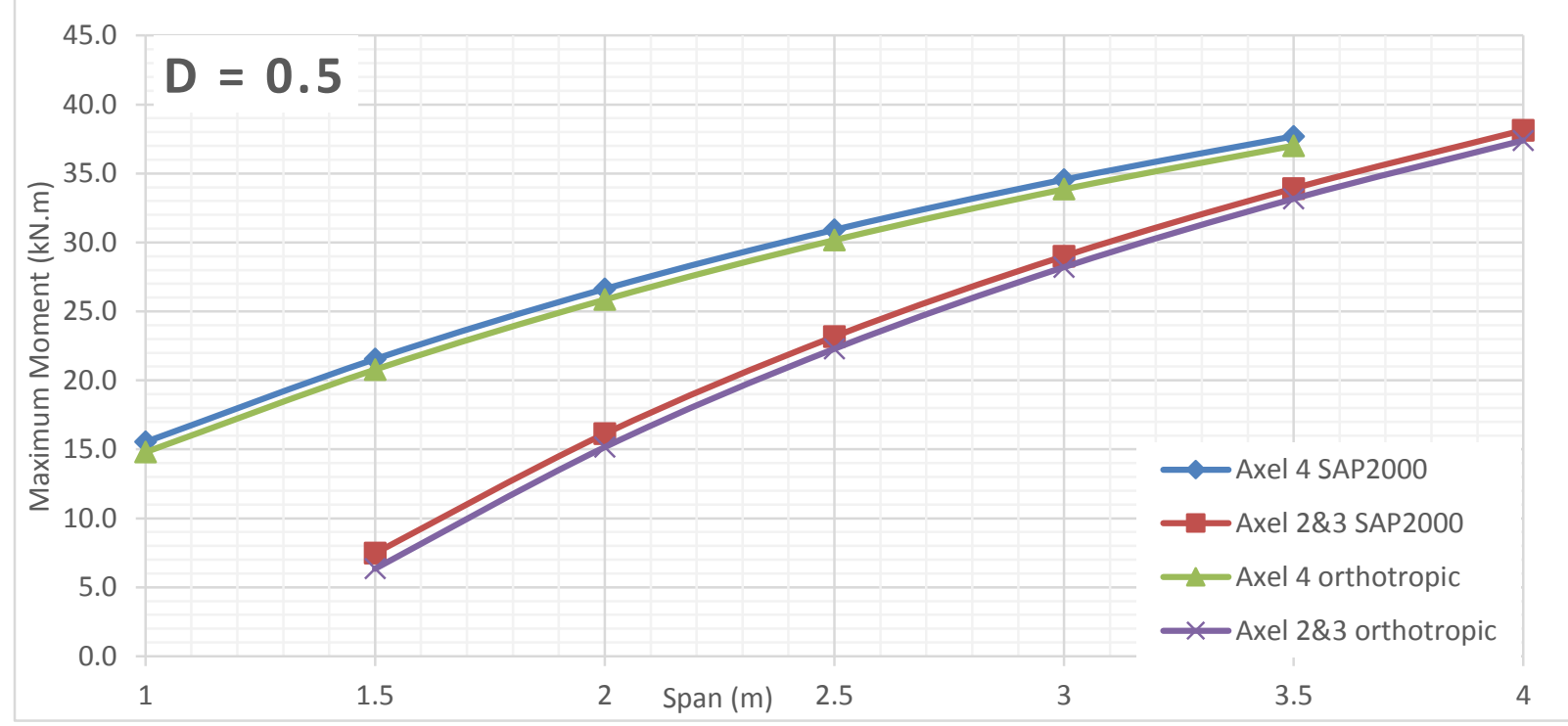

Figure 575 Moment comparison between FEA and Orthotropic Plate Theory for D $=0.5$ of alpha 2 (main bars parallel traffic) 


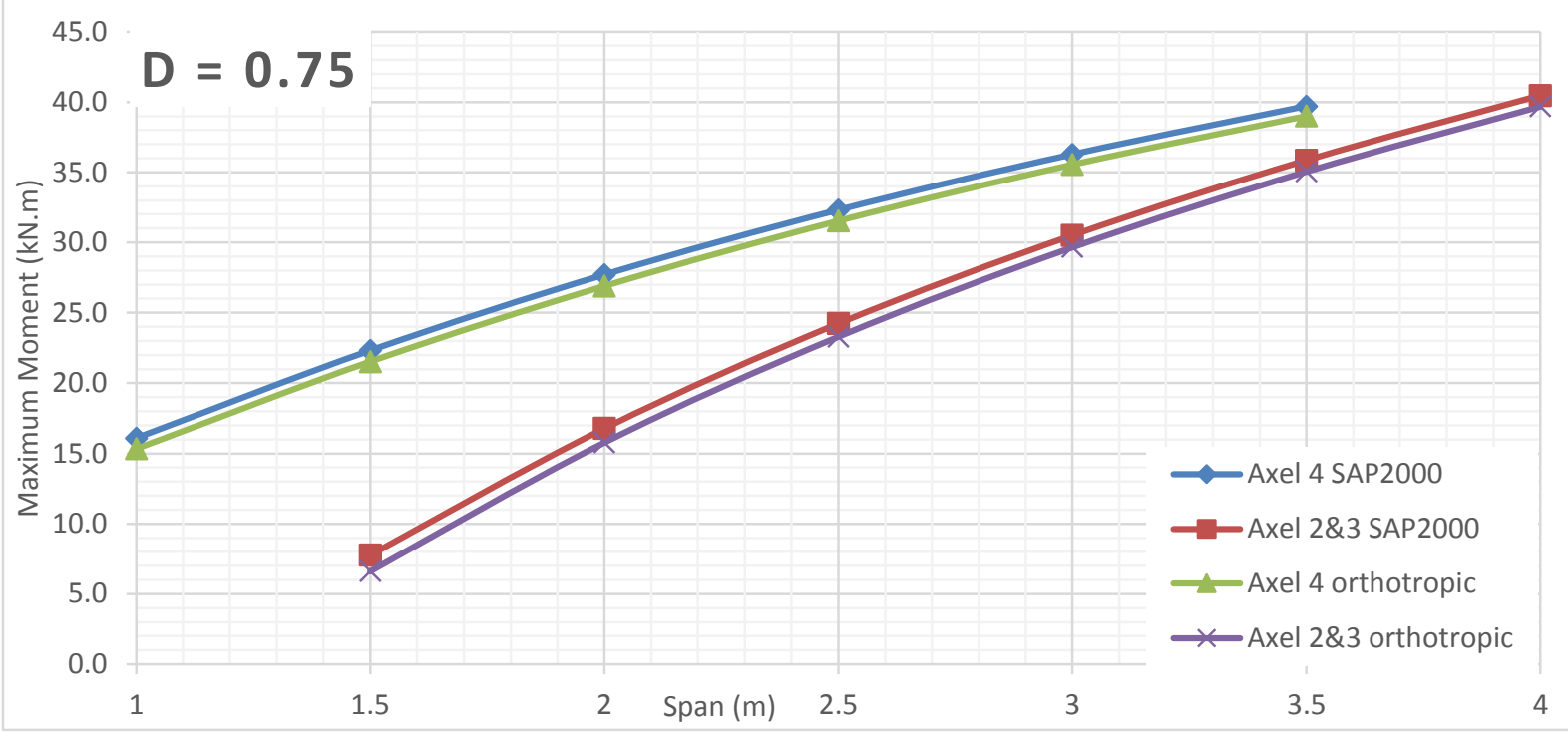

Figure 576 Moment comparison between FEA and Orthotropic Plate Theory for D $=0.75$ of alpha 2 (main bars parallel traffic)

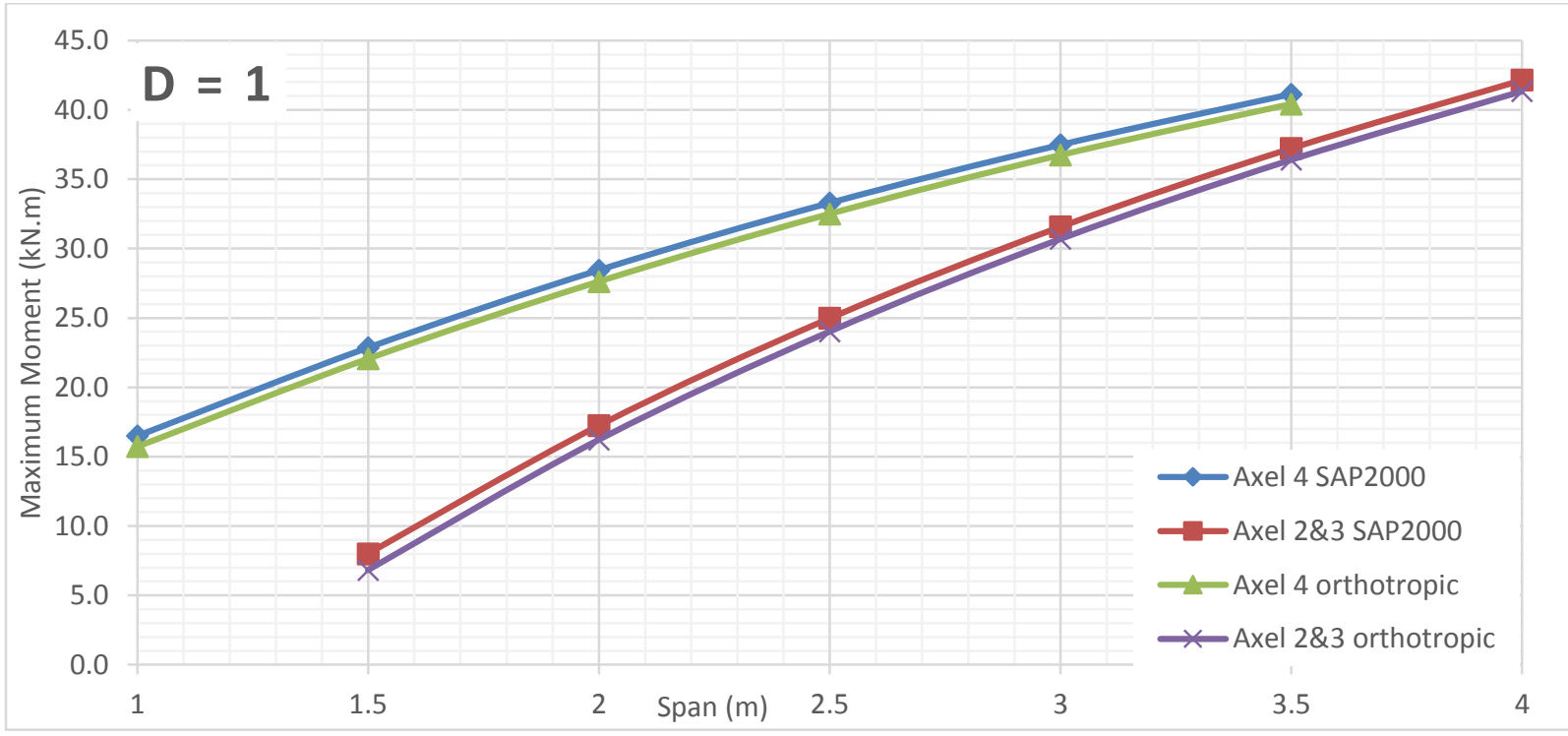

Figure 577 Moment comparison between FEA and Orthotropic Plate Theory for D = 1 of alpha 2 (main bars parallel traffic)

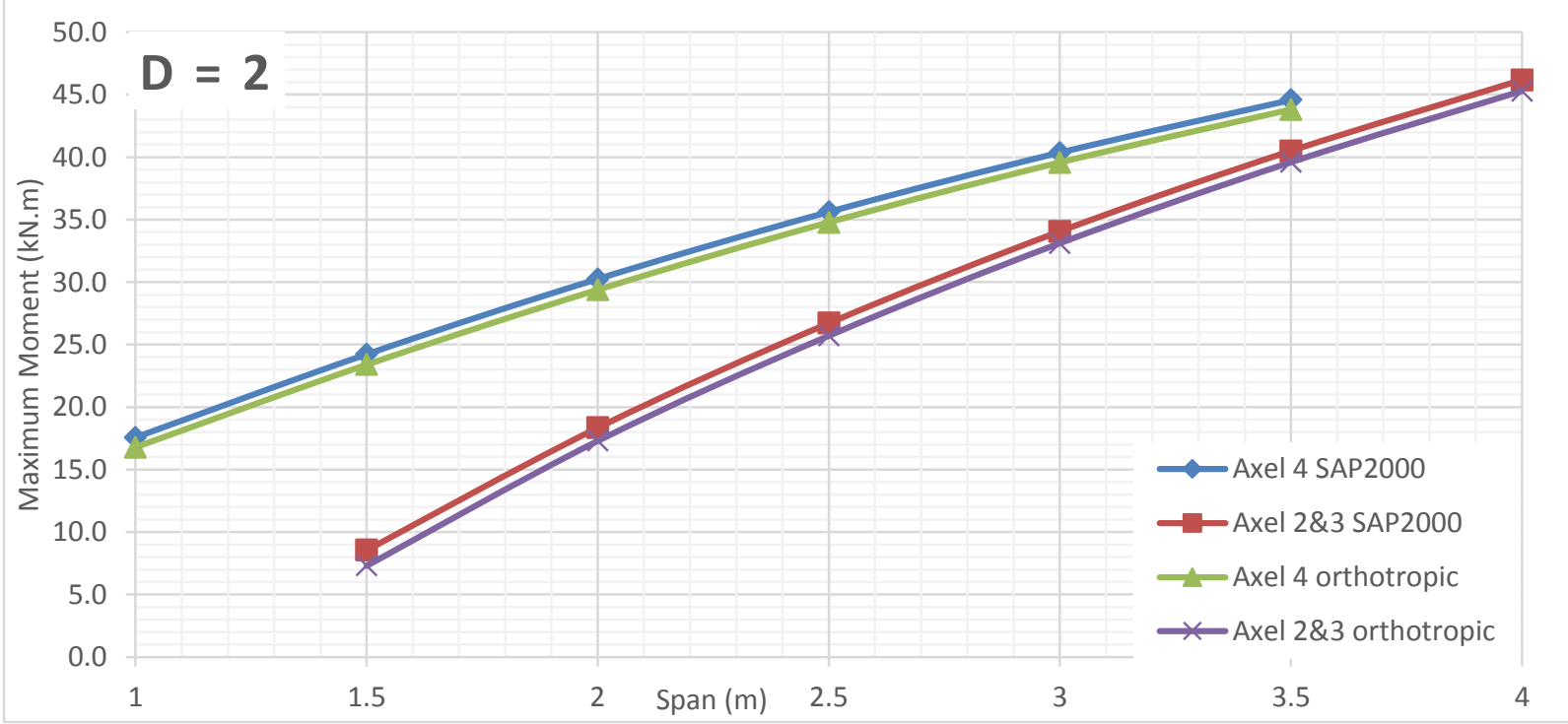

Figure 578 Moment comparison between FEA and Orthotropic Plate Theory for $D=2$ of alpha 2 (main bars parallel traffic) 


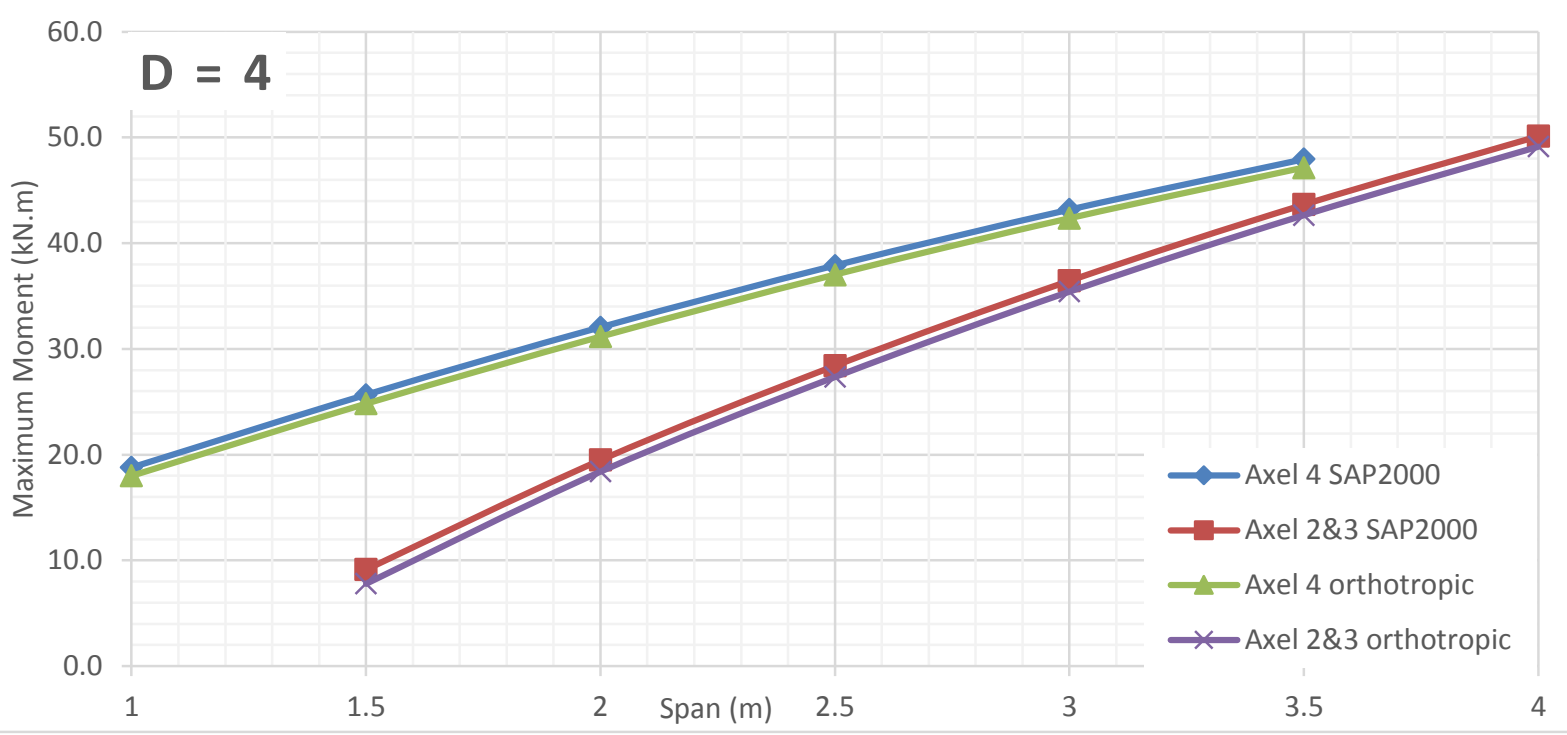

Figure 579 Moment comparison between FEA and Orthotropic Plate Theory for D $=4$ of alpha 2 (main bars parallel traffic)

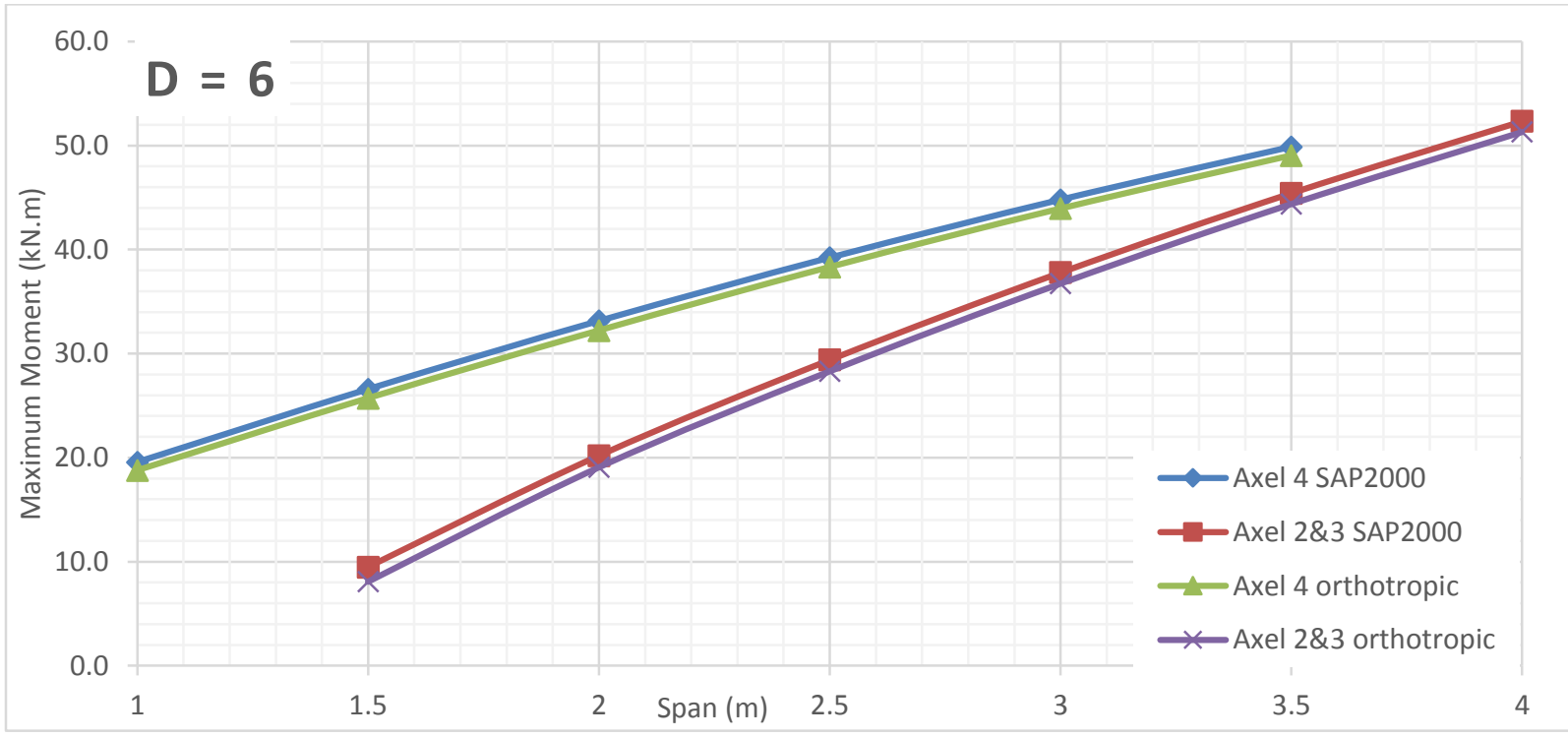

Figure 580 Moment comparison between FEA and Orthotropic Plate Theory for D $=6$ of alpha 2 (main bars parallel traffic)

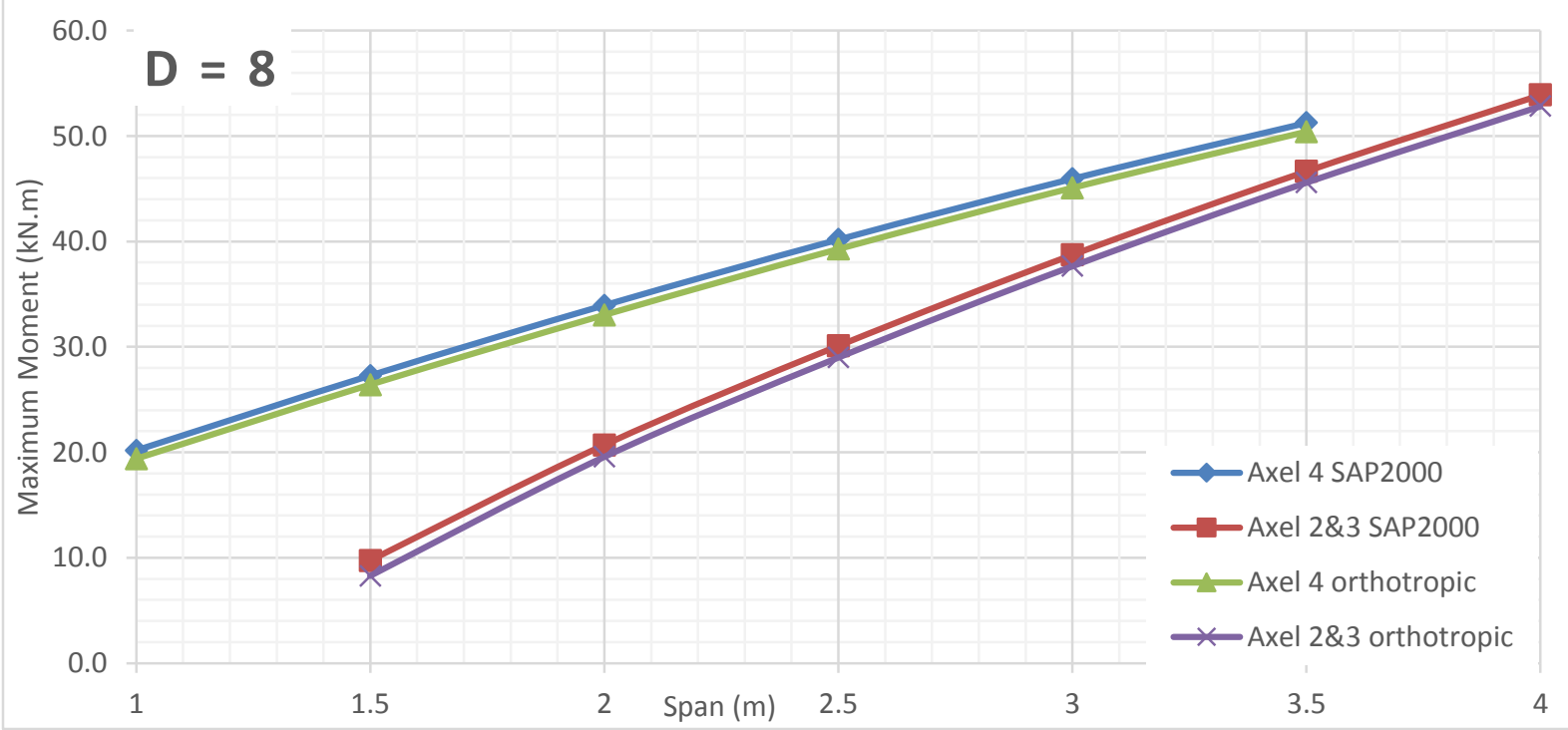

Figure 581 Moment comparison between FEA and Orthotropic Plate Theory for $D=8$ of alpha 2 (main bars parallel traffic) 


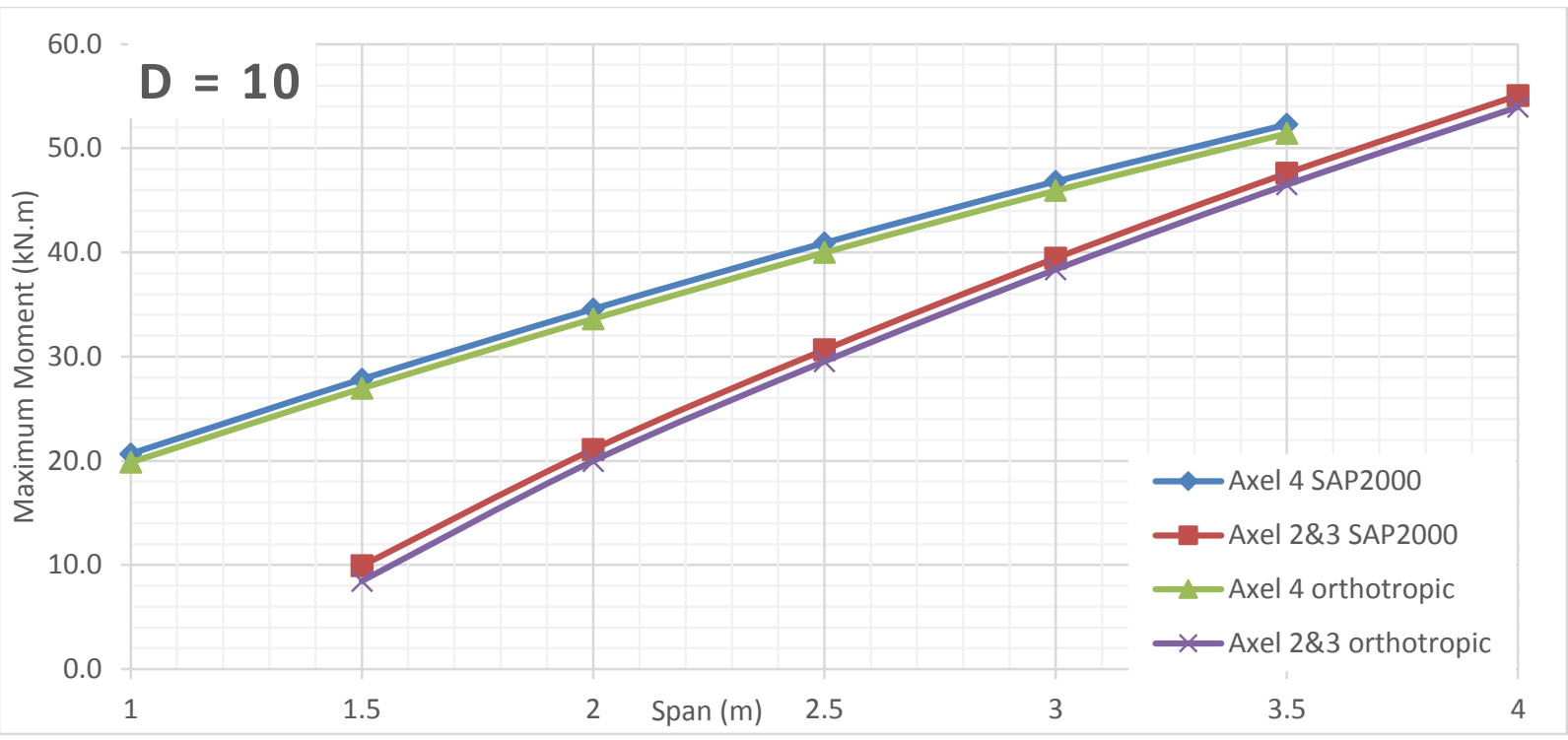

Figure 582 Moment comparison between FEA and Orthotropic Plate Theory for D = 10 of alpha 2 (main bars parallel traffic) 


\section{Alpha 4 Bending Moment VS Span Length for Different D Values (Main bars perpendicular to traffic)}

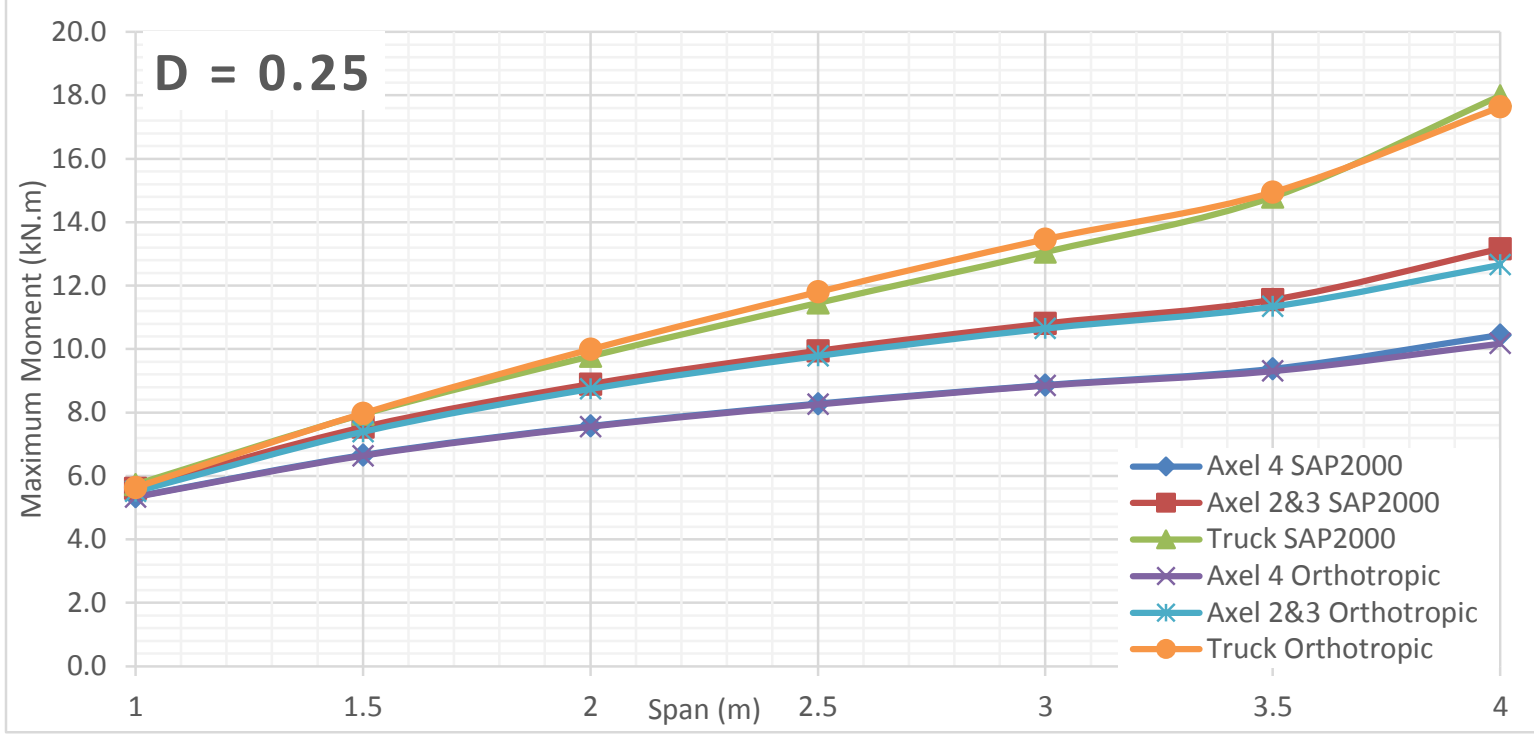

Figure 583 Moment comparison between FEA and Orthotropic Plate Theory for D $=0.25$ of alpha 4 (main bars perpendicular traffic)

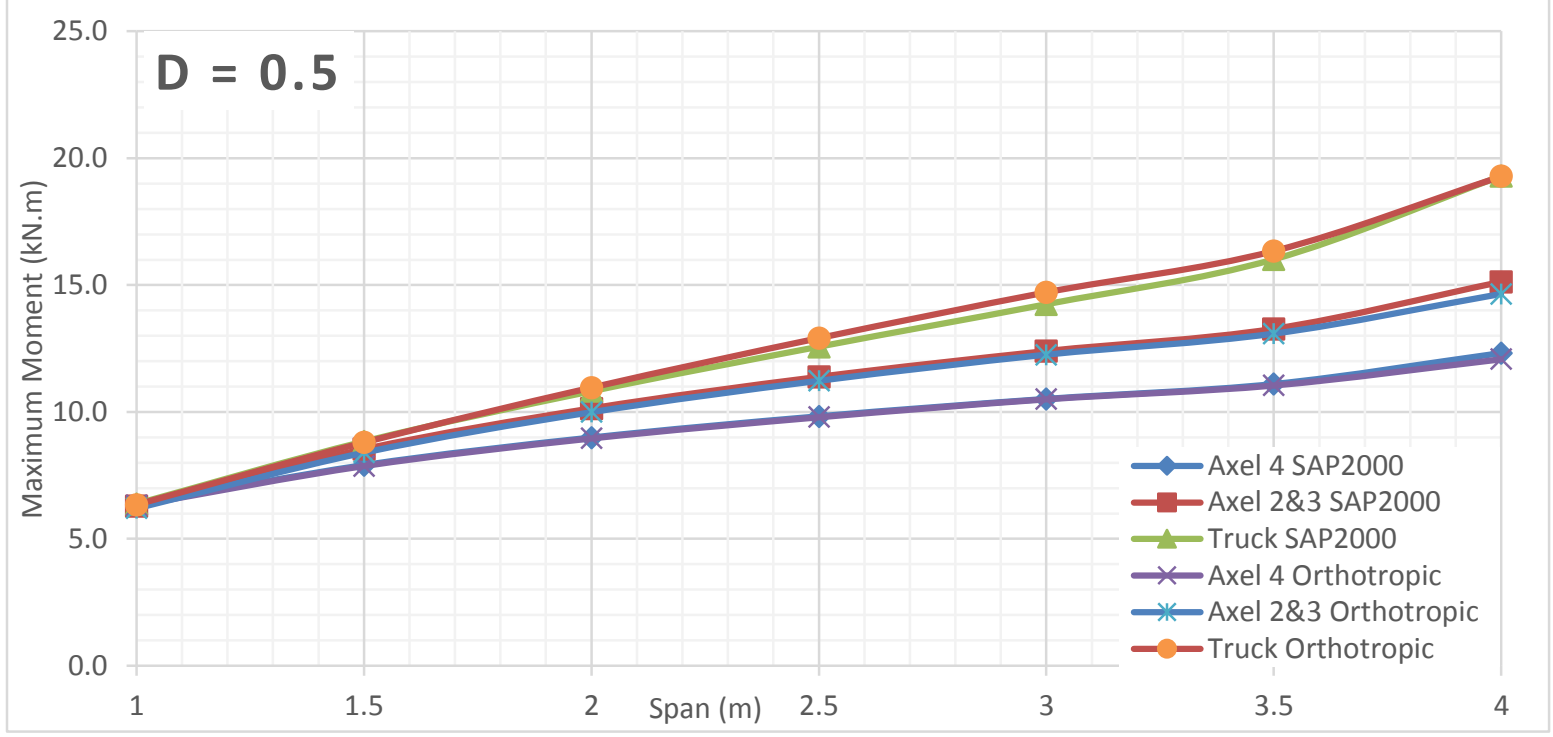

Figure 584 Moment comparison between FEA and Orthotropic Plate Theory for $D=0.5$ of alpha 4 (main bars perpendicular traffic) 


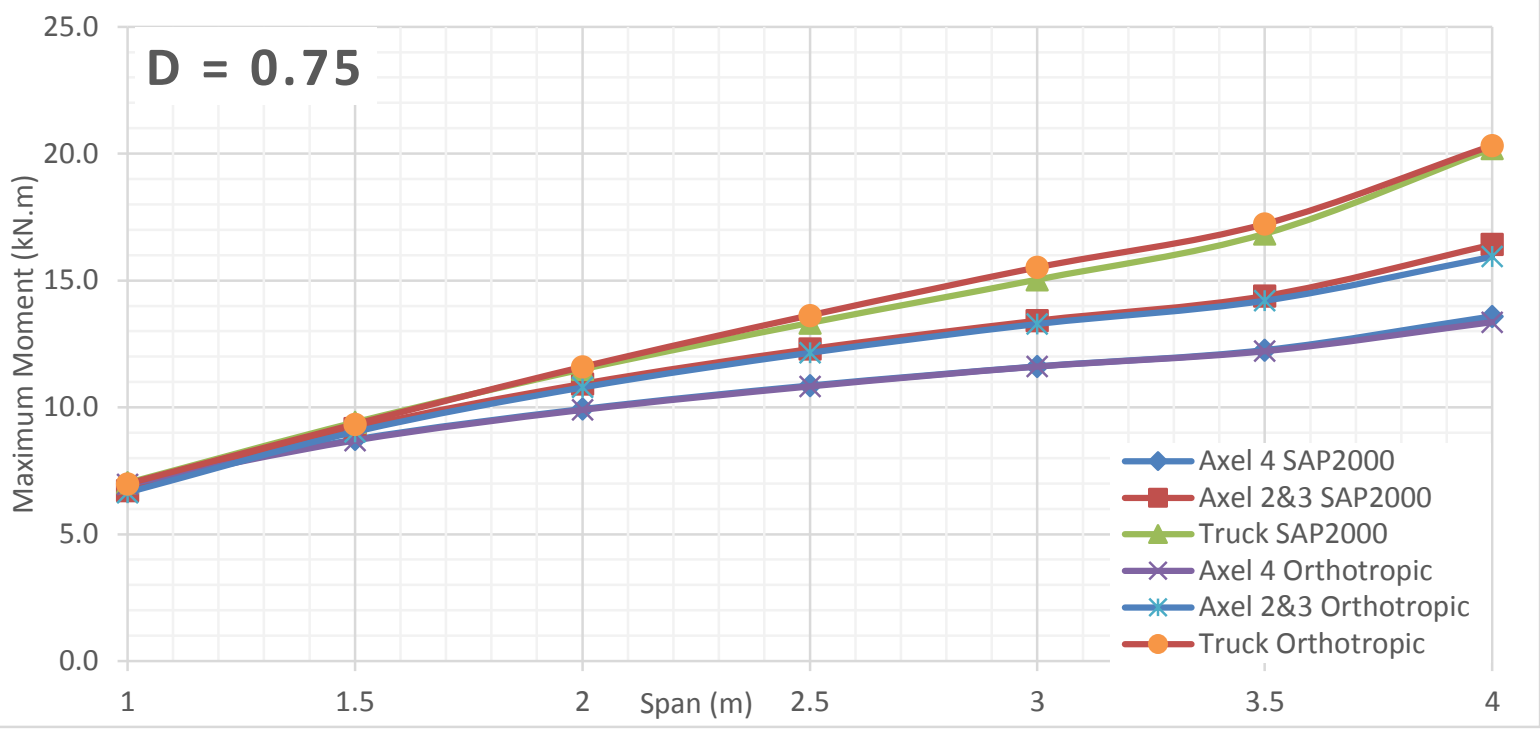

Figure 585 Moment comparison between FEA and Orthotropic Plate Theory for D $=0.75$ of alpha 4 (main bars perpendicular traffic)

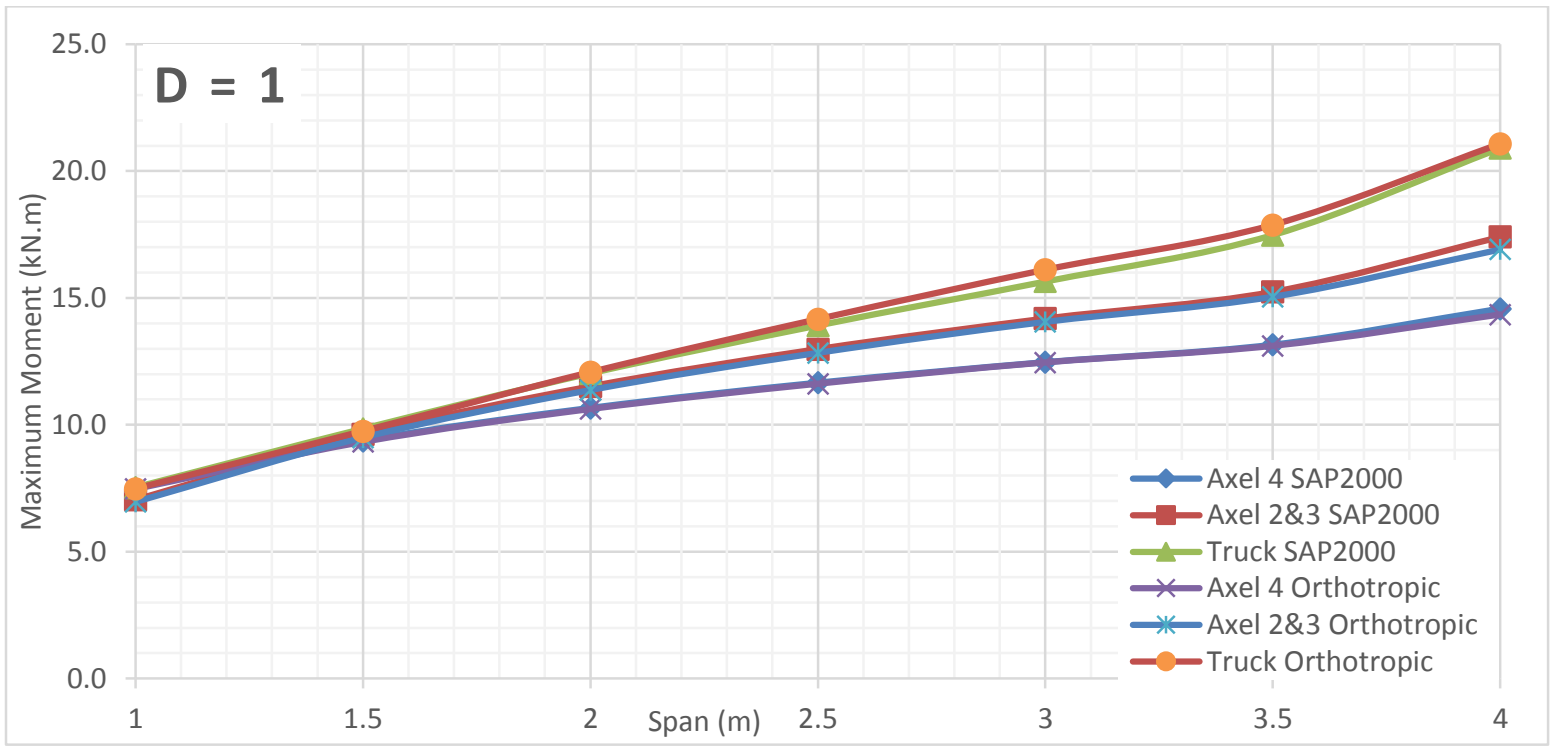

Figure 586 Moment comparison between FEA and Orthotropic Plate Theory for $D=1$ of alpha 4 (main bars perpendicular traffic)

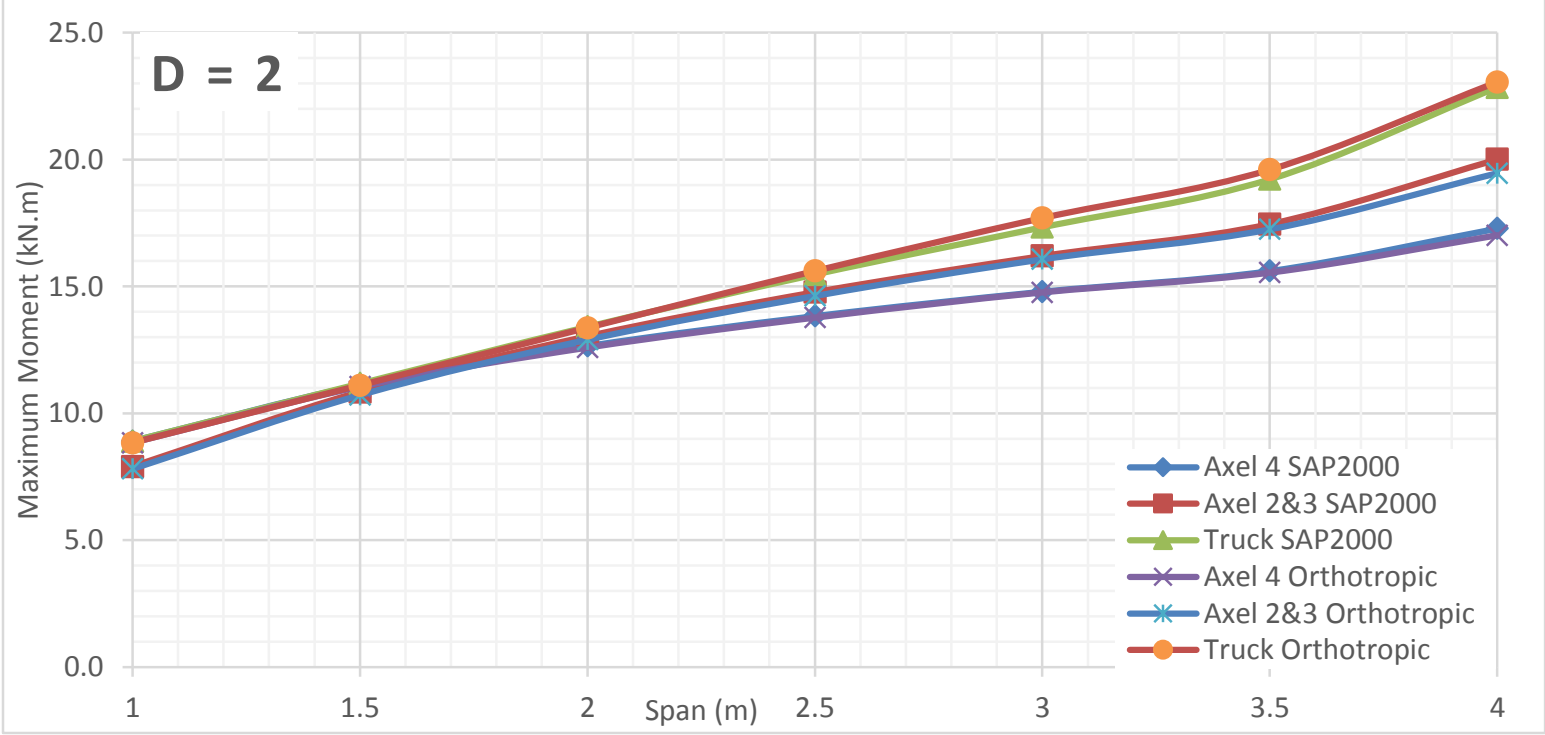

Figure 587 Moment comparison between FEA and Orthotropic Plate Theory for $D=2$ of alpha 4 (main bars perpendicular traffic) 


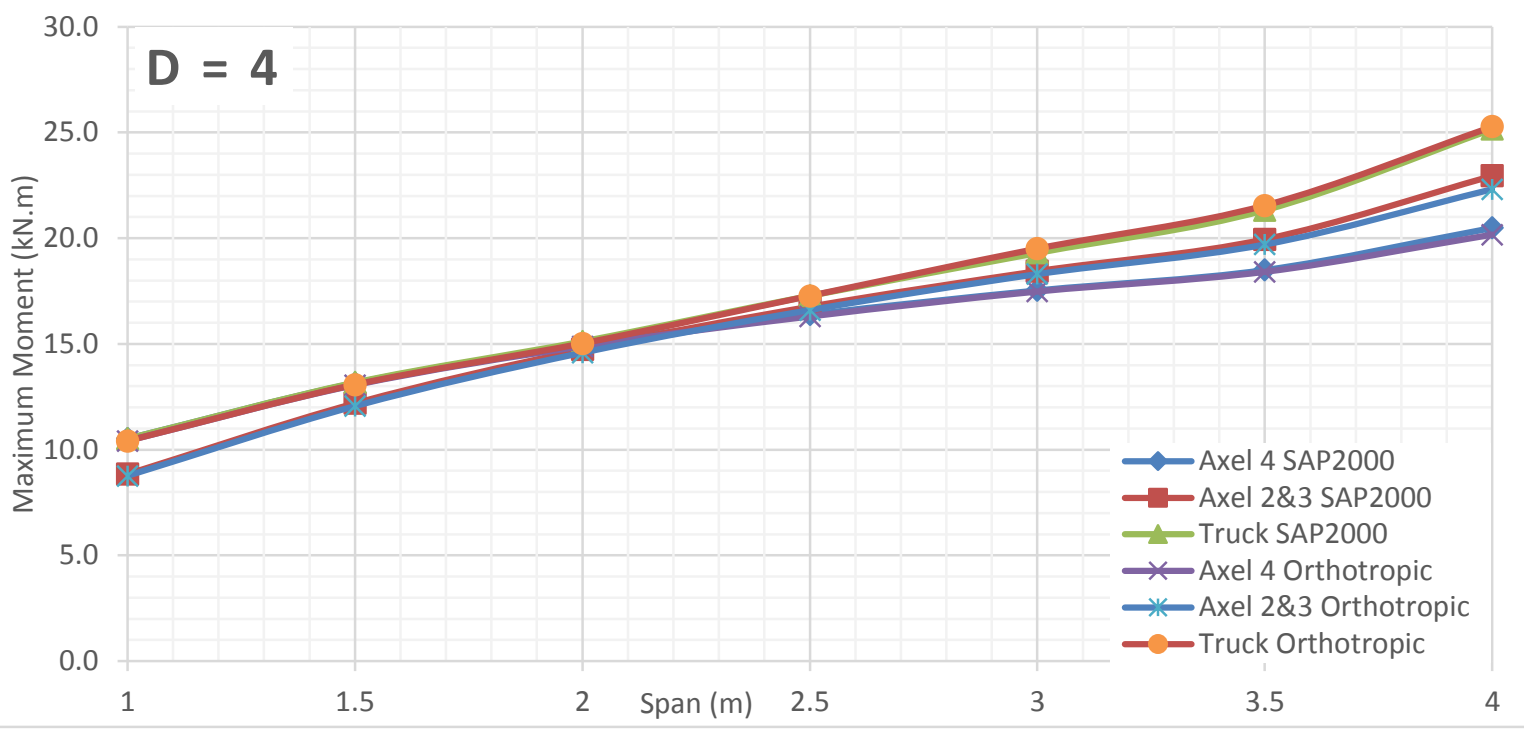

Figure 588 Moment comparison between FEA and Orthotropic Plate Theory for D = 4 of alpha 4 (main bars perpendicular traffic)

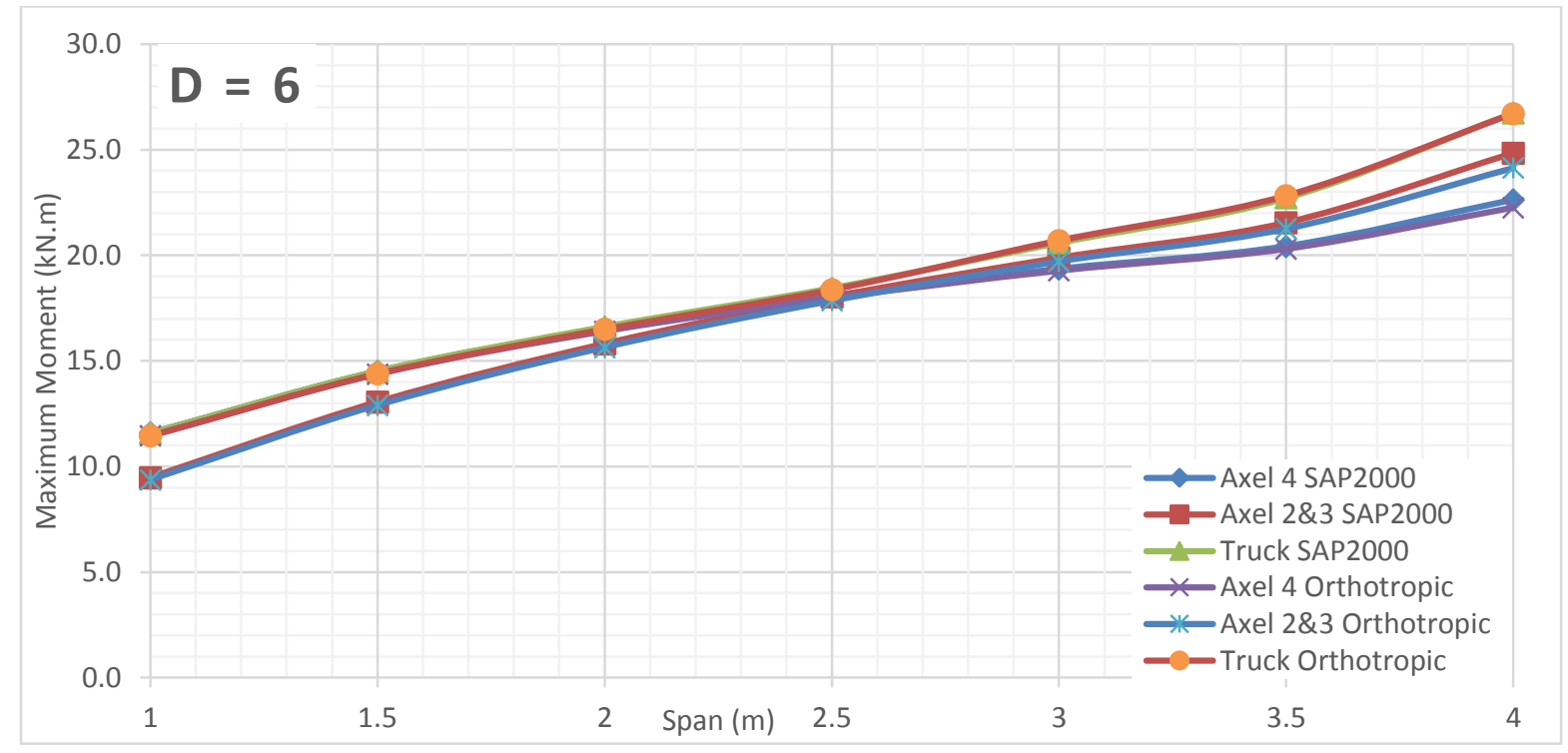

Figure 589 Moment comparison between FEA and Orthotropic Plate Theory for D $=6$ of alpha 4 (main bars perpendicular traffic)

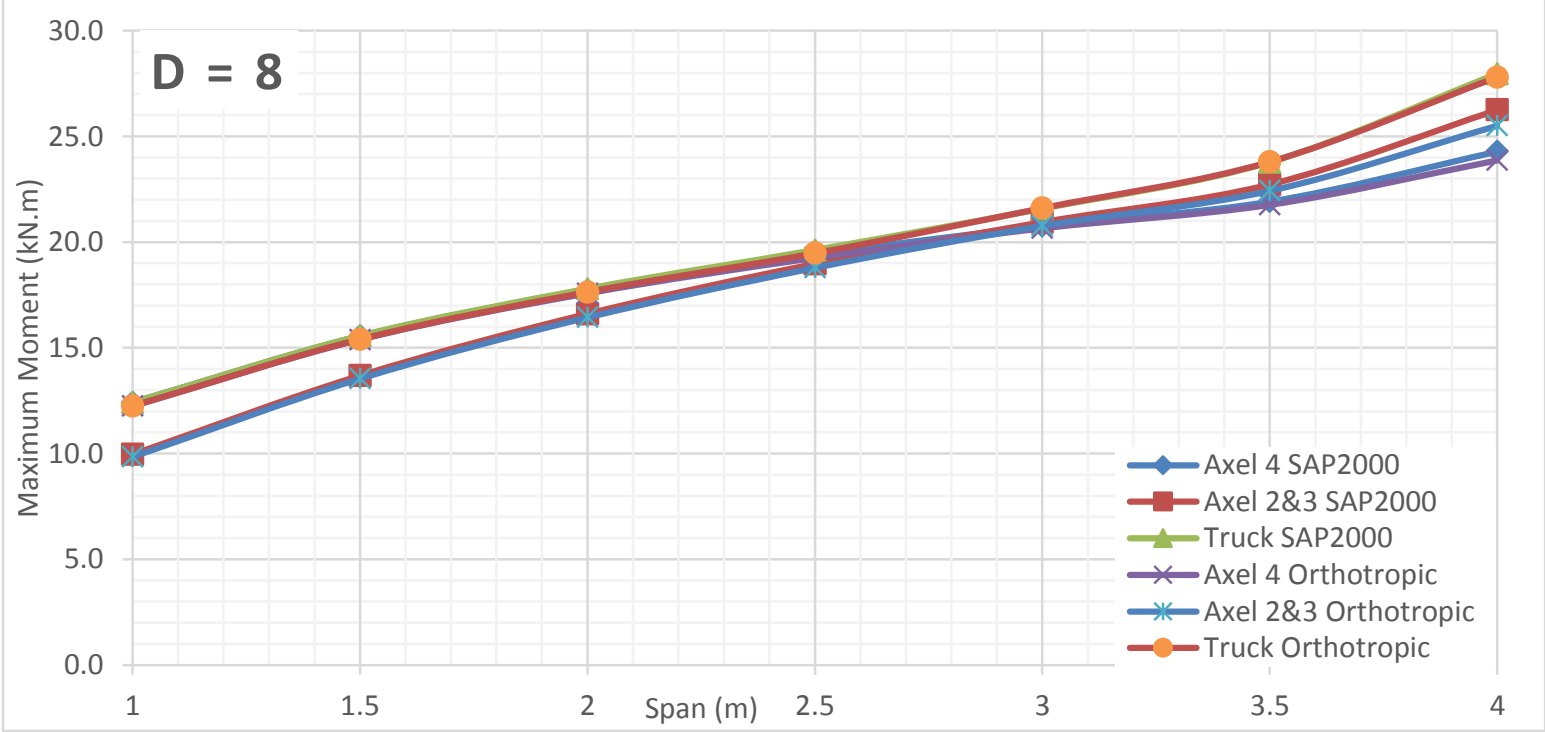

Figure 590 Moment comparison between FEA and Orthotropic Plate Theory for $D=8$ of alpha 4 (main bars perpendicular traffic) 


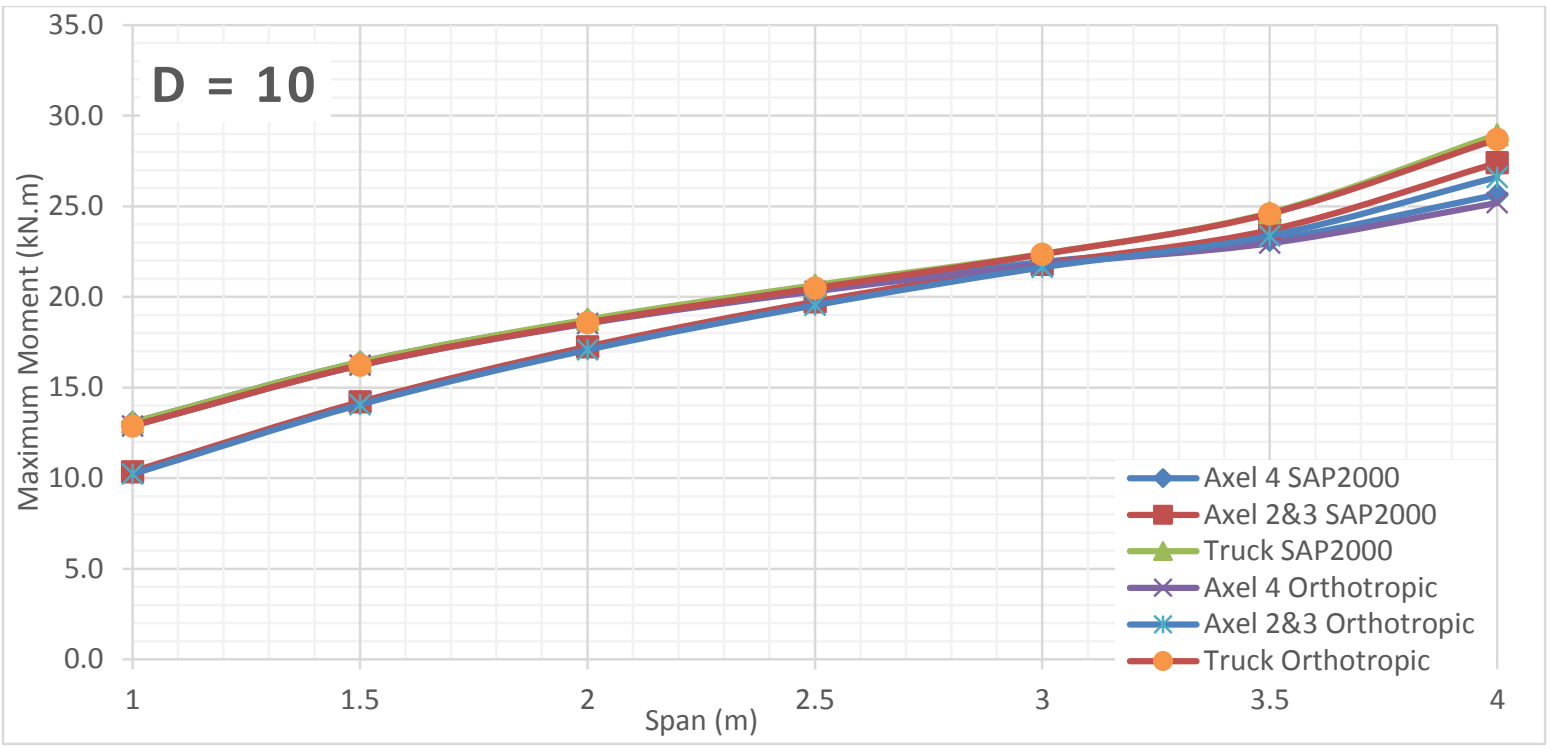

Figure 591 Moment comparison between FEA and Orthotropic Plate Theory for $D=10$ of alpha 4 (main bars perpendicular traffic) 


\section{Alpha 4 Bending Moment VS Span Length for Different D Values (Main bars parallel to traffic)}

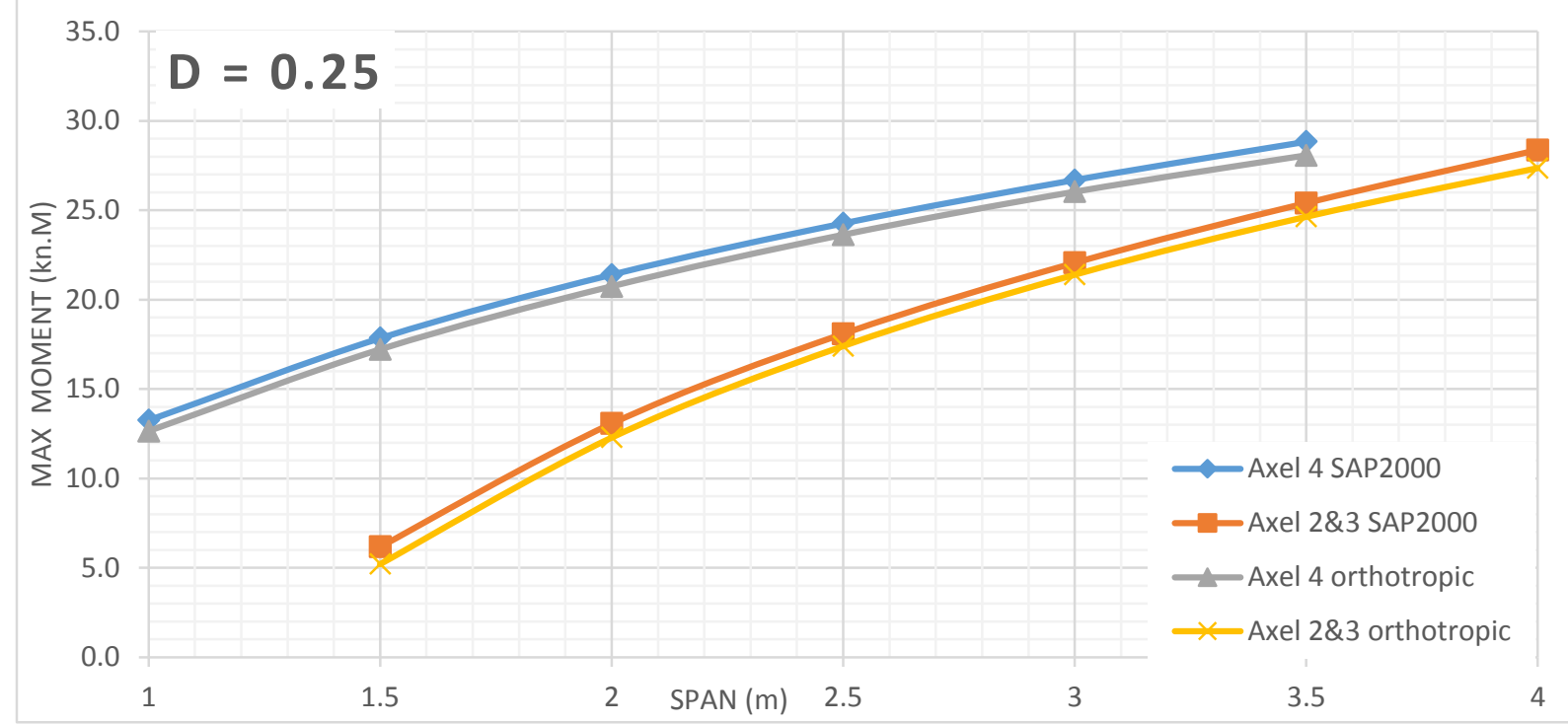

Figure 592 Moment comparison between FEA and Orthotropic Plate Theory for $D=0.25$ of alpha 4 (main bars parallel traffic)

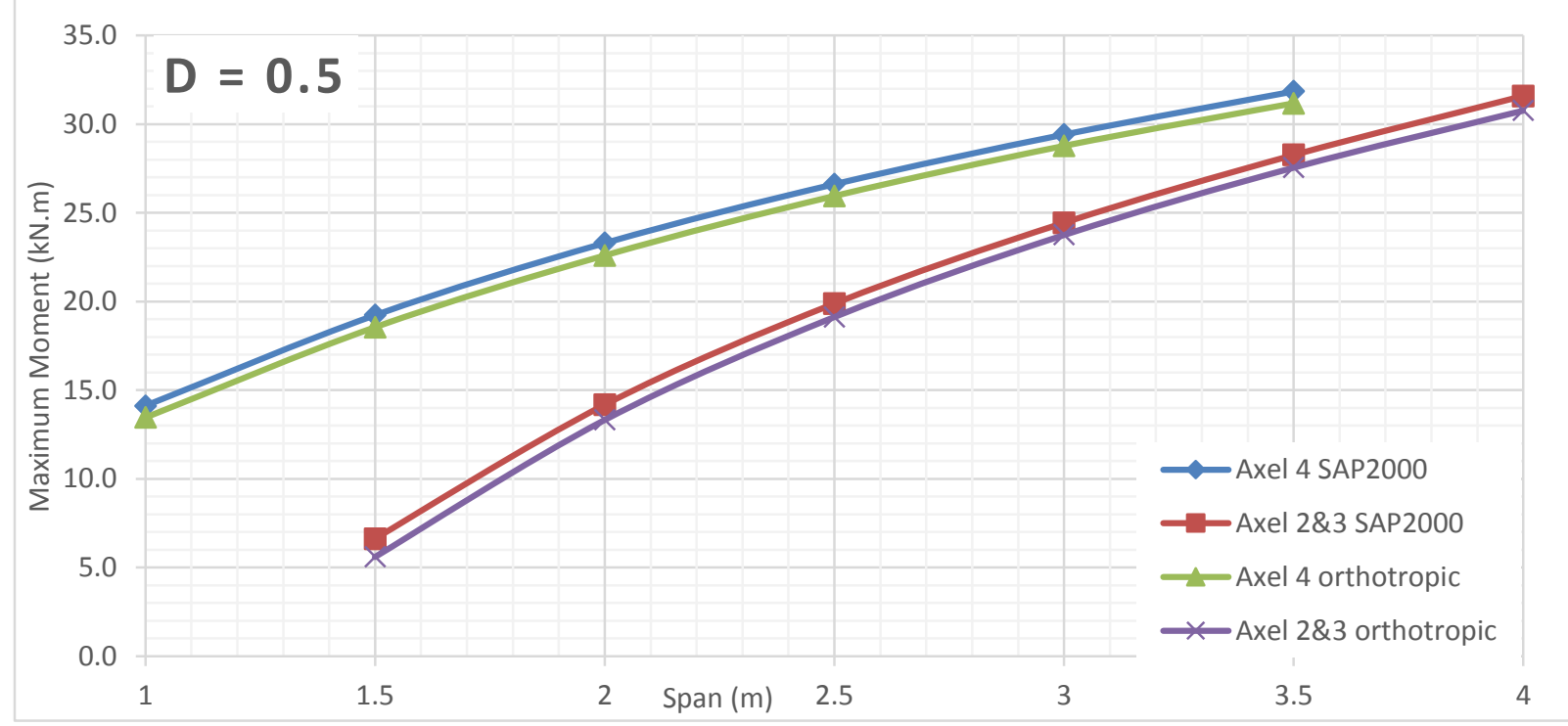

Figure 593 Moment comparison between FEA and Orthotropic Plate Theory for $D=0.5$ of alpha 4 (main bars parallel traffic) 


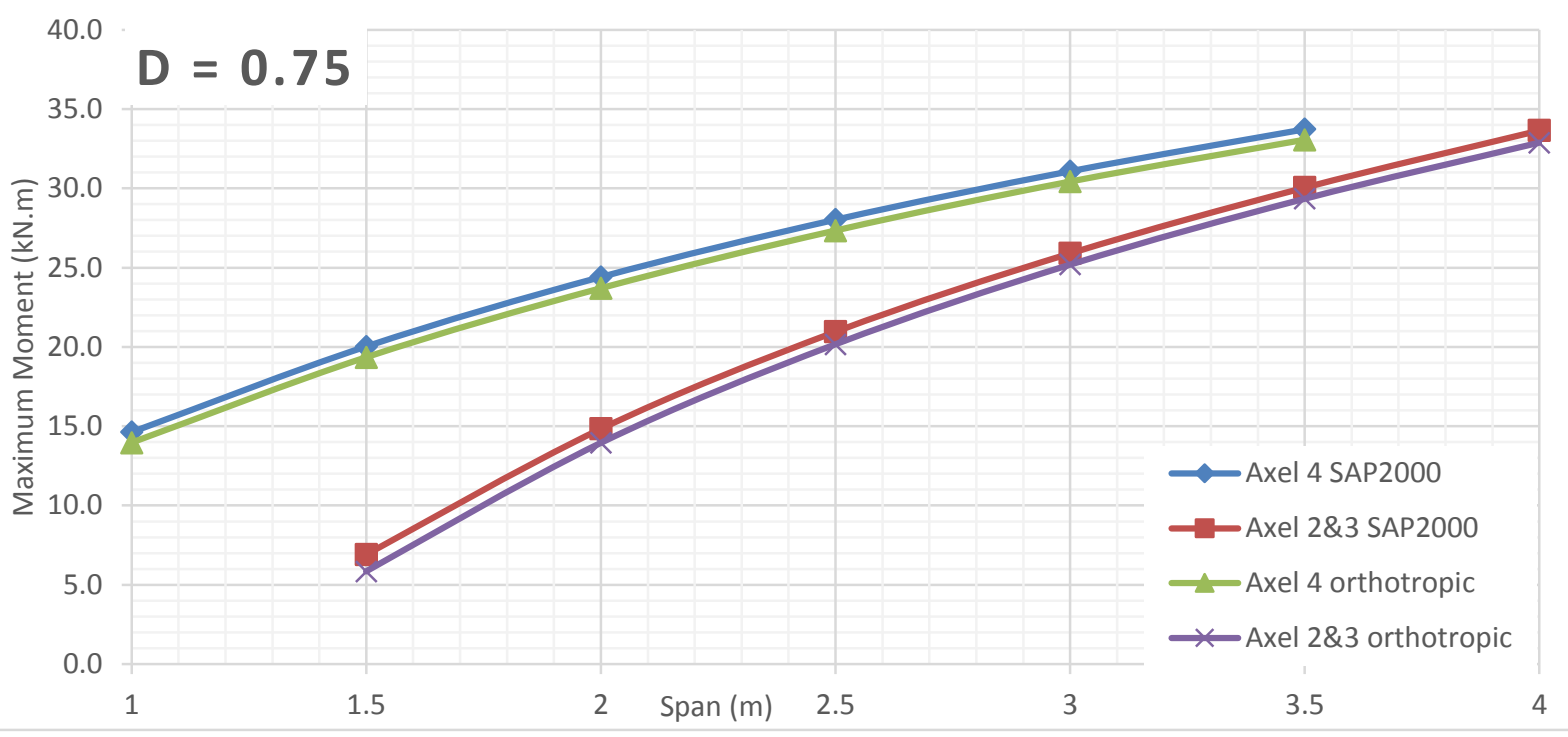

Figure 594 Moment comparison between FEA and Orthotropic Plate Theory for D $=0.75$ of alpha 4 (main bars parallel traffic)

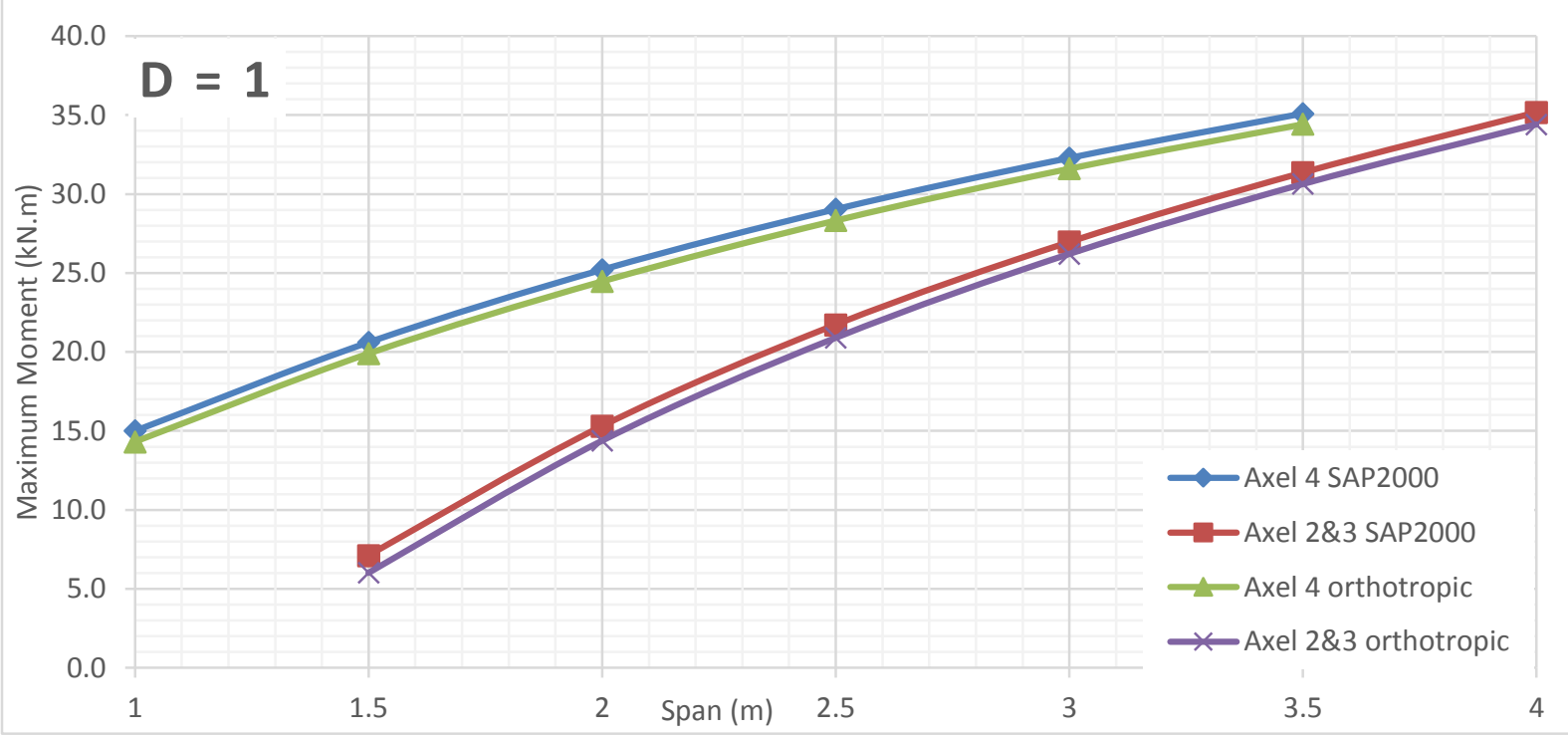

Figure 595 Moment comparison between FEA and Orthotropic Plate Theory for D = 1 of alpha 4 (main bars parallel traffic)

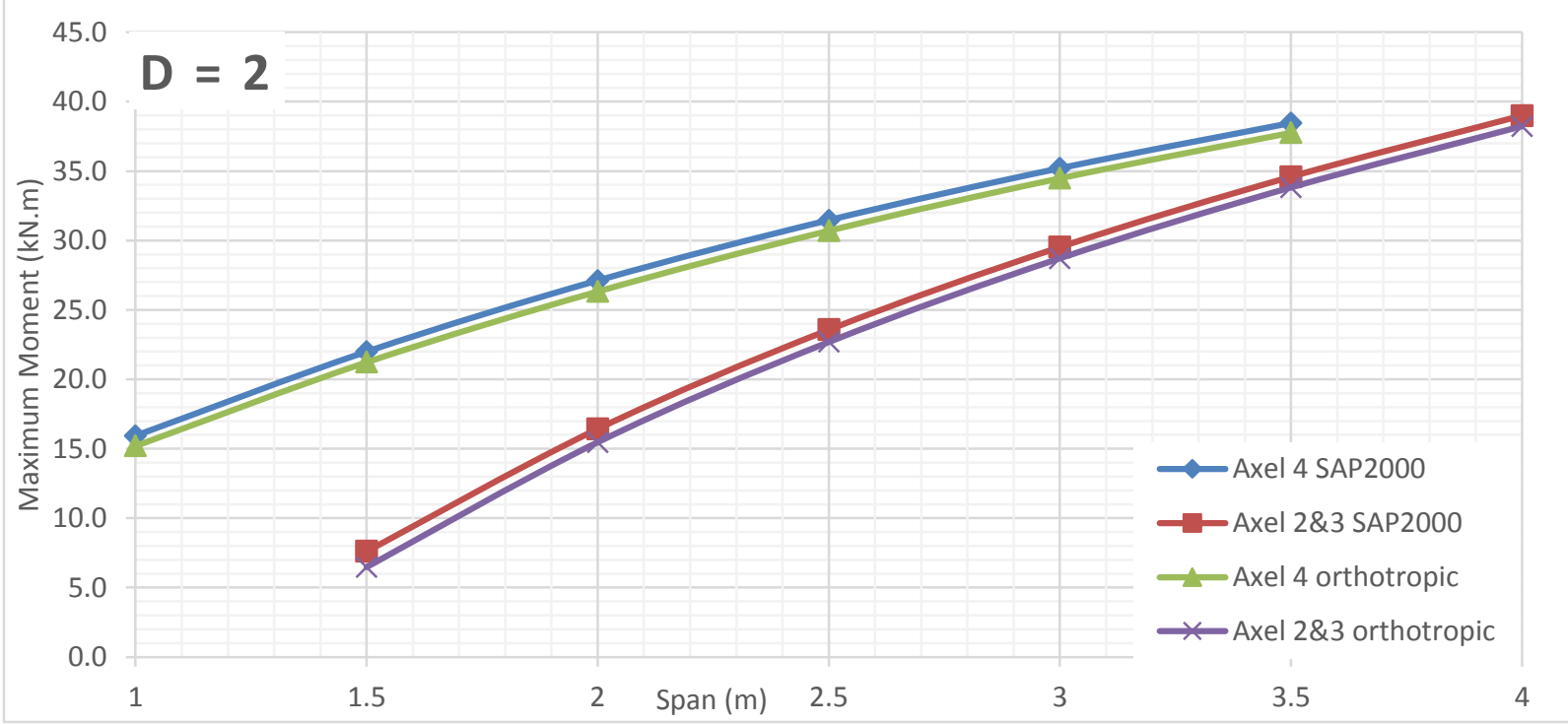

Figure 596 Moment comparison between FEA and Orthotropic Plate Theory for D = 2 of alpha 4 (main bars parallel traffic) 


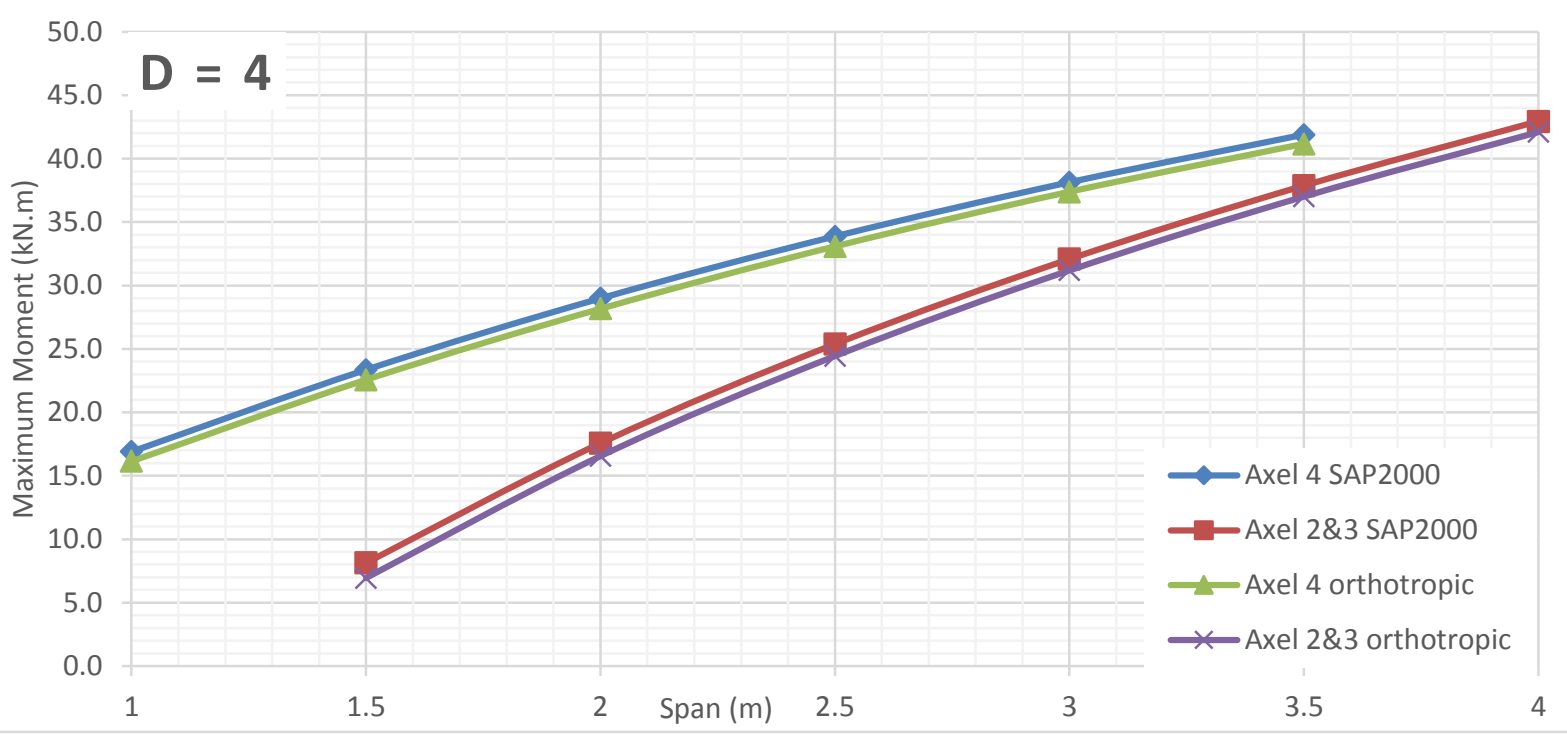

Figure 597 Moment comparison between FEA and Orthotropic Plate Theory for D $=4$ of alpha 4 (main bars parallel traffic)

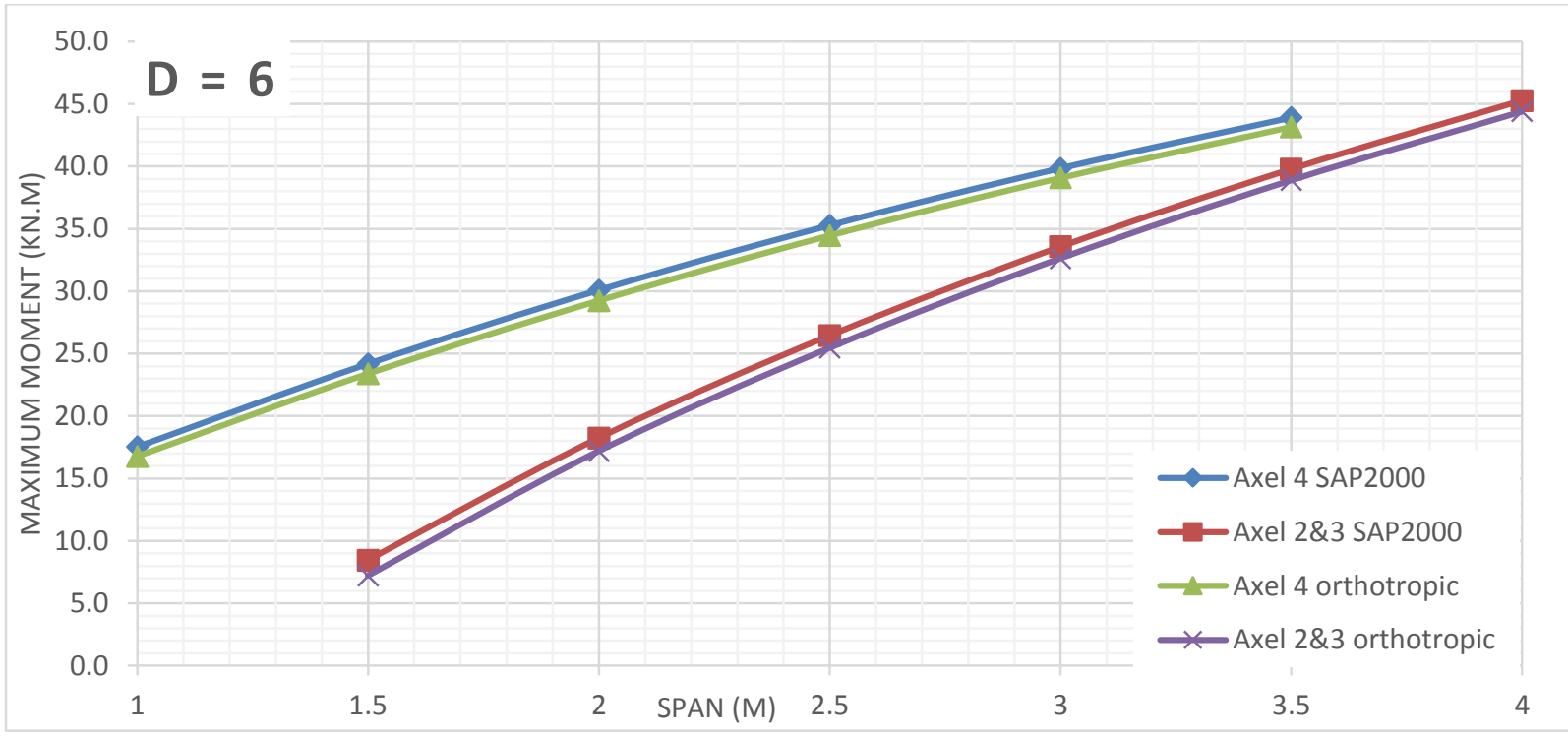

Figure 598 Moment comparison between FEA and Orthotropic Plate Theory for D $=6$ of alpha 4 (main bars parallel traffic)

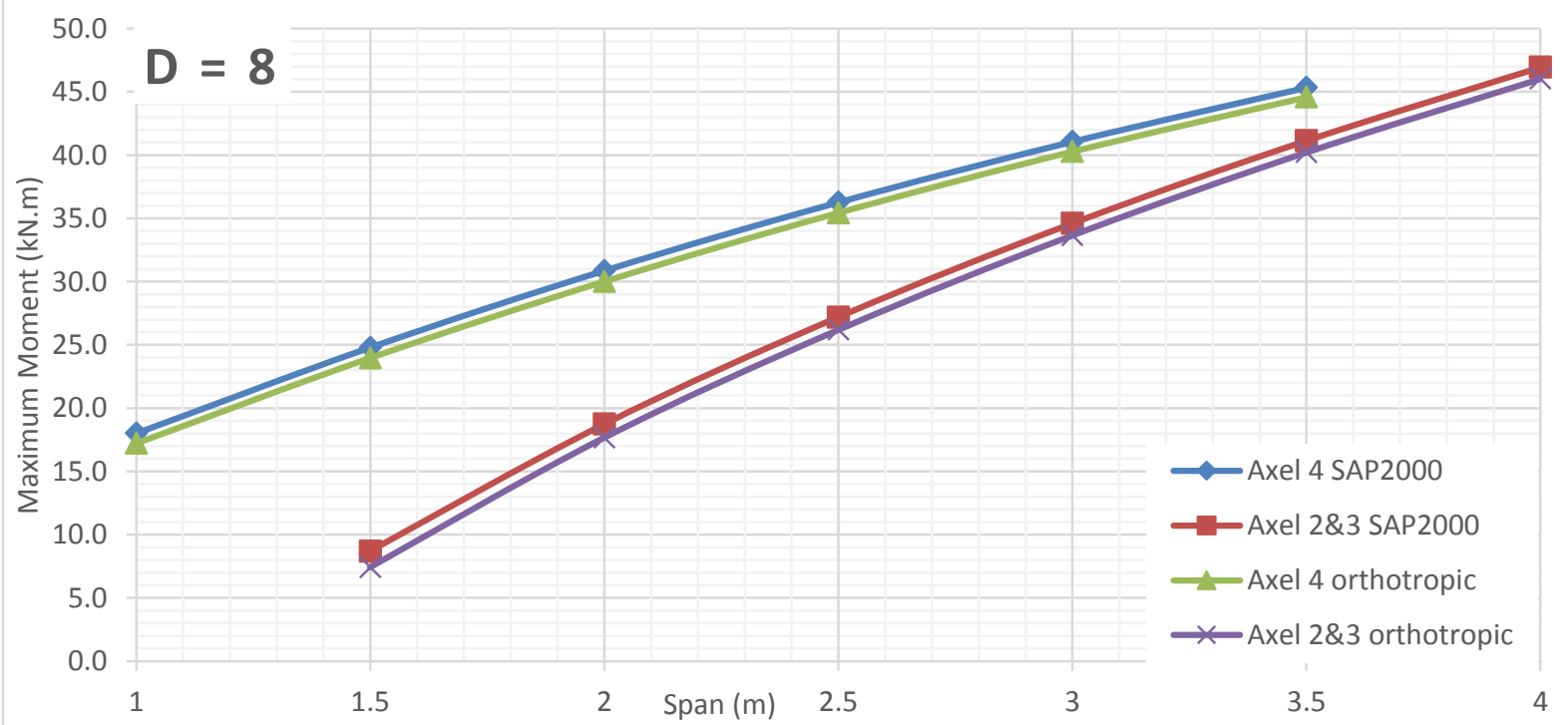

Figure 599 Moment comparison between FEA and Orthotropic Plate Theory for $D=8$ of alpha 4 (main bars parallel traffic) 


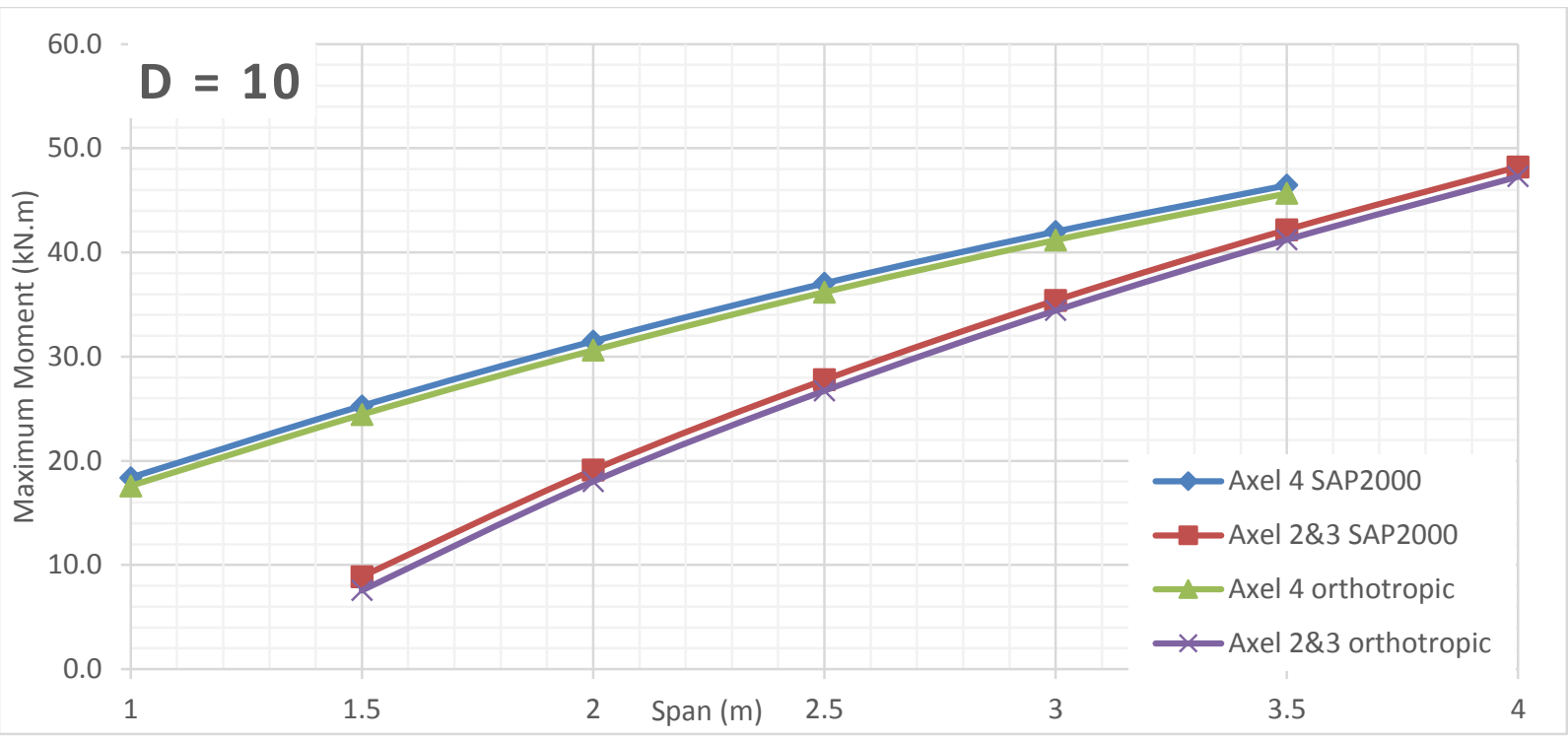

Figure 600 Moment comparison between FEA and Orthotropic Plate Theory for $D=10$ of alpha 4 (main bars parallel traffic) 


\section{Alpha 6 Bending Moment VS Span Length for Different D Values (Main bars perpendicular to traffic)}

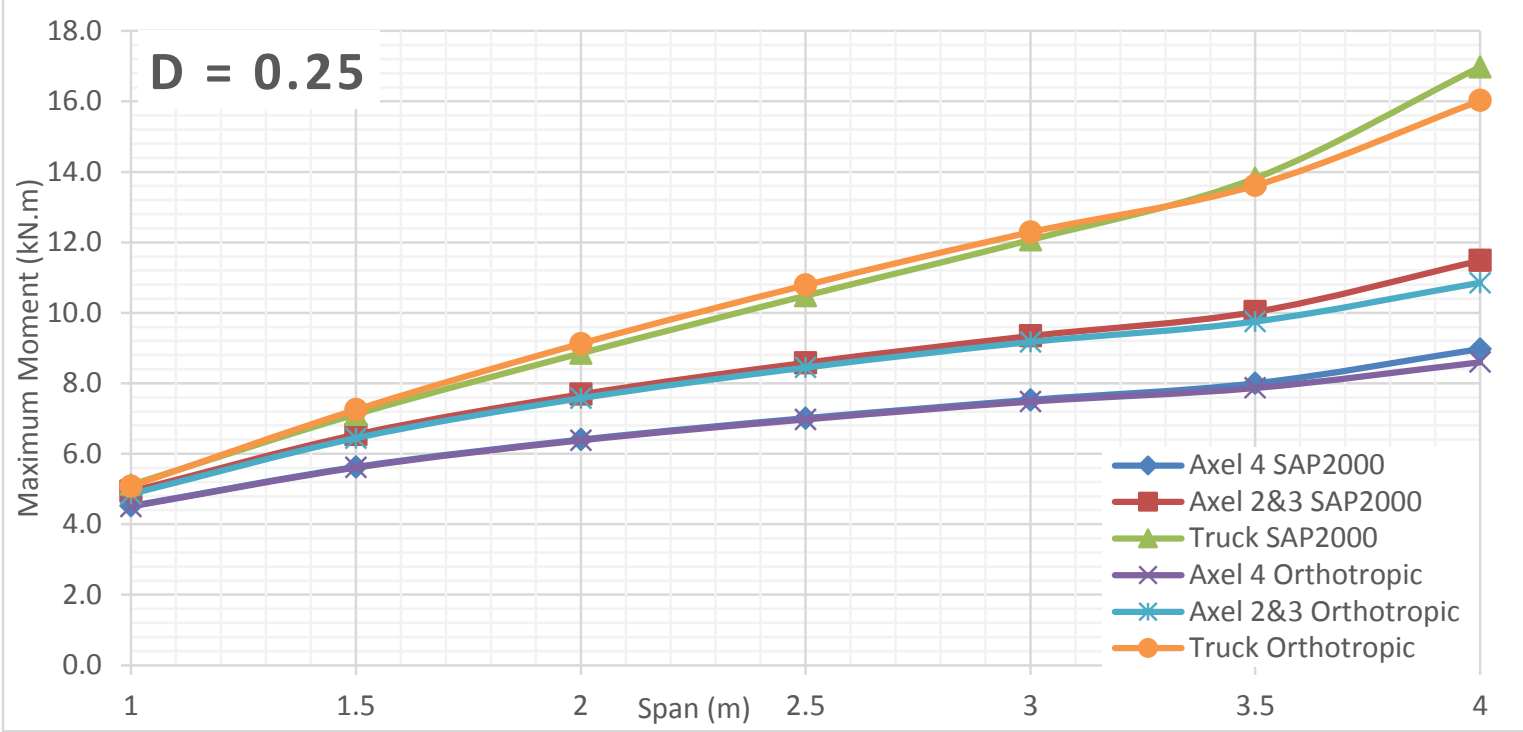

Figure 601 Moment comparison between FEA and Orthotropic Plate Theory for $D=0.25$ of alpha 6 (main bars perpendicular traffic)

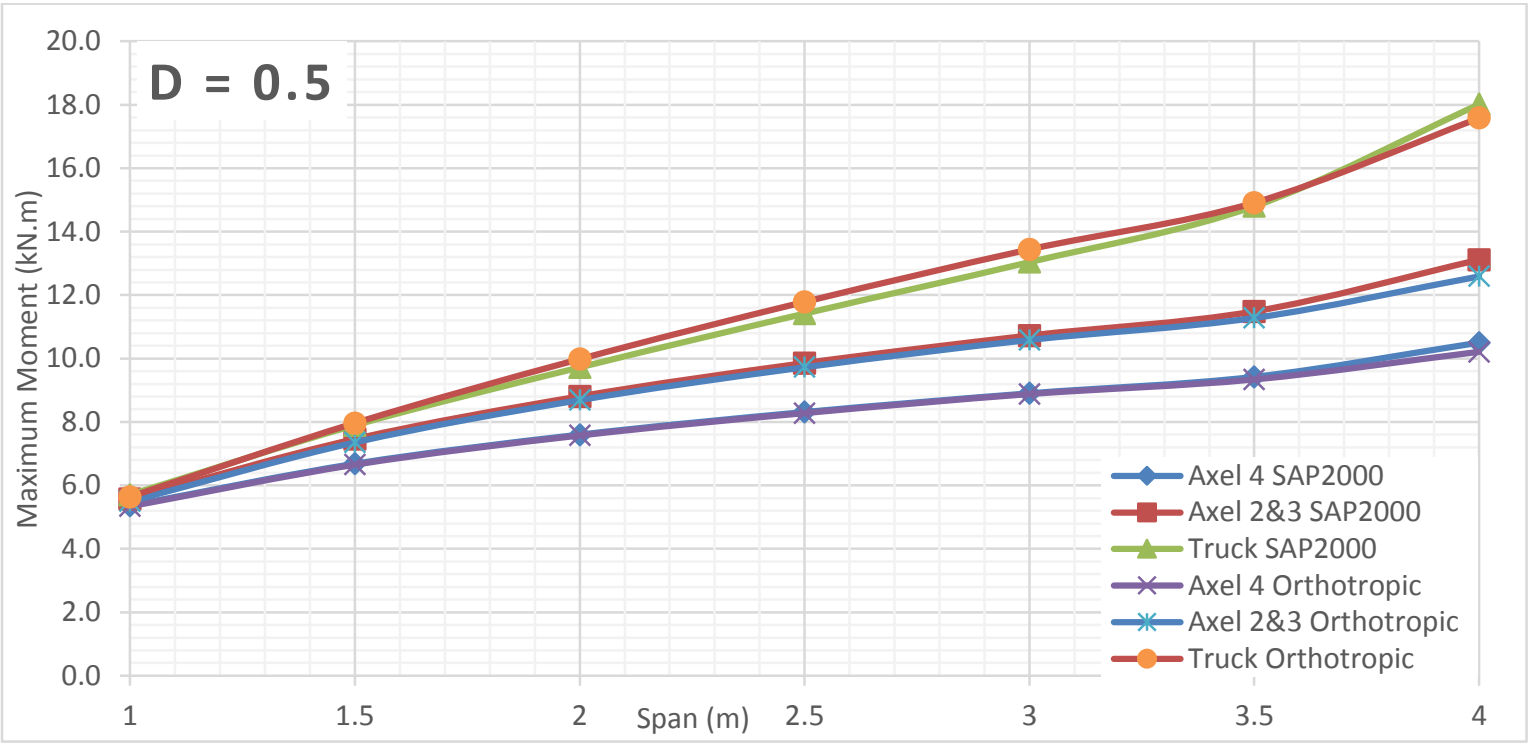

Figure 602 Moment comparison between FEA and Orthotropic Plate Theory for $D=0.5$ of alpha 6 (main bars perpendicular traffic) 


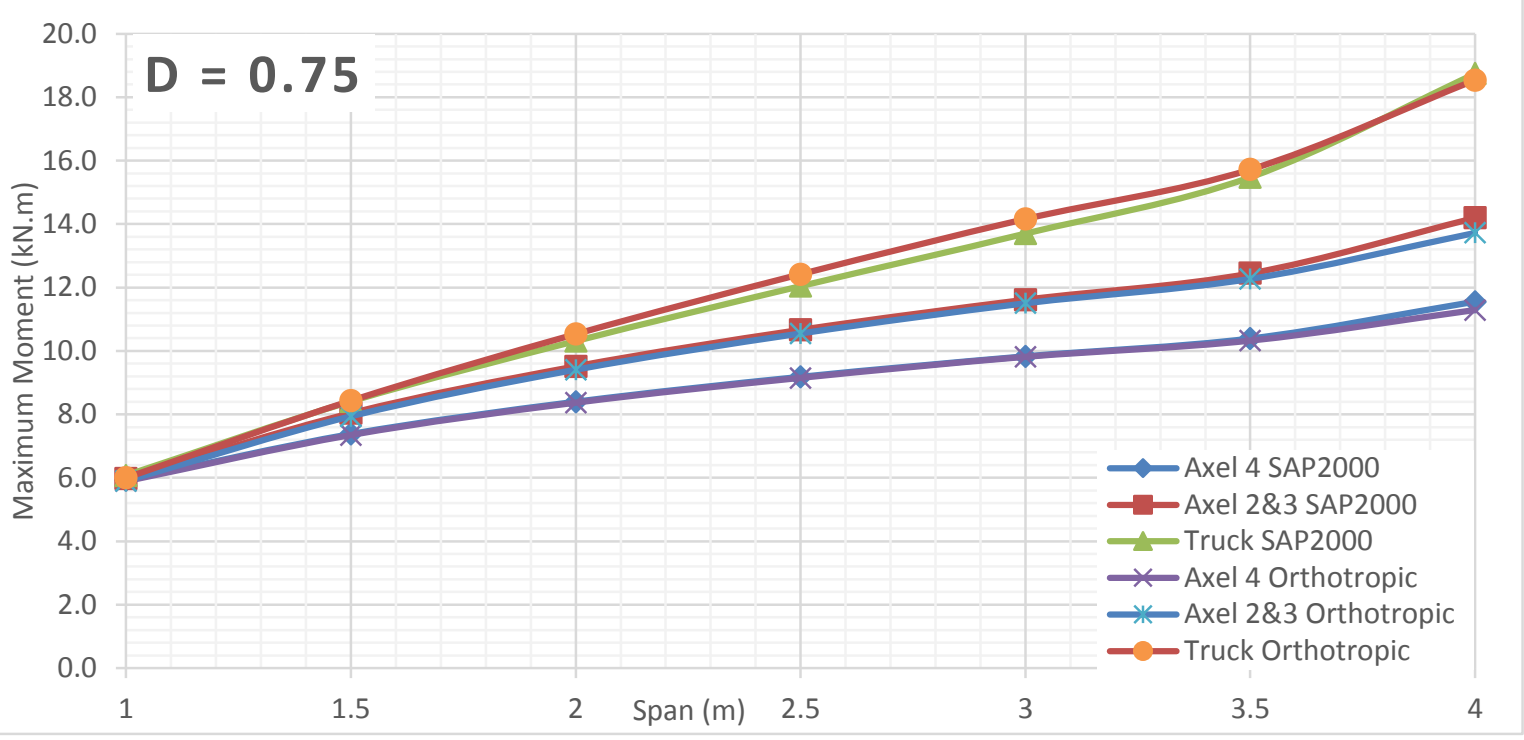

Figure 603 Moment comparison between FEA and Orthotropic Plate Theory for $D=0.75$ of alpha 6 (main bars perpendicular traffic)

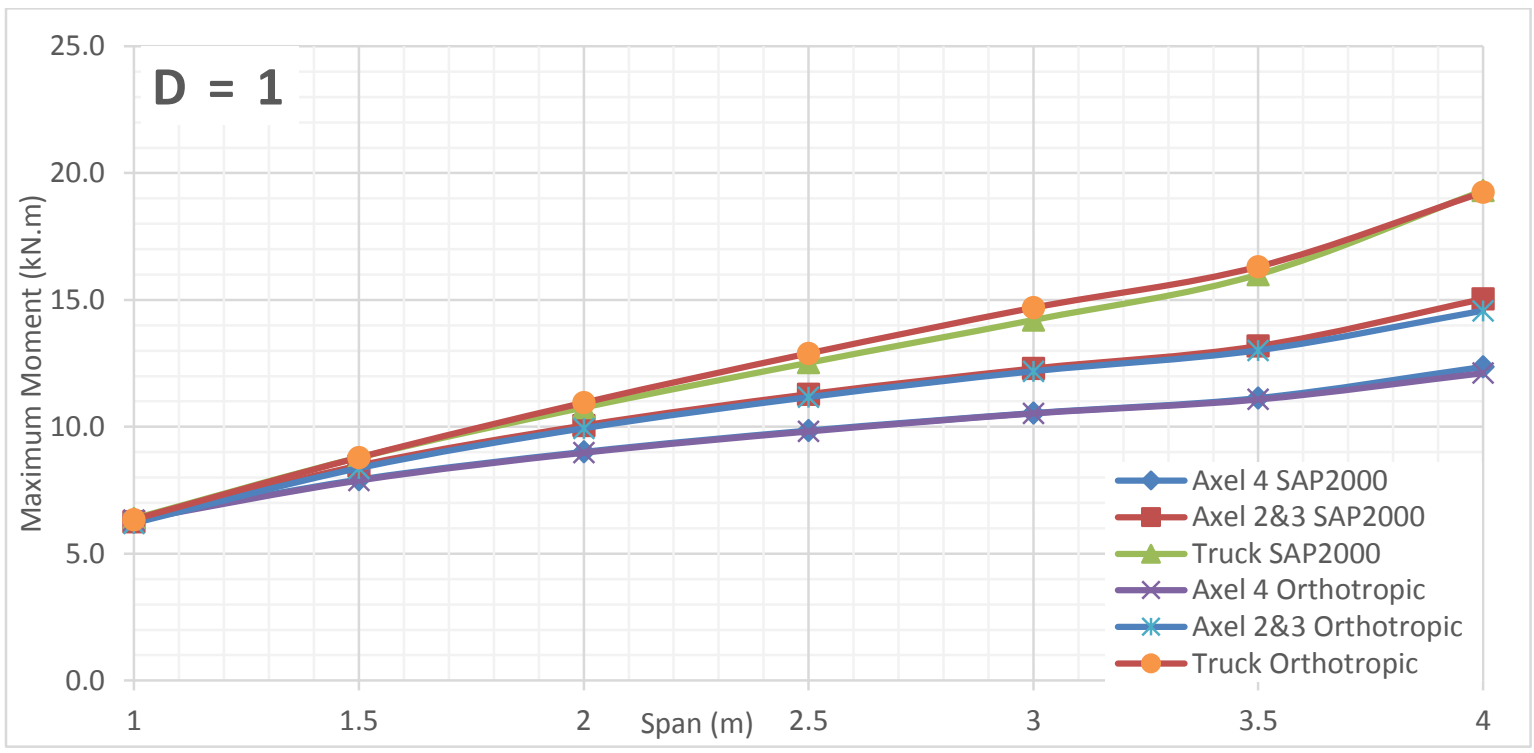

Figure 604 Moment comparison between FEA and Orthotropic Plate Theory for D = 1 of alpha 6 (main bars perpendicular traffic)

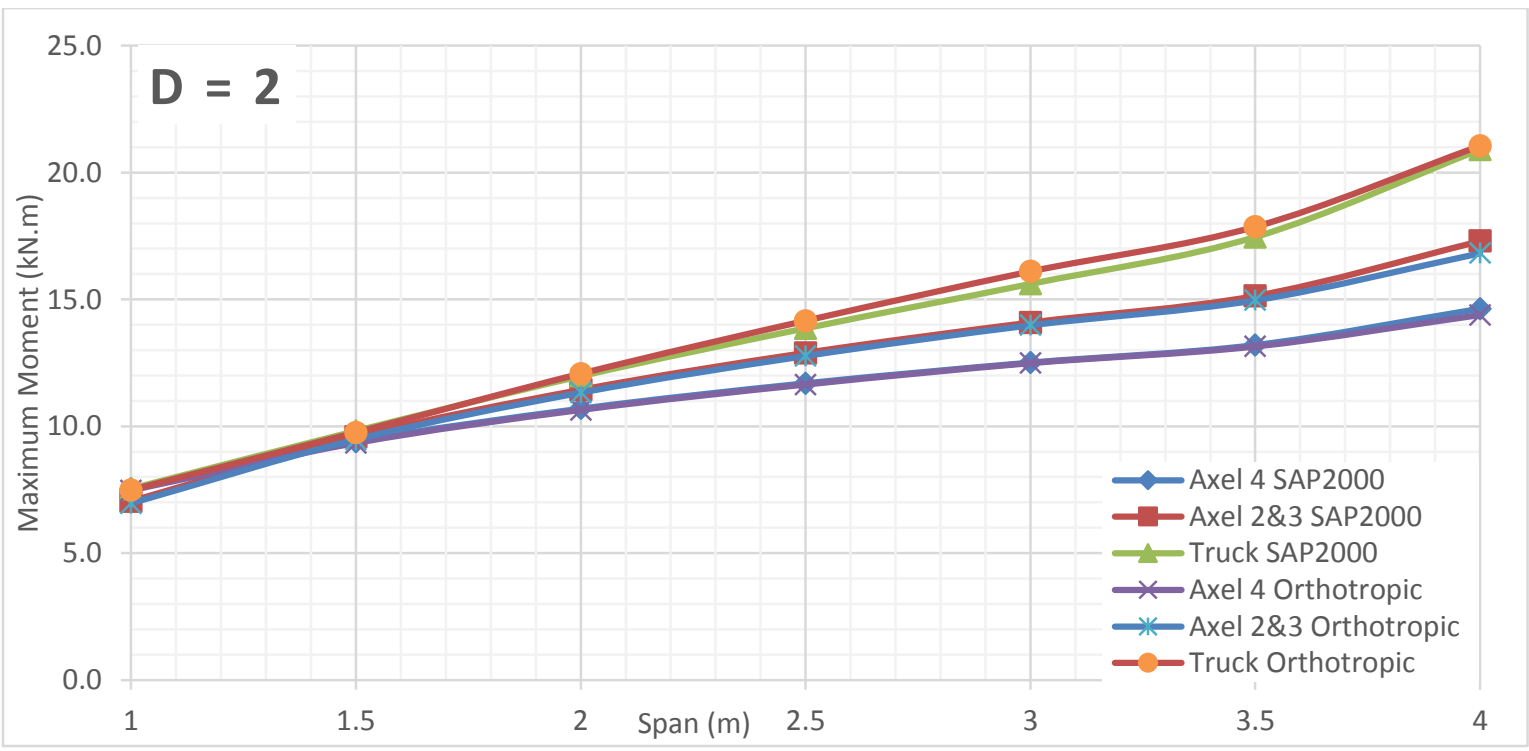

Figure 605 Moment comparison between FEA and Orthotropic Plate Theory for $D=2$ of alpha 6 (main bars perpendicular traffic) 


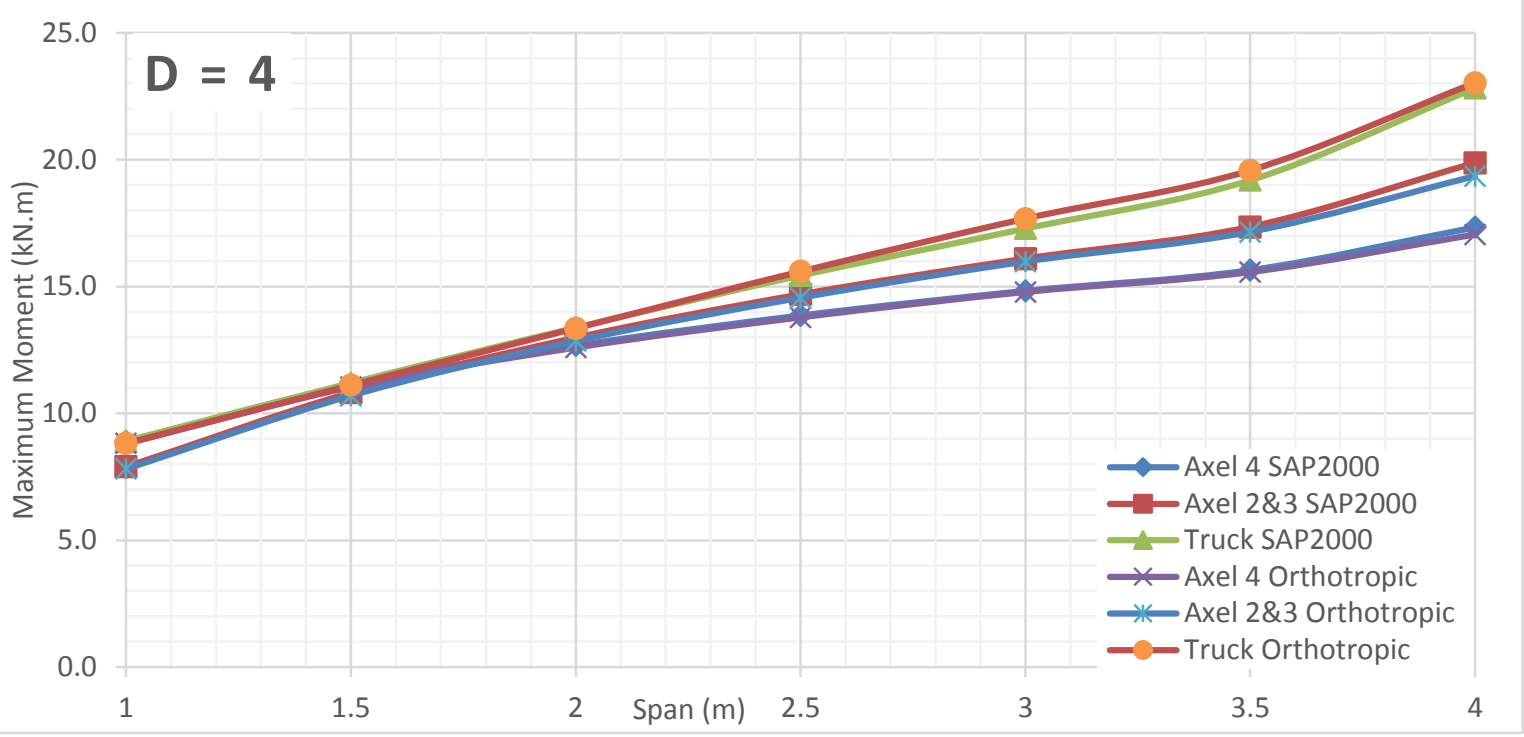

Figure 606 Moment comparison between FEA and Orthotropic Plate Theory for $D=4$ of alpha 6 (main bars perpendicular traffic)

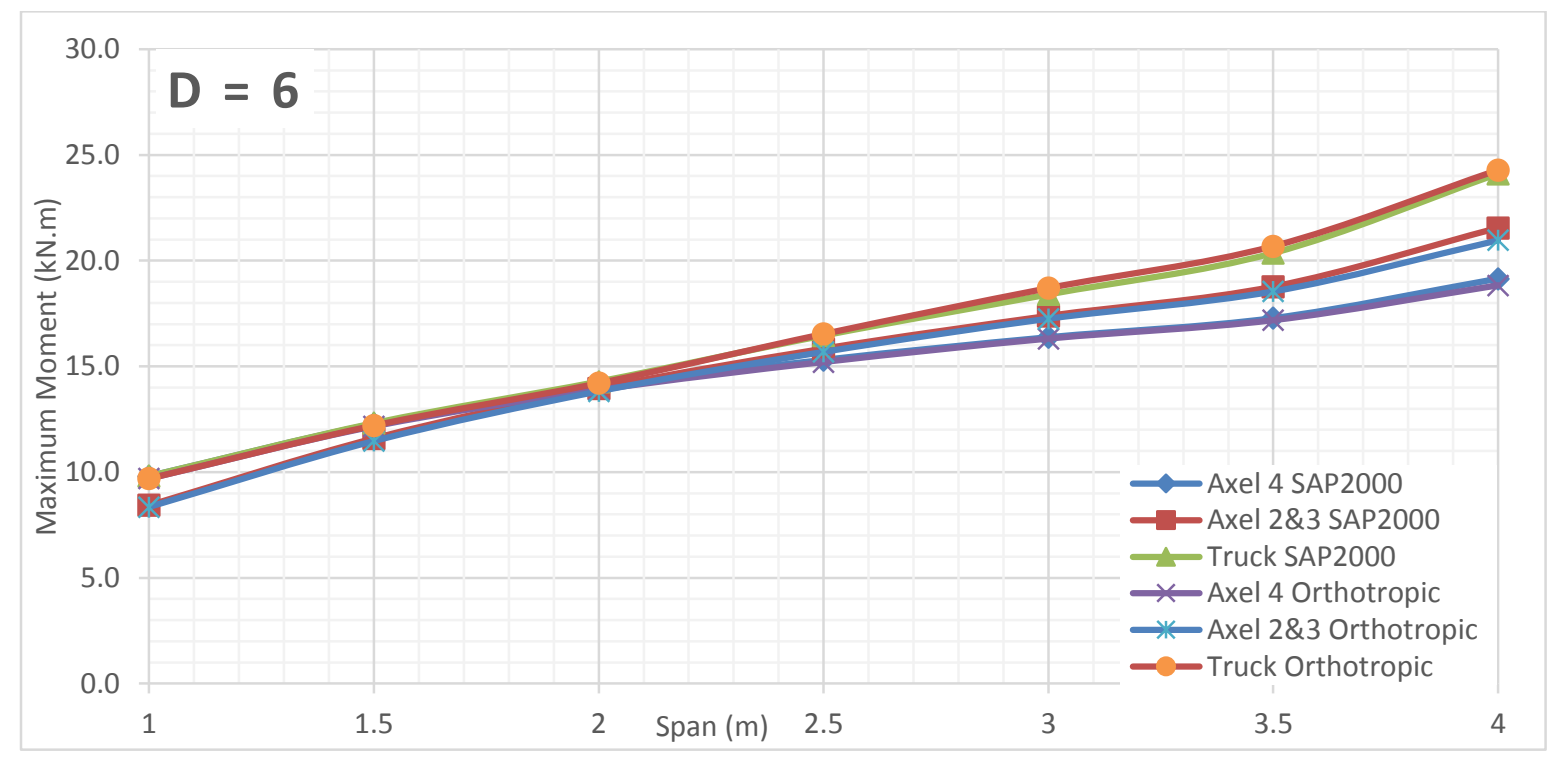

Figure 607 Moment comparison between FEA and Orthotropic Plate Theory for D $=6$ of alpha 6 (main bars perpendicular traffic)

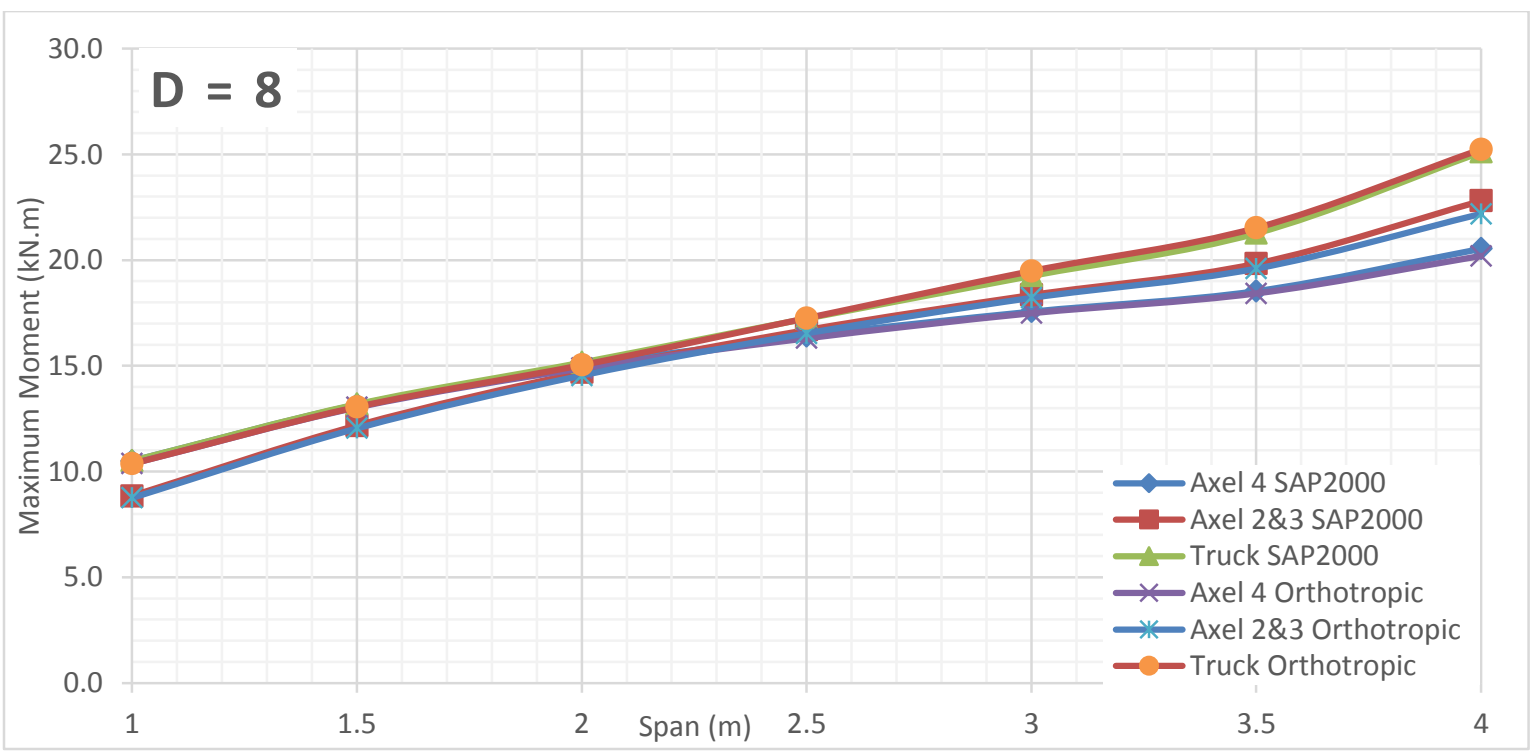

Figure 608 Moment comparison between FEA and Orthotropic Plate Theory for $D=8$ of alpha 6 (main bars perpendicular traffic) 


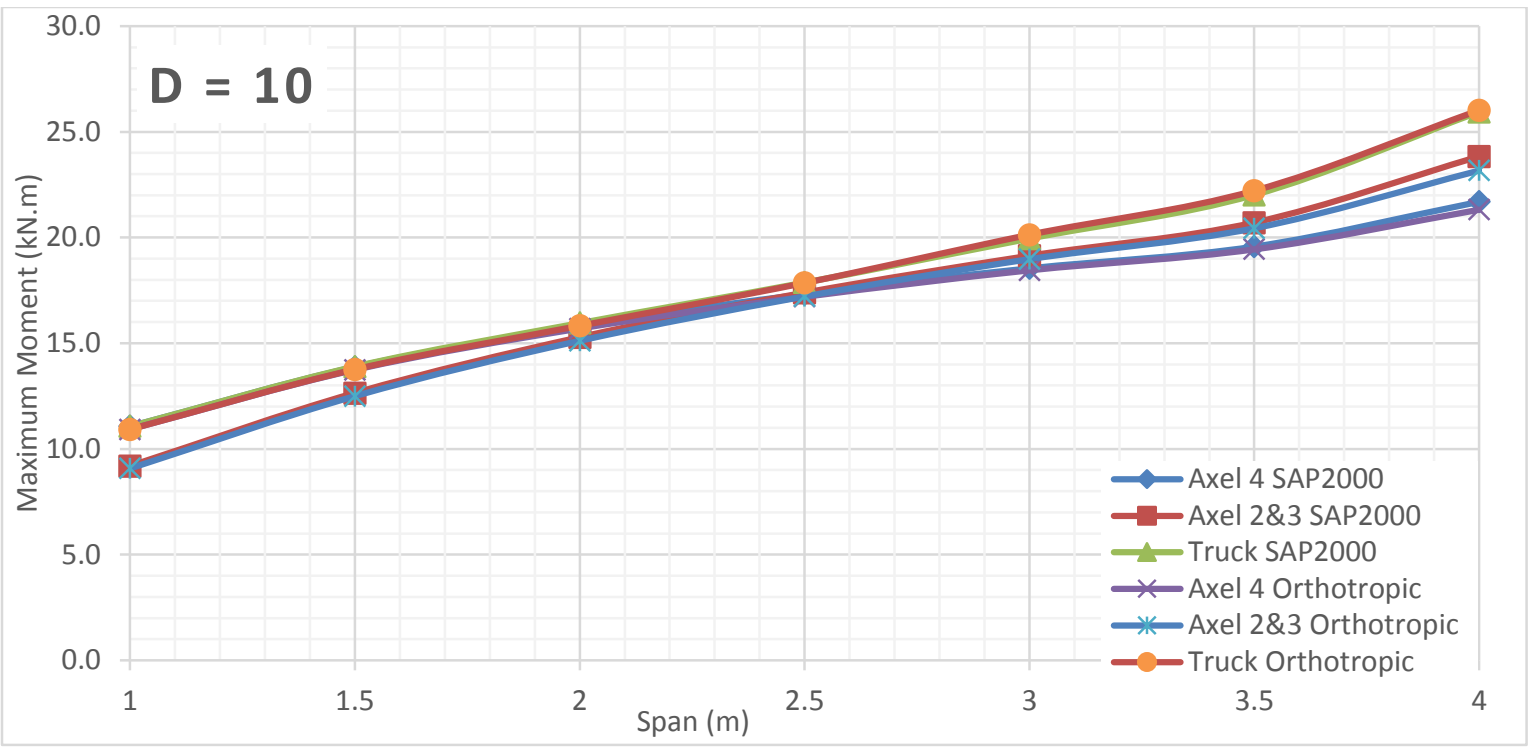

Figure 609 Moment comparison between FEA and Orthotropic Plate Theory for $D=10$ of alpha 6 (main bars perpendicular traffic) 


\section{Alpha 6 Bending Moment VS Span Length for Different D Values (Main bars parallel to traffic)}

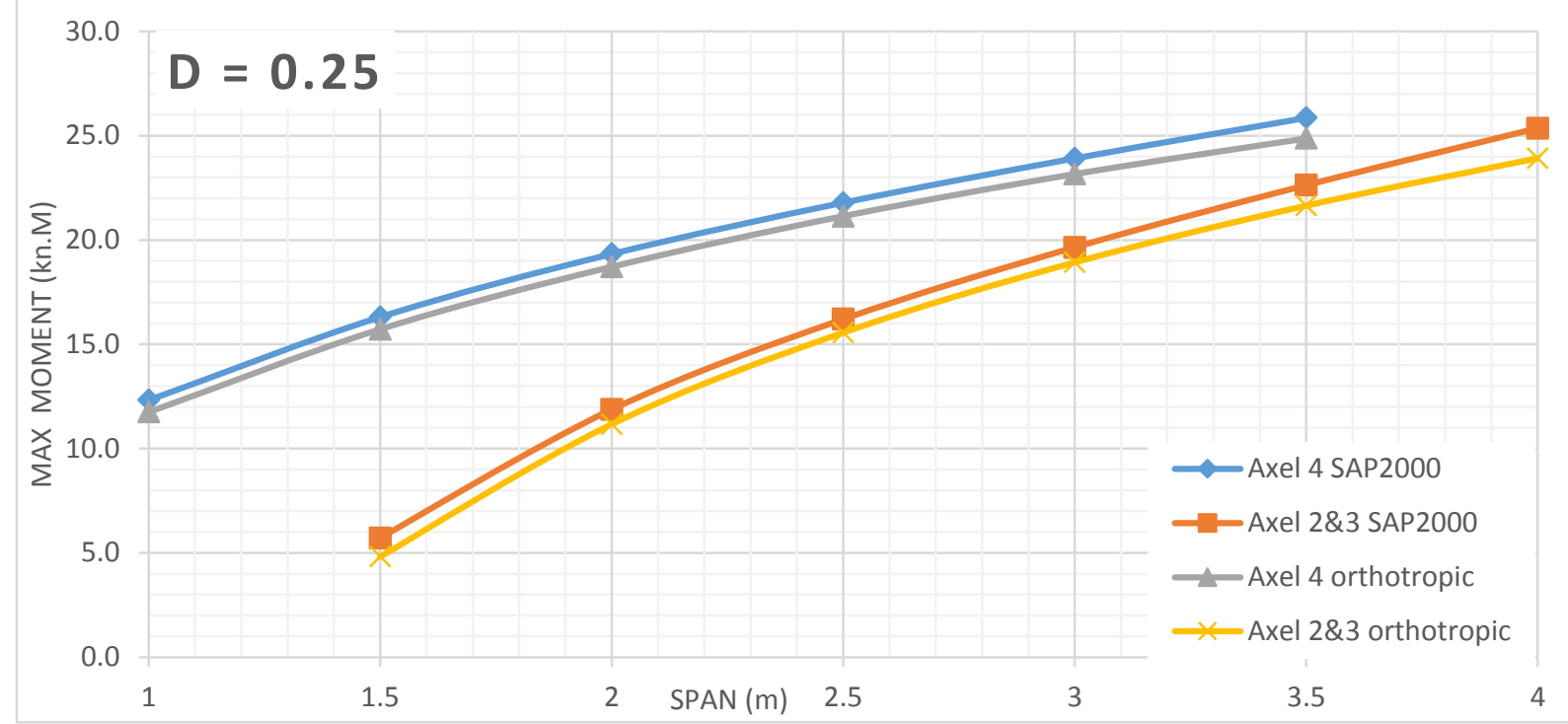

Figure 610 Moment comparison between FEA and Orthotropic Plate Theory for $D=0.25$ of alpha 6 (main bars parallel traffic)

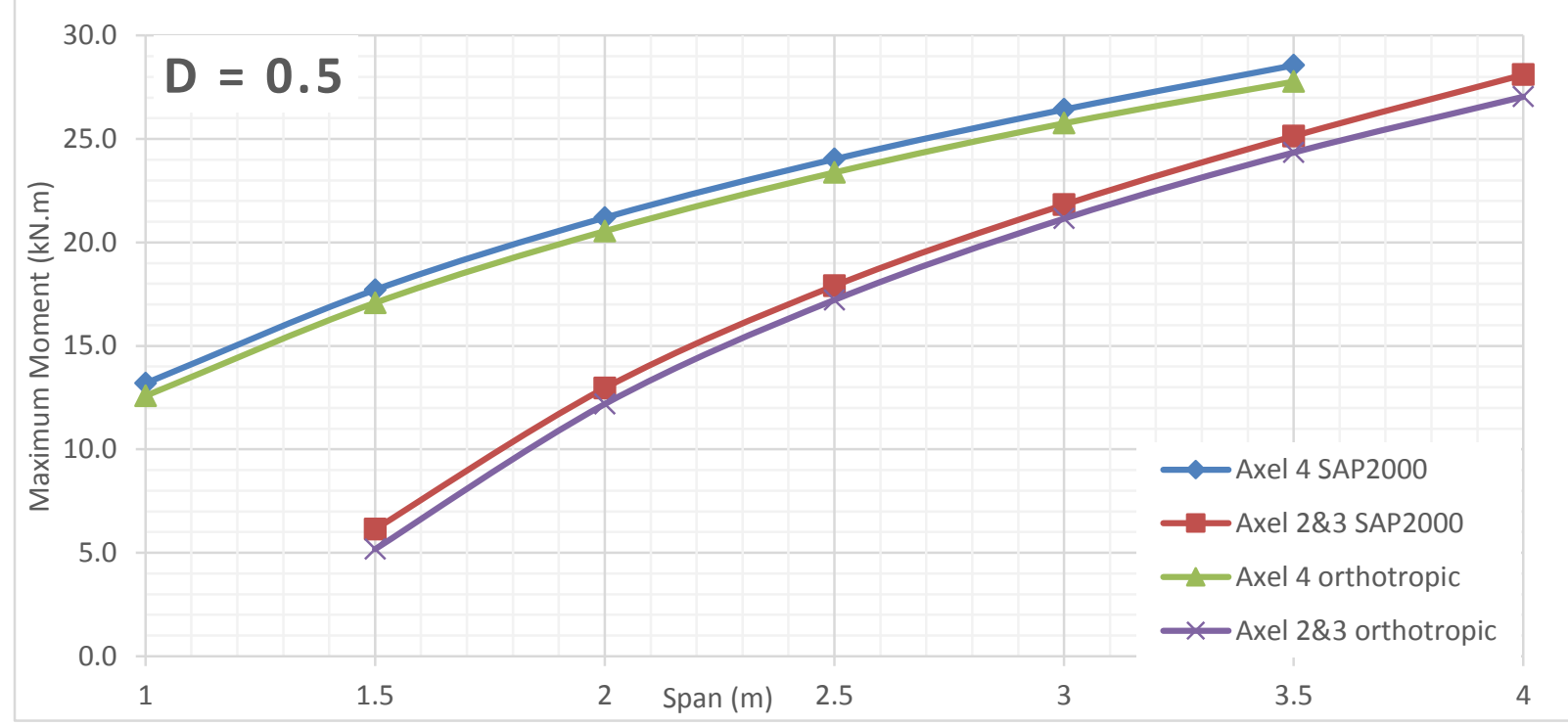

Figure 611 Moment comparison between FEA and Orthotropic Plate Theory for $D=0.5$ of alpha 6 (main bars parallel traffic) 


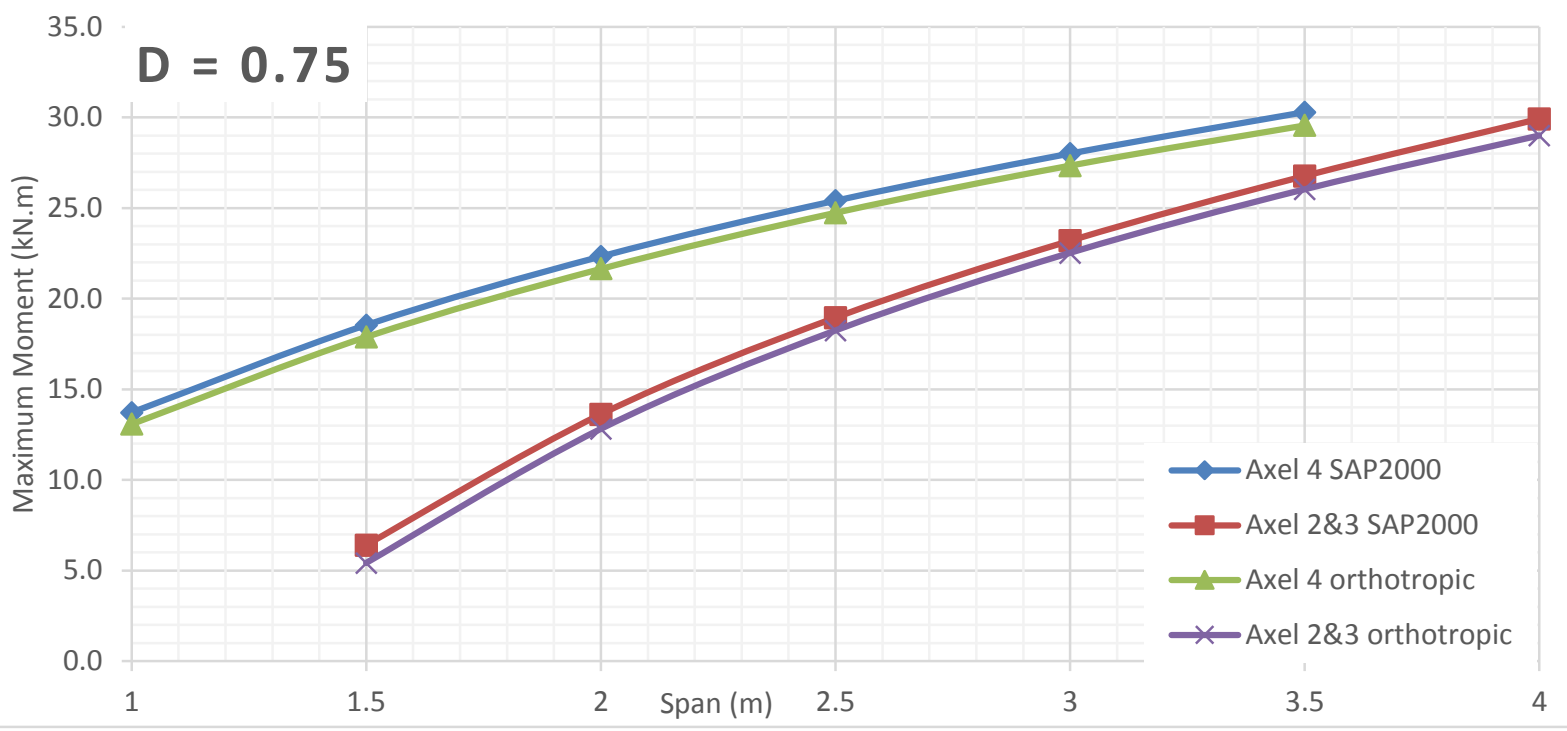

Figure 612 Moment comparison between FEA and Orthotropic Plate Theory for $D=0.75$ of alpha 6 (main bars parallel traffic)

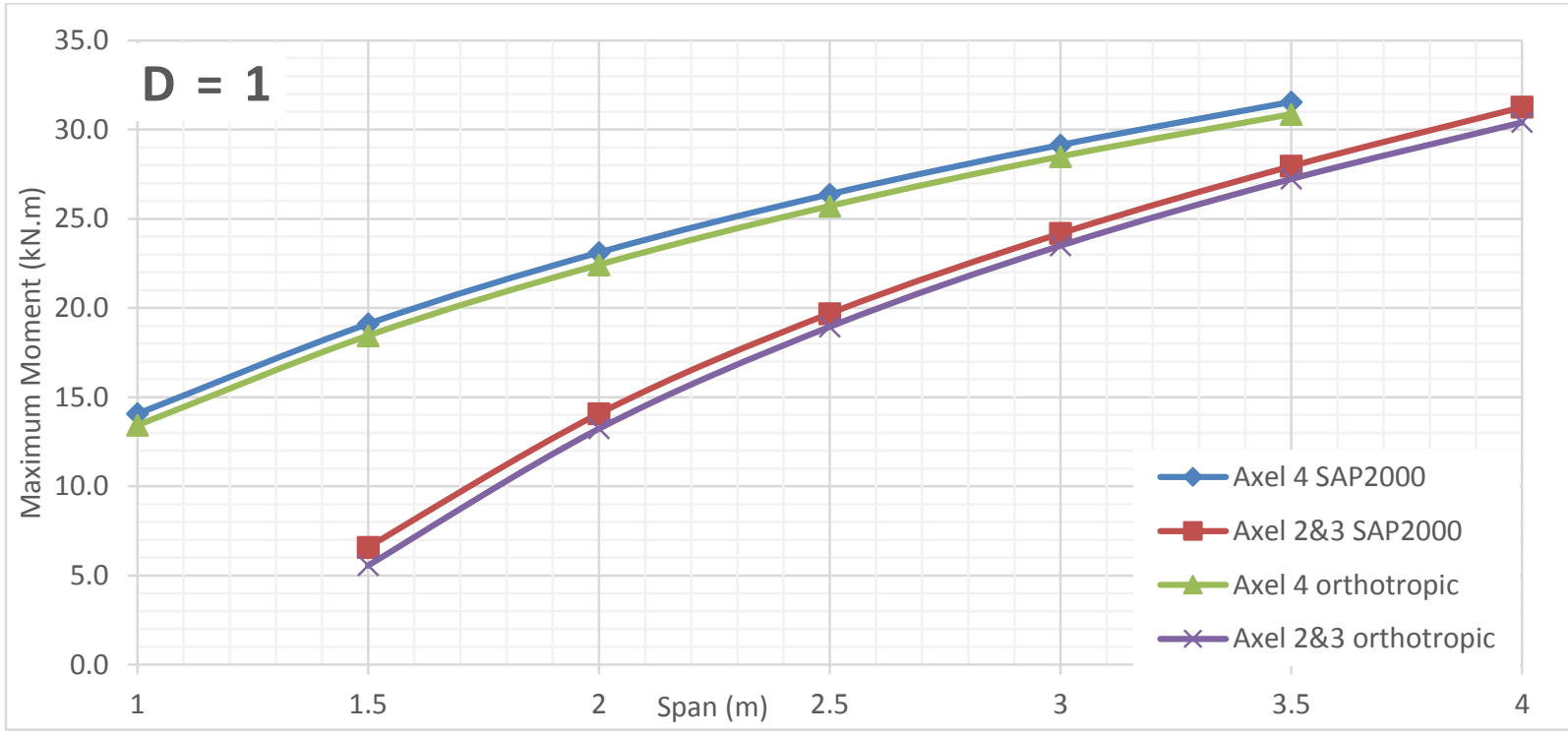

Figure 613 Moment comparison between FEA and Orthotropic Plate Theory for $D=1$ of alpha 6 (main bars parallel traffic)

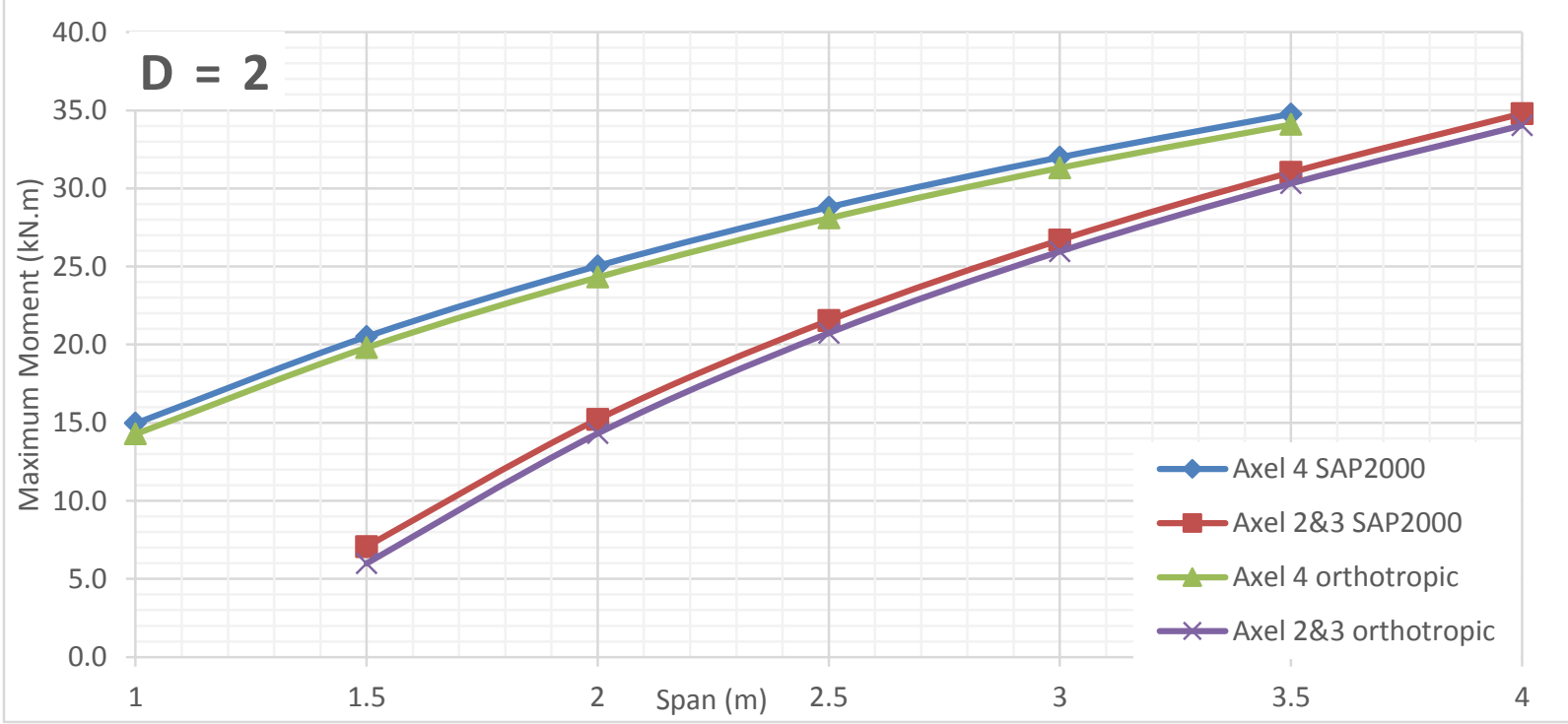

Figure 614 Moment comparison between FEA and Orthotropic Plate Theory for $D=2$ of alpha 6 (main bars parallel traffic) 


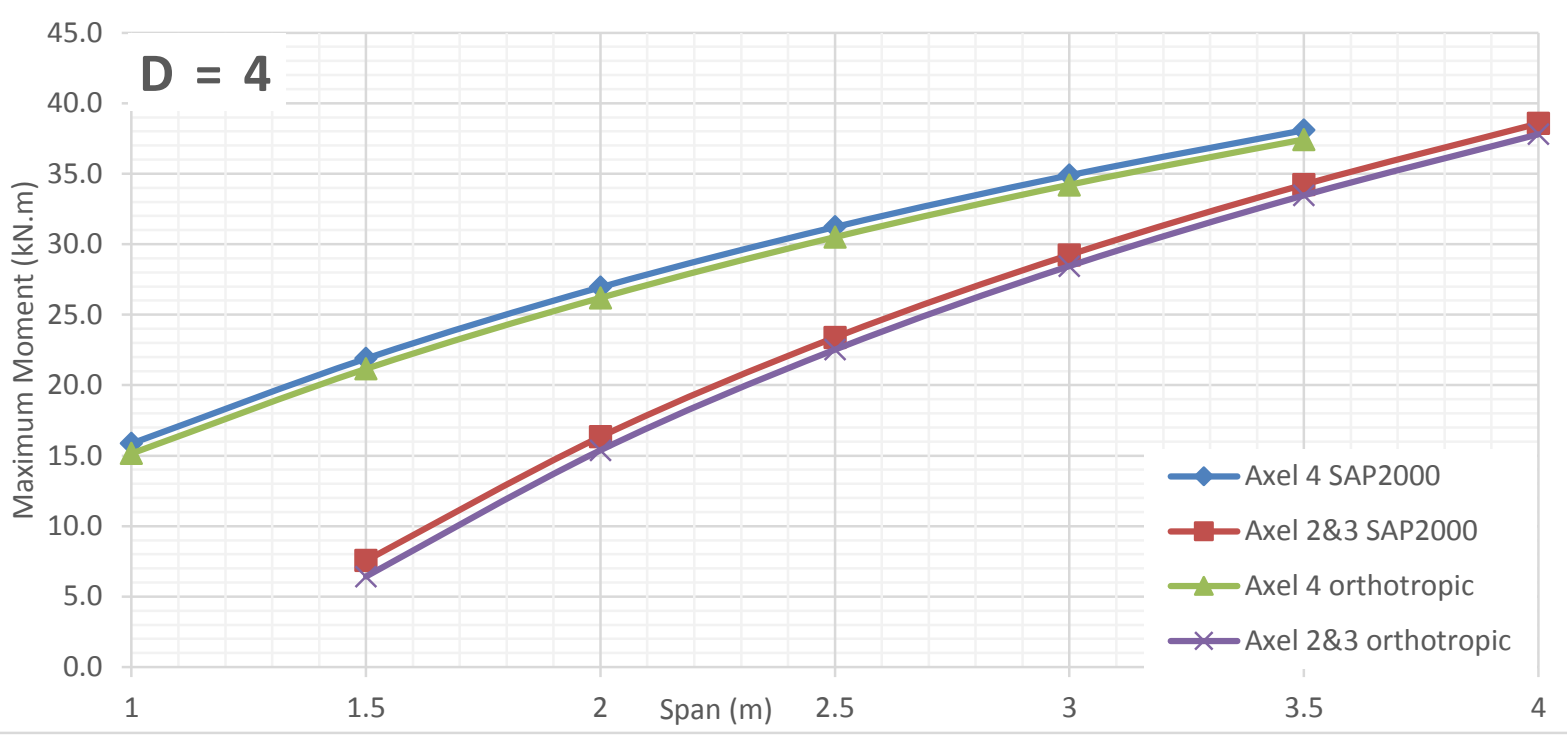

Figure 615 Moment comparison between FEA and Orthotropic Plate Theory for D $=4$ of alpha 6 (main bars parallel traffic)

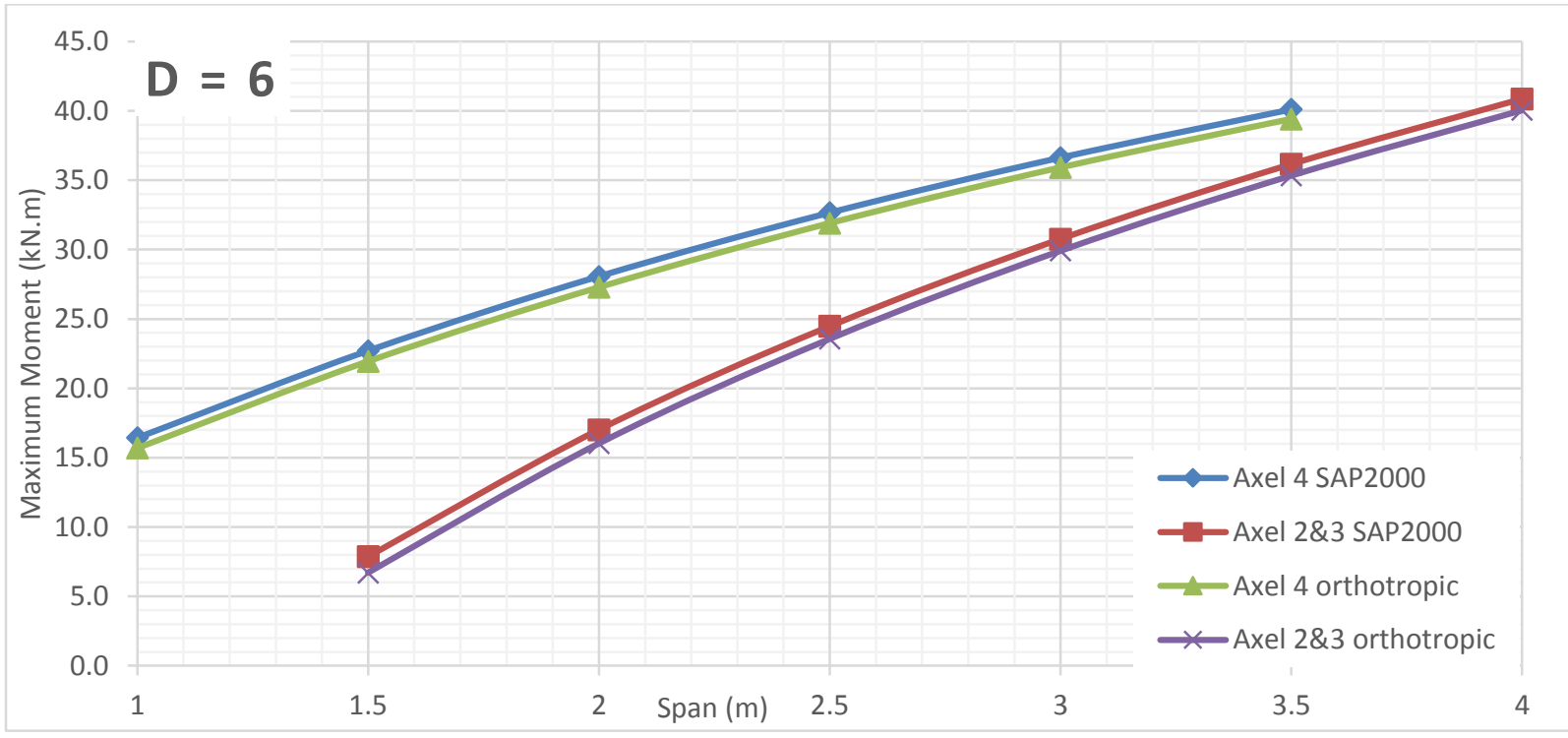

Figure 616 Moment comparison between FEA and Orthotropic Plate Theory for D $=6$ of alpha 6 (main bars parallel traffic)

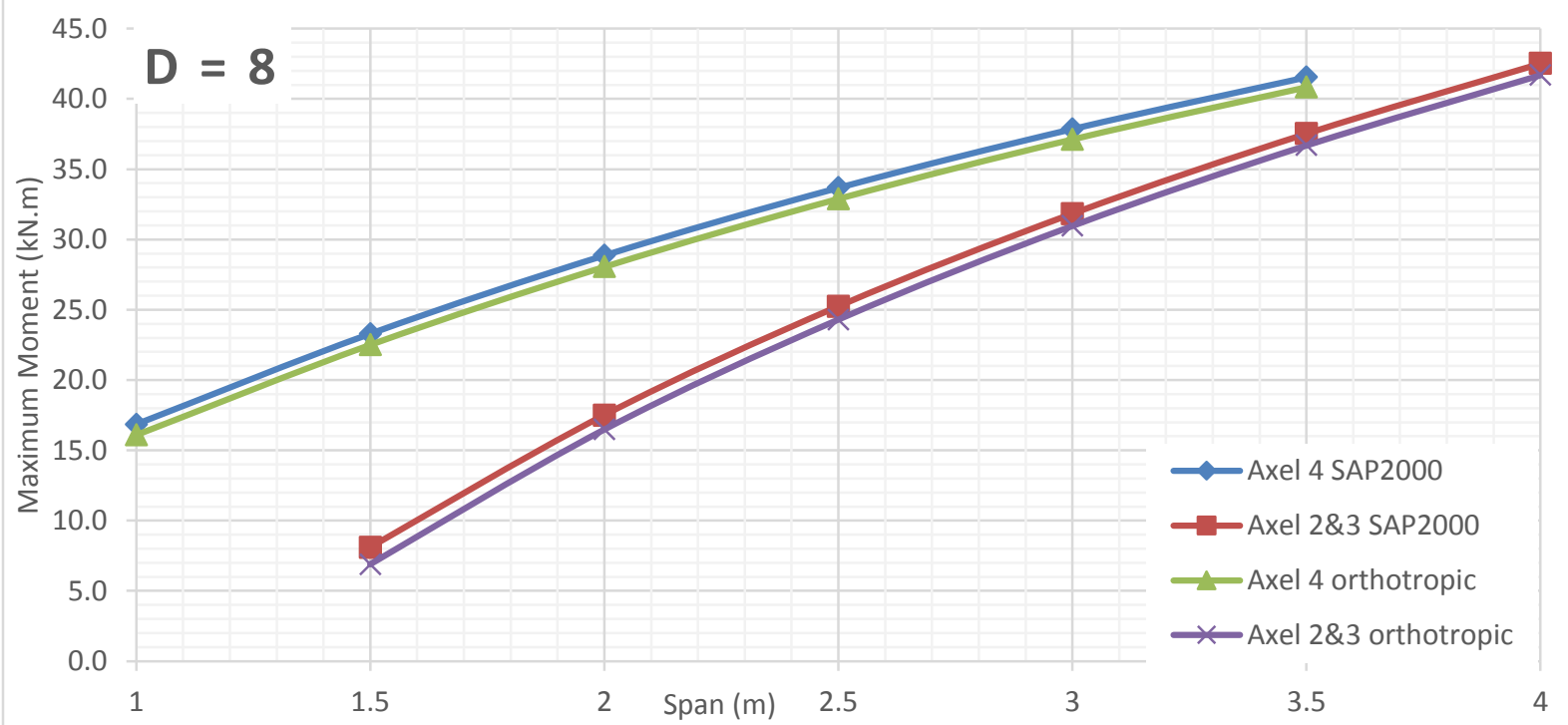

Figure 617 Moment comparison between FEA and Orthotropic Plate Theory for $D=8$ of alpha 6 (main bars parallel traffic) 


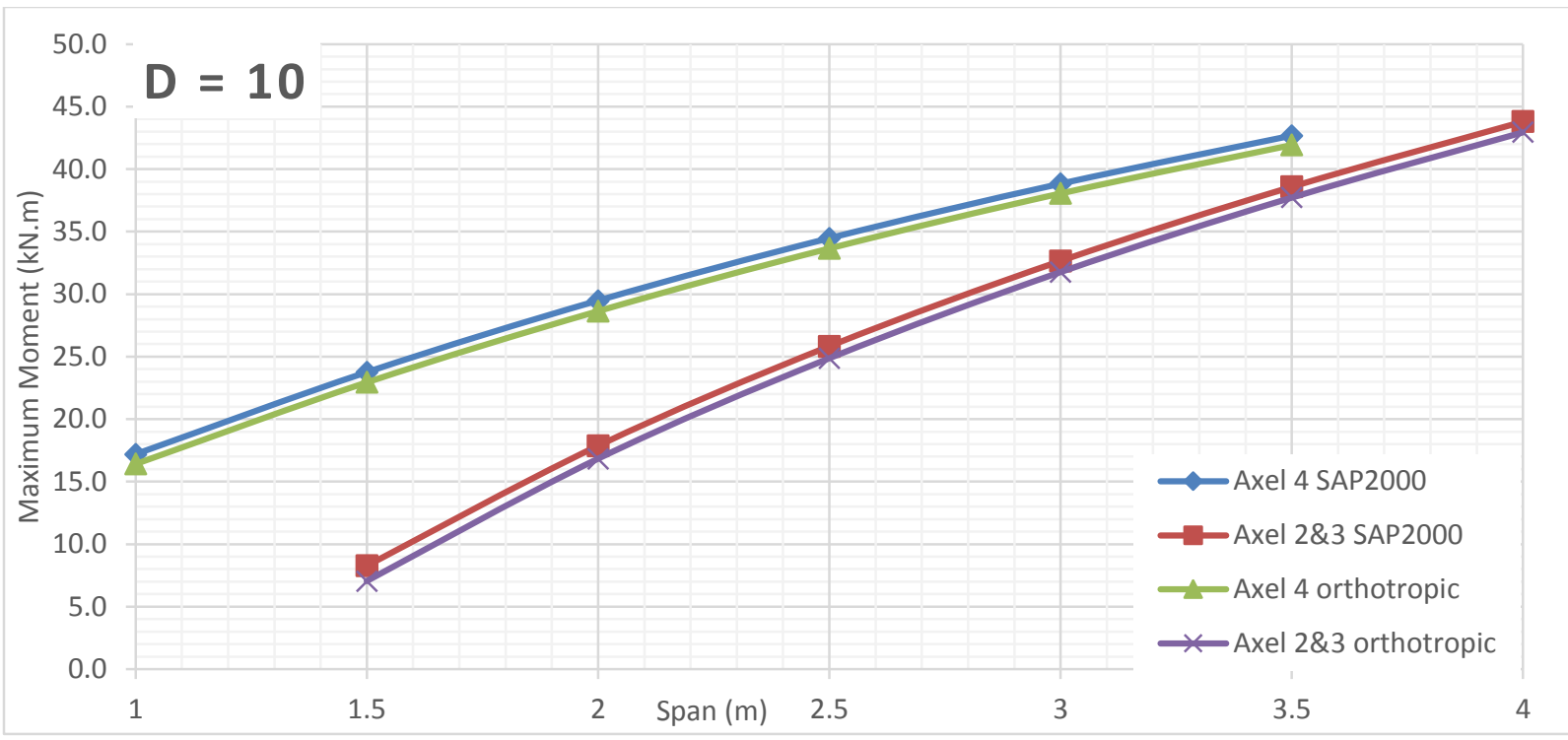

Figure 618 Moment comparison between FEA and Orthotropic Plate Theory for $D=10$ of alpha 6 (main bars parallel traffic) 


\section{Alpha 8 Bending Moment VS Span Length for Different D Values (Main bars perpendicular to traffic)}

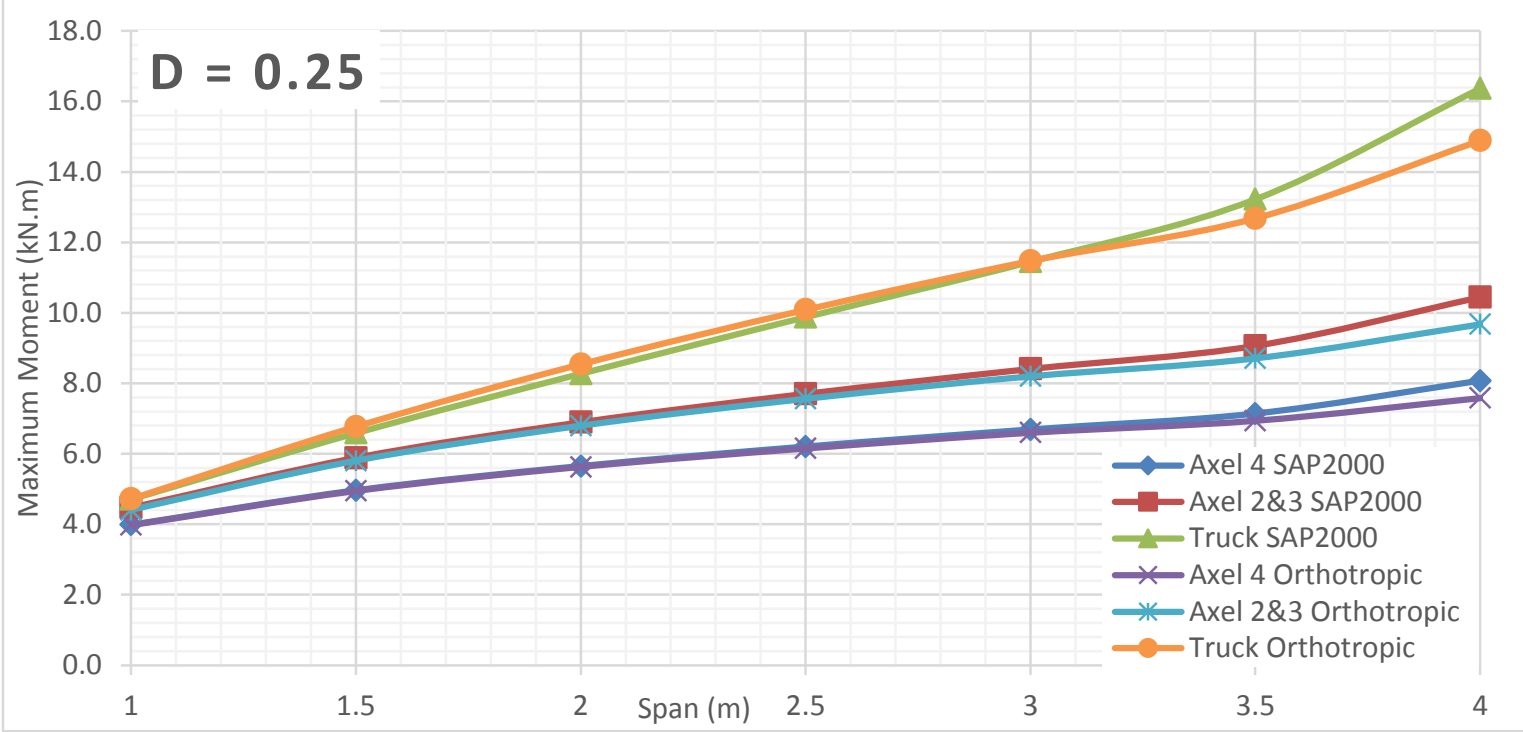

Figure 619 Moment comparison between FEA and Orthotropic Plate Theory for $D=0.25$ of alpha 8 (main bars perpendicular traffic)

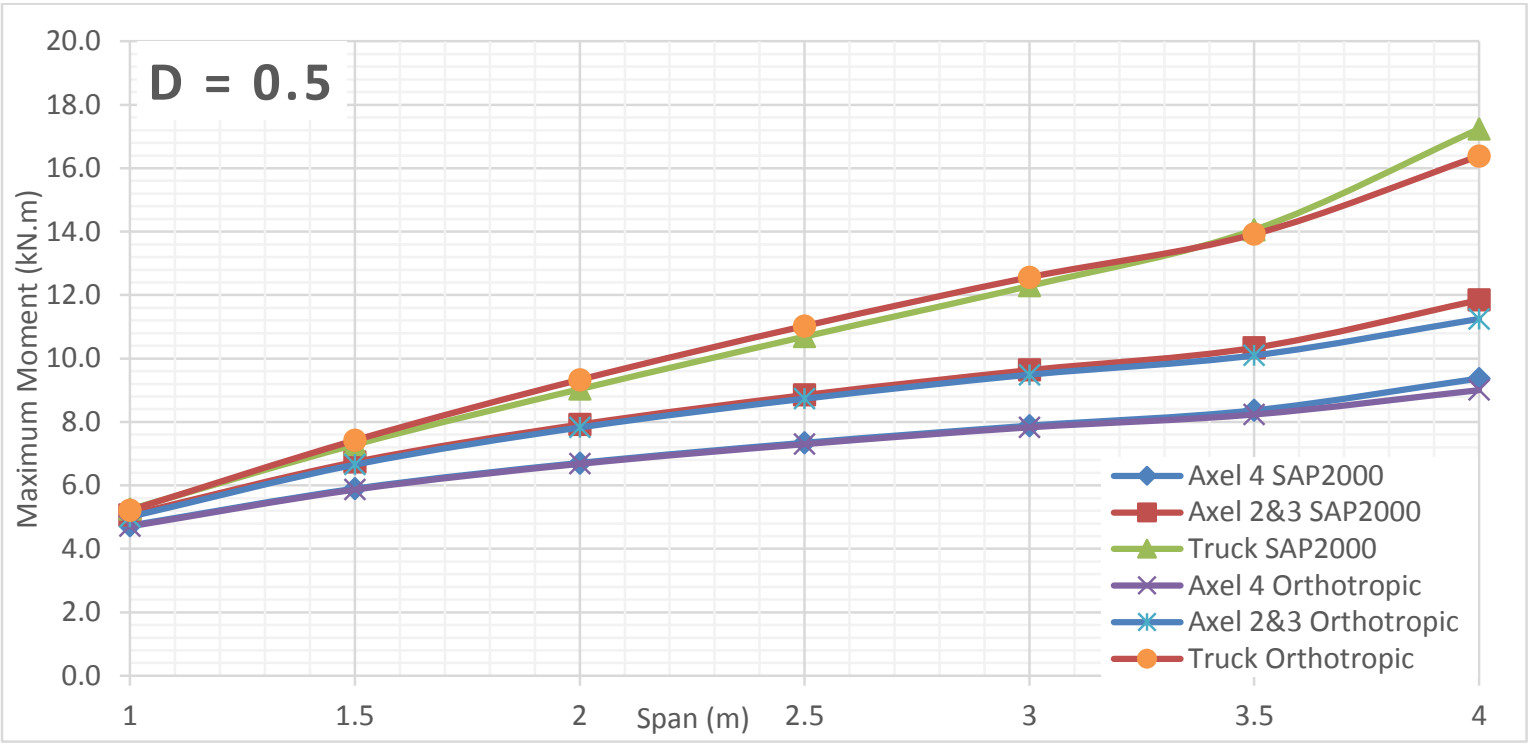

Figure 620 Moment comparison between FEA and Orthotropic Plate Theory for $D=0.5$ of alpha 8 (main bars perpendicular traffic) 


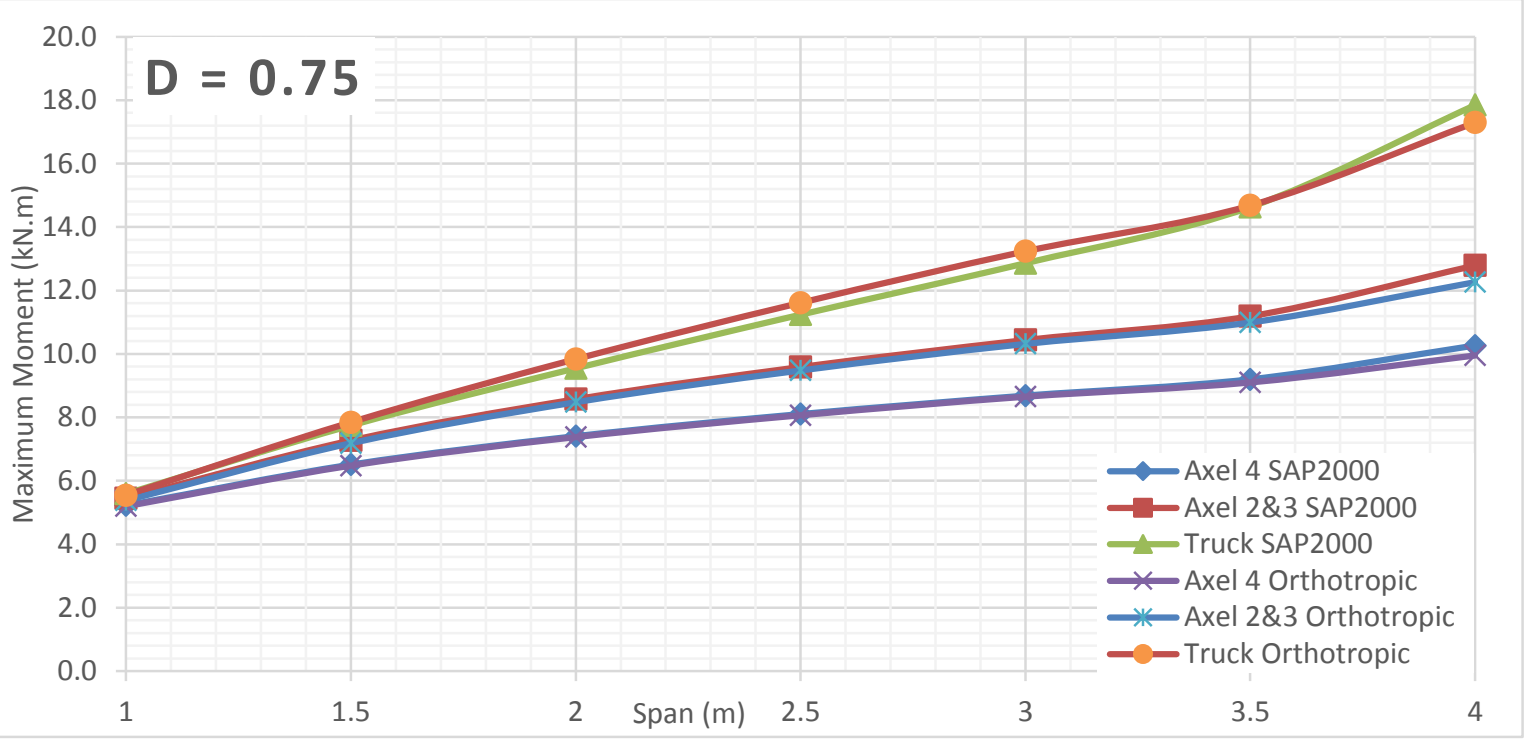

Figure 621 Moment comparison between FEA and Orthotropic Plate Theory for $D=0.75$ of alpha 8 (main bars perpendicular traffic)

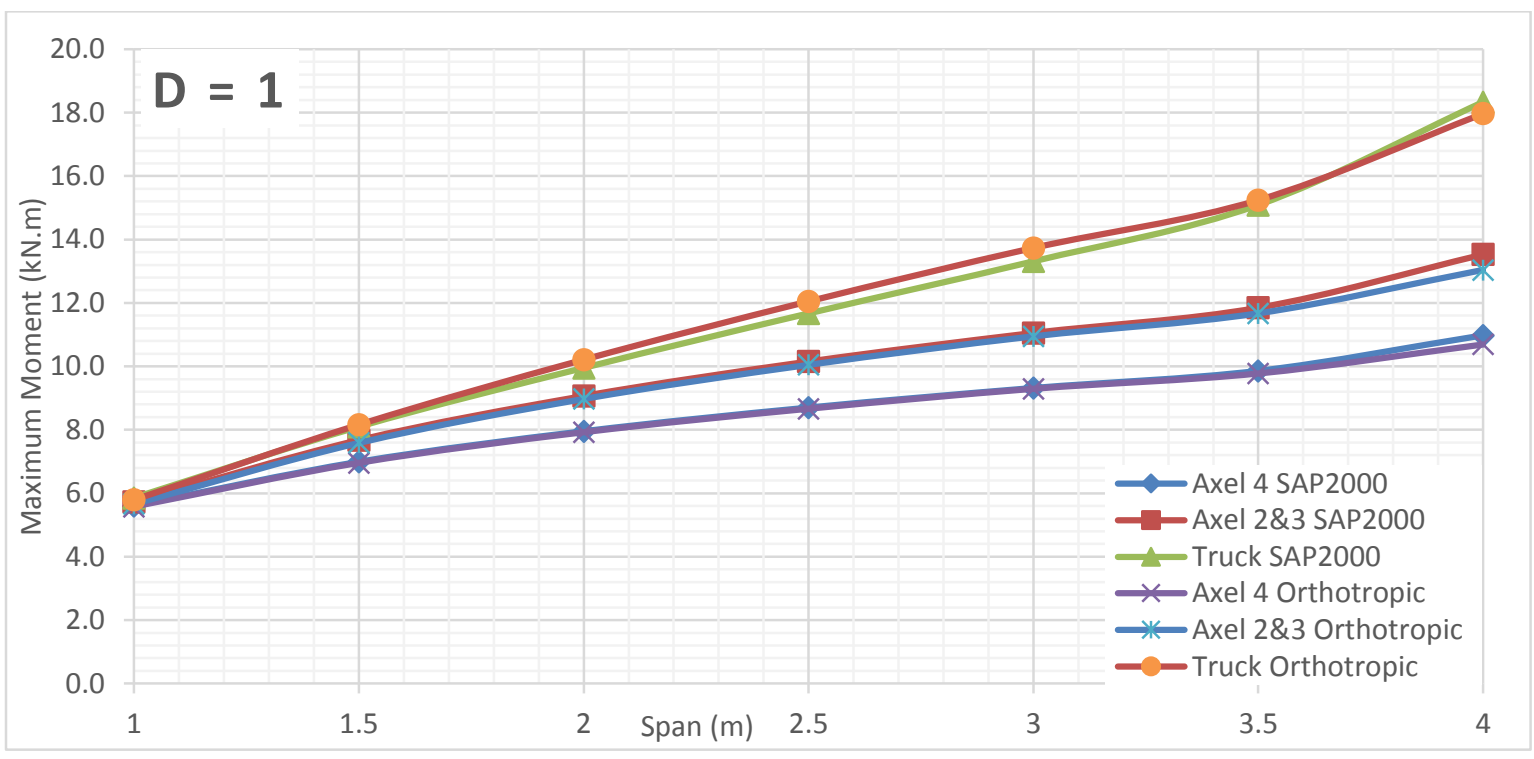

Figure 622 Moment comparison between FEA and Orthotropic Plate Theory for $D=1$ of alpha 8 (main bars perpendicular traffic)

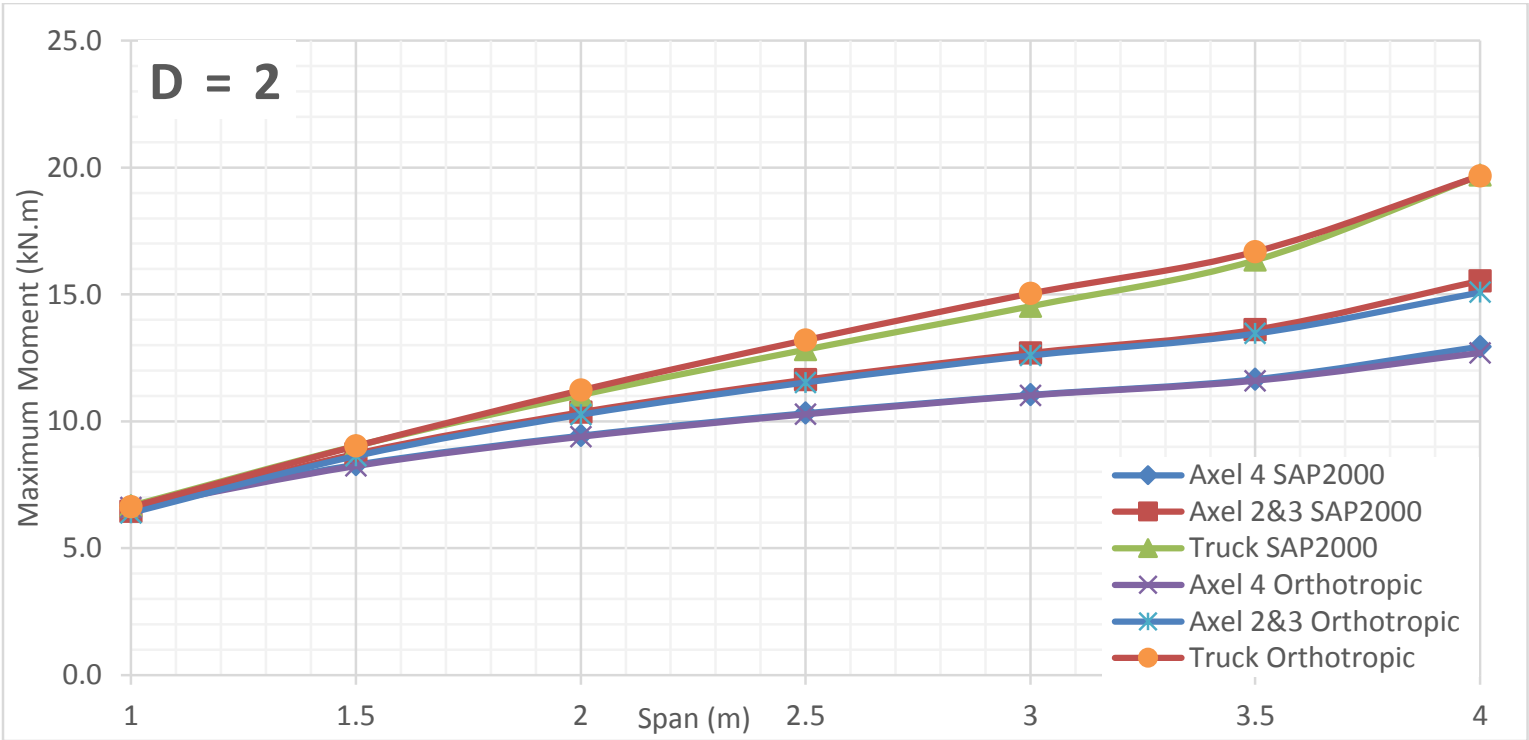

Figure 623 Moment comparison between FEA and Orthotropic Plate Theory for $D=2$ of alpha 8 (main bars perpendicular traffic) 


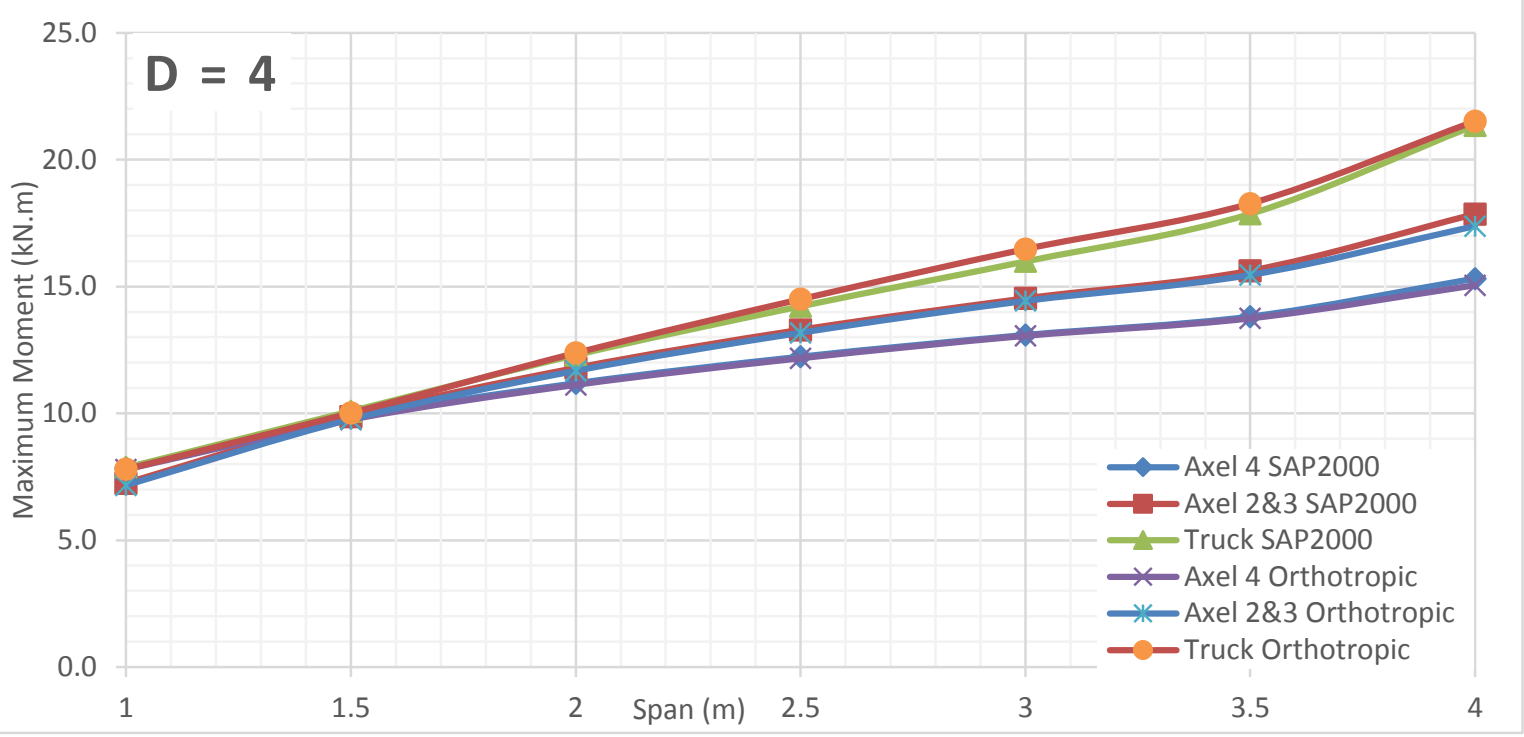

Figure 624 Moment comparison between FEA and Orthotropic Plate Theory for $D=4$ of alpha 8 (main bars perpendicular traffic)

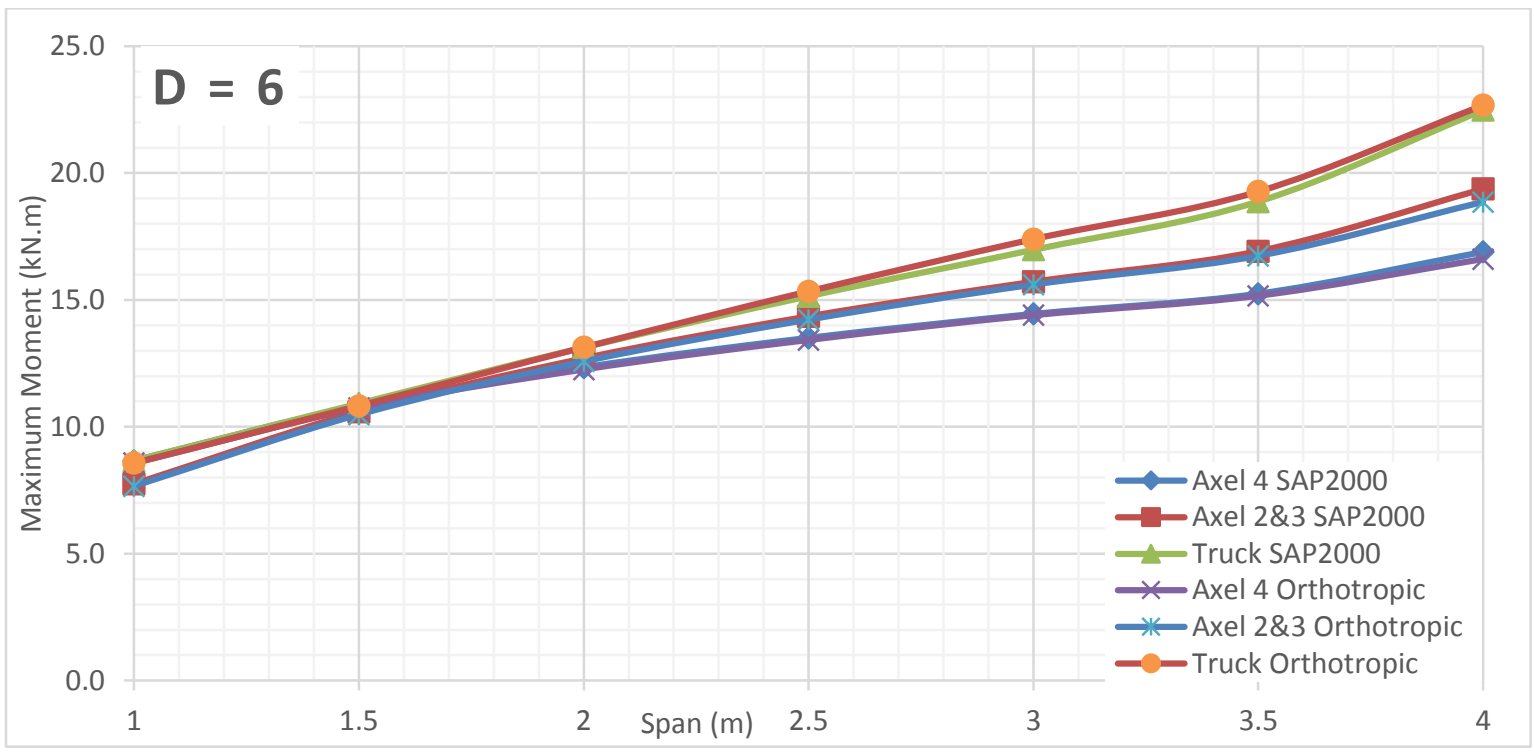

Figure 625 Moment comparison between FEA and Orthotropic Plate Theory for $D=6$ of alpha 8 (main bars perpendicular traffic)

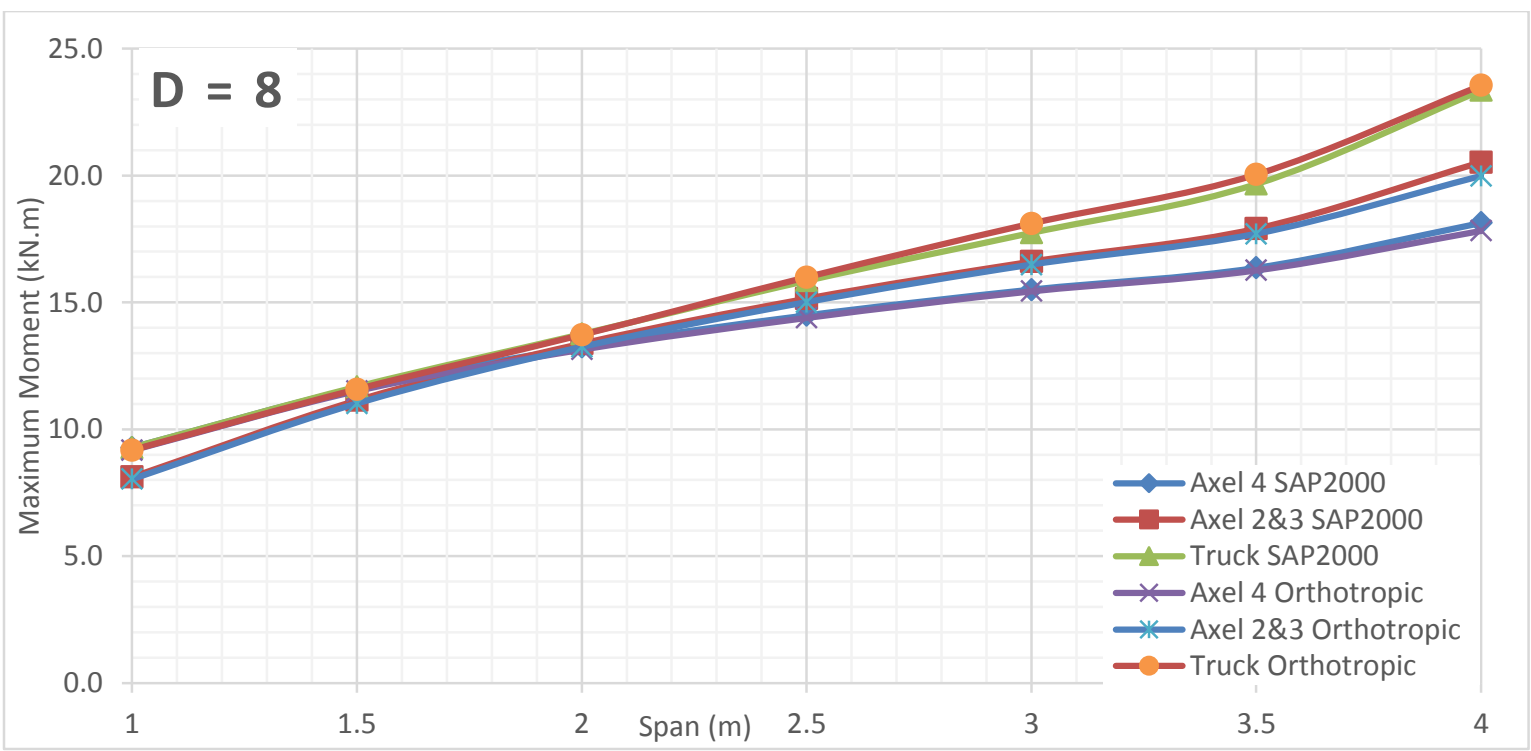

Figure 626 Moment comparison between FEA and Orthotropic Plate Theory for $D=8$ of alpha 8 (main bars perpendicular traffic) 


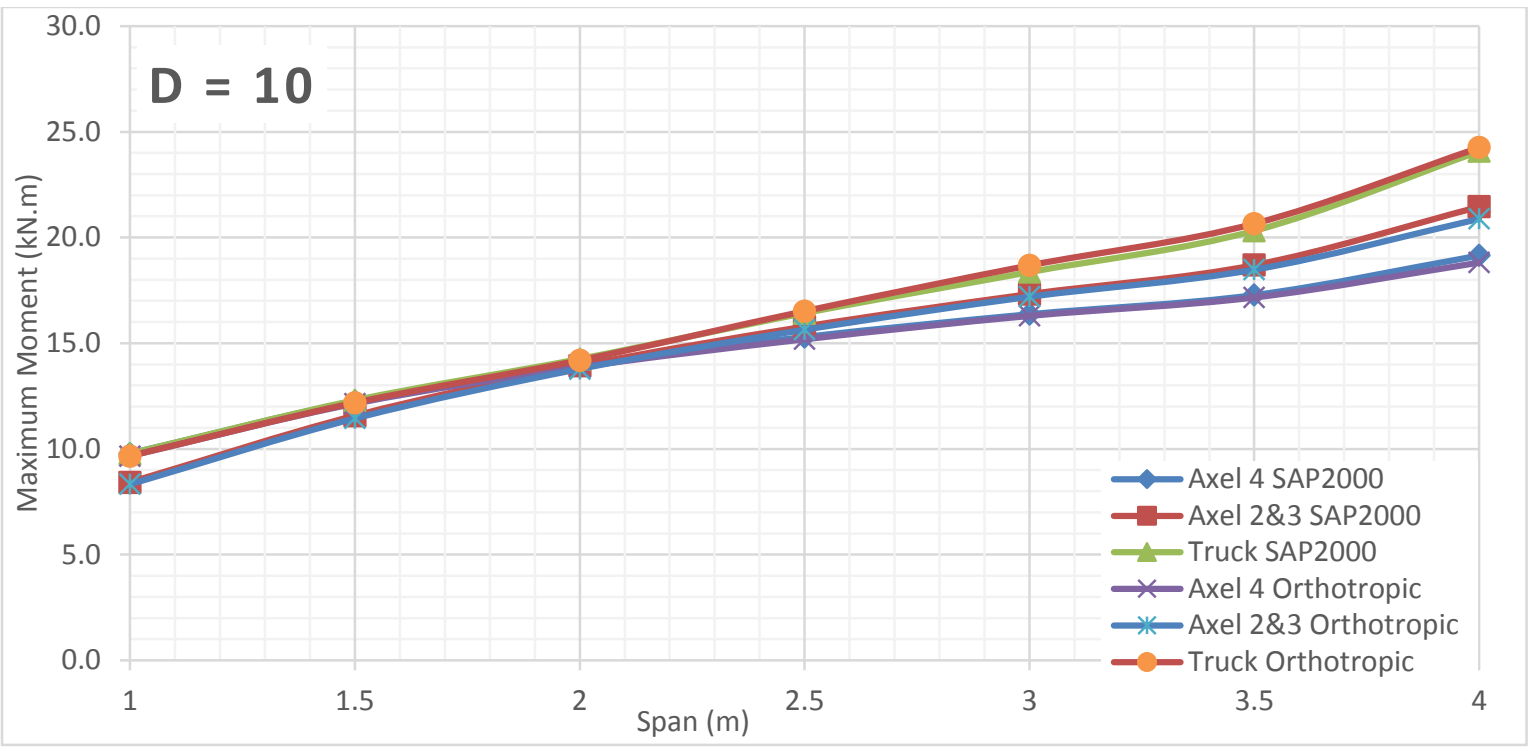

Figure 627 Moment comparison between FEA and Orthotropic Plate Theory for $D=10$ of alpha 8 (main bars perpendicular traffic) 


\section{Alpha 8 Bending Moment VS Span Length for Different D Values (Main bars parallel to traffic)}

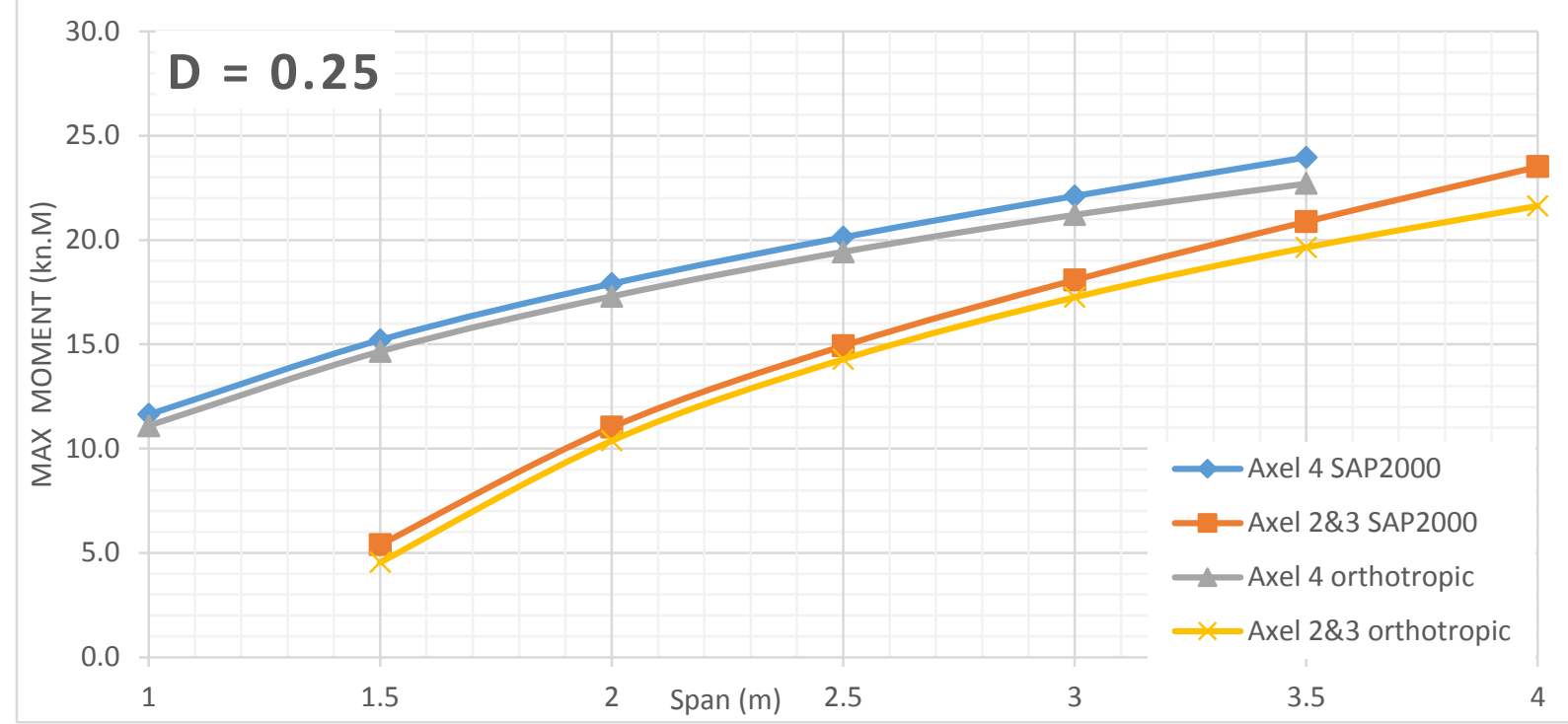

Figure 628 Moment comparison between FEA and Orthotropic Plate Theory for $D=0.25$ of alpha 8 (main bars parallel traffic)

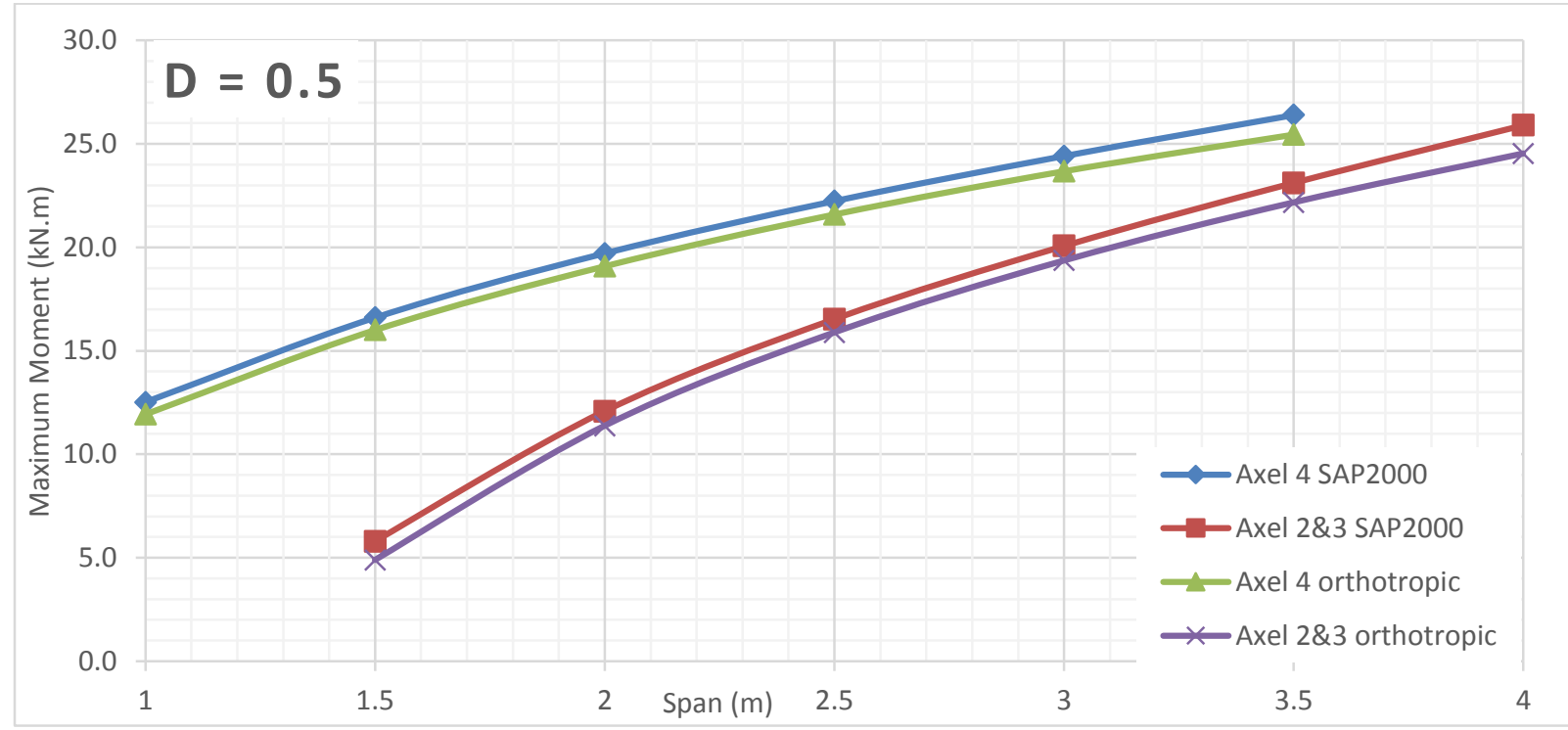

Figure 629 Moment comparison between FEA and Orthotropic Plate Theory for D $=0.5$ of alpha 8 (main bars parallel traffic) 


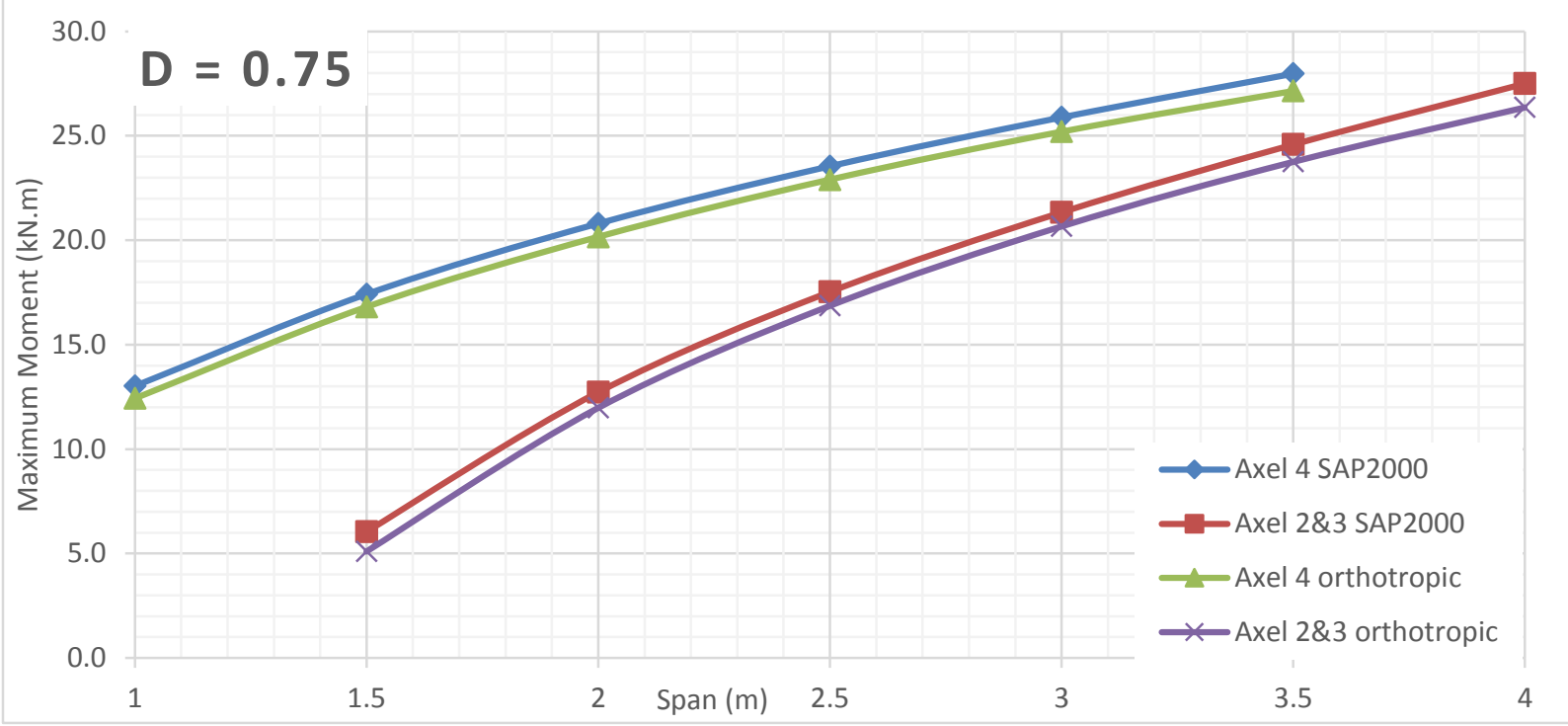

Figure 630 Moment comparison between FEA and Orthotropic Plate Theory for $D=0.75$ of alpha 8 (main bars parallel traffic)

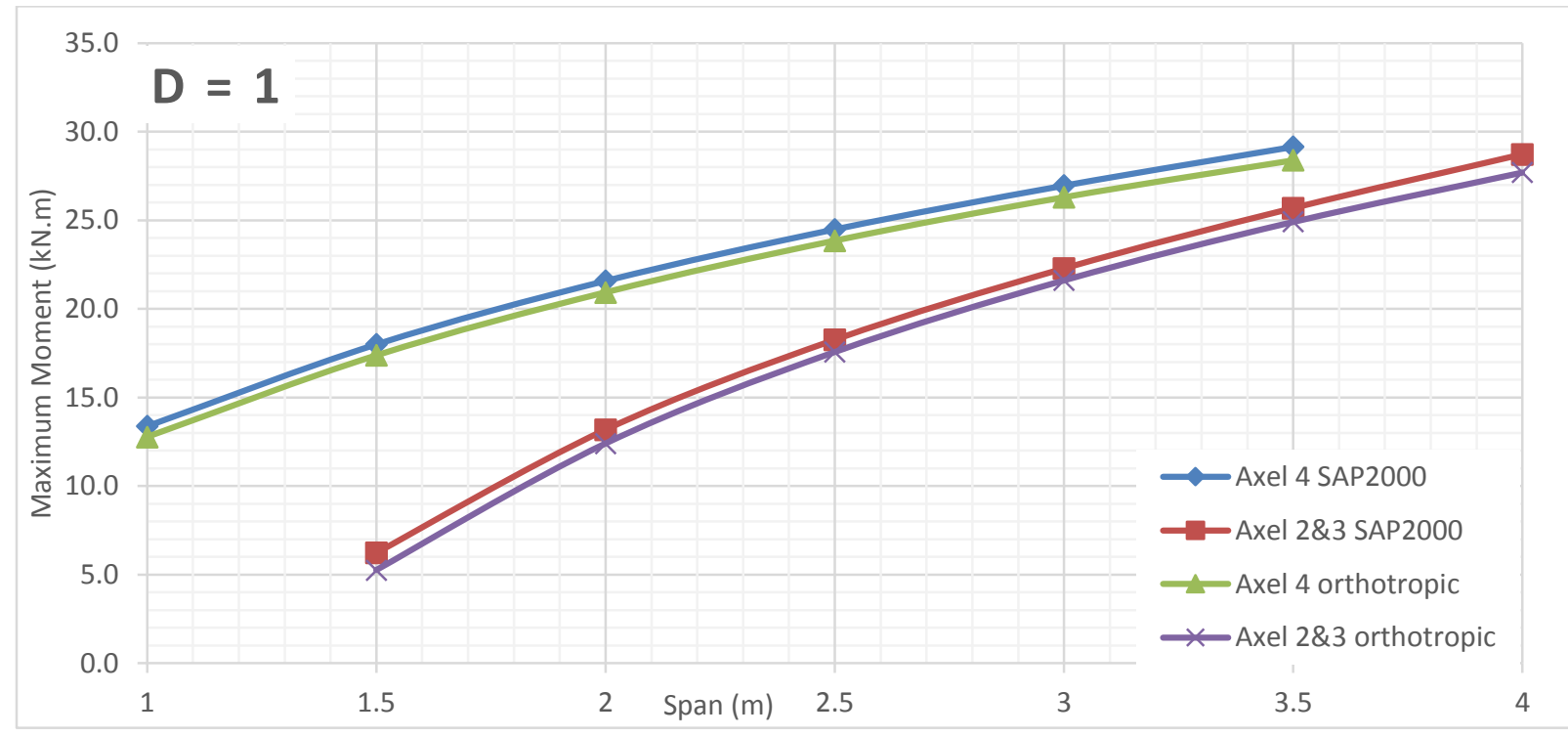

Figure 631 Moment comparison between FEA and Orthotropic Plate Theory for D = 1 of alpha 8 (main bars parallel traffic)

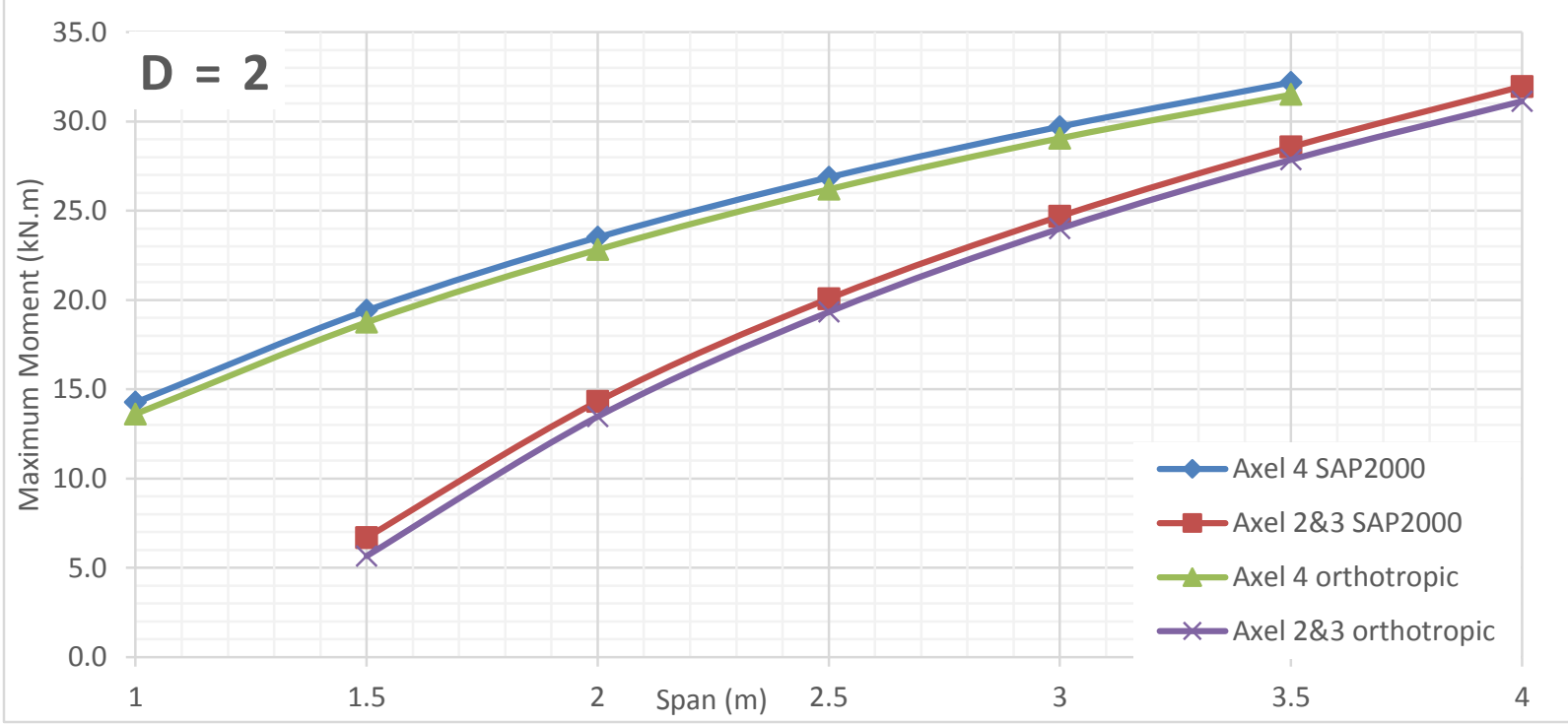

Figure 632 Moment comparison between FEA and Orthotropic Plate Theory for $D=2$ of alpha 8 (main bars parallel traffic) 


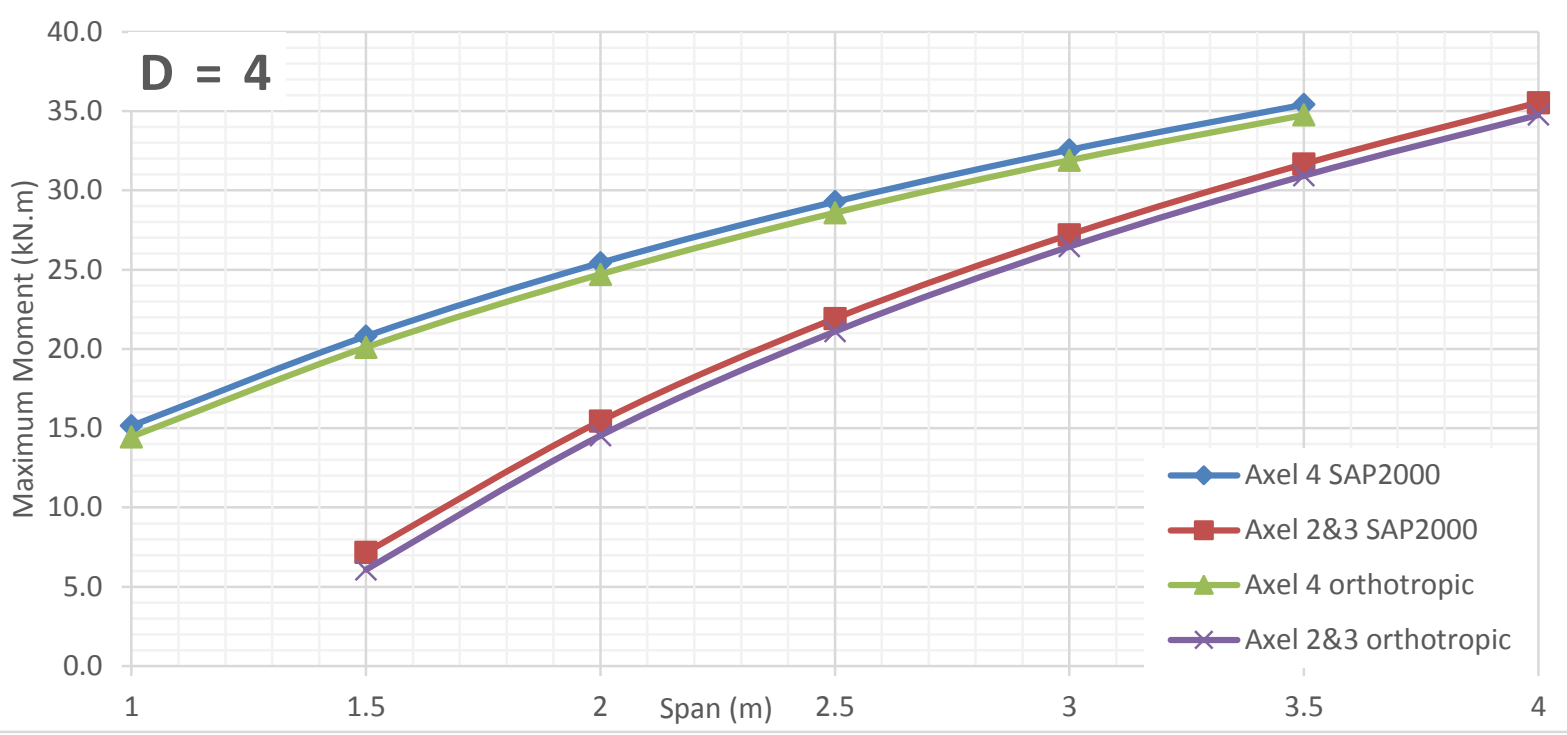

Figure 633 Moment comparison between FEA and Orthotropic Plate Theory for D $=4$ of alpha 8 (main bars parallel traffic)

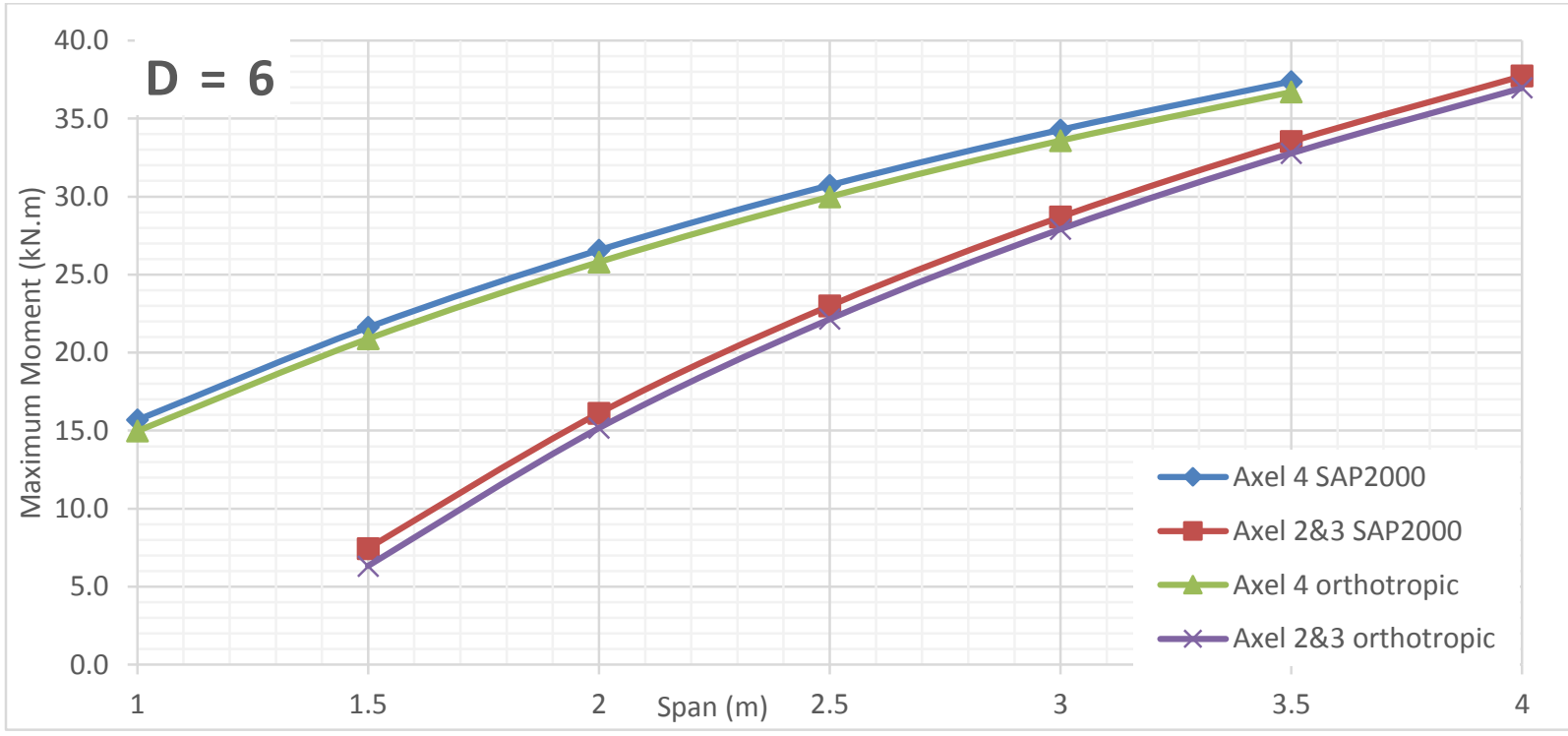

Figure 634 Moment comparison between FEA and Orthotropic Plate Theory for D $=6$ of alpha 8 (main bars parallel traffic)

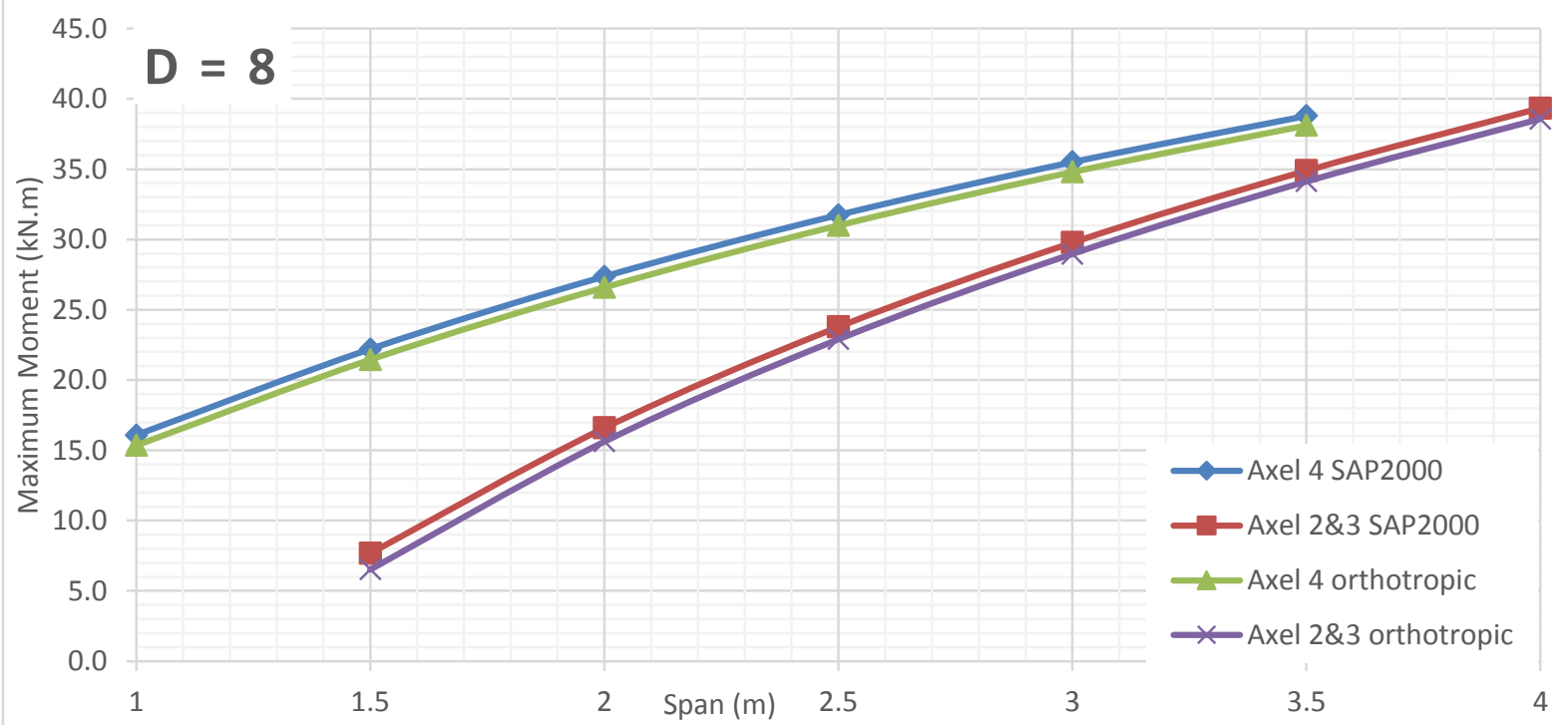

Figure 635 Moment comparison between FEA and Orthotropic Plate Theory for $D=8$ of alpha 8 (main bars parallel traffic) 


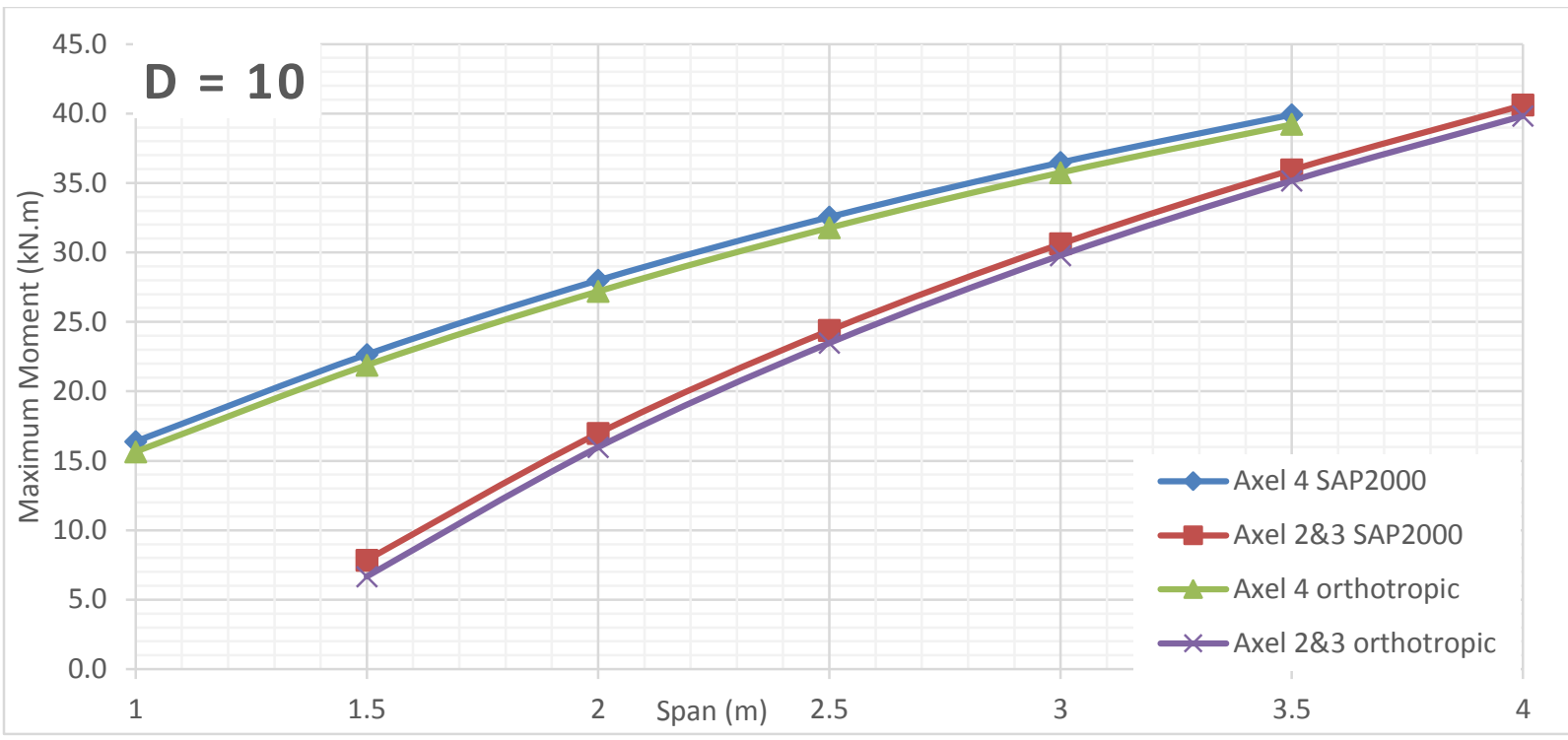

Figure 636 Moment comparison between FEA and Orthotropic Plate Theory for D $=10$ of alpha 8 (main bars parallel traffic) 


\section{Alpha 10 Bending Moment VS Span Length for Different D Values (Main bars perpendicular to traffic)}

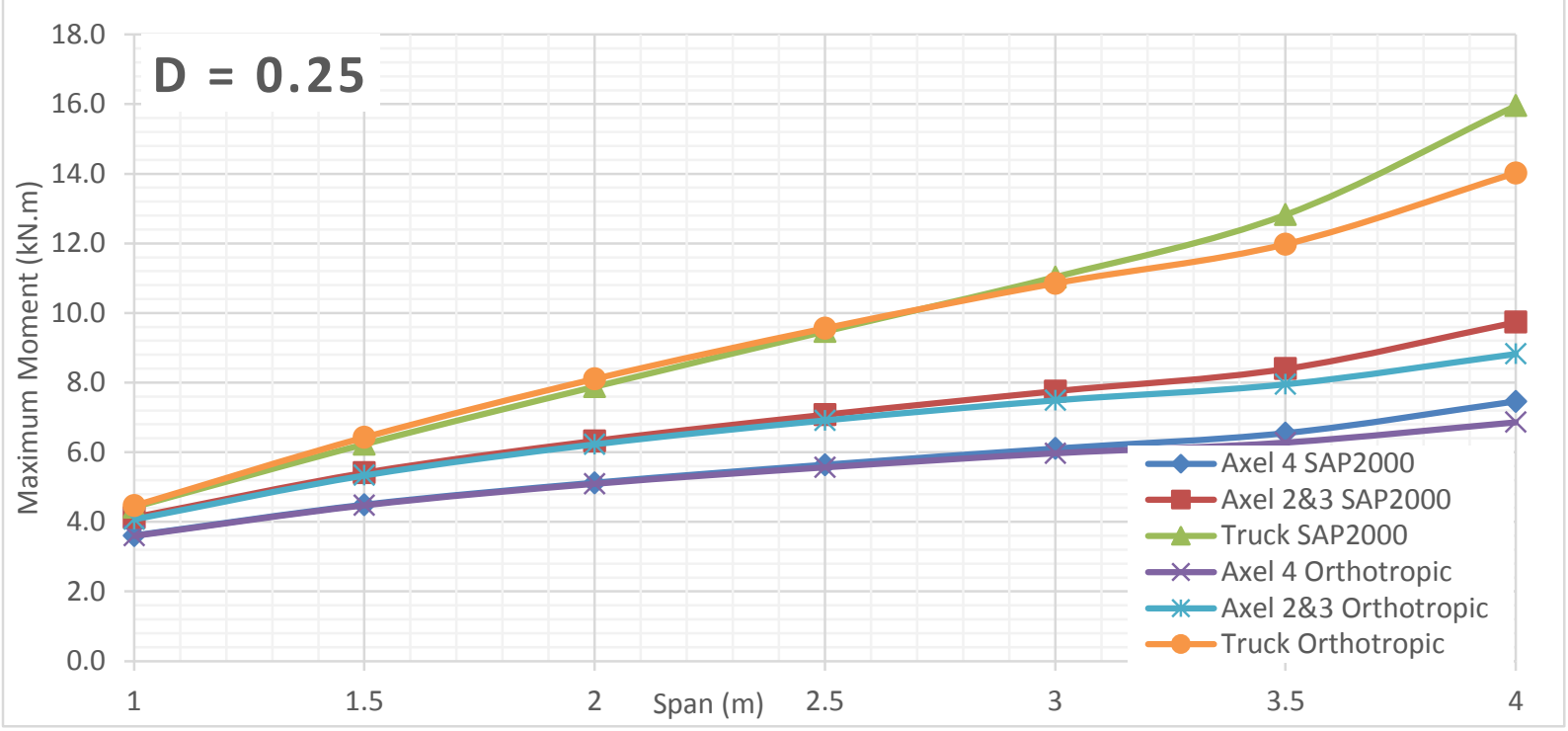

Figure 637 Moment comparison between FEA and Orthotropic Plate Theory for D $=0.25$ of alpha 10 (main bars perpendicular traffic)

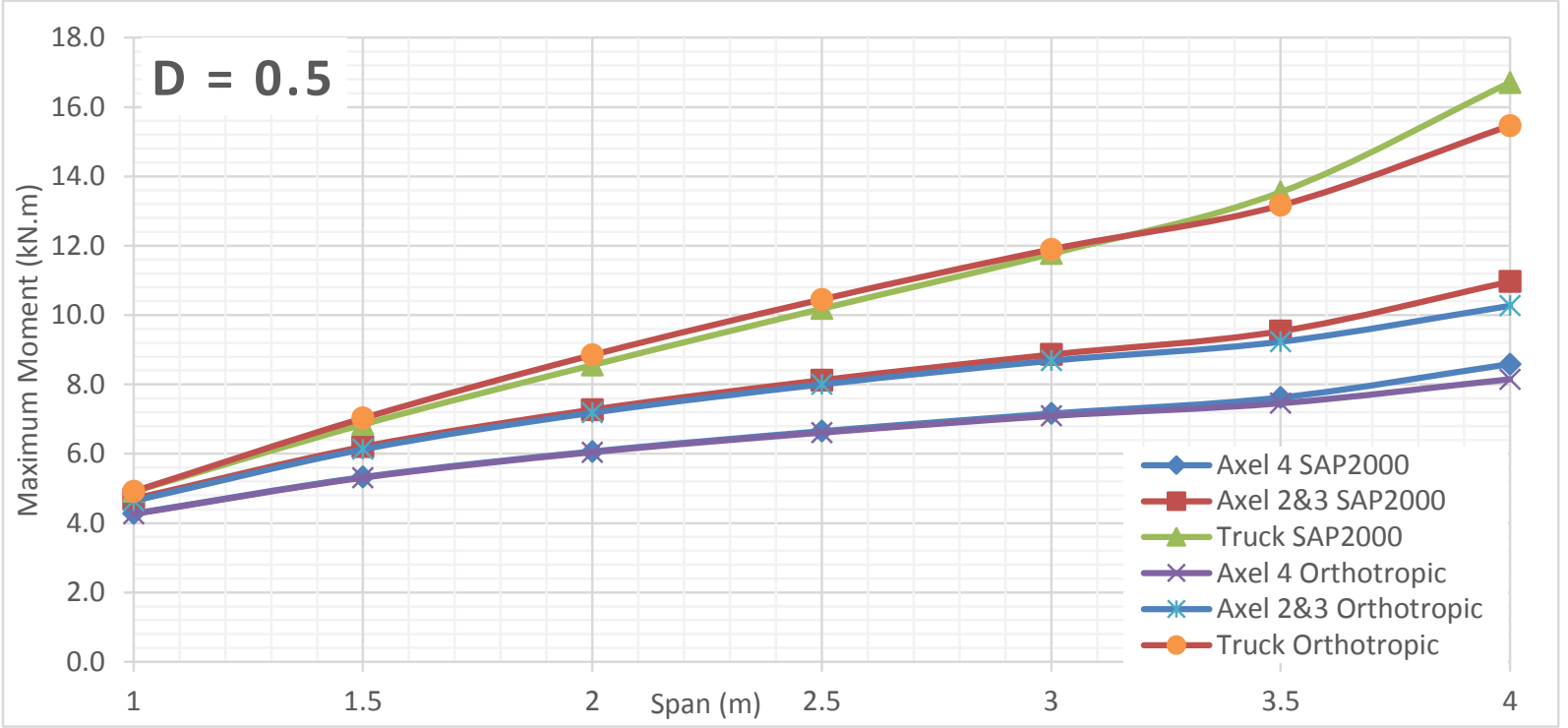

Figure 638 Moment comparison between FEA and Orthotropic Plate Theory for $D=0.5$ of alpha 10 (main bars perpendicular traffic) 


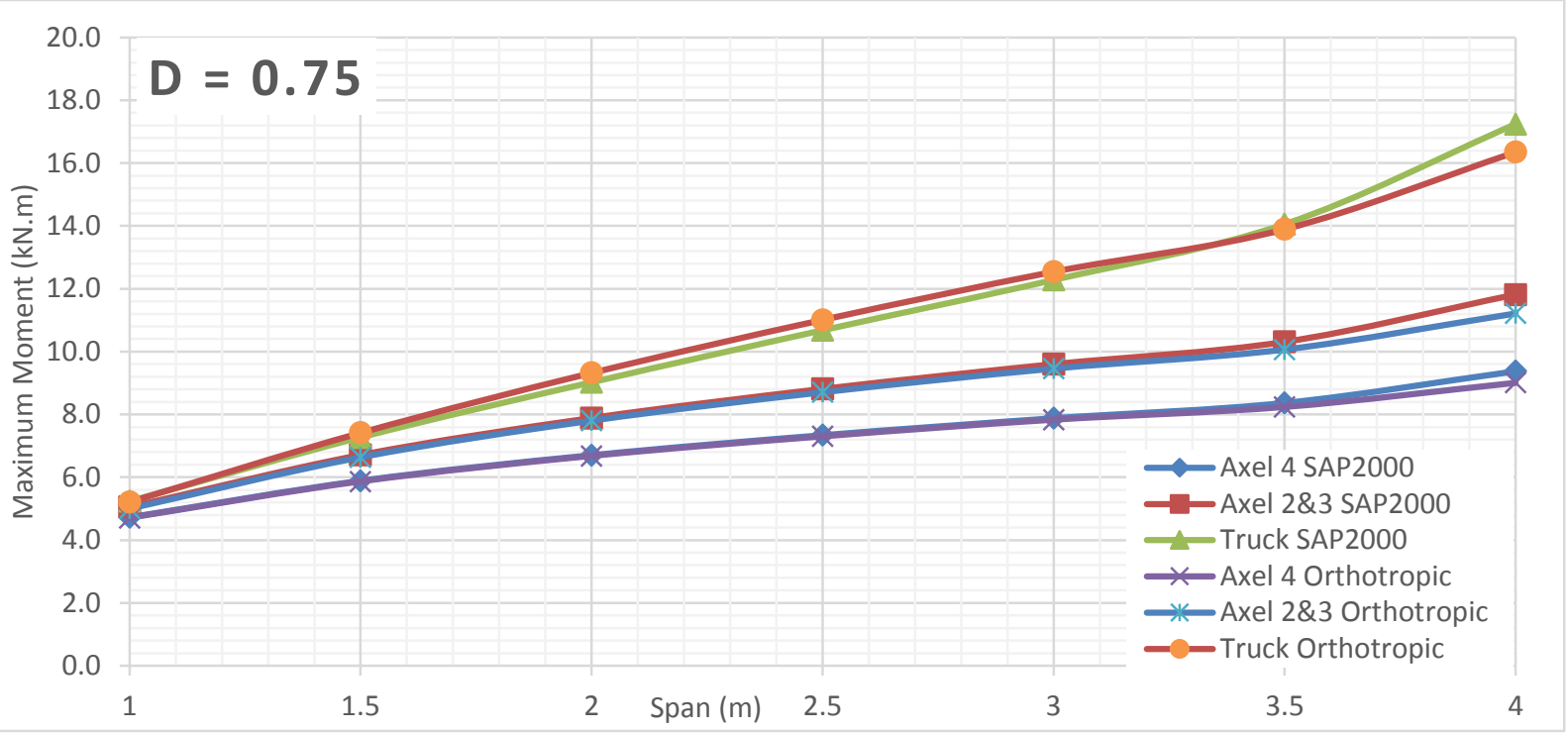

Figure 639 Moment comparison between FEA and Orthotropic Plate Theory for $D=0.75$ of alpha 10 (main bars perpendicular traffic)

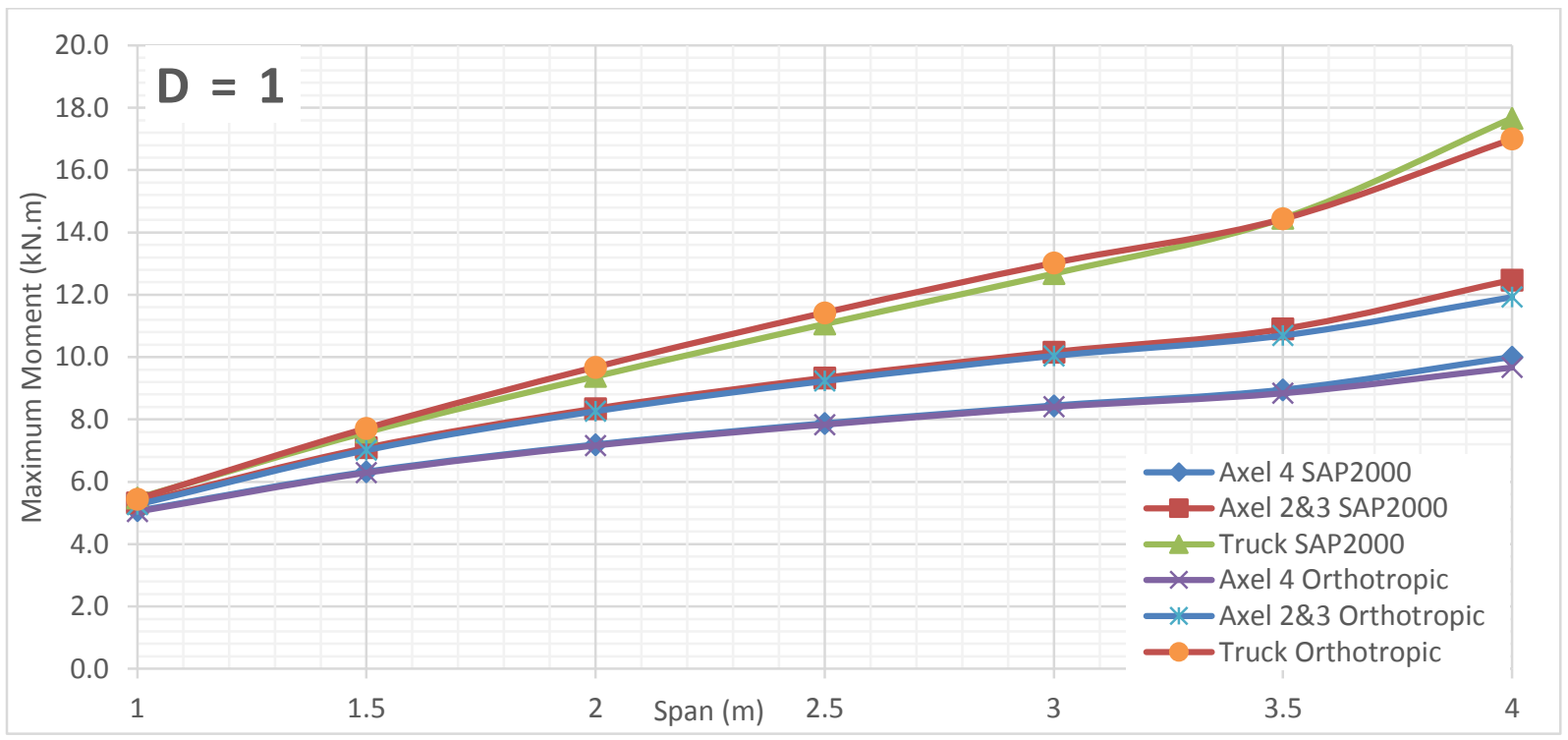

Figure 640 Moment comparison between FEA and Orthotropic Plate Theory for $D=1$ of alpha 10 (main bars perpendicular traffic)

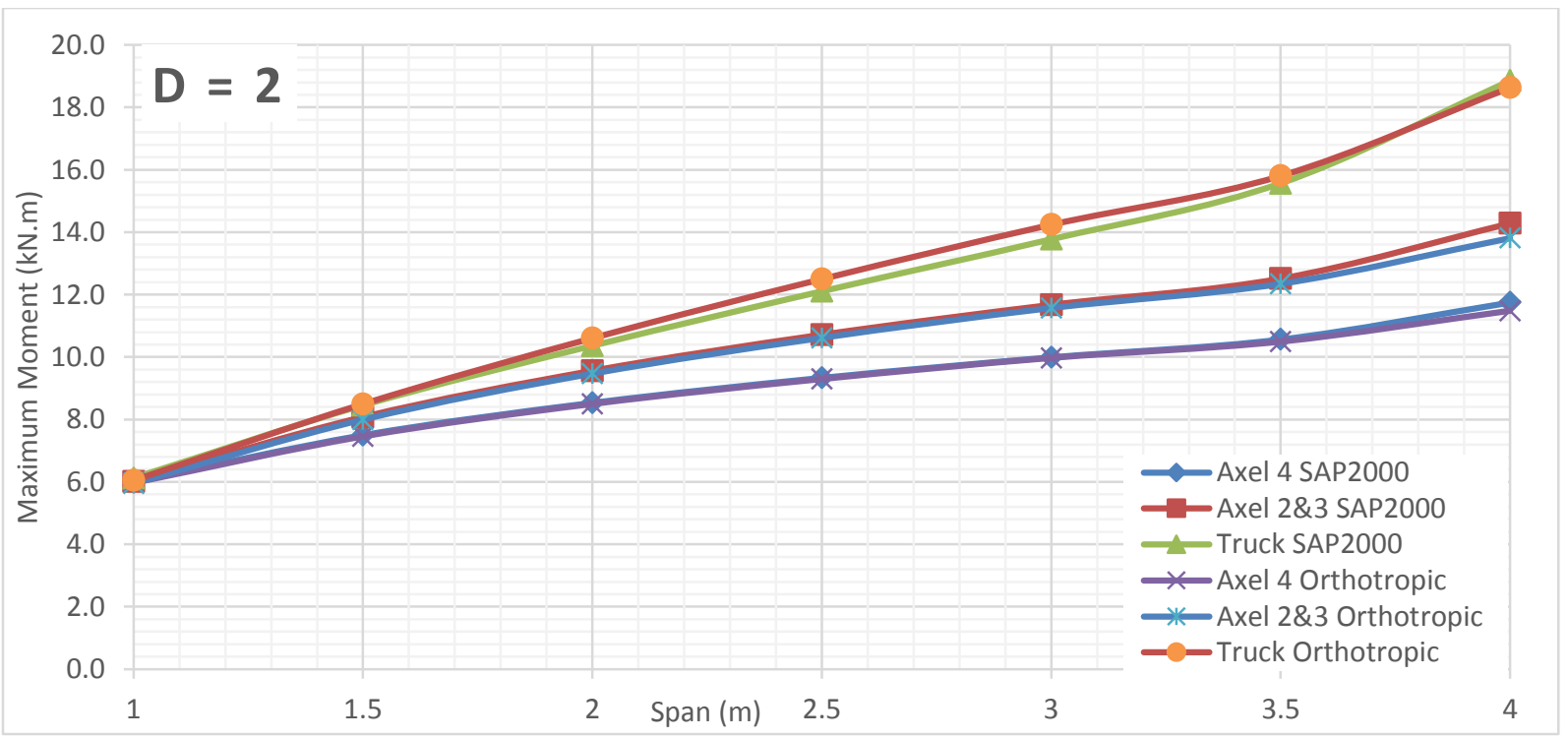

Figure 641 Moment comparison between FEA and Orthotropic Plate Theory for $D=2$ of alpha 10 (main bars perpendicular traffic) 


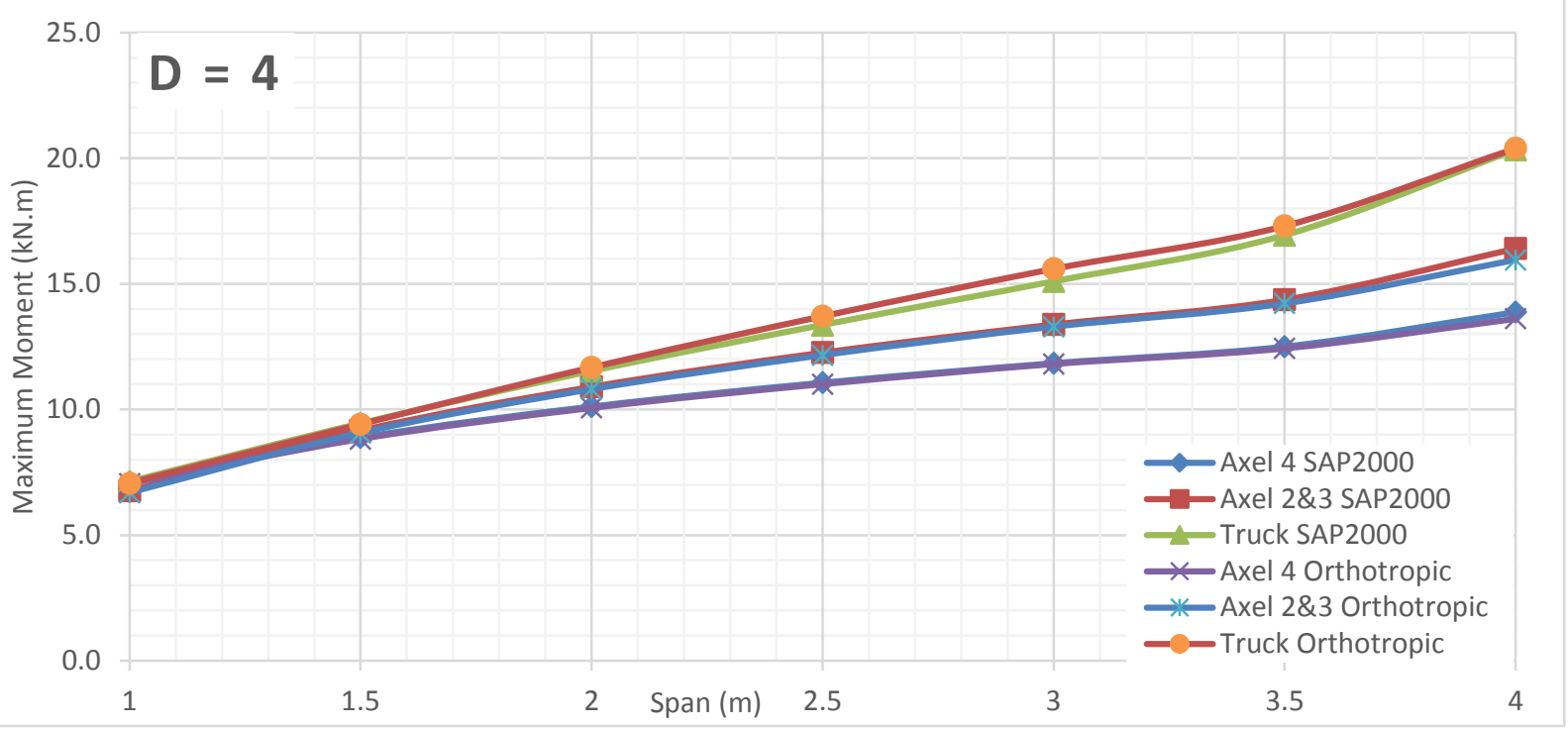

Figure 642 Moment comparison between FEA and Orthotropic Plate Theory for D = 4 of alpha 10 (main bars perpendicular traffic)

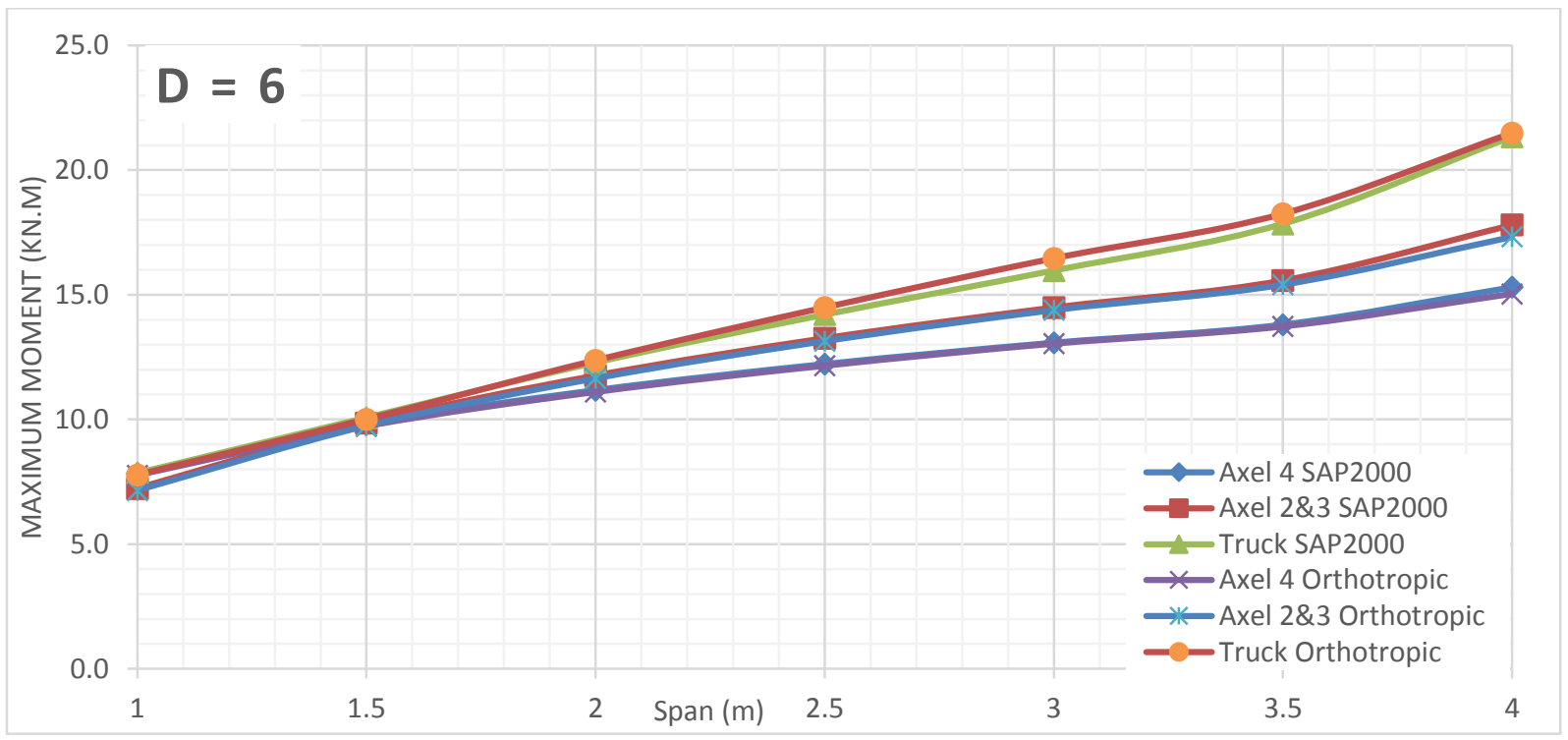

Figure 643 Moment comparison between FEA and Orthotropic Plate Theory for D = 6 of alpha 10 (main bars perpendicular traffic)

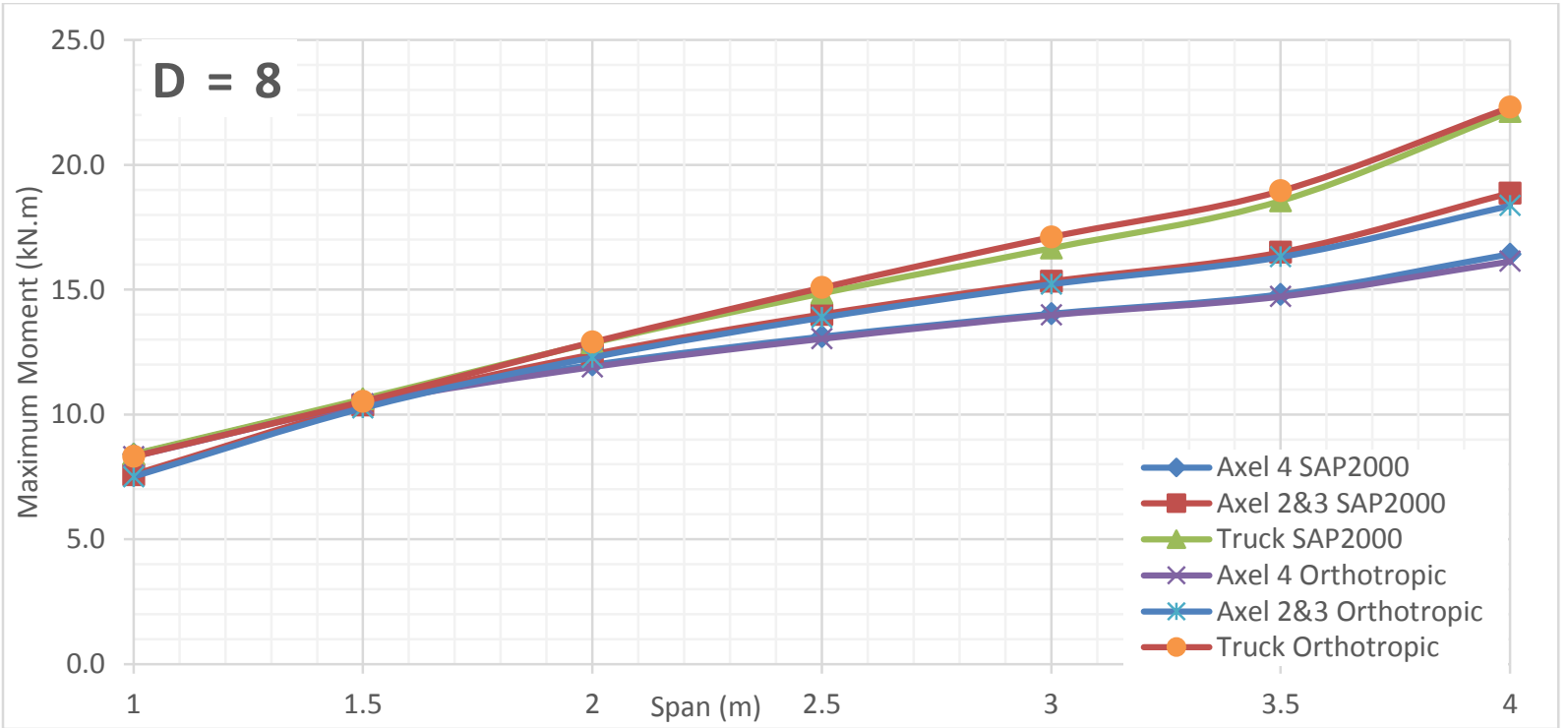

Figure 644 Moment comparison between FEA and Orthotropic Plate Theory for $D=8$ of alpha 10 (main bars perpendicular traffic) 


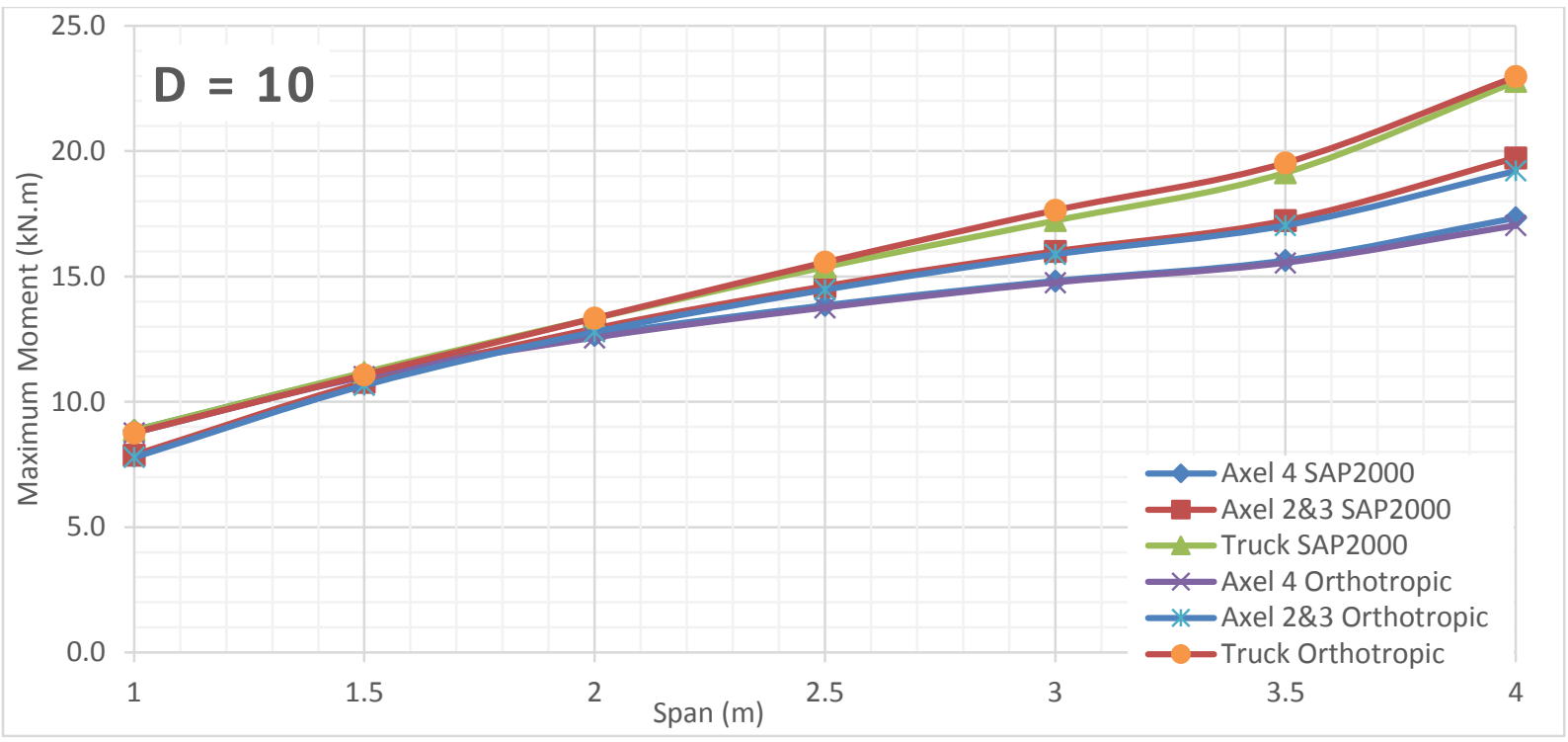

Figure 645 Moment comparison between FEA and Orthotropic Plate Theory for $D=10$ of alpha 10 (main bars perpendicular traffic) 


\section{Alpha 10 Bending Moment VS Span Length for Different D Values (Main bars parallel to traffic)}

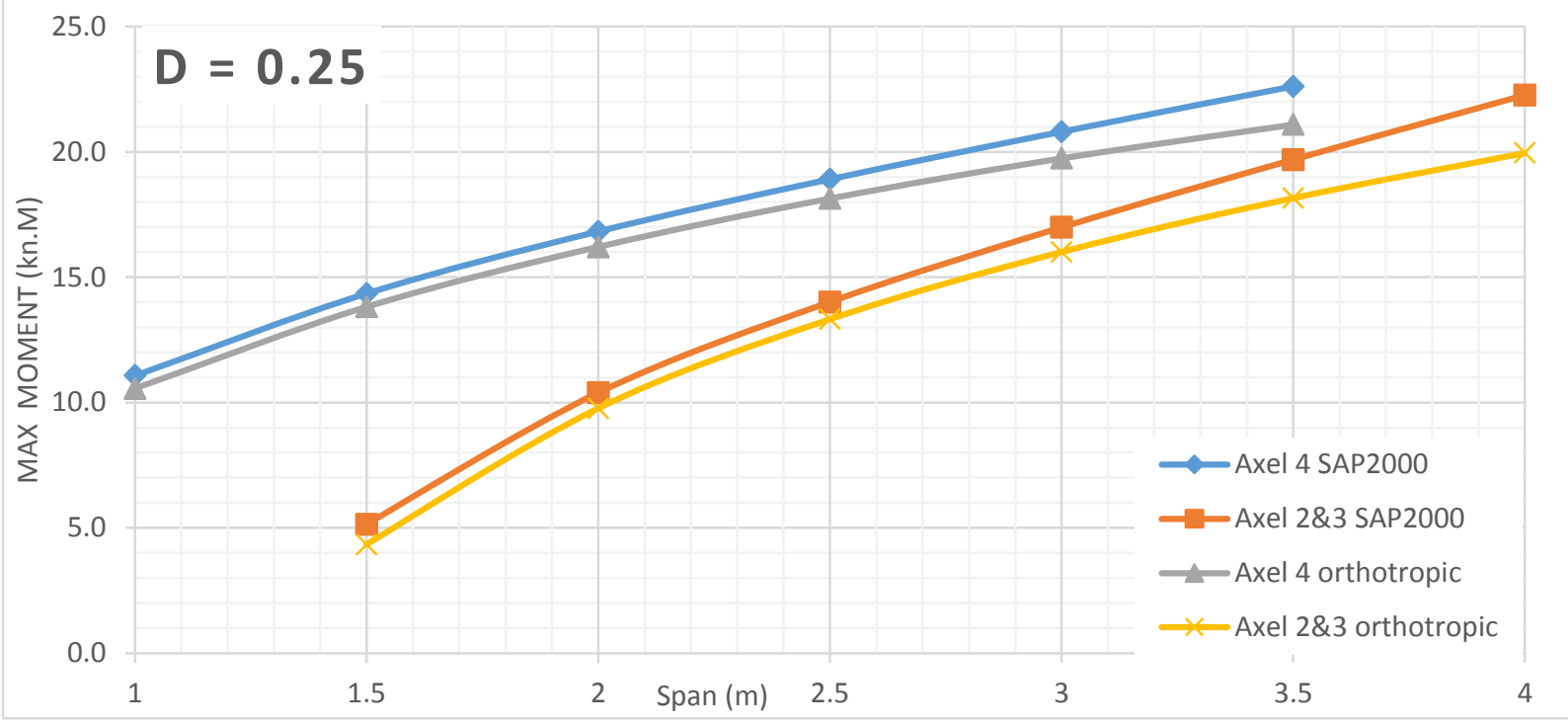

Figure 646 Moment comparison between FEA and Orthotropic Plate Theory for D $=0.25$ of alpha 10 (main bars parallel traffic)

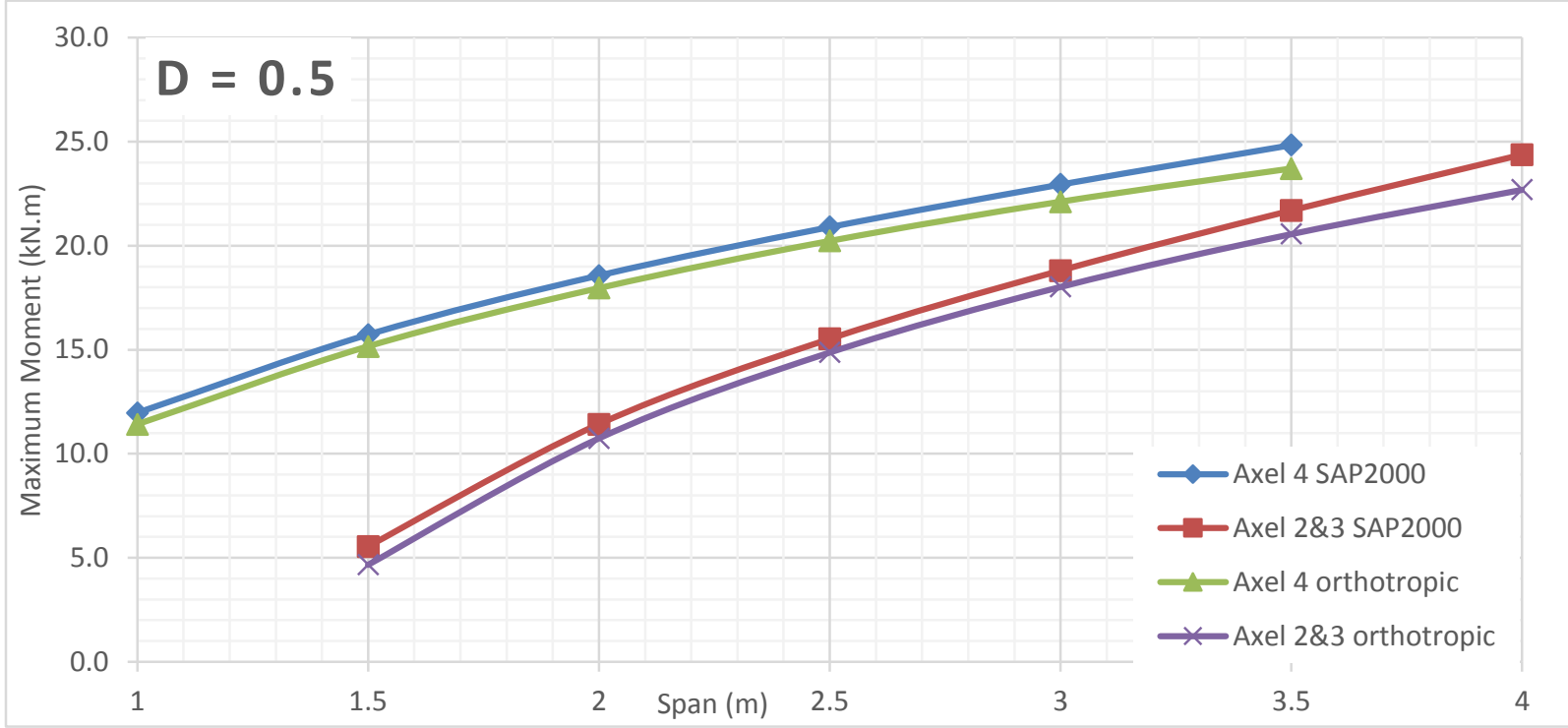

Figure 647 Moment comparison between FEA and Orthotropic Plate Theory for $D=0.5$ of alpha 10 (main bars parallel traffic) 


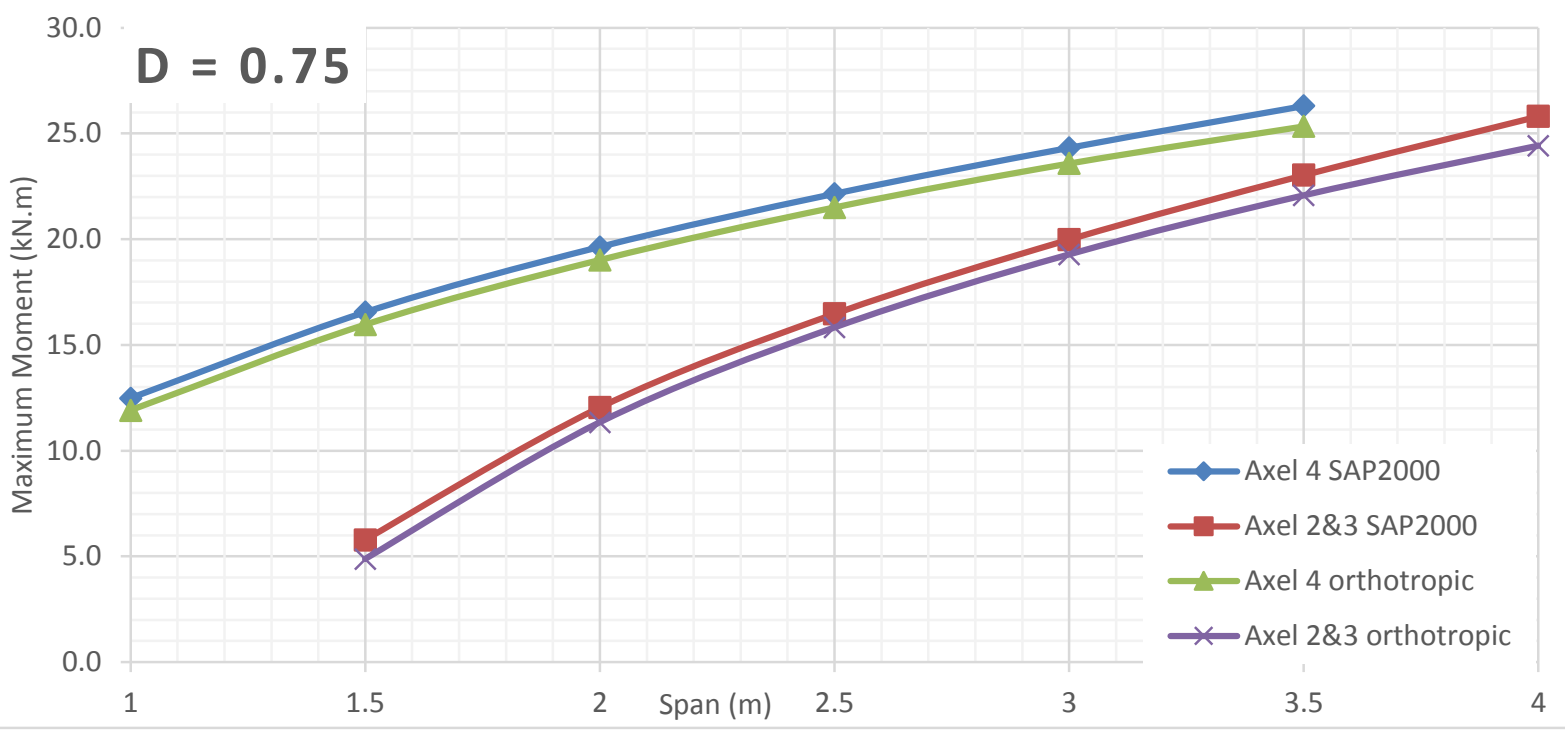

Figure 648 Moment comparison between FEA and Orthotropic Plate Theory for $D=0.75$ of alpha 10 (main bars parallel traffic)

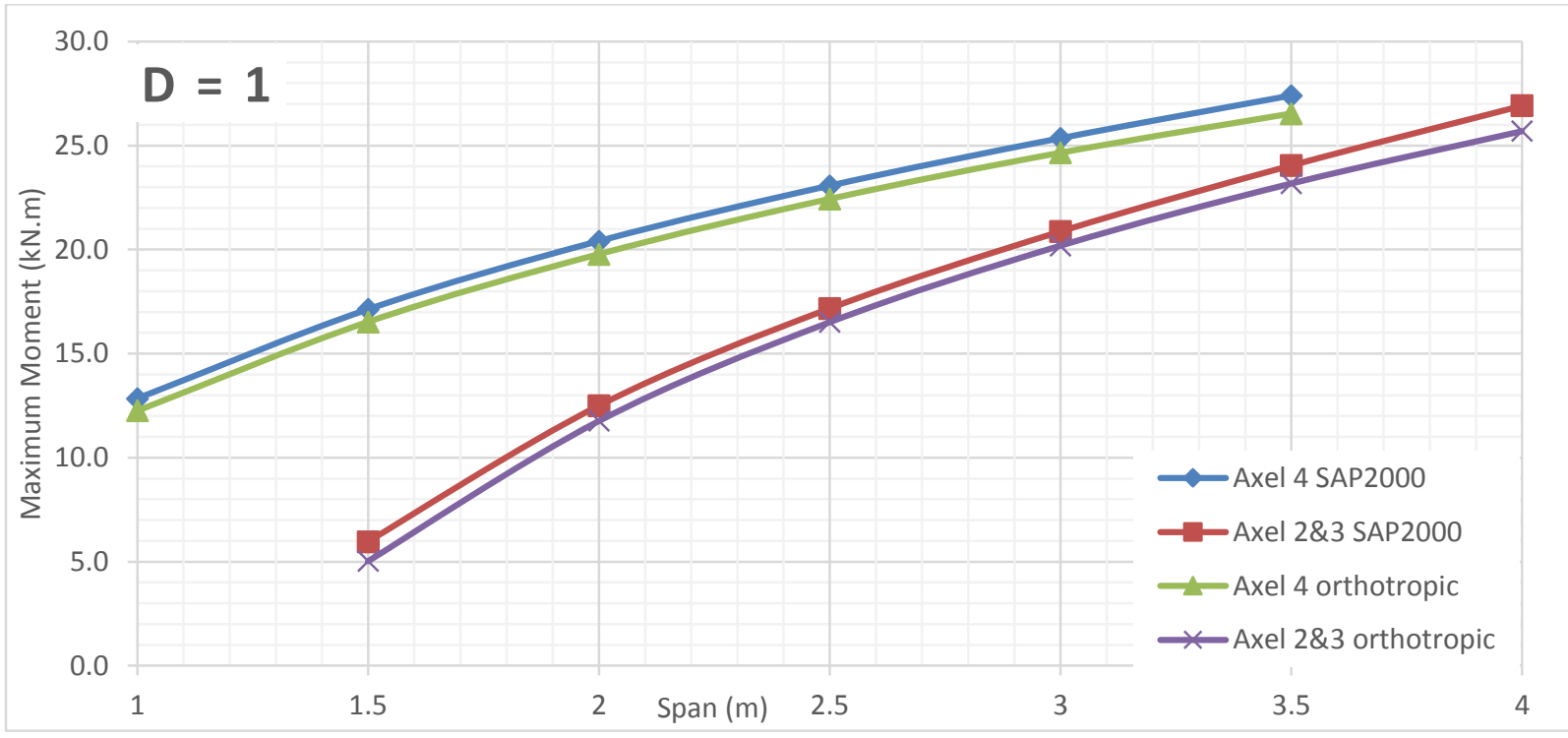

Figure 649 Moment comparison between FEA and Orthotropic Plate Theory for $D=1$ of alpha 10 (main bars parallel traffic)

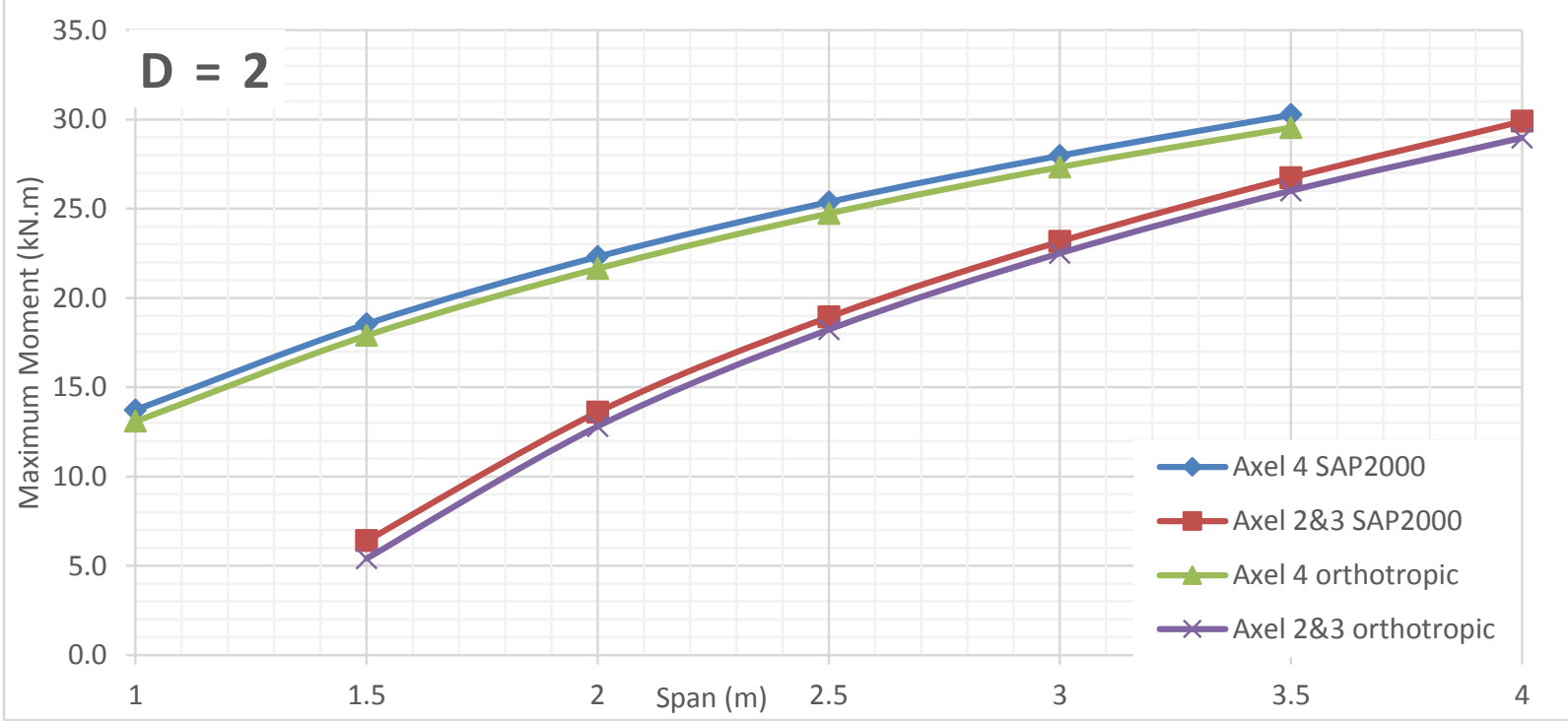

Figure 650 Moment comparison between FEA and Orthotropic Plate Theory for $D=2$ of alpha 10 (main bars parallel traffic) 


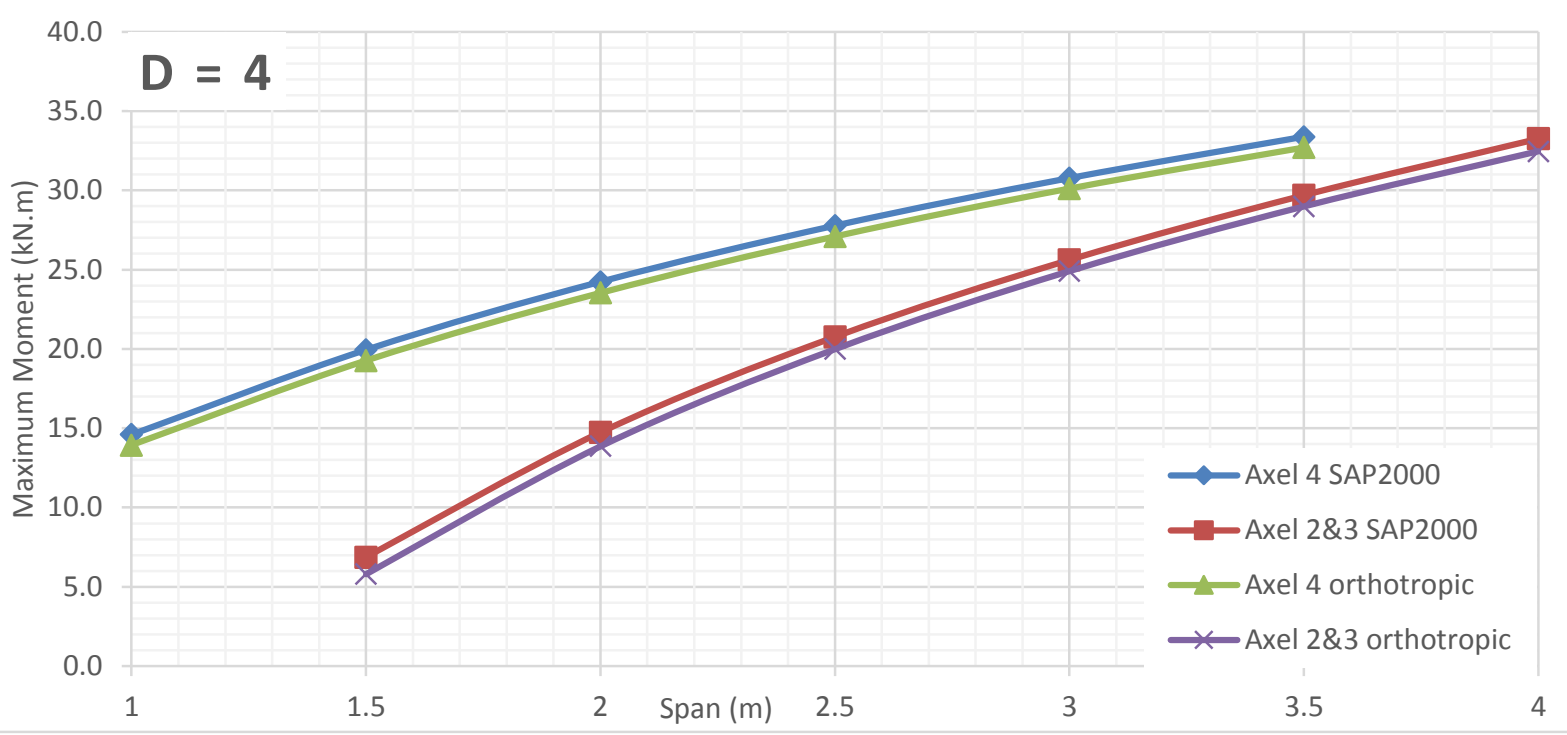

Figure 651 Moment comparison between FEA and Orthotropic Plate Theory for D = 4 of alpha 10 (main bars parallel traffic)

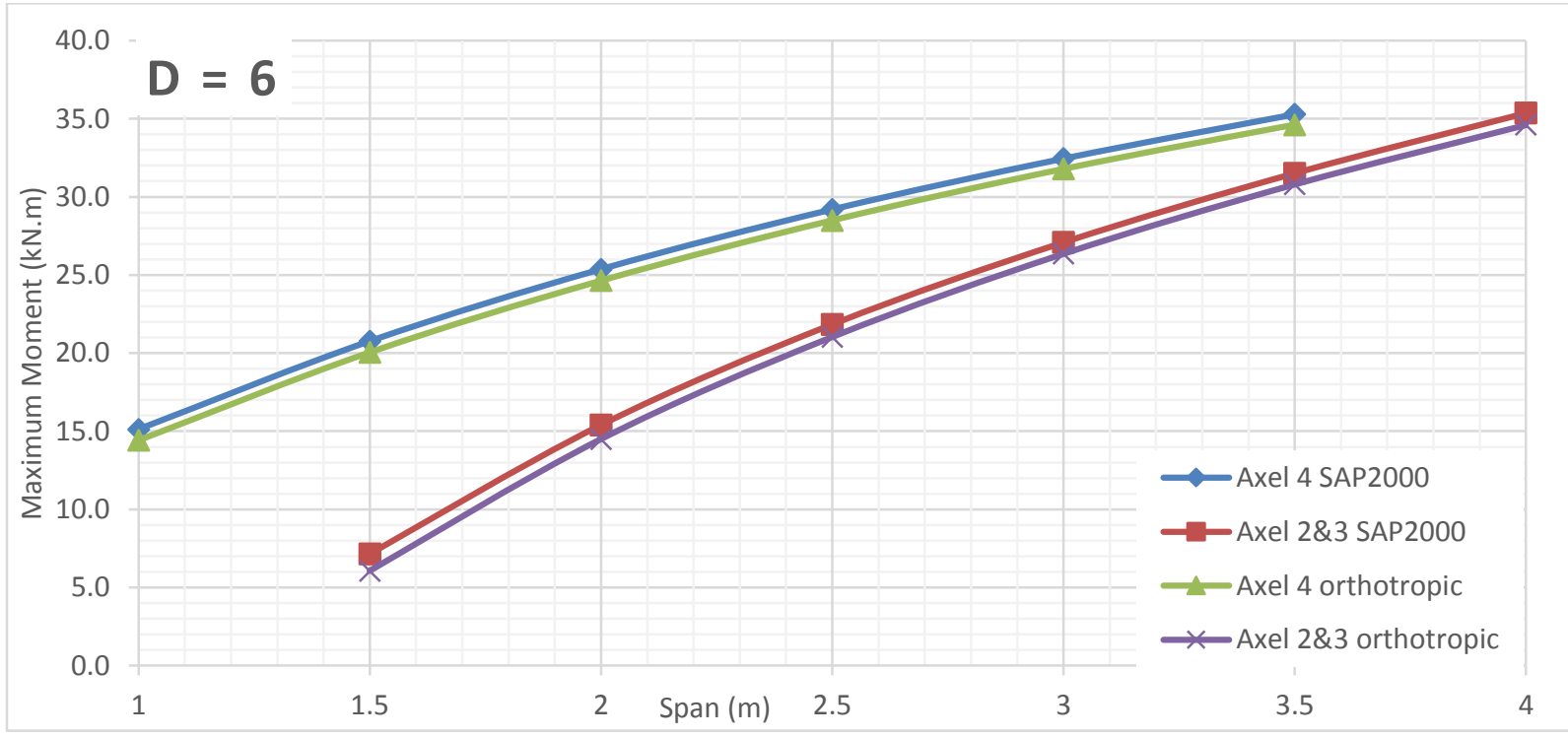

Figure 652 Moment comparison between FEA and Orthotropic Plate Theory for $D=6$ of alpha 10 (main bars parallel traffic)

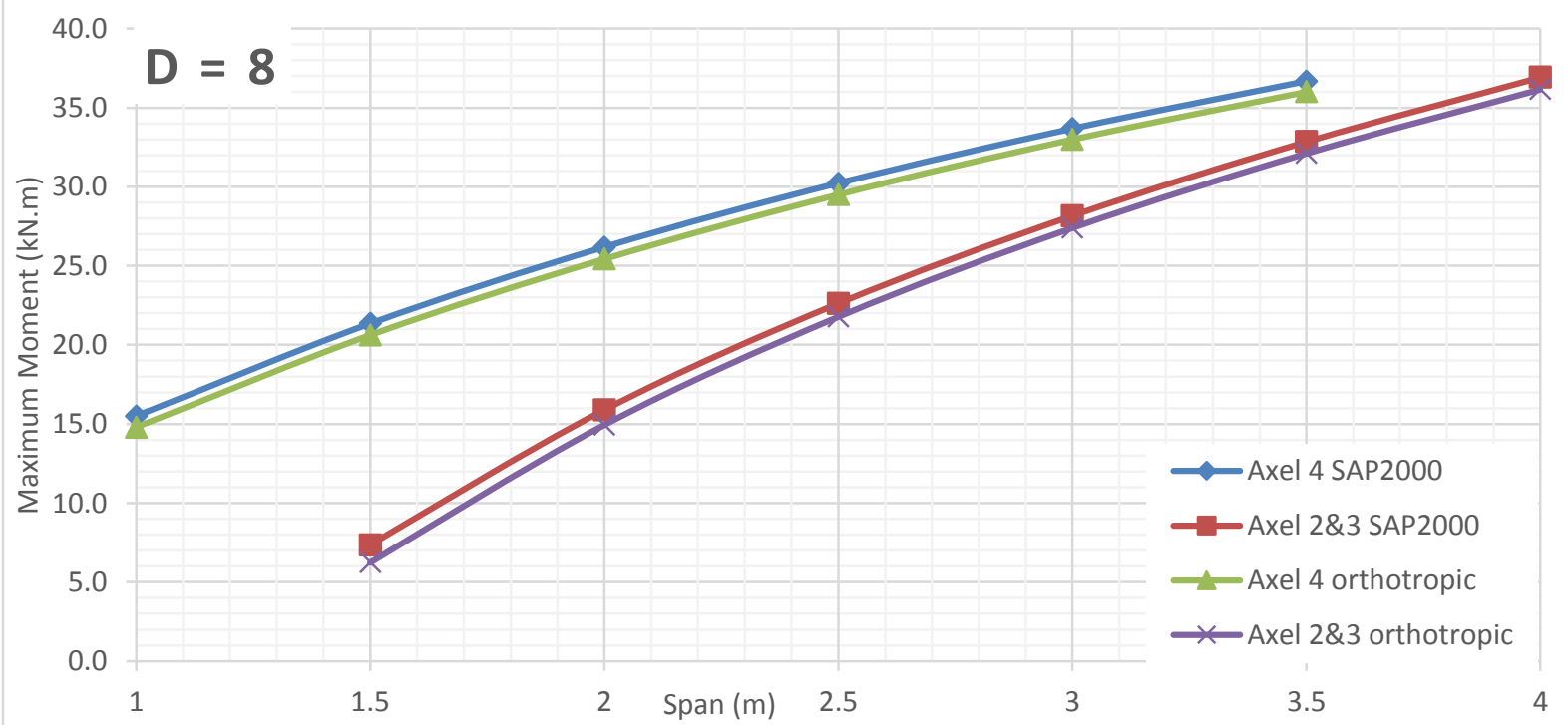

Figure 653 Moment comparison between FEA and Orthotropic Plate Theory for $D=8$ of alpha 10 (main bars parallel traffic) 


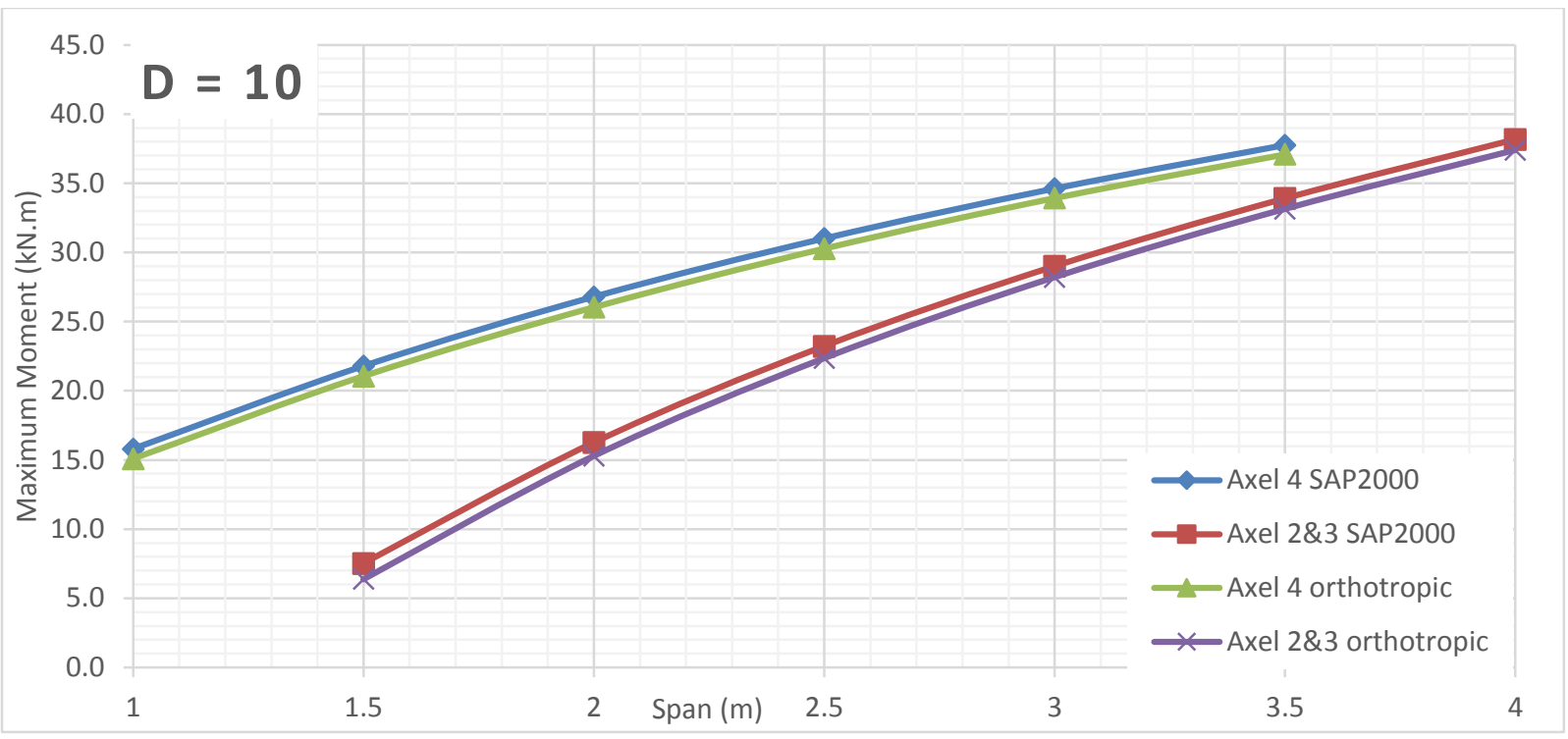

Figure 654 Moment comparison between FEA and Orthotropic Plate Theory for $D=10$ of alpha 10 (main bars parallel traffic) 


\section{D.1.2 MAXIMUM BENDING}

MOMENT VS FLEXURAL RIGIDITY 


\section{Alpha 0.25 Moment VS Flexural Rigidity for Different Span Length (Main bars perpendicular to traffic)}

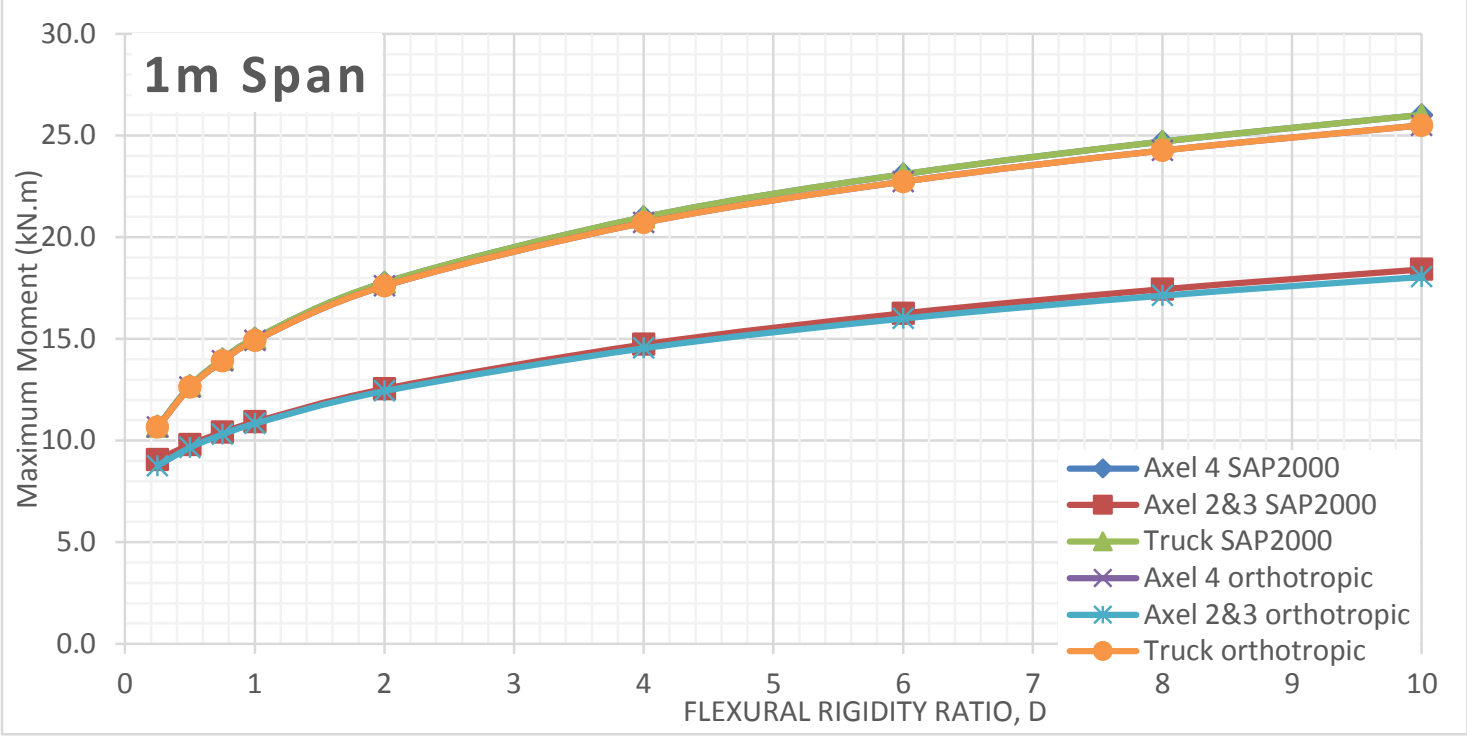

Figure 655 Moment comparison between FEA and Orthotropic Plate Theory for $1 \mathrm{~m}$ span of alpha 0.25 (main bars perpendicular to traffic)

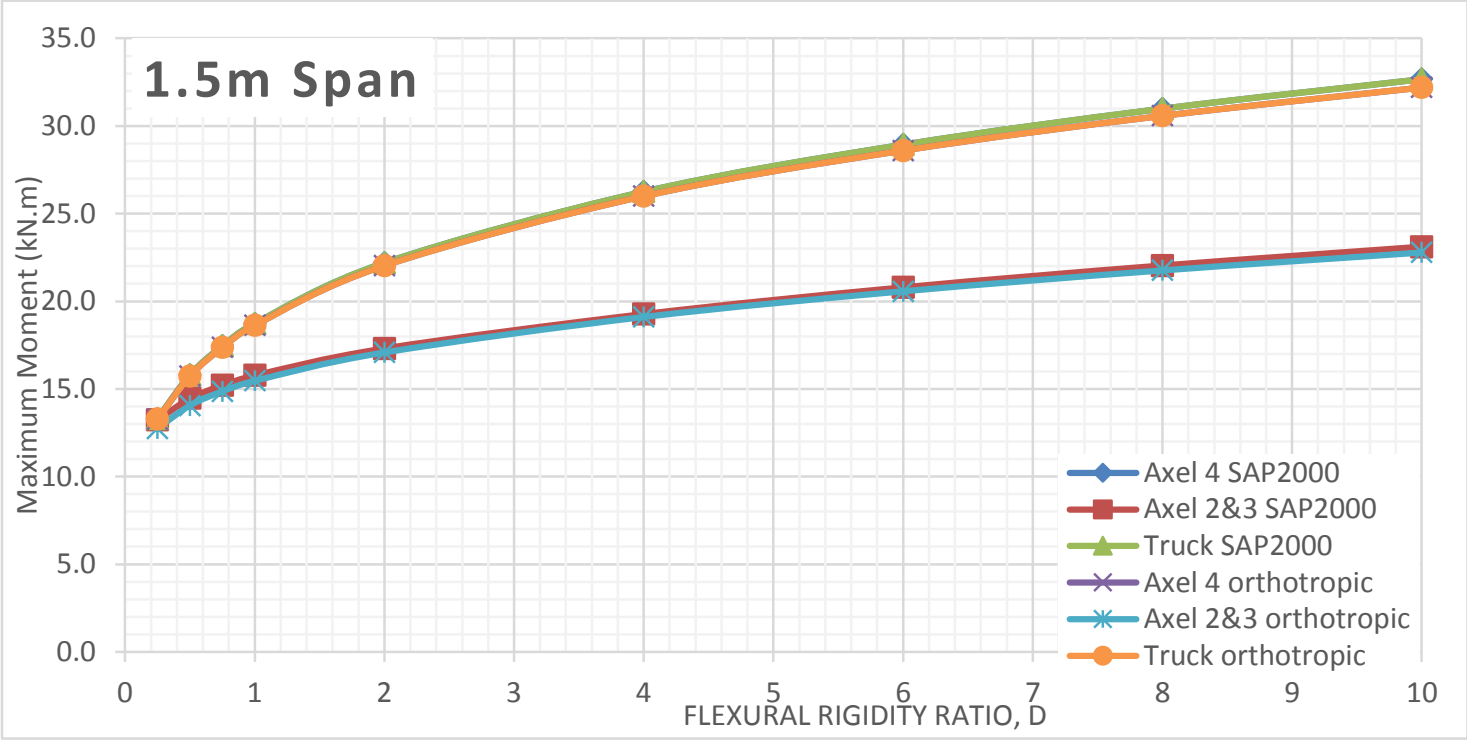

Figure 656 Moment comparison between FEA and Orthotropic Plate Theory for $1.5 \mathrm{~m}$ span of alpha 0.25 (main bars perpendicular to traffic) 


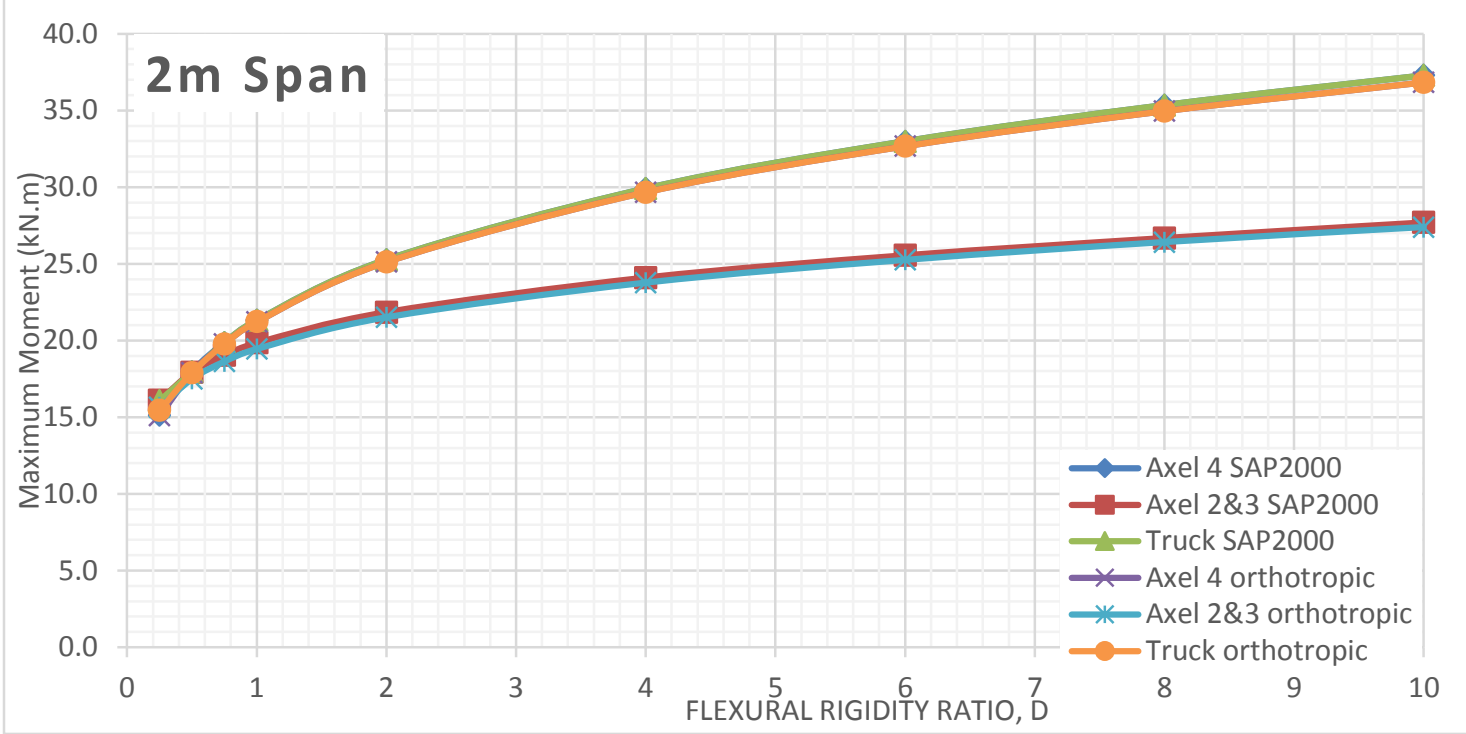

Figure 657 Moment comparison between FEA and Orthotropic Plate Theory for $2 \mathrm{~m}$ span of alpha 0.25 (main bars perpendicular to traffic)

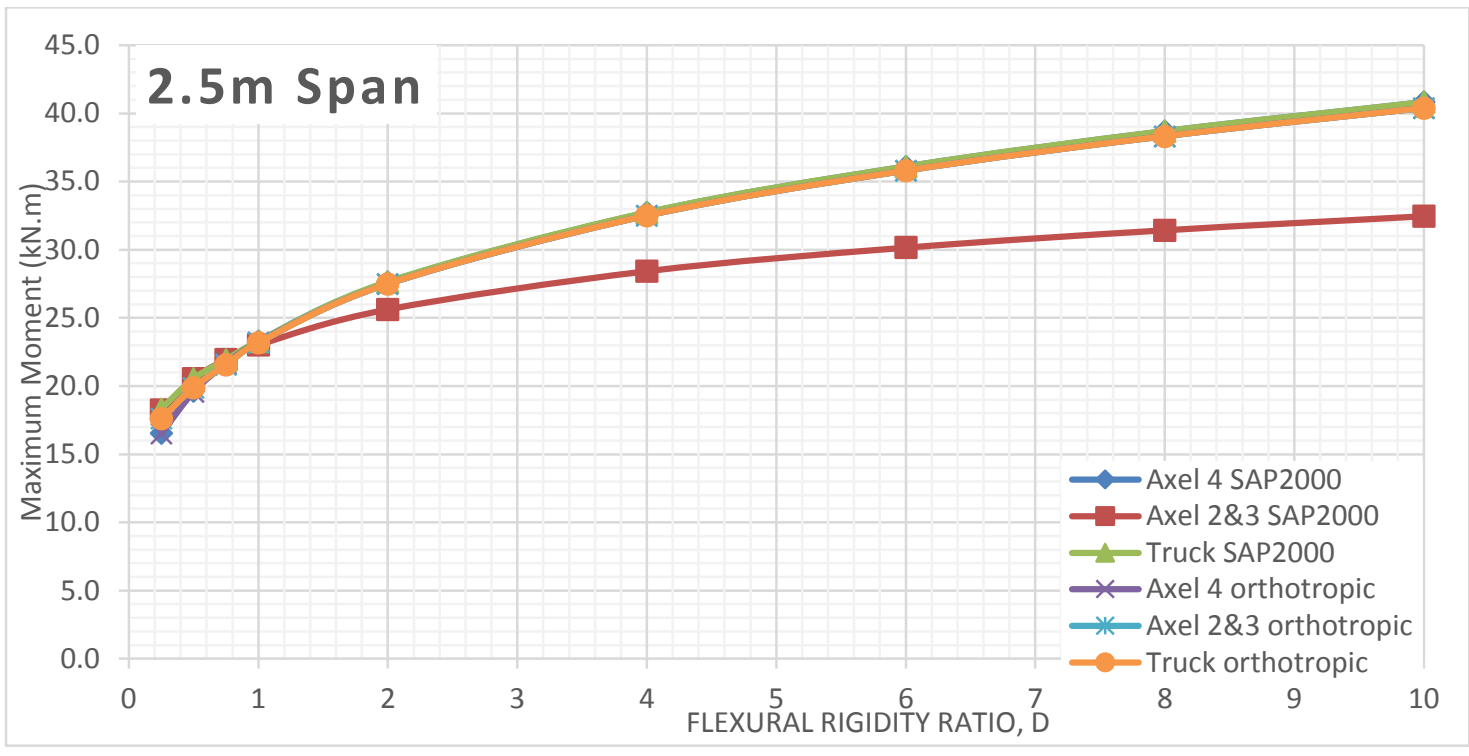

Figure 658 Moment comparison between FEA and Orthotropic Plate Theory for $2.5 \mathrm{~m}$ span of alpha 0.25 (main bars perpendicular to traffic)

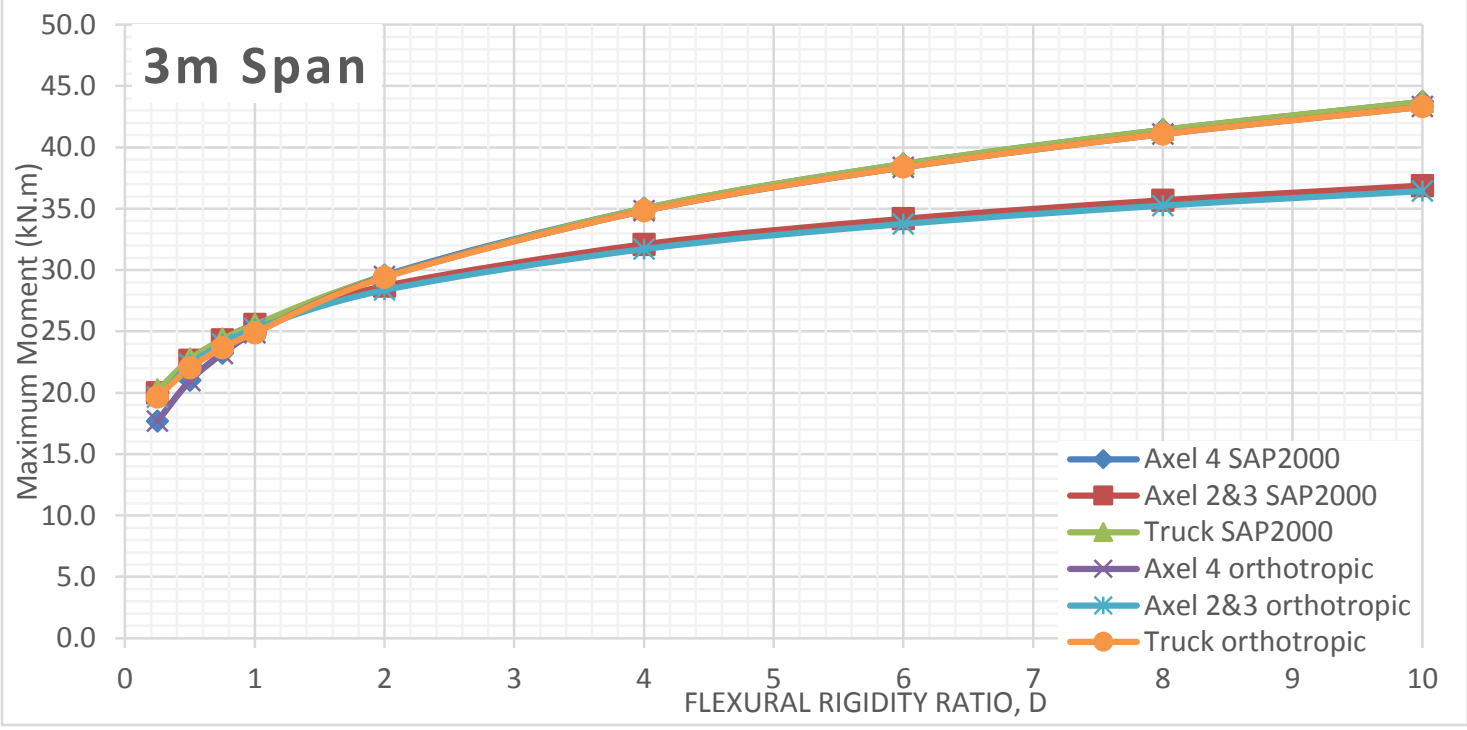

Figure 659 Moment comparison between FEA and Orthotropic Plate Theory for $3 \mathrm{~m}$ span of alpha 0.25 (main bars perpendicular to traffic) 


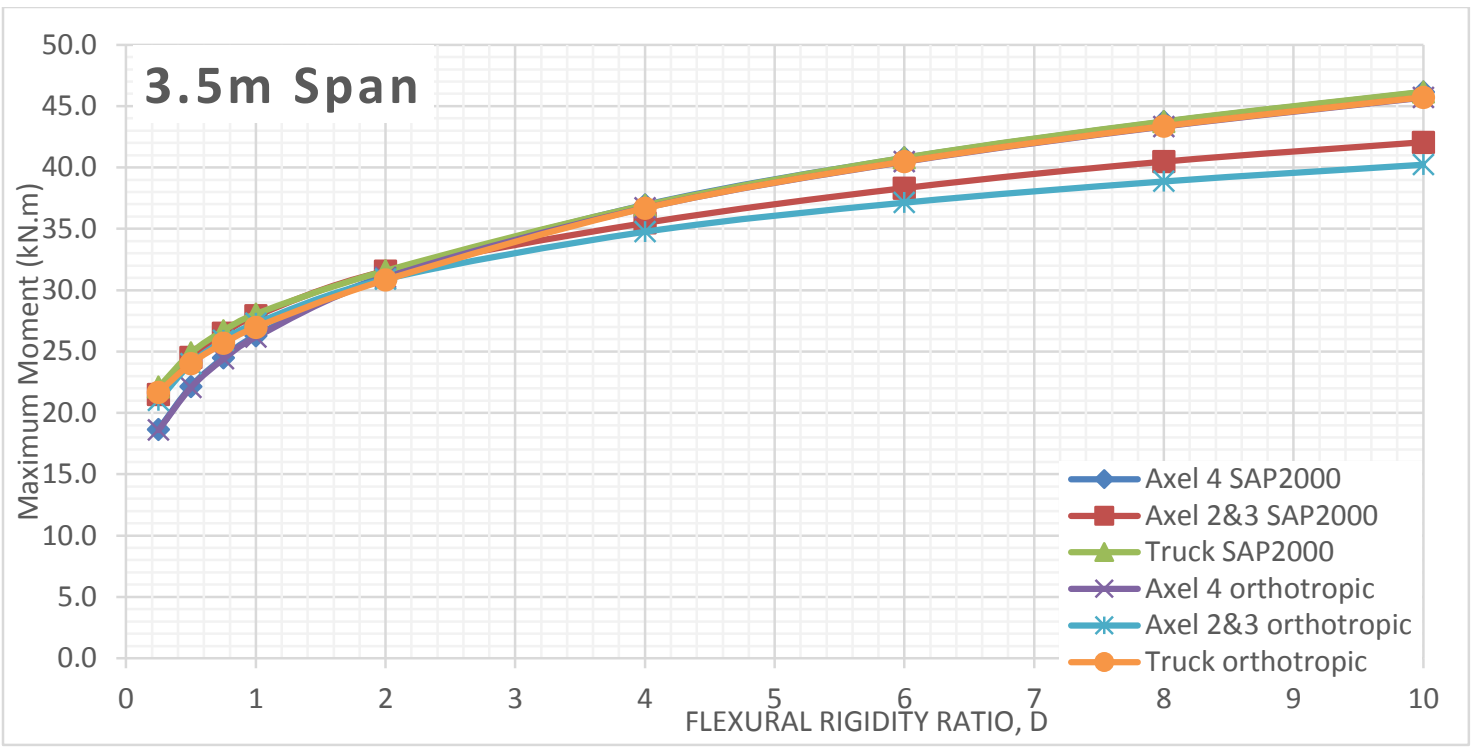

Figure 660 Moment comparison between FEA and Orthotropic Plate Theory for $3.5 \mathrm{~m}$ span of alpha 0.25 (main bars perpendicular to traffic)

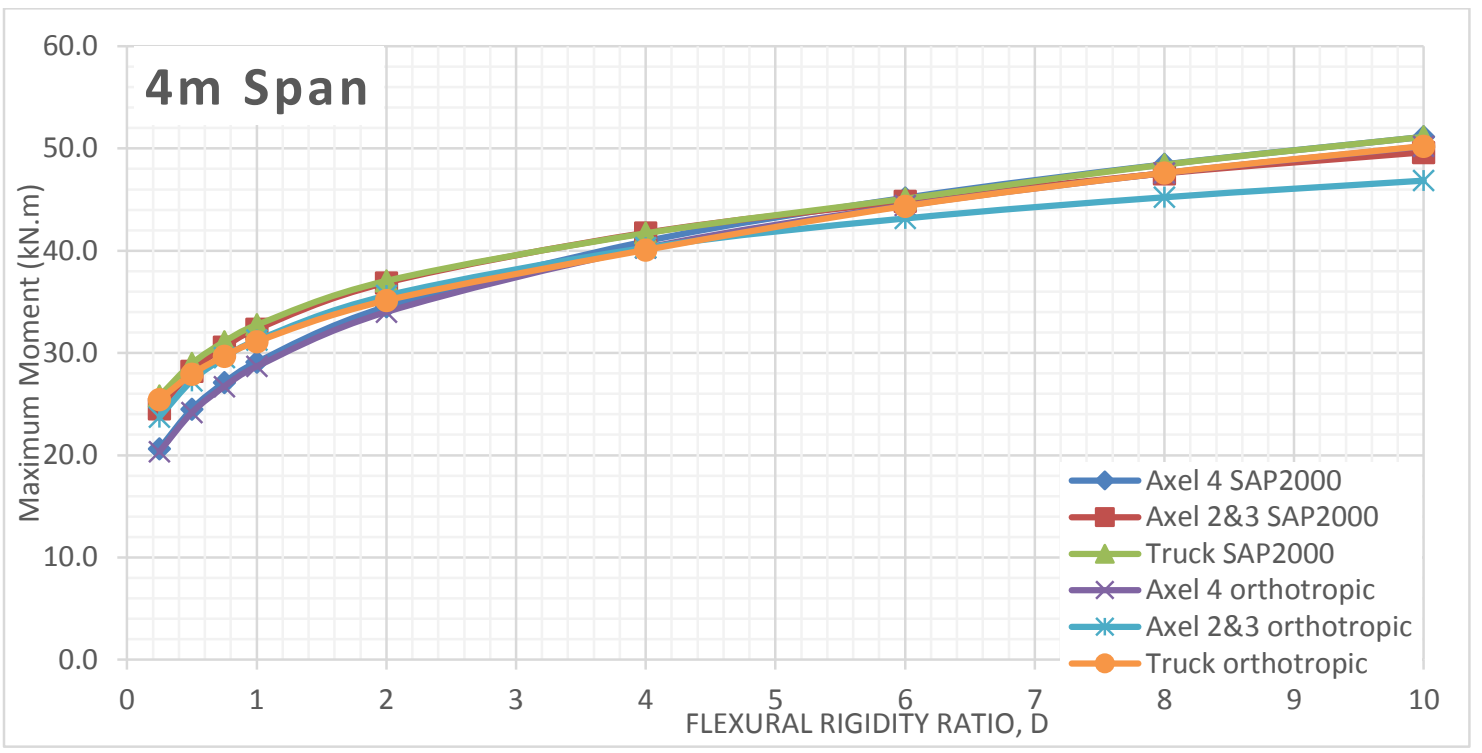

Figure 661 Moment comparison between FEA and Orthotropic Plate Theory for $4 \mathrm{~m}$ span of alpha 0.25 (main bars perpendicular to traffic) 


\section{Alpha 0.25 Bending Moment VS Flexural Rigidity for Different Span Length (Main bars parallel to traffic)}

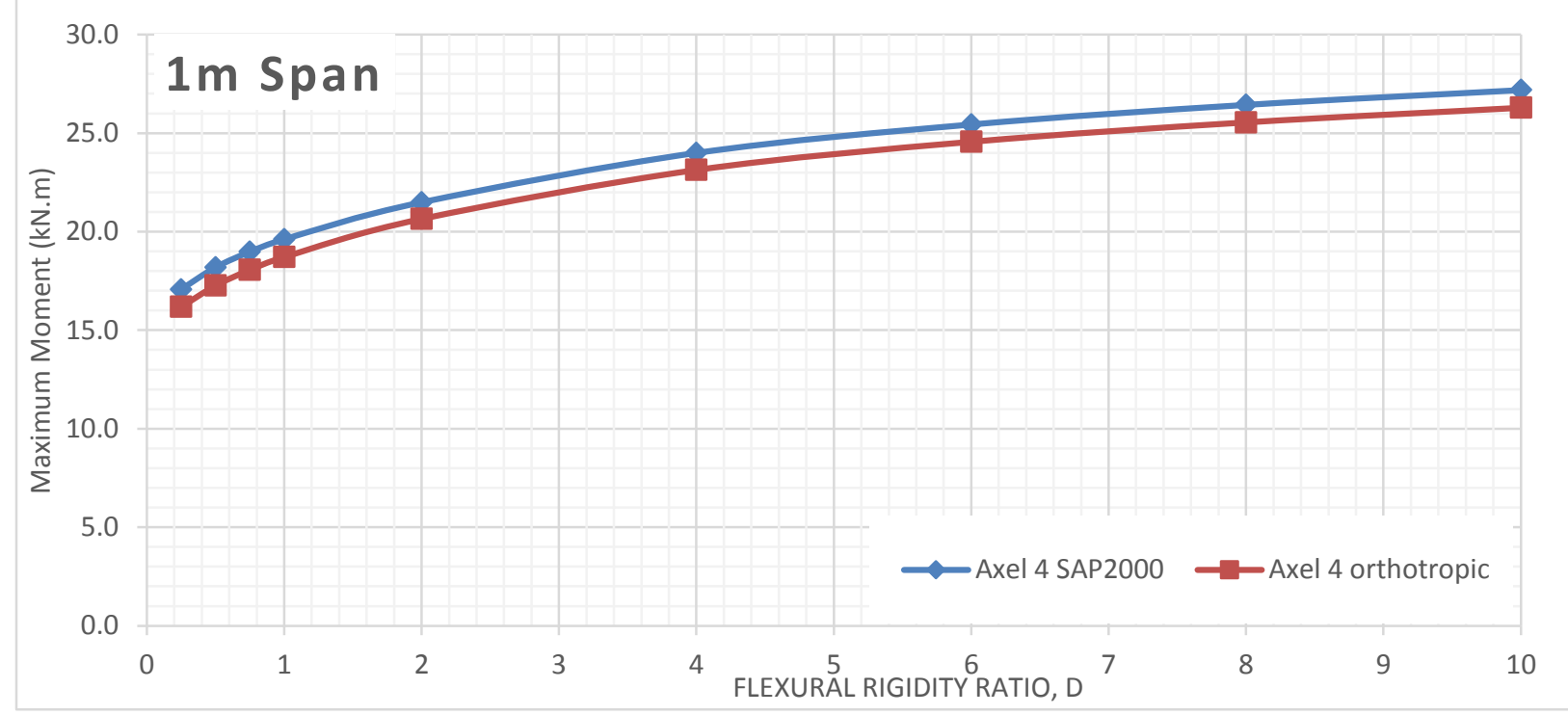

Figure 662 Moment comparison between FEA and Orthotropic Plate Theory for $1 \mathrm{~m}$ span of alpha 0.25 (main bars parallel to traffic)

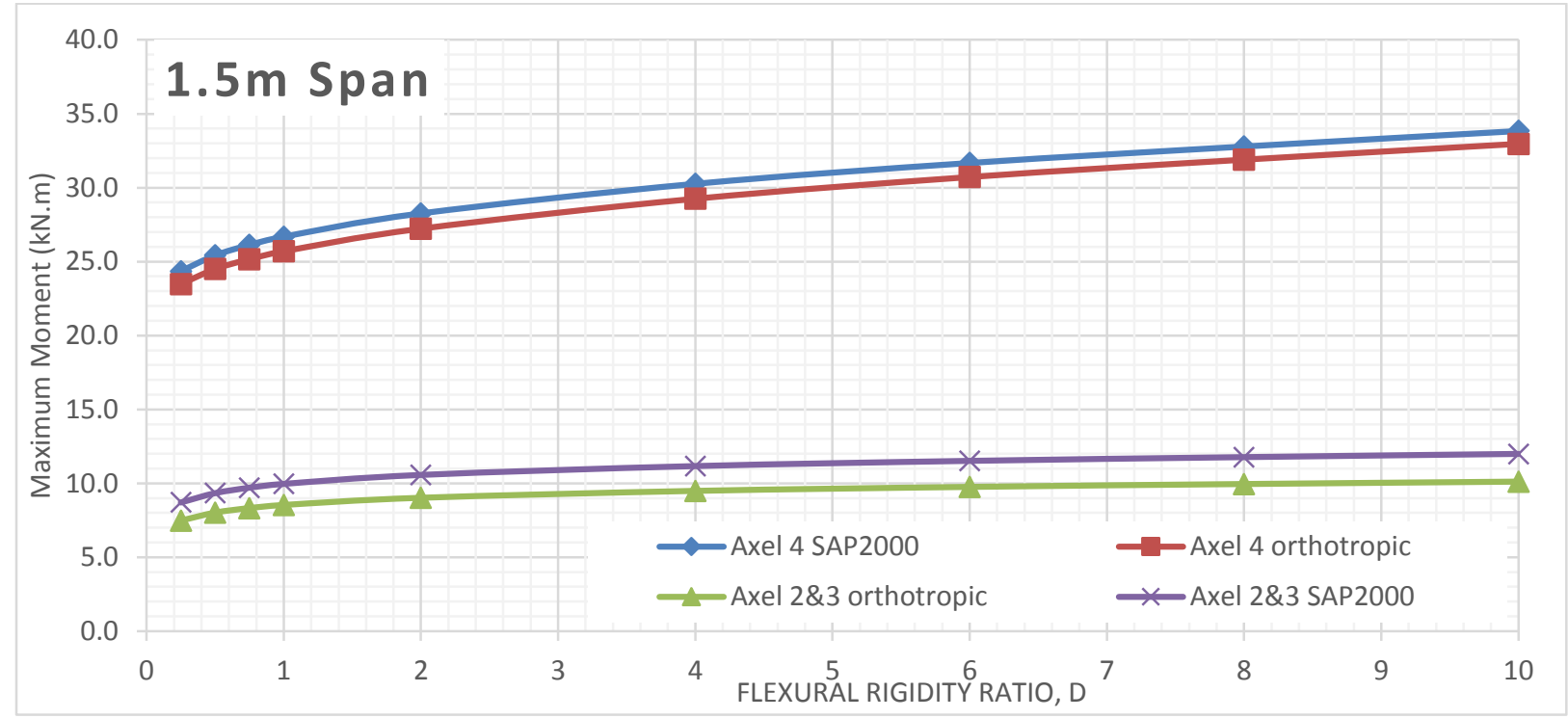

Figure 663 Moment comparison between FEA and Orthotropic Plate Theory for $1.5 \mathrm{~m}$ span of alpha 0.25 (main bars parallel to traffic) 


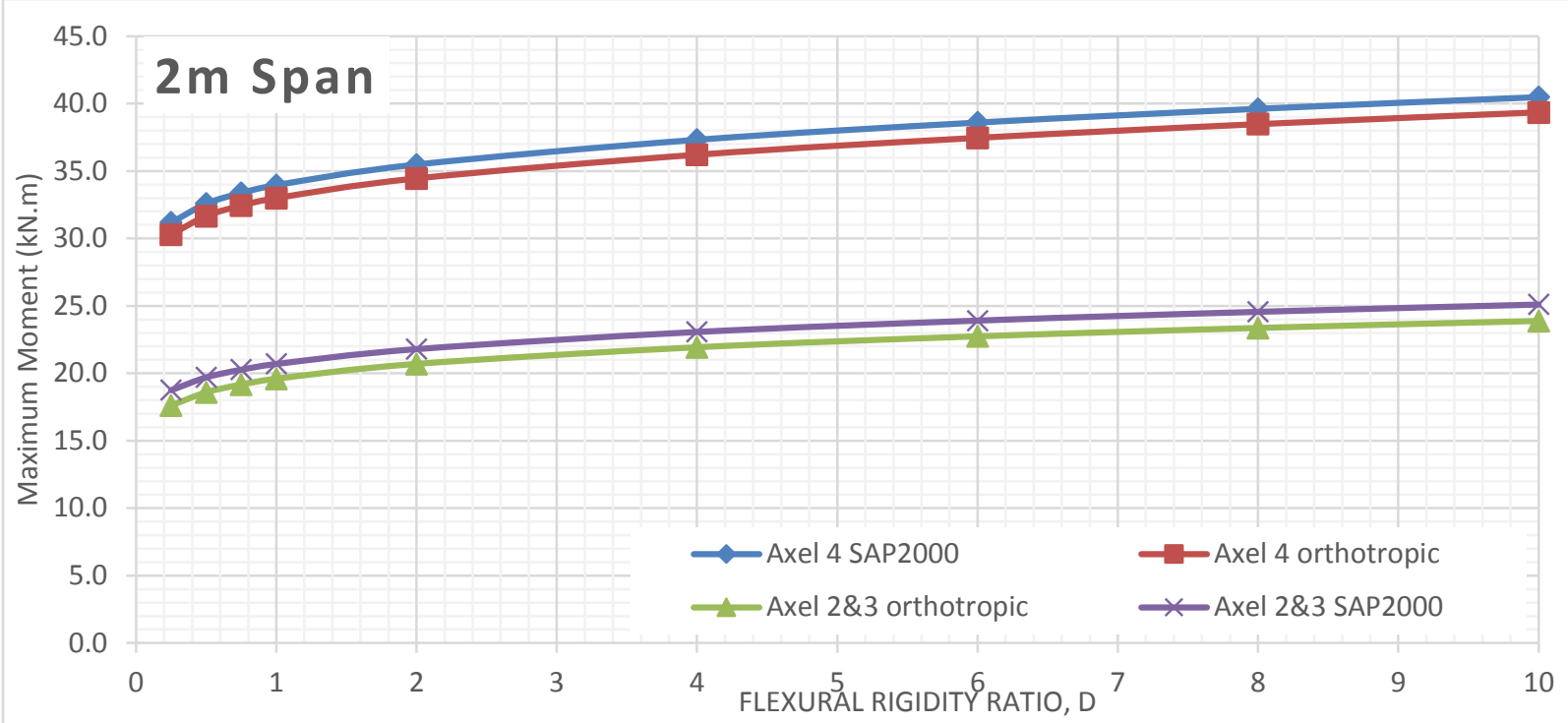

Figure 664 Moment comparison between FEA and Orthotropic Plate Theory for $2 \mathrm{~m}$ span of alpha 0.25 (main bars parallel to traffic)

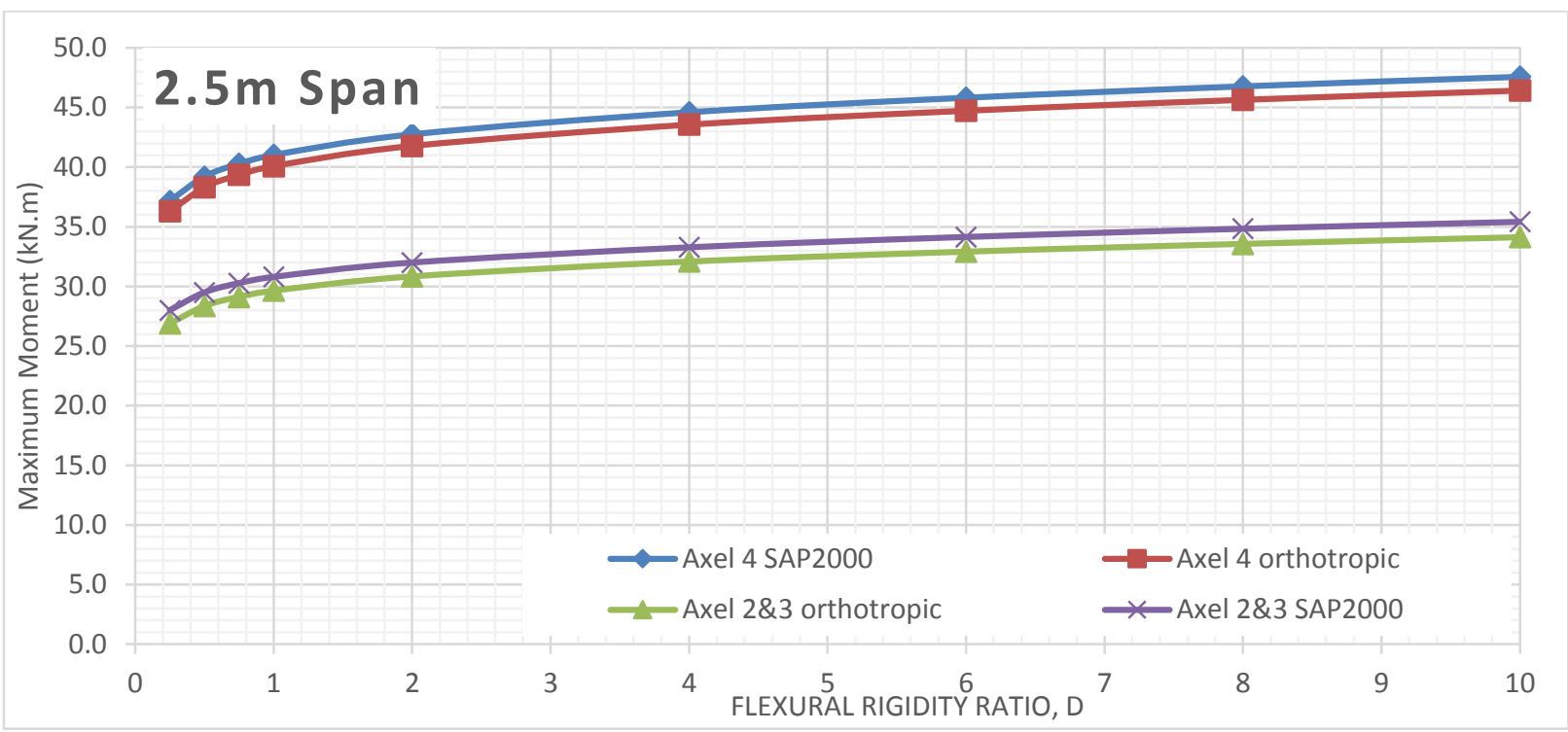

Figure 665 Moment comparison between FEA and Orthotropic Plate Theory for $2.5 \mathrm{~m}$ span of alpha 0.25 (main bars parallel to traffic)

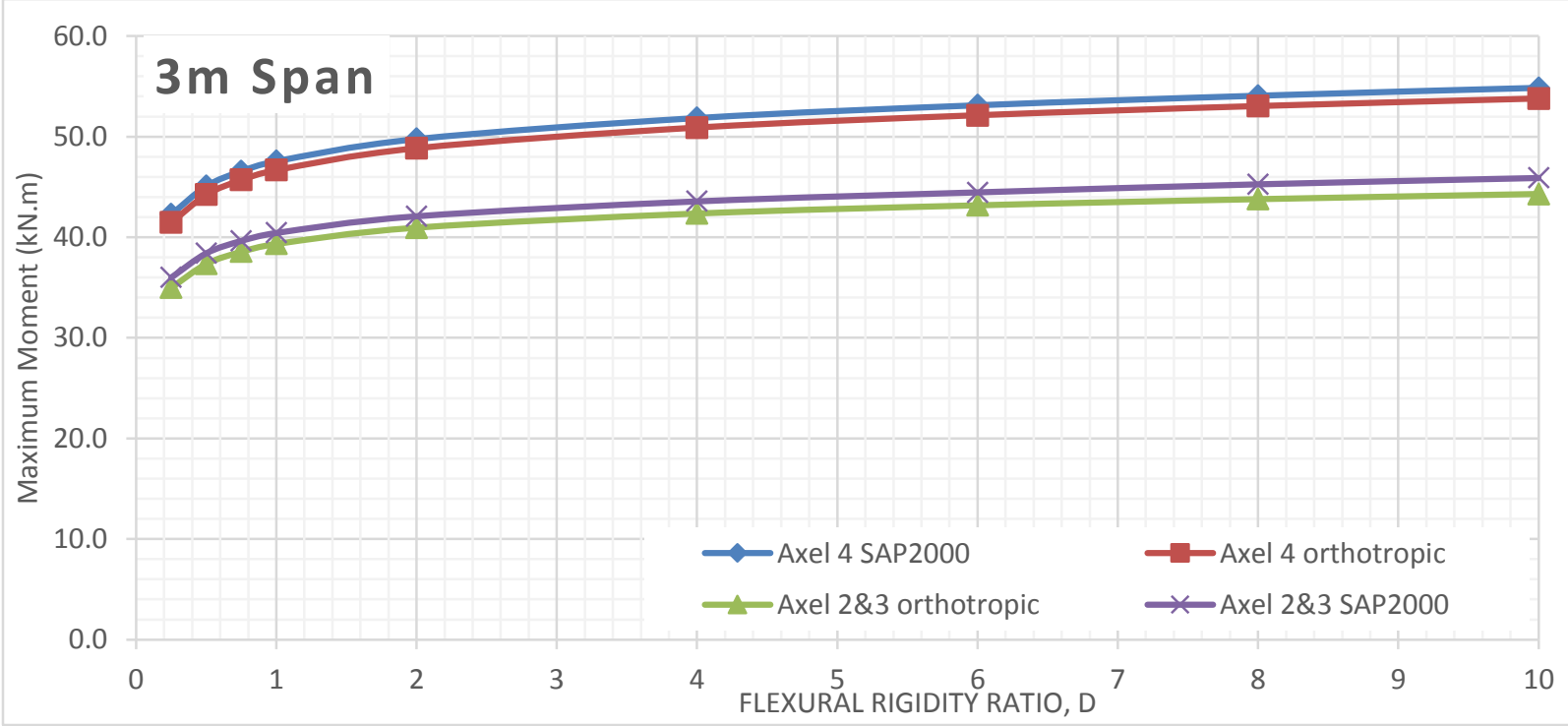

Figure 666 Moment comparison between FEA and Orthotropic Plate Theory for $3 \mathrm{~m}$ span of alpha 0.25 (main bars parallel to traffic) 


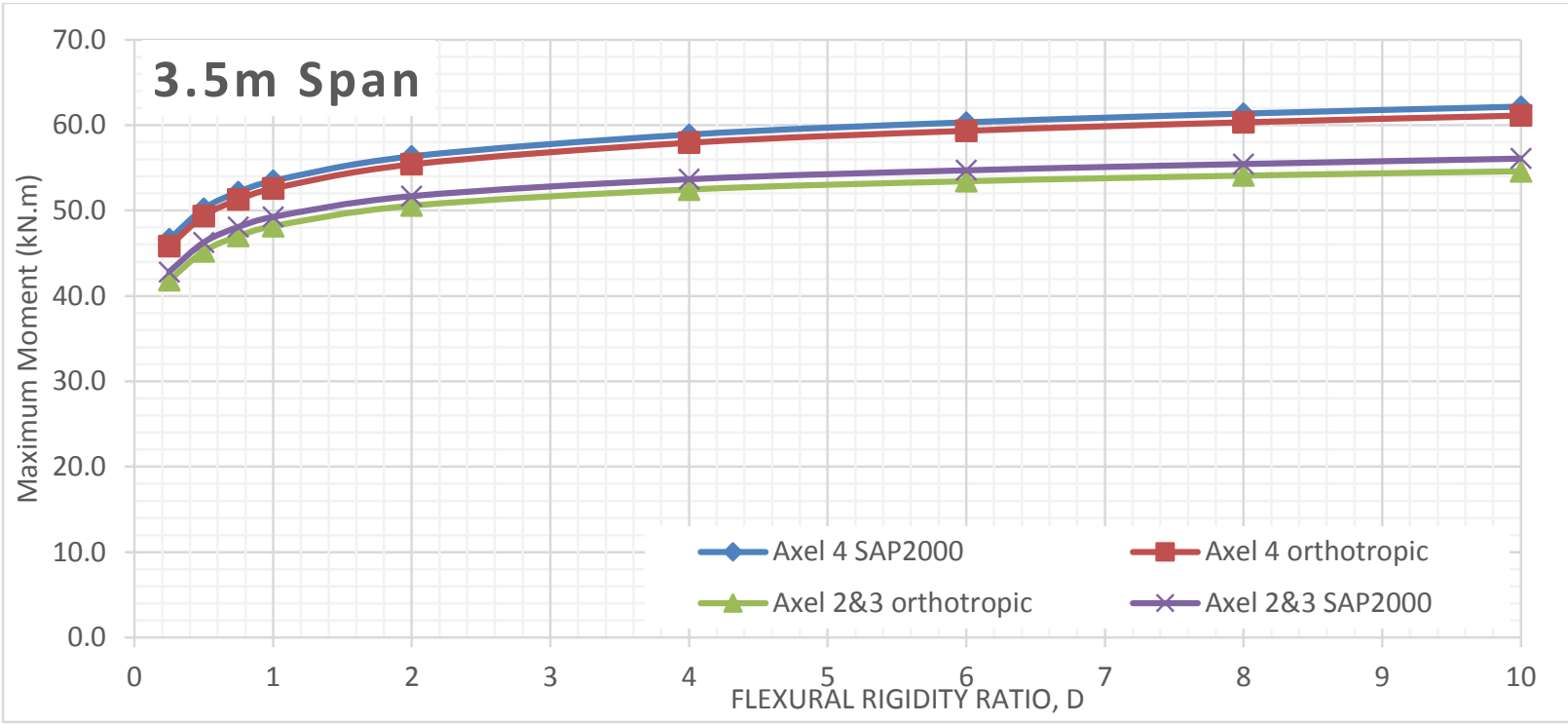

Figure 667 Moment comparison between FEA and Orthotropic Plate Theory for $3.5 \mathrm{~m}$ span of alpha 0.25 (main bars parallel to traffic)

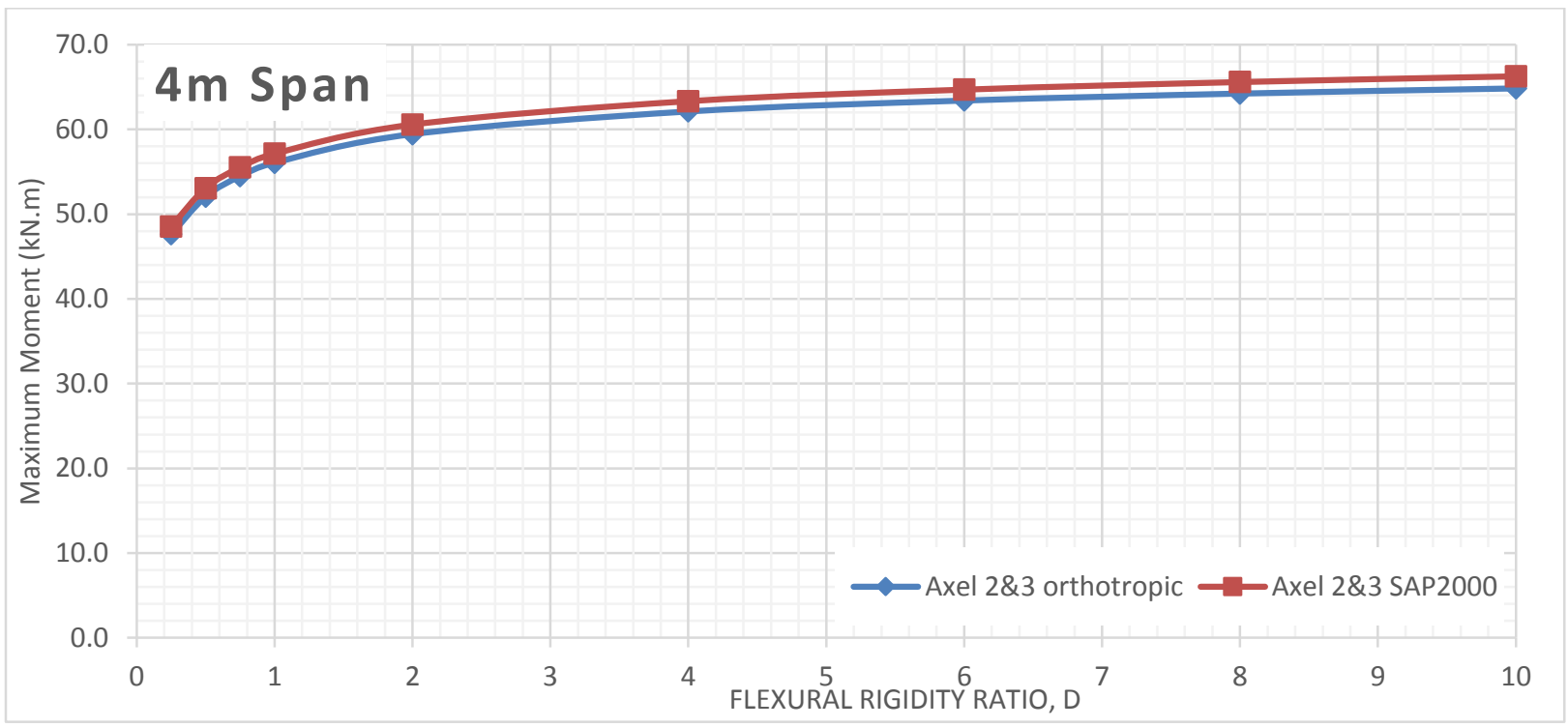

Figure 668 Moment comparison between FEA and Orthotropic Plate Theory for $4 \mathrm{~m}$ span of alpha 0.25 (main bars parallel to traffic) 


\section{Alpha 0.5 Bending Moment VS Flexural Rigidity for Different Span Length (Main bars perpendicular to traffic)}

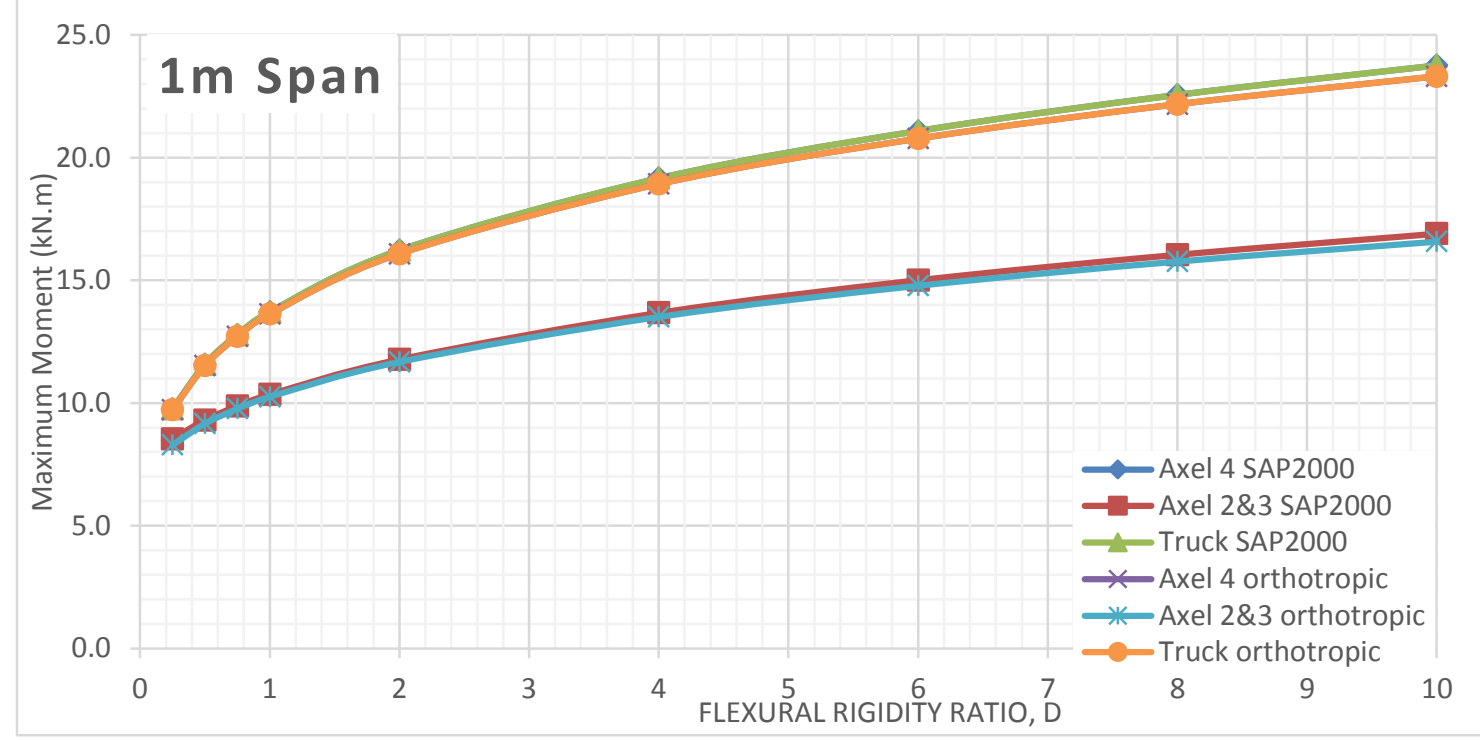

Figure 669 Moment comparison between FEA and Orthotropic Plate Theory for $1 \mathrm{~m}$ span of alpha 0.5 (main bars perpendicular to traffic)

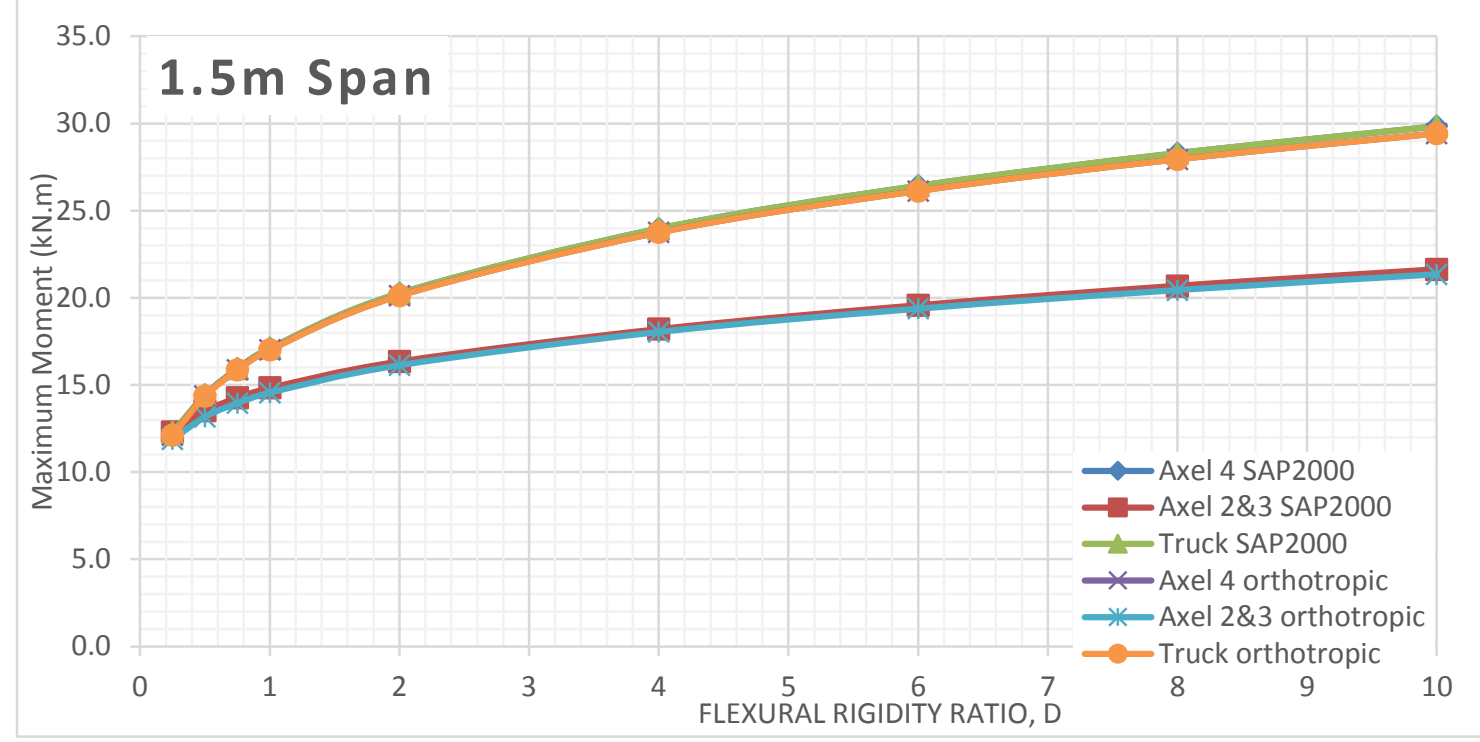

Figure 670 Moment comparison between FEA and Orthotropic Plate Theory for $1.5 \mathrm{~m}$ span of alpha 0.5 (main bars perpendicular to traffic) 


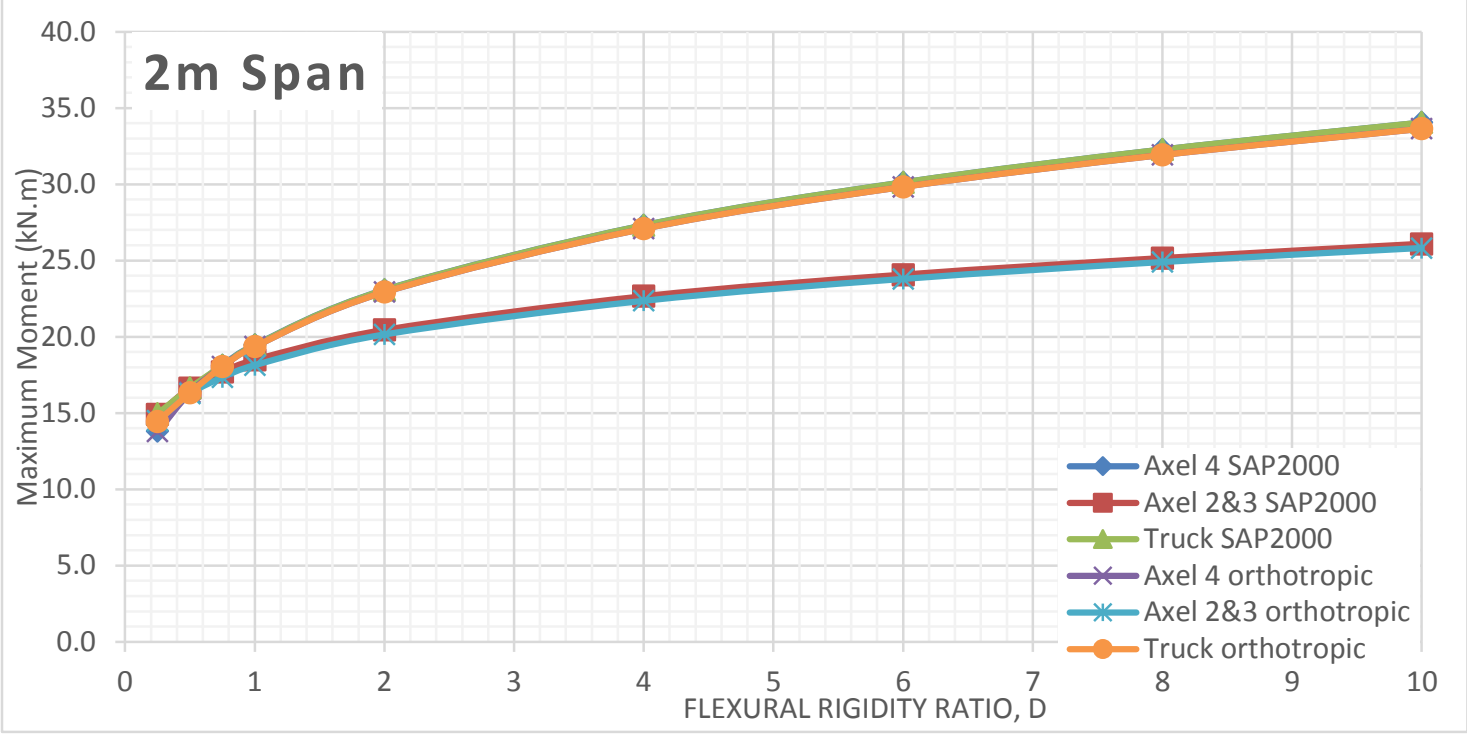

Figure 671 Moment comparison between FEA and Orthotropic Plate Theory for $2 \mathrm{~m}$ span of alpha 0.5 (main bars perpendicular to traffic)

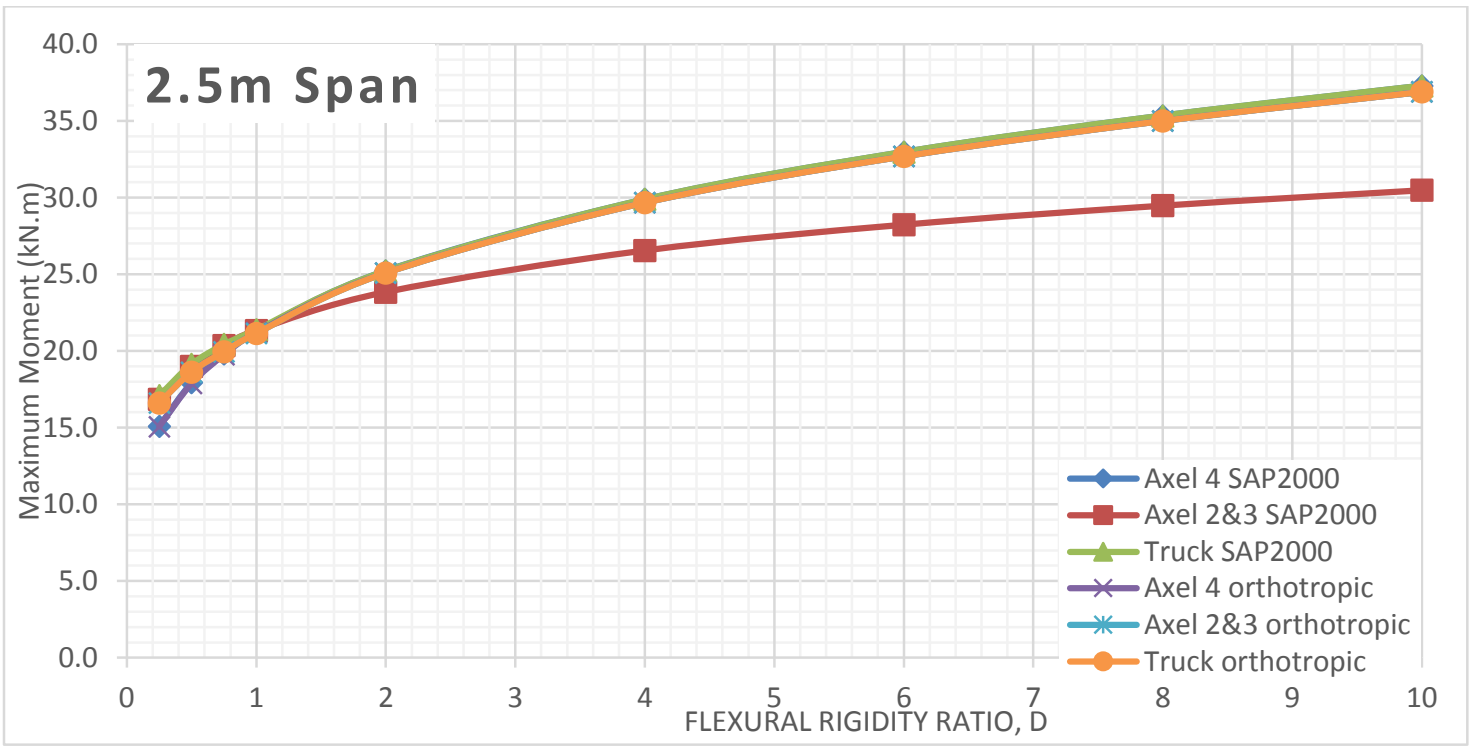

Figure 672 Moment comparison between FEA and Orthotropic Plate Theory for $2.5 \mathrm{~m}$ span of alpha 0.5 (main bars perpendicular to traffic)

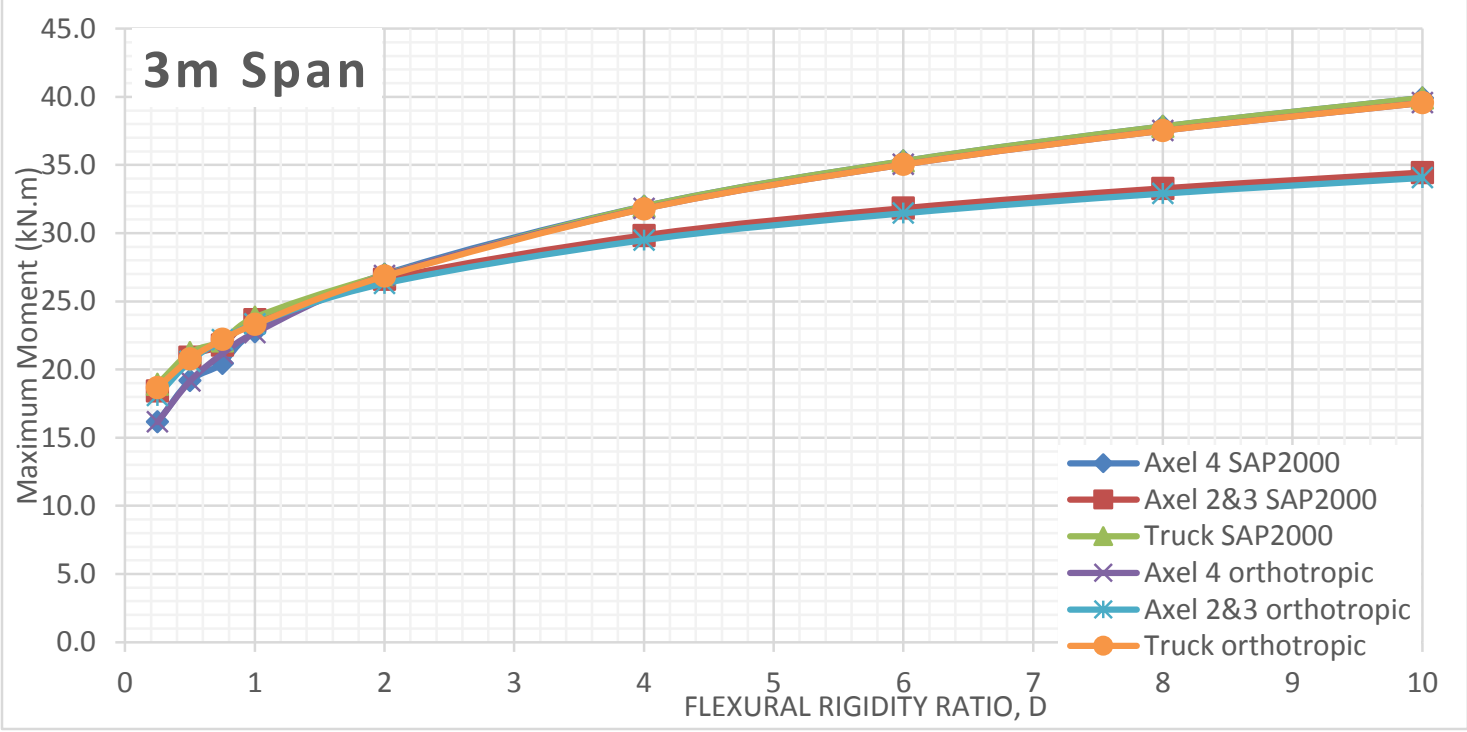

Figure 673 Moment comparison between FEA and Orthotropic Plate Theory for $3 \mathrm{~m}$ span of alpha 0.5 (main bars perpendicular to traffic) 


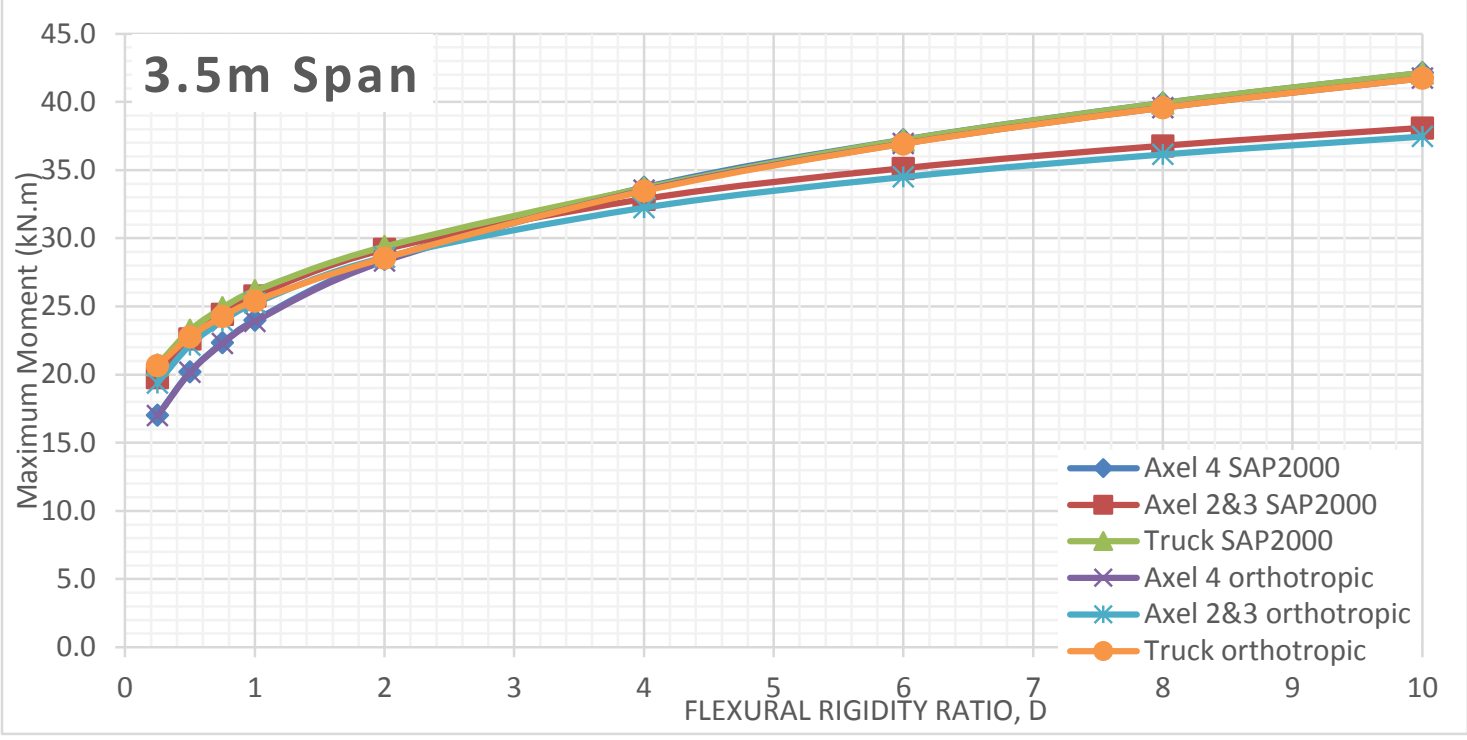

Figure 674 Moment comparison between FEA and Orthotropic Plate Theory for $3.5 \mathrm{~m}$ span of alpha 0.5 (main bars perpendicular to traffic)

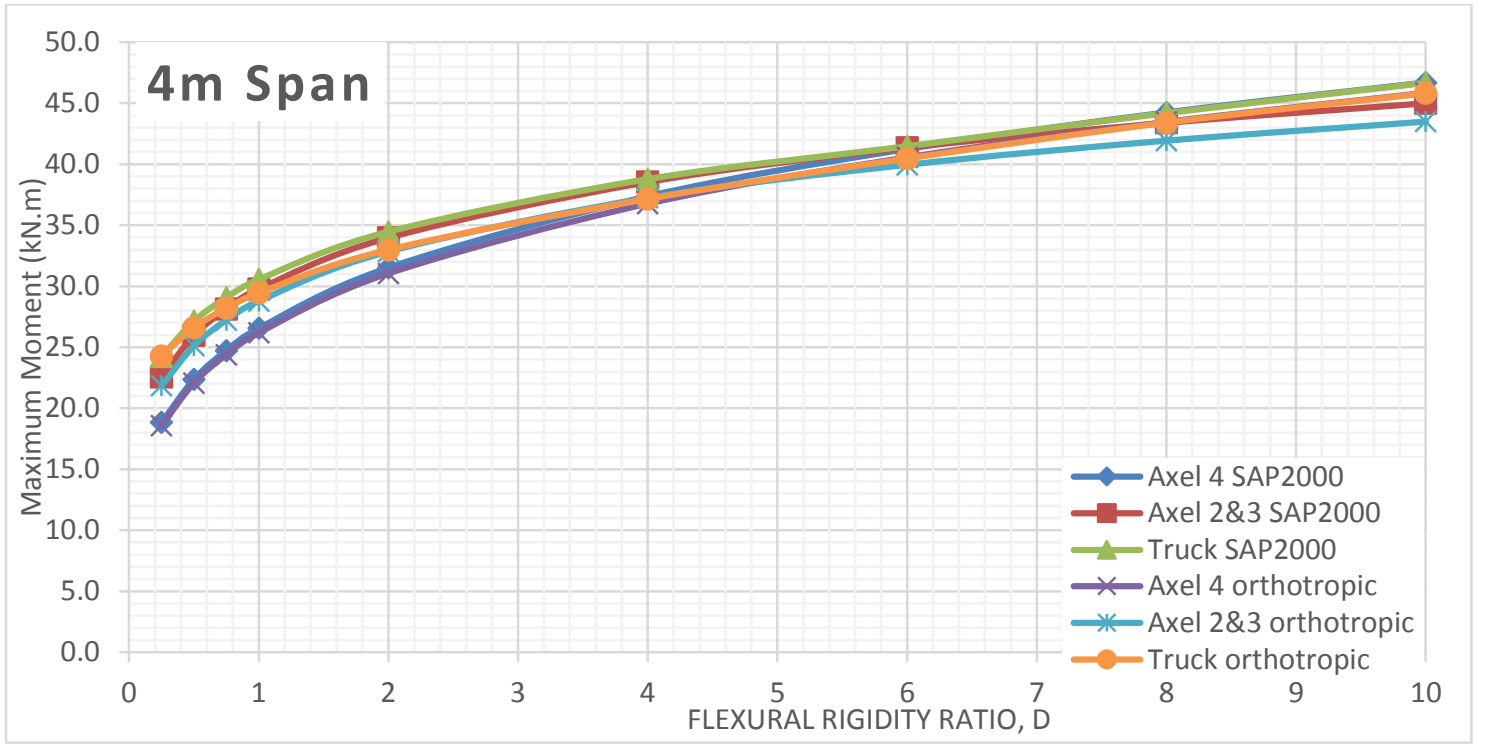

Figure 675 Moment comparison between FEA and Orthotropic Plate Theory for $4 \mathrm{~m}$ span of alpha 0.5 (main bars perpendicular to traffic) 


\section{Alpha 0.5 Bending Moment VS Flexural Rigidity for Different Span Length (Main bars parallel to traffic)}

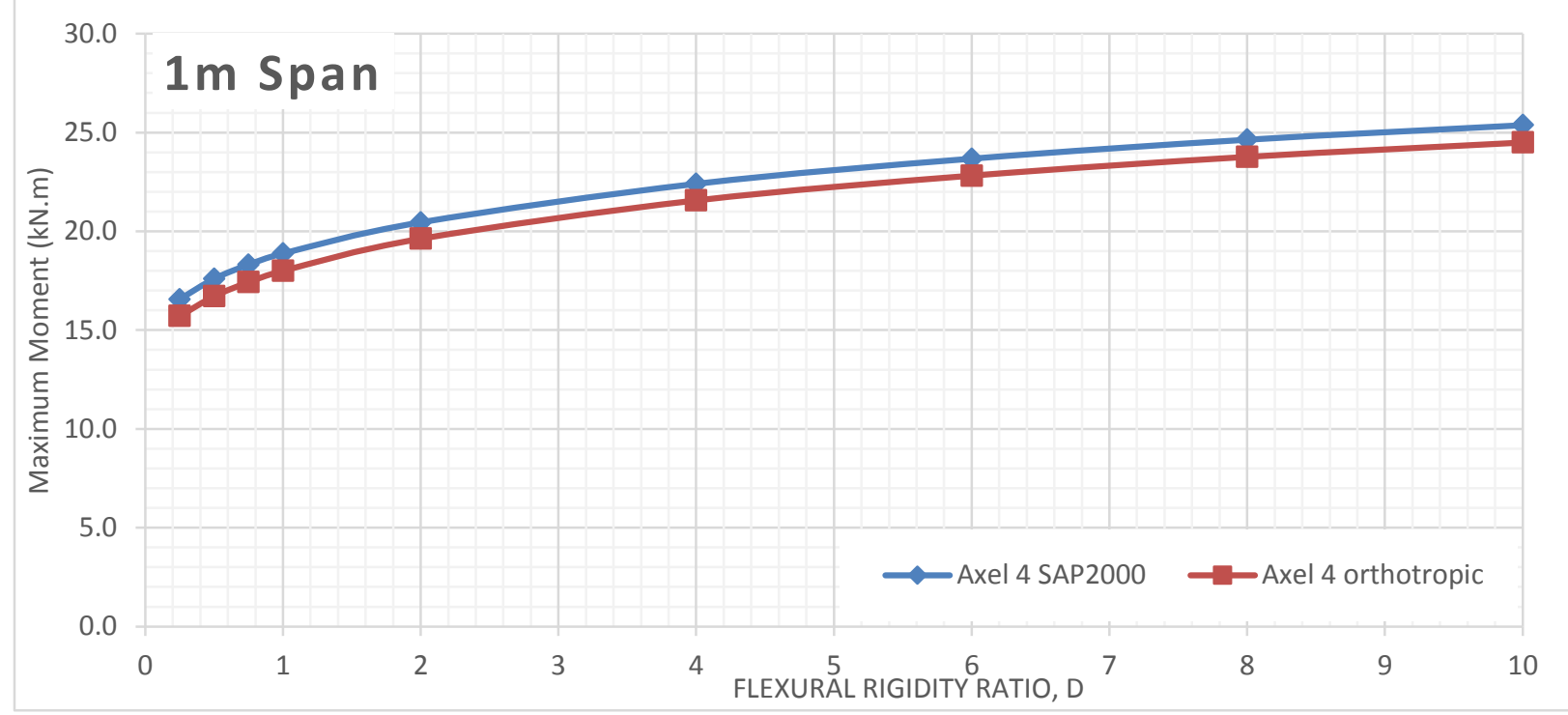

Figure 676 Moment comparison between FEA and Orthotropic Plate Theory for $1 \mathrm{~m}$ span of alpha 0.5 (main bars parallel to traffic)

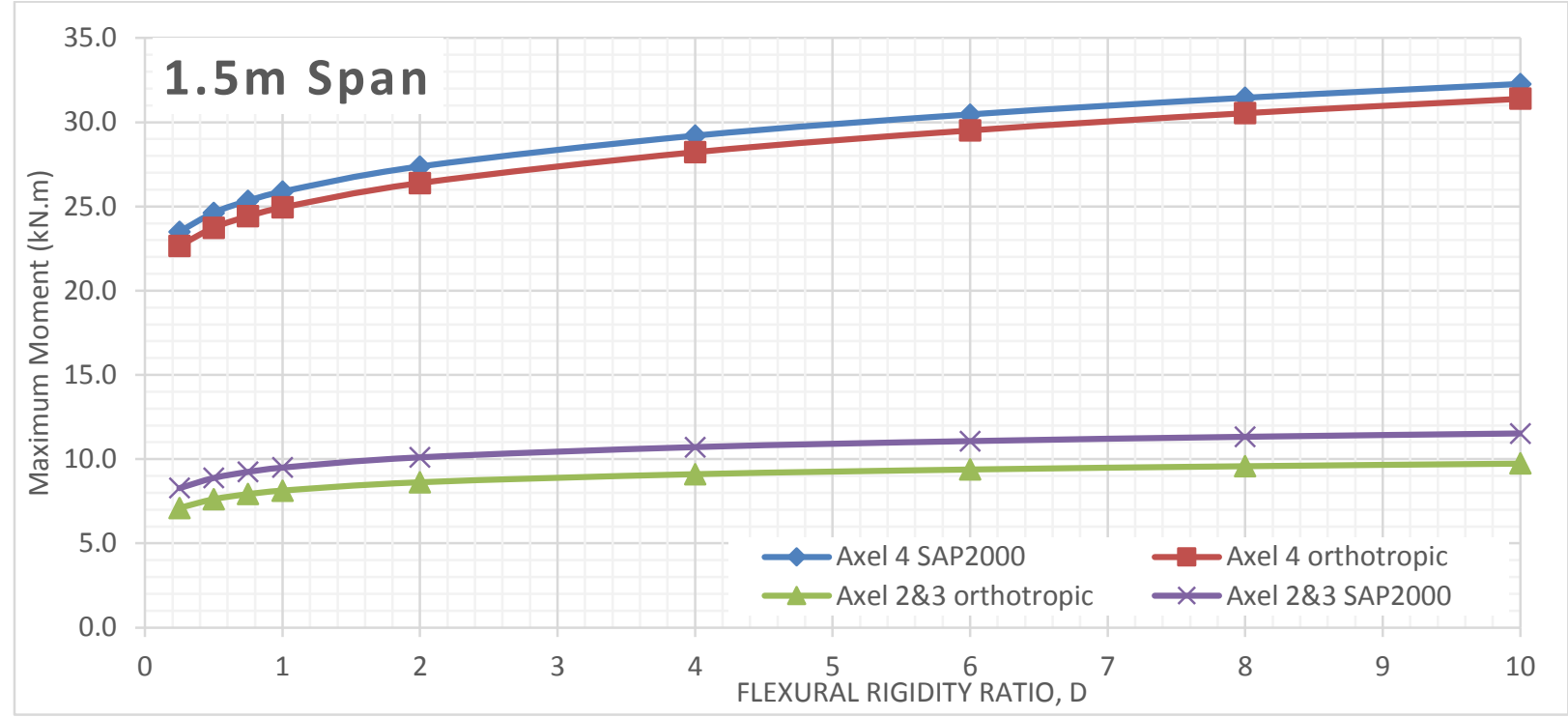

Figure 677 Moment comparison between FEA and Orthotropic Plate Theory for $1.5 \mathrm{~m}$ span of alpha 0.5 (main bars parallel to traffic) 


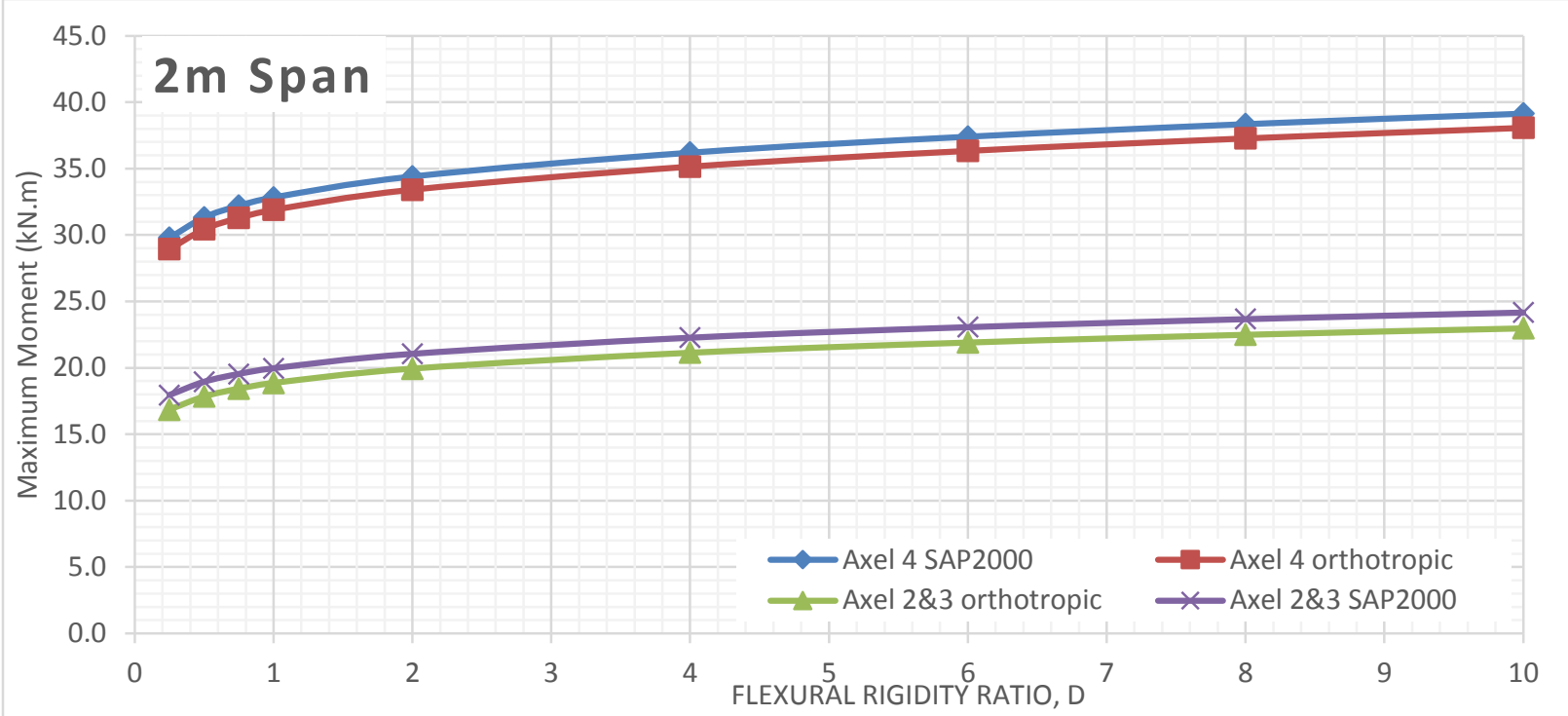

Figure 678 Moment comparison between FEA and Orthotropic Plate Theory for $2 \mathrm{~m}$ span of alpha 0.5 (main bars parallel to traffic)

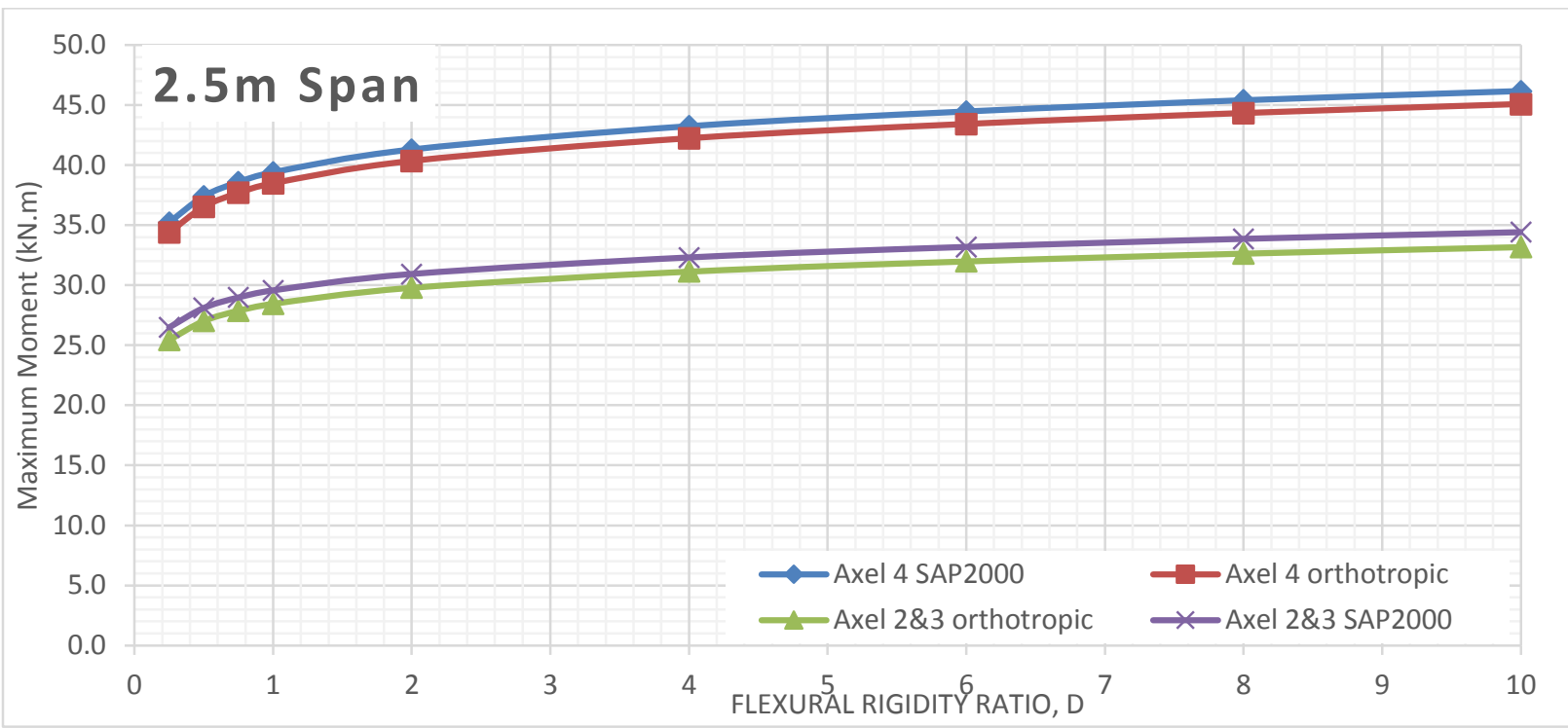

Figure 679 Moment comparison between FEA and Orthotropic Plate Theory for $2.5 \mathrm{~m}$ span of alpha 0.5 (main bars parallel to traffic)

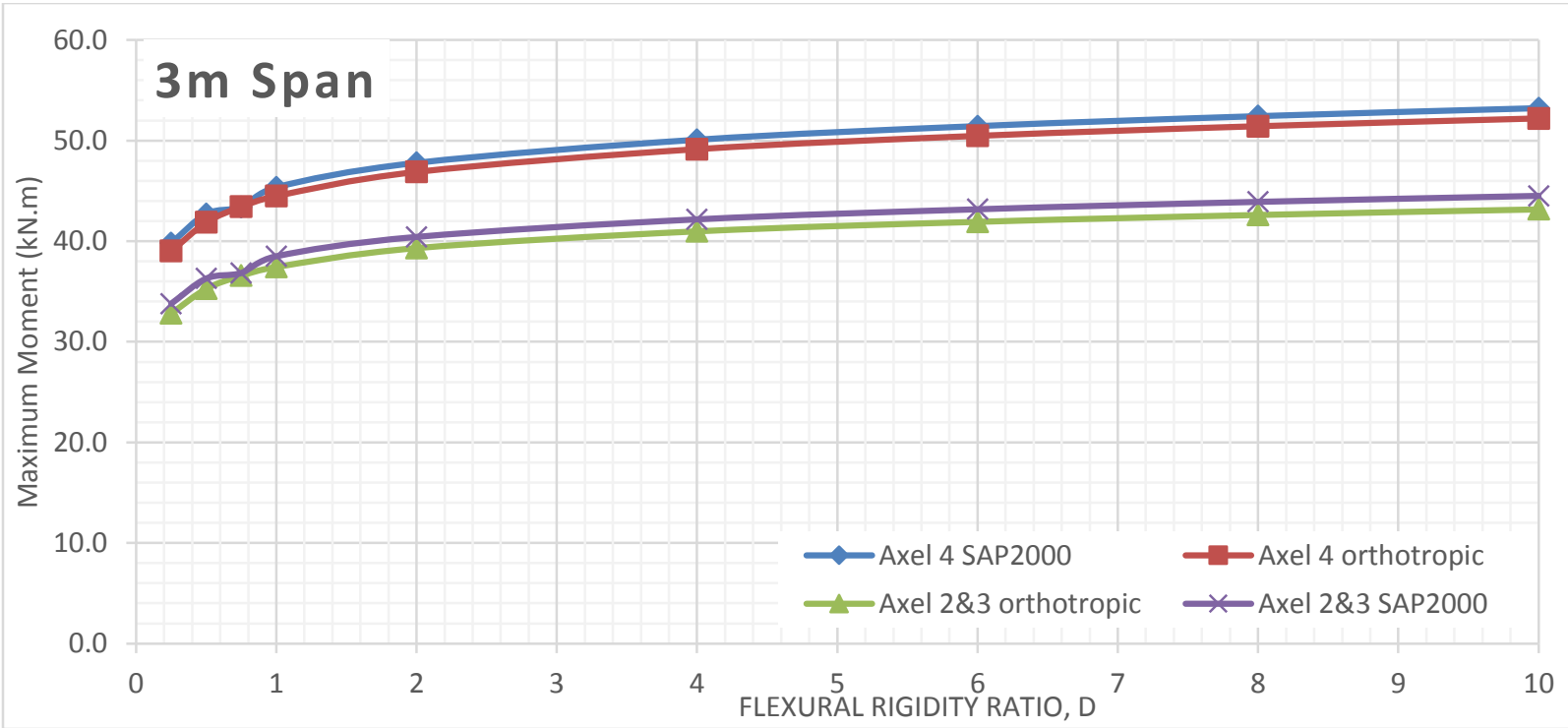

Figure 680 Moment comparison between FEA and Orthotropic Plate Theory for $3 \mathrm{~m}$ span of alpha 0.5 (main bars parallel to traffic) 


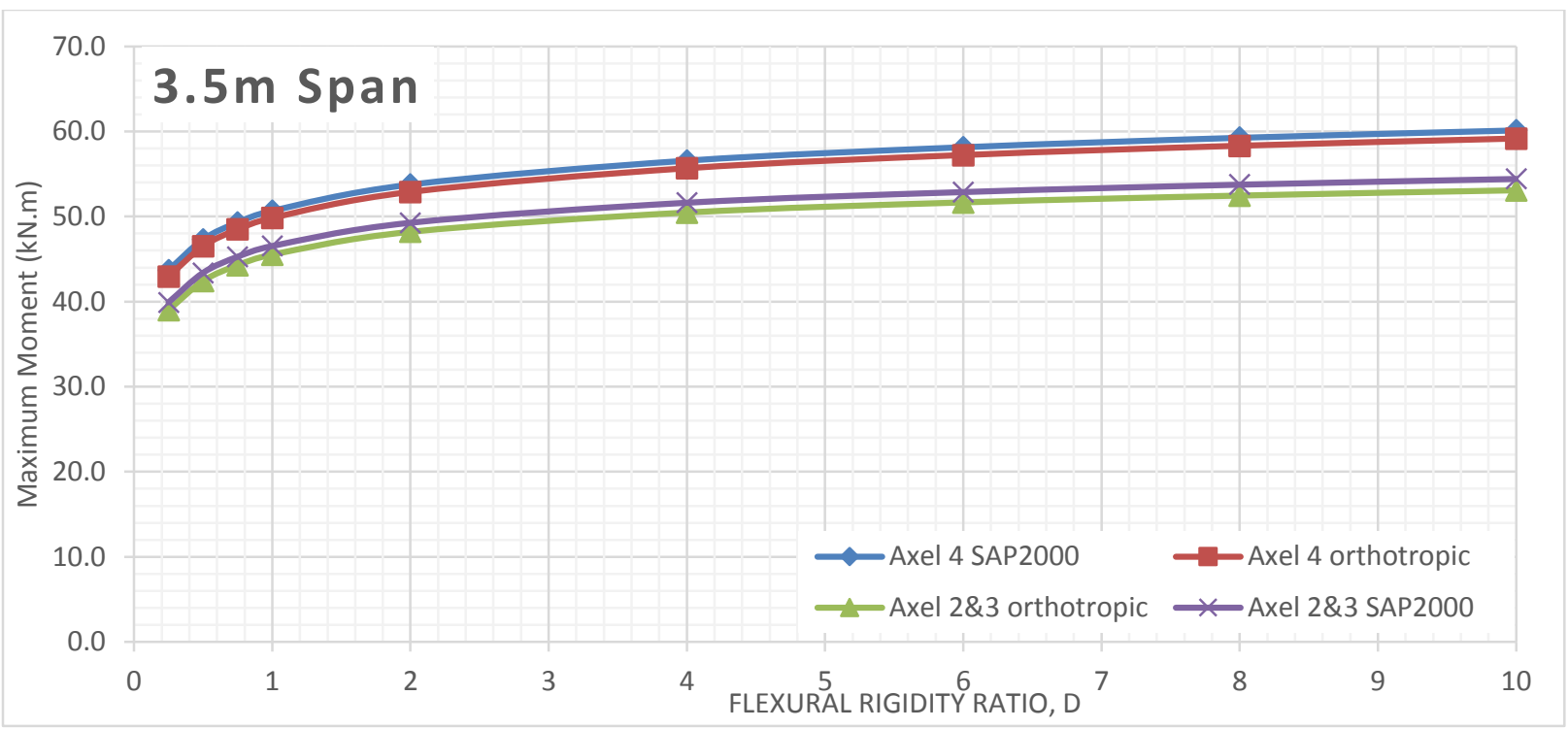

Figure 681 Moment comparison between FEA and Orthotropic Plate Theory for $3.5 \mathrm{~m}$ span of alpha 0.5 (main bars parallel to traffic)

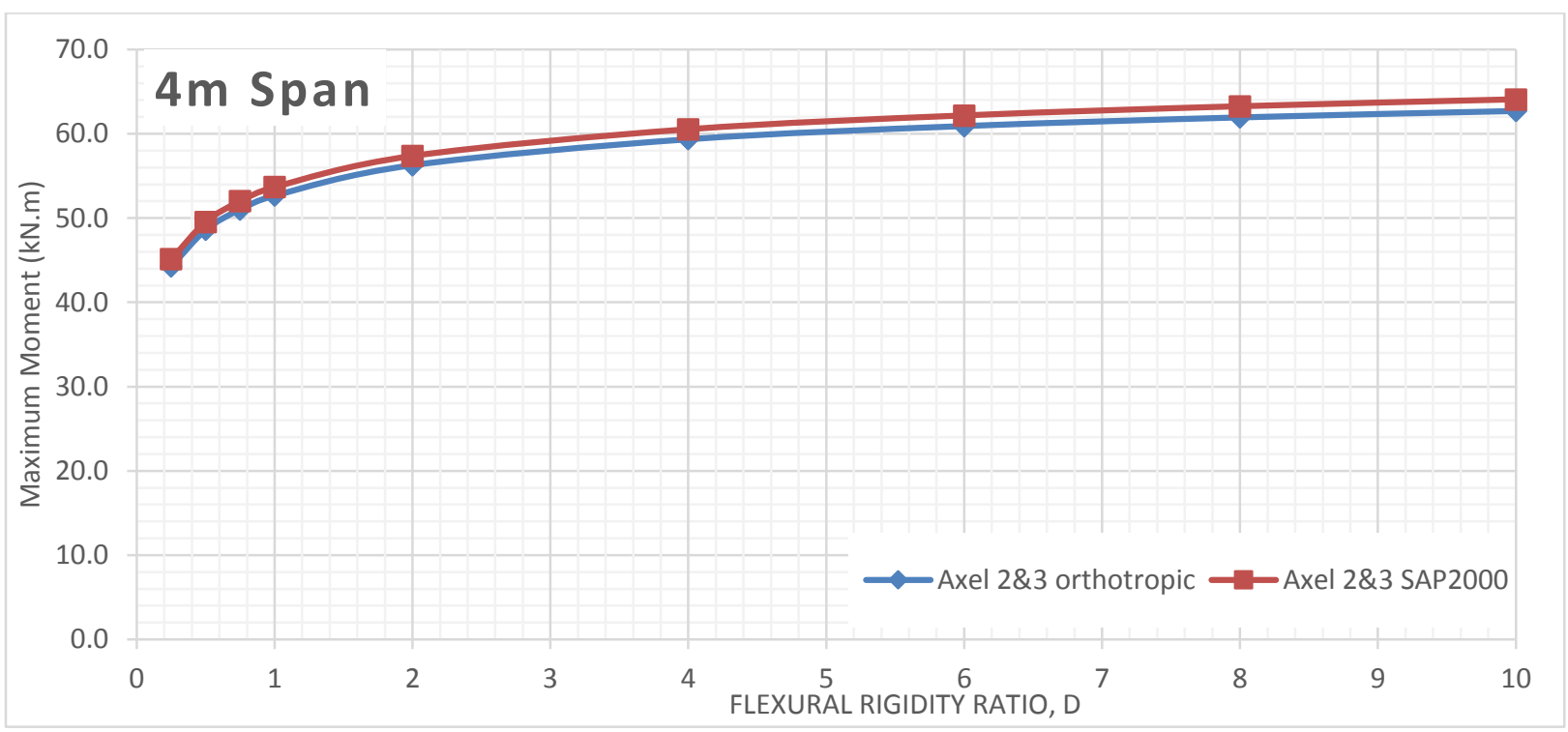

Figure 682 Moment comparison between FEA and Orthotropic Plate Theory for $4 \mathrm{~m}$ span of alpha 0.5 (main bars parallel to traffic) 


\section{Alpha 0.75 Bending Moment VS Flexural Rigidity for Different Span Length (Main bars perpendicular to traffic)}

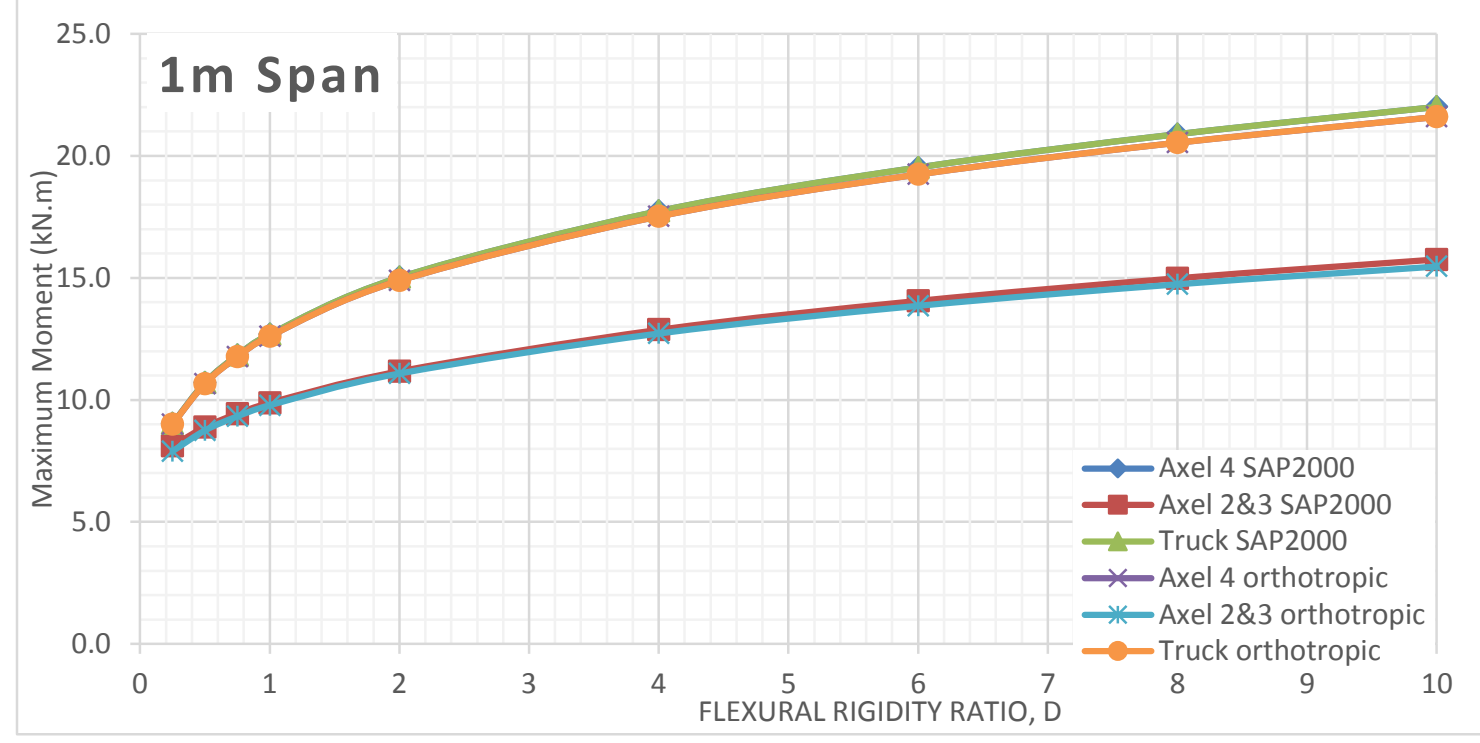

Figure 683 Moment comparison between FEA and Orthotropic Plate Theory for $1 \mathrm{~m}$ span of alpha 0.75 (main bars perpendicular to traffic)

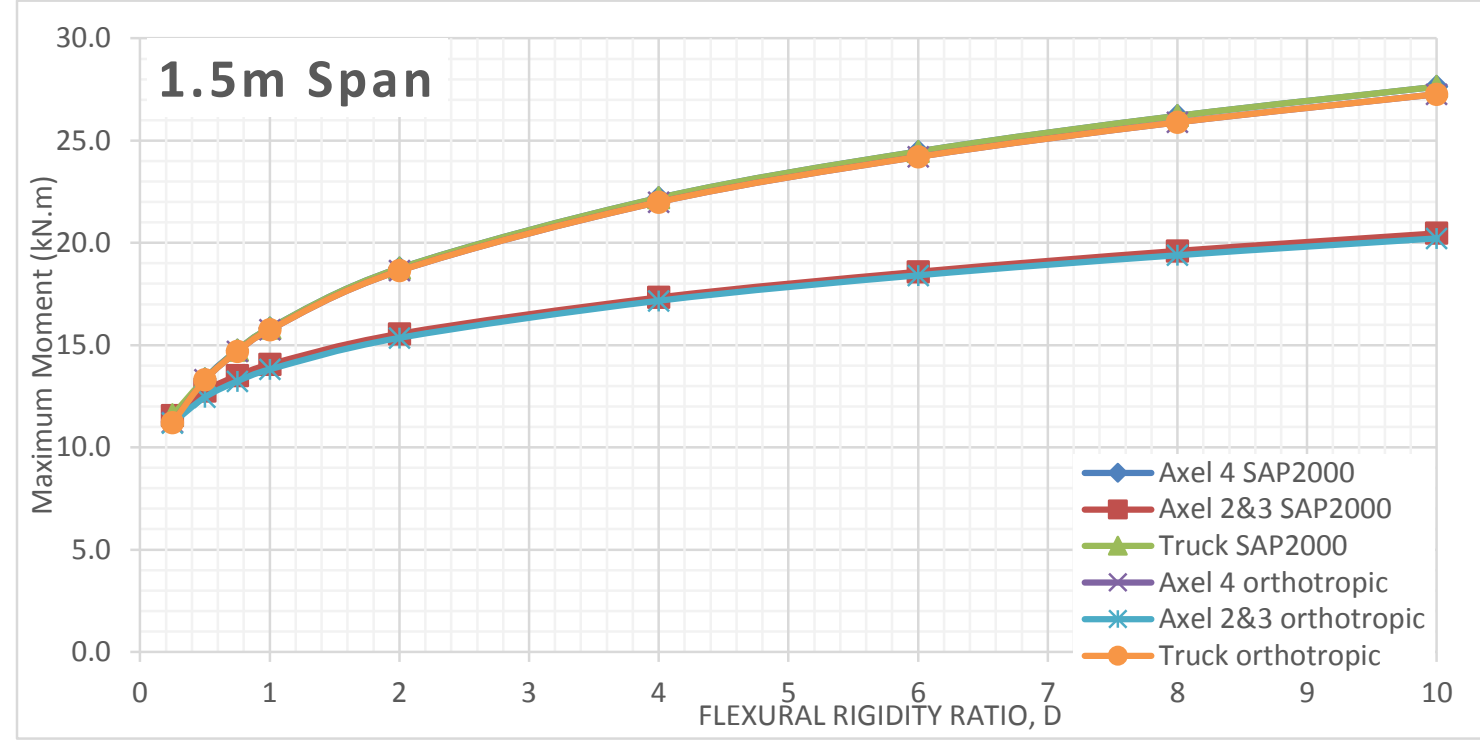

Figure 684 Moment comparison between FEA and Orthotropic Plate Theory for $1.5 \mathrm{~m}$ span of alpha 0.75 (main bars perpendicular to traffic) 


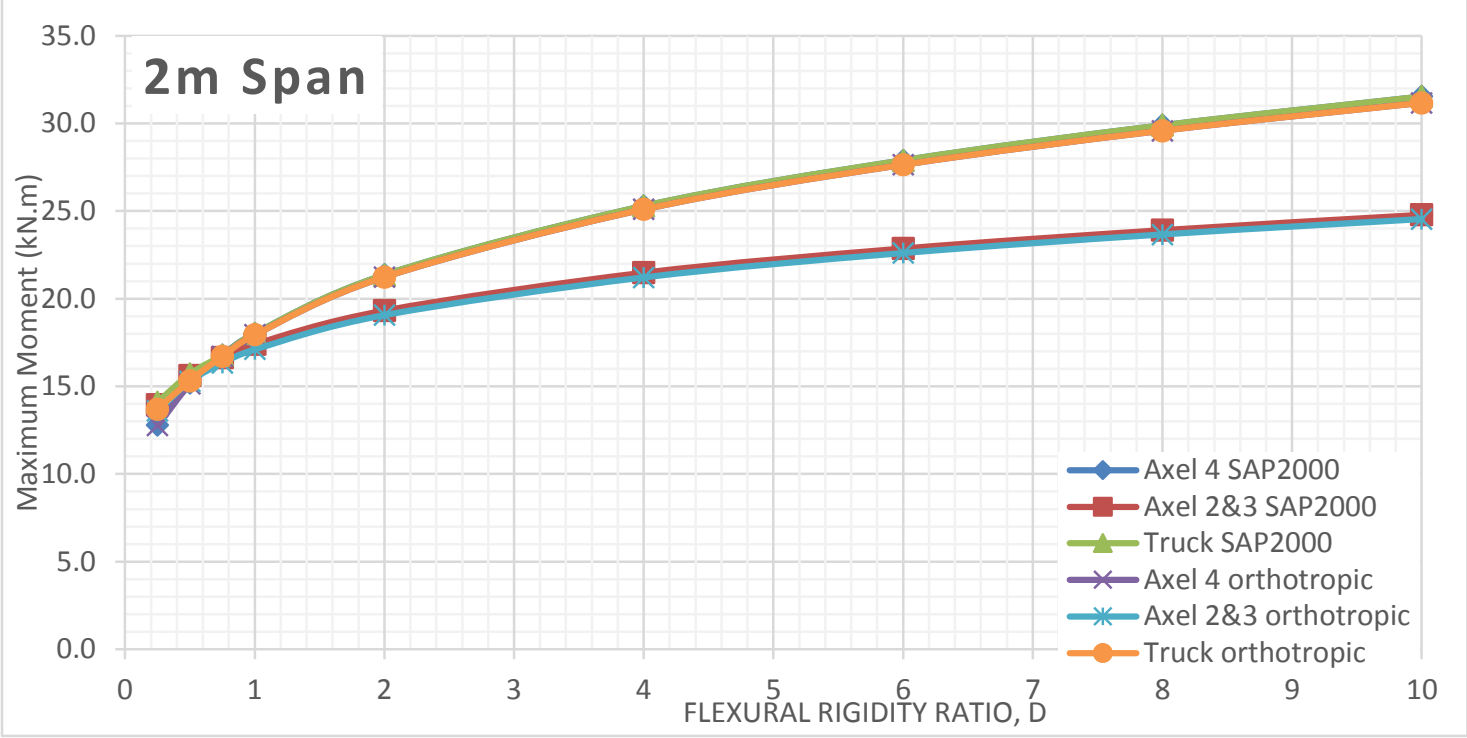

Figure 685 Moment comparison between FEA and Orthotropic Plate Theory for $2 \mathrm{~m}$ span of alpha 0.75 (main bars perpendicular to traffic)

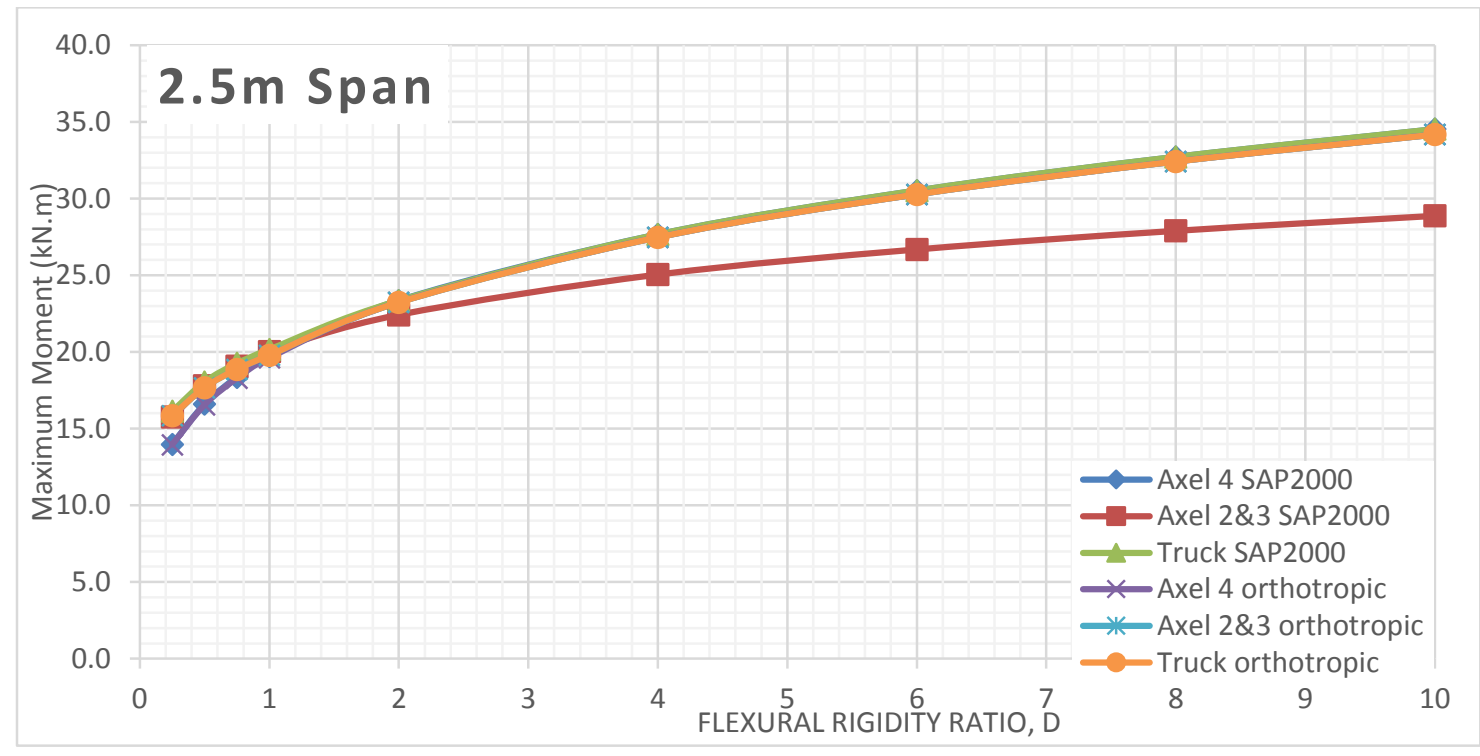

Figure 686 Moment comparison between FEA and Orthotropic Plate Theory for $2.5 \mathrm{~m}$ span of alpha 0.75 (main bars perpendicular to traffic)

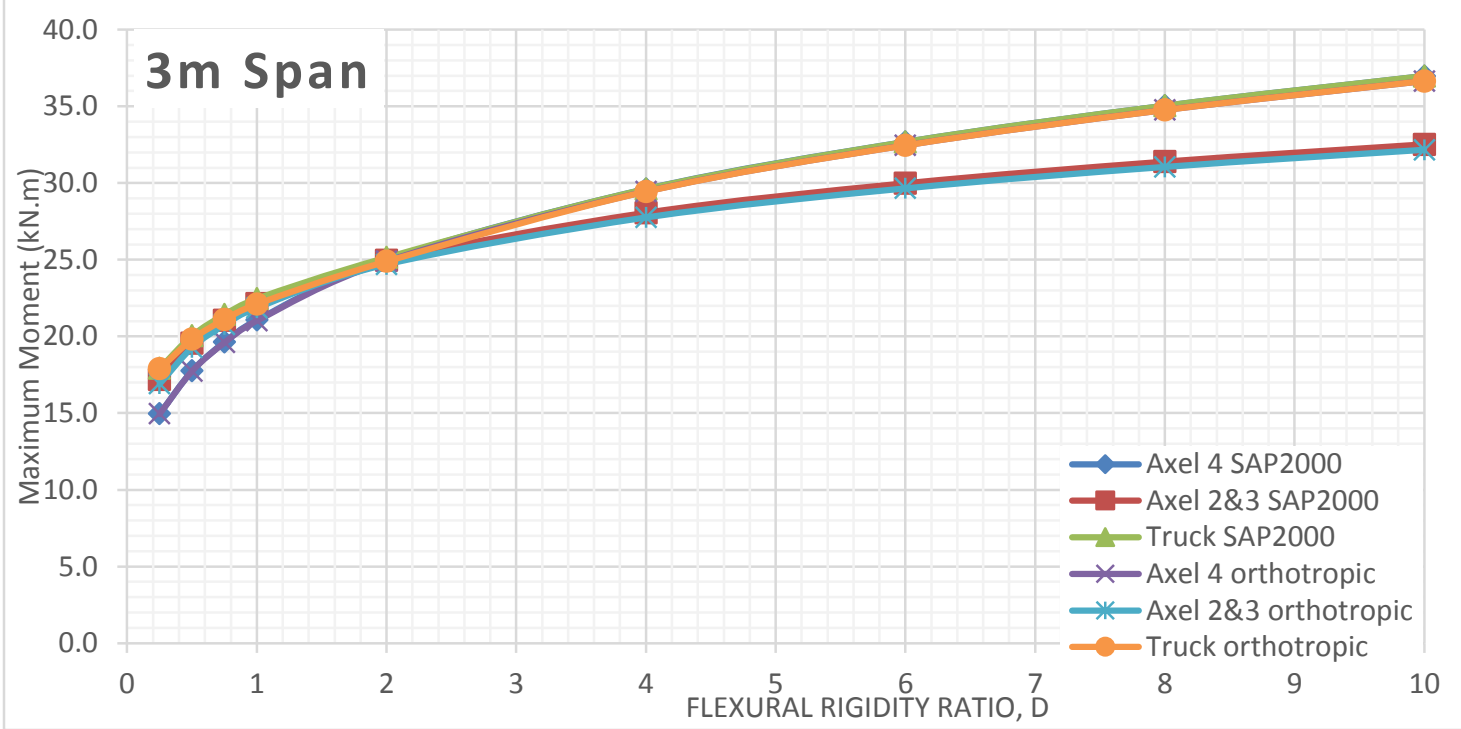

Figure 687 Moment comparison between FEA and Orthotropic Plate Theory for $3 \mathrm{~m}$ span of alpha 0.75 (main bars perpendicular to traffic) 


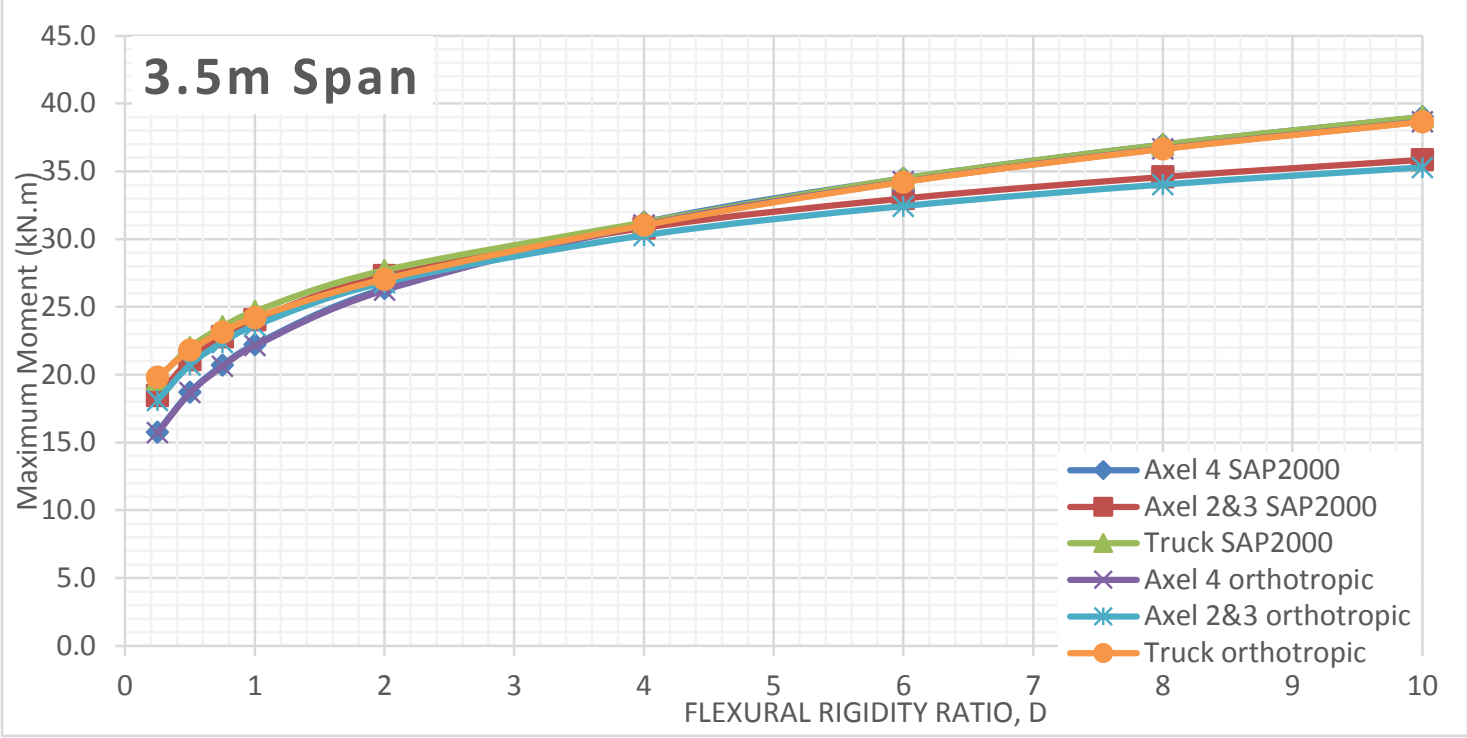

Figure 688 Moment comparison between FEA and Orthotropic Plate Theory for $3.5 \mathrm{~m}$ span of alpha 0.75 (main bars perpendicular to traffic)

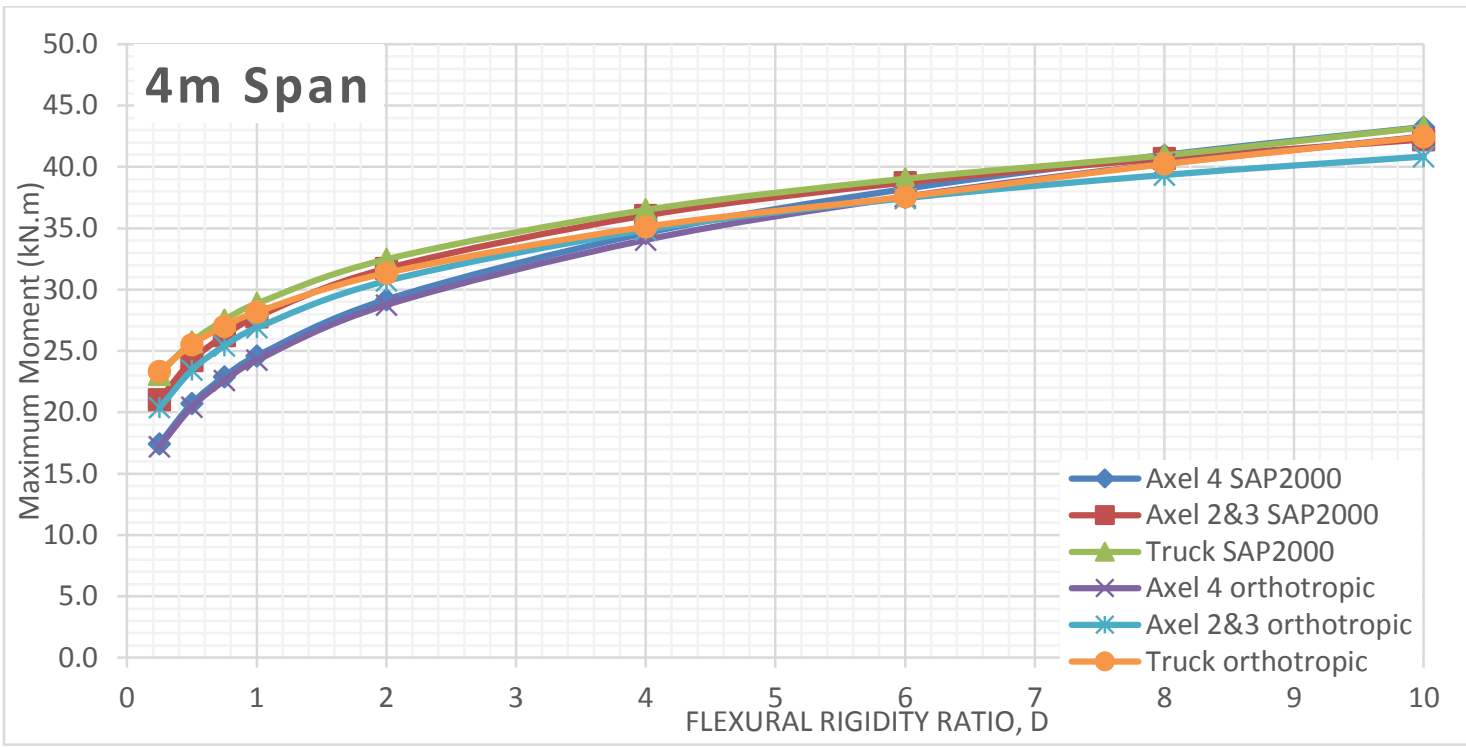

Figure 689 Moment comparison between FEA and Orthotropic Plate Theory for $4 \mathrm{~m}$ span of alpha 0.75 (main bars perpendicular to traffic) 


\section{Alpha 0.75 Bending Moment VS Flexural Rigidity for Different Span Length (Main bars parallel to traffic)}

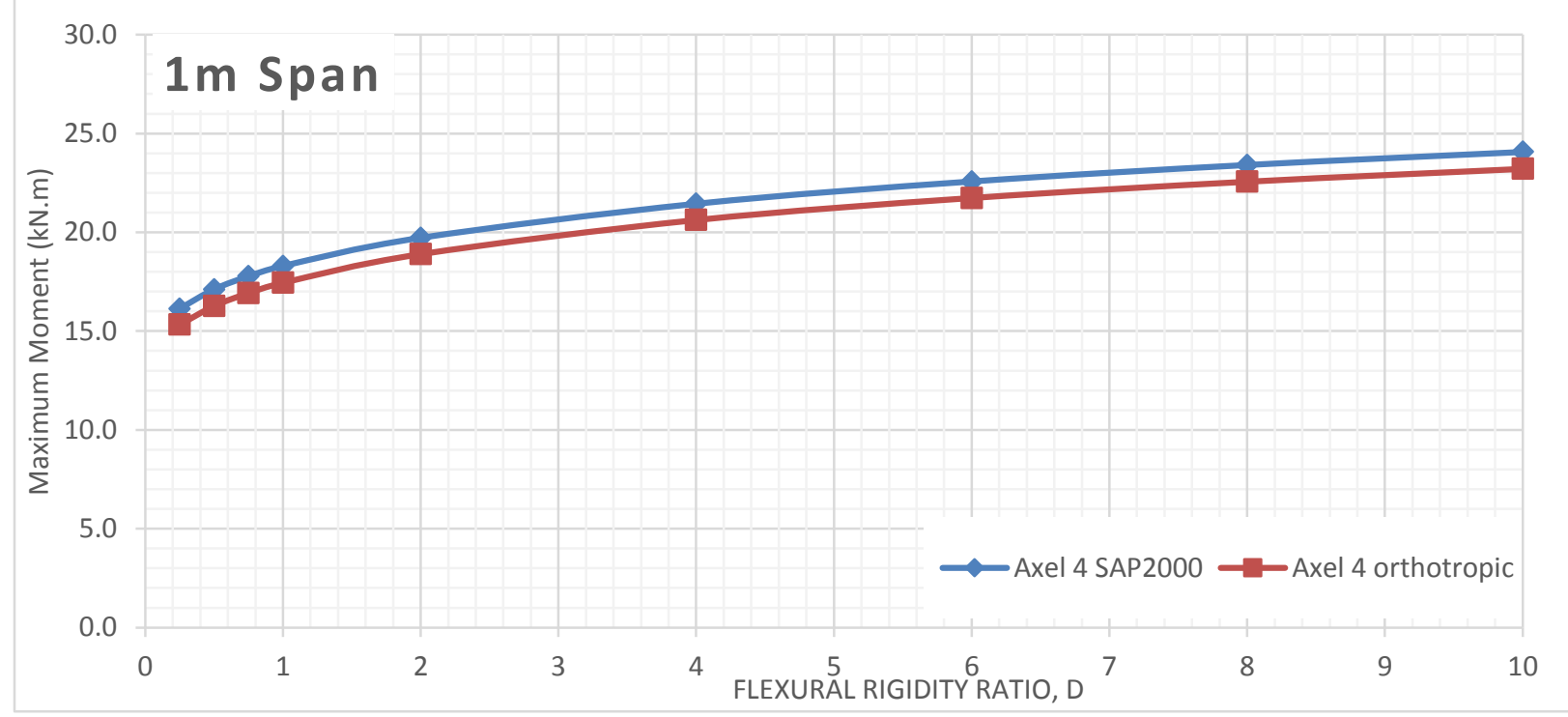

Figure 690 Moment comparison between FEA and Orthotropic Plate Theory for $1 \mathrm{~m}$ span of alpha 0.75 (main bars parallel to traffic)

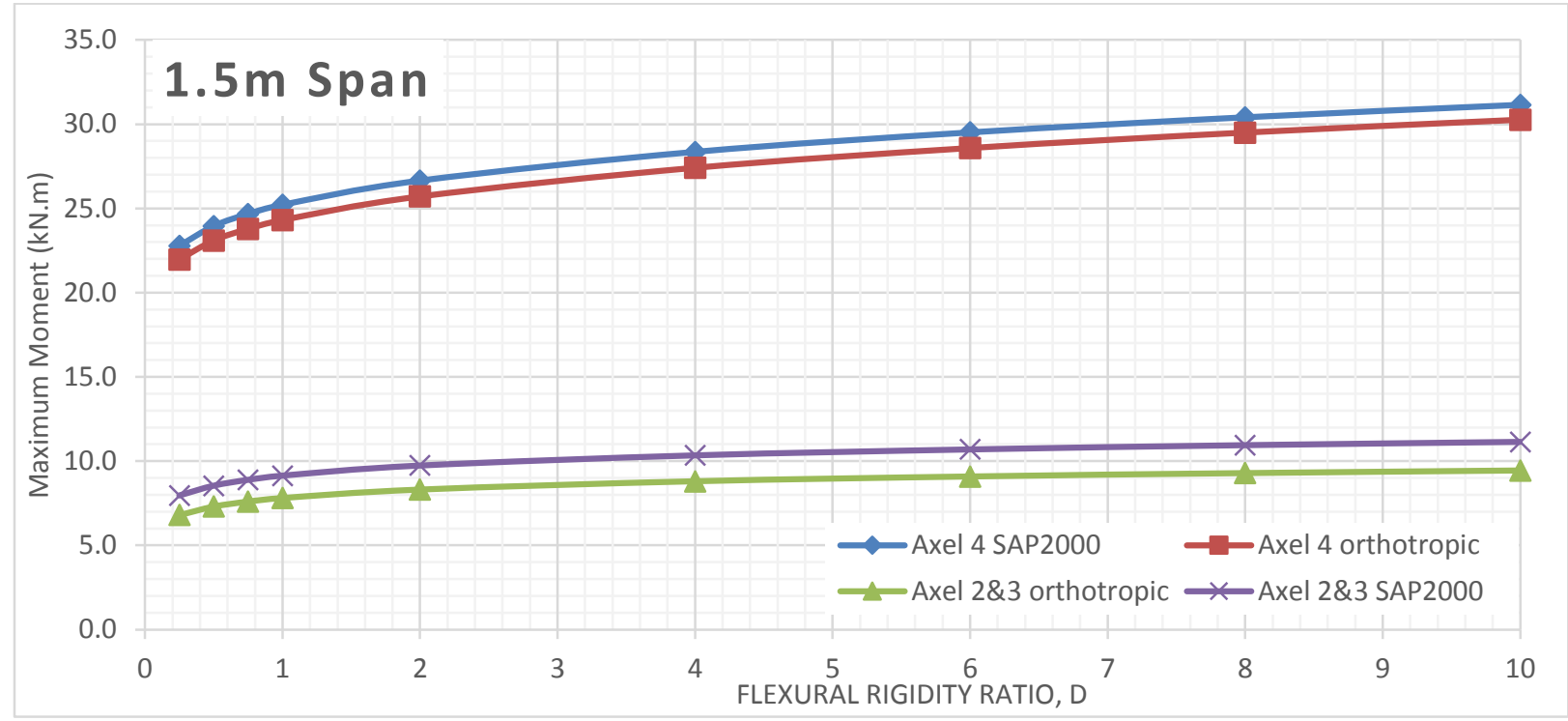

Figure 691 Moment comparison between FEA and Orthotropic Plate Theory for $1.5 \mathrm{~m}$ span of alpha 0.75 (main bars parallel to traffic) 


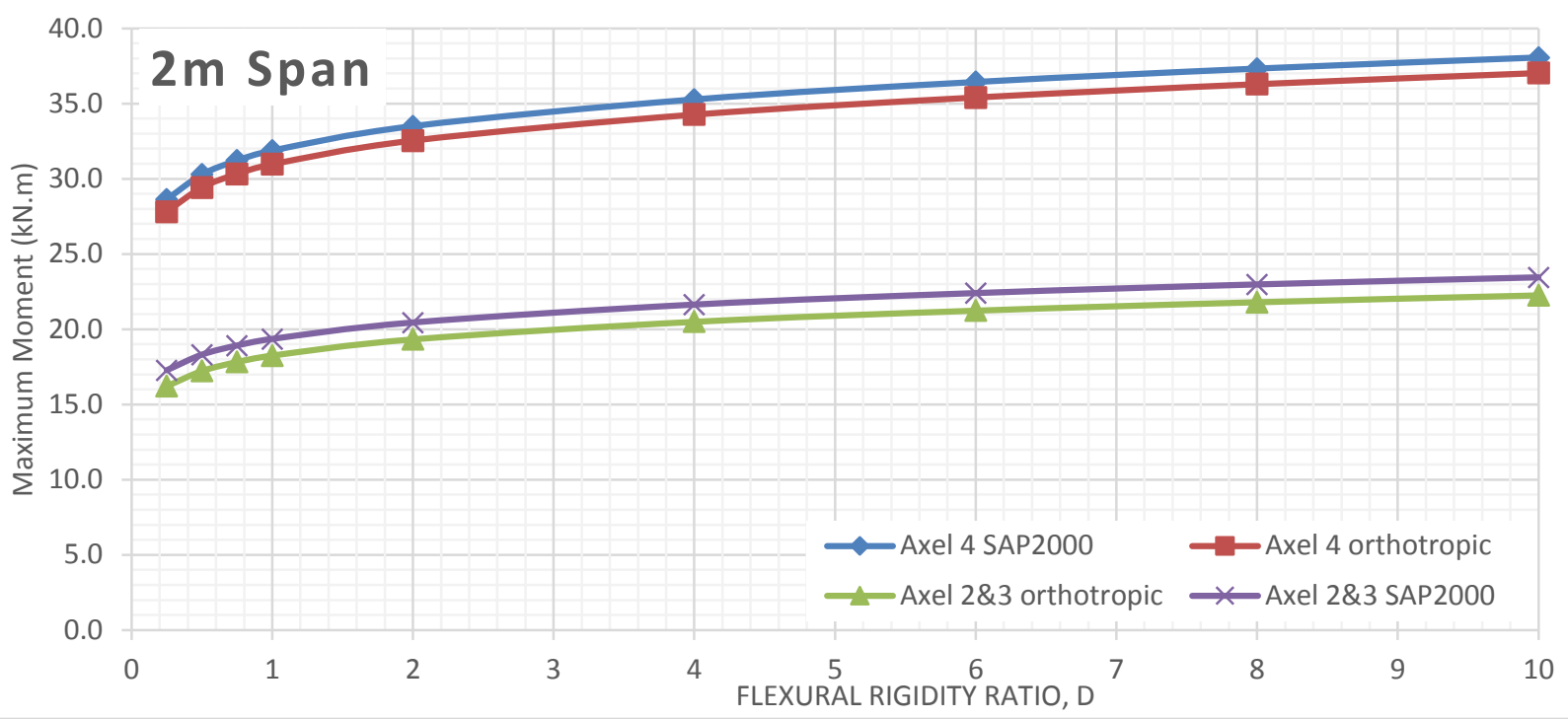

Figure 692 Moment comparison between FEA and Orthotropic Plate Theory for $2 \mathrm{~m}$ span of alpha 0.75 (main bars parallel to traffic)

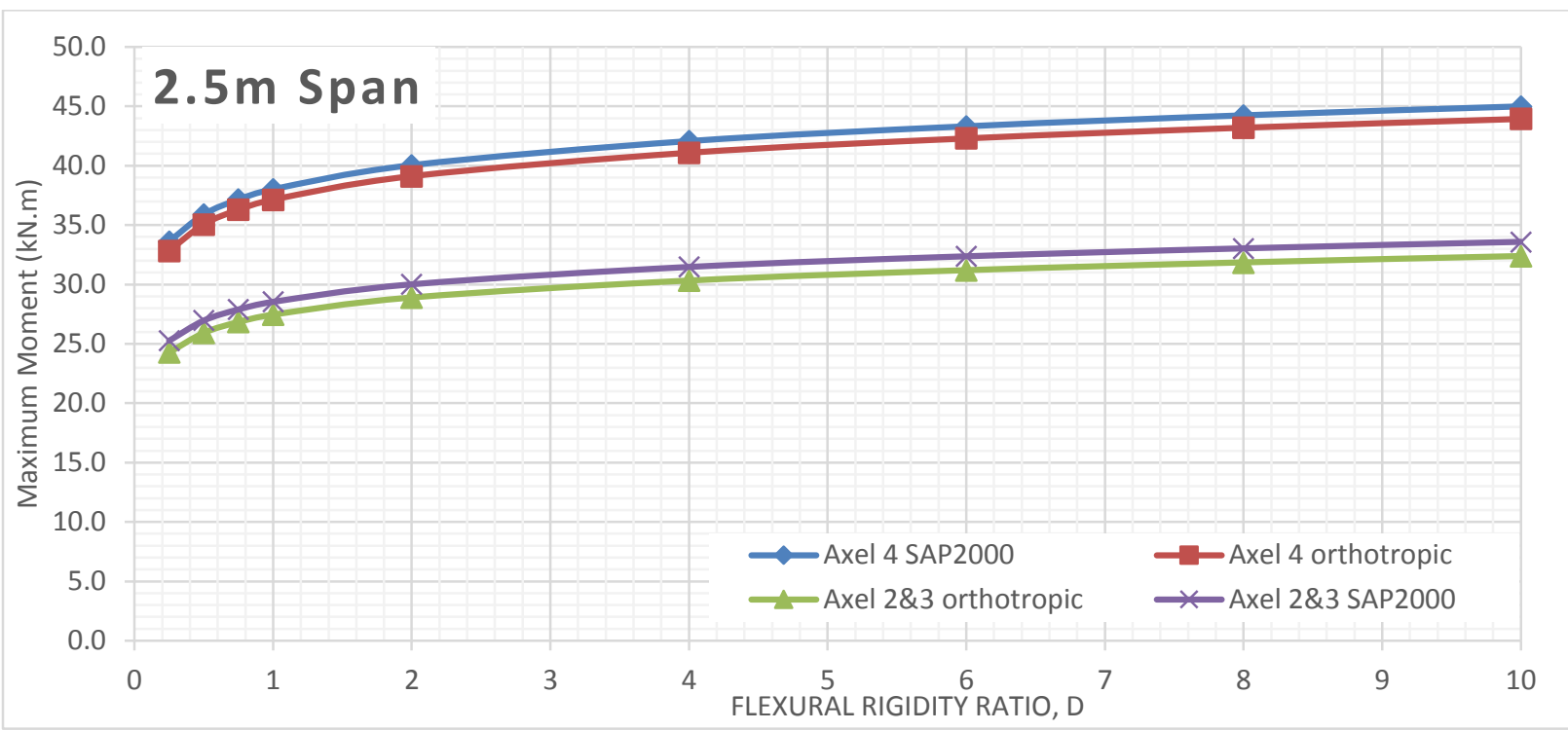

Figure 693 Moment comparison between FEA and Orthotropic Plate Theory for $2.5 \mathrm{~m}$ span of alpha 0.75 (main bars parallel to traffic)

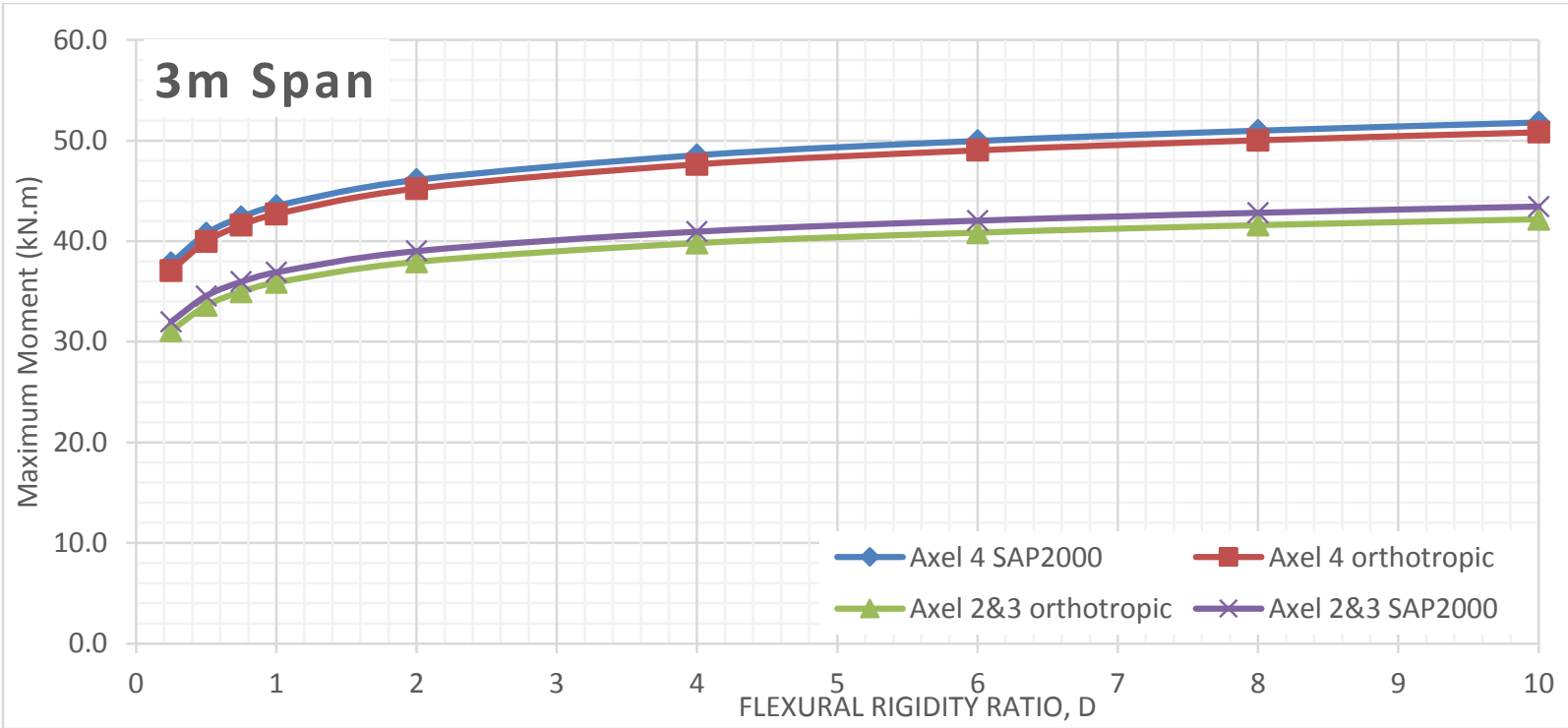

Figure 694 Moment comparison between FEA and Orthotropic Plate Theory for $3 \mathrm{~m}$ span of alpha 0.75 (main bars parallel to traffic) 


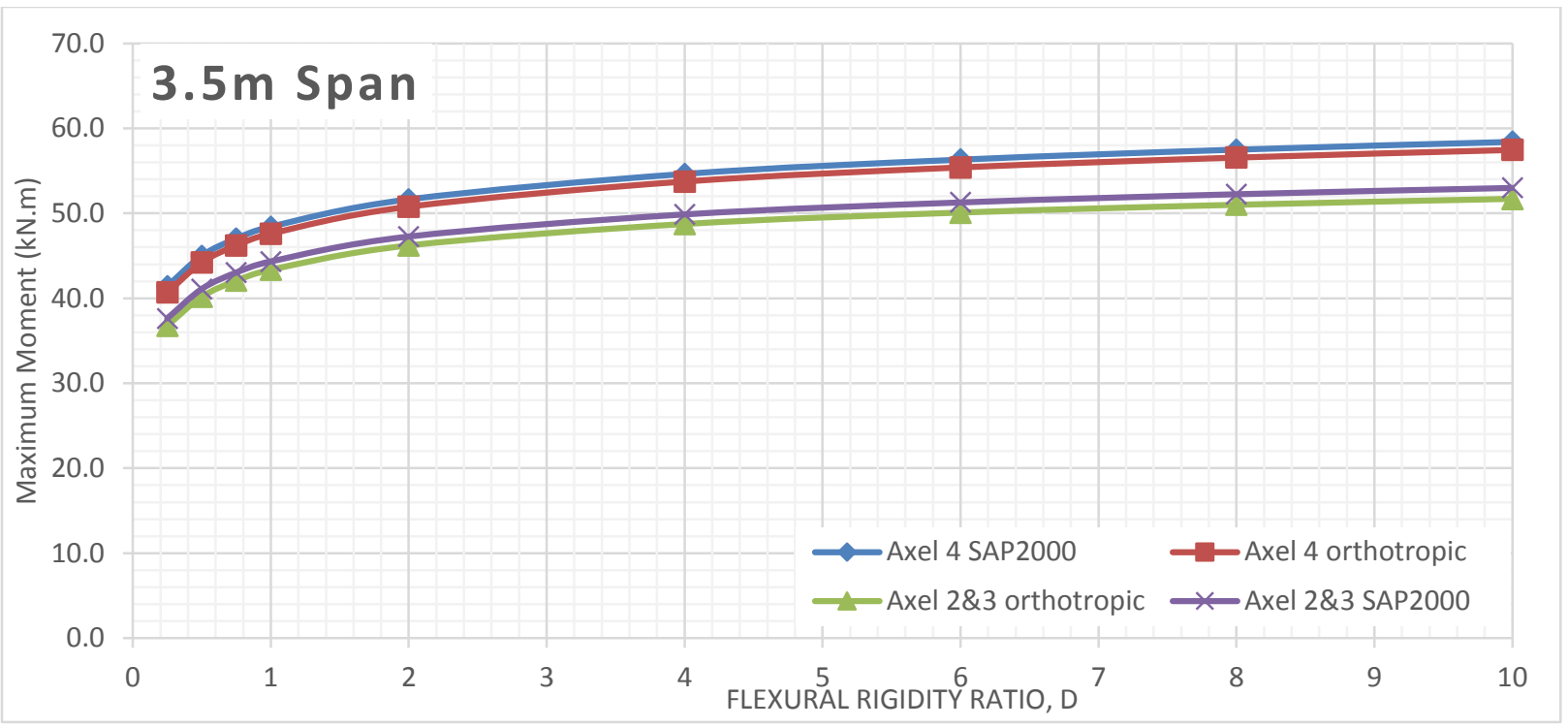

Figure 695 Moment comparison between FEA and Orthotropic Plate Theory for $3.5 \mathrm{~m}$ span of alpha 0.75 (main bars parallel to traffic)

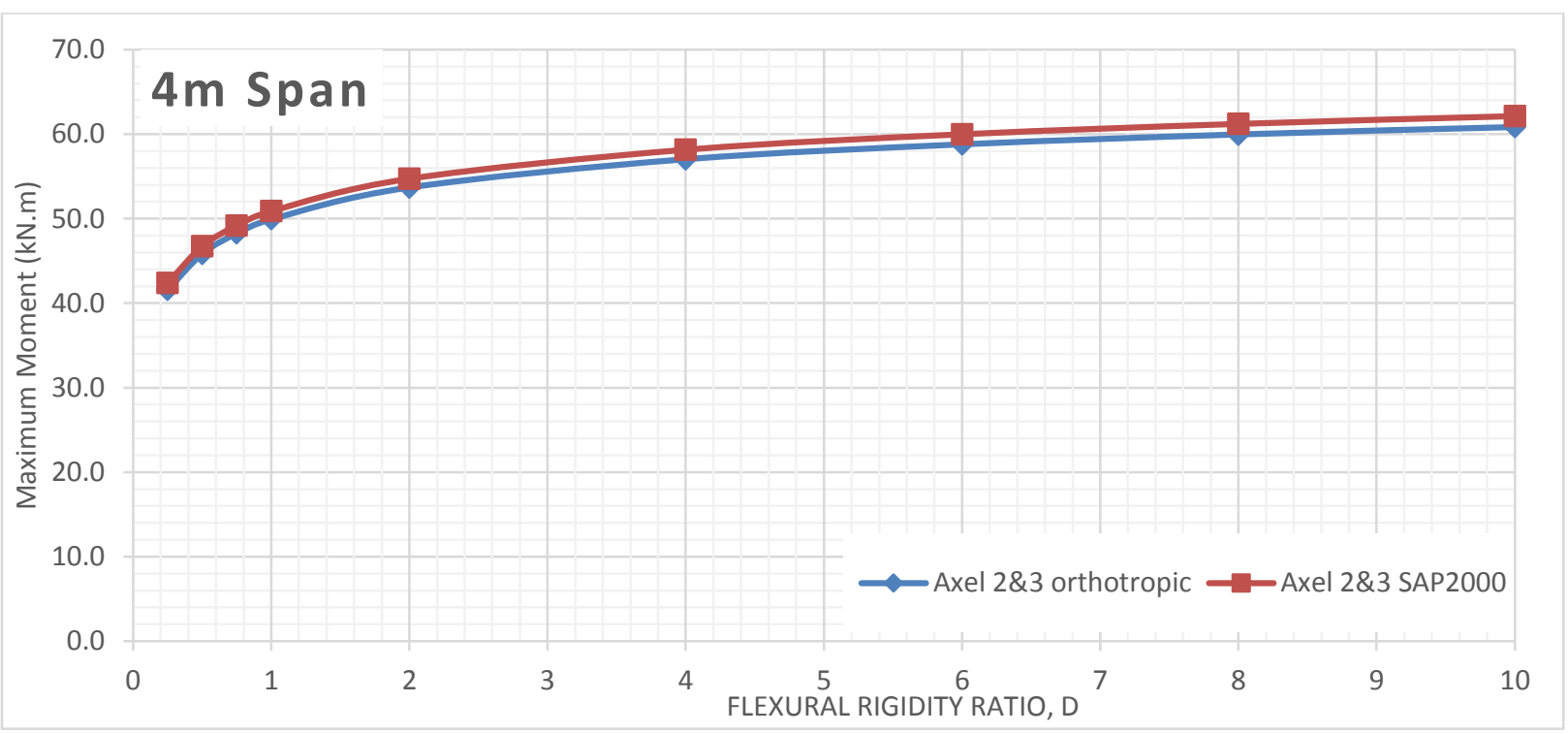

Figure 696 Moment comparison between FEA and Orthotropic Plate Theory for $4 \mathrm{~m}$ span of alpha 0.75 (main bars parallel to traffic) 


\section{Alpha 1 Bending Moment VS Flexural Rigidity for Different Span Length (Main bars perpendicular to traffic)}

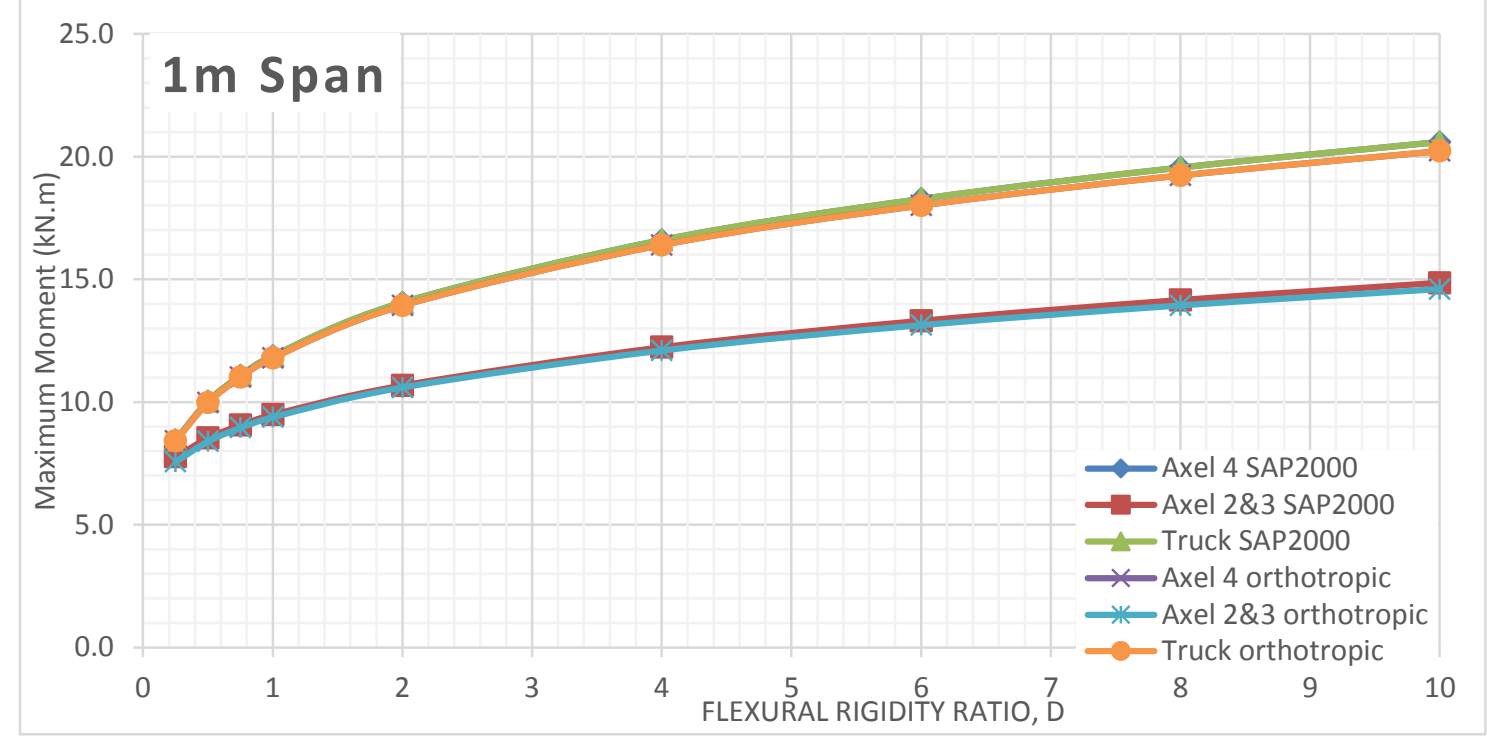

Figure 697 Moment comparison between FEA and Orthotropic Plate Theory for $1 \mathrm{~m}$ span of alpha 1 (main bars perpendicular to traffic)

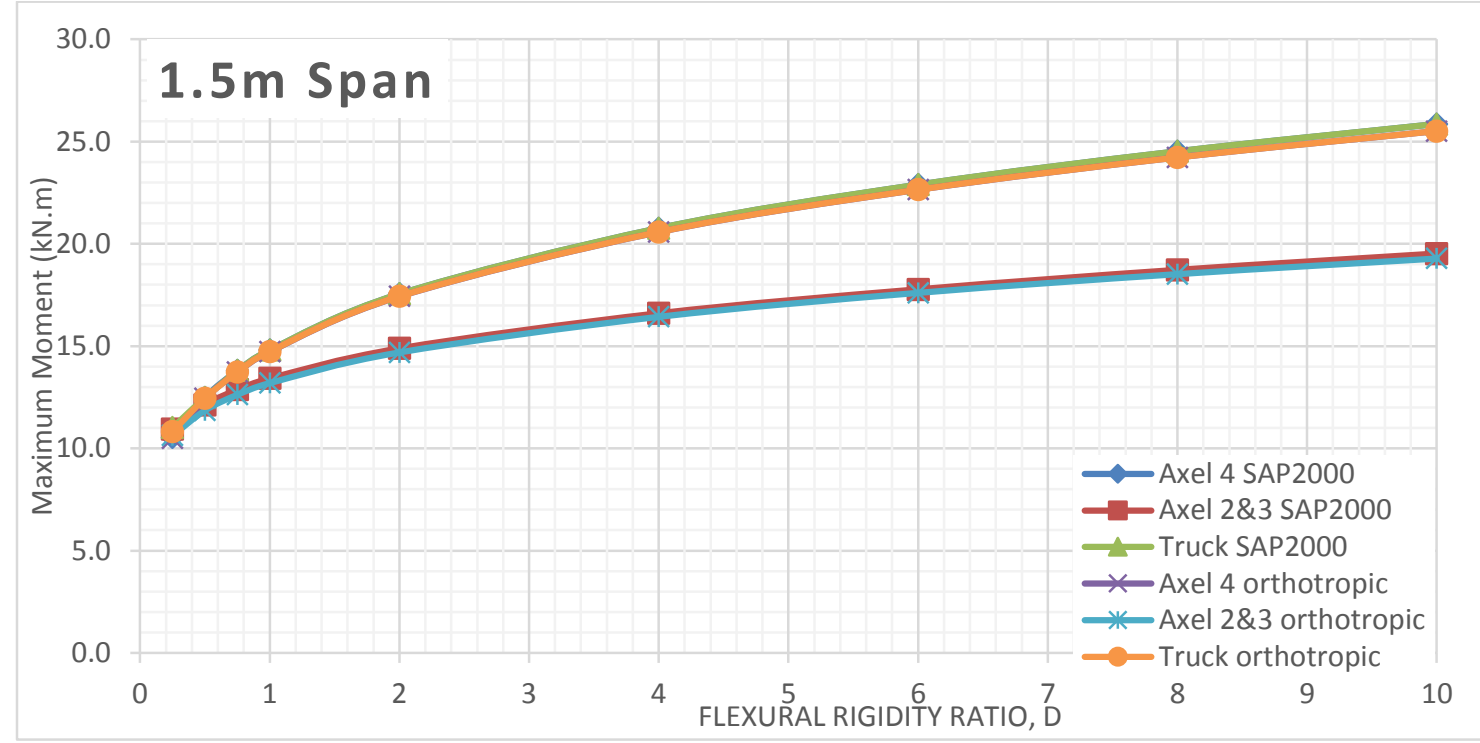

Figure 698 Moment comparison between FEA and Orthotropic Plate Theory for $1.5 \mathrm{~m}$ span of alpha 1 (main bars perpendicular to traffic) 


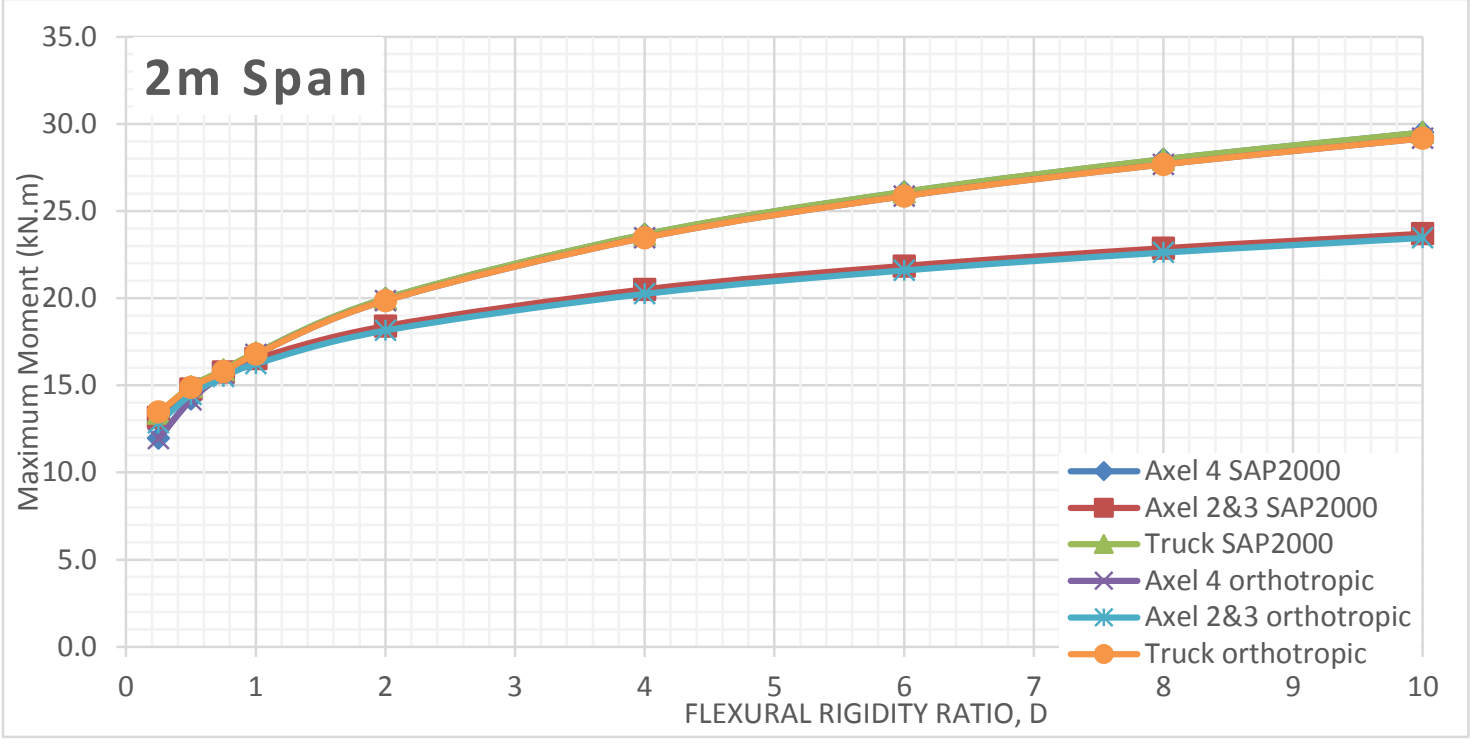

Figure 699 Moment comparison between FEA and Orthotropic Plate Theory for $2 \mathrm{~m}$ span of alpha 1 (main bars perpendicular to traffic)

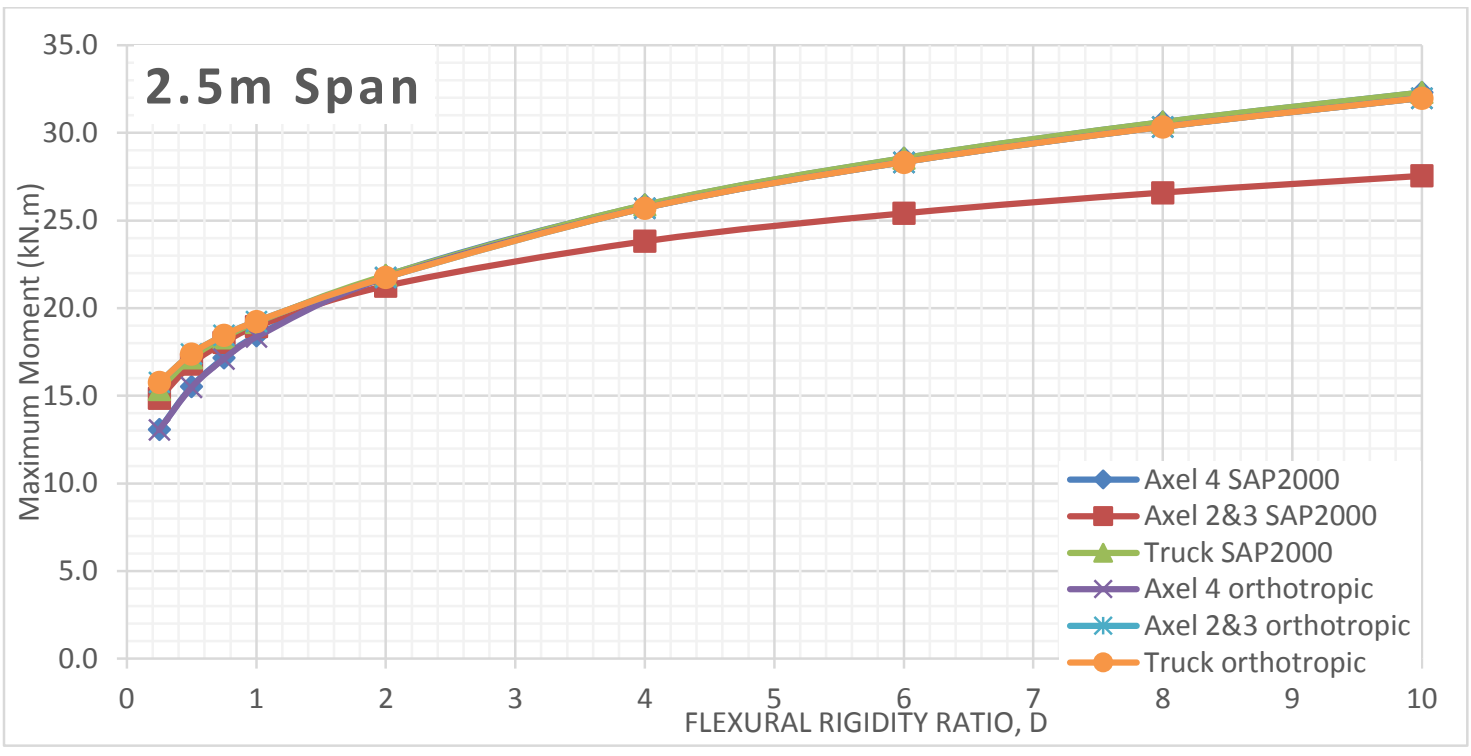

Figure 700 Moment comparison between FEA and Orthotropic Plate Theory for $2.5 \mathrm{~m}$ span of alpha 1 (main bars perpendicular to traffic)

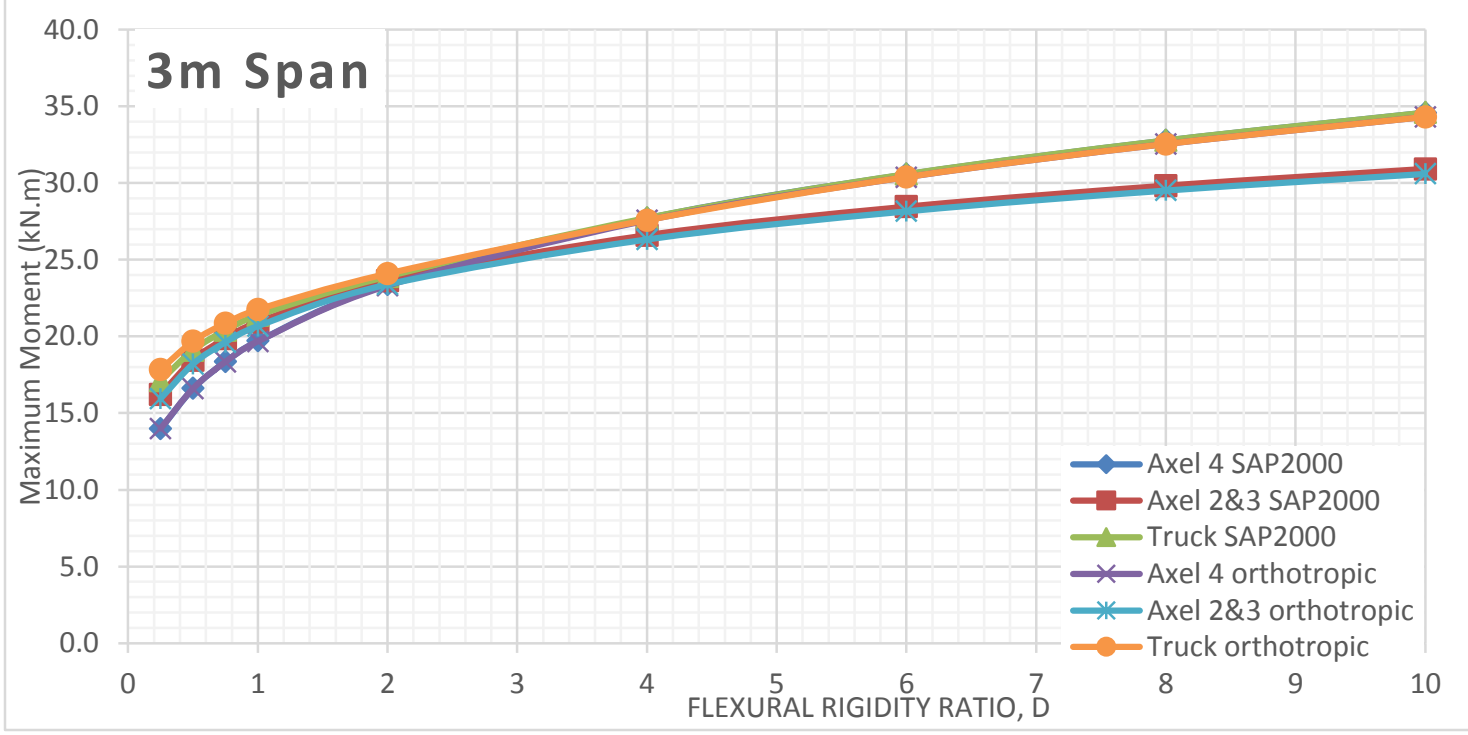

Figure 701 Moment comparison between FEA and Orthotropic Plate Theory for $3 \mathrm{~m}$ span of alpha 1 (main bars perpendicular to traffic) 


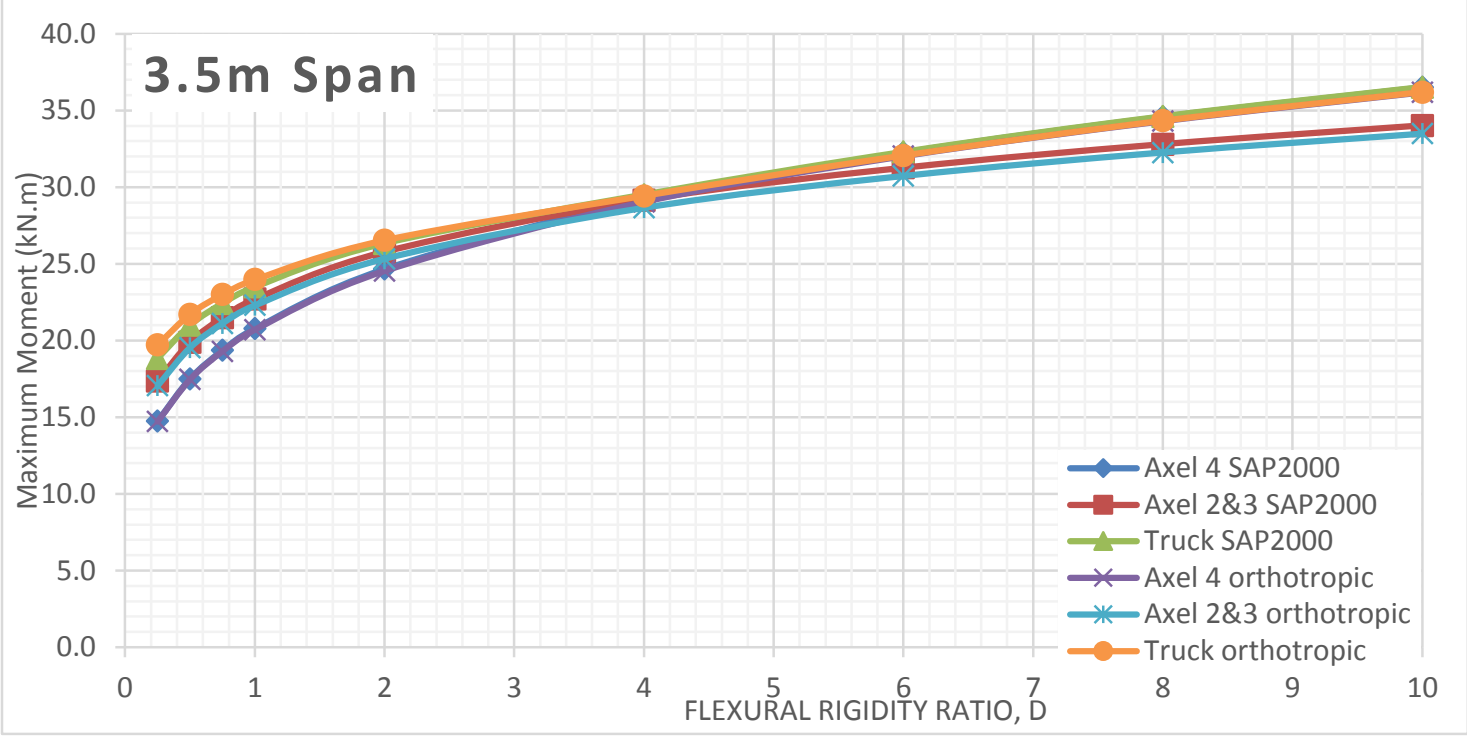

Figure 702 Moment comparison between FEA and Orthotropic Plate Theory for $3.5 \mathrm{~m}$ span of alpha 1 (main bars perpendicular to traffic)

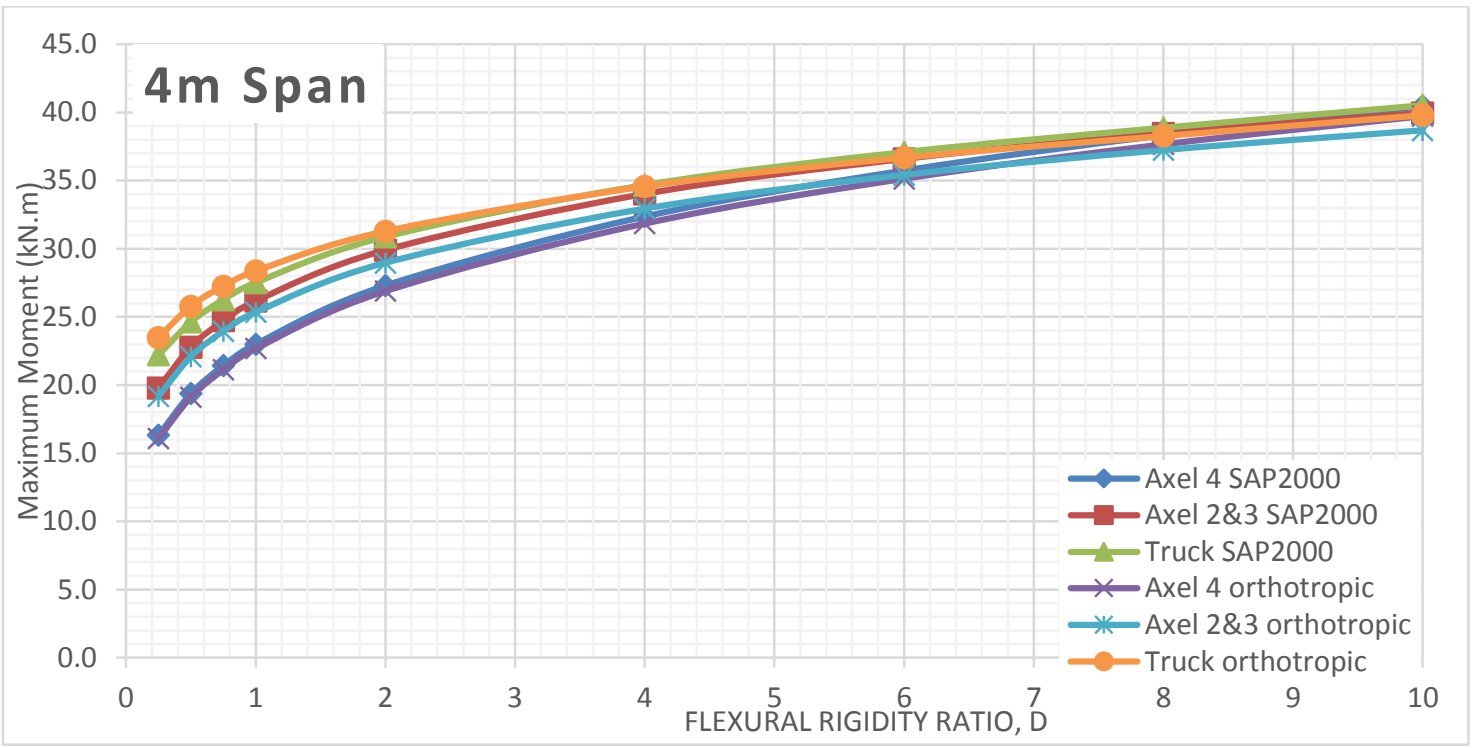

Figure 703 Moment comparison between FEA and Orthotropic Plate Theory for $4 \mathrm{~m}$ span of alpha 1 (main bars perpendicular to traffic) 


\section{Alpha 1 Bending Moment VS Flexural Rigidity for Different Span Length (Main bars parallel to traffic)}

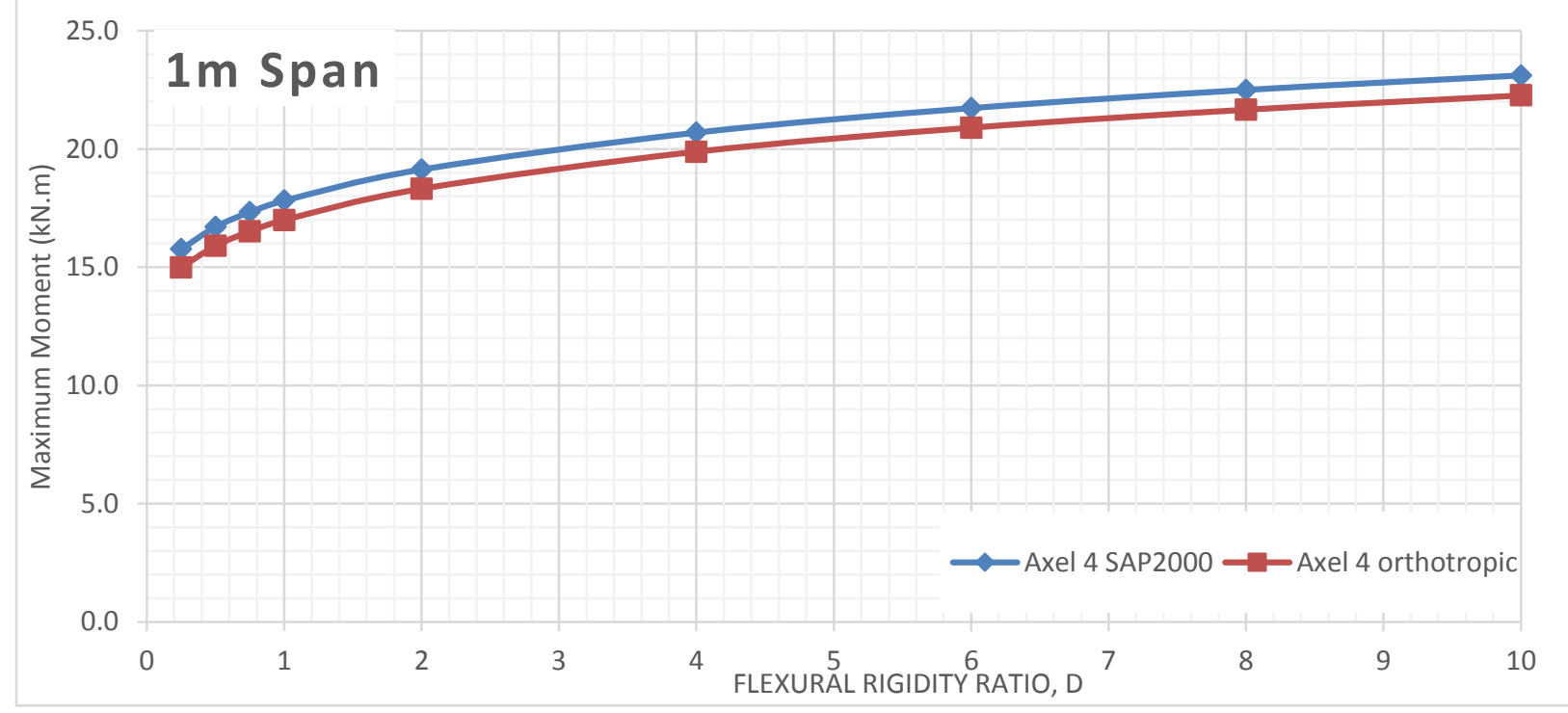

Figure 704 Moment comparison between FEA and Orthotropic Plate Theory for $1 \mathrm{~m}$ span of alpha 1 (main bars parallel to traffic)

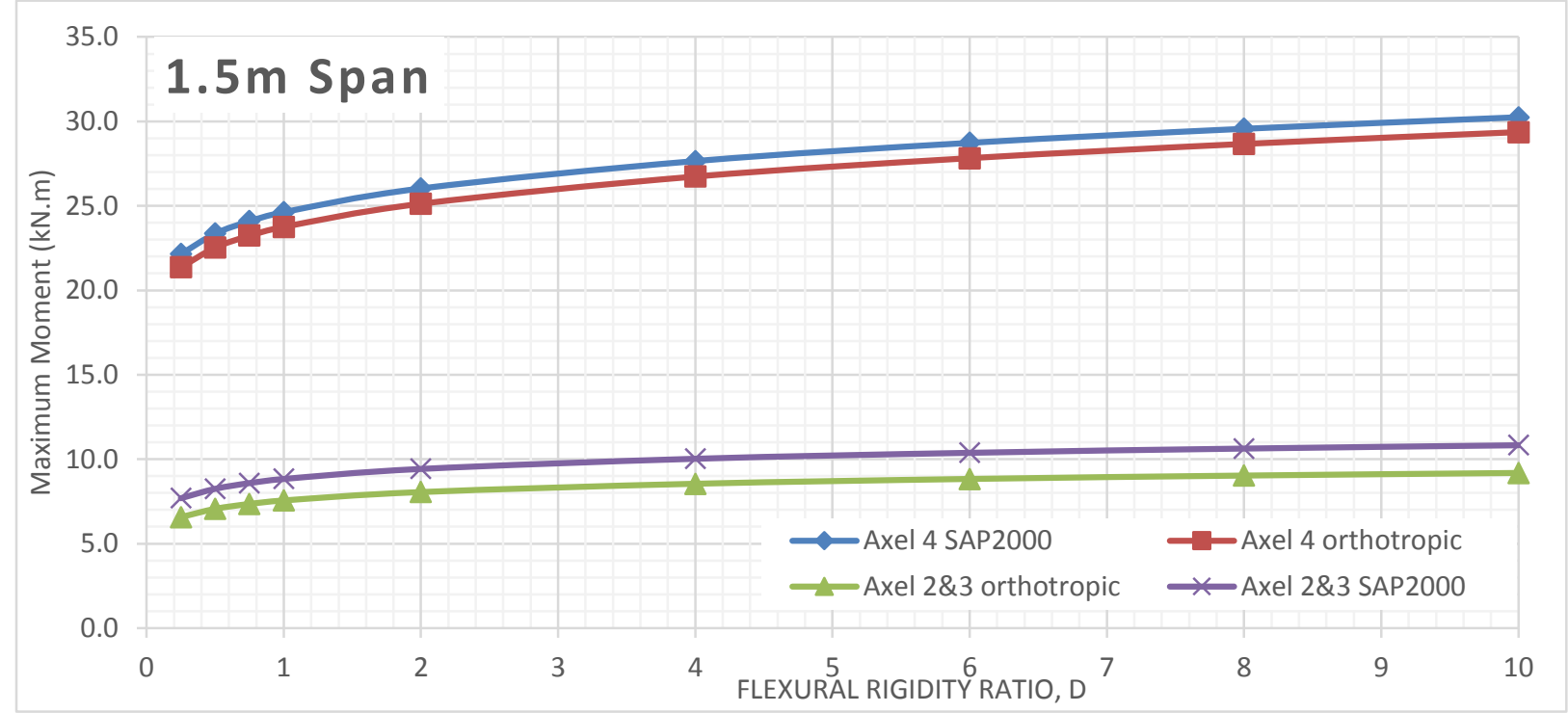

Figure 705 Moment comparison between FEA and Orthotropic Plate Theory for $1.5 \mathrm{~m}$ span of alpha 1 (main bars parallel to traffic) 


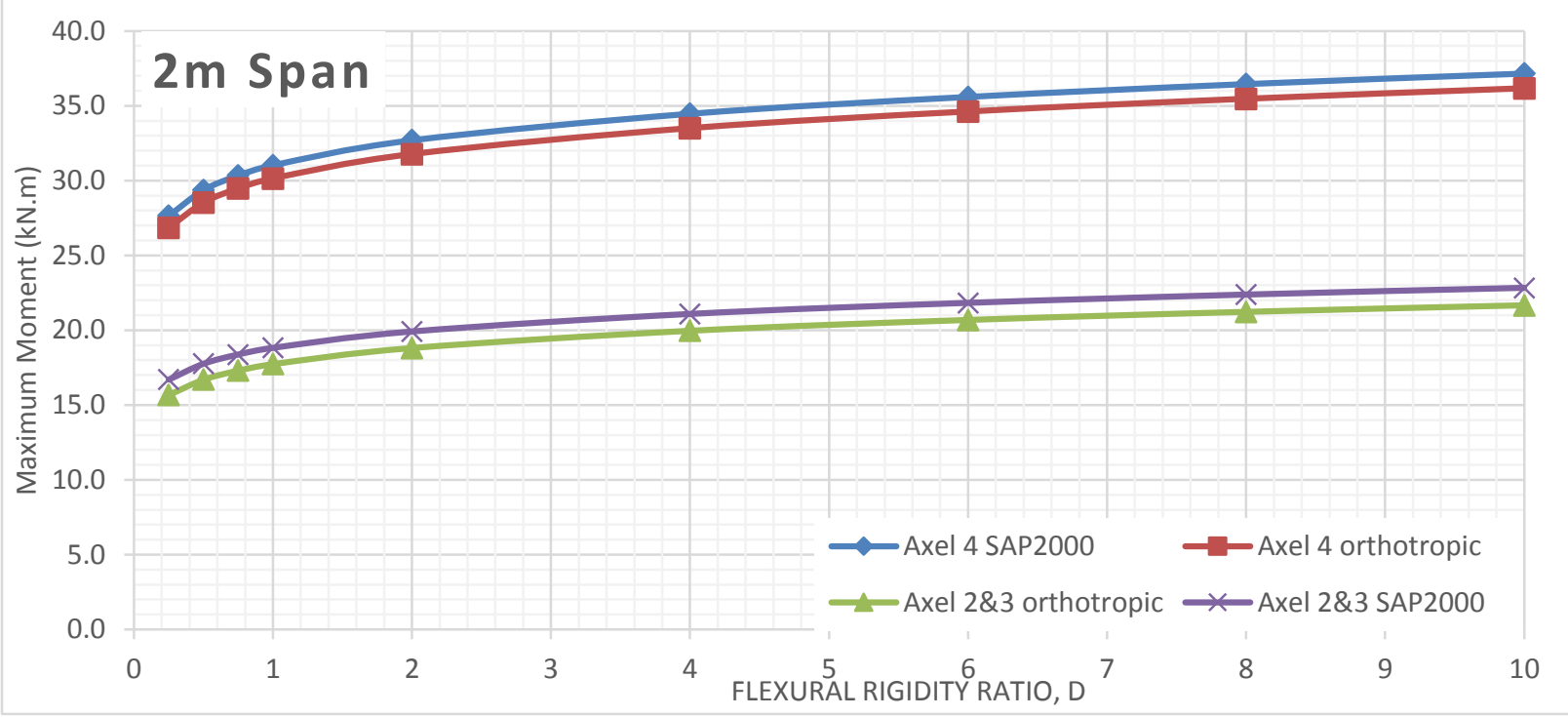

Figure 706 Moment comparison between FEA and Orthotropic Plate Theory for $2 \mathrm{~m}$ span of alpha 1 (main bars parallel to traffic)

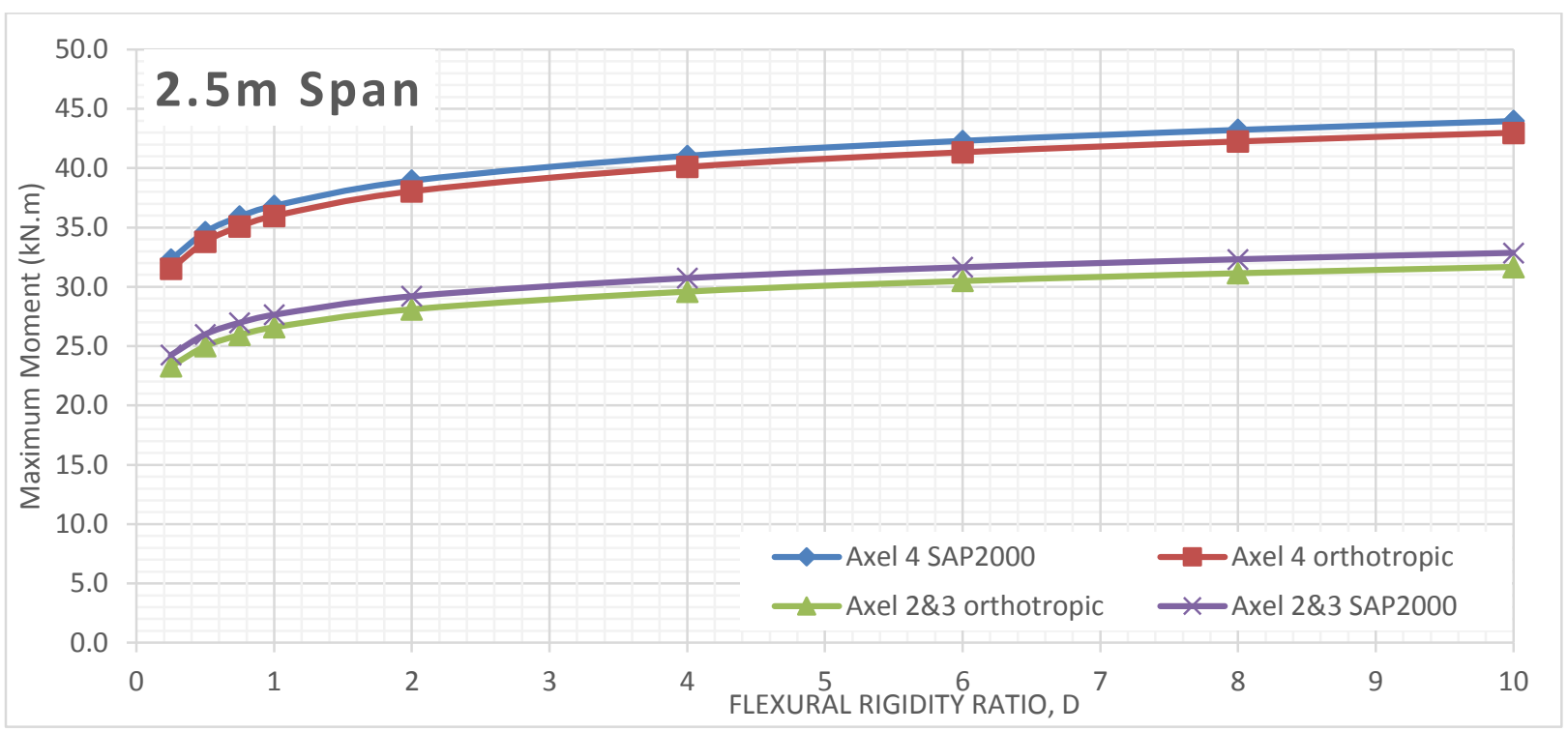

Figure 707 Moment comparison between FEA and Orthotropic Plate Theory for $2.5 \mathrm{~m}$ span of alpha 1 (main bars parallel to traffic)

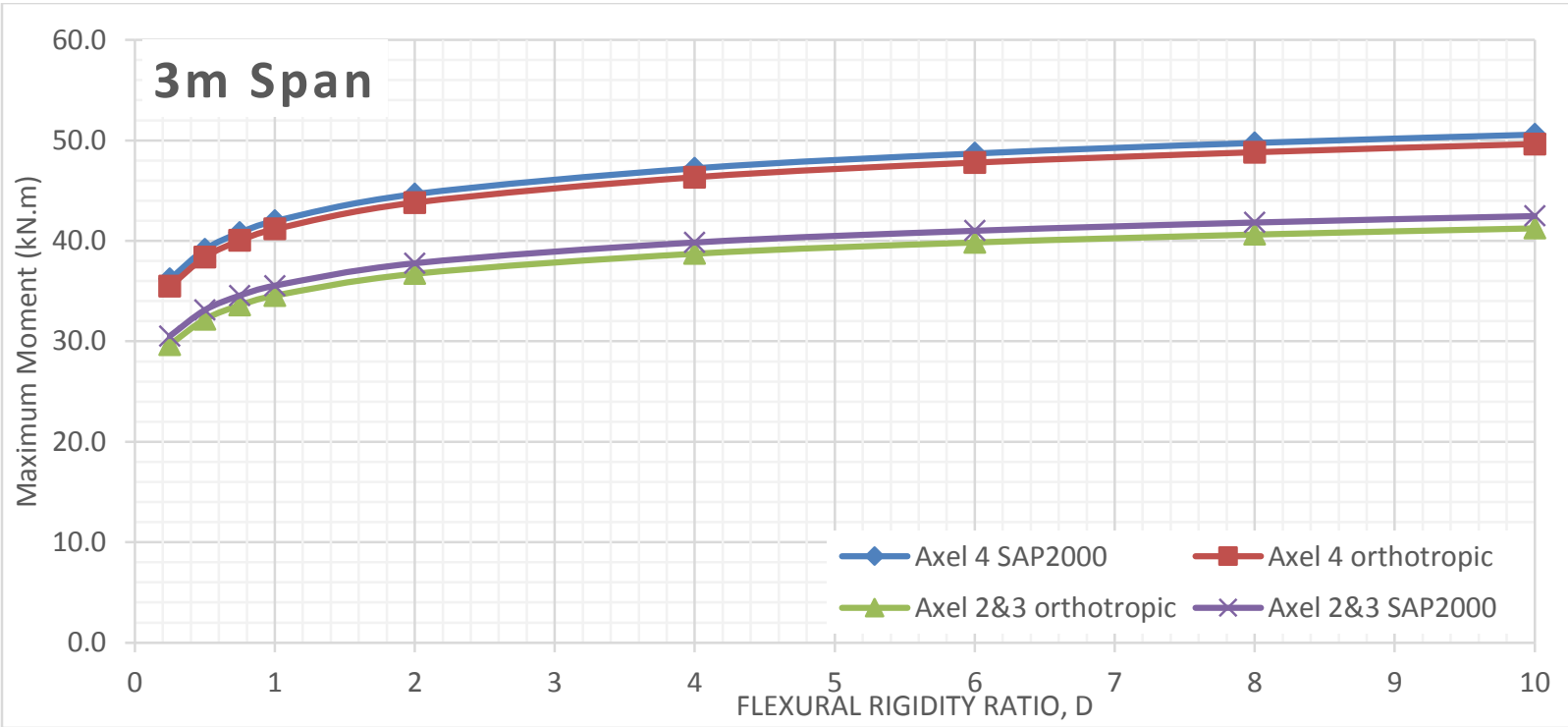

Figure 708 Moment comparison between FEA and Orthotropic Plate Theory for $3 \mathrm{~m}$ span of alpha 1 (main bars parallel to traffic) 


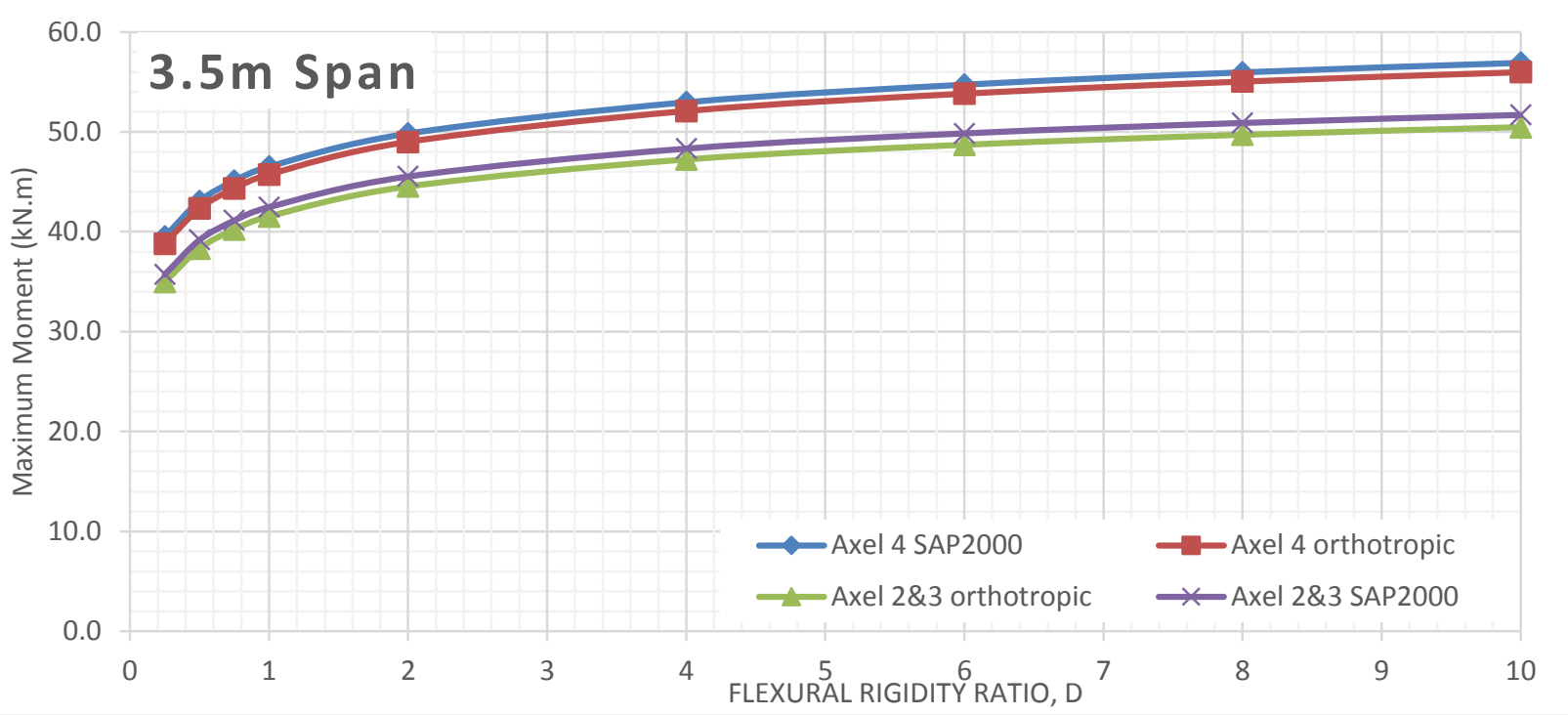

Figure 709 Moment comparison between FEA and Orthotropic Plate Theory for $3.5 \mathrm{~m}$ span of alpha 1 (main bars parallel to traffic)

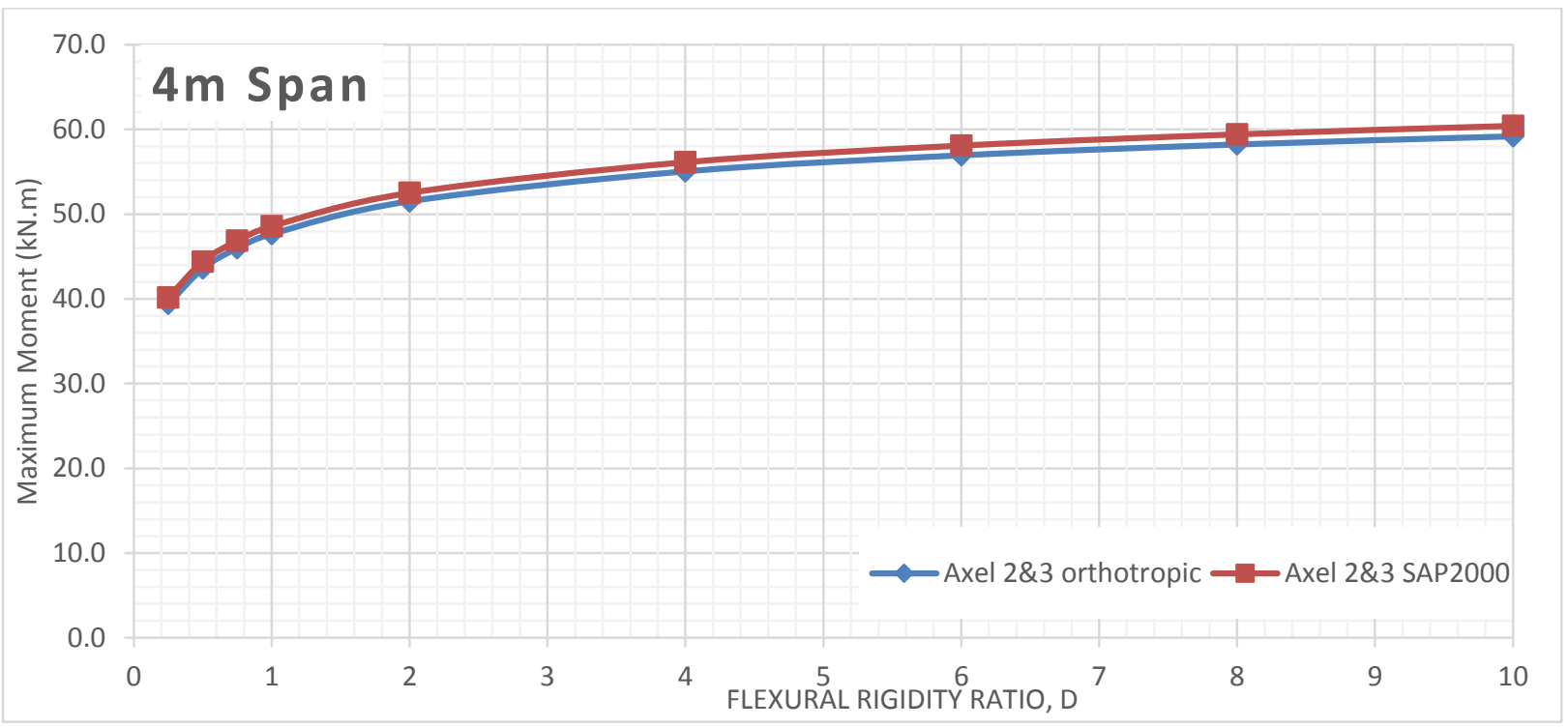

Figure 710 Moment comparison between FEA and Orthotropic Plate Theory for $4 \mathrm{~m}$ span of alpha 1 (main bars parallel to traffic) 


\section{Alpha 2 Bending Moment VS Flexural Rigidity for Different Span Length (Main bars perpendicular to traffic)}

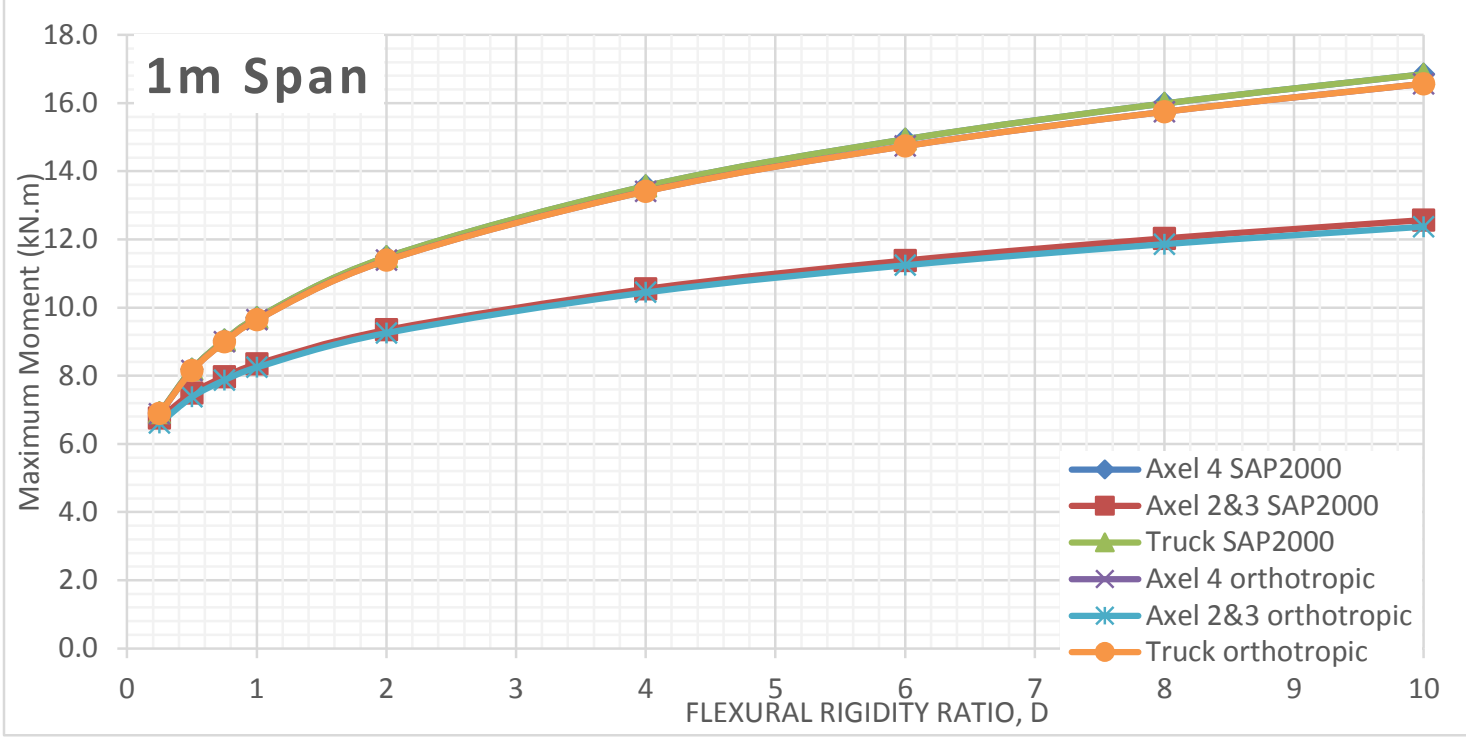

Figure 711 Moment comparison between FEA and Orthotropic Plate Theory for $1 \mathrm{~m}$ span of alpha 2 (main bars perpendicular to traffic)

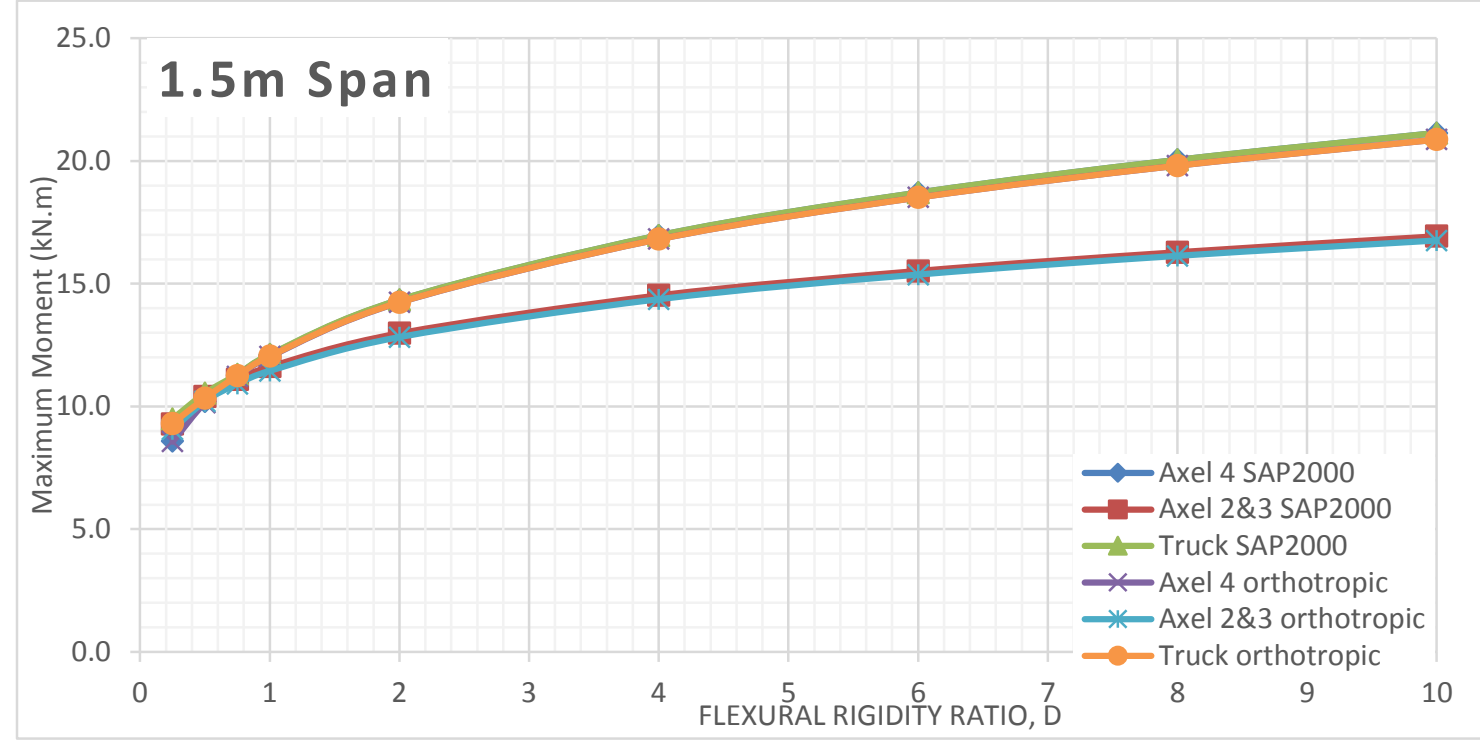

Figure 712 Moment comparison between FEA and Orthotropic Plate Theory for $1.5 \mathrm{~m}$ span of alpha 2 (main bars perpendicular to traffic) 


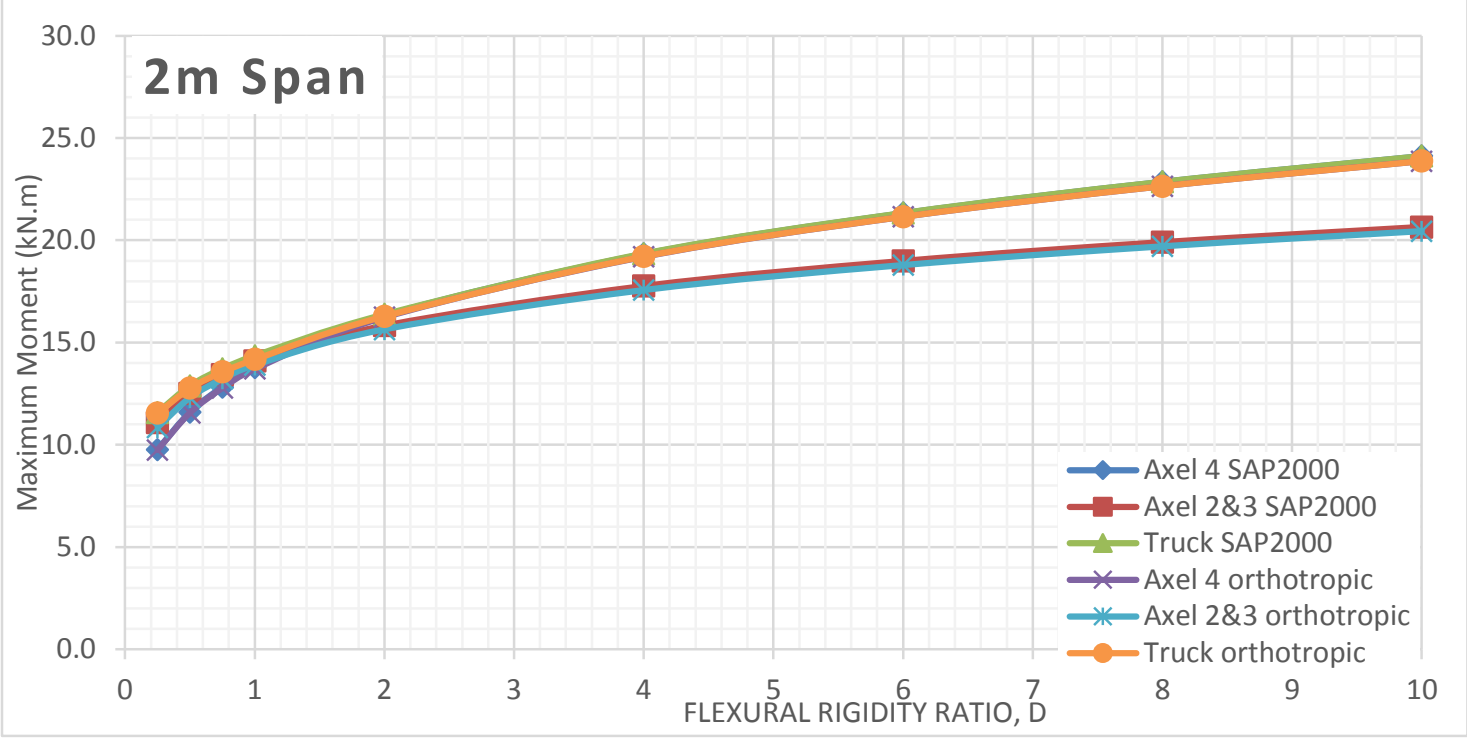

Figure 713 Moment comparison between FEA and Orthotropic Plate Theory for $2 \mathrm{~m}$ span of alpha 2 (main bars perpendicular to traffic)

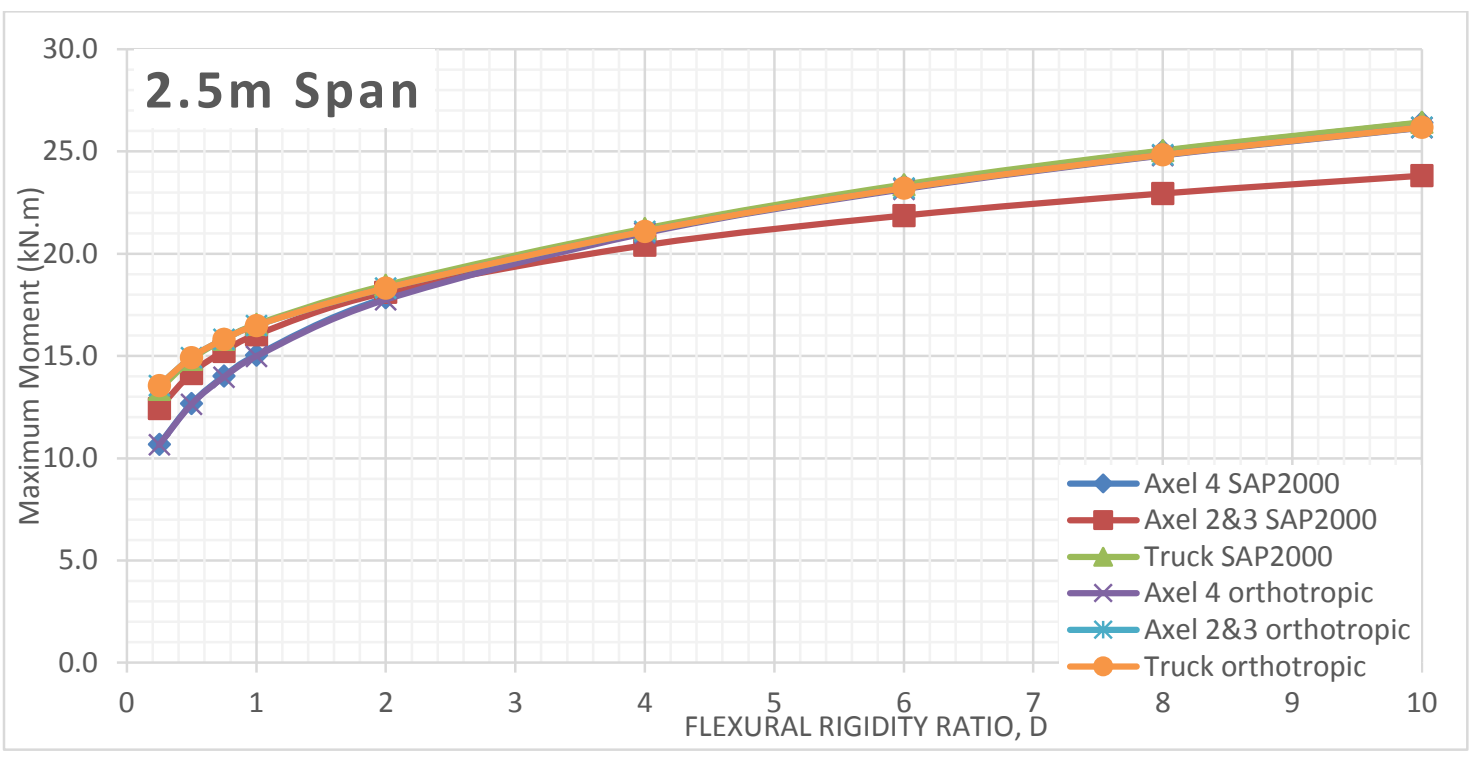

Figure 714 Moment comparison between FEA and Orthotropic Plate Theory for $2.5 \mathrm{~m}$ span of alpha 2 (main bars perpendicular to traffic)

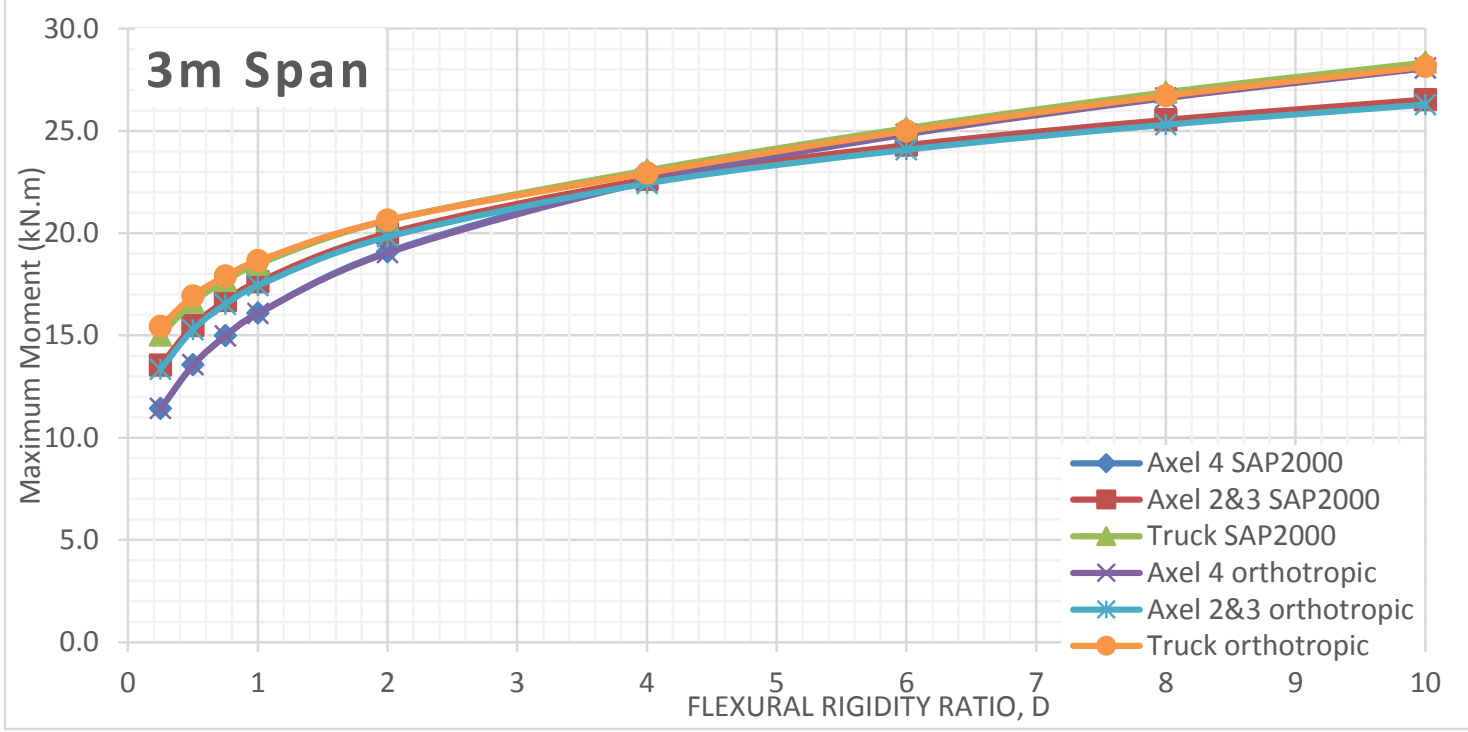

Figure 715 Moment comparison between FEA and Orthotropic Plate Theory for $3 \mathrm{~m}$ span of alpha 2 (main bars perpendicular to traffic) 


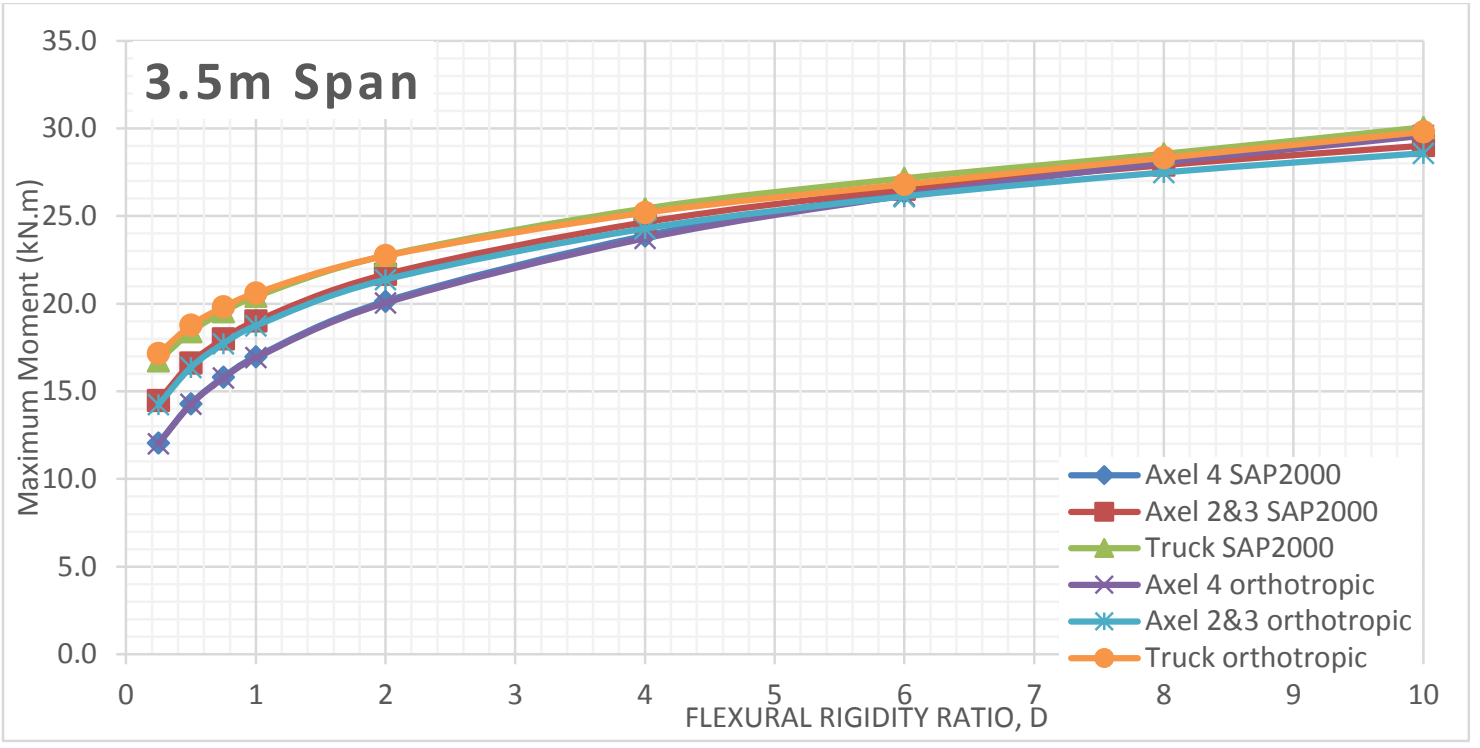

Figure 716 Moment comparison between FEA and Orthotropic Plate Theory for $3.5 \mathrm{~m}$ span of alpha 2 (main bars perpendicular to traffic)

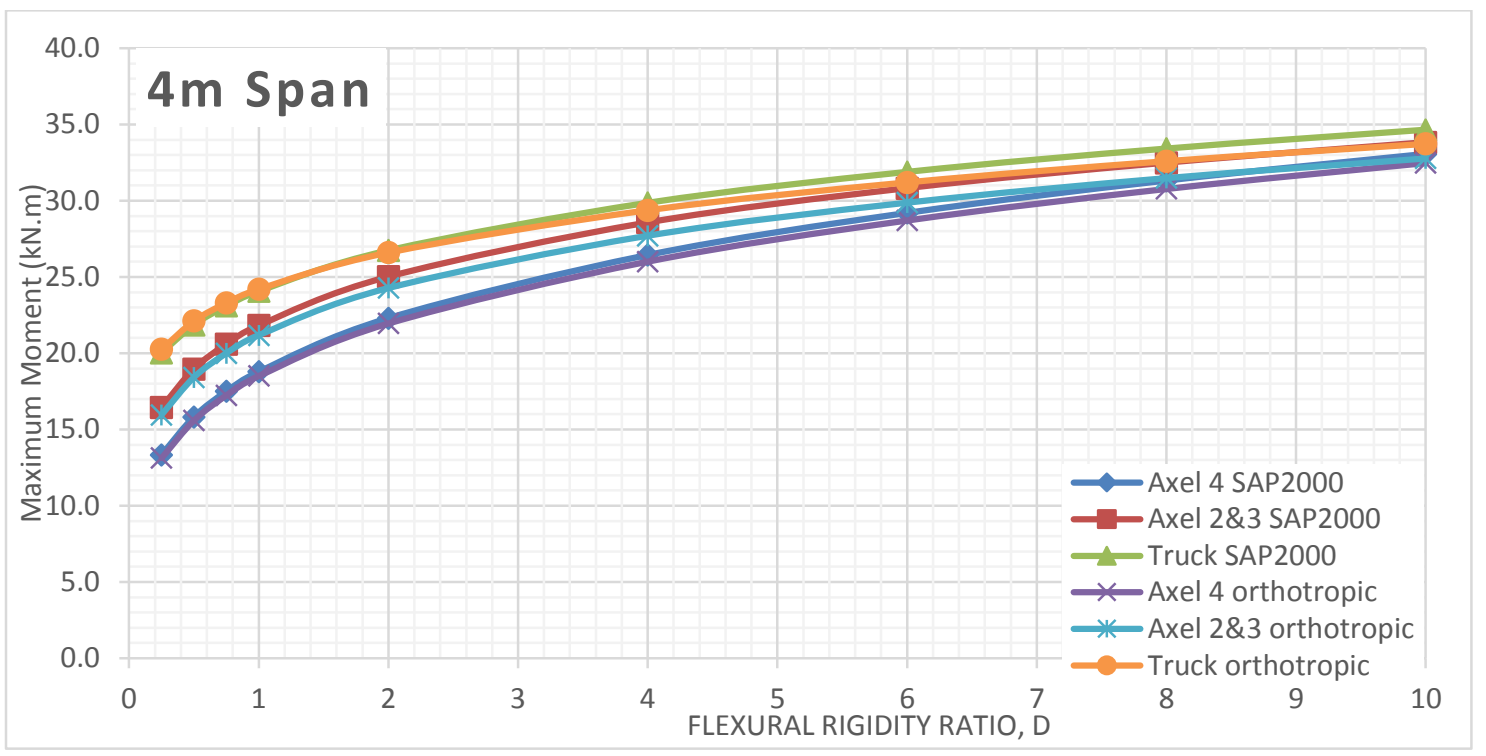

Figure 717 Moment comparison between FEA and Orthotropic Plate Theory for $4 \mathrm{~m}$ span of alpha 2 (main bars perpendicular to traffic) 


\section{Alpha 2 Bending Moment VS Flexural Rigidity for Different Span Length (Main bars parallel to traffic)}

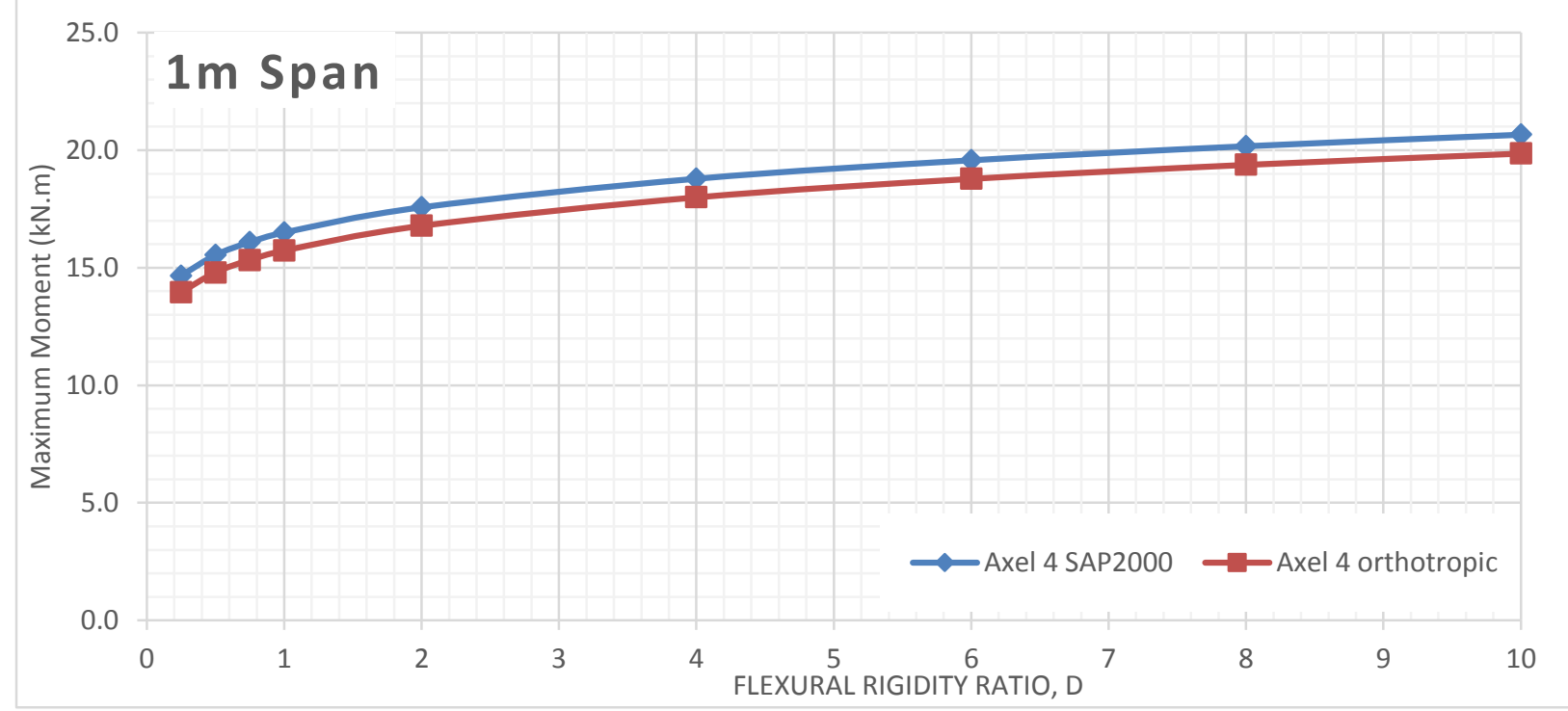

Figure 718 Moment comparison between FEA and Orthotropic Plate Theory for $1 \mathrm{~m}$ span of alpha 2 (main bars parallel to traffic)

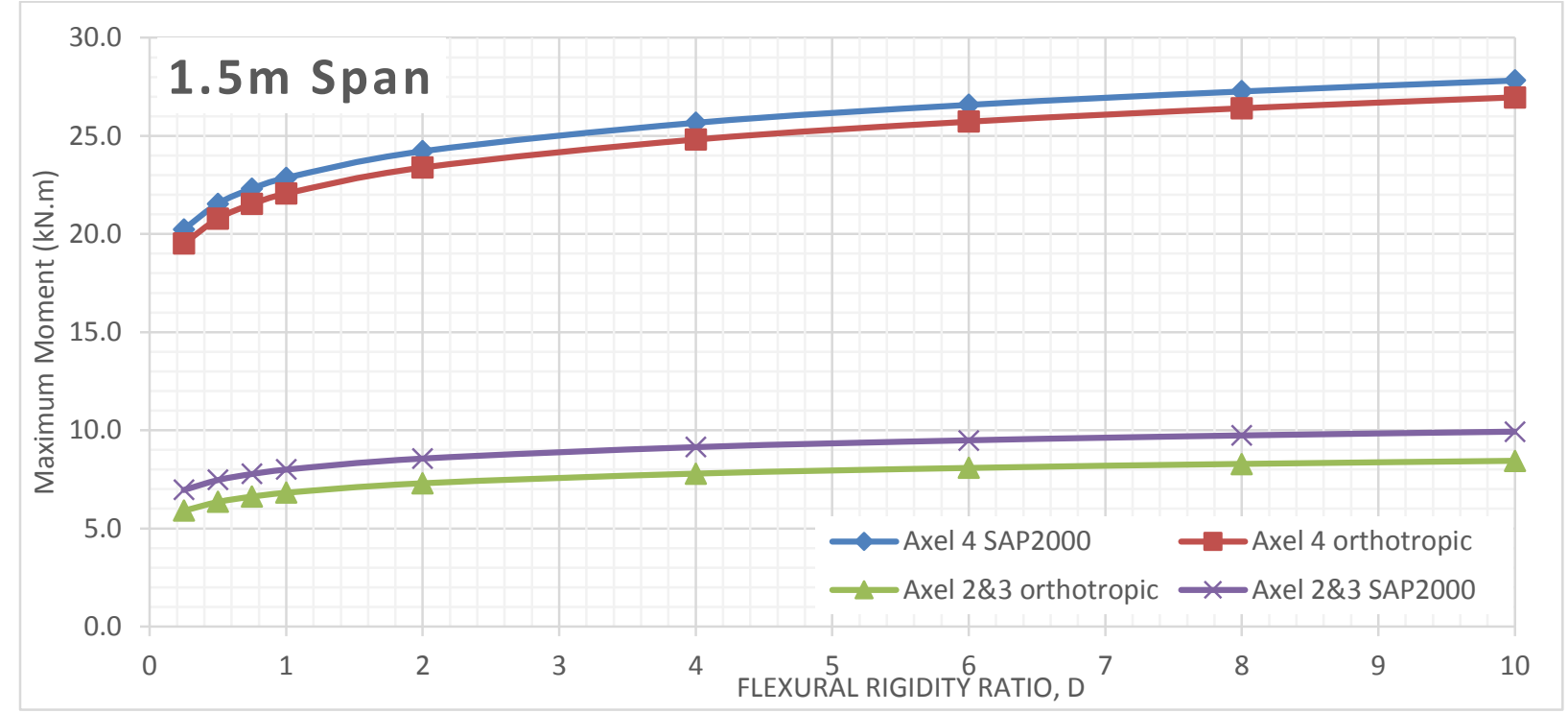

Figure 719 Moment comparison between FEA and Orthotropic Plate Theory for $1.5 \mathrm{~m}$ span of alpha 2 (main bars parallel to traffic) 


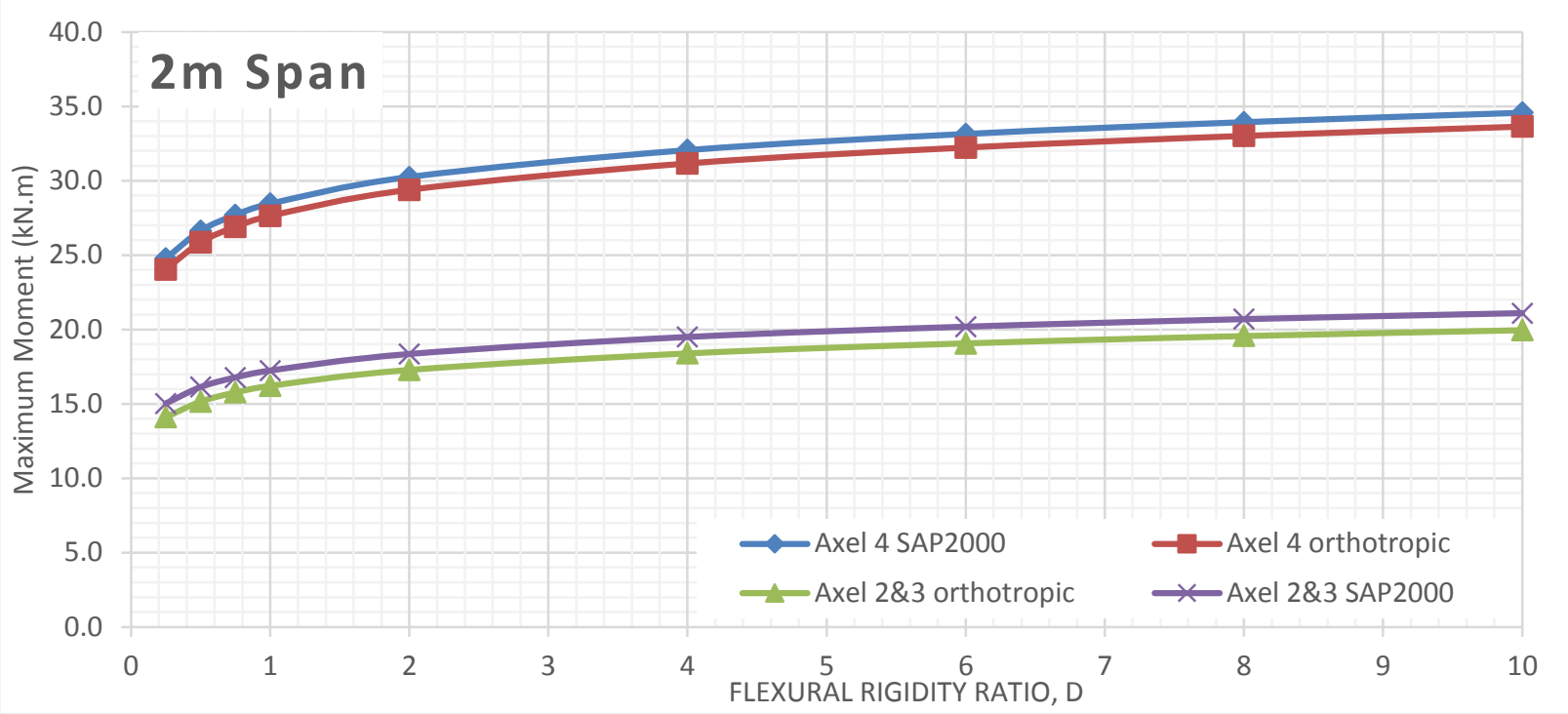

Figure 720 Moment comparison between FEA and Orthotropic Plate Theory for $2 \mathrm{~m}$ span of alpha 2 (main bars parallel to traffic)

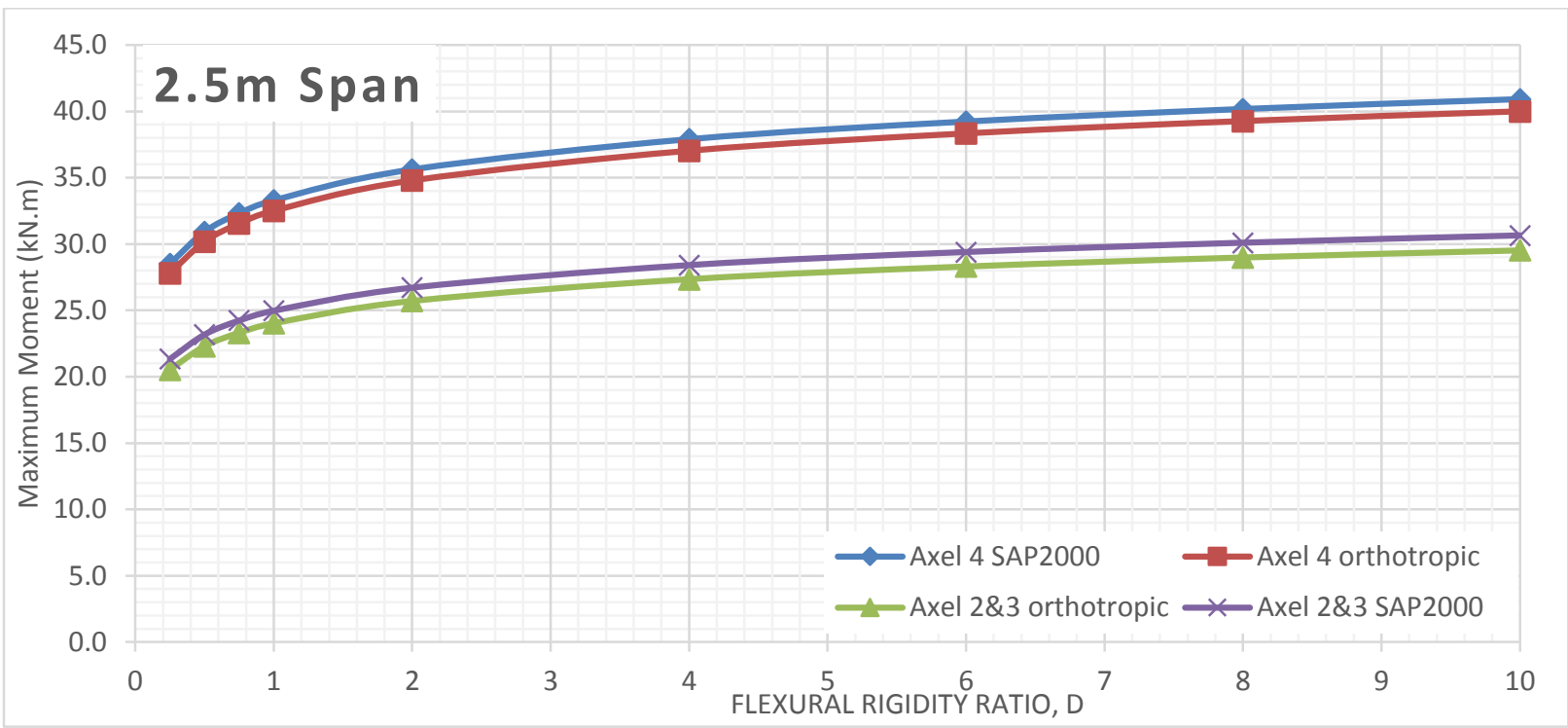

Figure 721 Moment comparison between FEA and Orthotropic Plate Theory for $2.5 \mathrm{~m}$ span of alpha 2 (main bars parallel to traffic)

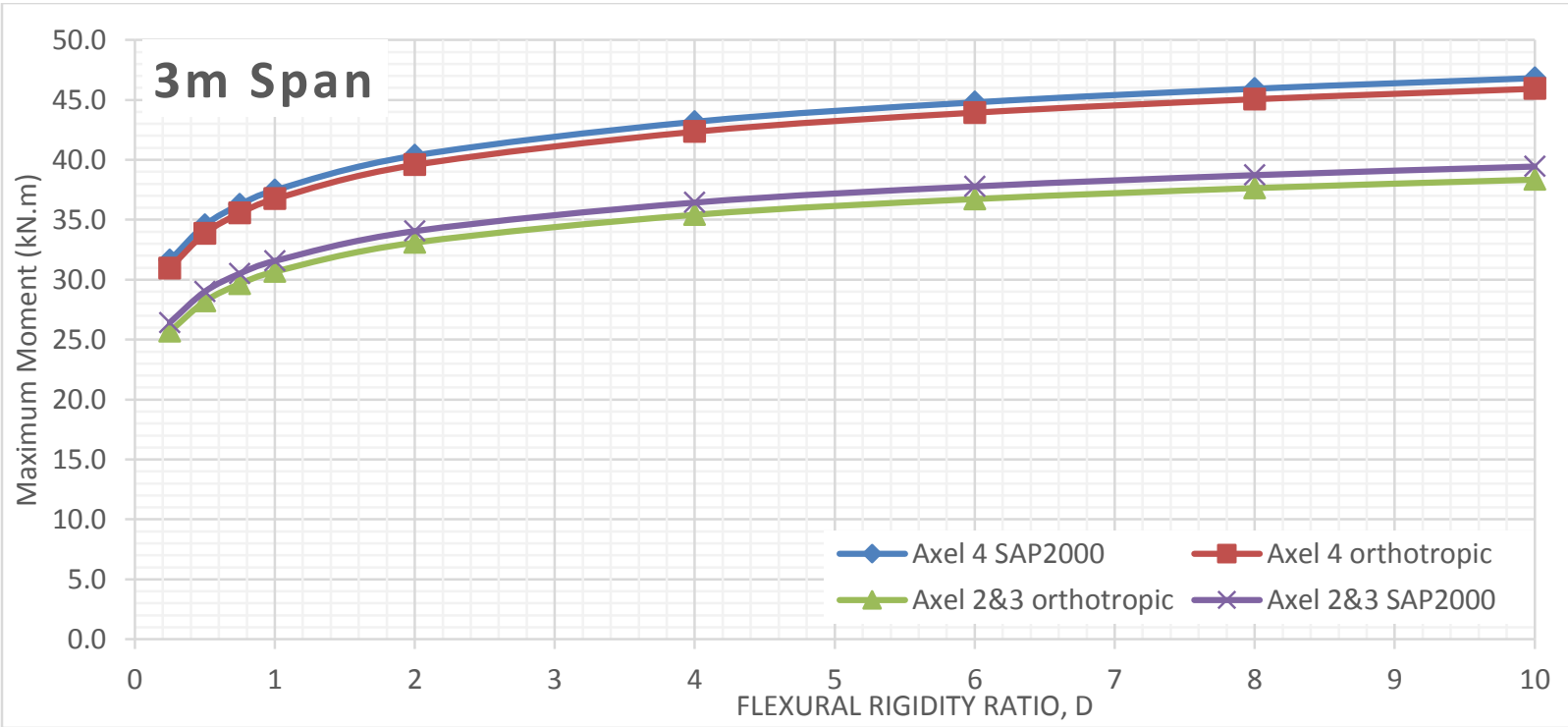

Figure 722 Moment comparison between FEA and Orthotropic Plate Theory for $3 \mathrm{~m}$ span of alpha 2 (main bars parallel to traffic) 


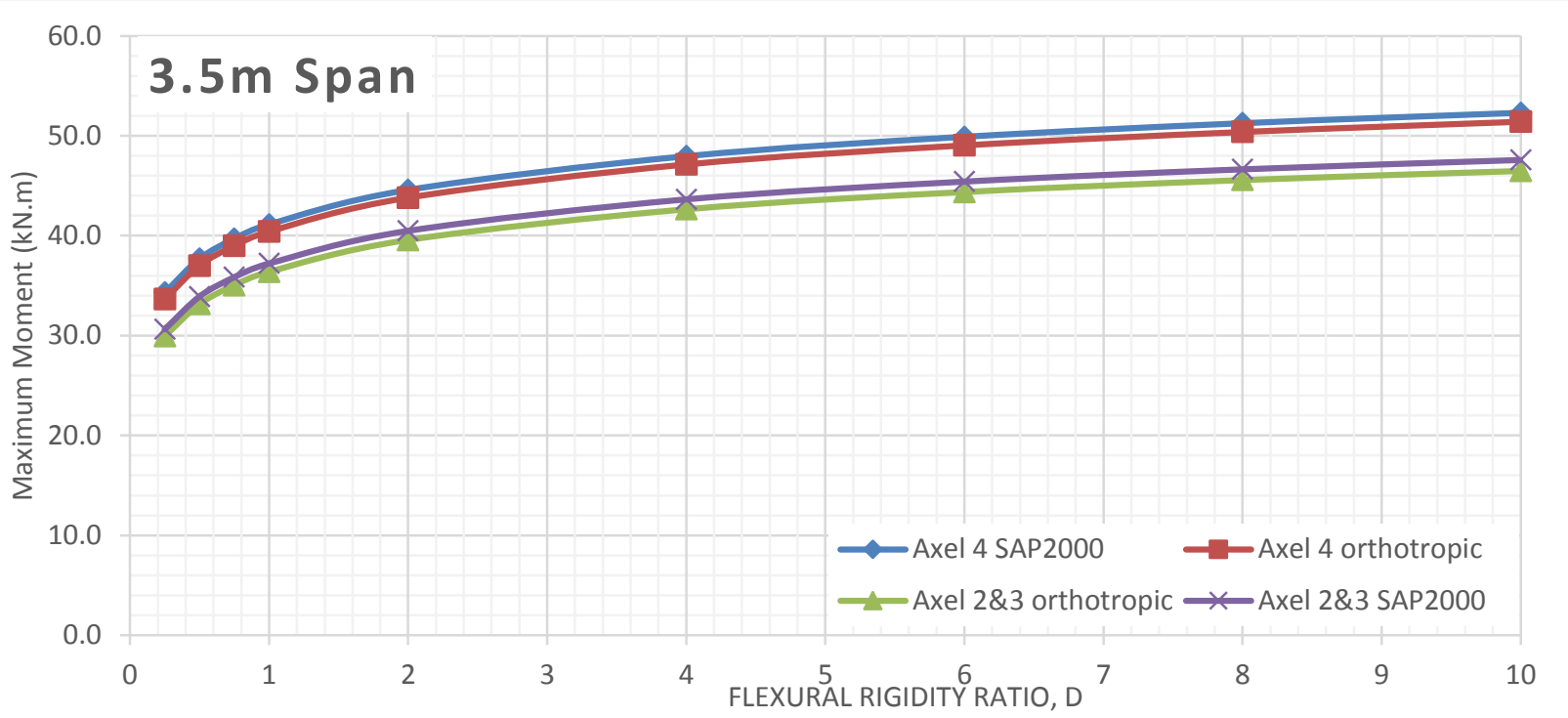

Figure 723 Moment comparison between FEA and Orthotropic Plate Theory for $3.5 \mathrm{~m}$ span of alpha 2 (main bars parallel to traffic)

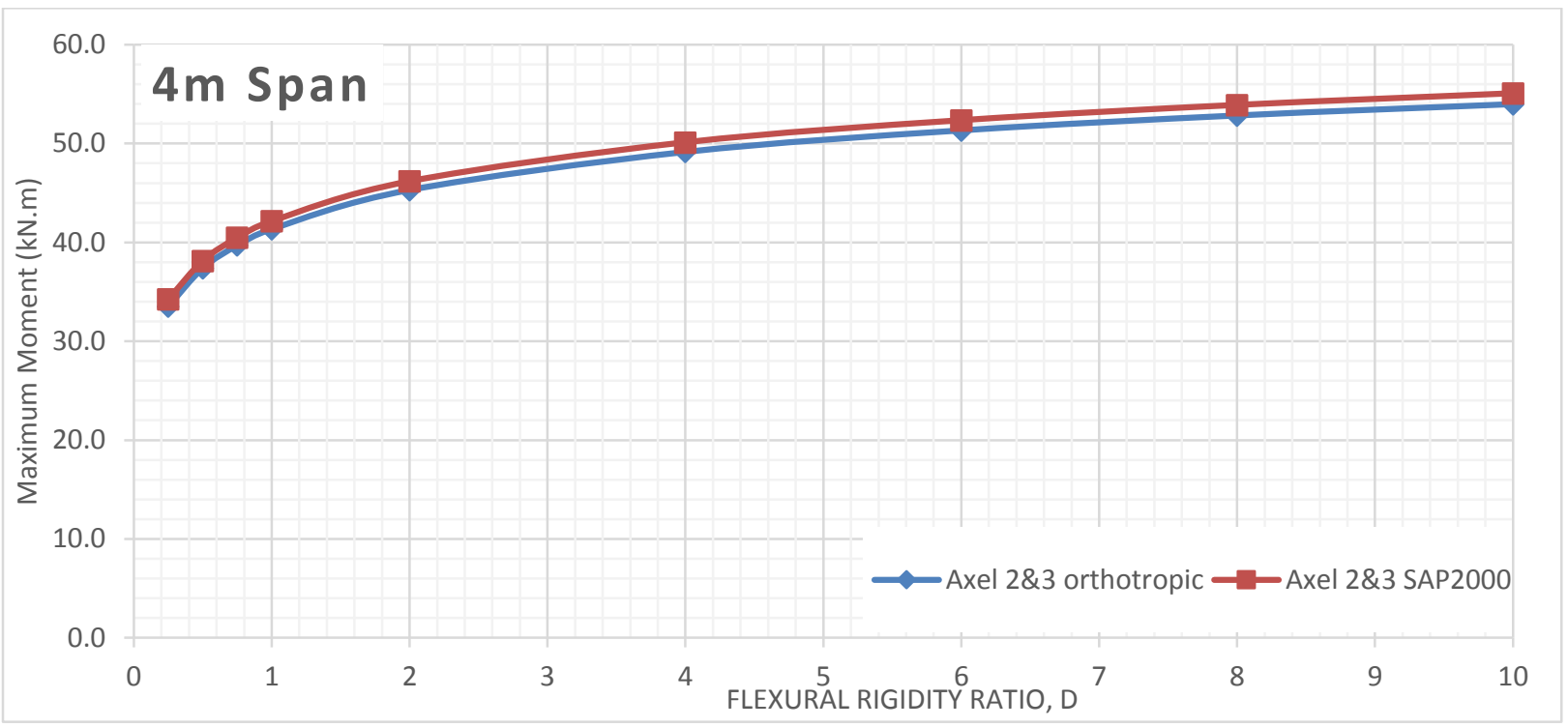

Figure 724 Moment comparison between FEA and Orthotropic Plate Theory for $4 \mathrm{~m}$ span of alpha 2 (main bars parallel to traffic) 


\section{Alpha 4 Bending Moment VS Flexural Rigidity for Different Span Length (Main bars perpendicular to traffic)}

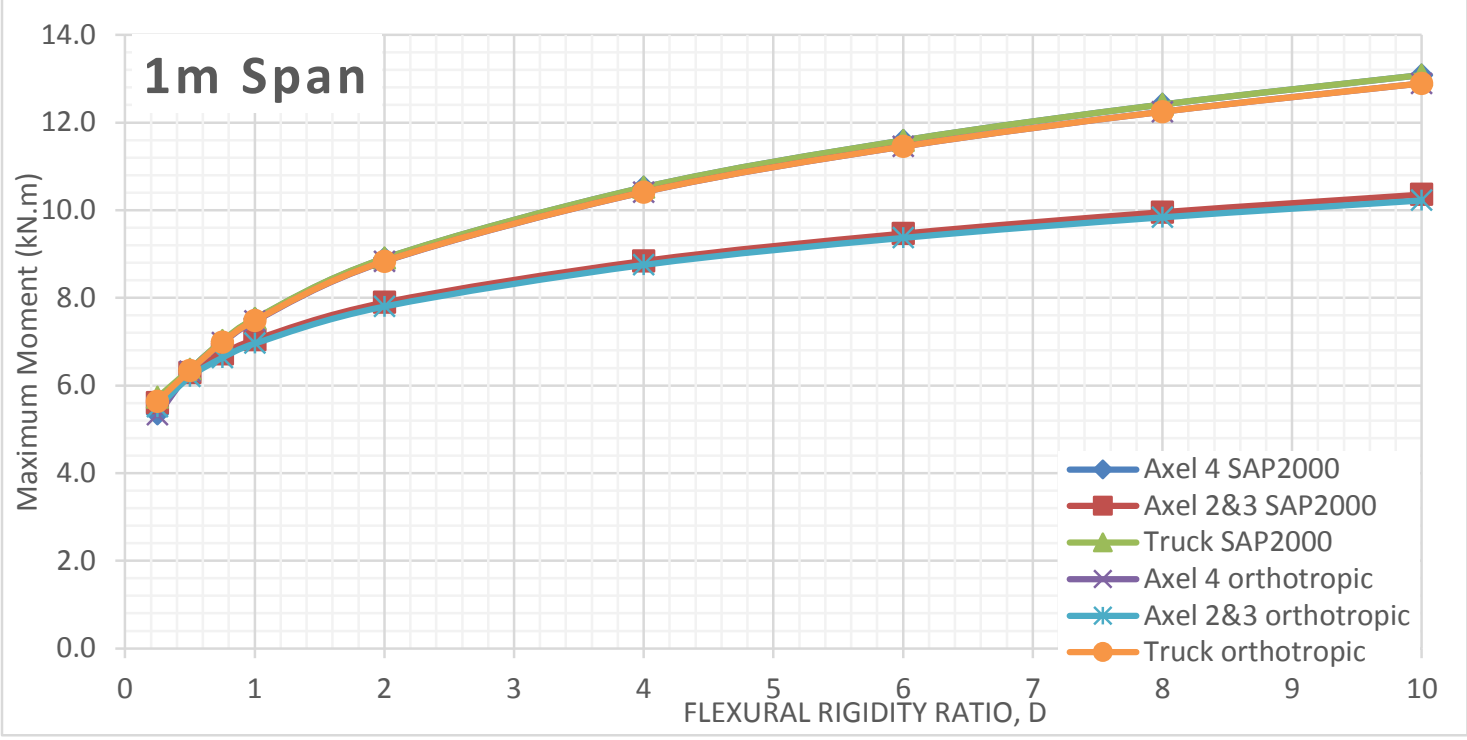

Figure 725 Moment comparison between FEA and Orthotropic Plate Theory for $1 \mathrm{~m}$ span of alpha 4 (main bars perpendicular to traffic)

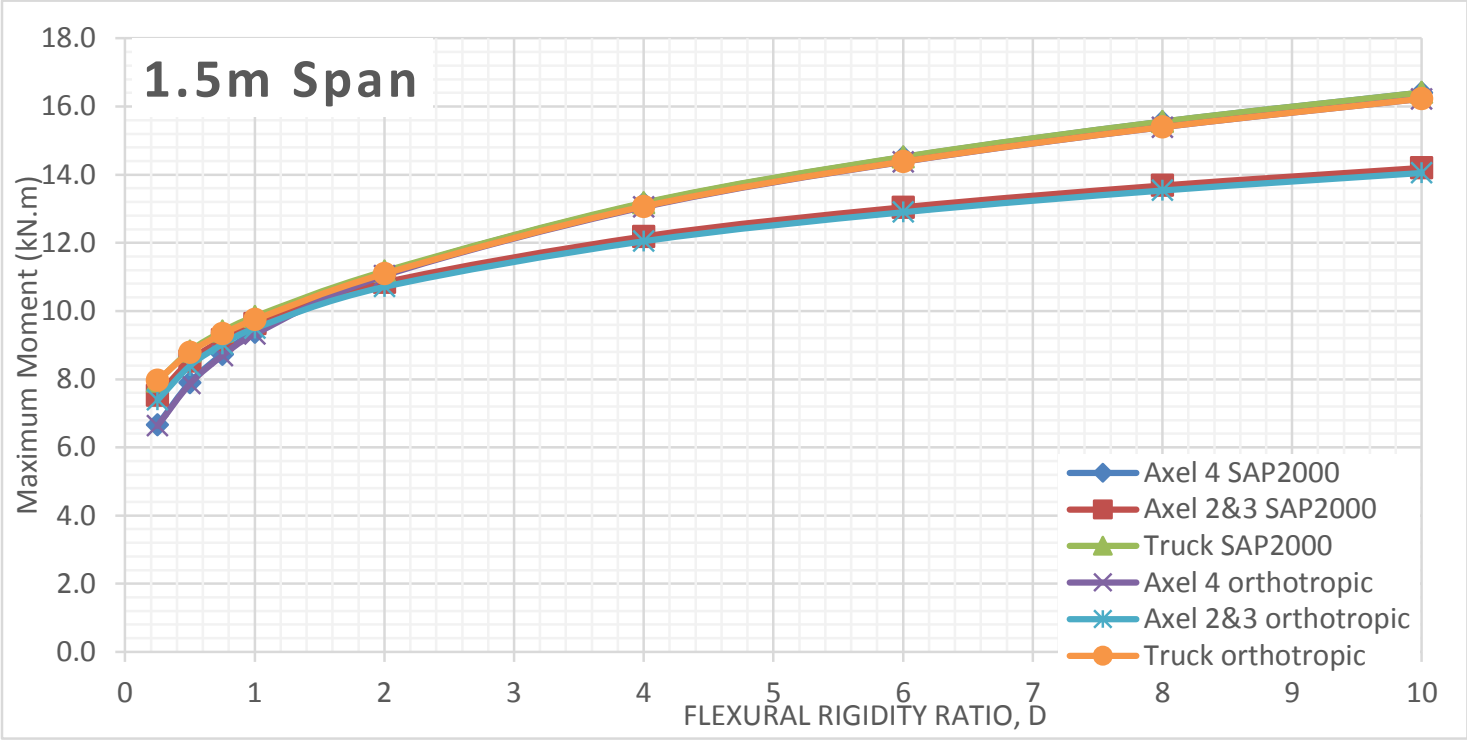

Figure 726 Moment comparison between FEA and Orthotropic Plate Theory for $1.5 \mathrm{~m}$ span of alpha 4 (main bars perpendicular to traffic) 


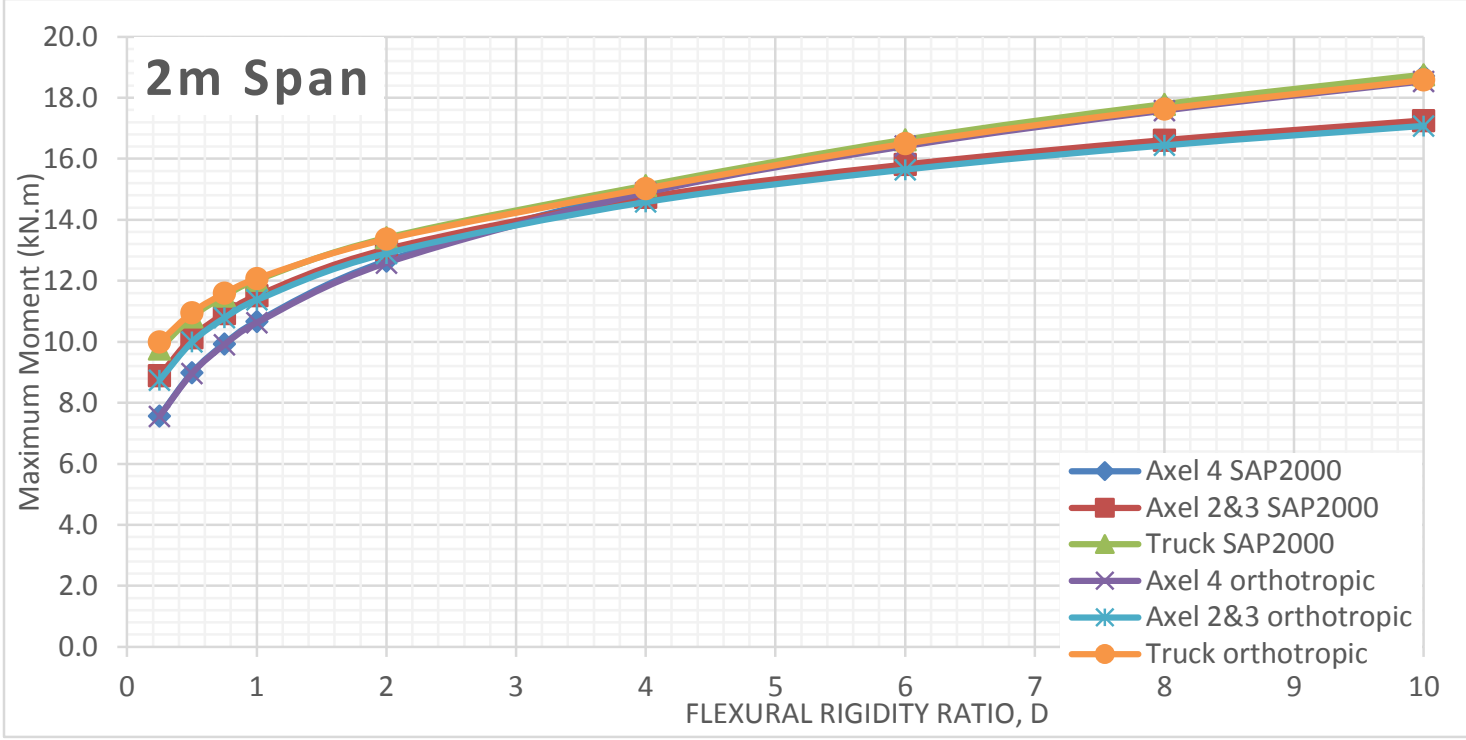

Figure 727 Moment comparison between FEA and Orthotropic Plate Theory for $2 \mathrm{~m}$ span of alpha 4 (main bars perpendicular to traffic)

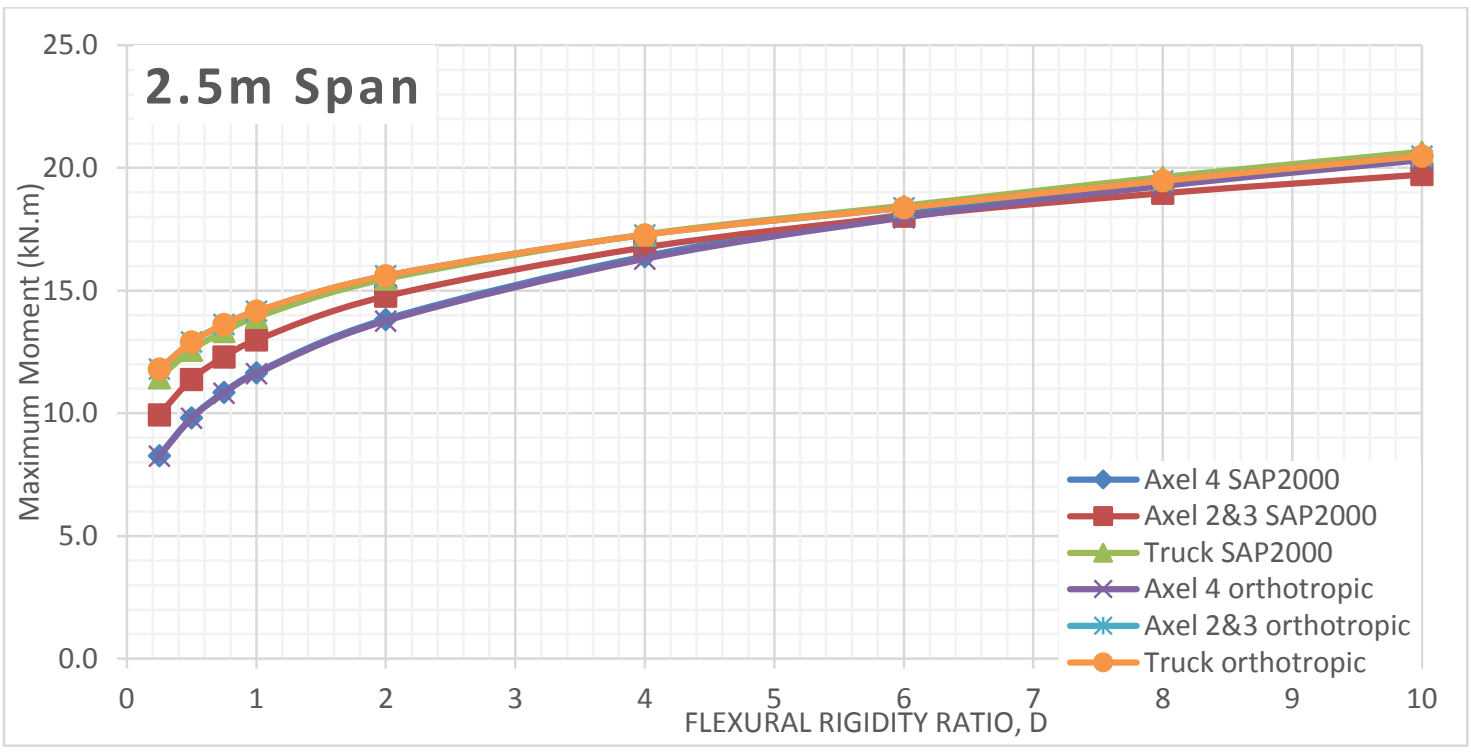

Figure 728 Moment comparison between FEA and Orthotropic Plate Theory for $2.5 \mathrm{~m}$ span of alpha 4 (main bars perpendicular to traffic)

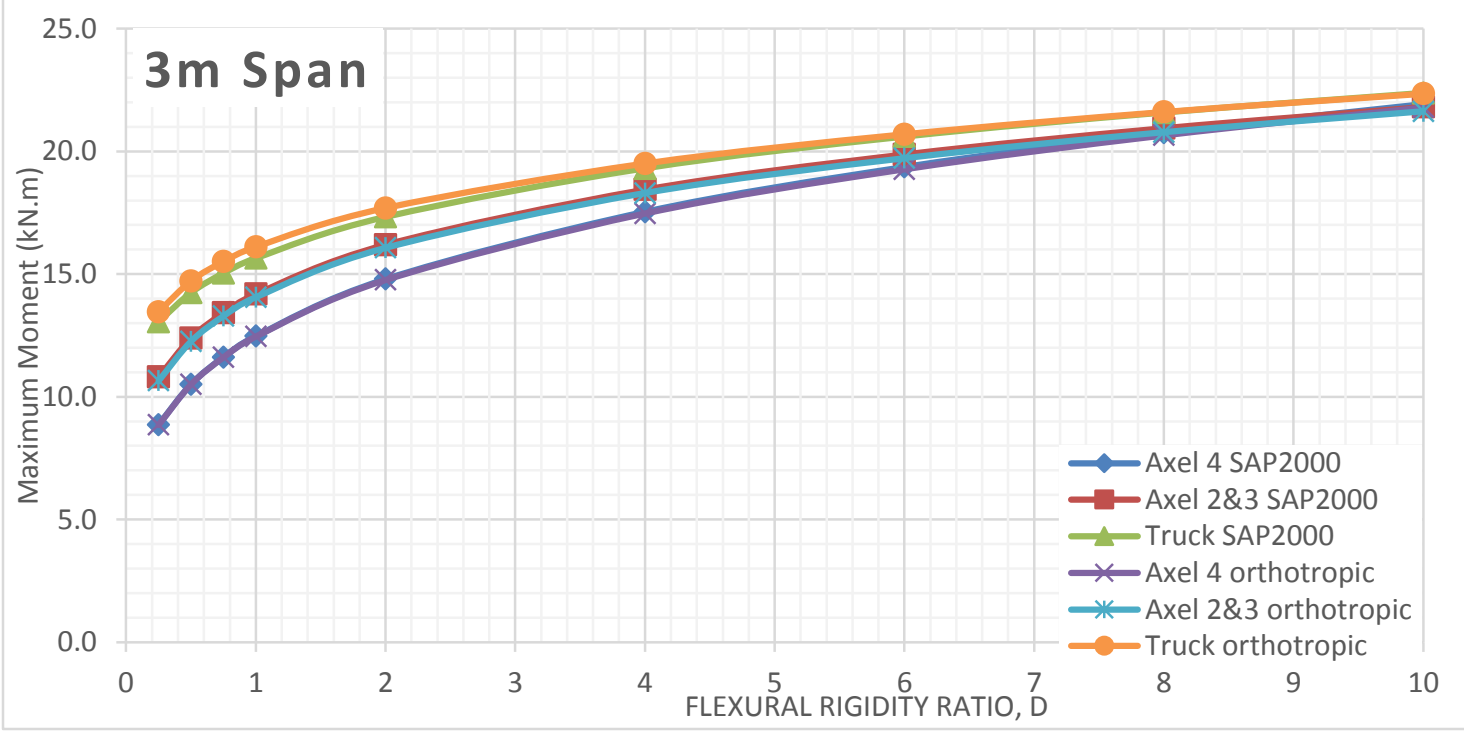

Figure 729 Moment comparison between FEA and Orthotropic Plate Theory for $3 \mathrm{~m}$ span of alpha 4 (main bars perpendicular to traffic) 


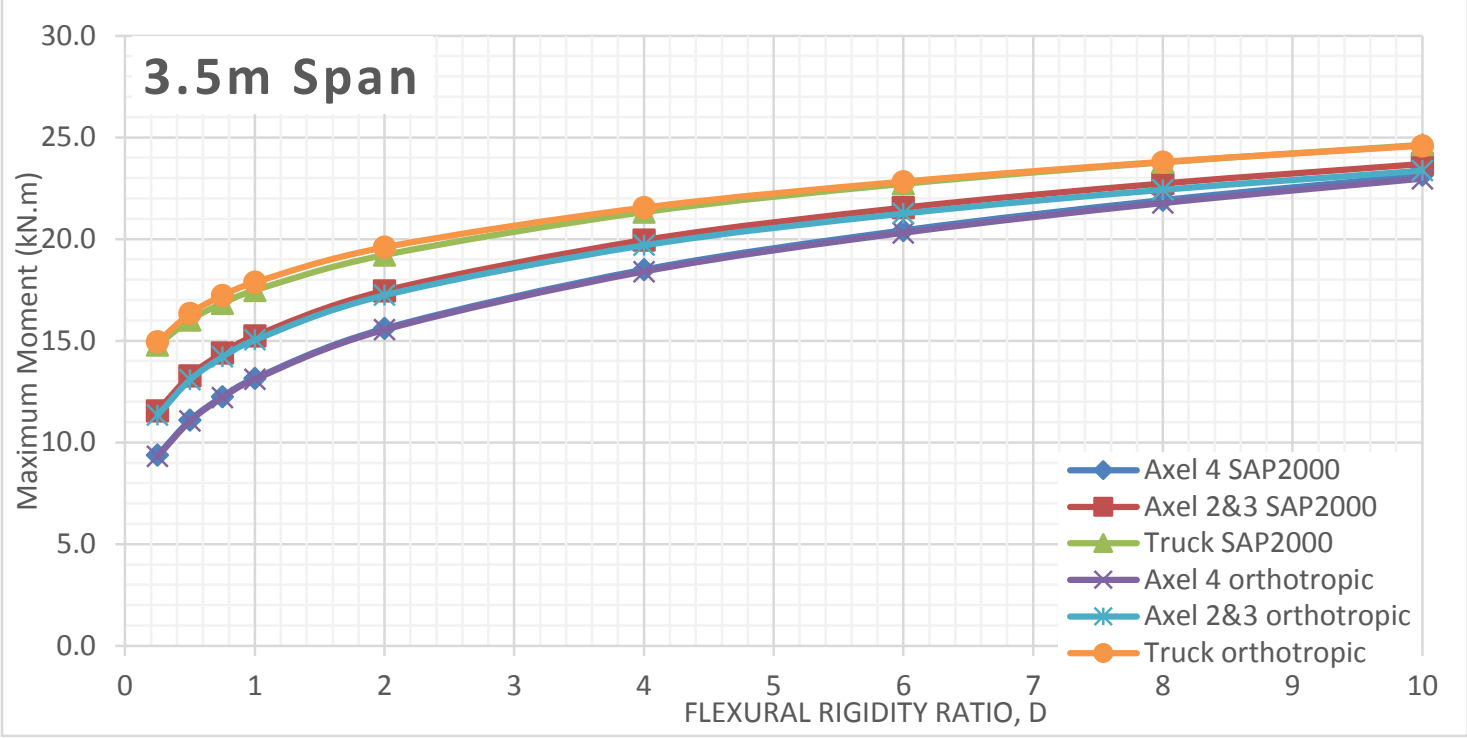

Figure 730 Moment comparison between FEA and Orthotropic Plate Theory for $3.5 \mathrm{~m}$ span of alpha 4 (main bars perpendicular to traffic)

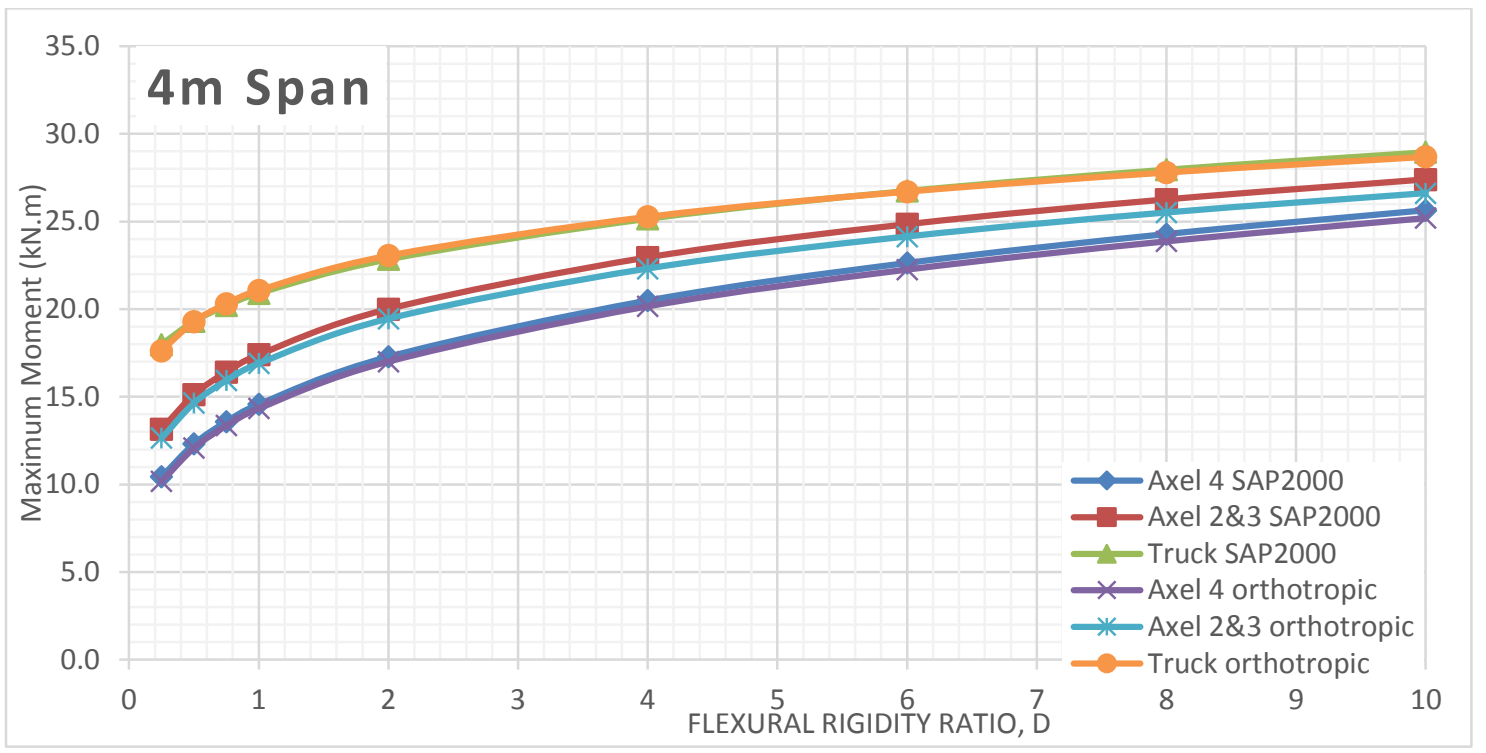

Figure 731 Moment comparison between FEA and Orthotropic Plate Theory for $4 \mathrm{~m}$ span of alpha 4 (main bars perpendicular to traffic) 


\section{Alpha 4 Bending Moment VS Flexural Rigidity for Different Span Length (Main bars parallel to traffic)}

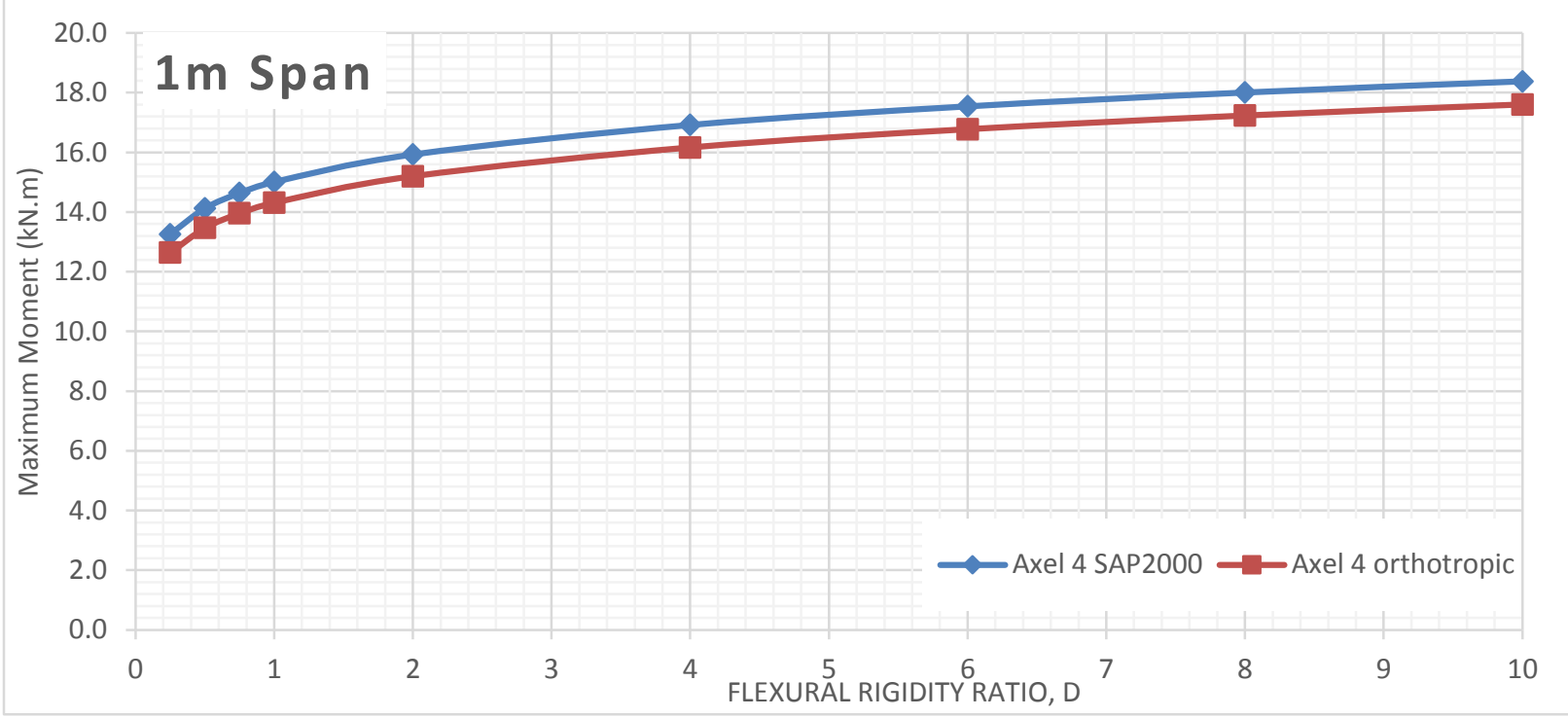

Figure 732 Moment comparison between FEA and Orthotropic Plate Theory for $1 \mathrm{~m}$ span of alpha 4 (main bars parallel to traffic)

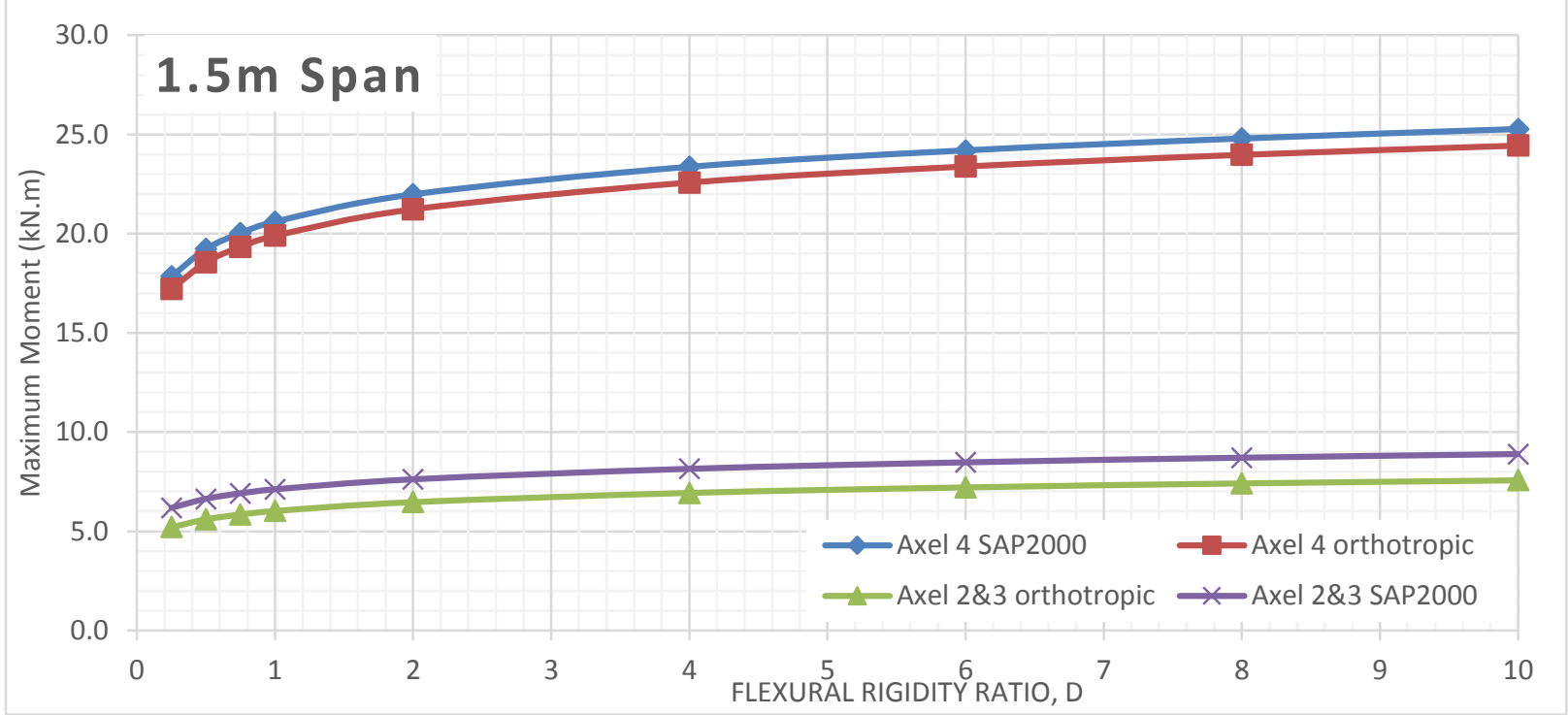

Figure 733 Moment comparison between FEA and Orthotropic Plate Theory for $1.5 \mathrm{~m}$ span of alpha 4 (main bars parallel to traffic) 


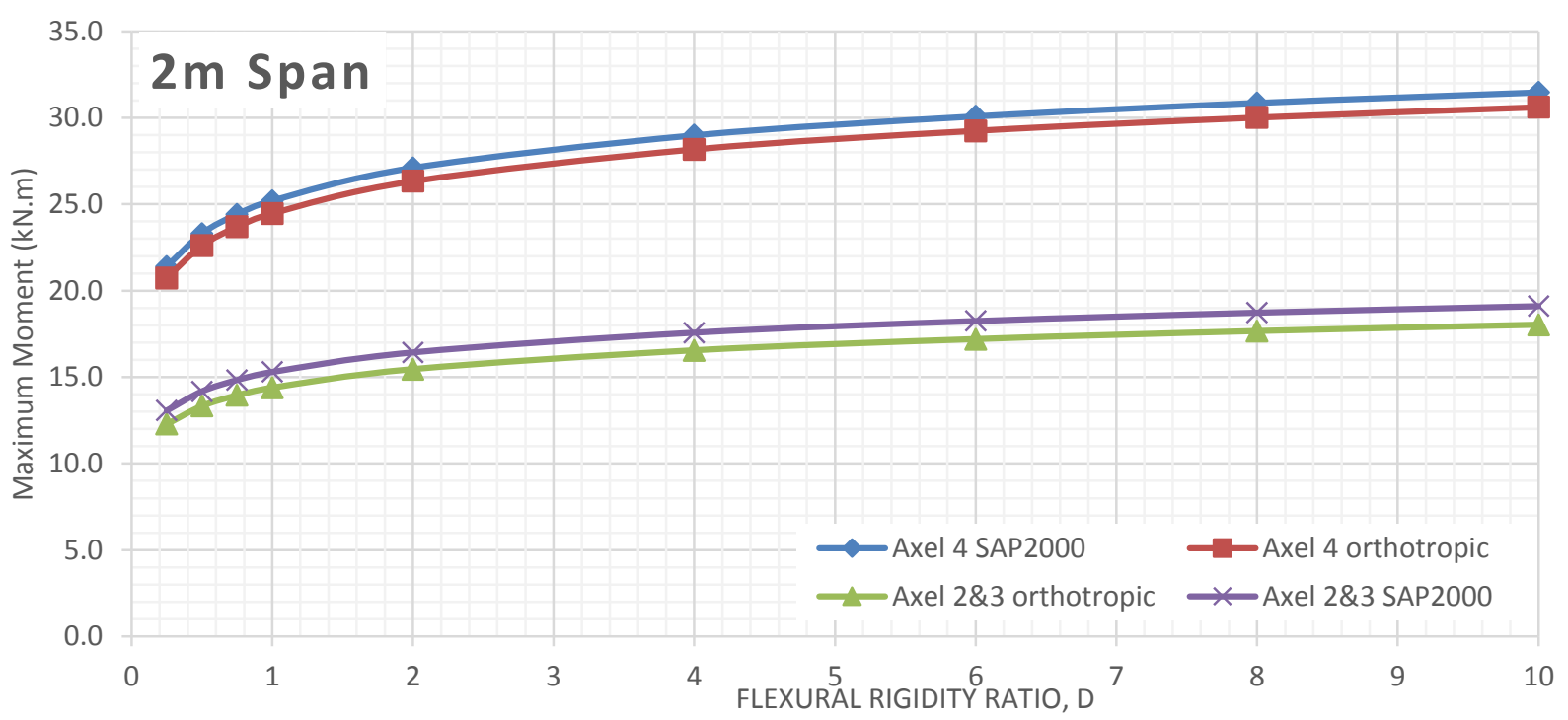

Figure 734 Moment comparison between FEA and Orthotropic Plate Theory for $2 \mathrm{~m}$ span of alpha 4 (main bars parallel to traffic)

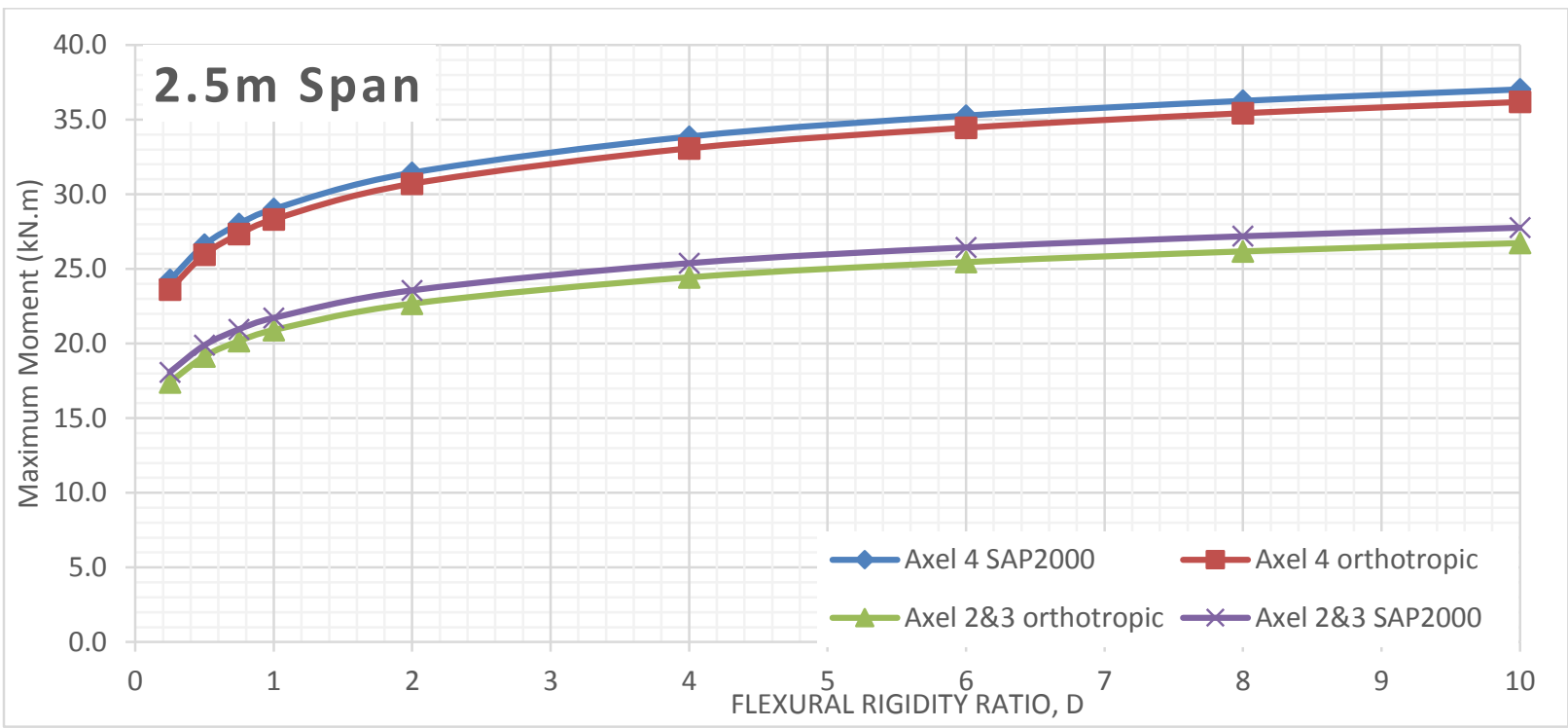

Figure 735 Moment comparison between FEA and Orthotropic Plate Theory for $2.5 \mathrm{~m}$ span of alpha 4 (main bars parallel to traffic)

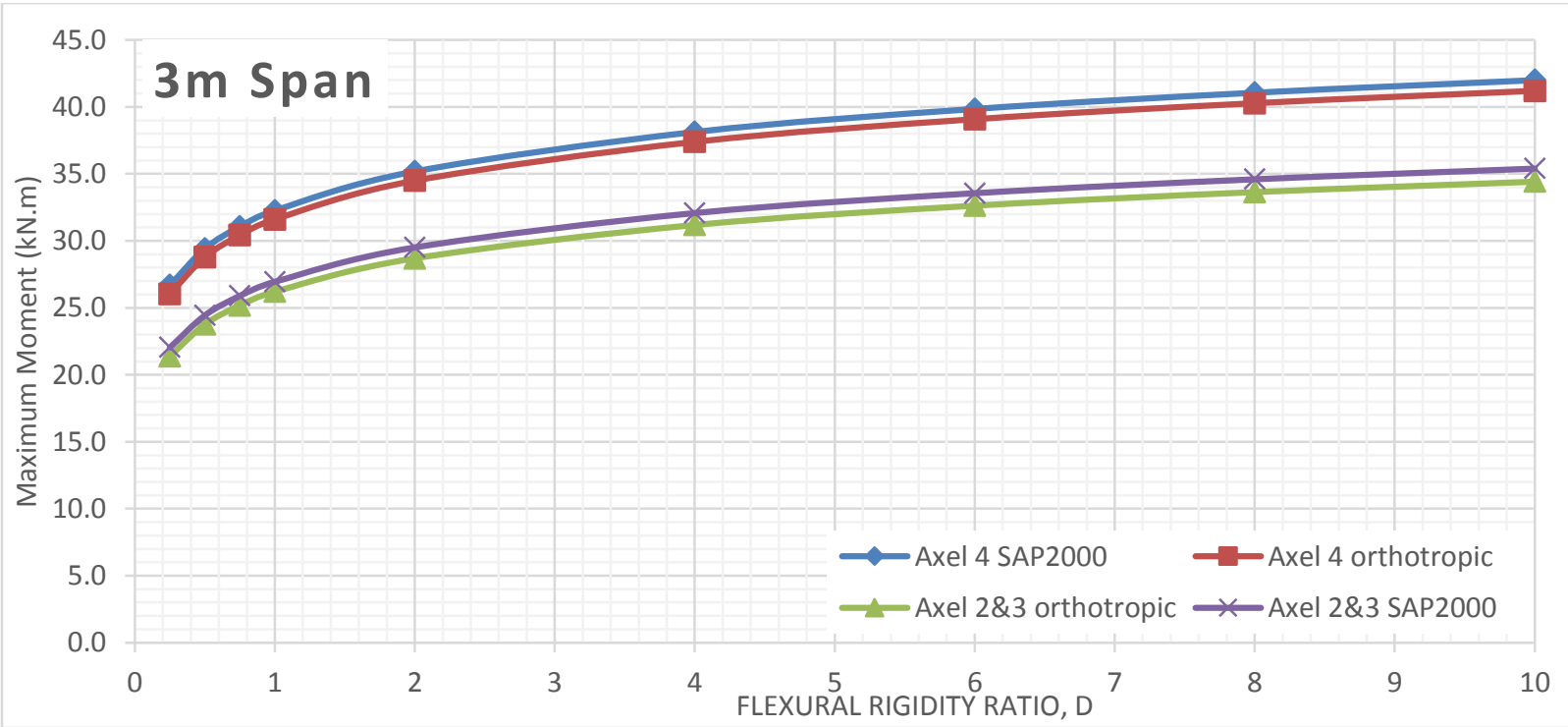

Figure 736 Moment comparison between FEA and Orthotropic Plate Theory for $3 \mathrm{~m}$ span of alpha 4 (main bars parallel to traffic) 


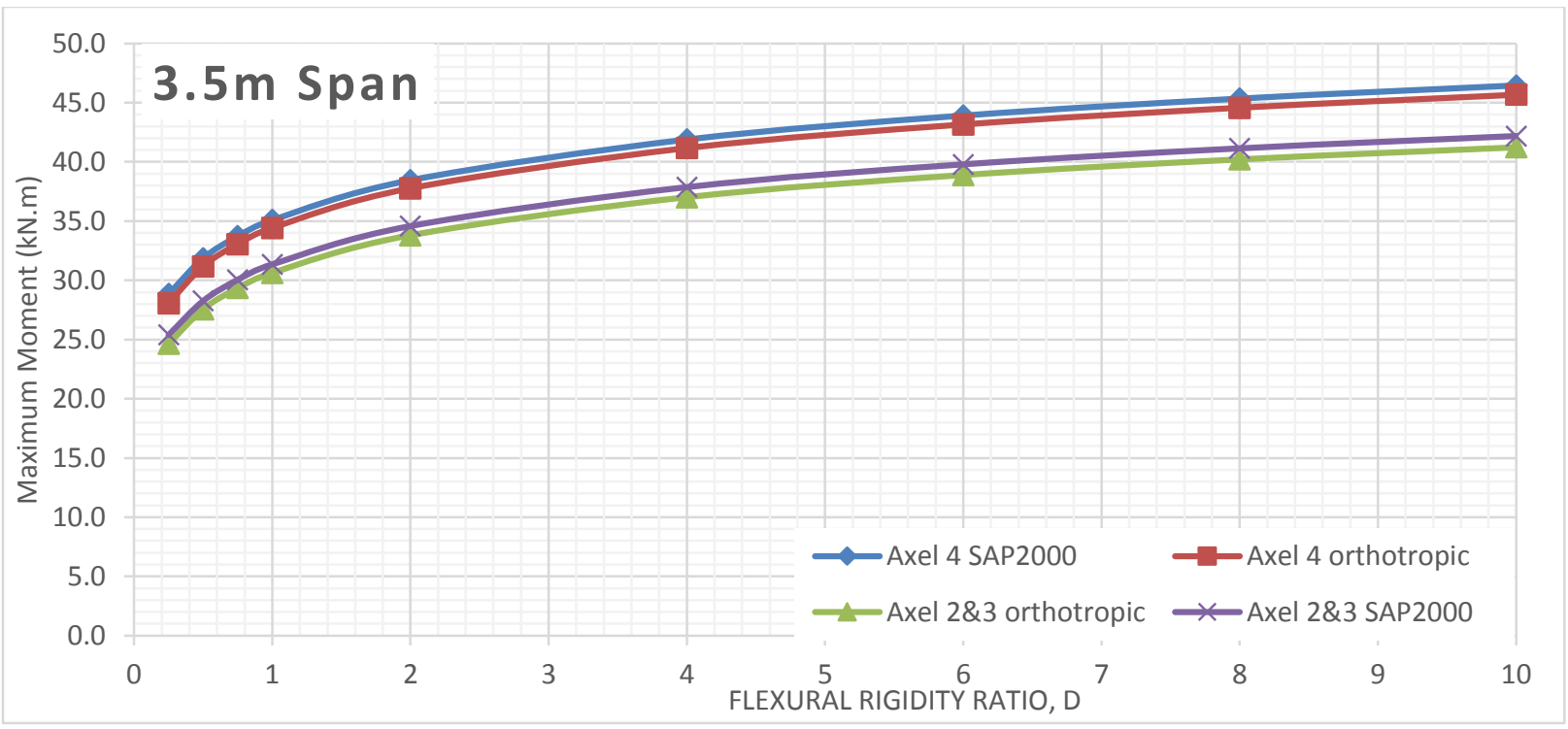

Figure 737 Moment comparison between FEA and Orthotropic Plate Theory for $3.5 \mathrm{~m}$ span of alpha 4 (main bars parallel to traffic)

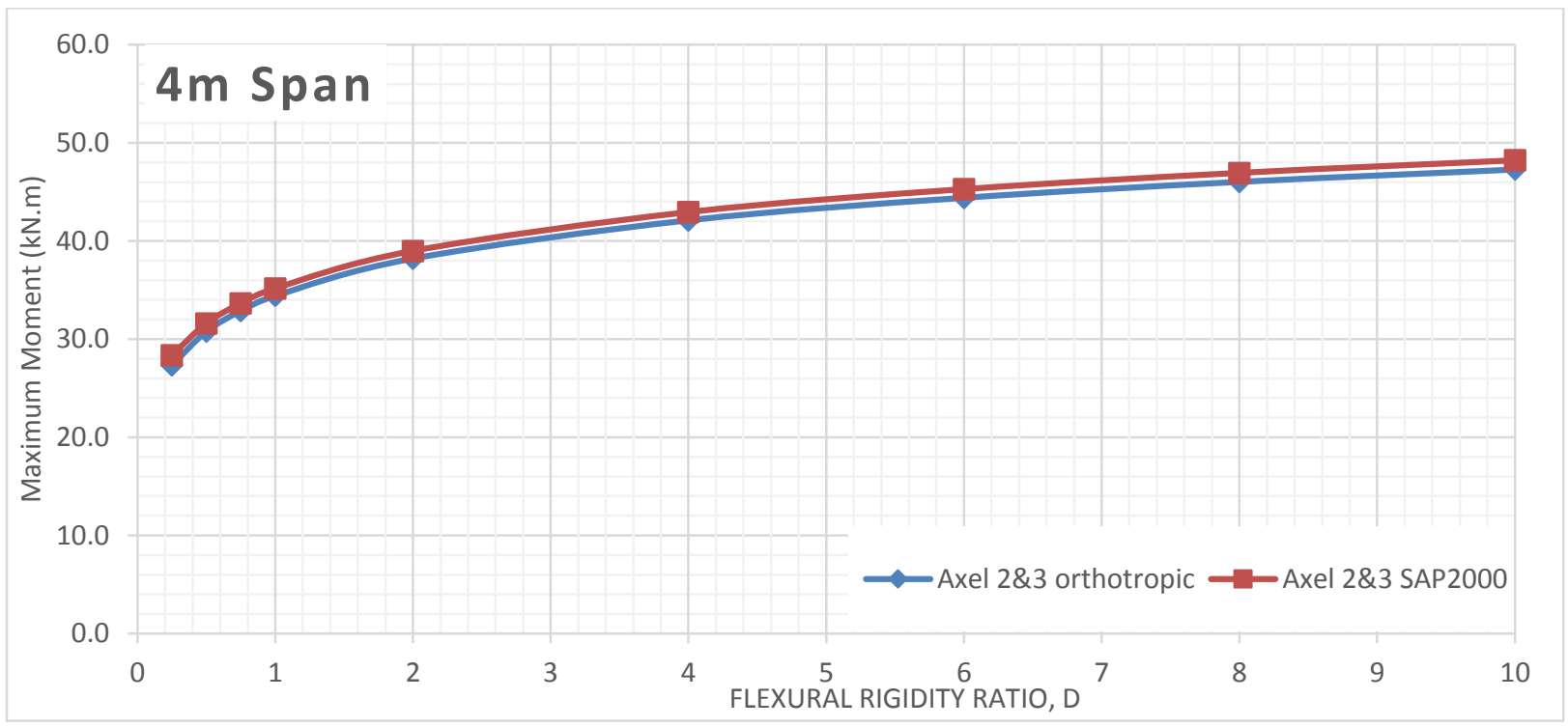

Figure 738 Moment comparison between FEA and Orthotropic Plate Theory for $4 \mathrm{~m}$ span of alpha 4 (main bars parallel to traffic) 


\section{Alpha 6 Bending Moment VS Flexural Rigidity for Different Span Length (Main bars perpendicular to traffic)}

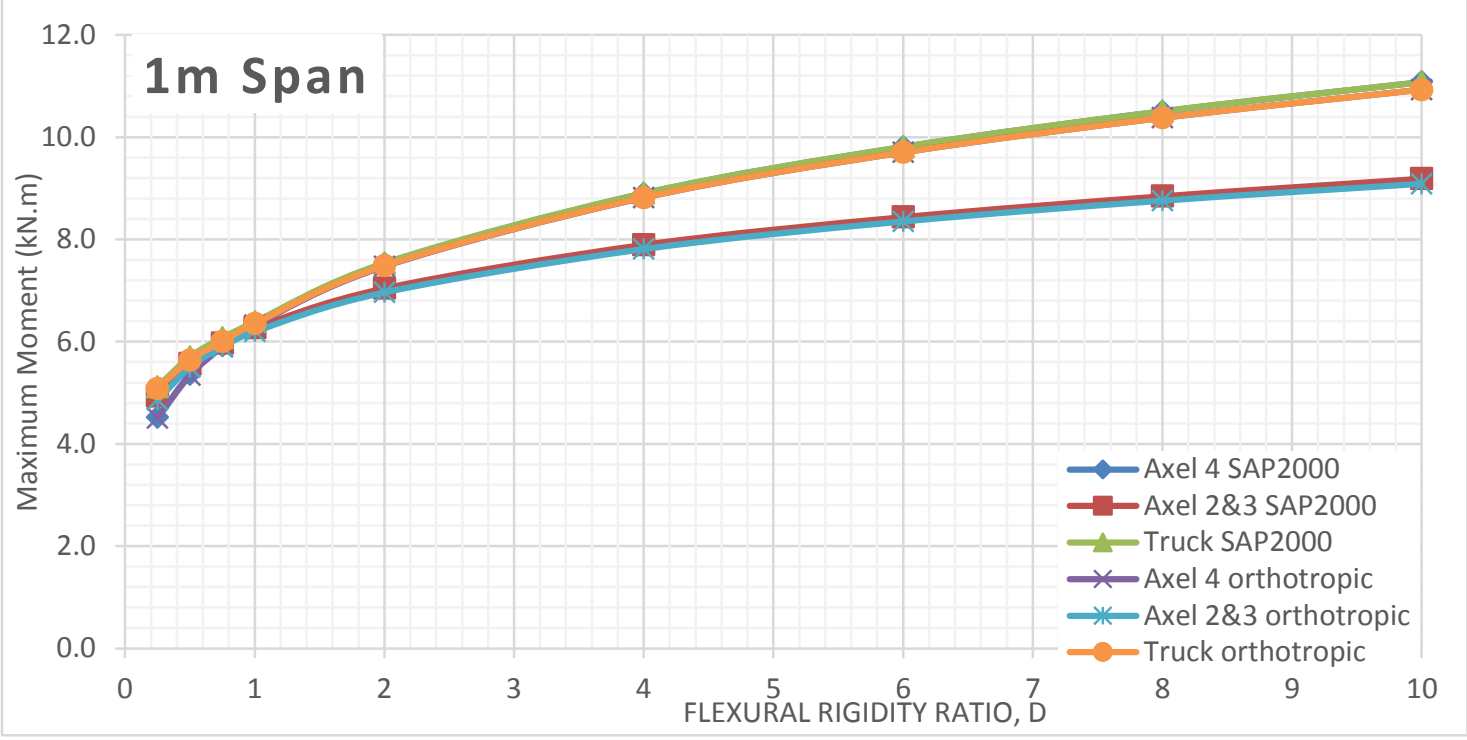

Figure 739 Moment comparison between FEA and Orthotropic Plate Theory for $1 \mathrm{~m}$ span of alpha 6 (main bars perpendicular to traffic)

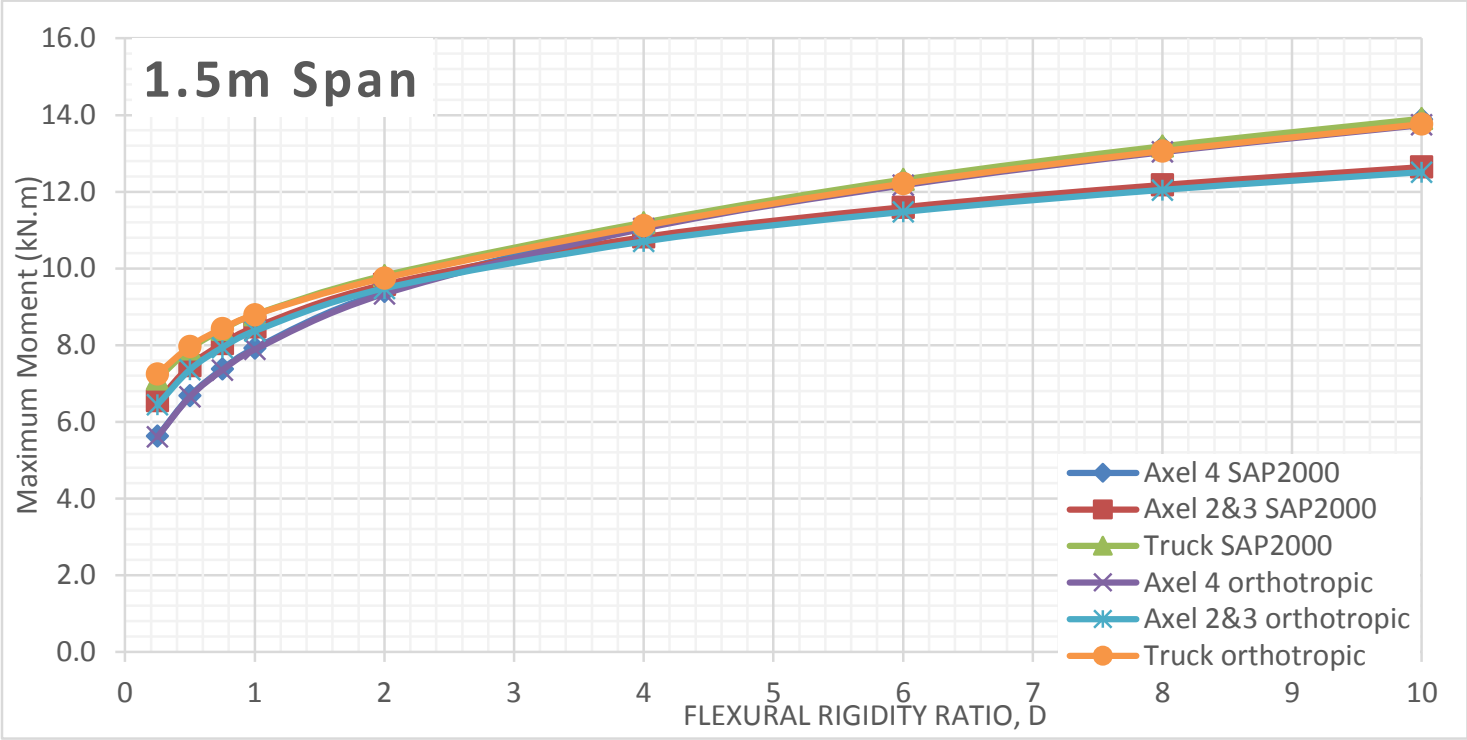

Figure 740 Moment comparison between FEA and Orthotropic Plate Theory for $1.5 \mathrm{~m}$ span of alpha 6 (main bars perpendicular to traffic) 


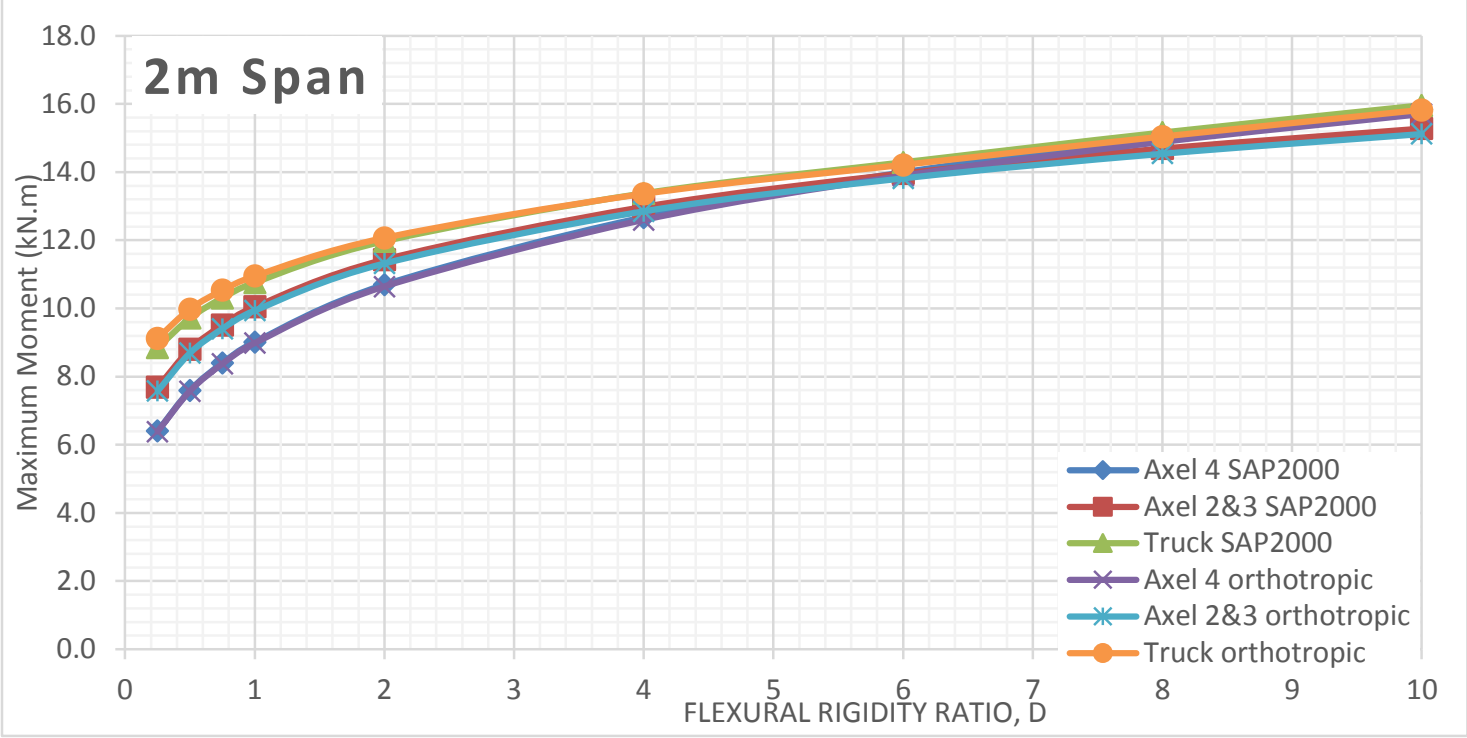

Figure 741 Moment comparison between FEA and Orthotropic Plate Theory for $2 \mathrm{~m}$ span of alpha 6 (main bars perpendicular to traffic)

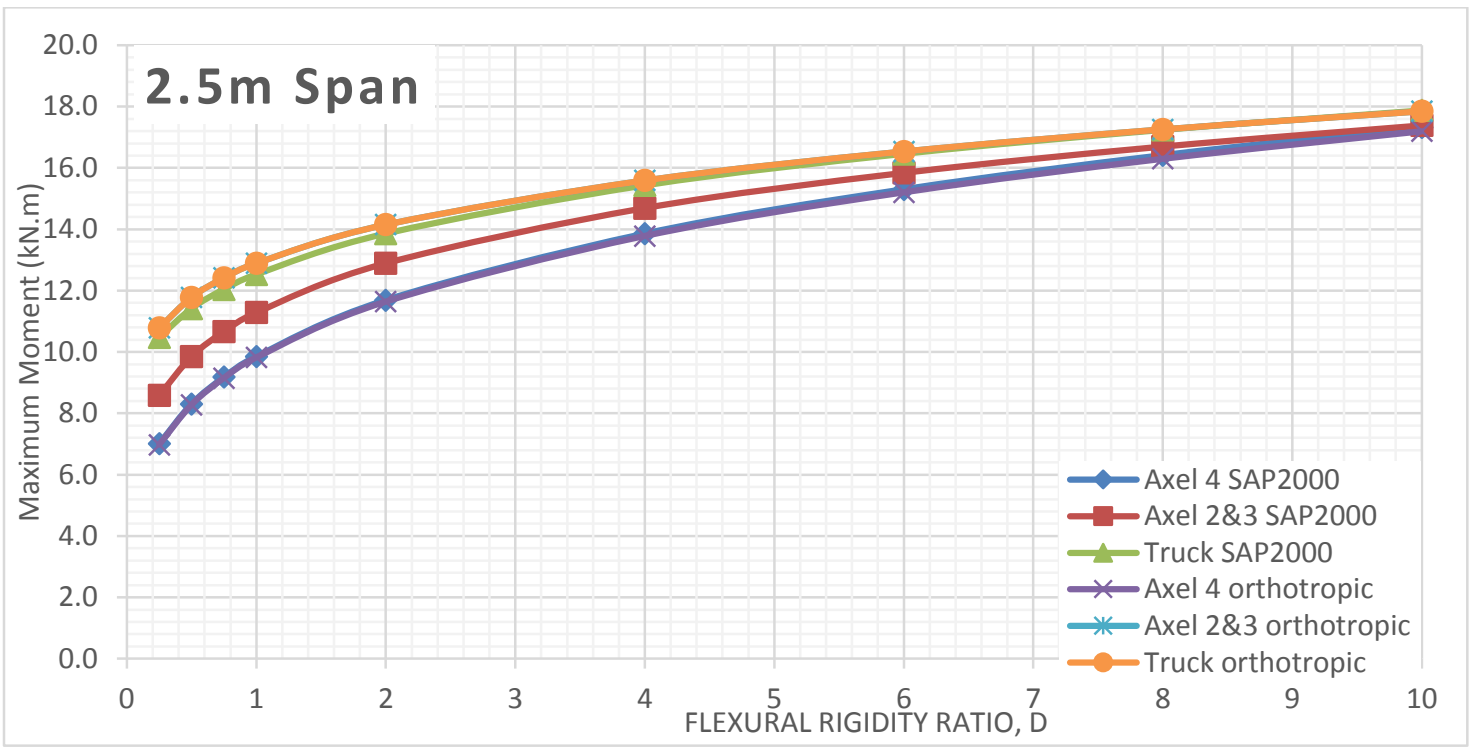

Figure 742 Moment comparison between FEA and Orthotropic Plate Theory for $2.5 \mathrm{~m}$ span of alpha 6 (main bars perpendicular to traffic)

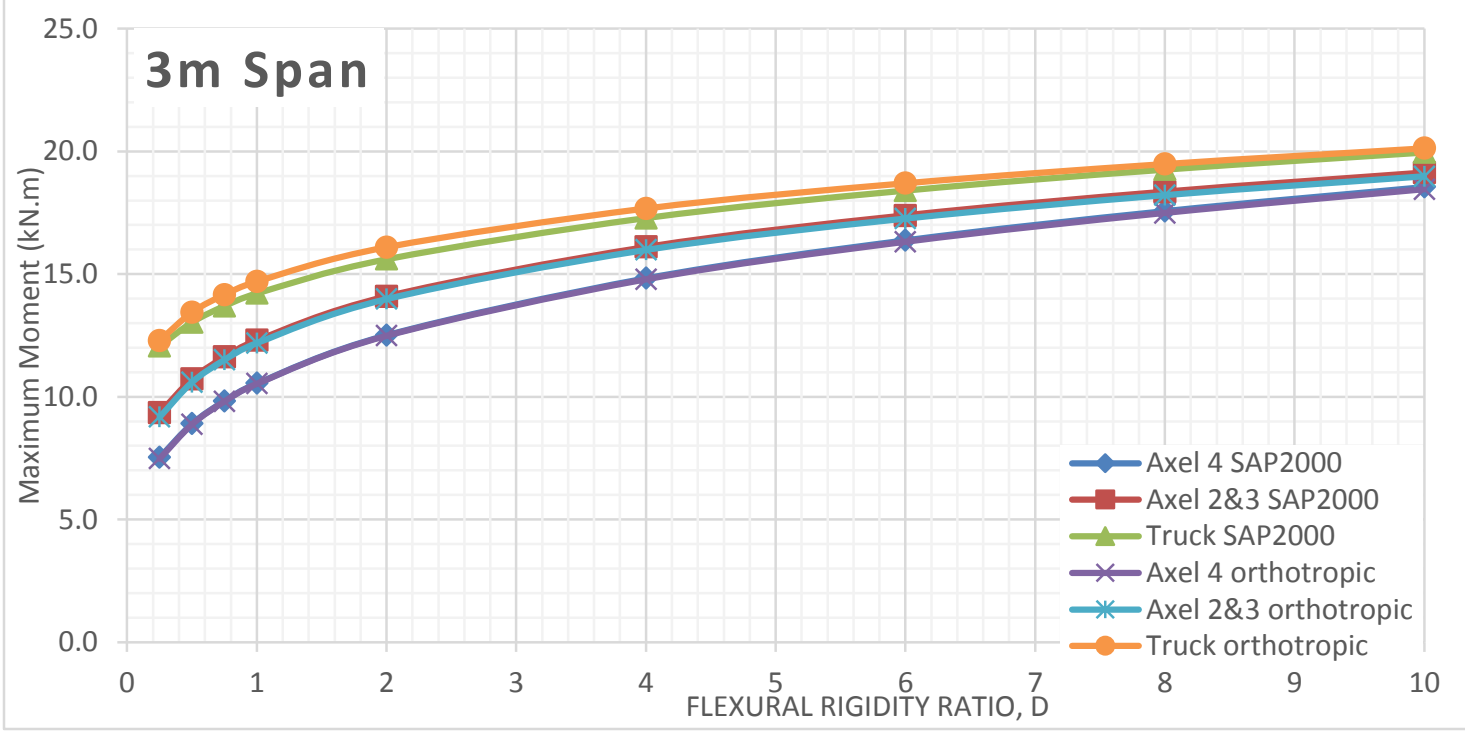

Figure 743 Moment comparison between FEA and Orthotropic Plate Theory for $3 \mathrm{~m}$ span of alpha 6 (main bars perpendicular to traffic) 


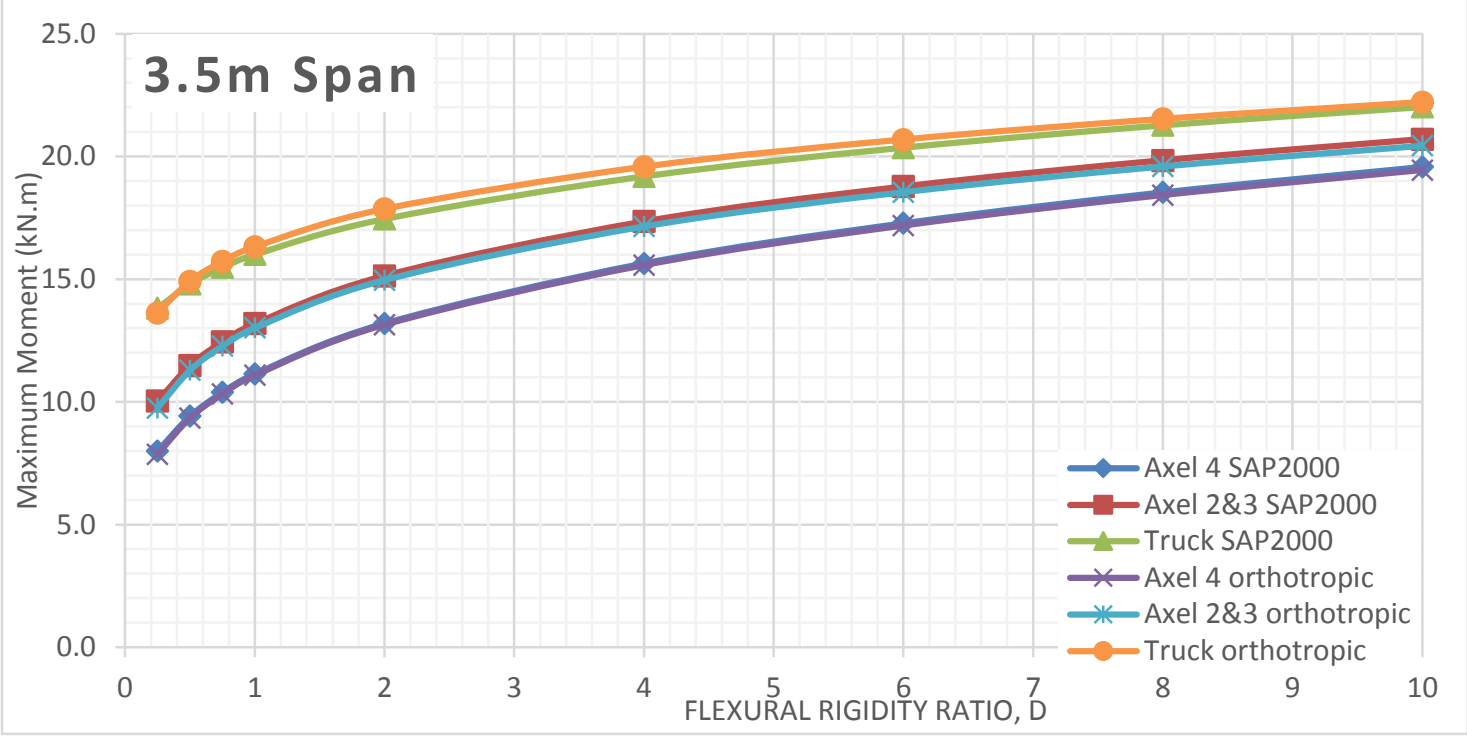

Figure 744 Moment comparison between FEA and Orthotropic Plate Theory for $3.5 \mathrm{~m}$ span of alpha 6 (main bars perpendicular to traffic)

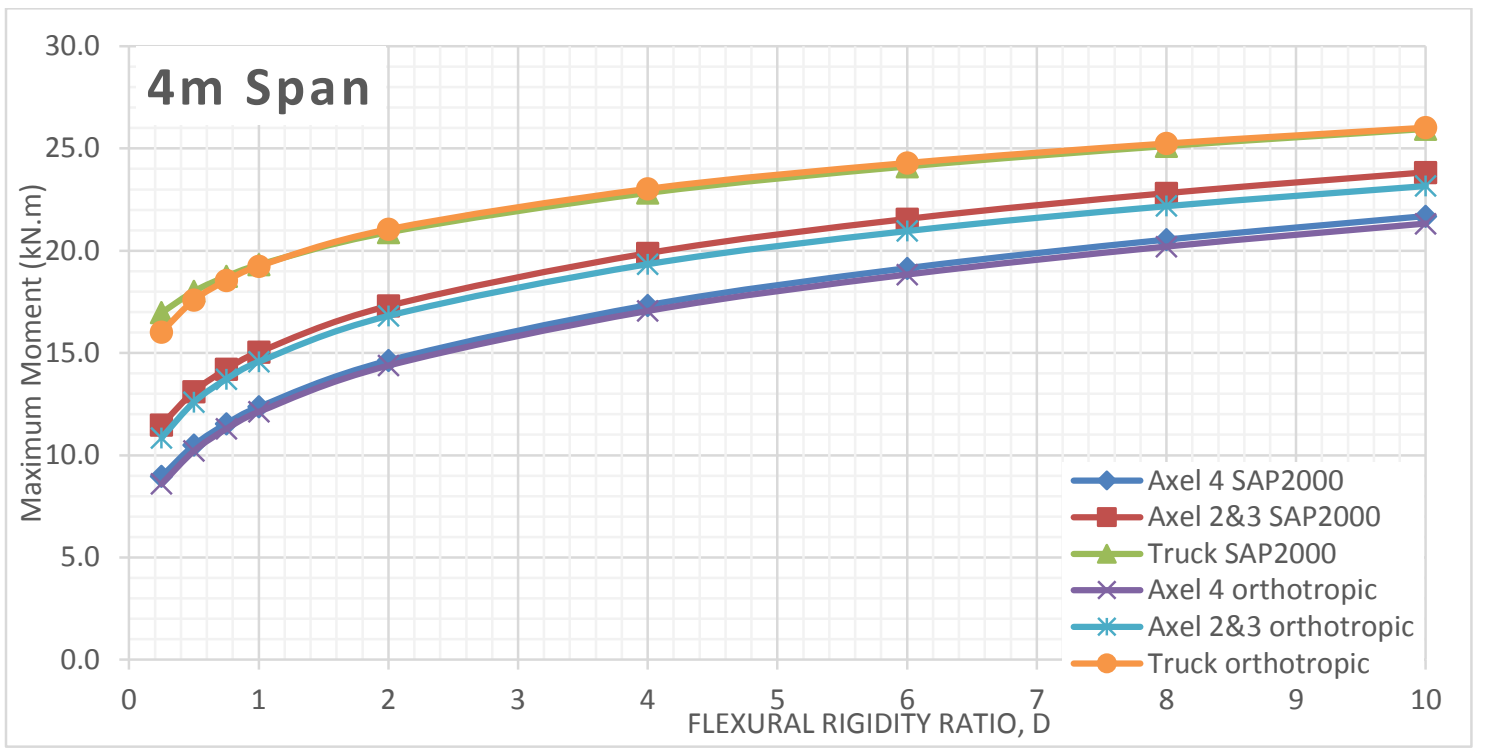

Figure 745 Moment comparison between FEA and Orthotropic Plate Theory for $4 \mathrm{~m}$ span of alpha 6 (main bars perpendicular to traffic) 


\section{Alpha 6 Bending Moment VS Flexural Rigidity for Different Span Length (Main bars parallel to traffic)}

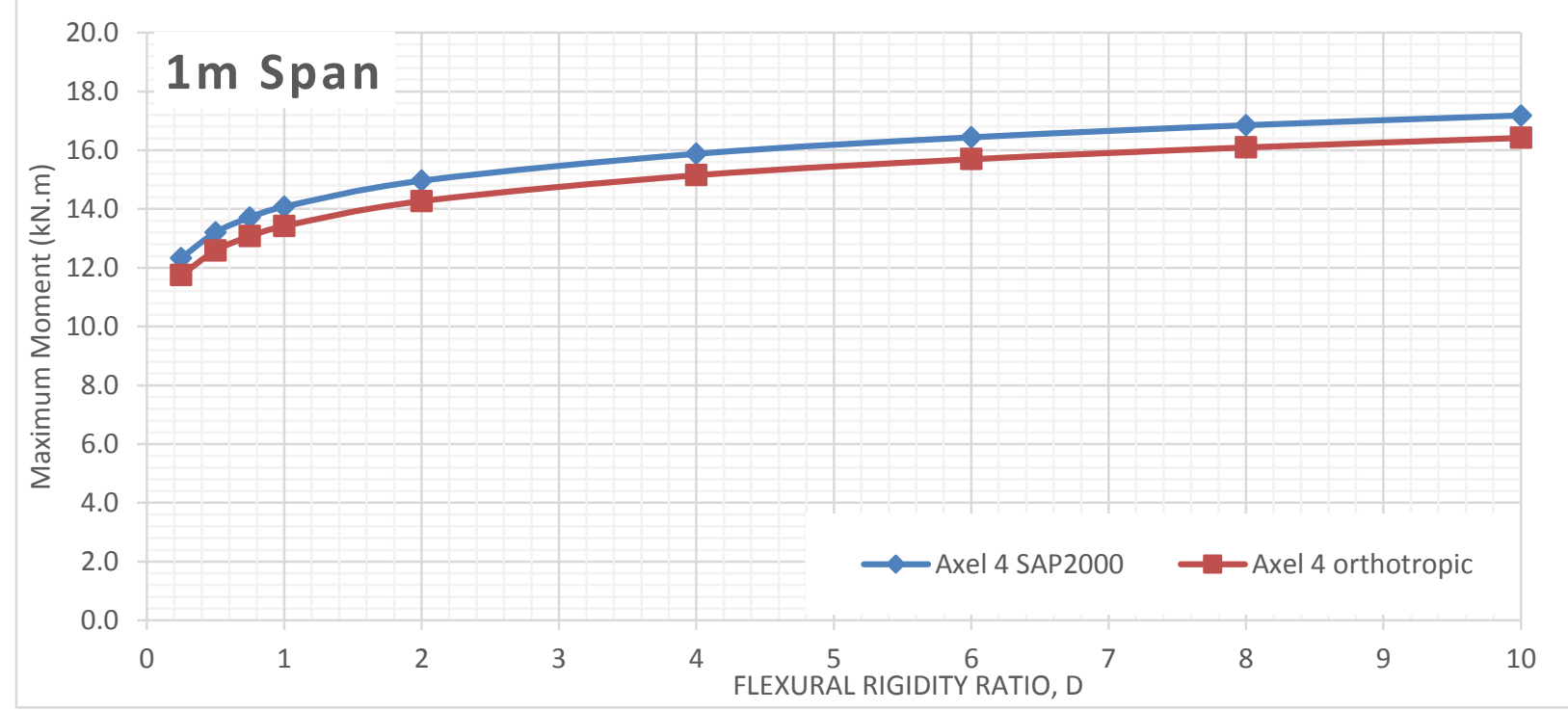

Figure 746 Moment comparison between FEA and Orthotropic Plate Theory for $1 \mathrm{~m}$ span of alpha 6 (main bars parallel to traffic)

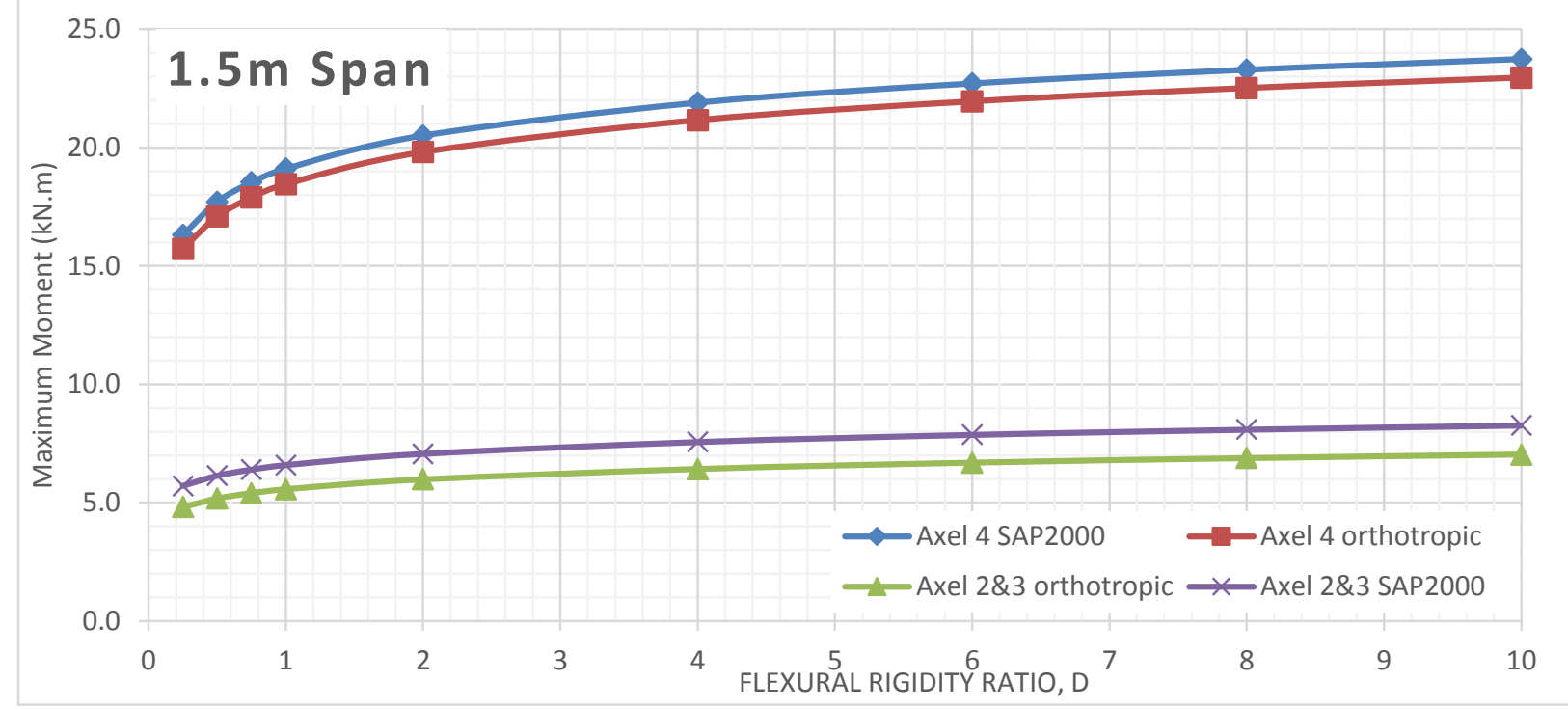

Figure 747 Moment comparison between FEA and Orthotropic Plate Theory for $1.5 \mathrm{~m}$ span of alpha 6 (main bars parallel to traffic) 


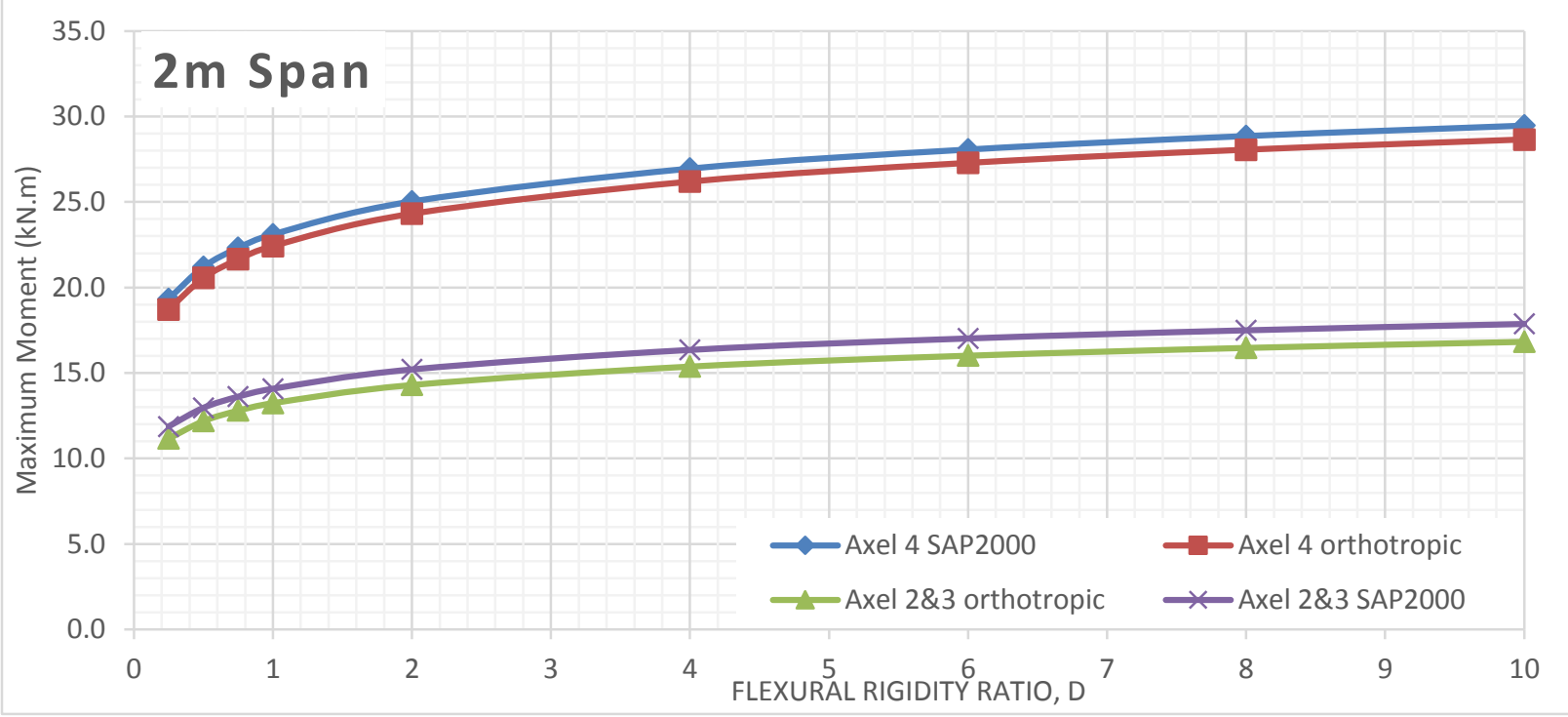

Figure 748 Moment comparison between FEA and Orthotropic Plate Theory for $2 \mathrm{~m}$ span of alpha 6 (main bars parallel to traffic)

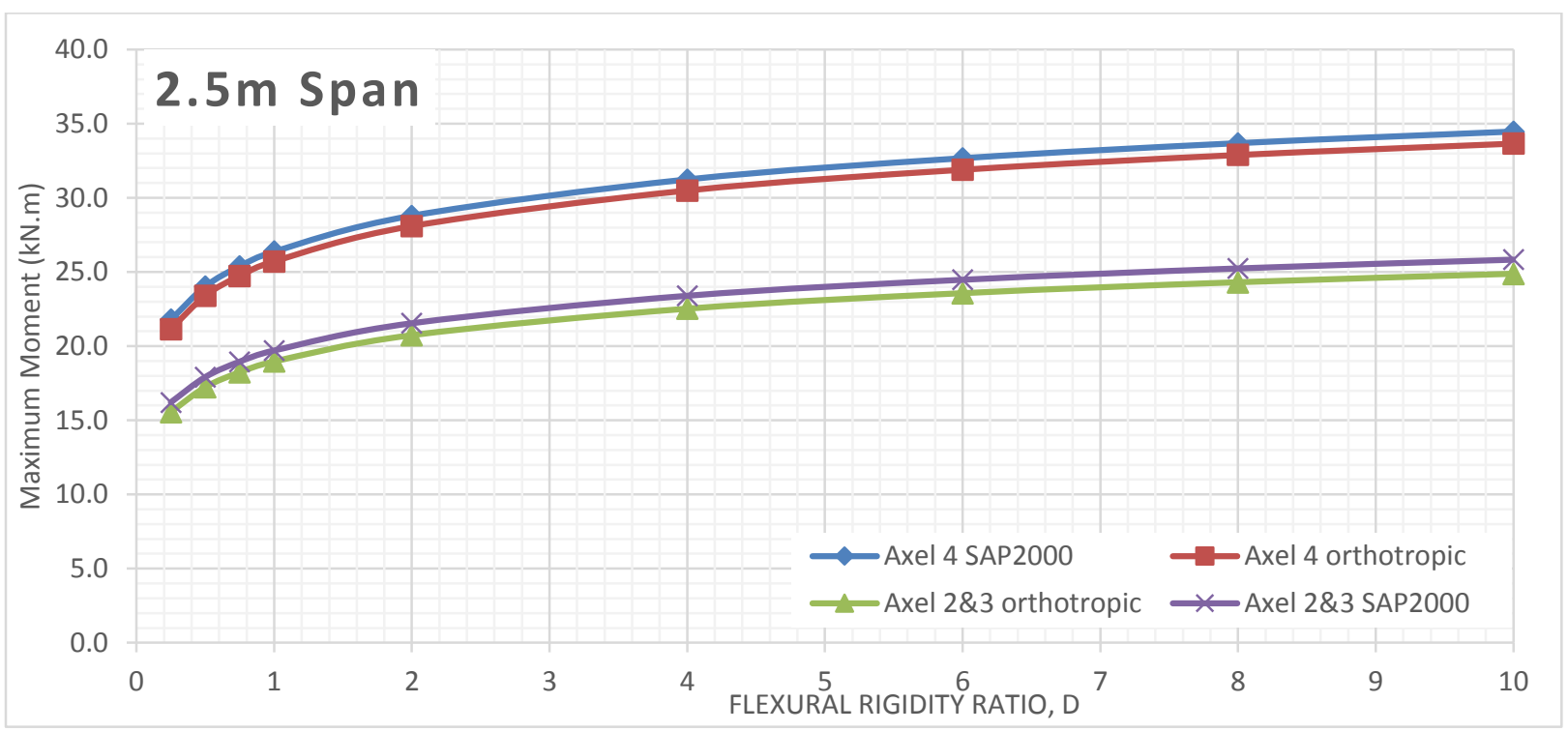

Figure 749 Moment comparison between FEA and Orthotropic Plate Theory for $2.5 \mathrm{~m}$ span of alpha 6 (main bars parallel to traffic)

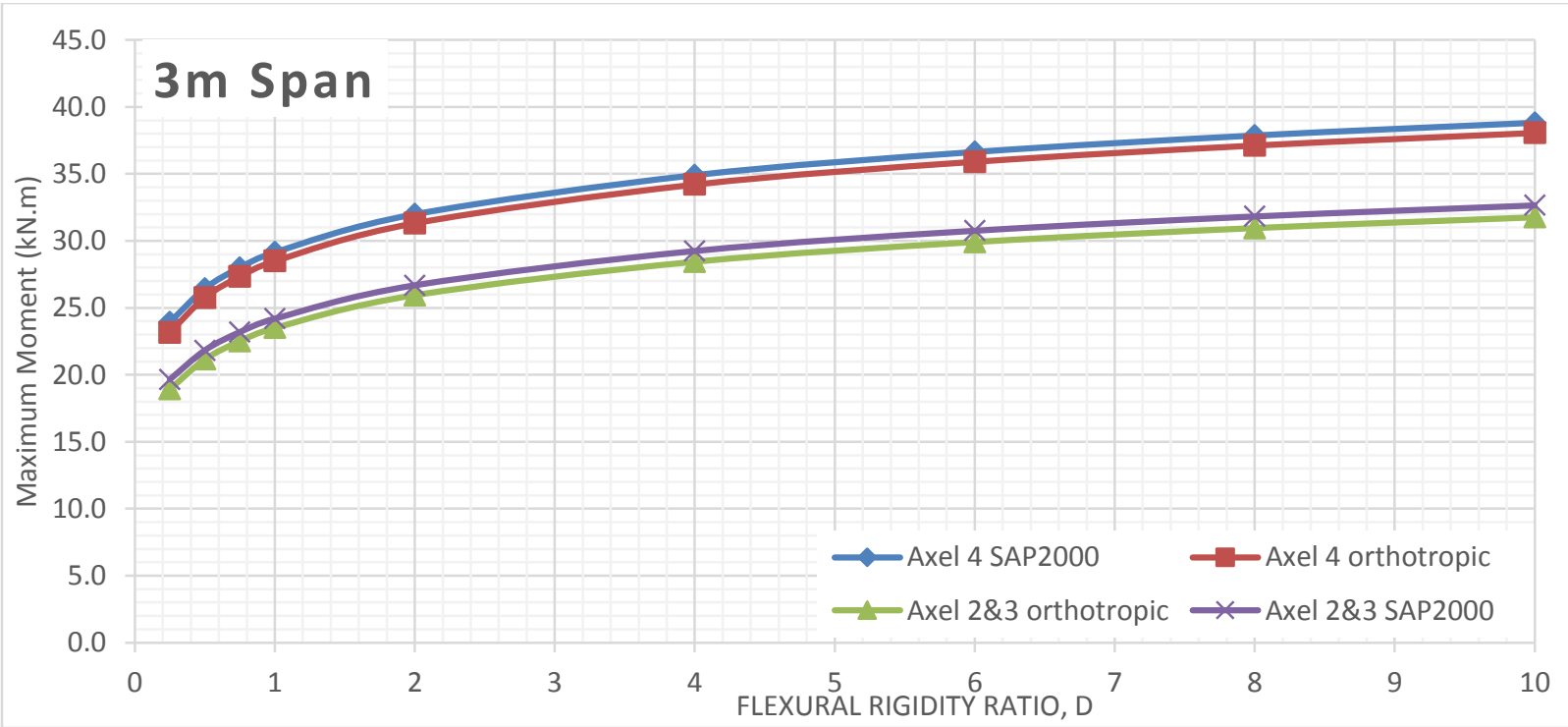

Figure 750 Moment comparison between FEA and Orthotropic Plate Theory for $3 \mathrm{~m}$ span of alpha 6 (main bars parallel to traffic) 


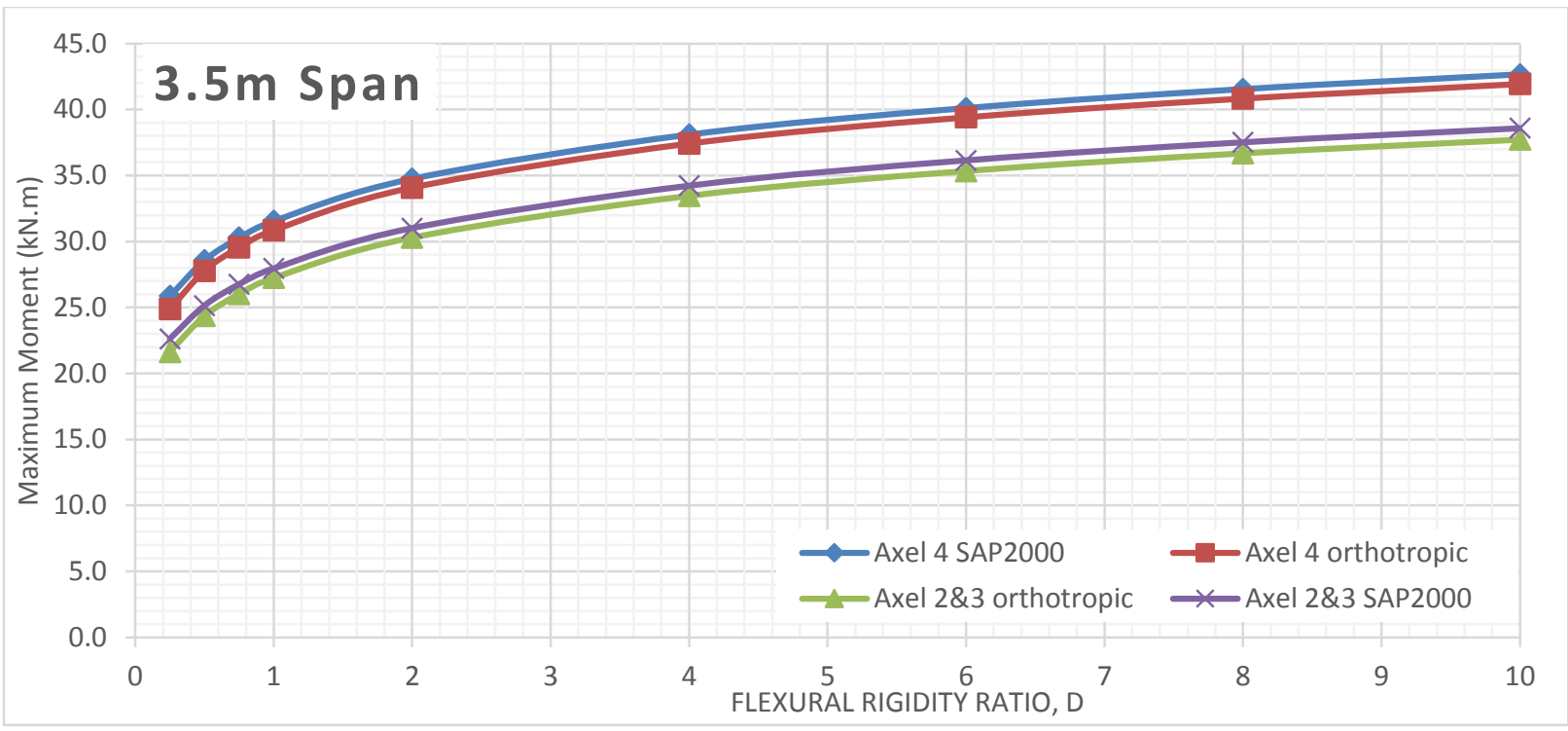

Figure 751 Moment comparison between FEA and Orthotropic Plate Theory for $3.5 \mathrm{~m}$ span of alpha 6 (main bars parallel to traffic)

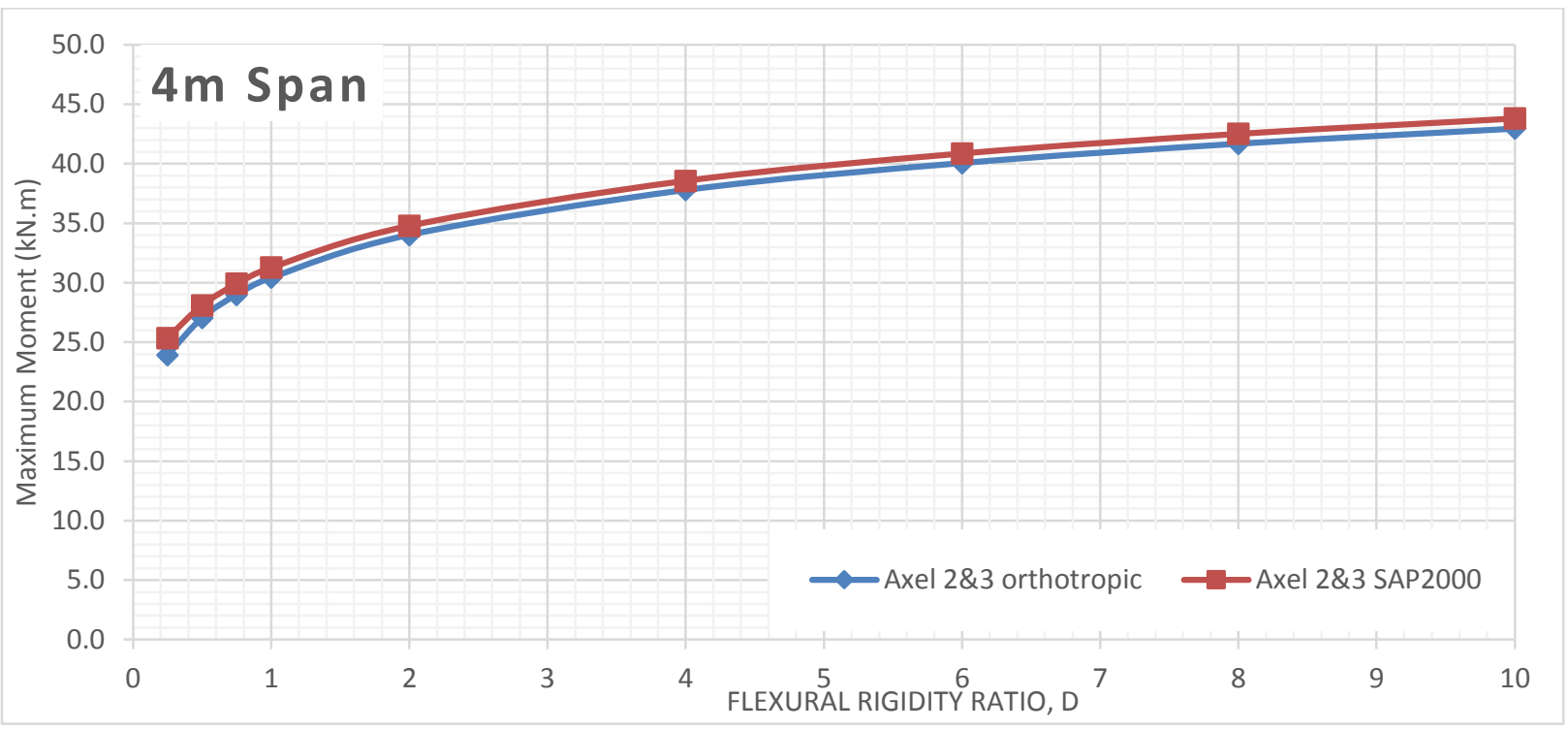

Figure 752 Moment comparison between FEA and Orthotropic Plate Theory for $4 \mathrm{~m}$ span of alpha 6 (main bars parallel to traffic) 


\section{Alpha 8 Bending Moment VS Flexural Rigidity for Different Span Length (Main bars perpendicular to traffic)}

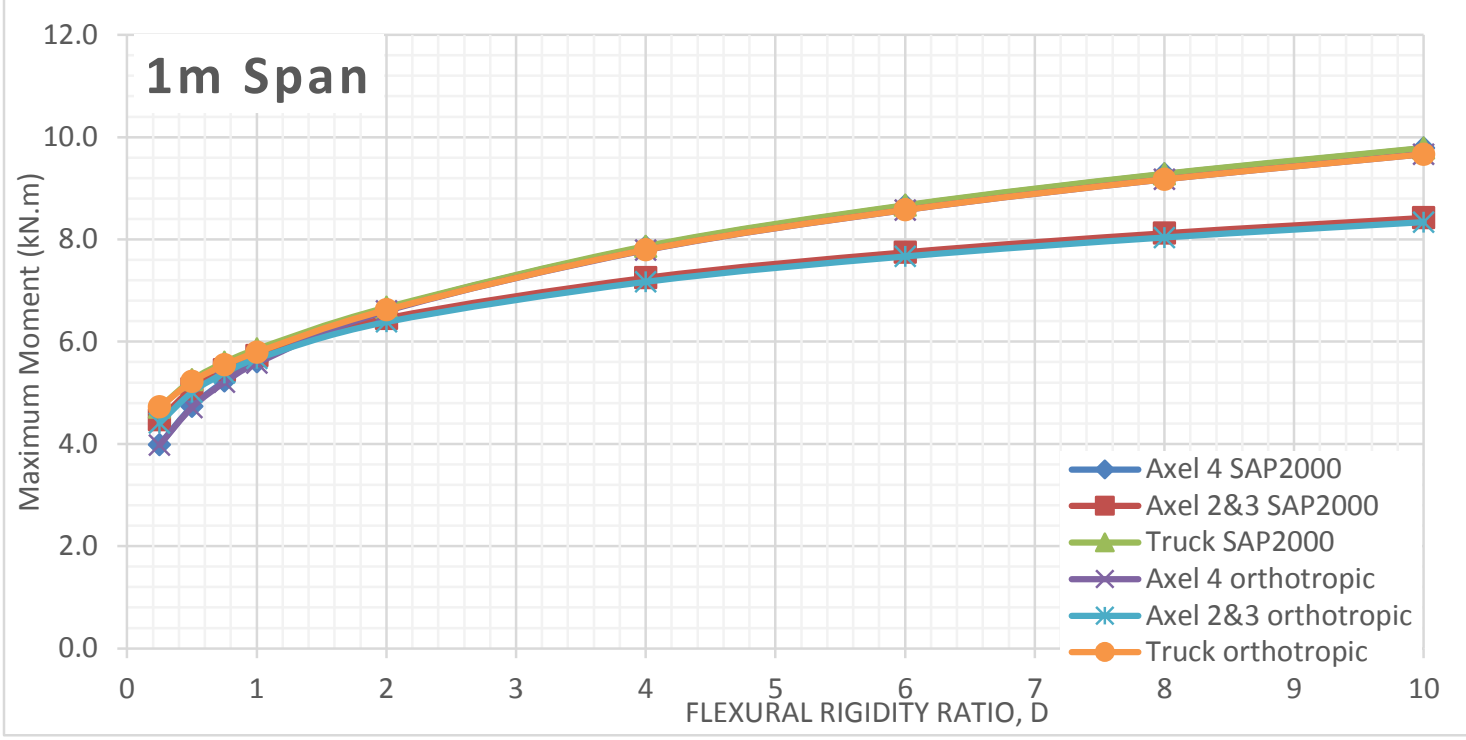

Figure 753 Moment comparison between FEA and Orthotropic Plate Theory for $1 \mathrm{~m}$ span of alpha 8 (main bars perpendicular to traffic)

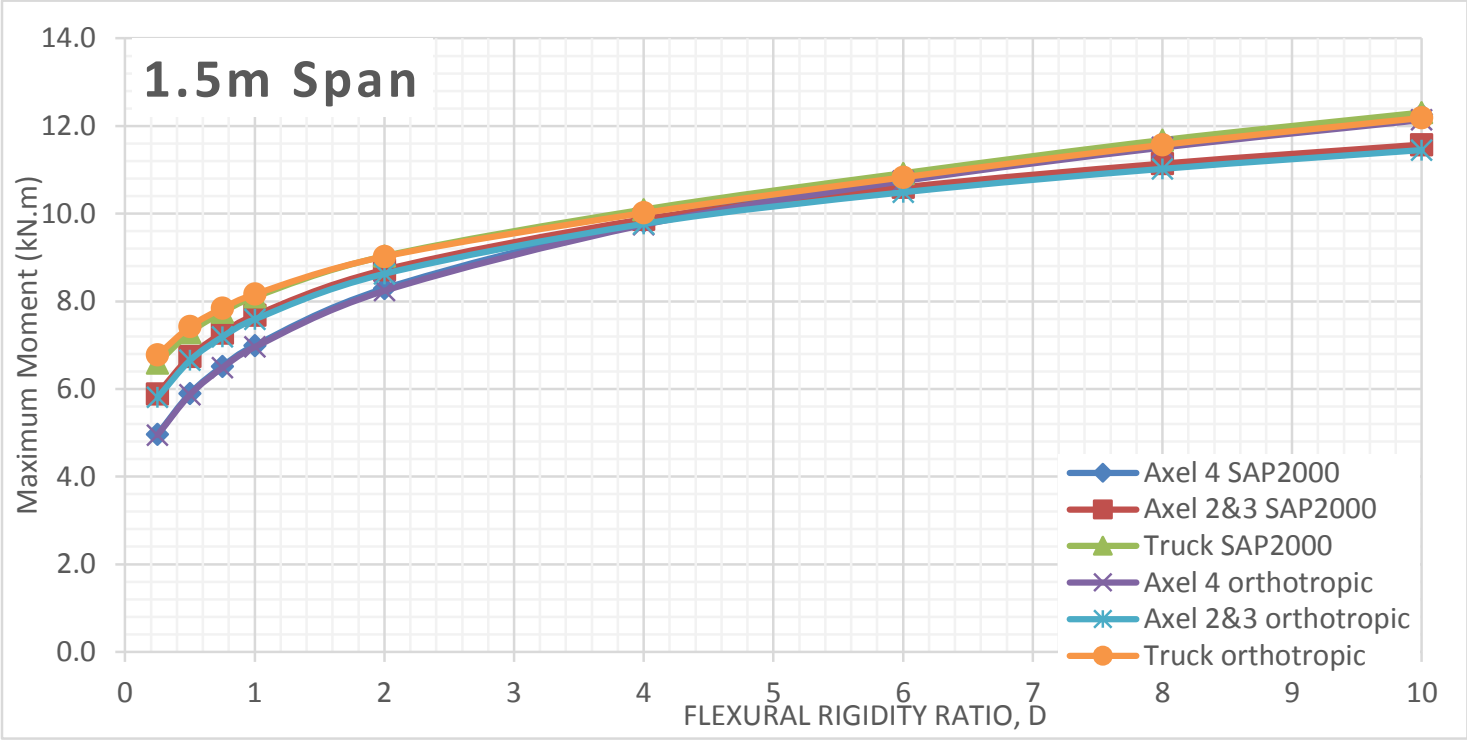

Figure 754 Moment comparison between FEA and Orthotropic Plate Theory for $1.5 \mathrm{~m}$ span of alpha 8 (main bars perpendicular to traffic) 


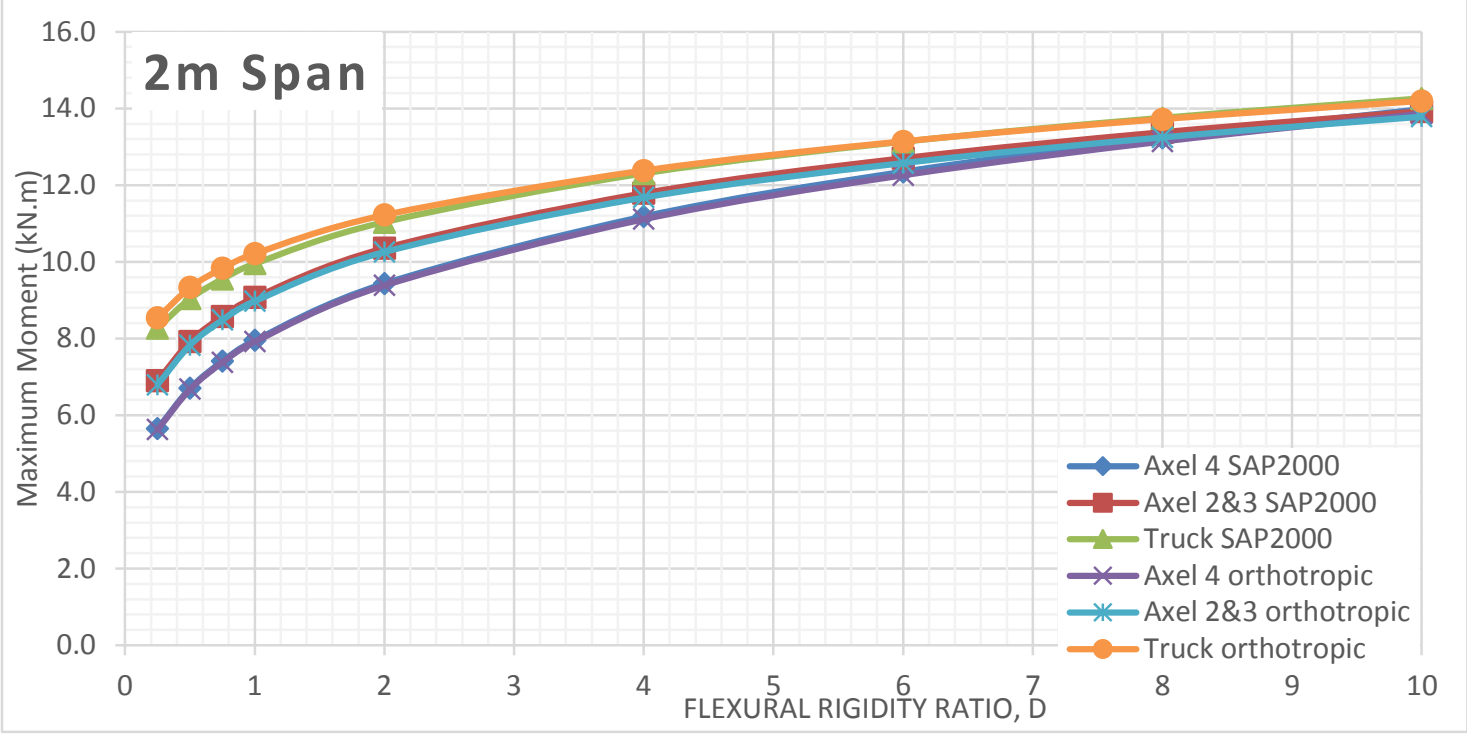

Figure 755 Moment comparison between FEA and Orthotropic Plate Theory for $2 \mathrm{~m}$ span of alpha 8 (main bars perpendicular to traffic)

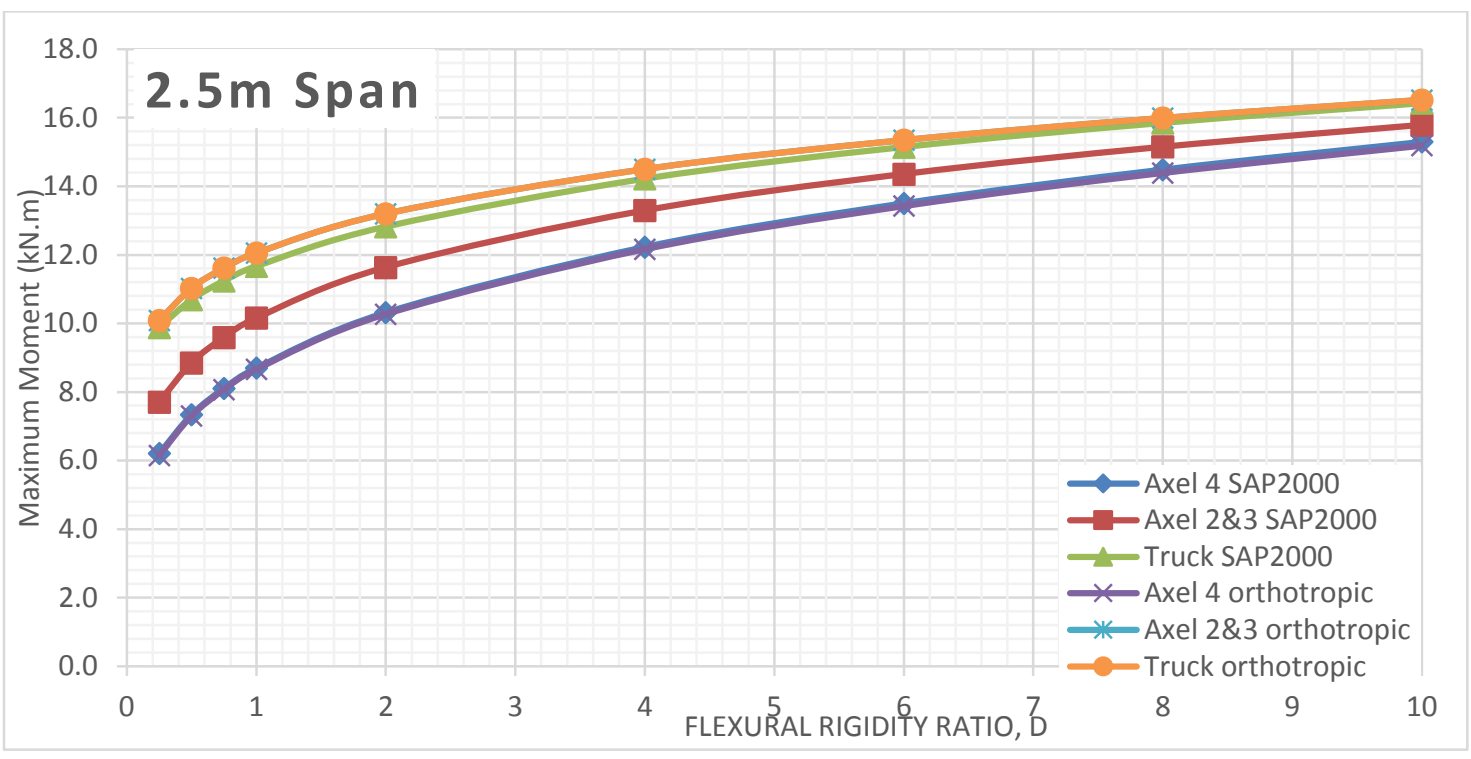

Figure 756 Moment comparison between FEA and Orthotropic Plate Theory for $2.5 \mathrm{~m}$ span of alpha 8 (main bars perpendicular to traffic)

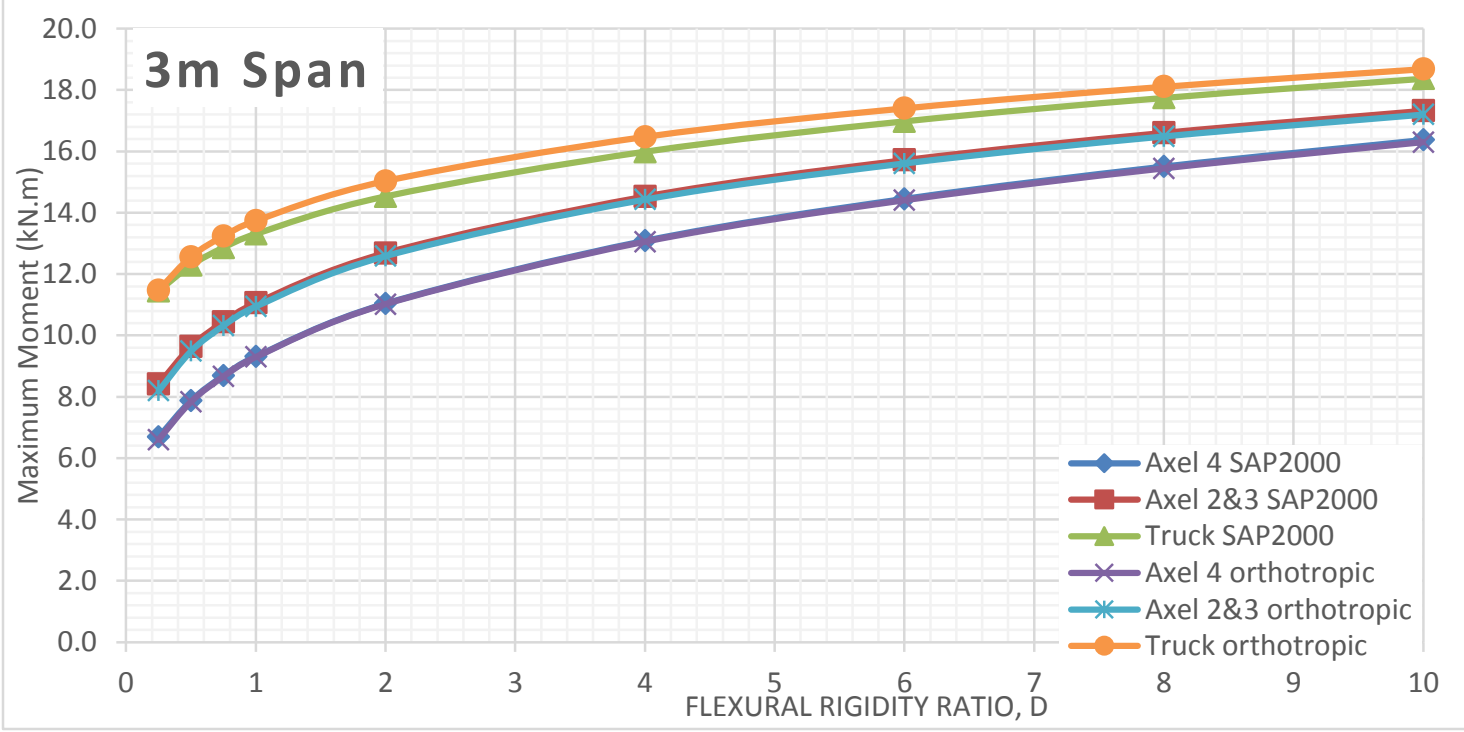

Figure 757 Moment comparison between FEA and Orthotropic Plate Theory for $3 \mathrm{~m}$ span of alpha 8 (main bars perpendicular to traffic) 


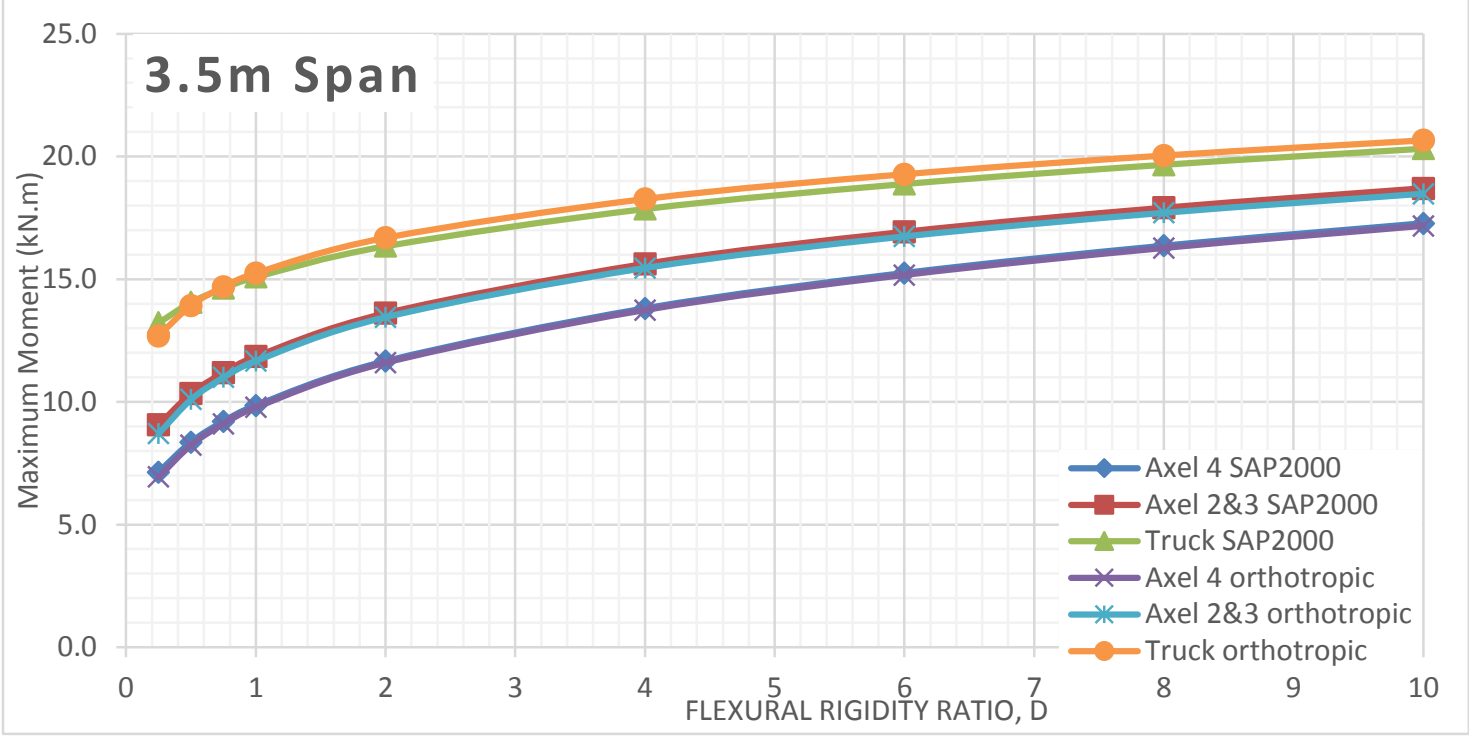

Figure 758 Moment comparison between FEA and Orthotropic Plate Theory for $3.5 \mathrm{~m}$ span of alpha 8 (main bars perpendicular to traffic)

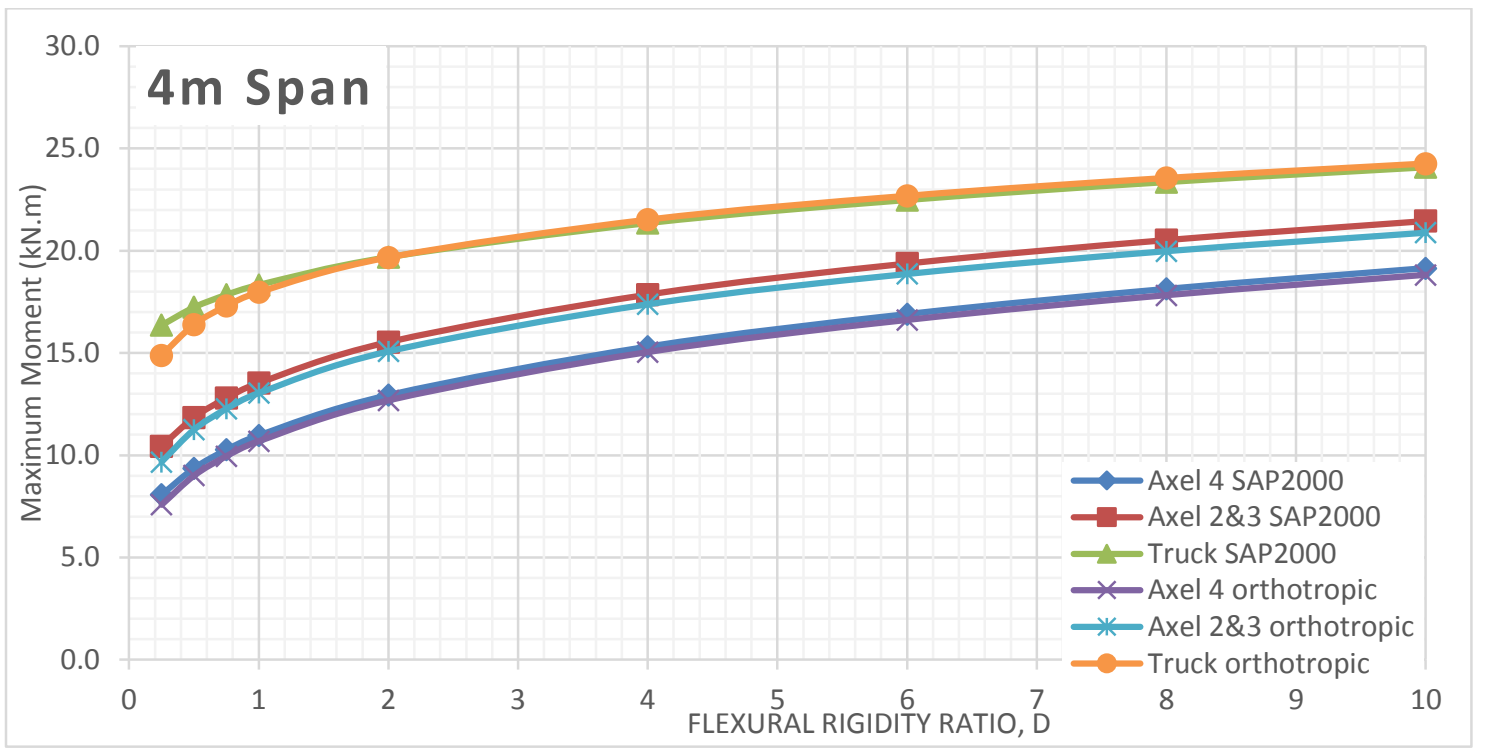

Figure 759 Moment comparison between FEA and Orthotropic Plate Theory for $4 \mathrm{~m}$ span of alpha 8 (main bars perpendicular to traffic) 


\section{Alpha 8 Bending Moment VS Flexural Rigidity for Different Span Length (Main bars parallel to traffic)}

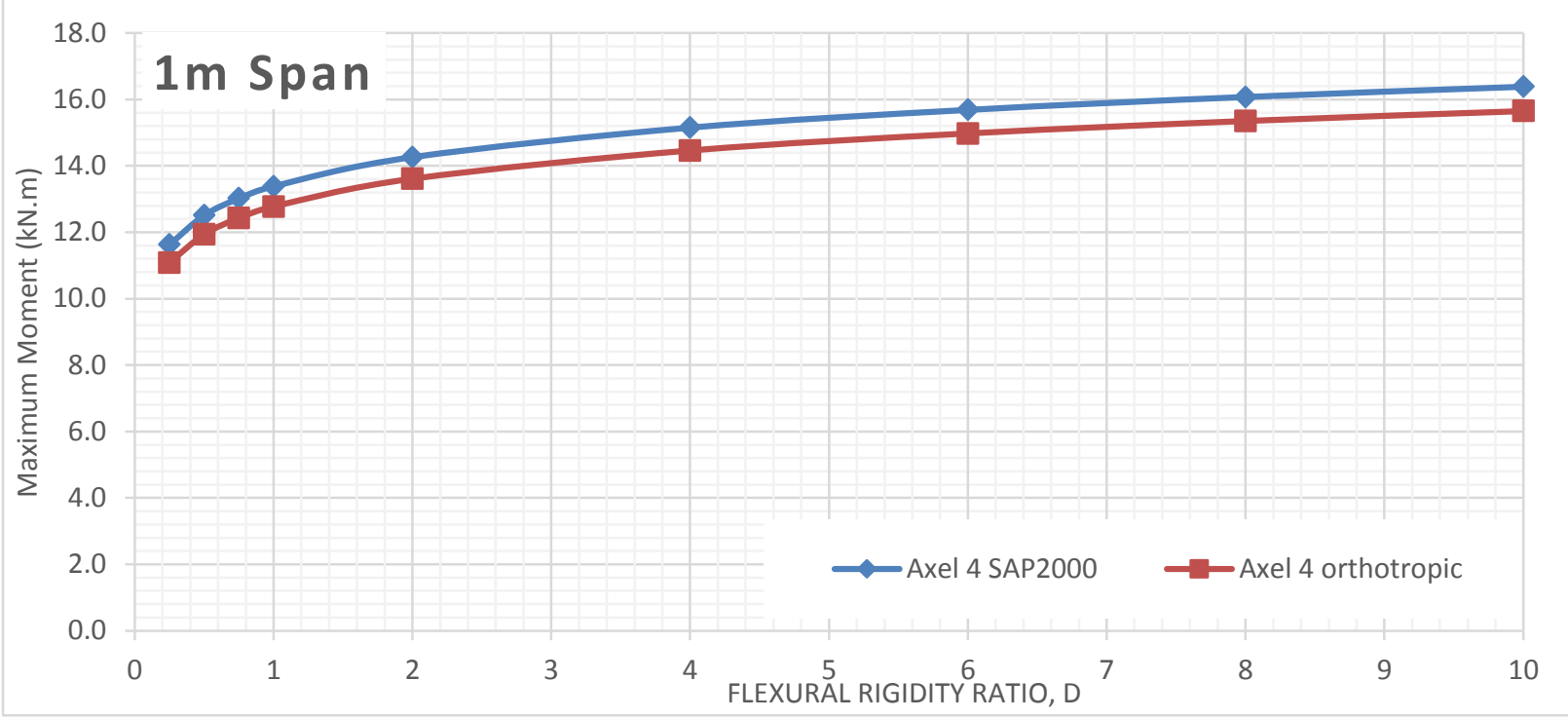

Figure 760 Moment comparison between FEA and Orthotropic Plate Theory for $1 \mathrm{~m}$ span of alpha 8 (main bars parallel to traffic)

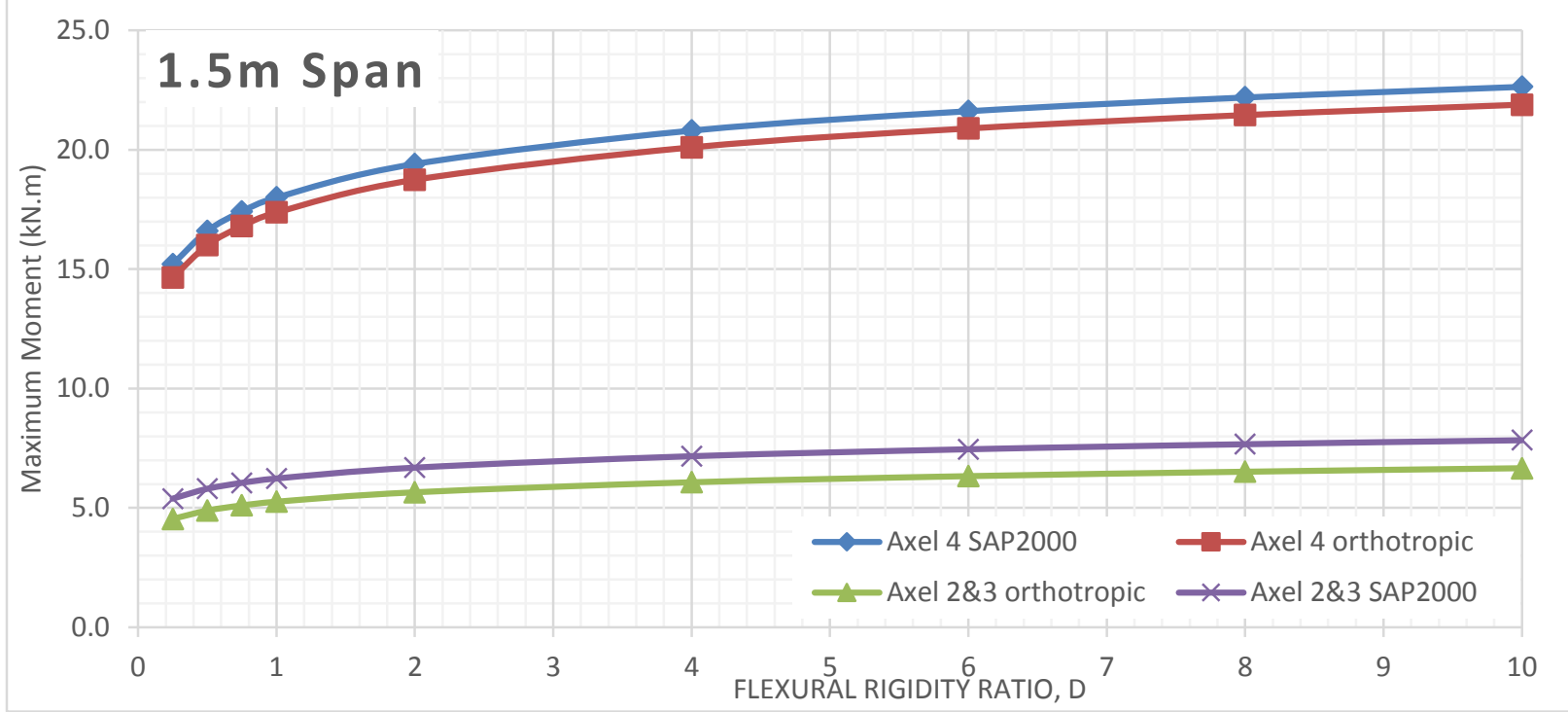

Figure 761 Moment comparison between FEA and Orthotropic Plate Theory for $1.5 \mathrm{~m}$ span of alpha 8 (main bars parallel to traffic) 


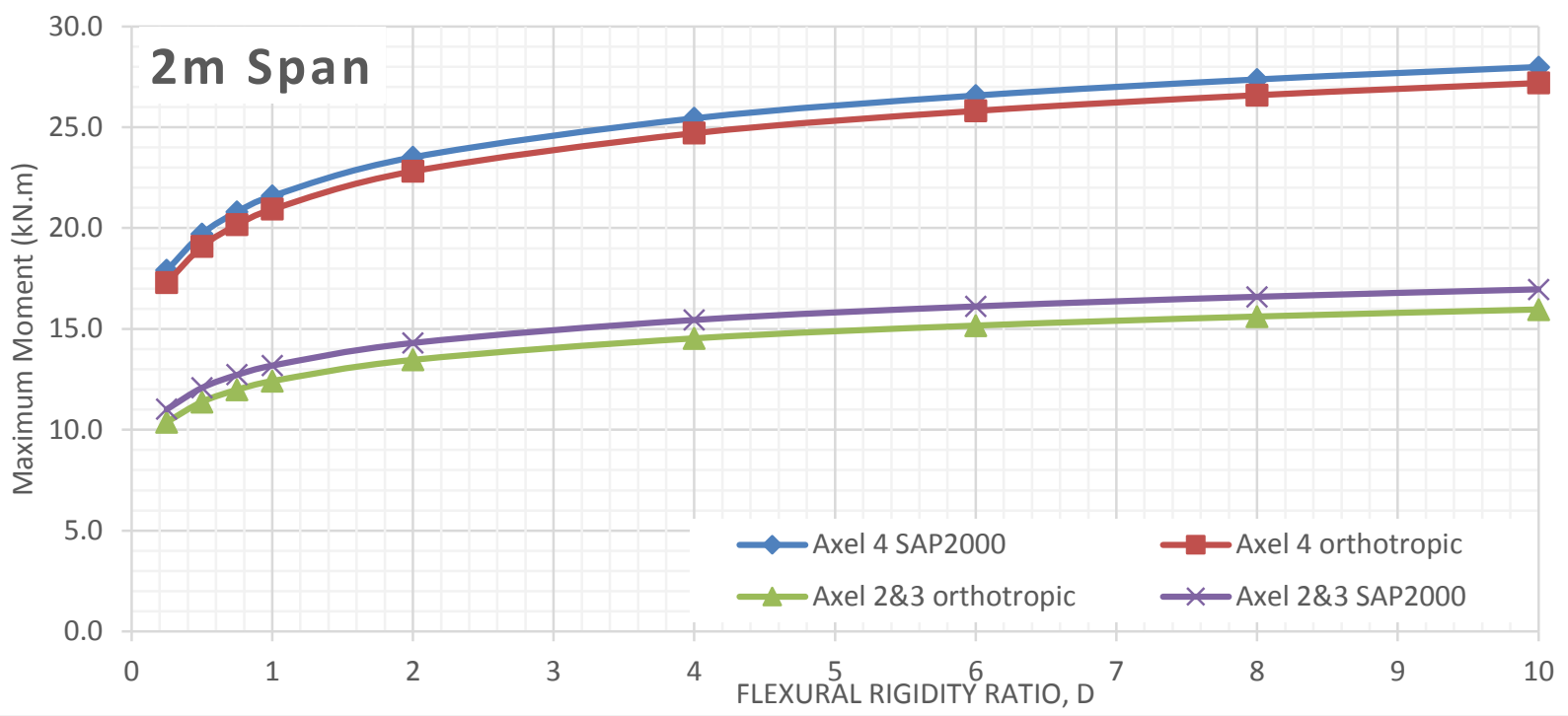

Figure 762 Moment comparison between FEA and Orthotropic Plate Theory for $2 \mathrm{~m}$ span of alpha 8 (main bars parallel to traffic)

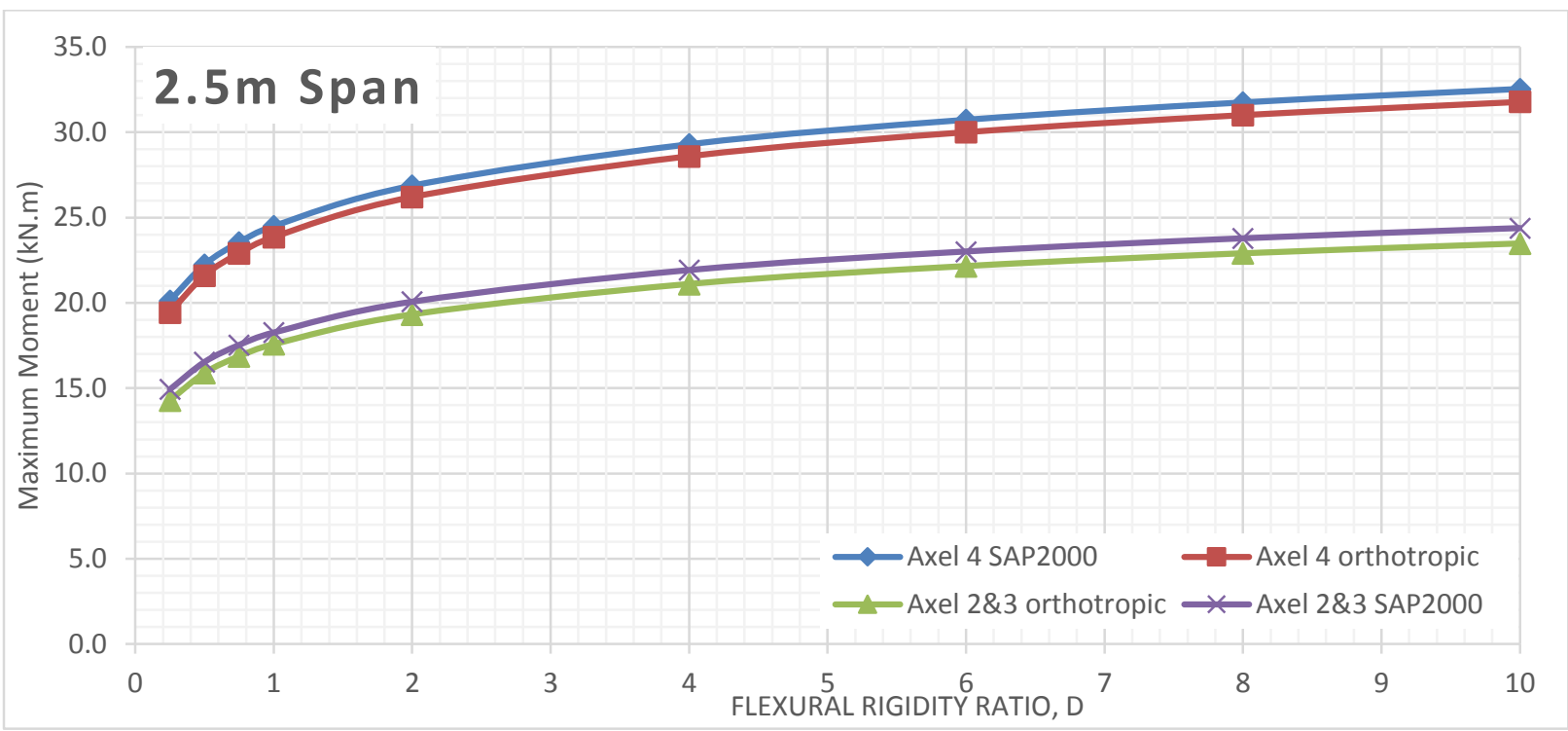

Figure 763 Moment comparison between FEA and Orthotropic Plate Theory for $2.5 \mathrm{~m}$ span of alpha 8 (main bars parallel to traffic)

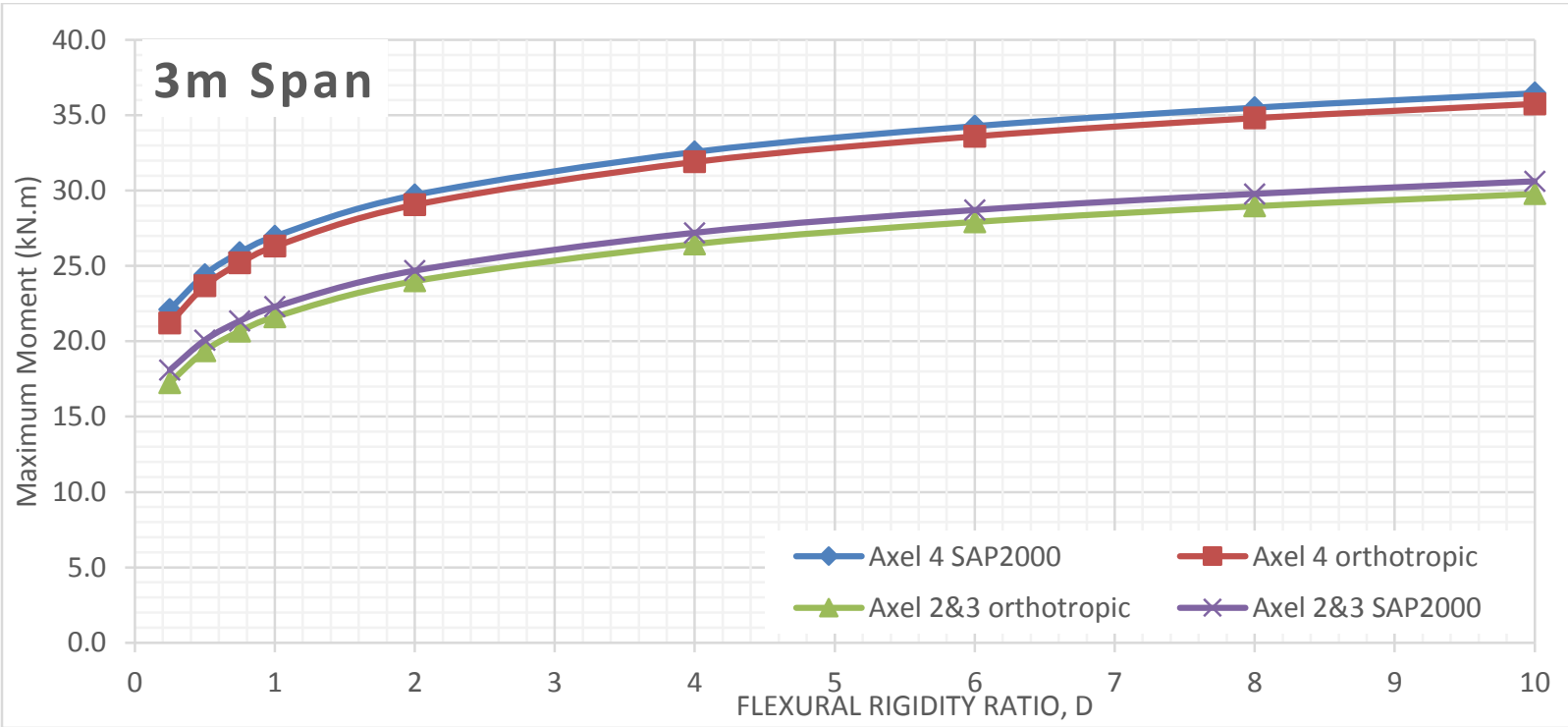

Figure 764 Moment comparison between FEA and Orthotropic Plate Theory for $3 \mathrm{~m}$ span of alpha 8 (main bars parallel to traffic) 


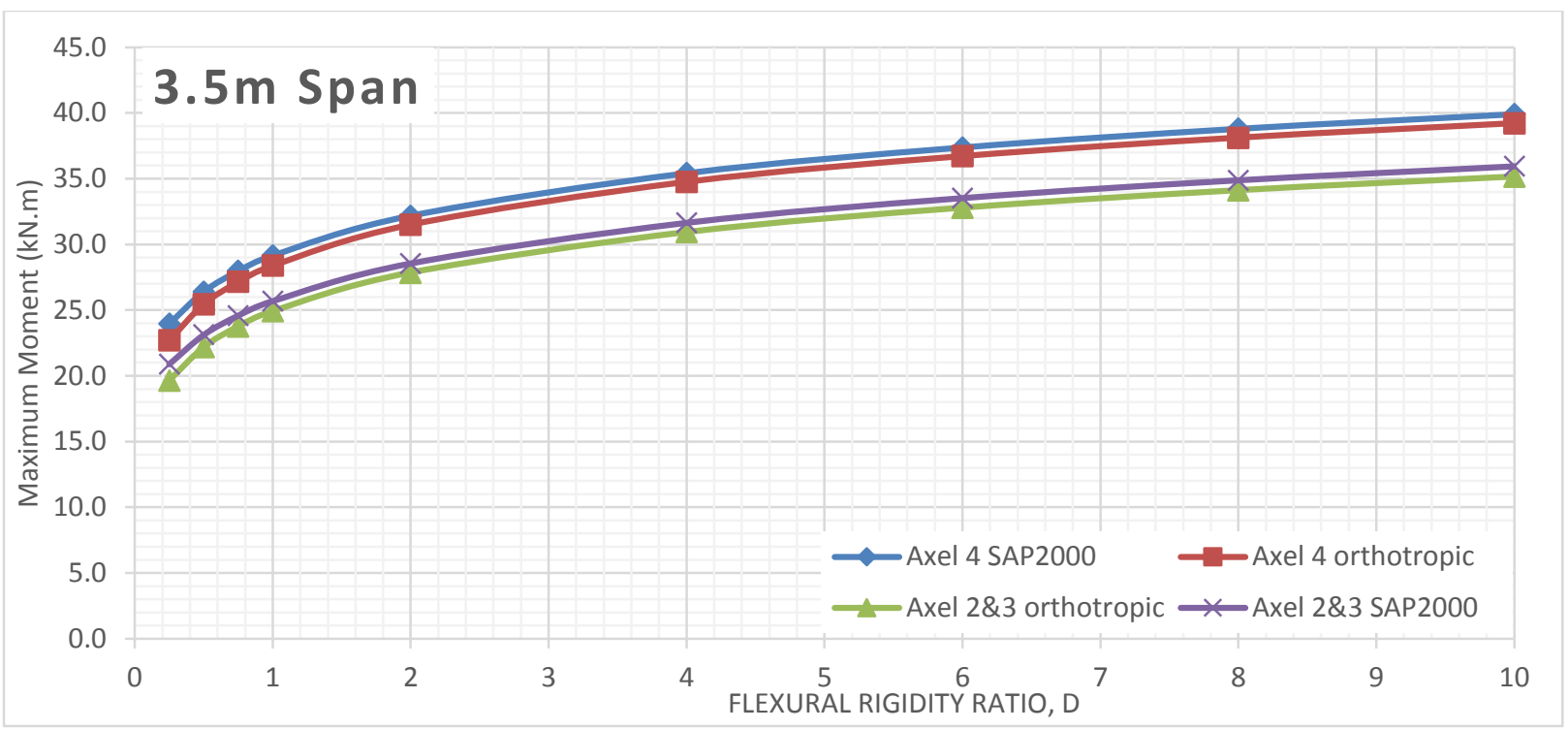

Figure 765 Moment comparison between FEA and Orthotropic Plate Theory for $3.5 \mathrm{~m}$ span of alpha 8 (main bars parallel to traffic)

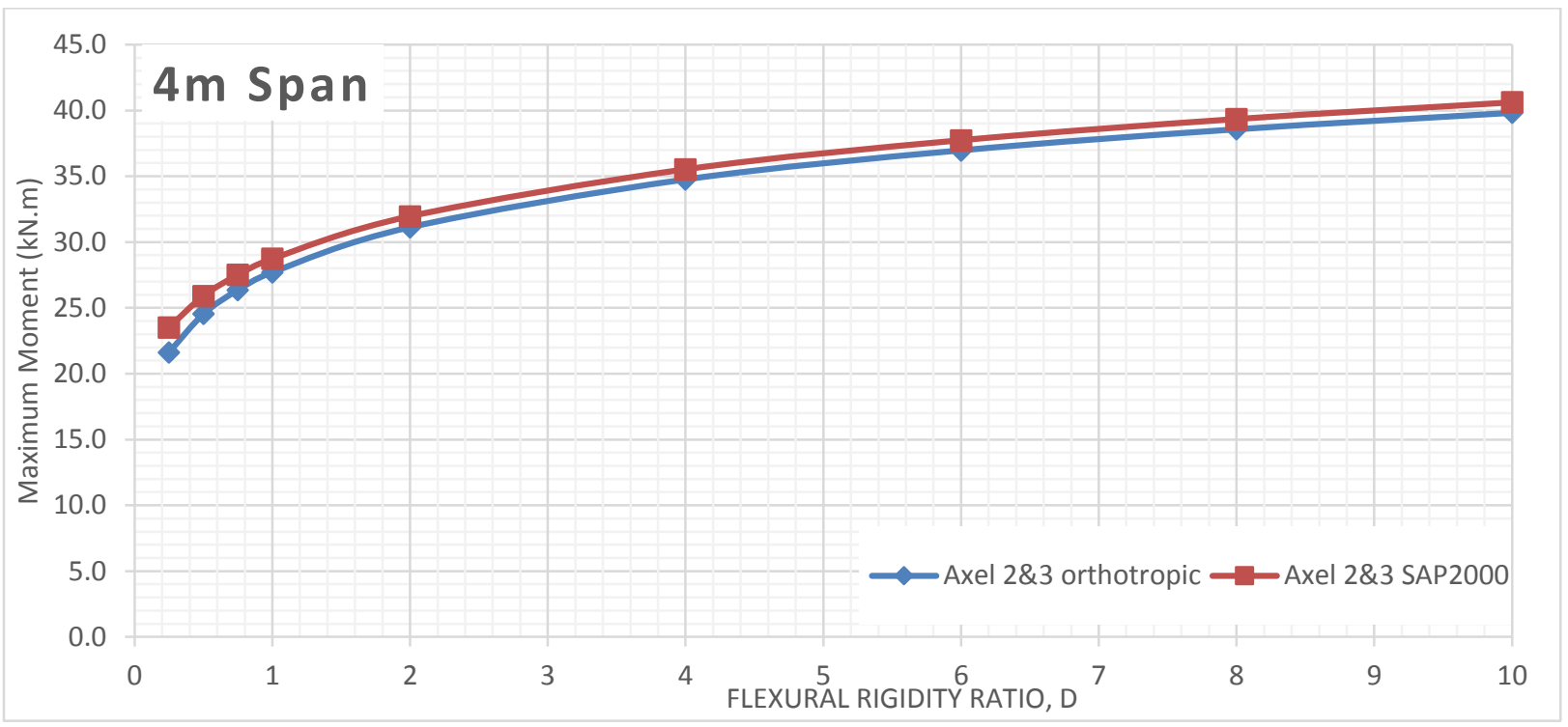

Figure 766 Moment comparison between FEA and Orthotropic Plate Theory for $4 \mathrm{~m}$ span of alpha 8 (main bars parallel to traffic) 


\section{Alpha 10 Bending Moment VS Flexural Rigidity for Different Span Length (Main bars perpendicular to traffic)}

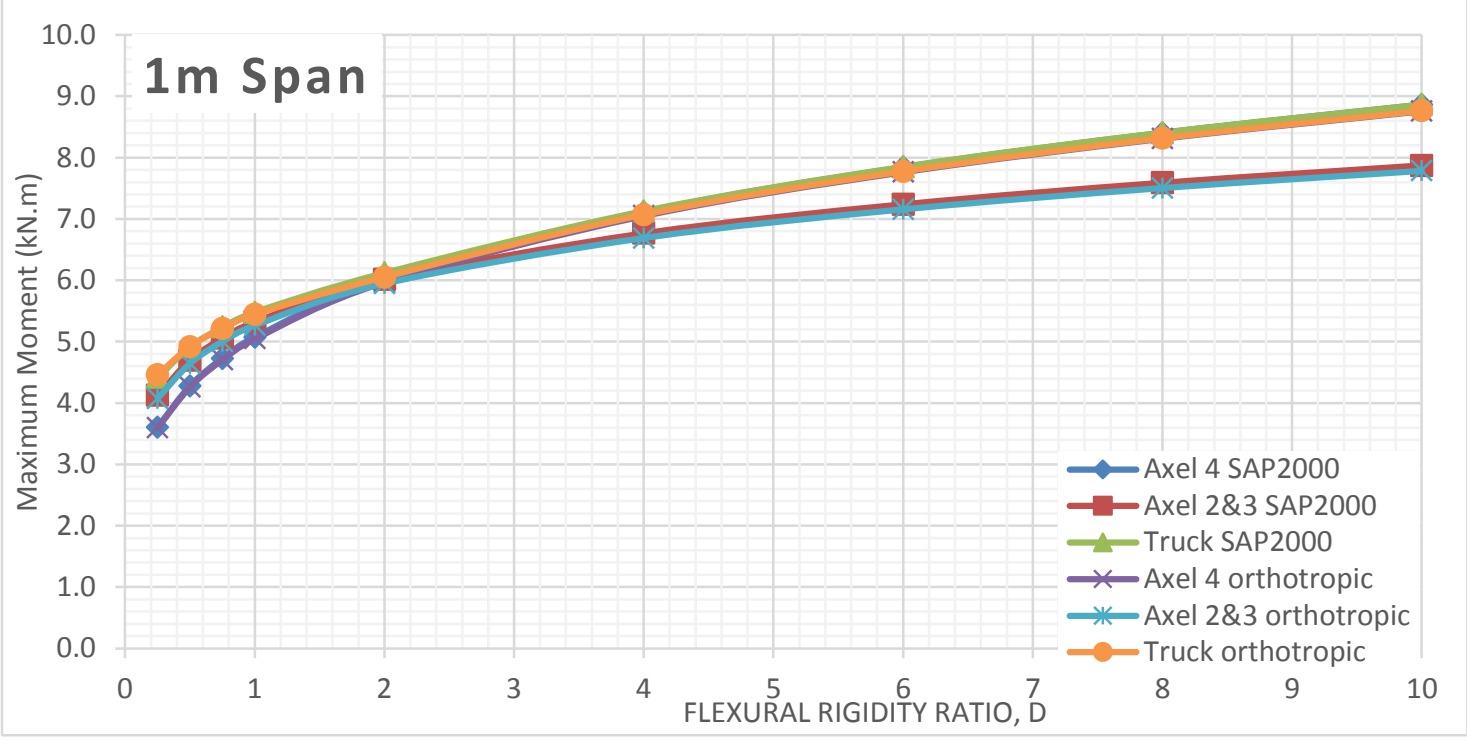

Figure 767 Moment comparison between FEA and Orthotropic Plate Theory for $1 \mathrm{~m}$ span of alpha 10 (main bars perpendicular to traffic)

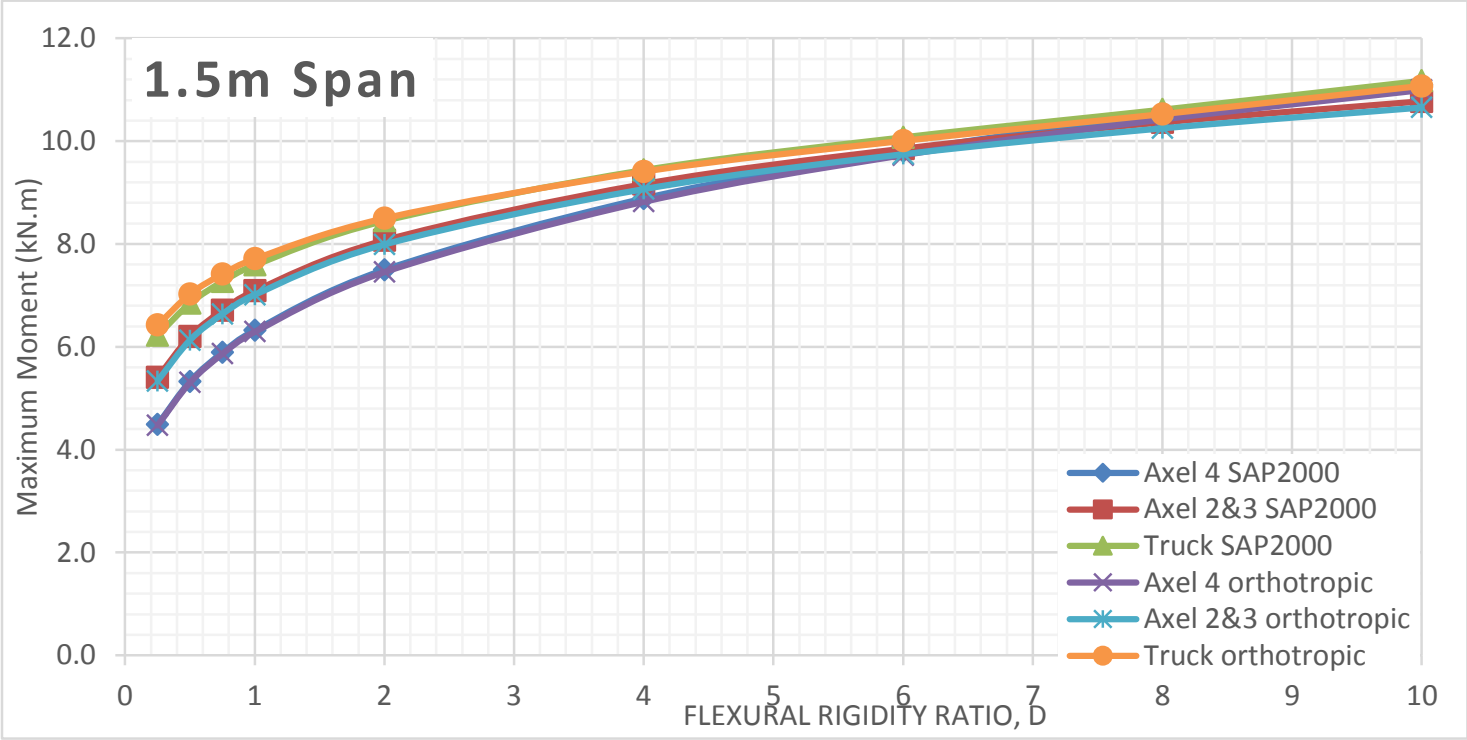

Figure 768 Moment comparison between FEA and Orthotropic Plate Theory for $1.5 \mathrm{~m}$ span of alpha 10 (main bars perpendicular to traffic) 


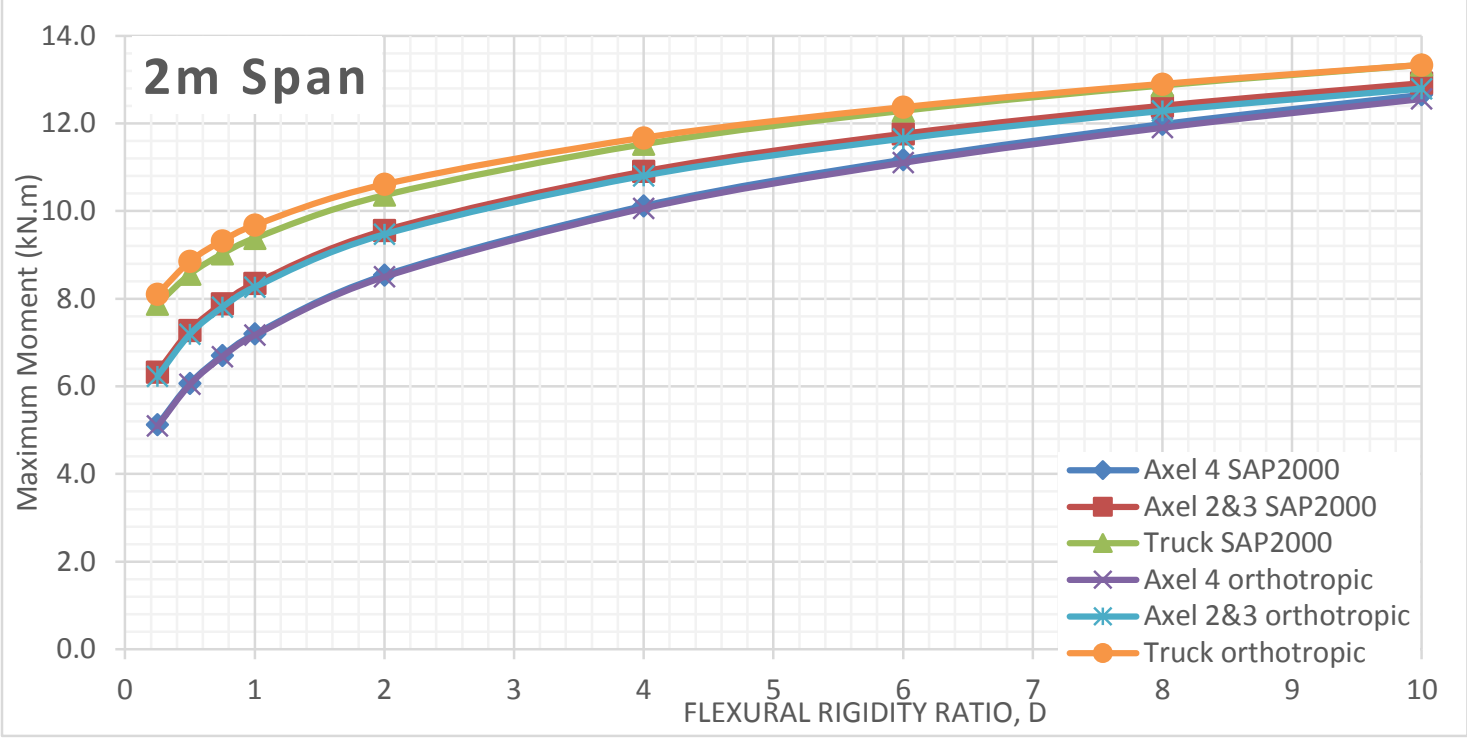

Figure 769 Moment comparison between FEA and Orthotropic Plate Theory for $2 \mathrm{~m}$ span of alpha 10 (main bars perpendicular to traffic)

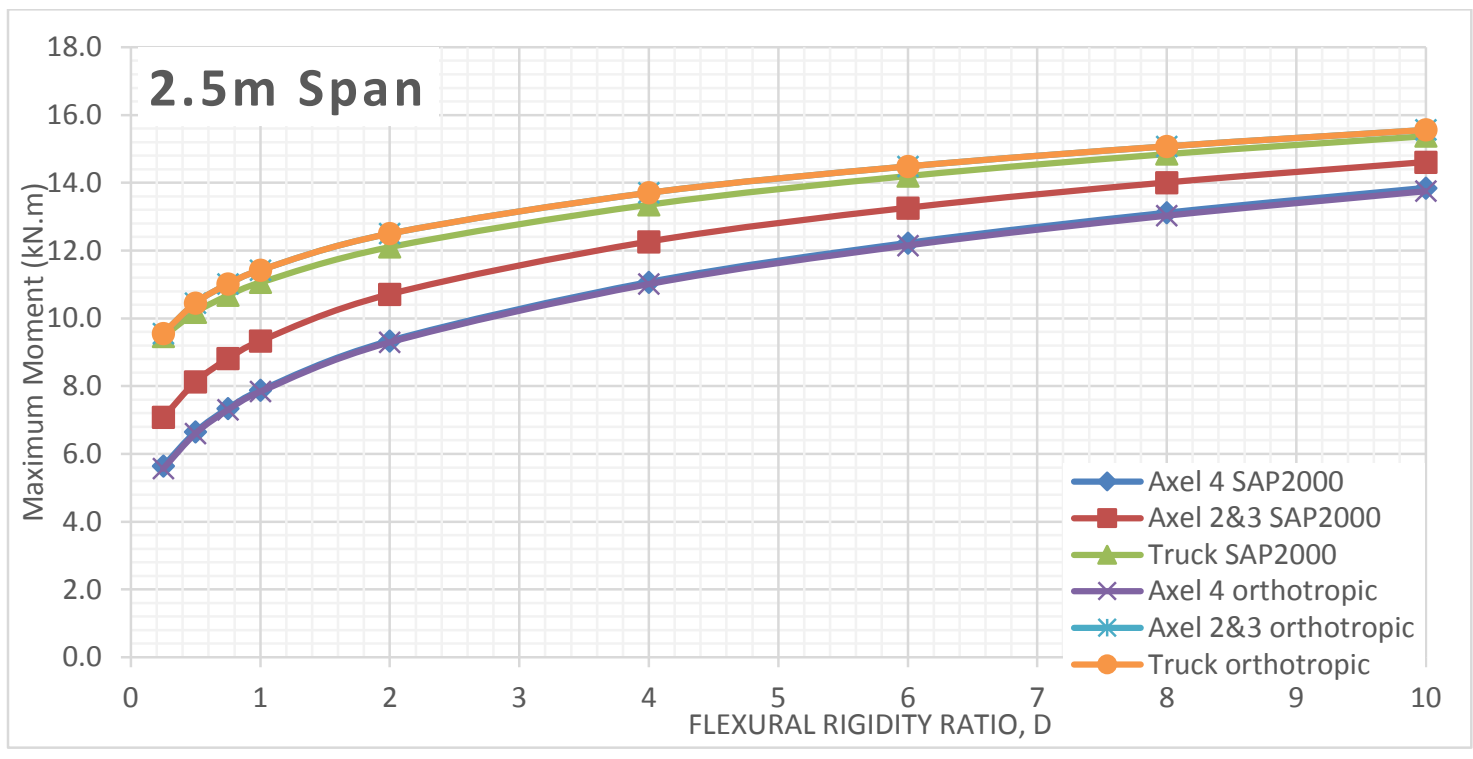

Figure 770 Moment comparison between FEA and Orthotropic Plate Theory for $2.5 \mathrm{~m}$ span of alpha 10 (main bars perpendicular to traffic)

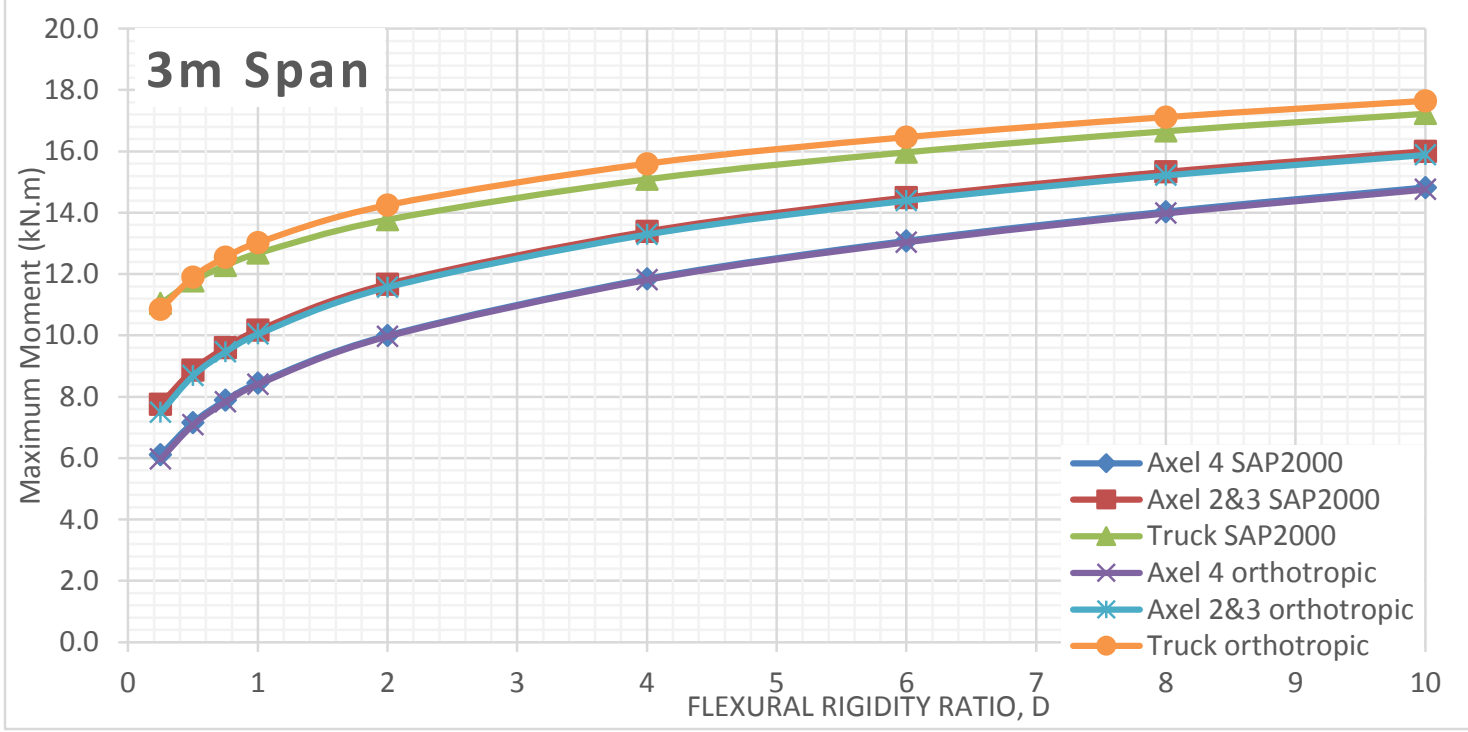

Figure 771 Moment comparison between FEA and Orthotropic Plate Theory for $3 \mathrm{~m}$ span of alpha 10 (main bars perpendicular to traffic) 


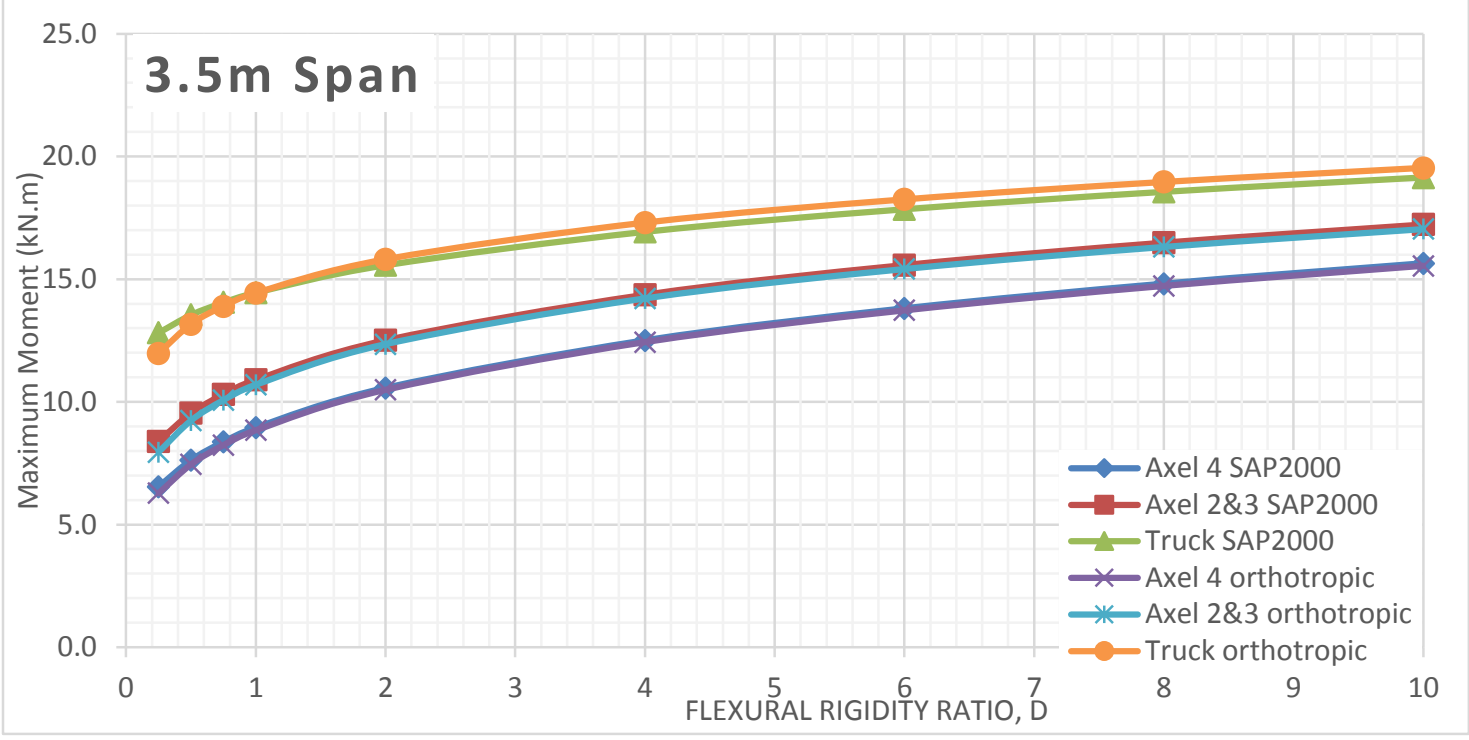

Figure 772 Moment comparison between FEA and Orthotropic Plate Theory for $3.5 \mathrm{~m}$ span of alpha 10 (main bars perpendicular to traffic)

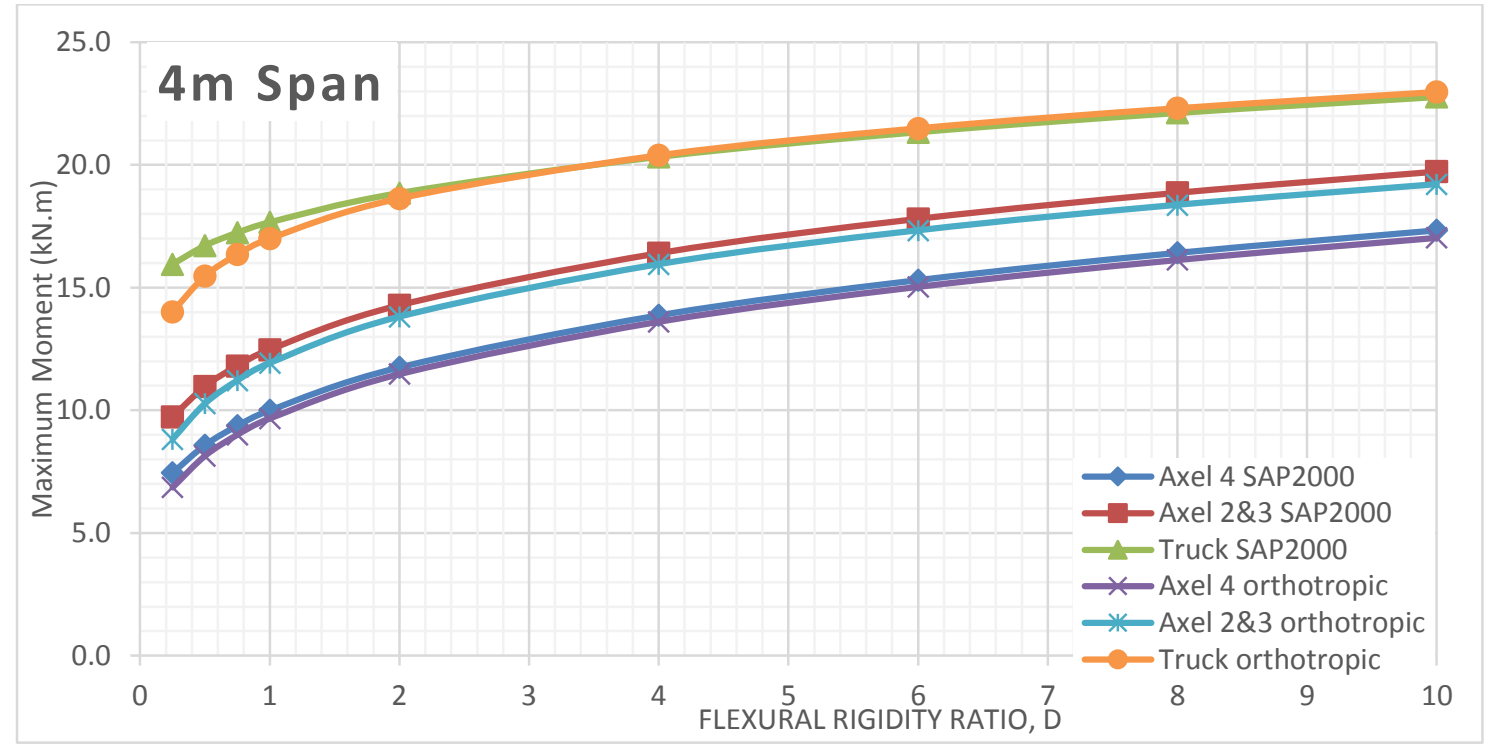

Figure 773 Moment comparison between FEA and Orthotropic Plate Theory for $4 \mathrm{~m}$ span of alpha 10 (main bars perpendicular to traffic) 


\section{Alpha 10 Bending Moment VS Flexural Rigidity for Different Span Length (Main bars parallel to traffic)}

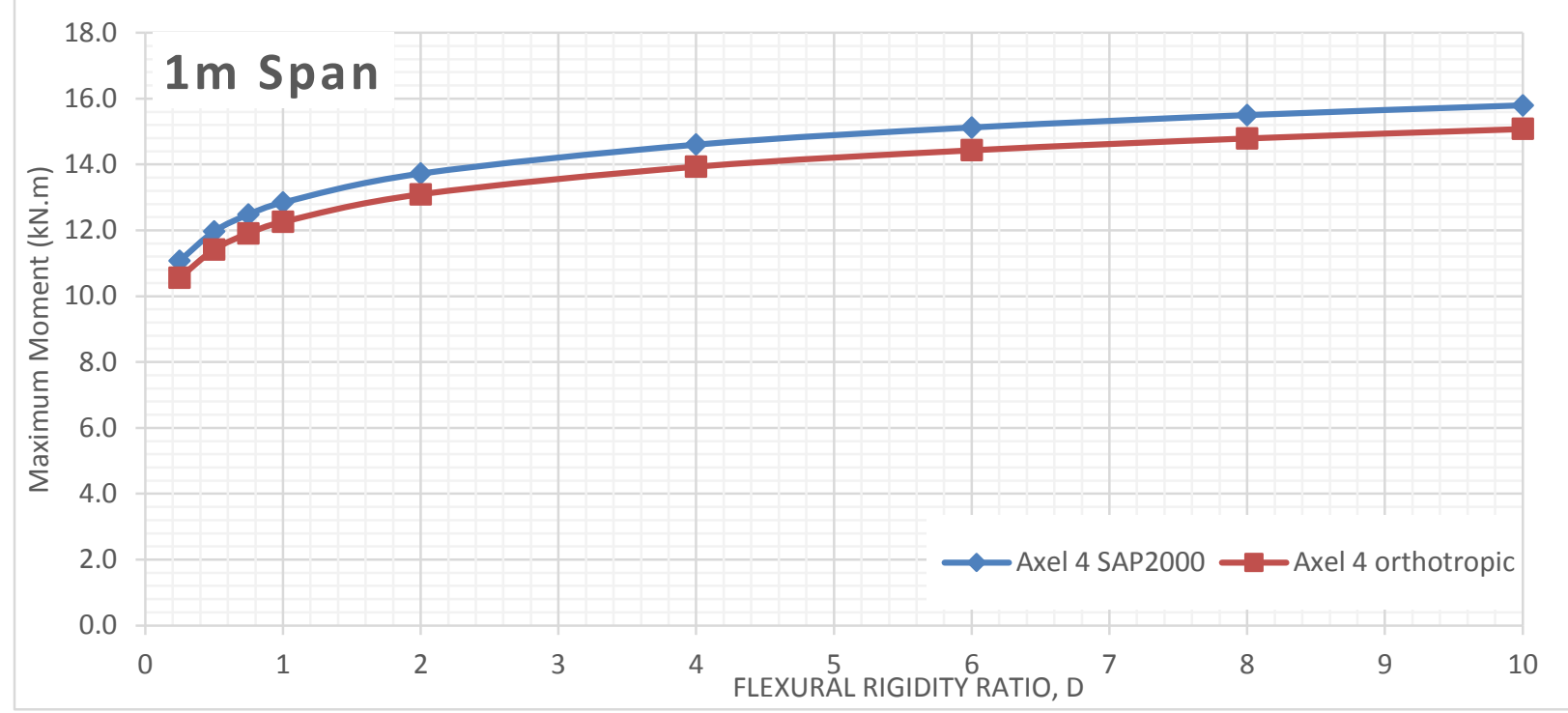

Figure 774 Moment comparison between FEA and Orthotropic Plate Theory for $1 \mathrm{~m}$ span of alpha 10 (main bars parallel to traffic)

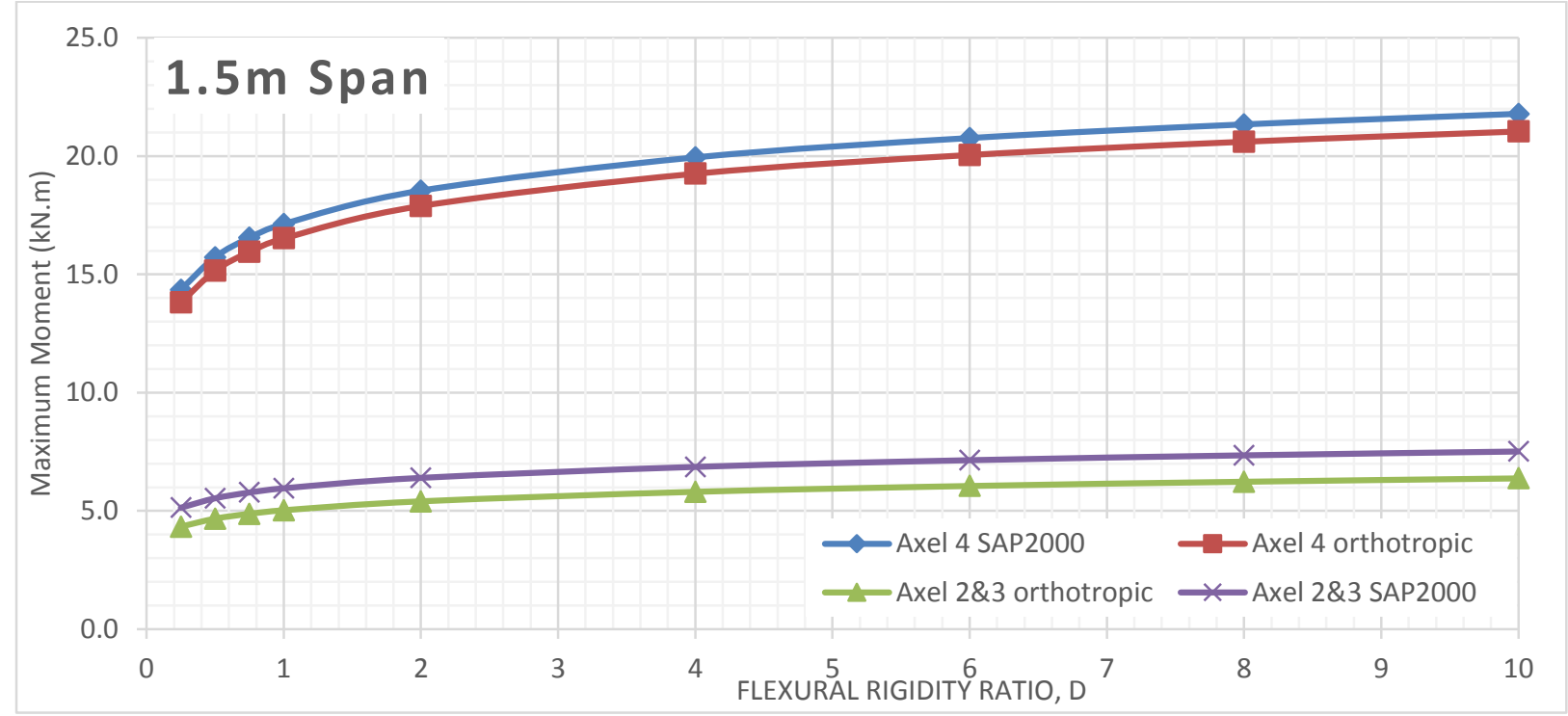

Figure 775 Moment comparison between FEA and Orthotropic Plate Theory for $1.5 \mathrm{~m}$ span of alpha 10 (main bars parallel to traffic) 


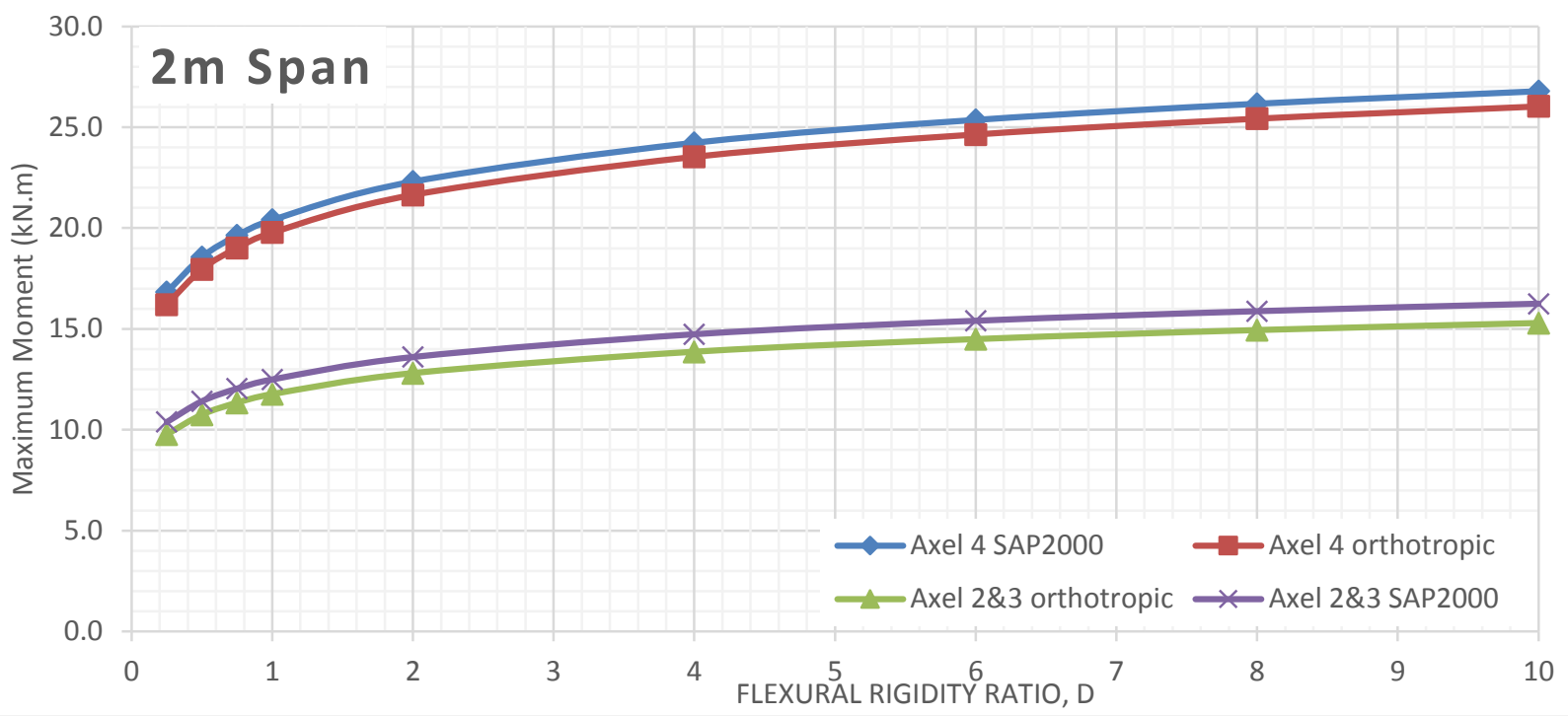

Figure 776 Moment comparison between FEA and Orthotropic Plate Theory for $2 \mathrm{~m}$ span of alpha 10 (main bars parallel to traffic)

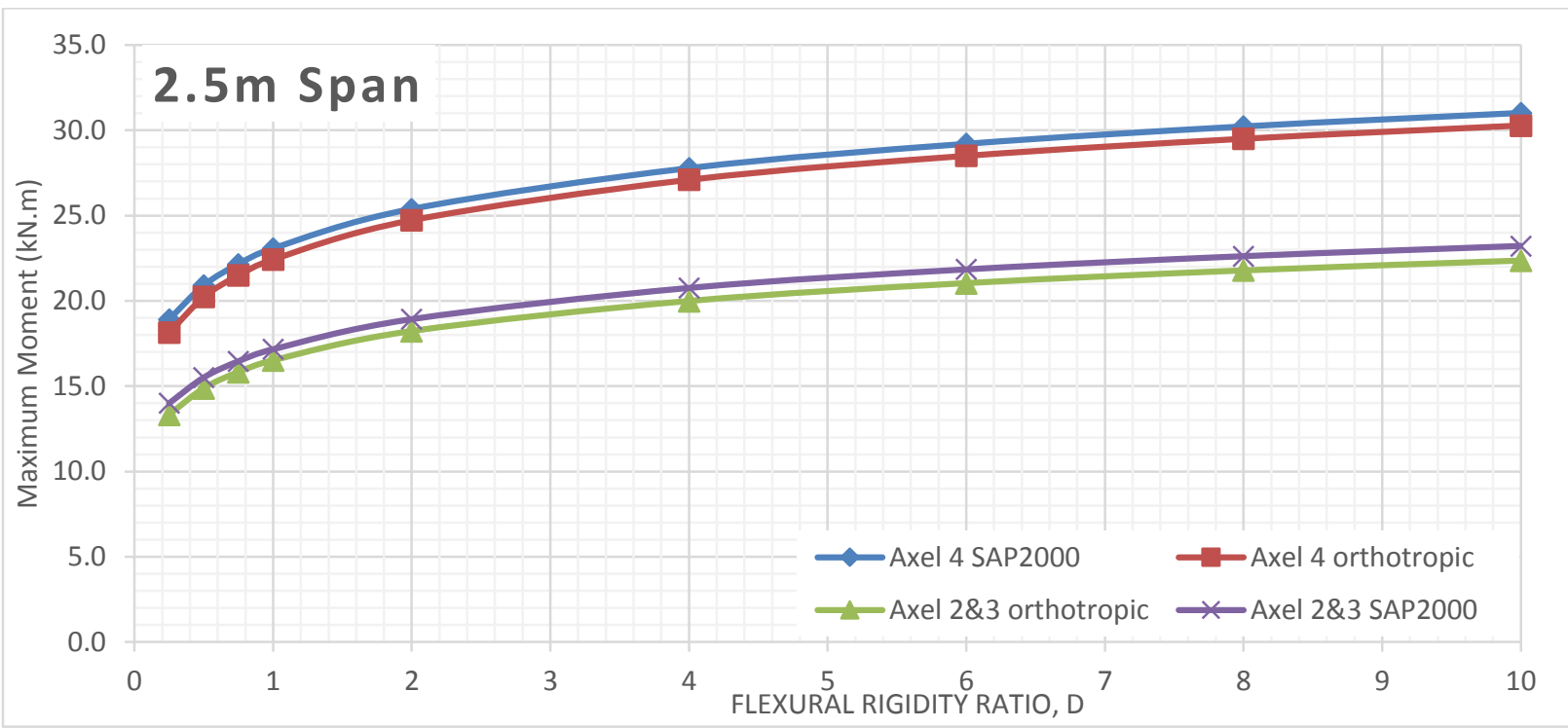

Figure 777 Moment comparison between FEA and Orthotropic Plate Theory for $2.5 \mathrm{~m}$ span of alpha 10 (main bars parallel to traffic)

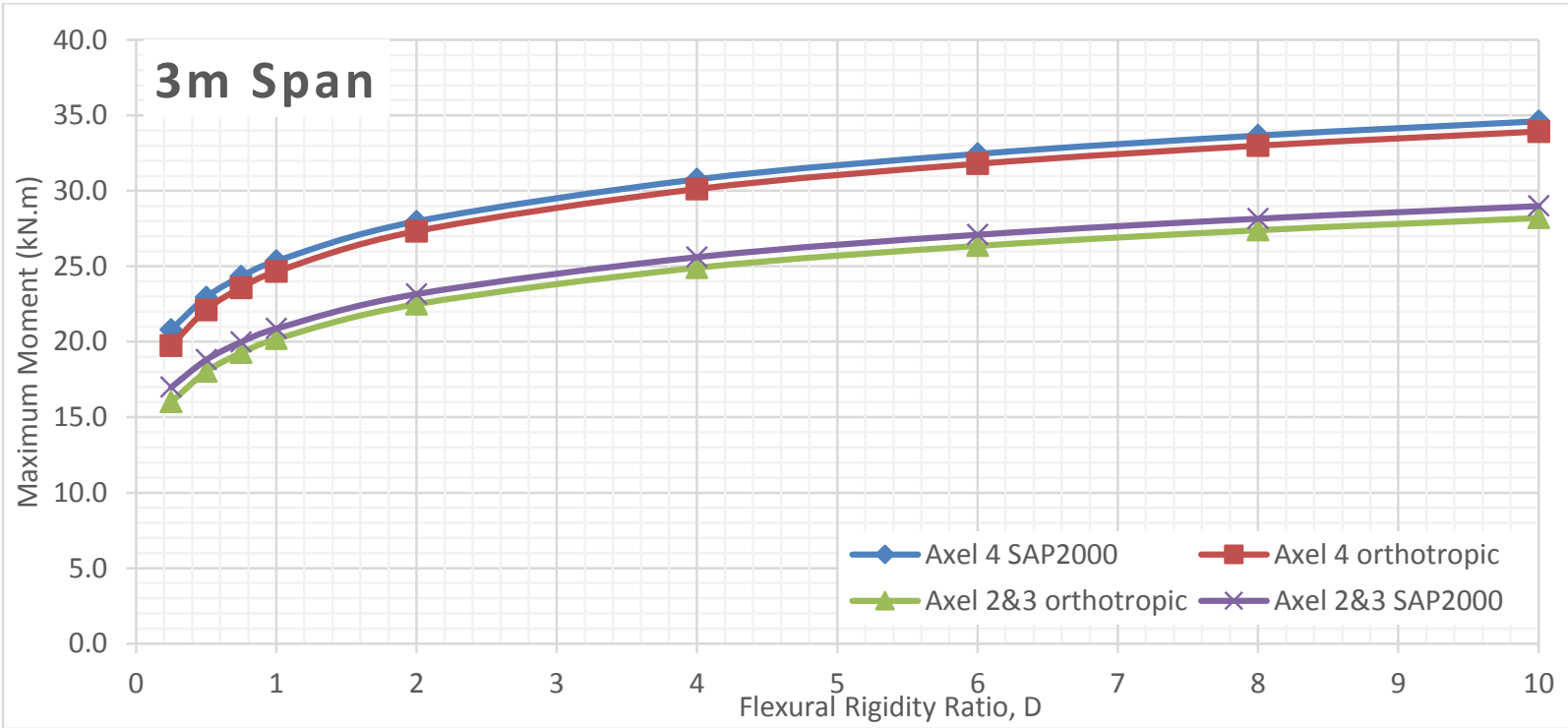

Figure 778 Moment comparison between FEA and Orthotropic Plate Theory for $3 \mathrm{~m}$ span of alpha 10 (main bars parallel to traffic) 


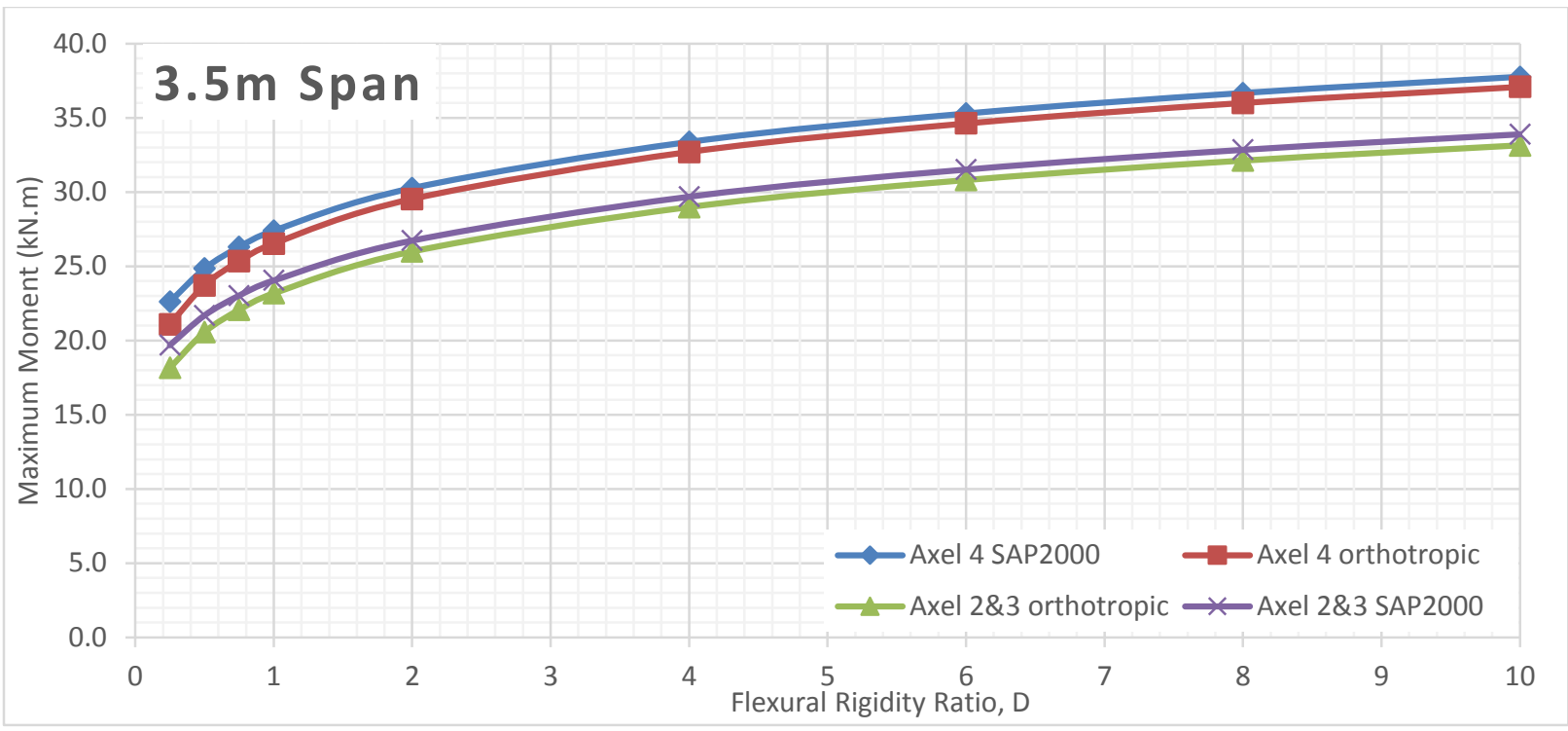

Figure 779 Moment comparison between FEA and Orthotropic Plate Theory for $3.5 \mathrm{~m}$ span of alpha 10 (main bars parallel to traffic)

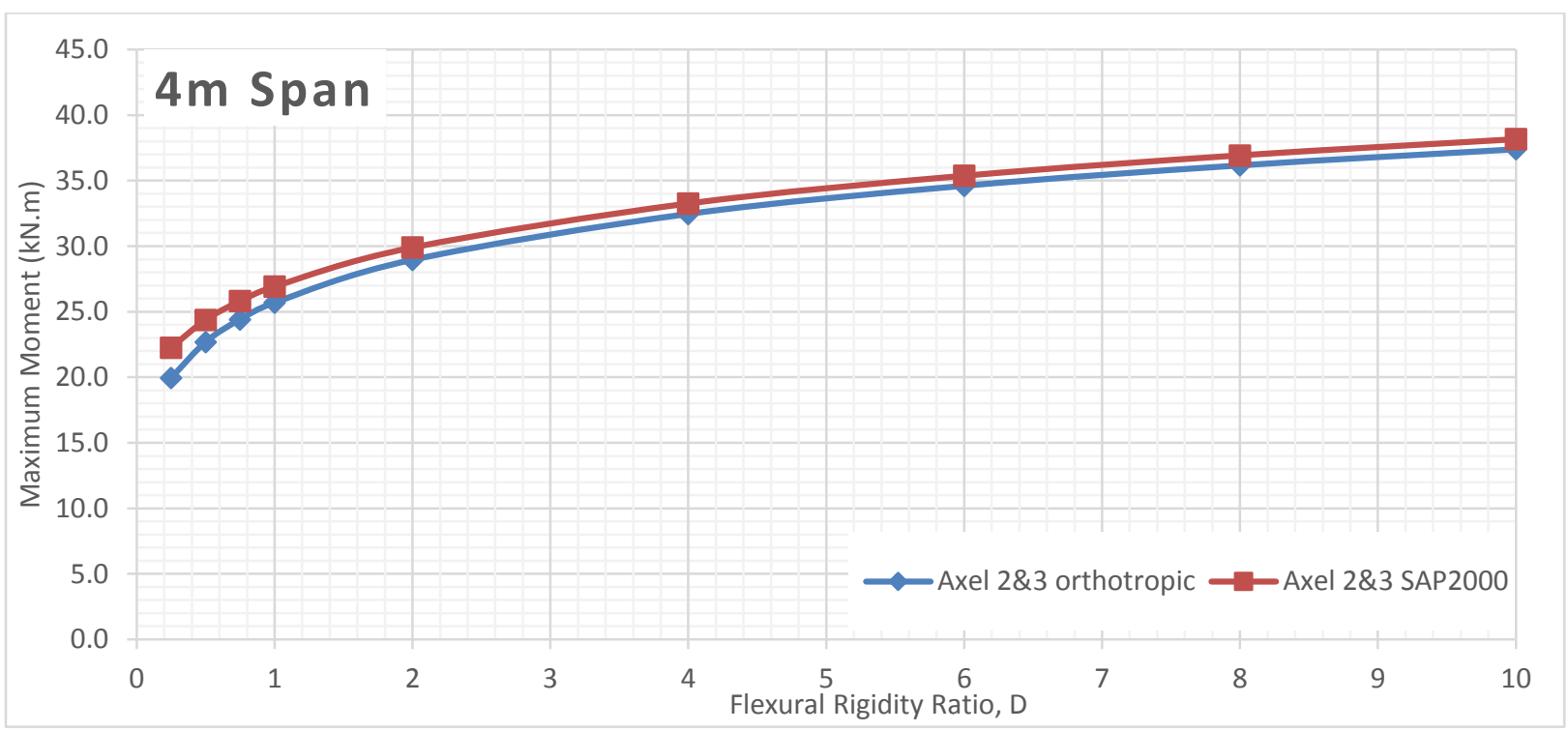

Figure 780 Moment comparison between FEA and Orthotropic Plate Theory for $4 \mathrm{~m}$ span of alpha 10 (main bars parallel to traffic) 


\section{D.2 Results Comparison (Deflection)}




\section{D.2.1 DEFLECTION COMPARISON RESULTS TABLES}




\section{Alpha 0.25 Deflection Comparison Results}

Table 235 Maximum deflection results comparison for alpha 0.25 for slabs subjected to CHBDC axle 4 loading (main bars perpendicular to traffic)

\begin{tabular}{|c|c|c|c|c|c|c|c|c|c|c|}
\hline & \multicolumn{9}{|c|}{ Deflection (m) } \\
\hline \multirow{9}{*}{$\begin{array}{l}+ \\
\frac{0}{x} \\
\dot{x}\end{array}$} & $\mathrm{D}$ & \multirow{2}{*}{0.25} & \multirow{2}{*}{0.5} & \multirow{2}{*}{0.75} & \multirow[b]{2}{*}{1} & \multirow{2}{*}{2} & \multirow[b]{2}{*}{4} & \multirow[b]{2}{*}{0} & \multirow{2}{*}{8} & \multirow{2}{*}{10} \\
\hline & SPAN & & & & & & & & & \\
\hline & 1 & $0.9807 \%$ & $0.8086 \%$ & $0.7753 \%$ & $0.6081 \%$ & $1.0889 \%$ & $0.9814 \%$ & $1.3772 \%$ & $1.7457 \%$ & $1.9403 \%$ \\
\hline & 1.5 & $0.1216 \%$ & $0.3394 \%$ & $0.1414 \%$ & $0.2735 \%$ & $0.4578 \%$ & $0.4944 \%$ & $0.7883 \%$ & $0.9801 \%$ & $1.0484 \%$ \\
\hline & 2 & $0.2038 \%$ & $0.2054 \%$ & $0.1867 \%$ & $0.1021 \%$ & $0.1864 \%$ & $0.3822 \%$ & $0.4673 \%$ & $0.6104 \%$ & $0.6799 \%$ \\
\hline & 2.5 & $0.0499 \%$ & $0.0504 \%$ & $0.0727 \%$ & $0.0736 \%$ & $0.2384 \%$ & $0.2299 \%$ & $0.3596 \%$ & $0.4002 \%$ & $0.4127 \%$ \\
\hline & 3 & $0.0091 \%$ & $0.0185 \%$ & $0.0021 \%$ & $0.0829 \%$ & $0.0920 \%$ & $0.1274 \%$ & $0.1172 \%$ & $0.1386 \%$ & $0.1902 \%$ \\
\hline & 3.5 & $0.0319 \%$ & $0.0406 \%$ & $0.0382 \%$ & $0.0595 \%$ & $0.0788 \%$ & $0.0770 \%$ & $0.1152 \%$ & $0.1290 \%$ & $0.1469 \%$ \\
\hline & 4 & $0.0003 \%$ & $0.0409 \%$ & $0.0262 \%$ & $0.0358 \%$ & $0.0419 \%$ & $0.0558 \%$ & $0.0916 \%$ & $0.0893 \%$ & $0.1149 \%$ \\
\hline
\end{tabular}

Table 236 Maximum deflection results comparison for alpha 0.25 for slabs subjected to CHBDC axle 2 \& 3 loading (main bars perpendicular to traffic)

\begin{tabular}{|c|c|c|c|c|c|c|c|c|c|c|}
\hline & \multicolumn{9}{|c|}{ Deflection (m) } \\
\hline \multirow{9}{*}{ 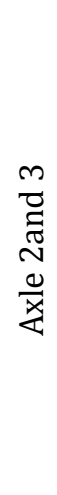 } & $\mathrm{D}$ & \multirow{2}{*}{0.25} & \multirow{2}{*}{0.5} & \multirow{2}{*}{0.75} & \multirow{2}{*}{1} & \multirow[b]{2}{*}{2} & \multirow{2}{*}{4} & \multirow{2}{*}{6} & \multirow{2}{*}{8} & \multirow{2}{*}{10} \\
\hline & SPAN & & & & & & & & & \\
\hline & 1 & $2.2179 \%$ & $1.2812 \%$ & $1.3157 \%$ & $0.8814 \%$ & $1.0938 \%$ & $1.1240 \%$ & $1.1073 \%$ & $2.0976 \%$ & $2.3331 \%$ \\
\hline & 1.5 & $0.0361 \%$ & $0.0763 \%$ & $0.7675 \%$ & $2.6082 \%$ & $1.6925 \%$ & $0.9890 \%$ & $0.5469 \%$ & $0.9502 \%$ & $0.9743 \%$ \\
\hline & 2 & $0.1365 \%$ & $0.0430 \%$ & $0.0307 \%$ & $0.1363 \%$ & $0.4746 \%$ & $2.4350 \%$ & $1.7339 \%$ & $1.2344 \%$ & $1.1666 \%$ \\
\hline & 2.5 & $0.0616 \%$ & $0.0727 \%$ & $0.0627 \%$ & $0.0296 \%$ & $0.0116 \%$ & $0.2338 \%$ & $1.6562 \%$ & $2.8273 \%$ & $2.3112 \%$ \\
\hline & 3 & $0.0542 \%$ & $0.0209 \%$ & $0.0236 \%$ & $0.0619 \%$ & $0.0712 \%$ & $0.0699 \%$ & $0.0280 \%$ & $0.0467 \%$ & $0.0322 \%$ \\
\hline & 3.5 & $0.0405 \%$ & $0.0364 \%$ & $0.0409 \%$ & $0.0492 \%$ & $0.0415 \%$ & $0.0476 \%$ & $0.0488 \%$ & $0.0318 \%$ & $0.0370 \%$ \\
\hline & 4 & $0.0235 \%$ & $0.0130 \%$ & $0.0363 \%$ & $0.0106 \%$ & $0.0412 \%$ & $0.0343 \%$ & $0.0497 \%$ & $0.0363 \%$ & $0.0469 \%$ \\
\hline
\end{tabular}

Table 237 Maximum deflection results comparison for alpha 0.25 for slabs subjected to CHBDC truck loading (main bars perpendicular to traffic)

\begin{tabular}{|c|c|c|c|c|c|c|c|c|c|c|}
\hline & \multicolumn{9}{|c|}{ Deflection (m) } \\
\hline \multirow{9}{*}{ 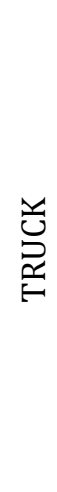 } & $\mathrm{D}$ & \multirow{2}{*}{0.25} & \multirow{2}{*}{0.5} & \multirow{2}{*}{0.75} & \multirow[b]{2}{*}{1} & \multirow[b]{2}{*}{$z$} & \multirow[b]{2}{*}{4} & \multirow{2}{*}{6} & \multirow{2}{*}{8} & \multirow{2}{*}{10} \\
\hline & SPAN & & & & & & & & & \\
\hline & 1 & $0.9813 \%$ & $0.8089 \%$ & $0.7753 \%$ & $0.6081 \%$ & $1.0889 \%$ & $0.9814 \%$ & $1.3772 \%$ & $1.7457 \%$ & $1.9403 \%$ \\
\hline & 1.5 & $0.1747 \%$ & $0.3126 \%$ & $0.1341 \%$ & $0.2723 \%$ & $0.4584 \%$ & $0.4944 \%$ & $0.7883 \%$ & $0.9801 \%$ & $1.0484 \%$ \\
\hline & 2 & $0.5878 \%$ & $0.6645 \%$ & $0.5390 \%$ & $0.4263 \%$ & $0.3699 \%$ & $0.3827 \%$ & $0.4679 \%$ & $0.6107 \%$ & $0.6800 \%$ \\
\hline & 2.5 & $0.4976 \%$ & $0.3862 \%$ & $0.5670 \%$ & $0.5318 \%$ & $0.3466 \%$ & $0.3097 \%$ & $0.3535 \%$ & $0.3995 \%$ & $0.4133 \%$ \\
\hline & 3 & $2.1969 \%$ & $0.5143 \%$ & $0.0634 \%$ & $0.3695 \%$ & $0.6707 \%$ & $0.4998 \%$ & $0.3217 \%$ & $0.2304 \%$ & $0.1747 \%$ \\
\hline & 3.5 & $4.0251 \%$ & $1.9621 \%$ & $0.9363 \%$ & $0.4067 \%$ & $0.4486 \%$ & $0.6340 \%$ & $0.5441 \%$ & $0.4566 \%$ & $0.3538 \%$ \\
\hline & 4 & $5.6738 \%$ & $3.4912 \%$ & $2.2905 \%$ & $1.5307 \%$ & $0.1421 \%$ & $0.5357 \%$ & $0.6418 \%$ & $0.6226 \%$ & $0.5549 \%$ \\
\hline
\end{tabular}


Table 238 Maximum deflection results comparison for alpha 0.25 for slabs subjected to CHBDC axle 4 loading (main bars parallel to traffic)

\begin{tabular}{|c|c|c|c|c|c|c|c|c|c|c|}
\hline & & \multicolumn{9}{|c|}{ Deflection (m) } \\
\hline \multirow{7}{*}{ 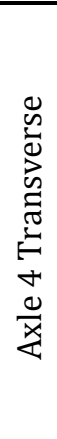 } & $\frac{\mathrm{D}}{\mathrm{SPAN}}$ & 0.25 & 0.5 & 0.75 & 1 & 2 & 4 & 6 & 8 & 10 \\
\hline & 1 & $3.2589 \%$ & $2.2668 \%$ & $1.6293 \%$ & $1.7818 \%$ & $1.0582 \%$ & $0.7458 \%$ & $0.8133 \%$ & $0.6917 \%$ & $0.9324 \%$ \\
\hline & 1.5 & $2.7921 \%$ & $2.9280 \%$ & $3.1481 \%$ & $2.9787 \%$ & $2.4410 \%$ & $1.5810 \%$ & $1.1314 \%$ & $0.5961 \%$ & $0.4337 \%$ \\
\hline & 2 & $2.4906 \%$ & $2.3486 \%$ & $2.5501 \%$ & $2.5662 \%$ & $2.7898 \%$ & $2.6122 \%$ & $2.3704 \%$ & $1.9422 \%$ & $1.5907 \%$ \\
\hline & 2.5 & $2.3675 \%$ & $2.3216 \%$ & $2.3116 \%$ & $2.3090 \%$ & $2.3695 \%$ & $2.6205 \%$ & $2.6685 \%$ & $2.6645 \%$ & $2.4871 \%$ \\
\hline & 3 & $2.1977 \%$ & $2.3007 \%$ & $2.3161 \%$ & $2.2958 \%$ & $2.2453 \%$ & $2.3470 \%$ & $2.4937 \%$ & $2.5841 \%$ & $2.5820 \%$ \\
\hline & 3.5 & $1.9952 \%$ & $2.1669 \%$ & $2.2315 \%$ & $2.2586 \%$ & $2.2483 \%$ & $2.1921 \%$ & $2.2444 \%$ & $2.3183 \%$ & $2.3843 \%$ \\
\hline
\end{tabular}

Table 239 Maximum deflection results comparison for alpha 0.25 for slabs subjected to CHBDC axle 2 \& 3 loading (main bars parallel to traffic)

\begin{tabular}{|c|c|c|c|c|c|c|c|c|c|c|}
\hline & & \multicolumn{9}{|c|}{ Deflection (m) } \\
\hline \multirow{7}{*}{ 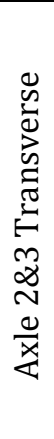 } & $\frac{\mathrm{D}}{\text { SPAN }}$ & 0.25 & 0.5 & 0.75 & 1 & 2 & 4 & 6 & 8 & 10 \\
\hline & 1.5 & $0.1765 \%$ & $0.0561 \%$ & $0.5521 \%$ & $0.1258 \%$ & $1.7321 \%$ & $1.3834 \%$ & $1.1265 \%$ & $0.5204 \%$ & $0.6123 \%$ \\
\hline & 2 & $0.0902 \%$ & $0.1961 \%$ & $0.1508 \%$ & $0.0876 \%$ & $0.2751 \%$ & $0.4453 \%$ & $2.2373 \%$ & $2.6573 \%$ & $1.9966 \%$ \\
\hline & 2.5 & $0.1398 \%$ & $0.1448 \%$ & $0.0779 \%$ & $0.0728 \%$ & $0.1370 \%$ & $0.0893 \%$ & $0.1170 \%$ & $0.4368 \%$ & $1.0212 \%$ \\
\hline & 3 & $0.0757 \%$ & $0.0755 \%$ & $0.0881 \%$ & $0.0660 \%$ & $0.0830 \%$ & $0.0826 \%$ & $0.0876 \%$ & $0.0798 \%$ & $0.0934 \%$ \\
\hline & 3.5 & $0.0547 \%$ & $0.0503 \%$ & $0.0526 \%$ & $0.0632 \%$ & $0.0616 \%$ & $0.0708 \%$ & $0.0609 \%$ & $0.0637 \%$ & $0.0748 \%$ \\
\hline & 4 & $0.0499 \%$ & $0.0428 \%$ & $0.0494 \%$ & $0.0526 \%$ & $0.0502 \%$ & $0.0494 \%$ & $0.0537 \%$ & $0.0441 \%$ & $0.0460 \%$ \\
\hline
\end{tabular}




\section{Alpha 0.5 Deflection Comparison Results}

Table 240 Maximum deflection results comparison for alpha 0.5 for slabs subjected to CHBDC axle 4 loading (main bars perpendicular to traffic)

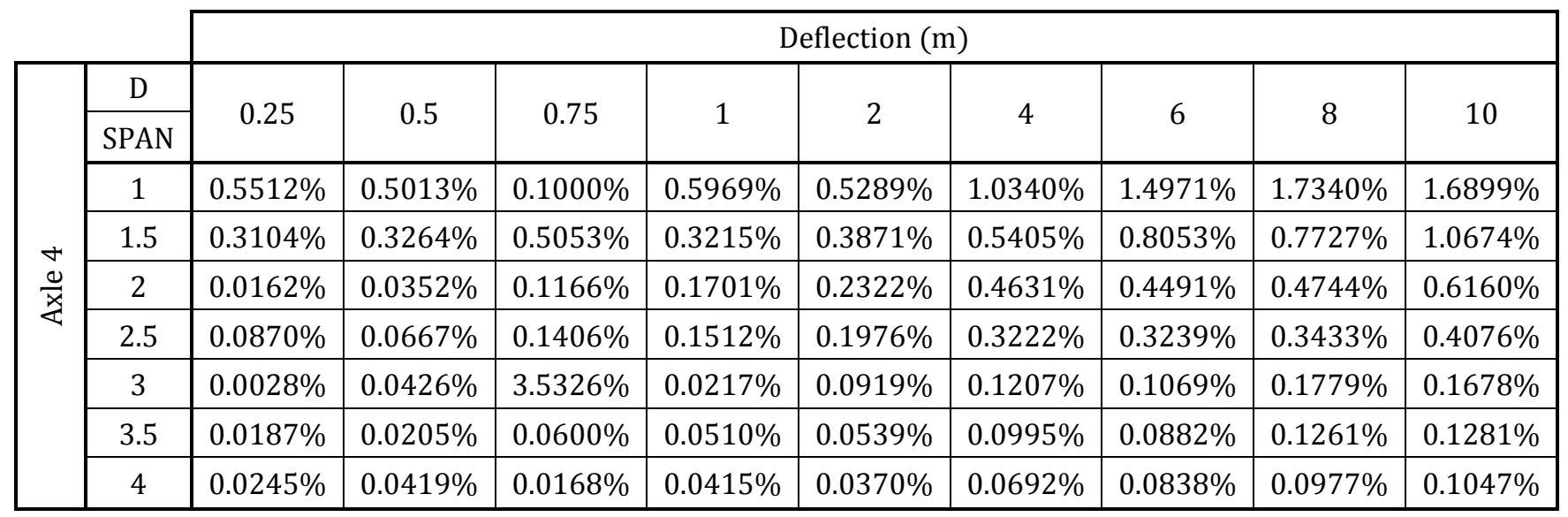

Table 241 Maximum deflection results comparison for alpha 0.5 for slabs subjected to CHBDC axle 2 \& 3 loading (main bars perpendicular to traffic)

\begin{tabular}{|c|c|c|c|c|c|c|c|c|c|c|}
\hline & \multicolumn{9}{|c|}{ Deflection (m) } \\
\hline \multirow{9}{*}{ 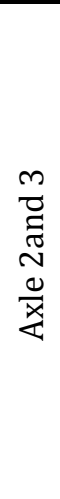 } & $\mathrm{D}$ & \multirow{2}{*}{0.25} & \multirow{2}{*}{0.5} & \multirow{2}{*}{0.75} & & & & \multirow{2}{*}{6} & \multirow{2}{*}{8} & \multirow{2}{*}{10} \\
\hline & SPAN & & & & & & & & & \\
\hline & 1 & $2.1590 \%$ & $1.4150 \%$ & $0.1752 \%$ & $0.2080 \%$ & $0.6362 \%$ & $1.5600 \%$ & $1.7048 \%$ & $1.5760 \%$ & $1.5460 \%$ \\
\hline & 1.5 & $0.2312 \%$ & $0.0157 \%$ & $1.1352 \%$ & $2.6889 \%$ & $1.8507 \%$ & $0.8076 \%$ & $0.6149 \%$ & $0.8886 \%$ & $0.7418 \%$ \\
\hline & 2 & $0.0387 \%$ & $0.1040 \%$ & $0.1435 \%$ & $0.0277 \%$ & $0.7963 \%$ & $2.1300 \%$ & $1.7059 \%$ & $1.3439 \%$ & $1.0906 \%$ \\
\hline & 2.5 & $0.0803 \%$ & $0.0091 \%$ & $0.0024 \%$ & $0.0638 \%$ & $0.0107 \%$ & $0.3638 \%$ & $1.8619 \%$ & $2.5040 \%$ & $2.0864 \%$ \\
\hline & 3 & $0.0657 \%$ & $0.0590 \%$ & $3.4422 \%$ & $0.0588 \%$ & $0.0117 \%$ & $0.0391 \%$ & $0.0349 \%$ & $0.0012 \%$ & $0.0333 \%$ \\
\hline & 3.5 & $0.0171 \%$ & $0.0398 \%$ & $0.0180 \%$ & $0.0019 \%$ & $0.0328 \%$ & $0.0264 \%$ & $0.0398 \%$ & $0.0296 \%$ & $0.0198 \%$ \\
\hline & 4 & $0.0052 \%$ & $0.0168 \%$ & $0.0270 \%$ & $0.0185 \%$ & $0.0198 \%$ & $0.0248 \%$ & $0.0244 \%$ & $0.0339 \%$ & $0.0356 \%$ \\
\hline
\end{tabular}

Table 242 Maximum deflection results comparison for alpha 0.5 for slabs subjected to CHBDC truck loading (main bars perpendicular to traffic)

\begin{tabular}{|c|c|c|c|c|c|c|c|c|c|c|}
\hline & \multicolumn{9}{|c|}{ Deflection (m) } \\
\hline \multirow{9}{*}{ 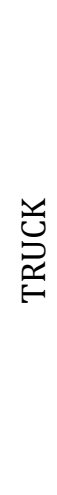 } & $\mathrm{D}$ & \multirow{2}{*}{0.25} & \multirow{2}{*}{0.5} & \multirow{2}{*}{0.75} & \multirow{2}{*}{1} & \multirow[b]{2}{*}{2} & \multirow[b]{2}{*}{4} & \multirow{2}{*}{6} & \multirow{2}{*}{8} & \multirow{2}{*}{10} \\
\hline & SPAN & & & & & & & & & \\
\hline & 1 & $0.5502 \%$ & $0.5013 \%$ & $0.1000 \%$ & $0.5969 \%$ & $0.5289 \%$ & $1.0340 \%$ & $1.4971 \%$ & $1.7340 \%$ & $1.6899 \%$ \\
\hline & 1.5 & $0.1113 \%$ & $0.3249 \%$ & $0.5022 \%$ & $0.3196 \%$ & $0.3870 \%$ & $0.5405 \%$ & $0.8053 \%$ & $0.7727 \%$ & $1.0674 \%$ \\
\hline & 2 & $0.4403 \%$ & $0.0209 \%$ & $0.1307 \%$ & $0.2405 \%$ & $0.2290 \%$ & $0.4621 \%$ & $0.4489 \%$ & $0.4744 \%$ & $0.6160 \%$ \\
\hline & 2.5 & $1.5055 \%$ & $0.5475 \%$ & $0.1553 \%$ & $0.0209 \%$ & $0.1604 \%$ & $0.3202 \%$ & $0.3210 \%$ & $0.3416 \%$ & $0.4067 \%$ \\
\hline & 3 & $3.4300 \%$ & $1.6544 \%$ & $3.9175 \%$ & $0.5896 \%$ & $0.0036 \%$ & $0.1939 \%$ & $0.1660 \%$ & $0.1440 \%$ & $0.1335 \%$ \\
\hline & 3.5 & $5.1278 \%$ & $3.1390 \%$ & $2.1546 \%$ & $1.5185 \%$ & $0.4639 \%$ & $0.0637 \%$ & $0.1612 \%$ & $0.2104 \%$ & $0.1874 \%$ \\
\hline & 4 & $6.5719 \%$ & $4.6278 \%$ & $3.4931 \%$ & $2.7169 \%$ & $1.2417 \%$ & $0.3124 \%$ & $0.0029 \%$ & $0.1144 \%$ & $0.1644 \%$ \\
\hline
\end{tabular}

Table 243 Maximum deflection results comparison for alpha 0.5 for slabs subjected to CHBDC axle 4 loading (main bars parallel to traffic) Deflection (m) 


\begin{tabular}{|c|c|c|c|c|c|c|c|c|c|c|}
\hline \multirow{7}{*}{ 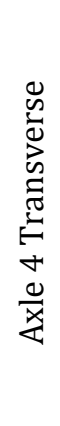 } & $\frac{\mathrm{D}}{\text { SPAN }}$ & 25 & 0.5 & 0.75 & & & 4 & & & 10 \\
\hline & 1 & $3.1713 \%$ & $2.8175 \%$ & $1.7059 \%$ & $1.3968 \%$ & $0.8136 \%$ & $1.0285 \%$ & $1.2482 \%$ & $1.3242 \%$ & $0.9341 \%$ \\
\hline & 1.5 & $2.7178 \%$ & $2.7521 \%$ & $2.5215 \%$ & $2.3945 \%$ & $1.9963 \%$ & $1.2256 \%$ & $1.0448 \%$ & $0.9108 \%$ & $0.5217 \%$ \\
\hline & 2 & $2.4131 \%$ & $2.2712 \%$ & $2.3736 \%$ & $2.2984 \%$ & $2.3427 \%$ & $2.1429 \%$ & $1.9374 \%$ & $1.7144 \%$ & $1.4243 \%$ \\
\hline & 2.5 & $2.2485 \%$ & $2.2902 \%$ & $2.2273 \%$ & $2.2192 \%$ & $2.2042 \%$ & $2.2478 \%$ & $2.2269 \%$ & $2.1230 \%$ & $2.0478 \%$ \\
\hline & 3 & $2.0368 \%$ & $2.1972 \%$ & $0.0577 \%$ & $2.2121 \%$ & $2.1285 \%$ & $2.1569 \%$ & $2.2198 \%$ & $2.2064 \%$ & $2.2295 \%$ \\
\hline & 3.5 & $1.8584 \%$ & $2.0332 \%$ & $2.1021 \%$ & $2.1326 \%$ & $2.1756 \%$ & $2.0990 \%$ & $2.0953 \%$ & $2.1333 \%$ & $2.1686 \%$ \\
\hline
\end{tabular}

Table 244 Maximum deflection results comparison for alpha 0.5 for slabs subjected to CHBDC axle 2 \& 3 loading (main bars parallel to traffic)

\begin{tabular}{|c|c|c|c|c|c|c|c|c|c|c|}
\hline & & \multicolumn{9}{|c|}{ Deflection (m) } \\
\hline \multirow{7}{*}{ 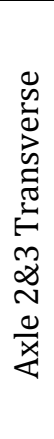 } & $\begin{array}{c}\mathrm{D} \\
\text { SPAN }\end{array}$ & 0.25 & 0.5 & 0.75 & 1 & 2 & 4 & 6 & 8 & 10 \\
\hline & 1.5 & $0.1085 \%$ & $0.1077 \%$ & $0.5176 \%$ & $0.1783 \%$ & $2.6478 \%$ & $1.5286 \%$ & $0.7629 \%$ & $0.9376 \%$ & $0.3182 \%$ \\
\hline & 2 & $0.2497 \%$ & $0.2571 \%$ & $0.1134 \%$ & $0.1183 \%$ & $0.1235 \%$ & $0.8518 \%$ & $2.6461 \%$ & $2.1108 \%$ & $1.6448 \%$ \\
\hline & 2.5 & $0.0676 \%$ & $0.0752 \%$ & $0.1449 \%$ & $0.0807 \%$ & $0.0789 \%$ & $0.1147 \%$ & $0.2206 \%$ & $0.6265 \%$ & $1.3416 \%$ \\
\hline & 3 & $0.0876 \%$ & $0.0888 \%$ & $2.0882 \%$ & $0.0629 \%$ & $0.0857 \%$ & $0.0792 \%$ & $0.0797 \%$ & $0.0830 \%$ & $0.1582 \%$ \\
\hline & 3.5 & $0.0540 \%$ & $0.0481 \%$ & $0.0458 \%$ & $0.0474 \%$ & $0.0713 \%$ & $0.0647 \%$ & $0.0744 \%$ & $0.0771 \%$ & $0.0598 \%$ \\
\hline & 4 & $0.0489 \%$ & $0.0442 \%$ & $0.0538 \%$ & $0.0418 \%$ & $0.0562 \%$ & $0.0560 \%$ & $0.0533 \%$ & $0.0477 \%$ & $0.0542 \%$ \\
\hline
\end{tabular}




\section{Alpha 0.75 Deflection Comparison Results}

Table 245 Maximum deflection results comparison for alpha 0.75 for slabs subjected to CHBDC axle 4 loading (main bars perpendicular to traffic)

\begin{tabular}{|c|c|c|c|c|c|c|c|c|c|c|}
\hline & \multicolumn{9}{|c|}{ Deflection (m) } \\
\hline \multirow{9}{*}{$\begin{array}{l}+ \\
\frac{0}{x} \\
\dot{x}\end{array}$} & $\mathrm{D}$ & \multirow{2}{*}{0.25} & \multirow{2}{*}{0.5} & \multirow{2}{*}{0.75} & \multirow[b]{2}{*}{1} & \multirow{2}{*}{2} & \multirow[b]{2}{*}{4} & \multirow[b]{2}{*}{0} & \multirow{2}{*}{8} & \multirow{2}{*}{10} \\
\hline & SPAN & & & & & & & & & \\
\hline & 1 & $0.4531 \%$ & $0.8923 \%$ & $1.1671 \%$ & $0.8684 \%$ & $0.8619 \%$ & $1.5962 \%$ & $1.0383 \%$ & $1.8096 \%$ & $2.1314 \%$ \\
\hline & 1.5 & $0.3979 \%$ & $0.4438 \%$ & $0.2832 \%$ & $0.1318 \%$ & $0.6056 \%$ & $0.4962 \%$ & $0.8531 \%$ & $0.7155 \%$ & $0.8512 \%$ \\
\hline & 2 & $0.2276 \%$ & $0.1646 \%$ & $0.1121 \%$ & $0.1653 \%$ & $0.3204 \%$ & $0.4225 \%$ & $0.4468 \%$ & $0.5105 \%$ & $0.6046 \%$ \\
\hline & 2.5 & $0.0336 \%$ & $0.0530 \%$ & $0.1559 \%$ & $0.1974 \%$ & $0.1868 \%$ & $0.2236 \%$ & $0.3226 \%$ & $0.3662 \%$ & $0.3646 \%$ \\
\hline & 3 & $0.0491 \%$ & $0.0492 \%$ & $0.0430 \%$ & $0.0821 \%$ & $0.1169 \%$ & $0.0824 \%$ & $0.1308 \%$ & $0.1640 \%$ & $0.1482 \%$ \\
\hline & 3.5 & $0.0247 \%$ & $0.0409 \%$ & $0.0498 \%$ & $0.0523 \%$ & $0.0694 \%$ & $0.0875 \%$ & $0.1056 \%$ & $0.1310 \%$ & $0.1431 \%$ \\
\hline & 4 & $0.0032 \%$ & $0.0184 \%$ & $0.0133 \%$ & $0.0356 \%$ & $0.0483 \%$ & $0.0645 \%$ & $0.0739 \%$ & $0.0871 \%$ & $0.1068 \%$ \\
\hline
\end{tabular}

Table 246 Maximum deflection results comparison for alpha 0.75 for slabs subjected to CHBDC axle 2 \& 3 loading (main bars perpendicular to traffic)

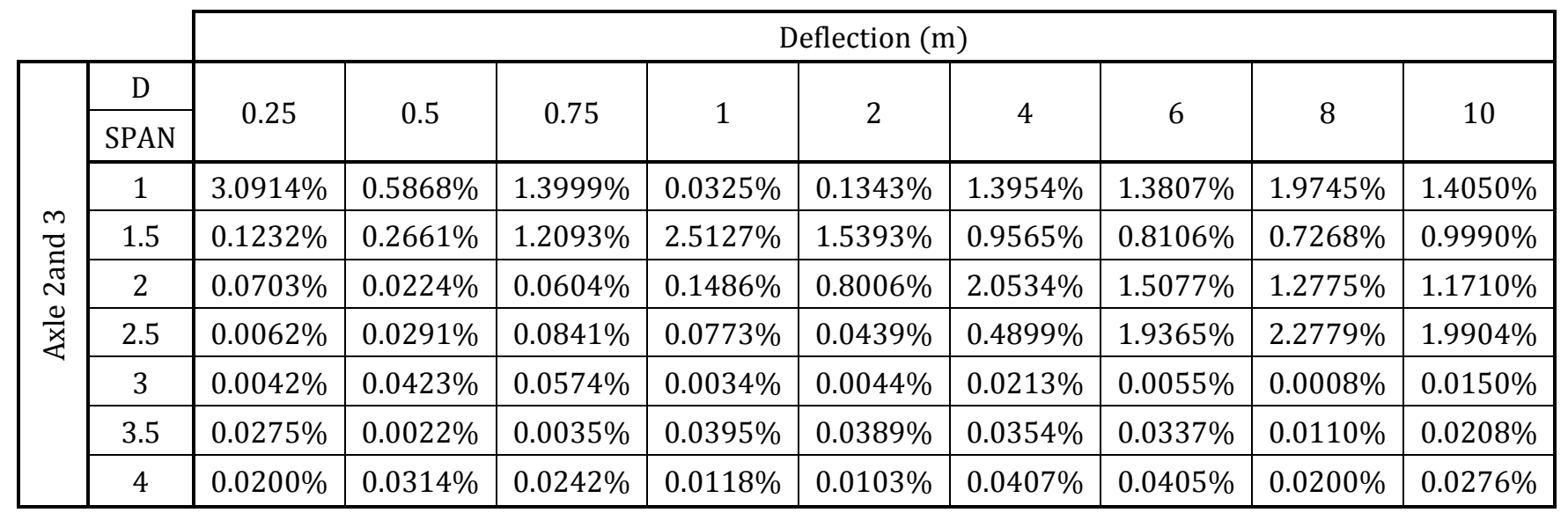

Table 247 Maximum deflection results comparison for alpha 0.75 for slabs subjected to CHBDC truck loading (main bars perpendicular to traffic)

\begin{tabular}{|c|c|c|c|c|c|c|c|c|c|c|}
\hline & \multicolumn{9}{|c|}{ Deflection (m) } \\
\hline \multirow{9}{*}{ 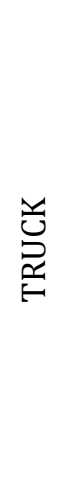 } & $\mathrm{D}$ & \multirow{2}{*}{0.25} & \multirow{2}{*}{0.5} & \multirow{2}{*}{0.75} & \multirow[b]{2}{*}{1} & \multirow[b]{2}{*}{$z$} & \multirow[b]{2}{*}{4} & \multirow{2}{*}{6} & \multirow{2}{*}{8} & \multirow{2}{*}{10} \\
\hline & SPAN & & & & & & & & & \\
\hline & 1 & $0.4528 \%$ & $0.8923 \%$ & $1.1671 \%$ & $0.8684 \%$ & $0.8619 \%$ & $1.5962 \%$ & $1.0383 \%$ & $1.8096 \%$ & $2.1314 \%$ \\
\hline & 1.5 & $0.4010 \%$ & $0.2357 \%$ & $0.2859 \%$ & $0.1327 \%$ & $0.6056 \%$ & $0.4962 \%$ & $0.8531 \%$ & $0.7155 \%$ & $0.8512 \%$ \\
\hline & 2 & $0.8941 \%$ & $0.3512 \%$ & $0.0990 \%$ & $0.0450 \%$ & $0.3249 \%$ & $0.4229 \%$ & $0.4468 \%$ & $0.5105 \%$ & $0.6046 \%$ \\
\hline & 2.5 & $2.5236 \%$ & $1.2310 \%$ & $0.8243 \%$ & $0.5348 \%$ & $0.2122 \%$ & $0.2313 \%$ & $0.3249 \%$ & $0.3670 \%$ & $0.3649 \%$ \\
\hline & 3 & $4.2592 \%$ & $2.6136 \%$ & $1.8614 \%$ & $1.3390 \%$ & $0.5293 \%$ & $0.1267 \%$ & $0.0400 \%$ & $0.0300 \%$ & $0.0131 \%$ \\
\hline & 3.5 & $5.8128 \%$ & $4.0320 \%$ & $3.0750 \%$ & $2.4439 \%$ & $1.2532 \%$ & $0.4820 \%$ & $0.2153 \%$ & $0.1199 \%$ & $0.0450 \%$ \\
\hline & 4 & $7.0240 \%$ & $5.3748 \%$ & $4.3468 \%$ & $3.6529 \%$ & $2.1141 \%$ & $1.0279 \%$ & $0.6003 \%$ & $0.3728 \%$ & $0.2448 \%$ \\
\hline
\end{tabular}


Table 248 Maximum deflection results comparison for alpha 0.75 for slabs subjected to CHBDC axle 4 loading (main bars parallel to traffic)

\begin{tabular}{|c|c|c|c|c|c|c|c|c|c|c|}
\hline & & \multicolumn{9}{|c|}{ Deflection (m) } \\
\hline \multirow{8}{*}{ 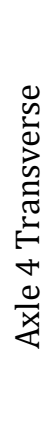 } & $\mathrm{D}$ & \multirow{2}{*}{0.25} & \multirow[t]{2}{*}{0.5} & \multirow{2}{*}{0.75} & \multirow[t]{2}{*}{1} & & & \multirow{2}{*}{6} & \multirow[t]{2}{*}{8} & \multirow{2}{*}{10} \\
\hline & SPAN & & & & & & & & & \\
\hline & 1 & $2.7840 \%$ & $1.7066 \%$ & $2.1955 \%$ & $1.1906 \%$ & $0.8140 \%$ & $0.5615 \%$ & $0.7838 \%$ & $0.7595 \%$ & $0.7678 \%$ \\
\hline & 1.5 & $2.3264 \%$ & $2.3537 \%$ & $2.3947 \%$ & $2.2652 \%$ & $1.7983 \%$ & $1.4077 \%$ & $0.8952 \%$ & $0.9702 \%$ & $0.6977 \%$ \\
\hline & 2 & $2.3239 \%$ & $2.2580 \%$ & $2.1969 \%$ & $2.0821 \%$ & $2.1375 \%$ & $1.9594 \%$ & $1.6596 \%$ & $1.5276 \%$ & $1.3282 \%$ \\
\hline & 2.5 & $2.1748 \%$ & $2.1878 \%$ & $2.1353 \%$ & $2.1369 \%$ & $2.0658 \%$ & $2.0526 \%$ & $1.9400 \%$ & $1.8454 \%$ & $1.8247 \%$ \\
\hline & 3 & $1.9694 \%$ & $2.0845 \%$ & $2.0881 \%$ & $2.1013 \%$ & $2.0365 \%$ & $1.9879 \%$ & $1.9813 \%$ & $1.9741 \%$ & $1.9745 \%$ \\
\hline & 3.5 & $1.7403 \%$ & $1.9062 \%$ & $2.0121 \%$ & $2.0297 \%$ & $2.0786 \%$ & $1.9787 \%$ & $1.9768 \%$ & $1.9817 \%$ & $1.9613 \%$ \\
\hline
\end{tabular}

Table 249 Maximum deflection results comparison for alpha 0.75 for slabs subjected to CHBDC axle $2 \& 3$ loading (main bars parallel to traffic)

\begin{tabular}{|c|c|c|c|c|c|c|c|c|c|c|}
\hline & & \multicolumn{9}{|c|}{ Deflection (m) } \\
\hline \multirow{7}{*}{ 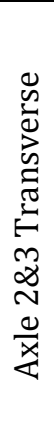 } & $\frac{\mathrm{D}}{\text { SPAN }}$ & 0.25 & 0.5 & 0.75 & 1 & 2 & 4 & 6 & 8 & 10 \\
\hline & 1.5 & $0.5129 \%$ & $0.0977 \%$ & $0.7260 \%$ & $0.3792 \%$ & $2.7664 \%$ & $1.7715 \%$ & $0.8995 \%$ & $0.9129 \%$ & $0.7425 \%$ \\
\hline & 2 & $0.1045 \%$ & $0.2297 \%$ & $0.2469 \%$ & $0.1254 \%$ & $0.1925 \%$ & $1.0956 \%$ & $2.3569 \%$ & $1.9761 \%$ & $1.5795 \%$ \\
\hline & 2.5 & $0.0710 \%$ & $0.1528 \%$ & $0.0776 \%$ & $0.1324 \%$ & $0.1012 \%$ & $0.1566 \%$ & $0.3058 \%$ & $0.8609 \%$ & $1.4915 \%$ \\
\hline & 3 & $0.0757 \%$ & $0.0683 \%$ & $0.0975 \%$ & $0.0948 \%$ & $0.0597 \%$ & $0.1040 \%$ & $0.0953 \%$ & $0.1062 \%$ & $0.2312 \%$ \\
\hline & 3.5 & $0.0514 \%$ & $0.0483 \%$ & $0.0565 \%$ & $0.0539 \%$ & $0.0621 \%$ & $0.0515 \%$ & $0.0516 \%$ & $0.0622 \%$ & $0.0660 \%$ \\
\hline & 4 & $0.0376 \%$ & $0.0563 \%$ & $0.0453 \%$ & $0.0417 \%$ & $0.0492 \%$ & $0.0561 \%$ & $0.0422 \%$ & $0.0446 \%$ & $0.0567 \%$ \\
\hline
\end{tabular}




\section{Alpha 1 Deflection Comparison Results}

Table 250 Maximum deflection results comparison for alpha 1 for slabs subjected to CHBDC axle 4 loading (main bars perpendicular to traffic)

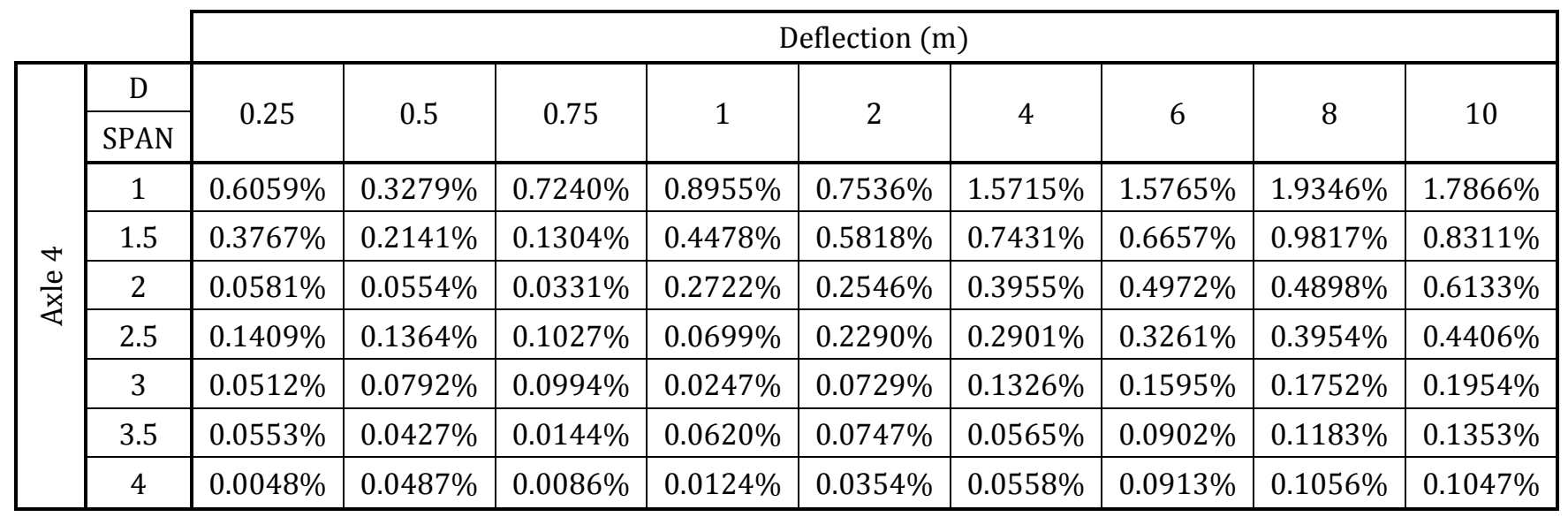

Table 251 Maximum deflection results comparison for alpha 1 for slabs subjected to CHBDC axle 2 \& 3 loading (main bars perpendicular to traffic)

\begin{tabular}{|c|c|c|c|c|c|c|c|c|c|c|}
\hline & \multicolumn{9}{|c|}{ Deflection (m) } \\
\hline \multirow{9}{*}{ 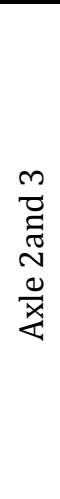 } & $\mathrm{D}$ & \multirow{2}{*}{0.25} & \multirow{2}{*}{0.5} & \multirow{2}{*}{0.75} & & & & \multirow{2}{*}{6} & \multirow{2}{*}{8} & \multirow{2}{*}{10} \\
\hline & SPAN & & & & & & & & & \\
\hline & 1 & $3.3002 \%$ & $0.8879 \%$ & $0.1465 \%$ & $0.7708 \%$ & $0.0962 \%$ & $1.2268 \%$ & $0.7637 \%$ & $1.9984 \%$ & $1.8368 \%$ \\
\hline & 1.5 & $0.2101 \%$ & $0.0268 \%$ & $1.4253 \%$ & $2.3554 \%$ & $1.5180 \%$ & $1.3059 \%$ & $1.0671 \%$ & $0.8919 \%$ & $0.6619 \%$ \\
\hline & 2 & $0.1100 \%$ & $0.0319 \%$ & $0.1093 \%$ & $0.0682 \%$ & $0.9437 \%$ & $2.0891 \%$ & $1.6277 \%$ & $1.2942 \%$ & $1.1075 \%$ \\
\hline & 2.5 & $0.0012 \%$ & $0.0272 \%$ & $0.0173 \%$ & $0.0549 \%$ & $0.0283 \%$ & $0.6253 \%$ & $1.9558 \%$ & $2.1448 \%$ & $1.8902 \%$ \\
\hline & 3 & $0.0226 \%$ & $0.0080 \%$ & $0.0127 \%$ & $0.0048 \%$ & $0.0092 \%$ & $0.0096 \%$ & $0.0039 \%$ & $0.0095 \%$ & $0.0369 \%$ \\
\hline & 3.5 & $0.0427 \%$ & $0.0075 \%$ & $0.0078 \%$ & $0.0146 \%$ & $0.0025 \%$ & $0.0465 \%$ & $0.0194 \%$ & $0.0047 \%$ & $0.0354 \%$ \\
\hline & 4 & $0.0329 \%$ & $0.0173 \%$ & $0.0168 \%$ & $0.0194 \%$ & $0.0094 \%$ & $0.0171 \%$ & $0.0239 \%$ & $0.0308 \%$ & $0.0215 \%$ \\
\hline
\end{tabular}

Table 252 Maximum deflection results comparison for alpha 1 for slabs subjected to CHBDC truck loading (main bars perpendicular to traffic)

\begin{tabular}{|c|c|c|c|c|c|c|c|c|c|c|}
\hline & \multicolumn{9}{|c|}{ Deflection (m) } \\
\hline \multirow{9}{*}{ 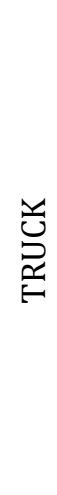 } & $\mathrm{D}$ & \multirow{2}{*}{0.25} & \multirow{2}{*}{0.5} & \multirow{2}{*}{0.75} & \multirow{2}{*}{1} & \multirow[b]{2}{*}{2} & \multirow[b]{2}{*}{4} & \multirow{2}{*}{6} & \multirow{2}{*}{8} & \multirow{2}{*}{10} \\
\hline & SPAN & & & & & & & & & \\
\hline & 1 & $0.6048 \%$ & $0.3280 \%$ & $0.7240 \%$ & $0.8955 \%$ & $0.7536 \%$ & $1.5715 \%$ & $1.5765 \%$ & $1.9346 \%$ & $1.7866 \%$ \\
\hline & 1.5 & $0.6938 \%$ & $0.2630 \%$ & $0.1245 \%$ & $0.4454 \%$ & $0.5816 \%$ & $0.7431 \%$ & $0.6657 \%$ & $0.9817 \%$ & $0.8311 \%$ \\
\hline & 2 & $1.6627 \%$ & $0.9054 \%$ & $0.5658 \%$ & $0.3213 \%$ & $0.2449 \%$ & $0.3944 \%$ & $0.4970 \%$ & $0.4897 \%$ & $0.6133 \%$ \\
\hline & 2.5 & $3.1660 \%$ & $1.9977 \%$ & $1.3898 \%$ & $1.0698 \%$ & $0.4032 \%$ & $0.5563 \%$ & $0.3208 \%$ & $0.3933 \%$ & $0.4396 \%$ \\
\hline & 3 & $5.9847 \%$ & $4.0792 \%$ & $3.1018 \%$ & $2.4689 \%$ & $1.3428 \%$ & $0.6136 \%$ & $0.3293 \%$ & $0.2581 \%$ & $0.1815 \%$ \\
\hline & 3.5 & $7.5618 \%$ & $5.6984 \%$ & $4.6087 \%$ & $3.8972 \%$ & $2.3447 \%$ & $1.2198 \%$ & $0.8022 \%$ & $0.5532 \%$ & $0.4056 \%$ \\
\hline & 4 & $8.7018 \%$ & $7.1299 \%$ & $6.0349 \%$ & $5.2514 \%$ & $3.4595 \%$ & $2.0226 \%$ & $1.3897 \%$ & $1.0391 \%$ & $0.7941 \%$ \\
\hline
\end{tabular}

Table 253 Maximum deflection results comparison for alpha 1 for slabs subjected to CHBDC axle 4 loading (main bars parallel to traffic) Deflection (m) 


\begin{tabular}{|c|c|c|c|c|c|c|c|c|c|c|}
\hline \multirow{7}{*}{ 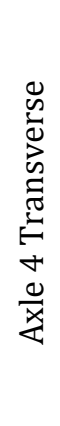 } & $\frac{\mathrm{D}}{\text { SPAN }}$ & 25 & 0.5 & 0.75 & & 2 & 4 & & 8 & 10 \\
\hline & 1 & $2.1597 \%$ & $2.5724 \%$ & $2.2193 \%$ & $1.4935 \%$ & $0.9527 \%$ & $0.7675 \%$ & $0.6906 \%$ & $1.0559 \%$ & $1.3255 \%$ \\
\hline & 1.5 & $2.0520 \%$ & $2.1402 \%$ & $2.0798 \%$ & $1.9327 \%$ & $1.6432 \%$ & $1.4259 \%$ & $1.0305 \%$ & $0.8633 \%$ & $0.9039 \%$ \\
\hline & 2 & $2.2236 \%$ & $2.0501 \%$ & $2.0731 \%$ & $1.9588 \%$ & $1.9032 \%$ & $1.6991 \%$ & $1.5256 \%$ & $1.4080 \%$ & $1.2294 \%$ \\
\hline & 2.5 & $2.0815 \%$ & $2.0332 \%$ & $2.0030 \%$ & $1.9942 \%$ & $1.9162 \%$ & $1.8278 \%$ & $1.7820 \%$ & $1.6737 \%$ & $1.6013 \%$ \\
\hline & 3 & $1.8216 \%$ & $1.9505 \%$ & $2.0002 \%$ & $2.0198 \%$ & $1.9322 \%$ & $1.8917 \%$ & $1.8627 \%$ & $1.7833 \%$ & $1.7644 \%$ \\
\hline & 3.5 & $1.6588 \%$ & $1.8338 \%$ & $1.8885 \%$ & $1.9521 \%$ & $1.9936 \%$ & $1.9053 \%$ & $1.8605 \%$ & $1.8479 \%$ & $1.8298 \%$ \\
\hline
\end{tabular}

Table 254 Maximum deflection results comparison for alpha 1 for slabs subjected to CHBDC axle 2 \& 3 loading (main bars parallel to traffic)

\begin{tabular}{|c|c|c|c|c|c|c|c|c|c|c|}
\hline & & \multicolumn{9}{|c|}{ Deflection (m) } \\
\hline \multirow{8}{*}{ 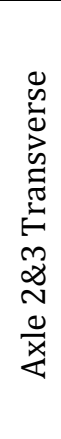 } & $\mathrm{D}$ & \multirow{2}{*}{0.25} & \multirow{2}{*}{0.5} & \multirow{2}{*}{0.75} & \multirow{2}{*}{1} & \multirow{2}{*}{2} & \multirow{2}{*}{4} & \multirow{2}{*}{6} & \multirow{2}{*}{8} & \multirow{2}{*}{10} \\
\hline & SPAN & & & & & & & & & \\
\hline & 1.5 & $0.5744 \%$ & $0.0609 \%$ & $0.5182 \%$ & $0.1231 \%$ & $2.0385 \%$ & $1.5529 \%$ & $1.1644 \%$ & $0.8395 \%$ & $1.0193 \%$ \\
\hline & 2 & $0.2634 \%$ & $0.2088 \%$ & $0.2350 \%$ & $0.1979 \%$ & $0.2762 \%$ & $1.0658 \%$ & $1.9075 \%$ & $1.6987 \%$ & $1.4770 \%$ \\
\hline & 2.5 & $0.1118 \%$ & $0.1503 \%$ & $0.1111 \%$ & $0.0860 \%$ & $0.1202 \%$ & $0.1002 \%$ & $0.4040 \%$ & $0.9911 \%$ & $1.5800 \%$ \\
\hline & 3 & $0.0593 \%$ & $0.0552 \%$ & $0.0623 \%$ & $0.0552 \%$ & $0.0785 \%$ & $0.1001 \%$ & $0.0939 \%$ & $0.1396 \%$ & $0.3347 \%$ \\
\hline & 3.5 & $0.0611 \%$ & $0.0516 \%$ & $0.0739 \%$ & $0.0642 \%$ & $0.0487 \%$ & $0.0596 \%$ & $0.0643 \%$ & $0.0591 \%$ & $0.0675 \%$ \\
\hline & 4 & $0.0469 \%$ & $0.0481 \%$ & $0.0509 \%$ & $0.0539 \%$ & $0.0528 \%$ & $0.0554 \%$ & $0.0564 \%$ & $0.0560 \%$ & $0.0589 \%$ \\
\hline
\end{tabular}




\section{Alpha 2 Deflection Comparison Results}

Table 255 Maximum deflection results comparison for alpha 2 for slabs subjected to CHBDC axle 4 loading (main bars perpendicular to traffic)

\begin{tabular}{|c|c|c|c|c|c|c|c|c|c|c|}
\hline & \multicolumn{9}{|c|}{ Deflection (m) } \\
\hline \multirow{9}{*}{$\begin{array}{l}+ \\
\frac{0}{x} \\
\dot{x}\end{array}$} & $\mathrm{D}$ & \multirow{2}{*}{0.25} & \multirow{2}{*}{0.5} & \multirow{2}{*}{0.75} & \multirow[b]{2}{*}{1} & \multirow{2}{*}{2} & \multirow[b]{2}{*}{4} & \multirow[b]{2}{*}{0} & \multirow{2}{*}{8} & \multirow{2}{*}{10} \\
\hline & SPAN & & & & & & & & & \\
\hline & 1 & $0.5106 \%$ & $0.0082 \%$ & $0.2904 \%$ & $0.2099 \%$ & $0.3074 \%$ & $1.0163 \%$ & $0.8063 \%$ & $1.6251 \%$ & $1.5263 \%$ \\
\hline & 1.5 & $0.2270 \%$ & $0.3998 \%$ & $0.2436 \%$ & $0.1323 \%$ & $0.4253 \%$ & $0.7336 \%$ & $0.5234 \%$ & $0.7585 \%$ & $0.9524 \%$ \\
\hline & 2 & $0.0719 \%$ & $0.1723 \%$ & $0.3305 \%$ & $0.3290 \%$ & $0.1544 \%$ & $0.2277 \%$ & $0.3674 \%$ & $0.5639 \%$ & $0.6418 \%$ \\
\hline & 2.5 & $0.0935 \%$ & $0.0072 \%$ & $0.1669 \%$ & $0.0791 \%$ & $0.1739 \%$ & $0.2331 \%$ & $0.3619 \%$ & $0.3336 \%$ & $0.4186 \%$ \\
\hline & 3 & $0.1364 \%$ & $0.0511 \%$ & $0.0656 \%$ & $0.0860 \%$ & $0.0462 \%$ & $0.0953 \%$ & $0.1531 \%$ & $0.1667 \%$ & $0.1752 \%$ \\
\hline & 3.5 & $0.0446 \%$ & $0.0088 \%$ & $0.0382 \%$ & $0.0500 \%$ & $0.0426 \%$ & $0.0615 \%$ & $0.0932 \%$ & $0.1396 \%$ & $0.1158 \%$ \\
\hline & 4 & $0.2015 \%$ & $0.1033 \%$ & $0.0479 \%$ & $0.0188 \%$ & $0.0686 \%$ & $0.0650 \%$ & $0.0764 \%$ & $0.0824 \%$ & $0.0902 \%$ \\
\hline
\end{tabular}

Table 256 Maximum deflection results comparison for alpha 2 for slabs subjected to CHBDC axle 2 \& 3 loading (main bars perpendicular to traffic)

\begin{tabular}{|c|c|c|c|c|c|c|c|c|c|c|}
\hline & \multicolumn{9}{|c|}{ Deflection (m) } \\
\hline \multirow{9}{*}{ 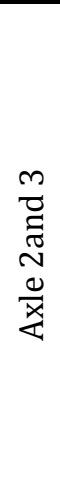 } & $\mathrm{D}$ & \multirow{2}{*}{0.25} & \multirow{2}{*}{0.5} & \multirow{2}{*}{0.75} & & & & \multirow{2}{*}{6} & \multirow[b]{2}{*}{0} & \multirow{2}{*}{10} \\
\hline & SPAN & & & & & & & & & \\
\hline & 1 & $1.0522 \%$ & $1.5491 \%$ & $1.3948 \%$ & $0.7492 \%$ & $0.4077 \%$ & $1.5330 \%$ & $1.6146 \%$ & $1.8412 \%$ & $1.6029 \%$ \\
\hline & 1.5 & $0.1964 \%$ & $0.2188 \%$ & $1.5778 \%$ & $1.8167 \%$ & $1.6110 \%$ & $0.8778 \%$ & $1.1578 \%$ & $0.8909 \%$ & $0.9750 \%$ \\
\hline & 2 & $0.0229 \%$ & $0.0029 \%$ & $0.0220 \%$ & $0.0834 \%$ & $1.1872 \%$ & $1.6412 \%$ & $1.3329 \%$ & $1.1339 \%$ & $1.3156 \%$ \\
\hline & 2.5 & $0.0836 \%$ & $0.0676 \%$ & $0.0065 \%$ & $0.0457 \%$ & $0.0236 \%$ & $0.8965 \%$ & $1.9970 \%$ & $1.8377 \%$ & $1.6303 \%$ \\
\hline & 3 & $0.0437 \%$ & $0.0381 \%$ & $0.0348 \%$ & $0.0403 \%$ & $0.0190 \%$ & $0.0299 \%$ & $0.0127 \%$ & $0.0297 \%$ & $0.0973 \%$ \\
\hline & 3.5 & $0.0777 \%$ & $0.0138 \%$ & $0.0271 \%$ & $0.0222 \%$ & $0.0200 \%$ & $0.0020 \%$ & $0.0109 \%$ & $0.0220 \%$ & $0.0038 \%$ \\
\hline & 4 & $0.2706 \%$ & $0.0868 \%$ & $0.0150 \%$ & $0.0071 \%$ & $0.0353 \%$ & $0.0088 \%$ & $0.0023 \%$ & $0.0133 \%$ & $0.0200 \%$ \\
\hline
\end{tabular}

Table 257 Maximum deflection results comparison for alpha 2 for slabs subjected to CHBDC truck loading (main bars perpendicular to traffic)

\begin{tabular}{|c|c|c|c|c|c|c|c|c|c|c|}
\hline & \multicolumn{9}{|c|}{ Deflection (m) } \\
\hline \multirow{9}{*}{ 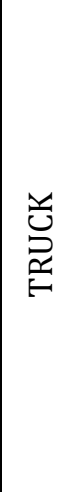 } & $\mathrm{D}$ & \multirow{2}{*}{0.25} & \multirow{2}{*}{0.5} & \multirow{2}{*}{0.75} & \multirow[b]{2}{*}{1} & \multirow{2}{*}{2} & \multirow[b]{2}{*}{$\Psi$} & \multirow{2}{*}{6} & \multirow{2}{*}{8} & \multirow{2}{*}{10} \\
\hline & SPAN & & & & & & & & & \\
\hline & 1 & $0.6324 \%$ & $0.0204 \%$ & $0.3012 \%$ & $0.2150 \%$ & $0.3068 \%$ & $1.0163 \%$ & $0.8062 \%$ & $1.6251 \%$ & $1.5263 \%$ \\
\hline & 1.5 & $1.8129 \%$ & $0.3554 \%$ & $0.8539 \%$ & $0.0553 \%$ & $0.3777 \%$ & $0.7242 \%$ & $0.5202 \%$ & $0.7571 \%$ & $0.9517 \%$ \\
\hline & 2 & $3.5740 \%$ & $2.2179 \%$ & $1.7380 \%$ & $1.1645 \%$ & $0.6934 \%$ & $0.3652 \%$ & $0.3145 \%$ & $0.5358 \%$ & $0.6251 \%$ \\
\hline & 2.5 & $4.9113 \%$ & $3.8605 \%$ & $3.0893 \%$ & $2.6822 \%$ & $1.5397 \%$ & $0.1173 \%$ & $1.6895 \%$ & $0.2957 \%$ & $0.4331 \%$ \\
\hline & 3 & $6.0099 \%$ & $5.1151 \%$ & $4.4942 \%$ & $3.9812 \%$ & $2.8659 \%$ & $1.8470 \%$ & $1.3271 \%$ & $1.0558 \%$ & $0.7225 \%$ \\
\hline & 3.5 & $6.3672 \%$ & $5.9473 \%$ & $5.4486 \%$ & $5.0150 \%$ & $3.8695 \%$ & $2.6974 \%$ & $2.0993 \%$ & $1.7502 \%$ & $1.4711 \%$ \\
\hline & 4 & $6.1053 \%$ & $6.3320 \%$ & $6.0771 \%$ & $5.7702 \%$ & $4.7490 \%$ & $3.5648 \%$ & $2.9123 \%$ & $2.4601 \%$ & $2.1456 \%$ \\
\hline
\end{tabular}

Table 258 Maximum deflection results comparison for alpha 2 for slabs subjected to CHBDC axle 4 loading (main bars parallel to traffic) Deflection (m) 


\begin{tabular}{|c|c|c|c|c|c|c|c|c|c|c|}
\hline \multirow{7}{*}{ 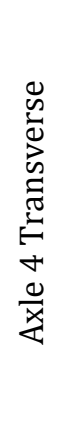 } & $\frac{\mathrm{D}}{\text { SPAN }}$ & 25 & 0.5 & 0.75 & & $?$ & 4 & & 8 & 10 \\
\hline & 1 & $1.9518 \%$ & $1.5772 \%$ & $1.9002 \%$ & $1.7847 \%$ & $1.0107 \%$ & $1.2851 \%$ & $0.7715 \%$ & $1.3118 \%$ & $0.5387 \%$ \\
\hline & 1.5 & $1.7731 \%$ & $1.7540 \%$ & $1.7276 \%$ & $1.4309 \%$ & $1.3186 \%$ & $1.0371 \%$ & $0.9233 \%$ & $0.9361 \%$ & $1.0705 \%$ \\
\hline & 2 & $1.8918 \%$ & $1.7919 \%$ & $1.7142 \%$ & $1.6950 \%$ & $1.4973 \%$ & $1.3215 \%$ & $1.1480 \%$ & $1.1625 \%$ & $1.1502 \%$ \\
\hline & 2.5 & $1.7968 \%$ & $1.8011 \%$ & $1.7045 \%$ & $1.6409 \%$ & $1.5852 \%$ & $1.4576 \%$ & $1.3191 \%$ & $1.3365 \%$ & $1.2463 \%$ \\
\hline & 3 & $1.5939 \%$ & $1.6767 \%$ & $1.7066 \%$ & $1.7045 \%$ & $1.6552 \%$ & $1.5412 \%$ & $1.4437 \%$ & $1.4162 \%$ & $1.3742 \%$ \\
\hline & 3.5 & $1.5355 \%$ & $1.5975 \%$ & $1.6613 \%$ & $1.6873 \%$ & $1.6761 \%$ & $1.5727 \%$ & $1.5305 \%$ & $1.5045 \%$ & $1.4544 \%$ \\
\hline
\end{tabular}

Table 259 Maximum deflection results comparison for alpha 2 for slabs subjected to CHBDC axle 2 \& 3 loading (main bars parallel to traffic)

\begin{tabular}{|c|c|c|c|c|c|c|c|c|c|c|}
\hline & & \multicolumn{9}{|c|}{ Deflection (m) } \\
\hline \multirow{7}{*}{ 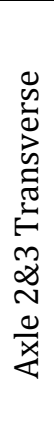 } & $\begin{array}{c}\mathrm{D} \\
\text { SPAN }\end{array}$ & 0.25 & 0.5 & 0.75 & 1 & 2 & 4 & 6 & 8 & 10 \\
\hline & 1.5 & $0.1590 \%$ & $0.6513 \%$ & $0.8317 \%$ & $1.0385 \%$ & $1.6406 \%$ & $1.3175 \%$ & $1.1410 \%$ & $0.9215 \%$ & $1.1435 \%$ \\
\hline & 2 & $0.2796 \%$ & $0.2423 \%$ & $0.1667 \%$ & $0.1939 \%$ & $0.3135 \%$ & $1.3794 \%$ & $1.3928 \%$ & $1.2744 \%$ & $1.1937 \%$ \\
\hline & 2.5 & $0.1020 \%$ & $0.0687 \%$ & $0.1267 \%$ & $0.0907 \%$ & $0.0812 \%$ & $0.2290 \%$ & $0.6726 \%$ & $1.1183 \%$ & $1.5623 \%$ \\
\hline & 3 & $0.0871 \%$ & $0.0867 \%$ & $0.0755 \%$ & $0.0963 \%$ & $0.0864 \%$ & $0.0738 \%$ & $0.1130 \%$ & $0.2902 \%$ & $0.4896 \%$ \\
\hline & 3.5 & $0.1550 \%$ & $0.0960 \%$ & $0.0799 \%$ & $0.0682 \%$ & $0.0490 \%$ & $0.0536 \%$ & $0.0620 \%$ & $0.0554 \%$ & $0.1069 \%$ \\
\hline & 4 & $0.3389 \%$ & $0.1401 \%$ & $0.0807 \%$ & $0.0691 \%$ & $0.0506 \%$ & $0.0477 \%$ & $0.0474 \%$ & $0.0518 \%$ & $0.0501 \%$ \\
\hline
\end{tabular}




\section{Alpha 4 Deflection Comparison Results}

Table 260 Maximum deflection results comparison for alpha 4 for slabs subjected to CHBDC axle 4 loading (main bars perpendicular to traffic)

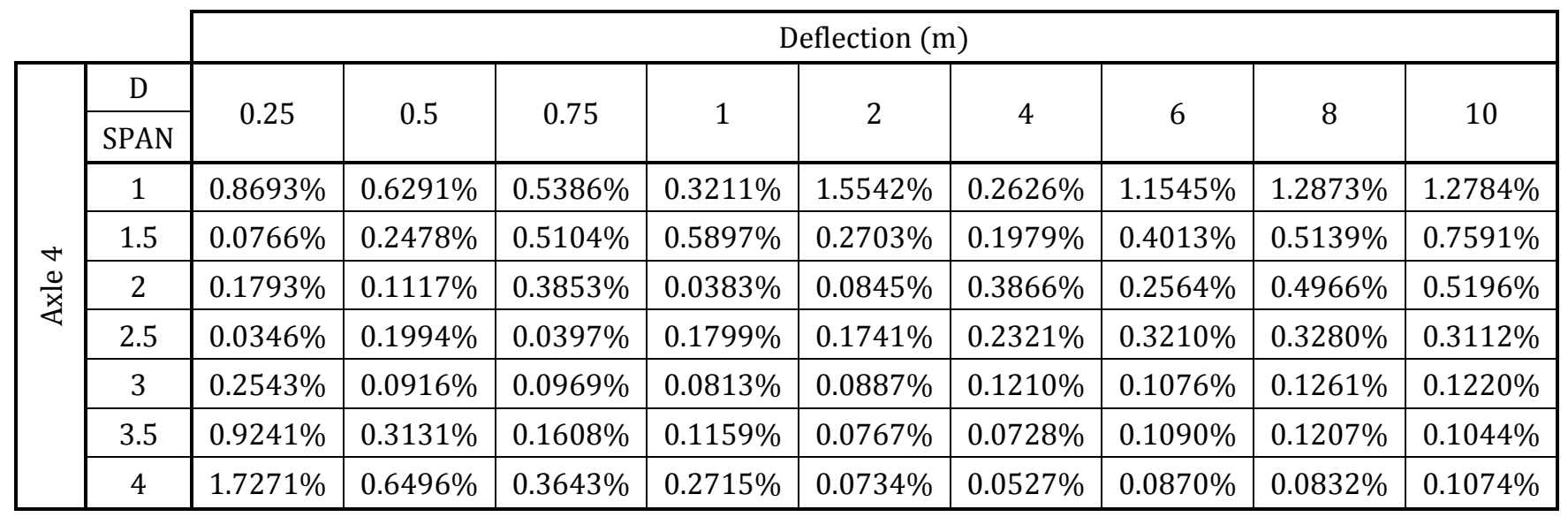

Table 261 Maximum deflection results comparison for alpha 4 for slabs subjected to CHBDC axle 2 \& 3 loading (main bars perpendicular to traffic)

\begin{tabular}{|c|c|c|c|c|c|c|c|c|c|c|}
\hline & \multicolumn{9}{|c|}{ Deflection (m) } \\
\hline \multirow{9}{*}{ 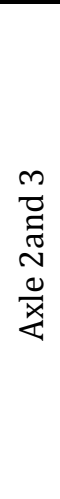 } & $\mathrm{D}$ & \multirow{2}{*}{0.25} & \multirow{2}{*}{0.5} & \multirow{2}{*}{0.75} & & & & \multirow{2}{*}{6} & \multirow[b]{2}{*}{0} & \multirow{2}{*}{10} \\
\hline & SPAN & & & & & & & & & \\
\hline & 1 & $0.5303 \%$ & $2.4308 \%$ & $0.6169 \%$ & $0.6092 \%$ & $0.1939 \%$ & $0.5294 \%$ & $0.8970 \%$ & $1.0690 \%$ & $0.4686 \%$ \\
\hline & 1.5 & $0.0045 \%$ & $0.9567 \%$ & $1.7433 \%$ & $1.8765 \%$ & $1.3983 \%$ & $1.3591 \%$ & $0.8871 \%$ & $0.8779 \%$ & $1.1725 \%$ \\
\hline & 2 & $0.2366 \%$ & $0.1663 \%$ & $0.1020 \%$ & $0.3054 \%$ & $1.2575 \%$ & $1.2763 \%$ & $1.3896 \%$ & $1.1564 \%$ & $1.0286 \%$ \\
\hline & 2.5 & $0.1980 \%$ & $0.0924 \%$ & $0.0154 \%$ & $0.0541 \%$ & $0.1847 \%$ & $0.9652 \%$ & $1.6400 \%$ & $1.4952 \%$ & $1.3507 \%$ \\
\hline & 3 & $0.3234 \%$ & $0.1892 \%$ & $0.0557 \%$ & $0.0627 \%$ & $0.0287 \%$ & $0.0096 \%$ & $0.0264 \%$ & $0.0712 \%$ & $0.2951 \%$ \\
\hline & 3.5 & $0.9228 \%$ & $0.3424 \%$ & $0.1922 \%$ & $0.0775 \%$ & $0.0355 \%$ & $0.0399 \%$ & $0.0106 \%$ & $0.0255 \%$ & $0.0249 \%$ \\
\hline & 4 & $1.7742 \%$ & $0.6960 \%$ & $0.3612 \%$ & $0.2160 \%$ & $0.0886 \%$ & $0.0067 \%$ & $0.0223 \%$ & $0.0012 \%$ & $0.0038 \%$ \\
\hline
\end{tabular}

Table 262 Maximum deflection results comparison for alpha 4 for slabs subjected to CHBDC truck loading (main bars perpendicular to traffic)

\begin{tabular}{|c|c|c|c|c|c|c|c|c|c|c|}
\hline & \multicolumn{9}{|c|}{ Deflection (m) } \\
\hline \multirow{9}{*}{ 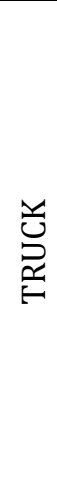 } & $\mathrm{D}$ & \multirow{2}{*}{0.25} & \multirow{2}{*}{0.5} & \multirow{2}{*}{0.75} & \multirow[b]{2}{*}{1} & \multirow{2}{*}{2} & \multirow[b]{2}{*}{4} & \multirow[b]{2}{*}{0} & \multirow{2}{*}{8} & \multirow{2}{*}{10} \\
\hline & SPAN & & & & & & & & & \\
\hline & 1 & $1.3534 \%$ & $0.2076 \%$ & $0.3239 \%$ & $0.1938 \%$ & $1.5228 \%$ & $0.2568 \%$ & $1.1526 \%$ & $1.2865 \%$ & $1.2780 \%$ \\
\hline & 1.5 & $2.9088 \%$ & $1.3955 \%$ & $0.2888 \%$ & $0.4451 \%$ & $1.8590 \%$ & $0.6228 \%$ & $0.8710 \%$ & $0.4631 \%$ & $0.7276 \%$ \\
\hline & 2 & $4.9772 \%$ & $4.0620 \%$ & $3.4399 \%$ & $2.7435 \%$ & $0.6529 \%$ & $2.2780 \%$ & $1.7145 \%$ & $0.3650 \%$ & $0.4984 \%$ \\
\hline & 2.5 & $5.7480 \%$ & $5.4695 \%$ & $4.9993 \%$ & $4.6286 \%$ & $3.1646 \%$ & $1.3195 \%$ & $0.1555 \%$ & $1.3520 \%$ & $2.4147 \%$ \\
\hline & 3 & $5.1540 \%$ & $5.7752 \%$ & $5.7444 \%$ & $5.5709 \%$ & $4.8273 \%$ & $3.8105 \%$ & $3.1071 \%$ & $2.4407 \%$ & $1.8842 \%$ \\
\hline & 3.5 & $3.7071 \%$ & $5.2955 \%$ & $5.6837 \%$ & $5.7712 \%$ & $5.5044 \%$ & $4.6957 \%$ & $4.0746 \%$ & $3.6558 \%$ & $3.2156 \%$ \\
\hline & 4 & $1.6831 \%$ & $4.2686 \%$ & $5.1360 \%$ & $5.5210 \%$ & $5.7808 \%$ & $5.3472 \%$ & $4.8712 \%$ & $4.4529 \%$ & $4.1254 \%$ \\
\hline
\end{tabular}

Table 263 Maximum deflection results comparison for alpha 4 for slabs subjected to CHBDC axle 4 loading (main bars parallel to traffic) Deflection (m) 


\begin{tabular}{|c|c|c|c|c|c|c|c|c|c|c|}
\hline \multirow{7}{*}{ 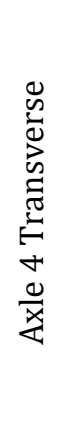 } & $\frac{\mathrm{D}}{\text { SPAN }}$ & 25 & 0.5 & 0.75 & & $?$ & 4 & & 8 & 10 \\
\hline & 1 & $1.5630 \%$ & $1.0698 \%$ & $1.6839 \%$ & $1.8931 \%$ & $1.1120 \%$ & $1.0408 \%$ & $1.8551 \%$ & $1.2947 \%$ & $1.2427 \%$ \\
\hline & 1.5 & $1.3212 \%$ & $1.3640 \%$ & $1.3307 \%$ & $1.1844 \%$ & $1.1903 \%$ & $1.2155 \%$ & $1.2383 \%$ & $1.0432 \%$ & $0.9685 \%$ \\
\hline & 2 & $1.5222 \%$ & $1.4373 \%$ & $1.2778 \%$ & $1.2951 \%$ & $1.1931 \%$ & $1.1352 \%$ & $0.9888 \%$ & $1.0383 \%$ & $0.9657 \%$ \\
\hline & 2.5 & $1.5217 \%$ & $1.4135 \%$ & $1.3902 \%$ & $1.2742 \%$ & $1.2590 \%$ & $1.1425 \%$ & $1.1197 \%$ & $1.0735 \%$ & $1.0147 \%$ \\
\hline & 3 & $1.7456 \%$ & $1.5137 \%$ & $1.3990 \%$ & $1.3742 \%$ & $1.2683 \%$ & $1.2115 \%$ & $1.1725 \%$ & $1.1241 \%$ & $1.0976 \%$ \\
\hline & 3.5 & $2.2294 \%$ & $1.6854 \%$ & $1.5105 \%$ & $1.4298 \%$ & $1.3202 \%$ & $1.2320 \%$ & $1.1968 \%$ & $1.1492 \%$ & $1.1422 \%$ \\
\hline
\end{tabular}

Table 264 Maximum deflection results comparison for alpha 4 for slabs subjected to CHBDC axle 2 \& 3 loading (main bars parallel to traffic)

\begin{tabular}{|c|c|c|c|c|c|c|c|c|c|c|}
\hline & & \multicolumn{9}{|c|}{ Deflection (m) } \\
\hline \multirow{7}{*}{ 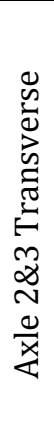 } & $\begin{array}{c}\text { D } \\
\text { SPAN }\end{array}$ & 0.25 & 0.5 & 0.75 & 1 & 2 & 4 & 6 & 8 & 10 \\
\hline & 1.5 & $0.4914 \%$ & $0.0004 \%$ & $0.5941 \%$ & $1.3321 \%$ & $1.7207 \%$ & $1.6073 \%$ & $1.0291 \%$ & $1.3434 \%$ & $1.2400 \%$ \\
\hline & 2 & $0.2763 \%$ & $0.2316 \%$ & $0.1795 \%$ & $0.0561 \%$ & $0.5024 \%$ & $1.2340 \%$ & $1.1521 \%$ & $1.0240 \%$ & $1.0265 \%$ \\
\hline & 2.5 & $0.3100 \%$ & $0.1467 \%$ & $0.1141 \%$ & $0.0595 \%$ & $0.0812 \%$ & $0.3470 \%$ & $0.6639 \%$ & $1.0463 \%$ & $1.1590 \%$ \\
\hline & 3 & $0.5619 \%$ & $0.2325 \%$ & $0.1623 \%$ & $0.1351 \%$ & $0.0955 \%$ & $0.0875 \%$ & $0.1964 \%$ & $0.3628 \%$ & $0.5775 \%$ \\
\hline & 3.5 & $1.1230 \%$ & $0.4404 \%$ & $0.2508 \%$ & $0.1684 \%$ & $0.1040 \%$ & $0.0567 \%$ & $0.0549 \%$ & $0.1249 \%$ & $0.2108 \%$ \\
\hline & 4 & $2.1304 \%$ & $0.9269 \%$ & $0.5208 \%$ & $0.3515 \%$ & $0.1453 \%$ & $0.0711 \%$ & $0.0551 \%$ & $0.0626 \%$ & $0.0592 \%$ \\
\hline
\end{tabular}




\section{Alpha 6 Deflection Comparison Results}

Table 265 Maximum deflection results comparison for alpha 6 for slabs subjected to CHBDC axle 4 loading (main bars perpendicular to traffic)

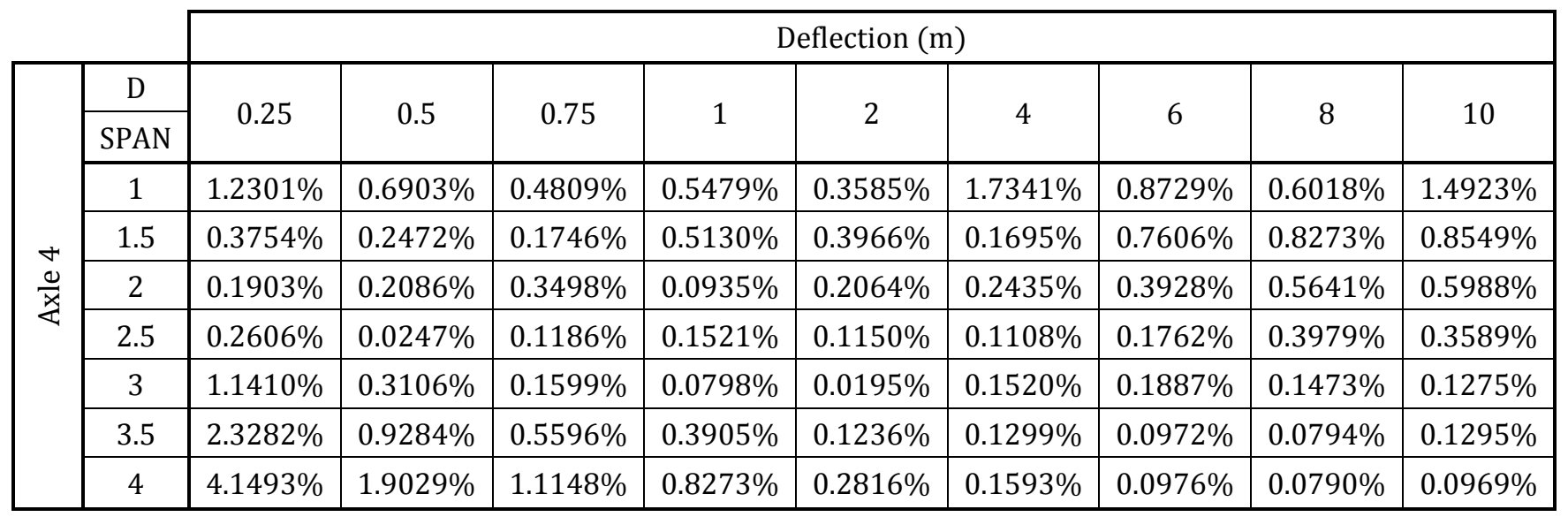

Table 266 Maximum deflection results comparison for alpha 6 for slabs subjected to CHBDC axle 2 \& 3 loading (main bars perpendicular to traffic)

\begin{tabular}{|c|c|c|c|c|c|c|c|c|c|c|}
\hline & \multicolumn{9}{|c|}{ Deflection (m) } \\
\hline \multirow{9}{*}{ 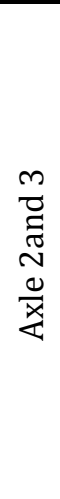 } & $\mathrm{D}$ & \multirow{2}{*}{0.25} & \multirow{2}{*}{0.5} & \multirow{2}{*}{0.75} & & & & \multirow{2}{*}{6} & \multirow[b]{2}{*}{0} & \multirow{2}{*}{10} \\
\hline & SPAN & & & & & & & & & \\
\hline & 1 & $0.6295 \%$ & $0.7564 \%$ & $2.1790 \%$ & $0.1050 \%$ & $0.6020 \%$ & $0.1450 \%$ & $1.4903 \%$ & $0.5124 \%$ & $0.4558 \%$ \\
\hline & 1.5 & $0.0929 \%$ & $1.0157 \%$ & $1.2140 \%$ & $1.6769 \%$ & $1.3265 \%$ & $0.8027 \%$ & $0.9310 \%$ & $0.7354 \%$ & $0.8289 \%$ \\
\hline & 2 & $0.1508 \%$ & $0.2184 \%$ & $0.2637 \%$ & $0.2267 \%$ & $1.1998 \%$ & $1.3097 \%$ & $1.0061 \%$ & $1.1839 \%$ & $1.0570 \%$ \\
\hline & 2.5 & $0.3584 \%$ & $0.2326 \%$ & $0.0174 \%$ & $0.0156 \%$ & $0.3381 \%$ & $0.9695 \%$ & $1.2251 \%$ & $1.3436 \%$ & $1.1602 \%$ \\
\hline & 3 & $1.1258 \%$ & $0.4863 \%$ & $0.2043 \%$ & $0.0955 \%$ & $0.0277 \%$ & $0.0115 \%$ & $0.0025 \%$ & $0.2272 \%$ & $0.3983 \%$ \\
\hline & 3.5 & $2.3910 \%$ & $1.0393 \%$ & $0.6107 \%$ & $0.4199 \%$ & $0.1493 \%$ & $0.0496 \%$ & $0.0038 \%$ & $0.0155 \%$ & $0.0766 \%$ \\
\hline & 4 & $4.2258 \%$ & $1.9813 \%$ & $1.2134 \%$ & $0.7923 \%$ & $0.2826 \%$ & $0.0881 \%$ & $0.0450 \%$ & $0.0028 \%$ & $0.0224 \%$ \\
\hline
\end{tabular}

Table 267 Maximum deflection results comparison for alpha 6 for slabs subjected to CHBDC truck loading (main bars perpendicular to traffic)

\begin{tabular}{|c|c|c|c|c|c|c|c|c|c|c|}
\hline & \multicolumn{9}{|c|}{ Deflection (m) } \\
\hline \multirow{9}{*}{ 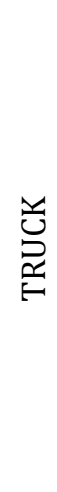 } & $\mathrm{D}$ & \multirow{2}{*}{0.25} & \multirow{2}{*}{0.5} & \multirow{2}{*}{0.75} & \multirow[b]{2}{*}{1} & \multirow{2}{*}{2} & \multirow[b]{2}{*}{$\Psi$} & \multirow{2}{*}{6} & \multirow{2}{*}{8} & \multirow{2}{*}{10} \\
\hline & SPAN & & & & & & & & & \\
\hline & 1 & $0.8645 \%$ & $3.3437 \%$ & $1.5093 \%$ & $0.0497 \%$ & $0.2016 \%$ & $1.6936 \%$ & $0.8568 \%$ & $0.5939 \%$ & $1.4878 \%$ \\
\hline & 1.5 & $4.1485 \%$ & $2.4211 \%$ & $1.6410 \%$ & $0.5594 \%$ & $2.3708 \%$ & $0.9283 \%$ & $0.3831 \%$ & $0.5922 \%$ & $0.6960 \%$ \\
\hline & 2 & $5.6508 \%$ & $4.9132 \%$ & $4.4415 \%$ & $4.0584 \%$ & $1.9677 \%$ & $0.4408 \%$ & $2.2557 \%$ & $3.6111 \%$ & $2.7543 \%$ \\
\hline & 2.5 & $4.9760 \%$ & $5.5859 \%$ & $5.4350 \%$ & $5.2771 \%$ & $4.3224 \%$ & $2.4969 \%$ & $1.1635 \%$ & $0.1384 \%$ & $0.8210 \%$ \\
\hline & 3 & $2.7501 \%$ & $4.6832 \%$ & $5.3695 \%$ & $5.5474 \%$ & $5.5620 \%$ & $4.9000 \%$ & $4.1597 \%$ & $3.5705 \%$ & $3.0201 \%$ \\
\hline & 3.5 & $0.0651 \%$ & $3.1337 \%$ & $4.3631 \%$ & $4.9587 \%$ & $5.6738 \%$ & $5.5023 \%$ & $5.1253 \%$ & $4.7331 \%$ & $4.3698 \%$ \\
\hline & 4 & $3.4024 \%$ & $1.0132 \%$ & $2.8372 \%$ & $3.7978 \%$ & $5.2667 \%$ & $5.6903 \%$ & $5.5806 \%$ & $5.3653 \%$ & $5.1535 \%$ \\
\hline
\end{tabular}

Table 268 Maximum deflection results comparison for alpha 6 for slabs subjected to CHBDC axle 4 loading (main bars parallel to traffic) Deflection (m) 


\begin{tabular}{|c|c|c|c|c|c|c|c|c|c|c|}
\hline \multirow{7}{*}{ 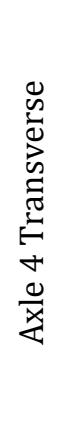 } & $\frac{\mathrm{D}}{\text { SPAN }}$ & 25 & 0.5 & 0.75 & 1 & $?$ & 4 & 6 & 8 & 10 \\
\hline & 1 & $1.1642 \%$ & $1.8698 \%$ & $1.0066 \%$ & $1.2572 \%$ & $2.0322 \%$ & $1.2807 \%$ & $1.4692 \%$ & $1.3188 \%$ & $1.6337 \%$ \\
\hline & 1.5 & $1.3073 \%$ & $1.5423 \%$ & $1.2733 \%$ & $1.4298 \%$ & $1.1044 \%$ & $1.0013 \%$ & $1.0788 \%$ & $0.9763 \%$ & $1.0181 \%$ \\
\hline & 2 & $1.4157 \%$ & $1.3110 \%$ & $1.2620 \%$ & $1.1634 \%$ & $1.1277 \%$ & $1.0882 \%$ & $0.9406 \%$ & $0.9027 \%$ & $0.9590 \%$ \\
\hline & 2.5 & $1.6515 \%$ & $1.4151 \%$ & $1.1808 \%$ & $1.1816 \%$ & $1.1156 \%$ & $1.0011 \%$ & $0.9668 \%$ & $0.9655 \%$ & $0.9868 \%$ \\
\hline & 3 & $2.5210 \%$ & $1.7014 \%$ & $1.4550 \%$ & $1.2849 \%$ & $1.1658 \%$ & $1.0158 \%$ & $1.0019 \%$ & $0.9956 \%$ & $0.9701 \%$ \\
\hline & 3.5 & $3.7790 \%$ & $2.3402 \%$ & $1.8369 \%$ & $1.6084 \%$ & $1.2594 \%$ & $1.1102 \%$ & $1.0349 \%$ & $1.0150 \%$ & $0.9966 \%$ \\
\hline
\end{tabular}

Table 269 Maximum deflection results comparison for alpha 6 for slabs subjected to CHBDC axle 2 \& 3 loading (main bars parallel to traffic)

\begin{tabular}{|c|c|c|c|c|c|c|c|c|c|c|}
\hline & & \multicolumn{9}{|c|}{ Deflection (m) } \\
\hline \multirow{7}{*}{ 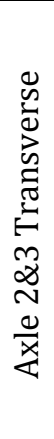 } & $\begin{array}{c}\mathrm{D} \\
\text { SPAN }\end{array}$ & 0.25 & 0.5 & 0.75 & 1 & 2 & 4 & 6 & 8 & 10 \\
\hline & 1.5 & $0.4980 \%$ & $0.7199 \%$ & $0.9493 \%$ & $0.2888 \%$ & $1.2297 \%$ & $0.9185 \%$ & $1.2944 \%$ & $0.7706 \%$ & $0.7834 \%$ \\
\hline & 2 & $0.2009 \%$ & $0.1825 \%$ & $0.2870 \%$ & $0.2725 \%$ & $0.4500 \%$ & $1.1858 \%$ & $1.1333 \%$ & $1.0997 \%$ & $1.0336 \%$ \\
\hline & 2.5 & $0.6653 \%$ & $0.3039 \%$ & $0.2265 \%$ & $0.1661 \%$ & $0.0907 \%$ & $0.4317 \%$ & $0.6760 \%$ & $0.9529 \%$ & $1.0222 \%$ \\
\hline & 3 & $1.5040 \%$ & $0.6255 \%$ & $0.3578 \%$ & $0.2424 \%$ & $0.0974 \%$ & $0.1315 \%$ & $0.2264 \%$ & $0.3938 \%$ & $0.5212 \%$ \\
\hline & 3.5 & $2.9206 \%$ & $1.3341 \%$ & $0.8190 \%$ & $0.5316 \%$ & $0.2063 \%$ & $0.0937 \%$ & $0.0944 \%$ & $0.1385 \%$ & $0.2290 \%$ \\
\hline & 4 & $4.9340 \%$ & $2.4403 \%$ & $1.5177 \%$ & $1.0697 \%$ & $0.4248 \%$ & $0.1608 \%$ & $0.0939 \%$ & $0.0821 \%$ & $0.1022 \%$ \\
\hline
\end{tabular}




\section{Alpha 8 Deflection Comparison Results}

Table 270 Maximum deflection results comparison for alpha 8 for slabs subjected to CHBDC axle 4 loading (main bars perpendicular to traffic)

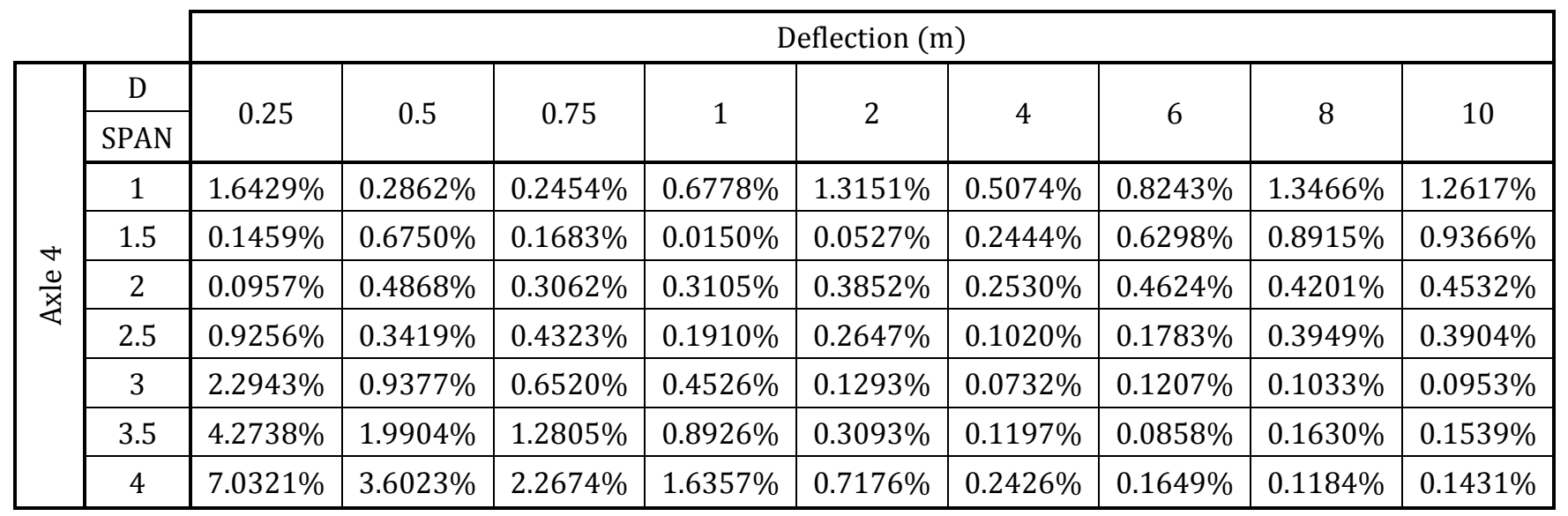

Table 271 Maximum deflection results comparison for alpha 8 for slabs subjected to CHBDC axle 2 \& 3 loading (main bars perpendicular to traffic)

\begin{tabular}{|c|c|c|c|c|c|c|c|c|c|c|}
\hline & \multicolumn{9}{|c|}{ Deflection (m) } \\
\hline \multirow{9}{*}{ 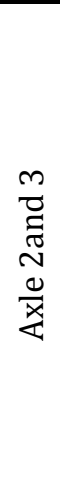 } & $\mathrm{D}$ & \multirow{2}{*}{0.25} & \multirow{2}{*}{0.5} & \multirow{2}{*}{0.75} & & & & \multirow{2}{*}{6} & \multirow[b]{2}{*}{0} & \multirow{2}{*}{10} \\
\hline & SPAN & & & & & & & & & \\
\hline & 1 & $0.1882 \%$ & $0.8442 \%$ & $0.1730 \%$ & $0.6484 \%$ & $2.0979 \%$ & $0.0045 \%$ & $0.0873 \%$ & $1.3885 \%$ & $1.6574 \%$ \\
\hline & 1.5 & $0.3761 \%$ & $0.3380 \%$ & $0.9483 \%$ & $0.7712 \%$ & $1.3287 \%$ & $0.7264 \%$ & $1.3295 \%$ & $0.7153 \%$ & $1.0832 \%$ \\
\hline & 2 & $0.3949 \%$ & $0.2736 \%$ & $0.2902 \%$ & $0.6398 \%$ & $0.9804 \%$ & $1.1201 \%$ & $0.9195 \%$ & $1.1041 \%$ & $0.8876 \%$ \\
\hline & 2.5 & $0.8579 \%$ & $0.3122 \%$ & $0.1603 \%$ & $0.0862 \%$ & $0.3898 \%$ & $0.8972 \%$ & $1.1367 \%$ & $1.2321 \%$ & $1.1201 \%$ \\
\hline & 3 & $2.4354 \%$ & $1.0731 \%$ & $0.4834 \%$ & $0.2601 \%$ & $0.1091 \%$ & $0.0303 \%$ & $0.0543 \%$ & $0.2898 \%$ & $0.3620 \%$ \\
\hline & 3.5 & $4.5076 \%$ & $2.1213 \%$ & $1.2585 \%$ & $0.8170 \%$ & $0.3548 \%$ & $0.0642 \%$ & $0.0225 \%$ & $0.0631 \%$ & $0.1030 \%$ \\
\hline & 4 & $7.2373 \%$ & $3.7464 \%$ & $2.4259 \%$ & $1.7136 \%$ & $0.6905 \%$ & $0.2117 \%$ & $0.1324 \%$ & $0.0759 \%$ & $0.0600 \%$ \\
\hline
\end{tabular}

Table 272 Maximum deflection results comparison for alpha 8 for slabs subjected to CHBDC truck loading (main bars perpendicular to traffic)

\begin{tabular}{|c|c|c|c|c|c|c|c|c|c|c|}
\hline & \multicolumn{9}{|c|}{ Deflection (m) } \\
\hline \multirow{9}{*}{ 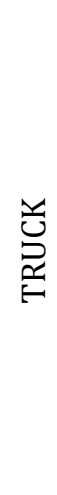 } & D & \multirow{2}{*}{0.25} & \multirow{2}{*}{0.5} & \multirow{2}{*}{0.75} & \multirow[b]{2}{*}{1} & \multirow{2}{*}{2} & \multirow[b]{2}{*}{4} & \multirow[b]{2}{*}{0} & \multirow{2}{*}{8} & \multirow{2}{*}{10} \\
\hline & SPAN & & & & & & & & & \\
\hline & 1 & $0.3604 \%$ & $1.2039 \%$ & $2.6386 \%$ & $3.9969 \%$ & $0.9004 \%$ & $0.3816 \%$ & $0.7671 \%$ & $1.3154 \%$ & $1.2429 \%$ \\
\hline & 1.5 & $4.9237 \%$ & $3.4083 \%$ & $2.1841 \%$ & $1.7479 \%$ & $0.9442 \%$ & $3.7828 \%$ & $1.9872 \%$ & $0.3090 \%$ & $0.5215 \%$ \\
\hline & 2 & $5.1372 \%$ & $5.2184 \%$ & $4.7733 \%$ & $4.5246 \%$ & $2.8788 \%$ & $0.8888 \%$ & $0.9339 \%$ & $2.1419 \%$ & $2.9754 \%$ \\
\hline & 2.5 & $3.4254 \%$ & $5.0194 \%$ & $5.3061 \%$ & $5.3764 \%$ & $4.8577 \%$ & $3.5157 \%$ & $2.3180 \%$ & $1.3697 \%$ & $0.5573 \%$ \\
\hline & 3 & $0.0799 \%$ & $3.1354 \%$ & $4.3523 \%$ & $4.8918 \%$ & $5.6095 \%$ & $5.3848 \%$ & $4.9360 \%$ & $4.4184 \%$ & $3.9023 \%$ \\
\hline & 3.5 & $3.9849 \%$ & $0.5152 \%$ & $2.4383 \%$ & $3.4923 \%$ & $5.0615 \%$ & $5.5659 \%$ & $5.5207 \%$ & $5.2849 \%$ & $5.0717 \%$ \\
\hline & 4 & $8.4390 \%$ & $2.5386 \%$ & $0.0590 \%$ & $1.5203 \%$ & $4.0633 \%$ & $5.3345 \%$ & $5.5947 \%$ & $5.5960 \%$ & $5.5235 \%$ \\
\hline
\end{tabular}

Table 273 Maximum deflection results comparison for alpha 8 for slabs subjected to CHBDC axle 4 loading (main bars parallel to traffic) Deflection (m) 


\begin{tabular}{|c|c|c|c|c|c|c|c|c|c|c|}
\hline \multirow{7}{*}{ 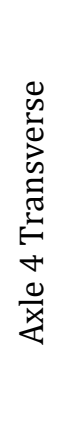 } & $\frac{\mathrm{D}}{\text { SPAN }}$ & .25 & 0.5 & 0.75 & & 2 & & & 8 & 10 \\
\hline & 1 & $2.2531 \%$ & $1.1435 \%$ & $1.6555 \%$ & $1.8501 \%$ & $1.2482 \%$ & $1.9931 \%$ & $1.1413 \%$ & $1.2007 \%$ & $1.7226 \%$ \\
\hline & 1.5 & $1.4528 \%$ & $1.0574 \%$ & $1.2108 \%$ & $1.2916 \%$ & $1.2003 \%$ & $0.9045 \%$ & $0.9322 \%$ & $1.2271 \%$ & $0.8832 \%$ \\
\hline & 2 & $1.3710 \%$ & $1.1731 \%$ & $1.1520 \%$ & $1.0343 \%$ & $1.1029 \%$ & $1.0622 \%$ & $0.9715 \%$ & $1.0330 \%$ & $0.8433 \%$ \\
\hline & 2.5 & $2.2206 \%$ & $1.5454 \%$ & $1.2991 \%$ & $1.0884 \%$ & $1.0797 \%$ & $0.9839 \%$ & $0.9547 \%$ & $0.8659 \%$ & $0.9226 \%$ \\
\hline & 3 & $3.5920 \%$ & $2.1919 \%$ & $1.7015 \%$ & $1.4866 \%$ & $1.0873 \%$ & $0.9955 \%$ & $0.9462 \%$ & $0.8897 \%$ & $0.8782 \%$ \\
\hline & 3.5 & $5.8762 \%$ & $3.4300 \%$ & $2.5319 \%$ & $2.0439 \%$ & $1.3539 \%$ & $1.0477 \%$ & $0.9689 \%$ & $0.9489 \%$ & $0.9124 \%$ \\
\hline
\end{tabular}

Table 274 Maximum deflection results comparison for alpha 8 for slabs subjected to CHBDC axle 2 \& 3 loading (main bars parallel to traffic)

\begin{tabular}{|c|c|c|c|c|c|c|c|c|c|c|}
\hline & & \multicolumn{9}{|c|}{ Deflection (m) } \\
\hline \multirow{7}{*}{ 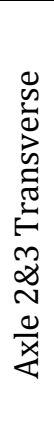 } & $\begin{array}{c}\mathrm{D} \\
\text { SPAN }\end{array}$ & 0.25 & 0.5 & 0.75 & 1 & 2 & 4 & 6 & 8 & 10 \\
\hline & 1.5 & $0.2468 \%$ & $0.3319 \%$ & $0.3910 \%$ & $0.7184 \%$ & $1.3415 \%$ & $0.7616 \%$ & $1.0692 \%$ & $1.4732 \%$ & $1.4749 \%$ \\
\hline & 2 & $0.4922 \%$ & $0.3156 \%$ & $0.1172 \%$ & $0.3685 \%$ & $0.5703 \%$ & $0.8880 \%$ & $0.9851 \%$ & $1.0814 \%$ & $0.9348 \%$ \\
\hline & 2.5 & $1.2442 \%$ & $0.5046 \%$ & $0.3041 \%$ & $0.1792 \%$ & $0.2509 \%$ & $0.4018 \%$ & $0.5557 \%$ & $0.7641 \%$ & $0.9924 \%$ \\
\hline & 3 & $2.8474 \%$ & $1.2635 \%$ & $0.7464 \%$ & $0.5461 \%$ & $0.1892 \%$ & $0.1842 \%$ & $0.2571 \%$ & $0.3856 \%$ & $0.4693 \%$ \\
\hline & 3.5 & $5.1131 \%$ & $2.5615 \%$ & $1.6256 \%$ & $1.1698 \%$ & $0.4575 \%$ & $0.2066 \%$ & $0.1513 \%$ & $0.2072 \%$ & $0.2532 \%$ \\
\hline & 4 & $8.1557 \%$ & $4.3919 \%$ & $2.8993 \%$ & $2.1125 \%$ & $0.9278 \%$ & $0.3754 \%$ & $0.2033 \%$ & $0.1531 \%$ & $0.1549 \%$ \\
\hline
\end{tabular}




\section{Alpha 10 Deflection Comparison Results}

Table 275 Maximum deflection results comparison for alpha 10 for slabs subjected to CHBDC axle 4 loading (main bars perpendicular to traffic)

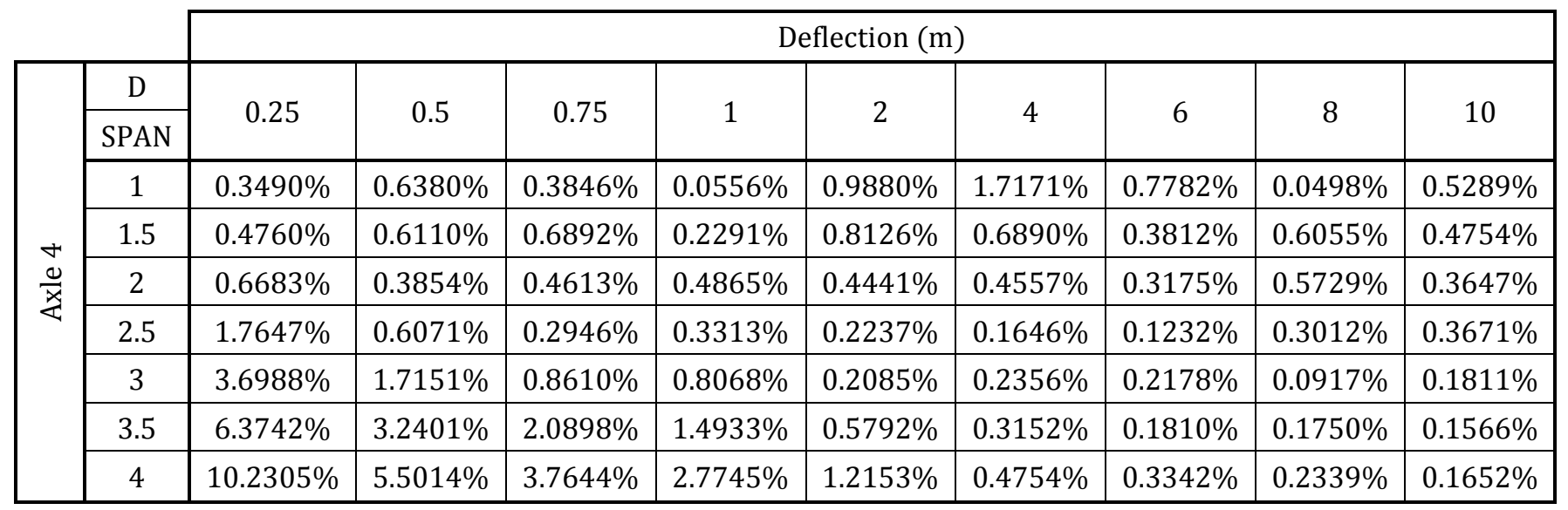

Table 276 Maximum deflection results comparison for alpha 10 for slabs subjected to CHBDC axle 2 \& 3 loading (main bars perpendicular to traffic)

\begin{tabular}{|c|c|c|c|c|c|c|c|c|c|c|}
\hline & \multicolumn{9}{|c|}{ Deflection (m) } \\
\hline \multirow{9}{*}{ 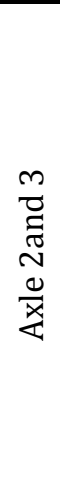 } & $\mathrm{D}$ & \multirow{2}{*}{0.25} & \multirow{2}{*}{0.5} & \multirow{2}{*}{0.75} & \multirow{2}{*}{1} & \multirow{2}{*}{2} & \multirow{2}{*}{4} & \multirow{2}{*}{6} & \multirow{2}{*}{8} & \multirow{2}{*}{10} \\
\hline & SPAN & & & & & & & & & \\
\hline & 1 & $0.0486 \%$ & $1.8143 \%$ & $1.0343 \%$ & $2.1224 \%$ & $1.3801 \%$ & $0.1458 \%$ & $0.1660 \%$ & $0.1321 \%$ & $0.4644 \%$ \\
\hline & 1.5 & $0.0076 \%$ & $0.1800 \%$ & $1.1934 \%$ & $1.3114 \%$ & $0.5878 \%$ & $0.6849 \%$ & $0.9034 \%$ & $1.2984 \%$ & $1.1397 \%$ \\
\hline & 2 & $0.3031 \%$ & $0.1080 \%$ & $0.4764 \%$ & $0.6202 \%$ & $1.1458 \%$ & $1.1321 \%$ & $0.9348 \%$ & $1.0400 \%$ & $1.0301 \%$ \\
\hline & 2.5 & $1.6726 \%$ & $0.5673 \%$ & $0.3062 \%$ & $0.3115 \%$ & $0.3104 \%$ & $0.7929 \%$ & $0.9776 \%$ & $0.9631 \%$ & $1.1024 \%$ \\
\hline & 3 & $3.8404 \%$ & $1.8447 \%$ & $1.0355 \%$ & $0.6737 \%$ & $0.1686 \%$ & $0.0742 \%$ & $0.0995 \%$ & $0.2732 \%$ & $0.3211 \%$ \\
\hline & 3.5 & $6.8080 \%$ & $3.4206 \%$ & $2.2643 \%$ & $1.5434 \%$ & $0.5727 \%$ & $0.2334 \%$ & $0.0921 \%$ & $0.1240 \%$ & $0.1410 \%$ \\
\hline & 4 & $10.5587 \%$ & $5.7886 \%$ & $3.8577 \%$ & $2.9169 \%$ & $1.2824 \%$ & $0.4507 \%$ & $0.2653 \%$ & $0.1554 \%$ & $0.1006 \%$ \\
\hline
\end{tabular}

Table 277 Maximum deflection results comparison for alpha 10 for slabs subjected to CHBDC truck loading (main bars perpendicular to traffic)

\begin{tabular}{|c|c|c|c|c|c|c|c|c|c|c|}
\hline & \multicolumn{9}{|c|}{ Deflection (m) } \\
\hline \multirow{9}{*}{ 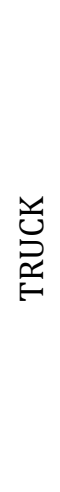 } & $\mathrm{D}$ & \multirow{2}{*}{0.25} & \multirow{2}{*}{0.5} & \multirow{2}{*}{0.75} & \multirow{2}{*}{1} & \multirow{2}{*}{2} & \multirow{2}{*}{4} & \multirow{2}{*}{6} & \multirow{2}{*}{8} & \multirow{2}{*}{10} \\
\hline & SPAN & & & & & & & & & \\
\hline & 1 & $1.8997 \%$ & $0.1907 \%$ & $1.8500 \%$ & $4.6723 \%$ & $2.8993 \%$ & $1.4391 \%$ & $0.6426 \%$ & $0.0281 \%$ & $0.4791 \%$ \\
\hline & 1.5 & $5.4609 \%$ & $4.4439 \%$ & $2.8308 \%$ & $2.1677 \%$ & $0.1259 \%$ & $2.5029 \%$ & $4.4251 \%$ & $2.5904 \%$ & $1.1359 \%$ \\
\hline & 2 & $4.2207 \%$ & $4.9756 \%$ & $5.2249 \%$ & $4.7476 \%$ & $3.8394 \%$ & $1.6543 \%$ & $0.2627 \%$ & $0.7889 \%$ & $1.7604 \%$ \\
\hline & 2.5 & $1.9430 \%$ & $4.2372 \%$ & $4.8827 \%$ & $5.0527 \%$ & $5.0558 \%$ & $4.0629 \%$ & $3.1531 \%$ & $2.3632 \%$ & $1.5565 \%$ \\
\hline & 3 & $2.9900 \%$ & $1.1387 \%$ & $2.9255 \%$ & $3.8268 \%$ & $5.1976 \%$ & $5.3939 \%$ & $5.2177 \%$ & $4.9064 \%$ & $4.5172 \%$ \\
\hline & 3.5 & $7.8947 \%$ & $2.1532 \%$ & $0.2655 \%$ & $1.7383 \%$ & $4.0955 \%$ & $5.2743 \%$ & $5.5041 \%$ & $5.4416 \%$ & $5.3027 \%$ \\
\hline & 4 & $13.2053 \%$ & $6.0842 \%$ & $2.8671 \%$ & $0.9030 \%$ & $2.5524 \%$ & $4.5479 \%$ & $5.1719 \%$ & $5.4158 \%$ & $5.4750 \%$ \\
\hline
\end{tabular}

Table 278 Maximum deflection results comparison for alpha 10 for slabs subjected to CHBDC axle 4 loading (main bars parallel to traffic) Deflection (m) 


\begin{tabular}{|c|c|c|c|c|c|c|c|c|c|c|}
\hline \multirow{7}{*}{ 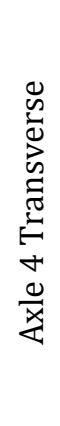 } & $\frac{\mathrm{D}}{\text { SPAN }}$ & .25 & 0.5 & 0.75 & & 2 & 4 & & 8 & 10 \\
\hline & 1 & $2.2350 \%$ & $0.9189 \%$ & $1.3687 \%$ & $1.5198 \%$ & $2.2483 \%$ & $1.6566 \%$ & $0.8786 \%$ & $1.0487 \%$ & $1.6936 \%$ \\
\hline & 1.5 & $1.0507 \%$ & $1.2755 \%$ & $1.3907 \%$ & $1.4259 \%$ & $1.1773 \%$ & $1.1654 \%$ & $1.1076 \%$ & $0.9480 \%$ & $0.9923 \%$ \\
\hline & 2 & $1.5277 \%$ & $1.2663 \%$ & $1.0516 \%$ & $0.9617 \%$ & $1.0291 \%$ & $0.8889 \%$ & $0.9193 \%$ & $0.9180 \%$ & $0.8644 \%$ \\
\hline & 2.5 & $3.0001 \%$ & $1.7889 \%$ & $1.3891 \%$ & $1.2685 \%$ & $0.9833 \%$ & $0.9120 \%$ & $0.8474 \%$ & $0.8257 \%$ & $0.8439 \%$ \\
\hline & 3 & $5.0717 \%$ & $2.8874 \%$ & $2.1922 \%$ & $1.7205 \%$ & $1.2212 \%$ & $0.9516 \%$ & $0.9332 \%$ & $0.8709 \%$ & $0.8443 \%$ \\
\hline & 3.5 & $8.1596 \%$ & $4.7339 \%$ & $3.4670 \%$ & $2.7164 \%$ & $1.6059 \%$ & $1.1020 \%$ & $0.9634 \%$ & $0.9373 \%$ & $0.8696 \%$ \\
\hline
\end{tabular}

Table 279 Maximum deflection results comparison for alpha 10 for slabs subjected to CHBDC axle 2 \& 3 loading (main bars parallel to traffic)

\begin{tabular}{|c|c|c|c|c|c|c|c|c|c|c|}
\hline & & \multicolumn{9}{|c|}{ Deflection (m) } \\
\hline \multirow{8}{*}{ 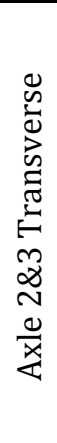 } & $\mathrm{D}$ & \multirow{2}{*}{0.25} & \multirow{2}{*}{0.5} & \multirow{2}{*}{0.75} & \multirow[t]{2}{*}{1} & \multirow[t]{2}{*}{2} & \multirow{2}{*}{4} & \multirow[t]{2}{*}{6} & \multirow{2}{*}{8} & \multirow{2}{*}{10} \\
\hline & SPAN & & & & & & & & & \\
\hline & 1.5 & $1.0236 \%$ & $1.0107 \%$ & $0.9359 \%$ & $1.1542 \%$ & $1.5668 \%$ & $0.7415 \%$ & $0.9572 \%$ & $1.3212 \%$ & $1.2935 \%$ \\
\hline & 2 & $0.7130 \%$ & $0.4203 \%$ & $0.2785 \%$ & $0.2318 \%$ & $0.3613 \%$ & $0.7154 \%$ & $1.0220 \%$ & $1.0383 \%$ & $1.0635 \%$ \\
\hline & 2.5 & $2.0827 \%$ & $1.0181 \%$ & $0.5110 \%$ & $0.3322 \%$ & $0.2570 \%$ & $0.3656 \%$ & $0.5334 \%$ & $0.7505 \%$ & $0.8954 \%$ \\
\hline & 3 & $4.4110 \%$ & $2.1946 \%$ & $1.3421 \%$ & $0.9406 \%$ & $0.3697 \%$ & $0.2731 \%$ & $0.2745 \%$ & $0.3682 \%$ & $0.4652 \%$ \\
\hline & 3.5 & $7.5858 \%$ & $4.0827 \%$ & $2.7017 \%$ & $1.9514 \%$ & $0.8592 \%$ & $0.3439 \%$ & $0.2391 \%$ & $0.2387 \%$ & $0.2839 \%$ \\
\hline & 4 & $11.6070 \%$ & $6.6171 \%$ & $4.5390 \%$ & $3.4217 \%$ & $1.5869 \%$ & $0.6815 \%$ & $0.3825 \%$ & $0.2919 \%$ & $0.2499 \%$ \\
\hline
\end{tabular}




\section{D.2.2 MAXIMUM DEFLECTION VS SPAN LENGTH}




\section{Alpha 0.25 Deflection VS Span Length for Different D Values (Main bars perpendicular to traffic)}

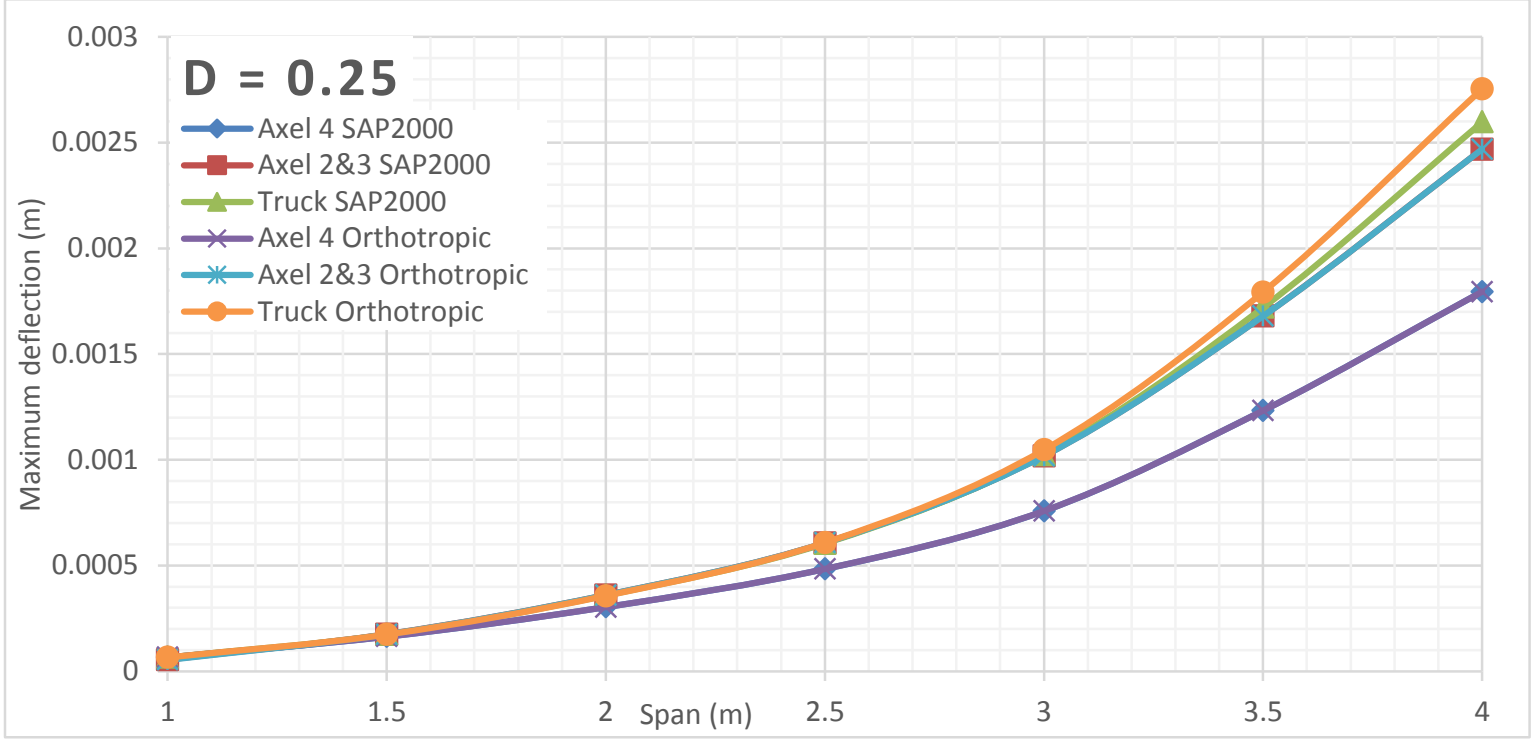

Figure 781 Deflection comparison between FEA and Orthotropic Plate Theory for D $=0.25$ of alpha 0.25 (main bars perpendicular to traffic)

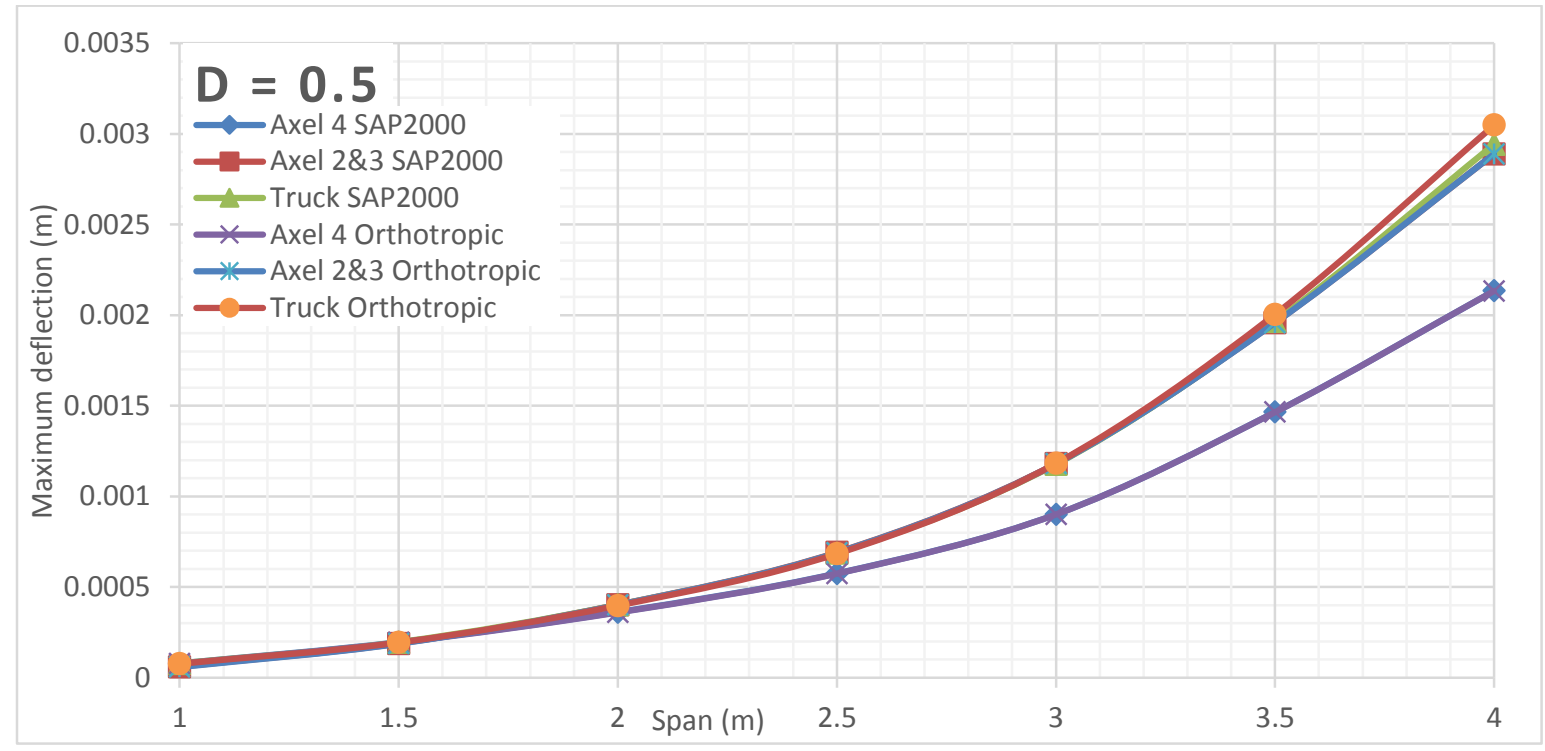

Figure 782 Deflection comparison between FEA and Orthotropic Plate Theory for $D=0.5$ of alpha 0.25 (main bars perpendicular to traffic) 


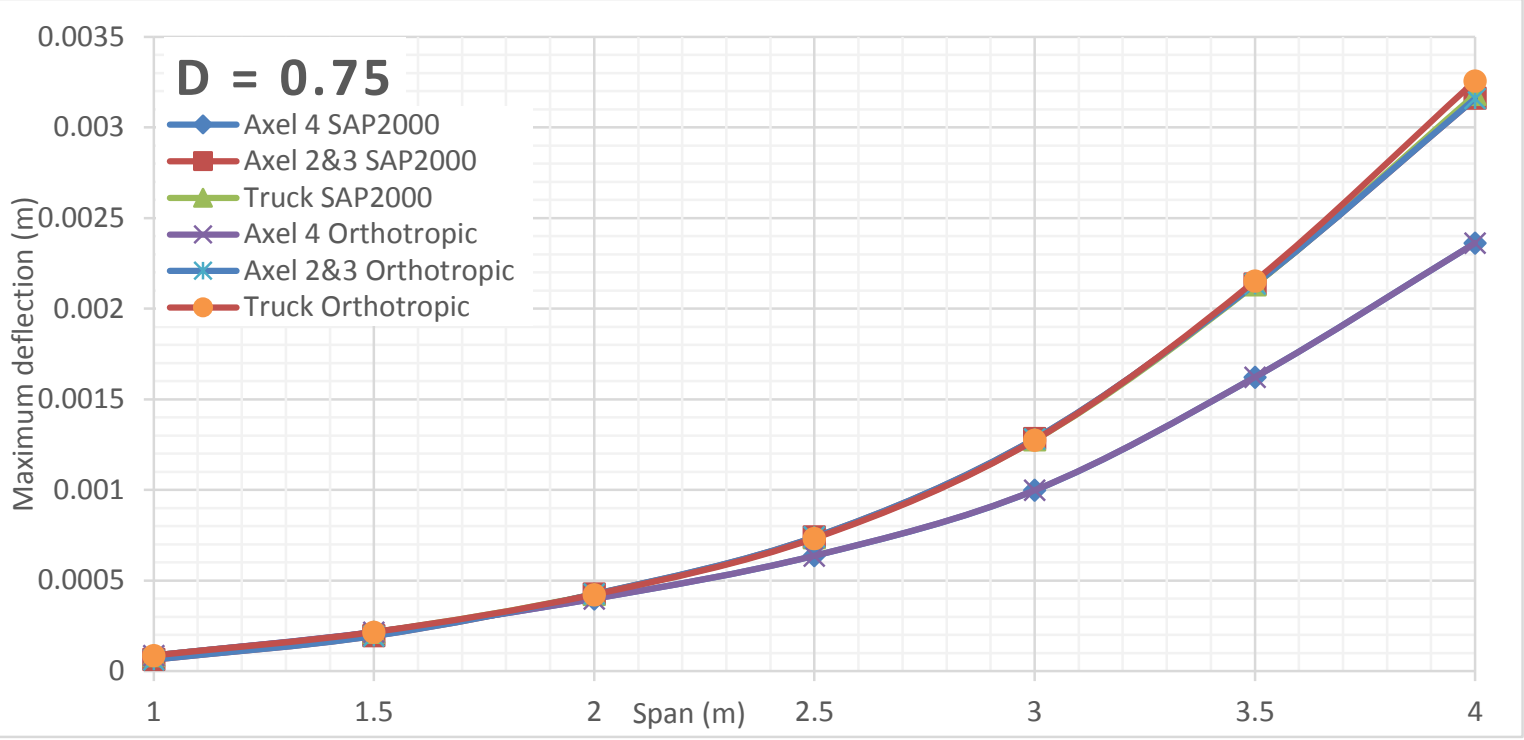

Figure 783 Deflection comparison between FEA and Orthotropic Plate Theory for D $=0.75$ of alpha 0.25 (main bars perpendicular to traffic)

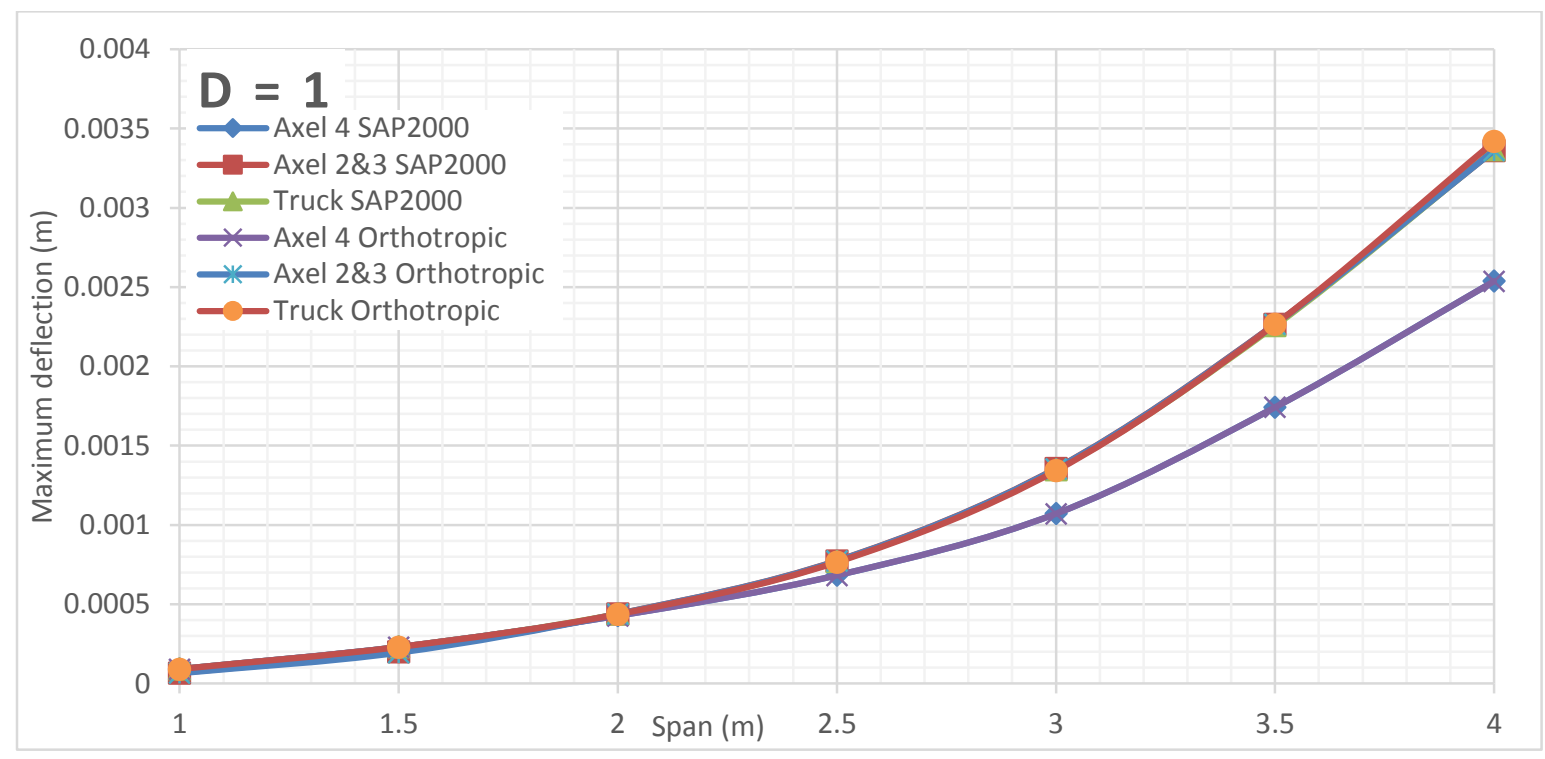

Figure 784 Deflection comparison between FEA and Orthotropic Plate Theory for $D=1$ of alpha 0.25 (main bars perpendicular to traffic)

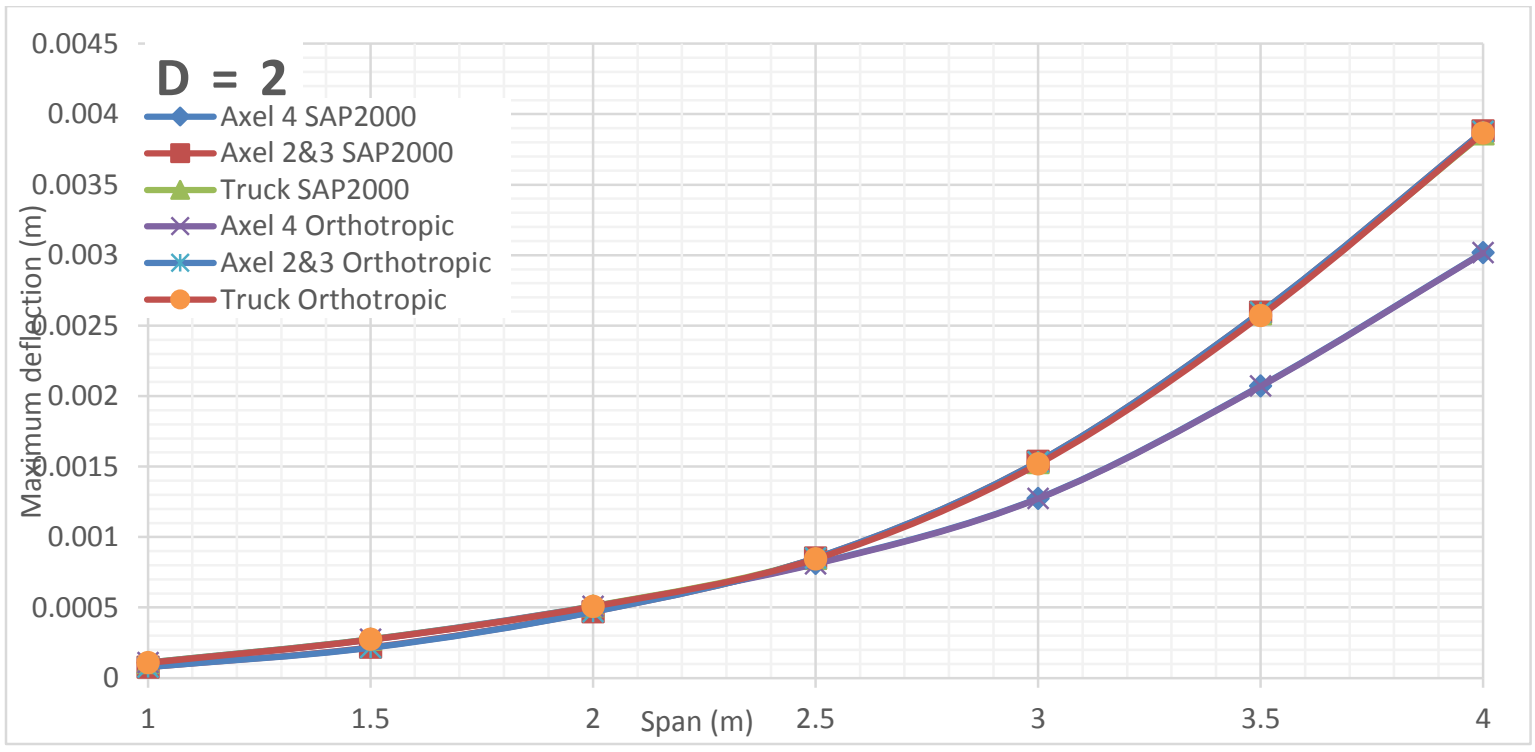

Figure 785 Deflection comparison between FEA and Orthotropic Plate Theory for $D=2$ of alpha 0.25 (main bars perpendicular to traffic) 


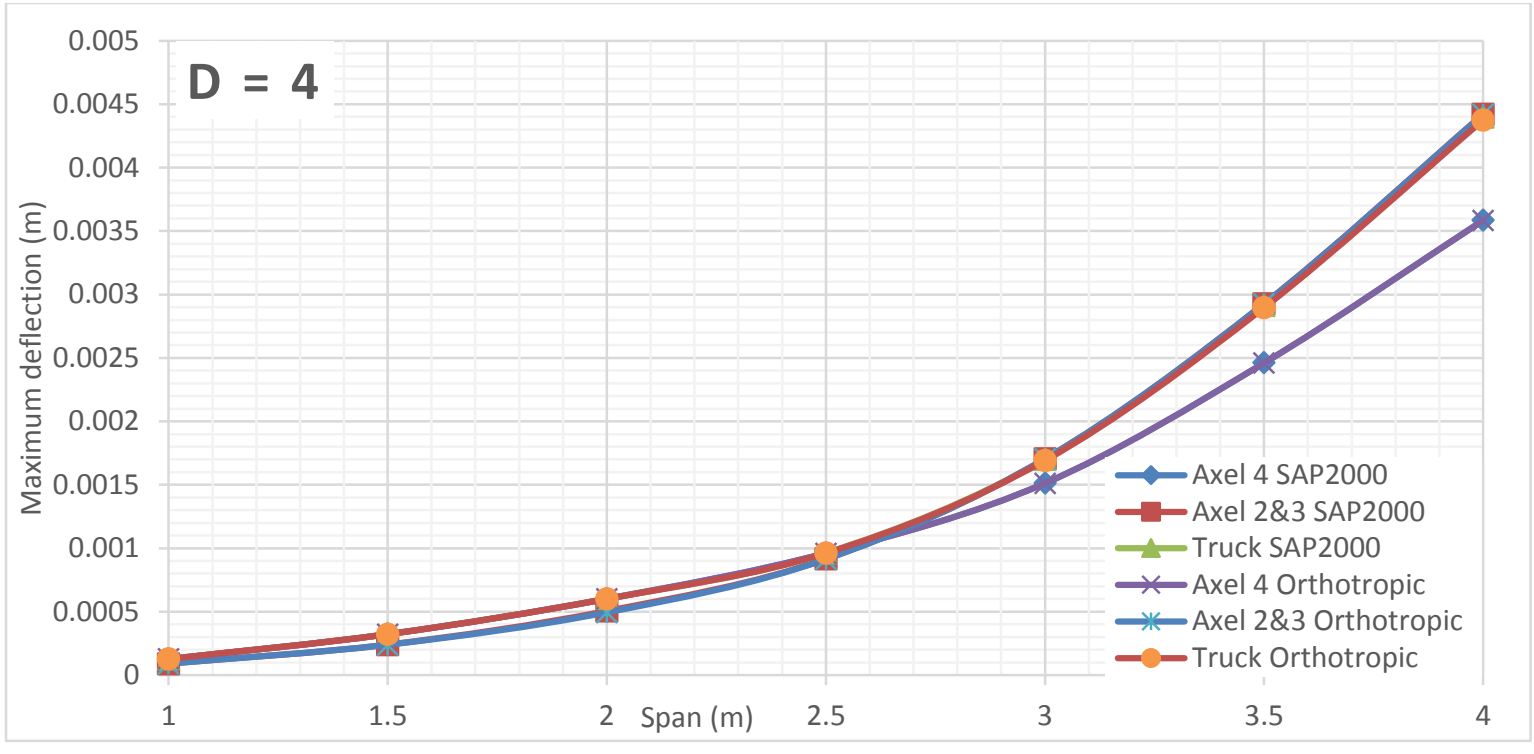

Figure 786 Deflection comparison between FEA and Orthotropic Plate Theory for $D=4$ of alpha 0.25 (main bars perpendicular to traffic)

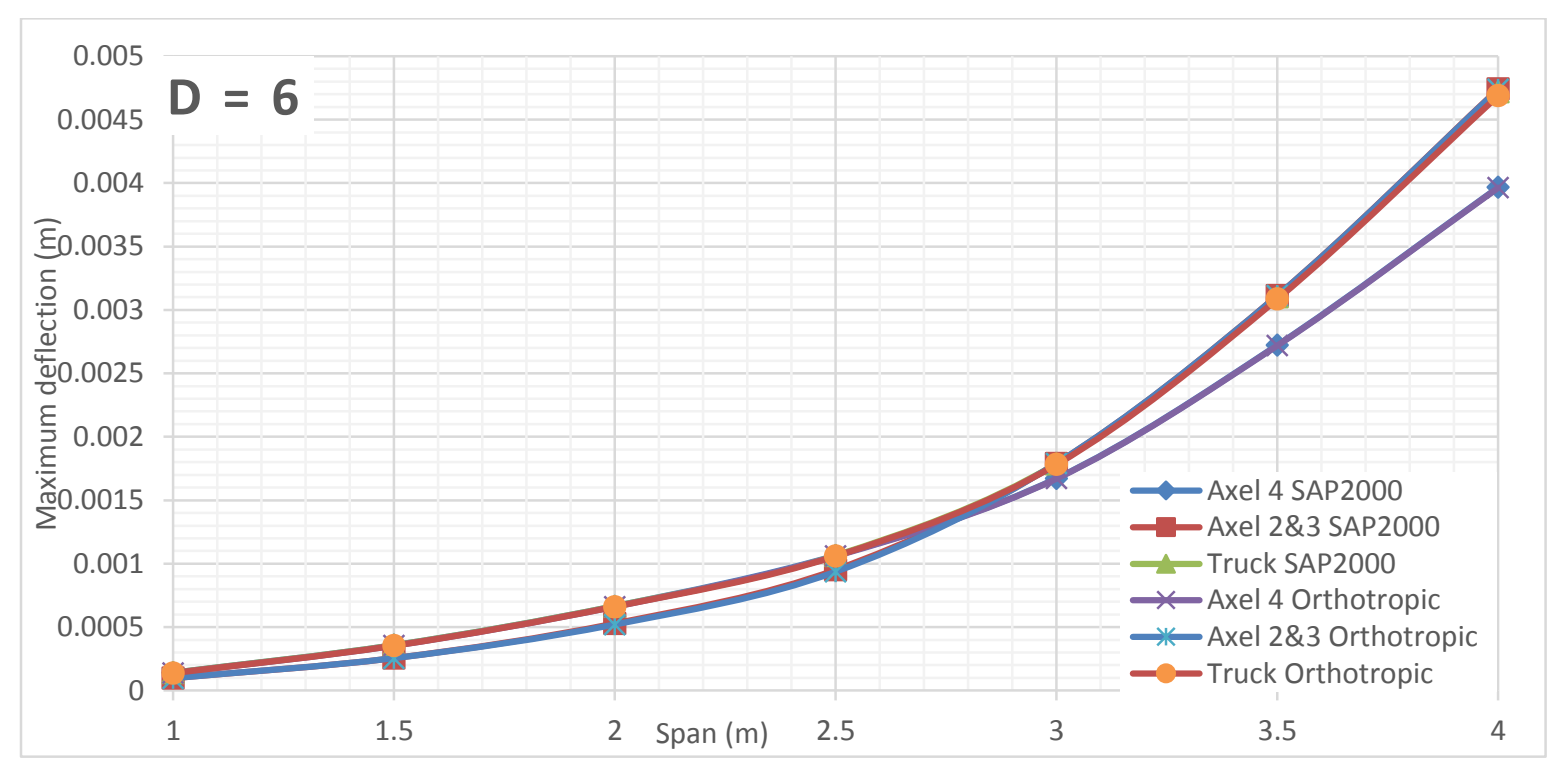

Figure 787 Deflection comparison between FEA and Orthotropic Plate Theory for $D=6$ of alpha 0.25 (main bars perpendicular to traffic)

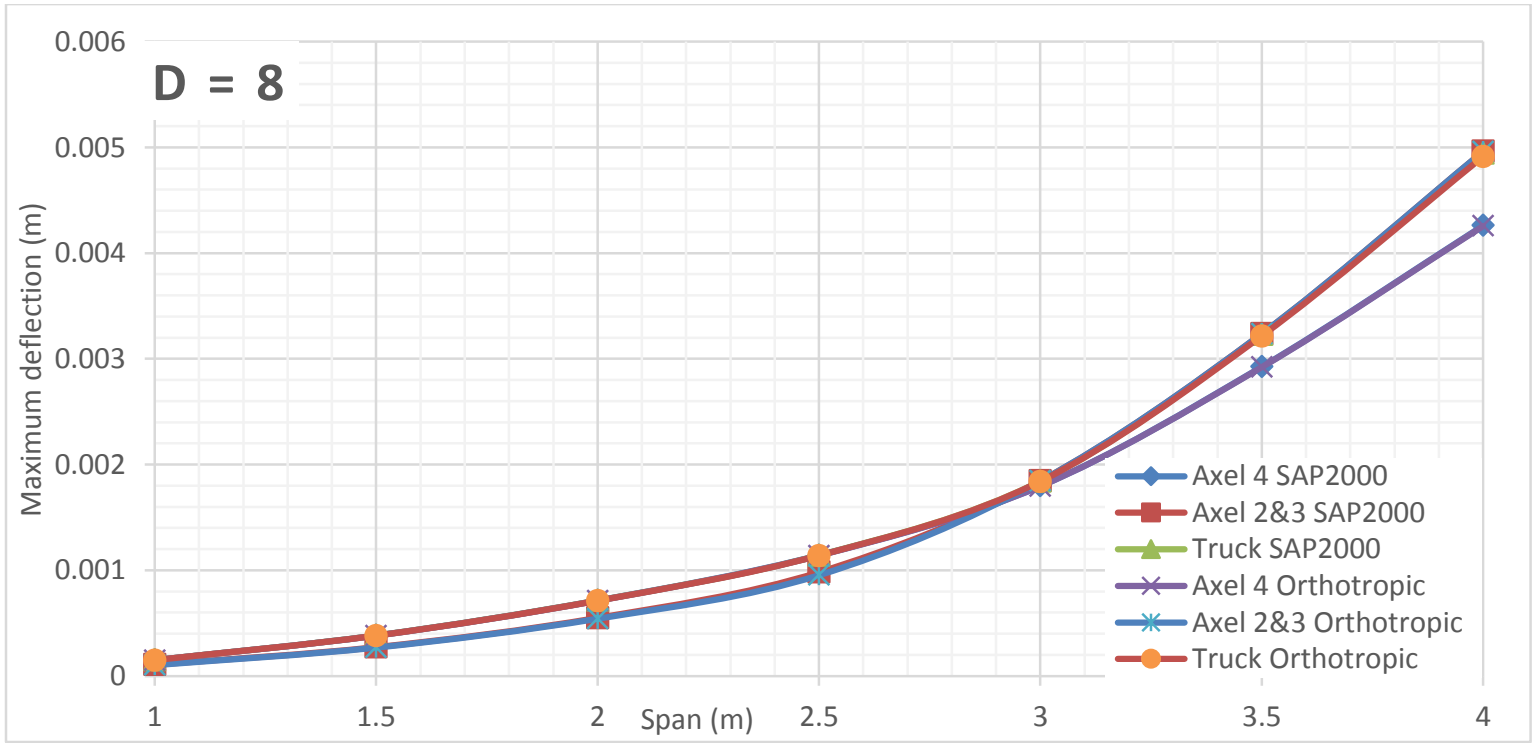

Figure 788 Deflection comparison between FEA and Orthotropic Plate Theory for $D=8$ of alpha 0.25 (main bars perpendicular to traffic) 


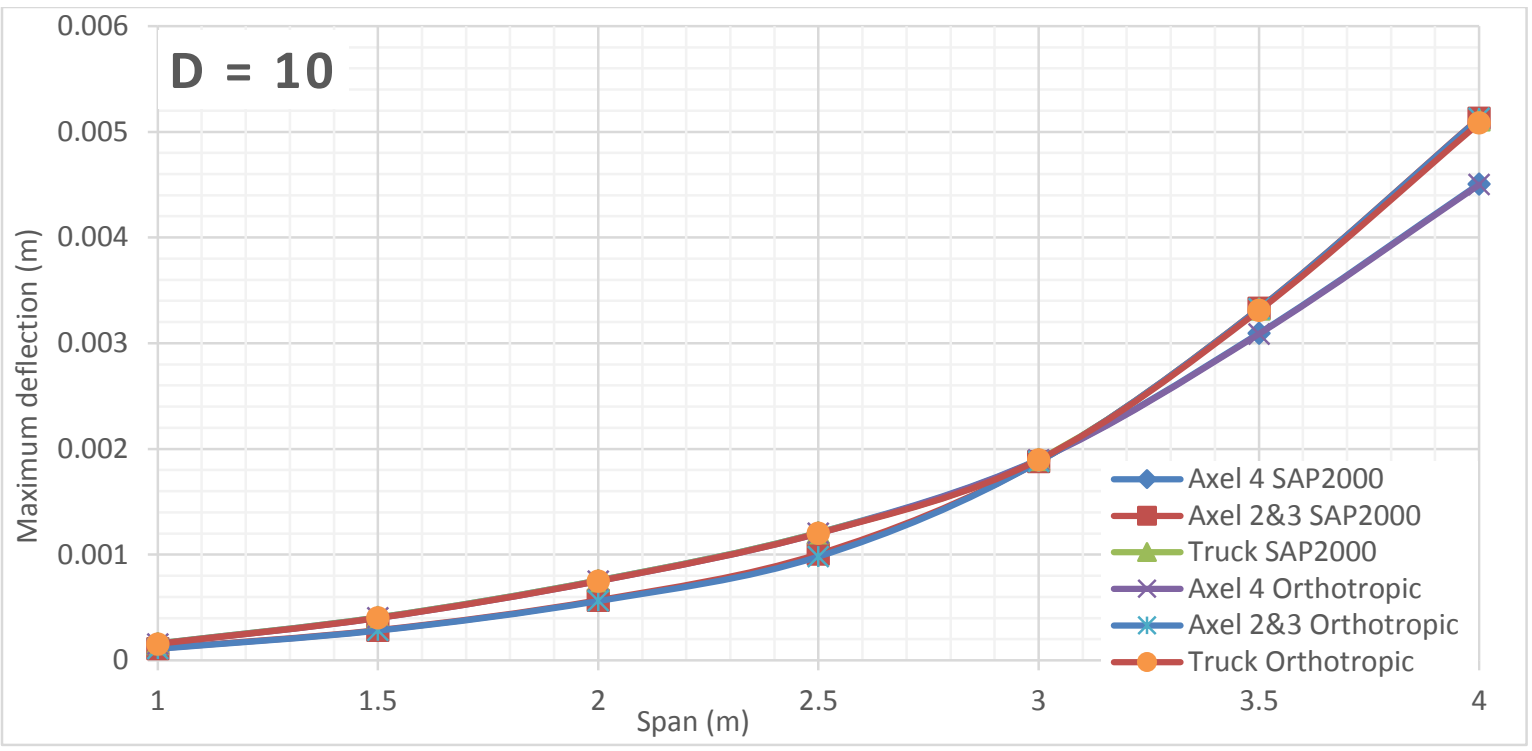

Figure 789 Deflection comparison between FEA and Orthotropic Plate Theory for $D=10$ of alpha 0.25 (main bars perpendicular to traffic) 


\section{Alpha 0.25 Deflection VS Span Length for Different D Values (Main bars parallel to traffic)}

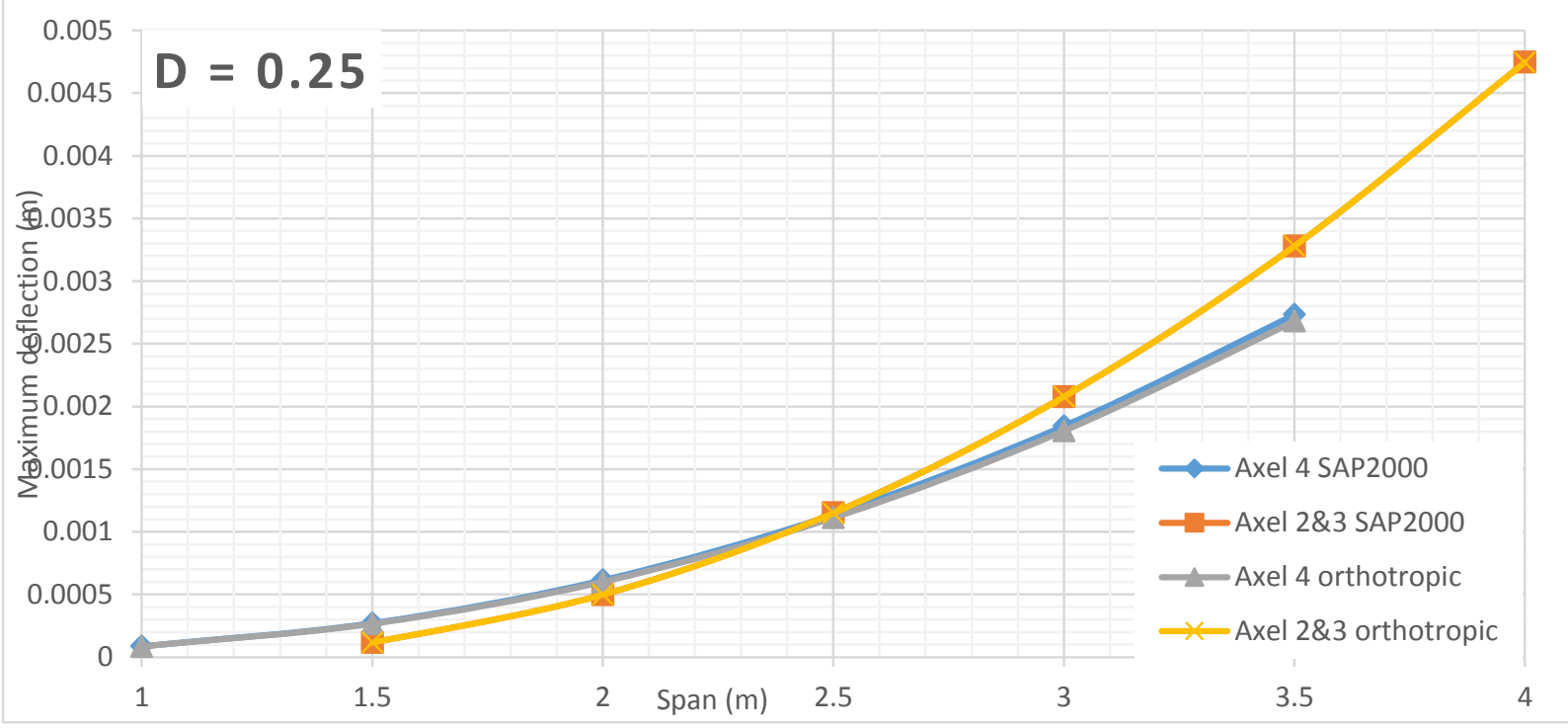

Figure 790 Deflection comparison between FEA and Orthotropic Plate Theory for $D=0.25$ of alpha 0.25 (main bars parallel to traffic)

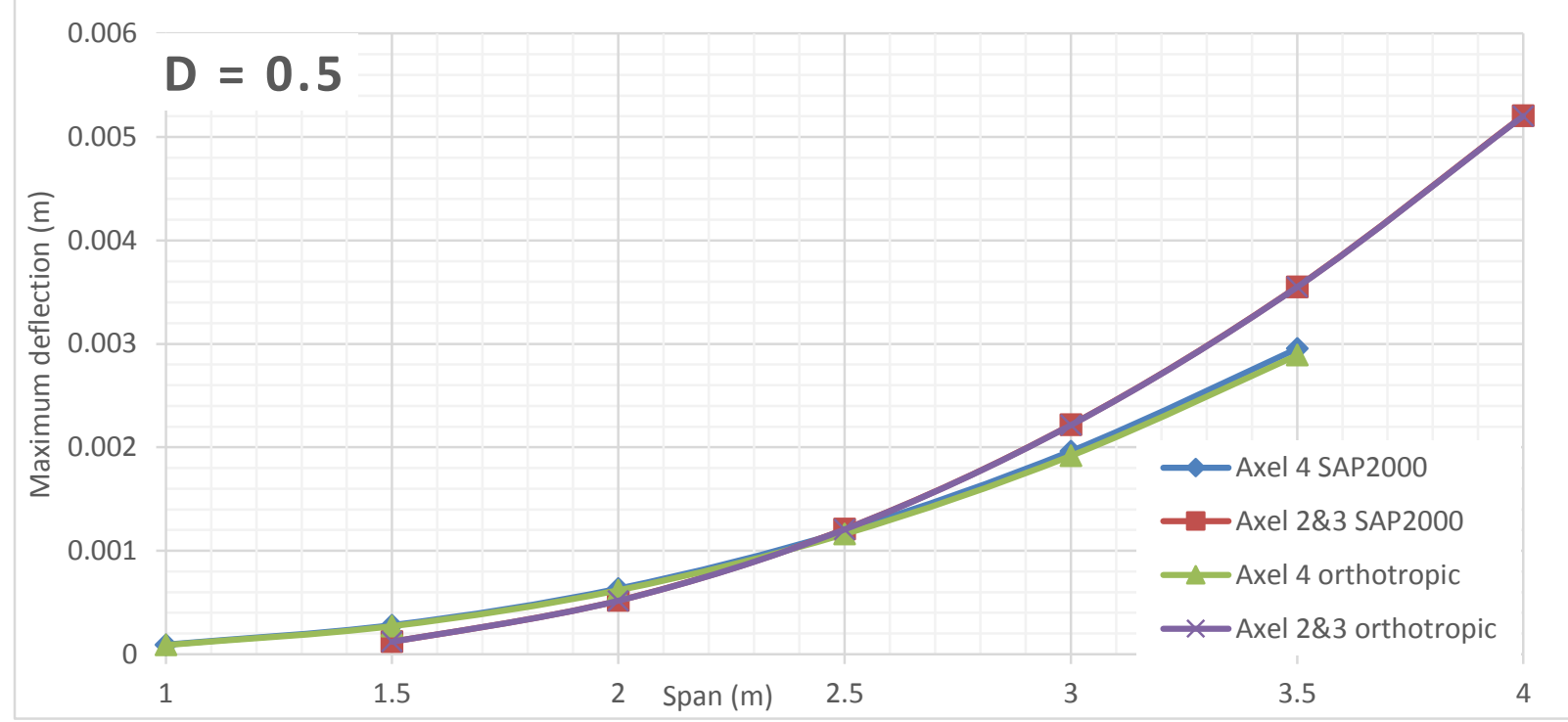

Figure 791 Deflection comparison between FEA and Orthotropic Plate Theory for $\mathrm{D}=0.5$ of alpha 0.25 (main bars parallel to traffic) 


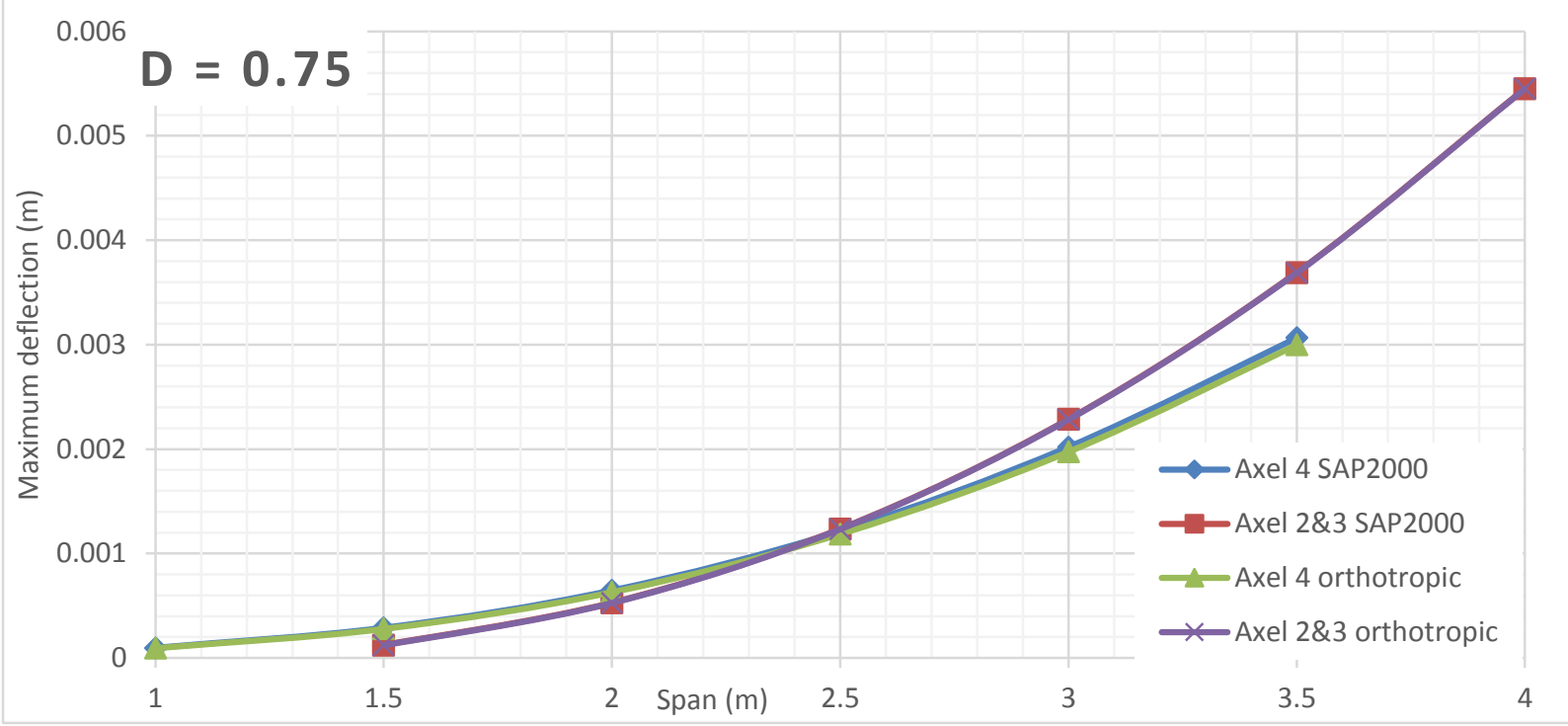

Figure 792 Deflection comparison between FEA and Orthotropic Plate Theory for $D=0.75$ of alpha 0.25 (main bars parallel to traffic)

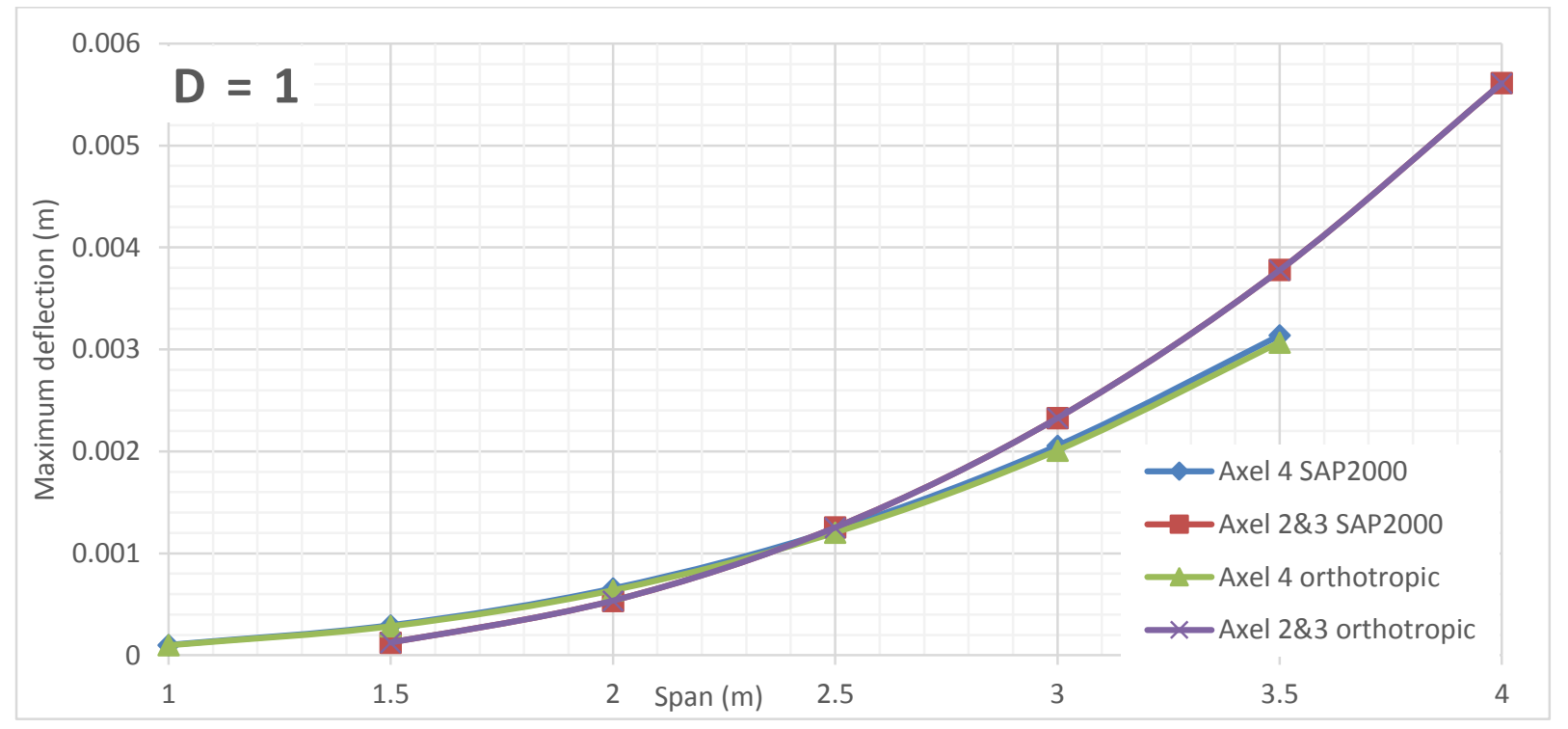

Figure 793 Deflection comparison between FEA and Orthotropic Plate Theory for $\mathrm{D}=1$ of alpha 0.25 (main bars parallel to traffic)

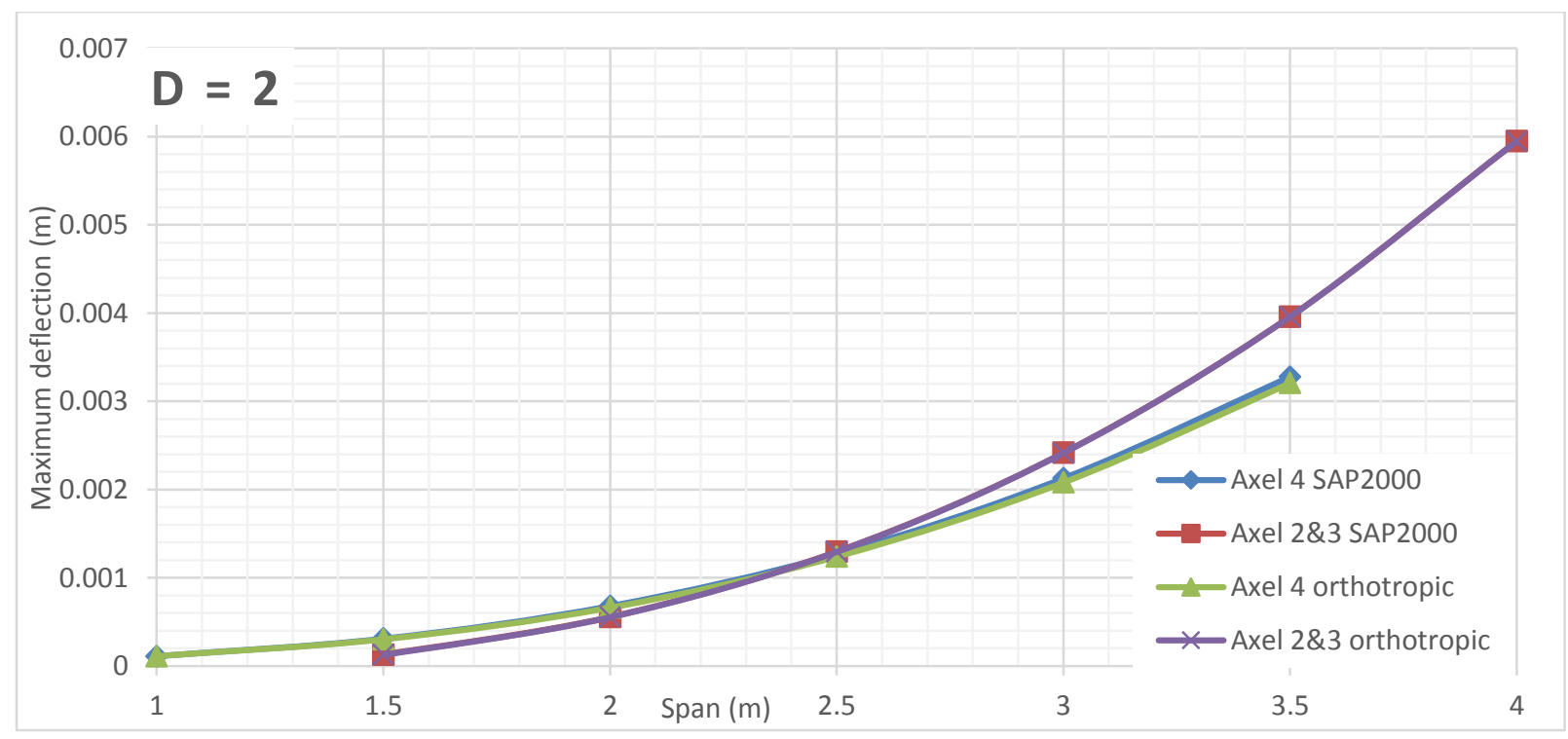

Figure 794 Deflection comparison between FEA and Orthotropic Plate Theory for $\mathrm{D}=2$ of alpha 0.25 (main bars parallel to traffic) 


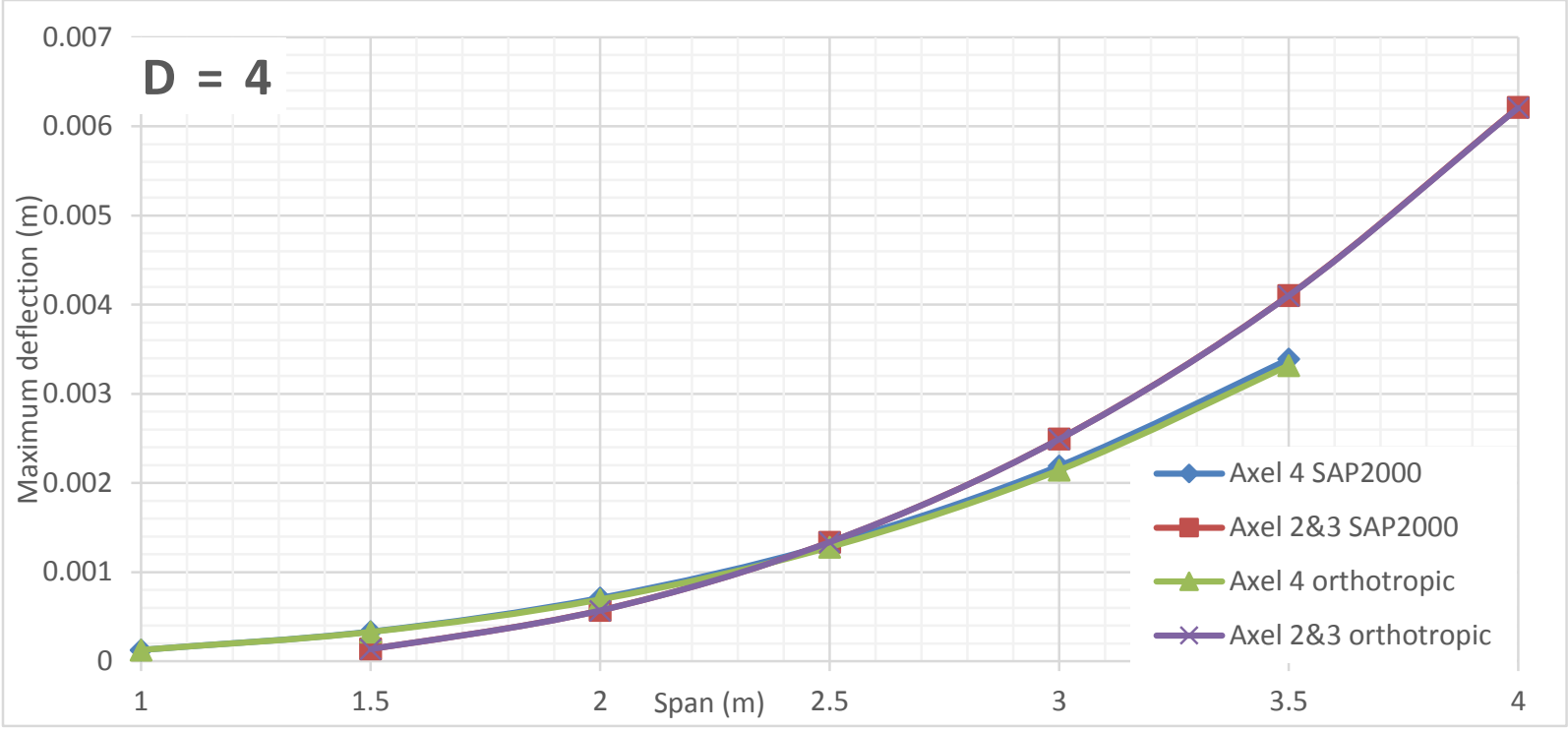

Figure 795 Deflection comparison between FEA and Orthotropic Plate Theory for $D=4$ of alpha 0.25 (main bars parallel to traffic)

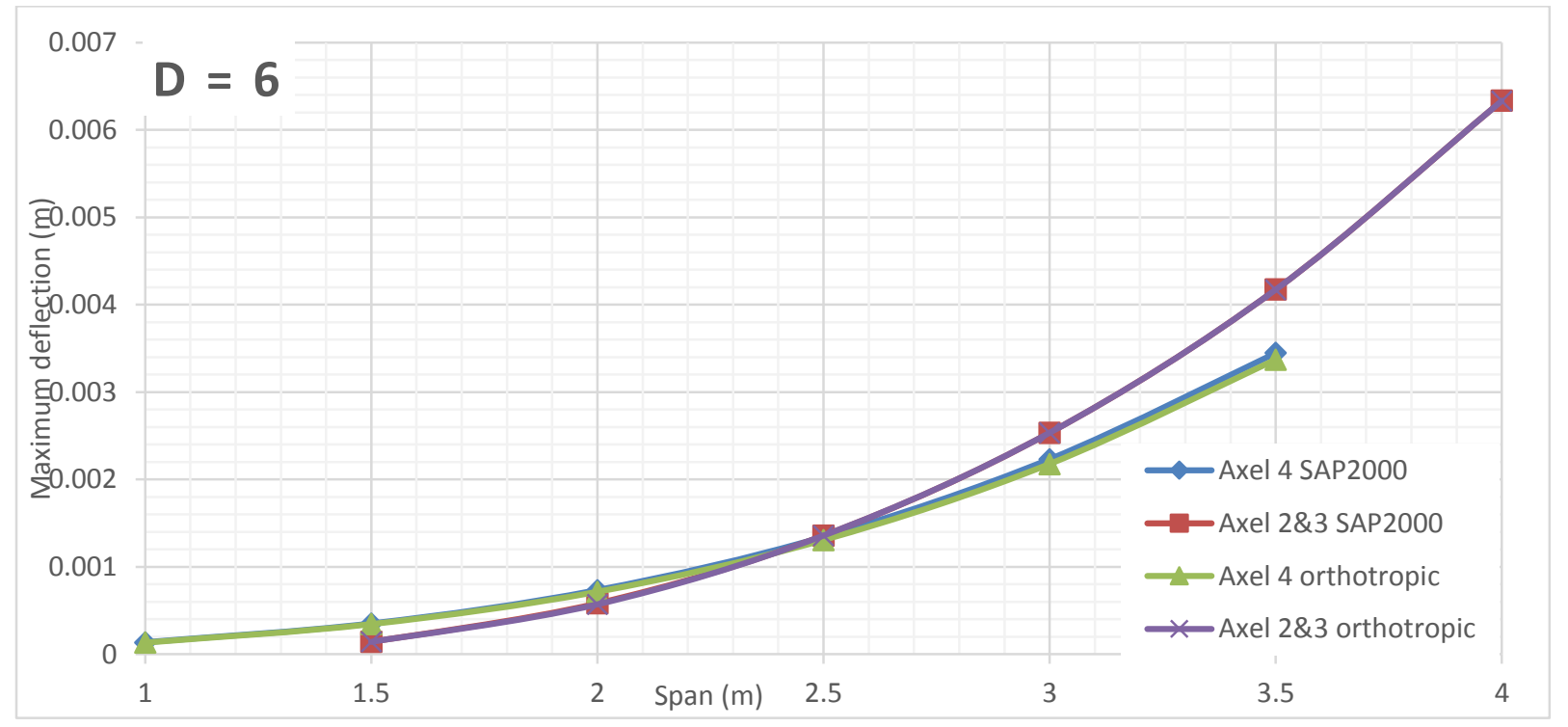

Figure 796 Deflection comparison between FEA and Orthotropic Plate Theory for $D=6$ of alpha 0.25 (main bars parallel to traffic)

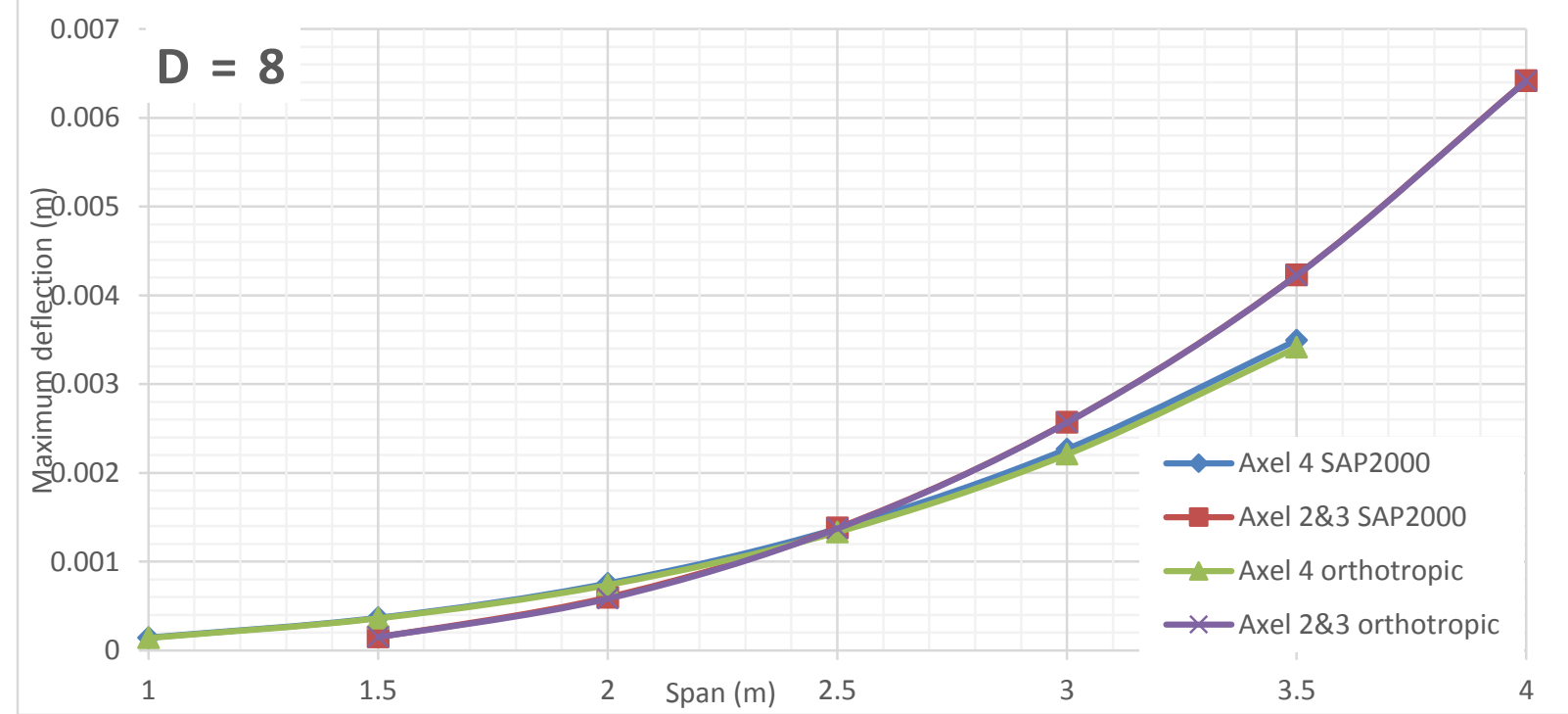

Figure 797 Deflection comparison between FEA and Orthotropic Plate Theory for $\mathrm{D}=8$ of alpha 0.25 (main bars parallel to traffic) 


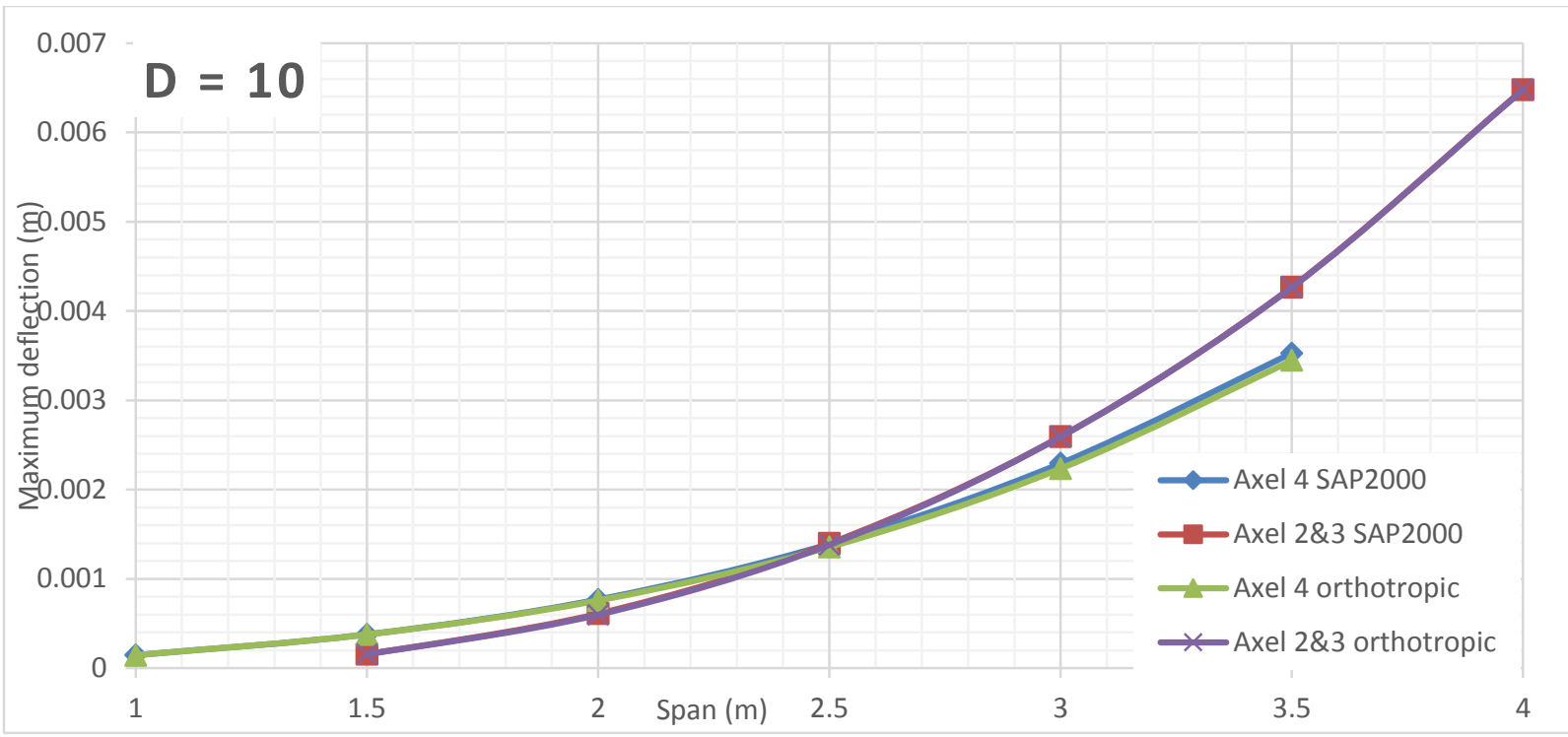

Figure 798 Deflection comparison between FEA and Orthotropic Plate Theory for $D=10$ of alpha 0.25 (main bars parallel to traffic) 


\section{Alpha 0.5 Deflection VS Span Length for Different D Values (Main bars perpendicular to traffic)}

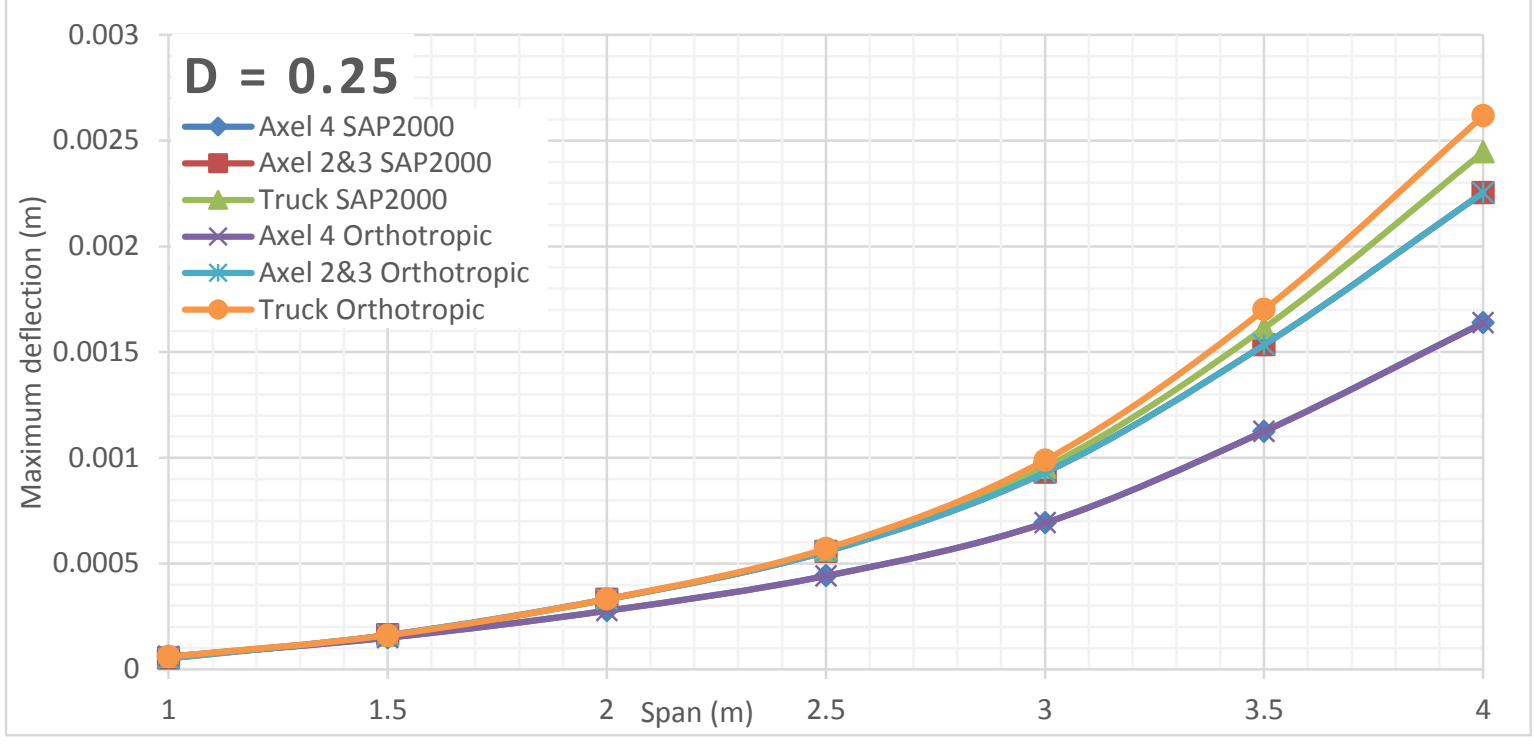

Figure 799 Deflection comparison between FEA and Orthotropic Plate Theory for $D=0.25$ of alpha 0.5 (main bars perpendicular to traffic)

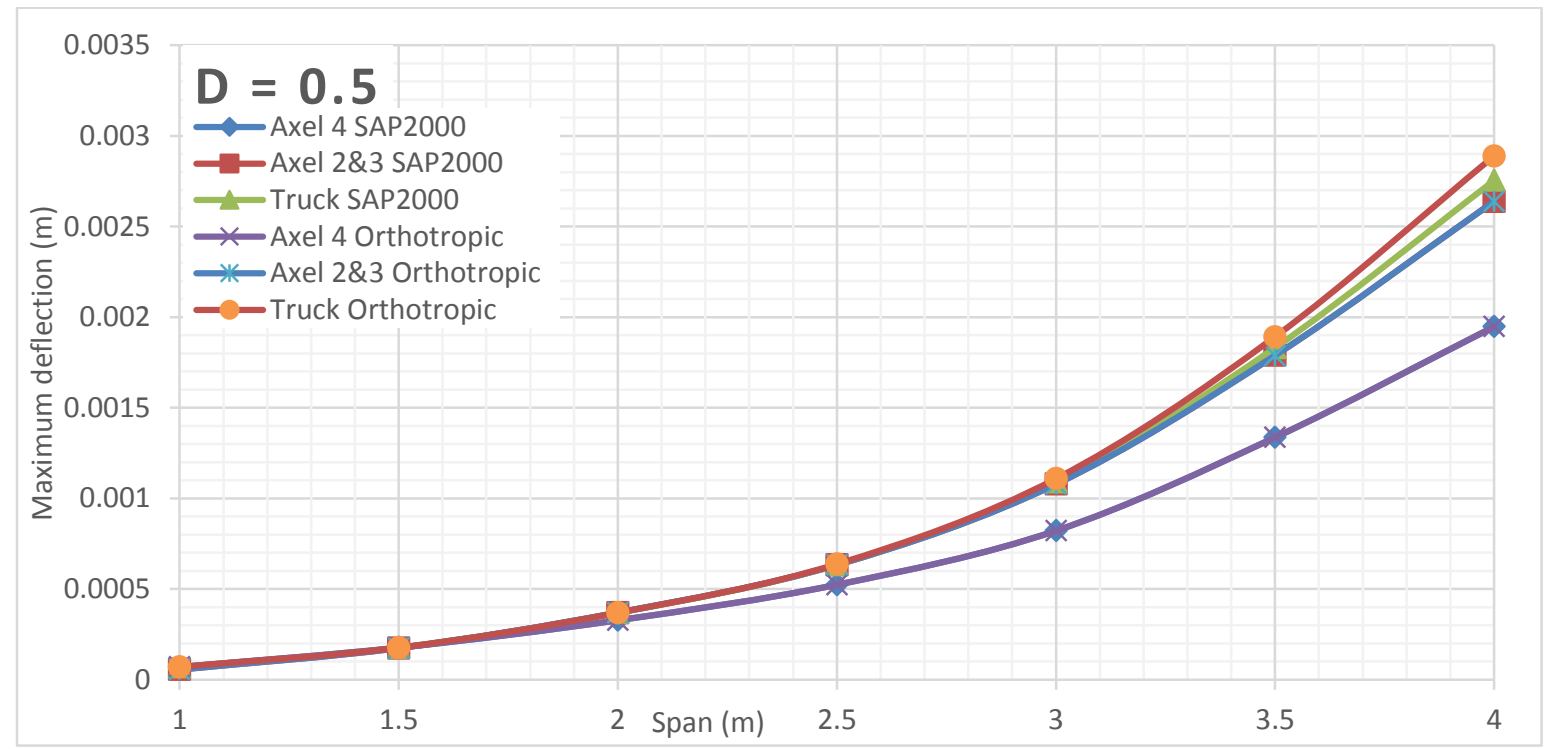

Figure 800 Deflection comparison between FEA and Orthotropic Plate Theory for $D=0.5$ of alpha 0.5 (main bars perpendicular to traffic) 


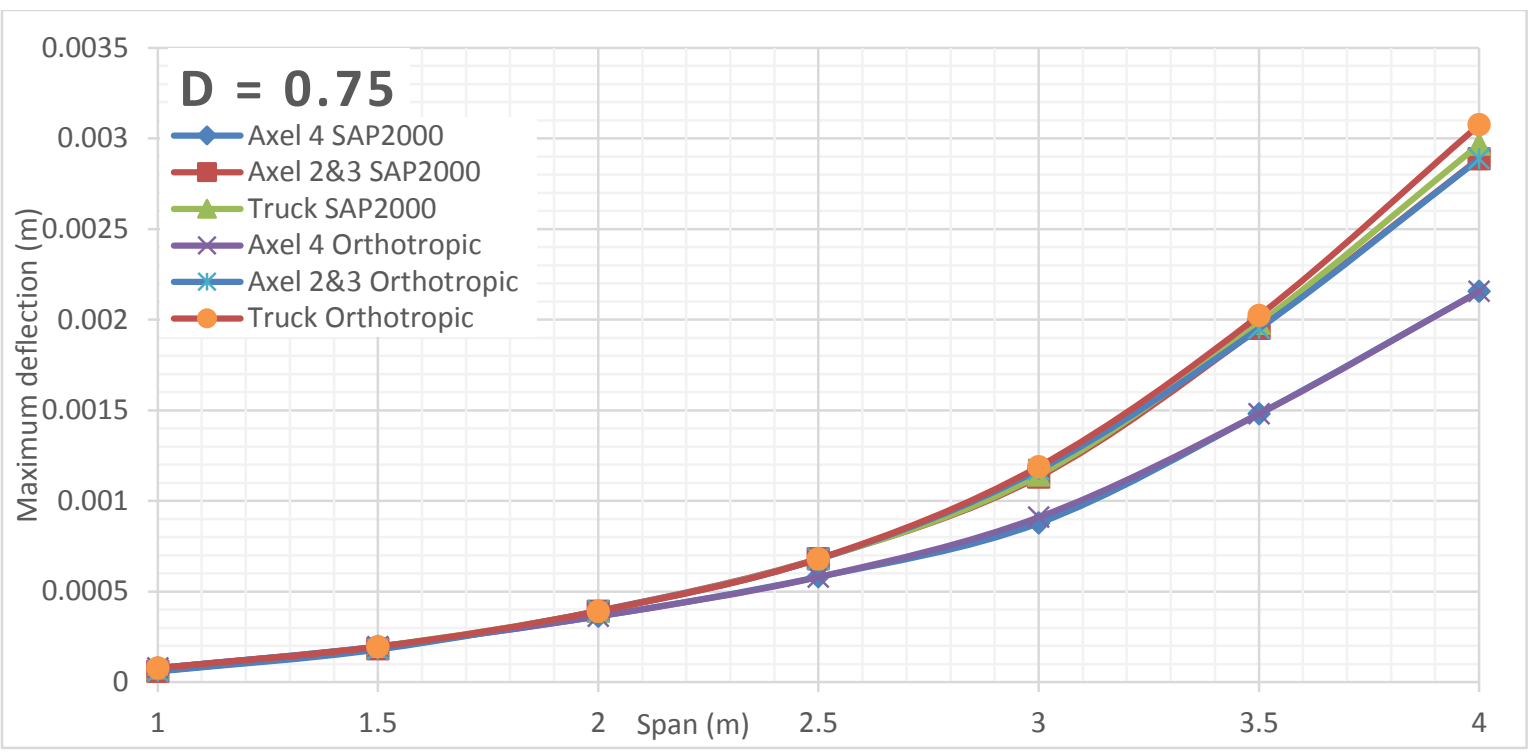

Figure 801 Deflection comparison between FEA and Orthotropic Plate Theory for $D=0.75$ of alpha 0.5 (main bars perpendicular to traffic)

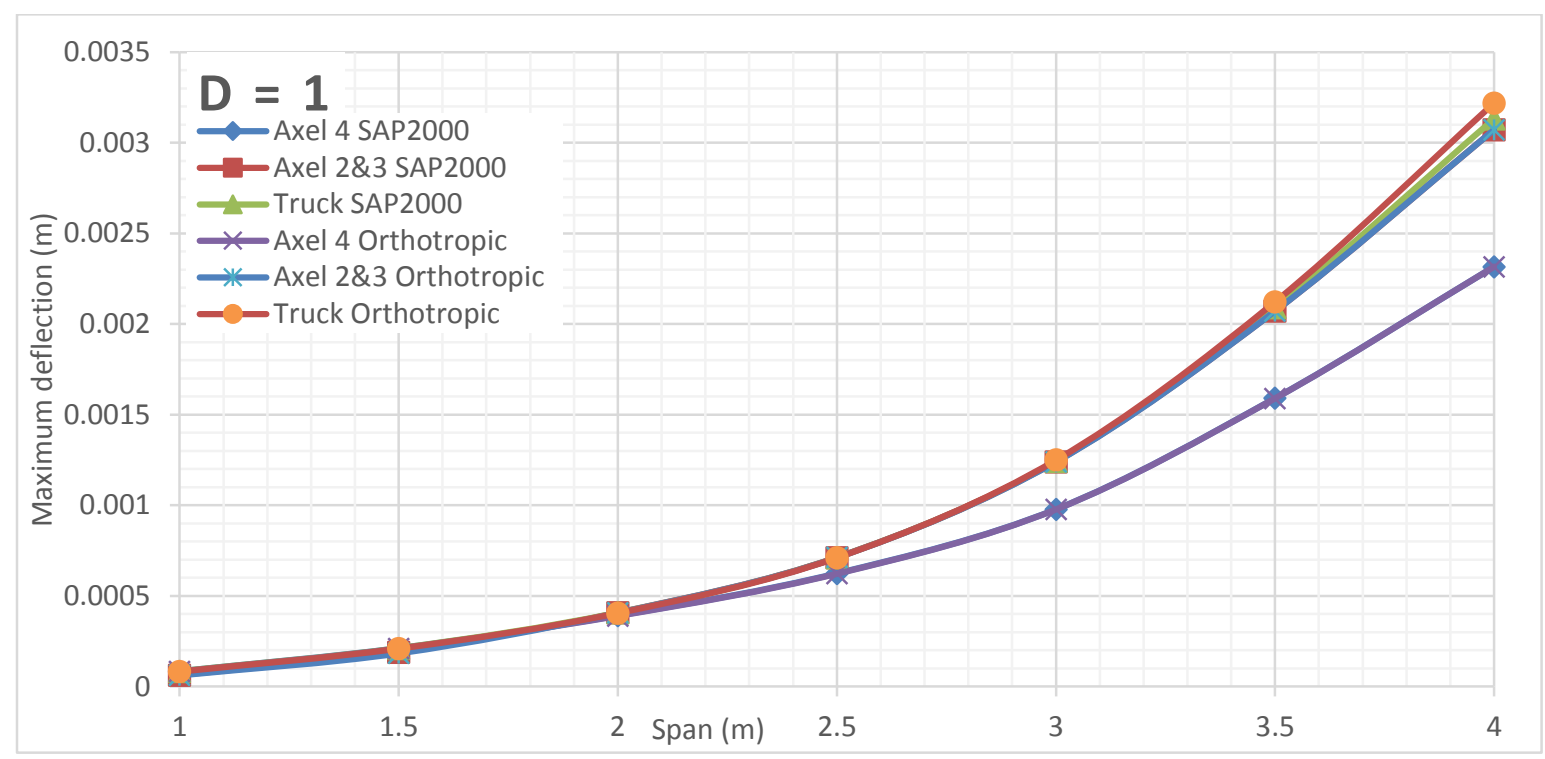

Figure 802 Deflection comparison between FEA and Orthotropic Plate Theory for $D=1$ of alpha 0.5 (main bars perpendicular to traffic) 


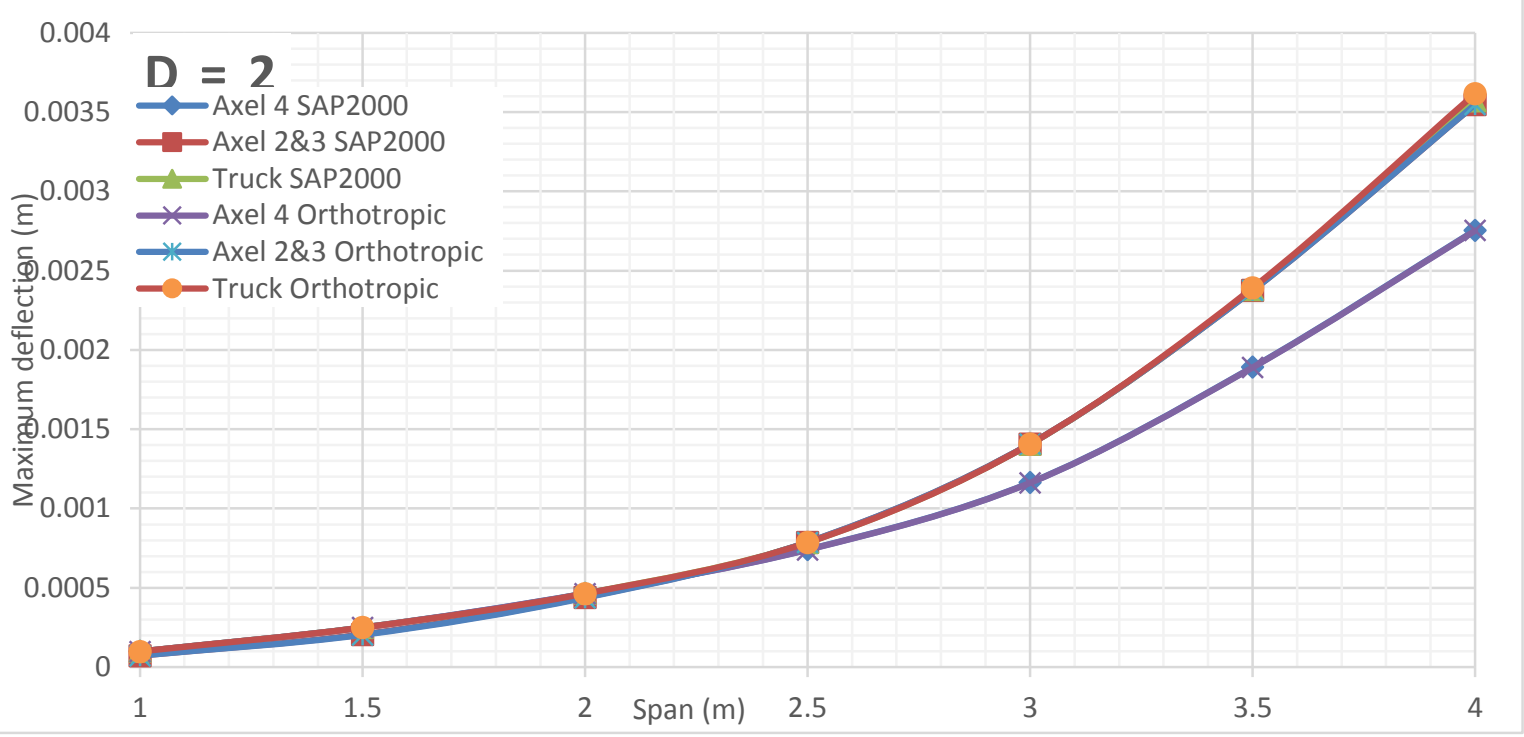

Figure 803 Deflection comparison between FEA and Orthotropic Plate Theory for $D=2$ of alpha 0.5 (main bars perpendicular to traffic)

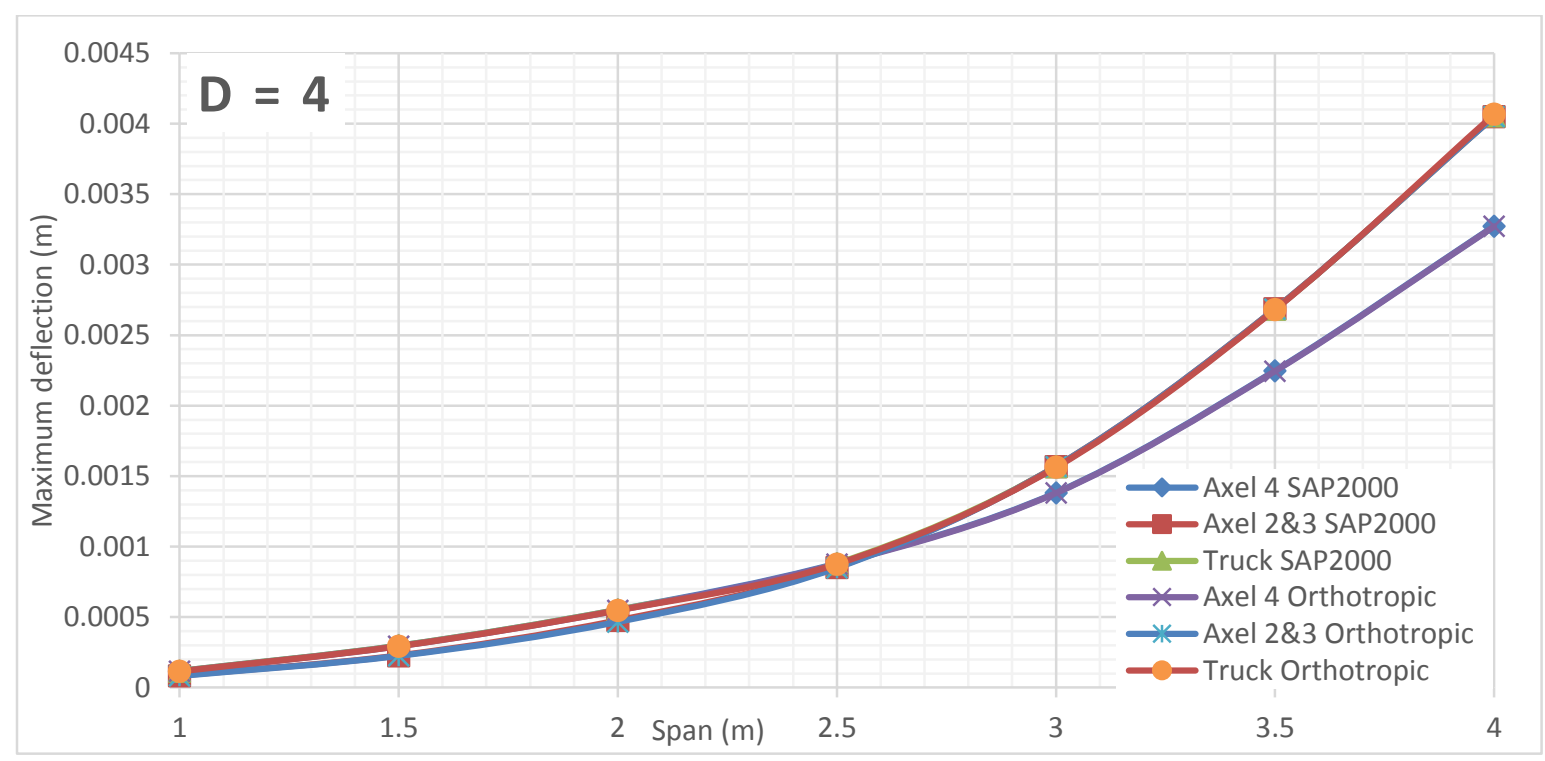

Figure 804 Deflection comparison between FEA and Orthotropic Plate Theory for $D=4$ of alpha 0.5 (main bars perpendicular to traffic)

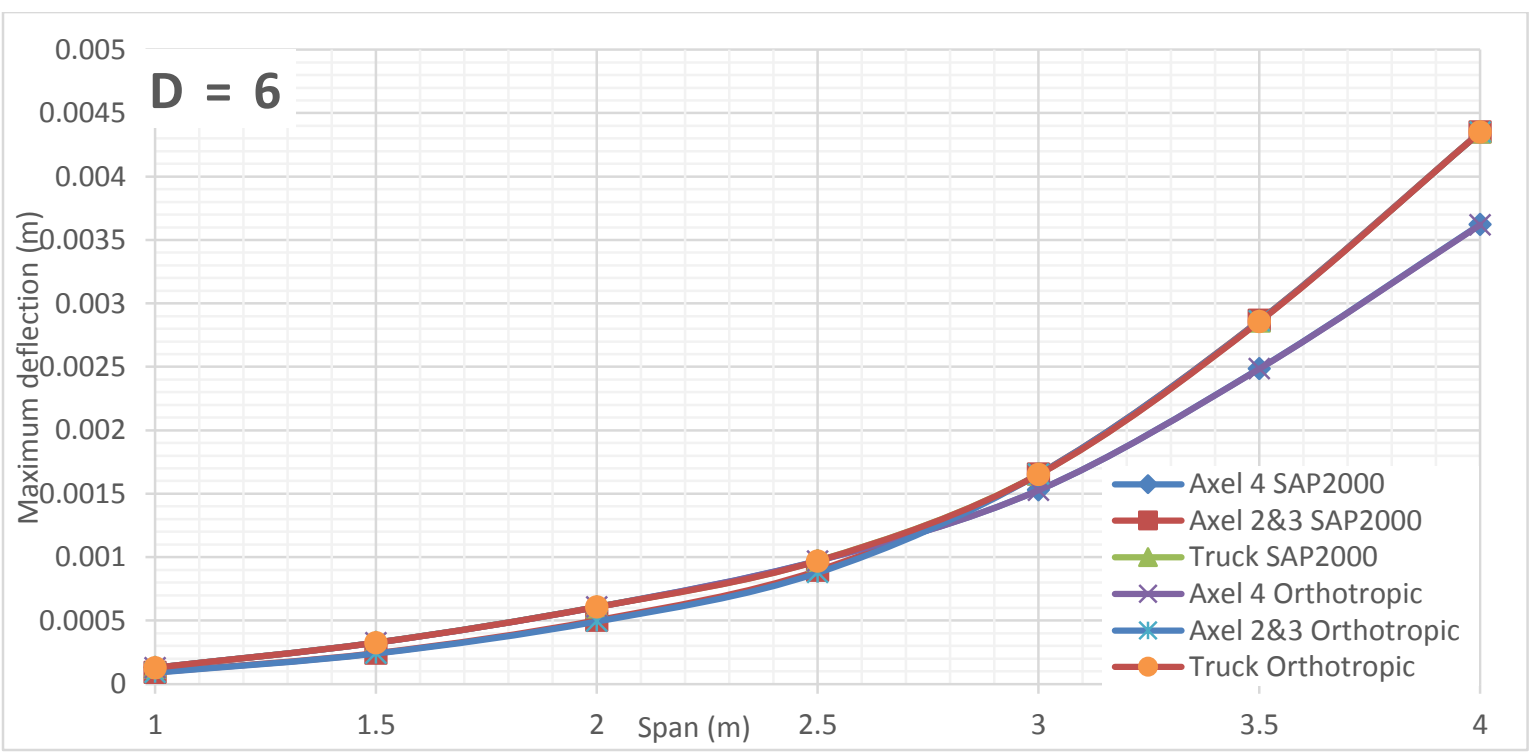

Figure 805 Deflection comparison between FEA and Orthotropic Plate Theory for $D=6$ of alpha 0.5 (main bars perpendicular to traffic) 


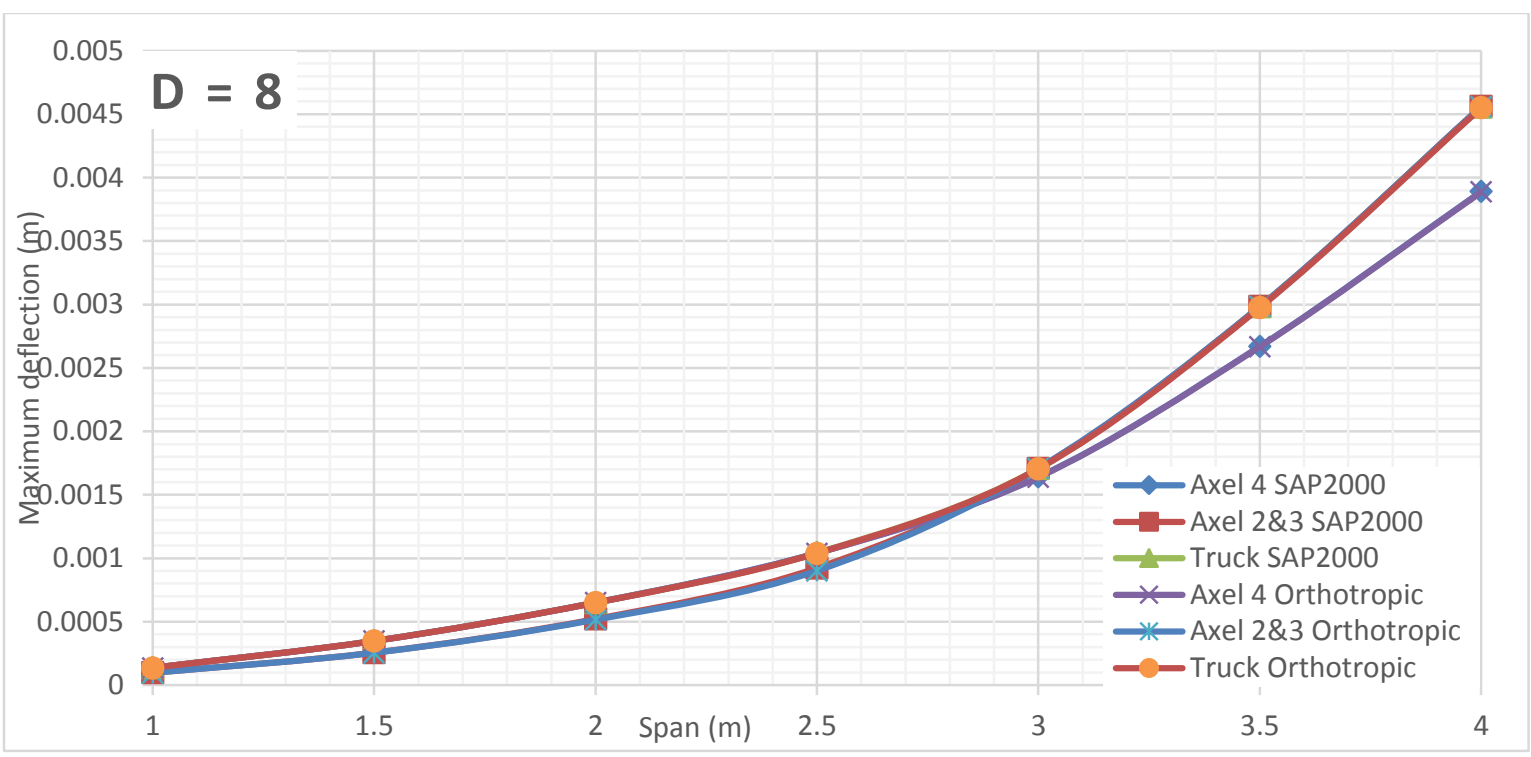

Figure 806 Deflection comparison between FEA and Orthotropic Plate Theory for $D=8$ of alpha 0.5 (main bars perpendicular to traffic)

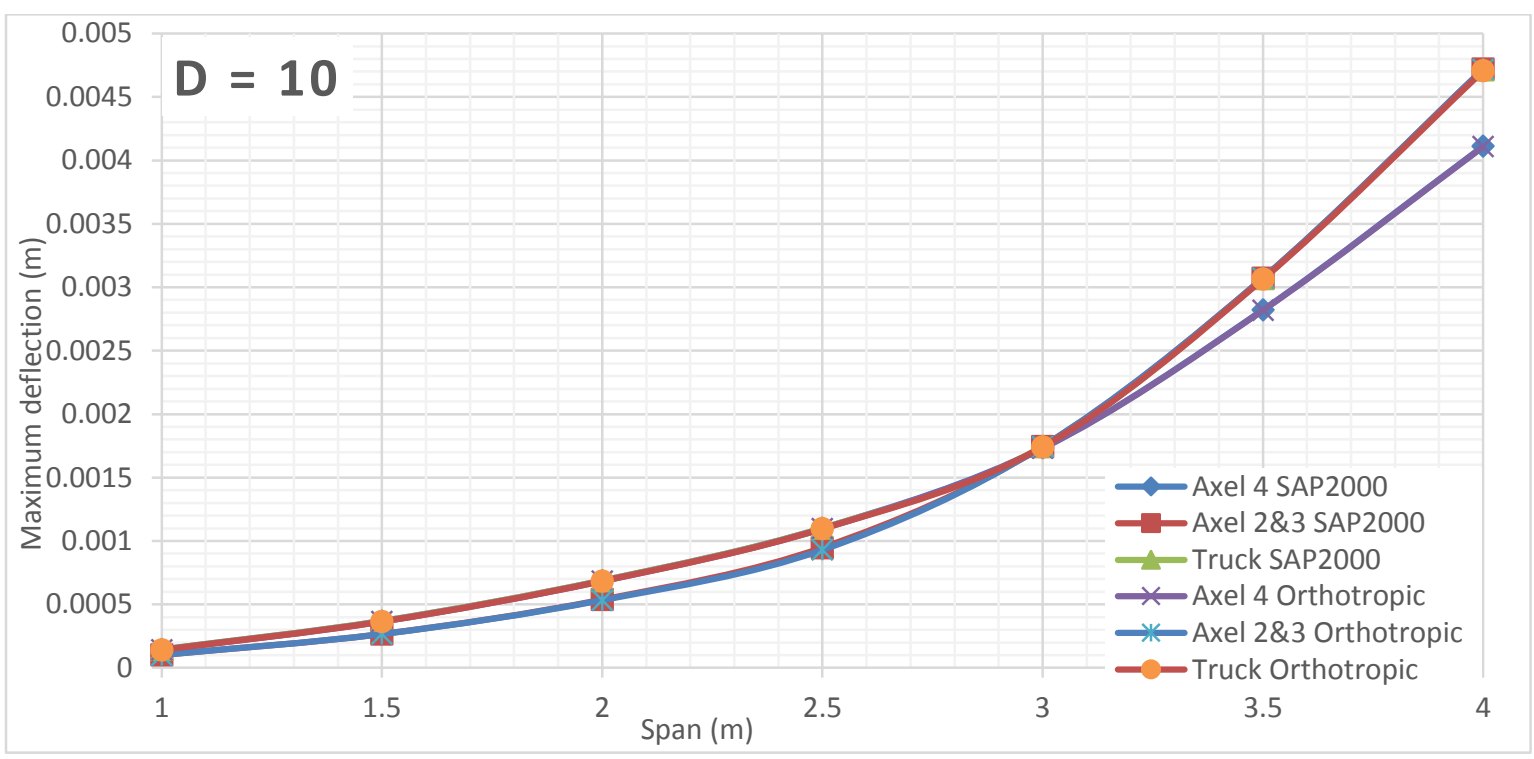

Figure 807 Deflection comparison between FEA and Orthotropic Plate Theory for $D=10$ of alpha 0.5 (main bars perpendicular to traffic) 


\section{Alpha 0.5 Deflection VS Span Length for Different D Values (Main bars parallel to traffic)}

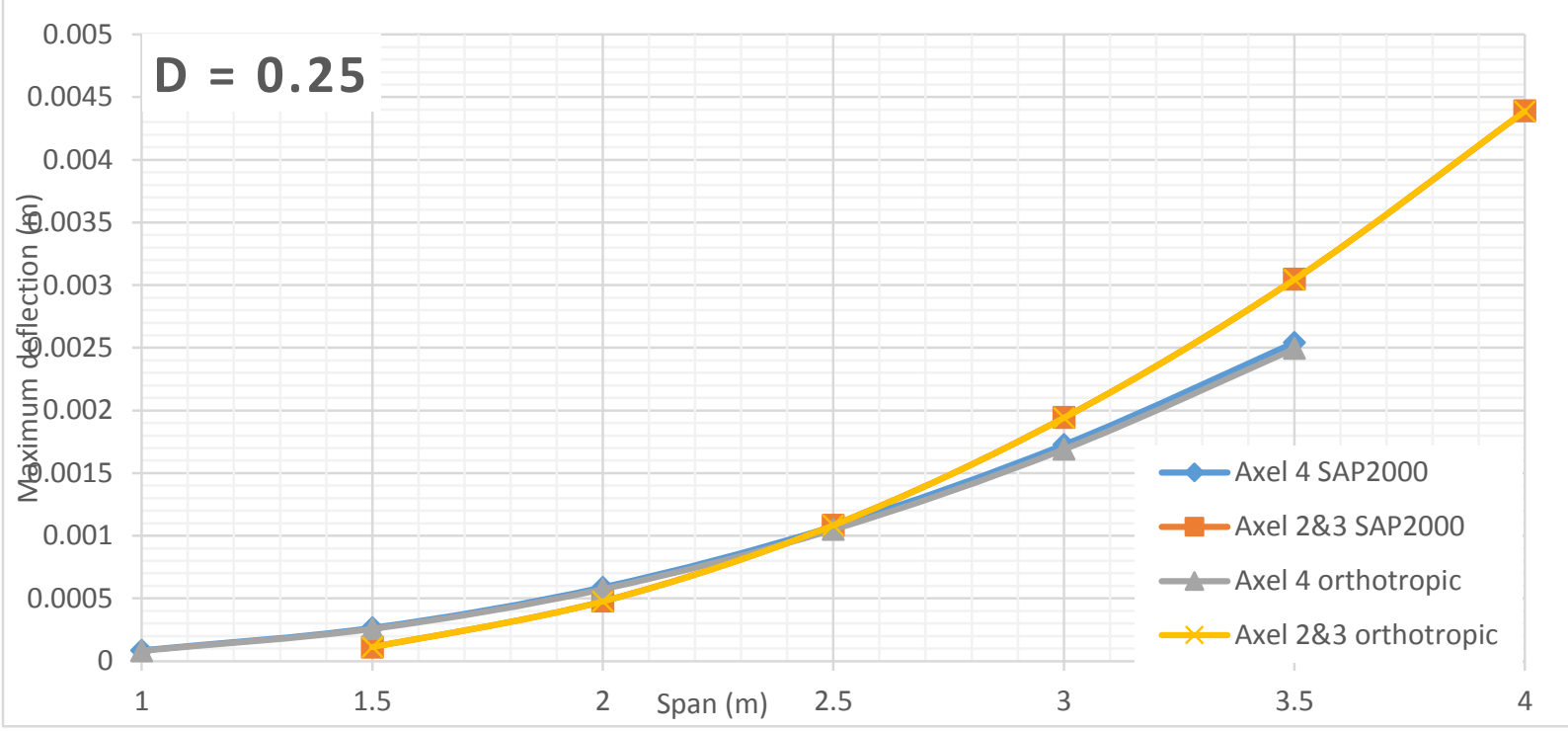

Figure 808 Deflection comparison between FEA and Orthotropic Plate Theory for $D=0.25$ of alpha 0.5 (main bars parallel to traffic)

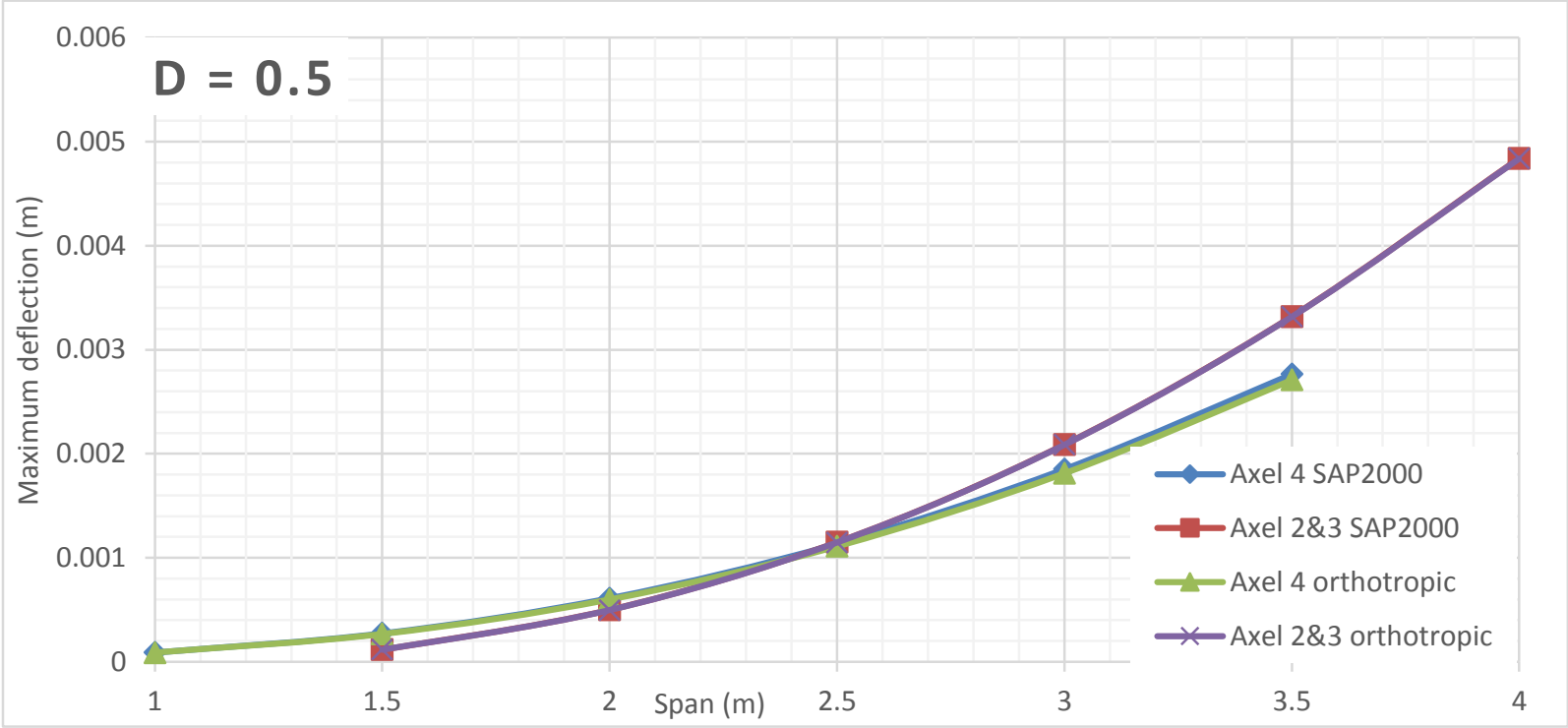

Figure 809 Deflection comparison between FEA and Orthotropic Plate Theory for $D=0.5$ of alpha 0.5 (main bars parallel to traffic) 


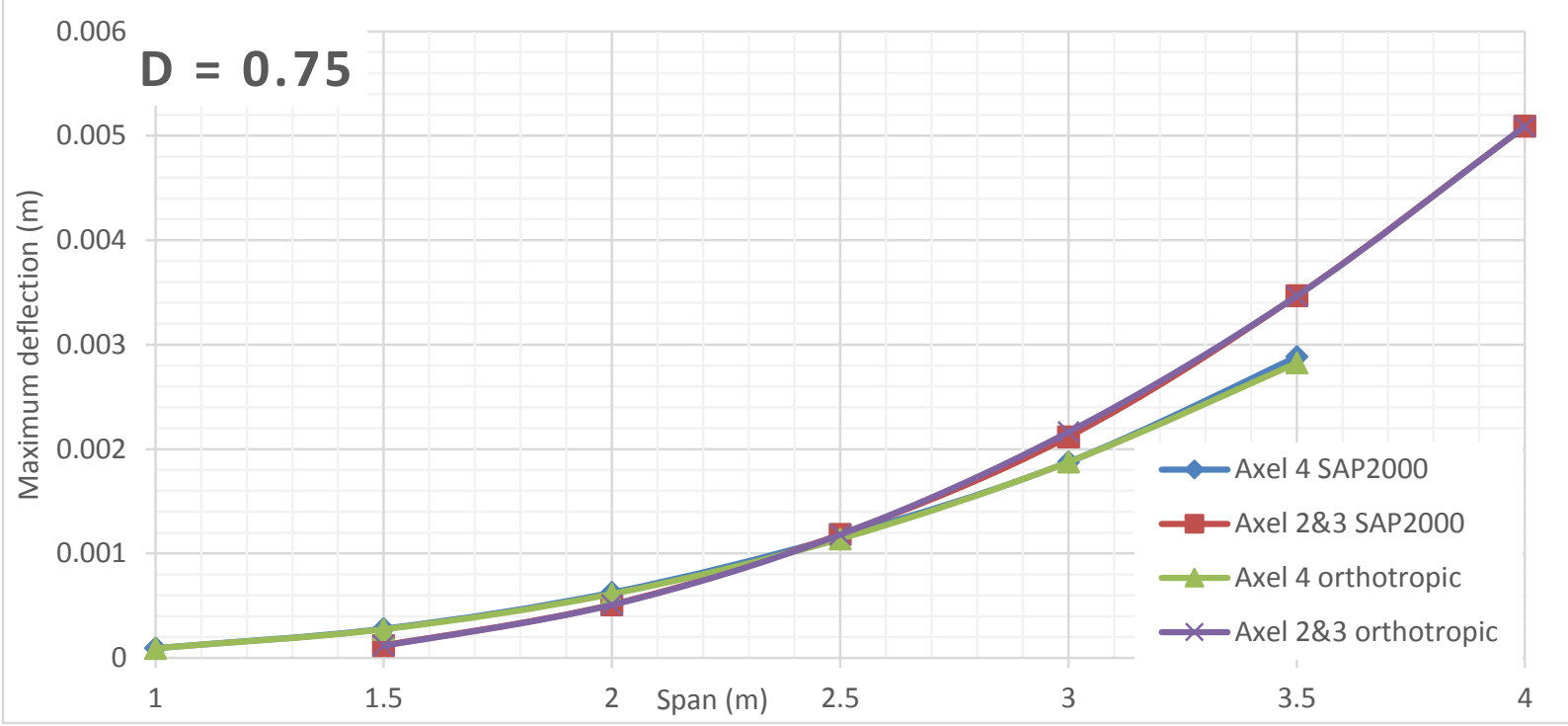

Figure 810 Deflection comparison between FEA and Orthotropic Plate Theory for $D=0.75$ of alpha 0.5 (main bars parallel to traffic)

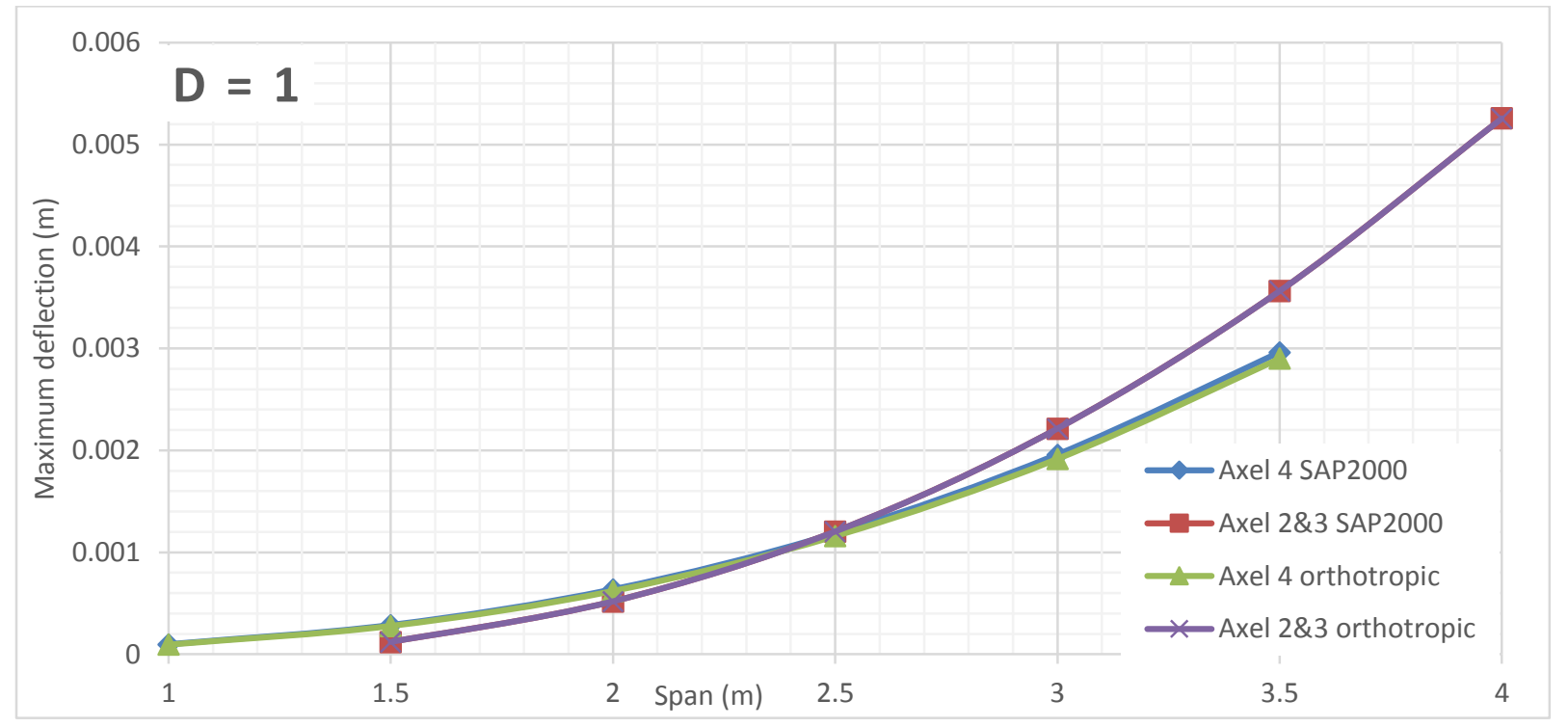

Figure 811 Deflection comparison between FEA and Orthotropic Plate Theory for $D=1$ of alpha 0.5 (main bars parallel to traffic)

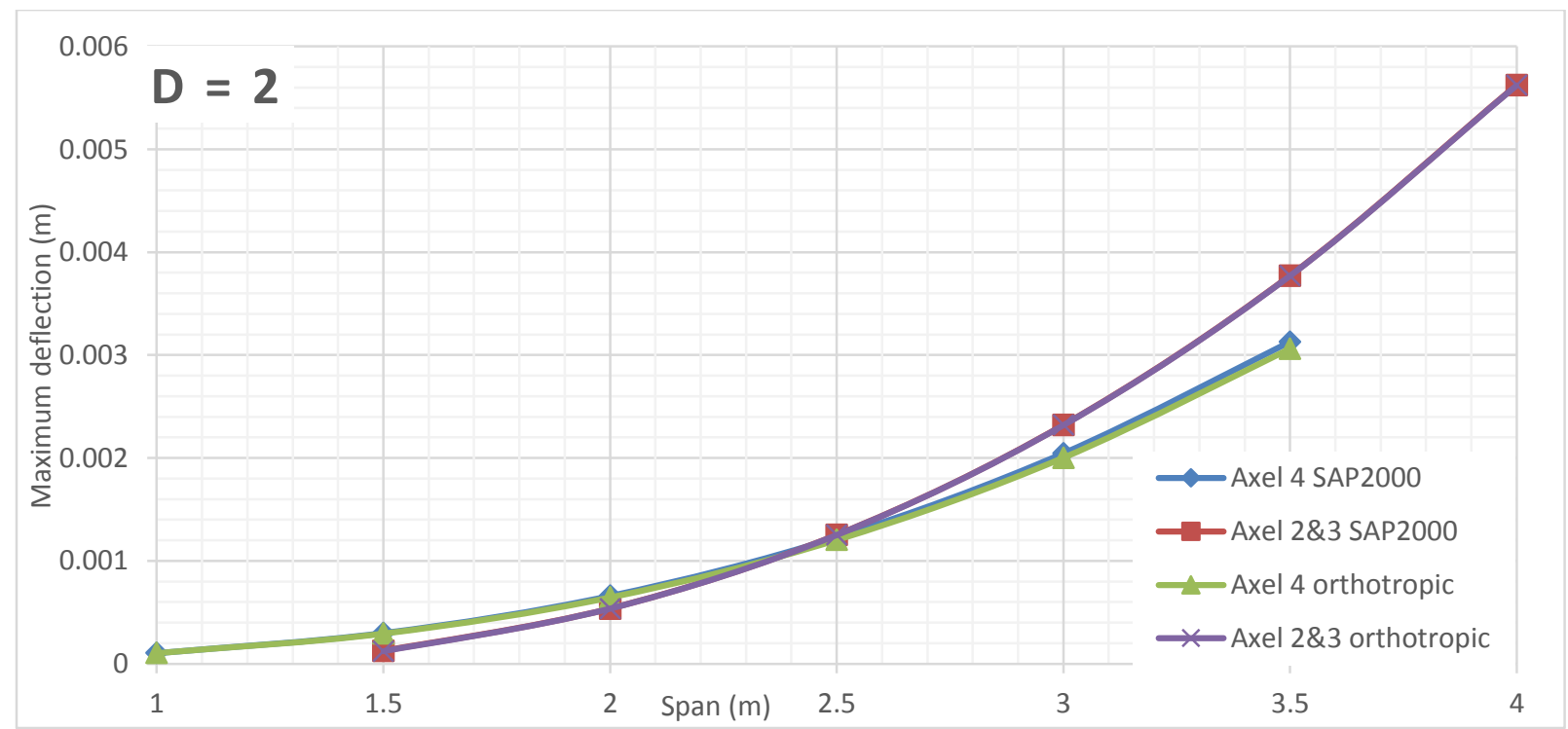

Figure 812 Deflection comparison between FEA and Orthotropic Plate Theory for $D=2$ of alpha 0.5 (main bars parallel to traffic) 


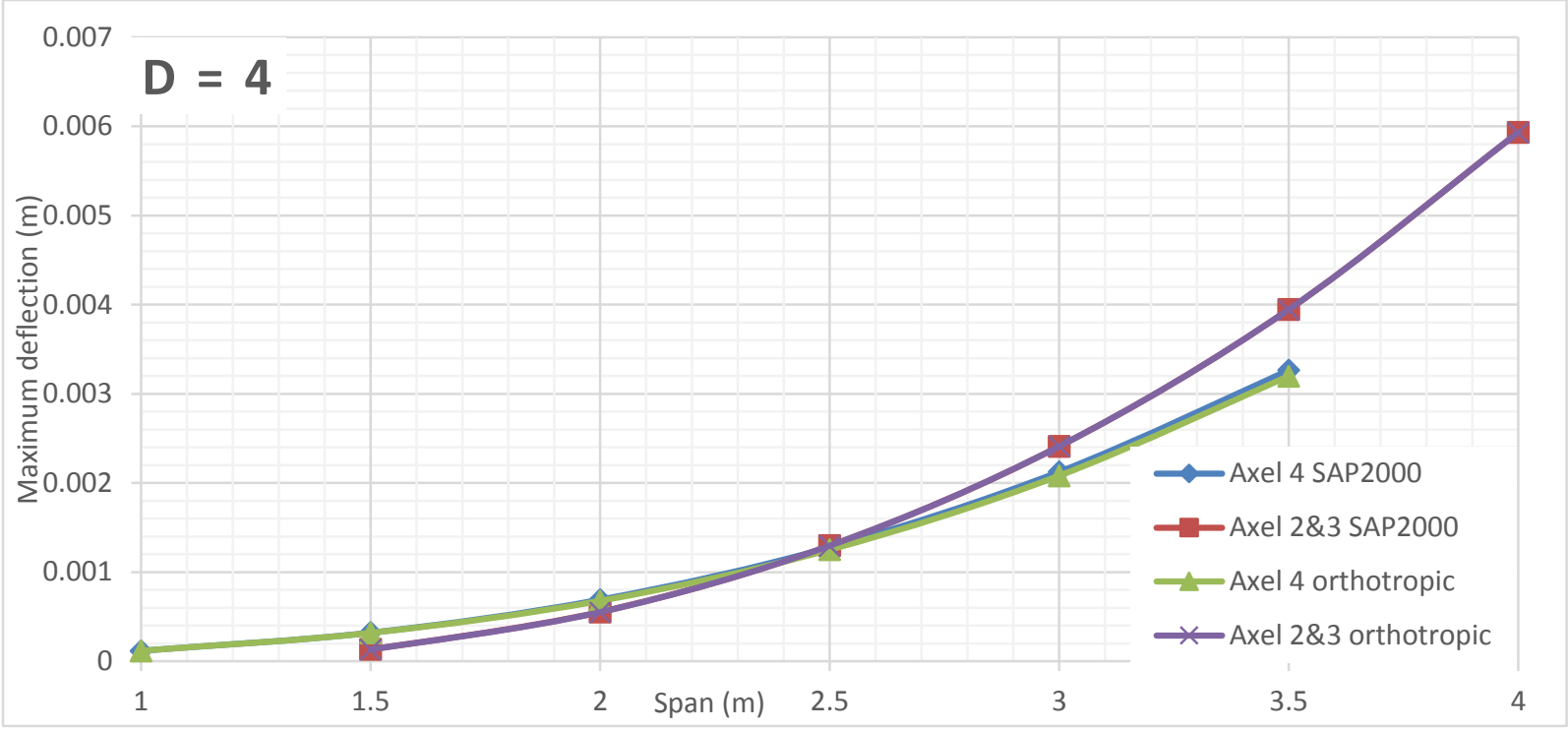

Figure 813 Deflection comparison between FEA and Orthotropic Plate Theory for D $=4$ of alpha 0.5 (main bars parallel to traffic)

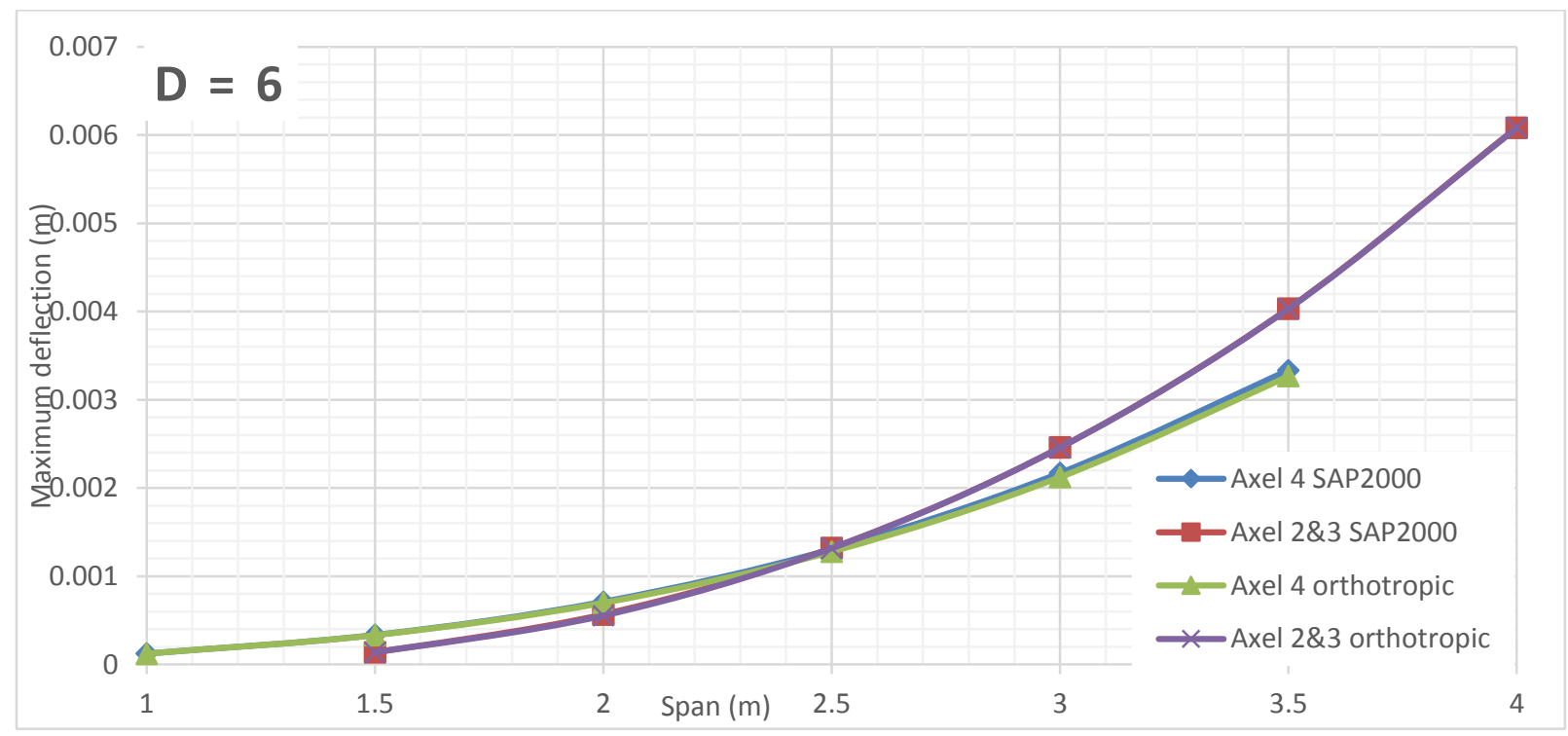

Figure 814 Deflection comparison between FEA and Orthotropic Plate Theory for $D=6$ of alpha 0.5 (main bars parallel to traffic)

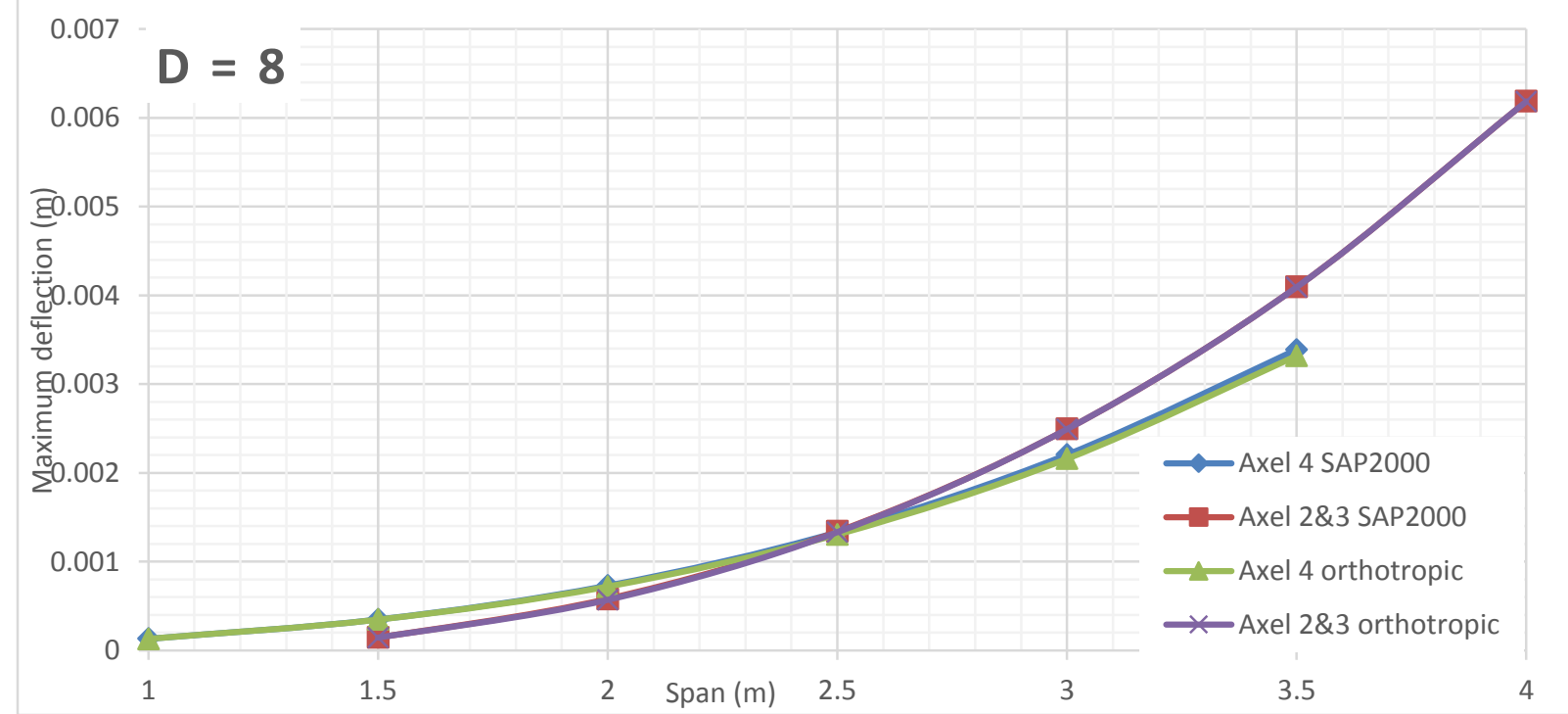

Figure 815 Deflection comparison between FEA and Orthotropic Plate Theory for $D=8$ of alpha 0.5 (main bars parallel to traffic) 


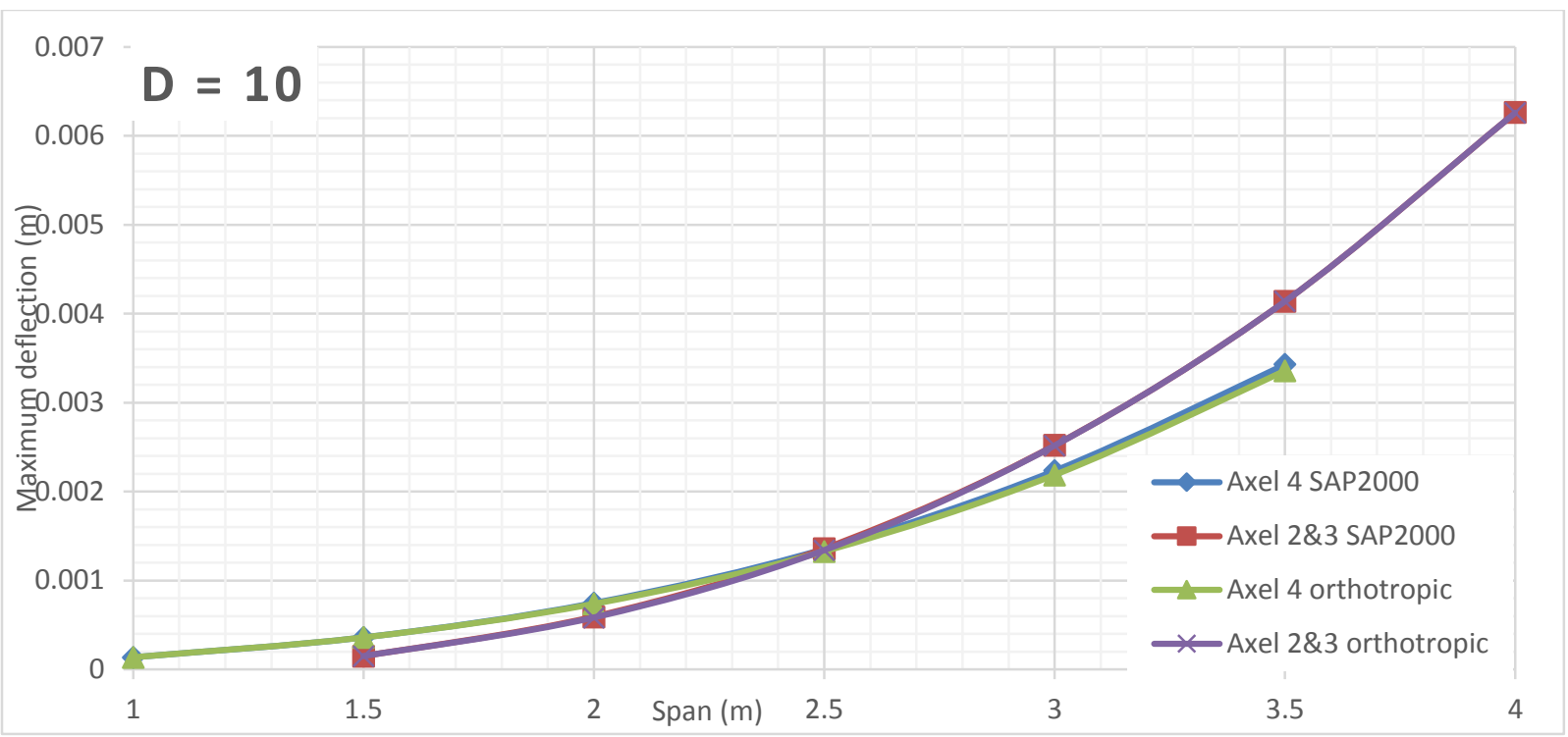

Figure 816 Deflection comparison between FEA and Orthotropic Plate Theory for $\mathrm{D}=10$ of alpha 0.5 (main bars parallel to traffic) 


\section{Alpha 0.75 Deflection VS Span Length for Different D Values (Main bars perpendicular to traffic)}

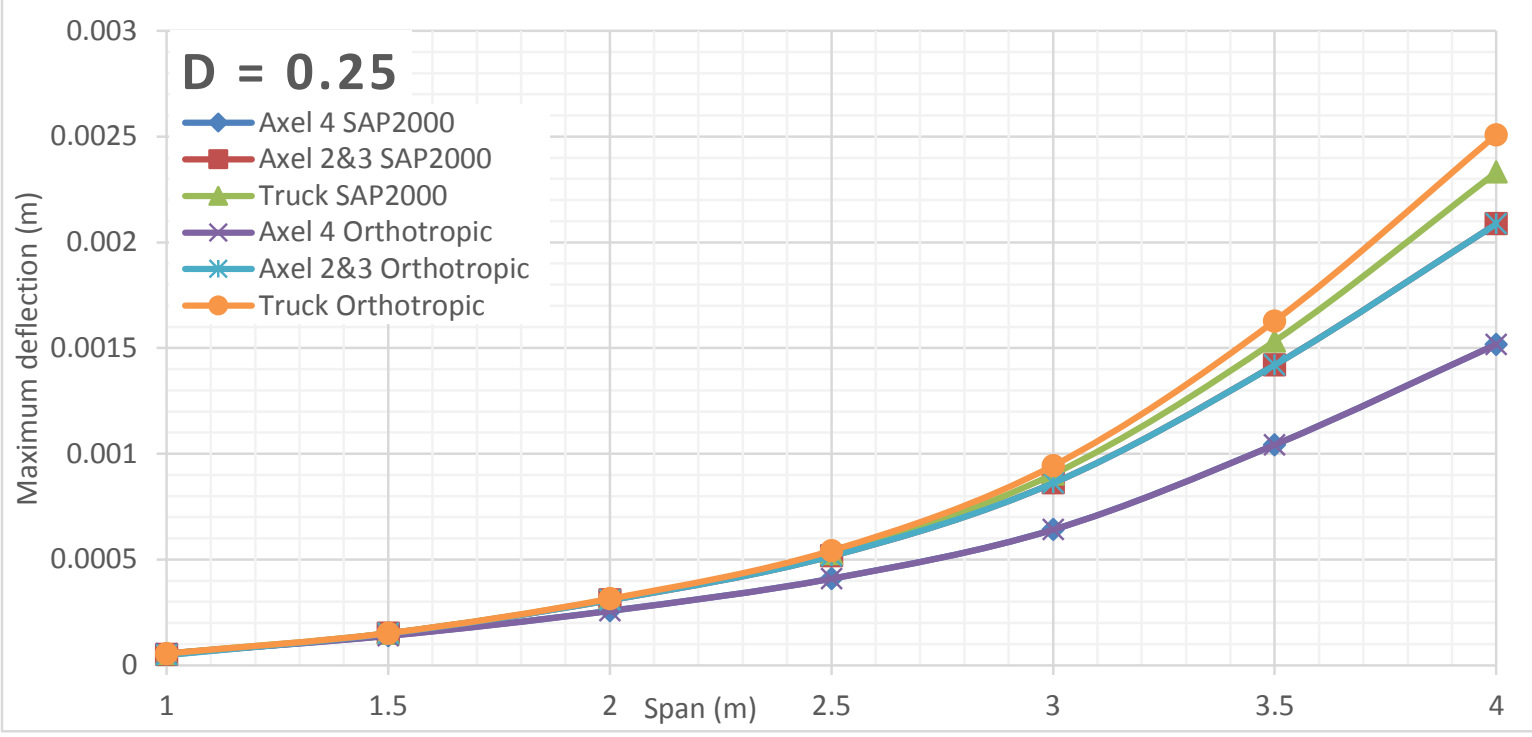

Figure 817 Deflection comparison between FEA and Orthotropic Plate Theory for D $=0.25$ of alpha 0.75 (main bars perpendicular to traffic)

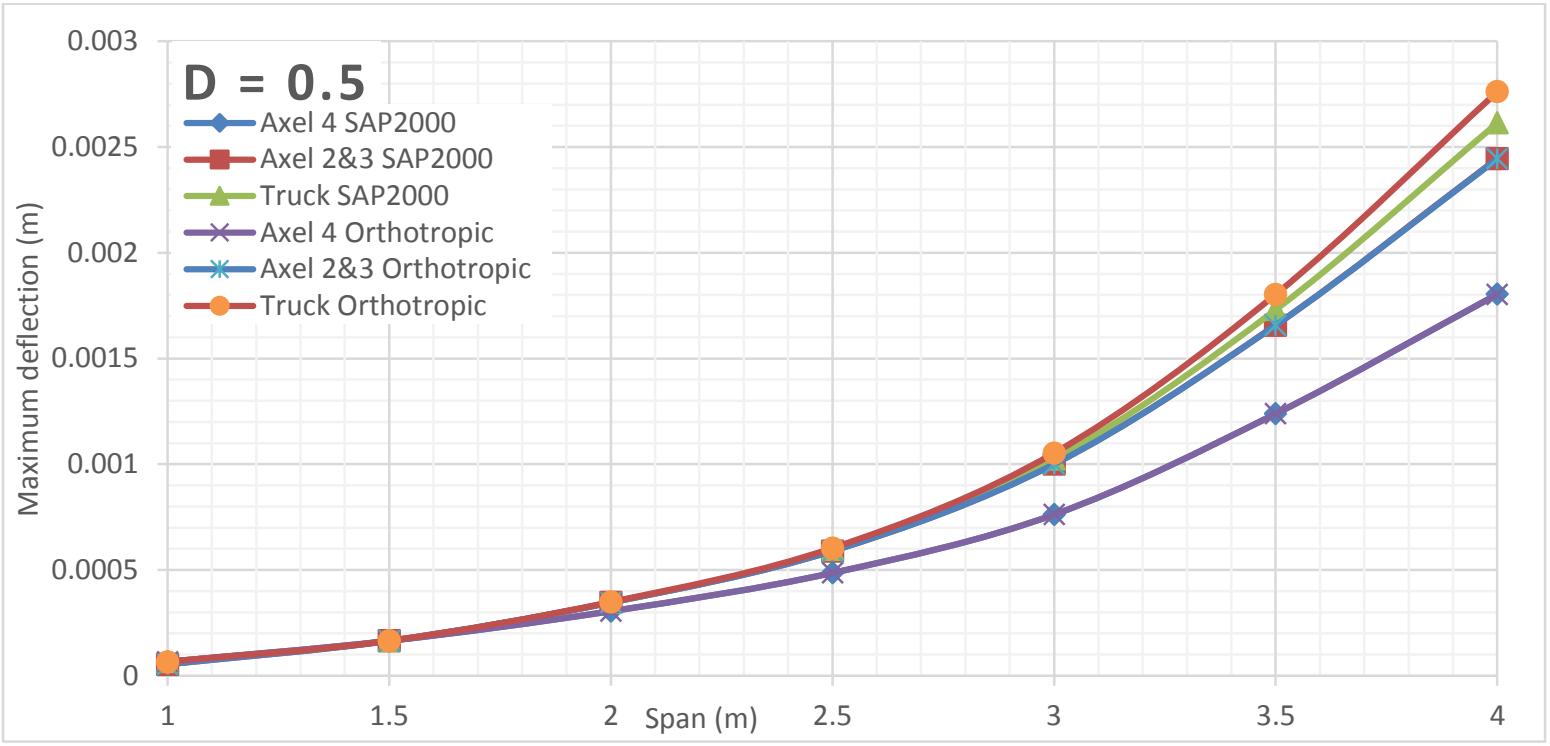

Figure 818 Deflection comparison between FEA and Orthotropic Plate Theory for $\mathrm{D}=0.5$ of alpha 0.75 (main bars perpendicular to traffic) 


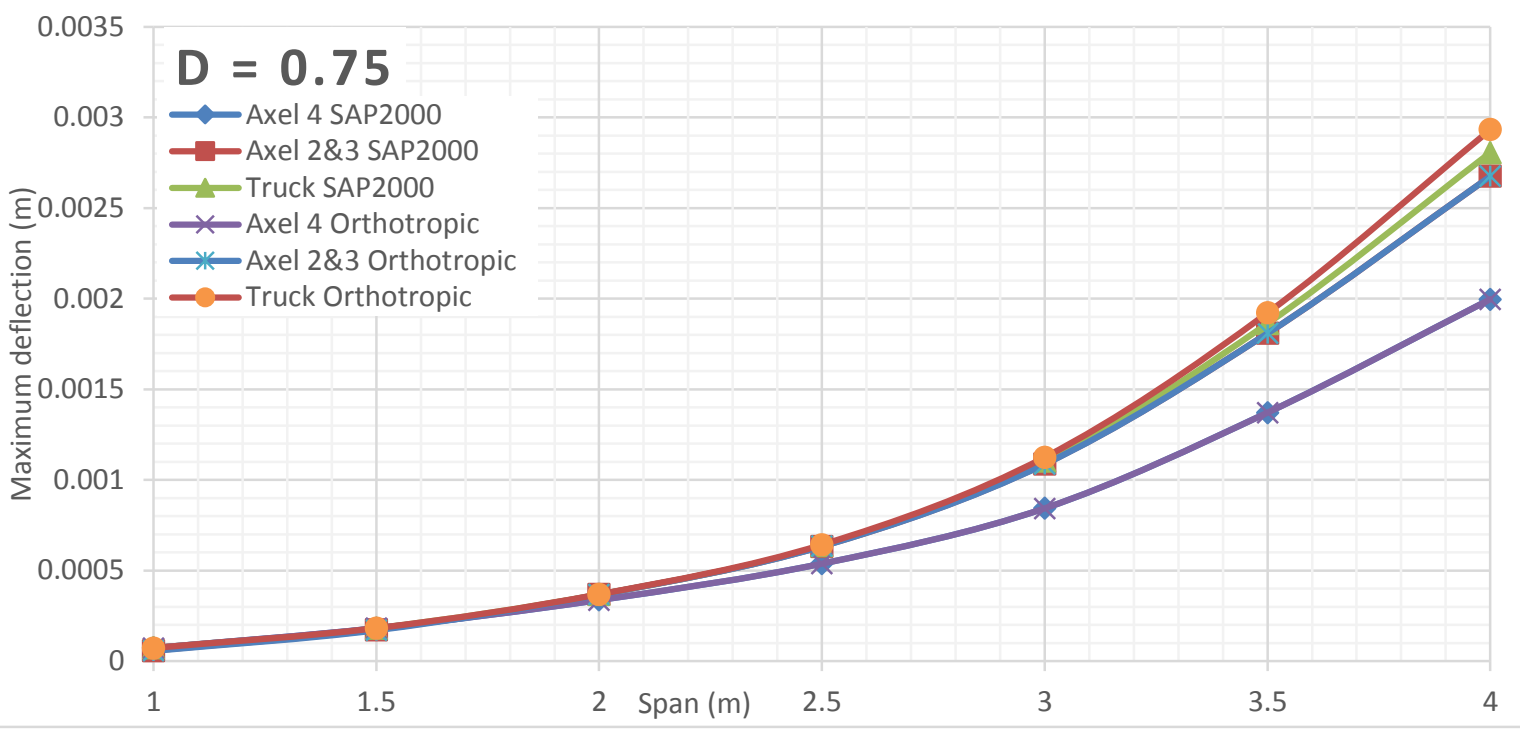

Figure 819 Deflection comparison between FEA and Orthotropic Plate Theory for D $=0.75$ of alpha 0.75 (main bars perpendicular to traffic)

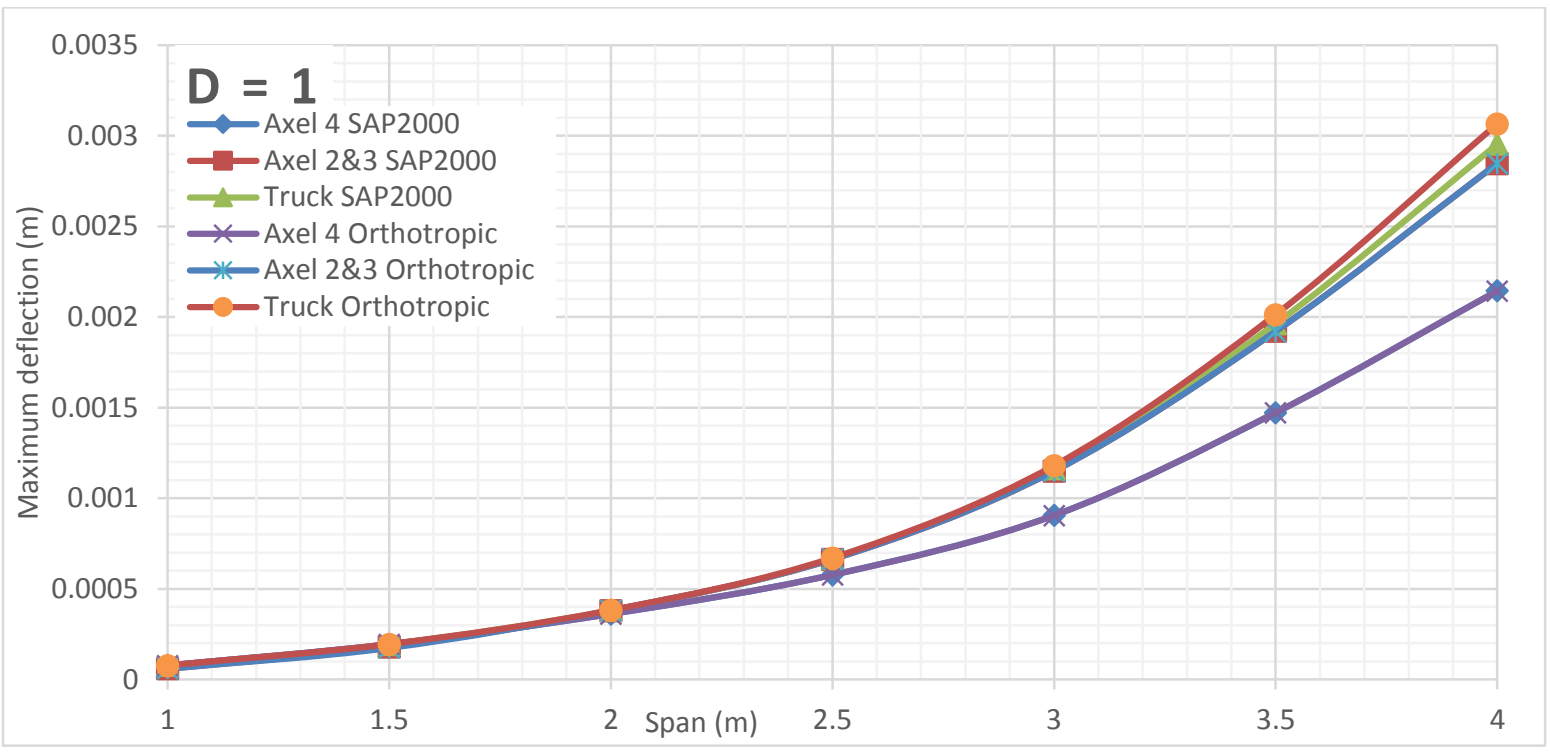

Figure 820 Deflection comparison between FEA and Orthotropic Plate Theory for $D=1$ of alpha 0.75 (main bars perpendicular to traffic)

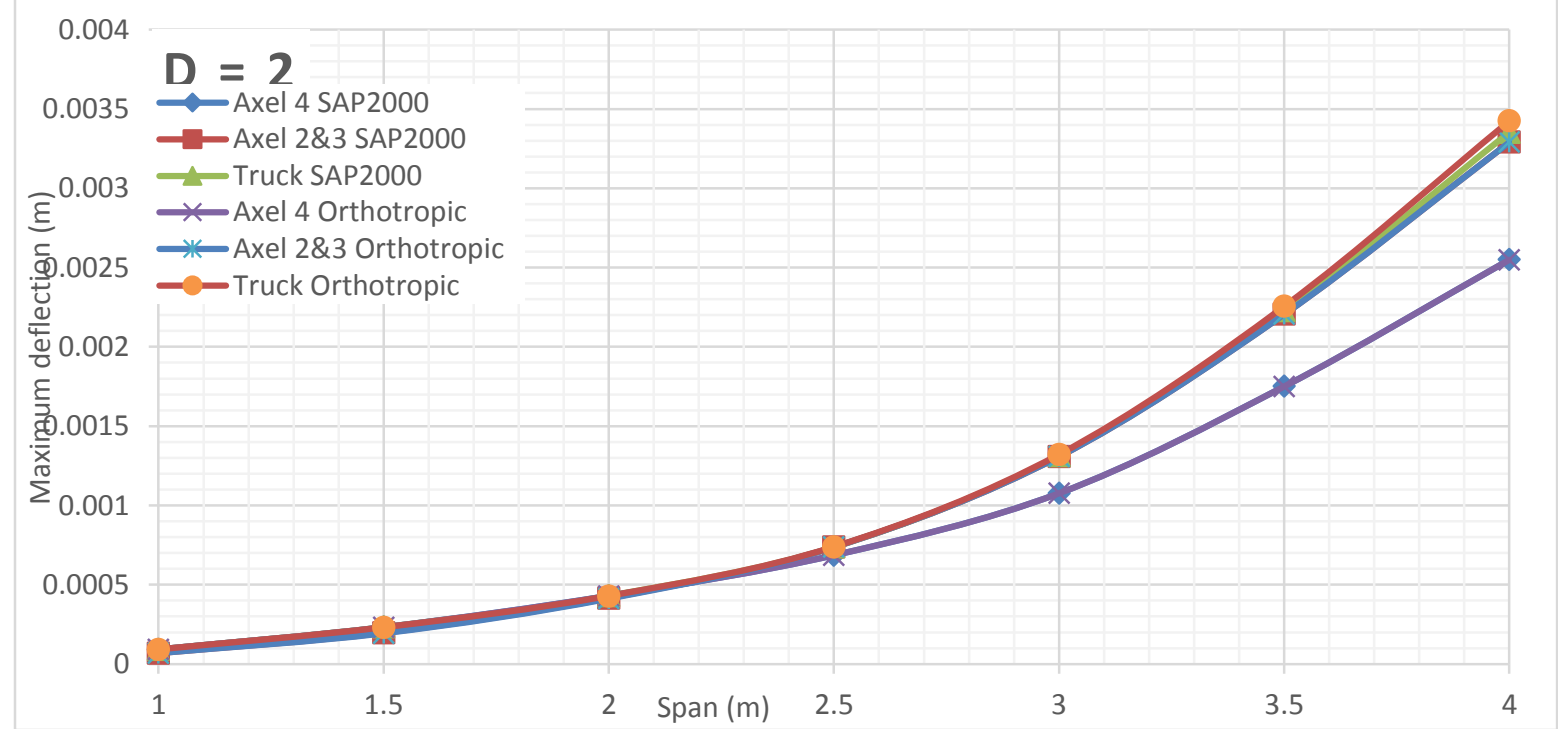

Figure 821 Deflection comparison between FEA and Orthotropic Plate Theory for $D=2$ of alpha 0.75 (main bars perpendicular to traffic) 


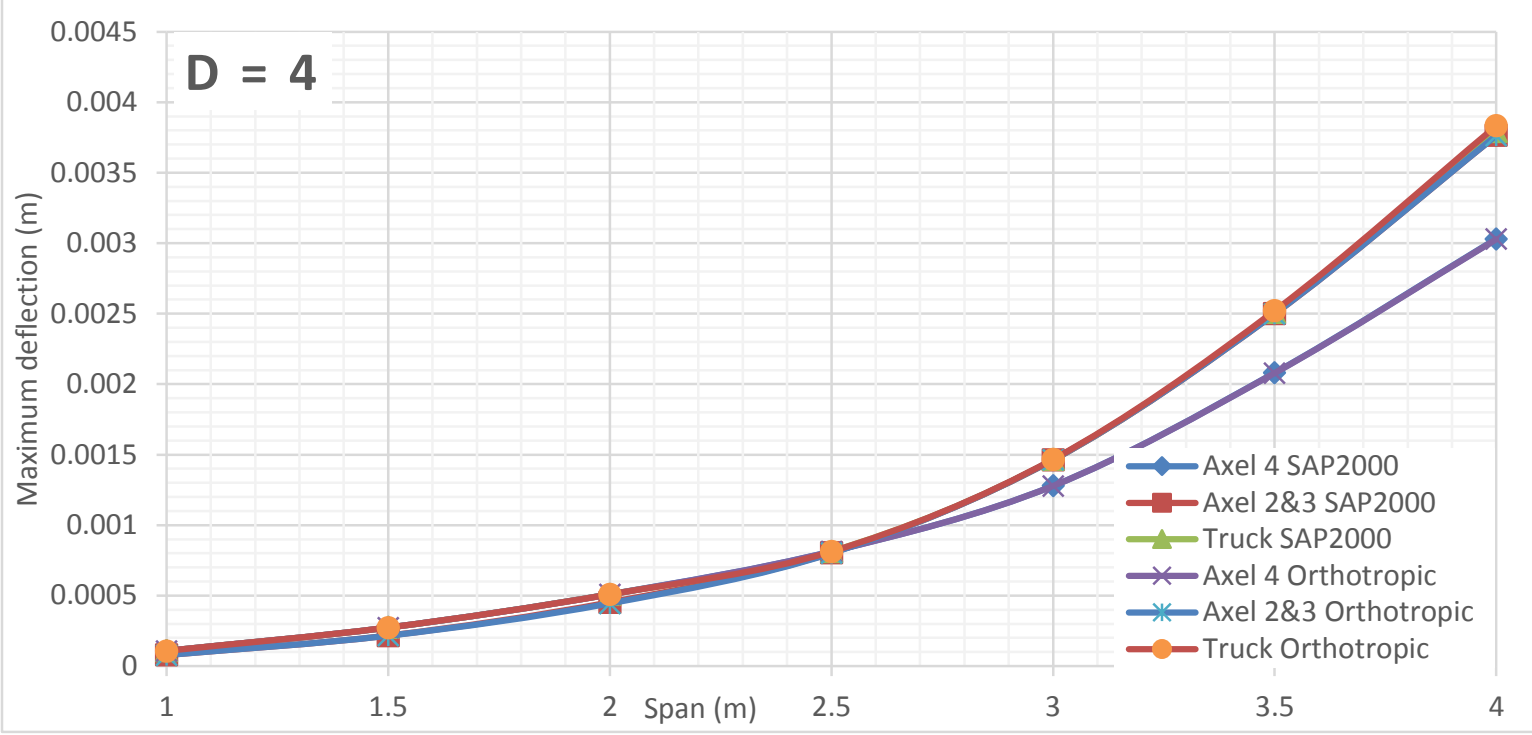

Figure 822 Deflection comparison between FEA and Orthotropic Plate Theory for D = 4 of alpha 0.75 (main bars perpendicular to traffic)

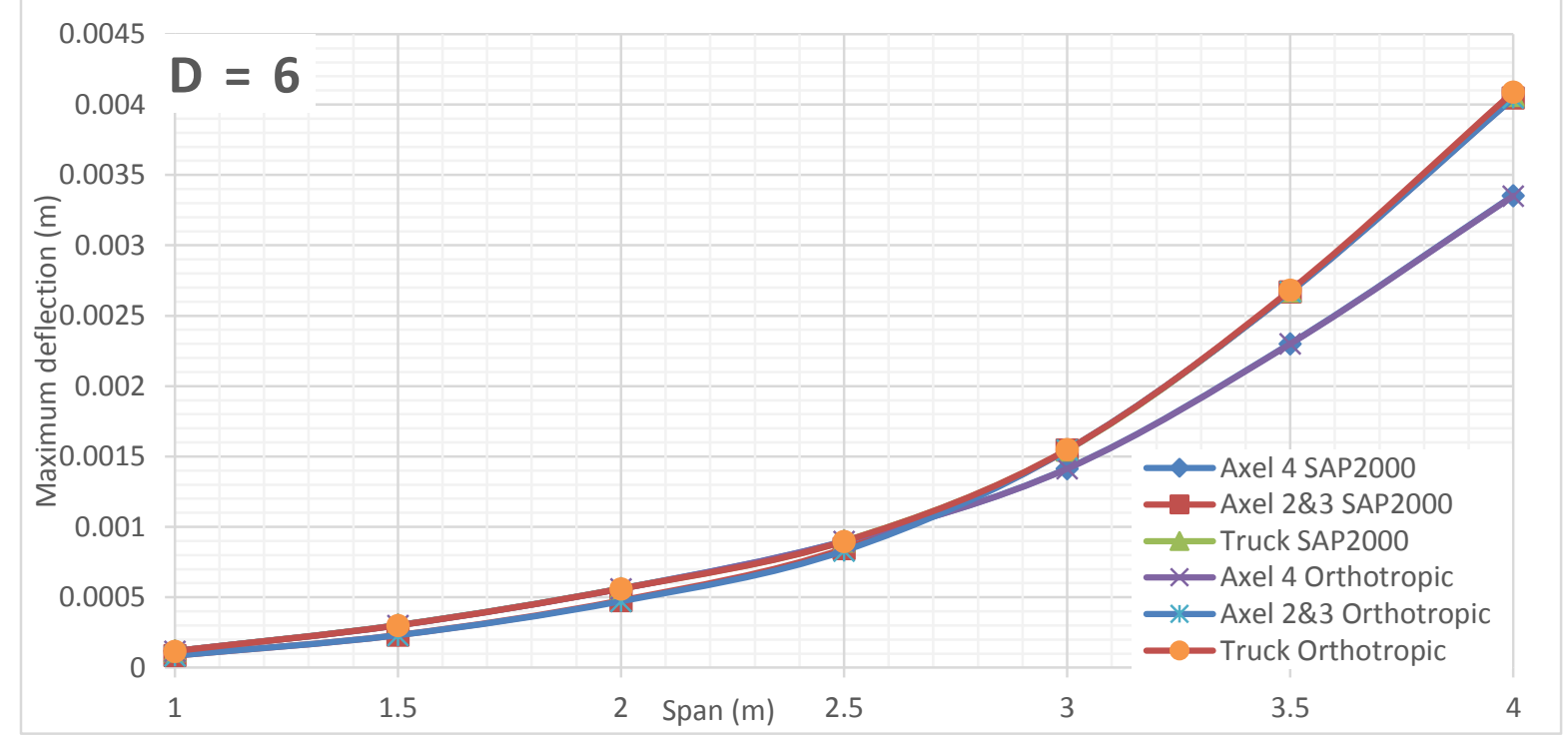

Figure 823 Deflection comparison between FEA and Orthotropic Plate Theory for $D=6$ of alpha 0.75 (main bars perpendicular to traffic)

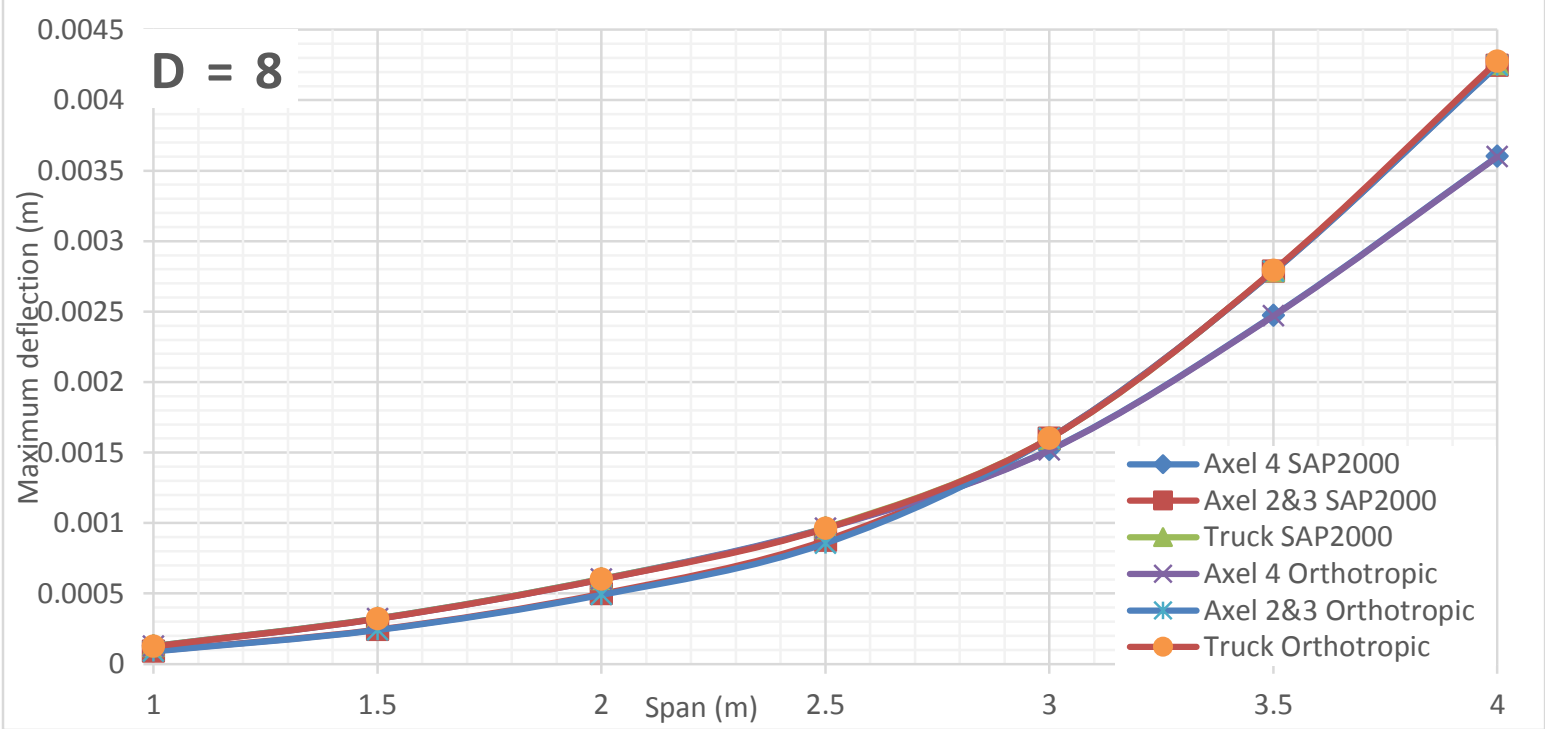

Figure 824 Deflection comparison between FEA and Orthotropic Plate Theory for $D=8$ of alpha 0.75 (main bars perpendicular to traffic) 


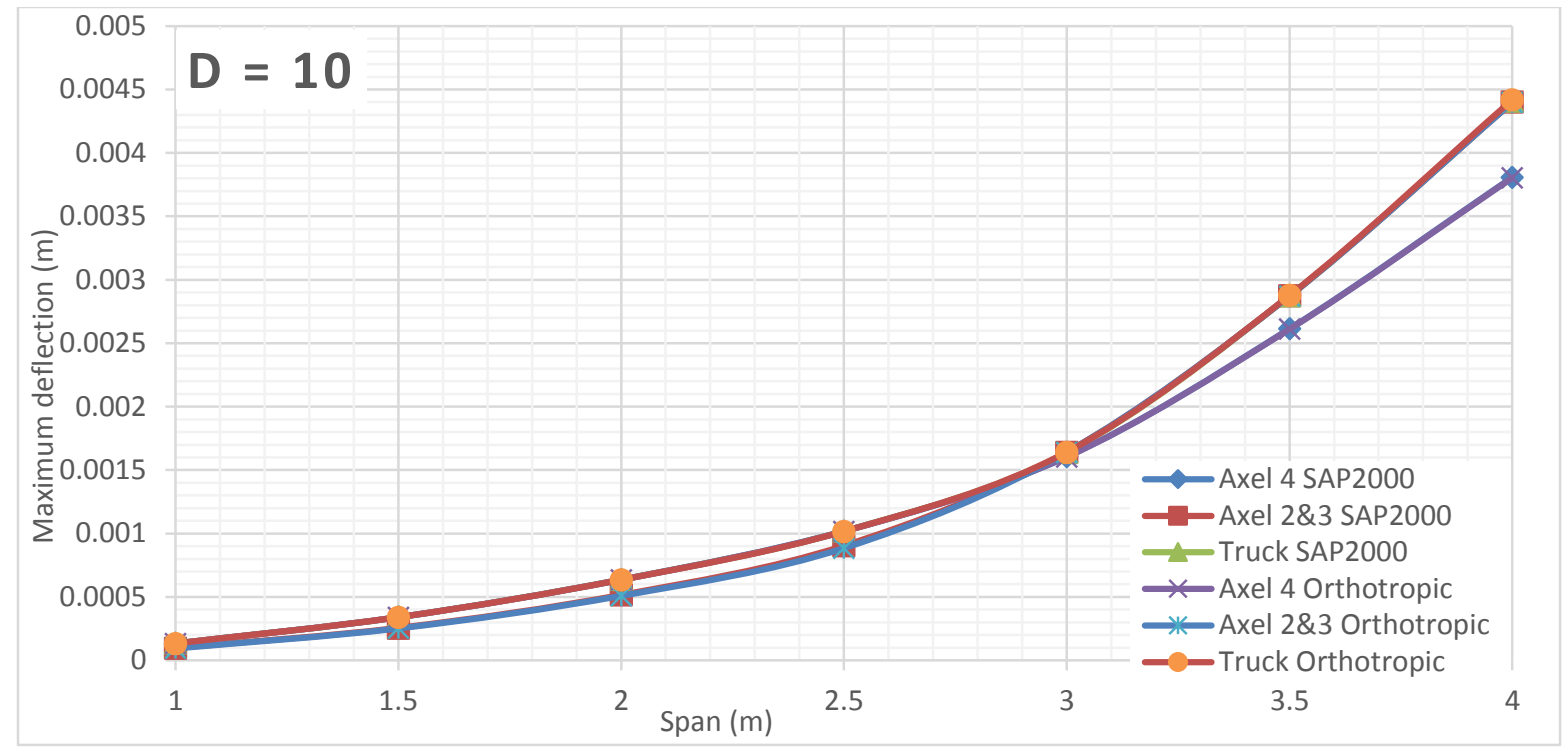

Figure 825 Deflection comparison between FEA and Orthotropic Plate Theory for $D=10$ of alpha 0.75 (main bars perpendicular to traffic) 


\section{Alpha 0.75 Deflection VS Span Length for Different D Values (Main bars parallel to traffic)}

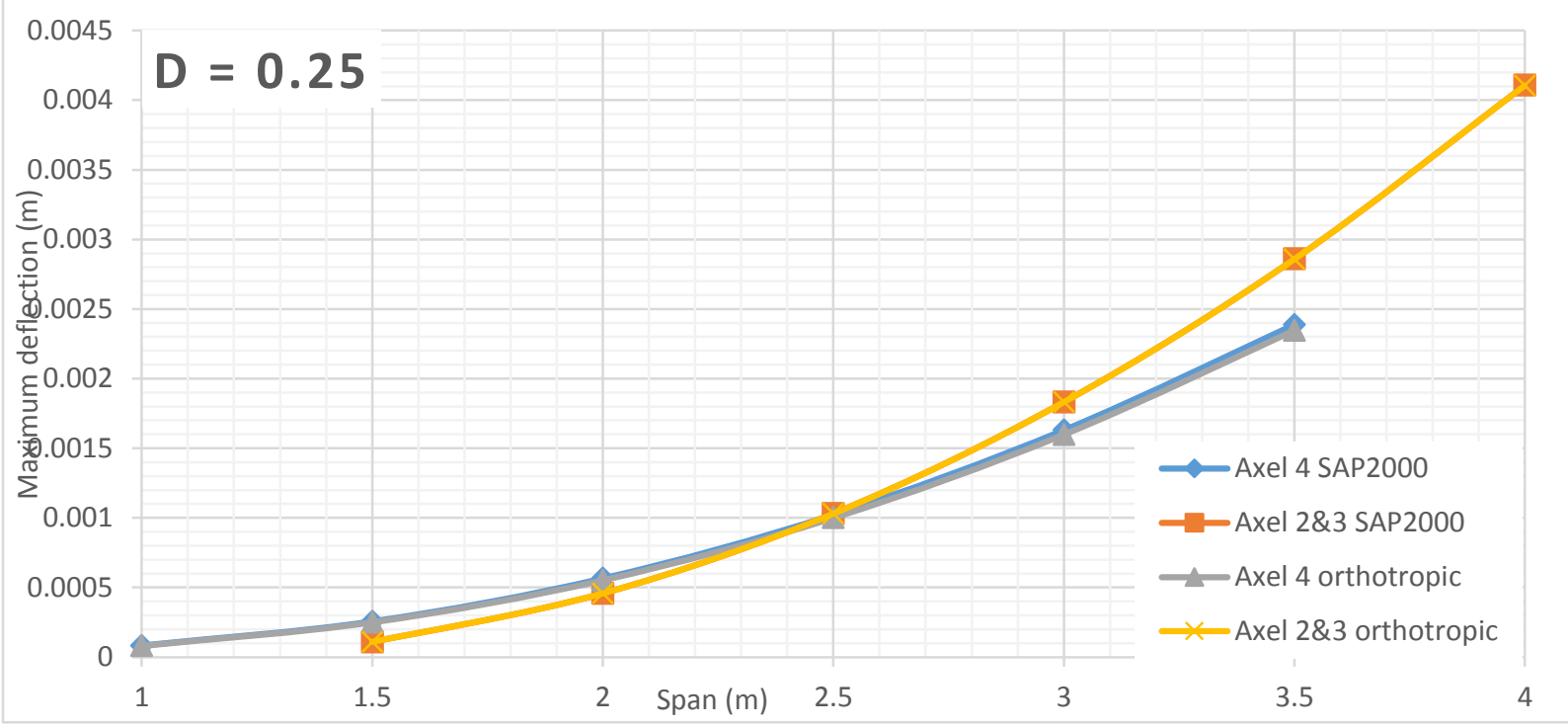

Figure 826 Deflection comparison between FEA and Orthotropic Plate Theory for $D=0.25$ of alpha 0.75 (main bars parallel to traffic)

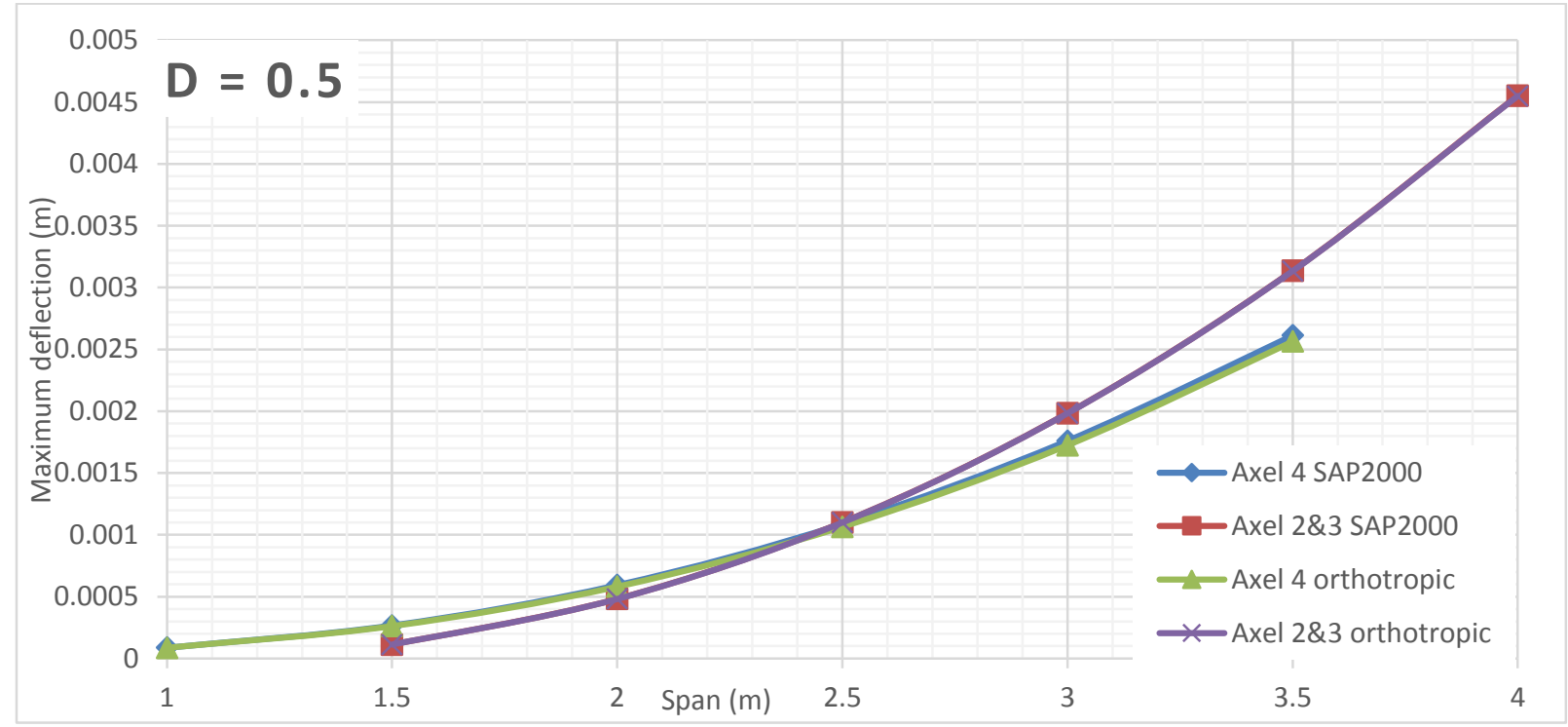

Figure 827 Deflection comparison between FEA and Orthotropic Plate Theory for $D=0.5$ of alpha 0.75 (main bars parallel to traffic) 


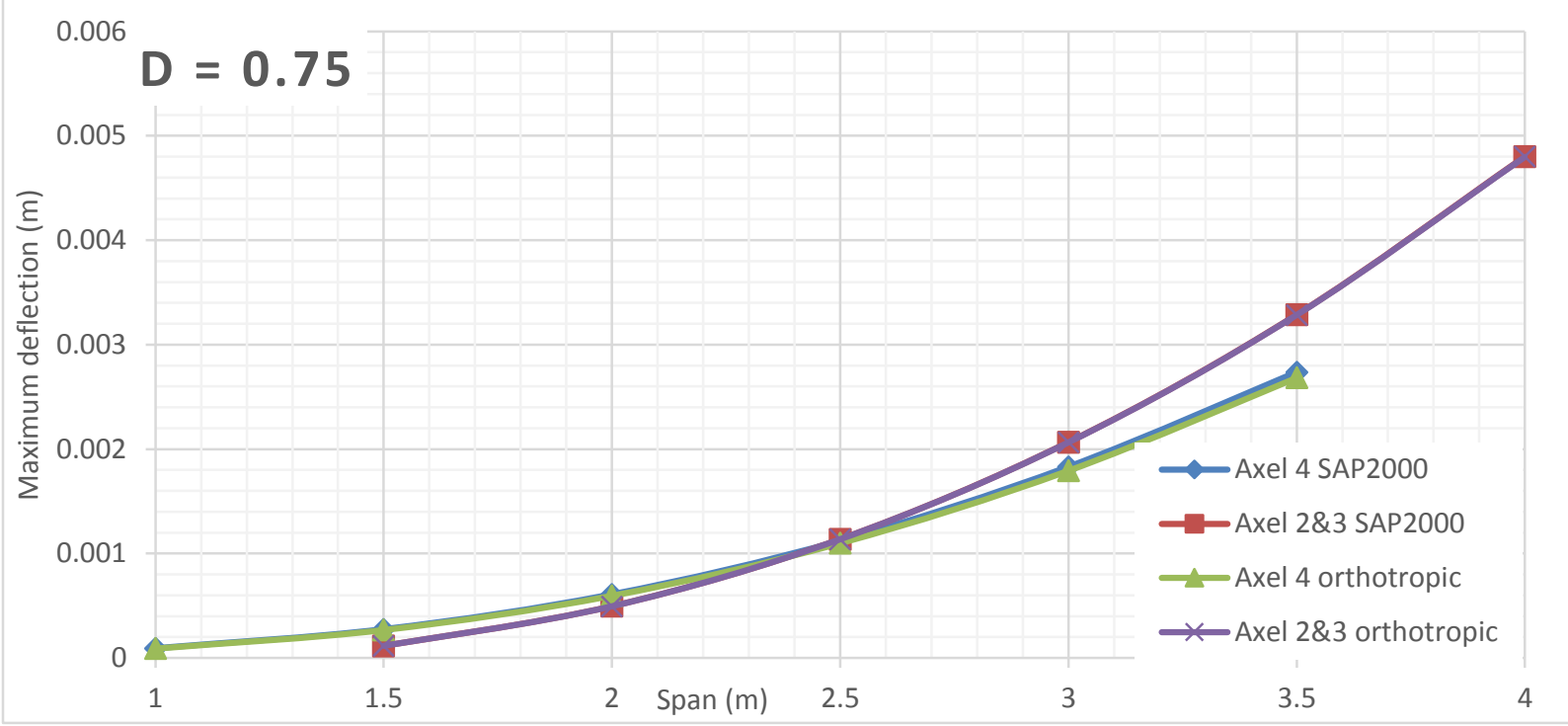

Figure 828 Deflection comparison between FEA and Orthotropic Plate Theory for $D=0.75$ of alpha 0.75 (main bars parallel to traffic)

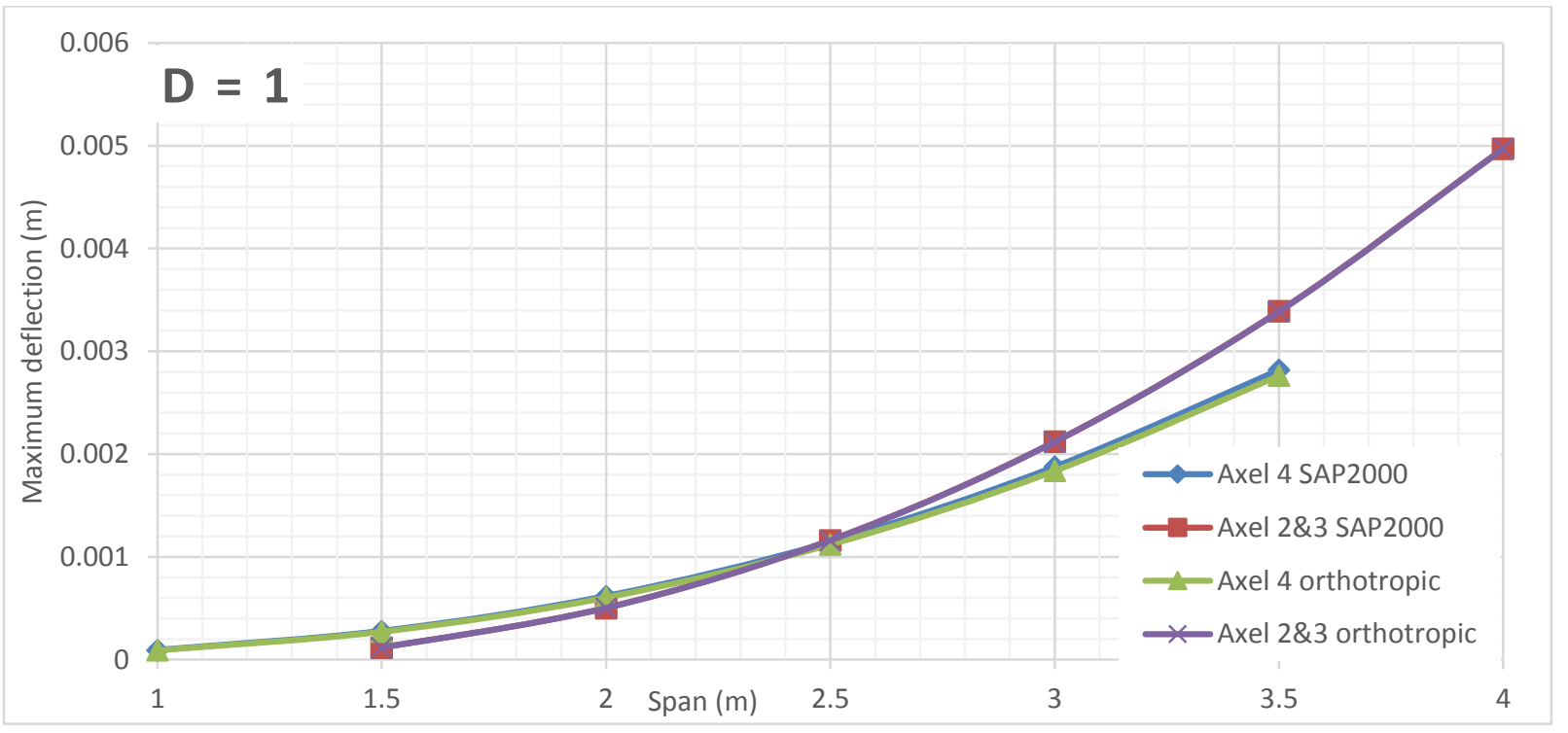

Figure 829 Deflection comparison between FEA and Orthotropic Plate Theory for $\mathrm{D}=1$ of alpha 0.75 (main bars parallel to traffic)

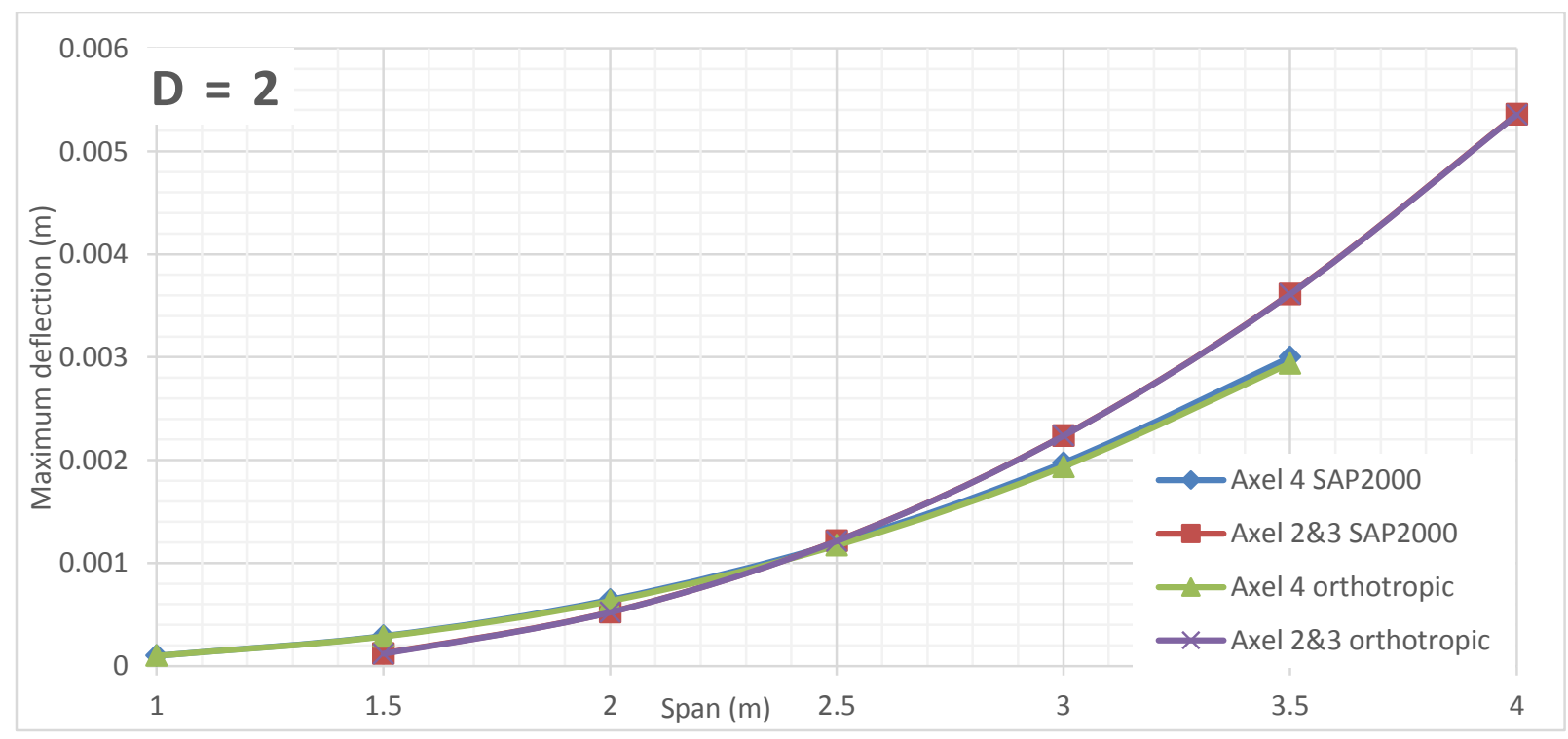

Figure 830 Deflection comparison between FEA and Orthotropic Plate Theory for $\mathrm{D}=2$ of alpha 0.75 (main bars parallel to traffic) 


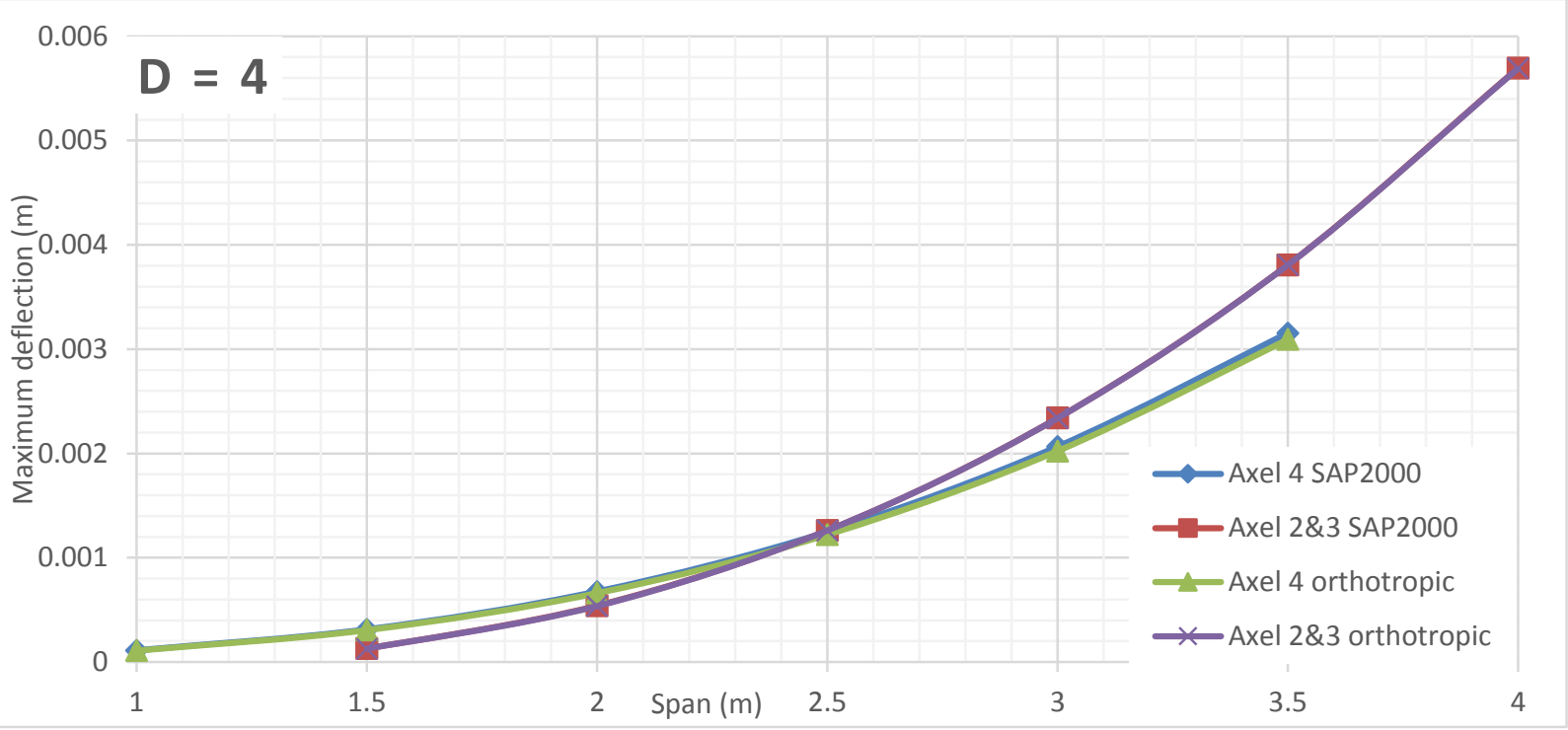

Figure 831 Deflection comparison between FEA and Orthotropic Plate Theory for $D=4$ of alpha 0.75 (main bars parallel to traffic)

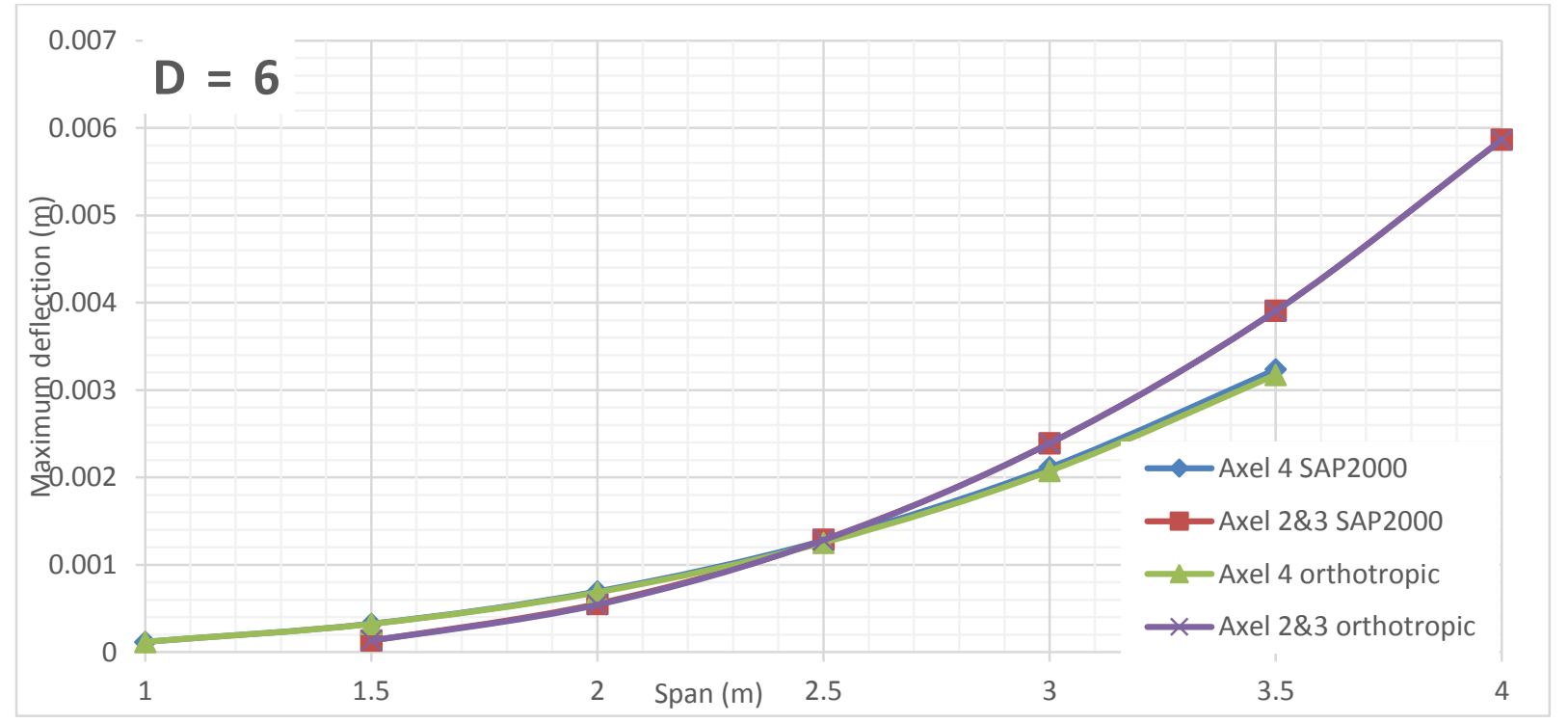

Figure 832 Deflection comparison between FEA and Orthotropic Plate Theory for $D=6$ of alpha 0.75 (main bars parallel to traffic)

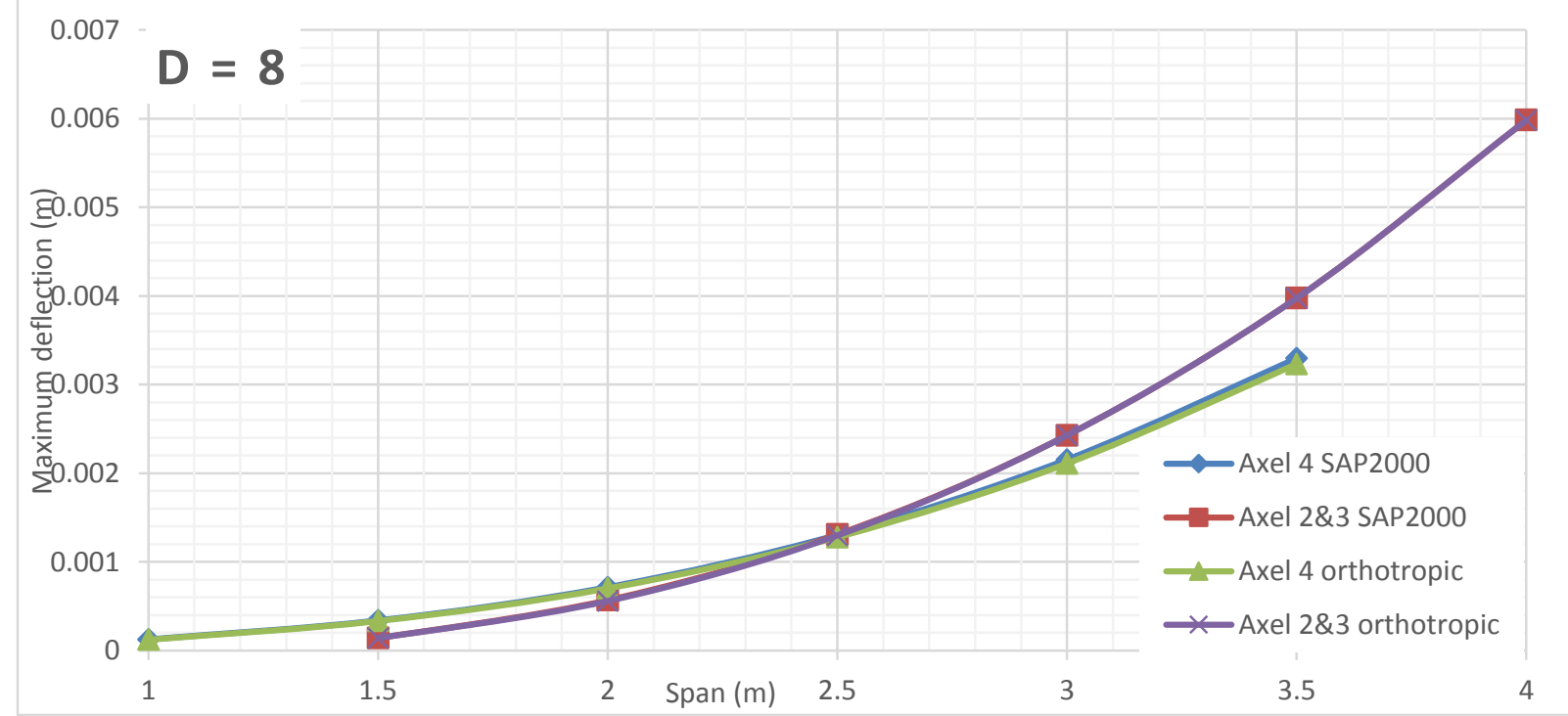

Figure 833 Deflection comparison between FEA and Orthotropic Plate Theory for $\mathrm{D}=8$ of alpha 0.75 (main bars parallel to traffic) 


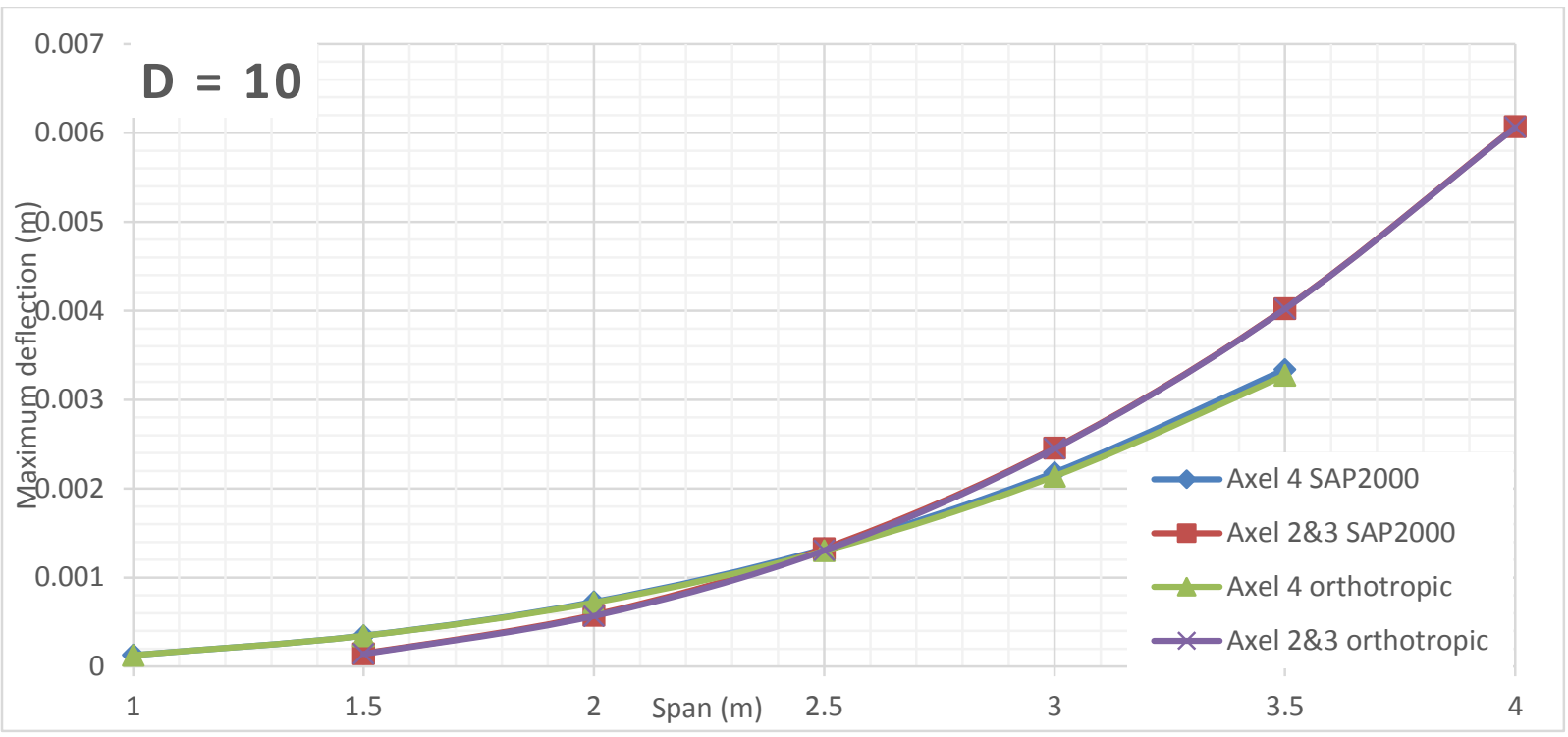

Figure 834 Deflection comparison between FEA and Orthotropic Plate Theory for $D=10$ of alpha 0.75 (main bars parallel to traffic) 


\section{Alpha 1 Deflection VS Span Length for Different D Values (Main bars perpendicular to traffic)}

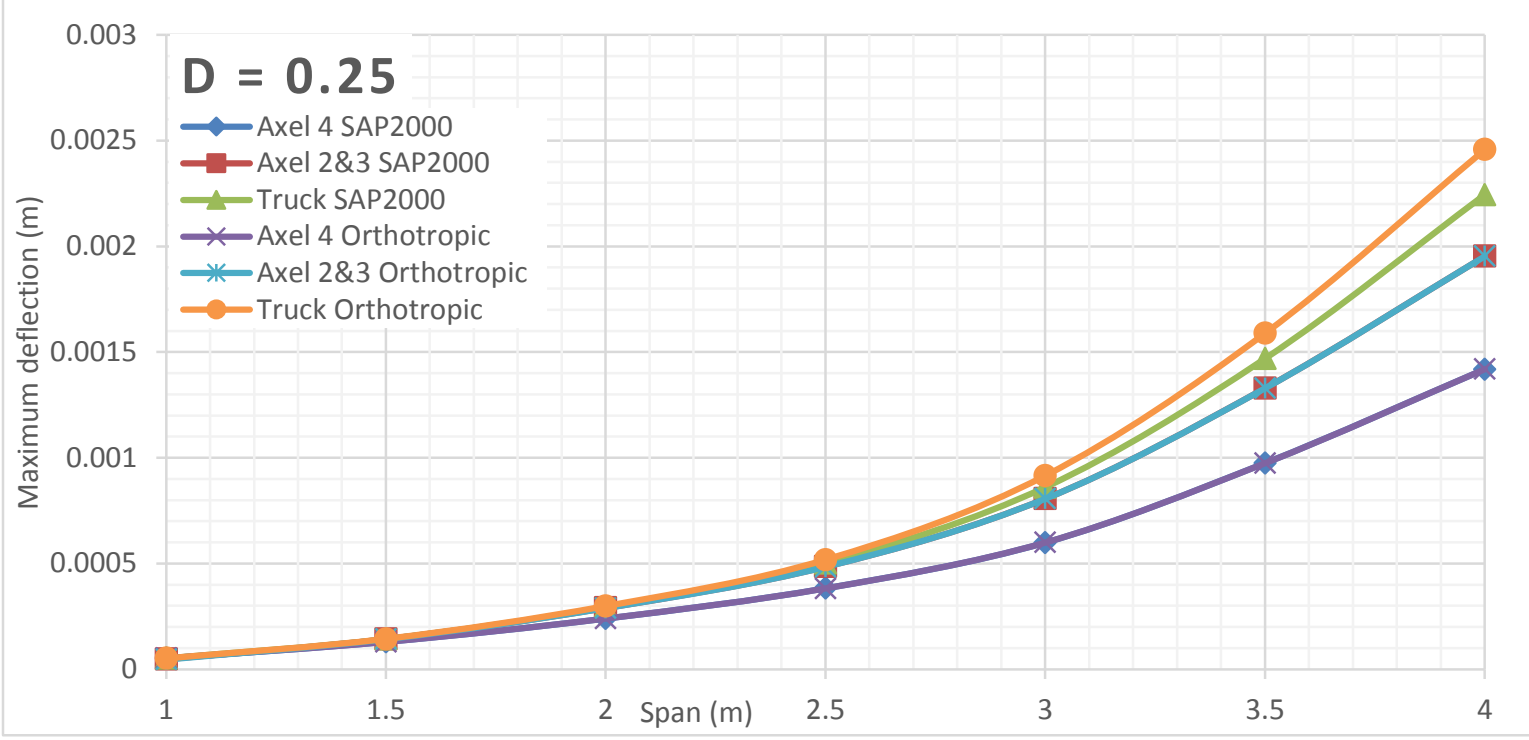

Figure 835 Deflection comparison between FEA and Orthotropic Plate Theory for $D=0.25$ of alpha 1 (main bars perpendicular to traffic)

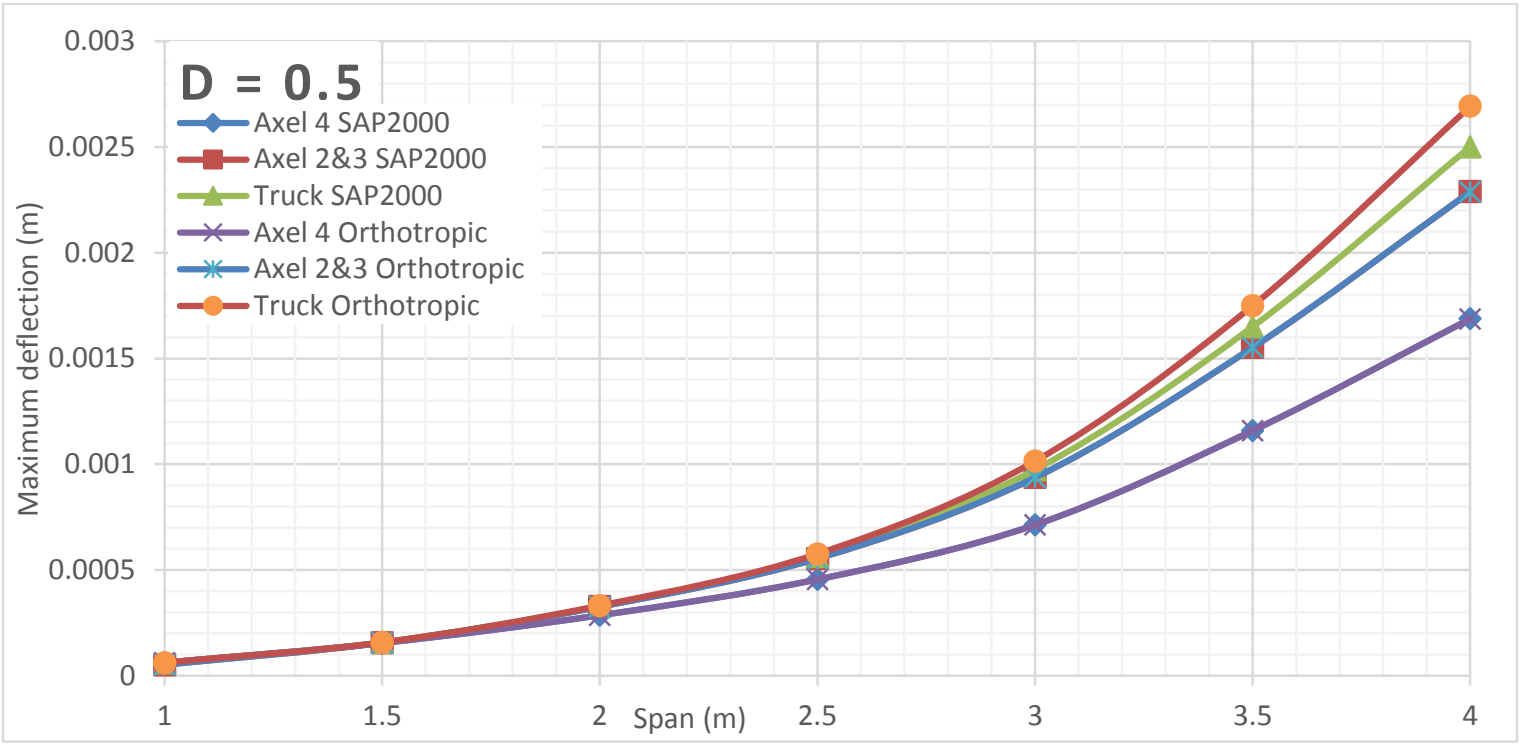

Figure 836 Deflection comparison between FEA and Orthotropic Plate Theory for $D=0.5$ of alpha 1 (main bars perpendicular to traffic) 


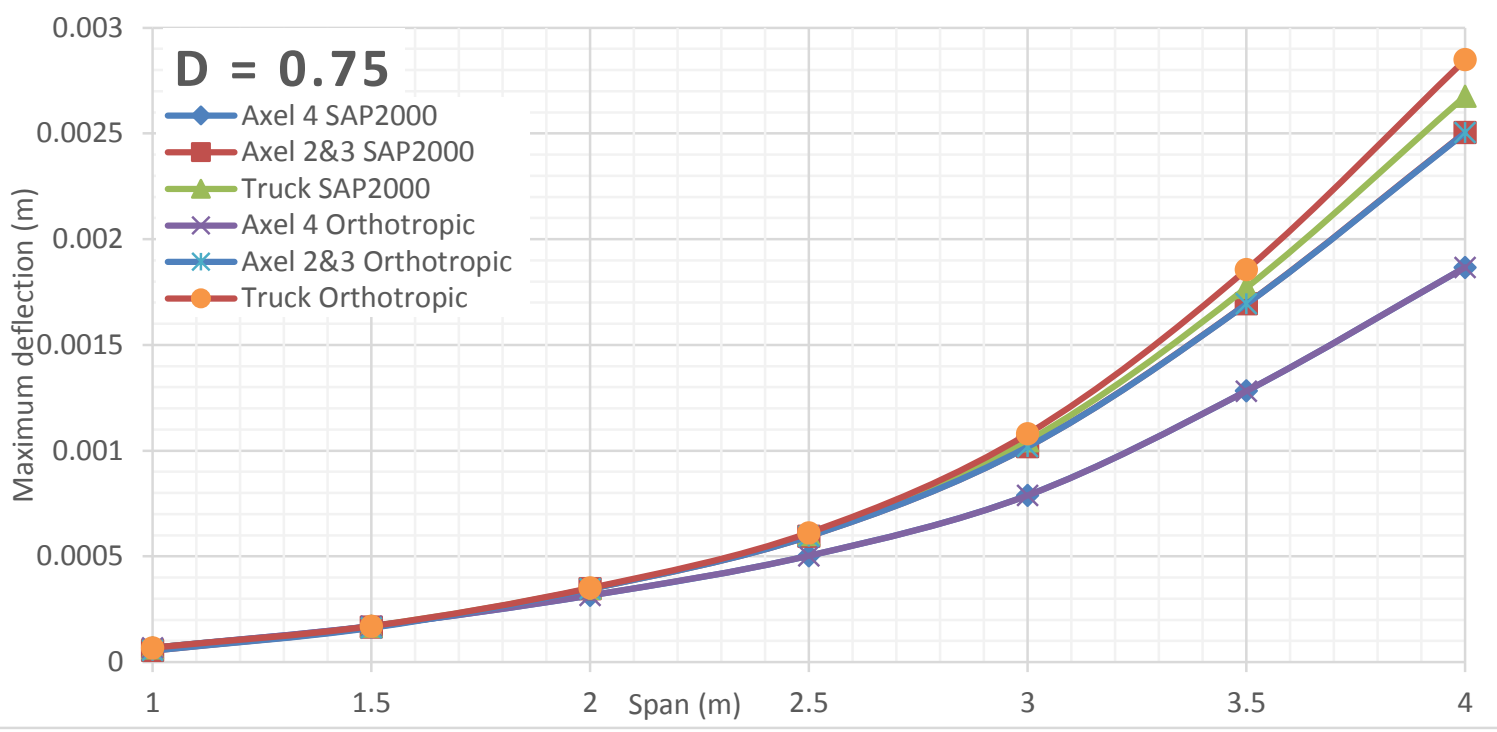

Figure 837 Deflection comparison between FEA and Orthotropic Plate Theory for $D=0.75$ of alpha 1 (main bars perpendicular to traffic)

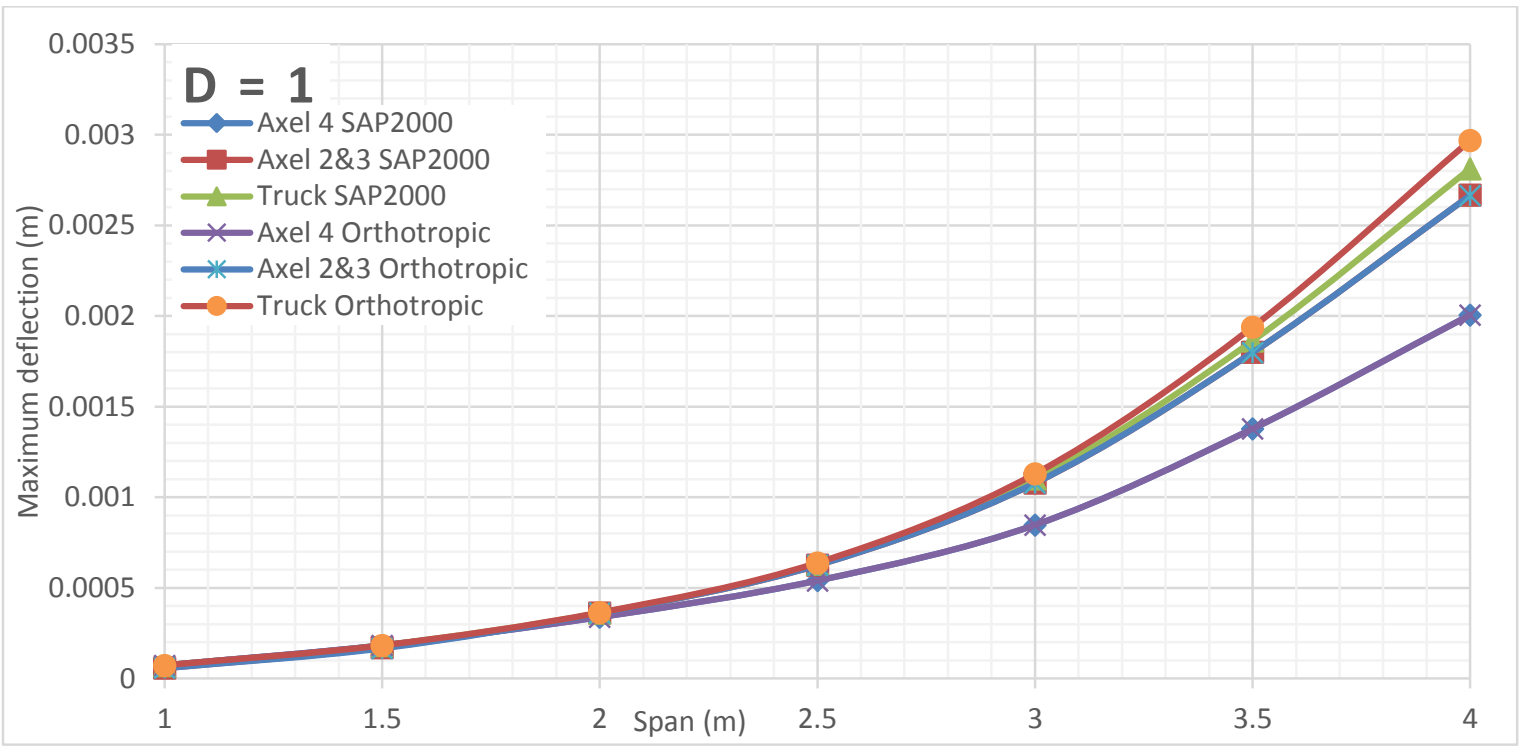

Figure 838 Deflection comparison between FEA and Orthotropic Plate Theory for $D=1$ of alpha 1 (main bars perpendicular to traffic)

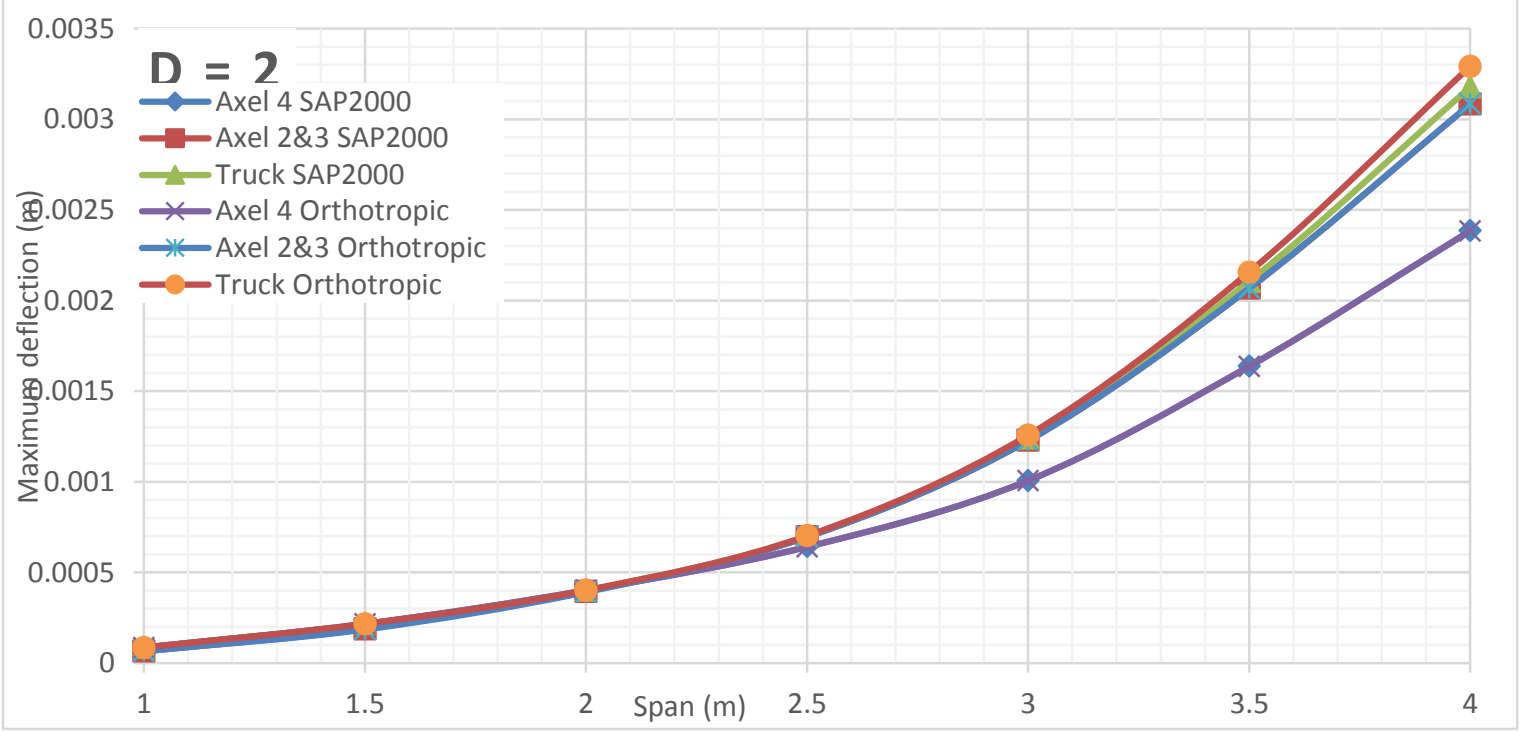

Figure 839 Deflection comparison between FEA and Orthotropic Plate Theory for $D=2$ of alpha 1 (main bars perpendicular to traffic) 


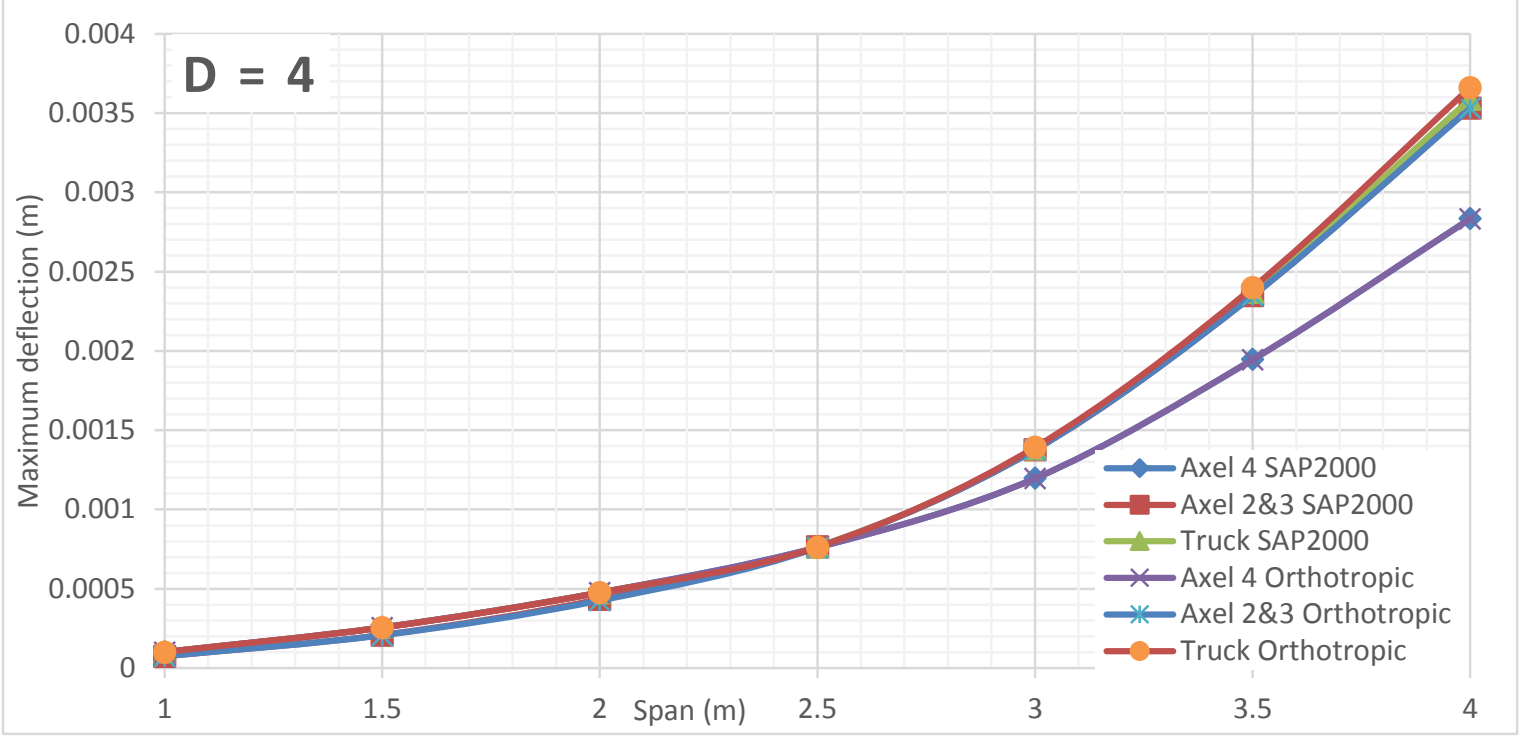

Figure 840 Deflection comparison between FEA and Orthotropic Plate Theory for $D=4$ of alpha 1 (main bars perpendicular to traffic)

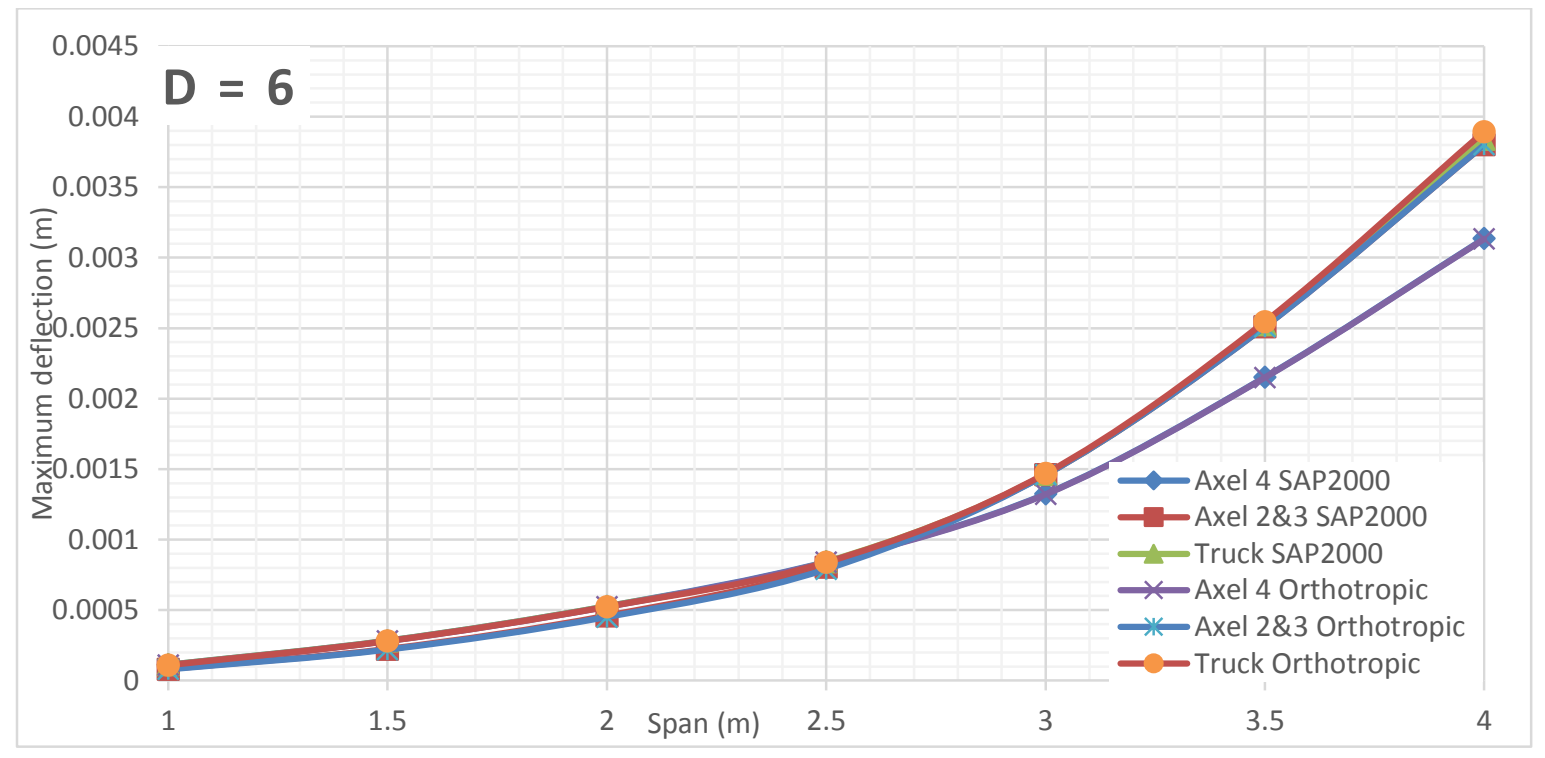

Figure 841 Deflection comparison between FEA and Orthotropic Plate Theory for $D=6$ of alpha 1 (main bars perpendicular to traffic)

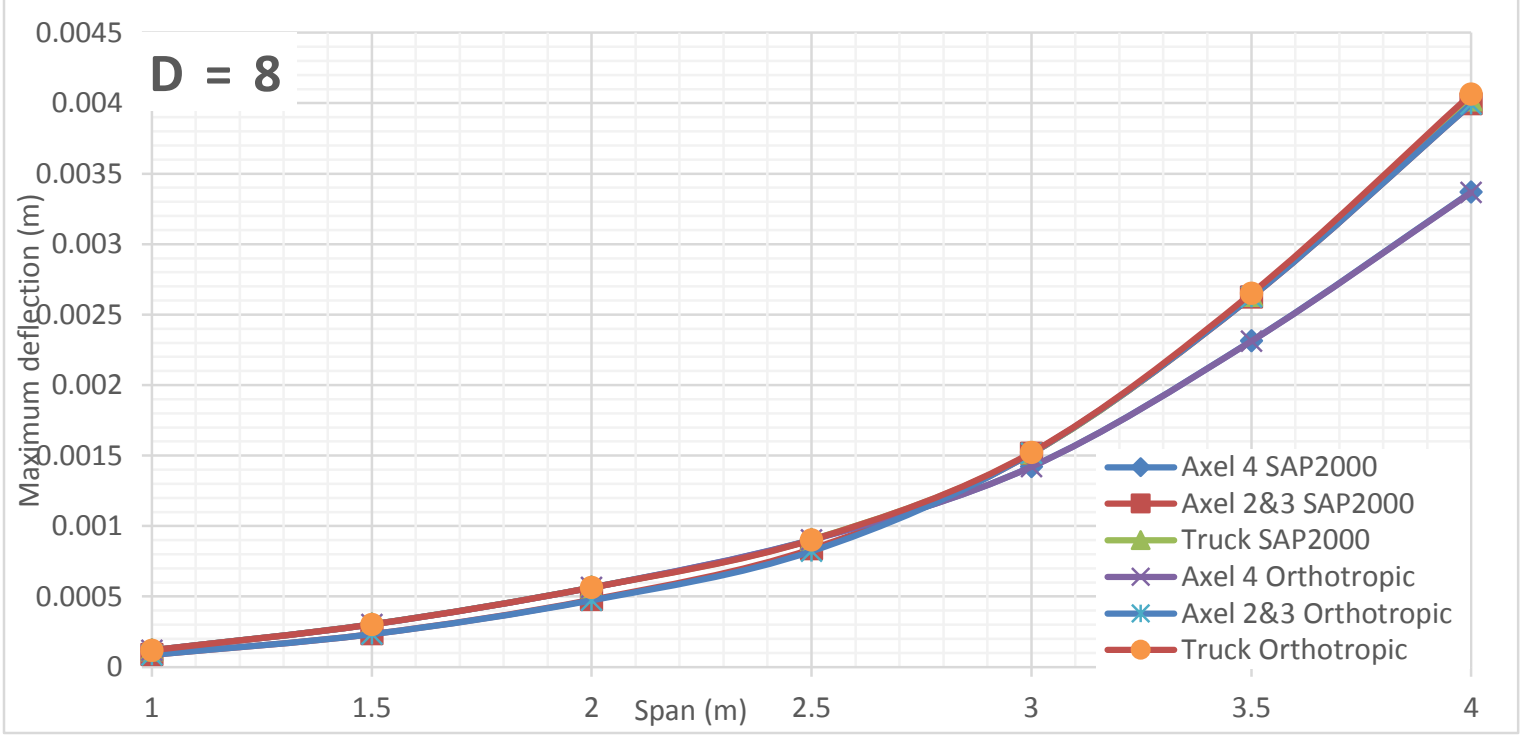

Figure 842 Deflection comparison between FEA and Orthotropic Plate Theory for $D=8$ of alpha 1 (main bars perpendicular to traffic) 


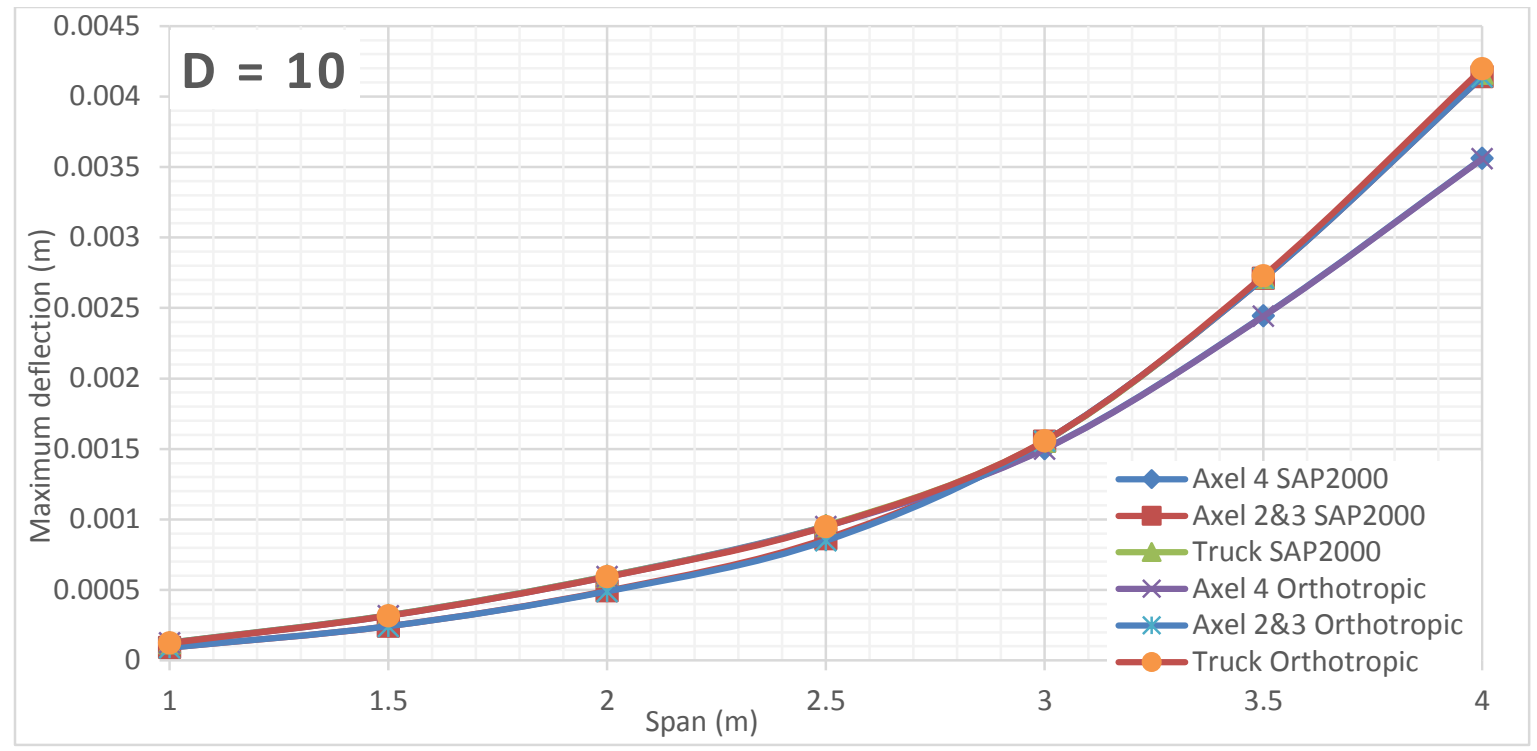

Figure 843 Deflection comparison between FEA and Orthotropic Plate Theory for $D=10$ of alpha 1 (main bars perpendicular to traffic) 


\section{Alpha 1 Deflection VS Span Length for Different D Values (Main bars parallel to traffic)}

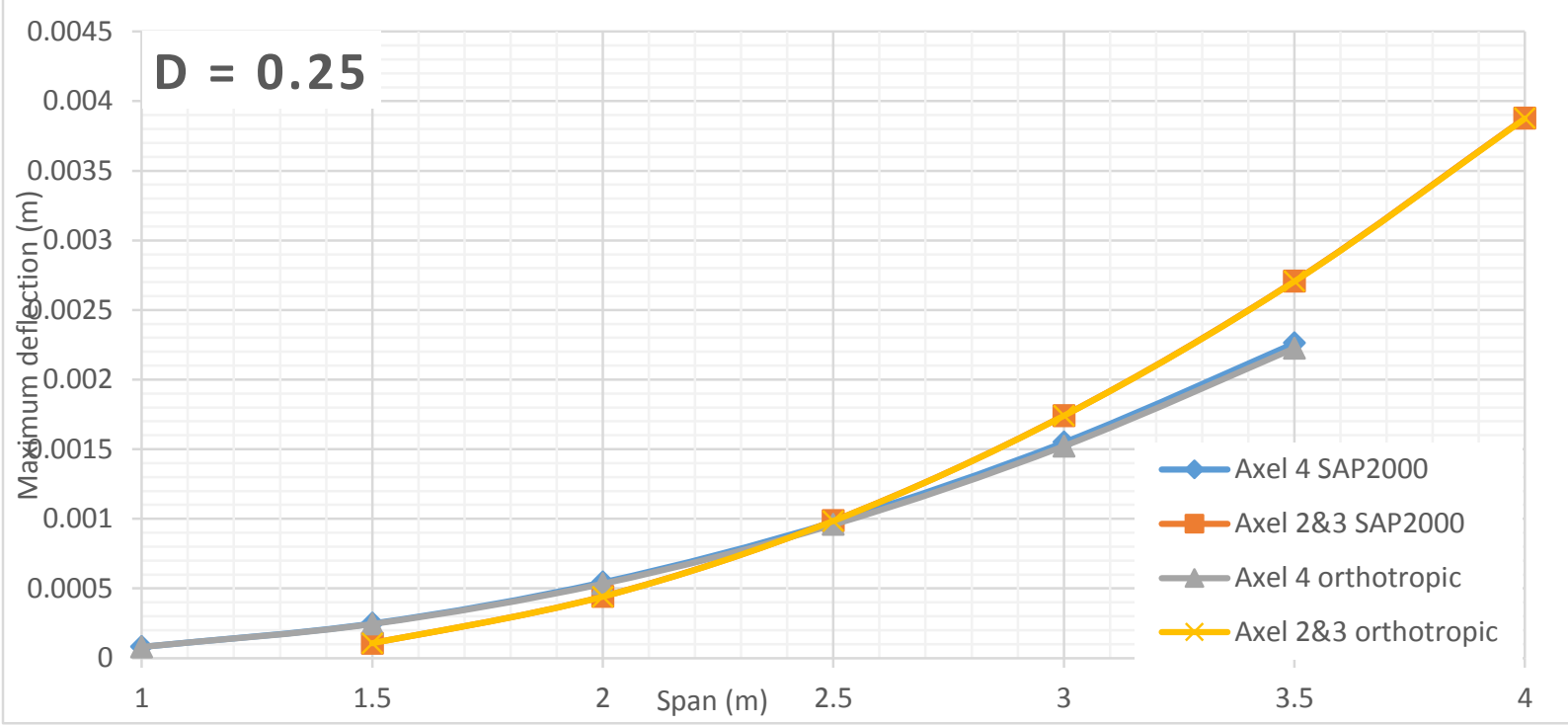

Figure 844 Deflection comparison between FEA and Orthotropic Plate Theory for $D=0.25$ of alpha 1 (main bars parallel to traffic)

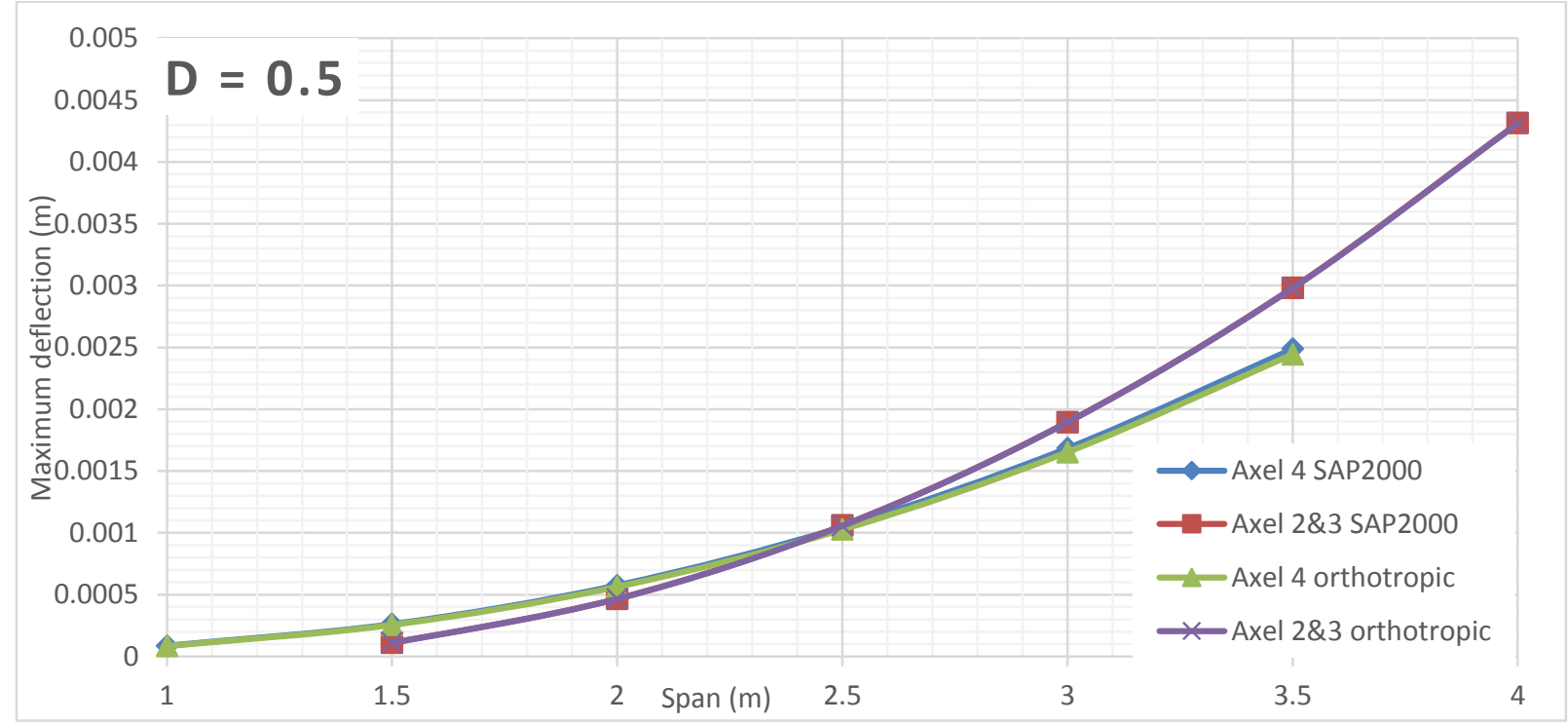

Figure 845 Deflection comparison between FEA and Orthotropic Plate Theory for $D=0.5$ of alpha 1 (main bars parallel to traffic) 


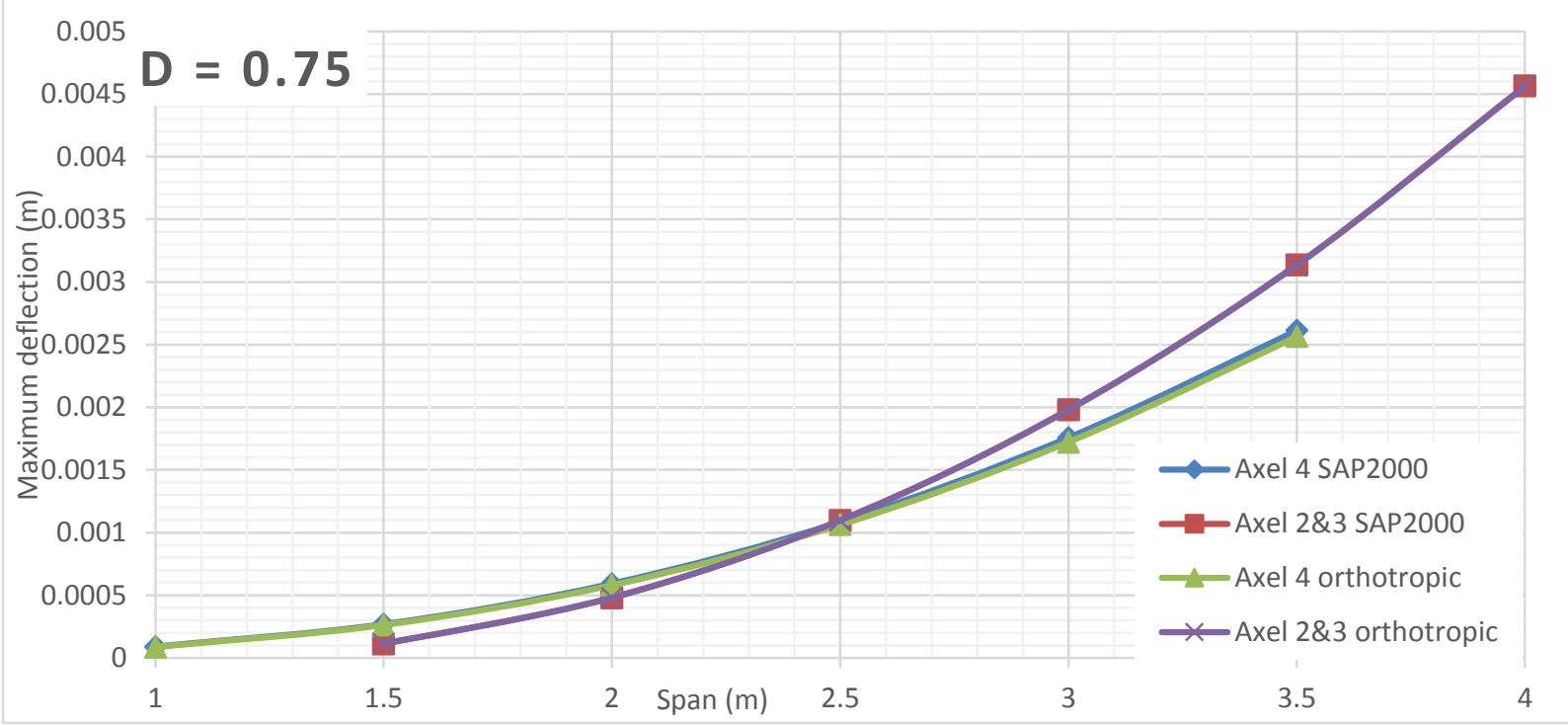

Figure 846 Deflection comparison between FEA and Orthotropic Plate Theory for $D=0.75$ of alpha 1 (main bars parallel to traffic)

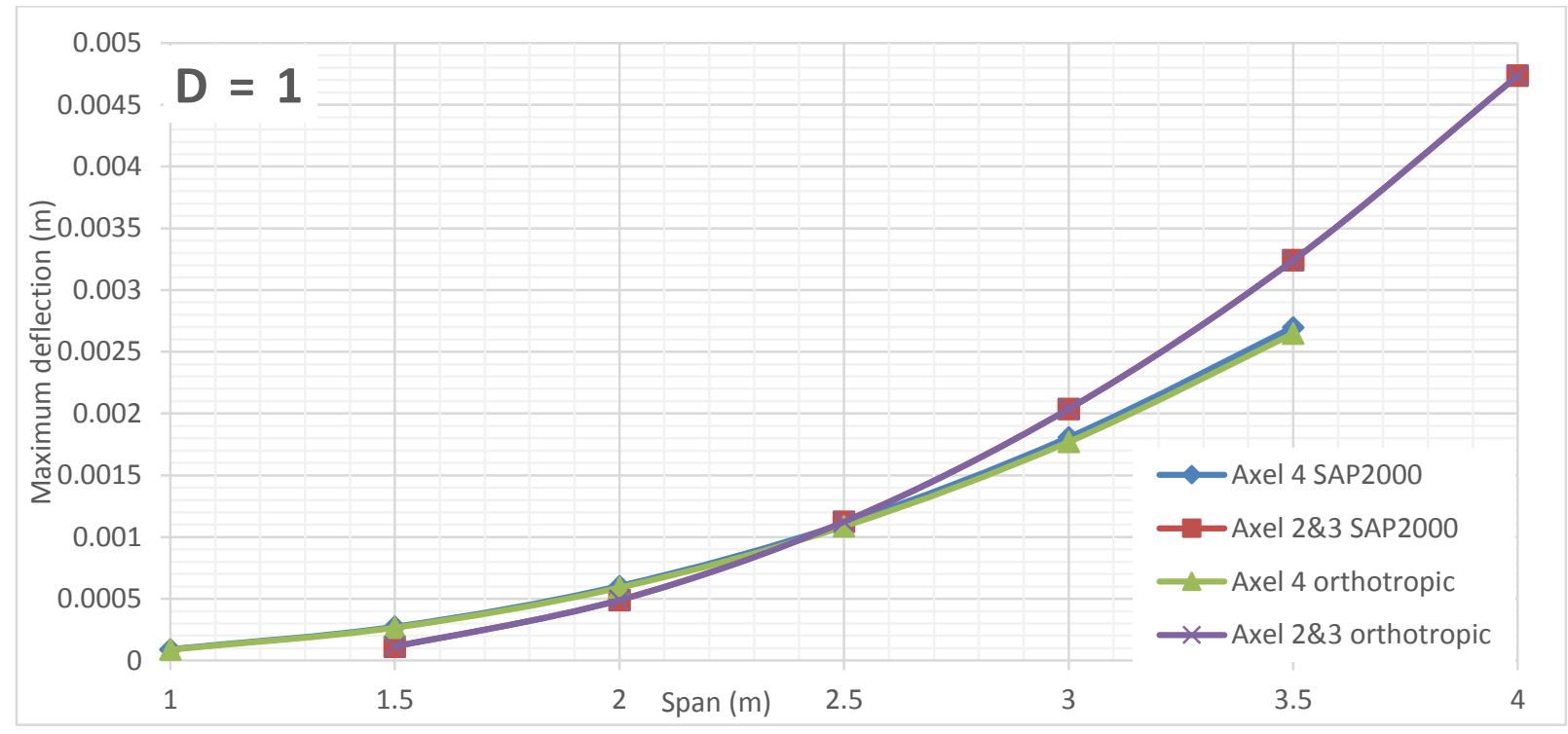

Figure 847 Deflection comparison between FEA and Orthotropic Plate Theory for $D=1$ of alpha 1 (main bars parallel to traffic)

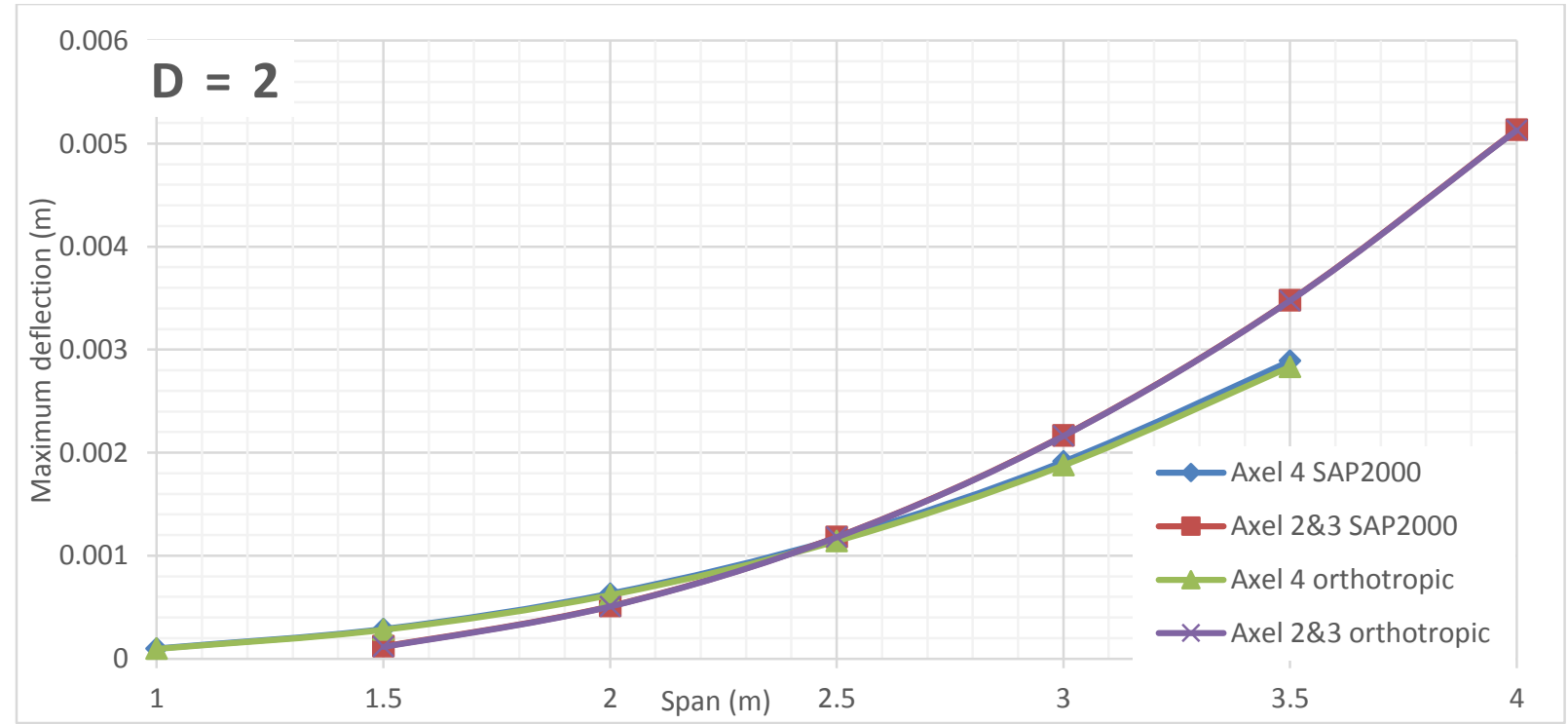

Figure 848 Deflection comparison between FEA and Orthotropic Plate Theory for $\mathrm{D}=2$ of alpha 1 (main bars parallel to traffic) 


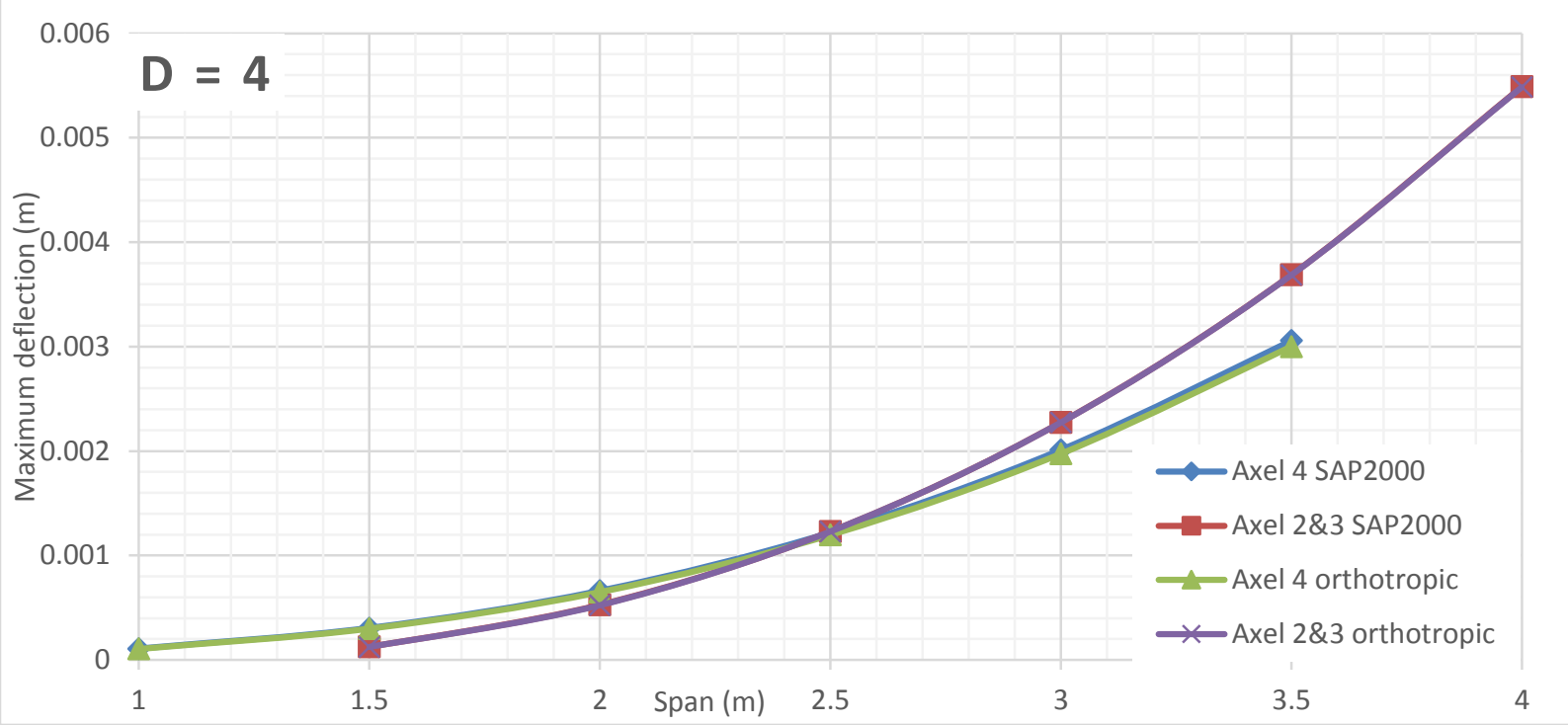

Figure 849 Deflection comparison between FEA and Orthotropic Plate Theory for $D=4$ of alpha 1 (main bars parallel to traffic)

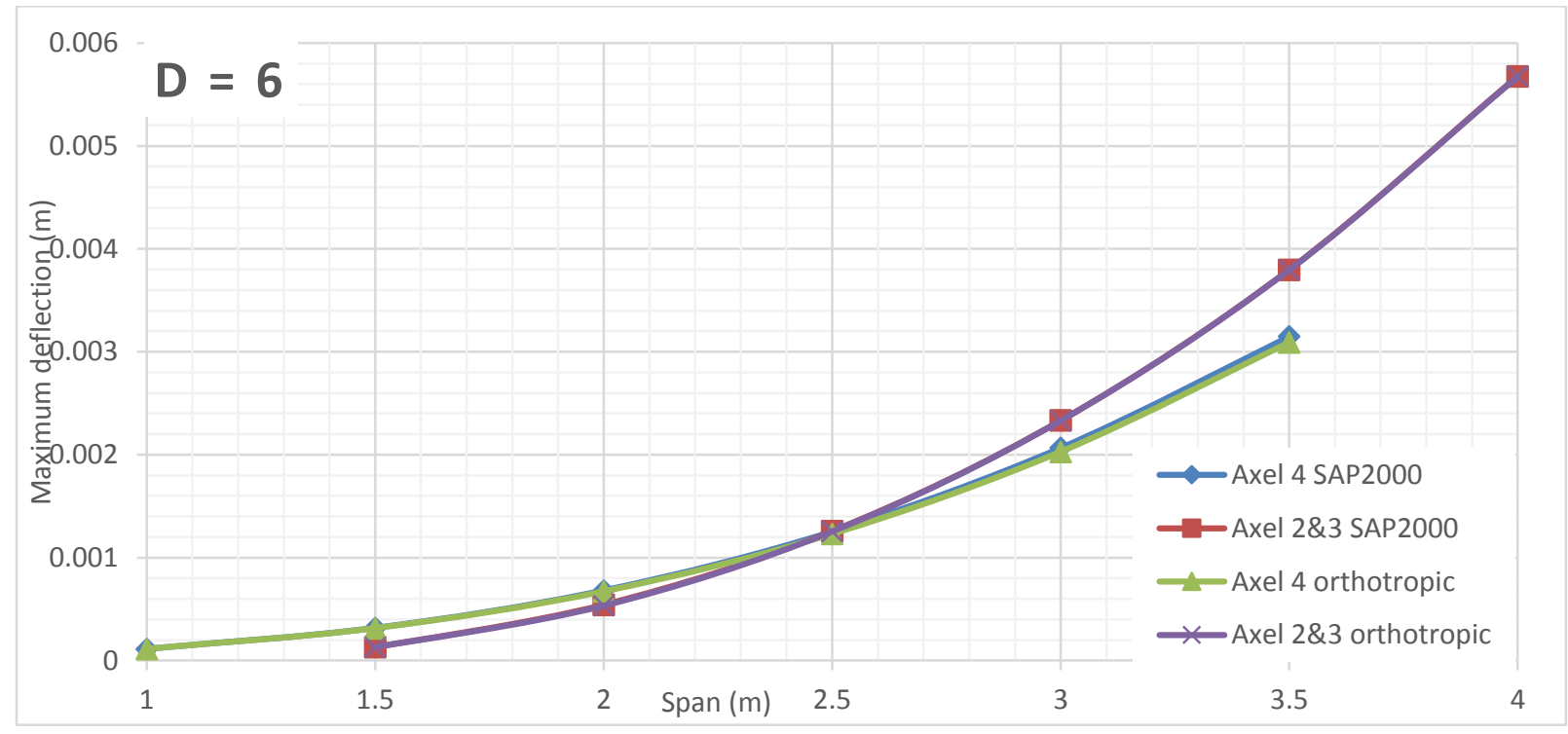

Figure 850 Deflection comparison between FEA and Orthotropic Plate Theory for $D=6$ of alpha 1 (main bars parallel to traffic)

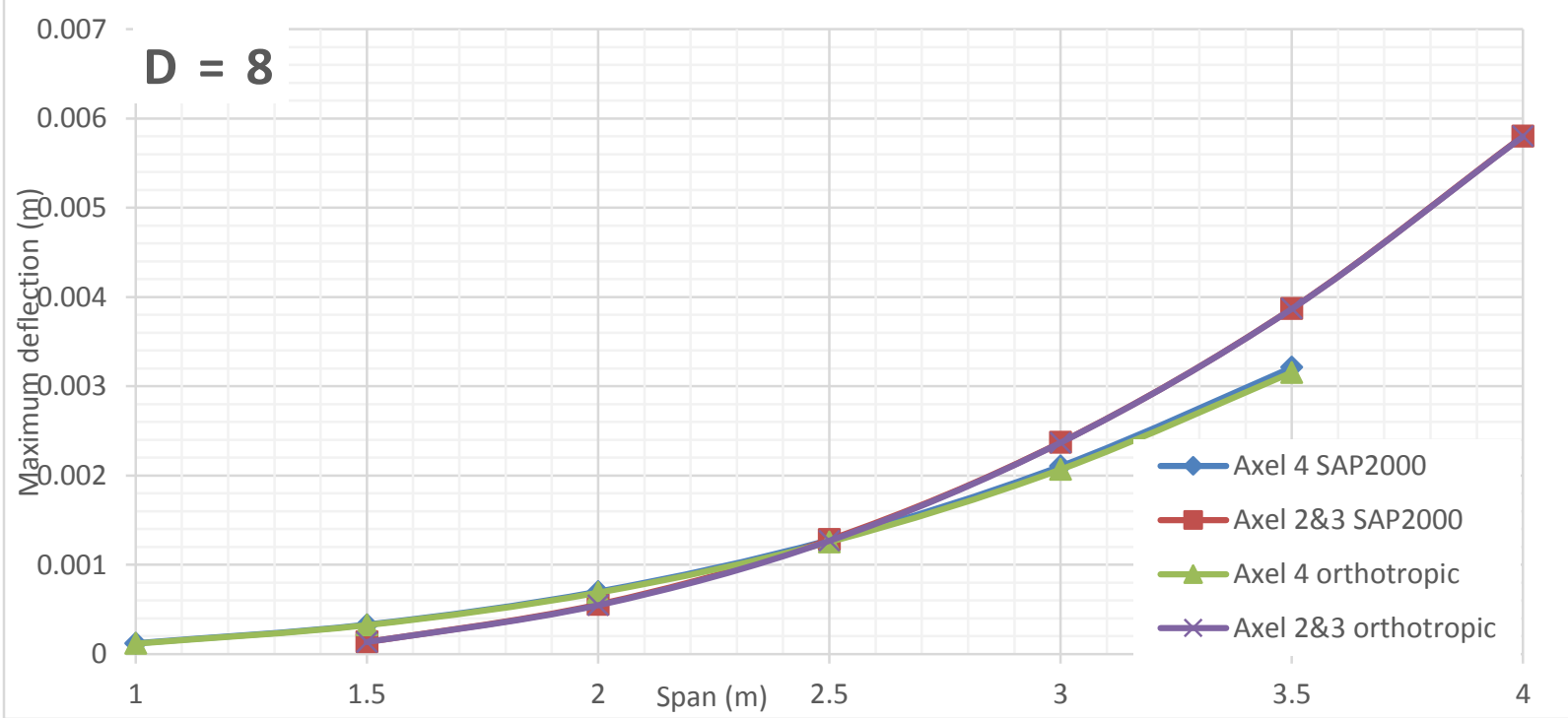

Figure 851 Deflection comparison between FEA and Orthotropic Plate Theory for $\mathrm{D}=8$ of alpha 1 (main bars parallel to traffic) 


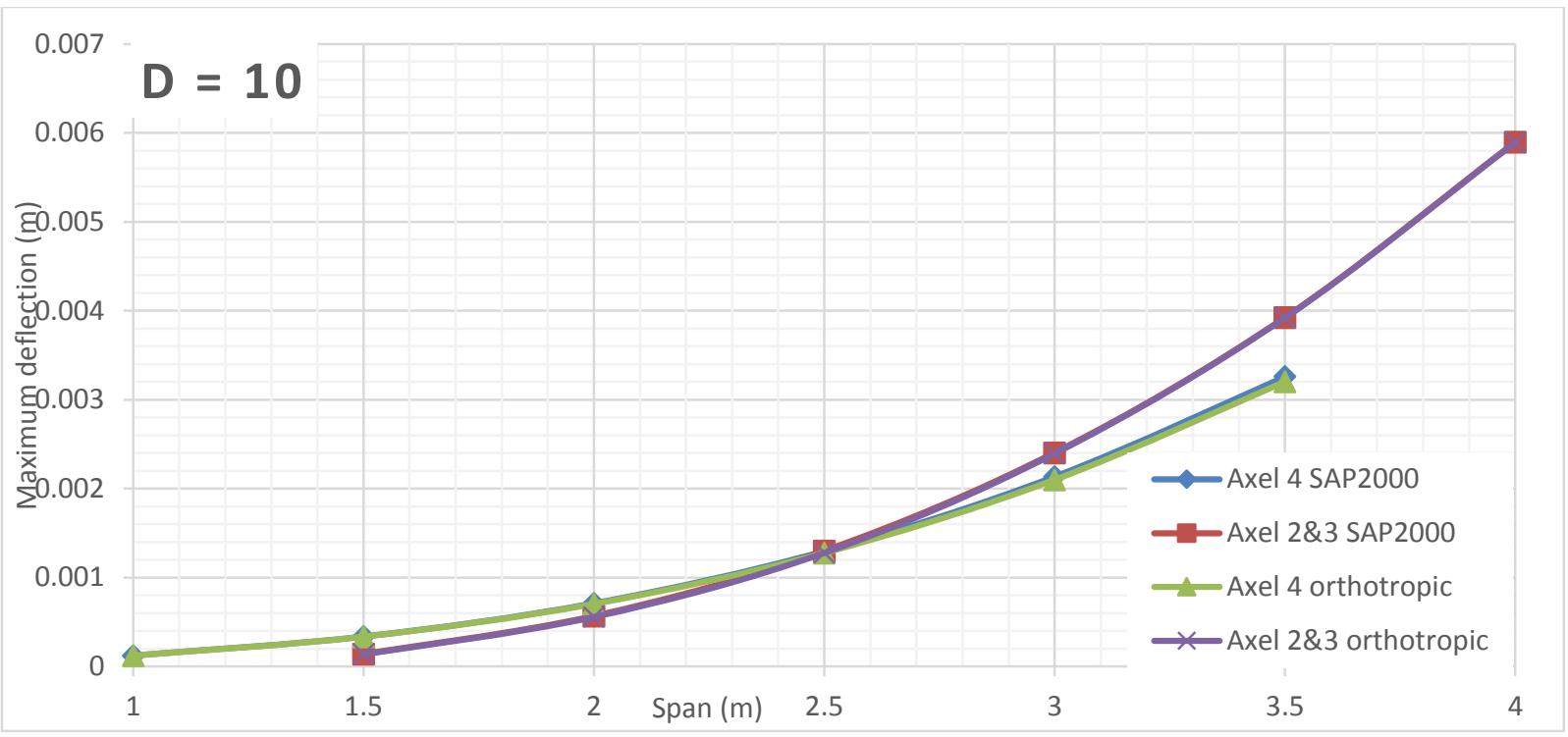

Figure 852 Deflection comparison between FEA and Orthotropic Plate Theory for $D=10$ of alpha 1 (main bars parallel to traffic) 


\section{Alpha 2 Deflection VS Span Length for Different D Values (Main bars perpendicular to traffic)}

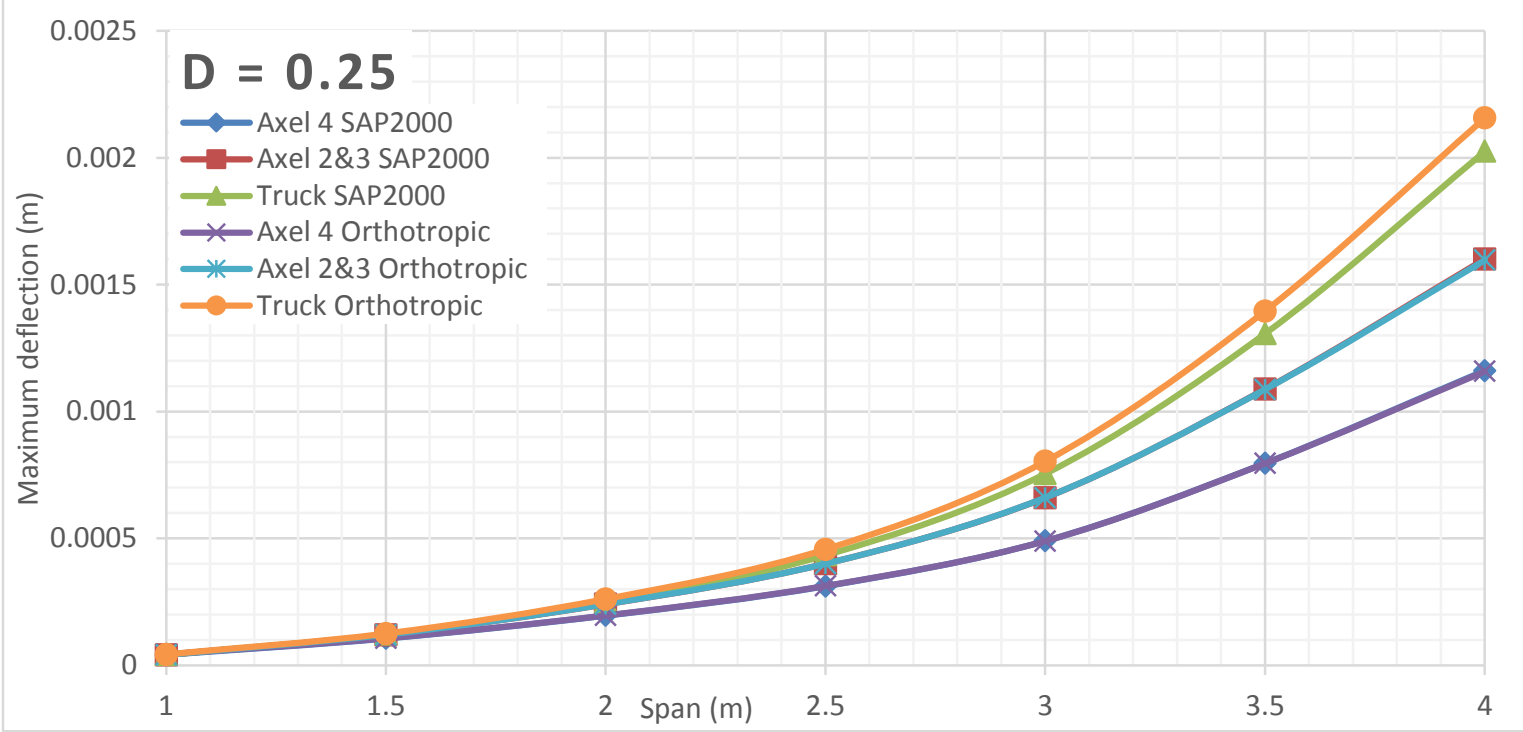

Figure 853 Deflection comparison between FEA and Orthotropic Plate Theory for $D=0.25$ of alpha 2 (main bars perpendicular to traffic)

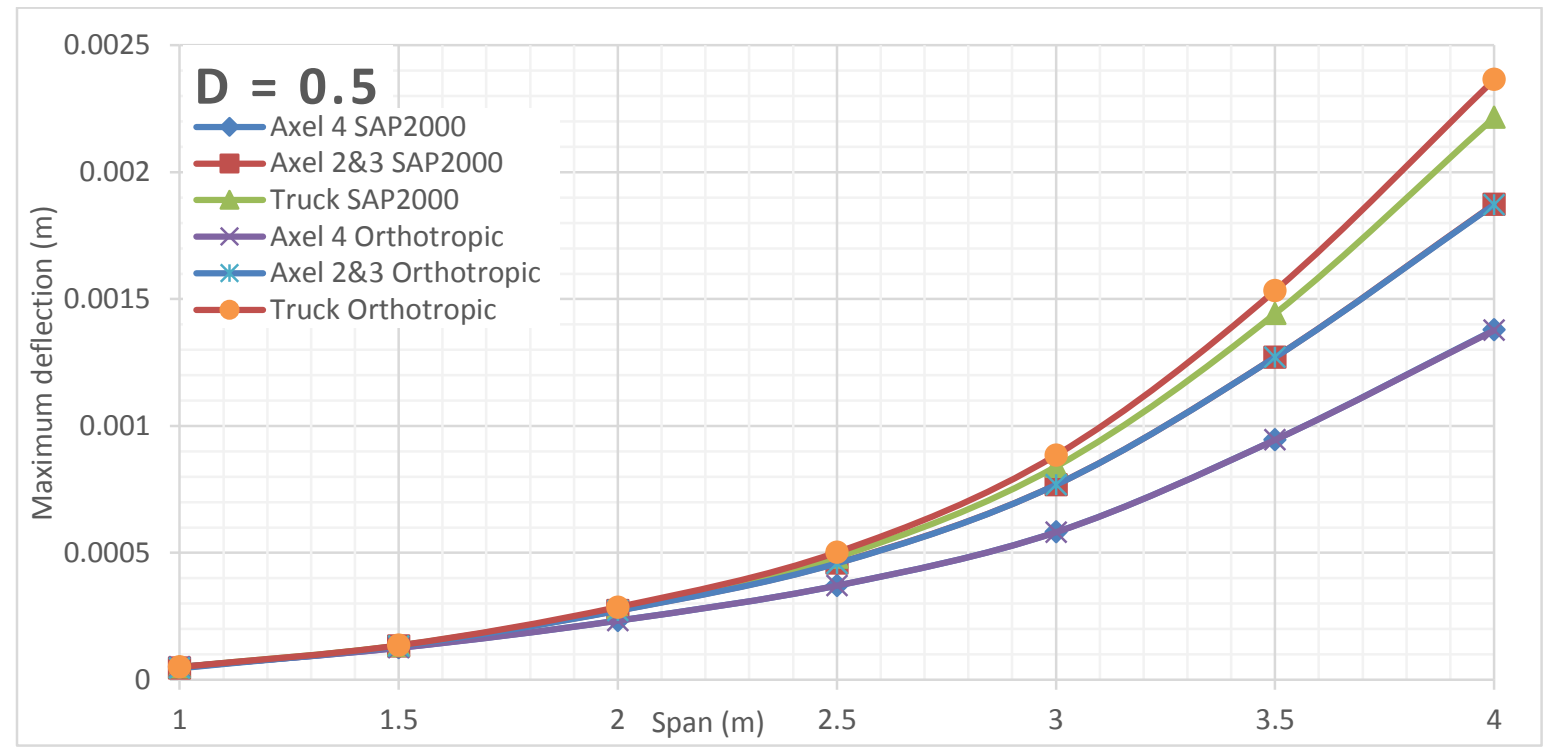

Figure 854 Deflection comparison between FEA and Orthotropic Plate Theory for D $=0.5$ of alpha 2 (main bars perpendicular to traffic) 


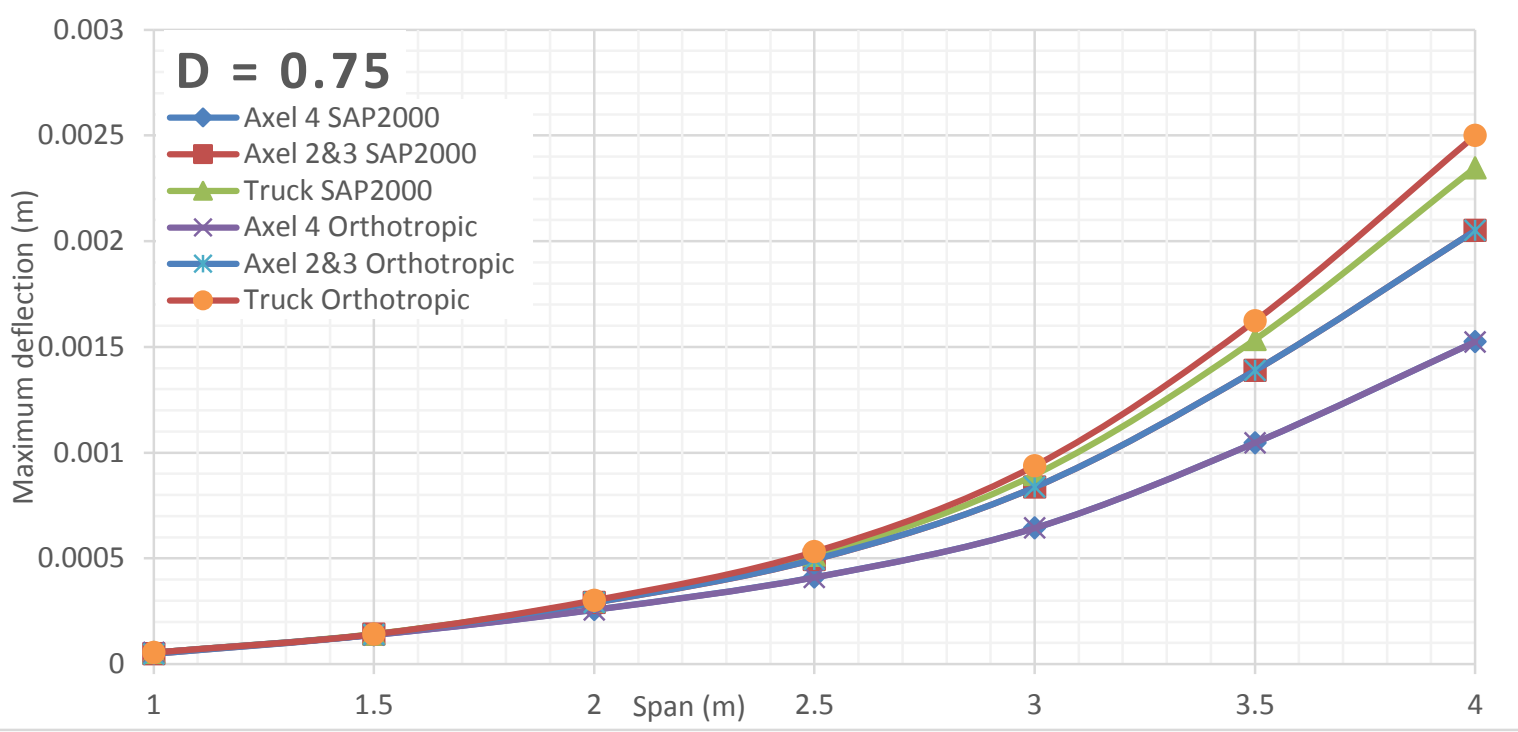

Figure 855 Deflection comparison between FEA and Orthotropic Plate Theory for $D=0.75$ of alpha 2 (main bars perpendicular to traffic)

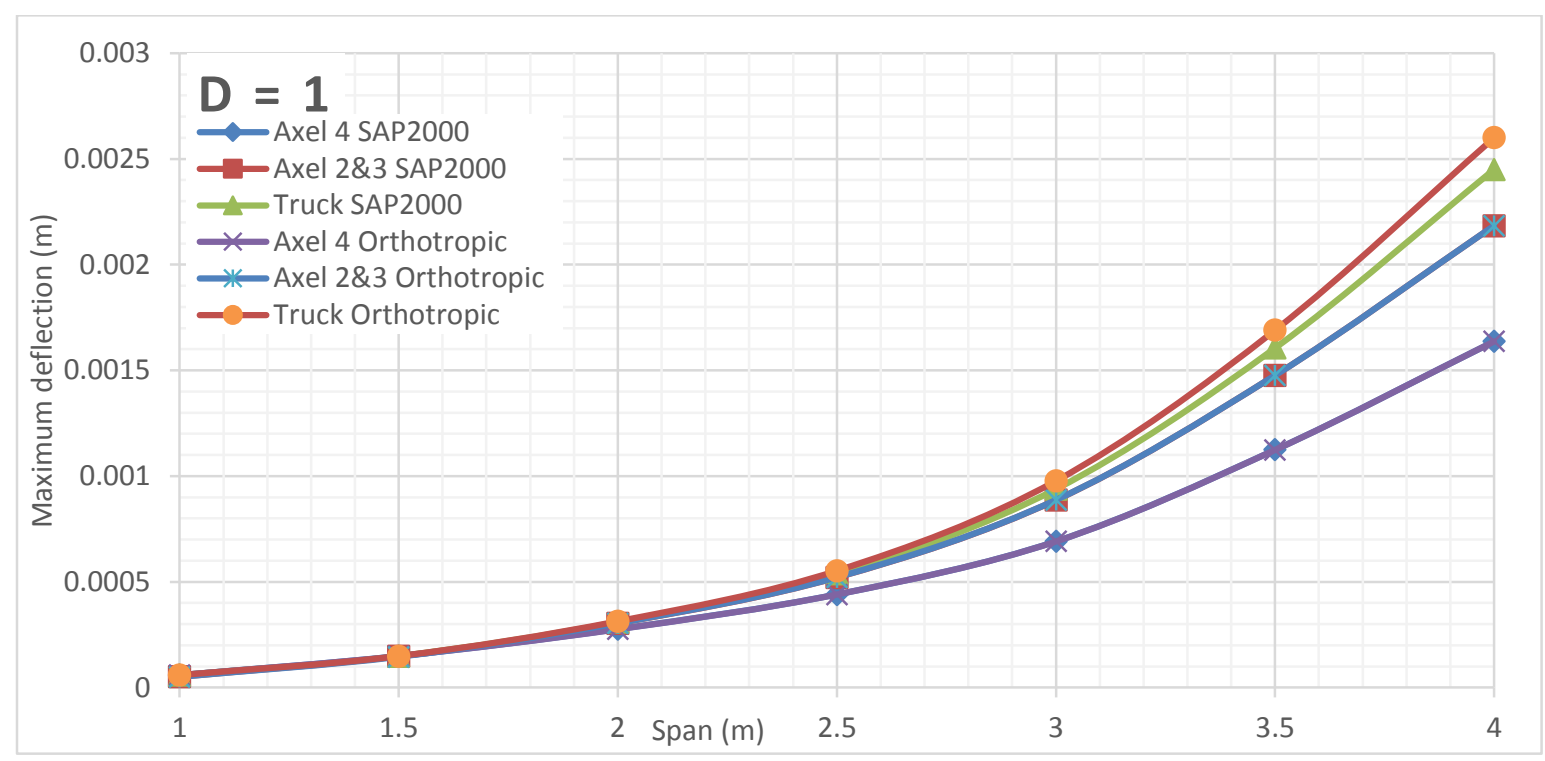

Figure 856 Deflection comparison between FEA and Orthotropic Plate Theory for $D=1$ of alpha 2 (main bars perpendicular to traffic)

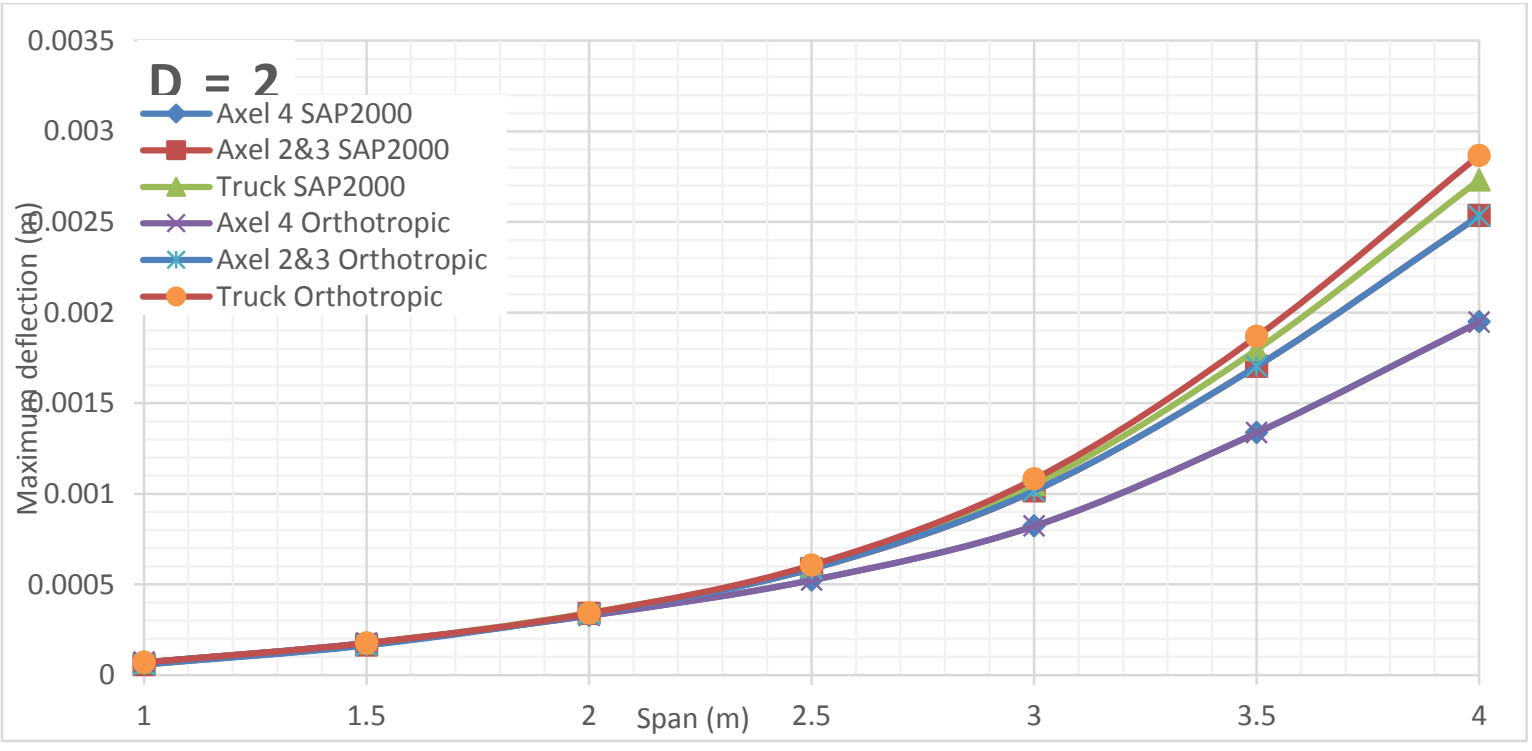

Figure 857 Deflection comparison between FEA and Orthotropic Plate Theory for $D=2$ of alpha 2 (main bars perpendicular to traffic) 


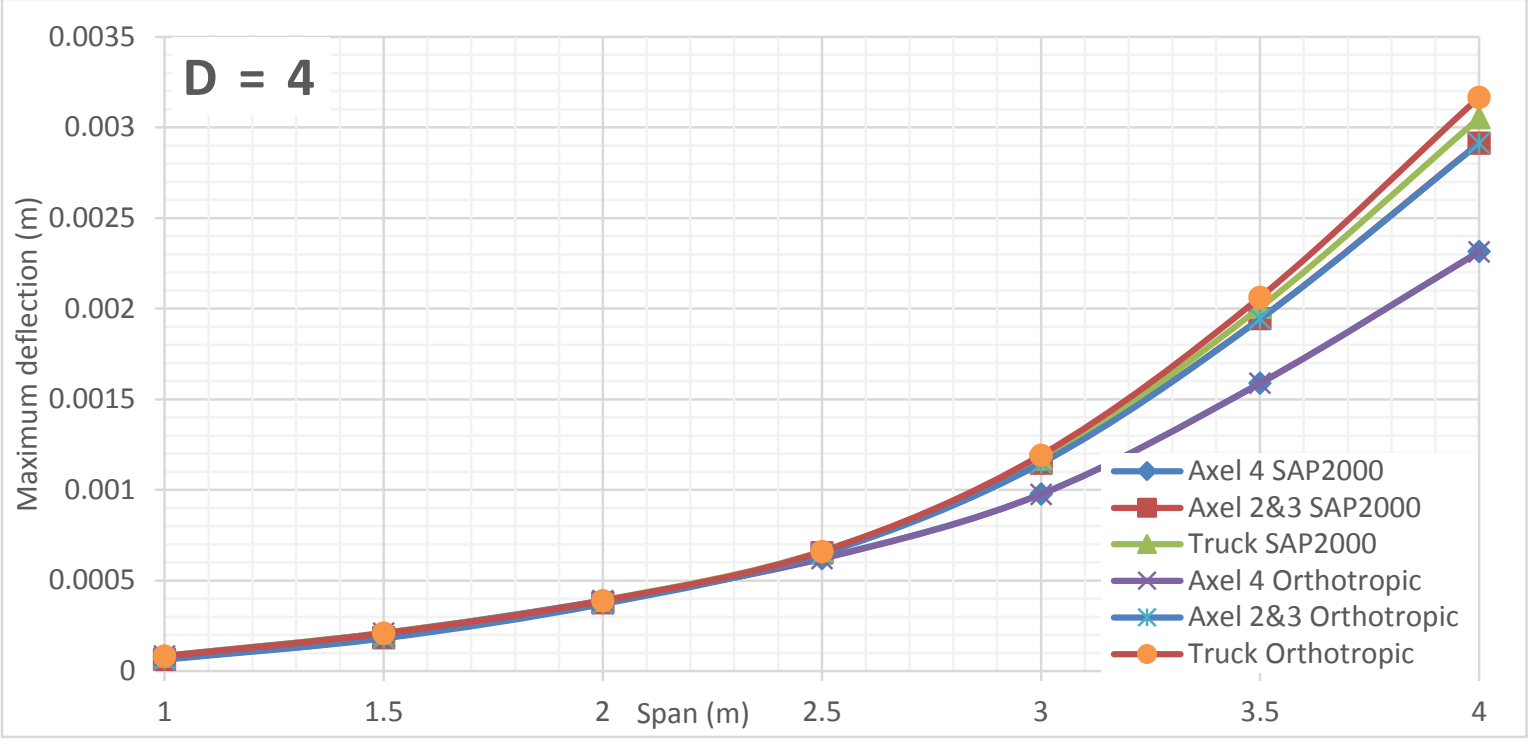

Figure 858 Deflection comparison between FEA and Orthotropic Plate Theory for $D=4$ of alpha 2 (main bars perpendicular to traffic)

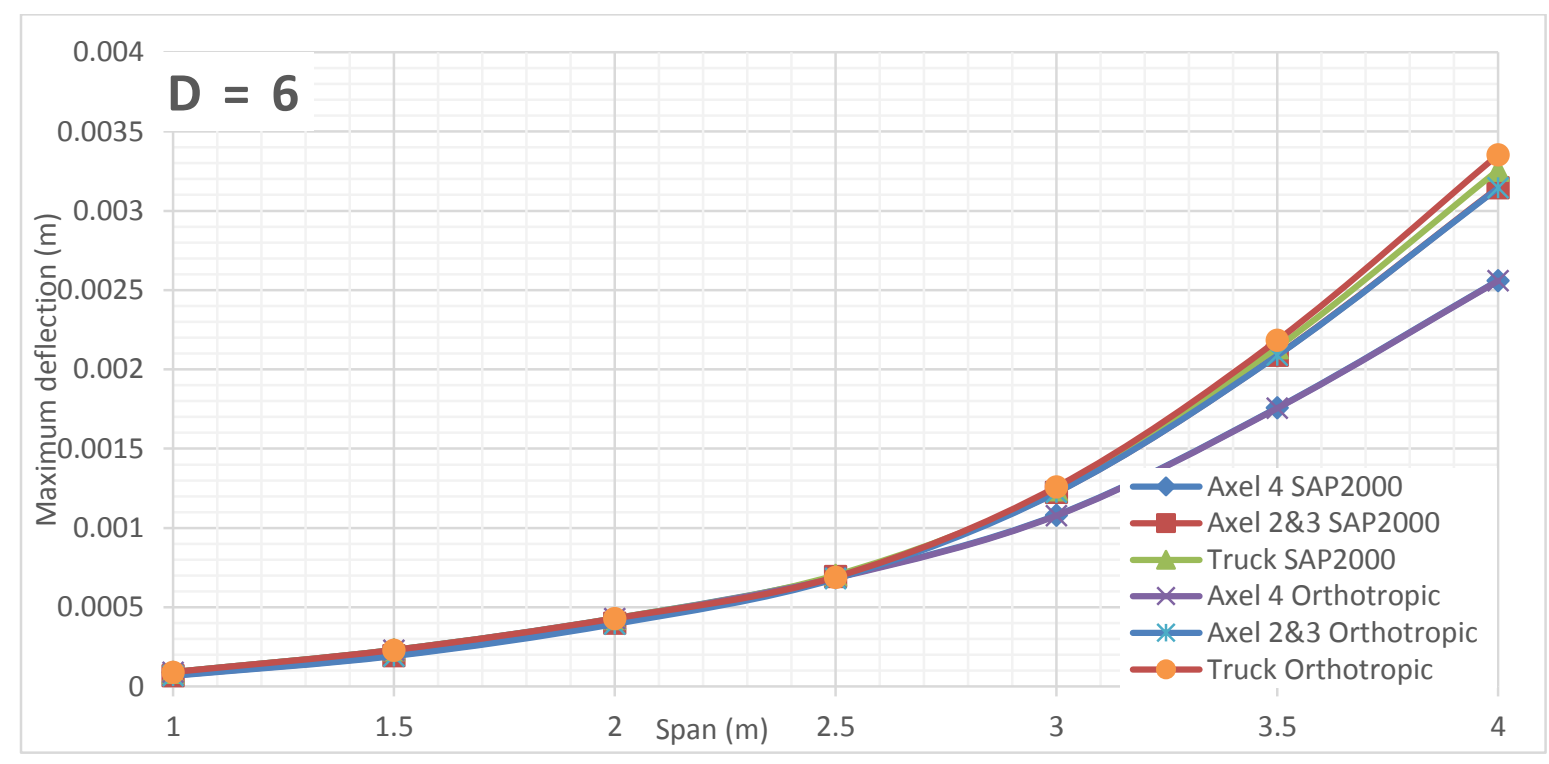

Figure 859 Deflection comparison between FEA and Orthotropic Plate Theory for $D=6$ of alpha 2 (main bars perpendicular to traffic)

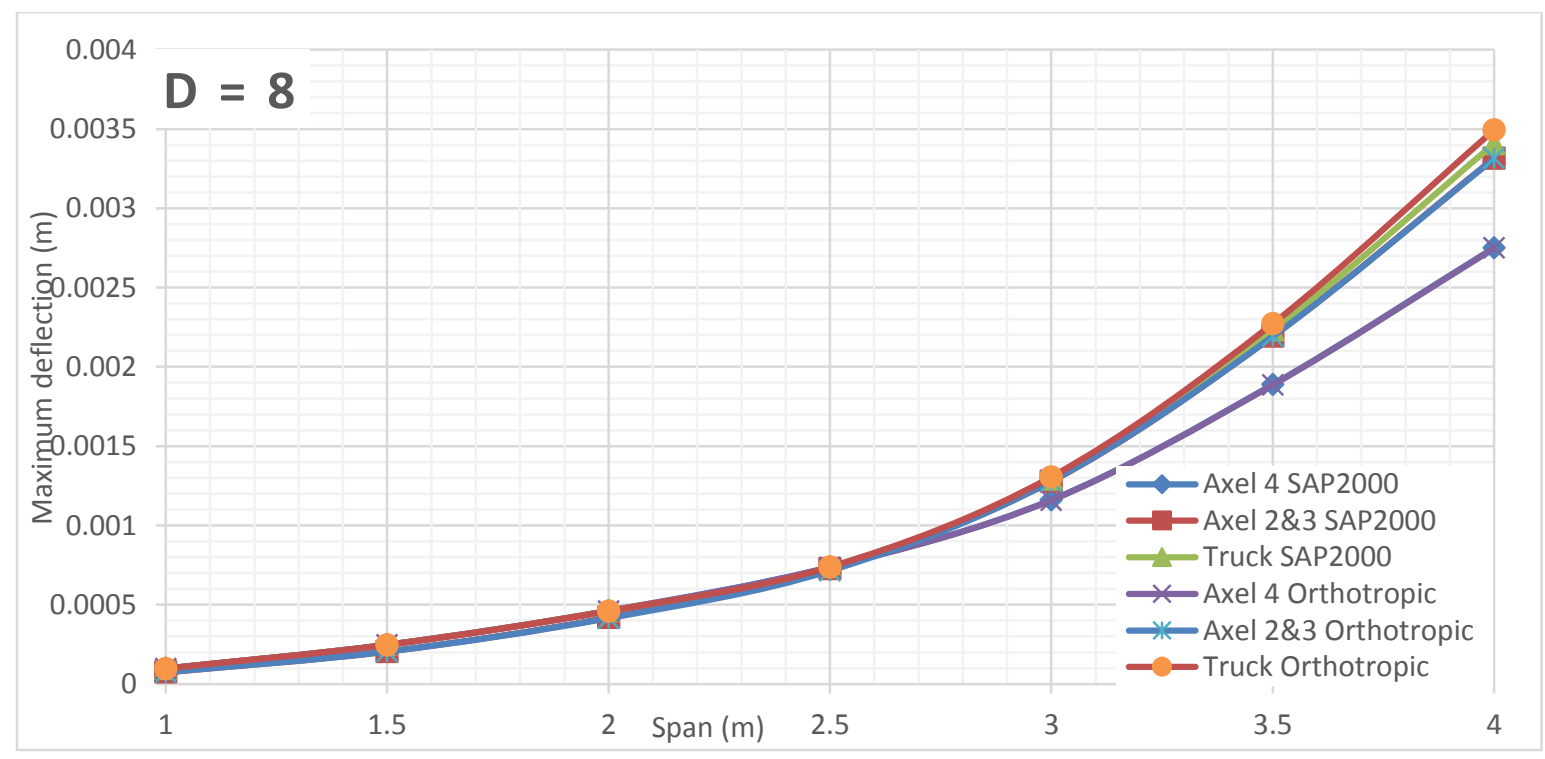

Figure 860 Deflection comparison between FEA and Orthotropic Plate Theory for $D=8$ of alpha 2 (main bars perpendicular to traffic) 


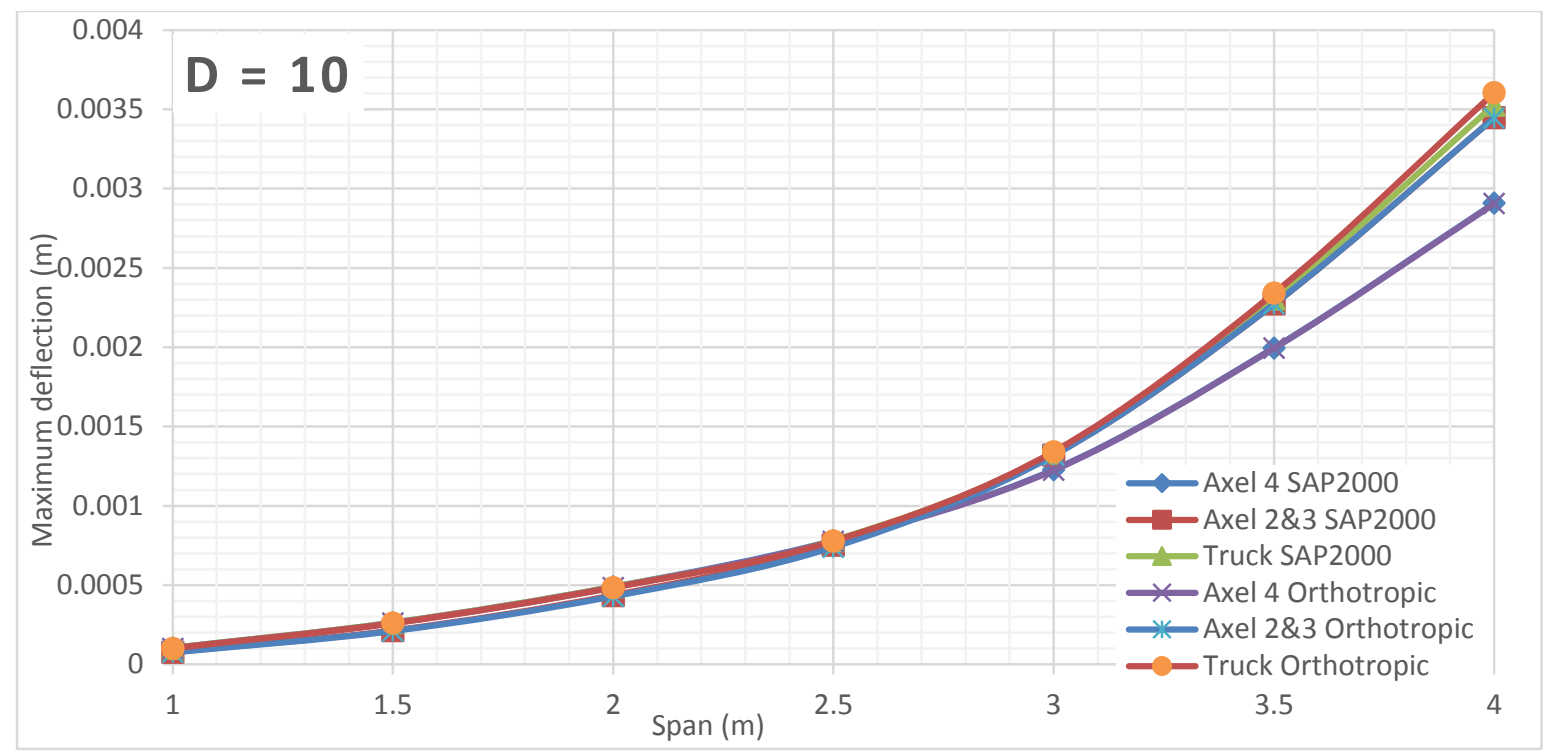

Figure 861 Deflection comparison between FEA and Orthotropic Plate Theory for $D=10$ of alpha 2 (main bars perpendicular to traffic) 


\section{Alpha 2 Deflection VS Span Length for Different D Values (Main bars parallel to traffic)}

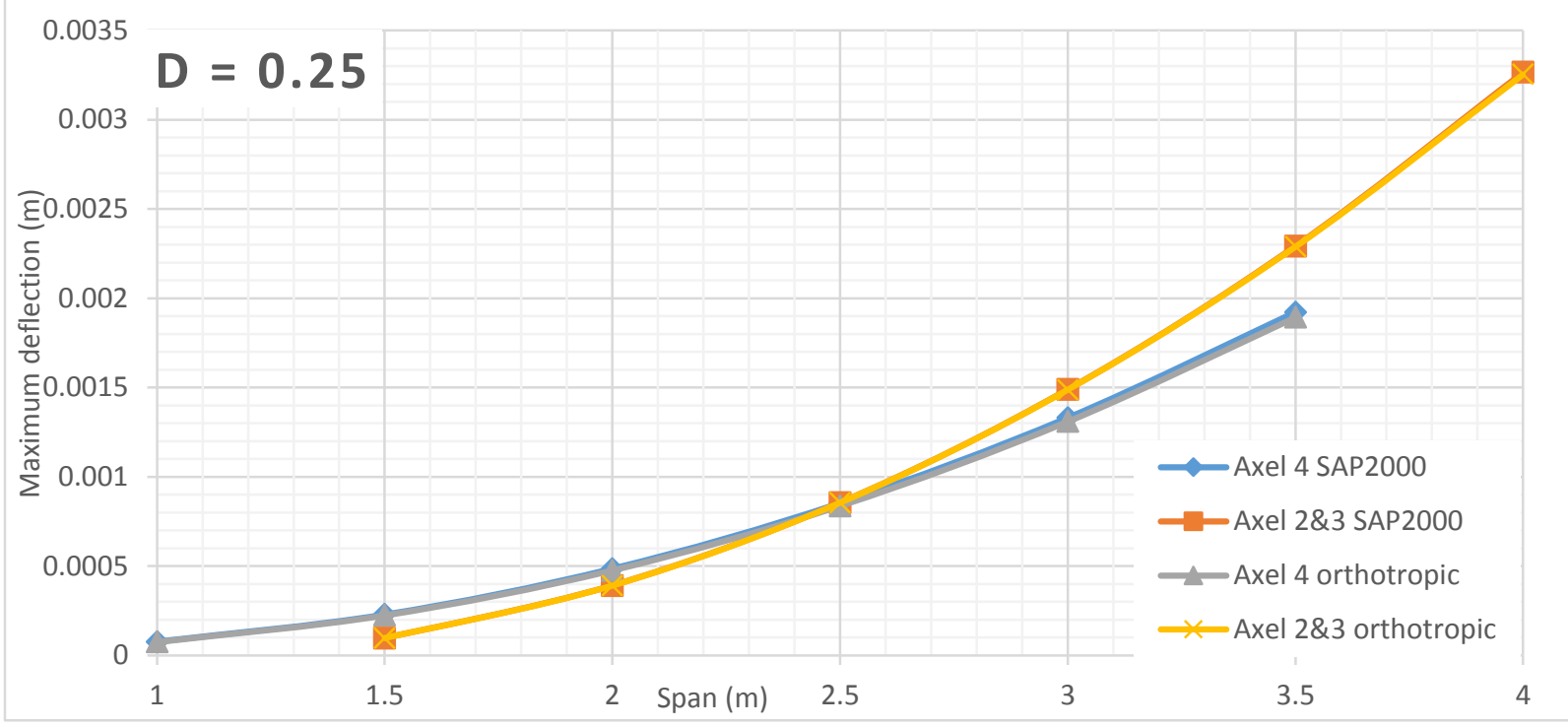

Figure 862 Deflection comparison between FEA and Orthotropic Plate Theory for $D=0.25$ of alpha 2 (main bars parallel to traffic)

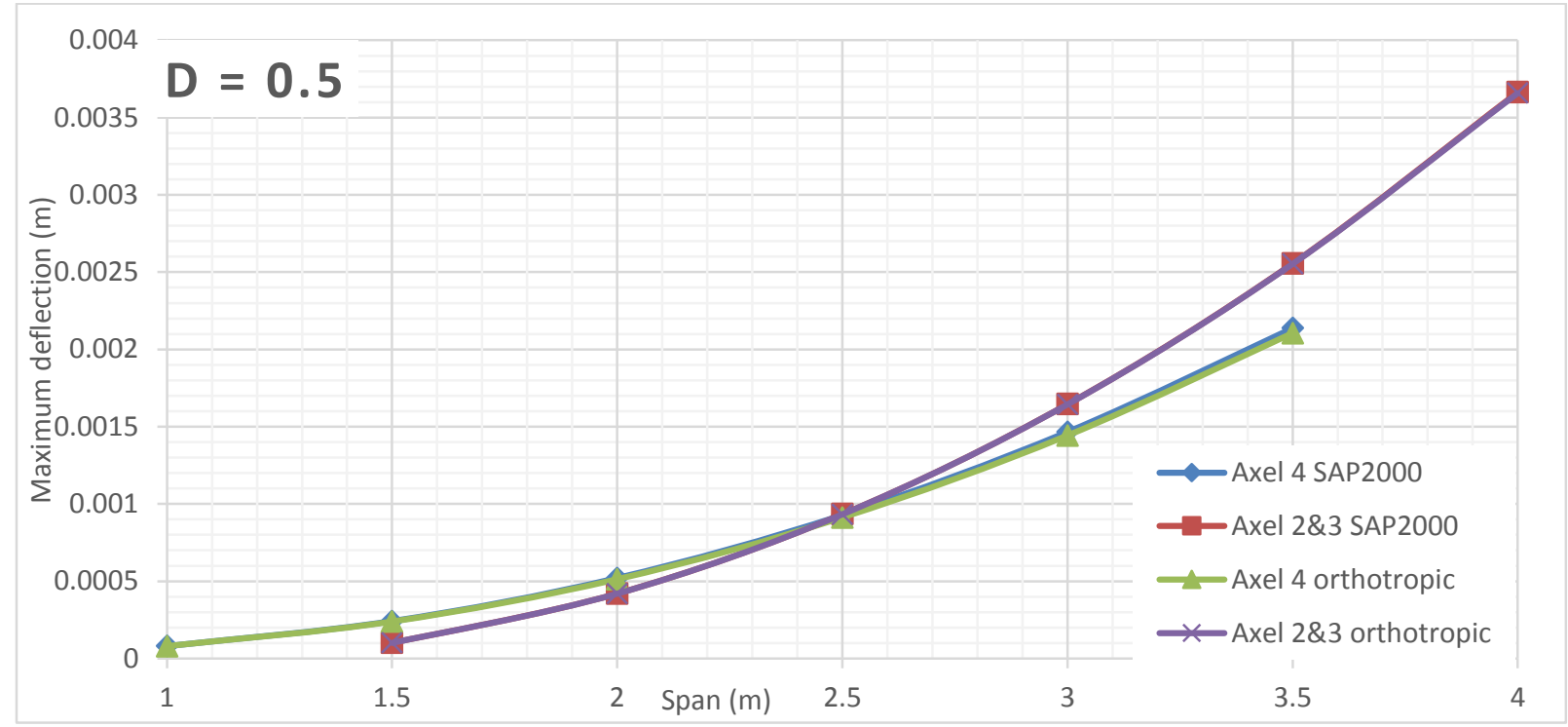

Figure 863 Deflection comparison between FEA and Orthotropic Plate Theory for $D=0.5$ of alpha 2 (main bars parallel to traffic) 


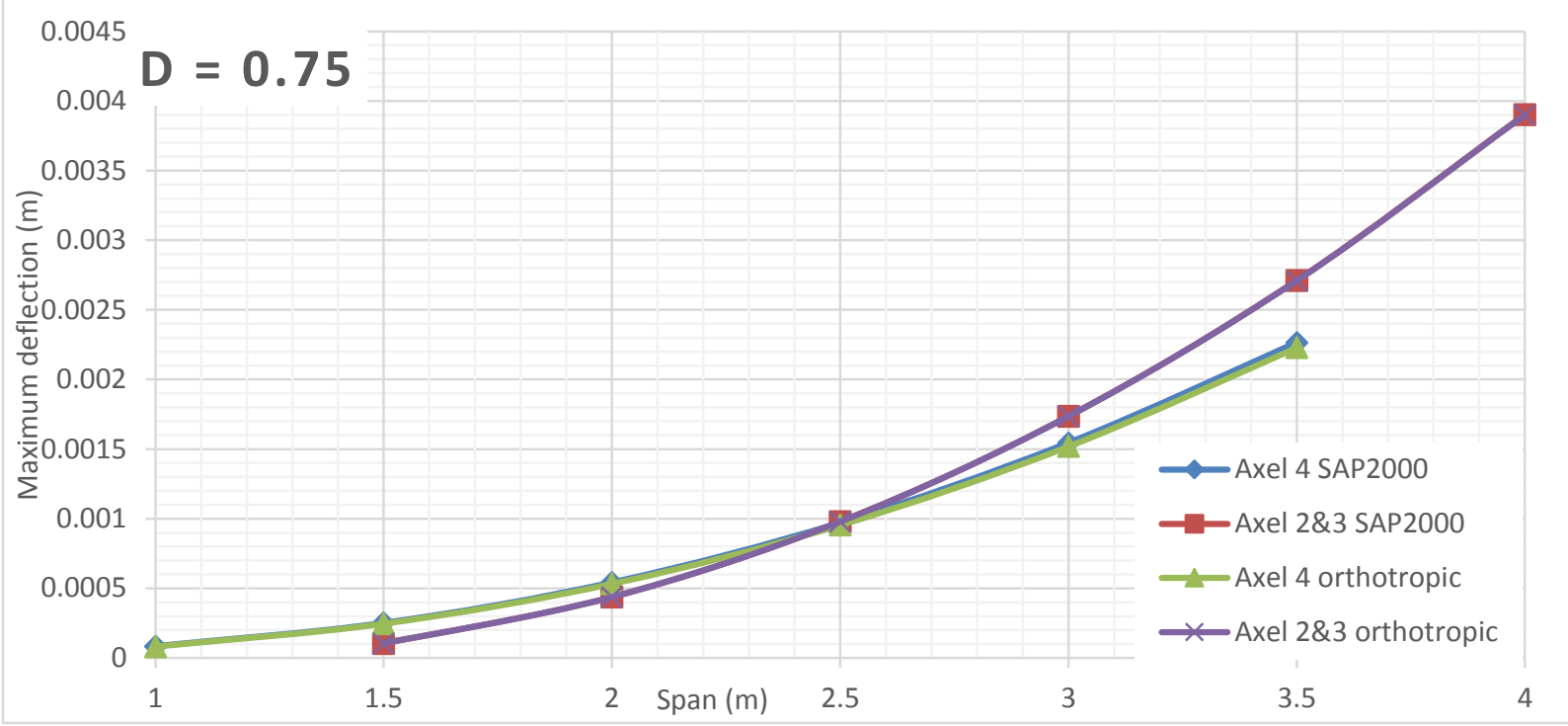

Figure 864 Deflection comparison between FEA and Orthotropic Plate Theory for D $=0.75$ of alpha 2 (main bars parallel to traffic)

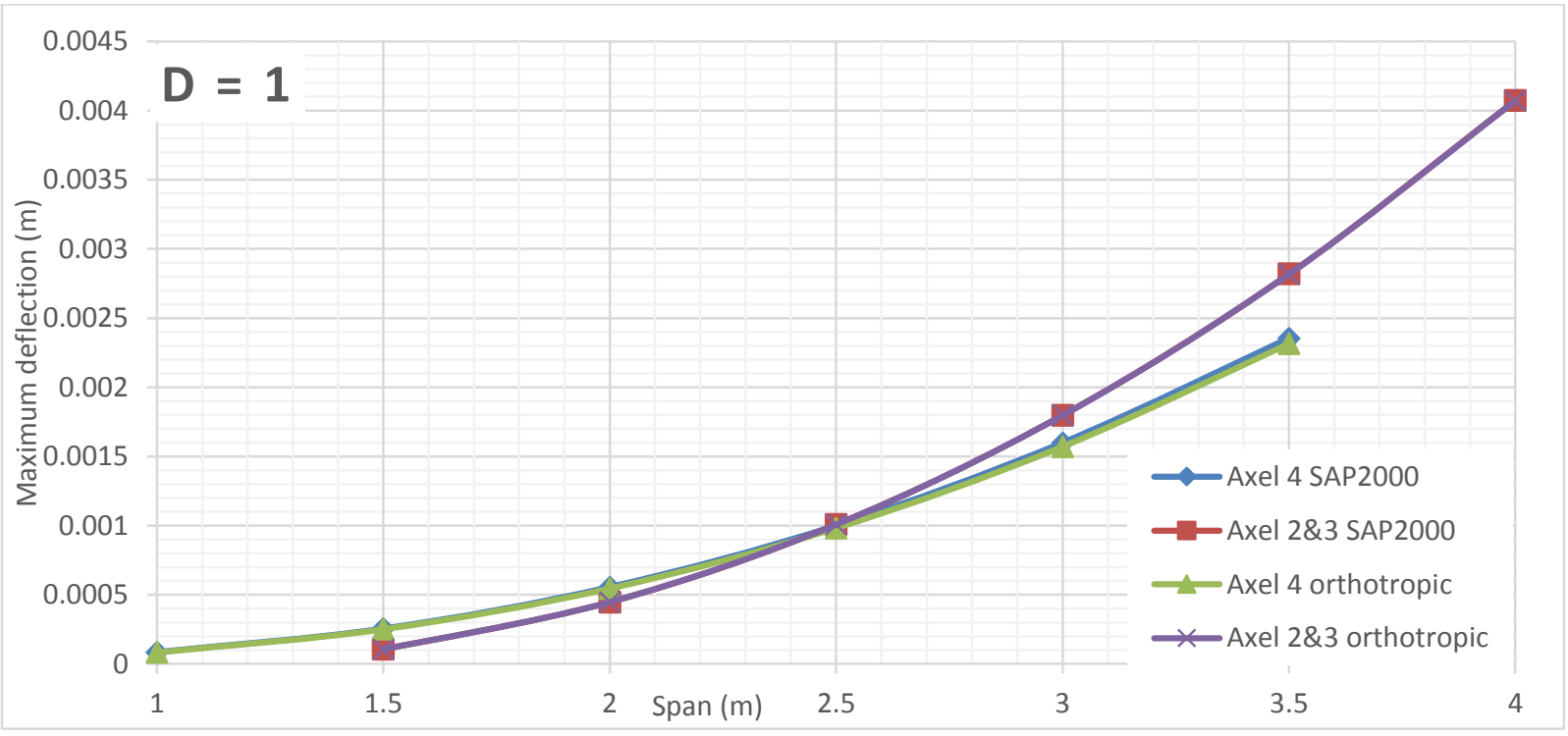

Figure 865 Deflection comparison between FEA and Orthotropic Plate Theory for $D=1$ of alpha 2 (main bars parallel to traffic)

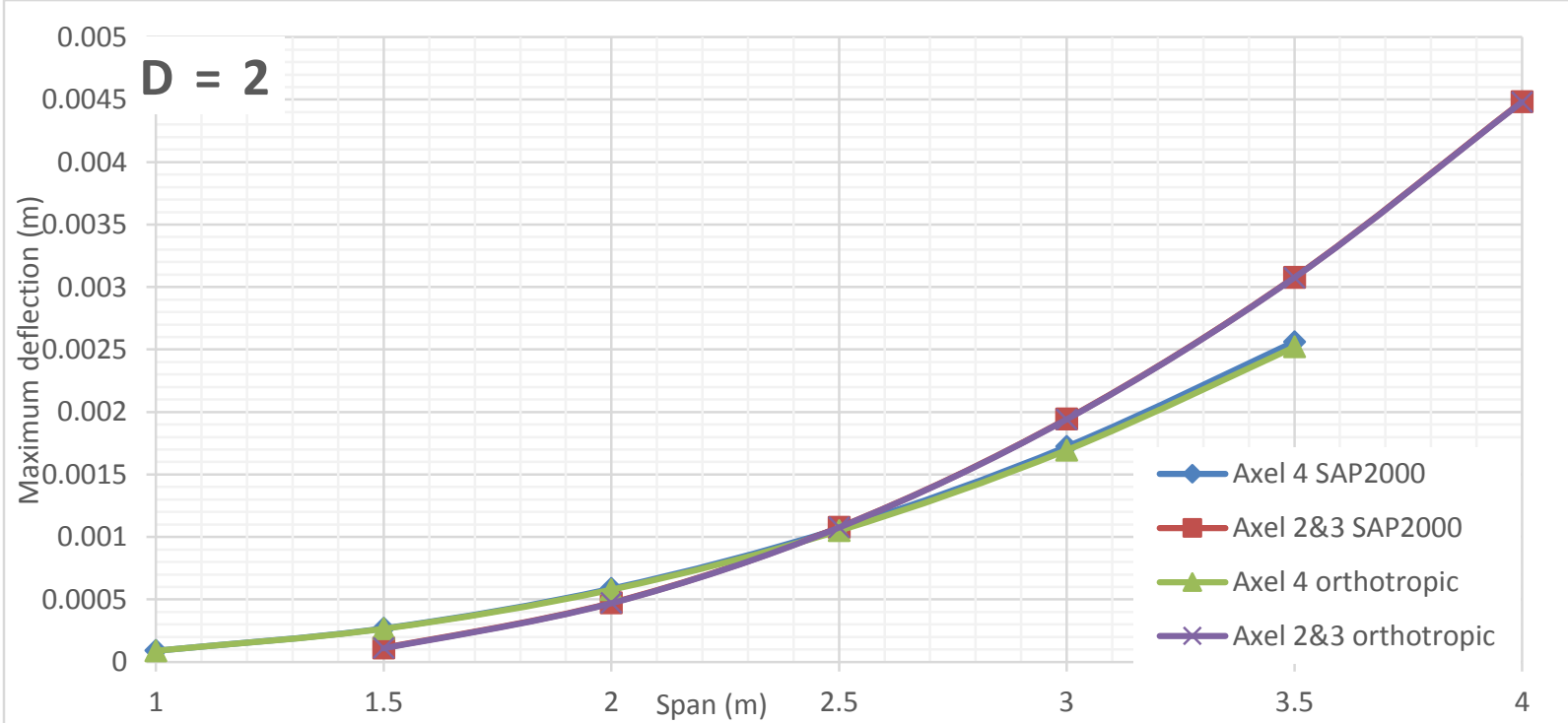

Figure 866 Deflection comparison between FEA and Orthotropic Plate Theory for $\mathrm{D}=2$ of alpha 2 (main bars parallel to traffic) 


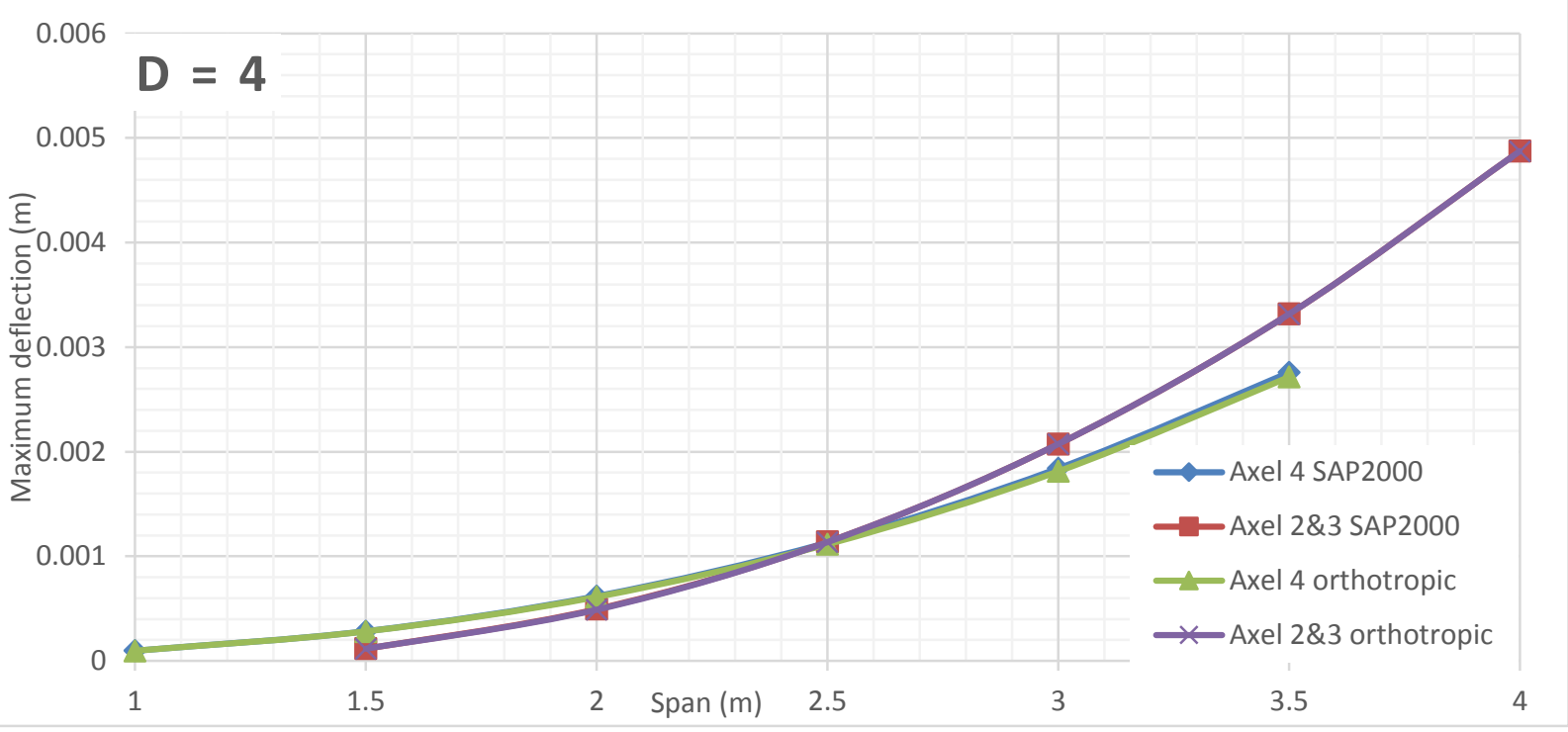

Figure 867 Deflection comparison between FEA and Orthotropic Plate Theory for D $=4$ of alpha 2 (main bars parallel to traffic)

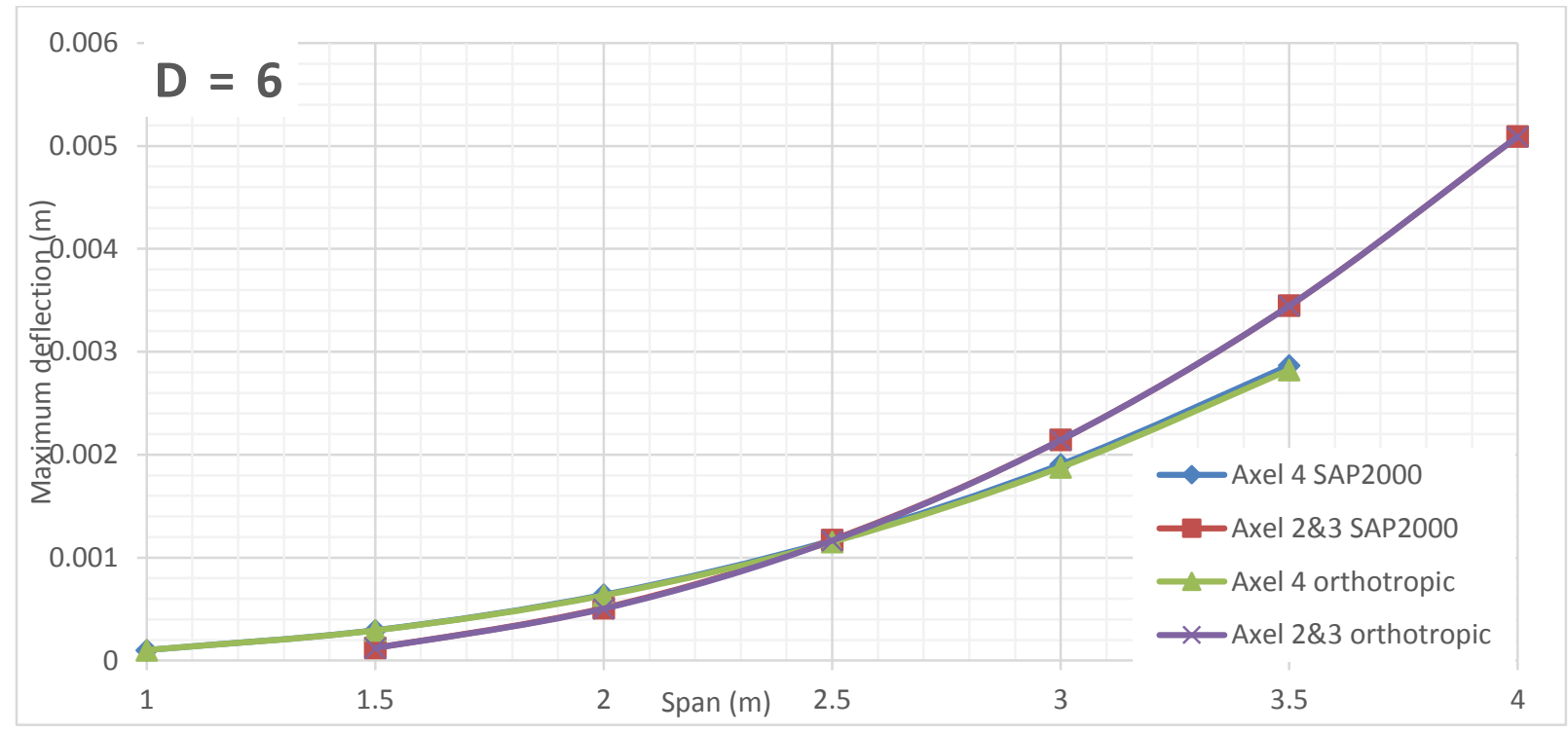

Figure 868 Deflection comparison between FEA and Orthotropic Plate Theory for $D=6$ of alpha 2 (main bars parallel to traffic)

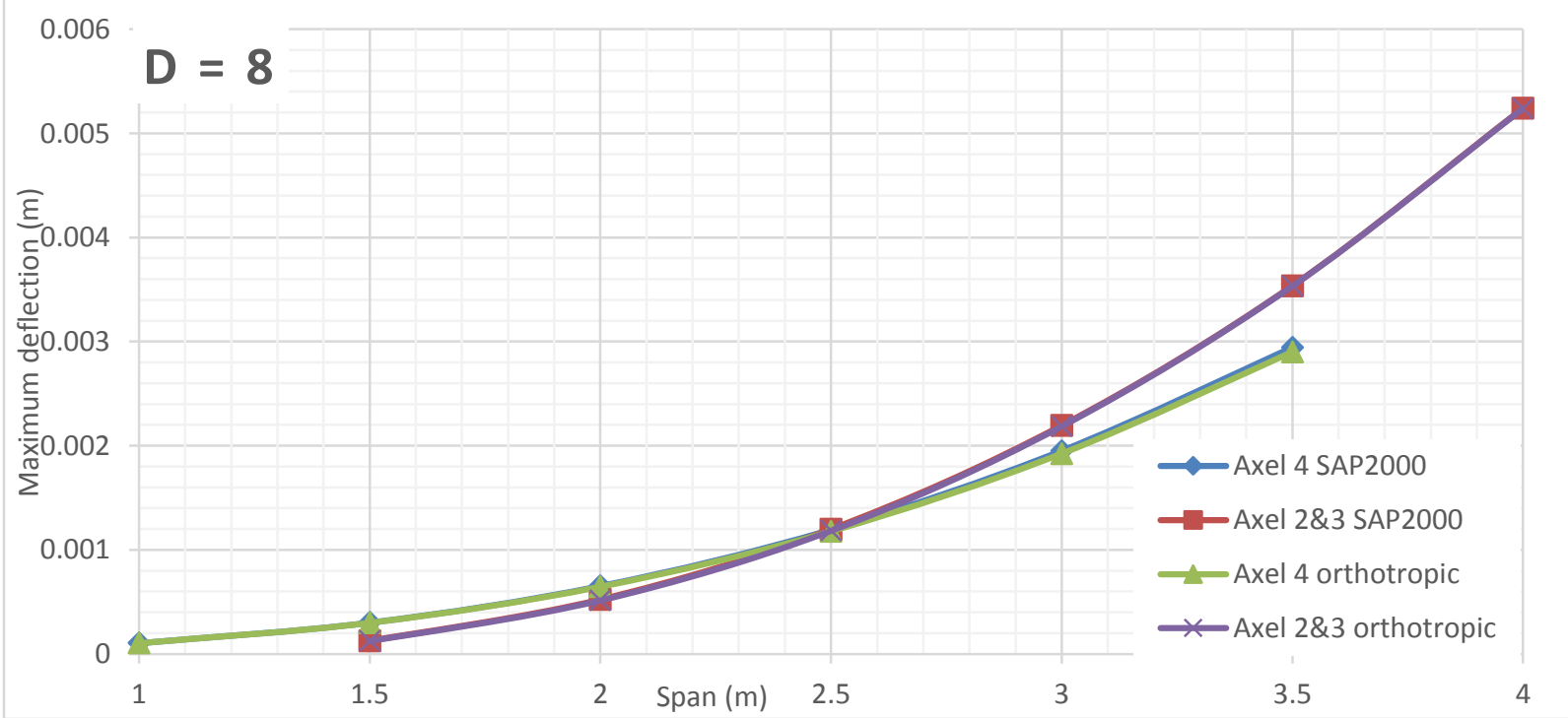

Figure 869 Deflection comparison between FEA and Orthotropic Plate Theory for $D=8$ of alpha 2 (main bars parallel to traffic) 


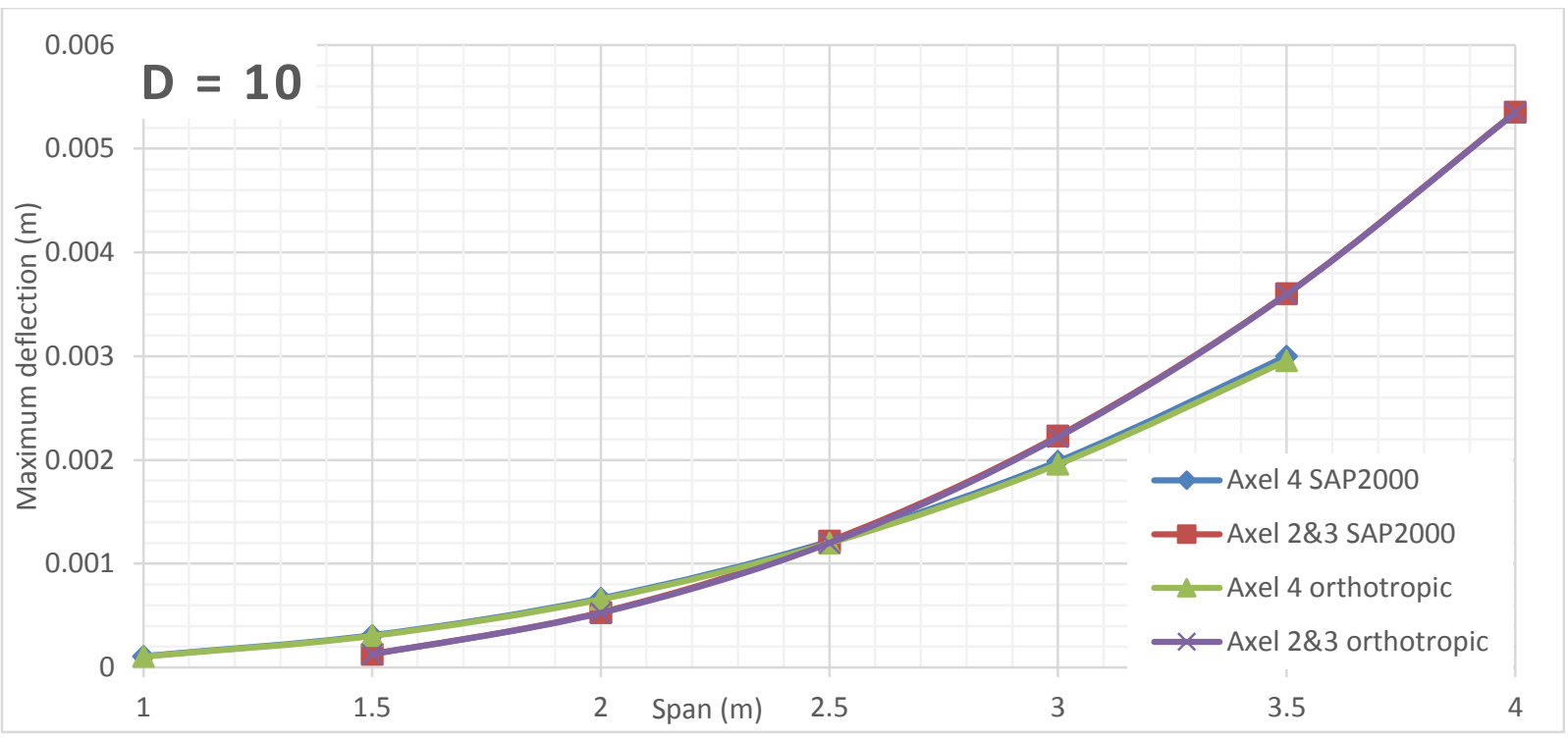

Figure 870 Deflection comparison between FEA and Orthotropic Plate Theory for $D=10$ of alpha 2 (main bars parallel to traffic) 


\section{Alpha 4 Deflection VS Span Length for Different D Values (Main bars perpendicular to traffic)}

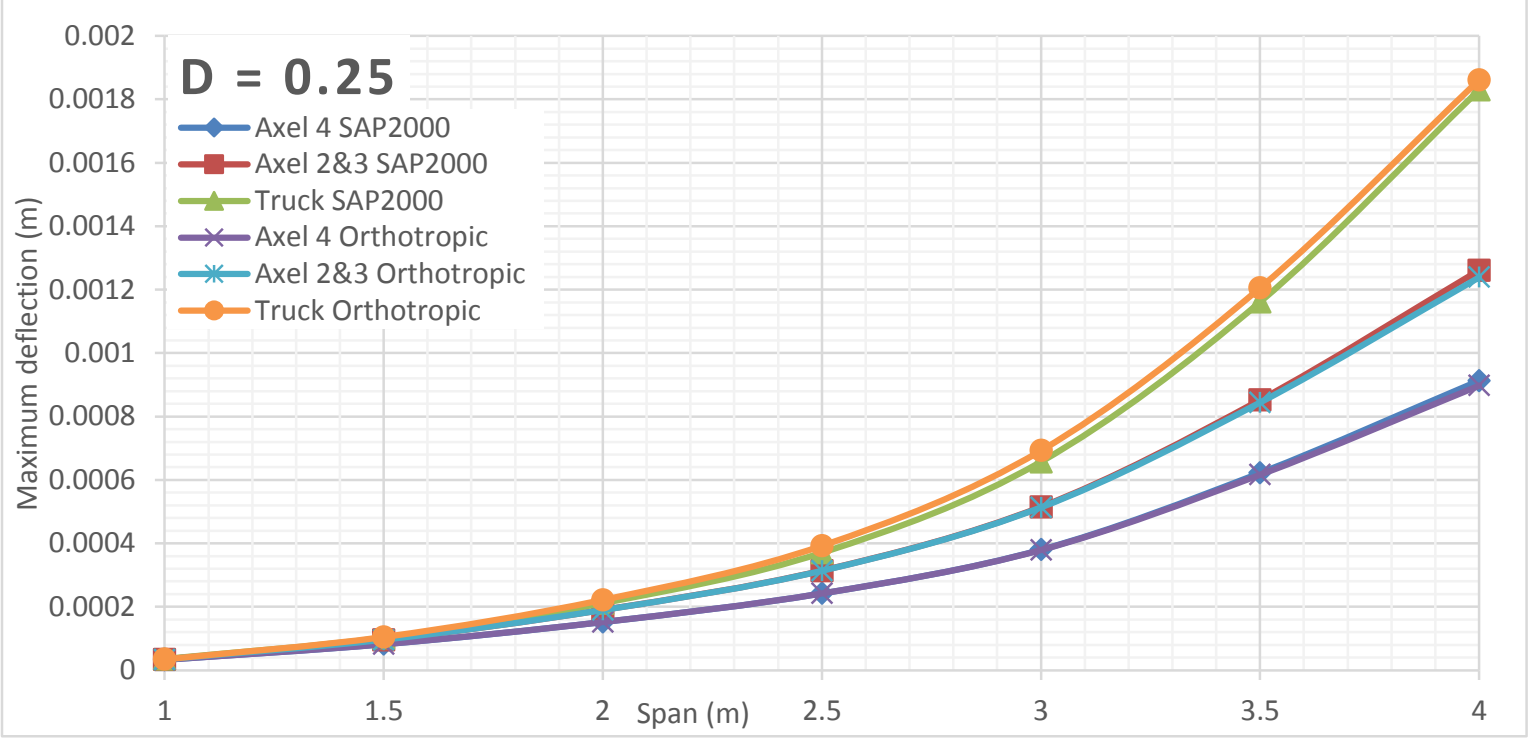

Figure 871 Deflection comparison between FEA and Orthotropic Plate Theory for $D=0.25$ of alpha 4 (main bars perpendicular to traffic)

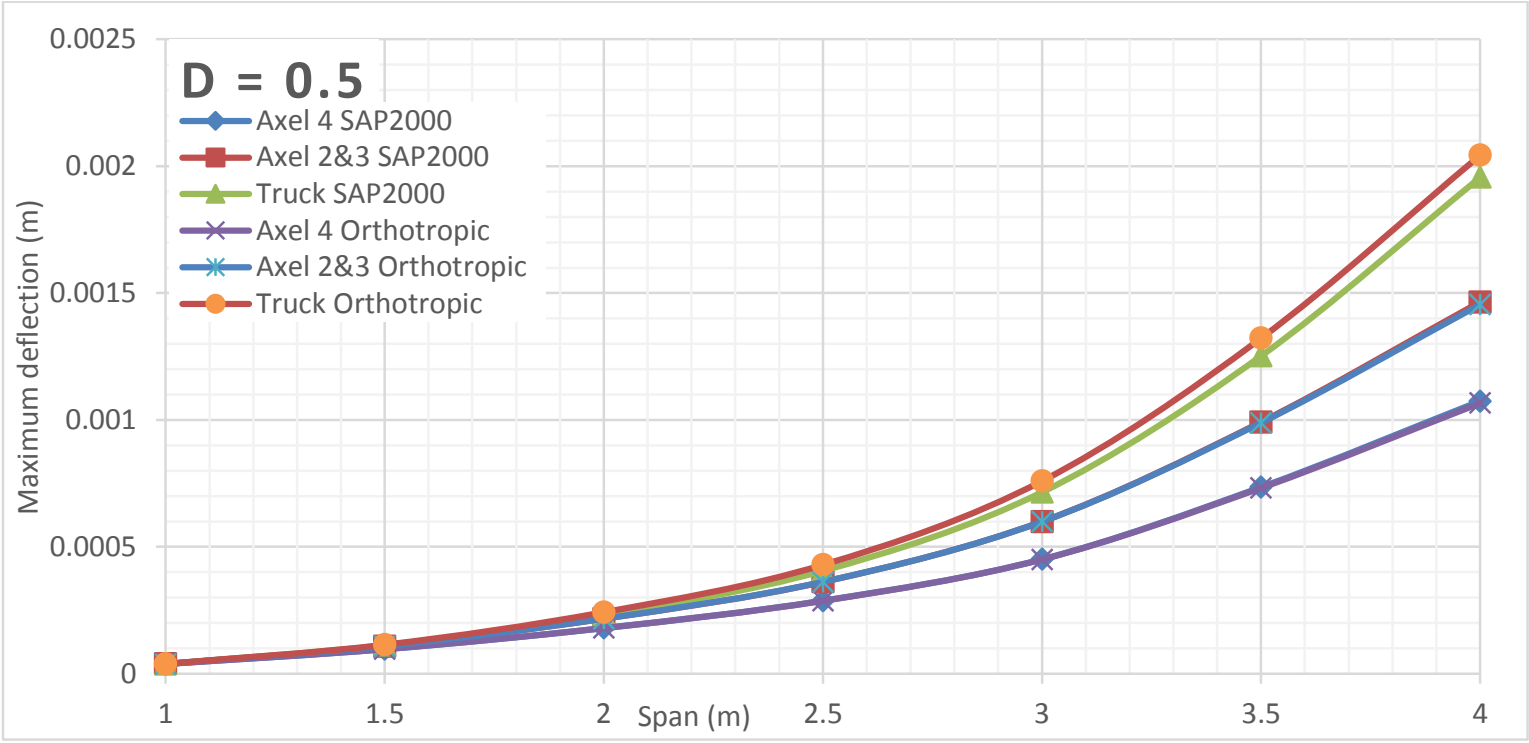

Figure 872 Deflection comparison between FEA and Orthotropic Plate Theory for $D=0.5$ of alpha 4 (main bars perpendicular to traffic) 


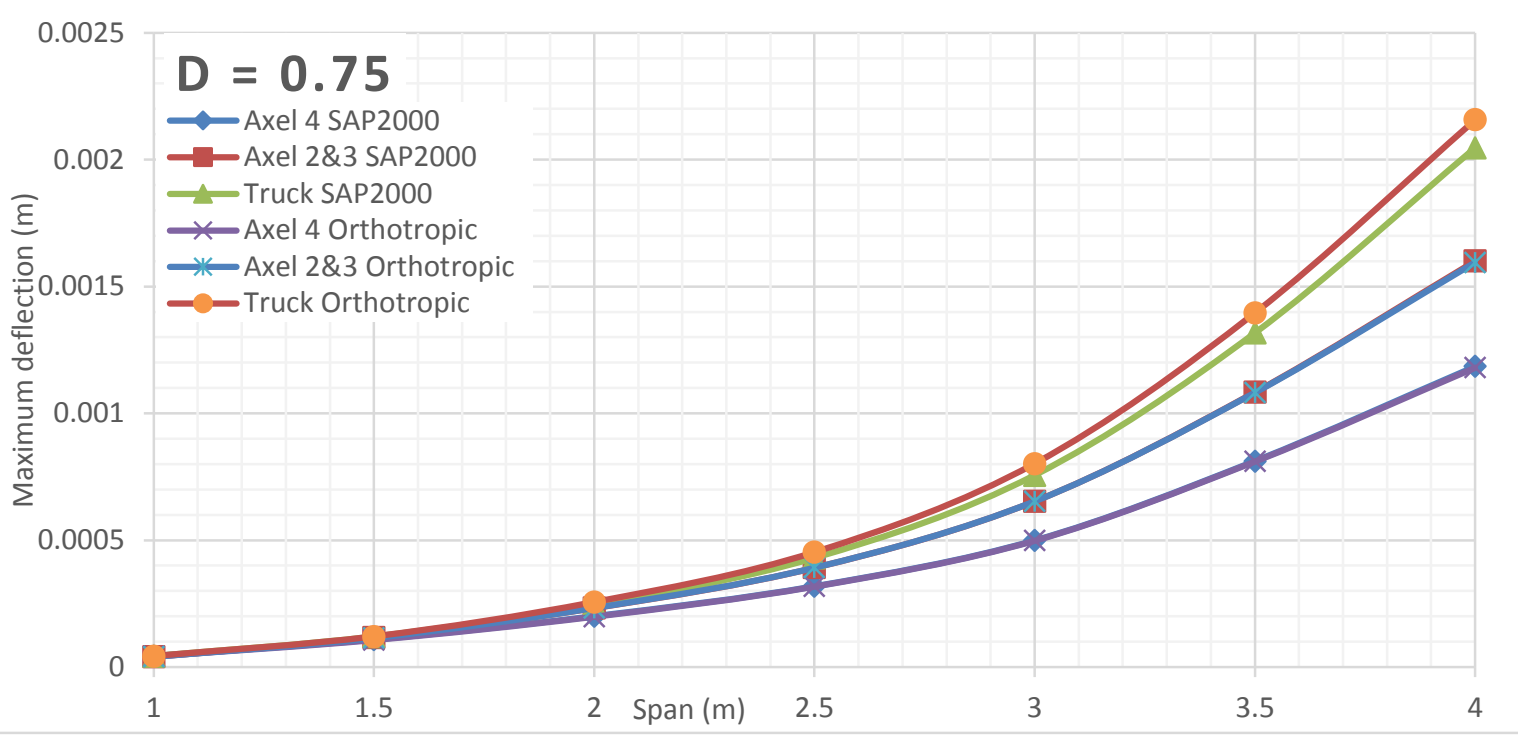

Figure 873 Deflection comparison between FEA and Orthotropic Plate Theory for $D=0.75$ of alpha 4 (main bars perpendicular to traffic)

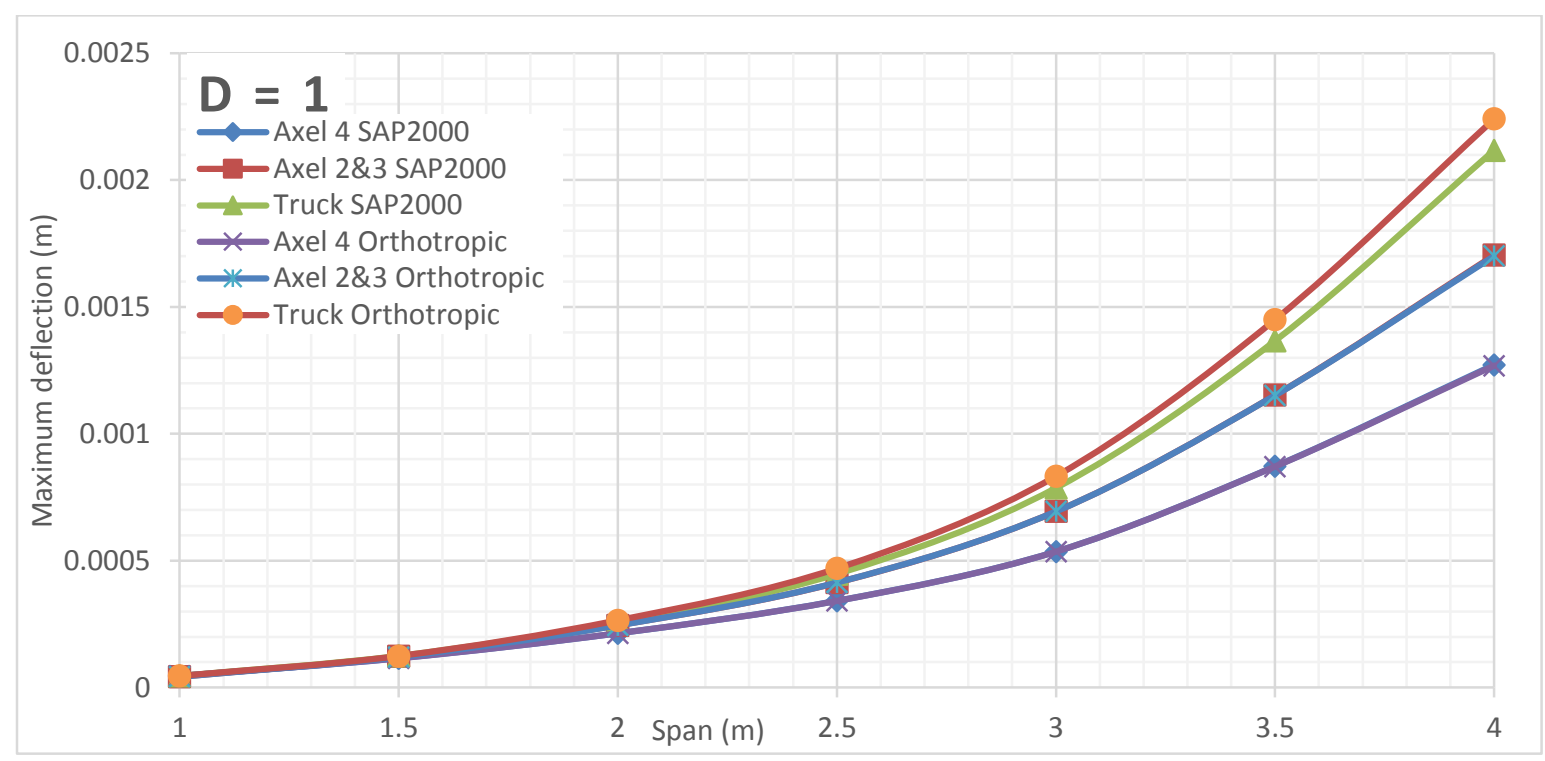

Figure 874 Deflection comparison between FEA and Orthotropic Plate Theory for $D=1$ of alpha 4 (main bars perpendicular to traffic)

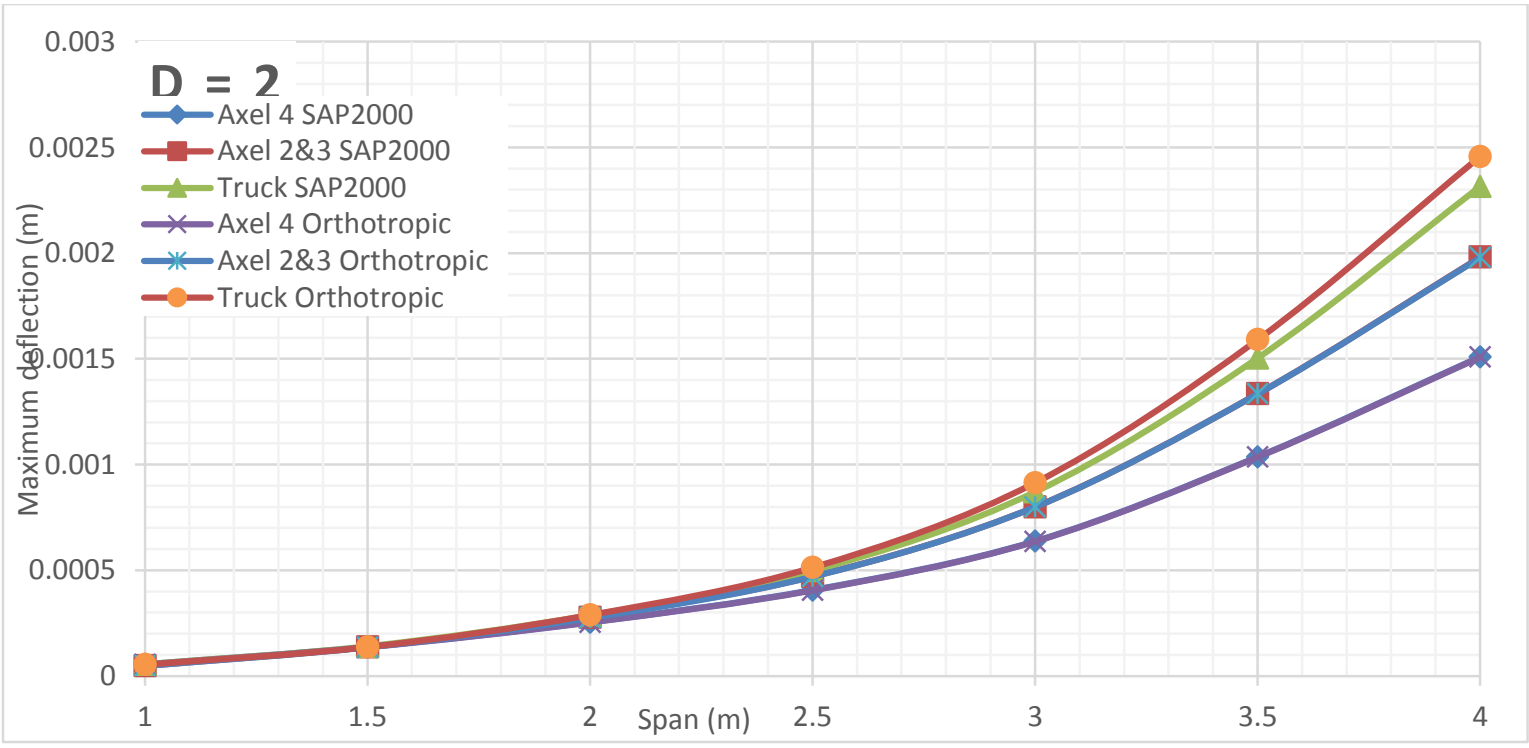

Figure 875 Deflection comparison between FEA and Orthotropic Plate Theory for $D=2$ of alpha 4 (main bars perpendicular to traffic) 


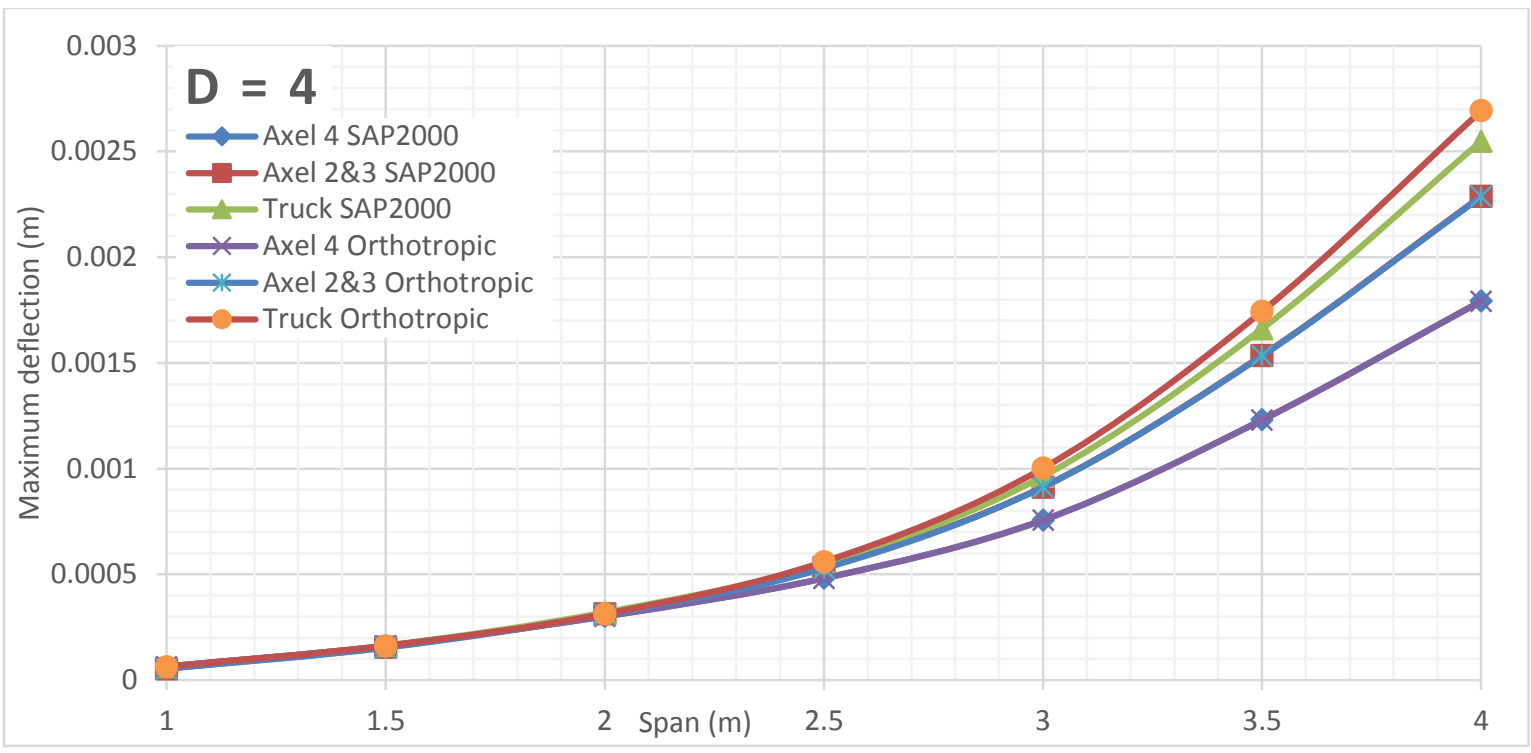

Figure 876 Deflection comparison between FEA and Orthotropic Plate Theory for D $=4$ of alpha 4 (main bars perpendicular to traffic)

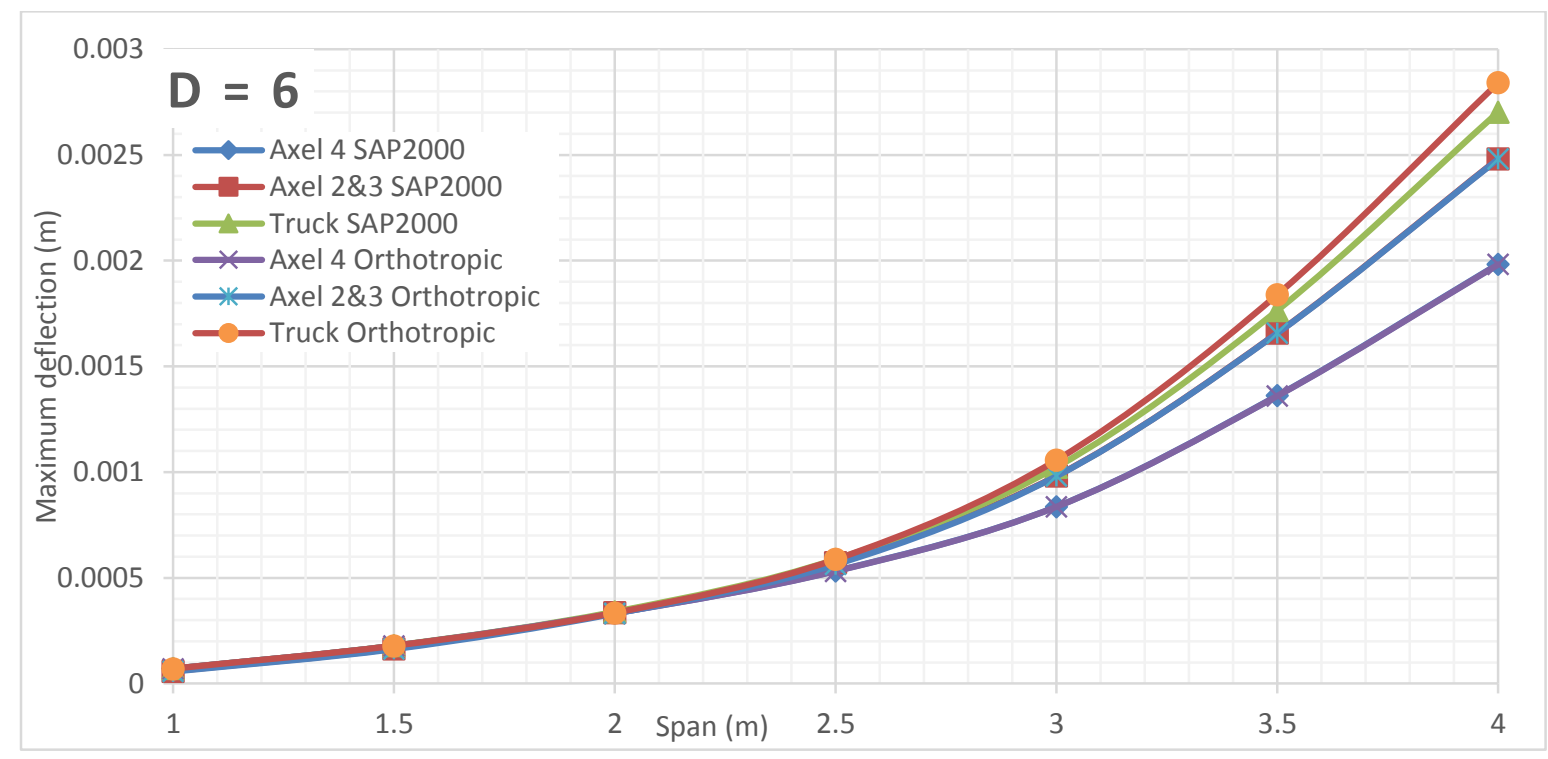

Figure 877 Deflection comparison between FEA and Orthotropic Plate Theory for D $=6$ of alpha 4 (main bars perpendicular to traffic)

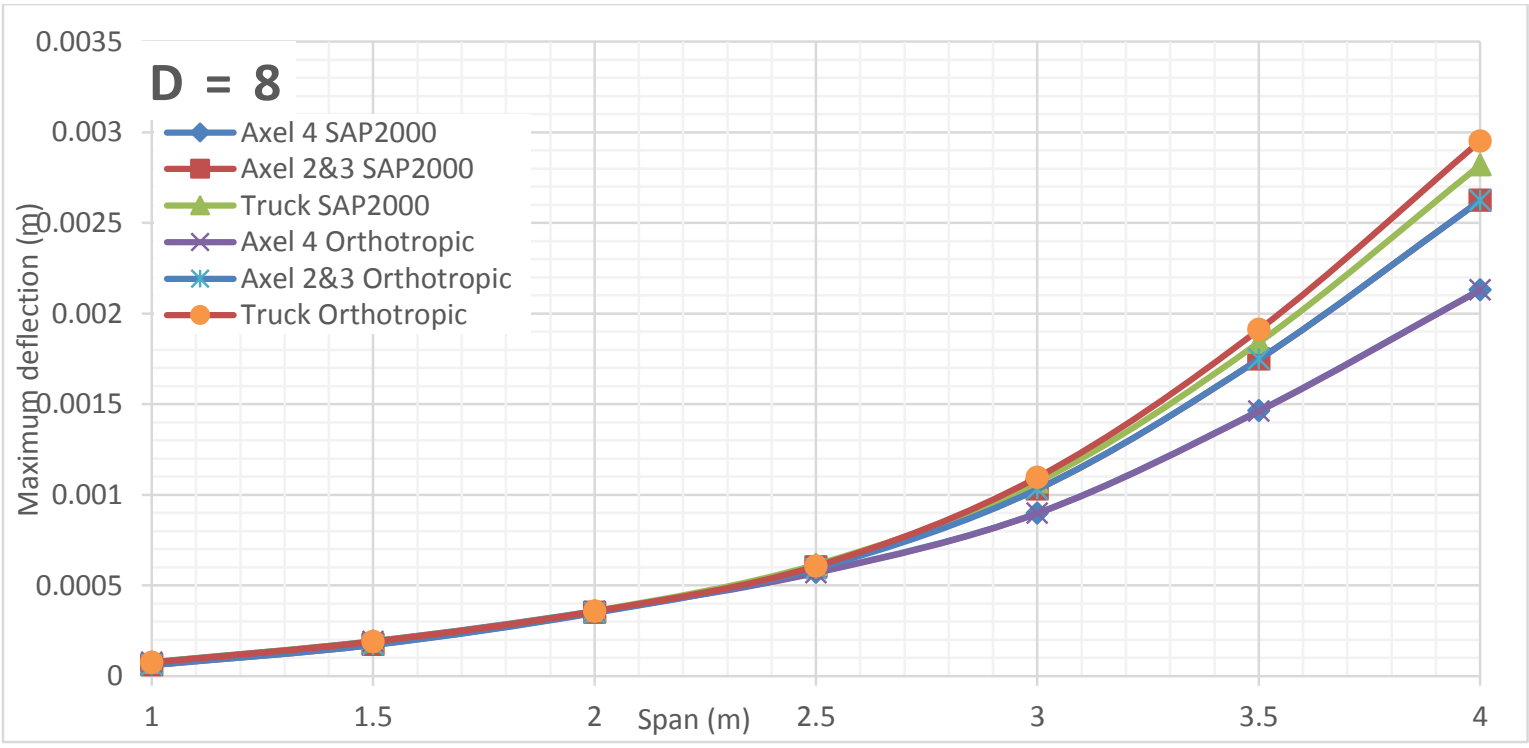

Figure 878 Deflection comparison between FEA and Orthotropic Plate Theory for $D=8$ of alpha 4 (main bars perpendicular to traffic) 


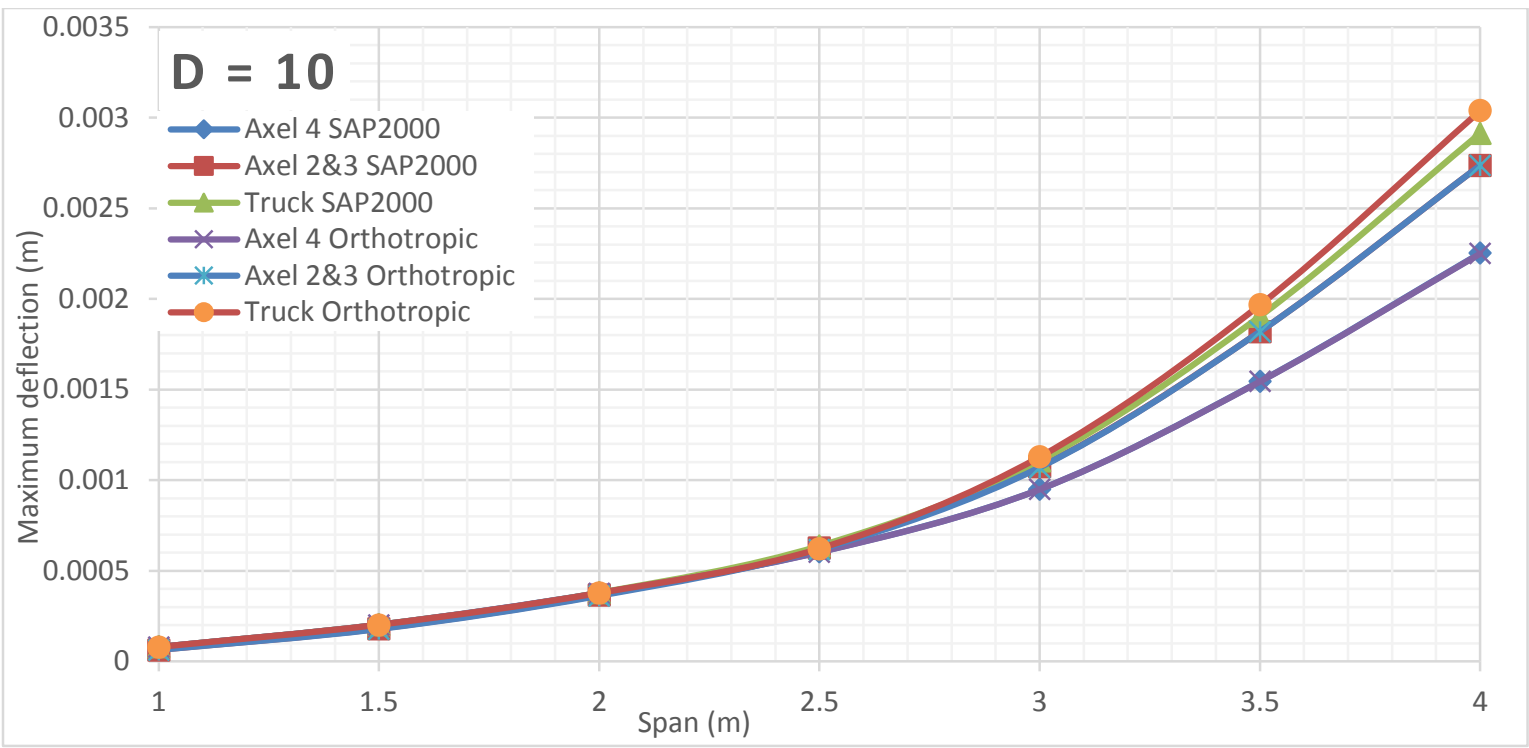

Figure 879 Deflection comparison between FEA and Orthotropic Plate Theory for $D=10$ of alpha 4 (main bars perpendicular to traffic) 


\section{Alpha 4 Deflection VS Span Length for Different D Values (Main bars parallel to traffic)}

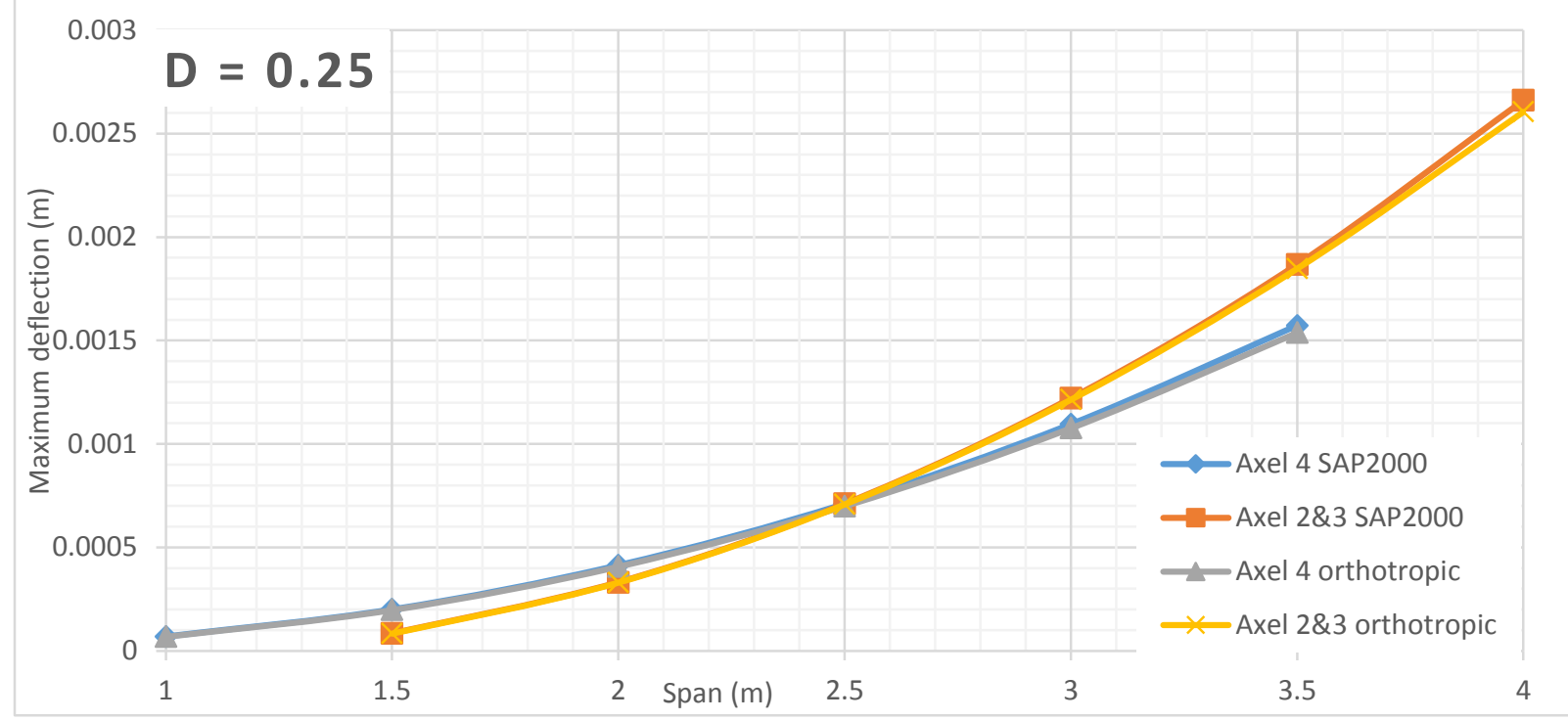

Figure 880 Deflection comparison between FEA and Orthotropic Plate Theory for $D=0.25$ of alpha 4 (main bars parallel to traffic)

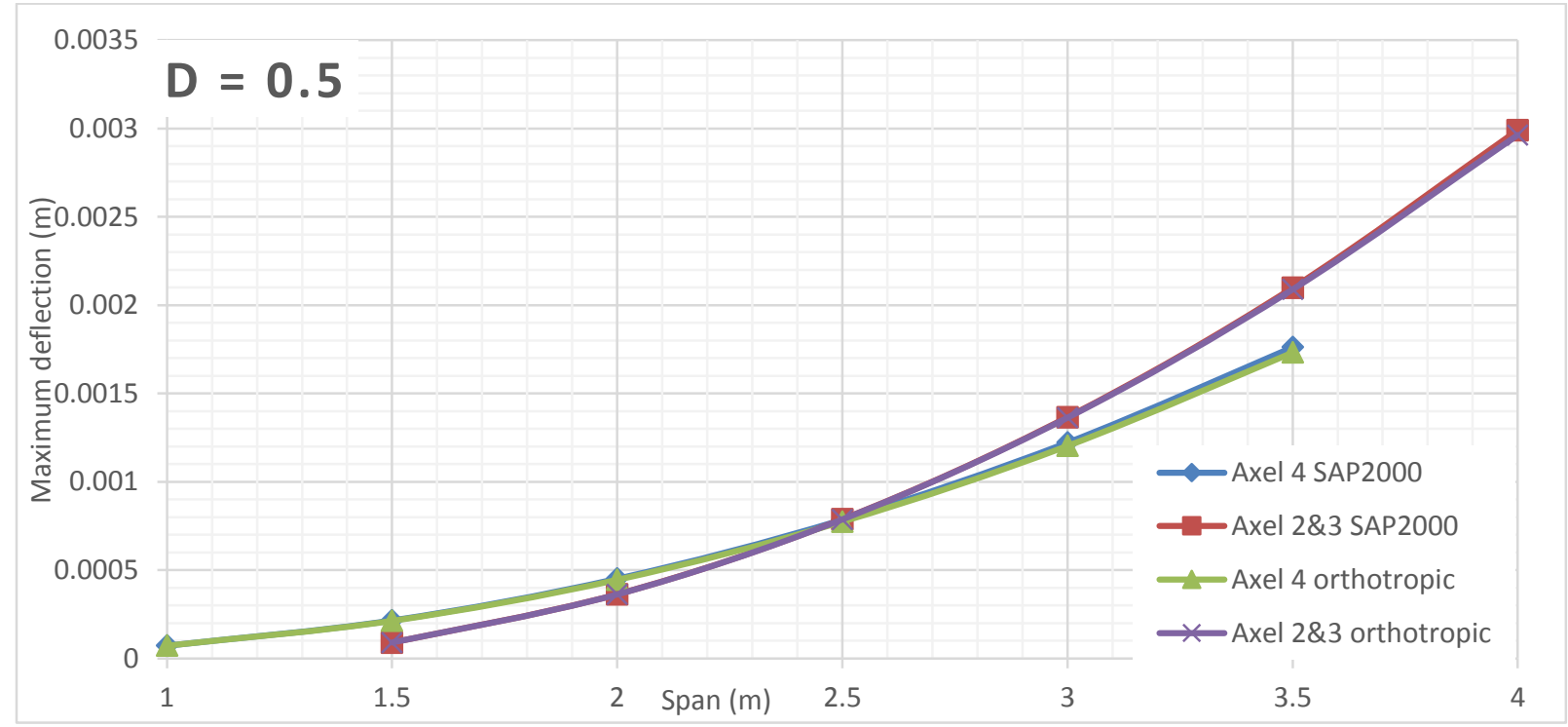

Figure 881 Deflection comparison between FEA and Orthotropic Plate Theory for $D=0.5$ of alpha 4 (main bars parallel to traffic) 


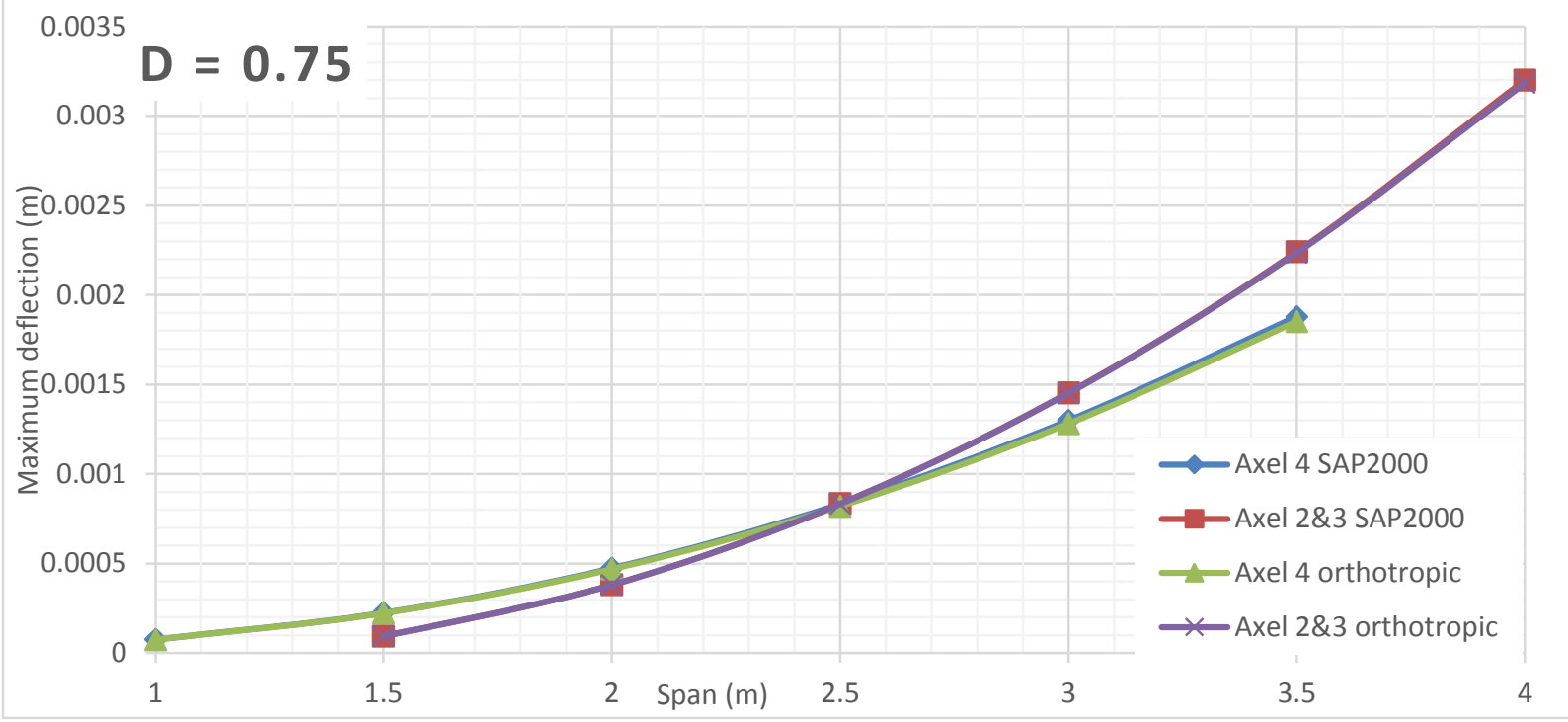

Figure 882 Deflection comparison between FEA and Orthotropic Plate Theory for $D=0.75$ of alpha 4 (main bars parallel to traffic)

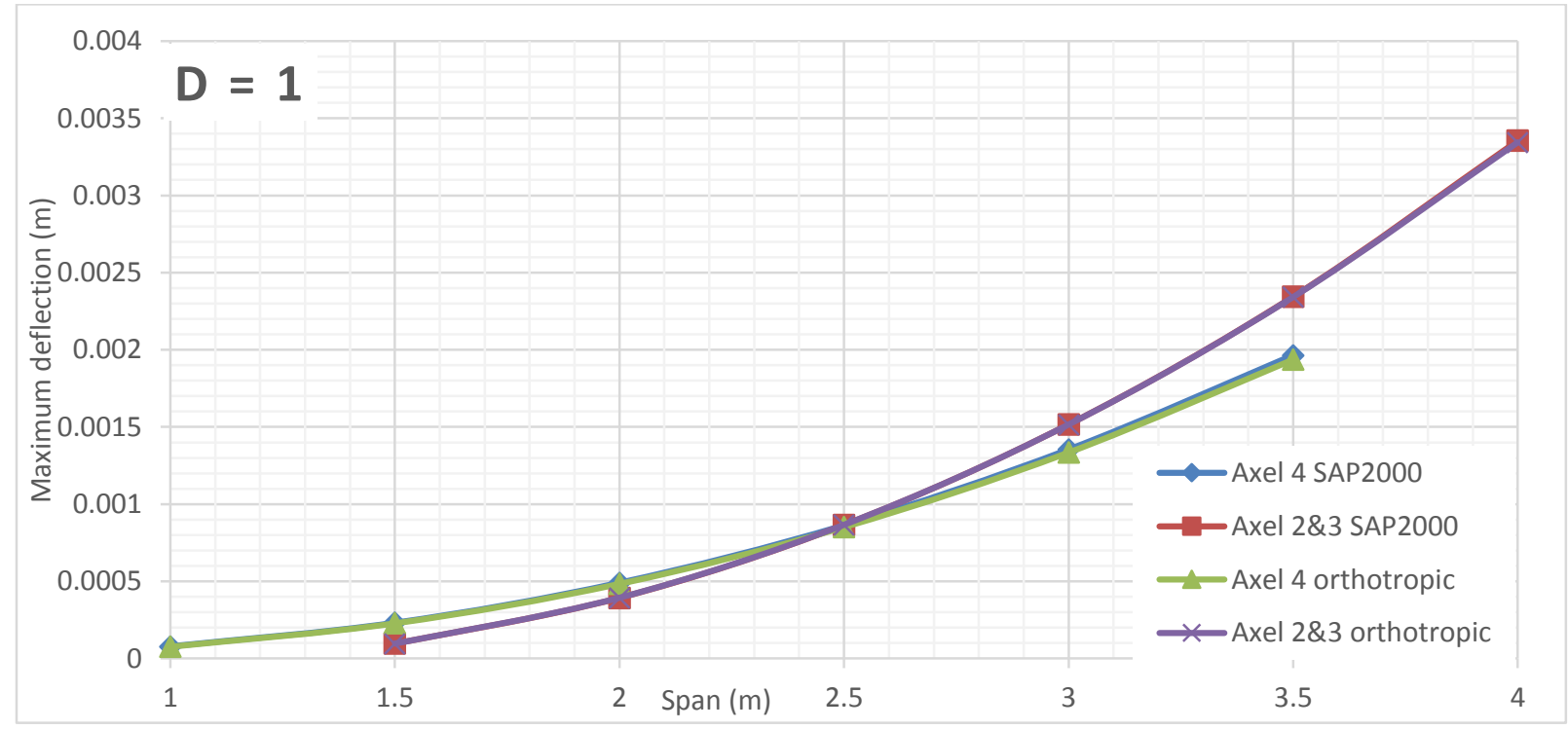

Figure 883 Deflection comparison between FEA and Orthotropic Plate Theory for $D=1$ of alpha 4 (main bars parallel to traffic)

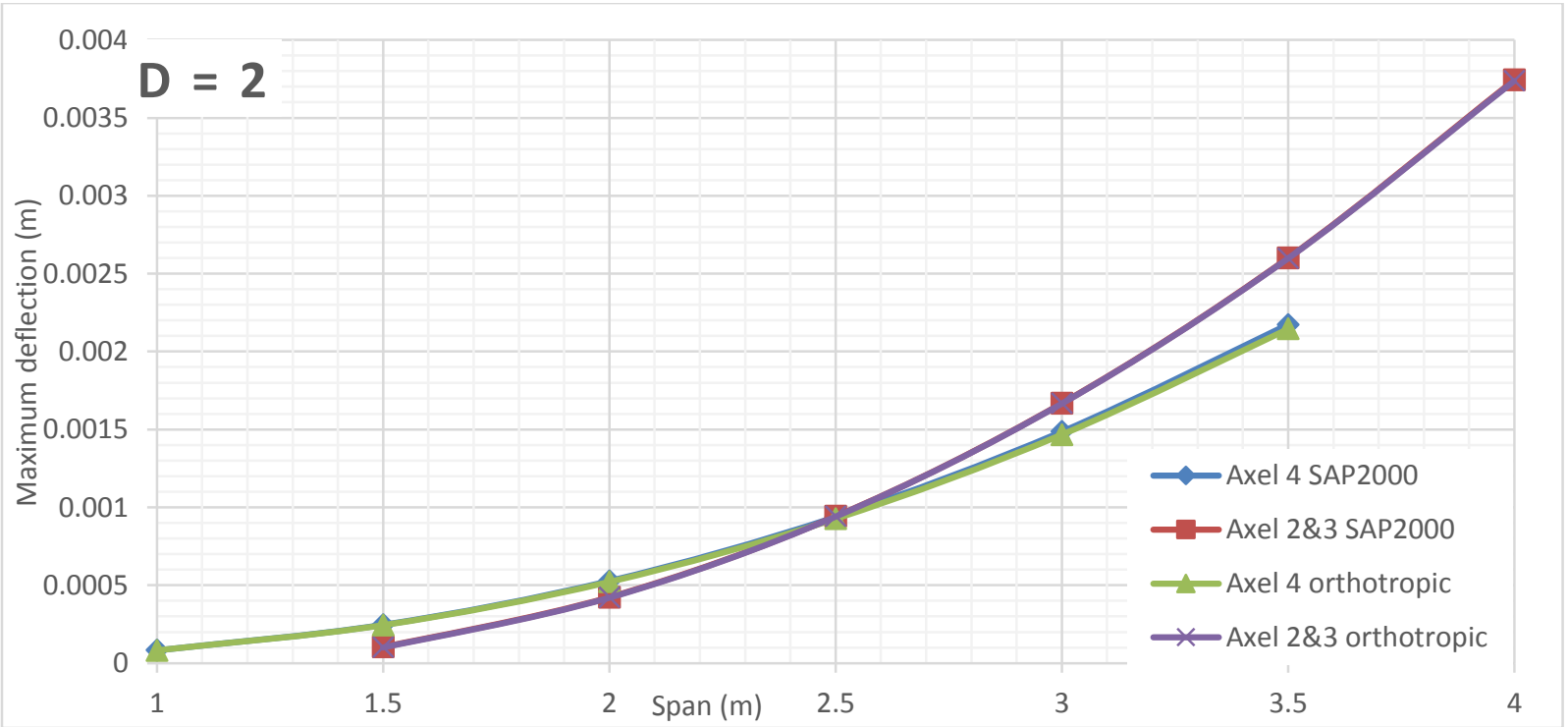

Figure 884 Deflection comparison between FEA and Orthotropic Plate Theory for $\mathrm{D}=2$ of alpha 4 (main bars parallel to traffic) 


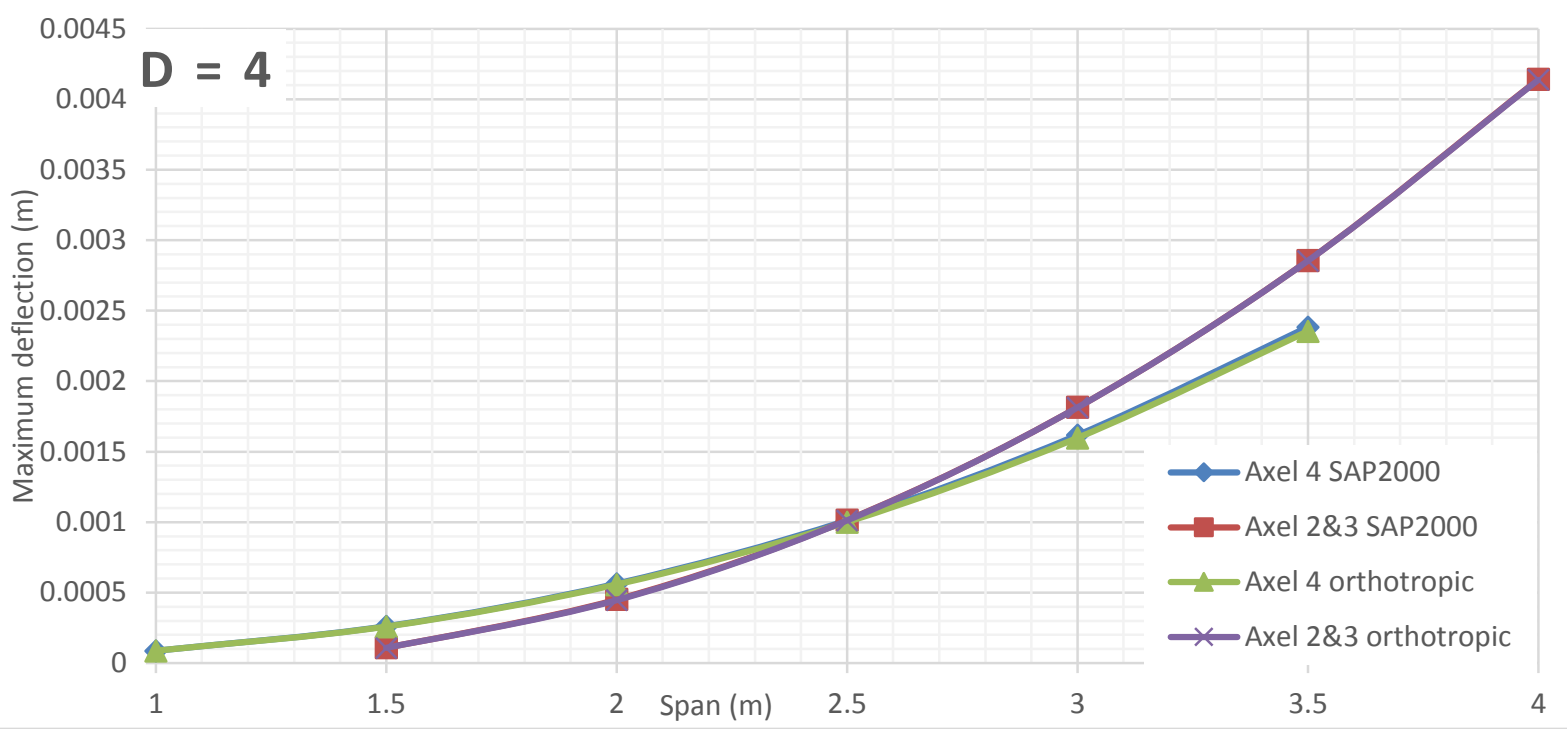

Figure 885 Deflection comparison between FEA and Orthotropic Plate Theory for $D=4$ of alpha 4 (main bars parallel to traffic)

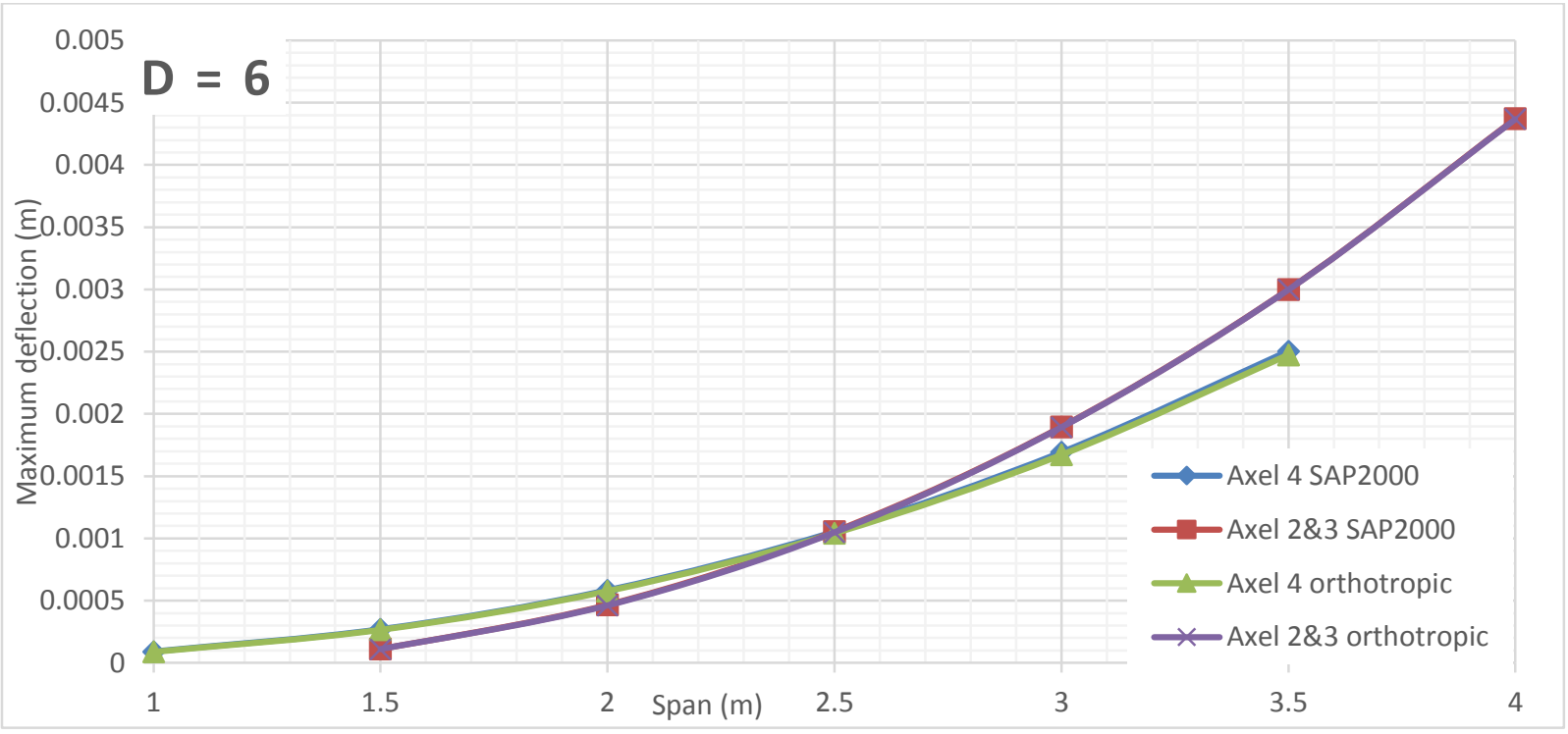

Figure 886 Deflection comparison between FEA and Orthotropic Plate Theory for $D=6$ of alpha 4 (main bars parallel to traffic)

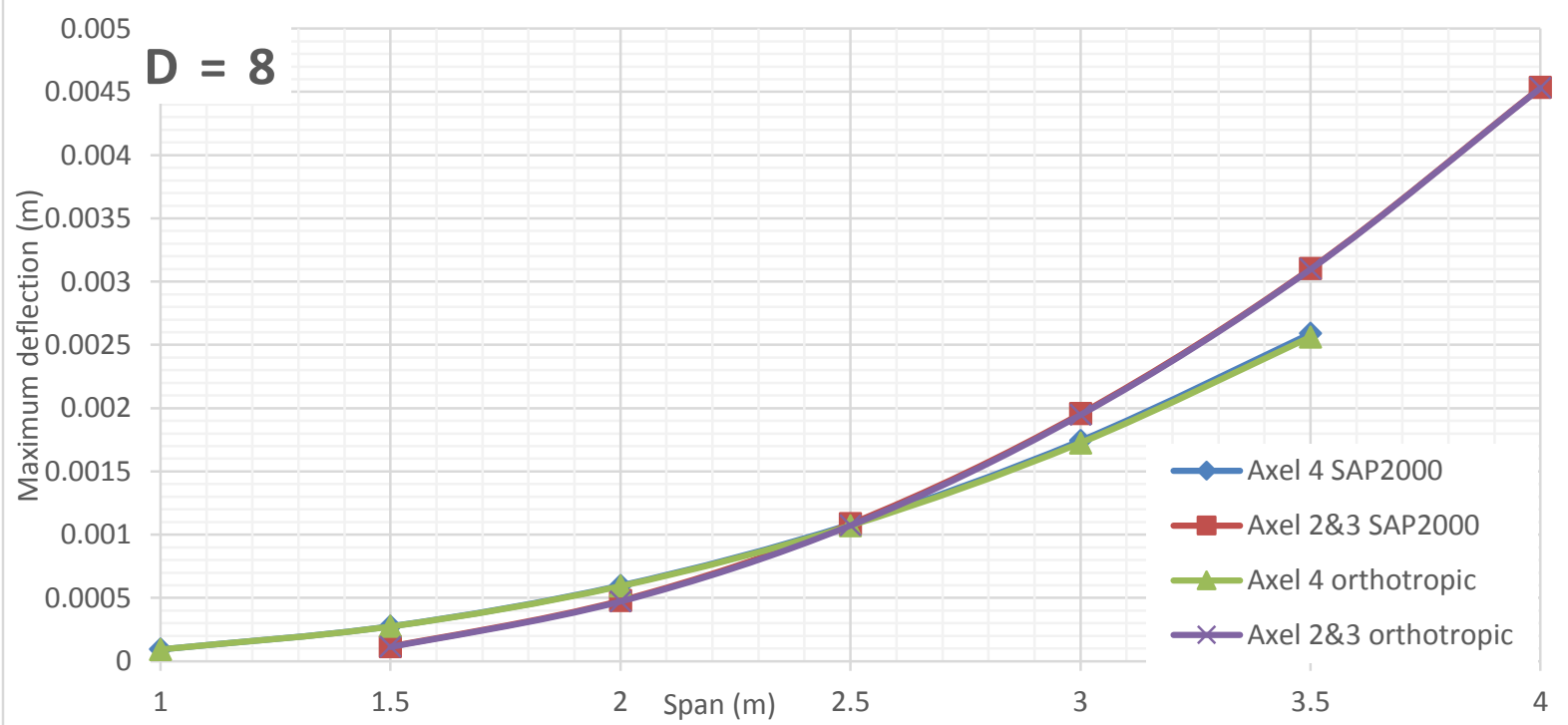

Figure 887 Deflection comparison between FEA and Orthotropic Plate Theory for $\mathrm{D}=8$ of alpha 4 (main bars parallel to traffic) 


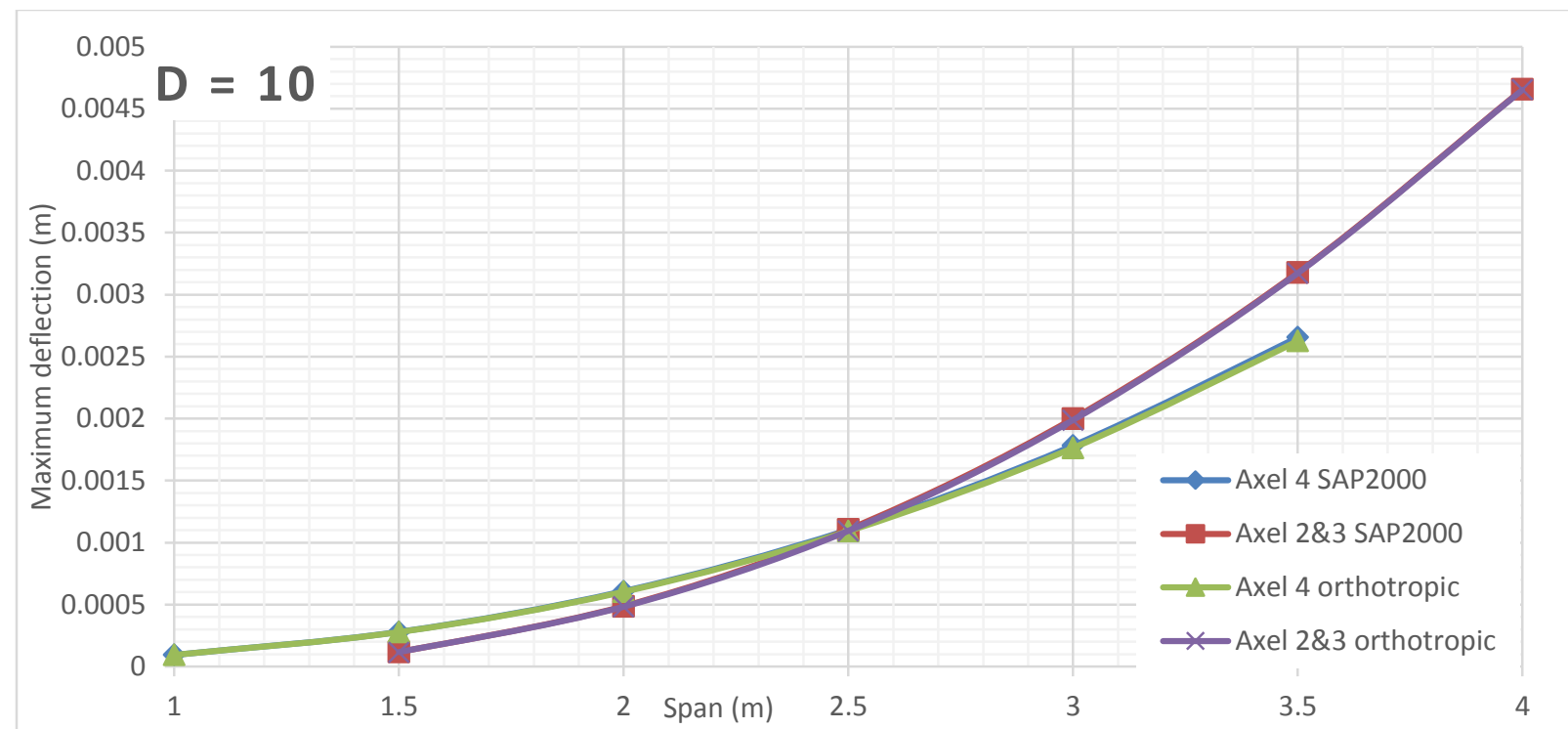

Figure 888 Deflection comparison between FEA and Orthotropic Plate Theory for $D=10$ of alpha 4 (main bars parallel to traffic) 


\section{Alpha 6 Deflection VS Span Length for Different D Values (Main bars perpendicular to traffic)}

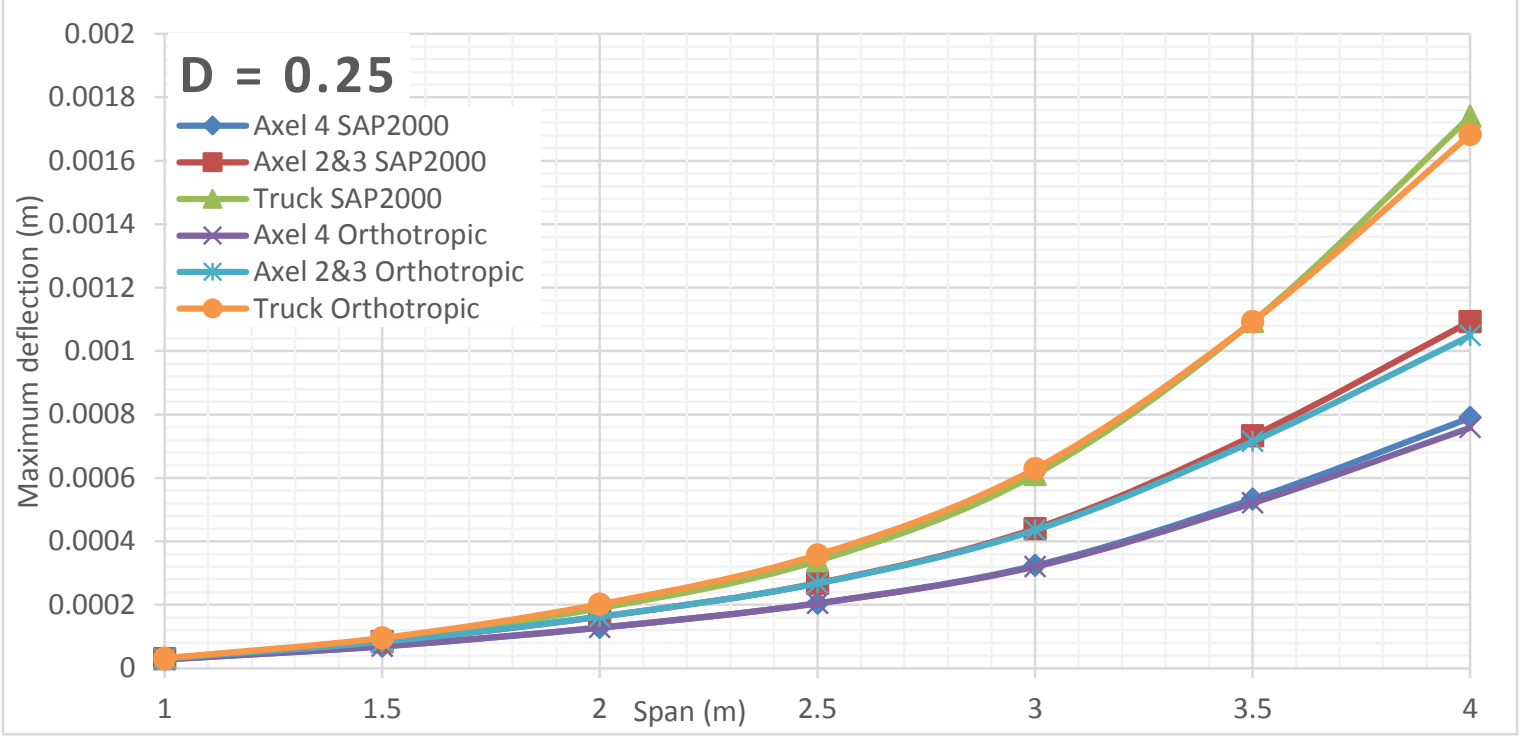

Figure 889 Deflection comparison between FEA and Orthotropic Plate Theory for D $=0.25$ of alpha 6 (main bars perpendicular to traffic)

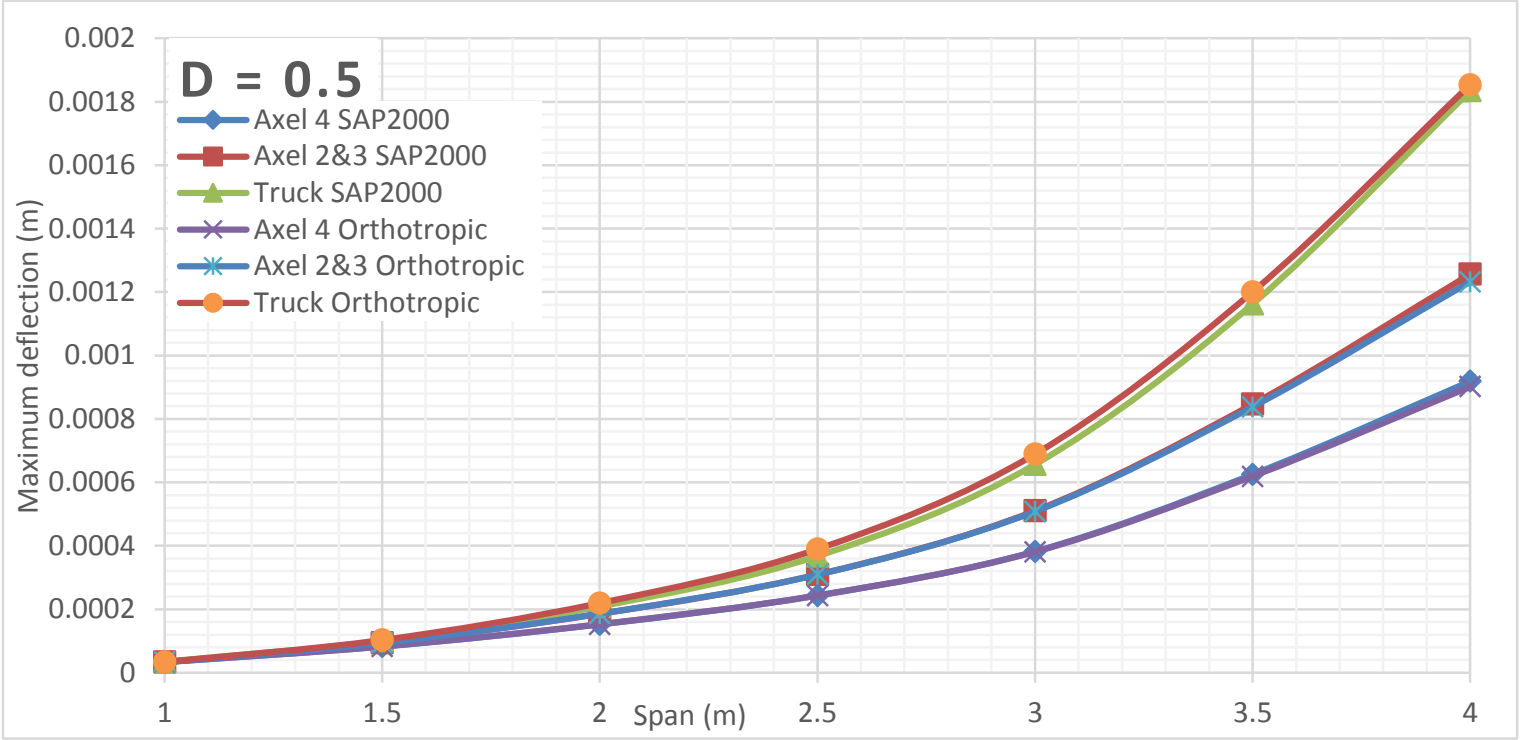

Figure 890 Deflection comparison between FEA and Orthotropic Plate Theory for $D=0.5$ of alpha 6 (main bars perpendicular to traffic) 


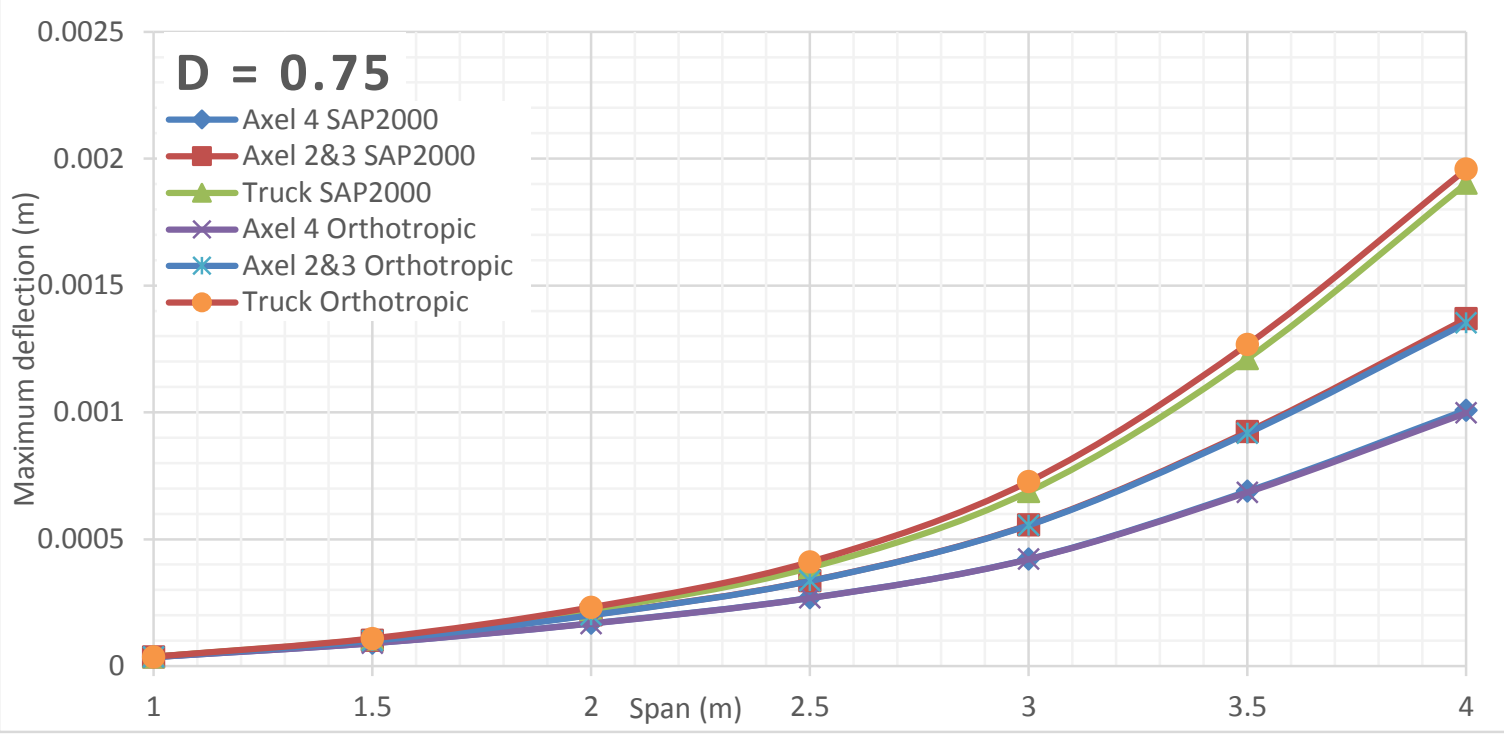

Figure 891 Deflection comparison between FEA and Orthotropic Plate Theory for D $=0.75$ of alpha 6 (main bars perpendicular to traffic)

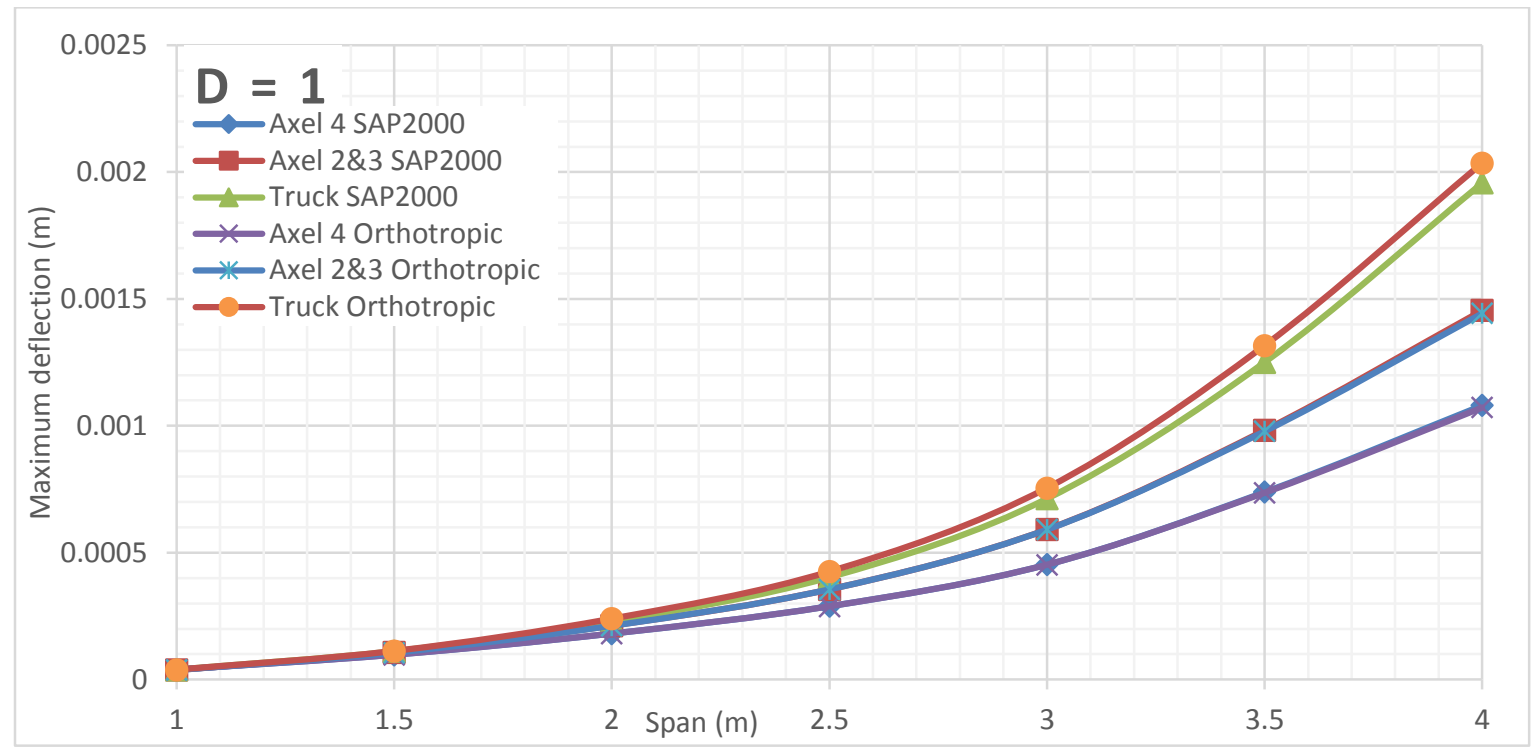

Figure 892 Deflection comparison between FEA and Orthotropic Plate Theory for D = 1 of alpha 6 (main bars perpendicular to traffic)

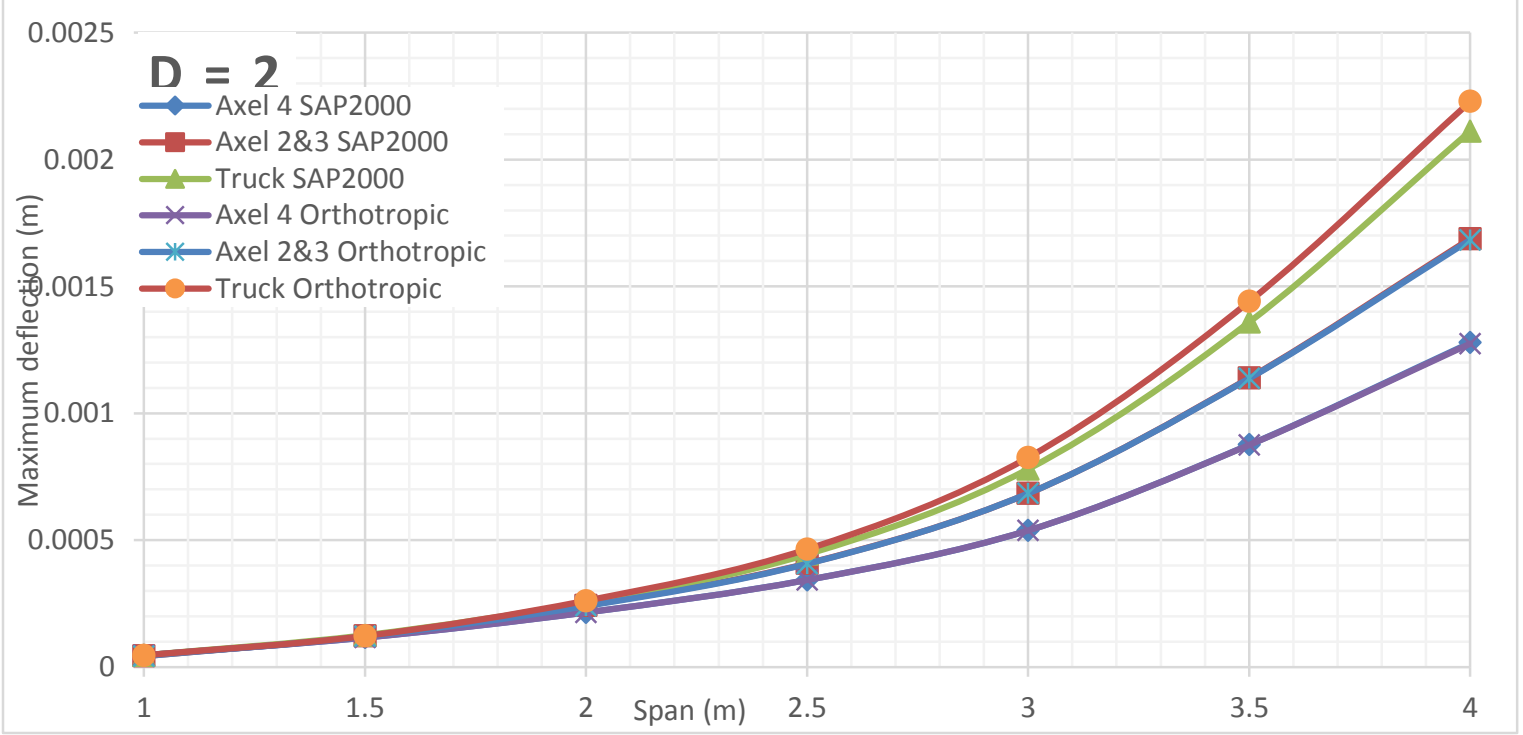

Figure 893 Deflection comparison between FEA and Orthotropic Plate Theory for $D=2$ of alpha 6 (main bars perpendicular to traffic) 


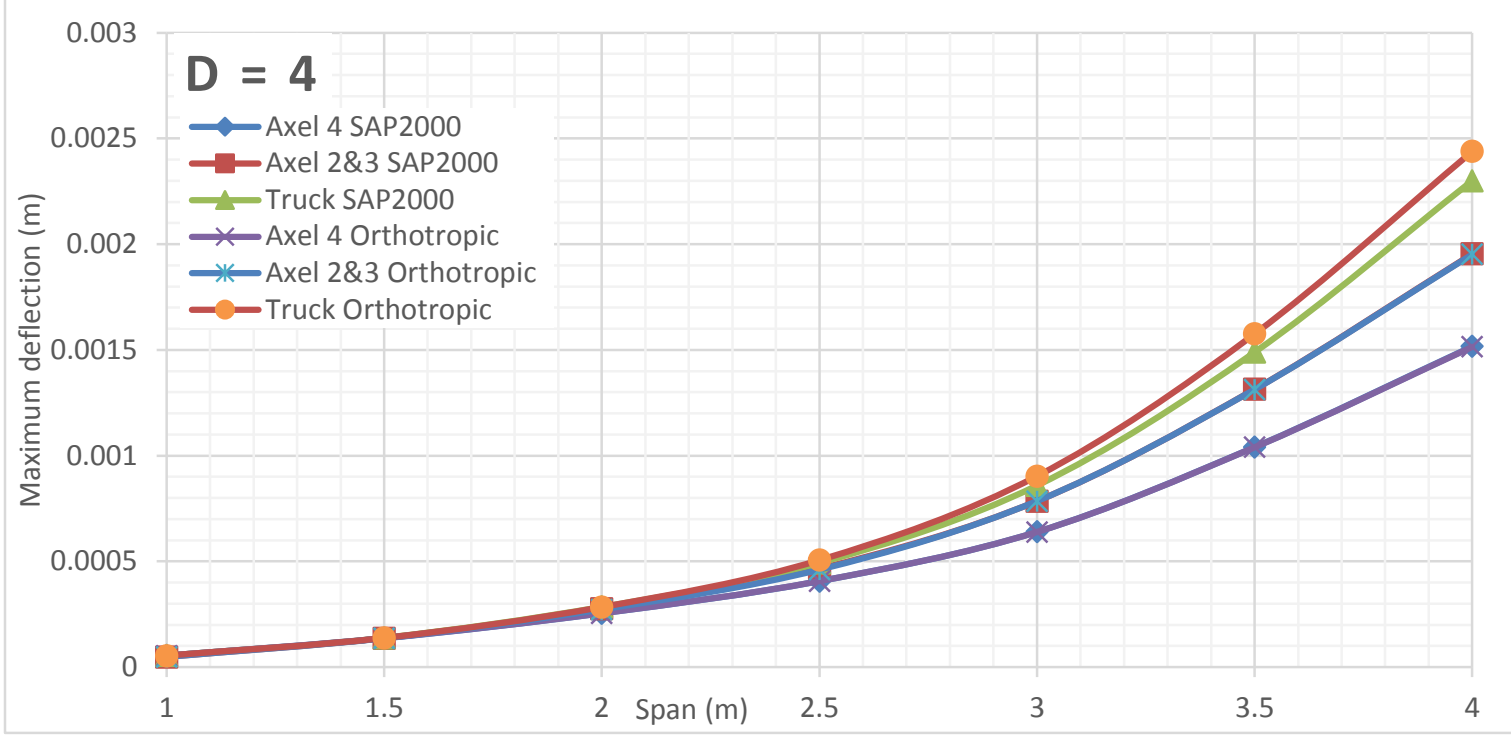

Figure 894 Deflection comparison between FEA and Orthotropic Plate Theory for $D=4$ of alpha 6 (main bars perpendicular to traffic)

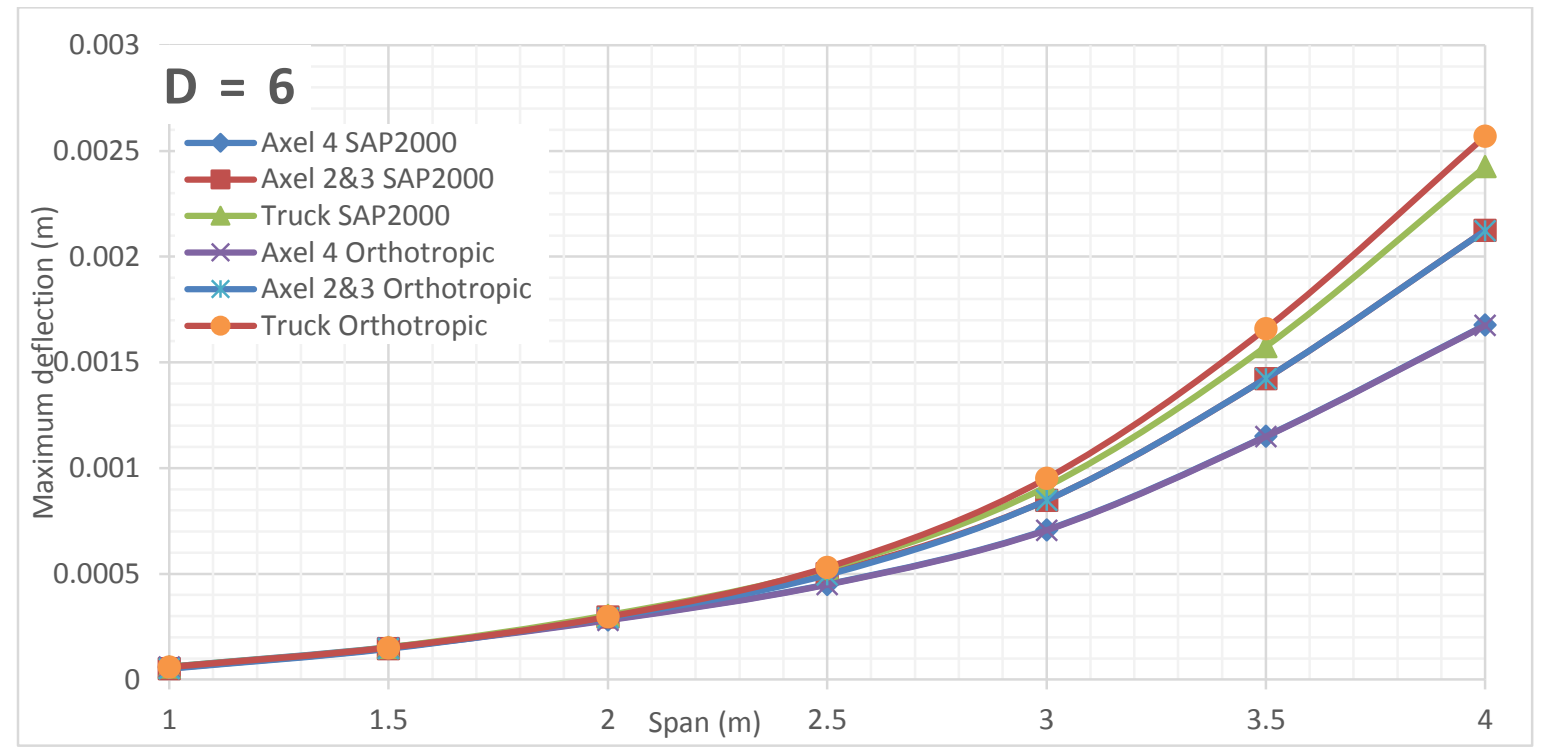

Figure 895 Deflection comparison between FEA and Orthotropic Plate Theory for D = 6 of alpha 6 (main bars perpendicular to traffic)

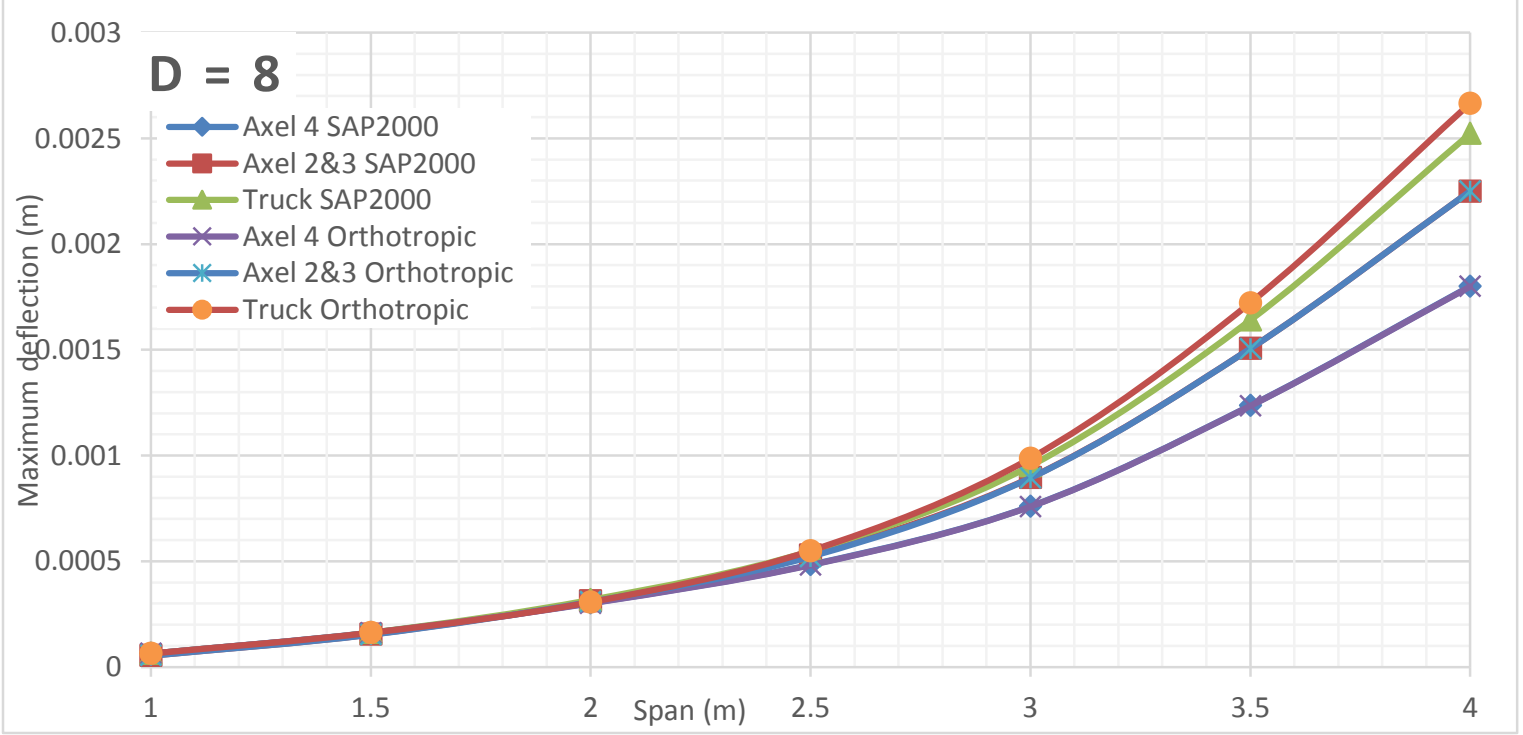

Figure 896 Deflection comparison between FEA and Orthotropic Plate Theory for $D=8$ of alpha 6 (main bars perpendicular to traffic) 


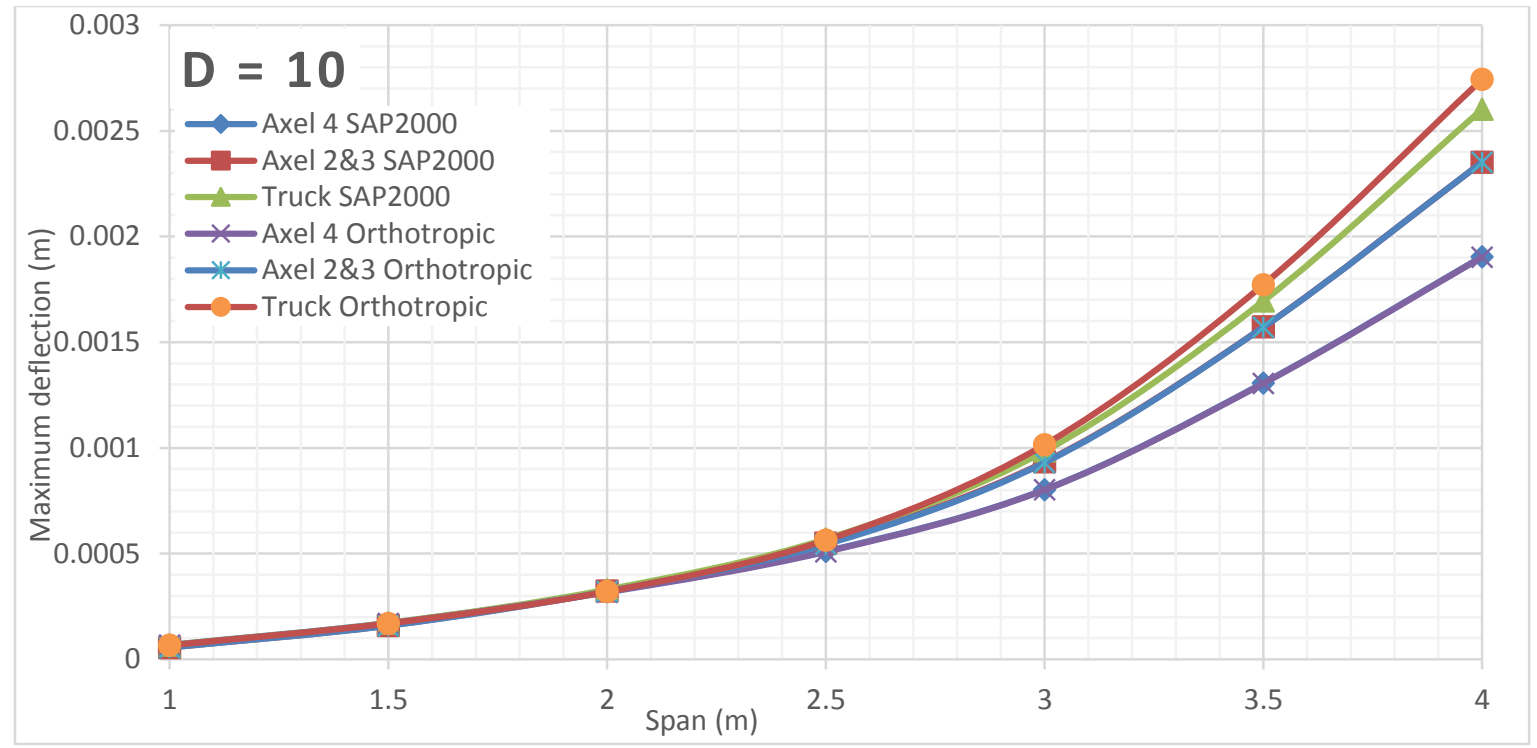

Figure 897 Deflection comparison between FEA and Orthotropic Plate Theory for $D=10$ of alpha 6 (main bars perpendicular to traffic) 


\section{Alpha 6 Deflection VS Span Length for Different D Values (Main bars parallel to traffic)}

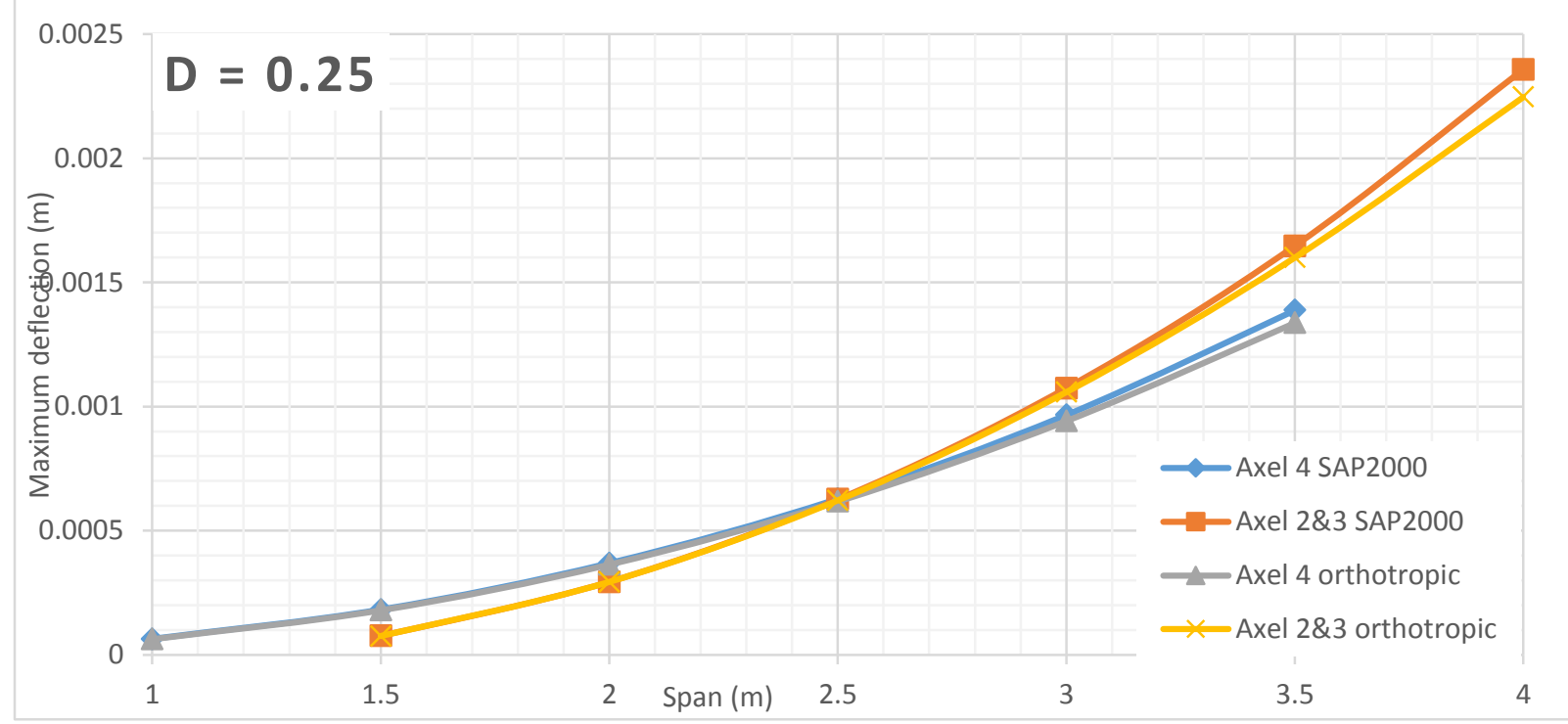

Figure 898 Deflection comparison between FEA and Orthotropic Plate Theory for $D=0.25$ of alpha 6 (main bars parallel to traffic)

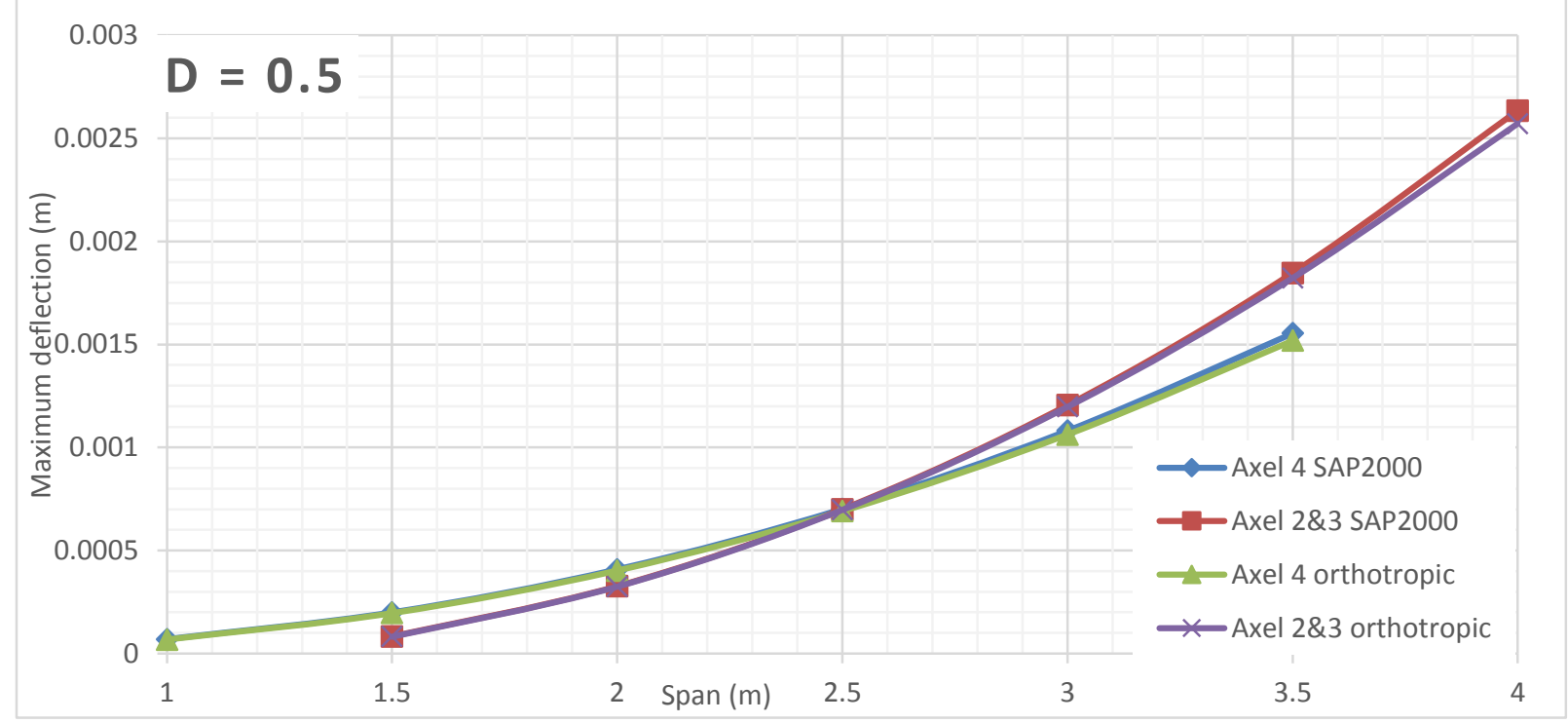

Figure 899 Deflection comparison between FEA and Orthotropic Plate Theory for $D=0.5$ of alpha 6 (main bars parallel to traffic) 


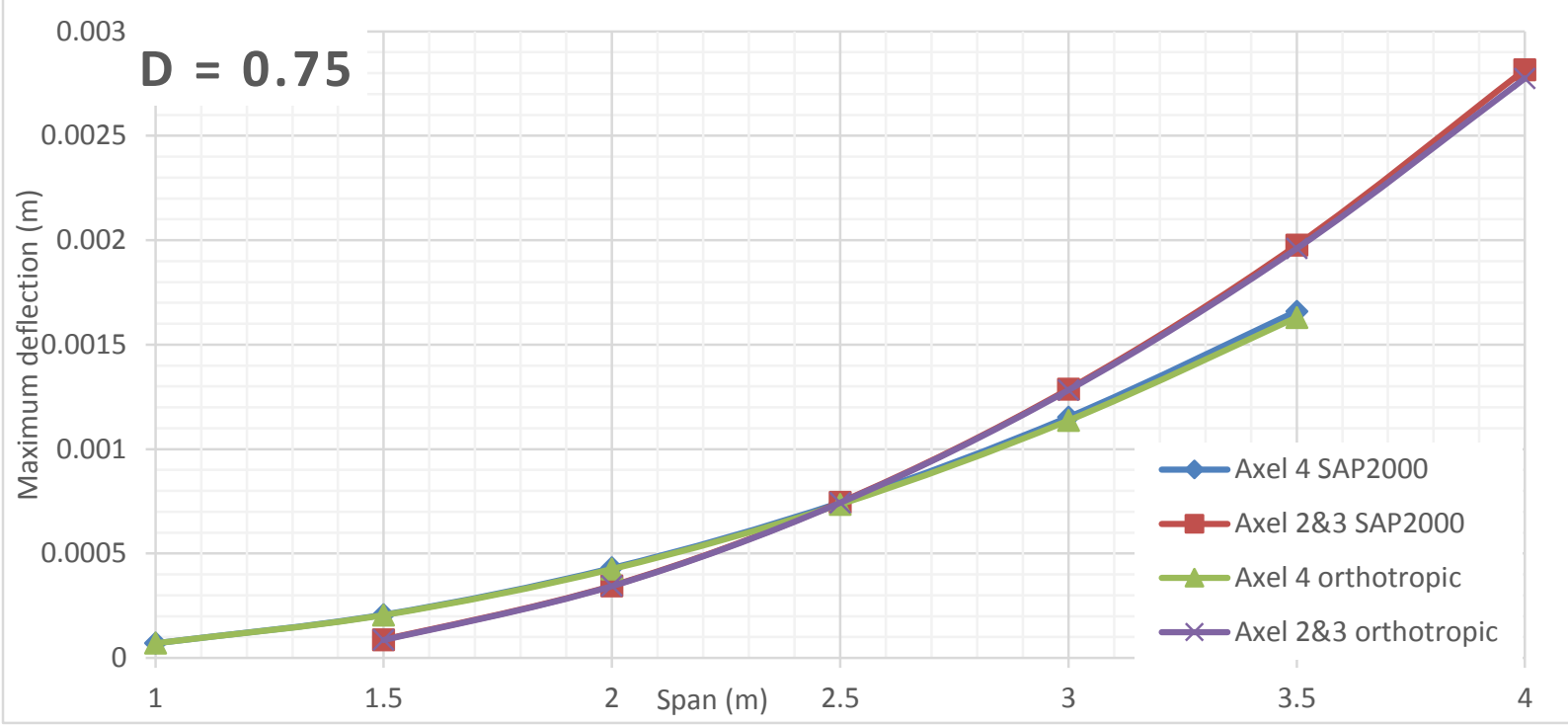

Figure 900 Deflection comparison between FEA and Orthotropic Plate Theory for $D=0.75$ of alpha 6 (main bars parallel to traffic)

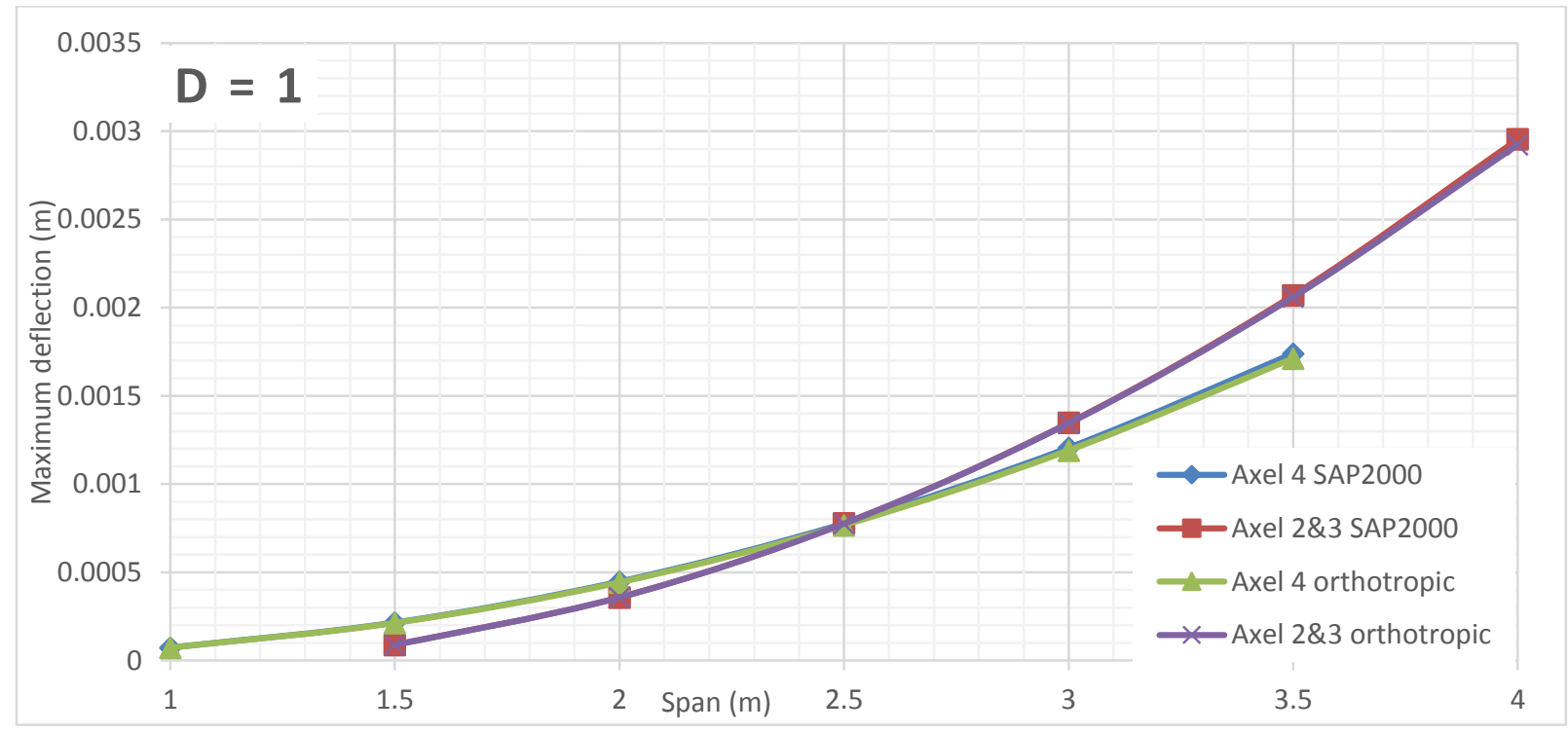

Figure 901 Deflection comparison between FEA and Orthotropic Plate Theory for $D=1$ of alpha 6 (main bars parallel to traffic)

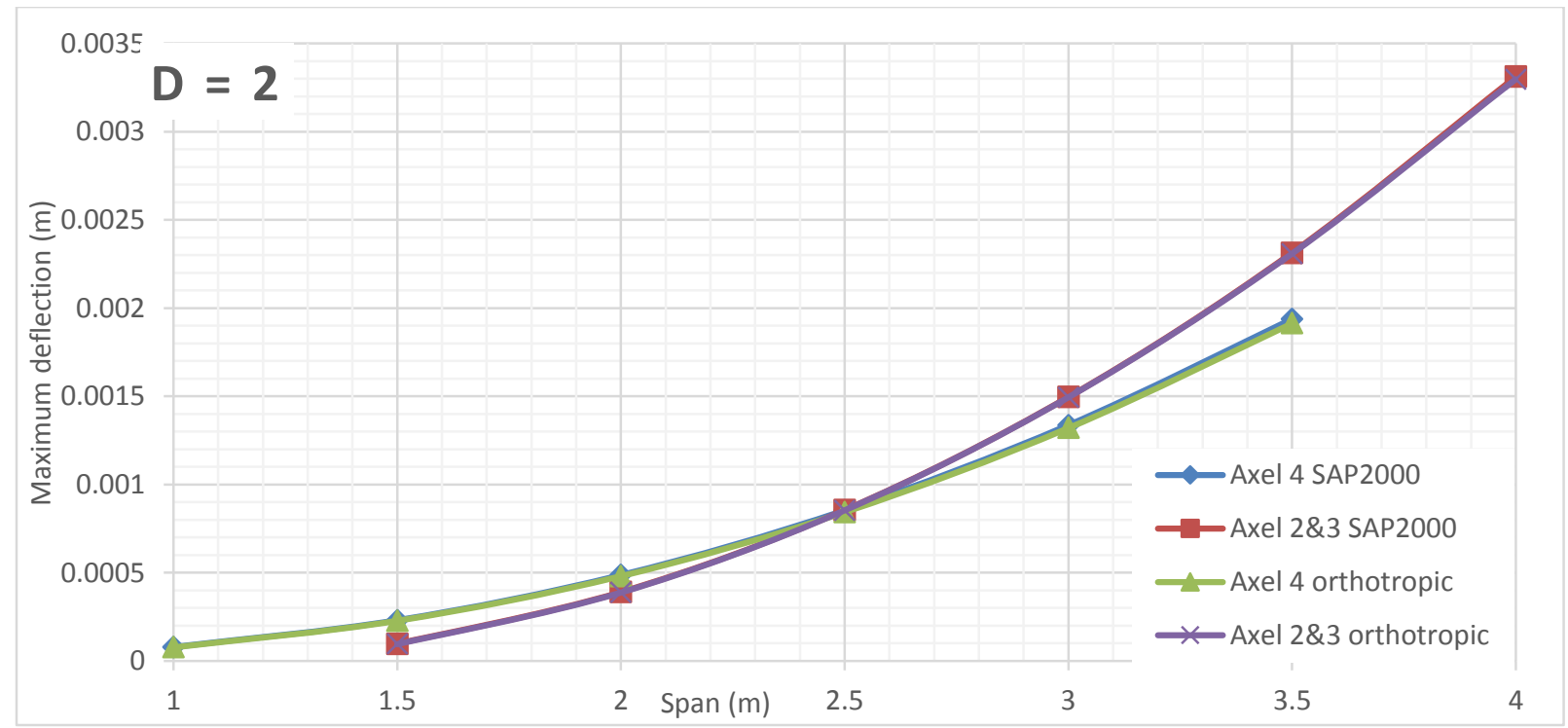

Figure 902 Deflection comparison between FEA and Orthotropic Plate Theory for $D=2$ of alpha 6 (main bars parallel to traffic) 


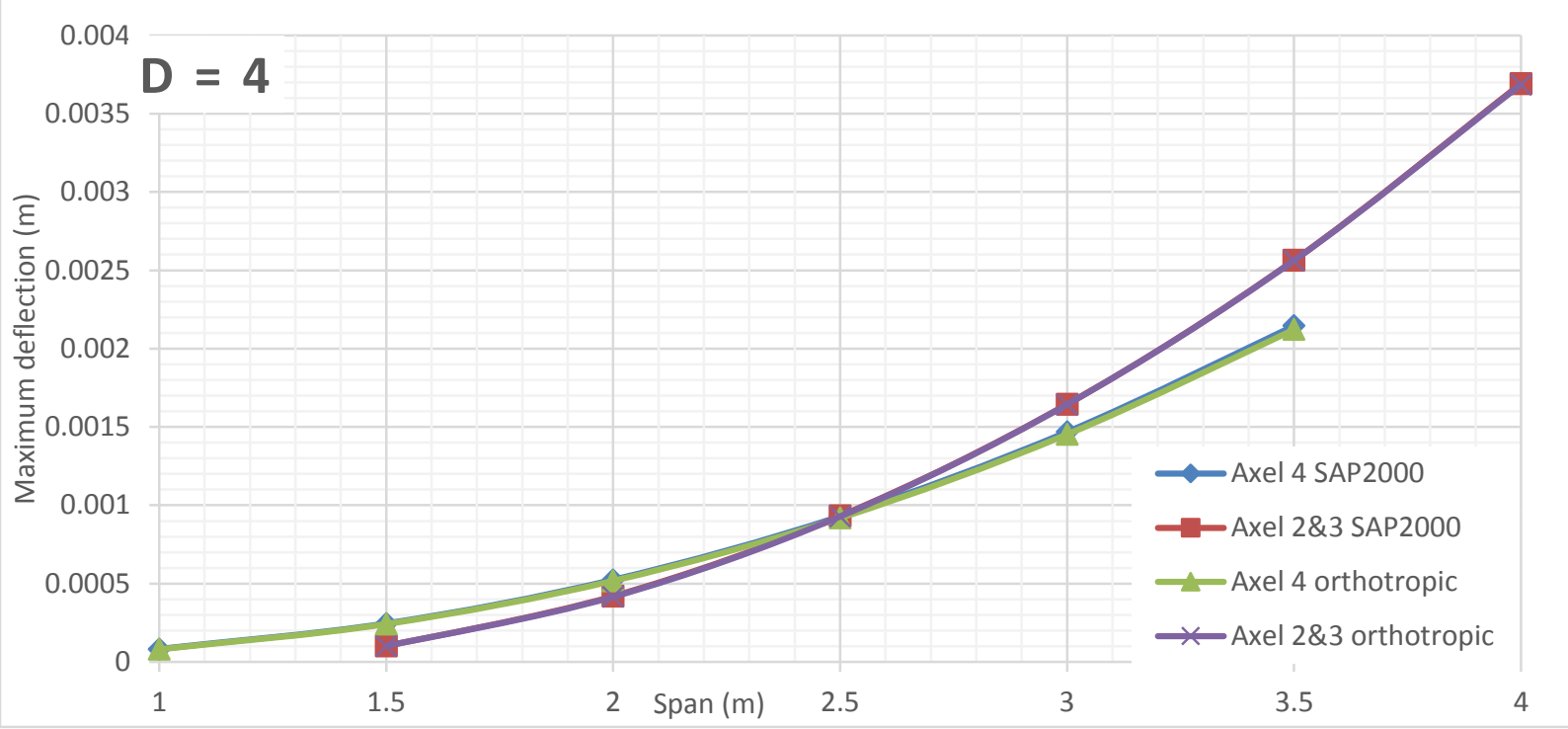

Figure 903 Deflection comparison between FEA and Orthotropic Plate Theory for $D=4$ of alpha 6 (main bars parallel to traffic)

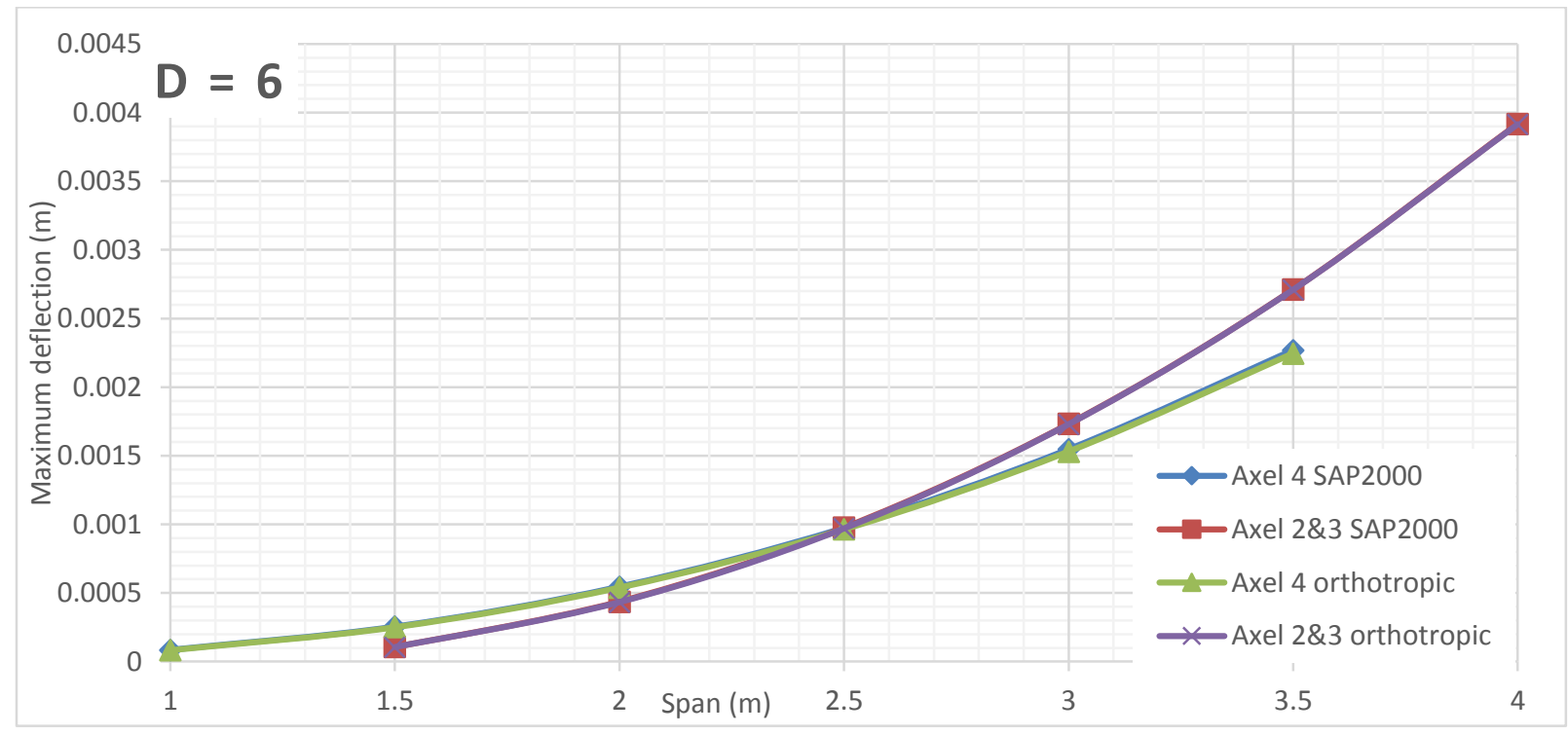

Figure 904 Deflection comparison between FEA and Orthotropic Plate Theory for D $=6$ of alpha 6 (main bars parallel to traffic)

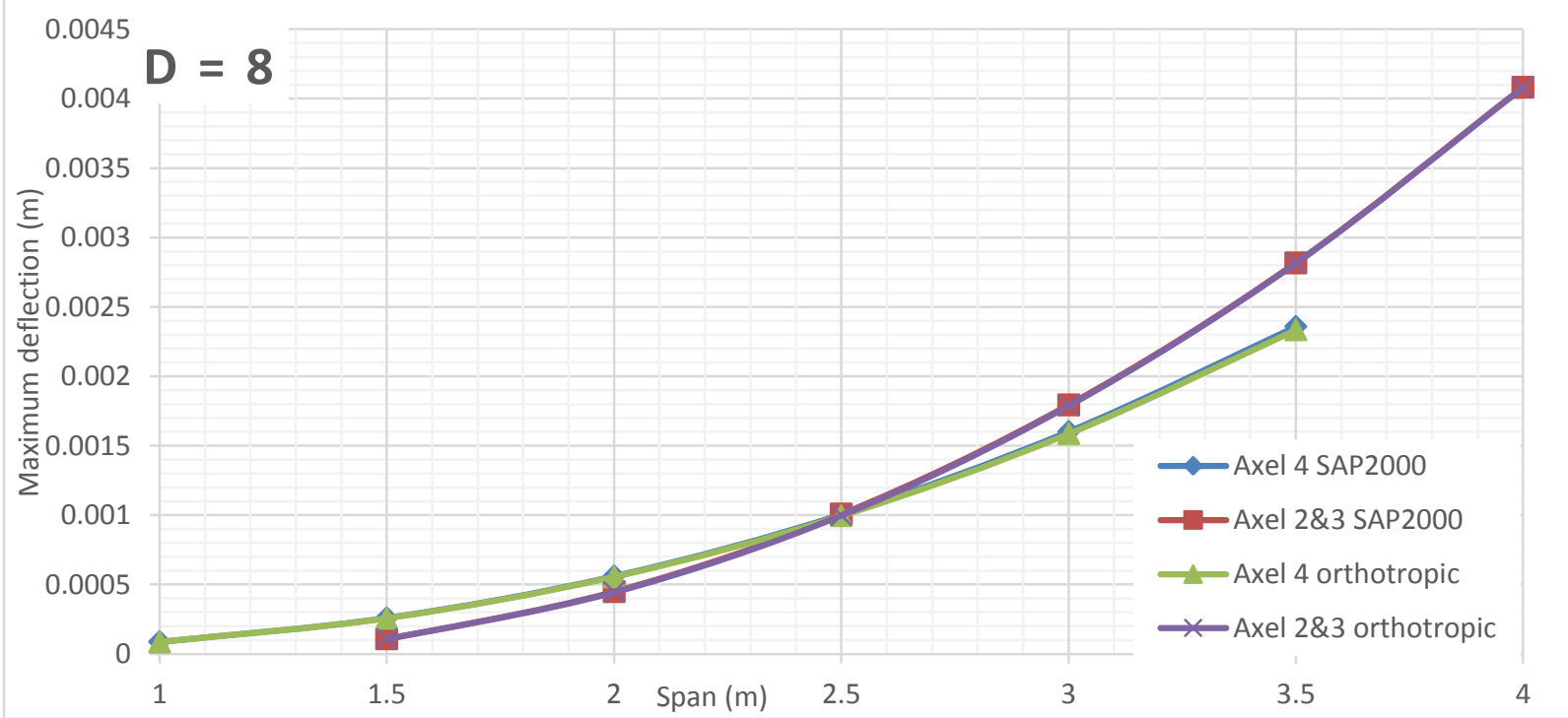

Figure 905 Deflection comparison between FEA and Orthotropic Plate Theory for $D=8$ of alpha 6 (main bars parallel to traffic) 


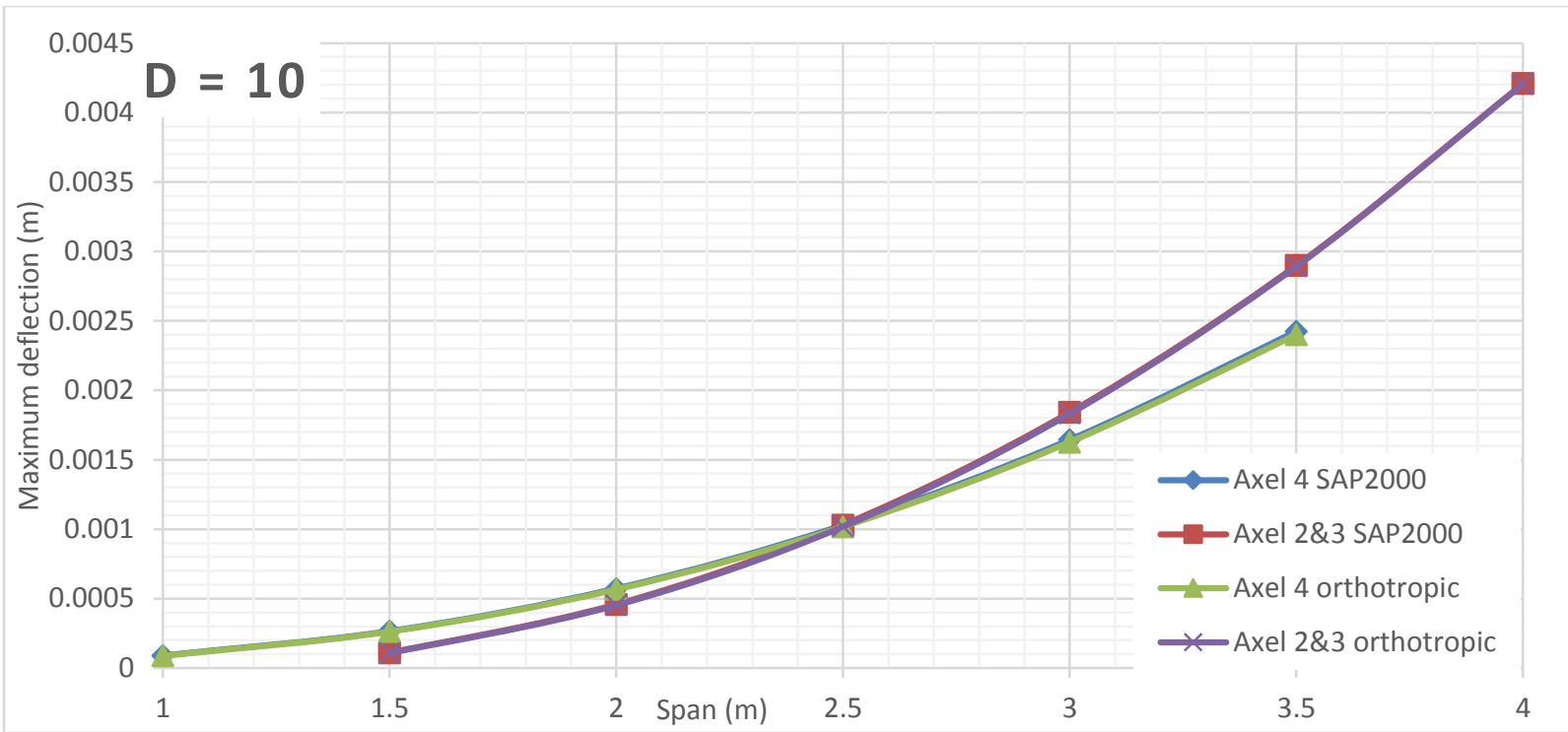

Figure 906 Deflection comparison between FEA and Orthotropic Plate Theory for $D=10$ of alpha 6 (main bars parallel to traffic) 


\section{Alpha 8 Deflection VS Span Length for Different D Values (Main bars perpendicular to traffic)}

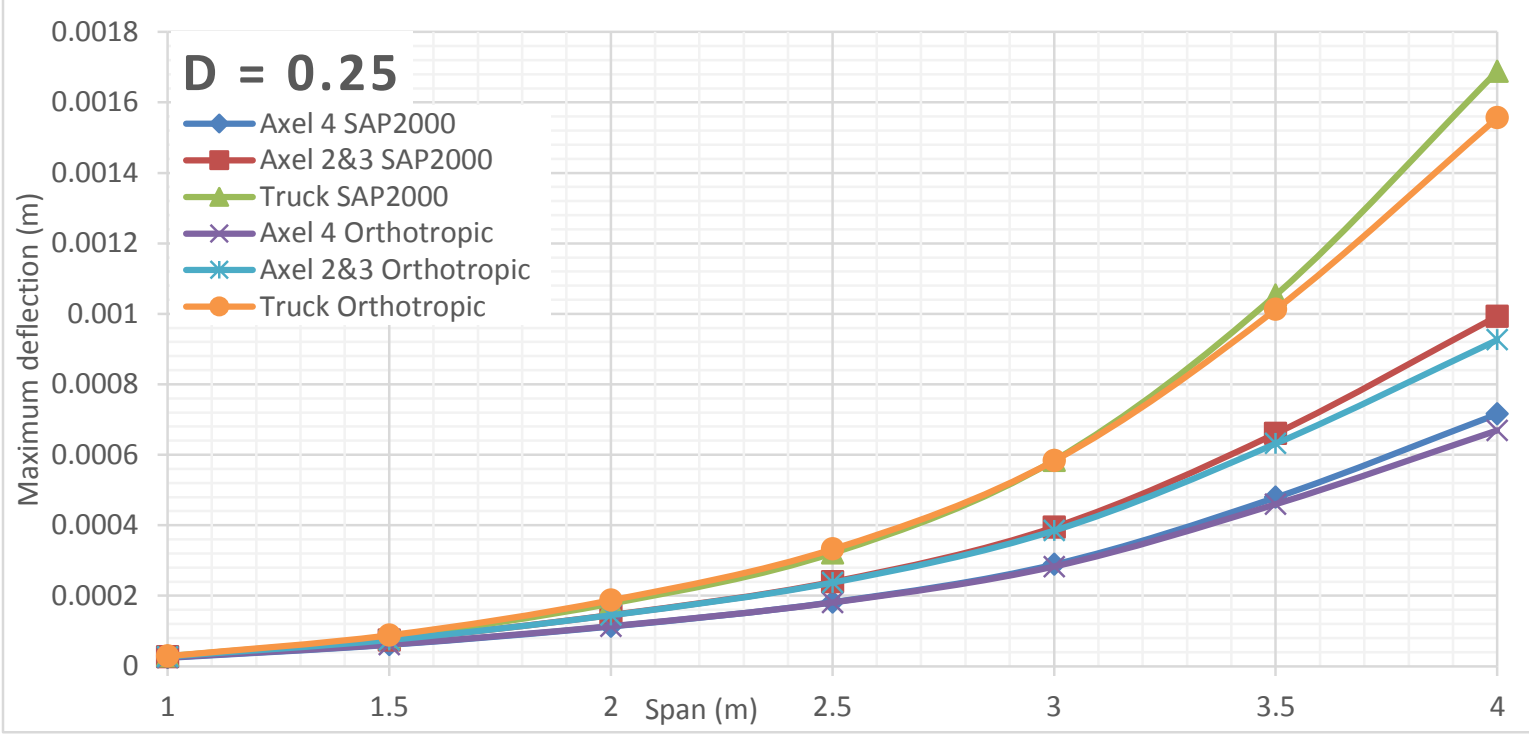

Figure 907 Deflection comparison between FEA and Orthotropic Plate Theory for $D=0.25$ of alpha 8 (main bars perpendicular to traffic)

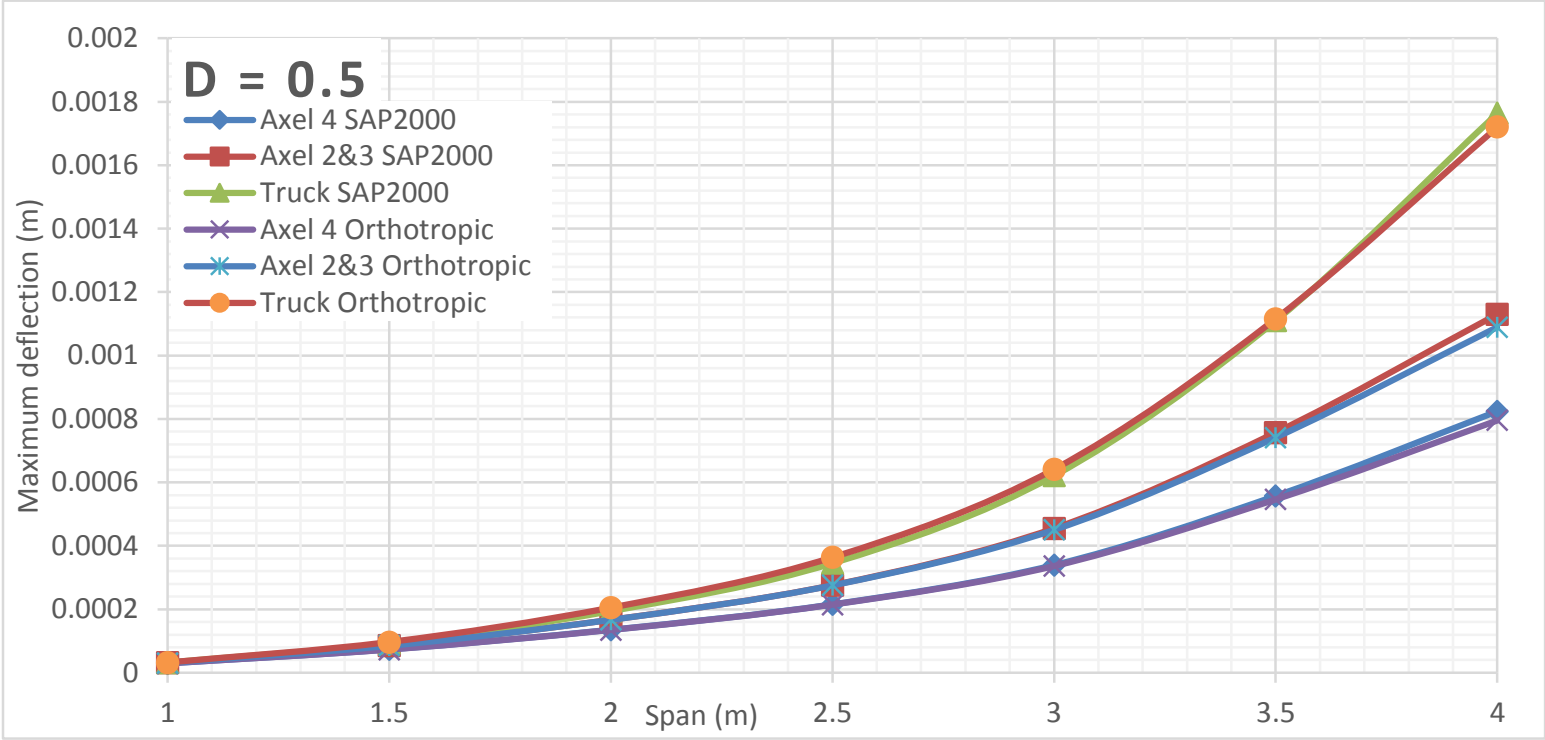

Figure 908 Deflection comparison between FEA and Orthotropic Plate Theory for $\mathrm{D}=0.5$ of alpha 8 (main bars perpendicular to traffic) 


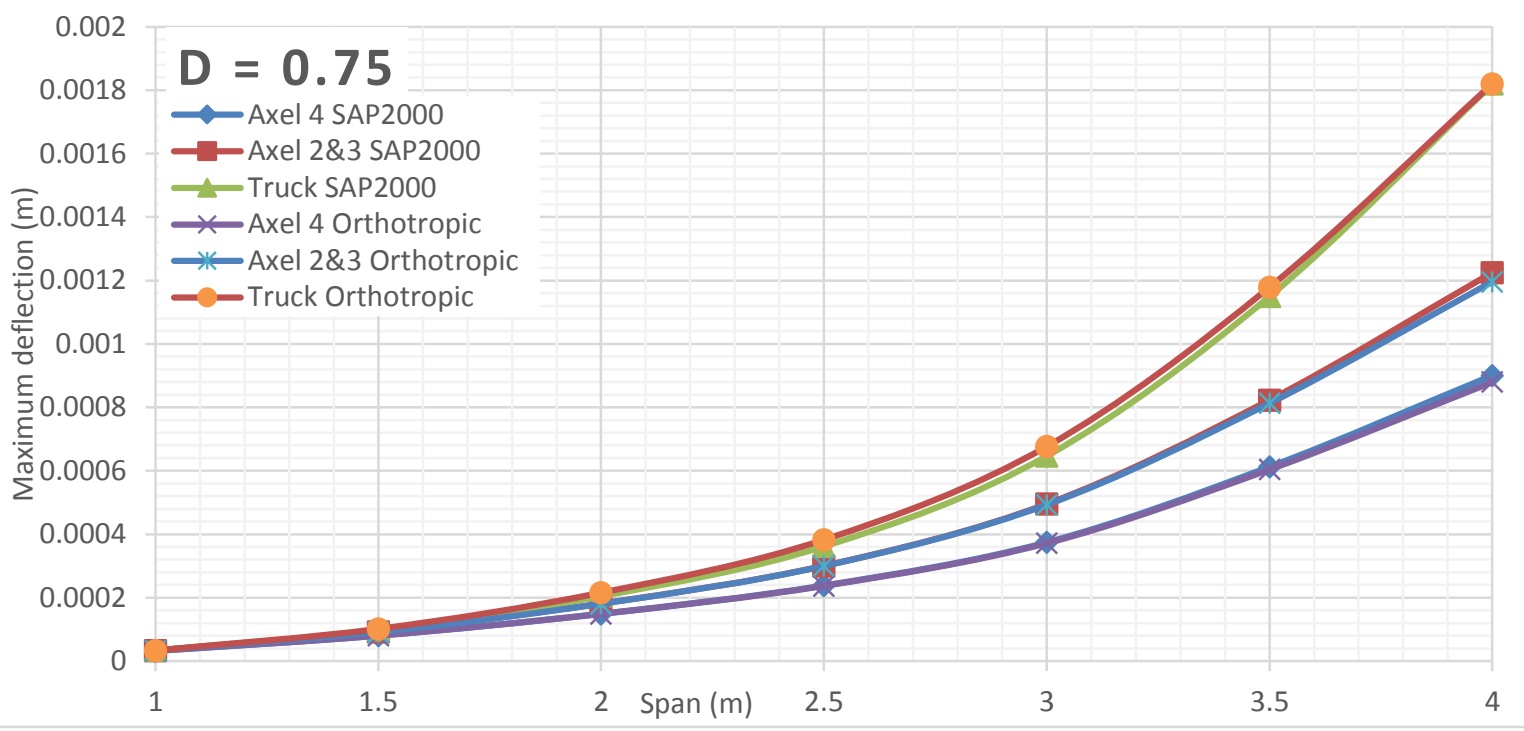

Figure 909 Deflection comparison between FEA and Orthotropic Plate Theory for $D=0.75$ of alpha 8 (main bars perpendicular to traffic)

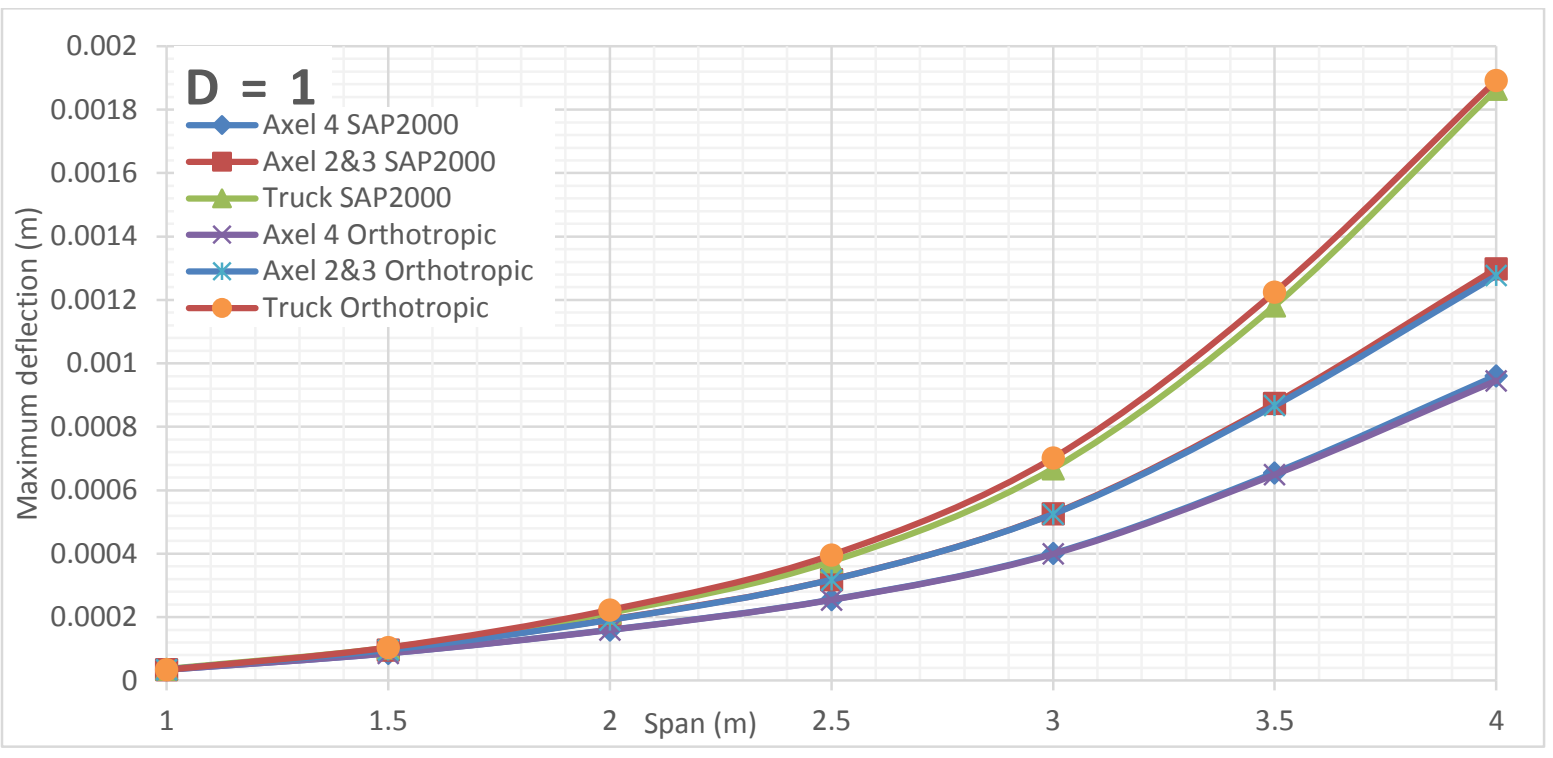

Figure 910 Deflection comparison between FEA and Orthotropic Plate Theory for D = 1 of alpha 8 (main bars perpendicular to traffic)

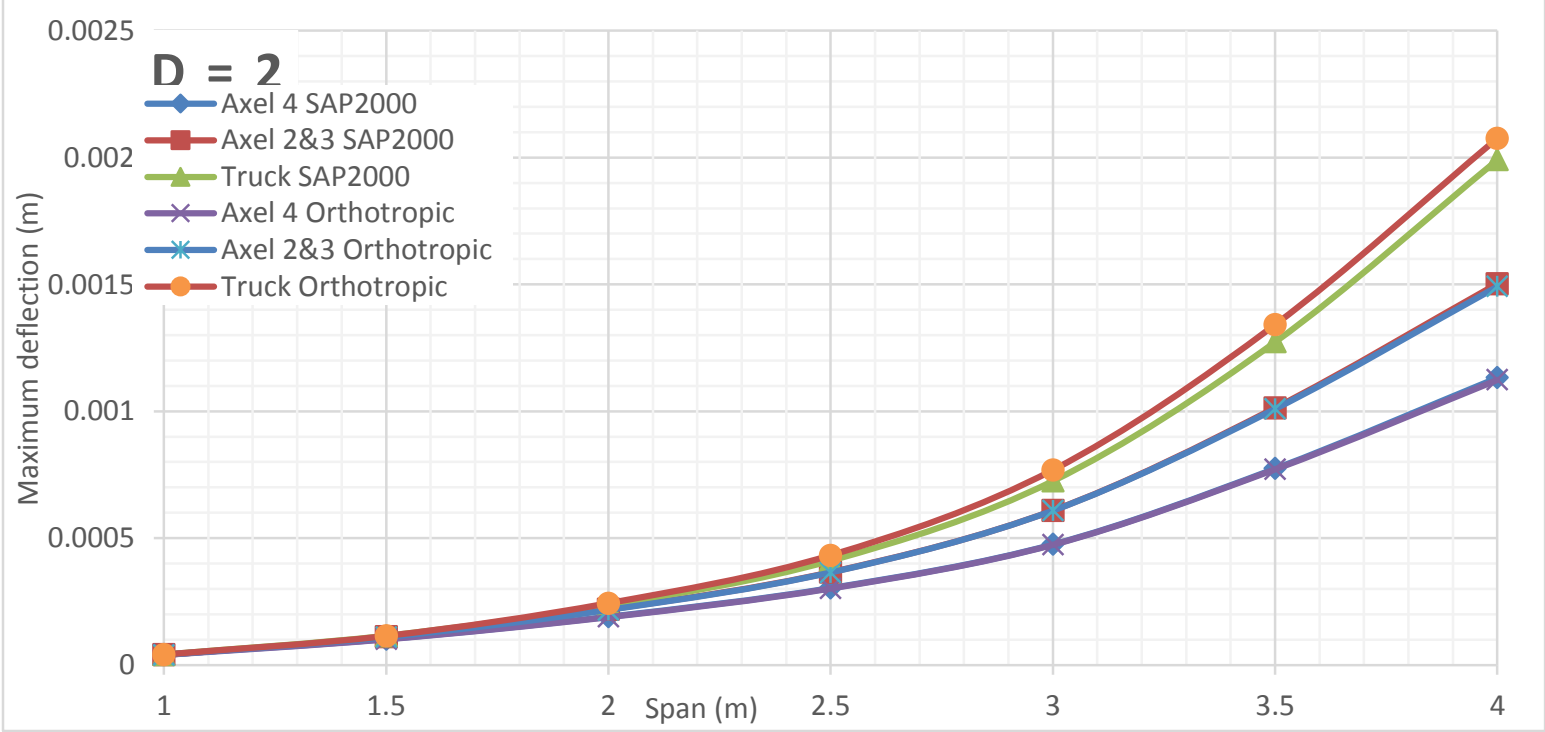

Figure 911 Deflection comparison between FEA and Orthotropic Plate Theory for $D=2$ of alpha 8 (main bars perpendicular to traffic) 


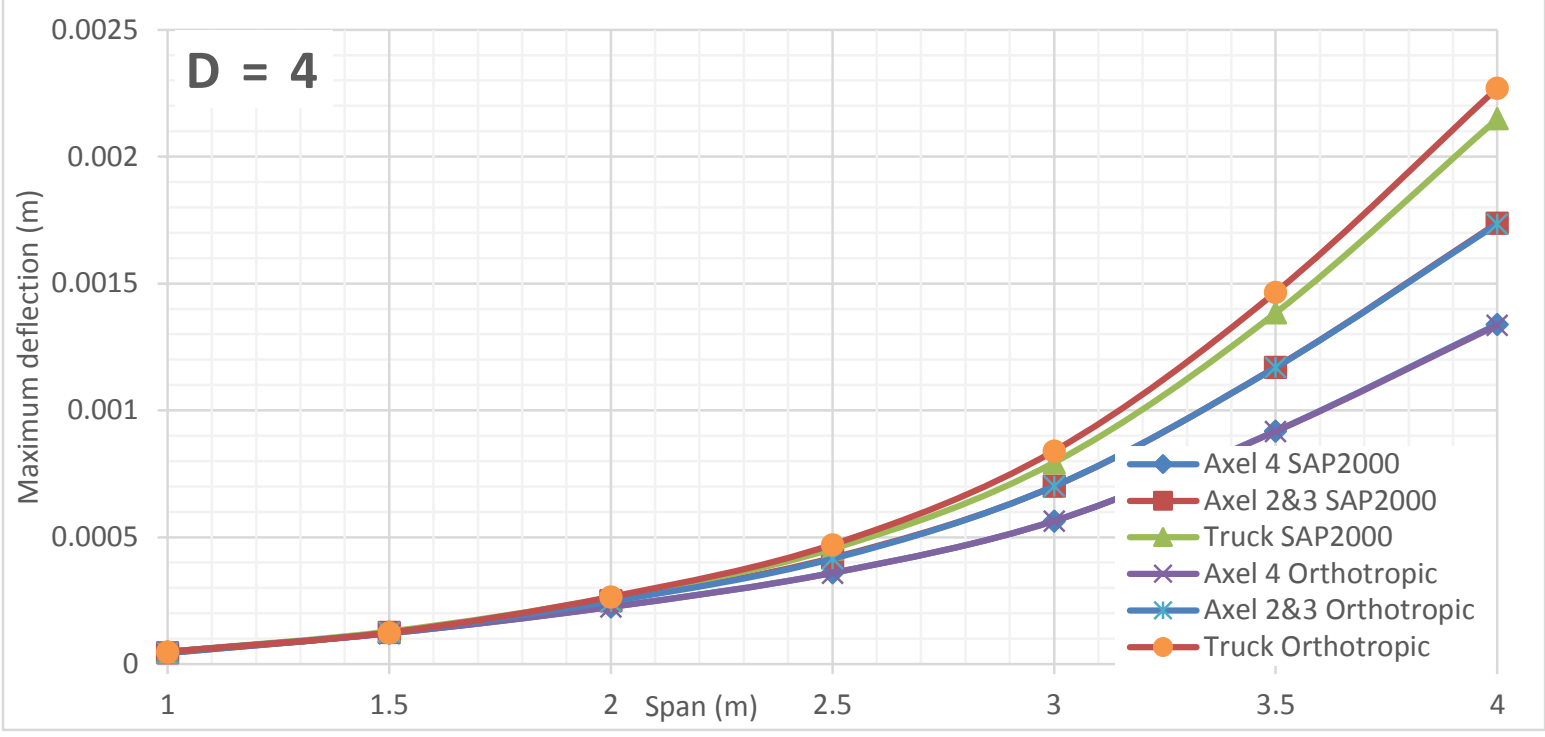

Figure 912 Deflection comparison between FEA and Orthotropic Plate Theory for $D=4$ of alpha 8 (main bars perpendicular to traffic)

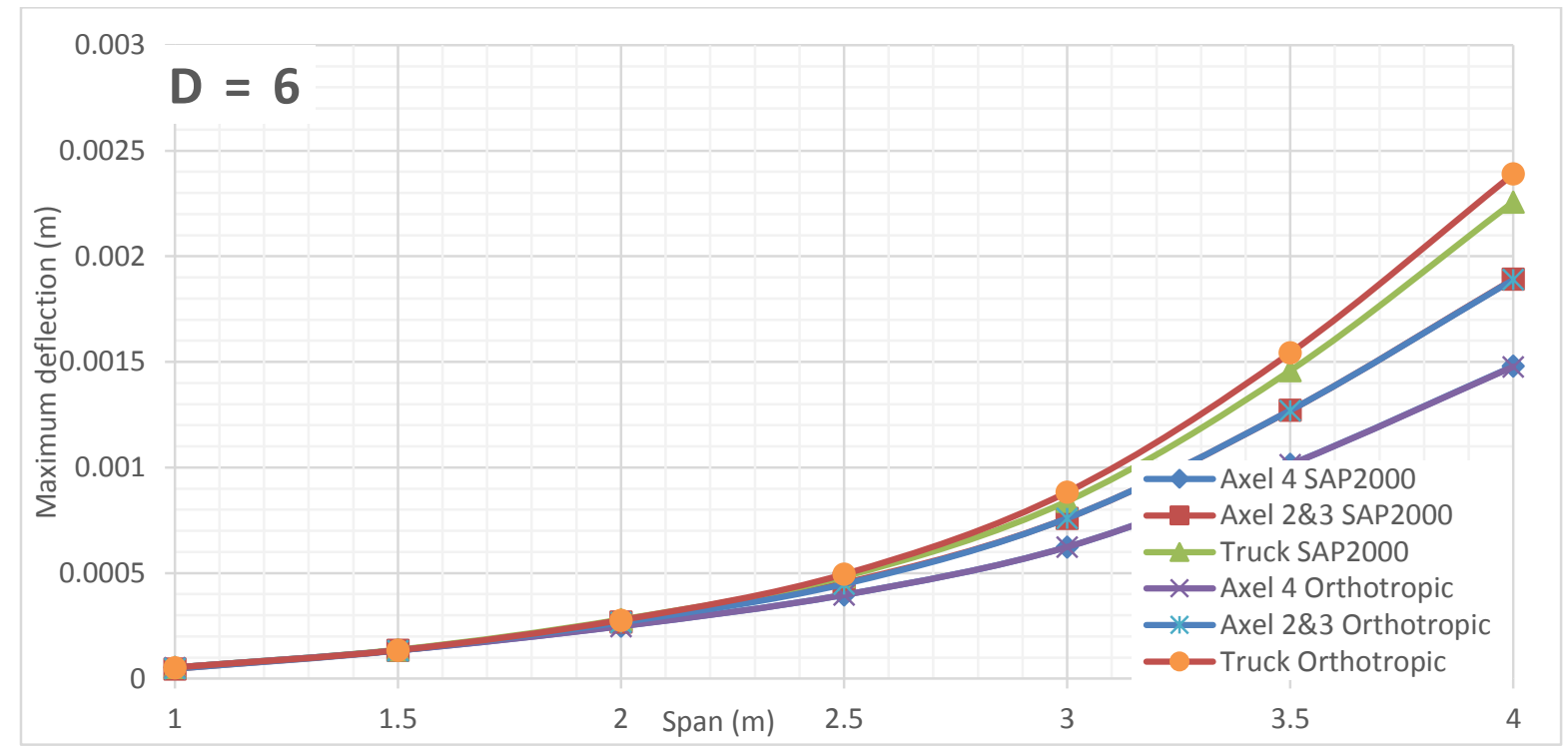

Figure 913 Deflection comparison between FEA and Orthotropic Plate Theory for $D=6$ of alpha 8 (main bars perpendicular to traffic)

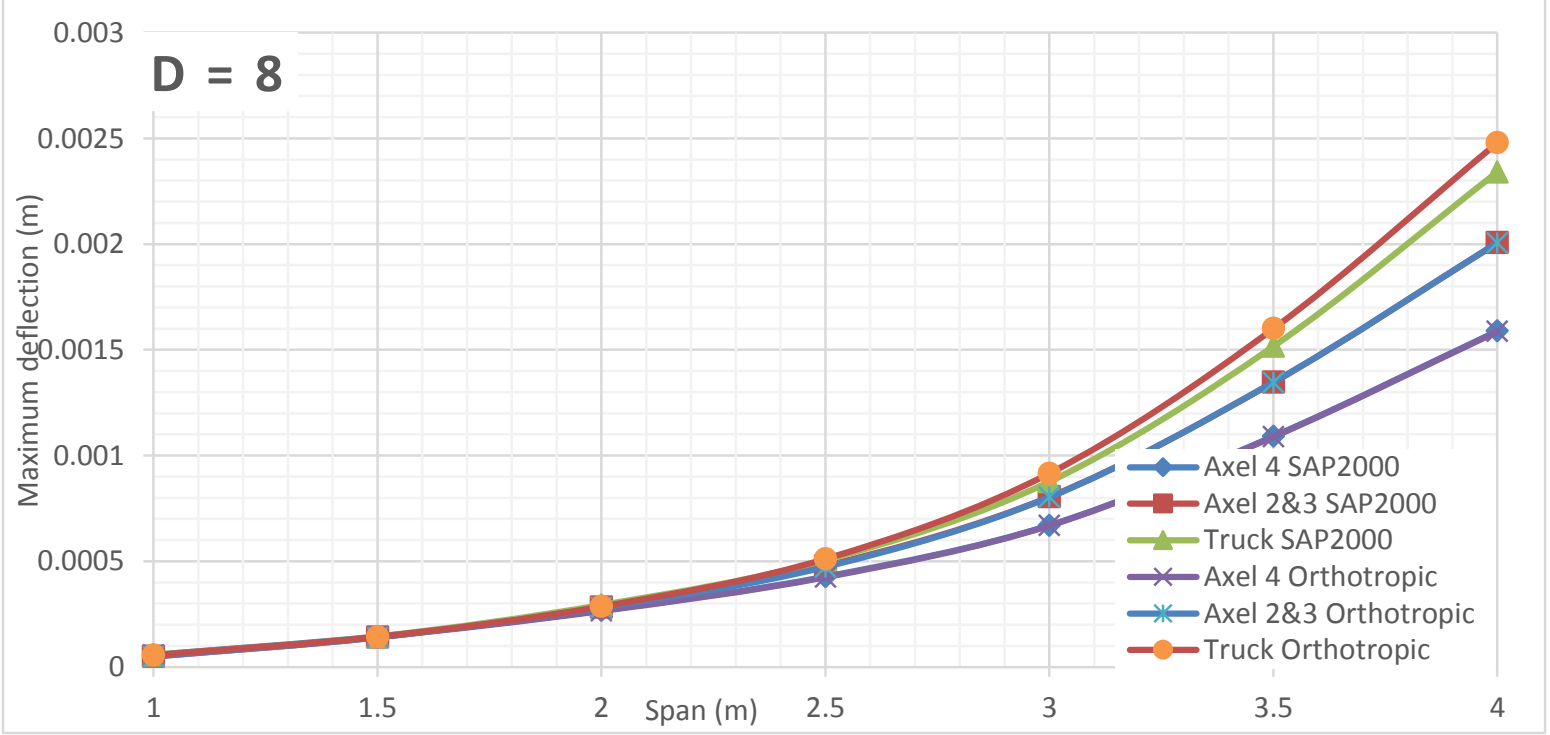

Figure 914 Deflection comparison between FEA and Orthotropic Plate Theory for $D=8$ of alpha 8 (main bars perpendicular to traffic) 


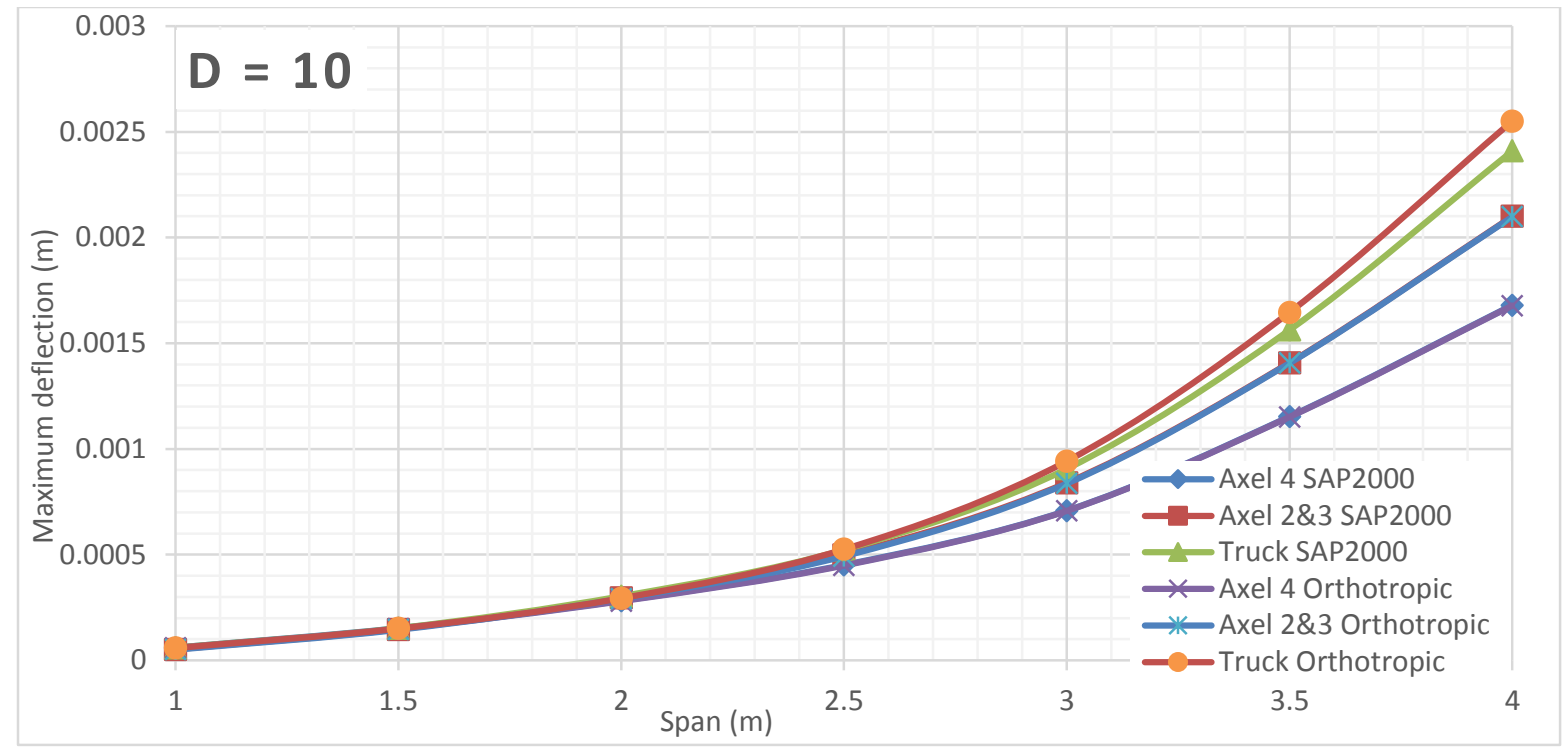

Figure 915 Deflection comparison between FEA and Orthotropic Plate Theory for $D=10$ of alpha 8 (main bars perpendicular to traffic) 


\section{Alpha 8 Deflection VS Span Length for Different D Values (Main bars parallel to traffic)}

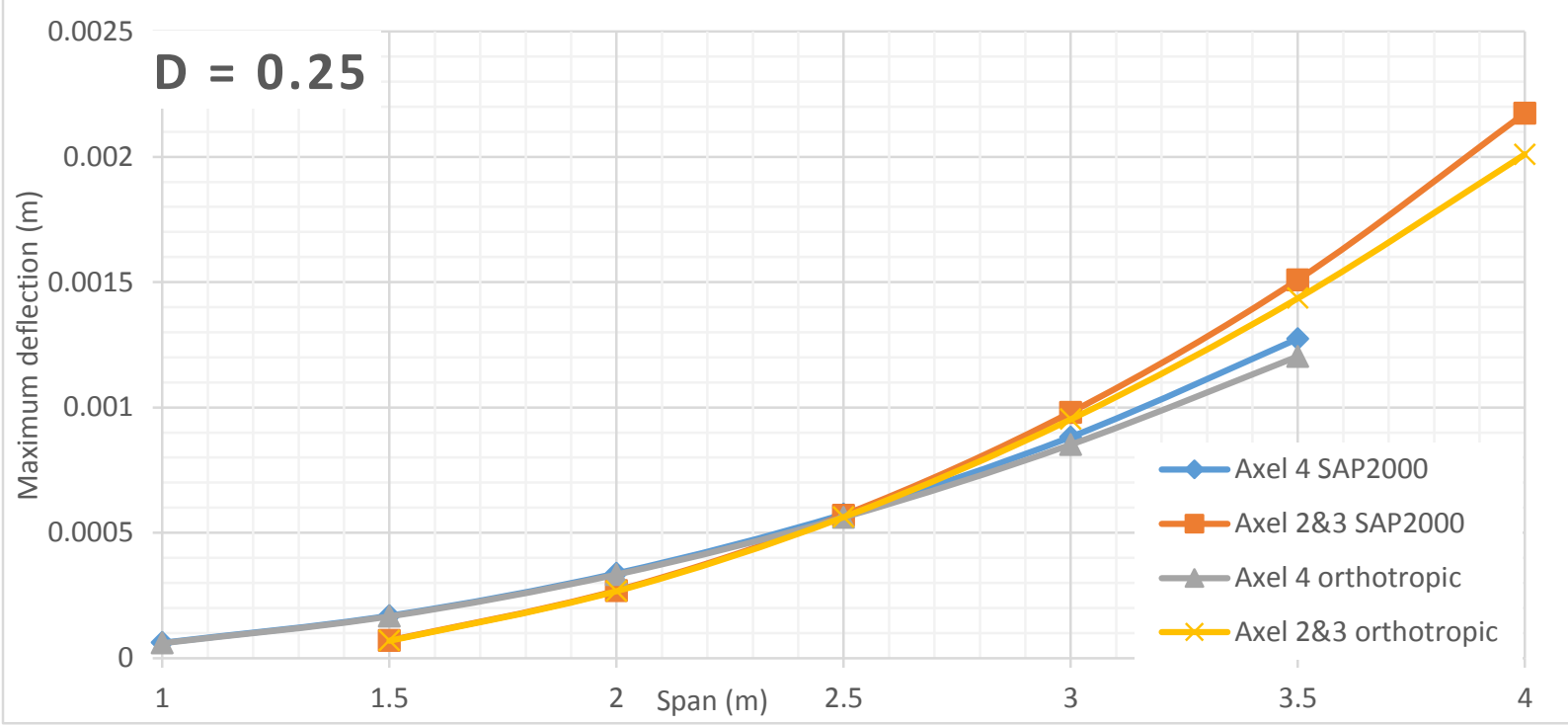

Figure 916 Deflection comparison between FEA and Orthotropic Plate Theory for $D=0.25$ of alpha 8 (main bars parallel to traffic)

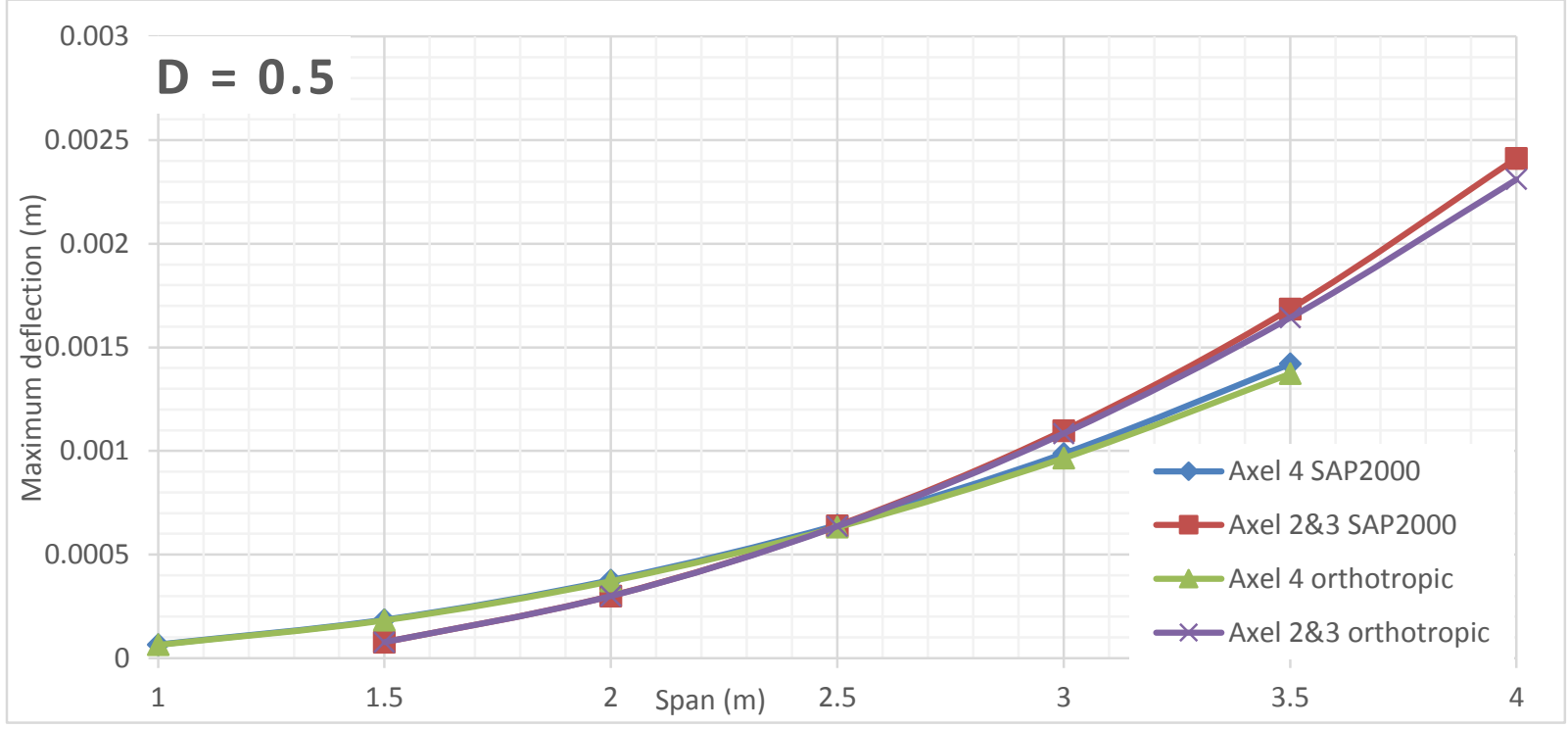

Figure 917 Deflection comparison between FEA and Orthotropic Plate Theory for $D=0.5$ of alpha 8 (main bars parallel to traffic) 


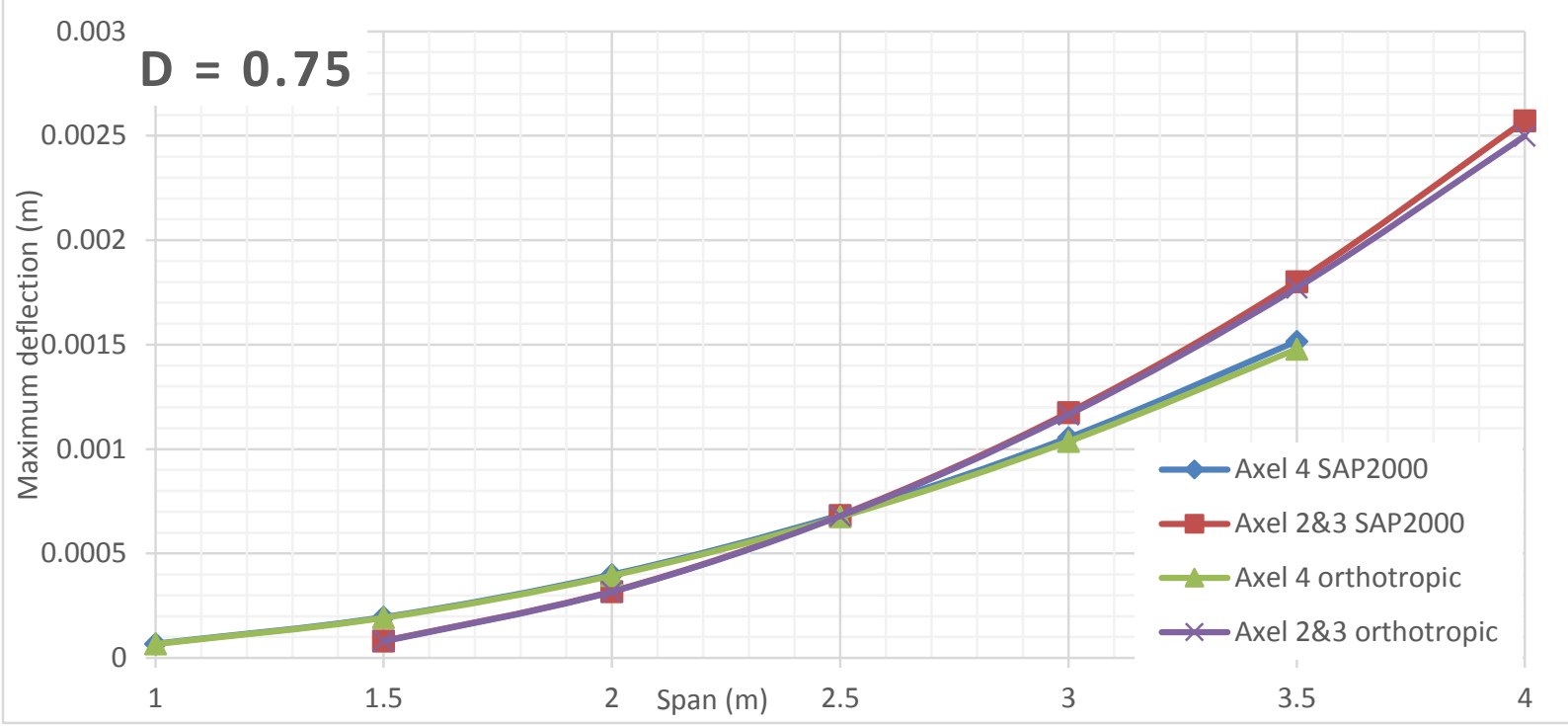

Figure 918 Deflection comparison between FEA and Orthotropic Plate Theory for $D=0.75$ of alpha 8 (main bars parallel to traffic)

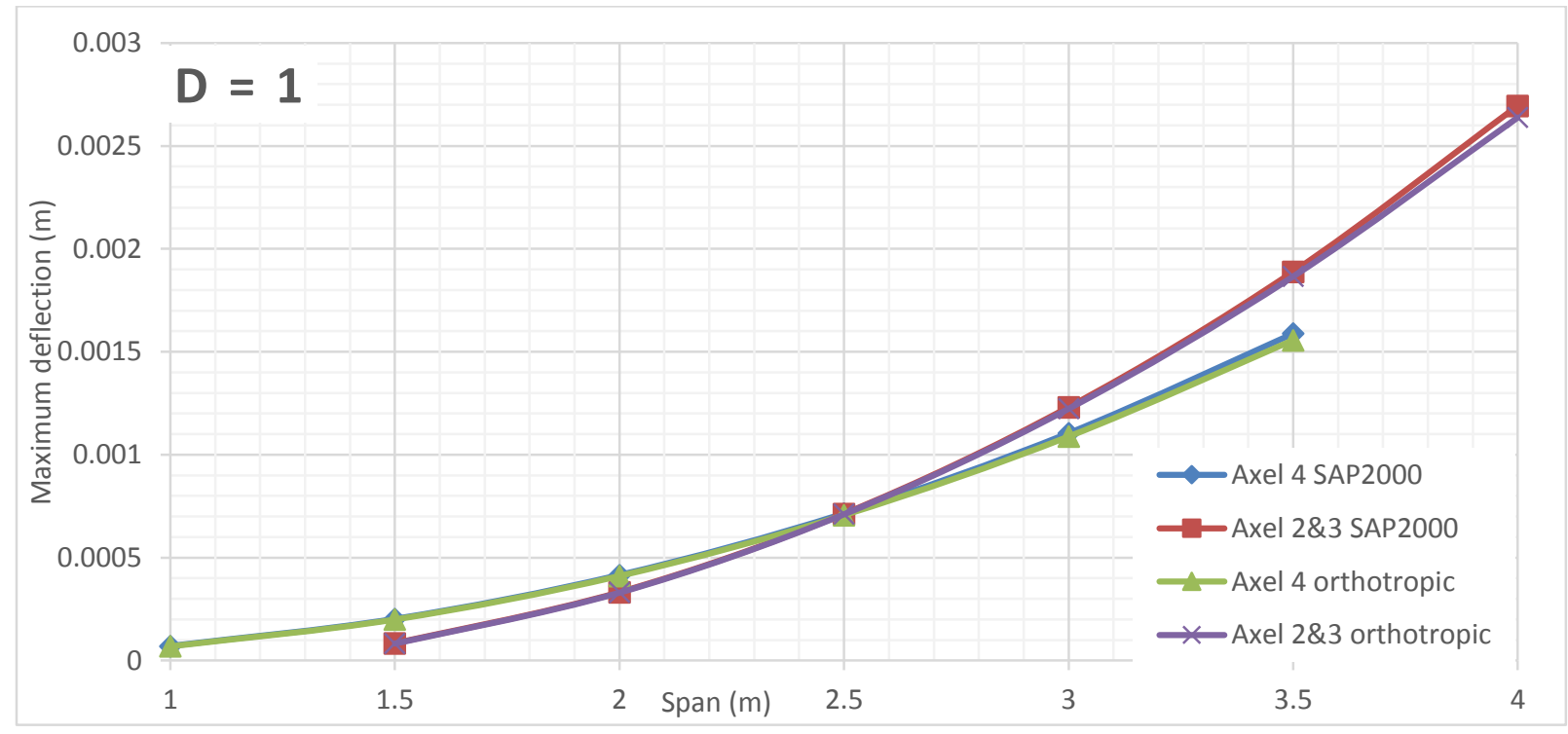

Figure 919 Deflection comparison between FEA and Orthotropic Plate Theory for D = 1 of alpha 8 (main bars parallel to traffic)

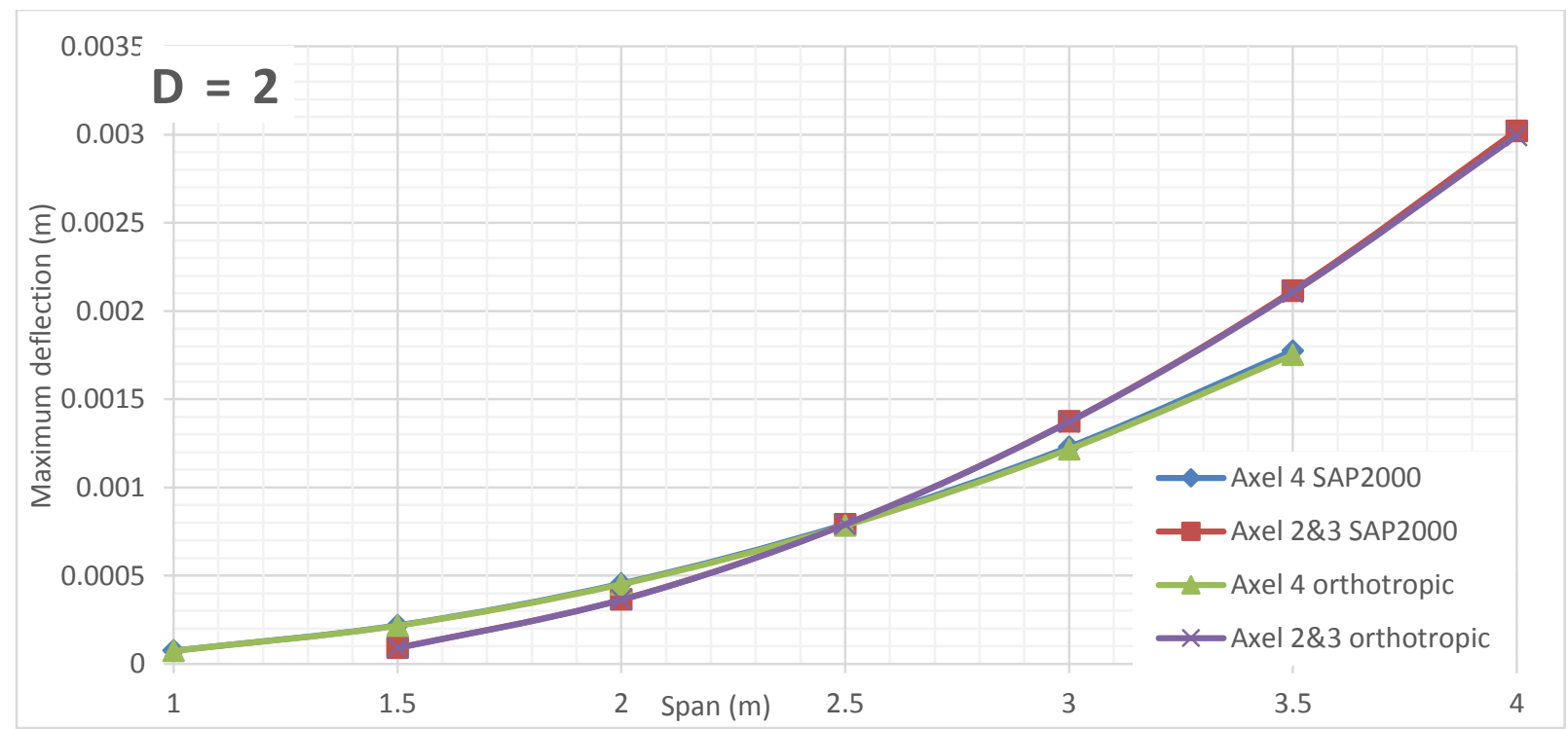

Figure 920 Deflection comparison between FEA and Orthotropic Plate Theory for $\mathrm{D}=2$ of alpha 8 (main bars parallel to traffic) 


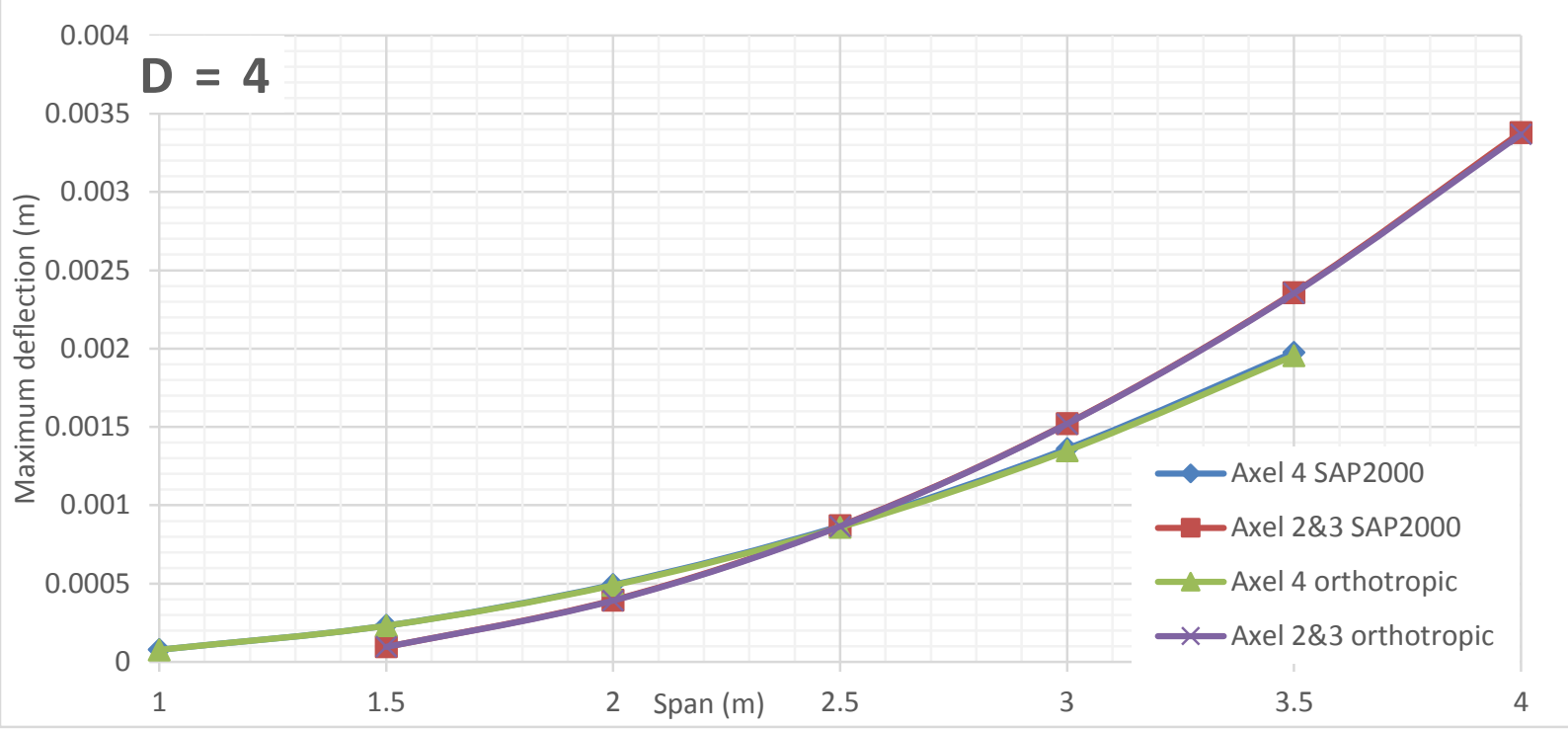

Figure 921 Deflection comparison between FEA and Orthotropic Plate Theory for $D=4$ of alpha 8 (main bars parallel to traffic)

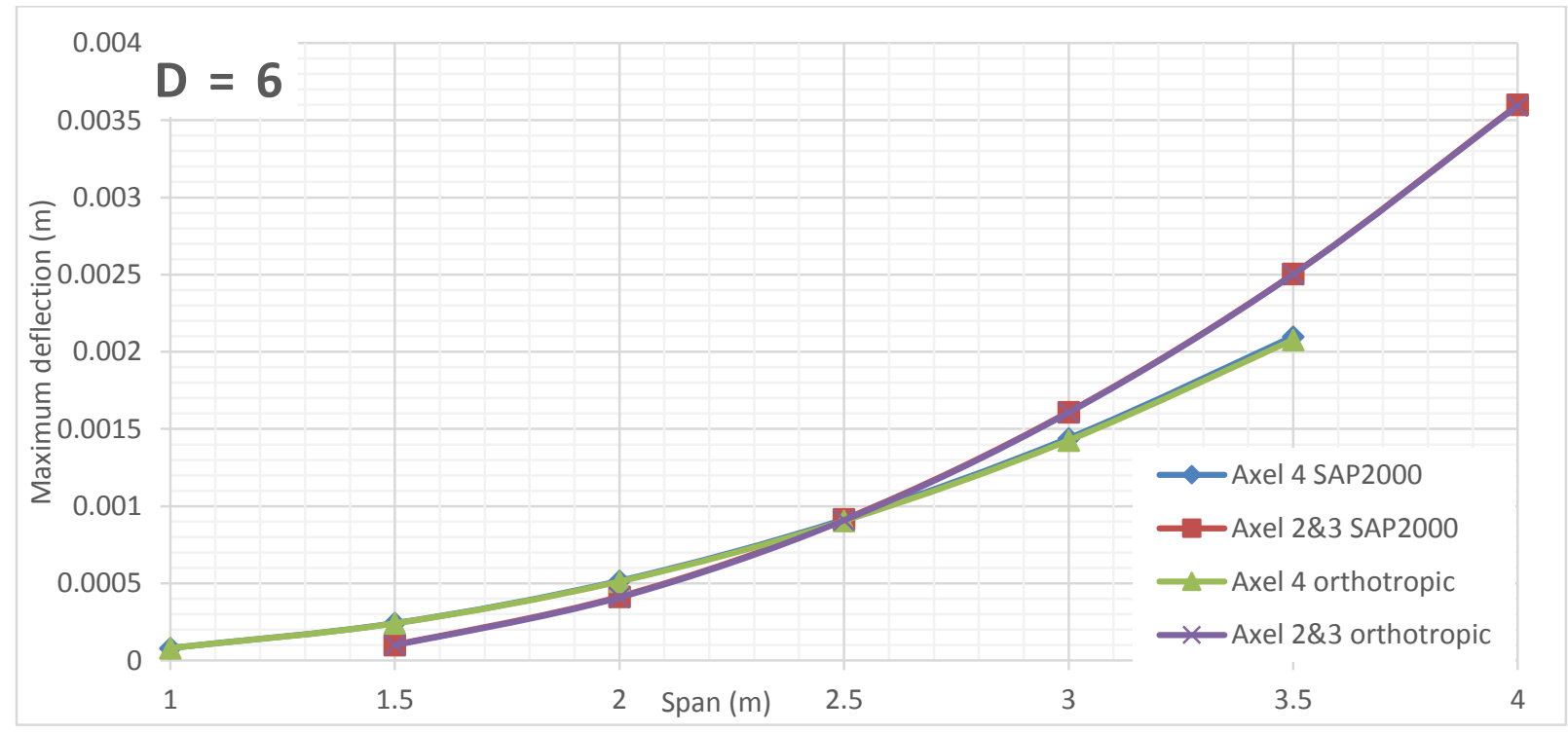

Figure 922 Deflection comparison between FEA and Orthotropic Plate Theory for $D=6$ of alpha 8 (main bars parallel to traffic)

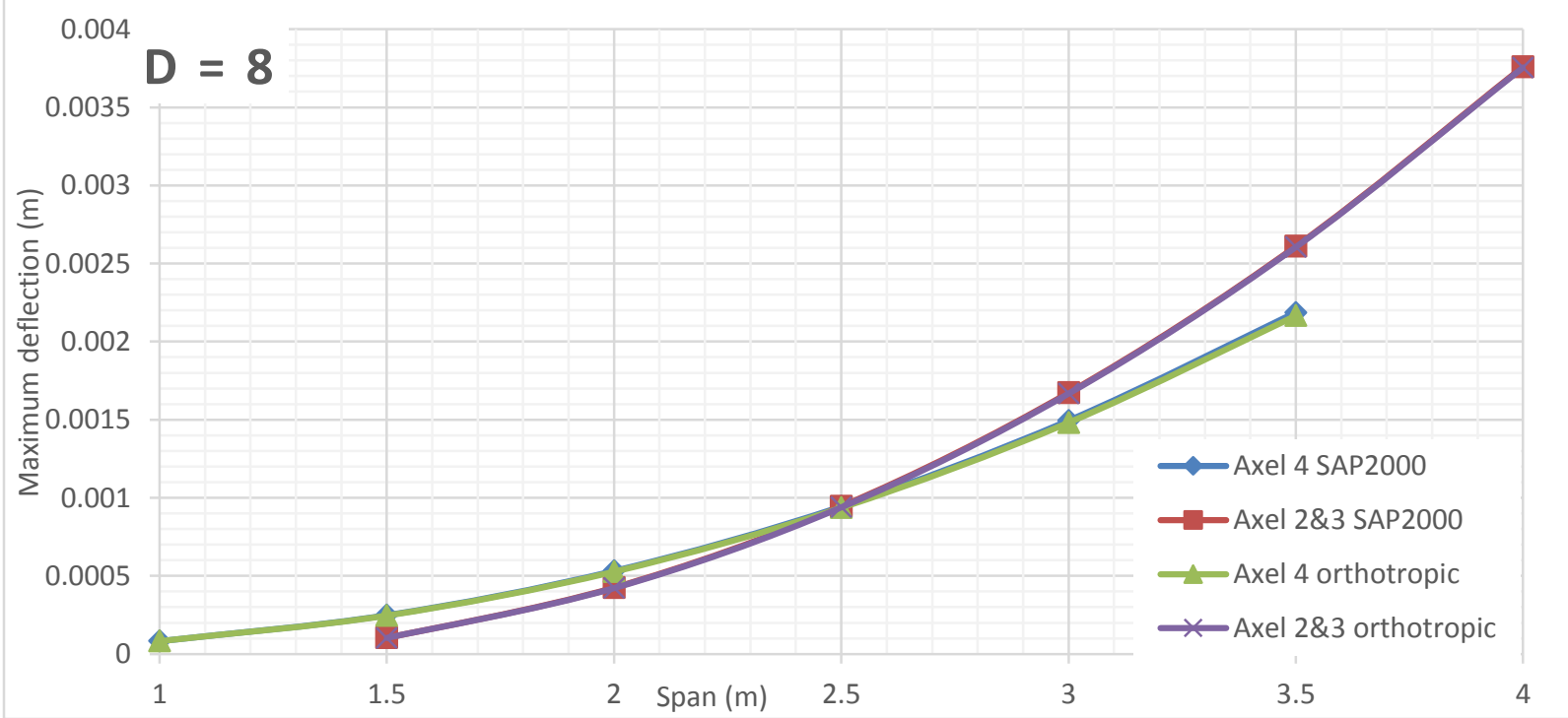

Figure 923 Deflection comparison between FEA and Orthotropic Plate Theory for $\mathrm{D}=8$ of alpha 8 (main bars parallel to traffic) 


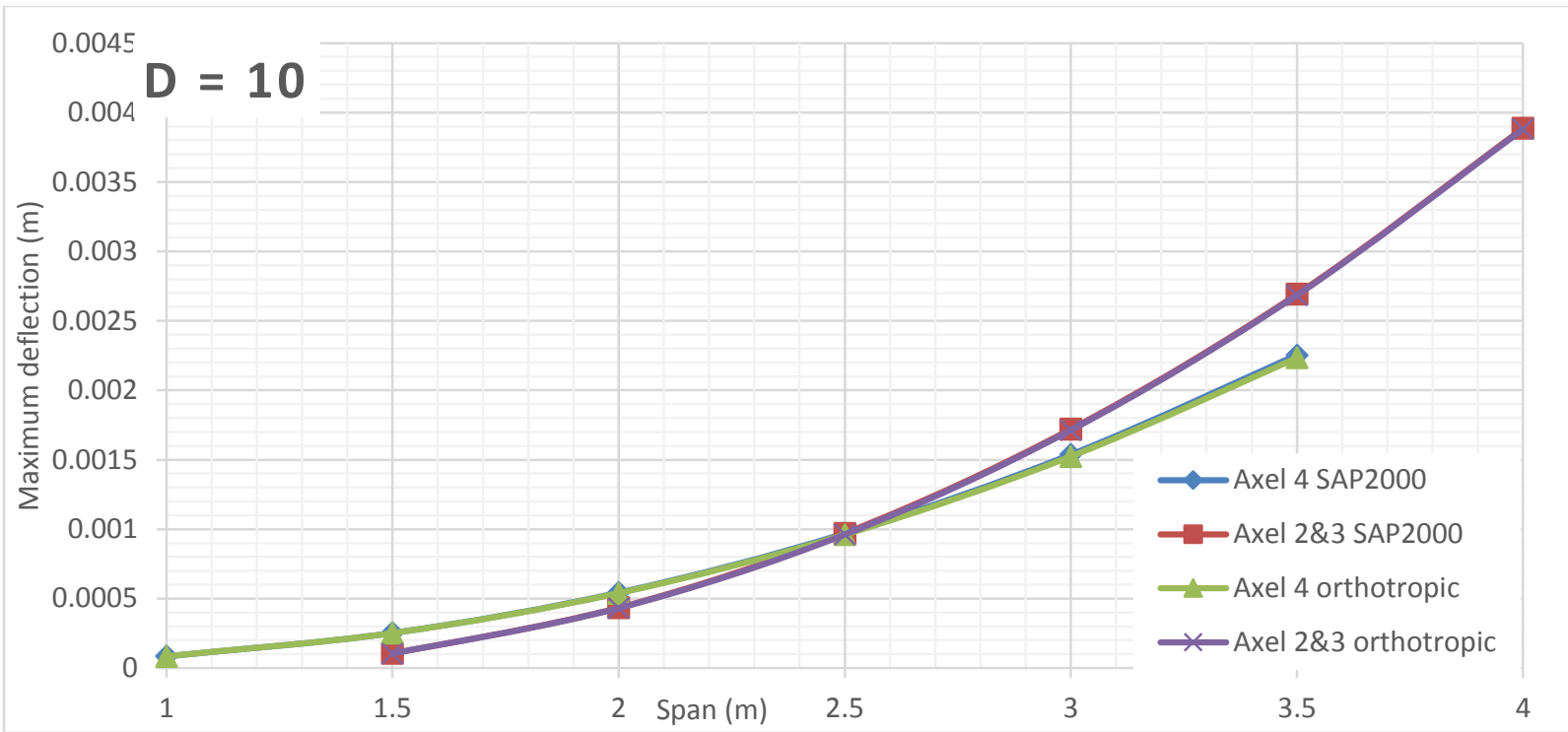

Figure 924 Deflection comparison between FEA and Orthotropic Plate Theory for $D=10$ of alpha 8 (main bars parallel to traffic) 


\section{Alpha 10 Deflection VS Span Length for Different D Values (Main bars perpendicular to traffic)}

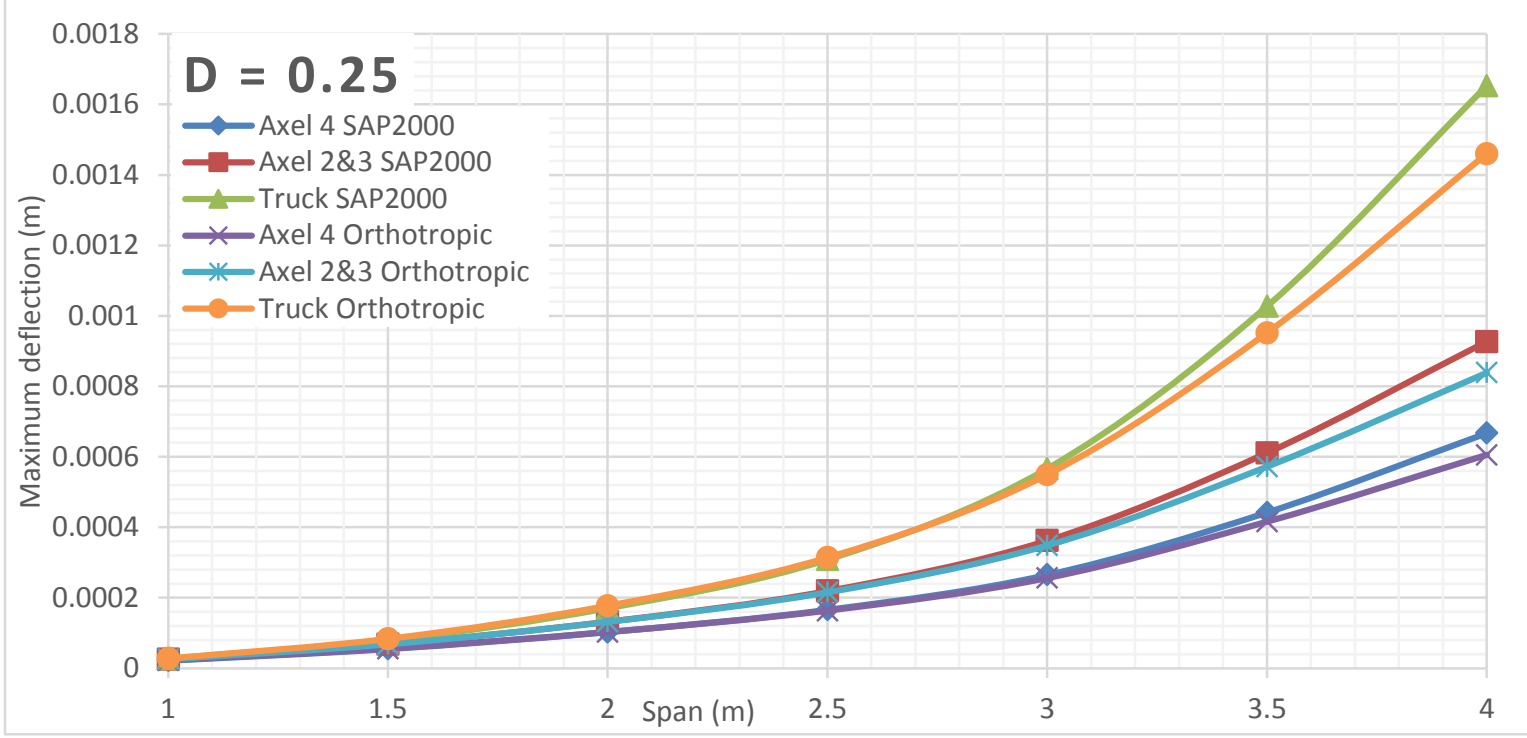

Figure 925 Deflection comparison between FEA and Orthotropic Plate Theory for $D=0.25$ of alpha 10 (main bars perpendicular to traffic)

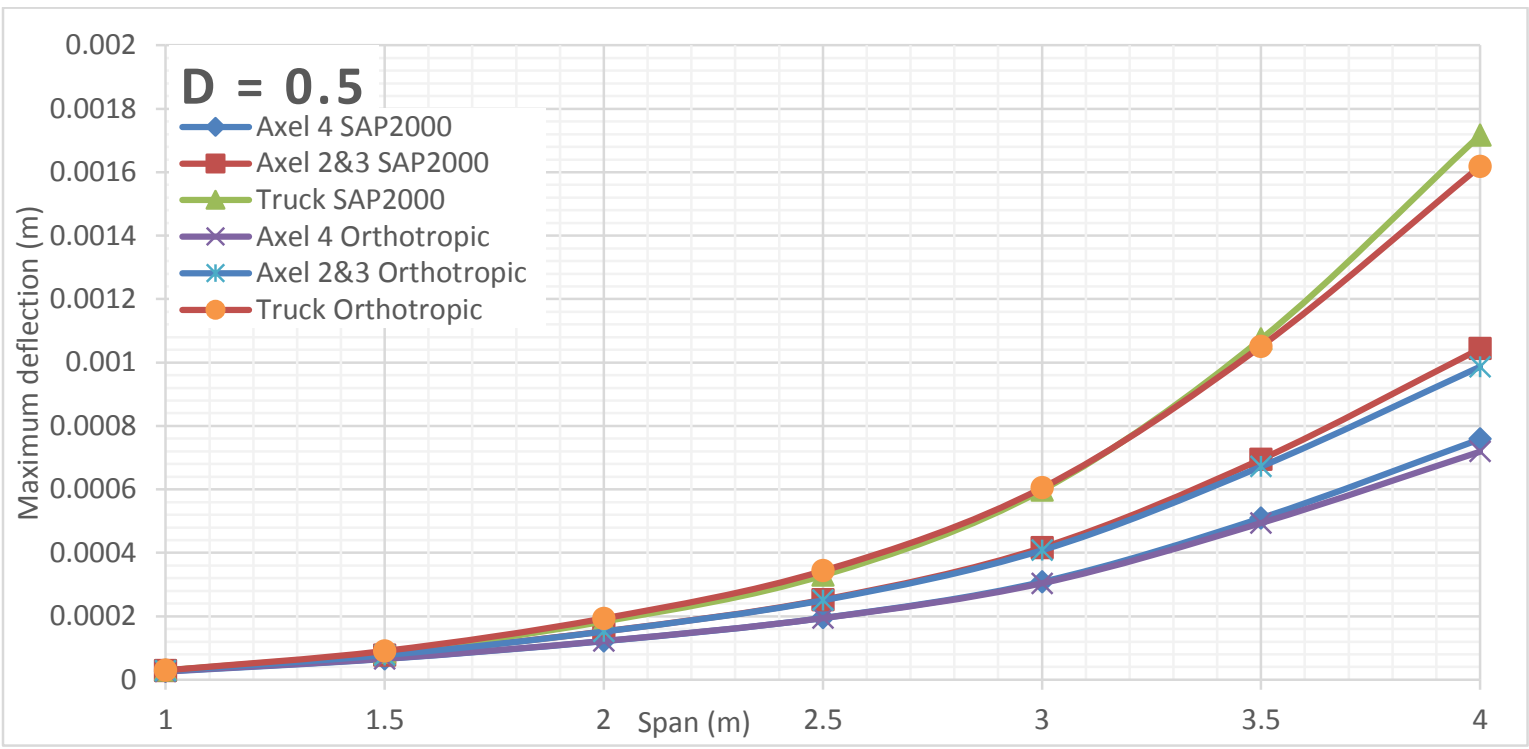

Figure 926 Deflection comparison between FEA and Orthotropic Plate Theory for $D=0.5$ of alpha 10 (main bars perpendicular to traffic) 


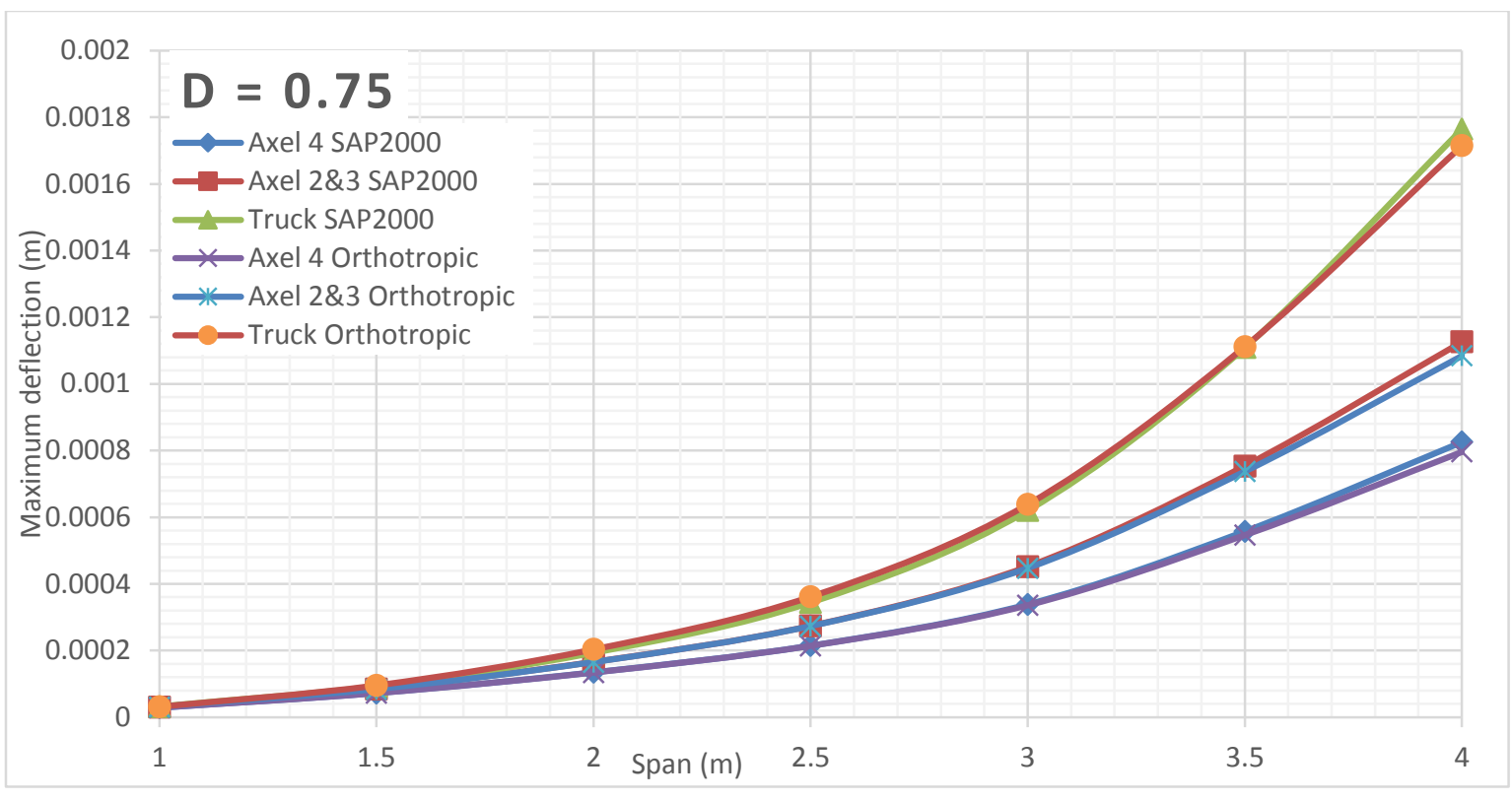

Figure 927 Deflection comparison between FEA and Orthotropic Plate Theory for $D=0.75$ of alpha 10 (main bars perpendicular to traffic)

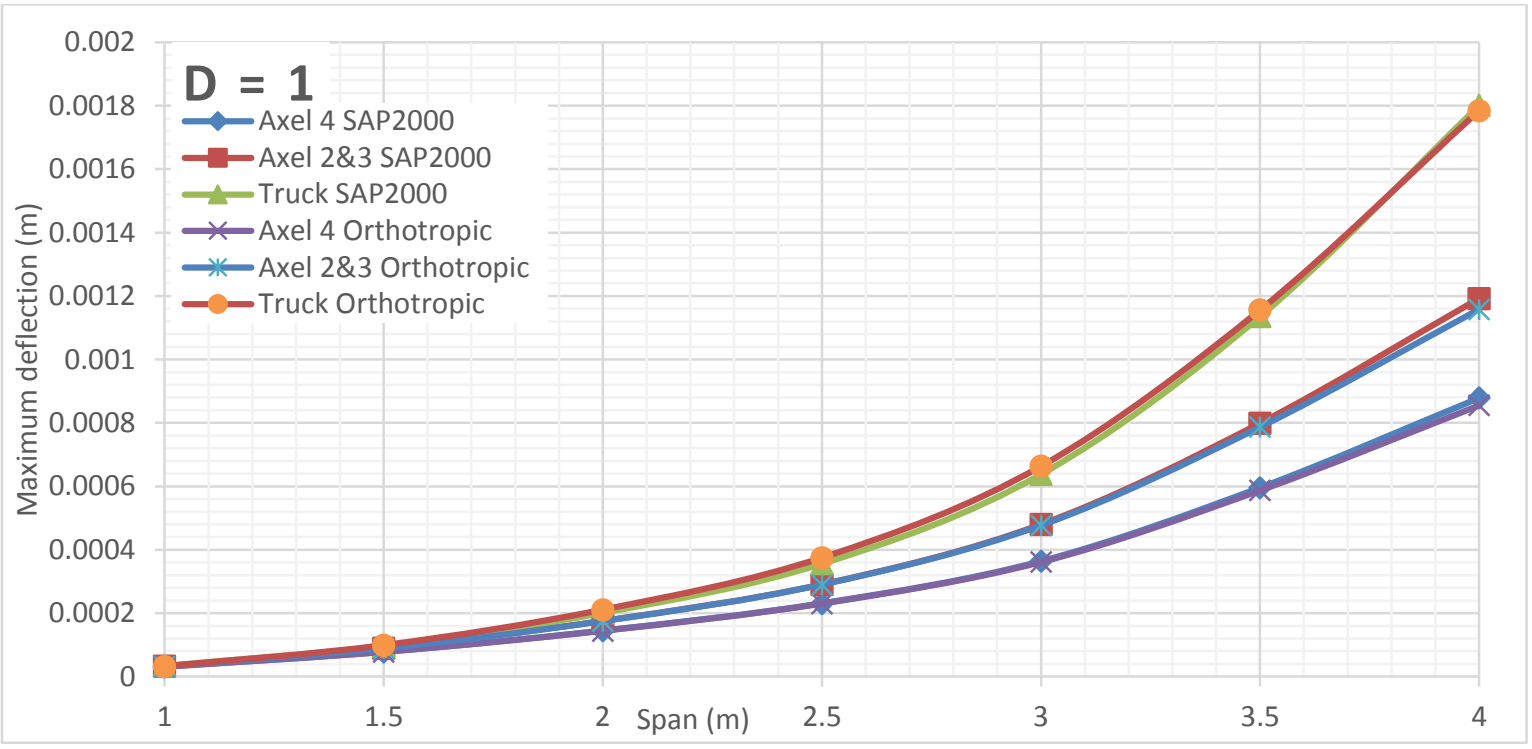

Figure 928 Deflection comparison between FEA and Orthotropic Plate Theory for $D=1$ of alpha 10 (main bars perpendicular to traffic) 


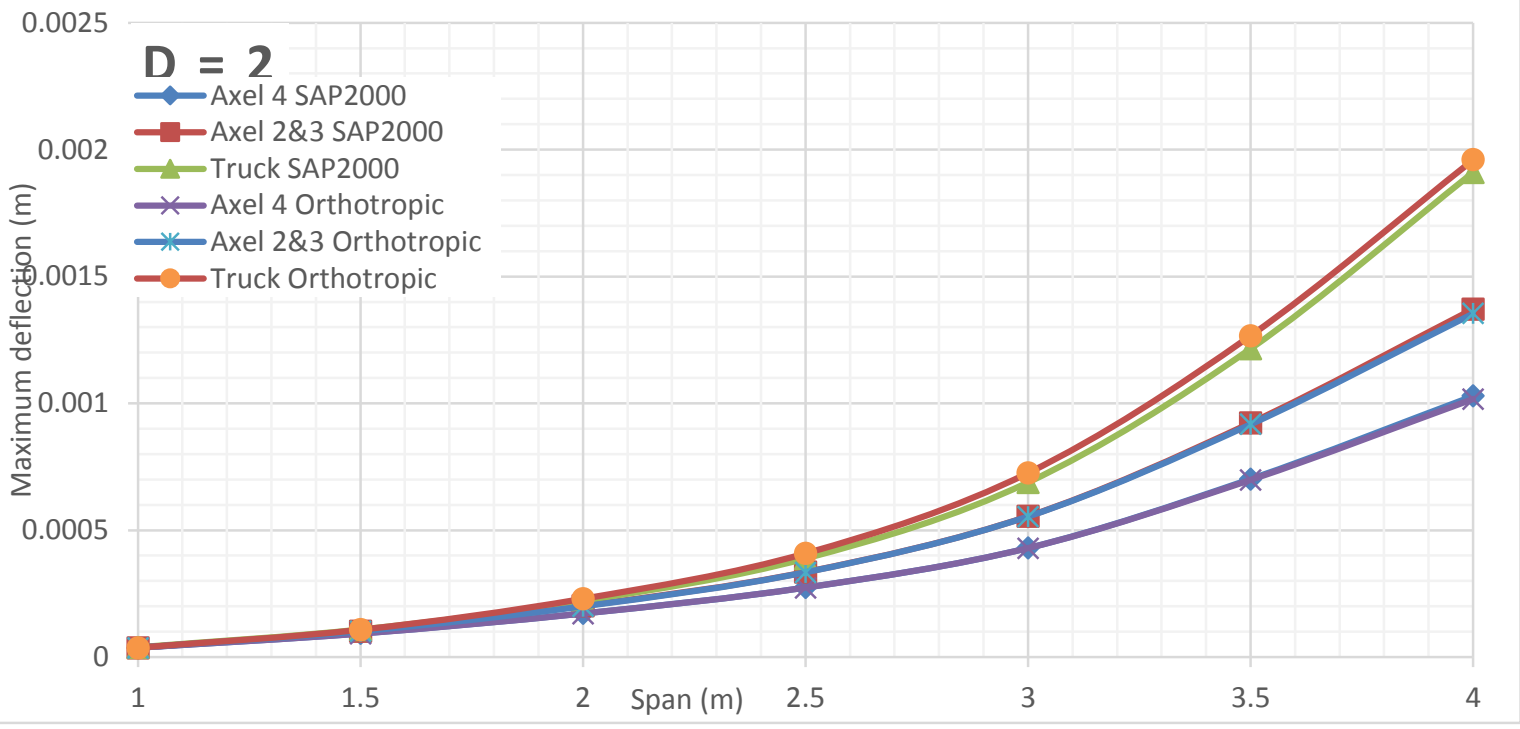

Figure 929 Deflection comparison between FEA and Orthotropic Plate Theory for $D=2$ of alpha 10 (main bars perpendicular to traffic)

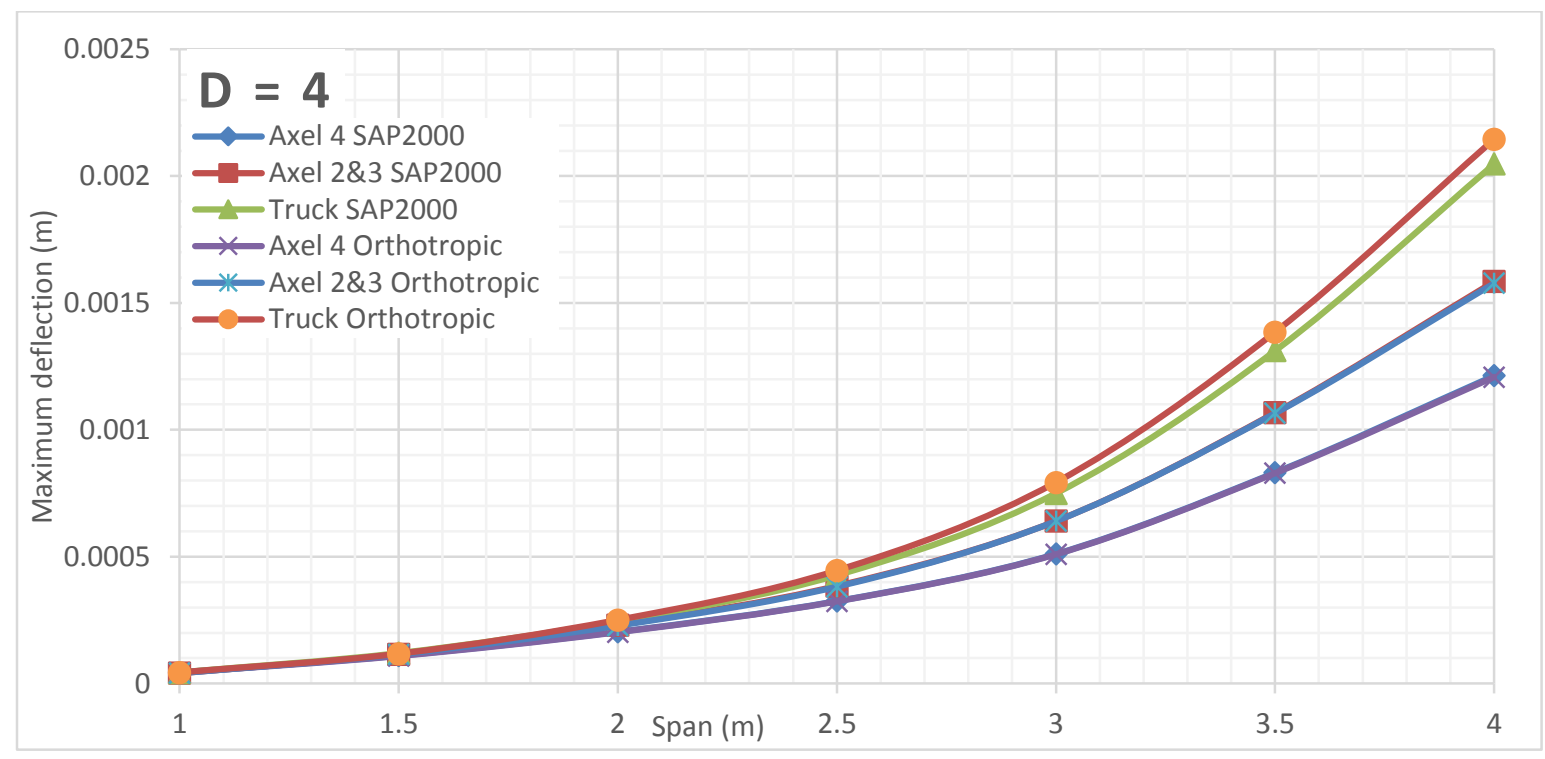

Figure 930 Deflection comparison between FEA and Orthotropic Plate Theory for $D=4$ of alpha 10 (main bars perpendicular to traffic)

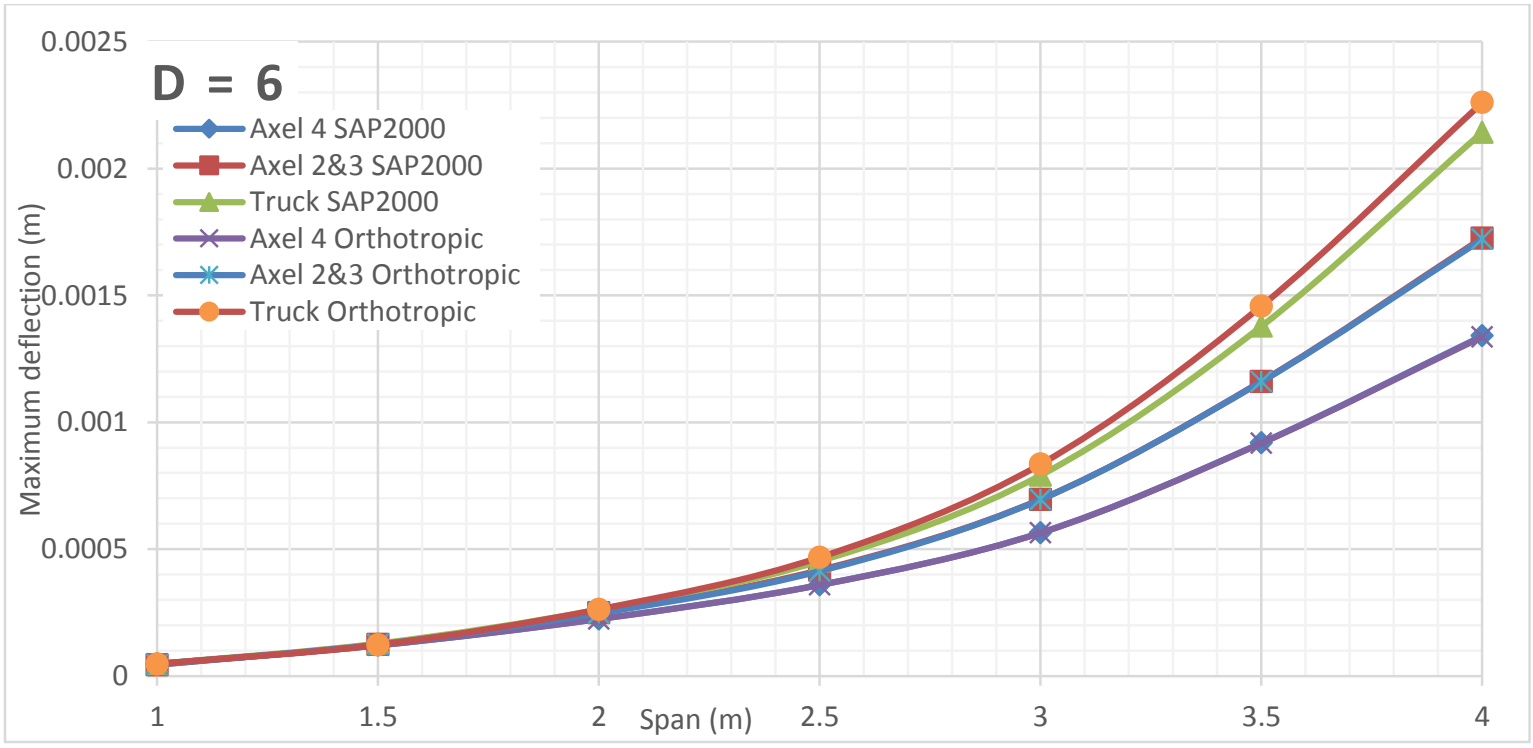

Figure 931 Deflection comparison between FEA and Orthotropic Plate Theory for $D=6$ of alpha 10 (main bars perpendicular to traffic) 


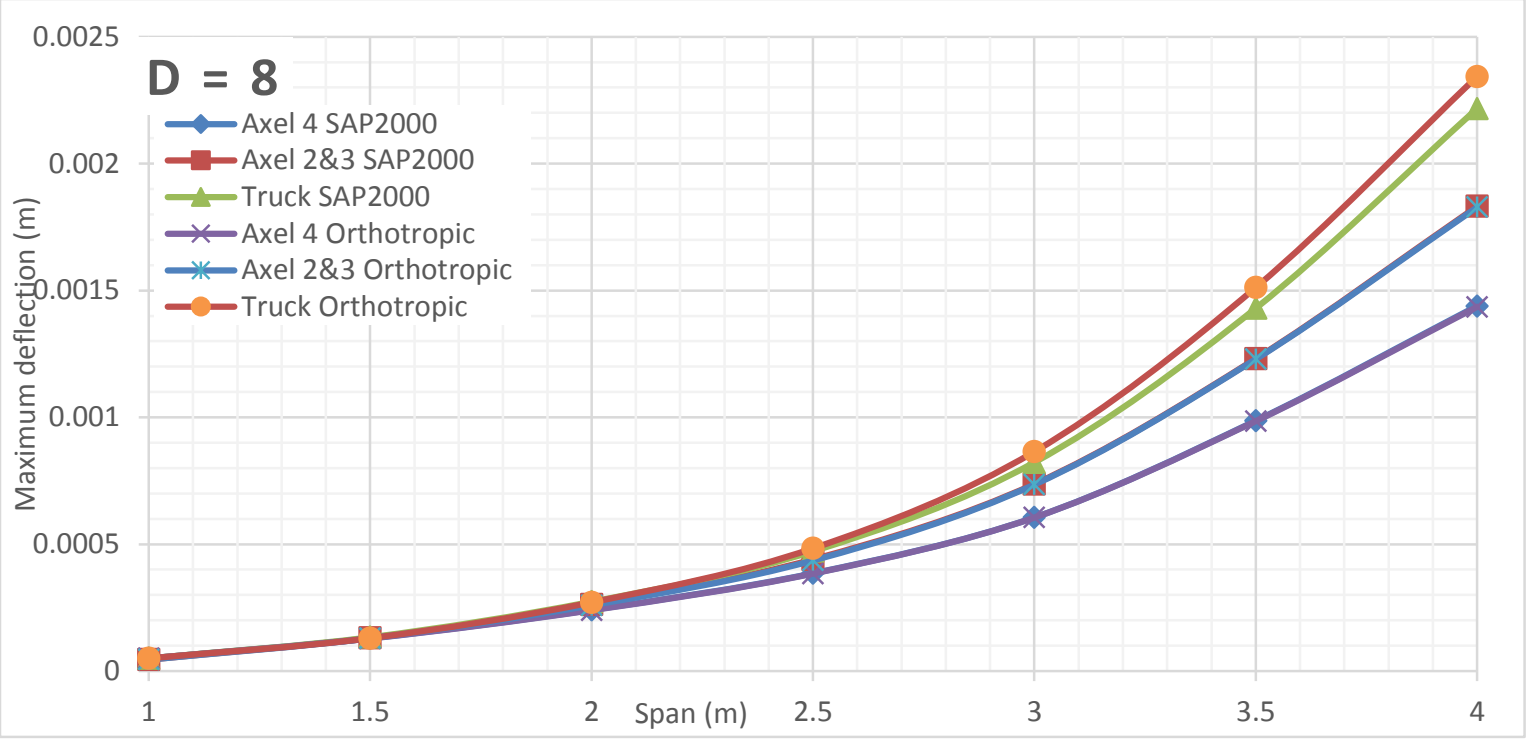

Figure 932 Deflection comparison between FEA and Orthotropic Plate Theory for $D=8$ of alpha 10 (main bars perpendicular to traffic)

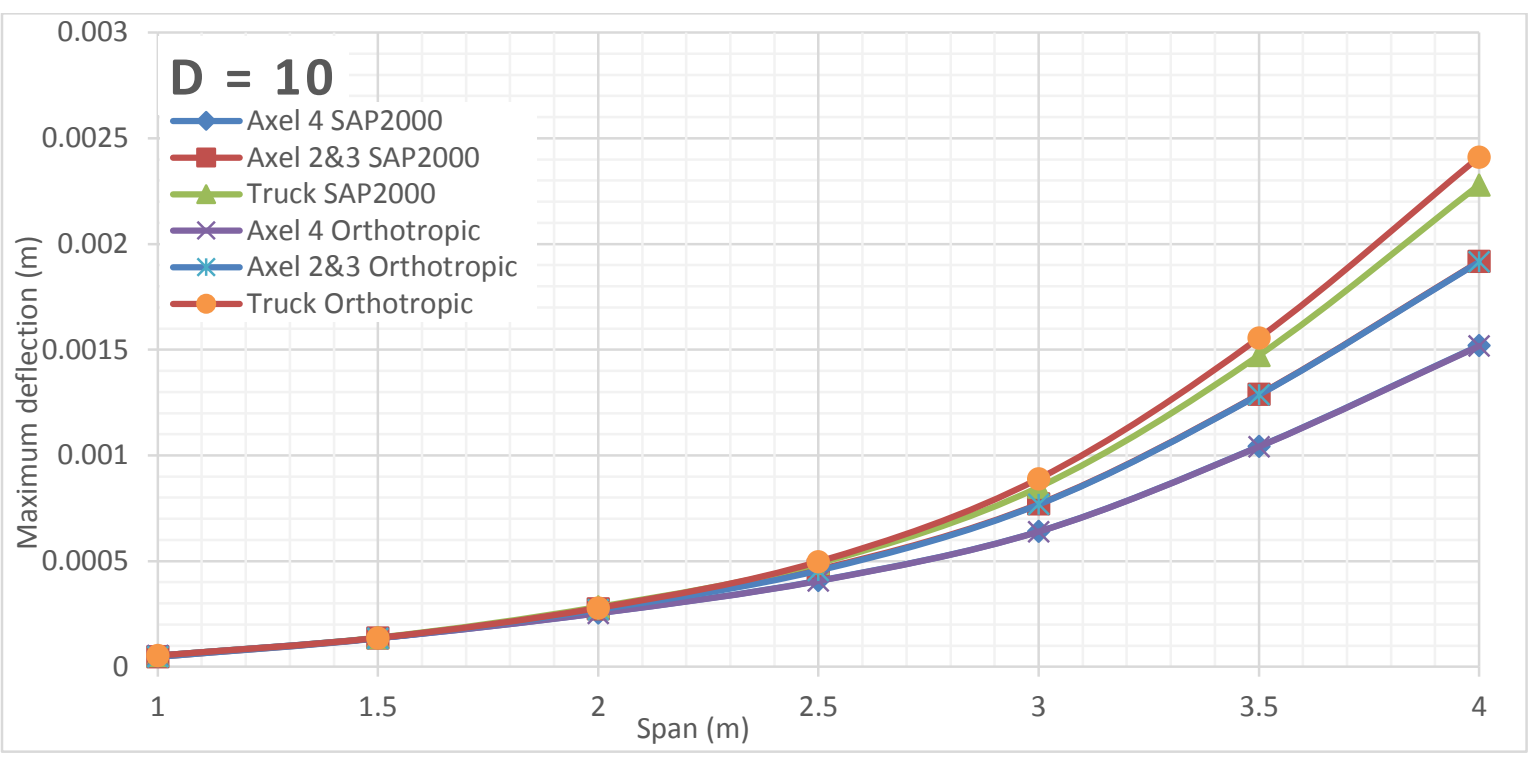

Figure 933 Deflection comparison between FEA and Orthotropic Plate Theory for D = 10 of alpha 10 (main bars perpendicular to traffic) 


\section{Alpha 10 Deflection VS Span Length for Different D Values (Main bars parallel to traffic)}

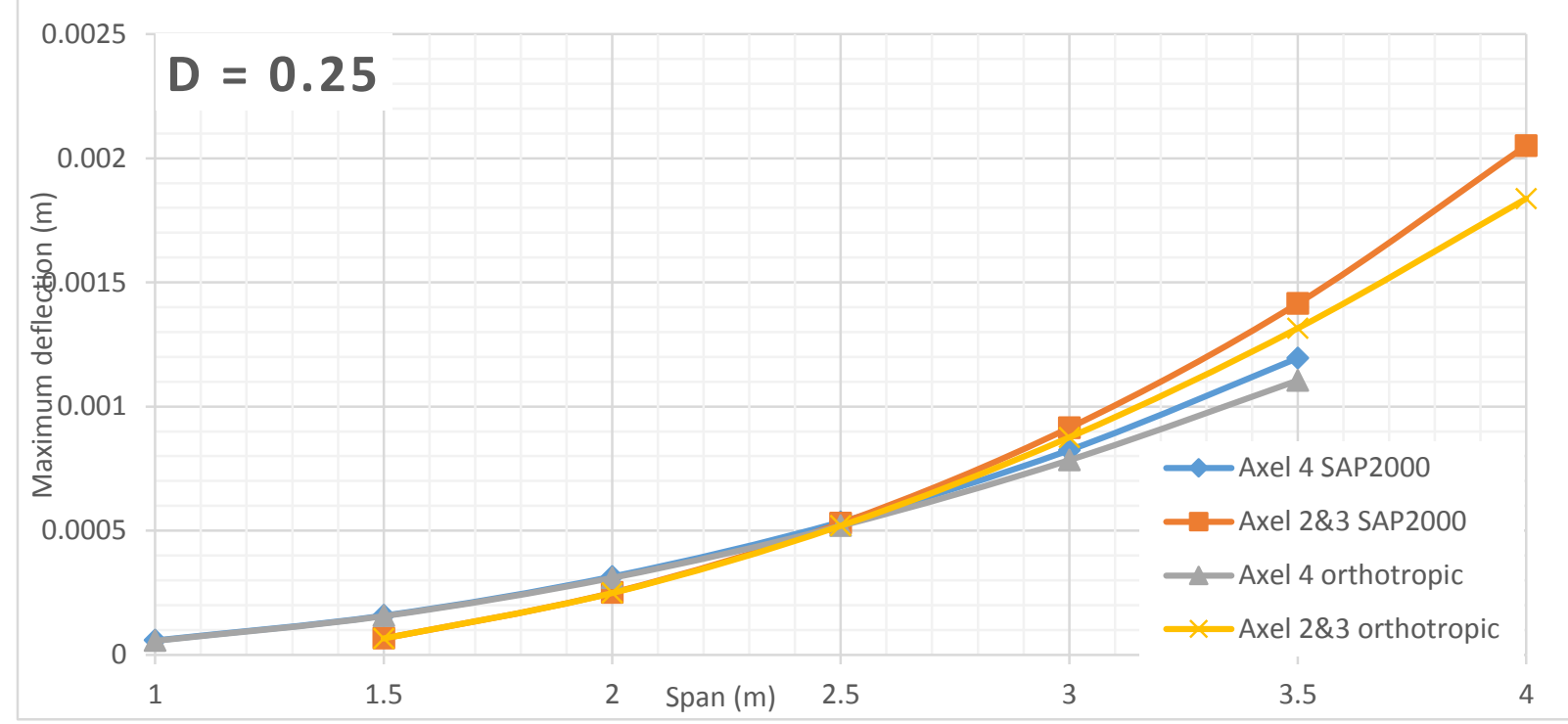

Figure 934 Deflection comparison between FEA and Orthotropic Plate Theory for $D=0.25$ of alpha 10 (main bars parallel to traffic)

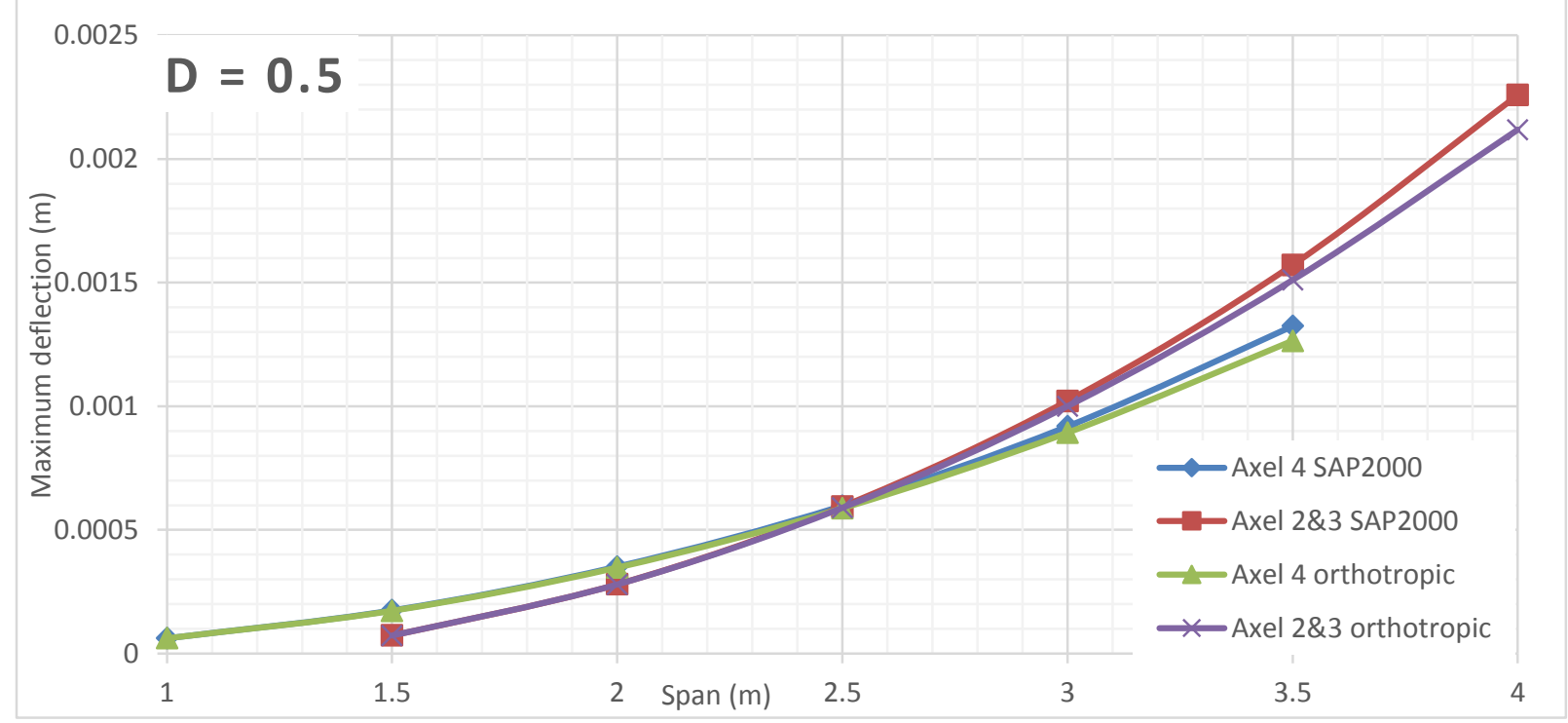

Figure 935 Deflection comparison between FEA and Orthotropic Plate Theory for $D=0.5$ of alpha 10 (main bars parallel to traffic) 


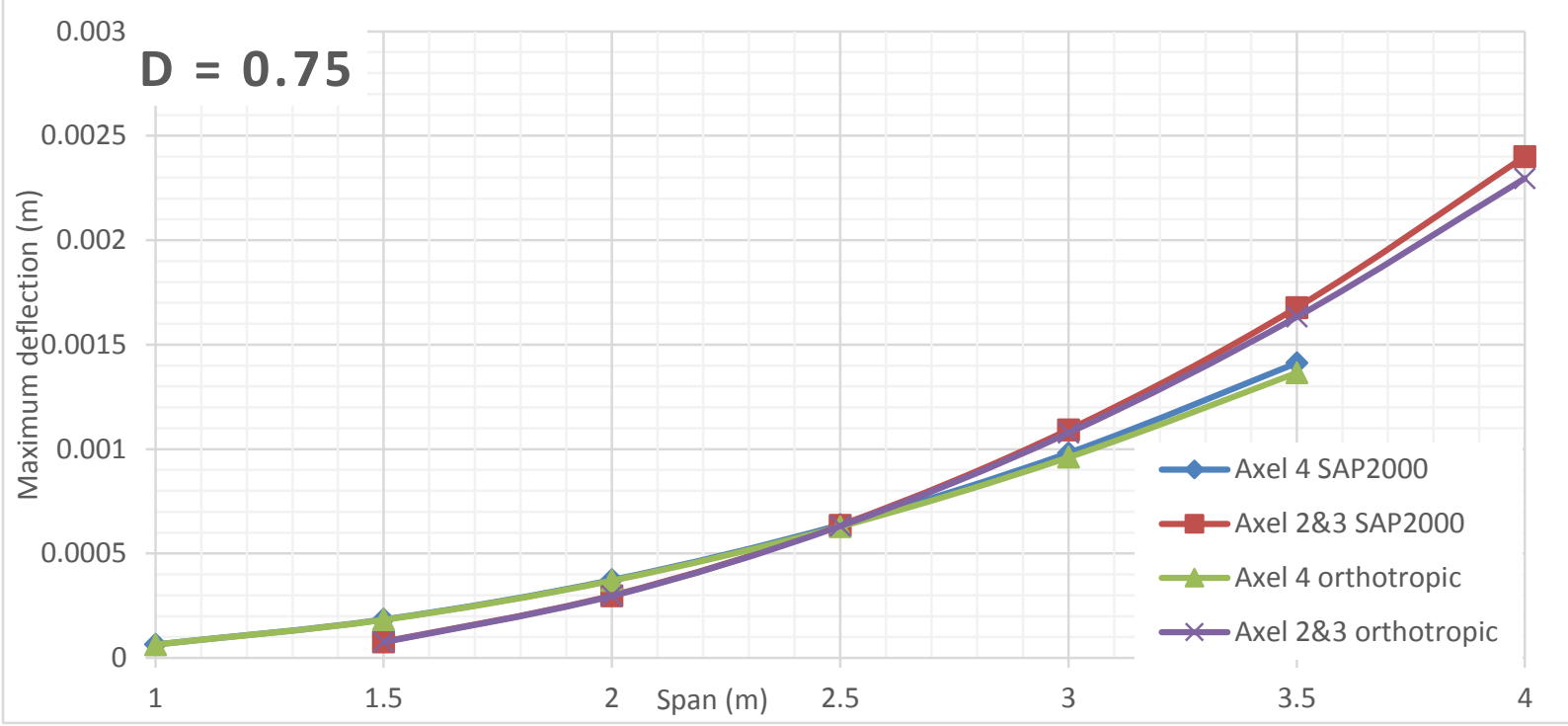

Figure 936 Deflection comparison between FEA and Orthotropic Plate Theory for D $=0.75$ of alpha 10 (main bars parallel to traffic)

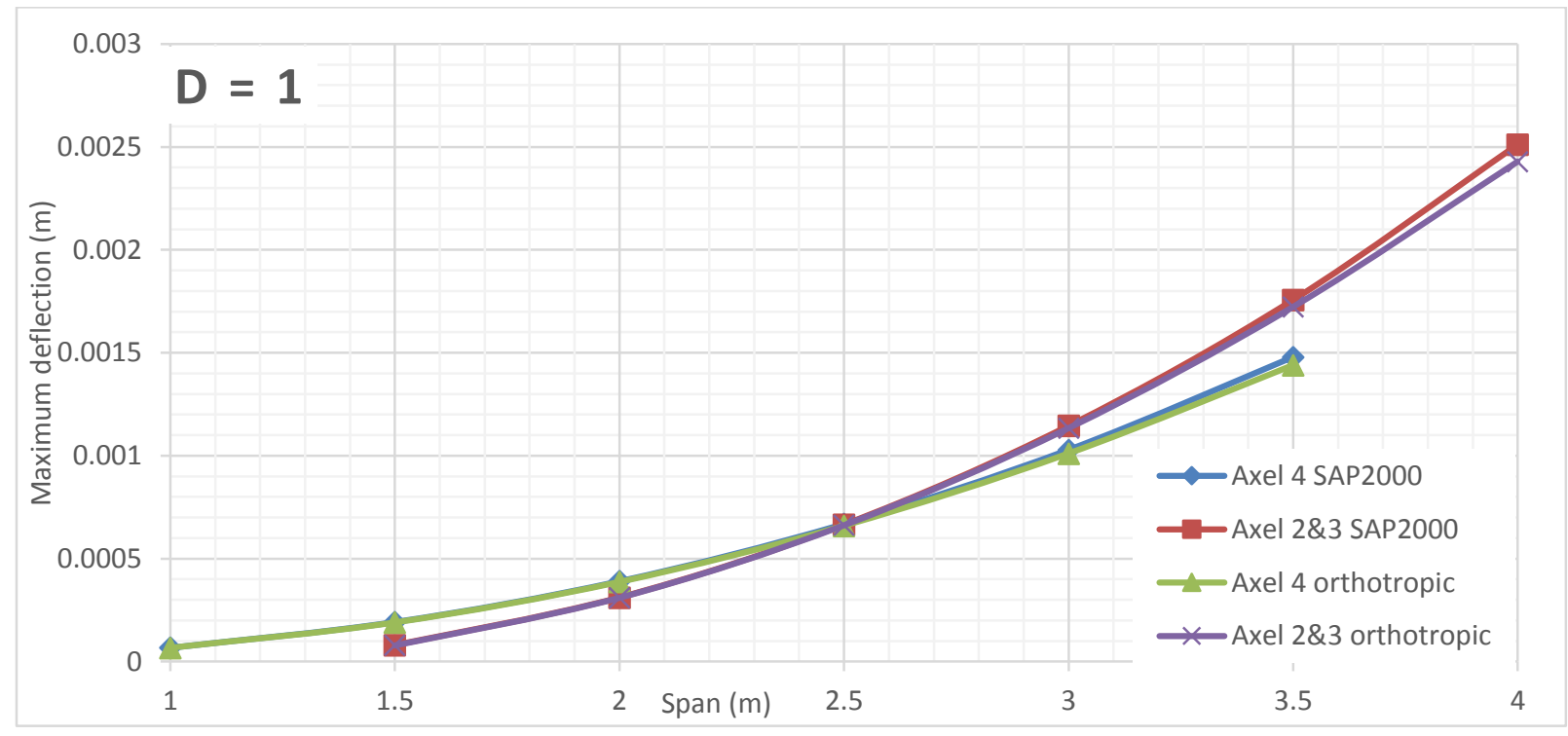

Figure 937 Deflection comparison between FEA and Orthotropic Plate Theory for $D=1$ of alpha 10 (main bars parallel to traffic)

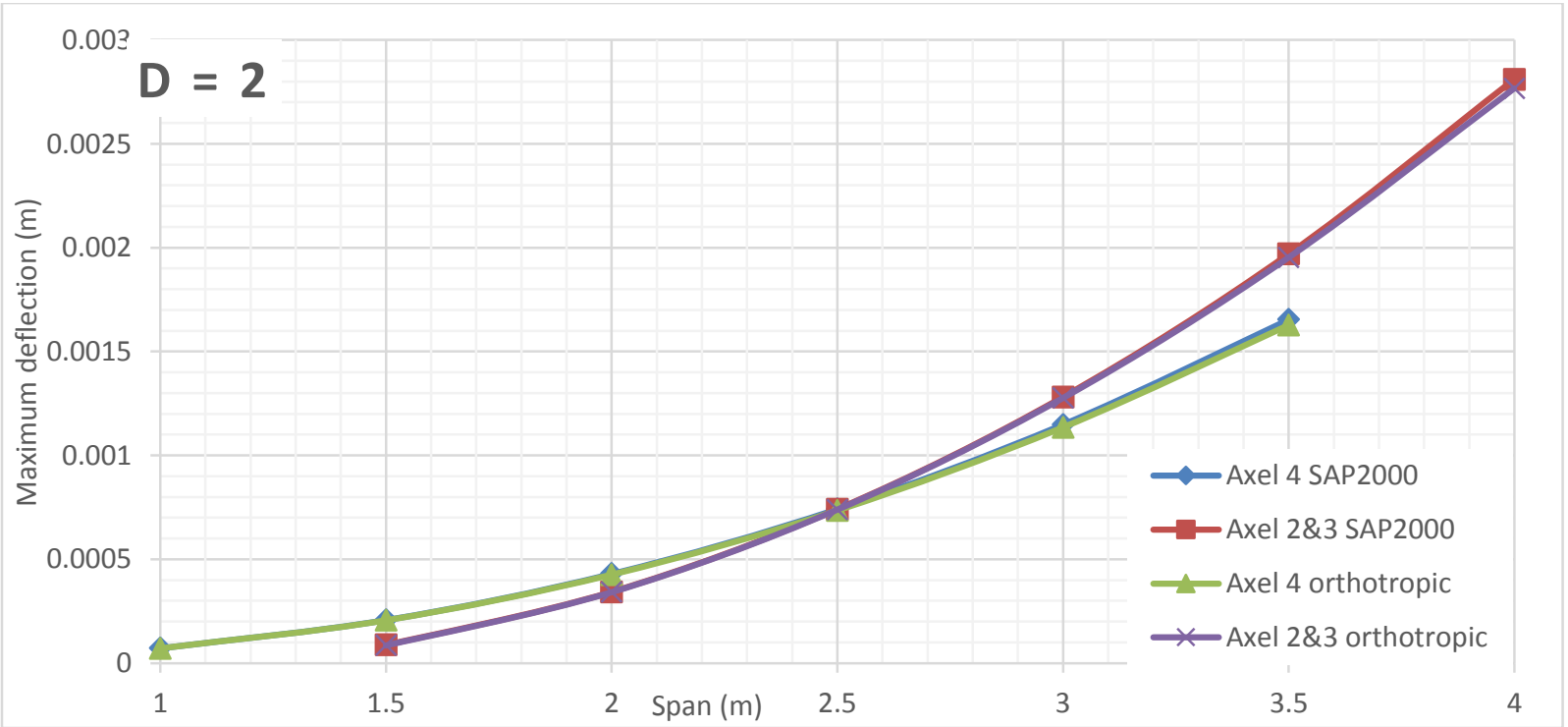

Figure 938 Deflection comparison between FEA and Orthotropic Plate Theory for $D=2$ of alpha 10 (main bars parallel to traffic) 


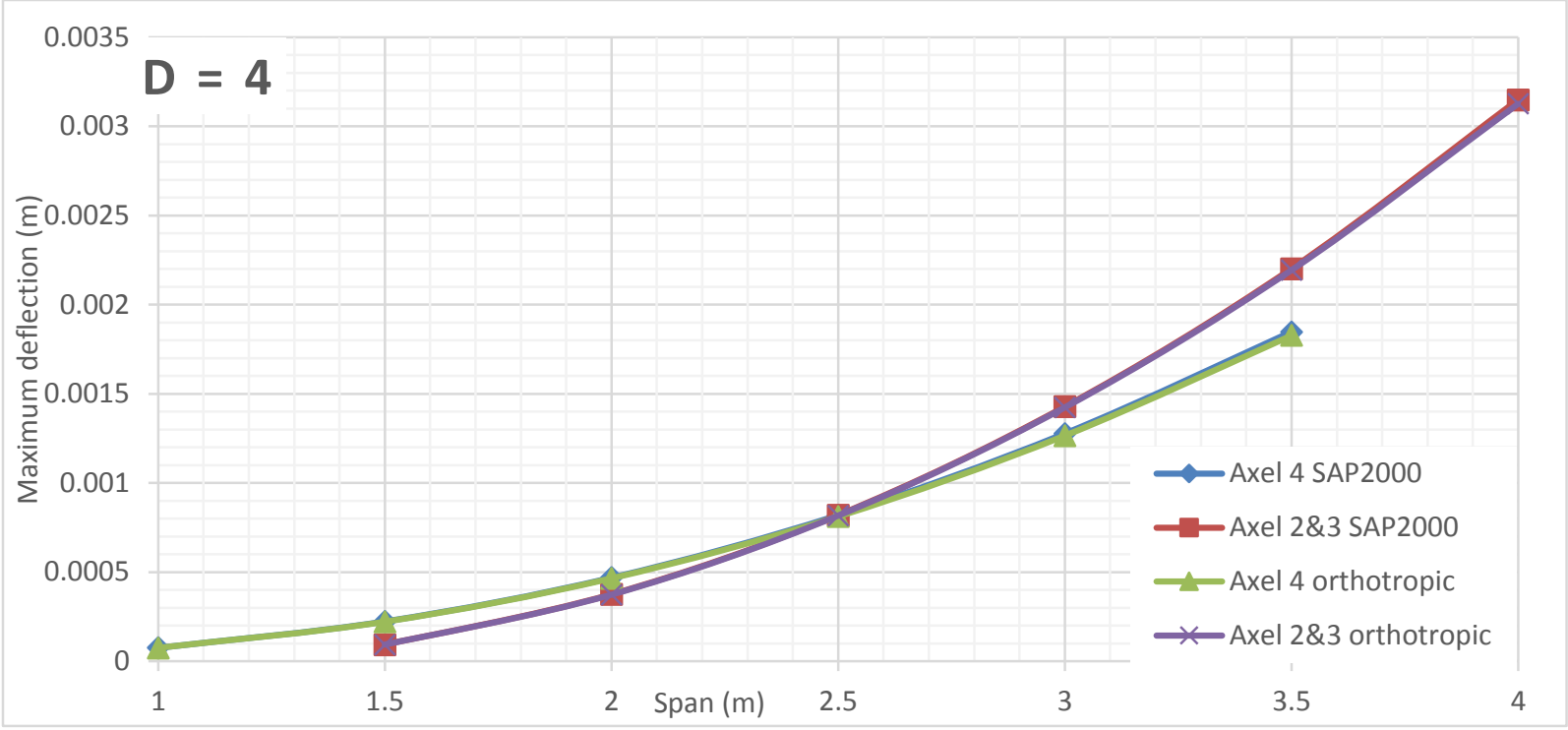

Figure 939 Deflection comparison between FEA and Orthotropic Plate Theory for D $=4$ of alpha 10 (main bars parallel to traffic)

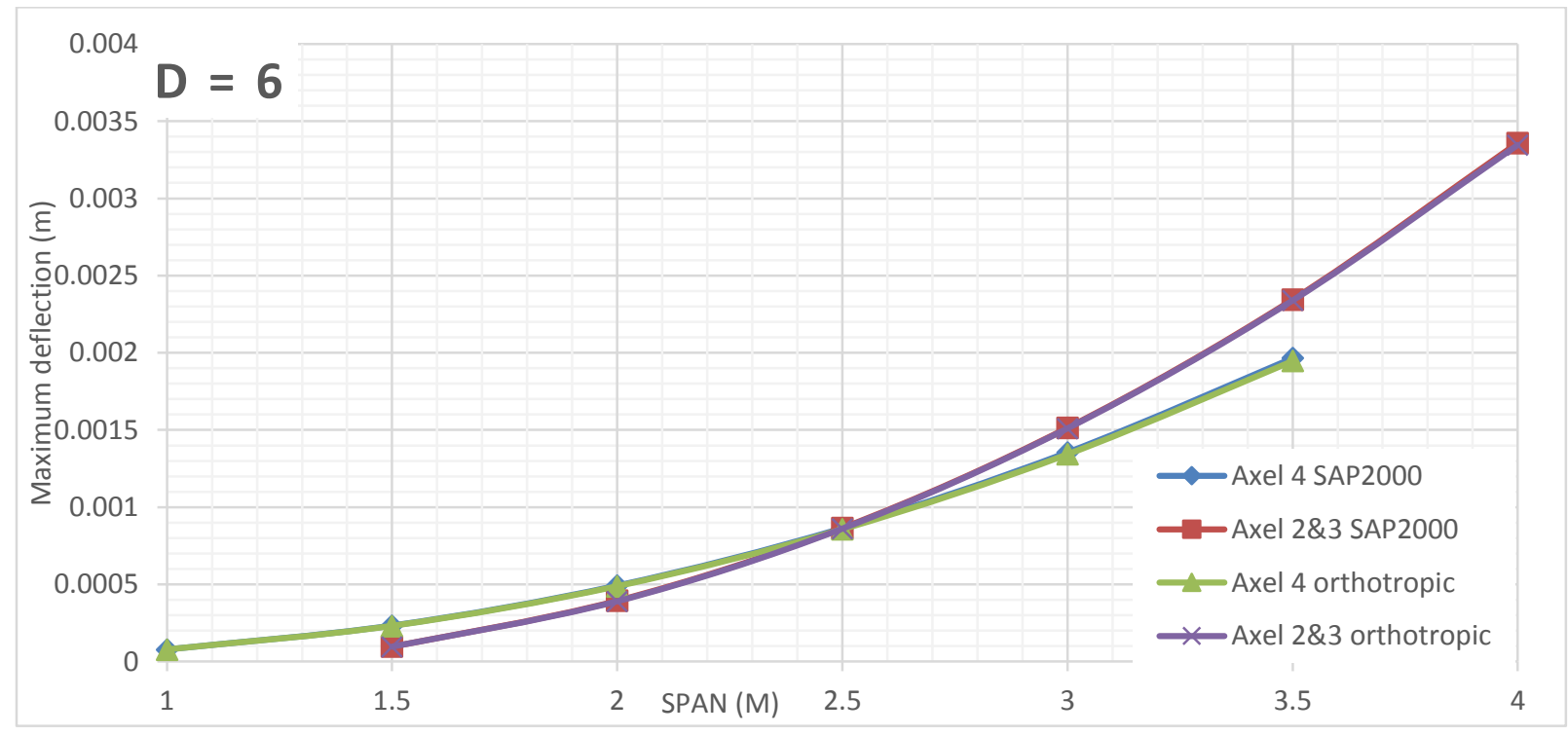

Figure 940 Deflection comparison between FEA and Orthotropic Plate Theory for $D=6$ of alpha 10 (main bars parallel to traffic)

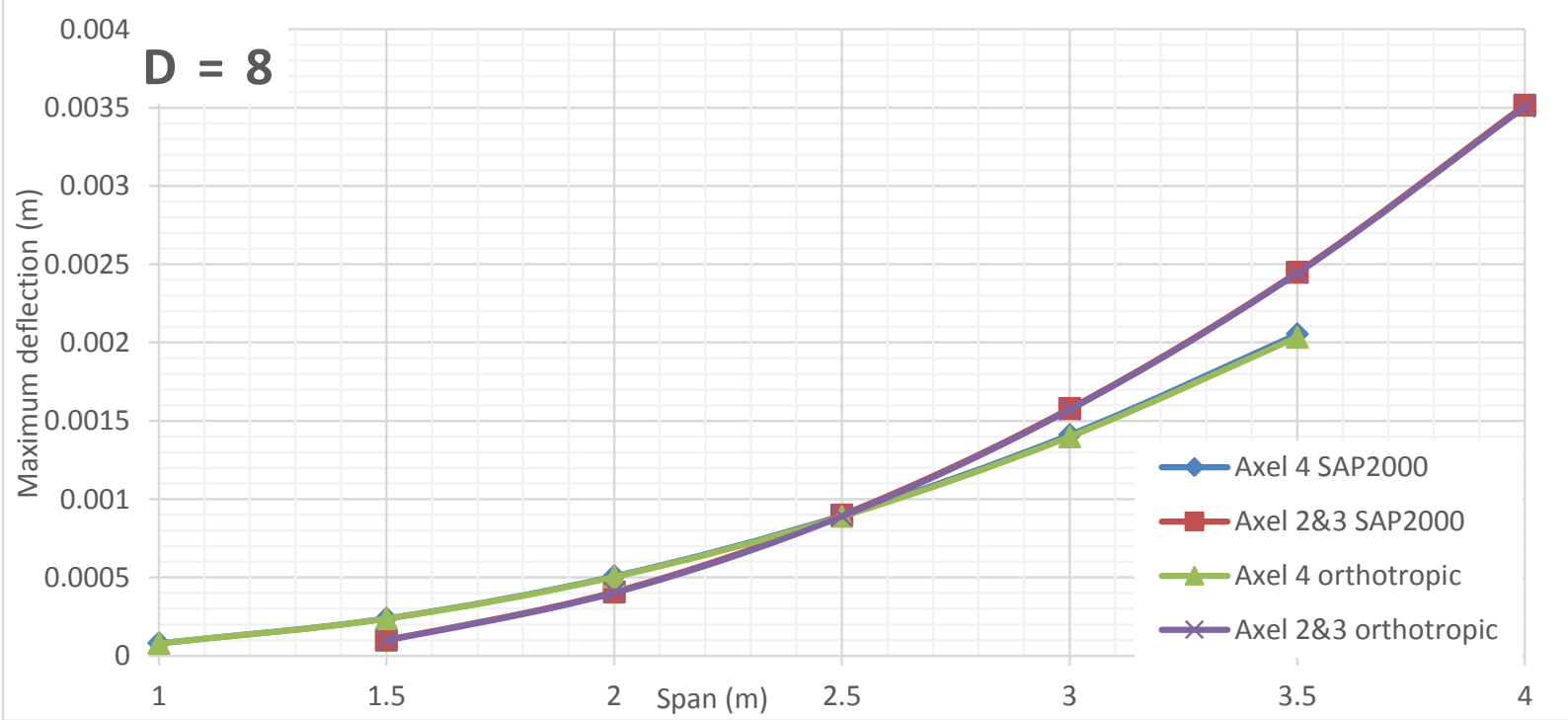

Figure 941 Deflection comparison between FEA and Orthotropic Plate Theory for $D=8$ of alpha 10 (main bars parallel to traffic) 


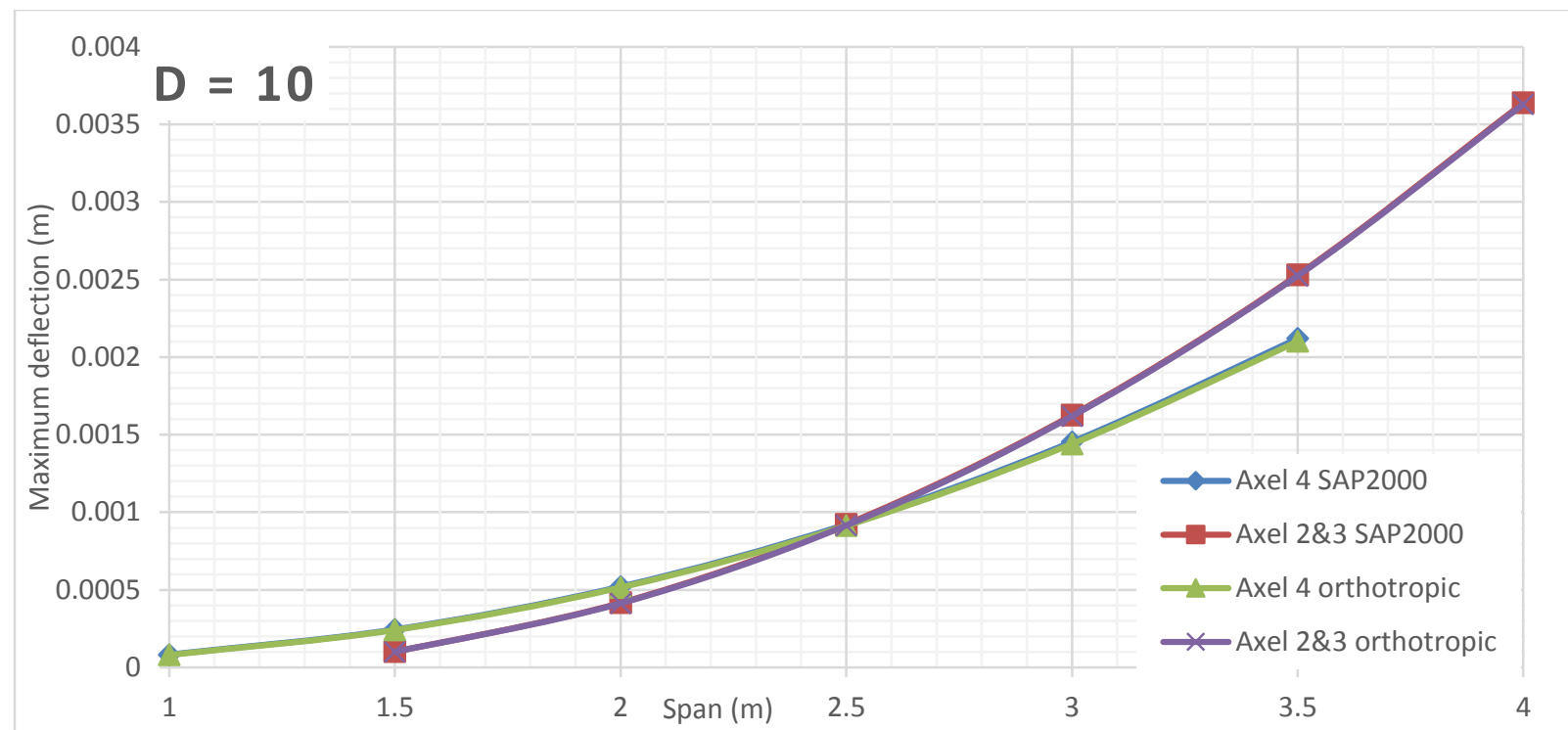

Figure 942 Deflection comparison between FEA and Orthotropic Plate Theory for $D=10$ of alpha 10 (main bars parallel to traffic) 


\section{D.2.2 MAXIMUM DEFLECTION VS FLEXURAL RIGIDITY}




\section{Alpha 0.25 Deflection VS Flexural Rigidity for Different Span Length (Main bars perpendicular to traffic)}

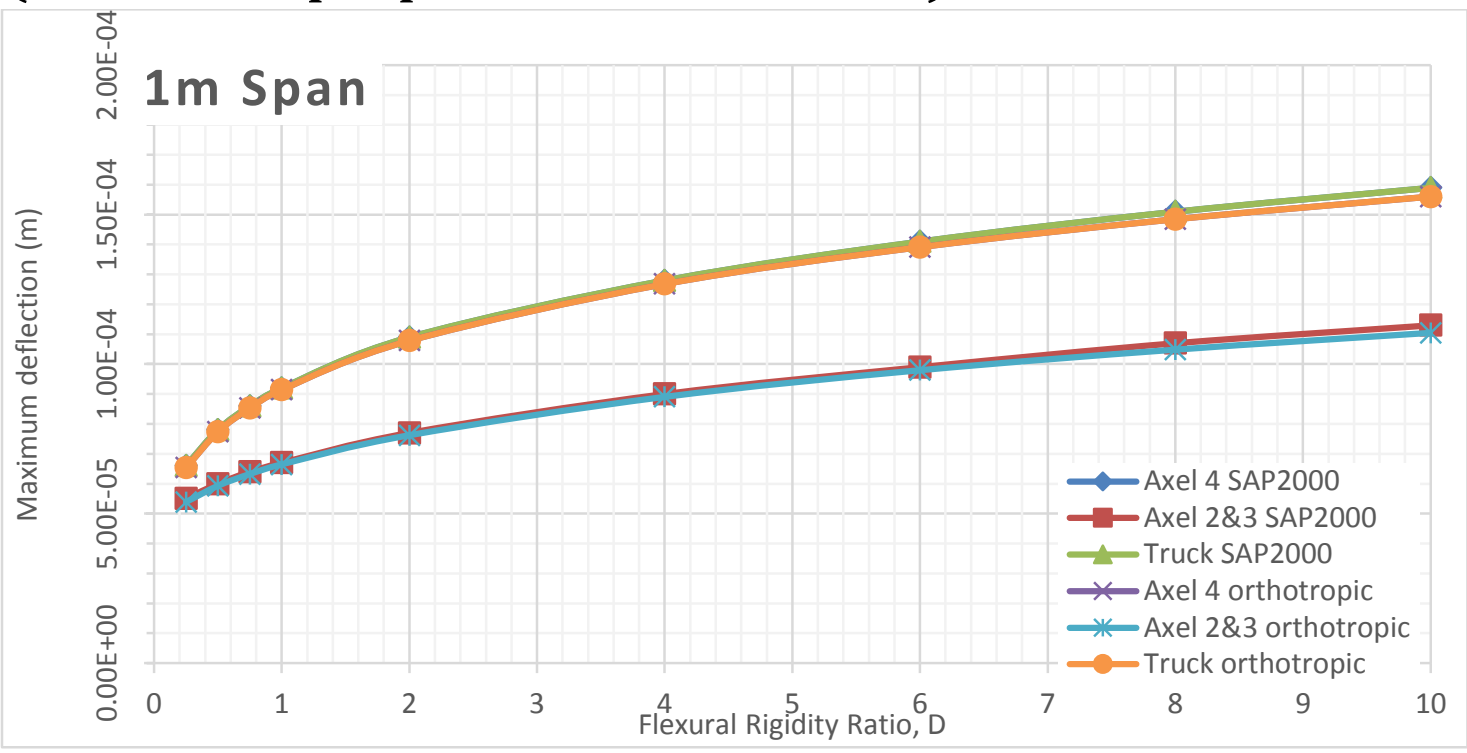

Figure 943 Deflection comparison between FEA and Orthotropic Plate Theory for $1 \mathrm{~m}$ span of alpha 0.25 (main bars perpendicular to traffic)

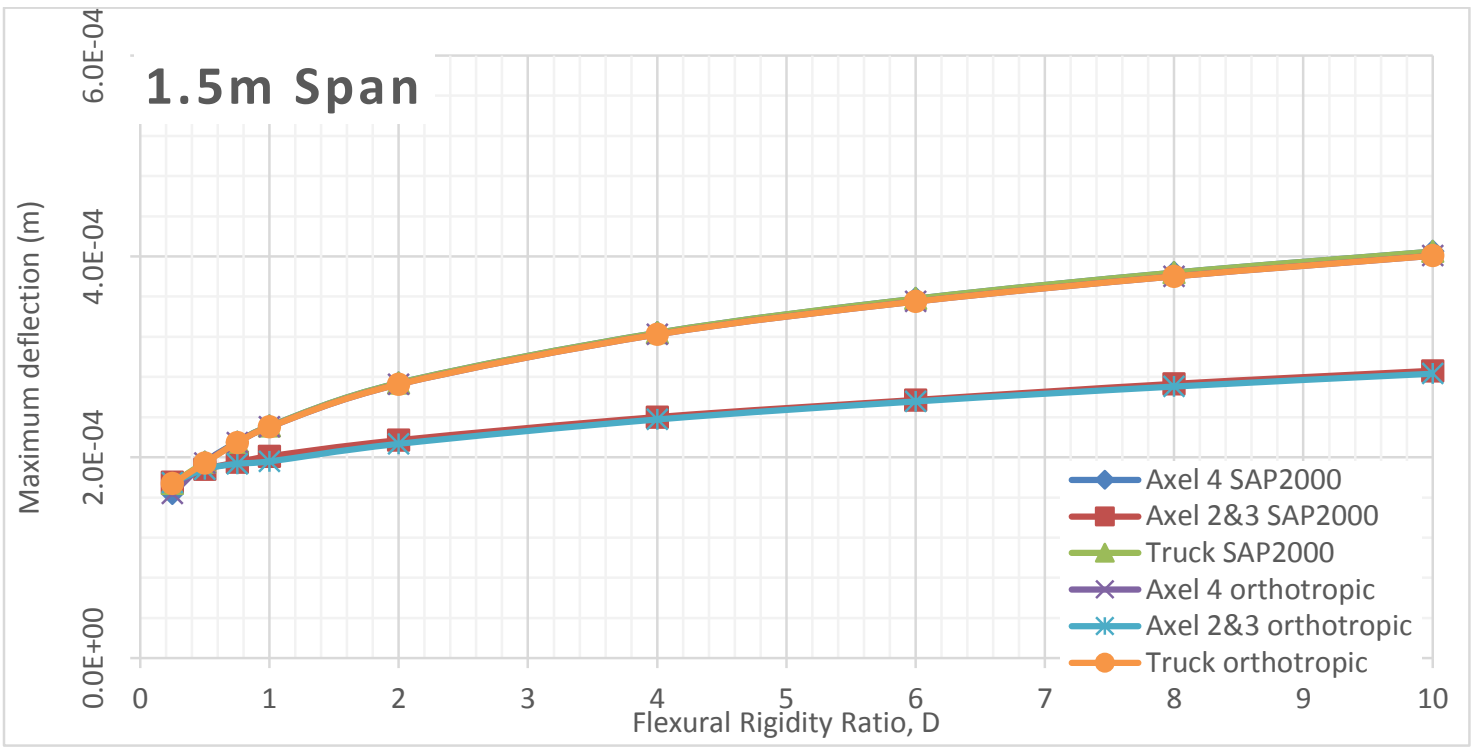

Figure 944 Deflection comparison between FEA and Orthotropic Plate Theory for $1.5 \mathrm{~m}$ span of alpha 0.25 (main bars perpendicular to traffic) 


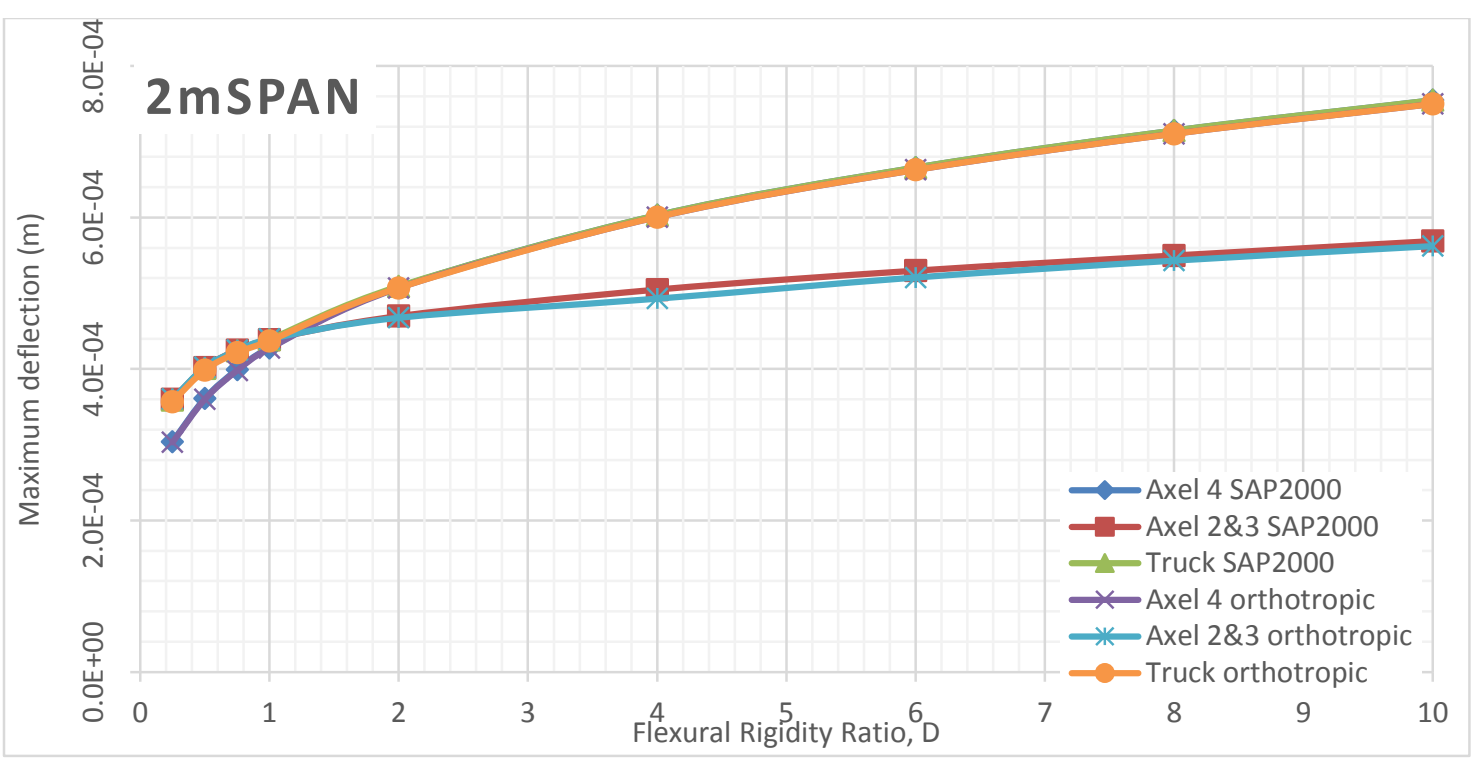

Figure 945 Deflection comparison between FEA and Orthotropic Plate Theory for $2 \mathrm{~m}$ span of alpha 0.25 (main bars perpendicular to traffic)

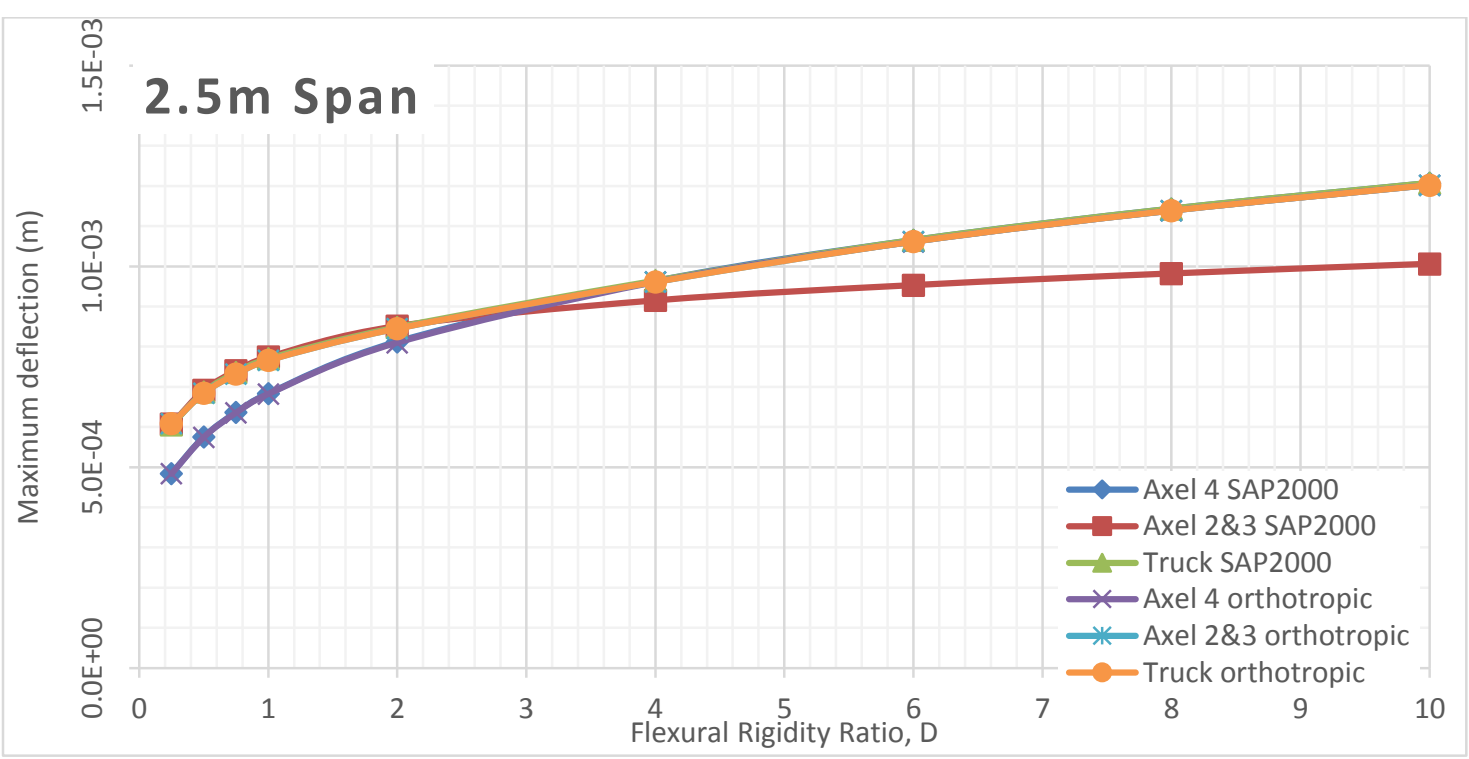

Figure 946 Deflection comparison between FEA and Orthotropic Plate Theory for $2.5 \mathrm{~m}$ span of alpha 0.25 (main bars perpendicular to traffic)

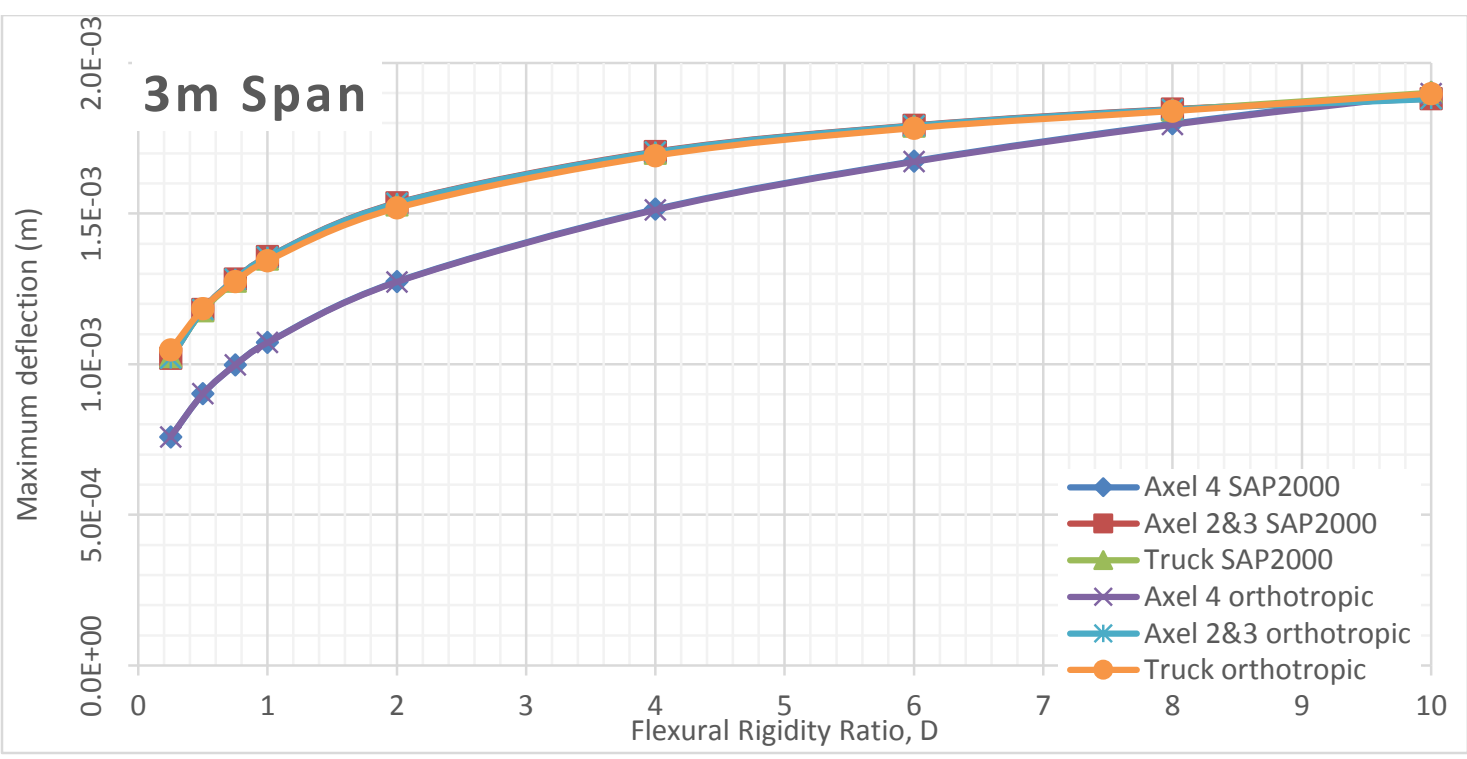

Figure 947 Deflection comparison between FEA and Orthotropic Plate Theory for $3 \mathrm{~m}$ span of alpha 0.25 (main bars perpendicular to traffic) 


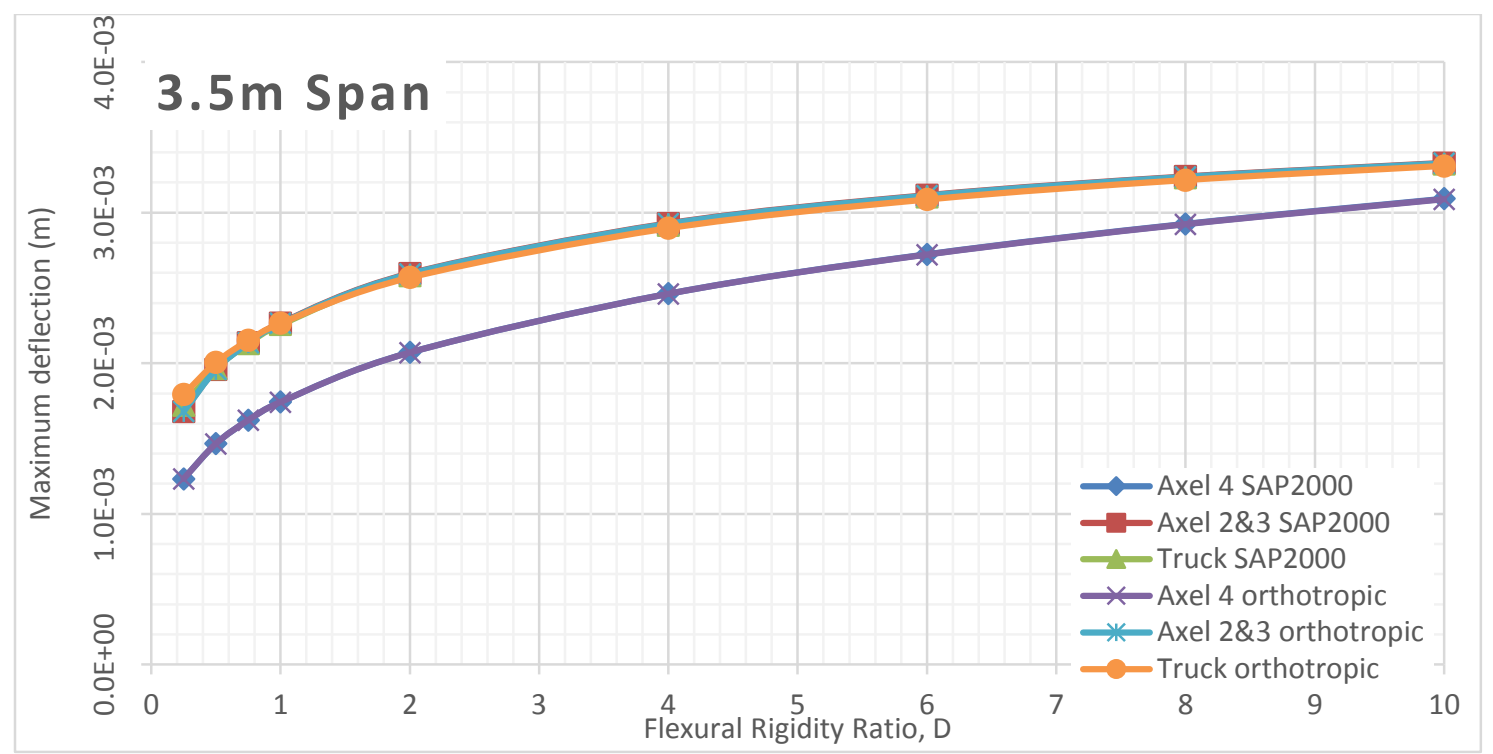

Figure 948 Deflection comparison between FEA and Orthotropic Plate Theory for $3.5 \mathrm{~m}$ span of alpha 0.25 (main bars perpendicular to traffic)

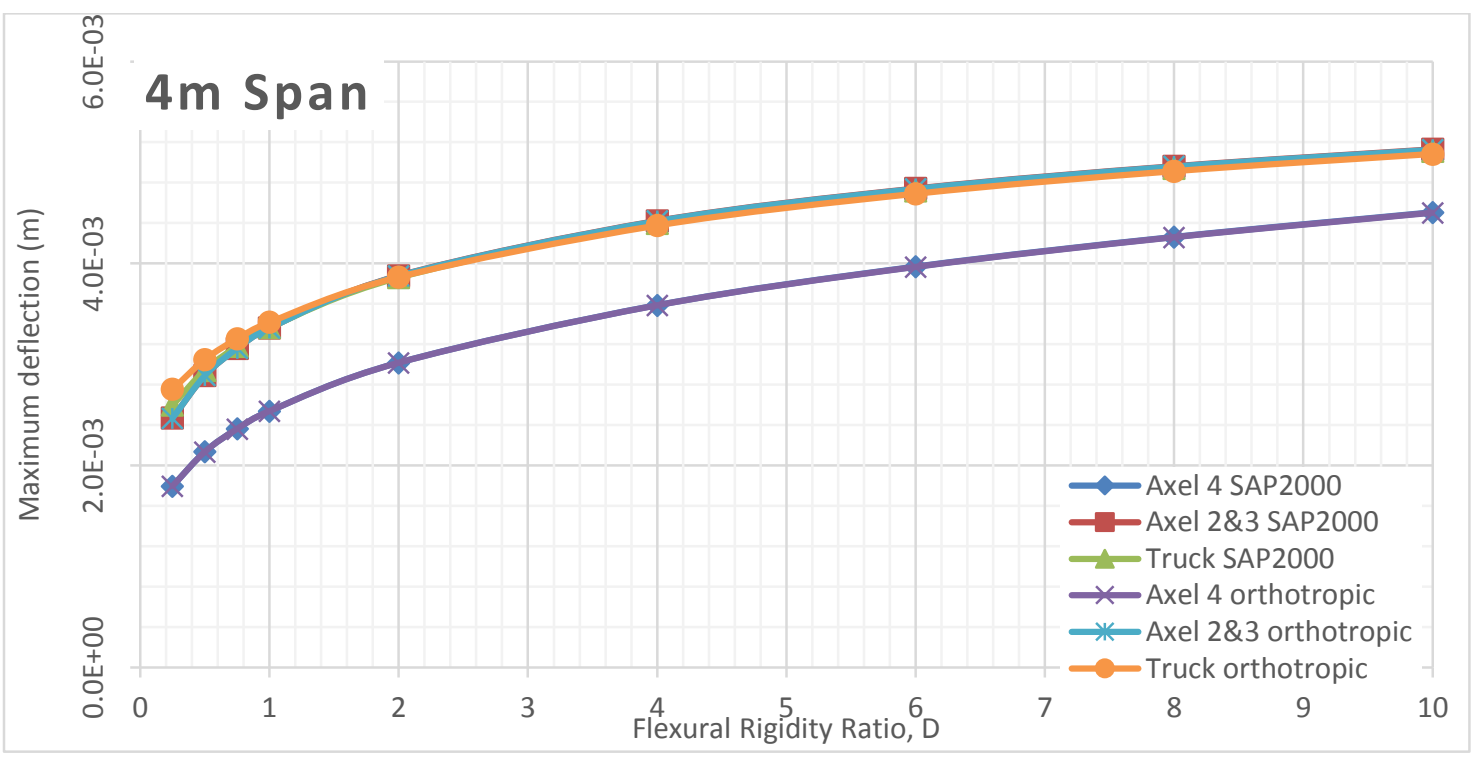

Figure 949 Deflection comparison between FEA and Orthotropic Plate Theory for $4 \mathrm{~m}$ span of alpha 0.25 (main bars perpendicular to traffic) 


\section{Alpha 0.25 Deflection VS Flexural Rigidity for Different Span Length (Main bars parallel to traffic)}

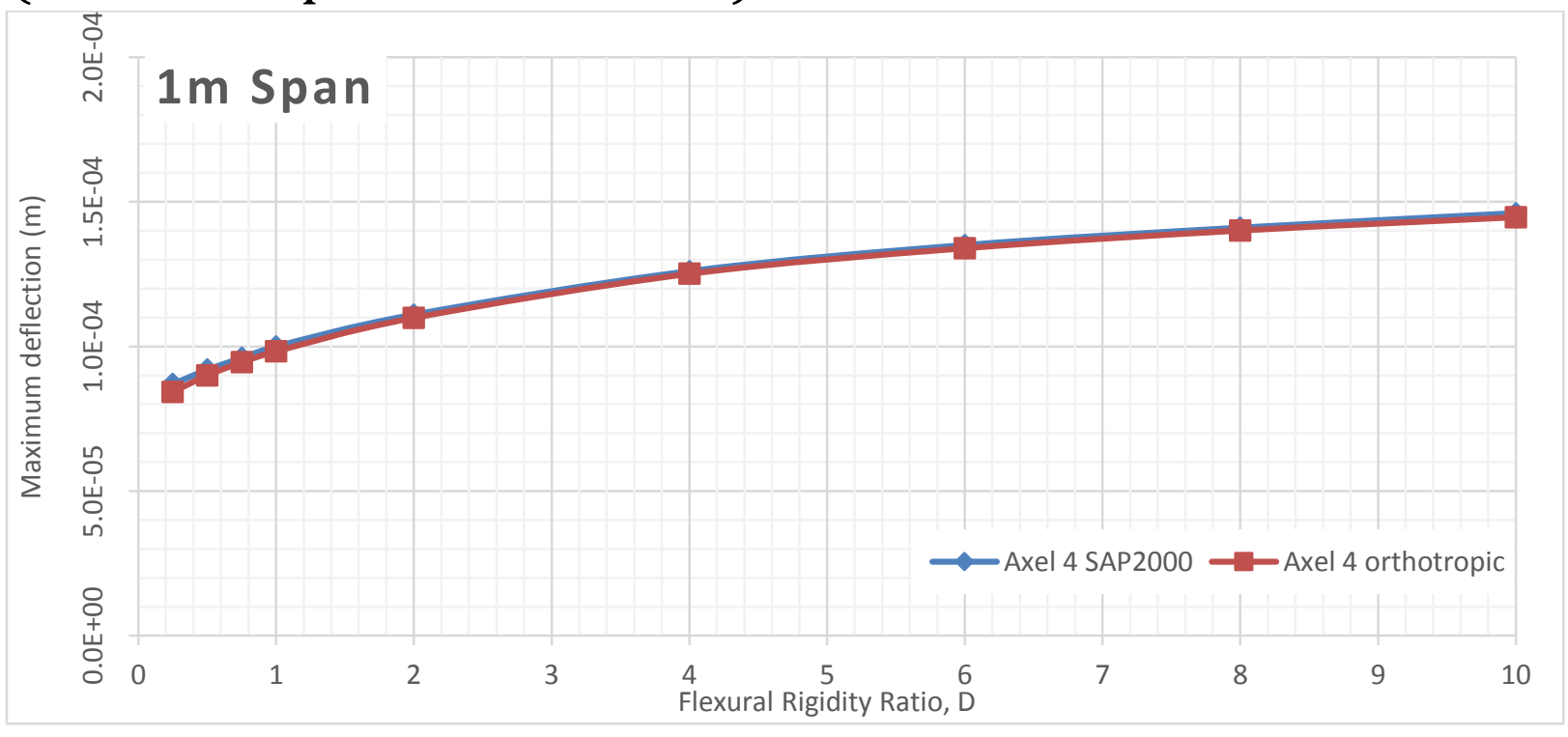

Figure 950 Deflection comparison between FEA and Orthotropic Plate Theory for $1 \mathrm{~m}$ span of alpha 0.25 (main bars parallel to traffic)

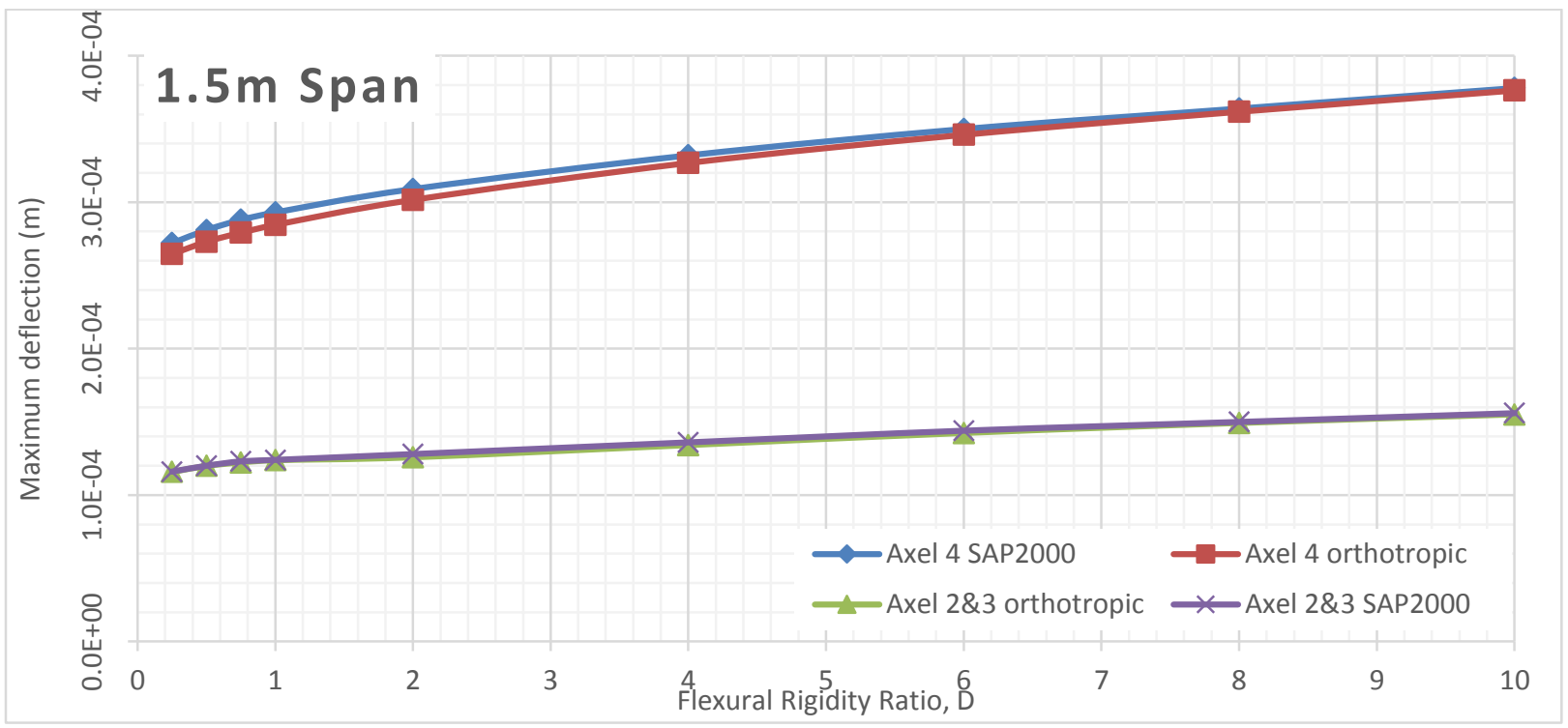

Figure 951 Deflection comparison between FEA and Orthotropic Plate Theory for $1.5 \mathrm{~m}$ span of alpha 0.25 (main bars parallel to traffic) 


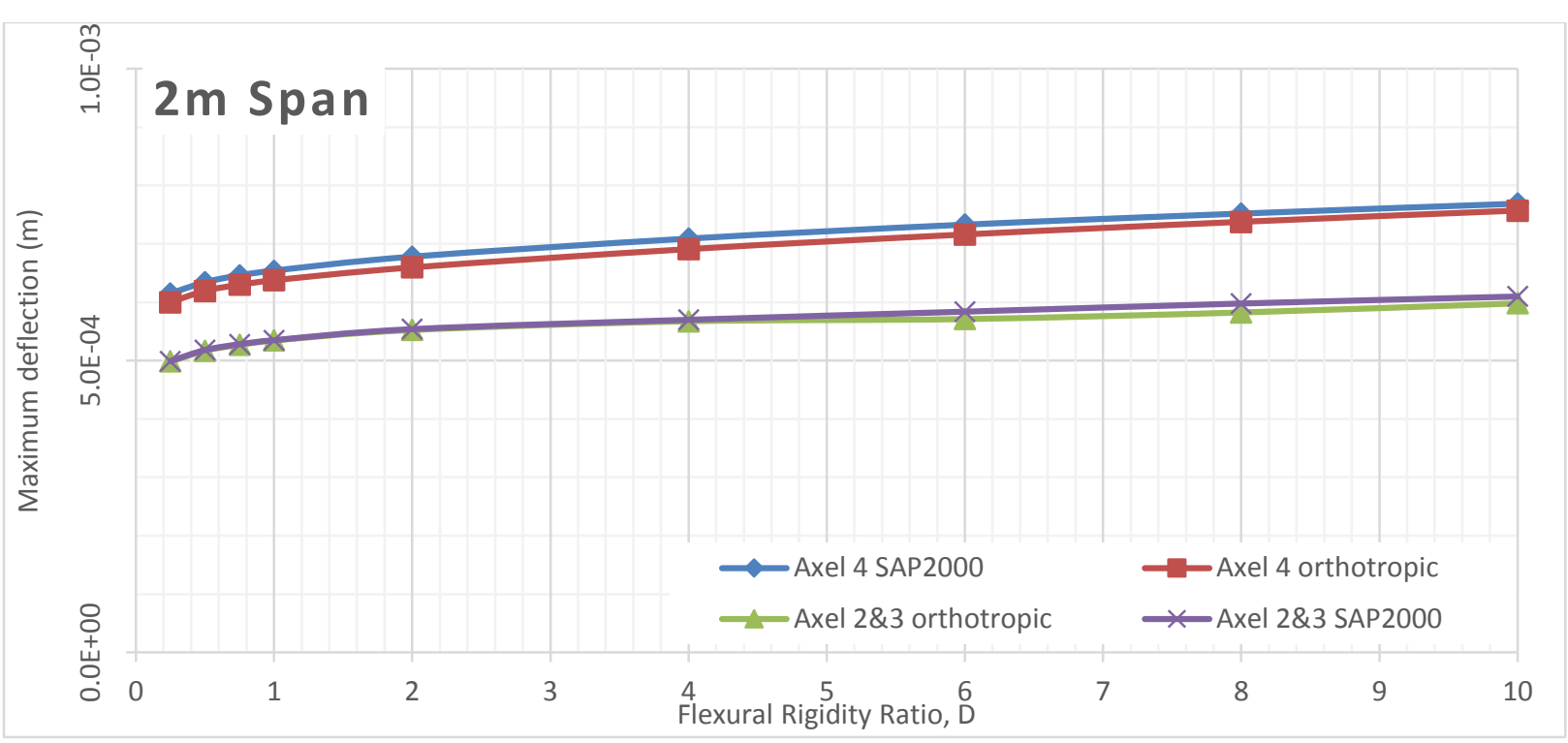

Figure 952 Deflection comparison between FEA and Orthotropic Plate Theory for $2 \mathrm{~m}$ span of alpha 0.25 (main bars parallel to traffic)

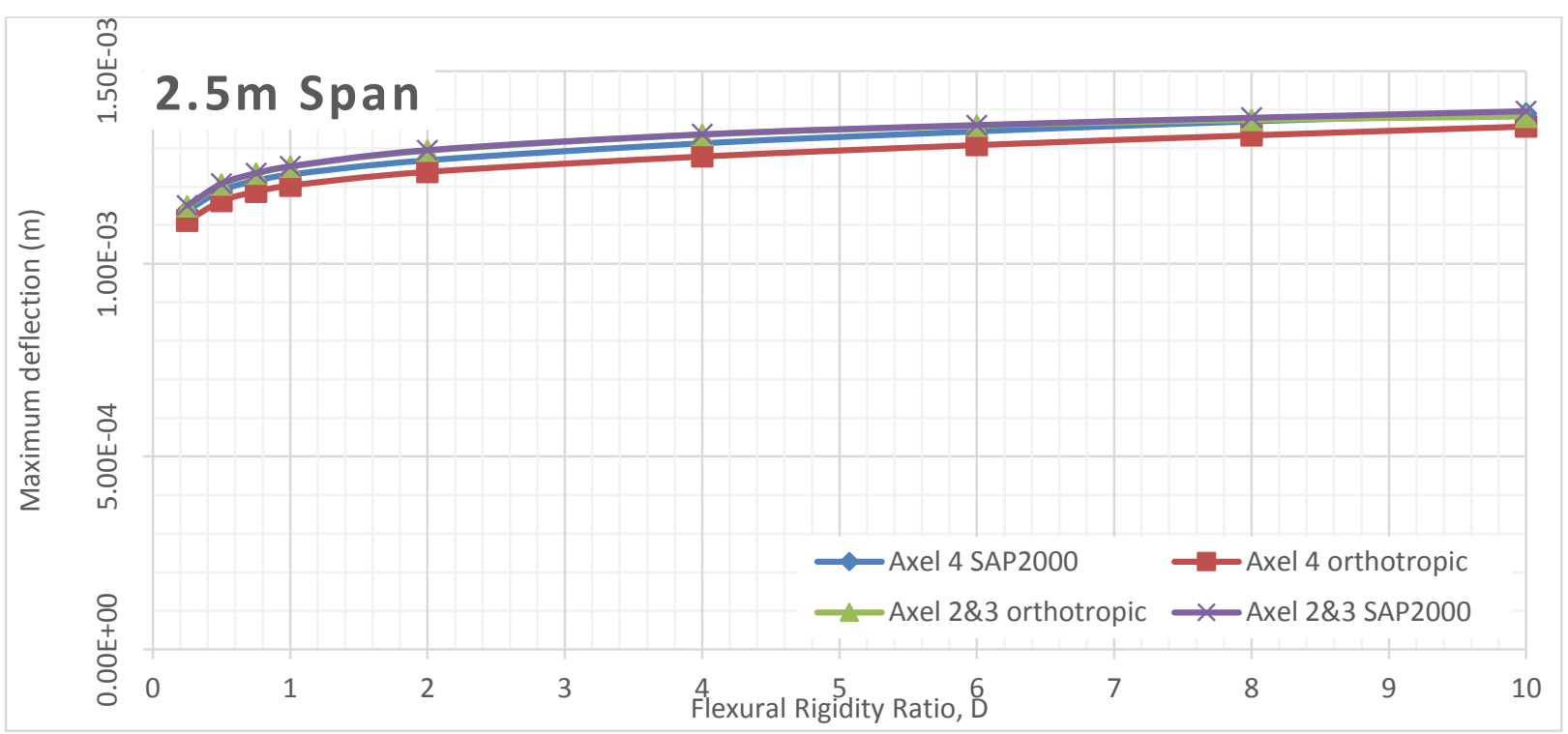

Figure 953 Deflection comparison between FEA and Orthotropic Plate Theory for $2.5 \mathrm{~m}$ span of alpha 0.25 (main bars parallel to traffic)

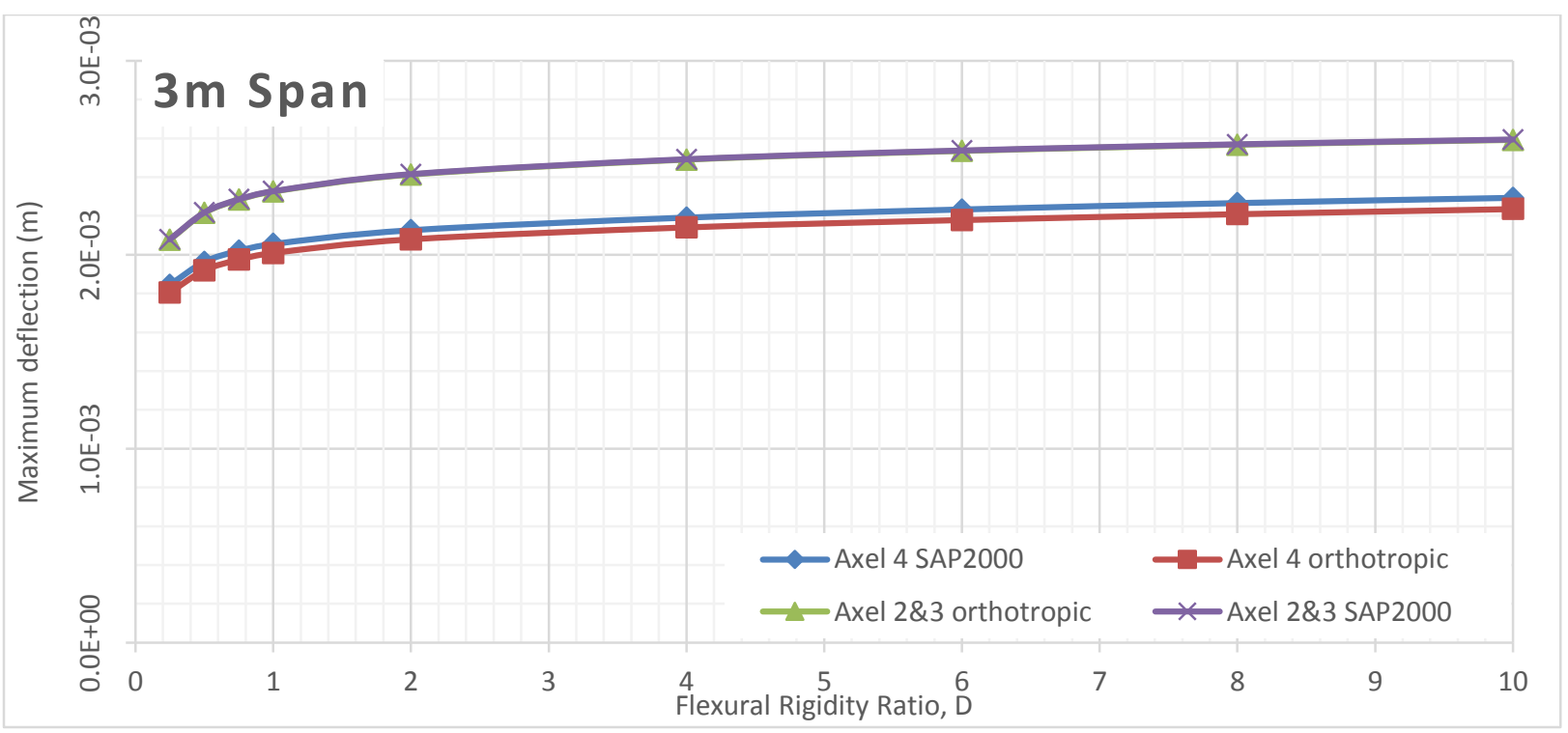

Figure 954 Deflection comparison between FEA and Orthotropic Plate Theory for $3 \mathrm{~m}$ span of alpha 0.25 (main bars parallel to traffic) 


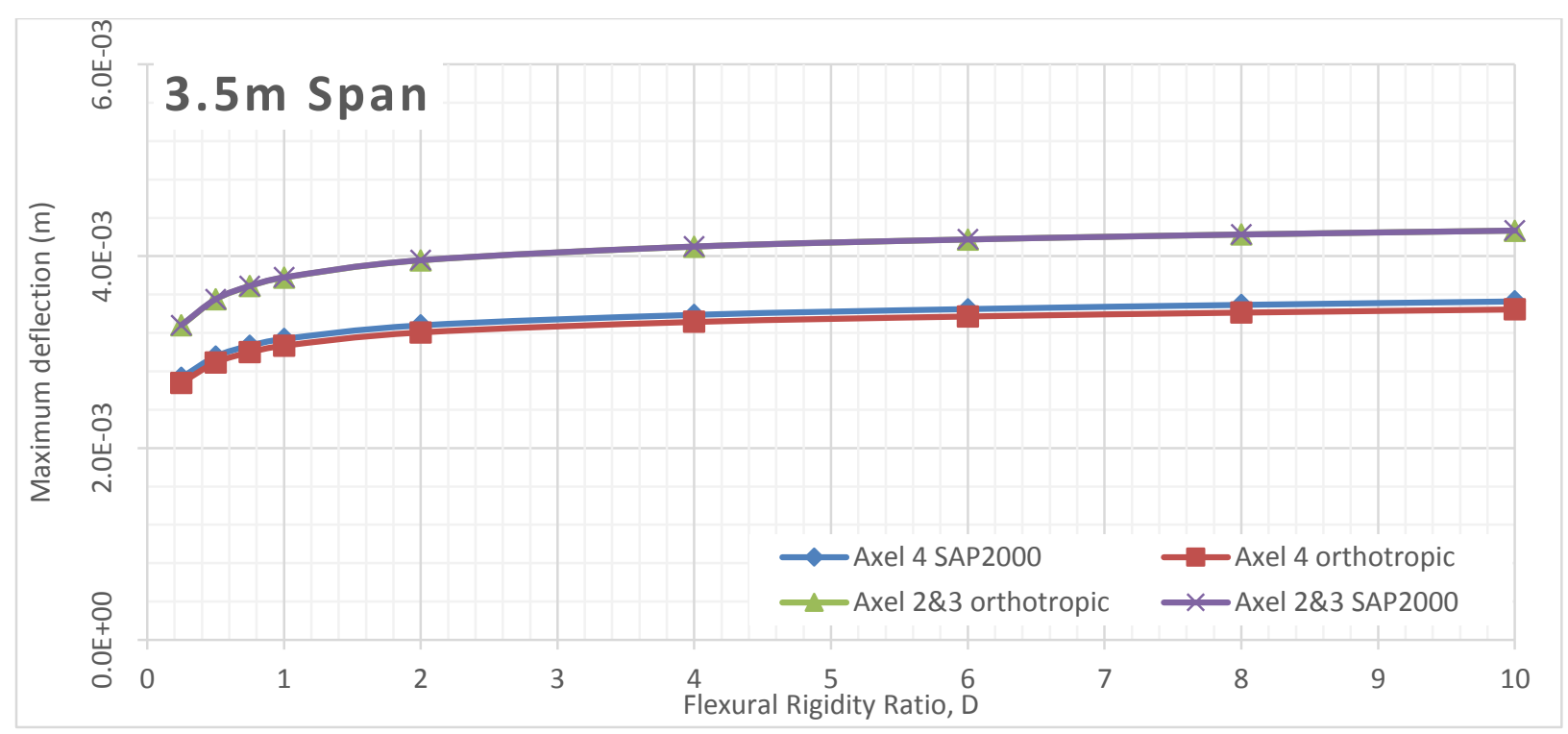

Figure 955 Deflection comparison between FEA and Orthotropic Plate Theory for $3.5 \mathrm{~m}$ span of alpha 0.25 (main bars parallel to traffic)

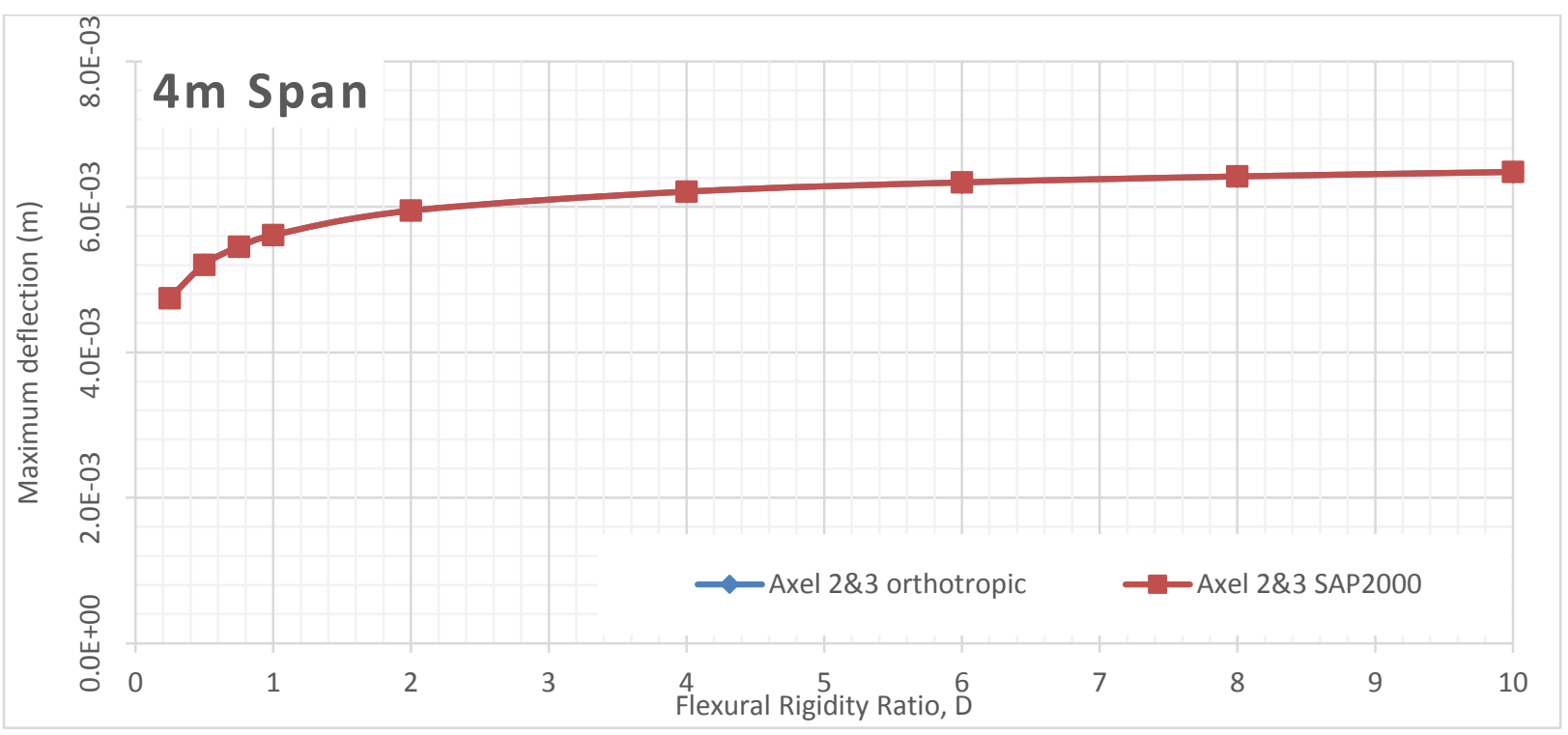

Figure 956 Deflection comparison between FEA and Orthotropic Plate Theory for $4 \mathrm{~m}$ span of alpha 0.25 (main bars parallel to traffic) 


\section{Alpha 0.5 Deflection VS Flexural Rigidity for Different Span Length (Main bars perpendicular to traffic)}

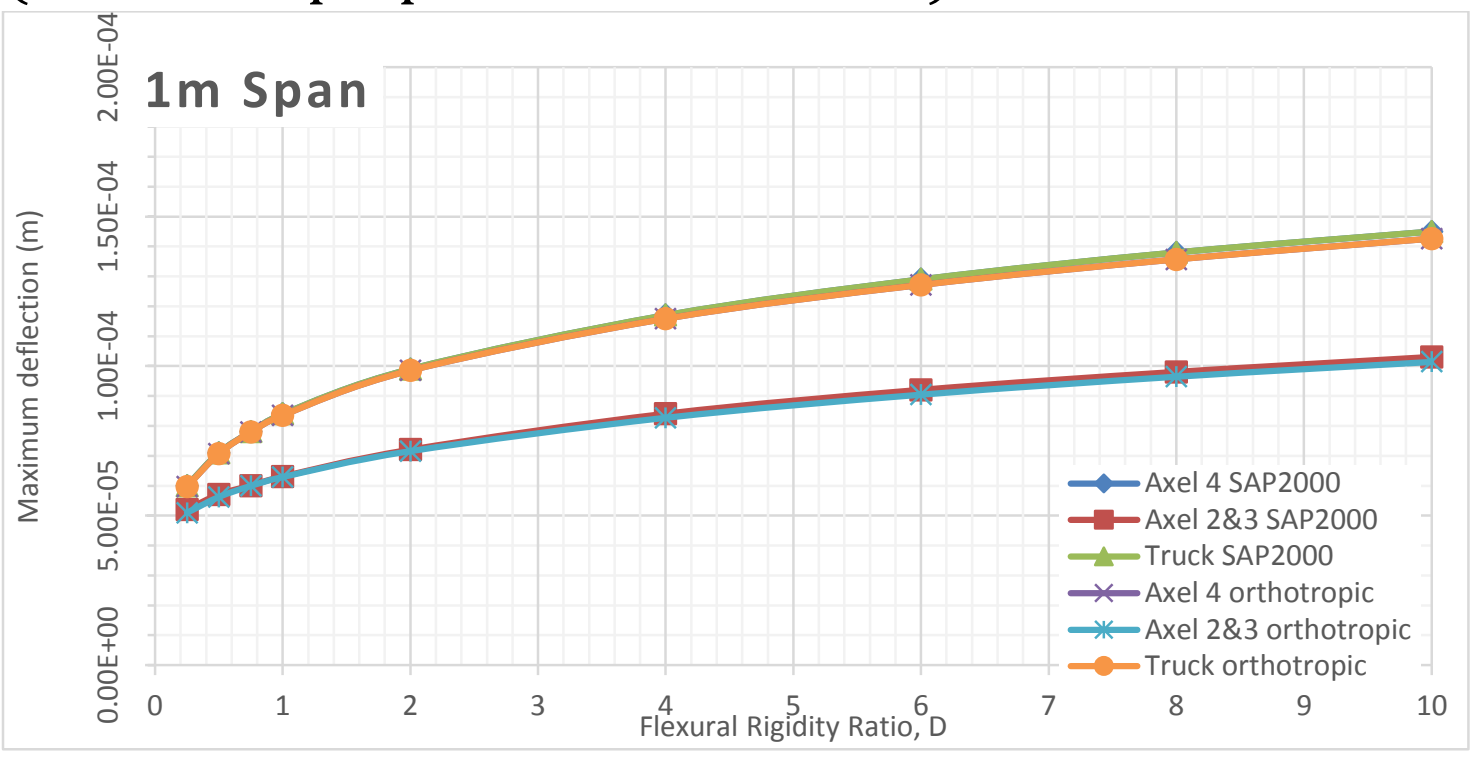

Figure 957 Deflection comparison between FEA and Orthotropic Plate Theory for $1 \mathrm{~m}$ span of alpha 0.5 (main bars perpendicular to traffic)

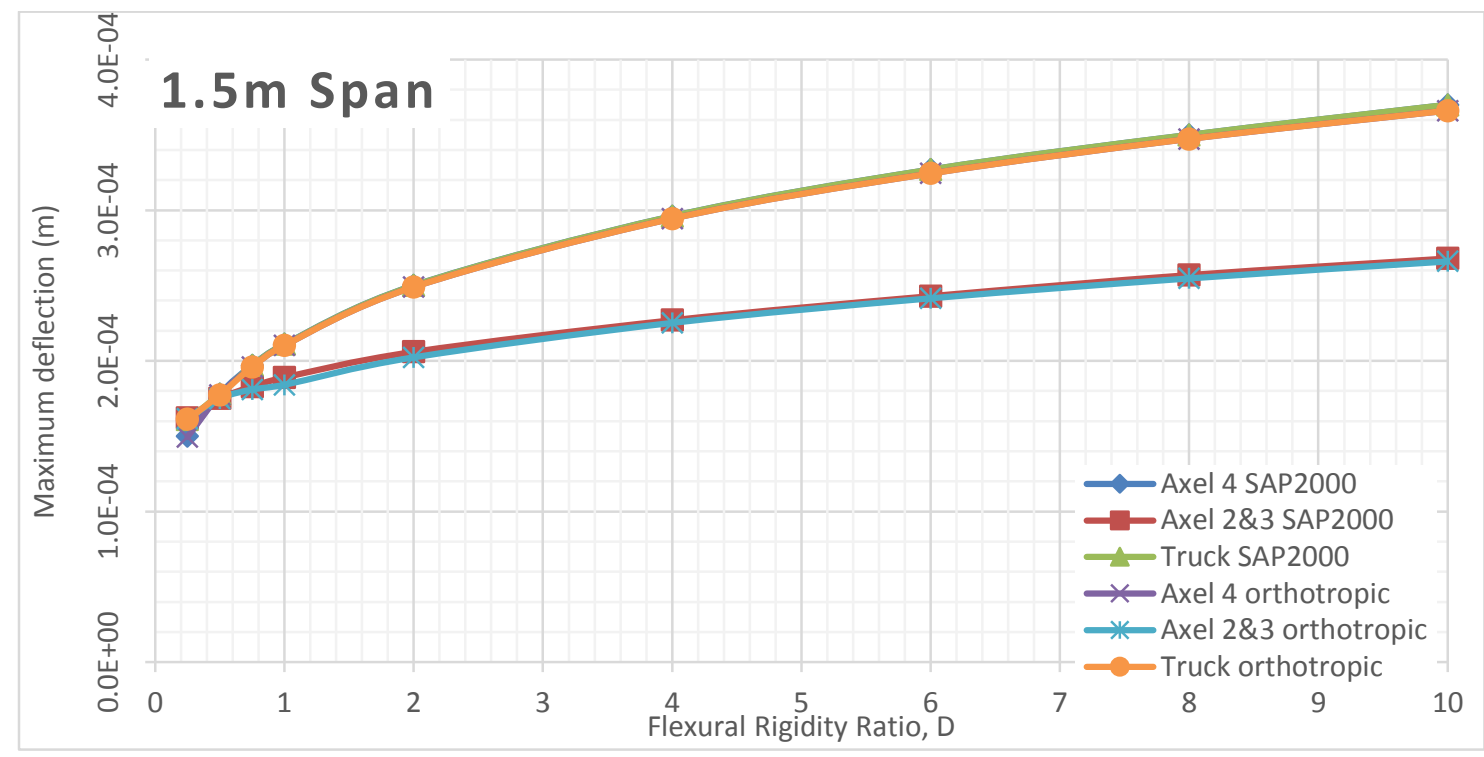

Figure 958 Deflection comparison between FEA and Orthotropic Plate Theory for $1.5 \mathrm{~m}$ span of alpha 0.5 (main bars perpendicular to traffic) 


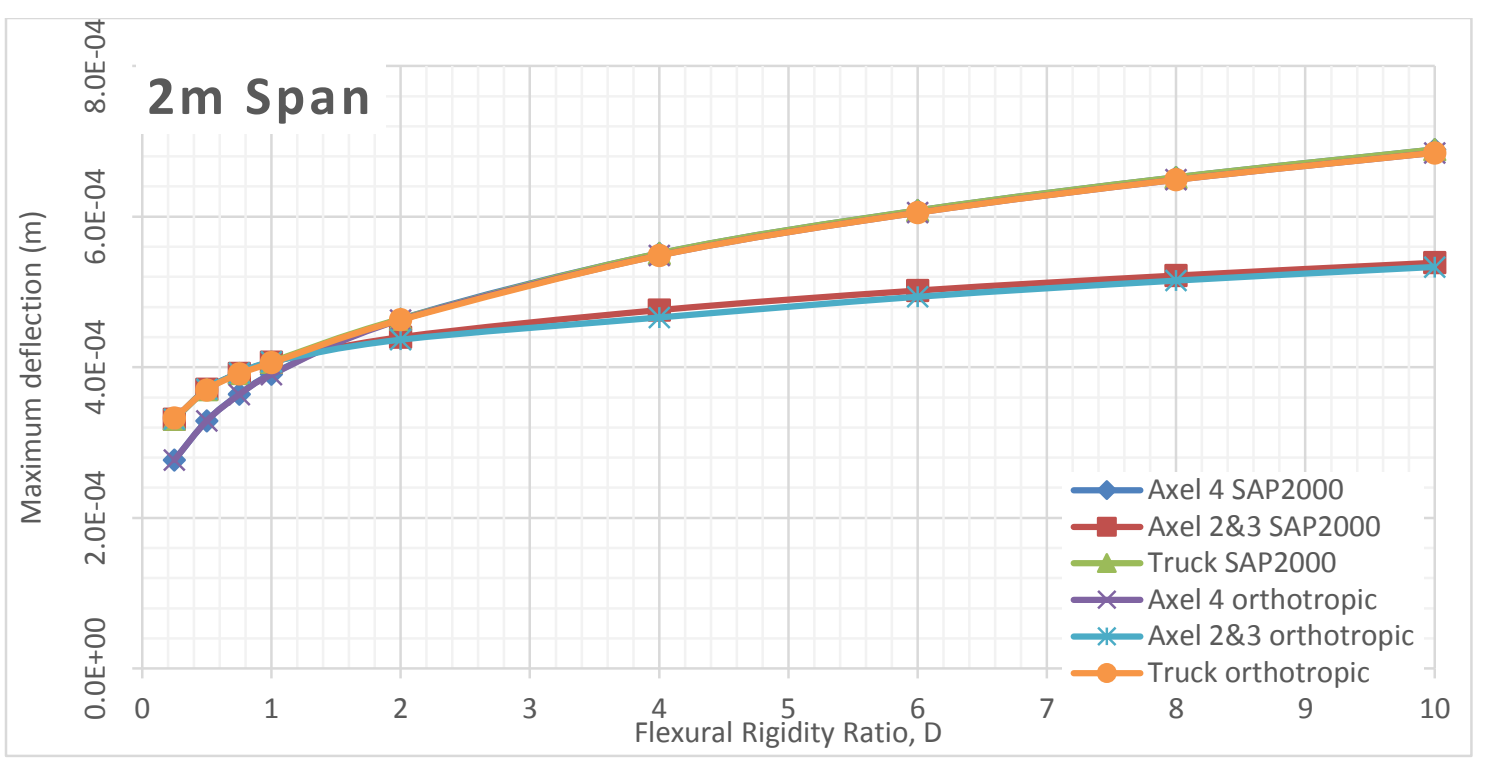

Figure 959 Deflection comparison between FEA and Orthotropic Plate Theory for $2 \mathrm{~m}$ span of alpha 0.5 (main bars perpendicular to traffic)

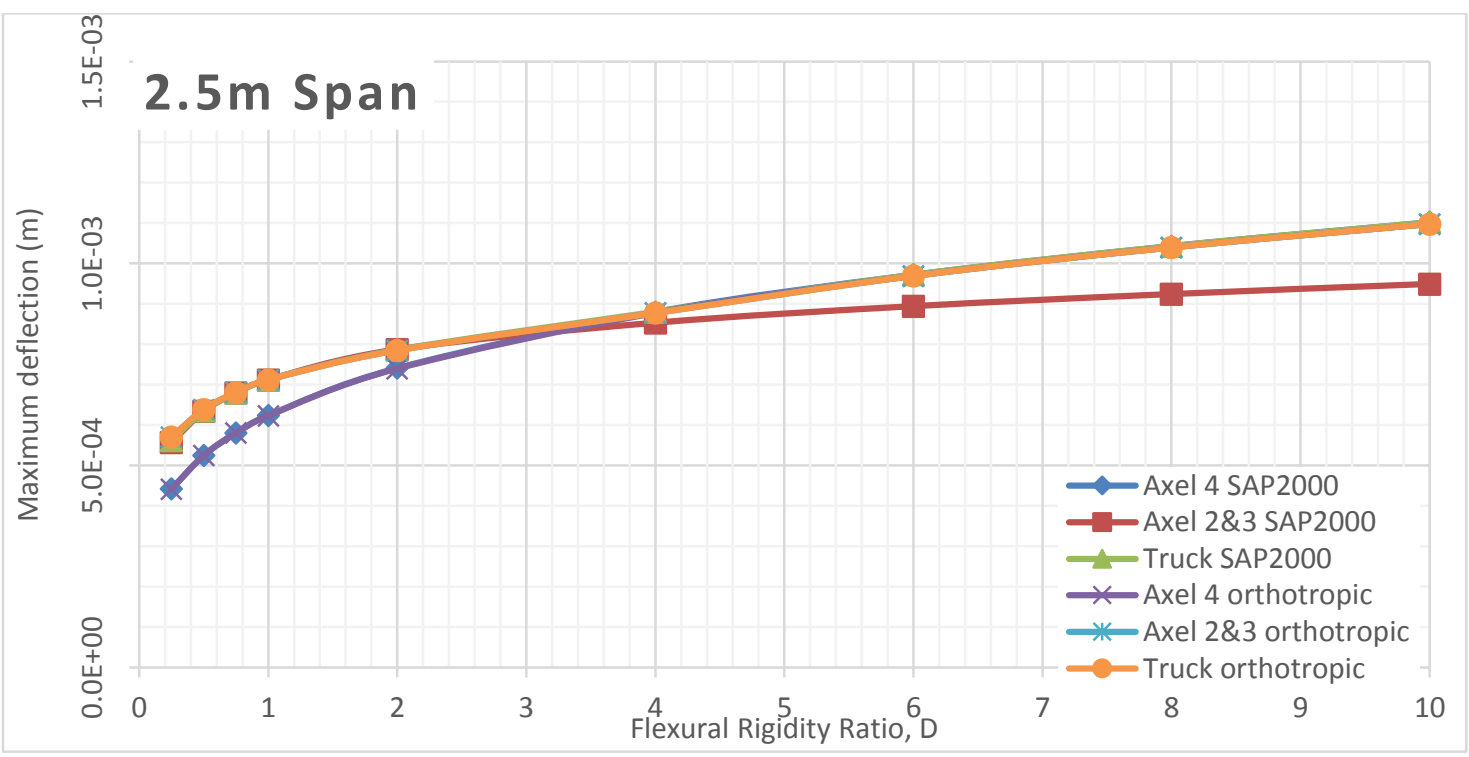

Figure 960 Deflection comparison between FEA and Orthotropic Plate Theory for $2.5 \mathrm{~m}$ span of alpha 0.5 (main bars perpendicular to traffic)

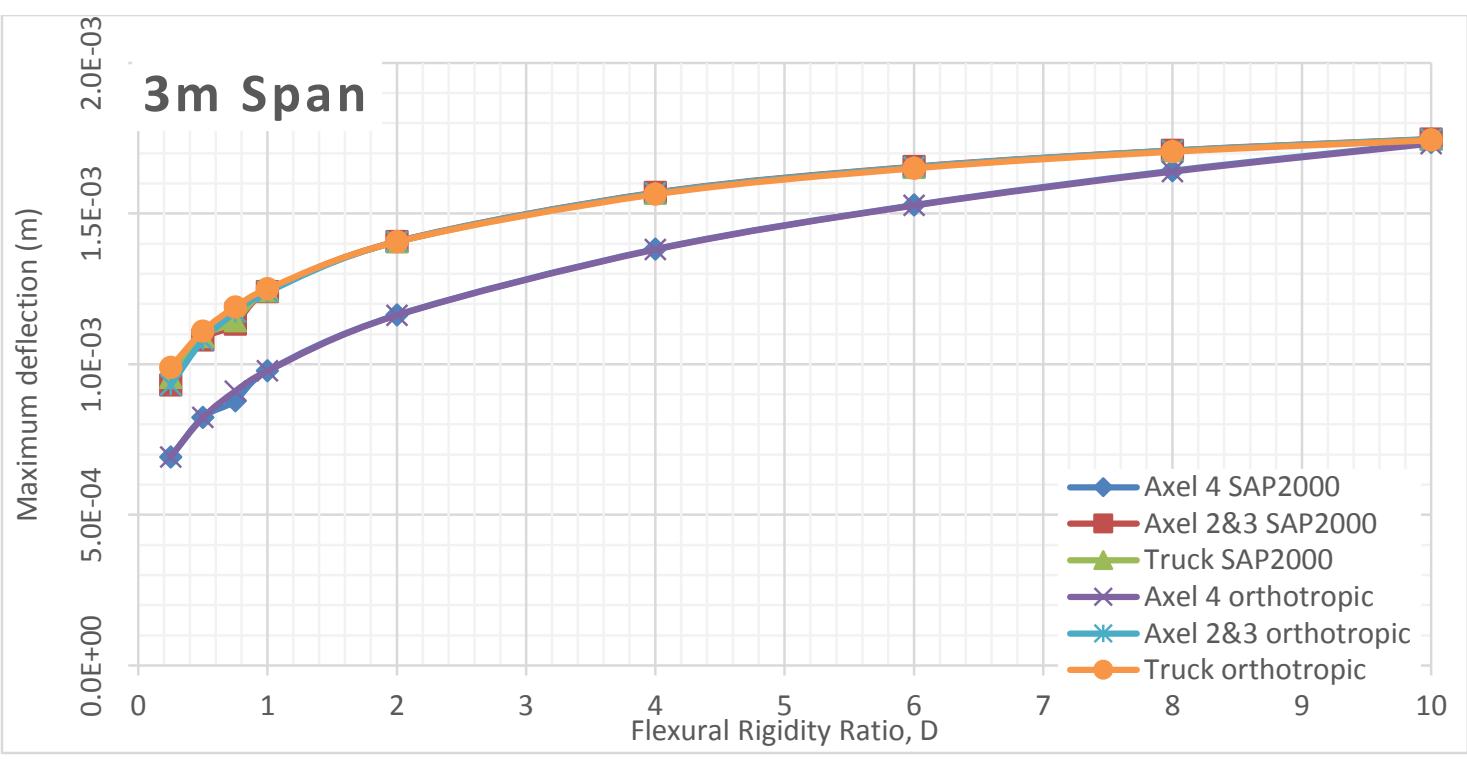

Figure 961 Deflection comparison between FEA and Orthotropic Plate Theory for $3 \mathrm{~m}$ span of alpha 0.5 (main bars perpendicular to traffic) 


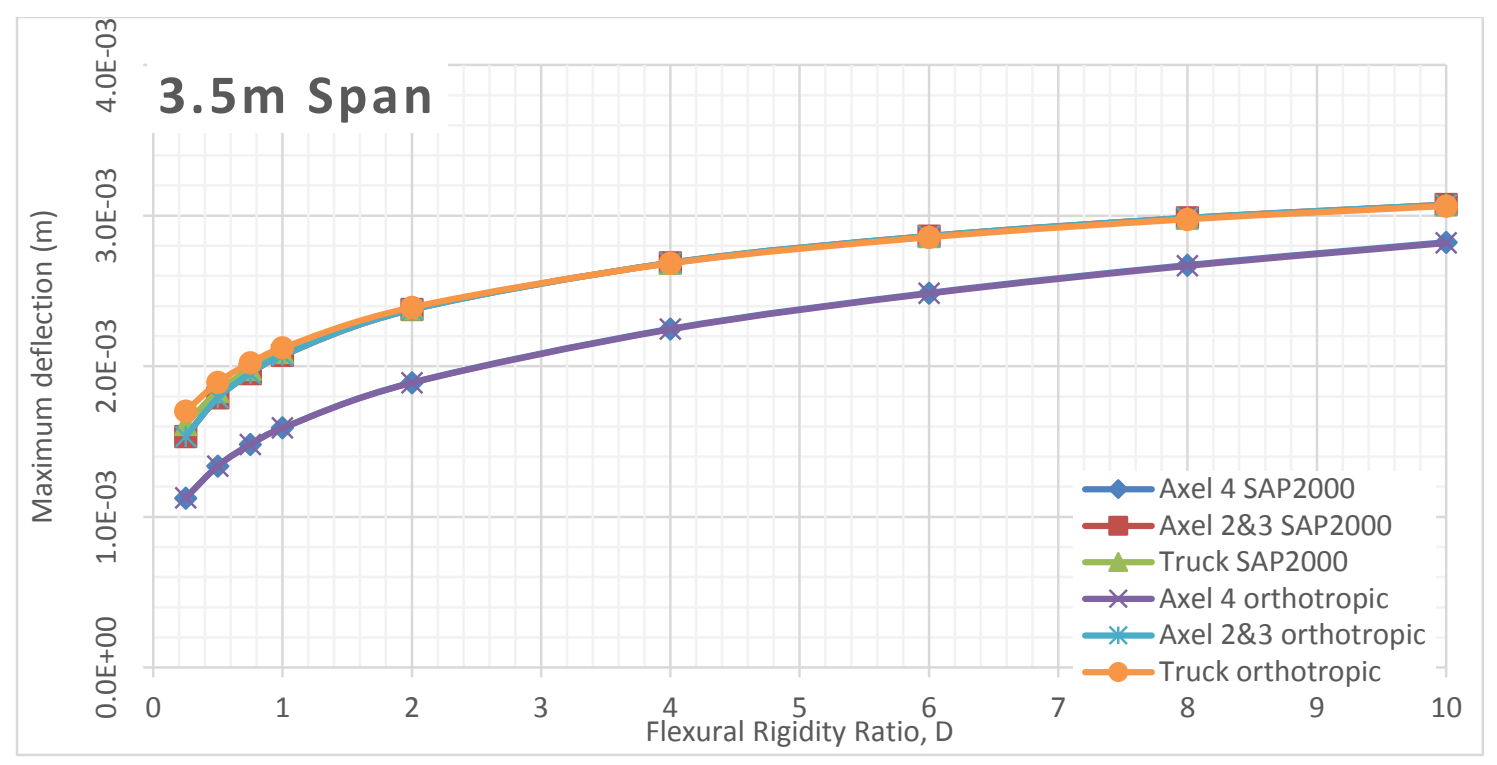

Figure 962 Deflection comparison between FEA and Orthotropic Plate Theory for $3.5 \mathrm{~m}$ span of alpha 0.5 (main bars perpendicular to traffic)

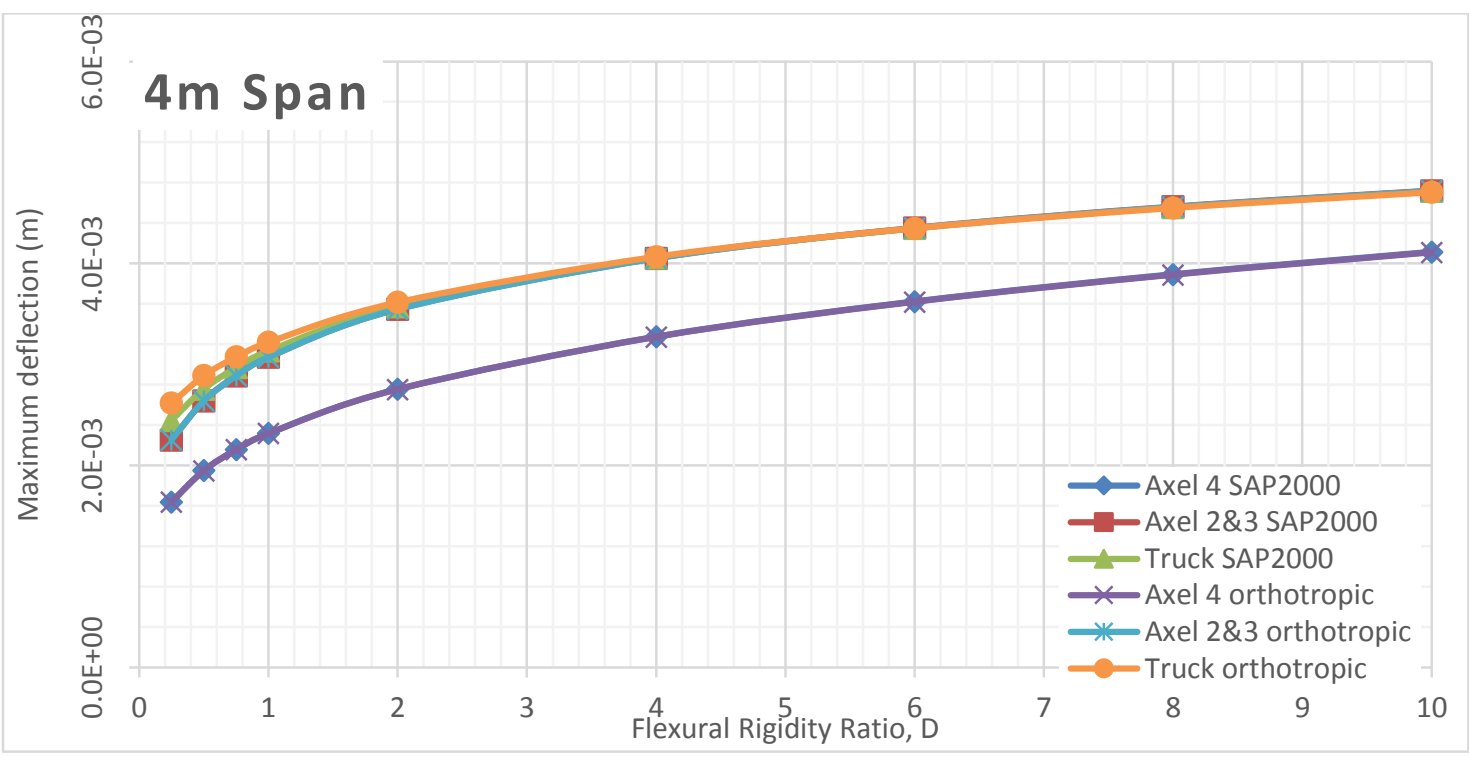

Figure 963 Deflection comparison between FEA and Orthotropic Plate Theory for $4 \mathrm{~m}$ span of alpha 0.5 (main bars perpendicular to traffic) 


\section{Alpha 0.5 Deflection VS Flexural Rigidity for Different Span Length (Main bars parallel to traffic)}

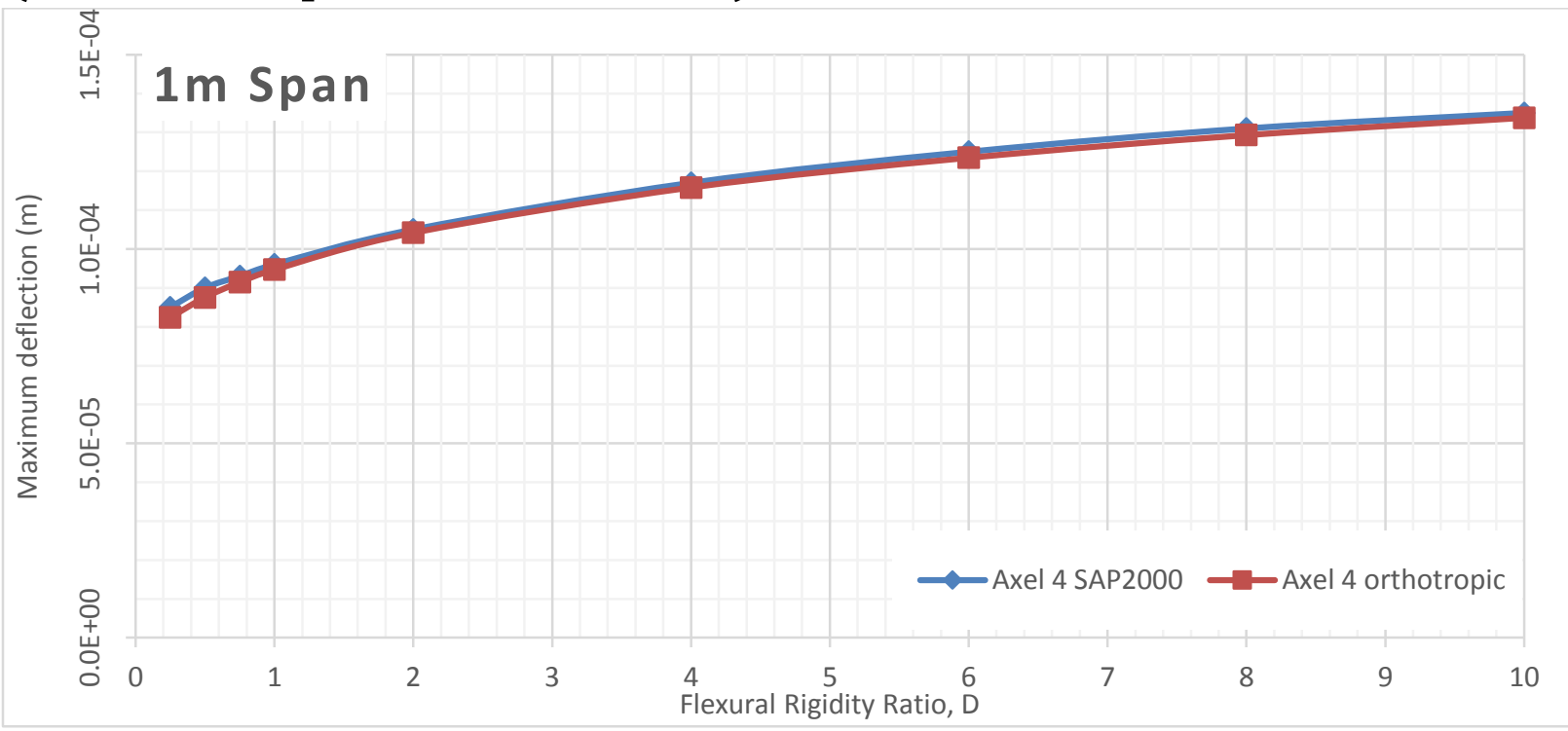

Figure 964 Deflection comparison between FEA and Orthotropic Plate Theory for $1 \mathrm{~m}$ span of alpha 0.5 (main bars parallel to traffic)

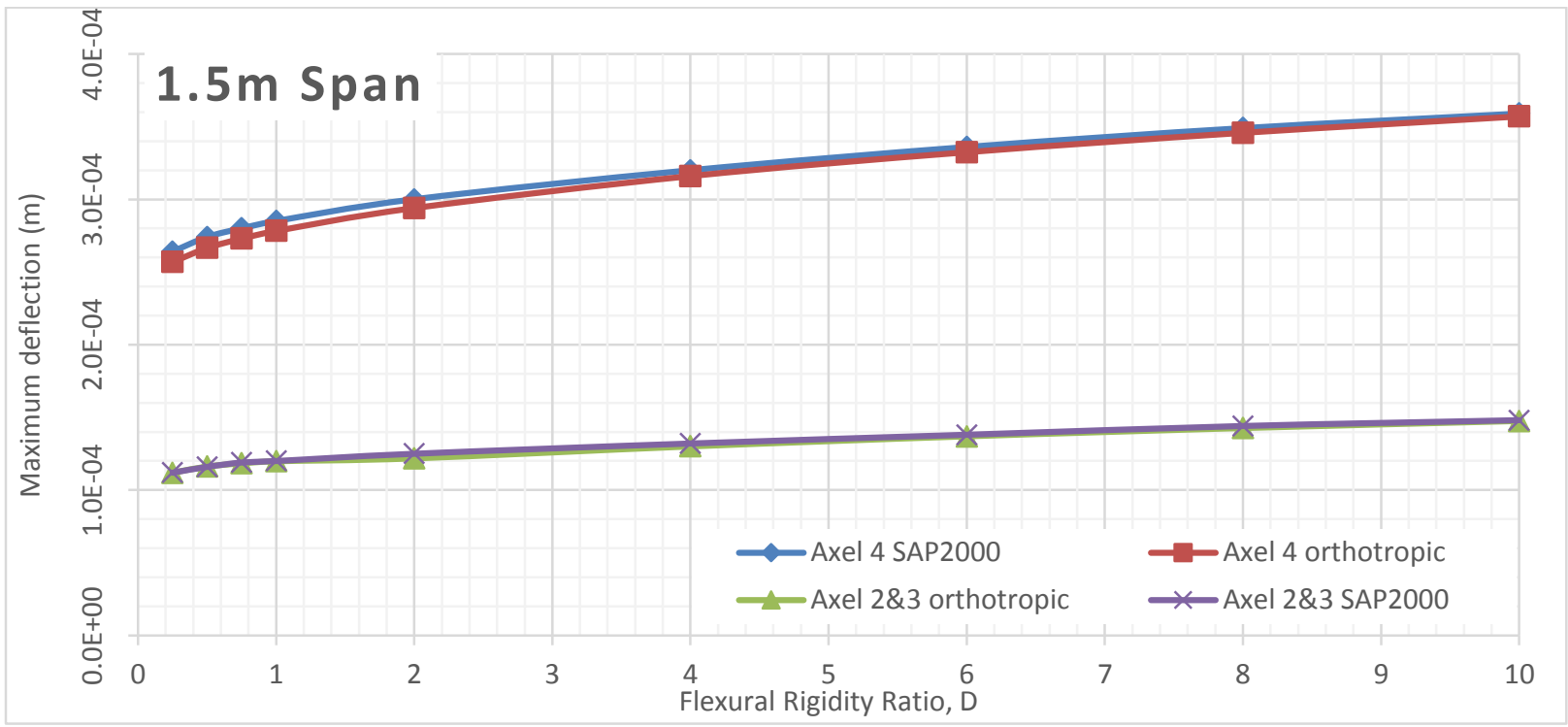

Figure 965 Deflection comparison between FEA and Orthotropic Plate Theory for $1.5 \mathrm{~m}$ span of alpha 0.5 (main bars parallel to traffic) 


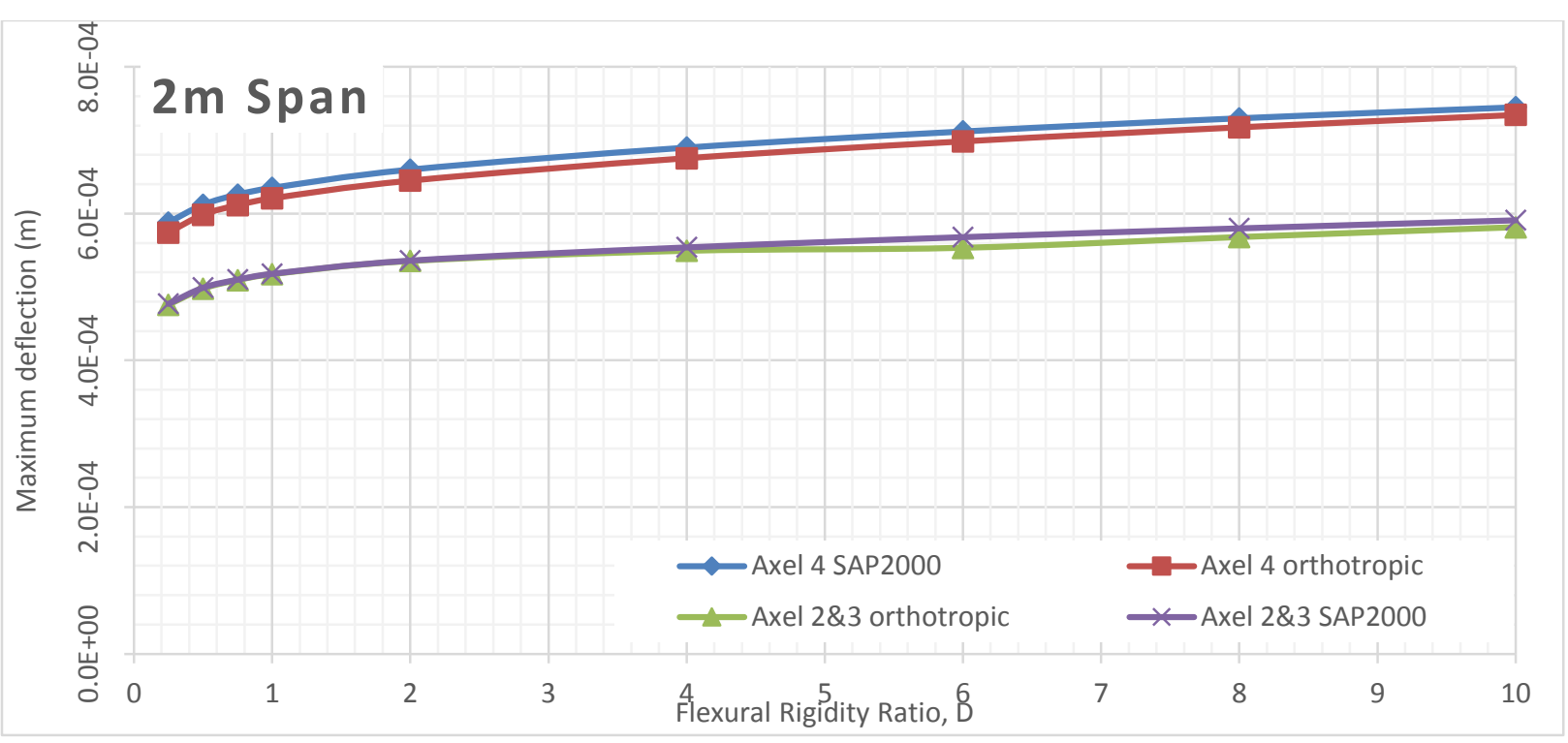

Figure 966 Deflection comparison between FEA and Orthotropic Plate Theory for $2 \mathrm{~m}$ span of alpha 0.5 (main bars parallel to traffic)

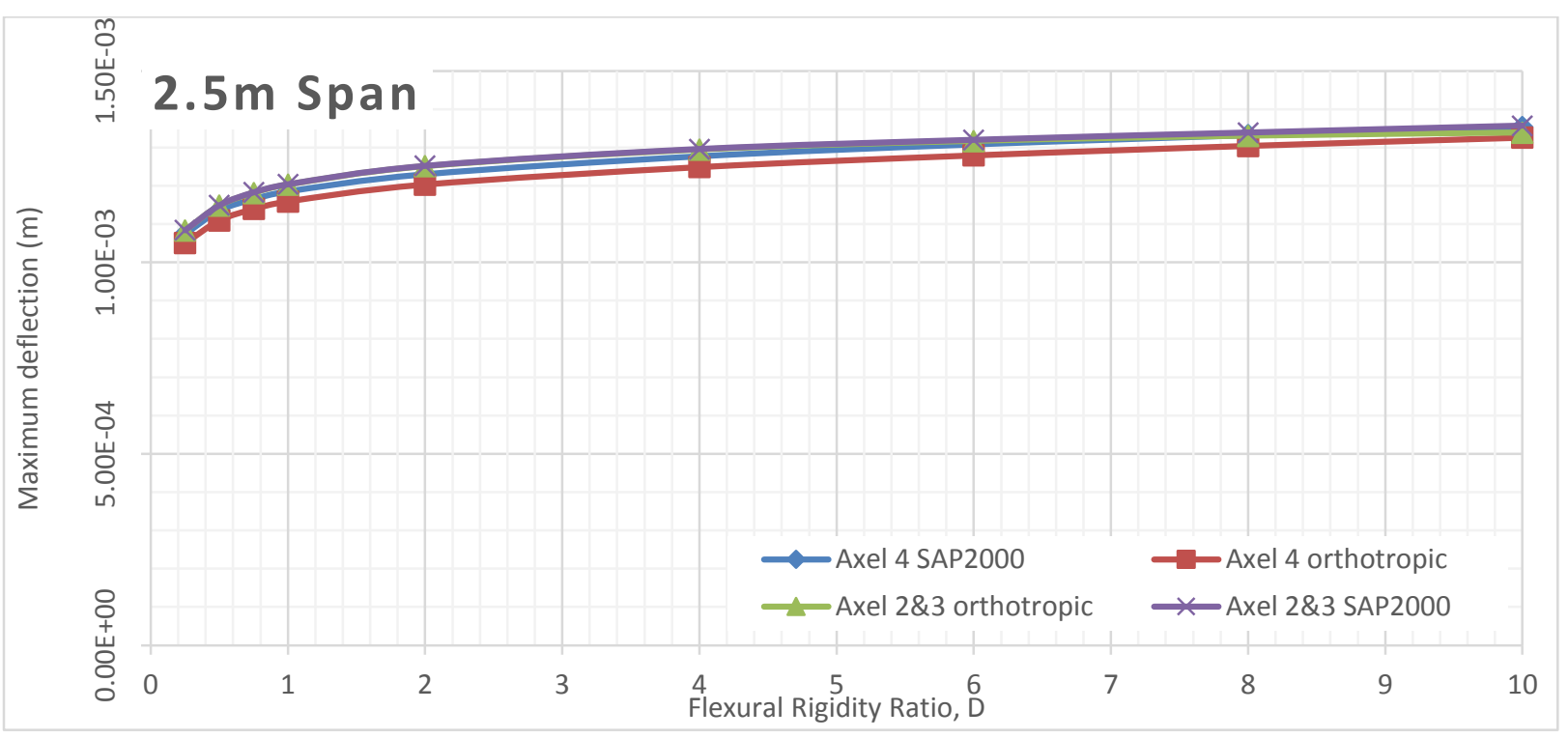

Figure 967 Deflection comparison between FEA and Orthotropic Plate Theory for $2.5 \mathrm{~m}$ span of alpha 0.5 (main bars parallel to traffic)

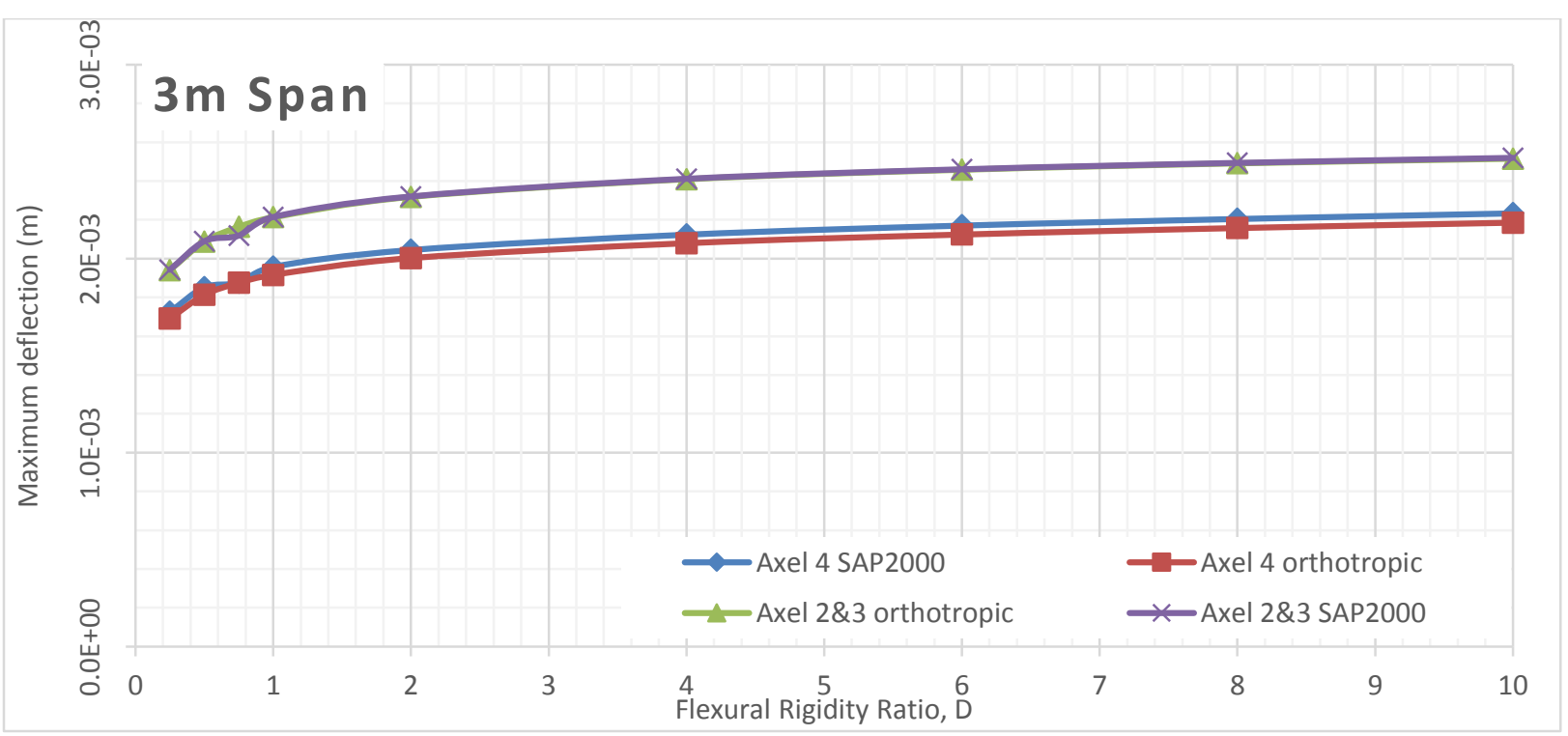

Figure 968 Deflection comparison between FEA and Orthotropic Plate Theory for $3 \mathrm{~m}$ span of alpha 0.5 (main bars parallel to traffic) 


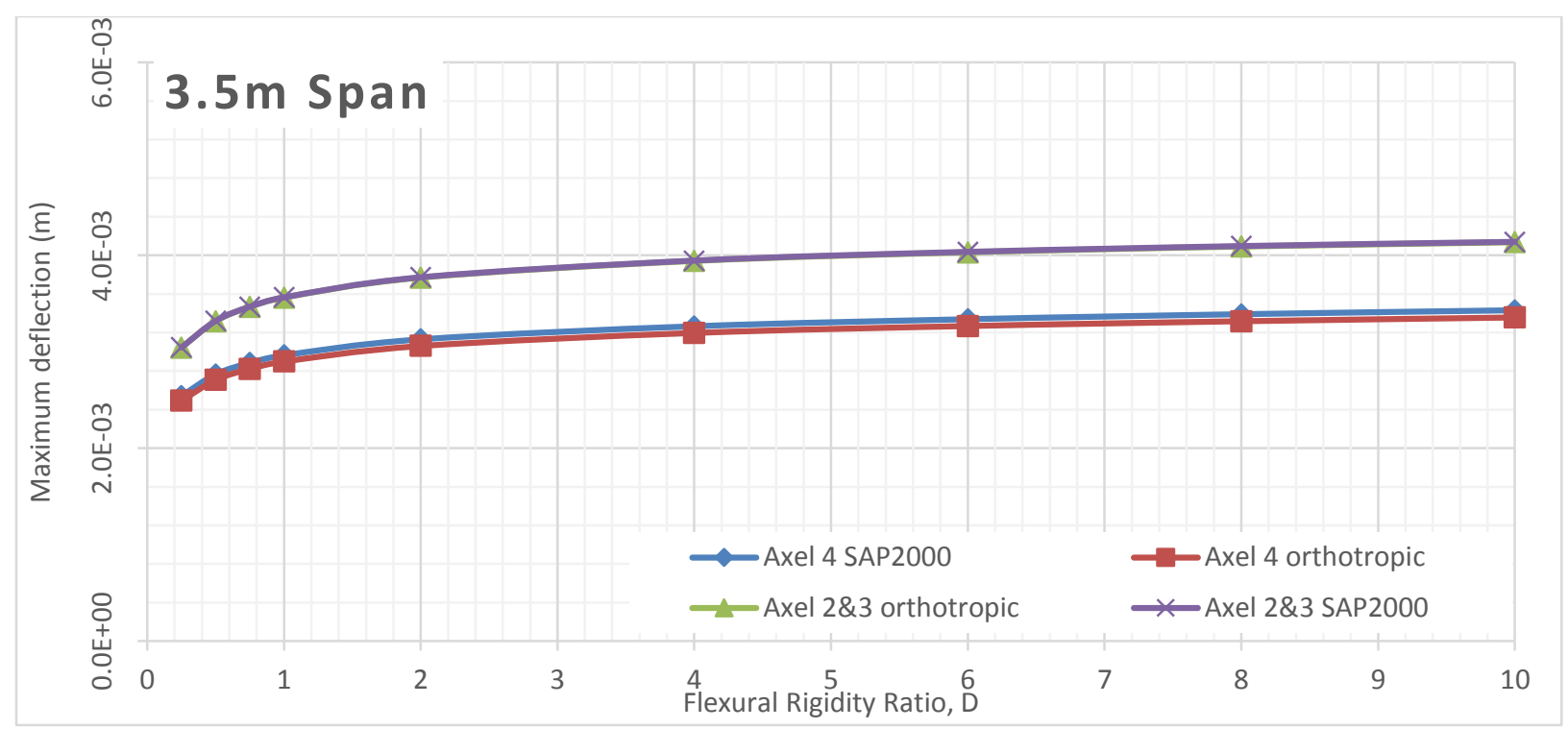

Figure 969 Deflection comparison between FEA and Orthotropic Plate Theory for $3.5 \mathrm{~m}$ span of alpha 0.5 (main bars parallel to traffic)

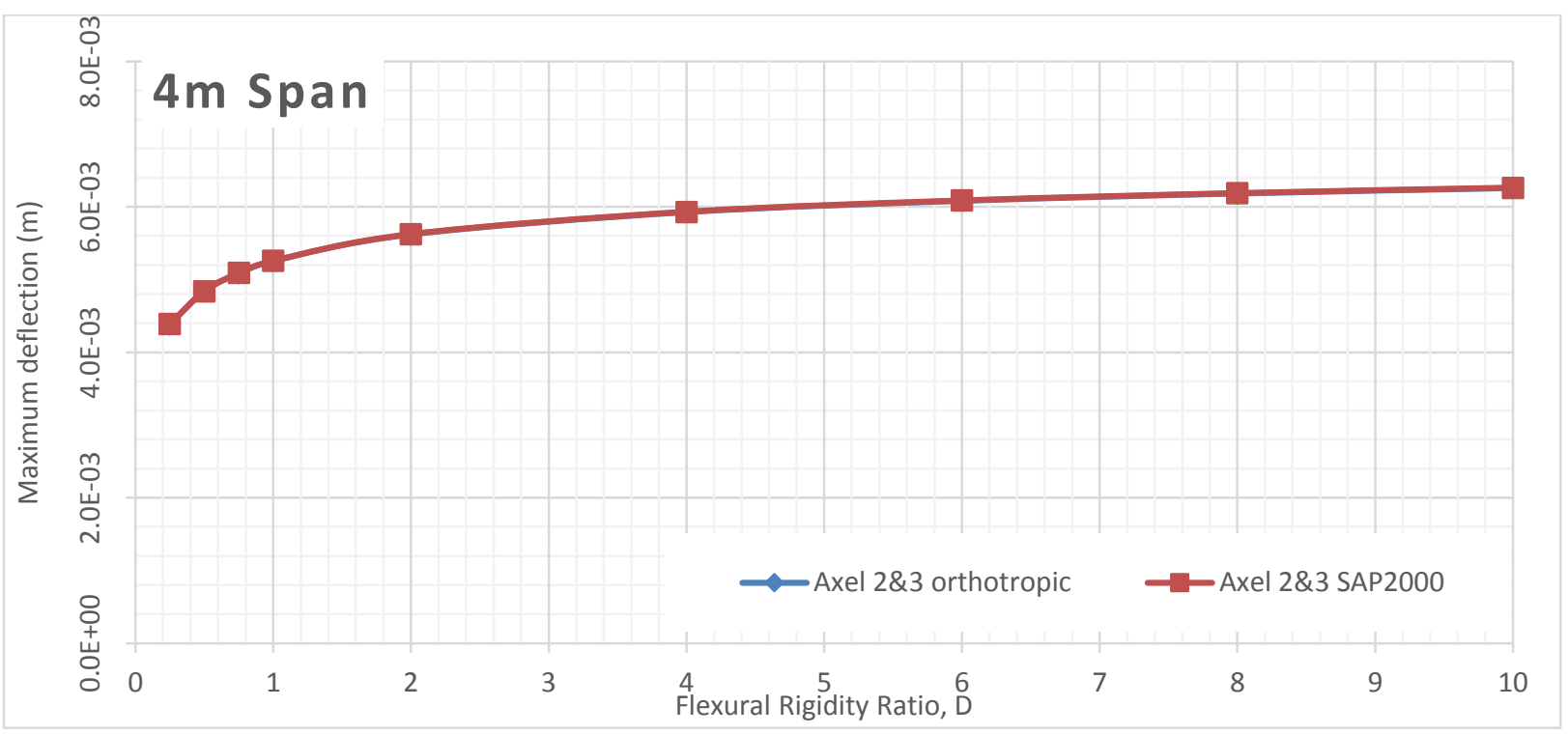

Figure 970 Deflection comparison between FEA and Orthotropic Plate Theory for $4 \mathrm{~m}$ span of alpha 0.5 (main bars parallel to traffic) 


\section{Alpha 0.75 Deflection VS Flexural Rigidity for Different Span Length (Main bars perpendicular to traffic)}

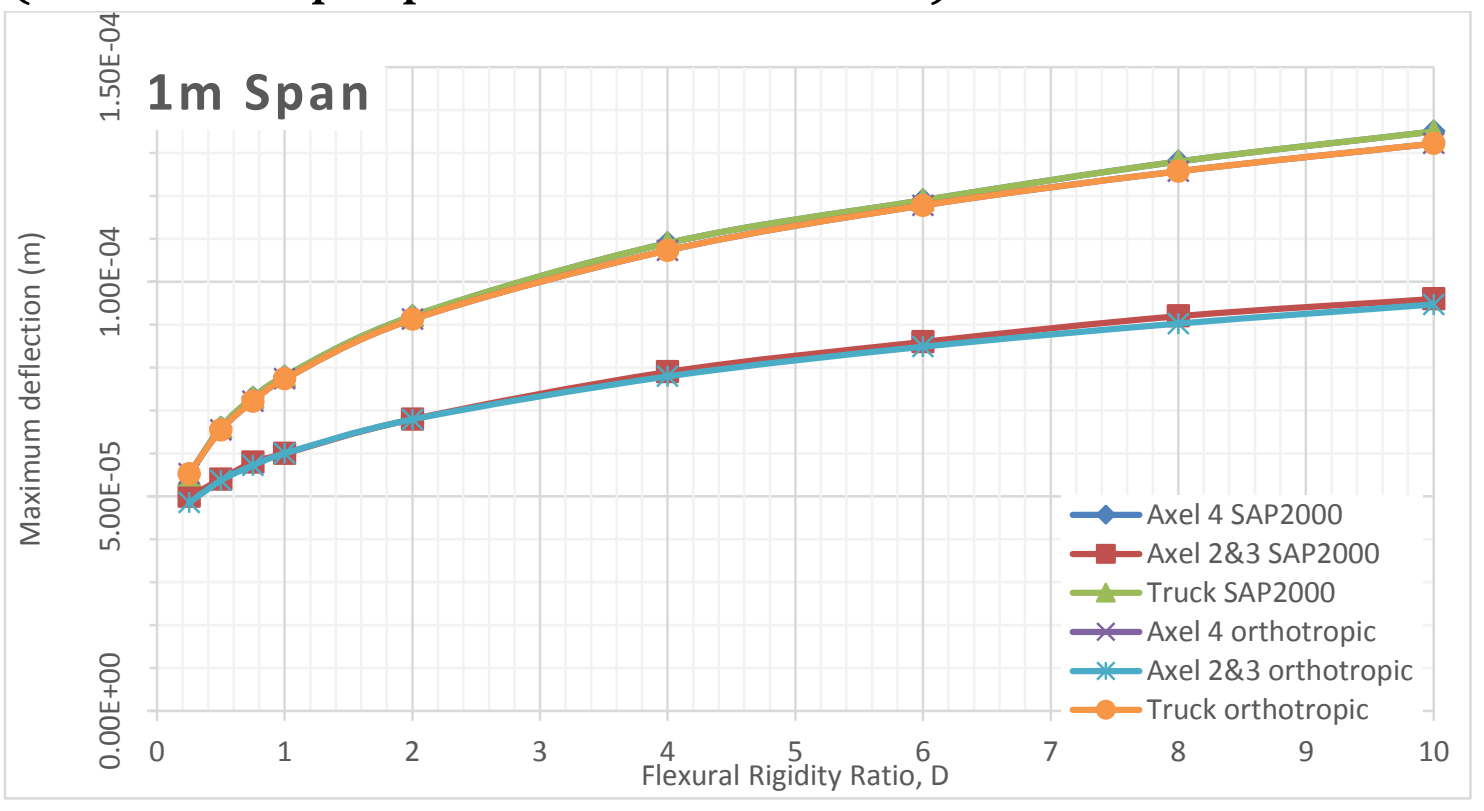

Figure 971 Deflection comparison between FEA and Orthotropic Plate Theory for $1 \mathrm{~m}$ span of alpha 0.75 (main bars perpendicular to traffic)

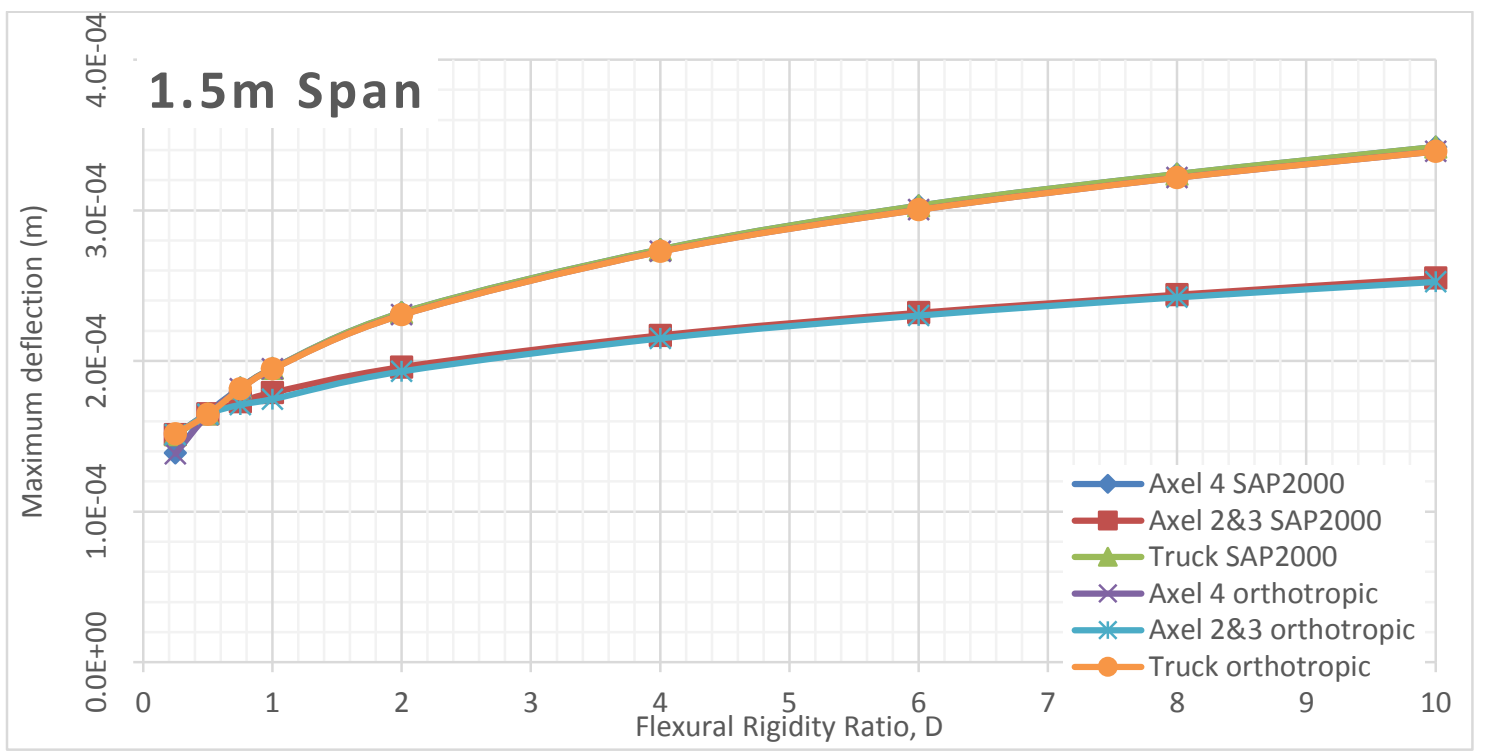

Figure 972 Deflection comparison between FEA and Orthotropic Plate Theory for $1.5 \mathrm{~m}$ span of alpha 0.75 (main bars perpendicular to traffic) 


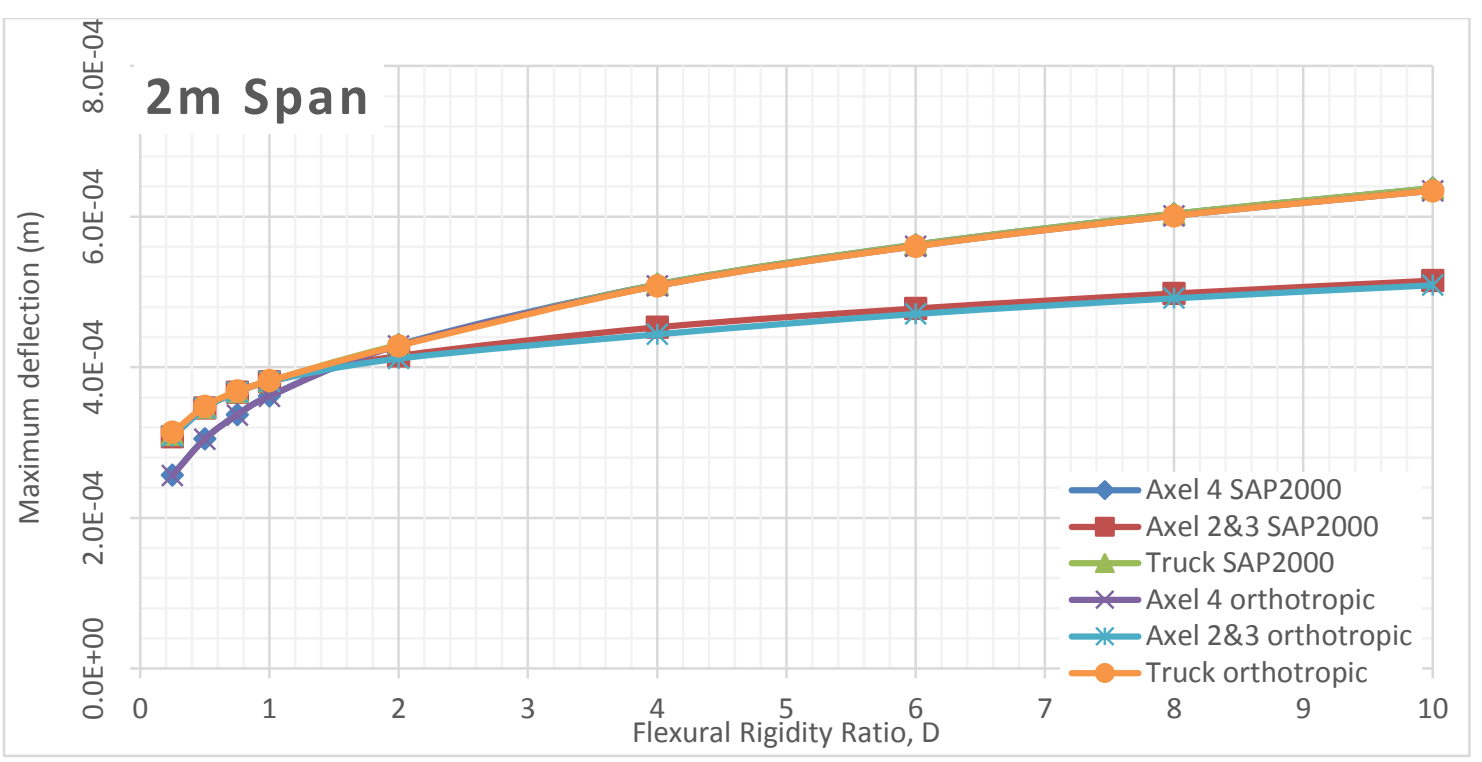

Figure 973 Deflection comparison between FEA and Orthotropic Plate Theory for $2 \mathrm{~m}$ span of alpha 0.75 (main bars perpendicular to traffic)

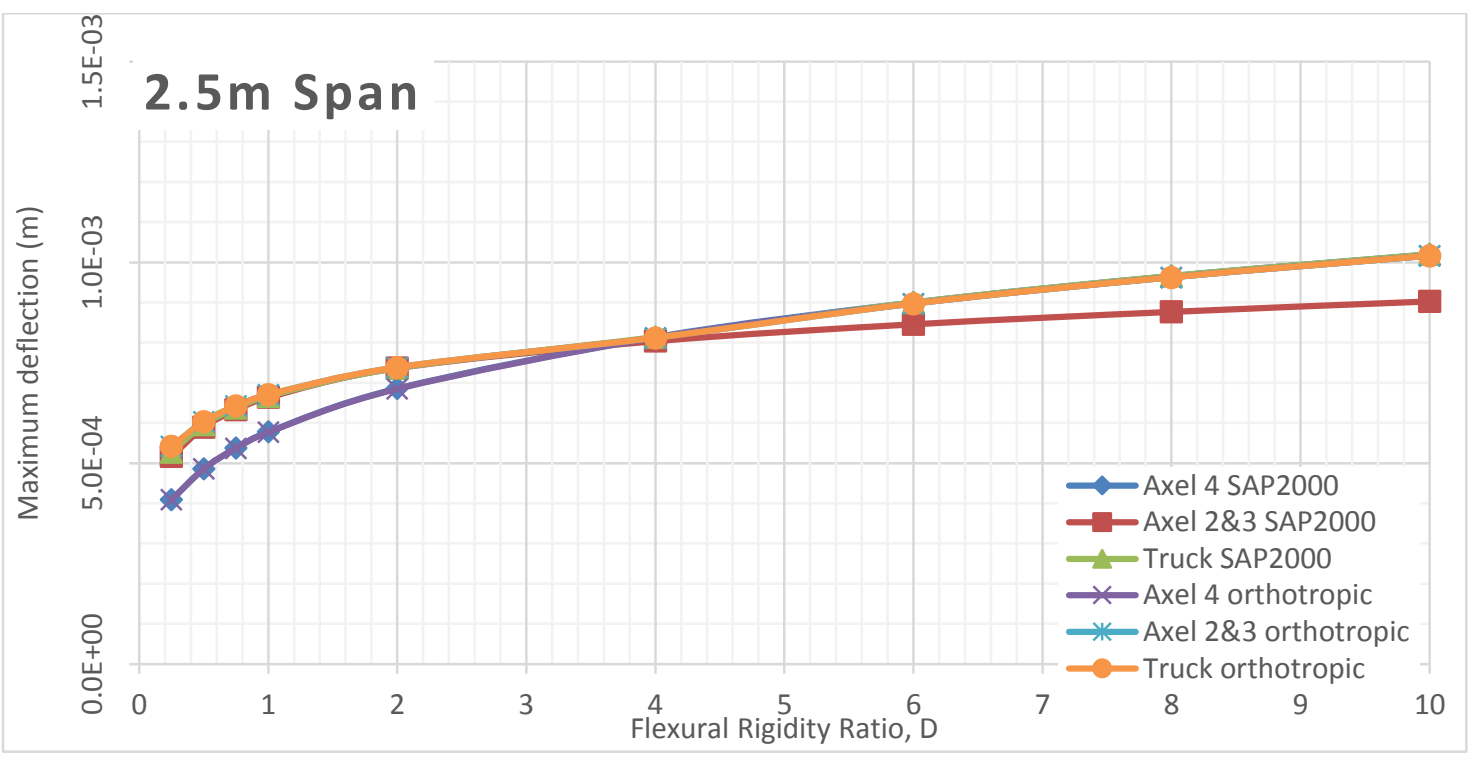

Figure 974 Deflection comparison between FEA and Orthotropic Plate Theory for $2.5 \mathrm{~m}$ span of alpha 0.75 (main bars perpendicular to traffic)

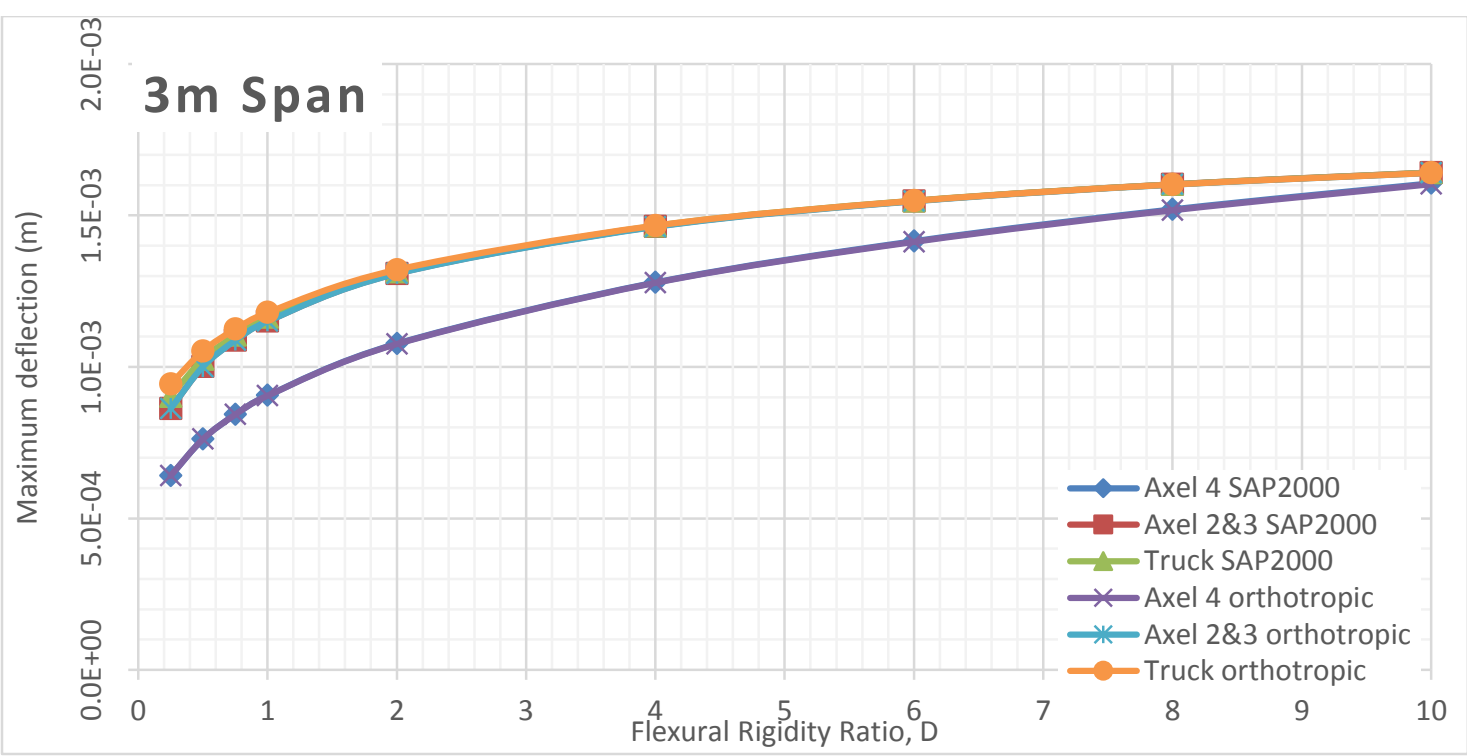

Figure 975 Deflection comparison between FEA and Orthotropic Plate Theory for $3 \mathrm{~m}$ span of alpha 0.75 (main bars perpendicular to traffic) 


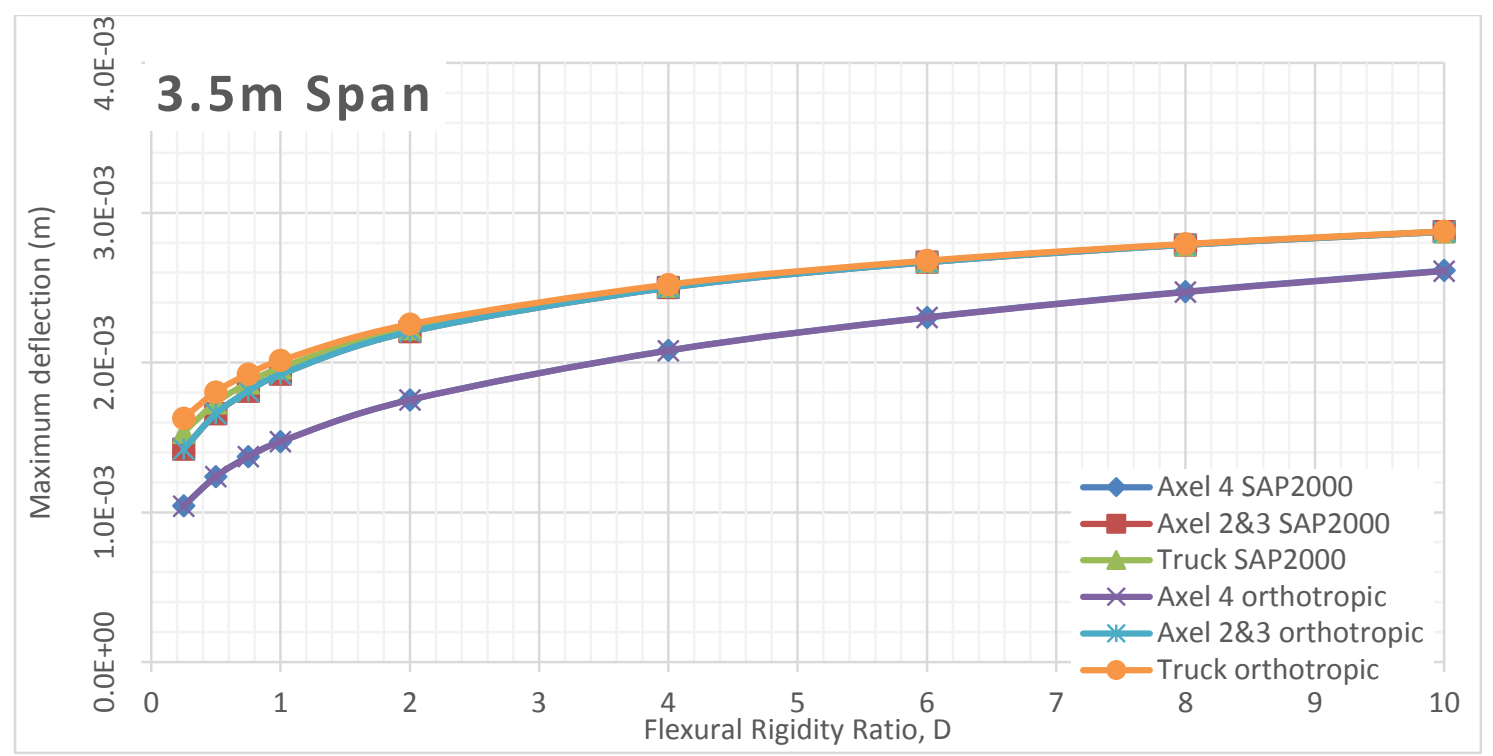

Figure 976 Deflection comparison between FEA and Orthotropic Plate Theory for $3.5 \mathrm{~m}$ span of alpha 0.75 (main bars perpendicular to traffic)

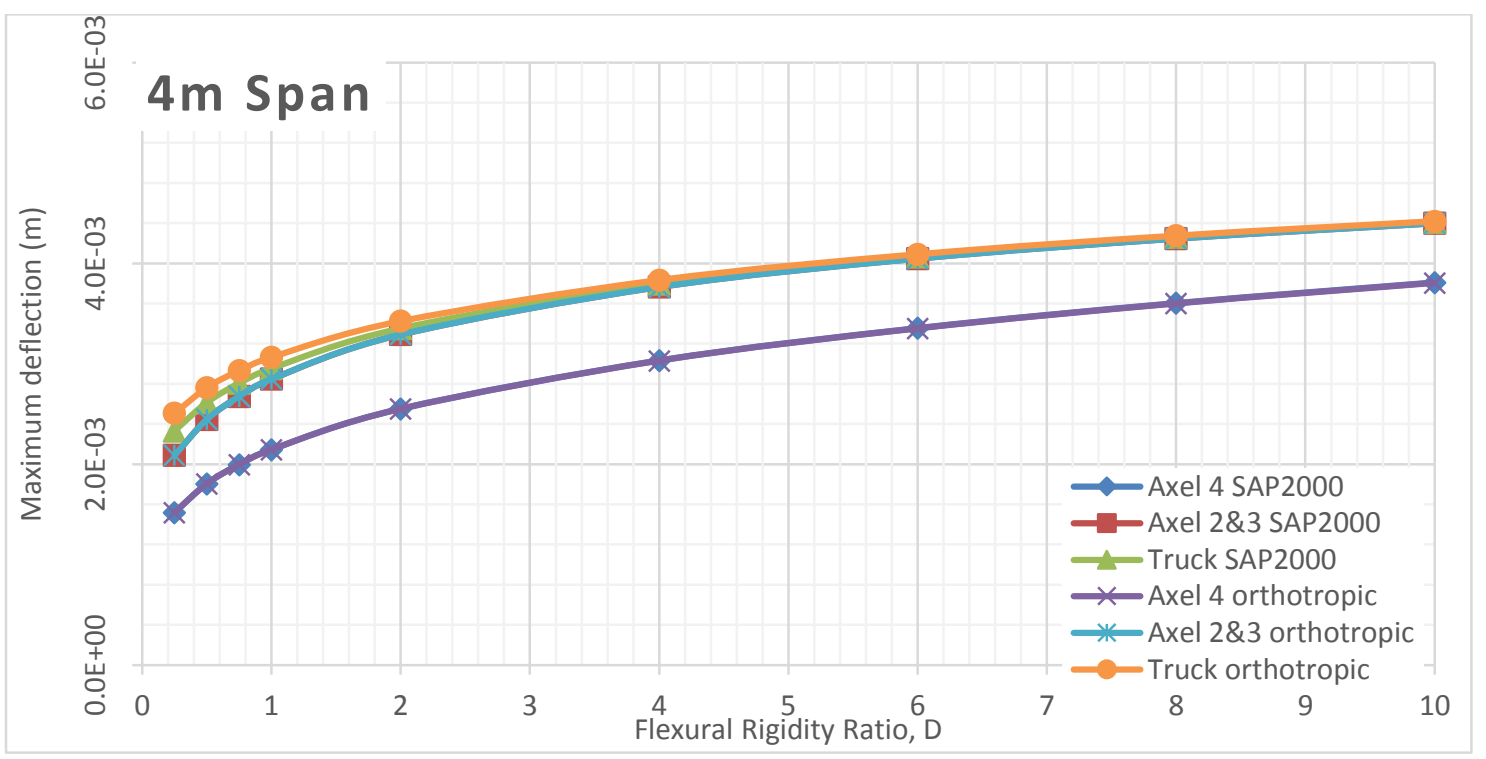

Figure 977 Deflection comparison between FEA and Orthotropic Plate Theory for $4 \mathrm{~m}$ span of alpha 0.75 (main bars perpendicular to traffic) 


\section{Alpha 0.75 Deflection VS Flexural Rigidity for Different Span Length (Main bars parallel to traffic)}

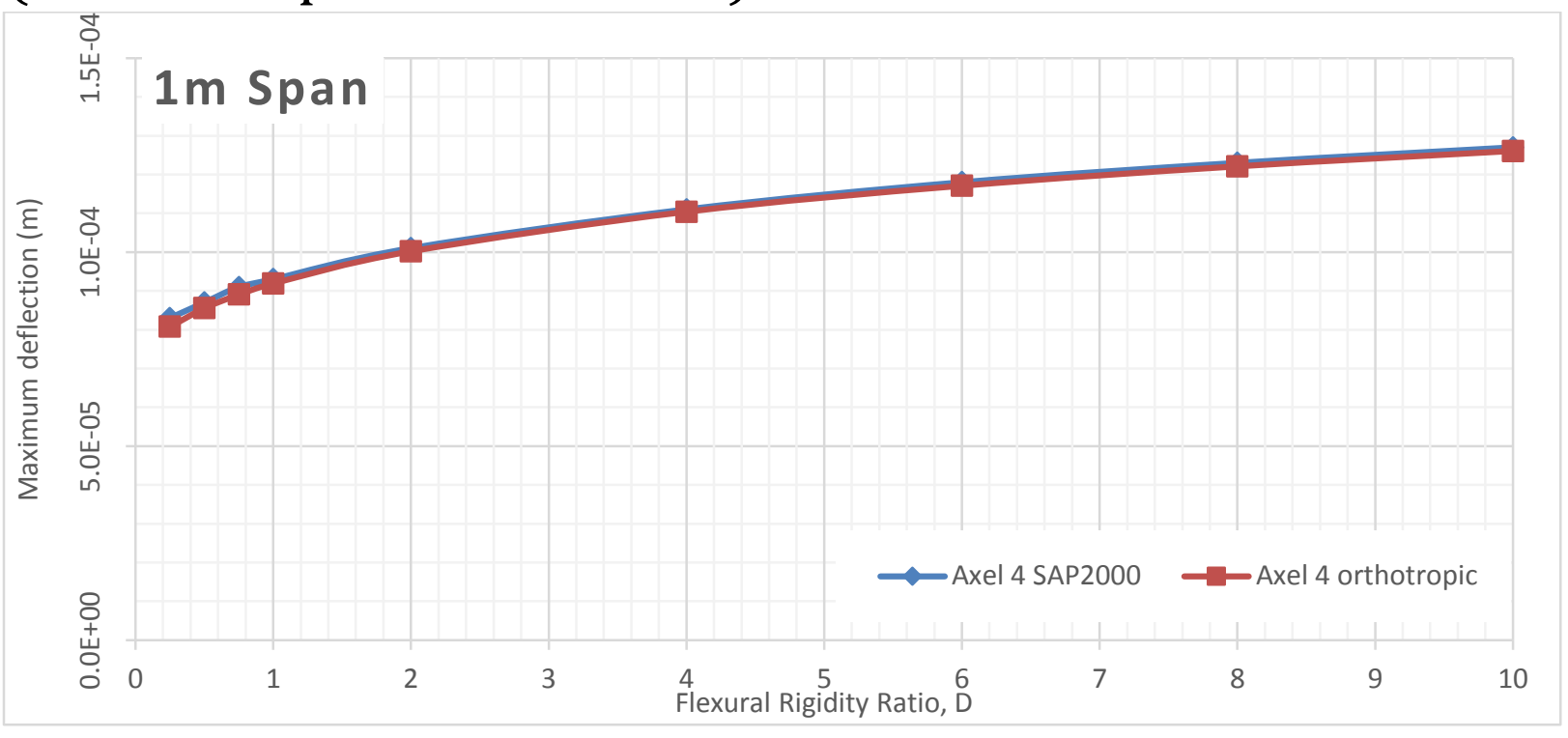

Figure 978 Deflection comparison between FEA and Orthotropic Plate Theory for $1 \mathrm{~m}$ span of alpha 0.75 (main bars parallel to traffic)

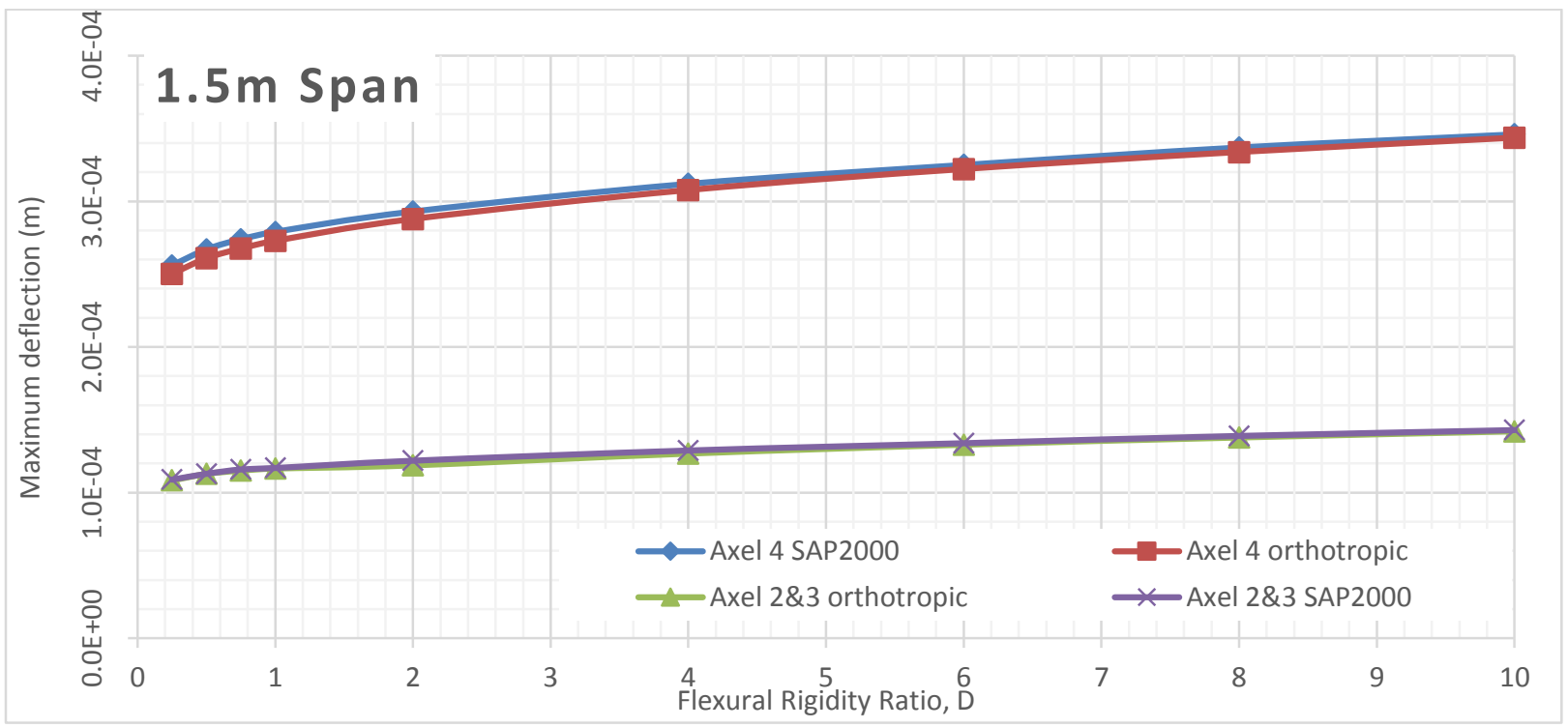

Figure 979 Deflection comparison between FEA and Orthotropic Plate Theory for $1.5 \mathrm{~m}$ span of alpha 0.75 (main bars parallel to traffic) 


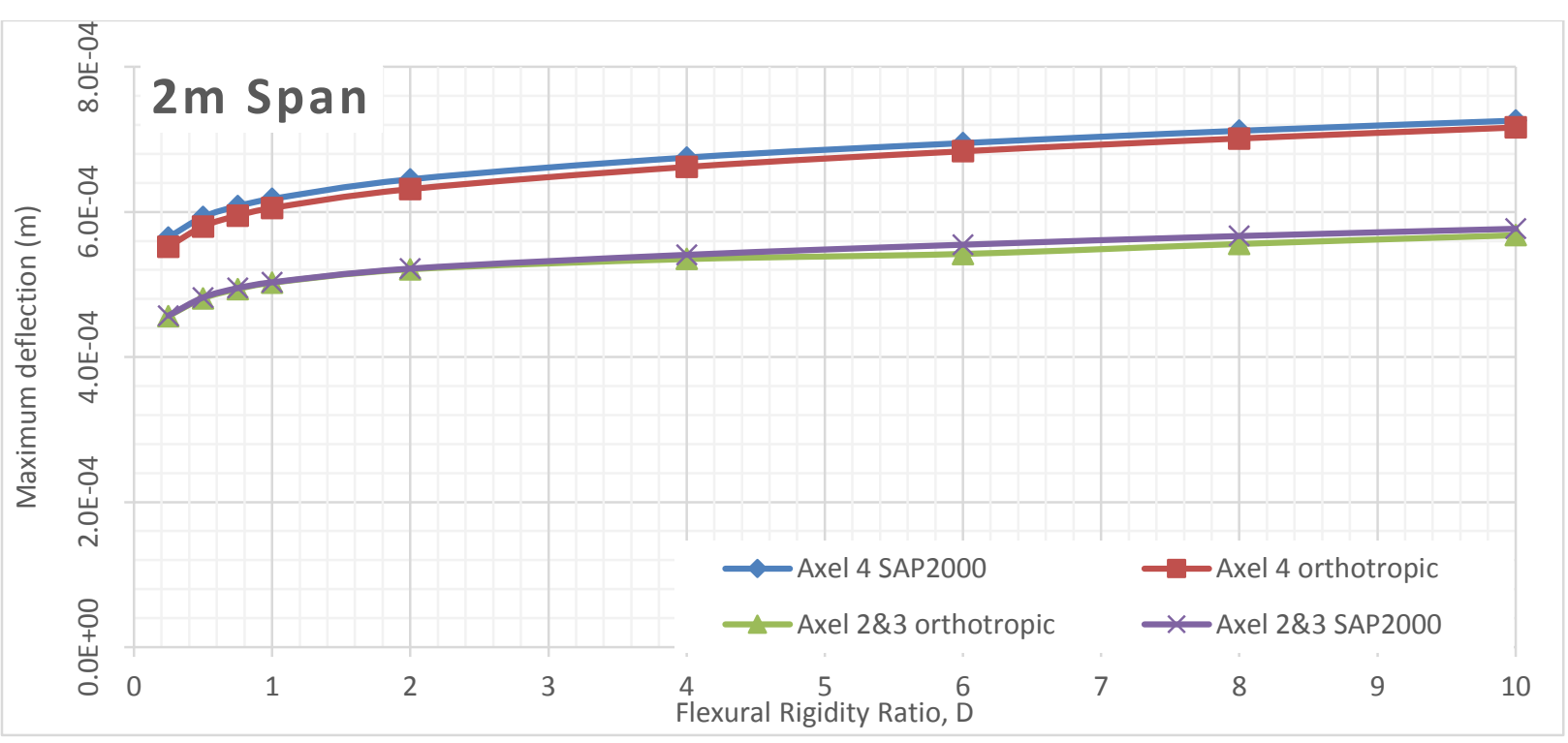

Figure 980 Deflection comparison between FEA and Orthotropic Plate Theory for $2 \mathrm{~m}$ span of alpha 0.75 (main bars parallel to traffic)

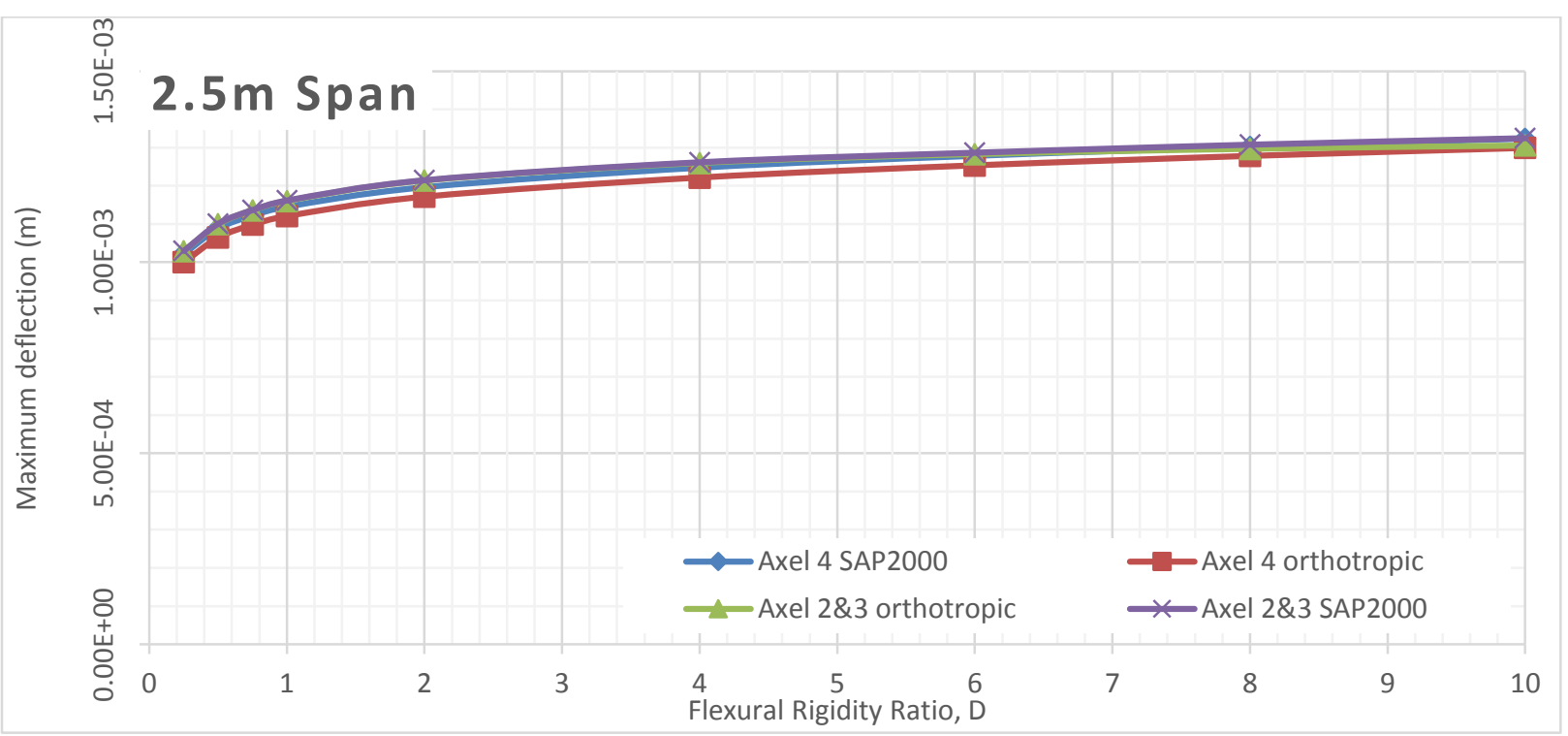

Figure 981 Deflection comparison between FEA and Orthotropic Plate Theory for $2.5 \mathrm{~m}$ span of alpha 0.75 (main bars parallel to traffic)

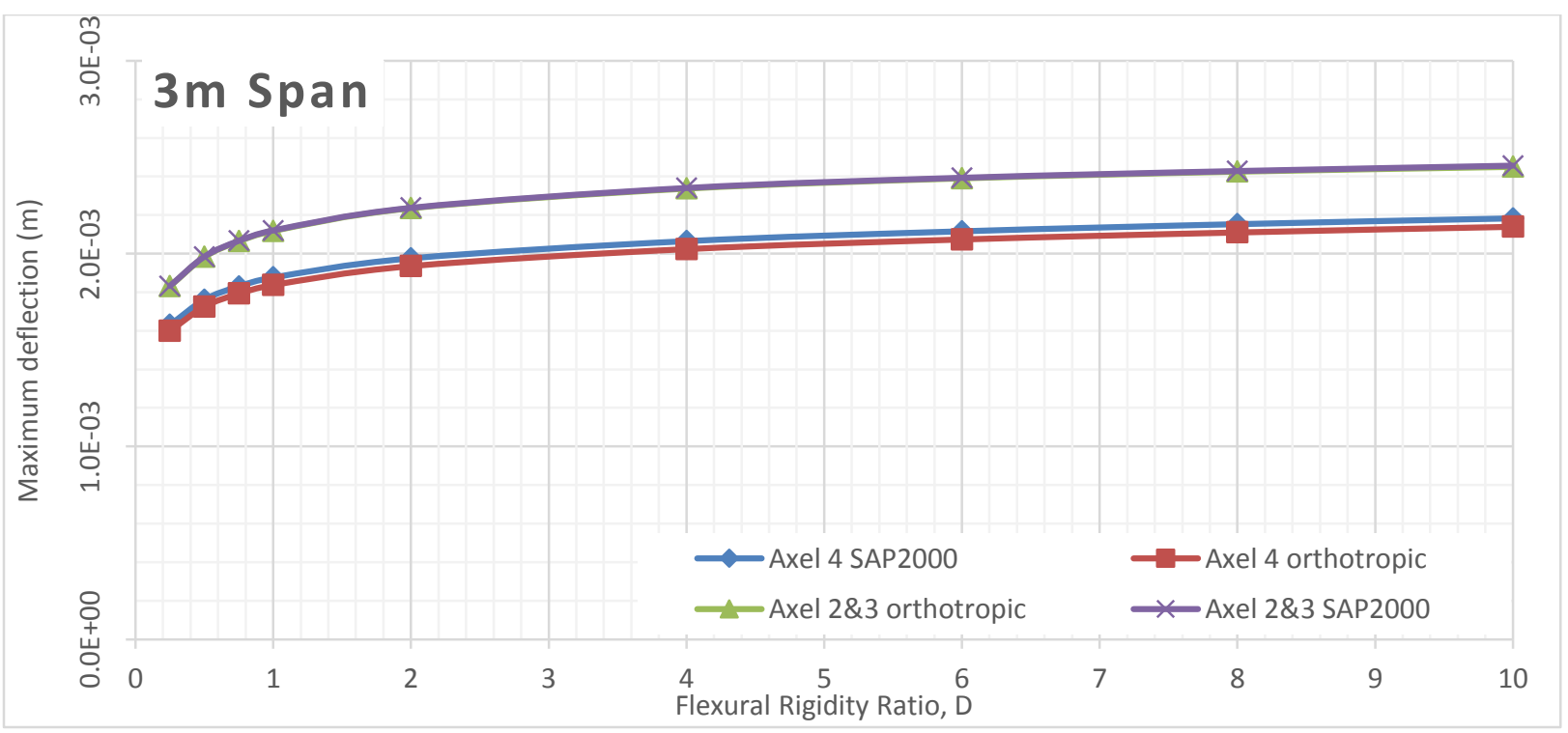

Figure 982 Deflection comparison between FEA and Orthotropic Plate Theory for $3 \mathrm{~m}$ span of alpha 0.75 (main bars parallel to traffic) 


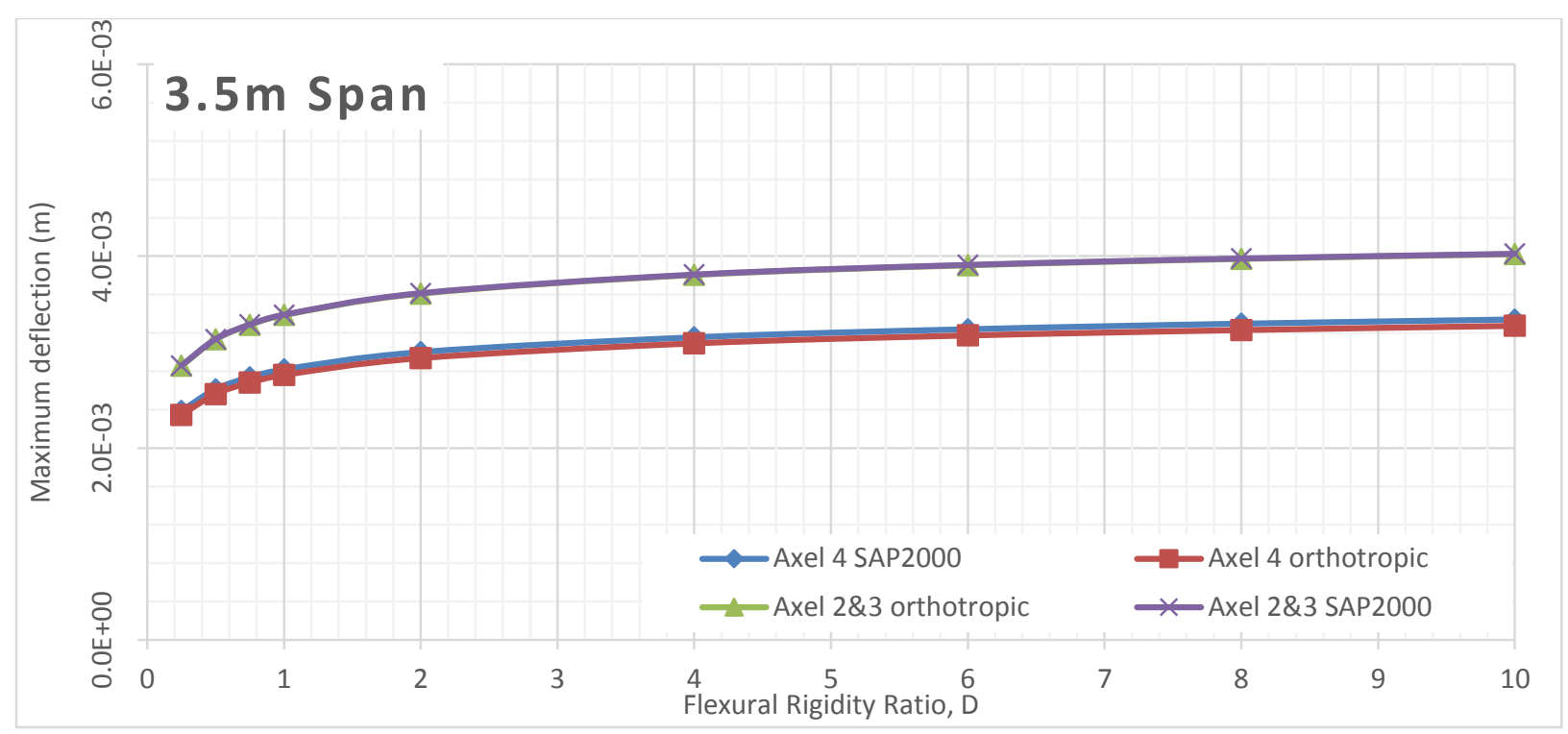

Figure 983 Deflection comparison between FEA and Orthotropic Plate Theory for $3.5 \mathrm{~m}$ span of alpha 0.75 (main bars parallel to traffic)

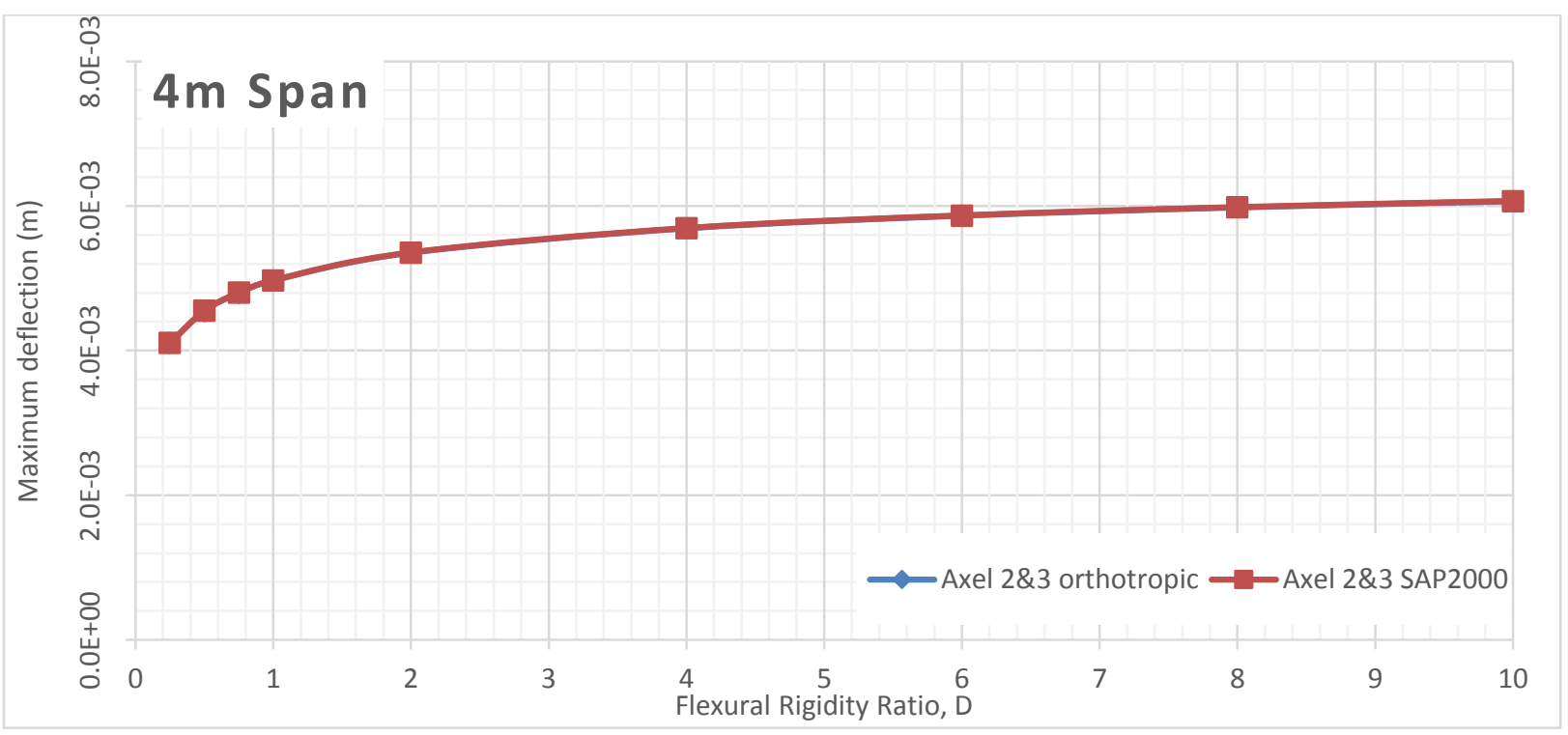

Figure 984 Deflection comparison between FEA and Orthotropic Plate Theory for $4 \mathrm{~m}$ span of alpha 0.75 (main bars parallel to traffic) 


\section{Alpha 1 Deflection VS Flexural Rigidity for Different Span Length (Main bars perpendicular to traffic)}

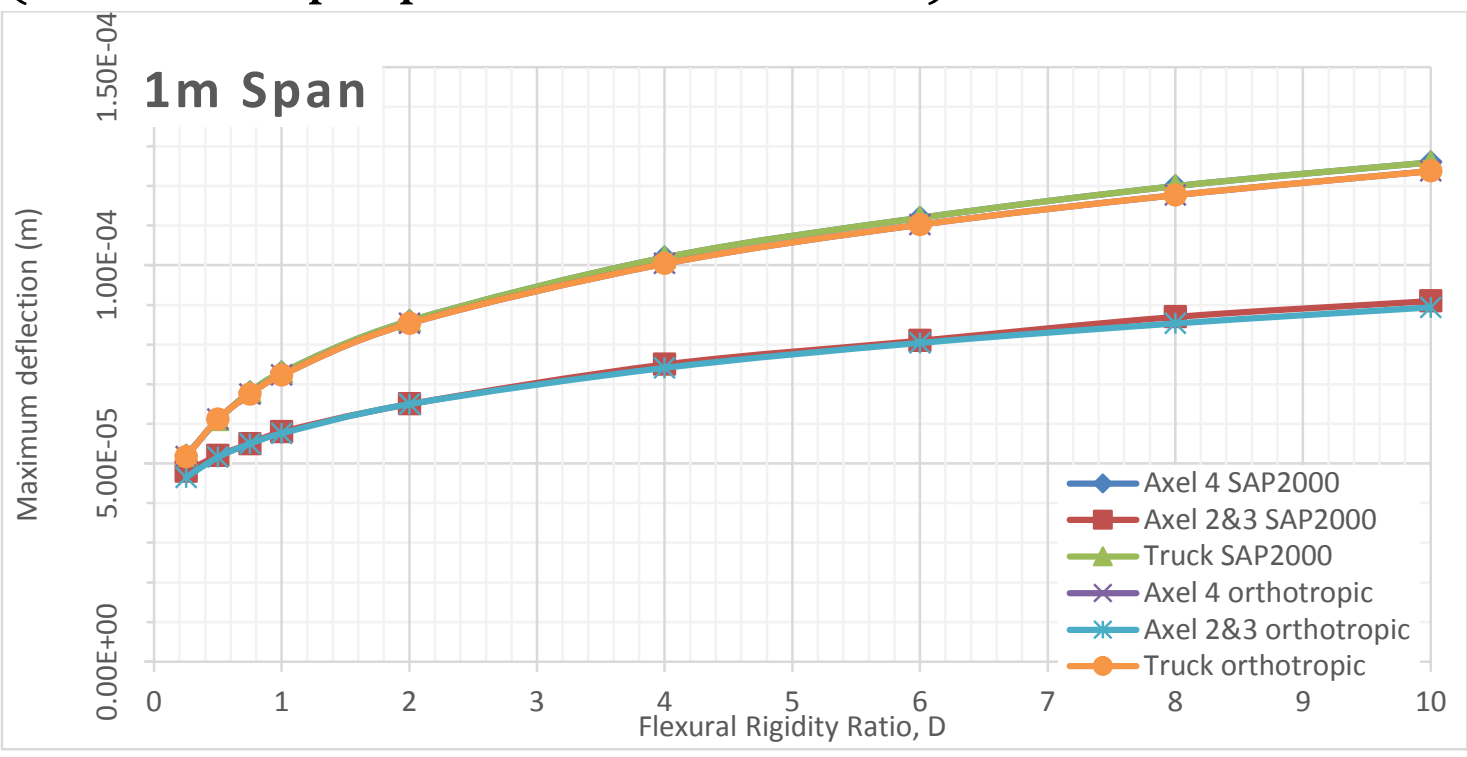

Figure 985 Deflection comparison between FEA and Orthotropic Plate Theory for $1 \mathrm{~m}$ span of alpha 1 (main bars perpendicular to traffic)

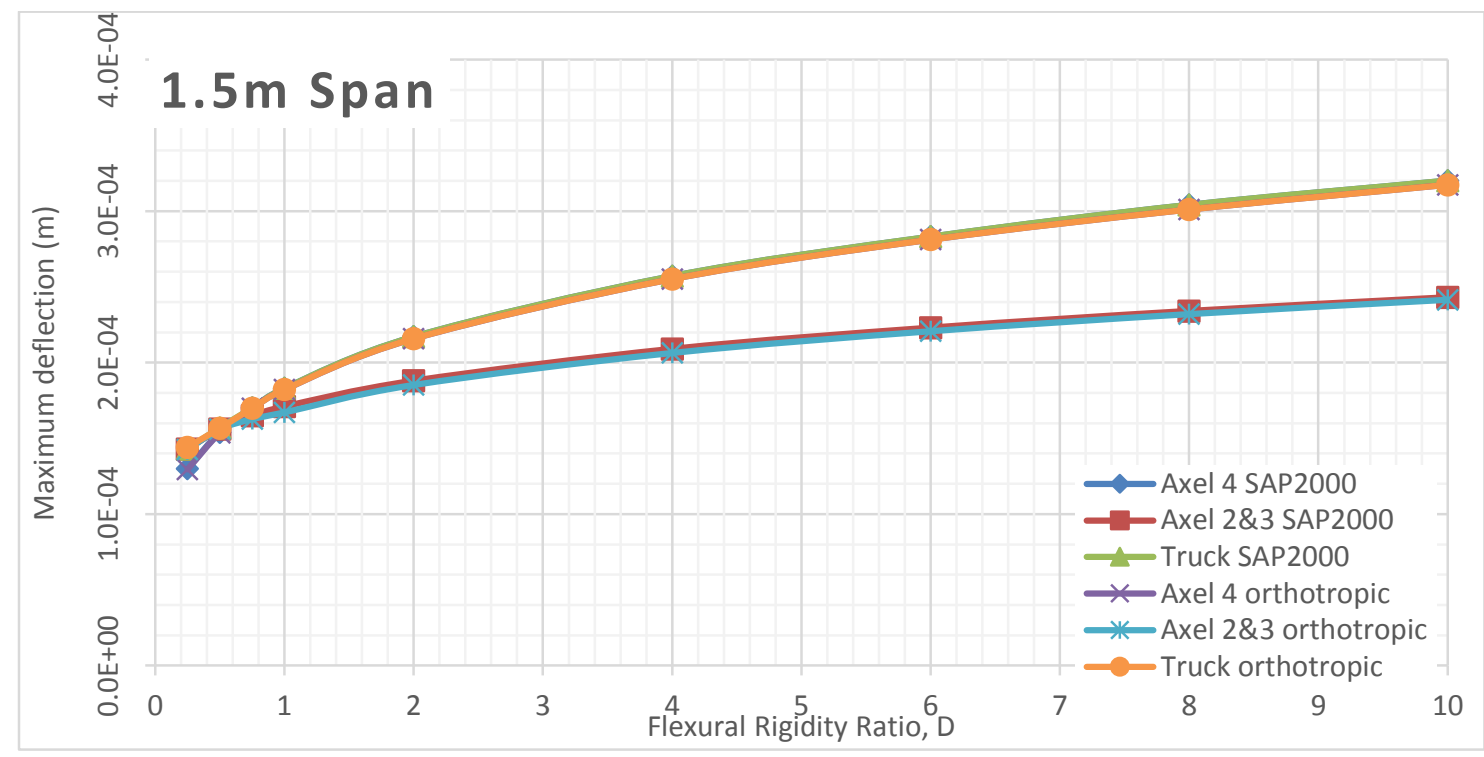

Figure 986 Deflection comparison between FEA and Orthotropic Plate Theory for $1.5 \mathrm{~m}$ span of alpha 1 (main bars perpendicular to traffic) 


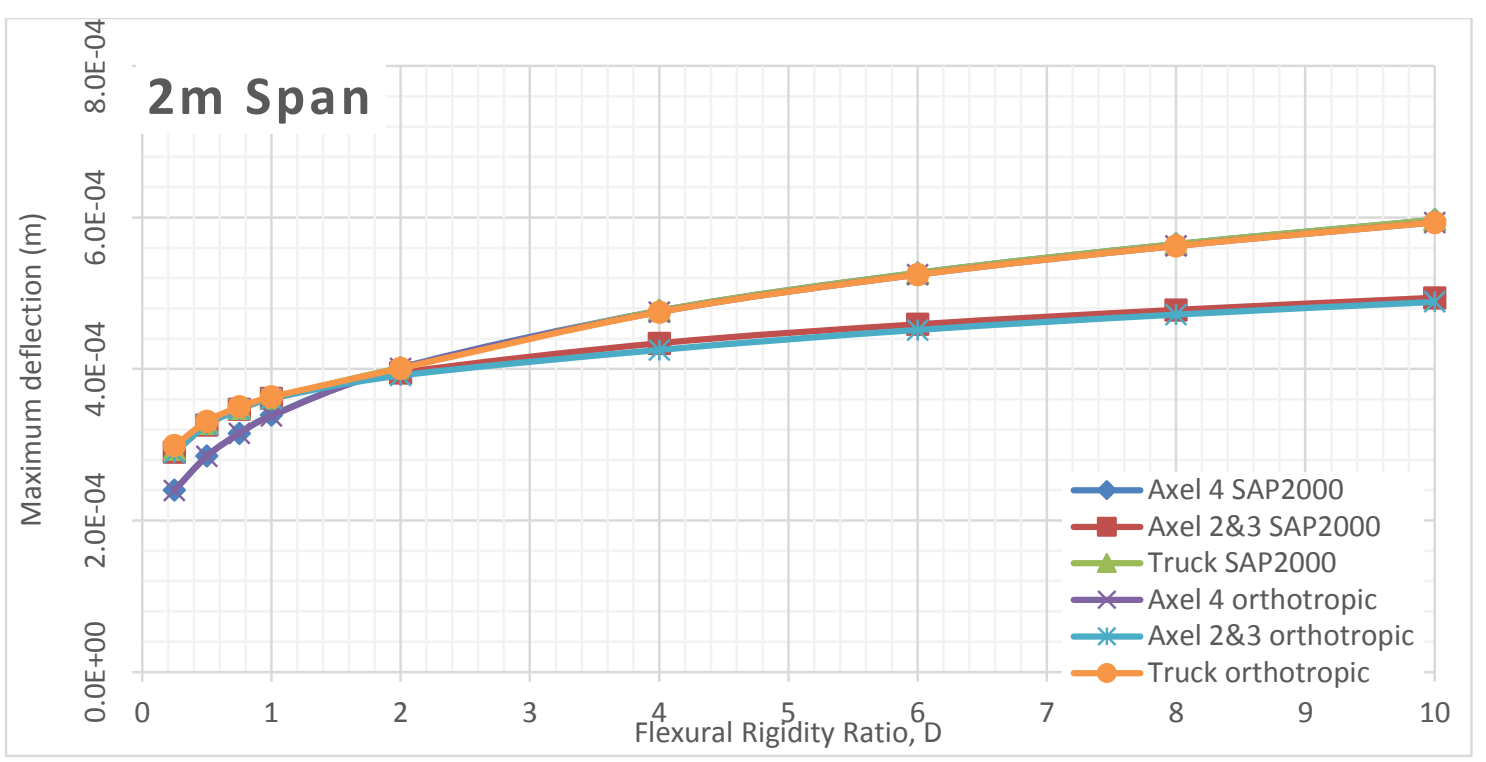

Figure 987 Deflection comparison between FEA and Orthotropic Plate Theory for $2 \mathrm{~m}$ span of alpha 1 (main bars perpendicular to traffic)

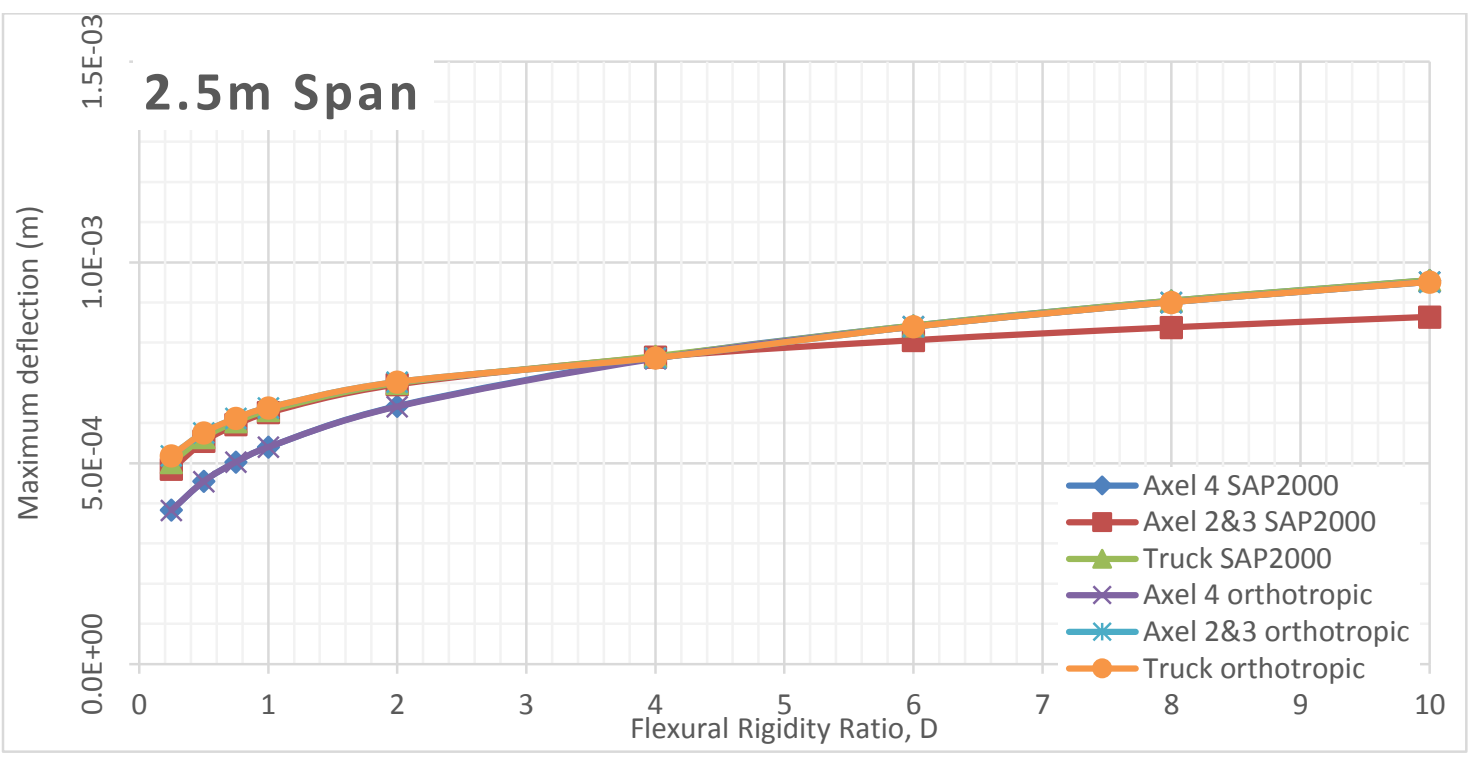

Figure 988 Deflection comparison between FEA and Orthotropic Plate Theory for $2.5 \mathrm{~m}$ span of alpha 1 (main bars perpendicular to traffic)

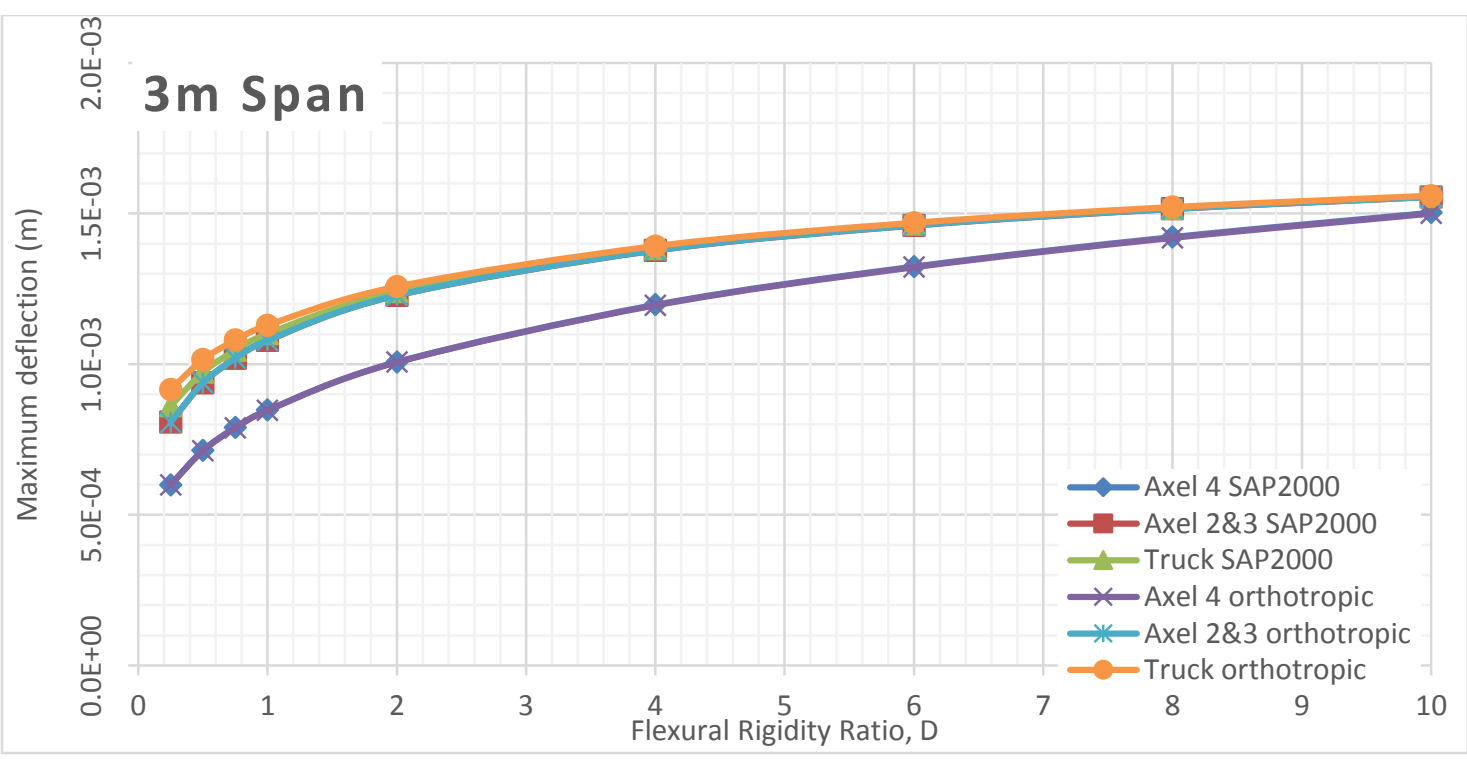

Figure 989 Deflection comparison between FEA and Orthotropic Plate Theory for $3 \mathrm{~m}$ span of alpha 1 (main bars perpendicular to traffic) 


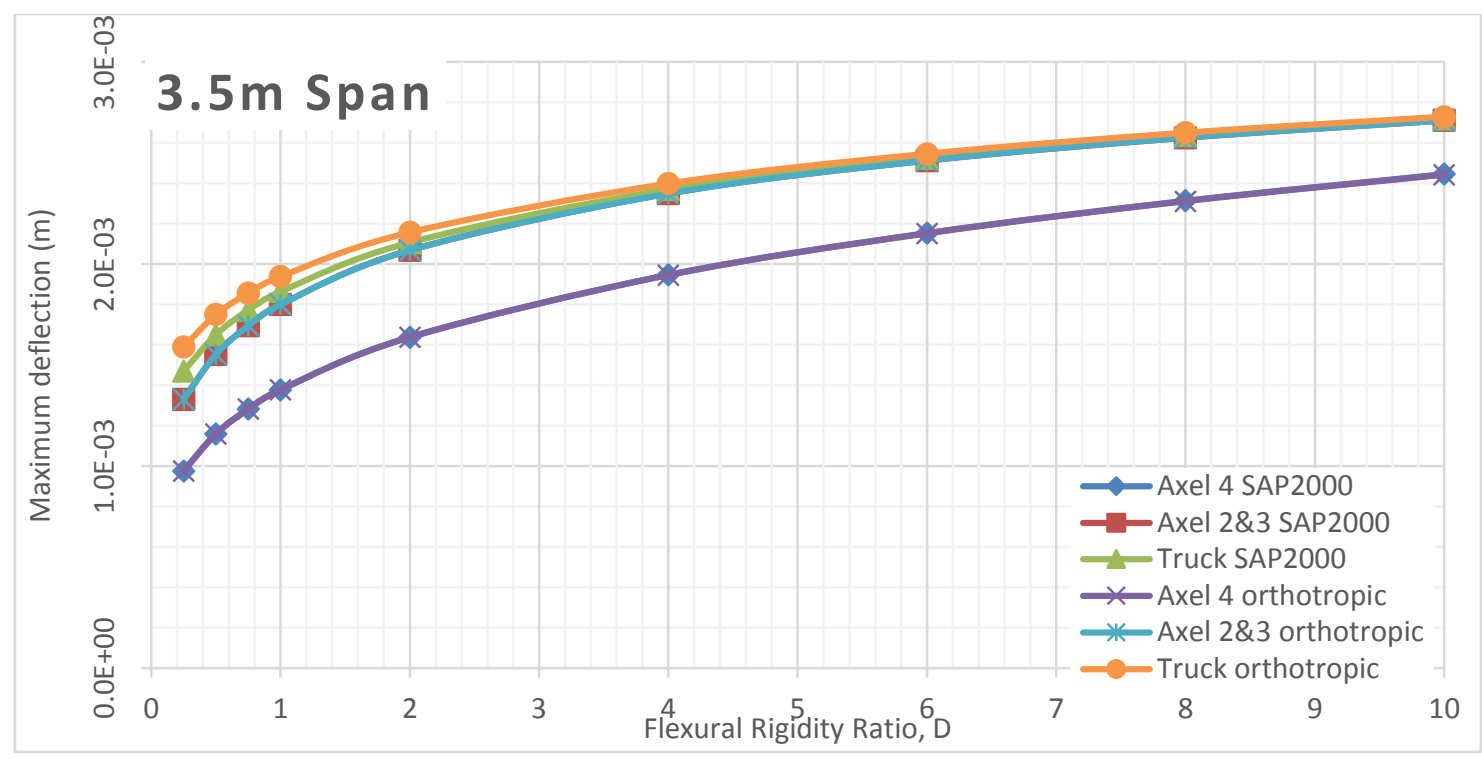

Figure 990 Deflection comparison between FEA and Orthotropic Plate Theory for $3.5 \mathrm{~m}$ span of alpha 1 (main bars perpendicular to traffic)

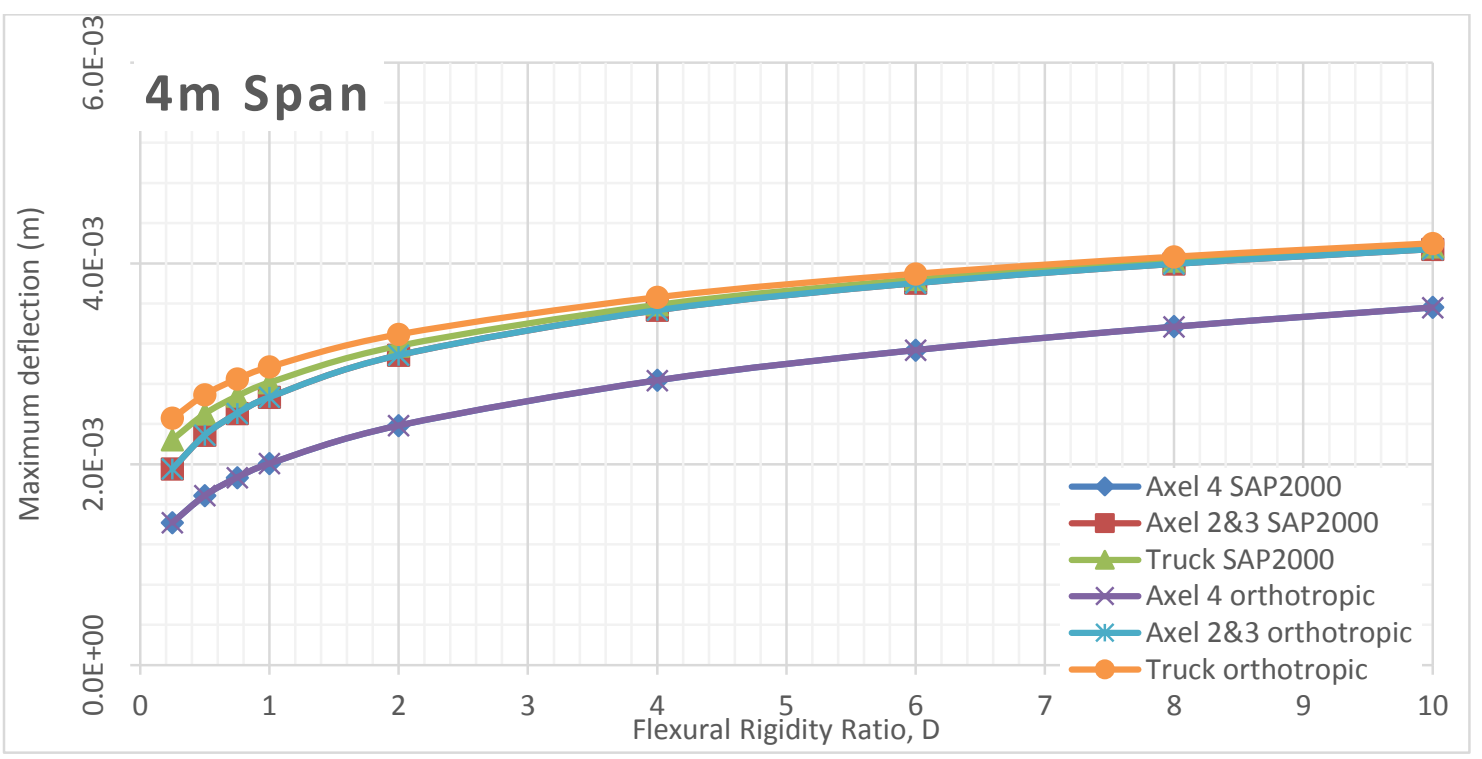

Figure 991 Deflection comparison between FEA and Orthotropic Plate Theory for $4 \mathrm{~m}$ span of alpha 1 (main bars perpendicular to traffic) 


\section{Alpha 1 Deflection VS Flexural Rigidity for Different Span Length (Main bars parallel to traffic)}

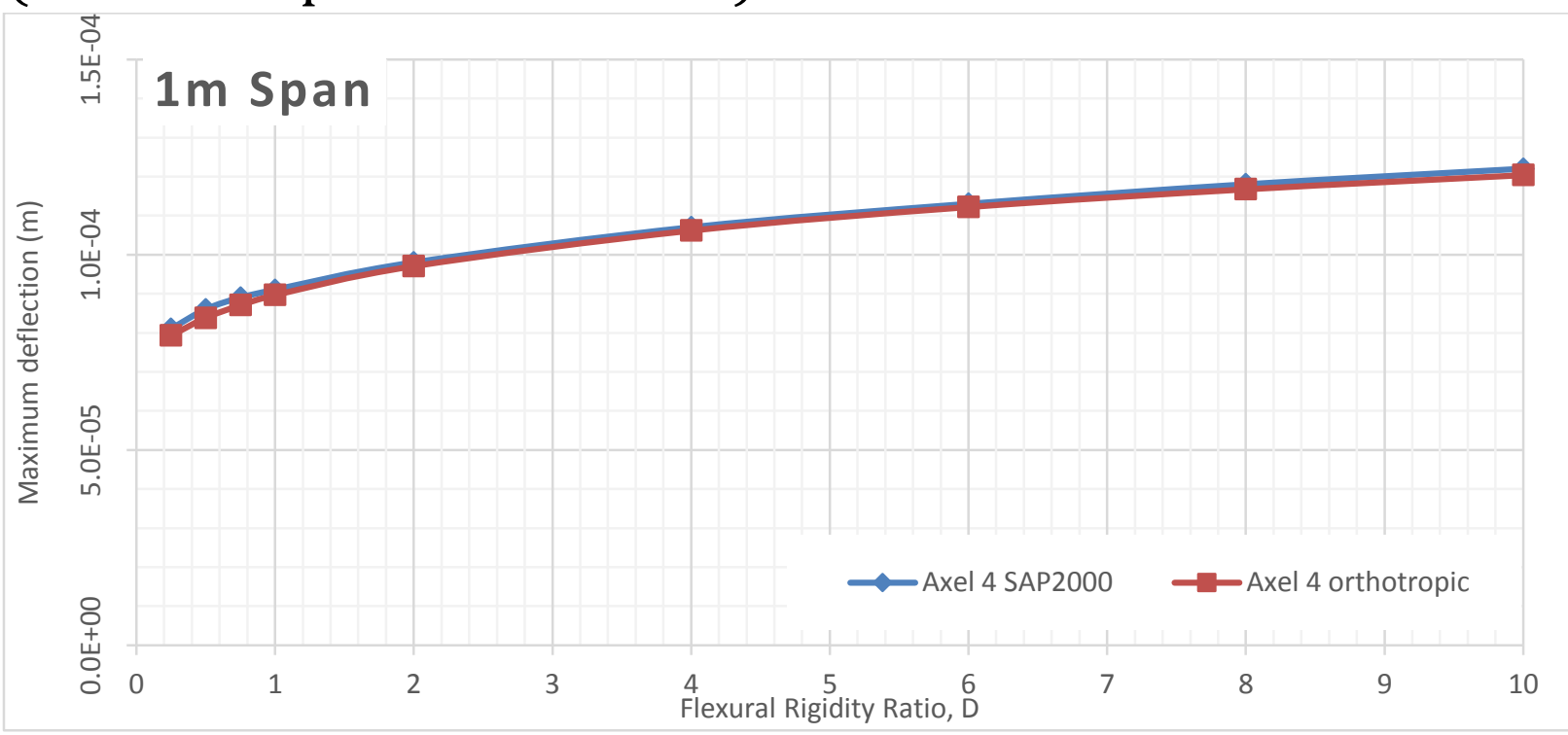

Figure 992 Deflection comparison between FEA and Orthotropic Plate Theory for $1 \mathrm{~m}$ span of alpha 1 (main bars parallel to traffic)

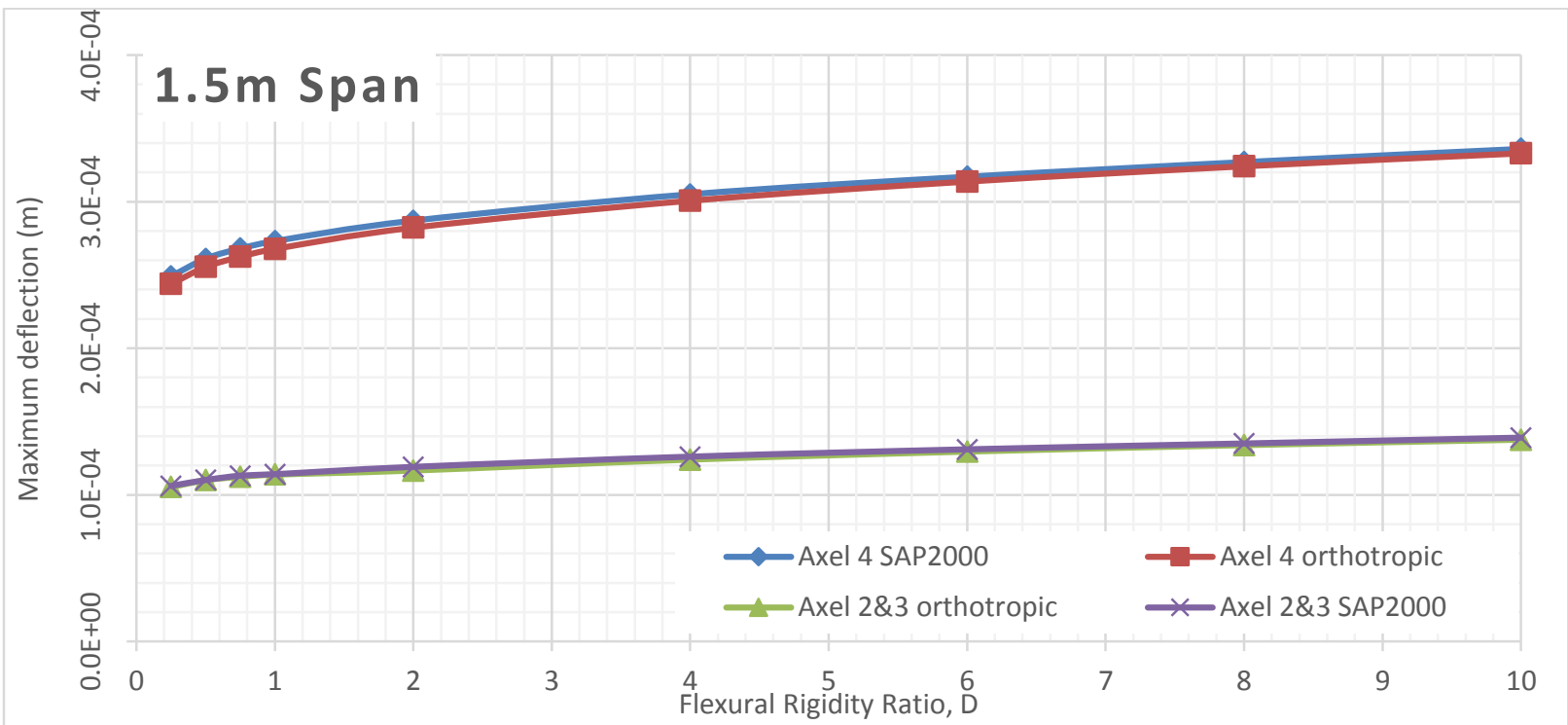

Figure 993 Deflection comparison between FEA and Orthotropic Plate Theory for $1.5 \mathrm{~m}$ span of alpha 1 (main bars parallel to traffic) 


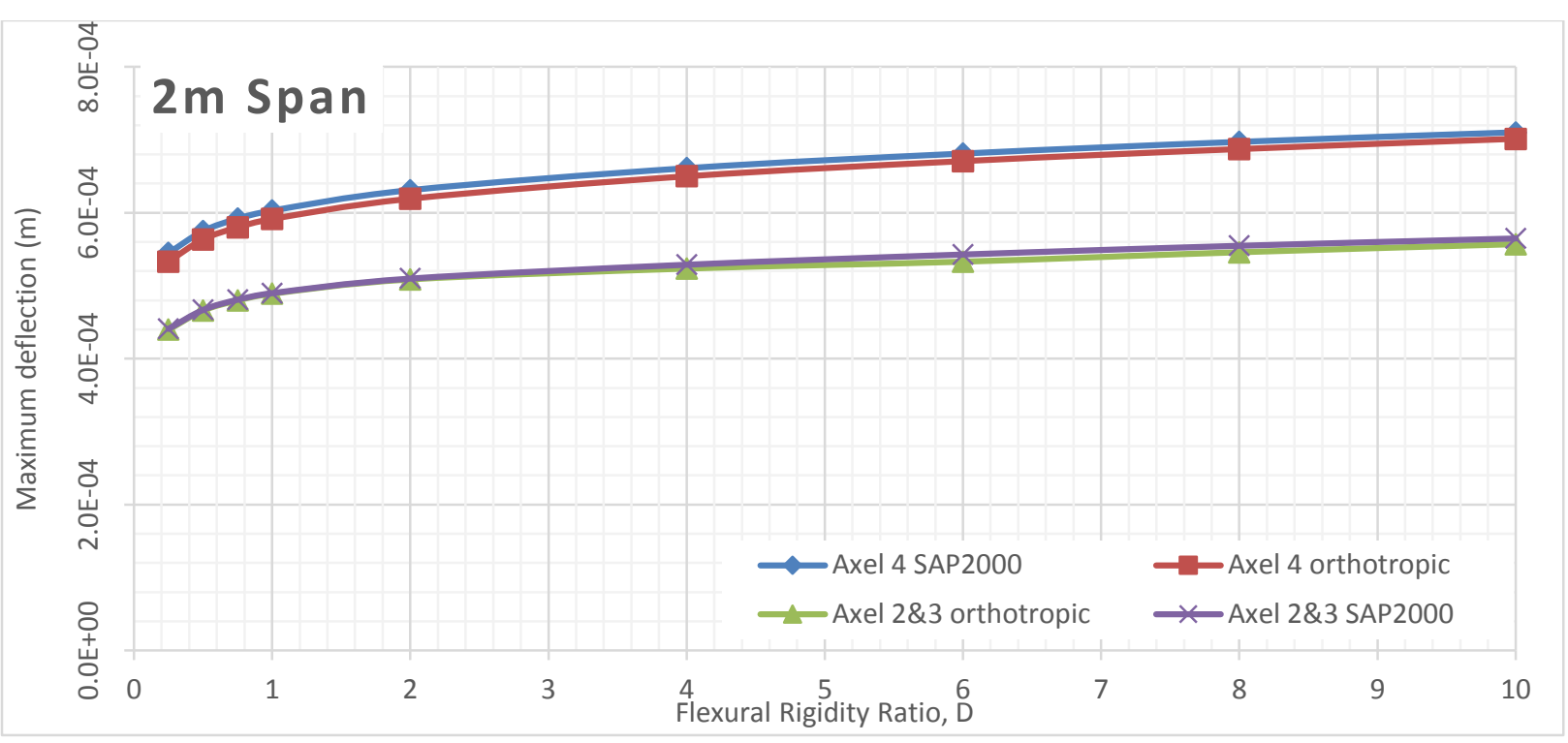

Figure 994 Deflection comparison between FEA and Orthotropic Plate Theory for $2 \mathrm{~m}$ span of alpha 1 (main bars parallel to traffic)

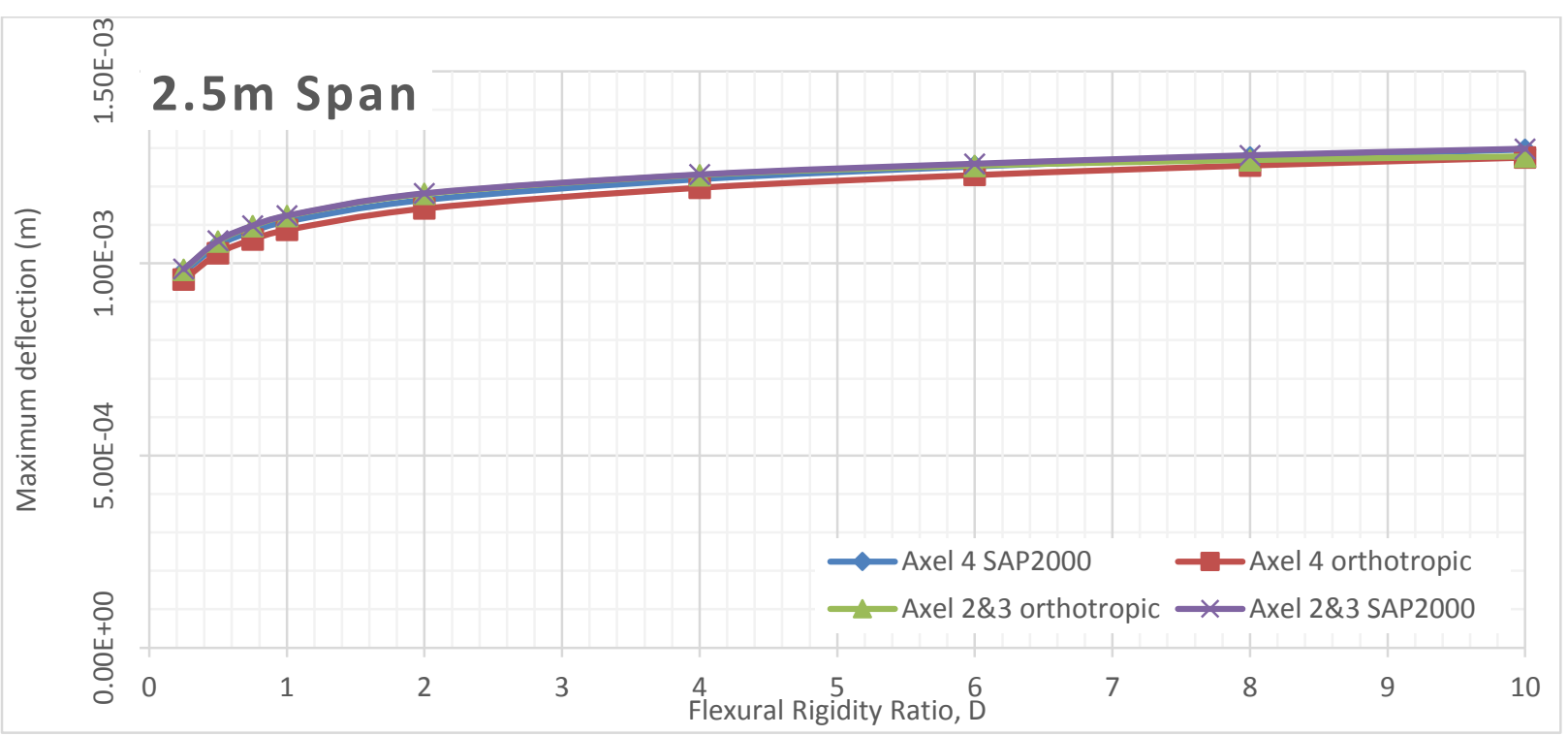

Figure 995 Deflection comparison between FEA and Orthotropic Plate Theory for $2.5 \mathrm{~m}$ span of alpha 1 (main bars parallel to traffic)

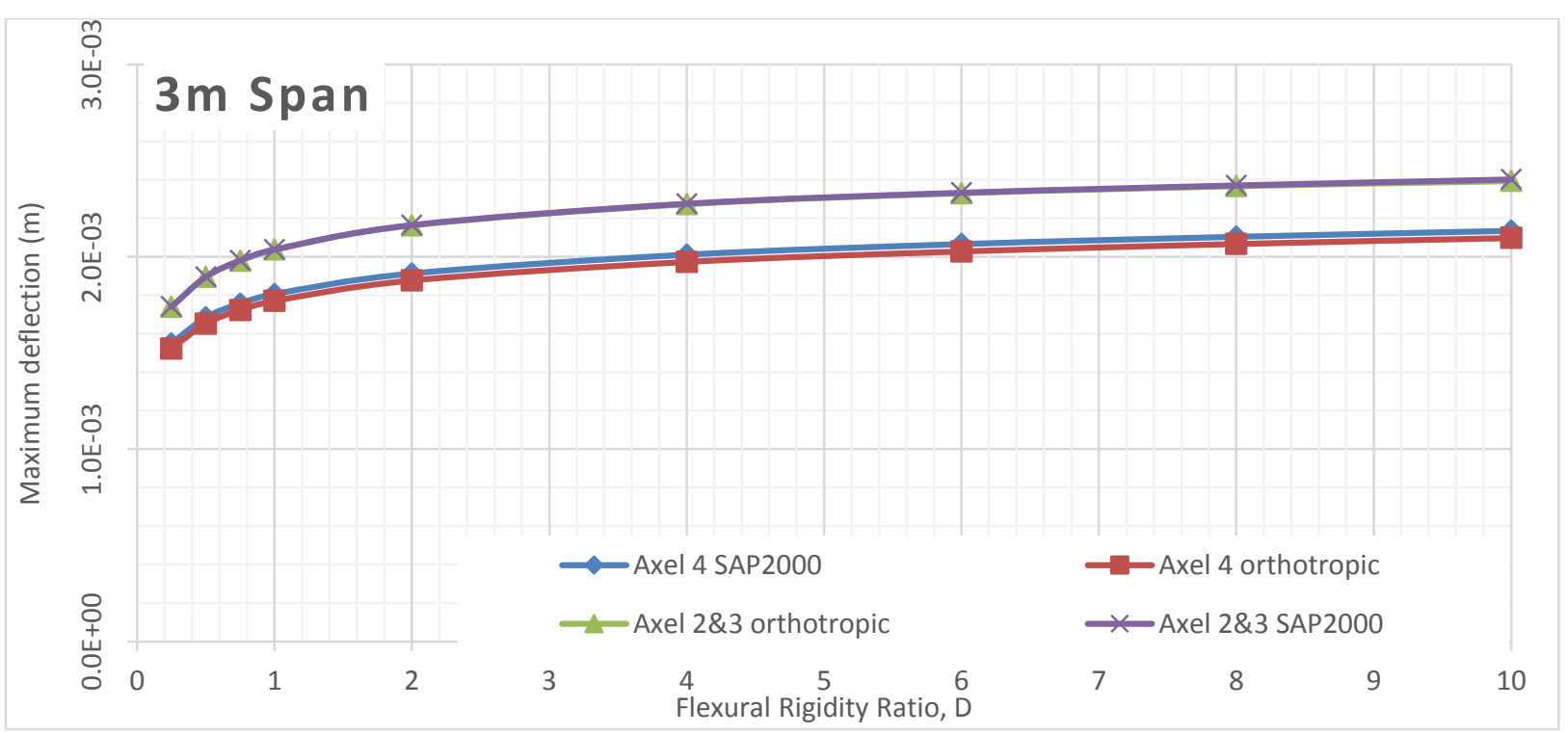

Figure 996 Deflection comparison between FEA and Orthotropic Plate Theory for $3 \mathrm{~m}$ span of alpha 1 (main bars parallel to traffic) 


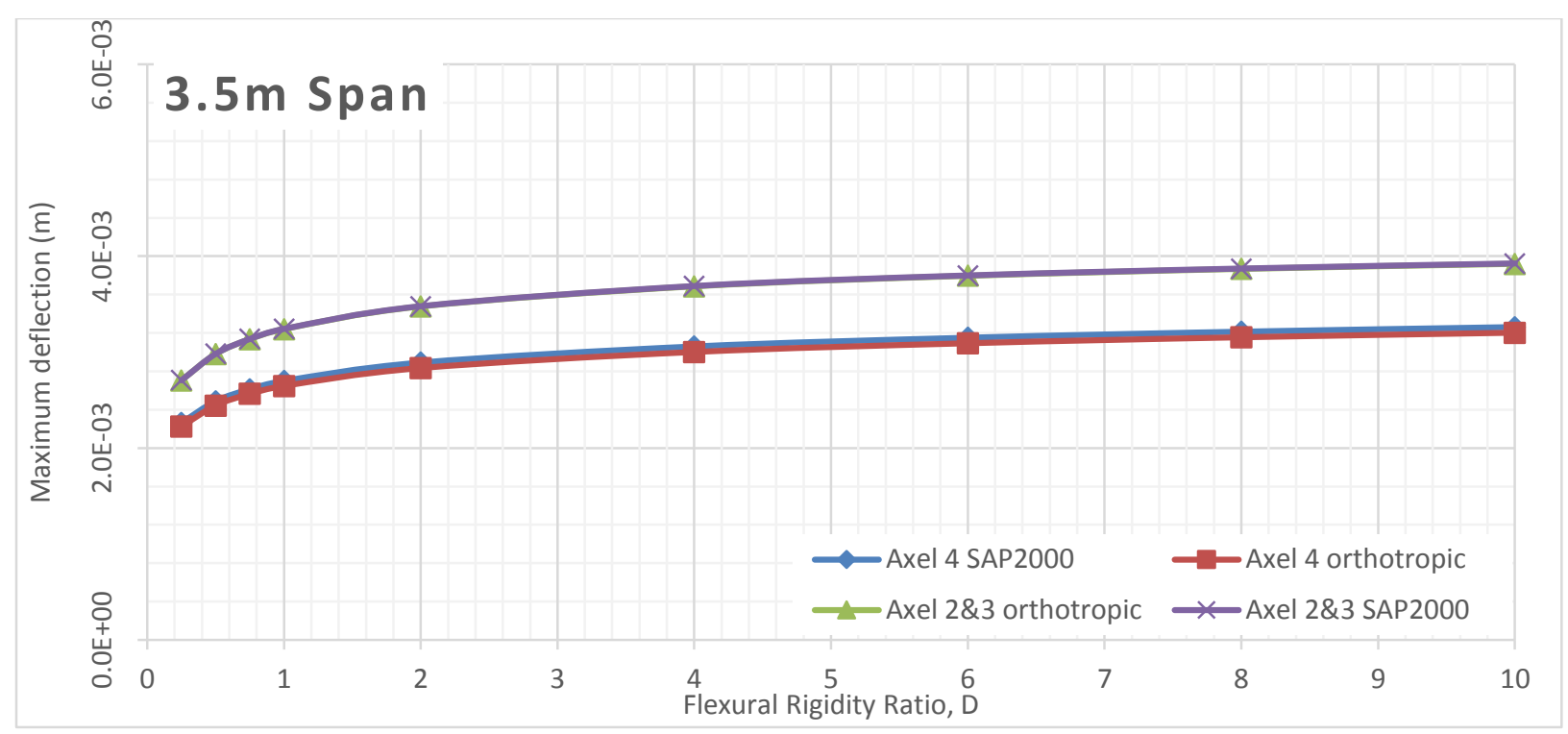

Figure 997 Deflection comparison between FEA and Orthotropic Plate Theory for $3.5 \mathrm{~m}$ span of alpha 1 (main bars parallel to traffic)

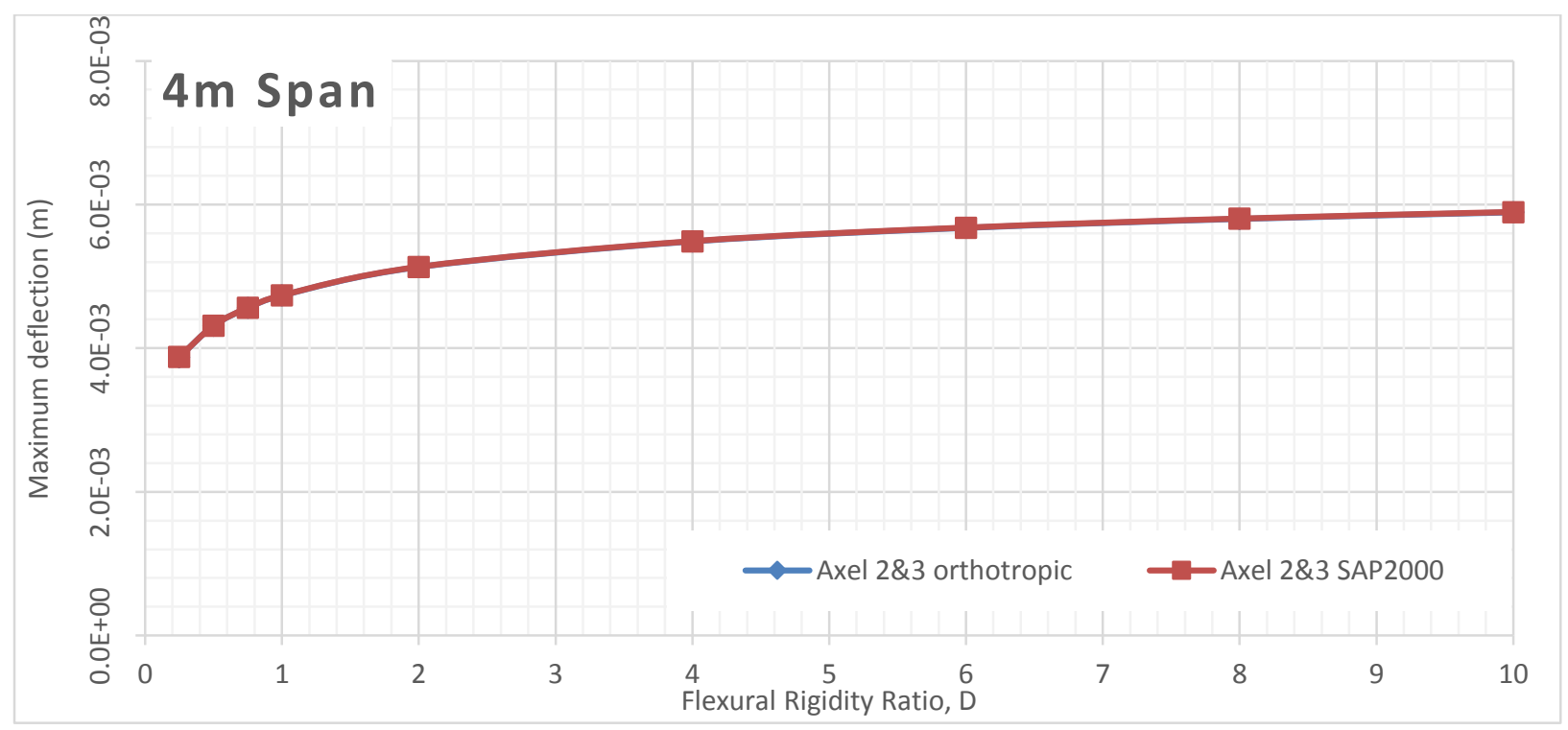

Figure 998 Deflection comparison between FEA and Orthotropic Plate Theory for $4 \mathrm{~m}$ span of alpha 1 (main bars parallel to traffic) 


\section{Alpha 2 Deflection VS Flexural Rigidity for Different Span Length (Main bars perpendicular to traffic)}

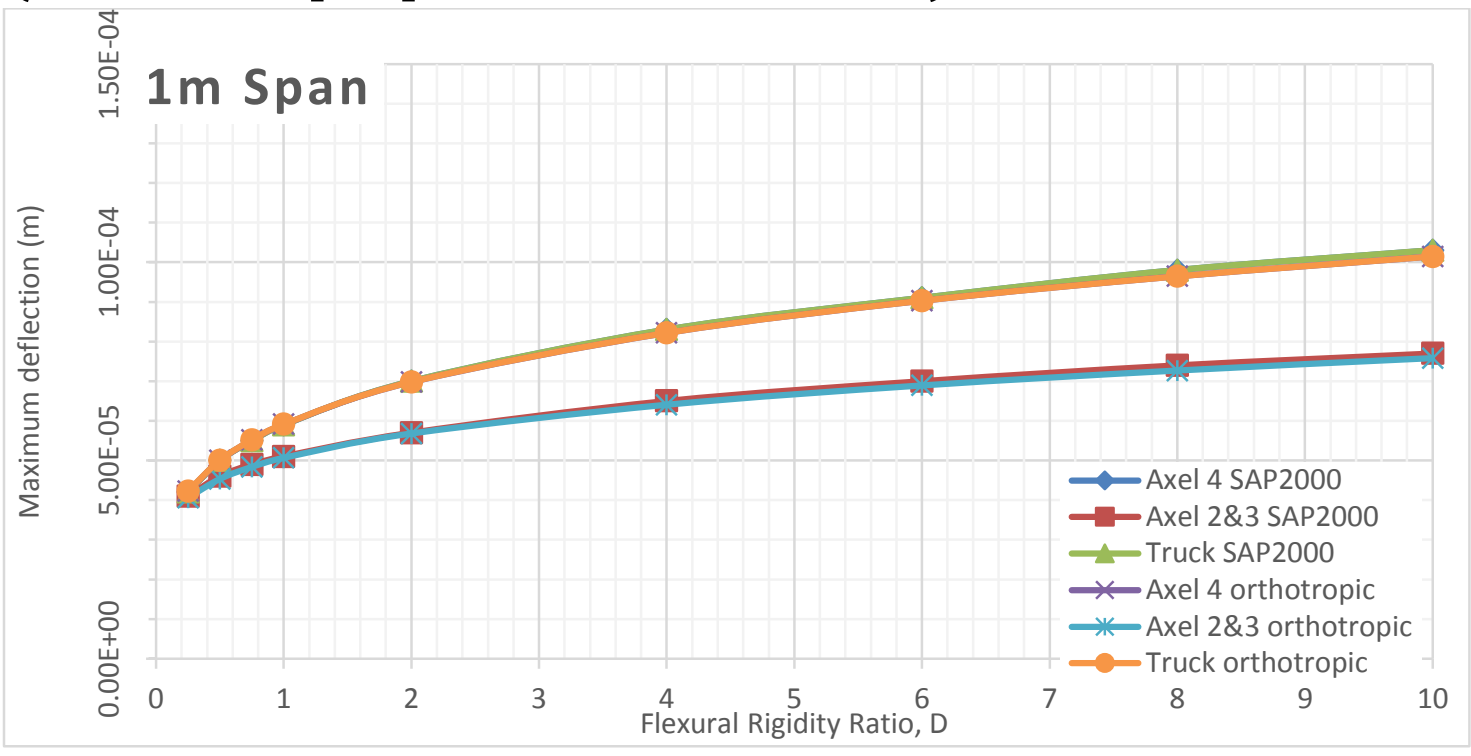

Figure 999 Deflection comparison between FEA and Orthotropic Plate Theory for $1 \mathrm{~m}$ span of alpha 2 (main bars perpendicular to traffic)

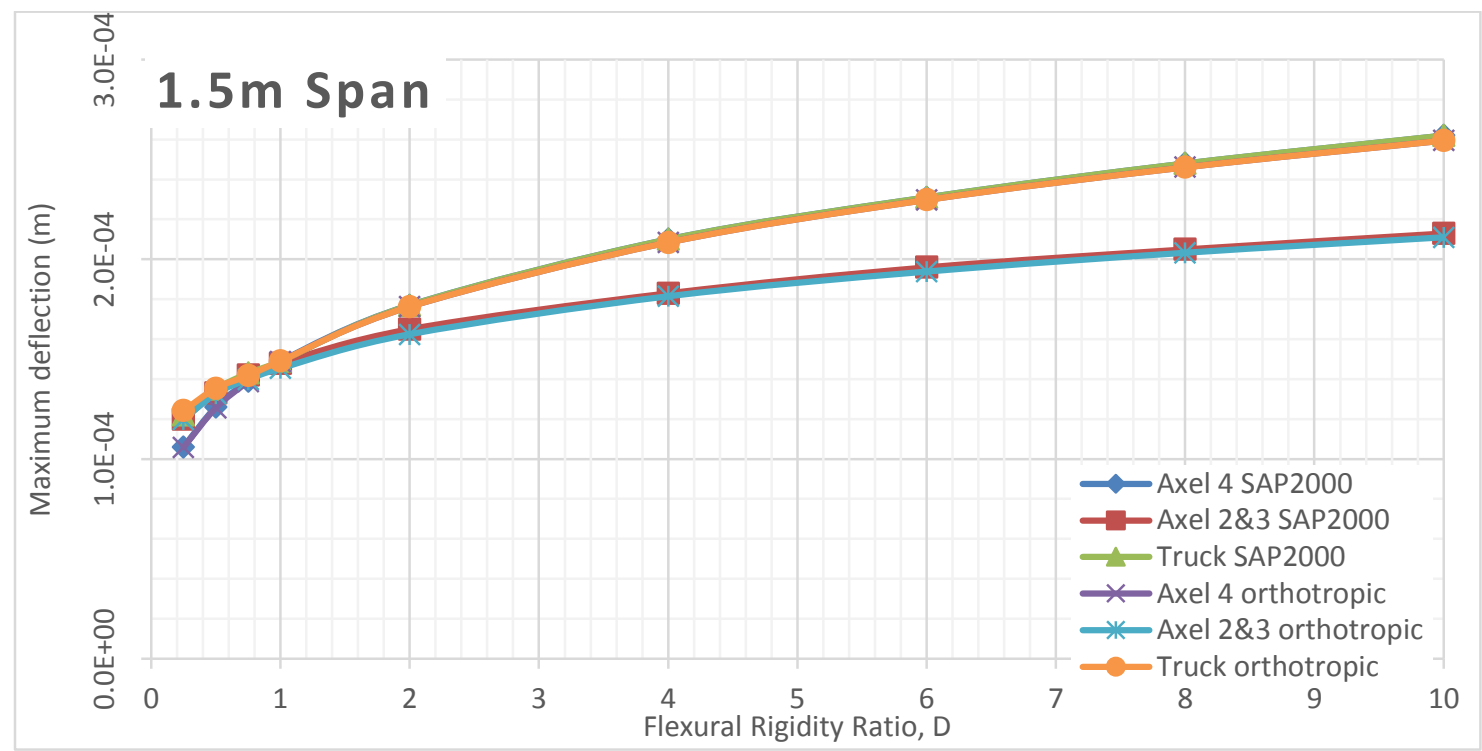

Figure 1000 Deflection comparison between FEA and Orthotropic Plate Theory for $1.5 \mathrm{~m}$ span of alpha 2 (main bars perpendicular to traffic) 


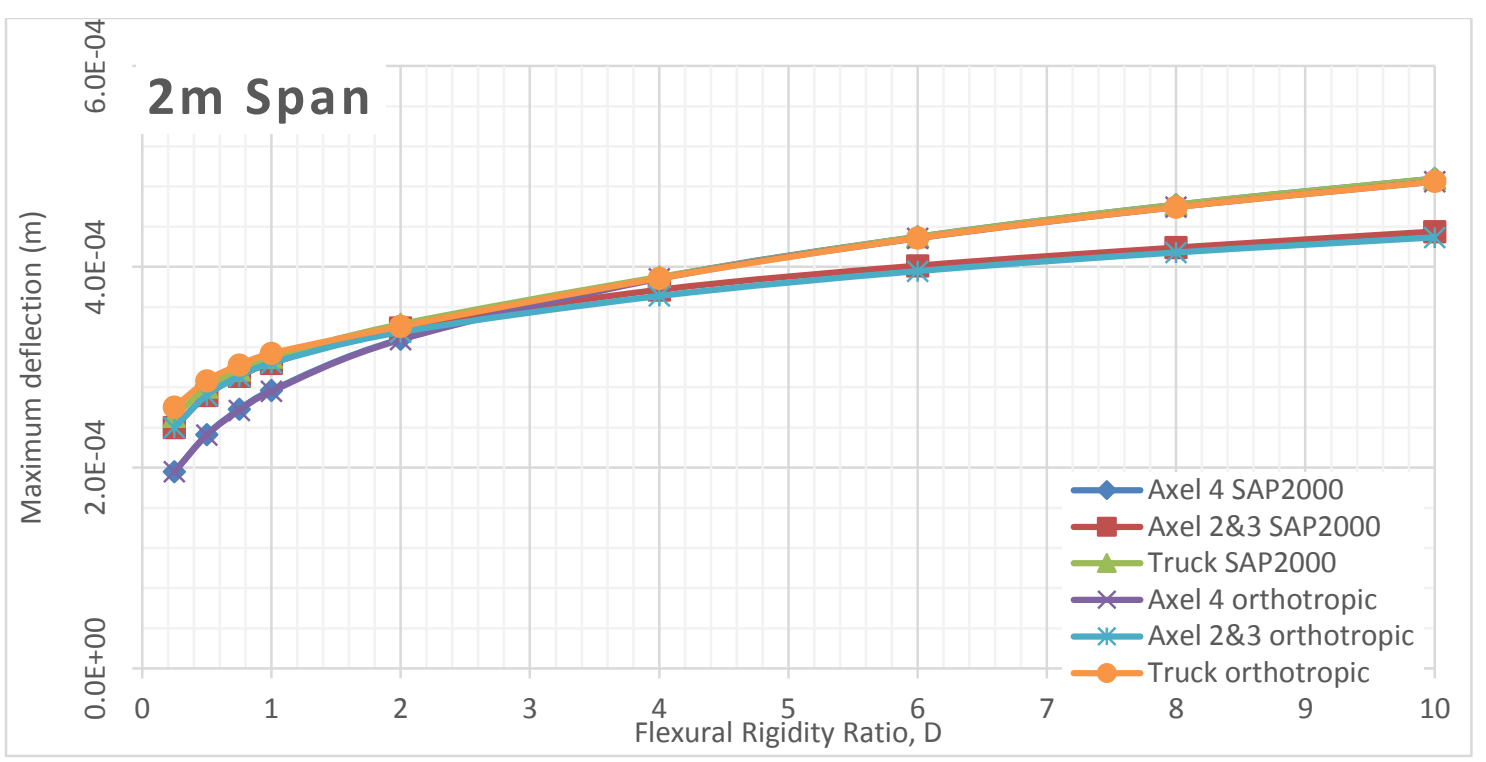

Figure 1001 Deflection comparison between FEA and Orthotropic Plate Theory for $2 \mathrm{~m}$ span of alpha 2 (main bars perpendicular to traffic)

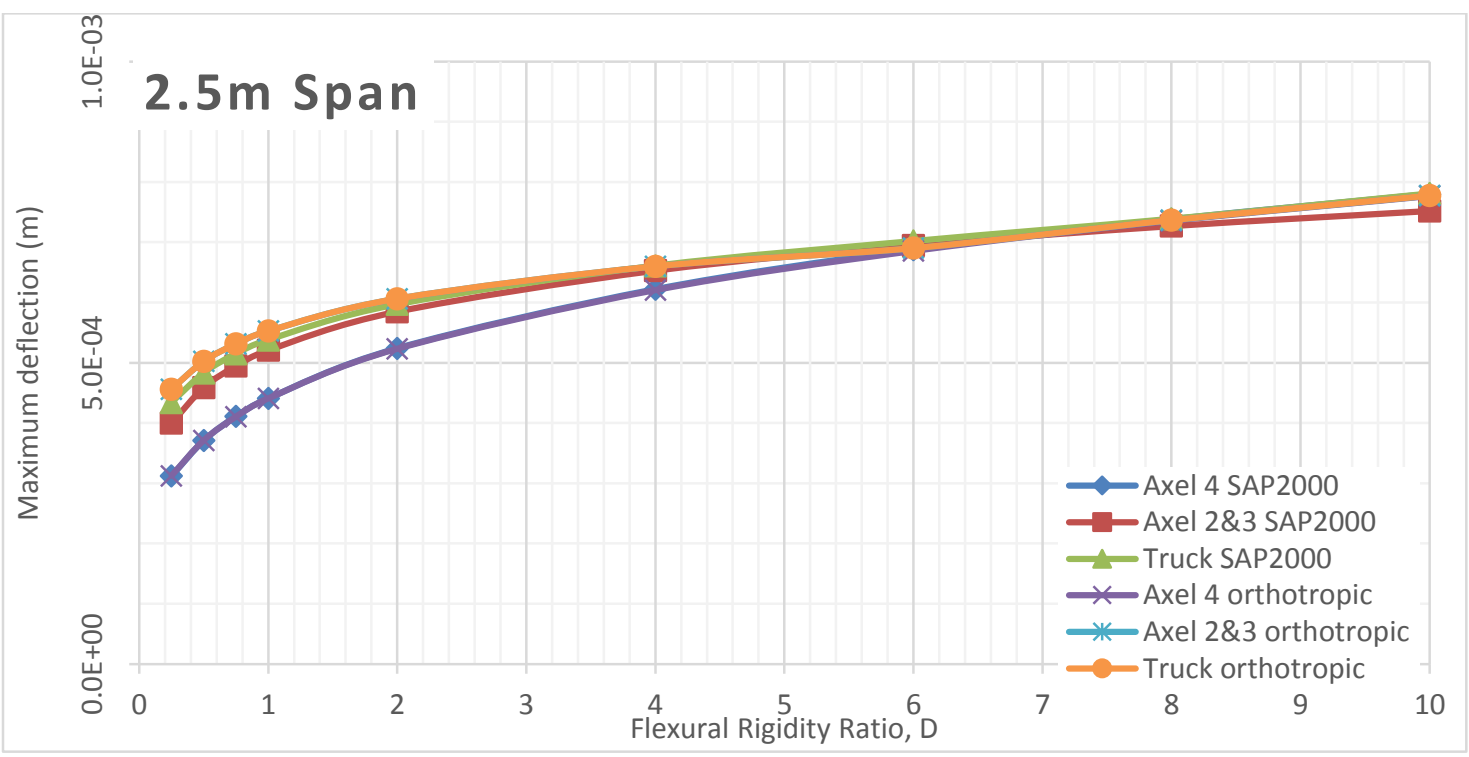

Figure 1002 Deflection comparison between FEA and Orthotropic Plate Theory for $2.5 \mathrm{~m}$ span of alpha 2 (main bars perpendicular to traffic)

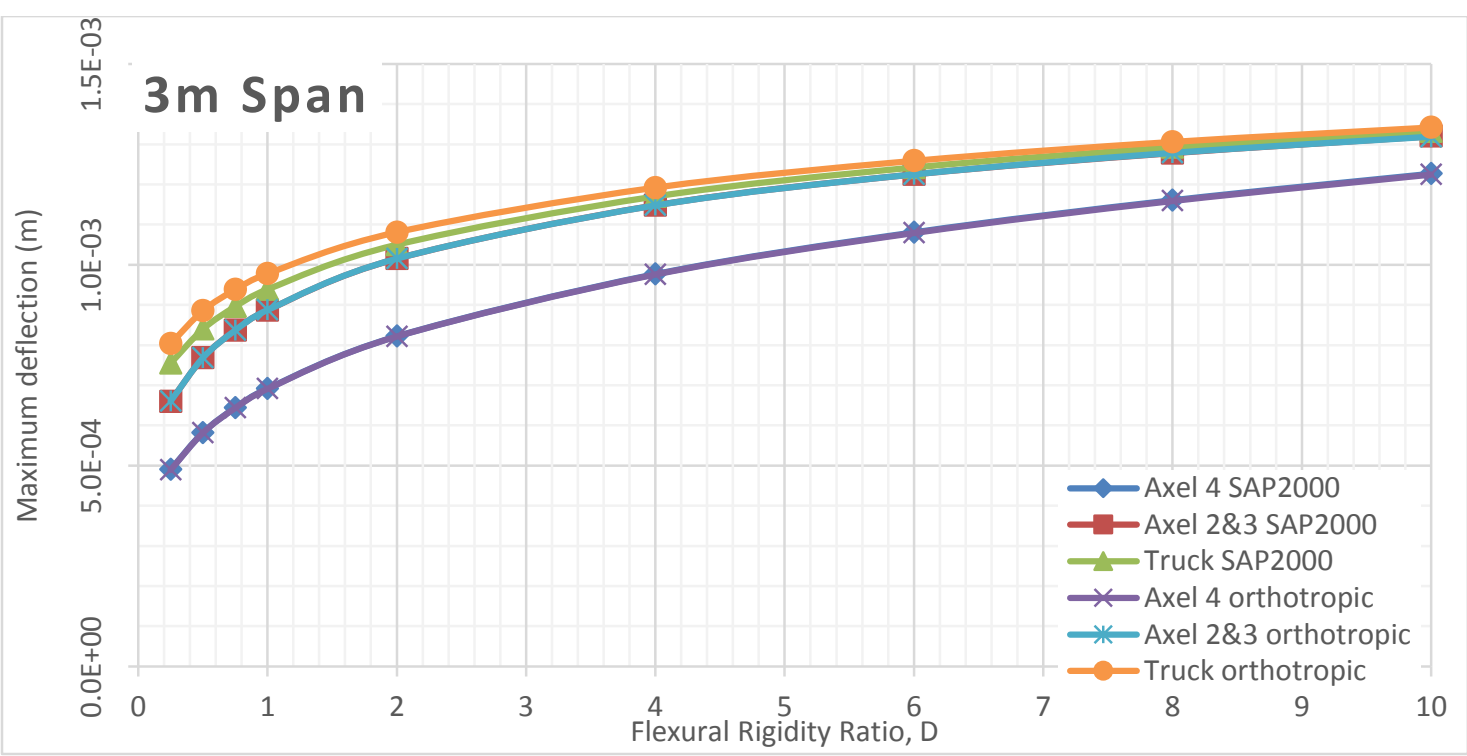

Figure 1003 Deflection comparison between FEA and Orthotropic Plate Theory for $3 \mathrm{~m}$ span of alpha 2 (main bars perpendicular to traffic) 


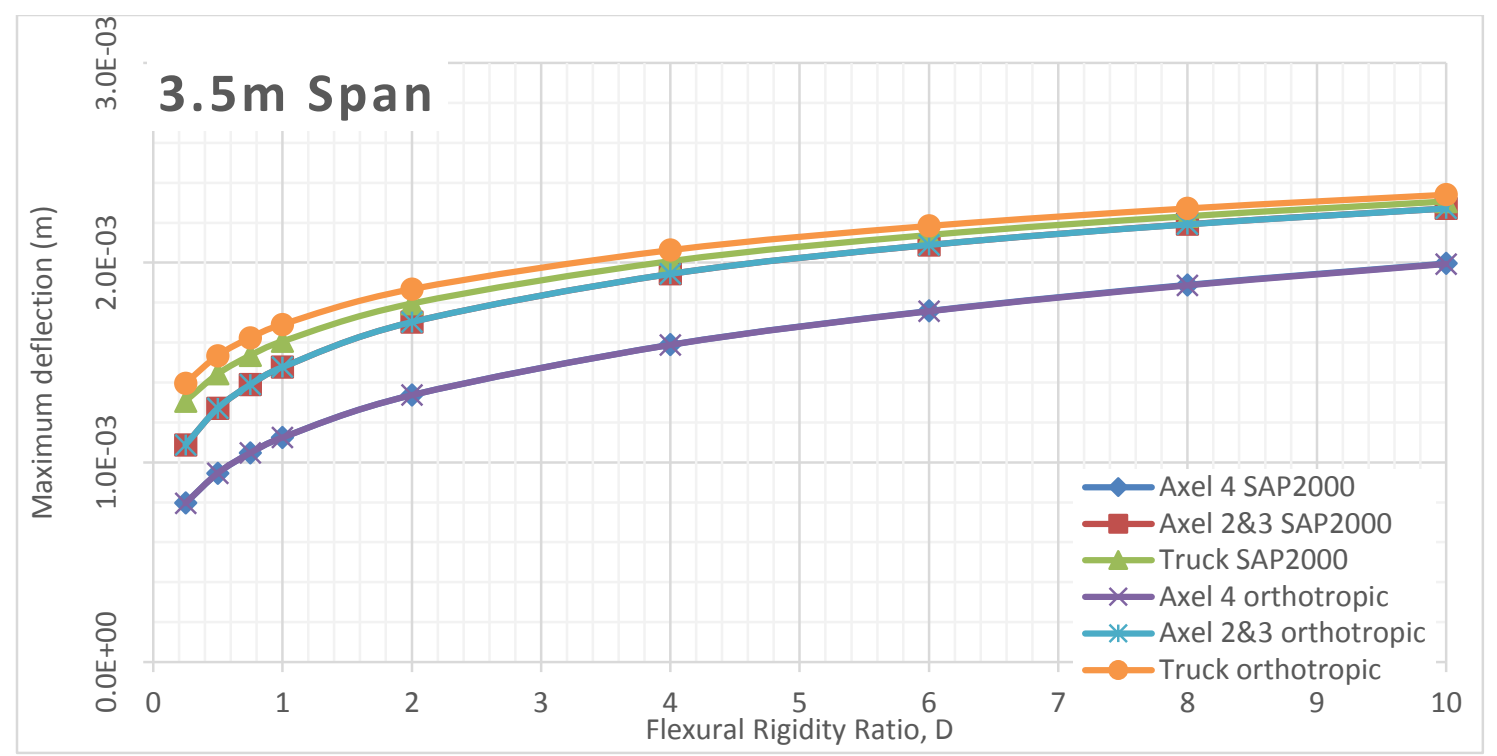

Figure 1004 Deflection comparison between FEA and Orthotropic Plate Theory for $3.5 \mathrm{~m}$ span of alpha 2 (main bars perpendicular to traffic)

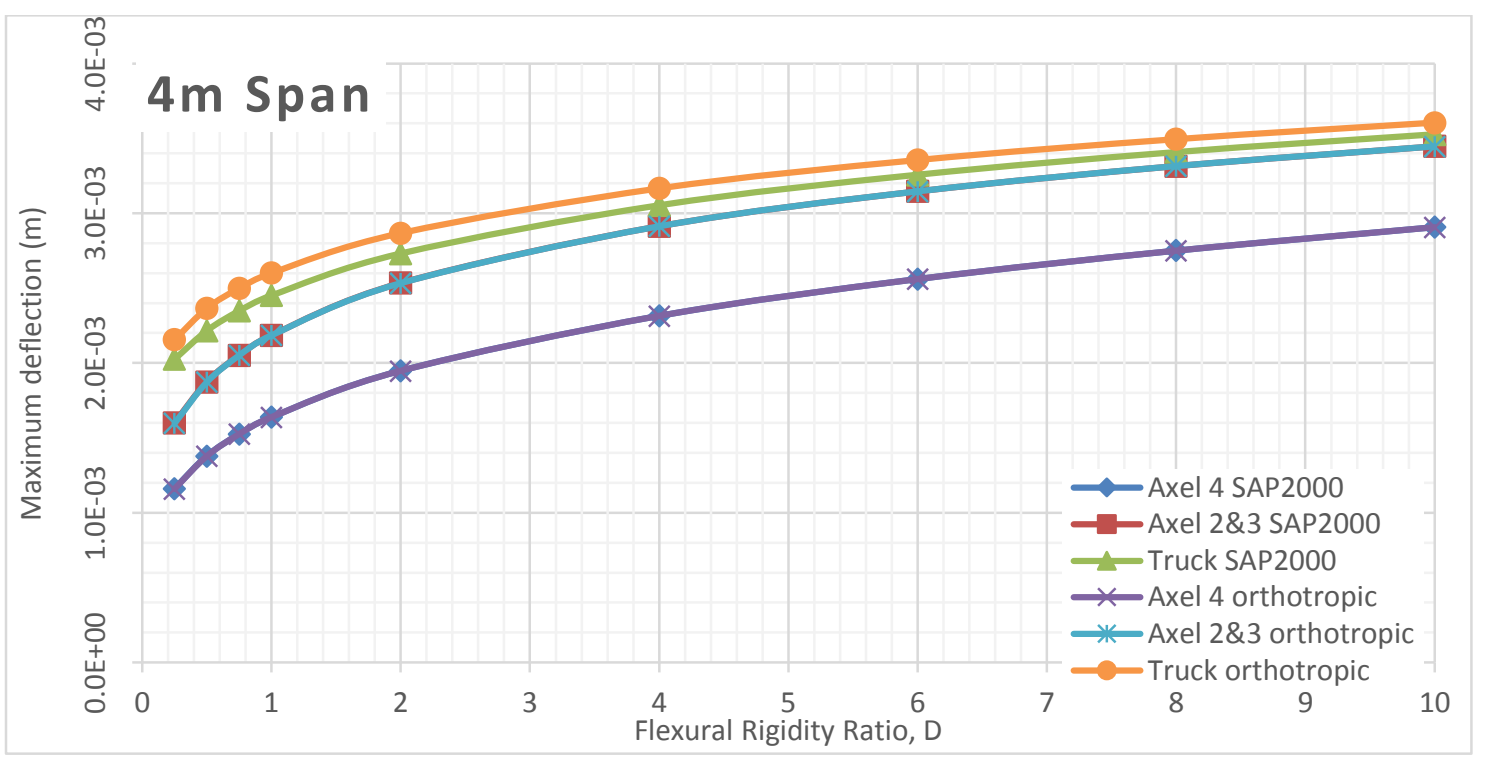

Figure 1005 Deflection comparison between FEA and Orthotropic Plate Theory for $4 \mathrm{~m}$ span of alpha 2 (main bars perpendicular to traffic) 


\section{Alpha 2 Deflection VS Flexural Rigidity for Different Span Length (Main bars parallel to traffic)}

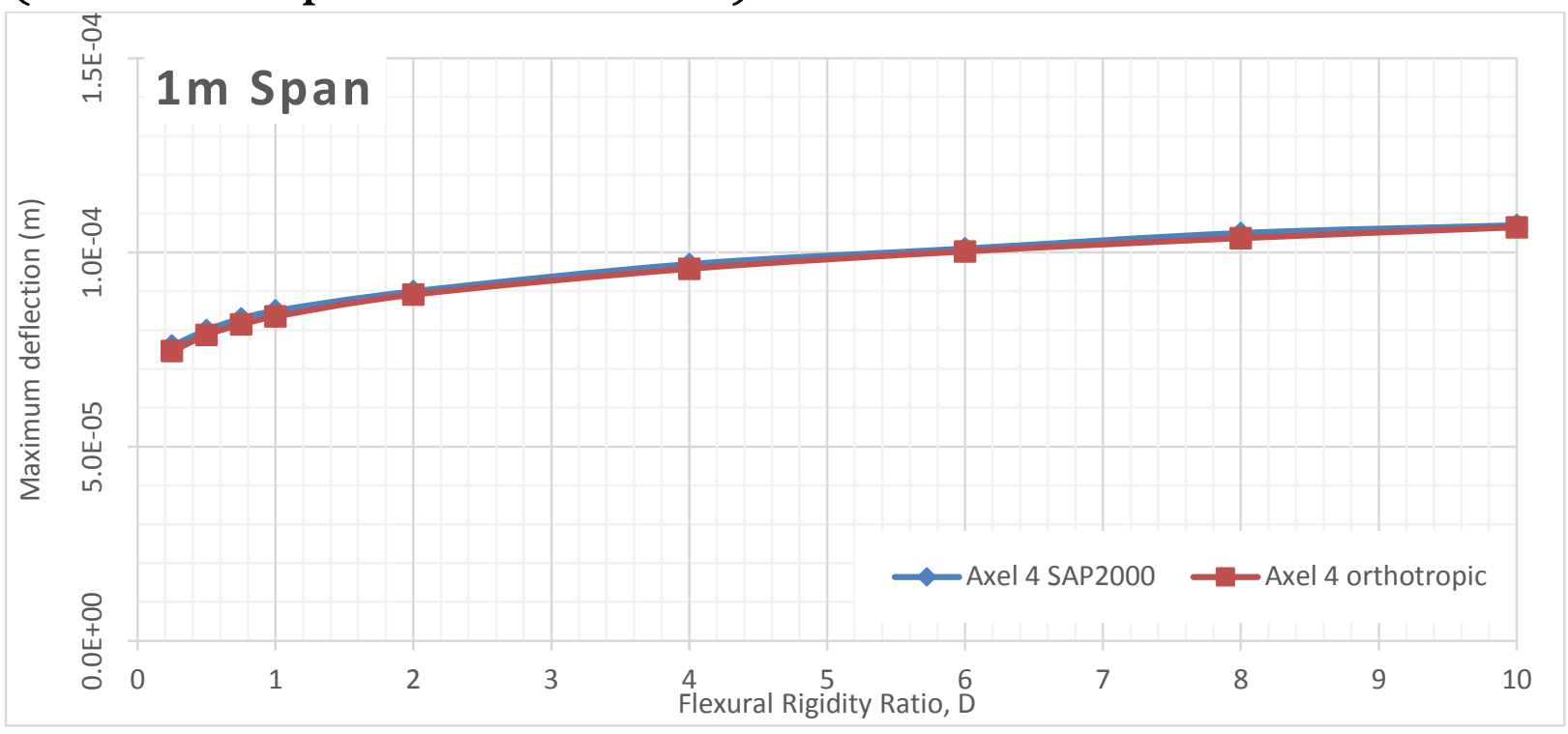

Figure 1006 Deflection comparison between FEA and Orthotropic Plate Theory for $1 \mathrm{~m}$ span of alpha 2 (main bars parallel to traffic)

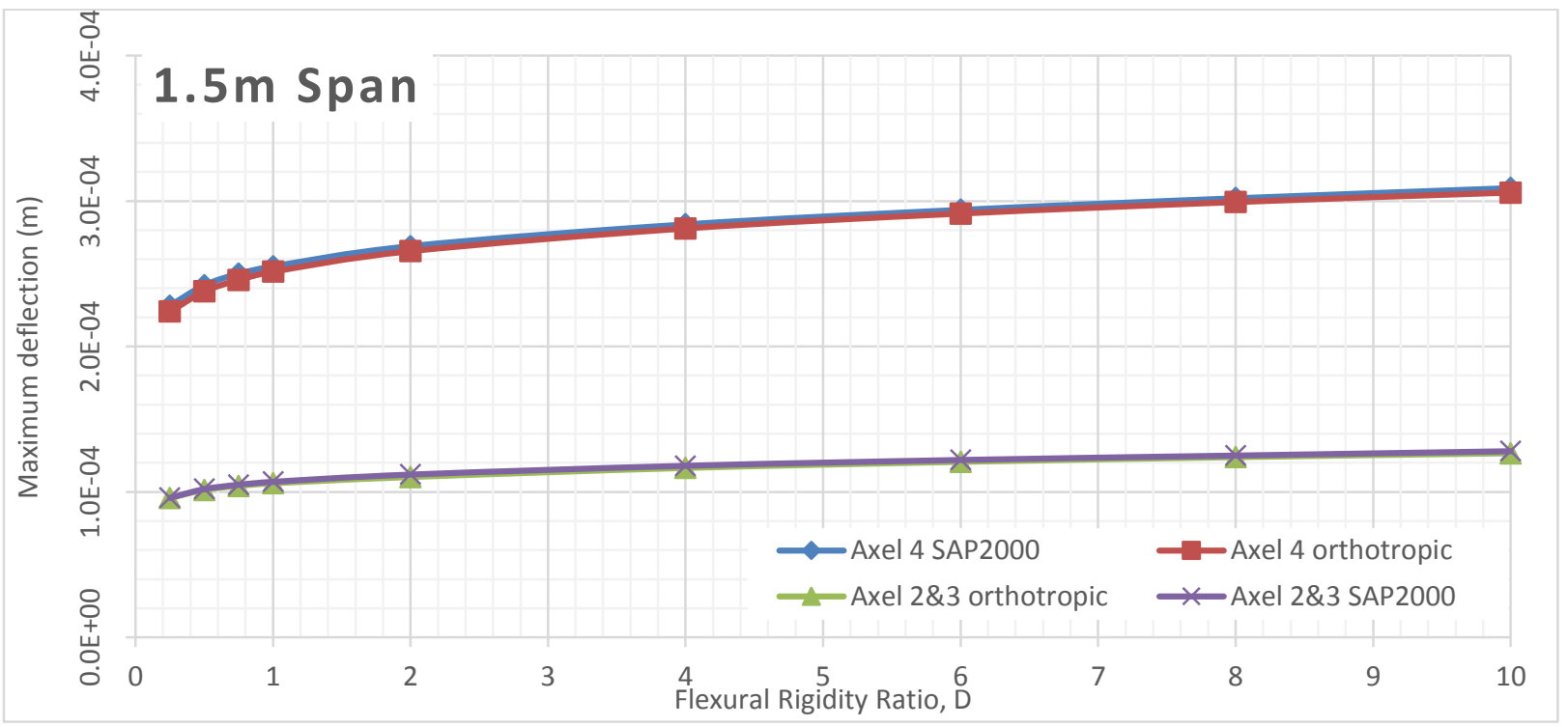

Figure 1007 Deflection comparison between FEA and Orthotropic Plate Theory for $1.5 \mathrm{~m}$ span of alpha 2 (main bars parallel to traffic) 


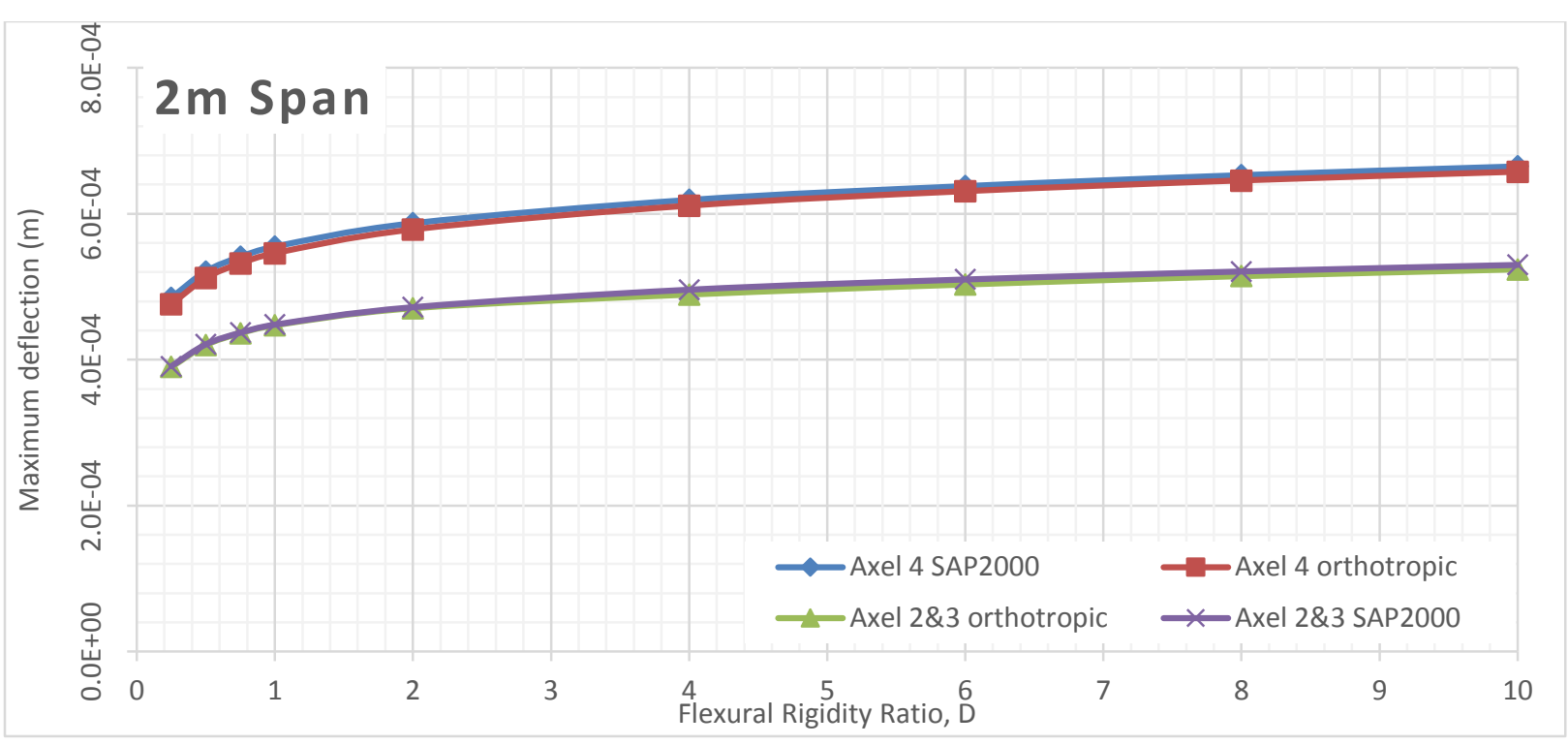

Figure 1008 Deflection comparison between FEA and Orthotropic Plate Theory for $2 \mathrm{~m}$ span of alpha 2 (main bars parallel to traffic)

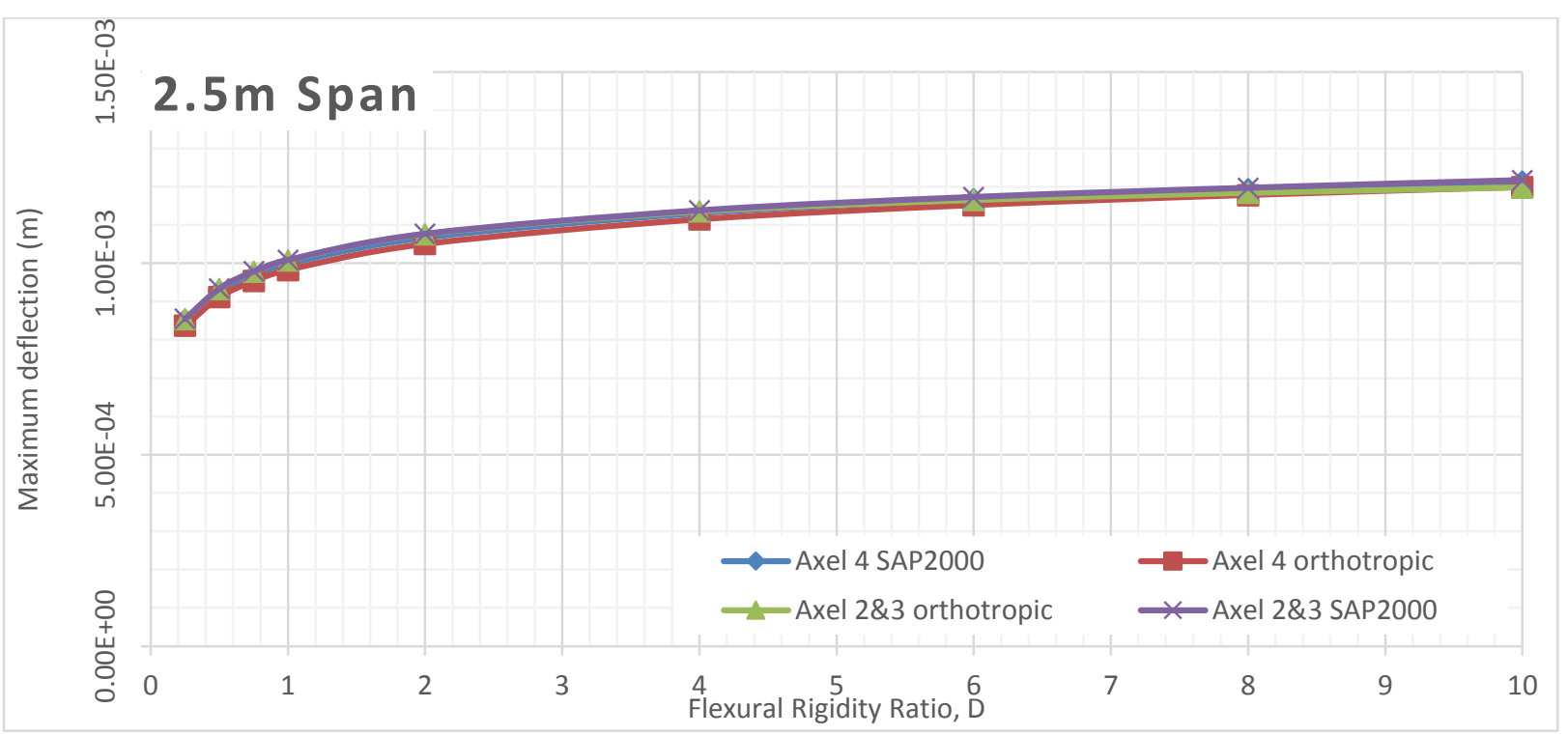

Figure 1009 Deflection comparison between FEA and Orthotropic Plate Theory for $2.5 \mathrm{~m}$ span of alpha 2 (main bars parallel to traffic)

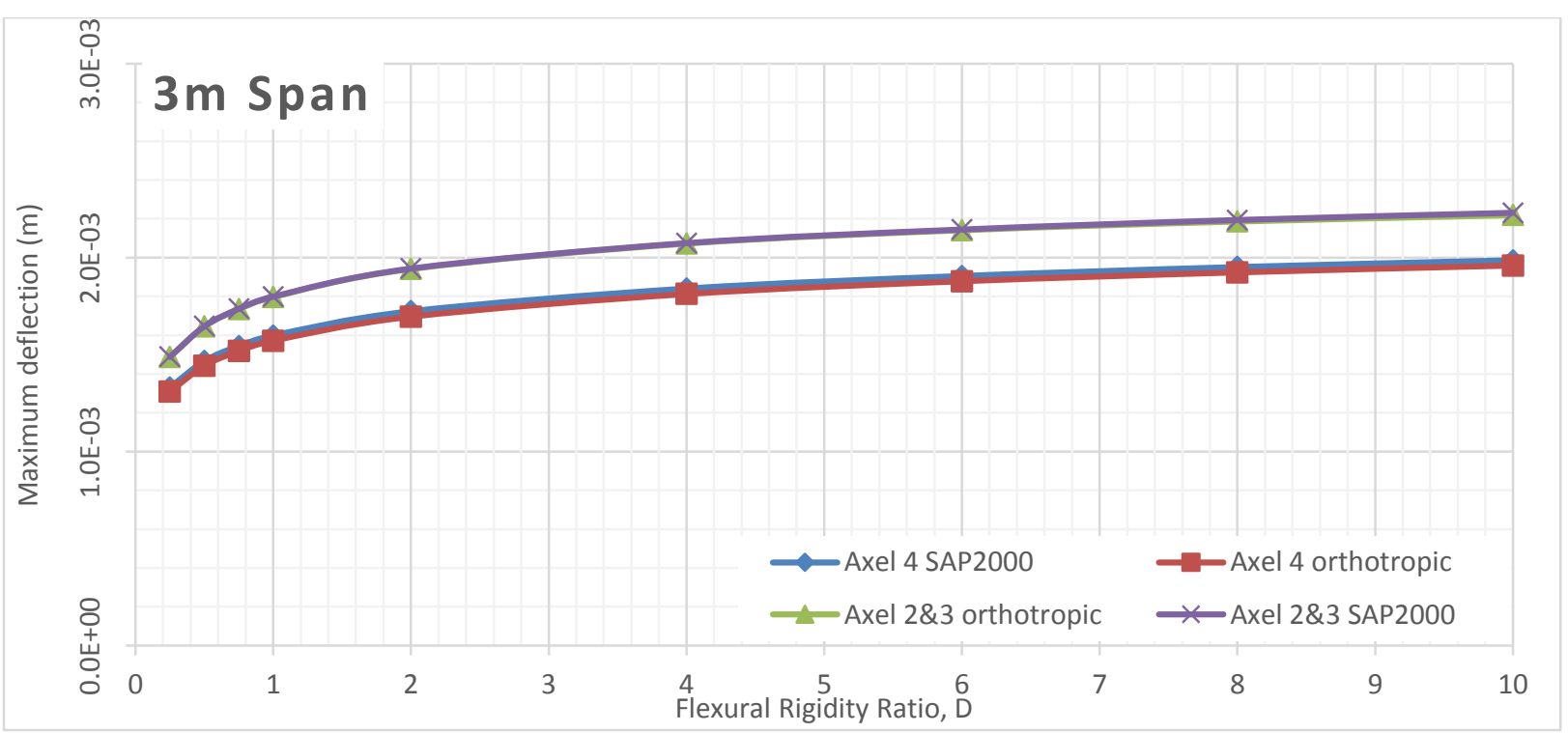

Figure 1010 Deflection comparison between FEA and Orthotropic Plate Theory for $3 \mathrm{~m}$ span of alpha 2 (main bars parallel to traffic) 


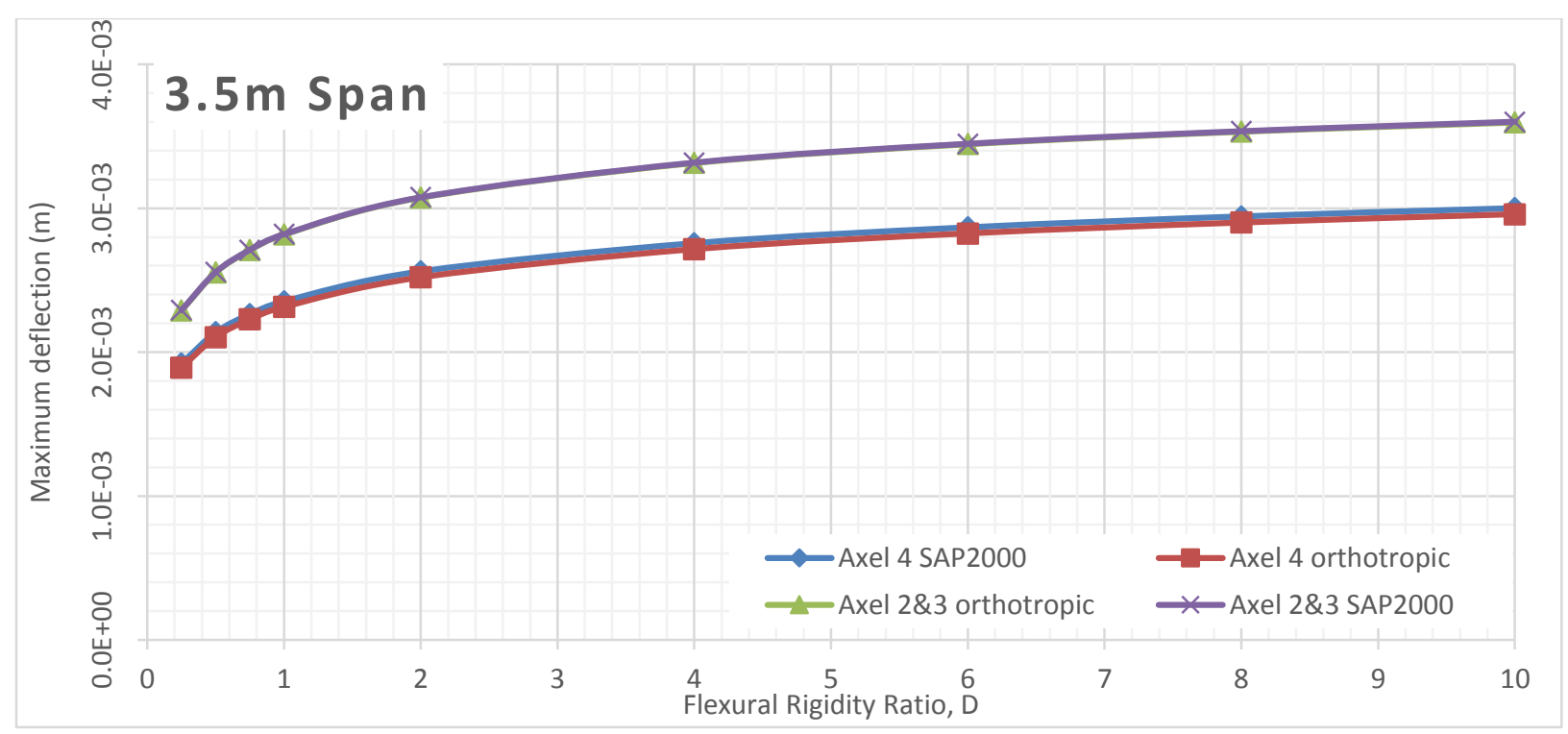

Figure 1011 Deflection comparison between FEA and Orthotropic Plate Theory for $3.5 \mathrm{~m}$ span of alpha 2 (main bars parallel to traffic)

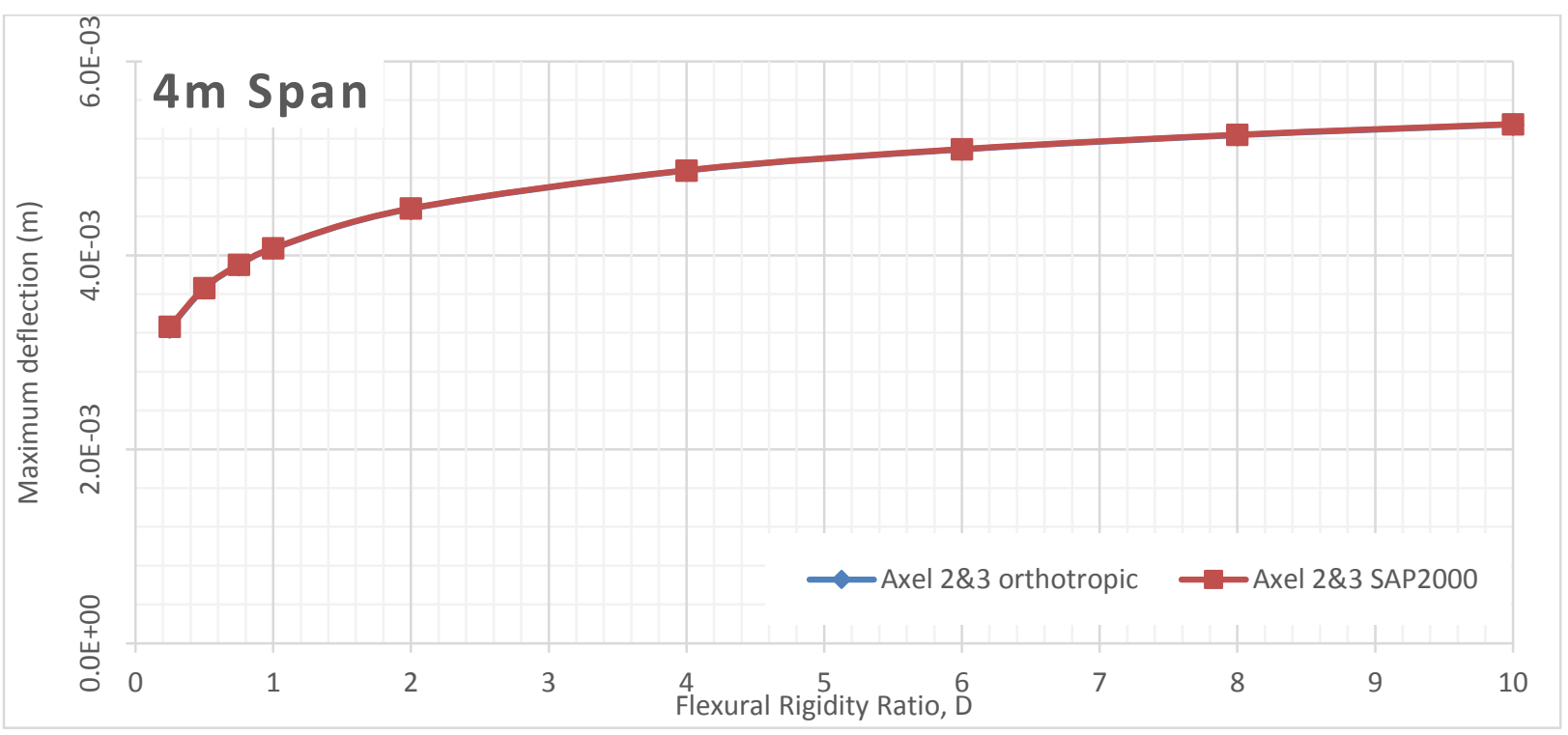

Figure 1012 Deflection comparison between FEA and Orthotropic Plate Theory for $4 \mathrm{~m}$ span of alpha 2 (main bars parallel to traffic) 


\section{Alpha 4 Deflection VS Flexural Rigidity for Different Span Length (Main bars perpendicular to traffic)}

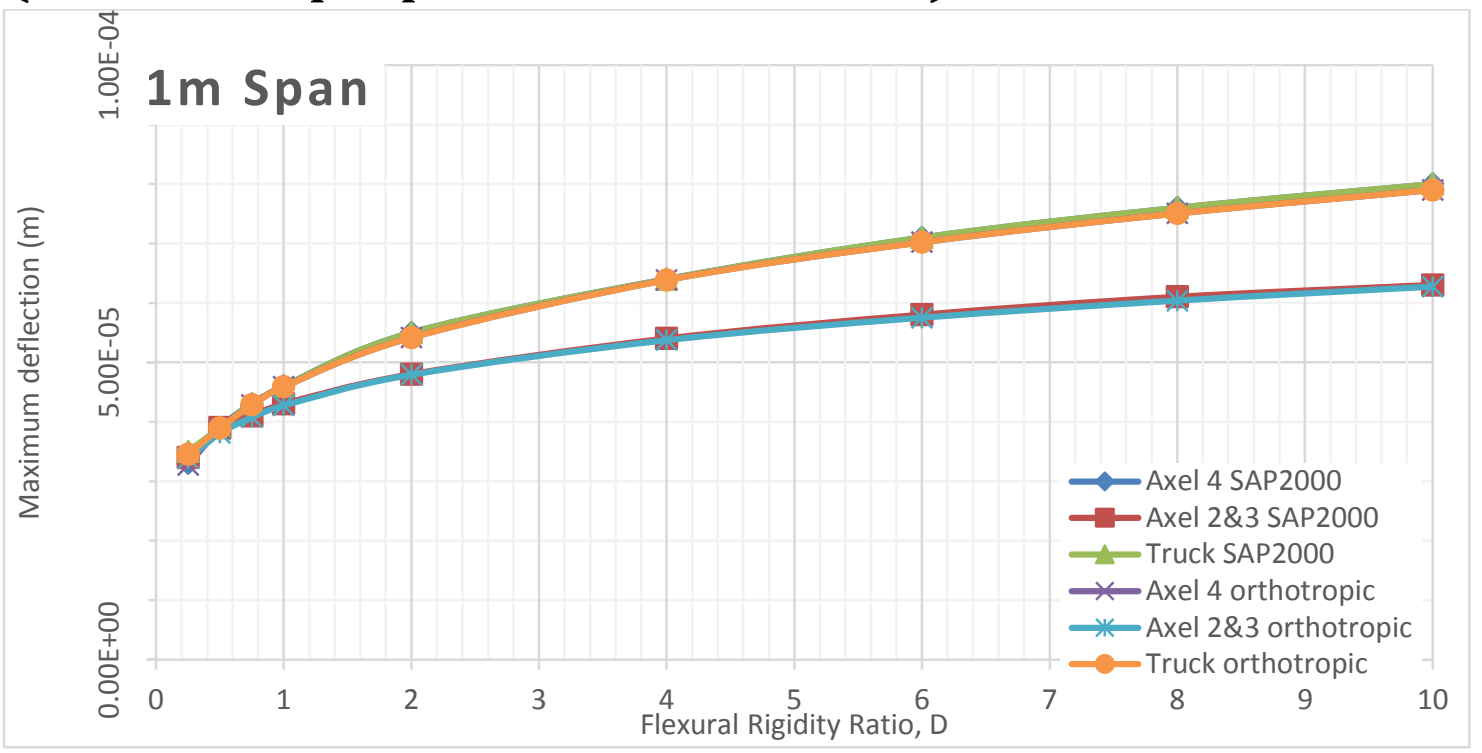

Figure 1013 Deflection comparison between FEA and Orthotropic Plate Theory for $1 \mathrm{~m}$ span of alpha 4 (main bars perpendicular to traffic)

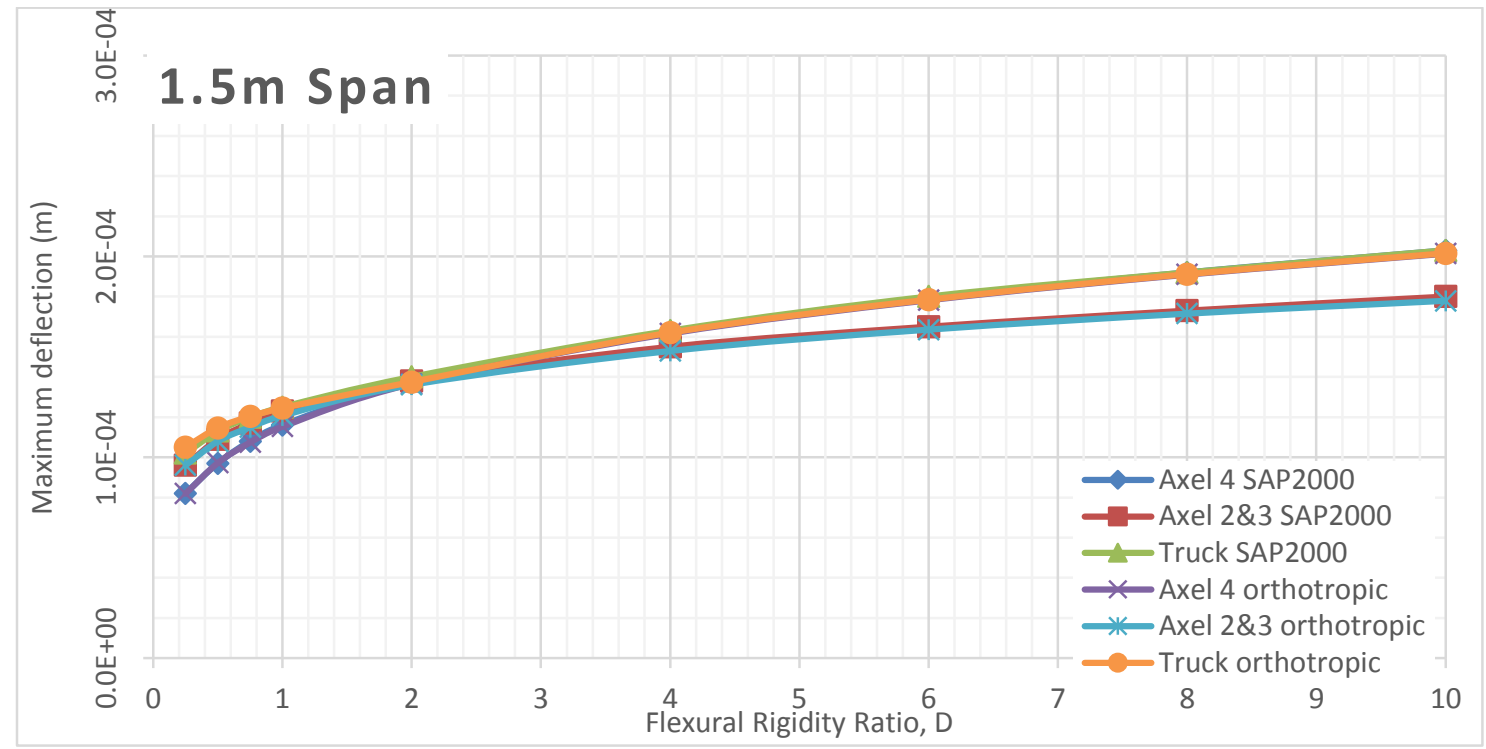

Figure 1014 Deflection comparison between FEA and Orthotropic Plate Theory for $1.5 \mathrm{~m}$ span of alpha 4 (main bars perpendicular to traffic) 


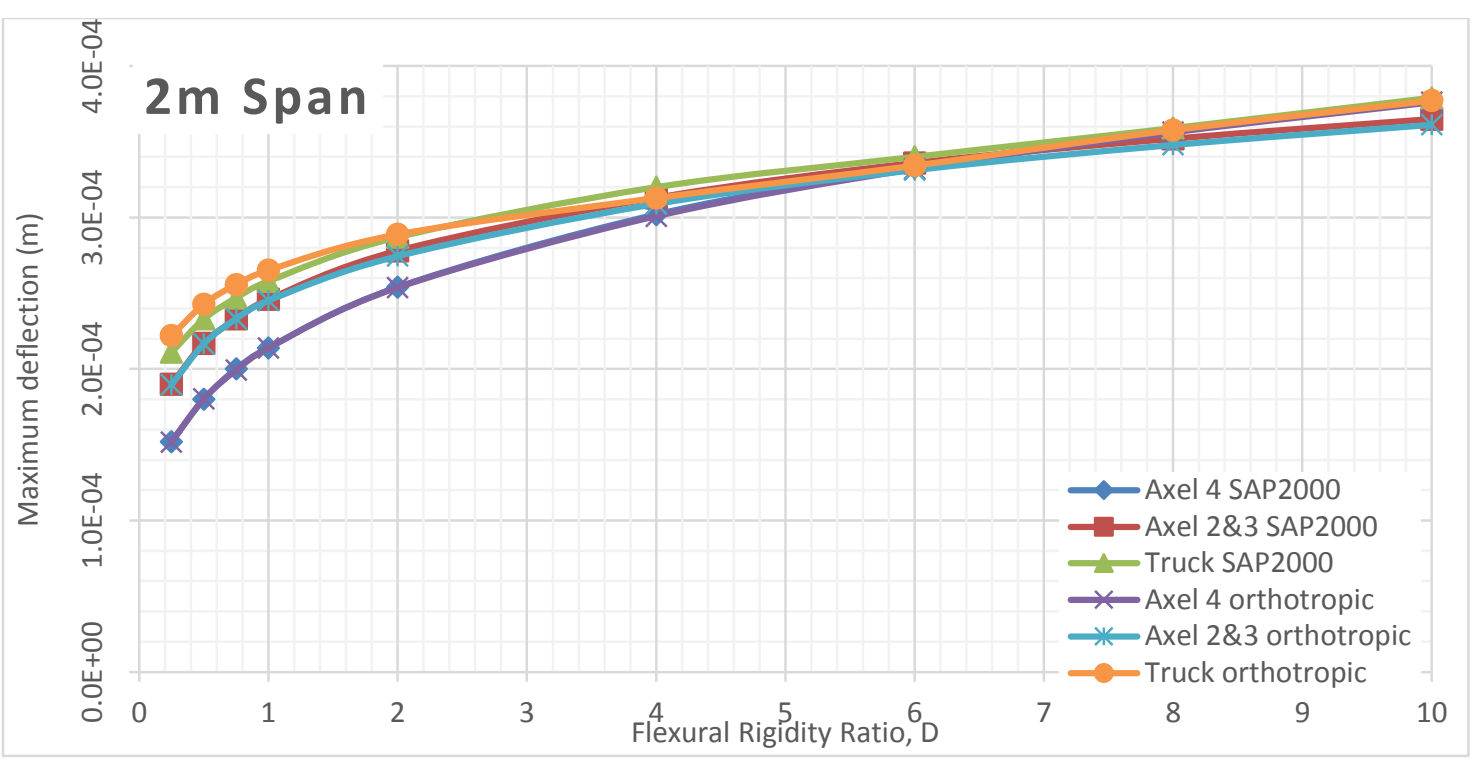

Figure 1015 Deflection comparison between FEA and Orthotropic Plate Theory for $2 \mathrm{~m}$ span of alpha 4 (main bars perpendicular to traffic)

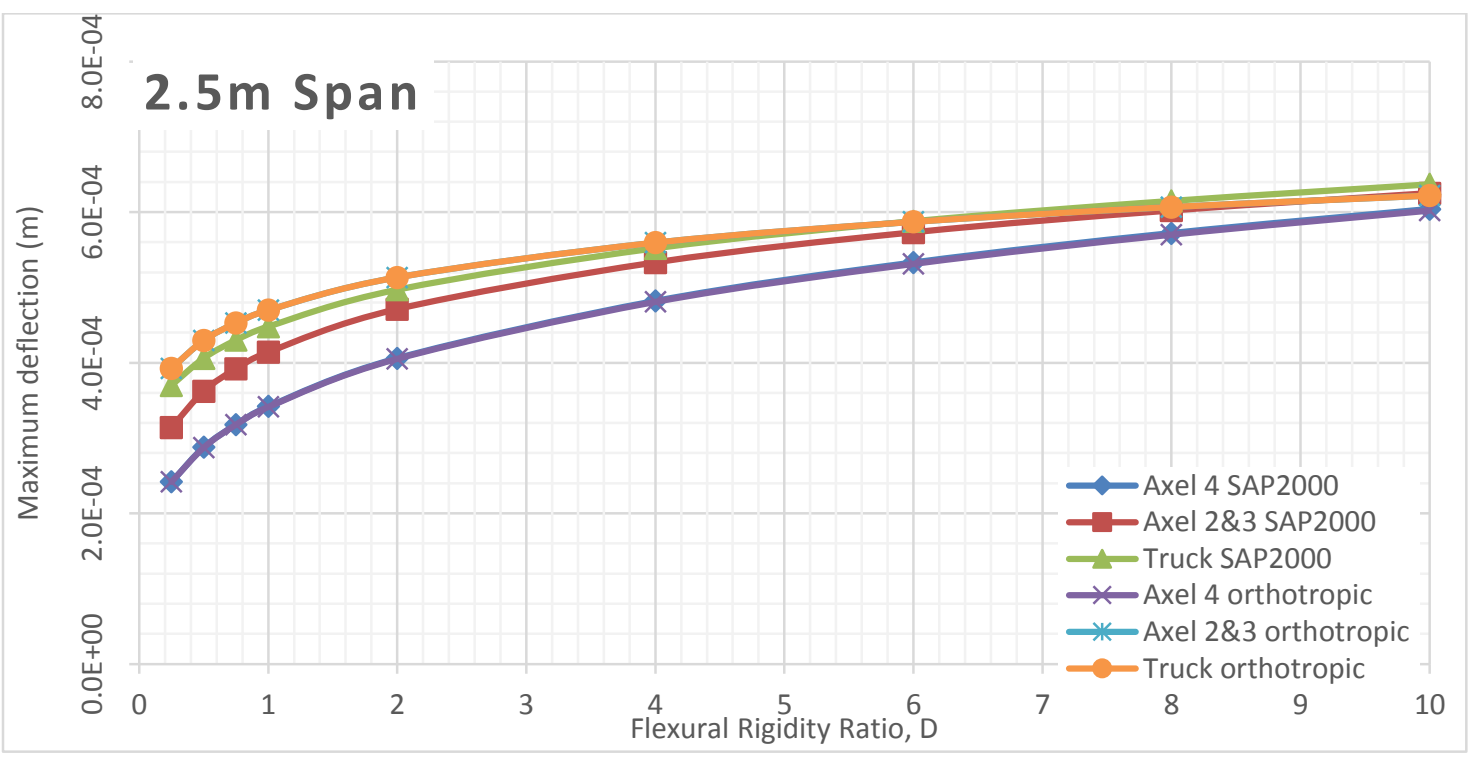

Figure 1016 Deflection comparison between FEA and Orthotropic Plate Theory for $2.5 \mathrm{~m}$ span of alpha 4 (main bars perpendicular to traffic)

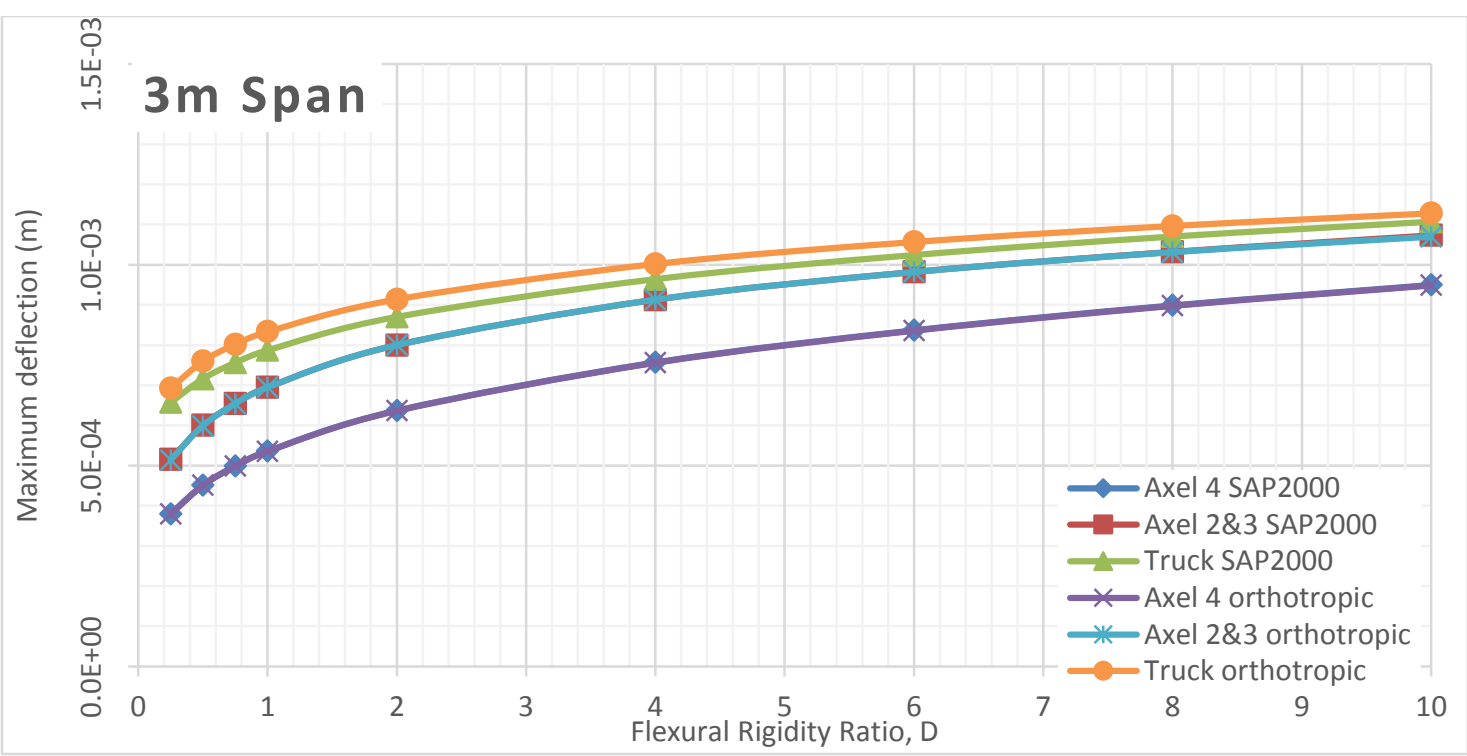

Figure 1017 Deflection comparison between FEA and Orthotropic Plate Theory for $3 \mathrm{~m}$ span of alpha 4 (main bars perpendicular to traffic) 


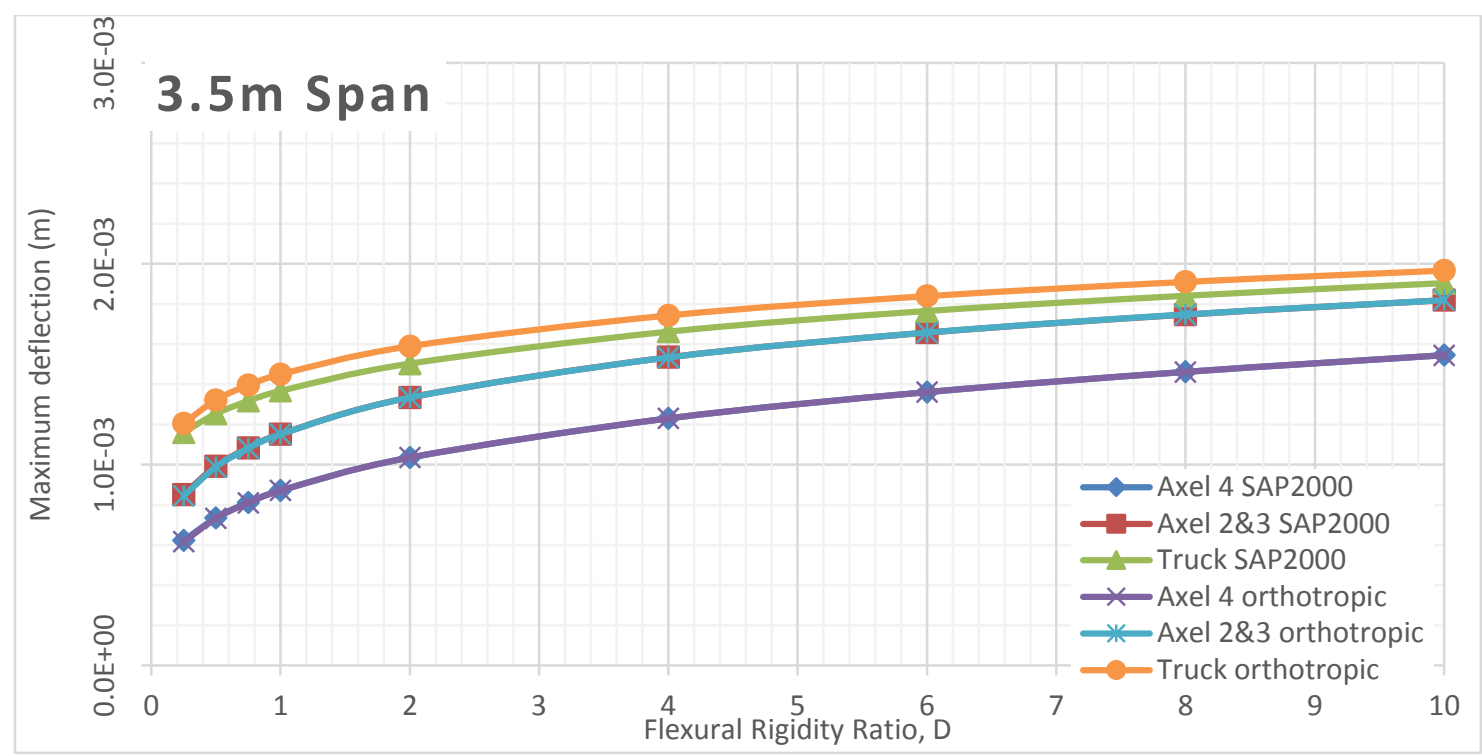

Figure 1018 Deflection comparison between FEA and Orthotropic Plate Theory for $3.5 \mathrm{~m}$ span of alpha 4 (main bars perpendicular to traffic)

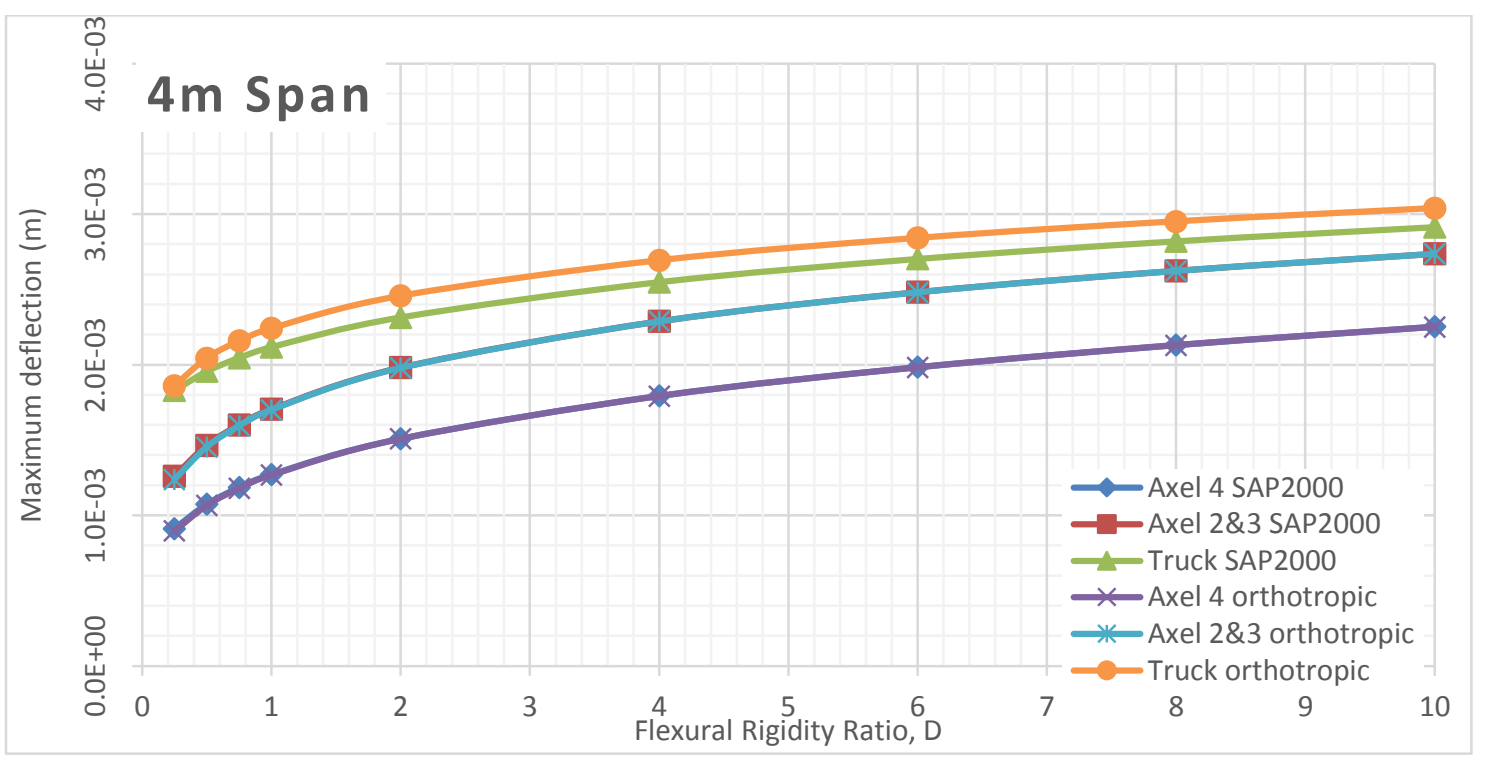

Figure 1019 Deflection comparison between FEA and Orthotropic Plate Theory for $4 \mathrm{~m}$ span of alpha 4 (main bars perpendicular to traffic) 


\section{Alpha 4 Deflection VS Flexural Rigidity for Different Span Length (Main bars parallel to traffic)}

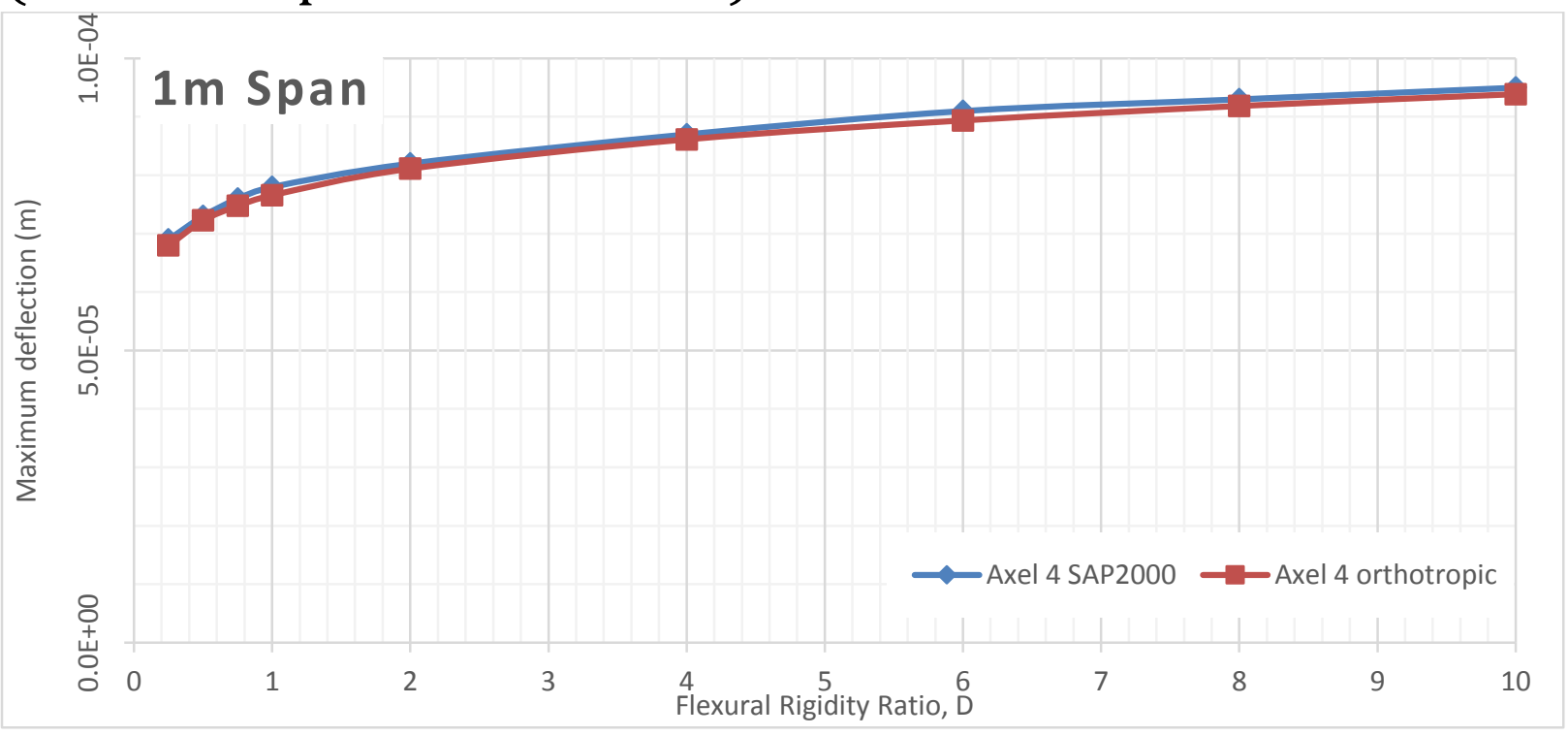

Figure 1020 Deflection comparison between FEA and Orthotropic Plate Theory for $1 \mathrm{~m}$ span of alpha 4 (main bars parallel to traffic)

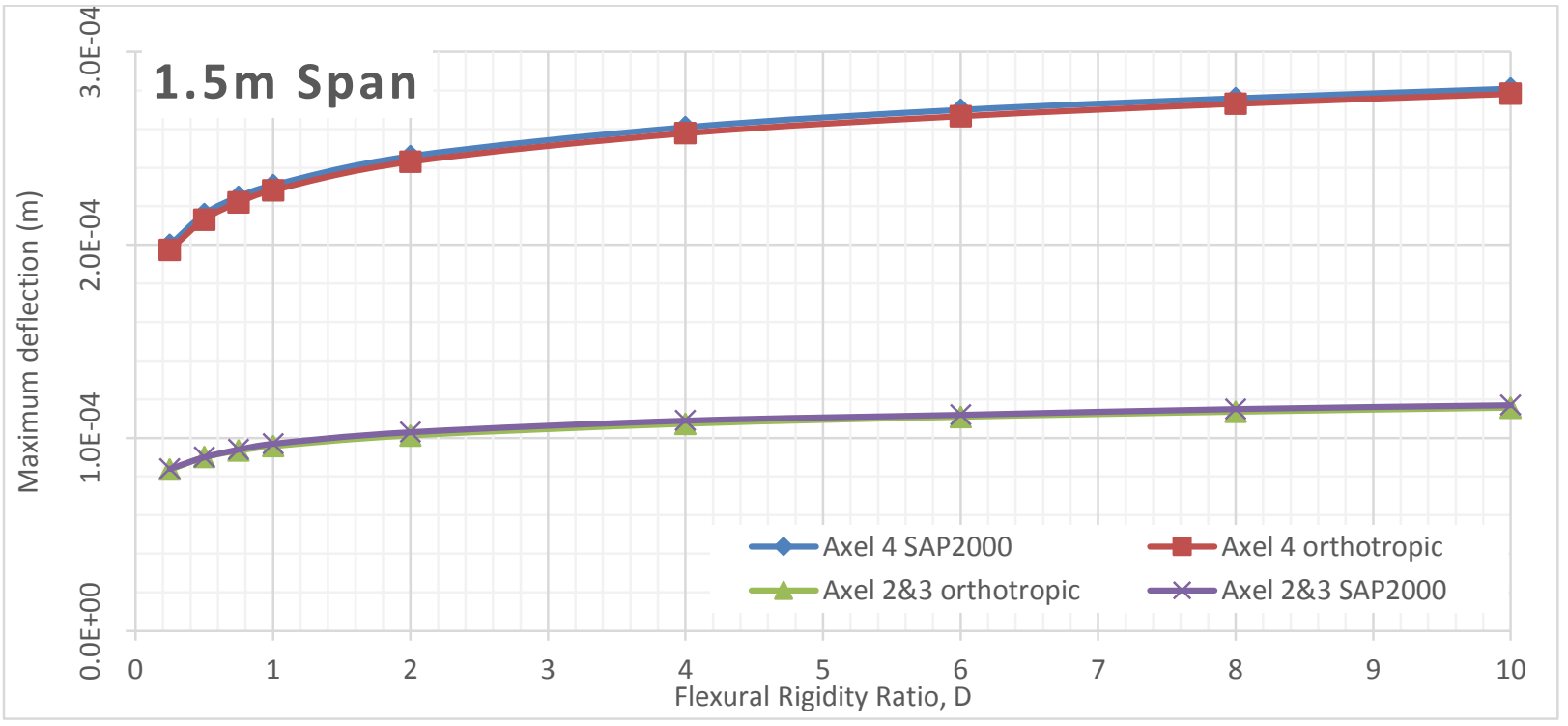

Figure 1021 Deflection comparison between FEA and Orthotropic Plate Theory for $1.5 \mathrm{~m}$ span of alpha 4 (main bars parallel to traffic) 


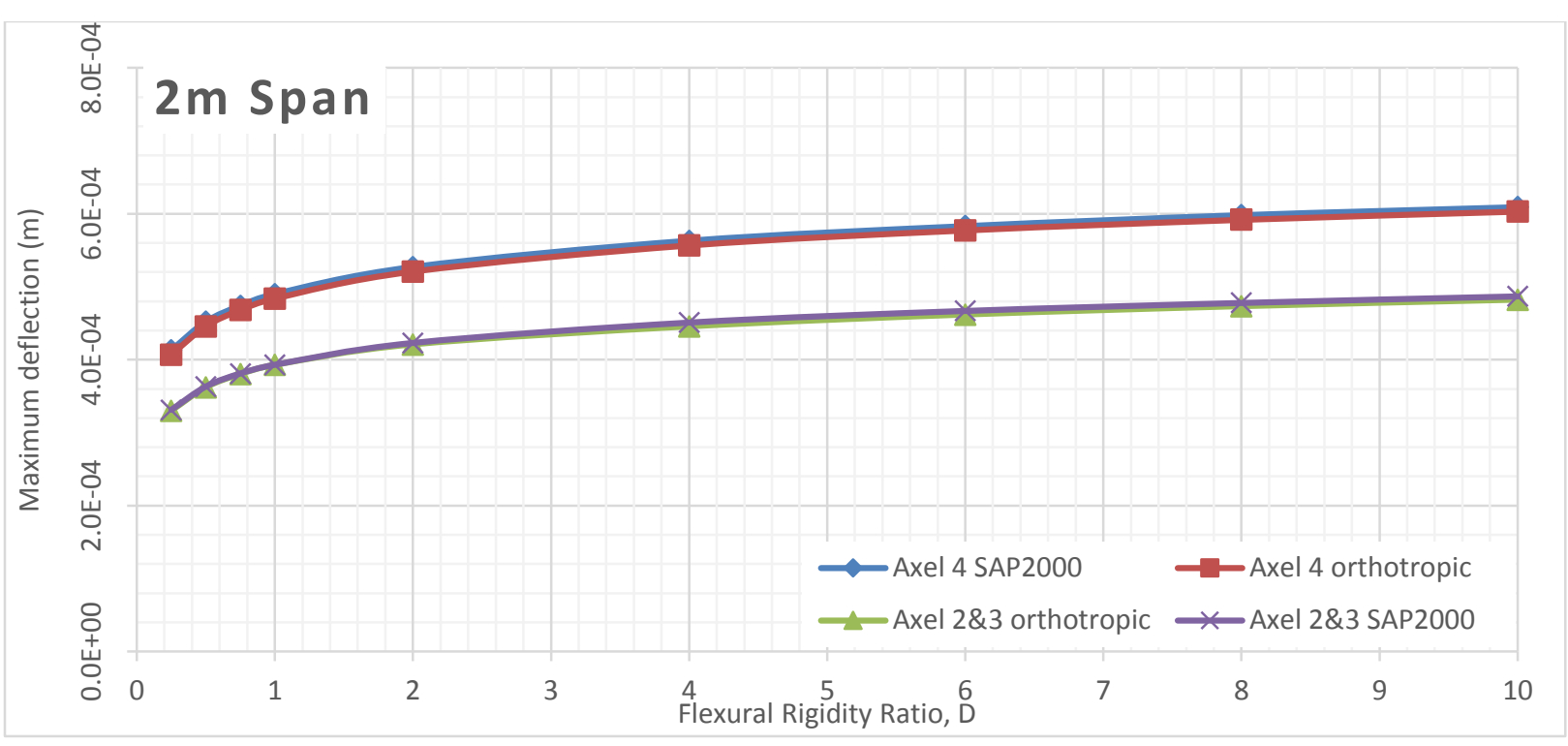

Figure 1022 Deflection comparison between FEA and Orthotropic Plate Theory for $2 \mathrm{~m}$ span of alpha 4 (main bars parallel to traffic)

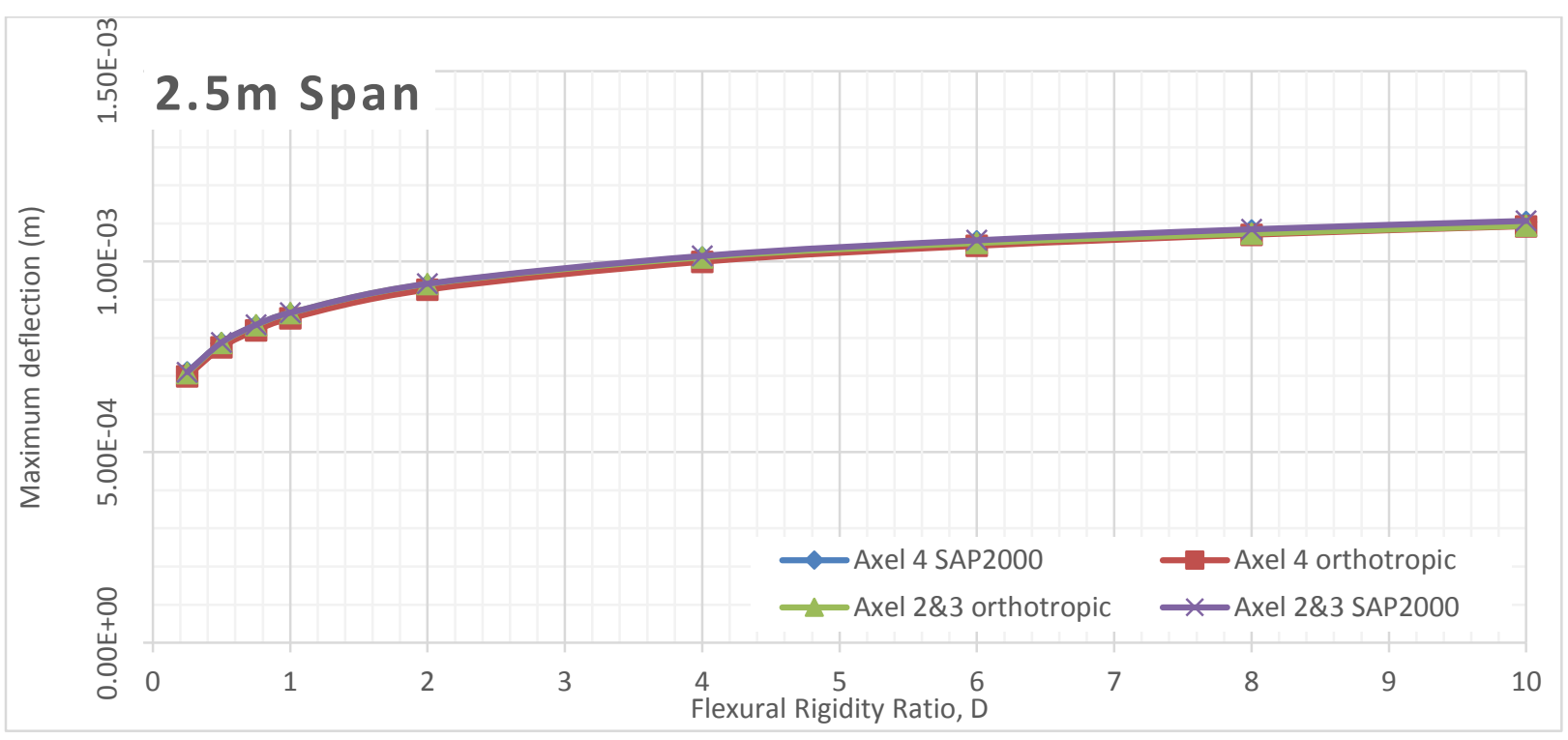

Figure 1023 Deflection comparison between FEA and Orthotropic Plate Theory for $2.5 \mathrm{~m}$ span of alpha 4 (main bars parallel to traffic)

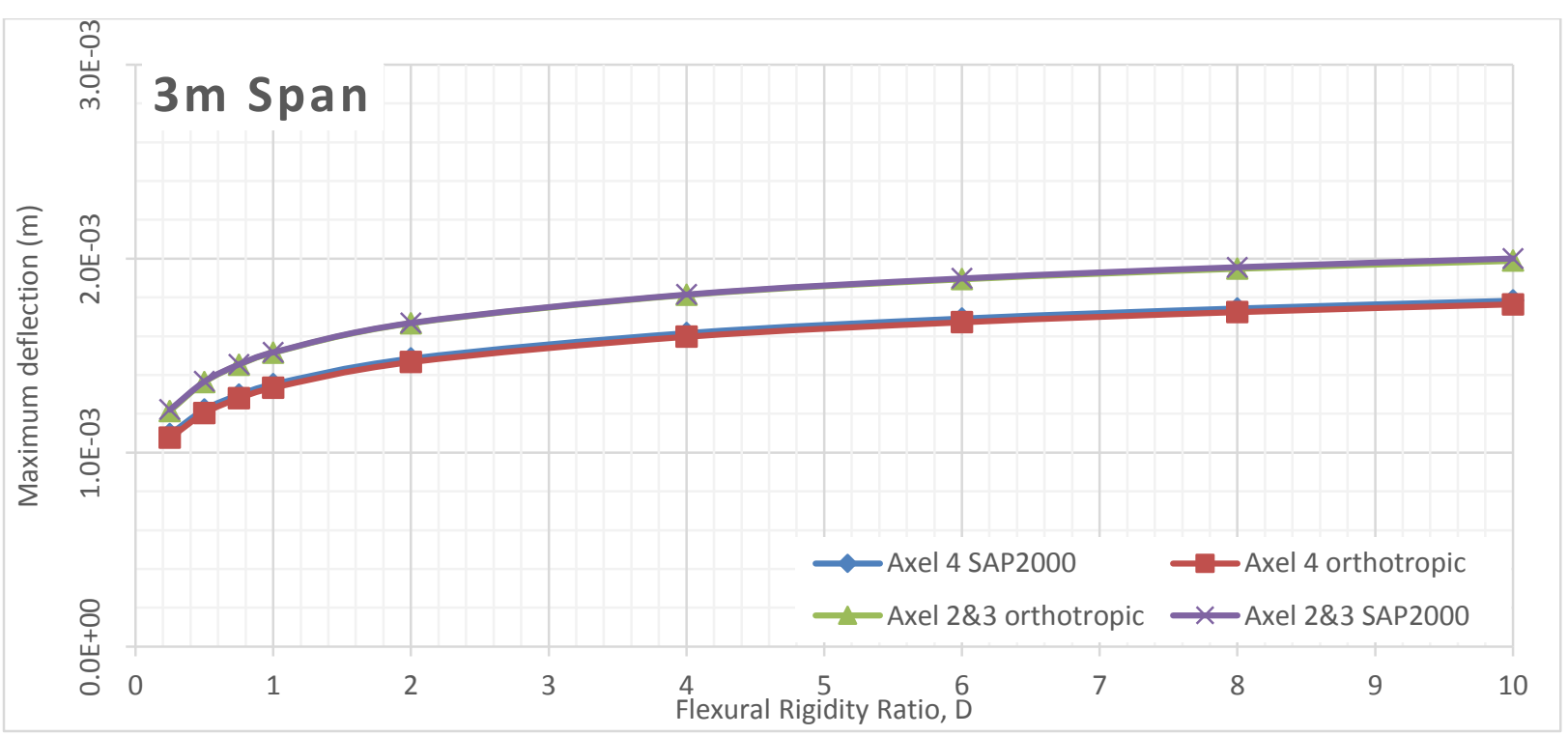

Figure 1024 Deflection comparison between FEA and Orthotropic Plate Theory for $3 \mathrm{~m}$ span of alpha 4 (main bars parallel to traffic) 


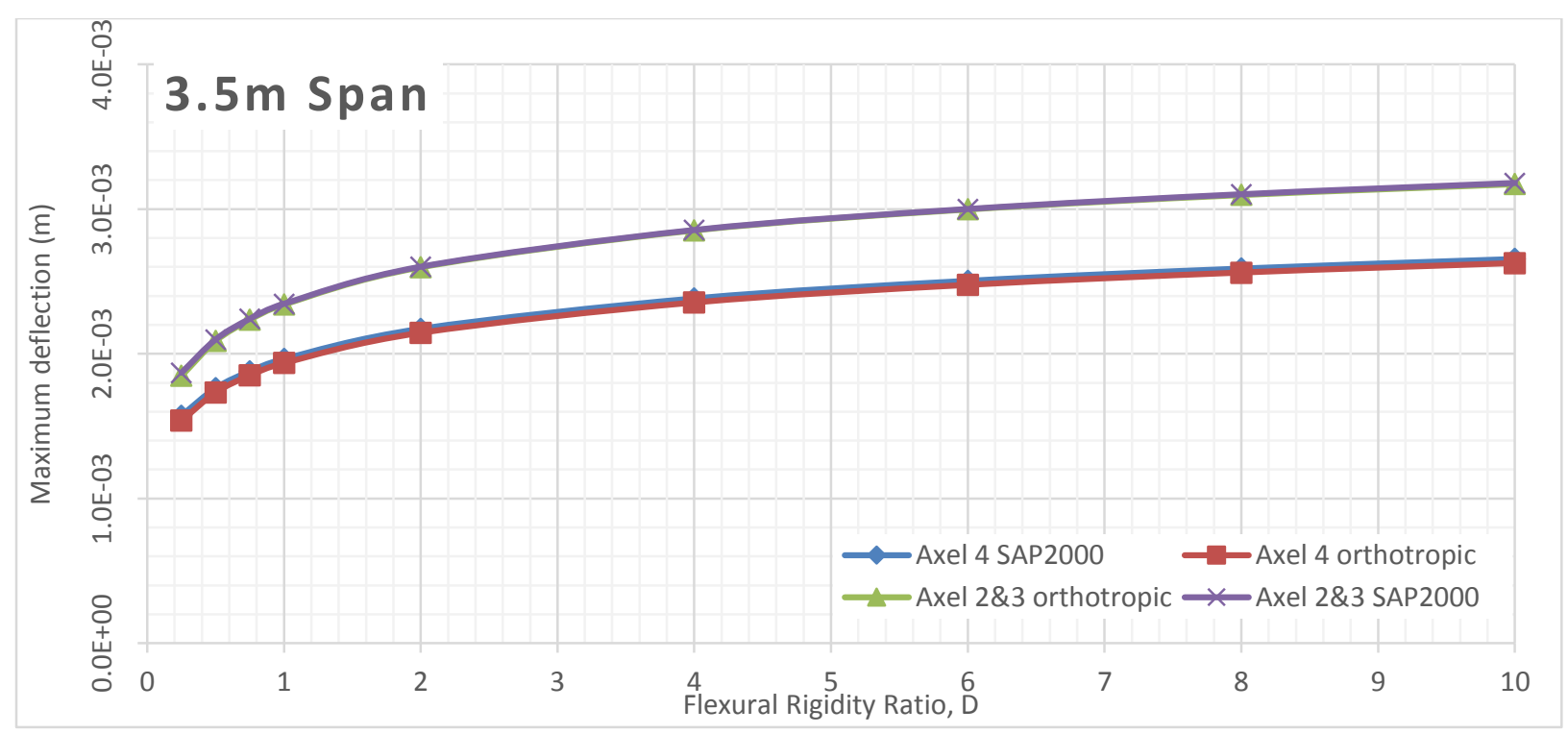

Figure 1025 Deflection comparison between FEA and Orthotropic Plate Theory for $3.5 \mathrm{~m}$ span of alpha 4 (main bars parallel to traffic)

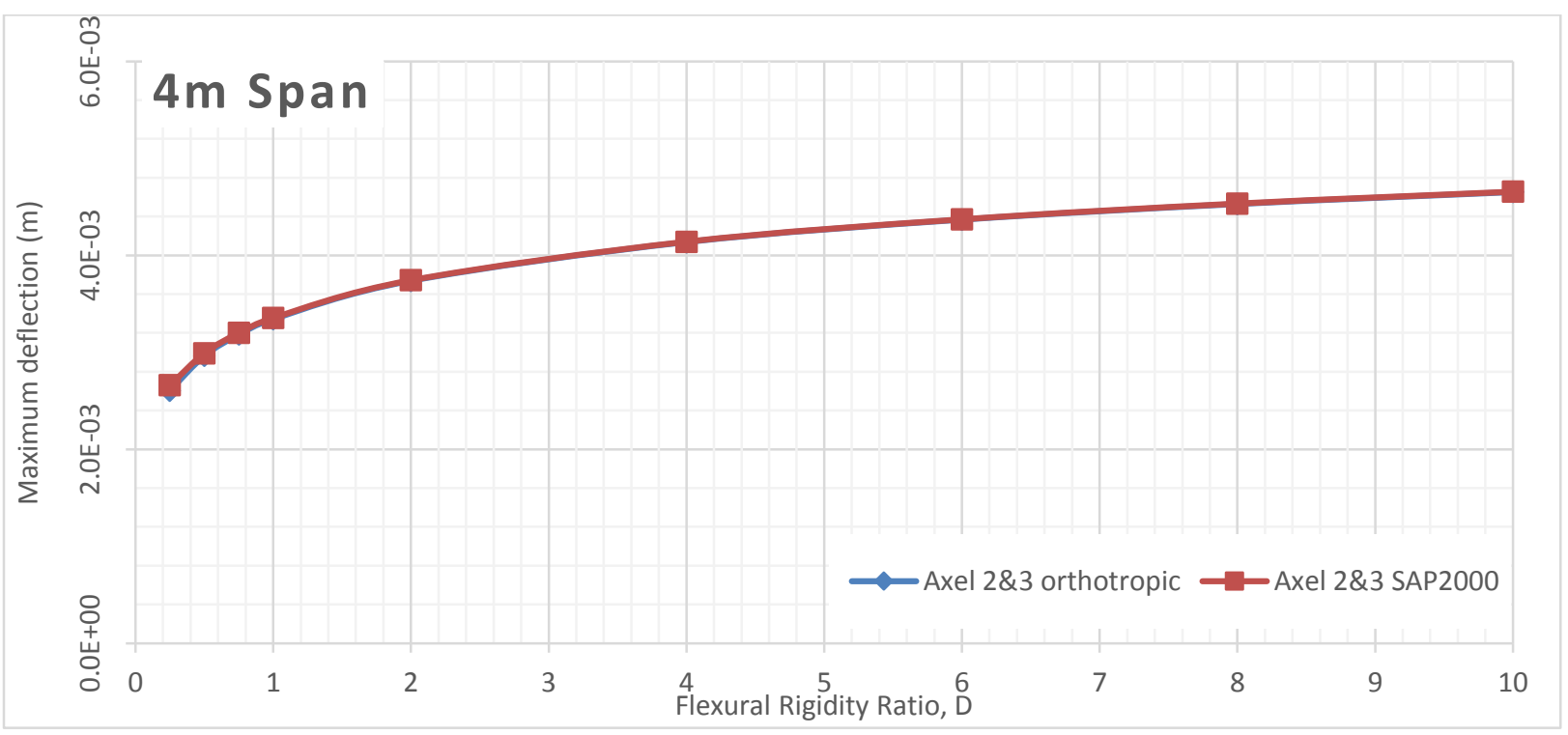

Figure 1026 Deflection comparison between FEA and Orthotropic Plate Theory for $4 \mathrm{~m}$ span of alpha 4 (main bars parallel to traffic) 


\section{Alpha 6 Deflection VS Flexural Rigidity for Different Span Length (Main bars perpendicular to traffic)}

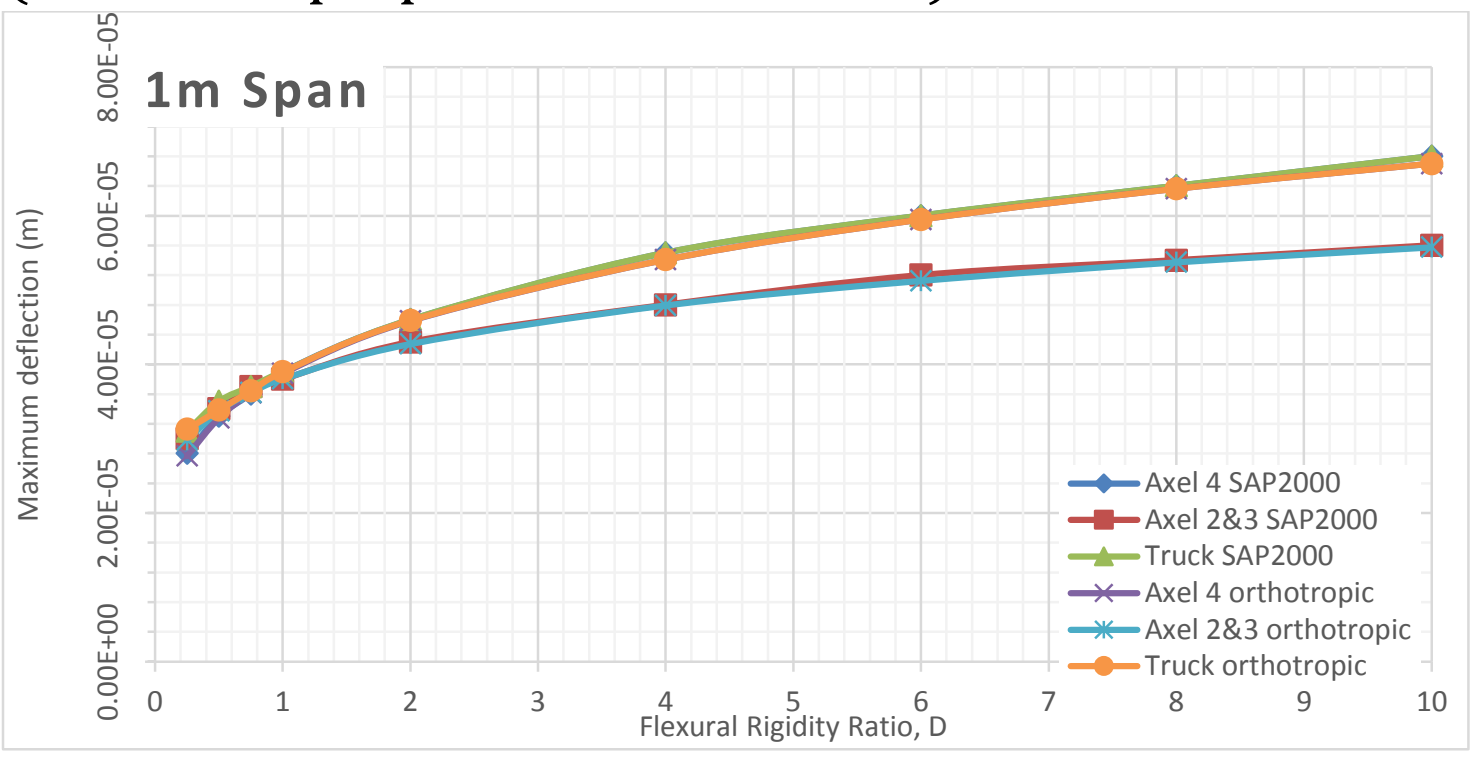

Figure 1027 Deflection comparison between FEA and Orthotropic Plate Theory for $1 \mathrm{~m}$ span of alpha 6 (main bars perpendicular to traffic)

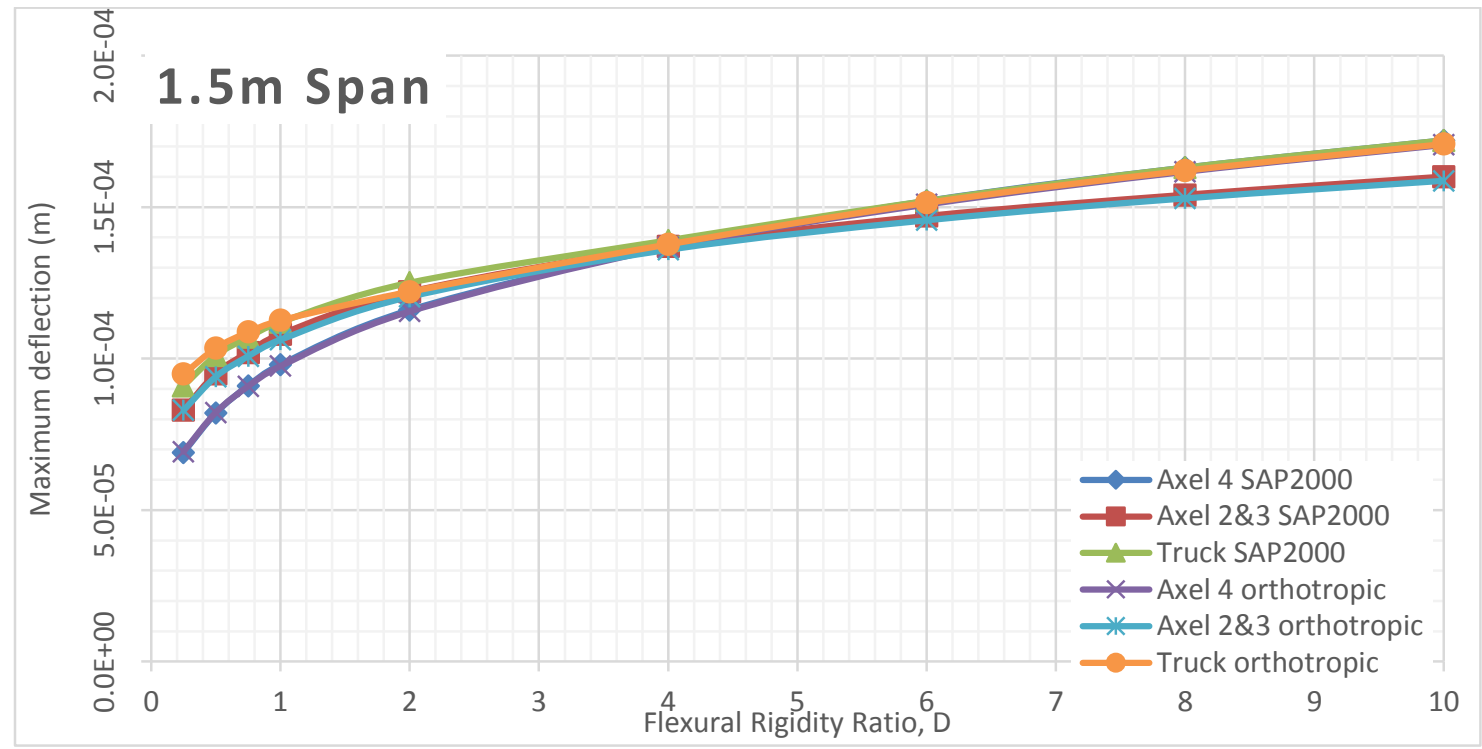

Figure 1028 Deflection comparison between FEA and Orthotropic Plate Theory for $1.5 \mathrm{~m}$ span of alpha 6 (main bars perpendicular to traffic) 


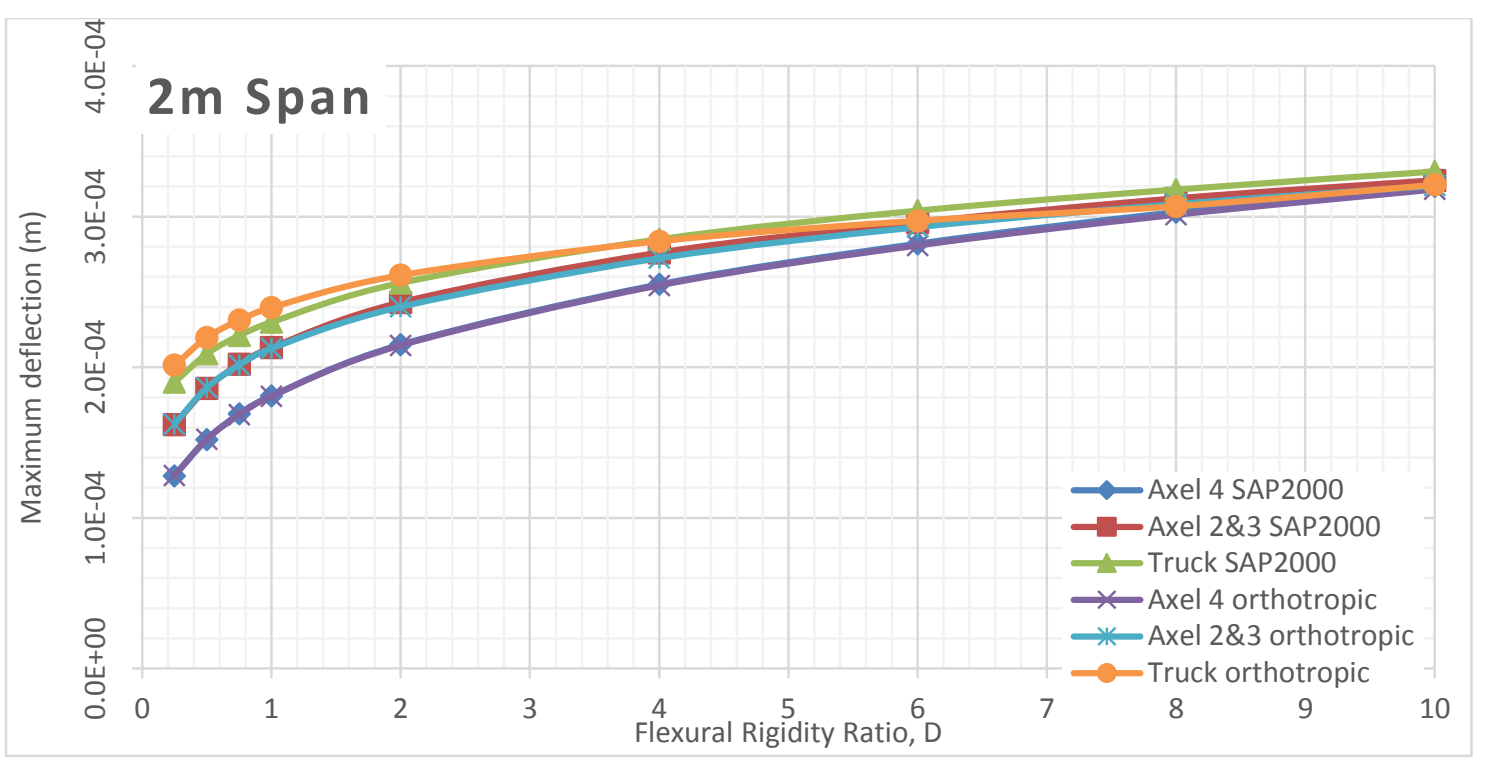

Figure 1029 Deflection comparison between FEA and Orthotropic Plate Theory for $2 \mathrm{~m}$ span of alpha 6 (main bars perpendicular to traffic)

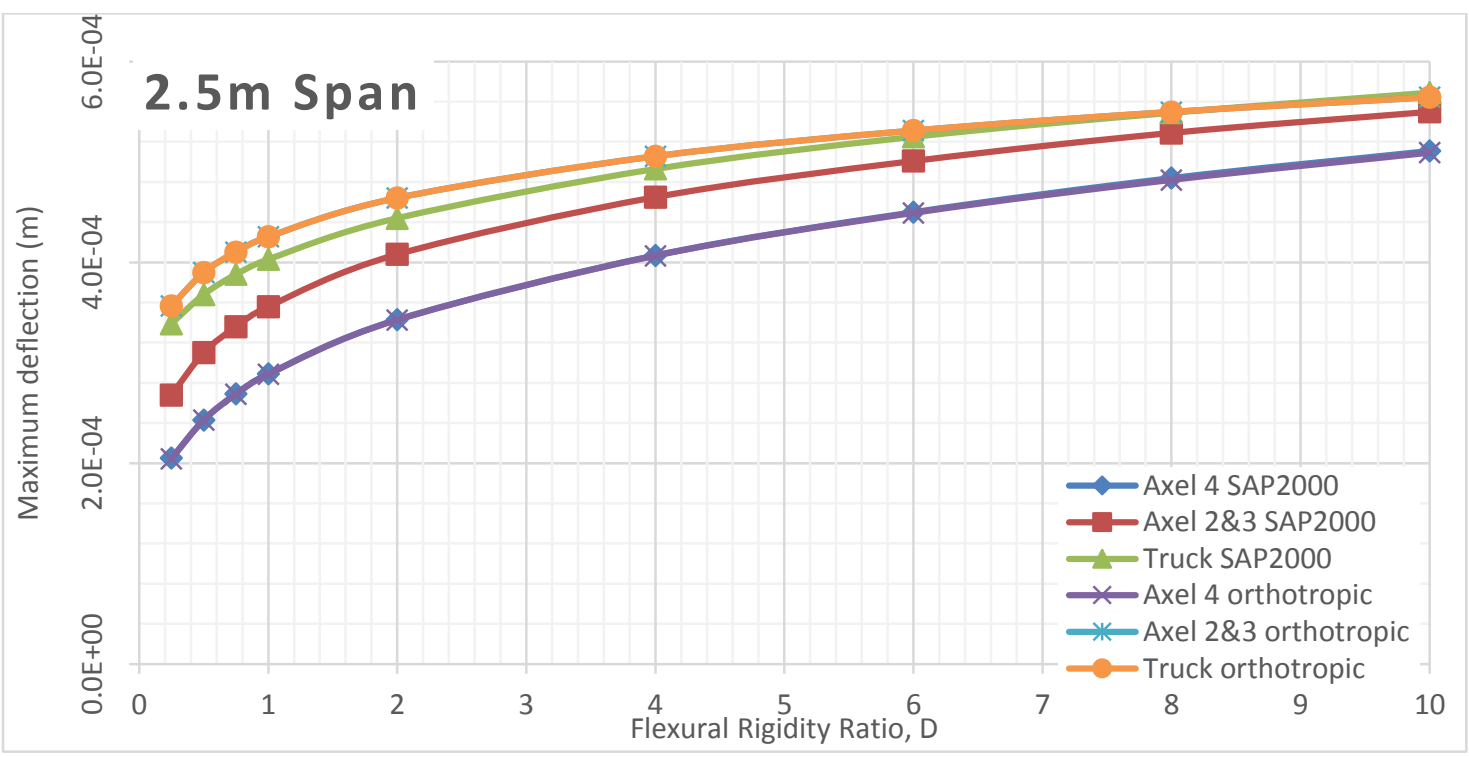

Figure 1030 Deflection comparison between FEA and Orthotropic Plate Theory for $2.5 \mathrm{~m}$ span of alpha 6 (main bars perpendicular to traffic)

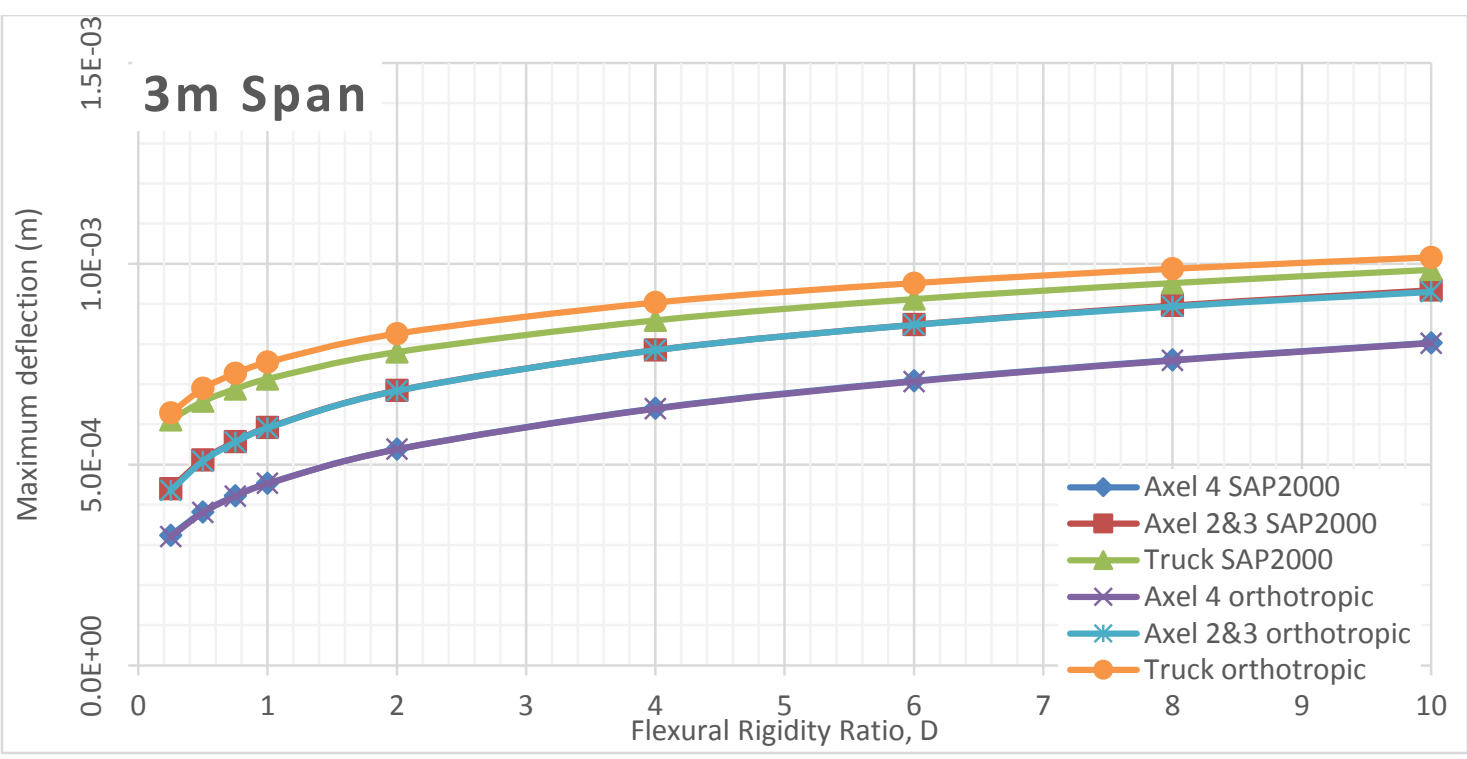

Figure 1031 Deflection comparison between FEA and Orthotropic Plate Theory for $3 \mathrm{~m}$ span of alpha 6 (main bars perpendicular to traffic) 


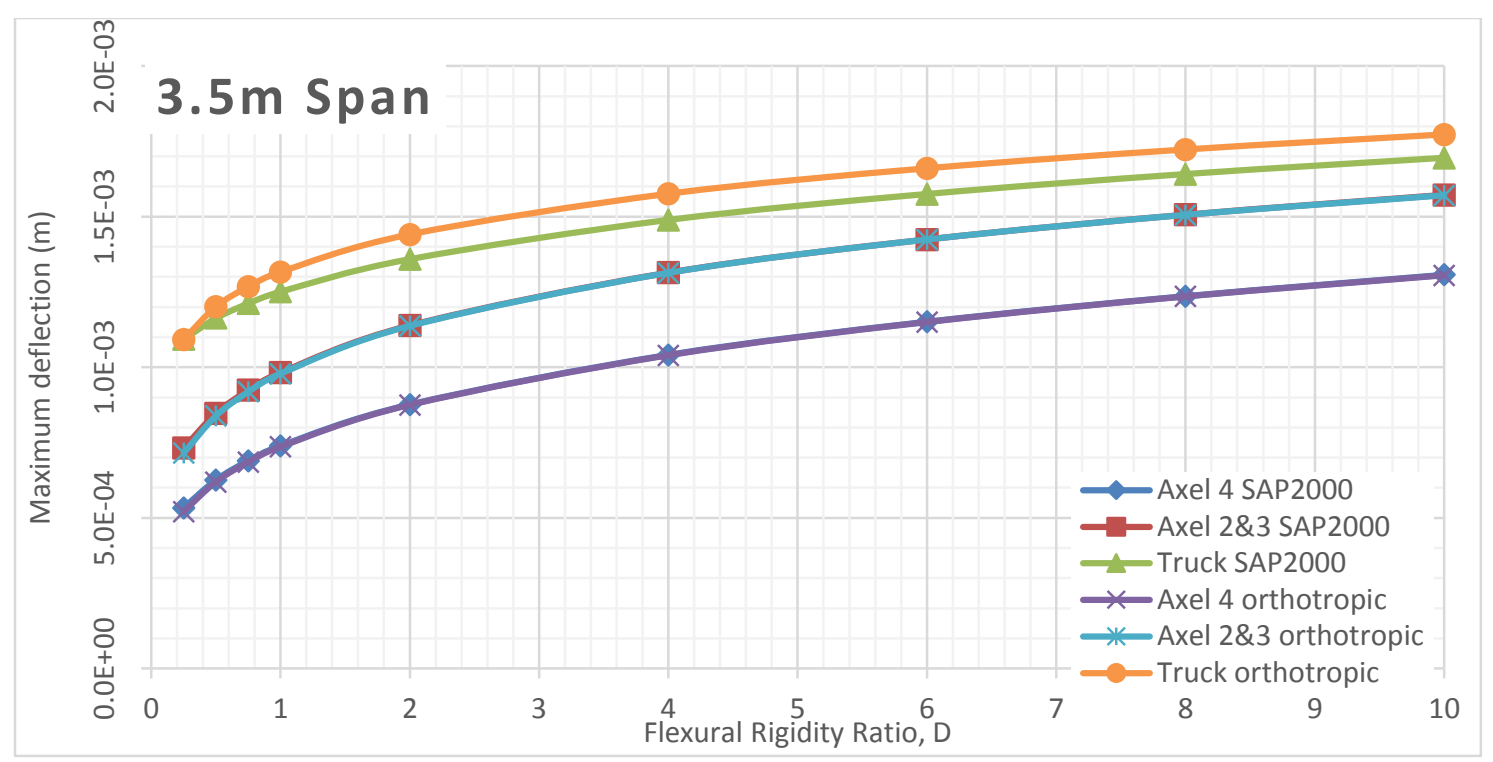

Figure 1032 Deflection comparison between FEA and Orthotropic Plate Theory for $3.5 \mathrm{~m}$ span of alpha 6 (main bars perpendicular to traffic)

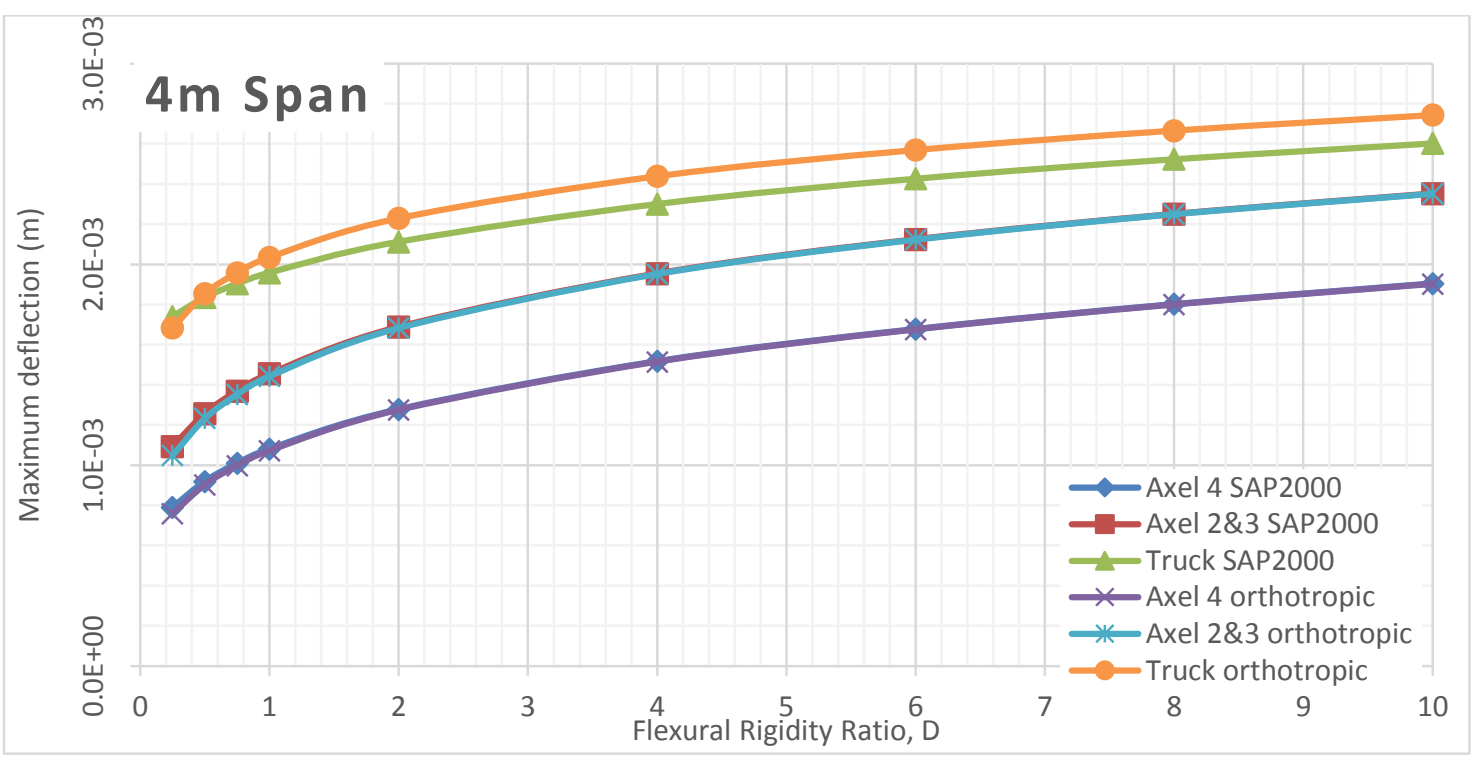

Figure 1033 Deflection comparison between FEA and Orthotropic Plate Theory for $4 \mathrm{~m}$ span of alpha 6 (main bars perpendicular to traffic) 


\section{Alpha 6 Deflection VS Flexural Rigidity for Different Span Length (Main bars parallel to traffic)}

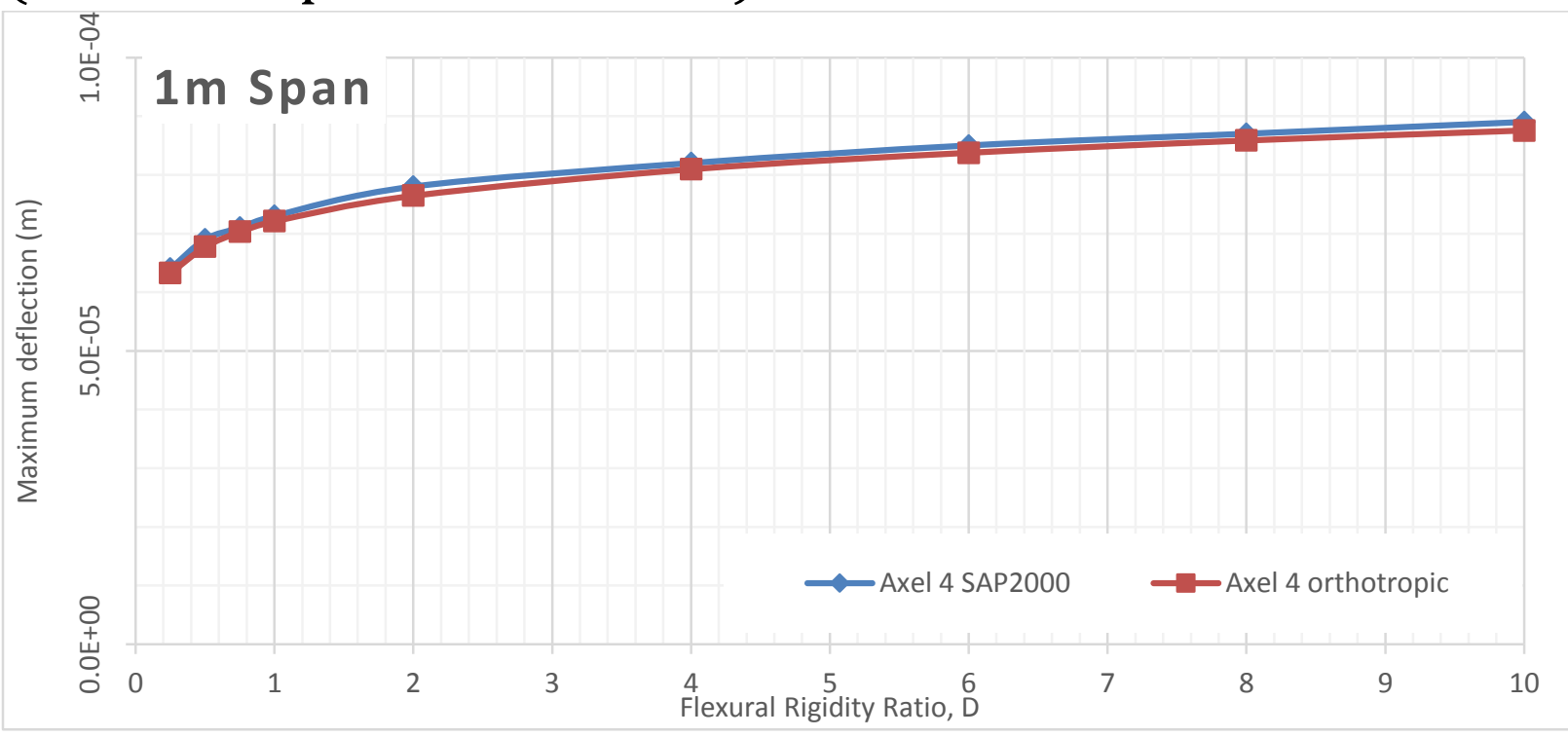

Figure 1034 Deflection comparison between FEA and Orthotropic Plate Theory for $1 \mathrm{~m}$ span of alpha 6 (main bars parallel to traffic)

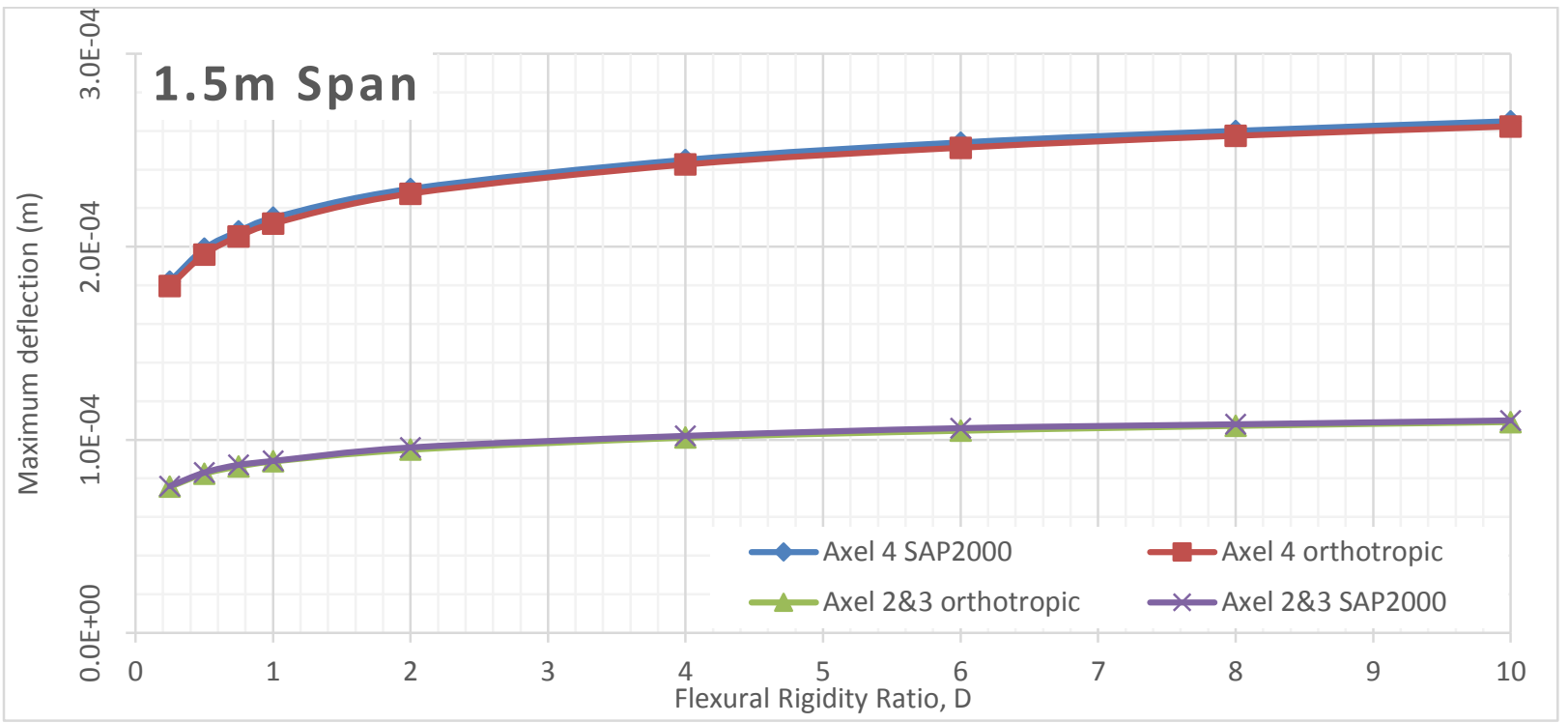

Figure 1035 Deflection comparison between FEA and Orthotropic Plate Theory for $1.5 \mathrm{~m}$ span of alpha 6 (main bars parallel to traffic) 


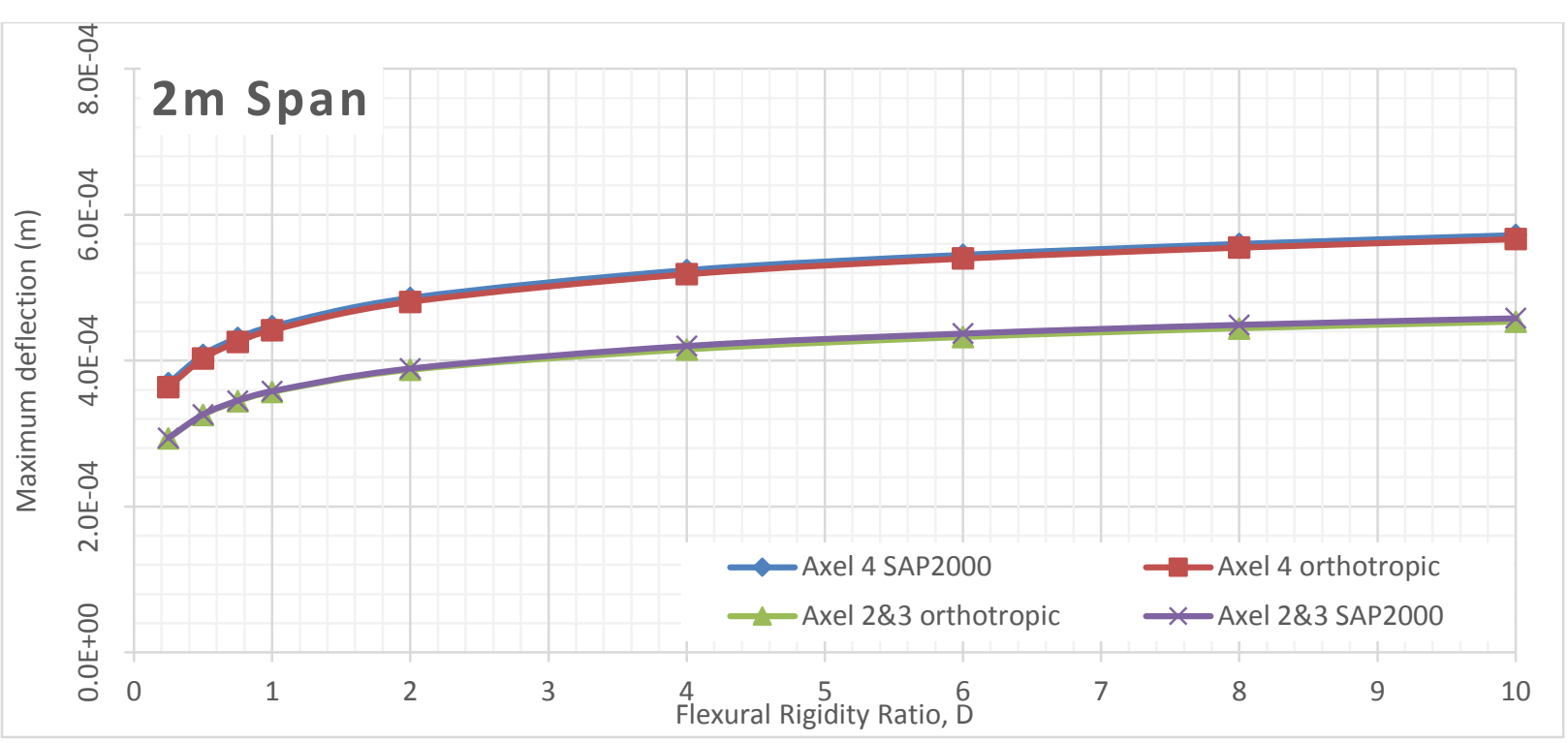

Figure 1036 Deflection comparison between FEA and Orthotropic Plate Theory for $2 \mathrm{~m}$ span of alpha 6 (main bars parallel to traffic)

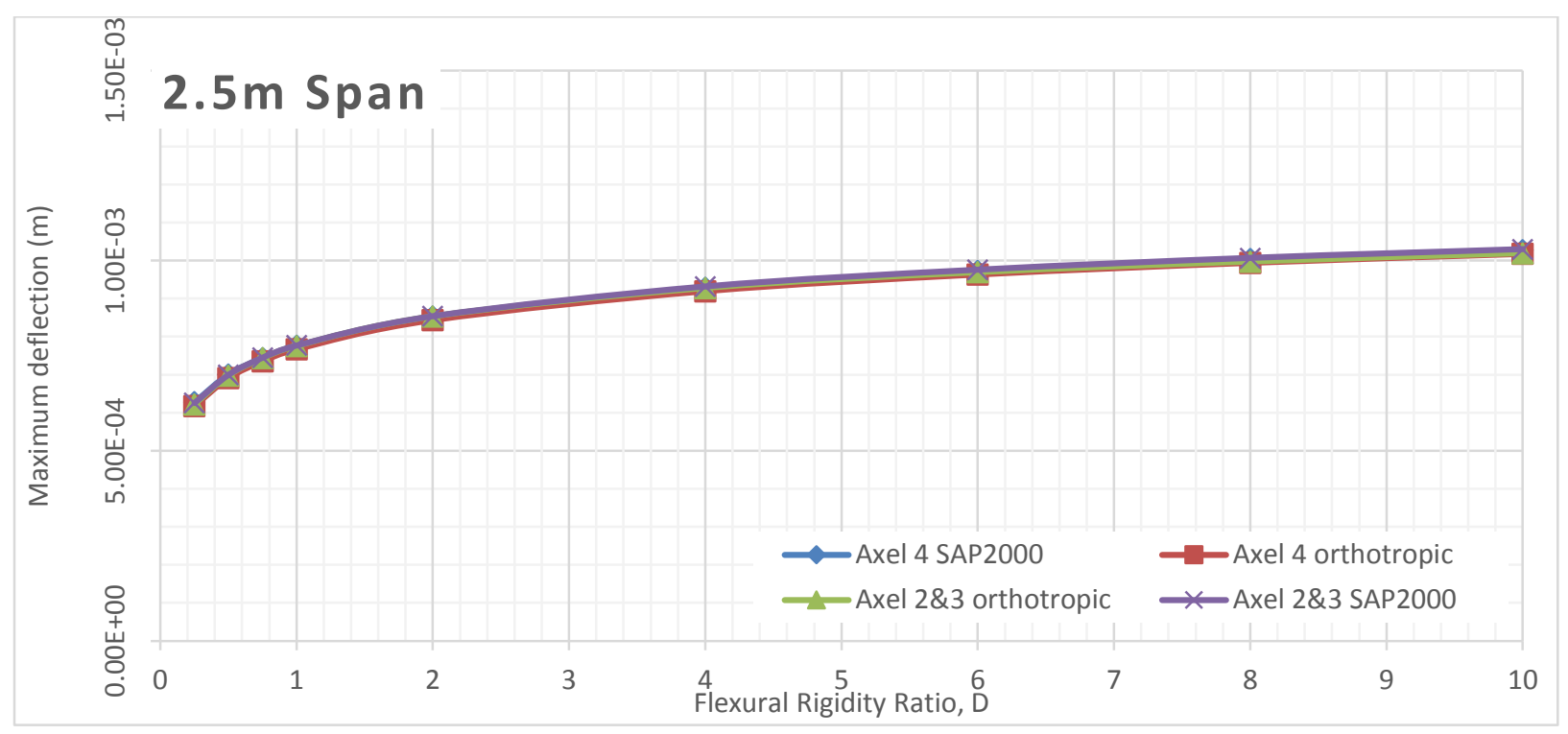

Figure 1037 Deflection comparison between FEA and Orthotropic Plate Theory for $2.5 \mathrm{~m}$ span of alpha 6 (main bars parallel to traffic)

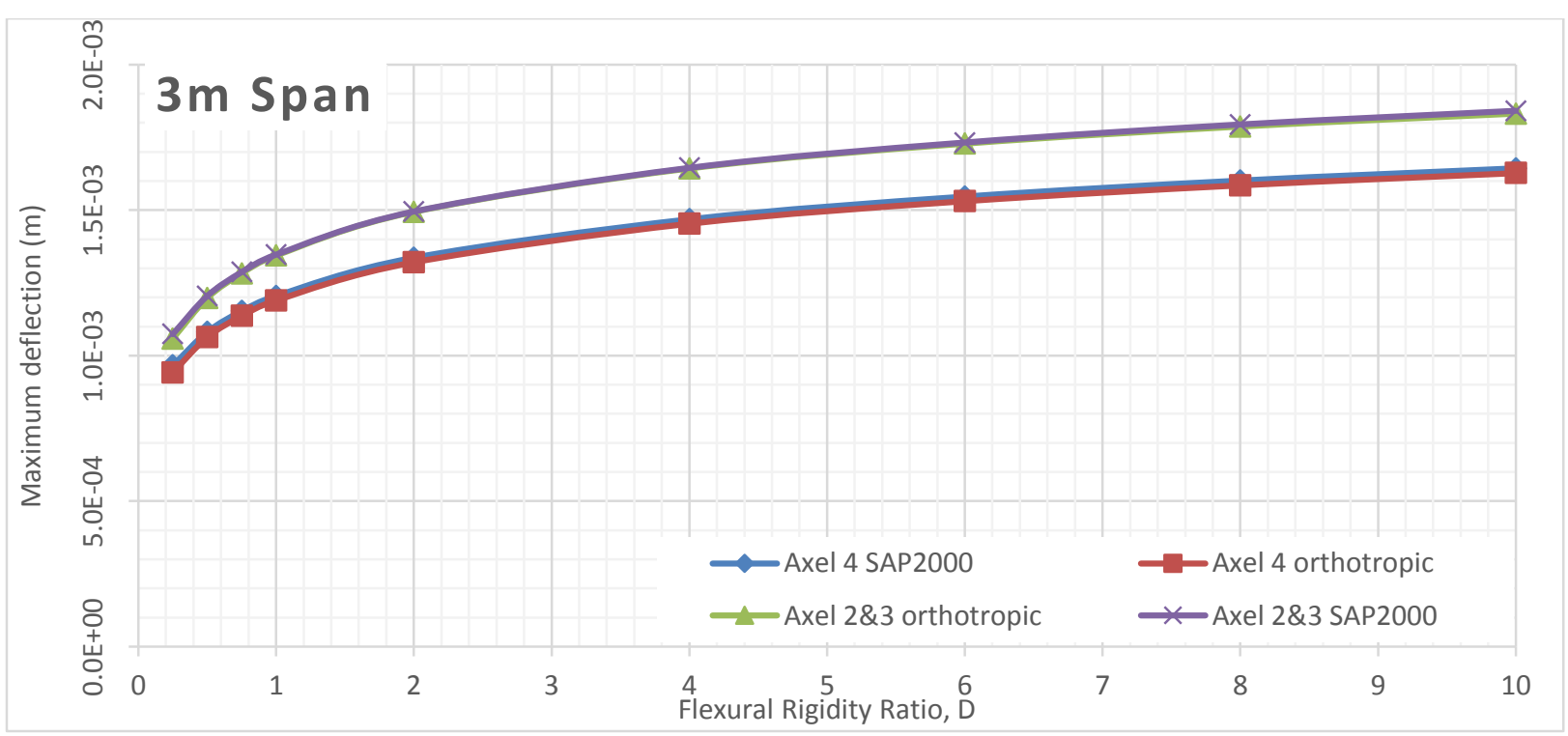

Figure 1038 Deflection comparison between FEA and Orthotropic Plate Theory for $3 \mathrm{~m}$ span of alpha 6 (main bars parallel to traffic) 


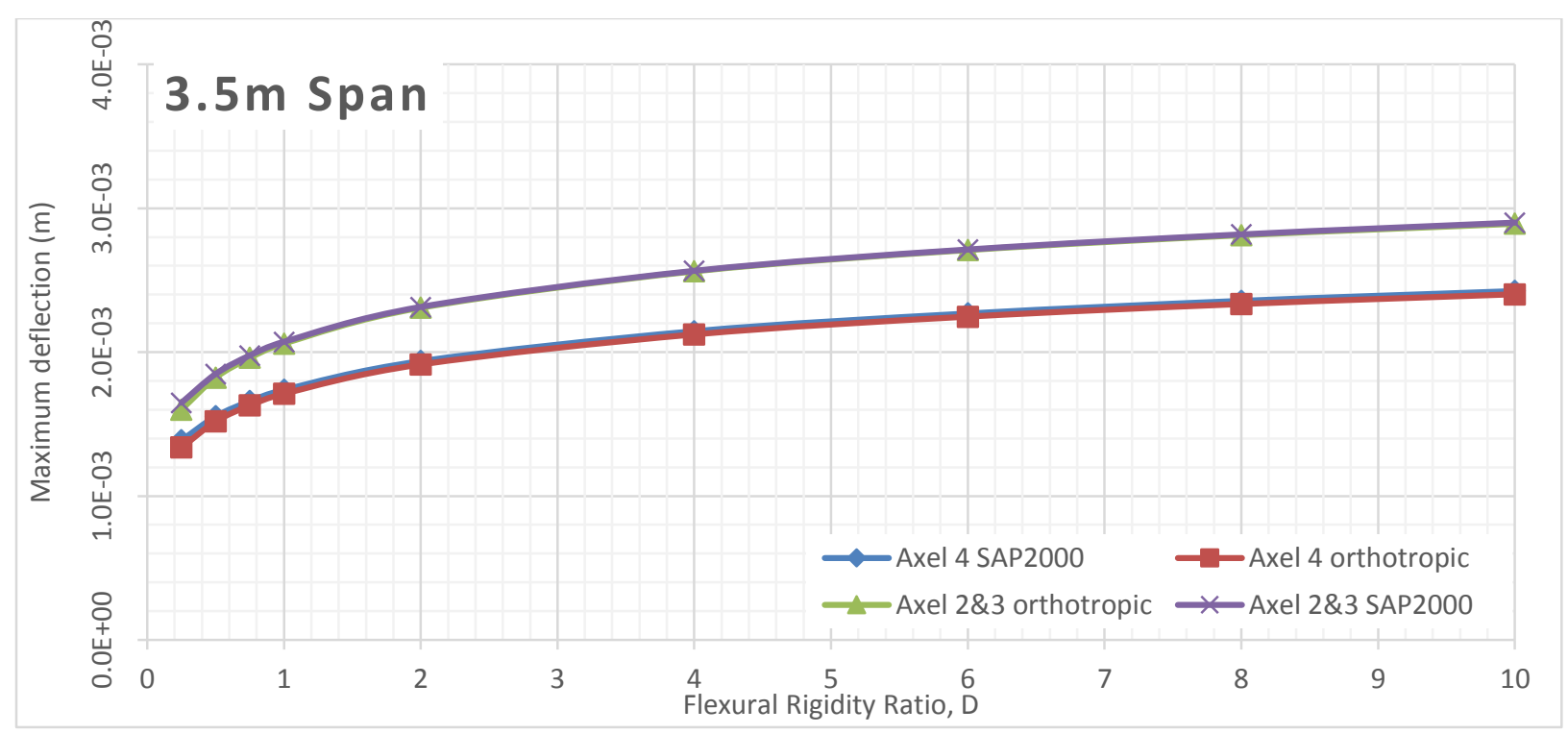

Figure 1039 Deflection comparison between FEA and Orthotropic Plate Theory for $3.5 \mathrm{~m}$ span of alpha 6 (main bars parallel to traffic)

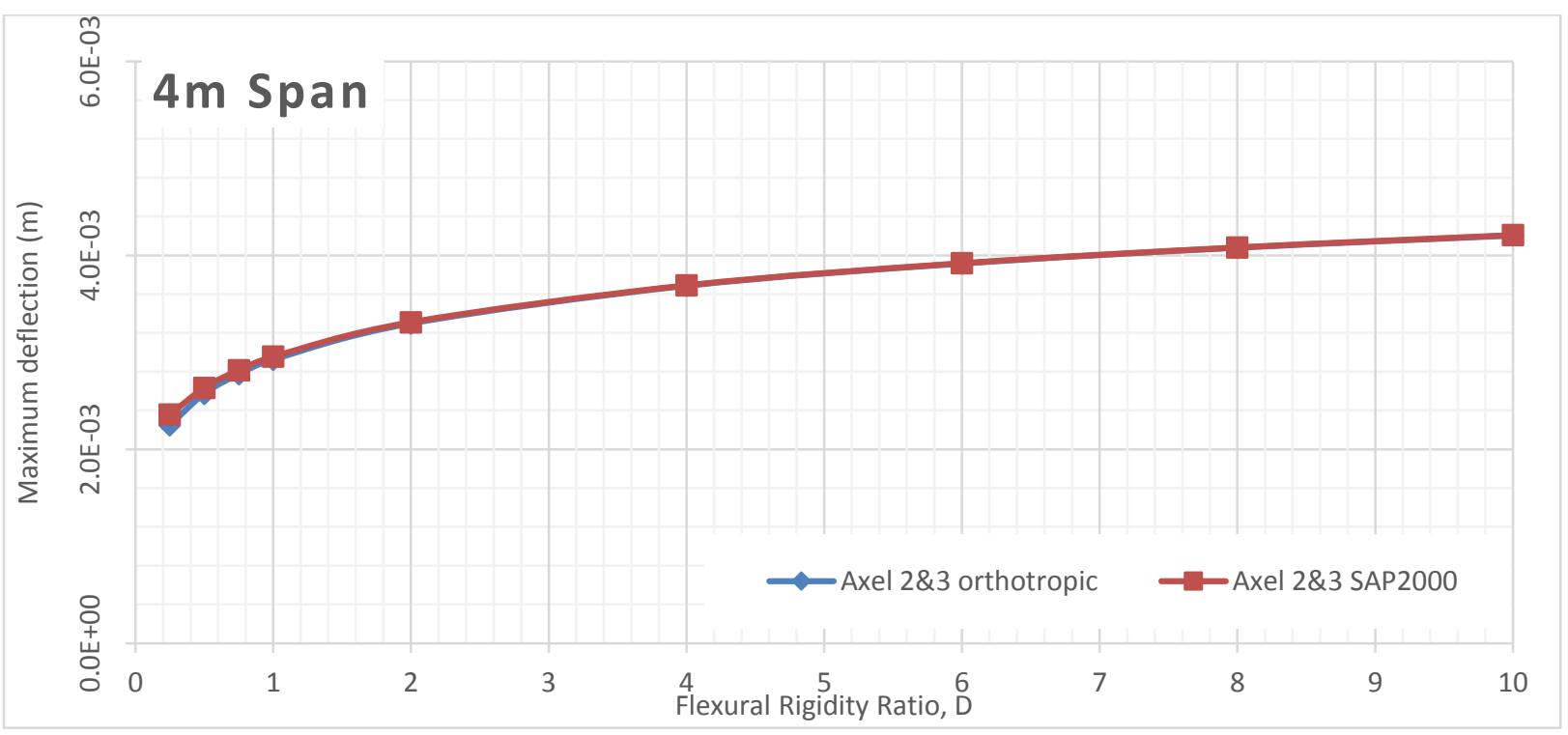

Figure 1040 Deflection comparison between FEA and Orthotropic Plate Theory for $4 \mathrm{~m}$ span of alpha 6 (main bars parallel to traffic) 


\section{Alpha 8 Deflection VS Flexural Rigidity for Different Span Length (Main bars perpendicular to traffic)}

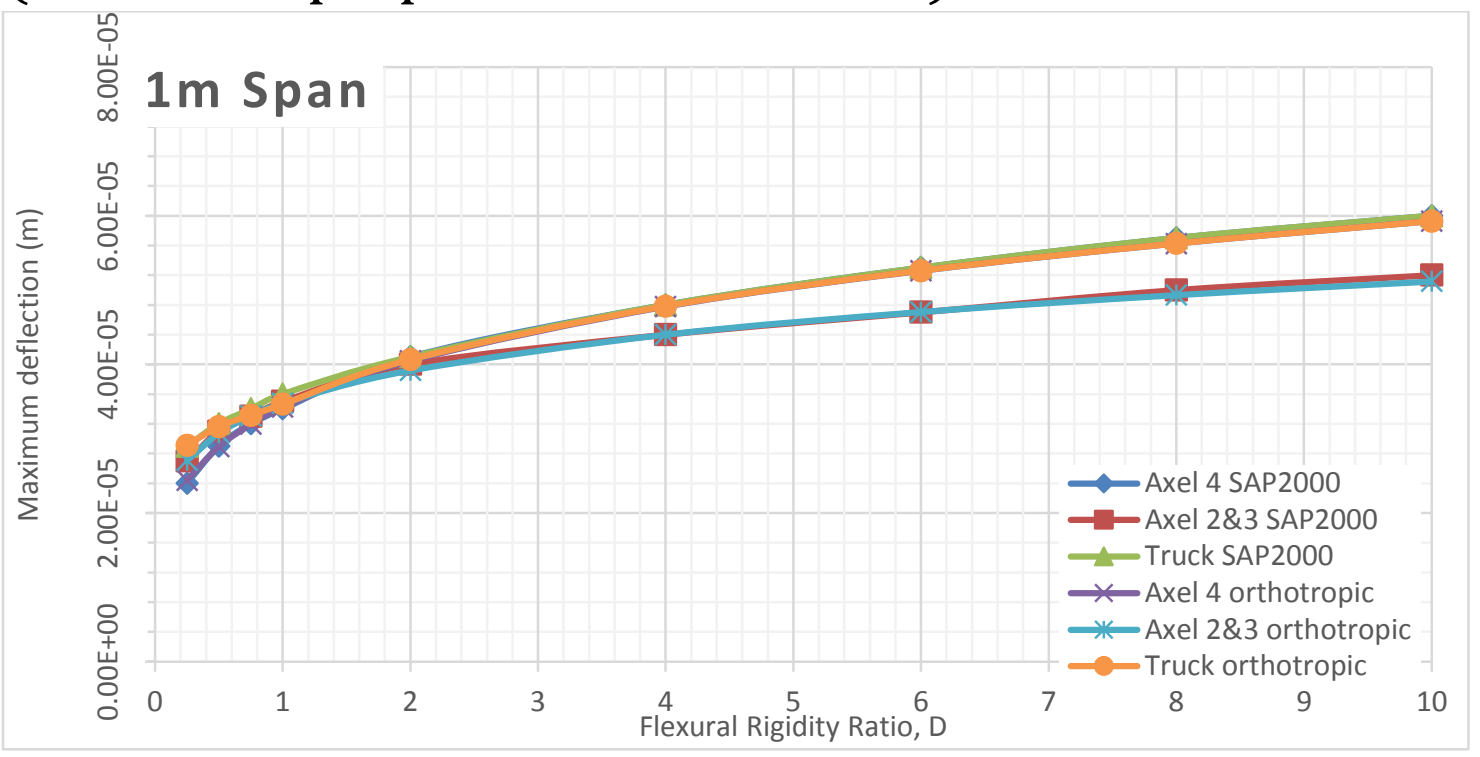

Figure 1041 Deflection comparison between FEA and Orthotropic Plate Theory for $1 \mathrm{~m}$ span of alpha 8 (main bars perpendicular to traffic)

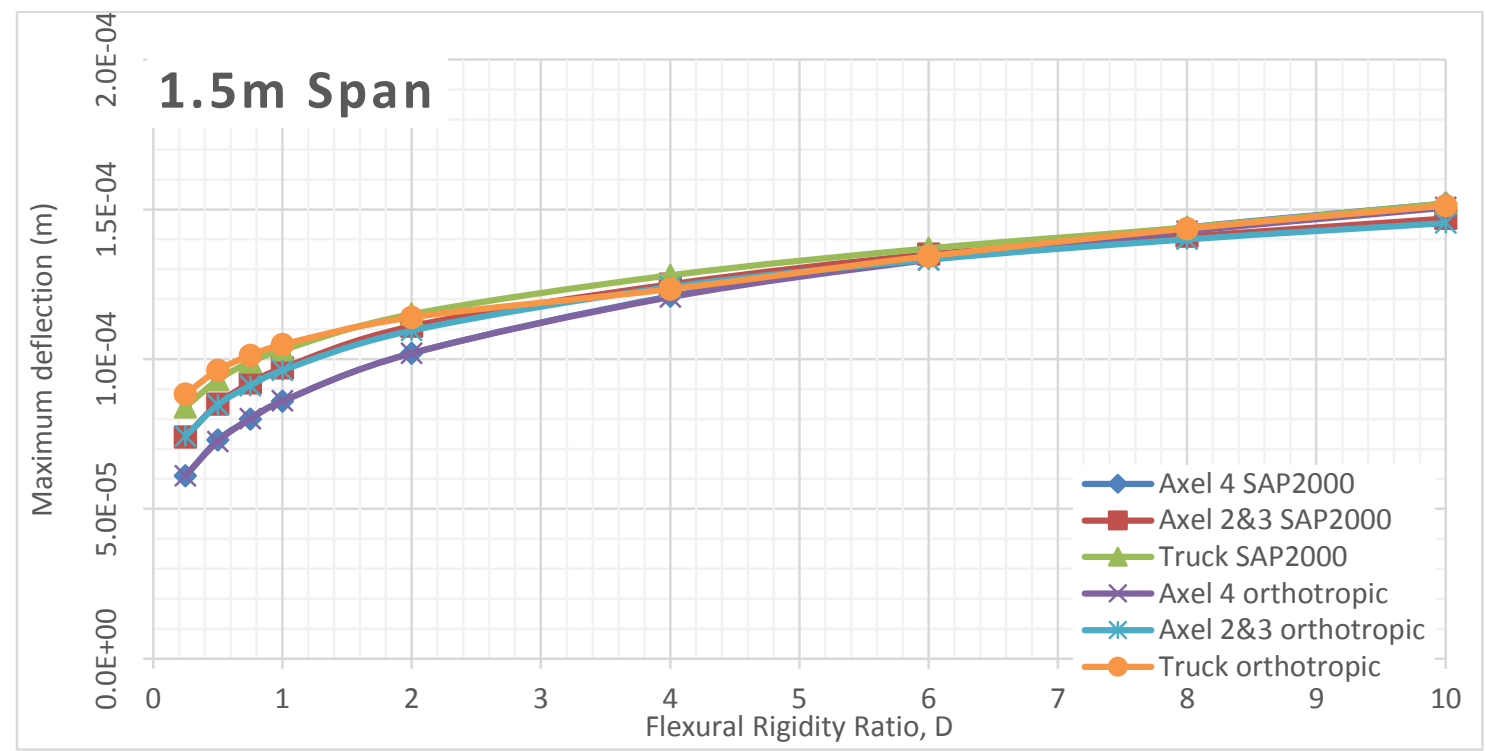

Figure 1042 Deflection comparison between FEA and Orthotropic Plate Theory for $1.5 \mathrm{~m}$ span of alpha 8 (main bars perpendicular to traffic) 


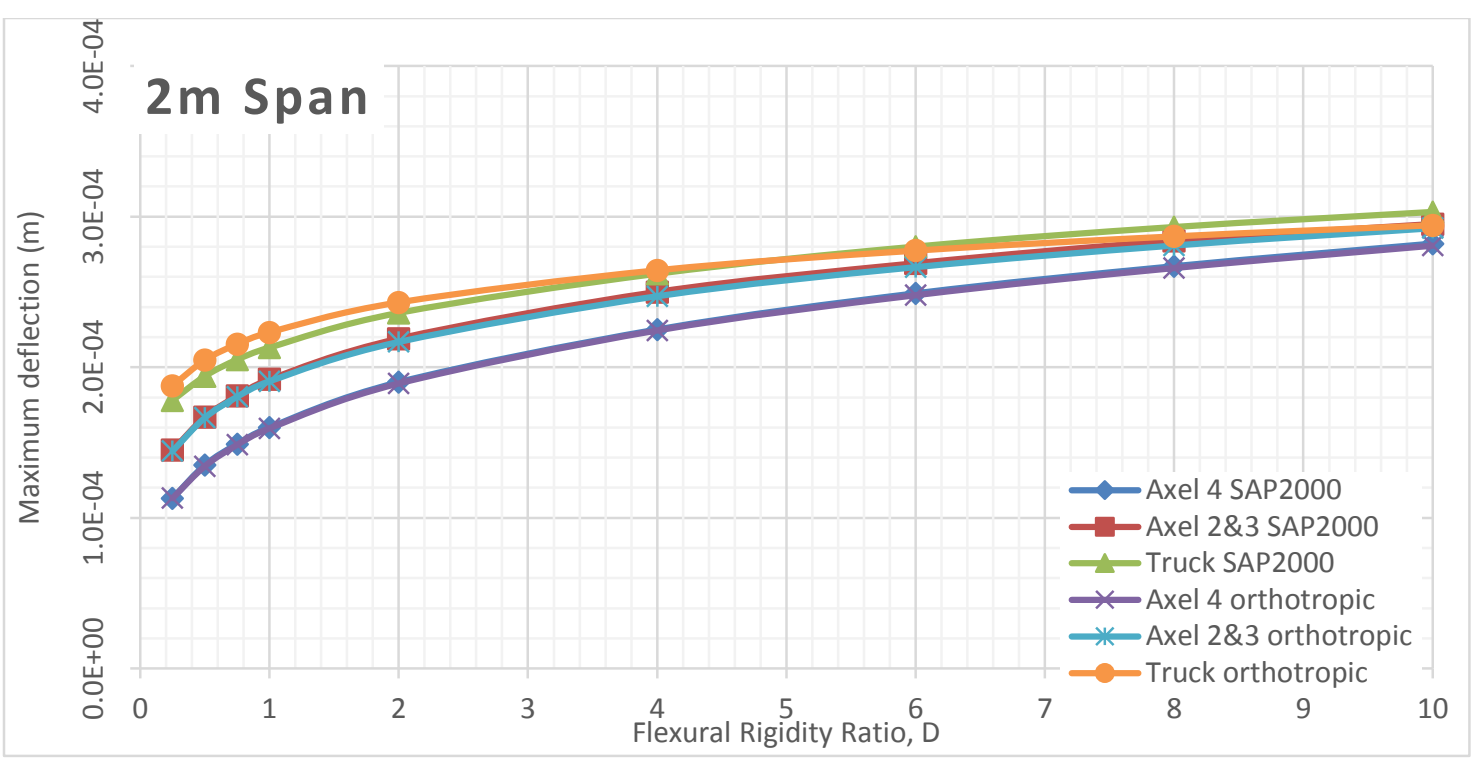

Figure 1043 Deflection comparison between FEA and Orthotropic Plate Theory for $2 \mathrm{~m}$ span of alpha 8 (main bars perpendicular to traffic)

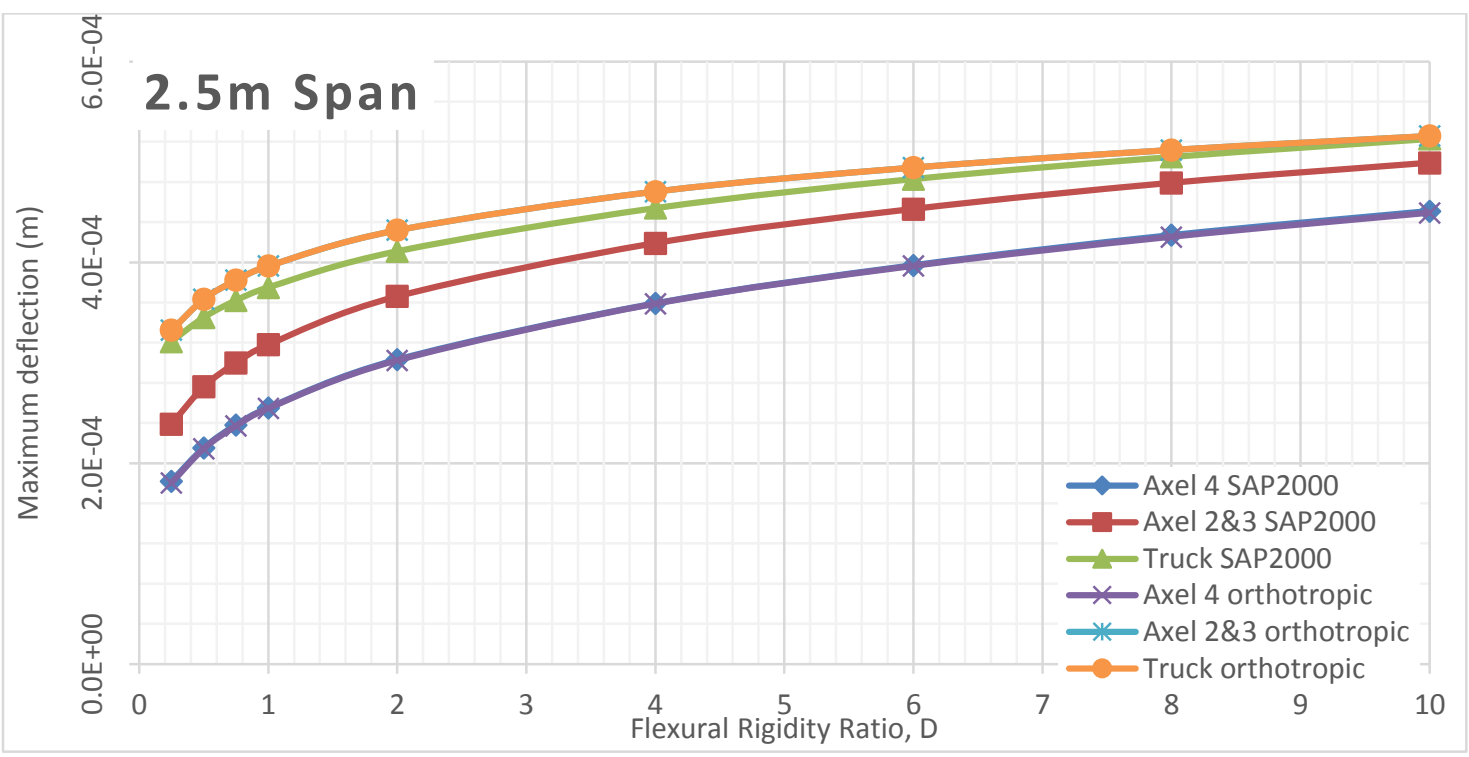

Figure 1044 Deflection comparison between FEA and Orthotropic Plate Theory for $2.5 \mathrm{~m}$ span of alpha 8 (main bars perpendicular to traffic)

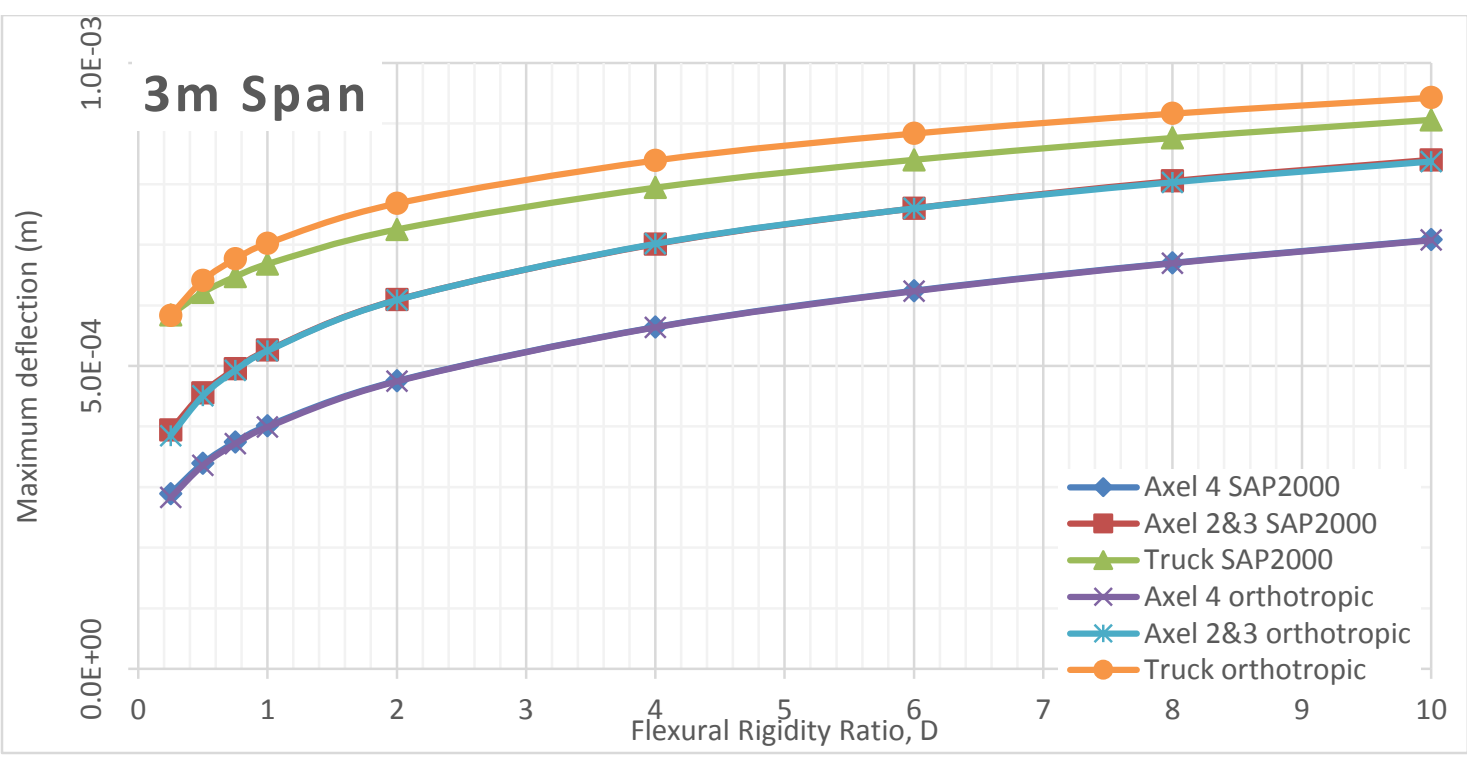

Figure 1045 Deflection comparison between FEA and Orthotropic Plate Theory for $3 \mathrm{~m}$ span of alpha 8 (main bars perpendicular to traffic) 


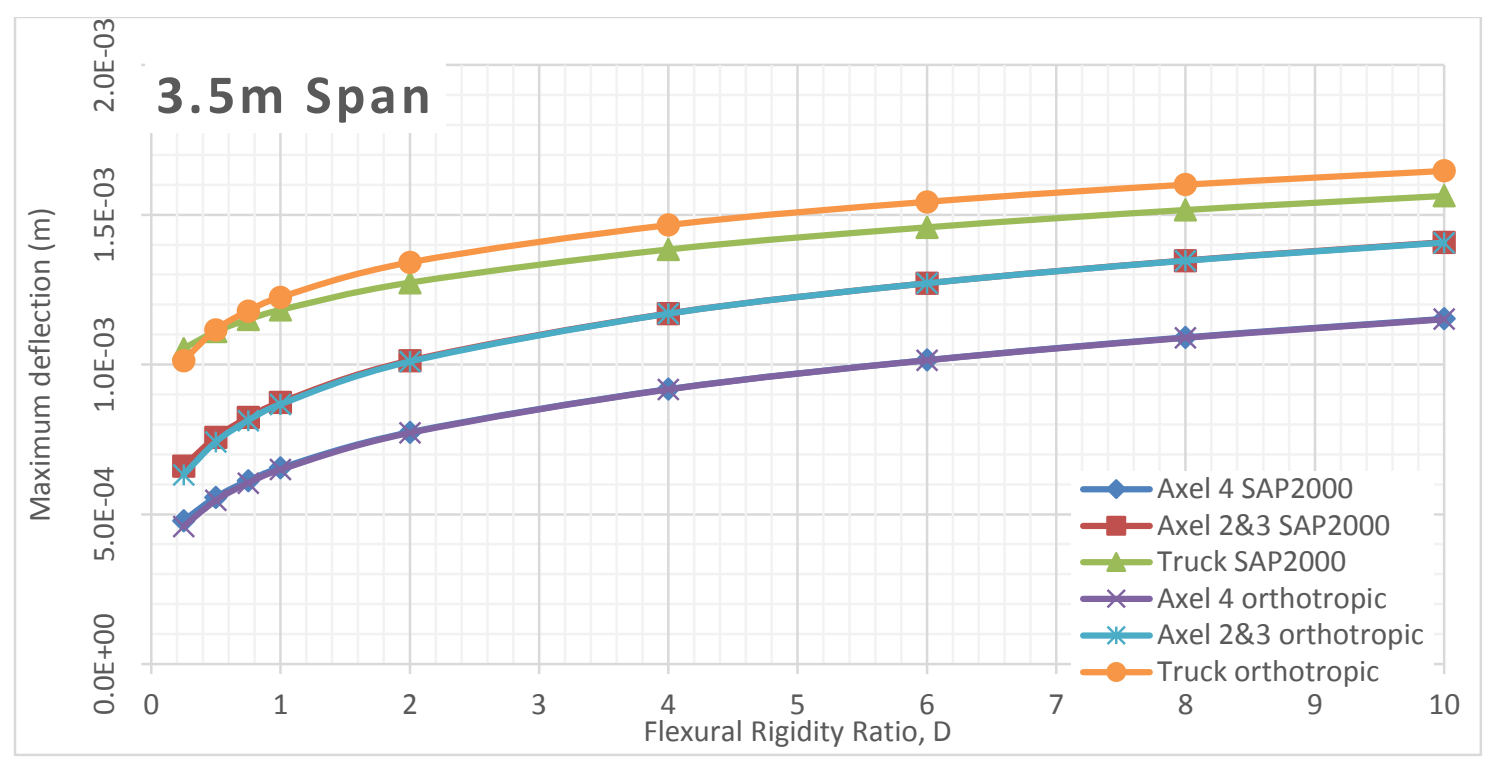

Figure 1046 Deflection comparison between FEA and Orthotropic Plate Theory for $3.5 \mathrm{~m}$ span of alpha 8 (main bars perpendicular to traffic)

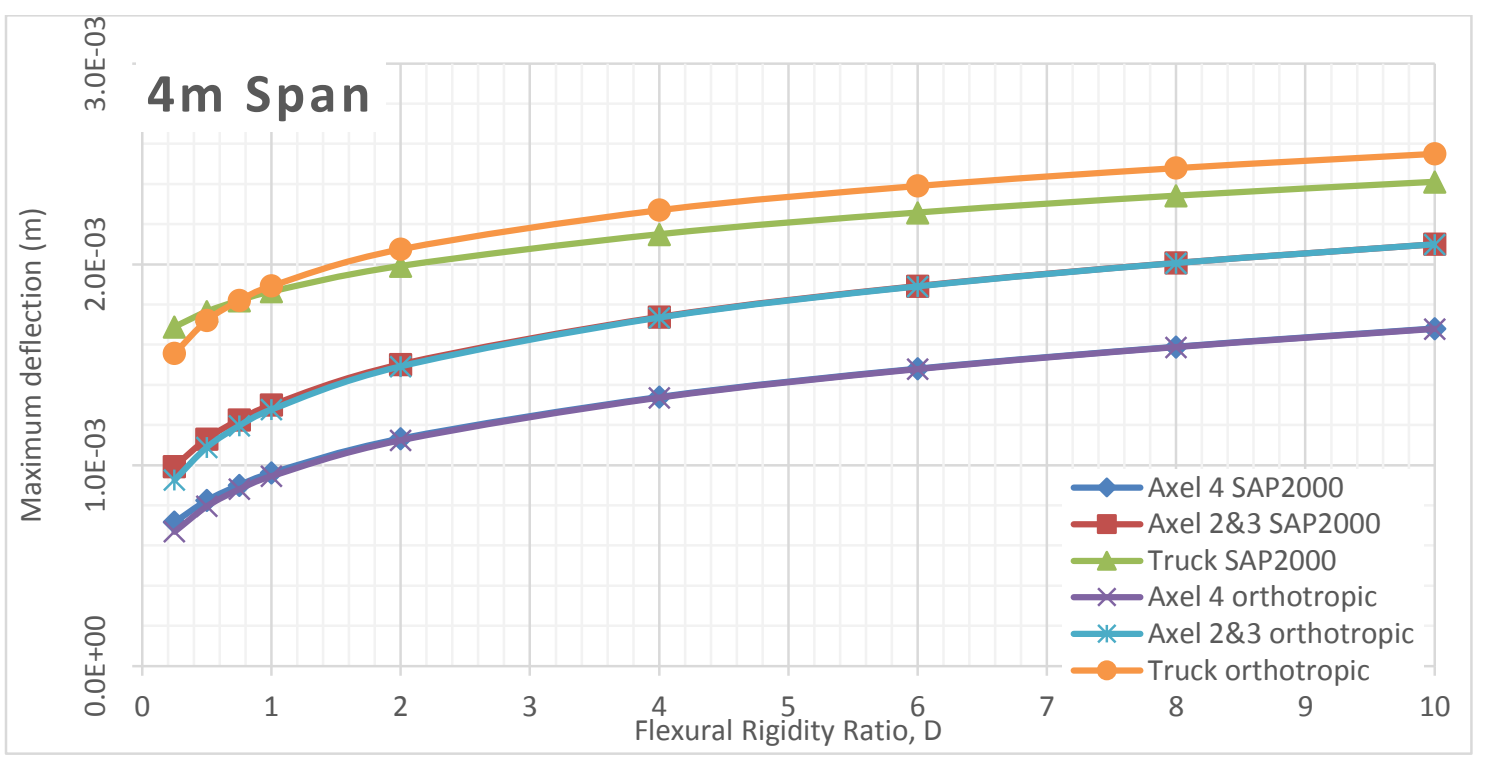

Figure 1047 Deflection comparison between FEA and Orthotropic Plate Theory for $4 \mathrm{~m}$ span of alpha 8 (main bars perpendicular to traffic) 


\section{Alpha 8 Deflection VS Flexural Rigidity for Different Span Length (Main bars parallel to traffic)}

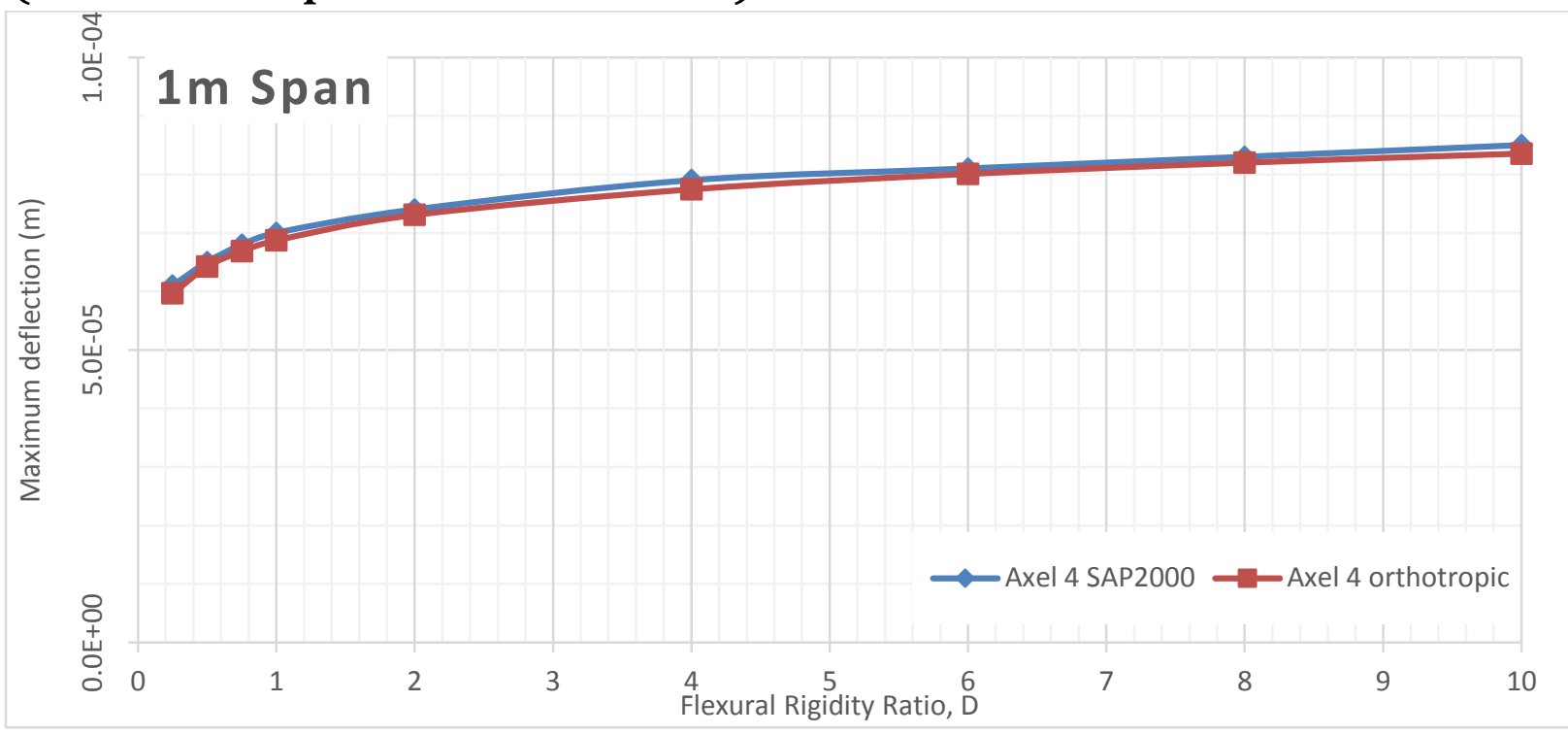

Figure 1048 Deflection comparison between FEA and Orthotropic Plate Theory for $1 \mathrm{~m}$ span of alpha 8 (main bars parallel to traffic)

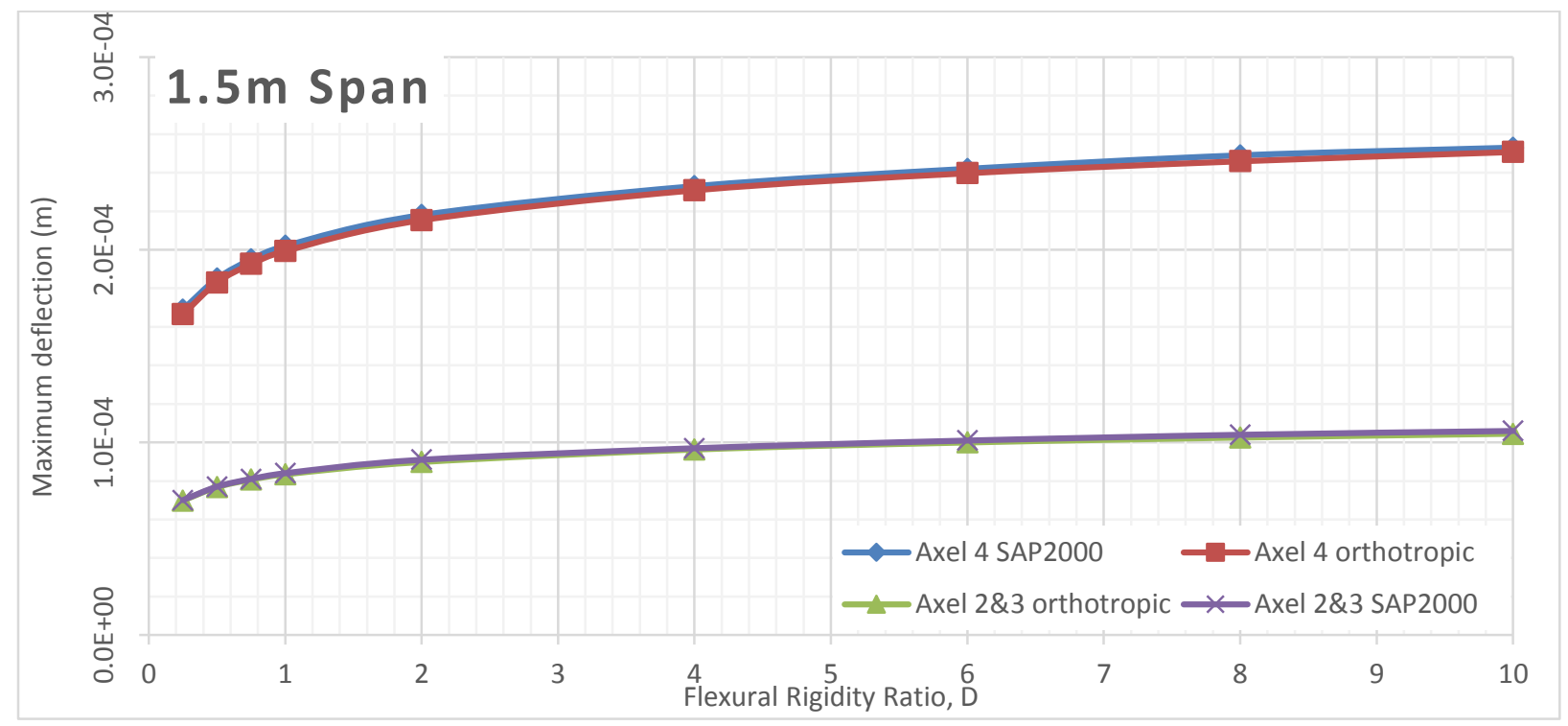

Figure 1049 Deflection comparison between FEA and Orthotropic Plate Theory for $1.5 \mathrm{~m}$ span of alpha 8 (main bars parallel to traffic) 


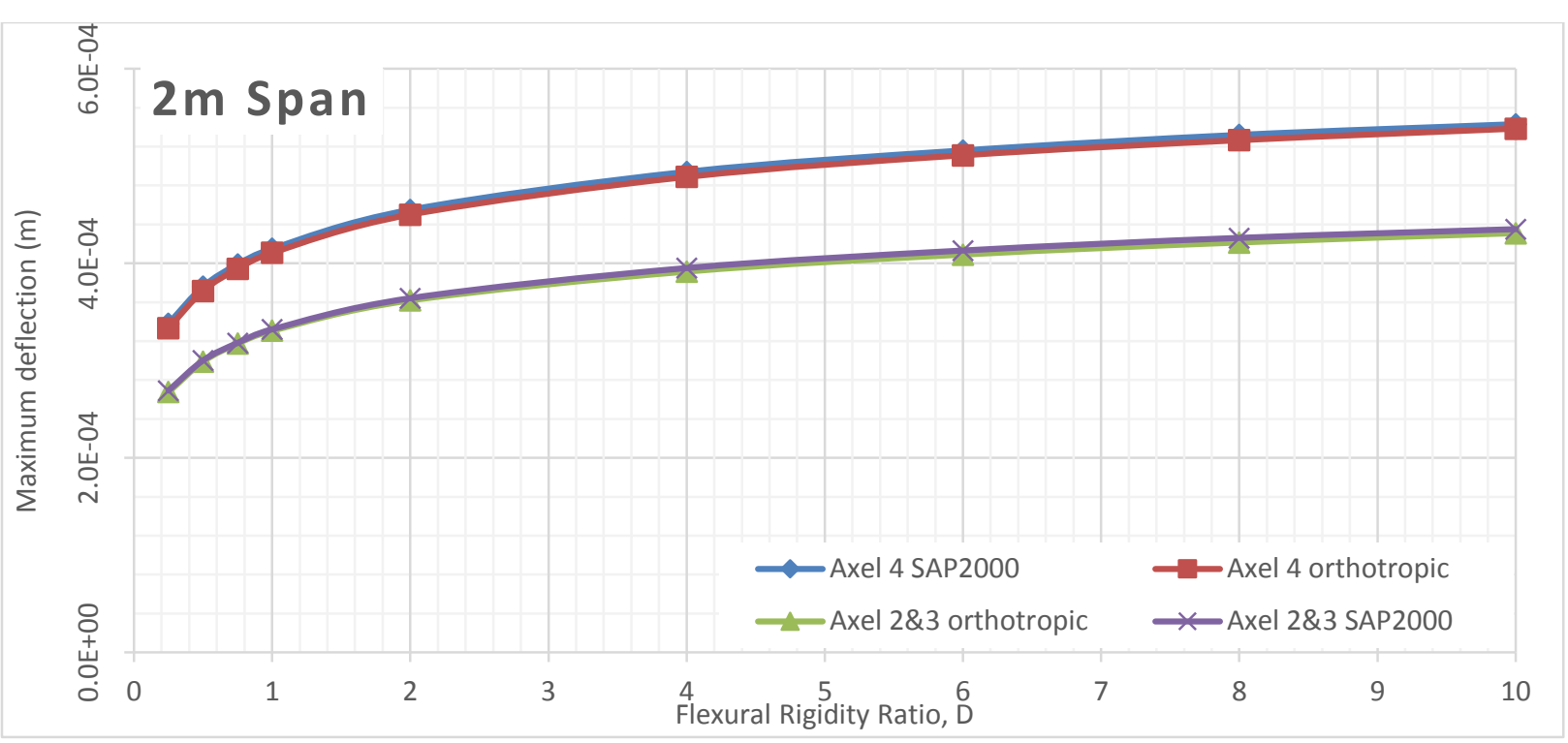

Figure 1050 Deflection comparison between FEA and Orthotropic Plate Theory for $2 \mathrm{~m}$ span of alpha 8 (main bars parallel to traffic)

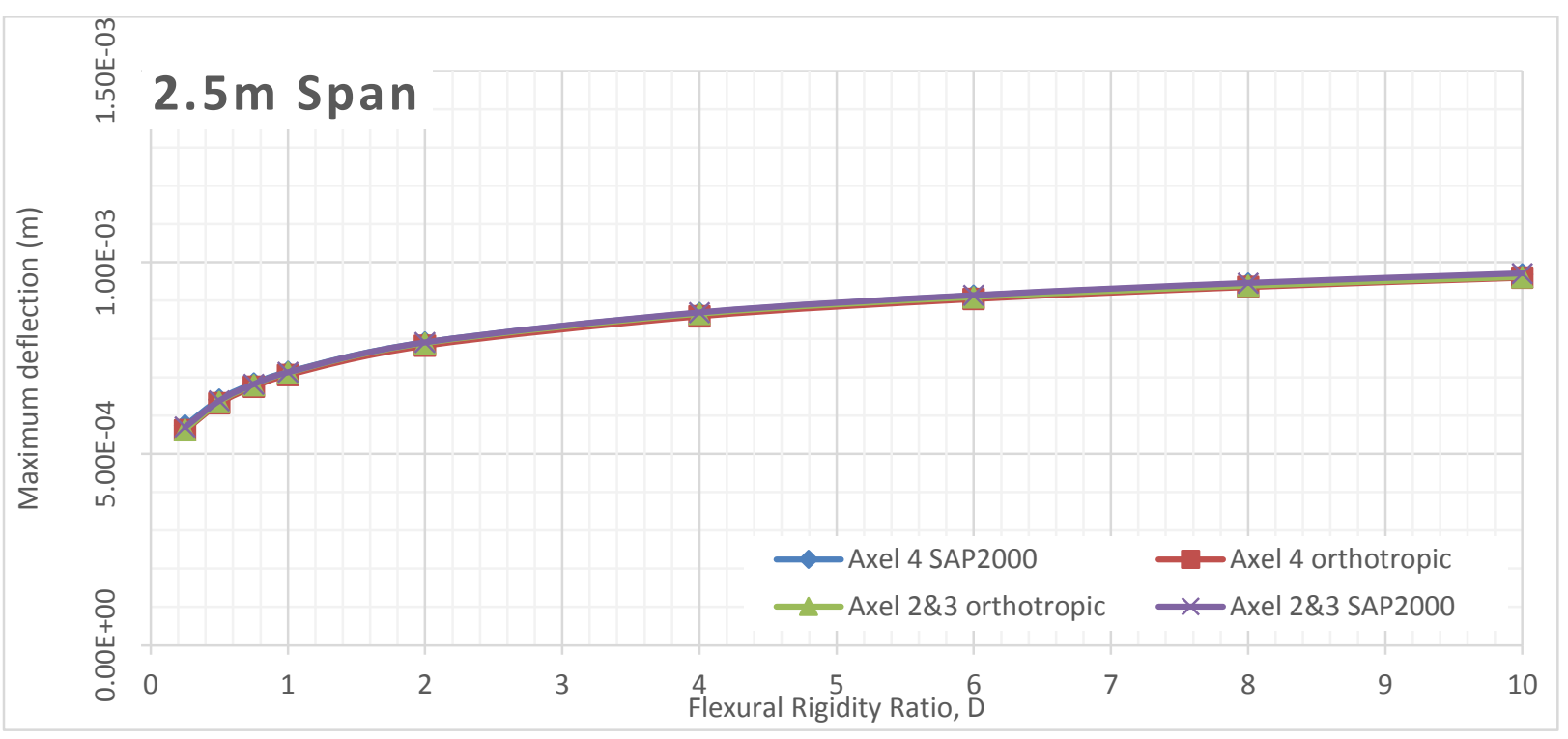

Figure 1051 Deflection comparison between FEA and Orthotropic Plate Theory for $2.5 \mathrm{~m}$ span of alpha 8 (main bars parallel to traffic)

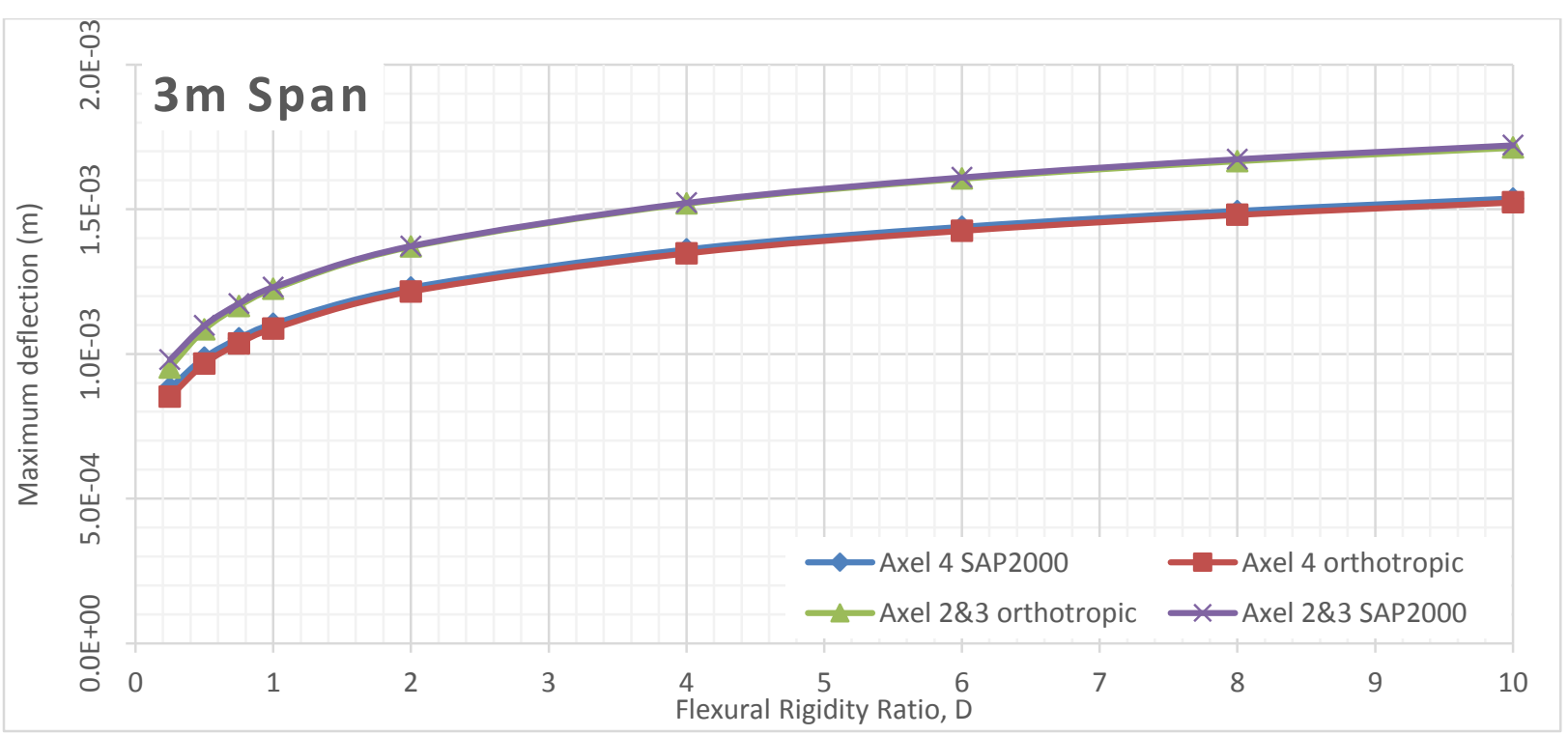

Figure 1052 Deflection comparison between FEA and Orthotropic Plate Theory for $3 \mathrm{~m}$ span of alpha 8 (main bars parallel to traffic) 


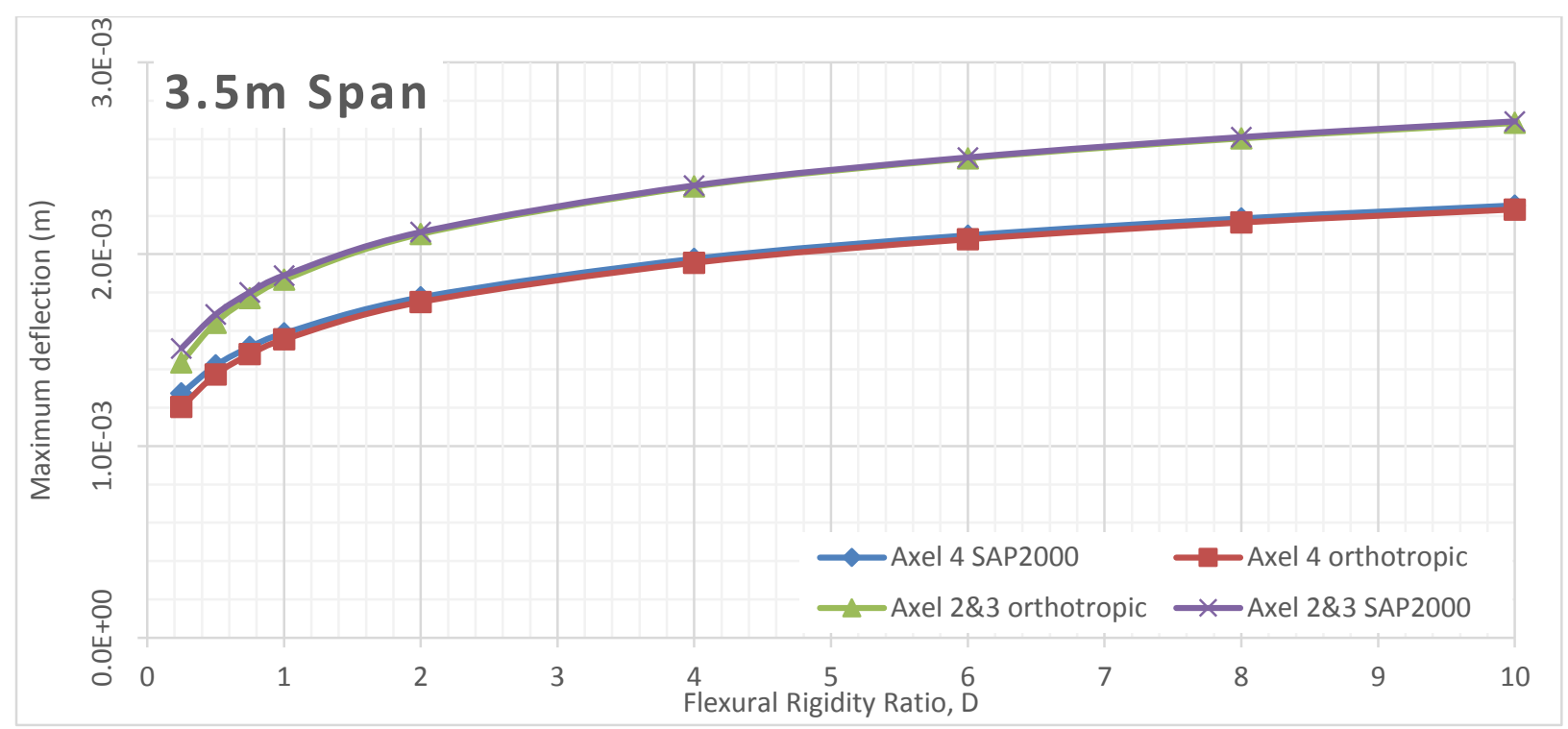

Figure 1053 Deflection comparison between FEA and Orthotropic Plate Theory for $3.5 \mathrm{~m}$ span of alpha 8 (main bars parallel to traffic)

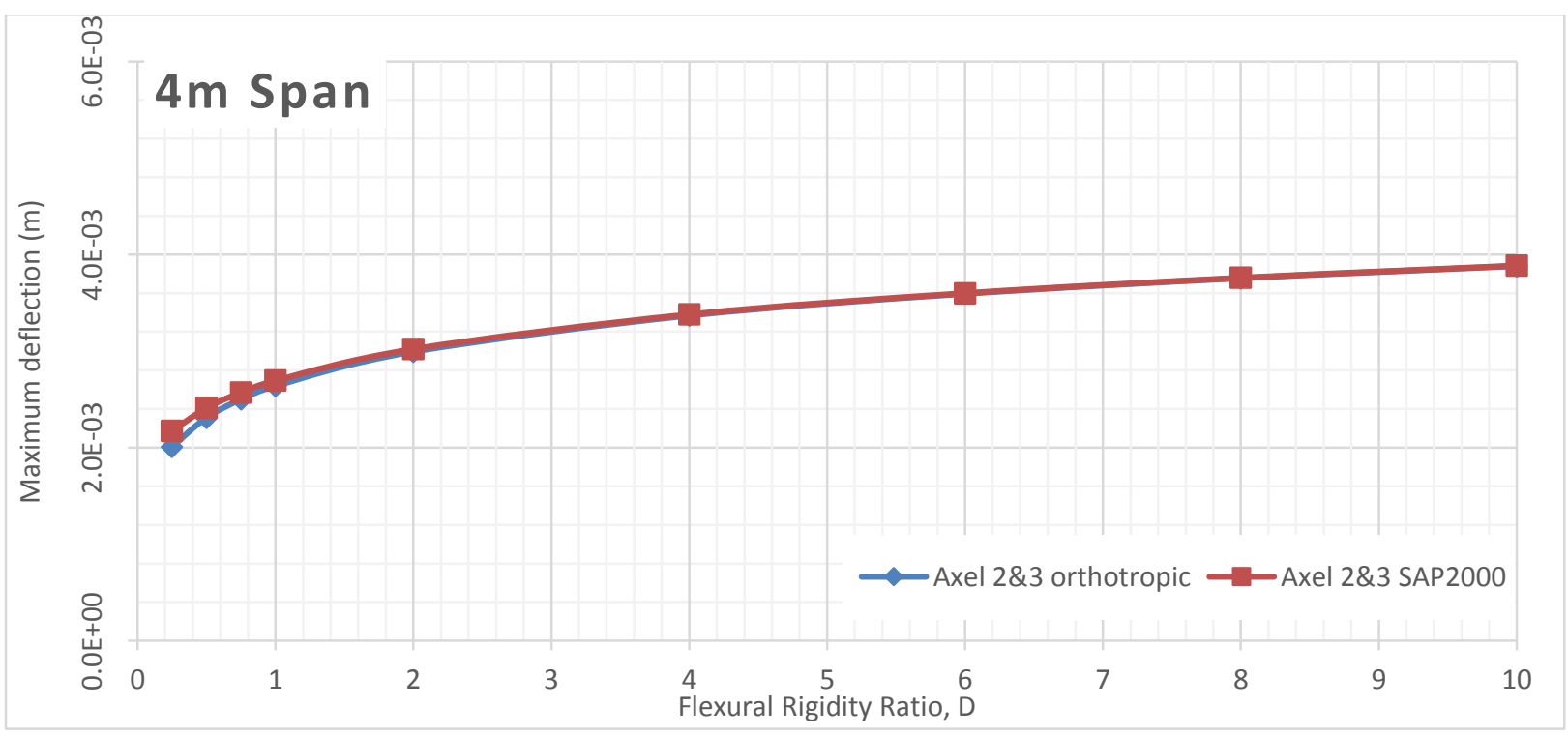

Figure 1054 Deflection comparison between FEA and Orthotropic Plate Theory for $4 \mathrm{~m}$ span of alpha 8 (main bars parallel to traffic) 


\section{Alpha 10 Deflection VS Flexural Rigidity for Different Span Length (Main bars perpendicular to traffic)}

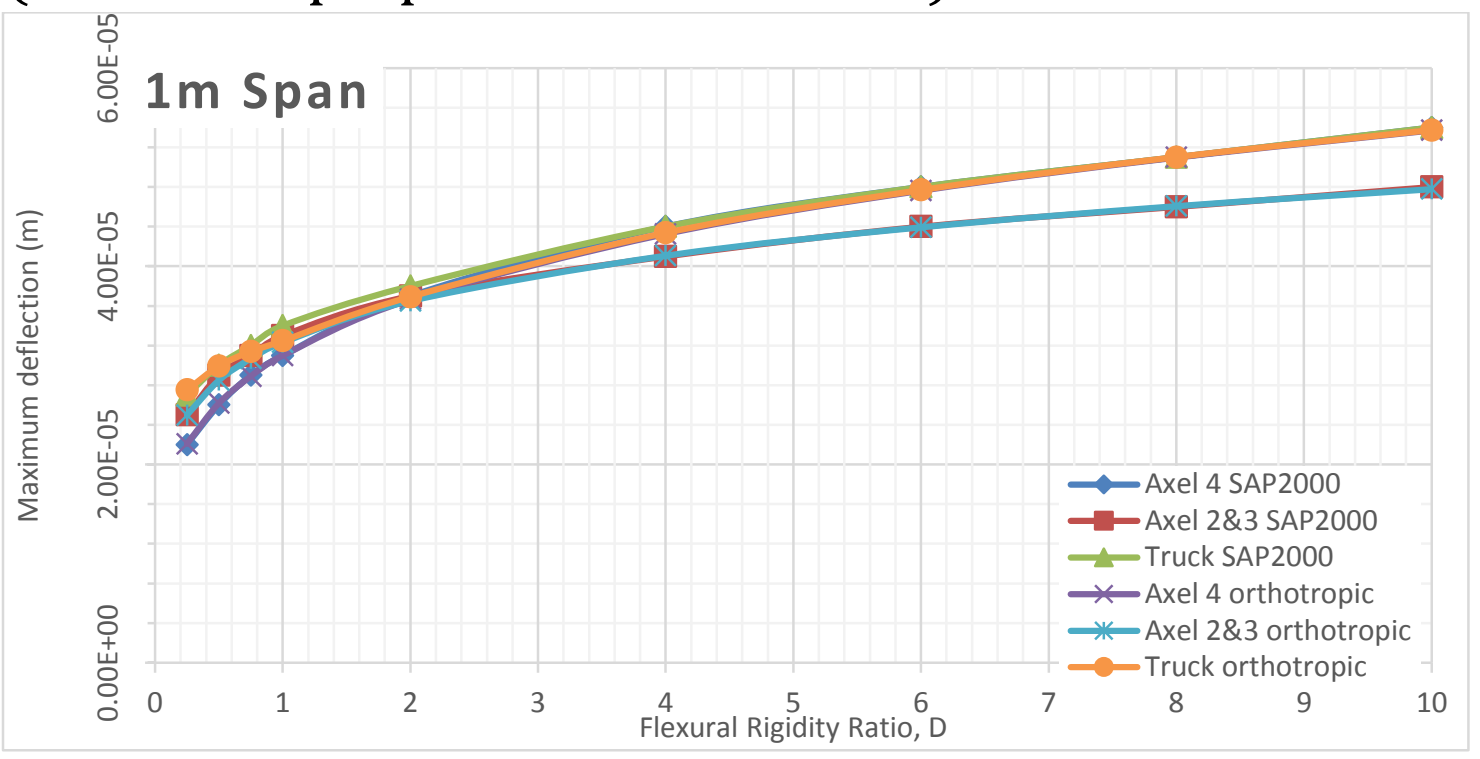

Figure 1055 Deflection comparison between FEA and Orthotropic Plate Theory for $1 \mathrm{~m}$ span of alpha 10 (main bars perpendicular to traffic)

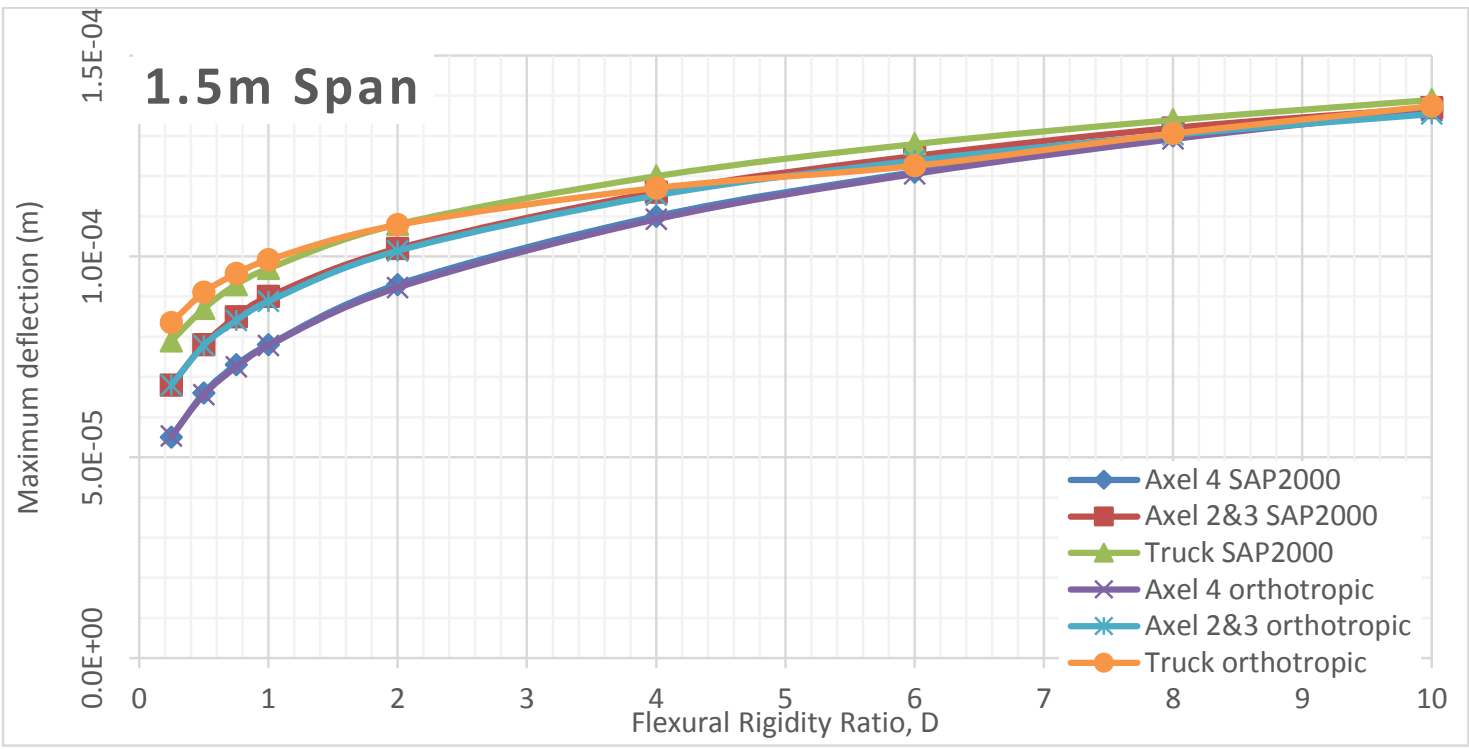

Figure 1056 Deflection comparison between FEA and Orthotropic Plate Theory for $1.5 \mathrm{~m}$ span of alpha 10 (main bars perpendicular to traffic) 


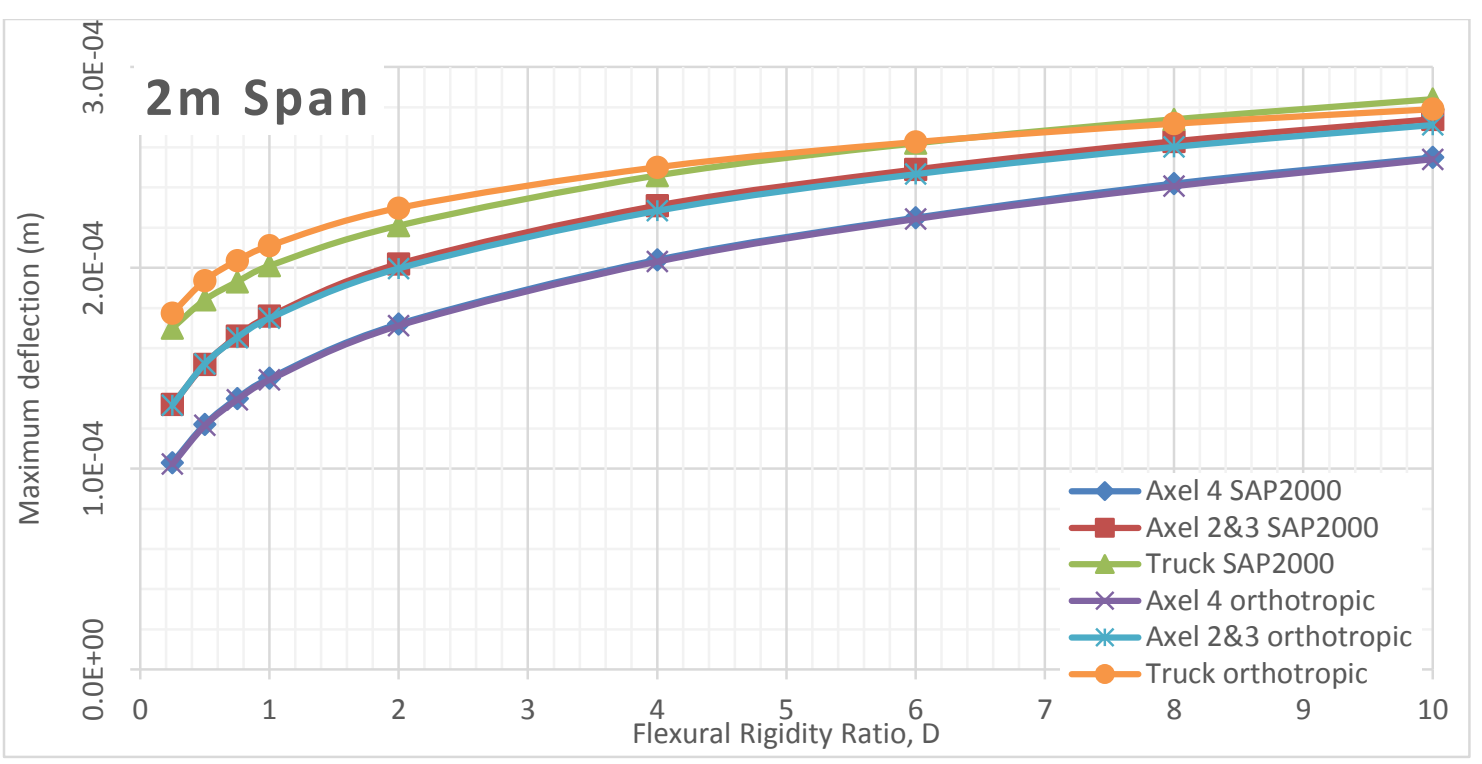

Figure 1057 Deflection comparison between FEA and Orthotropic Plate Theory for $2 \mathrm{~m}$ span of alpha 10 (main bars perpendicular to traffic)

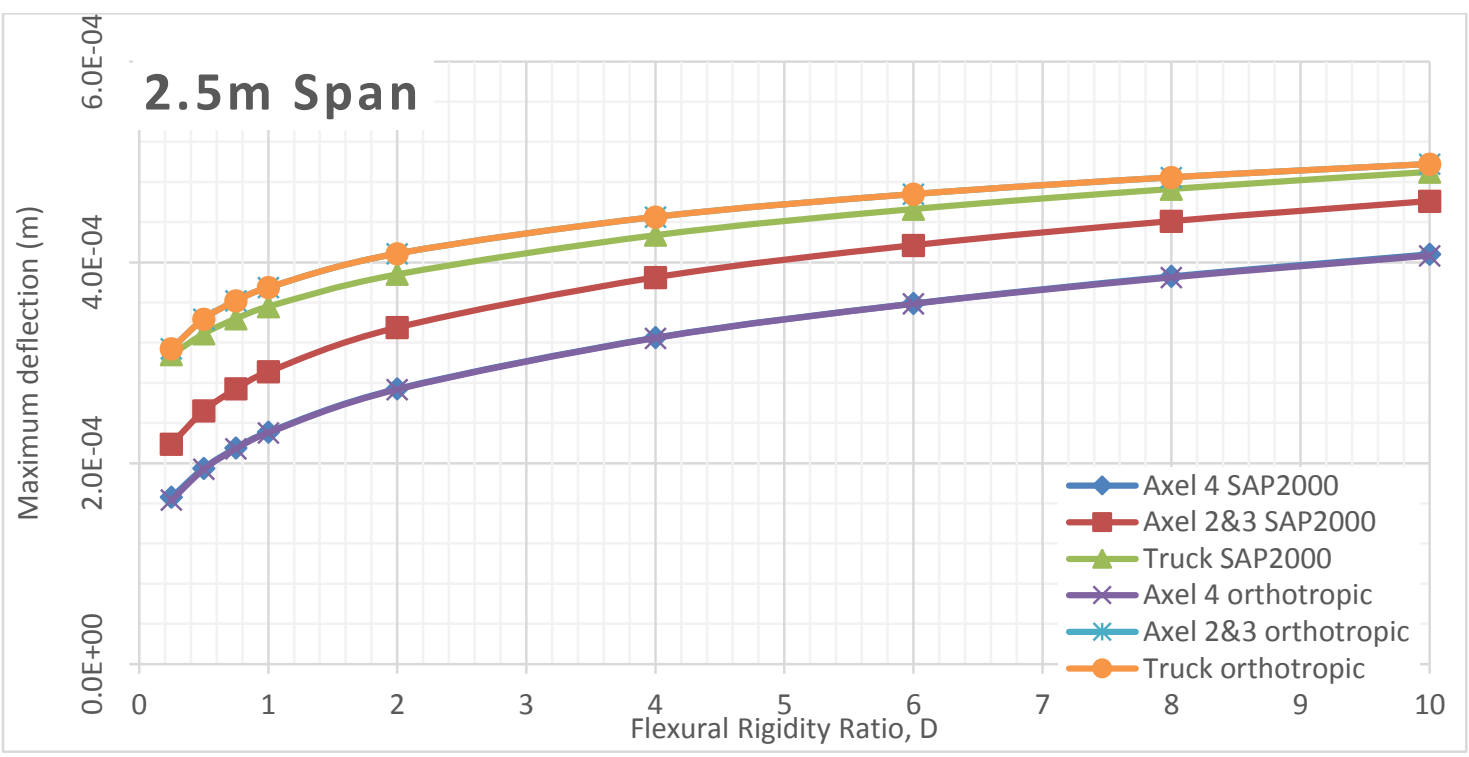

Figure 1058 Deflection comparison between FEA and Orthotropic Plate Theory for $2.5 \mathrm{~m}$ span of alpha 10 (main bars perpendicular to traffic)

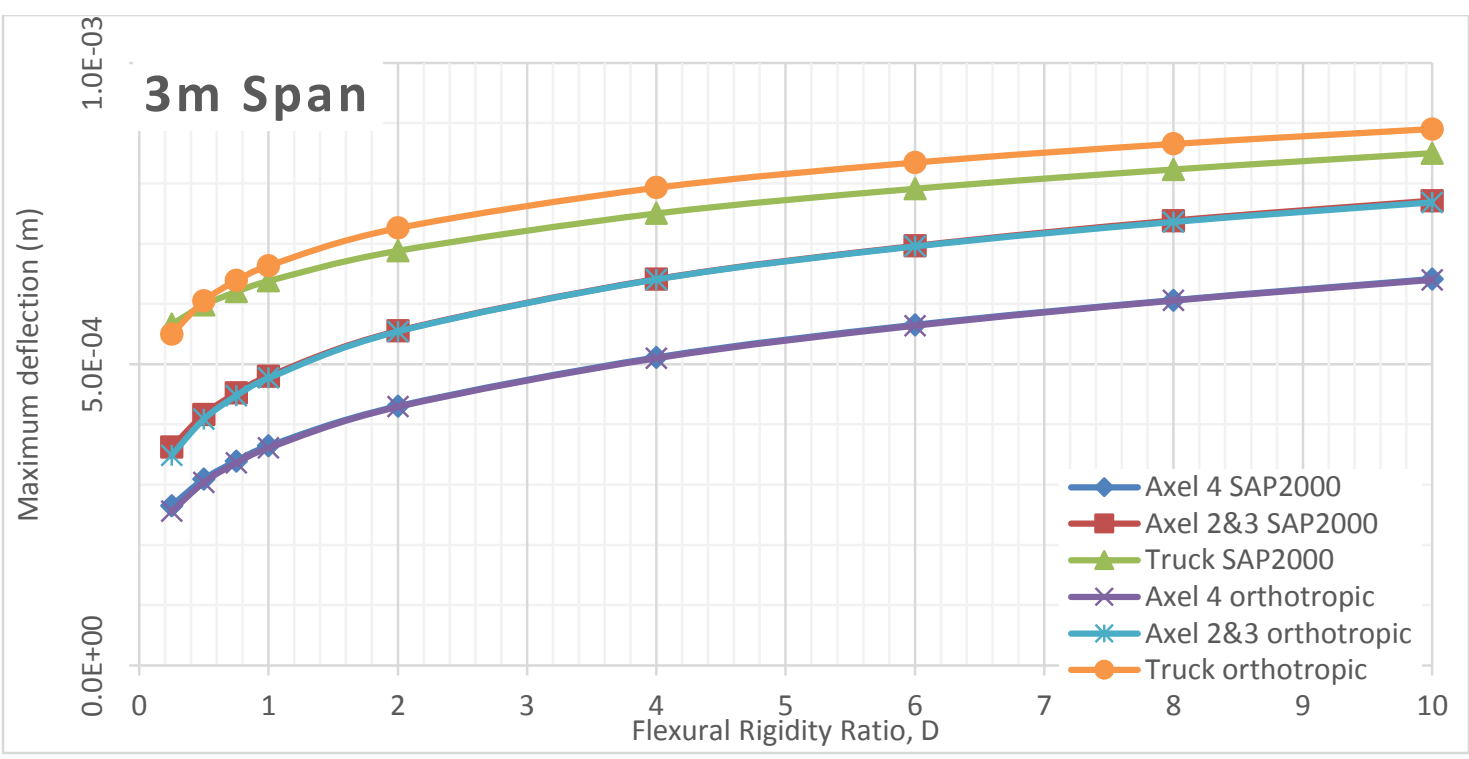

Figure 1059 Deflection comparison between FEA and Orthotropic Plate Theory for $3 \mathrm{~m}$ span of alpha 10 (main bars perpendicular to traffic) 


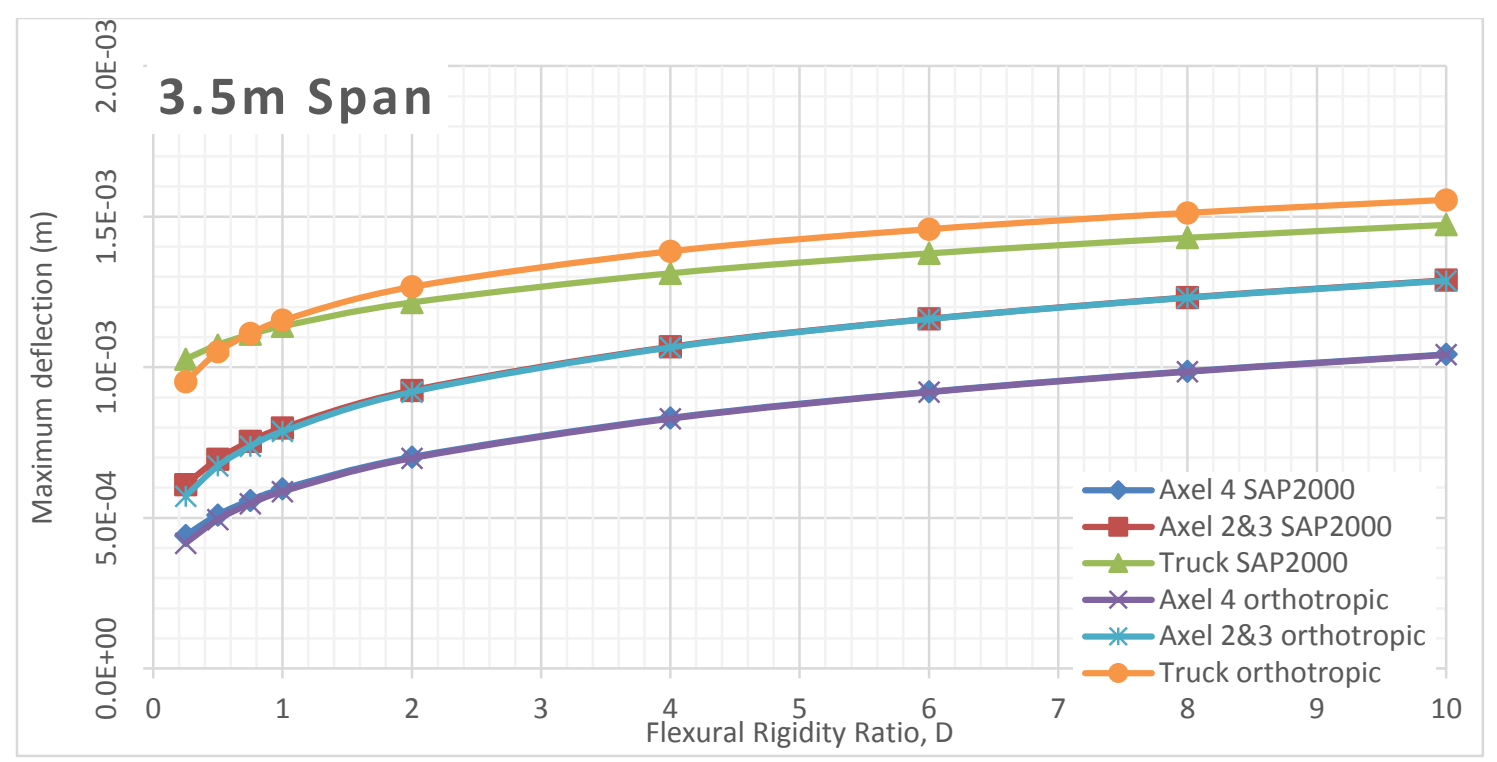

Figure 1060 Deflection comparison between FEA and Orthotropic Plate Theory for $3.5 \mathrm{~m}$ span of alpha 10 (main bars perpendicular to traffic)

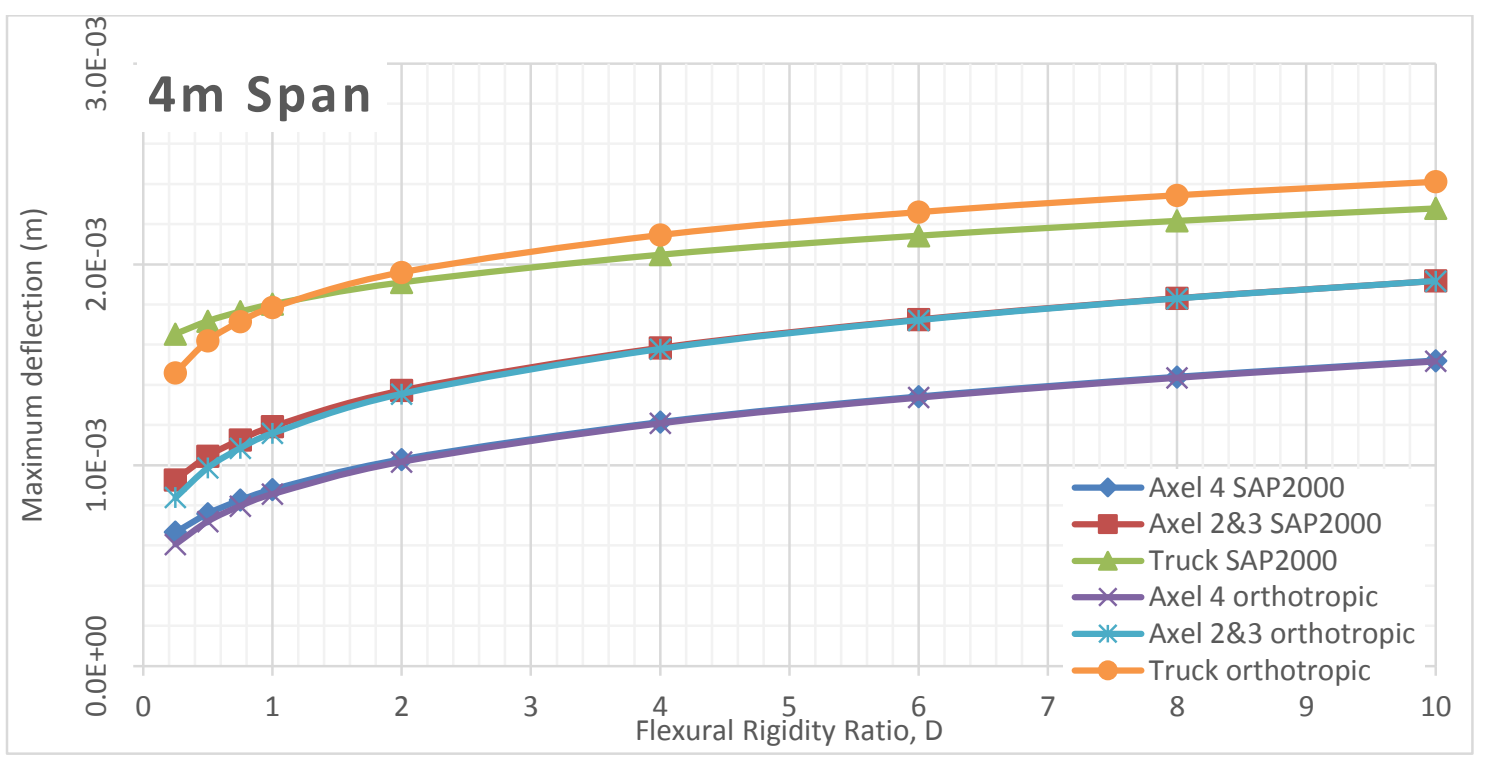

Figure 1061 Deflection comparison between FEA and Orthotropic Plate Theory for $4 \mathrm{~m}$ span of alpha 10 (main bars perpendicular to traffic) 


\section{Alpha 10 Deflection VS Flexural Rigidity for Different Span Length (Main bars parallel to traffic)}

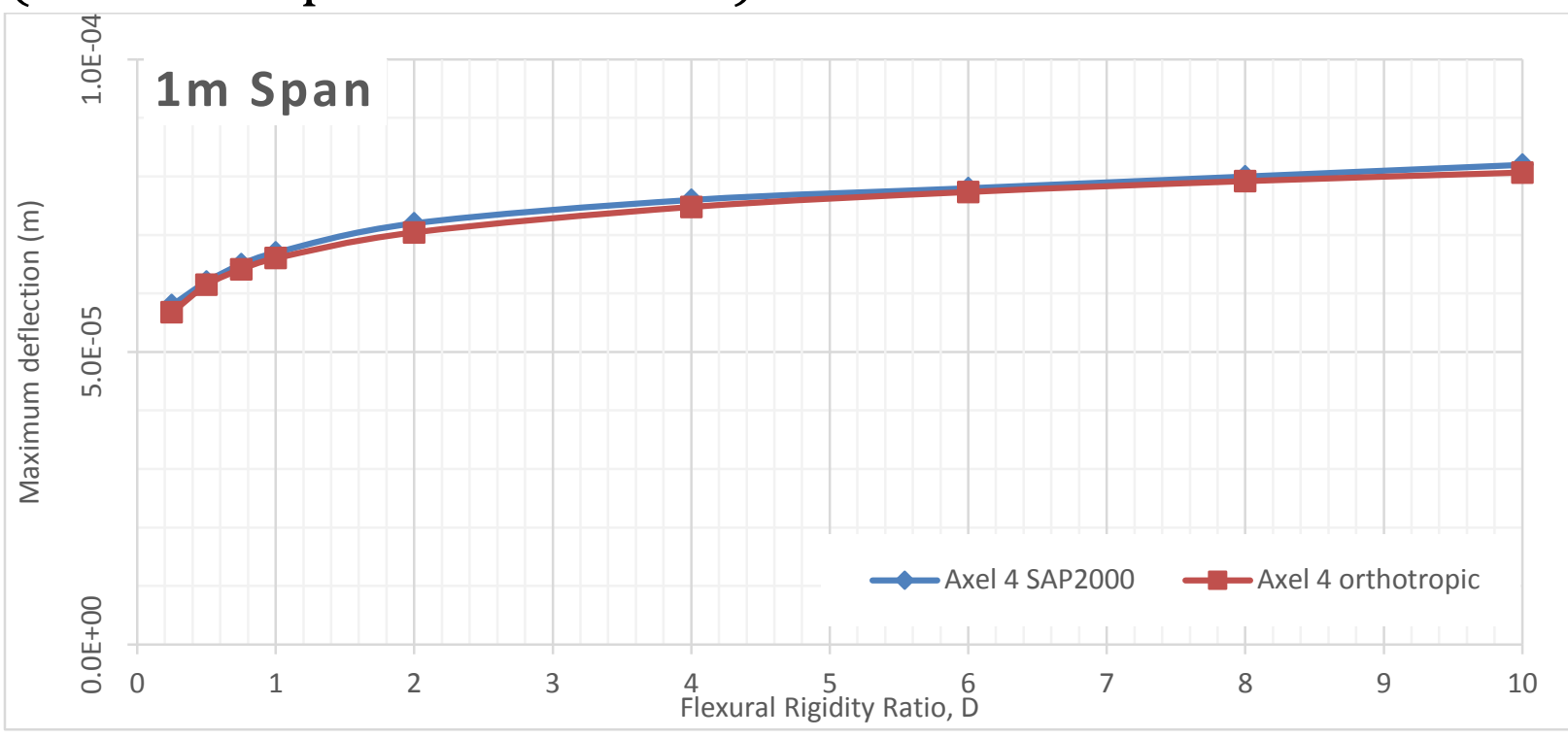

Figure 1062 Deflection comparison between FEA and Orthotropic Plate Theory for $1 \mathrm{~m}$ span of alpha 10 (main bars parallel to traffic)

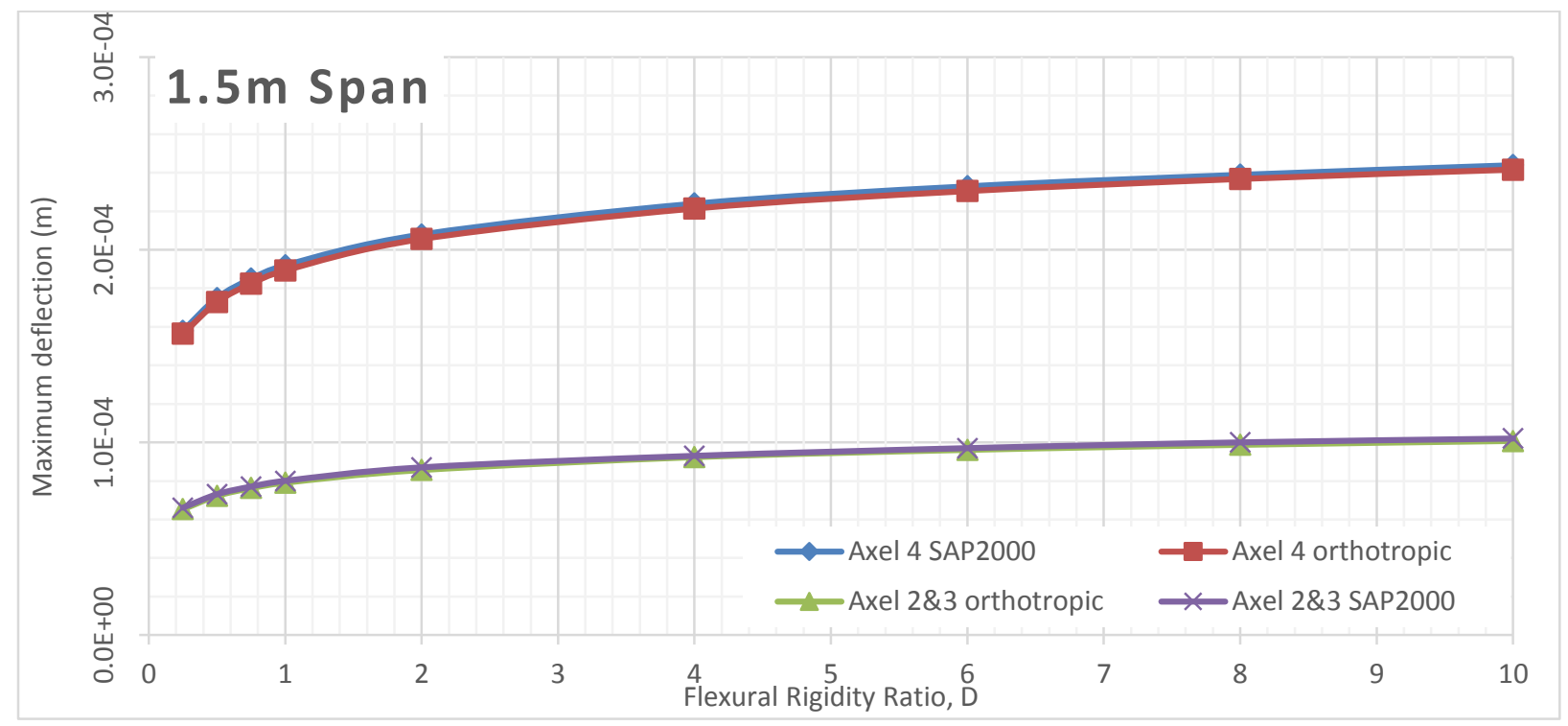

Figure 1063 Deflection comparison between FEA and Orthotropic Plate Theory for $1.5 \mathrm{~m}$ span of alpha 10 (main bars parallel to traffic) 


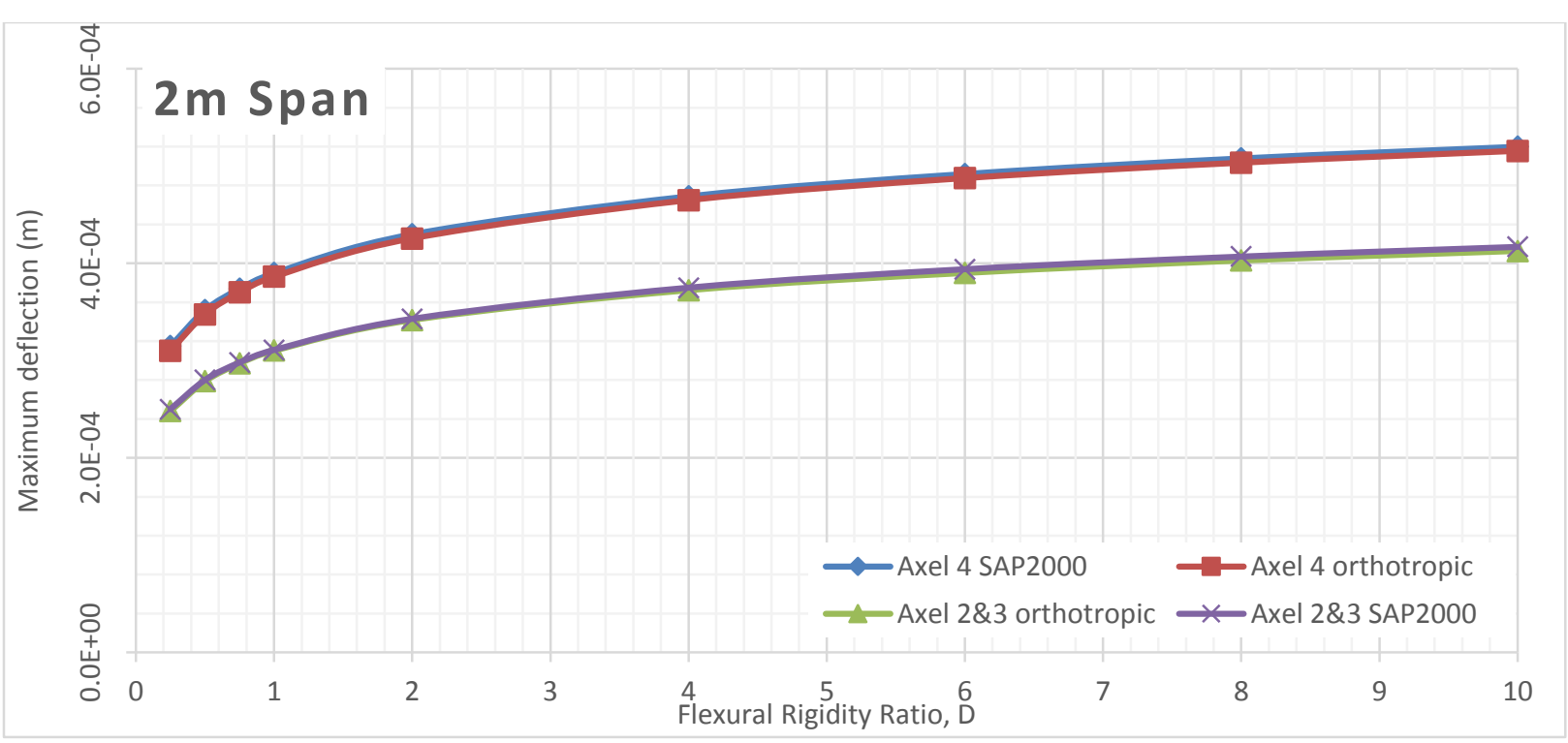

Figure 1064 Deflection comparison between FEA and Orthotropic Plate Theory for $2 \mathrm{~m}$ span of alpha 10 (main bars parallel to traffic)

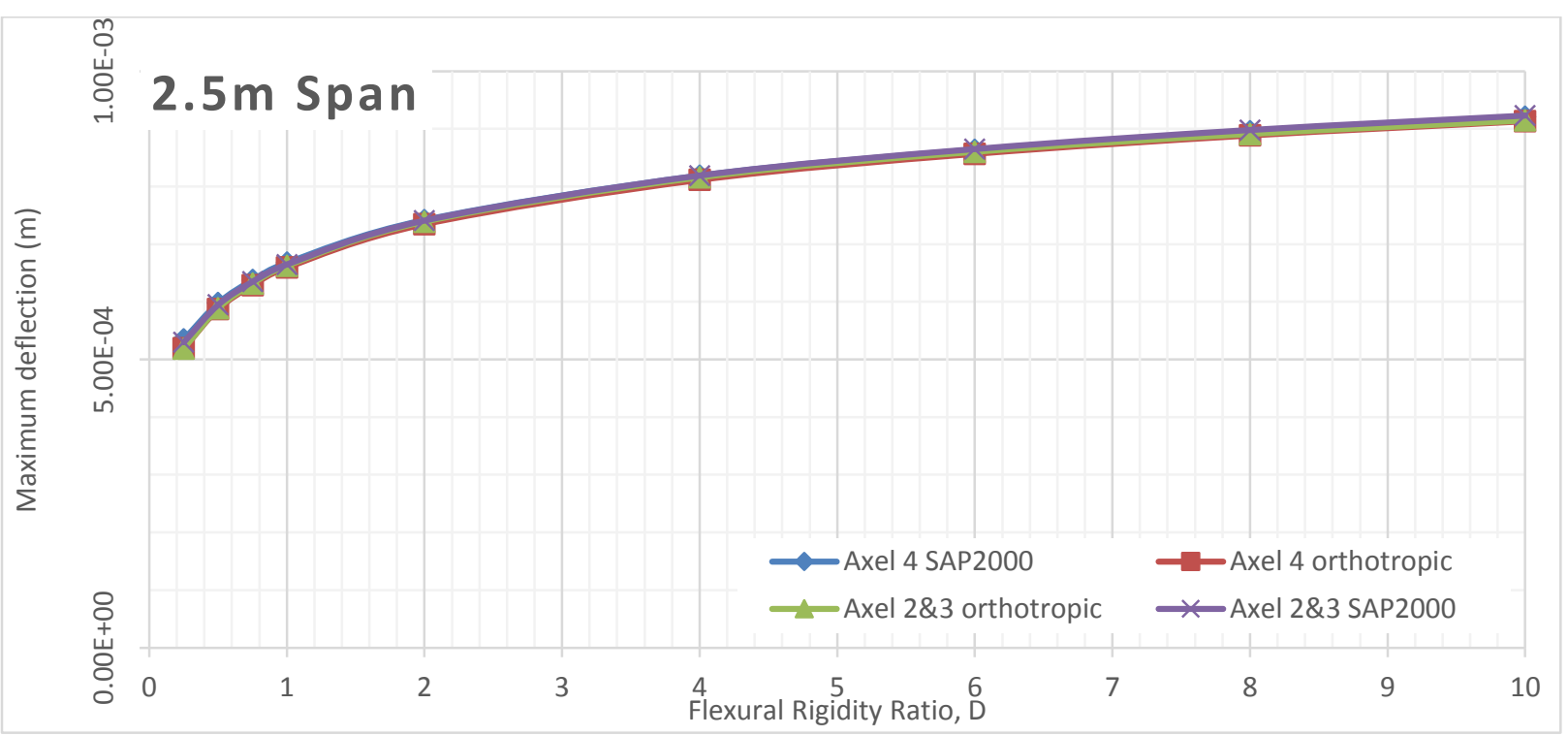

Figure 1065 Deflection comparison between FEA and Orthotropic Plate Theory for $2.5 \mathrm{~m}$ span of alpha 10 (main bars parallel to traffic)

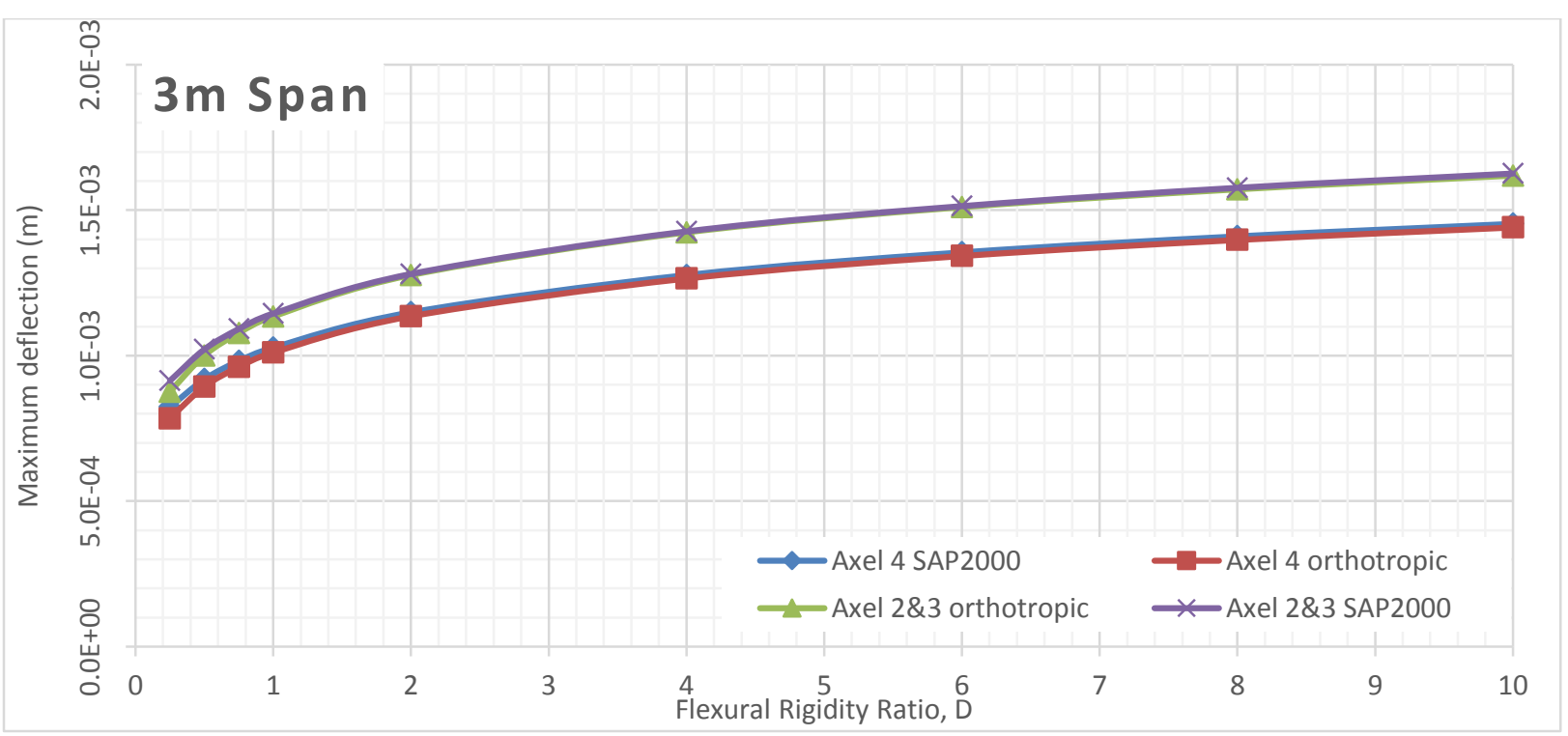

Figure 1066 Deflection comparison between FEA and Orthotropic Plate Theory for $3 \mathrm{~m}$ span of alpha 10 (main bars parallel to traffic) 


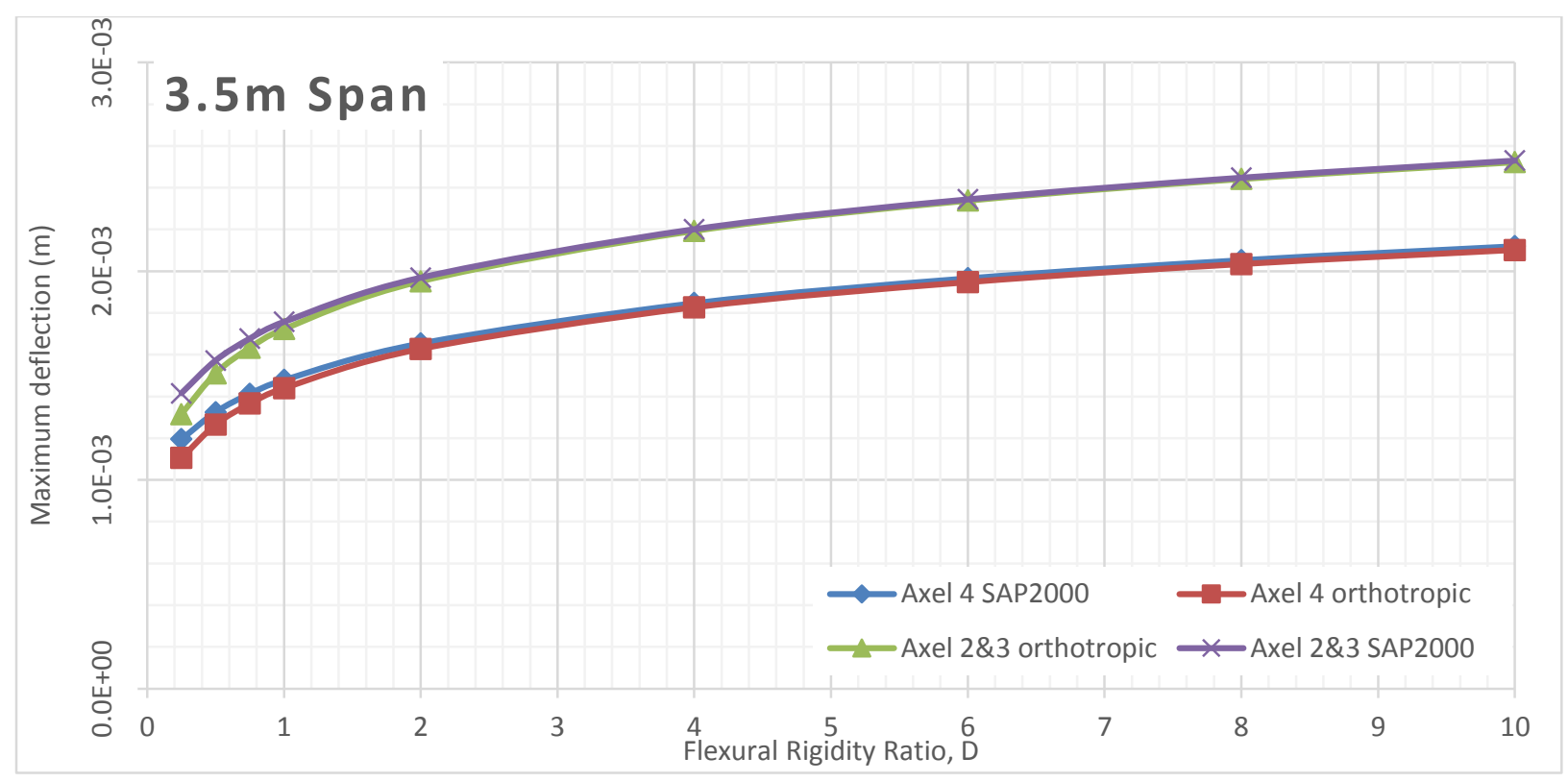

Figure 1067 Deflection comparison between FEA and Orthotropic Plate Theory for $3.5 \mathrm{~m}$ span of alpha 10 (main bars parallel to traffic)

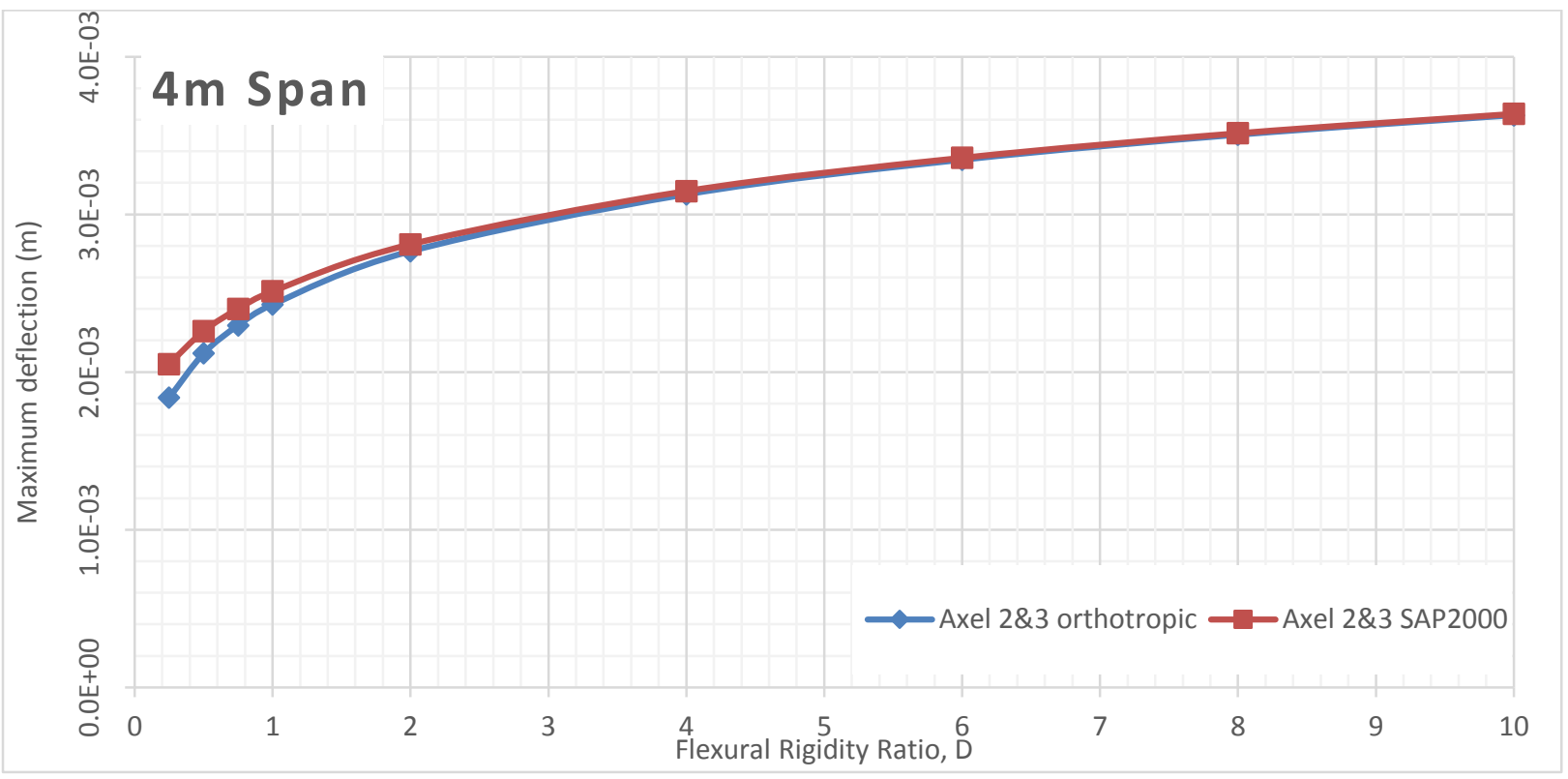

Figure 1068 Deflection comparison between FEA and Orthotropic Plate Theory for $4 \mathrm{~m}$ span of alpha 10 (main bars parallel to traffic) 


\section{E.1 Factored Bending Moment}




\section{E.1.1 BENDING MOMENT RESULTS TABLES}




\section{Alpha 0.25 Bending Moment Results}

Table 280 Factored maximum moment results for alpha 0.25 (main bars perpendicular to traffic)

\begin{tabular}{|c|c|c|c|c|c|c|c|c|c|c|}
\hline & & \multicolumn{9}{|c|}{ Maximum Moment (kN.m) } \\
\hline \multirow{9}{*}{ 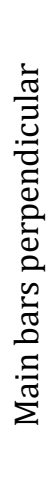 } & $\mathrm{D}$ & \multirow{2}{*}{25} & \multirow{2}{*}{0.5} & \multirow{2}{*}{0.75} & \multirow{2}{*}{1} & & \multirow{2}{*}{4} & & \multirow{2}{*}{8} & \multirow{2}{*}{10} \\
\hline & SPAN & & & & & & & & & \\
\hline & 1 & 10.6927 & 12.6817 & 14.0059 & 15.0245 & 17.7734 & 20.9820 & 23.0925 & 24.7007 & 26.0135 \\
\hline & 1.5 & 13.3125 & 15.8001 & 17.4593 & 18.7376 & 22.1970 & 26.2556 & 28.9397 & 30.9937 & 32.6766 \\
\hline & 2 & 15.1364 & 17.9700 & 19.8615 & 21.3196 & 25.2701 & 29.9146 & 32.9927 & 35.3523 & 37.2883 \\
\hline & 2.5 & 16.9517 & 19.6406 & 21.7107 & 23.3071 & 27.6348 & 32.7287 & 36.1086 & 38.7021 & 40.8316 \\
\hline & 3 & 18.5467 & 21.0188 & 23.2161 & 24.9248 & 29.5593 & 35.0184 & 38.6434 & 41.4268 & 43.7134 \\
\hline & 3.5 & 18.6493 & 22.1482 & 24.4861 & 26.2897 & 31.1828 & 36.9497 & 40.7813 & 43.7245 & 46.1435 \\
\hline & 4 & 20.5267 & 23.5864 & 25.5575 & 27.0280 & 31.0740 & 36.8336 & 40.6642 & 43.6088 & 46.0305 \\
\hline
\end{tabular}

Table 281 Factored maximum moment results for alpha 0.25 (main bars parallel to traffic)

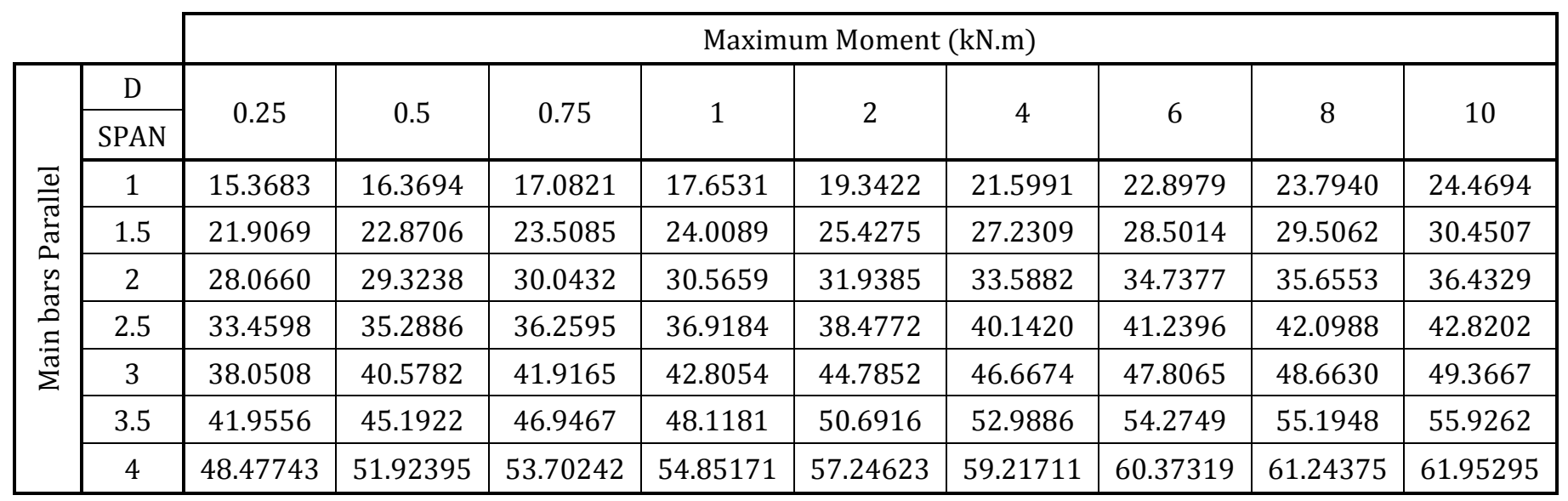




\section{Alpha 0.5 Bending Moment Results}

Table 282 Factored maximum moment results for alpha 0.5 (main bars perpendicular to traffic)

\begin{tabular}{|c|c|c|c|c|c|c|c|c|c|c|}
\hline & & \multicolumn{9}{|c|}{ Maximum Moment (kN.m) } \\
\hline \multirow{9}{*}{ 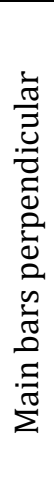 } & $\mathrm{D}$ & \multirow{2}{*}{0.25} & \multirow{2}{*}{0.5} & \multirow{2}{*}{0.75} & \multirow{2}{*}{1} & & \multirow{2}{*}{4} & & \multirow{2}{*}{8} & \multirow{2}{*}{10} \\
\hline & SPAN & & & & & & & & & \\
\hline & 1 & 9.7609 & 11.5768 & 12.7858 & 13.7158 & 16.2263 & 19.1578 & 21.0871 & 22.5580 & 23.7592 \\
\hline & 1.5 & 12.1524 & 14.4234 & 15.9383 & 17.1054 & 20.2644 & 23.9718 & 26.4244 & 28.3021 & 29.8409 \\
\hline & 2 & 13.8332 & 16.4043 & 18.1312 & 19.4625 & 23.0698 & 27.3119 & 30.1243 & 32.2808 & 34.0507 \\
\hline & 2.5 & 15.6497 & 17.9293 & 19.8193 & 21.2767 & 25.2284 & 29.8808 & 32.9687 & 35.3388 & 37.2853 \\
\hline & 3 & 17.1030 & 19.4137 & 20.4417 & 22.7535 & 26.9852 & 31.9710 & 35.2827 & 37.8260 & 39.9160 \\
\hline & 3.5 & 17.0242 & 20.2184 & 22.3529 & 23.9995 & 28.4673 & 33.7340 & 37.2343 & 39.9236 & 42.1344 \\
\hline & 4 & 18.8757 & 21.7059 & 23.5300 & 24.8915 & 28.3919 & 33.6281 & 37.1273 & 39.8179 & 42.0311 \\
\hline
\end{tabular}

Table 283 Factored maximum moment results for alpha 0.5 (main bars parallel to traffic)

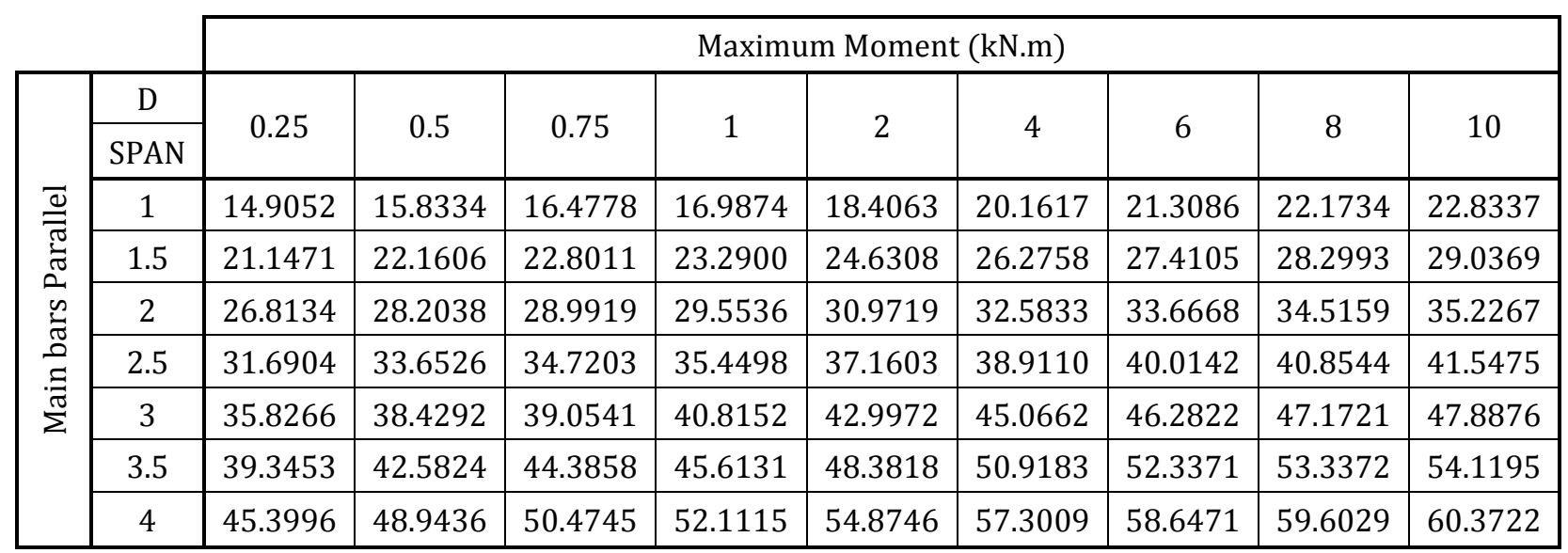




\section{Alpha 0.75 Bending Moment Results}

Table 284 Factored maximum moment results for alpha 0.75 (main bars perpendicular to traffic)

\begin{tabular}{|c|c|c|c|c|c|c|c|c|c|c|}
\hline & & \multicolumn{9}{|c|}{ Maximum Moment (kN.m) } \\
\hline \multirow{9}{*}{ 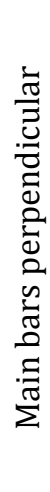 } & $\mathrm{D}$ & \multirow{2}{*}{.25} & \multirow{2}{*}{0.5} & \multirow{2}{*}{0.75} & \multirow{2}{*}{1} & & \multirow{2}{*}{4} & & \multirow{2}{*}{8} & \multirow{2}{*}{10} \\
\hline & SPAN & & & & & & & & & \\
\hline & 1 & 0368 & 10.7181 & 11.8376 & 12.6989 & 15.0241 & 17.7405 & 19.5290 & 20.8932 & 22.0077 \\
\hline & 1.5 & 11.2509 & 13.3536 & 14.7563 & 15.8370 & 18.7626 & 22.1970 & 24.4700 & 26.2106 & 27.6374 \\
\hline & 2 & 12.9520 & 15.1875 & 16.7865 & 18.0192 & 21.3599 & 25.2894 & 27.8953 & 29.8941 & 31.5349 \\
\hline & 2.5 & 14.6280 & 16.5994 & 18.3494 & 19.6989 & 23.3584 & 27.6677 & 30.5288 & 32.7252 & 34.5295 \\
\hline & 3 & 15.9712 & 18.1549 & 19.6216 & 21.0662 & 24.9849 & 29.6029 & 32.6711 & 35.0279 & 36.9651 \\
\hline & 3.5 & 15.7613 & 18.7187 & 20.6950 & 22.2197 & 26.3570 & 31.2351 & 34.4779 & 36.9699 & 39.0188 \\
\hline & 4 & 17.5843 & 20.2376 & 21.9454 & 23.2227 & 26.5102 & 31.1371 & 34.3788 & 36.8718 & 38.9229 \\
\hline
\end{tabular}

Table 285 Factored maximum moment results for alpha 0.75 (main bars parallel to traffic)

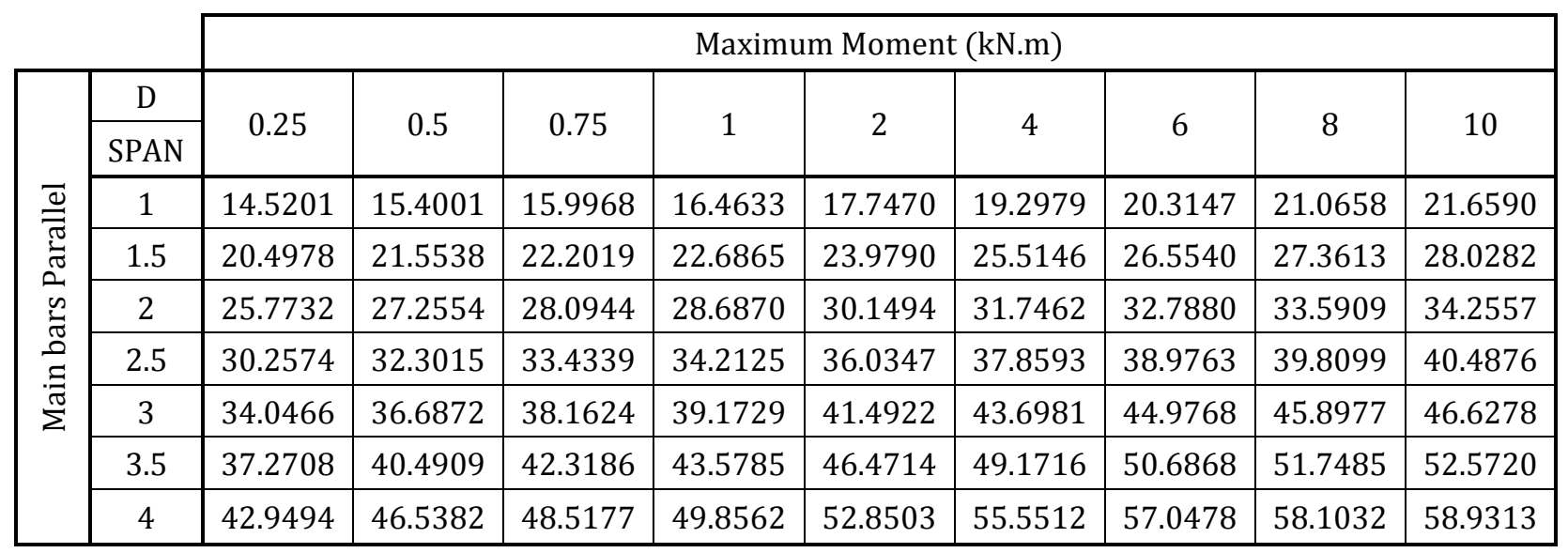




\section{Alpha 1 Bending Moment Results}

Table 286 Factored maximum moment results for alpha 1 (main bars perpendicular to traffic)

\begin{tabular}{|c|c|c|c|c|c|c|c|c|c|c|}
\hline & & \multicolumn{9}{|c|}{ Maximum Moment (kN.m) } \\
\hline \multirow{9}{*}{ 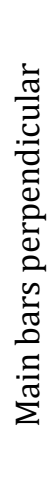 } & $\mathrm{D}$ & \multirow{2}{*}{25} & \multirow{2}{*}{0.5} & \multirow{2}{*}{0.75} & \multirow{2}{*}{1} & & \multirow{2}{*}{4} & & \multirow{2}{*}{8} & \multirow{2}{*}{10} \\
\hline & SPAN & & & & & & & & & \\
\hline & 1 & 8.4531 & 10.0260 & 11.0734 & 11.8793 & 14.0553 & 16.5982 & 18.2733 & 19.5514 & 20.5961 \\
\hline & 1.5 & 10.5243 & 12.4913 & 13.8035 & 14.8147 & 17.5522 & 20.7667 & 22.8947 & 24.5248 & 25.8615 \\
\hline & 2 & 12.2343 & 14.2067 & 15.7027 & 16.8560 & 19.9817 & 23.6593 & 26.0988 & 27.9704 & 29.5071 \\
\hline & 2.5 & 13.7972 & 15.6176 & 17.1646 & 18.4272 & 21.8512 & 25.8840 & 28.5622 & 30.6186 & 32.3083 \\
\hline & 3 & 15.0517 & 17.1315 & 18.4429 & 19.7061 & 23.3726 & 27.6942 & 30.5661 & 32.7727 & 34.5865 \\
\hline & 3.5 & 14.7434 & 17.5099 & 19.3588 & 20.7852 & 24.6561 & 29.2210 & 32.2563 & 34.5892 & 36.5077 \\
\hline & 4 & 16.5395 & 19.0476 & 20.6614 & 21.8707 & 24.9900 & 29.1293 & 32.1635 & 34.4973 & 36.4176 \\
\hline
\end{tabular}

Table 287 Factored maximum moment results for alpha 1 (main bars parallel to traffic)

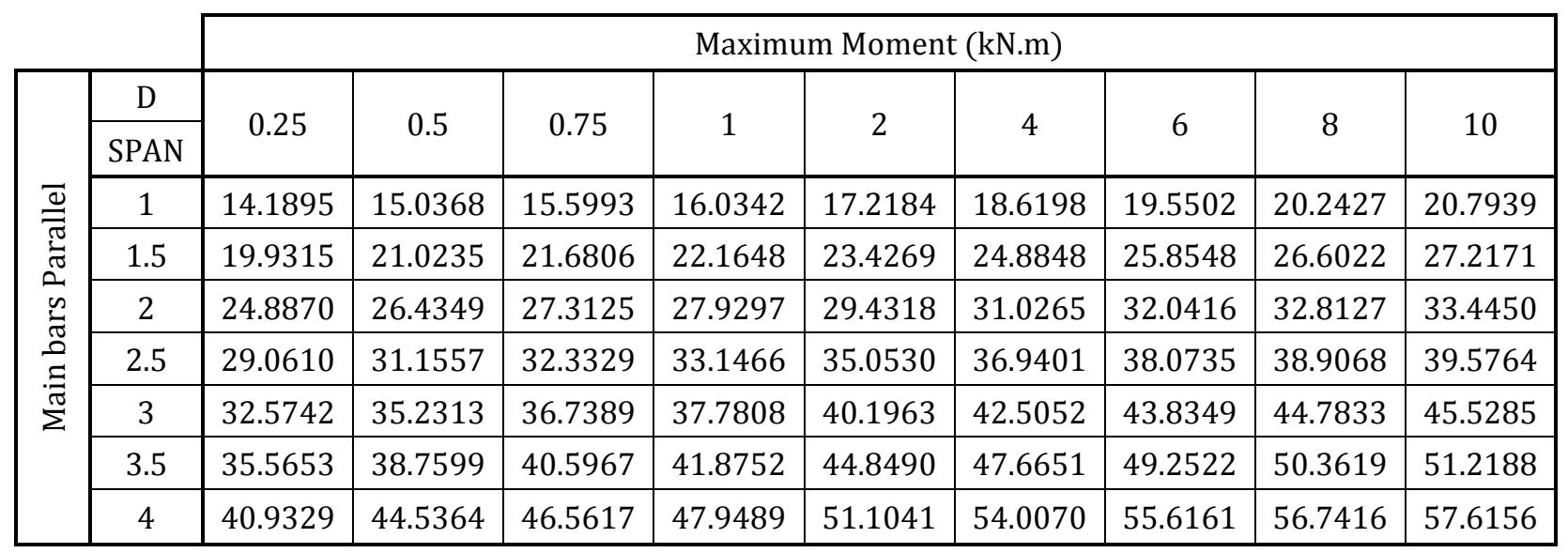




\section{Alpha 2 Bending Moment Results}

Table 288 Factored maximum moment results for alpha 2 (main bars perpendicular to traffic)

\begin{tabular}{|c|c|c|c|c|c|c|c|c|c|c|}
\hline & & \multicolumn{9}{|c|}{ Maximum Moment (kN.m) } \\
\hline \multirow{9}{*}{ 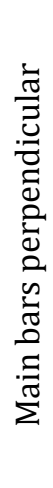 } & $\mathrm{D}$ & \multirow{2}{*}{25} & \multirow{2}{*}{.5} & \multirow{2}{*}{0.75} & \multirow{2}{*}{1} & & & & \multirow{2}{*}{8} & \multirow{2}{*}{10} \\
\hline & SPAN & & & & & & & & & \\
\hline & 1 & 6.9021 & 8.1869 & 9.0428 & 9.7014 & 11.4809 & 13.5630 & 14.9366 & 15.9861 & 16.8448 \\
\hline & 1.5 & 8.6272 & 10.1998 & 11.2718 & 12.0980 & 14.3358 & 16.9658 & 18.7088 & 20.0451 & 21.1417 \\
\hline & 2 & 10.2870 & 11.6267 & 12.8225 & 13.7647 & 16.3195 & 19.3276 & 21.3247 & 22.8581 & 24.1179 \\
\hline & 2.5 & 11.5513 & 13.1421 & 14.1425 & 15.0476 & 17.8459 & 21.1440 & 23.3360 & 25.0203 & 26.4050 \\
\hline & 3 & 12.5720 & 14.3663 & 15.5035 & 16.3617 & 19.0881 & 22.6220 & 24.9722 & 26.7790 & 28.2652 \\
\hline & 3.5 & 12.0978 & 14.2990 & 15.8082 & 16.9732 & 20.1361 & 23.8686 & 26.3522 & 28.2623 & 29.8338 \\
\hline & 4 & 13.7539 & 15.8563 & 17.2156 & 18.2413 & 20.9063 & 23.8757 & 26.2759 & 28.1863 & 29.7591 \\
\hline
\end{tabular}

Table 289 Factored maximum moment results for alpha 2 (main bars parallel to traffic)

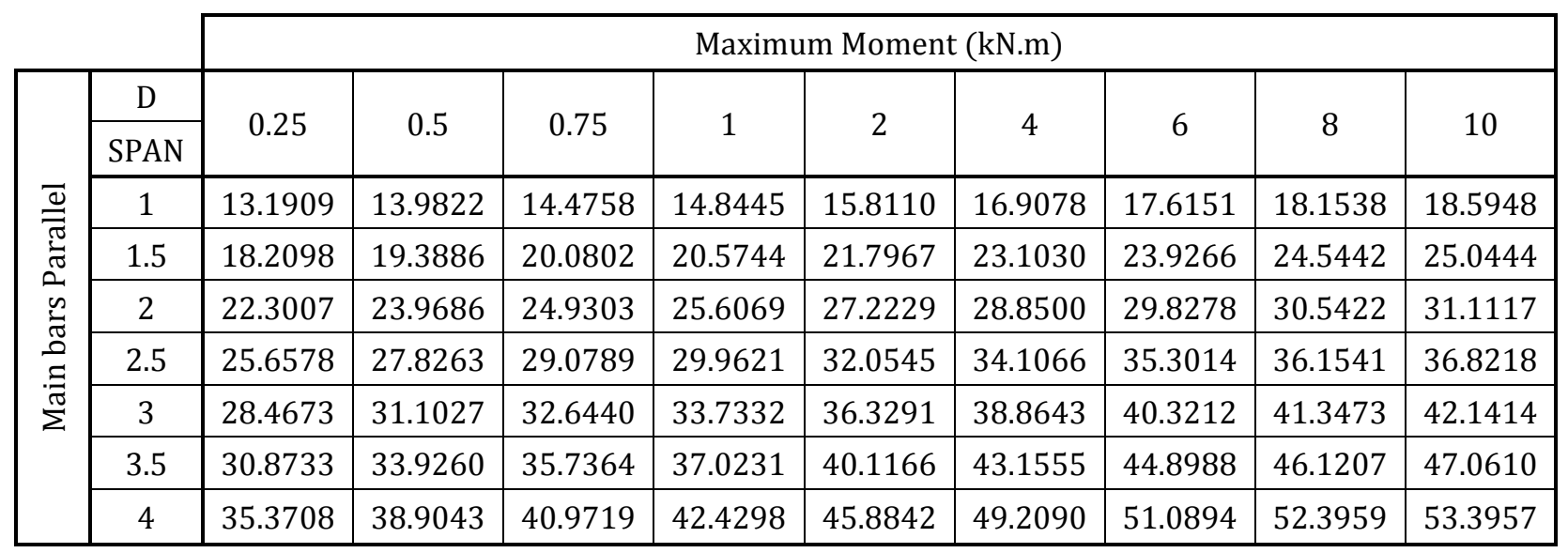




\section{Alpha 4 Bending Moment Results}

Table 290 Factored maximum moment results for alpha 4 (main bars perpendicular to traffic)

\begin{tabular}{|c|c|c|c|c|c|c|c|c|c|c|}
\hline & & \multicolumn{9}{|c|}{ Maximum Moment (kN.m) } \\
\hline \multirow{9}{*}{ 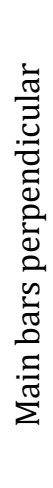 } & $\mathrm{D}$ & \multirow{2}{*}{25} & \multirow{2}{*}{0.5} & \multirow{2}{*}{0.75} & \multirow{2}{*}{1} & & \multirow{2}{*}{4} & & \multirow{2}{*}{8} & \multirow{2}{*}{10} \\
\hline & SPAN & & & & & & & & & \\
\hline & 1 & 5.3469 & 6.3429 & 7.0067 & 7.5178 & 8.8997 & 10.5196 & 11.5904 & 12.4099 & 13.0815 \\
\hline & 1.5 & 6.9964 & 7.9203 & 8.7332 & 9.3740 & 11.1106 & 13.1542 & 14.5105 & 15.5515 & 16.4067 \\
\hline & 2 & 8.2585 & 9.4127 & 10.1430 & 10.6925 & 12.6471 & 14.9834 & 16.5365 & 17.7300 & 18.7115 \\
\hline & 2.5 & 9.2321 & 10.5672 & 11.4173 & 12.0590 & 13.8294 & 16.3904 & 18.0943 & 19.4048 & 20.4830 \\
\hline & 3 & 10.0341 & 11.5102 & 12.4586 & 13.1760 & 15.0404 & 17.5353 & 19.3617 & 20.7671 & 21.9238 \\
\hline & 3.5 & 9.6589 & 11.0963 & 12.2575 & 13.1567 & 15.6052 & 18.5012 & 20.4308 & 21.9160 & 23.1388 \\
\hline & 4 & 11.0019 & 12.6405 & 13.7203 & 14.5457 & 16.7219 & 19.1813 & 20.7615 & 21.9450 & 23.0793 \\
\hline
\end{tabular}

Table 291 Factored maximum moment results for alpha 4 (main bars parallel to traffic)

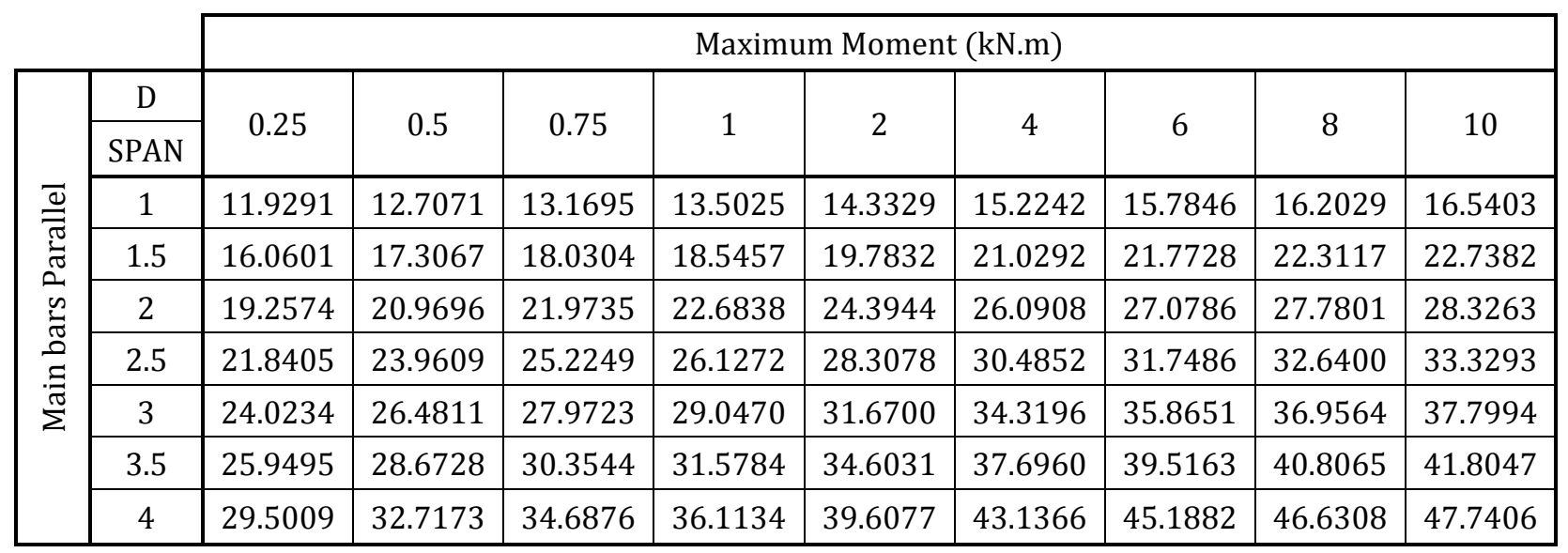




\section{Alpha 6 Bending Moment Results}

Table 292 Factored maximum moment results for alpha 6 (main bars perpendicular to traffic)

\begin{tabular}{|c|c|c|c|c|c|c|c|c|c|c|}
\hline & & \multicolumn{9}{|c|}{ Maximum Moment (kN.m) } \\
\hline \multirow{9}{*}{ 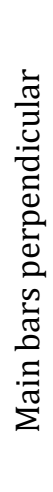 } & $\mathrm{D}$ & \multirow{2}{*}{0.25} & \multirow{2}{*}{0.5} & \multirow{2}{*}{0.75} & \multirow{2}{*}{1} & & & & \multirow{2}{*}{8} & \multirow{2}{*}{10} \\
\hline & SPAN & & & & & & & & & \\
\hline & 1 & 4.5821 & 5.3618 & 5.9234 & 6.3560 & 7.5263 & 8.8999 & 9.8091 & 10.5058 & 11.0772 \\
\hline & 1.5 & 6.0803 & 6.9268 & 7.4651 & 7.9246 & 9.3945 & 11.1257 & 12.2757 & 13.1592 & 13.8853 \\
\hline & 2 & 7.1401 & 8.1765 & 8.8375 & 9.3353 & 10.6930 & 12.6715 & 13.9878 & 15.0000 & 15.8329 \\
\hline & 2.5 & 7.9710 & 9.1488 & 9.9066 & 10.4803 & 11.9720 & 13.8606 & 15.3043 & 16.4153 & 17.3299 \\
\hline & 3 & 8.6766 & 9.9561 & 10.7892 & 11.4221 & 13.0821 & 14.9487 & 16.3756 & 17.5667 & 18.5476 \\
\hline & 3.5 & 8.3820 & 9.5968 & 10.4032 & 11.1401 & 13.1999 & 15.6465 & 17.2798 & 18.5381 & 19.5747 \\
\hline & 4 & 9.5968 & 10.9565 & 11.8676 & 12.5717 & 14.4539 & 16.6102 & 18.0096 & 19.0630 & 19.9154 \\
\hline
\end{tabular}

Table 293 Factored maximum moment results for alpha 6 (main bars parallel to traffic)

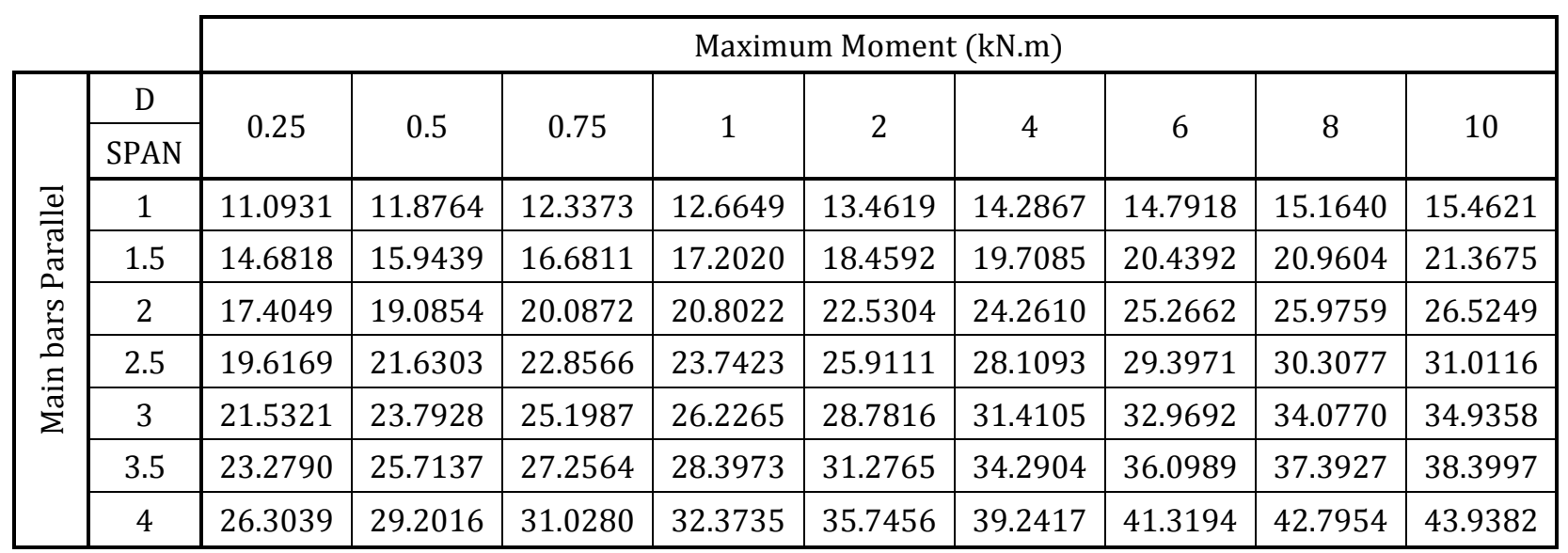




\section{Alpha 8 Bending Moment Results}

Table 294 Factored maximum moment results for alpha 8 (main bars perpendicular to traffic)

\begin{tabular}{|c|c|c|c|c|c|c|c|c|c|c|}
\hline & & \multicolumn{9}{|c|}{ Maximum Moment (kN.m) } \\
\hline \multirow{9}{*}{ 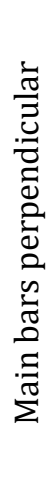 } & $\mathrm{D}$ & \multirow{2}{*}{0.25} & \multirow{2}{*}{0.5} & \multirow{2}{*}{0.75} & \multirow{2}{*}{1} & \multirow{2}{*}{2} & \multirow{2}{*}{4} & \multirow{2}{*}{6} & \multirow{2}{*}{8} & \multirow{2}{*}{10} \\
\hline & SPAN & & & & & & & & & \\
\hline & 1 & 4.1520 & 4.7296 & 5.2253 & 5.6072 & 6.6411 & 7.8556 & 8.6605 & 9.2776 & 9.7842 \\
\hline & 1.5 & 5.4679 & 6.2550 & 6.7572 & 7.1314 & 8.2883 & 9.8180 & 10.8348 & 11.6164 & 12.2591 \\
\hline & 2 & 6.4041 & 7.3537 & 7.9634 & 8.4234 & 9.6155 & 11.1812 & 12.3445 & 13.2396 & 13.9763 \\
\hline & 2.5 & 7.1537 & 8.2165 & 8.9069 & 9.4316 & 10.8039 & 12.3438 & 13.5056 & 14.4877 & 15.2965 \\
\hline & 3 & 7.8097 & 8.9473 & 9.6967 & 10.2690 & 11.7822 & 13.4930 & 14.5954 & 15.5034 & 16.3705 \\
\hline & 3.5 & 7.5772 & 8.6435 & 9.3550 & 9.9056 & 11.6575 & 13.8097 & 15.2501 & 16.3612 & 17.2770 \\
\hline & 4 & 8.7299 & 9.8990 & 10.6930 & 11.3108 & 12.9830 & 14.9234 & 16.1936 & 17.1542 & 17.9338 \\
\hline
\end{tabular}

Table 295 Factored maximum moment results for alpha 8 (main bars parallel to traffic)

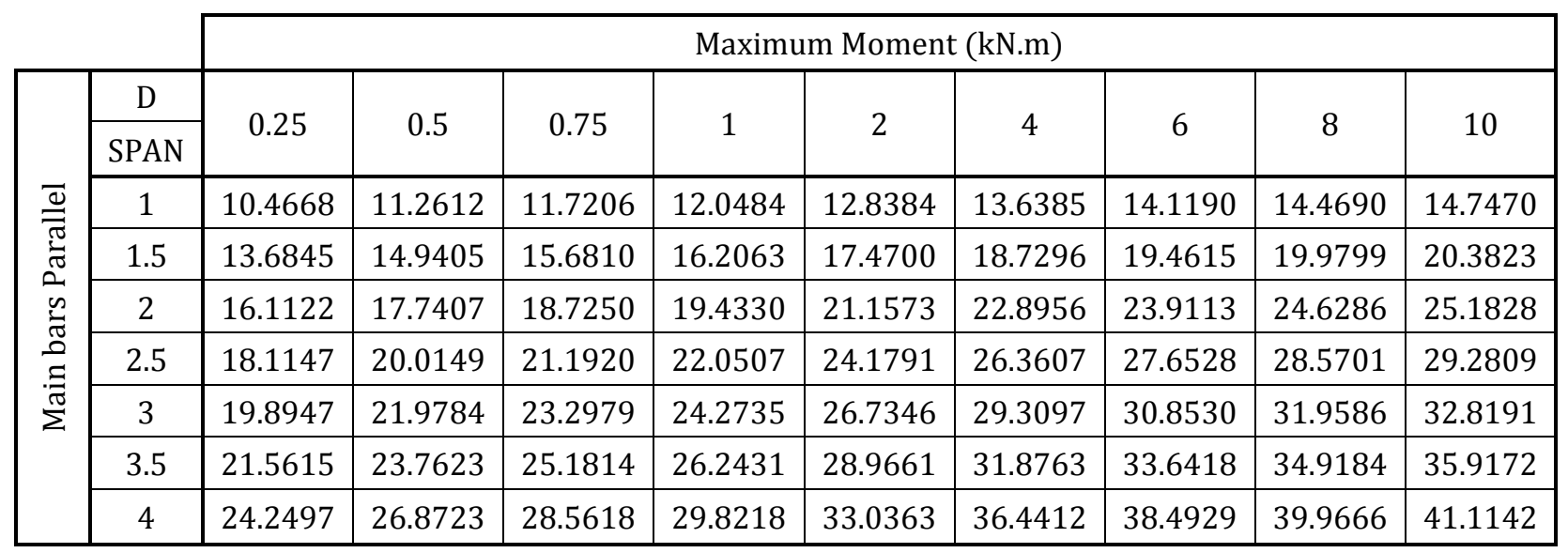




\section{Alpha 10 Bending Moment Results}

Table 296 Factored maximum moment results for alpha 10 (main bars perpendicular to traffic)

\begin{tabular}{|c|c|c|c|c|c|c|c|c|c|c|}
\hline & & & & & Maxir & m Mom & nt (kN.m) & & & \\
\hline \multirow{9}{*}{ 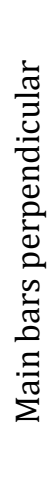 } & D & \multirow{2}{*}{0.25} & \multirow[t]{2}{*}{5} & \multirow{2}{*}{0.75} & \multirow[t]{2}{*}{1} & & \multirow{2}{*}{4} & & \multirow{2}{*}{8} & \multirow{2}{*}{10} \\
\hline & SPAN & & & & & & & & & \\
\hline & 1 & 3.8316 & 4.3631 & 4.7275 & 5.0733 & 6.0099 & 7.1109 & 7.8410 & 8.4013 & 8.8615 \\
\hline & 1.5 & 5.0200 & 5.7593 & 6.2324 & 6.5857 & 7.4996 & 8.8853 & 9.8070 & 10.5158 & 11.0988 \\
\hline & 2 & 5.8734 & 6.7538 & 7.3229 & 7.7532 & 8.8730 & 10.1246 & 11.1724 & 11.9838 & 12.6518 \\
\hline & 2.5 & 6.5727 & 7.5448 & 8.1821 & 8.6683 & 9.9472 & 11.3872 & 12.3122 & 13.1128 & 13.8459 \\
\hline & 3 & 7.2009 & 8.2291 & 8.9131 & 9.4380 & 10.8362 & 12.4267 & 13.4560 & 14.2294 & 14.8545 \\
\hline & 3.5 & 7.0170 & 7.9718 & 8.6142 & 9.1116 & 10.5658 & 12.5039 & 13.8051 & 14.8100 & 15.6392 \\
\hline & 4 & 8.1361 & 9.1662 & 9.8724 & 10.4250 & 11.9356 & 13.7084 & 14.8786 & 15.7671 & 16.4901 \\
\hline
\end{tabular}

Table 297 Factored maximum moment results for alpha 10 (main bars parallel to traffic)

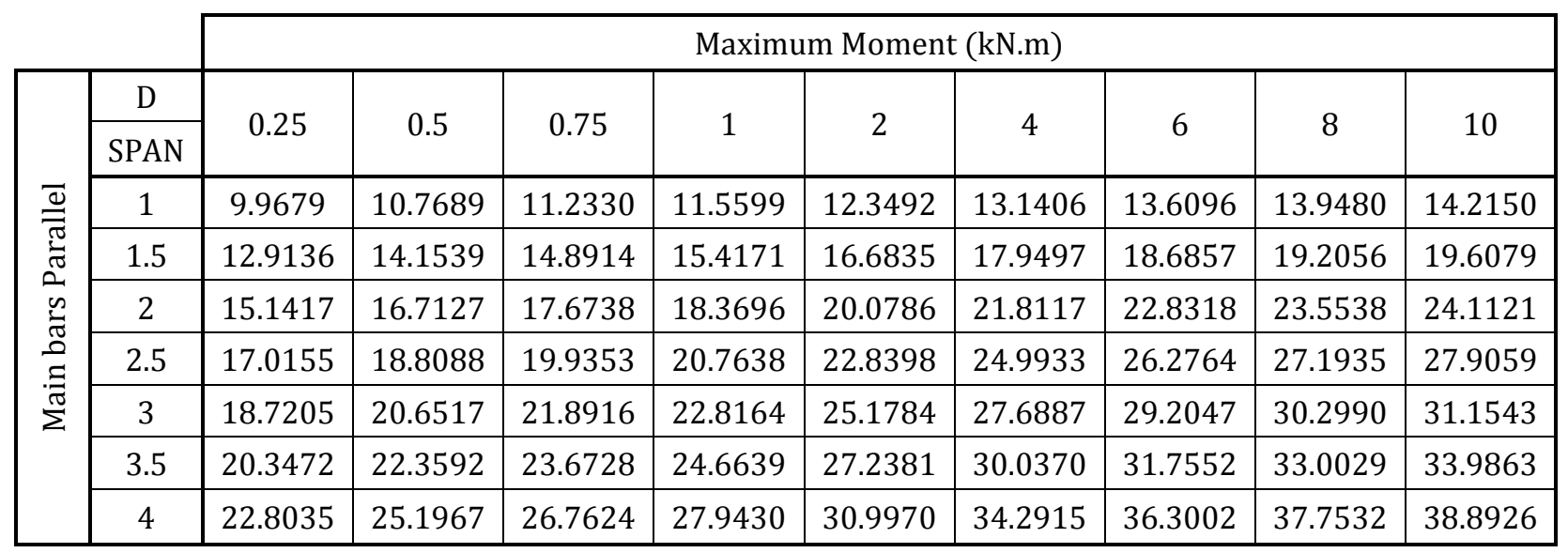




\section{E.1.2 MAXIMUM BENDING MOMENT VS SPAN LENGTH}




\section{Bending Moment VS Span Length for Different D Values (Main bars perpendicular to traffic)}

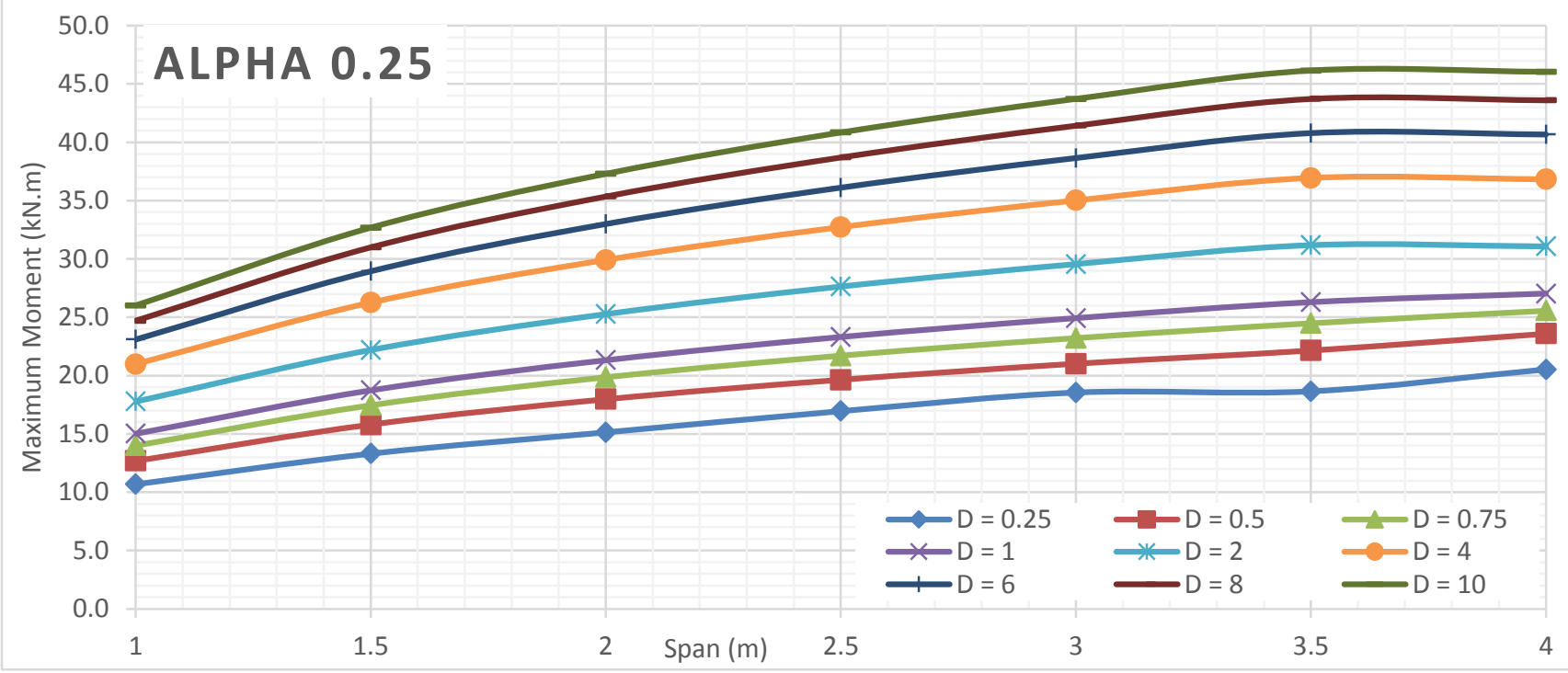

Figure 1069 Factored maximum moment results for alpha 0.25 at different $D$ values (main bars perpendicular to traffic)

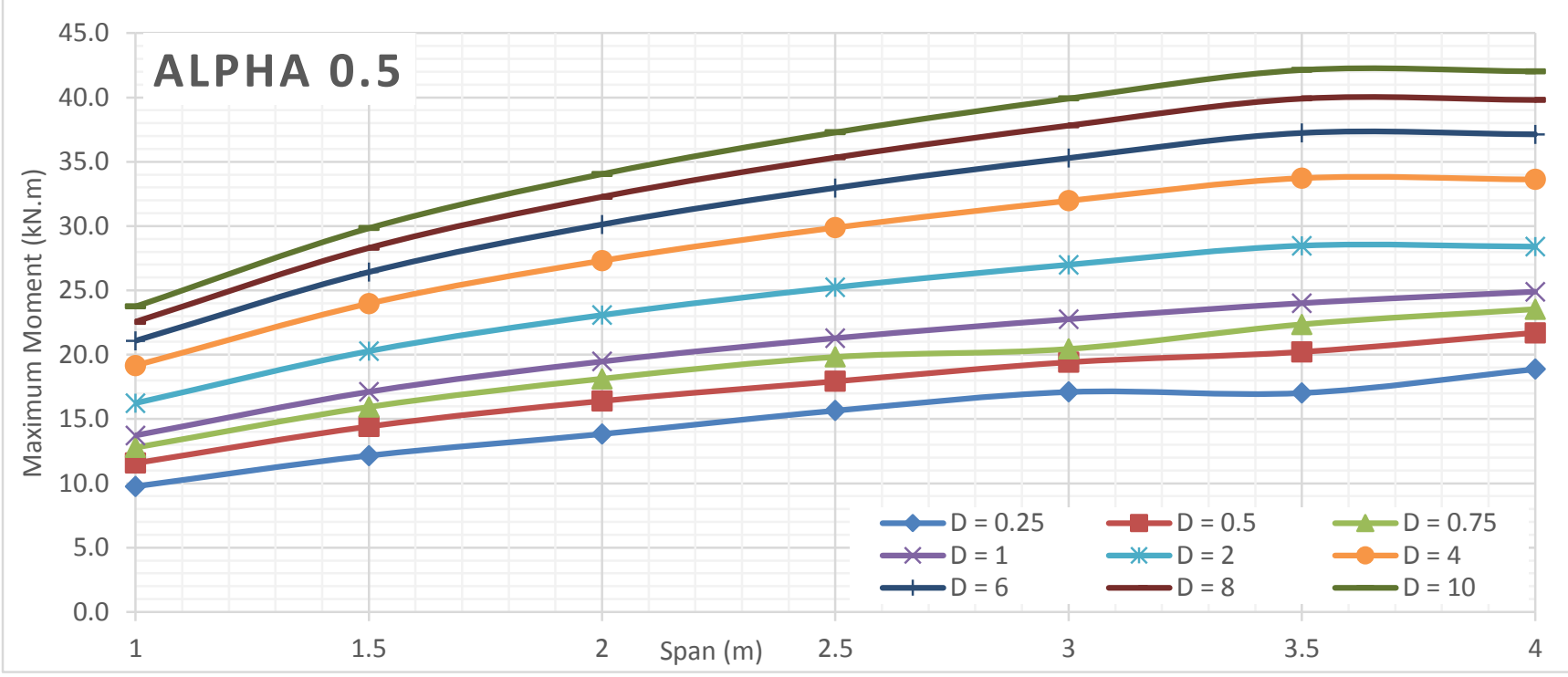

Figure 1070 Factored maximum moment results for alpha 0.5 at different $D$ values (main bars perpendicular to traffic) 


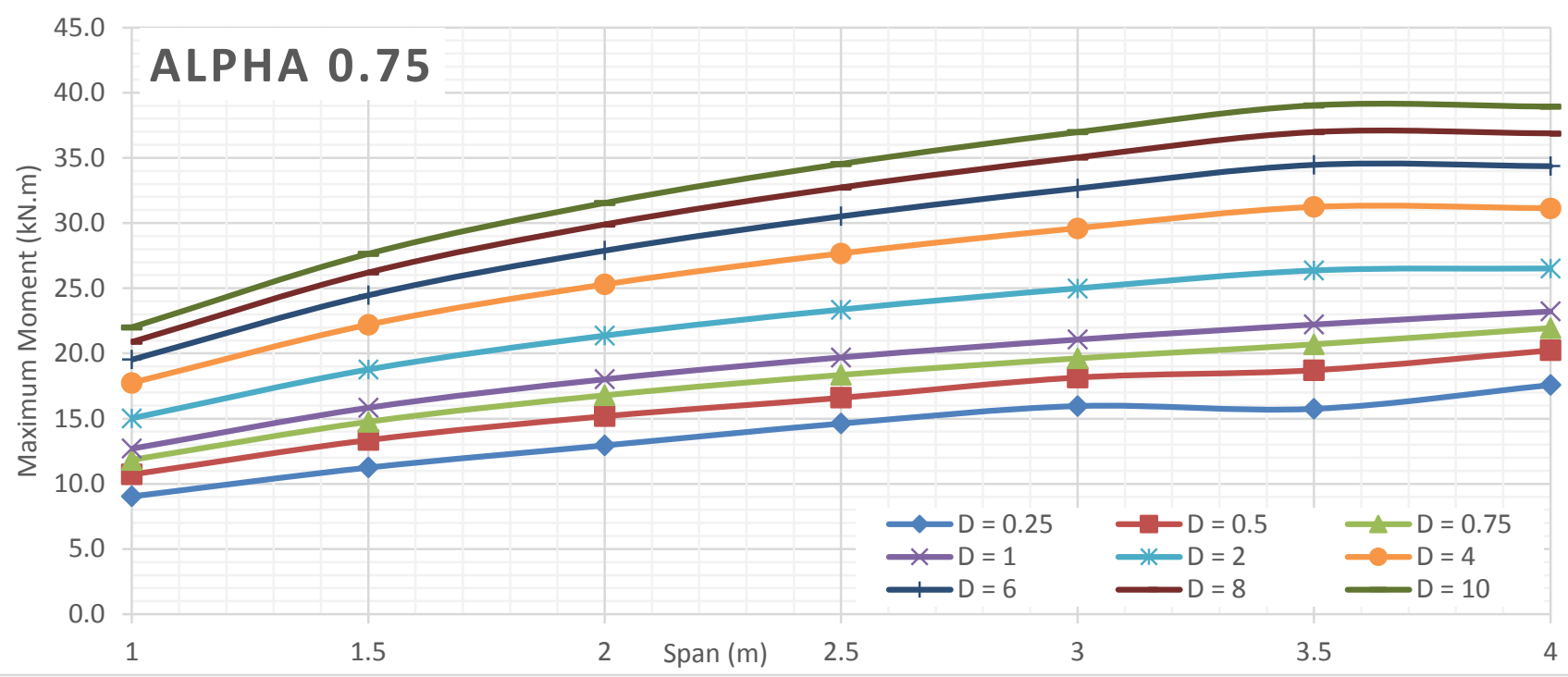

Figure 1071 Factored maximum moment results for alpha 0.75 at different $D$ values (main bars perpendicular to traffic)

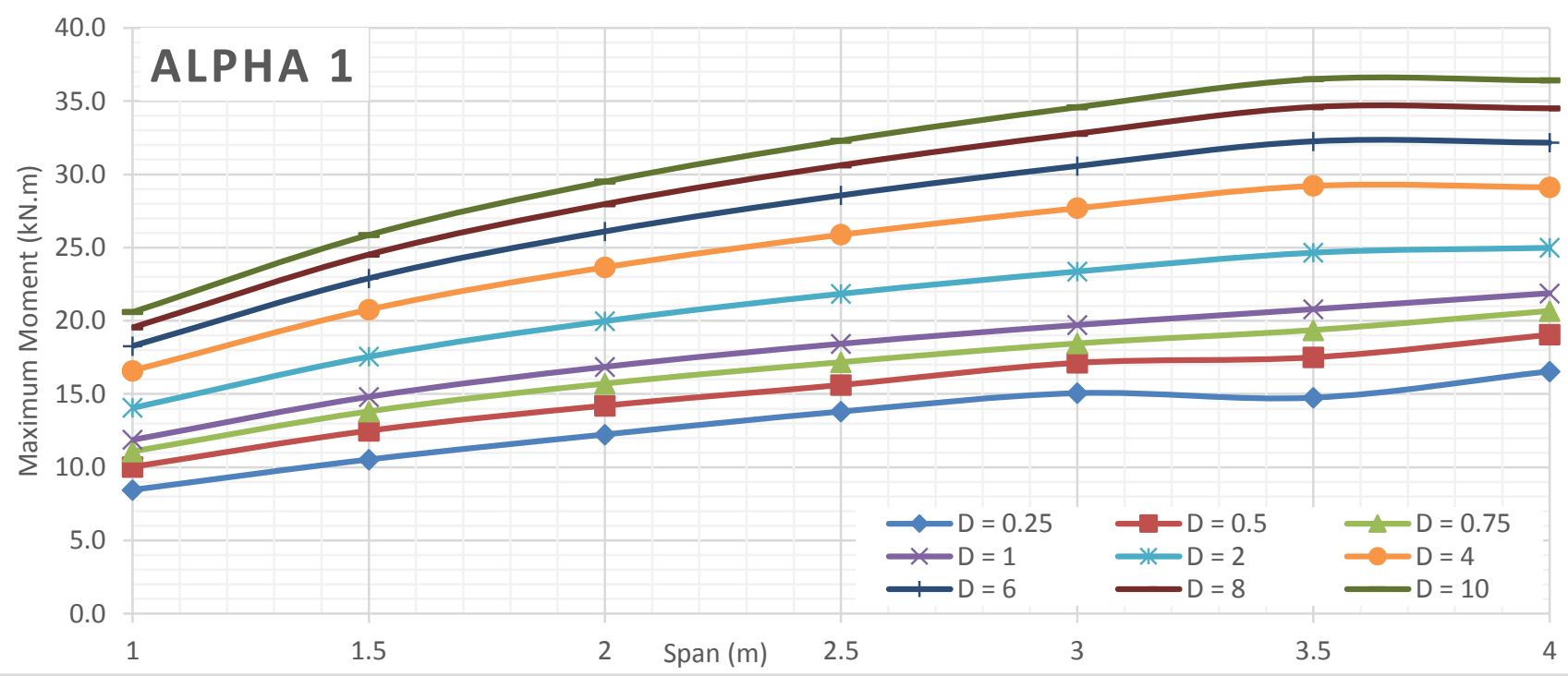

Figure 1072 Factored maximum moment results for alpha 1 at different D values (main bars perpendicular to traffic)

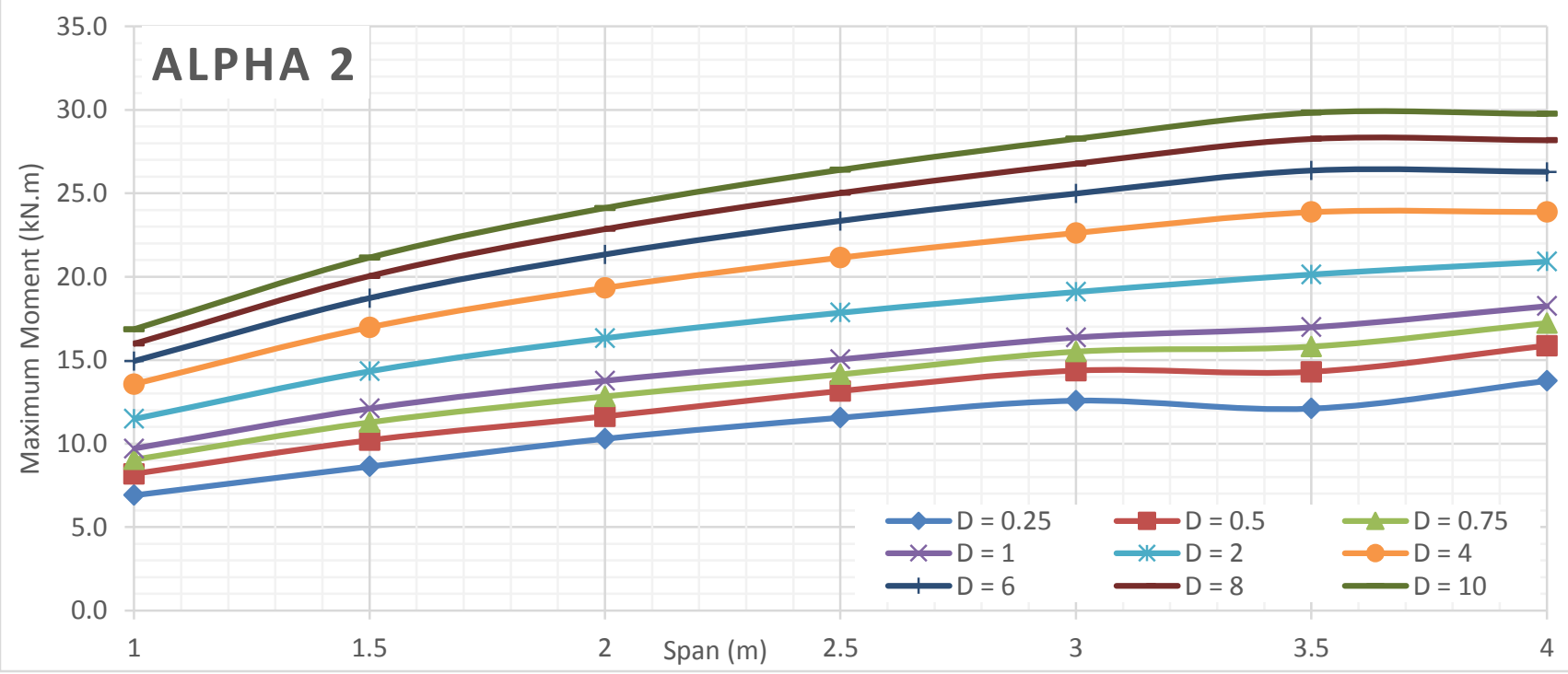

Figure 1073 Factored maximum moment results for alpha 2 at different D values (main bars perpendicular to traffic) 


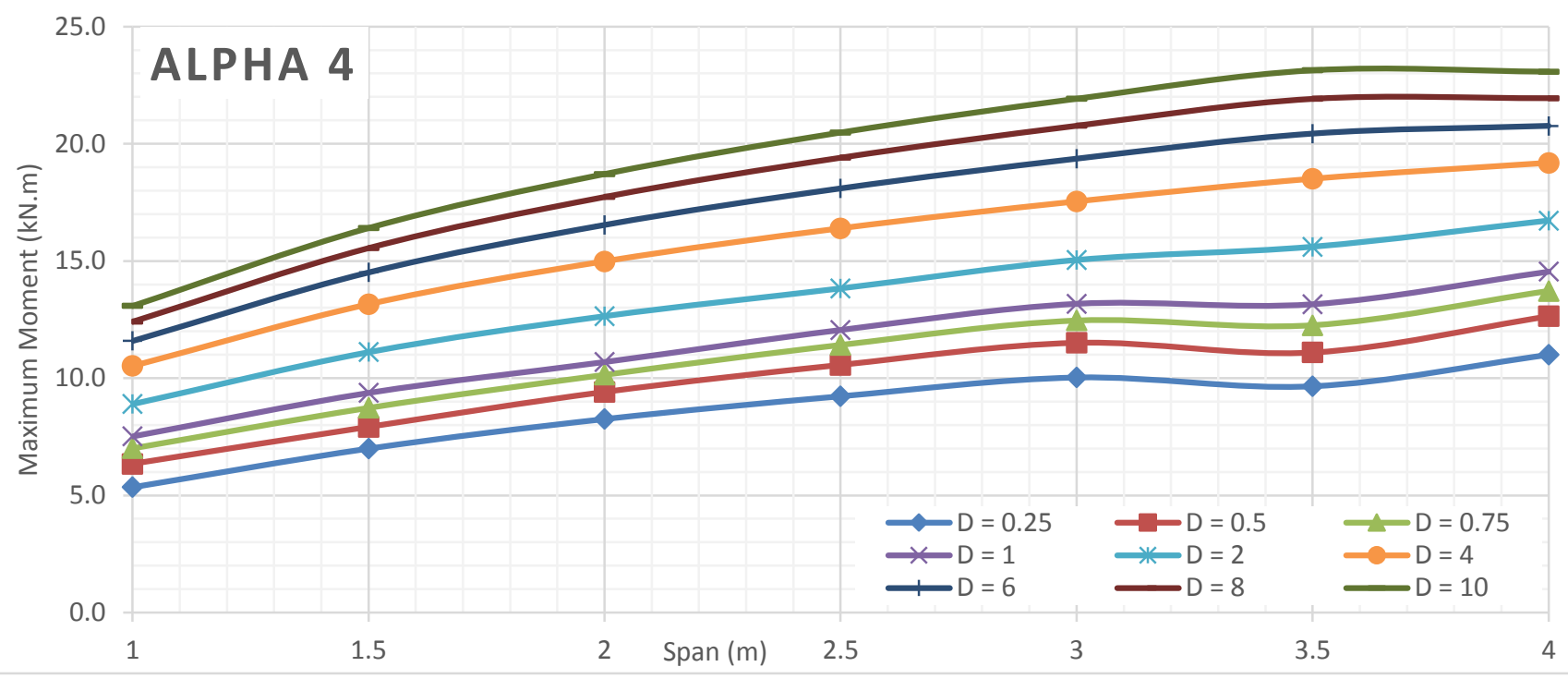

Figure 1074 Factored maximum moment results for alpha 4 at different D values (main bars perpendicular to traffic)

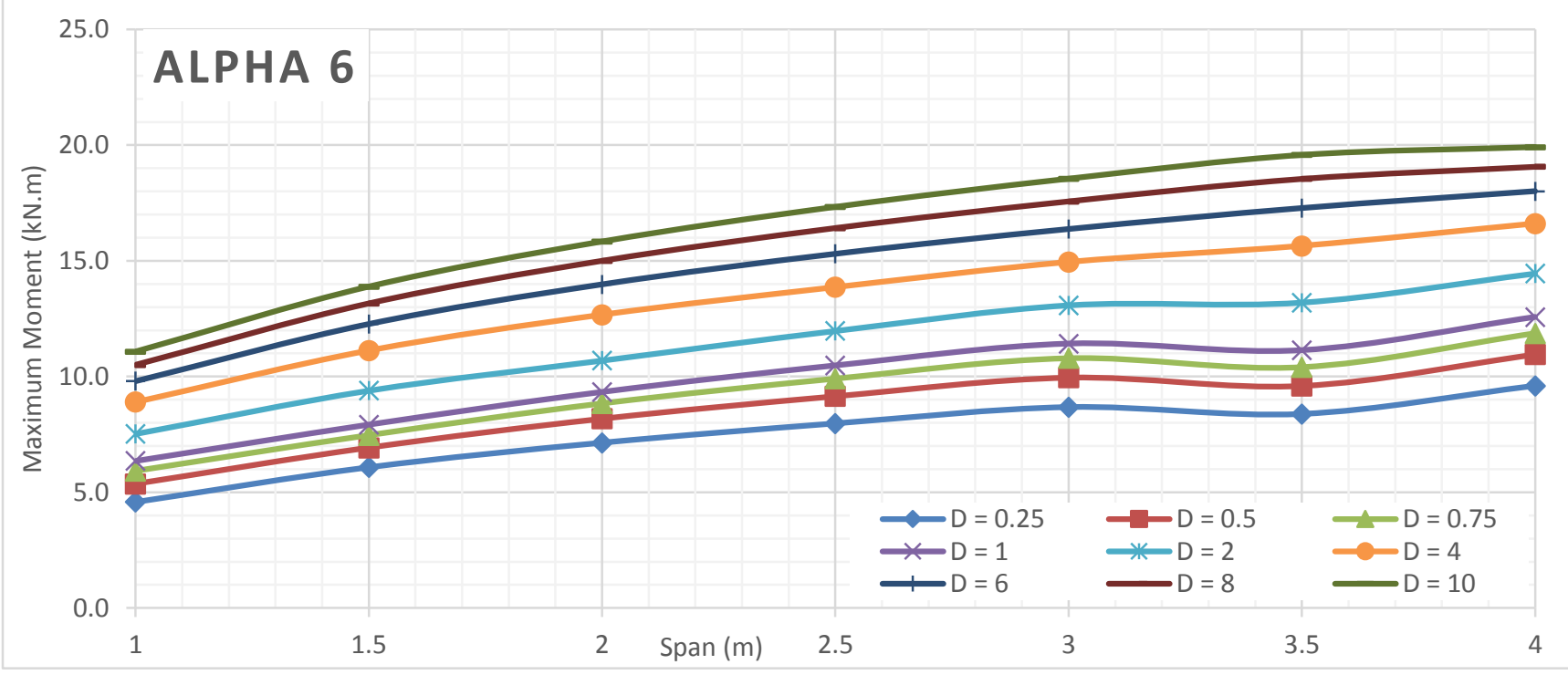

Figure 1075 Factored maximum moment results for alpha 6 at different D values (main bars perpendicular to traffic)

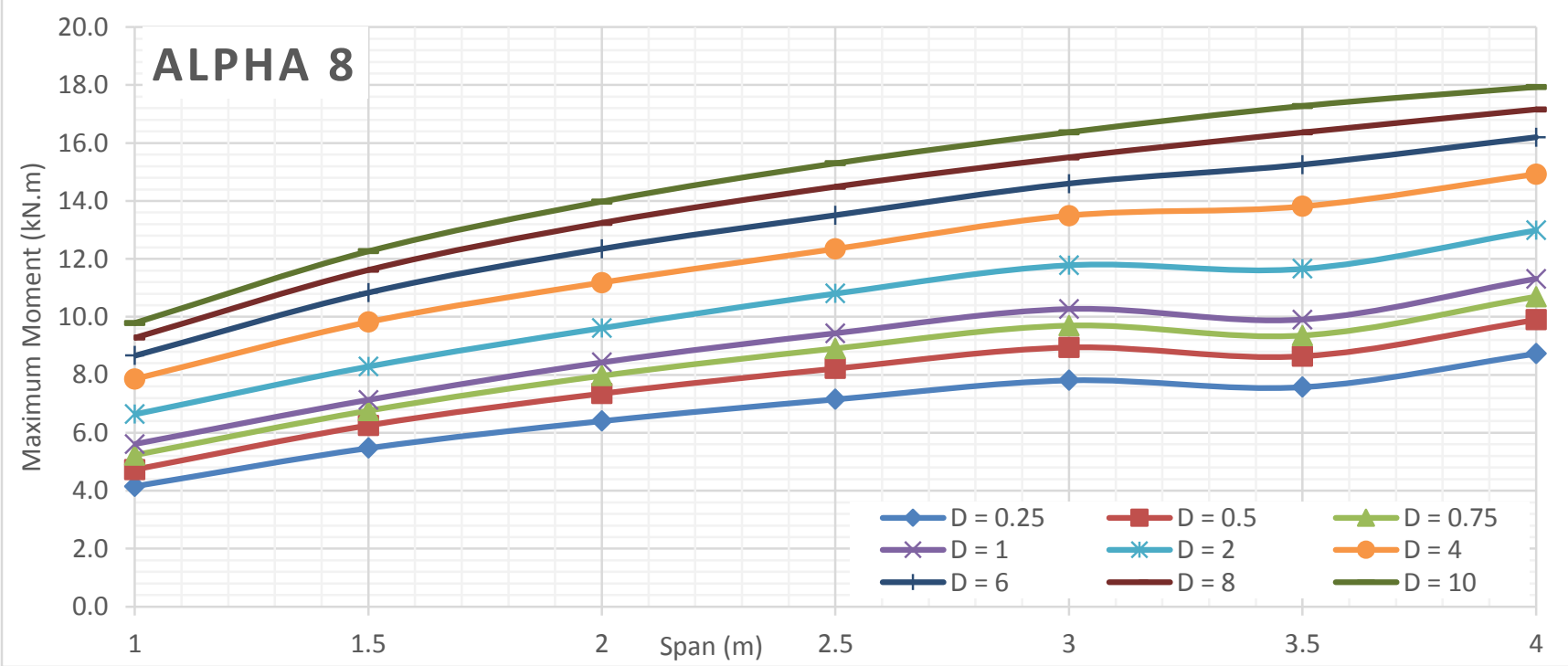

Figure 1076 Factored maximum moment results for alpha 8 at different D values (main bars perpendicular to traffic) 


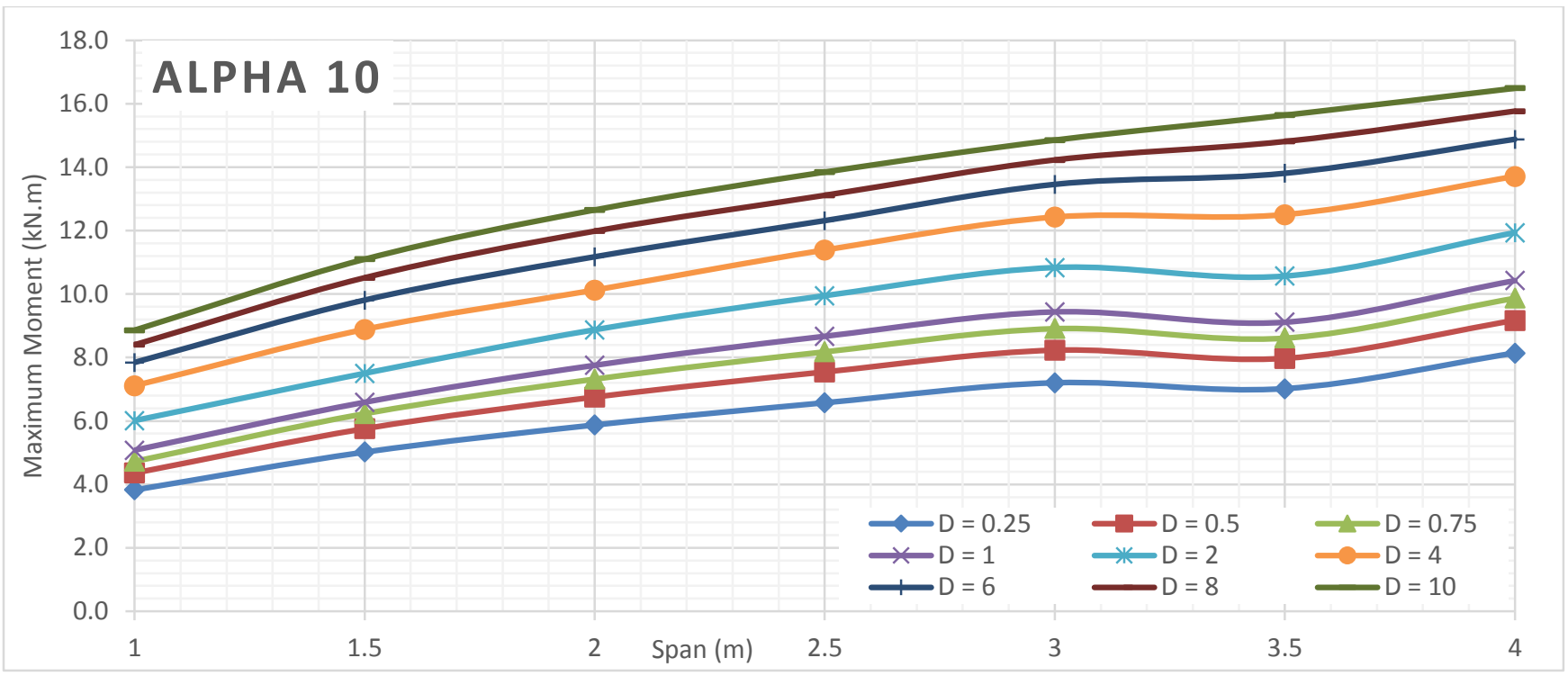

Figure 1077 Factored maximum moment results for alpha 10 at different $D$ values (main bars perpendicular to traffic) 


\section{Bending Moment VS Span Length for Different D Values (Main bars parallel to traffic)}

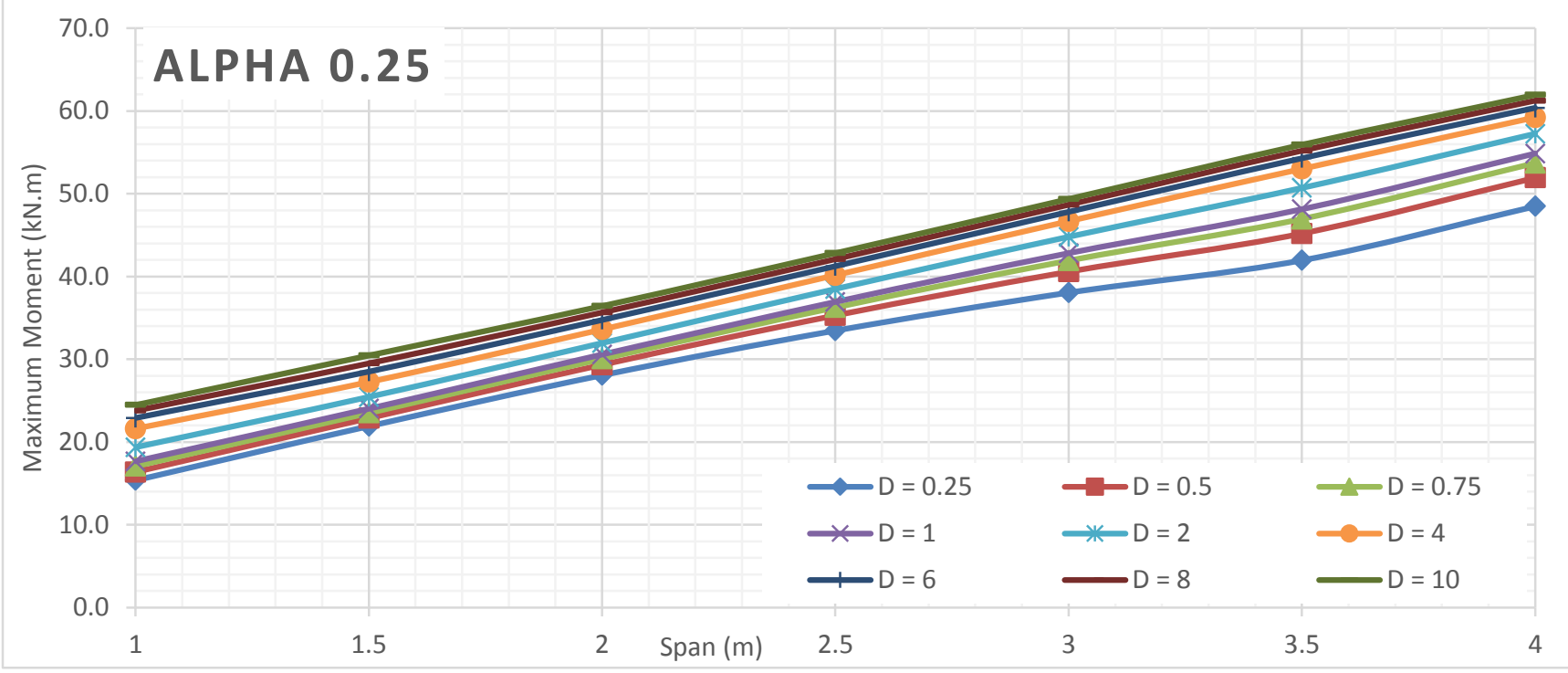

Figure 1078 Factored maximum moment results for alpha 0.25 at different $D$ values (main bars parallel to traffic)

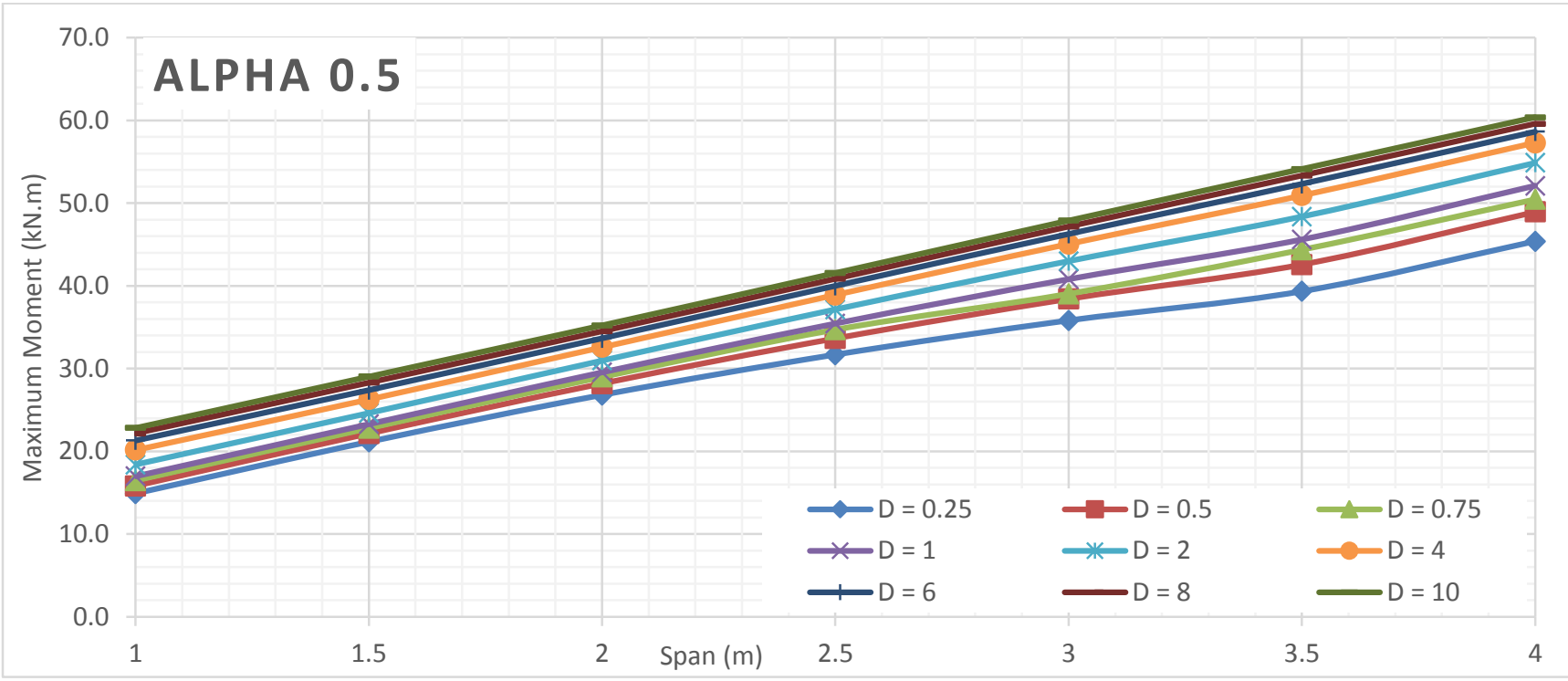

Figure 1079 Factored maximum moment results for alpha 0.5 at different $D$ values (main bars parallel to traffic) 


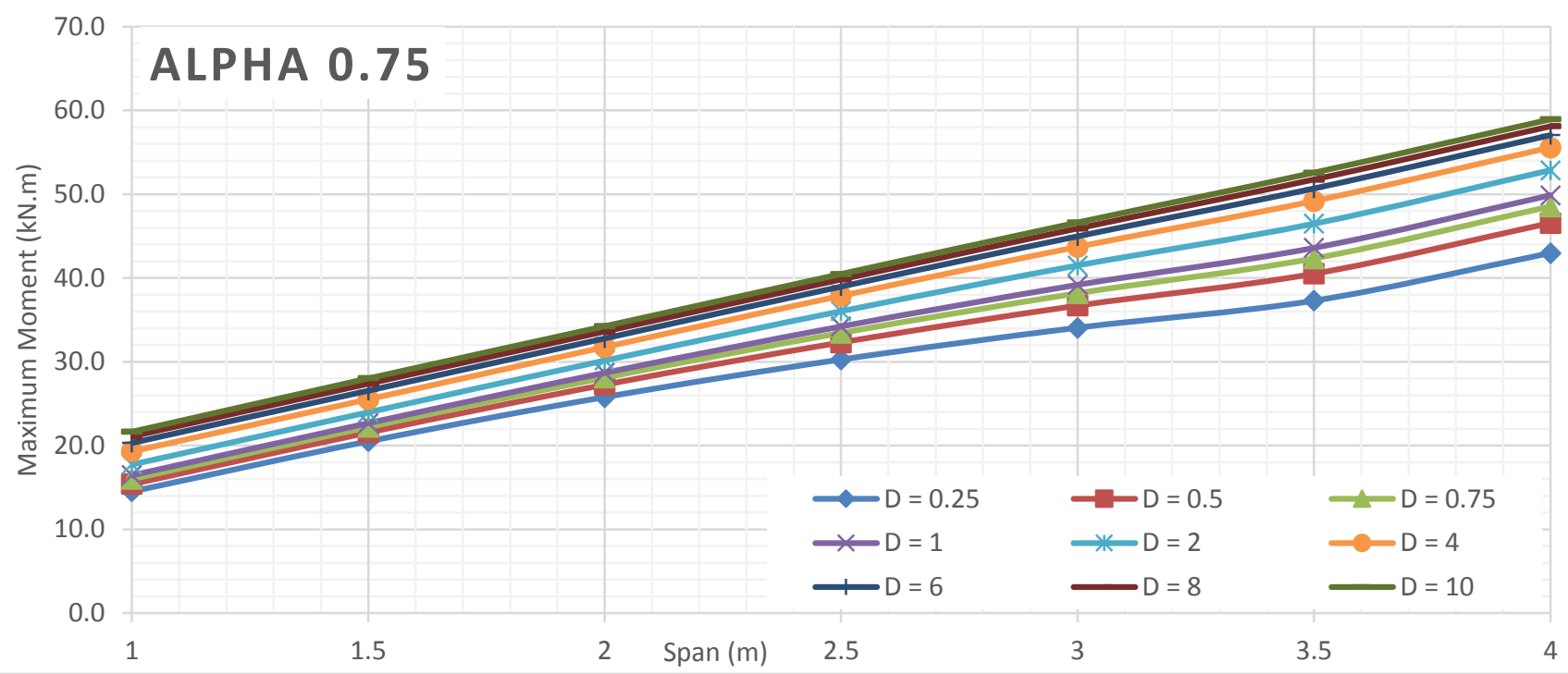

Figure 1080 Factored maximum moment results for alpha 0.75 at different $D$ values (main bars parallel to traffic)

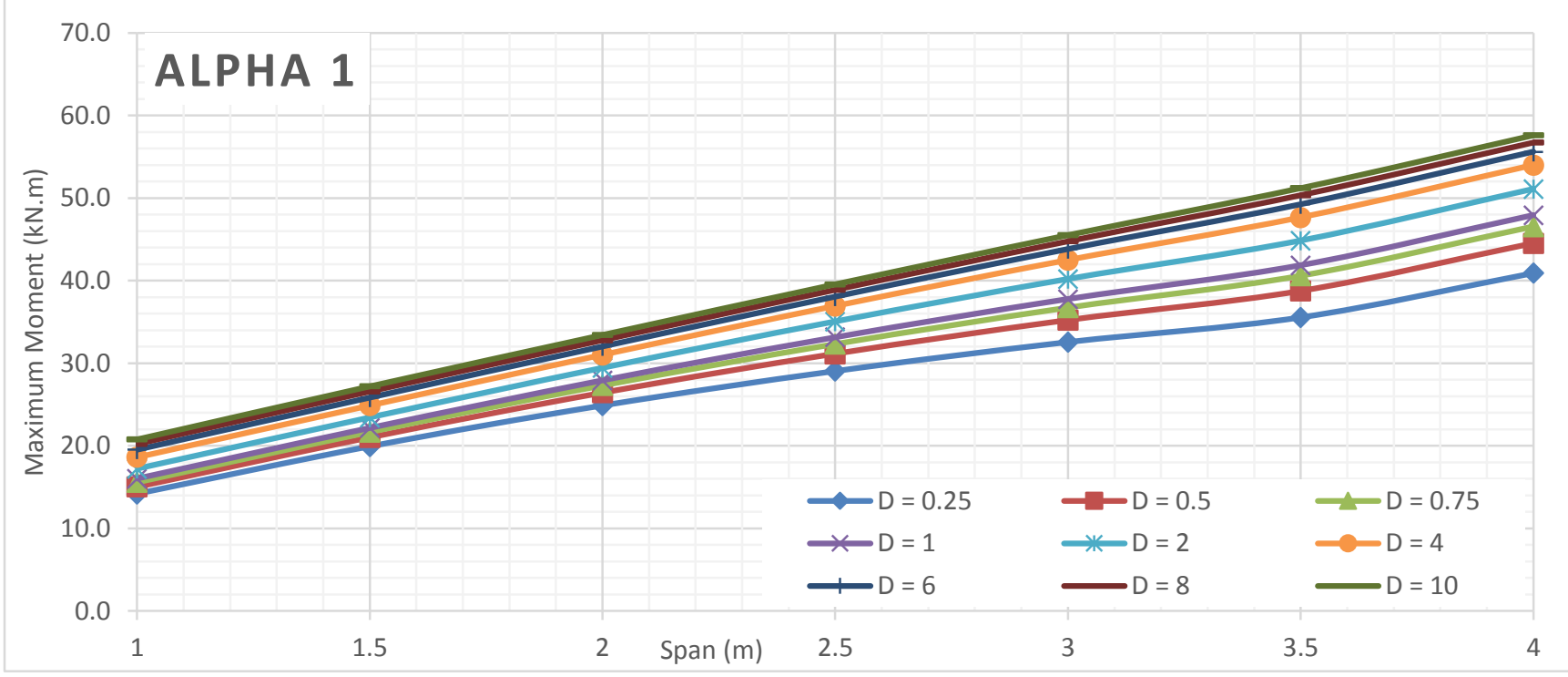

Figure 1081 Factored maximum moment results for alpha 1 at different D values (main bars parallel to traffic)

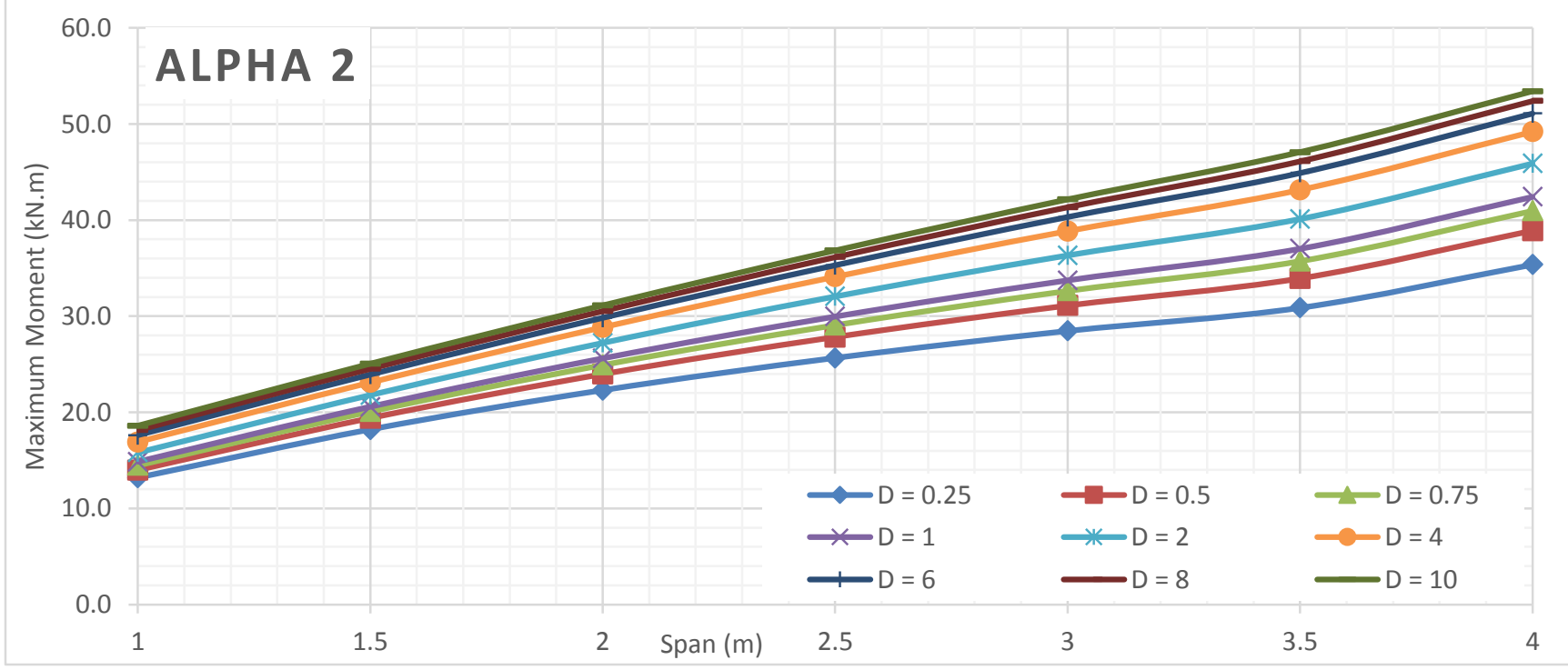

Figure 1082 Factored maximum moment results for alpha 2 at different $D$ values (main bars parallel to traffic) 


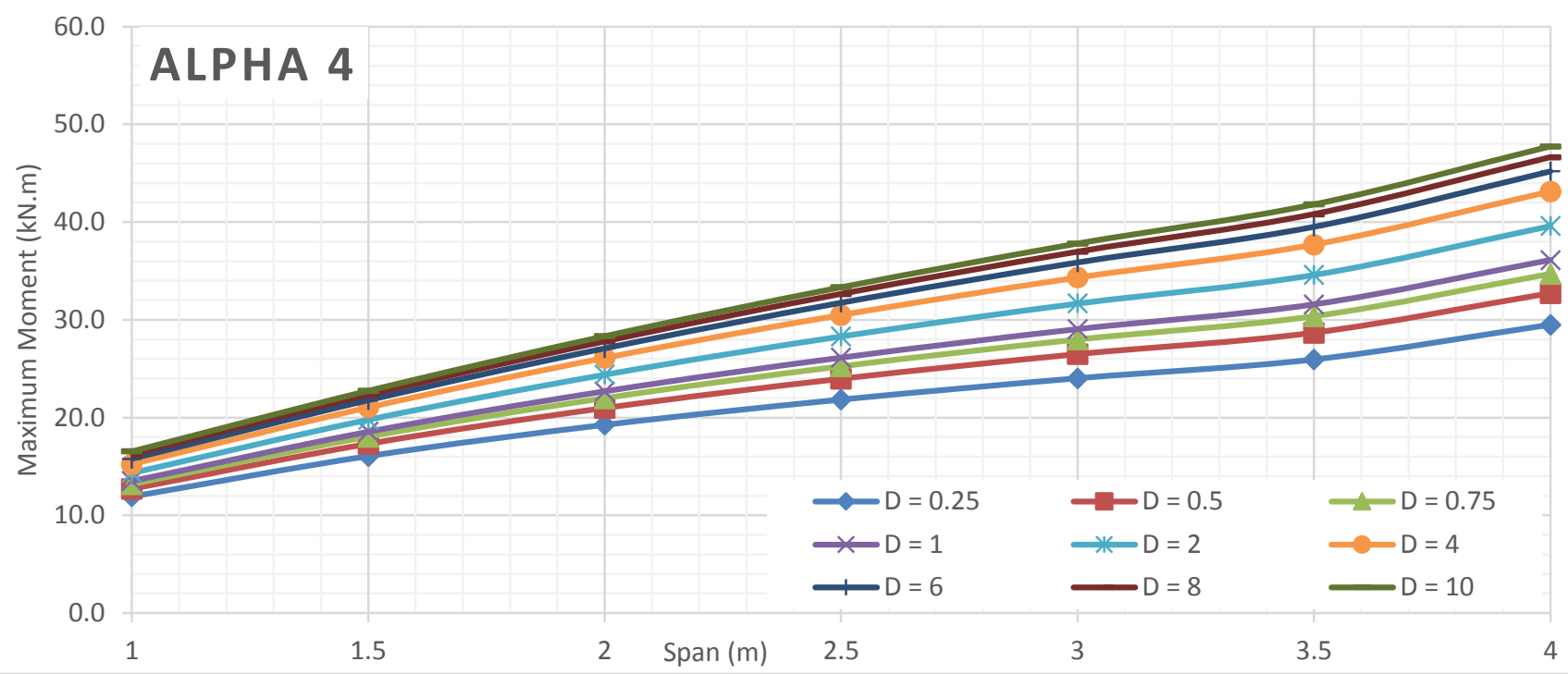

Figure 1083 Factored maximum moment results for alpha 4 at different D values (main bars parallel to traffic)

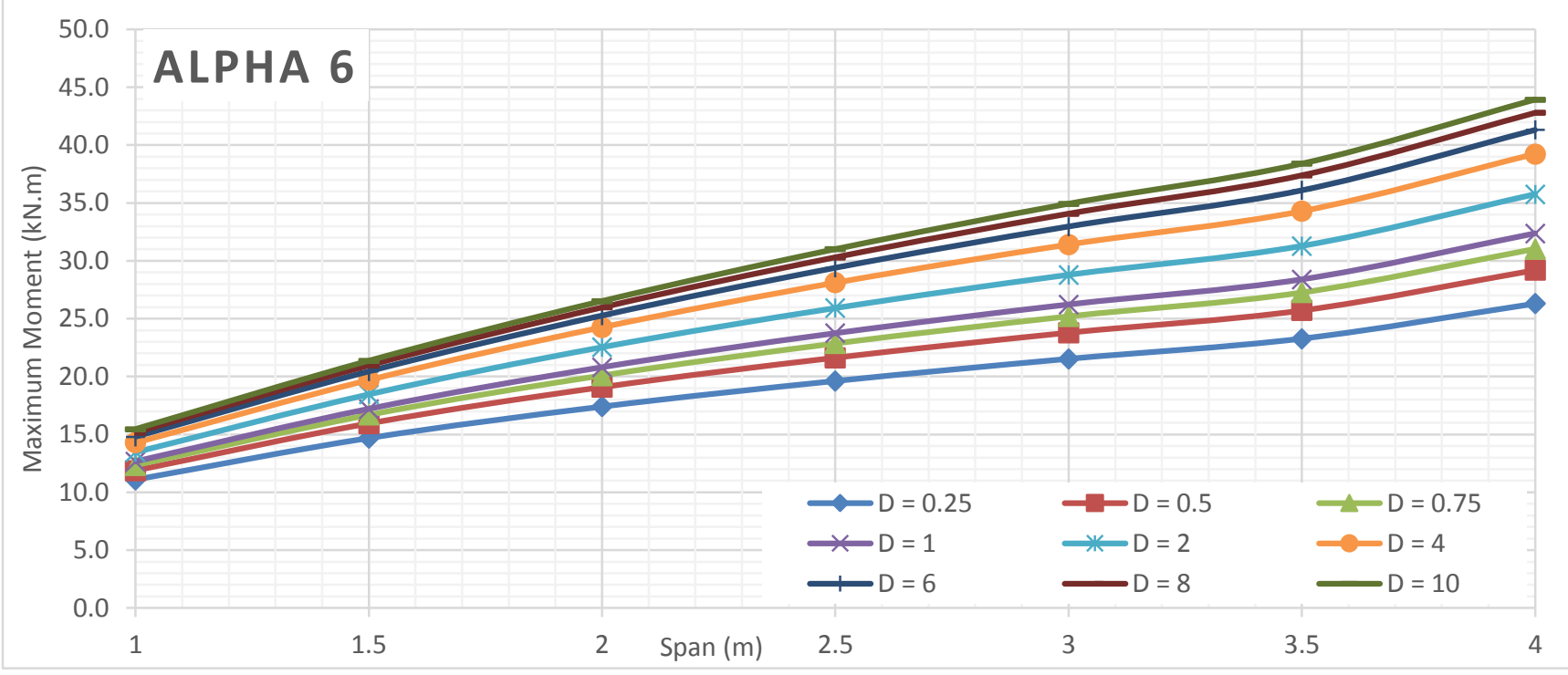

Figure 1084 Factored maximum moment results for alpha 6 at different $D$ values (main bars parallel to traffic)

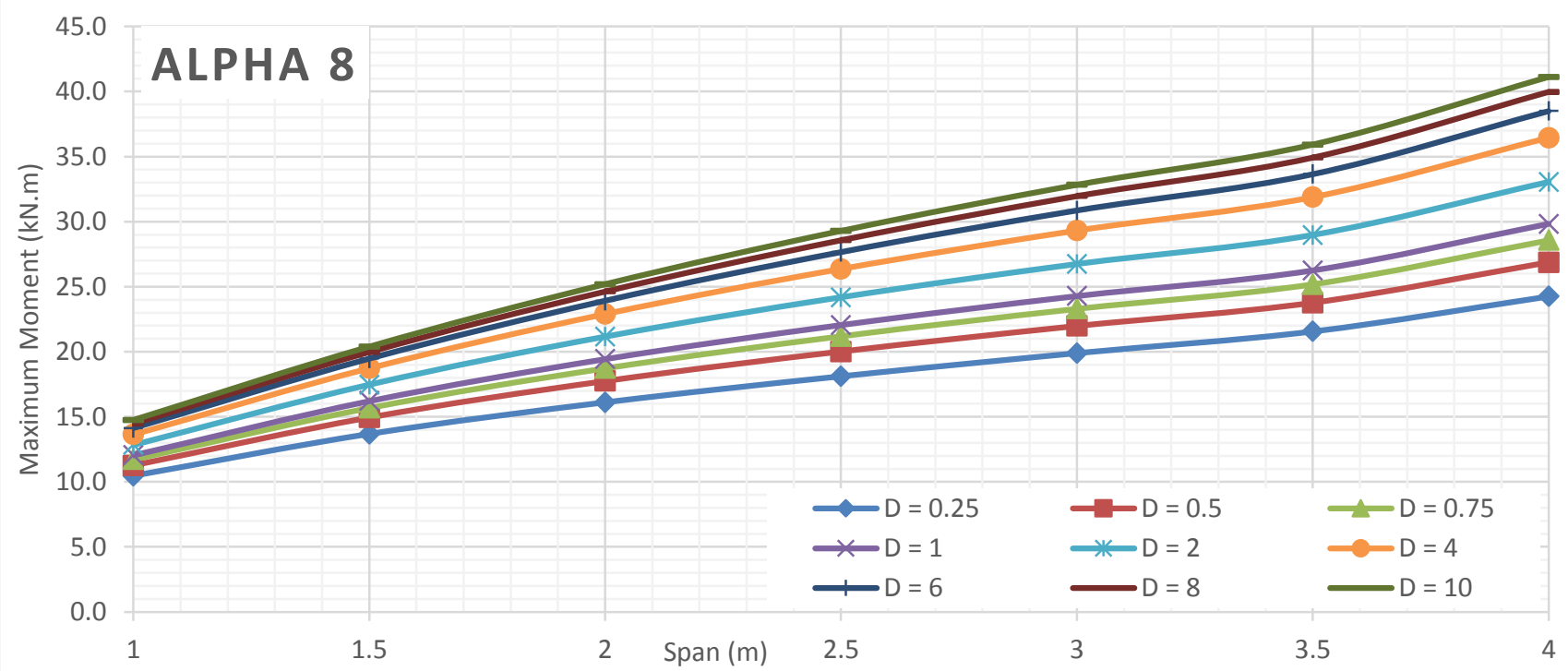

Figure 1085 Factored maximum moment results for alpha 8 at different D values (main bars parallel to traffic) 


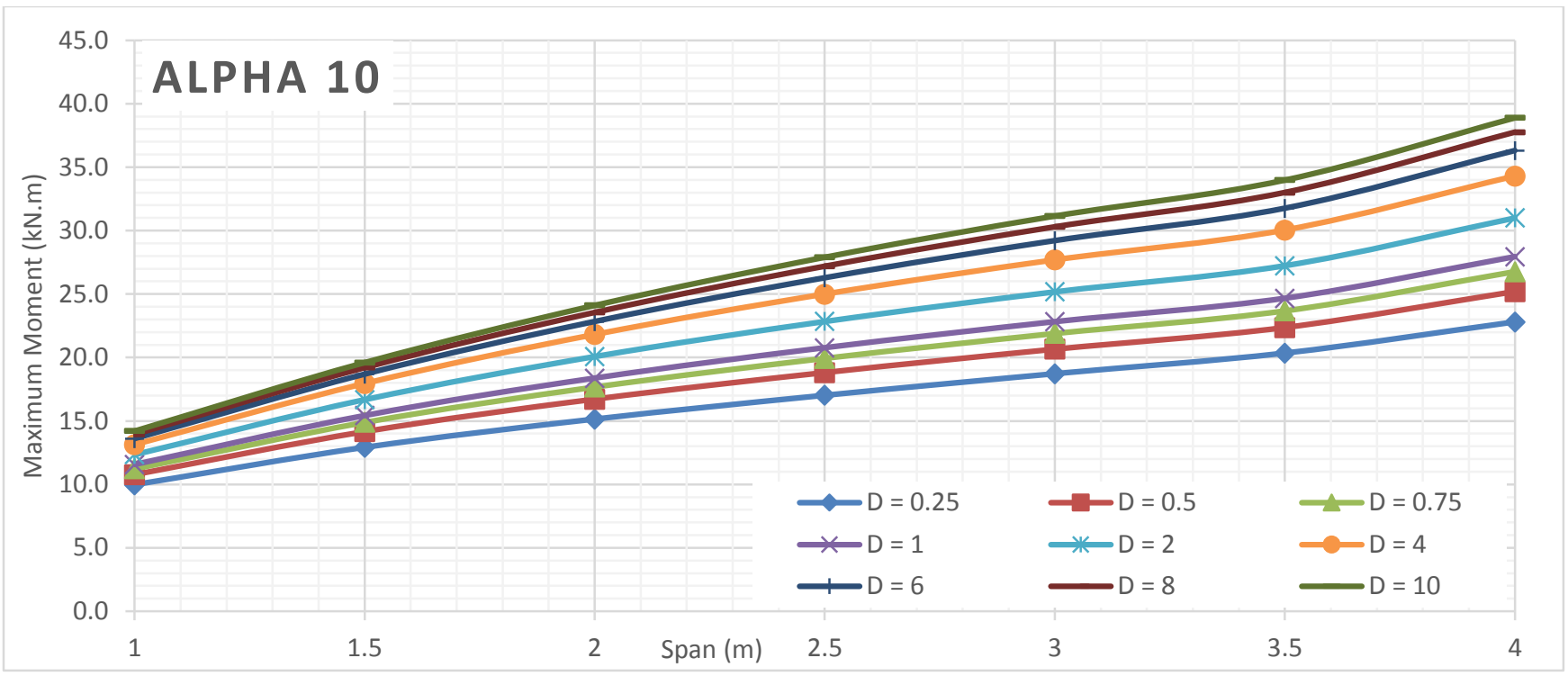

Figure 1086 Factored maximum moment results for alpha 10 at different $D$ values (main bars parallel to traffic) 


\section{E.1.3 MAXIMUM BENDING}

MOMENT VS FLEXURAL RIGIDITY 


\section{Bending Moment VS Flexural Rigidity at Different Spans (Main bars perpendicular to traffic)}

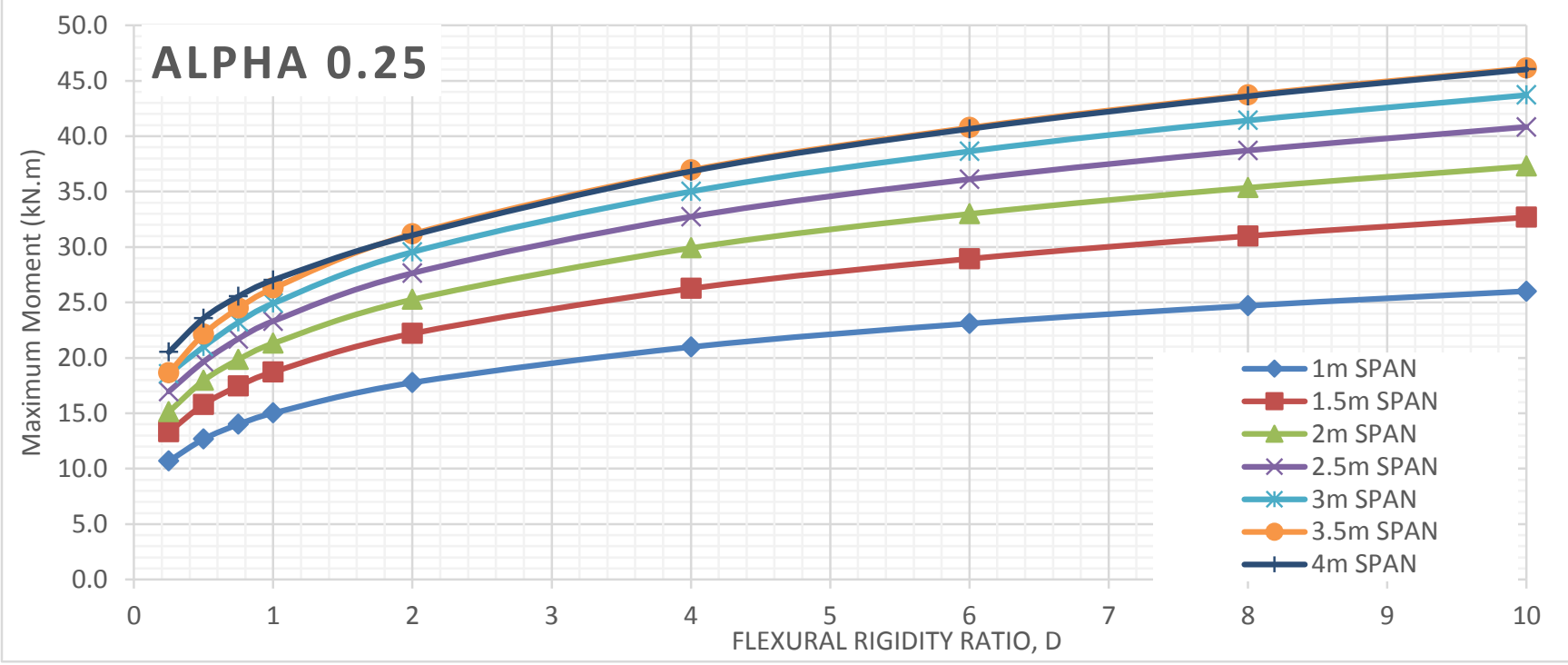

Figure 1087 Factored maximum moment results for alpha 0.25 at different span length (main bars perpendicular to traffic)

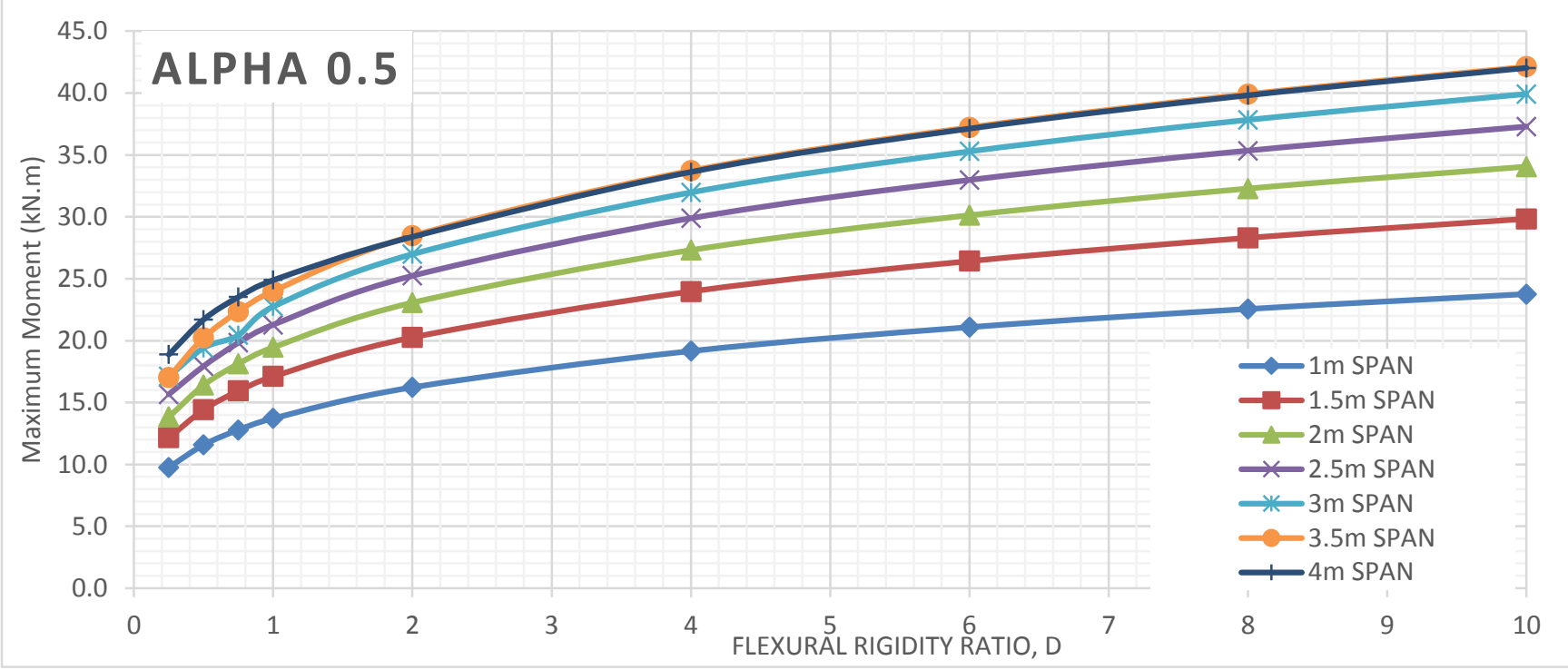

Figure 1088 Factored maximum moment results for alpha 0.5 at different span length (main bars perpendicular to traffic) 


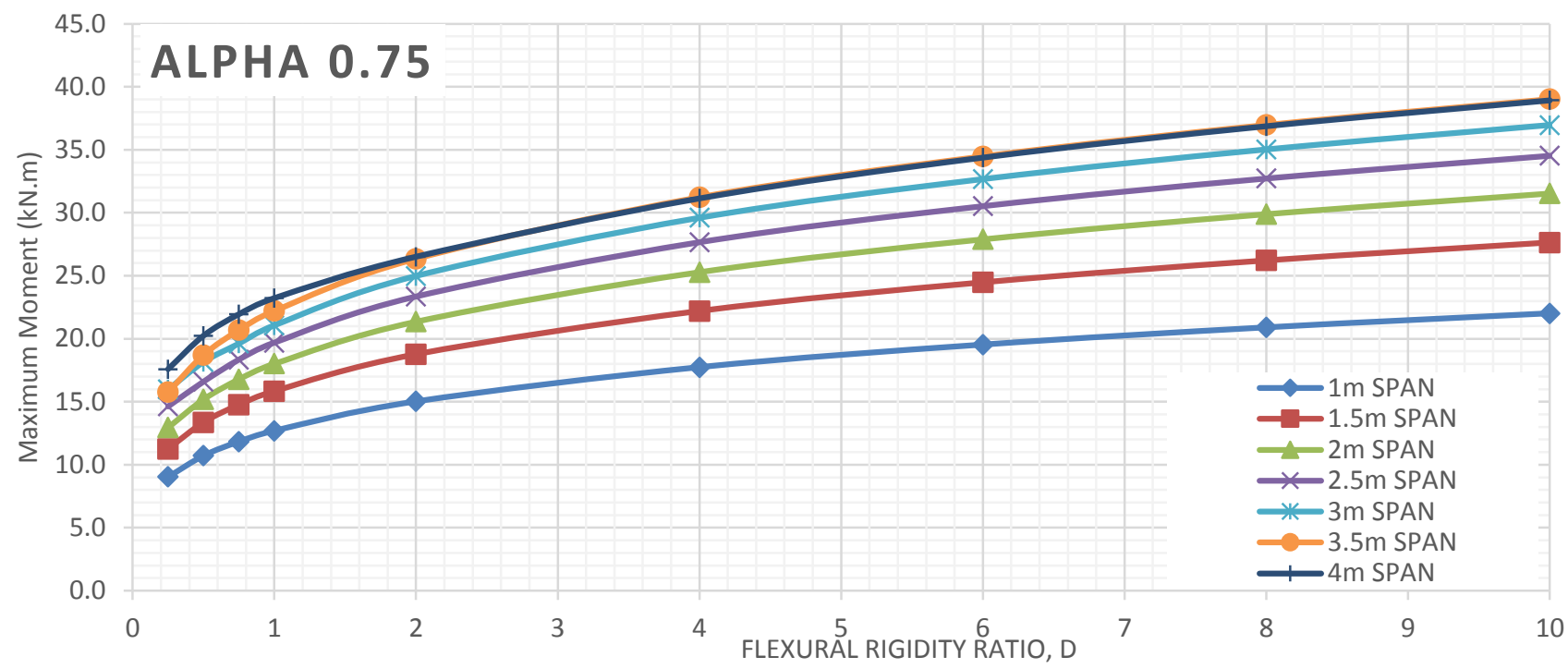

Figure 1089 Factored maximum moment results for alpha 0.75 at different span length (main bars perpendicular to traffic)

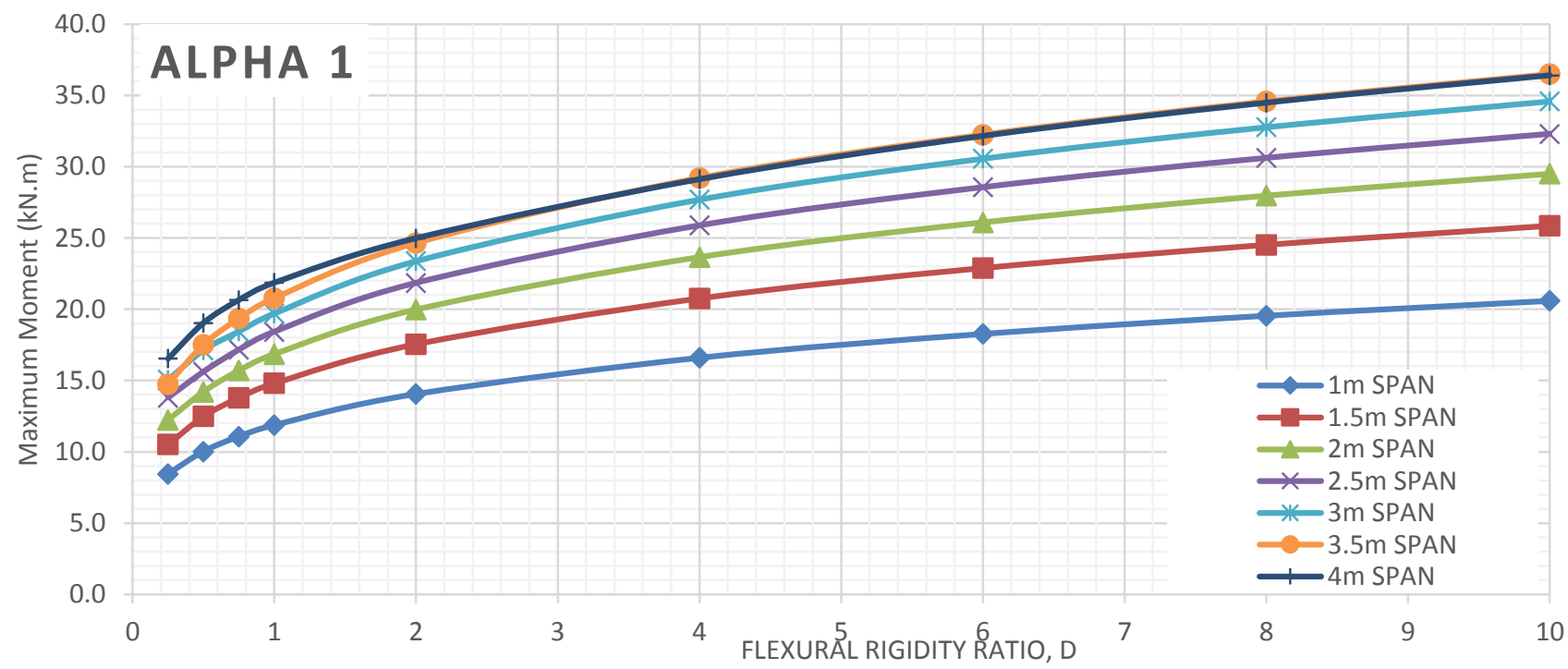

Figure 1090 Factored maximum moment results for alpha 1 at different span length (main bars perpendicular to traffic)

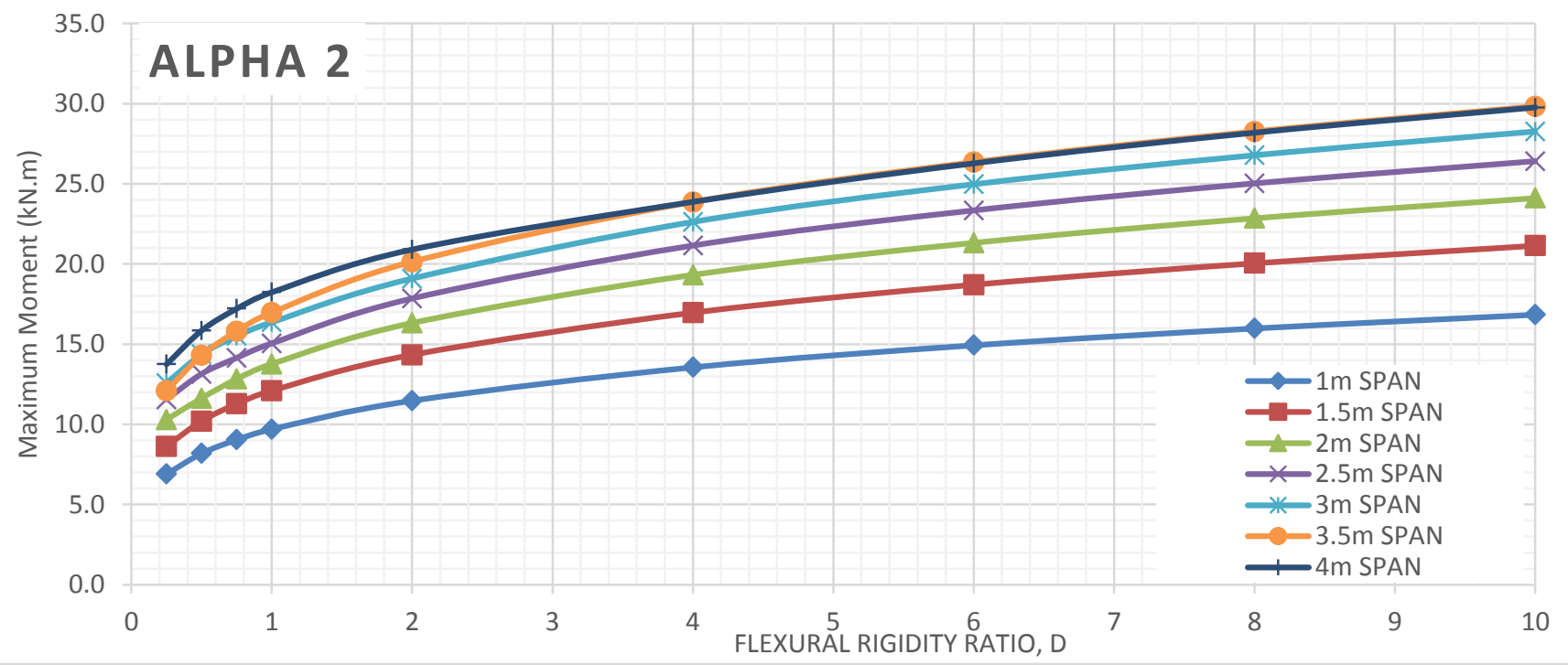

Figure 1091 Factored maximum moment results for alpha 2 at different span length (main bars perpendicular to traffic) 


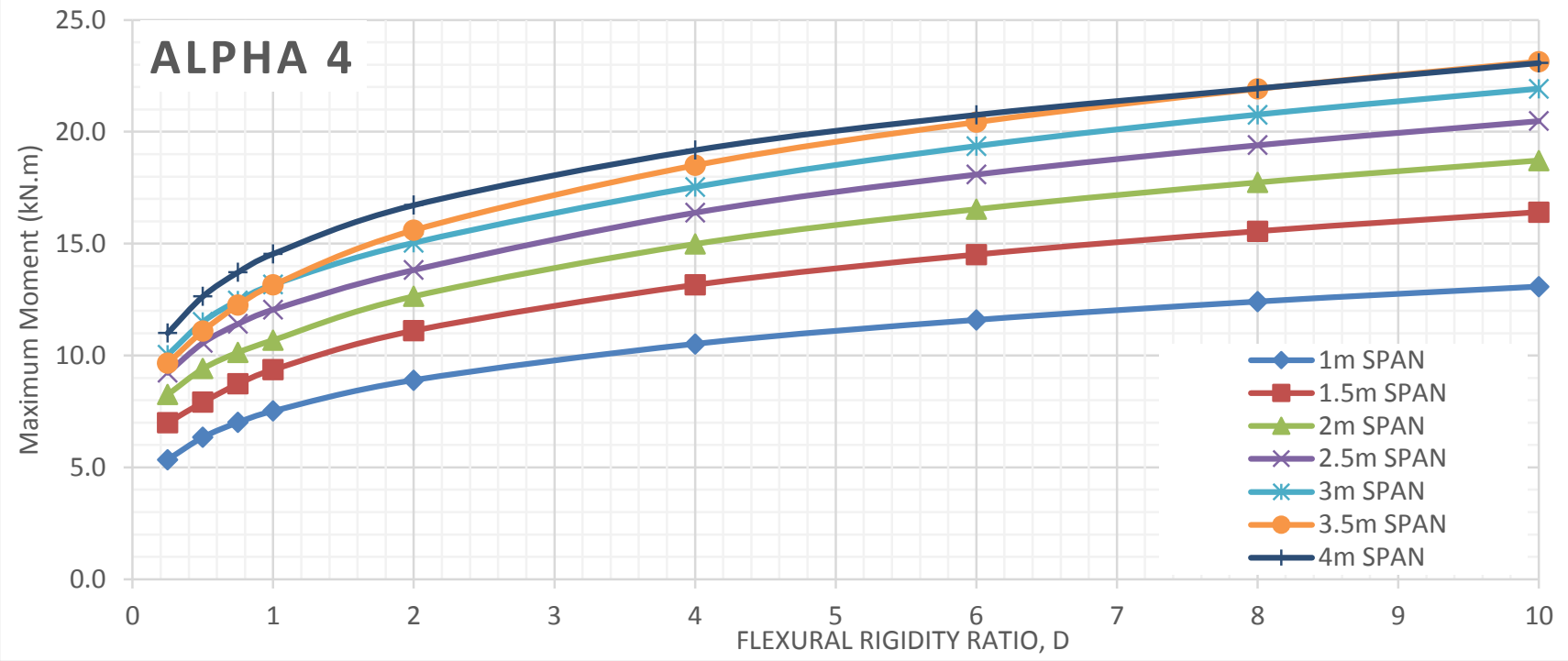

Figure 1092 Factored maximum moment results for alpha 4 at different span length (main bars perpendicular to traffic)

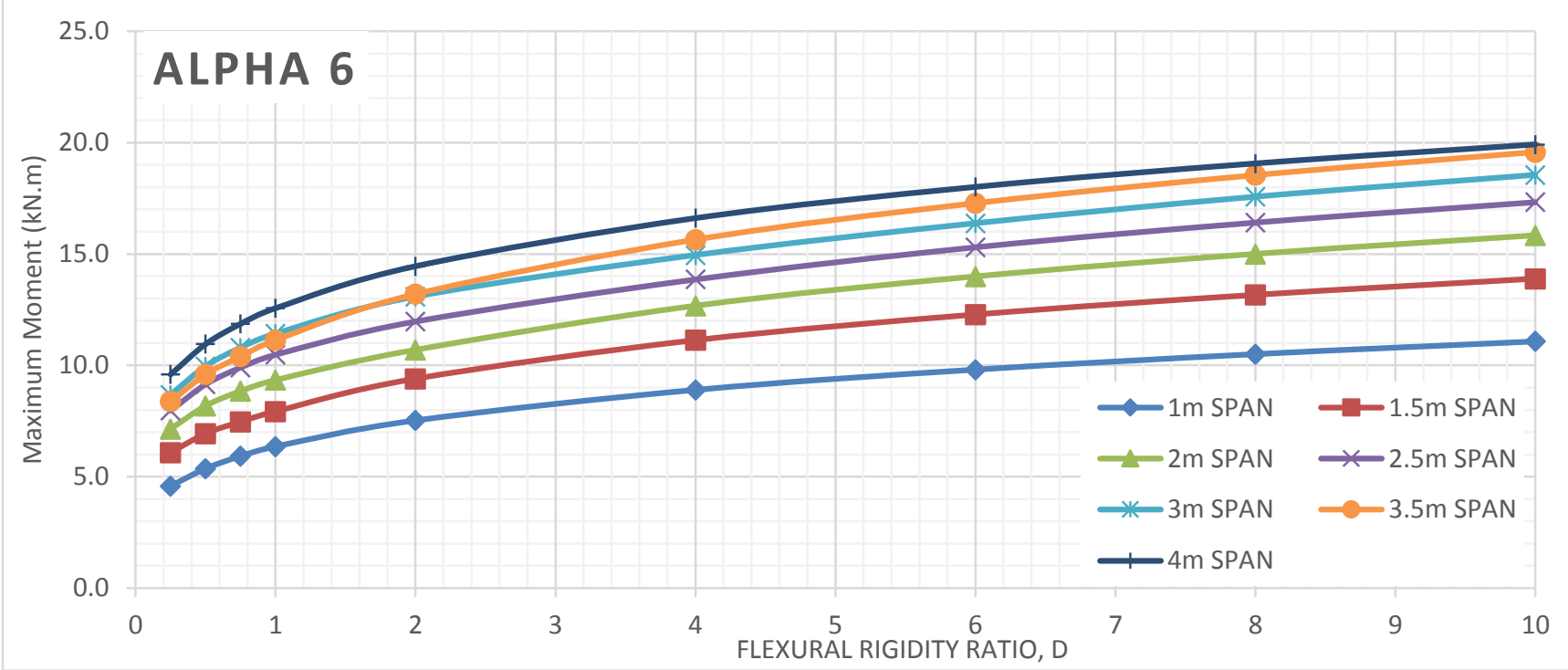

Figure 1093 Factored maximum moment results for alpha 6 at different span length (main bars perpendicular to traffic)

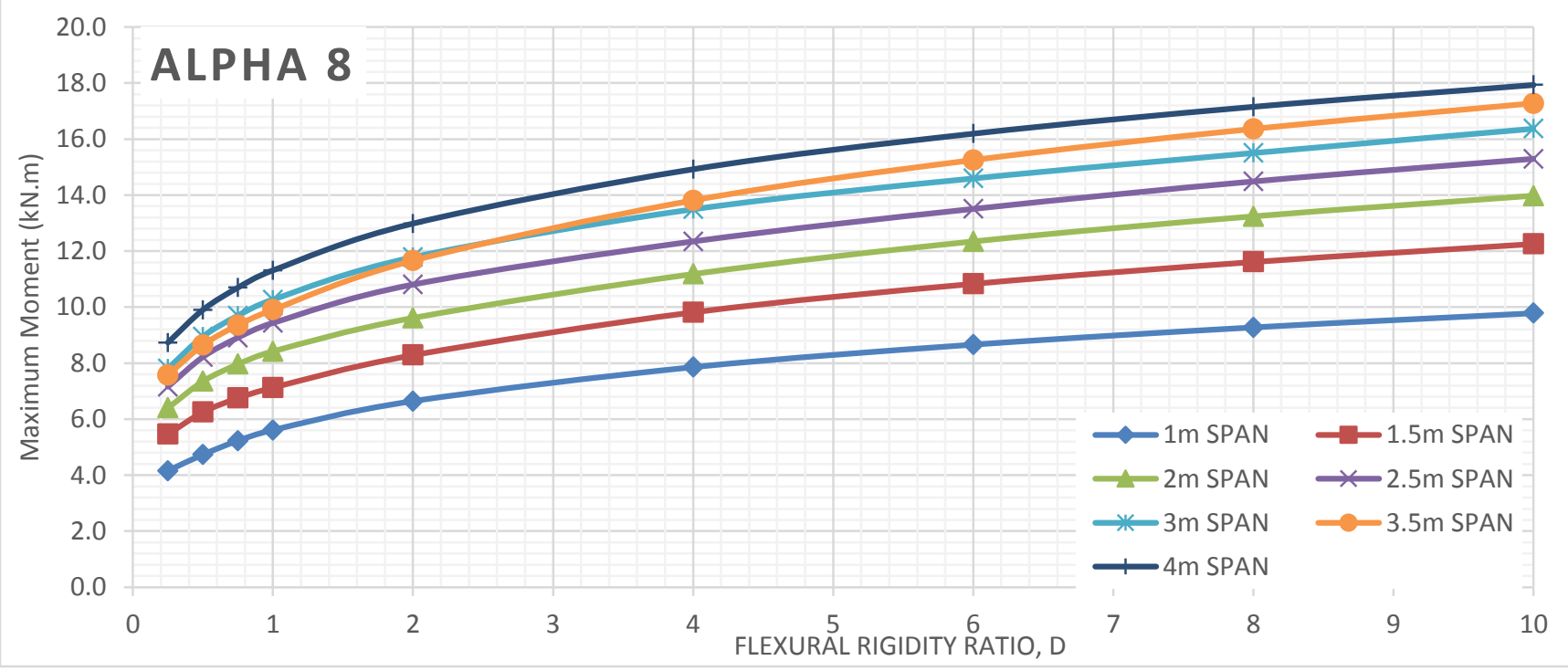

Figure 1094 Factored maximum moment results for alpha 8 at different span length (main bars perpendicular to traffic) 


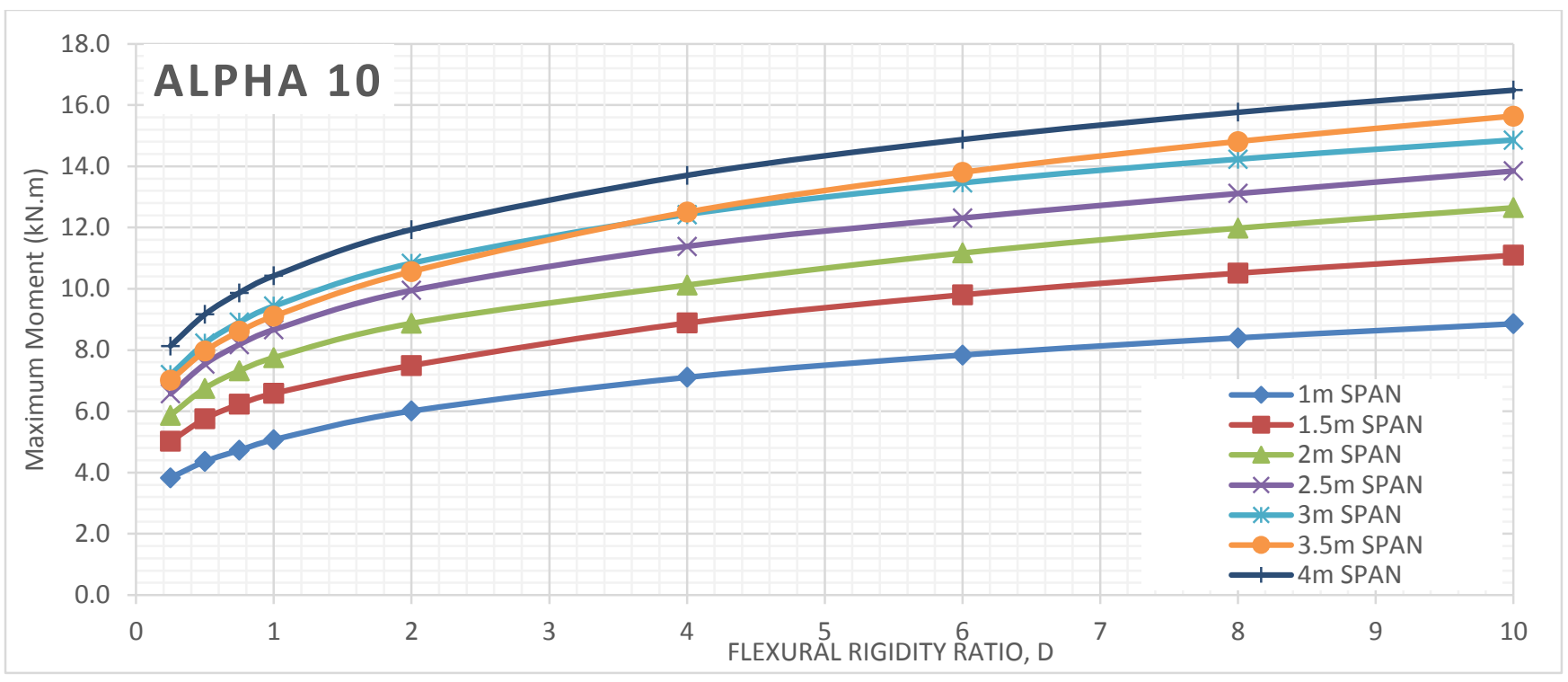

Figure 1095 Factored maximum moment results for alpha 10 at different span length (main bars perpendicular to traffic) 


\section{Bending Moment VS Flexural Rigidity at Different Spans (Main bars parallel to traffic)}

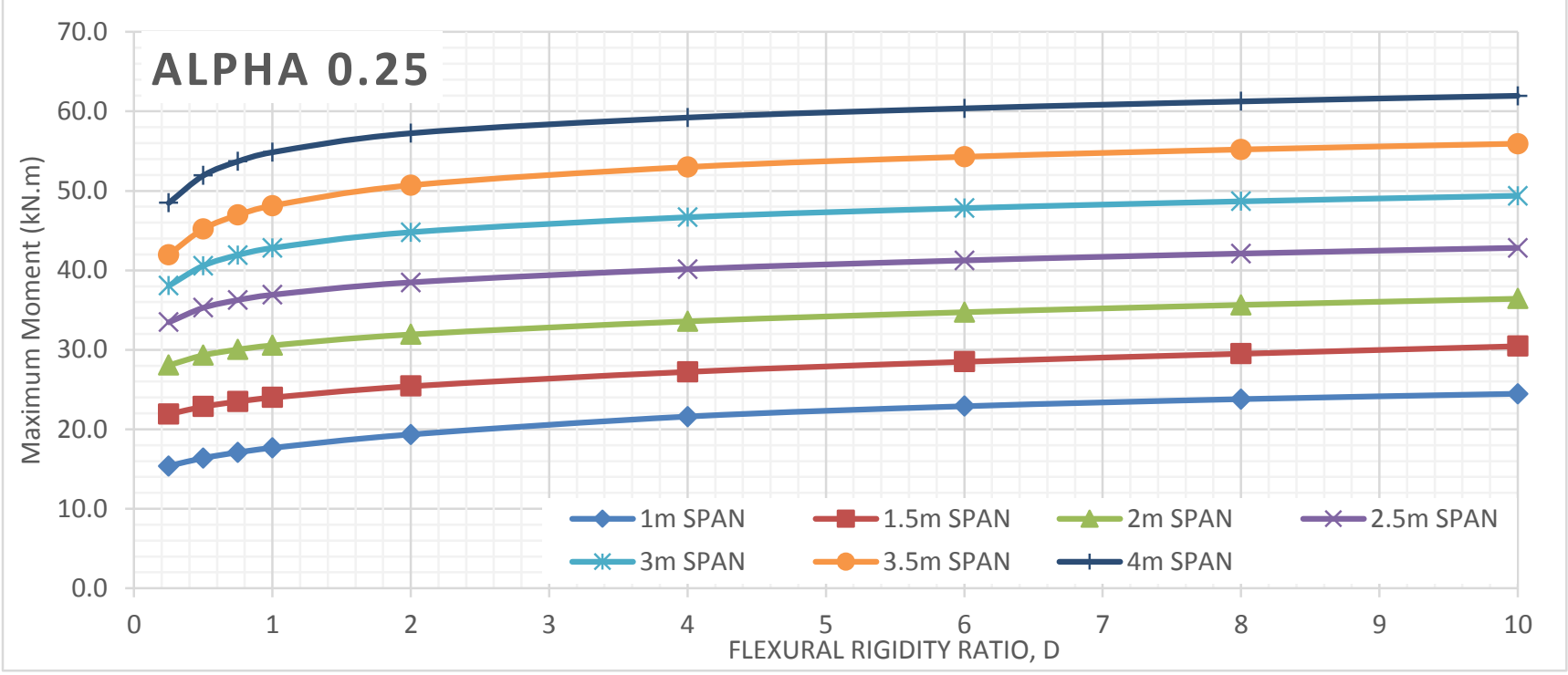

Figure 1096 Factored maximum moment results for alpha 0.25 at different span length (main bars parallel to traffic)

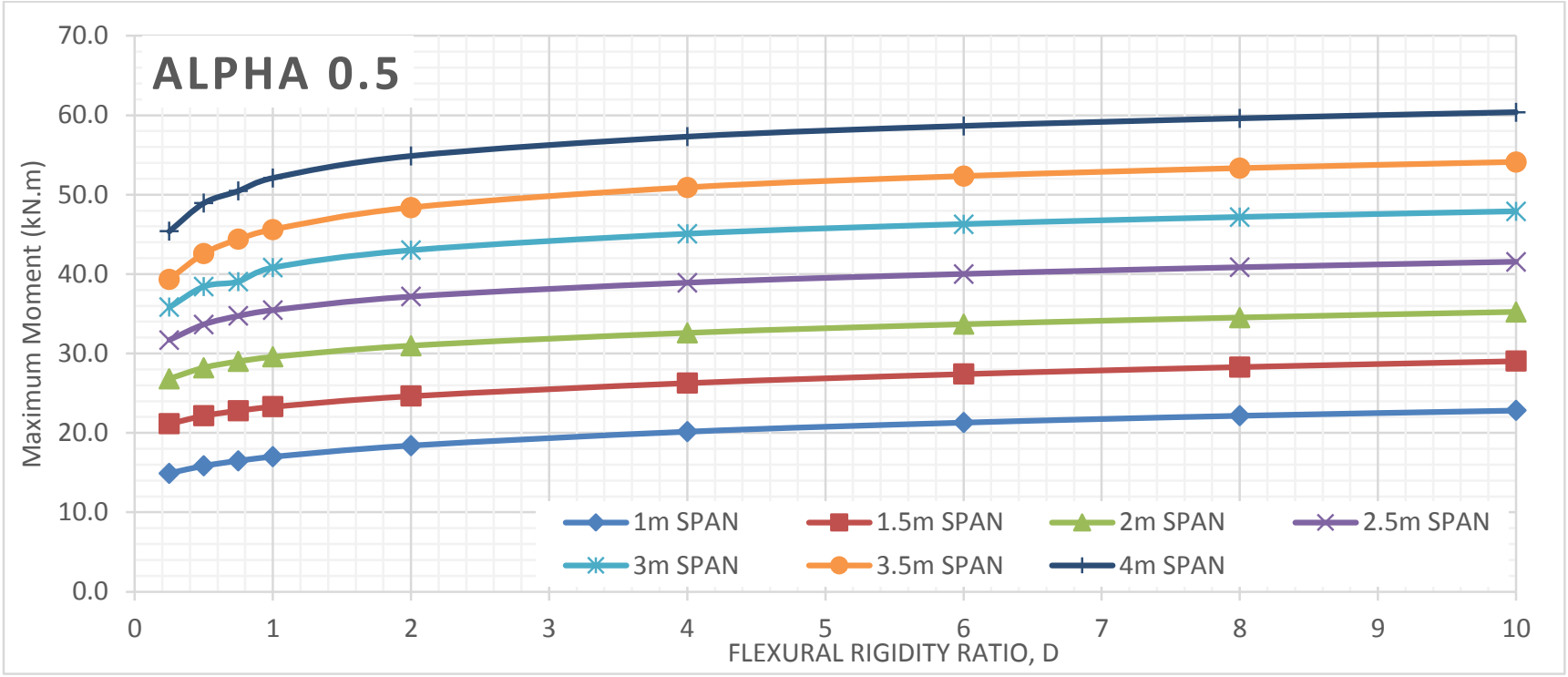

Figure 1097 Factored maximum moment results for alpha 0.5 at different span length (main bars parallel to traffic) 


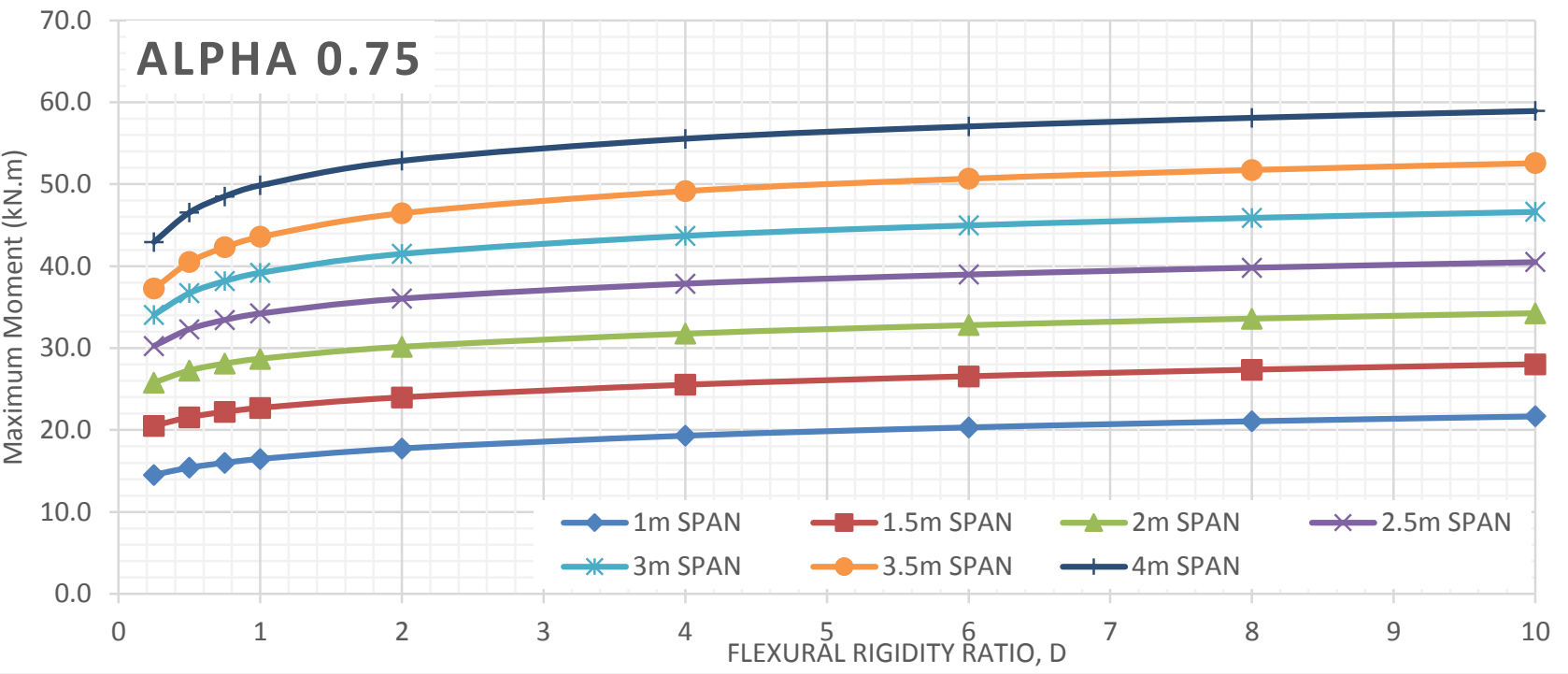

Figure 1098 Factored maximum moment results for alpha 0.75 at different span length (main bars parallel to traffic)

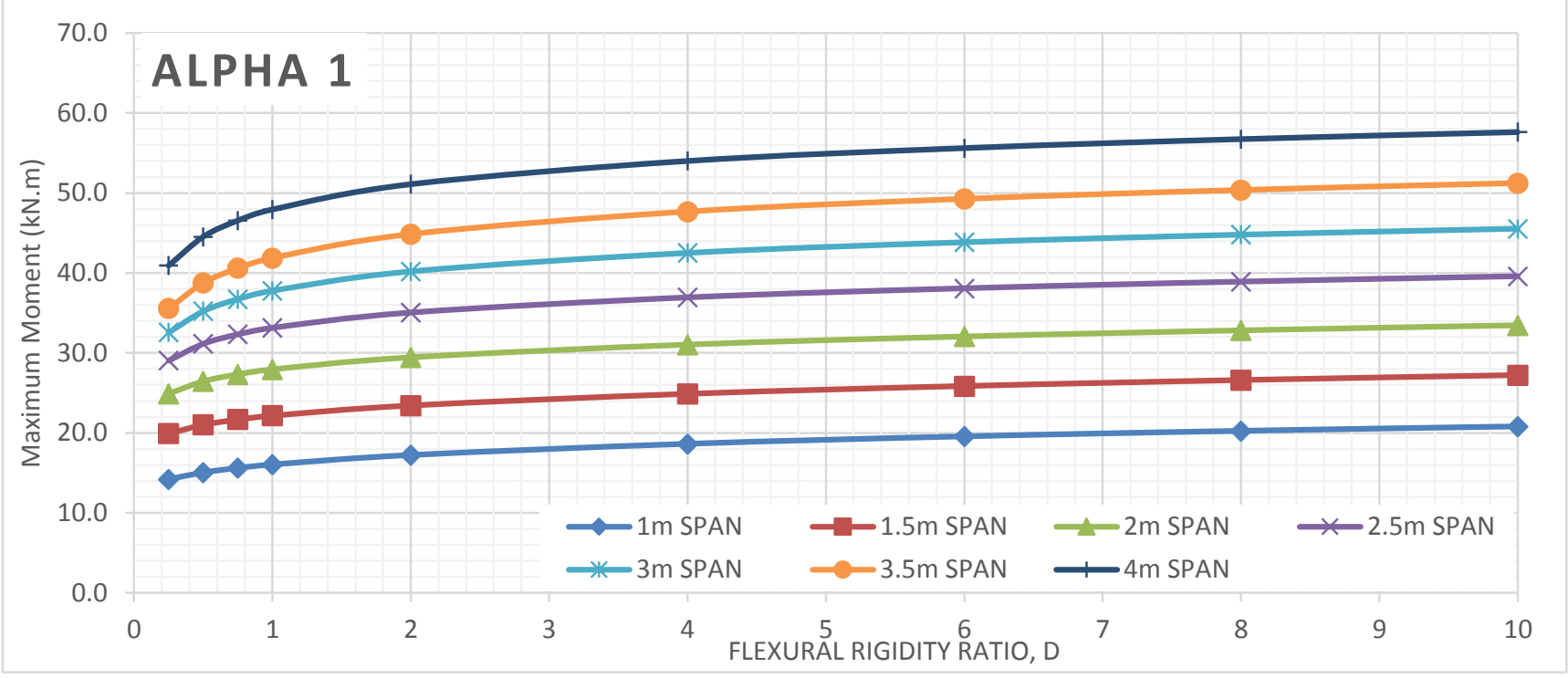

Figure 1099 Factored maximum moment results for alpha 1 at different span length (main bars parallel to traffic)

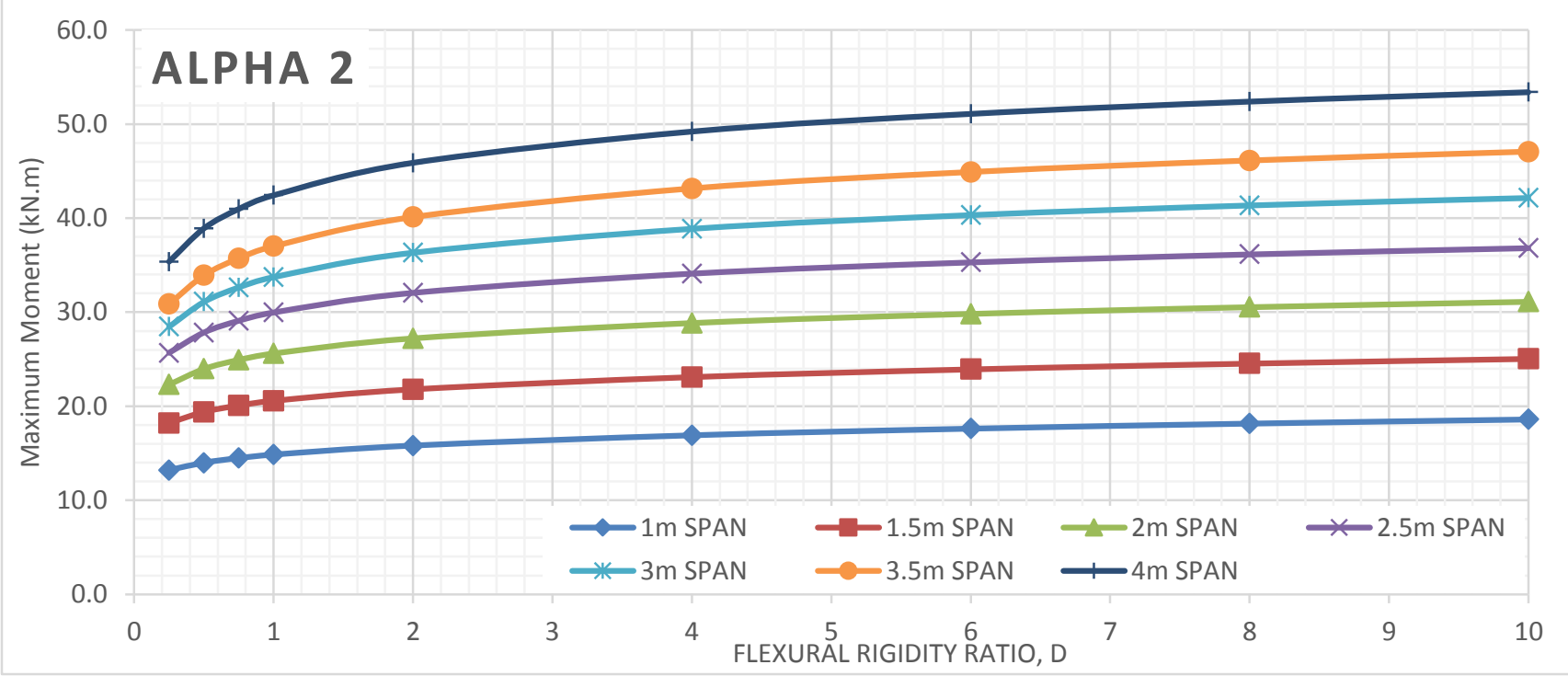

Figure 1100 Factored maximum moment results for alpha 2 at different span length (main bars parallel to traffic) 


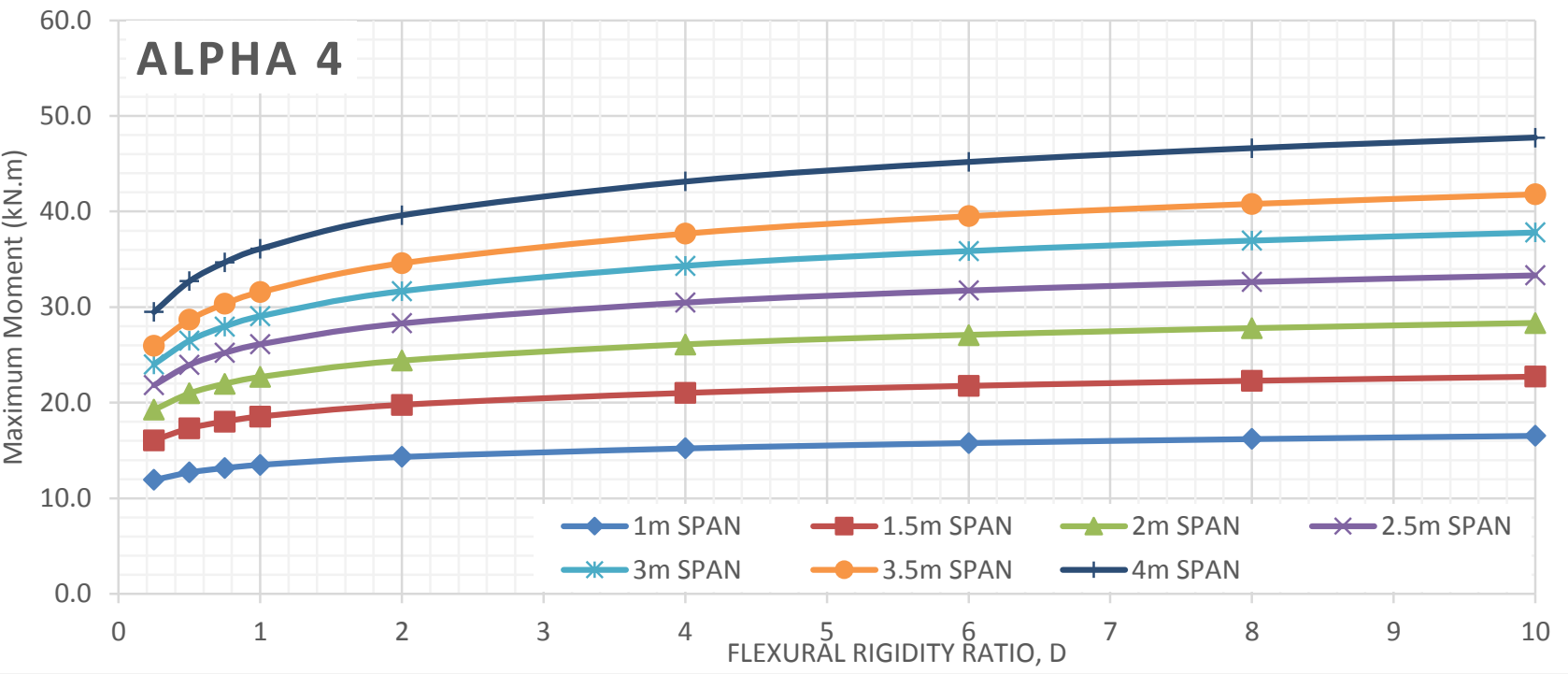

Figure 1101 Factored maximum moment results for alpha 4 at different span length (main bars parallel to traffic)

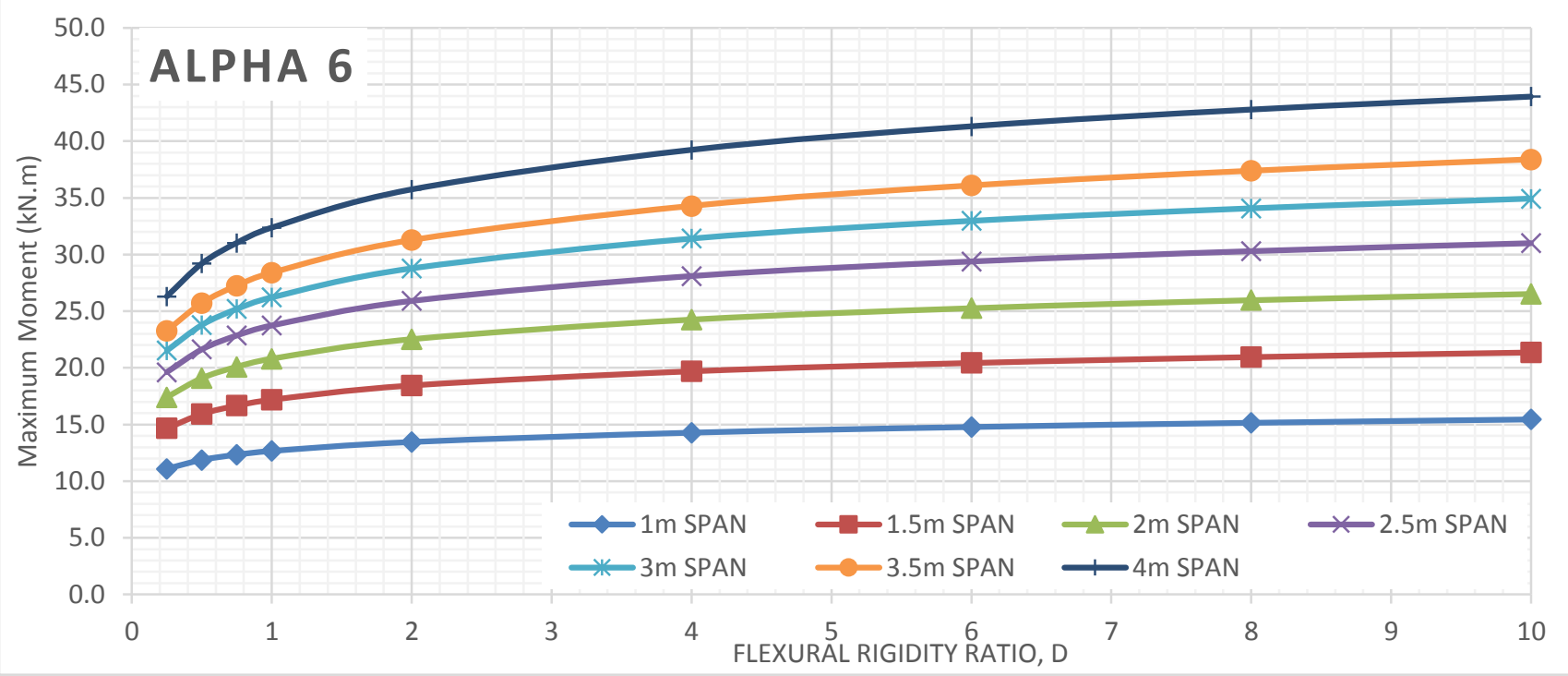

Figure 1102 Factored maximum moment results for alpha 6 at different span length (main bars parallel to traffic)

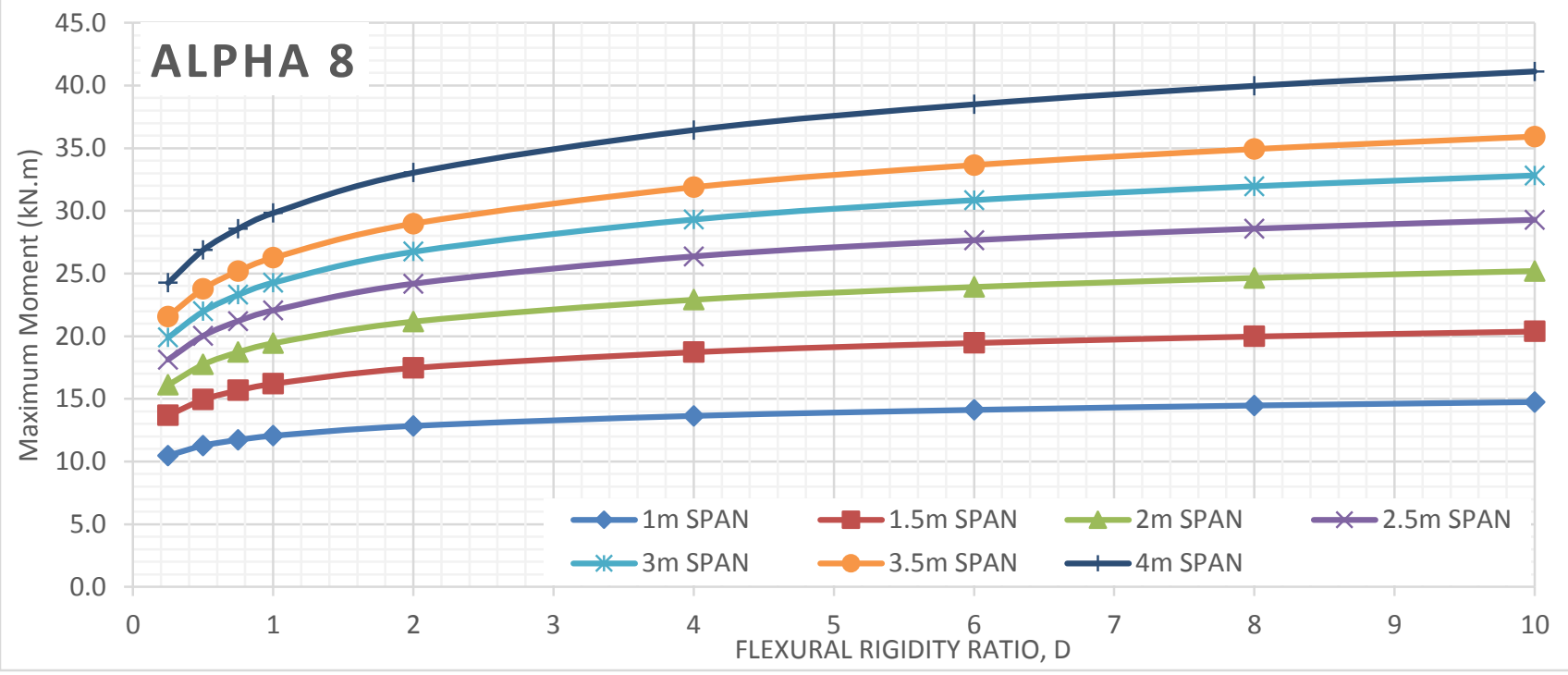

Figure 1103 Factored maximum moment results for alpha 8 at different span length (main bars parallel to traffic) 


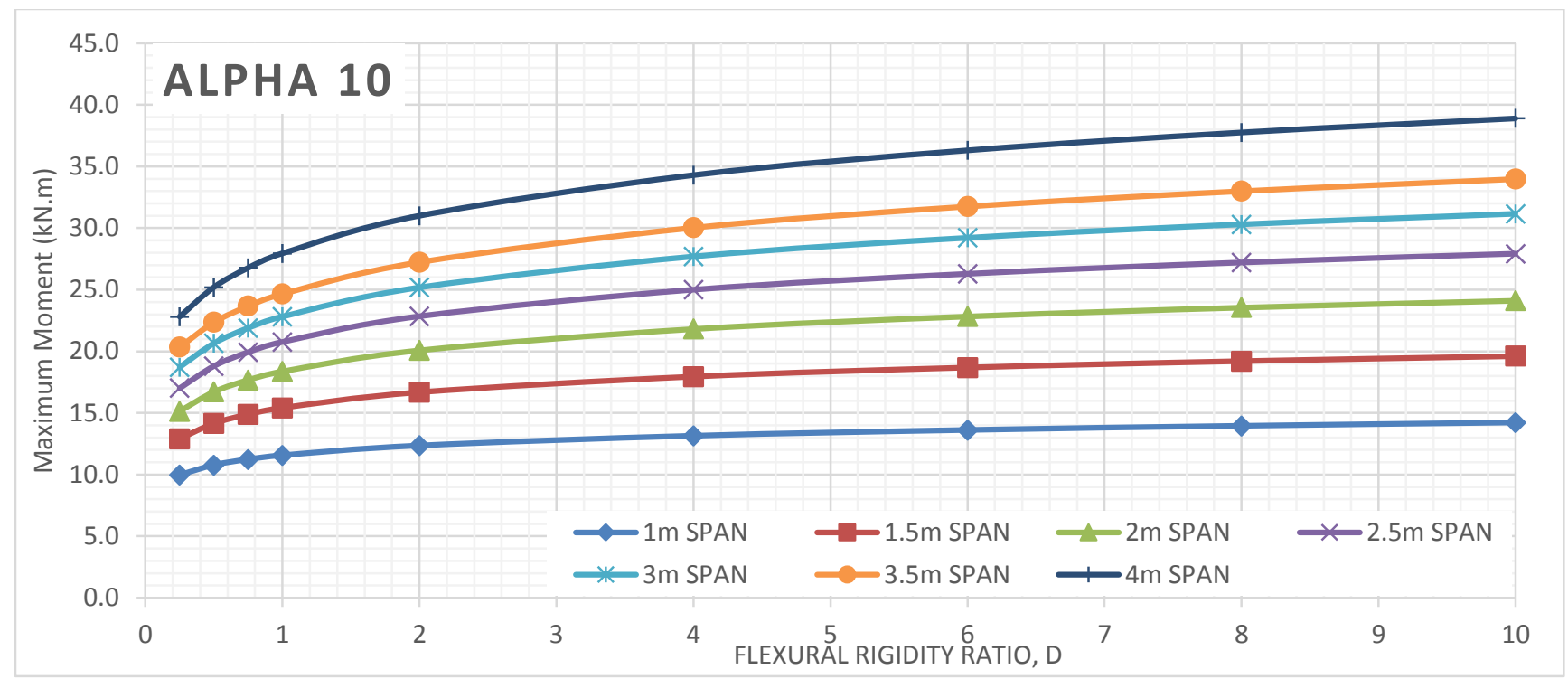

Figure 1104 Factored maximum moment results for alpha 10 at different span length (main bars parallel to traffic) 
E.2 Factored Deflection 


\section{E.2.1 DEFLECTION RESULTS TABLES}




\section{Alpha 0.25 Deflection Results}

Table 298 Factored maximum deflection results for alpha 0.25 (main bars perpendicular to traffic)

\begin{tabular}{|c|c|c|c|c|c|c|c|c|c|c|}
\hline & & & & & $\mathrm{Ma}$ & Deflection & & & & \\
\hline \multirow{9}{*}{ 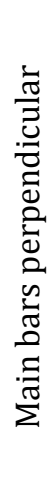 } & $\mathrm{D}$ & \multirow{2}{*}{0.25} & \multirow{2}{*}{0.5} & \multirow{2}{*}{0.75} & \multirow{2}{*}{1} & & \multirow{2}{*}{4} & \multirow{2}{*}{6} & & \multirow{2}{*}{10} \\
\hline & SPAN & & & & & & & & & \\
\hline & 1 & $6.60 \mathrm{E}-05$ & $7.80 \mathrm{E}-05$ & $8.60 \mathrm{E}-05$ & $9.20 \mathrm{E}-05$ & $1.09 \mathrm{E}-04$ & $1.28 \mathrm{E}-04$ & $1.41 \mathrm{E}-04$ & $1.51 \mathrm{E}-04$ & $1.59 \mathrm{E}-04$ \\
\hline & 1.5 & $1.64 \mathrm{E}-04$ & $1.95 \mathrm{E}-04$ & $2.15 \mathrm{E}-04$ & $2.31 \mathrm{E}-04$ & $2.74 \mathrm{E}-04$ & $3.24 \mathrm{E}-04$ & $3.58 \mathrm{E}-04$ & $3.84 \mathrm{E}-04$ & $4.05 \mathrm{E}-04$ \\
\hline & 2 & $3.34 \mathrm{E}-04$ & $3.73 \mathrm{E}-04$ & $3.99 \mathrm{E}-04$ & $4.28 \mathrm{E}-04$ & $5.08 \mathrm{E}-04$ & $6.03 \mathrm{E}-04$ & $6.66 \mathrm{E}-04$ & $7.15 \mathrm{E}-04$ & $7.55 \mathrm{E}-04$ \\
\hline & 2.5 & $5.64 \mathrm{E}-04$ & $6.42 \mathrm{E}-04$ & $6.87 \mathrm{E}-04$ & 7.19E-04 & 8.12E-04 & $9.63 \mathrm{E}-04$ & $1.07 \mathrm{E}-03$ & $1.14 \mathrm{E}-03$ & $1.21 \mathrm{E}-03$ \\
\hline & 3 & $8.52 \mathrm{E}-04$ & $9.87 \mathrm{E}-04$ & $1.07 \mathrm{E}-03$ & $1.13 \mathrm{E}-03$ & $1.28 \mathrm{E}-03$ & $1.42 \mathrm{E}-03$ & $1.51 \mathrm{E}-03$ & $1.62 \mathrm{E}-03$ & $1.71 \mathrm{E}-03$ \\
\hline & 3.5 & $1.40 \mathrm{E}-03$ & $1.64 \mathrm{E}-03$ & $1.79 \mathrm{E}-03$ & $1.89 \mathrm{E}-03$ & $2.17 \mathrm{E}-03$ & $2.45 \mathrm{E}-03$ & $2.60 \mathrm{E}-03$ & $2.71 \mathrm{E}-03$ & $2.78 \mathrm{E}-03$ \\
\hline & 4 & $2.06 \mathrm{E}-03$ & $2.42 \mathrm{E}-03$ & $2.64 \mathrm{E}-03$ & $2.81 \mathrm{E}-03$ & $3.24 \mathrm{E}-03$ & $3.70 \mathrm{E}-03$ & $3.96 \mathrm{E}-03$ & $4.15 \mathrm{E}-03$ & $4.29 \mathrm{E}-03$ \\
\hline
\end{tabular}

Table 299 Factored maximum deflection results for alpha 0.25 (main bars parallel to traffic)

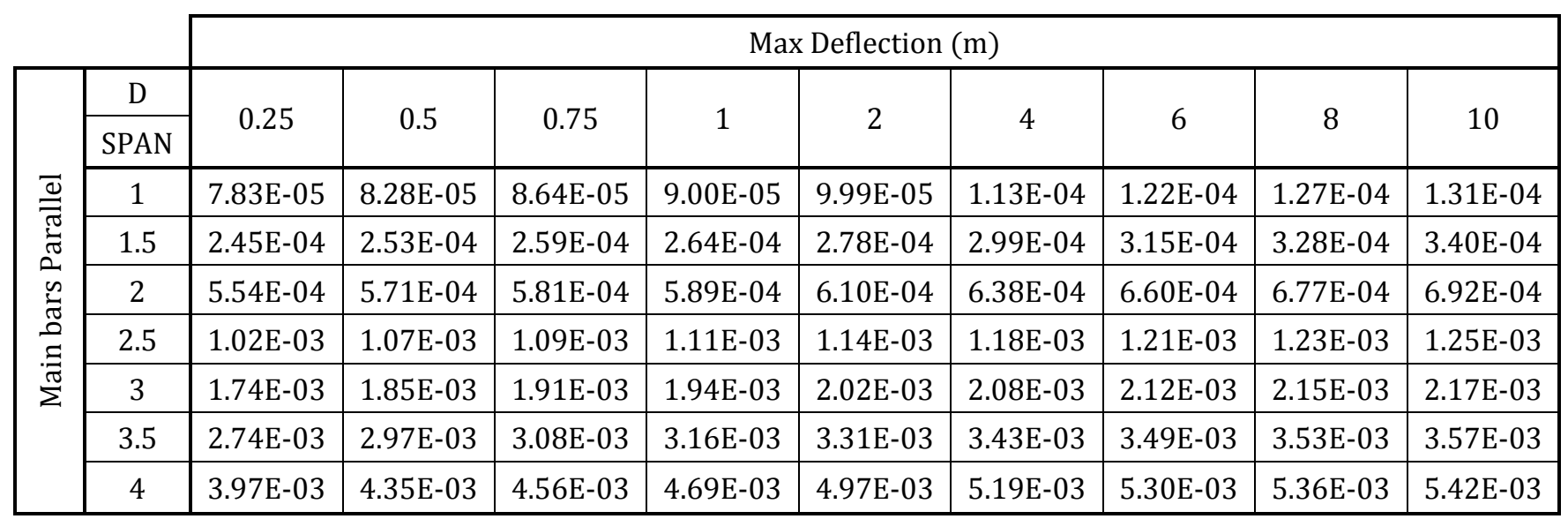




\section{Alpha 0.5 Deflection Results}

Table 300 Factored maximum deflection results for alpha 0.5 (main bars perpendicular to traffic)

\begin{tabular}{|c|c|c|c|c|c|c|c|c|c|c|}
\hline & & \multicolumn{9}{|c|}{ Max Deflection (m) } \\
\hline \multirow{9}{*}{ 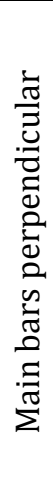 } & $\mathrm{D}$ & \multirow{2}{*}{0.25} & \multirow{2}{*}{0.5} & \multirow{2}{*}{0.75} & \multirow{2}{*}{1} & & \multirow{2}{*}{4} & \multirow{2}{*}{6} & \multirow{2}{*}{8} & \multirow{2}{*}{10} \\
\hline & SPAN & & & & & & & & & \\
\hline & 1 & $6.00 \mathrm{E}-05$ & $7.10 \mathrm{E}-05$ & $7.80 \mathrm{E}-05$ & $8.40 \mathrm{E}-05$ & $9.90 \mathrm{E}-05$ & 1.17E-04 & $1.29 \mathrm{E}-04$ & $1.38 \mathrm{E}-04$ & $1.45 \mathrm{E}-04$ \\
\hline & 1.5 & $1.50 \mathrm{E}-04$ & $1.78 \mathrm{E}-04$ & $1.97 \mathrm{E}-04$ & $2.11 \mathrm{E}-04$ & $2.50 \mathrm{E}-04$ & $2.96 \mathrm{E}-04$ & $3.27 \mathrm{E}-04$ & $3.50 \mathrm{E}-04$ & $3.70 \mathrm{E}-04$ \\
\hline & 2 & $3.07 \mathrm{E}-04$ & $3.45 \mathrm{E}-04$ & $3.64 \mathrm{E}-04$ & $3.91 \mathrm{E}-04$ & 4.64E-04 & $5.51 \mathrm{E}-04$ & $6.08 \mathrm{E}-04$ & $6.52 \mathrm{E}-04$ & $6.89 \mathrm{E}-04$ \\
\hline & 2.5 & $5.17 \mathrm{E}-04$ & $5.89 \mathrm{E}-04$ & $6.31 \mathrm{E}-04$ & $6.61 \mathrm{E}-04$ & $7.41 \mathrm{E}-04$ & $8.80 \mathrm{E}-04$ & $9.72 \mathrm{E}-04$ & $1.04 \mathrm{E}-03$ & $1.10 \mathrm{E}-03$ \\
\hline & 3 & $7.78 \mathrm{E}-04$ & $9.03 \mathrm{E}-04$ & $9.46 \mathrm{E}-04$ & $1.04 \mathrm{E}-03$ & $1.18 \mathrm{E}-03$ & $1.31 \mathrm{E}-03$ & $1.38 \mathrm{E}-03$ & $1.48 \mathrm{E}-03$ & $1.56 \mathrm{E}-03$ \\
\hline & 3.5 & $1.28 \mathrm{E}-03$ & $1.50 \mathrm{E}-03$ & $1.63 \mathrm{E}-03$ & $1.73 \mathrm{E}-03$ & $1.99 \mathrm{E}-03$ & $2.25 \mathrm{E}-03$ & 2.39E-03 & $2.49 \mathrm{E}-03$ & $2.57 \mathrm{E}-03$ \\
\hline & 4 & $1.88 \mathrm{E}-03$ & $2.21 \mathrm{E}-03$ & $2.41 \mathrm{E}-03$ & $2.57 \mathrm{E}-03$ & $2.97 \mathrm{E}-03$ & $3.39 \mathrm{E}-03$ & $3.64 \mathrm{E}-03$ & $3.81 \mathrm{E}-03$ & $3.94 \mathrm{E}-03$ \\
\hline
\end{tabular}

Table 301 Factored maximum deflection results for alpha 0.5 (main bars parallel to traffic)

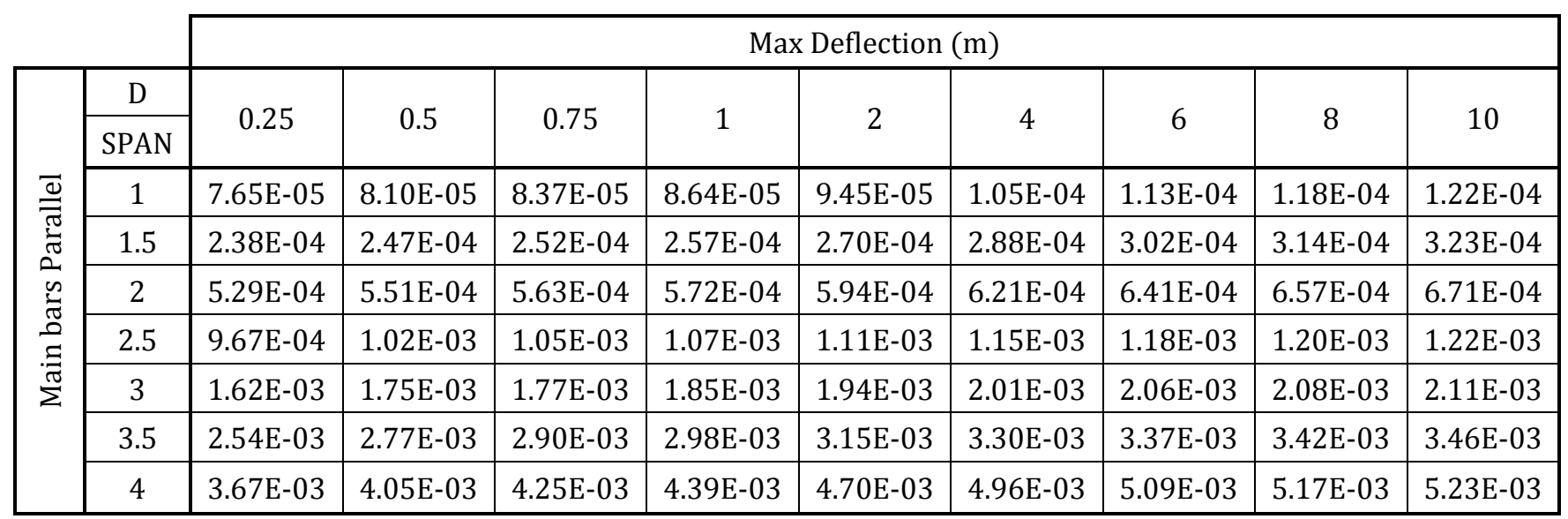




\section{Alpha 0.75 Deflection Results}

Table 302 Factored maximum deflection results for alpha 0.75 (main bars perpendicular to traffic)

\begin{tabular}{|c|c|c|c|c|c|c|c|c|c|c|}
\hline & & & & & $\mathrm{Ma}$ & Deflection & & & & \\
\hline \multirow{9}{*}{ 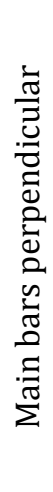 } & $\mathrm{D}$ & \multirow{2}{*}{0.25} & \multirow{2}{*}{0.5} & \multirow{2}{*}{0.75} & \multirow{2}{*}{1} & & \multirow{2}{*}{4} & & & \multirow{2}{*}{10} \\
\hline & SPAN & & & & & & & & & \\
\hline & 1 & $5.50 \mathrm{E}-05$ & $6.60 \mathrm{E}-05$ & $7.30 \mathrm{E}-05$ & $7.80 \mathrm{E}-05$ & $9.20 \mathrm{E}-05$ & $1.09 \mathrm{E}-04$ & $1.19 \mathrm{E}-04$ & $1.28 \mathrm{E}-04$ & 1.35E-04 \\
\hline & 1.5 & $1.40 \mathrm{E}-04$ & $1.65 \mathrm{E}-04$ & $1.82 \mathrm{E}-04$ & $1.95 \mathrm{E}-04$ & $2.32 \mathrm{E}-04$ & $2.74 \mathrm{E}-04$ & $3.03 \mathrm{E}-04$ & $3.24 \mathrm{E}-04$ & $3.42 \mathrm{E}-04$ \\
\hline & 2 & $2.86 \mathrm{E}-04$ & $3.21 \mathrm{E}-04$ & $3.41 \mathrm{E}-04$ & $3.62 \mathrm{E}-04$ & $4.30 \mathrm{E}-04$ & $5.10 \mathrm{E}-04$ & $5.63 \mathrm{E}-04$ & $6.04 \mathrm{E}-04$ & $6.38 \mathrm{E}-04$ \\
\hline & 2.5 & $4.80 \mathrm{E}-04$ & $5.48 \mathrm{E}-04$ & $5.88 \mathrm{E}-04$ & $6.17 \mathrm{E}-04$ & $6.86 \mathrm{E}-04$ & 8.14E-04 & $9.00 \mathrm{E}-04$ & $9.66 \mathrm{E}-04$ & $1.02 \mathrm{E}-03$ \\
\hline & 3 & $7.20 \mathrm{E}-04$ & 8.37E-04 & $9.09 \mathrm{E}-04$ & $9.62 \mathrm{E}-04$ & $1.09 \mathrm{E}-03$ & $1.22 \mathrm{E}-03$ & $1.29 \mathrm{E}-03$ & $1.37 \mathrm{E}-03$ & $1.45 \mathrm{E}-03$ \\
\hline & 3.5 & $1.19 \mathrm{E}-03$ & $1.39 \mathrm{E}-03$ & $1.51 \mathrm{E}-03$ & $1.61 \mathrm{E}-03$ & $1.84 \mathrm{E}-03$ & $2.09 \mathrm{E}-03$ & $2.23 \mathrm{E}-03$ & $2.33 \mathrm{E}-03$ & $2.40 \mathrm{E}-03$ \\
\hline & 4 & $1.74 \mathrm{E}-03$ & $2.04 \mathrm{E}-03$ & $2.24 \mathrm{E}-03$ & $2.38 \mathrm{E}-03$ & $2.75 \mathrm{E}-03$ & $3.15 \mathrm{E}-03$ & $3.38 \mathrm{E}-03$ & $3.55 \mathrm{E}-03$ & $3.68 \mathrm{E}-03$ \\
\hline
\end{tabular}

Table 303 Factored maximum deflection results for alpha 0.75 (main bars parallel to traffic)

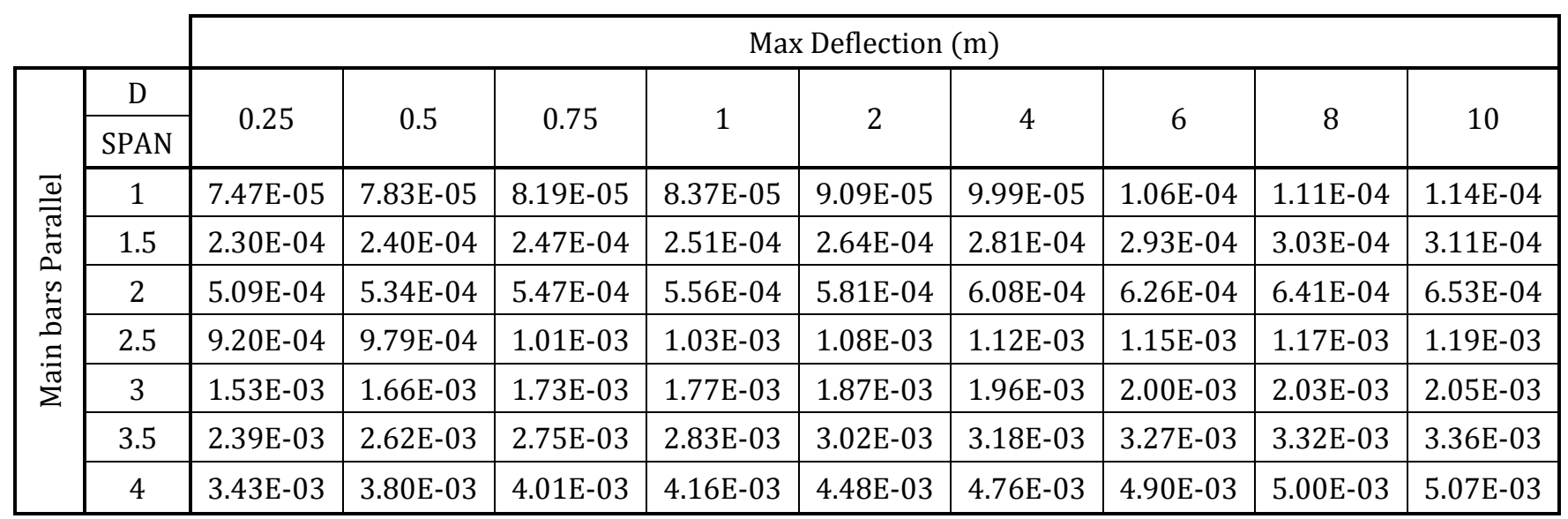




\section{Alpha 1 Deflection Results}

Table 304 Factored maximum deflection results for alpha 1 (main bars perpendicular to traffic)

\begin{tabular}{|c|c|c|c|c|c|c|c|c|c|c|}
\hline & & \multicolumn{9}{|c|}{ Max Deflection (m) } \\
\hline \multirow{9}{*}{ 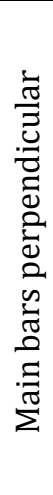 } & $\mathrm{D}$ & \multirow{2}{*}{0.25} & \multirow{2}{*}{0.5} & \multirow{2}{*}{0.75} & \multirow{2}{*}{1} & & \multirow{2}{*}{4} & \multirow{2}{*}{6} & \multirow{2}{*}{8} & \multirow{2}{*}{10} \\
\hline & SPAN & & & & & & & & & \\
\hline & 1 & $5.20 \mathrm{E}-05$ & $6.10 \mathrm{E}-05$ & $6.80 \mathrm{E}-05$ & $7.30 \mathrm{E}-05$ & $8.60 \mathrm{E}-05$ & $1.02 \mathrm{E}-04$ & $1.12 \mathrm{E}-04$ & $1.20 \mathrm{E}-04$ & $1.26 \mathrm{E}-04$ \\
\hline & 1.5 & $1.33 \mathrm{E}-04$ & $1.54 \mathrm{E}-04$ & $1.70 \mathrm{E}-04$ & $1.83 \mathrm{E}-04$ & $2.17 \mathrm{E}-04$ & $2.57 \mathrm{E}-04$ & $2.83 \mathrm{E}-04$ & $3.04 \mathrm{E}-04$ & $3.20 \mathrm{E}-04$ \\
\hline & 2 & $2.69 \mathrm{E}-04$ & $3.03 \mathrm{E}-04$ & $3.22 \mathrm{E}-04$ & $3.39 \mathrm{E}-04$ & $4.02 \mathrm{E}-04$ & 4.77E-04 & $5.27 \mathrm{E}-04$ & $5.65 \mathrm{E}-04$ & $5.97 \mathrm{E}-04$ \\
\hline & 2.5 & $4.50 \mathrm{E}-04$ & $5.14 \mathrm{E}-04$ & $5.53 \mathrm{E}-04$ & $5.81 \mathrm{E}-04$ & $6.46 \mathrm{E}-04$ & 7.62E-04 & 8.42E-04 & $9.04 \mathrm{E}-04$ & $9.55 \mathrm{E}-04$ \\
\hline & 3 & $6.74 \mathrm{E}-04$ & $7.83 \mathrm{E}-04$ & $8.52 \mathrm{E}-04$ & $9.02 \mathrm{E}-04$ & $1.03 \mathrm{E}-03$ & $1.15 \mathrm{E}-03$ & $1.22 \mathrm{E}-03$ & $1.28 \mathrm{E}-03$ & $1.35 \mathrm{E}-03$ \\
\hline & 3.5 & $1.11 \mathrm{E}-03$ & $1.30 \mathrm{E}-03$ & $1.42 \mathrm{E}-03$ & $1.50 \mathrm{E}-03$ & $1.73 \mathrm{E}-03$ & $1.96 \mathrm{E}-03$ & $2.10 \mathrm{E}-03$ & $2.19 \mathrm{E}-03$ & $2.27 \mathrm{E}-03$ \\
\hline & 4 & $1.63 \mathrm{E}-03$ & $1.91 \mathrm{E}-03$ & $2.09 \mathrm{E}-03$ & $2.23 \mathrm{E}-03$ & $2.58 \mathrm{E}-03$ & $2.95 \mathrm{E}-03$ & $3.18 \mathrm{E}-03$ & $3.34 \mathrm{E}-03$ & $3.46 \mathrm{E}-03$ \\
\hline
\end{tabular}

Table 305 Factored maximum deflection results for alpha 1 (main bars parallel to traffic)

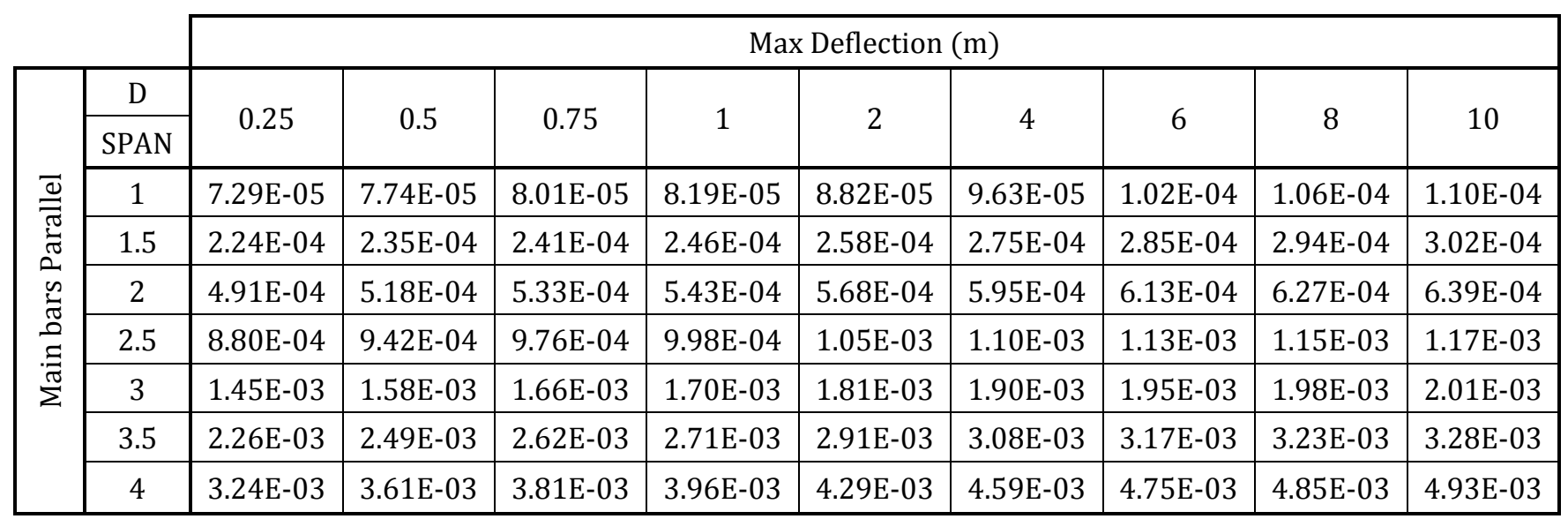




\section{Alpha 2 Deflection Results}

Table 306 Factored maximum deflection results for alpha 2 (main bars perpendicular to traffic)

\begin{tabular}{|c|c|c|c|c|c|c|c|c|c|c|}
\hline & & \multicolumn{9}{|c|}{ Max Deflection (m) } \\
\hline \multirow{9}{*}{ 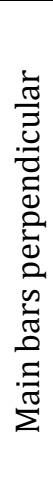 } & $\mathrm{D}$ & \multirow{2}{*}{0.25} & \multirow{2}{*}{0.5} & \multirow{2}{*}{0.75} & \multirow{2}{*}{1} & \multirow{2}{*}{2} & \multirow{2}{*}{4} & \multirow{2}{*}{6} & \multirow[b]{2}{*}{8} & \multirow{2}{*}{10} \\
\hline & SPAN & & & & & & & & & \\
\hline & 1 & $4.20 \mathrm{E}-05$ & $5.00 \mathrm{E}-05$ & $5.50 \mathrm{E}-05$ & $5.90 \mathrm{E}-05$ & $7.00 \mathrm{E}-05$ & 8.30E-05 & $9.10 \mathrm{E}-05$ & $9.80 \mathrm{E}-05$ & $1.03 \mathrm{E}-04$ \\
\hline & 1.5 & $1.11 \mathrm{E}-04$ & $1.26 \mathrm{E}-04$ & $1.39 \mathrm{E}-04$ & $1.49 \mathrm{E}-04$ & $1.77 \mathrm{E}-04$ & $2.10 \mathrm{E}-04$ & $2.31 \mathrm{E}-04$ & $2.48 \mathrm{E}-04$ & $2.62 \mathrm{E}-04$ \\
\hline & 2 & $2.23 \mathrm{E}-04$ & $2.53 \mathrm{E}-04$ & $2.70 \mathrm{E}-04$ & $2.82 \mathrm{E}-04$ & $3.28 \mathrm{E}-04$ & $3.89 \mathrm{E}-04$ & $4.30 \mathrm{E}-04$ & $4.62 \mathrm{E}-04$ & $4.88 \mathrm{E}-04$ \\
\hline & 2.5 & $3.71 \mathrm{E}-04$ & $4.26 \mathrm{E}-04$ & $4.60 \mathrm{E}-04$ & $4.84 \mathrm{E}-04$ & $5.43 \mathrm{E}-04$ & $6.22 \mathrm{E}-04$ & $6.88 \mathrm{E}-04$ & $7.38 \mathrm{E}-04$ & $7.80 \mathrm{E}-04$ \\
\hline & 3 & $5.52 \mathrm{E}-04$ & $6.42 \mathrm{E}-04$ & $6.99 \mathrm{E}-04$ & $7.41 \mathrm{E}-04$ & $8.48 \mathrm{E}-04$ & $9.59 \mathrm{E}-04$ & $1.02 \mathrm{E}-03$ & $1.07 \mathrm{E}-03$ & $1.10 \mathrm{E}-03$ \\
\hline & 3.5 & $9.09 \mathrm{E}-04$ & $1.06 \mathrm{E}-03$ & $1.16 \mathrm{E}-03$ & $1.23 \mathrm{E}-03$ & $1.42 \mathrm{E}-03$ & $1.62 \mathrm{E}-03$ & $1.75 \mathrm{E}-03$ & $1.83 \mathrm{E}-03$ & $1.90 \mathrm{E}-03$ \\
\hline & 4 & $1.34 \mathrm{E}-03$ & $1.57 \mathrm{E}-03$ & $1.71 \mathrm{E}-03$ & $1.83 \mathrm{E}-03$ & $2.12 \mathrm{E}-03$ & $2.43 \mathrm{E}-03$ & $2.63 \mathrm{E}-03$ & $2.77 \mathrm{E}-03$ & $2.88 \mathrm{E}-03$ \\
\hline
\end{tabular}

Table 307 Factored maximum deflection results for alpha 2 (main bars parallel to traffic)

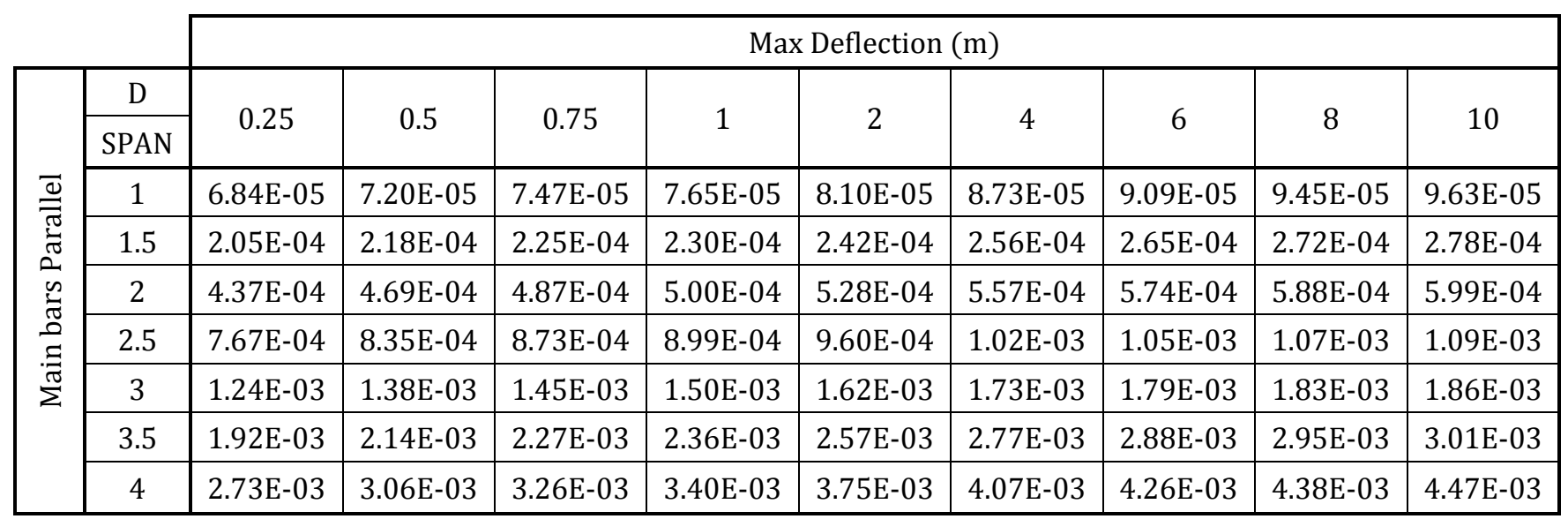




\section{Alpha 4 Deflection Results}

Table 308 Factored maximum deflection results for alpha 4 (main bars perpendicular to traffic)

\begin{tabular}{|c|c|c|c|c|c|c|c|c|c|c|}
\hline & & \multicolumn{9}{|c|}{ Max Deflection (m) } \\
\hline \multirow{9}{*}{ 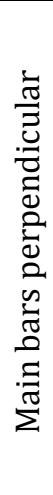 } & $\mathrm{D}$ & \multirow{2}{*}{0.25} & \multirow{2}{*}{0.5} & \multirow{2}{*}{0.75} & \multirow{2}{*}{1} & & \multirow{2}{*}{4} & \multirow{2}{*}{6} & \multirow{2}{*}{8} & \multirow{2}{*}{10} \\
\hline & SPAN & & & & & & & & & \\
\hline & 1 & $3.30 \mathrm{E}-05$ & $3.90 \mathrm{E}-05$ & $4.30 \mathrm{E}-05$ & $4.60 \mathrm{E}-05$ & $5.50 \mathrm{E}-05$ & $6.40 \mathrm{E}-05$ & $7.10 \mathrm{E}-05$ & $7.60 \mathrm{E}-05$ & $8.00 \mathrm{E}-05$ \\
\hline & 1.5 & $8.91 \mathrm{E}-05$ & $1.01 \mathrm{E}-04$ & $1.09 \mathrm{E}-04$ & $1.16 \mathrm{E}-04$ & $1.37 \mathrm{E}-04$ & $1.62 \mathrm{E}-04$ & $1.79 \mathrm{E}-04$ & $1.92 \mathrm{E}-04$ & $2.03 \mathrm{E}-04$ \\
\hline & 2 & $1.76 \mathrm{E}-04$ & $2.02 \mathrm{E}-04$ & $2.16 \mathrm{E}-04$ & $2.28 \mathrm{E}-04$ & $2.58 \mathrm{E}-04$ & $3.02 \mathrm{E}-04$ & $3.33 \mathrm{E}-04$ & $3.58 \mathrm{E}-04$ & $3.78 \mathrm{E}-04$ \\
\hline & 2.5 & 2.92E-04 & $3.36 \mathrm{E}-04$ & $3.64 \mathrm{E}-04$ & $3.84 \mathrm{E}-04$ & $4.37 \mathrm{E}-04$ & $4.95 \mathrm{E}-04$ & 5.33E-04 & $5.72 \mathrm{E}-04$ & $6.04 \mathrm{E}-04$ \\
\hline & 3 & $4.30 \mathrm{E}-04$ & $5.01 \mathrm{E}-04$ & $5.47 \mathrm{E}-04$ & $5.81 \mathrm{E}-04$ & $6.69 \mathrm{E}-04$ & $7.63 \mathrm{E}-04$ & $8.21 \mathrm{E}-04$ & $8.62 \mathrm{E}-04$ & 8.97E-04 \\
\hline & 3.5 & 7.12E-04 & 8.29E-04 & $9.06 \mathrm{E}-04$ & $9.64 \mathrm{E}-04$ & $1.12 \mathrm{E}-03$ & $1.28 \mathrm{E}-03$ & 1.39E-03 & $1.46 \mathrm{E}-03$ & $1.52 \mathrm{E}-03$ \\
\hline & 4 & $1.05 \mathrm{E}-03$ & $1.22 \mathrm{E}-03$ & $1.34 \mathrm{E}-03$ & $1.42 \mathrm{E}-03$ & $1.66 \mathrm{E}-03$ & $1.91 \mathrm{E}-03$ & $2.07 \mathrm{E}-03$ & $2.19 \mathrm{E}-03$ & $2.29 \mathrm{E}-03$ \\
\hline
\end{tabular}

Table 309 Factored maximum deflection results for alpha 4 (main bars parallel to traffic)

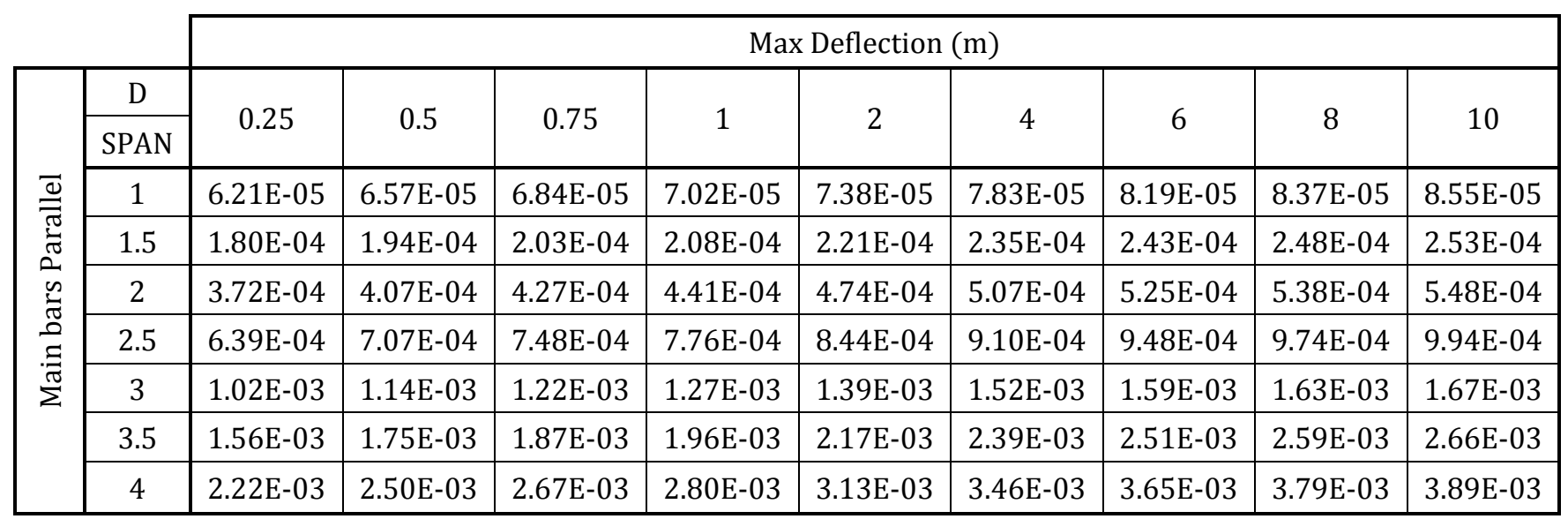




\section{Alpha 6 Deflection Results}

Table 310 Factored maximum deflection results for alpha 6 (main bars perpendicular to traffic)

\begin{tabular}{|c|c|c|c|c|c|c|c|c|c|c|}
\hline & & \multicolumn{9}{|c|}{ Max Deflection (m) } \\
\hline \multirow{9}{*}{ 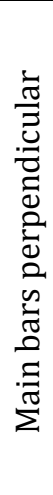 } & $\mathrm{D}$ & \multirow{2}{*}{0.25} & \multirow{2}{*}{0.5} & \multirow{2}{*}{0.75} & \multirow{2}{*}{1} & & \multirow{2}{*}{4} & \multirow{2}{*}{6} & \multirow{2}{*}{8} & \multirow{2}{*}{10} \\
\hline & SPAN & & & & & & & & & \\
\hline & 1 & $2.80 \mathrm{E}-05$ & $3.30 \mathrm{E}-05$ & $3.60 \mathrm{E}-05$ & $3.90 \mathrm{E}-05$ & $4.60 \mathrm{E}-05$ & $5.50 \mathrm{E}-05$ & $6.00 \mathrm{E}-05$ & $6.40 \mathrm{E}-05$ & $6.80 \mathrm{E}-05$ \\
\hline & 1.5 & $7.71 \mathrm{E}-05$ & $8.82 \mathrm{E}-05$ & $9.47 \mathrm{E}-05$ & $1.00 \mathrm{E}-04$ & $1.16 \mathrm{E}-04$ & $1.37 \mathrm{E}-04$ & $1.52 \mathrm{E}-04$ & $1.63 \mathrm{E}-04$ & $1.72 \mathrm{E}-04$ \\
\hline & 2 & $1.50 \mathrm{E}-04$ & $1.73 \mathrm{E}-04$ & $1.88 \mathrm{E}-04$ & $1.98 \mathrm{E}-04$ & $2.26 \mathrm{E}-04$ & $2.56 \mathrm{E}-04$ & $2.82 \mathrm{E}-04$ & $3.03 \mathrm{E}-04$ & $3.20 \mathrm{E}-04$ \\
\hline & 2.5 & $2.49 \mathrm{E}-04$ & $2.88 \mathrm{E}-04$ & $3.12 \mathrm{E}-04$ & $3.31 \mathrm{E}-04$ & $3.79 \mathrm{E}-04$ & 4.32E-04 & $4.65 \mathrm{E}-04$ & $4.91 \mathrm{E}-04$ & $5.11 \mathrm{E}-04$ \\
\hline & 3 & $3.68 \mathrm{E}-04$ & $4.27 \mathrm{E}-04$ & $4.65 \mathrm{E}-04$ & $4.95 \mathrm{E}-04$ & $5.72 \mathrm{E}-04$ & $6.56 \mathrm{E}-04$ & $7.09 \mathrm{E}-04$ & 7.49E-04 & $7.81 \mathrm{E}-04$ \\
\hline & 3.5 & $6.12 \mathrm{E}-04$ & $7.08 \mathrm{E}-04$ & $7.72 \mathrm{E}-04$ & $8.22 \mathrm{E}-04$ & $9.52 \mathrm{E}-04$ & $1.10 \mathrm{E}-03$ & $1.19 \mathrm{E}-03$ & $1.26 \mathrm{E}-03$ & $1.31 \mathrm{E}-03$ \\
\hline & 4 & $9.13 \mathrm{E}-04$ & $1.05 \mathrm{E}-03$ & $1.14 \mathrm{E}-03$ & $1.22 \mathrm{E}-03$ & $1.41 \mathrm{E}-03$ & $1.63 \mathrm{E}-03$ & $1.78 \mathrm{E}-03$ & $1.88 \mathrm{E}-03$ & $1.97 \mathrm{E}-03$ \\
\hline
\end{tabular}

Table 311 Factored maximum deflection results for alpha 6 (main bars parallel to traffic)

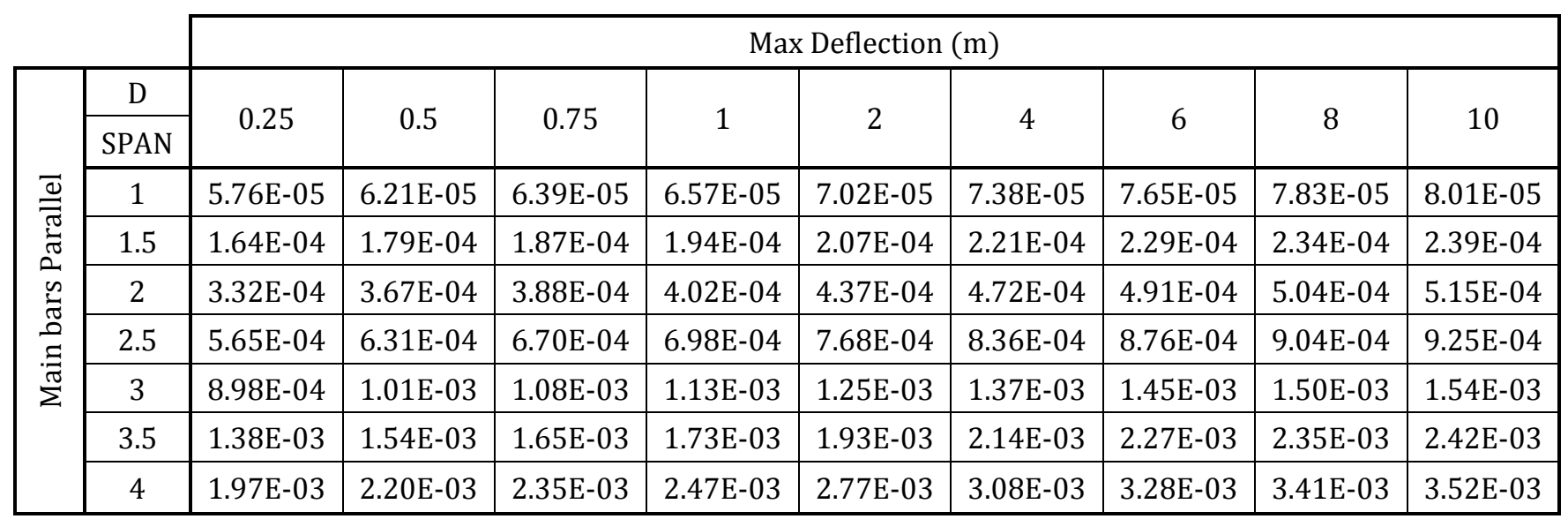




\section{Alpha 8 Deflection Results}

Table 312 Factored maximum deflection results for alpha 8 (main bars perpendicular to traffic)

\begin{tabular}{|c|c|c|c|c|c|c|c|c|c|c|}
\hline & & \multicolumn{9}{|c|}{ Max Deflection (m) } \\
\hline \multirow{9}{*}{ 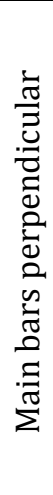 } & $\mathrm{D}$ & \multirow{2}{*}{0.25} & \multirow{2}{*}{0.5} & \multirow{2}{*}{0.75} & \multirow{2}{*}{1} & & \multirow{2}{*}{4} & \multirow{2}{*}{6} & \multirow{2}{*}{8} & \multirow{2}{*}{10} \\
\hline & SPAN & & & & & & & & & \\
\hline & 1 & $2.51 \mathrm{E}-05$ & $2.90 \mathrm{E}-05$ & $3.20 \mathrm{E}-05$ & $3.40 \mathrm{E}-05$ & $4.10 \mathrm{E}-05$ & $4.80 \mathrm{E}-05$ & $5.30 \mathrm{E}-05$ & $5.70 \mathrm{E}-05$ & $6.00 \mathrm{E}-05$ \\
\hline & 1.5 & $6.87 \mathrm{E}-05$ & $7.89 \mathrm{E}-05$ & $8.54 \mathrm{E}-05$ & $9.01 \mathrm{E}-05$ & $1.03 \mathrm{E}-04$ & $1.21 \mathrm{E}-04$ & $1.34 \mathrm{E}-04$ & $1.44 \mathrm{E}-04$ & $1.52 \mathrm{E}-04$ \\
\hline & 2 & $1.35 \mathrm{E}-04$ & $1.55 \mathrm{E}-04$ & $1.68 \mathrm{E}-04$ & $1.78 \mathrm{E}-04$ & $2.03 \mathrm{E}-04$ & $2.32 \mathrm{E}-04$ & $2.50 \mathrm{E}-04$ & $2.67 \mathrm{E}-04$ & $2.82 \mathrm{E}-04$ \\
\hline & 2.5 & $2.22 \mathrm{E}-04$ & $2.56 \mathrm{E}-04$ & $2.79 \mathrm{E}-04$ & $2.95 \mathrm{E}-04$ & $3.40 \mathrm{E}-04$ & $3.89 \mathrm{E}-04$ & $4.21 \mathrm{E}-04$ & $4.45 \mathrm{E}-04$ & $4.63 \mathrm{E}-04$ \\
\hline & 3 & $3.29 \mathrm{E}-04$ & $3.80 \mathrm{E}-04$ & $4.14 \mathrm{E}-04$ & $4.40 \mathrm{E}-04$ & $5.09 \mathrm{E}-04$ & $5.86 \mathrm{E}-04$ & $6.35 \mathrm{E}-04$ & $6.73 \mathrm{E}-04$ & $7.02 \mathrm{E}-04$ \\
\hline & 3.5 & 5.52E-04 & $6.33 \mathrm{E}-04$ & $6.88 \mathrm{E}-04$ & 7.30E-04 & 8.47E-04 & $9.78 \mathrm{E}-04$ & $1.06 \mathrm{E}-03$ & $1.13 \mathrm{E}-03$ & $1.18 \mathrm{E}-03$ \\
\hline & 4 & $8.30 \mathrm{E}-04$ & $9.44 \mathrm{E}-04$ & $1.02 \mathrm{E}-03$ & $1.09 \mathrm{E}-03$ & $1.26 \mathrm{E}-03$ & $1.45 \mathrm{E}-03$ & $1.58 \mathrm{E}-03$ & $1.68 \mathrm{E}-03$ & $1.76 \mathrm{E}-03$ \\
\hline
\end{tabular}

Table 313 Factored maximum deflection results for alpha 8 (main bars parallel to traffic)

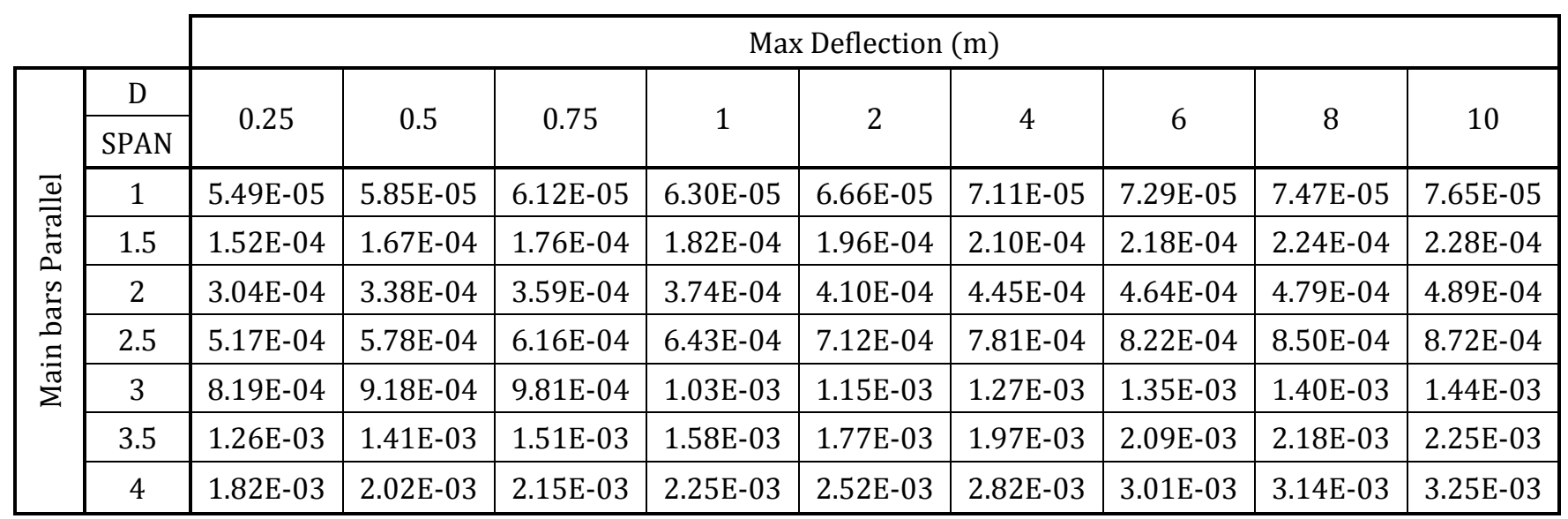




\section{Alpha 10 Deflection Results}

Table 314 Factored maximum deflection results for alpha 10 (main bars perpendicular to traffic)

\begin{tabular}{|c|c|c|c|c|c|c|c|c|c|c|}
\hline & & & & & $\mathrm{Ma}$ & Deflection & & & & \\
\hline \multirow{9}{*}{ 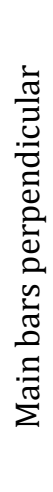 } & $\mathrm{D}$ & \multirow{2}{*}{0.25} & \multirow{2}{*}{0.5} & \multirow{2}{*}{0.75} & \multirow{2}{*}{1} & & \multirow{2}{*}{4} & & & \multirow{2}{*}{10} \\
\hline & SPAN & & & & & & & & & \\
\hline & 1 & $2.32 \mathrm{E}-05$ & 2.69E-05 & $2.90 \mathrm{E}-05$ & $3.10 \mathrm{E}-05$ & $3.70 \mathrm{E}-05$ & $4.40 \mathrm{E}-05$ & $4.80 \mathrm{E}-05$ & $5.10 \mathrm{E}-05$ & $5.40 \mathrm{E}-05$ \\
\hline & 1.5 & $6.31 \mathrm{E}-05$ & $7.24 \mathrm{E}-05$ & $7.89 \mathrm{E}-05$ & $8.36 \mathrm{E}-05$ & $9.47 \mathrm{E}-05$ & $1.10 \mathrm{E}-04$ & $1.21 \mathrm{E}-04$ & $1.30 \mathrm{E}-04$ & $1.37 \mathrm{E}-04$ \\
\hline & 2 & $1.23 \mathrm{E}-04$ & $1.41 \mathrm{E}-04$ & $1.54 \mathrm{E}-04$ & $1.63 \mathrm{E}-04$ & $1.88 \mathrm{E}-04$ & $2.15 \mathrm{E}-04$ & $2.31 \mathrm{E}-04$ & $2.44 \mathrm{E}-04$ & $2.55 \mathrm{E}-04$ \\
\hline & 2.5 & $2.03 \mathrm{E}-04$ & $2.34 \mathrm{E}-04$ & $2.54 \mathrm{E}-04$ & $2.70 \mathrm{E}-04$ & $3.11 \mathrm{E}-04$ & $3.58 \mathrm{E}-04$ & $3.87 \mathrm{E}-04$ & $4.10 \mathrm{E}-04$ & $4.28 \mathrm{E}-04$ \\
\hline & 3 & $3.03 \mathrm{E}-04$ & $3.48 \mathrm{E}-04$ & $3.78 \mathrm{E}-04$ & $4.01 \mathrm{E}-04$ & $4.64 \mathrm{E}-04$ & $5.36 \mathrm{E}-04$ & $5.82 \mathrm{E}-04$ & $6.17 \mathrm{E}-04$ & $6.44 \mathrm{E}-04$ \\
\hline & 3.5 & $5.11 \mathrm{E}-04$ & $5.81 \mathrm{E}-04$ & $6.30 \mathrm{E}-04$ & $6.68 \mathrm{E}-04$ & $7.71 \mathrm{E}-04$ & 8.93E-04 & $9.70 \mathrm{E}-04$ & $1.03 \mathrm{E}-03$ & $1.08 \mathrm{E}-03$ \\
\hline & 4 & $7.75 \mathrm{E}-04$ & 8.72E-04 & $9.41 \mathrm{E}-04$ & $9.96 \mathrm{E}-04$ & $1.15 \mathrm{E}-03$ & $1.32 \mathrm{E}-03$ & $1.44 \mathrm{E}-03$ & $1.53 \mathrm{E}-03$ & $1.60 \mathrm{E}-03$ \\
\hline
\end{tabular}

Table 315 Factored maximum deflection results for alpha 10 (main bars parallel to traffic)

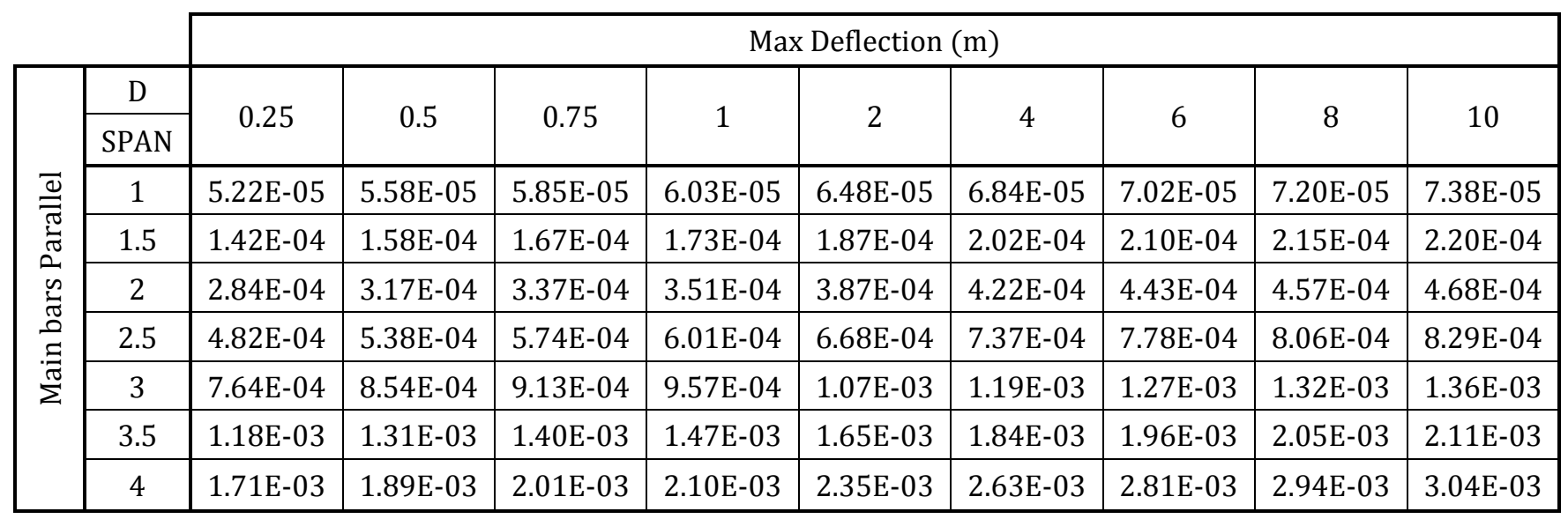




\section{E.2.2 MAXIMUM DEFLECTION VS SPAN LENGTH}




\section{Deflection VS Span Length for Different D Values (Main bars perpendicular to traffic)}

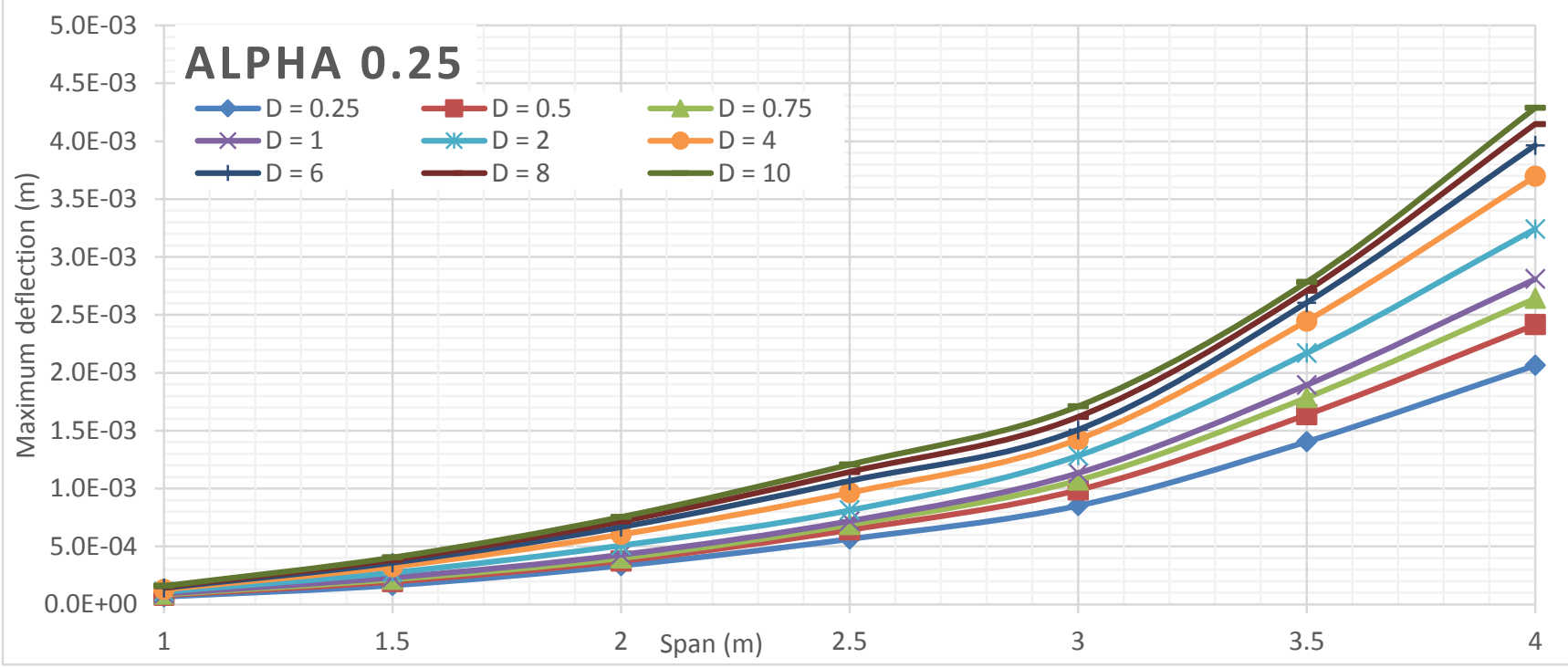

Figure 1105 Factored maximum deflection results for alpha 0.25 at different $D$ values (main bars perpendicular to traffic)

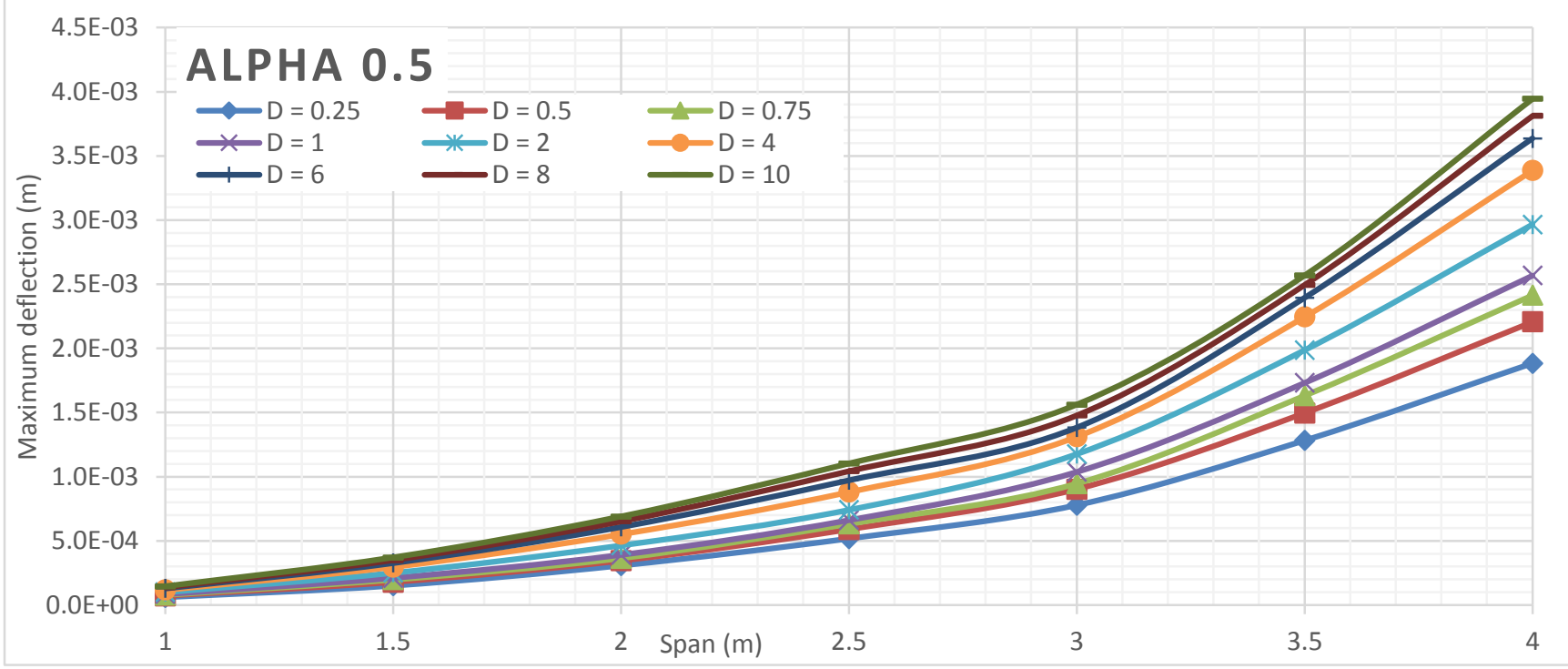

Figure 1106 Factored maximum deflection results for alpha 0.5 at different $D$ values (main bars perpendicular to traffic) 


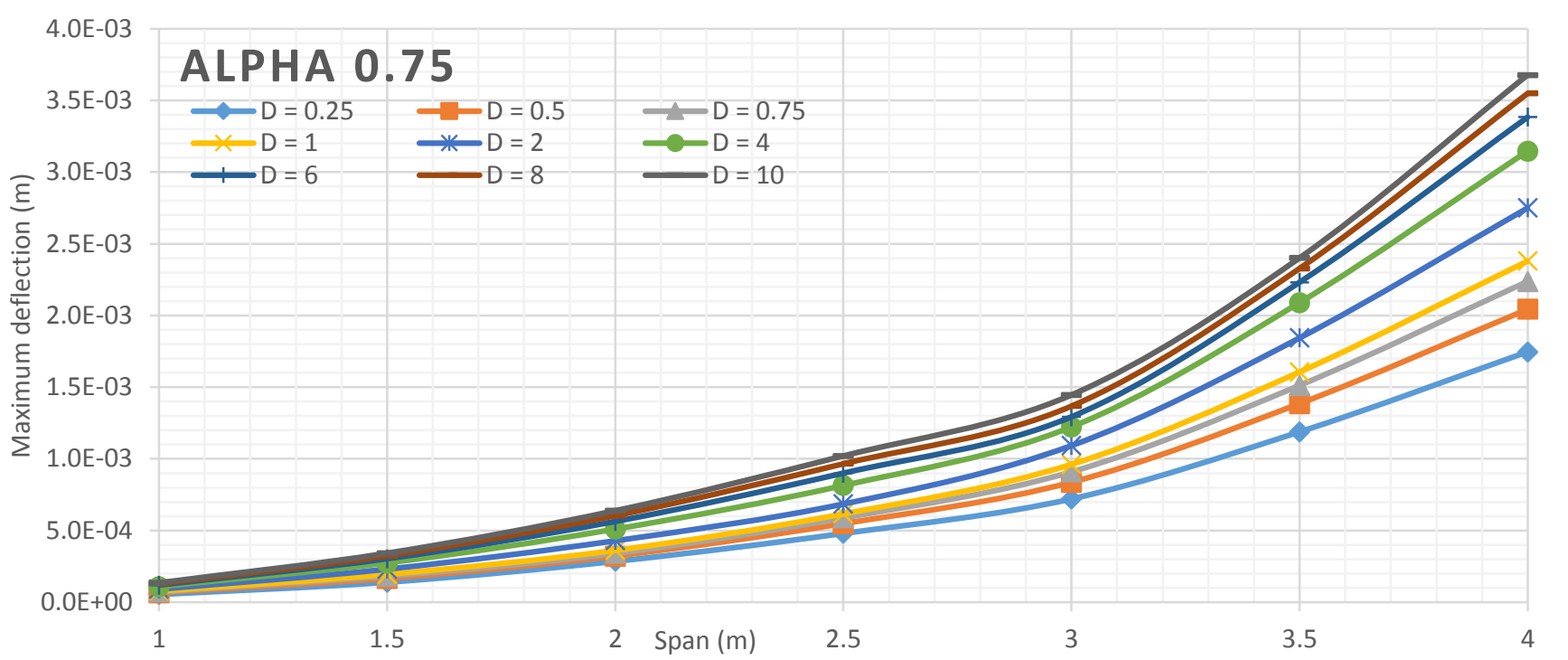

Figure 1107 Factored maximum deflection results for alpha 0.75 at different $D$ values (main bars perpendicular to traffic)

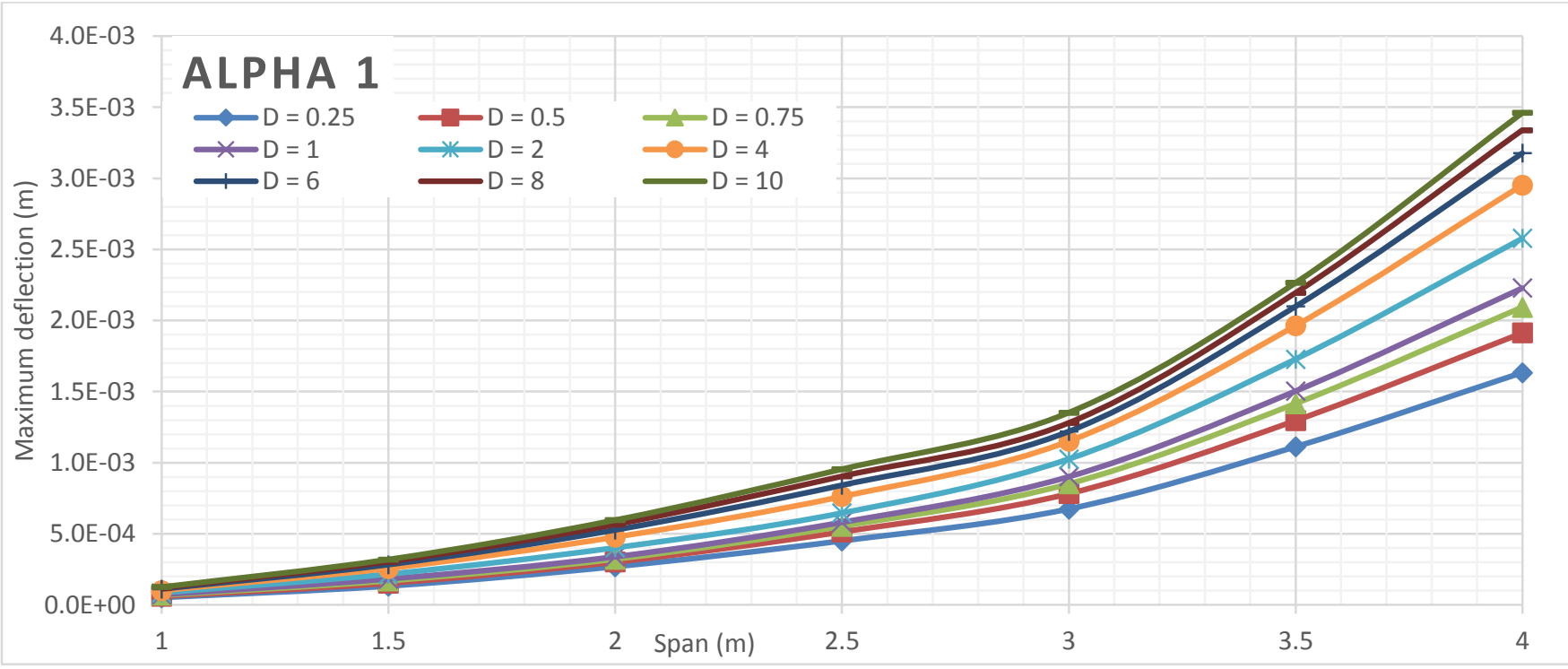

Figure 1108 Factored maximum deflection results for alpha 1 at different D values (main bars perpendicular to traffic)

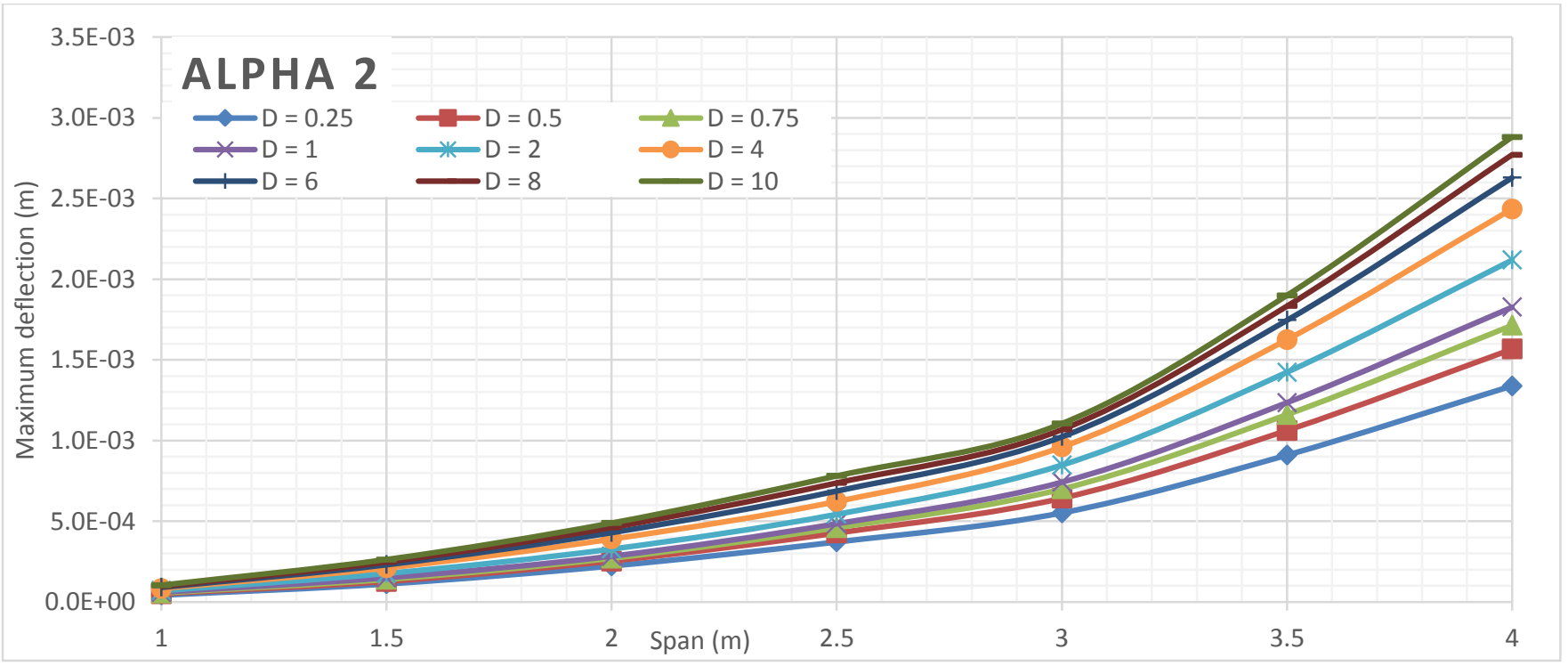

Figure 1109 Factored maximum deflection results for alpha 2 at different $D$ values (main bars perpendicular to traffic) 


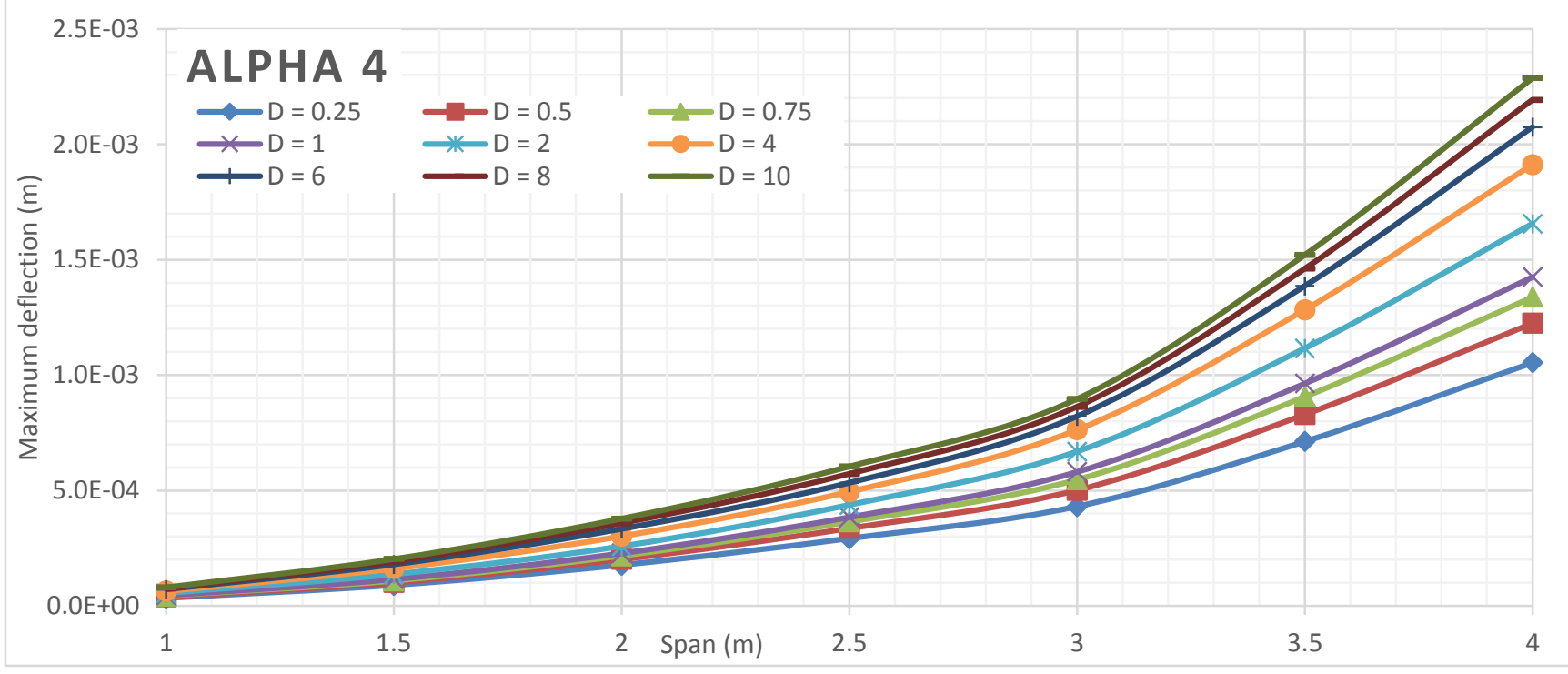

Figure 1110 Factored maximum deflection results for alpha 4 at different $D$ values (main bars perpendicular to traffic)

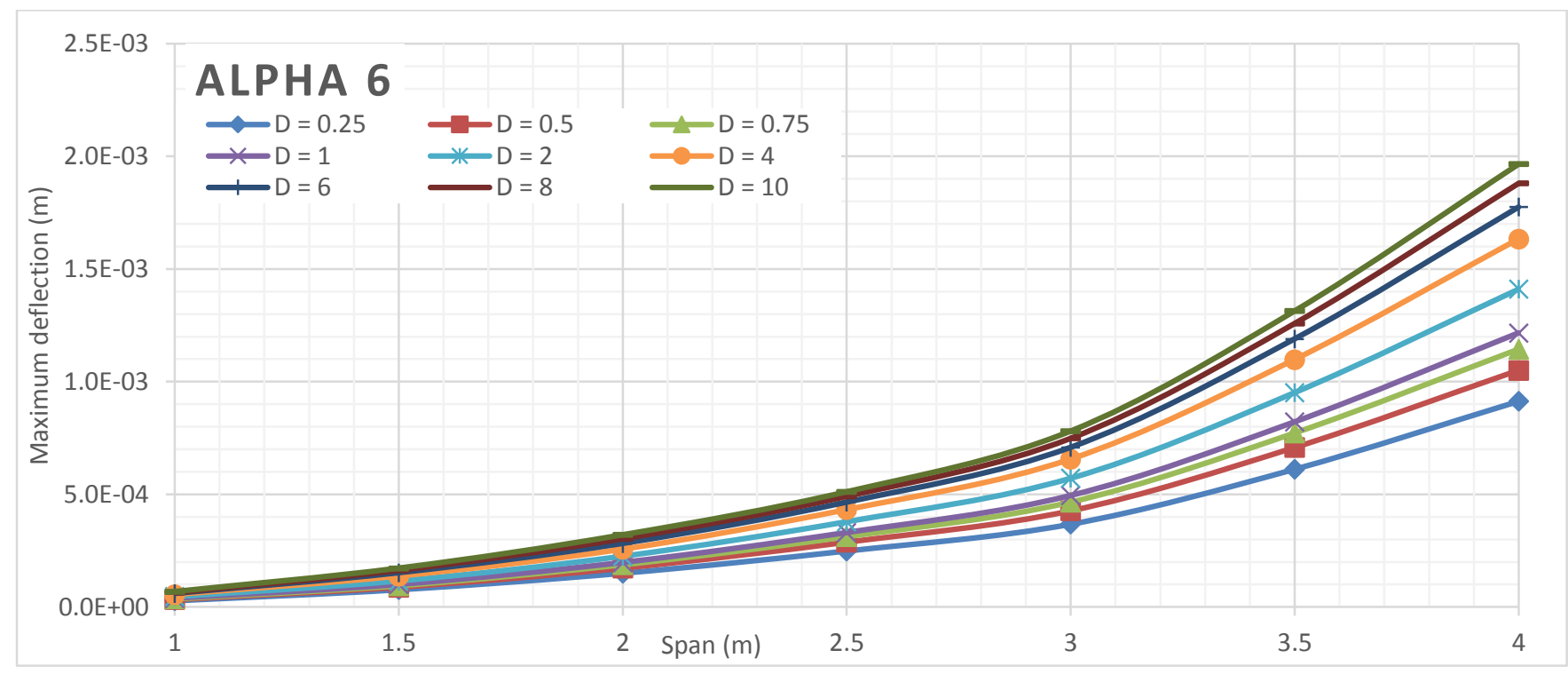

Figure 1111 Factored maximum deflection results for alpha 6 at different D values (main bars perpendicular to traffic)

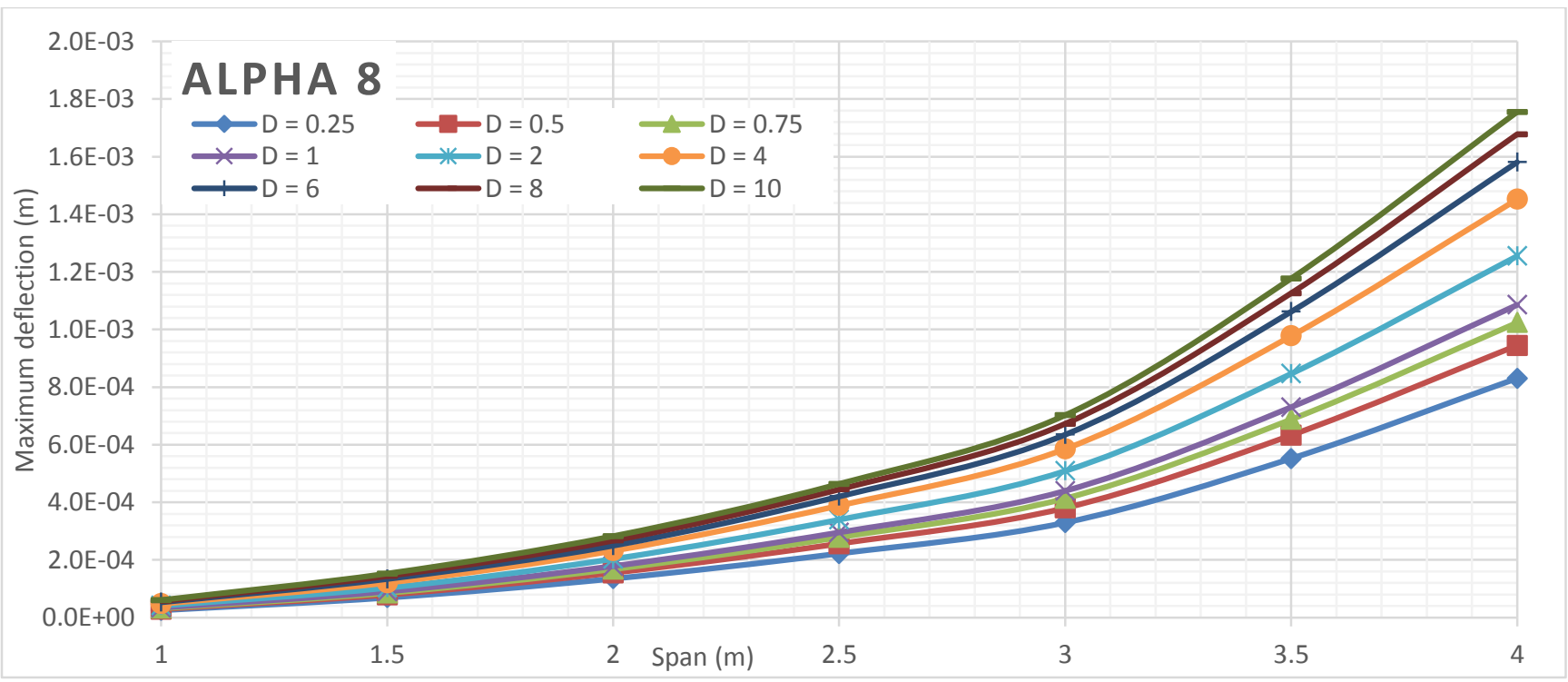

Figure 1112 Factored maximum deflection results for alpha 8 at different D values (main bars perpendicular to traffic) 


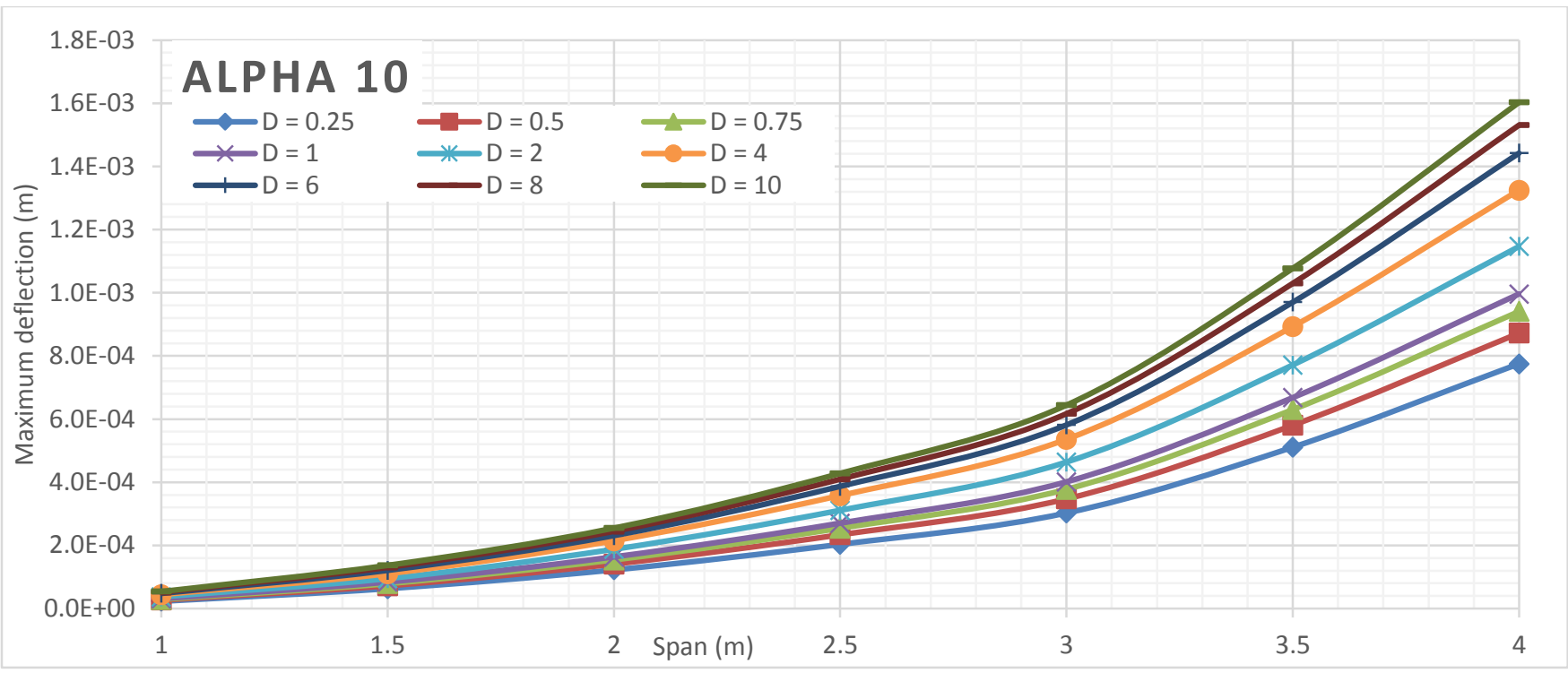

Figure 1113 Factored maximum deflection results for alpha 10 at different $D$ values (main bars perpendicular to traffic) 


\section{Deflection VS Span Length for Different D Values (Main bars parallel to traffic)}

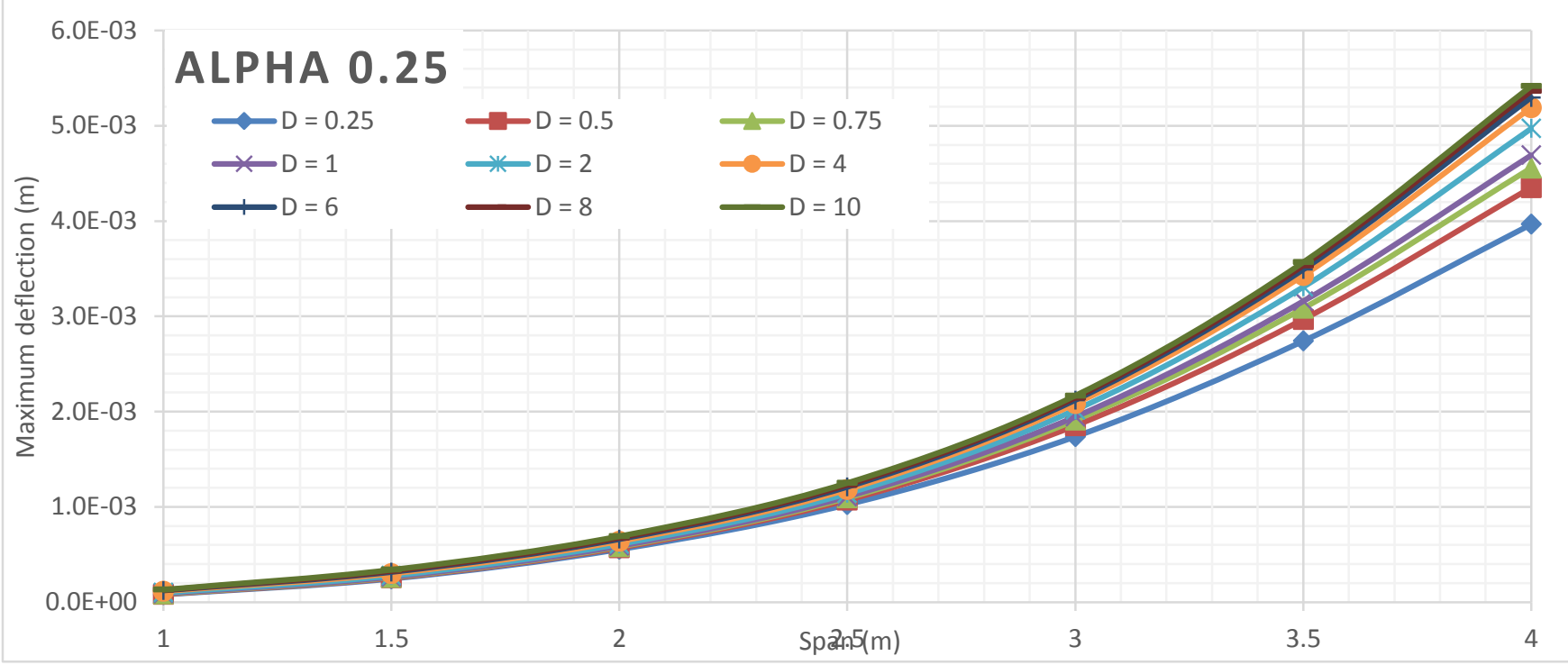

Figure 1114 Factored maximum deflection results for alpha 0.25 at different $D$ values (main bars parallel to traffic)

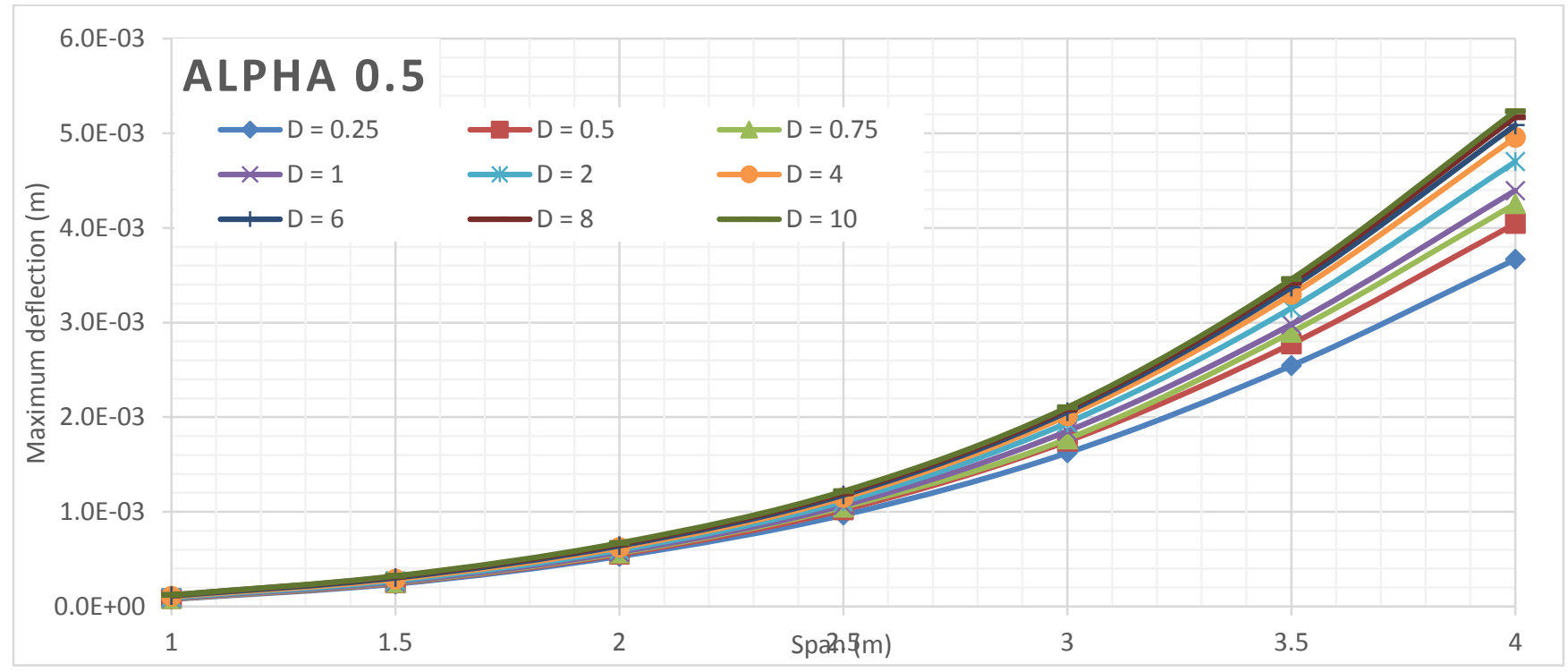

Figure 1115 Factored maximum deflection results for alpha 0.5 at different $D$ values (main bars parallel to traffic) 


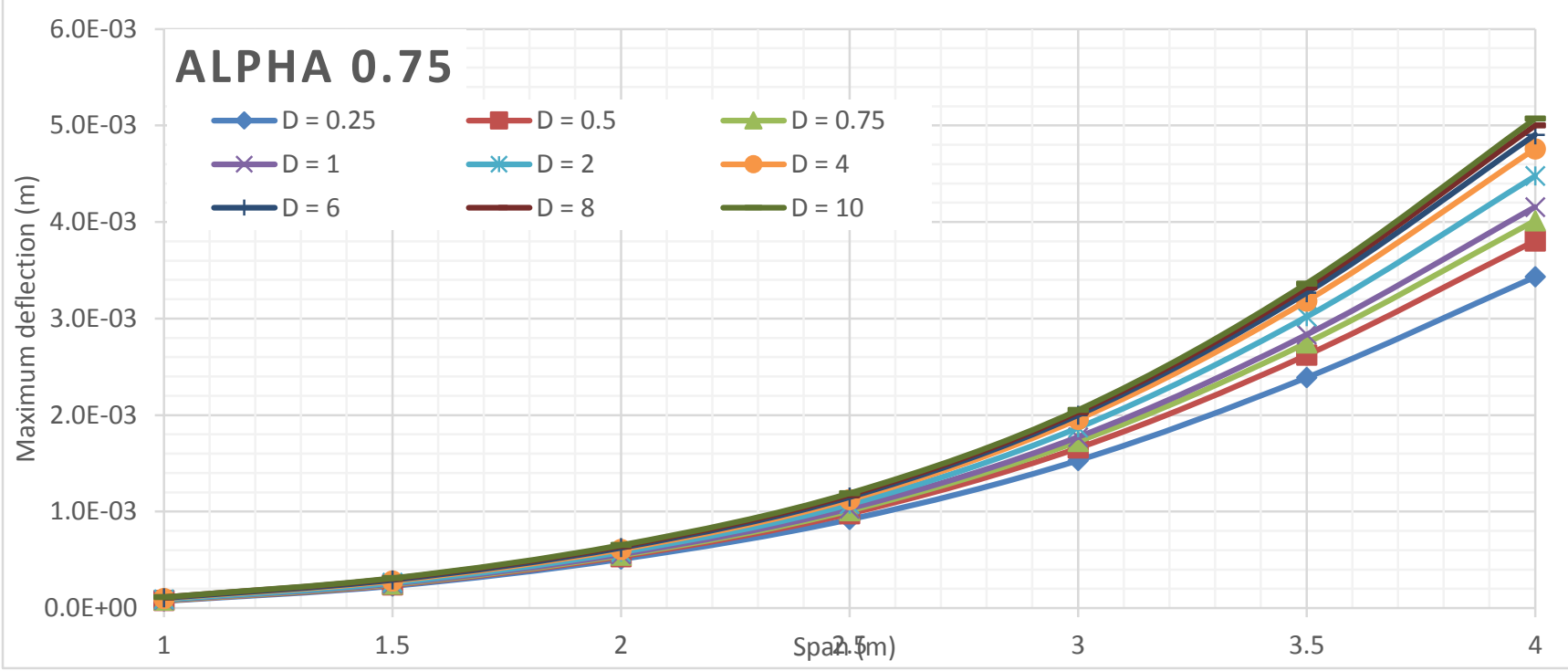

Figure 1116 Factored maximum deflection results for alpha 0.75 at different $D$ values (main bars parallel to traffic)

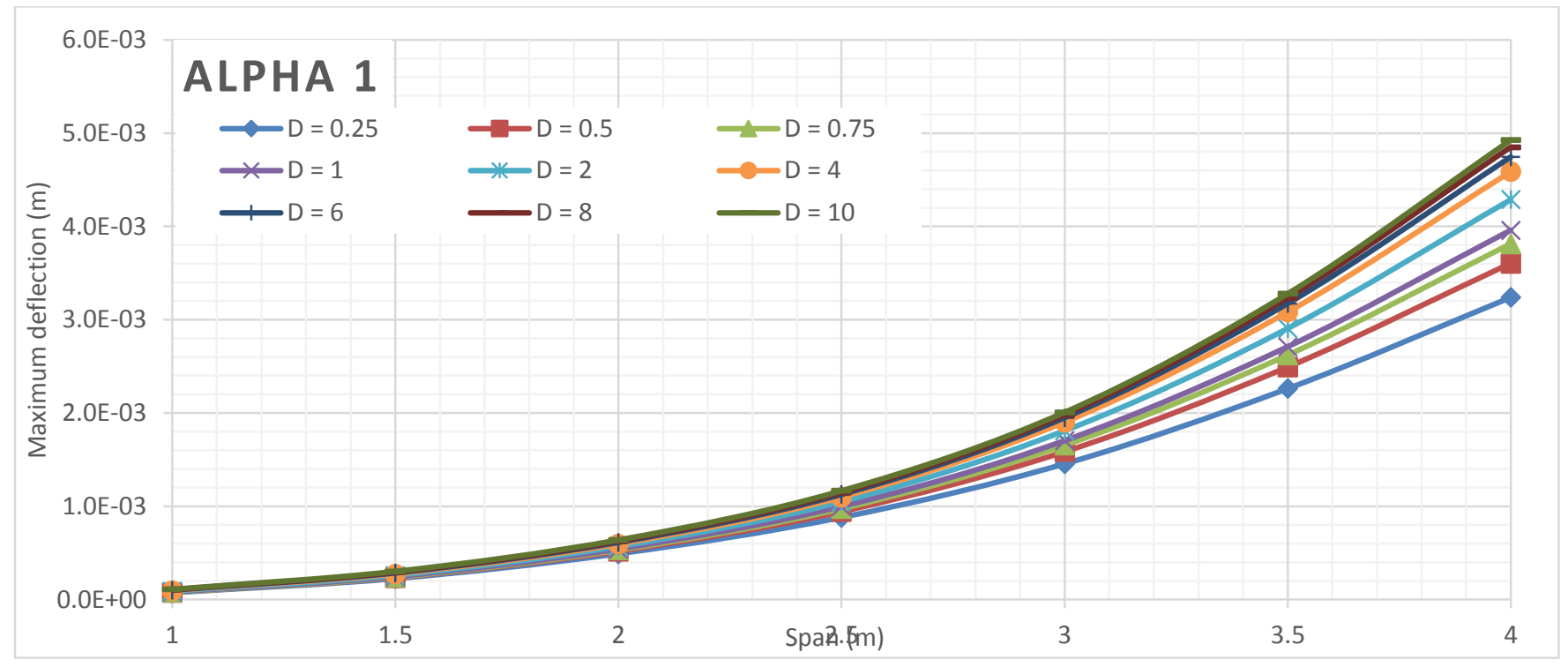

Figure 1117 Factored maximum deflection results for alpha 1 at different D values (main bars parallel to traffic)

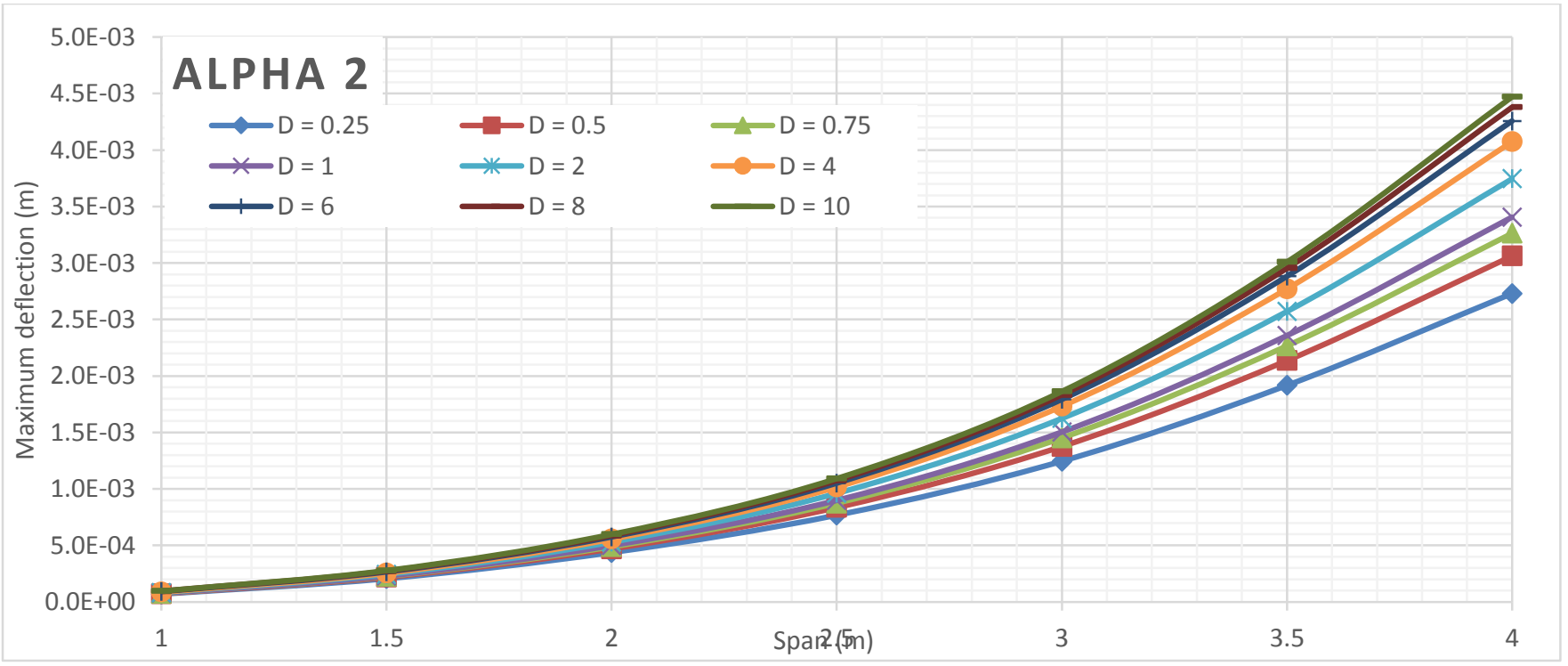

Figure 1118 Factored maximum deflection results for alpha 2 at different $D$ values (main bars parallel to traffic) 


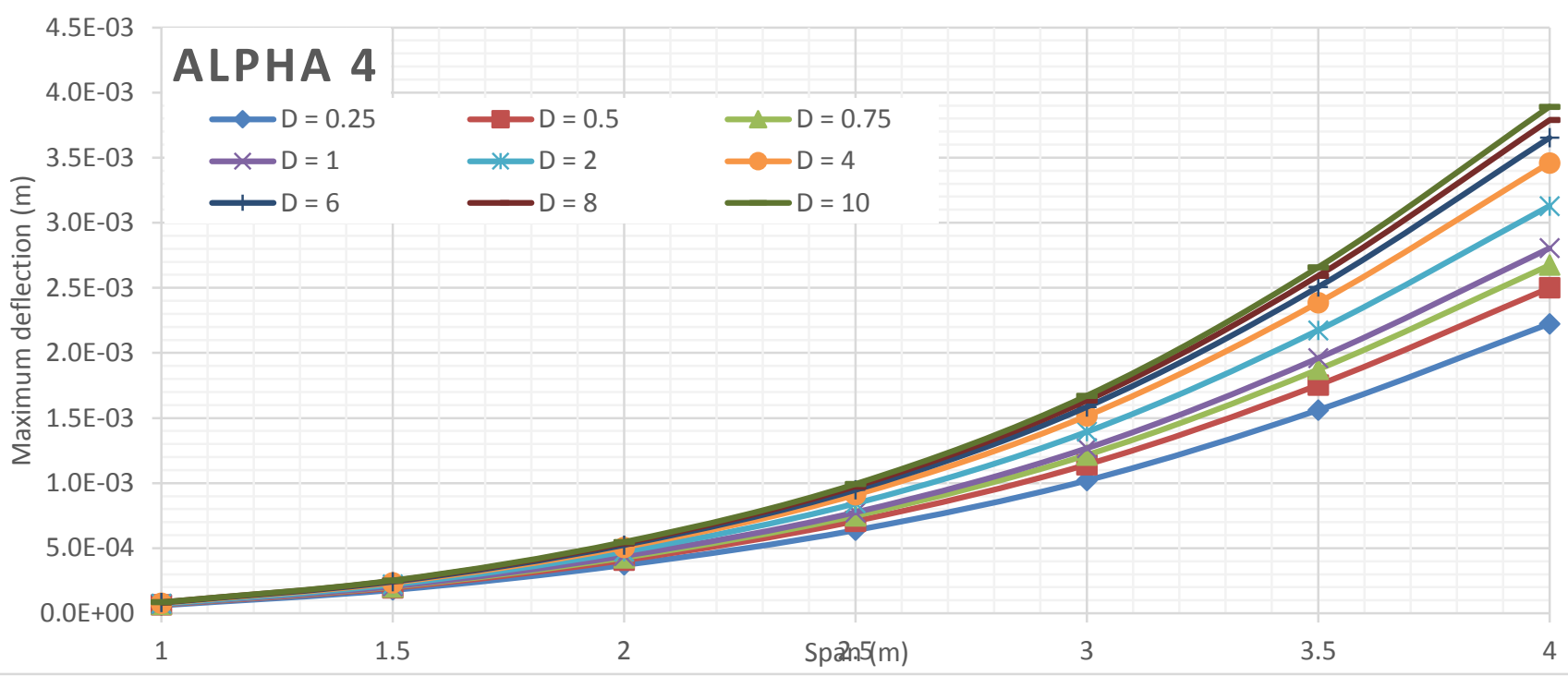

Figure 1119 Factored maximum deflection results for alpha 4 at different D values (main bars parallel to traffic)

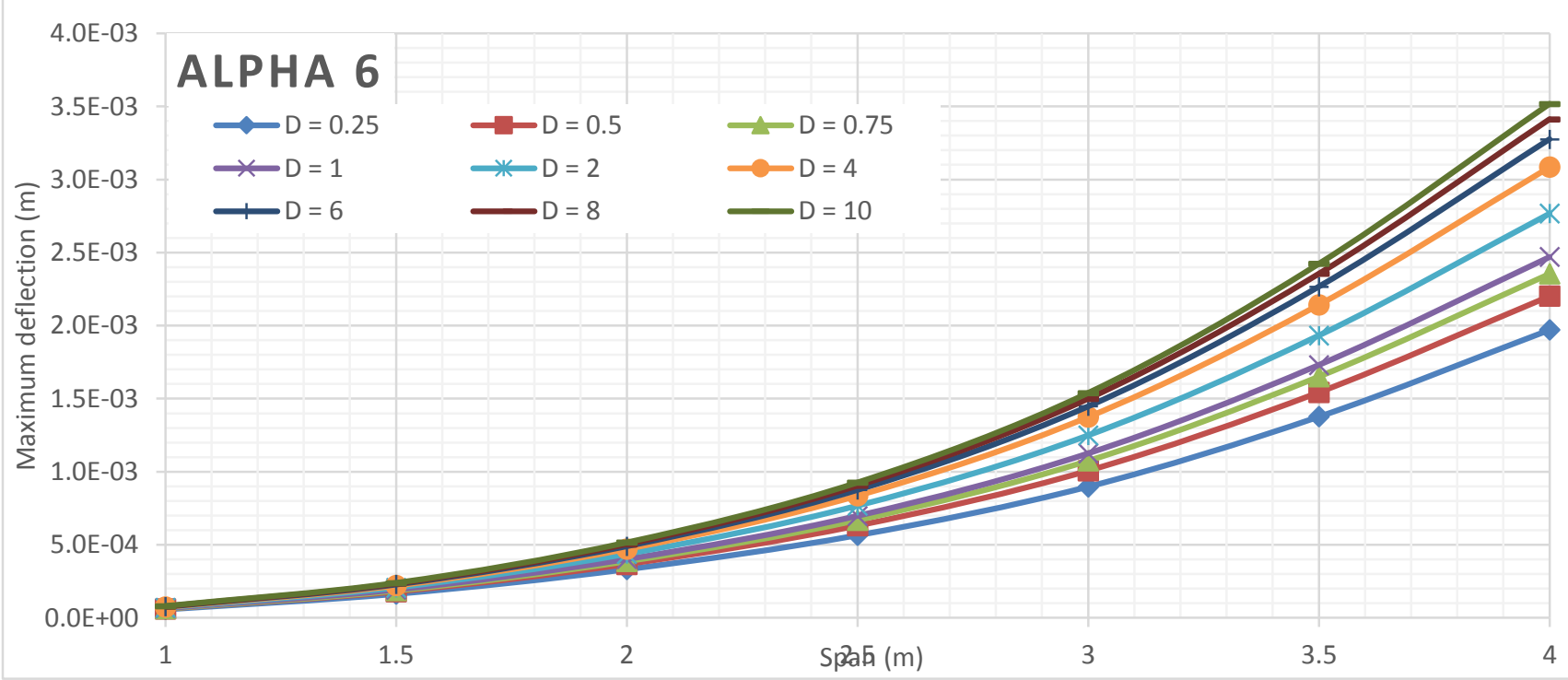

Figure 1120 Factored maximum deflection results for alpha 6 at different D values (main bars parallel to traffic)

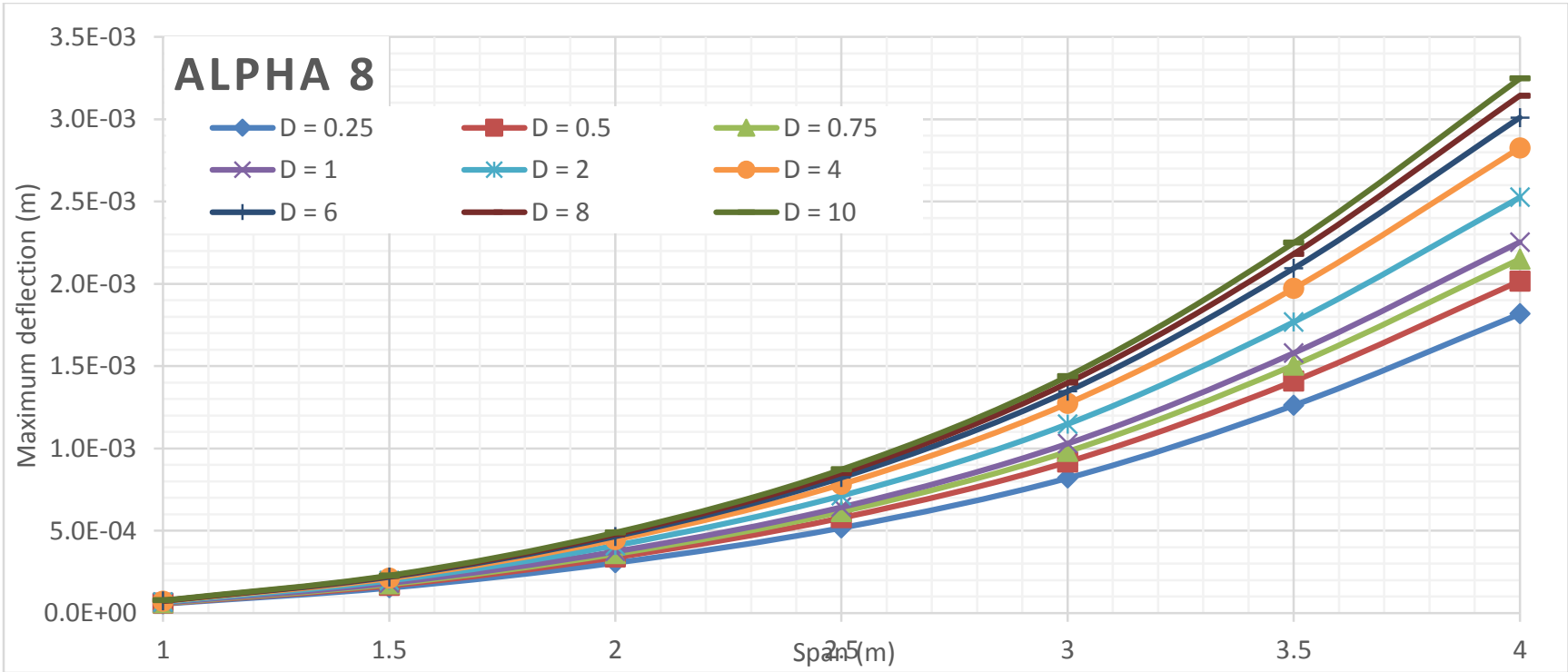

Figure 1121 Factored maximum deflection results for alpha 8 at different $D$ values (main bars parallel to traffic) 


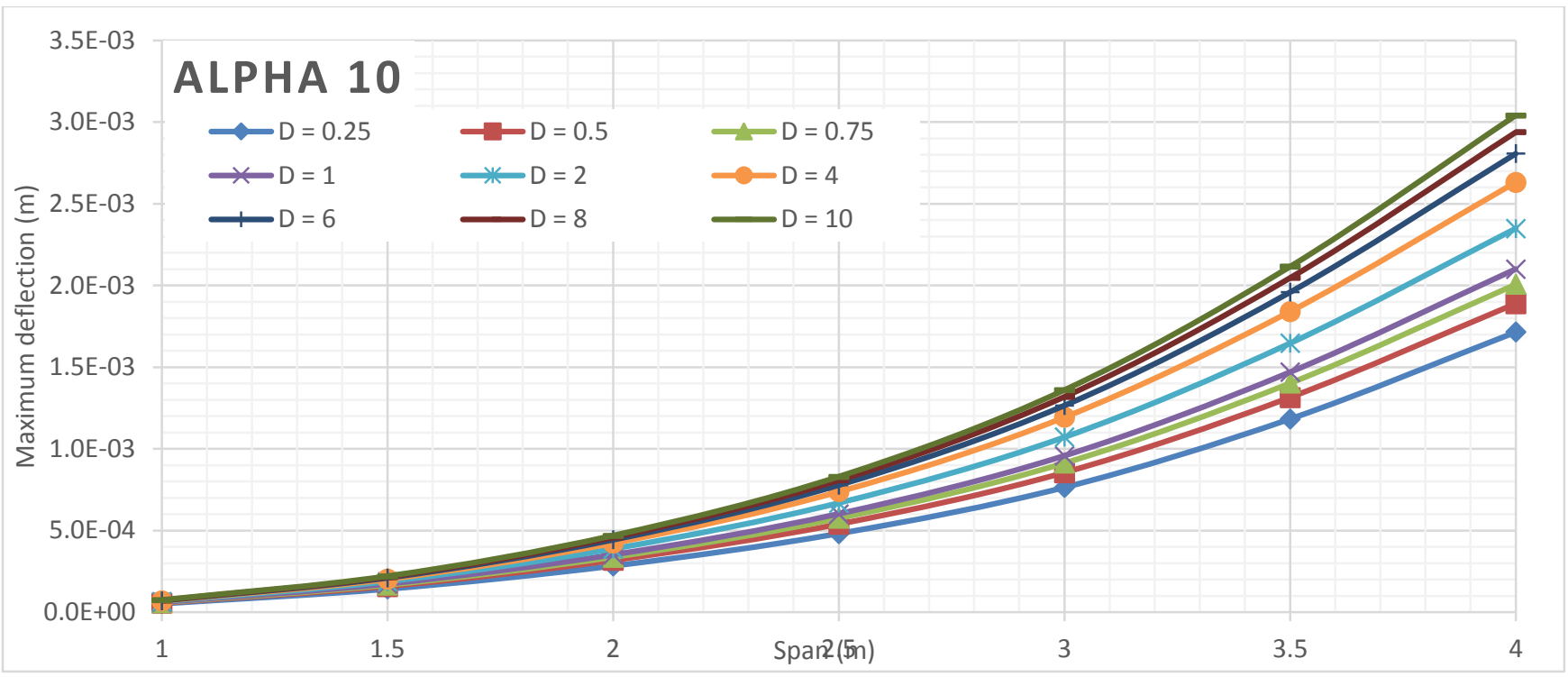

Figure 1122 Factored maximum deflection results for alpha 10 at different $D$ values (main bars parallel to traffic) 


\section{E.2.3 MAXIMUM DEFLECTION VS FLEXURAL RIGIDITY}




\section{Deflection VS Flexural Rigidity for Different Spans (Main bars perpendicular to traffic)}

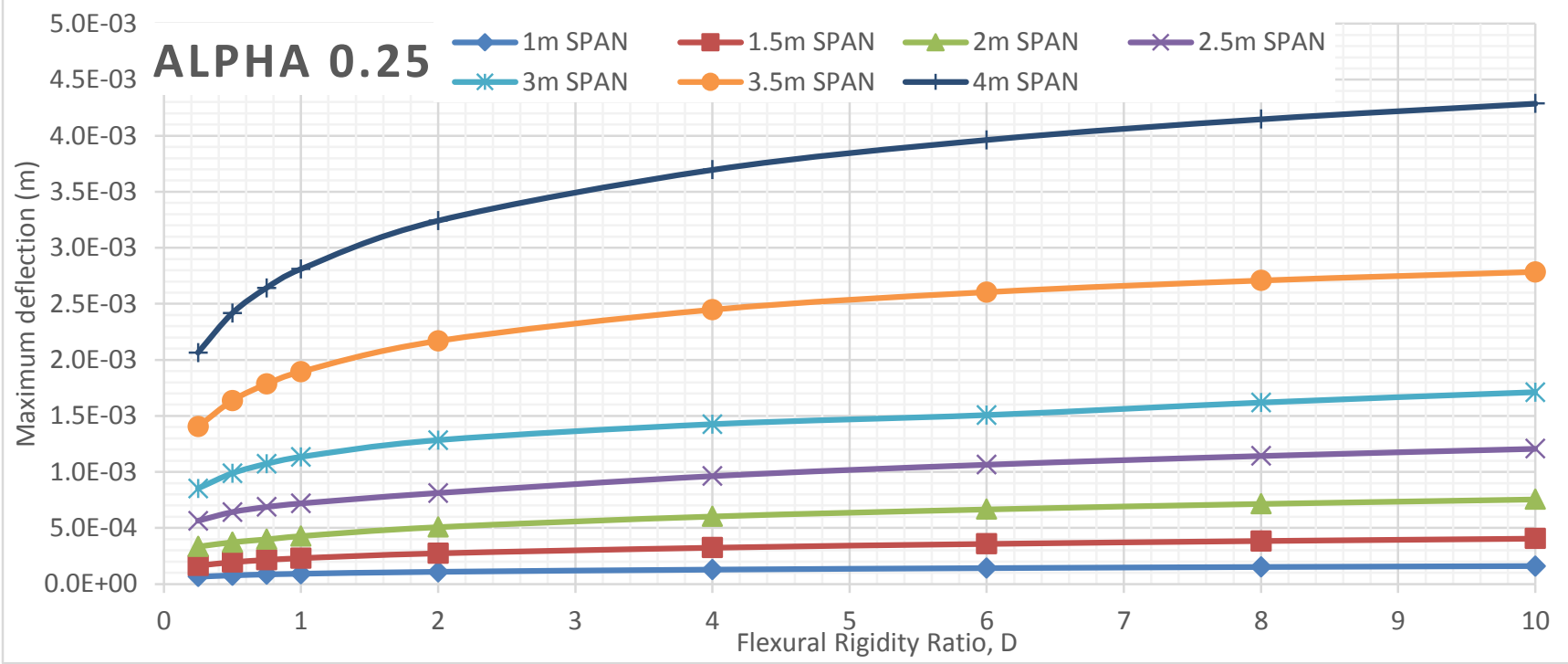

Figure 1123 Factored maximum deflection results for alpha 0.25 at different span length (main bars perpendicular to traffic)

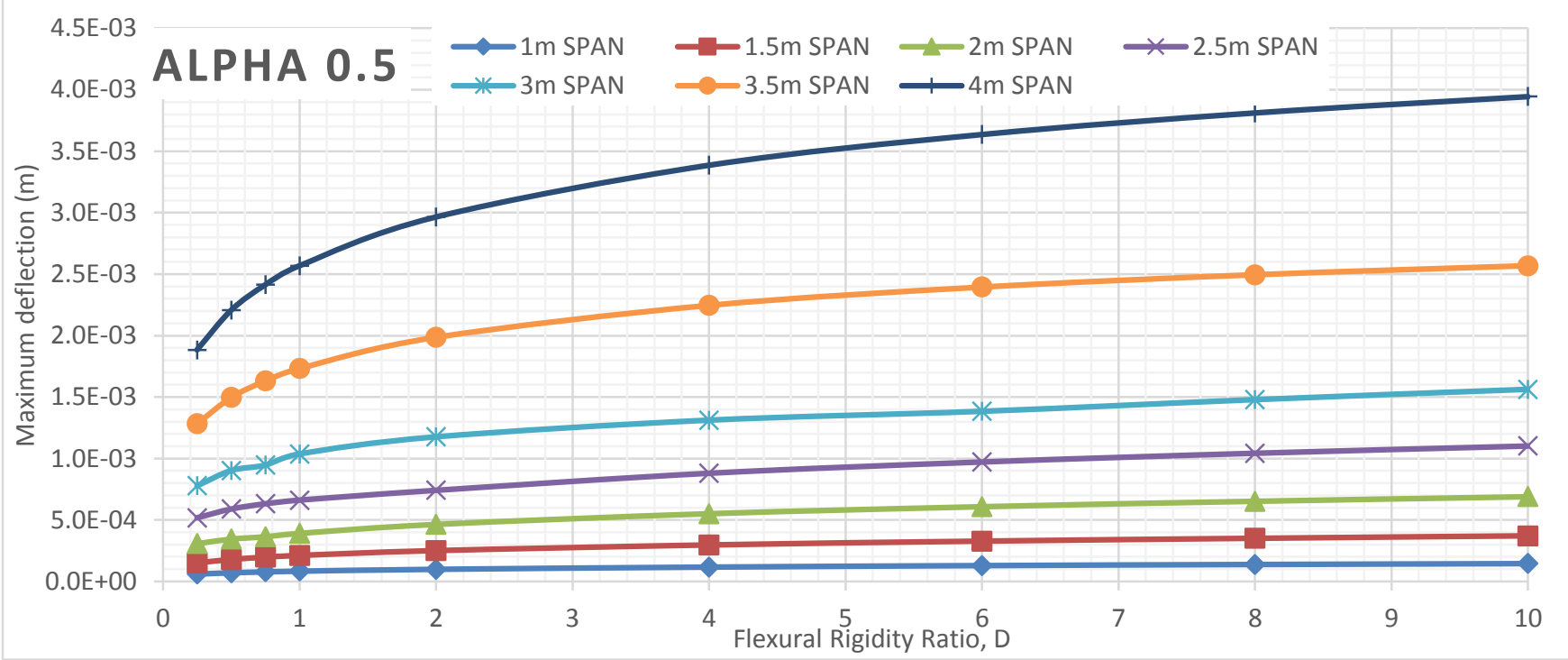

Figure 1124 Factored maximum deflection results for alpha 0.5 at different span length (main bars perpendicular to traffic) 


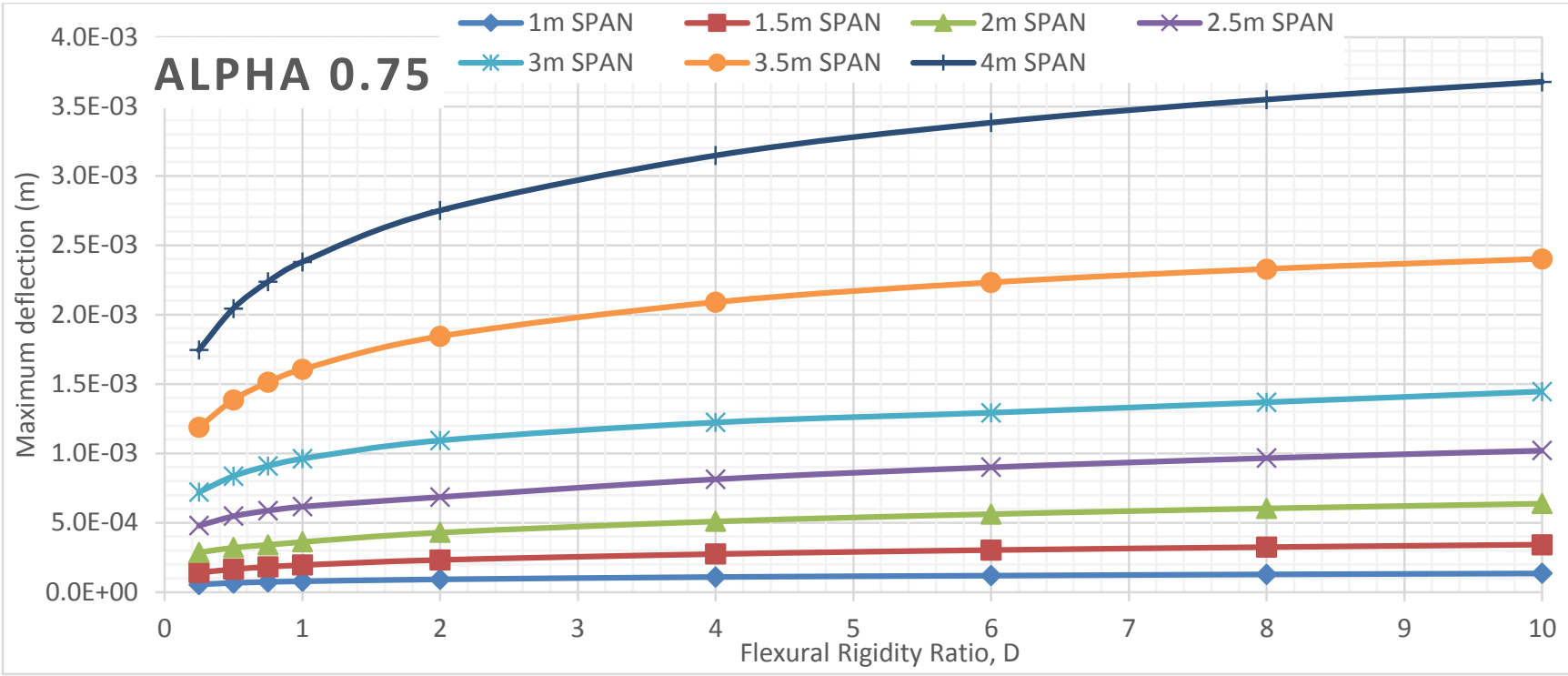

Figure 1125 Factored maximum deflection results for alpha 0.75 at different span length (main bars perpendicular to traffic)

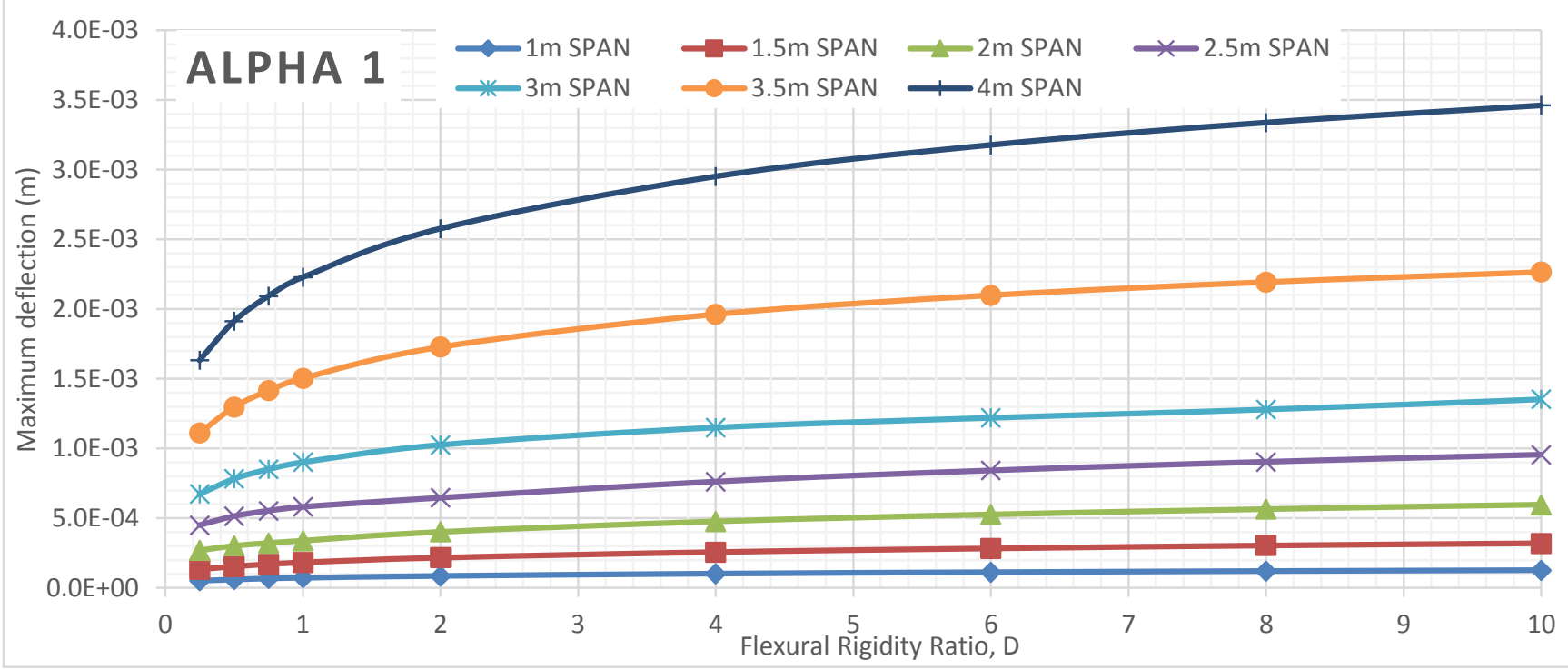

Figure 1126 Factored maximum deflection results for alpha 1 at different span length (main bars perpendicular to traffic)

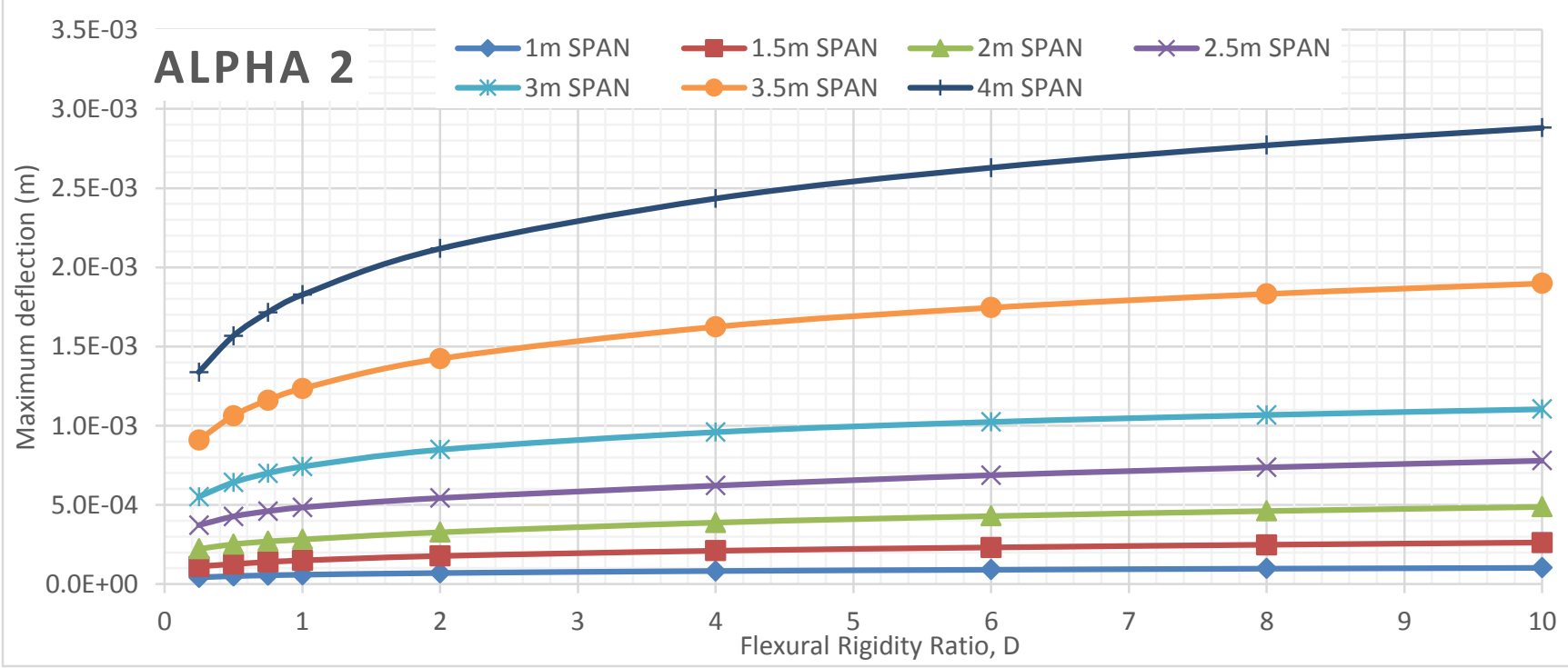

Figure 1127 Factored maximum deflection results for alpha 2 at different span length (main bars perpendicular to traffic) 


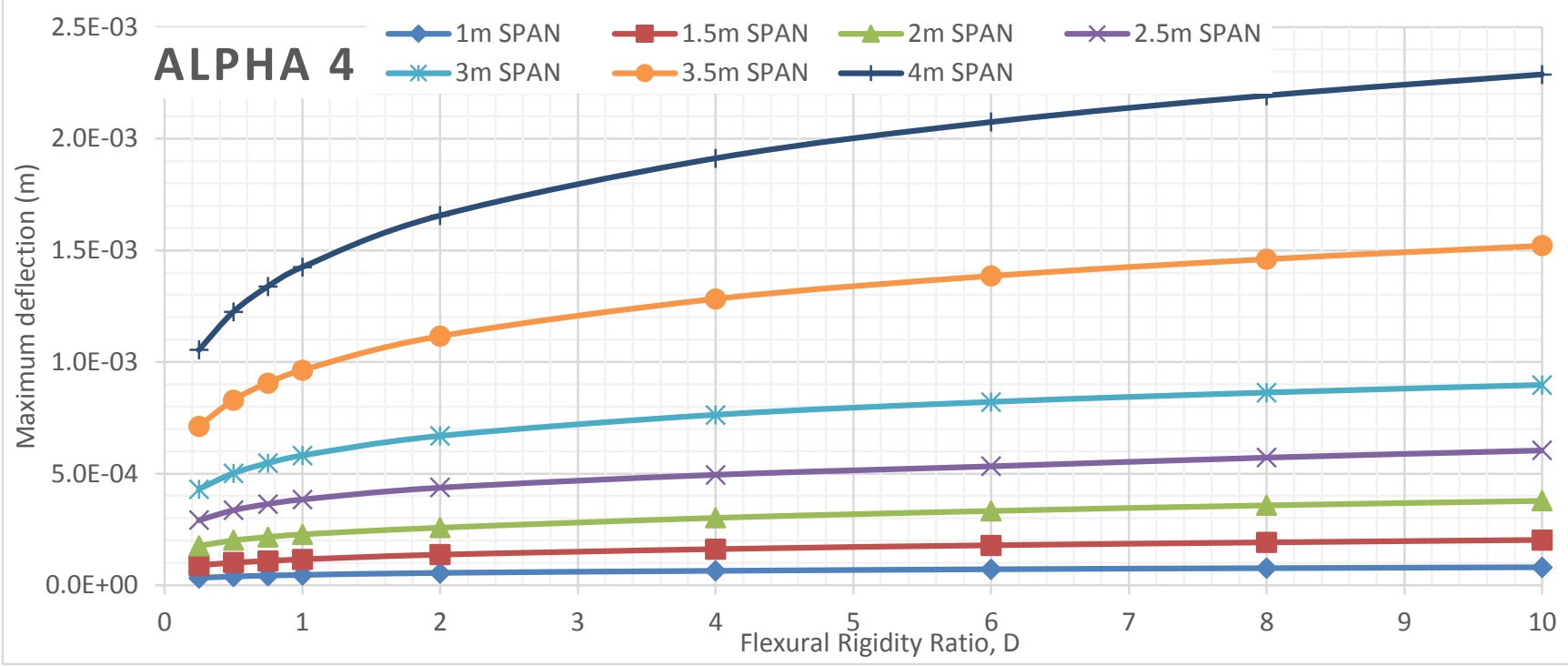

Figure 1128 Factored maximum deflection results for alpha 4 at different span length (main bars perpendicular to traffic)

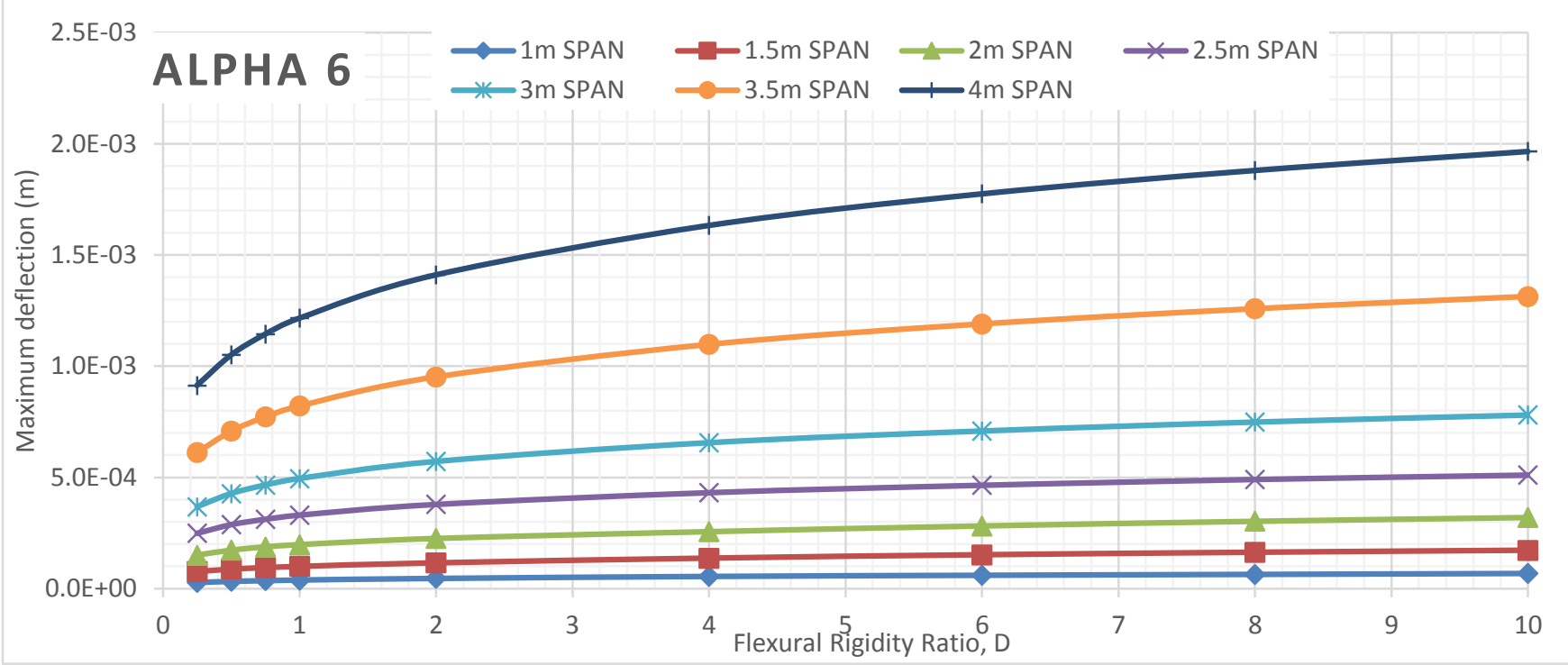

Figure 1129 Factored maximum deflection results for alpha 6 at different span length (main bars perpendicular to traffic)

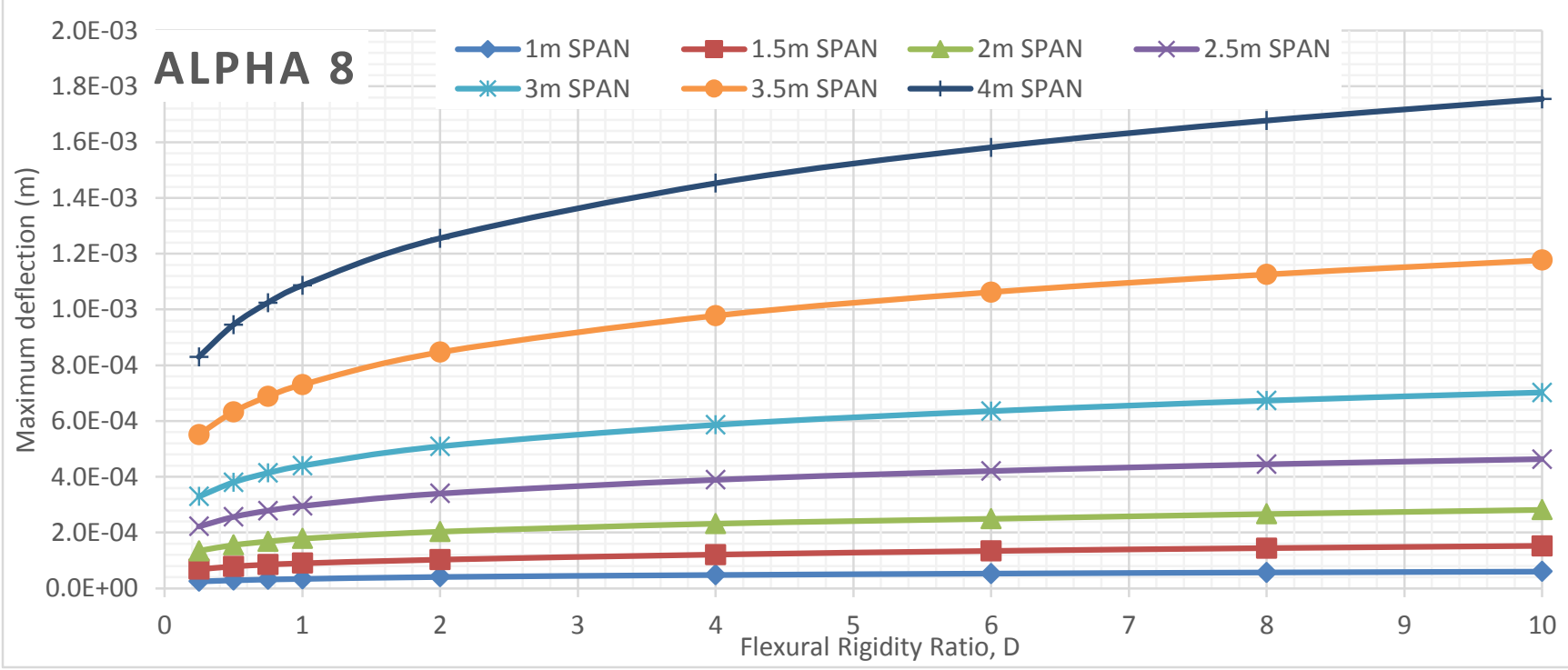

Figure 1130 Factored maximum deflection results for alpha 8 at different span length (main bars perpendicular to traffic) 


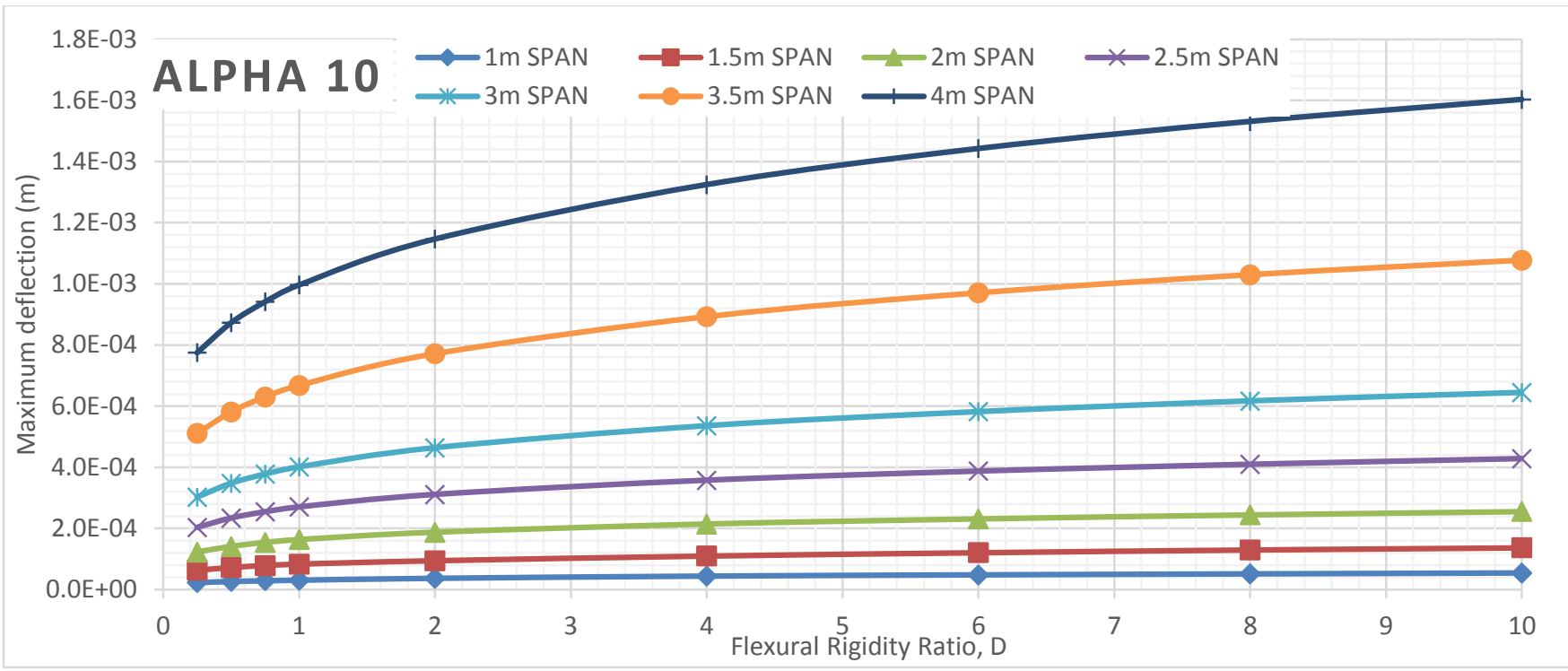

Figure 1131 Factored maximum deflection results for alpha 10 at different span length (main bars perpendicular to traffic) 


\section{Deflection VS Flexural Rigidity for Different Spans (Main bars parallel to traffic)}

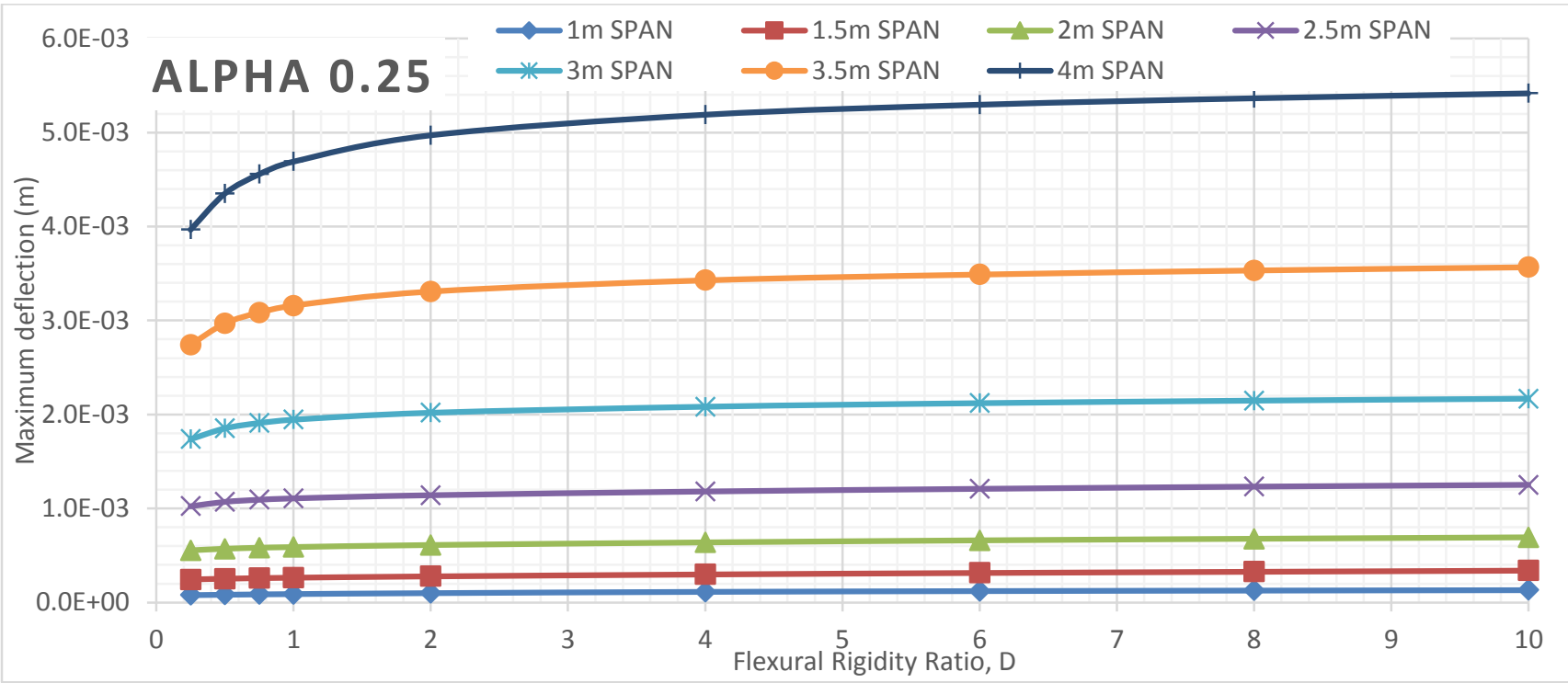

Figure 1132 Factored maximum deflection results for alpha 0.25 at different span length (main bars parallel to traffic)

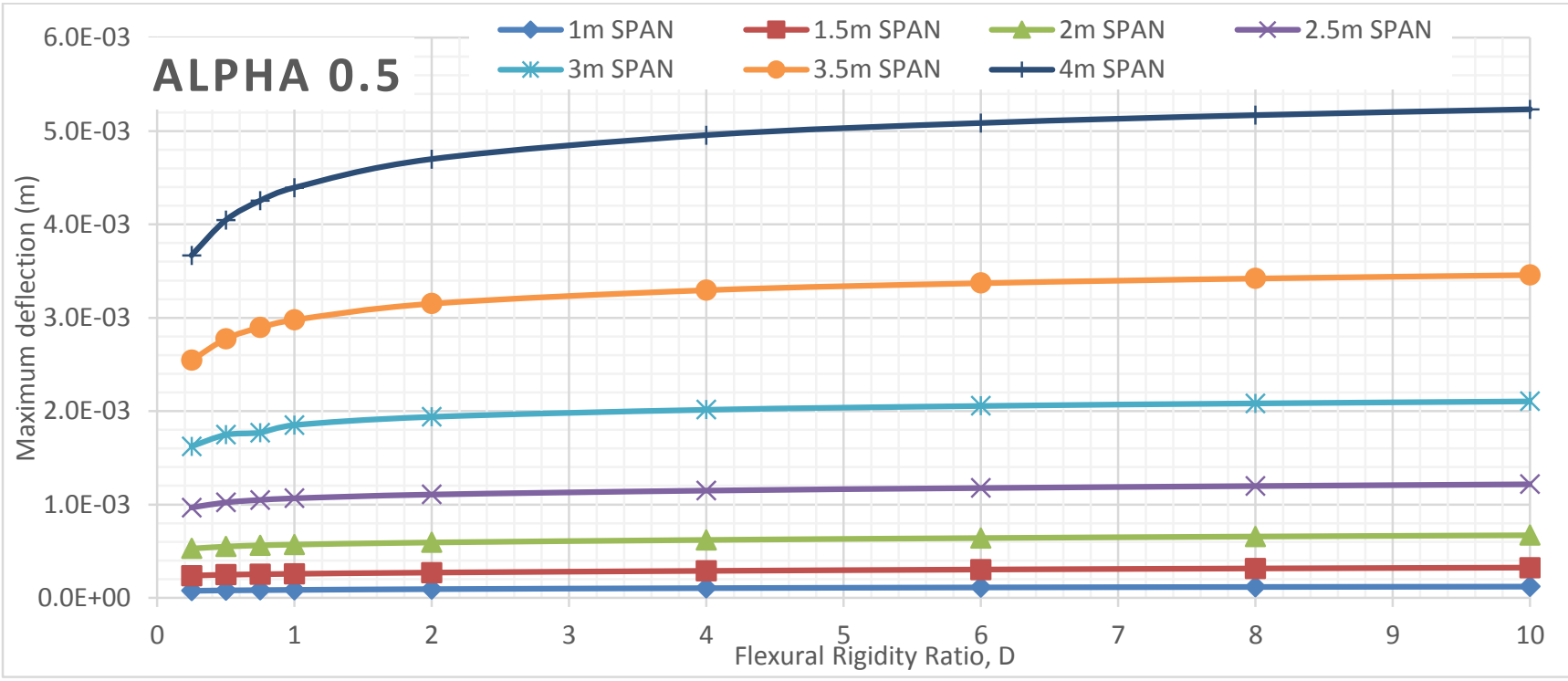

Figure 1133 Factored maximum deflection results for alpha 0.5 at different span length (main bars parallel to traffic) 


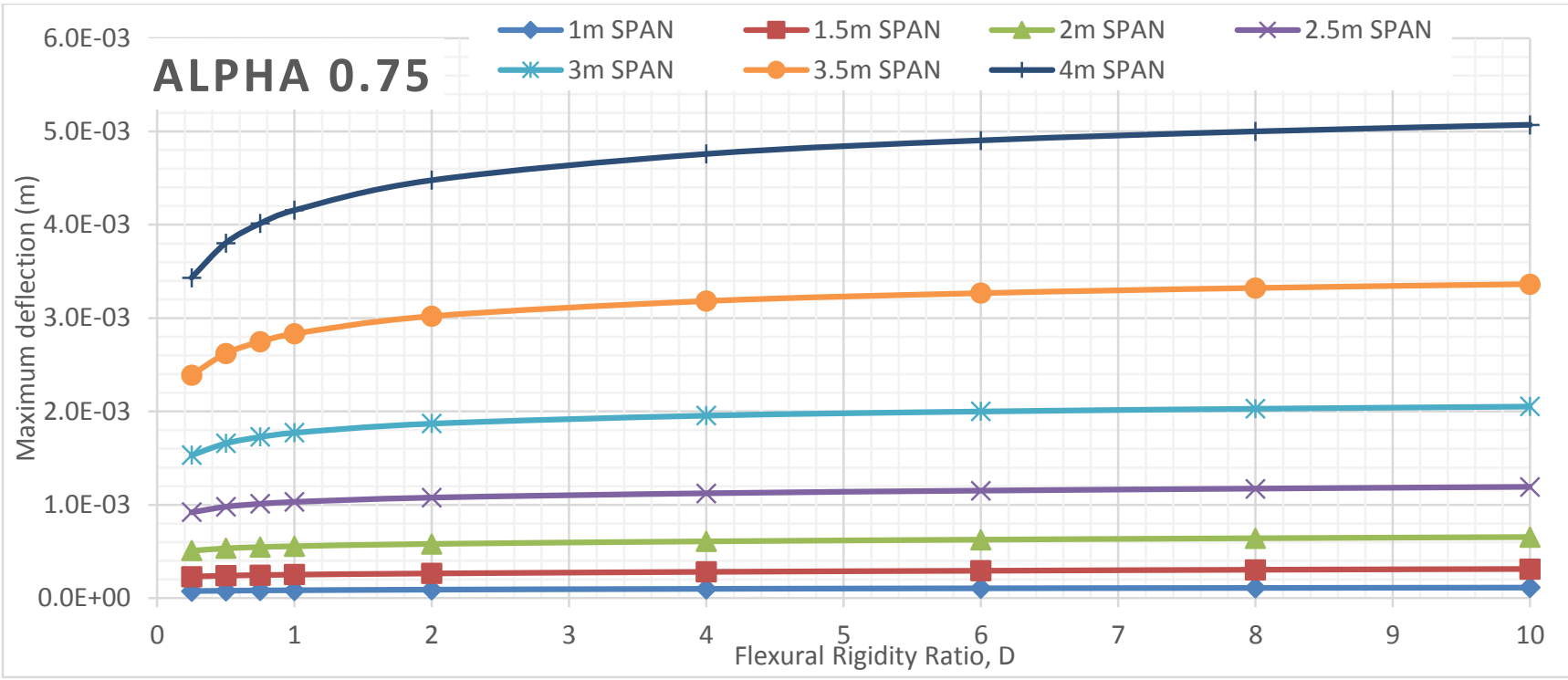

Figure 1134 Factored maximum deflection results for alpha 0.75 at different span length (main bars parallel to traffic)

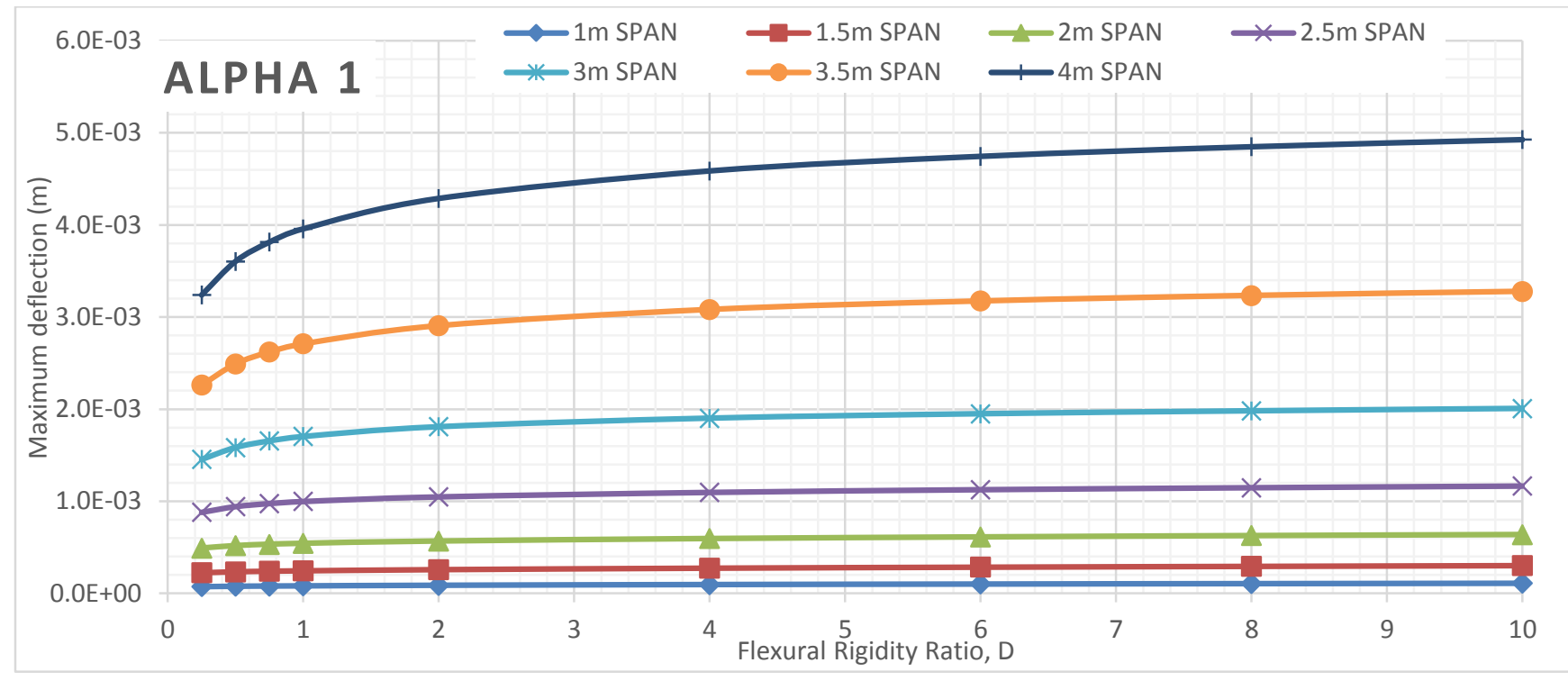

Figure 1135 Factored maximum deflection results for alpha 1 at different span length (main bars parallel to traffic)

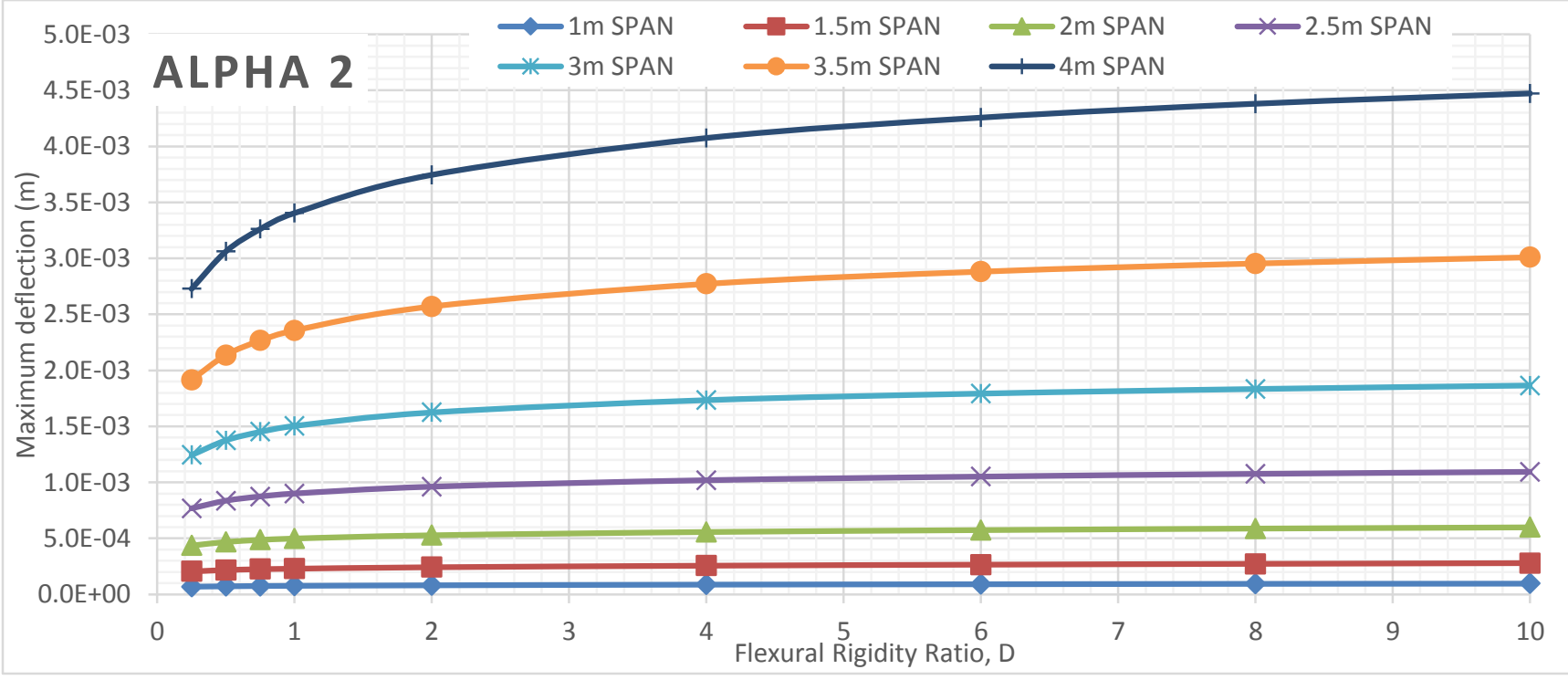

Figure 1136 Factored maximum deflection results for alpha 2 at different span length (main bars parallel to traffic) 


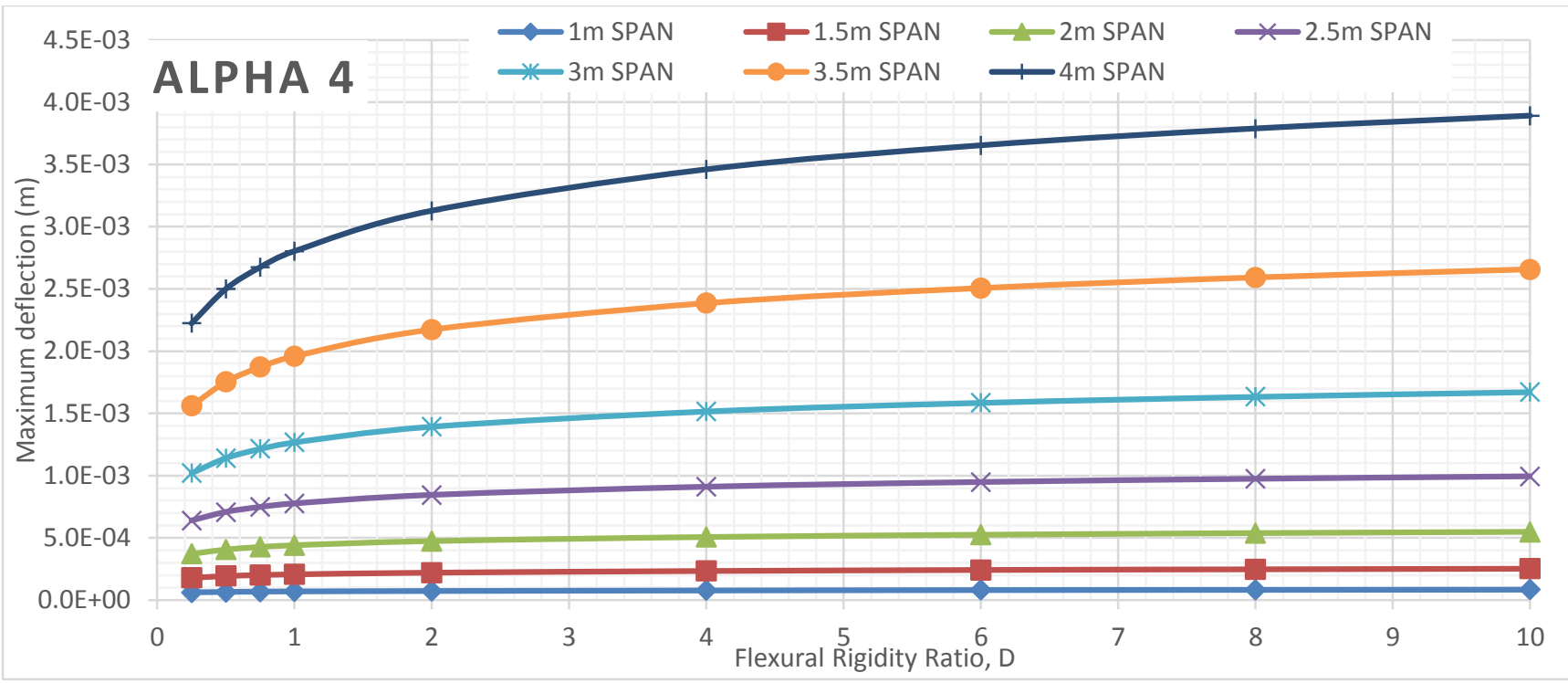

Figure 1137 Factored maximum deflection results for alpha 4 at different span length (main bars parallel to traffic)

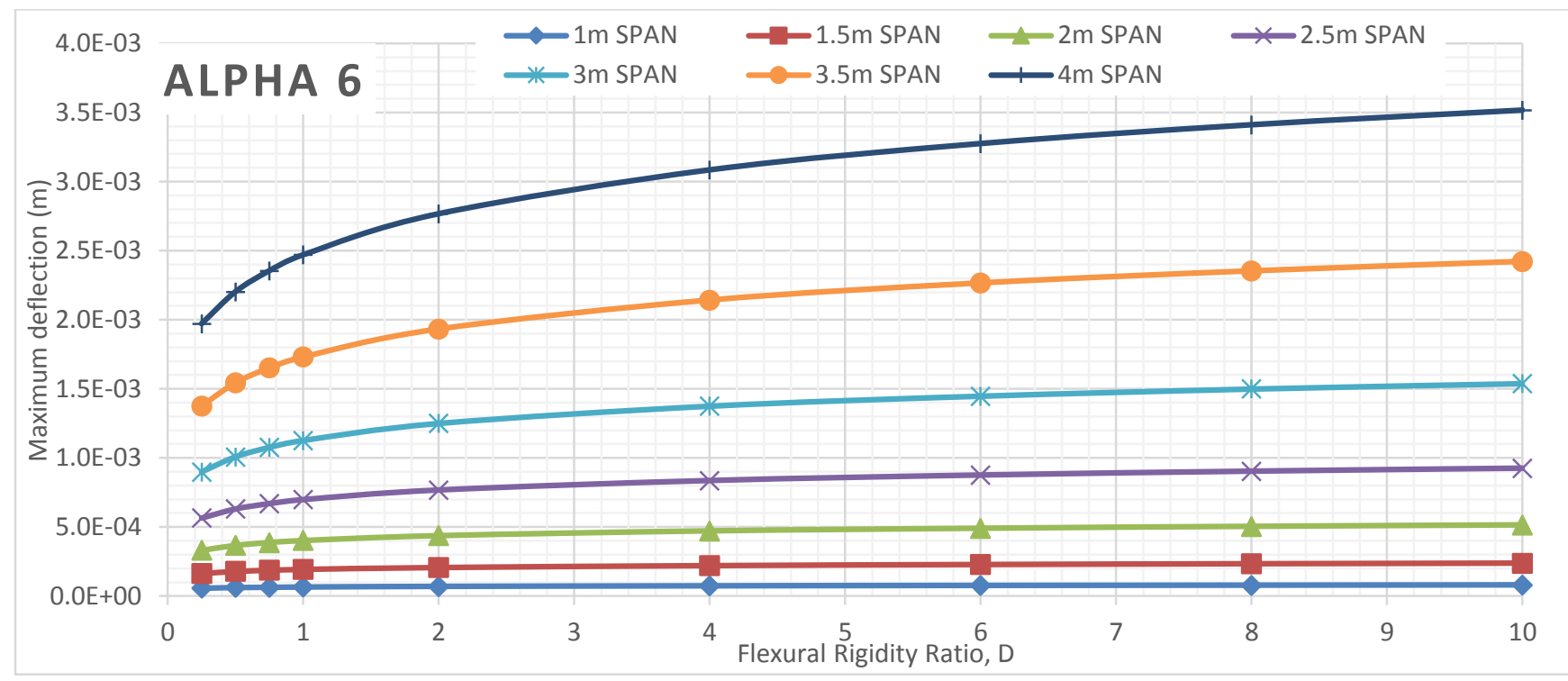

Figure 1138 Factored maximum deflection results for alpha 6 at different span length (main bars parallel to traffic)

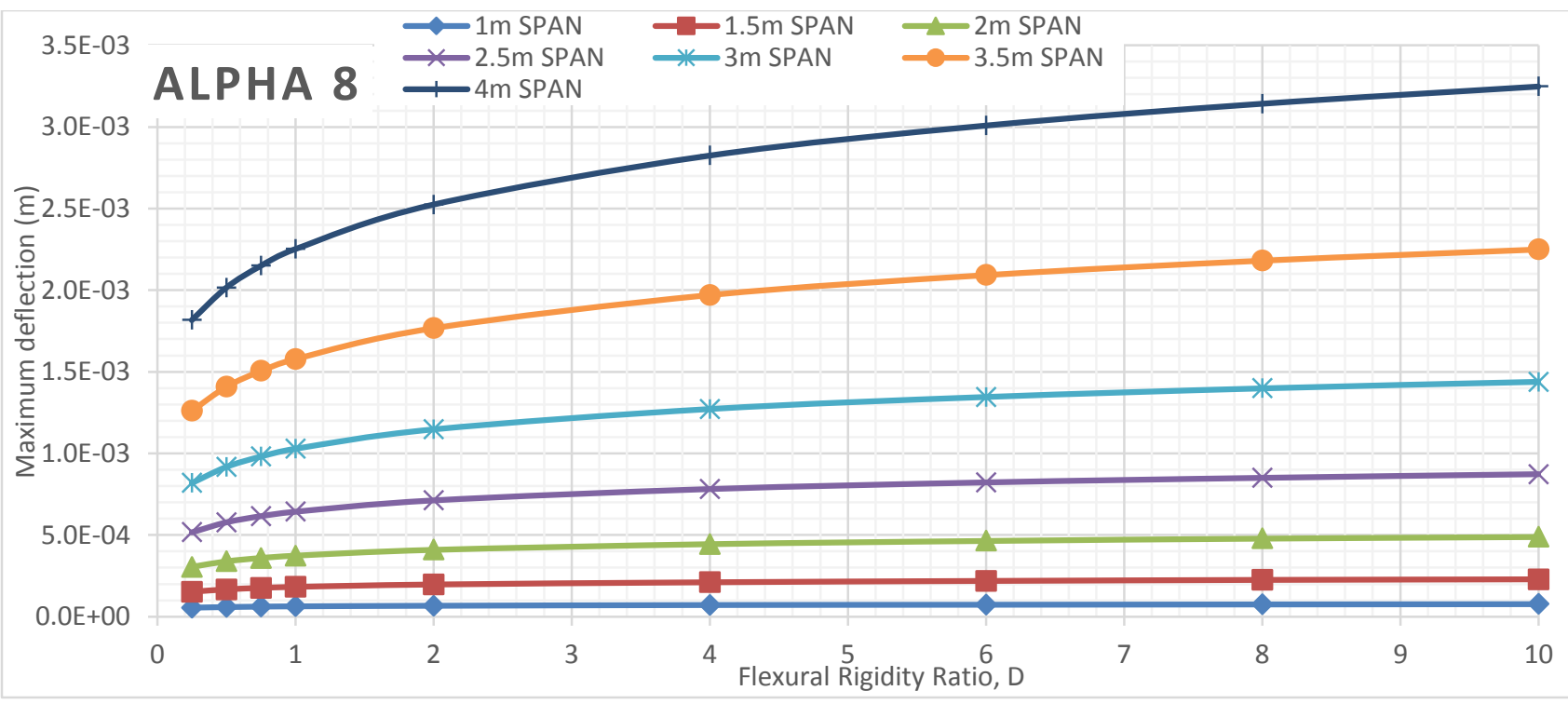

Figure 1139 Factored maximum deflection results for alpha 8 at different span length (main bars parallel to traffic) 


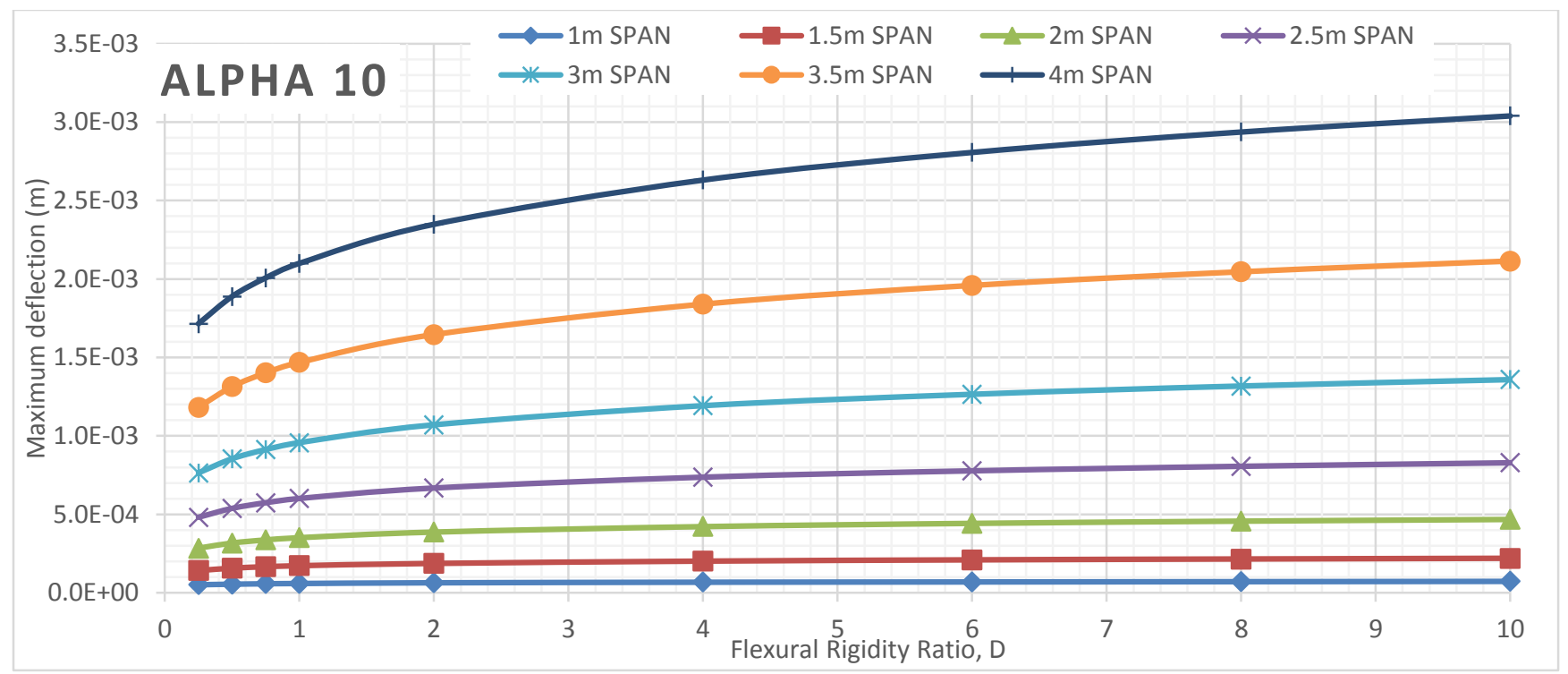

Figure 1140 Factored maximum deflection results for alpha 10 at different span length (main bars parallel to traffic) 


\section{References}

AASHTO LRFD Bridge Design Specifications. (2014). Washington, DC: American Association of State Highway and Transportation Officials.

Baker, T. (1991). Plate stiffness constants for concrete filled steel grid decks: Static and fatigue strength determination of design properties for grid decks. Research Rep. St-9, Vol. I.

BGFMA. (2015). http://www.bgfma.org/grids.htm. Retrieved 2016, from http://www.bgfma.org. Canadian Highway Bridge Design Code "CHBDC". (2014). Toronto: Canadian Standards Association. GangaRao, H., Raju, P., \& Koppula, N. (1992). BEHAVIOR OF CONCRETE-FILLED STEEL GRID DECKS. Transportation Research Record No. 1371, 1-7.

Haoxiong Huang, M. J. (2002). Behavior of open steel grid decks for bridges. Journal of Constructional Steel Research, Volume 58, Issues 5-8, 819-842.

Higgins, C. (2003). LRFD Orthotropic Plate Model for Live Load Moment in Filled Grid Decks . Journal of Bridge Engineering , 20 - 28.

Higgins, C. (2004). Orthotropic Plate Model for Estimating Deflections in Filled Grid Decks. Journal of Bridge Engineering, 599-605.

Higgins, Turan, O. T., Connor, R. J., \& Liu, J. (2011). Unified Approach for LRFD Live Load Moments in Bridge Decks. Journal of Bridge Engineering, 804-811.

Huang, H., Kaliakin, V., Chajes, M., Mertz, D., \& Shenton, H. (2007). Application of Orthotropic Thin Plate Theory to Filled Steel Grid Decks for Bridges. Journal of Bridge Engineering, Vol. 12, No. 6, 807-810.

Mangelsdorf, C., Baker, T., \& Swanson, J. (2002). Predicting deflection in concrete-filled grid decks panels . Transportation Research Record 1814, 17 - 24.

SW., T. (1965). Experimental Determination of the Elastic Behavior of Orthotropic Plates. Journal of Engineering for Industry, Volume 87, Issue 3, 315-317.

Timoshenko, \& Woinowski-Krieger. (1959). Theory of Plates and Shells. New York: McGraw-Hill.

Turan, O. (2009). Design, analysis and evaluation of bridge superstructures for live loads. Oregon State Univ. 